\title{
Digest of Education Statistics 1998
}

NCES 1999-036

\author{
March 1999
}

National Center for Education Statistics

U.S. Department of Education Washington, DC 


\section{FOREWORD}

This 1998 edition of the Digest of Education Statistics is the 34th in a series of publications initiated in 1962. (The Digest has been issued annually except for combined editions for the years 1977-78, 198384 , and 1985-86.) Its primary purpose is to provide a compilation of statistical information covering the broad field of American education from kindergarten through graduate school. The Digest includes a selection of data from many sources, both government and private, and draws especially on the results of surveys and activities carried out by the National Center for Education Statistics (NCES). The publication contains information on a variety of subjects in the field of education statistics, including the number of schools and colleges, teachers, enrollments, and graduates, in addition to educational attainment, finances, federal funds for education, employment and income of graduates, libraries, and international education. Supplemental information on population trends, attitudes on education comparisons, education characteristics of the labor force, government finances, and economic trends provides background for evaluating education data. Although the Digest contains important information on federal education funding, more detailed information on federal activities is available from federal education program offices. For example, the Office of Bilingual Education and Minority Languages Affairs supports the National Clearinghouse on Bilingual Education, which compiles information on students and teachers involved in bilingual education.

The Digest is divided into seven chapters: "All Levels of Education," "Elementary and Secondary Education," "Postsecondary Education," "Federal Programs for Education and Related Activities," "Outcomes of Education," "International Comparisons of Education," and "Learning Resources and Tech- nology." To qualify for inclusion, material must be nationwide in scope and of current interest and value. The introduction includes a brief overview of current trends in American education, which supplements the tabular materials in chapters 1 through 7 . Information on the structure of the statistical tables is contained in the "Guide to Tabular Presentation." The "Guide to Sources" provides a brief synopsis of the surveys used to generate the tabulations for the Digest. Also, a "Definitions" section is included to help readers understand terms. In addition to updating many of the statistics that have appeared in previous years, this edition contains a significant amount of new material, including:

- Parental involvement in education-related activities, tables 25 and 26;

- Number of hours young children spend in day care programs, table 51;

- Performance of eighth-grade students in music, theatre, and visual arts, table 130;

- Finances of nonprofit institutions of higher education, tables 327 and 350;

- International comparisons of the performance of twelfth-grade students in mathematics and science, tables 405 and 406; and

- Percent of home computer users using specific applications, tables 426 and 427.

Martin E. Orland

Associate Commissioner,

Early Childhood, International, and Crosscutting Studies Division

National Center for Education Statistics

March 1999 



\section{ACKNOWLEDGMENTS}

Many people have contributed in one way or another to the development of the Digest. Thomas D. Snyder was responsible for the overall development and preparation of this Digest, which was prepared under the general direction of Martin Orland.

Charlene M. Hoffman provided technical assistance in all phases of its preparation and was responsible for chapter 4, "Federal Programs for Education and Related Activities," and for tables on degrees conferred. Claire Geddes developed text for chapter introductions and was responsible for materials dealing with higher education enrollment and faculty characteristics. William Sonnenberg provided statistical computing consultation on all phases of the report. Celestine Davis provided statistical assistance on materials dealing with educational attainment and student assessment. Debra Gerald and William Hussar prepared projections of school enrollment and finance statistics.

A number of individuals outside the Center also expended large amounts of time and effort on the Digest. Jennifer Sable and Rabab Saab of Pinkerton Computer Consultants, Inc. provided research and statistical assistance. In the office of Media and Information Services, Robert LeGrand and Diane
Magarity provided editorial assistance and Phil Carr designed the cover. Jerry Fairbanks of the U.S. Government Printing Office managed the typesetting.

This year's edition of the Digest has received extensive reviews by individuals within and outside the U.S. Department of Education. We wish to thank them for their time and expert advice. In the Office of Educational Research and Improvement (OERI), W. Vance Grant and Mary Frase. Ellen Bradburn, Molly Soule, and Chris Calsyn of the Education Statistics Services Institute also provided technical review, and Rosemary Clark (U.S. Bureau of the Census) also reviewed the entire document. OERI staff who reviewed portions of the manuscript were: Marilyn McMillen (Chief Statistician), Sam Barbett, Jonaki Bose, Patricia Q. Brown, Susan Broyles, Chris Chapman, Adrienne Chute, Mike Cohen, Rosa Fernandez, Debra Gerald, Arnold Goldstein, Kerry Gruber, Frank Johnson, Austin Lin, Aurora D'Amico, Drew Malizio, Frank Morgan, Jeffrey Owings, John Sietsema, Shi-Chang Wu, Shelley Burns, and Linda Zimbler. Agency reviews were conducted by the Office of Bilingual Education and Minority Languages Affairs and the Planning and Evaluation Service. 



\section{Contents}

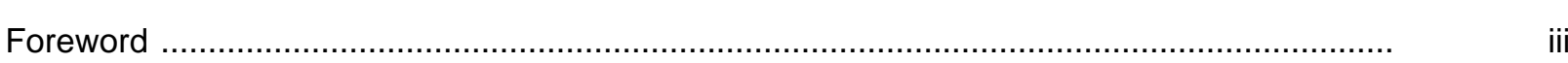

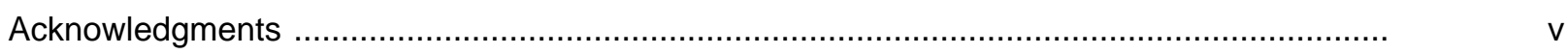

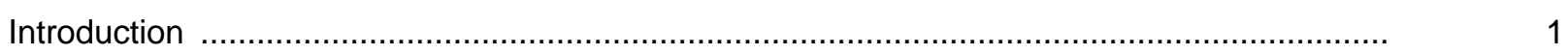

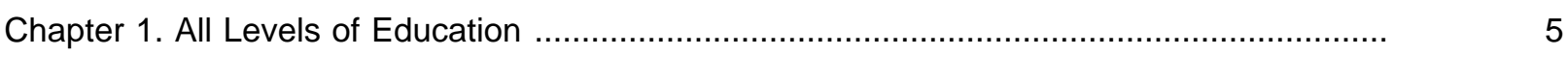

Chapter 2. Elementary and Secondary Education ....................................................... 43

Chapter 3. Postsecondary Education ............................................................................. 187

College and University Education ...................................................................... 194

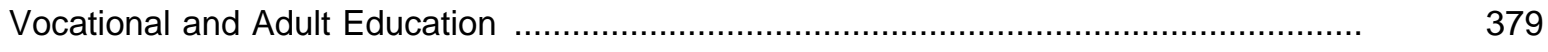

Chapter 4. Federal Programs for Education and Related Activities ................................. 385

Chapter 5. Outcomes of Education ......................................................................... 427

Chapter 6. International Comparisons of Education .........................................................

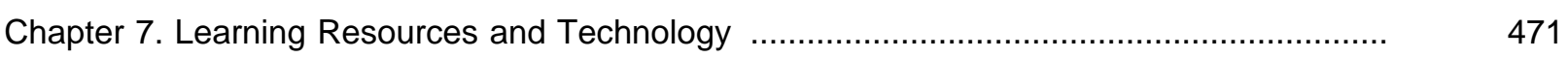

Appendix

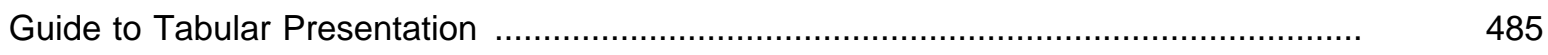

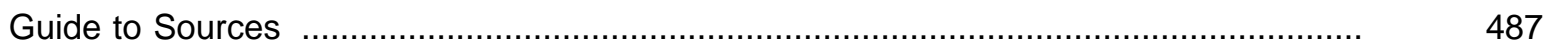

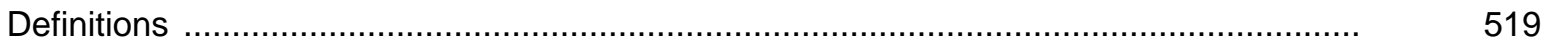

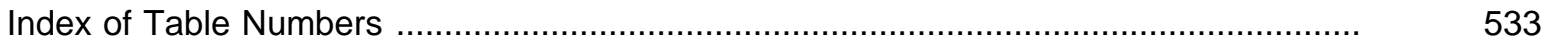




\section{Figures}

1. The structure of education in the United States

2. Enrollment and total expenditures in current and constant dollars, by level of education: $1960-61$ to $1997-98$

3. Years of school completed by persons 25 years old and over: 1940 to 1997

4. Years of school completed by persons 25 to 29 years of age: 1940 to 1997

5. Highest level of education attained by persons 25 years and older: March $1997 \ldots \ldots . .$.

6. Items most frequently cited by the public as a major problem facing the local public schools: 1980 to 1998

7. Preprimary enrollment of 3- to 5-year-olds, by attendance status: October 1970 to October 1997

8. Enrollment, number of teachers, pupi//teacher ratios, and expenditures in public schools: $1960-61$ to $1997-98$

9. Percentage change in public elementary and secondary enrollment, by state: Fall 1992 to fall 1997

10. Average annual salary for public elementary and secondary school teachers: 1969-70 to 1997-98

11. Sources of revenue for public elementary and secondary schools: 1970-71 to 1995-96

12. Current expenditure per pupil in average daily attendance in public elementary and secondary schools: $1970-71$ to $1997-98$

13. Enrollment, degrees conferred, and expenditures in institutions of higher education: $1960-61$ to $1997-98$

14. Percentage change in total enrollment of institutions of higher education, by state: Fall 1990 to fall 1996

15. Enrollment in institutions of higher education, by age: Fall 1970 to fall 2008

16. Full-time-equivalent students per staff member in public and private institutions of higher education: 1976 and 1995

17. Trends in bachelor's degrees conferred in selected fields of study: 1985-86, 1990-91, and 1995-96

18. Sources of current-fund revenue for public institutions of higher education: 1995-96 .

19. Sources of current-fund revenue for private institutions of higher education: 1995-96

20. Federal on-budget funds for education, by agency: Fiscal year 1998

21. Federal on-budget funds for education, by level or other educational purpose: 1965 to 1998

22. Department of Education outlays, by type of recipient: Fiscal year 1998

23. Labor force participation of persons 16 years old and over, by age and highest level of education: 1997 
24. Unemployment rates of persons 25 years old and over, by highest degree attained: 1997

25. Labor force status of 1996-97 high school dropouts and graduates not enrolled in college: October 1997

26. Median annual income of persons with income 25 years old and over, by highest degree attained and sex: 1996

27. Salaries of recent bachelor's degree recipients 1 year after graduation, by field: 1987, 1991, and 1994

28. Percent change in enrollment, by area of the world and level of education: 1980 to 1995

29. Public expenditures for education as a percentage of the gross domestic product: Selected countries, 1994

30. Bachelor's degree recipients as a percentage of population of the theoretical age of graduation, by sex: Selected countries, 1995

31. Average mathematics performance of other countries compared with the United States: 1995

32. Average science performance of other countries compared with the United States: 1995

33. Percent of all public schools and instructional rooms having Internet access: Fall 1994 to fall 1998

\section{Tables}

\section{All Levels of Education}

\section{Enrollment, Teachers, and Schools}

1. Estimated number of participants in elementary and secondary education and in higher education: Fall 1998

2. Enrollment in educational institutions, by level and control of institution:

Fall 1980 to fall 2005

3. Enrollment in educational institutions, by level and by control of institution: $1869-70$ to fall 2008

4. Teachers in elementary and secondary schools, and senior instructional staff in institutions of higher education, by control of institution:

Fall 1970 to fall 2008

5. Educational institutions, by level and control of institution: 1980-81 to 1996-97

\section{Enrollment Rates}

6. Percent of the population 3 to 34 years old enrolled in school, by age: April 1940 to October 1997

7. Percent of the population 3 to 34 years old enrolled in school, by race/ethnicity, sex, and age: October 1980 to October 1997

\section{Educational Attainment}

8. Years of school completed by persons age 25 and over and 25 to 29 , by race/ethnicity and sex: 1910 to 1997 
9. Highest level of education attained by persons age 18 and over, by age, sex, and race/ethnicity: March 1997

10. Number of persons age 18 and over who hold a bachelor's or higher degree, by field of study, sex, race, and age: Spring 1993

11. Educational attainment of persons 25 years old and over, by state: April 1990

12. Educational attainment of persons 25 years old and over, by state and race/ethnicity: April 1990

13. Educational attainment of persons 25 years old and over, for the 25 largest states: March 1996

14. Educational attainment of persons 25 years old and over, for the 15 largest metropolitan areas: March 1995

\section{Population}

15. Estimates of resident population, by age group: July 1, 1970 to July 1, 1997

16. Estimates of school-age resident population, by race and sex: July 1,1970 to July 1,1997

17. Estimated total and school-age resident populations, by state: 1970 to 1997

\section{Characteristics of Families with Children}

18. Families, by family status and presence of own children under 18: 1970 to 1996

19. Characteristics of families with own children under 18 , by family status and race/ethnicity: 1996

20. Household income and poverty rates, by state: 1990, 1995, and 1996

21. Poverty status of persons, families, and children under 18 , by race/ethnicity: 1959 to 1996

\section{Opinions on Education}

22. Average grade that the public would give the schools in their community and in the nation at large: 1974 to 1998

23. Items most frequently cited by the general public as a major problem facing the local public schools: 1970 to 1998

24. Public opinion of public and private school choice: 1989 to 1998

25. Percent of elementary and secondary school children whose parents are involved in school activities and distribution of children by average grades, by selected child, parent, and school characteristics: 1996

26. Percent of elementary school children whose parents are involved in educationrelated activities, by selected child, parent, and school characteristics: 1996

27. Teachers' perceptions about serious problems in their schools, by type and control of school: 1990-91 and 1993-94

28. Teachers' perceptions about teaching and school conditions, by type and control of school: 1993-94

29. Public's level of confidence in various institutions: 1996 and 1998 


\section{Charitable Contributions}

30. Percentage of households contributing to education and other charitable organizations and average annual donation, by type of charity: 1989, 1991, 1993, and 1995

\section{Finances}

31. Total expenditures of educational institutions related to the gross domestic product, by level of institution: $1959-60$ to $1997-98$

32. Total expenditures of educational institutions, by level and control of institution: $1899-1900$ to $1997-98$

33. Estimated total expenditures of educational institutions, by level, control of institution, and source of funds: $1979-80$ to $1995-96$

34. Governmental expenditures, by level of government and function: 1970-71 to $1993-94$

35. Direct general expenditures of state and local governments for all functions and for education, by level and state: 1994-95

36. Direct general expenditures per capita of state and local governments for all functions and for education, by level and state: 1994-95

37. Gross domestic product, state and local expenditures, personal income, disposable personal income, median family income, and population: 1929 to 1997

38. Gross domestic product deflator, Consumer Price Index, education price indexes, and federal budget composite deflator: 1919 to 1998

\section{Elementary and Secondary Education}

\section{Enrollment}

39. Historical summary of public elementary and secondary school statistics: 1869-70 to 1995-96

40. Enrollment in public elementary and secondary schools, by level and state:

Fall 1982 to fall 1997

41. Enrollment in public elementary and secondary schools, by grade and state: Fall 1996

42. Enrollment in public elementary and secondary schools, by grade and state: Fall 1995

43. Enrollment in public elementary and secondary schools, by grade: Fall 1982 to fall 1996

44. Average daily attendance in public elementary and secondary schools, by state: 1969-70 to $1995-96$

45. Enrollment in public elementary and secondary schools, by race or ethnicity and state: Fall 1986 and fall 1996

46. Enrollment of 3-, 4-, and 5-year-old children in preprimary programs, by level and control of program and by attendance status: October 1965 to October 1997

47. Children of prekindergarten through second grade age, by enrollment status, maternal characteristics, and household income: 1991, 1993, and 1995 
48. Percent of public school kindergarten teachers indicating the importance of various factors for kindergarten readiness: Spring 1993

49. Child care arrangements of preschool children, by age and household characteristics: 1991 and 1995

50. Participation of public kindergarten children in selected activities 5 days a week, by length and size of class and teacher preparation: Spring 1993

51. Number of hours children age 5 and under spend in center-based programs, by child and maternal characteristics, and household income: 1995

52. Public school pupils transported at public expense and current expenditures for transportation: $1929-30$ to $1995-96$

53. Children 0 to 21 years old served in federally supported programs for the disabled, by type of disability: 1976-77 to 1996-97

54. Percentage distribution of disabled persons 3 to 21 years old receiving education services for the disabled, by age group and educational environment: 1995-96 .....

55. State legislation on gifted and talented programs and number and percent of students receiving services in public elementary and secondary schools, by state: 1993-94 and 1995-96

56. Number of children served under Individuals with Disabilities Education Act and Chapter 1 of the Education Consolidation and Improvement Act, State Operated Programs, by age group and state: 1990-91 to 1996-97

57. Enrollment in grades 9 to 12 in public and private schools compared with population 14 to 17 years of age: $1889-90$ to fall 1997

58. Enrollment in foreign language courses compared with enrollment in grades 9 to 12 in public secondary schools: Fall 1948 to fall 1994

59. Student participation in school programs and services, by control, level of school, and type of community: 1993-94

Private Elementary and Secondary Schools

60. Private elementary and secondary enrollment, teachers, and schools, by selected characteristics: Fall 1995

61. Private elementary and secondary staff and student/staff ratios, by level and orientation of school: 1993-94

62. Private elementary and secondary enrollment and schools, by amount of tuition, level, and orientation of school: 1993-94

63. Summary statistics on Catholic elementary and secondary schools, by level: 1919-20 to 1997-98

64. Private elementary and secondary schools, enrollment, teachers, and high school graduates, by state: Fall 1995

Teachers and Other Instructional Staff

65. Public and private elementary and secondary teachers and pupil/teacher ratios, by level: Fall 1955 to fall 1998

66. Public elementary and secondary teachers, by level and state:

Fall 1992 to fall 1997 
67. Teachers, enrollment, and pupil/teacher ratios in public elementary and secondary schools, by state: Fall 1991 to fall 1996

68. Teachers in public and private elementary and secondary schools, by selected characteristics: 1993-94

69. Highest degree earned, number of years teaching experience, and average class size for teachers in public elementary and secondary schools, by state: 1993-94 ..

70. Selected characteristics of public school teachers: Spring 1961 to spring 1996

71. Public secondary school teachers, by subject taught: Spring 1966 to spring $1996 \ldots . .$.

72. Percent of vocational and nonvocational public school teachers of grades 9 to 12 , by selected demographic and educational characteristics: 1993-94

73. Mobility of public and private elementary and secondary teachers, by selected school and teacher characteristics: $1987-88$ to $1994-95$

74. Average salaries for full-time teachers in public and private elementary and secondary schools, by selected characteristics: 1993-94

75. Opinions of public school teachers on the overall quality of education that students received at their school, by selected characteristics: 1987 and 1997

76. Percent of public school teachers who reported opinions on various aspects of their schools: 1987 and 1997

77. Percent of public school students who reported various levels of parental/guardian involvement in their education, by selected student characteristics: 1997

78. Estimated average annual salary of teachers in public elementary and secondary schools: $1959-60$ to $1997-98$

79. Estimated average annual salary of teachers in public elementary and secondary schools, by state: $1969-70$ to $1997-98$

80. Minimum and average teacher salaries, by state: 1990-91, 1995-96, and 1996-97 ..

81. Average annual salary of instructional staff in public elementary and secondary schools, by state: $1939-40$ to $1997-98$

82. Estimated average annual salary of instructional staff in public elementary and secondary schools and average annual earnings of full-time employees in all industries: $1929-30$ to $1997-98$

83. Staff employed in public elementary and secondary school systems, by functional area: $1949-50$ to fall 1996

84. Staff employed in public school systems, by type of assignment and state:

Fall 1996

85. Staff employed in public school systems, by type of assignment and state: Fall 1995

86. Staff and teachers in public elementary and secondary schools, by state:

Fall 1990 to fall 1996

87. Staff, enrollment, and pupil/staff ratios in public elementary and secondary schools, by state: Fall 1990 to fall 1996 
88. Principals in public and private elementary and secondary schools, by selected characteristics: 1993-94

\section{Schools and School Districts}

89. Public elementary and secondary students, schools, pupi//teacher ratios, and finances, by type of locale: 1995 and 1996

90. Public school districts and public and private elementary and secondary schools: 1929-30 to 1996-97

91. Public school districts and enrollment, by size of district: $1988-89$ to $1996-97$

92. Number and percentage of public elementary and secondary education agencies, by state and type of agency: 1995-96 and 1996-97

93. Selected statistics on enrollment, teachers, graduates, and dropouts in public school districts enrolling more than 15,000 pupils, by state: 1989 and 1996

94. Revenues and expenditures of public school districts enrolling more than 15,000 pupils, by state: $1994-95$

95. Enrollment of the 130 largest public school districts: Fall 1996

96. Public elementary and secondary schools, by type of school: 1967-68 to 1996-97 ...

97. Public elementary and secondary schools, by type and size of school: 1996-97 ........

98. Public elementary and secondary schools, by type and state: 1990-91 to 1996-97 ...

99. Public elementary schools, by grade span and average school size, by state: 1996-97

100. Public secondary schools, by grade span and average school size, by state: 1996-97

High School Seniors, Completions, and Dropouts

101. High school graduates compared with population 17 years of age, by sex and control of school: $1869-70$ to $1997-98$

102. Public high school graduates, by state: $1969-70$ to $1997-98$

103. High school graduates and dropouts in public elementary and secondary schools, by race/ethnicity and state: 1995-96

104. General Educational Development (GED) credentials issued, and number and age of test takers: United States and outlying areas, 1971 to 1996

105. Percent of high school dropouts (status dropouts) among persons 16 to 24 years old, by sex and race/ethnicity: April 1960 to October 1997

106. Percent of high school dropouts (status dropouts) among persons 16 to 34 years old, by age, sex, and race/ethnicity: October 1970 to October 1997

107. Students with disabilities exiting the educational system, by age, type of disability, and basis of exit: United States and outlying areas, 1993-94 and 1994-95

108. Postsecondary education and employment status, wages earned, and living arrangements of special education students out of secondary school up to 3 years, by type of disability: 1990 


\section{Educational Achievement}

109. Average student proficiency in reading, by age and selected characteristics of students: 1971 to 1996

110. Student proficiency in reading, by percentile and age: 1971 to 1996

111. Student proficiency in reading, by age, amount of time spent on homework, and reading habits: 1984, 1994, and 1996

112. Percent of students at or above selected reading proficiency levels, by sex, race/ethnicity, and age: 1971 to 1996

113. Average proficiency in reading for 4th-graders in public schools, by selected characteristics, region, and state: 1994

114. Percentage distribution of 4th-graders in public schools, by time spent on homework and television viewing each day: 1992 and 1996

115. Average writing performance of 4th-, 8th-, and 11th-graders, by selected characteristics of students: 1984 to 1996

116. Student values and attitudes toward writing, by grade level: 1984, 1990, 1992, and 1994

117. Percent of students at or above selected history proficiency levels, by selected characteristics and grade level: 1994

118. Average student proficiency in geography and U.S. history, by student characteristics: 1994

119. Percent of students at or above selected geography proficiency levels, by selected characteristics and grade level: 1994

120. Average mathematics proficiency, by age and by selected characteristics of students: 1973 to 1996

121. Percent of students at or above selected mathematics proficiency levels, by sex, race/ethnicity, control of school, and age: 1978 to 1996

122. Mathematics attainment for 8th-graders in public schools, by region and state: 1996

123. Mathematics attainment for 4th-graders in public schools, by region and state: 1996

124. Selected characteristics of 8th-grade students in public schools, by region and state: 1992

125. Mathematics proficiency of 17-year-olds, by highest mathematics course taken, sex, and race/ethnicity: 1978 to 1996

126. Percent of students at or above selected science proficiency levels, by sex, race/ethnicity, control of school, and age: 1977 to 1996

127. Average proficiency in science for 8th-graders in public schools, by selected characteristics and state: 1996

128. Average science proficiency, by age and by selected characteristics of students: 1970 to 1996

129. Twelfth graders' achievement on history, mathematics, reading, and science tests: 1992 
130. Performance of 8th-grade students in music, theatre, and visual arts, by selected characteristics of students: 1997

131. Scholastic Assessment Test score averages, by race/ethnicity: 1987, 1996, and 1997

132. Scholastic Assessment Test score averages for college-bound high school seniors, by sex: $1966-67$ to $1997-98$

133. Scholastic Assessment Test score averages, by selected student characteristics: 1996 and 1997

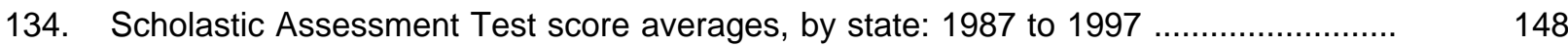

135. American College Testing (ACT) score averages, by sex: 1970 to 1997

136. Average number of Carnegie units earned by public high school graduates in various subject fields, by student characteristics: 1982 to 1994

137. Average number of Carnegie units earned by public school graduates in vocational education courses, by student characteristics: 1982 to 1994

138. Percentage of high school graduates taking selected mathematics and science courses in high school, by sex and race/ethnicity: 1982 to 1994

139. Percent of high school graduates earning minimum credits in selected combinations of academic courses, by sex and race/ethnicity: 1982 to 1994

\section{Student Activities and Behavior}

140. Reasons given by 12th-graders for taking current mathematics and science classes, by selected student and school characteristics: 1992

141. Expected occupations of 8th-, 10th-, and 12th-graders at age 30, by selected student and school characteristics: 1988, 1990, and 1992

142. Eighth-, 10th-, and 12th-graders' attitudes about school climate, by student and school characteristics: 1988, 1990, and 1992

143. Percentage of 3- to 5 -year-olds who were read to every day in the last week by a family member: 1993, 1995, and 1996

144. Participation of 10th- and 12th-graders in extracurricular activities, by selected student characteristics: 1990 and 1992

145. Percent of high school seniors who plan to go to college after graduation, by student characteristics: 1982 and 1992

146. Percent of high school seniors who say they engage in various activities, by student characteristics: 1982 and 1992

147. Percent of high school seniors who participate in selected school-sponsored extracurricular activities, by student characteristics: 1980 and 1992

148. Percentage of students in grades 9 through 12 who reported experience with drugs and violence on school property, by race/ethnicity, grade, and sex: 1995 and 1997

149. Percent of 12- to 17-year-olds reporting drug use during the past 30 days and the past year: 1982 to 1996

150. Percent of high school seniors reporting drug use, by type of drug and frequency of use: 1975 to 1997 
151. Percent of students (grades 7 to 12) who feel that certain problems are very serious: 1996

\section{State Regulations}

152. Ages for compulsory school attendance, special education services for students, policies for kindergarten programs, and year-round schools, by state: 1997 and 1995

153. Tenth- and 12th-graders' attendance patterns, by selected student and school characteristics: 1990 and 1992

154. State requirements for high school graduation, in Carnegie units: 1993 and 1996

155. States using minimum-competency testing, by government level setting standards, grade levels assessed, and expected uses of standards: 1995-96

156. States requiring testing for initial certification of teachers, by authorization, year enacted, year effective, and test used: 1990 and 1998

\section{Revenues and Expenditures}

157. Revenues for public elementary and secondary schools, by source of funds: 1919-20 to 1995-96

158. Revenues for public elementary and secondary schools, by source and state: 1995-96

159. Revenues for public elementary and secondary schools, by source and state: 1994-95

160. Funds and staff for state education agencies, by source of funding and state: 1992-93

161. Summary of expenditures for public elementary and secondary education, by purpose: 1919-20 to 1995-96

162. Total expenditures for public elementary and secondary education, by function and subfunction: 1990-91 to 1995-96

163. Expenditures for instruction in public elementary and secondary schools, by subfunction and state: 1994-95 and 1995-96

164. Current expenditures for public elementary and secondary education, by state: $1969-70$ to $1997-98$

165. Total expenditures for public elementary and secondary education, by function and state: $1995-96$

166. Total expenditures for public elementary and secondary education, by function and state: $1994-95$

167. Current expenditure per pupil in average daily attendance in public elementary and secondary schools, by state: $1959-60$ to $1995-96$

168. Current expenditure per pupil in fall enrollment in public elementary and secondary schools, by state: 1969-70 to 1995-96

169. Total and current expenditure per pupil in public elementary and secondary schools: 1919-20 to 1997-98 


\section{3-A. Postsecondary Education: College and University Education}

\section{Enrollment}

170. Enrollment and staff in, and degrees conferred by, degree-granting and nondegreegranting postsecondary institutions: 1995-96 and fall 1995 and 1996

171. Historical summary of faculty, students, degrees, and finances in institutions of higher education: $1869-70$ to $1995-96$

172. Total fall enrollment in institutions of higher education, by attendance status, sex of student, and control of institution: 1947 to 1996

173. Total fall enrollment in institutions of higher education and degree-granting institutions, by control and type of institution: 1965 to 1996

174. Total fall enrollment in institutions of higher education, by attendance status, sex, and age: 1970 to 2008

175. Total fall enrollment in institutions of higher education, by level, sex, age, and attendance status of student: 1995

176. Total fall enrollment in institutions of higher education, by type and control of institution, and age and attendance status of student: 1995

177. Total fall enrollment in institutions of higher education and degree-granting institutions, by level of enrollment, sex, attendance status, and type and control of institution: 1996

178. Total fall enrollment in institutions of higher education and degree-granting institutions, by type and control of institution, attendance status, and sex of student: 1970 to 1996

179. Fall enrollment and number of institutions of higher education, by affiliation of institution: 1980 to 1996

180. Total fall enrollment in institutions of higher education and degree-granting institutions, by type and control of institution, and attendance status, sex, and level of student: 1994 to 1996

181. Total first-time freshmen enrolled in institutions of higher education and degree-granting institutions, by sex of student, attendance status, and type and control of institution: Fall 1955 to fall 1996

182. Total first-time freshmen enrolled in institutions of higher education,

by attendance status, sex, control of institution, and state: Fall 1992 to fall $1996 \ldots$

207

183. College enrollment rates of high school graduates, by race/ethnicity: 1960 to $1997 \ldots \quad 208$

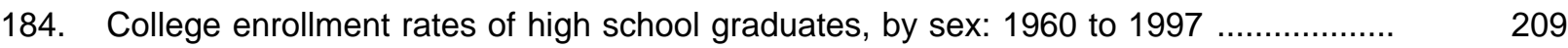

185. Graduation, college preparation, and college application rates of high school students, by selected school characteristics: 1993-94

186. Enrollment rates of 18- to 24-year-olds in institutions of higher education, by race/ethnicity: 1967 to 1997

187. Total undergraduate fall enrollment in institutions of higher education, by sex of student, attendance status, and control of institution: 1969 to 1996

188. Total graduate fall enrollment in institutions of higher education, by attendance status, sex of student, and control of institution: 1969 to 1996 
189. Total first-professional fall enrollment in institutions of higher education, by attendance status, sex of student, and control of institution: 1969 to 1996

190. Total fall enrollment in institutions of higher education and degree-granting institutions, by state: 1970 to 1996

191. Total fall enrollment in public institutions of higher education and degree-granting institutions, by state: 1970 to 1996

192. Total fall enrollment in private institutions of higher education and degree-granting institutions, by state: 1970 to 1996

193. Total fall enrollment in all institutions of higher education, by attendance status, sex, and state: 1995 and 1996

194. Total fall enrollment in public institutions of higher education, by attendance status, sex, and state: 1995 and 1996

195. Total fall enrollment in private institutions of higher education, by attendance status, sex, and state: 1995 and 1996

196. Total fall enrollment in institutions of higher education, by control, type of institution, and state: 1995 and 1996

197. Total fall enrollment in institutions of higher education, by level of enrollment and state: 1994 to 1996

198. Total fall enrollment in institutions of higher education, by control, level of enrollment, and state: 1996

199. Total fall enrollment in institutions of higher education, by control, level of enrollment, and state: 1995

200. Full-time-equivalent fall enrollment in institutions of higher education and degreegranting institutions, by control and type of institution: 1969 to 1996

201. Full-time-equivalent fall enrollment in institutions of higher education, by control, type of institution, and state: 1994 to 1996

202. Full-time-equivalent fall enrollment in institutions of higher education, by control and state: 1980 to 1996

203. Residence and migration of all freshmen students in degree-granting institutions, by state: Fall 1996

204. Residence and migration of all freshmen students in degree-granting institutions graduating from high school in the past 12 months, by state: Fall 1996

205. Residence and migration of all freshmen students in 4-year colleges graduating from high school in the past 12 months, by state: Fall 1996

206. Total fall enrollment in institutions of higher education and degree-granting institutions, by type and control of institution and race/ethnicity of student: 1976 to 1996

207. Total fall enrollment in institutions of higher education and degree-granting institutions, by level of study, sex, and race/ethnicity of student: 1976 to 1996

208. Total fall enrollment in institutions of higher education and degree-granting institutions, by level, attendance status, sex, and race/ethnicity of student: 1995 and 1996 
209. Total number of institutions and fall enrollment in institutions of higher education and degree-granting institutions, by percentage minority enrollment: 1996

210. Total fall enrollment in institutions of higher education, by race/ethnicity of student and by state: 1992 to 1996

211. Number and percent of students enrolled in postsecondary institutions, by disability status and selected student characteristics: 1995-96

212. Enrollment of persons 14 to 34 years of age in institutions of higher education, by race/ethnicity, sex, and year of college: October 1965 to October 1997

213. Enrollment in postsecondary education, by major field of study, age, and level of student: 1995-96

214. Graduate enrollment in science and engineering programs in institutions of higher education, by field of study: United States and outlying areas,

fall 1985 to fall 1996

215. Degree-granting 2-year and 4-year institutions, by type, control, and size of enrollment: Fall 1996

216. Selected statistics for college and university campuses enrolling more than 14,600 students in 1996

217. Enrollment of the 120 largest college and university campuses: Fall 1996

218. Selected statistics on historically black colleges and universities: 1980, 1990, and 1996

219. Fall enrollment, degrees conferred, and expenditures in historically black colleges and universities, by institution: 1996

220. Fall enrollment in historically black colleges and universities, by type and control of institution: 1976 to 1996

Staff

221. Employees in institutions of higher education, by primary occupation, employment status, and control of institution: Fall 1976, fall 1991, and fall 1995

222. Employees in institutions of higher education, by race/ethnicity, primary occupation, employment status and type and control of institution: Fall 1995

223. Employees in institutions of higher education, by primary occupation, sex, employment status, and by type and control of institution: Fall 1995

224. Staff and student/staff ratios in institutions of higher education, by type and control of institution and by state: Fall 1995

Faculty

225. Full-time and part-time senior instructional faculty in institutions of higher education, by employment status, control, and type of institution: Fall 1970 to fall 1995

226. Full-time instructional faculty in institutions of higher education, by race/ethnicity, academic rank, and sex: Fall 1995

227. Full-time instructional faculty and staff in institutions of higher education, by instruction activities and type and control of institution: Fall 1992

228. Part-time instructional faculty and staff in institutions of higher education, by instruction activities and type and control of institution: Fall 1992 
229. Percentage distribution of full-time and part-time instructional faculty and staff in institutions of higher education, by program area, race/ethnicity, and sex:

Fall 1992

230. Full-time and part-time instructional faculty and staff in institutions of higher education, by selected characteristics and type and control of institution:

Fall 1992

231. Full-time and part-time instructional faculty and staff in institutions of higher education, by type and control, academic rank, age, salary, race/ethnicity, and sex: Fall 1992

232. Full-time and part-time instructional faculty and staff in institutions of higher education, by faculty characteristics and field: Fall 1992

233. Average base salaries of full-time instructional faculty and staff in institutions of higher education, by type and control of institution and by field of instruction: 1987-88 and 1992-93

234. Average salary of full-time instructional faculty on 9-month contracts in institutions of higher education, by academic rank, sex, and by type and control of institution: 1980-81, 1990-91, 1995-96, and 1996-97

235. Average salary of full-time instructional faculty on 9-month contracts in institutions of higher education, by academic rank, sex, and control and type of institution: $1970-71$ to $1996-97$

236. Average salary of full-time instructional faculty on 9-month contracts in degreegranting institutions, by type and control of institution and by state: 1996-97

237. Average salary of full-time instructional faculty on 9-month contracts in institutions of higher education, by type and control of institution and by state: 1995-96

238. Average salary of full-time instructional faculty on 9-month contracts in 4-year degree-granting institutions, by type and control of institution and rank of faculty and by state: $1996-97$

239. Average salary of full-time instructional faculty on 9-month contracts in 4-year institutions of higher education, by type and control of institution and rank of faculty and by state: 1995-96

240. Full-time instructional faculty with tenure for institutions reporting tenure status, by academic rank, sex, and type and control of institution: 1980-81, 1990-91, 1995-96, and 1996-97

Institutions

241. Institutions of higher education, by control and type of institution: 1949-50 to 1995-96

242. Degree-granting institutions of higher education and branches, by type, control of institution, and state: 1996-97

243. Institutions of higher education that have closed their doors, by control and type of institution: $1960-61$ to $1996-97$

\section{Degrees}

244. Earned degrees conferred by institutions of higher education, by level of degree and sex of student: $1869-70$ to $2007-08$

245. Degrees awarded by institutions of higher education, by control, level of degree, and state: $1995-96$ 
246. Earned degrees conferred by institutions of higher education, by level of degree and by state: 1994-95 and 1995-96

247. Associate degrees conferred by institutions of higher education, by sex of student and field of study: 1989-90 to 1993-94

248. Associate degrees and other subbaccalaureate awards conferred by institutions of higher education, by length of curriculum, sex of student, and field of study: 1995-96

249. Associate degrees and other subbaccalaureate awards conferred by institutions of higher education, by length of curriculum, sex of student, and field of study: 1994-95

250. Bachelor's degrees conferred by institutions of higher education, by discipline division: $1970-71$ to $1995-96$

251. Master's degrees conferred by institutions of higher education, by discipline division: $1970-71$ to $1995-96$

252. Doctor's degrees conferred by institutions of higher education, by discipline division: 1970-71 to 1995-96

253. Bachelor's, master's, and doctor's degrees conferred by institutions of higher education, by sex of student and field of study: 1995-96

254. Degrees conferred by institutions of higher education, by control of institution: 1969-70 to 1995-96

255. Degrees conferred by institutions of higher education, by control of institution, level of degree, and discipline division: 1995-96

256. Degrees conferred by institutions of higher education, by control of institution, level of degree, and discipline division: 1994-95

257. Number of institutions of higher education conferring degrees, by level of degree and discipline division: 1995-96

258. Number of institutions of higher education conferring degrees, by level of degree and discipline division: 1994-95

259. First-professional degrees conferred by institutions of higher education in dentistry, medicine, and law, by sex, and number of institutions conferring degrees: $1949-50$ to $1995-96$

260. First-professional degrees conferred by institutions of higher education, by sex of student, control of institution, and field of study: 1984-85 to 1995-96

261. Associate degrees conferred by institutions of higher education, by racial/ethnic group and sex of student: 1976-77 to 1995-96

262. Associate degrees conferred by institutions of higher education, by racial/ethnic group, major field of study, and sex of student: 1995-96

263. Associate degrees conferred by institutions of higher education, by racial/ethnic group, major field of study, and sex of student: 1994-95

264. Bachelor's degrees conferred by institutions of higher education, by racial/ethnic group and sex of student: 1976-77 to 1995-96

265. Bachelor's degrees conferred by institutions of higher education, by racial/ethnic group, major field of study, and sex of student: 1995-96 
266. Bachelor's degrees conferred by institutions of higher education, by racial/ethnic group, major field of study, and sex of student: 1994-95

267. Master's degrees conferred by institutions of higher education, by racial/ethnic group and sex of student: $1976-77$ to $1995-96$

268. Master's degrees conferred by institutions of higher education, by racial/ethnic group, major field of study, and sex of student: 1995-96

269. Master's degrees conferred by institutions of higher education, by racial/ethnic group, major field of study, and sex of student: 1994-95

270. Doctor's degrees conferred by institutions of higher education, by racial/ethnic group and sex of student: $1976-77$ to $1995-96$

271. Doctor's degrees conferred by institutions of higher education, by racial/ethnic group, major field of study, and sex of student: 1995-96

272. Doctor's degrees conferred by institutions of higher education, by racial/ethnic group, major field of study, and sex of student: 1994-95

273. First-professional degrees conferred by institutions of higher education, by racial/ethnic group and sex of student: 1976-77 to 1995-96

274. First-professional degrees conferred by institutions of higher education, by racial/ethnic group, major field of study, and sex of student: 1995-96

275. First-professional degrees conferred by institutions of higher education, by racial/ethnic group, major field of study, and sex of student: 1994-95

276. Earned degrees in agriculture and natural resources conferred by institutions of higher education, by level of degree and sex of student: 1970-71 to 1995-96

277. Earned degrees in architecture and related programs conferred by institutions of higher education, by level of degree and sex of student: 1949-50 to 1995-96 ........

278. Earned degrees in the biological/life sciences conferred by institutions of higher education, by level of degree and sex of student: 1951-52 to 1995-96

279. Earned degrees in biology, microbiology, and zoology conferred by institutions of higher education, by level of degree: $1970-71$ to 1995-96

280. Earned degrees in business conferred by institutions of higher education, by level of degree and sex of student: $1955-56$ to 1995-96

281. Earned degrees in communications conferred by institutions of higher education, by level of degree and sex of student: 1970-71 to 1995-96

282. Earned degrees in computer and information sciences conferred by institutions of higher education, by level of degree and sex of student: 1970-71 to 1995-96

283. Earned degrees in education conferred by institutions of higher education, by level of degree and sex of student: $1949-50$ to 1995-96

284. Earned degrees in engineering conferred by institutions of higher education, by level of degree and sex of student: $1949-50$ to $1995-96$

285. Earned degrees in chemical, civil, electrical, and mechanical engineering conferred by institutions of higher education, by level of degree: 1970-71 to 1995-96

286. Earned degrees in English language and literature/letters conferred by institutions of higher education, by level of degree and sex of student: 1949-50 to 1995-96 
287. Earned degrees in modern foreign languages and literatures conferred by institutions of higher education, by level of degree and sex of student: $1949-50$ to $1995-96$

288. Earned degrees in French, German, and Spanish conferred by institutions of higher education, by level of degree: $1949-50$ to $1995-96$

289. Earned degrees in the health professions and related sciences conferred by institutions of higher education, by level of degree and sex of student: $1970-71$ to $1995-96$

290. Earned degrees in mathematics conferred by institutions of higher education, by level of degree and sex of student: 1949-50 to 1995-96

291. Earned degrees in the physical sciences conferred by institutions of higher education, by level of degree and sex of student: 1959-60 to 1995-96

292. Earned degrees in chemistry, geology, and physics conferred by institutions of higher education, by level of degree: $1970-71$ to $1995-96$

293. Earned degrees in psychology conferred by institutions of higher education, by level of degree and by sex of student: 1949-50 to 1995-96

294. Earned degrees in public administration and services conferred by institutions of higher education, by level of degree and sex of student: 1970-71 to 1995-96 ...

295. Earned degrees in the social sciences and history conferred by institutions of higher education, by level of degree and sex of student: 1970-71 to 1995-96

296. Earned degrees in economics, history, political science and government, and sociology conferred by institutions of higher education, by level of degree: $1949-50$ to $1995-96$

297. Earned degrees in visual and performing arts conferred by institutions of higher education, by level of degree and sex of student: 1970-71 to 1995-96

298. Statistical profile of persons receiving doctor's degrees, by field of study: 1995-96 ...

299. Statistical profile of persons receiving doctor's degrees in education: $1979-80$ to $1995-96$

300. Statistical profile of persons receiving doctor's degrees in engineering: $1979-80$ to $1995-96$

301. Statistical profile of persons receiving doctor's degrees in the humanities: 1979-80 to $1995-96$

302. Statistical profile of persons receiving doctor's degrees in the life sciences: 1979-80 to 1995-96

303. Statistical profile of persons receiving doctor's degrees in the physical sciences: 1979-80 to 1995-96

304. Statistical profile of persons receiving doctor's degrees in the social sciences: 1979-80 to $1995-96$

305. Doctor's degrees conferred by 60 large institutions of higher education: $1986-87$ to $1995-96$

\section{Outcomes}

306. Percentage distribution of 1980 high school sophomores, by highest level of education completed through 1992, by selected student characteristics: 1980 to 1992 
307. Mean number of semester credits completed by bachelor's degree recipients, by major and course area: 1976, 1984, and 1992-93

308. Colleges and universities offering remedial services, by type and control of institution: $1987-88$ to $1996-97$

309. Percent distribution of enrollment and completion status of first-time postsecondary students starting during the 1989-90 academic year, by type of institution and other student characteristics: 1994

310. Scores on Graduate Record Examination (GRE) and subject matter tests: 1965 to 1997

\section{Student Charges and Student Financial Assistance}

311. Average undergraduate tuition and fees and room and board rates paid by full-time-equivalent students in institutions of higher education, by type and control of institution: 1964-65 to 1997-98

312. Average undergraduate tuition and fees and room and board rates paid by full-time-equivalent students in institutions of higher education, by control of institution and by state: 1996-97 and 1997-98

313. Average graduate and first-professional tuition in institutions of higher education: 1987-88 to $1997-98$

314. Percent of undergraduates receiving financial aid, by type and source of aid and selected student characteristics: 1995-96

315. Average amount of financial aid awarded in 1995-96 per student, by type and source of aid and selected characteristics

316. Undergraduates enrolled full time and part time, by aid status and source of aid during 1995-96, and control and level of institution

317. Percent of undergraduates receiving aid, by type and source of aid received, and by control and level of institution: 1992-93 and 1995-96

318. Undergraduates enrolled full time and part time, by federal aid program and by control and level of institution: 1995-96

319. Postbaccalaureate students enrolled full time and part time, by aid status, source of aid, and by level of study and control and level of institution:

1992-93 and 1995-96

320. Postbaccalaureate students enrolled full time and part time, by type of aid and by level of study, control, and level of institution: 1992-93 and 1995-96

321. Scholarship and fellowship awards of institutions of higher education and degreegranting institutions, by control of institution: 1959-60 to 1995-96

322. Pell Grant revenue of institutions of higher education and degree-granting institutions compared to current-fund revenue and tuition, by type and control of institution: 1985-86 to 1995-96

323. State awards for need-based undergraduate scholarship and grant programs, by state: $1983-84$ to $1995-96$

Income

324. Current-fund revenue of institutions of higher education, by source: 
325. Current-fund revenue of public institutions of higher education, by source: 1980-81 to $1995-96$

326. Current-fund revenue of private institutions of higher education, by source: 1980-81 to 1995-96

327. Current-fund revenue of private nonprofit institutions of higher education, by source: $1980-81$ to $1995-96$

328. Current-fund revenue of institutions of higher education and degree-granting institutions, by source of funds: 1919-20 to 1995-96

329. Revenue of degree-granting institutions, by source of funds, and by control and type of institution: 1995-96

330. Current-fund revenue of public institutions of higher education and degreegranting institutions, by state: $1980-81$ to $1995-96$

331. Current-fund revenue of public degree-granting institutions, by source of funds and state: $1995-96$

332. Current-fund revenue of public institutions of higher education, by source of funds and state: 1994-95

333. Current-fund revenue from state and local governments of institutions of higher education and degree-granting institutions, by state: 1985-86 to 1995-96

334. Current-fund revenue received from the federal government by the 120 institutions of higher education receiving the largest amounts: 1995-96

\section{Expenditures}

335. Current-fund expenditures and expenditures per full-time-equivalent student in institutions of higher education, by type and control of institution:

1970-71 to $1995-96$

336. Current-fund expenditures and educational and general expenditures of institutions of higher education and degree-granting institutions, by purpose and per student: 1929-30 to 1995-96

337. Expenditures of and degree-granting institutions, by purpose and by control and type of institution: 1995-96

338. Current-fund expenditures of institutions of higher education, by purpose: $1980-81$ to $1995-96$

339. Current-fund expenditures of public institutions of higher education, by purpose: $1980-81$ to $1995-96$

340. Current-fund expenditures of private institutions of higher education, by purpose: 1980-81 to $1995-96$

341. Voluntary support for institutions of higher education, by source and purpose of support: 1959-60 to 1995-96

342. Educational and general expenditures of public universities, by purpose: $1976-77$ to $1995-96$

343. Educational and general expenditures of public 4-year colleges, by purpose: 1976-77 to $1995-96$

344. Educational and general expenditures of public 2-year colleges, by purpose: 1976-77 to 1995-96 
345. Educational and general expenditures of private (nonprofit) universities, by purpose: 1976-77 to $1995-96$

346. Educational and general expenditures of private (nonprofit) 4-year colleges, by purpose: $1976-77$ to $1995-96$

347. Current-fund expenditures of public institutions of higher education and degreegranting institutions, by state: $1980-81$ to $1995-96$

348. Educational and general expenditures of public institutions of higher education and degree-granting institutions, by state: $1980-81$ to $1995-96$

349. Current-fund expenditures and educational and general expenditures of private institutions of higher education and degree-granting institutions, by state:

1985-86 to 1995-96

350. Current-fund expenditures and educational and general expenditures of private nonprofit institutions of higher education, by state: 1985-86 to 1995-96

351. Current-fund expenditures per full-time-equivalent student in institutions of higher education, by control and type of institution and purpose of expenditure: 1995-96

\section{Property}

352. Additions to physical plant value of institutions of higher education, by type of addition and control of institution: 1969-70 to 1995-96

353. Value of property and liabilities of institutions of higher education: 1899-1900 to 1995-96

354. Endowment funds of the 120 institutions of higher education with the largest amounts: Fiscal year 1996

\section{3-B. Postsecondary Education: Vocational and Adult Education}

\section{Adult Education}

355. Participation of employed persons, 17 years old and over, in adult education during the previous 12 months, by selected characteristics of participants: 1995

356. Participation in adult education during the previous 12 months by adults 17 years old and older, by selected characteristics of participants: 1991 and 1995

357. Participants in adult basic and secondary education programs, by level of enrollment and state: Fiscal years 1980, 1990, and 1995

\section{Vocational Education}

358. Number of noncollegiate institutions offering postsecondary education, by control and state: 1993-94, 1994-95, and 1995-96

\section{Federal Programs for Education and Related Activities}

359. Federal support and estimated federal tax expenditures for education, by category: Fiscal years 1965 to 1998

360. Federal on-budget funds for education, by agency: Fiscal years 1965 to 1998

361. Federal on-budget funds for education, by level or other educational purpose, by agency and program: Fiscal years 1965 to 1998

362. Estimated federal support for education, by agency and type of ultimate recipient: Fiscal year 1998 
363. Federal on-budget funds obligated for programs administered by the

U.S. Department of Education: Fiscal years 1980 to 1998

364. U.S. Department of Education outlays, by level of education and type of recipient: Fiscal years 1980 to 1998

365. U.S. Department of Education obligations for major programs, by state or other area: Fiscal year 1997

366. U.S. Department of Education obligations for major programs, by state or other area: Fiscal year 1996

367. Appropriations for Title I and Title VI, Elementary and Secondary Education Act (ESEA) of 1994, by state or other area: 1996-97 and 1997-98

368. Federal science and engineering obligations to colleges and universities, by agency and state: Fiscal year 1996

369. Summary of federal funds for research, development, and R\&D plant: Fiscal years 1990 to 1998

370. Federal obligations to colleges and universities for research and development, by field: United States and outlying areas, 1980 to 1995

371. U.S. Department of Agriculture obligations for child nutrition programs, by state or other area: Fiscal years 1996 and 1997

372. U.S. Department of Health and Human Services allocations for Head Start and enrollment in Head Start, by state or other area: Fiscal years 1994 to 1997

373. Public school students receiving federally funded free or reduced price lunches, by selected school characteristics: School year 1993-94

374. Public and private school students receiving federally funded Chapter I services, by selected school characteristics: School year 1993-94

\section{Outcomes of Education}

\section{Educational Characteristics of the Workforce}

375. Percent of 18- to 25-year-olds reporting drug use during the past 30 days and the past year: 1982 to 1996

376. Percent of 1972, 1982, and 1992 high school seniors who felt that certain life values were "very important," by sex: 1972 to 1994

377. Labor force participation of persons 16 years old and over, by age, sex, race/ethnicity, and highest level of education: 1997

378. Occupation of employed persons 25 years old and over, by educational attainment and sex: 1997

379. Unemployment rate of persons 16 years old and over, by age, sex, race/ethnicity, and highest degree attained: 1995, 1996, and 1997

380. Median annual income of year-round full-time workers 25 years old and over, by level of education completed and sex: 1989 to 1997

381. Total annual money income and median income of persons 25 years old and over, by educational attainment and sex: 1996

382. College enrollment and labor force status of 1996 and 1997 high school graduates, by sex and race/ethnicity: October 1996 and October 1997 


\section{Recent High School and College Graduates}

383. Labor force status of 1979-80 to 1996-97 high school dropouts, by sex and race/ ethnicity: October 1980 to October 1997

384. Employment of 12th-graders, by selected student characteristics: 1992

385. Full-time employment status of bachelor's degree recipients 1 year after graduation, by field of study: 1976 to 1991

386. Employment status of 1992-93 bachelor's degree recipients 1 year after graduation, by field of study and occupational area: 1994

387. Percentage of 1992-93 bachelor's degree recipients pursuing further education within one year after graduation, by type of enrollment and undergraduate major: April 1994

388. Average annual salary of bachelor's degree recipients employed full time 1 year after graduation, by field of study: 1976 to 1994

389. Participation of young adults in voluntary or community service activities, by selected characteristics: 1992 to 1994

390. Literacy skills of adults, 16 years old and over, by selected characteristics: 1992

\section{International Comparisons of Education}

391. School-age populations as a percent of total population: Selected countries, 1985, 1990, and 1995

392. Percent of population enrolled in secondary and postsecondary institutions, by age group: Selected countries, 1985, 1990, and 1995

393. Estimated population, school enrollment, teachers, and public expenditures for education in major areas of the world: 1980, 1990, 1994, and 1995

394. Selected statistics for countries with populations over 10 million, by continent: 1980, 1990, and 1995

395. Pupils per teacher in public and private elementary and secondary schools, by level of education: Selected countries, 1985 to 1995

396. Geography proficiency of 13-year-olds in educational systems participating in the International Assessment of Educational Progress: 1991

397. Average 8th-grade mathematics scores by content areas, and average time spent studying out of school, by country: 1994-95

398. Instructional practices and time spent teaching mathematics in 8th-grade, by country: 1994-95

399. Average 8th-grade science scores by content areas, and average time spent studying out of school, by country: 1994-95

400. Instructional practices and time spent teaching science in 8th-grade, by country: 1994-95

401. Average size of 8th-grade mathematics classes, and frequency teachers assign mathematics homework, by country: 1994-95

402. Eighth-grade students' perceptions about mathematics achievement and hours spent on leisure activities, by country: 1994-95 
403. Average 4th-grade mathematics scores, by content areas, and average time spent studying mathematics out of school, by country: 1994-95

404. Average 4th-grade science scores, by content areas, and average time spent teaching science in school, by country: 1994-95

405. Average 12th-grade mathematics scores, by sex, and average time spent studying mathematics out of school, by country: 1994-95

406. Average 12th-grade science scores, by sex, and average time spent studying science out of school, by country: 1994-95

407. Reading literacy test scores of 9-year-olds: Selected countries, 1992

408. Reading literacy test scores of 14-year-olds: Selected countries, 1992

409. Number of bachelor's degree recipients per 100 persons of the theoretical age of graduation, by sex: Selected countries, 1989 to 1995

410. Percent of bachelor's degrees awarded in science:

Selected countries, 1985 to 1995

411. Percent of graduate degrees awarded in science: Selected countries, 1985, 1990, and 1991

412. Public education expenditures per student, by level of student: Selected countries, 1985 to 1993

413. Total public direct expenditures for education as a percentage of gross domestic product, by level of education: Selected countries, 1985 to 1994

414. Foreign students enrolled in institutions of higher education in the United States and outlying areas, by continent, region, and selected countries of origin: $1980-81$ to $1996-97$

\section{Learning Resources and Technology}

\section{Libraries}

415. Percentage of school library/media centers that offered selected services and equipment, and library/media center expenditures, by control and level of school: 1993-94

416. Selected statistics on of public school library/media centers, by level and enrollment size of school: 1993-94

417. Selected statistics on public school library/media centers, by state: 1993-94

418. Percent of public and private schools having access to selected telecommunication capabilities, by location of access site and level of school: 1995

419. Percent of public schools and school classrooms having access to the Internet, by school charecteristics: 1994 to 1998

420. General statistics of college and university libraries: $1974-75$ to $1994-95$

421. Selected statistics on the collections, staff, and operating expenditures of 60 large college and university libraries: 1994

422. General statistics of public libraries, by population of legal service area: 1995

423. Public libraries, books and serial volumes, library visits, and reference transactions, by state: 1995 


\section{Computers and Technology}

424. Percent of workers, 18 years old and over, using computers on the job, by selected characteristics and computer activities:

October 1993 and October 1997

425. Access to and use of home computers, by selected characteristics of students and other users: October 1997

426. Percent of home computer users using specific applications, by selected characteristics: October 1997

427. Percent of student home computer users using specific applications, by selected characteristics: October 1997

428. Student use of computers, by level of instruction and selected characteristics: 1984 to 1997

\section{Guide to Sources}

\section{Appendix Tables}

A1. Respondent counts for selected High School and Beyond surveys

A2. Design effects (DEFF) and root design effects (DEFT) for selected High School and Beyond surveys and subsamples

A3. Respondent counts for the National Educational Longitudinal Study: 1988, 1990, and 1992

A4. Design effects (DEFF) and root design effects (DEFT) for selected National Educational Longitudinal Survey samples

A5. Respondent counts of full-time workers from the Recent College Graduate survey: 1976 to 1991

A6. Estimated standard errors for enrollment rates in the October Current Population Survey: 1996 or 1997

A7. Estimated education attainment rates and standard errors in the March Current Population Survey

A8. Standard errors for the proportion of seniors who had used drugs in the previous 12 months: 1975 to 1995

A9. Sampling errors (95 percent confidence level) for percentages estimated from the Gallup Poll: 1992 and 1993

A10. Sampling errors (95 percent confidence level) for the difference in 2 percentages estimated from the Gallup Poll: 1992 and 1993

A11. Maximum differences required for significance (90 percent confidence level) between sample subgroups of the "Status of the American Public School Teacher" survey 


\section{INTRODUCTION}

In the fall of 1998, about 67.3 million persons were enrolled in American schools and colleges (table 1). About 3.8 million were employed as elementary and secondary school teachers and as college faculty. Other professional, administrative, and support staff of educational institutions numbered 4.2 million. Thus about 75 million people were involved, directly or indirectly, in providing or receiving formal education. In a nation with a population of about 270 million, more than 1 out of every 4 persons participated in formal education.

\section{Elementary/Secondary Enrollment}

Since the enrollment rates of kindergarten and elementary school age children have not changed much in recent years, increases in elementary school enrollment have been driven primarily by increases in the number of young people. Enrollment in public elementary and secondary schools rose 19 percent between 1985 and 1998. The fastest growth occurred in the elementary grades, where enrollment rose 24 percent over the same period, from 27.0 million to a record high of 33.5 million in 1998 (table 2). Secondary enrollments declined 8 percent from 1985 to 1990 , but then rose by 17 percent from 1990 to 1998, for a net increase of 7 percent. Private school enrollment grew more slowly than public school enrollment over this period, rising 7 percent, from 5.6 million in 1985 to 5.9 million in 1998. As a result, the percentage of students enrolled in private schools declined slightly from 12 percent in 1985 to 11 percent in 1998. The National Center for Education Statistics (NCES) forecasts record levels of enrollment during the late 1990s. The fall 1998 public school enrollment marks a new record and new records are expected every year through the early 2000s (table 3). Public elementary enrollment is projected to grow slowly over the next few years and then decline slightly, so that the fall 2008 projection is almost the same as the 1998 enrollment. In contrast, public secondary school enrollment is expected to have a substantial increase of 11 percent between 1998 and 2008.

\section{Higher Education}

College enrollment hit a record level of 14.5 million in fall 1992 and was expected to reach a new high in 1998, after falling slightly between 1993 and 1995 (table 3). Despite decreases in the traditional collegeage population during the 1980s and early 1990s, total enrollment has increased because of the high enrollment rate of older women and a rising rate of college attendance for recent high school graduates (tables 183 and 184). Since 1980, the number of part-time students has generally increased at a faster rate than full-time students (table 172).

\section{Teachers}

An estimated 3.1 million elementary and secondary school teachers were engaged in classroom instruction in the fall of 1998 (table 4). This number has risen in recent years, up about 17 percent since 1988. The number of public school teachers in 1998 was about 2.7 million and the number in private schools was about 0.4 million. About 1.9 million teachers taught in elementary schools, while about 1.2 million were teaching at the secondary level (table 4).

The number of public school teachers has risen at about the same rate as the number of students over the past 10 years, resulting in very small changes in the pupil/teacher ratio. In the fall of 1998, there were 17.2 public school pupils per teacher compared with 17.3 public school pupils per teacher 10 years earlier. During the same time period, the pupil/teacher ratio in private schools fell from 15.2 to 14.9 (table 65). Despite the historical trend towards lower pupil/ teacher ratios, the fluctuations since 1990 suggest stability in the pupil/teacher ratio.

The salaries of public school teachers, which lost purchasing power to inflation during the 1970 s, rose faster than the inflation rate in the 1980s. The rising salaries reflected an interest by state and local education agencies in boosting teacher salary schedules and, to some extent, an increase in teachers' experience and education levels (tables 70 and 78). Since 1990-91, salaries for teachers have fallen slightly after adjusting for inflation. The average salary for teachers in 1997-98 was $\$ 39,385$.

\section{Public Perception}

Public perception about problems facing the local public schools has shifted in the past several years. Between 1985 and 1990, an increasing proportion of people believed that drug use was a major problem facing schools. Then, the proportion of people who 
felt drug use was a major problem facing schools fell, from 38 percent in 1990 to 10 percent in 1998. In the latest survey, lack of discipline was cited by 14 percent of the population; fighting, gangs, and violence was cited by 15 percent; and the lack of financial support was cited as a major problem by 12 percent of the population (table 23).

\section{Faculty and Staff}

During the fall of 1995 , there were 932,000 faculty members in higher education institutions. Making up this figure were 551,000 full-time, and 381,000 parttime faculty (table 223). In 1992, full-time instructors generally taught more hours and more students than part-time instructors, with 61 percent of full-time instructors teaching 8 or more hours per week and two-thirds teaching 50 or more students. About 30 percent of part-time instructors taught 8 or more hours per week and 30 percent taught 50 or more students (tables 227 and 228).

White males constituted a disproportionate share of full-time college faculty in 1995. Overall, about 57 percent of full-time faculty are white males. However, this distribution varies substantially by rank of faculty. Among full professors, the proportion of white males is 75 percent. The proportion is somewhat lower among the lower ranked faculty, with white males making up 39 percent of the lecturers (table 230).

\section{Student Performance}

\section{Reading}

Overall, the reading achievement scores for the country's 9-, 13-, and 17-year-old students are mixed. Reading performance scores for 9- and 13year-olds were somewhat higher in 1996 than they were in 1971. However, there has been little change since the mid-1980s. The reading performance of 17year-olds was about the same in 1996 as it was in 1971. Black 13- and 17-year-olds exhibited higher reading performance in 1996 than in 1971. Black 9year-olds' performance improved significantly between 1971 and 1980, but it has not improved further. The performance levels of white 9- and 13-yearolds also rose between 1971 and 1996. Separate data for Hispanics were not gathered in 1971, but changes between 1975 and 1996 indicate an increase among 9-year-olds. There was no significant difference between the 1975 and 1996 reading performance of 13- and 17-year-old Hispanics (table 109).

\section{Mathematics}

Results from assessments of mathematics proficiency indicate that 9- and 13-year-old students improved their performance between 1973 and 1996. However, there has been very little change for 9- year-olds since 1990, and the performance of older students on advanced mathematical operations has been stable. The proportion of 17-year-olds who demonstrated skill with moderately complex procedures and reasoning rose from 52 percent in 1978 to 60 percent in 1996. During the same time period, the proportion of 17-year-olds with skill in multistep problem solving and algebra remain unchanged (tables 120 and 121).

White, black, and Hispanic students improved their mathematics performance between 1973 and 1996, among all three age groups. Mathematics scores for white, black, and Hispanic 9-, 13-, and 17-year-olds improved between 1986 and 1996 (table 120).

A 1996 voluntary assessment of the states found that mathematics proficiency varied widely among eighth-graders in the 42 jurisdictions (40 states, Guam, and the District of Columbia) that participated in the program (table 122). Overall, 62 percent of eighth-grade students performed at or above the basic level in mathematics. Only four states, the District of Columbia, and Guam had fewer than 50 percent of students performing at least at the basic level in math. Ten states had 70 percent or more of their students performing at or above the basic level.

\section{Science}

Long-term changes in science performance have been mixed, though changes over the past 10 years have been generally positive. In 1996, science performance among 17-year-olds was lower than in 1970 , but higher than in 1986 . The science performance level of 13-year-olds was higher in 1996 than in 1986, recouping the earlier declines. The science performance of 9-year-olds increased between 1986 and 1996, after showing no significant change between 1970 and 1986 (table 128).

The science performance of white 9- and 13-yearolds was about the same in 1996 as it was in 1970, and the performance of 17-year-olds was lower in 1996. However, the performance at each of the three age groups was higher in 1996 than in 1986. Black and Hispanic 9- and 13-year-olds had higher science performance in 1996 than in the 1970s. Black 17year-olds showed a decline through 1982 and an increase by 1996. Despite significant gains by younger black and Hispanic students, their average performance remains lower than for white students. Although the performance gap between black and white students has narrowed, the science performance for black 13-year-olds was slightly lower than the average for white 9-year-olds in 1996 (table 128).

\section{International Comparisons}

The results of a 1995 international assessment in math and science show that U.S. 4th- and 8th-graders compare more favorably with other countries in 
science than in mathematics. In mathematics, U.S. 8th-graders scored below the international average, falling below 20 of the 41 countries tested. Fourthgraders performed above the international average of 26 countries tested, scoring below seven countries, including Singapore, Korea, and Japan. Students at both the fourth- and eighth-grade levels scored above the international average in science. Eighthgrade students in the United States were outperformed by 4 out of 41 countries. Fourth-grade students once again compared more favorably with their international counterparts than 8th-grade students. Only one country outperformed the U.S. students in science out of 26 countries who participated in the fourth-grade assessment (tables 397, 399, 403, and 404).

The international standing of U.S. students was stronger at the 8th-grade than at the 12th-grade in both mathematics and science among the countries that participated in the assessments at both grade levels. U.S. 12th-graders performed below the international average and among the lowest of the 21 countries on the assessment of mathematics general knowledge. U.S. students were outperformed by those in 14 countries, and outperformed those in 2 countries. U.S. 12th-graders also performed below the international average and among the lowest scoring of the 21 countries on the assessment of science general knowledge. U.S. students were outperformed by students in 11 countries, and they outperformed students in 2 countries. Our students' scores were not significantly different from those of seven countries, including France, Germany, Italy and the Russian Federation (Pursuing Excellence, 12th grade, pages 17 and 18) (tables 405 and 406).

\section{Graduates and Degrees}

The number of high school graduates in 1997-98 totaled about 2.7 million. Approximately 2.4 million graduated from public schools and less than 0.3 million graduated from private schools. The number of high school graduates has declined from its peak in 1976-77 when 3.2 million people earned their diplomas. The dropout rate declined over this period, from 14 percent of all 16- to 24-year-olds in 1977 to 11 percent in 1997 (tables 101 and 105). The number of degrees conferred by institutions of higher education during the 1997-98 school year by degree level has been projected: 520,000 associate degrees; $1,172,000$ bachelor's degrees; 406,000 master's degrees; 78,400 first-professional degrees; and 45,200 doctor's degrees (table 244). The Bureau of the Census has collected annual statistics on the educational attainment of the population in terms of years of school completed. Between 1980 and 1997, the proportion of the adult population 25 years of age and over with 4 years of high school or more rose from 69 percent to 82 percent, and the proportion of adults with at least 4 years of college increased from 17 percent to 24 percent. In contrast, the proportion of young adults (25- to 29-year-olds) completing high school showed a small increase of about 2 percentage points (table 8).

\section{Expenditures}

Expenditures for public and private education, from preprimary through graduate school, are estimated at \$584 billion for 1997-98. The expenditures of elementary and secondary schools are expected to total about $\$ 351$ billion for 1997-98, while those for institutions of higher education will be about $\$ 233$ billion. Viewed in another context, the total expenditures for education are expected to amount to about 7.2 percent of the gross domestic product in 1997-98, about the same percentage as in the recent past (table 31).

\section{Summary}

The statistical highlights in this section of the report provide a quantitative description of the current American education scene. Clearly, from the large number of participants, the number of years that people spend in school, and the large sums expended by educational institutions, it is evident that the American people have a high regard for education. Assessment data indicate that there have been improvements in mathematics and science performance between 1986 and 1996. A high proportion of high school graduates are going on to college. Yet, wide variations in student proficiency from state to state and mediocre mathematics scores of American students in international assessments pose challenges.

NOTE: Readers should be aware of the limitations of statistics. These limitations vary with the exact nature of a particular survey. For example, estimates based on a sample of institutions will differ somewhat from the figures that would have been obtained if a complete census had been taken using the same survey procedures. Although some of the surveys conducted by the National Center for Education Statistics are census-type surveys, all surveys are subject to design, reporting, and processing errors and errors due to nonresponse. More information on survey methodologies can be found in the "Guide to Sources" in the appendix. Price indexes for inflation adjustments can be found in table 38. 



\section{CHAPTER 1}

\section{All Levels of Education}

This chapter provides a broad overview of education in the United States. It brings together material from preprimary, elementary, secondary, and postsecondary education and from the general population to present a composite picture of the American educational system. Tables illustrate the total number of persons enrolled in school, the number of teachers, the number of schools, and total expenditures for education at all levels. This chapter also includes statistics on education-related topics such as educational attainment, family characteristics, population, and opinions about schools. Economic indicators and price indexes have been added to assist researchers in preparing comparative analyses.

Figure 1 shows the structure of education in the United States. It presents the three levels of education (elementary, secondary, and postsecondary) and gives the approximate age range of persons at each level. Pupils ordinarily spend from 6 to 8 years in the elementary grades, which may be preceded by 1 or 2 years in nursery school and kindergarten. The elementary school program is followed by a 4- to 6year program in secondary school. Pupils normally complete the entire program through grade 12 by age 17 or 18 .

High school graduates who decide to continue their education may enter a technical or vocational institution, a 2-year college, or a 4-year college or university. A 2-year college normally offers the first 2 years of a standard 4-year college curriculum and a selection of terminal vocational programs. Academic courses completed at a 2-year college are usually transferable for credit at a 4-year college or university. A technical or vocational institution offers postsecondary technical training leading to a specific career.

An associate degree requires at least 2 years of college-level work, and a bachelor's degree normally can be earned in 4 years. At least 1 year beyond the bachelor's is necessary for a master's degree, while a doctor's degree usually requires a minimum of 3 or 4 years beyond the bachelor's.

Professional schools differ widely in admission requirements and in program length. Medical students, for example, generally complete a 4-year program of premedical studies at a college or university before they can enter the 4-year program at a medical school. Law programs normally require 3 years of coursework beyond the bachelor's degree level.

Many of the statistics in this chapter are derived from the statistical activities of the National Center for Education Statistics. In addition, substantial contributions have been drawn from the work of other groups, both government and nongovernment, as shown in the source notes of the appropriate tables. Information on survey methodologies is in the "Guide to Sources" in the appendix and in the publications cited in the source notes.

\section{Enrollment, Teachers, and Schools}

Enrollment in elementary and secondary schools grew rapidly during the 1950s and 1960s and peaked in 1971 (table 3). This enrollment rise was caused by what is known as the "baby boom," a dramatic increase in births following World War II. From 1971 to 1984, total elementary and secondary school enrollment decreased every year, reflecting the decline in the school-age population over that period. After these years of decline, enrollment in elementary and secondary schools started increasing in fall 1985, and began hitting record enrollment levels in the mid 1990s (table 3).

Public school enrollment in kindergarten through grade eight rose from 28.5 million in fall 1988 to an estimated 33.5 million in fall 1998. Enrollment in the upper grades declined from 11.7 million in 1988 to 11.3 million in 1990, but then began rising, reaching 13.3 million in 1998.

The increase from 1988 to 1998 was most rapid in the elementary grades, but this pattern is expected to change. The growing numbers of young pupils that have been filling the elementary schools will cause significant increases at the secondary school level during the next decade. Between fall 1998 and fall 2008, public elementary enrollment is expected to remain fairly stable, while public secondary school enrollment is expected to rise by 11 percent. Public school enrollment is projected to set new records every year until 2006.

The proportion of students in private schools and colleges has changed little over the past 10 years. The percentage of private elementary and secondary students decreased slightly, from 12 percent in 1988 to 11 percent in 1998, and the percentage of college 
students who attended private colleges and universities remained at 22 percent. In 1998, about 5.9 million students were enrolled in private schools at the elementary and secondary levels and 3.2 million students in institutions of higher education (table 3 ).

College enrollment fell from 14.5 million in fall 1992 to 14.3 million in fall 1996. However, total college enrollment is expected to increase during the remainder of the 1990s, as increasing numbers of high school graduates pursue higher education.

Although school attendance rates among 5- to 17year-olds have remained relatively steady over the past 10 years, the proportion of 18- and 19-year-olds attending high school or college rose from 56 percent in 1987 to 62 percent in 1997. The proportion of 20to 24-year-olds enrolled in school rose from 26 percent to 34 percent during the same time period (table 6).

Americans have become more educated. In 1997, 82 percent of the population 25 years old and over had completed high school and 24 percent had completed 4 or more years of college. This represents an increase from 1980, when 69 percent had completed high school and 17 percent had 4 years of college (table 8). In 1997, about 5 percent of persons, 25 years old or over, held a master's degree as their highest degree, slightly more than 1 percent held a professional degree (e.g., medicine or law), and 1 percent held a doctor's degree (table 9).

An estimated 3.1 million elementary and secondary school teachers were engaged in classroom instruc- tion in the fall of 1998 (table 4). This number has risen about 17 percent since 1988. The number of public school teachers in 1998 was about 2.7 million and the number in private schools was estimated at 0.4 million. About 1.9 million teachers were teaching in elementary schools, while about 1.2 million were employed at the secondary level (table 4).

\section{Expenditures}

Education expenditures rose to an estimated high of $\$ 584$ billion in the 1997-98 school year. Elementary and secondary schools spent about 60 percent of this total, and colleges and universities accounted for the remaining 40 percent (table 31 ). An estimated 7.2 percent of the gross domestic product was spent by elementary and secondary schools and colleges and universities in 1997-98 (table 31).

The proportion of total state and local government funds spent on education declined between 1980-81 and 1993-94, at least partly as a result of the drop in elementary and secondary enrollment in the early part of the decade, and the expansion of other governmental services. During this same time period, the proportion of federal funds spent on education rose (table 34). Of the 1994-95 state and local funds spent on education, about 70 percent went to elementary and secondary schools, 26 percent to colleges and universities, and 4 percent to other education programs (table 35 ). 
insert fig 1 here

NOTE-Adult education programs, while not separately delineated above, may provide instruction at the elementary, secondary, or higher education level. Chart reflects typical patterns of progression rather than all possible variations.

SOURCE: U.S. Department of Education, National Center for Education Statistics. 


\section{Figure 2.-Enrollment and total expenditures in current and constant dollars, by level of education: $1960-61$ to $1997-98$}

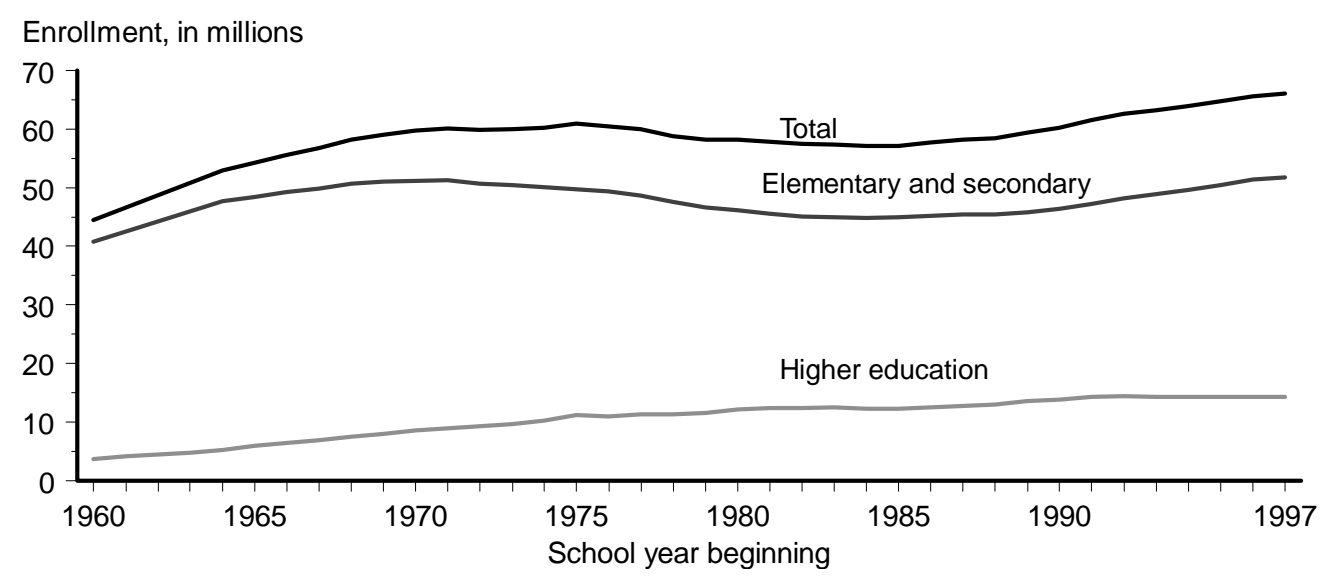

Expenditures, in billions of current dollars

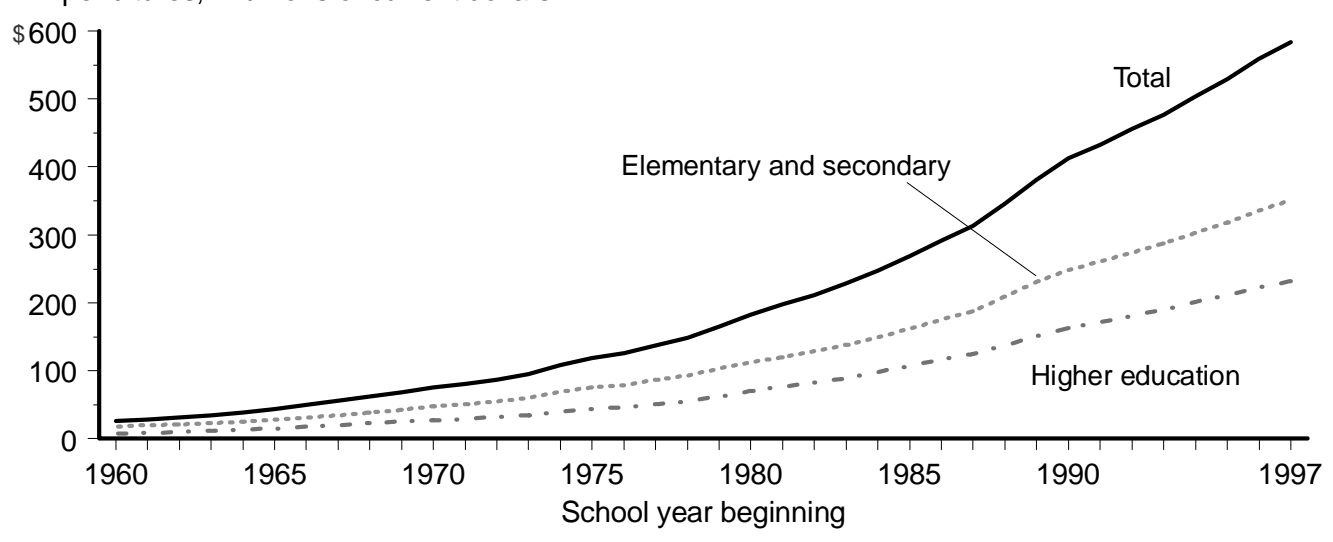

Expenditures, in billions of constant 1997-98 dollars

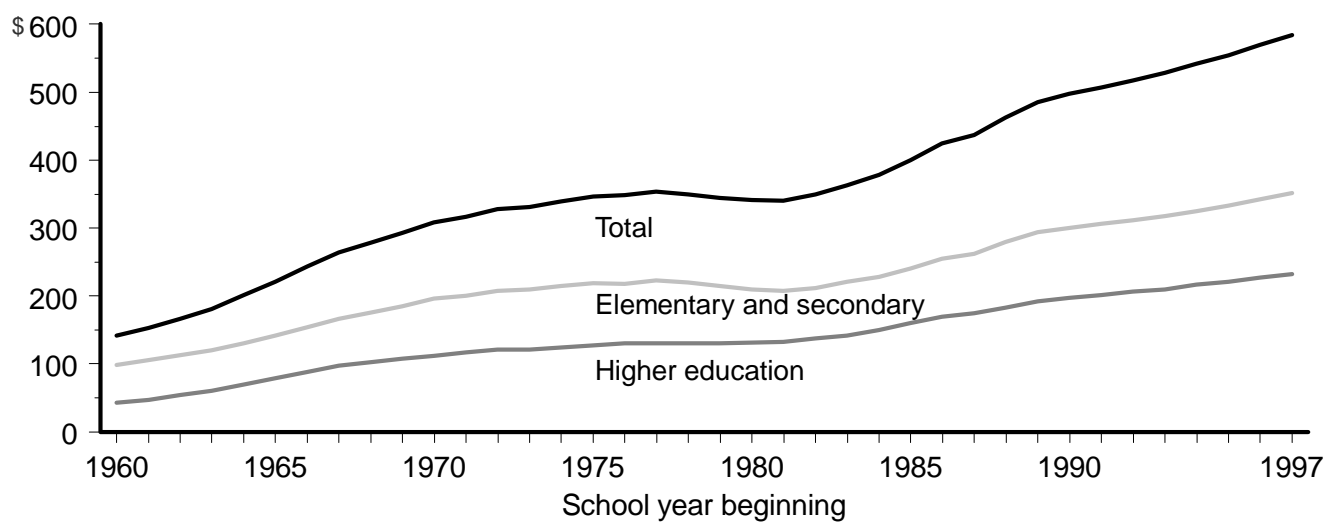

NOTE.-Data for 1996-97 are preliminary and data for 1997-98 are estimates.

SOURCE: U.S. Department of Education, National Center for Education Statistics, Statistics of State School Systems; Statistics of Public Elementary and Secondary School Systems; Statistics of Nonpublic Secondary Schools; Statistics of Nonpublic Elementary and Secondary Schools; Revenues and Expenditures for Public Elementary and Secondary Education; Fall Enrollment in Institutions of Higher Education; Financial Statistics of Institutions of Higher Education; Common Core of Data surveys; and Integrated Postsecondary Education Data System surveys. 
Figure 3.- Years of school completed by persons 25 years old and over: 1940 to 1997

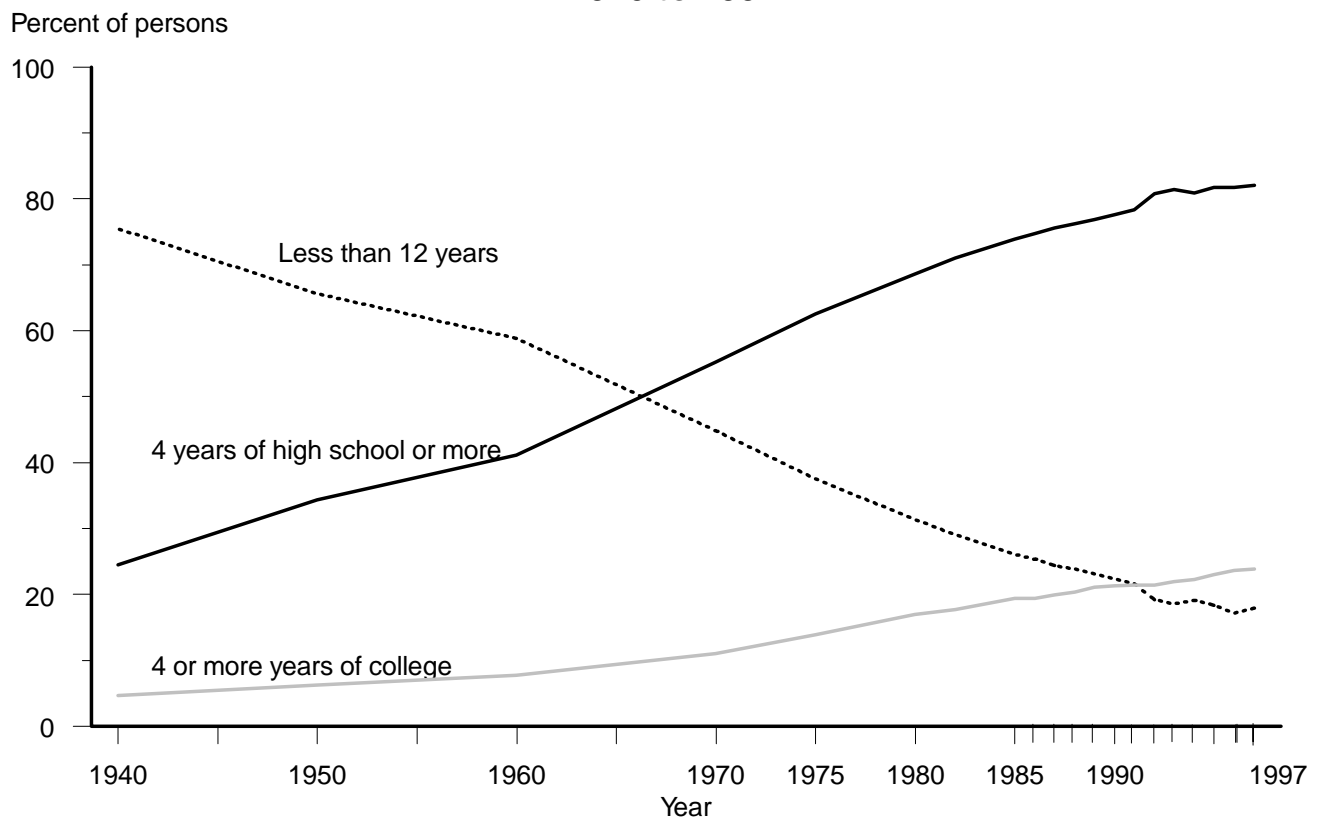

SOURCE: U.S. Department of Commerce, Bureau of the Census, 1960 Census of Population, Vol. 1, part 1; and Current Population Reports, Series P-20; and Current Population Survey, unpublished data.

Figure 4.-Years of school completed by persons 25 to 29 years of age: 1940 to 1997

Percent of persons

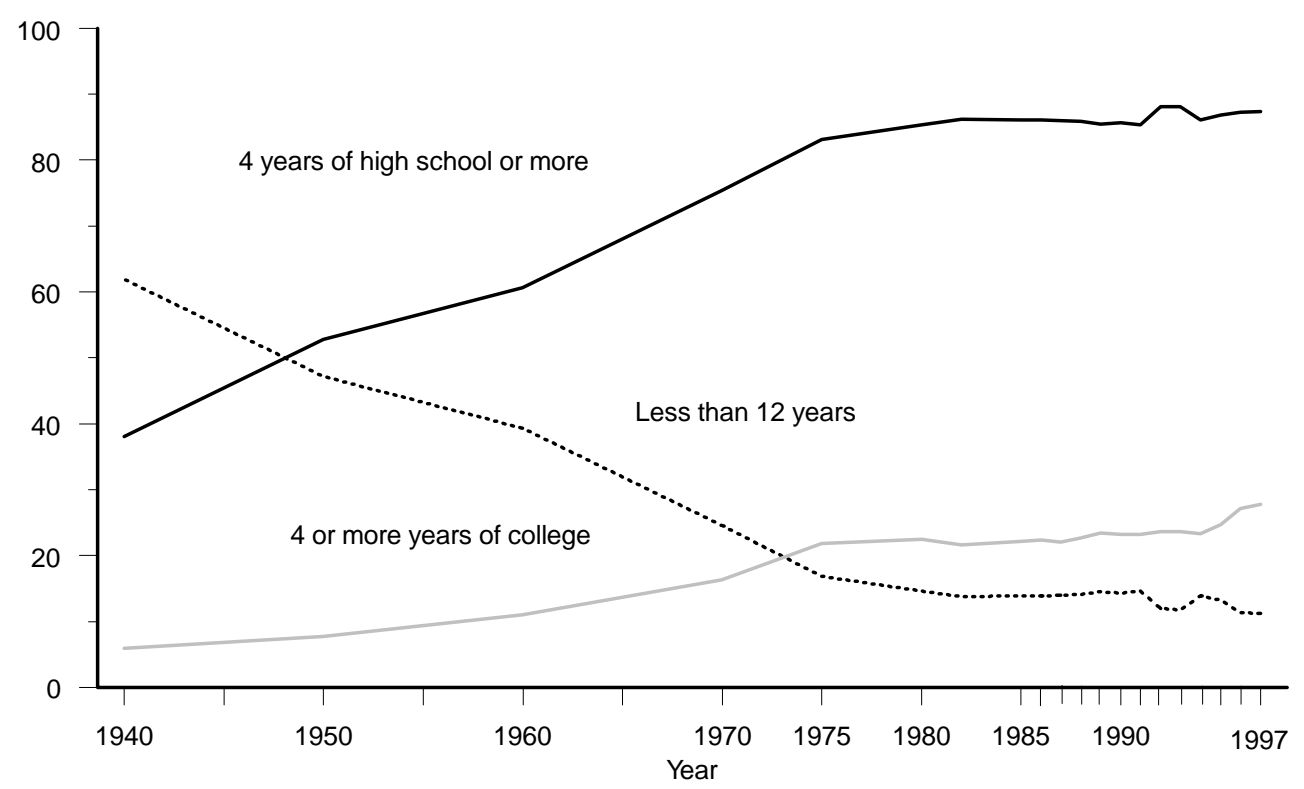

SOURCE: U.S. Department of Commerce, Bureau of the Census, 1960 Census of Population, Vol. 1, part 1; and Current Population Reports, Series P-20; and Current Population Survey, unpublished data. 
Figure 5.-Highest level of education attained by persons 25 years and older: March 1997

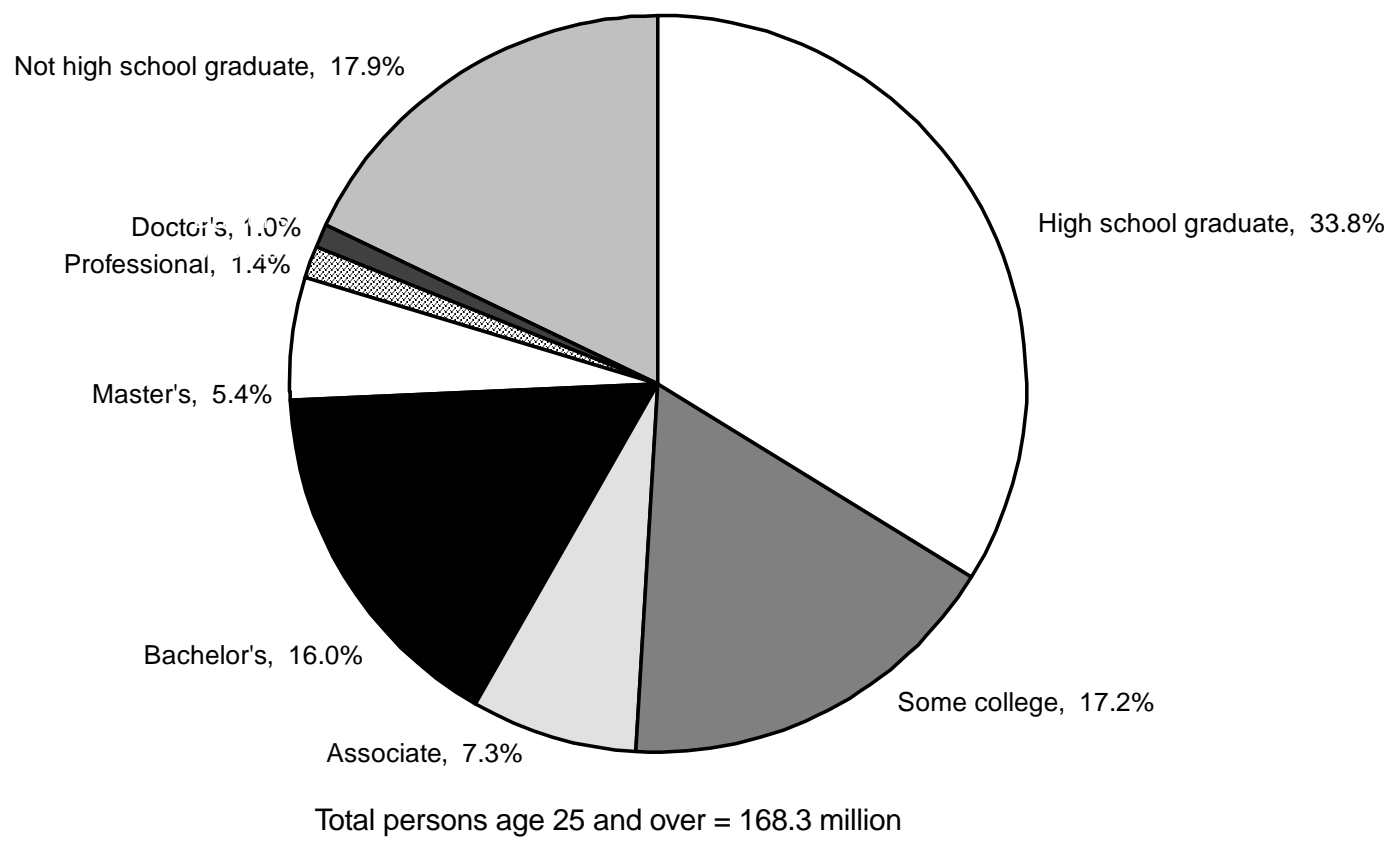

SOURCE: U.S. Department of Commerce, Bureau of the Census, Current Population Survey, unpublished data.

Figure 6.-Items most frequently cited by the public as a major problem Percent citing problem facing the local public schools: 1980 to 1998

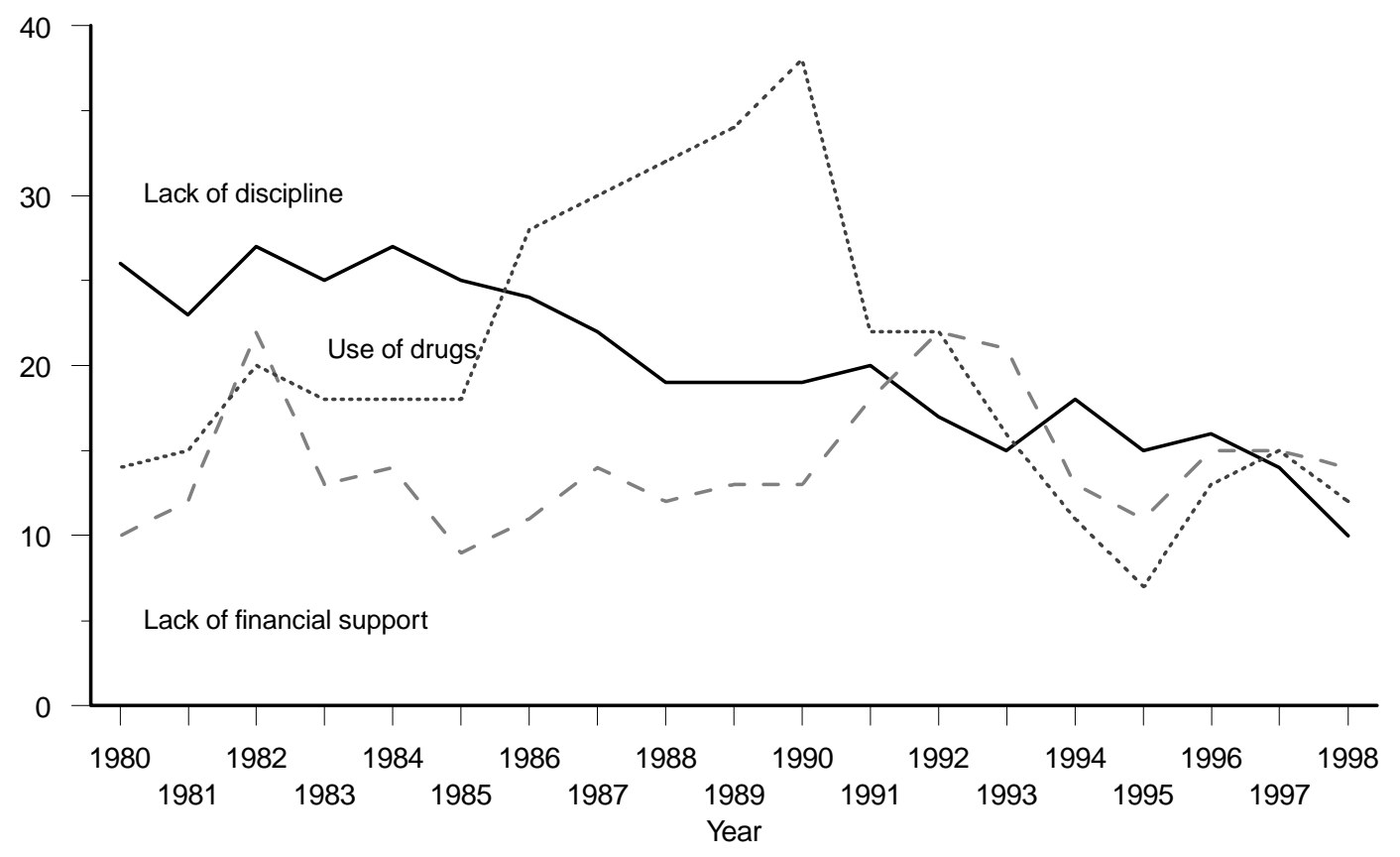

SOURCE: "The Annual Gallup Poll of the Public's Attitudes Toward the Public Schools," Phi Delta Kappan, various years. 
Table 1.-Estimated number of participants in elementary and secondary education and in higher education: Fall 1998

[In millions]

\begin{tabular}{|c|c|c|c|c|c|c|c|}
\hline \multirow[b]{2}{*}{ Participants } & \multirow{2}{*}{$\begin{array}{l}\text { All levels } \\
\text { (elementary, } \\
\text { secondary, } \\
\text { and higher } \\
\text { education) }\end{array}$} & \multicolumn{3}{|c|}{ Elementary and secondary schools } & \multicolumn{3}{|c|}{ Institutions of higher education } \\
\hline & & Total & Public & Private & Total & Public & Private \\
\hline 1 & 2 & 3 & 4 & 5 & 6 & 7 & 8 \\
\hline Total & 75.4 & 58.6 & 52.0 & 6.6 & 16.8 & 12.9 & 3.9 \\
\hline Enrollment ${ }^{1}$ & 67.3 & 52.7 & 46.8 & 5.9 & 14.6 & 11.4 & 3.2 \\
\hline Teachers and faculty . & 3.8 & 3.1 & 2.7 & 0.4 & 0.7 & 0.5 & 0.2 \\
\hline Other professional, administrative, and support staff & 4.2 & 2.8 & 2.5 & 0.2 & 1.5 & 1.0 & 0.5 \\
\hline
\end{tabular}

1 Includes enrollments in local public school systems and in most private schools (religiously affiliated and nonsectarian). Excludes subcollegiate departments of institutions of higher education, residential schools for exceptional children, and federal schools. Elementary and secondary includes most kindergarten and some nursery school enrollment. Excludes preprimary enrollment in schools that do not offer first grade or above. Higher education comprises full-time and part-time students enrolled in degree-credit and nondegree-credit programs in universities, other 4-year colleges, and 2-year colleges.
NOTE.-The enrollment figures include all students in elementary and secondary schools and colleges and universities. However, the data for teachers and other staff in public and private elementary and secondary schools and colleges and universities are reported in terms of full-time equivalents. Because of rounding, details may not add to totals.

SOURCE: U.S. Department of Education, National Center for Education Statistics, unpublished projections and estimates. (This table was prepared July 1998.)

Table 2.-Enrollment in educational institutions, by level and control of institution: Fall 1980 to fall 2005 [In thousands]

\begin{tabular}{|c|c|c|c|c|c|c|c|c|c|c|c|c|c|c|}
\hline Level of instruction and type of control & $\begin{array}{l}\text { Fall } \\
1980\end{array}$ & $\begin{array}{c}\text { Fall } \\
1985\end{array}$ & $\begin{array}{c}\text { Fall } \\
1990\end{array}$ & $\begin{array}{c}\text { Fall } \\
1991\end{array}$ & $\begin{array}{l}\text { Fall } \\
1992\end{array}$ & $\begin{array}{l}\text { Fall } \\
1993\end{array}$ & $\begin{array}{c}\text { Fall } \\
1994\end{array}$ & $\begin{array}{l}\text { Fall } \\
1995\end{array}$ & $\begin{array}{c}\text { Fall } \\
1996{ }^{1}\end{array}$ & $\begin{array}{c}\text { Pro- } \\
\text { jected } \\
\text { fall } \\
1997\end{array}$ & $\begin{array}{c}\text { Pro- } \\
\text { jected } \\
\text { fall } \\
1998\end{array}$ & $\begin{array}{c}\text { Pro- } \\
\text { jected } \\
\text { fall } \\
1999\end{array}$ & $\begin{array}{l}\text { Pro- } \\
\text { jected } \\
\text { fall } \\
2000\end{array}$ & $\begin{array}{c}\text { Pro- } \\
\text { jected } \\
\text { fall } \\
2005\end{array}$ \\
\hline 1 & 2 & 3 & 4 & 5 & 6 & 7 & 8 & 9 & 10 & 11 & 12 & 13 & 14 & 15 \\
\hline All levels & 58,305 & 57,226 & 60,267 & 61,605 & 62,686 & 63,241 & 63,986 & 64,803 & 65,674 & 66,170 & 67,309 & 67,871 & 68,334 & 69,942 \\
\hline Public & 50,335 & 48,901 & 52,061 & 53,356 & 54,208 & 54,654 & 55,245 & 55,933 & 56,682 & 57,161 & 58,187 & 58,668 & 59,065 & 60,436 \\
\hline Private .. & 7,971 & 8,325 & 8,206 & 8,248 & 8,478 & 8,587 & 8,741 & 8,869 & 8,993 & 9,010 & 9,121 & 9,203 & 9,269 & 9,506 \\
\hline $\begin{array}{l}\text { Elementary and } \\
\text { secondary education } 2\end{array}$ & 46,208 & 44,979 & 46,448 & 47,246 & 48,198 & 48,936 & 49,707 & 50,540 & 51,375 & 51,821 & 52,718 & 53,112 & 53,445 & 54,426 \\
\hline Public & $\begin{array}{r}40,877 \\
5,331\end{array}$ & $\begin{array}{r}39,422 \\
5557\end{array}$ & $\begin{array}{r}41,217 \\
5232\end{array}$ & $\begin{array}{r}42,047 \\
5,199\end{array}$ & $\begin{array}{r}42,823 \\
5,375\end{array}$ & $\begin{array}{r}43,465 \\
5,471\end{array}$ & $\begin{array}{r}44,111 \\
35596\end{array}$ & $\begin{array}{r}44,840 \\
35700\end{array}$ & 45,592 & 45,953 & 46,792 & 47,143 & 47,439 & 48,335 \\
\hline ate & & & & & & & & & & & & & & \\
\hline Grades $\mathrm{K}-8^{4} \ldots \ldots$ & 31,639 & 31,229 & 33,973 & 34,580 & 35,300 & 35,784 & 36,258 & 36,772 & 37,245 & 37,495 & 38,110 & 38,338 & 38,543 & 38,376 \\
\hline Public . & 27,647 & 27,034 & 29,878 & 30,506 & 31,088 & 31,504 & 31,898 & 32,341 & 32,759 & 32,951 & 33,522 & 33,722 & 33,903 & 33,756 \\
\hline 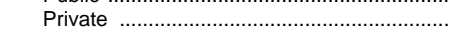 & 3,992 & 4,195 & 4,095 & 34,074 & ${ }^{3} 4,212$ & 34,280 & 34,360 & 34,431 & 34,486 & 4,545 & 4,588 & 4,616 & 4,640 & 4,620 \\
\hline Grades 9-12 & 14,570 & 13,750 & 12,475 & 12,666 & 12,898 & 13,152 & 13,449 & 13,769 & 14,131 & 14,324 & 14,608 & 14,774 & 14,902 & 16,050 \\
\hline Public & 13,231 & 12,388 & 11,338 & 11,541 & 11,735 & 11,961 & 12,213 & 12,500 & 12,834 & 13,003 & 13,270 & 13,420 & 13,537 & 14,579 \\
\hline 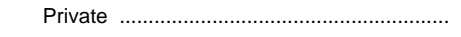 & 1,339 & 1,362 & 1,137 & 31,125 & ${ }^{3} 1,163$ & 31,191 & 31,236 & 31,269 & 31,297 & 1,322 & 1,339 & 1,354 & 1,366 & 1,471 \\
\hline Higher education 5 ...... & 12,097 & 12,247 & 13,819 & 14,359 & 14,487 & 14,305 & 14,279 & 14,262 & 14,300 & 14,350 & 14,590 & 14,758 & 14,889 & 15,516 \\
\hline Public & 9,457 & 9,479 & 10,845 & 11,310 & 11,385 & 11,189 & 11,134 & 11,092 & 11,090 & 11,208 & 11,395 & 11,525 & 11,626 & 12,101 \\
\hline Undergraduate 6 & 8,442 & 8,477 & 9,710 & 10,148 & 10,216 & 10,012 & 9,945 & 9,904 & 9,905 & 10,024 & 10,213 & 10,345 & 10,452 & 10,910 \\
\hline 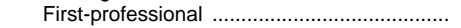 & 114 & 112 & 112 & 111 & 111 & 114 & 114 & 115 & 116 & 107 & 106 & 105 & 104 & 108 \\
\hline Graduate $^{7}$ & 901 & 890 & 1,023 & 1,050 & 1,058 & 1,064 & 1,075 & 1,074 & 1,068 & 1,076 & 1,077 & 1,075 & 1,070 & 1,084 \\
\hline 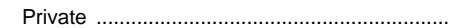 & 2,640 & 2,768 & 2,974 & 3,049 & 3,103 & 3,116 & 3,145 & 3,169 & 3,210 & 3,143 & 3,194 & 3,233 & 3,263 & 3,415 \\
\hline Undergraduate $^{6} \ldots \ldots$ & 2,033 & 2,120 & 2,250 & 2,291 & 2,321 & 2,312 & 2,317 & 2,328 & 2,354 & 2,333 & 2,387 & 2,428 & 2,462 & 2,601 \\
\hline First-professional .. & 163 & 162 & 162 & 169 & 170 & 179 & 181 & 183 & 181 & 169 & 167 & 166 & 165 & 170 \\
\hline 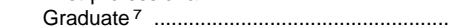 & 443 & 486 & 563 & 589 & 611 & 625 & 647 & 659 & 675 & 640 & 640 & 639 & 636 & 644 \\
\hline
\end{tabular}

1 Higher education data are preliminary.

${ }^{2}$ Includes enrollments in local public school systems and in most private schools (religiously affiliated and nonsectarian). Excludes subcollegiate departments of institutions of higher education, residential schools for exceptional children, federal schools, and homeschooled children. Based on Department estimates, the home-schooled children numbered approximately 800,000 to $1,000,000$ in 1997-98. Excludes preprimary pupils in schools that do not offer first grade or above.

${ }^{3}$ Estimated.

${ }^{4}$ Includes kindergarten and some nursery school pupils.

5 Includes full-time and part-time students enrolled in degree-credit and nondegreecredit programs in universities and 2-year and 4-year colleges.

6 Includes unclassified students below the baccalaureate level.
${ }_{7}$ Includes unclassified postbaccalaureate students.

NOTE.- Higher education enrollment projections are based on the middle alternative projections published by the National Center for Education Statistics. Because of rounding, details may not add to totals. Some data have been revised from previously published figures.

SOURCE: U.S. Department of Education, National Center for Education Statistics, Common Core of Data and "Fall Enrollment in Institutions of Higher Education" surveys: Integrated Postsecondary Education Data System (IPEDS), Higher Education General Information Survey (HEGIS), "Fall Enrollment" surveys, and Projections of Education Statistics to 2008. (This table was prepared July 1998.) 
Table 3.-Enrollment in educational institutions, by level and by control of institution: $1869-70$ to fall 2008

[In thousands]

\begin{tabular}{|c|c|c|c|c|c|c|c|c|c|c|c|}
\hline \multirow[b]{2}{*}{ Year } & \multirow[b]{2}{*}{$\begin{array}{l}\text { Total } \\
\text { enrollment, } \\
\text { all levels }\end{array}$} & \multirow[b]{2}{*}{$\begin{array}{c}\text { Elementary } \\
\text { and } \\
\text { secondary, } \\
\text { total }\end{array}$} & \multicolumn{3}{|c|}{$\begin{array}{l}\text { Public elementary and } \\
\text { secondary schools }\end{array}$} & \multicolumn{3}{|c|}{$\begin{array}{l}\text { Private elementary and } \\
\text { secondary schools }{ }^{1}\end{array}$} & \multicolumn{3}{|c|}{ Higher education ${ }^{2}$} \\
\hline & & & Total & $\begin{array}{l}\text { Pre- } \\
\text { kinder- } \\
\text { garten } \\
\text { through } \\
\text { grade } 8\end{array}$ & $\begin{array}{c}\text { Grades } 9 \\
\text { through } \\
12\end{array}$ & Total & $\begin{array}{l}\text { Kinder- } \\
\text { garten } \\
\text { through } \\
\text { grade } 8\end{array}$ & $\begin{array}{c}\text { Grades } 9 \\
\text { through } \\
12\end{array}$ & Total & Public & Private \\
\hline 1 & 2 & 3 & 4 & 5 & 6 & 7 & 8 & 9 & 10 & 11 & 12 \\
\hline $\begin{array}{l}1869-70 \\
1879-80 \\
1889-90 \\
1899-1900 \\
1909-10\end{array}$ & $\begin{array}{r}- \\
14,491 \\
17,092 \\
19,728\end{array}$ & $\begin{array}{r}\overline{-} \\
14,334 \\
16,855 \\
19,372\end{array}$ & $\begin{array}{r}6,872 \\
9,868 \\
12,723 \\
15,503 \\
17,814\end{array}$ & $\begin{array}{r}6,792 \\
9,757 \\
12,520 \\
14,984 \\
16,899\end{array}$ & $\begin{array}{r}80 \\
110 \\
203 \\
519 \\
915\end{array}$ & $\begin{array}{r}- \\
1,611 \\
1,352 \\
1,558\end{array}$ & $\begin{array}{r}- \\
1,516 \\
1,241 \\
1,441\end{array}$ & $\begin{array}{r}- \\
\overline{95} \\
111 \\
117\end{array}$ & $\begin{array}{r}52 \\
116 \\
157 \\
238 \\
355\end{array}$ & $\begin{array}{l}- \\
- \\
-\end{array}$ & $\begin{array}{l}- \\
- \\
-\end{array}$ \\
\hline $\begin{array}{l}1919-20 \\
1929-30 \\
1939-40 \\
1949-50 \\
\text { Fall 1959 }\end{array}$ & $\begin{array}{l}23,876 \\
29,430 \\
29,539 \\
31,151 \\
44,497\end{array}$ & $\begin{array}{l}23,278 \\
28,329 \\
28,045 \\
28,492 \\
40,857\end{array}$ & $\begin{array}{l}21,578 \\
25,678 \\
25,434 \\
25,111 \\
35,182\end{array}$ & $\begin{array}{l}19,378 \\
21,279 \\
18,832 \\
19,387 \\
26,911\end{array}$ & $\begin{array}{l}2,200 \\
4,399 \\
6,601 \\
5,725 \\
8,271\end{array}$ & $\begin{array}{l}1,699 \\
2,651 \\
2,611 \\
3,380 \\
5,675\end{array}$ & $\begin{array}{l}1,486 \\
2,310 \\
2,153 \\
2,708 \\
4,640\end{array}$ & $\begin{array}{r}214 \\
341 \\
458 \\
672 \\
1,035\end{array}$ & $\begin{array}{r}598 \\
1,101 \\
1,494 \\
2,659 \\
3,640\end{array}$ & $\begin{array}{r}- \\
797 \\
1,355 \\
2,181\end{array}$ & $\begin{array}{r}- \\
698 \\
1,304 \\
1,459\end{array}$ \\
\hline $\begin{array}{l}\text { Fall } 1964 \\
\text { Fall } 1965 \text { Fall } 1966 \\
\text { Fall } 1967 \\
\text { Fall } 1968\end{array}$ & $\begin{array}{l}52,996 \\
54,394 \\
55,629 \\
56,803 \\
58,257\end{array}$ & $\begin{array}{l}47,716 \\
48,473 \\
49,239 \\
49,891 \\
50,744\end{array}$ & $\begin{array}{l}41,416 \\
42,173 \\
43,039 \\
43,891 \\
44,944\end{array}$ & $\begin{array}{l}30,025 \\
30,563 \\
31,145 \\
31,641 \\
32,226\end{array}$ & $\begin{array}{l}11,391 \\
11,610 \\
11,894 \\
12,250 \\
12,718\end{array}$ & $\begin{array}{r}36,300 \\
6,300 \\
36,200 \\
36,000 \\
5,800\end{array}$ & $\begin{array}{r}35,000 \\
4,900 \\
34,800 \\
34,600 \\
4,400\end{array}$ & $\begin{array}{r}1,300 \\
1,400 \\
31,400 \\
31,400 \\
1,400\end{array}$ & $\begin{array}{l}5,280 \\
5,921 \\
6,390 \\
6,912 \\
7,513\end{array}$ & $\begin{array}{l}3,468 \\
3,970 \\
4,349 \\
4,816 \\
5,431\end{array}$ & $\begin{array}{l}1,812 \\
1,951 \\
2,041 \\
2,096 \\
2,082\end{array}$ \\
\hline $\begin{array}{l}\text { Fall } 1969 \\
\text { Fall } 1970 \\
\text { Fall } 1971 \\
\text { Fall } 1972 \\
\text { Fall } 1973\end{array}$ & $\begin{array}{l}59,055 \\
59,838 \\
60,220 \\
59,941 \\
60,047\end{array}$ & $\begin{array}{l}51,050 \\
51,257 \\
51,271 \\
50,726 \\
50,445\end{array}$ & $\begin{array}{l}45,550 \\
45,894 \\
46,071 \\
45,726 \\
45,445\end{array}$ & $\begin{array}{l}32,513 \\
32,558 \\
32,318 \\
31,879 \\
31,401\end{array}$ & $\begin{array}{l}13,037 \\
13,336 \\
13,753 \\
13,848 \\
14,044\end{array}$ & $\begin{array}{r}35,500 \\
5,363 \\
35,200 \\
35,000 \\
35,000\end{array}$ & $\begin{array}{r}34,200 \\
4,052 \\
33,900 \\
33,700 \\
33,700\end{array}$ & $\begin{array}{r}31,300 \\
1,311 \\
31,300 \\
31,300 \\
31,300\end{array}$ & $\begin{array}{l}8,005 \\
8,581 \\
8,949 \\
9,215 \\
9,602\end{array}$ & $\begin{array}{l}5,897 \\
6,428 \\
6,804 \\
7,071 \\
7,420\end{array}$ & $\begin{array}{l}2,108 \\
2,153 \\
2,144 \\
2,144 \\
2,183\end{array}$ \\
\hline $\begin{array}{l}\text { Fall } 1974 \\
\text { Fall } 1975 \text { Fall } 1976 \\
\text { Fall } 1977 \\
\text { Fall } 1978\end{array}$ & $\begin{array}{l}60,297 \\
61,004 \\
60,490 \\
60,003 \\
58,897\end{array}$ & $\begin{array}{l}50,073 \\
49,819 \\
49,478 \\
48,717 \\
47,637\end{array}$ & $\begin{array}{l}45,073 \\
44,819 \\
44,311 \\
43,577 \\
42,551\end{array}$ & $\begin{array}{l}30,971 \\
30,515 \\
29,997 \\
29,375 \\
28,463\end{array}$ & $\begin{array}{l}14,103 \\
14,304 \\
14,314 \\
14,203 \\
14,088\end{array}$ & $\begin{array}{r}35,000 \\
35,000 \\
5,167 \\
5,140 \\
5,086\end{array}$ & $\begin{array}{r}33,700 \\
33,700 \\
3,825 \\
3,797 \\
3,732\end{array}$ & $\begin{array}{r}31,300 \\
31,300 \\
1,342 \\
1,343 \\
1,353\end{array}$ & $\begin{array}{l}10,224 \\
11,185 \\
11,012 \\
11,286 \\
11,260\end{array}$ & $\begin{array}{l}7,989 \\
8,835 \\
8,653 \\
8,847 \\
8,786\end{array}$ & $\begin{array}{l}2,235 \\
2,350 \\
2,359 \\
2,439 \\
2,474\end{array}$ \\
\hline $\begin{array}{l}\text { Fall } 1979 \\
\text { Fall } 1980 \\
\text { Fall } 1981 \\
\text { Fall } 1982 \\
\text { Fall } 1983\end{array}$ & $\begin{array}{l}58,221 \\
58,305 \\
57,916 \\
57,591 \\
57,432\end{array}$ & $\begin{array}{l}46,651 \\
46,208 \\
45,544 \\
45,166 \\
44,967\end{array}$ & $\begin{array}{l}41,651 \\
40,877 \\
40,044 \\
39,566 \\
39,252\end{array}$ & $\begin{array}{l}28,034 \\
27,647 \\
27,280 \\
27,161 \\
26,981\end{array}$ & $\begin{array}{l}13,616 \\
13,231 \\
12,764 \\
12,405 \\
12,271\end{array}$ & $\begin{array}{r}35,000 \\
5,331 \\
35,500 \\
35,600 \\
5,715\end{array}$ & $\begin{array}{r}33,700 \\
3,992 \\
34,100 \\
34,200 \\
4,315\end{array}$ & $\begin{array}{r}31,300 \\
1,339 \\
31,400 \\
31,400 \\
1,400\end{array}$ & $\begin{array}{l}11,570 \\
12,097 \\
12,372 \\
12,426 \\
12,465\end{array}$ & $\begin{array}{l}9,037 \\
9,457 \\
9,647 \\
9,696 \\
9,683\end{array}$ & $\begin{array}{l}2,533 \\
2,640 \\
2,725 \\
2,730 \\
2,782\end{array}$ \\
\hline $\begin{array}{l}\text { Fall } 1984 \\
\text { Fall } 1985 \text { Fall } 1986 \\
\text { Fall } 1987 \\
\text { Fall } 1988\end{array}$ & $\begin{array}{l}57,150 \\
57,226 \\
57,709 \\
58,254 \\
58,485\end{array}$ & $\begin{array}{l}44,908 \\
44,979 \\
45,205 \\
45,488 \\
45,430\end{array}$ & $\begin{array}{l}39,208 \\
39,422 \\
39,753 \\
40,008 \\
40,189\end{array}$ & $\begin{array}{l}26,905 \\
27,034 \\
27,420 \\
27,933 \\
28,501\end{array}$ & $\begin{array}{l}12,304 \\
12,388 \\
12,333 \\
12,076 \\
11,687\end{array}$ & $\begin{array}{r}35,700 \\
5,557 \\
35,452 \\
5,479 \\
35,241\end{array}$ & $\begin{array}{r}34,300 \\
4,195 \\
34,116 \\
4,232 \\
34,036\end{array}$ & $\begin{array}{r}31,400 \\
1,362 \\
31,336 \\
1,247 \\
31,206\end{array}$ & $\begin{array}{l}12,242 \\
12,247 \\
12,504 \\
12,767 \\
13,055\end{array}$ & $\begin{array}{r}9,477 \\
9,479 \\
9,714 \\
9,973 \\
10,161\end{array}$ & $\begin{array}{l}2,765 \\
2,768 \\
2,790 \\
2,793 \\
2,894\end{array}$ \\
\hline $\begin{array}{l}\text { Fall } 1989 \\
\text { Fall } 1990 \\
\text { Fall } 1991 \\
\text { Fall } 1992 \\
\text { Fall } 1993\end{array}$ & $\begin{array}{l}59,436 \\
60,267 \\
61,605 \\
62,686 \\
63,241\end{array}$ & $\begin{array}{l}45,898 \\
46,448 \\
47,246 \\
48,198 \\
48,936\end{array}$ & $\begin{array}{l}40,543 \\
41,217 \\
42,047 \\
42,823 \\
43,465\end{array}$ & $\begin{array}{l}29,152 \\
29,878 \\
30,506 \\
31,088 \\
31,504\end{array}$ & $\begin{array}{l}11,390 \\
11,338 \\
11,541 \\
11,735 \\
11,961\end{array}$ & $\begin{array}{r}35,355 \\
5,232 \\
35,199 \\
35,375 \\
35,471\end{array}$ & $\begin{array}{r}34,162 \\
4,095 \\
34,074 \\
34,212 \\
34,280\end{array}$ & $\begin{array}{rl}3 & 1,193 \\
1,137 \\
31,125 \\
31,163 \\
31,191\end{array}$ & $\begin{array}{l}13,539 \\
13,819 \\
14,359 \\
14,487 \\
14,305\end{array}$ & $\begin{array}{l}10,578 \\
10,845 \\
11,310 \\
11,385 \\
11,189\end{array}$ & $\begin{array}{l}2,961 \\
2,974 \\
3,049 \\
3,103 \\
3,116\end{array}$ \\
\hline 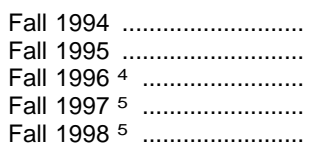 & $\begin{array}{l}63,986 \\
64,803 \\
65,674 \\
66,170 \\
67,309\end{array}$ & $\begin{array}{l}49,707 \\
50,540 \\
51,375 \\
51,821 \\
52,718\end{array}$ & $\begin{array}{l}44,111 \\
44,840 \\
45,592 \\
45,953 \\
46,792\end{array}$ & $\begin{array}{l}31,898 \\
32,341 \\
32,759 \\
32,951 \\
33,522\end{array}$ & $\begin{array}{l}12,213 \\
12,500 \\
12,834 \\
13,003 \\
13,270\end{array}$ & $\begin{array}{r}35,596 \\
35,700 \\
35,783 \\
5,867 \\
5,927\end{array}$ & $\begin{array}{r}34,360 \\
34,431 \\
34,486 \\
4,545 \\
4,588\end{array}$ & $\begin{array}{r}31,236 \\
31,269 \\
31,297 \\
1,322 \\
1,339\end{array}$ & $\begin{array}{l}14,279 \\
14,262 \\
14,300 \\
14,350 \\
14,590\end{array}$ & $\begin{array}{l}11,134 \\
11,092 \\
11,090 \\
11,208 \\
11,395\end{array}$ & $\begin{array}{l}3,145 \\
3,169 \\
3,210 \\
3,143 \\
3,194\end{array}$ \\
\hline $\begin{array}{l}\text { Fall } 199955 \\
\text { Fall } 20005 \\
\text { Fall } 20015^{5} \\
\text { Fall } 20025^{5} \\
\text { Fall } 20035^{5}\end{array}$ & $\begin{array}{l}67,871 \\
68,334 \\
68,728 \\
69,040 \\
69,338\end{array}$ & $\begin{array}{l}53,112 \\
53,445 \\
53,736 \\
53,987 \\
54,153\end{array}$ & $\begin{array}{l}47,143 \\
47,439 \\
47,698 \\
47,924 \\
48,075\end{array}$ & $\begin{array}{l}33,722 \\
33,903 \\
34,055 \\
34,124 \\
34,124\end{array}$ & $\begin{array}{l}13,420 \\
13,537 \\
13,643 \\
13,800 \\
13,951\end{array}$ & $\begin{array}{l}5,970 \\
6,006 \\
6,038 \\
6,063 \\
6,078\end{array}$ & $\begin{array}{l}4,616 \\
4,640 \\
4,661 \\
4,671 \\
4,671\end{array}$ & $\begin{array}{l}1,354 \\
1,366 \\
1,376 \\
1,392 \\
1,407\end{array}$ & $\begin{array}{l}14,758 \\
14,889 \\
14,992 \\
15,053 \\
15,185\end{array}$ & $\begin{array}{l}11,525 \\
11,626 \\
11,705 \\
11,751 \\
11,849\end{array}$ & $\begin{array}{l}3,233 \\
3,263 \\
3,287 \\
3,303 \\
3,335\end{array}$ \\
\hline $\begin{array}{l}\text { Fall } 20045^{5} \\
\text { Fall } 20055^{5} \\
\text { Fall } 20065^{5} \\
\text { Fall } 20075^{5} \\
\text { Fall } 20085^{5}\end{array}$ & $\begin{array}{l}69,657 \\
69,942 \\
70,160 \\
70,305 \\
70,351\end{array}$ & $\begin{array}{l}54,308 \\
54,426 \\
54,457 \\
54,425 \\
54,268\end{array}$ & $\begin{array}{l}48,221 \\
48,335 \\
48,368 \\
48,342 \\
48,201\end{array}$ & $\begin{array}{l}33,958 \\
33,756 \\
33,584 \\
33,489 \\
33,455\end{array}$ & $\begin{array}{l}14,263 \\
14,579 \\
14,785 \\
14,854 \\
14,746\end{array}$ & $\begin{array}{l}6,087 \\
6,091 \\
6,088 \\
6,082 \\
6,067\end{array}$ & $\begin{array}{l}4,648 \\
4,620 \\
4,597 \\
4,584 \\
4,579\end{array}$ & $\begin{array}{l}1,439 \\
1,471 \\
1,491 \\
1,498 \\
1,488\end{array}$ & $\begin{array}{l}15,349 \\
15,516 \\
15,703 \\
15,880 \\
16,083\end{array}$ & $\begin{array}{l}11,975 \\
12,101 \\
12,242 \\
12,378 \\
12,534\end{array}$ & $\begin{array}{l}3,374 \\
3,415 \\
3,461 \\
3,502 \\
3,549\end{array}$ \\
\hline
\end{tabular}

1 Beginning in fall 1980, data include estimates for an expanded universe of private schools. Therefore, these totals may differ from figures shown in other tables, and direct comparisons with earlier years should be avoided.

2 Data for 1869-70 through 1949-50 include resident degree-credit students enrolled at any time during the academic year. Beginning in 1959, data include all resident and extension students enrolled at the beginning of the fall term.

${ }^{3}$ Estimated.

4 Preliminary data.

${ }^{5}$ Projected.

-Data not available.

NOTE.-Elementary and secondary enrollment includes pupils in public school systems and in most private schools (religiously affiliated and nonsectarian), but generally excludes pupils in subcollegiate departments of colleges, residential schools for excep tional children, federal schools, and home-schooled children. Based on Department esti- mates, the home-schooled children numbered approximately 800,000 to $1,000,000$ in 1997-98. Public elementary enrollment includes most preprimary school pupils. Private elementary enrollment includes some preprimary students. Higher education includes colleges, universities, professional schools, and 2-year colleges. Higher education enroll-
ment projections are based on the middle alternative projections published by the $\mathrm{Na}$ ment projections are based on the middle alternative projections published by the $\mathrm{Na}$ -
tional Center for Education Statistics. Some data have been revised from previously published figures. Because of rounding, details may not add to totals.

SOURCE: U.S. Department of Education, National Center for Education Statistics, Statistics of State School Systems; Statistics of Public Elementary and Secondary School Systems; Statistics of Nonpublic Elementary and Secondary Schools; Projections of Education Statistics to 2008; Common Core of Data; Higher Education General Information Survey (HEGIS), "Fall Enrollment in Institutions of Higher Education" surveys; and Integrated Postsecondary Education Data System (IPEDS), "Fall Enrollment" surveys. (This table was prepared July 1998. . 
Table 4.-Teachers in elementary and secondary schools, and senior instructional staff in institutions of higher education, by control of institution: Fall 1970 to fall 2008

[In thousands]

\begin{tabular}{|c|c|c|c|c|c|c|c|c|c|c|c|c|c|c|c|}
\hline \multirow{3}{*}{ Fall } & \multicolumn{3}{|c|}{ All levels } & \multicolumn{9}{|c|}{ Elementary and secondary teachers ${ }^{1}$} & \multicolumn{3}{|c|}{$\begin{array}{l}\text { Higher education senior } \\
\text { instructional staff } 2\end{array}$} \\
\hline & \multirow{2}{*}{ Total } & \multirow{2}{*}{ Public } & \multirow{2}{*}{ Private } & \multicolumn{3}{|c|}{ Total } & \multicolumn{3}{|c|}{ Elementary teachers } & \multicolumn{3}{|c|}{ Secondary teachers } & \multirow[b]{2}{*}{ Total } & \multirow[b]{2}{*}{ Public } & \multirow[b]{2}{*}{ Private } \\
\hline & & & & Total & Public & Private & Total & Public & Private & Total & Public & Private & & & \\
\hline 1 & 2 & 3 & 4 & 5 & 6 & 7 & 8 & 9 & 10 & 11 & 12 & 13 & 14 & 15 & 16 \\
\hline 1970. & 2,766 & 2,373 & 393 & 2,292 & 2,059 & 233 & 1,283 & 1,130 & 153 & 1,009 & 929 & 80 & 474 & 314 & 160 \\
\hline $1975 \ldots$ & 3,081 & 2,641 & 440 & 2,453 & 2,198 & 3255 & 1,353 & 1,181 & 3172 & 1,100 & 1,017 & 383 & 628 & 443 & 185 \\
\hline $1980 \ldots$ & 3,171 & 2,679 & 492 & 2,485 & 2,184 & 301 & 1,401 & 1,189 & 212 & 1,084 & 995 & 89 & 3686 & 3495 & 3191 \\
\hline $1981 .$. & 3,145 & 2,636 & 509 & 2,440 & 2,127 & ${ }^{3} 313$ & 1,404 & 1,183 & 3221 & 1,037 & 945 & 392 & 705 & 509 & 196 \\
\hline $1982 \ldots$ & 3,168 & 2,639 & 529 & 2,458 & 2,133 & 3 325 & 1,413 & 1,182 & 3231 & 1,045 & 951 & 394 & 3710 & 3506 & 3204 \\
\hline $1983 \ldots \ldots \ldots$ & 3,200 & 2,651 & 549 & 2,476 & 2,139 & 337 & 1,426 & 1,186 & 240 & 1,050 & 953 & 97 & 724 & 512 & 212 \\
\hline 1984. & 3,225 & 2,673 & 552 & 2,508 & 2,168 & ${ }^{3} 340$ & 1,451 & 1,208 & ${ }^{3} 243$ & 1,057 & 960 & 397 & 3717 & 3505 & 3212 \\
\hline 1985. & 3,264 & 2,709 & 555 & 2,549 & 2,206 & 343 & 1,483 & 1,237 & 246 & 1,066 & 969 & 97 & 3715 & 3503 & 3212 \\
\hline 1986. & 3,314 & 2,754 & 560 & 2,592 & 2,244 & з 348 & 1,521 & 1,271 & 3250 & 1,071 & 973 & 398 & 3722 & 3510 & 3212 \\
\hline 1987 & 3,424 & 2,831 & 593 & 2,631 & 2,279 & 3353 & 1,563 & 1,306 & 3257 & 1,068 & 973 & 395 & 4793 & 4553 & 4240 \\
\hline 1988 & 3,472 & 2,882 & 590 & 2,668 & 2,323 & ${ }^{3} 345$ & 1,604 & 1,353 & ${ }^{3} 251$ & 1,064 & 970 & 394 & ${ }^{3} 804$ & 3559 & ${ }^{3} 245$ \\
\hline 1989 & 3,558 & 2,934 & 624 & 2,734 & 2,357 & 3 377 & 1,662 & 1,387 & 3275 & 1,072 & 970 & 3102 & 824 & 577 & 247 \\
\hline 1990. & 3,570 & 2,972 & 599 & 2,753 & 2,398 & 3 355 & 1,683 & 1,429 & 3254 & 1,070 & 969 & 3101 & 3817 & 3574 & 3244 \\
\hline 1991 .. & 3,613 & 3,013 & 600 & 2,787 & 2,432 & 3 355 & 1,722 & 1,468 & 3254 & 1,065 & 964 & 3101 & 826 & 581 & 245 \\
\hline $1992 \ldots \ldots \ldots$ & 3,699 & 3,080 & 620 & 2,822 & 2,459 & ${ }^{3} 363$ & 1,752 & 1,492 & ${ }^{3} 260$ & 1,070 & 967 & 3103 & 3877 & ${ }^{3} 621$ & ${ }^{3} 257$ \\
\hline 1993. & 3,785 & 3,154 & 631 & 2,870 & 2,504 & 3366 & 1,775 & 1,513 & 3 262 & 1,095 & 991 & 3104 & 915 & 650 & 265 \\
\hline $1994 \ldots$ & 3,849 & 3,205 & 644 & 2,926 & 2,552 & 3374 & 1,791 & 1,525 & 3266 & 1,135 & 1,027 & 3108 & з923 & 3653 & 3270 \\
\hline 1995 ...... & 3,910 & 3,255 & 655 & 2,978 & 2,598 & 3380 & 1,794 & 1,525 & 3269 & 1,184 & 1,073 & 3111 & 932 & 657 & 275 \\
\hline $1996 \ldots$ & 3,988 & 3,323 & 665 & 3,053 & 2,666 & ${ }^{3} 387$ & 1,856 & 1,582 & ${ }^{3} 274$ & 1,197 & 1,084 & 3113 & 3935 & ${ }^{3} 657$ & ${ }^{3} 278$ \\
\hline $1997^{5} .$. & 4,040 & 3,374 & 667 & 3,103 & 2,710 & 3394 & 1,882 & 1,604 & 3278 & 1,222 & 1,106 & 3116 & 3936 & 3664 & 3273 \\
\hline $1998^{5}$ & 4,079 & 3,403 & 676 & 3,126 & 2,728 & 399 & 1,894 & 1,612 & 281 & 1,233 & 1,116 & 117 & 952 & 675 & 277 \\
\hline $1999^{5}$ & 4,131 & 3,446 & 684 & 3,167 & 2,764 & 404 & 1,916 & 1,632 & 285 & 1,251 & 1,132 & 119 & 963 & 682 & 280 \\
\hline $2000^{5}$ & 4,182 & 3,490 & 692 & 3,211 & 2,802 & 409 & 1,939 & 1,651 & 288 & 1,272 & 1,151 & 121 & 971 & 688 & 283 \\
\hline $2001^{5}$ & - & - & - & 3,245 & 2,832 & 413 & 1,957 & 1,666 & 291 & 1,288 & 1,166 & 123 & - & - & - \\
\hline $2002^{5}$ & - & - & - & 3,284 & 2,866 & 418 & 1,972 & 1,679 & 293 & 1,312 & 1,187 & 125 & - & - & - \\
\hline $2003^{5}$ & - & - & - & 3,325 & 2,903 & 423 & 1,989 & 1,693 & 295 & 1,336 & 1,209 & 127 & - & - & - \\
\hline $2004^{5}$ & - & - & - & 3,362 & 2,935 & 427 & 2,001 & 1,704 & 297 & 1,361 & 1,231 & 129 & - & - & - \\
\hline $2005^{5} \ldots$ & - & - & - & 3,394 & 2,963 & 430 & 2,012 & 1,713 & 299 & 1,382 & 1,250 & 131 & - & - & - \\
\hline $2006^{5} \ldots$ & - & - & - & 3,418 & 2,985 & 433 & 2,021 & 1,721 & 300 & 1,397 & 1,264 & 133 & - & - & - \\
\hline $2007^{5}$ & - & - & - & 3,441 & 3,005 & 436 & 2,033 & 1,731 & 302 & 1,408 & 1,274 & 134 & - & - & - \\
\hline $2008^{5} \ldots$ & - & - & - & 3,460 & 3,022 & 438 & 2,047 & 1,743 & 304 & 1,413 & 1,279 & 134 & - & - & - \\
\hline
\end{tabular}

1 Includes teachers in local public school systems and in most private schools (religiously affiliated and nonsectarian). Excludes subcollegiate departments of institutions of higher education, residential schools for exceptional children, and federal schools Teachers are reported in terms of full-time equivalents.

${ }^{2}$ Includes full-time and part-time faculty with the rank of instructor or above in colleges, universities, professional schools, teachers colleges, and 2-year colleges. Excludes teaching assistants.

${ }^{3}$ Estimated.

${ }^{4}$ Based on actual survey data. Methodology for this year and later years is not consistent with figures for earlier years.
${ }^{5}$ Projected.

-Data not available.

NOTE.-Because of rounding, details may not add to totals. Some data have been revised from previously published figures.

SOURCE: U.S. Department of Education, National Center for Education Statistics, Common Core of Data; Projections of Education Statistics, various years; Integrated Postsecondary Education Data System (IPEDS), "Fall Staff" survey; and U.S. Equal Employment Opportunity Commission, Higher Education General Information (EE0-6) Survey (HEGIS), and unpublished data. (This table was prepared July 1998.) 
Table 5.-Educational institutions, by level and control of institution: 1980-81 to 1996-97

\begin{tabular}{|c|c|c|c|c|c|c|c|c|c|c|c|c|}
\hline Level and control of institution & $1980-81$ & $1986-87$ & $1987-88$ & $1988-89$ & $1989-90$ & $1990-91$ & $1991-92$ & $1992-93$ & 1993-94 & 1994-95 & 1995-96 & $1996-97$ \\
\hline 1 & 2 & 3 & 4 & 5 & 6 & 7 & 8 & 9 & 10 & 11 & 12 & 13 \\
\hline All institutions ..... & 117,707 & 121,433 & 122,111 & - & - & 119,242 & 一 & - & 121,855 & - & 124,773 & - \\
\hline Elementary and secondary schools & 106,746 & 109,071 & 110,055 & - & - & 109,228 & - & - & 111,486 & - & 114,811 & 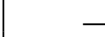 \\
\hline Elementary & 72,659 & 74,104 & 74,511 & - & - & 74,716 & - & - & 75,591 & - & 77,909 & 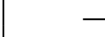 \\
\hline Secondary & 24,856 & 23,844 & 24,057 & - & - & 23,602 & - & - & 23,256 & - & 23,530 & 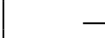 \\
\hline 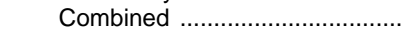 & 5,202 & 6,932 & 8,202 & - & - & 8,847 & - & - & 10,678 & - & 11,205 & 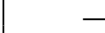 \\
\hline Other $^{1} \ldots \ldots \ldots . . . .$. & 4,029 & 4,191 & 3,285 & - & - & 2,063 & 一 & - & 1,962 & - & 2,167 & _ \\
\hline Public schools & 85,982 & 83,455 & 83,248 & 83,165 & 83,425 & 84,538 & 84,578 & 84,497 & 85,393 & 86,221 & 87,125 & 88,223 \\
\hline Elementary .... & 59,326 & 58,801 & 57,575 & 57,941 & 58,419 & 59,015 & 59,258 & 59,676 & 60,052 & 60,808 & 61,165 & 61,805 \\
\hline Secondary .......... & 22,619 & 21,406 & 21,662 & 21,403 & 21,181 & 21,135 & 20,767 & 20,671 & 20,705 & 20,904 & 20,997 & 21,307 \\
\hline Combined .. & 1,743 & 1,983 & 2,179 & 2,235 & 2,280 & 2,325 & 2,481 & 2,549 & 2,674 & 2,764 & 2,796 & 2,980 \\
\hline Other $^{1}$ & 2,294 & 1,265 & 1,832 & 1,586 & 1,545 & 2,063 & 2,072 & 1,601 & 1,962 & 1,745 & 2,167 & 2,131 \\
\hline Private schools & 20,764 & 225,616 & 26,807 & - & - & 24,690 & 25,998 & - & 26,093 & - & 27,686 & - \\
\hline Elementary ... & 13,333 & 215,303 & 16,936 & - & - & 15,701 & 15,716 & - & 15,539 & - & 16,744 & - \\
\hline Secondary . & 2,237 & 22,438 & 2,395 & - & - & 2,467 & 2,475 & - & 2,551 & - & 2,533 & 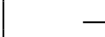 \\
\hline Combined ....... & 3,459 & 24,949 & 6,023 & - & - & 6,522 & 7,807 & - & 8,004 & - & 8,409 & \\
\hline Other ${ }^{1} \ldots \ldots \ldots . . . .$. & 1,735 & 22,926 & 1,453 & - & - & (3) & $(3)$ & 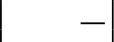 & (3) & - & (3) & - \\
\hline ndary institutions & 961 & 12,362 & 12,056 & 11,389 & 10,606 & 10,014 & 9,983 & 10,601 & 10,369 & 10,246 & 9,962 & 9,837 \\
\hline Public & 42,393 & 2,363 & 2,250 & 2,169 & 2,120 & 2,096 & 2,129 & 2,146 & 2,152 & 2,179 & 2,189 & 2,169 \\
\hline Private nonprofit .......................... & 42,359 & 3,432 & 3,254 & 3,092 & 2,942 & 2,808 & 2,810 & 2,926 & 2,890 & 2,916 & 2,877 & 2,855 \\
\hline 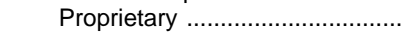 & 46,209 & 6,567 & 6,552 & 6,128 & 5,544 & 5,110 & 5,044 & 5,529 & 5,327 & 5,151 & 4,896 & 4,813 \\
\hline Noncollegiate institutions ${ }^{5}$. & 47,730 & 8,956 & 8,469 & 7,824 & 7,071 & 6,455 & 6,382 & 6,963 & 6,737 & 6,558 & 6,256 & 5,828 \\
\hline 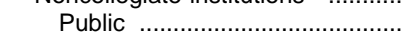 & 4896 & 830 & 659 & 587 & 557 & 529 & 531 & 522 & 527 & 538 & 534 & 467 \\
\hline 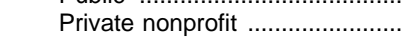 & 4790 & 1,797 & 1,581 & 1,434 & 1,286 & 1,159 & 1,148 & 1,254 & 1,203 & 1,214 & 1,171 & 1,162 \\
\hline 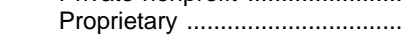 & ${ }^{4} 6,044$ & 6,329 & 6,229 & 5,803 & 5,228 & 4,767 & 4,703 & 5,187 & 5,007 & 4,806 & 4,551 & 4,199 \\
\hline Institutions of higher education ${ }^{5} \ldots \ldots$ & 3,231 & 3,406 & 3,587 & 3,565 & 3,535 & 3,559 & 3,601 & 3,638 & 3,632 & 3,688 & 3,706 & 4,009 \\
\hline 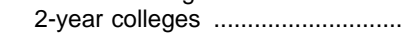 & 1,274 & 1,336 & 1,452 & 1,436 & 1,408 & 1,418 & 1,444 & 1,469 & 1,442 & 1,473 & 1,462 & 1,742 \\
\hline Public & 945 & 960 & 992 & 984 & 968 & 972 & 999 & 1,024 & 1,021 & 1,036 & 1,047 & 1,088 \\
\hline Private nonprofit . & 182 & 173 & 186 & 180 & 177 & 167 & 176 & 179 & 181 & 192 & 187 & 184 \\
\hline Proprietary ........... & 147 & 203 & 274 & 272 & 263 & 279 & 269 & 266 & 240 & 245 & 228 & 470 \\
\hline 4-year colleges & 1,957 & 2,070 & 2,135 & 2,129 & 2,127 & 2,141 & 2,157 & 2,169 & 2,190 & 2,215 & 2,244 & 2,267 \\
\hline Public . . & 552 & 573 & 599 & 598 & 595 & 595 & 599 & 600 & 604 & 605 & 608 & 614 \\
\hline Private nonprofit ........................... & 1,387 & 1,462 & 1,487 & 1,478 & 1,479 & 1,482 & 1,486 & 1,493 & 1,506 & 1,510 & 1,519 & 1,509 \\
\hline Proprietary .................................. & 18 & 35 & 49 & 53 & 53 & 64 & 72 & 76 & 80 & 100 & 117 & 144 \\
\hline
\end{tabular}

1 Includes special education, alternative, and other schools not classified by grade span. Because of changes in survey definitions, figures for "other" schools are not comparable from year to year.

2Data are for 1985-86. Data were collected from a sample survey that differed significantly from earlier surveys. The sample survey was designed to correct an undercount of about 10 percent that was known to have occurred in earlier surveys.

3 Included in other categories.

${ }^{4}$ Because of changes in survey procedures, figures are not directly comparable with data for later years.

5 Includes those colleges designated as institutions of higher education by the Higher Education General Information Survey system, even if they have a less than 2-year program. Includes branch campuses. Beginning in 1980, total includes some schools ac- credited by the Accrediting Commission of Career Schools and Colleges of Technology. In 1996-97, data for institutions of higher education are for degree-granting institutions. Degree-granting institutions include those institutions which award degrees at the associate level or higher and were eligible to participate in Title IV federal financial aid programs. Institutions not meeting these criteria were classified as noncollegiate institutions. —Data not available.

SOURCE: U.S. Department of Education, National Center for Education Statistics, Common Core of Data and Private School surveys; Higher Education General Information Survey, "Institutional Characteristics of Colleges and Universities;" and Integrated Postsecondary Education Data System, "Institutional Characteristics" surveys. (This table was prepared October 1998.) 
Table 6.-Percent of the population 3 to 34 years old enrolled in school, 1 by age: April 1940 to October 1997

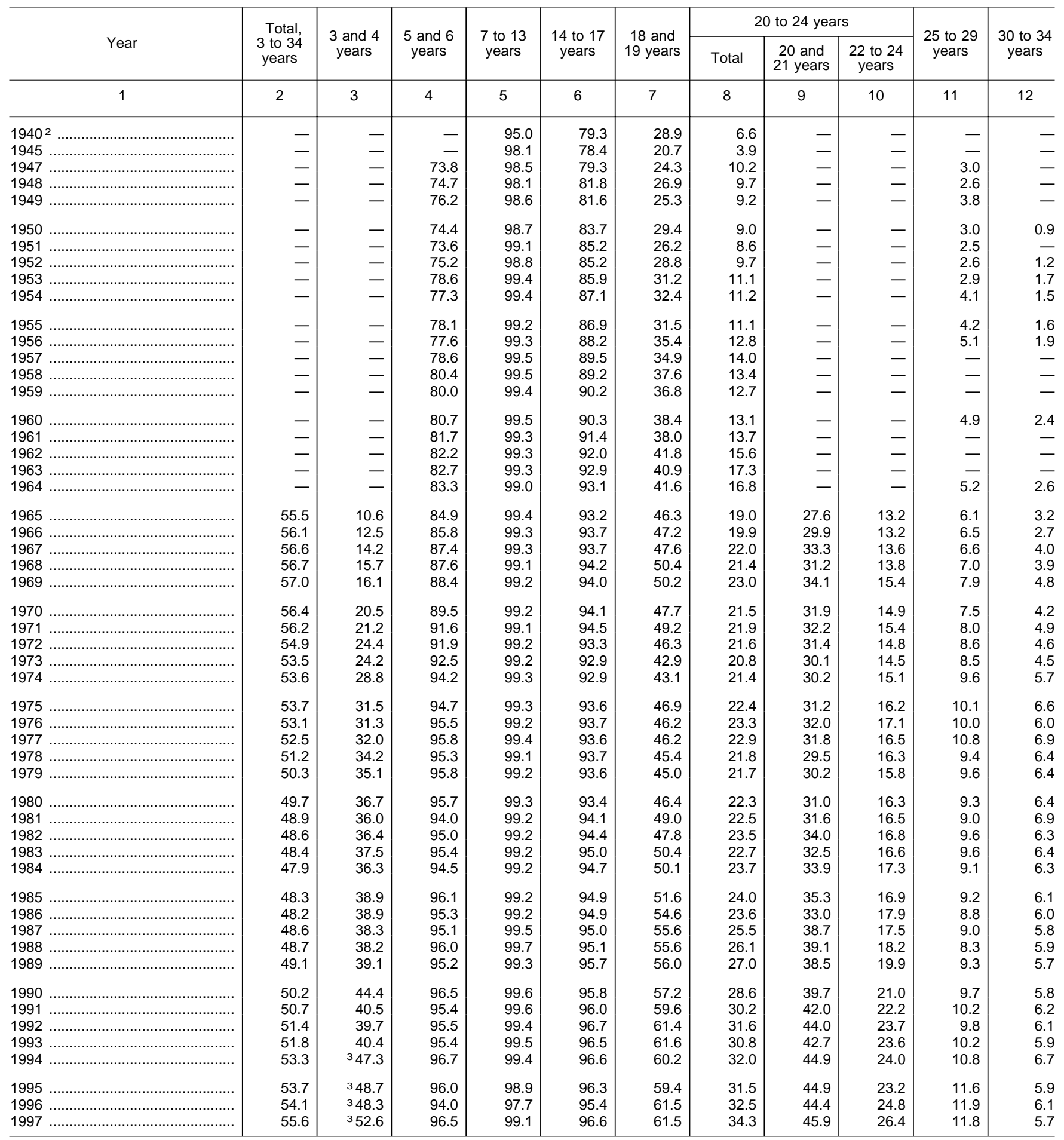

${ }^{1}$ Includes enrollment in any type of graded public, parochial, or other private schools. Includes nursery schools, kindergartens, elementary schools, high schools, colleges, universities, and professional schools. Attendance may be on either a full-time or part-time basis and during the day or night. Enrollments in "special" schools, such as trade schools, business colleges, or correspondence schools, are not included.

2 Data are as of April 1940. Data for all other years are as of October.

${ }^{3}$ Preprimary enrollment collected using new procedures. May not be comparable to figures for earlier years.

\section{-Data not available}

NOTE.-Data are based upon sample surveys of the civilian noninstitutional population.

SOURCE: U.S. Department of Commerce, Bureau of the Census, Historical Statistics of the United States, Colonial Times to 1970; Current Population Reports, Series P-20, various years; and Current Population Survey, unpublished data. (This table was prepared August 1998.) 
Table 7.-Percent of the population 3 to 34 years old enrolled in school, $\mathbf{1}$ by race/ethnicity, sex, and age: October 1980 to October 1997

\begin{tabular}{|c|c|c|c|c|c|c|c|c|c|c|c|c|}
\hline \multirow[b]{2}{*}{ Year and age } & \multicolumn{4}{|c|}{ Total } & \multicolumn{4}{|c|}{ Male } & \multicolumn{4}{|c|}{ Female } \\
\hline & $\begin{array}{c}\text { All } \\
\text { races }\end{array}$ & $\begin{array}{c}\text { White, } \\
\text { non- } \\
\text { Hispanic }\end{array}$ & $\begin{array}{c}\text { Black, } \\
\text { non- } \\
\text { Hispanic }\end{array}$ & $\begin{array}{c}\text { Hispanic } \\
\text { origin }\end{array}$ & $\begin{array}{c}\text { All } \\
\text { races }\end{array}$ & $\begin{array}{c}\text { White, } \\
\text { non- } \\
\text { Hispanic }\end{array}$ & $\begin{array}{c}\text { Black, } \\
\text { non- } \\
\text { Hispanic }\end{array}$ & $\begin{array}{l}\text { Hispanic } \\
\text { origin }\end{array}$ & $\begin{array}{c}\text { All } \\
\text { races }\end{array}$ & $\begin{array}{c}\text { White, } \\
\text { non- } \\
\text { Hispanic }\end{array}$ & $\begin{array}{c}\text { Black, } \\
\text { non- } \\
\text { Hispanic }\end{array}$ & $\begin{array}{c}\text { Hispanic } \\
\text { origin }\end{array}$ \\
\hline 1 & 2 & 3 & 4 & 5 & 6 & 7 & 8 & 9 & 10 & 11 & 12 & 13 \\
\hline \multicolumn{13}{|l|}{1975} \\
\hline Total, 3 to 34 years ............... & 53.7 & 53.0 & 57.7 & 54.8 & 56.1 & 55.2 & 60.4 & 58.1 & 51.5 & 50.8 & 55.3 & 51.7 \\
\hline 3 and 4 years ................... & 31.5 & 31.0 & 34.4 & 27.3 & 30.9 & 31.1 & 31.4 & 26.7 & 32.1 & 30.9 & 37.5 & 27.9 \\
\hline 5 and 6 years .................... & 94.7 & 95.1 & 94.4 & 92.1 & 94.4 & 94.8 & 94.8 & 89.7 & 95.1 & 95.4 & 94.0 & 94.4 \\
\hline 7 to 9 years ....................... & 99.3 & 99.4 & 99.3 & 99.6 & 99.2 & 99.2 & 99.4 & 99.6 & 99.5 & 99.6 & 99.2 & 99.5 \\
\hline 10 to 13 years ....................... & 99.3 & 99.3 & 99.1 & 99.2 & 98.9 & 99.0 & 98.9 & 98.8 & 99.6 & 99.6 & 99.3 & 99.7 \\
\hline 14 and 15 years ................. & 98.2 & 98.5 & 97.4 & 95.6 & 98.4 & 98.6 & 97.6 & 97.4 & 98.0 & 98.4 & 97.2 & 93.8 \\
\hline 16 and 17 years ................. & 89.0 & 89.5 & 86.8 & 86.2 & 90.7 & 91.2 & 88.1 & 88.3 & 87.2 & 87.8 & 85.5 & 84.0 \\
\hline 18 and 19 years .................... & 46.9 & 46.8 & 46.9 & 44.0 & 49.9 & 49.4 & 49.6 & 51.9 & 44.2 & 44.2 & 44.6 & 37.1 \\
\hline 20 and 21 years .............. & 31.2 & 32.1 & 26.7 & 27.5 & 35.3 & 36.7 & 28.4 & 31.3 & 27.4 & 27.8 & 25.3 & 24.3 \\
\hline 22 to 24 years ...................... & 16.2 & 16.4 & 13.9 & 14.1 & 20.0 & 20.8 & 14.5 & 15.9 & 12.6 & 12.2 & 13.4 & 12.5 \\
\hline 25 to 29 years .................. & 10.1 & 10.1 & 9.4 & 8.3 & 13.1 & 13.2 & 11.6 & 11.9 & 7.2 & 7.2 & 7.6 & 5.3 \\
\hline 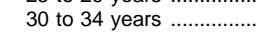 & 6.6 & 6.6 & 7.1 & 5.5 & 7.7 & 7.5 & 8.7 & 7.2 & 5.6 & 5.8 & 5.9 & 4.1 \\
\hline \multicolumn{13}{|l|}{1980} \\
\hline Total, 3 to 34 years ............. & 49.7 & 48.8 & 54.0 & 49.8 & 50.9 & 50.0 & 56.2 & 49.9 & 48.5 & 47.7 & 52.1 & 49.8 \\
\hline 3 and 4 years .................... & 36.7 & 37.4 & 38.2 & 28.5 & 37.8 & 39.2 & 36.4 & 30.1 & 35.5 & 35.5 & 40.0 & 26.6 \\
\hline 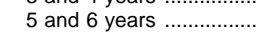 & 95.7 & 95.9 & 95.5 & 94.5 & 95.0 & 95.4 & 94.1 & 94.0 & 96.4 & 96.5 & 97.0 & 94.9 \\
\hline 7 to 9 years ...................... & 99.1 & 99.1 & 99.4 & 98.4 & 99.0 & 99.0 & 99.5 & 97.7 & 99.2 & 99.2 & 99.3 & 99.0 \\
\hline 10 to 13 years ..................... & 99.4 & 99.4 & 99.4 & 99.7 & 99.4 & 99.4 & 99.4 & 99.4 & 99.4 & 99.3 & 99.3 & 99.9 \\
\hline 14 and 15 years ................. & 98.2 & 98.7 & 97.9 & 94.3 & 98.7 & 98.9 & 98.4 & 96.7 & 97.7 & 98.5 & 97.3 & 92.1 \\
\hline 16 and 17 years .................. & 89.0 & 89.2 & 90.7 & 81.8 & 89.1 & 89.4 & 90.7 & 81.5 & 88.8 & 89.0 & 90.6 & 82.2 \\
\hline 18 and 19 years .................... & 46.4 & 47.0 & 45.8 & 37.8 & 47.0 & 48.5 & 42.9 & 36.9 & 45.8 & 45.7 & 48.3 & 38.8 \\
\hline 20 and 21 years ............... & 31.0 & 33.0 & 23.3 & 19.5 & 32.6 & 34.8 & 22.8 & 21.4 & 29.5 & 31.3 & 23.7 & 17.6 \\
\hline 22 to 24 years ...................... & 16.3 & 16.8 & 13.6 & 11.7 & 17.8 & 18.7 & 13.4 & 10.7 & 14.9 & 15.0 & 13.7 & 12.6 \\
\hline 25 to 29 years ................... & 9.3 & 9.4 & 8.8 & 6.9 & 9.8 & 9.8 & 10.6 & 6.8 & 8.8 & 9.1 & 7.5 & 6.9 \\
\hline 30 to 34 years ................... & 6.4 & 6.4 & 6.9 & 5.1 & 5.9 & 5.6 & 7.2 & 6.2 & 7.0 & 7.2 & 6.6 & 4.1 \\
\hline \multicolumn{13}{|l|}{1985} \\
\hline Total, 3 to 34 years ............ & 48.3 & 47.8 & 50.8 & 47.7 & 49.2 & 48.7 & 52.6 & 47.5 & 47.4 & 46.9 & 49.2 & 47.9 \\
\hline 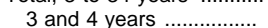 & 38.9 & 40.3 & 42.8 & 27.0 & 36.7 & 39.1 & 34.6 & 26.4 & 41.2 & 41.6 & 50.3 & 27.7 \\
\hline 5 and 6 years .................... & 96.1 & 96.6 & 95.7 & 94.5 & 95.3 & 95.6 & 94.5 & 95.3 & 97.0 & 97.6 & 97.1 & 93.7 \\
\hline 7 to 9 years ......................... & 99.1 & 99.4 & 98.6 & 98.4 & 99.0 & 99.3 & 98.4 & 98.9 & 99.2 & 99.4 & 98.9 & 98.0 \\
\hline 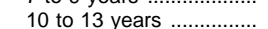 & 99.3 & 99.3 & 99.5 & 99.4 & 99.2 & 99.2 & 99.1 & 99.1 & 99.4 & 99.3 & 99.9 & 99.7 \\
\hline 14 and 15 years ................. & 98.1 & 98.3 & 98.1 & 96.1 & 98.3 & 98.4 & 98.5 & 96.2 & 97.9 & 98.1 & 97.6 & 96.0 \\
\hline 16 and 17 years ..................... & 91.7 & 92.5 & 91.8 & 84.5 & 92.4 & 92.9 & 92.0 & 88.9 & 90.9 & 92.2 & 91.6 & 80.0 \\
\hline 18 and 19 years ................. & 51.6 & 53.7 & 43.5 & 41.8 & 52.2 & 53.4 & 49.4 & 38.6 & 51.0 & 54.0 & 37.8 & 44.7 \\
\hline 20 and 21 years ................ & 35.3 & 37.2 & 27.7 & 24.0 & 36.5 & 38.8 & 29.9 & 20.3 & 34.1 & 35.7 & 25.8 & 27.4 \\
\hline 22 to 24 years .......................... & 16.9 & 17.5 & 13.8 & 11.6 & 18.8 & 19.8 & 13.5 & 12.6 & 15.1 & 15.4 & 14.0 & 10.4 \\
\hline 25 to 29 years .................. & 9.2 & 9.6 & 7.4 & 6.6 & 9.4 & 9.7 & 5.8 & 8.2 & 9.1 & 9.4 & 8.7 & 4.9 \\
\hline 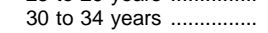 & 6.1 & 6.2 & 5.2 & 5.7 & 5.4 & 5.6 & 3.9 & 4.0 & 6.8 & 6.9 & 6.2 & 7.5 \\
\hline \multicolumn{13}{|l|}{1990} \\
\hline Total, 3 to 34 years ............ & 50.2 & 49.8 & 52.2 & 47.2 & 50.9 & 50.4 & 54.3 & 46.8 & 49.5 & 49.2 & 50.3 & 47.7 \\
\hline 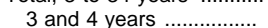 & 44.4 & 47.2 & 41.8 & 30.7 & 43.9 & 47.9 & 38.1 & 28.0 & 44.9 & 46.6 & 45.5 & 33.6 \\
\hline 5 and 6 years .................... & 96.5 & 96.7 & 96.5 & 94.9 & 96.5 & 96.8 & 96.2 & 95.8 & 96.4 & 96.7 & 96.9 & 93.9 \\
\hline 7 to 9 years .......................... & 99.7 & 99.7 & 99.8 & 99.5 & 99.7 & 99.7 & 99.9 & 99.5 & 99.6 & 99.7 & 99.8 & 99.4 \\
\hline 10 to 13 years ..................... & 99.6 & 99.7 & 99.9 & 99.1 & 99.6 & 99.6 & 99.9 & 99.0 & 99.7 & 99.7 & 99.8 & 99.1 \\
\hline 14 and 15 years ................. & 99.0 & 99.0 & 99.4 & 99.0 & 99.1 & 99.2 & 99.7 & 99.1 & 98.9 & 98.9 & 99.1 & 98.8 \\
\hline 16 and 17 years ..................... & 92.5 & 93.5 & 91.7 & 85.4 & 92.6 & 93.4 & 93.0 & 85.5 & 92.4 & 93.7 & 90.5 & 85.3 \\
\hline 18 and 19 years ................ & 57.2 & 59.1 & 55.0 & 44.0 & 58.2 & 59.7 & 60.4 & 40.7 & 56.3 & 58.5 & 49.8 & 47.2 \\
\hline 20 and 21 years ................... & 39.7 & 43.1 & 28.3 & 27.2 & 40.3 & 44.2 & 31.0 & 21.7 & 39.2 & 42.0 & 25.8 & 33.1 \\
\hline 22 to 24 years ..................... & 21.0 & 21.9 & 19.7 & 9.9 & 22.3 & 23.7 & 19.3 & 11.2 & 19.9 & 20.3 & 20.0 & 8.4 \\
\hline 25 to 29 years .................. & 9.7 & 10.4 & 6.1 & 6.3 & 9.2 & 10.0 & 4.7 & 4.6 & 10.2 & 10.7 & 7.3 & 8.1 \\
\hline 30 to 34 years ...................... & 5.8 & 6.2 & 4.5 & 3.6 & 4.8 & 5.0 & 2.3 & 4.0 & 6.9 & 7.4 & 6.3 & 3.1 \\
\hline \multicolumn{13}{|l|}{1997} \\
\hline Total, 3 to 34 years ............ & 55.6 & 55.6 & 58.6 & 50.8 & 55.8 & 55.9 & 59.7 & 49.0 & 55.4 & 55.2 & 57.5 & 52.7 \\
\hline 3 and 4 years ${ }^{2}$ & 52.6 & 54.9 & 60.0 & 36.6 & 51.9 & 54.9 & 57.4 & 35.5 & 53.2 & 55.0 & 62.9 & 37.7 \\
\hline 5 and 6 years .................. & 96.5 & 96.9 & 95.7 & 96.6 & 96.7 & 97.3 & 94.0 & 97.7 & 96.4 & 96.4 & 97.1 & 95.7 \\
\hline 7 to 9 years .......................... & 98.8 & 98.9 & 99.2 & 98.6 & 98.6 & 98.8 & 98.7 & 97.7 & 99.1 & 99.0 & 99.8 & 99.6 \\
\hline 10 to 13 years & 99.3 & 99.2 & 99.4 & 99.6 & 99.4 & 99.3 & 99.1 & 99.8 & 99.3 & 99.1 & 99.7 & 99.5 \\
\hline 14 and 15 years ...................... & 98.9 & 98.9 & 99.2 & 98.4 & 99.1 & 99.0 & 99.5 & 99.5 & 98.7 & 98.8 & 98.9 & 97.3 \\
\hline 16 and 17 years .................... & 94.3 & 95.1 & 93.5 & 91.1 & 94.2 & 94.5 & 93.8 & 92.5 & 94.4 & 95.7 & 93.2 & 89.6 \\
\hline 18 and 19 years ................ & 61.5 & 64.0 & 57.8 & 49.4 & 60.5 & 63.3 & 56.2 & 45.4 & 62.4 & 64.9 & 59.4 & 53.9 \\
\hline 20 and 21 years ................. & 45.9 & 49.9 & 36.0 & 28.9 & 44.4 & 48.5 & 35.1 & 27.6 & 47.4 & 51.3 & 36.7 & 30.4 \\
\hline 22 to 24 years & 26.4 & 27.8 & 25.7 & 16.4 & 25.4 & 27.5 & 21.8 & 14.0 & 27.4 & 28.1 & 28.9 & 19.2 \\
\hline 25 to 29 years ................... & 11.8 & 12.2 & 10.6 & 7.3 & 11.7 & 12.0 & 10.1 & 5.9 & 11.9 & 12.4 & 10.9 & 8.8 \\
\hline 30 to 34 years ........................ & 5.7 & 5.6 & 6.5 & 3.7 & 4.7 & 4.6 & 5.8 & 2.7 & 6.6 & 6.6 & 7.2 & 4.9 \\
\hline
\end{tabular}

1 Includes enrollment in any type of graded public, parochial, or other private schools. Includes nursery schools, kindergartens, elementary schools, high schools, colleges, universities, and professional schools. Attendance may be on either a full-time or part-time basis and during the day or night. Enrollments in "special" schools, such as trade schools, business colleges, or correspondence schools, are not included.

${ }^{2}$ Preprimary enrollment collected using new procedures. May not be comparable to figures for earlier years.
NOTE.-Data are based upon sample surveys of the civilian noninstitutional population.

SOURCE: U.S. Department of Commerce, Bureau of the Census, Current Population Survey, unpublished data. (This table was prepared August 1998.) 
Table 8.-Years of school completed by persons age 25 and over and 25 to 29 , by race/ethnicity and sex: 1910 to 1997

\begin{tabular}{|c|c|c|c|c|c|c|c|c|c|c|c|c|}
\hline \multirow[b]{3}{*}{ Age, year, and sex } & \multicolumn{12}{|c|}{ Percent, by years of school completed } \\
\hline & \multicolumn{3}{|c|}{ All races } & \multicolumn{3}{|c|}{ White, non-Hispanic ${ }^{1}$} & \multicolumn{3}{|c|}{ Black, non-Hispanic ${ }^{1}$} & \multicolumn{3}{|c|}{ Hispanic } \\
\hline & $\begin{array}{l}\text { Less } \\
\text { than } 5 \\
\text { years of } \\
\text { elemen- } \\
\text { tary } \\
\text { school }\end{array}$ & $\begin{array}{l}\text { High } \\
\text { school } \\
\text { comple- } \\
\text { tion or } \\
\text { higher }^{2}\end{array}$ & $\begin{array}{c}4 \text { or } \\
\text { more } \\
\text { years of } \\
\text { college }^{3}\end{array}$ & $\begin{array}{l}\text { Less } \\
\text { than } 5 \\
\text { years of } \\
\text { elemen- } \\
\text { tary } \\
\text { school }\end{array}$ & $\begin{array}{c}\text { High } \\
\text { school } \\
\text { comple- } \\
\text { tion or } \\
\text { higher }^{2}\end{array}$ & $\begin{array}{c}4 \text { or } \\
\text { more } \\
\text { years of } \\
\text { college }^{3}\end{array}$ & $\begin{array}{l}\text { Less } \\
\text { than } 5 \\
\text { years of } \\
\text { elemen- } \\
\text { tary } \\
\text { school }\end{array}$ & $\begin{array}{l}\text { High } \\
\text { school } \\
\text { comple- } \\
\text { tion or } \\
\text { higher } 2\end{array}$ & $\begin{array}{c}4 \text { or } \\
\text { more } \\
\text { years of } \\
\text { college }^{3}\end{array}$ & $\begin{array}{l}\text { Less } \\
\text { than } 5 \\
\text { years of } \\
\text { elemen- } \\
\text { tary } \\
\text { school }\end{array}$ & $\begin{array}{l}\text { High } \\
\text { school } \\
\text { comple- } \\
\text { tion or } \\
\text { higher }^{2}\end{array}$ & $\begin{array}{c}4 \text { or } \\
\text { more } \\
\text { years of } \\
\text { college }^{3}\end{array}$ \\
\hline \multirow[t]{2}{*}{1} & 2 & 3 & 4 & 5 & 6 & 7 & 8 & 9 & 10 & 11 & 12 & 13 \\
\hline & \multicolumn{12}{|c|}{ Males and females } \\
\hline $\begin{array}{l}25 \text { and over } \\
1910^{4} \\
1920^{4} \\
1930^{4} \\
\text { April } 1940 \\
\text { April } 1950\end{array}$ & $\begin{array}{l}23.8 \\
22.0 \\
17.5 \\
13.7 \\
11.1\end{array}$ & $\begin{array}{l}13.5 \\
16.4 \\
19.1 \\
24.5 \\
34.3\end{array}$ & $\begin{array}{l}2.7 \\
3.3 \\
3.9 \\
4.6 \\
6.2\end{array}$ & $\begin{array}{r}\overline{-} \\
\overline{-} \\
10.9 \\
8.9\end{array}$ & $\begin{array}{r}- \\
\overline{-} \\
26.1 \\
36.4\end{array}$ & $\begin{array}{c}\overline{-} \\
\overline{-} \\
4.9 \\
6.6\end{array}$ & $\begin{array}{r}- \\
\overline{-} \\
41.8 \\
32.6\end{array}$ & $\begin{array}{r}- \\
\overline{-} \\
7.7 \\
13.7\end{array}$ & $\begin{array}{l}\overline{-} \\
\overline{-} \\
1.3 \\
2.2\end{array}$ & $\begin{array}{l}- \\
- \\
-\end{array}$ & $\begin{array}{l}- \\
- \\
- \\
-\end{array}$ & $\begin{array}{l}- \\
- \\
-\end{array}$ \\
\hline $\begin{array}{l}\text { April } 1960 \\
\text { March } 1970 \\
\text { March } 1980 \\
\text { March } 1985 \\
\text { March } 1986 \\
\text { March } 1987 \\
\text { March } 1988 \ldots \ldots \ldots \ldots \ldots \ldots \ldots \ldots \ldots \ldots \ldots \ldots \\
\text { March } 1989\end{array}$ & $\begin{array}{l}8.3 \\
5.3 \\
3.4 \\
2.7 \\
2.7 \\
2.4 \\
2.5 \\
2.5\end{array}$ & $\begin{array}{l}41.1 \\
55.2 \\
68.6 \\
73.9 \\
74.7 \\
75.6 \\
76.2 \\
76.9\end{array}$ & $\begin{array}{r}7.7 \\
11.0 \\
17.0 \\
19.4 \\
19.4 \\
19.9 \\
20.3 \\
21.1\end{array}$ & $\begin{array}{l}6.7 \\
4.2 \\
1.9 \\
1.4 \\
1.4 \\
1.3 \\
1.2 \\
1.2\end{array}$ & $\begin{array}{l}43.2 \\
57.4 \\
71.9 \\
77.5 \\
78.2 \\
79.0 \\
79.8 \\
80.7\end{array}$ & $\begin{array}{r}8.1 \\
11.6 \\
18.4 \\
20.8 \\
20.1 \\
20.5 \\
21.8 \\
22.8\end{array}$ & $\begin{array}{r}23.5 \\
14.7 \\
9.1 \\
6.1 \\
5.3 \\
4.9 \\
4.8 \\
5.2\end{array}$ & $\begin{array}{l}21.7 \\
36.1 \\
51.4 \\
59.9 \\
62.5 \\
63.6 \\
63.5 \\
64.7\end{array}$ & \begin{tabular}{r|}
3.5 \\
6.1 \\
7.9 \\
11.1 \\
10.9 \\
10.8 \\
11.2 \\
11.7
\end{tabular} & $\begin{array}{r}- \\
15.8 \\
13.5 \\
12.9 \\
11.9 \\
12.2 \\
12.2\end{array}$ & $\begin{array}{r}- \\
44.5 \\
47.9 \\
48.5 \\
50.9 \\
51.0 \\
50.9\end{array}$ & $\begin{array}{r}\overline{-} \\
7.6 \\
8.5 \\
8.4 \\
8.6 \\
10.0 \\
9.9\end{array}$ \\
\hline 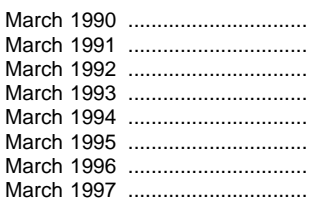 & $\begin{array}{l}2.5 \\
2.4 \\
2.1 \\
2.1 \\
1.9 \\
1.9 \\
1.8 \\
1.7\end{array}$ & $\begin{array}{l}77.6 \\
78.4 \\
79.4 \\
80.2 \\
80.9 \\
81.7 \\
81.7 \\
82.1\end{array}$ & $\begin{array}{l}21.3 \\
21.4 \\
21.4 \\
21.9 \\
22.2 \\
23.0 \\
23.6 \\
23.9\end{array}$ & $\begin{array}{l}1.1 \\
1.1 \\
0.9 \\
0.8 \\
0.8 \\
0.7 \\
0.6 \\
0.6\end{array}$ & $\begin{array}{l}81.4 \\
82.4 \\
83.4 \\
84.1 \\
84.9 \\
85.9 \\
86.0 \\
86.3\end{array}$ & $\begin{array}{l}23.1 \\
23.3 \\
23.2 \\
23.8 \\
24.3 \\
23.4 \\
25.9 \\
26.2\end{array}$ & $\begin{array}{l}5.1 \\
4.7 \\
3.9 \\
3.7 \\
2.7 \\
2.5 \\
2.2 \\
2.0\end{array}$ & $\begin{array}{l}66.2 \\
66.8 \\
67.7 \\
70.5 \\
73.0 \\
73.8 \\
74.6 \\
75.3\end{array}$ & $\begin{array}{l}11.3 \\
11.5 \\
11.9 \\
12.2 \\
12.9 \\
13.3 \\
13.8 \\
13.3\end{array}$ & $\begin{array}{r}12.3 \\
12.5 \\
11.8 \\
11.8 \\
10.8 \\
10.6 \\
10.4 \\
9.4\end{array}$ & $\begin{array}{l}50.8 \\
51.3 \\
52.6 \\
53.1 \\
53.3 \\
53.4 \\
53.1 \\
54.7\end{array}$ & $\begin{array}{r}9.2 \\
9.7 \\
9.3 \\
9.0 \\
9.1 \\
9.3 \\
9.3 \\
10.3\end{array}$ \\
\hline \multicolumn{13}{|l|}{$\begin{array}{l}25 \text { to } 29 \\
1920^{4}\end{array}$} \\
\hline 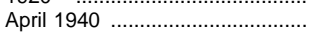 & 5.9 & 38.1 & 5.9 & 3.4 & 41.2 & 6.4 & 27.0 & 12.3 & 1.6 & - & - & - \\
\hline April 1950 & 4.6 & 52.8 & 7.7 & 3.3 & 56.3 & 8.2 & 16.1 & 23.6 & 2.8 & - & - & - \\
\hline April 1960 & 2.8 & 60.7 & 11.0 & 2.2 & 63.7 & 11.8 & 7.2 & 38.6 & 5.4 & - & - & - \\
\hline March 1970 & 1.1 & 75.4 & 16.4 & 0.9 & 77.8 & 17.3 & 2.2 & 58.4 & 10.0 & - & - & - \\
\hline March 1980 & 0.8 & 85.4 & 22.5 & 0.3 & 89.2 & 25.0 & 0.7 & 76.7 & 11.6 & 6.7 & 58.0 & 7.7 \\
\hline March 1985 & 0.7 & 86.1 & 22.2 & 0.2 & 89.5 & 24.4 & 0.4 & 80.5 & 11.6 & 6.0 & 60.9 & 11.1 \\
\hline March 1986 & 0.9 & 86.1 & 22.4 & 0.4 & 89.6 & 25.2 & 0.5 & 83.5 & 11.8 & 5.6 & 59.1 & 9.0 \\
\hline March 1987 .................................... & 0.9 & 86.0 & 22.0 & 0.4 & 89.4 & 24.7 & 0.4 & 83.5 & 11.5 & 4.8 & 59.8 & 8.7 \\
\hline 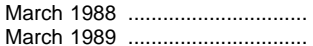 & $\begin{array}{l}1.0 \\
1.0\end{array}$ & $\begin{array}{l}85.9 \\
85.5\end{array}$ & $\begin{array}{l}22.7 \\
23.4\end{array}$ & $\begin{array}{l}0.3 \\
0.3\end{array}$ & $\begin{array}{l}89.7 \\
89.3\end{array}$ & $\begin{array}{l}25.1 \\
26.3\end{array}$ & $\begin{array}{l}0.3 \\
0.5\end{array}$ & $\begin{array}{l}80.9 \\
82.3\end{array}$ & $\begin{array}{l}12.0 \\
12.7\end{array}$ & $\begin{array}{l}6.0 \\
5.4\end{array}$ & $\begin{array}{l}62.3 \\
61.0\end{array}$ & $\begin{array}{l}11.3 \\
10.1\end{array}$ \\
\hline March 1990 & 1.2 & 85.7 & 23.2 & 0.3 & 90.1 & 26.4 & 1.0 & 81.7 & 13.4 & 7.3 & 58.2 & 8.2 \\
\hline March 1991 & 1.0 & 85.4 & 23.2 & 0.3 & 89.8 & 26.7 & 0.5 & 81.8 & 11.0 & 5.8 & 56.7 & 9.2 \\
\hline 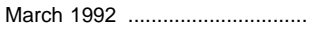 & 0.9 & 86.3 & 23.6 & 0.3 & 90.7 & 27.2 & 0.8 & 80.9 & 11.1 & 5.2 & 60.9 & 9.5 \\
\hline 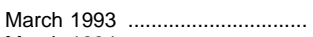 & 0.7 & 86.7 & 23.7 & 0.3 & 91.2 & 27.2 & 0.2 & 82.7 & 13.3 & 4.0 & 60.9 & 8.3 \\
\hline March 1994 ............................. & 0.8 & 86.1 & 23.3 & 0.3 & 91.1 & 27.1 & 0.6 & 84.1 & 13.6 & 3.6 & 60.3 & 8.0 \\
\hline March 1995 & 1.0 & 86.9 & 24.7 & 0.3 & 92.5 & 28.8 & 0.2 & 86.7 & 15.4 & 4.9 & 57.2 & 8.9 \\
\hline March 1996 & 0.8 & 87.3 & 27.1 & 0.2 & 92.6 & 31.6 & 0.4 & 86.0 & 14.6 & 4.3 & 61.1 & 10.0 \\
\hline \multirow[t]{2}{*}{ 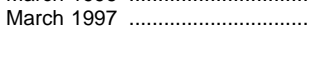 } & 0.8 & 87.4 & 27.8 & 0.1 & 92.9 & 32.6 & 0.6 & 86.9 & 14.2 & 4.2 & 61.8 & 11.0 \\
\hline & \multicolumn{12}{|c|}{ Males } \\
\hline 25 and over & & & & & & & & & & & & \\
\hline April $1940 \ldots \ldots$ & 15.1 & 22.7 & 5.5 & 12.0 & 24.2 & 5.9 & 46.2 & 6.9 & 1.4 & - & - & - \\
\hline April 1950 & 12.2 & 32.6 & 7.3 & 9.8 & 34.6 & 7.9 & 36.9 & 12.6 & 2.1 & - & - & - \\
\hline April 1960 & 9.4 & 39.5 & 9.7 & 7.4 & 41.6 & 10.3 & 27.7 & 20.0 & 3.5 & - & - & - \\
\hline March $1970 \ldots \ldots \ldots \ldots \ldots \ldots \ldots \ldots \ldots \ldots$ & 5.9 & 55.0 & 14.1 & 4.5 & 57.2 & 15.0 & 17.9 & 35.4 & 6.8 & - & - & - \\
\hline March 1980 .............................. & 3.6 & 69.2 & 20.9 & 2.0 & 72.4 & 22.8 & 11.3 & 51.2 & 7.7 & 16.5 & 44.9 & 9.2 \\
\hline March 1990 & 2.7 & 77.7 & 24.4 & 1.3 & 81.6 & 26.7 & 6.4 & 65.8 & 11.9 & 12.9 & 50.3 & 9.8 \\
\hline March 1994 & 2.1 & 81.1 & 25.1 & 0.8 & 85.1 & 27.8 & 3.9 & 71.8 & 12.7 & 11.4 & 53.4 & 9.6 \\
\hline March 1995 & 2.0 & 81.7 & 26.0 & 0.8 & 86.0 & 28.9 & 3.4 & 73.5 & 13.7 & 10.8 & 52.9 & 10.1 \\
\hline March 1996 & 1.9 & 81.9 & 26.0 & 0.7 & 86.1 & 28.8 & 2.9 & 74.6 & 12.5 & 10.2 & 53.0 & 10.3 \\
\hline \multirow[t]{2}{*}{ 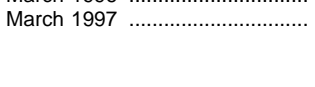 } & 1.8 & 82.0 & 26.2 & 0.6 & 86.3 & 29.0 & 2.9 & 73.8 & 12.5 & 9.2 & 54.9 & 10.6 \\
\hline & \multicolumn{12}{|c|}{ Females } \\
\hline $\begin{array}{l}25 \text { and over } \\
\text { April } 1940\end{array}$ & 12.4 & 26.3 & 3.8 & 98 & 28.1 & 40 & 375 & 8.4 & 12 & -1 & -1 & 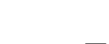 \\
\hline April 1950 & $\begin{array}{l}12.4 \\
10.0\end{array}$ & $\begin{array}{l}20.3 \\
36.0\end{array}$ & $\begin{array}{l}3.0 \\
5.2\end{array}$ & $\begin{array}{l}9.0 \\
8.1\end{array}$ & $\begin{array}{l}20.1 \\
38.2\end{array}$ & $\begin{array}{l}4.0 \\
5.4\end{array}$ & $\begin{array}{l}37.5 \\
28.6\end{array}$ & $\begin{array}{r}0.4 \\
14.7\end{array}$ & $\begin{array}{l}1.2 \\
2.4\end{array}$ & $\overline{-}$ & - & - \\
\hline 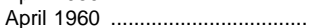 & 7.4 & 42.5 & 5.8 & 6.0 & 44.7 & 6.0 & 19.7 & 23.1 & 3.6 & - & - & - \\
\hline March 1970 & 4.7 & 55.4 & 8.2 & 3.9 & 57.7 & 8.6 & 11.9 & 36.6 & 5.6 & - & - & - \\
\hline March 1980 .................................. & 3.2 & 68.1 & 13.6 & 1.8 & 71.5 & 14.4 & 7.4 & 51.5 & 8.1 & 15.3 & 44.2 & 6.2 \\
\hline March 1990 & 2.2 & 77.5 & 18.4 & 1.0 & 81.3 & 19.8 & 4.1 & 66.5 & 10.8 & 11.7 & 51.3 & 8.7 \\
\hline March 1994 & 1.7 & 80.8 & 19.6 & 0.7 & 84.7 & 21.1 & 1.8 & 73.9 & 13.1 & 10.3 & 53.2 & 8.6 \\
\hline 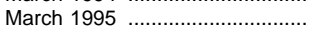 & 1.7 & 81.6 & 20.2 & 0.6 & 85.8 & 22.2 & 1.8 & 74.1 & 13.0 & 10.4 & 53.8 & 8.4 \\
\hline March 1996 & 1.7 & 81.6 & 21.4 & 0.5 & 85.9 & 23.2 & 1.6 & 74.6 & 14.8 & 10.6 & 53.3 & 8.3 \\
\hline March 1997 ................................. & 1.6 & 82.2 & 21.7 & 0.5 & 86.3 & 23.7 & 1.3 & 76.5 & 14.0 & 9.5 & 54.6 & 10.1 \\
\hline
\end{tabular}

${ }^{1}$ Includes persons of Hispanic origin for years prior to 1980.

2 Data for years prior to 1993 include all persons with at least 4 years of high school. ${ }^{3}$ Data for 1993 and later years are for persons with a bachelor's degree or higher.

${ }^{4}$ Estimates based on Bureau of the Census retrojection of 1940 Census data on education by age.

-Data not available.
SOURCE: U.S. Department of Commerce, Bureau of the Census, U.S. Census of Population, 1960, Vol. 1, part 1; Current Population Reports, Series P-20 and unpublished data; and 1960 Census Monograph, "Education of the American Population," by John K. Folger and Charles B. Nam. (This table was prepared July 1998.) 
Table 9.-Highest level of education attained by persons age 18 and over, by age, sex, and race/ethnicity: March 1997

[In thousands]

\begin{tabular}{|c|c|c|c|c|c|c|c|c|c|c|c|c|}
\hline \multirow[b]{2}{*}{ Age, sex, and race } & \multirow{2}{*}{$\begin{array}{c}\text { Total } \\
\text { population } 1\end{array}$} & \multicolumn{2}{|c|}{ Elementary level } & \multicolumn{3}{|c|}{ High school } & \multicolumn{6}{|c|}{ College } \\
\hline & & $\begin{array}{l}\text { Less than } \\
7 \text { years }\end{array}$ & $\begin{array}{l}7 \text { or } 8 \\
\text { years }\end{array}$ & $\begin{array}{l}1 \text { to } 3 \\
\text { years }\end{array}$ & 4 years & $\begin{array}{l}\text { Grad- } \\
\text { uate }\end{array}$ & $\begin{array}{c}\text { Some } \\
\text { college }\end{array}$ & $\begin{array}{l}\text { Associ- } \\
\text { ate }\end{array}$ & $\begin{array}{l}\text { Bach- } \\
\text { elor's }\end{array}$ & Master's & $\begin{array}{c}\text { Profes- } \\
\text { sional }\end{array}$ & $\begin{array}{c}\text { Doctor- } \\
\text { ate }\end{array}$ \\
\hline 1 & 2 & 3 & 4 & 5 & 6 & 7 & 8 & 9 & 10 & 11 & 12 & 13 \\
\hline 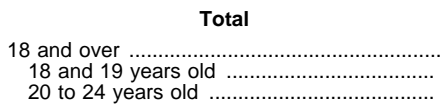 & $\begin{array}{r}195,568 \\
7,498 \\
17,489\end{array}$ & $\begin{array}{r}6,799 \\
71 \\
339\end{array}$ & $\begin{array}{r}7,250 \\
101 \\
225\end{array}$ & $\begin{array}{r}19,393 \\
2,646 \\
1,628\end{array}$ & $\begin{array}{r}2,868 \\
425 \\
350\end{array}$ & $\begin{array}{r}65,370 \\
2,312 \\
5,472\end{array}$ & $\begin{array}{r}38,041 \\
1,916 \\
6,757\end{array}$ & $\begin{array}{r}13,336 \\
17 \\
914\end{array}$ & $\begin{array}{r}29,089 \\
9 \\
1,723\end{array}$ & $\begin{array}{r}9,205 \\
1 \\
73\end{array}$ & $\frac{2,455}{8}$ & $\begin{array}{r}1,761 \\
-\end{array}$ \\
\hline 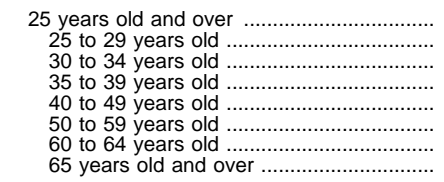 & $\begin{array}{r}170,581 \\
19,260 \\
20,996 \\
22,755 \\
39,559 \\
26,238 \\
9,896 \\
31,877\end{array}$ & $\begin{array}{r}6,389 \\
423 \\
509 \\
555 \\
995 \\
1,012 \\
572 \\
2,322\end{array}$ & $\begin{array}{r}6,924 \\
276 \\
298 \\
315 \\
744 \\
998 \\
622 \\
3,670\end{array}$ & $\begin{array}{r}15,119 \\
1,479 \\
1,591 \\
1,700 \\
2,531 \\
2,134 \\
1,151 \\
4,532\end{array}$ & $\begin{array}{r}2,093 \\
255 \\
299 \\
281 \\
370 \\
297 \\
132 \\
460\end{array}$ & $\begin{array}{r}57,586 \\
5,821 \\
6,889 \\
7,991 \\
13,061 \\
9,234 \\
3,657 \\
10,933\end{array}$ & $\begin{array}{r}29,367 \\
4,160 \\
3,883 \\
4,225 \\
7,351 \\
4,274 \\
1,370 \\
4,104\end{array}$ & $\begin{array}{r}12,406 \\
1,490 \\
1,991 \\
2,013 \\
3,540 \\
1,740 \\
487 \\
1,146\end{array}$ & $\begin{array}{r}27,357 \\
4,390 \\
4,099 \\
4,060 \\
6,972 \\
3,782 \\
1,083 \\
2,970\end{array}$ & $\begin{array}{r}9,132 \\
692 \\
972 \\
1,139 \\
2,766 \\
1,933 \\
540 \\
1,090\end{array}$ & $\begin{array}{r}2,447 \\
184 \\
291 \\
284 \\
743 \\
396 \\
149 \\
401\end{array}$ & $\begin{array}{r}1,761 \\
90 \\
174 \\
191 \\
486 \\
437 \\
132 \\
250\end{array}$ \\
\hline 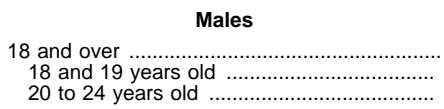 & $\begin{array}{r}94,154 \\
3,783 \\
8,751\end{array}$ & $\begin{array}{r}3,471 \\
42 \\
189\end{array}$ & $\begin{array}{r}3,434 \\
61 \\
136\end{array}$ & $\begin{array}{r}9,464 \\
1,486 \\
846\end{array}$ & $\begin{array}{r}1,551 \\
237 \\
233\end{array}$ & $\begin{array}{r}30,196 \\
1,134 \\
2,836\end{array}$ & $\begin{array}{r}18,183 \\
815 \\
3,335\end{array}$ & $\begin{array}{r}5,731 \\
7 \\
425\end{array}$ & $\begin{array}{r}14,387 \\
716\end{array}$ & $\frac{4,809}{33}$ & $\frac{1,711}{2}$ & $\begin{array}{r}1,218 \\
-\end{array}$ \\
\hline 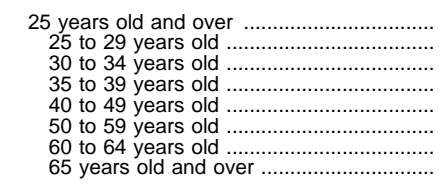 & $\begin{array}{r}81,620 \\
9,613 \\
10,426 \\
11,323 \\
19,439 \\
12,725 \\
4,689 \\
13,404\end{array}$ & $\begin{array}{r}3,240 \\
229 \\
282 \\
321 \\
530 \\
544 \\
280 \\
1,054\end{array}$ & $\begin{array}{r}3,237 \\
159 \\
153 \\
157 \\
345 \\
548 \\
311 \\
1,564\end{array}$ & $\begin{array}{r}7,132 \\
805 \\
852 \\
904 \\
1,340 \\
979 \\
471 \\
1,782\end{array}$ & $\begin{array}{r}1,080 \\
173 \\
178 \\
163 \\
198 \\
127 \\
59 \\
181\end{array}$ & $\begin{array}{r}26,226 \\
2,970 \\
3,512 \\
4,053 \\
6,103 \\
4,077 \\
1,537 \\
3,974\end{array}$ & $\begin{array}{r}14,033 \\
2,088 \\
1,826 \\
2,007 \\
3,619 \\
2,031 \\
673 \\
1,789\end{array}$ & $\begin{array}{r}5,299 \\
660 \\
905 \\
851 \\
1,550 \\
726 \\
216 \\
392\end{array}$ & $\begin{array}{r}13,672 \\
2,069 \\
1,962 \\
1,972 \\
3,529 \\
2,002 \\
592 \\
1,546\end{array}$ & $\begin{array}{r}4,776 \\
311 \\
481 \\
599 \\
1,384 \\
1,069 \\
336 \\
596\end{array}$ & $\begin{array}{r}1,708 \\
111 \\
175 \\
187 \\
508 \\
291 \\
112 \\
325\end{array}$ & $\begin{array}{r}1,218 \\
38 \\
102 \\
107 \\
336 \\
332 \\
103 \\
200\end{array}$ \\
\hline Females & & & & & & & & & & & & \\
\hline 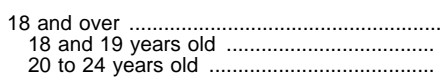 & $\begin{array}{r}101,414 \\
3,715 \\
8,737\end{array}$ & $\begin{array}{r}3,328 \\
29 \\
150\end{array}$ & $\begin{array}{r}3,816 \\
40 \\
89\end{array}$ & $\begin{array}{r}9,930 \\
1,160 \\
783\end{array}$ & $\begin{array}{r}1,317 \\
187 \\
117\end{array}$ & $\begin{array}{r}35,174 \\
1,178 \\
2,635\end{array}$ & $\begin{array}{r}19,858 \\
1,101 \\
3,422\end{array}$ & $\begin{array}{r}7,606 \\
10 \\
488\end{array}$ & $\begin{array}{r}14,702 \\
9 \\
1,008\end{array}$ & $\begin{array}{r}4,396 \\
1 \\
39\end{array}$ & $\frac{744}{5}$ & $\stackrel{543}{-}$ \\
\hline 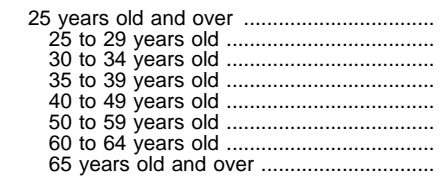 & $\begin{array}{r}88,961 \\
9,647 \\
10,570 \\
11,432 \\
20,120 \\
13,513 \\
5,207 \\
18,474\end{array}$ & $\begin{array}{r}3,149 \\
194 \\
228 \\
234 \\
465 \\
468 \\
293 \\
1,268\end{array}$ & $\begin{array}{r}3,687 \\
117 \\
145 \\
158 \\
400 \\
450 \\
311 \\
2,106\end{array}$ & $\begin{array}{r}7,987 \\
674 \\
739 \\
796 \\
1,192 \\
1,155 \\
681 \\
2,750\end{array}$ & $\begin{array}{r}1,013 \\
82 \\
120 \\
118 \\
172 \\
170 \\
73 \\
278\end{array}$ & $\begin{array}{r}31,360 \\
2,850 \\
3,377 \\
3,938 \\
6,959 \\
5,157 \\
2,120 \\
6,959\end{array}$ & $\begin{array}{r}15,335 \\
2,073 \\
2,057 \\
2,218 \\
3,732 \\
2,243 \\
697 \\
2,315\end{array}$ & $\begin{array}{r}7,107 \\
830 \\
1,086 \\
1,163 \\
1,990 \\
1,014 \\
270 \\
753\end{array}$ & $\begin{array}{r}13,685 \\
2,321 \\
2,137 \\
2,088 \\
3,443 \\
1,780 \\
491 \\
1,424\end{array}$ & $\begin{array}{r}4,356 \\
381 \\
491 \\
540 \\
1,383 \\
865 \\
204 \\
493\end{array}$ & $\begin{array}{r}739 \\
73 \\
116 \\
97 \\
235 \\
105 \\
37 \\
76\end{array}$ & $\begin{array}{r}543 \\
52 \\
72 \\
84 \\
150 \\
105 \\
30 \\
51\end{array}$ \\
\hline $\begin{array}{r}\text { White, non-Hispanic } \\
18 \text { and over } \\
18 \text { and } 19 \text { years old } \\
20 \text { to } 24 \text { years old }\end{array}$ & $\begin{array}{r}145,855 \\
4,971 \\
11,585\end{array}$ & $\begin{array}{r}1,834 \\
4 \\
34\end{array}$ & $\begin{array}{r}4,860 \\
61 \\
77\end{array}$ & $\begin{array}{r}12,372 \\
1,647 \\
713\end{array}$ & $\begin{array}{r}1,584 \\
242 \\
152\end{array}$ & $\begin{array}{r}50,200 \\
1,598 \\
3,561\end{array}$ & $\begin{array}{r}29,052 \\
1,399 \\
4,877\end{array}$ & $\begin{array}{r}10,595 \\
11 \\
731\end{array}$ & $\begin{array}{r}24,072 \\
7 \\
1,383\end{array}$ & $\begin{array}{r}7,731 \\
1 \\
53\end{array}$ & $\frac{2,076}{5}$ & $\frac{1,477}{-}$ \\
\hline 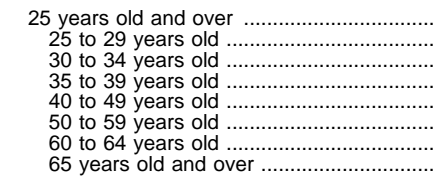 & $\begin{array}{r}129,299 \\
12,924 \\
14,486 \\
16,434 \\
30,010 \\
20,548 \\
7,864 \\
27,033\end{array}$ & $\begin{array}{r}1,797 \\
34 \\
35 \\
51 \\
180 \\
230 \\
157 \\
1,110\end{array}$ & $\begin{array}{r}4,722 \\
107 \\
101 \\
112 \\
332 \\
642 \\
437 \\
2,992\end{array}$ & $\begin{array}{r}10,012 \\
684 \\
824 \\
1,046 \\
1,501 \\
1,412 \\
829 \\
3,716\end{array}$ & $\begin{array}{r}1,190 \\
97 \\
137 \\
160 \\
182 \\
149 \\
93 \\
371\end{array}$ & $\begin{array}{r}45,042 \\
3,817 \\
4,870 \\
5,906 \\
9,995 \\
7,506 \\
3,116 \\
9,832\end{array}$ & $\begin{array}{r}22,775 \\
2,855 \\
2,677 \\
3,026 \\
5,716 \\
3,578 \\
1,190 \\
3,731\end{array}$ & $\begin{array}{r}9,853 \\
1,111 \\
1,488 \\
1,520 \\
2,912 \\
1,418 \\
393 \\
1,011\end{array}$ & $\begin{array}{r}22,681 \\
3,505 \\
3,270 \\
3,302 \\
5,767 \\
3,201 \\
927 \\
2,709\end{array}$ & $\begin{array}{r}7,677 \\
497 \\
748 \\
927 \\
2,375 \\
1,676 \\
465 \\
989\end{array}$ & $\begin{array}{r}2,071 \\
143 \\
213 \\
237 \\
633 \\
354 \\
135 \\
357\end{array}$ & $\begin{array}{r}1,477 \\
74 \\
122 \\
147 \\
417 \\
381 \\
123 \\
214\end{array}$ \\
\hline Black, non-Hispanic & & & & & & & & & & & & \\
\hline $\begin{array}{l}18 \text { and over } \\
18 \text { and } 19 \text { years old } \\
20 \text { to } 24 \text { years old }\end{array}$ & $\begin{array}{r}22,186 \\
1,148 \\
2,425\end{array}$ & $\begin{array}{r}789 \\
3 \\
15\end{array}$ & $\begin{array}{r}830 \\
10 \\
13\end{array}$ & $\begin{array}{r}3,395 \\
471 \\
334\end{array}$ & $\begin{array}{r}581 \\
72 \\
76\end{array}$ & $\begin{array}{r}8,060 \\
385 \\
950\end{array}$ & $\begin{array}{r}4,604 \\
206 \\
841\end{array}$ & $\frac{1,312}{63}$ & $\frac{1,904}{127}$ & $\frac{564}{5}$ & $\frac{84}{-}$ & $\frac{62}{-}$ \\
\hline 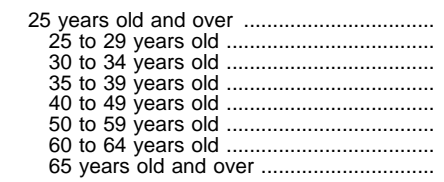 & $\begin{array}{r}18,613 \\
2,529 \\
2,653 \\
2,812 \\
4,528 \\
2,576 \\
962 \\
2,553\end{array}$ & $\begin{array}{r}771 \\
15 \\
33 \\
17 \\
74 \\
123 \\
93 \\
416\end{array}$ & $\begin{array}{r}807 \\
3 \\
29 \\
41 \\
129 \\
131 \\
79 \\
394\end{array}$ & $\begin{array}{r}2,589 \\
258 \\
289 \\
298 \\
540 \\
429 \\
212 \\
562\end{array}$ & $\begin{array}{r}433 \\
55 \\
63 \\
56 \\
98 \\
82 \\
28 \\
52\end{array}$ & $\begin{array}{r}6,725 \\
1,019 \\
1,019 \\
1,090 \\
1,745 \\
921 \\
299 \\
632\end{array}$ & $\begin{array}{r}3,557 \\
672 \\
614 \\
680 \\
915 \\
360 \\
106 \\
211\end{array}$ & $\begin{array}{r}1,249 \\
147 \\
248 \\
243 \\
335 \\
164 \\
43 \\
69\end{array}$ & $\begin{array}{r}1,777 \\
301 \\
296 \\
323 \\
478 \\
205 \\
58 \\
115\end{array}$ & $\begin{array}{r}559 \\
48 \\
51 \\
45 \\
166 \\
145 \\
34 \\
71\end{array}$ & \begin{tabular}{r|r}
84 \\
5 \\
7 \\
17 \\
31 \\
1 \\
7 \\
15
\end{tabular} & $\begin{array}{r}62 \\
6 \\
4 \\
2 \\
18 \\
14 \\
2 \\
15\end{array}$ \\
\hline Hispanic & & & & & & & & & & & & \\
\hline $\begin{array}{l}18 \text { and over } \\
18 \text { and } 19 \text { years old } \\
20 \text { to } 24 \text { years old }\end{array}$ & $\begin{array}{r}19,103 \\
1034 \\
2,592\end{array}$ & $\begin{array}{r}3,683 \\
61 \\
283\end{array}$ & $\begin{array}{r}1,324 \\
30 \\
130\end{array}$ & $\begin{array}{r}3,017 \\
423 \\
500\end{array}$ & $\begin{array}{r}607 \\
87 \\
112\end{array}$ & $\begin{array}{r}5,005 \\
259 \\
735\end{array}$ & $\begin{array}{r}2,892 \\
170 \\
668\end{array}$ & $\begin{array}{r}889 \\
5 \\
79\end{array}$ & $\frac{1,228}{75}$ & $\frac{282}{7}$ & $\frac{103}{3}$ & $\frac{73}{-}$ \\
\hline 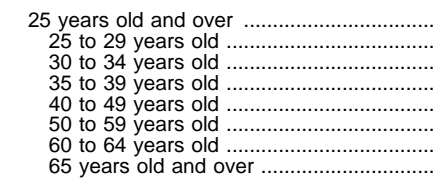 & $\begin{array}{r}15,477 \\
2,778 \\
2,717 \\
2,453 \\
3,290 \\
2,042 \\
682 \\
1,516\end{array}$ & $\begin{array}{r}3,338 \\
342 \\
399 \\
463 \\
665 \\
571 \\
241 \\
657\end{array}$ & $\begin{array}{r}1,164 \\
141 \\
156 \\
145 \\
251 \\
195 \\
75 \\
203\end{array}$ & $\begin{array}{r}2,094 \\
479 \\
431 \\
301 \\
381 \\
244 \\
95 \\
162\end{array}$ & $\begin{array}{r}409 \\
99 \\
86 \\
55 \\
74 \\
55 \\
9 \\
32\end{array}$ & $\begin{array}{r}4,011 \\
791 \\
724 \\
704 \\
881 \\
499 \\
145 \\
267\end{array}$ & $\begin{array}{r}2,054 \\
459 \\
429 \\
365 \\
476 \\
201 \\
44 \\
81\end{array}$ & $\begin{array}{r}805 \\
161 \\
166 \\
153 \\
181 \\
98 \\
19 \\
26\end{array}$ & $\begin{array}{r}1,153 \\
256 \\
248 \\
208 \\
253 \\
106 \\
34 \\
49\end{array}$ & $\begin{array}{r}275 \\
37 \\
50 \\
37 \\
76 \\
45 \\
14 \\
16\end{array}$ & $\begin{array}{r}100 \\
9 \\
20 \\
8 \\
32 \\
18 \\
3 \\
9\end{array}$ & $\begin{array}{r}73 \\
4 \\
9 \\
15 \\
21 \\
10 \\
1 \\
13\end{array}$ \\
\hline
\end{tabular}

${ }^{1}$ Civilian noninstitutional population.

-Data not applicable or not available.

NOTE.-Data are based on a sample survey of the noninstitutional population. Although cells with fewer than 75,000 people are subject to relatively wide sampling vari- ation, they are included in the table to permit various types of aggregations. Because of rounding, details may not add to totals.

SOURCE: U.S. Department of Commerce, Bureau of the Census, Current Population Survey, unpublished data. (This table was prepared May 1998.) 
Table 10.-Number of persons age 18 and over who hold a bachelor's or higher degree, by field of study, sex, race, and age: Spring 1993

[Numbers in thousands]

\begin{tabular}{|c|c|c|c|c|c|c|c|c|c|c|c|}
\hline \multirow[b]{2}{*}{ Field of study } & \multirow[b]{2}{*}{ Total } & \multicolumn{2}{|c|}{ Sex } & \multicolumn{2}{|c|}{ Race } & \multicolumn{6}{|c|}{ Age } \\
\hline & & Males & $\begin{array}{c}\text { Fe- } \\
\text { males }\end{array}$ & White ${ }^{1}$ & Black ${ }^{1}$ & $\begin{array}{c}18 \text { to } 24 \\
\text { years } \\
\text { old }\end{array}$ & $\begin{array}{c}25 \text { to } 34 \\
\text { years } \\
\text { old }\end{array}$ & $\begin{array}{c}35 \text { to } 44 \\
\text { years } \\
\text { old }\end{array}$ & $\begin{array}{c}45 \text { to } 54 \\
\text { years } \\
\text { old }\end{array}$ & $\begin{array}{c}55 \text { to } 64 \\
\text { years } \\
\text { old }\end{array}$ & $\begin{array}{c}65 \\
\text { years } \\
\text { old and } \\
\text { over }\end{array}$ \\
\hline 1 & 2 & 3 & 4 & 5 & 6 & 7 & 8 & 9 & 10 & 11 & 12 \\
\hline 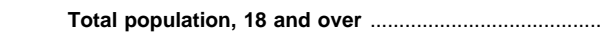 & 188,683 & 90,555 & 98,128 & 159,940 & 21,391 & 25,507 & 42,162 & 41,094 & 28,657 & 20,524 & 30,739 \\
\hline $\begin{array}{l}\text { Number of persons with bachelor's or higher degree } \\
\text { Percent of population }\end{array}$ & $\begin{array}{r}36,786 \\
19.5\end{array}$ & $\begin{array}{r}19,352 \\
21.4\end{array}$ & $\begin{array}{r}17,436 \\
17.8\end{array}$ & $\begin{array}{r}32,280 \\
20.2\end{array}$ & $\begin{array}{r}2,314 \\
10.8\end{array}$ & $\begin{array}{r}2,456 \\
9.6\end{array}$ & $\begin{array}{r}9,635 \\
22.9\end{array}$ & $\begin{array}{r}10,691 \\
26.0\end{array}$ & $\begin{array}{r}6,869 \\
24.0\end{array}$ & $\begin{array}{r}3,470 \\
16.9\end{array}$ & $\begin{array}{r}3,664 \\
11.9\end{array}$ \\
\hline Agriculture and forestry & 543 & 437 & 107 & 517 & 11 & 39 & 94 & 198 & 103 & 56 & 53 \\
\hline Biology & 827 & 525 & 302 & 674 & 59 & 102 & 190 & 283 & 156 & 65 & 30 \\
\hline 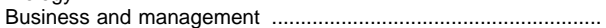 & 6,739 & 4,524 & 2,215 & 5,947 & 458 & 472 & 2,091 & 1,839 & 1,250 & 595 & 490 \\
\hline Economics ‥1-1) & 815 & 551 & 263 & 695 & 42 & 58 & 236 & 213 & 144 & 96 & 67 \\
\hline Education & 6,078 & 1,482 & 4,597 & 5,493 & 409 & 268 & 965 & 1,764 & 1,438 & 798 & 845 \\
\hline Engineering ..................... & 3,425 & 2,986 & 439 & 2,874 & 164 & 197 & 1,165 & 906 & 489 & 353 & 315 \\
\hline 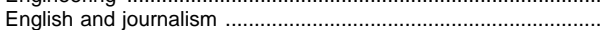 & 1,356 & 519 & 837 & 1,163 & 97 & 109 & 363 & 383 & 285 & 86 & 130 \\
\hline 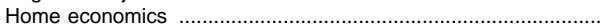 & 375 & 17 & 358 & 329 & 27 & 6 & 61 & 113 & 49 & 60 & 86 \\
\hline 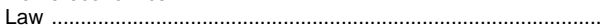 & 1,167 & 865 & 301 & 1,045 & 53 & 56 & 279 & 372 & 226 & 110 & 124 \\
\hline Liberal arts and humanities & 2,855 & 1,228 & 1,629 & 2,570 & 132 & 242 & 690 & 855 & 518 & 236 & 315 \\
\hline Mathematics and statistics & 754 & 477 & 276 & 637 & 80 & 44 & 223 & 188 & 146 & 54 & 99 \\
\hline Medicine and dentistry & 1,119 & 825 & 294 & 900 & 27 & 22 & 253 & 413 & 187 & 85 & 159 \\
\hline 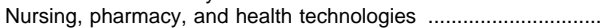 & 2,166 & 352 & 1,814 & 1,845 & 137 & 156 & 649 & 665 & 329 & 180 & 186 \\
\hline Physical and earth sciences & 918 & 650 & 270 & 837 & 31 & 48 & 270 & 198 & 192 & 77 & 133 \\
\hline 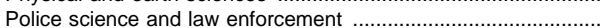 & 363 & 251 & 112 & 309 & 30 & 19 & 149 & 114 & 57 & 14 & 9 \\
\hline 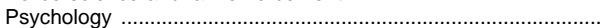 & 1,342 & 531 & 811 & 1,216 & 63 & 138 & 364 & 415 & 243 & 75 & 107 \\
\hline Religion and theology & 577 & 484 & 93 & 525 & 48 & 9 & 112 & 172 & 95 & 88 & 101 \\
\hline Social sciences & 2,341 & 1,023 & 1,318 & 2,028 & 232 & 226 & 576 & 689 & 440 & 210 & 200 \\
\hline Vocational and technical studies & 202 & 140 & 62 & 165 & 17 & 20 & 82 & 38 & 29 & 20 & 13 \\
\hline \multirow[t]{2}{*}{ 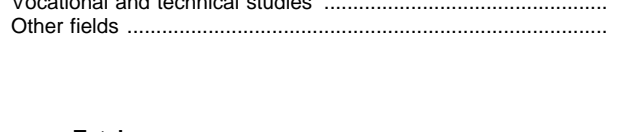 } & 2,825 & 1,487 & 1,338 & 2,507 & 198 & 226 & 824 & 872 & 492 & 213 & 199 \\
\hline & \multicolumn{11}{|c|}{ Percentage distribution of degree holders, by field } \\
\hline Total & 100.0 & 100.0 & 100.0 & 100.0 & 100.0 & 100.0 & 100.0 & 100.0 & 100.0 & 100.0 & 100.0 \\
\hline Agriculture and forestry . & 1.5 & 2.3 & 0.6 & 1.6 & 0.5 & 1.6 & 1.0 & 1.9 & 1.5 & 1.6 & 1.4 \\
\hline Biology & 2.2 & 2.7 & 1.7 & 2.1 & 2.5 & 4.2 & 2.0 & 2.6 & 2.3 & 1.9 & 0.8 \\
\hline 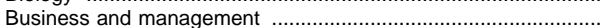 & 18.3 & 23.4 & 12.7 & 18.4 & 19.8 & 19.2 & 21.7 & 17.2 & 18.2 & 17.1 & 13.4 \\
\hline 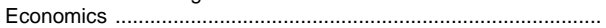 & 2.2 & 2.8 & 1.5 & 2.2 & 1.8 & 2.4 & 2.4 & 2.0 & 2.1 & 2.8 & 1.8 \\
\hline 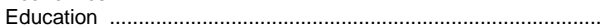 & 16.5 & 7.7 & 26.4 & 17.0 & 17.7 & 10.9 & 10.0 & 16.5 & 20.9 & 23.0 & 23.1 \\
\hline 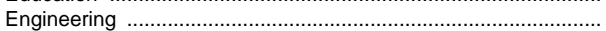 & 9.3 & 15.4 & 2.5 & 8.9 & 7.1 & 8.0 & 12.1 & 8.5 & 7.1 & 10.2 & 8.6 \\
\hline 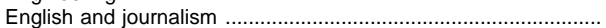 & 3.7 & 2.7 & 4.8 & 3.6 & 4.2 & 4.4 & 3.8 & 3.6 & 4.1 & 2.5 & 3.5 \\
\hline Home economics & 1.0 & 0.1 & 2.1 & 1.0 & 1.2 & 0.2 & 0.6 & 1.1 & 0.7 & 1.7 & 2.3 \\
\hline 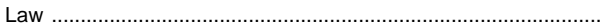 & 3.2 & 4.5 & 1.7 & 3.2 & 2.3 & 2.3 & 2.9 & 3.5 & 3.3 & 3.2 & 3.4 \\
\hline 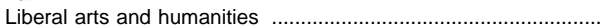 & 7.8 & 6.3 & 9.3 & 8.0 & 5.7 & 9.9 & 7.2 & 8.0 & 7.5 & 6.8 & 8.6 \\
\hline Mathematics and statistics & 2.0 & 2.5 & 1.6 & 2.0 & 3.5 & 1.8 & 2.3 & 1.8 & 2.1 & 1.6 & 2.7 \\
\hline Medicine and dentistry & 3.0 & 4.3 & 1.7 & 2.8 & 1.2 & 0.9 & 2.6 & 3.9 & 2.7 & 2.4 & 4.3 \\
\hline 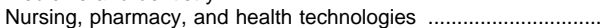 & 5.9 & 1.8 & 10.4 & 5.7 & 5.9 & 6.4 & 6.7 & 6.2 & 4.8 & 5.2 & 5.1 \\
\hline 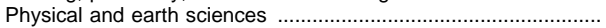 & 2.5 & 3.4 & 1.5 & 2.6 & 1.3 & 2.0 & 2.8 & 1.9 & 2.8 & 2.2 & 3.6 \\
\hline Police science and law enforcement & 1.0 & 1.3 & 0.6 & 1.0 & 1.3 & 0.8 & 1.5 & 1.1 & 0.8 & 0.4 & 0.2 \\
\hline Psychology & 3.6 & 2.7 & 4.7 & 3.8 & 2.7 & 5.6 & 3.8 & 3.9 & 3.5 & 2.2 & 2.9 \\
\hline Religion and theology & 1.6 & 2.5 & 0.5 & 1.6 & 2.1 & 0.4 & 1.2 & 1.6 & 1.4 & 2.5 & 2.8 \\
\hline 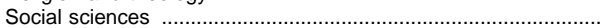 & 6.4 & 5.3 & 7.6 & 6.3 & 10.0 & 9.2 & 6.0 & 6.4 & 6.4 & 6.1 & 5.5 \\
\hline Vocational and technical studies & 0.5 & 0.7 & 0.4 & 0.5 & 0.7 & 0.8 & 0.9 & 0.4 & 0.4 & 0.6 & 0.4 \\
\hline 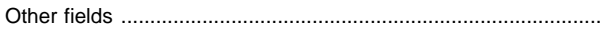 & 7.7 & 7.7 & 7.7 & 7.8 & 8.6 & 9.2 & 8.6 & 8.2 & 7.2 & 6.1 & 5.4 \\
\hline
\end{tabular}

${ }^{1}$ Includes persons of Hispanic origin.

NOTE.-Data are based on a sample survey of the civilian noninstitutional population. Because of rounding, details may not add to totals.
SOURCE: U.S. Department of Commerce, Bureau of the Census, Current Population Reports, Series P-70, No. 51, "What's It Worth? Educational Background and Economic Status: Spring 1993." (This table was prepared April 1996.) 
Table 11.-Educational attainment of persons 25 years old and over, by state: April 1990

\begin{tabular}{|c|c|c|c|c|c|c|c|c|}
\hline \multirow[b]{2}{*}{ State } & \multirow[b]{2}{*}{$\begin{array}{l}\text { Number of per- } \\
\text { sons } 25 \text { years } \\
\text { old and over }\end{array}$} & \multicolumn{7}{|c|}{ Distribution of population, by highest level of education attained } \\
\hline & & $\begin{array}{l}\text { Less than 9th } \\
\text { grade }\end{array}$ & $\begin{array}{l}\text { 9th to 12th } \\
\text { grade, no } \\
\text { diploma }\end{array}$ & $\begin{array}{l}\text { High school } \\
\text { graduate }\end{array}$ & $\begin{array}{l}\text { Some col- } \\
\text { lege, no } \\
\text { degree }\end{array}$ & $\begin{array}{l}\text { Associate } \\
\text { degree }\end{array}$ & $\begin{array}{l}\text { Bachelor's } \\
\text { degree }\end{array}$ & $\begin{array}{l}\text { Graduate } \\
\text { or profes- } \\
\text { sional de- } \\
\text { gree }\end{array}$ \\
\hline 1 & 2 & 3 & 4 & 5 & 6 & 7 & 8 & 9 \\
\hline United States & $158,868,436$ & 10.4 & 14.4 & 30.0 & 18.7 & 6.2 & 13.1 & 7.2 \\
\hline 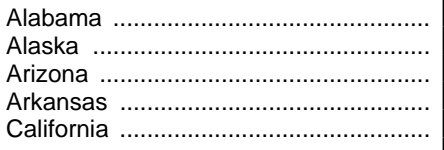 & $\begin{array}{r}2,545,969 \\
323,429 \\
2,301,177 \\
1,496,150 \\
18,695,499\end{array}$ & $\begin{array}{r}13.7 \\
5.1 \\
9.0 \\
15.2 \\
11.2\end{array}$ & $\begin{array}{r}19.4 \\
8.2 \\
12.3 \\
18.4 \\
12.6\end{array}$ & $\begin{array}{l}29.4 \\
28.7 \\
26.1 \\
32.7 \\
22.3\end{array}$ & $\begin{array}{l}16.8 \\
27.6 \\
25.4 \\
16.6 \\
22.6\end{array}$ & $\begin{array}{l}5.0 \\
7.2 \\
6.8 \\
3.7 \\
7.9\end{array}$ & $\begin{array}{r}10.1 \\
15.0 \\
13.3 \\
8.9 \\
15.3\end{array}$ & $\begin{array}{l}5.5 \\
8.0 \\
7.0 \\
4.5 \\
8.1\end{array}$ \\
\hline 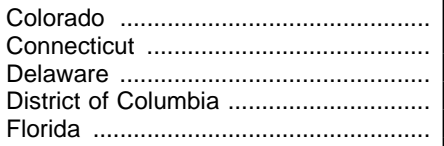 & $\begin{array}{r}2,107,072 \\
2,198,963 \\
428,499 \\
409,131 \\
8,887,168\end{array}$ & $\begin{array}{l}5.6 \\
8.4 \\
7.2 \\
9.6 \\
9.5\end{array}$ & $\begin{array}{l}10.0 \\
12.4 \\
15.3 \\
17.3 \\
16.1\end{array}$ & $\begin{array}{l}26.5 \\
29.5 \\
32.7 \\
21.2 \\
30.1\end{array}$ & $\begin{array}{l}24.0 \\
15.9 \\
16.9 \\
15.6 \\
19.4\end{array}$ & $\begin{array}{l}6.9 \\
6.6 \\
6.5 \\
3.1 \\
6.6\end{array}$ & $\begin{array}{l}18.0 \\
16.2 \\
13.7 \\
16.1 \\
12.0\end{array}$ & $\begin{array}{r}9.0 \\
11.0 \\
7.7 \\
17.2 \\
6.3\end{array}$ \\
\hline 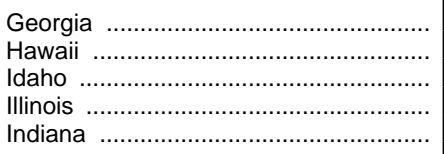 & $\begin{array}{r}4,023,420 \\
709,820 \\
601,292 \\
7,293,930 \\
3,489,470\end{array}$ & $\begin{array}{r}12.0 \\
10.1 \\
7.4 \\
10.3 \\
8.5\end{array}$ & $\begin{array}{r}17.1 \\
9.8 \\
12.9 \\
13.5 \\
15.8\end{array}$ & $\begin{array}{l}29.6 \\
28.7 \\
30.4 \\
30.0 \\
38.2\end{array}$ & $\begin{array}{l}17.0 \\
20.1 \\
24.2 \\
19.4 \\
16.6\end{array}$ & $\begin{array}{l}5.0 \\
8.3 \\
7.5 \\
5.8 \\
5.3\end{array}$ & $\begin{array}{r}12.9 \\
15.8 \\
12.4 \\
13.6 \\
9.2\end{array}$ & $\begin{array}{l}6.4 \\
7.1 \\
5.3 \\
7.5 \\
6.4\end{array}$ \\
\hline $\begin{array}{l}\text { lowa } \\
\text { Kansas } \\
\text { Kentucky } \\
\text { Louisiana } \\
\text { Maine }\end{array}$ & $\begin{array}{r}1,776,798 \\
1,565,936 \\
2,333,833 \\
2,536,994 \\
795,613\end{array}$ & $\begin{array}{r}9.2 \\
7.7 \\
19.0 \\
14.7 \\
8.8\end{array}$ & $\begin{array}{l}10.7 \\
11.0 \\
16.4 \\
17.0 \\
12.4\end{array}$ & $\begin{array}{l}38.5 \\
32.8 \\
31.8 \\
31.7 \\
37.1\end{array}$ & $\begin{array}{l}17.0 \\
21.9 \\
15.2 \\
17.2 \\
16.1\end{array}$ & $\begin{array}{l}7.7 \\
5.4 \\
4.1 \\
3.3 \\
6.9\end{array}$ & $\begin{array}{r}11.7 \\
14.1 \\
8.1 \\
10.5 \\
12.7\end{array}$ & $\begin{array}{l}5.2 \\
7.0 \\
5.5 \\
5.6 \\
6.1\end{array}$ \\
\hline 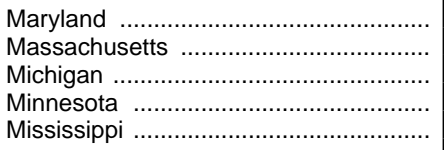 & $\begin{array}{l}3,122,665 \\
3,962,223 \\
5,842,642 \\
2,770,562 \\
1,538,997\end{array}$ & $\begin{array}{r}7.9 \\
8.0 \\
7.8 \\
8.6 \\
15.6\end{array}$ & $\begin{array}{r}13.7 \\
12.0 \\
15.5 \\
9.0 \\
20.1\end{array}$ & $\begin{array}{l}28.1 \\
29.7 \\
32.3 \\
33.0 \\
27.5\end{array}$ & $\begin{array}{l}18.6 \\
15.8 \\
20.4 \\
19.0 \\
16.9\end{array}$ & $\begin{array}{l}5.2 \\
7.2 \\
6.7 \\
8.6 \\
5.2\end{array}$ & $\begin{array}{r}15.6 \\
16.6 \\
10.9 \\
15.6 \\
9.7\end{array}$ & $\begin{array}{r}10.9 \\
10.6 \\
6.4 \\
6.3 \\
5.1\end{array}$ \\
\hline 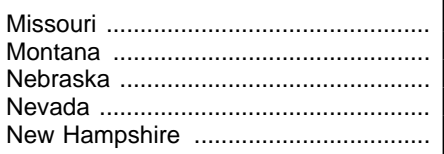 & $\begin{array}{r}3,291,579 \\
507,851 \\
996,049 \\
789,638 \\
713,894\end{array}$ & $\begin{array}{r}11.6 \\
8.1 \\
8.0 \\
6.0 \\
6.7\end{array}$ & $\begin{array}{l}14.5 \\
10.9 \\
10.2 \\
15.2 \\
11.2\end{array}$ & $\begin{array}{l}33.1 \\
33.5 \\
34.7 \\
31.5 \\
31.7\end{array}$ & $\begin{array}{l}18.4 \\
22.1 \\
21.1 \\
25.8 \\
18.0\end{array}$ & $\begin{array}{l}4.5 \\
5.6 \\
7.1 \\
6.2 \\
8.1\end{array}$ & $\begin{array}{l}11.7 \\
14.1 \\
13.1 \\
10.1 \\
16.4\end{array}$ & $\begin{array}{l}6.1 \\
5.7 \\
5.9 \\
5.2 \\
7.9\end{array}$ \\
\hline 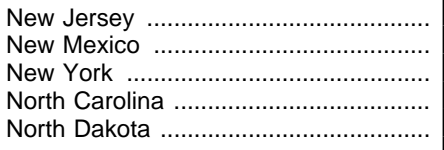 & $\begin{array}{r}5,166,233 \\
922,590 \\
11,818,569 \\
4,253,494 \\
396,550\end{array}$ & $\begin{array}{r}9.4 \\
11.4 \\
10.2 \\
12.7 \\
15.0\end{array}$ & $\begin{array}{r}13.9 \\
13.5 \\
15.0 \\
17.3 \\
8.3\end{array}$ & $\begin{array}{l}31.1 \\
28.7 \\
29.5 \\
29.0 \\
28.0\end{array}$ & $\begin{array}{l}15.5 \\
20.9 \\
15.7 \\
16.8 \\
20.5\end{array}$ & $\begin{array}{r}5.2 \\
5.0 \\
6.5 \\
6.8 \\
10.0\end{array}$ & $\begin{array}{l}16.0 \\
12.1 \\
13.2 \\
12.0 \\
13.5\end{array}$ & $\begin{array}{l}8.8 \\
8.3 \\
9.9 \\
5.4 \\
4.5\end{array}$ \\
\hline 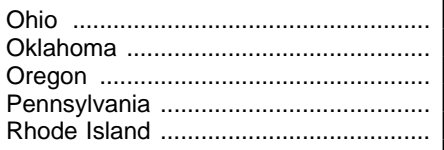 & $\begin{array}{r}6,924,764 \\
1,995,424 \\
1,855,369 \\
7,872,932 \\
658,956\end{array}$ & $\begin{array}{r}7.9 \\
9.8 \\
6.2 \\
9.4 \\
11.1\end{array}$ & $\begin{array}{l}16.4 \\
15.6 \\
12.3 \\
15.9 \\
16.9\end{array}$ & $\begin{array}{l}36.3 \\
30.5 \\
28.9 \\
38.6 \\
29.5\end{array}$ & $\begin{array}{l}17.0 \\
21.3 \\
25.0 \\
12.9 \\
15.0\end{array}$ & $\begin{array}{l}5.3 \\
5.0 \\
6.9 \\
5.2 \\
6.3\end{array}$ & $\begin{array}{l}11.1 \\
11.8 \\
13.6 \\
11.3 \\
13.5\end{array}$ & $\begin{array}{l}5.9 \\
6.0 \\
7.0 \\
6.6 \\
7.8\end{array}$ \\
\hline $\begin{array}{l}\text { South Carolina } \\
\text { South Dakota } \\
\text { Tennessee } \\
\text { Texas }\end{array}$ & $\begin{array}{r}2,167,590 \\
430,500 \\
3,139,066 \\
10,310,605 \\
897,321\end{array}$ & $\begin{array}{r}13.6 \\
13.4 \\
16.0 \\
13.5 \\
3.4\end{array}$ & $\begin{array}{r}18.1 \\
9.5 \\
17.0 \\
14.4 \\
11.5\end{array}$ & $\begin{array}{l}29.5 \\
33.7 \\
30.0 \\
25.6 \\
27.2\end{array}$ & $\begin{array}{l}15.8 \\
18.8 \\
16.9 \\
21.1 \\
27.9\end{array}$ & $\begin{array}{l}6.3 \\
7.4 \\
4.2 \\
5.2 \\
7.8\end{array}$ & $\begin{array}{l}11.2 \\
12.3 \\
10.5 \\
13.9 \\
15.4\end{array}$ & $\begin{array}{l}5.4 \\
4.9 \\
5.4 \\
6.5 \\
6.8\end{array}$ \\
\hline $\begin{array}{l}\text { Vermont } \\
\text { Virginia } \\
\text { Washington } \\
\text { West Virginia } \\
\text { Wisconsin } \\
\text { Wyoming }\end{array}$ & $\begin{array}{r}357,245 \\
3,974,814 \\
3,126,390 \\
1,171,766 \\
3,094,226 \\
277,769\end{array}$ & $\begin{array}{r}8.7 \\
11.2 \\
5.5 \\
16.8 \\
9.5 \\
5.7\end{array}$ & $\begin{array}{l}10.6 \\
13.7 \\
10.7 \\
17.3 \\
11.9 \\
11.2\end{array}$ & $\begin{array}{l}34.6 \\
26.6 \\
27.9 \\
36.6 \\
37.1 \\
33.2\end{array}$ & $\begin{array}{l}14.7 \\
18.5 \\
25.0 \\
13.2 \\
16.7 \\
24.2\end{array}$ & $\begin{array}{l}7.2 \\
5.5 \\
7.9 \\
3.8 \\
7.1 \\
6.9\end{array}$ & $\begin{array}{r}15.4 \\
15.4 \\
15.9 \\
7.5 \\
12.1 \\
13.1\end{array}$ & $\begin{array}{l}8.9 \\
9.1 \\
7.0 \\
4.8 \\
5.6 \\
5.7\end{array}$ \\
\hline
\end{tabular}


Table 12.-Educational attainment of persons 25 years old and over, by state and race/ethnicity: April 1990

\begin{tabular}{|c|c|c|c|c|c|c|c|c|c|c|c|c|}
\hline \multirow[b]{2}{*}{ State } & \multicolumn{6}{|c|}{ Percent with high school diploma or higher } & \multicolumn{6}{|c|}{ Percent with bachelor's degree or higher } \\
\hline & Total & White ${ }^{1}$ & Black ${ }^{1}$ & $\begin{array}{c}\text { His- } \\
\text { panic }^{2}\end{array}$ & $\begin{array}{l}\text { Asian/ } \\
\text { Pacific } \\
\text { Islander }{ }^{1}\end{array}$ & $\begin{array}{l}\text { American } \\
\text { Indian or } \\
\text { Alaskan } \\
\text { Native }^{1}\end{array}$ & Total & White ${ }^{1}$ & Black ${ }^{1}$ & $\begin{array}{c}\text { His- } \\
\text { panic }^{2}\end{array}$ & $\begin{array}{l}\text { Asian/ } \\
\text { Pacific } \\
\text { Islander }{ }^{1}\end{array}$ & $\begin{array}{c}\text { American } \\
\text { Indian or } \\
\text { Alaskan } \\
\text { Native }^{1}\end{array}$ \\
\hline 1 & 2 & 3 & 4 & 5 & 6 & 7 & 8 & 9 & 10 & 11 & 12 & 13 \\
\hline United States ........................ & 75.2 & 77.9 & 63.1 & 49.8 & 77.5 & 65.5 & 20.3 & 21.5 & 11.4 & 9.2 & 36.6 & 9.3 \\
\hline 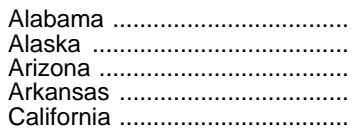 & $\begin{array}{l}66.9 \\
86.6 \\
78.7 \\
66.3 \\
76.2\end{array}$ & $\begin{array}{l}70.3 \\
91.1 \\
82.4 \\
68.6 \\
81.1\end{array}$ & $\begin{array}{l}54.6 \\
88.2 \\
75.1 \\
51.5 \\
75.6\end{array}$ & $\begin{array}{l}73.8 \\
80.4 \\
51.7 \\
59.1 \\
45.0\end{array}$ & $\begin{array}{l}78.9 \\
75.4 \\
80.2 \\
66.4 \\
77.2\end{array}$ & $\begin{array}{l}64.9 \\
63.1 \\
52.1 \\
65.4 \\
71.4\end{array}$ & $\begin{array}{l}15.7 \\
23.0 \\
20.3 \\
13.3 \\
23.4\end{array}$ & $\begin{array}{l}17.3 \\
26.8 \\
22.2 \\
14.1 \\
25.4\end{array}$ & $\begin{array}{r}9.3 \\
14.1 \\
14.3 \\
8.4 \\
14.8\end{array}$ & $\begin{array}{r}20.1 \\
14.6 \\
6.9 \\
11.1 \\
7.1\end{array}$ & $\begin{array}{l}43.7 \\
20.5 \\
37.5 \\
24.6 \\
34.1\end{array}$ & $\begin{array}{r}11.6 \\
4.1 \\
4.6 \\
9.8 \\
11.1\end{array}$ \\
\hline 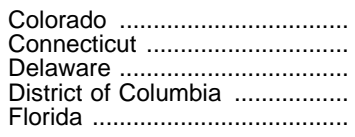 & $\begin{array}{l}84.4 \\
79.2 \\
77.5 \\
73.1 \\
74.4\end{array}$ & $\begin{array}{l}86.1 \\
80.9 \\
80.3 \\
93.1 \\
77.0\end{array}$ & $\begin{array}{l}80.8 \\
67.0 \\
63.2 \\
63.8 \\
56.4\end{array}$ & $\begin{array}{l}58.3 \\
53.5 \\
60.1 \\
52.6 \\
57.2\end{array}$ & $\begin{array}{l}78.3 \\
81.9 \\
86.1 \\
80.2 \\
77.8\end{array}$ & $\begin{array}{l}73.9 \\
68.9 \\
62.0 \\
66.3 \\
68.2\end{array}$ & $\begin{array}{l}27.0 \\
27.2 \\
21.4 \\
33.3 \\
18.3\end{array}$ & $\begin{array}{l}28.3 \\
28.5 \\
23.0 \\
69.0 \\
19.3\end{array}$ & $\begin{array}{r}17.1 \\
12.3 \\
10.6 \\
15.3 \\
9.8\end{array}$ & $\begin{array}{r}8.6 \\
12.1 \\
16.5 \\
24.0 \\
14.2\end{array}$ & $\begin{array}{l}32.1 \\
50.8 \\
55.9 \\
50.9 \\
33.6\end{array}$ & $\begin{array}{l}12.1 \\
12.5 \\
10.2 \\
17.7 \\
11.5\end{array}$ \\
\hline 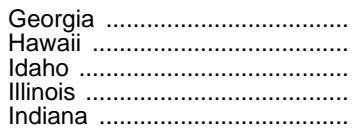 & $\begin{array}{l}70.9 \\
80.1 \\
79.7 \\
76.2 \\
75.6\end{array}$ & $\begin{array}{l}74.9 \\
89.3 \\
80.9 \\
79.1 \\
76.5\end{array}$ & $\begin{array}{l}58.6 \\
94.2 \\
82.8 \\
65.2 \\
65.4\end{array}$ & $\begin{array}{l}66.2 \\
73.9 \\
43.4 \\
45.0 \\
62.6\end{array}$ & $\begin{array}{l}77.5 \\
74.7 \\
80.3 \\
83.9 \\
85.8\end{array}$ & $\begin{array}{l}71.6 \\
84.4 \\
68.1 \\
71.4 \\
65.0\end{array}$ & $\begin{array}{l}19.3 \\
22.9 \\
17.7 \\
21.0 \\
15.6\end{array}$ & $\begin{array}{l}21.8 \\
30.2 \\
18.0 \\
22.4 \\
17.6\end{array}$ & $\begin{array}{r}11.0 \\
15.2 \\
15.8 \\
11.4 \\
9.3\end{array}$ & $\begin{array}{r}20.5 \\
10.3 \\
6.6 \\
8.0 \\
10.8\end{array}$ & $\begin{array}{l}38.6 \\
19.4 \\
27.6 \\
49.8 \\
53.1\end{array}$ & $\begin{array}{r}12.5 \\
17.7 \\
7.2 \\
13.4 \\
8.4\end{array}$ \\
\hline 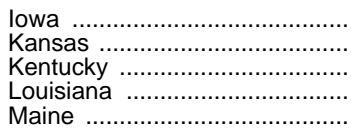 & $\begin{array}{l}80.1 \\
81.3 \\
64.6 \\
68.3 \\
78.8\end{array}$ & $\begin{array}{l}80.3 \\
82.4 \\
64.7 \\
74.2 \\
78.9\end{array}$ & $\begin{array}{l}70.1 \\
71.0 \\
61.7 \\
53.1 \\
87.6\end{array}$ & $\begin{array}{l}64.2 \\
58.1 \\
74.0 \\
67.6 \\
83.8\end{array}$ & $\begin{array}{l}76.4 \\
73.6 \\
77.9 \\
68.1 \\
74.3\end{array}$ & $\begin{array}{l}67.6 \\
75.4 \\
59.8 \\
49.1 \\
69.9\end{array}$ & $\begin{array}{l}16.9 \\
21.1 \\
13.6 \\
16.1 \\
18.8\end{array}$ & $\begin{array}{l}16.7 \\
21.7 \\
13.9 \\
18.7 \\
18.8\end{array}$ & $\begin{array}{r}12.8 \\
11.6 \\
7.7 \\
9.1 \\
22.3\end{array}$ & $\begin{array}{l}13.7 \\
10.1 \\
18.9 \\
16.6 \\
23.6\end{array}$ & $\begin{array}{l}47.3 \\
39.9 \\
44.2 \\
31.4 \\
44.9\end{array}$ & $\begin{array}{r}9.7 \\
10.8 \\
8.0 \\
5.5 \\
7.7\end{array}$ \\
\hline 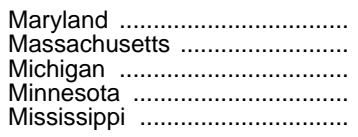 & $\begin{array}{l}78.4 \\
80.0 \\
76.8 \\
82.4 \\
64.3\end{array}$ & $\begin{array}{l}80.8 \\
81.2 \\
78.6 \\
82.8 \\
71.7\end{array}$ & $\begin{array}{l}70.6 \\
70.0 \\
64.9 \\
76.2 \\
47.3\end{array}$ & $\begin{array}{l}70.3 \\
52.0 \\
60.9 \\
71.1 \\
67.7\end{array}$ & $\begin{array}{l}84.8 \\
74.1 \\
83.3 \\
69.7 \\
68.2\end{array}$ & $\begin{array}{l}73.4 \\
71.1 \\
67.8 \\
68.2 \\
57.4\end{array}$ & $\begin{array}{l}26.5 \\
27.2 \\
17.4 \\
21.8 \\
14.7\end{array}$ & $\begin{array}{l}28.9 \\
27.7 \\
18.1 \\
21.9 \\
17.2\end{array}$ & $\begin{array}{r}16.1 \\
17.0 \\
10.1 \\
17.5 \\
8.8\end{array}$ & $\begin{array}{l}25.2 \\
13.6 \\
11.6 \\
17.2 \\
17.1\end{array}$ & $\begin{array}{l}50.3 \\
44.9 \\
54.1 \\
33.5 \\
35.1\end{array}$ & $\begin{array}{r}19.7 \\
14.9 \\
7.6 \\
7.7 \\
8.1\end{array}$ \\
\hline 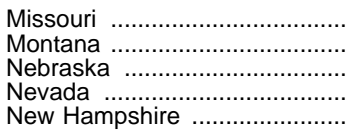 & $\begin{array}{l}73.9 \\
81.0 \\
81.8 \\
78.8 \\
82.2\end{array}$ & $\begin{array}{l}74.9 \\
81.7 \\
82.4 \\
80.9 \\
82.2\end{array}$ & $\begin{array}{l}65.1 \\
80.9 \\
73.2 \\
70.8 \\
86.1\end{array}$ & $\begin{array}{l}71.0 \\
66.4 \\
60.0 \\
53.7 \\
78.2\end{array}$ & $\begin{array}{l}81.5 \\
78.5 \\
80.0 \\
74.1 \\
82.7\end{array}$ & $\begin{array}{l}65.1 \\
68.1 \\
69.0 \\
69.8 \\
65.9\end{array}$ & $\begin{array}{l}17.8 \\
19.8 \\
18.9 \\
15.3 \\
24.4\end{array}$ & $\begin{array}{l}18.3 \\
20.3 \\
19.2 \\
15.9 \\
24.2\end{array}$ & $\begin{array}{r}11.2 \\
18.4 \\
12.4 \\
9.0 \\
25.7\end{array}$ & $\begin{array}{r}18.0 \\
10.9 \\
9.4 \\
7.0 \\
25.5\end{array}$ & $\begin{array}{l}47.3 \\
32.1 \\
39.5 \\
21.9 \\
26.1\end{array}$ & $\begin{array}{r}11.0 \\
7.9 \\
8.8 \\
8.0 \\
16.0\end{array}$ \\
\hline 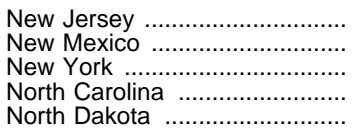 & $\begin{array}{l}76.7 \\
75.1 \\
76.7 \\
70.0 \\
76.7\end{array}$ & $\begin{array}{l}78.6 \\
78.6 \\
78.5 \\
73.1 \\
76.9\end{array}$ & $\begin{array}{l}67.0 \\
74.7 \\
64.7 \\
58.1 \\
95.9\end{array}$ & $\begin{array}{l}53.9 \\
59.6 \\
50.4 \\
71.0 \\
75.2\end{array}$ & $\begin{array}{l}86.8 \\
80.8 \\
72.4 \\
77.9 \\
83.7\end{array}$ & $\begin{array}{l}66.9 \\
58.2 \\
65.2 \\
51.5 \\
64.3\end{array}$ & $\begin{array}{l}24.9 \\
20.4 \\
23.1 \\
17.4 \\
18.1\end{array}$ & $\begin{array}{l}25.8 \\
23.4 \\
25.3 \\
19.3 \\
18.3\end{array}$ & $\begin{array}{r}13.6 \\
14.2 \\
12.6 \\
9.5 \\
17.1\end{array}$ & $\begin{array}{r}10.8 \\
8.7 \\
9.3 \\
17.9 \\
15.9\end{array}$ & $\begin{array}{l}57.1 \\
38.7 \\
38.7 \\
39.3 \\
37.8\end{array}$ & $\begin{array}{r}14.8 \\
5.8 \\
13.4 \\
7.9 \\
8.3\end{array}$ \\
\hline 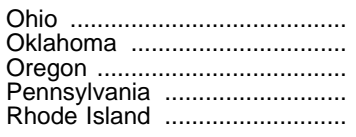 & $\begin{array}{l}75.7 \\
74.6 \\
81.5 \\
74.7 \\
72.0\end{array}$ & $\begin{array}{l}76.9 \\
75.7 \\
82.3 \\
75.9 \\
73.0\end{array}$ & $\begin{array}{l}64.6 \\
70.1 \\
75.0 \\
63.5 \\
65.9\end{array}$ & $\begin{array}{l}63.3 \\
55.9 \\
53.0 \\
52.2 \\
46.8\end{array}$ & $\begin{array}{l}83.5 \\
76.1 \\
79.4 \\
77.1 \\
59.6\end{array}$ & $\begin{array}{l}65.3 \\
68.1 \\
71.0 \\
67.8 \\
64.5\end{array}$ & $\begin{array}{l}17.0 \\
17.8 \\
20.6 \\
17.9 \\
21.3\end{array}$ & $\begin{array}{l}17.6 \\
18.7 \\
20.8 \\
18.5 \\
21.8\end{array}$ & $\begin{array}{r}9.1 \\
12.0 \\
9.1 \\
10.0 \\
12.7\end{array}$ & $\begin{array}{r}14.2 \\
10.5 \\
10.1 \\
11.8 \\
8.9\end{array}$ & $\begin{array}{l}53.2 \\
34.7 \\
32.3 \\
45.2 \\
30.6\end{array}$ & $\begin{array}{r}8.3 \\
10.8 \\
8.3 \\
12.0 \\
8.3\end{array}$ \\
\hline 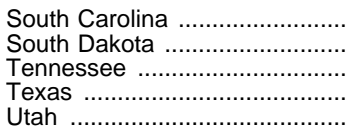 & $\begin{array}{l}68.3 \\
77.1 \\
67.1 \\
72.1 \\
85.1\end{array}$ & $\begin{array}{l}73.6 \\
77.8 \\
68.2 \\
76.2 \\
86.2\end{array}$ & $\begin{array}{l}53.3 \\
82.2 \\
59.4 \\
66.1 \\
77.0\end{array}$ & $\begin{array}{l}71.8 \\
71.3 \\
71.5 \\
44.6 \\
61.0\end{array}$ & $\begin{array}{l}77.4 \\
74.3 \\
79.3 \\
79.1 \\
80.7\end{array}$ & $\begin{array}{l}62.5 \\
62.5 \\
63.1 \\
70.9 \\
59.3\end{array}$ & $\begin{array}{l}16.6 \\
17.2 \\
16.0 \\
20.3 \\
22.3\end{array}$ & $\begin{array}{l}19.8 \\
17.6 \\
16.7 \\
22.6 \\
22.7\end{array}$ & $\begin{array}{r}7.6 \\
24.1 \\
10.2 \\
12.0 \\
15.9\end{array}$ & $\begin{array}{r}19.8 \\
13.4 \\
21.9 \\
7.3 \\
9.1\end{array}$ & $\begin{array}{l}34.4 \\
33.1 \\
42.6 \\
41.3 \\
29.4\end{array}$ & $\begin{array}{r}10.9 \\
6.8 \\
10.5 \\
13.9 \\
6.4\end{array}$ \\
\hline 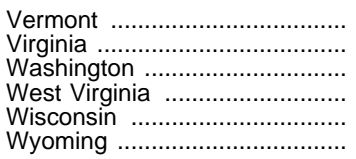 & $\begin{array}{l}80.8 \\
75.2 \\
83.8 \\
66.0 \\
78.6 \\
83.0\end{array}$ & $\begin{array}{l}80.8 \\
78.3 \\
85.0 \\
66.0 \\
79.6 \\
83.9\end{array}$ & $\begin{array}{l}82.9 \\
60.3 \\
81.2 \\
64.7 \\
61.3 \\
81.2\end{array}$ & $\begin{array}{l}84.7 \\
70.5 \\
56.7 \\
70.3 \\
54.1 \\
59.3\end{array}$ & $\begin{array}{l}87.1 \\
82.1 \\
77.3 \\
88.8 \\
71.5 \\
77.5\end{array}$ & $\begin{array}{l}66.8 \\
70.7 \\
72.3 \\
57.9 \\
66.8 \\
68.2\end{array}$ & $\begin{array}{l}24.3 \\
24.5 \\
22.9 \\
12.3 \\
17.7 \\
18.8\end{array}$ & $\begin{array}{l}24.2 \\
27.0 \\
23.3 \\
12.2 \\
18.1 \\
19.3\end{array}$ & $\begin{array}{r}30.5 \\
11.1 \\
15.4 \\
10.9 \\
8.3 \\
9.5\end{array}$ & $\begin{array}{r}28.2 \\
22.4 \\
11.0 \\
17.6 \\
10.0 \\
4.8\end{array}$ & $\begin{array}{l}52.1 \\
40.2 \\
30.2 \\
63.3 \\
40.4 \\
28.6\end{array}$ & $\begin{array}{r}11.1 \\
14.7 \\
9.1 \\
6.5 \\
5.5 \\
6.2\end{array}$ \\
\hline
\end{tabular}

1 Includes persons of Hispanic origin.

2 Persons of Hispanic origin may be of any race.
SOURCE: U.S. Department of Commerce, Bureau of the Census, Decennial Census, Minority Economic Profiles, unpublished data. (This table was prepared June 1993.) 
Table 13.-Educational attainment of persons 25 years old and over, for the 25 largest states: March 1996

\begin{tabular}{|c|c|c|c|c|c|c|c|c|c|}
\hline \multirow{3}{*}{ State } & \multirow{2}{*}{\multicolumn{3}{|c|}{$\begin{array}{c}\text { Number of persons } 25 \text { years old } \\
\text { and over } \\
\text { (in thousands) }\end{array}$}} & \multicolumn{3}{|c|}{ Percent high school completion or higher } & \multicolumn{3}{|c|}{$\begin{array}{l}\text { Percent completed bachelor's or higher de- } \\
\text { gree }\end{array}$} \\
\hline & & & & \multirow{2}{*}{ Total } & \multirow{2}{*}{ Male } & \multirow{2}{*}{ Female } & \multirow{2}{*}{ Total } & \multirow{2}{*}{ Male } & \multirow{2}{*}{ Female } \\
\hline & Total & Male & Female & & & & & & \\
\hline 1 & 2 & 3 & 4 & 5 & 6 & 7 & 8 & 9 & 10 \\
\hline 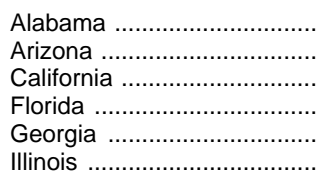 & $\begin{array}{r}2,771 \\
2,600 \\
19,849 \\
9,641 \\
4,645 \\
7,520\end{array}$ & $\begin{array}{l}1,273 \\
1,242 \\
9,773 \\
4,520 \\
2,173 \\
3,563\end{array}$ & $\begin{array}{r}1,498 \\
1,359 \\
10,076 \\
5,121 \\
2,472 \\
3,957\end{array}$ & $\begin{array}{l}75.7(2.3) \\
83.5(2.0) \\
79.8(0.8) \\
81.5(1.0) \\
76.5(2.2) \\
83.2(1.1)\end{array}$ & $\begin{array}{l}76.2(3.3) \\
83.9(2.8) \\
80.3(1.2) \\
81.0(1.4) \\
76.5(3.2) \\
83.3(1.6)\end{array}$ & $\begin{array}{l}75.2(3.1) \\
83.0(2.7) \\
79.2(1.2) \\
81.9(1.3) \\
76.6(3.0) \\
83.1(1.5)\end{array}$ & $\begin{array}{l}18.0(2.1) \\
20.4(2.1) \\
26.8(0.9) \\
20.4(1.0) \\
22.4(2.1) \\
24.5(1.3)\end{array}$ & $\begin{array}{l}18.6(3.1) \\
24.9(3.3) \\
29.8(1.4) \\
23.1(1.6) \\
24.8(3.2) \\
26.6(1.9)\end{array}$ & $\begin{array}{l}17.5(2.8) \\
16.3(2.7) \\
23.9(1.2) \\
18.1(1.3) \\
20.3(2.8) \\
22.5(1.7)\end{array}$ \\
\hline 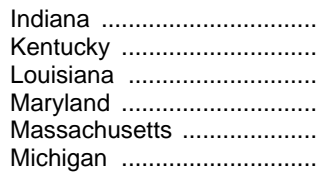 & $\begin{array}{l}3,728 \\
2,565 \\
2,697 \\
3,325 \\
4,110 \\
6,083\end{array}$ & $\begin{array}{l}1,783 \\
1,223 \\
1,274 \\
1,603 \\
2,011 \\
2,841\end{array}$ & $\begin{array}{l}1,945 \\
1,343 \\
1,424 \\
1,722 \\
2,099 \\
3,242\end{array}$ & $\begin{array}{l}83.7(2.1) \\
74.0(2.3) \\
74.6(2.5) \\
84.6(2.0) \\
84.9(1.0) \\
84.2(1.0)\end{array}$ & $\begin{array}{l}84.6(2.9) \\
74.4(3.4) \\
74.2(3.6) \\
85.4(2.8) \\
84.5(1.5) \\
83.3(1.6)\end{array}$ & $\begin{array}{l}82.8(2.9) \\
73.7(3.2) \\
75.0(3.4) \\
83.8(2.9) \\
85.2(1.4) \\
85.0(1.4)\end{array}$ & $\begin{array}{l}16.2(2.1) \\
17.5(2.0) \\
19.2(2.3) \\
32.5(2.6) \\
32.4(1.3) \\
21.1(1.2)\end{array}$ & $\begin{array}{l}17.6(3.1) \\
19.4(3.0) \\
20.9(3.4) \\
35.3(3.9) \\
35.2(2.0) \\
23.6(1.8)\end{array}$ & $\begin{array}{l}14.8(2.8) \\
15.8(2.7) \\
17.8(3.0) \\
29.8(3.6) \\
29.8(1.8) \\
18.8(1.5)\end{array}$ \\
\hline $\begin{array}{l}\text { Minnesota } \\
\text { Missouri } \ldots \ldots \ldots \ldots \ldots \ldots \ldots \ldots \ldots \ldots \\
\text { New Jersey } \ldots \ldots \ldots \ldots \ldots \ldots \ldots \ldots \ldots \ldots \\
\text { New York } \ldots \ldots \ldots \ldots \ldots \ldots \ldots \ldots \ldots \ldots \ldots \ldots \\
\text { North Carolina } \\
\text { Ohio }\end{array}$ & $\begin{array}{r}2,880 \\
3,384 \\
5,231 \\
11,839 \\
4,708 \\
7,186\end{array}$ & $\begin{array}{l}1,392 \\
1,599 \\
2,487 \\
5,513 \\
2,261 \\
3,430\end{array}$ & $\begin{array}{l}1,488 \\
1,785 \\
2,745 \\
6,326 \\
2,447 \\
3,756\end{array}$ & $\begin{array}{l}87.9(1.8) \\
83.9(2.1) \\
84.9(1.0) \\
81.6(0.8) \\
76.0(1.1) \\
84.9(1.0)\end{array}$ & $\begin{array}{l}88.2(2.6) \\
84.8(2.9) \\
85.4(1.4) \\
82.7(1.2) \\
73.9(1.7) \\
86.1(1.4)\end{array}$ & $\begin{array}{l}87.5(2.6) \\
83.0(2.9) \\
84.4(1.4) \\
80.7(1.2) \\
78.0(1.5) \\
83.8(1.4)\end{array}$ & $\begin{array}{l}26.3(2.5) \\
24.3(2.4) \\
28.3(1.3) \\
25.6(0.9) \\
21.0(1.1) \\
22.3(1.2)\end{array}$ & $\begin{array}{l}29.1(3.6) \\
24.3(3.5) \\
31.4(1.9) \\
27.7(1.4) \\
22.6(1.6) \\
25.5(1.8)\end{array}$ & $\begin{array}{l}23.7(3.3) \\
24.4(3.3) \\
25.5(1.7) \\
23.8(1.3) \\
19.6(1.5) \\
19.4(1.5)\end{array}$ \\
\hline 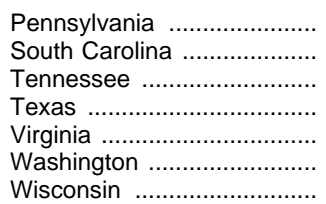 & $\begin{array}{r}7,941 \\
2,318 \\
3,466 \\
11,411 \\
4,240 \\
3,418 \\
3,259\end{array}$ & $\begin{array}{l}3,685 \\
1,088 \\
1,646 \\
5,524 \\
1,974 \\
1,677 \\
1,569\end{array}$ & $\begin{array}{l}4,256 \\
1,230 \\
1,819 \\
5,887 \\
2,265 \\
1,740 \\
1,690\end{array}$ & $\begin{array}{l}81.6(1.1) \\
73.8(2.2) \\
79.0(2.0) \\
76.4(1.2) \\
82.0(1.8) \\
90.2(1.6) \\
88.7(1.6)\end{array}$ & $\begin{array}{l}81.3(1.6) \\
75.5(3.1) \\
77.8(3.0) \\
76.5(1.7) \\
81.2(2.7) \\
89.4(2.3) \\
90.4(2.2)\end{array}$ & $\begin{array}{l}81.9(1.5) \\
72.3(3.0) \\
80.0(2.8) \\
76.3(1.6) \\
82.6(2.5) \\
91.0(2.1) \\
87.1(2.4)\end{array}$ & $\begin{array}{l}22.3(1.2) \\
18.1(1.9) \\
19.5(2.0) \\
21.9(1.1) \\
26.3(2.1) \\
25.6(2.3) \\
24.0(2.2)\end{array}$ & $\begin{array}{l}25.4(1.8) \\
19.7(2.8) \\
21.0(3.0) \\
24.2(1.7) \\
28.9(3.1) \\
27.6(3.3) \\
26.2(3.2)\end{array}$ & $\begin{array}{l}19.6(1.5) \\
16.6(2.5) \\
18.0(2.7) \\
19.8(1.5) \\
24.1(2.8) \\
23.6(3.1) \\
22.0(2.9)\end{array}$ \\
\hline
\end{tabular}

NOTE.-Because of rounding, details may not add to totals. Standard errors appear in parentheses.
SOURCE: U.S. Department of Commerce, Bureau of the Census, Current Population Reports, "Educational Attainment in the United States: March 1996." (This table was prepared September 1998.)

Table 14.-Educational attainment of persons 25 years old and over, for the 15 largest metropolitan areas: March 1995

\begin{tabular}{|c|c|c|c|c|c|c|c|}
\hline \multirow{2}{*}{ Metropolitan area } & \multicolumn{3}{|c|}{$\begin{array}{c}\text { Number of persons } 25 \text { years old and over } \\
\text { (in thousands) }\end{array}$} & \multicolumn{2}{|c|}{$\begin{array}{c}\text { Percent high school completion } \\
\text { or higher }\end{array}$} & \multicolumn{2}{|c|}{$\begin{array}{l}\text { Percent completed bachelor's } \\
\text { or higher degree }\end{array}$} \\
\hline & Total & Male & Female & Male & Female & Male & Female \\
\hline 1 & 2 & 3 & 4 & 5 & 6 & 7 & 8 \\
\hline 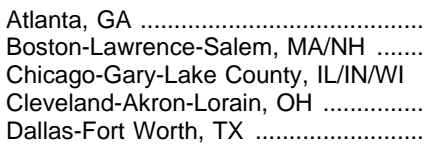 & $\begin{array}{l}1,883 \\
3,254 \\
5,306 \\
2,016 \\
2,595\end{array}$ & $\begin{array}{r}899 \\
1,548 \\
2,506 \\
925 \\
1,260\end{array}$ & $\begin{array}{r}984 \\
1,706 \\
2,800 \\
1,091 \\
1,336\end{array}$ & $\begin{array}{l}87.6(3.7) \\
88.2(1.5) \\
83.7(1.8) \\
81.0(3.1) \\
79.3(3.3)\end{array}$ & $\begin{array}{l}88.4(3.5) \\
87.1(1.5) \\
83.8(1.7) \\
79.3(2.9) \\
79.1(3.2)\end{array}$ & $\begin{array}{l}37.4(5.5) \\
38.8(2.3) \\
31.4(2.3) \\
24.9(3.4) \\
27.3(3.6)\end{array}$ & $\begin{array}{l}31.5(5.1) \\
32.5(2.1) \\
25.6(2.1) \\
16.4(2.7) \\
20.7(3.2)\end{array}$ \\
\hline 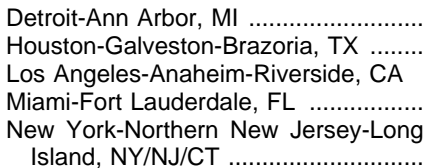 & $\begin{array}{r}3,472 \\
3,077 \\
9,467 \\
2,232 \\
12,525\end{array}$ & $\begin{array}{l}1,652 \\
1,475 \\
4,605 \\
1,055 \\
5,770\end{array}$ & $\begin{array}{l}1,820 \\
1,602 \\
4,862 \\
1,177\end{array}$ & $\begin{array}{l}80.9(2.1) \\
83.7(2.8) \\
77.5(1.5) \\
85.7(2.7) \\
84.4(1.1)\end{array}$ & $\begin{array}{l}80.7(2.1) \\
83.4(2.7) \\
75.2(1.5) \\
81.9(2.8) \\
82.5(1.1)\end{array}$ & $\begin{array}{l}27.2(2.4) \\
31.4(3.5) \\
28.4(1.6) \\
27.3(3.4) \\
32.8(1.4)\end{array}$ & $\begin{array}{l}18.8(2.0) \\
22.1(3.0) \\
19.7(1.4) \\
20.4(2.9) \\
25.3(1.2)\end{array}$ \\
\hline 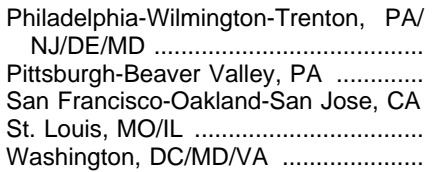 & $\begin{array}{l}4,248 \\
1,911 \\
4,298 \\
1,641 \\
2,872\end{array}$ & $\begin{array}{r}2,025 \\
926 \\
2,136 \\
775 \\
1,460\end{array}$ & $\begin{array}{r}2,223 \\
985 \\
2,162 \\
866 \\
1,411\end{array}$ & $\begin{array}{l}83.6(2.0) \\
81.1(3.2) \\
89.2(2.1) \\
81.1(4.9) \\
85.5(3.0)\end{array}$ & $\begin{array}{l}83.8(1.9) \\
81.4(3.1) \\
87.9(2.2) \\
83.2(4.4) \\
85.8(3.0)\end{array}$ & $\begin{array}{l}34.3(2.6) \\
26.6(3.6) \\
35.8(3.2) \\
27.5(5.6) \\
38.6(4.2)\end{array}$ & $\begin{array}{l}25.8(2.3) \\
19.8(3.1) \\
29.1(3.0) \\
20.8(4.8) \\
28.1(3.9)\end{array}$ \\
\hline
\end{tabular}

NOTE.-Because of rounding, details may not add to totals. Standard errors appear in parentheses.
SOURCE: U.S. Department of Commerce, Bureau of the Census, Current Population Reports, "Educational Attainment in the United States: March 1995." (This table was prepared July 1997.) 
Table 15.-Estimates of resident population, by age group: July 1, 1970 to July 1, 1997

[In thousands]

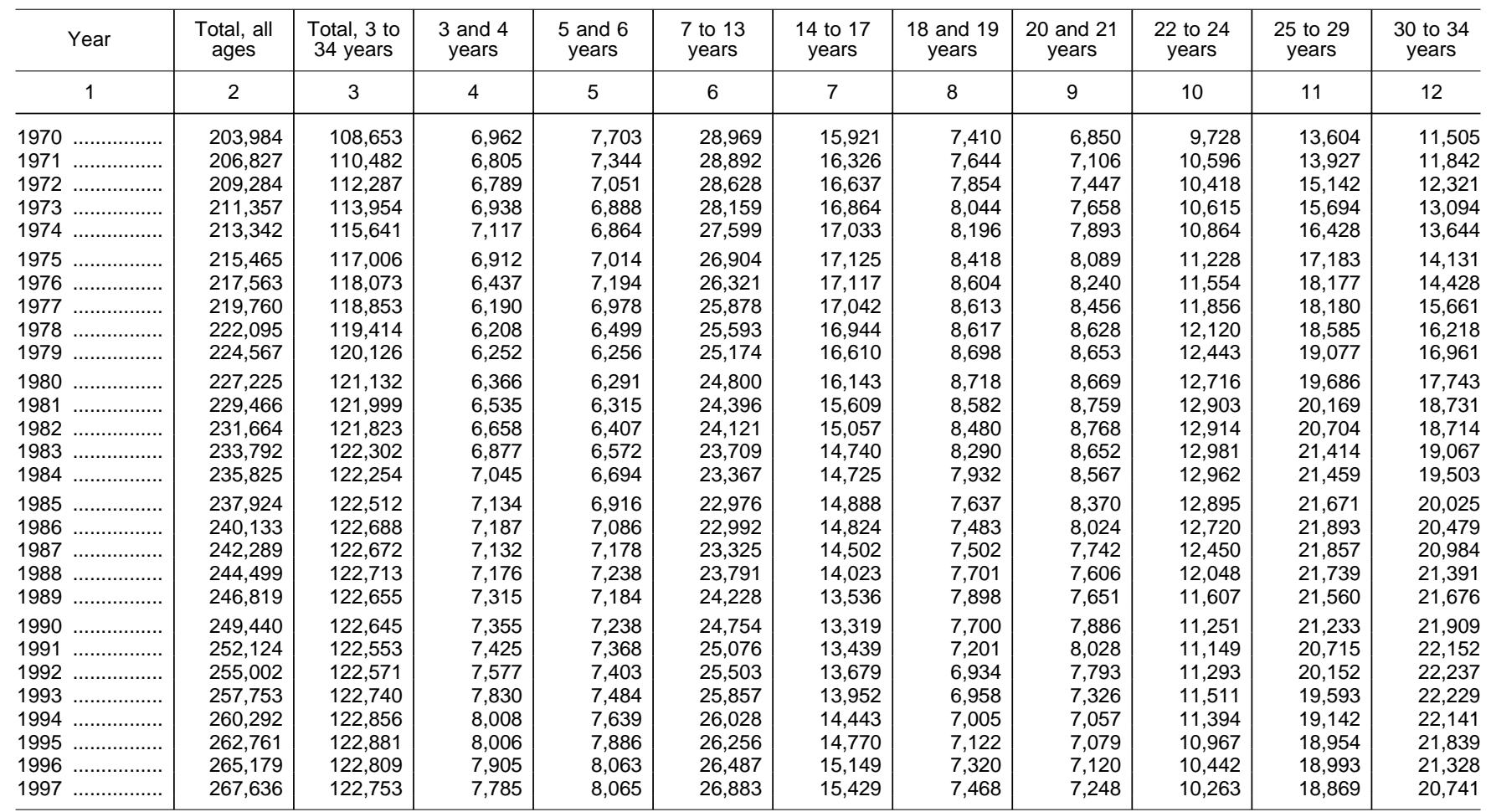

NOTE.-Some data have been revised from previously published figures. Because of rounding, details may not add to totals.
SOURCE: U.S. Department of Commerce, Bureau of the Census, Current Population Reports, Series P-25, Nos. 1000, 1022, 1045, 1057, 1059, 1092, 1095, and U.S. Population Estimates, by Age, Sex, Race, and Hispanic Origin: 1990-1997, PPL-91R; and unpublished data. (This table was prepared April 1998.)

Table 16.-Estimates of school-age ${ }^{1}$ resident population, by race and sex: July 1, 1970 to July 1, 1997 [In thousands]

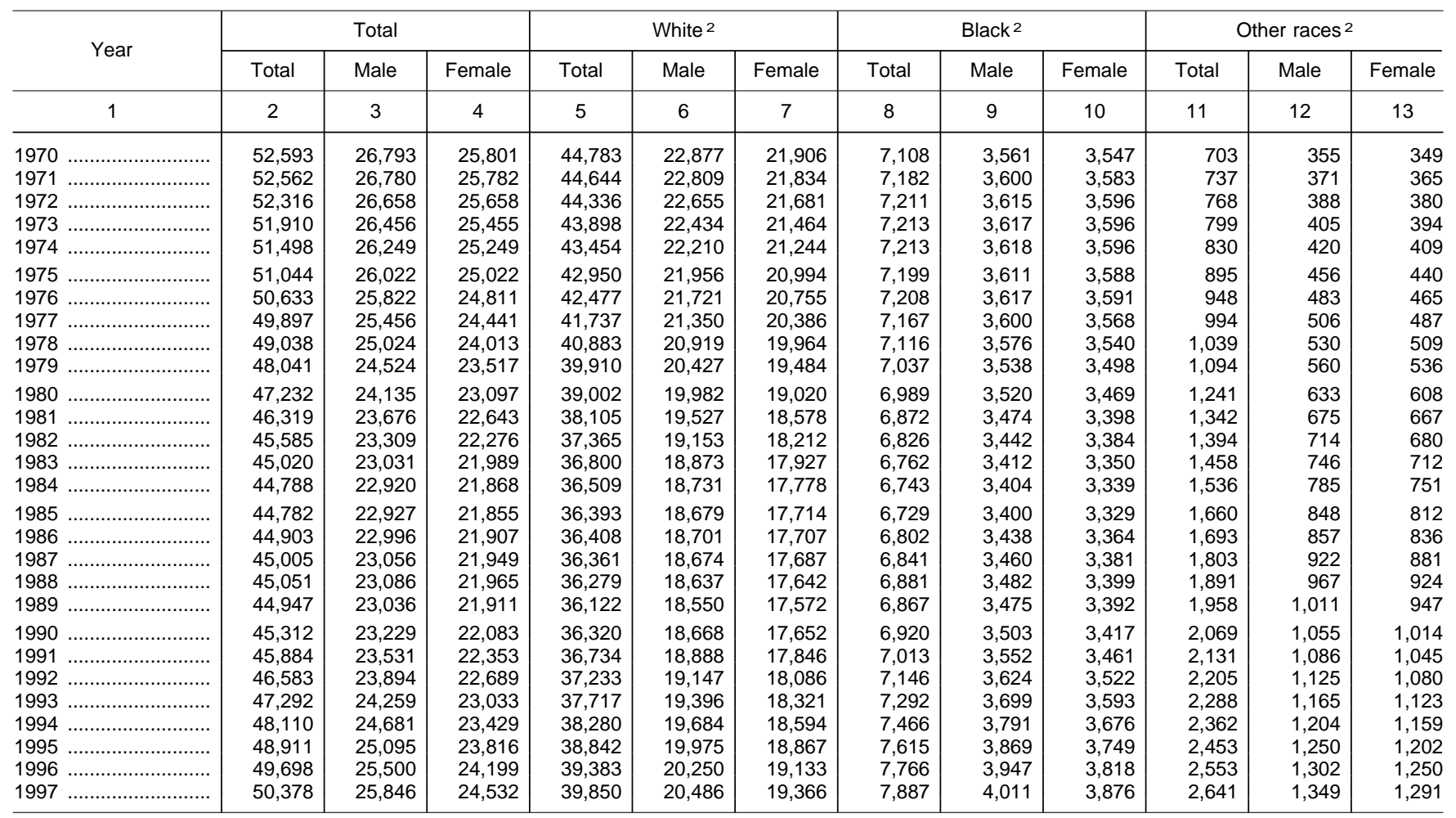

${ }^{1}$ Includes persons 5 to 17 years of age. ${ }^{2}$ Includes persons of Hispanic origin.

NOTE.-Some data have been revised from previously published figures. Because of rounding, details may not add to totals.
SOURCE: U.S. Department of Commerce, Bureau of the Census, Current Population Reports, Series P-25, Nos. 1000, 1022, 1045, 1057, 1092; U.S. Population Estimates, by Age, Sex, Race, and Hispanic Origin: 1990-1997, PPL-91R; and unpublished data. (This table was prepared April 1998.) 
Table 17.-Estimated total and school-age resident populations, by state: 11970 to 1997

[In thousands]

\begin{tabular}{|c|c|c|c|c|c|c|c|c|c|c|c|c|c|c|}
\hline \multirow[b]{2}{*}{ State } & \multicolumn{2}{|c|}{$1970^{2}$} & \multicolumn{2}{|c|}{$1980^{2}$} & \multicolumn{2}{|c|}{$1985^{3}$} & \multicolumn{2}{|c|}{$1990^{2}$} & \multicolumn{2}{|c|}{$1995^{3}$} & \multicolumn{2}{|c|}{$1996^{3}$} & \multicolumn{2}{|c|}{$1997^{3}$} \\
\hline & $\begin{array}{c}\text { Total, } \\
\text { all ages }\end{array}$ & $\begin{array}{l}5-\text { to } \\
17- \\
\text { year- } \\
\text { olds }\end{array}$ & $\begin{array}{l}\text { Total, } \\
\text { all ages }\end{array}$ & $\begin{array}{l}\text { 5- to } \\
17- \\
\text { year- } \\
\text { olds }\end{array}$ & \begin{tabular}{|c|} 
Total, \\
all ages
\end{tabular} & $\begin{array}{l}5-\text { to } \\
17- \\
\text { year- } \\
\text { olds }\end{array}$ & \begin{tabular}{|} 
Total, \\
all ages
\end{tabular} & $\begin{array}{l}5-\text { to } \\
17- \\
\text { year- } \\
\text { olds }\end{array}$ & $\begin{array}{l}\text { Total, } \\
\text { all ages }\end{array}$ & $\begin{array}{l}\text { 5- to } \\
17- \\
\text { year- } \\
\text { olds }\end{array}$ & $\begin{array}{c}\text { Total, } \\
\text { all ages }\end{array}$ & $\begin{array}{l}5-\text { to } \\
17- \\
\text { year- } \\
\text { olds }\end{array}$ & $\begin{array}{c}\text { Total, } \\
\text { all ages }\end{array}$ & $\begin{array}{l}5-\text { to } \\
17- \\
\text { year- } \\
\text { olds }\end{array}$ \\
\hline 1 & 2 & 3 & 4 & 5 & 6 & 7 & 8 & 9 & 10 & 11 & 12 & 13 & 14 & 15 \\
\hline United States & 03,302 & 52,540 & 26,546 & 47,407 & 37,924 & 44,782 & 248,710 & 45,166 & 262,761 & 48,911 & 265,179 & 49,698 & 267,636 & 50,378 \\
\hline $\begin{array}{l}\text { Alabama } \\
\text { Alaska } \\
\text { Arizona } \\
\text { Arkansas } \\
\text { California }\end{array}$ & $\begin{array}{r}3,444 \\
303 \\
1,775 \\
1,923 \\
19,971\end{array}$ & $\begin{array}{r}934 \\
88 \\
486 \\
498 \\
4,999\end{array}$ & $\begin{array}{r}3,894 \\
402 \\
2,718 \\
2,286 \\
23,668\end{array}$ & $\begin{array}{r}866 \\
92 \\
578 \\
496 \\
4,681\end{array}$ & $\begin{array}{r}3,973 \\
532 \\
3,184 \\
2,327 \\
26,441\end{array}$ & $\begin{array}{r}798 \\
112 \\
601 \\
461 \\
4,752\end{array}$ & $\begin{array}{r}4,041 \\
550 \\
3,665 \\
2,351 \\
29,760\end{array}$ & $\begin{array}{r}774 \\
117 \\
686 \\
455 \\
5,337\end{array}$ & $\begin{array}{r}4,262 \\
602 \\
4,308 \\
2,481 \\
31,558\end{array}$ & $\begin{array}{r}781 \\
134 \\
823 \\
478 \\
5,963\end{array}$ & $\begin{array}{r}4,287 \\
605 \\
4,434 \\
2,506 \\
31,858\end{array}$ & $\begin{array}{r}781 \\
136 \\
864 \\
483 \\
6,157\end{array}$ & $\begin{array}{r}4,319 \\
609 \\
4,555 \\
2,523 \\
32,268\end{array}$ & $\begin{array}{r}779 \\
139 \\
904 \\
486 \\
6,291\end{array}$ \\
\hline $\begin{array}{l}\text { Colorado } \\
\text { Connecticut } \\
\text { Delaware ............... } \\
\text { District of Columbia } \\
\text { Florida }\end{array}$ & $\begin{array}{r}2,210 \\
3,032 \\
548 \\
757 \\
6,791\end{array}$ & $\begin{array}{r}589 \\
768 \\
148 \\
164 \\
1,609\end{array}$ & $\begin{array}{r}2,890 \\
3,108 \\
594 \\
638 \\
9,746\end{array}$ & $\begin{array}{r}592 \\
638 \\
125 \\
109 \\
1,789\end{array}$ & $\begin{array}{r}3,209 \\
3,201 \\
618 \\
635 \\
11,351\end{array}$ & $\begin{array}{r}599 \\
549 \\
113 \\
88 \\
1,792\end{array}$ & $\begin{array}{r}3,294 \\
3,287 \\
666 \\
607 \\
12,938\end{array}$ & $\begin{array}{r}607 \\
520 \\
114 \\
80 \\
2,011\end{array}$ & $\begin{array}{r}3,742 \\
3,267 \\
716 \\
552 \\
14,181\end{array}$ & $\begin{array}{r}707 \\
564 \\
125 \\
75 \\
2,386\end{array}$ & $\begin{array}{r}3,816 \\
3,267 \\
723 \\
539 \\
14,419\end{array}$ & $\begin{array}{r}724 \\
569 \\
127 \\
74 \\
2,455\end{array}$ & $\begin{array}{r}3,893 \\
3,270 \\
732 \\
529 \\
14,654\end{array}$ & $\begin{array}{r}742 \\
575 \\
128 \\
74 \\
2,520\end{array}$ \\
\hline $\begin{array}{l}\text { Georgia } \\
\text { Hawaii } \\
\text { Idaho } \\
\text { Illinois } \\
\text { Indiana }\end{array}$ & $\begin{array}{r}4,588 \\
770 \\
713 \\
11,110 \\
5,195\end{array}$ & $\begin{array}{r}1,223 \\
204 \\
200 \\
2,859 \\
1,386\end{array}$ & $\begin{array}{r}5,463 \\
965 \\
944 \\
11,427 \\
5,490\end{array}$ & $\begin{array}{r}1,231 \\
198 \\
213 \\
2,401 \\
1,200\end{array}$ & $\begin{array}{r}5,963 \\
1,040 \\
994 \\
11,400 \\
5,459\end{array}$ & $\begin{array}{r}1,195 \\
194 \\
223 \\
2,192 \\
1,087\end{array}$ & $\begin{array}{r}6,478 \\
1,108 \\
1,007 \\
11,431 \\
5,544\end{array}$ & $\begin{array}{r}1,230 \\
196 \\
228 \\
2,095 \\
1,056\end{array}$ & $\begin{array}{r}7,192 \\
1,179 \\
1,165 \\
11,795 \\
5,788\end{array}$ & $\begin{array}{r}1,367 \\
211 \\
255 \\
2,201 \\
1,076\end{array}$ & $\begin{array}{r}7,334 \\
1,183 \\
1,188 \\
11,845 \\
5,828\end{array}$ & $\begin{array}{r}1,399 \\
213 \\
257 \\
2,240 \\
1,084\end{array}$ & $\begin{array}{r}7,486 \\
1,187 \\
1,210 \\
11,896 \\
5,864\end{array}$ & $\begin{array}{r}1,430 \\
214 \\
260 \\
2,271 \\
1,090\end{array}$ \\
\hline 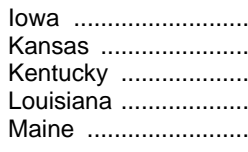 & $\begin{array}{r}3,221 \\
3,645 \\
994\end{array}$ & $\begin{array}{r}743 \\
573 \\
844 \\
1,041 \\
260\end{array}$ & $\begin{array}{l}2,914 \\
2,364 \\
3,661 \\
4,206 \\
1,125\end{array}$ & $\begin{array}{l}604 \\
468 \\
800 \\
969 \\
243\end{array}$ & $\begin{array}{l}2,830 \\
2,427 \\
3,695 \\
4,408 \\
1,163\end{array}$ & $\begin{array}{l}543 \\
452 \\
745 \\
937 \\
222\end{array}$ & $\begin{array}{l}2,777 \\
2,478 \\
3,685 \\
4,220 \\
1,228\end{array}$ & $\begin{array}{l}525 \\
472 \\
703 \\
890 \\
223\end{array}$ & $\begin{array}{l}4,329 \\
1,234\end{array}$ & $\begin{array}{l}538 \\
504 \\
708 \\
899 \\
228\end{array}$ & $\begin{array}{l}2,848 \\
2,579 \\
3,882\end{array}$ & $\begin{array}{l}707 \\
889 \\
228\end{array}$ & $\begin{array}{l}2,852 \\
2,595 \\
3,908 \\
4,352 \\
1,242\end{array}$ & $\begin{array}{l}542 \\
509 \\
704 \\
877 \\
228\end{array}$ \\
\hline 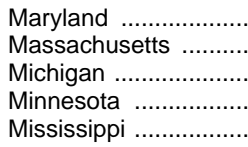 & $\begin{array}{l}689 \\
882 \\
806 \\
217\end{array}$ & $\begin{array}{l}38 \\
07 \\
50 \\
51 \\
35\end{array}$ & $\begin{array}{l}5,737 \\
9,262 \\
4,076 \\
2,521\end{array}$ & $\begin{array}{r}895 \\
1,153 \\
2,067 \\
865 \\
599\end{array}$ & $\begin{array}{l}5,881 \\
9,076 \\
4,184 \\
2,588\end{array}$ & $\begin{array}{r}788 \\
989 \\
1,824 \\
796 \\
576\end{array}$ & & $\begin{array}{r}803 \\
940 \\
1,754 \\
828 \\
550\end{array}$ & $\begin{array}{l}51 \\
55 \\
57\end{array}$ & $\begin{array}{r}9 \\
1,0 \\
18\end{array}$ &, 7111 & 1, & $\begin{array}{l}, 118 \\
, 774 \\
686 \\
731\end{array}$ & $\begin{array}{r}922 \\
1,052 \\
1,852 \\
935 \\
551\end{array}$ \\
\hline 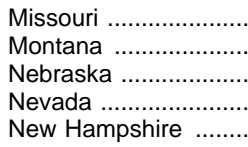 & $\begin{array}{r}4,678 \\
694 \\
1,485 \\
489 \\
738\end{array}$ & $\begin{array}{l}183 \\
197 \\
389 \\
127 \\
189\end{array}$ & $\begin{array}{r}4,917 \\
787 \\
1,570 \\
800 \\
921\end{array}$ & $\begin{array}{r}1,008 \\
167 \\
324 \\
160 \\
196\end{array}$ & $\begin{array}{r}5,000 \\
822 \\
1,585 \\
951 \\
997\end{array}$ & $\begin{array}{l}941 \\
167 \\
305 \\
166 \\
182\end{array}$ & $\begin{array}{r}75 \\
1,57\end{array}$ & $\begin{array}{l}204 \\
194\end{array}$ & 1,146 & $\begin{array}{l}176 \\
326 \\
276 \\
216\end{array}$ & $\begin{array}{r}5,364 \\
877 \\
1,649 \\
1,601 \\
1,160\end{array}$ & $\begin{array}{l}176 \\
328 \\
294 \\
219\end{array}$ & $\begin{array}{r}5,402 \\
879 \\
1,657 \\
1,677 \\
1,173\end{array}$ & $\begin{array}{r}1,040 \\
175 \\
330 \\
313 \\
222\end{array}$ \\
\hline 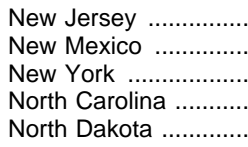 & $\begin{array}{r}7,171 \\
1,017 \\
18,241 \\
5,084 \\
618\end{array}$ & $\begin{array}{r}1,797 \\
311 \\
4,358 \\
1,323 \\
175\end{array}$ & $\begin{array}{r}17,558 \\
5,882 \\
653\end{array}$ & $\begin{array}{r}1,528 \\
303 \\
3,552 \\
1,254 \\
136\end{array}$ & $\begin{array}{r}7,566 \\
1,438 \\
17,792 \\
6,254 \\
677\end{array}$ & $\begin{array}{r}1,340 \\
304 \\
3,173 \\
1,175 \\
133\end{array}$ & $\begin{array}{r}7,730 \\
1,515 \\
17,990 \\
6,629 \\
639\end{array}$ & $\begin{array}{r}1,265 \\
320 \\
3,000 \\
1,147 \\
127\end{array}$ & $\begin{array}{r}7,956 \\
1,686 \\
18,146 \\
7,187 \\
641\end{array}$ & $\begin{array}{r}1,385 \\
358 \\
3,166 \\
1,280 \\
128\end{array}$ & $\begin{array}{r}8,002 \\
1,711 \\
18,134 \\
7,309 \\
643\end{array}$ & $\begin{array}{r}3,212 \\
1,317 \\
126\end{array}$ & $\begin{array}{r}1,730 \\
18,137 \\
7,425 \\
641\end{array}$ & $\begin{array}{r}1,430 \\
365 \\
3,246 \\
1,355 \\
125\end{array}$ \\
\hline $\begin{array}{l}\text { Oregon } \\
\text { Pennsylvania } \\
\text { Rhode Island }\end{array}$ & $\begin{array}{r}10,657 \\
2,559 \\
2,092 \\
11,801 \\
950\end{array}$ & $\begin{array}{r}2,820 \\
640 \\
534 \\
2,925 \\
225\end{array}$ & $\begin{array}{r}10,798 \\
3,025 \\
2,633 \\
11,864 \\
947\end{array}$ & $\begin{array}{r}2,307 \\
622 \\
525 \\
2,376 \\
186\end{array}$ & $\begin{array}{r}10,735 \\
3,271 \\
2,673 \\
11,771 \\
969\end{array}$ & $\begin{array}{r}2,090 \\
635 \\
504 \\
2,079 \\
163\end{array}$ & $\begin{array}{r}3,146 \\
2,842 \\
11,882 \\
1,003\end{array}$ & $\begin{array}{r}2,012 \\
609 \\
521 \\
1,996 \\
159\end{array}$ & $\begin{array}{l}143 \\
046 \\
990\end{array}$ & $\begin{array}{r}2,073 \\
644 \\
585 \\
2,109 \\
170\end{array}$ & $\begin{array}{r}3,295 \\
3,196 \\
12,040 \\
988\end{array}$ & $\begin{array}{r}2,083 \\
648 \\
592 \\
2,118 \\
171\end{array}$ & $\begin{array}{r}3,317 \\
3,243 \\
12,020 \\
987\end{array}$ & $\begin{array}{r}2,090 \\
652 \\
598 \\
2,126 \\
171\end{array}$ \\
\hline 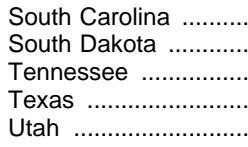 & $\begin{array}{r}2,591 \\
666 \\
3,926 \\
11,199 \\
1,059\end{array}$ & $\begin{array}{r}720 \\
187 \\
1,002 \\
3,002 \\
312\end{array}$ & $\begin{array}{r}3,122 \\
691 \\
4,591 \\
14,229 \\
1,461\end{array}$ & $\begin{array}{r}703 \\
147 \\
972 \\
3,137 \\
350\end{array}$ & $\begin{array}{r}3,303 \\
698 \\
4,715 \\
16,273 \\
1,643\end{array}$ & $\begin{array}{r}663 \\
139 \\
903 \\
3,318 \\
418\end{array}$ & $\begin{array}{r}3,487 \\
696 \\
4,877 \\
16,987 \\
1,723\end{array}$ & $\begin{array}{r}663 \\
144 \\
882 \\
3,437 \\
457\end{array}$ & $\begin{array}{r}735 \\
5,235\end{array}$ & $\begin{array}{r}681 \\
153 \\
942 \\
3,782 \\
489\end{array}$ & $\begin{array}{r}3,717 \\
738 \\
5,307 \\
19,091 \\
2,018\end{array}$ & $\begin{array}{r}69 \\
15 \\
95 \\
3,87 \\
49\end{array}$ & $\begin{array}{r}3,760 \\
738 \\
5,368 \\
19,439 \\
2,059\end{array}$ & $\begin{array}{r}702 \\
148 \\
963 \\
3,969 \\
492\end{array}$ \\
\hline 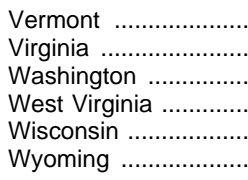 & $\begin{array}{r}445 \\
4,651 \\
3,413 \\
1,744 \\
4,418 \\
332\end{array}$ & $\begin{array}{r}1,197 \\
881 \\
442 \\
1,203 \\
92\end{array}$ & $\begin{array}{r}511 \\
5,347 \\
4,132 \\
1,950 \\
4,706 \\
470\end{array}$ & $\begin{array}{r}109 \\
1,114 \\
826 \\
414 \\
1,011 \\
101\end{array}$ & $\begin{array}{r}530 \\
5,715 \\
4,400 \\
1,907 \\
4,748 \\
500\end{array}$ & $\begin{array}{r}100 \\
1,039 \\
816 \\
383 \\
908 \\
108\end{array}$ & $\begin{array}{r}6,187 \\
4,867 \\
1,793 \\
4,892 \\
454\end{array}$ & $\begin{array}{r}1,060 \\
893 \\
337 \\
927 \\
101\end{array}$ & $\begin{array}{r}1,822 \\
5,113 \\
479\end{array}$ & $\begin{array}{r}1,154 \\
1,027 \\
318 \\
1,000 \\
103\end{array}$ & $\begin{array}{r}6,666 \\
5,520 \\
1,820 \\
5,146 \\
480\end{array}$ & $\begin{array}{r}1,173 \\
1,047 \\
314 \\
1,005 \\
102\end{array}$ & $\begin{array}{r}6,734 \\
5,610 \\
1,816 \\
5,170 \\
480\end{array}$ & $\begin{array}{r}1,192 \\
1,068 \\
308 \\
1,011 \\
101\end{array}$ \\
\hline
\end{tabular}

${ }^{1}$ Includes Armed Forces residing in each state.

${ }^{2}$ As of April 1.

${ }^{3}$ Estimates as of July 1 .

NOTE.-Some data have been revised from previously published figures. Because of rounding, details may not add to totals.
SOURCE: U.S. Department of Commerce, Bureau of the Census, Current Population Reports, Series P-25, No. 1095 at the national level, CPH-L-74 (1990 data); and forthcoming state level P-25 Reports. (This table was prepared October 1998.) 
Table 18.-Families, by family status and presence of own children under 18: 1970 to 1996

\begin{tabular}{|c|c|c|c|c|c|c|c|c|c|c|c|c|c|}
\hline Family status & 1970 & 1980 & 1985 & 1988 & 1989 & 1990 & 1992 & 1993 & 1994 & 1995 & 1996 & $\begin{array}{c}\text { Change, } \\
1970 \text { to } \\
1980\end{array}$ & $\begin{array}{c}\text { Change, } \\
1980 \text { to } \\
1996\end{array}$ \\
\hline 1 & 2 & 3 & 4 & 5 & 6 & 7 & 8 & 9 & 10 & 11 & 12 & 13 & 14 \\
\hline & \multicolumn{11}{|c|}{ In thousands } & \multicolumn{2}{|c|}{ Percent change } \\
\hline All families & 51,456 & 59,550 & 62,706 & 65,133 & 65,837 & 66,090 & 67,173 & 68,144 & 68,490 & 69,305 & 69,594 & 15.7 & 16.9 \\
\hline Married-couple family & 44,728 & 49,112 & 50,350 & 51,809 & 52,100 & 52,317 & 52,457 & 53,171 & 53,171 & 53,858 & 53,567 & 9.8 & 9.1 \\
\hline No own children under $18 \ldots \ldots \ldots .$. & 19,196 & 24,151 & 26,140 & 27,209 & 27,365 & 27,780 & 28,037 & 28,464 & 28,113 & 28,617 & 28,647 & 25.8 & 18.6 \\
\hline With own children under $18 \ldots \ldots$. & 25,532 & 24,961 & 24,210 & 24,600 & 24,735 & 24,537 & 24,420 & 24,707 & 25,058 & 25,241 & 24,920 & -2.2 & -0.2 \\
\hline One own child under $18 \ldots \ldots \ldots$ & 8,163 & 9,671 & 9,640 & 9,904 & 9,829 & 9,583 & 9,520 & 9,466 & 9,452 & 9,564 & 9,352 & 18.5 & -3.3 \\
\hline $\begin{array}{l}\text { Two own children under } 18 \ldots . . \\
\text { Three or more own children }\end{array}$ & 8,045 & 9,488 & 9,456 & 9,576 & 9,870 & 9,784 & 9,728 & 10,007 & 10,188 & 10,358 & 10,278 & 17.9 & 8.3 \\
\hline $\begin{array}{l}\text { Three or more own children } \\
\quad \text { under } 18\end{array}$ & 9,325 & 5,802 & 5,115 & 5,120 & 5,035 & 5,170 & 5,173 & 5,234 & 5,418 & 5,319 & 5,350 & -37.8 & -7.8 \\
\hline \multirow{2}{*}{\multicolumn{14}{|c|}{$\begin{array}{l}\text { Other family, male householder, } \\
\text { no spouse present }\end{array}$}} \\
\hline & $\begin{array}{r}1,228 \\
887\end{array}$ & 1,733 & 2,228 & 2,715 & 2,847 & 2,884 & 3,025 & 3,026 & 2,913 & 3,226 & 3,513 & 41.1 & 102.7 \\
\hline ren under $18 \ldots \ldots \ldots$. & 887 & 1,117 & 1,331 & 1,669 & 1,779 & 1,731 & 1,742 & 1,702 & 1,599 & 1,786 & 1,885 & 25.9 & 68.8 \\
\hline $\begin{array}{l}\text { With own children under } 18 \\
\text { One own child under } 18\end{array}$ & $\begin{array}{l}341 \\
179\end{array}$ & 616 & 896 & 1,047 & 1,068 & 1,153 & $\begin{array}{r}1,283 \\
768\end{array}$ & $\begin{array}{r}1,324 \\
799\end{array}$ & 1,314 & 1,440 & 1,628 & 80.6 & \\
\hline Two own children under $18 \ldots \ldots . . .$. & $\begin{array}{r}179 \\
87\end{array}$ & $\begin{array}{l}374 \\
165\end{array}$ & $\begin{array}{l}584 \\
213\end{array}$ & $\begin{array}{l}657 \\
296\end{array}$ & $\begin{array}{l}619 \\
326\end{array}$ & $\begin{array}{l}723 \\
307\end{array}$ & $\begin{array}{l}168 \\
391\end{array}$ & $\begin{array}{l}799 \\
397\end{array}$ & $\begin{array}{l}805 \\
368\end{array}$ & $\begin{array}{l}891 \\
405\end{array}$ & $\begin{array}{r}1,005 \\
471\end{array}$ & $\begin{array}{r}108.9 \\
89.7\end{array}$ & $\begin{array}{l}168.7 \\
185.5\end{array}$ \\
\hline \multicolumn{14}{|l|}{ Three or more own children } \\
\hline \multicolumn{14}{|l|}{$\begin{array}{l}\text { Other family, female householder, } \\
\text { no spouse present }\end{array}$} \\
\hline No own children under 18 & 2,642 & 3,261 & 4,123 & 4,335 & 4,371 & 4,290 & 4,648 & 4,721 & 4,759 & 4,606 & 4,859 & 23.4 & 49.0 \\
\hline With own children under $18 \ldots \ldots$. & 2,858 & 5,445 & 6,006 & 6,273 & 6,519 & 6,599 & 7,043 & 7,226 & 7,647 & 7,615 & 7,656 & 90.5 & 40.6 \\
\hline One own child under $18 \ldots \ldots \ldots \ldots$ & 1,008 & 2,398 & 2,885 & 3,017 & 3,164 & 3,225 & 3,327 & 3,425 & 3,566 & 3,633 & 3,683 & 137.9 & 53.6 \\
\hline $\begin{array}{l}\text { Two own children under } 18 \ldots \ldots \ldots . \\
\text { Three or more own children }\end{array}$ & 810 & 1,817 & 1,977 & 2,039 & 2,095 & 2,173 & 2,244 & 2,400 & 2,531 & 2,450 & 2,457 & 124.3 & 35.2 \\
\hline \multirow{2}{*}{$\begin{array}{l}\text { Three or more own children } \\
\quad \text { under } 18\end{array}$} & 1,040 & 1,230 & 1,144 & 1,217 & 1,260 & 1,202 & 1,472 & 1,400 & 1,550 & 1,531 & 1,514 & 18.3 & 23.1 \\
\hline & \multicolumn{11}{|c|}{ Percent of all families } & \multicolumn{2}{|c|}{$\begin{array}{l}\text { Change in } \\
\text { percentage points }\end{array}$} \\
\hline All families & 100.0 & 100.0 & 100.0 & 100.0 & 100.0 & 100.0 & 100.0 & 100.0 & 100.0 & 100.0 & 100.0 & - & 一 \\
\hline Married-couple family & 86.9 & 82.5 & 80.3 & 79.5 & 79.1 & 79.2 & 78.1 & 78.0 & 77.6 & 77.7 & 77.0 & -4.5 & -5.5 \\
\hline No own children under 18 & 37.3 & 40.6 & 41.7 & 41.8 & 41.6 & 42.0 & 41.7 & 41.8 & 41.0 & 41.3 & 41.2 & 3.3 & 0.6 \\
\hline With own children under $18 \ldots \ldots$. & 49.6 & 41.9 & 38.6 & 37.8 & 37.6 & 37.1 & 36.4 & 36.3 & 36.6 & 36.4 & 35.8 & -7.7 & -6.1 \\
\hline One own child under $18 \ldots \ldots . .$. & 15.9 & 16.2 & 15.4 & 15.2 & 14.9 & 14.5 & 14.2 & 13.9 & 13.8 & 13.8 & 13.4 & 0.4 & -2.8 \\
\hline Two own children under $18 \ldots$. & 15.6 & 15.9 & 15.1 & 14.7 & 15.0 & 14.8 & 14.5 & 14.7 & 14.9 & 14.9 & 14.8 & 0.3 & -1.2 \\
\hline 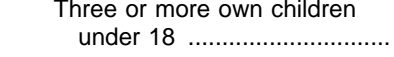 & 18.1 & 9.7 & 8.2 & 7.9 & 7.6 & 7.8 & 7.7 & 7.7 & 7.9 & 7.7 & 7.7 & -8.4 & -2.1 \\
\hline \multicolumn{14}{|l|}{ Other family, male householder, } \\
\hline no spouse present .................. & 2.4 & 2.9 & 3.6 & 4.2 & 4.3 & 4.4 & 4.5 & 4.4 & 4.3 & 4.7 & 5.0 & 0.5 & 2.1 \\
\hline No own children under 18 & 1.7 & 1.9 & 2.1 & 2.6 & 2.7 & 2.6 & 2.6 & 2.5 & 2.3 & 2.6 & 2.7 & 0.2 & 0.8 \\
\hline With own children under $18 \ldots \ldots$. & 0.7 & 1.0 & 1.4 & 1.6 & 1.6 & 1.7 & 1.9 & 1.9 & 1.9 & 2.1 & 2.3 & 0.4 & 1.3 \\
\hline One own child under $18 \ldots \ldots \ldots \ldots$ & 0.3 & 0.6 & 0.9 & 1.0 & 0.9 & 1.1 & 1.1 & 1.2 & 1.2 & 1.3 & 1.4 & 0.3 & 0.8 \\
\hline \multicolumn{12}{|l|}{ Three or more own children } & 0.1 & 0.4 \\
\hline under $18 \ldots \ldots \ldots \ldots \ldots \ldots \ldots \ldots \ldots$ & 0.1 & 0.1 & 0.2 & 0.1 & 0.2 & 0.2 & 0.2 & 0.2 & 0.2 & 0.2 & 0.2 & $\left({ }^{1}\right)$ & 0.1 \\
\hline \multicolumn{14}{|l|}{ Other family, female householder, } \\
\hline no spou & 10.7 & 14.6 & 16.2 & 16.3 & 16.5 & 16.5 & 17.4 & 17.5 & 18.1 & 17.6 & 18.0 & 3.9 & 3.4 \\
\hline No own children under $18 \ldots \ldots . . .$. & 5.1 & 5.5 & 6.6 & 6.7 & 6.6 & 6.5 & 6.9 & 6.9 & 6.9 & 6.6 & 7.0 & 0.3 & 1.5 \\
\hline With own children under $18 \ldots \ldots$. & 5.6 & 9.1 & 9.6 & 9.6 & 9.9 & 10.0 & 10.5 & 10.6 & 11.2 & 11.0 & 11.0 & 3.6 & 1.9 \\
\hline One own child under $18 \ldots \ldots \ldots \ldots$ & 2.0 & 4.0 & 4.6 & 4.6 & 4.8 & 4.9 & 5.0 & 5.0 & 5.2 & 5.2 & 5.3 & 2.1 & 1.3 \\
\hline $\begin{array}{l}\text { Two own children under } 18 \ldots \ldots . . . \\
\text { Three or more own children }\end{array}$ & 1.6 & Three or more own children & 3.2 & 3.1 & 3.2 & 3.3 & 3.3 & 3.5 & 3.7 & 3.5 & 3.5 & 1.5 & 0.5 \\
\hline 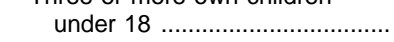 & 2.0 & 2.1 & 1.8 & 1.9 & 1.9 & 1.8 & 2.2 & 2.1 & 2.3 & 2.2 & 2.2 & $(1)$ & 0.1 \\
\hline
\end{tabular}

${ }^{1}$ Less than .05 percent

-Data not applicable.

NOTE.-Because of rounding, details may not add to totals.
SOURCE: U.S. Department of Commerce, Bureau of the Census, Current Population Reports, Series P-20-495, Household and Family Characteristics, various years; and unpublished data. (This table was prepared May 1998.) 
Table 19.-Characteristics of families with own children under 18, by family status and race/ethnicity: ${ }^{1} 1996$

[Numbers in thousands]

\begin{tabular}{|c|c|c|c|c|c|c|c|c|c|c|c|c|c|c|c|c|}
\hline \multirow[b]{3}{*}{ Family characteristics } & \multicolumn{4}{|c|}{ All races } & \multicolumn{4}{|c|}{ White $^{2}$} & \multicolumn{4}{|c|}{ Black $^{2}$} & \multicolumn{4}{|c|}{ Hispanic origin ${ }^{3}$} \\
\hline & \multirow[b]{2}{*}{ Total } & \multirow[b]{2}{*}{$\begin{array}{l}\text { Married- } \\
\text { couple } \\
\text { families }\end{array}$} & \multicolumn{2}{|c|}{ Other families } & \multirow[b]{2}{*}{ Total } & \multirow[b]{2}{*}{$\begin{array}{l}\text { Married- } \\
\text { couple } \\
\text { families }\end{array}$} & \multicolumn{2}{|c|}{ Other families } & \multirow[b]{2}{*}{ Total } & \multirow[b]{2}{*}{$\begin{array}{l}\text { Mar- } \\
\text { ried- } \\
\text { couple } \\
\text { families }\end{array}$} & \multicolumn{2}{|c|}{ Other families } & \multirow[b]{2}{*}{ Total } & \multirow[b]{2}{*}{$\begin{array}{l}\text { Mar- } \\
\text { ried- } \\
\text { couple } \\
\text { families }\end{array}$} & \multicolumn{2}{|c|}{ Other families } \\
\hline & & & $\begin{array}{c}\text { Male } \\
\text { house- } \\
\text { holder, } \\
\text { no } \\
\text { spouse } \\
\text { present }\end{array}$ & $\begin{array}{l}\text { Female } \\
\text { house- } \\
\text { holder, } \\
\text { no } \\
\text { spouse } \\
\text { present }\end{array}$ & & & $\begin{array}{l}\text { Male } \\
\text { house- } \\
\text { holder, } \\
\text { no } \\
\text { spouse } \\
\text { present }\end{array}$ & $\begin{array}{c}\text { Female } \\
\text { house- } \\
\text { holder, } \\
\text { no } \\
\text { spouse } \\
\text { present }\end{array}$ & & & $\begin{array}{l}\text { Male } \\
\text { house- } \\
\text { holder, } \\
\text { no } \\
\text { spouse } \\
\text { present }\end{array}$ & $\begin{array}{c}\text { Female } \\
\text { house- } \\
\text { holder, } \\
\text { no } \\
\text { spouse } \\
\text { present }\end{array}$ & & & $\begin{array}{l}\text { Male } \\
\text { house- } \\
\text { holder, } \\
\text { no } \\
\text { spouse } \\
\text { present }\end{array}$ & $\begin{array}{l}\text { Female } \\
\text { house- } \\
\text { holder, } \\
\text { no } \\
\text { spouse } \\
\text { present }\end{array}$ \\
\hline 1 & 2 & 3 & 4 & 5 & 6 & 7 & 8 & 9 & 10 & 11 & 12 & 13 & 14 & 15 & 16 & 17 \\
\hline Total families & 69,594 & 53,567 & 3,513 & 12,514 & 58,869 & 47,873 & 2,712 & 8,284 & 8,055 & 3,713 & 573 & 3,769 & 6,287 & 4,247 & 436 & 1,604 \\
\hline 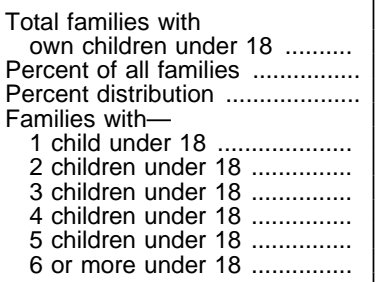 & $\begin{array}{r}34,203 \\
49.1 \\
100.0 \\
\\
14,041 \\
13,206 \\
4,913 \\
1,440 \\
416 \\
188\end{array}$ & $\begin{array}{r}24,920 \\
46.5 \\
72.9 \\
\\
9,352 \\
10,278 \\
3,804 \\
1,060 \\
298 \\
128\end{array}$ & $\begin{array}{r}1,628 \\
46.3 \\
4.8 \\
1,005 \\
471 \\
109 \\
30 \\
6 \\
7\end{array}$ & $\begin{array}{r}7,656 \\
61.2 \\
22.4 \\
3,683 \\
2,457 \\
1,000 \\
350 \\
112 \\
52\end{array}$ & $\begin{array}{r}28,086 \\
47.7 \\
100.0 \\
\\
11,455 \\
11,110 \\
4,006 \\
1,088 \\
296 \\
131\end{array}$ & $\begin{array}{r}21,835 \\
45.6 \\
77.7 \\
\\
8,132 \\
9,080 \\
3,348 \\
929 \\
236 \\
111\end{array}$ & $\begin{array}{r}1,276 \\
47.1 \\
4.5 \\
786 \\
381 \\
81 \\
19 \\
4 \\
5\end{array}$ & $\begin{array}{r}4,975 \\
60.1 \\
17.7 \\
\\
2,537 \\
1,649 \\
577 \\
140 \\
56 \\
16\end{array}$ & $\begin{array}{r}4,583 \\
56.9 \\
100.0 \\
1,958 \\
1,485 \\
729 \\
281 \\
88 \\
42\end{array}$ & $\begin{array}{r}1,901 \\
51.2 \\
41.5 \\
778 \\
692 \\
309 \\
79 \\
38 \\
7\end{array}$ & $\begin{array}{r}278 \\
48.5 \\
6.1 \\
\\
173 \\
63 \\
26 \\
10 \\
3 \\
2\end{array}$ & $\begin{array}{r}2,404 \\
63.8 \\
52.5 \\
1,007 \\
731 \\
394 \\
192 \\
47 \\
33\end{array}$ & $\begin{array}{r}4,048 \\
64.4 \\
100.0 \\
1,450 \\
1,437 \\
742 \\
286 \\
95 \\
37\end{array}$ & $\begin{array}{r}2,731 \\
64.3 \\
67.5 \\
896 \\
998 \\
533 \\
223 \\
54 \\
27\end{array}$ & $\begin{array}{r}179 \\
41.1 \\
4.4 \\
93 \\
50 \\
27 \\
6 \\
3 \\
-\end{array}$ & $\begin{array}{r}1,138 \\
70.9 \\
28.1 \\
462 \\
389 \\
183 \\
57 \\
38 \\
10\end{array}$ \\
\hline $\begin{array}{l}\text { Total own children under } 18 \ldots . . . \\
\text { Average number of children } \\
\text { per family with children ......... }\end{array}$ & $\begin{array}{r}63,783 \\
1.86\end{array}$ & $\begin{array}{r}47,467 \\
1.90\end{array}$ & $\begin{array}{r}2,425 \\
1.49\end{array}$ & $\begin{array}{r}13,890 \\
1.81\end{array}$ & $\begin{array}{r}51,694 \\
1.84\end{array}$ & $\begin{array}{r}41,349 \\
1.89\end{array}$ & $\begin{array}{r}1,852 \\
1.45\end{array}$ & $\begin{array}{r}8,493 \\
1.71\end{array}$ & $\begin{array}{r}9,027 \\
1.97\end{array}$ & $\begin{array}{r}3,721 \\
1.96\end{array}$ & $\begin{array}{r}461 \\
1.66\end{array}$ & $\begin{array}{r}4,845 \\
2.02\end{array}$ & $\begin{array}{r}8,904 \\
2.20\end{array}$ & $\begin{array}{r}6,169 \\
2.26\end{array}$ & $\begin{array}{r}335 \\
1.87\end{array}$ & $\begin{array}{r}2,400 \\
2.11\end{array}$ \\
\hline $\begin{array}{l}\text { Total families with } \\
\text { own children under } 6 \\
\text { Percent of all families .................. } \\
\text { Percent distribution ................. } \\
\text { Families with- } \\
1 \text { child under } 6 \\
2 \text { children under } 6 \ldots \ldots \ldots \ldots \ldots \ldots \ldots . . . \\
3 \text { children under } 6 \\
4 \text { or more under } 6\end{array}$ & $\begin{array}{r}15,450 \\
22.2 \\
100.0 \\
10,672 \\
4,081 \\
626 \\
71\end{array}$ & $\begin{array}{r}11,782 \\
22.0 \\
76.3 \\
8,024 \\
3,287 \\
430 \\
41\end{array}$ & $\begin{array}{r}624 \\
17.8 \\
4.0 \\
492 \\
107 \\
26 \\
-\end{array}$ & $\begin{array}{r}3,043 \\
24.3 \\
19.7 \\
2,157 \\
687 \\
170 \\
29\end{array}$ & $\begin{array}{r}12,656 \\
21.5 \\
100.0 \\
8,769 \\
3,387 \\
457 \\
43\end{array}$ & $\begin{array}{r}10,341 \\
21.6 \\
81.7 \\
7,021 \\
2,899 \\
389 \\
32\end{array}$ & $\begin{array}{r}474 \\
17.5 \\
3.7 \\
388 \\
72 \\
14 \\
-\end{array}$ & $\begin{array}{r}1,841 \\
22.2 \\
14.5 \\
1,360 \\
416 \\
54 \\
11\end{array}$ & $\begin{array}{r}2,084 \\
25.9 \\
100.0 \\
1,423 \\
501 \\
135 \\
24\end{array}$ & $\begin{array}{r}876 \\
23.6 \\
42.0 \\
614 \\
236 \\
20 \\
6\end{array}$ & $\begin{array}{r}113 \\
19.7 \\
5.4 \\
76 \\
26 \\
11 \\
-\end{array}$ & $\begin{array}{r}1,095 \\
29.1 \\
52.5 \\
732 \\
240 \\
104 \\
18\end{array}$ & $\begin{array}{r}2,138 \\
34.0 \\
100.0 \\
1,352 \\
654 \\
120 \\
12\end{array}$ & $\begin{array}{r}1,525 \\
35.9 \\
71.3 \\
966 \\
475 \\
81 \\
3\end{array}$ & $\begin{array}{r}101 \\
2.4 \\
4.7 \\
79 \\
14 \\
7 \\
-\end{array}$ & $\begin{array}{r}512 \\
31.9 \\
23.9 \\
307 \\
164 \\
32 \\
9\end{array}$ \\
\hline $\begin{array}{l}\text { Total own children under } 6 \ldots \ldots . . . . \\
\text { Average number of children } \\
\text { per family with children .......... }\end{array}$ & $\begin{array}{r}21,299 \\
1.38\end{array}$ & $\begin{array}{r}16,239 \\
1.38\end{array}$ & $\begin{array}{r}791 \\
1.27\end{array}$ & $\begin{array}{r}4,269 \\
1.40\end{array}$ & $\begin{array}{r}17,236 \\
1.36\end{array}$ & $\begin{array}{r}14,198 \\
1.37\end{array}$ & $\begin{array}{r}569 \\
1.20\end{array}$ & $\begin{array}{r}2,469 \\
1.34\end{array}$ & $\begin{array}{r}2,991 \\
1.44\end{array}$ & $\begin{array}{r}1,199 \\
1.37\end{array}$ & $\begin{array}{r}170 \\
1.51\end{array}$ & $\begin{array}{r}1,623 \\
1.48\end{array}$ & $\begin{array}{r}3,408 \\
1.59\end{array}$ & $\begin{array}{r}2,399 \\
1.57\end{array}$ & $\begin{array}{r}144 \\
1.42\end{array}$ & $\begin{array}{r}866 \\
1.69\end{array}$ \\
\hline $\begin{array}{l}\text { Total families with } \\
\text { own children under } 3 \\
\text { Percent of all families .................... } \\
\text { Percent distribution .................. } \\
\text { Families with- }\end{array}$ & $\begin{array}{r}8,818 \\
12.7 \\
100.0\end{array}$ & $\begin{array}{r}6,930 \\
12.9 \\
78.6\end{array}$ & $\begin{array}{r}396 \\
11.3 \\
4.5\end{array}$ & $\begin{array}{r}1,493 \\
11.9 \\
16.9\end{array}$ & $\begin{array}{r}7,256 \\
12.3 \\
100.0\end{array}$ & $\begin{array}{r}6,074 \\
12.7 \\
83.7\end{array}$ & $\begin{array}{r}306 \\
11.3 \\
4.2\end{array}$ & $\begin{array}{r}875 \\
10.6 \\
12.1\end{array}$ & $\begin{array}{r}1,149 \\
14.3 \\
100.0\end{array}$ & $\begin{array}{r}519 \\
14.0 \\
45.2\end{array}$ & $\begin{array}{r}68 \\
11.9 \\
5.9\end{array}$ & $\begin{array}{l}562 \\
14.9 \\
48.9\end{array}$ & $\begin{array}{r}1,307 \\
20.8 \\
100.0\end{array}$ & $\begin{array}{r}926 \\
21.8 \\
70.8\end{array}$ & $\begin{array}{r}74 \\
17.0 \\
5.7\end{array}$ & $\begin{array}{r}308 \\
19.2 \\
23.6\end{array}$ \\
\hline $\begin{array}{l}1 \text { child under } 3 \\
2 \text { or more under } 3\end{array}$ & $\begin{array}{r}7,874 \\
944\end{array}$ & $\begin{array}{r}6,228 \\
702\end{array}$ & $\begin{array}{r}353 \\
43\end{array}$ & $\begin{array}{r}1,293 \\
199\end{array}$ & $\begin{array}{r}6,498 \\
758\end{array}$ & $\begin{array}{r}5,451 \\
623\end{array}$ & $\begin{array}{r}275 \\
31\end{array}$ & $\begin{array}{l}772 \\
103\end{array}$ & $\begin{array}{r}1,025 \\
124\end{array}$ & $\begin{array}{r}482 \\
37\end{array}$ & $\begin{array}{l}58 \\
11\end{array}$ & $\begin{array}{r}485 \\
77\end{array}$ & $\begin{array}{r}1,130 \\
177\end{array}$ & $\begin{array}{l}816 \\
110\end{array}$ & $\begin{array}{r}65 \\
8\end{array}$ & $\begin{array}{r}249 \\
59\end{array}$ \\
\hline $\begin{array}{l}\text { Total own children under } 3 . . . . . . . \\
\text { Average number of children } \\
\text { per family with children ......... }\end{array}$ & $\begin{array}{r}10,191 \\
1.16\end{array}$ & $\begin{array}{r}7,918 \\
1.14\end{array}$ & $\begin{array}{r}451 \\
1.14\end{array}$ & $\begin{array}{r}1,822 \\
1.22\end{array}$ & $\begin{array}{r}8,289 \\
1.14\end{array}$ & $\begin{array}{r}6,907 \\
1.14\end{array}$ & $\begin{array}{r}337 \\
1.10\end{array}$ & $\begin{array}{r}1,046 \\
1.20\end{array}$ & $\begin{array}{r}1,382 \\
1.20\end{array}$ & $\begin{array}{r}597 \\
1.15\end{array}$ & $\begin{array}{l}89 \\
(4)\end{array}$ & $\begin{array}{r}696 \\
1.24\end{array}$ & $\begin{array}{r}1,699 \\
1.30\end{array}$ & $\begin{array}{r}1,184 \\
1.28\end{array}$ & $\begin{array}{l}94 \\
(4)\end{array}$ & $\begin{array}{r}421 \\
1.37\end{array}$ \\
\hline
\end{tabular}

1 Race of family is defined as race of head of household. 2 Includes persons of Hispanic origin.

3 Persons of Hispanic origin may be of any race.
${ }_{4}^{4}$ Averages and percents are shown only when the base is 75,000 or greater.

- Less than 500 .
NOTE.-Because of rounding, details may not add to totals.

SOURCE: U.S. Department of Commerce, Bureau of the Census, Current Population Reports, Series P20-495, Household and Family Characteristics: March 1996. (This table was prepared May 1998.) 
Table 20.-Household income and poverty rates, by state: 1990, 1995, and 1996

\begin{tabular}{|c|c|c|c|c|c|c|c|c|c|c|c|c|c|c|c|c|c|}
\hline \multirow{4}{*}{ State } & \multicolumn{3}{|c|}{ Median household income 1} & \multicolumn{10}{|c|}{ Percent of persons below the poverty level } & \multirow{2}{*}{\multicolumn{4}{|c|}{$\begin{array}{l}\text { Poverty status of related children } \\
\text { 5- to } 17 \text {-year-olds, } 1996\end{array}$}} \\
\hline & \multirow{3}{*}{$1990^{2}$} & \multirow[b]{3}{*}{1995} & \multirow[b]{3}{*}{1996} & \multicolumn{8}{|c|}{$1990^{2}$} & \multicolumn{2}{|c|}{1996} & & & & \\
\hline & & & & \multirow[b]{2}{*}{ Total } & & & & & & & & & & \multicolumn{2}{|c|}{$\begin{array}{c}\text { Number in } \\
\text { poverty }\end{array}$} & \multicolumn{2}{|c|}{$\begin{array}{l}\text { Percent in } \\
\text { poverty }\end{array}$} \\
\hline & & & & & $\begin{array}{c}\text { Under } \\
5 \\
\text { years }\end{array}$ & $\begin{array}{c}5 \\
\text { years }\end{array}$ & \begin{tabular}{|c|}
6 to \\
11 \\
years
\end{tabular} & $\begin{array}{c}12 \text { to } \\
17 \\
\text { years }\end{array}$ & \begin{tabular}{|c|}
18 to \\
64 \\
years
\end{tabular} & $\begin{array}{c}65 \text { to } \\
74 \\
\text { years }\end{array}$ & $\begin{array}{l}\text { years } \\
\text { and } \\
\text { over }\end{array}$ & Total & $\begin{array}{l}\text { Stand- } \\
\text { ard } \\
\text { error }\end{array}$ & $\begin{array}{l}\text { Num- } \\
\text { ber (in } \\
\text { thou- } \\
\text { sands) }\end{array}$ & $\begin{array}{l}\text { Stand- } \\
\text { ard } \\
\text { error }\end{array}$ & $\begin{array}{l}\text { Per- } \\
\text { cent }\end{array}$ & $\begin{array}{l}\text { Stand- } \\
\text { ard } \\
\text { error }\end{array}$ \\
\hline 1 & 2 & 3 & 4 & 5 & 6 & 7 & 8 & 9 & 10 & 11 & 12 & 13 & 14 & 15 & 16 & 17 & 18 \\
\hline United States & $\$ 37,888$ & $\$ 35,082$ & $\$ 35,492$ & 13.1 & 20.1 & 19.7 & 18.3 & 16.3 & 11.0 & 10.4 & 16.5 & 13.7 & 0.39 & 9,590 & 259 & 18.9 & 0.49 \\
\hline Alabama & 29,554 & 26,758 & 30,302 & 18.3 & 26.1 & 25.8 & 24.3 & 22.3 & 14.6 & 19.2 & 31.1 & 14.0 & 1.72 & 170 & 37 & 20.7 & 4.03 \\
\hline Alaska ... & 49,725 & 49,370 & 52,779 & 9.0 & 13.6 & 10.6 & 10.9 & 9.8 & 7.9 & 6.4 & 10.6 & 8.2 & 1.33 & 17 & 5 & 9.8 & 2.48 \\
\hline Arizona .. & 36,978 & 31,774 & 31,637 & 15.7 & 24.9 & 24.2 & 21.8 & 19.1 & 14.0 & 9.3 & 13.2 & 20.5 & 1.85 & 292 & 47 & 29.6 & 4.05 \\
\hline Arkansas ........ & 28,832 & 26,576 & 27,123 & 19.1 & 28.5 & 26.6 & 25.2 & 22.7 & 15.3 & 18.0 & 29.9 & 17.2 & 1.83 & 105 & 22 & 19.5 & 3.71 \\
\hline California & 42,123 & 38,102 & 38,812 & 12.5 & 19.0 & 19.3 & 18.3 & 17.1 & 10.9 & 6.5 & 9.5 & 16.9 & 0.76 & 1,474 & 122 & 23.5 & 1.72 \\
\hline Colorado & 38,887 & 41,908 & 40,950 & 11.7 & 17.9 & 16.5 & 15.3 & 12.5 & 10.3 & 8.5 & 15.1 & 10.6 & 1.54 & 88 & 26 & 11.2 & 3.08 \\
\hline Connecticut & 49,183 & 41,431 & 42,119 & 6.8 & 11.7 & 11.9 & 11.2 & 8.9 & 5.3 & 5.6 & 9.7 & 11.7 & 1.79 & 159 & 36 & 23.5 & 4.60 \\
\hline Delaware .... & 38,977 & 35,959 & 39,309 & 8.7 & 13.3 & 12.7 & 11.8 & 10.8 & 7.2 & 8.2 & 13.5 & 8.6 & 1.56 & 17 & 5 & 12.4 & 3.72 \\
\hline District of Columbia . & 34,660 & 31,656 & 31,966 & 16.9 & 27.0 & 25.5 & 25.0 & 24.4 & 14.3 & 15.5 & 19.7 & 24.1 & 2.38 & 31 & 6 & 38.1 & 6.06 \\
\hline 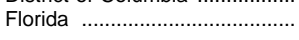 & 33,765 & 30,623 & 30,641 & 12.7 & 20.3 & 20.1 & 18.8 & 16.8 & 11.0 & 9.0 & 13.5 & 14.2 & 0.92 & 458 & 59 & 19.8 & 2.31 \\
\hline Georgia & 34,874 & 35,106 & 32,496 & 14.7 & 22.1 & 21.3 & 20.1 & 18.1 & 11.4 & 16.5 & 26.7 & 14.8 & 1.58 & 278 & 56 & 19.6 & 3.53 \\
\hline Hawaii ... & 49,248 & 44,116 & 41,772 & 8.3 & 12.6 & 12.6 & 11.2 & 10.8 & 6.9 & 6.7 & 10.4 & 12.1 & 1.82 & 32 & 10 & 15.7 & 4.24 \\
\hline Idaho ....... & 32,019 & 33,641 & 34,709 & 13.3 & 19.6 & 18.9 & 15.9 & 13.3 & 12.0 & 8.7 & 15.6 & 11.9 & 1.57 & 40 & 9 & 16.3 & 3.48 \\
\hline 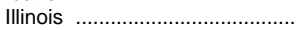 & 41,176 & 39,195 & 39,554 & 11.9 & 18.9 & 18.7 & 17.0 & 15.0 & 10.0 & 8.9 & 13.4 & 12.1 & 0.97 & 388 & 56 & 16.5 & 2.16 \\
\hline Indiana & 34,073 & 34,371 & 39,554 & 10.7 & 16.8 & 15.8 & 14.1 & 11.8 & 9.1 & 8.7 & 14.0 & 7.5 & 1.33 & 79 & 29 & 7.9 & 2.83 \\
\hline lowa & 34,528 & 36,568 & 33,209 & 11.5 & 17.5 & 15.4 & 14.1 & 11.7 & 10.3 & 8.1 & 15.3 & 9.6 & 1.49 & 71 & 20 & 11.8 & 3.15 \\
\hline Kansas & 37,855 & 31,237 & 32,585 & 11.5 & 16.8 & 16.5 & 14.1 & 11.6 & 10.1 & 8.5 & 16.8 & 11.2 & 1.61 & 56 & 17 & 10.7 & 3.09 \\
\hline Kentucky .................. & 31,355 & 30,690 & 32,413 & 19.0 & 27.9 & 26.5 & 24.6 & 22.4 & 16.2 & 17.5 & 25.3 & 17.0 & 1.86 & 203 & 39 & 27.0 & 4.39 \\
\hline Louisiana ............. & 28,350 & 28,774 & 30,262 & 23.6 & 33.4 & 33.0 & 31.1 & 29.7 & 19.6 & 20.5 & 30.1 & 20.5 & 1.94 & 235 & 42 & 27.7 & 4.23 \\
\hline 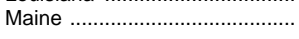 & 34,751 & 34,858 & 34,696 & 10.8 & 15.7 & 15.9 & 14.0 & 11.5 & 8.9 & 11.0 & 18.3 & 11.2 & 1.78 & 26 & 9 & 14.0 & 4.36 \\
\hline Mary & 49,167 & 42,253 & 43,993 & 8.3 & 11.9 & 11.9 & 11.5 & 10.2 & 6.8 & 8.8 & 13.6 & 10.3 & 1.61 & 137 & 39 & 14.9 & 3.91 \\
\hline Massachusetts & 45,864 & 39,713 & 39,494 & 8.9 & 14.5 & 14.8 & 13.8 & 11.0 & 7.3 & 7.3 & 12.6 & 10.1 & 1.12 & 144 & 31 & 13.1 & 2.58 \\
\hline Michigan ……........................ & 37,880 & 37,502 & 39,225 & 13.1 & 22.1 & 20.4 & 18.1 & 15.7 & 11.2 & 8.7 & 14.3 & 11.2 & 1.00 & 286 & 46 & 15.7 & 2.32 \\
\hline Minnesota & 39,813 & 39,053 & 40,991 & 10.2 & 14.8 & 14.6 & 12.5 & 10.6 & 8.8 & 8.4 & 17.2 & 9.8 & 1.47 & 130 & 34 & 13.0 & 3.16 \\
\hline 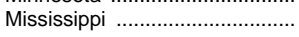 & 25,532 & 27,322 & 26,677 & 25.2 & 35.8 & 35.1 & 33.5 & 31.9 & 20.0 & 24.0 & 37.1 & 20.6 & 1.97 & 163 & 29 & 26.0 & 3.97 \\
\hline Missouri & 34,584 & 35,853 & 34,265 & 13.3 & 20.4 & 19.2 & 17.8 & 15.1 & 11.1 & 11.3 & 19.7 & 9.5 & 1.52 & 120 & 36 & 11.4 & 3.24 \\
\hline Montana ............... & 29,577 & 28,577 & 28,684 & 16.1 & 24.3 & 23.0 & 20.3 & 17.1 & 14.7 & 9.9 & 16.6 & 17.0 & 1.80 & 46 & 9 & 24.9 & 4.01 \\
\hline 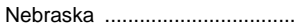 & 34,774 & 33,901 & 34,014 & 11.1 & 17.3 & 15.4 & 13.4 & 10.8 & 9.7 & 8.6 & 16.8 & 10.2 & 1.55 & 41 & 12 & 12.0 & 3.21 \\
\hline Nevada & 40,519 & 37,149 & 38,540 & 10.2 & 15.1 & 14.4 & 12.6 & 11.9 & 9.1 & 8.4 & 12.3 & 8.1 & 1.45 & 24 & 9 & 8.3 & 3.06 \\
\hline 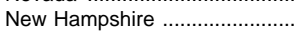 & 51,631 & 40,328 & 39,407 & 6.4 & 8.5 & 8.7 & 7.3 & 6.2 & 5.4 & 7.7 & 13.9 & 6.4 & 1.44 & 13 & 6 & 6.8 & 3.14 \\
\hline New Jersey & 49,011 & 45,221 & 47,468 & 7.6 & 11.7 & 12.6 & 11.7 & 10.4 & 6.0 & 6.8 & 11.3 & 9.2 & 0.95 & 181 & 34 & 13.9 & 2.45 \\
\hline New Mexico & 31,682 & 26,758 & 25,086 & 20.6 & 30.3 & 30.6 & 27.6 & 25.2 & 17.8 & 13.7 & 21.2 & 25.5 & 2.07 & 136 & 21 & 32.2 & 4.07 \\
\hline 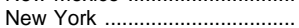 & 39,973 & 34,003 & 35,410 & 13.0 & 20.6 & 21.2 & 19.6 & 17.0 & 11.0 & 10.0 & 14.7 & 16.7 & 0.84 & 868 & 78 & 25.0 & 1.96 \\
\hline North Carolina ……............ & 33,315 & 32,923 & 35,601 & 13.0 & 19.2 & 18.5 & 17.2 & 15.3 & 10.1 & 15.7 & 25.9 & 12.2 & 1.20 & 222 & 41 & 17.5 & 2.93 \\
\hline North Dakota ........................ & 31,967 & 29,948 & 31,470 & 14.4 & 19.6 & 18.4 & 17.2 & 14.7 & 13.0 & 10.8 & 19.5 & 11.0 & 1.61 & 13 & 4 & 10.2 & 3.07 \\
\hline Ohio & 37,976 & 35,973 & 34,070 & 12.5 & 21.1 & 19.9 & 17.8 & 14.6 & 10.7 & 8.7 & 13.8 & 12.7 & 1.02 & 367 & 55 & 16.7 & 2.28 \\
\hline Oklahoma ……………… & 30,854 & 27,088 & 27,437 & 16.7 & 25.3 & 23.4 & 21.7 & 18.5 & 14.2 & 13.5 & 24.1 & 16.6 & 1.77 & 173 & 32 & 24.2 & 3.86 \\
\hline Oregon ....................... & 37,050 & 37,448 & 35,492 & 12.4 & 19.7 & 16.1 & 14.8 & 13.3 & 11.5 & 8.1 & 13.1 & 11.8 & 1.70 & 112 & 28 & 18.4 & 4.12 \\
\hline Pennsylvania ……....................... & 36,701 & 35,543 & 34,899 & 11.1 & 17.5 & 17.0 & 15.7 & 13.8 & 9.5 & 8.7 & 13.5 & 11.6 & 0.93 & 349 & 52 & 15.8 & 2.15 \\
\hline 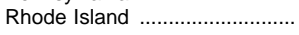 & 40,450 & 36,403 & 36,986 & 9.6 & 16.3 & 16.1 & 13.8 & 11.0 & 7.6 & 8.9 & 15.6 & 11.0 & 1.80 & 18 & 6 & 12.4 & 4.30 \\
\hline South Carolina & 36,359 & 29,929 & 34,665 & 15.4 & 22.8 & 21.8 & 21.2 & 19 & 12.0 & 17.3 & 26.5 & 13 & 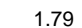 & 154 & 35 & 21.1 & 4.28 \\
\hline South Dakota & 31,090 & 30,451 & 29,526 & 15.9 & 23.6 & 22.2 & 20.2 & 17.3 & 13.6 & 11.1 & 21.3 & 11.8 & 1.62 & 16 & 5 & 11.6 & 3.17 \\
\hline Tennessee ............................. & 28,586 & 29,872 & 30,790 & 15.7 & 23.9 & 22.5 & 20.8 & 18.5 & 12.5 & 17.2 & 26.7 & 15.9 & 1.83 & 231 & 50 & 20.6 & 3.96 \\
\hline 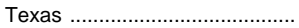 & 35,718 & 32,985 & 33,072 & 18.1 & 25.6 & 25.5 & 24.2 & 23.0 & 15.2 & 14.9 & 23.8 & 16.6 & 0.95 & 858 & 91 & 22.5 & 2.10 \\
\hline Utah . & 38,139 & 37,557 & 37,038 & 11.4 & 15.8 & 14.4 & 12.0 & 10.0 & 11.0 & 6.4 & 12.5 & 7.7 & 1.26 & 39 & 12 & 8.6 & 2.45 \\
\hline Vermont & 39,349 & 34,823 & 32,358 & 9.9 & 13.5 & 13.7 & 12.5 & 9.8 & 8.5 & 9.7 & 16.3 & 12.6 & 1.87 & 19 & 5 & 16.3 & 4.15 \\
\hline Virginia & 44,379 & 37,292 & 39,211 & 10.2 & 14.5 & 14.5 & 13.5 & 11.9 & 8.4 & 11.6 & 18.5 & 12.3 & 1.60 & 183 & 47 & 17.9 & 4.12 \\
\hline Washington . & 40,632 & 36,618 & 36,676 & 10.9 & 17.0 & 16.4 & 14.3 & 12.2 & 9.8 & 7.0 & 12.4 & 11.9 & 1.68 & 158 & 43 & 15.5 & 3.88 \\
\hline West Virginia & 28,010 & 25,615 & 25,247 & 19.7 & 31.7 & 30.3 & 25.9 & 22.4 & 17.7 & 14.1 & 20.8 & 18.5 & 1.87 & 56 & 13 & 22.4 & 4.67 \\
\hline 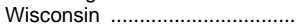 & 38,859 & 42,164 & 40,001 & 10.7 & 17.7 & 16.4 & 15.0 & 11.9 & 9.2 & 6.6 & 12.6 & 8.8 & 1.41 & 105 & 32 & 10.4 & 3.01 \\
\hline Wyoming. & 37,276 & 32,460 & 30,953 & 11.9 & 18.3 & 16.2 & 14.1 & 11.2 & 10.8 & 8.4 & 14.3 & 11.9 & 1.64 & 9 & 3 & 9.2 & 2.84 \\
\hline
\end{tabular}

1 In 1996 dollars adjusted by the Consumer Price Index for all urban consumers

${ }^{2}$ Based on 1989 incomes collected in the 1990 Census. Data may differ from figures derived from the Current Population Survey.

SOURCE: U.S. Department of Commerce, Bureau of the Census, Decennial Census, Minority Economic Profiles, unpublished data; and Current Population Reports, Series P-
60, "Poverty in the United States," "Money Income of Households, Families, and Persons in the United States," and "Income, Poverty, and Valuation of Noncash Benefits," various years, and "Money Income in the U.S.: 1996," P60-193. (This table was prepared June 1998.) 
Table 21.-Poverty status of persons, families, and children under 18, by race/ethnicity: 1959 to 1996

\begin{tabular}{|c|c|c|c|c|c|c|c|c|c|c|c|c|}
\hline \multirow{3}{*}{$\begin{array}{c}\text { Year and race/ } \\
\text { ethnicity }\end{array}$} & \multicolumn{6}{|c|}{ Number below the poverty level, in thousands } & \multicolumn{6}{|c|}{ Percent below the poverty level } \\
\hline & \multirow{2}{*}{$\begin{array}{c}\text { All } \\
\text { persons }\end{array}$} & \multicolumn{3}{|c|}{ In all families } & $\begin{array}{l}\text { In families v } \\
\text { househo } \\
\text { husband }\end{array}$ & $\begin{array}{l}\text { vith female } \\
\text { lder, no } \\
\text { present }\end{array}$ & & & In all famili & & $\begin{array}{c}\text { In families V } \\
\text { househo } \\
\text { husband }\end{array}$ & $\begin{array}{l}\text { ith female } \\
\text { der, no } \\
\text { present }\end{array}$ \\
\hline & & Total & $\begin{array}{l}\text { House- } \\
\text { holder }\end{array}$ & $\begin{array}{c}\text { Related } \\
\text { children } \\
\text { under } \\
18\end{array}$ & Total & $\begin{array}{c}\text { Related } \\
\text { children } \\
\text { under } 18\end{array}$ & & Total & $\begin{array}{l}\text { House- } \\
\text { holder }\end{array}$ & $\begin{array}{c}\text { Related } \\
\text { children } \\
\text { under } 18\end{array}$ & Total & $\begin{array}{c}\text { Related } \\
\text { children } \\
\text { under } 18\end{array}$ \\
\hline 1 & 2 & 3 & 4 & 5 & 6 & 7 & 8 & 9 & 10 & 11 & 12 & 13 \\
\hline All races & & & & & & & & & & & & \\
\hline 1959 & 39,490 & 34,562 & 8,320 & 17,208 & 7,014 & 4,145 & $22.4(0.3)$ & 20.8 & 18.5 & $26.9(0.4)$ & 49.4 & 72.2 \\
\hline 1960 & 39,851 & 34,925 & 8,243 & 17,288 & 7,247 & 4,095 & $22.2(0.3)$ & 20.7 & 18.1 & $26.5(0.4)$ & 48.9 & 68.4 \\
\hline $1965 \ldots \ldots . .$. & 33,185 & 28,358 & 6,721 & 14,388 & 7,524 & 4,562 & $17.3(0.2)$ & 15.8 & 13.9 & $20.7(0.4)$ & 46.0 & 64.2 \\
\hline 1970 & 25,420 & 20,330 & 5,260 & 10,235 & 7,503 & 4,689 & $12.6(0.2)$ & 10.9 & 10.1 & $14.9(0.3)$ & 38.1 & 53.0 \\
\hline 1975 & 25,877 & 20,789 & 5,450 & 10,882 & 8,846 & 5,597 & $12.3(0.2)$ & 10.9 & 9.7 & $16.8(0.4)$ & 37.5 & 52.7 \\
\hline $1980 \ldots$ & 29,272 & 22,601 & 6,217 & 11,114 & 10,120 & 5,866 & $13.0(0.2)$ & 11.5 & 10.3 & $17.9(0.4)$ & 36.7 & 50.8 \\
\hline 1981 & 31,822 & 24,850 & 6,851 & 12,068 & 11,051 & 6,305 & $14.0(0.2)$ & 12.5 & 11.2 & $19.5(0.4)$ & 38.7 & 52.3 \\
\hline $1982 \ldots \ldots$. & 34,398 & 27,349 & 7,512 & 13,139 & 11,701 & 6,696 & $15.0(0.2)$ & 13.6 & 12.2 & $21.3(0.4)$ & 40.6 & 56.0 \\
\hline 1983 & 35,303 & 27,933 & 7,647 & 13,427 & 12,072 & 6,747 & $15.2(0.2)$ & 13.9 & 12.3 & $21.8(0.4)$ & 40.2 & 55.4 \\
\hline 1984 & 33,700 & 26,458 & 7,277 & 12,929 & 11,831 & 6,772 & $14.4(0.2)$ & 13.1 & 11.6 & $21.0(0.4)$ & 38.4 & 54.0 \\
\hline 1985 & 33,064 & 25,729 & 7,223 & 12,483 & 11,600 & 6,716 & $14.0(0.2)$ & 12.6 & 11.4 & $20.1(0.4)$ & 37.6 & 53.6 \\
\hline 1986 & 32,370 & 24,754 & 7,023 & 12,257 & 11,944 & 6,943 & $13.6(0.2)$ & 12.0 & 10.9 & $19.8(0.4)$ & 38.3 & 54.4 \\
\hline $1987 \ldots . .$. & 32,221 & 24,725 & 7,005 & 12,275 & 12,148 & 7,074 & $13.4(0.2)$ & 12.0 & 10.7 & $19.7(0.4)$ & 38.1 & 54.7 \\
\hline $1988 \ldots \ldots$. & 31,745 & 24,048 & 6,876 & 11,935 & 11,972 & 6,742 & $13.0(0.2)$ & 11.6 & 10.4 & $19.0(0.4)$ & 37.2 & 50.6 \\
\hline $1989 \ldots \ldots .$. & 31,528 & 24,066 & 6,784 & 12,001 & 11,668 & 6,808 & $12.8(0.2)$ & 11.5 & 10.3 & $19.0(0.4)$ & 35.9 & 51.1 \\
\hline $1990 \ldots \ldots . . .$. & 33,585 & 25,232 & 7,098 & 12,715 & 12,578 & 7,363 & $13.5(0.2)$ & 12.0 & 10.7 & $19.9(0.4)$ & 37.2 & 53.4 \\
\hline $1991 \ldots \ldots$. & 35,708 & 27,143 & 7,712 & 13,658 & 13,824 & 8,065 & $14.2(0.2)$ & 12.8 & 11.5 & $21.1(0.4)$ & 39.7 & 55.5 \\
\hline $1992 \ldots \ldots \ldots$ & 36,880 & 27,947 & 7,960 & 13,876 & 13,716 & 8,032 & $14.8(0.2)$ & 13.3 & 11.7 & $21.1(0.4)$ & 39.0 & 54.3 \\
\hline 1993 & 39,265 & 29,927 & 8,393 & 14,961 & 14,636 & 8,503 & $15.1(0.2)$ & 13.6 & 12.3 & $22.0(0.4)$ & 38.7 & 53.7 \\
\hline 1994 & 38,059 & 28,985 & 8,053 & 14,610 & 14,380 & 8,427 & $14.5(0.2)$ & 13.1 & 11.6 & $21.2(0.4)$ & 38.6 & 52.9 \\
\hline 1995 & 36,425 & 27,501 & 7,532 & 13,999 & 14,205 & 8,364 & $13.8(0.2)$ & 12.3 & 10.8 & $20.2(0.4)$ & 36.5 & 50.3 \\
\hline $1996 \ldots . . .$. & 36,529 & 27,376 & 7,708 & 13,764 & 13,796 & 7,990 & $13.7(0.2)$ & 12.2 & 11.0 & $19.8(0.4)$ & 35.8 & 49.3 \\
\hline White 1 & & & & & & & & & & & & \\
\hline 1960 & 28,309 & 24,262 & 6,115 & 11,229 & 4,296 & 2,357 & $17.8(0.3)$ & 16.2 & 14.9 & $20.0(0.4)$ & 39.0 & 59.9 \\
\hline 1965 & 22,496 & 18,508 & 4,824 & 8,595 & 4,092 & 2,321 & $13.3(0.2)$ & 11.7 & 11.1 & $14.4(0.4)$ & 35.4 & 52.9 \\
\hline $1970 \ldots \ldots \ldots \ldots$ & 17,484 & \begin{tabular}{|l|}
13,323 \\
\end{tabular} & 3,708 & 6,138 & 3,761 & 2,247 & $9.9(0.2)$ & 8.1 & 8.0 & $10.5(0.3)$ & 28.4 & 43.1 \\
\hline $1975 \ldots \ldots \ldots$ & 17,770 & \begin{tabular}{|l|}
13,799 \\
\end{tabular} & 3,838 & 6,748 & 4,577 & 2,813 & $9.7(0.2)$ & 8.3 & 7.7 & $12.5(0.3)$ & 29.4 & 44.2 \\
\hline 1980 & 19,699 & 14,587 & 4,195 & 6,817 & 4,940 & 2,813 & $10.2(0.2)$ & 8.6 & 8.0 & $13.4(0.4)$ & 28.0 & 41.6 \\
\hline 1985 ………… & 22,860 & 17,125 & 4,983 & 7,838 & 5,990 & 3,372 & $11.4(0.2)$ & 9.9 & 9.1 & $15.6(0.4)$ & 29.8 & 45.2 \\
\hline 1990 & 22,326 & 15,916 & 4,622 & 7,696 & 6,210 & 3,597 & $10.7(0.2)$ & 9.0 & 8.1 & $15.1(0.4)$ & 29.8 & 45.9 \\
\hline 1991 ………….......... & 23,747 & 17,268 & 5,022 & 8,316 & 6,806 & 3,941 & $11.3(0.2)$ & 9.7 & 8.8 & $16.1(0.4)$ & 31.5 & 47.1 \\
\hline $1992 \ldots \ldots \ldots \ldots \ldots \ldots$ & 25,259 & 18,294 & 5,160 & 8,333 & 6,907 & 3,783 & $11.9(0.2)$ & 10.1 & 8.9 & $16.0(0.4)$ & 30.8 & 45.3 \\
\hline 1993 & 26,226 & 18,968 & 5,452 & 9,12 & 7,199 & 4,102 & $12.2(0.2)$ & 10.5 & 9.4 & $17.0(0.4)$ & 31.0 & 45.6 \\
\hline $1994 \ldots . .$. & 25,379 & $\mid 18,474$ & 5,312 & 8,82 & 7,228 & 4,099 & $11.7(0.2)$ & 10.1 & 9.1 & $16.3(0.4)$ & 31.8 & 45.7 \\
\hline 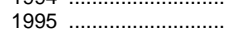 & 24,423 & \begin{tabular}{|l|}
17,593 \\
\end{tabular} & 4,994 & 8,47 & 7,047 & 4,051 & $11.2(0.2)$ & 9.6 & 8.5 & $15.5(0.4)$ & 29.7 & 42.5 \\
\hline 1996 & 24,650 & 17,621 & 5,059 & 8,488 & 7,073 & 4,029 & $11.2(0.2)$ & 9.6 & 8.6 & $15.5(0.4)$ & 29.8 & 43.1 \\
\hline Black 1 & & & & & & & & & & & & \\
\hline 1959 & 9,927 & 9,112 & 1,860 & 5,022 & 2,416 & 1,475 & $55.1(1.0)$ & 54.9 & 48.1 & $65.5(1.3)$ & 70.6 & 81.6 \\
\hline 1966 & 8,867 & 8,090 & 1,620 & 4,774 & 3,160 & 2,107 & $41.8(0.9)$ & 40.9 & 35.5 & $50.6(1.3)$ & 65.3 & 76.6 \\
\hline 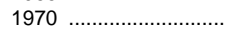 & 7,548 & 6,683 & 1,481 & 3,92 & 3,656 & 2,383 & $33.5(0.9)$ & 32.2 & 29.5 & $41.5(1.2)$ & 58.7 & 67.7 \\
\hline 1975 & 7,545 & 6,533 & 1,513 & 3,88 & 4,168 & 2,724 & $31.3(0.8)$ & 30.1 & 27.1 & $41.4(1.2)$ & 54.3 & 66.0 \\
\hline 1980 & 8,579 & 7,190 & 1,826 & 3,906 & 4,984 & 2,944 & $32.5(0.8)$ & 31.1 & 28.9 & $42.1(1.3)$ & 53.4 & 64.8 \\
\hline 1985 & 8,926 & 7,504 & 1,983 & 4,05 & 5,342 & 3,181 & $31.3(0.8)$ & 30.5 & 28.7 & $43.1(1.3)$ & 53.2 & 66.9 \\
\hline $1990 \ldots \ldots \ldots \ldots$ & 9,837 & 8,160 & 2,193 & 4,4 & 6,005 & 3,543 & $31.9(0.8)$ & 31.0 & 29.3 & $44.2(1.3)$ & 50.6 & 64.7 \\
\hline 1991 & 10,242 & 8,504 & 2,343 & 4,6 & 6,5 & 3,853 & $32.7(0.8)$ & 32.0 & 30.4 & & 54.8 & 68.2 \\
\hline 1992 & 10,827 & 9,134 & 2,435 & 4,8 & 6,799 & 3,967 & $33.4(0.8)$ & 32.9 & 30.9 & $46.3(1.3)$ & 54.0 & 67.1 \\
\hline $1993 \ldots \ldots \ldots \ldots . .$. & 10,877 & 9,242 & 2,499 & 5,0 & 6,955 & 4,104 & $33.1(0.8)$ & 32.9 & 31.3 & 45.9 (1.3) & 53.0 & 65.9 \\
\hline 1994 & 10,196 & 8,447 & 2,212 & 4,787 & 6,489 & 3,935 & $30.6(0.8)$ & 29.6 & 27.3 & $43.3(1.3)$ & 50.2 & 63.2 \\
\hline 1995 & 9,872 & 8,189 & 2,127 & 4,644 & 6,553 & 3,954 & $29.3(0.8)$ & 28.5 & 26.4 & 41.5 (1.3) & 48.2 & 61.6 \\
\hline 1996 & 9,694 & 7,993 & 2,206 & 4,411 & 6,123 & 3,619 & $28.4(0.8)$ & 27.6 & 26.1 & 39.5 (1.3) & 46.4 & 58.2 \\
\hline Hispanic origin ${ }^{2}$ & & & & & & & & & & & & \\
\hline 1975 & 2,991 & 2,755 & 627 & 1,619 & 1,053 & 694 & $26.9(1.4)$ & 26.3 & 25.1 & $33.1(1.7)$ & 57.2 & 68.4 \\
\hline $1980 \ldots$ & 3,491 & 3,143 & 751 & 1,7 & 1,319 & 809 & $25.7(1.3)$ & 25.1 & 23.2 & $33.0(1.6)$ & 54.5 & 65.0 \\
\hline 1985 & 5,236 & 4,605 & 1,074 & 2,512 & 1,983 & 1,247 & $29.0(1.0)$ & 28.3 & 25.5 & $39.6(1.6)$ & 55.7 & 72.4 \\
\hline $1990 \ldots$ & 6,006 & 5,091 & 1,244 & 2,750 & 2,115 & 1,314 & $28.1(1.0)$ & 26.9 & 25.0 & $37.7(1.5)$ & 53.0 & 68.4 \\
\hline 1991 & 6,339 & 5,541 & 1,3 & 2,9 & 2,28 & 1,3 & & 28.2 & 26.5 & & 52.7 & 68.6 \\
\hline 1992 & 7,592 & 6,455 & 1,3 & 2,9 & 2,47 & 1,2 & 29.6 & 28.4 & 26.2 & $38.8(1.5)$ & 51.5 & 65.7 \\
\hline 1993 & 8,126 & 6,876 & 1,625 & 3,6 & 2,837 & 1,6 & $30.6(0.9)$ & 29.3 & 27.3 & $39.9(1.4)$ & 53.2 & 66.1 \\
\hline 1994 & 8,416 & 7,357 & 1,724 & 3,95 & 2,920 & 1,804 & $30.7(0.9)$ & 30.2 & 27.8 & $41.1(1.4)$ & 54.8 & 68.3 \\
\hline 1995 & 8,574 & 7,341 & 1,695 & 3,938 & 3,053 & 1,872 & $30.3(0.9)$ & 29.2 & 27.0 & $39.3(1.4)$ & 52.8 & 65.7 \\
\hline $1996 \ldots$ & 8,697 & 7,515 & 1,748 & 4,090 & 3,020 & 1,779 & $29.4(0.9)$ & 28.5 & 26.4 & 39.9 (1.4) & 53.5 & 67.4 \\
\hline $\begin{array}{l}\text { Asian and } \\
\text { Paif }\end{array}$ & & & & & & & & & & & & \\
\hline Pacific Is & & & & & & & & & & & & \\
\hline 1990 & 858 & 712 & - & 356 & 132 & - & $12.2(1.2)$ & 11.3 & - & $17.0(2.2)$ & 20.7 & - \\
\hline 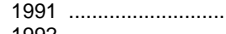 & 996 & 773 & - & 348 & 177 & - & $13.8(1.3)$ & 12.1 & - & $17.1(2.3)$ & 24.6 & - \\
\hline 1992 & 985 & 787 & - & 35 & 18 & - & $12.7(1.2)$ & 11.4 & - & $16.0(2.1)$ & 25.0 & - \\
\hline 1993 & 1,134 & 898 & - & 358 & 126 & - & $15.3(1.3)$ & 13.6 & - & $17.6(2.3)$ & 17.4 & - \\
\hline 1994 & 974 & 776 & - & 308 & 137 & - & $14.6(1.3)$ & 13.1 & - & $17.9(2.5)$ & 23.6 & - \\
\hline 1995 & 1,411 & 1,112 & - & 532 & 266 & - & $14.6(1.2)$ & 13.0 & - & $18.6(2.1)$ & 28.9 & - \\
\hline 1996. & 1,454 & 1,172 & - & 553 & 300 & - & $14.5(1.1)$ & 13.2 & - & $19.1(2.1)$ & 29.5 & - \\
\hline
\end{tabular}

${ }^{1}$ Includes persons of Hispanic origin.

${ }^{2}$ Persons of Hispanic origin may be of any race. -Data not available.
SOURCE: U.S. Department of Commerce, Bureau of the Census, Current Population Reports, Series P-60-198, "Poverty in the United States" and "Income, Poverty, and Valuation of Noncash Benefits," various years. (This table was prepared June 1998.)

NOTE.-Standard errors appear in parentheses. 
Table 22.-Average grade that the public would give the schools in their community and in the nation at large: 1974 to 1998

\begin{tabular}{|c|c|c|c|c|c|c|c|c|c|c|c|c|}
\hline \multirow[b]{2}{*}{ Year } & \multicolumn{3}{|c|}{ All adults } & \multicolumn{3}{|c|}{ No children in school } & \multicolumn{3}{|c|}{ Public school parents } & \multicolumn{3}{|c|}{ Private school parents } \\
\hline & Nation & $\begin{array}{l}\text { Local } \\
\text { community }\end{array}$ & $\begin{array}{c}\text { Local } \\
\text { neigh- } \\
\text { borhood }\end{array}$ & Nation & $\begin{array}{l}\text { Local } \\
\text { community }\end{array}$ & $\begin{array}{c}\text { Local } \\
\text { neigh- } \\
\text { borhood }\end{array}$ & Nation & $\begin{array}{c}\text { Local } \\
\text { community }\end{array}$ & $\begin{array}{c}\text { Local } \\
\text { neigh- } \\
\text { borhood }\end{array}$ & Nation & $\begin{array}{l}\text { Local } \\
\text { community }\end{array}$ & $\begin{array}{c}\text { Local } \\
\text { neigh- } \\
\text { borhood }\end{array}$ \\
\hline 1 & 2 & 3 & 4 & 5 & 6 & 7 & 8 & 9 & 10 & 11 & 12 & 13 \\
\hline 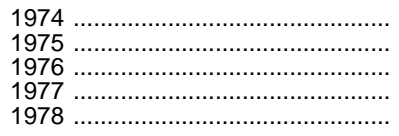 & $\begin{array}{l}\text { - } \\
\text { - } \\
-\end{array}$ & $\begin{array}{l}2.63 \\
2.38 \\
2.38 \\
2.33 \\
2.21\end{array}$ & $\begin{array}{l}- \\
- \\
-\end{array}$ & $\begin{array}{l}- \\
\text { - } \\
-\end{array}$ & $\begin{array}{l}2.57 \\
2.31 \\
2.34 \\
2.25 \\
2.11\end{array}$ & $\begin{array}{l}- \\
- \\
-\end{array}$ & $\begin{array}{l}- \\
- \\
-\end{array}$ & $\begin{array}{l}2.80 \\
2.49 \\
2.48 \\
2.59 \\
2.47\end{array}$ & $\begin{array}{l}- \\
- \\
-\end{array}$ & $\begin{array}{l}- \\
- \\
-\end{array}$ & $\begin{array}{l}2.15 \\
1.81 \\
2.22 \\
2.05 \\
1.69\end{array}$ & $\begin{array}{l}- \\
- \\
-\end{array}$ \\
\hline 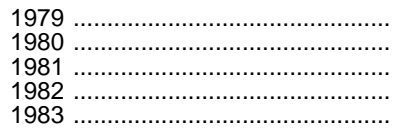 & $\begin{array}{l}-\overline{-} \\
1.94 \\
2.01 \\
1.91\end{array}$ & $\begin{array}{l}2.21 \\
2.26 \\
2.20 \\
2.24 \\
2.12\end{array}$ & $\begin{array}{l}- \\
- \\
-\end{array}$ & $\begin{array}{r}-\overline{-} \\
2 . \overline{04} \\
1.92\end{array}$ & $\begin{array}{l}2.15 \\
2.12 \\
2.18 \\
2.10\end{array}$ & $\begin{array}{l}- \\
- \\
-\end{array}$ & $\begin{array}{l}\overline{-} \\
2 . \overline{01} \\
1.92\end{array}$ & $\begin{array}{l}2.38 \\
2 . \overline{36} \\
2.35 \\
2.31\end{array}$ & $\begin{array}{l}- \\
- \\
-\end{array}$ & $\begin{array}{r}- \\
2 . \overline{0} \\
1.82\end{array}$ & $\begin{array}{l}1.88 \\
1 . \overline{88} \\
2.20 \\
1.89\end{array}$ & - \\
\hline 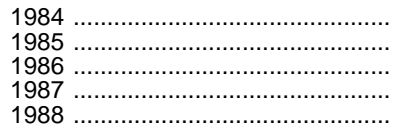 & $\begin{array}{l}2.09 \\
2.14 \\
2.13 \\
2.18 \\
2.08\end{array}$ & $\begin{array}{l}2.36 \\
2.39 \\
2.36 \\
2.44 \\
2.35\end{array}$ & $\begin{array}{l}- \\
- \\
-\end{array}$ & $\begin{array}{r}2.11 \\
2.16 \\
2 . \overline{20} \\
2.02\end{array}$ & $\begin{array}{l}2.30 \\
2.36 \\
2.29 \\
2.38 \\
2.32\end{array}$ & $\begin{array}{l}- \\
- \\
-\end{array}$ & $\begin{array}{l}2.11 \\
2.20 \\
2 . \overline{22} \\
2.13\end{array}$ & $\begin{array}{l}2.49 \\
2.44 \\
2.55 \\
2.61 \\
2.48\end{array}$ & $\begin{array}{l}- \\
- \\
-\end{array}$ & $\begin{array}{r}2.04 \\
1.93 \\
2 . \overline{03} \\
2.00\end{array}$ & $\begin{array}{l}2.17 \\
2.00 \\
2.14 \\
2.01 \\
2.13\end{array}$ & $\begin{array}{l}- \\
- \\
-\end{array}$ \\
\hline 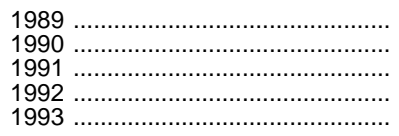 & $\begin{array}{l}2.01 \\
1.99 \\
2.00 \\
1.93 \\
1.95\end{array}$ & $\begin{array}{l}2.35 \\
2.29 \\
2.36 \\
2.30 \\
2.41\end{array}$ & $\begin{array}{l}- \\
- \\
-\end{array}$ & $\begin{array}{r}1.99 \\
1.98 \\
1 . \overline{9} \\
1.97\end{array}$ & $\begin{array}{r}2.27 \\
2.27 \\
-\overline{-} \\
2 . \overline{40}\end{array}$ & $\begin{array}{l}- \\
- \\
-\end{array}$ & $\begin{array}{l}2.06 \\
2.03 \\
1 . \overline{94} \\
1.97\end{array}$ & $\begin{array}{r}2.56 \\
2.44 \\
2.73 \\
2.48\end{array}$ & $\begin{array}{l}- \\
- \\
-\end{array}$ & $\begin{array}{l}1.93 \\
1.85 \\
1 . \overline{85} \\
1.80\end{array}$ & $\begin{array}{r}2.12 \\
2.09 \\
\frac{-}{2.11}\end{array}$ & $\begin{array}{l}- \\
- \\
-\end{array}$ \\
\hline 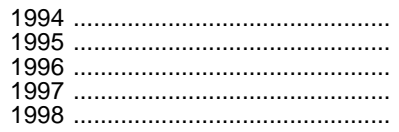 & $\begin{array}{l}1.95 \\
1.97 \\
1.93 \\
1.97 \\
1.93\end{array}$ & $\begin{array}{l}2.26 \\
2.28 \\
2.30 \\
2.35 \\
2.41\end{array}$ & $\begin{array}{r}2.43 \\
2.47 \\
- \\
-\end{array}$ & $\begin{array}{l}1.95 \\
1.98 \\
1.91 \\
1.99 \\
1.91\end{array}$ & $\begin{array}{l}2.16 \\
2.25 \\
2.22 \\
2.27 \\
2.36\end{array}$ & $\begin{array}{r}2.34 \\
2.43 \\
- \\
-\end{array}$ & $\begin{array}{l}1.90 \\
1.93 \\
2.00 \\
2.01 \\
1.96\end{array}$ & $\begin{array}{l}2.55 \\
2.41 \\
2.56 \\
2.56 \\
2.51\end{array}$ & $\begin{array}{r}2.64 \\
2.56 \\
- \\
-\end{array}$ & $\begin{array}{l}1.86 \\
1.81 \\
1.80 \\
1.99 \\
1.81\end{array}$ & $\begin{array}{l}1.90 \\
1.85 \\
1.86 \\
1.87 \\
2.20\end{array}$ & $\begin{array}{r}2.23 \\
2.09 \\
- \\
-\end{array}$ \\
\hline
\end{tabular}

-Data not available.

NOTE.-Average based on a scale where $A=4, B=3, C=2, D=1$, and $F=0$.
SOURCE: "The Annual Gallup Poll of the Public's Attitudes Toward the Public Schools," Phi Delta Kappan, various years. (This table was prepared September 1998.)

Table 23.- Items most frequently cited by the general public as a major problem facing the local public schools: 1970 to 1998

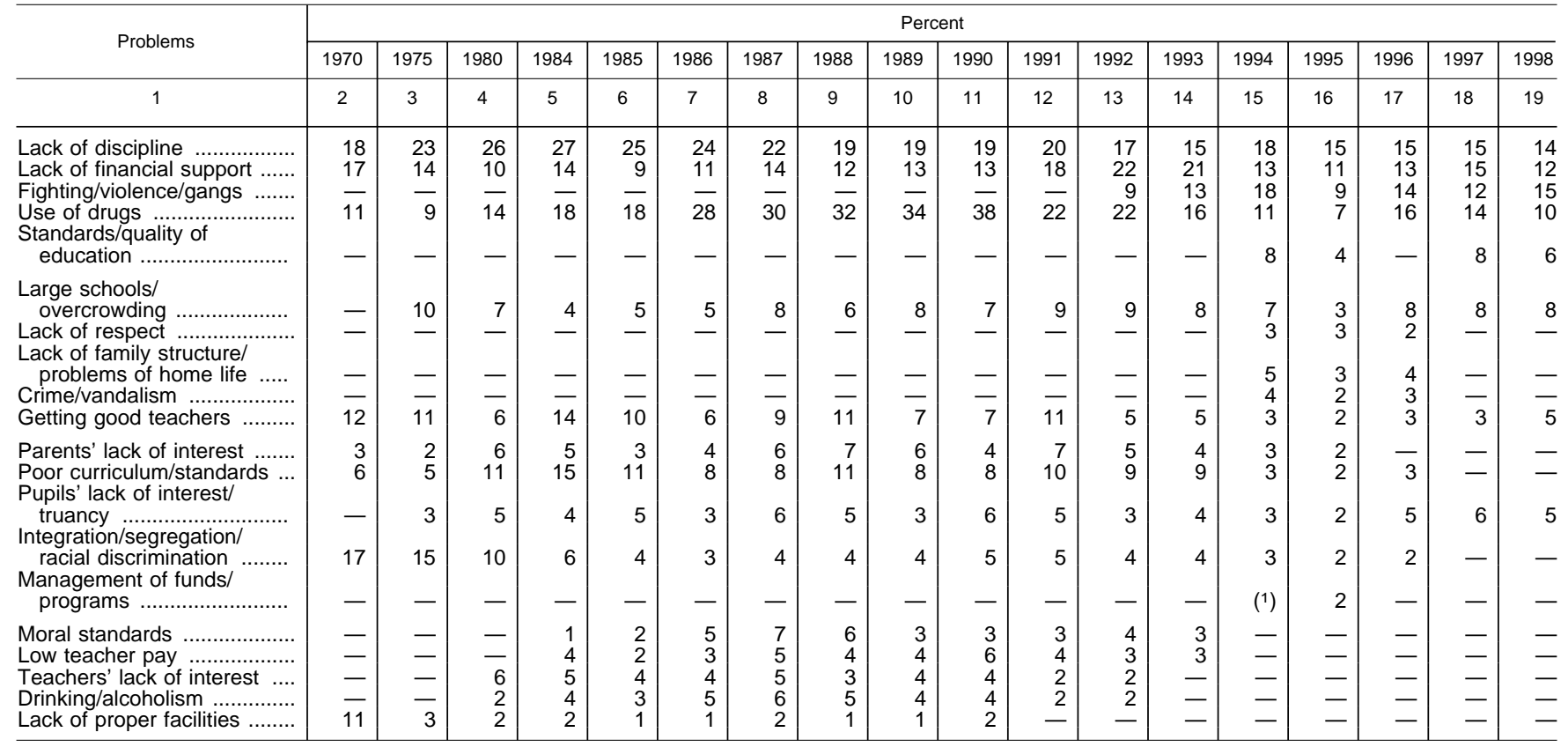


Table 24.-Public opinion of public and private school choice: 1989 to 1998

\begin{tabular}{|c|c|c|c|c|c|c|c|c|c|c|c|}
\hline \multirow[b]{3}{*}{ Question } & \multicolumn{11}{|c|}{ Percent who favor position } \\
\hline & \multirow[b]{2}{*}{1989} & \multirow[b]{2}{*}{1990} & \multirow[b]{2}{*}{1991} & \multirow[b]{2}{*}{1993} & \multirow[b]{2}{*}{1995} & \multirow[b]{2}{*}{1996} & \multirow[b]{2}{*}{1997} & \multicolumn{4}{|c|}{1998} \\
\hline & & & & & & & & Total & $\begin{array}{l}\text { No } \\
\text { chil- } \\
\text { dren } \\
\text { in } \\
\text { school }\end{array}$ & $\begin{array}{l}\text { Public } \\
\text { school } \\
\text { par- } \\
\text { ents }\end{array}$ & $\begin{array}{c}\text { Non- } \\
\text { public } \\
\text { school } \\
\text { par- } \\
\text { ents }\end{array}$ \\
\hline 1 & 2 & 3 & 4 & 5 & 6 & 7 & 8 & 9 & 10 & 11 & 12 \\
\hline $\begin{array}{l}\text { Do you favor or oppose allowing students and their parents to } \\
\text { choose which public schools in the community the students attend } \\
\text { regardless of where they live? }\end{array}$ & 60 & 62 & 62 & 65 & 69 & 一 & 一 & 一 & 一 & - & - \\
\hline $\begin{array}{l}\text { Do you favor or oppose allowing students and parents to choose } \\
\text { a private school to attend at public expense? }\end{array}$ & - & - & 26 & 24 & 33 & 36 & 44 & 44 & - & - & 一 \\
\hline $\begin{array}{l}\text { Do you think private schools that accept government tuition payments for } \\
\text { these students should be accountable to public authorities or not? }\end{array}$ & & & & & & & & & & & \\
\hline 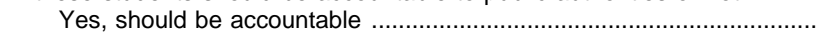 & - & - & - & 63 & 73 & - & - & 75 & 74 & 80 & 62 \\
\hline No, should not be accountable & - & - & - & 34 & 24 & - & - & 20 & 22 & 16 & 26 \\
\hline 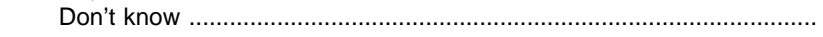 & - & - & - & 3 & 3 & - & - & 5 & 4 & 4 & 12 \\
\hline
\end{tabular}

-Data not available.

SOURCE: Phi Delta Kappan, "The Annual Gallup Poll of the Public's Attitudes Toward the Public Schools," various years. (This table was prepared September 1998.)

Table 25.-Percent of elementary and secondary school children whose parents are involved in school activities and distribution of children by average grades, by selected child, parent, and school characteristics: 1996

\begin{tabular}{|c|c|c|c|c|c|c|c|c|c|c|c|c|}
\hline \multirow[b]{2}{*}{$\begin{array}{l}\text { Characteristics of children, parents, and } \\
\text { schools }\end{array}$} & \multicolumn{4}{|c|}{$\begin{array}{l}\text { Percent of children whose parents }{ }^{1} \text { re- } \\
\text { port that they- }\end{array}$} & \multicolumn{4}{|c|}{$\begin{array}{c}\text { Distribution of children, by parental reports of } \\
\text { number of times spent helping with home- } \\
\text { work per week }{ }^{2}\end{array}$} & \multicolumn{4}{|c|}{$\begin{array}{l}\text { Distribution of children, by parental reports of av- } \\
\text { erage grades in all subjects }\end{array}$} \\
\hline & $\begin{array}{l}\text { At- } \\
\text { tended } \\
\text { a gen- } \\
\text { eral } \\
\text { school } \\
\text { meet- } \\
\text { ing }\end{array}$ & $\begin{array}{l}\text { At- } \\
\text { tended } \\
\text { parent- } \\
\text { teacher } \\
\text { con- } \\
\text { ference }\end{array}$ & $\begin{array}{l}\text { At- } \\
\text { tended } \\
\text { a class } \\
\text { event }\end{array}$ & $\begin{array}{l}\text { Volun- } \\
\text { teered at } \\
\text { school }\end{array}$ & $\begin{array}{l}\text { Less } \\
\text { than } \\
\text { once } \\
\text { per } \\
\text { week }\end{array}$ & $\begin{array}{l}1 \text { or } 2 \\
\text { times per } \\
\text { week }\end{array}$ & $\begin{array}{l}3 \text { or } 4 \\
\text { times per } \\
\text { week }\end{array}$ & $\begin{array}{l}5 \text { or more } \\
\text { times per } \\
\text { week }\end{array}$ & $\begin{array}{l}\text { Mostly } \\
\text { A's }\end{array}$ & Mostly B's & Mostly C's & $\begin{array}{l}\text { Mostly, } \\
\text { D's or F's }\end{array}$ \\
\hline 1 & 2 & 3 & 4 & 5 & 6 & 7 & 8 & 9 & 10 & 11 & 12 & 13 \\
\hline Total & 76.4 & 70.6 & 66.1 & 39.6 & 26.7 & 35.1 & 25.8 & 12.3 & 39.5 & 37.7 & 18.5 & 4.2 \\
\hline $\begin{array}{l}\text { Sex of child } \\
\text { Male } \ldots \ldots \ldots \ldots \ldots \ldots \ldots \ldots \ldots \ldots \ldots \ldots \ldots \ldots \ldots \ldots \ldots \ldots\end{array}$ & $\begin{array}{l}75.6 \\
77.3\end{array}$ & $\begin{array}{l}71.9 \\
69.3\end{array}$ & $\begin{array}{l}64.5 \\
67.8\end{array}$ & $\begin{array}{l}38.7 \\
40.6\end{array}$ & $\begin{array}{l}27.4 \\
25.9\end{array}$ & $\begin{array}{l}33.5 \\
36.9\end{array}$ & $\begin{array}{l}26.2 \\
25.4\end{array}$ & $\begin{array}{l}12.9 \\
11.8\end{array}$ & $\begin{array}{l}32.5 \\
46.9\end{array}$ & $\begin{array}{l}38.3 \\
37.2\end{array}$ & $\begin{array}{l}23.5 \\
13.2\end{array}$ & $\begin{array}{l}5.7 \\
2.7\end{array}$ \\
\hline $\begin{array}{l}\text { Race/ethnicity of child } \\
\text { White, non-Hispanic } \\
\text { Black, non-Hispanic ....................... } \\
\text { Hispanic ................................ } \\
\text { Other, non-Hispanic } \\
\text { Highest education level } \\
\text { of parents }\end{array}$ & $\begin{array}{l}78.5 \\
71.9 \\
72.7 \\
72.6\end{array}$ & $\begin{array}{l}71.2 \\
68.0 \\
70.7 \\
71.4\end{array}$ & $\begin{array}{l}70.9 \\
56.0 \\
54.8 \\
63.4\end{array}$ & $\begin{array}{l}44.5 \\
29.5 \\
27.7 \\
36.2\end{array}$ & $\begin{array}{l}28.2 \\
21.9 \\
25.4 \\
24.3\end{array}$ & $\begin{array}{l}37.0 \\
30.0 \\
31.1 \\
37.5\end{array}$ & $\begin{array}{l}24.8 \\
28.6 \\
27.9 \\
26.1\end{array}$ & $\begin{array}{l}10.1 \\
19.5 \\
15.6 \\
12.0\end{array}$ & $\begin{array}{l}43.7 \\
27.0 \\
31.9 \\
44.7\end{array}$ & $\begin{array}{l}36.1 \\
41.0 \\
43.6 \\
33.7\end{array}$ & $\begin{array}{l}16.5 \\
26.2 \\
19.6 \\
17.1\end{array}$ & $\begin{array}{l}3.7 \\
5.8 \\
4.9 \\
4.5\end{array}$ \\
\hline 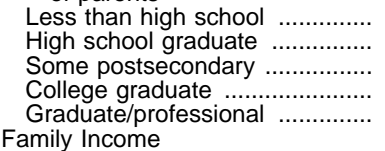 & $\begin{array}{l}57.6 \\
71.1 \\
77.4 \\
86.1 \\
87.6\end{array}$ & $\begin{array}{l}62.5 \\
68.2 \\
71.1 \\
75.1 \\
75.1\end{array}$ & $\begin{array}{l}42.4 \\
59.5 \\
68.4 \\
75.5 \\
81.0\end{array}$ & $\begin{array}{l}18.3 \\
31.1 \\
40.2 \\
52.2 \\
56.8\end{array}$ & $\begin{array}{l}28.7 \\
26.4 \\
26.4 \\
25.4 \\
27.9\end{array}$ & $\begin{array}{l}30.0 \\
34.2 \\
35.8 \\
38.8 \\
35.1\end{array}$ & $\begin{array}{l}24.5 \\
25.7 \\
26.1 \\
25.3 \\
26.8\end{array}$ & $\begin{array}{l}16.7 \\
13.6 \\
11.6 \\
10.5 \\
10.2\end{array}$ & $\begin{array}{l}29.0 \\
30.5 \\
36.9 \\
52.5 \\
58.2\end{array}$ & $\begin{array}{l}39.0 \\
40.5 \\
40.1 \\
32.9 \\
30.9\end{array}$ & $\begin{array}{r}23.9 \\
23.1 \\
19.1 \\
12.7 \\
9.8\end{array}$ & $\begin{array}{l}8.1 \\
5.9 \\
3.9 \\
1.9 \\
1.1\end{array}$ \\
\hline 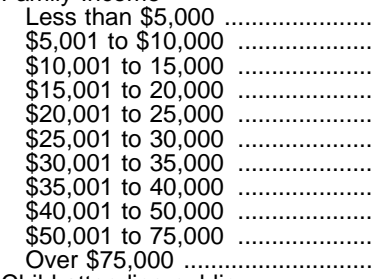 & $\begin{array}{l}67.0 \\
63.8 \\
67.4 \\
69.1 \\
69.0 \\
72.0 \\
79.0 \\
78.9 \\
80.7 \\
83.9 \\
88.2\end{array}$ & $\begin{array}{l}68.3 \\
67.4 \\
66.9 \\
67.4 \\
68.7 \\
69.2 \\
69.1 \\
72.8 \\
73.9 \\
72.2 \\
73.8\end{array}$ & $\begin{array}{l}49.8 \\
49.6 \\
60.3 \\
55.8 \\
58.5 \\
61.7 \\
68.8 \\
69.6 \\
72.8 \\
75.0 \\
79.1\end{array}$ & $\begin{array}{l}27.0 \\
24.4 \\
29.9 \\
26.8 \\
29.2 \\
33.0 \\
41.6 \\
41.7 \\
45.3 \\
49.1 \\
57.3\end{array}$ & $\begin{array}{l}23.7 \\
26.7 \\
26.8 \\
27.7 \\
25.9 \\
28.1 \\
27.9 \\
24.9 \\
27.1 \\
25.9 \\
28.3\end{array}$ & $\begin{array}{l}28.3 \\
32.1 \\
36.0 \\
33.3 \\
34.9 \\
34.8 \\
35.6 \\
37.3 \\
35.3 \\
37.0 \\
36.6\end{array}$ & $\begin{array}{l}27.7 \\
27.6 \\
22.7 \\
23.4 \\
26.5 \\
27.3 \\
24.8 \\
27.0 \\
25.3 \\
26.3 \\
25.1\end{array}$ & $\begin{array}{r}20.4 \\
13.7 \\
14.6 \\
15.6 \\
12.7 \\
9.8 \\
11.6 \\
10.7 \\
12.4 \\
10.8 \\
9.9\end{array}$ & $\begin{array}{l}28.9 \\
26.6 \\
28.0 \\
32.7 \\
34.4 \\
33.0 \\
40.0 \\
40.4 \\
43.2 \\
50.2 \\
51.0\end{array}$ & $\begin{array}{l}38.8 \\
41.9 \\
39.8 \\
38.4 \\
40.8 \\
42.0 \\
38.0 \\
37.3 \\
36.0 \\
32.7 \\
36.8\end{array}$ & $\begin{array}{l}23.3 \\
24.6 \\
26.0 \\
21.6 \\
20.6 \\
19.8 \\
18.1 \\
19.4 \\
16.8 \\
14.9 \\
10.9\end{array}$ & $\begin{array}{l}8.9 \\
6.9 \\
6.2 \\
7.3 \\
4.2 \\
5.2 \\
3.9 \\
2.8 \\
4.0 \\
2.2 \\
1.3\end{array}$ \\
\hline $\begin{array}{l}\text { Child attending public } \\
\text { schools } 4 \text {..................... } \\
\text { Elementary (kindergarten }\end{array}$ & 75.3 & 70.6 & 64.8 & 35.4 & 26.6 & 35.9 & 25.4 & 12.1 & 38.2 & 37.9 & 19.3 & 4.6 \\
\hline $\begin{array}{l}\text { to grade } 8)^{4} \\
\text { Secondary (grades } 9 \text { to } 12)^{4} \ldots . \\
\text { Child attending private }\end{array}$ & $\begin{array}{l}80.2 \\
63.2\end{array}$ & $\begin{array}{l}79.8 \\
47.7\end{array}$ & $\begin{array}{l}67.8 \\
57.5\end{array}$ & $\begin{array}{l}39.4 \\
25.5\end{array}$ & $\begin{array}{l}15.5 \\
52.0\end{array}$ & $\begin{array}{l}35.1 \\
37.7\end{array}$ & $\begin{array}{r}33.2 \\
7.7\end{array}$ & $\begin{array}{r}16.2 \\
2.5\end{array}$ & $\begin{array}{l}43.2 \\
29.6\end{array}$ & $\begin{array}{l}36.6 \\
40.2\end{array}$ & $\begin{array}{l}16.3 \\
24.5\end{array}$ & $\begin{array}{l}3.9 \\
5.7\end{array}$ \\
\hline $\begin{array}{l}\text { schools }{ }^{4} \text {.................................. } \\
\text { Elementary (kindergarten }\end{array}$ & 90.2 & 82.3 & 82.8 & 66.4 & 27.2 & 28.7 & 29.2 & 14.9 & 50.8 & 36.1 & 11.8 & 1.3 \\
\hline 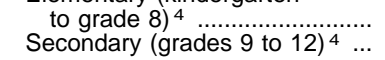 & $\begin{array}{l}92.2 \\
85.0\end{array}$ & $\begin{array}{l}87.8 \\
67.4\end{array}$ & $\begin{array}{l}86.1 \\
73.7\end{array}$ & $\begin{array}{l}70.8 \\
54.4\end{array}$ & $\begin{array}{l}14.5 \\
57.4\end{array}$ & $\begin{array}{l}28.5 \\
29.0\end{array}$ & $\begin{array}{l}37.0 \\
10.8\end{array}$ & $\begin{array}{r}19.9 \\
2.8\end{array}$ & $\begin{array}{l}55.7 \\
40.9\end{array}$ & $\begin{array}{l}35.3 \\
37.7\end{array}$ & $\begin{array}{r}7.5 \\
20.4\end{array}$ & $\begin{array}{l}1.4 \\
1.0\end{array}$ \\
\hline
\end{tabular}

1 The respondent was the parent most knowledgeable about the child's education. The responding parent reported on their own and their spouse's or other household adults' activities. Except where noted, includes children enrolled in nursery school through grade 12.

2 Includes children enrolled in grades 1 through 12 .

${ }^{3}$ Excludes children whose programs have no classes with lettered grades.

${ }^{4}$ Excludes home-schooled children.
NOTE.-Because of rounding, details may not add to totals.

SOURCE: U.S. Department of Education, National Center for Education Statistics, National Household Education Survey, 1996, unpublished data. (This table was prepared December 1998.) 
Table 26.-Percent of elementary school children whose parents are involved in education-related activities, by selected child, parent, and school characteristics: 1996

\begin{tabular}{|c|c|c|c|c|c|c|c|c|c|c|c|c|c|c|}
\hline \multirow[b]{2}{*}{$\begin{array}{l}\text { Characteristics of children, parents, } \\
\text { and schools }\end{array}$} & \multicolumn{6}{|c|}{$\begin{array}{l}\text { Percent of children } 1 \text { whose parents report that they did the } \\
\text { following things in the past month- }\end{array}$} & \multicolumn{3}{|c|}{$\begin{array}{l}\text { Percent of children }{ }^{2} \text { whose } \\
\text { families have rules about- }\end{array}$} & \multicolumn{5}{|c|}{$\begin{array}{l}\text { Percent of children whose parents involved them in } \\
\text { the following activities during the past week }{ }^{1}\end{array}$} \\
\hline & $\begin{array}{c}\text { Vis- } \\
\text { ited a } \\
\text { library }\end{array}$ & $\begin{array}{l}\text { Went to } \\
\text { a play, } \\
\text { concert, } \\
\text { or other } \\
\text { live } \\
\text { show }\end{array}$ & $\begin{array}{l}\text { Visited an } \\
\text { art gal- } \\
\text { lery, mu- } \\
\text { seum, or } \\
\text { historical } \\
\text { site }\end{array}$ & $\begin{array}{l}\text { Visited } \\
\text { a zoo } \\
\text { or } \\
\text { aquar- } \\
\text { ium }\end{array}$ & $\begin{array}{l}\text { Talked } \\
\text { about } \\
\text { family } \\
\text { history } \\
\text { or eth- } \\
\text { nic her- } \\
\text { itage }\end{array}$ & $\begin{array}{l}\text { Attended } \\
\text { an event } \\
\text { sponsored } \\
\text { by a com- } \\
\text { munity, reli- } \\
\text { gious, or } \\
\text { ethnic } \\
\text { group }\end{array}$ & $\begin{array}{l}\text { Time for } \\
\text { bed on } \\
\text { school } \\
\text { nights }\end{array}$ & $\begin{array}{l}\text { Amount } \\
\text { of time } \\
\text { child is } \\
\text { allowed } \\
\text { to watch } \\
\text { tele- } \\
\text { vision }\end{array}$ & $\begin{array}{l}\text { Tele- } \\
\text { vision } \\
\text { pro- } \\
\text { grams } \\
\text { child is } \\
\text { allowed } \\
\text { to watch }\end{array}$ & $\begin{array}{l}\text { Told a } \\
\text { story }\end{array}$ & $\begin{array}{c}\text { Worked } \\
\text { on art or } \\
\text { crafts }\end{array}$ & $\begin{array}{l}\text { Played } \\
\text { a game } \\
\text { or sport } \\
\text { together }\end{array}$ & $\begin{array}{l}\text { Built or } \\
\text { made } \\
\text { project } \\
\text { or fixed } \\
\text { some- } \\
\text { thing }^{3}\end{array}$ & $\begin{array}{l}\text { Worked } \\
\text { on } \\
\text { house- } \\
\text { hold } \\
\text { chores }\end{array}$ \\
\hline 1 & 2 & 3 & 4 & 5 & 6 & 7 & 8 & 9 & 10 & 11 & 12 & 13 & 14 & 15 \\
\hline Total & 48.7 & 32.5 & 21.2 & 15.7 & 56.4 & 53.3 & 97.2 & 80.0 & 92.0 & 70.4 & 67.0 & 91.3 & 65.0 & 96.5 \\
\hline 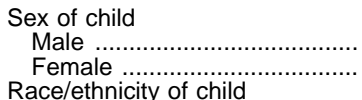 & $\begin{array}{l}48.5 \\
49.0\end{array}$ & $\begin{array}{l}30.3 \\
34.7\end{array}$ & $\begin{array}{l}20.6 \\
21.8\end{array}$ & $\begin{array}{l}15.3 \\
16.0\end{array}$ & $\begin{array}{l}55.8 \\
57.0\end{array}$ & $\begin{array}{l}52.6 \\
53.9\end{array}$ & $\begin{array}{l}97.8 \\
96.6\end{array}$ & $\begin{array}{l}80.3 \\
79.8\end{array}$ & $\begin{array}{l}92.0 \\
92.1\end{array}$ & $\begin{array}{l}69.8 \\
71.0\end{array}$ & $\begin{array}{l}64.2 \\
70.0\end{array}$ & $\begin{array}{l}91.9 \\
90.7\end{array}$ & $\begin{array}{l}66.6 \\
63.3\end{array}$ & $\begin{array}{l}96.1 \\
97.0\end{array}$ \\
\hline $\begin{array}{l}\text { White, non-Hispanic } \\
\text { Black, non-Hispanic ................... } \\
\text { Hispanic ................................ } \\
\text { Other, non-Hispanic ............. } \\
\text { Highest education level } \\
\text { of parents }\end{array}$ & $\begin{array}{l}51.7 \\
43.9 \\
38.9 \\
52.3\end{array}$ & $\begin{array}{l}32.2 \\
38.1 \\
26.6 \\
33.2\end{array}$ & $\begin{array}{l}21.0 \\
22.2 \\
19.6 \\
24.3\end{array}$ & $\begin{array}{l}13.3 \\
21.6 \\
19.3 \\
18.3\end{array}$ & $\begin{array}{l}52.1 \\
69.5 \\
58.4 \\
64.8\end{array}$ & $\begin{array}{l}54.9 \\
54.6 \\
44.3 \\
49.6\end{array}$ & $\begin{array}{l}97.7 \\
97.3 \\
95.1 \\
95.5\end{array}$ & $\begin{array}{l}77.3 \\
88.5 \\
83.5 \\
78.6\end{array}$ & $\begin{array}{l}93.4 \\
90.8 \\
88.0 \\
89.0\end{array}$ & $\begin{array}{l}71.1 \\
66.9 \\
70.0 \\
73.8\end{array}$ & $\begin{array}{l}68.5 \\
63.5 \\
63.3 \\
68.5\end{array}$ & $\begin{array}{l}92.4 \\
92.5 \\
84.7 \\
90.8\end{array}$ & $\begin{array}{l}68.1 \\
59.6 \\
56.9 \\
61.9\end{array}$ & $\begin{array}{l}97.4 \\
97.0 \\
91.8 \\
94.9\end{array}$ \\
\hline $\begin{array}{l}\text { Less than high school } \ldots \ldots \ldots \ldots . . \\
\text { High school graduate } \\
\text { Some postsecondary } \\
\text { Colle.............. } \\
\text { Graduate/professional } \\
\text { Family Income....... }\end{array}$ & $\begin{array}{l}30.1 \\
40.0 \\
49.7 \\
60.1 \\
65.3\end{array}$ & $\begin{array}{l}25.6 \\
27.9 \\
33.3 \\
35.8 \\
41.6\end{array}$ & $\begin{array}{l}16.7 \\
15.0 \\
20.4 \\
27.3 \\
32.5\end{array}$ & $\begin{array}{l}18.9 \\
14.4 \\
15.4 \\
16.3 \\
16.3\end{array}$ & $\begin{array}{l}53.5 \\
50.9 \\
57.1 \\
59.5 \\
65.4\end{array}$ & $\begin{array}{l}37.8 \\
44.7 \\
54.9 \\
63.6 \\
67.2\end{array}$ & $\begin{array}{l}95.2 \\
97.0 \\
97.8 \\
97.7 \\
97.2\end{array}$ & $\begin{array}{l}80.1 \\
80.1 \\
80.8 \\
77.7 \\
81.0\end{array}$ & $\begin{array}{l}85.8 \\
91.7 \\
93.5 \\
93.3 \\
92.6\end{array}$ & $\begin{array}{l}66.1 \\
66.8 \\
71.8 \\
72.7 \\
75.4\end{array}$ & $\begin{array}{l}59.7 \\
65.7 \\
67.5 \\
71.1 \\
69.0\end{array}$ & $\begin{array}{l}81.9 \\
92.0 \\
91.6 \\
93.9 \\
92.5\end{array}$ & $\begin{array}{l}56.9 \\
63.2 \\
65.9 \\
69.1 \\
68.2\end{array}$ & $\begin{array}{l}91.3 \\
97.2 \\
97.4 \\
96.7 \\
96.3\end{array}$ \\
\hline 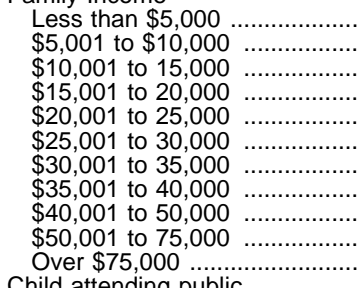 & $\begin{array}{l}40.4 \\
37.2 \\
37.3 \\
41.1 \\
42.3 \\
43.3 \\
50.5 \\
56.4 \\
55.1 \\
55.5 \\
59.6\end{array}$ & $\begin{array}{l}38.1 \\
27.3 \\
29.6 \\
25.7 \\
30.8 \\
27.1 \\
30.0 \\
32.6 \\
32.7 \\
33.3 \\
42.6\end{array}$ & $\begin{array}{l}19.8 \\
16.1 \\
16.8 \\
13.9 \\
20.9 \\
17.7 \\
21.3 \\
17.3 \\
21.1 \\
25.1 \\
31.4\end{array}$ & $\begin{array}{l}19.2 \\
17.0 \\
15.6 \\
16.8 \\
14.9 \\
16.0 \\
15.9 \\
13.2 \\
13.2 \\
13.4 \\
19.0\end{array}$ & $\begin{array}{l}57.4 \\
58.2 \\
57.5 \\
55.7 \\
58.2 \\
54.6 \\
54.4 \\
53.5 \\
54.1 \\
54.9 \\
60.5\end{array}$ & $\begin{array}{l}43.1 \\
41.9 \\
48.0 \\
47.0 \\
48.4 \\
50.4 \\
56.9 \\
55.8 \\
58.3 \\
59.7 \\
62.2\end{array}$ & $\begin{array}{l}97.7 \\
93.6 \\
95.8 \\
98.0 \\
97.3 \\
97.1 \\
98.1 \\
97.8 \\
98.6 \\
97.8 \\
97.3\end{array}$ & $\begin{array}{l}85.5 \\
81.0 \\
78.1 \\
79.2 \\
82.1 \\
80.3 \\
78.6 \\
81.3 \\
80.1 \\
78.9 \\
77.7\end{array}$ & $\begin{array}{l}90.9 \\
88.7 \\
88.7 \\
89.8 \\
93.3 \\
90.5 \\
91.4 \\
95.0 \\
93.9 \\
94.4 \\
92.2\end{array}$ & $\begin{array}{l}70.3 \\
67.1 \\
65.3 \\
66.7 \\
73.1 \\
69.3 \\
72.0 \\
71.8 \\
69.2 \\
71.7 \\
73.9\end{array}$ & $\begin{array}{l}64.1 \\
67.3 \\
60.9 \\
60.5 \\
64.5 \\
67.1 \\
69.3 \\
69.3 \\
69.6 \\
68.5 \\
70.0\end{array}$ & $\begin{array}{l}89.0 \\
89.3 \\
86.6 \\
88.5 \\
91.8 \\
91.7 \\
92.4 \\
92.4 \\
93.5 \\
92.0 \\
93.8\end{array}$ & $\begin{array}{l}62.9 \\
60.4 \\
53.6 \\
64.8 \\
62.1 \\
65.1 \\
68.1 \\
70.0 \\
66.6 \\
67.3 \\
68.8\end{array}$ & $\begin{array}{l}94.9 \\
95.9 \\
95.2 \\
97.1 \\
95.6 \\
95.2 \\
97.7 \\
96.8 \\
97.7 \\
97.5 \\
96.6\end{array}$ \\
\hline $\begin{array}{l}\text { Child attending public } \\
\text { schools }{ }^{4} \text {.................... } \\
\text { Child attending private }\end{array}$ & 48.3 & 31.7 & 19.9 & 14.7 & 57.1 & 51.9 & 97.3 & 79.9 & 91.5 & 66.7 & 64.4 & 90.5 & 63.9 & 97.3 \\
\hline schools ${ }^{4}$ & 58.2 & 37.2 & 27.8 & 16.9 & 61.3 & 66.9 & 96.3 & 79.6 & 95.5 & 74.2 & 67.2 & 91.7 & 70.9 & 96.5 \\
\hline
\end{tabular}

1 Includes children enrolled in nursery school through grade 5 2 Includes children enrolled in kindergarten through grade 5.

${ }^{3}$ Includes children enrolled in 1st through 5th grade.

${ }^{4}$ Excludes nursery school and home-schooled children.
SOURCE: U.S. Department of Education, National Center for Education Statistics, National Household Education Survey, 1996, unpublished data. (This table was prepared December 1998.)

Table 27.-Teachers' perceptions about serious problems in their schools, by type and control of school: 1990-91 and 1993-94

\begin{tabular}{|c|c|c|c|c|c|c|c|c|c|c|}
\hline \multirow{4}{*}{ Problem area } & \multicolumn{10}{|c|}{ Percent of teachers indicating item is a serious problem } \\
\hline & \multicolumn{5}{|c|}{ Public school teachers } & \multicolumn{5}{|c|}{ Private school teachers } \\
\hline & \multirow{2}{*}{$\begin{array}{c}\text { 1990-91 } \\
\text { Total }\end{array}$} & \multicolumn{4}{|c|}{ 1993-94 } & \multirow{2}{*}{$\begin{array}{c}\text { 1990-91 } \\
\text { Total }\end{array}$} & \multicolumn{4}{|c|}{ 1993-94 } \\
\hline & & Total & $\begin{array}{l}\text { Elementary } \\
\text { schools }\end{array}$ & $\begin{array}{l}\text { Secondary } \\
\text { schools }\end{array}$ & $\begin{array}{l}\text { Combined } \\
\text { schools }\end{array}$ & & Total & $\begin{array}{l}\text { Elementary } \\
\text { schools }\end{array}$ & $\begin{array}{l}\text { Secondary } \\
\text { schools }\end{array}$ & $\begin{array}{l}\text { Combined } \\
\text { schools }\end{array}$ \\
\hline 1 & 2 & 3 & 4 & 5 & 6 & 7 & 8 & 9 & 10 & 11 \\
\hline Student tardiness ........................... & 11.2 & 10.5 & 6.3 & 18.3 & 7.8 & 3.4 & 2.6 & 1.8 & 4.3 & 2.6 \\
\hline Student absenteeism & 14.1 & 14.4 & 7.2 & & 15.0 & ? & 2.2 & 0.8 & 5.2 & 2.7 \\
\hline Teacher absenteeism & 1.6 & 1.5 & 1.3 & 1.9 & 2.0 & 0.7 & 0.8 & 0.7 & 1.2 & 0.9 \\
\hline Students cutting class . & 4.6 & 5.1 & 1.3 & 11.9 & 4.6 & 0.7 & 0.7 & 0.2 & 2.4 & 0.7 \\
\hline Physical conflicts among students & 6.5 & 8.2 & 7.8 & 8.6 & 8.1 & 1.1 & 1.5 & 0.9 & 2.1 & 2.1 \\
\hline Robbery or theft ..................................... & 3.4 & 4.1 & 3.0 & 5.8 & 3.6 & 0.8 & 0.8 & 0.4 & 1.4 & 1.1 \\
\hline Vandalism of school property & 5.4 & 6.7 & 5.2 & 9.0 & 5.9 & 0.9 & 1.2 & 0.9 & 2.0 & 1.2 \\
\hline Student pregnancy ........... & 6.4 & 7.3 & 1.1 & 18.4 & 10.1 & 0.3 & 0.4 & 0.2 & 1.1 & 0.4 \\
\hline Student use of alcohol. & 8.2 & 9.3 & 1.6 & 23.1 & 14.2 & 2.4 & 3.1 & 0.3 & 11.0 & 2.7 \\
\hline Student drug abuse. & 4.2 & 5.7 & 1.0 & 14.2 & 7.1 & 0.5 & 1.3 & 0.2 & 4.0 & 1.4 \\
\hline Student possessio & 1.2 & 2.8 & 1.2 & 5.6 & 2.7 & 0. & 0.3 & 0. & & 0.3 \\
\hline Verbal abuse of teac & 7.5 & 11.1 & 8.6 & 14.8 & 14.3 & 1.7 & 2.3 & 0.7 & 2.8 & 4.4 \\
\hline Student disrespect fo & 13.0 & 18.5 & 15.3 & 23.6 & 20.3 & 2.9 & 3.4 & 2.2 & 4.2 & 4.7 \\
\hline Students dropping ou & 6.3 & 5.8 & 1.2 & 14.1 & 7.7 & 0.2 & 0.6 & 0 . & 1.3 & 0.7 \\
\hline Student apathy ....... & 20.6 & 23.6 & 15.6 & 38.0 & 28.9 & 4.1 & 4.5 & 2.2 & 9.7 & 5.1 \\
\hline Lack of academic challenge & 5.7 & 6.5 & 4.2 & 10.4 & 9.9 & 1.3 & 1.5 & 1.0 & 2.5 & 1.6 \\
\hline Lack of parental inv & 25.4 & 27.6 & 23.0 & 34.5 & 35.5 & 4.3 & 4.0 & 2.8 & 7.1 & 4.7 \\
\hline Parental alcoholism/drug abuse ... & 12.0 & 13.1 & 12.9 & 12.3 & 18.7 & 2.2 & 2.6 & 1.6 & 4.2 & 3.4 \\
\hline Poverty ….................. & 17.1 & 19.5 & 20.8 & 15.9 & 26.8 & 2.0 & 2.7 & 2.2 & 3.2 & 3.0 \\
\hline Racial tension ............ & 3.8 & 5.1 & 4.0 & 6.7 & 5.5 & 0.7 & 0.9 & 0.6 & 1.7 & 0.8 \\
\hline $\begin{array}{l}\text { Students come unprepared to } \\
\text { learn }\end{array}$ & - & 28.8 & 24.3 & 36.0 & 30.9 & - & 4.1 & 2.6 & 7.6 & 4.6 \\
\hline
\end{tabular}

—Data not available.

SOURCE: U.S. Department of Education, National Center for Education Statistics, "Schools and Staffing Survey," 1990-91 and 1993-94. (This table was prepared September 1996.) 
Table 28.-Teachers' perceptions about teaching and school conditions, by type and control of school: 1993-94

\begin{tabular}{|c|c|c|c|c|c|c|c|c|}
\hline \multirow{3}{*}{ Statement } & \multicolumn{8}{|c|}{ Percent of teachers somewhat agreeing or strongly agreeing with statement } \\
\hline & \multicolumn{4}{|c|}{ Public school teachers } & \multicolumn{4}{|c|}{ Private school teachers } \\
\hline & Total & $\begin{array}{l}\text { Elemen- } \\
\text { tary } \\
\text { schools }\end{array}$ & $\begin{array}{l}\text { Second- } \\
\text { ary } \\
\text { schools }\end{array}$ & $\begin{array}{l}\text { Com- } \\
\text { bined } \\
\text { schools }\end{array}$ & Total & $\begin{array}{l}\text { Elemen- } \\
\text { tary } \\
\text { schools }\end{array}$ & $\begin{array}{l}\text { Second- } \\
\text { ary } \\
\text { schools }\end{array}$ & $\begin{array}{l}\text { Com- } \\
\text { bined } \\
\text { schools }\end{array}$ \\
\hline 1 & 2 & 3 & 4 & 5 & 6 & 7 & 8 & 9 \\
\hline $\begin{array}{l}\text { The school administration's behavior toward the staff is supportive ... } \\
\text { My principal enforces school rules for student conduct and backs me }\end{array}$ & 79.2 & 80.7 & 76.8 & 77.0 & 88.2 & 89.4 & 83.3 & 88.7 \\
\hline up when I need it & 80.8 & 82.0 & 78.6 & 81.4 & 88.4 & 89.3 & 84.4 & 88.5 \\
\hline 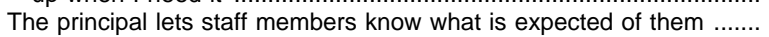 & 85.6 & 86.9 & 83.5 & 82.1 & 88.2 & 89.1 & 86.6 & 88.2 \\
\hline Principal talks to me frequently about my instructional practices ......... & 44.3 & 49.0 & 35.6 & 45.7 & 54.0 & 58.3 & 41.2 & 53.7 \\
\hline 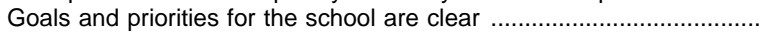 & 82.8 & 85.4 & 78.1 & 79.3 & 90.2 & 90.9 & 88.3 & 90.2 \\
\hline Teachers in this school are evaluated fairly & 87.9 & 88.6 & 86.6 & 85.3 & 89.8 & 90.4 & 87.3 & 90.3 \\
\hline In this school, staff members are recognized for a job well done & 67.9 & 71.7 & 61.7 & 62.6 & 81.1 & 82.4 & 74.7 & 82.1 \\
\hline $\begin{array}{l}\text { Principal knows what kind of school he/she wants and has } \\
\text { communicated it to the staff }\end{array}$ & 80.5 & 82.8 & 76.7 & 77.1 & 88.6 & 89.1 & 85.5 & 89.9 \\
\hline $\begin{array}{l}\text { Principal does a poor job in getting resources for this school ........................... } \\
\text { Most of my colleagues share my beliefs and values about what the }\end{array}$ & 16.1 & 15.1 & 18.1 & 19.6 & 10.5 & 10.6 & 12.9 & 8.7 \\
\hline 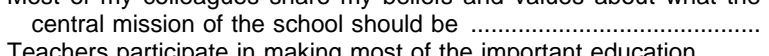 & 84.2 & 87.3 & 79.1 & 81.4 & 93.2 & 95.0 & 88.4 & 93.7 \\
\hline $\begin{array}{l}\text { Teachers participate in makıng most of the important education } \\
\text { decisions in this school }\end{array}$ & 58.3 & 62.8 & 50.3 & 58.4 & 74.0 & 75.1 & 66.1 & 75.3 \\
\hline There is a great deal of cooperative effort among staff. & 77.5 & 80.9 & 71.8 & 76.3 & 90.5 & 90.3 & 86.2 & 93.0 \\
\hline I receive a great deal of support from parents for the work I do .......... & 52.5 & 58.4 & 43.2 & 47.4 & 84.6 & 87.3 & 77.7 & 83.1 \\
\hline $\begin{array}{l}\text { I make a conscious effort to coordinate the content of my courses } \\
\text { with that of other teachers }\end{array}$ & 85.0 & 88.0 & 79.8 & 82.9 & 85.2 & 86.6 & 78.5 & 86.1 \\
\hline $\begin{array}{l}\text { Routine duties and paperwork interfere with my job of teaching } \\
\text { I have to follow rules in this school that conflict with my best }\end{array}$ & 70.8 & 70.9 & 71.4 & 65.7 & 40.1 & 40.5 & 45.2 & 36.2 \\
\hline 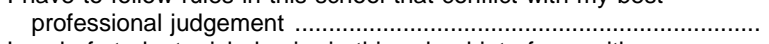 & 24.2 & 22.0 & 27.4 & 26.4 & 15.0 & 15.1 & 19.1 & 13.0 \\
\hline $\begin{array}{l}\text { Level of student misbehavior in this school interferes with my } \\
\text { teaching }\end{array}$ & 44.1 & 42.9 & 45.5 & 43.9 & 22.4 & 22.7 & 20.2 & 25.1 \\
\hline $\begin{array}{l}\text { Amount of student tardiness and class cutting in this school } \\
\text { interferes with my teaching }\end{array}$ & 27.9 & 18.4 & 45.3 & 24.6 & 8.6 & 6.4 & 13.4 & 9.2 \\
\hline $\begin{array}{l}\text { Rules for student behavior are consistently enforced by teachers in } \\
\text { this school, even for students who are not in their classes .................. }\end{array}$ & 61.8 & 70.9 & 45.8 & 59.5 & 77.6 & 83.1 & 63.6 & 77.0 \\
\hline I am satisfied with my class sizes & 64.9 & 62.9 & 68.2 & 78.1 & 84.4 & 82.2 & 84.0 & 89.3 \\
\hline $\begin{array}{l}\text { I am satisfied with my teaching salary } \\
\text { I sometimes feel it is a waste of time to try to do my best as a }\end{array}$ & 44.9 & 44.1 & 47.2 & 43.1 & 41.6 & 35.5 & 43.6 & 49.5 \\
\hline 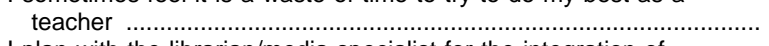 & 26.8 & 23.4 & 32.6 & 30.8 & 13.4 & 12.1 & 16.5 & 13.7 \\
\hline $\begin{array}{l}\text { I plan with the librarian/media specialist for the integration of } \\
\text { services into my teaching }\end{array}$ & 66.9 & 67.8 & 65.8 & 64.5 & 60.6 & 58.6 & 65.4 & 61.2 \\
\hline $\begin{array}{l}\text { Library/media materials are adequate to support my instructional } \\
\text { objectives }\end{array}$ & 65.6 & 64.9 & 67.7 & 59.9 & 61.0 & 56.4 & 67.2 & 63.4 \\
\hline 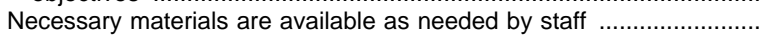 & 73.1 & 73.7 & 73.0 & 72.3 & 85.7 & 84.5 & 85.3 & 87.3 \\
\hline
\end{tabular}

SOURCE: U.S. Department of Education, National Center for Education Statistics,

"Schools and Staffing Survey, 1993-94." (This table was prepared September 1996.) 
Table 29._Public's level of confidence in various institutions: 1996 and 1998

\begin{tabular}{|c|c|c|c|c|c|c|c|c|c|c|}
\hline \multirow{3}{*}{ Institution } & \multicolumn{5}{|c|}{$\begin{array}{l}\text { Percent of respondents by levels of con- } \\
\text { fidence }\end{array}$} & \multicolumn{5}{|c|}{$\begin{array}{l}\text { Percent of respondents by levels of con- } \\
\text { fidence }\end{array}$} \\
\hline & \multicolumn{5}{|c|}{1996} & \multicolumn{5}{|c|}{1998} \\
\hline & $\begin{array}{l}\text { A great } \\
\text { deal }\end{array}$ & $\begin{array}{l}\text { Quite a } \\
\text { lot }\end{array}$ & Some & $\begin{array}{l}\text { Very } \\
\text { little }\end{array}$ & $\begin{array}{c}\text { No } \\
\text { opinion }\end{array}$ & $\begin{array}{l}\text { A great } \\
\text { deal }\end{array}$ & $\begin{array}{l}\text { Quite a } \\
\text { lot }\end{array}$ & Some & $\begin{array}{l}\text { Very } \\
\text { little }\end{array}$ & $\begin{array}{l}\text { No } \\
\text { opinion }\end{array}$ \\
\hline 1 & 2 & 3 & 4 & 5 & 6 & 7 & 8 & 9 & 10 & 11 \\
\hline Private higher education ... & 18.3 & 38.7 & 28.3 & 7.5 & 7.1 & - & - & - & - & - \\
\hline Small businesses ................ & 15.3 & 40.8 & 32.6 & 7.6 & 3.6 & 25.0 & 31.0 & 34.0 & 9.0 & 1.0 \\
\hline Religious organizations & 23.6 & 31.1 & 31.3 & 12.3 & 1.7 & 34.0 & 25.0 & 26.0 & 12.0 & 2.0 \\
\hline$\ldots$ & 16.9 & 37.0 & 31.0 & 12.1 & 3.1 & 33.0 & 31.0 & 25.0 & 8.0 & 2.0 \\
\hline Public higher education & 15.0 & 36.4 & 34.2 & 11.6 & 2.8 & - & - & - & - & - \\
\hline 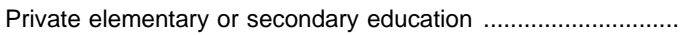 & 15.1 & 35.3 & 33.4 & 9.7 & 6.5 & - & - & - & - & - \\
\hline Youth development and recreation & 14.8 & 35.2 & 32.7 & 11.6 & 5.7 & - & - & - & - & - \\
\hline 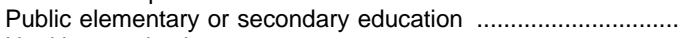 & 13.3 & 31.7 & 37.2 & 15.3 & 2.4 & 16.0 & 21.0 & 40.0 & 20.0 & 1.0 \\
\hline Health organizations & 10.8 & 28.2 & 42.0 & 15.9 & 3.1 & - & - & - & - & 一 \\
\hline Federated charitable appeals, e.g., United Way ........................ & 12.6 & 26.3 & 34.9 & 21.6 & 4.5 & - & - & - & - & 一 \\
\hline 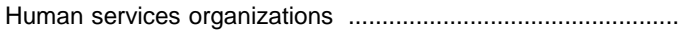 & 9.1 & 28.1 & 42.6 & 15.1 & 5.0 & - & - & - & - & - \\
\hline Arts, culture, and humanities organizations & 9.3 & 26.7 & 39.8 & 14.3 & 9.9 & - & - & - & - & - \\
\hline Recreation for adults & 7.8 & 27.5 & 41.9 & 13.4 & 9.4 & - & - & - & - & - \\
\hline Environmental organizations $\ldots \ldots \ldots \ldots \ldots \ldots \ldots$ & 9.4 & 23.1 & 41.0 & 20.3 & 6.2 & - & - & - & - & 一 \\
\hline Private and community foundations & 7.6 & 24.0 & 42.3 & 13.5 & 12.6 & - & - & - & - & - \\
\hline Local government & 5.4 & 25.9 & 43.3 & 23.1 & 2.3 & - & - & - & - & - \\
\hline $\begin{array}{l}\text { Public/society benefit, e.g., civil rights, social justice, } \\
\text { community improvement organizations }\end{array}$ & 7.5 & 22.7 & 43.4 & 20.8 & 5.6 & - & - & - & - & - \\
\hline Media, e.g., newspapers, TV, radio ...................................... & 6.3 & 22.7 & 39.5 & 29.7 & 1.8 & - & - & - & - & - \\
\hline 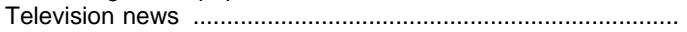 & - & - & - & - & - & 15.0 & 19.0 & 40.0 & 24.0 & 1.0 \\
\hline Work-related organizations & 6.1 & 21.5 & 47.2 & 17.4 & 7.9 & - & - & - & - & - \\
\hline State government $\ldots \ldots \ldots \ldots \ldots \ldots . . . .$. & 4.1 & 22.2 & 44.9 & 26.4 & 2.5 & - & - & - & - & 一 \\
\hline $\begin{array}{l}\text { International/foreign, e.g., culture exchange, relief organiza- } \\
\text { tions }\end{array}$ & 6.3 & 19.1 & 37.5 & 24.2 & 12.8 & - & - & - & - & - \\
\hline Organized labor .......... & 6.6 & 17.7 & 40.9 & 29.3 & 5.6 & 11.0 & 15.0 & 45.0 & 22.0 & 5.0 \\
\hline Major corporations ....... & 4.9 & 18.7 & 44.2 & 27.4 & 4.8 & - & - & - & - & - \\
\hline Federal government & 5.2 & 17.5 & 43.9 & 31.1 & 2.2 & - & - & - & - & - \\
\hline Organizations that advocate a particular cause ................... & 4.0 & 15.7 & 42.7 & 29.5 & 8.1 & - & - & - & - & - \\
\hline Congress & 3.4 & 12.4 & 41.7 & 39.0 & 3.5 & 10.0 & 18.0 & 48.0 & 20.0 & 2.0 \\
\hline Political organizations, e.g., Republican or Democratic parties & 3.8 & 10.8 & 39.2 & 42.6 & 3.7 & - & - & - & - & - \\
\hline
\end{tabular}

Data not available.

NOTE.-Institutions are listed in rank order as determined by the combined responses of "a great deal" and "quite a lot" of confidence for 1996.
SOURCE: Independent Sector, The Gallup Organization, Giving and Volunteering in the United States, 1996 and 1998. (This table was prepared September 1998.)

Table 30.-Percentage of households contributing to education and other charitable organizations and average annual donation, by type of charity: 1989, 1991, 1993, and 1995

\begin{tabular}{|c|c|c|c|c|c|c|c|c|c|c|c|c|}
\hline \multirow{3}{*}{ Type of charity } & \multicolumn{3}{|c|}{1989} & \multicolumn{3}{|c|}{1991} & \multicolumn{3}{|c|}{1993} & \multicolumn{3}{|c|}{1995} \\
\hline & \multirow{2}{*}{$\begin{array}{c}\text { Percent- } \\
\text { age of } \\
\text { total } \\
\text { house- } \\
\text { holds }^{1}\end{array}$} & \multicolumn{2}{|c|}{$\begin{array}{c}\text { Average } \\
\text { annual } \\
\text { contribution }\end{array}$} & \multirow{2}{*}{$\begin{array}{c}\text { Percent- } \\
\text { age of } \\
\text { total } \\
\text { house- } \\
\text { holds }^{1}\end{array}$} & \multicolumn{2}{|c|}{$\begin{array}{l}\text { Average } \\
\text { annual } \\
\text { contribution }\end{array}$} & \multirow{2}{*}{$\begin{array}{c}\text { Percent- } \\
\text { age of } \\
\text { total } \\
\text { house- } \\
\text { holds }^{1}\end{array}$} & \multicolumn{2}{|c|}{$\begin{array}{l}\text { Average } \\
\text { annual } \\
\text { contribution }\end{array}$} & \multirow{2}{*}{$\begin{array}{c}\text { Percent- } \\
\text { age of } \\
\text { total } \\
\text { house- } \\
\text { holds }{ }^{1}\end{array}$} & \multicolumn{2}{|c|}{$\begin{array}{l}\text { Average } \\
\text { annual } \\
\text { contribution }\end{array}$} \\
\hline & & $\begin{array}{c}\text { Per con- } \\
\text { tributing } \\
\text { house- } \\
\text { hold }\end{array}$ & $\begin{array}{l}\text { Per total } \\
\text { house- } \\
\text { hold }\end{array}$ & & $\begin{array}{c}\text { Per con- } \\
\text { tributing } \\
\text { house- } \\
\text { hold }\end{array}$ & $\begin{array}{c}\text { Per total } \\
\text { house- } \\
\text { hold }\end{array}$ & & $\begin{array}{l}\text { Per con- } \\
\text { tributing } \\
\text { house- } \\
\text { hold }\end{array}$ & $\begin{array}{c}\text { Per total } \\
\text { house- } \\
\text { hold }\end{array}$ & & $\begin{array}{l}\text { Per con- } \\
\text { tributing } \\
\text { house- } \\
\text { hold }\end{array}$ & $\begin{array}{l}\text { Per total } \\
\text { house- } \\
\text { hold }\end{array}$ \\
\hline 1 & 2 & 3 & 4 & 5 & 6 & 7 & 8 & 9 & 10 & 11 & 12 & 13 \\
\hline Total & 75.1 & $\$ 978$ & $\$ 734$ & 72.2 & $\$ 899$ & $\$ 649$ & 73.4 & $\$ 880$ & $\$ 646$ & 68.5 & $\$ 1,017$ & $\$ 696$ \\
\hline 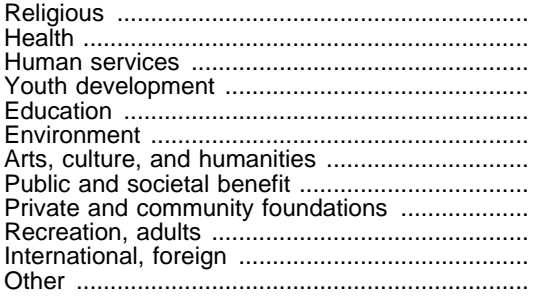 & \begin{tabular}{r|}
53.2 \\
32.4 \\
23.0 \\
21.6 \\
19.1 \\
13.4 \\
9.6 \\
11.2 \\
6.4 \\
6.2 \\
4.2 \\
3.0
\end{tabular} & $\begin{array}{r}896 \\
143 \\
263 \\
129 \\
291 \\
88 \\
193 \\
120 \\
116 \\
135 \\
202 \\
195\end{array}$ & $\begin{array}{r}477 \\
46 \\
60 \\
28 \\
56 \\
12 \\
19 \\
13 \\
7 \\
8 \\
8 \\
6\end{array}$ & \begin{tabular}{r|}
51.3 \\
32.9 \\
27.5 \\
22.1 \\
21.1 \\
16.3 \\
9.4 \\
11.2 \\
6.0 \\
6.3 \\
3.5 \\
2.8
\end{tabular} & $\begin{array}{r}800 \\
154 \\
260 \\
114 \\
225 \\
99 \\
194 \\
132 \\
113 \\
164 \\
198 \\
233\end{array}$ & $\begin{array}{r}410 \\
51 \\
71 \\
25 \\
47 \\
16 \\
18 \\
15 \\
7 \\
10 \\
7 \\
7\end{array}$ & $\begin{array}{r}49.2 \\
25.7 \\
26.7 \\
17.9 \\
17.5 \\
11.6 \\
8.1 \\
11.2 \\
5.3 \\
4.6 \\
2.8 \\
4.7\end{array}$ & $\begin{array}{r}817 \\
139 \\
208 \\
106 \\
424 \\
89 \\
139 \\
160 \\
144 \\
193 \\
(2) \\
81\end{array}$ & $\begin{array}{r}402 \\
36 \\
56 \\
19 \\
74 \\
10 \\
11 \\
18 \\
8 \\
9 \\
(2) \\
4\end{array}$ & $\begin{array}{r}48.0 \\
27.3 \\
25.1 \\
20.9 \\
20.3 \\
11.5 \\
9.4 \\
10.3 \\
6.1 \\
7.0 \\
6.1 \\
2.1\end{array}$ & $\begin{array}{l}868 \\
214 \\
271 \\
137 \\
318 \\
106 \\
216 \\
122 \\
181 \\
161 \\
283 \\
160\end{array}$ & $\begin{array}{r}417 \\
58 \\
68 \\
29 \\
65 \\
12 \\
20 \\
13 \\
11 \\
11 \\
17 \\
3\end{array}$ \\
\hline
\end{tabular}

1 Percents do not add to total because of respondents giving to more than one type of charity.

2 Sample size too small for reliable data.

NOTE.-Details for total households do not add to total because details only include households which reported a donation amount for the particular type of charity. The per- centage of total includes households who reported giving donations, but did not specify amount.

SOURCE: Independent Sector, The Gallup Organization, Giving and Volunteering in the United States, 1989, 1991, 1993, and 1996. (This table was prepared April 1997.) 
Table 31.-Total expenditures of educational institutions related to the gross domestic product, by level of institution: $1959-60$ to $1997-98$

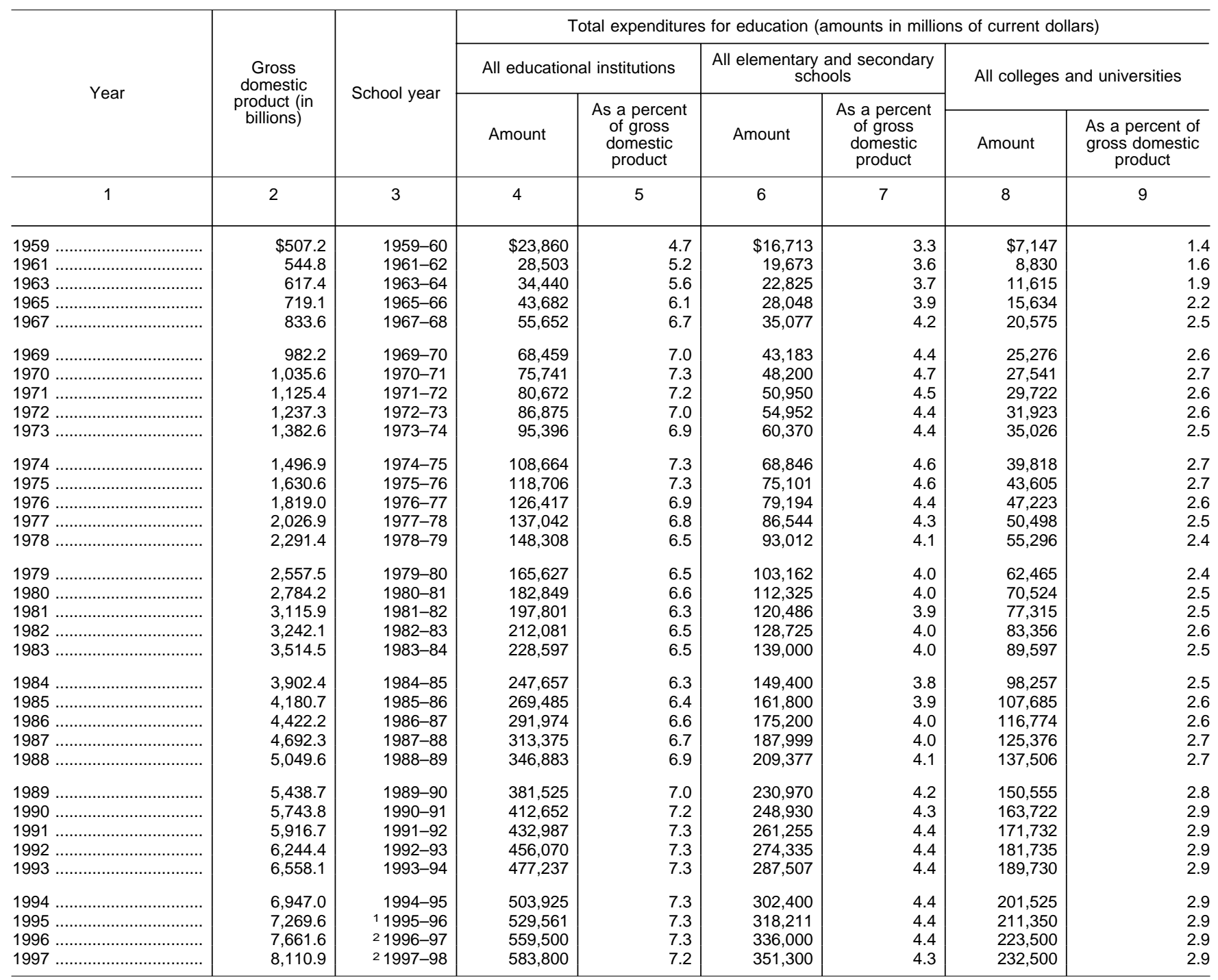

1 Preliminary

2 Estimated.

NOTE.-Total expenditures for public elementary and secondary schools include current expenditures, interest on school debt, and capital outlay. Data for private elementary and secondary schools are estimated. Total expenditures for colleges and universities include current-fund expenditures and additions to plant value. Excludes expenditures of noncollegiate postsecondary institutions. Data for 1995-96 through 1997-98 are for 4 year and 2-year degree-granting institutions that were eligible to participate in Title IV federal financial aid programs. Some data revised from previously published figures. Because of rounding, details may not add to totals.
SOURCE: U.S. Department of Education, National Center for Education Statistics, Statistics of State School Systems; Revenues and Expenditures for Public Elementary and Secondary Education; Financial Statistics of Institutions of Higher Education; Common Core of Data survey; Higher Education General Information Survey (HEGIS), "Financial Statistics of Institutions of Higher Education" survey, Integrated Postsecondary Education Data System (IPEDS) "Finance" survey, and unpublished data; Council of nomic Advisers, Economic Indicators; and National Education Association, Estimates of School Statistics, various years. (This table was prepared November 1998.) 
Table 32.-Total expenditures of educational institutions, by level and control of institution: $1899-1900$ to $1997-98$

[In millions of current dollars]

\begin{tabular}{|c|c|c|c|c|c|c|c|}
\hline \multirow{2}{*}{ School year } & \multirow{2}{*}{ Total } & \multicolumn{3}{|c|}{ Elementary and secondary schools } & \multicolumn{3}{|c|}{ Colleges and universities } \\
\hline & & Total & Public & Private 1 & Total & Public & Private \\
\hline 1 & 2 & 3 & 4 & 5 & 6 & 7 & 8 \\
\hline $\begin{array}{l}1899-1900 \\
1909-10 \\
1919-20 \\
1929-30 \\
1939-40\end{array}$ & $\begin{array}{l}- \\
\overline{-} \\
-\end{array}$ & $\begin{array}{l}- \\
- \\
- \\
-\end{array}$ & $\begin{array}{r}\$ 215 \\
426 \\
1,036 \\
2,317 \\
2,344\end{array}$ & $\begin{array}{l}- \\
- \\
- \\
-\end{array}$ & $\begin{array}{r}- \\
\overline{-} \\
\$ 632 \\
758\end{array}$ & $\begin{array}{r}- \\
\overline{-} \\
392 \\
392\end{array}$ & $\begin{array}{r}- \\
\overline{-} \\
\$ 341 \\
367\end{array}$ \\
\hline $\begin{array}{l}1949-50 \\
1951-52 \\
1953-54 \\
1955-56 \\
1957-58\end{array}$ & $\begin{array}{l}\$ 8,911 \\
10,735 \\
13,147 \\
15,907 \\
20,055\end{array}$ & $\begin{array}{r}\$ 6,249 \\
7,861 \\
9,733 \\
11,727 \\
14,525\end{array}$ & $\begin{array}{r}5,838 \\
7,344 \\
9,092 \\
10,955 \\
13,569\end{array}$ & $\begin{array}{r}\$ 411 \\
517 \\
641 \\
772 \\
956\end{array}$ & $\begin{array}{l}2,662 \\
2,874 \\
3,414 \\
4,180 \\
5,530\end{array}$ & $\begin{array}{l}1,430 \\
1,565 \\
1,912 \\
2,348 \\
3,237\end{array}$ & $\begin{array}{l}1,233 \\
1,309 \\
1,502 \\
1,832 \\
2,293\end{array}$ \\
\hline $\begin{array}{l}1959-60 \\
1961-62 \\
1963-64 \\
1965-66 \\
1967-68\end{array}$ & $\begin{array}{l}23,860 \\
28,503 \\
34,440 \\
43,682 \\
55,652\end{array}$ & $\begin{array}{l}16,713 \\
19,673 \\
22,825 \\
28,048 \\
35,077\end{array}$ & $\begin{array}{l}15,613 \\
18,373 \\
21,325 \\
26,248 \\
32,977\end{array}$ & $\begin{array}{l}1,100 \\
1,300 \\
1,500 \\
1,800 \\
2,100\end{array}$ & $\begin{array}{r}7,147 \\
8,830 \\
11,615 \\
15,634 \\
20,575\end{array}$ & $\begin{array}{r}3,904 \\
4,919 \\
6,558 \\
9,047 \\
12,750\end{array}$ & $\begin{array}{l}3,244 \\
3,911 \\
5,057 \\
6,588 \\
7,824\end{array}$ \\
\hline 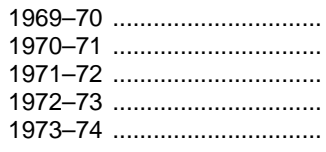 & $\begin{array}{l}68,459 \\
75,741 \\
80,672 \\
86,875 \\
95,396\end{array}$ & $\begin{array}{l}43,183 \\
48,200 \\
50,950 \\
54,952 \\
60,370\end{array}$ & $\begin{array}{l}40,683 \\
45,500 \\
48,050 \\
51,852 \\
56,970\end{array}$ & $\begin{array}{l}2,500 \\
2,700 \\
2,900 \\
3,100 \\
3,400\end{array}$ & $\begin{array}{l}25,276 \\
27,541 \\
29,722 \\
31,923 \\
35,026\end{array}$ & $\begin{array}{l}16,234 \\
18,028 \\
19,538 \\
21,144 \\
23,542\end{array}$ & $\begin{array}{r}9,041 \\
9,513 \\
10,184 \\
10,779 \\
11,484\end{array}$ \\
\hline $\begin{array}{l}1974-75 \\
1975-76 \\
1976-77 \\
1977-78 \\
1978-79\end{array}$ & $\begin{array}{l}108,664 \\
118,706 \\
126,417 \\
137,042 \\
148,308\end{array}$ & $\begin{array}{l}68,846 \\
75,101 \\
79,194 \\
86,544 \\
93,012\end{array}$ & $\begin{array}{l}64,846 \\
70,601 \\
74,194 \\
80,844 \\
86,712\end{array}$ & $\begin{array}{l}4,000 \\
4,500 \\
5,000 \\
5,700 \\
6,300\end{array}$ & $\begin{array}{l}39,818 \\
43,605 \\
47,223 \\
50,498 \\
55,296\end{array}$ & $\begin{array}{l}26,966 \\
29,736 \\
31,997 \\
34,031 \\
37,110\end{array}$ & $\begin{array}{l}12,852 \\
13,869 \\
15,226 \\
16,467 \\
18,187\end{array}$ \\
\hline $\begin{array}{l}1979-80 \\
1980-81 \\
1981-82 \\
1982-83 \\
1983-84\end{array}$ & $\begin{array}{l}165,627 \\
182,849 \\
197,801 \\
212,081 \\
228,597\end{array}$ & $\begin{array}{l}103,162 \\
112,325 \\
120,486 \\
128,725 \\
139,000\end{array}$ & $\begin{array}{r}95,962 \\
104,125 \\
111,186 \\
118,425 \\
127,500\end{array}$ & $\begin{array}{r}7,200 \\
8,200 \\
9,300 \\
10,300 \\
11,500\end{array}$ & $\begin{array}{l}62,465 \\
70,524 \\
77,315 \\
83,356 \\
89,597\end{array}$ & $\begin{array}{l}41,434 \\
46,559 \\
50,813 \\
54,338 \\
58,124\end{array}$ & $\begin{array}{l}21,031 \\
23,965 \\
26,502 \\
29,018 \\
31,473\end{array}$ \\
\hline $\begin{array}{l}1984-85 \text {. } \\
1985-86 \\
1986-87 \\
1987-88 \text {. } \\
1988-89\end{array}$ & $\begin{array}{l}247,657 \\
269,485 \\
291,974 \\
313,375 \\
346,883\end{array}$ & $\begin{array}{l}149,400 \\
161,800 \\
175,200 \\
187,999 \\
209,377\end{array}$ & $\begin{array}{l}137,000 \\
148,600 \\
160,900 \\
172,699 \\
192,977\end{array}$ & $\begin{array}{l}12,400 \\
13,200 \\
14,300 \\
15,300 \\
16,400\end{array}$ & $\begin{array}{r}98,257 \\
107,685 \\
116,774 \\
125,376 \\
137,506\end{array}$ & $\begin{array}{l}63,705 \\
70,069 \\
74,552 \\
79,859 \\
87,107\end{array}$ & $\begin{array}{l}34,553 \\
37,616 \\
42,222 \\
45,516 \\
50,398\end{array}$ \\
\hline $\begin{array}{l}1989-90 \\
1990-91 \\
1991-92\end{array}$ & $\begin{array}{l}381,525 \\
412,652 \\
432,987 \\
456,070 \\
477,237 \\
503,925\end{array}$ & $\begin{array}{l}230,970 \\
248,930 \\
261,255 \\
274,335 \\
287,507 \\
302,400\end{array}$ & $\begin{array}{l}212,770 \\
229,430 \\
241,055 \\
252,935 \\
265,307 \\
279,000\end{array}$ & $\begin{array}{l}18,200 \\
19,500 \\
20,200 \\
21,400 \\
22,200 \\
23,400\end{array}$ & $\begin{array}{l}150,555 \\
163,722 \\
171,732 \\
181,735 \\
189,730 \\
201,525\end{array}$ & $\begin{array}{r}96,387 \\
104,433 \\
108,667 \\
115,169 \\
119,573 \\
127,594\end{array}$ & $\begin{array}{l}54,169 \\
59,288 \\
63,065 \\
66,566 \\
70,157 \\
73,930\end{array}$ \\
\hline $\begin{array}{l}1995-96^{2} \\
1996-971 \\
1997-98^{1}\end{array}$ & $\begin{array}{l}529,561 \\
559,500 \\
583,800\end{array}$ & $\begin{array}{l}318,211 \\
336,000 \\
351,300\end{array}$ & $\begin{array}{l}293,611 \\
310,200 \\
324,300\end{array}$ & $\begin{array}{l}24,600 \\
25,800 \\
27,000\end{array}$ & $\begin{array}{l}211,350 \\
223,500 \\
232,500\end{array}$ & $\begin{array}{l}132,752 \\
140,000 \\
145,500\end{array}$ & $\begin{array}{l}78,597 \\
83,500 \\
87,000\end{array}$ \\
\hline
\end{tabular}

${ }^{1}$ Estimated.

2 Preliminary.

-Data not available.

NOTE.-Total expenditures for public elementary and secondary schools include current expenditures, interest on school debt, and capital outlay. Data for private elementary and secondary schools are estimated. Total expenditures for colleges and universities include current-fund expenditures and additions to plant value. Excludes expenditures of noncollegiate postsecondary institutions. Higher education data for 1995-96 through 1997-98 are for 4-year and 2-year degree-granting institutions that were eligible to par- ticipate in Title IV federal financial aid programs. Some data have been revised from published figures. Because of rounding, details may not add to totals.

SOURCE: U.S. Department of Education, National Center for Education Statistics, Statistics of State School Systems; Revenues and Expenditures for Public Elementary and Secondary Education; Higher Education General Information Survey (HEGIS), "Financial Statistics of Institutions of Higher Education" survey; Common Core of Data survey; "Financial Statistics of Institutions of Higher Education" survey; Integrated Postsecondary Education Data System (IPEDS) "Finance" survey; and National Education Association, Estimates of School Statistics, various years. (This table was prepared November 1998.) 
Table 33.-Estimated total expenditures of educational institutions, by level, control of institution, and source of funds: $1979-80$ to $1995-96$

[In billions of current dollars]

\begin{tabular}{|c|c|c|c|c|c|c|c|c|c|c|c|c|}
\hline \multirow{2}{*}{$\begin{array}{l}\text { Level and control of institution and source of } \\
\text { funds }\end{array}$} & \multicolumn{2}{|c|}{$1979-80$} & \multicolumn{2}{|c|}{$1984-85$} & \multicolumn{2}{|c|}{ 1989-90 } & \multicolumn{2}{|c|}{$1990-91$} & \multicolumn{2}{|c|}{$1994-95^{1}$} & \multicolumn{2}{|c|}{$1995-96^{2}$} \\
\hline & Amount & Percent & Amount & Percent & Amount & Percent & Amount & Percent & Amount & Percent & Amount & Percent \\
\hline 1 & 2 & 3 & 4 & 5 & 6 & 7 & 8 & 9 & 10 & 11 & 12 & 13 \\
\hline $\begin{array}{r}\text { All levels } \\
\text { Total public and private }\end{array}$ & $\$ 165.6$ & 100.0 & $\$ 247.7$ & 100.0 & $\$ 381.5$ & 100.0 & $\$ 412.7$ & 100.0 & $\$ 503.9$ & 100.0 & $\$ 529.6$ & 100.0 \\
\hline 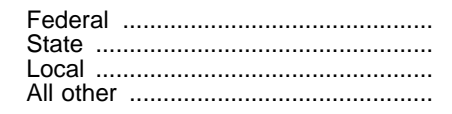 & $\begin{array}{l}18.9 \\
64.3 \\
43.3 \\
39.1\end{array}$ & $\begin{array}{l}11.4 \\
38.8 \\
26.1 \\
23.6\end{array}$ & $\begin{array}{l}21.3 \\
96.1 \\
63.3 \\
66.9\end{array}$ & $\begin{array}{r}8.6 \\
38.8 \\
25.6 \\
27.0\end{array}$ & $\begin{array}{r}31.6 \\
142.2 \\
97.9 \\
109.8\end{array}$ & $\begin{array}{l}8.3 \\
37.3 \\
25.7 \\
28.8\end{array}$ & $\begin{array}{r}34.1 \\
151.6 \\
105.5 \\
121.5\end{array}$ & $\begin{array}{r}8.3 \\
36.7 \\
25.6 \\
29.4\end{array}$ & $\begin{array}{r}43.7 \\
177.9 \\
127.6 \\
154.7\end{array}$ & $\begin{array}{r}8.7 \\
35.3 \\
25.3 \\
30.7\end{array}$ & $\begin{array}{r}45.0 \\
188.6 \\
132.9 \\
163.1\end{array}$ & $\begin{array}{r}8.5 \\
35.6 \\
25.1 \\
30.8\end{array}$ \\
\hline Total public & 137.4 & 100.0 & 200.7 & 100.0 & 309.2 & 100.0 & 333.9 & 100.0 & 406.6 & 100.0 & 426.4 & 100.0 \\
\hline 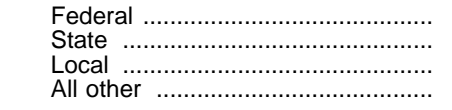 & $\begin{array}{l}14.8 \\
63.9 \\
43.1 \\
15.6\end{array}$ & $\begin{array}{l}10.8 \\
46.5 \\
31.4 \\
11.3\end{array}$ & $\begin{array}{l}15.8 \\
95.5 \\
63.1 \\
26.3\end{array}$ & $\begin{array}{l}7.9 \\
47.6 \\
31.4 \\
13.1\end{array}$ & $\begin{array}{r}23.0 \\
140.8 \\
97.5 \\
47.9\end{array}$ & $\begin{array}{r}7.4 \\
45.5 \\
31.6 \\
15.5\end{array}$ & $\begin{array}{r}24.9 \\
150.3 \\
105.0 \\
53.7\end{array}$ & $\begin{array}{r}7.5 \\
45.0 \\
31.5 \\
16.1\end{array}$ & $\begin{array}{r}33.1 \\
176.3 \\
127.2 \\
70.0\end{array}$ & $\begin{array}{r}8.1 \\
43.4 \\
31.3 \\
17.2\end{array}$ & $\begin{array}{r}34.2 \\
187.0 \\
132.3 \\
72.8\end{array}$ & $\begin{array}{r}8.0 \\
43.9 \\
31.0 \\
17.1\end{array}$ \\
\hline Total private & 28.2 & 100.0 & 47.0 & 100.0 & 72.4 & 100.0 & 78.8 & 100.0 & 97.3 & 100.0 & 103.2 & 100.0 \\
\hline 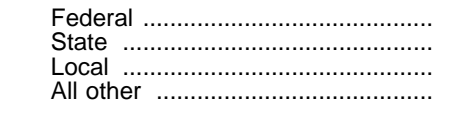 & $\begin{array}{r}4.1 \\
0.4 \\
0.2 \\
23.5\end{array}$ & $\begin{array}{r}14.5 \\
1.6 \\
0.6 \\
83.4\end{array}$ & $\begin{array}{r}5.5 \\
0.7 \\
0.2 \\
40.6\end{array}$ & $\begin{array}{r}11.7 \\
1.4 \\
0.5 \\
86.4\end{array}$ & $\begin{array}{r}8.6 \\
1.4 \\
0.4 \\
62.0\end{array}$ & $\begin{array}{r}11.9 \\
1.9 \\
0.6 \\
85.6\end{array}$ & $\begin{array}{r}9.2 \\
1.3 \\
0.4 \\
67.9\end{array}$ & $\begin{array}{r}11.6 \\
1.7 \\
0.5 \\
86.1\end{array}$ & $\begin{array}{r}10.6 \\
1.6 \\
0.4 \\
84.7\end{array}$ & $\begin{array}{r}10.9 \\
1.6 \\
0.4 \\
87.0\end{array}$ & $\begin{array}{r}10.8 \\
1.5 \\
0.6 \\
90.3\end{array}$ & $\begin{array}{r}10.5 \\
1.5 \\
0.5 \\
87.5\end{array}$ \\
\hline Elementary and secondary schools & & & & & & & & & & & & \\
\hline Total public and private $\ldots \ldots \ldots \ldots \ldots \ldots \ldots \ldots$ & 103.2 & 100.0 & 149.4 & 100.0 & 231.0 & 100.0 & 248.9 & 100.0 & 302.4 & 100.0 & 318.2 & 100.0 \\
\hline 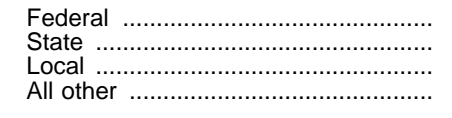 & $\begin{array}{r}9.4 \\
44.7 \\
41.6 \\
7.5\end{array}$ & $\begin{array}{r}9.1 \\
43.3 \\
40.3 \\
7.3\end{array}$ & $\begin{array}{r}9.1 \\
66.8 \\
60.8 \\
12.8 \\
\end{array}$ & $\begin{array}{r}6.1 \\
44.7 \\
40.7 \\
8.6\end{array}$ & $\begin{array}{r}13.0 \\
100.6 \\
94.0 \\
23.3 \\
\end{array}$ & $\begin{array}{r}5.6 \\
43.6 \\
40.7 \\
10.1 \\
\end{array}$ & $\begin{array}{r}14.2 \\
108.2 \\
101.2 \\
25.4 \\
\end{array}$ & $\begin{array}{r}5.7 \\
43.5 \\
40.6 \\
10.2 \\
\end{array}$ & $\begin{array}{r}19.0 \\
130.5 \\
122.1 \\
30.9 \\
\end{array}$ & $\begin{array}{r}6.3 \\
43.1 \\
40.4 \\
10.2 \\
\end{array}$ & $\begin{array}{r}19.5 \\
139.5 \\
126.9 \\
32.4 \\
\end{array}$ & $\begin{array}{r}6.1 \\
43.8 \\
39.9 \\
10.2 \\
\end{array}$ \\
\hline 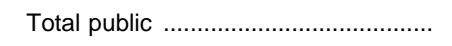 & 96.0 & 100.0 & 137.0 & 100.0 & 212.8 & 100.0 & 229.4 & 100.0 & 279.0 & 100.0 & 293.6 & 100.0 \\
\hline 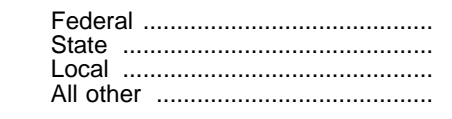 & $\begin{array}{r}9.4 \\
44.7 \\
41.6 \\
0.3\end{array}$ & $\begin{array}{r}9.8 \\
46.6 \\
43.3 \\
0.3\end{array}$ & $\begin{array}{r}9.1 \\
66.8 \\
60.8 \\
0.4\end{array}$ & $\begin{array}{r}6.6 \\
48.7 \\
44.3 \\
0.3\end{array}$ & $\begin{array}{r}13.0 \\
100.6 \\
94.0 \\
35.1\end{array}$ & $\begin{array}{r}6.1 \\
47.3 \\
44.2 \\
32.4 \\
\end{array}$ & $\begin{array}{r}14.2 \\
108.2 \\
101.2 \\
35.9 \\
\end{array}$ & $\begin{array}{r}6.2 \\
47.2 \\
44.1 \\
32.6 \\
\end{array}$ & $\begin{array}{r}19.0 \\
130.5 \\
122.1 \\
37.5\end{array}$ & $\begin{array}{r}6.8 \\
46.8 \\
43.8 \\
32.7\end{array}$ & $\begin{array}{r}19.5 \\
139.5 \\
126.9 \\
37.8\end{array}$ & $\begin{array}{r}6.6 \\
47.5 \\
43.2 \\
32.6\end{array}$ \\
\hline Total private ${ }^{4}$ & 7.2 & 100.0 & 12.4 & 100.0 & 18.2 & 100.0 & 19.5 & 100.0 & 23.4 & 100.0 & 24.6 & 100.0 \\
\hline 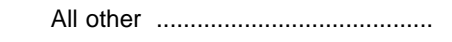 & 7.2 & 100.0 & 12.4 & 100.0 & 18.2 & 100.0 & 19.5 & 100.0 & 23.4 & 100.0 & 24.6 & 100.0 \\
\hline $\begin{array}{l}\text { Institutions of higher education } \\
\text { Total public and private }\end{array}$ & 62.5 & 100.0 & 98.3 & 100.0 & 150.6 & 100.0 & 163.7 & 100.0 & 201.5 & 100.0 & 211.3 & 100.0 \\
\hline 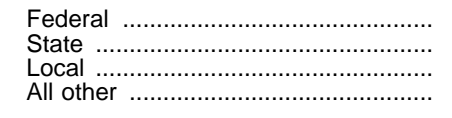 & $\begin{array}{r}9.5 \\
19.6 \\
1.7 \\
31.6\end{array}$ & $\begin{array}{r}15.2 \\
31.4 \\
2.7 \\
50.6\end{array}$ & $\begin{array}{r}12.2 \\
29.4 \\
2.5 \\
54.1\end{array}$ & $\begin{array}{r}12.4 \\
29.9 \\
2.6 \\
55.1\end{array}$ & $\begin{array}{r}18.6 \\
41.6 \\
3.9 \\
86.5 \\
\end{array}$ & $\begin{array}{r}12.3 \\
27.6 \\
2.6 \\
57.4 \\
\end{array}$ & $\begin{array}{r}19.9 \\
43.4 \\
4.3 \\
96.1 \\
\end{array}$ & $\begin{array}{r}12.2 \\
26.5 \\
2.6 \\
58.7\end{array}$ & $\begin{array}{r}24.8 \\
47.4 \\
5.5 \\
123.8 \\
\end{array}$ & $\begin{array}{r}12.3 \\
23.5 \\
2.7 \\
61.5 \\
\end{array}$ & $\begin{array}{r}25.5 \\
49.1 \\
6.0 \\
130.7\end{array}$ & $\begin{array}{r}12.1 \\
23.2 \\
2.8 \\
61.8 \\
\end{array}$ \\
\hline Total public ......... & 41.4 & 100.0 & 63.7 & 100.0 & 96.4 & 100.0 & 104.4 & 100.0 & 127.6 & 100.0 & 132.8 & 100.0 \\
\hline 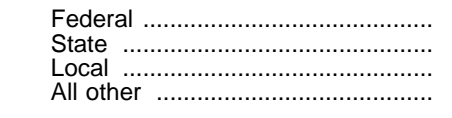 & $\begin{array}{r}5.4 \\
19.2 \\
1.5 \\
15.3 \\
\end{array}$ & $\begin{array}{r}13.1 \\
46.3 \\
3.7 \\
36.9 \\
\end{array}$ & $\begin{array}{r}6.7 \\
28.7 \\
2.3 \\
25.9 \\
\end{array}$ & $\begin{array}{r}10.6 \\
45.1 \\
3.6 \\
40.7\end{array}$ & $\begin{array}{r}9.9 \\
40.2 \\
3.5 \\
42.7 \\
\end{array}$ & $\begin{array}{r}10.3 \\
41.7 \\
3.7 \\
44.3 \\
\end{array}$ & $\begin{array}{r}10.7 \\
42.1 \\
3.9 \\
47.7 \\
\end{array}$ & $\begin{array}{r}10.3 \\
40.3 \\
3.7 \\
45.7\end{array}$ & $\begin{array}{r}14.1 \\
45.8 \\
5.1 \\
62.6 \\
\end{array}$ & $\begin{array}{r}11.1 \\
35.9 \\
4.0 \\
49.0\end{array}$ & $\begin{array}{r}14.7 \\
47.6 \\
5.5 \\
65.0\end{array}$ & $\begin{array}{r}11.1 \\
35.8 \\
4.1 \\
49.0\end{array}$ \\
\hline Total private & 21.0 & 100.0 & 34.6 & 100.0 & 54.2 & 100.0 & 59.3 & 100.0 & 73.9 & 100.0 & 78.6 & 100.0 \\
\hline 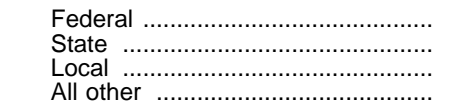 & $\begin{array}{r}4.1 \\
0.4 \\
0.2 \\
16.3\end{array}$ & $\begin{array}{r}19.4 \\
2.1 \\
0.8 \\
77.7\end{array}$ & $\begin{array}{r}5.5 \\
0.7 \\
0.2 \\
28.2\end{array}$ & $\begin{array}{r}15.9 \\
1.9 \\
0.6 \\
81.6\end{array}$ & $\begin{array}{r}8.6 \\
1.4 \\
0.4 \\
43.8\end{array}$ & $\begin{array}{r}15.9 \\
2.6 \\
0.7 \\
80.8\end{array}$ & $\begin{array}{r}9.2 \\
1.3 \\
0.4 \\
48.4\end{array}$ & $\begin{array}{r}15.4 \\
2.3 \\
0.7 \\
81.6\end{array}$ & $\begin{array}{r}10.6 \\
1.6 \\
0.4 \\
61.3\end{array}$ & $\begin{array}{r}14.4 \\
2.1 \\
0.6 \\
82.9\end{array}$ & $\begin{array}{r}10.8 \\
1.5 \\
0.6 \\
65.7\end{array}$ & $\begin{array}{r}13.8 \\
1.9 \\
0.7 \\
83.6\end{array}$ \\
\hline
\end{tabular}

1 Revised from previously published data.

2 Preliminary data.

${ }^{3}$ Revenues from individuals including fees for transportation and books and food serv ice receipts. This expenditure includes only the individual contributions for these categories and excludes contributions from public sources.

${ }^{4}$ Some private elementary and secondary school revenues come from federal, state, and local sources. However, comprehensive data are not available to delineate the sources of revenues for private schools.

NOTE.-Estimated distribution of expenditures by source of funds are obtained from distribution of revenue sources for current funds. Federally-supported student aid that goes to higher education institutions through students' tuition payments is shown under "All other" rather than "federal." Such payments would add substantial amounts and several percentage points to the federal share. Other federal programs, not included in this table because they do not support regular educational institutions, would increase the federal share even further. Typical examples of these payments would be federal support for libraries and museums. Additionally, the federal contribution to education through tax expenditures is not reflected in this table. Because of rounding, details may not add to totals.

SOURCE: U.S. Department of Education, National Center for Education Statistics, Common Core of Data; Higher Education General Information Survey (HEGIS), "Financial Statistics of Institutions of Higher Education" survey; Integrated Postsecondary Education Data System (IPEDS) "Finance" survey, unpublished data. (This table was prepared November 1998. 
Table 34.-Governmental expenditures, by level of government and function: 1970-71 to 1993-94

\begin{tabular}{|c|c|c|c|c|c|c|c|c|c|c|c|c|c|c|c|}
\hline \multirow{2}{*}{ Expenditure, by function } & \multicolumn{5}{|c|}{ All governments ${ }^{1}$} & \multicolumn{5}{|c|}{ Federal government } & \multicolumn{5}{|c|}{ State and local governments ${ }^{2}$} \\
\hline & $1970-71$ & $1980-81$ & $1990-91$ & 1992-93 & $1993-94$ & $1970-71$ & $1980-81$ & $1990-91$ & 1992-93 & 1993-94 & 1970-71 & $1980-81$ & 1990-91 & 1992-93 & 1993-94 \\
\hline \multirow[t]{2}{*}{1} & 2 & 3 & 4 & 5 & 6 & 7 & 8 & 9 & 10 & 11 & 12 & 13 & 14 & 15 & 16 \\
\hline & \multicolumn{15}{|c|}{ In millions } \\
\hline General expenditures . & $\$ 301,096$ & $\$ 827,877$ & $\$ 1,804,005$ & $\$ 1,902,366$ & $\$ 1,963,558$ & $\$ 150,422$ & $\$ 422,301$ & $\$ 1,060,407$ & $\$ 1,083,257$ & $\$ 1,107,501$ & $\$ 150,674$ & $\$ 407,449$ & $\$ 908,108$ & $\$ 1,027,488$ & $\$ 1,077,665$ \\
\hline \multicolumn{16}{|l|}{ Selected federal programs } \\
\hline National defense and internation & 80,910 & 174,564 & 366,112 & 344,008 & 333,380 & 80,910 & 174,564 & 366,112 & 344,008 & 333,380 & - & - & - & - & - \\
\hline Postal service .. & 8,683 & 20,466 & 43,102 & 44,528 & 46,110 & 8,683 & 20,466 & 43,102 & 44,528 & 46,110 & - & - & - & - & - \\
\hline Space research and technology . & 3,334 & 5,523 & 13,514 & 13,873 & 13,553 & 3,334 & 5,523 & 13,514 & 13,873 & 13,553 & & - & - & & - \\
\hline Education and libraries .............................. & 64,042 & 158,012 & 334,333 & 373,411 & 381,991 & 4,629 & 12,408 & 46,025 & 55,365 & 50,502 & 60,174 & 147,649 & 313,744 & 347,236 & 358,241 \\
\hline \multicolumn{16}{|l|}{$\begin{array}{l}\text { Education and librarles ........ } \\
\text { Social services and income } n\end{array}$} \\
\hline Hospitals and health .................. & $\begin{array}{l}20,446 \\
14,835\end{array}$ & $\begin{array}{l}74,643 \\
47,378\end{array}$ & $\begin{array}{l}16,6,811 \\
102,817\end{array}$ & $\begin{array}{l}2118,655 \\
118,969\end{array}$ & $\begin{array}{l}236,0,33 \\
125,596\end{array}$ & $\begin{array}{l}2,220 \\
3,630\end{array}$ & $\begin{array}{l}22,395 \\
11,277\end{array}$ & $\begin{array}{r}111,135 \\
28,207\end{array}$ & $\begin{array}{r}15,130 \\
32,654\end{array}$ & $\begin{array}{r}111,112 \\
34,424\end{array}$ & $\begin{array}{l}18,226 \\
11,205\end{array}$ & $\begin{array}{l}54,121 \\
36,101\end{array}$ & $\begin{array}{r}130,402 \\
81,110\end{array}$ & $\begin{array}{r}16,7,046 \\
94,651\end{array}$ & $\begin{array}{l}1 / 9,829 \\
100,429\end{array}$ \\
\hline Social insura & 2,031 & 5,075 & 8,193 & 5,920 & 6,506 & 1,086 & 2,799 & $\begin{array}{r}r \\
4,943\end{array}$ & $\begin{array}{r}5,642 \\
\end{array}$ & 5,790 & 945 & 2,276 & 3,250 & 3,945 & 4,071 \\
\hline Transportation . & 23,722 & 46,578 & 84,048 & 90,386 & 95,224 & 4,062 & 7,724 & 23,250 & 26,646 & 29,220 & 19,819 & 39,231 & 75,410 & 80,600 & 85,203 \\
\hline \multicolumn{16}{|l|}{ Public safety } \\
\hline Police protection & 5,706 & 16,851 & 38,942 & 42,778 & 45,231 & 478 & 1,904 & 6,170 & 7,356 & 7,328 & 5,228 & 14,947 & 32,772 & 36,146 & 38,645 \\
\hline $\begin{array}{l}\text { Correction .. } \\
\text {. }\end{array}$ & 1,979 & 7,806 & 29,297 & 31,768 & 34,603 & 94 & 413 & 1,941 & 2,422 & 2,587 & 1,885 & 7,393 & 27,356 & 29,614 & 32,270 \\
\hline \multicolumn{16}{|l|}{ Environment and housing } \\
\hline & 13,740 & 43,599 & 56,949 & 64,446 & 66,778 & 10,658 & 38,896 & 48,415 & 53,859 & 55,568 & 3,082 & 6,175 & 12,575 & 13,168 & 13,987 \\
\hline Housing and community development ... & 4,467 & 13,894 & 33,346 & 31,121 & 35,716 & 1,913 & 6,808 & 30,199 & 31,321 & 36,916 & 2,554 & 7,086 & 16,648 & 18,539 & 19,899 \\
\hline \multicolumn{16}{|l|}{ Governmental administration } \\
\hline & $\begin{array}{l}3,612 \\
3,567\end{array}$ & $\begin{array}{l}10,944 \\
11,514\end{array}$ & $\begin{array}{l}27,204 \\
36,977\end{array}$ & $\begin{array}{l}30,841 \\
39,450\end{array}$ & $\begin{array}{l}32,324 \\
41,609\end{array}$ & $\begin{array}{r}1,341 \\
540\end{array}$ & $\begin{array}{l}3,714 \\
1,973\end{array}$ & $\begin{array}{r}10,209 \\
5,511\end{array}$ & $\begin{array}{r}11,647 \\
6,357\end{array}$ & $\begin{array}{r}11,788 \\
6,470\end{array}$ & $\begin{array}{l}2,271 \\
4,432\end{array}$ & $\begin{array}{r}7,230 \\
12,771\end{array}$ & $\begin{array}{l}16,995 \\
31,466\end{array}$ & 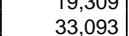 & $\begin{array}{l}2,5 / 1 \\
35,139\end{array}$ \\
\hline Interest on general debt & 21,688 & 97,641 & 247,376 & 253,878 & 257,623 & 16,599 & 80,510 & 195,142 & 198,795 & 202,663 & 5,089 & 17,131 & 52,234 & 55,083 & 54,960 \\
\hline \multirow{2}{*}{ 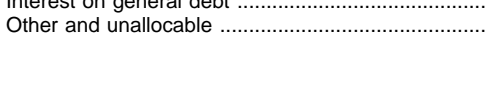 } & 28,334 & 93,389 & 214,115 & 198,332 & 211,280 & 10,245 & 30,927 & 118,532 & 91,654 & 100,090 & 15,764 & 55,338 & 114,147 & 129,057 & 134,414 \\
\hline & \multicolumn{15}{|c|}{ Percentage distribution } \\
\hline General expenditures. & 100.0 & 100.0 & 100.0 & 100.0 & 100.0 & 100.0 & 100.0 & 100.0 & 100.0 & 100.0 & 100.0 & 100.0 & 100.0 & 100.0 & 100.0 \\
\hline \multicolumn{16}{|l|}{ Selected federal progra } \\
\hline National defense and & 26.9 & 21.1 & 20.3 & 18.1 & 17.0 & 53.8 & 41.3 & 34.5 & 31.8 & 30.1 & - & - & - & - & - \\
\hline Postal s & 2.9 & 2.5 & 2.4 & 2.3 & 2.3 & 5.8 & 4.8 & 4.1 & 4.1 & 4.2 & - & - & - & - & - \\
\hline Space research and technology & 1.1 & 0.7 & 0.7 & 0.7 & 0.7 & $\begin{array}{l}2.0 \\
2.2\end{array}$ & 1.3 & $\begin{array}{l}4.1 \\
1.3\end{array}$ & 1.3 & $\begin{array}{l}4.2 \\
1.2\end{array}$ & - & - & - & - & - \\
\hline Education and I & 21.3 & 19.1 & 18.5 & 19.6 & 19.5 & 3.1 & 2.9 & 4.3 & 5.1 & 4.6 & 39.9 & 36.2 & 34.5 & 33.9 & 33.4 \\
\hline \multicolumn{16}{|l|}{$\begin{array}{l}\text { Education and libraries ......................... } \\
\text { Social services and income maintenance. }\end{array}$} \\
\hline Public & 6.8 & 9.0 & 9.3 & 11.5 & 12.0 & 1.5 & 5.3 & 11.2 & 14.5 & 15.5 & 12.1 & 13.3 & 14.4 & 16.3 & 16.7 \\
\hline allut & 4.9 & 5.7 & 5.7 & 6.3 & 6.4 & 2.4 & 2.7 & 2.7 & 3.0 & 3.1 & 7.4 & 8.9 & 8.9 & 9.2 & 9.4 \\
\hline dministration ...... & 0.7 & 0.6 & 0.5 & 0.3 & 0.3 & 0.7 & 0.7 & 0.5 & 0.5 & 0.5 & 0.6 & 0.6 & 0.4 & 0.4 & 0.4 \\
\hline Transportation & 7.9 & 5.6 & 4.7 & 4.8 & 4.8 & 2.7 & 1.8 & 2.2 & 2.5 & 2.6 & 13.2 & 9.6 & 8.3 & 7.9 & 7.9 \\
\hline \multicolumn{16}{|l|}{ Public safety } \\
\hline Police protection & 1.9 & 2.0 & 2.2 & 2.2 & 2.3 & 0.3 & 0.5 & 0.6 & 0.7 & 0.7 & 3.5 & 3.7 & 3.6 & 3.5 & 3.6 \\
\hline \multirow{2}{*}{\multicolumn{16}{|c|}{ Environment and housing }} \\
\hline & & & & & & & & & & & & & & & \\
\hline Natural resources .......... & 4.6 & 5.3 & 3.2 & 3.4 & 3.4 & 7.1 & 9.2 & 4.6 & 5.0 & 5.0 & 2.0 & 1.5 & 1.4 & 1.3 & 1.3 \\
\hline Housing and community development ... & 1.5 & 1.7 & 1.8 & 1.6 & 1.8 & 1.3 & 1.6 & 2.8 & 2.9 & 3.3 & 1.7 & 1.7 & 1.8 & 1.8 & 1.9 \\
\hline \multicolumn{16}{|l|}{ Governmental administration } \\
\hline $\begin{array}{l}\text { Financial administration .. } \\
\text { General control }{ }^{3}\end{array}$ & $\begin{array}{c}1.2 \\
1.2\end{array}$ & $\begin{array}{l}1.3 \\
1.4\end{array}$ & $\begin{array}{r}1.5 \\
20\end{array}$ & $\begin{array}{l}1.6 \\
21\end{array}$ & $\begin{array}{l}1.6 \\
2.1\end{array}$ & $\begin{array}{l}0.9 \\
0.4\end{array}$ & 0.9 & $\begin{array}{l}1.0 \\
0.5\end{array}$ & $\begin{array}{l}1.1 \\
0.6\end{array}$ & $\begin{array}{l}1.1 \\
0.6\end{array}$ & $\begin{array}{c}1.5 \\
29\end{array}$ & $\begin{array}{c}1.8 \\
3.1\end{array}$ & $\begin{array}{r}1.9 \\
35\end{array}$ & $\begin{array}{l}1.9 \\
32\end{array}$ & 1.9 \\
\hline $\begin{array}{r}\text { General control }{ }^{3} \\
\text { Interest on general deb..... }\end{array}$ & $\begin{array}{l}1.2 \\
7.2\end{array}$ & $\begin{array}{r}1.4 \\
11.8\end{array}$ & $\begin{array}{r}2.0 \\
13.7\end{array}$ & $\begin{array}{r}2.1 \\
13.3\end{array}$ & $\begin{array}{r}2.1 \\
13.1\end{array}$ & $\begin{array}{r}0.4 \\
11.0\end{array}$ & $\begin{array}{r}0.5 \\
19.1\end{array}$ & $\begin{array}{r}0.5 \\
18.4\end{array}$ & $\begin{array}{r}0.6 \\
18.4\end{array}$ & $\begin{array}{r}0.6 \\
18.3\end{array}$ & $\begin{array}{l}2.9 \\
3.4\end{array}$ & $\begin{array}{r}3.1 \\
4.2\end{array}$ & $\begin{array}{l}3.5 \\
58\end{array}$ & $\begin{array}{l}3.2 \\
5.4\end{array} \mid$ & $\begin{array}{l}3.3 \\
5.1\end{array}$ \\
\hline $\begin{array}{l}\text { Interest on general debt } \\
\text { Other and unallocable }\end{array}$ & $\begin{array}{l}9.4 \\
9.4\end{array}$ & 11.3 & $\begin{array}{l}11.9 \\
11.9\end{array}$ & $\begin{array}{l}13.3 \\
10.4\end{array}$ & 10.8 & $\begin{array}{r}6.0 \\
6.8\end{array}$ & $\begin{array}{r}19.1 \\
7.3\end{array}$ & $\begin{array}{r}11.2 \\
11.2\end{array}$ & $\begin{array}{r}0.4 \\
8.5\end{array}$ & $\begin{array}{r}r 8.3 \\
9.0\end{array}$ & $\begin{array}{r}3.4 \\
10.5\end{array}$ & 13.6 & $\begin{array}{r}5.8 \\
12.6\end{array}$ & $\begin{array}{r}5.4 \\
12.6\end{array}$ & $\begin{array}{r}5.1 \\
12.5\end{array}$ \\
\hline
\end{tabular}

\section{Excludes duplicative intergovernmental transactions}

${ }^{2}$ General expenditures include monies paid by states to the federal government, which are excluded from direct general expenditures.

-Data not applicable.

${ }^{3}$ Includes judicial and legal expenditures and expenditures on general and public buildings and other governmental

SOURCE: U.S. Department of Commerce, Bureau of the Census, unpublished data. (This table was prepared October 1998.) 
Table 35.-Direct general expenditures of state and local governments for all functions and for education, by level and state: 1994-95

[In millions]

\begin{tabular}{|c|c|c|c|c|c|c|c|c|c|}
\hline \multirow{3}{*}{ State } & \multirow{3}{*}{$\begin{array}{l}\text { Total direct } \\
\text { general } \\
\text { expenditures }{ }^{1}\end{array}$} & \multicolumn{8}{|c|}{ Education expenditures } \\
\hline & & \multirow[b]{2}{*}{ Total } & \multicolumn{3}{|c|}{ Elementary and secondary education } & \multicolumn{3}{|c|}{ Higher education } & \multirow{2}{*}{$\begin{array}{l}\text { Other } \\
\text { education }{ }^{3}\end{array}$} \\
\hline & & & Total & $\begin{array}{c}\text { Current } \\
\text { expenditure }\end{array}$ & $\begin{array}{l}\text { Capital } \\
\text { outlay }^{2}\end{array}$ & Total & $\begin{array}{c}\text { Current } \\
\text { expenditure }\end{array}$ & $\begin{array}{l}\text { Capital } \\
\text { outlay }\end{array}$ & \\
\hline 1 & 2 & 3 & 4 & 5 & 6 & 7 & 8 & 9 & 10 \\
\hline United States ........... & $\$ 1,146,188$ & $\$ 378,273$ & $\$ 264,240$ & $\$ 239,433$ & $\$ 24,808$ & $\$ 97,048$ & $\$ 86,587$ & $\$ 10,461$ & $\$ 16,984$ \\
\hline 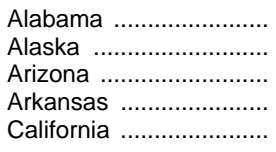 & $\begin{array}{r}15,736 \\
6,253 \\
15,853 \\
8,020 \\
145,425\end{array}$ & $\begin{array}{r}5,269 \\
1,502 \\
5,706 \\
2,938 \\
41,155\end{array}$ & $\begin{array}{r}3,021 \\
1,136 \\
3,814 \\
1,879 \\
28,351\end{array}$ & $\begin{array}{r}2,774 \\
1,006 \\
3,137 \\
1,714 \\
26,019\end{array}$ & $\begin{array}{r}248 \\
129 \\
677 \\
165 \\
2,332\end{array}$ & $\begin{array}{r}1,877 \\
298 \\
1,696 \\
757 \\
10,967\end{array}$ & $\begin{array}{r}1,705 \\
287 \\
1,532 \\
675 \\
9,842\end{array}$ & $\begin{array}{r}172 \\
11 \\
164 \\
82 \\
1,124\end{array}$ & $\begin{array}{r}370 \\
68 \\
197 \\
302 \\
1,838\end{array}$ \\
\hline 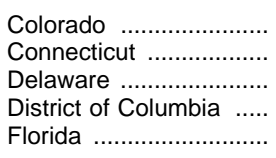 & $\begin{array}{r}15,678 \\
16,997 \\
3,492 \\
4,303 \\
57,825\end{array}$ & $\begin{array}{r}5,700 \\
5,059 \\
1,293 \\
706 \\
17,445\end{array}$ & $\begin{array}{r}3,669 \\
3,946 \\
756 \\
615 \\
13,201\end{array}$ & $\begin{array}{r}3,170 \\
3,854 \\
705 \\
583 \\
11,136\end{array}$ & $\begin{array}{r}498 \\
92 \\
50 \\
32 \\
2,066\end{array}$ & $\begin{array}{r}1,770 \\
899 \\
438 \\
92 \\
3,614\end{array}$ & $\begin{array}{r}1,613 \\
879 \\
434 \\
88 \\
3,017\end{array}$ & $\begin{array}{r}157 \\
20 \\
4 \\
4 \\
597\end{array}$ & $\begin{array}{r}261 \\
214 \\
99 \\
0 \\
630\end{array}$ \\
\hline 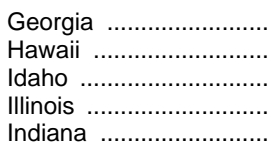 & $\begin{array}{r}29,098 \\
6,713 \\
4,337 \\
48,722 \\
21,144\end{array}$ & $\begin{array}{r}10,067 \\
1,646 \\
1,655 \\
15,936 \\
8,517\end{array}$ & $\begin{array}{r}7,057 \\
959 \\
1,090 \\
11,242 \\
5,633\end{array}$ & $\begin{array}{r}6,098 \\
799 \\
953 \\
9,863 \\
5,000\end{array}$ & $\begin{array}{r}959 \\
160 \\
138 \\
1,379 \\
634\end{array}$ & $\begin{array}{r}2,384 \\
665 \\
473 \\
3,826 \\
2,559\end{array}$ & $\begin{array}{r}1,872 \\
557 \\
402 \\
3,332 \\
2,296\end{array}$ & $\begin{array}{r}512 \\
107 \\
71 \\
494 \\
263\end{array}$ & $\begin{array}{r}625 \\
23 \\
92 \\
867 \\
325\end{array}$ \\
\hline $\begin{array}{l}\text { lowa } \\
\text { Kansas } \\
\text { Kentucky } \\
\text { Louisiana } \\
\text { Maine }\end{array}$ & $\begin{array}{r}11,960 \\
10,221 \\
13,659 \\
18,625 \\
5,196\end{array}$ & $\begin{array}{l}4,402 \\
3,938 \\
4,723 \\
5,464 \\
1,670\end{array}$ & $\begin{array}{l}2,680 \\
2,560 \\
3,015 \\
3,670 \\
1,221\end{array}$ & $\begin{array}{l}2,510 \\
2,375 \\
2,865 \\
3,457 \\
1,154\end{array}$ & $\begin{array}{r}169 \\
186 \\
149 \\
213 \\
67\end{array}$ & $\begin{array}{r}1,509 \\
1,234 \\
1,316 \\
1,482 \\
372\end{array}$ & $\begin{array}{r}1,412 \\
1,104 \\
1,163 \\
1,381 \\
330\end{array}$ & $\begin{array}{r}97 \\
130 \\
153 \\
100 \\
42\end{array}$ & $\begin{array}{r}213 \\
144 \\
393 \\
312 \\
77\end{array}$ \\
\hline 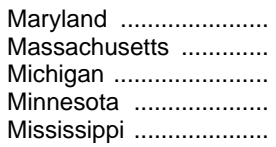 & $\begin{array}{r}21,190 \\
29,857 \\
41,503 \\
23,797 \\
9,635\end{array}$ & $\begin{array}{r}7,415 \\
7,943 \\
16,360 \\
8,152 \\
3,468\end{array}$ & $\begin{array}{r}5,158 \\
6,095 \\
11,099 \\
5,913 \\
2,190\end{array}$ & $\begin{array}{r}4,698 \\
5,658 \\
10,404 \\
5,143 \\
1,963\end{array}$ & $\begin{array}{l}460 \\
438 \\
695 \\
770 \\
227\end{array}$ & $\begin{array}{l}1,931 \\
1,421 \\
4,643 \\
1,892 \\
1,096\end{array}$ & $\begin{array}{r}1,761 \\
1,364 \\
4,042 \\
1,719 \\
993\end{array}$ & $\begin{array}{r}170 \\
56 \\
601 \\
173 \\
104\end{array}$ & $\begin{array}{l}327 \\
427 \\
619 \\
347 \\
182\end{array}$ \\
\hline 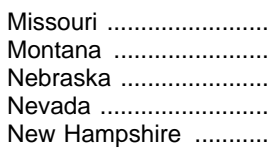 & $\begin{array}{r}17,765 \\
3,535 \\
6,643 \\
6,436 \\
4,509\end{array}$ & $\begin{array}{l}6,623 \\
1,404 \\
2,704 \\
1,806 \\
1,528\end{array}$ & $\begin{array}{r}4,816 \\
949 \\
1,838 \\
1,297 \\
1,132\end{array}$ & $\begin{array}{r}4,263 \\
904 \\
1,583 \\
1,176 \\
1,060\end{array}$ & $\begin{array}{r}553 \\
44 \\
254 \\
121 \\
72\end{array}$ & $\begin{array}{r}1,561 \\
356 \\
789 \\
466 \\
345\end{array}$ & $\begin{array}{r}1,410 \\
298 \\
694 \\
401 \\
320\end{array}$ & $\begin{array}{r}151 \\
58 \\
95 \\
65 \\
25\end{array}$ & $\begin{array}{r}246 \\
100 \\
78 \\
43 \\
51\end{array}$ \\
\hline 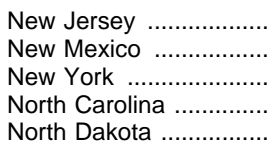 & $\begin{array}{r}42,219 \\
7,370 \\
118,702 \\
27,438 \\
2,765\end{array}$ & $\begin{array}{r}14,188 \\
2,574 \\
33,375 \\
9,764 \\
1,008\end{array}$ & $\begin{array}{r}11,046 \\
1,492 \\
26,001 \\
6,102 \\
564\end{array}$ & $\begin{array}{r}10,365 \\
1,327 \\
23,887 \\
5,504 \\
526\end{array}$ & $\begin{array}{r}682 \\
165 \\
2,114 \\
598 \\
38\end{array}$ & $\begin{array}{r}2,623 \\
965 \\
6,039 \\
3,230 \\
394\end{array}$ & $\begin{array}{r}2,309 \\
871 \\
5,588 \\
2,906 \\
357\end{array}$ & $\begin{array}{r}315 \\
94 \\
452 \\
325 \\
36\end{array}$ & $\begin{array}{r}518 \\
117 \\
1,335 \\
431 \\
50\end{array}$ \\
\hline 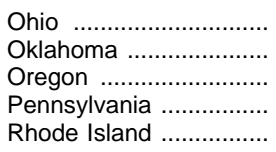 & $\begin{array}{r}44,033 \\
11,230 \\
14,429 \\
50,375 \\
4,849\end{array}$ & $\begin{array}{r}15,494 \\
4,452 \\
4,878 \\
16,420 \\
1,462\end{array}$ & $\begin{array}{r}10,930 \\
3,082 \\
3,263 \\
11,334 \\
1,038\end{array}$ & $\begin{array}{r}10,244 \\
2,804 \\
3,064 \\
10,402 \\
1,019\end{array}$ & $\begin{array}{r}686 \\
278 \\
199 \\
933 \\
19\end{array}$ & $\begin{array}{r}3,874 \\
1,207 \\
1,424 \\
3,910 \\
319\end{array}$ & $\begin{array}{r}3,433 \\
1,074 \\
1,263 \\
3,474 \\
303\end{array}$ & $\begin{array}{r}441 \\
133 \\
161 \\
436 \\
16\end{array}$ & $\begin{array}{r}690 \\
163 \\
191 \\
1,176 \\
106\end{array}$ \\
\hline 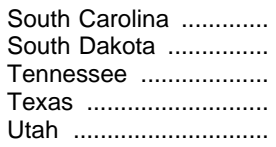 & $\begin{array}{r}14,286 \\
2,817 \\
19,063 \\
67,965 \\
7,662\end{array}$ & $\begin{array}{r}4,902 \\
942 \\
6,121 \\
25,785 \\
3,211\end{array}$ & $\begin{array}{r}3,232 \\
678 \\
3,968 \\
18,266 \\
1,994\end{array}$ & $\begin{array}{r}2,965 \\
611 \\
3,546 \\
16,488 \\
1,649\end{array}$ & $\begin{array}{r}267 \\
66 \\
422 \\
1,778 \\
346\end{array}$ & $\begin{array}{r}1,427 \\
222 \\
1,929 \\
6,919 \\
1,109\end{array}$ & $\begin{array}{r}1,275 \\
205 \\
1,556 \\
6,323 \\
965\end{array}$ & $\begin{array}{r}152 \\
17 \\
373 \\
596 \\
144\end{array}$ & $\begin{array}{r}243 \\
42 \\
224 \\
600 \\
108\end{array}$ \\
\hline 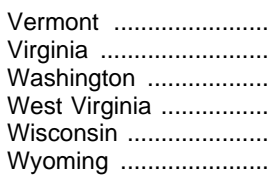 & $\begin{array}{r}2,502 \\
25,106 \\
26,411 \\
7,141 \\
23,079 \\
2,622\end{array}$ & $\begin{array}{r}984 \\
9,315 \\
9,044 \\
2,601 \\
8,610 \\
947\end{array}$ & $\begin{array}{r}619 \\
6,322 \\
6,078 \\
1,779 \\
5,825 \\
625\end{array}$ & $\begin{array}{r}586 \\
5,725 \\
5,070 \\
1,649 \\
5,398 \\
577\end{array}$ & $\begin{array}{r}32 \\
597 \\
1,008 \\
131 \\
426 \\
48\end{array}$ & $\begin{array}{r}298 \\
2,524 \\
2,547 \\
620 \\
2,461 \\
283\end{array}$ & $\begin{array}{r}271 \\
2,274 \\
2,189 \\
576 \\
2,204 \\
253\end{array}$ & $\begin{array}{r}27 \\
250 \\
358 \\
44 \\
257 \\
30\end{array}$ & $\begin{array}{r}67 \\
470 \\
419 \\
202 \\
324 \\
39\end{array}$ \\
\hline
\end{tabular}

1 Includes state and local government expenditures for education services, social services and income maintenance, transportation, public safety, environment and housing governmental administration, interest on general debt, and other general expenditures. Includes intergovernmental expenditure to the federal government.

2 Includes outlays for "other education."

3 Includes assistance and subsidies to individuals and private institutions for elementary, secondary, and higher education, as well as miscellaneous education expenditures.
—Data not applicable.

NOTE.-Current expenditure data in this table differ from figures appearing in other tables because of slightly varying definitions used in the Governmental Finances and Common Core of Data surveys. Because of rounding, details may not add to totals.

SOURCE: U.S. Department of Commerce, Bureau of the Census, unpublished data (This table was prepared February 1999.) 
Table 36.-Direct general expenditures per capita of state and local governments for all functions and for education, by level and state: 1994-95

\begin{tabular}{|c|c|c|c|c|c|c|c|c|c|}
\hline \multirow{3}{*}{ State } & \multirow{3}{*}{$\begin{array}{l}\text { Total, all direct } \\
\text { general } \\
\text { expenditures } \\
\text { per capita }{ }^{1}\end{array}$} & \multicolumn{8}{|c|}{ Education expenditures } \\
\hline & & \multicolumn{2}{|c|}{ Total } & \multicolumn{2}{|c|}{$\begin{array}{l}\text { Elementary and secondary } \\
\text { education }\end{array}$} & \multicolumn{2}{|c|}{ Higher education } & \multicolumn{2}{|c|}{ Other education ${ }^{2}$} \\
\hline & & $\begin{array}{l}\text { Amount } \\
\text { per capita }\end{array}$ & $\begin{array}{l}\text { As a percent } \\
\text { of all } \\
\text { functions }\end{array}$ & $\begin{array}{l}\text { Amount } \\
\text { per capita }\end{array}$ & $\begin{array}{l}\text { As a percent } \\
\text { of all } \\
\text { functions }\end{array}$ & $\begin{array}{l}\text { Amount } \\
\text { per capita }\end{array}$ & $\begin{array}{l}\text { As a percent } \\
\text { of all } \\
\text { functions }\end{array}$ & $\begin{array}{l}\text { Amount } \\
\text { per capita }\end{array}$ & $\begin{array}{c}\text { As a percent } \\
\text { of all } \\
\text { functions }\end{array}$ \\
\hline 1 & 2 & 3 & 4 & 5 & 6 & 7 & 8 & 9 & 10 \\
\hline United States ….......... & $\$ 4,362$ & $\$ 1,440$ & 33.0 & $\$ 1,006$ & 23.1 & $\$ 369$ & 8.5 & $\$ 65$ & 1.5 \\
\hline 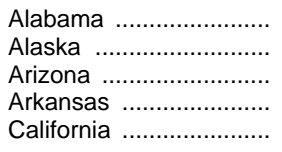 & $\begin{array}{r}3,692 \\
10,393 \\
3,680 \\
3,233 \\
4,608\end{array}$ & $\begin{array}{l}1,236 \\
2,496 \\
1,325 \\
1,184 \\
1,304\end{array}$ & $\begin{array}{l}33.5 \\
24.0 \\
36.0 \\
36.6 \\
28.3\end{array}$ & $\begin{array}{r}709 \\
1,888 \\
885 \\
757 \\
898\end{array}$ & $\begin{array}{l}19.2 \\
18.2 \\
24.1 \\
23.4 \\
19.5\end{array}$ & $\begin{array}{l}440 \\
495 \\
394 \\
305 \\
348\end{array}$ & $\begin{array}{r}11.9 \\
4.8 \\
10.7 \\
9.4 \\
7.5\end{array}$ & $\begin{array}{r}87 \\
114 \\
46 \\
122 \\
58\end{array}$ & $\begin{array}{l}2.4 \\
1.1 \\
1.2 \\
3.8 \\
1.3\end{array}$ \\
\hline 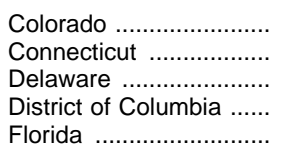 & $\begin{array}{l}4,190 \\
5,203 \\
4,879 \\
7,792 \\
4,078\end{array}$ & $\begin{array}{l}1,523 \\
1,549 \\
1,807 \\
1,279 \\
1,230\end{array}$ & $\begin{array}{l}36.4 \\
29.8 \\
37.0 \\
16.4 \\
30.2\end{array}$ & $\begin{array}{r}981 \\
1,208 \\
1,056 \\
1,113 \\
931\end{array}$ & $\begin{array}{l}23.4 \\
23.2 \\
21.6 \\
14.3 \\
22.8\end{array}$ & $\begin{array}{l}473 \\
275 \\
612 \\
166 \\
255\end{array}$ & $\begin{array}{r}11.3 \\
5.3 \\
12.5 \\
2.1 \\
6.3\end{array}$ & $\begin{array}{r}70 \\
65 \\
139 \\
\overline{44}\end{array}$ & $\begin{array}{l}1.7 \\
1.3 \\
2.8 \\
\overline{1.1}\end{array}$ \\
\hline 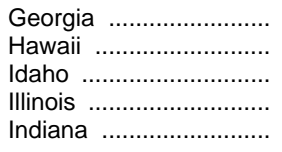 & $\begin{array}{l}4,046 \\
5,695 \\
3,723 \\
4,131 \\
3,653\end{array}$ & $\begin{array}{l}1,400 \\
1,396 \\
1,421 \\
1,351 \\
1,472\end{array}$ & $\begin{array}{l}34.6 \\
24.5 \\
38.2 \\
32.7 \\
40.3\end{array}$ & $\begin{array}{l}981 \\
813 \\
936 \\
953 \\
973\end{array}$ & $\begin{array}{l}24.3 \\
14.3 \\
25.1 \\
23.1 \\
26.6\end{array}$ & $\begin{array}{l}331 \\
564 \\
406 \\
324 \\
442\end{array}$ & $\begin{array}{r}8.2 \\
9.9 \\
10.9 \\
7.9 \\
12.1\end{array}$ & $\begin{array}{l}87 \\
19 \\
79 \\
74 \\
56\end{array}$ & $\begin{array}{l}2.1 \\
0.3 \\
2.1 \\
1.8 \\
1.5\end{array}$ \\
\hline 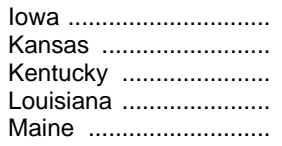 & $\begin{array}{l}4,210 \\
3,978 \\
3,542 \\
4,303 \\
4,211\end{array}$ & $\begin{array}{l}1,550 \\
1,532 \\
1,225 \\
1,262 \\
1,353\end{array}$ & $\begin{array}{l}36.8 \\
38.5 \\
34.6 \\
29.3 \\
32.1\end{array}$ & $\begin{array}{l}943 \\
996 \\
782 \\
848 \\
989\end{array}$ & $\begin{array}{l}22.4 \\
25.0 \\
22.1 \\
19.7 \\
23.5\end{array}$ & $\begin{array}{l}531 \\
480 \\
341 \\
342 \\
301\end{array}$ & $\begin{array}{r}12.6 \\
12.1 \\
9.6 \\
8.0 \\
7.2\end{array}$ & $\begin{array}{r}75 \\
56 \\
102 \\
72 \\
62\end{array}$ & $\begin{array}{l}1.8 \\
1.4 \\
2.9 \\
1.7 \\
1.5\end{array}$ \\
\hline 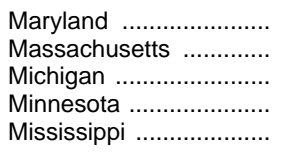 & $\begin{array}{l}4,215 \\
4,926 \\
4,298 \\
5,166 \\
3,581\end{array}$ & $\begin{array}{l}1,475 \\
1,311 \\
1,694 \\
1,770 \\
1,289\end{array}$ & $\begin{array}{l}35.0 \\
26.6 \\
39.4 \\
34.3 \\
36.0\end{array}$ & $\begin{array}{r}1,026 \\
1,006 \\
1,149 \\
1,284 \\
814\end{array}$ & $\begin{array}{l}24.3 \\
20.4 \\
26.7 \\
24.8 \\
22.7\end{array}$ & $\begin{array}{l}384 \\
234 \\
481 \\
411 \\
407\end{array}$ & $\begin{array}{r}9.1 \\
4.8 \\
11.2 \\
7.9 \\
11.4\end{array}$ & $\begin{array}{l}65 \\
70 \\
64 \\
75 \\
68\end{array}$ & $\begin{array}{l}1.5 \\
1.4 \\
1.5 \\
1.5 \\
1.9\end{array}$ \\
\hline 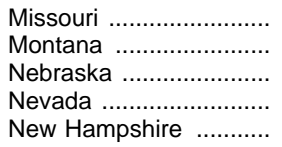 & $\begin{array}{l}3,336 \\
4,069 \\
4,060 \\
4,208 \\
3,933\end{array}$ & $\begin{array}{l}1,244 \\
1,616 \\
1,653 \\
1,180 \\
1,333\end{array}$ & $\begin{array}{l}37.3 \\
39.7 \\
40.7 \\
28.1 \\
33.9\end{array}$ & $\begin{array}{r}904 \\
1,092 \\
1,123 \\
848 \\
987\end{array}$ & $\begin{array}{l}27.1 \\
26.8 \\
27.7 \\
20.2 \\
25.1\end{array}$ & $\begin{array}{l}293 \\
409 \\
482 \\
305 \\
301\end{array}$ & $\begin{array}{r}8.8 \\
10.1 \\
11.9 \\
7.2 \\
7.6\end{array}$ & $\begin{array}{r}46 \\
115 \\
48 \\
28 \\
44\end{array}$ & $\begin{array}{l}1.4 \\
2.8 \\
1.2 \\
0.7 \\
1.1\end{array}$ \\
\hline 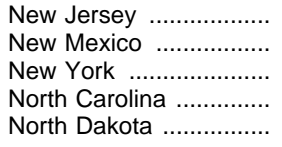 & $\begin{array}{l}5,307 \\
4,370 \\
6,542 \\
3,818 \\
4,312\end{array}$ & $\begin{array}{l}1,783 \\
1,526 \\
1,839 \\
1,359 \\
1,571\end{array}$ & $\begin{array}{l}33.6 \\
34.9 \\
28.1 \\
35.6 \\
36.4\end{array}$ & $\begin{array}{r}1,388 \\
885 \\
1,433 \\
849 \\
879\end{array}$ & $\begin{array}{l}26.2 \\
20.2 \\
21.9 \\
22.2 \\
20.4\end{array}$ & $\begin{array}{l}330 \\
572 \\
333 \\
449 \\
614\end{array}$ & $\begin{array}{r}6.2 \\
13.1 \\
5.1 \\
11.8 \\
14.2\end{array}$ & $\begin{array}{l}65 \\
70 \\
74 \\
60 \\
78\end{array}$ & $\begin{array}{l}1.2 \\
1.6 \\
1.1 \\
1.6 \\
1.8\end{array}$ \\
\hline 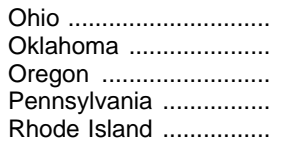 & $\begin{array}{l}3,955 \\
3,433 \\
4,591 \\
4,182 \\
4,898\end{array}$ & $\begin{array}{l}1,392 \\
1,361 \\
1,552 \\
1,363 \\
1,477\end{array}$ & $\begin{array}{l}35.2 \\
39.6 \\
33.8 \\
32.6 \\
30.2\end{array}$ & $\begin{array}{r}982 \\
942 \\
1,038 \\
941 \\
1,049\end{array}$ & $\begin{array}{l}24.8 \\
27.4 \\
22.6 \\
22.5 \\
21.4\end{array}$ & $\begin{array}{l}348 \\
369 \\
453 \\
325 \\
322\end{array}$ & $\begin{array}{r}8.8 \\
10.7 \\
9.9 \\
7.8 \\
6.6\end{array}$ & $\begin{array}{r}62 \\
50 \\
61 \\
98 \\
107\end{array}$ & $\begin{array}{l}1.6 \\
1.5 \\
1.3 \\
2.3 \\
2.2\end{array}$ \\
\hline 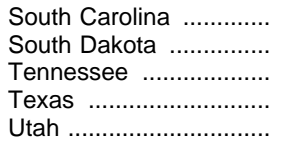 & $\begin{array}{l}3,878 \\
3,833 \\
3,641 \\
3,627 \\
3,881\end{array}$ & $\begin{array}{l}1,331 \\
1,282 \\
1,169 \\
1,376 \\
1,627\end{array}$ & $\begin{array}{l}34.3 \\
33.4 \\
32.1 \\
37.9 \\
41.9\end{array}$ & $\begin{array}{r}877 \\
922 \\
758 \\
975 \\
1,010\end{array}$ & $\begin{array}{l}22.6 \\
24.1 \\
20.8 \\
26.9 \\
26.0\end{array}$ & $\begin{array}{l}388 \\
302 \\
368 \\
369 \\
562\end{array}$ & $\begin{array}{r}10.0 \\
7.9 \\
10.1 \\
10.2 \\
14.5\end{array}$ & $\begin{array}{l}66 \\
58 \\
43 \\
32 \\
55\end{array}$ & $\begin{array}{l}1.7 \\
1.5 \\
1.2 \\
0.9 \\
1.4\end{array}$ \\
\hline 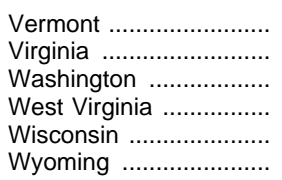 & $\begin{array}{l}4,292 \\
3,803 \\
4,859 \\
3,919 \\
4,514 \\
5,478\end{array}$ & $\begin{array}{l}1,688 \\
1,411 \\
1,664 \\
1,428 \\
1,684 \\
1,979\end{array}$ & $\begin{array}{l}39.3 \\
37.1 \\
34.2 \\
36.4 \\
37.3 \\
36.1\end{array}$ & $\begin{array}{r}1,061 \\
958 \\
1,118 \\
977 \\
1,139 \\
1,307\end{array}$ & $\begin{array}{l}24.7 \\
25.2 \\
23.0 \\
24.9 \\
25.2 \\
23.9\end{array}$ & $\begin{array}{l}511 \\
382 \\
468 \\
340 \\
481 \\
591\end{array}$ & $\begin{array}{r}11.9 \\
10.1 \\
9.6 \\
8.7 \\
10.7 \\
10.8\end{array}$ & $\begin{array}{r}116 \\
71 \\
77 \\
111 \\
63 \\
82\end{array}$ & $\begin{array}{l}2.7 \\
1.9 \\
1.6 \\
2.8 \\
1.4 \\
1.5\end{array}$ \\
\hline
\end{tabular}

1 Includes state and local government expenditures for education services, social services and income maintenance, transportation, public safety, environment and housing, governmental administration, interest on general debt, and other general expenditures. Includes intergovernmental expenditure to the federal government.

2 Includes assistance and subsidies to individuals and private institutions for elementary, secondary, and higher education, as well as miscellaneous education expenditures. -Data not applicable.
NOTE.-Per capita amounts are based on population figures as of July 1, 1995, and are computed on the basis of amounts rounded to the nearest thousand. Because of rounding, details may not add to totals.

SOURCE: U.S. Department of Commerce, Bureau of the Census, unpublished data (This table was prepared February 1999.) 
Table 37.-Gross domestic product, state and local expenditures, personal income, disposable personal income, median family income, and population: 1929 to 1997

\begin{tabular}{|c|c|c|c|c|c|c|c|c|c|c|c|c|}
\hline \multirow{2}{*}{\multicolumn{2}{|c|}{ Year }} & \multicolumn{2}{|c|}{$\begin{array}{l}\text { Gross domestic } \\
\text { product, in billions }\end{array}$} & \multicolumn{2}{|c|}{$\begin{array}{c}\text { State and local } \\
\text { expenditures, }{ }^{1} \text { in millions }\end{array}$} & \multirow{2}{*}{$\begin{array}{l}\text { Personal } \\
\text { income, in } \\
\text { billions }\end{array}$} & \multirow{2}{*}{$\begin{array}{c}\text { Disposable } \\
\text { personal } \\
\text { income, in } \\
\text { billions of } \\
\text { chained } 1992 \\
\text { dollars }\end{array}$} & \multicolumn{2}{|c|}{$\begin{array}{l}\text { Disposable personal } \\
\text { income per capita }\end{array}$} & \multirow{2}{*}{$\begin{array}{c}\text { Median } \\
\text { family } \\
\text { income }\end{array}$} & \multicolumn{2}{|c|}{$\begin{array}{l}\text { Total population in } \\
\text { thousands }\end{array}$} \\
\hline & & $\begin{array}{l}\text { Current } \\
\text { dollars }\end{array}$ & $\begin{array}{c}\text { Chained } \\
1992 \\
\text { dollars }\end{array}$ & $\begin{array}{c}\text { All } \\
\text { general } \\
\text { expenditures }\end{array}$ & $\begin{array}{l}\text { Education } \\
\text { expenditures }\end{array}$ & & & $\begin{array}{l}\text { Current } \\
\text { dollars }\end{array}$ & $\begin{array}{c}\text { Chained } \\
1992 \\
\text { dollars }\end{array}$ & & $\begin{array}{c}\text { Annual } \\
\text { averages } \\
\text { of quar- } \\
\text { terly data }{ }^{2}\end{array}$ & $\begin{array}{l}\text { As of } \\
\text { July } 1^{3}\end{array}$ \\
\hline & 1 & 2 & 3 & 4 & 5 & 6 & 7 & 8 & 9 & 10 & 11 & 12 \\
\hline $\begin{array}{l}1929 \\
1933 \\
1939 \\
1940\end{array}$ & '. & $\begin{array}{r}\$ 103.8 \\
56.2 \\
91.9 \\
101.2\end{array}$ & $\begin{array}{l}790.9 \\
577.3 \\
866.5 \\
941.2\end{array}$ & $\frac{-}{\overline{-}}$ & $\frac{-}{\$ 2,638}$ & $\begin{array}{r}\$ 85.2 \\
46.8 \\
72.8 \\
78.3\end{array}$ & $\begin{array}{r}\$ 635.3 \\
481.6 \\
687.9 \\
734.3\end{array}$ & $\begin{array}{r}\$ 680 \\
363 \\
539 \\
575\end{array}$ & $\begin{array}{r}\$ 5,213 \\
3,831 \\
5,250 \\
5,558\end{array}$ & $\begin{array}{l}- \\
-\end{array}$ & $\begin{array}{l}- \\
- \\
-\end{array}$ & $\begin{array}{l}121,878 \\
125,690 \\
131,028 \\
132,122\end{array}$ \\
\hline $\begin{array}{l}1941 \\
1942 \\
1943 \\
1944 \\
1945\end{array}$ & $\begin{array}{l} \\
\ldots \ldots \ldots \\
\ldots \ldots \ldots \\
\ldots \ldots \ldots \\
\ldots \ldots \ldots \\
\ldots \ldots \ldots \\
\ldots \ldots \ldots\end{array}$ & $\begin{array}{l}126.7 \\
161.6 \\
198.3 \\
219.7 \\
223.2\end{array}$ & $\begin{array}{l}1,101.8 \\
1,308.9 \\
1,523.0 \\
1,644.7 \\
1,626.7\end{array}$ & $\begin{array}{r}9,1 \overline{90} \\
8,863 \\
-\end{array}$ & $\begin{array}{r}2,5 \overline{86} \\
2,793 \\
-\end{array}$ & $\begin{array}{r}96.0 \\
123.3 \\
151.8 \\
165.7 \\
171.3\end{array}$ & $\begin{array}{r}845.6 \\
952.8 \\
995.8 \\
1,031.3 \\
1,016.8\end{array}$ & $\begin{array}{r}697 \\
872 \\
982 \\
1,062 \\
1,077\end{array}$ & $\begin{array}{l}6,339 \\
7,065 \\
7,282 \\
7,452 \\
7,267\end{array}$ & $\begin{array}{l}- \\
\text { - } \\
-\end{array}$ & $\begin{array}{l}- \\
- \\
-\end{array}$ & $\begin{array}{l}133,402 \\
134,860 \\
136,739 \\
138,397 \\
139,928\end{array}$ \\
\hline $\begin{array}{l}1946 \\
1947 \\
1948 \\
1949 \\
1950\end{array}$ & $\begin{array}{l}\ldots \ldots . \\
\ldots \ldots . \\
\ldots \ldots . \\
\ldots \ldots . \\
\ldots \ldots . \\
\ldots \ldots\end{array}$ & $\begin{array}{l}222.6 \\
244.6 \\
269.7 \\
267.8 \\
294.6\end{array}$ & $\begin{array}{l}1,447.7 \\
1,430.7 \\
1,491.0 \\
1,479.8 \\
1,611.3\end{array}$ & $\begin{array}{r}11,028 \\
17,6 \overline{84} \\
22,787\end{array}$ & $\begin{array}{r}3,356 \\
5,3 \overline{79} \\
7,177\end{array}$ & $\begin{array}{l}179.0 \\
191.8 \\
210.7 \\
207.8 \\
229.7\end{array}$ & $\begin{array}{r}1,011.0 \\
974.1 \\
1,025.6 \\
1,031.6 \\
1,124.7\end{array}$ & $\begin{array}{l}1,136 \\
1,185 \\
1,297 \\
1,272 \\
1,382\end{array}$ & $\begin{array}{l}7,150 \\
6,759 \\
6,994 \\
6,915 \\
7,415\end{array}$ & $\begin{array}{r}-\overline{\$} 3,031 \\
3,187 \\
3,107 \\
3,319\end{array}$ & $\begin{array}{l}- \\
- \\
-\end{array}$ & $\begin{array}{l}141,389 \\
144,126 \\
146,631 \\
149,188 \\
151,684\end{array}$ \\
\hline $\begin{array}{l}1951 \\
1952 \\
1953 \\
1954 \\
1955\end{array}$ & $\begin{array}{l}\ldots \ldots \ldots \\
\ldots \ldots \ldots \\
\ldots \ldots \ldots \\
\ldots \ldots \ldots\end{array}$ & $\begin{array}{l}339.7 \\
358.6 \\
379.7 \\
381.3 \\
415.1\end{array}$ & $\begin{array}{l}1,734.0 \\
1,798.7 \\
1,881.4 \\
1,868.2 \\
2,001.1\end{array}$ & $\begin{array}{l}-\overline{26}, 098 \\
27,910 \\
30,701 \\
33,724\end{array}$ & $\begin{array}{r}-\overline{8}, 318 \\
9,390 \\
10,557 \\
11,907\end{array}$ & $\begin{array}{l}258.6 \\
276.0 \\
292.9 \\
255.7 \\
317.3\end{array}$ & $\begin{array}{l}1,157.3 \\
1,194.8 \\
1,254.3 \\
1,270.2 \\
1,355.6\end{array}$ & $\begin{array}{l}1,492 \\
1,545 \\
1,617 \\
1,625 \\
1,710\end{array}$ & $\begin{array}{l}7,501 \\
7,613 \\
7,861 \\
7,822 \\
8,202\end{array}$ & $\begin{array}{l}3,709 \\
3,890 \\
4,242 \\
4,167 \\
4,418\end{array}$ & $\begin{array}{l}- \\
- \\
-\end{array}$ & $\begin{array}{l}154,287 \\
156,954 \\
159,565 \\
162,391 \\
165,275\end{array}$ \\
\hline $\begin{array}{l}1956 \\
1957 \\
1958 \\
1959 \\
1960\end{array}$ & $\begin{array}{l}\ldots \ldots . \\
\ldots \ldots . \\
\ldots \ldots . \\
\ldots \ldots . \\
\ldots \ldots . \\
\ldots \ldots .\end{array}$ & $\begin{array}{l}438.0 \\
461.0 \\
467.3 \\
507.2 \\
526.6\end{array}$ & $\begin{array}{l}2,040.2 \\
2,078.5 \\
2,057.5 \\
2,210.2 \\
2,262.9\end{array}$ & $\begin{array}{l}36,711 \\
40,375 \\
44,851 \\
48,887 \\
51,876\end{array}$ & $\begin{array}{l}13,220 \\
14,134 \\
15,919 \\
17,283 \\
18,719\end{array}$ & $\begin{array}{l}340.5 \\
359.6 \\
370.3 \\
394.4 \\
412.5\end{array}$ & $\begin{array}{l}1,418.5 \\
1,452.6 \\
1,466.4 \\
1,530.1 \\
1,565.4\end{array}$ & $\begin{array}{l}1,794 \\
1,859 \\
1,892 \\
1,971 \\
2,008\end{array}$ & $\begin{array}{l}8,432 \\
8,481 \\
8,421 \\
8,641 \\
8,660\end{array}$ & $\begin{array}{l}4,780 \\
4,966 \\
5,087 \\
5,417 \\
5,620\end{array}$ & $\begin{array}{r}- \\
- \\
177,073 \\
180,760\end{array}$ & $\begin{array}{l}168,221 \\
171,274 \\
174,882 \\
177,830 \\
180,671\end{array}$ \\
\hline $\begin{array}{l}1961 \\
1962 \\
1963 \\
1964 \\
1965\end{array}$ & $\begin{array}{l}\ldots \ldots \\
\ldots \ldots \\
\ldots \ldots \\
\ldots . .\end{array}$ & $\begin{array}{l}544.8 \\
585.2 \\
617.4 \\
663.0 \\
719.1\end{array}$ & $\begin{array}{l}2,314.3 \\
2,454.8 \\
2,559.4 \\
2,708.4 \\
2,881.1\end{array}$ & $\begin{array}{l}56,201 \\
60,206 \\
63,977 \\
69,302 \\
74,678\end{array}$ & $\begin{array}{l}20,574 \\
22,216 \\
23,729 \\
26,286 \\
28,563\end{array}$ & $\begin{array}{l}430.0 \\
457.0 \\
480.0 \\
514.5 \\
556.7\end{array}$ & $\begin{array}{r}1,615.8 \\
1,693.7 \\
1,755.5 \\
1,881.9 \\
2,000.2\end{array}$ & $\begin{array}{l}2,062 \\
2,151 \\
2,225 \\
2,384 \\
2,541\end{array}$ & $\begin{array}{r}8,794 \\
9,077 \\
9,274 \\
9,805 \\
10,292\end{array}$ & $\begin{array}{l}5,735 \\
5,956 \\
6,249 \\
6,569 \\
6,957\end{array}$ & $\begin{array}{l}183,742 \\
186,590 \\
189,300 \\
191,927 \\
194,347\end{array}$ & $\begin{array}{l}183,691 \\
186,538 \\
189,242 \\
191,889 \\
194,303\end{array}$ \\
\hline $\begin{array}{l}1966 \\
1967 \\
1968 \\
1969 \\
1970\end{array}$ & … & $\begin{array}{r}787.8 \\
833.6 \\
910.6 \\
982.2 \\
1,035.6\end{array}$ & $\begin{array}{l}3,069.2 \\
3,147.2 \\
3,293.9 \\
3,393.6 \\
3,397.6\end{array}$ & $\begin{array}{r}82,843 \\
93,350 \\
102,411 \\
116,728 \\
131,332\end{array}$ & $\begin{array}{l}33,287 \\
37,919 \\
41,158 \\
47,238 \\
52,718\end{array}$ & $\begin{array}{l}605.7 \\
650.7 \\
714.5 \\
779.3 \\
837.1\end{array}$ & $\begin{array}{l}2,106.6 \\
2,198.4 \\
2,298.2 \\
2,373.6 \\
2,465.6\end{array}$ & $\begin{array}{l}2,715 \\
2,877 \\
3,096 \\
3,297 \\
3,545\end{array}$ & $\begin{array}{l}10,715 \\
11,061 \\
11,448 \\
11,708 \\
12,022\end{array}$ & $\begin{array}{l}7,532 \\
7,933 \\
8,632 \\
9,433 \\
9,867\end{array}$ & $\begin{array}{l}196,599 \\
198,752 \\
200,745 \\
202,736 \\
205,089\end{array}$ & $\begin{array}{l}196,560 \\
198,712 \\
200,706 \\
202,677 \\
205,052\end{array}$ \\
\hline $\begin{array}{l}1971 \\
1972 \\
1973 \\
1974 \\
1975\end{array}$ & ….................... & $\begin{array}{l}1,125.4 \\
1,237.3 \\
1,382.6 \\
1,496.9 \\
1,630.6\end{array}$ & $\begin{array}{l}3,510.0 \\
3,702.3 \\
3,916.3 \\
3,891.2 \\
3,873.9\end{array}$ & $\begin{array}{l}150,674 \\
168,550 \\
181,357 \\
198,959 \\
230,721\end{array}$ & $\begin{array}{l}59,413 \\
65,814 \\
69,714 \\
75,833 \\
87,858\end{array}$ & $\begin{array}{r}900.2 \\
988.8 \\
1,107.5 \\
1,215.9 \\
1,319.0\end{array}$ & $\begin{array}{l}2,564.0 \\
2,680.8 \\
2,869.4 \\
2,847.0 \\
2,895.0\end{array}$ & $\begin{array}{l}3,805 \\
4,074 \\
4,553 \\
4,928 \\
5,367\end{array}$ & $\begin{array}{l}12,345 \\
12,770 \\
13,539 \\
13,310 \\
13,404\end{array}$ & $\begin{array}{l}10,285 \\
11,116 \\
12,051 \\
12,902 \\
13,719\end{array}$ & $\begin{array}{l}207,692 \\
209,924 \\
211,939 \\
213,898 \\
215,981\end{array}$ & $\begin{array}{l}207,661 \\
209,896 \\
211,909 \\
213,854 \\
215,973\end{array}$ \\
\hline $\begin{array}{l}1976 \\
1977 \\
1978 \\
1979 \\
1980\end{array}$ & & $\begin{array}{l}1,819.0 \\
2,026.9 \\
2,291.4 \\
2,557.5 \\
2,784.2\end{array}$ & $\begin{array}{l}4,082.9 \\
4,273.6 \\
4,503.0 \\
4,630.6 \\
4,615.0\end{array}$ & $\begin{array}{l}256,731 \\
274,215 \\
296,984 \\
327,517 \\
369,086\end{array}$ & $\begin{array}{r}97,216 \\
102,780 \\
110,758 \\
119,448 \\
133,211\end{array}$ & $\begin{array}{l}1,459.4 \\
1,616.1 \\
1,825.9 \\
2,055.8 \\
2,293.0\end{array}$ & $\begin{array}{l}3,008.0 \\
3,105.1 \\
3,264.2 \\
3,353.9 \\
3,373.3\end{array}$ & $\begin{array}{l}5,837 \\
6,362 \\
7,097 \\
7,861 \\
8,665\end{array}$ & $\begin{array}{l}13,793 \\
14,095 \\
14,662 \\
14,899 \\
14,813\end{array}$ & $\begin{array}{l}14,958 \\
16,009 \\
17,640 \\
19,587 \\
21,023\end{array}$ & $\begin{array}{l}218,086 \\
220,289 \\
222,629 \\
225,106 \\
227,726\end{array}$ & $\begin{array}{l}218,035 \\
220,239 \\
222,585 \\
225,055 \\
227,726\end{array}$ \\
\hline $\begin{array}{l}1981 \\
1982 \\
1983 \\
1984 \\
1985\end{array}$ & & $\begin{array}{l}3,115.9 \\
3,242.1 \\
3,514.5 \\
3,902.4 \\
4,180.7\end{array}$ & $\begin{array}{l}4,720.7 \\
4,620.3 \\
4,803.7 \\
5,140.1 \\
5,323.5\end{array}$ & $\begin{array}{l}407,449 \\
436,733 \\
466,516 \\
505,008 \\
553,899\end{array}$ & $\begin{array}{l}145,784 \\
154,282 \\
163,876 \\
176,108 \\
192,686\end{array}$ & $\begin{array}{l}2,568.5 \\
2,724.1 \\
2,894.4 \\
3,211.4 \\
3,440.9\end{array}$ & $\begin{array}{l}3,452.3 \\
3,483.0 \\
3,579.9 \\
3,841.9 \\
3,958.6\end{array}$ & $\begin{array}{r}9,566 \\
10,108 \\
10,764 \\
11,887 \\
12,587\end{array}$ & $\begin{array}{l}15,009 \\
14,999 \\
15,277 \\
16,252 \\
16,597\end{array}$ & $\begin{array}{l}22,388 \\
23,433 \\
24,674 \\
26,433 \\
27,735\end{array}$ & $\begin{array}{l}230,008 \\
232,218 \\
234,332 \\
236,394 \\
238,506\end{array}$ & $\begin{array}{l}229,966 \\
232,188 \\
234,307 \\
236,348 \\
238,466\end{array}$ \\
\hline $\begin{array}{l}1986 \\
1987 \\
1988 \\
1989 \\
1990\end{array}$ & & $\begin{array}{l}4,422.2 \\
4,692.3 \\
5,049.6 \\
5,438.7 \\
5,743.8\end{array}$ & $\begin{array}{l}5,487.7 \\
5,649.5 \\
5,865.2 \\
6,062.0 \\
6,136.3\end{array}$ & $\begin{array}{l}605,623 \\
657,134 \\
704,921 \\
762,360 \\
834,818\end{array}$ & $\begin{array}{l}210,819 \\
226,619 \\
242,683 \\
263,898 \\
288,148\end{array}$ & $\begin{array}{l}3,639.6 \\
3,877.8 \\
4,178.9 \\
4,496.4 \\
4,796.2\end{array}$ & $\begin{array}{l}4,087.0 \\
4,154.1 \\
4,318.1 \\
4,403.7 \\
4,484.6\end{array}$ & $\begin{array}{l}13,244 \\
13,849 \\
14,857 \\
15,742 \\
16,670\end{array}$ & $\begin{array}{l}16,981 \\
17,106 \\
17,621 \\
17,801 \\
17,942\end{array}$ & $\begin{array}{r}29,458 \\
430,970 \\
432,191 \\
434,213 \\
435,353\end{array}$ & $\begin{array}{l}240,682 \\
242,842 \\
245,061 \\
247,387 \\
249,956\end{array}$ & $\begin{array}{l}240,651 \\
242,804 \\
245,021 \\
247,342 \\
249,949\end{array}$ \\
\hline $\begin{array}{l}1991 \\
1992 \\
1993 \\
1994 \\
1995\end{array}$ & & $\begin{array}{l}5,916.7 \\
6,244.4 \\
6,558.1 \\
6,947.0 \\
7,269.6\end{array}$ & $\begin{array}{l}6,079.4 \\
6,244.4 \\
6,389.6 \\
6,610.7 \\
6,761.7\end{array}$ & $\begin{array}{r}908,108 \\
981,253 \\
1,033,167 \\
1,077,665 \\
1,149,863\end{array}$ & $\begin{array}{l}309,302 \\
324,652 \\
342,287 \\
353,287 \\
378,273\end{array}$ & $\begin{array}{l}4,965.6 \\
5,255.7 \\
5,481.0 \\
5,757.9 \\
6,072.1\end{array}$ & $\begin{array}{l}4,483.5 \\
4,605.1 \\
4,666.7 \\
4,772.9 \\
4,906.0\end{array}$ & $\begin{array}{l}17,179 \\
18,029 \\
18,558 \\
19,251 \\
20,050\end{array}$ & $\begin{array}{l}17,744 \\
18,029 \\
18,077 \\
18,308 \\
18,640\end{array}$ & $\begin{array}{l}435,939 \\
436,573 \\
436,959 \\
438,782 \\
440,611\end{array}$ & $\begin{array}{l}252,680 \\
255,432 \\
258,161 \\
260,705 \\
263,194\end{array}$ & $\begin{array}{l}252,636 \\
255,382 \\
258,089 \\
260,602 \\
263,039\end{array}$ \\
\hline $\begin{array}{l}1996 \\
1997\end{array}$ & 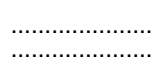 & $\begin{array}{l}7,661.6 \\
8,110.9\end{array}$ & $\begin{array}{l}6,994.8 \\
7,269.8\end{array}$ & 1,193,276 & 398,859 & $\begin{array}{l}6,425.2 \\
6,784.0\end{array}$ & $\begin{array}{l}5,043.0 \\
5,183.1\end{array}$ & $\begin{array}{l}20,840 \\
21,633\end{array}$ & $\begin{array}{l}18,989 \\
19,349\end{array}$ & $\begin{array}{l}442,300 \\
444,568\end{array}$ & $\begin{array}{l}265,579 \\
267,880\end{array}$ & $\begin{array}{l}265,453 \\
267,901\end{array}$ \\
\hline
\end{tabular}

1 Data for years prior to 1963 include expenditures for government fiscal years ending during that particular calendar year. Data for 1963 and later years are the aggregations of expenditures for government fiscal years which ended on June 30 of the stated year. General expenditures exclude expenditures of publicly owned utilities and liquor stores, and of insurance-trust activities. Intergovernmental payments between state and local governments are excluded. Payments to the federal government are included.

2 Population of the United States including Armed Forces overseas; includes Alaska and Hawaii beginning 1960. Quarterly data are averages for the period.

${ }^{3}$ Population of the United States including Armed Forces overseas; includes Alaska and Hawaii beginning 1958. Includes revisions based on the 1990 Census.

\section{-Data not available.}

NOTE.-Gross domestic product data are adjusted by the GDP chained weight price deflator. Personal income data are adjusted by the personal consumption deflator. Some data have been revised from previously published figures.

SOURCE: Executive Office of the President, Economic Report of the President, February 1998, and Economic Indicators, September 1998; and U.S. Department of Commerce, Bureau of the Census, Money Income in the United States, Series P-60, No. 200; and Bureau of Economic Analysis, Survey of Current Business. (This table was prepared February 1999.) 
Table 38.-Gross domestic product deflator, Consumer Price Index, education price indexes, and federal budget composite deflator: 1919 to 1998

\begin{tabular}{|c|c|c|c|c|c|c|c|c|c|}
\hline \multicolumn{3}{|c|}{ Calendar year } & \multicolumn{5}{|c|}{ School year } & \multicolumn{2}{|c|}{ Federal fiscal year } \\
\hline Year & $\begin{array}{l}\text { Gross } \\
\text { domestic } \\
\text { product chain } \\
\text { weight } \\
\text { deflator }\end{array}$ & $\begin{array}{l}\text { Consumer } \\
\text { Price Index }{ }^{1}\end{array}$ & Year & $\begin{array}{l}\text { Consumer } \\
\text { Price Index }{ }^{2}\end{array}$ & $\begin{array}{c}\text { Higher } \\
\text { Education Price } \\
\text { Index }\end{array}$ & $\begin{array}{l}\text { Research and } \\
\text { Development } \\
\text { Index }\end{array}$ & $\begin{array}{l}\text { Academic } \\
\text { Library } \\
\text { Operations } \\
\text { Index }\end{array}$ & Year & $\begin{array}{l}\text { Federal budget } \\
\text { composite } \\
\text { deflator }\end{array}$ \\
\hline 1 & 2 & 3 & 4 & 5 & 6 & 7 & 8 & 9 & 10 \\
\hline 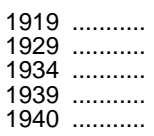 & $\begin{array}{l}- \\
- \\
-\end{array}$ & $\begin{array}{l}17.3 \\
17.1 \\
13.4 \\
13.9 \\
14.0\end{array}$ & 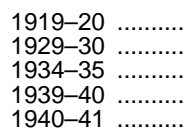 & $\begin{array}{l}19.1 \\
17.1 \\
13.6 \\
14.0 \\
14.2\end{array}$ & $\begin{array}{l}- \\
- \\
-\end{array}$ & $\begin{array}{l}- \\
- \\
-\end{array}$ & $\begin{array}{l}- \\
- \\
-\end{array}$ & $\begin{array}{l}1919 \ldots \ldots \ldots . . \\
1929 \ldots \ldots \ldots \ldots \\
1934 \ldots \ldots \ldots \ldots \\
1939 \ldots \ldots \ldots \ldots \\
1940 \ldots \ldots \ldots \ldots\end{array}$ & $\frac{-}{-}$ \\
\hline $\begin{array}{l}1941 \ldots \ldots \ldots \ldots \\
1942 \ldots \ldots \ldots \ldots \\
1943 \quad \ldots \ldots \ldots \ldots . . \\
1944 \\
1945\end{array}$ & $\begin{array}{l}- \\
- \\
-\end{array}$ & $\begin{array}{l}14.7 \\
16.3 \\
17.3 \\
17.6 \\
18.0\end{array}$ & 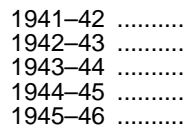 & $\begin{array}{l}15.6 \\
16.9 \\
17.4 \\
17.8 \\
18.2\end{array}$ & $\begin{array}{l}- \\
- \\
-\end{array}$ & $\begin{array}{l}- \\
- \\
-\end{array}$ & $\begin{array}{l}- \\
- \\
-\end{array}$ & 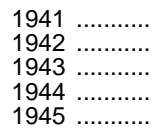 & $\begin{array}{l}0.0954 \\
0.1048 \\
0.1199 \\
0.1218 \\
0.1195\end{array}$ \\
\hline $\begin{array}{l}1946 \quad \ldots \ldots \ldots \ldots \\
1947 \ldots \ldots \ldots \ldots \\
1948 \ldots \ldots \ldots \ldots \\
1949 \ldots \ldots \ldots \ldots \\
1950 \ldots \ldots \ldots \ldots\end{array}$ & $\begin{array}{l}- \\
- \\
-\end{array}$ & $\begin{array}{l}19.5 \\
22.3 \\
24.1 \\
23.8 \\
24.1\end{array}$ & 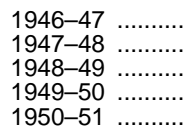 & $\begin{array}{l}21.2 \\
23.3 \\
24.1 \\
23.7 \\
25.1\end{array}$ & $\begin{array}{l}- \\
- \\
-\end{array}$ & $\begin{array}{l}- \\
- \\
-\end{array}$ & $\begin{array}{l}- \\
- \\
-\end{array}$ & $\begin{array}{l}1946 \ldots \ldots \ldots \ldots \\
1947 \ldots \ldots \ldots \ldots \\
1948 \ldots \ldots \ldots \ldots \\
1949 \\
1950 \ldots \ldots \ldots \ldots \\
195 \ldots \ldots \ldots\end{array}$ & $\begin{array}{l}0.1148 \\
0.1296 \\
0.1331 \\
0.1344 \\
0.1414\end{array}$ \\
\hline $\begin{array}{l}1951 \ldots \ldots \ldots \ldots \\
1952 \ldots \ldots \ldots \ldots \\
1953 \\
1954\end{array}$ & $\begin{array}{l}\text { - } \\
\text { - }\end{array}$ & $\begin{array}{l}26.0 \\
26.5 \\
26.7 \\
26.9 \\
26.8\end{array}$ & $\begin{array}{l}1951-52 \\
1952-53 \\
1953-54 \ldots \ldots \ldots \\
1954-55 \ldots \ldots \ldots \\
1955-56 \ldots \ldots \ldots \\
\ldots \ldots \ldots . . .\end{array}$ & $\begin{array}{l}26.3 \\
26.7 \\
26.9 \\
26.8 \\
26.9\end{array}$ & $\begin{array}{l}- \\
- \\
-\end{array}$ & $\begin{array}{l}- \\
- \\
-\end{array}$ & $\begin{array}{l}- \\
- \\
-\end{array}$ & $\begin{array}{l}1951 \ldots \ldots \ldots \ldots \\
1952 \ldots \ldots \ldots \ldots \\
1953 \ldots \ldots \ldots \ldots \\
1954 \ldots \ldots \ldots \ldots \\
1955 \ldots \ldots \ldots \ldots\end{array}$ & $\begin{array}{l}0.1473 \\
0.1513 \\
0.1588 \\
0.1640 \\
0.1664\end{array}$ \\
\hline 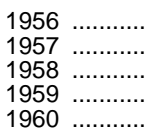 & $\begin{array}{r}- \\
23.0 \\
23.3\end{array}$ & $\begin{array}{l}27.2 \\
28.1 \\
28.9 \\
29.1 \\
29.6\end{array}$ & $\begin{array}{c}1956-57 \ldots \ldots \ldots \\
1957-58 \ldots \ldots \ldots \\
1958-59 \\
1959-60\end{array}$ & $\begin{array}{l}27.7 \\
28.6 \\
29.0 \\
29.4 \\
29.8\end{array}$ & $\frac{-}{-}$ & $\frac{-}{-}$ & $\begin{array}{l}- \\
- \\
-\end{array}$ & $\begin{array}{l}1956 \ldots \ldots \ldots . \\
1957 \ldots \ldots \ldots \ldots \\
1958 \ldots \ldots \ldots \ldots \\
1959 \ldots \ldots \ldots \ldots \\
1960 \ldots \ldots \ldots . .\end{array}$ & $\begin{array}{l}0.1749 \\
0.1833 \\
0.1925 \\
0.1987 \\
0.1994\end{array}$ \\
\hline 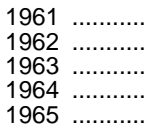 & $\begin{array}{l}23.6 \\
23.9 \\
24.2 \\
24.6 \\
25.0\end{array}$ & $\begin{array}{l}29.9 \\
30.2 \\
30.6 \\
31.0 \\
31.5\end{array}$ & 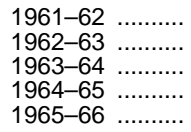 & $\begin{array}{l}30.1 \\
30.4 \\
30.8 \\
31.2 \\
31.9\end{array}$ & $\begin{array}{l}26.5 \\
27.6 \\
28.6 \\
29.8 \\
31.3\end{array}$ & $\begin{array}{l}27.5 \\
28.5 \\
29.5 \\
30.7 \\
32.0\end{array}$ & $\begin{array}{l}- \\
- \\
-\end{array}$ & $\begin{array}{l}1961 \\
1962\end{array}$ & $\begin{array}{l}0.2046 \\
0.2077 \\
0.2154 \\
0.2192 \\
0.2224\end{array}$ \\
\hline $\begin{array}{l}1966 \quad \ldots \ldots \ldots \ldots \\
1967 \quad \ldots \ldots \ldots \ldots \\
1968 \ldots \ldots \ldots \ldots \\
1969 \ldots \ldots \ldots \ldots \\
1970 \quad \ldots \ldots \ldots \ldots\end{array}$ & $\begin{array}{l}25.7 \\
26.6 \\
27.7 \\
29.0 \\
30.6\end{array}$ & $\begin{array}{l}32.4 \\
33.4 \\
34.8 \\
36.7 \\
38.8\end{array}$ & 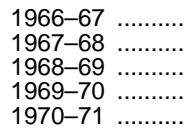 & $\begin{array}{l}32.9 \\
34.0 \\
35.7 \\
37.8 \\
39.7\end{array}$ & $\begin{array}{l}32.9 \\
34.9 \\
37.1 \\
39.5 \\
42.1\end{array}$ & $\begin{array}{l}33.8 \\
35.7 \\
38.0 \\
40.3 \\
42.7\end{array}$ & $\begin{array}{l}- \\
- \\
-\end{array}$ & $\begin{array}{l}1966 \ldots \ldots \ldots . . \\
1967 \ldots \ldots \ldots . . \\
1968 \ldots \ldots \ldots \ldots \\
1969 \ldots \ldots \ldots . . \\
1970 \ldots \ldots \ldots . . .\end{array}$ & $\begin{array}{l}0.2293 \\
0.2365 \\
0.2465 \\
0.2597 \\
0.2753\end{array}$ \\
\hline 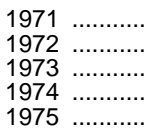 & $\begin{array}{l}32.1 \\
33.5 \\
35.4 \\
38.5 \\
42.2\end{array}$ & $\begin{array}{l}40.5 \\
41.8 \\
44.4 \\
49.3 \\
53.8\end{array}$ & 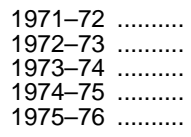 & $\begin{array}{l}41.2 \\
42.8 \\
46.6 \\
51.8 \\
55.5\end{array}$ & $\begin{array}{l}44.3 \\
46.7 \\
49.9 \\
54.3 \\
57.8\end{array}$ & $\begin{array}{l}45.0 \\
47.1 \\
50.1 \\
54.8 \\
59.0\end{array}$ & $\frac{-}{-}$ & 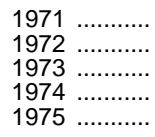 & $\begin{array}{l}0.2925 \\
0.3118 \\
0.3277 \\
0.3454 \\
0.3545\end{array}$ \\
\hline $\begin{array}{l}1976 \quad \ldots \ldots \ldots \ldots \\
1977 \ldots \ldots \ldots \\
1978 \ldots \ldots \ldots \\
1979 \ldots \ldots \ldots \\
1980 \ldots \ldots \ldots . . . \\
\end{array}$ & $\begin{array}{l}44.6 \\
47.5 \\
50.9 \\
55.3 \\
60.4\end{array}$ & $\begin{array}{l}56.9 \\
60.6 \\
65.2 \\
72.6 \\
82.4\end{array}$ & 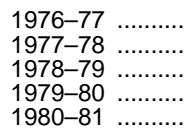 & $\begin{array}{l}58.7 \\
62.6 \\
68.5 \\
77.6 \\
86.6\end{array}$ & $\begin{array}{l}61.5 \\
65.7 \\
70.5 \\
77.5 \\
85.8\end{array}$ & $\begin{array}{l}62.7 \\
66.8 \\
71.7 \\
78.3 \\
86.6\end{array}$ & $\begin{array}{l}61.6 \\
65.8 \\
71.4 \\
78.5 \\
86.1\end{array}$ & $\begin{array}{l}1976 \ldots \ldots \ldots \ldots \\
1977 \ldots \ldots \ldots \ldots \\
1978 \ldots \ldots \ldots \ldots \\
1979 \ldots \ldots \ldots \ldots \\
1980 \ldots \ldots \ldots \ldots\end{array}$ & $\begin{array}{l}0.4196 \\
0.4539 \\
0.4855 \\
0.5265 \\
0.5817\end{array}$ \\
\hline 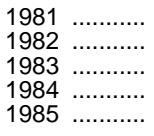 & $\begin{array}{l}66.1 \\
70.2 \\
73.2 \\
75.9 \\
78.6\end{array}$ & $\begin{array}{r}90.9 \\
96.5 \\
99.6 \\
103.9 \\
107.6\end{array}$ & 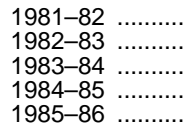 & $\begin{array}{r}94.1 \\
98.2 \\
101.8 \\
105.8 \\
108.8\end{array}$ & $\begin{array}{r}93.9 \\
100.0 \\
104.8 \\
110.8 \\
116.3\end{array}$ & $\begin{array}{r}94.0 \\
100.0 \\
104.3 \\
109.8 \\
115.2\end{array}$ & $\begin{array}{r}94.0 \\
100.0 \\
105.1 \\
111.2 \\
117.6\end{array}$ & $\begin{array}{l}1981 \ldots \ldots \ldots . . \\
1982 \ldots \ldots \ldots \ldots \\
1983 \ldots \ldots \ldots \ldots \\
1984 \ldots \ldots \ldots \ldots \\
1985 \ldots \ldots \ldots . . \\
\ldots\end{array}$ & $\begin{array}{l}0.6421 \\
0.6867 \\
0.7198 \\
0.7544 \\
0.7828\end{array}$ \\
\hline $\begin{array}{l}1986 \quad \ldots \ldots \ldots \ldots \\
1987 \ldots \ldots \ldots \ldots \\
1988 \ldots \ldots \ldots \ldots \\
1989 \ldots \ldots \ldots \ldots \\
1990 \ldots \ldots \ldots \ldots\end{array}$ & $\begin{array}{l}80.6 \\
83.1 \\
86.1 \\
89.7 \\
93.6\end{array}$ & $\begin{array}{l}109.6 \\
113.6 \\
118.3 \\
124.0 \\
130.7\end{array}$ & 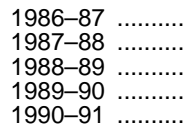 & $\begin{array}{l}111.2 \\
115.8 \\
121.2 \\
127.0 \\
133.9\end{array}$ & $\begin{array}{l}120.9 \\
126.1 \\
132.8 \\
140.8 \\
148.2\end{array}$ & $\begin{array}{l}120.0 \\
126.8 \\
132.1 \\
139.0 \\
145.8\end{array}$ & $\begin{array}{l}124.2 \\
130.0 \\
138.6 \\
147.4 \\
155.7\end{array}$ & $\begin{array}{l}1986 \ldots \ldots \ldots . . \\
1987 \ldots \ldots \ldots . . \\
1988 \ldots \ldots \ldots \ldots \\
1989 \ldots \ldots \ldots \ldots \\
1990 \ldots \ldots \ldots \ldots\end{array}$ & $\begin{array}{l}0.8049 \\
0.8271 \\
0.8544 \\
0.8901 \\
0.9257\end{array}$ \\
\hline 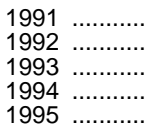 & $\begin{array}{r}97.3 \\
100.0 \\
102.6 \\
105.1 \\
107.5\end{array}$ & $\begin{array}{l}136.2 \\
140.3 \\
144.5 \\
148.2 \\
152.4\end{array}$ & 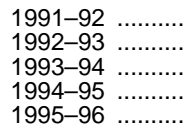 & $\begin{array}{l}138.2 \\
142.5 \\
146.2 \\
150.4 \\
154.5\end{array}$ & $\begin{array}{l}153.5 \\
158.0 \\
163.3 \\
168.3 \\
173.3\end{array}$ & $\begin{array}{l}150.6 \\
155.2 \\
160.1 \\
165.4 \\
170.8\end{array}$ & $\begin{array}{l}163.3 \\
169.8 \\
176.7 \\
183.9 \\
192.6\end{array}$ & $\begin{array}{l}1991 \ldots \ldots \ldots \ldots \\
1992 \ldots \ldots \ldots \ldots \\
1993 \ldots \ldots \ldots \ldots \\
1994 \ldots \ldots \ldots \ldots \\
1995 \quad \ldots \ldots \ldots \ldots . . .\end{array}$ & $\begin{array}{l}0.9695 \\
1.0000 \\
1.0252 \\
1.0495 \\
1.0767\end{array}$ \\
\hline $\begin{array}{l}1996 \quad \ldots \ldots \ldots \ldots \\
1997 \quad \ldots \ldots \ldots \ldots . . \\
1998 \ldots \ldots \ldots . .\end{array}$ & $\begin{array}{r}109.5 \\
111.6 \\
\end{array}$ & $\begin{array}{l}156.9 \\
160.5 \\
163.0\end{array}$ & $\begin{array}{l}1996-97 \\
1997-98 \ldots \ldots \ldots \\
1998-99\end{array}$ & $\begin{array}{r}158.9 \\
161.7 \\
-\end{array}$ & - & - & - & $\begin{array}{l}1996 \ldots \ldots \ldots . . \\
1997 \ldots \ldots \ldots . . \\
1998 \ldots \ldots \ldots . .\end{array}$ & $\begin{array}{l}1.1052 \\
1.1324 \\
1.1574\end{array}$ \\
\hline
\end{tabular}

1 Index for urban wage earners and clerical workers through 1977; 1978 and later figures are for all urban consumers.

${ }^{2}$ Consumer Price Index adjusted to a school-year basis (July through June).

-Data not available.

NOTE.-Some data have been revised from previously published figures.
SOURCE: Council of Economic Advisers, Economic Indicators, February 1991 and September 1998, and Economic Report of the President, February 1999; U.S. Department of Labor, Bureau of Labor Statistics, Consumer Price Index; Research Associates of Washington, "Inflation Measures for Schools and Colleges, 1990 Update," and unpublished data; and U.S. Office of Management and Budget, Budget of the U.S. Government, Fiscal Year 1999. (This table was prepared February 1999.) 



\section{CHAPTER 2}

\section{Elementary and Secondary Education}

This chapter contains a variety of statistics on public and private elementary and secondary education. Data are presented for enrollments, teachers, schools, student performance, graduates, and expenditures. These data are derived from surveys conducted by the National Center for Education Statistics (NCES) and other public and private organizations. The variety of information ranges from simple counts of students and schools, to opinions of teachers and students concerning the state of education today.

\section{Enrollments}

Public elementary and secondary school enrollments increased by 15 percent from 1987 to 1997 , but when examined separately, enrollment at the elementary and secondary levels exhibited different patterns. Between 1987 and 1997, public elementary enrollment rose by 18 percent, while secondary enrollment increased by 8 percent. Secondary enrollment declined during the beginning of this period (tables 3 and 39).

Preprimary education enrollment has grown substantially. Between 1987 and 1997, preprimary enrollment of 3- to 5-year-olds rose by 33 percent. An important feature of the increasing participation of young children in preprimary schools is the increasing proportion in full-day programs. In 1997 about 50 percent of the children attended school all day compared with 35 percent in 1987 (table 46).

Slightly increasing numbers and proportions of children are being served in programs for the disabled. During the 1980-81 school year, 10 percent of students were served in these programs compared with 13 percent in 1996-97. Much of the rise since 1980 81 may be attributed to the increasing proportion of children identified as learning disabled, which rose from 4 percent of enrollment in 1980-81 to 6 percent of enrollment in 1996-97 (table 53).

\section{Tuition at Private Schools}

The average full tuition (highest tuition charged) for private schools was $\$ 3,116$ in 1993-94. Schools with religious orientation charged significantly lower tuition than nonsectarian schools. Students at Catholic schools paid $\$ 2,178$ on average and students at schools with other religious orientations paid $\$ 2,915$ on average, compared with the average tuition of $\$ 6,631$ for nonsectarian private schools. Mean tuition paid for private elementary school students was lower than that paid by other schools' students, with Catholic school students paying $\$ 1,628$. Students at schools with other religious orientations paid $\$ 2,606$, and students at nonsectarian schools paid $\$ 4,693$. Mean tuition paid for private secondary school students was substantially higher than that for private elementary school students, averaging $\$ 3,643$ at Catholic schools, $\$ 5,261$ at other religiously oriented schools, and $\$ 9,525$ at nonsectarian schools (table $62)$.

\section{Teachers and Other School Staff}

During the 1970s and early 1980s, public school enrollment decreased, while the number of teachers rose. As a result, the pupil/teacher ratio fell from 22.3 in 1970 to 17.9 in 1985. After 1985, the number of pupils per teacher continued downward, reaching 17.2 in 1990. Between 1990 and 1998, enrollment rose at about the same rate as the number of teachers, and the pupil/teacher ratio was estimated at 17.2 in fall 1998 (table 65).

In 1993-94, 73 percent of public school teachers were women, 33 percent were under 40, and more than 47 percent had a master's degree or above. By comparison, about 75 percent of the 378,000 fulltime and part-time private school teachers were women. About 42 percent of the private school teachers were under age 40 , and 34 percent had a master's or higher degree (table 68).

Principals tended to be older and have higher level credentials than teachers. Also, they were more likely to be male. About 7 percent of the public school principals were under age 40 and 99 percent had a master's degree or above. About 35 percent of the principals were women (table 88).

In general, public school teachers have higher salaries than private school teachers. In 1993-94, the average base salary for public school teachers was $\$ 34,153$, compared with $\$ 21,968$ for private school teachers (table 74). The average salary for public school teachers grew slowly during the 1990s, reaching $\$ 39,385$ in 1997-98. After adjustment for infla- 
tion, teachers' salaries rose one percent between 1987-88 and 1997-98 (table 78).

The number of nonteaching staff employed by public schools grew at a faster rate than the number of pupils and teachers in the 1970s. During the 1970s, the proportion of the total staff who were teachers declined from 60 percent to 52 percent in fall 1980 . From the 1980s through the mid-1990s, the number of teachers grew at about the same rate as other public school staff. In 1980, there were 9.8 pupils per staff member (total staff) compared with 8.9 pupils per staff member in 1996. In 1993-94, the number of pupils per staff member at private schools was 9.3 (tables 61 and 83).

\section{Schools}

Over the past several decades, the trend to consolidate small schools has brought a large decline in the total number of public schools in the United States. In 1930, there were more than 262,000 public schools, compared with around 88,000 today. But this number has grown in recent years, with an increase of about 4,800 schools between 1989-90 and 1996-97 (table 90).

The shift in structure of public school systems toward middle schools (grades 4,5 , or 6 to 6,7 , or 8 ) is continuing. The number of elementary schools rose by 5 percent to 62,000 between 1986-87 and 1996-97, but middle schools accounted for a disproportionate share of this increase, rising by 41 percent. Meanwhile, the number of junior high schools (grades 7 to 8 and 7 to 9 ) declined by 28 percent (table 96).

Elementary enrollment has risen faster than the number of schools, with the average elementary school size increasing as a result. Elementary schools grew from an average of 403 students in 1984-85 to 478 in 1996-97. During the same time period, the average secondary school size fell from 721 to 703 . To some extent, the average size of secondary schools has been affected by increasing numbers of alternative schools, which tend to be small. Schools tend to be smaller in predominantly rural states, such as Nebraska, South Dakota, and Montana, and larger in states with large urban populations, such as California, Hawaii, and Florida (tables 97, 99, and 100).

\section{Completions and Achievement}

The dropout rate among 16- to 24-year-olds (which counts GED recipients and special program completers as graduates) suggests some improvements have been made over the past 20 years. This dropout rate includes all persons in the 16- to 24year-old age group regardless of when they dropped out. Between 1977 and 1987, the dropout rate fell from 14.1 percent to 12.6 percent. The dropout rate for 1997 was 11.0, which is lower than the 1987 figure. The dropout rate statistic is based on the civilian noninstitutionalized population, which excludes persons in prisons and persons not living in households (table 103). Comparisons of the number of public and private high school graduates with the 17-yearold population suggest that the proportion of young people earning regular high school diplomas has not increased over the past 20 years. At its highest point in 1968-69, there were 77 graduates for every 100 persons 17 years of age. This ratio declined during the 1970s, falling to 71 in 1979-80. The ratio has fluctuated since then and was 69 in 1997-98. This indicator is not a completion rate, however, because many students complete their high school education through alternative programs, such as night schools and the General Educational Development (GED) program (tables 101 and 104).

Student achievement has improved in a number of areas. An overall increase was seen in reading proficiency scores for 9- and 13-year-olds since 1971, with 17-year-olds scoring about the same in 1996 as in 1971. After significant gains during the 1970s, 9year-old reading proficiency fell during the 1980 s, but the 1996 score remained above the 1971 level. The increase in reading ability was reflected by higher average proficiencies in other subjects for 9- and 13year-old students. Significant gaps in performance continue to exist between racial/ethnic subgroups and between male and female students. Gender gaps favoring female students in reading were essentially the same in 1996 as in 1971 (table 109).

The results of assessments in average writing achievement from 1984 to 1996 reveal a shift at grades 4 and 8 . After declining between 1984 and 1990, average performance at grade 8 increased, and by 1996 had again returned to the earlier level. Also, at grade 4 there was an increase in performance between 1990 and 1996, countering downward fluctuations in the 1980s, so that performance was essentially unchanged between 1984 and 1996. Overall grade 11 writing performance declined between 1984 and 1996. Females outperformed males at the 4th, 8th, and 11th grade levels (table 115).

Results from national assessments of mathematics achievement indicated a significant improvement at ages 9 and 13, between 1973 and 1996. Performance of 17-year-olds declined between 1973 and 1982, but an upturn during the following decade returned average performance back up to 1973 levels. For 9-, 13-, and 17-year-olds, there were increases in average mathematics proficiency between 1986 and 1996, including increases among black and Hispanic 9- and 17-year-olds. Gender gaps in mathematics among 17-year-olds narrowed between 1973 and 1996. However, the gap among 9- and 13-year- 
olds favoring females in 1973 reversed, and in 1996 the gap favored males (table 120).

Average science proficiency increased for 9-, 13-, and 17-year-old black students between 1970 and 1996. Although the average science proficiency of white students at all three age groups (ages 9, 13, and 17) remained significantly higher than the average proficiencies of black and Hispanic students, there was some evidence of gaps narrowing between 1970 and 1996. The performance gap between white and black students decreased for 9-year-olds and 13-year-olds between 1970 and 1996, but the gaps for 17-year-olds remained about the same. The performance gaps among white and Hispanic 9- and 17year-olds was about the same in 1996 as they were in 1977 (table 128). Gender gaps favoring 9-year-old and 13-year-old males in science did not narrow significantly between 1970 and 1996, but there was a narrowing of the gap between 17-year-old males and females (table 128).

The Scholastic Assessment Test (SAT, formerly known as the Scholastic Aptitude Test) was not designed as an indicator of student achievement, but rather to help predict how well students will do in college. Between 1986-87 and 1996-97, mathematics SAT scores increased by 10 points, while verbal scores fell by 2 points (table 131).

Over the past 12 years, the average number of science and mathematics courses completed by public high school graduates increased substantially. The mean number of mathematics courses (Carnegie units) completed in high school rose from 2.6 in 1982 to 3.4 in 1994, and the number of science courses rose from 2.2 to 3.0. The average number of courses in vocational-technical areas completed by all high school graduates dropped gradually, from 4.7 units in 1982 to 3.9 units in 1994. As a result of the increased academic course load, the proportion of students completing the recommendations of the $\mathrm{Na}$ tional Commission on Excellence (4 units of English, 3 units of social studies, 3 units of science, 3 units of mathematics, and .5 units of computer science) rose from 3 percent in 1982 to 32 percent in 1994 (tables 136 and 139).

\section{Drugs and Violence}

Twelfth-grade students at public schools were less likely to feel safe at school and were more likely to report fights between racial/ethnic groups and gangs at school than students at Catholic and other private schools. About 10 percent of all 1992 high school seniors reported that they did not feel safe at school and 23 percent reported that there were often fights between different racial/ethnic groups (table 142). The proportion of public and private high school seniors who reported ever using an illicit drug rose from 55 percent in 1975 to 66 percent in 1981. After 1981, the proportion of seniors who had ever used drugs fell. After reaching 41 percent in 1992, the proportion rose again to 51 percent in 1996. Also, the proportion of high school seniors who had ever used cocaine fell from 17 percent in 1985 to 7 percent in 1996. Alcohol remained the most often used drug. The proportion of seniors who had used alcohol within the previous 30 days declined from 72 percent in 1980 to 51 percent in 1996 (table 150).

\section{Resources and Expenditures}

The state share of revenues for public elementary and secondary schools had grown steadily for many decades, but this trend began to reverse in the late 1980s. Between 1986-87 and 1995-96, the state share declined from 49.7 percent of all revenues to 47.5 percent, while the local share rose from 43.9 percent to 45.9 percent. The federal share was 6.6 percent in 1995-96, after fluctuating slightly over the period (table 157).

The expenditure per student in public schools rose significantly during the late 1980 s, but increased more slowly during the first part of the 1990s. Between 1985-86 and 1990-91, current expenditures per student in average daily attendance grew 14 percent, after adjustment for inflation. From 1990-91 to 1997-98, expenditures per student grew by 4 percent. In 1997-98, the estimated current expenditure per student in average daily attendance was $\$ 6,624$ (table 169). 
Figure 7.-Preprimary enrollment of 3- to 5-year-olds, by attendance status: October 1970 to October 1997

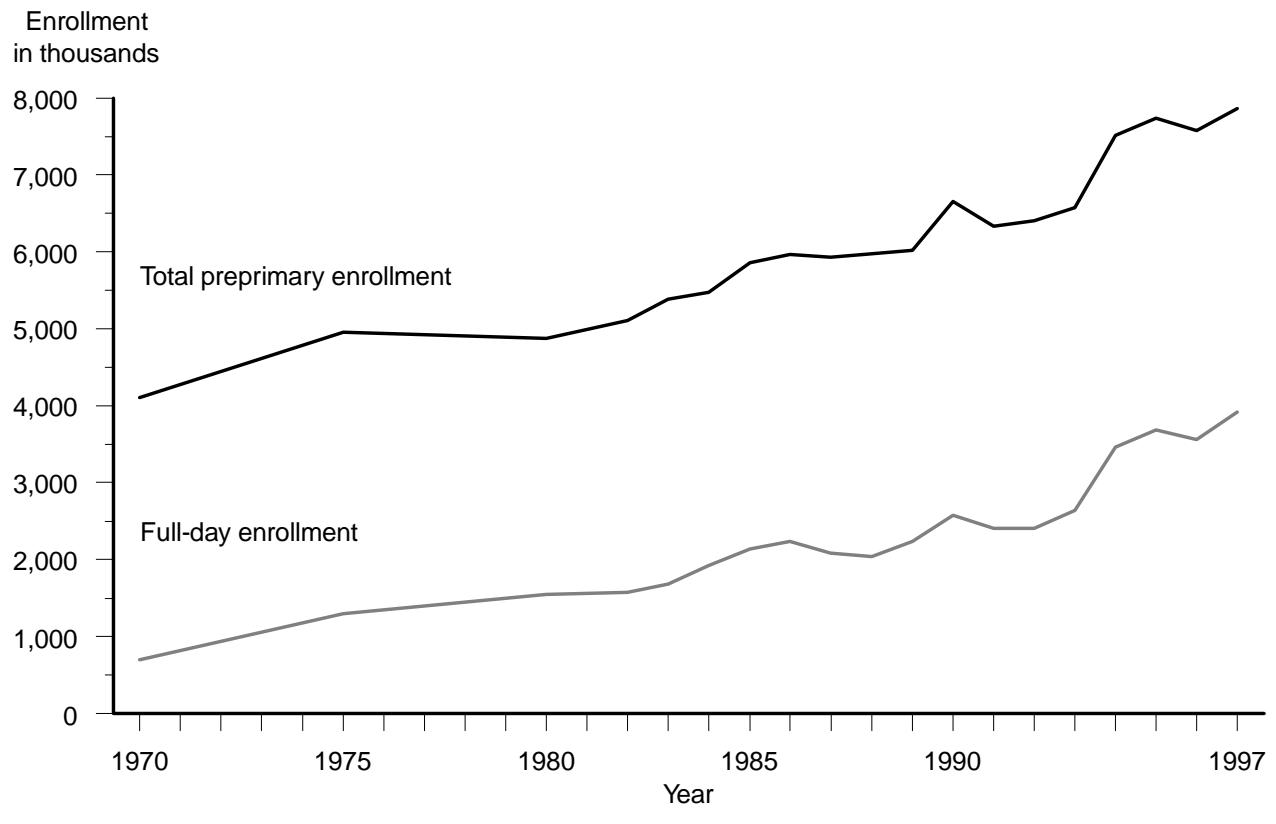

NOTE._Data for 1994 and later years were collected using new procedures and may not be comparable with figures for earlier years.

SOURCE: U.S. Department of Education, National Center for Education Statistics, Preprimary Enrollment, various years; and U.S. Department of Commerce, Bureau of the Census, Current Population Survey, unpublished data. 
Figure 8.-Enrollment, number of teachers, pupil/teacher ratios, and expenditures in public schools: $1960-61$ to $1997-98$

Fall enrollment,

in millions

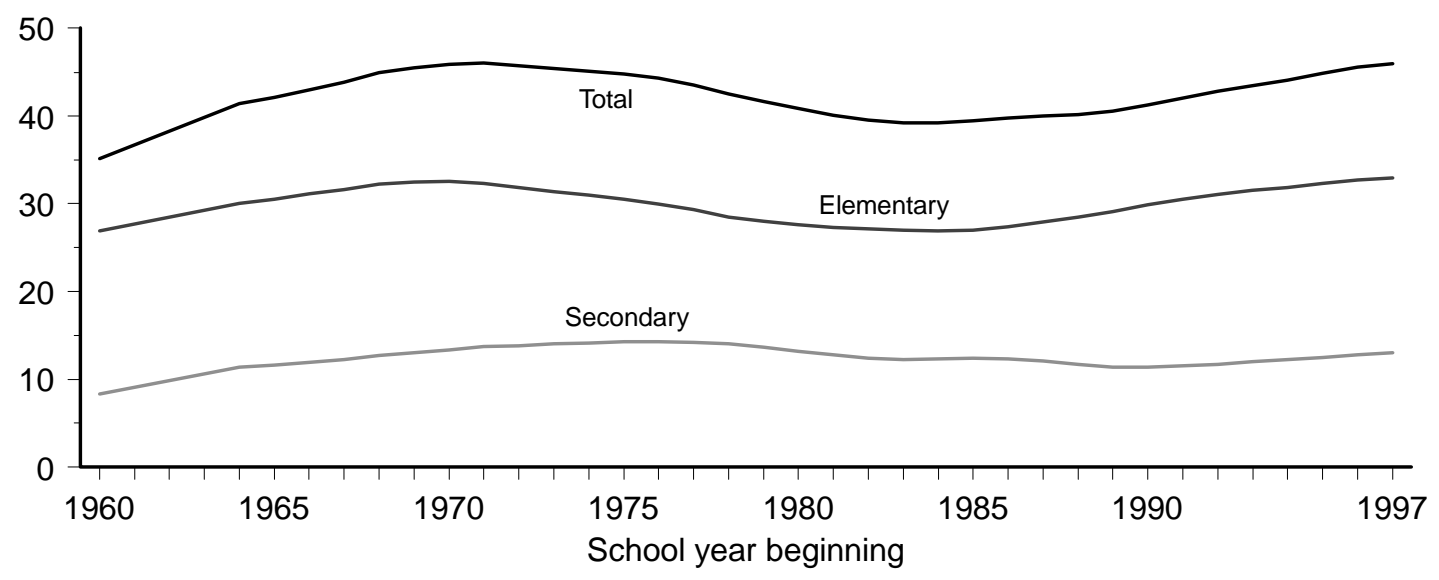

Teachers,

in thousands

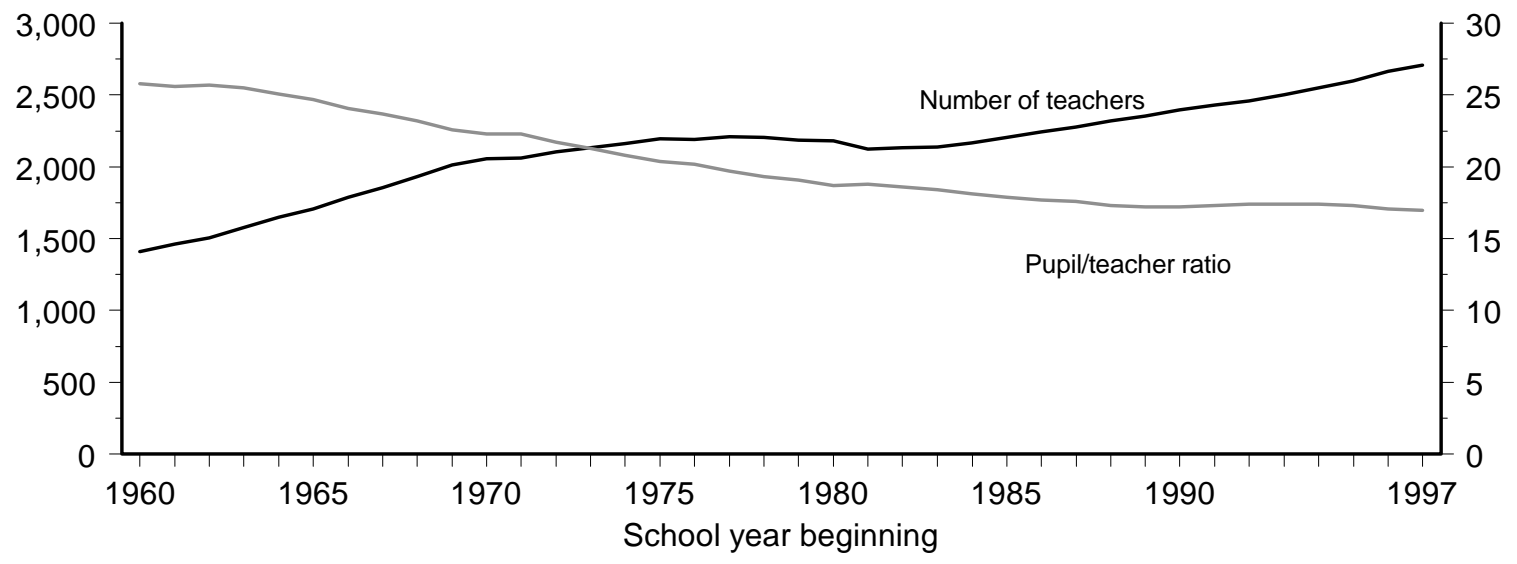

Current expenditures,

in billions

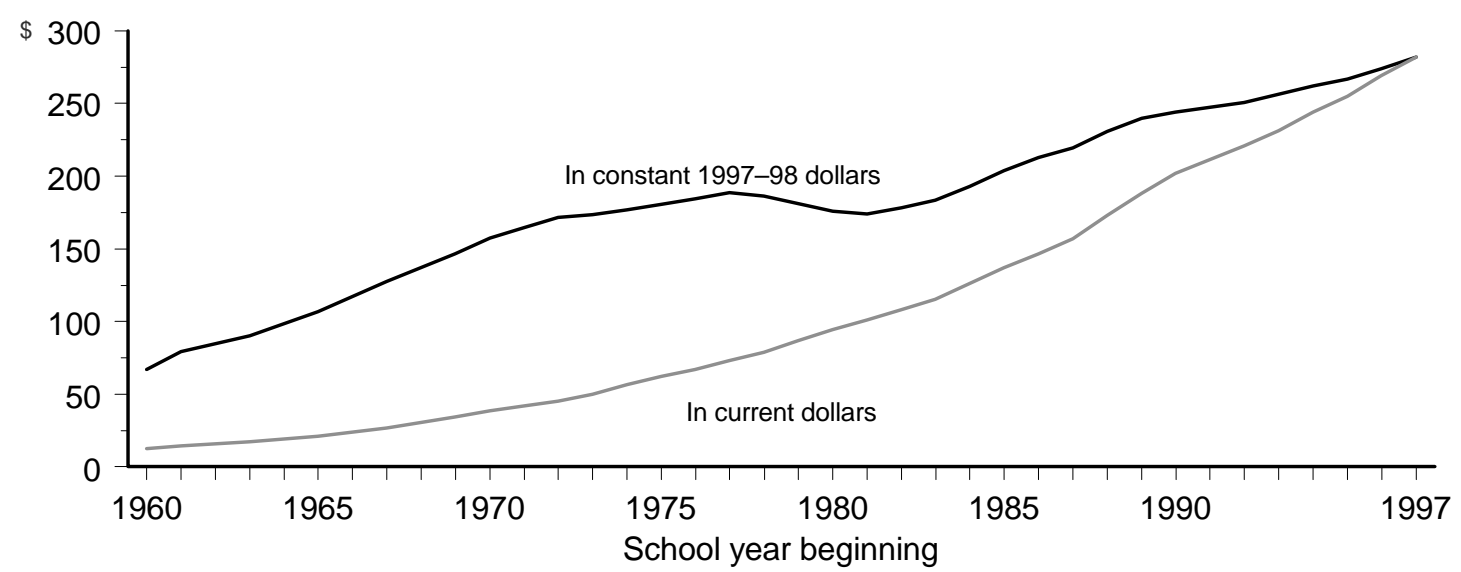

SOURCE: U.S. Department of Education, National Center for Education Statistics, Statistics of State School Systems; Statistics of Public Elementary and Secondary School Systems; Revenues and Expenditures for Public Elementary and Secondary Education; and Common Core of Data surveys. 
Figure 9.-Percentage change in public elementary and secondary enrollment, by state: Fall 1992 to fall 1997

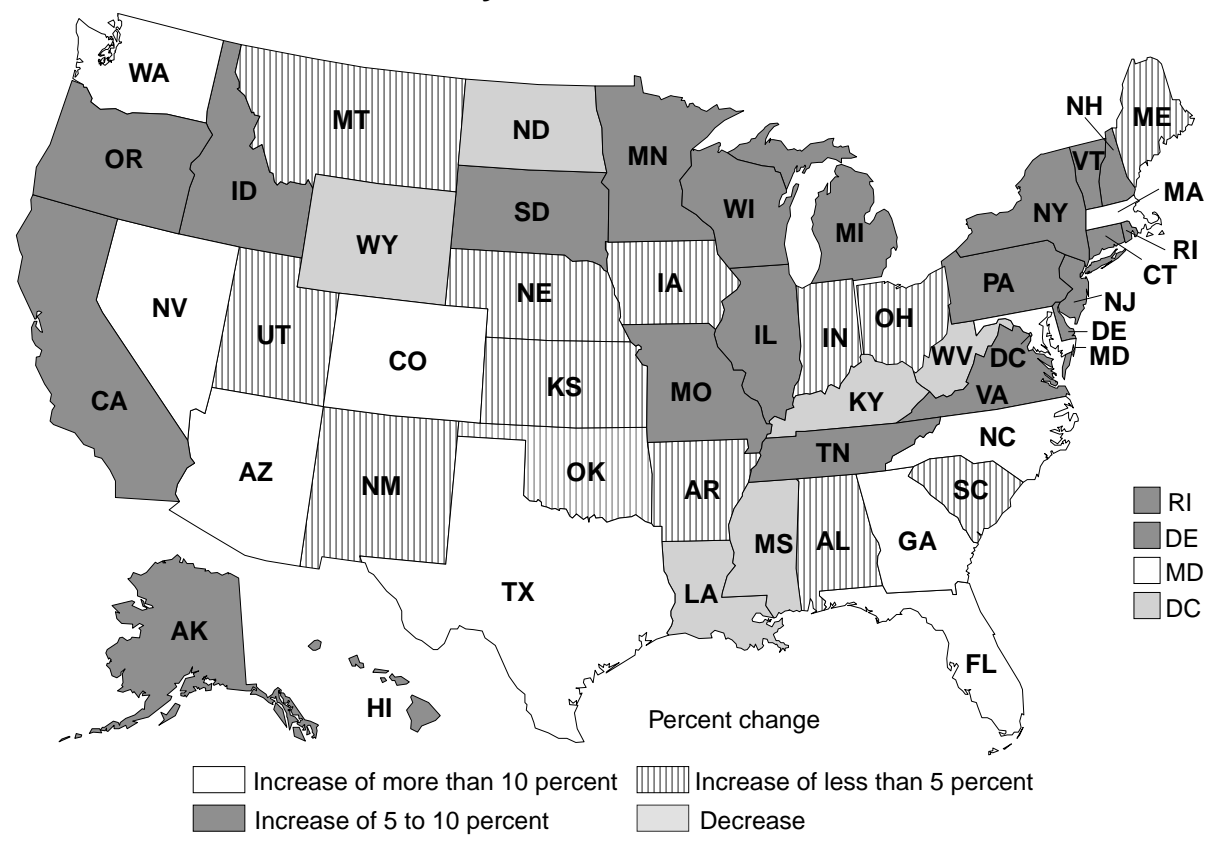

SOURCE: U.S. Department of Education, National Center for Education Statistics, Common Core of Data surveys.

Figure 10.-Average annual salary for public elementary and secondary school teachers: $1969-70$ to 1997-98

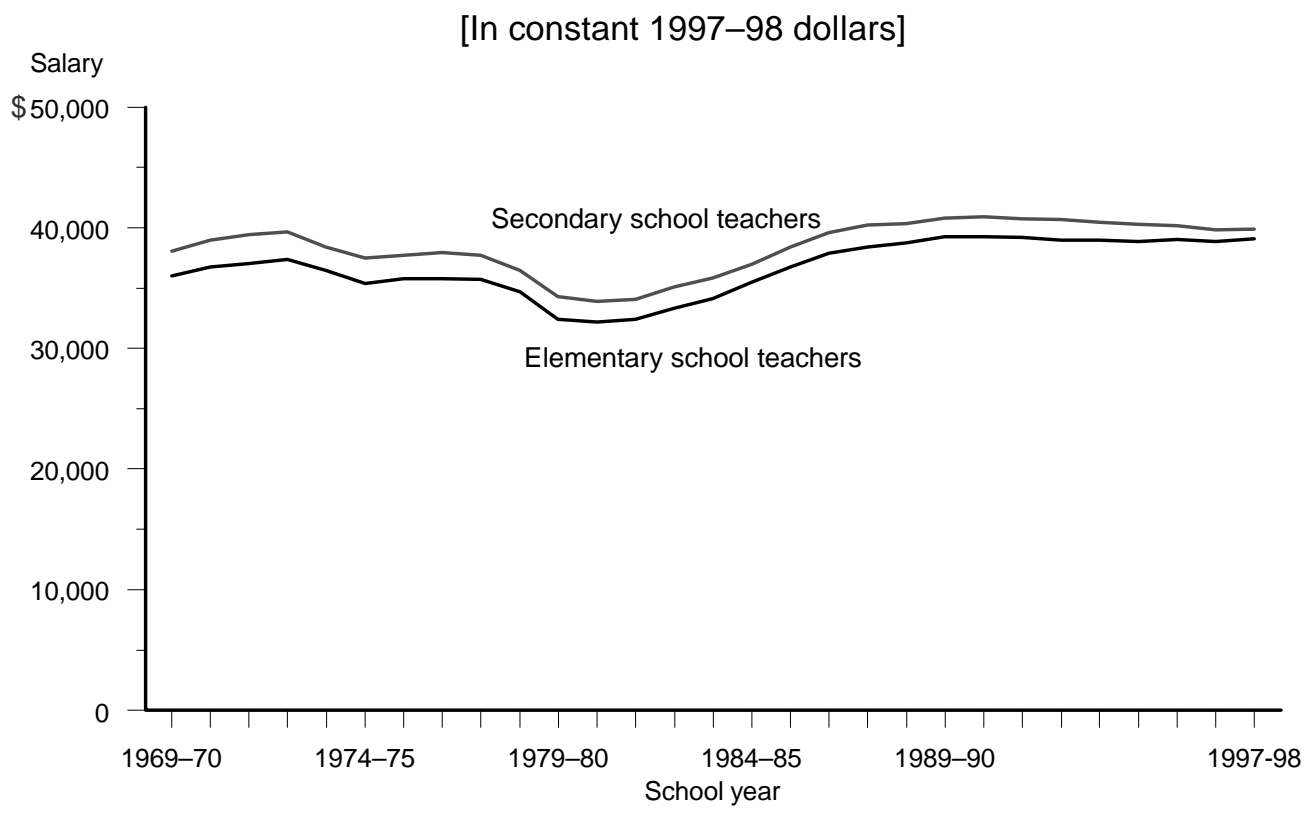

SOURCE: National Education Association, Estimates of School Statistics, latest edition 1997-98. Copyright 1998 by the National Education Association. (All rights reserved.) 
Figure 11.-Sources of revenue for public elementary and secondary schools: $1970-71$ to $1995-96$

Percent of revenue

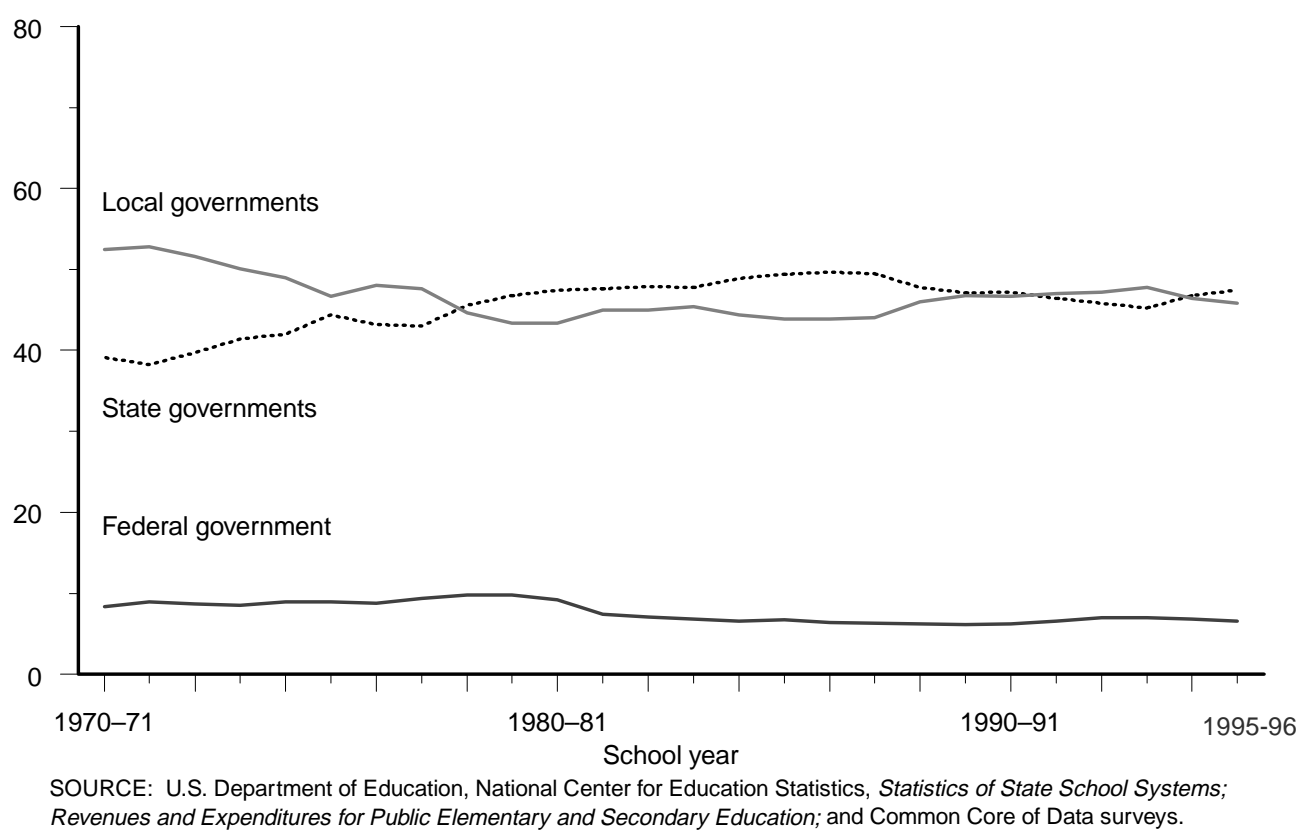

\section{Figure 12.-Current expenditure per pupil in average daily attendance} in public elementary and secondary schools: $1970-71$ to $1997-98$ Per pupil expenditure

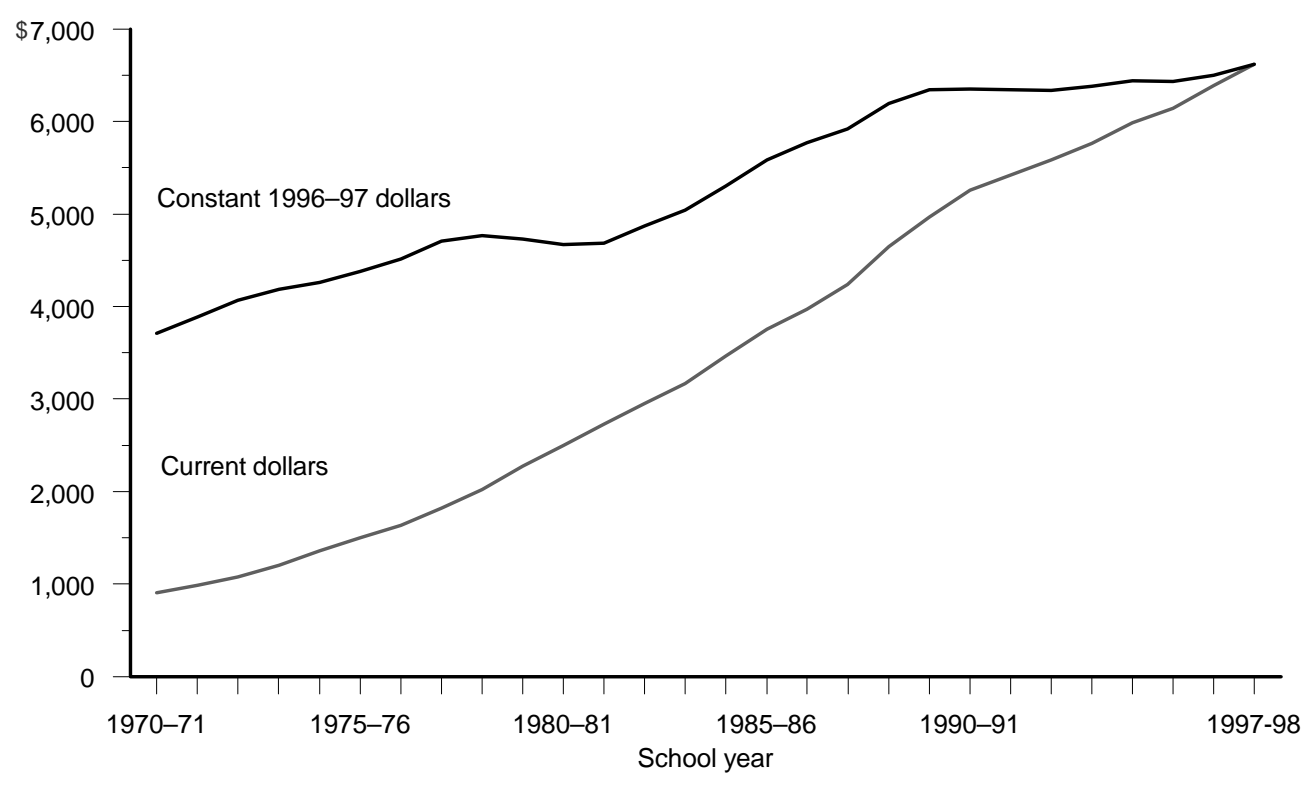

SOURCE: U.S. Department of Education, National Center for Education Statistics, Statistics of State School Systems; Revenues and Expenditures for Public Elementary and Secondary Education; and Common Core of Data surveys. 
Table 39.-Historical summary of public elementary and secondary school statistics: 1869-70 to 1995-96

\begin{tabular}{|c|c|c|c|c|c|c|c|c|c|c|c|c|c|c|c|c|}
\hline Item & $1869-70$ & $1879-80$ & $1889-90$ & $\begin{array}{l}1899- \\
1900\end{array}$ & $1909-10$ & 1919-20 & $1929-30$ & $1939-40$ & $1949-50$ & $1959-60$ & $1969-70$ & $1979-80$ & $1989-90$ & $1990-91$ & $1994-95$ & $1995-96$ \\
\hline 1 & 2 & 3 & 4 & 5 & 6 & 7 & 8 & 9 & 10 & 11 & 12 & 13 & 14 & 15 & 16 & 17 \\
\hline \multicolumn{17}{|l|}{$\begin{array}{l}\text { Population, pupils, and instructional } \\
\text { staff }\end{array}$} \\
\hline Total population, ${ }^{1}$ in thousands ..................... & 38,558 & 50,156 & 62,622 & 75,995 & 90,490 & 104,514 & 121,878 & 131,028 & 149,188 & 177,830 & 201,385 & 224,567 & 246,819 & 249,440 & 260,292 & 262,761 \\
\hline $\begin{array}{l}\text { Population aged 5-17 years, }, \text { in thousands } \\
\text { Percent of total population 5-17 }\end{array}$ & $\begin{array}{r}11,683 \\
30.3\end{array}$ & $\begin{array}{r}15,066 \\
30.0\end{array}$ & $\begin{array}{r}18,473 \\
29.5\end{array}$ & $\begin{array}{r}21,573 \\
28.4\end{array}$ & $\begin{array}{r}24,011 \\
26.5\end{array}$ & $\begin{array}{r}27,571 \\
26.4\end{array}$ & $\begin{array}{r}31,414 \\
25.8\end{array}$ & $\begin{array}{r}30,151 \\
23.0\end{array}$ & $\begin{array}{r}30,223 \\
20.3\end{array}$ & $\begin{array}{r}43,881 \\
24.7\end{array}$ & $\begin{array}{r}52,386 \\
26.0\end{array}$ & $\begin{array}{r}48,041 \\
21.4\end{array}$ & $\begin{array}{r}44,947 \\
18.2\end{array}$ & $\begin{array}{r}45,312 \\
18.2\end{array}$ & $\begin{array}{r}48,110 \\
18.5\end{array}$ & $\begin{array}{r}48,911 \\
18.6\end{array}$ \\
\hline $\begin{array}{l}\text { Total enrollment in elementary and } \\
\text { secondary schools, in thousands }{ }^{2} \ldots \ldots \ldots . .\end{array}$ & ${ }^{3} 7,562$ & 9,867 & 12,723 & 15,503 & 17,814 & 21,578 & 25,678 & 25,434 & 25,112 & 36,087 & 45,550 & 41,651 & 40,543 & 41,217 & 44,111 & 44,840 \\
\hline 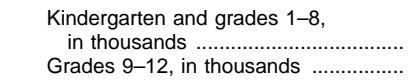 & $\begin{array}{r}37,481 \\
380\end{array}$ & $\begin{array}{r}9,757 \\
110\end{array}$ & $\begin{array}{r}12,520 \\
203\end{array}$ & $\begin{array}{r}14,984 \\
519\end{array}$ & $\begin{array}{r}16,899 \\
915\end{array}$ & $\begin{array}{r}19,378 \\
2,200\end{array}$ & $\begin{array}{r}21,279 \\
4,399\end{array}$ & $\begin{array}{r}18,833 \\
6,601\end{array}$ & $\begin{array}{r}19,387 \\
5,725\end{array}$ & $\begin{array}{r}27,602 \\
8,485\end{array}$ & $\begin{array}{l}32,513 \\
13,037\end{array}$ & $\begin{array}{l}28,034 \\
13,616\end{array}$ & $\begin{array}{l}29,152 \\
11,390\end{array}$ & $\begin{array}{l}29,878 \\
11,338\end{array}$ & $\begin{array}{l}31,898 \\
12,213\end{array}$ & $\begin{array}{l}32,341 \\
12,500\end{array}$ \\
\hline $\begin{array}{l}\text { Enrollment as a percent of total population } \\
\text { Enrollment as a percent of } 5 \text { - to }\end{array}$ & 319.6 & 19.7 & 20.3 & 20.4 & 19.7 & 20.6 & 21.1 & 19.4 & 16.8 & 20.3 & 22.6 & 18.5 & 16.4 & 16.5 & 16.9 & 17.1 \\
\hline $\begin{array}{l}17 \text {-year-olds .................................... } \\
\text { Pert of total enrollment in hia schools }\end{array}$ & ${ }^{3} 64.7$ & 65.5 & 68.9 & 71.9 & 74.2 & 78.3 & 81.7 & 84.4 & 83.1 & 82.2 & 87.0 & 86.7 & 90.2 & 91.0 & 91.7 & 91.7 \\
\hline $\begin{array}{l}\text { enroolment in nign scrools } \\
\text { tand postgraduate) ............ }\end{array}$ & з 1.1 & 1.1 & 1.6 & 3.3 & 5.1 & 10.2 & 17.1 & 26.0 & 22.8 & 23.5 & 28.6 & 32.7 & 28.1 & 27.5 & 27.7 & 27.9 \\
\hline High school graduates, in thousands .......... & & & 22 & 62 & 111 & 231 & 592 & 1,143 & 1,063 & 1,627 & 2,589 & 2,748 & 2,320 & 2,235 & 2,274 & 2,281 \\
\hline Average daily attendance, in th & 4,077 & 6,144 & 8,154 & 10,633 & 12,827 & 16,150 & 21,265 & 22,042 & 22,284 & 32,477 & 41,934 & 38,289 & 37,799 & 38,427 & 40,721 & 41,502 \\
\hline $\begin{array}{l}\text { lotal number of days a } \\
\text { enrolled, in millions. }\end{array}$ & 539 & 801 & 1,098 & 1,535 & 2,011 & 2,615 & 3,673 & 3,858 & 3,964 & 5,782 & 7,501 & 46,835 & - & - & - & - \\
\hline Percent of enrolled pupils attending daily & 59.3 & 62.3 & 64.1 & 68.6 & 72.1 & 74.8 & 82.8 & 86.7 & 88.7 & 90.0 & 90.4 & 490.1 & - & - & - & - \\
\hline Average length of school term, & 132.2 & 130.3 & 134.7 & 144.3 & 157.5 & 161.9 & 172.7 & 175.0 & 177.9 & 178.0 & 178.9 & 4178.5 & - & 179.8 & - & - \\
\hline $\begin{array}{l}\text { Average number of days attended per } \\
\text { pupil }\end{array}$ & 78.4 & 81.1 & 86.3 & 99.0 & 113 & 121.2 & 143 & 151.7 & 157.9 & 160.2 & 161.7 & 4160.8 & - & - & - & - \\
\hline Total instructional staff, in thousands .......... & - & - & - & - & - & 678 & 880 & 912 & 963 & 1,457 & 2,286 & 2,406 & 2,986 & 3,051 & 3,281 & 3,352 \\
\hline $\begin{array}{l}\text { Supervisors, in thousands } \\
\text { Principals, in thousands }\end{array}$ & - & 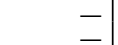 & $=$ & $z$ & - & $\begin{array}{r}7 \\
14\end{array}$ & $\begin{array}{r}7 \\
31\end{array}$ & $\begin{array}{r}5 \\
32\end{array}$ & $\overline{43}$ & $\overline{64}$ & $\overline{91}$ & $\overline{106}$ & 126 & $\overline{127}$ & $\overline{120}$ & $\overline{121}$ \\
\hline \multirow{6}{*}{ 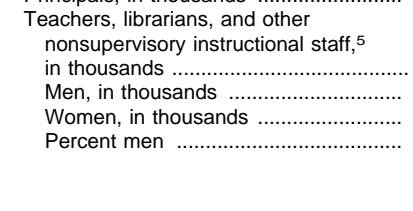 } & & & & & & 14 & 31 & 32 & 43 & 64 & 91 & 100 & $1<6$ & 127 & $1<0$ & $1<1$ \\
\hline & 201 & 287 & 364 & 423 & 523 & 657 & 843 & 875 & 920 & 1,393 & 2,195 & 2,300 & 2,860 & 2,924 & 3,161 & 3,231 \\
\hline & 78 & 123 & 126 & 127 & 110 & 93 & 140 & 195 & 196 & 4404 & ${ }^{4} 711$ & 47 & & & & - \\
\hline & 123 & 164 & 238 & 296 & 413 & 585 & 703 & 681 & 724 & 4989 & ${ }^{4} 1,484$ & 41,5 & - & 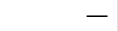 & - & - \\
\hline & 38.7 & 42.8 & 34.5 & 29.9 & 21.1 & 14.1 & 16.6 & 22.2 & 21.3 & 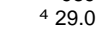 & 432.4 & 434.0 & - & - & - & - \\
\hline & \multicolumn{16}{|c|}{ Amounts in millions of current dollars } \\
\hline \multicolumn{17}{|l|}{ Revenues and expenditures } \\
\hline Total re & - & - & $\$ 143$ & $\$ 220$ & $\$ 433$ & $\$ 970$ & $\$ 2,089$ & $\$ 2,261$ & $\$ 5,437$ & $\$ 14,747$ & $\$ 40,267$ & $\$ 96,881$ & $\$ 208,548$ & $\$ 223,341$ & $\$ 273,149$ & $\$ 287,703$ \\
\hline Fede & - & - & - & - & - & 2 & 7 & 40 & 156 & & 3,220 & 9,504 & 12 & 13,776 & 18,582 & 19,104 \\
\hline & - & - & - & - & - & 160 & 354 & 684 & 2,166 & 5,768 & 16,063 & 45,349 & 98,239 & 105,325 & 127,730 & 136,671 \\
\hline Local sources, including intermediate & - & - & - & - & - & 808 & 1,728 & 1,536 & 3,116 & 8,327 & 20,985 & 42,029 & 97,608 & 104,240 & 126,838 & 131,928 \\
\hline \multicolumn{17}{|l|}{ Percent distribution of revenue receipts } \\
\hline Federal government & - & - & - & - & - & 0.3 & 0.4 & 1.8 & 2.9 & 4.4 & 8.0 & 9.8 & 6.1 & 6.2 & 6.8 & 6.6 \\
\hline State governmes & - & - & - & - & - & 16.5 & 16.9 & 30.3 & 39.8 & 39.1 & 39.9 & 46.8 & 47.1 & 47.2 & 46.8 & 47.5 \\
\hline Local sources & - & - & - & - & - & 83.2 & 82.7 & 68.0 & 57.3 & 56.5 & 52.1 & 43.4 & 46.8 & 46.7 & 46.4 & 45.9 \\
\hline Total expenditures for public schools .......... & $\$ 63$ & $\$ 78$ & $\$ 141$ & $\$ 215$ & $\$ 426$ & $\$ 1,036$ & $\$ 2,317$ & $\$ 2,344$ & $\$ 5,838$ & $\$ 15,613$ & $\$ 40,683$ & $\$ 95,962$ & $\$ 212,770$ & $\$ 229,430$ & $\$ 279,000$ & $\$ 293,611$ \\
\hline Curre & 40 & 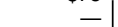 & 114 & 180 & 356 & 861 & 1,844 & 1,942 & 4,687 & 712,329 & 734,218 & 786,984 & 7188,229 & 7202,038 & 7243,878 & 7255,080 \\
\hline & - & - & 26 & 35 & 70 & 154 & 371 & 258 & 1,014 & 2,662 & 4,659 & $\begin{array}{r}r, 506 \\
6,506\end{array}$ & 17,781 & 19,771 & 24,456 & 27,548 \\
\hline & - & - & - & - & - & 18 & 93 & 131 & 101 & 490 & 1,171 & 1,8 & 3,776 & 4,325 & 5,518 & 6,259 \\
\hline er currer & - & - & - & - & - & 3 & 10 & 13 & 36 & 133 & 636 & 10598 & 2,983 & 3,296 & 5,149 & 4,725 \\
\hline \multicolumn{17}{|l|}{ Percent distribution of total expenditures } \\
\hline Current expenditures $^{6} \ldots$ & - & - & 81.3 & 83.5 & 83.6 & 83.1 & 79.6 & 82.8 & 80.3 & 779.0 & 784.1 & 790.6 & 788.5 & 788.1 & 787.4 & 786.9 \\
\hline 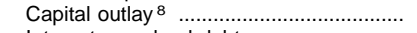 & - & - & 18.7 & 16.5 & 16.4 & 14.8 & 16.0 & 11.0 & 17.4 & 17.0 & 11.5 & 6.8 & 8.4 & 8.6 & 8.8 & 9.4 \\
\hline Interest on school debt ........................ & - & - & - & - & - & 1.8 & 4.0 & 5.6 & 1.7 & 3.1 & 2.9 & 2.0 & 1.8 & 1.9 & 2.0 & 2.1 \\
\hline Other current expenditures ${ }^{9} \ldots \ldots \ldots \ldots \ldots$. & - & - & - & - & - & 0.3 & 0.4 & 0.6 & 0.6 & 0.8 & 1.6 & ${ }^{10} 0.6$ & 1.4 & 1.4 & 1.8 & 1.6 \\
\hline
\end{tabular}


Table 39.-Historical summary of public elementary and secondary school statistics: 1869-70 to 1995-96-Continued

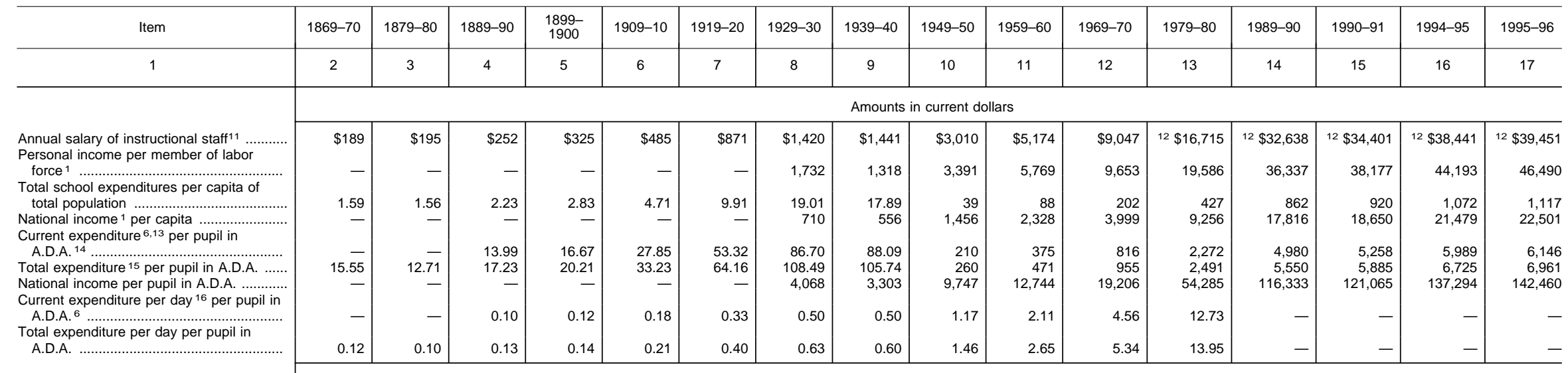

Amounts in constant $1995-96$ dollars

Annual salary of instructional staff 11 Personal income per member of labor

Total school expenditures per capita of total population
National income

Current expenditure 6,13 per

A.D.A. ${ }^{14}$

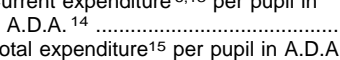

Tational income per pupil in A.D.A.

Current expenditure per day ${ }^{16}$ per pup......

Total expenditure per day per pupil in

\begin{tabular}{|c|c|c|c|c|}
\hline- & - & - & - & - \\
- & - & - & - & - \\
- & - & - & - & - \\
- & - & - & - & - \\
- & - & - & - & - \\
- & - & - & - & - \\
- & - & - & - & - \\
- & - & - & - & - \\
- & - & - & - & -
\end{tabular}

\begin{tabular}{r|r|r|r|r|}
$\$ 7,061$ & $\$ 12,817$ & $\$ 15,931$ & $\$ 19,636$ & $\$ 27,206$ \\
- & 15,637 & 14,572 & 22,120 & 30,333 \\
80 & 172 & 198 & 255 & 462 \\
- & 6,406 & 6,142 & 9,498 & 12,238 \\
432 & 783 & 974 & 1,370 & 1,973 \\
520 & 979 & 1,169 & 1,699 & 2,477 \\
- & 36,716 & 36,514 & 63,586 & 67,012 \\
2.68 & 4.51 & 5.53 & 7.63 & 11.09 \\
2.81 & 4.93 & 5.75 & 8.26 & 12.08 \\
\hline
\end{tabular}

\begin{tabular}{r|r}
$\$ 37,002$ & 1 \\
39,480 & \\
826 & \\
16,357 & \\
3,337 & 3,906 \\
78,554 & \\
18.65 & \\
18.93 &
\end{tabular}

\begin{tabular}{r|r|r|r|r}
$2 \$ 33,265$ & $12 \$ 39,713$ & $12 \$ 39,688$ & $12 \$ 39,487$ & $12 \$ 39,451$ \\
38,979 & 44,214 & 44,045 & 45,396 & 46,490 \\
850 & 1,049 & 1,061 & 1,101 & 1,117 \\
18,420 & 21,678 & 21,517 & 22,063 & 22,501 \\
4,521 & 6,059 & 6,066 & 6,152 & 6,146 \\
4,957 & 6,753 & 6,789 & 6,908 & 6,961 \\
108,034 & 141,551 & 139,672 & 141,029 & 142,460 \\
25.33 & - & - & - & - \\
24.06 & - & - & - & -
\end{tabular}

1 Data on population and labor force are from the Bureau of the Census, and data on personal income and national income are from the Bureau of Economic Analysis, U.S. Department of Commerce. Population data through 1900 are including armed forces overseas, as of July 1. Data for later years are for resident population that excludes armed forces overseas.

${ }^{2}$ Data for 1869-70 through 1959-60 are school year enrollment. Data for later years are fall enrollment. 3 Data for $1870-71$.

Estimated by the National Center for Education Statistics.

sons employed rather than number of positions.

.

the scope of "current expenditures for elementary and secondary schools," data for 1959-60 and later years are not entirely comparable with prior years.

Beginning in 1969-70, includes capital oullay by slate and local school bullding a

9 Includes summer schools, community colleges, and adult education. Beginning in 1959-60, also includes commu-

nity services, formerly classified with "current expenditures for elementary and secondary schools."

Average includes supervisors, principals, teachers, a

${ }^{12}$ Estimated by the National Education Association.

${ }^{13}$ Excludes current expenditures not allocable to pupil costs.

15 Expenditure figure is the sum of current expenditures allocable to pupil costs, capital outlay, and interest on school debt.

16 Per-day rates derived by dividing annual rates by average length of term.

-Data not collected.

NOTE.-Kindergarten enrollment includes a relatively small number of nursery school pupils. Because of rounding details may not add to totals. Some data have been revised from previously published figures. Beginning in 195960, data include Alaska and Hawaii.

SOURCE: U.S. Department of Education, National Center for Education Statistics, Statistics of State School Systems Statistics of Public Elementary and Secondary School Systems; Rever of the President. (This table was prepared June 1998.) 
Table 40.-Enrollment in public elementary and secondary schools, by level and state: Fall 1982 to fall 1997

\begin{tabular}{|c|c|c|c|c|c|c|c|c|c|c|c|}
\hline \multirow{2}{*}{ State or other area } & Fall 1982 & Fall 1983 & Fall 1984 & Fall 1985 & Fall 1986 & Fall 1987 & Fall 1988 & Fall 1989 & Fall 1990 & Fall 1991 & Fall 1992 \\
\hline & Total & Total & Total & Total & Total & Total & Total & Total & Total & Total & Total \\
\hline 1 & 2 & 3 & 4 & 5 & 6 & 7 & 8 & 9 & 10 & 11 & 12 \\
\hline United States & $39,565,610$ & $39,252,308$ & $39,208,252$ & $39,421,961$ & $39,753,172$ & $40,008,213$ & $40,188,690$ & $40,542,707$ & $41,216,683$ & $42,046,878$ & $42,823,312$ \\
\hline Alabama & 724,037 & 721,901 & 712,586 & 730,460 & 733,735 & 729,234 & 724,751 & 723,743 & 721,806 & 722,004 & 731,634 \\
\hline Alaska $^{3} \ldots .$. & 89,413 & 98,206 & 104,599 & 107,345 & 107,848 & 106,869 & 106,481 & 109,280 & 113,903 & 118,680 & 122,487 \\
\hline Arizona .... & 510,296 & 506,682 & 530,062 & 548,252 & 534,538 & 572,421 & 574,890 & 607,615 & 639,853 & 656,980 & 673,477 \\
\hline Arkansas ....... & 432,565 & 432,120 & 432,668 & 433,410 & 437,438 & 437,036 & 436,387 & 434,960 & 436,286 & 438,518 & 441,490 \\
\hline 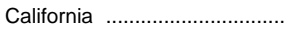 & $4,065,486$ & $4,089,017$ & $4,151,110$ & $4,255,554$ & $4,377,989$ & $4,488,398$ & $4,618,120$ & $4,771,978$ & $4,950,474$ & $5,107,145$ & $5,254,844$ \\
\hline Colorado ................. & 545,209 & 542,196 & 545,427 & 550,642 & 558,415 & 560,236 & 560,081 & 562,755 & 574,213 & 593,030 & 612,635 \\
\hline Connecticut ${ }^{5}$ & 486,470 & 477,585 & 468,145 & 462,026 & 468,847 & 465,465 & 460,637 & 461,560 & 469,123 & 481,050 & 488,476 \\
\hline Delaware ..... & 92,646 & 91,406 & 91,767 & 92,901 & 94,410 & 95,659 & 96,678 & 97,808 & 99,658 & 102,196 & 104,321 \\
\hline District of Columbia ...................... & 91,105 & 88,843 & 87,397 & 87,092 & 85,612 & 86,435 & 84,792 & 81,301 & 80,694 & 80,618 & 80,937 \\
\hline 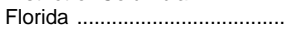 & $1,484,734$ & $1,495,543$ & $1,524,107$ & $1,562,283$ & $1,607,320$ & $1,664,774$ & $1,720,930$ & $1,789,925$ & $1,861,592$ & $1,932,131$ & $1,981,407$ \\
\hline Georgia & $1,053,689$ & $1,050,859$ & $1,062,315$ & $1,079,594$ & $1,096,425$ & $1,110,947$ & $1,107,994$ & $1,126,535$ & $1,151,687$ & $1,177,569$ & $1,207,186$ \\
\hline Hawaii ....... & 162,024 & 162,241 & 163,860 & 164,169 & 164,640 & 166,160 & 167,488 & 169,493 & 171,708 & 174,747 & 177,448 \\
\hline Idaho & 202,973 & 206,352 & 208,080 & 208,669 & 208,391 & 212,444 & 214,615 & 214,932 & 220,840 & 225,680 & 231,668 \\
\hline Illinois ...... & $1,880,289$ & $1,853,316$ & $1,834,355$ & $1,826,478$ & $1,825,185$ & $1,811,446$ & $1,794,916$ & $1,797,355$ & $1,821,407$ & $1,848,166$ & $1,873,567$ \\
\hline Indiana .......................... & 999,542 & 984,384 & 972,659 & 966,106 & 966,780 & 964,129 & 960,994 & 954,165 & 954,525 & 956,988 & 960,630 \\
\hline lowa & 504,983 & 497,287 & 491,011 & 485,332 & 481,286 & 480,826 & 478,200 & 478,486 & 483,652 & 491,363 & 494,839 \\
\hline 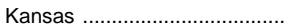 & 407,074 & 405,222 & 405,347 & 410,229 & 416,091 & 421,112 & 426,596 & 430,864 & 437,034 & 445,390 & 451,536 \\
\hline 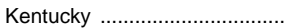 & 651,084 & 647,414 & 644,421 & 643,833 & 642,778 & 642,696 & 637,627 & 630,688 & 636,401 & 646,024 & 655,041 \\
\hline Louisiana .................................. & 784,027 & 800,193 & 800,941 & 788,349 & 795,188 & 793,093 & 786,683 & 783,025 & 784,757 & 794,128 & 797,985 \\
\hline 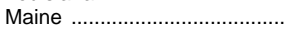 & 211,986 & 209,753 & 207,537 & 206,101 & 211,752 & 211,817 & 212,902 & 213,775 & 215,149 & 216,400 & 216,453 \\
\hline Maryland & 699,201 & 683,491 & 673,840 & 671,560 & 675,747 & 683,797 & 688,947 & 698,806 & 715,176 & 736,238 & 751,850 \\
\hline Massachusetts ............................. & 908,984 & 878,844 & 859,391 & 844,330 & 833,918 & 825,320 & 823,428 & 825,588 & 834,314 & 846,155 & 859,948 \\
\hline 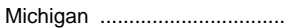 & $1,674,697$ & $1,635,963$ & $1,609,448$ & $1,602,747$ & $1,597,154$ & $1,589,287$ & $1,582,785$ & $1,576,785$ & $1,584,431$ & $1,593,561$ & $1,603,610$ \\
\hline Minnesota & 715,190 & 705,236 & 701,697 & 705,140 & 711,134 & 721,481 & 726,950 & 739,553 & 756,374 & 773,571 & 793,724 \\
\hline 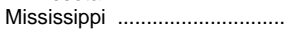 & 468,294 & 467,744 & 466,058 & 471,195 & 498,639 & 505,550 & 503,326 & 502,020 & 502,417 & 504,127 & 506,668 \\
\hline Missouri ............... & 802,535 & 795,453 & 793,793 & 795,107 & 800,606 & 802,060 & 806,639 & 807,934 & 816,558 & 842,965 & 859,357 \\
\hline Montana .......................... & 152,335 & 153,646 & 154,412 & 153,869 & 153,327 & 152,207 & 152,191 & 151,265 & 152,974 & 155,779 & 160,011 \\
\hline 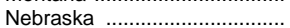 & 269,009 & 266,998 & 265,599 & 265,819 & 267,139 & 268,100 & 269,434 & 270,920 & 274,081 & 279,552 & 282,414 \\
\hline Nevada & 151,104 & 150,442 & 151,633 & 154,948 & 161,239 & 168,353 & 176,474 & 186,834 & 201,316 & 211,810 & 222,974 \\
\hline New Hampshire ......... & 160,197 & 159,030 & 158,614 & 160,974 & 163,717 & 166,045 & 169,413 & 171,696 & 172,785 & 177,138 & 181,247 \\
\hline New Jersey & $1,172,520$ & $1,147,841$ & $1,129,223$ & $1,116,194$ & $1,107,467$ & $1,092,982$ & $1,080,871$ & $1,076,005$ & $1,089,646$ & $1,109,796$ & $1,130,560$ \\
\hline New Mexico & 268,632 & 269,711 & 272,478 & 277,551 & 281,943 & 287,229 & 292,425 & 296,057 & 301,881 & 308,667 & 315,668 \\
\hline 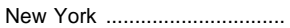 & $2,718,678$ & $2,674,818$ & $2,645,811$ & $2,621,378$ & $2,607,719$ & $2,594,070$ & $2,573,715$ & $2,565,841$ & $2,598,337$ & $2,643,993$ & $2,689,686$ \\
\hline North Carolina ........................... & $1,096,815$ & $1,089,606$ & $1,088,724$ & $1,086,165$ & $1,085,248$ & $1,085,976$ & $1,083,156$ & $1,080,744$ & $1,086,871$ & $1,097,598$ & $1,114,083$ \\
\hline 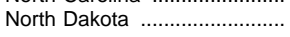 & 117,078 & 117,213 & 118,711 & 118,570 & 118,703 & 119,004 & 118,809 & 117,816 & 117,825 & 118,376 & 118,734 \\
\hline Ohio & $1,860,245$ & $1,827,300$ & $1,805,440$ & $1,793,965$ & $1,793,508$ & $1,793,431$ & $1,778,544$ & $1,764,410$ & $1,771,089$ & $1,783,767$ & $1,795,199$ \\
\hline Oklahoma ............... & 593,825 & 591,389 & 589,690 & 592,327 & 593,183 & 584,212 & 580,426 & 578,580 & 579,087 & 588,263 & 597,096 \\
\hline Oregon ……....... & 448,184 & 447,109 & 446,884 & 447,527 & 449,307 & 455,895 & 461,752 & 472,394 & 472,394 & 498,614 & 510,122 \\
\hline Pennsylvania .................................. & $1,783,969$ & $1,737,952$ & $1,701,880$ & $1,683,221$ & $1,674,161$ & $1,668,542$ & $1,659,714$ & $1,655,279$ & $1,667,834$ & $1,692,797$ & $1,717,613$ \\
\hline 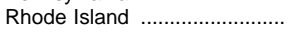 & 139,959 & 136,412 & 134,610 & 133,949 & 134,690 & 134,800 & 133,585 & 135,729 & 138,813 & 142,144 & 143,798 \\
\hline South Carolina & 608,518 & 604,553 & 602,718 & 606,643 & 611,629 & 614,921 & 615,774 & 616,177 & 622,112 & 627,470 & 640,464 \\
\hline South Dakota ..................... & 123,897 & 123,060 & 123,314 & 124,291 & 125,458 & 126,817 & 126,910 & 127,329 & 129,164 & 131,576 & 134,573 \\
\hline 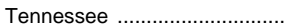 & 828,264 & 822,057 & 817,212 & 813,753 & 818,073 & 823,783 & 821,580 & 819,660 & 824,595 & 833,651 & 855,231 \\
\hline 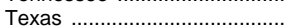 & $2,985,659$ & $2,989,796$ & $3,040,305$ & $3,131,705$ & $3,209,515$ & $3,236,787$ & $3,283,707$ & $3,328,514$ & $3,382,887$ & $3,464,371$ & $3,541,769$ \\
\hline 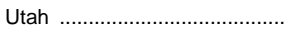 & 370,183 & 378,208 & 390,141 & 403,305 & 415,994 & 423,386 & 431,119 & 438,554 & 446,652 & 456,430 & 463,870 \\
\hline Vermont ………………......... & 91,454 & 90,416 & 90,089 & 90,157 & 92,112 & 92,755 & 93,381 & 94,779 & 95,762 & 97,137 & 98,558 \\
\hline Virginia . & 975,727 & 966,110 & 965,222 & 968,104 & 975,135 & 979,417 & 982,393 & 985,346 & 998,601 & $1,016,204$ & $1,031,925$ \\
\hline Washington ............................... & 739,215 & 736,239 & 741,177 & 749,706 & 761,428 & 775,755 & 790,918 & 810,232 & 839,709 & 869,327 & 896,475 \\
\hline West Virginia ............................ & 375,115 & 371,251 & 362,941 & 357,923 & 351,837 & 344,236 & 335,912 & 327,540 & 322,389 & 320,249 & 318,296 \\
\hline Wisconsin ........ & 784,830 & 774,646 & 767,542 & 768,234 & 767,819 & 772,363 & 774,857 & 782,905 & 797,621 & 814,671 & 829,415 \\
\hline 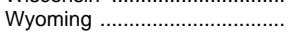 & 101,665 & 99,254 & 101,261 & 102,779 & 100,955 & 98,455 & 97,793 & 97,172 & 98,226 & 102,074 & 100,313 \\
\hline Outlying areas & & & & & & & & & & & \\
\hline American Samoa .......... & - & 10,124 & - & - & 11,055 & 11,248 & 11,764 & 12,258 & 12,463 & 13,365 & 13,994 \\
\hline$\ldots \ldots \ldots \ldots \ldots \ldots \ldots$ & 25,676 & 26,249 & - & 26,043 & 25,676 & 25,936 & 26,041 & 26,493 & 26,391 & 28,334 & 30,077 \\
\hline Northern Marianas & - & 4,499 & 4,841 & - & - & 5,819 & 6,079 & 6,101 & 6,449 & 7,096 & 8,086 \\
\hline Puerto Rico ................................ & 708,794 & 701,925 & 692,923 & 686,914 & 679,489 & 672,837 & 661,693 & 651,225 & 644,734 & 642,392 & 637,034 \\
\hline Virgin Islands & 25,699 & 26,126 & 26,122 & 25,448 & 24,435 & 24,020 & 23,492 & 21,193 & 21,750 & 22,346 & 22,887 \\
\hline
\end{tabular}


Table 40.-Enrollment in public elementary and secondary schools, by level and state: Fall 1982 to fall 1997-Continued

\begin{tabular}{|c|c|c|c|c|c|c|c|c|c|c|c|}
\hline \multirow[b]{2}{*}{ State or other area } & \multirow{2}{*}{$\begin{array}{c}\text { Fall } 1993 \\
\text { Total }\end{array}$} & \multicolumn{3}{|c|}{ Fall 1994} & \multicolumn{3}{|c|}{ Fall 1995} & \multicolumn{3}{|c|}{ Fall 1996} & \multirow{2}{*}{$\begin{array}{c}\begin{array}{c}\text { Estimated fall } \\
19971\end{array} \\
\text { Total }\end{array}$} \\
\hline & & Total & $\begin{array}{l}\text { Kinder- } \\
\text { garten } \\
\text { through } \\
\text { grade } 8^{2}\end{array}$ & $\begin{array}{l}\text { Grades } 9 \text { to } \\
12\end{array}$ & Total & $\begin{array}{l}\text { Kinder- } \\
\text { garten } \\
\text { through } \\
\text { grade } 8^{2}\end{array}$ & $\begin{array}{c}\text { Grades } 9 \text { to } \\
12\end{array}$ & Total & $\begin{array}{l}\text { Kinder- } \\
\text { garten } \\
\text { through } \\
\text { grade } 82\end{array}$ & $\underset{12}{\text { Grades } 9}$ to & \\
\hline 1 & 13 & 14 & 15 & 16 & 17 & 18 & 19 & 20 & 21 & 22 & 23 \\
\hline United States. & $43,464,916$ & $44,111,482$ & $31,898,249$ & $12,213,233$ & $44,840,481$ & $32,340,501$ & $12,499,980$ & $45,592,213$ & $32,758,548$ & $12,833,665$ & $45,953,018$ \\
\hline $\begin{array}{l}\text { Alabama } \\
\text { Alaska }^{3} \\
\text { Arizona } \\
\text { Arkansas } \\
\text { California }\end{array}$ & $\begin{array}{r}734,288 \\
125,948 \\
709,453 \\
444,271 \\
5,327,231\end{array}$ & $\begin{array}{r}736,531 \\
127,057 \\
737,424 \\
447,565 \\
5,407,475\end{array}$ & $\begin{array}{r}535,246 \\
93,719 \\
542,904 \\
319,282 \\
3,955,868\end{array}$ & $\begin{array}{r}201,285 \\
33,338 \\
194,520 \\
128,283 \\
1,451,607\end{array}$ & $\begin{array}{r}746,149 \\
127,618 \\
743,566 \\
453,257 \\
5,536,406\end{array}$ & $\begin{array}{r}539,309 \\
93,434 \\
548,526 \\
322,440 \\
4,041,224\end{array}$ & $\begin{array}{r}206,840 \\
34,184 \\
195,040 \\
130,817 \\
1,495,182\end{array}$ & $\begin{array}{r}748,156 \\
129,919 \\
799,250 \\
457,349 \\
5,687,901\end{array}$ & $\begin{array}{r}540,176 \\
94,362 \\
588,409 \\
324,448 \\
4,131,084\end{array}$ & $\begin{array}{r}207,980 \\
35,557 \\
210,841 \\
132,901 \\
1,556,817\end{array}$ & $\begin{array}{r}738,473 \\
132,258 \\
4859,104 \\
4461,478 \\
5,640,269\end{array}$ \\
\hline 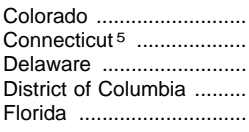 & \begin{tabular}{r|}
625,062 \\
496,298 \\
105,547 \\
80,678 \\
$2,040,763$
\end{tabular} & $\begin{array}{r}640,521 \\
506,824 \\
106,813 \\
80,450 \\
2,111,188\end{array}$ & \begin{tabular}{r|}
469,755 \\
375,638 \\
76,819 \\
62,126 \\
$1,569,666$
\end{tabular} & $\begin{array}{r}170,766 \\
131,186 \\
29,994 \\
18,324 \\
541,522\end{array}$ & $\begin{array}{r}656,279 \\
517,935 \\
108,461 \\
79,802 \\
2,176,222\end{array}$ & $\begin{array}{r}478,881 \\
384,274 \\
77,028 \\
61,836 \\
1,613,510\end{array}$ & $\begin{array}{r}177,398 \\
133,661 \\
31,433 \\
17,966 \\
562,712\end{array}$ & $\begin{array}{r}673,438 \\
527,129 \\
110,549 \\
78,648 \\
2,242,212\end{array}$ & \begin{tabular}{r|}
487,304 \\
389,374 \\
77,981 \\
61,138 \\
$1,653,162$
\end{tabular} & $\begin{array}{r}186,134 \\
137,755 \\
32,568 \\
17,510 \\
589,050\end{array}$ & $\begin{array}{r}688,438 \\
535,000 \\
6111,960 \\
477,511 \\
62,291,681\end{array}$ \\
\hline $\begin{array}{l}\text { Georgia } \\
\text { Hawaii } \\
\text { Idaho } \\
\text { Illinois } \\
\text { Indiana }\end{array}$ & $\begin{array}{r}1,235,304 \\
180,410 \\
236,774 \\
1,893,078 \\
965,633\end{array}$ & $\begin{array}{r}1,270,948 \\
183,795 \\
240,448 \\
1,916,172 \\
969,022\end{array}$ & $\begin{array}{r}934,650 \\
133,675 \\
168,887 \\
1,368,041 \\
678,970\end{array}$ & $\begin{array}{r}336,298 \\
50,120 \\
71,561 \\
548,131 \\
290,052\end{array}$ & $\begin{array}{r}1,311,126 \\
187,180 \\
243,097 \\
1,943,623 \\
977,263\end{array}$ & \begin{tabular}{r|}
965,707 \\
135,671 \\
169,556 \\
$1,390,475$ \\
684,348
\end{tabular} & $\begin{array}{r}345,419 \\
51,509 \\
73,541 \\
553,148 \\
292,915\end{array}$ & $\begin{array}{r}1,346,761 \\
187,653 \\
245,252 \\
1,973,040 \\
983,415\end{array}$ & $\begin{array}{r}990,850 \\
136,184 \\
169,419 \\
1,412,176 \\
689,578\end{array}$ & $\begin{array}{r}355,911 \\
51,469 \\
75,833 \\
560,864 \\
293,837\end{array}$ & $\begin{array}{r}1,375,918 \\
6189,281 \\
250,300 \\
2,000,550 \\
988,750\end{array}$ \\
\hline $\begin{array}{l}\text { lowa } \\
\text { Kansas } \\
\text { Kentucky } \\
\text { Louisiana } \\
\text { Maine }\end{array}$ & $\begin{array}{l}498,519 \\
457,614 \\
655,265 \\
800,560 \\
216,995\end{array}$ & $\begin{array}{l}500,440 \\
460,838 \\
657,642 \\
797,933 \\
212,601\end{array}$ & $\begin{array}{l}345,865 \\
329,211 \\
467,005 \\
583,892 \\
155,903\end{array}$ & $\begin{array}{r}154,575 \\
131,627 \\
190,637 \\
214,041 \\
56,698\end{array}$ & $\begin{array}{l}502,343 \\
463,008 \\
659,821 \\
797,366 \\
213,569\end{array}$ & $\begin{array}{l}343,997 \\
328,701 \\
468,242 \\
580,348 \\
156,016\end{array}$ & $\begin{array}{r}158,346 \\
134,307 \\
191,579 \\
217,018 \\
57,553\end{array}$ & $\begin{array}{l}502,941 \\
466,293 \\
656,089 \\
793,296 \\
213,593\end{array}$ & $\begin{array}{l}341,630 \\
328,023 \\
466,177 \\
575,318 \\
155,611\end{array}$ & $\begin{array}{r}161,311 \\
138,270 \\
189,912 \\
217,978 \\
57,982\end{array}$ & $\begin{array}{r}503,540 \\
469,740 \\
639,579 \\
6780,758 \\
217,081\end{array}$ \\
\hline 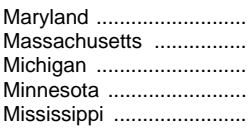 & $\begin{array}{r}772,638 \\
877,726 \\
1,599,377 \\
810,233 \\
505,907\end{array}$ & $\begin{array}{r}790,938 \\
893,727 \\
1,614,784 \\
821,693 \\
505,962\end{array}$ & $\begin{array}{r}580,903 \\
658,507 \\
1,170,251 \\
581,426 \\
366,846\end{array}$ & $\begin{array}{l}210,035 \\
235,220 \\
444,533 \\
240,267 \\
139,116\end{array}$ & $\begin{array}{r}805,544 \\
915,007 \\
1,641,456 \\
835,166 \\
506,272\end{array}$ & $\begin{array}{r}590,155 \\
674,588 \\
1,191,671 \\
586,080 \\
366,186\end{array}$ & $\begin{array}{l}215,389 \\
240,419 \\
449,785 \\
249,086 \\
140,086\end{array}$ & $\begin{array}{r}818,583 \\
933,898 \\
1,684,386 \\
847,204 \\
503,967\end{array}$ & $\begin{array}{r}596,643 \\
687,693 \\
1,221,755 \\
588,752 \\
363,864\end{array}$ & $\begin{array}{l}221,940 \\
246,205 \\
462,631 \\
258,452 \\
140,103\end{array}$ & $\begin{array}{r}833,489 \\
954,335 \\
1,728,500 \\
845,700 \\
504,995\end{array}$ \\
\hline $\begin{array}{l}\text { Missouri } \\
\text { Montana } \\
\text { Nebraska } \\
\text { Nevada } \\
\text { New Hampshire }\end{array}$ & $\begin{array}{l}866,378 \\
163,009 \\
285,097 \\
235,800 \\
185,360\end{array}$ & $\begin{array}{l}878,541 \\
164,341 \\
287,100 \\
250,747 \\
189,319\end{array}$ & $\begin{array}{l}628,286 \\
116,748 \\
203,055 \\
185,336 \\
138,851\end{array}$ & $\begin{array}{r}250,255 \\
47,593 \\
84,045 \\
65,411 \\
50,468\end{array}$ & $\begin{array}{l}889,881 \\
165,547 \\
289,744 \\
265,041 \\
194,171\end{array}$ & $\begin{array}{l}635,771 \\
116,403 \\
203,022 \\
195,892 \\
141,721\end{array}$ & $\begin{array}{r}254,110 \\
49,144 \\
86,722 \\
69,149 \\
52,450\end{array}$ & $\begin{array}{l}900,042 \\
164,627 \\
291,967 \\
282,131 \\
198,308\end{array}$ & $\begin{array}{l}643,053 \\
114,672 \\
202,846 \\
207,724 \\
143,880\end{array}$ & $\begin{array}{r}256,989 \\
49,955 \\
89,121 \\
74,407 \\
54,428\end{array}$ & $\begin{array}{r}4910,319 \\
163,999 \\
292,681 \\
6296,621 \\
6196,647\end{array}$ \\
\hline $\begin{array}{l}\text { New Jersey } \\
\text { New Mexico } \\
\text { New York }\end{array}$ & $\begin{array}{r}1,151,307 \\
322,292 \\
2,733,813 \\
1,133,231 \\
119,127\end{array}$ & $\begin{array}{r}1,174,206 \\
327,248 \\
2,766,208 \\
1,156,767 \\
119,288\end{array}$ & $\begin{array}{r}862,331 \\
229,168 \\
1,949,245 \\
847,463 \\
83,419\end{array}$ & $\begin{array}{r}311,875 \\
98,080 \\
816,963 \\
309,304 \\
35,869\end{array}$ & $\begin{array}{r}1,197,381 \\
329,640 \\
2,813,230 \\
1,183,090 \\
119,100\end{array}$ & $\begin{array}{r}880,350 \\
229,239 \\
1,980,208 \\
871,320 \\
82,333\end{array}$ & $\begin{array}{r}317,031 \\
100,401 \\
833,022 \\
311,770 \\
36,767\end{array}$ & $\begin{array}{r}41,208,179 \\
332,632 \\
2,843,131 \\
1,210,108 \\
120,123\end{array}$ & $\begin{array}{r}4884,389 \\
230,012 \\
2,000,001 \\
886,153 \\
82,171\end{array}$ & $\begin{array}{r}4323,790 \\
102,620 \\
843,130 \\
323,955 \\
37,952\end{array}$ & $\begin{array}{r}41,231,059 \\
6316,754 \\
2,831,900 \\
61,226,293 \\
116,813\end{array}$ \\
\hline $\begin{array}{l}\text { Ohio } \\
\text { Oklahoma } \\
\text { Oregon } \\
\text { Pennsylvania } \\
\text { Rhode Island }\end{array}$ & $\begin{array}{r}1,807,319 \\
604,076 \\
516,611 \\
1,744,082 \\
145,676\end{array}$ & $\begin{array}{r}1,814,290 \\
609,718 \\
521,945 \\
1,764,946 \\
147,487\end{array}$ & $\begin{array}{r}1,295,289 \\
442,607 \\
371,967 \\
1,243,983 \\
107,913\end{array}$ & $\begin{array}{r}519,001 \\
167,111 \\
149,978 \\
520,963 \\
39,574\end{array}$ & $\begin{array}{r}1,836,015 \\
616,393 \\
527,914 \\
1,787,533 \\
149,799\end{array}$ & $\begin{array}{r}1,297,313 \\
445,780 \\
375,966 \\
1,256,621 \\
109,815\end{array}$ & $\begin{array}{r}538,702 \\
170,613 \\
151,948 \\
530,912 \\
39,984\end{array}$ & $\begin{array}{r}1,844,389 \\
620,695 \\
537,854 \\
1,804,256 \\
151,324\end{array}$ & $\begin{array}{r}1,298,719 \\
445,496 \\
380,239 \\
1,263,576 \\
110,476\end{array}$ & $\begin{array}{r}545,670 \\
175,199 \\
157,615 \\
540,680 \\
40,848\end{array}$ & $\begin{array}{r}1,845,000 \\
625,011 \\
6540,584 \\
1,812,880 \\
152,042\end{array}$ \\
\hline $\begin{array}{l}\text { South Carolina } \\
\text { South Dakota } \\
\text { Tennessee } \\
\text { Texas }\end{array}$ & $\begin{array}{r}643,696 \\
142,825 \\
866,557 \\
3,608,262 \\
471,365\end{array}$ & $\begin{array}{r}648,725 \\
143,482 \\
881,425 \\
3,677,171 \\
474,675\end{array}$ & $\begin{array}{r}468,850 \\
101,805 \\
640,604 \\
2,720,623 \\
328,482\end{array}$ & $\begin{array}{r}179,875 \\
41,677 \\
240,821 \\
956,548 \\
146,193\end{array}$ & $\begin{array}{r}645,586 \\
144,685 \\
893,770 \\
3,748,167 \\
477,121\end{array}$ & $\begin{array}{r}463,305 \\
101,491 \\
650,601 \\
2,757,273 \\
327,790\end{array}$ & $\begin{array}{r}182,281 \\
43,194 \\
243,169 \\
990,894 \\
149,331\end{array}$ & $\begin{array}{r}653,011 \\
143,331 \\
905,089 \\
3,828,975 \\
481,812\end{array}$ & $\begin{array}{r}467,885 \\
99,160 \\
657,541 \\
2,800,017 \\
327,981\end{array}$ & $\begin{array}{r}185,126 \\
44,171 \\
247,548 \\
1,028,958 \\
153,831\end{array}$ & $\begin{array}{r}647,430 \\
141,390 \\
905,860 \\
3,905,256 \\
479,150\end{array}$ \\
\hline $\begin{array}{l}\text { Vermont } \\
\text { Virginia } \\
\text { Washington } \\
\text { West Virginia } \\
\text { Wisconsin } \\
\text { Wyoming }\end{array}$ & $\begin{array}{r}102,755 \\
1,045,471 \\
915,952 \\
314,383 \\
844,001 \\
100,899\end{array}$ & $\begin{array}{r}104,533 \\
1,060,809 \\
938,314 \\
310,511 \\
860,581 \\
100,314\end{array}$ & $\begin{array}{r}75,590 \\
774,319 \\
673,107 \\
212,808 \\
601,215 \\
70,130\end{array}$ & $\begin{array}{r}28,943 \\
286,490 \\
265,207 \\
97,703 \\
259,366 \\
30,184\end{array}$ & $\begin{array}{r}105,565 \\
1,079,854 \\
956,572 \\
307,112 \\
870,175 \\
99,859\end{array}$ & $\begin{array}{r}75,227 \\
787,945 \\
680,009 \\
211,008 \\
602,964 \\
68,931\end{array}$ & $\begin{array}{r}30,338 \\
291,909 \\
276,563 \\
96,104 \\
267,211 \\
30,928\end{array}$ & $\begin{array}{r}106,341 \\
1,096,093 \\
974,504 \\
304,052 \\
879,259 \\
99,058\end{array}$ & $\begin{array}{r}76,076 \\
796,302 \\
687,445 \\
208,970 \\
605,322 \\
67,331\end{array}$ & $\begin{array}{r}30,265 \\
299,791 \\
287,059 \\
95,082 \\
273,937 \\
31,727\end{array}$ & $\begin{array}{r}105,687 \\
61,110,815 \\
6991,235 \\
6300,737 \\
891,588 \\
696,579\end{array}$ \\
\hline 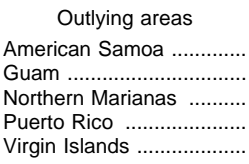 & $\begin{array}{r}14,484 \\
30,920 \\
8,188 \\
631,460 \\
22,752\end{array}$ & $\begin{array}{r}14,445 \\
32,185 \\
8,429 \\
621,121 \\
23,126\end{array}$ & $\begin{array}{r}11,054 \\
24,189 \\
6,559 \\
455,653 \\
16,659\end{array}$ & $\begin{array}{r}3,391 \\
7,996 \\
1,870 \\
165,468 \\
6,467\end{array}$ & $\begin{array}{r}14,576 \\
32,960 \\
8,809 \\
627,620 \\
22,737\end{array}$ & $\begin{array}{r}11,207 \\
24,877 \\
6,825 \\
460,585 \\
16,342\end{array}$ & $\begin{array}{r}3,369 \\
8,083 \\
1,984 \\
167,035 \\
6,395\end{array}$ & $\begin{array}{r}14,766 \\
33,393 \\
9,041 \\
618,861 \\
22,385\end{array}$ & $\begin{array}{r}11,346 \\
25,217 \\
7,077 \\
454,132 \\
15,703\end{array}$ & $\begin{array}{r}3,420 \\
8,176 \\
1,964 \\
164,729 \\
6,682\end{array}$ & $\begin{array}{r}615,220 \\
32,923 \\
69,246 \\
617,157 \\
21,714\end{array}$ \\
\hline
\end{tabular}

1 Data estimated by state education agencies.

2 Includes a number of prekindergarten students.

${ }^{3}$ Beginning in 1983, data include students enrolled in public schools on federal bases and other special arrangements.

${ }^{4}$ Data imputed by the National Center for Education Statistics based on previous year's data.

${ }^{5}$ Beginning in 1986, data include state vocational/technical schools.
${ }^{6}$ Actual data.

NOTE.-Some data have been revised from previously published figures.

SOURCE: U.S. Department of Education, National Center for Education Statistics, Common Core of Data surveys. (This table was prepared May 1998.) 
Table 41.-Enrollment in public elementary and secondary schools, by grade and state: Fall 1996

\begin{tabular}{|c|c|c|c|c|c|c|c|c|c|}
\hline \multirow{2}{*}{ State or other area } & \multirow{2}{*}{$\begin{array}{c}\text { Total, } \\
\text { all } \\
\text { levels }\end{array}$} & \multicolumn{8}{|c|}{ Prekindergarten through grade 8 and elementary unclassified } \\
\hline & & Total & $\begin{array}{l}\text { Prekinder- } \\
\text { garten } 1\end{array}$ & Kindergarten & Grade 1 & Grade 2 & Grade 3 & Grade 4 & Grade 5 \\
\hline 1 & 2 & 3 & 4 & 5 & 6 & 7 & 8 & 9 & 10 \\
\hline United States ......... & $45,592,213$ & $32,758,548$ & 673,581 & $3,534,098$ & $3,768,600$ & $3,595,878$ & $3,517,594$ & $3,446,576$ & $3,447,099$ \\
\hline 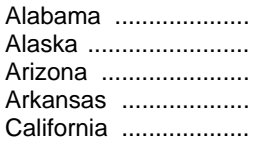 & $\begin{array}{r}748,156 \\
129,919 \\
799,250 \\
457,349 \\
5,687,901\end{array}$ & $\begin{array}{r}540,176 \\
94,362 \\
588,409 \\
324,448 \\
4,131,084\end{array}$ & $\begin{array}{r}29,857 \\
2,186 \\
4,495 \\
1,980 \\
274,936\end{array}$ & $\begin{array}{r}60,949 \\
10,451 \\
64,613 \\
36,442 \\
469,965\end{array}$ & $\begin{array}{r}63,665 \\
10,670 \\
70,180 \\
37,370 \\
491,159\end{array}$ & $\begin{array}{r}58,683 \\
10,453 \\
65,505 \\
35,236 \\
463,864\end{array}$ & $\begin{array}{r}57,435 \\
10,361 \\
64,627 \\
34,021 \\
452,225\end{array}$ & $\begin{array}{r}57,098 \\
10,055 \\
62,793 \\
33,855 \\
435,217\end{array}$ & $\begin{array}{r}56,550 \\
10,268 \\
63,375 \\
34,270 \\
427,682\end{array}$ \\
\hline $\begin{array}{l}\text { Colorado ................... } \\
\text { Connecticut ............... } \\
\text { Delaware ................. } \\
\text { District of Columbia ... } \\
\text { Florida ....................... }\end{array}$ & $\begin{array}{r}673,438 \\
527,129 \\
110,549 \\
78,648 \\
2,242,212\end{array}$ & $\begin{array}{r}487,304 \\
389,374 \\
77,981 \\
61,138 \\
1,653,162\end{array}$ & $\begin{array}{r}12,520 \\
9,147 \\
597 \\
5,044 \\
53,979\end{array}$ & $\begin{array}{r}50,707 \\
43,213 \\
8,002 \\
7,469 \\
176,512\end{array}$ & $\begin{array}{r}54,565 \\
46,391 \\
8,831 \\
7,912 \\
185,614\end{array}$ & $\begin{array}{r}52,947 \\
44,172 \\
8,480 \\
7,114 \\
181,795\end{array}$ & $\begin{array}{r}52,377 \\
43,092 \\
8,752 \\
6,271 \\
178,378\end{array}$ & $\begin{array}{r}52,524 \\
41,969 \\
8,329 \\
5,442 \\
175,240\end{array}$ & $\begin{array}{r}53,400 \\
41,354 \\
8,618 \\
5,332 \\
175,623\end{array}$ \\
\hline 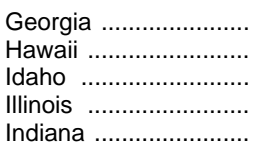 & $\begin{array}{r}1,346,761 \\
187,653 \\
245,252 \\
1,973,040 \\
983,415\end{array}$ & $\begin{array}{r}990,850 \\
136,184 \\
169,419 \\
1,412,176 \\
689,578\end{array}$ & $\begin{array}{r}25,522 \\
694 \\
1,689 \\
50,857 \\
5,263\end{array}$ & $\begin{array}{r}112,385 \\
16,129 \\
17,562 \\
152,268 \\
74,803\end{array}$ & $\begin{array}{r}114,978 \\
16,683 \\
18,805 \\
162,304 \\
82,221\end{array}$ & $\begin{array}{r}110,641 \\
15,789 \\
18,262 \\
154,385 \\
77,275\end{array}$ & $\begin{array}{r}107,050 \\
15,104 \\
18,366 \\
151,499 \\
75,069\end{array}$ & $\begin{array}{r}105,333 \\
14,864 \\
18,085 \\
145,919 \\
72,250\end{array}$ & $\begin{array}{r}104,059 \\
14,455 \\
17,950 \\
146,745 \\
72,737\end{array}$ \\
\hline 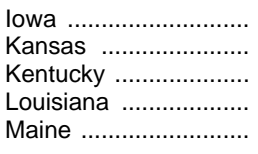 & $\begin{array}{l}502,941 \\
466,293 \\
656,089 \\
793,296 \\
213,593\end{array}$ & $\begin{array}{l}341,630 \\
328,023 \\
466,177 \\
575,318 \\
155,611\end{array}$ & $\begin{array}{r}5,042 \\
3,723 \\
19,428 \\
20,066 \\
828\end{array}$ & $\begin{array}{l}37,101 \\
32,890 \\
46,450 \\
61,170 \\
15,864\end{array}$ & $\begin{array}{l}36,614 \\
36,285 \\
48,209 \\
64,136 \\
17,116\end{array}$ & $\begin{array}{l}35,706 \\
34,777 \\
47,697 \\
59,025 \\
16,601\end{array}$ & $\begin{array}{l}35,004 \\
35,003 \\
54,703 \\
58,244 \\
16,826\end{array}$ & $\begin{array}{l}34,918 \\
35,077 \\
47,018 \\
59,082 \\
16,621\end{array}$ & $\begin{array}{l}36,450 \\
36,134 \\
46,850 \\
59,815 \\
17,421\end{array}$ \\
\hline 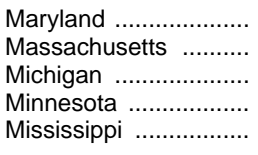 & $\begin{array}{r}818,583 \\
933,898 \\
1,684,386 \\
847,204 \\
503,967\end{array}$ & $\begin{array}{r}596,643 \\
687,693 \\
1,221,755 \\
588,752 \\
363,864\end{array}$ & $\begin{array}{r}19,639 \\
15,695 \\
16,510 \\
8,902 \\
1,052\end{array}$ & $\begin{array}{r}61,856 \\
76,519 \\
137,978 \\
62,383 \\
39,459\end{array}$ & $\begin{array}{r}68,645 \\
81,375 \\
140,553 \\
64,508 \\
43,401\end{array}$ & $\begin{array}{r}66,645 \\
77,953 \\
130,494 \\
63,465 \\
39,406\end{array}$ & $\begin{array}{r}64,728 \\
75,468 \\
124,399 \\
63,203 \\
38,145\end{array}$ & $\begin{array}{r}63,693 \\
73,659 \\
123,233 \\
63,024 \\
37,315\end{array}$ & $\begin{array}{r}62,178 \\
72,121 \\
122,404 \\
65,090 \\
37,795\end{array}$ \\
\hline 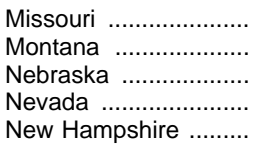 & $\begin{array}{l}900,042 \\
164,627 \\
291,967 \\
282,131 \\
198,308\end{array}$ & $\begin{array}{l}643,053 \\
114,672 \\
202,846 \\
207,724 \\
143,880\end{array}$ & $\begin{array}{r}16,099 \\
500 \\
4,104 \\
1,868 \\
1,535\end{array}$ & $\begin{array}{r}69,239 \\
11,757 \\
21,874 \\
22,875 \\
8,569\end{array}$ & $\begin{array}{l}70,822 \\
12,706 \\
22,224 \\
25,398 \\
18,322\end{array}$ & $\begin{array}{l}69,002 \\
11,916 \\
21,443 \\
24,090 \\
16,744\end{array}$ & $\begin{array}{l}67,308 \\
12,317 \\
21,158 \\
23,154 \\
16,620\end{array}$ & $\begin{array}{l}67,529 \\
12,479 \\
21,440 \\
22,597 \\
16,643\end{array}$ & $\begin{array}{l}68,653 \\
12,968 \\
22,120 \\
22,570 \\
16,367\end{array}$ \\
\hline $\begin{array}{l}\text { New Jersey }{ }^{3} \\
\text { New Mexico ...................... } \\
\text { New York .................. } \\
\text { North Carolina ............ } \\
\text { North Dakota } . . . \ldots \ldots \ldots . . .\end{array}$ & $\begin{array}{r}1,208,179 \\
332,632 \\
2,843,131 \\
1,210,108 \\
120,123\end{array}$ & $\begin{array}{r}884,389 \\
230,012 \\
2,000,001 \\
886,153 \\
82,171\end{array}$ & $\begin{array}{r}10,127 \\
3,894 \\
31,566 \\
8,535 \\
619\end{array}$ & $\begin{array}{r}93,772 \\
24,324 \\
210,795 \\
102,435 \\
8,464\end{array}$ & $\begin{array}{r}104,405 \\
26,283 \\
235,237 \\
105,756 \\
8,788\end{array}$ & $\begin{array}{r}97,608 \\
25,132 \\
223,231 \\
102,288 \\
8,702\end{array}$ & $\begin{array}{r}92,629 \\
24,163 \\
214,604 \\
98,400 \\
8,698\end{array}$ & $\begin{array}{r}88,378 \\
25,029 \\
205,572 \\
94,840 \\
8,736\end{array}$ & $\begin{array}{r}86,801 \\
23,933 \\
200,936 \\
93,888 \\
9,170\end{array}$ \\
\hline 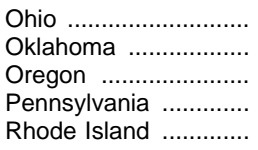 & $\begin{array}{r}1,844,389 \\
620,695 \\
537,854 \\
1,804,256 \\
151,324\end{array}$ & $\begin{array}{r}1,298,719 \\
445,496 \\
380,239 \\
1,263,576 \\
110,476\end{array}$ & $\begin{array}{r}21,317 \\
4,600 \\
878 \\
3,005 \\
666\end{array}$ & $\begin{array}{r}140,222 \\
50,387 \\
39,829 \\
133,608 \\
11,366\end{array}$ & $\begin{array}{r}149,371 \\
54,554 \\
42,819 \\
147,895 \\
13,177\end{array}$ & $\begin{array}{r}142,259 \\
47,182 \\
42,299 \\
139,897 \\
12,390\end{array}$ & $\begin{array}{r}139,219 \\
46,451 \\
41,405 \\
138,776 \\
12,136\end{array}$ & $\begin{array}{r}137,711 \\
46,526 \\
41,373 \\
136,710 \\
11,829\end{array}$ & $\begin{array}{r}139,054 \\
47,647 \\
42,301 \\
138,106 \\
11,518\end{array}$ \\
\hline $\begin{array}{l}\text { South Carolina ........... } \\
\text { South Dakota } \ldots \ldots \ldots \ldots \ldots \\
\text { Tennessee ................... } \\
\text { Texas } \\
\text { Utah }\end{array}$ & $\begin{array}{r}653,011 \\
143,331 \\
905,089 \\
3,828,975 \\
481,812\end{array}$ & $\begin{array}{r}467,885 \\
99,160 \\
657,541 \\
2,800,017 \\
327,981\end{array}$ & $\begin{array}{r}28,603 \\
1,192 \\
211,924 \\
133,303 \\
3,784\end{array}$ & $\begin{array}{r}47,374 \\
10,284 \\
74,529 \\
285,002 \\
34,882\end{array}$ & $\begin{array}{r}49,497 \\
10,625 \\
77,450 \\
312,533 \\
35,848\end{array}$ & $\begin{array}{r}53,547 \\
10,454 \\
71,962 \\
299,334 \\
34,914\end{array}$ & $\begin{array}{r}51,849 \\
10,264 \\
69,451 \\
295,300 \\
35,088\end{array}$ & $\begin{array}{r}50,598 \\
10,668 \\
67,330 \\
294,431 \\
34,227\end{array}$ & $\begin{array}{r}51,214 \\
10,905 \\
68,002 \\
294,703 \\
34,890\end{array}$ \\
\hline 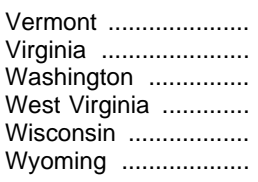 & $\begin{array}{r}106,341 \\
1,096,093 \\
974,504 \\
304,052 \\
879,259 \\
99,058\end{array}$ & $\begin{array}{r}76,076 \\
796,302 \\
687,445 \\
208,970 \\
605,322 \\
67,331\end{array}$ & $\begin{array}{r}2,318 \\
3,917 \\
5,353 \\
4,433 \\
19,790 \\
\end{array}$ & $\begin{array}{r}7,530 \\
86,542 \\
73,577 \\
22,485 \\
62,455 \\
6,782\end{array}$ & $\begin{array}{r}8,256 \\
91,234 \\
78,077 \\
23,092 \\
64,925 \\
7,116\end{array}$ & $\begin{array}{r}8,255 \\
87,710 \\
76,008 \\
22,233 \\
63,921 \\
6,987\end{array}$ & $\begin{array}{r}8,060 \\
83,443 \\
74,718 \\
21,615 \\
63,286 \\
7,132\end{array}$ & $\begin{array}{r}8,152 \\
82,571 \\
74,697 \\
21,944 \\
64,670 \\
7,283\end{array}$ & $\begin{array}{r}8,319 \\
82,768 \\
75,883 \\
22,224 \\
65,943 \\
7,540\end{array}$ \\
\hline Outlying areas & & & & & & & & & \\
\hline $\begin{array}{l}\text { American Samoa ........ } \\
\text { Guam ....................... } \\
\text { Northern Marianas .... } \\
\text { Puerto Rico ............... } \\
\text { Virgin Islands ............. }\end{array}$ & $\begin{array}{r}14,766 \\
33,393 \\
9,041 \\
618,861 \\
22,385\end{array}$ & $\begin{array}{r}11,346 \\
25,217 \\
7,077 \\
454,132 \\
15,703\end{array}$ & $\begin{array}{r}1,494 \\
453 \\
590 \\
373 \\
-\end{array}$ & $\begin{array}{r}1,136 \\
3,022 \\
692 \\
42,399 \\
1,626\end{array}$ & $\begin{array}{r}1,210 \\
3,162 \\
872 \\
54,821 \\
1,760\end{array}$ & $\begin{array}{r}1,181 \\
3,038 \\
771 \\
51,137 \\
1,559\end{array}$ & $\begin{array}{r}1,115 \\
2,846 \\
810 \\
49,959 \\
1,594\end{array}$ & $\begin{array}{r}1,174 \\
2,762 \\
784 \\
49,998 \\
1,691\end{array}$ & $\begin{array}{r}1,079 \\
2,713 \\
679 \\
49,308 \\
1,646\end{array}$ \\
\hline
\end{tabular}


Table 41.-Enrollment in public elementary and secondary schools, by grade and state: Fall 1996-Continued

\begin{tabular}{|c|c|c|c|c|c|c|c|c|c|c|}
\hline \multirow{2}{*}{ State or other area } & \multicolumn{4}{|c|}{$\begin{array}{c}\text { Prekindergarten through grade } 8 \text { and } \\
\text { elementary unclassified }\end{array}$} & \multicolumn{6}{|c|}{ Grades 9 through 12 and secondary unclassified } \\
\hline & Grade 6 & Grade 7 & Grade 8 & $\begin{array}{l}\text { Elementary } \\
\text { unclassified }\end{array}$ & Total & Grade 9 & Grade 10 & Grade 11 & Grade 12 & $\begin{array}{l}\text { Secondary } \\
\text { unclassified }\end{array}$ \\
\hline 1 & 11 & 12 & 13 & 14 & 15 & 16 & 17 & 18 & 19 & 20 \\
\hline United States ......... & $3,486,295$ & $3,456,871$ & $3,398,117$ & 433,839 & $12,833,665$ & $3,792,818$ & $3,316,015$ & $2,925,139$ & $2,581,941$ & 217,752 \\
\hline 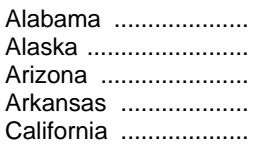 & $\begin{array}{r}57,332 \\
10,176 \\
62,791 \\
35,288 \\
423,701\end{array}$ & $\begin{array}{r}60,302 \\
10,115 \\
62,140 \\
36,779 \\
416,268\end{array}$ & $\begin{array}{r}58,305 \\
9,627 \\
60,514 \\
37,064 \\
406,456\end{array}$ & $\begin{array}{r}\overline{-} \\
7,376 \\
2,143 \\
69,611\end{array}$ & $\begin{array}{r}207,980 \\
35,557 \\
210,841 \\
132,901 \\
1,556,817\end{array}$ & $\begin{array}{r}64,205 \\
10,621 \\
64,566 \\
37,160 \\
450,820\end{array}$ & $\begin{array}{r}52,848 \\
9,426 \\
56,109 \\
35,335 \\
413,725\end{array}$ & $\begin{array}{r}48,417 \\
8,140 \\
47,573 \\
31,889 \\
362,404\end{array}$ & $\begin{array}{r}42,510 \\
7,370 \\
42,041 \\
27,613 \\
298,669\end{array}$ & $\begin{array}{r}- \\
552 \\
904 \\
31,199\end{array}$ \\
\hline $\begin{array}{l}\text { Colorado } \\
\text { Connecticut } \\
\text { Delaware } \\
\text { District of Columbia .......................... } \\
\text { Florida }\end{array}$ & $\begin{array}{r}52,942 \\
40,511 \\
8,610 \\
4,742 \\
179,951\end{array}$ & $\begin{array}{r}52,486 \\
39,816 \\
8,942 \\
4,875 \\
176,413\end{array}$ & $\begin{array}{r}52,269 \\
37,991 \\
8,820 \\
4,625 \\
169,657\end{array}$ & $\begin{array}{r}567 \\
1,718 \\
- \\
2,312 \\
-\end{array}$ & $\begin{array}{r}186,134 \\
137,755 \\
32,568 \\
17,510 \\
589,050\end{array}$ & $\begin{array}{r}55,219 \\
41,003 \\
10,057 \\
4,951 \\
193,153\end{array}$ & $\begin{array}{r}49,058 \\
35,800 \\
8,956 \\
4,554 \\
161,606\end{array}$ & $\begin{array}{r}44,244 \\
32,068 \\
7,108 \\
3,694 \\
128,822\end{array}$ & $\begin{array}{r}37,179 \\
28,882 \\
6,447 \\
3,042 \\
105,469\end{array}$ & $\begin{array}{r}434 \\
2 \\
1,269 \\
-\end{array}$ \\
\hline 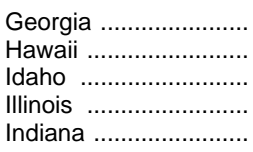 & $\begin{array}{r}104,926 \\
14,612 \\
18,806 \\
157,949 \\
74,331\end{array}$ & $\begin{array}{r}103,601 \\
14,016 \\
19,896 \\
146,397 \\
76,300\end{array}$ & $\begin{array}{r}102,355 \\
13,786 \\
19,998 \\
141,348 \\
76,573\end{array}$ & $\begin{array}{r}\overline{52} \\
\overline{-} \\
2,505 \\
2,756\end{array}$ & $\begin{array}{r}355,911 \\
51,469 \\
75,833 \\
560,864 \\
293,837\end{array}$ & $\begin{array}{r}119,617 \\
16,265 \\
21,023 \\
157,259 \\
83,587\end{array}$ & $\begin{array}{r}92,630 \\
13,265 \\
19,458 \\
145,471 \\
75,447\end{array}$ & $\begin{array}{r}78,137 \\
11,431 \\
18,277 \\
132,762 \\
69,453\end{array}$ & $\begin{array}{r}65,527 \\
10,466 \\
17,075 \\
123,783 \\
62,923\end{array}$ & $\begin{array}{r}\overline{42} \\
1,589 \\
2,427\end{array}$ \\
\hline 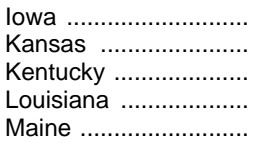 & $\begin{array}{l}37,604 \\
37,046 \\
48,695 \\
61,493 \\
17,512\end{array}$ & $\begin{array}{l}37,890 \\
36,890 \\
49,675 \\
61,343 \\
17,481\end{array}$ & $\begin{array}{l}38,801 \\
37,164 \\
49,641 \\
57,344 \\
17,124\end{array}$ & $\begin{array}{r}6,500 \\
3,034 \\
7,811 \\
13,600 \\
2,217\end{array}$ & $\begin{array}{r}161,311 \\
138,270 \\
189,912 \\
217,978 \\
57,982\end{array}$ & $\begin{array}{l}40,892 \\
39,108 \\
55,989 \\
68,328 \\
15,849\end{array}$ & $\begin{array}{l}40,277 \\
36,064 \\
48,867 \\
54,975 \\
15,010\end{array}$ & $\begin{array}{l}38,093 \\
32,702 \\
43,346 \\
47,525 \\
13,562\end{array}$ & $\begin{array}{l}35,650 \\
29,244 \\
38,460 \\
41,759 \\
12,851\end{array}$ & $\begin{array}{r}6,399 \\
1,152 \\
3,250 \\
5,391 \\
710\end{array}$ \\
\hline 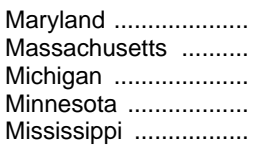 & $\begin{array}{r}61,962 \\
71,768 \\
124,160 \\
66,003 \\
38,102\end{array}$ & $\begin{array}{r}61,268 \\
69,867 \\
121,529 \\
66,293 \\
40,558\end{array}$ & $\begin{array}{r}59,236 \\
67,029 \\
118,292 \\
65,881 \\
38,879\end{array}$ & $\begin{array}{r}6,793 \\
6,239 \\
62,203 \\
-\overline{9} \\
9,752\end{array}$ & $\begin{array}{l}221,940 \\
246,205 \\
462,631 \\
258,452 \\
140,103\end{array}$ & $\begin{array}{r}65,307 \\
70,811 \\
130,936 \\
68,569 \\
43,295\end{array}$ & $\begin{array}{r}56,261 \\
64,182 \\
114,485 \\
66,904 \\
35,243\end{array}$ & $\begin{array}{r}49,695 \\
58,643 \\
102,613 \\
62,566 \\
29,357\end{array}$ & $\begin{array}{l}44,232 \\
52,569 \\
90,348 \\
60,413 \\
25,711\end{array}$ & $\begin{array}{r}6,445 \\
24,249 \\
-\overline{-} \\
6,497\end{array}$ \\
\hline 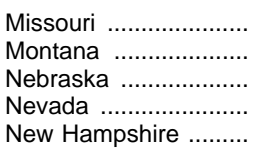 & $\begin{array}{l}69,619 \\
13,164 \\
22,548 \\
22,064 \\
16,626\end{array}$ & $\begin{array}{l}68,903 \\
13,307 \\
23,023 \\
21,432 \\
15,955\end{array}$ & $\begin{array}{l}69,187 \\
13,183 \\
22,912 \\
21,041 \\
15,738\end{array}$ & $\begin{array}{r}6,692 \\
375 \\
- \\
635 \\
761\end{array}$ & $\begin{array}{r}256,989 \\
49,955 \\
89,121 \\
74,407 \\
54,428\end{array}$ & $\begin{array}{l}72,441 \\
13,957 \\
24,047 \\
21,162 \\
15,999\end{array}$ & $\begin{array}{l}67,015 \\
13,013 \\
23,790 \\
19,999 \\
14,321\end{array}$ & $\begin{array}{l}60,653 \\
11,826 \\
21,498 \\
17,912 \\
12,875\end{array}$ & $\begin{array}{l}54,437 \\
11,018 \\
19,786 \\
15,316 \\
11,158\end{array}$ & $\begin{array}{r}2,443 \\
141 \\
-18 \\
75\end{array}$ \\
\hline 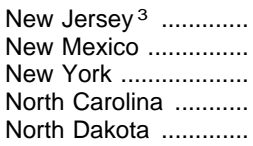 & $\begin{array}{r}86,348 \\
25,474 \\
200,565 \\
94,929 \\
9,352\end{array}$ & $\begin{array}{r}84,287 \\
25,763 \\
200,259 \\
93,141 \\
9,699\end{array}$ & $\begin{array}{r}82,628 \\
26,017 \\
196,724 \\
91,793 \\
9,943\end{array}$ & $\begin{array}{r}57,406 \\
80,512 \\
148 \\
-\end{array}$ & $\begin{array}{r}323,790 \\
102,620 \\
843,130 \\
323,955 \\
37,952\end{array}$ & $\begin{array}{r}86,418 \\
29,906 \\
241,927 \\
105,771 \\
10,230\end{array}$ & $\begin{array}{r}77,521 \\
25,242 \\
206,802 \\
85,120 \\
9,785\end{array}$ & $\begin{array}{r}72,807 \\
21,061 \\
173,915 \\
71,471 \\
9,251\end{array}$ & $\begin{array}{r}67,781 \\
17,073 \\
146,738 \\
61,593 \\
8,686\end{array}$ & $\begin{array}{r}19,263 \\
9,338 \\
73,748 \\
- \\
-\end{array}$ \\
\hline 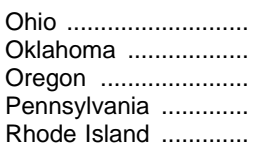 & $\begin{array}{r}141,355 \\
48,635 \\
42,643 \\
136,933 \\
11,472\end{array}$ & $\begin{array}{r}139,994 \\
48,856 \\
42,215 \\
136,632 \\
11,758\end{array}$ & $\begin{array}{r}140,245 \\
49,065 \\
42,862 \\
136,746 \\
11,104\end{array}$ & $\begin{array}{r}7,972 \\
1,593 \\
1,615 \\
15,268 \\
3,060\end{array}$ & $\begin{array}{r}545,670 \\
175,199 \\
157,615 \\
540,680 \\
40,848\end{array}$ & $\begin{array}{r}160,479 \\
51,709 \\
44,713 \\
152,058 \\
12,191\end{array}$ & $\begin{array}{r}140,454 \\
45,970 \\
40,751 \\
136,714 \\
10,609\end{array}$ & $\begin{array}{r}127,673 \\
40,757 \\
36,762 \\
124,788 \\
9,453\end{array}$ & $\begin{array}{r}117,064 \\
36,113 \\
34,794 \\
114,183 \\
8,428\end{array}$ & $\begin{array}{r}- \\
650 \\
595 \\
12,937 \\
167\end{array}$ \\
\hline 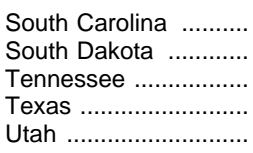 & $\begin{array}{r}52,384 \\
11,235 \\
68,216 \\
298,077 \\
35,307\end{array}$ & $\begin{array}{r}52,194 \\
11,430 \\
68,098 \\
296,668 \\
36,225\end{array}$ & $\begin{array}{r}50,625 \\
11,377 \\
66,465 \\
290,666 \\
36,860\end{array}$ & $\begin{array}{r}7 \overline{26} \\
14,114 \\
5,956\end{array}$ & $\begin{array}{r}185,126 \\
44,171 \\
247,548 \\
1,028,958 \\
153,831\end{array}$ & $\begin{array}{r}61,962 \\
12,497 \\
75,906 \\
343,867 \\
38,742\end{array}$ & $\begin{array}{r}48,314 \\
11,313 \\
65,631 \\
264,238 \\
38,071\end{array}$ & $\begin{array}{r}39,304 \\
10,521 \\
55,679 \\
225,778 \\
37,623\end{array}$ & $\begin{array}{r}35,546 \\
9,552 \\
50,332 \\
195,075 \\
34,795\end{array}$ & $\begin{array}{r}\overline{288} \\
\overline{-} \\
4,600\end{array}$ \\
\hline 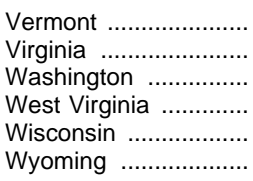 & $\begin{array}{r}8,331 \\
85,407 \\
76,591 \\
22,709 \\
67,317 \\
7,981\end{array}$ & $\begin{array}{r}8,481 \\
82,668 \\
76,508 \\
23,478 \\
66,527 \\
8,230\end{array}$ & $\begin{array}{r}8,374 \\
80,842 \\
76,033 \\
24,150 \\
66,488 \\
8,270\end{array}$ & $\begin{array}{r}-29,200 \\
\frac{607}{10}\end{array}$ & $\begin{array}{r}30,265 \\
299,791 \\
287,059 \\
95,082 \\
273,937 \\
31,727\end{array}$ & $\begin{array}{r}8,486 \\
88,721 \\
81,336 \\
25,994 \\
75,097 \\
8,612\end{array}$ & $\begin{array}{r}7,697 \\
77,806 \\
75,648 \\
24,561 \\
71,308 \\
8,366\end{array}$ & $\begin{array}{r}7,130 \\
68,649 \\
67,840 \\
22,787 \\
66,990 \\
7,615\end{array}$ & $\begin{array}{r}6,622 \\
64,497 \\
62,235 \\
21,215 \\
60,542 \\
7,129\end{array}$ & $\begin{array}{r}330 \\
118 \\
-525 \\
5\end{array}$ \\
\hline 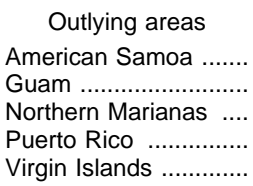 & $\begin{array}{r}1,035 \\
2,502 \\
662 \\
48,425 \\
1,642\end{array}$ & $\begin{array}{r}1,010 \\
2,341 \\
637 \\
50,640 \\
1,959\end{array}$ & $\begin{array}{r}912 \\
2,370 \\
580 \\
47,449 \\
1,517\end{array}$ & $\begin{array}{r}\overline{8} \\
\overline{-} \\
9,623 \\
709\end{array}$ & $\begin{array}{r}3,420 \\
8,176 \\
1,964 \\
164,729 \\
6,682\end{array}$ & $\begin{array}{r}1,004 \\
3,285 \\
617 \\
45,691 \\
2,429\end{array}$ & $\begin{array}{r}876 \\
2,133 \\
487 \\
44,692 \\
1,204\end{array}$ & $\begin{array}{r}731 \\
1,500 \\
497 \\
37,755 \\
1,402\end{array}$ & $\begin{array}{r}739 \\
1,258 \\
363 \\
32,361 \\
1,063\end{array}$ & $\begin{array}{r}70 \\
-\overline{-} \\
4,230 \\
584\end{array}$ \\
\hline
\end{tabular}

1 Data include imputations for nonrespondents.

2 Includes imputations for underreporting

${ }^{3}$ Data imputed by the National Center for Education Statistics based on previous year's data.
—Data not reported or not applicable.

SOURCE: U.S. Department of Education, National Center for Education Statistics, Common Core of Data survey. (This table was prepared May 1998.) 
Table 42.-Enrollment in public elementary and secondary schools, by grade and state: Fall 1995

\begin{tabular}{|c|c|c|c|c|c|c|c|c|c|}
\hline \multirow{2}{*}{ State or other area } & \multirow{2}{*}{$\begin{array}{c}\text { Total, } \\
\text { all } \\
\text { levels }\end{array}$} & \multicolumn{8}{|c|}{ Prekindergarten through grade 8 and elementary unclassified } \\
\hline & & Total & $\begin{array}{l}\text { Prekinder- } \\
\text { garten } 1\end{array}$ & Kindergarten & Grade 1 & Grade 2 & Grade 3 & Grade 4 & Grade 5 \\
\hline 1 & 2 & 3 & 4 & 5 & 6 & 7 & 8 & 9 & 10 \\
\hline United States ......... & $44,840,481$ & $32,340,501$ & 636,846 & $3,536,227$ & $3,670,903$ & $3,507,022$ & $3,444,740$ & $3,430,583$ & $3,437,943$ \\
\hline 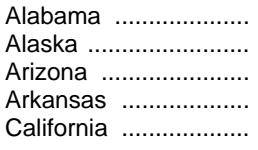 & $\begin{array}{r}746,149 \\
127,618 \\
743,566 \\
453,257 \\
5,536,406\end{array}$ & $\begin{array}{r}539,309 \\
93,434 \\
548,526 \\
322,440 \\
4,041,224\end{array}$ & $\begin{array}{r}29,324 \\
2,419 \\
4,027 \\
1,525 \\
269,182\end{array}$ & $\begin{array}{r}59,739 \\
10,567 \\
61,420 \\
36,731 \\
472,334\end{array}$ & $\begin{array}{r}61,694 \\
10,444 \\
64,215 \\
36,369 \\
466,167\end{array}$ & $\begin{array}{r}57,452 \\
10,352 \\
61,418 \\
34,257 \\
453,020\end{array}$ & $\begin{array}{r}57,732 \\
10,030 \\
59,828 \\
33,621 \\
435,380\end{array}$ & $\begin{array}{r}56,486 \\
10,222 \\
60,202 \\
33,955 \\
428,553\end{array}$ & $\begin{array}{r}57,142 \\
10,112 \\
59,894 \\
34,875 \\
424,838\end{array}$ \\
\hline $\begin{array}{l}\text { Colorado ................... } \\
\text { Connecticut ............... } \\
\text { Delaware ................. } \\
\text { District of Columbia ... } \\
\text { Florida ....................... }\end{array}$ & $\begin{array}{r}656,279 \\
517,935 \\
108,461 \\
79,802 \\
2,176,222\end{array}$ & $\begin{array}{r}478,881 \\
384,274 \\
77,028 \\
61,836 \\
1,613,510\end{array}$ & $\begin{array}{r}10,472 \\
8,093 \\
670 \\
5,387 \\
51,123\end{array}$ & $\begin{array}{r}50,316 \\
44,148 \\
7,775 \\
7,736 \\
176,767\end{array}$ & $\begin{array}{r}52,767 \\
45,969 \\
8,579 \\
7,931 \\
180,182\end{array}$ & $\begin{array}{r}51,786 \\
43,030 \\
8,721 \\
6,533 \\
175,891\end{array}$ & $\begin{array}{r}52,030 \\
42,010 \\
8,425 \\
6,063 \\
172,039\end{array}$ & $\begin{array}{r}52,783 \\
41,365 \\
8,527 \\
5,852 \\
173,169\end{array}$ & $\begin{array}{r}52,646 \\
40,650 \\
8,362 \\
5,332 \\
175,358\end{array}$ \\
\hline 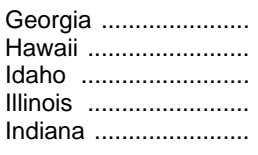 & $\begin{array}{r}1,311,126 \\
187,180 \\
243,097 \\
1,943,623 \\
977,263\end{array}$ & $\begin{array}{r}965,707 \\
135,671 \\
169,556 \\
1,390,475 \\
684,348\end{array}$ & $\begin{array}{r}22,621 \\
609 \\
1,665 \\
45,947 \\
4,901\end{array}$ & $\begin{array}{r}111,462 \\
16,562 \\
17,750 \\
151,485 \\
73,833\end{array}$ & $\begin{array}{r}110,955 \\
16,013 \\
18,260 \\
154,534 \\
80,279\end{array}$ & $\begin{array}{r}105,752 \\
15,546 \\
18,285 \\
149,128 \\
74,964\end{array}$ & $\begin{array}{r}103,936 \\
15,106 \\
17,952 \\
142,500 \\
71,585\end{array}$ & $\begin{array}{r}103,072 \\
14,867 \\
17,640 \\
142,660 \\
72,356\end{array}$ & $\begin{array}{r}102,516 \\
14,489 \\
18,626 \\
142,836 \\
73,101\end{array}$ \\
\hline 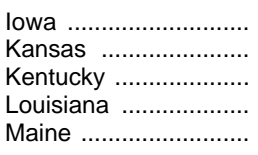 & $\begin{array}{l}502,343 \\
463,008 \\
659,821 \\
797,366 \\
213,569\end{array}$ & $\begin{array}{l}343,997 \\
328,701 \\
468,242 \\
580,348 \\
156,016\end{array}$ & $\begin{array}{r}5,957 \\
3,209 \\
20,290 \\
19,440 \\
821\end{array}$ & $\begin{array}{l}37,629 \\
33,925 \\
45,038 \\
61,323 \\
16,826\end{array}$ & $\begin{array}{l}36,107 \\
35,538 \\
47,250 \\
63,719 \\
17,250\end{array}$ & $\begin{array}{l}35,029 \\
35,037 \\
45,845 \\
59,414 \\
17,003\end{array}$ & $\begin{array}{l}34,884 \\
35,100 \\
56,613 \\
59,552 \\
16,568\end{array}$ & $\begin{array}{l}36,431 \\
36,004 \\
46,834 \\
61,315 \\
17,419\end{array}$ & $\begin{array}{l}37,204 \\
36,596 \\
48,572 \\
61,232 \\
17,397\end{array}$ \\
\hline 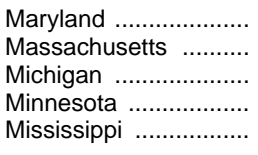 & $\begin{array}{r}805,544 \\
915,007 \\
1,641,456 \\
835,166 \\
506,272\end{array}$ & $\begin{array}{r}590,155 \\
674,588 \\
1,191,671 \\
586,080 \\
366,186\end{array}$ & $\begin{array}{r}19,092 \\
14,792 \\
8,870 \\
8,340 \\
1,083\end{array}$ & $\begin{array}{r}63,232 \\
79,163 \\
141,238 \\
63,896 \\
39,632\end{array}$ & $\begin{array}{r}67,348 \\
79,565 \\
134,513 \\
63,268 \\
42,510\end{array}$ & $\begin{array}{r}65,055 \\
75,647 \\
125,809 \\
62,511 \\
39,015\end{array}$ & $\begin{array}{r}63,940 \\
73,380 \\
124,197 \\
62,564 \\
37,304\end{array}$ & $\begin{array}{r}62,207 \\
71,800 \\
122,266 \\
64,545 \\
38,004\end{array}$ & $\begin{array}{r}61,814 \\
71,606 \\
123,894 \\
65,191 \\
38,332\end{array}$ \\
\hline 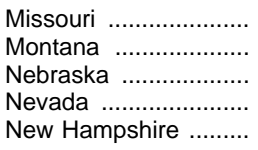 & $\begin{array}{l}889,881 \\
165,547 \\
289,744 \\
265,041 \\
194,171\end{array}$ & $\begin{array}{l}635,771 \\
116,403 \\
203,022 \\
195,892 \\
141,721\end{array}$ & $\begin{array}{r}16,225 \\
519 \\
3,853 \\
1,631 \\
1,357\end{array}$ & $\begin{array}{r}68,513 \\
12,214 \\
22,282 \\
22,074 \\
8,859\end{array}$ & $\begin{array}{l}69,659 \\
12,519 \\
21,748 \\
23,301 \\
17,973\end{array}$ & $\begin{array}{l}67,080 \\
12,279 \\
21,082 \\
22,368 \\
16,601\end{array}$ & $\begin{array}{l}66,928 \\
12,535 \\
21,210 \\
21,752 \\
16,566\end{array}$ & $\begin{array}{l}68,159 \\
12,899 \\
21,886 \\
21,784 \\
16,275\end{array}$ & $\begin{array}{l}68,889 \\
13,200 \\
22,351 \\
21,253 \\
16,480\end{array}$ \\
\hline $\begin{array}{l}\text { New Jersey } . . . . . . . . . . . . . \\
\text { New Mexico ................ } \\
\text { New York .................. } \\
\text { North Carolina ............ } \\
\text { North Dakota } . . . \ldots \ldots \ldots . . .\end{array}$ & $\begin{array}{r}1,197,381 \\
329,640 \\
2,813,230 \\
1,183,090 \\
119,100\end{array}$ & $\begin{array}{r}880,350 \\
229,239 \\
1,980,208 \\
871,320 \\
82,333\end{array}$ & $\begin{array}{r}9,301 \\
3,426 \\
32,087 \\
9,013 \\
551\end{array}$ & $\begin{array}{r}93,978 \\
24,329 \\
216,112 \\
100,525 \\
8,573\end{array}$ & $\begin{array}{r}102,521 \\
26,152 \\
231,136 \\
101,945 \\
8,824\end{array}$ & $\begin{array}{r}95,581 \\
24,703 \\
218,744 \\
96,229 \\
8,678\end{array}$ & $\begin{array}{r}91,352 \\
24,395 \\
209,174 \\
92,552 \\
8,590\end{array}$ & $\begin{array}{r}88,686 \\
24,200 \\
203,089 \\
90,795 \\
9,017\end{array}$ & $\begin{array}{r}86,889 \\
24,407 \\
200,446 \\
90,445 \\
9,201\end{array}$ \\
\hline 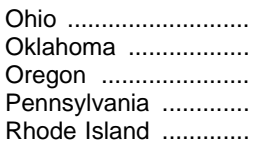 & $\begin{array}{r}1,836,015 \\
616,393 \\
527,914 \\
1,787,533 \\
149,799\end{array}$ & $\begin{array}{r}1,297,313 \\
445,780 \\
375,966 \\
1,256,621 \\
109,815\end{array}$ & $\begin{array}{r}18,997 \\
5,470 \\
855 \\
3,502 \\
531\end{array}$ & $\begin{array}{r}141,589 \\
48,635 \\
39,875 \\
134,584 \\
10,947\end{array}$ & $\begin{array}{r}148,354 \\
54,178 \\
41,952 \\
146,077 \\
13,868\end{array}$ & $\begin{array}{r}140,090 \\
46,642 \\
40,802 \\
139,562 \\
12,343\end{array}$ & $\begin{array}{r}138,135 \\
46,456 \\
40,790 \\
136,887 \\
12,053\end{array}$ & $\begin{array}{r}138,942 \\
47,407 \\
41,721 \\
137,850 \\
11,596\end{array}$ & $\begin{array}{r}140,465 \\
48,073 \\
42,083 \\
135,565 \\
11,439\end{array}$ \\
\hline $\begin{array}{l}\text { South Carolina ........... } \\
\text { South Dakota } \ldots \ldots \ldots \ldots \ldots \\
\text { Tennessee ................... } \\
\text { Texas } \\
\text { Utah }\end{array}$ & $\begin{array}{r}645,586 \\
144,685 \\
893,770 \\
3,748,167 \\
477,121\end{array}$ & $\begin{array}{r}463,305 \\
101,491 \\
650,601 \\
2,757,273 \\
327,790\end{array}$ & $\begin{array}{r}28,067 \\
1,475 \\
211,168 \\
133,754 \\
3,455\end{array}$ & $\begin{array}{r}39,964 \\
10,609 \\
73,962 \\
281,708 \\
34,645\end{array}$ & $\begin{array}{r}55,944 \\
10,700 \\
76,015 \\
303,928 \\
34,857\end{array}$ & $\begin{array}{r}51,837 \\
10,365 \\
69,266 \\
294,298 \\
34,782\end{array}$ & $\begin{array}{r}50,451 \\
10,675 \\
67,326 \\
291,993 \\
33,937\end{array}$ & $\begin{array}{r}50,860 \\
10,937 \\
67,705 \\
292,191 \\
34,598\end{array}$ & $\begin{array}{r}51,338 \\
11,234 \\
67,859 \\
293,834 \\
34,976\end{array}$ \\
\hline 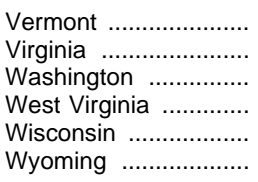 & $\begin{array}{r}105,565 \\
1,079,854 \\
956,572 \\
307,112 \\
870,175 \\
99,859\end{array}$ & $\begin{array}{r}75,227 \\
787,945 \\
680,009 \\
211,008 \\
602,964 \\
68,931\end{array}$ & $\begin{array}{r}1,111 \\
3,111 \\
5,984 \\
3,499 \\
18,045 \\
-\end{array}$ & $\begin{array}{r}7,953 \\
87,618 \\
73,581 \\
22,577 \\
62,859 \\
7,135\end{array}$ & $\begin{array}{r}8,371 \\
89,183 \\
75,721 \\
22,875 \\
64,574 \\
7,102\end{array}$ & $\begin{array}{r}8,067 \\
83,414 \\
73,810 \\
21,610 \\
63,141 \\
7,148\end{array}$ & $\begin{array}{r}8,200 \\
82,713 \\
73,888 \\
21,991 \\
64,541 \\
7,311\end{array}$ & $\begin{array}{r}8,287 \\
82,797 \\
75,186 \\
22,178 \\
65,427 \\
7,577\end{array}$ & $\begin{array}{r}8,327 \\
83,955 \\
75,599 \\
22,478 \\
66,577 \\
7,965\end{array}$ \\
\hline Outlying areas & & & & & & & & & \\
\hline $\begin{array}{l}\text { American Samoa ........ } \\
\text { Guam ....................... } \\
\text { Northern Marianas .... } \\
\text { Puerto Rico ............... } \\
\text { Virgin Islands ............. }\end{array}$ & $\begin{array}{r}14,576 \\
32,960 \\
8,809 \\
627,620 \\
22,737\end{array}$ & $\begin{array}{r}11,207 \\
24,877 \\
6,825 \\
460,585 \\
16,342\end{array}$ & $\begin{array}{r}1,458 \\
962 \\
560 \\
255 \\
-\end{array}$ & $\begin{array}{r}1,162 \\
2,961 \\
598 \\
44,566 \\
1,638\end{array}$ & $\begin{array}{r}1,189 \\
2,994 \\
781 \\
54,545 \\
1,647\end{array}$ & $\begin{array}{r}1,142 \\
2,856 \\
781 \\
50,423 \\
1,654\end{array}$ & $\begin{array}{r}1,181 \\
2,739 \\
805 \\
49,531 \\
1,717\end{array}$ & $\begin{array}{r}1,089 \\
2,722 \\
683 \\
49,762 \\
1,655\end{array}$ & $\begin{array}{r}1,052 \\
2,549 \\
667 \\
49,863 \\
1,712\end{array}$ \\
\hline
\end{tabular}


Table 42.-Enrollment in public elementary and secondary schools, by grade and state: Fall 1995-Continued

\begin{tabular}{|c|c|c|c|c|c|c|c|c|c|c|}
\hline \multirow{2}{*}{ State or other area } & \multicolumn{4}{|c|}{$\begin{array}{c}\text { Prekindergarten through grade } 8 \text { and } \\
\text { elementary unclassified }\end{array}$} & \multicolumn{6}{|c|}{ Grades 9 through 12 and secondary unclassified } \\
\hline & Grade 6 & Grade 7 & Grade 8 & $\begin{array}{l}\text { Elementary } \\
\text { unclassified }\end{array}$ & Total & Grade 9 & Grade 10 & Grade 11 & Grade 12 & $\begin{array}{l}\text { Secondary } \\
\text { unclassified }\end{array}$ \\
\hline 1 & 11 & 12 & 13 & 14 & 15 & 16 & 17 & 18 & 19 & 20 \\
\hline United States ......... & $3,395,307$ & $3,422,290$ & $3,356,338$ & 502,302 & $12,499,980$ & $3,704,455$ & $3,237,391$ & $2,826,023$ & $2,487,135$ & 244,976 \\
\hline 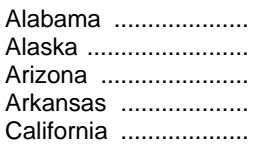 & $\begin{array}{r}58,704 \\
9,870 \\
58,281 \\
35,104 \\
413,776\end{array}$ & $\begin{array}{r}61,122 \\
9,845 \\
58,829 \\
37,023 \\
409,978\end{array}$ & $\begin{array}{r}59,914 \\
9,573 \\
56,407 \\
36,696 \\
399,039\end{array}$ & $\begin{array}{r}\overline{-} \\
4,005 \\
2,284 \\
68,957\end{array}$ & $\begin{array}{r}206,840 \\
34,184 \\
195,040 \\
130,817 \\
1,495,182\end{array}$ & $\begin{array}{r}65,299 \\
10,263 \\
59,346 \\
37,005 \\
437,974\end{array}$ & $\begin{array}{r}53,780 \\
9,045 \\
52,654 \\
35,209 \\
396,020\end{array}$ & $\begin{array}{r}46,780 \\
7,765 \\
43,547 \\
30,566 \\
343,419\end{array}$ & $\begin{array}{r}40,981 \\
7,111 \\
39,197 \\
27,083 \\
287,428\end{array}$ & $\begin{array}{r}- \\
296 \\
954 \\
30,341\end{array}$ \\
\hline 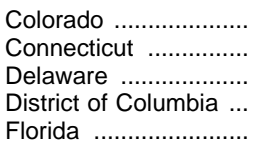 & $\begin{array}{r}51,856 \\
39,468 \\
8,520 \\
4,980 \\
174,079\end{array}$ & $\begin{array}{r}52,282 \\
38,253 \\
8,883 \\
5,052 \\
171,381\end{array}$ & $\begin{array}{r}51,180 \\
37,320 \\
8,566 \\
4,749 \\
163,521\end{array}$ & $\begin{array}{r}763 \\
3,968 \\
- \\
2,221 \\
-\end{array}$ & $\begin{array}{r}177,398 \\
133,661 \\
31,433 \\
17,966 \\
562,712\end{array}$ & $\begin{array}{r}52,472 \\
39,380 \\
10,112 \\
5,159 \\
182,980\end{array}$ & $\begin{array}{r}47,128 \\
34,797 \\
8,325 \\
4,896 \\
154,030\end{array}$ & $\begin{array}{r}41,751 \\
31,198 \\
6,785 \\
3,700 \\
126,183\end{array}$ & $\begin{array}{r}35,480 \\
28,282 \\
6,211 \\
2,972 \\
99,519\end{array}$ & $\begin{array}{r}567 \\
4 \\
1,239 \\
-\end{array}$ \\
\hline 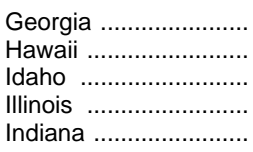 & $\begin{array}{r}103,015 \\
14,617 \\
19,392 \\
138,679 \\
74,734\end{array}$ & $\begin{array}{r}102,287 \\
14,022 \\
19,857 \\
133,484 \\
77,279\end{array}$ & $\begin{array}{r}100,091 \\
13,793 \\
20,129 \\
132,678 \\
78,278\end{array}$ & $\begin{array}{r}\overline{47} \\
\overline{-} \\
56,544 \\
3,038\end{array}$ & $\begin{array}{r}345,419 \\
51,509 \\
73,541 \\
553,148 \\
292,915\end{array}$ & $\begin{array}{r}117,429 \\
16,277 \\
20,195 \\
149,289 \\
83,436\end{array}$ & $\begin{array}{r}90,117 \\
13,274 \\
19,349 \\
139,115 \\
76,232\end{array}$ & $\begin{array}{r}74,137 \\
11,442 \\
17,904 \\
122,384 \\
67,902\end{array}$ & $\begin{array}{r}63,736 \\
10,478 \\
16,093 \\
107,244 \\
62,659\end{array}$ & $\begin{array}{r}-\overline{38} \\
35,116 \\
2,686\end{array}$ \\
\hline $\begin{array}{l}\text { lowa } \\
\text { Kansas } \\
\text { Kentucky } \\
\text { Louisiana } \\
\text { Maine }\end{array}$ & $\begin{array}{l}37,117 \\
36,534 \\
49,131 \\
60,647 \\
17,280\end{array}$ & $\begin{array}{l}38,833 \\
37,317 \\
51,000 \\
62,873 \\
17,206\end{array}$ & $\begin{array}{l}38,715 \\
36,782 \\
50,091 \\
57,918 \\
16,771\end{array}$ & $\begin{array}{r}6,091 \\
2,659 \\
7,578 \\
12,915 \\
1,475\end{array}$ & $\begin{array}{r}158,346 \\
134,307 \\
191,579 \\
217,018 \\
57,553\end{array}$ & $\begin{array}{l}41,385 \\
38,484 \\
56,572 \\
68,655 \\
16,007\end{array}$ & $\begin{array}{l}39,680 \\
35,290 \\
49,429 \\
55,225 \\
14,636\end{array}$ & $\begin{array}{l}36,861 \\
31,064 \\
43,614 \\
47,422 \\
13,773\end{array}$ & $\begin{array}{l}34,565 \\
28,491 \\
38,797 \\
40,663 \\
12,670\end{array}$ & $\begin{array}{r}5,855 \\
978 \\
3,167 \\
5,053 \\
467\end{array}$ \\
\hline 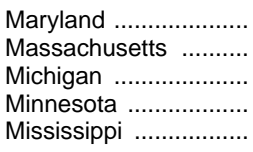 & $\begin{array}{r}61,099 \\
69,122 \\
120,347 \\
64,439 \\
38,737\end{array}$ & $\begin{array}{r}60,747 \\
67,176 \\
120,121 \\
65,677 \\
41,223\end{array}$ & $\begin{array}{r}58,835 \\
65,724 \\
118,996 \\
65,649 \\
39,809\end{array}$ & $\begin{array}{r}6,786 \\
6,613 \\
51,420 \\
- \\
10,537\end{array}$ & $\begin{array}{l}215,389 \\
240,419 \\
449,785 \\
249,086 \\
140,086\end{array}$ & $\begin{array}{r}64,468 \\
68,623 \\
129,820 \\
67,226 \\
43,241\end{array}$ & $\begin{array}{r}54,286 \\
62,856 \\
112,588 \\
64,478 \\
35,552\end{array}$ & $\begin{array}{l}47,345 \\
57,029 \\
99,551 \\
59,589 \\
28,587\end{array}$ & $\begin{array}{l}42,974 \\
51,911 \\
87,840 \\
57,793 \\
25,741\end{array}$ & $\begin{array}{r}6,316 \\
19,986 \\
6,965\end{array}$ \\
\hline 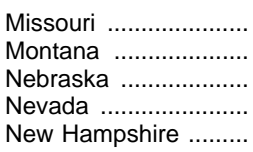 & $\begin{array}{l}67,847 \\
13,153 \\
22,777 \\
20,616 \\
15,805\end{array}$ & $\begin{array}{l}69,368 \\
13,407 \\
22,817 \\
20,449 \\
15,798\end{array}$ & $\begin{array}{l}66,493 \\
13,342 \\
23,016 \\
19,970 \\
15,487\end{array}$ & $\begin{array}{r}6,610 \\
336 \\
- \\
694 \\
520\end{array}$ & $\begin{array}{r}254,110 \\
49,144 \\
86,722 \\
69,149 \\
52,450\end{array}$ & $\begin{array}{l}72,575 \\
13,921 \\
23,813 \\
19,661 \\
15,420\end{array}$ & $\begin{array}{l}66,804 \\
12,569 \\
23,184 \\
18,773 \\
13,597\end{array}$ & $\begin{array}{l}59,378 \\
11,635 \\
20,450 \\
16,553 \\
12,387\end{array}$ & $\begin{array}{l}52,939 \\
10,897 \\
19,275 \\
14,143 \\
10,996\end{array}$ & $\begin{array}{r}2,414 \\
122 \\
19 \\
50\end{array}$ \\
\hline 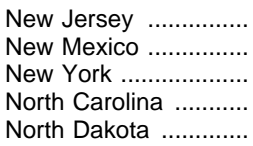 & $\begin{array}{r}84,950 \\
25,300 \\
197,470 \\
88,925 \\
9,270\end{array}$ & $\begin{array}{r}83,920 \\
26,434 \\
199,440 \\
89,747 \\
9,770\end{array}$ & $\begin{array}{r}81,997 \\
25,893 \\
194,347 \\
88,056 \\
9,859\end{array}$ & $\begin{array}{r}61,175 \\
78,163 \\
23,088 \\
-\end{array}$ & $\begin{array}{r}317,031 \\
100,401 \\
833,022 \\
311,770 \\
36,767\end{array}$ & $\begin{array}{r}84,649 \\
29,164 \\
235,320 \\
100,505 \\
9,927\end{array}$ & $\begin{array}{r}76,042 \\
24,981 \\
205,305 \\
82,512 \\
9,377\end{array}$ & $\begin{array}{r}70,493 \\
20,195 \\
178,043 \\
69,100 \\
8,950\end{array}$ & $\begin{array}{r}65,647 \\
17,078 \\
142,841 \\
59,653 \\
8,513\end{array}$ & $\begin{array}{r}20,200 \\
8,983 \\
71,513 \\
-\end{array}$ \\
\hline 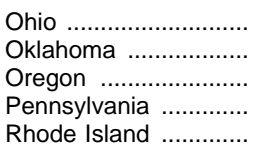 & $\begin{array}{r}137,737 \\
48,683 \\
41,735 \\
133,770 \\
11,586\end{array}$ & $\begin{array}{r}141,979 \\
49,709 \\
42,449 \\
137,376 \\
11,515\end{array}$ & $\begin{array}{r}142,469 \\
49,012 \\
42,141 \\
136,069 \\
11,032\end{array}$ & $\begin{array}{r}8,556 \\
1,515 \\
1,563 \\
15,379 \\
2,905\end{array}$ & $\begin{array}{r}538,702 \\
170,613 \\
151,948 \\
530,912 \\
39,984\end{array}$ & $\begin{array}{r}159,777 \\
49,992 \\
42,438 \\
150,460 \\
11,922\end{array}$ & $\begin{array}{r}138,771 \\
45,289 \\
39,326 \\
134,653 \\
10,530\end{array}$ & $\begin{array}{r}125,275 \\
38,997 \\
36,420 \\
121,885 \\
9,113\end{array}$ & $\begin{array}{r}114,879 \\
35,733 \\
33,202 \\
111,050 \\
8,263\end{array}$ & $\begin{array}{r}- \\
602 \\
562 \\
12,864 \\
156\end{array}$ \\
\hline 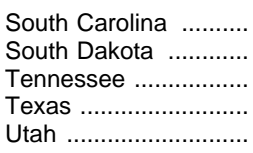 & $\begin{array}{r}51,322 \\
11,143 \\
66,227 \\
288,502 \\
35,877\end{array}$ & $\begin{array}{r}52,214 \\
11,583 \\
68,309 \\
292,190 \\
36,693\end{array}$ & $\begin{array}{r}51,308 \\
11,654 \\
66,513 \\
284,875 \\
38,090\end{array}$ & $\begin{array}{r}1, \overline{16} \\
16,251 \\
\overline{-} \\
5,880\end{array}$ & $\begin{array}{r}182,281 \\
43,194 \\
243,169 \\
990,894 \\
149,331\end{array}$ & $\begin{array}{r}60,808 \\
12,176 \\
74,398 \\
335,819 \\
37,941\end{array}$ & $\begin{array}{r}48,165 \\
11,388 \\
64,144 \\
255,132 \\
38,485\end{array}$ & $\begin{array}{r}38,508 \\
10,090 \\
55,308 \\
213,714 \\
36,487\end{array}$ & $\begin{array}{r}34,800 \\
9,116 \\
49,319 \\
186,229 \\
32,006\end{array}$ & $\frac{4 \overline{7}}{\overline{-}}$ \\
\hline 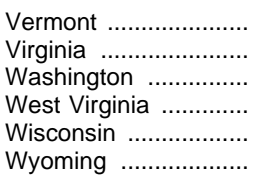 & $\begin{array}{r}8,553 \\
82,996 \\
75,313 \\
22,825 \\
65,289 \\
8,108\end{array}$ & $\begin{array}{r}8,352 \\
81,619 \\
75,875 \\
24,521 \\
66,723 \\
8,283\end{array}$ & $\begin{array}{r}8,006 \\
81,254 \\
75,052 \\
25,089 \\
65,788 \\
8,302\end{array}$ & $\begin{array}{r}-29,285 \\
- \\
1,365 \\
- \\
-\end{array}$ & $\begin{array}{r}30,338 \\
291,909 \\
276,563 \\
96,104 \\
267,211 \\
30,928\end{array}$ & $\begin{array}{r}8,125 \\
86,779 \\
78,514 \\
26,261 \\
74,700 \\
8,293\end{array}$ & $\begin{array}{r}7,465 \\
76,045 \\
73,402 \\
24,769 \\
70,262 \\
8,430\end{array}$ & $\begin{array}{r}6,909 \\
66,764 \\
65,035 \\
22,052 \\
64,458 \\
7,526\end{array}$ & $\begin{array}{r}6,507 \\
62,204 \\
59,612 \\
21,844 \\
57,791 \\
6,679\end{array}$ & $\begin{array}{r}1,332 \\
117 \\
1,178 \\
-\end{array}$ \\
\hline 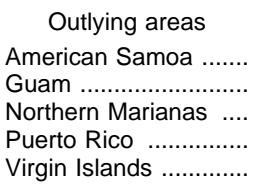 & $\begin{array}{r}1,042 \\
2,384 \\
642 \\
47,978 \\
1,577\end{array}$ & $\begin{array}{r}941 \\
2,342 \\
712 \\
51,731 \\
2,285\end{array}$ & $\begin{array}{r}951 \\
2,368 \\
596 \\
48,934 \\
1,607\end{array}$ & $\begin{array}{r}- \\
\overline{-} \\
12,997 \\
850\end{array}$ & $\begin{array}{r}3,369 \\
8,083 \\
1,984 \\
167,035 \\
6,395\end{array}$ & $\begin{array}{r}915 \\
2,862 \\
575 \\
45,673 \\
1,774\end{array}$ & $\begin{array}{r}837 \\
2,122 \\
536 \\
44,939 \\
1,629\end{array}$ & $\begin{array}{r}796 \\
1,666 \\
406 \\
38,184 \\
1,251\end{array}$ & $\begin{array}{r}756 \\
1,433 \\
467 \\
32,535 \\
1,102\end{array}$ & $\begin{array}{r}65 \\
\overline{-} \\
5,704 \\
639\end{array}$ \\
\hline
\end{tabular}


Table 43.-Enrollment in public elementary and secondary schools, by grade: Fall 1982 to fall 1996

\begin{tabular}{|c|c|c|c|c|c|c|c|c|c|c|c|c|c|c|c|}
\hline Grade & $\begin{array}{c}\text { Fall } \\
1982 \\
\end{array}$ & $\begin{array}{c}\text { Fall } \\
1983\end{array}$ & $\begin{array}{c}\text { Fall } \\
1984 \\
\end{array}$ & $\begin{array}{c}\text { Fall } \\
1985\end{array}$ & $\begin{array}{c}\text { Fall } \\
1986 \\
\end{array}$ & $\begin{array}{c}\text { Fall } \\
1987 \\
\end{array}$ & $\begin{array}{c}\text { Fall } \\
1988\end{array}$ & $\begin{array}{c}\text { Fall } \\
1989 \\
\end{array}$ & $\begin{array}{c}\text { Fall } \\
1990\end{array}$ & $\begin{array}{c}\text { Fall } \\
1991\end{array}$ & $\begin{array}{c}\text { Fall } \\
1992 \\
\end{array}$ & $\begin{array}{c}\text { Fall } \\
1993\end{array}$ & $\begin{array}{c}\text { Fall } \\
1994 \\
\end{array}$ & $\begin{array}{c}\text { Fall } \\
1995\end{array}$ & $\begin{array}{c}\text { Fall } \\
1996\end{array}$ \\
\hline 1 & 2 & 3 & 4 & 5 & 6 & 7 & 8 & 9 & 10 & 11 & 12 & 13 & 14 & 15 & 16 \\
\hline & \multicolumn{15}{|c|}{ In thousands } \\
\hline All grades & 39,566 & 39,252 & 39,208 & 39,422 & 39,753 & 40,008 & 40,189 & 40,543 & 41,217 & 42,047 & 42,823 & 43,465 & 44,111 & 44,840 & 45,592 \\
\hline Elementary & 27,161 & 26,981 & 26,905 & 27,034 & 27,420 & 27,933 & 28,501 & 29,152 & 29,878 & 30,506 & 31,088 & 31,504 & 31,898 & 32,341 & 32,759 \\
\hline Prekindergarten & 106 & 105 & 109 & 151 & 183 & 193 & 225 & 262 & 303 & 375 & 505 & 545 & 603 & 637 & 674 \\
\hline Kindergarten & 2,740 & 2,754 & 2,900 & 3,041 & 3,127 & 3,196 & 3,208 & 3,225 & 3,306 & 3,311 & 3,313 & 3,377 & 3,444 & 3,536 & 3,534 \\
\hline 1 st gr & 2,937 & 3,080 & 3,113 & 3,239 & 3,358 & 3,407 & 3,460 & 3,485 & 3,499 & 3,556 & 3,542 & 3,529 & 3,593 & 3,671 & 3,769 \\
\hline 2nd grade. & 2,790 & 2,781 & 2,904 & 2,941 & 3,054 & 3,173 & 3,223 & 3,289 & 3,327 & 3,360 & 3,431 & 3,429 & 3,440 & 3,507 & 3,596 \\
\hline 3rd grade & 2,763 & 2,772 & 2,765 & 2,895 & 2,933 & 3,046 & 3,167 & 3,235 & 3,297 & 3,334 & 3,361 & 3,437 & 3,439 & 3,445 & 3,518 \\
\hline 4th grade & 2,798 & 2,758 & 2,772 & 2,771 & 2,896 & 2,938 & 3,051 & 3,182 & 3,248 & 3,315 & 3,342 & 361 & 3,426 & 3,431 & 3,447 \\
\hline 5th grade & 2,912 & 2,798 & 2,761 & 2,776 & 2,775 & 2,901 & 2,945 & 3,067 & 3,197 & 3,268 & 3,325 & 350 & 3,372 & 438 & 3,447 \\
\hline 6th grade & 3,142 & 2,928 & 2,831 & 2,789 & 2,806 & 2,811 & 2,937 & 2,987 & 3,110 & 3,239 & 3,303 & 356 & ,381 & 95 & 3,486 \\
\hline 7th grade & 3,288 & 3,247 & 3,036 & 2,938 & 2,899 & 2,910 & 2,905 & 3,027 & 3,067 & 3,181 & 3,299 & 355 & ,404 & 422 & 3,457 \\
\hline 8th $\mathrm{g}$ & 3,123 & 3,222 & 3,186 & 2,982 & 2,870 & 2,839 & 2,853 & 2,853 & 2,979 & 3,020 & 3,129 & 3,249 & 3,302 & 3,356 & 3,398 \\
\hline Elementary ungraded & 563 & 535 & 528 & 511 & 520 & 520 & 527 & 540 & 543 & 545 & 539 & 515 & 494 & 502 & 434 \\
\hline Secondary . & 12,405 & 12,271 & 12,304 & 12,388 & 12,333 & 12,076 & 11,687 & 11,390 & 11,338 & 11,541 & 11,735 & 11,961 & 12,213 & 12,500 & 12,834 \\
\hline 9th & 3,248 & 330 & 440 & 439 & 256 & 3,143 & 106 & 141 & 169 & 313 & 352 & 487 & 3,604 & 704 & 3,793 \\
\hline 10 & 3,137 & 3 & 145 & 230 & 215 & 3,020 & 895 & 868 & 896 & 2,915 & 3,027 & 050 & 31 & 37 & 3,316 \\
\hline 11 & 917 & 2,861 & 2,819 & 866 & 954 & 2,936 & 2,749 & 2,629 & 2,612 & 2,645 & 2,656 & 2,751 & 2,748 & 26 & 2,925 \\
\hline 12th & 2,787 & 2,678 & 2,599 & 2,550 & 2,601 & 2,681 & 2,650 & 2,473 & 2,381 & 2,392 & 2,431 & 2,424 & 2,488 & 2,487 & 2,582 \\
\hline \multirow[t]{2}{*}{ Secondary ungraded } & 315 & 299 & 300 & 303 & 308 & 296 & 288 & 279 & 282 & 275 & 269 & 248 & 242 & 245 & 218 \\
\hline & \multicolumn{15}{|c|}{ Percent } \\
\hline All grades & 100.0 & 100.0 & 100.0 & 100.0 & 100.0 & 100.0 & 100.0 & 100.0 & 100.0 & 100.0 & 100.0 & 100.0 & 100.0 & 100.0 & 100.0 \\
\hline Elementary & 68.6 & 68.7 & 68.6 & 68.6 & 69.0 & 69.8 & 70.9 & 71.9 & 72.5 & 72.6 & 72.6 & 72.5 & 72.3 & 72.1 & 71.9 \\
\hline $\mathrm{P}$ & 0.3 & & 0.3 & 0.4 & 0.5 & 0.5 & 0.6 & 0.6 & 0.7 & 0.9 & 1.2 & 1. & 1.4 & 1.4 & 1.5 \\
\hline $\mathrm{K}$ & 6.9 & 7.0 & 7.4 & 7.7 & 7.9 & 8.0 & 8.0 & 8.0 & 8.0 & 7.9 & 7.7 & 7.8 & 7.8 & 7.9 & 7.8 \\
\hline 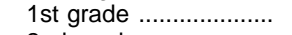 & 7.4 & 8 & 7.9 & 8.2 & 8.4 & 8.5 & 8.6 & 8.6 & 8.5 & 8.5 & 8.3 & 8.1 & 8.1 & 8.2 & 8.3 \\
\hline 2 & 7.1 & 7.1 & 7.4 & 7.5 & 7.7 & 7.9 & 8.0 & 8.1 & 8.1 & 8.0 & 8.0 & 7.9 & 7.8 & 7.8 & 7.9 \\
\hline 3 & 7.0 & & 7.1 & 7.3 & 7.4 & 7.6 & 7.9 & 8.0 & 8.0 & 7.9 & 7.8 & 7.9 & 7.8 & 7.7 & 7.7 \\
\hline 4 & 7.1 & 7.0 & 7.1 & 7.0 & 7.3 & 7.3 & 7.6 & 7.8 & 7.9 & 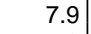 & 7.8 & 7. & 7.8 & 7.7 & 7.6 \\
\hline 5 & 7.4 & & 7.0 & 7.0 & 7.0 & 7.2 & 7.3 & 7.6 & 7.8 & 7.8 & 7.8 & 7.7 & 7.6 & 7.7 & 7.6 \\
\hline $6 \mathrm{t}$ & 7.9 & 7.5 & 7.2 & 7.1 & 7.1 & 7.0 & 7.3 & 7.4 & 7.5 & 7.7. & 7.7 & 7.7 & 7.7 & 7.6 & 7.6 \\
\hline 7 & 8.3 & 8.3 & 7.7 & 7.5 & 7.3 & 7.3 & 7.2 & 7.5 & 7.4 & 7. & 7.7 & 7.7 & 7.7 & 7.6 & 7.6 \\
\hline & 7.9 & 8.2 & 8.1 & 7.6 & 7.2 & 7.1 & 7.1 & 7.0 & 7.2 & 7.2 & 7.3 & 7.5 & 7.5 & 7.5 & 7.5 \\
\hline Elementary ungraded & 1.4 & 1.4 & 1.3 & 1.3 & 1.3 & 1.3 & 1.3 & 1.3 & 1.3 & 1.3 & 1.3 & 1.2 & 1.1 & 1.1 & 1.0 \\
\hline Secondary & 31.4 & 31.3 & 31.4 & 31.4 & 31.0 & 30.2 & 29.1 & 28.1 & 27.5 & 27.4 & 27.4 & 27.5 & 27.7 & 27.9 & 28.1 \\
\hline & 8 & & 8. & 8. & 8. & 7.9 & 7. & 7.7 & 7.7 & 7. & 7. & 8. & 8.2 & 8.3 & 8.3 \\
\hline 10 & 7.9 & & 8.0 & 8.2 & 8.1 & 7.5 & 7.2 & 7.1 & $7 .($ & 6.9 & 7.1 & 7. & 7.1 & 7.2 & 7.3 \\
\hline 1 & 7.4 & & 7.2 & 7.3 & 7.4 & 7.3 & 6.8 & 6.5 & 6.3 & 6.3 & 6.2 & 6.3 & 6.2 & 6.3 & 6.4 \\
\hline ................... & 7.0 & 6.8 & 6.6 & 6.5 & 6.5 & 6.7 & 6.6 & 6.1 & 5.8 & 5.7 & 5.7 & 5.6 & 5.6 & 5.5 & 5.7 \\
\hline Secondary ungraded & 0.8 & 0.8 & 0.8 & 0.8 & 0.8 & 0.7 & 0.7 & 0.7 & 0.7 & 0.7 & 0.6 & 0.6 & 0.5 & 0.5 & 0.5 \\
\hline
\end{tabular}

NOTE.-Because of changes in reporting practices and imputation of data for nonrespondents in later years, data for prekindergarten enrollment are not comparable over time. Some data have been revised from previously published figures. Because of rounding, details may not add to totals.
SOURCE: U.S. Department of Education, National Center for Education Statistics, Statistics of Public Elementary and Secondary School Systems; and Common Core of Data surveys. (This table was prepared May 1998.) 
Table 44.-Average daily attendance in public elementary and secondary schools, by state: 1969-70 to 1995-96

\begin{tabular}{|c|c|c|c|c|c|c|c|c|c|}
\hline State or other area & 1969-70 & $1979-80$ & $1980-81$ & $1985-86$ & 1989-90 & $1990-91$ & 1993-94 & 1994-95 & 1995-96 \\
\hline 1 & 2 & 3 & 4 & 5 & 6 & 7 & 8 & 9 & 10 \\
\hline United States ......... & $41,934,376$ & $38,288,911$ & $37,703,744$ & $36,523,103$ & $37,799,296$ & $38,426,543$ & $40,146,393$ & $40,720,763$ & $41,501,596$ \\
\hline 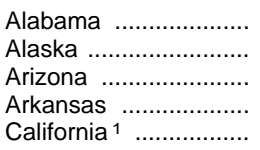 & $\begin{array}{r}777,123 \\
72,489 \\
391,526 \\
414,158 \\
4,418,423\end{array}$ & $\begin{array}{r}711,432 \\
79,945 \\
481,905 \\
423,610 \\
4,044,736\end{array}$ & $\begin{array}{r}701,925 \\
83,745 \\
476,149 \\
417,080 \\
4,014,917\end{array}$ & $\begin{array}{r}686,716 \\
98,535 \\
494,504 \\
408,601 \\
4,245,090\end{array}$ & $\begin{array}{r}683,833 \\
98,213 \\
557,252 \\
403,025 \\
4,893,341\end{array}$ & $\begin{array}{r}682,524 \\
102,585 \\
573,140 \\
408,145 \\
5,065,647\end{array}$ & $\begin{array}{r}696,071 \\
112,869 \\
631,450 \\
416,479 \\
5,108,907\end{array}$ & $\begin{array}{r}687,047 \\
113,874 \\
658,084 \\
420,229 \\
5,198,308\end{array}$ & $\begin{array}{r}687,076 \\
115,958 \\
684,740 \\
423,520 \\
5,351,475\end{array}$ \\
\hline 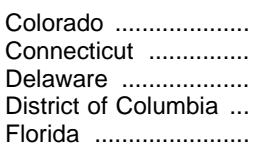 & \begin{tabular}{r|}
500,388 \\
618,881 \\
120,819 \\
138,600 \\
$1,312,693$
\end{tabular} & $\begin{array}{r}513,475 \\
507,362 \\
94,058 \\
91,576 \\
1,464,461\end{array}$ & $\begin{array}{r}508,750 \\
501,085 \\
89,609 \\
85,773 \\
1,389,487\end{array}$ & $\begin{array}{r}507,876 \\
452,058 \\
84,936 \\
76,241 \\
1,442,921\end{array}$ & $\begin{array}{r}519,419 \\
439,524 \\
89,838 \\
71,468 \\
1,646,583\end{array}$ & $\begin{array}{r}521,899 \\
450,808 \\
91,052 \\
69,092 \\
1,714,394\end{array}$ & $\begin{array}{r}579,682 \\
465,487 \\
97,247 \\
70,079 \\
1,873,199\end{array}$ & $\begin{array}{r}594,019 \\
481,742 \\
98,793 \\
71,446 \\
1,927,172\end{array}$ & $\begin{array}{r}608,633 \\
495,188 \\
99,941 \\
71,001 \\
1,947,777\end{array}$ \\
\hline 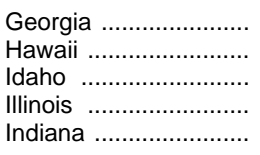 & $\begin{array}{r}1,019,427 \\
168,140 \\
170,920 \\
2,084,844 \\
1,111,043\end{array}$ & $\begin{array}{r}989,433 \\
151,563 \\
189,199 \\
1,770,435 \\
983,444\end{array}$ & $\begin{array}{r}988,612 \\
151,713 \\
190,144 \\
1,765,357 \\
944,424\end{array}$ & $\begin{array}{r}1,004,799 \\
151,174 \\
198,141 \\
1,604,265 \\
870,463\end{array}$ & $\begin{array}{r}1,054,097 \\
157,360 \\
203,987 \\
1,587,733 \\
884,568\end{array}$ & $\begin{array}{r}1,075,728 \\
160,193 \\
209,085 \\
1,618,101 \\
888,177\end{array}$ & $\begin{array}{r}1,148,319 \\
169,779 \\
223,489 \\
1,709,915 \\
899,585\end{array}$ & $\begin{array}{r}1,181,724 \\
169,254 \\
225,986 \\
1,734,175 \\
900,017\end{array}$ & $\begin{array}{r}1,232,852 \\
171,977 \\
228,371 \\
1,750,417 \\
909,553\end{array}$ \\
\hline 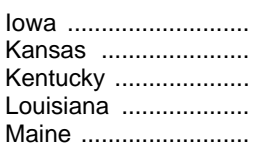 & $\begin{array}{l}624,403 \\
470,296 \\
647,970 \\
776,555 \\
225,146\end{array}$ & $\begin{array}{l}510,081 \\
382,019 \\
619,868 \\
727,601 \\
211,400\end{array}$ & $\begin{array}{l}501,403 \\
374,451 \\
614,676 \\
715,844 \\
207,554\end{array}$ & $\begin{array}{l}454,341 \\
371,655 \\
577,190 \\
732,230 \\
198,358\end{array}$ & $\begin{array}{l}450,224 \\
388,986 \\
569,795 \\
727,125 \\
195,089\end{array}$ & $\begin{array}{l}456,614 \\
397,609 \\
569,713 \\
720,551 \\
196,229\end{array}$ & $\begin{array}{l}477,916 \\
410,862 \\
578,020 \\
732,202 \\
199,125\end{array}$ & $\begin{array}{l}478,285 \\
413,699 \\
572,952 \\
730,148 \\
199,387\end{array}$ & $\begin{array}{l}477,053 \\
416,674 \\
571,934 \\
710,925 \\
200,700\end{array}$ \\
\hline $\begin{array}{l}\text { Maryland .................. } \\
\text { Massachusetts .......... } \\
\text { Michigan ................... } \\
\text { Minnesota .................. } \\
\text { Mississippi ................. }\end{array}$ & \begin{tabular}{r|}
785,989 \\
$1,056,207$ \\
$1,991,235$ \\
864,595 \\
524,623
\end{tabular} & $\begin{array}{r}686,336 \\
935,960 \\
1,758,427 \\
748,606 \\
454,401\end{array}$ & $\begin{array}{r}664,866 \\
950,675 \\
1,711,139 \\
710,836 \\
446,515\end{array}$ & $\begin{array}{r}592,383 \\
745,991 \\
1,481,068 \\
669,385 \\
448,117\end{array}$ & $\begin{array}{r}620,617 \\
763,231 \\
1,446,996 \\
699,001 \\
476,048\end{array}$ & $\begin{array}{r}637,370 \\
770,802 \\
1,452,700 \\
714,072 \\
474,029\end{array}$ & $\begin{array}{r}687,455 \\
810,028 \\
1,474,413 \\
756,725 \\
471,367\end{array}$ & $\begin{array}{r}701,594 \\
831,918 \\
1,492,653 \\
770,549 \\
470,974\end{array}$ & $\begin{array}{r}719,433 \\
845,270 \\
1,554,358 \\
786,241 \\
470,657\end{array}$ \\
\hline $\begin{array}{l}\text { Missouri ..................... } \\
\text { Montana .................... } \\
\text { Nebraska .................... } \\
\text { Nevada ..................... } \\
\text { New Hampshire .......... }\end{array}$ & $\begin{array}{l}906,132 \\
162,664 \\
314,516 \\
113,421 \\
140,203\end{array}$ & $\begin{array}{l}777,269 \\
144,608 \\
270,524 \\
134,995 \\
154,187\end{array}$ & $\begin{array}{l}756,536 \\
141,641 \\
263,797 \\
138,481 \\
150,316\end{array}$ & $\begin{array}{l}714,230 \\
138,829 \\
250,975 \\
143,941 \\
147,561\end{array}$ & $\begin{array}{l}729,693 \\
135,406 \\
254,754 \\
173,149 \\
154,915\end{array}$ & $\begin{array}{l}733,680 \\
138,341 \\
257,587 \\
185,755 \\
156,579\end{array}$ & $\begin{array}{l}778,605 \\
146,849 \\
267,931 \\
217,681 \\
175,968\end{array}$ & $\begin{array}{l}794,177 \\
148,325 \\
268,732 \\
229,862 \\
179,892\end{array}$ & $\begin{array}{l}805,404 \\
148,616 \\
270,938 \\
243,718 \\
187,067\end{array}$ \\
\hline $\begin{array}{l}\text { New Jersey } . . . . . . . . . . . . . \\
\text { New Mexico ............... } \\
\text { New York ................. } \\
\text { North Carolina } . . . \ldots \ldots . . . \\
\text { North Dakota ............. }\end{array}$ & $\begin{array}{r}1,322,124 \\
259,997 \\
3,099,192 \\
1,104,295 \\
141,961\end{array}$ & $\begin{array}{r}1,140,111 \\
253,453 \\
2,530,289 \\
1,072,150 \\
118,986\end{array}$ & $\begin{array}{r}1,121,272 \\
240,496 \\
2,475,055 \\
1,055,651 \\
111,759\end{array}$ & $\begin{array}{r}1,029,797 \\
252,892 \\
2,276,842 \\
1,014,795 \\
108,947\end{array}$ & $\begin{array}{r}997,561 \\
290,245 \\
2,244,110 \\
1,012,274 \\
109,659\end{array}$ & $\begin{array}{r}1,016,159 \\
291,215 \\
2,278,531 \\
1,012,613 \\
109,691\end{array}$ & $\begin{array}{r}1,079,653 \\
310,610 \\
2,404,426 \\
1,051,295 \\
111,770\end{array}$ & $\begin{array}{r}1,102,565 \\
314,822 \\
2,388,973 \\
1,071,640 \\
111,502\end{array}$ & $\begin{array}{r}1,125,877 \\
330,851 \\
2,463,349 \\
1,096,812 \\
111,870\end{array}$ \\
\hline $\begin{array}{l}\text { Ohio } \\
\text { Oklahoma .................... } \\
\text { Oregon ..................... } \\
\text { Pennsylvania .............. } \\
\text { Rhode Island ............. }\end{array}$ & $\begin{array}{r}2,246,282 \\
560,993 \\
436,736 \\
2,169,225 \\
163,205\end{array}$ & $\begin{array}{r}1,849,283 \\
548,065 \\
418,593 \\
1,808,630 \\
139,195\end{array}$ & $\begin{array}{r}1,801,914 \\
542,800 \\
417,009 \\
1,754,782 \\
135,096\end{array}$ & $\begin{array}{r}1,660,718 \\
553,370 \\
401,476 \\
1,560,746 \\
122,109\end{array}$ & $\begin{array}{r}1,584,735 \\
543,170 \\
419,771 \\
1,524,839 \\
125,934\end{array}$ & $\begin{array}{r}1,603,025 \\
548,387 \\
431,806 \\
1,542,077 \\
129,856\end{array}$ & $\begin{array}{r}1,609,855 \\
566,155 \\
455,492 \\
1,609,125 \\
135,016\end{array}$ & $\begin{array}{r}1,627,984 \\
570,381 \\
458,107 \\
1,629,877 \\
136,229\end{array}$ & $\begin{array}{r}1,661,014 \\
574,538 \\
462,108 \\
1,651,741 \\
137,870\end{array}$ \\
\hline 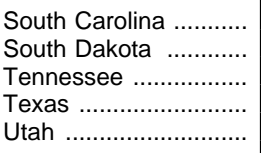 & $\begin{array}{r}600,292 \\
158,543 \\
836,010 \\
2,432,420 \\
287,405\end{array}$ & $\begin{array}{r}569,612 \\
124,934 \\
806,696 \\
2,608,817 \\
312,813\end{array}$ & $\begin{array}{r}580,132 \\
121,663 \\
797,237 \\
2,647,288 \\
323,048\end{array}$ & $\begin{array}{r}558,716 \\
118,269 \\
762,225 \\
2,923,741 \\
379,249\end{array}$ & $\begin{array}{r}569,029 \\
119,823 \\
761,766 \\
3,075,333 \\
408,917\end{array}$ & $\begin{array}{r}573,138 \\
121,403 \\
767,738 \\
3,085,648 \\
417,609\end{array}$ & $\begin{array}{r}586,178 \\
127,550 \\
796,744 \\
3,306,297 \\
439,484\end{array}$ & $\begin{array}{r}608,699 \\
128,335 \\
806,895 \\
3,364,830 \\
442,617\end{array}$ & $\begin{array}{r}605,526 \\
127,754 \\
819,831 \\
3,435,010 \\
444,679\end{array}$ \\
\hline 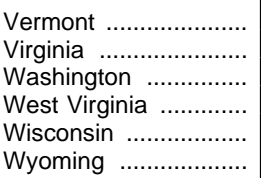 & $\begin{array}{r}97,772 \\
995,580 \\
764,735 \\
372,278 \\
880,609 \\
81,293\end{array}$ & $\begin{array}{r}95,045 \\
955,105 \\
710,929 \\
353,264 \\
770,554 \\
89,471\end{array}$ & $\begin{array}{r}90,884 \\
938,794 \\
704,655 \\
351,823 \\
743,505 \\
91,381\end{array}$ & $\begin{array}{r}85,875 \\
904,347 \\
696,372 \\
330,145 \\
694,351 \\
95,547\end{array}$ & $\begin{array}{r}87,832 \\
989,197 \\
755,141 \\
301,947 \\
711,466 \\
91,277\end{array}$ & $\begin{array}{r}88,901 \\
1,011,513 \\
781,371 \\
300,067 \\
731,088 \\
92,506\end{array}$ & $\begin{array}{r}97,550 \\
1,065,071 \\
850,813 \\
291,238 \\
769,717 \\
94,650\end{array}$ & $\begin{array}{r}98,608 \\
1,079,496 \\
870,163 \\
287,937 \\
782,395 \\
93,691\end{array}$ & $\begin{array}{r}100,166 \\
1,098,862 \\
888,142 \\
285,548 \\
799,391 \\
93,190\end{array}$ \\
\hline $\begin{array}{l}\text { Outlying areas } \\
\text { American Samoa ........ } \\
\text { Guam ...................... } \\
\text { Northern Marianas .... } \\
\text { Puerto Rico ............... } \\
\text { Virgin Islands ............. }\end{array}$ & $\begin{array}{r}- \\
20,315 \\
- \\
-\end{array}$ & $\begin{array}{r}- \\
656,709 \\
-\end{array}$ & $\begin{array}{r}- \\
22,343 \\
- \\
671,661 \\
23,312\end{array}$ & $\begin{array}{r}10,816 \\
23,220 \\
4,921 \\
636,268 \\
23,811\end{array}$ & $\begin{array}{r}11,448 \\
23,883 \\
6,809 \\
597,436 \\
18,924\end{array}$ & $\begin{array}{r}12,272 \\
25,330 \\
6,062 \\
597,418 \\
19,984\end{array}$ & $\begin{array}{r}14,094 \\
31,711 \\
7,278 \\
588,484 \\
20,381\end{array}$ & $\begin{array}{r}14,000 \\
31,779 \\
7,351 \\
547,561 \\
20,339\end{array}$ & $\begin{array}{r}14,074 \\
31,998 \\
7,511 \\
548,788 \\
19,867\end{array}$ \\
\hline
\end{tabular}

1 Data for California are not strictly comparable with those for other states because California's attendance figures through 1990-91 include excused absences.

-Data not available.
SOURCE: U.S. Department of Education, National Center for Education Statistics, Revenues and Expenditures for Public Elementary and Secondary Education; Statistics of State School Systems; and Common Core of Data survey. (This table was prepared May 1998.) 
Table 45.-Enrollment in public elementary and secondary schools, by race or ethnicity and state: Fall 1986 and fall 1996

\begin{tabular}{|c|c|c|c|c|c|c|c|c|c|c|c|c|}
\hline \multirow[b]{2}{*}{ State or other area } & \multicolumn{6}{|c|}{ Percent distribution, fall 1986} & \multicolumn{6}{|c|}{ Percent distribution, fall 1996} \\
\hline & Total & White ${ }^{1}$ & Black ${ }^{1}$ & Hispanic & $\begin{array}{l}\text { Asian or } \\
\text { Pacific } \\
\text { Islander }\end{array}$ & $\begin{array}{l}\text { American } \\
\text { Indian/ } \\
\text { Alaskan } \\
\text { Native }\end{array}$ & Total & White 1 & Black ${ }^{1}$ & Hispanic & $\begin{array}{l}\text { Asian or } \\
\text { Pacific } \\
\text { Islander }\end{array}$ & $\begin{array}{l}\text { American } \\
\text { Indian/ } \\
\text { Alaskan } \\
\text { Native }\end{array}$ \\
\hline 1 & 2 & 3 & 4 & 5 & 6 & 7 & 8 & 9 & 10 & 11 & 12 & 13 \\
\hline United States $^{2} \ldots \ldots \ldots$ & 100.0 & 70.4 & 16.1 & 9.9 & 2.8 & 0.9 & 100.0 & 64.2 & 16.9 & 14.0 & 3.8 & 1.1 \\
\hline 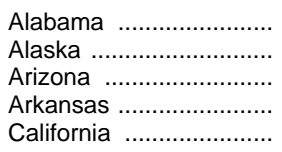 & $\begin{array}{l}100.0 \\
100.0 \\
100.0 \\
100.0 \\
100.0\end{array}$ & $\begin{array}{l}62.0 \\
65.7 \\
62.2 \\
74.7 \\
53.7\end{array}$ & $\begin{array}{r}37.0 \\
4.3 \\
4.0 \\
24.2 \\
9.0\end{array}$ & $\begin{array}{r}0.1 \\
1.7 \\
26.4 \\
0.4 \\
27.5\end{array}$ & $\begin{array}{l}0.4 \\
3.3 \\
1.3 \\
0.6 \\
9.1\end{array}$ & $\begin{array}{r}0.5 \\
25.1 \\
6.1 \\
0.2 \\
0.7\end{array}$ & $\begin{array}{l}100.0 \\
100.0 \\
100.0 \\
100.0 \\
100.0\end{array}$ & $\begin{array}{l}61.5 \\
63.1 \\
56.6 \\
73.5 \\
39.5\end{array}$ & $\begin{array}{r}36.4 \\
4.7 \\
4.3 \\
23.5 \\
8.7\end{array}$ & $\begin{array}{r}0.7 \\
2.9 \\
30.1 \\
1.8 \\
39.7\end{array}$ & $\begin{array}{r}0.6 \\
4.5 \\
1.8 \\
0.7 \\
11.2\end{array}$ & $\begin{array}{r}0.7 \\
24.8 \\
7.2 \\
0.4 \\
0.9\end{array}$ \\
\hline 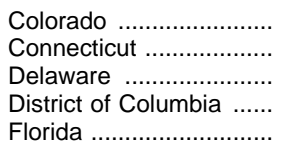 & $\begin{array}{l}100.0 \\
100.0 \\
100.0 \\
100.0 \\
100.0\end{array}$ & $\begin{array}{r}78.7 \\
77.2 \\
68.3 \\
4.0 \\
65.4\end{array}$ & $\begin{array}{r}4.5 \\
12.1 \\
27.7 \\
91.1 \\
23.7\end{array}$ & $\begin{array}{r}13.7 \\
8.9 \\
2.5 \\
3.9 \\
9.5\end{array}$ & $\begin{array}{l}2.0 \\
1.5 \\
1.4 \\
0.9 \\
1.2\end{array}$ & $\begin{array}{l}1.0 \\
0.2 \\
0.2 \\
0.1 \\
0.2\end{array}$ & $\begin{array}{l}100.0 \\
100.0 \\
100.0 \\
100.0 \\
100.0\end{array}$ & $\begin{array}{r}72.0 \\
71.7 \\
63.9 \\
4.0 \\
56.7\end{array}$ & $\begin{array}{r}5.5 \\
13.6 \\
29.9 \\
87.3 \\
25.4\end{array}$ & $\begin{array}{r}18.8 \\
11.9 \\
4.3 \\
7.2 \\
75.9\end{array}$ & $\begin{array}{l}2.6 \\
2.5 \\
1.8 \\
1.4 \\
1.8\end{array}$ & $\begin{array}{l}1.1 \\
0.3 \\
0.2 \\
0.1 \\
0.2\end{array}$ \\
\hline 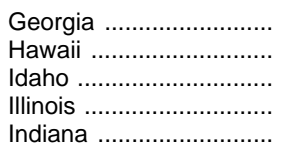 & $\begin{array}{l}100.0 \\
100.0 \\
100.0 \\
100.0 \\
100.0\end{array}$ & $\begin{array}{l}60.7 \\
23.5 \\
92.6 \\
69.8 \\
88.7\end{array}$ & $\begin{array}{r}37.9 \\
2.3 \\
0.3 \\
18.7 \\
9.0\end{array}$ & $\begin{array}{l}0.6 \\
2.2 \\
4.9 \\
9.2 \\
1.7\end{array}$ & $\begin{array}{r}0.8 \\
71.7 \\
0.8 \\
2.3 \\
0.5\end{array}$ & $\begin{array}{l}(3) \\
0.3 \\
1.3 \\
0.1 \\
0.1\end{array}$ & $\begin{array}{l}100.0 \\
100.0 \\
100.0 \\
100.0 \\
100.0\end{array}$ & $\begin{array}{l}57.9 \\
25.0 \\
88.0 \\
62.8 \\
85.4\end{array}$ & $\begin{array}{r}37.6 \\
3.3 \\
0.7 \\
21.2 \\
11.2\end{array}$ & $\begin{array}{r}2.6 \\
4.9 \\
8.9 \\
12.8 \\
2.4\end{array}$ & $\begin{array}{r}1.7 \\
66.4 \\
1.2 \\
3.1 \\
0.8\end{array}$ & $\begin{array}{l}0.1 \\
0.4 \\
1.3 \\
0.1 \\
0.2\end{array}$ \\
\hline 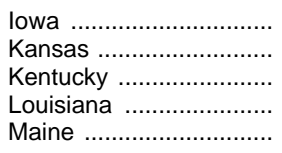 & $\begin{array}{l}100.0 \\
100.0 \\
100.0 \\
100.0 \\
100.0\end{array}$ & $\begin{array}{l}94.6 \\
85.6 \\
89.2 \\
56.5 \\
98.3\end{array}$ & $\begin{array}{r}3.0 \\
7.6 \\
10.2 \\
41.3 \\
0.5\end{array}$ & $\begin{array}{l}0.9 \\
4.4 \\
0.1 \\
0.8 \\
0.2\end{array}$ & $\begin{array}{l}1.2 \\
1.9 \\
0.5 \\
1.1 \\
0.8\end{array}$ & $\begin{array}{l}0.3 \\
0.6 \\
(3) \\
0.3 \\
0.2\end{array}$ & $\begin{array}{l}100.0 \\
100.0 \\
100.0 \\
100.0 \\
100.0\end{array}$ & $\begin{array}{l}92.2 \\
81.9 \\
88.9 \\
50.6 \\
97.2\end{array}$ & $\begin{array}{r}3.4 \\
8.6 \\
9.9 \\
46.4 \\
0.9\end{array}$ & $\begin{array}{l}2.4 \\
6.5 \\
0.5 \\
1.2 \\
0.4\end{array}$ & $\begin{array}{l}1.6 \\
1.9 \\
0.6 \\
1.3 \\
0.9\end{array}$ & $\begin{array}{l}0.5 \\
1.1 \\
0.1 \\
0.6 \\
0.6\end{array}$ \\
\hline 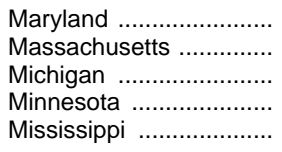 & $\begin{array}{l}100.0 \\
100.0 \\
100.0 \\
100.0 \\
100.0\end{array}$ & $\begin{array}{l}59.7 \\
83.7 \\
76.4 \\
93.9 \\
43.9\end{array}$ & $\begin{array}{r}35.3 \\
7.4 \\
19.8 \\
2.1 \\
55.5\end{array}$ & $\begin{array}{l}1.7 \\
6.0 \\
1.8 \\
0.9 \\
0.1\end{array}$ & $\begin{array}{l}3.1 \\
2.8 \\
1.2 \\
1.7 \\
0.4\end{array}$ & $\begin{array}{l}0.2 \\
0.1 \\
0.8 \\
1.5 \\
0.1\end{array}$ & $\begin{array}{l}100.0 \\
100.0 \\
100.0 \\
100.0 \\
100.0\end{array}$ & $\begin{array}{l}56.7 \\
77.9 \\
75.8 \\
86.5 \\
47.9\end{array}$ & $\begin{array}{r}35.6 \\
8.4 \\
18.8 \\
5.2 \\
51.0\end{array}$ & $\begin{array}{l}3.5 \\
9.6 \\
2.8 \\
2.2 \\
0.4\end{array}$ & $\begin{array}{l}3.9 \\
4.0 \\
1.5 \\
4.1 \\
0.6\end{array}$ & $\begin{array}{l}0.3 \\
0.2 \\
1.0 \\
1.9 \\
0.2\end{array}$ \\
\hline 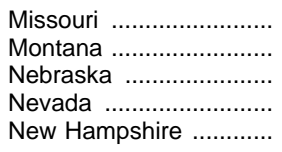 & $\begin{array}{l}100.0 \\
100.0 \\
100.0 \\
100.0 \\
100.0\end{array}$ & $\begin{array}{l}83.4 \\
92.7 \\
91.4 \\
77.4 \\
98.0\end{array}$ & $\begin{array}{r}14.9 \\
0.3 \\
4.4 \\
9.6 \\
0.7\end{array}$ & $\begin{array}{l}0.7 \\
0.9 \\
2.4 \\
7.5 \\
0.5\end{array}$ & $\begin{array}{l}0.8 \\
0.5 \\
0.8 \\
3.2 \\
0.8\end{array}$ & $\begin{array}{l}0.2 \\
5.5 \\
1.0 \\
2.3 \\
0.1\end{array}$ & $\begin{array}{l}100.0 \\
100.0 \\
100.0 \\
100.0 \\
100.0\end{array}$ & $\begin{array}{l}81.1 \\
87.2 \\
86.4 \\
65.1 \\
96.4\end{array}$ & $\begin{array}{r}16.5 \\
0.6 \\
6.0 \\
9.6 \\
1.0\end{array}$ & $\begin{array}{r}1.1 \\
1.5 \\
4.9 \\
18.8 \\
1.3\end{array}$ & $\begin{array}{l}1.0 \\
0.8 \\
1.3 \\
4.6 \\
1.1\end{array}$ & $\begin{array}{l}0.3 \\
9.9 \\
1.4 \\
1.9 \\
0.2\end{array}$ \\
\hline 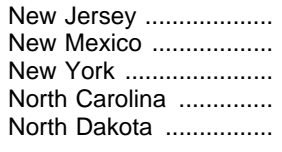 & $\begin{array}{l}100.0 \\
100.0 \\
100.0 \\
100.0 \\
100.0\end{array}$ & $\begin{array}{l}69.1 \\
43.1 \\
68.4 \\
68.4 \\
92.4\end{array}$ & $\begin{array}{r}17.4 \\
2.3 \\
16.5 \\
28.9 \\
0.6\end{array}$ & $\begin{array}{r}10.7 \\
45.1 \\
12.3 \\
0.4 \\
1.1\end{array}$ & $\begin{array}{l}2.7 \\
0.8 \\
2.7 \\
0.6 \\
0.8\end{array}$ & $\begin{array}{l}0.1 \\
8.7 \\
0.2 \\
1.7 \\
5.0\end{array}$ & $\begin{array}{l}10 \overline{.} \\
100.0 \\
100.0 \\
100.0\end{array}$ & $\begin{array}{l}-\overline{-} \\
58.8 \\
63.9 \\
89.1\end{array}$ & $\begin{array}{r}-\overline{2.4} \\
20.3 \\
30.8 \\
0.9\end{array}$ & $\begin{array}{r}-\overline{4} \\
47.7 \\
17.6 \\
2.3 \\
1.1\end{array}$ & $\begin{array}{l}-\overline{1.0} \\
5.2 \\
1.5 \\
0.7\end{array}$ & $\begin{array}{r}10.2 \\
0.5 \\
1.5 \\
8.1\end{array}$ \\
\hline 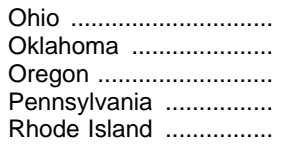 & $\begin{array}{l}100.0 \\
100.0 \\
100.0 \\
100.0 \\
100.0\end{array}$ & $\begin{array}{l}83.1 \\
79.0 \\
89.8 \\
84.4 \\
87.9\end{array}$ & $\begin{array}{r}15.0 \\
7.8 \\
2.2 \\
12.6 \\
5.6\end{array}$ & $\begin{array}{l}1.0 \\
1.6 \\
3.9 \\
1.8 \\
3.7\end{array}$ & $\begin{array}{l}0.7 \\
1.0 \\
2.4 \\
1.2 \\
2.4\end{array}$ & $\begin{array}{r}0.1 \\
10.6 \\
1.7 \\
0.1 \\
0.3\end{array}$ & $\begin{array}{l}100.0 \\
100.0 \\
100.0 \\
100.0 \\
100.0\end{array}$ & $\begin{array}{l}82.0 \\
68.8 \\
84.6 \\
80.2 \\
78.3\end{array}$ & $\begin{array}{r}15.4 \\
10.5 \\
2.6 \\
14.2 \\
7.3\end{array}$ & $\begin{array}{r}1.4 \\
4.3 \\
7.4 \\
3.7 \\
10.7\end{array}$ & $\begin{array}{l}1.0 \\
1.3 \\
3.4 \\
1.8 \\
3.3\end{array}$ & $\begin{array}{r}0.1 \\
15.1 \\
2.0 \\
0.1 \\
0.5\end{array}$ \\
\hline $\begin{array}{l}\text { South Carolina } \\
\text { South Dakota } \\
\text { Tennessee }\end{array}$ & $\begin{array}{l}100.0 \\
100.0 \\
100.0 \\
100.0 \\
100.0\end{array}$ & $\begin{array}{l}54.6 \\
90.6 \\
76.5 \\
51.0 \\
93.7\end{array}$ & $\begin{array}{r}44.5 \\
0.5 \\
22.6 \\
14.4 \\
0.4\end{array}$ & $\begin{array}{r}0.2 \\
0.6 \\
0.2 \\
32.5 \\
3.0\end{array}$ & $\begin{array}{l}0.6 \\
0.7 \\
0.6 \\
2.0 \\
1.5\end{array}$ & $\begin{array}{r}0.1 \\
7.6 \\
(3) \\
0.2 \\
1.5\end{array}$ & $\begin{array}{l}100.0 \\
100.0 \\
100.0 \\
100.0 \\
100.0\end{array}$ & $\begin{array}{l}56.0 \\
83.7 \\
74.6 \\
45.6 \\
89.5\end{array}$ & $\begin{array}{r}42.2 \\
1.0 \\
23.4 \\
14.3 \\
0.7\end{array}$ & $\begin{array}{r}0.8 \\
0.8 \\
0.9 \\
37.4 \\
6.0\end{array}$ & $\begin{array}{l}0.8 \\
0.8 \\
1.0 \\
2.4 \\
2.4\end{array}$ & $\begin{array}{r}0.2 \\
13.8 \\
0.1 \\
0.3 \\
1.5\end{array}$ \\
\hline 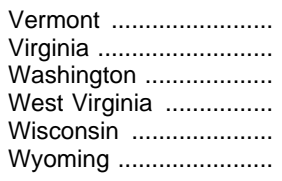 & $\begin{array}{l}100.0 \\
100.0 \\
100.0 \\
100.0 \\
100.0 \\
100.0\end{array}$ & $\begin{array}{l}98.4 \\
72.6 \\
84.5 \\
95.9 \\
86.6 \\
90.7\end{array}$ & $\begin{array}{r}0.3 \\
23.7 \\
4.2 \\
3.7 \\
8.9 \\
0.9\end{array}$ & $\begin{array}{l}0.2 \\
1.0 \\
3.8 \\
0.1 \\
1.9 \\
5.9\end{array}$ & $\begin{array}{l}0.6 \\
2.6 \\
5.1 \\
0.3 \\
1.7 \\
0.6\end{array}$ & $\begin{array}{l}0.6 \\
0.1 \\
2.3 \\
(3) \\
1.0 \\
1.9\end{array}$ & $\begin{array}{l}100.0 \\
100.0 \\
100.0 \\
100.0 \\
100.0 \\
100.0\end{array}$ & $\begin{array}{l}97.3 \\
67.7 \\
77.5 \\
95.2 \\
82.6 \\
89.0\end{array}$ & $\begin{array}{r}0.8 \\
25.5 \\
4.8 \\
4.0 \\
9.6 \\
1.2\end{array}$ & $\begin{array}{l}0.4 \\
3.3 \\
8.3 \\
0.5 \\
3.5 \\
6.2\end{array}$ & $\begin{array}{l}1.0 \\
3.4 \\
6.7 \\
0.3 \\
2.9 \\
0.8\end{array}$ & $\begin{array}{l}0.6 \\
0.2 \\
2.7 \\
0.1 \\
1.3 \\
2.8\end{array}$ \\
\hline $\begin{array}{l}\text { Outlying areas } \\
\text { American Samoa ........... } \\
\text { Guam ...................... } \\
\text { Northern Marianas ........ } \\
\text { Puerto Rico ................. } \\
\text { Virgin Islands ............... }\end{array}$ & $\begin{array}{l}- \\
- \\
-\end{array}$ & $\begin{array}{l}- \\
- \\
-\end{array}$ & $\begin{array}{l}- \\
z \\
- \\
-\end{array}$ & $\begin{array}{l}- \\
- \\
-\end{array}$ & $\begin{array}{l}- \\
- \\
-\end{array}$ & $\begin{array}{l}- \\
z \\
-\end{array}$ & $\begin{array}{l}100.0 \\
100.0 \\
100.0 \\
100.0 \\
100.0\end{array}$ & $\begin{array}{l}\overline{5.3} \\
0.8 \\
\overline{1.1}\end{array}$ & $\begin{array}{r}\overline{1.2} \\
\overline{-} \\
84.6\end{array}$ & $\begin{array}{r}\overline{0.9} \\
0.0 \\
100.0 \\
14.0\end{array}$ & $\begin{array}{r}100.0 \\
92.6 \\
99.2 \\
\overline{0.2}\end{array}$ & $\begin{array}{l}0.1 \\
- \\
-\end{array}$ \\
\hline
\end{tabular}

1 Excludes persons of Hispanic origin.

2U.S. totals for 1996 include estimate for New Jersey.

${ }^{3}$ Less than 0.05 percent.

-Data not available.

NOTE.-The 1986-87 data were derived from the 1986 Elementary and Secondary School Civil Rights sample survey of public school districts. Because of rounding, details may not add to totals.
SOURCE: U.S. Department of Education, Office for Civil Rights, 1986 State Summaries of Elementary and Secondary School Civil Rights Survey; and National Center for Education Statistics, Common Core of Data survey. (This table was prepared May 1998.) 
Table 46.-Enrollment of 3-, 4-, and 5-year-old children in preprimary programs, by level and control of program and by attendance status: October 1965 to October 1997 [In thousands]

\begin{tabular}{|c|c|c|c|c|c|c|c|c|c|c|}
\hline \multirow{3}{*}{ Year and age } & \multirow{3}{*}{$\begin{array}{c}\text { Total } \\
\text { population, } \\
3 \text { to } 5 \text { years } \\
\text { old }\end{array}$} & \multicolumn{6}{|c|}{ Enrollment by level and control } & \multicolumn{3}{|c|}{ Enrollment by attendance } \\
\hline & & \multirow{2}{*}{ Total } & \multirow{2}{*}{$\begin{array}{l}\text { Percent } \\
\text { enrolled }\end{array}$} & \multicolumn{2}{|c|}{ Nursery school } & \multicolumn{2}{|c|}{ Kindergarten } & \multirow{2}{*}{ Full-day } & \multirow{2}{*}{ Part-day } & \multirow{2}{*}{$\begin{array}{l}\text { Percent } \\
\text { full-day }\end{array}$} \\
\hline & & & & Public & Private & Public & Private & & & \\
\hline 1 & 2 & 3 & 4 & 5 & 6 & 7 & 8 & 9 & 10 & 11 \\
\hline 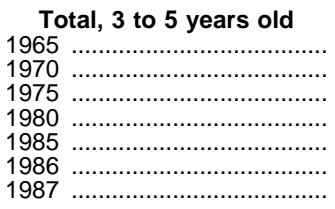 & $\begin{array}{r}12,549 \\
10,949 \\
10,185 \\
9,284 \\
10,733 \\
10,866 \\
10,872\end{array}$ & $\begin{array}{l}3,407 \\
4,104 \\
4,955 \\
4,878 \\
5,865 \\
5,971 \\
5,931\end{array}$ & $\begin{array}{l}27.1 \\
37.5 \\
48.7 \\
52.5 \\
54.6 \\
55.0 \\
54.6\end{array}$ & $\begin{array}{l}127 \\
332 \\
570 \\
628 \\
846 \\
829 \\
819\end{array}$ & $\begin{array}{r}393 \\
762 \\
1,174 \\
1,353 \\
1,631 \\
1,715 \\
1,736\end{array}$ & $\begin{array}{l}2,291 \\
2,498 \\
2,682 \\
2,438 \\
2,847 \\
2,859 \\
2,842\end{array}$ & $\begin{array}{l}596 \\
511 \\
528 \\
459 \\
541 \\
567 \\
534\end{array}$ & $\begin{array}{r}6 \overline{-} \\
1,295 \\
1,551 \\
2,144 \\
2,241 \\
2,090\end{array}$ & $\begin{array}{l}3,405 \\
3,659 \\
3,327 \\
3,722 \\
3,730 \\
3,841\end{array}$ & $\begin{array}{l}17 . \overline{0} \\
26.1 \\
31.8 \\
36.6 \\
37.5 \\
35.2\end{array}$ \\
\hline $\begin{array}{l}1988 \\
1989 \\
1990 \\
1991 \\
1992 \\
1993 \\
19941 \ldots \ldots \ldots \ldots \ldots \\
1995 \ldots \ldots \ldots \ldots \ldots \ldots\end{array}$ & $\begin{array}{l}10,993 \\
11,039 \\
11,207 \\
11,370 \\
11,545 \\
11,954 \\
12,328 \\
12,518 \\
12,378 \\
12,121\end{array}$ & $\begin{array}{l}5,978 \\
6,026 \\
6,659 \\
6,334 \\
6,402 \\
6,581 \\
7,514 \\
7,739 \\
7,580 \\
7,860\end{array}$ & $\begin{array}{l}54.4 \\
54.6 \\
59.4 \\
55.7 \\
55.5 \\
55.1 \\
61.0 \\
61.8 \\
61.2 \\
64.9\end{array}$ & $\begin{array}{r}851 \\
930 \\
1,199 \\
996 \\
1,073 \\
1,205 \\
1,848 \\
1,950 \\
1,830 \\
2,207\end{array}$ & $\begin{array}{l}1,770 \\
1,894 \\
2,180 \\
1,828 \\
1,783 \\
1,779 \\
2,314 \\
2,381 \\
2,317 \\
2,231\end{array}$ & $\begin{array}{l}2,875 \\
2,704 \\
2,772 \\
2,967 \\
2,995 \\
3,020 \\
2,819 \\
2,800 \\
2,853 \\
2,847\end{array}$ & $\begin{array}{l}481 \\
497 \\
509 \\
543 \\
550 \\
577 \\
534 \\
608 \\
580 \\
575\end{array}$ & $\begin{array}{l}2,044 \\
2,238 \\
2,577 \\
2,408 \\
2,410 \\
2,642 \\
3,468 \\
3,689 \\
3,562 \\
3,922\end{array}$ & $\begin{array}{l}3,935 \\
3,789 \\
4,082 \\
3,926 \\
3,992 \\
3,939 \\
4,046 \\
4,051 \\
4,019 \\
3,939\end{array}$ & $\begin{array}{l}34.2 \\
37.1 \\
38.7 \\
38.0 \\
37.6 \\
40.1 \\
46.2 \\
47.7 \\
47.0 \\
49.9\end{array}$ \\
\hline 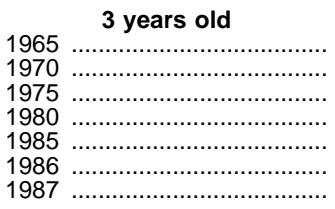 & $\begin{array}{l}4,149 \\
3,516 \\
3,177 \\
3,143 \\
3,594 \\
3,607 \\
3,569\end{array}$ & $\begin{array}{r}203 \\
454 \\
683 \\
857 \\
1,035 \\
1,041 \\
1,022\end{array}$ & \begin{tabular}{r|}
4.9 \\
12.9 \\
21.5 \\
27.3 \\
28.8 \\
28.9 \\
28.6
\end{tabular} & $\begin{array}{r}41 \\
110 \\
179 \\
221 \\
278 \\
257 \\
264\end{array}$ & $\begin{array}{l}153 \\
322 \\
474 \\
604 \\
679 \\
737 \\
703\end{array}$ & $\begin{array}{r}5 \\
12 \\
11 \\
16 \\
52 \\
26 \\
24\end{array}$ & $\begin{array}{r}4 \\
10 \\
18 \\
17 \\
26 \\
21 \\
31\end{array}$ & $\begin{array}{l}1 \overline{142} \\
259 \\
321 \\
350 \\
399 \\
378\end{array}$ & $\begin{array}{l}-\overline{312} \\
423 \\
536 \\
685 \\
642 \\
644\end{array}$ & $\begin{array}{l}31 . \overline{1} \\
37.9 \\
37.5 \\
33.8 \\
38.3 \\
37.0\end{array}$ \\
\hline 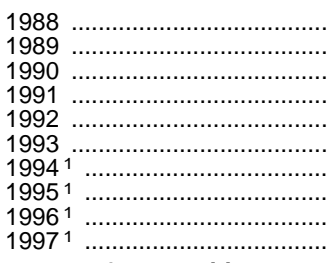 & $\begin{array}{l}3,719 \\
3,713 \\
3,692 \\
3,811 \\
3,905 \\
4,053 \\
4,081 \\
4,148 \\
4,045 \\
3,947\end{array}$ & $\begin{array}{l}1,027 \\
1,005 \\
1,205 \\
1,074 \\
1,081 \\
1,097 \\
1,385 \\
1,489 \\
1,506 \\
1,528\end{array}$ & $\begin{array}{l}27.6 \\
27.1 \\
32.6 \\
28.2 \\
27.7 \\
27.1 \\
33.9 \\
35.9 \\
37.2 \\
38.7\end{array}$ & $\begin{array}{l}298 \\
277 \\
347 \\
313 \\
336 \\
369 \\
469 \\
511 \\
511 \\
643\end{array}$ & $\begin{array}{l}678 \\
707 \\
840 \\
702 \\
685 \\
687 \\
887 \\
947 \\
947 \\
843\end{array}$ & $\begin{array}{r}24 \\
3 \\
11 \\
38 \\
26 \\
20 \\
19 \\
15 \\
22 \\
25\end{array}$ & $\begin{array}{r}26 \\
18 \\
7 \\
22 \\
34 \\
20 \\
9 \\
17 \\
26 \\
18\end{array}$ & $\begin{array}{l}369 \\
390 \\
447 \\
388 \\
371 \\
426 \\
670 \\
754 \\
657 \\
754\end{array}$ & $\begin{array}{l}658 \\
615 \\
758 \\
687 \\
711 \\
670 \\
715 \\
736 \\
848 \\
774\end{array}$ & $\begin{array}{l}35.9 \\
38.8 \\
37.1 \\
36.1 \\
34.3 \\
38.9 \\
48.4 \\
50.6 \\
43.7 \\
49.4\end{array}$ \\
\hline 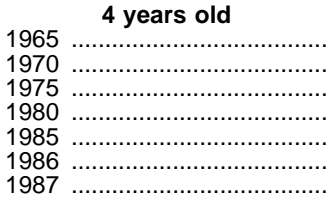 & $\begin{array}{l}4,238 \\
3,620 \\
3,499 \\
3,072 \\
3,598 \\
3,616 \\
3,597\end{array}$ & $\begin{array}{r}683 \\
1,007 \\
1,418 \\
1,423 \\
1,766 \\
1,772 \\
1,717\end{array}$ & $\begin{array}{l}16.1 \\
27.8 \\
40.5 \\
46.3 \\
49.1 \\
49.0 \\
47.7\end{array}$ & $\begin{array}{r}68 \\
176 \\
332 \\
363 \\
496 \\
498 \\
431\end{array}$ & $\begin{array}{l}213 \\
395 \\
644 \\
701 \\
859 \\
903 \\
881\end{array}$ & $\begin{array}{l}284 \\
318 \\
313 \\
239 \\
276 \\
257 \\
280\end{array}$ & $\begin{array}{l}118 \\
117 \\
129 \\
120 \\
135 \\
115 \\
125\end{array}$ & $\begin{array}{l}230 \\
411 \\
467 \\
643 \\
622 \\
548\end{array}$ & $\begin{array}{r}7 \overline{76} \\
1,008 \\
956 \\
1,123 \\
1,150 \\
1,169\end{array}$ & $\begin{array}{l}22 . \overline{8} \\
29.0 \\
32.8 \\
36.4 \\
35.1 \\
31.9\end{array}$ \\
\hline 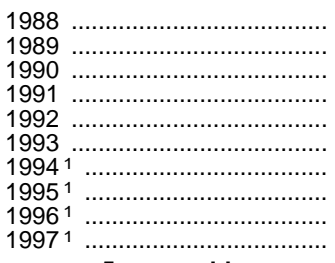 & $\begin{array}{l}3,598 \\
3,692 \\
3,723 \\
3,763 \\
3,807 \\
4,044 \\
4,202 \\
4,145 \\
4,148 \\
4,033\end{array}$ & $\begin{array}{l}1,768 \\
1,882 \\
2,087 \\
1,994 \\
1,982 \\
2,178 \\
2,532 \\
2,553 \\
2,454 \\
2,665\end{array}$ & $\begin{array}{l}49.1 \\
51.0 \\
56.1 \\
53.0 \\
52.1 \\
53.9 \\
60.3 \\
61.6 \\
59.2 \\
66.1\end{array}$ & $\begin{array}{r}481 \\
524 \\
695 \\
584 \\
602 \\
719 \\
1,020 \\
1,054 \\
1,029 \\
1,197\end{array}$ & $\begin{array}{r}922 \\
1,055 \\
1,144 \\
982 \\
971 \\
957 \\
1,232 \\
1,208 \\
1,168 \\
1,169\end{array}$ & $\begin{array}{l}261 \\
202 \\
157 \\
287 \\
282 \\
349 \\
198 \\
207 \\
180 \\
207\end{array}$ & $\begin{array}{r}104 \\
100 \\
91 \\
140 \\
126 \\
154 \\
82 \\
84 \\
77 \\
92\end{array}$ & $\begin{array}{r}519 \\
592 \\
716 \\
667 \\
632 \\
765 \\
1,095 \\
1,104 \\
1,034 \\
1,161\end{array}$ & $\begin{array}{l}1,249 \\
1,290 \\
1,371 \\
1,326 \\
1,350 \\
1,413 \\
1,438 \\
1,449 \\
1,420 \\
1,505\end{array}$ & $\begin{array}{l}29.4 \\
31.4 \\
34.3 \\
33.5 \\
31.9 \\
35.1 \\
43.2 \\
43.3 \\
42.1 \\
43.5\end{array}$ \\
\hline 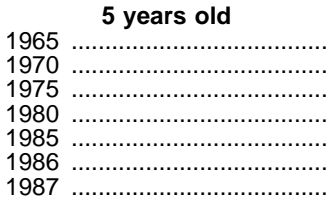 & $\begin{array}{l}4,162 \\
3,814 \\
3,509 \\
3,069 \\
3,542 \\
3,643 \\
3,706\end{array}$ & $\begin{array}{l}2,521 \\
2,643 \\
2,854 \\
2,598 \\
3,065 \\
3,157 \\
3,192\end{array}$ & $\begin{array}{l}60.6 \\
69.3 \\
81.3 \\
84.7 \\
86.5 \\
86.7 \\
86.1\end{array}$ & $\begin{array}{r}18 \\
45 \\
59 \\
44 \\
73 \\
75 \\
124\end{array}$ & $\begin{array}{r}27 \\
45 \\
57 \\
48 \\
94 \\
75 \\
152\end{array}$ & $\begin{array}{l}2,002 \\
2,168 \\
2,358 \\
2,183 \\
2,519 \\
2,576 \\
2,538\end{array}$ & $\begin{array}{l}474 \\
384 \\
381 \\
322 \\
379 \\
432 \\
378\end{array}$ & $\begin{array}{r}-\overline{326} \\
625 \\
763 \\
1,151 \\
1,220 \\
1,163\end{array}$ & $\begin{array}{r}- \\
2,317 \\
2,228 \\
1,835 \\
1,914 \\
1,937 \\
2,028\end{array}$ & $\begin{array}{r}12.3 \\
21.9 \\
29.4 \\
37.6 \\
38.6 \\
36.4\end{array}$ \\
\hline 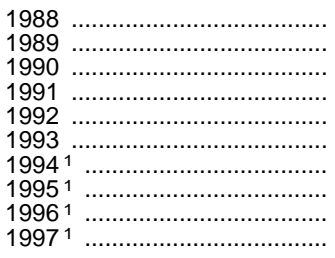 & $\begin{array}{l}3,676 \\
3,633 \\
3,792 \\
3,796 \\
3,832 \\
3,857 \\
4,044 \\
4,224 \\
4,185 \\
4,141\end{array}$ & $\begin{array}{l}3,184 \\
3,139 \\
3,367 \\
3,267 \\
3,339 \\
3,306 \\
3,597 \\
3,697 \\
3,621 \\
3,667\end{array}$ & $\begin{array}{l}86.6 \\
86.4 \\
88.8 \\
86.0 \\
87.1 \\
85.7 \\
88.9 \\
87.5 \\
86.5 \\
88.5\end{array}$ & $\begin{array}{r}72 \\
129 \\
157 \\
100 \\
135 \\
116 \\
359 \\
385 \\
290 \\
368\end{array}$ & $\begin{array}{l}170 \\
132 \\
196 \\
143 \\
127 \\
136 \\
194 \\
226 \\
202 \\
219\end{array}$ & $\begin{array}{l}2,590 \\
2,499 \\
2,604 \\
2,642 \\
2,688 \\
2,651 \\
2,601 \\
2,578 \\
2,652 \\
2,616\end{array}$ & $\begin{array}{l}351 \\
378 \\
411 \\
382 \\
390 \\
403 \\
442 \\
507 \\
477 \\
465\end{array}$ & $\begin{array}{l}1,155 \\
1,255 \\
1,414 \\
1,354 \\
1,408 \\
1,451 \\
1,704 \\
1,830 \\
1,870 \\
2,007\end{array}$ & $\begin{array}{l}2,028 \\
1,883 \\
1,953 \\
1,913 \\
1,931 \\
1,856 \\
1,893 \\
1,867 \\
1,750 \\
1,660\end{array}$ & $\begin{array}{l}36.3 \\
40.0 \\
42.0 \\
41.4 \\
42.2 \\
43.9 \\
47.4 \\
49.5 \\
51.7 \\
54.7\end{array}$ \\
\hline
\end{tabular}

1 Data collected using new procedures. May not be comparable with figures prior to 1994.

$$
\text { -Data not available. }
$$

NOTE.-Data are based on sample surveys of the civilian noninstitutional population Although cells with fewer than 75,000 children are subject to wide sampling variation, they are included in the table to permit various types of aggregations. Enrollment data for 5-year-olds include only those students in preprimary programs. Because of rounding, details may not add to totals.
SOURCE: U.S. Department of Education, National Center for Education Statistics, Preprimary Enrollment, various years; and U.S. Department of Commerce, Bureau of the Census, Current Population Survey, unpublished data. (This table was prepared September 1998.) 
Table 47.-Children of prekindergarten through second grade age, by enrollment status, maternal characteristics, and household income: 1991, 1993, and 1995

\begin{tabular}{|c|c|c|c|c|c|c|c|c|c|c|c|c|c|c|c|}
\hline \multirow{3}{*}{$\begin{array}{l}\text { Maternal characteristics and } \\
\text { household income }\end{array}$} & \multirow{2}{*}{\multicolumn{3}{|c|}{$\begin{array}{l}\text { 3- to } 5 \text {-year-olds, not } \\
\text { enrolled in school }{ }^{1}\end{array}$}} & \multirow{2}{*}{\multicolumn{3}{|c|}{$\begin{array}{l}\text { Enrolled in nursery } \\
\text { school or prekinder- } \\
\text { garten }\end{array}$}} & \multicolumn{3}{|c|}{ Enrolled in kindergarten } & \multicolumn{3}{|c|}{ Enrolled in 1st grade } & \multicolumn{3}{|c|}{ Enrolled in 2nd grade } \\
\hline & & \multirow[b]{2}{*}{1993} & \multirow[b]{2}{*}{1995} & & & & \multirow{2}{*}{1991} & \multirow{2}{*}{1993} & \multirow{2}{*}{1995} & \multirow{2}{*}{1991} & \multirow{2}{*}{1993} & \multirow{2}{*}{1995} & \multirow{2}{*}{1991} & \multirow{2}{*}{1993} & \multirow{2}{*}{1995} \\
\hline & 1991 & & & 1991 & 1993 & 1995 & & & & & & & & & \\
\hline 1 & 2 & 3 & 4 & 5 & 6 & 7 & 8 & 9 & 10 & 11 & 12 & 13 & 14 & 15 & 16 \\
\hline \multirow[t]{2}{*}{$\begin{array}{l}\text { Total children, in. } \\
\text { thousands }\end{array}$} & 4,853 & 4,670 & 4,595 & 3,571 & 3,938 & 4,655 & 4,022 & 4,027 & 4,149 & 4,001 & 3,988 & 4,025 & 3,724 & 3,436 & 3,777 \\
\hline & \multicolumn{15}{|c|}{ Percent distribution } \\
\hline Mother's highest education 2 & 100 & 100 & 100 & 100 & 100 & 100 & 100 & 100 & 100 & 100 & 100 & 100 & 100 & 100 & 100 \\
\hline Less than high school .... & 18 & 19 & 22 & 8 & 11 & 10 & 16 & 14 & 17 & 16 & 14 & 16 & 16 & 16 & 20 \\
\hline High school diploma ${ }^{3} \ldots$. & 43 & 42 & 35 & 32 & 29 & 28 & 40 & 38 & 33 & 38 & 38 & 31 & 38 & 35 & 31 \\
\hline Some postsecondary ........ & 23 & 24 & 21 & 29 & 31 & 23 & 24 & 27 & 22 & 24 & 26 & 24 & 26 & 27 & 21 \\
\hline Associate degree ……............ & 4 & 3 & 7 & 5 & 5 & 9 & 4 & 5 & 7 & 4 & 5 & 7 & 4 & 4 & 8 \\
\hline Bachelor's degree ............... & 9 & 8 & 10 & 17 & 14 & 19 & 11 & 10 & 14 & 12 & 11 & 14 & 10 & 10 & 13 \\
\hline $\begin{array}{l}\text { Graduate/professional } \\
\text { school }\end{array}$ & 4 & 4 & 5 & 10 & 11 & 12 & 5 & 6 & 8 & 7 & 7 & 8 & 6 & 8 & 8 \\
\hline $\begin{array}{l}\text { Mother's employment sta- } \\
\text { tus }^{2}\end{array}$ & 100 & 100 & 100 & 100 & 100 & 100 & 100 & 100 & 100 & 100 & 100 & 100 & 100 & 100 & 100 \\
\hline $\begin{array}{l}\text { Working } 35 \text { hours/week } \\
\text { or more }\end{array}$ & 34 & 30 & 33 & 34 & 35 & 38 & 35 & 38 & 36 & 38 & 38 & 39 & 39 & 37 & 41 \\
\hline Working less than 35 & & & & & & & & & & & & & & & \\
\hline hours/week ....................... & 21 & 19 & 18 & 27 & 23 & 24 & 22 & 20 & 21 & 24 & 22 & 21 & 22 & 22 & 21 \\
\hline Looking for work ................ & 7 & 8 & 7 & 5 & 6 & 6 & 6 & 6 & 6 & 6 & 7 & 5 & 7 & 6 & 5 \\
\hline Not in labor force ................ & 39 & 43 & 42 & 34 & 35 & 32 & 37 & 36 & 38 & 32 & 34 & 36 & 32 & 34 & 33 \\
\hline Household incom & 100 & 100 & 100 & 100 & 100 & 100 & 100 & 100 & 100 & 100 & 100 & 100 & 100 & 100 & 100 \\
\hline$\$ 10,000$ or less & 20 & 19 & 23 & 15 & 17 & 16 & 18 & 19 & 19 & 19 & 18 & 17 & 18 & 17 & 19 \\
\hline$\$ 10,001$ to $\$ 20,000 \ldots \ldots$ & 19 & 22 & 16 & 14 & 14 & 10 & 17 & 18 & 13 & 17 & 18 & 13 & 17 & 17 & 12 \\
\hline$\$ 20,001$ to $\$ 30,000 \ldots \ldots .$. & 23 & 21 & 19 & 17 & 14 & 13 & 21 & 17 & 16 & 20 & 17 & 17 & 19 & 18 & 16 \\
\hline$\$ 30,001$ to $\$ 40,000 \ldots \ldots$. & 16 & 17 & 16 & 16 & 15 & 12 & 15 & 15 & 15 & 15 & 15 & 14 & 15 & 15 & 16 \\
\hline$\$ 40,001$ to $\$ 50,000 \ldots$. & 10 & 9 & 11 & 12 & 11 & 12 & 11 & 10 & 12 & 11 & 11 & 11 & 12 & 11 & 11 \\
\hline$\$ 50,000$ to $\$ 75,000 \ldots \ldots$. & 8 & 8 & 11 & 16 & 16 & 19 & 12 & 13 & 14 & 11 & 12 & 16 & 12 & 14 & 15 \\
\hline More than $\$ 75,000 \ldots \ldots . .$. & 3 & 4 & 5 & 11 & 13 & 17 & 7 & 8 & 11 & 7 & 8 & 12 & 7 & 8 & 10 \\
\hline
\end{tabular}

1 Includes a very small number of older children of first and second grade age.

${ }^{2}$ Excludes data for households with no mother present.

${ }^{3}$ Includes equivalency certificates.

SOURCE: U.S. Department of Education, National Center for Education Statistics, $\mathrm{Na}$

NOTE.-Because of rounding, details may not add to totals. tional Household Education Survey (NHES), 1991, 1993, and 1995. (This table was prepared October 1997.)

Table 48.-Percent of public school kindergarten teachers indicating the importance of various factors for kindergarten readiness: Spring 1993

\begin{tabular}{|c|c|c|c|c|c|c|c|c|}
\hline \multirow[t]{2}{*}{ Kindergarten readiness factors } & \multirow[t]{2}{*}{$\begin{array}{l}\text { Not at all } \\
\text { important }\end{array}$} & \multirow[t]{2}{*}{$\begin{array}{l}\text { Not very } \\
\text { important }\end{array}$} & \multirow[t]{2}{*}{$\begin{array}{l}\text { Somewhat } \\
\text { important }\end{array}$} & \multirow[t]{2}{*}{$\begin{array}{c}\text { Very } \\
\text { important }\end{array}$} & \multirow[t]{2}{*}{ Essential } & \multicolumn{3}{|c|}{$\begin{array}{l}\text { Percent rating readiness factor as } \\
\text { "Very important" or "Essential," by } \\
\text { percentage of school's students } \\
\text { eligible for free or reduced-price lunches }\end{array}$} \\
\hline & & & & & & $\begin{array}{c}\text { Less than } 20 \\
\text { percent }\end{array}$ & $\begin{array}{l}20 \text { to } 49 \\
\text { percent }\end{array}$ & $\begin{array}{c}50 \text { percent or } \\
\text { more }\end{array}$ \\
\hline 1 & 2 & 3 & 4 & 5 & 6 & 7 & 8 & 9 \\
\hline Is physically healthy, rested, and well nourished & 0 & $\left({ }^{1}\right)$ & 4 & 24 & 72 & 97 & 95 & 95 \\
\hline 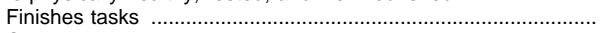 & 3 & 11 & 47 & 31 & 9 & 43 & 40 & 37 \\
\hline Can count to 20 or more & 33 & 34 & 26 & 5 & 3 & 8 & 6 & 9 \\
\hline Takes turns and shares & 2 & 8 & 34 & 37 & 19 & 64 & 55 & 52 \\
\hline 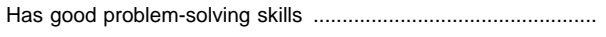 & 8 & 23 & 44 & 20 & 5 & 29 & 23 & 23 \\
\hline Is enthusiastic and curious in approaching new activities .......... & 1 & 3 & 19 & 43 & 33 & 83 & 76 & 73 \\
\hline Is able to use pencils or paint brushes & 15 & 27 & 38 & 16 & 5 & 23 & 21 & 19 \\
\hline Is not disruptive of the class & 2 & 8 & 30 & 36 & 24 & 61 & 58 & 61 \\
\hline Knows the English language & 13 & 12 & 33 & 24 & 17 & 40 & 45 & 39 \\
\hline Is sensitive to other children's feelings. & 1 & 6 & 35 & 41 & 17 & 61 & 58 & 56 \\
\hline (1) & 3 & 12 & 43 & 30 & 12 & 46 & 37 & 43 \\
\hline Knows the letters of the alphabet & 27 & 30 & 33 & 6 & 4 & 7 & 9 & 13 \\
\hline Can follow directions & 2 & 7 & 31 & 41 & 19 & 61 & 61 & 58 \\
\hline 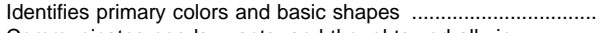 & 13 & 24 & 40 & 17 & 7 & 22 & 21 & 27 \\
\hline $\begin{array}{l}\text { Communicates needs, wants, and thoughts verbally in } \\
\text { child's primary language }\end{array}$ & 1 & 1 & 15 & 41 & 43 & 85 & 84 & 83 \\
\hline
\end{tabular}

1 Less than 0.5 percent. 
Table 49.-Child care arrangements of preschool children, by age and household characteristics: 1991 and 1995

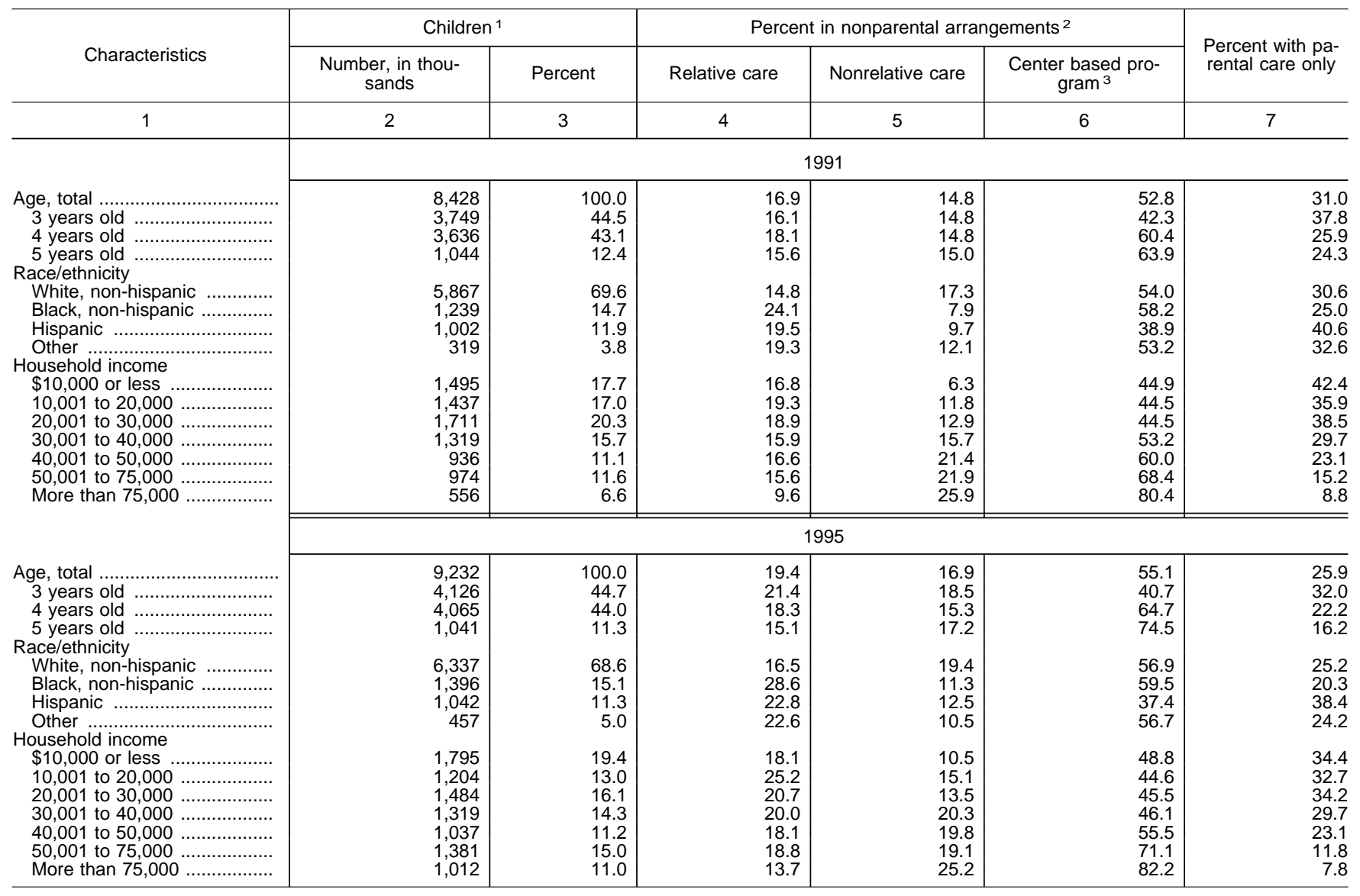

${ }^{1}$ Estimates are based only on children 3 to 5 years old who have not entered kindergarten.

${ }^{2}$ Columns do not add up to total because some children participated in more than one type of nonparental arrangement.
${ }^{3}$ Center based programs include day care centers, nursery schools, prekindergarten, preschools and Head Start programs.

SOURCE: U.S. Department of Education, National Center for Education Statistics, National Household Education Survey (NHES), 1991 and 1995. (This table was prepared July 1996.)

Table 50.-Participation of public kindergarten children in selected activities 5 days a week, by length and size of class and teacher preparation: Spring 1993

\begin{tabular}{|c|c|c|c|c|c|c|c|c|}
\hline \multirow{4}{*}{ Activity } & \multirow{4}{*}{ Total } & \multicolumn{7}{|c|}{ Percent of kindergarten classes participating in activity every day } \\
\hline & & \multirow{2}{*}{\multicolumn{2}{|c|}{$\begin{array}{c}\text { Length of kindergarten } \\
\text { class }\end{array}$}} & \multicolumn{3}{|c|}{ Size of kindergarten class } & \multirow{2}{*}{\multicolumn{2}{|c|}{$\begin{array}{l}\text { Teacher majored in } \\
\quad \text { early } \\
\text { childhood education }\end{array}$}} \\
\hline & & & & \multirow{2}{*}{$\begin{array}{c}\text { Less than } \\
20\end{array}$} & \multirow{2}{*}{20 to 25} & \multirow{2}{*}{$\begin{array}{l}\text { More than } \\
25\end{array}$} & & \\
\hline & & Full-day & Half-day & & & & Yes & No \\
\hline 1 & 2 & 3 & 4 & 5 & 6 & 7 & 8 & 9 \\
\hline Listening to stories read aloud & 90 & 91 & 90 & 87 & 92 & 91 & 91 & 89 \\
\hline Running, climbing, jumping, and other gross motor activities .... & 58 & 72 & 48 & 55 & 57 & 64 & 60 & 56 \\
\hline Free play & 66 & 72 & 62 & 64 & 67 & 67 & 67 & 66 \\
\hline Choosing from a set of specific options (like building blocks, & 69 & 72 & 67 & & & & & 66 \\
\hline 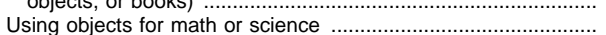 & $\begin{array}{l}69 \\
49\end{array}$ & $\begin{array}{l}72 \\
61\end{array}$ & $\begin{array}{l}67 \\
41\end{array}$ & $\begin{array}{l}69 \\
48\end{array}$ & $\begin{array}{l}71 \\
51\end{array}$ & $\begin{array}{l}65 \\
48\end{array}$ & $\begin{array}{l}72 \\
53\end{array}$ & $\begin{array}{l}66 \\
45\end{array}$ \\
\hline 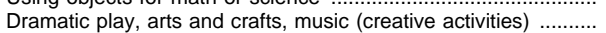 & 64 & 66 & 63 & 62 & 65 & 66 & 68 & 60 \\
\hline Using worksheets for literary skills & 14 & 25 & 13 & 21 & 18 & 17 & 19 & 18 \\
\hline 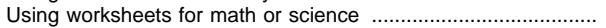 & 18 & 20 & 9 & 17 & 12 & 15 & 16 & 12 \\
\hline
\end{tabular}

SOURCE: U.S. Department of Education, National Center for Education Statistics, Kindergarten Teacher Survey on Student Readiness. (This table was prepared April 1994.) 
Table 51.-Number of hours children age 5 and under spend in center-based programs, by child and maternal characteristics, and household income: 1995

\begin{tabular}{|c|c|c|c|c|c|c|c|c|}
\hline \multirow{2}{*}{ Child and maternal characteristics, and household income } & \multirow{2}{*}{$\begin{array}{l}\text { Number of } \\
\text { children, age } \\
0 \text { to } 5,{ }^{1} \text { in } \\
\text { thousands }\end{array}$} & \multicolumn{2}{|c|}{$\begin{array}{l}\text { Children in center-based } \\
\text { progrqams }{ }^{1}\end{array}$} & \multicolumn{5}{|c|}{$\begin{array}{l}\text { Percentage distribution of children, by hours in } \\
\text { center-based programs per week } 1\end{array}$} \\
\hline & & $\begin{array}{l}\text { Number in } \\
\text { thousands }\end{array}$ & Percent & 1 to 10 & 11 to 20 & 21 to 30 & 31 to 40 & Over 40 \\
\hline 1 & 2 & 3 & 4 & 5 & 6 & 7 & 8 & 9 \\
\hline Total children & 21,421 & 6,536 & 30.5 & 31.6 & 20.2 & 12.5 & 22.1 & 13.6 \\
\hline $\begin{array}{l}\text { Age } \\
\text { Under } 1 \text { year } \\
1 \text { year old } \\
2 \text { years old } \\
3 \text { years old } \\
4 \text { years old } \\
5 \text { years old }\end{array}$ & $\begin{array}{l}4,158 \\
4,027 \\
4,007 \\
4,126 \\
4,065 \\
1,038\end{array}$ & $\begin{array}{r}270 \\
434 \\
749 \\
1,679 \\
2,631 \\
774\end{array}$ & $\begin{array}{r}6.5 \\
10.8 \\
18.7 \\
40.7 \\
64.7 \\
74.5\end{array}$ & \begin{tabular}{r|}
9.2 \\
15.2 \\
23.7 \\
35.5 \\
37.3 \\
32.9
\end{tabular} & $\begin{array}{l}17.9 \\
14.2 \\
13.2 \\
16.5 \\
25.3 \\
25.1\end{array}$ & $\begin{array}{l}11.7 \\
13.9 \\
10.8 \\
13.4 \\
11.4 \\
15.2\end{array}$ & $\begin{array}{l}47.9 \\
34.1 \\
29.2 \\
20.3 \\
16.4 \\
18.1\end{array}$ & $\begin{array}{r}13.2 \\
22.5 \\
23.1 \\
14.3 \\
9.6 \\
8.7\end{array}$ \\
\hline 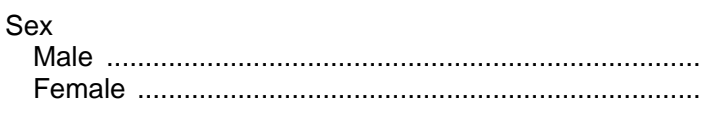 & $\begin{array}{l}10,993 \\
10,429\end{array}$ & $\begin{array}{l}3,276 \\
3,260\end{array}$ & $\begin{array}{l}29.8 \\
31.3\end{array}$ & $\begin{array}{l}31.4 \\
31.8\end{array}$ & $\begin{array}{l}19.8 \\
20.6\end{array}$ & $\begin{array}{l}13.9 \\
11.1\end{array}$ & $\begin{array}{l}21.1 \\
23.2\end{array}$ & $\begin{array}{l}13.9 \\
13.3\end{array}$ \\
\hline $\begin{array}{c}\text { Race/ethnicity of child } \\
\text { White } \ldots \ldots \ldots \ldots \ldots \ldots \\
\text { Black } \\
\text { Hispanic }\end{array}$ & $\begin{array}{r}13,996 \\
3,344 \\
2,838 \\
1,243\end{array}$ & $\begin{array}{r}4,600 \\
1,103 \\
484 \\
349\end{array}$ & $\begin{array}{l}32.9 \\
33.0 \\
17.0 \\
28.1\end{array}$ & $\begin{array}{r}37.6 \\
6.7 \\
20.9 \\
20.9\end{array}$ & $\begin{array}{l}20.2 \\
15.2 \\
29.6 \\
21.5\end{array}$ & $\begin{array}{l}12.2 \\
13.0 \\
14.3 \\
13.8\end{array}$ & $\begin{array}{l}17.6 \\
45.8 \\
24.5 \\
23.8\end{array}$ & $\begin{array}{l}12.4 \\
19.2 \\
10.7 \\
20.0\end{array}$ \\
\hline $\begin{array}{l}\text { Mother's highest education } \\
\text { Less than high school } \\
\text { High school diploma }{ }^{2} \\
\text { Some postsecondary } \\
\text { Associate degree } \\
\text { Bachelor's degree } \\
\text { Some graduate or master. } \\
\text { Doctor's or professional degree }\end{array}$ & $\begin{array}{r}4,205 \\
6,475 \\
4,537 \\
1,479 \\
3,069 \\
1,368 \\
288\end{array}$ & $\begin{array}{r}824 \\
1,678 \\
1,510 \\
507 \\
1,262 \\
640 \\
115\end{array}$ & $\begin{array}{l}19.6 \\
25.9 \\
33.3 \\
34.3 \\
41.1 \\
46.8 \\
39.9\end{array}$ & $\begin{array}{l}16.5 \\
32.8 \\
32.2 \\
34.6 \\
36.3 \\
30.7 \\
23.9\end{array}$ & $\begin{array}{l}20.1 \\
17.8 \\
23.7 \\
21.4 \\
19.6 \\
20.0 \\
12.5\end{array}$ & \begin{tabular}{r|r}
18.9 \\
13.1 \\
8.9 \\
15.4 \\
9.3 \\
15.9 \\
19.7
\end{tabular} & $\begin{array}{l}29.2 \\
25.2 \\
19.9 \\
14.8 \\
20.1 \\
20.8 \\
36.0\end{array}$ & $\begin{array}{r}15.4 \\
11.2 \\
15.3 \\
13.8 \\
14.8 \\
12.6 \\
7.9\end{array}$ \\
\hline $\begin{array}{l}\text { Marital status of mother } \\
\text { No mother in household } \\
\text { Married } \\
\text { Separated } \\
\text { Divorced } \\
\text { Widowed }\end{array}$ & $\begin{array}{r}298 \\
15,141 \\
725 \\
1,258 \\
172 \\
3,826\end{array}$ & $\begin{array}{r}117 \\
4,678 \\
207 \\
537 \\
63 \\
934\end{array}$ & $\begin{array}{l}39.2 \\
30.9 \\
28.6 \\
42.7 \\
36.4 \\
24.4\end{array}$ & $\begin{array}{l}14.6 \\
36.7 \\
13.3 \\
20.2 \\
29.9 \\
13.9\end{array}$ & \begin{tabular}{r|}
2.4 \\
22.1 \\
23.1 \\
15.7 \\
16.8 \\
13.5
\end{tabular} & $\begin{array}{l}11.3 \\
11.1 \\
15.3 \\
15.3 \\
20.9 \\
18.2\end{array}$ & $\begin{array}{r}34.3 \\
18.7 \\
18.9 \\
26.2 \\
5.5 \\
40.7\end{array}$ & $\begin{array}{l}37.5 \\
11.5 \\
29.4 \\
22.5 \\
26.9 \\
13.7\end{array}$ \\
\hline 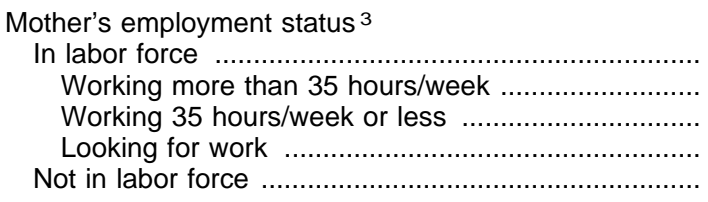 & $\begin{array}{r}12,770 \\
7,101 \\
4,034 \\
1,635 \\
8,354\end{array}$ & $\begin{array}{r}4,576 \\
2,760 \\
1,413 \\
403 \\
1,842\end{array}$ & $\begin{array}{l}35.8 \\
38.9 \\
35.0 \\
24.7 \\
22.1\end{array}$ & $\begin{array}{l}24.5 \\
16.4 \\
40.9 \\
22.5 \\
51.2\end{array}$ & $\begin{array}{l}17.5 \\
12.4 \\
27.7 \\
16.8 \\
28.4\end{array}$ & $\begin{array}{r}13.6 \\
11.1 \\
15.3 \\
27.5 \\
9.6\end{array}$ & $\begin{array}{r}27.0 \\
33.8 \\
12.9 \\
30.2 \\
8.6\end{array}$ & $\begin{array}{r}17.4 \\
26.4 \\
3.3 \\
3.0 \\
2.3\end{array}$ \\
\hline $\begin{array}{l}\text { Household income } \\
\$ 5,000 \text { or less } \\
\$ 5,001 \text { to } \$ 10,000 \\
\$ 10,001 \text { to } \$ 15,001 \\
\$ 20,001 \text { to } \$ 20,000\end{array} 25,000$ & $\begin{array}{l}2,066 \\
2,437 \\
1,521 \\
1,388 \\
1,603 \\
1,783 \\
1,453 \\
1,595 \\
2,304 \\
3,063 \\
2,211\end{array}$ & $\begin{array}{r}509 \\
619 \\
342 \\
351 \\
347 \\
506 \\
371 \\
439 \\
743 \\
1,229 \\
1,080\end{array}$ & $\begin{array}{l}24.6 \\
25.4 \\
22.5 \\
25.3 \\
21.6 \\
28.4 \\
25.6 \\
27.5 \\
32.2 \\
40.1 \\
48.8\end{array}$ & $\begin{array}{l}17.1 \\
18.0 \\
17.5 \\
23.5 \\
23.9 \\
25.0 \\
37.6 \\
33.1 \\
41.3 \\
37.1 \\
36.7\end{array}$ & $\begin{array}{l}26.5 \\
22.8 \\
19.1 \\
22.2 \\
11.1 \\
19.8 \\
15.9 \\
21.5 \\
19.2 \\
17.0 \\
24.5\end{array}$ & $\begin{array}{r}15.3 \\
18.3 \\
17.6 \\
16.3 \\
14.6 \\
14.7 \\
11.1 \\
10.3 \\
7.1 \\
11.7 \\
11.2\end{array}$ & $\begin{array}{l}32.2 \\
32.2 \\
27.2 \\
22.1 \\
31.4 \\
22.3 \\
27.5 \\
20.1 \\
21.7 \\
18.0 \\
15.3\end{array}$ & $\begin{array}{r}8.9 \\
8.7 \\
18.6 \\
15.9 \\
19.0 \\
18.1 \\
8.0 \\
15.0 \\
10.7 \\
16.2 \\
12.2\end{array}$ \\
\hline
\end{tabular}

1 Excludes children who have entered kindergarten.

2 Includes equivalency certificates.

${ }^{3}$ Excludes data for households with no mother present in household.

SOURCE: U.S. Department of Education, National Center for Education Statistics, National Household Education Survey (NHES), 1995. (This table was prepared March 1999.)

NOTE.—Details may not add to totals because of rounding. 
Table 52.-Public school pupils transported at public expense and current expenditures for transportation: 1929-30 to $1995-96$

\begin{tabular}{|c|c|c|c|c|c|c|c|}
\hline \multirow{2}{*}{ School year } & \multirow{2}{*}{$\begin{array}{l}\text { Average daily } \\
\text { attendance, } \\
\text { all } \\
\text { students }\end{array}$} & \multicolumn{2}{|c|}{ Pupils transported at public expense } & \multicolumn{2}{|c|}{$\begin{array}{l}\text { Expenditures for transportation } \\
\text { (in current dollars) }\end{array}$} & \multicolumn{2}{|c|}{$\begin{array}{l}\text { Expenditures for transportation (in } \\
\text { constant 1995-96 dollars) }\end{array}$} \\
\hline & & Number & Percent of total & $\begin{array}{c}\text { Total }^{1} \\
\text { (in thousands) }\end{array}$ & $\begin{array}{c}\text { Average per } \\
\text { pupil transported }\end{array}$ & $\begin{array}{c}\text { Total }{ }^{1} \\
\text { (in thousands) }\end{array}$ & $\begin{array}{c}\text { Average per } \\
\text { pupil transported }\end{array}$ \\
\hline 1 & 2 & 3 & 4 & 5 & 6 & 7 & 8 \\
\hline $1929-30$ & $21,265,000$ & $1,902,826$ & 8.9 & $\$ 54,823$ & $\$ 29$ & $\$ 494,839$ & $\$ 260$ \\
\hline $1931-32 \ldots$ & $22,245,000$ & $2,419,173$ & 10.9 & 58,078 & 24 & 622,394 & 257 \\
\hline 1933-34 ............ & $22,458,000$ & $2,794,724$ & 12.4 & 53,908 & 19 & 628,967 & 225 \\
\hline $1935-36 \ldots$ & $22,299,000$ & $3,250,658$ & 14.6 & 62,653 & 19 & 704,402 & 217 \\
\hline 1937-38 & $22,298,000$ & $3,769,242$ & 16.9 & 75,637 & 20 & 815,771 & 216 \\
\hline $1939-40$ & $22,042,000$ & $4,144,161$ & 18.8 & 83,283 & 20 & 920,732 & 222 \\
\hline $1941-42$ & $21,031,000$ & $4,503,081$ & 21.4 & 92,922 & 21 & 920,757 & 204 \\
\hline $1943-44 \ldots \ldots$ & $19,603,000$ & $4,512,412$ & 23.0 & 107,754 & 24 & 955,408 & 212 \\
\hline $1945-46 \ldots \ldots$ & $19,849,000$ & $5,056,966$ & 25.5 & 129,756 & 26 & $1,098,964$ & 217 \\
\hline $1947-48 \quad \ldots \ldots \ldots . . .$. & $20,910,000$ & $5,854,041$ & 28.0 & 176,265 & 30 & $1,168,796$ & 200 \\
\hline $1949-50$ & $22,284,000$ & $6,947,384$ & 31.2 & 214,504 & 31 & $1,399,353$ & 201 \\
\hline $1951-52 \ldots \ldots$ & $23,257,000$ & $7,697,130$ & 33.1 & 268,827 & 35 & $1,580,252$ & 205 \\
\hline $1953-54 \ldots$. & $25,643,871$ & $8,411,719$ & 32.8 & 307,437 & 37 & $1,766,288$ & 210 \\
\hline $1955-56$ & $27,740,149$ & $9,695,819$ & 35.0 & 353,972 & 37 & $2,034,322$ & 210 \\
\hline $1957-58$ & $29,722,275$ & $10,861,689$ & 36.5 & 416,491 & 38 & $2,253,234$ & 207 \\
\hline $1959-60$ & $32,477,440$ & $12,225,142$ & 37.6 & 486,338 & 40 & $2,557,234$ & 209 \\
\hline $1961-62 \ldots \ldots$ & $34,682,340$ & $13,222,667$ & 38.1 & 576,361 & 44 & $2,962,532$ & 224 \\
\hline $1963-64 \ldots \ldots$ & $37,405,058$ & $14,475,778$ & 38.7 & 673,845 & 47 & $3,375,561$ & 233 \\
\hline 1965-66 ....... & $39,154,497$ & $15,536,567$ & 39.7 & 787,358 & 51 & $3,812,424$ & 245 \\
\hline $1967-68 \ldots \ldots$ & $40,827,965$ & $17,130,873$ & 42.0 & 981,006 & 57 & $4,456,758$ & 260 \\
\hline 1969-70 & $41,934,376$ & $18,198,577$ & 43.4 & $1,218,557$ & 67 & $4,983,906$ & 274 \\
\hline 1971-72 ....... & $42,254,272$ & $19,474,355$ & 46.1 & $1,507,830$ & 77 & $5,661,233$ & 291 \\
\hline $1973-74 \ldots \ldots$ & $41,438,054$ & $21,347,039$ & 51.5 & $1,858,141$ & 87 & $6,157,272$ & 288 \\
\hline $1975-76 \ldots \ldots$ & $41,269,720$ & $21,772,483$ & 52.8 & $2,377,313$ & 109 & $6,622,937$ & 304 \\
\hline $1977-78 \ldots \ldots$ & $40,079,590$ & $221,800,000$ & 54.4 & $2,731,041$ & 125 & $6,736,797$ & 2309 \\
\hline 1979-80 & $38,288,911$ & $21,713,515$ & 56.7 & $3,833,145$ & 177 & $7,628,469$ & 351 \\
\hline $1980-81 \ldots \ldots$ & $37,703,744$ & $222,272,000$ & 59.1 & $24,408,000$ & 198 & $27,862,000$ & 2353 \\
\hline $1981-82 \ldots \ldots$ & $37,094,652$ & $222,246,000$ & 60.0 & $24,793,000$ & 215 & $27,869,000$ & 2354 \\
\hline 1982-83 ...... & $36,635,868$ & $222,199,000$ & 60.6 & $25,000,000$ & 225 & $27,871,000$ & 2355 \\
\hline $1983-84 \ldots$. & $36,362,978$ & $222,031,000$ & 60.6 & $25,284,000$ & 240 & $28,021,000$ & 2364 \\
\hline $1984-85$ & $36,404,261$ & $222,320,000$ & 61.3 & $25,722,000$ & 256 & $28,358,000$ & 2374 \\
\hline 1985-86 ........ & $36,523,103$ & $222,041,000$ & 60.3 & $26,123,000$ & 278 & $28,694,000$ & 2394 \\
\hline 1986-87 …........ & $36,863,867$ & $222,397,000$ & 60.8 & $26,551,000$ & 292 & $29,099,000$ & 2406 \\
\hline $1987-88 \ldots \ldots$ & $37,050,707$ & $222,158,000$ & 59.8 & $26,888,000$ & 311 & $29,187,000$ & 2415 \\
\hline 1988-89 ....... & $37,268,072$ & $222,635,000$ & 60.7 & $27,550,000$ & 334 & $29,625,000$ & 2425 \\
\hline $1989-90$ & $37,799,296$ & $222,459,000$ & 59.4 & $8,030,990$ & 358 & $9,771,908$ & 2435 \\
\hline 1990-91 ...... & $38,426,543$ & ${ }^{2} 22,000,000$ & 57.3 & $8,678,954$ & 394 & $10,012,907$ & 2455 \\
\hline $1991-92$ & $38,960,783$ & $223,165,000$ & 59.5 & $8,769,754$ & 379 & $9,803,535$ & 2423 \\
\hline 1992-93 ........ & $39,570,462$ & $223,439,000$ & 59.2 & $9,252,300$ & 395 & $10,029,682$ & 2428 \\
\hline 1993-94 ........ & $40,146,393$ & $223,858,000$ & 59.4 & $9,627,155$ & 404 & $10,172,521$ & 2426 \\
\hline 1994-95 & $40,720,763$ & $223,693,000$ & 58.2 & $9,889,034$ & 417 & $10,158,075$ & 2429 \\
\hline 1995-96 ........... & $41,501,596$ & $224,155,000$ & 58.2 & $10,394,695$ & 430 & $10,394,695$ & 2430 \\
\hline
\end{tabular}

${ }^{1}$ Excludes capital outlay for years through 1979-80, and 1989-90 to 1995-96. From $1980-81$ to $1988-89$ total transportation figures include capital outlay.

2 Estimate based on data appearing in January issues of School Bus Fleet.

NOTE.-Constant dollars are adjusted for inflation using the Consumer Price Index computed on a school year basis. Some data have been revised from previously published figures.
SOURCE: U.S. Department of Education, National Center for Education Statistics, Statistics of State School Systems; Revenues and Expenditures for Public Elementary and Secondary Education, and unpublished data; and Bobit Publishing Co., School Bus Fleet, January issues. (This table was prepared September 1998.) 
Table 53.-Children 0 to 21 years old served in federally supported programs for the disabled, by type of disability: 1976-77 to $1996-97$

\begin{tabular}{|c|c|c|c|c|c|c|c|c|c|c|c|c|c|c|c|}
\hline Type of disability & $\begin{array}{c}1976- \\
77\end{array}$ & $\begin{array}{c}1980- \\
81\end{array}$ & $\begin{array}{c}1984- \\
85\end{array}$ & $\begin{array}{c}1985- \\
86\end{array}$ & $\begin{array}{c}1986- \\
87\end{array}$ & $\begin{array}{c}1987- \\
88\end{array}$ & $\begin{array}{c}1988- \\
89\end{array}$ & $\begin{array}{c}1989- \\
90\end{array}$ & $\begin{array}{c}1990- \\
91\end{array}$ & $\begin{array}{c}1991- \\
92\end{array}$ & $\begin{array}{c}1992- \\
93\end{array}$ & $\begin{array}{c}1993- \\
94\end{array}$ & $\begin{array}{c}1994- \\
95\end{array}$ & $\begin{array}{c}1995- \\
96\end{array}$ & $\begin{array}{c}1996- \\
97\end{array}$ \\
\hline 1 & 2 & 3 & 4 & 5 & 6 & 7 & 8 & 9 & 10 & 11 & 12 & 13 & 14 & 15 & 16 \\
\hline & \multicolumn{14}{|c|}{ Number served, ${ }^{1}$ in thousands } & \\
\hline All disabilities & 3,692 & 4,142 & 4,315 & 4,317 & 4,374 & 4,446 & 4,527 & 4,641 & 4,762 & 4,949 & 5,176 & 5,365 & 5,539 & 5,745 & 5,920 \\
\hline Specific learning disabilities & 796 & 1,462 & 1,832 & 1,862 & 1,914 & 1,928 & 1,970 & 2,050 & 2,130 & 2,234 & 2,351 & 2,408 & 2,489 & 2,579 & 2,651 \\
\hline Speech or language impairments ............ & 1,302 & 1,168 & 1,126 & 1,125 & 1,136 & 953 & 967 & 973 & 985 & 997 & 994 & 1,014 & 1,015 & 1,022 & 1,045 \\
\hline Mental retardation & 959 & 829 & 694 & 660 & 643 & 582 & 564 & 548 & 534 & 538 & 518 & 536 & 555 & 570 & 579 \\
\hline Serious emotional disturbance $\ldots \ldots \ldots \ldots \ldots \ldots$ & 283 & 346 & 372 & 375 & 383 & 373 & 376 & 381 & 390 & 399 & 400 & 414 & 427 & 438 & 446 \\
\hline Hearing impairments & 87 & 79 & 69 & 66 & 65 & 56 & 56 & 57 & 58 & 60 & 60 & 64 & 64 & 67 & 68 \\
\hline 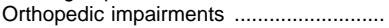 & 87 & 58 & 56 & 57 & 57 & 47 & 47 & 48 & 49 & 51 & 52 & 56 & 60 & 63 & 66 \\
\hline Other health impairments .............................. & 141 & 98 & 68 & 57 & 52 & 45 & 43 & 52 & 55 & 58 & 65 & 82 & 106 & 133 & 160 \\
\hline Visual impairments & 38 & 31 & 28 & 27 & 26 & 22 & 23 & 22 & 23 & 24 & 23 & 24 & 24 & 25 & 25 \\
\hline Multiple disabilities & - & 68 & 69 & 86 & 97 & 77 & 85 & 86 & 96 & 97 & 102 & 108 & 88 & 93 & 98 \\
\hline Deaf-blindness ……............................... & - & 3 & 2 & 2 & 2 & 1 & 2 & 2 & 1 & 1 & 1 & 1 & 1 & 1 & 1 \\
\hline Autism and other ...... & - & - & - & - & - & - & - & - & - & 5 & 19 & 24 & 30 & 38 & 45 \\
\hline \multirow[t]{2}{*}{ 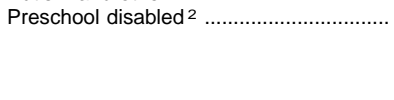 } & $\left({ }^{3}\right)$ & $\left({ }^{3}\right)$ & $\left({ }^{3}\right)$ & $\left({ }^{3}\right)$ & $\left({ }^{3}\right)$ & 363 & 394 & 422 & 441 & 484 & 590 & 634 & 680 & 717 & 737 \\
\hline & \multicolumn{14}{|c|}{ Percentage distribution of children served } & \\
\hline All disabilities & 100.0 & 100.0 & 100.0 & 100.0 & 100.0 & 100.0 & 100.0 & 100.0 & 100.0 & 100.0 & 100.0 & 100.0 & 100.0 & 100.0 & 100.0 \\
\hline Specific learning disabilitie & 21.6 & 35.3 & 42.4 & 43.1 & 43.8 & 43.4 & 43.6 & 44.2 & 44.7 & 45.1 & 45.4 & 44.9 & 44.9 & 44.9 & 44.8 \\
\hline Speech or language impairments & 35.3 & 28.2 & 26.1 & 26.1 & 26.0 & 21.4 & 21.1 & 21.0 & 20.7 & 20.2 & 19.2 & 18.9 & 18.3 & 17.8 & 17.6 \\
\hline Mental retardation & 26.0 & 20.0 & 16.1 & 15.3 & 14.7 & 13.1 & 12.7 & 11.8 & 11.2 & 10.9 & 10.0 & 10.0 & 10.0 & 9.9 & 9.8 \\
\hline Serious emotional disturbance ................. & 7.7 & 8.4 & 8.6 & 8.7 & 8.8 & 8.4 & 8.3 & 8.2 & 8.2 & 8.1 & 7.7 & 7.7 & 7.7 & 7.6 & 7.5 \\
\hline 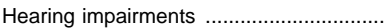 & 2.4 & 1.9 & 1.6 & 1.5 & 1.5 & 1.3 & 1.3 & 1.2 & 1.2 & 1.2 & 1.2 & 1.2 & 1.2 & 1.2 & 1.1 \\
\hline 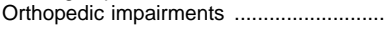 & 2.4 & 1.4 & 1.3 & 1.3 & 1.3 & 1.1 & 1.1 & 1.0 & 1.0 & 1.0 & 1.0 & 1.0 & 1.1 & 1.1 & 1.1 \\
\hline 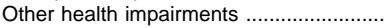 & 3.8 & 2.4 & 1.6 & 1.3 & 1.2 & 1.0 & 1.0 & 1.1 & 1.2 & 1.2 & 1.3 & 1.5 & 1.9 & 2.3 & 2.7 \\
\hline Visual impairments ……........................................ & 1.0 & 0.7 & 0.7 & 0.6 & 0.6 & 0.5 & 0.5 & 0.5 & 0.5 & 0.5 & 0.4 & 0.4 & 0.4 & 0.4 & 0.4 \\
\hline Multiple disabilities & - & 1.6 & 1.6 & 2.0 & 2.2 & 1.7 & 1.8 & 1.9 & 2.0 & 2.0 & 2.0 & 2.0 & 1.6 & 1.6 & 1.7 \\
\hline 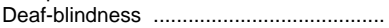 & - & 0.1 & (4) & $(4)$ & $(4)$ & $(4)$ & $(4)$ & $(4)$ & $(4)$ & $(4)$ & (4) & $(4)$ & $(4)$ & $(4)$ & $(4)$ \\
\hline 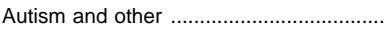 & - & - & - & - & - & - & - & - & - & 0.1 & 0.4 & 0.4 & 0.5 & 0.7 & 0.8 \\
\hline \multirow[t]{2}{*}{ 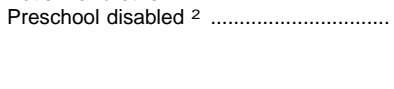 } & $\left({ }^{3}\right)$ & $\left({ }^{3}\right)$ & $\left({ }^{3}\right)$ & $\left({ }^{3}\right)$ & $\left({ }^{3}\right)$ & 8.2 & 8.7 & 9.1 & 9.3 & 9.8 & 11.4 & 11.8 & 12.3 & 12.5 & 12.4 \\
\hline & \multicolumn{14}{|c|}{ Number served as a percent of total enrollment ${ }^{5}$} & \\
\hline 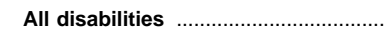 & 8.33 & 10.13 & 11.00 & 10.95 & 11.00 & 11.11 & 11.26 & 11.44 & 11.55 & 11.77 & 12.08 & 12.34 & 12.55 & 12.81 & 12.98 \\
\hline 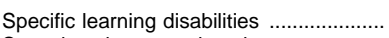 & 1.80 & 3.58 & 4.67 & 4.72 & 4.81 & 4.82 & 4.90 & 5.06 & 5.17 & 5.31 & 5.49 & 5.54 & 5.64 & 5.75 & 5.81 \\
\hline Speech or language impairments ............ & 2.94 & 2.86 & 2.87 & 2.85 & 2.86 & 2.38 & 2.41 & 2.40 & 2.39 & 2.37 & 2.32 & 2.33 & 2.30 & 2.28 & 2.29 \\
\hline Mental retardation & 2.16 & 2.03 & 1.77 & 1.68 & 1.62 & 1.45 & 1.40 & 1.35 & 1.30 & 1.28 & 1.21 & 1.23 & 1.26 & 1.27 & 1.27 \\
\hline Serious emotional disturbance $. . . \ldots \ldots \ldots \ldots \ldots . . . . . .$. & 0.64 & 0.85 & 0.95 & 0.95 & 0.96 & 0.93 & 0.94 & 0.94 & 0.95 & 0.95 & 0.94 & 0.95 & 0.97 & 0.98 & 0.98 \\
\hline Hearing impairments ………............................ & 0.20 & 0.19 & 0.18 & 0.17 & 0.16 & 0.14 & 0.14 & 0.14 & 0.14 & 0.14 & 0.14 & 0.15 & 0.15 & 0.15 & 0.15 \\
\hline Orthopedic impairments ............................. & 0.20 & 0.14 & 0.14 & 0.14 & 0.14 & 0.12 & 0.12 & 0.12 & 0.12 & 0.12 & 0.12 & 0.13 & 0.14 & 0.14 & 0.14 \\
\hline 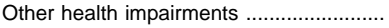 & 0.32 & 0.24 & 0.17 & 0.14 & 0.13 & 0.11 & 0.11 & 0.13 & 0.13 & 0.14 & 0.15 & 0.19 & 0.24 & 0.30 & 0.35 \\
\hline 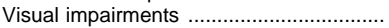 & 0.09 & 0.08 & 0.07 & 0.07 & 0.07 & 0.05 & 0.06 & 0.06 & 0.06 & 0.06 & 0.05 & 0.06 & 0.05 & 0.06 & 0.06 \\
\hline Multiple disabilities .................................. & - & 0.17 & 0.17 & 0.22 & 0.24 & 0.19 & 0.21 & 0.21 & 0.23 & 0.23 & 0.24 & 0.25 & 0.20 & 0.21 & 0.21 \\
\hline Deaf-blindness & - & 0.01 & (6) & 0.01 & (6) & (6) & $(6)$ & (6) & (6) & (6) & $(6)$ & $(6)$ & $(6)$ & $(6)$ & (6) \\
\hline Autism and other . & - & - & - & - & - & - & - & - & - & 0.01 & 0.04 & 0.06 & 0.07 & 0.09 & 0.10 \\
\hline Preschool disabled ${ }^{2}$ & $\left({ }^{3}\right)$ & $(3)$ & $\left({ }^{3}\right)$ & $\left({ }^{3}\right)$ & $\left({ }^{3}\right)$ & 0.91 & 0.98 & 1.04 & 1.07 & 1.15 & 1.38 & 1.46 & 1.54 & 1.60 & 1.62 \\
\hline
\end{tabular}

1 Includes students served under Chapter I and Individuals with Disabilities Education Act (IDEA), formerly the Education of the Handicapped Act.

${ }^{2}$ Includes preschool children 3-5 years and $0-5$ years served under Chapter I and IDEA, respectively.

${ }^{3}$ Prior to $1987-88$, these students were included in the counts by handicapping condition. Beginning in $1987-88$, states were no longer required to report preschool handicapped students ( $0-5$ years) by handicapping condition.

${ }^{4}$ Less than .05 percent.

${ }^{5}$ Based on the enrollment in public schools, kindergarten through 12th grade, including a relatively small number of prekindergarten students.

6 Less than .005 percent.

-Data not available.
NOTE.-Counts are based on reports from the 50 states and District of Columbia only (i.e., figures from U.S. territories are not included). Increases since 1987-88 are due in part to new legislation enacted fall 1986, which mandates public school special education services for all handicapped children ages 3 through 5 . Some data have been revised from previously published figures. Because of rounding, details may not add to totals.

SOURCE: U.S. Department of Education, Office of Special Education and Rehabilitative Services, Annual Report to Congress on the Implementation of The Individuals with Disabilities Education Act, various years, and unpublished tabulations; and National Center for Education Statistics, Common Core of Data survey. (This table was prepared May 1998.) 
Table 54.-Percentage distribution of disabled persons 3 to 21 years old receiving education services for the disabled, by age group and educational environment: 1995-96

\begin{tabular}{|c|c|c|c|c|c|c|c|c|c|}
\hline Type of disability & All environments & $\begin{array}{l}\text { Regular } \\
\text { class }\end{array}$ & $\begin{array}{l}\text { Resource } \\
\text { room }\end{array}$ & $\begin{array}{l}\text { Separate } \\
\text { class }\end{array}$ & $\begin{array}{l}\text { Public separate } \\
\text { school facility }\end{array}$ & $\begin{array}{l}\text { Private separate } \\
\text { school facility }\end{array}$ & $\begin{array}{l}\text { Public } \\
\text { residential } \\
\text { facility }\end{array}$ & $\begin{array}{l}\text { Private } \\
\text { residential } \\
\text { facility }\end{array}$ & $\begin{array}{l}\text { Homebound/hos- } \\
\text { pital environment }\end{array}$ \\
\hline 1 & 2 & 3 & 4 & 5 & 6 & 7 & 8 & 9 & 10 \\
\hline $\begin{array}{l}\text { All persons, } 3 \text { to } 21 \text { years } \\
\text { old }\end{array}$ & 100.0 & 45.4 & 26.8 & 23.2 & 2.2 & 1.0 & 0.4 & 0.2 & 0.7 \\
\hline 3 to 5 years old & 100.0 & 50.7 & 9.3 & 31.7 & 4.1 & 1.5 & 0.1 & 0.1 & 2.5 \\
\hline 6 to 21 years old & 100.0 & 44.8 & 28.5 & 22.4 & 2.0 & 1.0 & 0.5 & 0.3 & 0.6 \\
\hline Mental retardation .................... & 100.0 & 9.9 & 26.9 & 56.0 & 5.2 & 1.0 & 0.4 & 0.2 & 0.5 \\
\hline $\begin{array}{l}\text { Speech or language } \\
\text { impairments }\end{array}$ & 100.0 & 87.6 & 7.5 & 4.5 & 0.2 & 0.1 & (1) & (1) & 0.1 \\
\hline Visual impairments ................. & 100.0 & 46.8 & 20.1 & 17.4 & 2.9 & 1.9 & 9.4 & 0.9 & 0.5 \\
\hline $\begin{array}{l}\text { Serious emotional } \\
\quad \text { disturbance }\end{array}$ & 100.0 & 22.1 & 24.0 & 35.2 & 8.3 & 5.4 & 1.7 & 1.6 & 1.8 \\
\hline Orthopedic impairments ....... & 100.0 & 39.3 & 20.4 & 31.9 & 4.4 & 1.1 & 0.3 & 0.1 & 2.5 \\
\hline Other health impairments ... & 100.0 & 42.8 & 28.8 & 18.5 & 1.1 & 0.6 & 0.1 & 0.2 & 7.9 \\
\hline Specific learning disabilities & 100.0 & 41.3 & 39.3 & 18.4 & 0.3 & 0.3 & 0.1 & $\left({ }^{1}\right)$ & 0.2 \\
\hline Deaf-blindness & 100.0 & 9.7 & 8.7 & 37.2 & 17.7 & 3.8 & 17.8 & 2.7 & 2.3 \\
\hline Multiple disabilities ................... & 100.0 & 9.1 & 11.9 & 51.5 & 15.4 & 6.7 & 2.0 & 1.5 & 1.9 \\
\hline Hearing impairments ............. & 100.0 & 35.4 & 19.1 & 28.5 & 3.8 & 2.7 & 9.3 & 1.0 & 0.2 \\
\hline Autism & 100.0 & 10.8 & 9.4 & 54.7 & 15.2 & 6.6 & 0.7 & 2.2 & 0.5 \\
\hline Traumatic brain injury ........... & 100.0 & 26.1 & 24.2 & 30.3 & 3.1 & 11.3 & 0.3 & 2.0 & 2.7 \\
\hline
\end{tabular}

1 Less than 0.05 percent.

NOTE.-There are some reporting variations, e.g., estimated or incomplete data and nonstandard definitions, from state to state. Data for 3- to 5-year-old children are no longer collected by type of disability. Because of rounding, details may not add to totals.
SOURCE: U.S. Department of Education, Office of Special Education and Rehabilitative Services, Annual Report to Congress on the Implementation of The Individuals with Disabilities Education Act. (This table was prepared February 1998.)

Table 55.-State legislation on gifted and talented programs and number and percent of students receiving services in public elementary and secondary schools, by state: 1993-94 and 1995-96

\begin{tabular}{|c|c|c|c|c|c|c|c|c|c|}
\hline State & $\begin{array}{c}\text { State-man- } \\
\text { dated gifted } \\
\text { and talented } \\
\text { programs, } \\
1995-96^{1}\end{array}$ & $\begin{array}{c}\text { Discre- } \\
\text { tionary } \\
\text { state-sup- } \\
\text { ported gift- } \\
\text { ed and tal- } \\
\text { ented, } \\
\text { 1995-962 }\end{array}$ & $\begin{array}{c}\text { Gifted and } \\
\text { talented stu- } \\
\text { dents receiv- } \\
\text { ing services, } \\
\text { 1993-94 }\end{array}$ & $\begin{array}{l}\text { Gifted } \\
\text { and tal- } \\
\text { ented } \\
\text { students } \\
\text { as a per- } \\
\text { cent of } \\
\text { enroll- } \\
\text { ment, } \\
\text { 1993-94 }\end{array}$ & State & $\begin{array}{l}\text { State-man- } \\
\text { dated gifted } \\
\text { and talented } \\
\text { programs, } \\
1995-96^{1}\end{array}$ & $\begin{array}{c}\text { Discre- } \\
\text { tionary } \\
\text { state-sup- } \\
\text { ported gift- } \\
\text { ed and tal- } \\
\text { ented, } \\
\text { 1995-96 } 2\end{array}$ & $\begin{array}{c}\text { Gifted and } \\
\text { talented stu- } \\
\text { dents receiv- } \\
\text { ing services, } \\
1993-94\end{array}$ & $\begin{array}{c}\text { Gifted } \\
\text { and tal- } \\
\text { ented } \\
\text { students } \\
\text { as a per- } \\
\text { cent of } \\
\text { enroll- } \\
\text { ment, } \\
\text { 1993-94 }\end{array}$ \\
\hline 1 & 2 & 3 & 4 & 5 & 1 & 2 & 3 & 4 & 5 \\
\hline Alabama .... & $x$ & & 16,522 & 2.4 & Montana ................ & $x$ & & - & - \\
\hline Alaska ........... & $x$ & & 4,696 & 4.0 & Nebraska ................. & $x$ & & 18,600 & 10.0 \\
\hline Arizona & $\mathrm{X}$ & & 39,200 & - & Nevada ................... & & $X$ & 8,343 & 2.0 \\
\hline Arkansas ....... & $X$ & & 34,710 & 8.0 & New Hampshire ... & & $X$ & - & - \\
\hline California ..... & & $X$ & 290,000 & 5.0 & New Jersey ........... & 一 & - & - & - \\
\hline Colorado ...... & & $x$ & - & - & New Mexico ....... & $x$ & & - & - \\
\hline Connecticut . & $x$ & & 16,871 & 33.5 & New York ................ & $x$ & & 135,000 & 6.0 \\
\hline Delaware ..... & & $x$ & - & 5.0 & North Carolina ....... & $x$ & & 88,450 & 8.0 \\
\hline District of Columbia .. & - & - & & 9.0 & North Dakota ......... & & $x$ & 1,107 & 1.0 \\
\hline 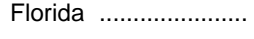 & $x$ & & 74,572 & 3.5 & Ohio ....................... & $x$ & & 244,670 & 13.0 \\
\hline Georgia & - & - & 一 & 5.0 & Oklahoma & $x$ & & 61,082 & 10.0 \\
\hline Hawaii ......................... & $x$ & & 18,000 & 11.0 & Oregon ..................... & $x$ & & - & 8.5 \\
\hline Idaho ............... & $x$ & & - & 1.3 & Pennsylvania ........ & $X$ & & 79,756 & 4.6 \\
\hline Illinois ......... & $x$ & & 4166,234 & 5.0 & Rhode Island ......... & & $x$ & - & $3.5-5.0$ \\
\hline Indiana ......................... & & $x$ & 85,192 & 8.9 & South Carolina ..... & $x$ & & 52,000 & 10.0 \\
\hline lowa ...... & $x$ & & - & 4.0 & South Dakota & & $x$ & 6,515 & 4.4 \\
\hline Kansas ...... & $X$ & & 一 & 3.1 & Tennessee ............. & $x$ & & 18,626 & 2.0 \\
\hline Kentucky .... & $x$ & & 52,600 & 5.0 & Texas ............... & $\mathrm{X}$ & & 248,769 & 7.0 \\
\hline Louisiana ..................... & $x$ & & 24,000 & 3.2 & 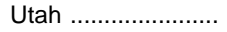 & $\mathrm{X}$ & & - & - \\
\hline Maine ............ & $X$ & & 10,100 & 5.0 & Vermont .................. & - & - & - & - \\
\hline Maryland ........... & & $x$ & 90,222 & 12.0 & Virginia ........ & $x$ & & 121,598 & 9.2 \\
\hline Massachusetts & & $x$ & - & - & Washington .......... & & $x$ & 38,781 & 1.5 \\
\hline Michigan ........... & & $x$ & 225,154 & 14.0 & West Virginia ......... & $x$ & & - & 3.5 \\
\hline Minnesota .......... & & $x$ & 55,467 & 7.2 & Wisconsin ................ & $x$ & & - & 15.0 \\
\hline Mississippi ................. & $X$ & & 21,678 & 4.3 & Wyoming ............... & & $x$ & - & 3.0 \\
\hline Missouri ............. & & $x$ & 24,877 & 5.0 & Guam ............ & $x$ & & - & - \\
\hline
\end{tabular}

1 Mandate requiring identification of and/or services for gifted/talented students. 2 No mandate requiring identification of or services for gifted/talented students. ${ }^{3}$ Grades 2 through 6 only.

${ }^{4}$ Data for 1991-92.

-Data not available.
SOURCE: Council of State Directors of Programs for the Gifted, The 1994 and 1996 State of the States Gifted and Talented Education Reports. (This table was prepared July 1997.) 
Table 56.-Number of children served under Individuals with Disabilities Education Act and Chapter 1 of the Education Consolidation and Improvement Act, State Operated Programs, by age group and state: 1990-91 to 1996-97

\begin{tabular}{|c|c|c|c|c|c|c|c|c|c|c|}
\hline \multirow[b]{2}{*}{ State } & \multicolumn{4}{|c|}{ Birth to age 21} & \multirow{2}{*}{$\begin{array}{l}\text { Percent of } \\
\text { students } \\
\text { that are } \\
\text { disabled, } \\
\text { 1996-971 }\end{array}$} & \multicolumn{4}{|c|}{ Ages 0 to 5} & \multirow{2}{*}{$\begin{array}{c}\text { Percent } \\
\text { change, } \\
\text { birth to } \\
21, \\
1990-91 \\
\text { to } \\
1996-97\end{array}$} \\
\hline & 1990-91 & 1994-95 & 1995-96 & 1996-97 & & 1990-91 & 1994-95 & 1995-96 & 1996-97 & \\
\hline 1 & 2 & 3 & 4 & 5 & 6 & 7 & 8 & 9 & 10 & 11 \\
\hline United States .............. & $4,761,742$ & $5,538,756$ & $5,745,338$ & $5,919,767$ & 13.0 & 440,661 & 679,634 & 716,624 & 737,025 & 24.3 \\
\hline 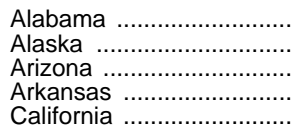 & $\begin{array}{r}94,945 \\
14,745 \\
57,235 \\
47,835 \\
469,282\end{array}$ & $\begin{array}{r}100,473 \\
17,942 \\
73,914 \\
54,279 \\
563,489\end{array}$ & $\begin{array}{r}99,594 \\
18,036 \\
77,688 \\
56,055 \\
583,789\end{array}$ & $\begin{array}{r}99,302 \\
18,061 \\
81,099 \\
57,475 \\
604,075\end{array}$ & $\begin{array}{l}13.3 \\
13.9 \\
10.1 \\
12.6 \\
10.6\end{array}$ & $\begin{array}{r}7,498 \\
1,813 \\
4,936 \\
5,274 \\
40,489\end{array}$ & $\begin{array}{r}9,800 \\
2,458 \\
8,748 \\
8,543 \\
71,461\end{array}$ & $\begin{array}{r}9,922 \\
2,447 \\
9,479 \\
9,695 \\
72,914\end{array}$ & $\begin{array}{r}9,798 \\
2,317 \\
9,357 \\
9,903 \\
75,802\end{array}$ & $\begin{array}{r}4.6 \\
22.5 \\
41.7 \\
20.2 \\
28.7\end{array}$ \\
\hline 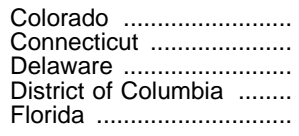 & $\begin{array}{r}57,102 \\
64,562 \\
14,294 \\
6,290 \\
236,013\end{array}$ & $\begin{array}{r}71,496 \\
75,695 \\
16,701 \\
6,831 \\
301,723\end{array}$ & $\begin{array}{r}73,633 \\
78,549 \\
17,012 \\
7,398 \\
320,955\end{array}$ & $\begin{array}{r}73,992 \\
84,412 \\
16,421 \\
7,059 \\
334,707\end{array}$ & $\begin{array}{r}11.0 \\
16.0 \\
14.9 \\
9.0 \\
14.9\end{array}$ & $\begin{array}{r}4,894 \\
6,142 \\
1,579 \\
411 \\
16,387\end{array}$ & $\begin{array}{r}10,212 \\
8,864 \\
3,287 \\
542 \\
32,292\end{array}$ & $\begin{array}{r}11,060 \\
9,764 \\
3,293 \\
727 \\
37,851\end{array}$ & $\begin{array}{r}9,717 \\
10,834 \\
2,578 \\
727 \\
38,945\end{array}$ & $\begin{array}{l}29.6 \\
30.7 \\
14.9 \\
12.2 \\
41.8\end{array}$ \\
\hline 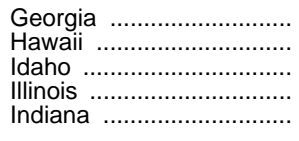 & $\begin{array}{r}101,997 \\
13,169 \\
22,017 \\
239,185 \\
114,643\end{array}$ & $\begin{array}{r}132,451 \\
19,020 \\
23,737 \\
258,461 \\
132,714\end{array}$ & $\begin{array}{r}138,514 \\
19,903 \\
24,671 \\
265,456 \\
138,150\end{array}$ & $\begin{array}{r}144,512 \\
20,350 \\
26,128 \\
275,198 \\
142,667\end{array}$ & $\begin{array}{l}10.7 \\
10.8 \\
10.7 \\
13.9 \\
14.5\end{array}$ & $\begin{array}{r}7,333 \\
1,273 \\
3,129 \\
26,122 \\
8,937\end{array}$ & $\begin{array}{r}16,028 \\
5,082 \\
3,849 \\
32,195 \\
15,203\end{array}$ & $\begin{array}{r}16,786 \\
5,180 \\
3,936 \\
33,461 \\
16,449\end{array}$ & $\begin{array}{r}17,656 \\
4,851 \\
4,144 \\
35,783 \\
17,454\end{array}$ & $\begin{array}{l}41.7 \\
54.5 \\
18.7 \\
15.1 \\
24.4\end{array}$ \\
\hline 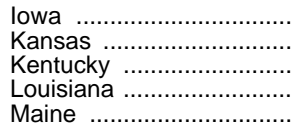 & $\begin{array}{l}60,695 \\
45,212 \\
79,421 \\
73,663 \\
27,987\end{array}$ & $\begin{array}{l}65,034 \\
52,861 \\
82,021 \\
91,344 \\
31,037\end{array}$ & $\begin{array}{l}66,914 \\
55,031 \\
84,524 \\
93,304 \\
32,719\end{array}$ & $\begin{array}{l}69,060 \\
56,845 \\
87,137 \\
94,727 \\
33,678\end{array}$ & $\begin{array}{l}13.7 \\
12.2 \\
13.3 \\
11.9 \\
15.8\end{array}$ & $\begin{array}{r}6,329 \\
4,308 \\
11,008 \\
7,541 \\
2,895\end{array}$ & $\begin{array}{r}6,679 \\
7,056 \\
15,343 \\
12,291 \\
3,695\end{array}$ & $\begin{array}{r}6,800 \\
7,564 \\
16,320 \\
11,833 \\
4,402\end{array}$ & $\begin{array}{r}6,899 \\
7,860 \\
17,105 \\
11,450 \\
4,316\end{array}$ & $\begin{array}{r}13.8 \\
25.7 \\
9.7 \\
28.6 \\
20.3\end{array}$ \\
\hline 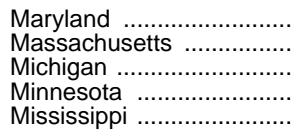 & $\begin{array}{r}91,940 \\
154,616 \\
166,927 \\
80,896 \\
60,934\end{array}$ & $\begin{array}{r}100,565 \\
164,784 \\
186,431 \\
96,539 \\
65,912\end{array}$ & $\begin{array}{r}104,558 \\
165,680 \\
193,152 \\
100,888 \\
67,520\end{array}$ & $\begin{array}{r}108,453 \\
168,082 \\
198,772 \\
103,929 \\
66,161\end{array}$ & $\begin{array}{l}13.2 \\
18.0 \\
11.8 \\
12.3 \\
13.1\end{array}$ & $\begin{array}{r}10,409 \\
17,014 \\
14,963 \\
10,529 \\
5,704\end{array}$ & $\begin{array}{r}12,846 \\
22,381 \\
21,262 \\
13,324 \\
6,871\end{array}$ & $\begin{array}{r}13,181 \\
22,725 \\
22,625 \\
13,399 \\
7,323\end{array}$ & $\begin{array}{r}13,613 \\
23,594 \\
23,553 \\
13,576 \\
6,881\end{array}$ & $\begin{array}{r}18.0 \\
8.7 \\
19.1 \\
28.5 \\
8.6\end{array}$ \\
\hline $\begin{array}{l}\text { Missouri ........................ } \\
\text { Montana ....................... } \\
\text { Nebraska ...................... } \\
\text { Nevada ......................... } \\
\text { New Hampshire .............. }\end{array}$ & $\begin{array}{r}101,955 \\
17,204 \\
32,761 \\
18,440 \\
19,658\end{array}$ & $\begin{array}{r}119,148 \\
18,161 \\
38,763 \\
27,091 \\
24,546\end{array}$ & $\begin{array}{r}123,811 \\
18,876 \\
39,926 \\
29,043 \\
26,163\end{array}$ & $\begin{array}{r}127,864 \\
19,119 \\
40,578 \\
30,913 \\
27,592\end{array}$ & $\begin{array}{l}14.2 \\
11.6 \\
13.9 \\
11.0 \\
13.9\end{array}$ & $\begin{array}{l}4,889 \\
1,934 \\
2,961 \\
1,742 \\
2,077\end{array}$ & $\begin{array}{r}10,297 \\
2,117 \\
4,048 \\
3,628 \\
2,788\end{array}$ & $\begin{array}{r}10,804 \\
2,278 \\
4,029 \\
4,007 \\
3,178\end{array}$ & $\begin{array}{r}10,972 \\
2,240 \\
4,003 \\
4,202 \\
3,461\end{array}$ & $\begin{array}{l}25.4 \\
11.1 \\
23.9 \\
67.6 \\
40.4\end{array}$ \\
\hline $\begin{array}{l}\text { New Jersey } \ldots \ldots \ldots \ldots \ldots \ldots \ldots \\
\text { New Mexico ..................... } \\
\text { New York ..................... } \\
\text { North Carolina ................ } \\
\text { North Dakota .................... }\end{array}$ & $\begin{array}{r}181,319 \\
36,037 \\
307,458 \\
123,126 \\
12,504\end{array}$ & $\begin{array}{r}194,940 \\
46,844 \\
383,822 \\
145,510 \\
12,386\end{array}$ & $\begin{array}{r}200,469 \\
49,325 \\
407,421 \\
151,414 \\
12,581\end{array}$ & $\begin{array}{r}206,252 \\
51,280 \\
427,907 \\
158,272 \\
12,991\end{array}$ & $\begin{array}{l}17.1 \\
15.4 \\
15.1 \\
13.1 \\
10.8\end{array}$ & $\begin{array}{r}17,190 \\
2,247 \\
26,353 \\
10,700 \\
1,374\end{array}$ & $\begin{array}{r}18,970 \\
5,596 \\
54,470 \\
21,130 \\
1,329\end{array}$ & $\begin{array}{r}20,046 \\
6,310 \\
61,289 \\
21,007 \\
1,434\end{array}$ & $\begin{array}{r}20,617 \\
6,840 \\
64,822 \\
21,259 \\
1,437\end{array}$ & $\begin{array}{r}13.8 \\
42.3 \\
39.2 \\
28.5 \\
3.9\end{array}$ \\
\hline 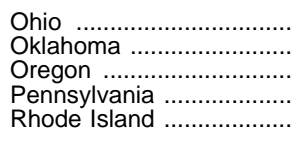 & $\begin{array}{r}205,440 \\
65,653 \\
55,149 \\
219,428 \\
21,076\end{array}$ & $\begin{array}{r}239,696 \\
72,496 \\
60,619 \\
213,785 \\
24,494\end{array}$ & $\begin{array}{r}242,734 \\
73,495 \\
66,156 \\
218,556 \\
26,048\end{array}$ & $\begin{array}{r}243,312 \\
75,601 \\
65,543 \\
222,494 \\
27,354\end{array}$ & $\begin{array}{l}13.2 \\
12.2 \\
12.2 \\
12.3 \\
18.1\end{array}$ & $\begin{array}{r}12,487 \\
5,359 \\
3,581 \\
23,156 \\
2,112\end{array}$ & $\begin{array}{r}34,249 \\
6,657 \\
6,030 \\
26,064 \\
2,932\end{array}$ & $\begin{array}{r}33,409 \\
7,079 \\
7,231 \\
27,525 \\
3,309\end{array}$ & $\begin{array}{r}35,634 \\
7,035 \\
7,431 \\
27,541 \\
3,210\end{array}$ & $\begin{array}{r}18.4 \\
15.2 \\
18.8 \\
1.4 \\
29.8\end{array}$ \\
\hline 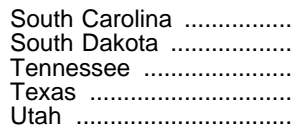 & $\begin{array}{r}77,765 \\
14,987 \\
104,898 \\
350,636 \\
47,747\end{array}$ & $\begin{array}{r}84,217 \\
16,114 \\
126,909 \\
430,010 \\
52,778\end{array}$ & $\begin{array}{r}88,419 \\
15,888 \\
129,617 \\
451,590 \\
54,527\end{array}$ & $\begin{array}{r}92,787 \\
15,485 \\
128,672 \\
472,661 \\
55,848\end{array}$ & $\begin{array}{l}14.2 \\
10.8 \\
14.2 \\
12.3 \\
11.6\end{array}$ & $\begin{array}{r}8,346 \\
2,366 \\
7,536 \\
30,955 \\
4,565\end{array}$ & $\begin{array}{r}11,495 \\
2,586 \\
12,981 \\
40,117 \\
6,128\end{array}$ & $\begin{array}{r}12,216 \\
2,552 \\
13,307 \\
42,304 \\
6,925\end{array}$ & $\begin{array}{r}12,518 \\
2,587 \\
13,400 \\
43,802 \\
7,189\end{array}$ & $\begin{array}{r}19.3 \\
3.3 \\
22.7 \\
34.8 \\
17.0\end{array}$ \\
\hline 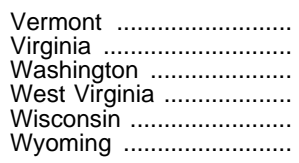 & $\begin{array}{r}12,263 \\
113,971 \\
85,395 \\
43,135 \\
86,930 \\
11,202\end{array}$ & $\begin{array}{r}11,034 \\
138,252 \\
106,725 \\
46,853 \\
105,536 \\
12,573\end{array}$ & $\begin{array}{r}11,587 \\
143,985 \\
108,851 \\
48,151 \\
110,029 \\
12,983\end{array}$ & $\begin{array}{r}12,076 \\
146,840 \\
109,227 \\
49,092 \\
114,407 \\
13,298\end{array}$ & $\begin{array}{l}11.4 \\
13.4 \\
11.2 \\
16.1 \\
13.0 \\
13.4\end{array}$ & $\begin{array}{r}1,200 \\
11,791 \\
11,409 \\
3,630 \\
12,213 \\
1,571\end{array}$ & $\begin{array}{r}1,498 \\
14,832 \\
15,072 \\
5,999 \\
16,391 \\
1,918\end{array}$ & $\begin{array}{r}1,556 \\
15,510 \\
14,526 \\
6,506 \\
17,161 \\
1,990\end{array}$ & $\begin{array}{r}1,542 \\
15,605 \\
14,198 \\
6,894 \\
17,918 \\
1,955\end{array}$ & $\begin{array}{l}-1.5 \\
28.8 \\
27.9 \\
13.8 \\
31.6 \\
18.7\end{array}$ \\
\hline Bureau of Indian Affairs .. & 6,997 & 7,676 & 7,669 & 8,192 & - & - & 258 & 244 & 310 & 17.1 \\
\hline Outlying areas ............. & 39,445 & 49,139 & 51,823 & 55,243 & 7.9 & - & 8,050 & 9,011 & 9,915 & 40.1 \\
\hline $\begin{array}{l}\text { American Samoa } \\
\text { Guam .................................. } \\
\text { Northern Marianas ........... } \\
\text { Palau ............................ } \\
\text { Puerto Rico ................... } \\
\text { Virgin Islands } \ldots \ldots \ldots \ldots \ldots \ldots \ldots . . .\end{array}$ & $\begin{array}{r}363 \\
1,750 \\
411 \\
459 \\
35,129 \\
1,333\end{array}$ & $\begin{array}{r}479 \\
1,909 \\
256 \\
152 \\
44,693 \\
1,650\end{array}$ & $\begin{array}{r}400 \\
1,980 \\
331 \\
120 \\
47,230 \\
1,762\end{array}$ & $\begin{array}{r}415 \\
2,099 \\
379 \\
116 \\
50,726 \\
1,508\end{array}$ & $\begin{array}{l}2.8 \\
6.3 \\
4.2 \\
8.2 \\
6.7\end{array}$ & $\begin{array}{l}- \\
- \\
- \\
-\end{array}$ & $\begin{array}{r}87 \\
307 \\
53 \\
10 \\
7,514 \\
79\end{array}$ & $\begin{array}{r}93 \\
301 \\
80 \\
10 \\
8,338 \\
189\end{array}$ & $\begin{array}{r}88 \\
336 \\
107 \\
7 \\
9,140 \\
237\end{array}$ & $\begin{array}{r}14.3 \\
19.9 \\
-7.8 \\
-74.7 \\
44.4 \\
13.1\end{array}$ \\
\hline
\end{tabular}

${ }^{1}$ Percent based on the enrollment in public schools, prekindergarten through 12 th grade.

-Data not available.

NOTE.-Individuals with Disabilities Education Act (IDEA), formerly known as the Education of the Handicapped Act, now extends the right to a free and appropriate education to 3 - to 5-year-old disabled children.
SOURCE: U.S. Department of Education, Office of Special Education and Rehabilitative Services, Annual Report to Congress on the Implementation of The Individuals with Disabilities Education Act, various years, and unpublished tabulations. (This table was prepared March 1998.) 
Table 57.-Enrollment in grades 9 to 12 in public and private schools compared with population 14 to 17 years of age: $1889-90$ to fall 1997

[Numbers in thousands]

\begin{tabular}{|c|c|c|c|c|c|}
\hline \multirow{2}{*}{ Year } & \multicolumn{3}{|c|}{ Enrollment, grades 9 to $12^{1}$} & \multirow{2}{*}{$\begin{array}{c}\text { Population } 14 \text { to } 17 \\
\text { years of age }\end{array}$} & \multirow{2}{*}{$\begin{array}{c}\text { Enrollment as a } \\
\text { percent of } \\
\text { population } 14 \text { to } 17 \\
\text { years of age } 4\end{array}$} \\
\hline & All schools & Public schools & Private schools ${ }^{2}$ & & \\
\hline 1 & 2 & 3 & 4 & 5 & 6 \\
\hline $\begin{array}{l}1889-90 \\
1899-1900 \\
1909-10 \\
1919-20 \\
1929-30\end{array}$ & $\begin{array}{r}298 \\
630 \\
1,032 \\
2,414 \\
4,741\end{array}$ & $\begin{array}{r}203 \\
519 \\
915 \\
2,200 \\
4,399\end{array}$ & $\begin{array}{r}95 \\
111 \\
117 \\
214 \\
5341\end{array}$ & $\begin{array}{l}5,355 \\
6,152 \\
7,220 \\
7,736 \\
9,341\end{array}$ & $\begin{array}{r}5.6 \\
10.2 \\
14.3 \\
31.2 \\
50.7\end{array}$ \\
\hline $\begin{array}{l}1939-40 \\
1949-50 \\
1951-52 \\
1953-54 \\
1955-56\end{array}$ & $\begin{array}{l}7,059 \\
6,397 \\
6,538 \\
7,038 \\
7,696\end{array}$ & $\begin{array}{l}6,601 \\
5,725 \\
5,882 \\
6,290 \\
6,873\end{array}$ & $\begin{array}{r}648 \\
672 \\
656 \\
747 \\
823\end{array}$ & $\begin{array}{l}9,720 \\
8,405 \\
8,516 \\
8,861 \\
9,207\end{array}$ & $\begin{array}{l}72.6 \\
76.1 \\
76.8 \\
79.4 \\
83.6\end{array}$ \\
\hline 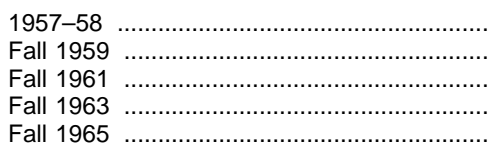 & $\begin{array}{r}8,790 \\
9,306 \\
10,489 \\
12,170 \\
13,010\end{array}$ & $\begin{array}{r}7,860 \\
8,271 \\
9,369 \\
10,883 \\
11,610\end{array}$ & $\begin{array}{r}931 \\
1,035 \\
1,120 \\
1,287 \\
1,400\end{array}$ & $\begin{array}{l}10,139 \\
11,155 \\
12,046 \\
13,492 \\
14,146\end{array}$ & $\begin{array}{l}86.7 \\
83.4 \\
87.1 \\
90.2 \\
92.0\end{array}$ \\
\hline 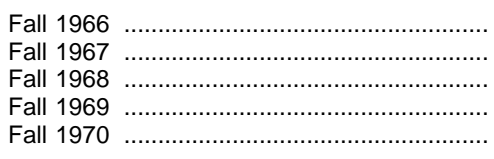 & $\begin{array}{l}13,294 \\
13,650 \\
14,118 \\
14,337 \\
14,647\end{array}$ & $\begin{array}{l}11,894 \\
12,250 \\
12,718 \\
13,037 \\
13,336\end{array}$ & $\begin{array}{l}1,400 \\
1,400 \\
1,400 \\
1,300 \\
1,311\end{array}$ & $\begin{array}{l}14,398 \\
14,727 \\
15,170 \\
15,549 \\
15,921\end{array}$ & $\begin{array}{l}92.3 \\
92.7 \\
93.1 \\
92.2 \\
92.0\end{array}$ \\
\hline 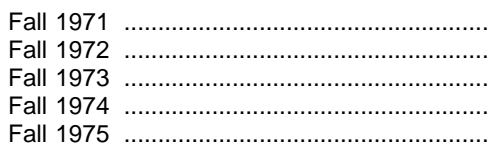 & $\begin{array}{l}15,053 \\
15,148 \\
15,344 \\
15,403 \\
15,604\end{array}$ & $\begin{array}{l}13,753 \\
13,848 \\
14,044 \\
14,103 \\
14,304\end{array}$ & $\begin{array}{l}71,300 \\
71,300 \\
71,300 \\
71,300 \\
71,300\end{array}$ & $\begin{array}{l}16,326 \\
16,637 \\
16,864 \\
17,033 \\
17,125\end{array}$ & $\begin{array}{l}92.2 \\
91.0 \\
91.0 \\
90.4 \\
91.1\end{array}$ \\
\hline 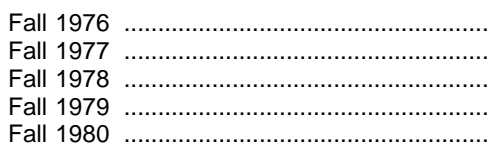 & $\begin{array}{l}15,656 \\
15,546 \\
15,441 \\
14,916 \\
14,570\end{array}$ & $\begin{array}{l}14,314 \\
14,203 \\
14,088 \\
13,616 \\
13,231\end{array}$ & $\begin{array}{r}1,342 \\
1,343 \\
1,353 \\
71,300 \\
1,339\end{array}$ & $\begin{array}{l}17,117 \\
17,042 \\
16,944 \\
16,610 \\
16,143\end{array}$ & $\begin{array}{l}91.5 \\
91.2 \\
91.1 \\
89.8 \\
90.3\end{array}$ \\
\hline 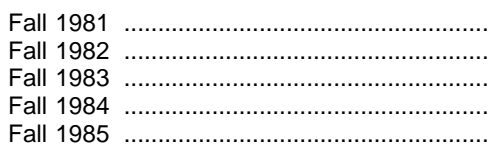 & $\begin{array}{l}14,164 \\
13,805 \\
13,671 \\
13,704 \\
13,750\end{array}$ & $\begin{array}{l}12,764 \\
12,405 \\
12,271 \\
12,304 \\
12,388\end{array}$ & $\begin{array}{r}71,400 \\
71,400 \\
71,400 \\
71,400 \\
1,362\end{array}$ & $\begin{array}{l}15,609 \\
15,057 \\
14,740 \\
14,725 \\
14,888\end{array}$ & $\begin{array}{l}90.7 \\
91.7 \\
92.7 \\
93.1 \\
92.4\end{array}$ \\
\hline 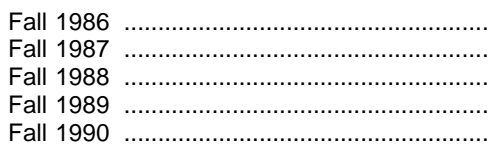 & $\begin{array}{l}13,669 \\
13,323 \\
12,893 \\
12,583 \\
12,475\end{array}$ & $\begin{array}{l}12,333 \\
12,076 \\
11,687 \\
11,390 \\
11,338\end{array}$ & $\begin{array}{r}71,336 \\
1,247 \\
71,206 \\
71,193 \\
71,137\end{array}$ & $\begin{array}{l}14,824 \\
14,502 \\
14,023 \\
13,536 \\
13,310\end{array}$ & $\begin{array}{l}92.2 \\
91.9 \\
91.9 \\
93.0 \\
93.7\end{array}$ \\
\hline 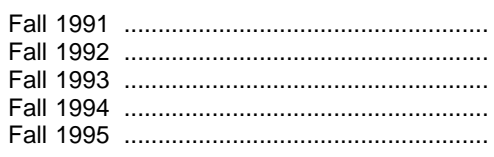 & $\begin{array}{l}12,666 \\
12,898 \\
13,152 \\
13,449 \\
13,769\end{array}$ & $\begin{array}{l}11,541 \\
11,735 \\
11,961 \\
12,213 \\
12,500\end{array}$ & $\begin{array}{l}71,125 \\
71,163 \\
71,191 \\
71,236 \\
71,269\end{array}$ & $\begin{array}{l}13,418 \\
13,653 \\
13,928 \\
14,427 \\
14,770\end{array}$ & $\begin{array}{l}94.4 \\
94.5 \\
94.4 \\
93.2 \\
93.2\end{array}$ \\
\hline $\begin{array}{l}\text { Fall } 1996 \\
\text { Fall } 19977\end{array}$ & $\begin{array}{l}14,131 \\
14,325\end{array}$ & $\begin{array}{l}12,834 \\
13,003\end{array}$ & $\begin{array}{r}71,297 \\
1,322\end{array}$ & $\begin{array}{l}15,149 \\
15,429\end{array}$ & $\begin{array}{l}93.3 \\
92.8\end{array}$ \\
\hline
\end{tabular}

1 Includes a relatively small number of secondary ungraded and postgraduate students.

2 Data for most years are partly estimated.

${ }^{3}$ Data for 1890 through 1950 are from the decennial censuses of population. The other figures are Bureau of the Census estimates as of July 1 preceding the opening of the school year.

4 Gross enrollment ratio based on school enrollment of all ages in grades 9 to 12 divided by the 14- to 17-year-old population. Differs from enrollment rates in other tables which are based on the enrollment of persons in the given age group only.

${ }^{5}$ Data are for $1927-28$

${ }^{6}$ Data are for $1940-41$

${ }^{7}$ Estimated.
NOTE.-Includes enrollment in public schools that are a part of state and local school systems and also in most private schools, both religiously affiliated and nonsectarian Excludes enrollment in subcollegiate departments of institutions of higher education, residential schools for exceptional children, and federal schools. Because of rounding, details may not add to totals. Some data have been revised from previously published figures.

SOURCE: U.S. Department of Education, National Center for Education Statistics, Statistics of State School Systems; Statistics of Public Elementary and Secondary School Systems; Statistics of Nonpublic Elementary and Secondary Schools; Common Core of Data survey; and Projections of Education Statistics to 2008. (This table was prepared February 1999.) 
Table 58.-Enrollment in foreign language courses compared with enrollment in grades 9 to 12 in public secondary schools: Fall 1948 to fall 1994

[In thousands]

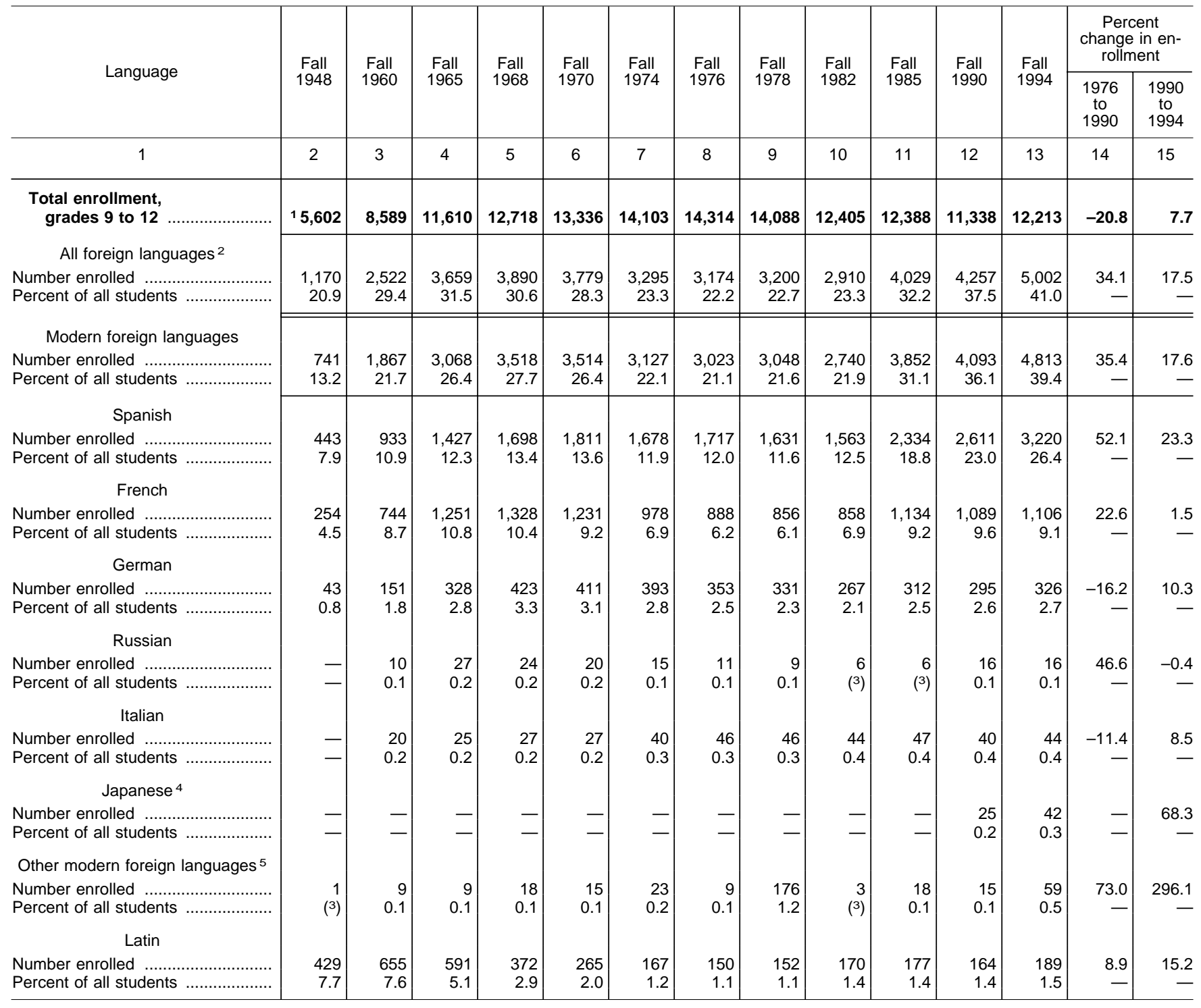

1 Estimated.

2 Includes enrollment in ancient Greek (not shown separately). Fewer than 1,000 students were enrolled in this language in each of the years shown.

${ }^{3}$ Less than 0.05 percent.

4 Until 1990, student enrollment in Japanese courses was included in the Other modern foreign languages category.

5 Includes students enrolled in unspecified modern foreign languages. In 1978, a relatively large number of students were not identified by field of study. Since 1990, enrollment in Japanese courses is reported as a separate category.

—Data not reported, not available, or not applicable.

SOURCE: U.S. Department of Education, National Center for Education Statistics, Common Core of Data survey; and American Council on the Teaching of Foreign Languages, Foreign Language Enrollments in Public Secondary Schools, Fall 1989, Fall 1990, and Fall 1994. (This table was prepared February 1999.) 
Table 59.-Student participation in school programs and services, by control, level of school, and type of community: 1993-94

\begin{tabular}{|c|c|c|c|c|c|c|c|c|c|c|}
\hline \multirow[b]{2}{*}{ Control, level, and community type } & \multicolumn{2}{|c|}{ Total students } & \multicolumn{8}{|c|}{ Percent of students participating in program or service } \\
\hline & Number & $\begin{array}{l}\text { Percent } \\
\text { distribu- } \\
\text { tion }\end{array}$ & $\begin{array}{l}\text { Bilingual } \\
\text { edu- } \\
\text { cation }\end{array}$ & $\begin{array}{l}\text { English } \\
\text { as a } \\
\text { second } \\
\text { lan- } \\
\text { guage }\end{array}$ & $\begin{array}{l}\text { Reme- } \\
\text { dial } \\
\text { reading }\end{array}$ & $\begin{array}{l}\text { Reme- } \\
\text { dial } \\
\text { mathe- } \\
\text { matics }\end{array}$ & $\begin{array}{l}\text { Pro- } \\
\text { grams } \\
\text { for the } \\
\text { disabled }\end{array}$ & $\begin{array}{l}\text { Pro- } \\
\text { grams } \\
\text { for the } \\
\text { gifted } \\
\text { and tal- } \\
\text { ented }\end{array}$ & $\begin{array}{l}\text { Diag- } \\
\text { nostic } \\
\text { and pre- } \\
\text { scriptive }\end{array}$ & $\begin{array}{l}\text { Ex- } \\
\text { tended } \\
\text { day }\end{array}$ \\
\hline 1 & 2 & 3 & 4 & 5 & 6 & 7 & 8 & 9 & 10 & 11 \\
\hline Public total $\ldots \ldots \ldots \ldots \ldots \ldots \ldots$ & $41,621,660$ & 100.0 & 3.07 & 3.97 & 10.88 & 6.90 & 6.88 & 6.43 & 0.27 & 2.50 \\
\hline 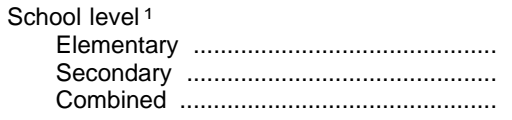 & $\begin{array}{r}26,886,026 \\
13,757,801 \\
977,833\end{array}$ & $\begin{array}{r}64.6 \\
33.1 \\
2.3\end{array}$ & $\begin{array}{l}3.98 \\
1.39 \\
1.80\end{array}$ & $\begin{array}{l}4.75 \\
2.58 \\
1.88\end{array}$ & $\begin{array}{r}13.46 \\
5.63 \\
13.70\end{array}$ & $\begin{array}{l}7.77 \\
5.03 \\
9.39\end{array}$ & $\begin{array}{r}6.76 \\
6.54 \\
14.84\end{array}$ & $\begin{array}{l}6.25 \\
6.90 \\
4.72\end{array}$ & $\begin{array}{l}0.31 \\
0.20 \\
0.44\end{array}$ & $\begin{array}{l}3.58 \\
0.48 \\
1.31\end{array}$ \\
\hline 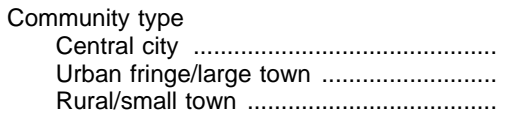 & $\begin{array}{l}12,163,036 \\
13,559,662 \\
15,898,962\end{array}$ & $\begin{array}{l}29.2 \\
32.6 \\
38.2\end{array}$ & $\begin{array}{l}6.30 \\
2.04 \\
1.48\end{array}$ & $\begin{array}{l}7.13 \\
3.90 \\
1.60\end{array}$ & $\begin{array}{r}12.86 \\
8.84 \\
11.09\end{array}$ & $\begin{array}{l}8.34 \\
5.60 \\
6.90\end{array}$ & $\begin{array}{l}7.05 \\
6.34 \\
7.20\end{array}$ & $\begin{array}{l}6.55 \\
7.26 \\
5.63\end{array}$ & $\begin{array}{l}0.23 \\
0.23 \\
0.35\end{array}$ & $\begin{array}{l}3.82 \\
2.69 \\
1.33\end{array}$ \\
\hline Private total & $4,970,548$ & 100.0 & 0.81 & 0.58 & 6.35 & 4.16 & 2.98 & 4.93 & 0.89 & 9.20 \\
\hline $\begin{array}{l}\text { School level } 1 \\
\text { Elementary } \\
\text { Secondary } \\
\text { Combined }\end{array}$ & $\begin{array}{r}2,803,359 \\
811,087 \\
1,356,102\end{array}$ & $\begin{array}{l}56.4 \\
16.3 \\
27.3\end{array}$ & $\begin{array}{l}0.77 \\
0.19 \\
1.25\end{array}$ & $\begin{array}{l}0.45 \\
0.62 \\
0.83\end{array}$ & $\begin{array}{l}7.22 \\
4.24 \\
5.82\end{array}$ & $\begin{array}{l}4.33 \\
3.06 \\
4.46\end{array}$ & $\begin{array}{l}0.93 \\
3.43 \\
6.95\end{array}$ & $\begin{array}{l}3.34 \\
8.56 \\
6.05\end{array}$ & $\begin{array}{l}0.94 \\
0.47 \\
1.03\end{array}$ & $\begin{array}{r}12.48 \\
0.23 \\
7.76\end{array}$ \\
\hline 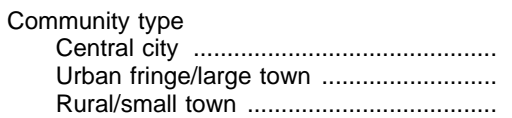 & $\begin{array}{r}2,261,125 \\
1,810,230 \\
899,193\end{array}$ & $\begin{array}{l}45.5 \\
36.4 \\
18.1\end{array}$ & $\begin{array}{l}0.83 \\
0.97 \\
0.42\end{array}$ & $\begin{array}{l}0.71 \\
0.57 \\
0.27\end{array}$ & $\begin{array}{l}7.33 \\
5.98 \\
4.63\end{array}$ & $\begin{array}{l}4.77 \\
4.15 \\
2.62\end{array}$ & $\begin{array}{l}2.68 \\
3.58 \\
2.50\end{array}$ & $\begin{array}{l}5.56 \\
5.24 \\
2.75\end{array}$ & $\begin{array}{l}0.72 \\
0.85 \\
1.48\end{array}$ & $\begin{array}{r}11.36 \\
8.89 \\
4.39\end{array}$ \\
\hline
\end{tabular}

1 Elementary schools have grade 6 or lower or a low grade of ungraded and no grade higher than 8 . Secondary schools have no grade lower than 7 . Combined schools have grades lower than 7 and higher than 8.

NOTE.-Students may participate in more than one program or service. Includes only kindergarten pupils who attend schools that offer first grade or above. Excludes pre- kindergarten students. Totals differ from data appearing in other tables because of varying survey processing procedures and time period coverages.

SOURCE: U.S. Department of Education, National Center for Education Statistics, "Schools and Staffing Survey, 1993-94." (This table was prepared September 1996.)

Table 60.-Private elementary and secondary enrollment, teachers, and schools, by selected characteristics: Fall 1995

\begin{tabular}{|c|c|c|c|c|c|c|c|c|c|c|c|c|}
\hline \multirow{2}{*}{$\begin{array}{l}\text { Selected school char- } \\
\text { acteristics }\end{array}$} & \multicolumn{4}{|c|}{ Kindergarten to 12 th grade enrollment ${ }^{1}$} & \multicolumn{4}{|c|}{ Teachers } & \multicolumn{4}{|c|}{ Schools } \\
\hline & Total & Catholic & $\begin{array}{l}\text { Other } \\
\text { religious }\end{array}$ & $\begin{array}{l}\text { Non- } \\
\text { sectarian }\end{array}$ & Total & Catholic & $\begin{array}{l}\text { Other } \\
\text { religious }\end{array}$ & $\begin{array}{l}\text { Non- } \\
\text { sectarian }\end{array}$ & Total & Catholic & $\begin{array}{l}\text { Other } \\
\text { religious }\end{array}$ & $\begin{array}{l}\text { Non- } \\
\text { sectarian }\end{array}$ \\
\hline 1 & 2 & 3 & 4 & 5 & 6 & 7 & 8 & 9 & 10 & 11 & 12 & 13 \\
\hline Total ....................... & $5,032,200$ & $2,519,205$ & $1,743,791$ & 769,204 & 361,909 & 140,941 & 136,513 & 84,455 & 27,686 & 8,248 & 13,081 & 6,357 \\
\hline $\begin{array}{l}\text { Level of school } \\
\text { Elementary } \ldots \ldots \ldots \ldots . . . \\
\text { Secondary } \\
\text { Combined ................ }\end{array}$ & $\begin{array}{r}2,835,247 \\
811,422 \\
1,385,531\end{array}$ & $\begin{array}{r}1,835,535 \\
606,239 \\
77,430\end{array}$ & $\begin{array}{l}743,112 \\
121,259 \\
879,420\end{array}$ & $\begin{array}{r}256,600 \\
83,924 \\
428,680\end{array}$ & $\begin{array}{r}176,148 \\
59,880 \\
125,881\end{array}$ & $\begin{array}{r}95,306 \\
38,863 \\
6,773\end{array}$ & $\begin{array}{l}54,623 \\
10,390 \\
71,499\end{array}$ & $\begin{array}{l}26,219 \\
10,628 \\
47,609\end{array}$ & $\begin{array}{r}16,744 \\
2,533 \\
8,409\end{array}$ & $\begin{array}{r}6,833 \\
1,149 \\
266\end{array}$ & $\begin{array}{r}6,761 \\
662 \\
5,657\end{array}$ & $\begin{array}{r}3,150 \\
722 \\
2,486\end{array}$ \\
\hline $\begin{array}{l}\text { School enrollment } \\
\text { Less than } 150 \ldots \ldots . . . \\
150 \text { to } 299 \ldots \ldots \ldots . . . \\
300 \text { to } 499 \\
500 \text { to } 749 \ldots \ldots \ldots \ldots . . . \\
750 \text { or more ............ }\end{array}$ & $\begin{array}{r}925,845 \\
1,443,244 \\
1,211,421 \\
790,747 \\
660,942\end{array}$ & $\begin{array}{l}152,653 \\
806,922 \\
733,555 \\
479,808 \\
346,265\end{array}$ & $\begin{array}{l}523,779 \\
474,656 \\
348,410 \\
203,282 \\
193,664\end{array}$ & $\begin{array}{l}249,412 \\
161,666 \\
129,456 \\
107,657 \\
121,013\end{array}$ & $\begin{array}{l}93,526 \\
97,255 \\
76,820 \\
49,810 \\
44,498\end{array}$ & $\begin{array}{l}12,091 \\
45,281 \\
39,582 \\
25,263 \\
18,725\end{array}$ & $\begin{array}{l}49,441 \\
34,663 \\
24,352 \\
14,026 \\
14,030\end{array}$ & $\begin{array}{l}31,994 \\
17,311 \\
12,885 \\
10,522 \\
11,744\end{array}$ & $\begin{array}{r}15,843 \\
6,667 \\
3,187 \\
1,333 \\
657\end{array}$ & $\begin{array}{r}1,537 \\
3,630 \\
1,923 \\
813 \\
344\end{array}$ & $\begin{array}{r}9,362 \\
2,261 \\
924 \\
340 \\
193\end{array}$ & $\begin{array}{r}4,944 \\
775 \\
340 \\
179 \\
120\end{array}$ \\
\hline $\begin{array}{l}\text { Percent minority stu- } \\
\text { dents } \\
\text { None } \\
1 \text { to } 9 \text { percent .......................... } \\
10 \text { to } 29 \text { percent ... } \\
30 \text { to } 49 \text { percent ... } \\
50 \text { percent or more }\end{array}$ & $\begin{array}{r}333,914 \\
2,269,371 \\
1,257,774 \\
385,183 \\
785,958\end{array}$ & $\begin{array}{r}68,327 \\
1,248,074 \\
560,629 \\
191,536 \\
450,639\end{array}$ & $\begin{array}{l}238,108 \\
773,237 \\
396,103 \\
118,286 \\
218,058\end{array}$ & $\begin{array}{r}27,479 \\
248,061 \\
301,042 \\
75,361 \\
117,260\end{array}$ & $\begin{array}{r}28,099 \\
151,276 \\
100,786 \\
29,139 \\
52,609\end{array}$ & $\begin{array}{r}4,264 \\
69,148 \\
33,279 \\
10,885 \\
23,364\end{array}$ & $\begin{array}{r}21,278 \\
56,896 \\
32,381 \\
8,994 \\
16,963\end{array}$ & $\begin{array}{r}2,557 \\
25,232 \\
35,125 \\
9,259 \\
12,282\end{array}$ & $\begin{array}{l}4,256 \\
9,619 \\
6,517 \\
2,261 \\
5,033\end{array}$ & $\begin{array}{r}465 \\
3,900 \\
1,712 \\
602 \\
1,569\end{array}$ & $\begin{array}{r}3,265 \\
4,294 \\
2,680 \\
865 \\
1,976\end{array}$ & $\begin{array}{r}525 \\
1,424 \\
2,126 \\
793 \\
1,488\end{array}$ \\
\hline $\begin{array}{l}\text { Community type } \\
\text { Central city .......... } \\
\text { Urban fringe/large } \\
\text { town ................. } \\
\text { Rural/small town ... }\end{array}$ & $\begin{array}{r}2,492,539 \\
1,968,029 \\
571,632\end{array}$ & $\begin{array}{r}1,325,035 \\
995,863 \\
198,307\end{array}$ & $\begin{array}{l}675,252 \\
258,754\end{array}$ & $\begin{array}{l}357,719 \\
296,914 \\
114,571\end{array}$ & $\begin{array}{r}173,755 \\
141,393 \\
46,761\end{array}$ & $\begin{array}{l}55,139 \\
12,897\end{array}$ & $\begin{array}{l}51,826 \\
22,354\end{array}$ & $\begin{array}{l}34,428 \\
11,510\end{array}$ & $\begin{array}{r}11,357 \\
10,325 \\
6,003\end{array}$ & $\begin{array}{l}3,154 \\
1,216\end{array}$ & $\begin{array}{l}4,590 \\
3,888\end{array}$ & $\begin{array}{r}2,581 \\
900\end{array}$ \\
\hline
\end{tabular}

1 Includes only kindergarten pupils who attend schools that offer first or higher grade.

NOTE-Includes only schools that offer first grade or above. Excludes prekindergarten students. Because of rounding, details may not add to totals.

SOURCE: U.S. Department of Education, National Center for Education Statistics, Private School Survey, 1995." (This table was prepared February 1999.) 
Table 61.-Private elementary and secondary staff and student/staff ratios, by level and orientation of school: 1993-94

\begin{tabular}{|c|c|c|c|c|c|c|c|c|}
\hline \multirow{2}{*}{ Orientation and type of staff } & \multicolumn{4}{|c|}{ Full-time-equivalent staff } & \multicolumn{4}{|c|}{ Students per full-time-equivalent staff member } \\
\hline & Total & Elementary ${ }^{1}$ & Secondary $^{2}$ & Combined $^{3}$ & Total & Elementary ${ }^{1}$ & Secondary $^{2}$ & Combined $^{3}$ \\
\hline 1 & 2 & 3 & 4 & 5 & 6 & 7 & 8 & 9 \\
\hline Total & 534,636 & 240,894 & 104,213 & 189,529 & 9.3 & 11.6 & 7.8 & 7.2 \\
\hline $\begin{array}{l}\text { Principals ....................... } \\
\text { Assistant principals ............. } \\
\text { Other managers ................ } \\
\text { Instruction coordinators ........ } \\
\text { Teachers ........................... } \\
\text { Teacher aides .................... } \\
\text { Guidance counselors .......... } \\
\text { Librarians/media specialists } \\
\text { Library/media center aides } . . \\
\text { Student support staff } 4 \\
\text { Secretaries/clerical staff .......... } \\
\text { Other employees } 5\end{array}$ & $\begin{array}{r}23,589 \\
8,361 \\
7,801 \\
6,063 \\
330,838 \\
33,905 \\
8,640 \\
8,946 \\
3,768 \\
11,003 \\
37,634 \\
54,092\end{array}$ & $\begin{array}{r}13,180 \\
3,094 \\
1,510 \\
1,837 \\
155,220 \\
16,516 \\
1,713 \\
4,320 \\
1,942 \\
2,207 \\
15,170 \\
24,187\end{array}$ & $\begin{array}{r}2,459 \\
2,113 \\
3,483 \\
1,293 \\
60,644 \\
2,566 \\
3,758 \\
1,950 \\
588 \\
2,684 \\
9,061 \\
13,615\end{array}$ & $\begin{array}{r}7,950 \\
3,154 \\
2,808 \\
2,933 \\
114,974 \\
14,823 \\
3,169 \\
2,676 \\
1,238 \\
6,112 \\
13,403 \\
16,290\end{array}$ & $\begin{array}{r}210.7 \\
594.5 \\
637.2 \\
819.8 \\
15.0 \\
146.6 \\
575.3 \\
555.6 \\
1,319.2 \\
451.8 \\
132.1 \\
91.9\end{array}$ & $\begin{array}{r}212.7 \\
906.1 \\
1,856.5 \\
1,526.1 \\
18.1 \\
169.7 \\
1,636.5 \\
648.9 \\
1,443.5 \\
1,270.2 \\
184.8 \\
115.9\end{array}$ & $\begin{array}{r}329.8 \\
383.9 \\
232.9 \\
627.3 \\
13.4 \\
316.1 \\
215.8 \\
415.9 \\
1,379.4 \\
302.2 \\
89.5 \\
59.6\end{array}$ & $\begin{array}{r}170.6 \\
430.0 \\
483.0 \\
462.4 \\
11.8 \\
91.5 \\
428.0 \\
506.8 \\
1,095.5 \\
221.9 \\
101.2 \\
83.3\end{array}$ \\
\hline Catholic & & & & & & & & \\
\hline 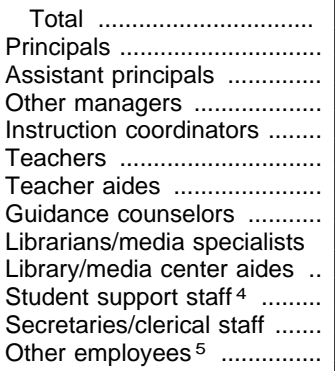 & $\begin{array}{r}206,094 \\
8,186 \\
2,854 \\
3,139 \\
1,138 \\
132,240 \\
9,078 \\
3,843 \\
4,291 \\
1,969 \\
2,287 \\
13,731 \\
23,338\end{array}$ & $\begin{array}{r}135,831 \\
6,702 \\
1,210 \\
717 \\
619 \\
88,524 \\
8,144 \\
1,144 \\
2,836 \\
1,489 \\
1,418 \\
8,139 \\
14,889\end{array}$ & $\begin{array}{r}59,239 \\
1,177 \\
1,475 \\
2,168 \\
477 \\
37,132 \\
176 \\
2,341 \\
1,230 \\
363 \\
568 \\
4,841 \\
7,291\end{array}$ & $\begin{array}{r}11,024 \\
307 \\
169 \\
254 \\
42 \\
6,584 \\
758 \\
358 \\
225 \\
117 \\
301 \\
751 \\
1,158\end{array}$ & $\begin{array}{r}12.2 \\
307.4 \\
881.6 \\
801.6 \\
2,211.0 \\
19.0 \\
277.2 \\
654.7 \\
586.4 \\
1,277.9 \\
1,100.2 \\
183.2 \\
107.8\end{array}$ & $\begin{array}{r}13.6 \\
275.8 \\
1,527.5 \\
2,577.8 \\
2,985.9 \\
20.9 \\
226.9 \\
1,615.6 \\
651.7 \\
1,241.3 \\
1,303.4 \\
227.1 \\
124.1\end{array}$ & $\begin{array}{r}10.0 \\
503.0 \\
401.4 \\
273.1 \\
1,241.1 \\
15.9 \\
3,363.7 \\
252.9 \\
481.3 \\
1,630.9 \\
1,042.3 \\
122.3 \\
81.2\end{array}$ & $\begin{array}{r}6.9 \\
247.1 \\
448.9 \\
298.7 \\
1,806.2 \\
11.5 \\
100.1 \\
211.9 \\
337.2 \\
648.4 \\
252.0 \\
101.0 \\
65.5\end{array}$ \\
\hline Other religious orientation & & & & & & & & \\
\hline 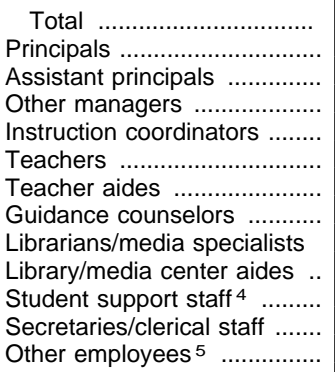 & $\begin{array}{r}184,521 \\
9,917 \\
3,184 \\
1,932 \\
2,298 \\
120,253 \\
10,021 \\
2,001 \\
2,596 \\
990 \\
1,318 \\
13,551 \\
16,460\end{array}$ & $\begin{array}{r}72,798 \\
4,535 \\
1,102 \\
584 \\
775 \\
46,973 \\
4,827 \\
473 \\
977 \\
330 \\
489 \\
5,033 \\
6,700\end{array}$ & $\begin{array}{r}16,970 \\
573 \\
278 \\
340 \\
153 \\
10,366 \\
171 \\
403 \\
349 \\
112 \\
231 \\
1,637 \\
2,357\end{array}$ & $\begin{array}{r}94,753 \\
4,809 \\
1,804 \\
1,008 \\
1,370 \\
62,914 \\
5,023 \\
1,125 \\
1,270 \\
548 \\
598 \\
6,881 \\
7,403\end{array}$ & $\begin{array}{r}9.1 \\
170.0 \\
529.5 \\
872.7 \\
733.7 \\
14.0 \\
168.3 \\
842.6 \\
649.5 \\
1,703.1 \\
1,279.3 \\
124.4 \\
102.4\end{array}$ & $\begin{array}{r}9.9 \\
158.4 \\
651.7 \\
1,229.7 \\
926.7 \\
15.3 \\
148.8 \\
1,518.3 \\
735.1 \\
2,176.3 \\
1,468.7 \\
142.7 \\
107.2\end{array}$ & $\begin{array}{r}7.3 \\
217.2 \\
447.7 \\
366.0 \\
813.4 \\
12.0 \\
727.8 \\
308.8 \\
356.6 \\
1,111.1 \\
538.7 \\
76.0 \\
52.8\end{array}$ & $\begin{array}{r}8.9 \\
175.4 \\
467.5 \\
836.8 \\
615.7 \\
13.4 \\
167.9 \\
749.7 \\
664.1 \\
1,539.1 \\
1,410.4 \\
122.6 \\
113.9\end{array}$ \\
\hline Non-sectarian & & & & & & & & \\
\hline Total ............................... & 144,025 & 32,267 & 28,005 & 83,753 & 5.3 & 7.3 & 3.4 & 5.2 \\
\hline 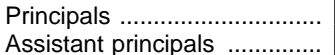 & $\begin{array}{l}5,486 \\
2,323\end{array}$ & $\begin{array}{r}1,943 \\
782\end{array}$ & $\begin{array}{l}709 \\
360\end{array}$ & $\begin{array}{l}2,834 \\
1,181\end{array}$ & $\begin{array}{l}140.1 \\
330.8\end{array}$ & $\begin{array}{l}121.9 \\
303.0\end{array}$ & $\begin{array}{l}133.5 \\
262.9\end{array}$ & $\begin{array}{l}154.2 \\
369.9\end{array}$ \\
\hline 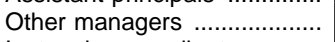 & 2,730 & 209 & 975 & 1,546 & 281.5 & $1,133.6$ & 97.1 & 282.6 \\
\hline Instruction coordinators ......... & 2,627 & 443 & 663 & 1,521 & 292.5 & 534.8 & 142.7 & 287.2 \\
\hline Teachers ................................ & 78,345 & 19,723 & 13,146 & 45,476 & 9.8 & 12.0 & 7.2 & 9.6 \\
\hline Teacher aides ....................... & 14,806 & 3,545 & 2,219 & 9,042 & 51.9 & 66.8 & 42.6 & 48.3 \\
\hline Guidance counselors ............. & 2,796 & 96 & 1,014 & 1,686 & 274.8 & $2,468.0$ & 93.3 & 259.1 \\
\hline Librarians/media specialists & 2,059 & 507 & 371 & 1,181 & 373.2 & 467.3 & 255.1 & 369.9 \\
\hline Library/media center aides .. & 809 & 123 & 113 & 573 & 949.9 & $1,926.3$ & 837.4 & 762.5 \\
\hline Student support staff 4 .............. & 7,398 & 300 & 1,885 & 5,213 & 103.9 & 789.8 & 50.2 & 83.8 \\
\hline Secretaries/clerical staff & 10,352 & 1,998 & 2,583 & 5,771 & 74.2 & 118.6 & 36.6 & 75.7 \\
\hline Other employees ${ }^{5}$ & 14,294 & 2,598 & 3,967 & 7,729 & 53.8 & 91.2 & 23.9 & 56.5 \\
\hline
\end{tabular}

1 Includes schools beginning with grade 6 or below and with no grade higher than 8 . 2 Schools have no grade lower than 7.

${ }^{3}$ Schools have grades lower than 7 and higher than 8 .

4 Includes student support services professional staff, such as school psychologists, social workers, occupational therapists, speech therapists, and nurses.

5 Includes cafeteria workers and maintenance staff.
NOTE.-Data are based upon a sample survey and may not be strictly comparable with data reported elsewhere. Includes only schools that offer first grade or above.

SOURCE: U.S. Department of Education, National Center for Education Statistics, "Schools and Staffing Survey, 1993-94." (This table was prepared August 1995.) 
Table 62.-Private elementary and secondary enrollment and schools, by amount of tuition, level, and orientation of school: 1993-94

\begin{tabular}{|c|c|c|c|c|c|c|c|c|c|c|c|c|}
\hline \multirow[b]{2}{*}{ Orientation and tuition } & \multicolumn{4}{|c|}{ Kindergarten through 12 th grade enrollment 1} & \multicolumn{4}{|c|}{ Schools } & \multicolumn{4}{|c|}{ Average tuition paid by students 2} \\
\hline & Total & Elementary & Secondary & Combined & Total & $\begin{array}{c}\text { Elemen- } \\
\text { tary }\end{array}$ & $\begin{array}{c}\text { Second- } \\
\text { ary }\end{array}$ & $\begin{array}{l}\text { Com- } \\
\text { bined }\end{array}$ & Total & $\underset{\text { tary }}{\text { Elemen }}$ & $\begin{array}{c}\text { Second- } \\
\text { ary }\end{array}$ & $\begin{array}{l}\text { Com- } \\
\text { bined }\end{array}$ \\
\hline 1 & 2 & 3 & 2 & 5 & 6 & ( & 8 & 9 & 10 & 11 & 12 & 13 \\
\hline Total & $4,970,646$ & $2,803,359$ & 811,087 & $1,356,199$ & 26,093 & 15,538 & 2,551 & 8,004 & $\$ 3,116$ & $\$ 2,138$ & $\$ 4,578$ & $\$ 4,266$ \\
\hline $\begin{array}{l}\text { Catholic } \\
\text { Less then } \$ 1,000 \\
\$ 1,000 \text { to } \$ 2,499\end{array}$ & $\begin{array}{r}2,516,130 \\
393,901 \\
1,368,046 \\
675,708 \\
71,929\end{array}$ & $\begin{array}{r}1,848,257 \\
378,724 \\
1,274,601 \\
188,123 \\
(3)\end{array}$ & $\begin{array}{r}592,011 \\
(3) \\
81,955 \\
452,901 \\
(3)\end{array}$ & $\begin{array}{r}75,862 \\
(3) \\
(3) \\
(3) \\
(3)\end{array}$ & $\begin{array}{r}8,351 \\
1,786 \\
4,834 \\
1,533 \\
(3)\end{array}$ & $\begin{array}{r}1,706 \\
4,542 \\
642 \\
(3)\end{array}$ & $\begin{array}{r}1,161 \\
\left({ }^{3}\right) \\
235 \\
782 \\
(3)\end{array}$ & $\begin{array}{r}266 \\
(3) \\
(3) \\
(3) \\
(3) \\
(3)\end{array}$ & $\begin{array}{r}178 \\
\text { 二 }\end{array}$ & $\begin{array}{r}, 628 \\
- \\
\end{array}$ & $\begin{array}{l}643 \\
- \\
-\end{array}$ & $\begin{array}{l}\text { Z } \\
\text { 二 }\end{array}$ \\
\hline $\begin{array}{r}\text { Other religious } \\
\text { Less then } \$ 1,000 \\
\$ 1,000 \text { to } \$ 2,499\end{array}$ & $\begin{array}{r}1,686,064 \\
113,382 \\
839,447 \\
513,773 \\
203,014\end{array}$ & $\begin{array}{r}718,170 \\
66,259 \\
387,917 \\
187,164 \\
68,255\end{array}$ & $\begin{array}{r}124,447 \\
(3) \\
(3) \\
62,993 \\
38,655\end{array}$ & $\begin{array}{r}843,448 \\
45,878 \\
435,788 \\
263,615 \\
96,104\end{array}$ & $\begin{array}{r}12,180 \\
2,435 \\
6,759 \\
2,198 \\
738\end{array}$ & $\begin{array}{r}6,328 \\
1,386 \\
3,645 \\
970 \\
303\end{array}$ & $\begin{array}{r}612 \\
(3) \\
(3) \\
316 \\
172\end{array}$ & $\begin{array}{r}5,240 \\
1,044 \\
3,012 \\
913 \\
263\end{array}$ & $\begin{array}{l}\text { - } \\
\text { - } \\
-\end{array}$ & $\begin{array}{l}606 \\
- \\
-\end{array}$ & $\begin{array}{l}\text { 261 } \\
\text { 二 } \\
-\end{array}$ & $\begin{array}{r}2,831 \\
\text { 二 } \\
-\end{array}$ \\
\hline 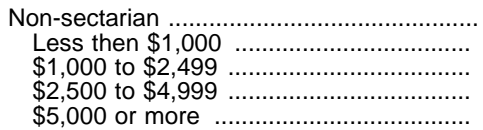 & $\begin{array}{r}768,451 \\
49,128 \\
121,869 \\
200,857 \\
396,244\end{array}$ & $\begin{array}{r}236,932 \\
(3) \\
(3) \\
119,326 \\
82,596\end{array}$ & $\begin{array}{r}94,629 \\
(3) \\
(3) \\
(3) \\
74,283\end{array}$ & $\begin{array}{r}436,890 \\
(3) \\
(3) \\
74,395 \\
239,364\end{array}$ & $\begin{array}{r}5,563 \\
912 \\
666 \\
1,810 \\
2,166\end{array}$ & $\begin{array}{r}2,287 \\
(3) \\
(3) \\
1,301 \\
456\end{array}$ & $\begin{array}{r}778 \\
(3) \\
(3) \\
(3) \\
408\end{array}$ & $\begin{array}{r}2,498 \\
(3) \\
(3) \\
465 \\
1,302\end{array}$ & $\begin{array}{r}6,631 \\
\text { 二 } \\
-\end{array}$ & $\begin{array}{r}4,693 \\
\text { 二 } \\
-\end{array}$ & $\begin{array}{r}9,525 \\
\text { 二 } \\
-\end{array}$ & $\begin{array}{r}7,056 \\
= \\
=\end{array}$ \\
\hline
\end{tabular}

${ }_{1}^{1}$ Only includes kindergarten students who attend schools that offer first grade or above.

2 Tuition weighted by the number of students enrolled in schools.

${ }^{3}$ Too few sample cases (fewer than 30 schools) for reliable estimates.

-Data not applicable.

NOTE.-Data are based upon a sample survey and may not be strictly comparable with data reported elsewhere. Elementary schools have grade 6 or lower and no grade higher than 8. Secondary schools have no grade lower than 7. Combined schools have grades lower than 7 and higher than 8 . Excludes prekindergarten students. Because of rounding and missing values in cells with too few sample cases, details may not add to totals.

SOURCE: U.S. Department of Education, National Center for Education Statistics, "Schools and Staffing Survey, 1993-94." (This table was prepared August 1995.)

Table 63.-Summary statistics on Catholic elementary and secondary schools, by level: 1919-20 to 1997-98

\begin{tabular}{|c|c|c|c|c|c|c|c|c|c|}
\hline \multirow{2}{*}{ School year } & \multicolumn{3}{|c|}{ Number of schools } & \multicolumn{3}{|c|}{ Enrollment } & \multicolumn{3}{|c|}{ Instructional staff } \\
\hline & Total & Elementary & Secondary & Total & Elementary & Secondary & Total & Elementary & Secondary \\
\hline 1 & 2 & 3 & 4 & 5 & 6 & 7 & 8 & 9 & 10 \\
\hline 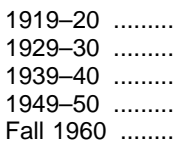 & $\begin{array}{r}8,103 \\
10,046 \\
10,049 \\
10,778 \\
12,893\end{array}$ & $\begin{array}{r}6,551 \\
7,923 \\
7,944 \\
8,589 \\
10,501\end{array}$ & $\begin{array}{l}1,552 \\
2,123 \\
2,105 \\
2,189 \\
2,392\end{array}$ & $\begin{array}{l}1,925,521 \\
2,464,467 \\
2,396,305 \\
3,066,387 \\
5,253,791\end{array}$ & $\begin{array}{l}1,795,673 \\
2,222,598 \\
2,035,182 \\
2,560,815 \\
4,373,422\end{array}$ & $\begin{array}{l}129,848 \\
241,869 \\
361,123 \\
505,572 \\
880,369\end{array}$ & $\begin{array}{r}149,516 \\
172,552 \\
181,057 \\
194,295 \\
1151,902\end{array}$ & $\begin{array}{r}141,592 \\
158,245 \\
160,081 \\
166,525 \\
1108,169\end{array}$ & $\begin{array}{r}17,924 \\
114,307 \\
120,976 \\
127,770 \\
143,733\end{array}$ \\
\hline $\begin{array}{rrr}1969-70 & \ldots \ldots \ldots \\
1970-71 & \ldots \ldots \ldots \\
1974-75 & \ldots \ldots \ldots \\
1975-76 & \ldots \ldots \ldots . . \\
1979-80 & \ldots \ldots \ldots . .\end{array}$ & $\begin{array}{r}11,771 \\
11,350 \\
10,127 \\
9,993 \\
9,640\end{array}$ & $\begin{array}{l}9,695 \\
9,370 \\
8,437 \\
8,340 \\
8,100\end{array}$ & $\begin{array}{l}2,076 \\
1,980 \\
1,690 \\
1,653 \\
1,540\end{array}$ & $\begin{array}{l}4,658,098 \\
4,363,566 \\
3,504,000 \\
3,415,000 \\
3,139,000\end{array}$ & $\begin{array}{l}3,607,168 \\
3,355,478 \\
2,602,000 \\
2,525,000 \\
2,293,000\end{array}$ & \begin{tabular}{r|}
$1,050,930$ \\
$1,008,088$ \\
902,000 \\
890,000 \\
846,000
\end{tabular} & $\begin{array}{r}2195,400 \\
166,208 \\
150,179 \\
149,276 \\
147,294\end{array}$ & $\begin{array}{r}2133,200 \\
112,750 \\
100,011 \\
99,319 \\
97,724\end{array}$ & $\begin{array}{r}262,200 \\
53,458 \\
50,168 \\
49,957 \\
49,570\end{array}$ \\
\hline $\begin{array}{rll}1980-81 & \ldots \ldots \ldots \\
1981-82 & \ldots \ldots \ldots \\
1982-83 & \ldots \ldots \ldots \\
1983-84 & \ldots \ldots \ldots \\
1984-85 & \ldots \ldots \ldots\end{array}$ & $\begin{array}{l}9,559 \\
9,494 \\
9,432 \\
9,401 \\
9,325\end{array}$ & $\begin{array}{l}8,043 \\
7,996 \\
7,950 \\
7,937 \\
7,876\end{array}$ & $\begin{array}{l}1,516 \\
1,498 \\
1,482 \\
1,464 \\
1,449\end{array}$ & $\begin{array}{l}3,106,000 \\
3,094,000 \\
3,007,189 \\
2,969,000 \\
2,903,000\end{array}$ & $\begin{array}{l}2,269,000 \\
2,266,000 \\
2,211,412 \\
2,179,000 \\
2,119,000\end{array}$ & $\begin{array}{l}837,000 \\
828,000 \\
795,777 \\
790,000 \\
784,000\end{array}$ & $\begin{array}{l}145,777 \\
146,172 \\
146,460 \\
146,913 \\
149,888\end{array}$ & $\begin{array}{l}96,739 \\
96,847 \\
97,337 \\
98,591 \\
99,820\end{array}$ & $\begin{array}{l}49,038 \\
49,325 \\
49,123 \\
48,322 \\
50,068\end{array}$ \\
\hline $\begin{array}{rrr}1985-86 & \ldots \ldots \ldots \\
1986-87 & \ldots \ldots \ldots . . \\
1987-88 & \ldots \ldots \ldots . . \\
1988-89 & \ldots \ldots \ldots . . \\
1989-90 & \ldots \ldots \ldots . .\end{array}$ & $\begin{array}{l}9,220 \\
9,102 \\
8,992 \\
8,867 \\
8,719\end{array}$ & $\begin{array}{l}7,790 \\
7,693 \\
7,601 \\
7,505 \\
7,395\end{array}$ & $\begin{array}{l}1,430 \\
1,409 \\
1,391 \\
1,362 \\
1,324\end{array}$ & $\begin{array}{l}2,821,000 \\
2,726,000 \\
2,623,031 \\
2,551,000 \\
2,499,000\end{array}$ & $\begin{array}{l}2,061,000 \\
1,998,000 \\
1,942,148 \\
1,912,000 \\
1,894,000\end{array}$ & $\begin{array}{l}760,000 \\
728,000 \\
680,883 \\
639,000 \\
606,000\end{array}$ & $\begin{array}{l}146,594 \\
141,930 \\
139,887 \\
137,700 \\
136,900\end{array}$ & $\begin{array}{l}96,741 \\
93,554 \\
93,199 \\
93,154 \\
94,197\end{array}$ & $\begin{array}{l}49,853 \\
48,376 \\
46,688 \\
44,546 \\
42,703\end{array}$ \\
\hline $\begin{array}{ll}1990-91 & \ldots \ldots \ldots \\
1991-92 & \ldots \ldots \ldots \\
1992-93 & \ldots \ldots \ldots \\
1993-94 & \ldots \ldots \ldots . \\
1994-95 & \ldots \ldots \ldots . .\end{array}$ & $\begin{array}{l}8,587 \\
8,508 \\
8,423 \\
8,345 \\
8,293\end{array}$ & $\begin{array}{l}7,291 \\
7,239 \\
7,174 \\
7,114 \\
7,055\end{array}$ & $\begin{array}{l}1,296 \\
1,269 \\
1,249 \\
1,231 \\
1,238\end{array}$ & $\begin{array}{l}2,475,439 \\
2,442,924 \\
2,444,842 \\
2,444,609 \\
2,475,207\end{array}$ & $\begin{array}{l}1,883,906 \\
1,856,302 \\
1,860,937 \\
1,859,947 \\
1,877,782\end{array}$ & $\begin{array}{l}591,533 \\
586,622 \\
583,905 \\
584,662 \\
597,425\end{array}$ & $\begin{array}{r}131,198 \\
153,334 \\
154,816 \\
157,201 \\
3164,219\end{array}$ & $\begin{array}{r}91,039 \\
109,084 \\
109,825 \\
112,199 \\
3117,620\end{array}$ & $\begin{array}{r}40,159 \\
44,250 \\
44,991 \\
45,002 \\
346,599\end{array}$ \\
\hline $\begin{aligned} 1995-96 & \ldots \ldots \ldots \\
1996-97 & \ldots \ldots \ldots \\
1997-98 & \ldots \ldots \ldots\end{aligned}$ & $\begin{array}{l}8,250 \\
8,231 \\
8,223\end{array}$ & $\begin{array}{l}7,022 \\
7,005 \\
7,004\end{array}$ & $\begin{array}{l}1,228 \\
1,226 \\
1,219\end{array}$ & $\begin{array}{l}2,491,111 \\
2,497,198 \\
2,497,894\end{array}$ & $\begin{array}{l}1,884,461 \\
1,885,037 \\
1,879,737\end{array}$ & $\begin{array}{l}606,650 \\
612,161 \\
618,157\end{array}$ & $\begin{array}{l}3166,759 \\
3153,276 \\
3152,259\end{array}$ & $\begin{array}{l}3118,753 \\
3107,548 \\
3105,717\end{array}$ & $\begin{array}{l}348,006 \\
345,728 \\
346,542\end{array}$ \\
\hline
\end{tabular}

${ }^{1}$ Includes part-time teachers

2 Includes estimates for the nonreporting schools.

${ }^{3}$ Full-time equivalent.

NOTE.-Data reported by the National Catholic Educational Association and data reported by the National Center for Education Statistics are not directly comparable because survey procedures and definitions differ. Excludes prekindergarten enrollment.
SOURCE: National Catholic Educational Association, A Statistical Report on Catholic Elementary and Secondary Schools for the Years 1967-68 to 1969-70, as compiled from the Official Catholic Directory (Copyright (C) 1970 by the National Catholic Educational Association); Catholic Schools in America (1978 edition, Copyright (C) 1978 by the Franklin Press); and United States Catholic Elementary and Secondary Schools, 1989-90, 1990-91, 1991-92, 1992-93, 1993-94, 1994-95, 1995-96, 1996-97 and 1997-98 (Copyright (C) 1990, 1991, 1992, 1993, 1994, 1995, 1996,1997, and 1998 by the National Catholic Educational Association. All rights reserved.) (This table was prepared August 1998.) 
Table 64.-Private elementary and secondary schools, enrollment, teachers, and high school graduates, ${ }^{1}$ by state: Fall 1995

\begin{tabular}{|c|c|c|c|c|c|c|c|c|}
\hline \multirow{2}{*}{ State } & \multicolumn{2}{|c|}{ Number of schools } & \multicolumn{2}{|c|}{ Enrollment } & \multicolumn{2}{|c|}{ Teachers } & \multicolumn{2}{|c|}{$\begin{array}{c}\text { High school graduates, } \\
1994-95\end{array}$} \\
\hline & Total & $\begin{array}{l}\text { Standard } \\
\text { error }\end{array}$ & Total & $\begin{array}{l}\text { Standard } \\
\text { error }\end{array}$ & Total & $\begin{array}{l}\text { Standard } \\
\text { error }\end{array}$ & Total & $\begin{array}{l}\text { Standard } \\
\text { error }\end{array}$ \\
\hline 1 & 2 & 3 & 4 & 5 & 6 & 7 & 8 & 9 \\
\hline United States ${ }^{2} \ldots \ldots \ldots$ & 27,686 & 252 & $5,032,200$ & 20,482 & 361,909 & 1,618 & 245,543 & 1,009 \\
\hline 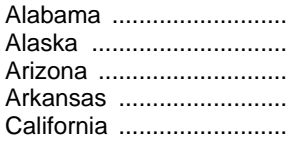 & $\begin{array}{r}287 \\
65 \\
296 \\
245 \\
3,470\end{array}$ & $\begin{array}{l}- \\
- \\
39 \\
50 \\
51\end{array}$ & $\begin{array}{r}66,958 \\
6,113 \\
44,134 \\
27,454 \\
629,344\end{array}$ & $\begin{array}{r}- \\
3,181 \\
547 \\
12,386\end{array}$ & $\begin{array}{r}4,814 \\
530 \\
3,070 \\
2,081 \\
41,073\end{array}$ & $\begin{array}{l}- \\
205 \\
108 \\
695\end{array}$ & $\begin{array}{r}3,581 \\
178 \\
2,221 \\
1,081 \\
26,353\end{array}$ & $\frac{-}{208}$ \\
\hline 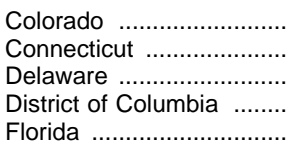 & $\begin{array}{r}342 \\
355 \\
112 \\
84 \\
1,284\end{array}$ & $\begin{array}{r}9 \\
14 \\
17 \\
19\end{array}$ & $\begin{array}{r}48,977 \\
70,605 \\
25,528 \\
17,468 \\
253,831\end{array}$ & $\begin{array}{r}147 \\
1,022 \\
1,850 \\
2,811\end{array}$ & $\begin{array}{r}3,843 \\
6,381 \\
1,878 \\
1,852 \\
19,093\end{array}$ & $\begin{array}{r}44 \\
107 \\
147 \\
-337\end{array}$ & $\begin{array}{r}1,928 \\
5,166 \\
1,436 \\
1,242 \\
10,151\end{array}$ & $\frac{-}{-}$ \\
\hline 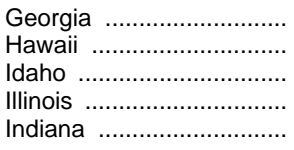 & $\begin{array}{r}525 \\
127 \\
77 \\
1,470 \\
661\end{array}$ & $\begin{array}{l}20 \\
- \\
52 \\
30\end{array}$ & $\begin{array}{r}97,807 \\
34,541 \\
9,210 \\
300,981 \\
99,258\end{array}$ & $\begin{array}{r}983 \\
- \\
1,597 \\
1,269\end{array}$ & $\begin{array}{r}8,282 \\
2,532 \\
607 \\
18,617 \\
6,653\end{array}$ & $\begin{array}{r}117 \\
- \\
194 \\
147\end{array}$ & $\begin{array}{r}5,075 \\
2,603 \\
380 \\
14,681 \\
4,055\end{array}$ & $\begin{array}{l}- \\
\overline{115} \\
181\end{array}$ \\
\hline 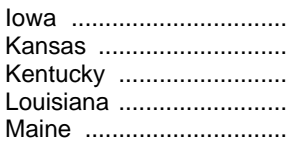 & $\begin{array}{l}274 \\
265 \\
382 \\
647 \\
134\end{array}$ & $\begin{array}{r}26 \\
52 \\
68 \\
108 \\
-\end{array}$ & $\begin{array}{r}49,461 \\
39,306 \\
67,181 \\
147,147 \\
16,896\end{array}$ & $\begin{array}{r}1,041 \\
775 \\
1,995 \\
4,944 \\
-\end{array}$ & $\begin{array}{l}3,309 \\
2,623 \\
4,581 \\
9,849 \\
1,531\end{array}$ & $\begin{array}{r}78 \\
105 \\
362 \\
517 \\
-\end{array}$ & $\begin{array}{l}2,601 \\
1,621 \\
3,242 \\
7,457 \\
1,759\end{array}$ & $\begin{array}{r}- \\
8 \\
96 \\
-\end{array}$ \\
\hline 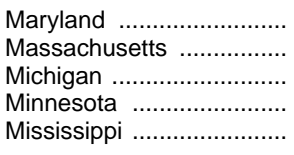 & $\begin{array}{r}606 \\
655 \\
1,034 \\
570 \\
182\end{array}$ & $\begin{array}{l}11 \\
38 \\
-36 \\
-\end{array}$ & $\begin{array}{r}125,092 \\
125,696 \\
189,065 \\
86,477 \\
50,166\end{array}$ & $\begin{array}{r}427 \\
2,936 \\
- \\
430 \\
-\end{array}$ & $\begin{array}{r}10,142 \\
11,068 \\
11,550 \\
5,835 \\
3,447\end{array}$ & $\begin{array}{r}64 \\
268 \\
-72 \\
-\end{array}$ & $\begin{array}{l}6,235 \\
8,561 \\
8,805 \\
3,373 \\
3,174\end{array}$ & $\begin{array}{l}- \\
- \\
-\end{array}$ \\
\hline 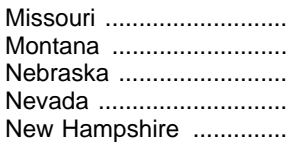 & $\begin{array}{r}775 \\
88 \\
279 \\
63 \\
210\end{array}$ & $\frac{104}{\frac{62}{72}}$ & $\begin{array}{r}126,985 \\
8,458 \\
41,320 \\
12,251 \\
22,633\end{array}$ & $\begin{array}{r}7,179 \\
\frac{2}{2,034} \\
2,311\end{array}$ & $\begin{array}{r}9,162 \\
673 \\
2,695 \\
711 \\
2,101\end{array}$ & $\begin{array}{r}\frac{816}{-} \\
\frac{160}{217}\end{array}$ & $\begin{array}{r}5,894 \\
356 \\
1,783 \\
381 \\
1,730\end{array}$ & $\frac{152}{\frac{50}{36}}$ \\
\hline $\begin{array}{l}\text { New Jersey } \ldots \ldots \ldots \ldots \ldots \ldots \\
\text { New Mexico ........................ } \\
\text { New York ........................ } \\
\text { North Carolina .................. } \\
\text { North Dakota ................... }\end{array}$ & $\begin{array}{r}914 \\
194 \\
1,997 \\
542 \\
55\end{array}$ & $\begin{array}{l}- \\
23 \\
35 \\
37 \\
-\end{array}$ & $\begin{array}{r}207,275 \\
22,893 \\
466,239 \\
81,437 \\
7,321\end{array}$ & $\begin{array}{r}-\overline{2,149} \\
936 \\
5,583 \\
-\end{array}$ & $\begin{array}{r}15,585 \\
1,756 \\
35,328 \\
6,990 \\
523\end{array}$ & $\begin{array}{r}114 \\
234 \\
442 \\
-\end{array}$ & $\begin{array}{r}12,030 \\
947 \\
25,489 \\
3,144 \\
381\end{array}$ & $\begin{array}{l}- \\
- \\
-\end{array}$ \\
\hline 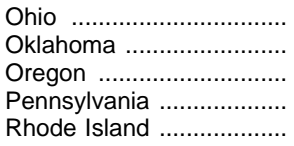 & $\begin{array}{r}1,071 \\
135 \\
410 \\
1,894 \\
128\end{array}$ & $\begin{array}{r}124 \\
-106 \\
27 \\
-\end{array}$ & $\begin{array}{r}255,277 \\
24,653 \\
43,501 \\
346,800 \\
23,543\end{array}$ & $\begin{array}{r}3,674 \\
- \\
3,843 \\
5,848 \\
-\end{array}$ & $\begin{array}{r}15,085 \\
2,014 \\
3,431 \\
23,085 \\
1,941\end{array}$ & $\begin{array}{r}228 \\
- \\
513 \\
356 \\
-\end{array}$ & $\begin{array}{r}12,639 \\
1,296 \\
2,042 \\
18,138 \\
1,354\end{array}$ & $\begin{array}{r}- \\
76 \\
927 \\
-\end{array}$ \\
\hline $\begin{array}{l}\text { South Carolina } \\
\text { South Dakota } \ldots \ldots \ldots \ldots \ldots \ldots \ldots \\
\text { Tennessee } \ldots \ldots \ldots \ldots \ldots \ldots \ldots \ldots \ldots \\
\text { Texas } \\
\text { Utah }\end{array}$ & $\begin{array}{r}282 \\
93 \\
504 \\
1,593 \\
97\end{array}$ & $\begin{array}{r}- \\
47 \\
120 \\
28\end{array}$ & $\begin{array}{r}50,162 \\
10,056 \\
80,701 \\
229,353 \\
12,840\end{array}$ & $\begin{array}{r}- \\
2,337 \\
6,768 \\
2,439\end{array}$ & $\begin{array}{r}3,943 \\
724 \\
6,388 \\
19,042 \\
1,013\end{array}$ & $\begin{array}{r}- \\
184 \\
717 \\
134\end{array}$ & $\begin{array}{r}2,378 \\
436 \\
4,427 \\
8,767 \\
590\end{array}$ & $\begin{array}{r}- \\
27 \\
209 \\
-\end{array}$ \\
\hline $\begin{array}{l}\text { Vermont } \\
\text { Virginia } \\
\text { Washington } \\
\text { West Virginia } \\
\text { Wisconsin } \\
\text { Wyoming }\end{array}$ & $\begin{array}{r}84 \\
493 \\
504 \\
135 \\
961 \\
37\end{array}$ & $\begin{array}{l}\overline{24} \\
44 \\
- \\
-\end{array}$ & $\begin{array}{r}9,669 \\
86,507 \\
74,890 \\
13,241 \\
143,231 \\
2,272\end{array}$ & $\begin{array}{r}782 \\
2,546 \\
- \\
-\end{array}$ & $\begin{array}{r}977 \\
7,723 \\
5,132 \\
1,113 \\
9,312 \\
221\end{array}$ & $\begin{array}{r}142 \\
231 \\
- \\
-\end{array}$ & $\begin{array}{r}1,081 \\
4,463 \\
2,998 \\
698 \\
5,119 \\
24\end{array}$ & $\begin{array}{l}- \\
- \\
- \\
-\end{array}$ \\
\hline
\end{tabular}

1 Includes special education, vocational/technical education, and alternative schools. Excludes prekindergarten enrollment.

${ }^{2}$ NCES employed an area frame sample to account for noninclusion of schools at the national level. However, caution should be exercised in interpreting state by state characteristics since the samples were not designed to produce such numbers.
- Insufficient data to compute a standard error.

NOTE.-Tabulation includes only schools that offer first grade or above.

SOURCE: U.S. Department of Education, National Center for Education Statistics, "Private School Survey, 1995-96." (This table was prepared July 1998.) 
Table 65.-Public and private elementary and secondary teachers and pupil/teacher ratios, by level: Fall 1955 to fall 1998

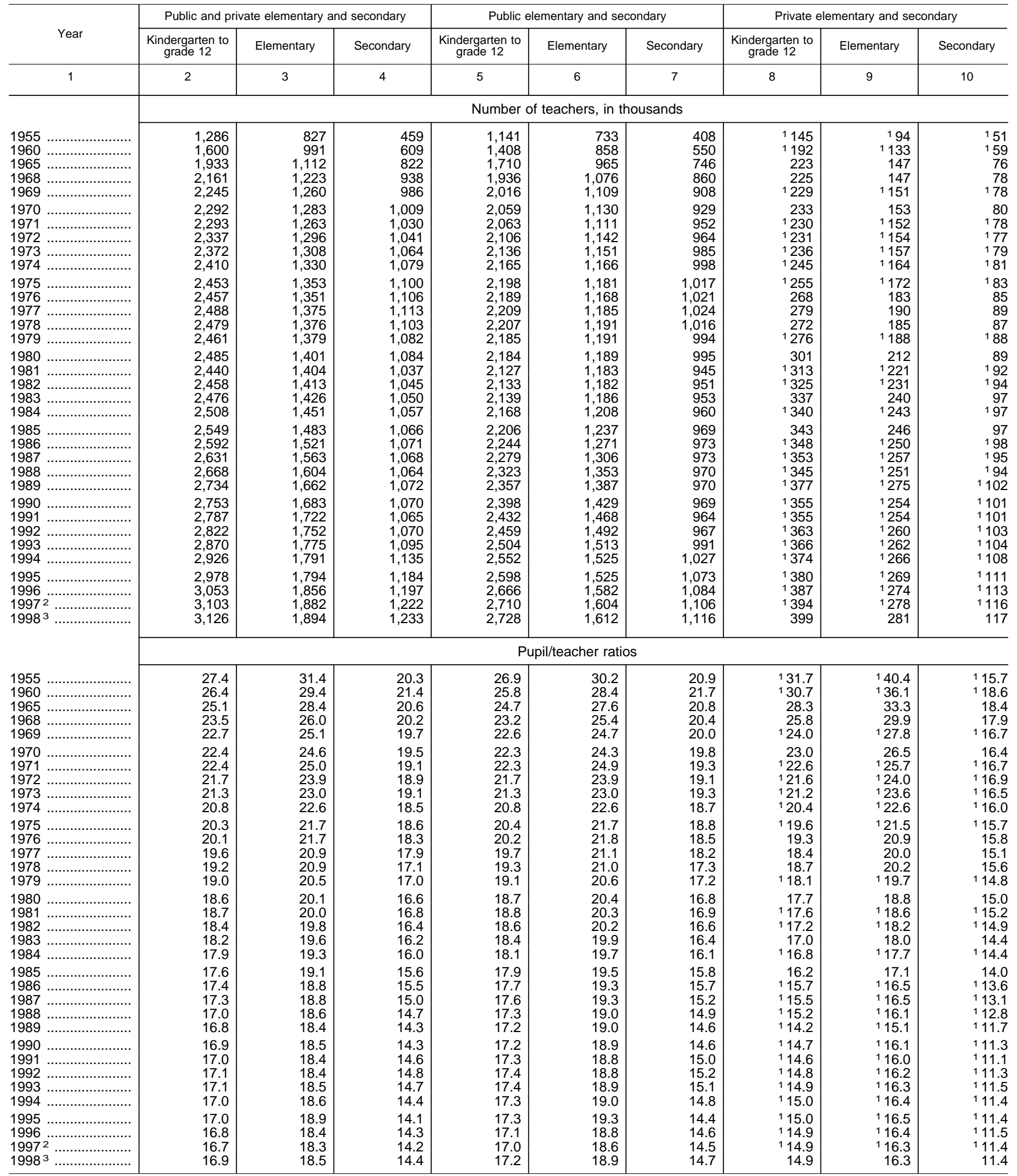

1 Estimated.

2 Preliminary data.

${ }^{3}$ Projected.

NOTE.-Data for teachers are expressed in full-time equivalents. Distribution of unclassified teachers by level is estimated. Distribution of elementary and secondary schoo teachers by level is determined by reporting units. Kindergarten includes a relatively small number of nursery school teachers and students. Some data have been revised from previously published figures. Because of rounding, details may not add to totals. SOURCE: U.S. Department of Education, National Center for Education Statistics, Statistics of Public Elementary and Secondary Day Schools; Common Core of Data surveys; and Projections of Education Statistics to 2008. (This table was prepared July 1998.) 
Table 66.-Public elementary and secondary teachers, by level and state: Fall 1992 to fall 1997

[In full-time equivalents]

\begin{tabular}{|c|c|c|c|c|c|c|c|c|c|c|c|c|}
\hline \multirow[b]{2}{*}{ State or other area } & \multirow[b]{2}{*}{$\begin{array}{c}\text { Fall } \\
1992\end{array}$} & \multirow[b]{2}{*}{$\begin{array}{c}\text { Fall } \\
1993\end{array}$} & \multirow[b]{2}{*}{$\begin{array}{c}\text { Fall } \\
1994\end{array}$} & \multicolumn{4}{|c|}{ Fall 1995} & \multicolumn{4}{|c|}{ Fall $19966^{1}$} & \multirow[b]{2}{*}{$\begin{array}{l}\text { Estimated, } \\
\text { fall } 1997^{2}\end{array}$} \\
\hline & & & & Total & $\begin{array}{c}\text { Elemen- } \\
\text { tary }\end{array}$ & $\begin{array}{l}\text { Second- } \\
\text { ary }\end{array}$ & $\begin{array}{l}\text { Un- } \\
\text { classi- } \\
\text { fied }\end{array}$ & Total & $\begin{array}{c}\text { Elemen- } \\
\text { tary }\end{array}$ & $\begin{array}{l}\text { Second- } \\
\text { ary }\end{array}$ & $\begin{array}{l}\text { Un- } \\
\text { classi- } \\
\text { fied }\end{array}$ & \\
\hline 1 & 2 & 3 & 4 & 5 & 6 & 7 & 8 & 9 & 10 & 11 & 12 & 13 \\
\hline United States ... & $2,458,956$ & $2,503,901$ & $2,551,875$ & $2,598,220$ & $1,428,852$ & 952,189 & 217,179 & $2,666,034$ & $1,485,683$ & 955,052 & 225,299 & $2,709,872$ \\
\hline Alabama & 41,961 & 43,003 & 42,791 & 44,056 & 24,935 & 19,121 & - & 45,040 & 25,398 & 19,642 & - & 44,969 \\
\hline Alaska .... & 7,282 & 7,193 & 7,205 & 7,379 & 4,780 & 2,599 & - & 7,418 & 4,806 & 2,612 & - & 7,826 \\
\hline Arizona ………................. & 36,076 & 37,493 & 38,132 & 38,017 & 27,518 & 10,499 & - & 40,521 & 29,581 & 10,940 & - & 343,931 \\
\hline Arkansas ......................... & 26,017 & 26,014 & 26,181 & 26,449 & 13,882 & 12,370 & 197 & 26,680 & 14,007 & 12,399 & 274 & 426,505 \\
\hline California …...................... & 218,566 & 221,787 & 225,016 & 230,849 & 145,601 & 60,743 & 24,505 & 248,857 & 160,179 & 63,609 & 25,069 & ${ }^{3} 248,234$ \\
\hline Colorado & 33,419 & 33,661 & 34,894 & 35,388 & 17,998 & 17,390 & 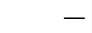 & 36,398 & 18,623 & 17,775 & - & 37,352 \\
\hline Connecticut . & 34,193 & 34,526 & 35,316 & 36,070 & 21,230 & 9,445 & 5,395 & 36,551 & 21,418 & 10,812 & 4,321 & 28,814 \\
\hline Delaware . & 6,252 & 6,380 & 6,416 & 6,463 & 3,205 & 3,258 & - & 6,642 & 3,278 & 3,364 & - & ${ }^{4} 6,850$ \\
\hline District of Columbia ....... & 6,064 & 6,056 & 6,110 & 5,305 & 3,083 & 1,815 & 407 & 5,288 & 3,066 & 1,815 & 407 & ${ }^{3} 5,256$ \\
\hline Florida & 107,590 & 110,653 & 110,674 & 114,938 & 50,660 & 42,745 & 21,533 & 120,471 & 52,755 & 44,902 & 22,814 & 4124,563 \\
\hline Georgia & 66,942 & 74,172 & 77,914 & 79,480 & 40,888 & 38,592 & - & 79,091 & 56,860 & 22,231 & - & 84,235 \\
\hline Hawaii .. & 10,083 & 10,111 & 10,240 & 10,500 & 5,843 & 4,616 & 41 & 10,576 & 6,020 & 4,513 & 43 & 10,600 \\
\hline Idaho ........... & 11,827 & 12,007 & 12,582 & 12,784 & 6,505 & 6,122 & 157 & 13,078 & 6,641 & 6,274 & 163 & 14,200 \\
\hline Illinois ......... & 111,461 & 110,874 & 110,830 & 113,538 & 67,972 & 29,208 & 16,358 & 116,274 & 69,592 & 29,826 & 16,856 & 119,814 \\
\hline Indiana ................... & 54,552 & 55,107 & 55,496 & 55,821 & 28,257 & 24,881 & 2,683 & 56,708 & 28,730 & 25,154 & 2,824 & 57,368 \\
\hline lowa . & 31,403 & 31,616 & 31,726 & 32,318 & 19,151 & 12,063 & 1,104 & 32,593 & 19,420 & 11,997 & 1,176 & 33,266 \\
\hline Kansas ................. & 29,753 & 30,283 & 30,579 & 30,729 & 14,752 & 12,878 & 3,099 & 30,875 & 14,700 & 13,133 & 3,042 & 30,906 \\
\hline Kentucky .. & 37,868 & 37,324 & 38,784 & 39,120 & 27,422 & 11,698 & - & 39,331 & 27,402 & 11,929 & - & 39,311 \\
\hline Louisiana . & 46,904 & 46,913 & 47,599 & 46,980 & 27,691 & 19,289 & - & 47,334 & 28,020 & 19,314 & - & 346,985 \\
\hline Maine ................................ & 15,375 & 15,344 & 15,404 & 15,392 & 10,553 & 4,839 & - & 15,551 & 10,638 & 4,913 & - & 14,700 \\
\hline Maryland. & 44,495 & 44,171 & 46,565 & 47,819 & 24,999 & 22,820 & - & 47,943 & 24,305 & 23,638 & - & 50,825 \\
\hline Massachusetts . & 57,225 & 58,766 & 60,489 & 62,710 & 23,121 & 30,891 & 8,698 & 64,574 & 23,850 & 31,983 & 8,741 & 66,944 \\
\hline 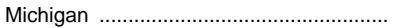 & 82,301 & 80,267 & 80,522 & 83,179 & 36,406 & 38,200 & 8,573 & 88,051 & 38,025 & 40,210 & 9,816 & 90,400 \\
\hline Minnesota & 45,050 & 46,956 & 46,958 & 46,971 & 23,979 & 22,983 & 9 & 48,245 & 25,136 & 23,096 & 13 & 48,400 \\
\hline Mississippi ........................................ & 27,829 & 28,376 & 28,866 & 28,997 & 15,047 & 9,070 & 4,880 & 29,293 & 14,925 & 9,283 & 5,085 & 29,844 \\
\hline Missouri & 52,984 & 54,860 & 56,606 & 57,951 & 29,386 & 27,817 & 748 & 59,436 & 30,120 & 28,596 & 720 & 60,403 \\
\hline Montana ..................... & 10,135 & 9,949 & 10,079 & 10,076 & 6,974 & 3,102 & - & 10,268 & 7,002 & 3,266 & - & 10,150 \\
\hline Nebraska & 19,323 & 19,616 & 19,774 & 20,028 & 11,452 & 8,506 & 70 & 20,174 & 11,570 & 8,523 & 81 & ${ }^{4} 20,132$ \\
\hline Nevada .......................... & 11,953 & 12,579 & 13,414 & 13,878 & 7,057 & 5,210 & 1,611 & 14,805 & 7,570 & 5,330 & 1,905 & 15,600 \\
\hline New Hampshire ...................................... & 11,654 & 11,972 & 12,109 & 12,346 & 8,447 & 3,899 & - & 12,692 & 8,895 & 3,797 & - & 12,606 \\
\hline New Jersey .. & 83,057 & 84,564 & 85,258 & 86,706 & 48,359 & 26,362 & 11,985 & 388,903 & 349,684 & ${ }^{3} 26,695$ & 312,524 & 390,172 \\
\hline New Mexico & 17,912 & 18,404 & 19,025 & 19,398 & 11,311 & 4,518 & 3,569 & 19,971 & 11,676 & 4,599 & 3,696 & 21,000 \\
\hline 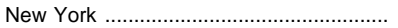 & 176,375 & 179,413 & 182,273 & 181,559 & 92,550 & 62,355 & 26,654 & 185,104 & 94,316 & 63,744 & 27,044 & 199,000 \\
\hline 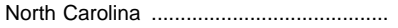 & 66,630 & 69,421 & 71,592 & 73,201 & 42,990 & 25,795 & 4,416 & 75,239 & 45,402 & 26,866 & 2,971 & 81,310 \\
\hline North Dakota …............................................. & 7,794 & 7,755 & 7,796 & 7,501 & 5,061 & 2,440 & - & 7,892 & 4,892 & 3,000 & - & 47,884 \\
\hline Ohio & 106,233 & 107,444 & 109,085 & 107,347 & 71,376 & 35,718 & 253 & 108,602 & 72,283 & 36,075 & 244 & 105,275 \\
\hline 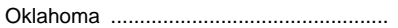 & 38,433 & 39,031 & 39,406 & 39,364 & 18,582 & 16,601 & 4,181 & 39,491 & 18,428 & 16,868 & 4,195 & 39,809 \\
\hline Oregon ....... & 26,634 & 26,488 & 26,208 & 26,680 & 13,889 & 8,981 & 3,810 & 26,757 & 14,137 & 8,675 & 3,945 & 26,914 \\
\hline 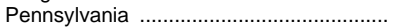 & 100,912 & 101,302 & 102,988 & 104,921 & 47,975 & 44,455 & 12,491 & 106,432 & 48,647 & 44,851 & 12,934 & 106,900 \\
\hline Rhode Island & 10,069 & 9,823 & 10,066 & 10,482 & 4,540 & 4,477 & 1,465 & 10,656 & 4,897 & 4,280 & 1,479 & 10,764 \\
\hline South Carolina .. & 37,295 & 38,620 & 39,437 & 39,922 & 27,122 & 12,800 & - & 41,463 & 28,381 & 13,082 & - & 41,360 \\
\hline South Dakota .......... & 8,767 & 9,557 & 9,985 & 9,641 & 5,889 & 2,676 & 1,076 & 9,625 & 5,902 & 2,700 & 1,023 & 9,749 \\
\hline 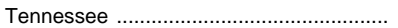 & 43,566 & 46,066 & 47,406 & 53,403 & 37,969 & 13,939 & 1,495 & 54,790 & 39,498 & 13,762 & 1,530 & 51,976 \\
\hline Texas & 219,385 & 224,830 & 234,213 & 240,371 & 118,881 & 88,843 & 32,647 & 247,650 & 121,146 & 88,160 & 38,344 & 254,185 \\
\hline 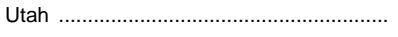 & 19,191 & 19,053 & 19,524 & 20,039 & 9,162 & 8,390 & 2,487 & 19,734 & 9,250 & 7,958 & 2,526 & 20,500 \\
\hline Vermont . & 7,521 & 7,330 & 7,566 & 7,676 & 3,129 & 2,969 & 1,578 & 7,751 & 3,095 & 3,024 & 1,632 & 7,833 \\
\hline Virginia & 68,181 & 70,859 & 72,505 & 74,731 & 46,225 & 28,506 & - & 74,523 & 45,735 & 28,788 & - & 372,113 \\
\hline 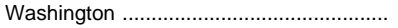 & 44,295 & 45,524 & 46,439 & 46,907 & 24,423 & 18,501 & 3,983 & 48,307 & 24,812 & 19,289 & 4,206 & 448,892 \\
\hline 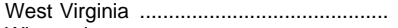 & 20,961 & 21,029 & 21,024 & 21,073 & 10,600 & 6,788 & 3,685 & 20,888 & 10,286 & 7,087 & 3,515 & 20,641 \\
\hline Wisconsin & 53,387 & 52,822 & 54,054 & 55,033 & 36,808 & 17,015 & 1,210 & 54,769 & 37,512 & 17,257 & - & 55,987 \\
\hline 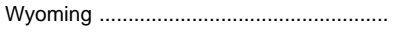 & 5,821 & 6,537 & 6,754 & 6,734 & 3,217 & 3,391 & 126 & 6,729 & 3,172 & 3,416 & 141 & 6,620 \\
\hline Outlyıng areas & & & & & & & & & & & & \\
\hline American Samoa ..................... & 725 & 656 & 698 & 728 & 521 & 192 & 15 & 734 & 519 & 200 & 15 & 4822 \\
\hline Guam & 1,628 & 1,644 & 1,826 & 1,802 & 801 & 825 & 176 & 1,552 & 698 & 703 & 151 & 1,731 \\
\hline 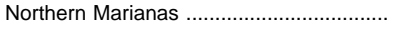 & 425 & 431 & 406 & 422 & 240 & 182 & - & 441 & 260 & 181 & - & 4465 \\
\hline - & 38,381 & 39,816 & 39,933 & 39,328 & 21,680 & 14,386 & 3,262 & 39,743 & 21,977 & 14,521 & 3,245 & 39,637 \\
\hline 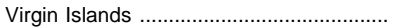 & 1,595 & 1,570 & 1,528 & 1,622 & 731 & 814 & 77 & 1,580 & 729 & 789 & 62 & 1,645 \\
\hline
\end{tabular}

1 Data have been revised from previously published figures.

2 Unless otherwise indicated, data were estimated by state education agencies.

${ }^{3}$ Data imputed by the National Center for Education Statistics based on previous year's data.

${ }^{4}$ Actual preliminary count by state.

-Data not available, not reported, or not applicable.
NOTE.-Distribution of elementary and secondary teachers determined by reporting units. Teachers reported in full-time equivalents.

SOURCE: U.S. Department of Education, National Center for Education Statistics, Common Core of Data surveys. (This table was prepared May 1998.) 
Table 67.-Teachers, enrollment, and pupil/teacher ratios in public elementary and secondary schools, by state: Fall 1991 to fall 1996

\begin{tabular}{|c|c|c|c|c|c|c|c|c|c|c|c|c|}
\hline \multirow[b]{2}{*}{ State or other area } & \multirow{2}{*}{$\begin{array}{l}\text { Pupil/ } \\
\text { teacher } \\
\text { ratio, } \\
\text { fall } \\
1991\end{array}$} & \multirow{2}{*}{$\begin{array}{c}\text { Pupil/ } \\
\text { teacher } \\
\text { ratio, } \\
\text { fall } \\
1992\end{array}$} & \multirow{2}{*}{\begin{tabular}{|c|} 
Pupil/ \\
teacher \\
ratio, \\
fall \\
1993
\end{tabular}} & \multicolumn{3}{|c|}{ Fall 1994} & \multicolumn{3}{|c|}{ Fall 1995} & \multicolumn{3}{|c|}{ Fall 1996} \\
\hline & & & & Teachers & Enrollment & $\begin{array}{c}\text { Pupil/ } \\
\text { teacher } \\
\text { ratio }\end{array}$ & Teachers & Enrollment & $\begin{array}{c}\text { Pupil/ } \\
\text { teacher } \\
\text { ratio }\end{array}$ & Teachers & Enrollment & $\begin{array}{l}\text { Pupil/ } \\
\text { teacher } \\
\text { ratio }\end{array}$ \\
\hline 1 & 2 & 3 & 4 & 5 & 6 & 7 & 8 & 9 & 10 & 11 & 12 & 13 \\
\hline United States & 17.3 & 17.4 & 17.4 & $2,551,875$ & $44,111,482$ & 17.3 & $2,598,220$ & $44,840,481$ & 17.3 & ,666,034 & $15,592,213$ & 17.1 \\
\hline $\begin{array}{l}\text { Alabama } \\
\text { Alaska } \\
\text { Arizona } \\
\text { Arkansas } \\
\text { California }\end{array}$ & $\begin{array}{l}17.8 \\
16.7 \\
19.3 \\
17.0 \\
22.8\end{array}$ & $\begin{array}{l}17.4 \\
16.8 \\
18.7 \\
17.0 \\
24.0\end{array}$ & $\begin{array}{l}17.1 \\
17.5 \\
18.9 \\
17.1 \\
24.0\end{array}$ & $\begin{array}{r}42,791 \\
7,205 \\
38,132 \\
26,181 \\
225,016\end{array}$ & $\begin{array}{r}736,531 \\
127,057 \\
737,424 \\
447,565 \\
5,407,475\end{array}$ & $\begin{array}{l}17.2 \\
17.6 \\
19.3 \\
17.1 \\
24.0\end{array}$ & $\begin{array}{r}44,056 \\
7,379 \\
38,017 \\
26,449 \\
230,849\end{array}$ & $\begin{array}{r}746,149 \\
127,618 \\
743,566 \\
453,257 \\
5,536,406\end{array}$ & $\begin{array}{l}16.9 \\
17.3 \\
19.6 \\
17.1 \\
24.0\end{array}$ & $\begin{array}{r}45,040 \\
7,418 \\
40,521 \\
26,680 \\
248,857\end{array}$ & $\begin{array}{r}748,156 \\
129,919 \\
799,250 \\
457,349 \\
5,687,901\end{array}$ & $\begin{array}{l}16.6 \\
17.5 \\
19.7 \\
17.1 \\
22.9\end{array}$ \\
\hline $\begin{array}{l}\text { Colorado } \\
\text { Connecticut } \\
\text { Delaware } \\
\text { District of Columbia } \\
\text { Florida }\end{array}$ & $\begin{array}{l}17.9 \\
14.0 \\
16.8 \\
12.7 \\
17.6\end{array}$ & $\begin{array}{l}18.3 \\
14.3 \\
16.7 \\
13.3 \\
18.4\end{array}$ & $\begin{array}{l}18.6 \\
14.4 \\
16.5 \\
13.3 \\
18.4\end{array}$ & $\begin{array}{r}34,894 \\
35,316 \\
6,416 \\
6,110 \\
110,674\end{array}$ & $\begin{array}{r}640,521 \\
506,824 \\
106,813 \\
80,450 \\
2,111,188\end{array}$ & $\begin{array}{l}18.4 \\
14.4 \\
16.6 \\
13.2 \\
19.1\end{array}$ & $\begin{array}{r}35,388 \\
36,070 \\
6,463 \\
5,305 \\
114,938\end{array}$ & $\begin{array}{r}656,279 \\
517,935 \\
108,461 \\
79,802 \\
2,176,222\end{array}$ & $\begin{array}{l}18.5 \\
14.4 \\
16.8 \\
15.0 \\
18.9\end{array}$ & $\begin{array}{r}36,398 \\
36,551 \\
6,642 \\
5,288 \\
120,471\end{array}$ & $\begin{array}{r}673,438 \\
527,129 \\
110,549 \\
78,648 \\
2,242,212\end{array}$ & $\begin{array}{l}18.5 \\
14.4 \\
16.6 \\
14.9 \\
18.6\end{array}$ \\
\hline $\begin{array}{l}\text { Georgia } \\
\text { Hawaii } \\
\text { Idaho } \\
\text { Illinois } \\
\text { Indiana }\end{array}$ & $\begin{array}{l}18.5 \\
18.5 \\
19.4 \\
16.8 \\
17.6\end{array}$ & $\begin{array}{r}18.0 \\
17.6 \\
19.6 \\
16.8 \\
17.6\end{array}$ & $\begin{array}{l}16.7 \\
17.8 \\
19.7 \\
17.1 \\
17.5\end{array}$ & $\begin{array}{r}77,914 \\
10,240 \\
12,582 \\
110,830 \\
55,496\end{array}$ & $\begin{array}{r}1,270,948 \\
183,795 \\
240,448 \\
1,916,172 \\
969,022\end{array}$ & $\begin{array}{l}16.3 \\
17.9 \\
19.1 \\
17.3 \\
17.5\end{array}$ & $\begin{array}{r}79,480 \\
10,500 \\
12,784 \\
113,538 \\
55,821\end{array}$ & $\begin{array}{r}1,311,126 \\
187,180 \\
243,097 \\
1,943,623 \\
977,263\end{array}$ & $\begin{array}{l}16.5 \\
17.8 \\
19.0 \\
17.1 \\
17.5\end{array}$ & $\begin{array}{r}79,091 \\
10,576 \\
13,078 \\
116,274 \\
56,708\end{array}$ & $\begin{array}{r}1,346,761 \\
187,653 \\
245,252 \\
1,973,040 \\
983,415\end{array}$ & $\begin{array}{l}17.0 \\
17.7 \\
18.8 \\
17.0 \\
17.3\end{array}$ \\
\hline $\begin{array}{l}\text { lowa } \\
\text { Kansas } \\
\text { Kentucky } \\
\text { Louisiana } \\
\text { Maine }\end{array}$ & $\begin{array}{l}15.7 \\
15.2 \\
17.2 \\
16.6 \\
14.0\end{array}$ & $\begin{array}{l}15.8 \\
15.2 \\
17.3 \\
17.0 \\
14.1\end{array}$ & $\begin{array}{l}15.8 \\
15.1 \\
17.6 \\
17.1 \\
14.1\end{array}$ & $\begin{array}{l}31,726 \\
30,579 \\
38,784 \\
47,599 \\
15,404\end{array}$ & $\begin{array}{l}500,440 \\
460,838 \\
657,642 \\
797,933 \\
212,601\end{array}$ & $\begin{array}{l}15.8 \\
15.1 \\
17.0 \\
16.8 \\
13.8\end{array}$ & $\begin{array}{l}32,318 \\
30,729 \\
39,120 \\
46,980 \\
15,392\end{array}$ & $\begin{array}{l}502,343 \\
463,008 \\
659,821 \\
797,366 \\
213,569\end{array}$ & $\begin{array}{l}15.5 \\
15.1 \\
16.9 \\
16.6 \\
13.9\end{array}$ & $\begin{array}{l}32,593 \\
30,875 \\
39,331 \\
47,334 \\
15,551\end{array}$ & $\begin{array}{l}502,941 \\
466,293 \\
656,089 \\
793,296 \\
213,593\end{array}$ & $\begin{array}{l}15.4 \\
15.1 \\
16.7 \\
16.6 \\
13.7\end{array}$ \\
\hline $\begin{array}{l}\text { Maryland } \\
\text { Massachusetts } \\
\text { Michigan } \\
\text { Minnesota } \\
\text { Mississippi }\end{array}$ & $\begin{array}{l}16.9 \\
15.1 \\
19.2 \\
17.2 \\
17.9\end{array}$ & $\begin{array}{l}16.9 \\
15.0 \\
19.5 \\
17.6 \\
18.2\end{array}$ & $\begin{array}{l}17.5 \\
14.9 \\
19.9 \\
17.3 \\
17.8\end{array}$ & $\begin{array}{l}46,565 \\
60,489 \\
80,522 \\
46,958 \\
28,866\end{array}$ & $\begin{array}{r}790,938 \\
893,727 \\
1,614,784 \\
821,693 \\
505,962\end{array}$ & $\begin{array}{l}17.0 \\
14.8 \\
20.1 \\
17.5 \\
17.5\end{array}$ & $\begin{array}{l}47,819 \\
62,710 \\
83,179 \\
46,971 \\
28,997\end{array}$ & $\begin{array}{r}805,544 \\
915,007 \\
1,641,456 \\
835,166 \\
506,272\end{array}$ & $\begin{array}{l}16.8 \\
14.6 \\
19.7 \\
17.8 \\
17.5\end{array}$ & $\begin{array}{l}47,943 \\
64,574 \\
88,051 \\
48,245 \\
29,293\end{array}$ & $\begin{array}{r}818,583 \\
933,898 \\
1,684,386 \\
847,204 \\
503,967\end{array}$ & $\begin{array}{l}17.1 \\
14.5 \\
19.1 \\
17.6 \\
17.2\end{array}$ \\
\hline $\begin{array}{l}\text { Missouri } \\
\text { Montana } \\
\text { Nebraska } \\
\text { Nevada } \\
\text { New Hampshire }\end{array}$ & $\begin{array}{l}16.0 \\
15.8 \\
14.7 \\
18.6 \\
15.5\end{array}$ & $\begin{array}{l}16.2 \\
15.8 \\
14.6 \\
18.7 \\
15.6\end{array}$ & $\begin{array}{l}15.8 \\
16.4 \\
14.5 \\
18.7 \\
15.5\end{array}$ & $\begin{array}{l}56,606 \\
10,079 \\
19,774 \\
13,414 \\
12,109\end{array}$ & $\begin{array}{l}878,541 \\
164,341 \\
287,100 \\
250,747 \\
189,319\end{array}$ & $\begin{array}{l}15.5 \\
16.3 \\
14.5 \\
18.7 \\
15.6\end{array}$ & $\begin{array}{l}57,951 \\
10,076 \\
20,028 \\
13,878 \\
12,346\end{array}$ & $\begin{array}{l}889,881 \\
165,547 \\
289,744 \\
265,041 \\
194,171\end{array}$ & $\begin{array}{l}15.4 \\
16.4 \\
14.5 \\
19.1 \\
15.7\end{array}$ & $\begin{array}{r}59,436 \\
10,268 \\
20,174 \\
14,805 \\
12,692\end{array}$ & $\begin{array}{l}900,042 \\
164,627 \\
291,967 \\
282,131 \\
198,308\end{array}$ & $\begin{array}{l}15.1 \\
16.0 \\
14.5 \\
19.1 \\
15.6\end{array}$ \\
\hline $\begin{array}{l}\text { New York } \\
\text { North Carolina } \\
\text { North Dakota }\end{array}$ & \begin{tabular}{l|}
13.8 \\
17.6 \\
15.4 \\
16.8 \\
15.3
\end{tabular} & \begin{tabular}{l|}
17.6 \\
15.2 \\
16.7 \\
15.2
\end{tabular} & $\begin{array}{l}13.6 \\
17.5 \\
15.2 \\
16.3 \\
15.4\end{array}$ & $\begin{array}{r}85,258 \\
19,025 \\
182,273 \\
71,592 \\
7,796\end{array}$ & $\begin{array}{r}1,174,206 \\
327,248 \\
2,766,208 \\
1,156,767 \\
119,288\end{array}$ & $\begin{array}{l}13.8 \\
17.2 \\
15.2 \\
16.2 \\
15.3\end{array}$ & $\begin{array}{r}86,706 \\
19,398 \\
181,559 \\
73,201 \\
7,501\end{array}$ & $\begin{array}{r}1,197,381 \\
329,640 \\
2,813,230 \\
1,183,090 \\
119,100\end{array}$ & $\begin{array}{l}13.8 \\
17.0 \\
15.5 \\
16.2 \\
15.9\end{array}$ & $\begin{array}{r}188,903 \\
19,971 \\
185,104 \\
75,239 \\
7,892\end{array}$ & $\begin{array}{r}1,208,179 \\
332,632 \\
2,843,131 \\
1,210,108 \\
120,123\end{array}$ & $\begin{array}{l}13.6 \\
16.7 \\
15.4 \\
16.1 \\
15.2\end{array}$ \\
\hline 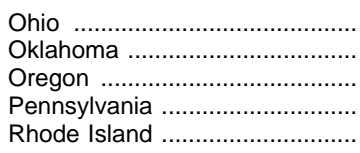 & $\begin{array}{l}17.3 \\
15.6 \\
18.6 \\
16.8 \\
14.6\end{array}$ & $\begin{array}{l}16.9 \\
15.5 \\
19.2 \\
17.0 \\
14.3\end{array}$ & $\begin{array}{l}16.8 \\
15.5 \\
19.5 \\
17.2 \\
14.8\end{array}$ & $\begin{array}{r}109,085 \\
39,406 \\
26,208 \\
102,988 \\
10,066\end{array}$ & $\begin{array}{r}1,814,290 \\
609,718 \\
521,945 \\
1,764,946 \\
147,487\end{array}$ & $\begin{array}{l}16.6 \\
15.5 \\
19.9 \\
17.1 \\
14.7\end{array}$ & $\begin{array}{r}107,347 \\
39,364 \\
26,680 \\
104,921 \\
10,482\end{array}$ & $\begin{array}{r}1,836,015 \\
616,393 \\
527,914 \\
1,787,533 \\
149,799\end{array}$ & $\begin{array}{l}17.1 \\
15.7 \\
19.8 \\
17.0 \\
14.3\end{array}$ & $\begin{array}{r}108,602 \\
39,491 \\
26,757 \\
106,432 \\
10,656\end{array}$ & $\begin{array}{r}1,844,389 \\
620,695 \\
537,854 \\
1,804,256 \\
151,324\end{array}$ & $\begin{array}{l}17.0 \\
15.7 \\
20.1 \\
17.0 \\
14.2\end{array}$ \\
\hline $\begin{array}{l}\text { South } \\
\text { South } \\
\text { Tenne } \\
\text { Texas } \\
\text { Utah }\end{array}$ & $\begin{array}{l}16.9 \\
14.8 \\
19.4 \\
15.8 \\
24.9\end{array}$ & $\begin{array}{l}17.2 \\
15.3 \\
19.6 \\
16.1 \\
24.2\end{array}$ & $\begin{array}{l}16.7 \\
14.9 \\
18.8 \\
16.0 \\
24.7\end{array}$ & $\begin{array}{r}39,437 \\
9,985 \\
47,406 \\
234,213 \\
19,524\end{array}$ & $\begin{array}{r}648,725 \\
143,482 \\
881,425 \\
3,677,171 \\
474,675\end{array}$ & $\begin{array}{l}16.4 \\
14.4 \\
18.6 \\
15.7 \\
24.3\end{array}$ & $\begin{array}{r}39,922 \\
9,641 \\
53,403 \\
240,371 \\
20,039\end{array}$ & $\begin{array}{r}645,586 \\
144,685 \\
893,770 \\
3,748,167 \\
477,121\end{array}$ & $\begin{array}{l}16.2 \\
15.0 \\
16.7 \\
15.6 \\
23.8\end{array}$ & $\begin{array}{r}41,463 \\
9,625 \\
54,790 \\
247,650 \\
19,734\end{array}$ & $\begin{array}{r}653,011 \\
143,331 \\
905,089 \\
3,828,975 \\
481,812\end{array}$ & $\begin{array}{l}15.7 \\
14.9 \\
16.5 \\
15.5 \\
24.4\end{array}$ \\
\hline $\begin{array}{l}\text { Vermont } \\
\text { Virginia } \\
\text { Washington } \\
\text { West Virginia } \\
\text { Wisconsin } \\
\text { Wyoming }\end{array}$ & $\begin{array}{l}13.8 \\
15.7 \\
20.2 \\
15.3 \\
15.7 \\
15.6\end{array}$ & $\begin{array}{l}13.1 \\
15.1 \\
20.2 \\
15.2 \\
15.5 \\
17.2\end{array}$ & $\begin{array}{l}14.0 \\
14.8 \\
20.1 \\
14.9 \\
16.0 \\
15.4\end{array}$ & $\begin{array}{r}7,566 \\
72,505 \\
46,439 \\
21,024 \\
54,054 \\
6,754\end{array}$ & $\begin{array}{r}104,533 \\
1,060,809 \\
938,314 \\
310,511 \\
860,581 \\
100,314\end{array}$ & $\begin{array}{l}13.8 \\
14.6 \\
20.2 \\
14.8 \\
15.9 \\
14.9\end{array}$ & $\begin{array}{r}7,676 \\
74,731 \\
46,907 \\
21,073 \\
55,033 \\
6,734\end{array}$ & $\begin{array}{r}105,565 \\
1,079,854 \\
956,572 \\
307,112 \\
870,175 \\
99,859\end{array}$ & $\begin{array}{l}13.8 \\
14.4 \\
20.4 \\
14.6 \\
15.8 \\
14.8\end{array}$ & $\begin{array}{r}7,751 \\
74,523 \\
48,307 \\
20,888 \\
54,769 \\
6,729\end{array}$ & $\begin{array}{r}106,341 \\
1,096,093 \\
974,504 \\
304,052 \\
879,259 \\
99,058\end{array}$ & $\begin{array}{l}13.7 \\
14.7 \\
20.2 \\
14.6 \\
16.1 \\
14.7\end{array}$ \\
\hline & & & & & & & & & & & & \\
\hline $\begin{array}{l}\text { American Samoa } \\
\text { Guam } \\
\text { Northern Marianas } \\
\text { Puerto Rico } \\
\text { Virgin Islands }\end{array}$ & $\begin{array}{l}19.9 \\
18.9 \\
16.5 \\
17.2 \\
14.1\end{array}$ & $\begin{array}{l}19.3 \\
18.5 \\
19.0 \\
16.6 \\
14.3\end{array}$ & $\begin{array}{l}22.1 \\
18.8 \\
19.0 \\
15.9 \\
14.5\end{array}$ & $\begin{array}{r}698 \\
1,826 \\
406 \\
39,933 \\
1,528\end{array}$ & $\begin{array}{r}14,445 \\
32,185 \\
8,429 \\
621,121 \\
23,126\end{array}$ & $\begin{array}{l}20.7 \\
17.6 \\
20.8 \\
15.6 \\
15.1\end{array}$ & $\begin{array}{r}728 \\
1,802 \\
422 \\
39,328 \\
1,622\end{array}$ & $\begin{array}{r}14,576 \\
32,960 \\
8,809 \\
627,620 \\
22,737\end{array}$ & $\begin{array}{l}20.0 \\
18.3 \\
20.9 \\
16.0 \\
14.0\end{array}$ & $\begin{array}{r}734 \\
1,552 \\
441 \\
39,743 \\
1,580\end{array}$ & $\begin{array}{r}14,766 \\
33,393 \\
9,041 \\
618,861 \\
22,385\end{array}$ & $\begin{array}{l}20.1 \\
21.5 \\
20.5 \\
15.6 \\
14.2\end{array}$ \\
\hline
\end{tabular}

1 Data imputed by the National Center for Education Statistics based on previous year's data.

NOTE.-Some data have been revised from previously published figures. Teachers reported in full-time equivalents.
SOURCE: U.S. Department of Education, National Center for Education Statistics, Common Core of Data surveys. (This table was prepared May 1998.) 
Table 68.-Teachers in public and private elementary and secondary schools, by selected characteristics: 1993-94

\begin{tabular}{|c|c|c|c|c|c|c|c|c|c|c|c|}
\hline \multirow[b]{2}{*}{ Selected characteristics } & \multirow[b]{2}{*}{ Total ${ }^{1}$} & \multicolumn{6}{|c|}{ Percent of teachers, by highest degree earned } & \multicolumn{4}{|c|}{$\begin{array}{l}\text { Percent of teachers, by years of } \\
\text { full-time teaching experience }\end{array}$} \\
\hline & & $\begin{array}{c}\text { No } \\
\text { degree }\end{array}$ & $\begin{array}{l}\text { Associ- } \\
\text { ate }\end{array}$ & $\begin{array}{l}\text { Bach- } \\
\text { elor's }\end{array}$ & Master's & $\begin{array}{l}\text { Edu- } \\
\text { cation } \\
\text { spe- } \\
\text { cialist }\end{array}$ & Doctor's & $\begin{array}{l}\text { Less } \\
\text { than } 3\end{array}$ & 3 to 9 & $\begin{array}{c}10 \text { to } \\
20\end{array}$ & $\begin{array}{l}\text { Over } \\
20\end{array}$ \\
\hline \multirow[t]{2}{*}{1} & 2 & 3 & 4 & 5 & 6 & 7 & 8 & 9 & 10 & 11 & 12 \\
\hline & \multicolumn{11}{|c|}{ Public schools } \\
\hline Total & $2,561,294$ & 0.6 & 0.2 & 52.0 & 42.0 & 4.6 & 0.7 & 9.7 & 25.5 & 35.0 & 29.8 \\
\hline Men & $\begin{array}{r}694,098 \\
1,867,195\end{array}$ & $\begin{array}{l}1.3 \\
0.3\end{array}$ & $\begin{array}{l}0.4 \\
0.1\end{array}$ & $\begin{array}{l}46.2 \\
54.1\end{array}$ & $\begin{array}{l}45.7 \\
40.6\end{array}$ & $\begin{array}{l}5.1 \\
4.4\end{array}$ & $\begin{array}{l}1.3 \\
0.5\end{array}$ & $\begin{array}{r}8.9 \\
10.0\end{array}$ & $\begin{array}{l}21.6 \\
26.9\end{array}$ & $\begin{array}{l}29.9 \\
37.0\end{array}$ & $\begin{array}{l}39.6 \\
26.1\end{array}$ \\
\hline \multicolumn{12}{|l|}{ Race/ethnicity } \\
\hline White ......... & $2,216,605$ & 0.5 & 0.1 & 51.8 & 42.5 & 4.4 & 0.7 & 9.4 & 25.5 & 35.1 & 30.0 \\
\hline 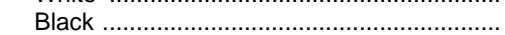 & 188,371 & 0.5 & 0.2 & 48.4 & 44.6 & 5.4 & 0.9 & 8.5 & 20.8 & 35.5 & 35.2 \\
\hline 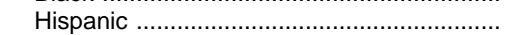 & 108,744 & 0.9 & 0.5 & 62.8 & 29.8 & 4.6 & 1.4 & 16.7 & 32.1 & 34.1 & 17.1 \\
\hline Asian or Pacific Islander & 27,510 & 0.9 & 0.4 & 49.3 & 34.7 & 13.1 & 1.7 & 14.9 & 29.7 & 29.2 & 26.2 \\
\hline American Indian or Alaskan . & 20,064 & 0.8 & 0.3 & 54.9 & 39.1 & 4.3 & 0.6 & 11.3 & 27.6 & 34.5 & 26.6 \\
\hline \multicolumn{12}{|l|}{ Age } \\
\hline Less than 30 & 280,342 & 0.5 & 0.1 & 83.9 & 14.5 & 1.0 & 0.1 & 47.8 & 52.2 & (2) & (2) \\
\hline 30 to 39 & 573,444 & 0.5 & 0.2 & 59.4 & 36.6 & 3.0 & 0.3 & 10.5 & 48.7 & 40.8 & $(2)$ \\
\hline 40 to 49 & $1,070,459$ & 0.4 & 0.1 & 46.3 & 47.0 & 5.4 & 0.7 & 4.3 & 16.9 & 47.5 & 31.3 \\
\hline 50 to 59 & 540,491 & 0.7 & 0.2 & 40.6 & 51.2 & 6.1 & 1.2 & 1.4 & 7.8 & 25.0 & 65.7 \\
\hline 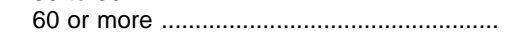 & 96,557 & 1.5 & 0.1 & 43.1 & 46.2 & 6.6 & 2.5 & 0.8 & 4.4 & 19.9 & 74.9 \\
\hline \multicolumn{12}{|l|}{ Level } \\
\hline Elementary & $1,331,281$ & 0.2 & $\left({ }^{2}\right)$ & 55.5 & 39.7 & 4.1 & 0.4 & 9.7 & 27.1 & 35.5 & 27.7 \\
\hline General . & 938,636 & 0.3 & $(2)$ & 58.0 & 38.0 & 3.5 & 0.3 & 9.2 & 26.5 & 34.9 & 29.4 \\
\hline English ......... & 2,093 & (2) & (2) & 46.0 & 52.3 & 1.0 & 0.8 & 12.5 & 11.2 & 17.9 & 58.4 \\
\hline Mathematics ............... & 3,372 & (2) & (2) & 74.6 & 24.4 & (2) & 1.0 & 11.6 & 13.1 & 40.9 & 34.3 \\
\hline Special education & 127,877 & $\left({ }^{2}\right)$ & $\left({ }^{2}\right)$ & 45.1 & 46.9 & 7.2 & 0.9 & 11.1 & 34.1 & 39.9 & 15.0 \\
\hline Other elementary .... & 259,304 & 0.3 & 0.1 & 51.3 & 42.6 & 4.9 & 0.8 & 11.1 & 25.8 & 35.6 & 27.5 \\
\hline Secondary ....................... & $1,230,013$ & 0.9 & 0.3 & 48.2 & 44.4 & 5.1 & 1.1 & 9.7 & 23.8 & 34.5 & 32.0 \\
\hline 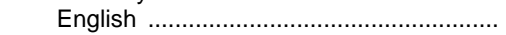 & 172,603 & 0.1 & $(2)$ & 48.3 & 44.8 & 5.5 & 1.3 & 9.2 & 22.9 & 33.6 & 34.3 \\
\hline 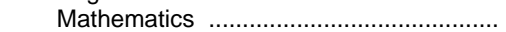 & 141,051 & 0.1 & (2) & 50.2 & 45.5 & 3.4 & 0.8 & 9.4 & 24.3 & 31.7 & 34.5 \\
\hline 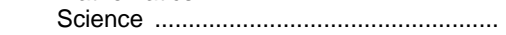 & 132,179 & 0.2 & $(2)$ & 47.9 & 45.8 & 4.8 & 1.2 & 9.5 & 26.1 & 31.2 & 33.2 \\
\hline 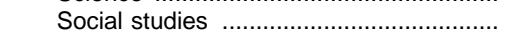 & 130,045 & 0.1 & $(2)$ & 47.8 & 46.0 & 4.9 & 1.2 & 10.3 & 20.5 & 28.7 & 40.5 \\
\hline Special education & 111,215 & 0.1 & 0.1 & 42.1 & 49.1 & 7.2 & 1.3 & 9.3 & 28.8 & 45.1 & 16.8 \\
\hline 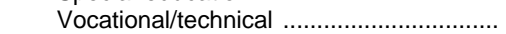 & 113,269 & 7.3 & 2.3 & 45.2 & 39.9 & 4.7 & 0.5 & 6.8 & 23.0 & 35.7 & 34.5 \\
\hline \multirow[t]{2}{*}{ 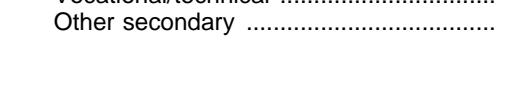 } & 429,653 & 0.5 & 0.2 & 50.1 & 43.0 & 5.1 & 1.1 & 10.7 & 23.1 & 35.6 & 30.7 \\
\hline & \multicolumn{11}{|c|}{ Private schools } \\
\hline Total & 378,365 & 5.2 & 1.5 & 59.0 & 29.8 & 2.9 & 1.7 & 20.9 & 33.9 & 29.6 & 15.6 \\
\hline Men & 93,130 & 4.4 & 0.9 & 47.3 & 40.6 & 2.6 & 4.3 & 21.7 & 28.2 & 28.7 & 21.4 \\
\hline Women ............................................... & 285,235 & 5.4 & 1.7 & 62.8 & 26.3 & 3.0 & 0.8 & 20.6 & 35.8 & 29.9 & 13.7 \\
\hline \multicolumn{12}{|l|}{ Race/ethnicity } \\
\hline White & 347,811 & 4.8 & 1.3 & 59.4 & 30.2 & 2.6 & 1.6 & 20.4 & 33.6 & 30.0 & 16.0 \\
\hline Black ......... & 11,664 & 8.3 & 3.7 & 55.8 & 26.4 & 4.8 & 1.0 & 26.9 & 34.9 & 27.9 & 10.3 \\
\hline Hispanic ... & 12,221 & 11.1 & 4.9 & 57.4 & 19.9 & 4.4 & 2.3 & 25.5 & 41.8 & 21.6 & 11.1 \\
\hline Asian or Pacific Islander. & 5,167 & 6.8 & 0.9 & 46.1 & 36.8 & 5.7 & 3.6 & 26.1 & 34.6 & 26.6 & 12.7 \\
\hline American Indian or Alaskan .............................. & 1,502 & 3.4 & 6.0 & 49.4 & 16.1 & 25.1 & (2) & 29.4 & 42.8 & 17.9 & 9.9 \\
\hline Age & & & & & & & & & & & \\
\hline Less than 30 & 65,168 & 7.7 & 1.6 & 78.8 & 10.8 & 1.0 & 0.2 & 54.9 & 44.9 & 0.1 & (2) \\
\hline 30 to 39 & 93,999 & 5.9 & 1.2 & 63.1 & 25.7 & 2.6 & 1.4 & 21.7 & 51.2 & 27.1 & $\left({ }^{2}\right)$ \\
\hline 40 to 49 & 131,492 & 3.9 & 1.6 & 54.0 & 35.1 & 3.4 & 2.0 & 12.6 & 29.8 & 45.5 & 12.1 \\
\hline 50 to 59 & 65,691 & 4.0 & 1.8 & 49.7 & 38.4 & 3.5 & 2.5 & 7.4 & 15.7 & 35.7 & 41.2 \\
\hline 60 or more & 22,015 & 5.6 & 0.9 & 39.4 & 46.6 & 4.4 & 2.9 & 6.6 & 6.5 & 13.8 & 73.1 \\
\hline Level & & & & & & & & & & & \\
\hline Elementa & 221,036 & 7.0 & 1.7 & 65.9 & 21.8 & 2.8 & 0.8 & 21.9 & 36.0 & 29.0 & 13.1 \\
\hline 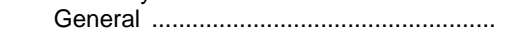 & 153,691 & 6.1 & 1.3 & 69.4 & 19.5 & 3.2 & 0.4 & 17.7 & 37.4 & 31.0 & 14.0 \\
\hline 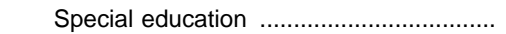 & 7,652 & 5.0 & 0.2 & 46.4 & 45.0 & 3.4 & 0.0 & 18.2 & 46.8 & 26.5 & 8.5 \\
\hline 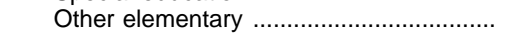 & 59,692 & 9.3 & 2.9 & 59.3 & 24.7 & 1.6 & 2.0 & 33.3 & 31.2 & 24.2 & 11.3 \\
\hline 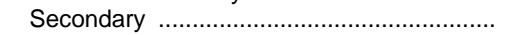 & 157,329 & 2.6 & 1.2 & 49.2 & 41.1 & 3.0 & 2.8 & 19.5 & 30.9 & 30.4 & 19.2 \\
\hline 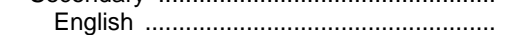 & 24,335 & 1.6 & (2) & 51.3 & 43.1 & 1.5 & 2.5 & 16.3 & 30.8 & 31.3 & 21.7 \\
\hline 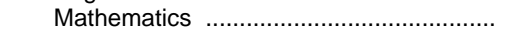 & 23,238 & 1.3 & 0.9 & 50.1 & 42.6 & 3.0 & 2.2 & 14.7 & 31.1 & 29.3 & 24.8 \\
\hline 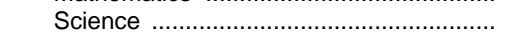 & 18,399 & 0.1 & $(2)$ & 49.5 & 42.3 & 4.2 & 4.0 & 21.3 & 27.7 & 31.2 & 19.9 \\
\hline Social studies & 20,059 & 0.2 & 0.4 & 53.5 & 38.7 & 4.1 & 3.1 & 21.0 & 27.8 & 30.8 & 20.4 \\
\hline … & 6,048 & 0.1 & 3.7 & 56.5 & 33.7 & 5.1 & 0.9 & 17.8 & 42.8 & 29.0 & 10.4 \\
\hline 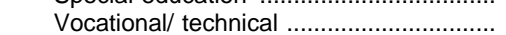 & 2,834 & 14.0 & 4.6 & 40.8 & 40.6 & (2) & $(2)$ & 12.7 & 22.6 & 42.1 & 22.6 \\
\hline Other secondary & 62,415 & 4.8 & 2.0 & 46.3 & 40.9 & 2.9 & 3.1 & 22.0 & 32.1 & 29.7 & 16.2 \\
\hline
\end{tabular}

1 Data are based upon a sample survey and may not be strictly comparable with data reported elsewhere.

${ }^{2}$ Less than .05 percent.
NOTE-Excludes prekindergarten teachers. Data are based on a head count of all teachers rather than on the number of full-time-equivalent teachers reported on other tateachers rather than on the number of full-time-equivalent teachers reported on other ta-
bles. Details may not add to totals because of survey item nonresponse and rounding.

SOURCE: U.S. Department of Education, National Center for Education Statistics, "Schools and Staffing Survey, 1993-94." (This table was prepared June 1997.) 
Table 69.-Highest degree earned, number of years teaching experience, and average class size for teachers in public elementary and secondary schools, by state: 1993-94

\begin{tabular}{|c|c|c|c|c|c|c|c|c|c|c|c|}
\hline \multirow{2}{*}{ State } & \multirow{2}{*}{ Total $^{1}$} & \multicolumn{4}{|c|}{ Percent of teachers, by highest degree ${ }^{2}$} & \multicolumn{4}{|c|}{$\begin{array}{c}\text { Percent of teachers, by years of full-time teaching } \\
\text { experience }\end{array}$} & \multicolumn{2}{|c|}{ Average class size $^{3}$} \\
\hline & & Bachelor's & Master's & $\begin{array}{l}\text { Education } \\
\text { specialist }\end{array}$ & Doctor's & Less than 3 & 3 to 9 & 10 to 20 & Over 20 & Elementary & Secondary \\
\hline 1 & 2 & 3 & 4 & 5 & 6 & 7 & 8 & 9 & 10 & 11 & 12 \\
\hline United States .. & $2,561,294$ & $52.0(0.3)$ & $42.0(0.3)$ & $4.6(0.1)$ & $0.7(0.1)$ & $9.7(0.2)$ & $25.5(0.3)$ & $35.0(0.3)$ & $29.8(0.3)$ & $24.1(0.1)$ & $23.6(0.1)$ \\
\hline Alabama & 44,791 & $38.5(1.9)$ & $52.6(1.7)$ & $7.8(0.8)$ & $0.7(0.3)$ & $11.1(0.8)$ & $22.0(1.5)$ & $42.2(1.9)$ & $24.7(1.5)$ & $21.7(0.4)$ & $24.2(0.2)$ \\
\hline Alaska & 8,152 & $59.0(1.1)$ & $35.3(1.0)$ & $4.2(0.5)$ & $0.2(0.1)$ & $8.0(0.6)$ & $29.3(1.4)$ & $42.7(1.4)$ & $20.0(1.1)$ & $22.6(0.5)$ & $22.0(0.5)$ \\
\hline Arizona & 37,600 & $51.4(1.8)$ & $43.3(1.7)$ & $4.0(0.6)$ & $0.7(0.2)$ & $13.1(1.0)$ & $29.1(1.6)$ & $38.1(1.7)$ & $19.8(1.4)$ & $25.8(0.4)$ & $25.5(0.3)$ \\
\hline Arkansas & 30,621 & $64.9(2.1)$ & $32.5(1.7)$ & $1.8(0.6)$ & $0.5(0.1)$ & $9.2(0.8)$ & $27.3(1.7)$ & $40.2(1.8)$ & $23.3(1.6)$ & $21.0(0.4)$ & $21.3(0.3)$ \\
\hline California & 209,032 & $58.6(1.8)$ & $32.6(1.8)$ & $6.8(0.7)$ & $1.0(0.2)$ & $9.8(0.8)$ & $27.8(1.9)$ & $31.8(1.7)$ & $30.7(1.7)$ & $29.3(0.3)$ & $29.7(0.4)$ \\
\hline Colorado & 35,723 & $46.5(1.7)$ & $49.4(1.7)$ & $2.5(0.6)$ & $0.5(0.1)$ & $9.4(0.8)$ & $26.1(1.6)$ & $38.7(1.6)$ & $25.7(1.4)$ & $24.7(0.3)$ & $24.5(0.4)$ \\
\hline Connecticut & 35,465 & $19.6(1.1)$ & $62.4(1.5)$ & $15.7(0.7)$ & $1.4(0.4)$ & $6.4(0.6)$ & $19.8(1.1)$ & $35.5(1.7)$ & $38.3(1.6)$ & $21.4(0.2)$ & $19.7(0.2)$ \\
\hline Delaware . & 7,027 & $46.0(1.6)$ & $48.3(1.8)$ & $5.1(0.9)$ & $0.2(0.1)$ & $7.7(1.0)$ & $24.1(1.9)$ & $36.2(2.3)$ & $32.0(2.1)$ & $24.8(0.4)$ & $24.1(0.4)$ \\
\hline District of Columbia & 5,185 & $41.2(1.8)$ & $54.4(1.7)$ & $2.4(0.8)$ & $2.0(0.7)$ & $10.8(1.4)$ & $14.7(2.1)$ & $30.6(2.2)$ & $43.9(3.4)$ & $21.8(0.3)$ & $20.7(0.6)$ \\
\hline Florida ......................... & 106,535 & $57.2(1.2)$ & $37.0(1.2)$ & $3.3(0.6)$ & $1.4(0.4)$ & $8.7(0.9)$ & $29.4(1.6)$ & $37.8(1.7)$ & $24.0(1.4)$ & $26.0(0.3)$ & $26.6(0.4)$ \\
\hline Georgia & 74,907 & $48.9(1.5)$ & $42.5(1.6)$ & $7.7(0.8)$ & $0.2(0.1)$ & $13.3(1.1)$ & $28.3(1.4)$ & $35.6(1.4)$ & $22.8(1.3)$ & $22.2(0.2)$ & $24.2(0.3)$ \\
\hline Hawaii & 11,137 & $47.8(2.1)$ & $21.7(1.5)$ & $27.5(2.2)$ & $1.1(0.4)$ & $16.2(1.4)$ & $28.1(1.6)$ & $22.0(1.4)$ & $33.7(2.2)$ & $23.6(0.3)$ & $23.6(0.8)$ \\
\hline Idaho & 12,166 & $74.4(1.6)$ & $21.7(1.5)$ & $2.6(0.5)$ & $0.6(0.2)$ & $12.4(1.2)$ & $33.3(1.5)$ & 33.7 (1.3) & $20.6(1.2)$ & $24.0(0.5)$ & $23.7(0.4)$ \\
\hline Illinois . & 111,511 & $49.7(1.3)$ & $46.1(1.4)$ & $3.4(0.5)$ & $0.5(0.2)$ & $9.0(0.6)$ & $25.1(1.0)$ & $30.8(1.3)$ & 35.1 (1.3) & $24.5(0.3)$ & $24.0(0.3)$ \\
\hline Indiana & 57,732 & $21.4(1.7)$ & $72.9(1.7)$ & $4.9(0.6)$ & $0.1(0.1)$ & $5.6(0.8)$ & $24.7(2.0)$ & $37.1(2.2)$ & $32.6(2.0)$ & $21.9(0.4)$ & $23.0(0.3)$ \\
\hline low & 35,861 & $67.3(1.8)$ & $31.3(1.9)$ & $1.2(0.5)$ & $0.2(0.1)$ & $10.1(1.0)$ & $23.3(1.7)$ & $32.1(2.1)$ & (2.3) & $22.5(0.6)$ & $21.4(0.5)$ \\
\hline Kansas & 31,164 & $53.5(1.4)$ & $42.8(1.2)$ & $2.3(0.5)$ & $1.1(0.3)$ & $12.3(0.8)$ & $28.2(1.3)$ & $35.2(1.3)$ & $3(1.1)$ & $20.6(0.3)$ & $20.7(0.4)$ \\
\hline Kentucky & 41,571 & $23.4(2.2)$ & $56.8(2.4)$ & $18.7(1.5)$ & $0.8(0.4)$ & $9.5(1.6)$ & $26.8(2.3)$ & $32.9(2.2)$ & $30.8(2.2)$ & $24.4(0.9)$ & $23.5(0.4)$ \\
\hline Louisiana & 48,948 & $60.5(1.6)$ & $31.2(1.5)$ & $6.9(0.7)$ & $0.5(0.1)$ & $9.7(0.8)$ & $29.8(1.3)$ & $35.1(1.4)$ & 25.5 (1.3) & $22.9(0.3)$ & $23.7(0.3)$ \\
\hline Maine.... & 15,658 & $68.4(1.9)$ & $28.4(1.9)$ & $1.6(0.4)$ & $0.2(0.1)$ & $7.0(0.7)$ & $28.7(1.9)$ & $37.4(1.8)$ & $26.9(1.8)$ & $21.5(1.1)$ & $18.5(0.4)$ \\
\hline Mar & 43,862 & $(1.9)$ & (2.3) & $6.2(1.1)$ & $0.2)$ & $11.7(0.9)$ & (1.6) & (1.4) & 1.5) & 26. & 25 \\
\hline Massachusetts & 58,416 & $38.8(1.2)$ & $54.8(1.4)$ & $3.9(0.5)$ & $(0.1)$ & $8.4(0.7)$ & $17.1(1.0)$ & $33.6(1.3)$ & (1.1) & $23.1(0.4)$ & 20 \\
\hline Michigan ............ & 83,288 & 46.6 (1.9) & $48.1(1.8)$ & $4.7(0.8)$ & $(0.3)$ & $7.4(1.0)$ & $21.5(1.8)$ & $29.4(2.1)$ & $41.9(2.2)$ & $27.3(1.9)$ & $25.5(0.3)$ \\
\hline Minnesota & 44,150 & $63.4(2.1)$ & $33.6(2.0)$ & $2.6(0.6)$ & $0.4(0.2)$ & $13.0(1.1)$ & $20.0(1.5)$ & $33.0(1.7)$ & $34.0(1.8)$ & $24.5(1.0)$ & $25.9(0.4)$ \\
\hline Mississippi & 29,851 & $56.3(1.5)$ & $37.5(1.7)$ & $4.3(0.9)$ & $0.4(0.2)$ & $10.5(0.8)$ & $22.8(1.4)$ & $39.8(1.8)$ & $26.9(1.2)$ & $23.6(0.4)$ & $22.5(0.4)$ \\
\hline Mis & 62,454 & $54.3(2.0)$ & $42.4(1.9)$ & $2.2(0.5)$ & $0.2)$ & 1) & (2.0) & (2.2) & 1.9) & 23 & $22.5(0.4)$ \\
\hline Montana & 12,851 & $71.3(1.3)$ & $26.0(1.1)$ & $1.8(0.4)$ & $0.5(0.2)$ & $11.1(0.7)$ & $27.5(1.3)$ & $39.0(1.3)$ & $22.5(1.1)$ & $21.2(0.8)$ & $19.3(0.4)$ \\
\hline Nebraska & 20,411 & $61.5(1.7)$ & $36.0(1.6)$ & $1.9(0.4)$ & $0.4(0.2)$ & $10.1(1.0)$ & $24.4(1.4)$ & $39.0(1.1)$ & $26.5(1.6)$ & $20.0(0.8)$ & $18.7(0.4)$ \\
\hline Nevada . & 12,822 & $50.5(2.2)$ & $42.8(2.3)$ & $5.7(0.9)$ & $0.6(0.3)$ & $12.0(1.1)$ & $33.2(2.4)$ & $35.0(1.8)$ & $19.8(1.8)$ & $24.4(0.7)$ & $26.6(0.6)$ \\
\hline New Hampshire & 12,299 & $60.2(2.0)$ & 35.9 (1.9) & $2.6(0.6)$ & $0.7(0.3)$ & $10.6(1.2)$ & $26.8(1.7)$ & $38.2(1.6)$ & $24.4(1.6)$ & $21.8(0.4)$ & $20.5(0.4)$ \\
\hline New Jersey & 83,935 & $56.2(2.9)$ & $37.4(2.7)$ & $4.8(1.0)$ & $1.0(0.3)$ & $5.8(0.8)$ & $21.1(2.0)$ & $34.6(2.4)$ & 38.5 (1.9) & 23.2 & 20 \\
\hline New Mexico & 19,265 & $53.2(1.6)$ & $43.6(1.6)$ & $2.2(0.5)$ & $0.4(0.2)$ & $12.5(1.0)$ & $32.5(1.4)$ & $33.9(1.6)$ & $21.1(1.5)$ & $21.9(0.3)$ & $24.5(0.4)$ \\
\hline New York & 178,701 & $25.0(1.9)$ & $68.1(1.9)$ & $5.3(0.8)$ & $1.5(0.6)$ & $10.3(1.2)$ & $23.9(1.7)$ & $29.7(1.6)$ & $36.1(2.0)$ & $23.9(0.4)$ & $23.2(0.4)$ \\
\hline North Carolina & 72,305 & $61.8(1.5)$ & $35.0(1.6)$ & $1.2(0.4)$ & $0.5(0.3)$ & $9.7(0.7)$ & $26.6(1.4)$ & $38.8(1.3)$ & $25.0(1.3)$ & $24.8(0.2)$ & $22.4(0.3)$ \\
\hline North Dakota . & 8,404 & $79.3(1.1)$ & $18.0(0.9)$ & $1.6(0.3)$ & $0.2(0.1)$ & $12.1(1.0)$ & $27.2(1.0)$ & 37.7 (1.5) & $23.0(1.4)$ & $20.7(0.7)$ & $19.7(0.5)$ \\
\hline Ohio & 111,518 & $53.2(2.2)$ & 41.8 (2.3) & $3.1(0.7)$ & $0.4(0.2)$ & $6.8(0.8)$ & $23.2(1.8)$ & $38.6(2.1)$ & $31.4(2.1)$ & 1.2) & 22 \\
\hline Oklah & 42,220 & $56.9(1.8)$ & 39.5 (1.9) & $(0.5)$ & $(0.2)$ & $10.4(0.8)$ & $(1.7)$ & $41.2(1.8)$ & $21.5(1.1)$ & $20.5(0.4)$ & $20.5(0.3)$ \\
\hline Oregon & 25,706 & 51.5 (1.9) & $43.1(1.9)$ & $4.0(0.9)$ & $0.8(0.5)$ & $7.4(0.8)$ & $27.0(1.6)$ & $39.6(1.7)$ & $26.0(1.7)$ & $24.4(0.3)$ & $23.9(0.4)$ \\
\hline Pennsylvania & 114,571 & $46.7(2.3)$ & $45.6(1.9)$ & $6.9(1.2)$ & $0.3(0.2)$ & $6.9(1.0)$ & $18.3(2.0)$ & $33.0(2.2)$ & $41.8(2.2)$ & $25.2(0.6)$ & $24.1(0.3)$ \\
\hline Rhode Island & 9,217 & $40.1(2.5)$ & $53.3(2.4)$ & $5.7(0.9)$ & $1.0(0.5)$ & $7.2(1.1)$ & $21.9(1.8)$ & $28.6(1.7)$ & $42.3(2.0)$ & $23.2(0.6)$ & $20.8(0.5)$ \\
\hline & 39,623 & $48.8(2.5)$ & $43.4(2.6)$ & & $0.7(0.3)$ & $10.5(1.4)$ & $25.1(1.9)$ & $42.3(1.9)$ & $22.1(1.7)$ & $23.3(0.7)$ & $22.5(0.4)$ \\
\hline Sol & 10,579 & $75.1(1.2)$ & $23.2(1.1)$ & $1.5(0.3)$ & $0.1(0.1)$ & $10.4(0.7)$ & $28.6(1.2)$ & $37.3(1.1)$ & $23.8(1.2)$ & $19.2(0.3)$ & $20.9(0.4)$ \\
\hline Tennessee & 47,662 & $51.2(2.0)$ & $42.0(2.0)$ & $4.8(0.8)$ & $1.2(0.4)$ & $12.4(1.1)$ & $22.9(1.9)$ & $35.5(2.0)$ & $29.2(2.2)$ & $24.4(1.2)$ & $25.2(0.4)$ \\
\hline Texas .......... & 223,800 & 69.7 (1.3) & $26.8(1.5)$ & $1.8(0.4)$ & $0.9(0.5)$ & $12.1(0.9)$ & $30.1(1.5)$ & $37.5(1.4)$ & $20.4(1.4)$ & $20.1(0.2)$ & $22.5(0.4)$ \\
\hline Utah & 19,884 & $70.6(1.4)$ & 23.5 (1.3) & $4.2(0.7)$ & $0.4(0.1)$ & $12.7(0.8)$ & $32.8(1.4)$ & $36.1(1.4)$ & $18.3(1.0)$ & $27.5(0.4)$ & $28.8(0.2)$ \\
\hline Vermont & 7,327 & $49.4(1.8)$ & $47.5(1.8)$ & $2.1(0.8)$ & $0.5(0.4)$ & $12.3(1.5)$ & $25.3(1.9)$ & 34.4 (1.9) & $28.0(1.8)$ & $19.7(0.8)$ & $19.2(0.4)$ \\
\hline Virginia & 64,937 & $64.4(2.1)$ & $31.3(2.0)$ & $2.4(0.6)$ & $0.5(0.2)$ & $10.5(1.2)$ & $26.0(2.2)$ & $37.5(2.0)$ & 26.1 (1.9) & $22.6(0.3)$ & $21.6(0.3)$ \\
\hline Washington & 48,452 & $56.3(1.9)$ & $37.5(2.2)$ & $3.6(0.9)$ & $1.0(0.3)$ & $10.8(0.9)$ & $30.1(2.0)$ & $32.2(1.9)$ & $26.9(1.6)$ & $25.9(1.3)$ & $25.5(0.2)$ \\
\hline West Virginia & 21,473 & 41.7 (1.7) & 53.1 (1.7) & $4.3(0.6)$ & -- & $4.4(0.8)$ & $21.6(1.6)$ & $42.7(1.5)$ & $31.4(1.7)$ & $20.9(0.5)$ & $22.5(0.3)$ \\
\hline Wisc & 62,958 & $59.3(1.7)$ & $38.1(1.6)$ & $1.7(0.4)$ & $0.6(0.3)$ & $9.1(0.8)$ & $24.7(1.8)$ & $29.5(2.2)$ & $36.7(2.2)$ & $23.1(0.4)$ & $23.1(0.4)$ \\
\hline Wyoming ........ & 7,567 & $71.3(1.0)$ & $26.5(0.9)$ & $1.4(0.3)$ & $0.4(0.1)$ & $9.4(0.8)$ & $22.6(1.2)$ & $41.6(1.3)$ & $26.5(1.3)$ & $21.0(0.3)$ & $19.3(0.3)$ \\
\hline
\end{tabular}

${ }^{1}$ Data are based on a head count of all teachers rather than on the number of fulltime-equivalent teachers appearing in other tables.

${ }^{2}$ Teachers with less than a bachelor's degree are not shown.

${ }^{3}$ Elementary teachers are those who taught self-contained classes at the elementary level and secondary teachers are those who taught departmentalized classes (e.g., science, art, social science, or other course subjects) at the secondary level. Excludes special education teachers. Teachers were classified as elementary or secondary on the basis of the grades they taught, rather than on the level of the school in which they taught.
—Data not available.

NOTE.-Excludes prekindergarten teachers. Details may not add to totals due to rounding. Standard errors appear in parentheses.

SOURCE: U.S. Department of Education, National Center for Education Statistics, "Schools and Staffing Survey, 1993-94;" and Condition of Education, 1997, Supplemental Tables. (This table was prepared February 1998.) 
Table 70.-Selected characteristics of public school teachers: Spring 1961 to spring 1996

\begin{tabular}{|c|c|c|c|c|c|c|c|c|}
\hline Item & 1961 & 1966 & 1971 & 1976 & 1981 & 1986 & 1991 & 1996 \\
\hline 1 & 2 & 3 & 4 & 5 & 6 & 7 & 8 & 9 \\
\hline Number of teachers, in thousands .......... & 1,408 & 1,710 & 2,055 & 2,196 & 2,185 & 2,206 & 2,398 & 2,164 \\
\hline 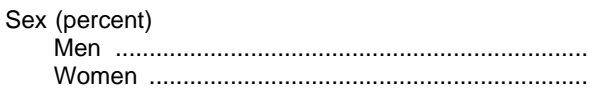 & $\begin{array}{l}31.3 \\
68.7\end{array}$ & $\begin{array}{l}31.1 \\
68.9\end{array}$ & $\begin{array}{l}34.3 \\
65.7\end{array}$ & $\begin{array}{l}32.9 \\
67.1\end{array}$ & $\begin{array}{l}33.1 \\
66.9\end{array}$ & $\begin{array}{l}31.2 \\
68.8\end{array}$ & $\begin{array}{l}27.9 \\
72.1\end{array}$ & $\begin{array}{l}25.6 \\
74.4\end{array}$ \\
\hline 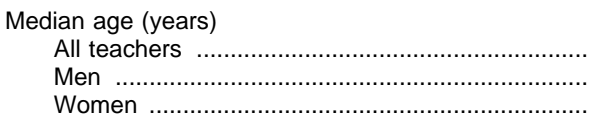 & $\begin{array}{l}41 \\
34 \\
46\end{array}$ & $\begin{array}{l}36 \\
33 \\
40\end{array}$ & $\begin{array}{l}35 \\
33 \\
37\end{array}$ & $\begin{array}{l}33 \\
33 \\
33\end{array}$ & $\begin{array}{l}37 \\
38 \\
36\end{array}$ & $\begin{array}{l}41 \\
42 \\
41\end{array}$ & $\begin{array}{l}42 \\
43 \\
42\end{array}$ & $\begin{array}{l}44 \\
46 \\
44\end{array}$ \\
\hline 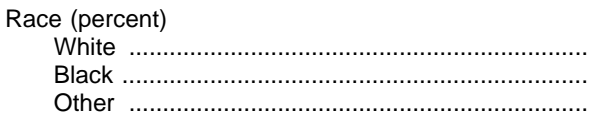 & - & $\begin{array}{l}- \\
-\end{array}$ & $\begin{array}{r}88.3 \\
8.1 \\
3.6\end{array}$ & $\begin{array}{r}90.8 \\
8.0 \\
1.2\end{array}$ & $\begin{array}{r}91.6 \\
7.8 \\
0.7\end{array}$ & $\begin{array}{r}89.6 \\
6.9 \\
3.4\end{array}$ & $\begin{array}{r}86.8 \\
8.0 \\
5.2\end{array}$ & $\begin{array}{r}90.7 \\
7.3 \\
2.0\end{array}$ \\
\hline 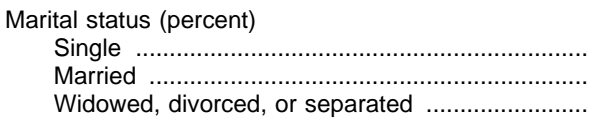 & $\begin{array}{r}22.3 \\
68.0 \\
9.7\end{array}$ & $\begin{array}{r}22.0 \\
69.1 \\
9.0\end{array}$ & $\begin{array}{r}19.5 \\
71.9 \\
8.6\end{array}$ & $\begin{array}{r}20.1 \\
71.3 \\
8.6\end{array}$ & $\begin{array}{r}18.5 \\
73.0 \\
8.5\end{array}$ & $\begin{array}{l}12.9 \\
75.7 \\
11.4\end{array}$ & $\begin{array}{l}11.7 \\
75.7 \\
12.6\end{array}$ & $\begin{array}{l}12.4 \\
75.9 \\
11.8\end{array}$ \\
\hline 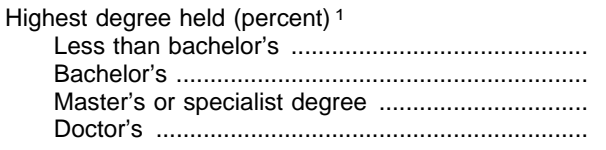 & $\begin{array}{r}14.6 \\
61.9 \\
23.1 \\
0.4\end{array}$ & $\begin{array}{r}7.0 \\
69.6 \\
23.2 \\
0.1\end{array}$ & $\begin{array}{r}2.9 \\
69.6 \\
27.1 \\
0.4\end{array}$ & $\begin{array}{r}0.9 \\
61.6 \\
37.1 \\
0.4\end{array}$ & $\begin{array}{r}0.4 \\
50.1 \\
49.3 \\
0.3\end{array}$ & $\begin{array}{r}0.3 \\
48.3 \\
50.7 \\
0.7\end{array}$ & $\begin{array}{r}0.6 \\
46.3 \\
52.6 \\
0.5\end{array}$ & $\begin{array}{r}0.3 \\
43.6 \\
54.5 \\
1.7\end{array}$ \\
\hline $\begin{array}{l}\text { College credits earned in last } 3 \text { years } \\
\text { Percent who earned credits } \ldots \ldots \ldots \ldots \ldots \ldots \ldots \ldots \ldots \ldots \ldots \ldots \ldots \ldots \ldots \ldots \ldots \ldots \ldots \ldots \ldots \ldots \ldots \ldots\end{array}$ & - & - & $\begin{array}{r}60.7 \\
14\end{array}$ & $\begin{array}{r}63.2 \\
-\end{array}$ & $\begin{array}{r}56.1 \\
9\end{array}$ & $\begin{array}{r}53.1 \\
4\end{array}$ & $\begin{array}{r}50.3 \\
4\end{array}$ & $\begin{array}{r}50.2 \\
-\end{array}$ \\
\hline Median years of teaching experience & 11 & 8 & 8 & 8 & 12 & 15 & 15 & 15 \\
\hline 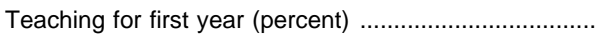 & 8.0 & 9.1 & 9.1 & 5.5 & 2.4 & 3.1 & 3.0 & 2.1 \\
\hline 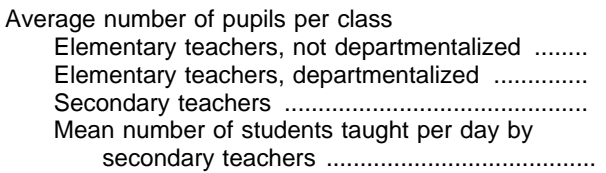 & $\frac{29}{28}$ & $\begin{array}{r}\frac{28}{26} \\
132\end{array}$ & $\begin{array}{r}27 \\
25 \\
27 \\
134\end{array}$ & $\begin{array}{r}25 \\
23 \\
25 \\
126\end{array}$ & $\begin{array}{r}25 \\
22 \\
23 \\
118\end{array}$ & $\frac{24}{25}$ & $\frac{24}{26}$ & $\begin{array}{l}\frac{24}{31} \\
97\end{array}$ \\
\hline $\begin{array}{l}\text { Average number of hours in required school day } \ldots \ldots \ldots \\
\text { Average number of hours per week spent on } \\
\text { all teaching duties } \\
\text { All teachers } \\
\text { Elementary teachers } \\
\text { Secondary teachers }\end{array}$ & $\begin{array}{l}47 \\
49 \\
46\end{array}$ & $\begin{array}{l}47 \\
47 \\
48\end{array}$ & $\begin{array}{l}47 \\
46 \\
48\end{array}$ & $\begin{array}{l}46 \\
44 \\
48\end{array}$ & $\begin{array}{l}46 \\
44 \\
48\end{array}$ & $\begin{array}{l}49 \\
47 \\
51\end{array}$ & $\begin{array}{l}47 \\
44 \\
50\end{array}$ & $\begin{array}{l}49 \\
47 \\
52\end{array}$ \\
\hline 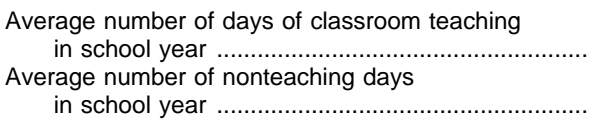 & - & $\begin{array}{r}181 \\
5\end{array}$ & $\begin{array}{r}181 \\
4\end{array}$ & $\begin{array}{r}180 \\
5\end{array}$ & $\begin{array}{r}180 \\
6\end{array}$ & $\begin{array}{r}180 \\
5\end{array}$ & $\begin{array}{r}180 \\
5\end{array}$ & $\begin{array}{r}180 \\
6\end{array}$ \\
\hline $\begin{array}{l}\text { Average annual salary as classroom teacher } \ldots \ldots \ldots \ldots . . . . . \\
\text { Total income, including spouse's (if married) } \ldots \ldots \ldots \ldots \ldots . . . . .\end{array}$ & ${ }^{3} \$ 5,264$ & $\$ 6,253$ & $\begin{array}{r}\$ 9,261 \\
\$ 15,021\end{array}$ & $\begin{array}{l}\$ 12,005 \\
\$ 19,957\end{array}$ & $\begin{array}{l}\$ 17,209 \\
\$ 29,831\end{array}$ & $\begin{array}{l}\$ 24,504 \\
\$ 43,413\end{array}$ & $\begin{array}{l}\$ 31,790 \\
\$ 55,491\end{array}$ & $\begin{array}{l}\$ 35,549 \\
\$ 63,171\end{array}$ \\
\hline $\begin{array}{l}\text { Willingness to teach again (percent) } \\
\text { Certainly would } \\
\text { Probably would } \\
\text { Chances about even } \\
\text { Probably would not } \\
\text { Certainly would not }\end{array}$ & $\begin{array}{r}49.9 \\
26.9 \\
12.5 \\
7.9 \\
2.8\end{array}$ & $\begin{array}{r}52.6 \\
25.4 \\
12.9 \\
7.1 \\
2.0\end{array}$ & $\begin{array}{r}44.9 \\
29.5 \\
13.0 \\
8.9 \\
3.7\end{array}$ & $\begin{array}{r}37.5 \\
26.1 \\
17.5 \\
13.4 \\
5.6\end{array}$ & $\begin{array}{l}21.8 \\
24.6 \\
17.6 \\
24.0 \\
12.0\end{array}$ & $\begin{array}{r}22.7 \\
26.3 \\
19.8 \\
22.0 \\
9.3\end{array}$ & $\begin{array}{r}28.6 \\
30.5 \\
18.5 \\
17.0 \\
5.4\end{array}$ & $\begin{array}{r}32.1 \\
30.5 \\
17.3 \\
15.8 \\
4.3\end{array}$ \\
\hline
\end{tabular}

${ }^{1}$ Figures for curriculum specialist or professional diploma based on six years of college study are not included.

2 Measured in semester hours.

${ }^{3}$ Includes extra pay for extra duties.

-Data not available.
NOTE.-Data are based upon sample surveys of public school teachers. Data differ from figures appearing in other tables because of varying processing procedures and time period coverages. Because of rounding, percents may not add to 100.0.

SOURCE: National Education Association, "Status of the American Public School Teacher, 1995-96." (Copyright @ 1997 by the National Education Association. All rights reserved.) (This table was prepared October 1997.) 
Table 71.-Public secondary school teachers, by subject taught: Spring 1966 to spring 1996

[Percentage distribution]

\begin{tabular}{|c|c|c|c|c|c|c|c|}
\hline $\begin{array}{l}\text { Teaching field in which largest portion } \\
\text { of time was spent }\end{array}$ & 1966 & 1971 & 1976 & 1981 & 1986 & 1991 & 1996 \\
\hline 1 & 2 & 3 & 4 & 5 & 6 & 7 & 8 \\
\hline $\begin{array}{l}\text { Total secondary school teachers, in } \\
\text { thousands }\end{array}$ & 746 & 927 & 1,016 & 995 & 970 & 1,012 & 1,049 \\
\hline All fields $\ldots \ldots \ldots \ldots \ldots \ldots \ldots$ & 100.0 & 100.0 & 100.0 & 100.0 & 100.0 & 100.0 & 100.0 \\
\hline Agriculture & 1.6 & 0.6 & 0.6 & 1.1 & 0.6 & 0.3 & 0.5 \\
\hline 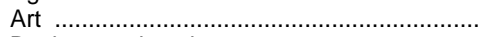 & 2.0 & 3.7 & 2.4 & 3.1 & 1.5 & 2.6 & 3.3 \\
\hline Business education & 7.0 & 5.9 & 4.6 & 6.2 & 6.5 & 3.5 & 4.1 \\
\hline English ..................................... & 18.1 & 20.4 & 19.9 & 23.8 & 21.8 & 25.0 & 23.9 \\
\hline Foreign language...$\ldots \ldots \ldots \ldots \ldots \ldots \ldots$ & 6.4 & 4.8 & 4.2 & 2.8 & 3.7 & 3.8 & 5.2 \\
\hline Health and physical education ..... & 6.9 & 8.3 & 7.9 & 6.5 & 5.6 & 7.5 & 5.9 \\
\hline Home economics …................................. & 5.9 & 5.1 & 2.8 & 3.6 & 2.6 & 3.1 & 2.2 \\
\hline Industrial arts & 5.1 & 4.1 & 3.9 & 5.2 & 2.2 & 2.1 & 0.5 \\
\hline 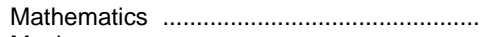 & 13.9 & 14.4 & 18.2 & 15.3 & 19.2 & 14.5 & 17.2 \\
\hline Music & 4.7 & 3.8 & 3.0 & 3.7 & 4.8 & 4.2 & 4.3 \\
\hline Science & 10.8 & 10.6 & 13.1 & 12.1 & 11.0 & 13.3 & 12.6 \\
\hline Social studies & 15.3 & 14.0 & 12.4 & 11.2 & 13.6 & 11.0 & 13.4 \\
\hline Special education & 0.4 & 1.1 & 3.0 & 2.1 & 3.5 & 5.2 & 1.7 \\
\hline 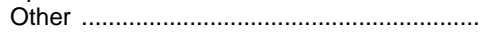 & 1.9 & 3.1 & 4.0 & 3.3 & 3.4 & 3.9 & 5.2 \\
\hline
\end{tabular}

NOTE.-Because of rounding, percents may not add to 100.0. Data are based upon sample surveys of public school teachers.
SOURCE: National Education Association, Status of the American Public School Teacher, 1995-96. (Copyright () 1997 by the National Education Association. All rights reserved.) (This table was prepared October 1997.)

Table 72.-Percent of vocational and nonvocational public school teachers of grades 9 to 12, by selected demographic and educational characteristics: 1993-94

\begin{tabular}{|c|c|c|c|c|c|c|c|}
\hline \multirow[b]{2}{*}{ Characteristics of teachers } & \multirow[b]{2}{*}{ Total } & \multicolumn{2}{|c|}{ Teacher type } & \multirow[b]{2}{*}{ Characteristics of teachers } & \multirow[b]{2}{*}{ Total } & \multicolumn{2}{|c|}{ Teacher type } \\
\hline & & $\begin{array}{l}\text { Non- } \\
\text { voca- } \\
\text { tional }\end{array}$ & $\begin{array}{l}\text { Voca- } \\
\text { tional }\end{array}$ & & & $\begin{array}{l}\text { Non- } \\
\text { voca- } \\
\text { tional }\end{array}$ & $\begin{array}{l}\text { Voca- } \\
\text { tional }\end{array}$ \\
\hline 1 & 2 & 3 & 4 & 1 & 2 & 3 & 4 \\
\hline Total & 100.0 & 100.0 & 100.0 & & & & \\
\hline Sex & & & & Major field of study & & & \\
\hline (n) & 48.3 & 46.2 & 63.2 & Business and management & 1.1 & 0.7 & 6.5 \\
\hline 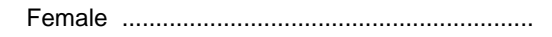 & 51.7 & 53.8 & 36.8 & 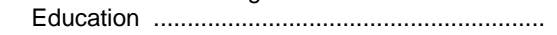 & 52.4 & 50.3 & 75.2 \\
\hline & & & & 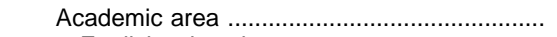 & 26.7 & 28.6 & 5.3 \\
\hline & & & & English education & 5.2 & 5.7 & 0.3 \\
\hline Race/ethnicity & & & & Music education .............. & 3.4 & 3.7 & 0.2 \\
\hline 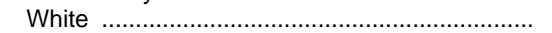 & 88.8 & 88.9 & 88.5 & Physical education ....................... & 9.1 & 9.5 & 3.8 \\
\hline 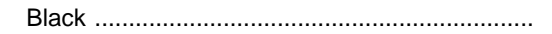 & 6.0 & 5.9 & 7.1 & 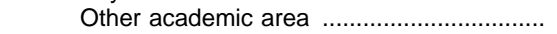 & 9.0 & 9.7 & 1.0 \\
\hline 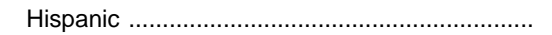 & 3.4 & 3.5 & 2.8 & Administration & 5.3 & 5.1 & 7.0 \\
\hline 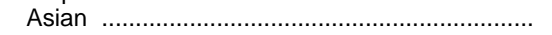 & 0.9 & 0.9 & 0.8 & General ............................. & 4.5 & 4.6 & 3.3 \\
\hline American Indian or Alaskan Native ................... & 0.8 & 0.8 & 0.8 & Special education ................. & 6.8 & 7.3 & 1.3 \\
\hline & & & & Vocational education ............ & 6.5 & 3.7 & 37.2 \\
\hline & & & & Other education ........... & 7.9 & 6.7 & 21.5 \\
\hline Age & & & & English $\ldots \ldots \ldots \ldots \ldots \ldots \ldots \ldots \ldots \ldots \ldots$ & 4.1 & 4.4 & 0.3 \\
\hline Under 30 years & 9.8 & 10.3 & 6.4 & Foreign language & 4.7 & 5.1 & 0.1 \\
\hline 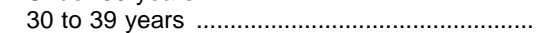 & 22.1 & 22.3 & 20.8 & Mathematics & 3.2 & 3.5 & 0.6 \\
\hline 40 to 49 years & 40.7 & 40.7 & 40.6 & Sciences & 7.8 & 8.1 & 4.3 \\
\hline 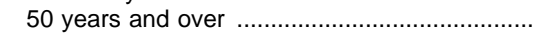 & 27.5 & 26.8 & 32.2 & 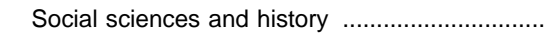 & 10.0 & 10.7 & 1.8 \\
\hline & & & & 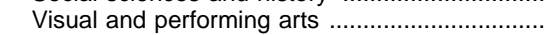 & 2.6 & 2.7 & 1.0 \\
\hline & & & & 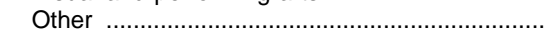 & 6.1 & 6.2 & 5.5 \\
\hline Highest college degree & & & & Age at which first began to & & & \\
\hline Less than a bachelor's degree & 1.7 & 0.5 & 10.3 & teach full-time or part-time & & & \\
\hline Bachelor's degree ........................ & 46.6 & 47.0 & 43.5 & 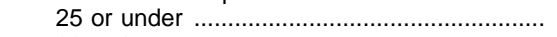 & 75.7 & 75.6 & 76.5 \\
\hline Master's degree ............. & 45.4 & 46.2 & 39.8 & 26 to $35 \ldots \ldots \ldots$ & 22.1 & 22.1 & 21.7 \\
\hline Education specialist ${ }^{1}$ & 5.3 & 5.2 & 5.6 & 36 to 45 & 2.2 & 2.2 & 1.9 \\
\hline Doctorate or first professional. & 1.1 & 1.1 & 0.7 & 46 to $55 \ldots \ldots$ & 0.1 & 0.1 & 0.0 \\
\hline
\end{tabular}

${ }^{1}$ Education specialist degrees or certificates are generally awarded for one year's work beyond the master's level.
SOURCE: U.S. Department of Education, National Center for Education Statistics, "Schools and Staffing Survey, 1993-94." (This table was prepared September 1996.) 
Table 73.-Mobility of public and private elementary and secondary teachers, by selected school and teacher characteristics: 1987-88 to 1994-95

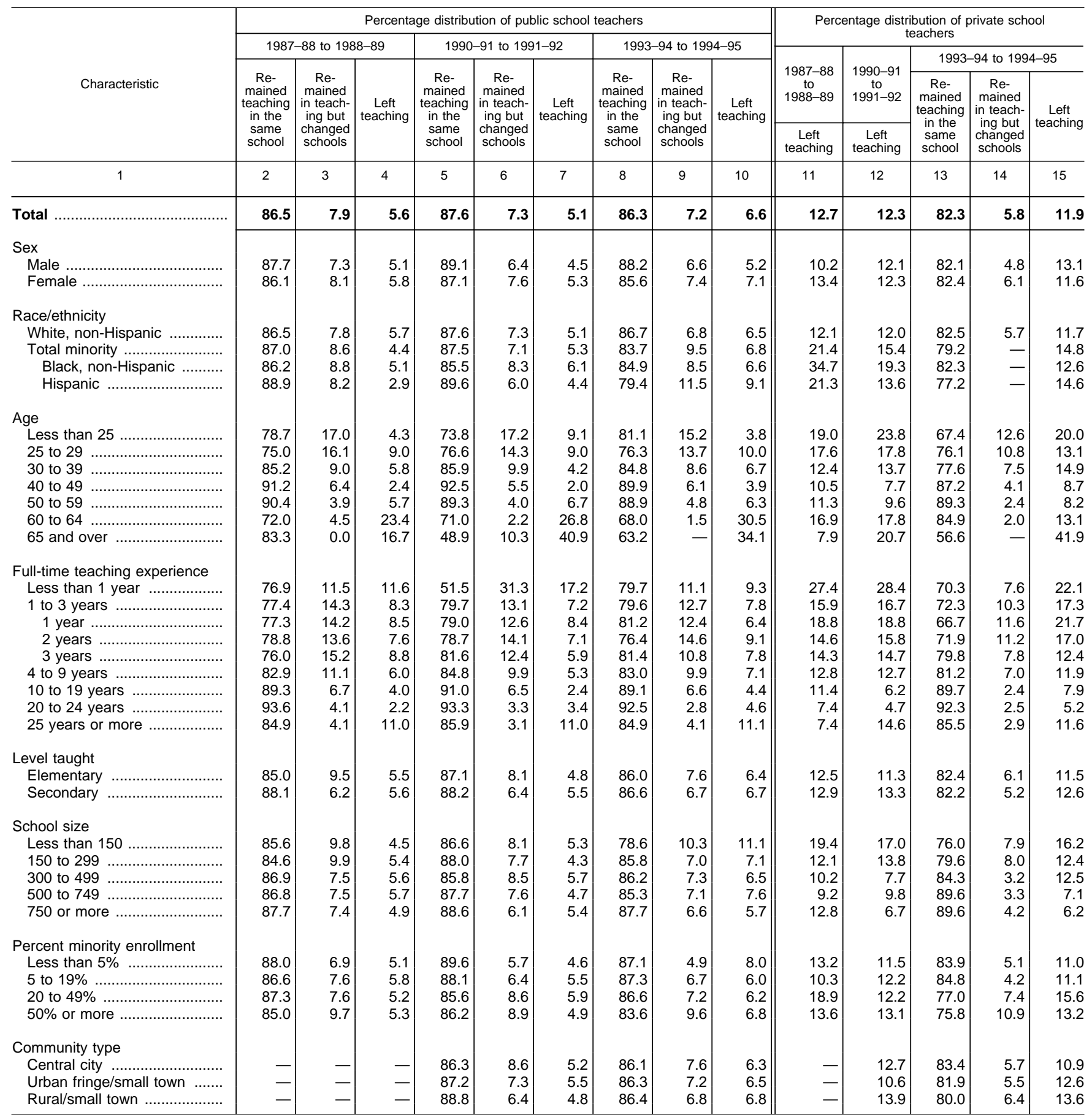

—Data not available or not applicable.

NOTE.-Details may not add to 100 percent due to rounding
SOURCE: US. Department of Education, National Center for Education Statistics, Characteristics of Stayers, Movers, and Leavers: Results from the Teacher Followup Survey: 1994-95. (This table was prepared April 1997.) 
Table 74.-Average salaries for full-time teachers in public and private elementary and secondary schools, by selected characteristics: $1993-94$

\begin{tabular}{|c|c|c|c|c|c|c|c|c|c|c|}
\hline \multirow[b]{2}{*}{ Selected characteristics } & \multirow{2}{*}{$\begin{array}{l}\text { Total } \\
\text { earned } \\
\text { income }\end{array}$} & \multirow[b]{2}{*}{$\begin{array}{l}\text { Base } \\
\text { salary }\end{array}$} & \multirow{2}{*}{$\begin{array}{l}\text { Number of } \\
\text { full-time } \\
\text { teachers }\end{array}$} & \multicolumn{2}{|c|}{$\begin{array}{l}\text { School year } \\
\text { supplemental } \\
\text { contract }\end{array}$} & \multicolumn{2}{|c|}{$\begin{array}{l}\text { Supplemental } \\
\text { contract during } \\
\text { summer }\end{array}$} & \multicolumn{3}{|c|}{$\begin{array}{l}\text { Number of teachers with } \\
\text { nonschool employment }\end{array}$} \\
\hline & & & & $\begin{array}{l}\text { Number } \\
\text { of } \\
\text { teachers }\end{array}$ & $\begin{array}{l}\text { Supple- } \\
\text { mental } \\
\text { salary }\end{array}$ & $\begin{array}{c}\text { Number } \\
\text { of } \\
\text { teachers }\end{array}$ & $\begin{array}{l}\text { Supple- } \\
\text { mental } \\
\text { salary }\end{array}$ & $\begin{array}{l}\text { Teach- } \\
\text { ing or } \\
\text { tutor }\end{array}$ & $\begin{array}{l}\text { Edu- } \\
\text { cation } \\
\text { related }\end{array}$ & $\begin{array}{l}\text { Not edu- } \\
\text { cation } \\
\text { related }\end{array}$ \\
\hline \multirow[t]{2}{*}{1} & 2 & 3 & 4 & 5 & 6 & 7 & 8 & 9 & 10 & 11 \\
\hline & \multicolumn{10}{|c|}{ Public schools } \\
\hline Total & $\$ 36,498$ & $\$ 34,153$ & $2,340,443$ & 815,827 & $\$ 2,075$ & 401,516 & $\$ 2,070$ & 118,603 & 80,014 & 237,177 \\
\hline 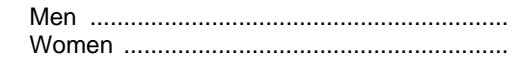 & $\begin{array}{l}41,031 \\
34,781\end{array}$ & $\begin{array}{l}36,182 \\
33,384\end{array}$ & $\begin{array}{r}642,807 \\
1,697,636\end{array}$ & $\begin{array}{l}348,855 \\
466,972\end{array}$ & $\begin{array}{l}2,923 \\
1,442\end{array}$ & $\begin{array}{l}147,299 \\
254,218\end{array}$ & $\begin{array}{l}2,530 \\
1,803\end{array}$ & $\begin{array}{l}37,297 \\
81,305\end{array}$ & $\begin{array}{l}39,150 \\
40,863\end{array}$ & $\begin{array}{l}124,487 \\
112,689\end{array}$ \\
\hline 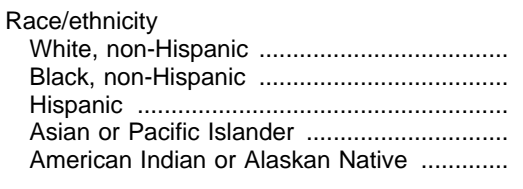 & $\begin{array}{l}36,576 \\
36,200 \\
35,197 \\
38,292 \\
35,635\end{array}$ & $\begin{array}{l}34,221 \\
33,889 \\
32,996 \\
36,134 \\
32,994\end{array}$ & $\begin{array}{r}2,012,142 \\
181,896 \\
102,965 \\
25,383 \\
18,057\end{array}$ & $\begin{array}{r}722,694 \\
48,968 \\
31,653 \\
6,391 \\
6,121\end{array}$ & $\begin{array}{l}2,067 \\
2,325 \\
1,930 \\
1,873 \\
2,068\end{array}$ & $\begin{array}{r}328,492 \\
40,819 \\
24,122 \\
5,381 \\
2,703\end{array}$ & $\begin{array}{l}2,015 \\
2,221 \\
2,477 \\
2,285 \\
2,305\end{array}$ & $\begin{array}{r}100,017 \\
10,734 \\
5,817 \\
1,298 \\
737\end{array}$ & $\begin{array}{r}68,991 \\
5,490 \\
3,644 \\
910 \\
979\end{array}$ & $\begin{array}{r}208,306 \\
16,336 \\
7,337 \\
2,327 \\
2,871\end{array}$ \\
\hline 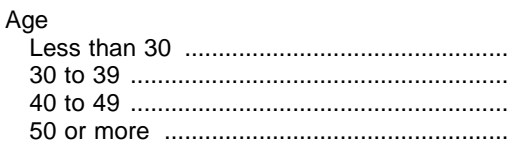 & $\begin{array}{l}27,151 \\
31,596 \\
38,106 \\
42,243\end{array}$ & $\begin{array}{l}24,737 \\
29,270 \\
35,751 \\
39,931\end{array}$ & $\begin{array}{l}258,692 \\
517,638 \\
974,299 \\
589,815\end{array}$ & $\begin{array}{l}113,918 \\
204,607 \\
328,974 \\
168,328\end{array}$ & $\begin{array}{l}1,777 \\
2,163 \\
2,107 \\
2,109\end{array}$ & $\begin{array}{r}51,862 \\
102,314 \\
161,320 \\
86,021\end{array}$ & $\begin{array}{l}1,819 \\
1,942 \\
2,053 \\
2,404\end{array}$ & $\begin{array}{l}11,924 \\
24,860 \\
50,193 \\
31,625\end{array}$ & $\begin{array}{r}8,078 \\
19,623 \\
34,480 \\
17,833\end{array}$ & $\begin{array}{r}28,228 \\
49,690 \\
100,528 \\
58,730\end{array}$ \\
\hline 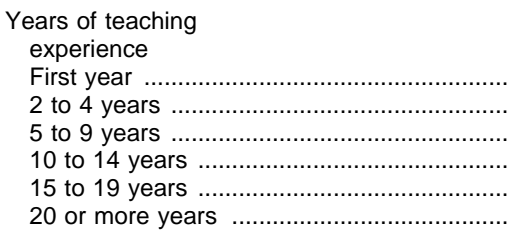 & $\begin{array}{l}26,641 \\
27,217 \\
30,709 \\
33,805 \\
37,984 \\
43,796\end{array}$ & $\begin{array}{l}23,544 \\
25,089 \\
28,451 \\
31,792 \\
35,809 \\
41,215\end{array}$ & $\begin{array}{r}99,833 \\
272,905 \\
388,370 \\
355,460 \\
380,168 \\
843,707\end{array}$ & $\begin{array}{r}35,238 \\
109,127 \\
145,326 \\
114,950 \\
131,094 \\
280,091\end{array}$ & $\begin{array}{l}1,573 \\
1,660 \\
1,998 \\
2,110 \\
2,177 \\
2,279\end{array}$ & $\begin{array}{r}16,007 \\
54,192 \\
79,198 \\
58,360 \\
65,105 \\
128,653\end{array}$ & $\begin{array}{l}2,516 \\
1,806 \\
2,046 \\
2,003 \\
1,842 \\
2,285\end{array}$ & $\begin{array}{r}4,554 \\
10,991 \\
23,195 \\
16,150 \\
19,878 \\
43,835\end{array}$ & $\begin{array}{r}2,463 \\
9,575 \\
11,272 \\
12,281 \\
14,175 \\
30,248\end{array}$ & $\begin{array}{l}13,210 \\
30,150 \\
36,451 \\
30,036 \\
35,835 \\
91,495\end{array}$ \\
\hline 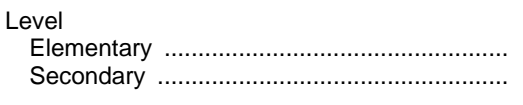 & $\begin{array}{l}34,944 \\
38,114\end{array}$ & $\begin{array}{l}33,517 \\
34,815\end{array}$ & $\begin{array}{l}1,193,257 \\
1,147,186\end{array}$ & $\begin{array}{l}254,890 \\
560,937\end{array}$ & $\begin{array}{l}1,503 \\
2,335\end{array}$ & $\begin{array}{l}170,059 \\
231,457\end{array}$ & $\begin{array}{l}1,801 \\
2,267\end{array}$ & $\begin{array}{l}47,820 \\
70,783\end{array}$ & $\begin{array}{l}27,084 \\
52,930\end{array}$ & $\begin{array}{r}90,749 \\
146,427\end{array}$ \\
\hline 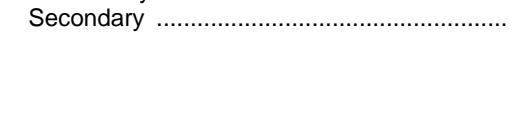 & \multicolumn{10}{|c|}{ Private schools } \\
\hline Total & $\$ 24,053$ & $\$ 21,968$ & 302,431 & 64,063 & $\$ 1,894$ & 62,847 & $\$ 2,122$ & 20,237 & 11,424 & 34,099 \\
\hline 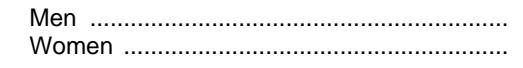 & $\begin{array}{l}30,215 \\
22,118\end{array}$ & $\begin{array}{l}26,120 \\
20,669\end{array}$ & $\begin{array}{r}72,264 \\
230,167\end{array}$ & $\begin{array}{l}27,418 \\
36,645\end{array}$ & $\begin{array}{l}2,408 \\
1,509\end{array}$ & $\begin{array}{l}21,317 \\
41,530\end{array}$ & $\begin{array}{l}2,584 \\
1,885\end{array}$ & $\begin{array}{r}3,993 \\
16,244\end{array}$ & $\begin{array}{l}4,969 \\
6,456\end{array}$ & $\begin{array}{l}14,283 \\
19,816\end{array}$ \\
\hline $\begin{array}{l}\text { Race/ethnicity } \\
\text { White, non-Hispanic } \\
\text { Black, non-Hispanic }\end{array}$ & $\begin{array}{l}24,084 \\
23,043 \\
22,256 \\
28,505 \\
25,082\end{array}$ & $\begin{array}{l}22,000 \\
20,796 \\
20,672 \\
25,861 \\
21,625\end{array}$ & $\begin{array}{r}278,749 \\
8,946 \\
9,862 \\
3,786 \\
1,088\end{array}$ & $\begin{array}{r}59,475 \\
1,350 \\
2,013 \\
997 \\
(1)\end{array}$ & $\begin{array}{r}1,903 \\
2,451 \\
1,209 \\
2,054 \\
\left({ }^{1}\right)\end{array}$ & $\begin{array}{r}55,950 \\
3,024 \\
2,269 \\
1,185 \\
(1)\end{array}$ & $\begin{array}{r}2,109 \\
2,173 \\
2,298 \\
2,643 \\
\left({ }^{1}\right)\end{array}$ & $\begin{array}{r}18,461 \\
(1) \\
(1) \\
(1) \\
(1)\end{array}$ & $\begin{array}{r}10,677 \\
(1) \\
(1) \\
(1) \\
(1)\end{array}$ & $\begin{array}{r}31,724 \\
(1) \\
(1) \\
(1) \\
(1)\end{array}$ \\
\hline Age & & & & & & & & & & \\
\hline $\begin{array}{l}\text { Less than } 30 \\
30 \text { to } 39 \\
40 \text { to } 49 \\
50 \text { or more }\end{array}$ & $\begin{array}{l}19,438 \\
23,334 \\
25,230 \\
26,845\end{array}$ & $\begin{array}{l}17,010 \\
20,925 \\
23,224 \\
25,273\end{array}$ & $\begin{array}{r}56,709 \\
73,855 \\
102,226 \\
69,641\end{array}$ & $\begin{array}{l}14,802 \\
16,590 \\
21,284 \\
11,388\end{array}$ & $\begin{array}{l}1,572 \\
1,947 \\
1,915 \\
2,193\end{array}$ & $\begin{array}{r}15,865 \\
17,227 \\
20,355 \\
9,400\end{array}$ & $\begin{array}{l}1,781 \\
2,161 \\
2,196 \\
2,467\end{array}$ & $\begin{array}{l}4,600 \\
4,636 \\
6,965 \\
4,035\end{array}$ & $\begin{array}{l}2,373 \\
3,247 \\
3,794 \\
2,010\end{array}$ & $\begin{array}{r}8,982 \\
10,087 \\
9,580 \\
5,449\end{array}$ \\
\hline $\begin{array}{l}\text { Years of teaching } \\
\text { experience }\end{array}$ & & & & & & & & & & \\
\hline 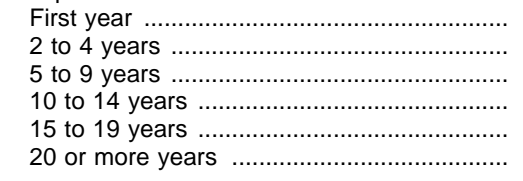 & $\begin{array}{l}19,408 \\
19,858 \\
21,764 \\
24,266 \\
27,238 \\
29,258\end{array}$ & $\begin{array}{l}16,318 \\
17,719 \\
19,748 \\
22,424 \\
25,351 \\
27,178\end{array}$ & $\begin{array}{l}22,922 \\
54,831 \\
66,567 \\
49,880 \\
42,209 \\
66,022\end{array}$ & $\begin{array}{r}4,832 \\
12,001 \\
13,905 \\
10,007 \\
8,985 \\
14,334\end{array}$ & $\begin{array}{l}1,539 \\
1,580 \\
1,816 \\
1,741 \\
2,129 \\
2,310\end{array}$ & $\begin{array}{r}4,545 \\
15,974 \\
14,111 \\
9,171 \\
8,460 \\
10,585\end{array}$ & $\begin{array}{l}1,973 \\
1,899 \\
2,112 \\
2,032 \\
2,257 \\
2,508\end{array}$ & $\begin{array}{l}1,798 \\
3,970 \\
4,625 \\
2,369 \\
3,601 \\
3,874\end{array}$ & $\begin{array}{r}\left({ }^{1}\right) \\
1,924 \\
3,184 \\
1,404 \\
1,812 \\
2,320\end{array}$ & $\begin{array}{l}3,395 \\
8,207 \\
8,044 \\
5,133 \\
3,452 \\
5,867\end{array}$ \\
\hline 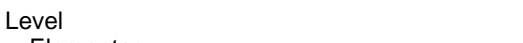 & & & & & & & & & & \\
\hline $\begin{array}{l}\text { Elementary } \\
\text { Secondary }\end{array}$ & $\begin{array}{l}21,485 \\
27,824\end{array}$ & $\begin{array}{l}19,977 \\
24,896\end{array}$ & $\begin{array}{l}179,936 \\
122,496\end{array}$ & $\begin{array}{l}23,015 \\
41,048\end{array}$ & $\begin{array}{l}1,514 \\
2,106\end{array}$ & $\begin{array}{l}33,338 \\
29,509\end{array}$ & $\begin{array}{l}1,846 \\
2,435\end{array}$ & $\begin{array}{r}11,805 \\
8,432\end{array}$ & $\begin{array}{l}5,645 \\
5,780\end{array}$ & $\begin{array}{l}18,137 \\
15,962\end{array}$ \\
\hline
\end{tabular}

1 Too few sample cases (fewer than 30 ) for a reliable estimate.

NOTE.-Details may not add to totals because of rounding or missing values in cells with too few cases, or survey item nonresponse.
SOURCE: U.S. Department of Education, National Center for Education Statistics, "Schools and Staffing Survey, 1993-94," unpublished data. (This table was prepared November 1997.) 
Table 75.-Opinions of public school teachers on the overall quality of education that students received at their school, by selected characteristics: 1987 and 1997

\begin{tabular}{|c|c|c|c|c|c|c|c|c|}
\hline \multirow{3}{*}{ Student characteristics } & \multicolumn{8}{|c|}{ Percent of teachers } \\
\hline & \multicolumn{4}{|c|}{1987} & \multicolumn{4}{|c|}{1997} \\
\hline & Excellent & Good & Fair & Poor & Excellent & Good & Fair & Poor \\
\hline 1 & 2 & 3 & 4 & 5 & 6 & 7 & 8 & 9 \\
\hline . & 26 & 64 & 9 & 1 & 37 & 55 & 7 & 1 \\
\hline 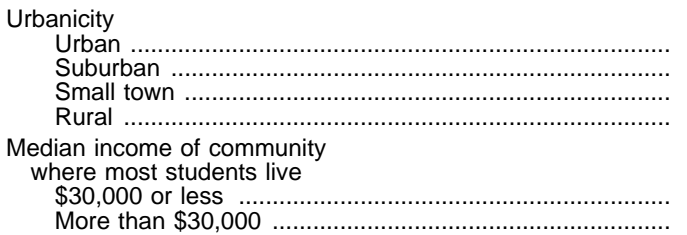 & $\begin{array}{l}18 \\
29 \\
26 \\
26\end{array}$ & $\begin{array}{l}65 \\
62 \\
64 \\
64 \\
- \\
-\end{array}$ & $\begin{array}{r}15 \\
8 \\
9 \\
8\end{array}$ & $\begin{array}{l}1 \\
1 \\
1 \\
2 \\
- \\
-\end{array}$ & $\begin{array}{l}30 \\
50 \\
36 \\
33\end{array}$ & $\begin{array}{l}56 \\
47 \\
59 \\
58 \\
\\
59 \\
48\end{array}$ & $\begin{array}{r}12 \\
3 \\
5 \\
8\end{array}$ & $\begin{array}{r}2 \\
0 \\
0 \\
(1)\end{array}$ \\
\hline
\end{tabular}

Table 76.-Percent of public school teachers who reported opinions on various aspects of their schools: 1987 and 1997

\begin{tabular}{|c|c|c|c|c|c|c|c|c|}
\hline \multirow{2}{*}{ Aspect of school } & \multicolumn{4}{|c|}{1987} & \multicolumn{4}{|c|}{1997} \\
\hline & Excellent & Good & Fair & Poor & Excellent & Good & Fair & Poor \\
\hline $\begin{array}{l}\text { The qualifications and competence of } \\
\text { teachers in your school }\end{array}$ & 45 & 48 & 7 & - & 54 & 41 & 4 & - \\
\hline $\begin{array}{l}\text { The relations between parents and } \\
\text { teachers in your school }\end{array}$ & 15 & 53 & 25 & 6 & 13 & 58 & 24 & 4 \\
\hline 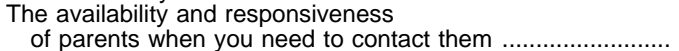 & 14 & 38 & 37 & 11 & 16 & 47 & 27 & 10 \\
\hline $\begin{array}{l}\text { The amount of support for the school } \\
\text { shown by the parents }\end{array}$ & 17 & 10 & 30 & . & . & . & . & \\
\hline The overall quality of the education & 17 & 40 & 30 & 12 & 19 & 44 & 28 & 10 \\
\hline 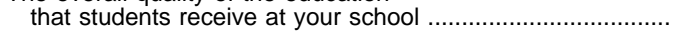 & 26 & 64 & 9 & 1 & 37 & 55 & 7 & 1 \\
\hline
\end{tabular}

Table 77.-Percent of public school students who reported various levels of parental/guardian involvement in their education, by selected student characteristics: 1997

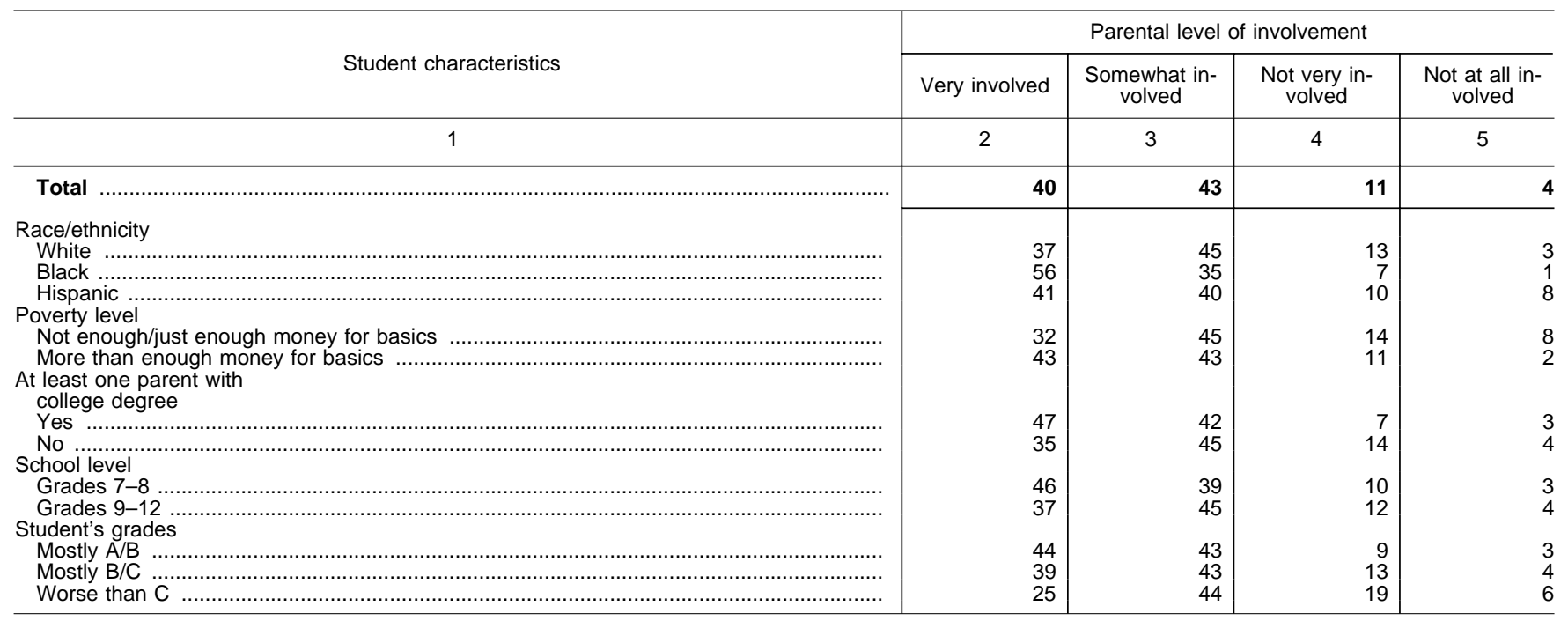

SOURCE: Metropolitan Life/Louis Harris Associates, Inc., The Metropolitan Life Survey of The American Teacher, 1998. "Building Family-School Partnerships: Views of Teachers and Students." (This table was prepared September 1998.) 
Table 78.-Estimated average annual salary of teachers in public elementary and secondary schools: $1959-60$ to $1997-98$

\begin{tabular}{|c|c|c|c|c|c|c|}
\hline \multirow[b]{2}{*}{ School year } & \multicolumn{3}{|c|}{ Current dollars } & \multicolumn{3}{|c|}{ Constant $1997-98$ dollars ${ }^{1}$} \\
\hline & All teachers & $\begin{array}{c}\text { Elementary } \\
\text { teachers }\end{array}$ & $\begin{array}{c}\text { Secondary } \\
\text { teachers }\end{array}$ & All teachers & $\begin{array}{c}\text { Elementary } \\
\text { teachers }\end{array}$ & $\begin{array}{c}\text { Secondary } \\
\text { teachers }\end{array}$ \\
\hline 1 & 2 & 3 & 4 & 5 & 6 & 7 \\
\hline 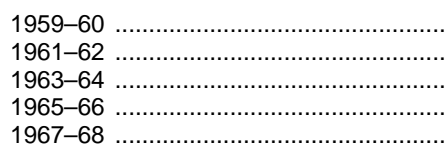 & $\begin{array}{r}\$ 4,995 \\
5,515 \\
5,995 \\
6,485 \\
7,423\end{array}$ & $\begin{array}{r}\$ 4,815 \\
5,340 \\
5,805 \\
6,279 \\
7,208\end{array}$ & $\begin{array}{r}\$ 5,276 \\
5,775 \\
6,266 \\
6,761 \\
7,692\end{array}$ & $\begin{array}{r}\$ 27,496 \\
29,676 \\
31,439 \\
32,873 \\
35,304\end{array}$ & $\begin{array}{r}\$ 26,505 \\
28,735 \\
30,443 \\
31,828 \\
34,281\end{array}$ & $\begin{array}{r}\$ 29,042 \\
31,075 \\
32,860 \\
34,272 \\
36,583\end{array}$ \\
\hline 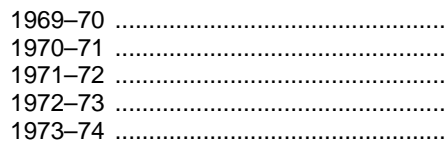 & $\begin{array}{r}8,626 \\
9,268 \\
9,705 \\
10,174 \\
10,770\end{array}$ & $\begin{array}{r}8,412 \\
9,021 \\
9,424 \\
9,893 \\
10,507\end{array}$ & $\begin{array}{r}8,891 \\
9,568 \\
10,031 \\
10,507 \\
11,077\end{array}$ & $\begin{array}{l}36,934 \\
37,735 \\
38,146 \\
38,441 \\
37,361\end{array}$ & $\begin{array}{l}36,018 \\
36,729 \\
37,041 \\
37,379 \\
36,449\end{array}$ & $\begin{array}{l}38,069 \\
38,957 \\
39,427 \\
39,699 \\
38,426\end{array}$ \\
\hline 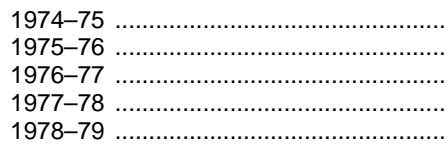 & $\begin{array}{l}11,641 \\
12,600 \\
13,354 \\
14,198 \\
15,032\end{array}$ & $\begin{array}{l}11,334 \\
12,280 \\
12,989 \\
13,845 \\
14,681\end{array}$ & $\begin{array}{l}12,000 \\
12,937 \\
13,776 \\
14,602 \\
15,450\end{array}$ & $\begin{array}{l}36,354 \\
36,748 \\
36,801 \\
36,665 \\
35,494\end{array}$ & $\begin{array}{l}35,395 \\
35,814 \\
35,795 \\
35,753 \\
34,665\end{array}$ & $\begin{array}{l}37,475 \\
37,730 \\
37,964 \\
37,708 \\
36,480\end{array}$ \\
\hline 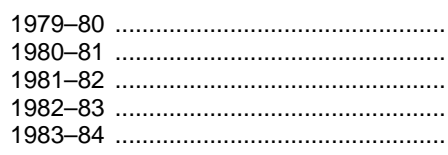 & $\begin{array}{l}15,970 \\
17,644 \\
19,274 \\
20,695 \\
21,935\end{array}$ & $\begin{array}{l}15,569 \\
17,230 \\
18,853 \\
20,227 \\
21,487\end{array}$ & $\begin{array}{l}16,459 \\
18,142 \\
19,805 \\
21,291 \\
22,554\end{array}$ & $\begin{array}{l}33,272 \\
32,944 \\
33,126 \\
34,103 \\
34,857\end{array}$ & $\begin{array}{l}32,437 \\
32,171 \\
32,402 \\
33,332 \\
34,145\end{array}$ & $\begin{array}{l}34,291 \\
33,874 \\
34,039 \\
35,086 \\
35,840\end{array}$ \\
\hline 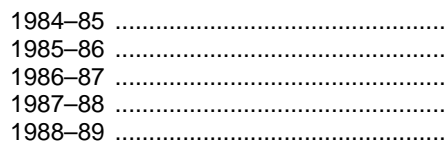 & $\begin{array}{l}23,600 \\
25,199 \\
26,569 \\
28,034 \\
29,564\end{array}$ & $\begin{array}{l}23,200 \\
24,718 \\
26,057 \\
27,519 \\
29,022\end{array}$ & $\begin{array}{l}24,187 \\
25,846 \\
27,244 \\
28,798 \\
30,218\end{array}$ & $\begin{array}{l}36,090 \\
37,455 \\
38,634 \\
39,142 \\
39,456\end{array}$ & $\begin{array}{l}35,478 \\
36,740 \\
37,889 \\
38,423 \\
38,733\end{array}$ & $\begin{array}{l}36,987 \\
38,417 \\
39,615 \\
40,209 \\
40,329\end{array}$ \\
\hline 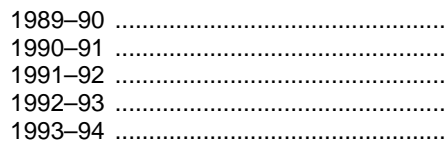 & $\begin{array}{l}31,367 \\
33,084 \\
34,063 \\
35,029 \\
35,737\end{array}$ & $\begin{array}{l}30,832 \\
32,490 \\
33,479 \\
34,350 \\
35,233\end{array}$ & $\begin{array}{l}32,049 \\
33,896 \\
34,827 \\
35,880 \\
36,566\end{array}$ & $\begin{array}{l}39,956 \\
39,958 \\
39,863 \\
39,752 \\
39,531\end{array}$ & $\begin{array}{l}39,274 \\
39,241 \\
39,180 \\
38,981 \\
38,974\end{array}$ & $\begin{array}{l}40,824 \\
40,939 \\
40,757 \\
40,718 \\
40,448\end{array}$ \\
\hline $\begin{array}{l}1994-95 \\
1995-96 \\
1996-97 \\
1997-98\end{array}$ & $\begin{array}{l}36,685 \\
37,716 \\
38,554 \\
39,385\end{array}$ & $\begin{array}{l}36,160 \\
37,295 \\
38,193 \\
39,075\end{array}$ & $\begin{array}{l}37,468 \\
38,371 \\
39,137 \\
39,889\end{array}$ & $\begin{array}{l}39,449 \\
39,484 \\
39,242 \\
39,385\end{array}$ & $\begin{array}{l}38,885 \\
39,043 \\
38,874 \\
39,075\end{array}$ & $\begin{array}{l}40,291 \\
40,170 \\
39,835 \\
39,889\end{array}$ \\
\hline
\end{tabular}

1 Based on the Consumer Price Index, prepared by the Bureau of Labor Statistics, U.S. Department of Labor.

NOTE.-Some data have been revised from previously published figures.
SOURCE: National Education Association, Estimates of School Statistics; and unpublished data. (Latest edition 1997-98. Copyright $\odot 1998$ by the National Education Association. All rights reserved.) (This table was prepared October 1998.) 
Table 79.-Estimated average annual salary of teachers in public elementary and secondary schools, by state: 1969-70 to $1997-98$

\begin{tabular}{|c|c|c|c|c|c|c|c|c|c|c|c|c|c|c|}
\hline \multirow[b]{2}{*}{ State } & \multicolumn{7}{|c|}{ Current dollars } & \multicolumn{6}{|c|}{ Constant $1997-98$ dollars ${ }^{1}$} & \multirow{2}{*}{$\begin{array}{c}\text { Percent } \\
\text { change, } \\
1979-80 \\
\text { to } \\
\begin{array}{c}1997-98 \\
\text { in } \\
\text { constant } \\
\text { dollars }\end{array}\end{array}$} \\
\hline & 1969-70 & $1979-80$ & $1989-90$ & 1994-95 & 1995-96 & $1996-97$ & 1997-98 & 1969-70 & $1979-80$ & 1989-90 & 1994-95 & 1995-96 & $1996-97$ & \\
\hline 1 & 2 & 3 & 4 & 5 & 6 & 7 & 8 & 9 & 10 & 11 & 12 & 13 & 14 & 15 \\
\hline United States ...... & $\$ 8,626$ & $\$ 15,970$ & $\$ 31,367$ & $\$ 36,685$ & $\$ 37,716$ & $\$ 38,554$ & $\$ 39,385$ & $\$ 36,934$ & $\$ 33,272$ & $\$ 39,956$ & $\$ 39,449$ & $\$ 39,484$ & $\$ 39,242$ & 18.4 \\
\hline Alabama .... & 6,818 & 13,060 & 24,828 & 31,144 & 31,313 & 32,549 & 32,818 & 29,193 & 27,209 & 31,626 & 33,491 & 32,781 & 33,129 & 20.6 \\
\hline Alaska ............ & 10,560 & 27,210 & 43,153 & 47,951 & 49,171 & 50,647 & 51,738 & 45,215 & 56,690 & 54,969 & 51,564 & 51,476 & 51,550 & -8.7 \\
\hline Arizona .................. & 8,711 & 15,054 & 29,402 & 32,574 & 33,300 & 33,300 & 33,850 & 37,298 & 31,364 & 37,453 & 35,029 & 34,861 & 33,894 & 7.9 \\
\hline Arkansas ...... & 6,307 & 12,299 & 22,352 & 28,934 & 29,533 & 30,319 & 30,578 & 27,005 & 25,624 & 28,472 & 31,114 & 30,917 & 30,860 & 19.3 \\
\hline California & 10,315 & 18,020 & 37,998 & 41,078 & 42,259 & 42,992 & 43,725 & 44,166 & 37,543 & 48,402 & 44,173 & 44,240 & 43,759 & 16.5 \\
\hline Colorado ......... & 7,761 & 16,205 & 30,758 & 34,571 & 35,364 & 36,271 & 37,052 & 33,230 & 33,762 & 39,180 & 37,176 & 37,022 & 36,918 & 9.7 \\
\hline Connecticut ... & 9,262 & 16,229 & 40,461 & 50,045 & 50,254 & 50,426 & 50,730 & 39,657 & 33,812 & 51,540 & 53,816 & 52,610 & 51,325 & 50.0 \\
\hline Delaware ...... & 9,015 & 16,148 & 33,377 & 39,076 & 40,533 & 41,436 & 42,439 & 38,600 & 33,643 & 42,516 & 42,021 & 42,433 & 42,175 & 26.1 \\
\hline District of Columbia .......... & 10,285 & 22,190 & 38,402 & 43,700 & 43,700 & 45,012 & 46,350 & 44,037 & 46,231 & 48,917 & 46,993 & 45,748 & 45,815 & 0.3 \\
\hline Florida & 8,412 & 14,149 & 28,803 & 32,588 & 33,330 & 33,889 & 34,475 & 36,018 & 29,478 & 36,690 & 35,044 & 34,892 & 34,493 & 17.0 \\
\hline Georgia & 7,276 & 13,853 & 28,006 & 32,291 & 34,002 & 35,596 & 37,378 & 31,154 & 28,862 & 35,674 & 34,724 & 35,596 & 36,231 & 29.5 \\
\hline Hawaii .. & 9,453 & 19,920 & 32,047 & 38,518 & 35,807 & 35,842 & 38,377 & 40,475 & 41,502 & 40,822 & 41,421 & 37,485 & 36,481 & -7.5 \\
\hline Idaho & 6,890 & 13,611 & 23,861 & 29,783 & 30,891 & 31,818 & 32,775 & 29,501 & 28,357 & 30,394 & 32,027 & 32,339 & 32,385 & 15.6 \\
\hline Illinois ...... & 9,569 & 17,601 & 32,794 & 39,431 & 40,919 & 42,125 & 43,873 & 40,972 & 36,670 & 41,773 & 42,402 & 42,837 & 42,876 & 19.6 \\
\hline Indiana ……....................... & 8,833 & 15,599 & 30,902 & 36,785 & 37,675 & 38,845 & 39,682 & 37,820 & 32,499 & 39,363 & 39,557 & 39,441 & 39,538 & 22.1 \\
\hline lowa & 8,355 & 15,203 & 26,747 & 31,511 & 32,372 & 33,272 & 34,040 & 5,774 & 31,674 & 34,071 & 33,886 & 33,889 & 33 & 7.5 \\
\hline 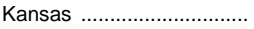 & 7,612 & 13,690 & 28,744 & 34,652 & 35,023 & 35,739 & 36,811 & 32,592 & 28,522 & 36,614 & 37,263 & 36,665 & 36,376 & 29.1 \\
\hline 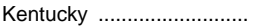 & 6,953 & 14,520 & 26,292 & 32,257 & 33,080 & 33,797 & 34,525 & 29,771 & 30,251 & 33,491 & 34,688 & 34,631 & 34,400 & 14.1 \\
\hline Louisiana ............................... & 7,028 & 13,760 & 24,300 & 26,461 & 27,530 & 29,025 & 29,650 & 30,092 & 28,668 & 30,954 & 28,455 & 28,820 & 29,543 & 3.4 \\
\hline 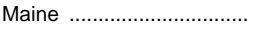 & 7,572 & 13,071 & 26,881 & 31,972 & 32,869 & 33,676 & 34,349 & 32,421 & 27,232 & 34,241 & 34,381 & 34,410 & 34,277 & 26.1 \\
\hline Maryland & 9,383 & 17,558 & 36,319 & 40,661 & 41,160 & 41,148 & 41,739 & 40,175 & 36,581 & 46,263 & 43,725 & 43,089 & 41,882 & 14.1 \\
\hline Massachusetts & 8,764 & 17,253 & 34,712 & 40,718 & 41,408 & 42,650 & 43,930 & 37,525 & 35,945 & 44,216 & 43,786 & 43,349 & 43,411 & 22.2 \\
\hline 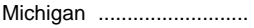 & 9,826 & 19,663 & 37,072 & 41,895 & 46,832 & 48,238 & 49,277 & 42,072 & 40,966 & 47,223 & 45,052 & 49,027 & 49,098 & 20.3 \\
\hline Minnesota .......................... & 8,658 & 15,912 & 32,190 & 35,948 & 36,937 & 38,281 & 39,106 & 37,071 & 33,151 & 41,004 & 38,657 & 38,668 & 38,964 & 18.0 \\
\hline Mississippi ........ & 5,798 & 11,850 & 24,292 & 26,818 & 27,692 & 27,720 & 29,547 & 24,825 & 24,689 & 30,943 & 28,839 & 28,990 & 28,214 & 19.7 \\
\hline Missouri ............ & 7,799 & 13,682 & 27,094 & 31,189 & 32,322 & 33,155 & 33,975 & 33,393 & 28,505 & 34,513 & 33,539 & 33,837 & 33,746 & 19.2 \\
\hline Montana ............ & 7,606 & 14,537 & 25,081 & 28,785 & 29,364 & 29,958 & 30,617 & 32,567 & 30,287 & 31,948 & 30,954 & 30,740 & 30,492 & 1.1 \\
\hline 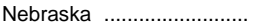 & 7,375 & 13,516 & 25,522 & 30,922 & 31,496 & 31,768 & 32,668 & 31,578 & 28,159 & 32,510 & 33,252 & 32,972 & 32,335 & 16.0 \\
\hline 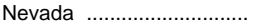 & 9,215 & 16,295 & 30,590 & 34,836 & 36,167 & 37,340 & 37,093 & 39,456 & 33,949 & 38,966 & 37,461 & 37,862 & 38,006 & 9.3 \\
\hline New Hampshire ................... & 7,771 & 13,017 & 28,986 & 34,720 & 35,792 & 36,029 & 36,640 & 33,273 & 27,120 & 36,923 & 37,336 & 37,470 & 36,672 & 35.1 \\
\hline New Jersey & 9,130 & 17,161 & 35,676 & 47,038 & 48,751 & 786 & 442 & 39,092 & 35,754 & 45,444 & 50,583 & 51,036 & 50,674 & 41.1 \\
\hline New Mexico ........................... & 7,796 & 14,887 & 24,756 & 28,493 & 29,074 & 30,131 & 30,152 & 33,380 & 31,016 & 31,534 & 30,640 & 30,437 & 30,668 & -2.8 \\
\hline New York .................. & 10,336 & 19,812 & 38,925 & 47,612 & 48,115 & 48,000 & 49,034 & 44,256 & 41,277 & 49,583 & 51,200 & 50,370 & 48,856 & 18.8 \\
\hline North Carolina & 7,494 & 14,117 & 27,883 & 30,793 & 30,411 & 31,167 & 33,315 & 32,087 & 29,412 & 35,518 & 33,113 & 31,836 & 31,723 & 13.3 \\
\hline North Dakota ...................... & 6,696 & 13,263 & 23,016 & 26,327 & 26,969 & 27,711 & 28,230 & 28,670 & 27,632 & 29,318 & 28,311 & 28,233 & 28,205 & 2.2 \\
\hline Ohio & 8,300 & 15,269 & 218 & 802 & 37,835 & $\$ 76$ & 77 & 38 & 31,812 & 66 & 75 & 008 & 366 & 22.5 \\
\hline Oklahoma & 6,882 & 13,107 & 23,070 & 28,172 & 28,404 & 30,369 & 30,606 & 29,467 & 27,307 & 29,387 & 30,295 & 29,735 & 30,911 & 12.1 \\
\hline Oregon ............. & 8,818 & 16,266 & 30,840 & 38,555 & 39,706 & 40,960 & 42,150 & 37,756 & 33,889 & 39,284 & 41,460 & 41,567 & 41,690 & 24.4 \\
\hline Pennsylvania ……................ & 8,858 & 16,515 & 33,338 & 44,510 & 46,087 & 47,147 & 47,650 & 37,927 & 34,408 & 42,466 & 47,864 & 48,247 & 47,988 & 38.5 \\
\hline Rhode Island & 8,776 & 18,002 & 36,057 & 40,729 & 41,765 & 43,019 & 44,300 & 37,576 & 37,506 & 45,930 & 43,798 & 43,723 & 43,786 & 18.1 \\
\hline South Carolina & 6,927 & 13,063 & 27,217 & 30,279 & 31,622 & 32,830 & 608 & 29,659 & 27,216 & 34,669 & 32 & 33,104 & 33,415 & 23.5 \\
\hline South Dakota & 6,403 & 12,348 & 21,300 & 25,994 & 26,346 & 26,764 & 27,341 & 27,416 & 25,726 & 27,132 & 27,953 & 27,581 & 27,241 & 6.3 \\
\hline Tennessee ............................. & 7,050 & 13,972 & 27,052 & 32,477 & 33,126 & 34,222 & 35,340 & 30,186 & 29,110 & 34,459 & 34,924 & 34,679 & 34,832 & 21.4 \\
\hline 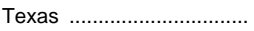 & 7,255 & 14,132 & 27,496 & 31,223 & 32,000 & 33,038 & 33,648 & 31,064 & 29,443 & 35,025 & 33,576 & 33,500 & 33,627 & 14.3 \\
\hline 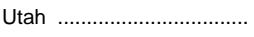 & 7,644 & 14,909 & 23,686 & 29,082 & 30,588 & 31,867 & 32,950 & 32,729 & 31,062 & 30,171 & 31,273 & 32,022 & 32,435 & 6.1 \\
\hline 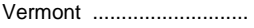 & 7,968 & 12,484 & 29,012 & 35,406 & 36,295 & 36,053 & 36,299 & 34,117 & 26,009 & 36,956 & 38,074 & 37,996 & 36,696 & 39.6 \\
\hline Virginia . & 8,070 & 14,060 & 30,938 & 33,987 & 34,792 & 35,691 & 36,654 & 34,553 & 29,293 & 39,409 & 36,548 & 36,423 & 36,328 & 25.1 \\
\hline Washington .......................... & 9,225 & 18,820 & 30,457 & 36,151 & 37,853 & 37,815 & 38,788 & 39,499 & 39,210 & 38,796 & 38,875 & 39,627 & 38,489 & -1.1 \\
\hline West Virginia & 7,650 & 13,710 & 22,842 & 31,944 & 32,155 & 33,257 & 33,398 & 32,755 & 28,564 & 29,096 & 34,351 & 33,662 & 33,850 & 16.9 \\
\hline Wisconsin & 8,963 & 16,006 & 31,921 & 37,746 & 38,182 & 39,057 & 39,899 & 38,377 & 33,347 & 40,661 & 40,590 & 39,972 & 39,754 & 19.6 \\
\hline Wyoming …….................... & 8,232 & 16,012 & 28,141 & 31,285 & 31,571 & 31,715 & 32,022 & 35,247 & 33,360 & 35,846 & 33,642 & 33,051 & 32,281 & -4.0 \\
\hline
\end{tabular}

1 Based on the Consumer Price Index prepared by the Bureau of Labor Statistics, U.S. Department of Labor. Price index does not account for different rates of change in the cost of living among states.
SOURCE: National Education Association, Estimates of School Statistics; and unpublished data. (Latest edition 1997-98. Copyright $\odot 1998$ by the National Education Association. All rights reserved.) (This table was prepared October 1998.)

NOTE.-Some data have been revised from previously published figures. 
Table 80.-Minimum and average teacher salaries, by state: 1990-91, 1995-96, and 1996-97

\begin{tabular}{|c|c|c|c|c|c|c|c|c|c|c|c|c|c|}
\hline \multirow{3}{*}{ State } & \multicolumn{4}{|c|}{$1990-91$} & \multicolumn{4}{|c|}{ 1995-96 } & \multicolumn{3}{|c|}{$1996-97$} & \multirow{2}{*}{\multicolumn{2}{|c|}{$\begin{array}{c}\text { Percent change, } \\
1990-91 \text { to } \\
1996-97 \\
\text { (constant dollars) }^{1}\end{array}$}} \\
\hline & \multirow[b]{2}{*}{$\begin{array}{l}\text { Minimum } \\
\text { (beginning) } \\
\text { salary }\end{array}$} & \multirow[b]{2}{*}{$\begin{array}{c}\text { Average } \\
\text { salary }\end{array}$} & \multirow{2}{*}{$\begin{array}{c}\text { Minimum } \\
\text { (beginning) } \\
\text { salary (in } \\
1996-97 \\
\text { dollars) }\end{array}$} & \multirow{2}{*}{\begin{tabular}{|} 
Average \\
salary \\
(in \\
$1996-97$ \\
dollars) 1
\end{tabular}} & \multirow[b]{2}{*}{$\begin{array}{l}\text { Minimum } \\
\text { (beginning) } \\
\text { salary }\end{array}$} & \multirow[b]{2}{*}{$\begin{array}{c}\text { Average } \\
\text { salary }\end{array}$} & \multirow{2}{*}{$\begin{array}{c}\text { Minimum } \\
\text { (beginning) } \\
\text { salary (in } \\
1996-97 \\
\text { dollars) }^{1}\end{array}$} & \multirow[b]{2}{*}{$\begin{array}{l}\text { Average } \\
\text { salary (in } \\
1996-97 \\
\text { dollars) }^{1}\end{array}$} & \multirow[b]{2}{*}{$\underset{\begin{array}{c}\text { Minimum } \\
\text { (beginning) } \\
\text { salary }\end{array}}{\mid}$} & & & & \\
\hline & & & & & & & & & & $\begin{array}{l}\text { Average } \\
\text { salary }\end{array}$ & $\begin{array}{c}\text { salary as a } \\
\text { percent of } \\
\text { average } \\
\text { salary }\end{array}$ & $\begin{array}{l}\text { Minimum } \\
\text { (beginning) } \\
\text { salary }\end{array}$ & $\begin{array}{c}\text { Average } \\
\text { salary }\end{array}$ \\
\hline 1 & 2 & 3 & 4 & 5 & 6 & 7 & 8 & 9 & 10 & 11 & 12 & 13 & 14 \\
\hline United States ....... & $\$ 21,542$ & $\$ 32,880$ & $\$ 25,561$ & $\$ 39,014$ & $\$ 24,507$ & $\$ 37,594$ & $\$ 25,205$ & $\$ 38,665$ & $\$ 25,012$ & $\$ 38,436$ & 65.1 & -2.1 & -1.5 \\
\hline Alabama . & 22,114 & 26,846 & 26,239 & 31,854 & 24,824 & 31,323 & 25,531 & 32,215 & 26,717 & 32,470 & 82.3 & 1.8 & 1.9 \\
\hline Alaska ………................... & 229,950 & 43,406 & 235,537 & 51,504 & 234,800 & 49,148 & 35,791 & 50,548 & 32,502 & 49,140 & 66.1 & -8.5 & -4.6 \\
\hline Arizona ............... & 221,375 & 30,773 & 225,363 & 36,514 & 224,042 & 32,843 & 24,727 & 33,778 & 24,286 & 33,208 & 73.1 & -4.2 & -9.1 \\
\hline Arkansas . & 3 17,458 & 423,735 & 3 20,715 & 428,163 & 221,189 & 429,964 & 21,792 & 30,817 & 220,680 & 30,987 & 66.7 & -0.2 & 10.0 \\
\hline 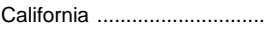 & 224,570 & 239,118 & 229,154 & 246,416 & 225,762 & 242,259 & 26,496 & 43,462 & 26,684 & 42,992 & 62.1 & -8.5 & -7.4 \\
\hline Colorado & 19,786 & 31,819 & 23,477 & 37,755 & 21,472 & 35,364 & 22,084 & 36,371 & 23,068 & 36,271 & 63.6 & -1.7 & -3.9 \\
\hline Connecticut & 25,312 & 43,398 & 30,034 & 51,494 & 28,840 & 50,938 & 29,661 & 52,389 & 29,154 & 51,181 & 57.0 & -2.9 & -0.6 \\
\hline Delaware ..... & 21,112 & 35,246 & 25,051 & 41,821 & 24,300 & 40,533 & 24,992 & 41,687 & 24,349 & 41,436 & 58.8 & -2.8 & -0.9 \\
\hline District of Columbia ............... & 23,327 & 239,362 & 27,679 & 246,705 & 25,937 & 42,424 & 26,676 & 43,632 & 225,937 & 242,424 & 61.1 & -6.3 & -9.2 \\
\hline Florida ........................ & 21,368 & 30,555 & 25,354 & 36,255 & 23,508 & 33,330 & 24,177 & 34,279 & 24,736 & 33,885 & 73.0 & -2.4 & -6.5 \\
\hline Georgia & 20,471 & 428,950 & 24,290 & 434,351 & 24,693 & 533,869 & 25,396 & 34,834 & 225,434 & 35,679 & 71.3 & 4.7 & 3.9 \\
\hline Hawaii ............... & 23,792 & 33,548 & 28,231 & 39,807 & 25,436 & 37,044 & 26,160 & 38,099 & 625,965 & 638,105 & 68.1 & -8.0 & -4.3 \\
\hline Idaho ......... & 15,685 & 25,510 & 18,611 & 30,269 & 19,667 & 30,891 & 20,227 & 31,771 & 19,715 & 31,818 & 62.0 & 5.9 & 5.1 \\
\hline 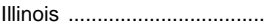 & 421,954 & ${ }^{4} 34,642$ & ${ }^{4} 26,050$ & 441,105 & 726,753 & 740,890 & 27,515 & 42,055 & ${ }^{6} 27,210$ & 642,339 & 64.3 & 4.5 & 3.0 \\
\hline Indiana ….................................. & 420,247 & 432,931 & 424,024 & 439,074 & 424,216 & 437,675 & 24,906 & 38,748 & 24,172 & 38,722 & 62.4 & 0.6 & -0.9 \\
\hline lowa ....................... & 19,404 & 27,949 & 23,024 & 33,163 & 21,338 & 32,372 & 21,946 & 33,294 & 21,884 & 33,272 & 65.8 & -5.0 & 0.3 \\
\hline Kansas .. & 818,954 & 828,188 & 822,490 & 833,447 & 821,607 & 832,429 & 22,222 & 33,353 & 821,909 & 833,150 & 66.1 & -2.6 & -0.9 \\
\hline Kentucky ........... & 19,311 & 29,115 & 22,914 & 34,547 & 222,457 & 32,935 & 23,097 & 33,873 & 223,018 & 433,802 & 68.1 & 0.5 & -2.2 \\
\hline Louisiana ............................ & 17,486 & 26,170 & 20,748 & 31,052 & 19,406 & 226,800 & 19,959 & 27,563 & 21,087 & 28,347 & 74.4 & 1.6 & -8.7 \\
\hline Maine …....................... & 18,878 & 28,531 & 22,400 & 33,854 & 20,725 & 32,869 & 21,315 & 33,805 & 21,108 & 33,676 & 62.7 & -5.8 & -0.5 \\
\hline Maryland & 23,548 & 438,312 & 27,941 & 445,459 & ${ }^{7} 26,846$ & 41,186 & 27,611 & 42,359 & 26,548 & 41,257 & 64.3 & -5.0 & -9.2 \\
\hline Massachusetts & 221,800 & 36,090 & 225,867 & 42,823 & 225,815 & 43,025 & 26,550 & 44,250 & 226,445 & 244,101 & 60.0 & 2.2 & 3.0 \\
\hline 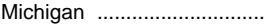 & 222,400 & 237,800 & 226,579 & 244,852 & 225,635 & 246,832 & 26,365 & 48,166 & 226,404 & 247,769 & 55.3 & -0.7 & 6.5 \\
\hline Minnesota ................................ & ${ }^{4} 21,029$ & 33,128 & ${ }^{4} 24,952$ & 39,308 & 23,998 & 37,161 & 24,681 & 38,219 & 225,600 & 38,276 & 66.9 & 2.6 & -2.6 \\
\hline Mississippi ............................. & 218,950 & 224,609 & 222,485 & 229,200 & 20,150 & 27,692 & 20,724 & 28,481 & 20,264 & 27,662 & 73.3 & -9.9 & -5.3 \\
\hline Miss & 220,293 & 227,636 & 224,079 & 232,792 & 21,996 & 32,323 & 22,622 & 33,244 & 23,205 & 33,143 & 70.0 & -3.6 & 1.1 \\
\hline Montana . & 218,400 & 26,696 & 221,833 & 31,676 & 219,992 & 29,364 & 20,561 & 30,200 & 220,592 & 29,958 & 68.7 & -5.7 & -5.4 \\
\hline 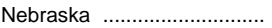 & 18,344 & 26,592 & 21,766 & 31,553 & 21,299 & 31,496 & 21,906 & 32,393 & 21,189 & 31,768 & 66.7 & -2.7 & 0.7 \\
\hline Nevada & ${ }^{6} 24,358$ & ${ }^{6} 35,269$ & ${ }^{6} 28,902$ & 641,849 & 25,576 & 639,535 & 26,304 & 40,661 & ${ }^{6} 28,538$ & 640,817 & 69.9 & -1.3 & -2.5 \\
\hline 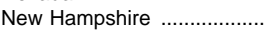 & 220,635 & 31,273 & 224,485 & 37,107 & 223,510 & 35,792 & 24,180 & 36,811 & 223,690 & 36,029 & 65.8 & -3.2 & -2.9 \\
\hline New Jersey & 24,500 & 38,411 & 29,071 & 45,577 & 231,435 & 48,751 & 32,330 & 50,139 & 28,039 & 49,786 & 56.3 & -3.5 & 9.2 \\
\hline New Mexico ........ & 19,124 & ${ }^{4} 25,800$ & 22,692 & 430,613 & 22,634 & 29,285 & 23,279 & 30,119 & 22,840 & 29,715 & 76.9 & 0.7 & -2.9 \\
\hline New York ............... & ${ }^{9} 26,375$ & 942,080 & ${ }^{9} 31,295$ & 949,930 & 28,749 & 48,115 & 29,568 & 49,485 & ${ }^{9} 28,749$ & ${ }^{9} 48,000$ & 59.9 & -8.1 & -3.9 \\
\hline North Carolina & 19,810 & 29,165 & 23,506 & 34,606 & $3,920,620$ & 430,411 & 21,207 & 31,277 & 221,136 & 31,167 & 67.8 & -10.1 & -9.9 \\
\hline North Dakota ......................... & 16,274 & 23,574 & 19,310 & 27,972 & 18,225 & 26,966 & 18,744 & 27,734 & 18,889 & 27,709 & 68.2 & -2.2 & -0.9 \\
\hline Ohio & 18,452 & 31,964 & 21,894 & 37,927 & ${ }^{4} 20,355$ & 438,087 & 20,935 & 39,172 & 22,146 & 38,944 & 56.9 & 1.1 & 2.7 \\
\hline Oklahoma & 818,575 & 824,378 & 822,040 & 828,926 & 24,187 & 829,177 & 24,876 & 30,008 & 23,847 & 30,187 & 79.0 & 8.2 & 4.4 \\
\hline Oregon .................................. & 620,357 & 632,295 & 624,155 & 638,320 & 624,592 & 639,706 & 25,292 & 40,837 & 625,373 & 641,093 & 61.7 & 5.0 & 7.2 \\
\hline Pennsylvania ......................... & 223,250 & 436,057 & 227,587 & 442,784 & 29,514 & 46,087 & 30,355 & 47,400 & 29,426 & 47,147 & 62.4 & 6.7 & 10.2 \\
\hline Rhode Island & 20,887 & 238,220 & 24,784 & 245,350 & 24,754 & 41,829 & 25,459 & 43,020 & 225,497 & 243,084 & 59.2 & 2.9 & -5.0 \\
\hline South Carolina & 419,757 & 428,174 & 423,443 & 433,430 & 21,791 & 431,622 & 22,412 & 32,523 & 22,681 & 32,659 & 69.4 & -3.2 & -2.3 \\
\hline akota ......................... & 16,676 & 22,363 & 19,787 & 26,535 & 19,609 & 26,346 & 20,167 & 27,096 & 19,820 & 27,072 & 73.2 & 0.2 & 2.0 \\
\hline 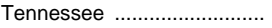 & 20,150 & 28,248 & 23,909 & 33,518 & 21,537 & 433,126 & 22,150 & 34,069 & 21,705 & 34,267 & 63.3 & -9.2 & 2.2 \\
\hline Texas ……........................... & 220,150 & 228,100 & 223,909 & 233,342 & 22,642 & 1031,400 & 23,287 & 32,294 & 24,079 & 32,426 & 74.3 & 0.7 & -2.7 \\
\hline Utah ...................................... & 17,234 & 425,415 & 20,449 & 430,156 & 20,544 & 30,587 & 21,129 & 31,458 & 21,475 & 431,310 & 68.6 & 5.0 & 3.8 \\
\hline Vern & 218,509 & 229,714 & 221,962 & 235,257 & 224,445 & 235,526 & 25,141 & 36,538 & 224,934 & 36,053 & 69.2 & 13.5 & 2.3 \\
\hline Virginia & ${ }^{4} 22,206$ & ${ }^{4} 32,692$ & ${ }^{4} 26,349$ & 438,791 & 225,500 & 34,792 & 26,226 & 35,783 & 24,774 & 36,116 & 68.6 & -6.0 & -6.9 \\
\hline Washington ................................ & 420,612 & 432,975 & 424,457 & 439,127 & 424,590 & 437,853 & 25,290 & 38,931 & 4 23,933 & 437,860 & 63.2 & -2.1 & -3.2 \\
\hline West Virginia .......................... & 18,728 & 25,966 & 22,222 & 30,810 & 22,011 & 32,155 & 22,638 & 33,071 & 22,278 & 33,258 & 67.0 & 0.3 & 7.9 \\
\hline Wisconsin & 20,689 & 33,077 & 24,549 & 39,248 & 24,560 & 236,964 & 25,259 & 38,017 & 24,830 & 37,878 & 65.6 & 1.1 & -3.5 \\
\hline 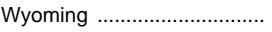 & 19,238 & 28,996 & 22,827 & 34,405 & 221,900 & 31,571 & 22,524 & 32,470 & 222,010 & 631,716 & 69.4 & -3.6 & -7.8 \\
\hline
\end{tabular}

${ }^{1}$ Based on the Consumer Price Index prepared by the Bureau of Labor Statistics, U.S. Department of Labor. Price index does not account for different rates of change in the cost of living among states.

${ }^{2}$ Estimated by the American Federation of Teachers. See NOTE.

${ }^{3}$ Excludes state-paid health insurance.

${ }^{4}$ Preliminary or state estimate.

${ }^{5}$ Reflects the redefinition of classroom teacher.

${ }^{6}$ Includes employer pick-up of employee pension contribution.

7 Preliminary or state estimate. Includes pay for extra duties.

${ }^{8}$ Estimated to exclude fringe benefits.

${ }^{9}$ Median salary.
10 Including incentive pay or career ladder stipends and revision of classroom teacher definition.

NOTE.-Data in this table reflect results of surveys conducted by the American Federation of Teachers. Because of differing survey and estimation methods, these data are not entirely comparable with figures appearing in other tables. Some data revised from previously published figures.

SOURCE: American Federation of Teachers, Survey and Analysis of Salary Trends, various years. (This table was prepared June 1998.) 
Table 81.-Average annual salary of instructional staff 1 in public elementary and secondary schools, by state: 1939-40 to 1997-98

\begin{tabular}{|c|c|c|c|c|c|c|c|c|c|c|c|c|c|c|}
\hline \multirow{2}{*}{ State or other area } & \multicolumn{9}{|c|}{ Current dollars } & \multicolumn{5}{|c|}{ Constant $1997-98$ dollars $^{2}$} \\
\hline & $1939-40$ & $1949-50$ & $1959-60$ & $1969-70$ & $1979-80$ & $1989-90$ & $1995-96$ & $1996-97$ & $1997-98$ & 1969-70 & $1979-80$ & 1989-90 & $1995-96$ & $1996-97$ \\
\hline 1 & 2 & 3 & 4 & 5 & 6 & 7 & 8 & 9 & 10 & 11 & 12 & 13 & 14 & 15 \\
\hline United States & $\$ 1,441$ & $\$ 3,010$ & $\$ 5,174$ & $\$ 9,047$ & $\$ 16,715$ & $\$ 32,638$ & ${ }^{3} \$ 39,465$ & ${ }^{3} \$ 40,562$ & ${ }^{3} \$ 41,598$ & $\$ 38,737$ & $\$ 34,824$ & $\$ 41,575$ & $\$ 41,315$ & $\$ 41,285$ \\
\hline Alabama & 744 & 2,111 & 4,002 & 6,954 & 13,338 & 26,200 & 32,459 & 33,744 & 34,040 & 29,775 & 27,789 & 33,374 & 33,980 & 34,346 \\
\hline Alaska ........... & - & - & 6,859 & 10,993 & 27,697 & 343,161 & 350,059 & 352,033 & 353,154 & 47,069 & 57,704 & 54,979 & 52,405 & 52,961 \\
\hline Arizona ...... & 1,544 & 3,556 & 5,590 & 8,975 & 16,180 & 33,592 & 343,542 & 344,157 & 344,819 & 38,428 & 33,710 & 42,790 & 45,583 & 44,945 \\
\hline Arkansas ............. & 584 & 1,801 & 3,295 & 6,461 & 12,704 & 23,296 & 30,025 & з 30,976 & 31,852 & 27,664 & 26,468 & 29,675 & 31,432 & 31,528 \\
\hline California .. & 2,351 & - & ${ }^{3} 6,600$ & 10,950 & 18,626 & ${ }^{3} 39,309$ & 344,027 & 345,349 & 345,610 & 46,885 & 38,806 & 50,072 & 46,091 & 46,158 \\
\hline Colorado & 1,393 & 2,821 & 4,997 & 8,105 & 16,840 & 31,832 & 36,353 & 37,473 & ${ }^{3} 38,280$ & 34,703 & 35,085 & 40,548 & 38,057 & 38,141 \\
\hline Connecticut & 1,861 & 3,558 & 6,008 & 9,597 & 16,989 & 41,888 & 51,951 & 52,067 & 52,480 & 41,092 & 35,395 & 53,357 & 54,386 & 52,996 \\
\hline Delaware ..... & 1,684 & 3,273 & 35,800 & 9,387 & 16,845 & 34,620 & 42,177 & 43,085 & 44,169 & 40,193 & 35,095 & 44,099 & 44,154 & 43,853 \\
\hline District of Columbia ........... & 2,350 & 3,920 & 6,280 & 10,700 & 23,027 & 43,637 & 39,663 & ${ }^{3} 40,854$ & ${ }^{3} 42,068$ & 45,814 & 47,975 & 55,585 & 41,522 & 41,583 \\
\hline Florida ...................... & 1,012 & 2,958 & 5,080 & 8,785 & 14,875 & 30,275 & 34,411 & 34,980 & 35,594 & 37,615 & 30,991 & 38,565 & 36,024 & 35,604 \\
\hline Georgia & 770 & 1,963 & 43,904 & 7,520 & 14,547 & 29,541 & 35,786 & 37,344 & 39,210 & 32,199 & 30,307 & 37,630 & 37,463 & 38,010 \\
\hline Hawaii .. & - & - & 5,390 & 9,600 & 20,436 & 32,956 & 37,057 & 36,986 & 39,751 & 41,105 & 42,577 & 41,980 & 38,794 & 37,646 \\
\hline Idaho .................. & 1,057 & 2,481 & 4,216 & 7,081 & 14,110 & 24,758 & 32,285 & 33,277 & ${ }^{3} 34,277$ & 30,319 & 29,397 & 31,537 & 33,798 & 33,870 \\
\hline Illinois ...... & 1,700 & 3,458 & 55,814 & 9,789 & 18,271 & 33,912 & 42,411 & 43,686 & 45,499 & 41,914 & 38,066 & 43,197 & 44,399 & 44,465 \\
\hline Indiana & 1,433 & 3,401 & 5,542 & 9,239 & 16,256 & 31,905 & 38,832 & 40,062 & 340,905 & 39,559 & 33,868 & 40,641 & 40,652 & 40,776 \\
\hline lowa & 1,017 & 2,420 & 34,030 & 8,779 & 15,776 & 27,619 & 33,529 & 34,477 & 35,277 & 37,589 & 32,868 & 35,181 & 35,101 & 35,092 \\
\hline Kansas & 1,014 & 2,628 & ${ }^{3} 4,450$ & 7,811 & 14,513 & 30,154 & 37,626 & 38,379 & 39,219 & 33,445 & 30,237 & 38,410 & 39,390 & 39,063 \\
\hline Kentucky ........................ & 826 & 1,936 & 3,327 & 7,325 & 15,350 & 27,482 & 33,115 & 33,797 & ${ }^{3} 34,525$ & 31,364 & 31,980 & 35,007 & 34,667 & 34,400 \\
\hline Louisiana ............................. & 1,006 & 2,983 & 4,978 & 7,264 & 14,020 & 25,036 & 29,005 & 30,499 & 3 30,346 & 31,102 & 29,210 & 31,891 & 30,365 & 31,043 \\
\hline Maine ….............................. & 894 & 2,115 & 3,694 & 8,059 & 13,743 & 27,831 & 33,994 & 34,796 & 35,484 & 34,506 & 28,632 & 35,451 & 35,587 & 35,417 \\
\hline Maryland & 1,642 & 3,594 & 5,557 & 9,885 & 18,308 & 37,520 & 42,958 & 42,988 & 43,618 & 42,325 & 8,143 & 47,793 & 44,972 & 43,755 \\
\hline Massachusetts ... & 2,037 & 3,338 & 65,545 & 9,347 & 18,900 & 40,175 & 52,663 & 354,244 & 3 55,630 & 40,021 & 39,377 & 51,175 & 55,132 & 55,211 \\
\hline Michigan & 1,576 & 3,420 & 5,654 & 10,125 & 20,682 & ${ }^{3} 37,286$ & 46,832 & ${ }^{3} 52,288$ & ${ }^{3} 58,228$ & 43,352 & 43,089 & 47,495 & 49,027 & 53,221 \\
\hline Minnesota . & 1,276 & 3,013 & 5,275 & 9,250 & 16,654 & 33,340 & ${ }^{3} 37,680$ & 39,470 & 340,320 & 39,606 & 34,697 & 42,469 & 39,446 & 40,174 \\
\hline Mississippi ……………....... & 559 & 1,416 & 3,314 & 5,959 & 12,274 & 25,079 & 28,712 & 28,648 & 29,857 & 25,515 & 25,572 & 31,946 & 30,058 & 29,159 \\
\hline Missouri & 1,159 & 2,581 & 4,536 & 8,064 & 14,543 & 28,166 & 33,878 & 34,788 & 35,657 & 34,528 & 30,299 & 35,878 & 35,466 & 35,408 \\
\hline Monta & 1,184 & 2,962 & 34,425 & 7,875 & 15,080 & 29,526 & 30,908 & ${ }^{3} 31,836$ & 32,536 & 33,719 & 31,418 & 37,611 & 32,357 & 32,404 \\
\hline Nebraska & 829 & 2,292 & 3,876 & 7,633 & 14,236 & 27,024 & 34,023 & 35,045 & 35,800 & 32,682 & 29,660 & 34,423 & 35,618 & 35,670 \\
\hline Nevada ......................... & 1,557 & 3,209 & 5,693 & 9,615 & 17,290 & 31,970 & 37,879 & 39,179 & 39,002 & 41,169 & 36,022 & 40,724 & 39,655 & 39,878 \\
\hline New Hampshire ............ & 1,258 & 2,712 & 4,455 & 8,016 & 13,508 & ${ }^{3} 29,798$ & 42,188 & 343,455 & 344,234 & 34,322 & 28,143 & 37,957 & 44,166 & 44,230 \\
\hline New Jerse & 2,093 & 3,511 & 5,871 & 9,650 & 18,851 & 37,485 & 51,296 & 52,411 & 53,196 & 41,319 & 9,275 & 47,749 & 53,700 & 53,346 \\
\hline New Mexico & 1,144 & 3,215 & 5,382 & 10,021 & 15,406 & 25,790 & 29,389 & 30,914 & 31,580 & 42,907 & 32,097 & 32,852 & 30,767 & 31,465 \\
\hline New York & 2,604 & 3,706 & 6,537 & 11,240 & 20,400 & 40,000 & 48,754 & 48,600 & 349,647 & 48,127 & 42,502 & 50,952 & 51,039 & 49,467 \\
\hline North Carolina …............ & 946 & 2,688 & 4,178 & 7,762 & 14,445 & 28,952 & 31,622 & 32,383 & 34,584 & 33,235 & 30,095 & 36,879 & 33,104 & 32,961 \\
\hline North Dakota ....................... & 745 & 2,324 & 3,695 & 6,840 & 13,684 & 23,788 & 27,153 & 27,905 & 28,438 & 29,287 & 28,509 & 30,301 & 28,426 & 28,403 \\
\hline Ohic & 1,587 & 3,088 & 5,124 & 8,594 & 00 & 32,467 & 39,038 & 39,938 & 45 & 36,797 & 43 & 57 & 40,868 & 40 \\
\hline Oklahoma & 1,014 & 2,736 & 4,659 & 7,257 & 13,500 & 23,944 & 30,584 & 31,894 & 32,164 & 31,072 & 28,126 & 30,500 & 32,018 & 32,463 \\
\hline Oregon ....... & 1,333 & 3,323 & 5,535 & 9,200 & 16,996 & 32,100 & 40,980 & 42,420 & ${ }^{3} 43,652$ & 39,392 & 35,410 & 40,889 & 42,901 & 43,177 \\
\hline Pennsylvania & 1,640 & 3,006 & 5,308 & 8,899 & 17,060 & 34,110 & 47,087 & 48,178 & 48,701 & 38,103 & 35,543 & 43,450 & 49,294 & 49,037 \\
\hline Rhode Island ..................... & 1,809 & 3,294 & 75,499 & 9,030 & 18,425 & 36,704 & 342,498 & 344,188 & 45,504 & 38,664 & 38,387 & 46,754 & 44,490 & 44,976 \\
\hline So & 743 & 1,891 & 3,450 & 7,069 & 13,670 & 28,453 & 33,155 & 34,421 & 238 & 30,267 & 480 & 244 & 34,709 & 35,035 \\
\hline South Dakota .............. & 807 & 2,064 & 3,725 & 7,200 & 13,010 & 22,120 & 27,354 & 27,767 & ${ }^{3} 28,365$ & 30,828 & 27,105 & 28,177 & 28,636 & 28,262 \\
\hline Tennesse & 862 & 2,302 & 3,929 & 7,187 & 14,193 & 27,949 & 34,412 & 35,555 & 36,700 & 30,773 & 29,570 & 602 & 36,025 & 36,189 \\
\hline Texas ……........................... & 1,079 & 3,122 & 4,708 & 7,598 & 14,729 & 28,549 & 33,861 & 34,937 & 36,158 & 32,533 & 30,687 & 36,366 & 35,448 & 35,560 \\
\hline Utah & 1,394 & 3,103 & 5,096 & 8,049 & 17,403 & 24,591 & 31,780 & 32,492 & ${ }^{3} 34,247$ & 34,464 & 36,258 & 31,324 & 33,270 & 33,071 \\
\hline Ver & 981 & 2,348 & 4,466 & 8,225 & & 29,012 & 37,054 & 36,053 & & 35,217 & 09 & 956 & 91 & 36,696 \\
\hline & 899 & 2,328 & 4,312 & 8,364 & 14,655 & 31,656 & 35,660 & 36,602 & 37,458 & 35,812 & 30,532 & 40,324 & 37,332 & 37,255 \\
\hline Washington ......................... & 1,706 & 3,487 & 75,643 & 9,792 & 19,735 & 31,828 & 39,594 & 39,594 & 40,624 & 41,927 & 41,116 & 40,543 & 41,450 & 40,300 \\
\hline West & 1,170 & 2,425 & 3,952 & 7,954 & 14,395 & 23,842 & 33,296 & 34,345 & 34,564 & 34,057 & 29,991 & 30,370 & 34,857 & 34,958 \\
\hline Wisconsin ……....................... & 1,379 & 3,007 & 84,870 & 9,150 & 16,335 & 32,445 & 39,212 & 41,848 & 342,750 & 39,178 & 34,033 & 41,329 & 41,050 & 42,594 \\
\hline Wyoming ……........................ & 1,169 & 2,798 & 4,937 & 8,496 & 16,830 & 29,047 & 32,493 & 32,620 & 32,979 & 36,377 & 35,064 & 37,000 & 34,016 & 33,202 \\
\hline Outlying areas & & & & & & & & & & & & & & \\
\hline American Samoa ............... & - & - & 852 & 5,130 & - & - & - & - & - & 21,965 & - & - & - & - \\
\hline . & - & - & 4,107 & 7,800 & - & - & - & - & - & 33,397 & - & - & - & - \\
\hline Puerto Rico ........................... & - & - & 92,360 & - & - & - & - & - & - & - & - & - & - & - \\
\hline Virgin Islands ......................... & - & - & 3,407 & - & - & - & - & - & - & - & - & - & - & 一 \\
\hline
\end{tabular}

1 Includes supervisors, principals, classroom teachers, and other instructional staff

${ }^{2}$ Based on the Consumer Price Index prepared by the Bureau of Labor Statistics, U.S. Department of Labor. Price index does not account for different rates of change in the cost of living among states.

${ }^{3}$ Estimated by National Education Association.

${ }^{4}$ Excludes kindergarten teachers.

5 Includes administrators.

${ }^{6}$ Includes clerical assistants to instructional personnel.

7 Includes attendance personnel.

8 Excludes vocational schools not operated as part of the regular public school system.
9 Median salary.

—Data not available.

NOTE.-Some data have been revised from previously published figures.

SOURCE: U.S. Department of Education, National Center for Education Statistics, Statistics of State School Systems; National Education Association, Estimates of School Statistics; (Latest edition 1997-98. Copyright @ $\odot 1998$ by the National Education Association. All rights reserved.) and unpublished data. (This table was prepared October 1998.) 
Table 82.-Estimated average annual salary of instructional staff ${ }^{1}$ in public elementary and secondary schools and average annual earnings of full-time employees in all industries: 1929-30 to 1997-98

\begin{tabular}{|c|c|c|c|c|c|}
\hline \multirow[b]{2}{*}{ School year } & \multicolumn{2}{|c|}{ Current dollars } & \multicolumn{3}{|c|}{ Constant $1997-98$ dollars $^{2}$} \\
\hline & $\begin{array}{l}\text { Average salary of } \\
\text { instructional staff }\end{array}$ & $\begin{array}{l}\text { Earnings per } \\
\text { full-time employee } \\
\text { working for wages } \\
\quad \text { or salary }^{3}\end{array}$ & $\begin{array}{l}\text { Average salary of } \\
\text { instructional staff }\end{array}$ & $\begin{array}{l}\text { Earnings per } \\
\text { full-time employee } \\
\text { working for wages } \\
\text { or salary }\end{array}$ & $\begin{array}{l}\text { Ratio of instructional } \\
\text { staff salary to } \\
\text { earnings per full- } \\
\text { time } \\
\text { employee }\end{array}$ \\
\hline 1 & 2 & 3 & 4 & 5 & 6 \\
\hline $\begin{array}{l}1929-30 \\
1931-32 \\
1933-34 \\
1935-36 \\
1937-38\end{array}$ & $\begin{array}{r}\$ 1,420 \\
1,417 \\
1,227 \\
1,283 \\
1,374\end{array}$ & $\begin{array}{r}\$ 1,386 \\
1,198 \\
1,070 \\
1,160 \\
1,224\end{array}$ & $\begin{array}{r}\$ 13,418 \\
15,897 \\
14,987 \\
15,101 \\
15,514\end{array}$ & $\begin{array}{r}\$ 13,097 \\
13,440 \\
13,069 \\
13,653 \\
13,820\end{array}$ & $\begin{array}{l}1.02 \\
1.18 \\
1.15 \\
1.11 \\
1.12\end{array}$ \\
\hline $\begin{array}{l}1939-40 \\
1941-42 \\
1943-44 \\
1945-46 \\
1947-48\end{array}$ & $\begin{array}{l}1,441 \\
1,507 \\
1,728 \\
1,995 \\
2,639\end{array}$ & $\begin{array}{l}1,282 \\
1,576 \\
2,030 \\
2,272 \\
2,692\end{array}$ & $\begin{array}{l}16,678 \\
15,633 \\
16,040 \\
17,689 \\
18,319\end{array}$ & $\begin{array}{l}14,837 \\
16,348 \\
18,843 \\
20,145 \\
18,687\end{array}$ & $\begin{array}{l}1.12 \\
0.96 \\
0.85 \\
0.88 \\
0.98\end{array}$ \\
\hline $\begin{array}{l}1949-50 \\
1951-52 \\
1953-54 \\
1955-56 \\
1957-58\end{array}$ & $\begin{array}{l}3,010 \\
3,450 \\
3,825 \\
4,156 \\
4,702\end{array}$ & $\begin{array}{l}2,930 \\
3,322 \\
3,628 \\
3,924 \\
4,276\end{array}$ & $\begin{array}{l}20,557 \\
21,231 \\
23,005 \\
25,005 \\
26,630\end{array}$ & $\begin{array}{l}20,010 \\
20,443 \\
21,821 \\
23,609 \\
24,218\end{array}$ & $\begin{array}{l}1.03 \\
1.04 \\
1.05 \\
1.06 \\
1.10\end{array}$ \\
\hline $\begin{array}{l}1959-60 \\
1961-62 \\
1963-64 \\
1965-66 \\
1967-68\end{array}$ & $\begin{array}{l}5,174 \\
5,700 \\
6,240 \\
6,935 \\
7,630\end{array}$ & $\begin{array}{l}4,632 \\
4,928 \\
5,373 \\
5,838 \\
6,444\end{array}$ & $\begin{array}{l}28,481 \\
30,672 \\
32,724 \\
35,154 \\
36,288\end{array}$ & $\begin{array}{l}25,497 \\
26,518 \\
28,177 \\
29,593 \\
30,648\end{array}$ & $\begin{array}{l}1.12 \\
1.16 \\
1.16 \\
1.19 \\
1.18\end{array}$ \\
\hline $\begin{array}{l}1969-70 \\
1970-71 \\
1971-72 \\
1972-73 \\
1973-74\end{array}$ & $\begin{array}{r}9,047 \\
9,698 \\
10,213 \\
10,634 \\
11,254\end{array}$ & $\begin{array}{l}7,334 \\
7,815 \\
8,334 \\
8,858 \\
9,647\end{array}$ & $\begin{array}{l}38,737 \\
39,486 \\
40,143 \\
40,179 \\
39,040\end{array}$ & $\begin{array}{l}31,402 \\
31,819 \\
32,757 \\
33,468 \\
33,465\end{array}$ & $\begin{array}{l}1.23 \\
1.24 \\
1.23 \\
1.20 \\
1.17\end{array}$ \\
\hline 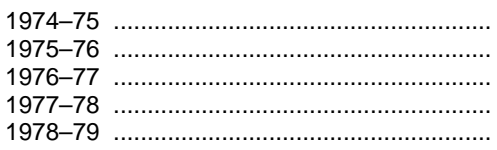 & $\begin{array}{l}12,167 \\
13,124 \\
13,840 \\
14,698 \\
15,764\end{array}$ & $\begin{array}{l}10,420 \\
11,218 \\
11,991 \\
12,829 \\
13,851\end{array}$ & $\begin{array}{l}37,997 \\
38,276 \\
38,140 \\
37,956 \\
37,222\end{array}$ & $\begin{array}{l}32,541 \\
32,717 \\
33,045 \\
33,128 \\
32,705\end{array}$ & $\begin{array}{l}1.17 \\
1.17 \\
1.15 \\
1.15 \\
1.14\end{array}$ \\
\hline $\begin{array}{l}1979-80 \\
1980-81 \\
1981-82 \\
1982-83 \\
1983-84\end{array}$ & $\begin{array}{l}16,715 \\
18,404 \\
20,327 \\
21,641 \\
23,005\end{array}$ & $\begin{array}{l}15,095 \\
16,495 \\
17,818 \\
18,883 \\
19,749\end{array}$ & $\begin{array}{l}34,824 \\
34,363 \\
34,936 \\
35,662 \\
36,557\end{array}$ & $\begin{array}{l}31,448 \\
30,799 \\
30,624 \\
31,117 \\
31,383\end{array}$ & $\begin{array}{l}1.11 \\
1.12 \\
1.14 \\
1.15 \\
1.16\end{array}$ \\
\hline 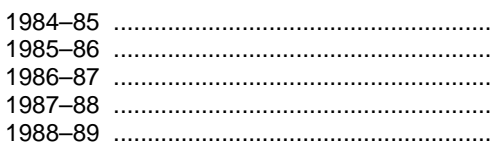 & $\begin{array}{l}24,666 \\
26,362 \\
27,706 \\
29,219 \\
30,850\end{array}$ & $\begin{array}{l}20,626 \\
21,518 \\
22,432 \\
23,467 \\
24,502\end{array}$ & $\begin{array}{l}37,720 \\
39,184 \\
40,287 \\
40,796 \\
41,172\end{array}$ & $\begin{array}{l}31,542 \\
31,983 \\
32,618 \\
32,765 \\
32,700\end{array}$ & $\begin{array}{l}1.20 \\
1.23 \\
1.24 \\
1.25 \\
1.26\end{array}$ \\
\hline 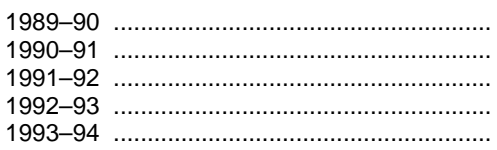 & $\begin{array}{l}32,638 \\
34,401 \\
35,556 \\
36,460 \\
37,446\end{array}$ & $\begin{array}{l}25,555 \\
26,668 \\
27,829 \\
29,060 \\
29,781\end{array}$ & $\begin{array}{l}41,575 \\
41,549 \\
41,610 \\
41,376 \\
41,422\end{array}$ & $\begin{array}{l}32,553 \\
32,209 \\
32,568 \\
32,978 \\
32,943\end{array}$ & $\begin{array}{l}1.28 \\
1.29 \\
1.28 \\
1.25 \\
1.26\end{array}$ \\
\hline $\begin{array}{l}1994-95 \\
1995-96 \\
1996-97 \\
1997-98\end{array}$ & $\begin{array}{l}38,331 \\
39,465 \\
40,562 \\
41,598\end{array}$ & $\begin{array}{r}30,573 \\
31,579 \\
32,850 \\
-\end{array}$ & $\begin{array}{l}41,219 \\
41,315 \\
41,285 \\
41,598\end{array}$ & $\begin{array}{r}32,876 \\
33,059 \\
33,436 \\
-\end{array}$ & $\begin{array}{l}1.25 \\
1.25 \\
1.23 \\
\end{array}$ \\
\hline
\end{tabular}

1 Includes supervisors, principals, classroom teachers, and other instructional staff.

${ }^{2}$ Based on the Consumer Price Index prepared by the Bureau of Labor Statistics, U.S Department of Labor.

${ }^{3}$ Calendar-year data from the U.S. Department of Commerce have been converted to a school-year basis by averaging the two appropriate calendar years in each case. Beginning in 1992-93, data are wage and salary accruals per full-time-equivalent employee.

-Data not available.
NOTE.-Some data have been revised from previously published figures.

SOURCE: U.S. Department of Education, National Center for Education Statistics, Statistics of State School Systems, and unpublished data; National Education Association, Estimates of School Statistics, 1997-98, (Copyright (c) 1998 by the National Education Association. All rights reserved.), unpublished data; and U.S. Department of Commerce, Survey of Current Business, July and August issues. (This table was prepared October 1998.) 
Table 83.-Staff employed in public elementary and secondary school systems, by functional area: 1949-50 to fall 1996

[In full-time equivalents]

\begin{tabular}{|c|c|c|c|c|c|c|c|c|c|c|c|c|c|c|c|c|c|c|c|c|c|}
\hline \multirow[b]{2}{*}{ School year } & \multirow[b]{2}{*}{ Total } & \multicolumn{5}{|c|}{ School district administrative staff } & \multicolumn{8}{|c|}{ Instructional staff } & \multicolumn{7}{|c|}{ Support staff } \\
\hline & & Total & \begin{tabular}{|c|} 
Inter- \\
mediate \\
district \\
staff
\end{tabular} & $\begin{array}{l}\text { School } \\
\text { distritct } \\
\text { super- } \\
\text { intend- } \\
\text { ents }\end{array}$ & $\begin{array}{l}\text { Officials } \\
\text { and ad- } \\
\text { ministra- } \\
\text { tors }\end{array}$ & $\begin{array}{l}\text { Instruction } \\
\text { coordina- } \\
\text { tors }\end{array}$ & Total & $\begin{array}{l}\text { Principals } \\
\text { and } \\
\text { assitant } \\
\text { principals }\end{array}$ & Teachers & $\begin{array}{l}\text { Instruc- } \\
\text { tional } \\
\text { aides }\end{array}$ & $\begin{array}{l}\text { Librar- } \\
\text { ians }\end{array}$ & $\begin{array}{l}\text { Guidance } \\
\text { coun- } \\
\text { selors }\end{array}$ & \begin{tabular}{|c|} 
Psycho- \\
logical \\
personnel
\end{tabular} & $\begin{array}{c}\text { Other } \\
\text { instructional } \\
\text { staff }\end{array}$ & Total & $\begin{array}{c}\text { Secretar- } \\
\text { ial and } \\
\text { clerical } \\
\text { personnel }\end{array}$ & $\mid$\begin{tabular}{|} 
Transpor- \\
tation staff
\end{tabular} & $\begin{array}{c}\text { Food } \\
\text { service }\end{array}$ & $\begin{array}{c}\text { Plant } \\
\text { operation } \\
\text { and main- } \\
\text { tenance }\end{array}$ & Health & $\begin{array}{l}\text { Recreational } \\
\text { and other } \\
\text { staff }\end{array}$ \\
\hline 1 & 2 & 3 & 4 & 5 & 6 & 7 & 8 & 9 & 10 & 11 & 12 & 13 & 14 & 15 & 16 & 17 & 18 & 19 & 20 & 21 & 22 \\
\hline $49-50$ & 00,031 & 3,642 & 843 & 025 & & & 10 & ,137 & 71 & (2) & & & (2) & 6,302 & 303,280 & 31,824 & 81,626 & 68,814 & 105,874 & 9,412 & 5,730 \\
\hline ) & 89,283 & 423 & 9,901 & 361 & 5,386 & & & 63,554 & & (2) & 17,363 & 14,643 & 2,121 & & 589,531 & 75,930 & 113,111 & 161,925 & $\mid 192,655$ & 16,104 & 29,807 \\
\hline 9- & 360,763 & 65,282 & 7,113 & 13,014 & 13,618 & 31,53 & $2,285,568$ & 90,593 & $2,016,244$ & 57,418 & 42,689 & 48,763 & 6,168 & 23,693 & $1,009,913$ & 164,476 & 175,351 & 270,338 & 273,395 & 26,562 & 99,791 \\
\hline 19 & 168,286 & 78,784 & & 13,269 & 44,961 & 20,554 & $2,859,573$ & 107,061 & $2,184,216$ & 325,755 & 48,018 & 63,973 & 14,033 & 116,517 & $1,229,929$ & 223,647 & $(4)$ & (4) & (4) & $\left({ }^{4}\right)$ & $1,006,282$ \\
\hline 15 & 59,624 & 367,404 & - & - & - & - & $\begin{array}{l}32,756,232 \\
\end{array}$ & 129,297 & $2,205,987$ & $\mid$ & 47,442 & 66,6 & (5) & $(5)$ & $\begin{array}{l}31,335,988 \\
\end{array}$ & (5) & (5) & (5) & (5) & (5) & $(5)$ \\
\hline 7. & 11,941 & $\begin{array}{l}374,191 \\
3\end{array}$ & - & - & - & - & $32,859,626$ & 125,927 & $2,279,241$ & \begin{tabular}{|l|}
30,000 \\
335,991
\end{tabular} & 48,185 & 70,2 & (5) & (5) & $\begin{array}{l}31,378,124 \\
\end{array}$ & (5) & (9) & (5) & (5) & (5) & (5) \\
\hline & 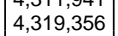 & 369,3 & - & - & - & 二 & 3,020 & 126,609 & $\mid$ & $\mid$ & $\begin{array}{l}40,100 \\
48,980\end{array}$ & 75,0 & 1 & (5) & $\begin{array}{l}31,319, \\
3\end{array}$ & (5) & (5) & (5) & (5) & (5) & (5) \\
\hline & 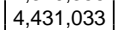 & 370, & - & - & - & - & 1 & 125,594 & & \begin{tabular}{|l}
374 \\
374
\end{tabular} & 49,769 & & 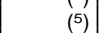 & (5) & & (5) & (5) & 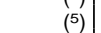 & (5) & (5) & (5) \\
\hline & $4, C$ & 375,8 & -1 & - & - & - & 051,404 & 127,417 & 2,39 & 395, & 49, & 79,9 & $(5$ & (5) & , 36 & (5) & & (5) & (5) & (5) & (5) \\
\hline & 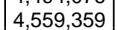 & 376,0 & - & - & - & t & & 129,304 & & & & & & 4 & & $(5)$ & & & & $(5)$ & \\
\hline & & 678,4 & (7) & (7) & 45,712 & 02 & & & & & & & ( & $(5$ & & $\left(5^{5}\right)$ & ( & & $1^{5}$ & 5) & ( \\
\hline & 0 & & (7) & (7) & & & & & & & & & $\left(^{5}\right.$ & (5) & & (5) & ) & (5) & (5) & (5) & 5) \\
\hline Fall 1 & 4,757 & ${ }^{6} \varepsilon$ & (7) & (7) & 48, & & & & & & & & $(5)$ & (5) & 31,54 & (5) & ) & (5) & $(5)$ & $(5)$ & (5) \\
\hline Fall 1995 . & $4,994,358$ & ${ }^{6} 82,998$ & (7) & (7) & 49,315 & 33,683 & ${ }^{3} 3,351$ & 120 & 2,598, & $\mid 494,289$ & 50, & 87,528 & (5) & (5) & $31,559,832$ & (5) & (5) & (5) & (5) & $(5)$ & (5) \\
\hline Fall 1996 & $5,117,616$ & 682,213 & (7) & (7) & 47,788 & 34,425 & $33,448,304$ & 123,163 & $2,666,034$ & 518,649 & 51,517 & 88,941 & (5) & (5) & $31,587,099$ & (5) & (5) & (5) & (5) & (5) & (5) \\
\hline
\end{tabular}

\begin{tabular}{|c|c|c|c|c|c|c|c|c|c|c|c|c|c|c|c|c|c|c|c|c|c|}
\hline \multirow[b]{2}{*}{$1949-50 \ldots \ldots \ldots \ldots \ldots \ldots . . . .}$. & \\
\hline & 100.0 & 2.6 & 0.4 & 1.4 & (1) & 0.8 & 74.1 & 3.3 & 70.3 & (2) & (2) & (2) & (2) & 0.5 & 23.3 & 2.4 & 6.3 & 5.3 & 8.1 & 0.7 & 0.4 \\
\hline $1959-60 \ldots$ & 100.0 & 2.0 & 0.5 & 0.6 & 0.3 & 0.7 & 69.8 & 3.0 & 64.8 & (2) & 0.8 & 0.7 & 0.1 & 0.3 & 28.2 & 3.6 & 5.4 & 7.8 & 9.2 & 0.8 & 1.4 \\
\hline $1969-70 \ldots$. & 100.0 & 1.9 & 0.2 & 0.4 & 0.4 & 0.9 & 68.0 & 2.7 & 60.0 & 1.7 & 1.3 & 1.5 & 0.2 & 0.7 & 30.1 & 4.9 & 5.2 & 8.0 & 8.1 & 0.8 & 3.0 \\
\hline Fall $1980 \ldots$ & 100.0 & 1.9 & - & 0.3 & 1.1 & 0.5 & 68.6 & 2.6 & 52.4 & 7.8 & 1.2 & 1.5 & 0.3 & 2.8 & 29.5 & 5.4 & (4) & (4) & (4) & (4) & 24.1 \\
\hline Fall $1985 \ldots$ & 100.0 & 31.6 & - & - & - & - & $\begin{array}{l}366.3 \\
\end{array}$ & 3.1 & 53.0 & 7.4 & 1.1 & 1.6 & (5) & (5) & $\begin{array}{l}332.1 \\
3\end{array}$ & (5) & (5) & (5) & (5) & (5) & (5) \\
\hline Fall 1987 & 100.0 & 31.7 & - & - & - & - & 366.3 & 2.9 & 52.9 & 7.8 & 1.1 & 1.6 & (5) & (5) & 332.0 & (5) & (5) & (5) & (5) & (5) & $\left(^{5}\right.$ \\
\hline Fall 1988 . & 100.0 & 31.6 & - & - & - & - & 367.8 & 2.9 & 53.8 & 8.3 & 1.1 & 1.7 & (5) & (5) & 330.5 & (5) & (5) & (5) & (5) & (5) & $(5$ \\
\hline Fall 1989 . & 100.0 & 31.6 & - & - & - & - & $\begin{array}{l}367.4 \\
\end{array}$ & 2.8 & 53.2 & 8.4 & 1.1 & 1.8 & (5) & (5) & 331.0 & (5) & (5) & (5) & (5) & (5) & \\
\hline Fall 1990 & 100.0 & 31.7 & - & - & - & - & ${ }^{3} 67.9$ & 2.8 & 53.4 & 8.8 & 1.1 & 1.8 & (5) & (5) & ${ }^{3} 30.4$ & (5) & (5) & (5) & (5) & (5) & \\
\hline Fall $1991 \ldots \ldots$ & 100.0 & 31.7 & - & - & - & - & 368.1 & 2.8 & 53.3 & 9.0 & 1.1 & 1.8 & (5) & (5) & ${ }_{3} 30.3$ & (5) & (5) & (5) & (5) & (5) & \\
\hline Fall $1992 \ldots$ & 100.0 & 61.7 & (7) & (7) & 1.0 & 0.7 & ${ }^{3} 66.7$ & 2.6 & 52.2 & 9.1 & 1.1 & 1.7 & (5) & (5) & 331.7 & (5) & (5) & (5) & (5) & (5) & \\
\hline Fall 1993 & 100.0 & 61.7 & (7) & $\left(7^{7}\right)$ & 1.0 & 0.7 & ${ }^{3} 66.7$ & 2.5 & 52.1 & 9.4 & 1.1 & 1.7 & (5) & (5) & ${ }^{3} 31.6$ & (5) & (5) & (5) & (5) & (5) & \\
\hline Fall 1994 & 100.0 & 61.7 & (7) & (7) & 1.0 & 0.7 & 366.9 & 2.4 & 52.0 & 9.7 & 1.0 & 1.7 & (5) & (5) & 331.4 & (5) & (5) & (5) & (5) & (5) & \\
\hline \multirow{3}{*}{$\begin{array}{l}\text { Fall } 1995 \\
\text { Fall } 1996 .\end{array}$} & 100.0 & 61.7 & (7) & (7) & 1.0 & 0.7 & 367.1 & 2.4 & 52.0 & 9.9 & 1.0 & 1.8 & (5) & (5) & 331.2 & (5) & (5) & (5) & (5) & (5) & (5) \\
\hline & 100.0 & 61.6 & (7) & $(7)$ & 0.9 & 0.7 & $\begin{array}{l}367.4 \\
\end{array}$ & 2.4 & 52.1 & 10.1 & 1.0 & 1.7 & (5) & (5) & $\begin{array}{ll}3 & 31.0 \\
\end{array}$ & (5) & (5) & (5) & (5) & (5) & \\
\hline & \multicolumn{21}{|c|}{ Pupils per staff member } \\
\hline $1949-50$. & & 746.4 & 44.2977 & 1.393 .1 & & 25692 & 26.1 & 582.1 & 27.5 & (2) & & & & 39847 & 828 & 789.1 & 3076 & 3649 & 2372 & 26680 & $4,382.4$ \\
\hline $1959-60$. & 16.8 & $\begin{array}{l}729.3 \\
82.3\end{array}$ & $\left|\begin{array}{l}\mid, 291.1 \\
3,553.4\end{array}\right|$ & $\left|\begin{array}{|l}1,050.1 \\
2,633.2\end{array}\right|$ & $6,532.2$ & $2,554.1$ & $\begin{array}{l}24.1 \\
24.1\end{array}$ & 553.6 & $\begin{array}{l}21.0 \\
26.0\end{array}$ & (2) & $2,026.3$ & $2,402.7$ & $16,589.1$ & $\begin{array}{l}0,504.1 \\
5,605.1\end{array}$ & $\begin{array}{l}50.0 \\
59.7\end{array}$ & 463.4 & 311.0 & 217.3 & 182.6 & $|2,184.7|$ & $\begin{array}{l}4,382.4 \\
1,180.3\end{array}$ \\
\hline $1969-70$ & 13.6 & 697.7 & $6,403.8$ & $3,500.1$ & $3,344.9$ & $1,444.3$ & 19.9 & 502.8 & 22.6 & 793.3 & $1,067.0$ & 934.1 & $7,384.9$ & $1,922.5$ & 45.1 & 276.9 & 259.8 & 168.5 & 166.6 & $1,714.9$ & \\
\hline Fall 1980 & 9.8 & 518.9 & - & $3,080.7$ & 909.2 & $\begin{array}{l}1,988.8 \\
\end{array}$ & 14.3 & 381.8 & 18.7 & 125.5 & 851.3 & 639.0 & $2,913.0$ & 350.8 & 33.2 & 182.8 & (4) & $(4)$ & (4) & (4) & 40.6 \\
\hline Fall 1985 & 9.5 & $\begin{array}{r}3584.9 \\
358.9\end{array}$ & - & - & - & - & $\begin{array}{l}314.3 \\
\end{array}$ & 304.9 & 17.9 & 128.5 & $\begin{array}{l}831.0 \\
831.0\end{array}$ & - 591.5 & (5) & $\begin{array}{r}(5) \\
\end{array}$ & $\begin{array}{r}30.2 \\
329.5\end{array}$ & (5) & (5) & (5) & (5) & (5) & \\
\hline Fall 1987 & 9.3 & 3539.3 & - & - & - & - & 314.0 & 317.7 & 17.6 & 119.1 & 830.3 & 569.3 & (5) & (5) & 329.0 & (5) & (5) & (5) & (5) & (5) & (5) \\
\hline Fall 1988 & 9.3 & 3579.6 & - & - & - & - & 313.7 & 317.4 & 17.3 & 112.7 & 820.5 & 535.4 & (5) & (5) & 330.5 & (5) & (5) & (5) & (5) & (5) & \\
\hline Fall 1989 & 9.1 & 3576.7 & - & - & - & - & 313.6 & & 17.2 & 108.4 & 814.6 & 509.2 & (5) & (5) & $\begin{array}{l}329.5 \\
\end{array}$ & (5) & (5) & (5) & (5) & (5) & \\
\hline Fall 1990 & 9.2 & 3543.3 & - & - & - & - & 313.5 & 323.5 & 17.2 & 104.1 & 825.8 & 515.5 & (5) & (5) & 330.2 & (5) & (5) & (5) & (5) & (5) & \\
\hline Fall 1991 & 9.2 & 3552.6 & - & - & - & & 313.5 & 325.2 & 17.3 & 102.4 & 842.3 & 513.2 & (5) & (5) & 330.5 & (5) & (5) & (5) & (5) & (5) & \\
\hline Fall 1992. & 9.1 & 6546.1 & (7) & (7) & 936.8 & $1,309.5$ & 313.6 & 351.2 & 17.4 & 100.2 & 851.0 & 528.4 & (5) & (5) & $\begin{array}{l}328.7 \\
\end{array}$ & (5) & (5) & (5) & (5) & (5) & \\
\hline Fall 1993 & 9.0 & 6537.5 & (7) & (7) & 912.9 & $1,307.3$ & 313.5 & 357.8 & 17.4 & 96.5 & 860.5 & 523.9 & (5) & (5) & $\begin{array}{l}328.6 \\
3\end{array}$ & (5) & (5) & (5) & (5) & (5) & \\
\hline Fall 1994 & 9.0 & 6538.8 & (7) & (7) & 903.4 & $1,335.1$ & $\begin{array}{l}313.4 \\
\end{array}$ & 367.5 & 17.3 & 93.2 & 870.6 & 519.9 & (5) & (5) & $\begin{array}{l}328.7 \\
\end{array}$ & (5) & (5) & (5) & (5) & (5) & \\
\hline Fall $1995 \ldots \ldots .$. & 9.0 & 6540.3 & (7) & $(7)$ & 909.3 & $1,331.2$ & 313.4 & 371.7 & 17.3 & 90.7 & 881.6 & 512.3 & (5) & (5) & 328.7 & (5) & (5) & (5) & (5) & (5) & \\
\hline Fall 1996 . & 8.9 & 6554.6 & (7) & (7) & 954.1 & $1,324.4$ & 313.2 & 370.2 & 17.1 & 87.9 & 885.0 & 512.6 & (5) & (5) & 328.7 & (5) & (5) & (5) & (5) & (5) & \\
\hline
\end{tabular}

1 Data included in column 5.
2 Data included in column 10 .

Data not comparable with figures for years prior to 1985

4 Data included in column 22.
5 Data included in column 16

${ }^{6}$ Because of classification revisions, data are not directly comparable with figures for prior years. 7 Data included in column 6 .

-Data not available.
NOTE.-Some data have been revised from previously published figures. Because of variations in data collection instruments, some categories are only roughly comparable over time. Because of rounding, details may not add to

SOURCE: U.S. Department of Education, National Center for Education Statistics, Statistics of State School Systems, Common Core of Data surveys, and unpublished estimates. (This table was prepared May 1998.) 
Table 84.-Staff employed in public school systems, by type of assignment and state: Fall 1996

[In full-time equivalents]

\begin{tabular}{|c|c|c|c|c|c|c|c|c|c|c|c|c|}
\hline \multirow[b]{2}{*}{ State or other area } & \multirow[b]{2}{*}{ Total } & \multicolumn{3}{|c|}{ School district staff } & \multicolumn{6}{|c|}{ School staff } & \multirow[b]{2}{*}{$\begin{array}{l}\text { Student } \\
\text { support } \\
\text { staff }\end{array}$} & \multirow[b]{2}{*}{$\begin{array}{l}\text { Other } \\
\text { support } \\
\text { services } \\
\text { staff }\end{array}$} \\
\hline & & $\begin{array}{l}\text { Officials } \\
\text { and } \\
\text { adminis- } \\
\text { trators }\end{array}$ & $\begin{array}{l}\text { Adminis- } \\
\text { trative } \\
\text { support } \\
\text { staff }\end{array}$ & $\begin{array}{l}\text { Instruction } \\
\text { coordina- } \\
\text { tors }\end{array}$ & $\begin{array}{l}\text { Principals } \\
\text { and } \\
\text { assistant } \\
\text { principals }\end{array}$ & $\begin{array}{c}\text { School } \\
\text { and } \\
\text { library } \\
\text { support } \\
\text { staff }\end{array}$ & Teachers & $\begin{array}{l}\text { Instruc- } \\
\text { tional } \\
\text { aides }\end{array}$ & $\begin{array}{c}\text { Guidance } \\
\text { counselors }\end{array}$ & Librarians & & \\
\hline 1 & 2 & 3 & 4 & 5 & 6 & 7 & 8 & 9 & 10 & 11 & 12 & 13 \\
\hline United States ${ }^{1} \ldots \ldots \ldots \ldots \ldots \ldots \ldots$ & $5,117,616$ & 47,788 & 160,562 & 34,425 & 123,163 & 238,898 & $2,666,034$ & 518,649 & 88,941 & 51,517 & 145,054 & $1,042,585$ \\
\hline Alabama $^{2}$ & 84,914 & 441 & 1,039 & 968 & 2,243 & 2,873 & 45,040 & 7,146 & 1,688 & 1,259 & 486 & 21,731 \\
\hline 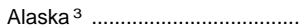 & 14,791 & 303 & 575 & 112 & 442 & 943 & 7,418 & 1,649 & 231 & 144 & 831 & 2,143 \\
\hline Arizona & 79,429 & 411 & 725 & 180 & 1,770 & 6,098 & 40,521 & 10,157 & 1,046 & 787 & 7,416 & 10,318 \\
\hline Arkansas $^{2}$ & 51,004 & 566 & 738 & 170 & 1,482 & 1,821 & 26,680 & 3,837 & 1,213 & 953 & 414 & 13,130 \\
\hline California $^{2}$ & 468,246 & 2,259 & 20,176 & 4,964 & 10,588 & 29,582 & 248,857 & 57,896 & 5,208 & 898 & 10,203 & 77,615 \\
\hline Colorado & 71,226 & 926 & 2,308 & 897 & 1,899 & 5,141 & 36,398 & 6,532 & 1,121 & 715 & 1,686 & 13,603 \\
\hline Connecticut .......... & 68,861 & 1,076 & 1,587 & 436 & 1,825 & 3,364 & 36,551 & 7,506 & 1,123 & 701 & 3,267 & 11,425 \\
\hline 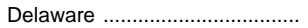 & 12,203 & 93 & 402 & 54 & 414 & 478 & 6,642 & 898 & 221 & 123 & 491 & 2,387 \\
\hline District of Columbia ....................... & 9,318 & 391 & 263 & 81 & 300 & 371 & 5,288 & 499 & 225 & 139 & 56 & 1,705 \\
\hline 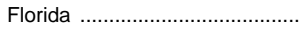 & 248,773 & 1,653 & 13,154 & 639 & 5,993 & 12,112 & 120,471 & 26,814 & 4,855 & 2,556 & 7,647 & 52,879 \\
\hline 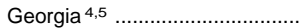 & 148,294 & 585 & 4,272 & 1,306 & 3,864 & 7,133 & 79,091 & 16,386 & 2,472 & 1,984 & 2,237 & 28,964 \\
\hline 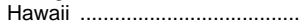 & 16,867 & 136 & 245 & 447 & 489 & 707 & 10,576 & 916 & 544 & 289 & 476 & 2,042 \\
\hline 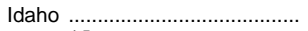 & 22,611 & 114 & 453 & 217 & 676 & 907 & 13,078 & 2,153 & 558 & 190 & 395 & 3,870 \\
\hline 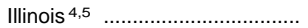 & 221,285 & 3,395 & 6,258 & 1,666 & 5,234 & 10,451 & 116,274 & 24,006 & 2,838 & 1,934 & 6,796 & 42,433 \\
\hline Indiana & 119,800 & 930 & 571 & 1,316 & 2,818 & 7,942 & 56,708 & 16,070 & 1,735 & 1,036 & 1,730 & 28,944 \\
\hline lowa & 63,003 & 809 & 751 & 389 & 1,770 & 4,513 & 32,593 & 6,421 & 1,332 & 749 & 2,186 & 11,490 \\
\hline Kansas. & 58,040 & 471 & 1,786 & 74 & 1,674 & 2,550 & 30,875 & 5,003 & 1,097 & 964 & 2,345 & 11,201 \\
\hline 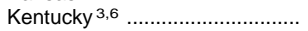 & 75,073 & 863 & 2,081 & 564 & 1,903 & 3,475 & 39,331 & 7,982 & 1,272 & 1,129 & 2,363 & 14,110 \\
\hline 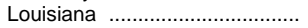 & 94,113 & 284 & 667 & 1,017 & 2,442 & 2,937 & 47,334 & 10,002 & 2,703 & 1,184 & 2,336 & 23,207 \\
\hline Maine & 29,988 & 449 & 751 & 116 & 880 & 1,356 & 15,551 & 4,028 & 593 & 243 & 1,097 & 4,924 \\
\hline Maryland & 85,522 & 764 & 718 & 657 & 2,843 & 3,814 & 47,943 & 6,989 & 1,825 & 1,081 & 1,393 & 17,495 \\
\hline Massachusetts & 116,749 & 1,003 & 6,271 & 1,157 & 2,155 & 2,942 & 64,574 & 13,868 & 2,125 & 679 & 1,873 & 20,102 \\
\hline Michigan ………...................... & 194,954 & 1,919 & 4,371 & 628 & 5,481 & 7,721 & 88,051 & 18,556 & 2,943 & 1,545 & 7,537 & 56,202 \\
\hline 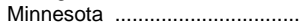 & 86,856 & 1,038 & 2,242 & 958 & 1,597 & 4,636 & 48,245 & 11,255 & 915 & 956 & 2,732 & 12,282 \\
\hline 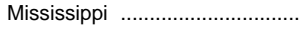 & 61,125 & 918 & 1,467 & 422 & 1,499 & 2,127 & 29,293 & 8,615 & 869 & 810 & 2,206 & 12,899 \\
\hline Missouri & 112,406 & 1,113 & 3,544 & 672 & 2,721 & 6,085 & 59,436 & 7,752 & 2,410 & 1,426 & 2,918 & 24,329 \\
\hline Montana ${ }^{4,5} \ldots \ldots \ldots \ldots$ & 18,862 & 162 & 522 & 156 & 497 & 872 & 10,268 & 2,003 & 411 & 353 & 77 & 3,541 \\
\hline 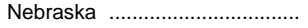 & 38,038 & 592 & 833 & 249 & 969 & 1,520 & 20,174 & 3,629 & 757 & 572 & 994 & 7,749 \\
\hline 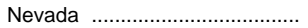 & 25,463 & 209 & 516 & 112 & 745 & 1,422 & 14,805 & 1,615 & 560 & 261 & 777 & 4,441 \\
\hline New Hampshire ............................ & 23,963 & 335 & 442 & 143 & 487 & 848 & 12,692 & 3,852 & 656 & 260 & 478 & 3,770 \\
\hline New Jersey ${ }^{7}$ & 168,441 & 1,666 & 7,633 & 1,373 & 4,465 & 8,444 & 88,903 & 14,925 & 3,231 & 1,803 & 9,084 & 26,914 \\
\hline 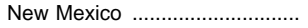 & 40,785 & 428 & 1,907 & 564 & 871 & 2,539 & 19,971 & 4,723 & 650 & 259 & 1,115 & 7,758 \\
\hline New York ............. & 363,586 & 2,762 & 24,413 & 1,285 & 6,851 & 7,206 & 185,104 & 29,467 & 5,467 & 2,982 & 8,879 & 89,170 \\
\hline North Carolina 8 & 145,110 & 1,331 & 3,471 & 653 & 4,132 & 5,785 & 75,239 & 23,537 & 3,025 & 2,201 & 2,970 & 22,766 \\
\hline North Dakota ................................ & 14,552 & 442 & 166 & 62 & 409 & 503 & 7,892 & 1,572 & 263 & 193 & 415 & 2,635 \\
\hline Ohio …........ & 196,969 & 5,277 & 9,573 & 361 & 1,009 & 12,982 & 108,602 & 10,567 & 3,247 & 1,640 & 1,248 & 42,463 \\
\hline Oklahoma ${ }^{8}$ & 83,483 & 546 & 5,129 & 620 & 1,449 & 1,074 & 39,491 & 7,379 & 1,730 & 912 & 12,204 & 12,949 \\
\hline 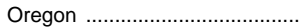 & 52,259 & 755 & 1,489 & 339 & 1,609 & 3,746 & 26,757 & 6,546 & 1,268 & 574 & 1,269 & 7,907 \\
\hline 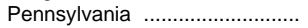 & 201,134 & 1,349 & 7,347 & 1,535 & 4,063 & 9,969 & 106,432 & 16,180 & 3,707 & 2,208 & 9,828 & 38,516 \\
\hline Rhode Island ........................... & 16,823 & 128 & 426 & 74 & 367 & 813 & 10,656 & 1,594 & 307 & 73 & 374 & 2,011 \\
\hline South Carolina 5,9 & 76,932 & 257 & 2,071 & 469 & 2,223 & 3,458 & 41,463 & 7,945 & 1,546 & 1,104 & 2,352 & 14,044 \\
\hline South Dakota ................................ & 18,108 & 259 & 392 & 142 & 461 & 792 & 9,625 & 2,450 & 345 & 194 & 348 & 3,100 \\
\hline 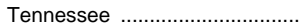 & 101,434 & 943 & 2,412 & 817 & 4,759 & 4,706 & 54,790 & 10,570 & 1,525 & 1,411 & 2,615 & 16,886 \\
\hline Texas & 477,896 & 2,693 & 2,532 & 1,082 & 11,591 & 20,524 & 247,650 & 42,686 & 8,359 & 4,304 & 3,834 & 132,641 \\
\hline Utah & 37,461 & 108 & 744 & 487 & 951 & 2,209 & 19,734 & 5,004 & 594 & 291 & 462 & 6,877 \\
\hline Vermont & 15,693 & 136 & 286 & 209 & 387 & 637 & 7,751 & 3,105 & 352 & 214 & 587 & 2,029 \\
\hline Virginia $^{2}$ & 139,174 & 2,193 & 3,343 & 1,315 & 3,492 & 5,780 & 74,523 & 12,056 & 3,202 & 2,034 & 2,879 & 28,357 \\
\hline 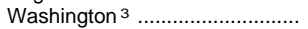 & 94,692 & 1,049 & 2,689 & 837 & 2,556 & 4,956 & 48,307 & 9,333 & 1,804 & 1,288 & 3,509 & 18,364 \\
\hline 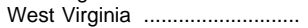 & 38,099 & 289 & 1,886 & 339 & 1,074 & 323 & 20,888 & 2,943 & 604 & 353 & 881 & 8,519 \\
\hline Wisconsin …........................... & 99,871 & 859 & 2,610 & 1,001 & 2,410 & 4,998 & 54,769 & 10,608 & 1,884 & 1,422 & 4,106 & 15,204 \\
\hline 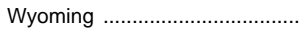 & 13,337 & 110 & 315 & 94 & 334 & 713 & 6,729 & 1,424 & 285 & 137 & 652 & 2,544 \\
\hline Outlying areas & & & & & & & & & & & & \\
\hline American Samoa ............ & 1,470 & 29 & 43 & 27 & 59 & 85 & 734 & 16 & 22 & 7 & 52 & 396 \\
\hline Guam & 3,263 & 13 & 260 & 17 & 52 & 36 & 1,552 & 438 & 71 & 27 & 126 & 671 \\
\hline Northern Marianas ……................. & 1,056 & 15 & 101 & 17 & 27 & 54 & 441 & 209 & 28 & 2 & 84 & 78 \\
\hline 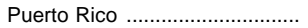 & 71,333 & 356 & 168 & 699 & 1,366 & 5,450 & 39,743 & - & 900 & 900 & 2,149 & 19,602 \\
\hline 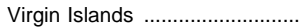 & 3,185 & 74 & 152 & 19 & 83 & 100 & 1,580 & 321 & 84 & 44 & 398 & 330 \\
\hline
\end{tabular}

1 Includes imputations for undercounts in designated states.

2 Includes imputation for prekindergarten teachers.

3 Includes imputation for instruction coordinators.

${ }^{4}$ Includes imputations for all support staff except student support staff.

5 Includes imputation for instructional aides.

${ }^{6}$ Includes imputations for all support staff and officials and administrators.

${ }^{7}$ Data imputed by the National Center for Education Statistics based on previous year's data.
8 Includes imputations for library support staff.

9 Includes imputations for all support staff.

—Data not available or not applicable.

SOURCE: U.S. Department of Education, National Center for Education Statistics, Common Core of Data survey; and unpublished estimates. (This table was prepared May 1998.) 
Table 85.-Staff employed in public school systems, by type of assignment and state: Fall 1995

[In full-time equivalents]

\begin{tabular}{|c|c|c|c|c|c|c|c|c|c|c|c|c|}
\hline \multirow[b]{2}{*}{ State or other area } & \multirow[b]{2}{*}{ Total } & \multicolumn{3}{|c|}{ School district staff } & \multicolumn{6}{|c|}{ School staff } & \multirow[b]{2}{*}{$\begin{array}{l}\text { Student } \\
\text { support } \\
\text { staff }\end{array}$} & \multirow[b]{2}{*}{$\begin{array}{l}\text { Other } \\
\text { support } \\
\text { services } \\
\text { staff }\end{array}$} \\
\hline & & $\begin{array}{l}\text { Officials } \\
\text { and } \\
\text { adminis- } \\
\text { trators }\end{array}$ & $\begin{array}{c}\text { Adminis- } \\
\text { trative } \\
\text { support } \\
\text { staff }\end{array}$ & $\begin{array}{l}\text { Instruction } \\
\text { coordina- } \\
\text { tors }\end{array}$ & $\begin{array}{c}\text { Principals } \\
\text { and } \\
\text { assistant } \\
\text { principals }\end{array}$ & $\begin{array}{c}\text { School } \\
\text { and } \\
\text { library } \\
\text { support } \\
\text { staff }\end{array}$ & Teachers & $\begin{array}{c}\text { Instruc- } \\
\text { tional } \\
\text { aides }\end{array}$ & $\begin{array}{l}\text { Guidance } \\
\text { counselors }\end{array}$ & Librarians & & \\
\hline 1 & 2 & 3 & 4 & 5 & 6 & 7 & 8 & 9 & 10 & 11 & 12 & 13 \\
\hline United States ${ }^{1}$ & $4,994,358$ & 49,315 & 144,842 & 33,683 & 120,629 & 237,389 & $2,598,220$ & 494,289 & 87,528 & 50,862 & 142,655 & $1,034,946$ \\
\hline Alabama & 83,256 & 428 & 1,039 & 980 & 2,221 & 2,768 & 44,056 & 6,657 & 1,684 & 1,259 & 468 & 21,696 \\
\hline Alaska $^{2} \ldots$ & 15,022 & 294 & 549 & 112 & 436 & 886 & 7,379 & 1,751 & 225 & 147 & 819 & 2,424 \\
\hline Arizona & 75,931 & 428 & 641 & 182 & 1,611 & 6,123 & 38,017 & 9,613 & 1,050 & 737 & 7,312 & 10,217 \\
\hline 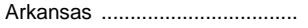 & 49,178 & 554 & 583 & 179 & 1,460 & 1,646 & 26,449 & 3,523 & 1,223 & 952 & 387 & 12,222 \\
\hline California $^{3}$ & 444,014 & 2,155 & 19,920 & 4,685 & 10,335 & 28,571 & 230,849 & 56,822 & 5,115 & 896 & 9,989 & 74,677 \\
\hline Colorado & 67,447 & 846 & 2,211 & 775 & 1,749 & 4,749 & 35,388 & 5,919 & 1,080 & 700 & 1,608 & 12,422 \\
\hline 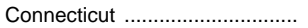 & 66,133 & 955 & 1,611 & 453 & 1,823 & 3,246 & 36,070 & 7,520 & 1,116 & 672 & 3,239 & 9,428 \\
\hline 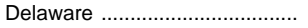 & 11,869 & 87 & 388 & 58 & 399 & 472 & 6,463 & 861 & 215 & 122 & 498 & 2,306 \\
\hline District of Columbia ...................... & 9,410 & 402 & 290 & 144 & 305 & 442 & 5,305 & 327 & 217 & 143 & 53 & 1,782 \\
\hline 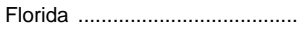 & 237,721 & 1,739 & 12,267 & 812 & 5,964 & 12,110 & 114,938 & 24,111 & 4,794 & 2,560 & 7,147 & 51,279 \\
\hline Georgia $^{4}$ & 165,058 & 2,127 & 3,488 & 691 & 3,754 & 6,423 & 79,480 & 21,709 & 2,476 & 1,987 & 2,699 & 40,224 \\
\hline Hawaii ..... & 16,841 & 141 & 263 & 438 & 483 & 704 & 10,500 & 937 & 540 & 287 & 512 & 2,036 \\
\hline Idaho & 21,814 & 114 & 443 & 210 & 661 & 876 & 12,784 & 1,914 & 520 & 185 & 381 & 3,726 \\
\hline 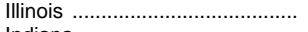 & 209,036 & 3,292 & 5,114 & 1,656 & 5,132 & 9,984 & 113,538 & 21,137 & 2,823 & 1,941 & 6,503 & 37,916 \\
\hline Indiana ……................................... & 116,363 & 928 & 496 & 1,368 & 2,818 & 7,872 & 55,821 & 14,421 & 1,720 & 1,021 & 1,650 & 28,248 \\
\hline lowa & 62,075 & 519 & 756 & 382 & 1,762 & 4,465 & 32,318 & 6,083 & 1,331 & 662 & 2,192 & 11,605 \\
\hline 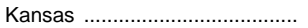 & 57,265 & 1,253 & 961 & 74 & 1,671 & 2,487 & 30,729 & 4,760 & 1,087 & 972 & 2,298 & 10,973 \\
\hline 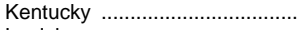 & 84,425 & 1,170 & 2,188 & 434 & 1,906 & 3,147 & 39,120 & 10,916 & 1,282 & 1,173 & 2,093 & 20,996 \\
\hline 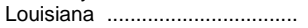 & 93,070 & 265 & 689 & 1,026 & 2,379 & 2,907 & 46,980 & 10,026 & 2,610 & 1,172 & 2,248 & 22,768 \\
\hline Maine & 29,413 & 448 & 660 & 113 & 853 & 1,393 & 15,392 & 3,776 & 600 & 238 & 1,049 & 4,891 \\
\hline Maryland ................. & 87,868 & 720 & 719 & 701 & 2,647 & 3,765 & 47,819 & 7,318 & 1,830 & 1,043 & 1,443 & 19,863 \\
\hline Massachusetts & 113,154 & 991 & 5,788 & 1,065 & 2,166 & 3,073 & 62,710 & 12,867 & 2,090 & 611 & 1,860 & 19,933 \\
\hline 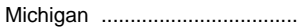 & 177,495 & 2,250 & 3,264 & 497 & 5,079 & 7,890 & 83,179 & 14,318 & 2,871 & 1,450 & 6,704 & 49,993 \\
\hline 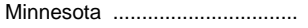 & 74,891 & 1,288 & 1,735 & 487 & 1,589 & 3,316 & 46,971 & 6,088 & 902 & 986 & 2,863 & 8,666 \\
\hline 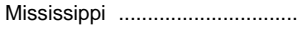 & 60,855 & 906 & 1,433 & 418 & 1,493 & 2,110 & 28,997 & 8,758 & 824 & 750 & 2,221 & 12,945 \\
\hline Missouri & 120,621 & 638 & 4,578 & 1,244 & 2,579 & 8,189 & 57,951 & 7,228 & 2,593 & 1,368 & 1,758 & 32,495 \\
\hline Montana 4,5 .................................. & 18,586 & 156 & 469 & 155 & 489 & 907 & 10,076 & 1,938 & 403 & 348 & 68 & 3,577 \\
\hline 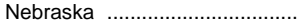 & 37,894 & 612 & 684 & 236 & 953 & 1,479 & 20,028 & 3,578 & 755 & 575 & 996 & 7,998 \\
\hline 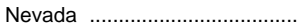 & 23,742 & 184 & 489 & 101 & 680 & 1,340 & 13,878 & 1,489 & 498 & 241 & 605 & 4,237 \\
\hline 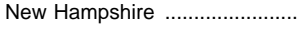 & 23,143 & 360 & 455 & 144 & 479 & 812 & 12,346 & 3,519 & 620 & 281 & 447 & 3,680 \\
\hline New Jersey & 163,069 & 1,680 & 6,826 & 1,305 & 4,383 & 8,393 & 86,706 & 13,936 & 3,150 & 1,781 & 8,767 & 26,142 \\
\hline 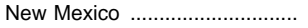 & 40,124 & 435 & 1,887 & 553 & 859 & 2,694 & 19,398 & 4,574 & 645 & 259 & 1,039 & 7,781 \\
\hline 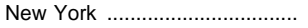 & 355,723 & 2,737 & 23,774 & 1,263 & 6,878 & 7,110 & 181,559 & 28,001 & 5,456 & 2,998 & 8,720 & 87,227 \\
\hline 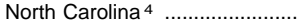 & 140,204 & 1,285 & 2,977 & 720 & 3,993 & 5,794 & 73,201 & 22,287 & 2,976 & 2,176 & 2,720 & 22,075 \\
\hline North Dakota ..................... & 13,804 & 435 & 164 & 54 & 394 & 475 & 7,501 & 1,471 & 248 & 183 & 364 & 2,515 \\
\hline Ohio ........ & 194,579 & 5,242 & 9,467 & 353 & 971 & 12,597 & 107,347 & 10,092 & 3,219 & 1,628 & 1,252 & 42,411 \\
\hline Oklahoma $^{4}$ & 83,802 & 533 & 94 & 590 & 1,456 & 5,754 & 39,364 & 7,186 & 1,390 & 902 & 12,589 & 13,944 \\
\hline Oregon ................................ & 51,458 & 874 & 1,315 & 341 & 1,622 & 3,410 & 26,680 & 6,381 & 1,229 & 612 & 997 & 7,997 \\
\hline 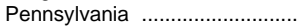 & 198,087 & 1,344 & 7,175 & 1,594 & 4,087 & 9,840 & 104,921 & 14,831 & 3,676 & 2,202 & 9,904 & 38,513 \\
\hline Rhode Island ............................... & 16,517 & 148 & 426 & 78 & 361 & 804 & 10,482 & 1,458 & 309 & 75 & 378 & 1,998 \\
\hline South Carolina ${ }^{4,5} \ldots \ldots \ldots . . . .$. & 74,859 & 264 & 1,830 & 467 & 2,224 & 3,537 & 39,922 & 7,558 & 1,517 & 1,097 & 2,494 & 13,949 \\
\hline South Dakota ${ }^{4}$............................. & 18,126 & 268 & 400 & 148 & 473 & 878 & 9,641 & 2,302 & 354 & 202 & 269 & 3,191 \\
\hline Tennessee ........................................... & 98,948 & 918 & 2,297 & 761 & 4,654 & 4,572 & 53,403 & 9,992 & 1,456 & 1,386 & 2,927 & 16,582 \\
\hline 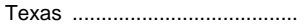 & 462,661 & 2,580 & 2,451 & 1,100 & 11,251 & 18,644 & 240,371 & 43,046 & 8,219 & 4,252 & 3,679 & 127,068 \\
\hline 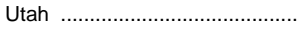 & 37,385 & 109 & 715 & 465 & 926 & 2,098 & 20,039 & 5,037 & 596 & 291 & 369 & 6,740 \\
\hline Vermont & 15,640 & 152 & 278 & 294 & 411 & 719 & 7,676 & 2,931 & 332 & 216 & 1,668 & 963 \\
\hline 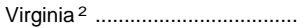 & 137,546 & 1,760 & 1,739 & 1,483 & 3,535 & 5,627 & 74,731 & 12,072 & 3,111 & 1,950 & 3,147 & 28,391 \\
\hline Washington ${ }^{2,4}$ & 91,322 & 1,015 & 2,540 & 841 & 2,501 & 4,760 & 46,907 & 8,582 & 1,758 & 1,263 & 3,695 & 17,460 \\
\hline 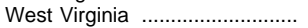 & 38,645 & 279 & 1,896 & 322 & 1,095 & 366 & 21,073 & 2,957 & 611 & 357 & 886 & 8,803 \\
\hline Wisconsin & 95,105 & 842 & 2,276 & 1,090 & 2,353 & 4,463 & 55,033 & 8,361 & 1,925 & 1,416 & 4,005 & 13,341 \\
\hline 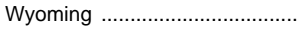 & 13,164 & 165 & 144 & 41 & 326 & 702 & 6,734 & 1,350 & 257 & 137 & 676 & 2,632 \\
\hline Outlying areas & & & & & & & & & & & & \\
\hline American Samoa ...................... & 1,417 & 30 & 38 & 26 & 60 & 81 & 728 & 15 & 19 & 6 & 48 & 366 \\
\hline Guam & 3,728 & 15 & 288 & 18 & 62 & 40 & 1,802 & 476 & 80 & 30 & 146 & 771 \\
\hline Northern Marianas ........................ & 1,054 & 9 & 88 & 17 & 30 & 54 & 422 & 216 & 28 & 4 & 75 & 111 \\
\hline 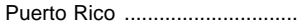 & 69,731 & 314 & 111 & 618 & 1,382 & 4,738 & 39,328 & - & 886 & 865 & 1,995 & 19,494 \\
\hline 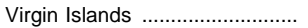 & 3,421 & 36 & 322 & 21 & 86 & 106 & 1,622 & 298 & 86 & 46 & 431 & 367 \\
\hline
\end{tabular}

1 Includes imputations for undercounts in designated states.

2 Includes imputation for instruction coordinators.

${ }^{3}$ Includes imputation for prekindergarten teachers.

${ }^{4}$ Includes imputation for support staff.

5 Includes imputation for instructional aides.
—Data not available or not applicable.

SOURCE: U.S. Department of Education, National Center for Education Statistics Common Core of Data survey; and unpublished estimates. (This table was prepared April 1997.) 
Table 86.-Staff and teachers in public elementary and secondary schools, by state: Fall 1990 to fall 1996

\begin{tabular}{|c|c|c|c|c|c|c|c|c|c|c|c|c|c|}
\hline \multirow[b]{2}{*}{ State or other area } & \multicolumn{4}{|c|}{ Teachers as a percent of staff } & \multicolumn{3}{|c|}{ Fall 1994} & \multicolumn{3}{|c|}{ Fall 1995} & \multicolumn{3}{|c|}{ Fall 1996} \\
\hline & $\begin{array}{c}\text { Fall } \\
1990\end{array}$ & $\begin{array}{c}\text { Fall } \\
1991\end{array}$ & $\begin{array}{c}\text { Fall } \\
1992\end{array}$ & $\begin{array}{c}\text { Fall } \\
1993\end{array}$ & Staff & Teachers & $\begin{array}{l}\text { Teach- } \\
\text { ers } \\
\text { as a } \\
\text { percent } \\
\text { of staff }\end{array}$ & Staff & Teachers & $\begin{array}{l}\text { Teach- } \\
\text { ers } \\
\text { as a } \\
\text { percent } \\
\text { of staff }\end{array}$ & Staff & Teachers & $\begin{array}{l}\text { Teach- } \\
\text { ers } \\
\text { as a } \\
\text { percent } \\
\text { of staff }\end{array}$ \\
\hline 1 & 2 & 3 & 4 & 5 & 6 & 7 & 8 & 9 & 10 & 11 & 12 & 13 & 14 \\
\hline United States 1 & 53.4 & 53.3 & 52.2 & 52.1 & $4,904,757$ & $2,551,875$ & 52.0 & $4,994,358$ & $2,598,220$ & 52.0 & $5,117,616$ & $2,666,034$ & 52.1 \\
\hline Alabama ... & 48.7 & 49.4 & 253.2 & 253.1 & 81,544 & 242,791 & 252.5 & 83,256 & 44,056 & 52.9 & 284,914 & 245,040 & 253.0 \\
\hline Alaska ... & 50.3 & 50.9 & 49.2 & 45.8 & 215,150 & 7,205 & 247.6 & 215,022 & 7,379 & 249.1 & 214,791 & 7,418 & 250.2 \\
\hline Arizona & 52.0 & 51.9 & 50.4 & 50.2 & 74,540 & 38,132 & 51.2 & 75,931 & 38,017 & 50.1 & 79,429 & 40,521 & 51.0 \\
\hline 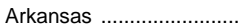 & 52.2 & 49.9 & 53.2 & 51.5 & 50,201 & 26,181 & 52.2 & 49,178 & 26,449 & 53.8 & 251,004 & 226,680 & 252.3 \\
\hline California ........................... & 51.7 & 52.2 & 251.1 & 251.4 & 436,140 & 2225,016 & 251.6 & 444,014 & 2230,849 & 252.0 & 2468,246 & 2248,857 & 253.1 \\
\hline Colorado & 52.6 & 52.9 & 53.2 & 53.5 & 64,985 & 34,894 & 53.7 & 67,447 & 35,388 & 52.5 & 71,226 & 36,398 & 51.1 \\
\hline Connecticut .................... & 56.3 & 56.8 & 53.7 & 55.7 & 64,742 & 35,316 & 54.5 & 66,133 & 36,070 & 54.5 & 68,861 & 36,551 & 53.1 \\
\hline Delaware ...... & 55.2 & 55.5 & 54.9 & 54.8 & 11,759 & 6,416 & 54.6 & 11,869 & 6,463 & 54.5 & 12,203 & 6,642 & 54.4 \\
\hline District of Columbia ........ & 58.3 & 57.0 & 57.4 & 57.2 & 10,507 & 6,110 & 58.2 & 9,410 & 5,305 & 56.4 & 9,318 & 5,288 & 56.8 \\
\hline Florida ............................ & 49.8 & 50.0 & 49.5 & 48.8 & 226,975 & 110,674 & 48.8 & 237,721 & 114,938 & 48.3 & 248,773 & 120,471 & 48.4 \\
\hline Georgia ..... & 48.9 & 48.0 & 246.9 & 247.5 & 2161,390 & 77,914 & 248.3 & 2165,058 & 79,480 & 248.2 & 2148,294 & 79,091 & 253.3 \\
\hline Hawaii .... & 59.9 & 60.7 & 56.9 & 55.3 & 16,567 & 10,240 & 61.8 & 16,841 & 10,500 & 62.3 & 16,867 & 10,576 & 62.7 \\
\hline Idaho & 62.3 & 62.4 & 60.4 & 60.1 & 21,194 & 12,582 & 59.4 & 21,814 & 12,784 & 58.6 & 22,611 & 13,078 & 57.8 \\
\hline Illinois ……....................... & 56.7 & 55.9 & 55.9 & 55.8 & 204,413 & 110,830 & 54.2 & 209,036 & 113,538 & 54.3 & 2221,285 & 116,274 & 252.5 \\
\hline 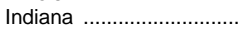 & 50.7 & 50.1 & 48.7 & 48.4 & 115,441 & 55,496 & 48.1 & 116,363 & 55,821 & 48.0 & 119,800 & 56,708 & 47.3 \\
\hline lowa ............ & 53.0 & 52.1 & 52.2 & 52.5 & 60,469 & 31,726 & 52.5 & 62,075 & 32,318 & 52.1 & 63,003 & 32,593 & 51.7 \\
\hline 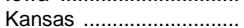 & 56.8 & 56.8 & 54.9 & 54.3 & 56,790 & 30,579 & 53.8 & 57,265 & 30,729 & 53.7 & 58,040 & 30,875 & 53.2 \\
\hline Kentucky .............................. & 49.5 & 48.7 & 47.8 & 45.9 & 81,720 & 38,784 & 47.5 & 84,425 & 39,120 & 46.3 & 275,073 & 39,331 & 252.4 \\
\hline Louisiana ............................ & 49.8 & 69.6 & 50.9 & 50.3 & 96,124 & 47,599 & 49.5 & 93,070 & 46,980 & 50.5 & 94,113 & 47,334 & 50.3 \\
\hline 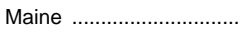 & 57.3 & 56.9 & 53.1 & 53.2 & 29,264 & 15,404 & 52.6 & 29,413 & 15,392 & 52.3 & 29,988 & 15,551 & 51.9 \\
\hline Maryland & 53.9 & 54.6 & 55.0 & 53.4 & 84,699 & 46,565 & 55.0 & 87,868 & 47,819 & 54.4 & 85,522 & 47,943 & 56.1 \\
\hline Massachusetts ........... & 57.2 & 56.5 & 56.5 & 56.4 & 108,281 & 60,489 & 55.9 & 113,154 & 62,710 & 55.4 & 116,749 & 64,574 & 55.3 \\
\hline 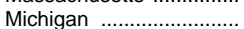 & 46.4 & 46.6 & 47.3 & 47.4 & 164,766 & 80,522 & 48.9 & 177,495 & 83,179 & 46.9 & 194,954 & 88,051 & 45.2 \\
\hline Minnesota ........................... & 56.2 & 57.4 & 56.9 & 62.7 & 74,914 & 46,958 & 62.7 & 74,891 & 46,971 & 62.7 & 86,856 & 48,245 & 55.5 \\
\hline Mississippi ……................ & 48.3 & 47.5 & 48.1 & 47.4 & 60,708 & 28,866 & 47.5 & 60,855 & 28,997 & 47.6 & 61,125 & 29,293 & 47.9 \\
\hline Missouri & 50.6 & 52.3 & 248.4 & 48.6 & 116,974 & 56,606 & 48.4 & 120,621 & 57,951 & 48.0 & 112,406 & 59,436 & 52.9 \\
\hline Montana & 376.4 & 375.6 & 254.0 & 253.2 & 218,452 & 10,079 & 254.6 & 218,586 & 10,076 & 254.2 & 218,862 & 10,268 & 254.4 \\
\hline Nebraska ........................ & 53.4 & 55.0 & 254.2 & 253.3 & 37,144 & 19,774 & 53.2 & 37,894 & 20,028 & 52.9 & 38,038 & 20,174 & 53.0 \\
\hline Nevada ............................ & 389.4 & 386.8 & 255.7 & 56.1 & 23,098 & 13,414 & 58.1 & 23,742 & 13,878 & 58.5 & 25,463 & 14,805 & 58.1 \\
\hline New Hampshire ................... & 51.8 & 56.0 & 54.8 & 54.6 & 22,336 & 12,109 & 54.2 & 23,143 & 12,346 & 53.3 & 23,963 & 12,692 & 53.0 \\
\hline New Jersey .............. & 54.2 & 54.2 & 54.8 & 52.8 & 161,586 & 85,258 & 52.8 & 163,069 & 86,706 & 53.2 & 4168,441 & 488,903 & ${ }^{4} 52.8$ \\
\hline New Mexico ......................... & 50.3 & 50.7 & 51.5 & 50.2 & 39,016 & 19,025 & 48.8 & 40,124 & 19,398 & 48.3 & 40,785 & 19,971 & 49.0 \\
\hline New York ......................... & 50.9 & 50.8 & 51.3 & 50.7 & 356,386 & 182,273 & 51.1 & 355,723 & 181,559 & 51.0 & 363,586 & 185,104 & 50.9 \\
\hline North Carolina ............. & 51.2 & 51.7 & 251.5 & 52.2 & 2137,791 & 71,592 & 252.0 & 2140,204 & 73,201 & 252.2 & 2145,110 & 75,239 & 251.8 \\
\hline North Dakota ...................... & 54.5 & 56.9 & 56.5 & 56.3 & 13,919 & 7,796 & 56.0 & 13,804 & 7,501 & 54.3 & 14,552 & 7,892 & 54.2 \\
\hline Ohio & 54.0 & 53.1 & 52.9 & 53.2 & 200,141 & 109,085 & 54.5 & 194,579 & 107,347 & 55.2 & 196,969 & 108,602 & 55.1 \\
\hline Oklahoma ...................... & 54.2 & 54.0 & 53.3 & 53.4 & 278,270 & 39,406 & 250.3 & 283,802 & 39,364 & 247.0 & 283,483 & 39,491 & 247.3 \\
\hline Oregon ......................... & 53.2 & 53.0 & 51.5 & 52.6 & 50,377 & 26,208 & 52.0 & 51,458 & 26,680 & 51.8 & 52,259 & 26,757 & 51.2 \\
\hline Pennsylvania ...................... & 52.5 & 52.7 & 52.7 & 53.1 & 193,696 & 102,988 & 53.2 & 198,087 & 104,921 & 53.0 & 201,134 & 106,432 & 52.9 \\
\hline 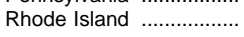 & 60.2 & 62.8 & 63.6 & 63.6 & 15,438 & 10,066 & 65.2 & 16,517 & 10,482 & 63.5 & 16,823 & 10,656 & 63.3 \\
\hline South Carolina & 56.0 & 55.7 & 55.6 & 254.1 & 274,196 & 39,437 & 253.2 & 274,859 & 39,922 & 253.3 & 276,932 & 41,463 & 253.9 \\
\hline South Dakota & 56.3 & 60.1 & 55.9 & 55.6 & 217,989 & 9,985 & 255.5 & 218,126 & 9,641 & 253.2 & 18,108 & 9,625 & 53.2 \\
\hline Tennessee ………................ & 49.4 & 51.0 & 50.2 & 249.9 & 96,281 & 47,406 & 49.2 & 98,948 & 53,403 & 54.0 & 101,434 & 54,790 & 54.0 \\
\hline Texas & 66.0 & 65.0 & 52.2 & 51.9 & 450,462 & 234,213 & 52.0 & 462,661 & 240,371 & 52.0 & 477,896 & 247,650 & 51.8 \\
\hline Utah & 55.2 & 55.0 & 55.1 & 54.0 & 36,186 & 19,524 & 54.0 & 37,385 & 20,039 & 53.6 & 37,461 & 19,734 & 52.7 \\
\hline 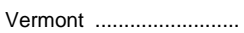 & 53.6 & 50.5 & 50.2 & 249.1 & 15,337 & 7,566 & 49.3 & 15,640 & 7,676 & 49.1 & 15,693 & 7,751 & 49.4 \\
\hline Virginia ........... & 49.0 & 449.4 & 453.8 & 54.5 & 133,485 & 272,505 & 254.3 & 137,546 & 274,731 & 254.3 & 2139,174 & 274,523 & 253.5 \\
\hline Washington ....................... & 55.1 & 55.0 & 54.4 & 51.9 & 290,438 & 46,439 & 251.3 & 291,322 & 46,907 & 251.4 & 294,692 & 48,307 & 251.0 \\
\hline West Virginia .................... & 54.9 & 54.5 & 54.5 & 54.6 & 38,481 & 21,024 & 54.6 & 38,645 & 21,073 & 54.5 & 38,099 & 20,888 & 54.8 \\
\hline Wisconsin ......................... & 58.1 & 59.0 & 57.9 & 59.6 & 100,996 & 54,054 & 53.5 & 95,105 & 55,033 & 57.9 & 99,871 & 54,769 & 54.8 \\
\hline 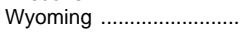 & 53.1 & 50.0 & 50.6 & 50.7 & 12,999 & 6,754 & 52.0 & 13,164 & 6,734 & 51.2 & 13,337 & 6,729 & 50.5 \\
\hline Outlying areas & & & & & & & & & & & & & \\
\hline American Samoa ............. & 52.6 & 52.5 & 53.7 & 49.0 & 1,340 & 698 & 52.1 & 1,417 & 728 & 51.4 & 1,470 & 734 & 49.9 \\
\hline Guam & 52.6 & 50.6 & 46.3 & 42.8 & 4,730 & 1,826 & 38.6 & 3,728 & 1,802 & 48.3 & 3,263 & 1,552 & 47.6 \\
\hline Northern Marianas ........... & 51.1 & 47.5 & 38.8 & 39.1 & 1,051 & 406 & 38.6 & 1,054 & 422 & 40.0 & 1,056 & 441 & 41.8 \\
\hline Puerto Rico ........................ & 55.4 & 54.9 & 56.7 & 58.5 & 68,868 & 39,933 & 58.0 & 69,731 & 39,328 & 56.4 & 71,333 & 39,743 & 55.7 \\
\hline 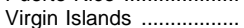 & 48.0 & 48.1 & 47.6 & 47.2 & 33,193 & 1,528 & 47.9 & 3,421 & 1,622 & 47.4 & 3,185 & 1,580 & 49.6 \\
\hline
\end{tabular}

${ }^{1}$ U.S. totals include imputations for underreporting and nonreporting states. 2 Includes imputations for underreporting.

${ }^{3}$ Support staff underreported.

${ }^{4}$ Data estimated by the National Center for Education Statistics.
SOURCE: U.S. Department of Education, National Center for Education Statistics, Common Core of Data survey; and unpublished estimates. (This table was prepared May 1998.) 
Table 87.-Staff, enrollment, and pupil/staff ratios in public elementary and secondary schools, by state: Fall 1990 to fall 1996

\begin{tabular}{|c|c|c|c|c|c|c|c|c|c|c|c|c|c|}
\hline \multirow[b]{2}{*}{ State or other area } & \multicolumn{4}{|c|}{ Pupil/staff ratio } & \multicolumn{3}{|c|}{ Fall 1994} & \multicolumn{3}{|c|}{ Fall 1995} & \multicolumn{3}{|c|}{ Fall 1996} \\
\hline & $\begin{array}{c}\text { Fall } \\
1990\end{array}$ & $\begin{array}{c}\text { Fall } \\
1991\end{array}$ & $\begin{array}{c}\text { Fall } \\
1992\end{array}$ & $\begin{array}{c}\text { Fall } \\
1993\end{array}$ & Staff & Enrollment & $\begin{array}{l}\text { Pupil/ } \\
\text { staff } \\
\text { ratio }\end{array}$ & Staff & Enrollment & $\begin{array}{l}\text { Pupil/ } \\
\text { staff } \\
\text { ratio }\end{array}$ & Staff & Enrollment & $\begin{array}{l}\text { Pupil/ } \\
\text { staff } \\
\text { ratio }\end{array}$ \\
\hline 1 & 2 & 3 & 4 & 5 & 6 & 7 & 8 & 9 & 10 & 11 & 12 & 13 & 14 \\
\hline United States ${ }^{1}$ & 9.2 & 9.2 & 9.1 & 9.0 & $4,904,757$ & $44,111,482$ & 9.0 & $4,994,358$ & $44,840,481$ & 9.0 & $5,117,616$ & $45,592,213$ & 8.9 \\
\hline Alabama . & 9.7 & 8.8 & 29.3 & 29.1 & 281,544 & 736,531 & 29.0 & 83,256 & 746,149 & 29.0 & 284,914 & 748,156 & 28.8 \\
\hline Alaska ............................ & 8.5 & 8.5 & 8.3 & 8.0 & 215,150 & 127,057 & 28.4 & 215,022 & 127,618 & 28.5 & 214,791 & 129,919 & 28.8 \\
\hline Arizona ……..................... & 10.1 & 10.0 & 9.4 & 9.5 & 74,540 & 737,424 & 9.9 & 75,931 & 743,566 & 9.8 & 79,429 & 799,250 & 10.1 \\
\hline Arkansas ......................... & 8.8 & 8.5 & 9.0 & 8.8 & 50,201 & 447,565 & 8.9 & 49,178 & 453,257 & 9.2 & 251,004 & 457,349 & 29.0 \\
\hline California .............................. & 11.8 & 11.9 & 212.3 & 212.4 & 2436,140 & $5,407,475$ & 212.4 & 2444,014 & $5,536,406$ & 212.5 & 2468,246 & $5,687,901$ & 212.1 \\
\hline Colorado & 9.3 & 9.5 & 9.8 & 9.9 & 64,985 & 640,521 & 9.9 & 67,447 & 656,279 & 9.7 & 71,226 & 673,438 & 9.5 \\
\hline Connecticut & 7.6 & 8.0 & 7.7 & 8.0 & 64,742 & 506,824 & 7.8 & 66,133 & 517,935 & 7.8 & 68,861 & 527,129 & 7.7 \\
\hline Delaware …......................... & 9.2 & 9.3 & 9.2 & 9.1 & 11,759 & 106,813 & 9.1 & 11,869 & 108,461 & 9.1 & 12,203 & 110,549 & 9.1 \\
\hline District of Columbia ....... & 7.9 & 7.2 & 7.7 & 7.6 & 10,507 & 80,450 & 7.7 & 9,410 & 79,802 & 8.5 & 9,318 & 78,648 & 8.4 \\
\hline Florida …........................ & 8.6 & 8.8 & 9.1 & 9.0 & 226,975 & $2,111,188$ & 9.3 & 237,721 & $2,176,222$ & 9.2 & 248,773 & $2,242,212$ & 9.0 \\
\hline Georgia & 8.9 & 8.9 & 28.5 & 27.9 & 2161,390 & $1,270,948$ & 27.9 & 2165,058 & $1,311,126$ & 27.9 & 2148,294 & $1,346,761$ & 29.1 \\
\hline Hawaii ….......................... & 11.3 & 11.2 & 10.0 & 9.9 & 16,567 & 183,795 & 11.1 & 16,841 & 187,180 & 11.1 & 16,867 & 187,653 & 11.1 \\
\hline Idaho ............................. & 12.2 & 12.1 & 11.8 & 11.8 & 21,194 & 240,448 & 11.3 & 21,814 & 243,097 & 11.1 & 22,611 & 245,252 & 10.8 \\
\hline Illinois …......................... & 9.5 & 9.4 & 9.4 & 9.5 & 204,413 & $1,916,172$ & 9.4 & 209,036 & $1,943,623$ & 9.3 & 2221,285 & $1,973,040$ & 28.9 \\
\hline Indiana & 8.8 & 8.8 & 8.6 & 8.5 & 115,441 & 969,022 & 8.4 & 116,363 & 977,263 & 8.4 & 119,800 & 983,415 & 8.2 \\
\hline lowa ............... & 8.3 & 8.1 & 8.2 & 8.3 & 60,469 & 500,440 & 8.3 & 62,075 & 502,343 & 8.1 & 63,003 & 502,941 & 8.0 \\
\hline Kansas ............. & 8.5 & 8.6 & 8.3 & 8.2 & 56,790 & 460,838 & 8.1 & 57,265 & 463,008 & 8.1 & 58,040 & 466,293 & 8.0 \\
\hline Kentucky ............................ & 8.6 & 8.4 & 8.3 & 8.1 & 81,720 & 657,642 & 8.0 & 84,425 & 659,821 & 7.8 & 275,073 & 656,089 & 28.7 \\
\hline Louisiana ............................. & 8.6 & 312.0 & 8.7 & 8.6 & 96,124 & 797,933 & 8.3 & 93,070 & 797,366 & 8.6 & 94,113 & 793,296 & 8.4 \\
\hline Maine …............................ & 8.0 & 8.0 & 7.5 & 7.5 & 29,264 & 212,601 & 7.3 & 29,413 & 213,569 & 7.3 & 29,988 & 213,593 & 7.1 \\
\hline Maryland & 9.1 & 9.2 & 9.3 & 9.3 & 84,699 & 790,938 & 9.3 & 87,868 & 805,544 & 9.2 & 85,522 & 818,583 & 9.6 \\
\hline Massachusetts ............... & 8.8 & 8.5 & 8.5 & 8.4 & 108,281 & 893,727 & 8.3 & 113,154 & 915,007 & 8.1 & 116,749 & 933,898 & 8.0 \\
\hline Michigan ........................... & 9.2 & 8.9 & 9.2 & 9.4 & 164,766 & $1,614,784$ & 9.8 & 177,495 & $1,641,456$ & 9.2 & 194,954 & $1,684,386$ & 8.6 \\
\hline Minnesota ........................ & 9.8 & 9.9 & 10.0 & 10.8 & 74,914 & 821,693 & 11.0 & 74,891 & 835,166 & 11.2 & 86,856 & 847,204 & 9.8 \\
\hline Mississippi ........................... & 8.6 & 8.5 & 8.8 & 8.5 & 60,708 & 505,962 & 8.3 & 60,855 & 506,272 & 8.3 & 61,125 & 503,967 & 8.2 \\
\hline Missouri & 7.9 & 8.4 & 27.9 & 7.7 & 116,974 & 878,541 & 7.5 & 120,621 & 889,881 & 7.4 & 112,406 & 900,042 & 8.0 \\
\hline Montana ............................ & 312.2 & 311.9 & 28.5 & 28.7 & 218,452 & 164,341 & 28.9 & 218,586 & 165,547 & 28.9 & 218,862 & 164,627 & 28.7 \\
\hline Nebraska ............................ & 7.8 & 8.1 & 27.9 & 27.7 & 37,144 & 287,100 & 7.7 & 37,894 & 289,744 & 7.6 & 38,038 & 291,967 & 7.7 \\
\hline Nevada ............................. & 317.3 & 316.1 & 210.4 & 10.5 & 23,098 & 250,747 & 10.9 & 23,742 & 265,041 & 11.2 & 25,463 & 282,131 & 11.1 \\
\hline New Hampshire ......... & 8.4 & 8.6 & 8.5 & 8.5 & 22,336 & 189,319 & 8.5 & 23,143 & 194,171 & 8.4 & 23,963 & 198,308 & 8.3 \\
\hline New Jersey & 7.4 & 7.5 & 7.5 & 7.2 & 161,586 & $1,174,206$ & 7.3 & 163,069 & $1,197,381$ & 7.3 & 4168,441 & ${ }^{4} 1,208,179$ & 47.2 \\
\hline New Mexico ....................... & 9.1 & 8.9 & 9.1 & 8.8 & 39,016 & 327,248 & 8.4 & 40,124 & 329,640 & 8.2 & 40,785 & 332,632 & 8.2 \\
\hline New York ........................... & 7.5 & 7.8 & 7.8 & 7.7 & 356,386 & $2,766,208$ & 7.8 & 355,723 & $2,813,230$ & 7.9 & 363,586 & $2,843,131$ & 7.8 \\
\hline North Carolina .................. & 8.7 & 8.7 & 28.6 & 8.5 & 2137,791 & $1,156,767$ & 28.4 & 2140,204 & $1,183,090$ & 28.4 & 2145,110 & $1,210,108$ & 28.3 \\
\hline North Dakota ...................... & 8.5 & 8.7 & 8.6 & 8.6 & 13,919 & 119,288 & 8.6 & 13,804 & 119,100 & 8.6 & 14,552 & 120,123 & 8.3 \\
\hline Ohio & 9.3 & 9.2 & 8.9 & 9.0 & 200,141 & $1,814,290$ & 9.1 & 194,579 & $1,836,015$ & 9.4 & 196,969 & $1,844,389$ & 9.4 \\
\hline Oklahoma ................... & 8.4 & 8.4 & 8.3 & 8.3 & 278,270 & 609,718 & 27.8 & 283,802 & 616,393 & 27.4 & 283,483 & 620,695 & 27.4 \\
\hline Oregon ……..................... & 9.6 & 9.9 & 9.9 & 10.3 & 50,377 & 521,945 & 10.4 & 51,458 & 527,914 & 10.3 & 52,259 & 537,854 & 10.3 \\
\hline Pennsylvania ............... & 8.7 & 8.9 & 9.0 & 9.1 & 193,696 & $1,764,946$ & 9.1 & 198,087 & $1,787,533$ & 9.0 & 201,134 & $1,804,256$ & 9.0 \\
\hline Rhode Island ..................... & 8.8 & 9.2 & 9.1 & 9.4 & 15,438 & 147,487 & 9.6 & 16,517 & 149,799 & 9.1 & 16,823 & 151,324 & 9.0 \\
\hline South Carolina & 9.4 & 9.4 & 9.5 & 29.0 & 274,196 & 648,725 & 28.7 & 274,859 & 645,586 & 28.6 & 276,932 & 653,011 & 28.5 \\
\hline South Dakota ................... & 8.5 & 8.9 & 8.6 & 8.3 & 217,989 & 143,482 & 28.0 & 218,126 & 144,685 & 28.0 & 18,108 & 143,331 & 7.9 \\
\hline Tennessee ........... & 9.5 & 9.9 & 9.9 & 29.4 & 96,281 & 881,425 & 29.2 & 98,948 & 893,770 & 29.0 & 101,434 & 905,089 & 8.9 \\
\hline Texas ……........................ & 10.2 & 10.3 & 8.4 & 8.3 & 450,462 & $3,677,171$ & 8.2 & 462,661 & $3,748,167$ & 8.1 & 477,896 & $3,828,975$ & 8.0 \\
\hline 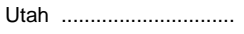 & 13.8 & 13.7 & 13.3 & 13.4 & 36,186 & 474,675 & 13.1 & 37,385 & 477,121 & 12.8 & 37,461 & 481,812 & 12.9 \\
\hline Vermont & 7.1 & 7.0 & 6.6 & 26.9 & 15,337 & 104,533 & 6.8 & 15,640 & 105,565 & 6.7 & 15,693 & 106,341 & 6.8 \\
\hline Virginia & 7.7 & ${ }^{4} 7.8$ & 8.1 & 8.0 & 2133,485 & $1,060,809$ & 27.9 & 2137,546 & $1,079,854$ & 27.9 & 2139,174 & $1,096,093$ & 27.9 \\
\hline Washington ....................... & 11.1 & 11.1 & 11.0 & 10.4 & 290,438 & 938,314 & 210.4 & 291,322 & 956,572 & 210.5 & 294,692 & 974,504 & 210.3 \\
\hline West Virginia .................... & 8.2 & 8.3 & 8.3 & 8.2 & 38,481 & 310,511 & 8.1 & 38,645 & 307,112 & 7.9 & 38,099 & 304,052 & 8.0 \\
\hline Wisconsin ......................... & 9.4 & 9.2 & 9.0 & 9.5 & 100,996 & 860,581 & 8.5 & 95,105 & 870,175 & 9.1 & 99,871 & 879,259 & 8.8 \\
\hline 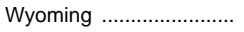 & 7.7 & 7.8 & 8.7 & 7.8 & 12,999 & 100,314 & 7.7 & 13,164 & 99,859 & 7.6 & 13,337 & 99,058 & 7.4 \\
\hline \multicolumn{14}{|l|}{ Outlying areas } \\
\hline American Samoa ..... & 9.9 & 10.5 & 10.4 & 10.8 & 1,340 & 14,445 & 10.8 & 1,417 & 14,576 & 10.3 & 1,470 & 14,766 & 10.0 \\
\hline Guam …….................... & 9.0 & 9.6 & 8.6 & 8.1 & 4,730 & 32,185 & 6.8 & 3,728 & 32,960 & 8.8 & 3,263 & 33,393 & 10.2 \\
\hline Northern Marianas ......... & 7.9 & 7.8 & 7.4 & 7.4 & 1,051 & 8,429 & 8.0 & 1,054 & 8,809 & 8.4 & 1,056 & 9,041 & 8.6 \\
\hline Puerto Rico ......................... & 10.4 & 9.5 & 9.4 & 9.3 & ${ }^{3} 68,868$ & 621,121 & 39.0 & 69,731 & 627,620 & 9.0 & 71,333 & 618,861 & 8.7 \\
\hline Virgin Islands .................... & 6.6 & 6.8 & 6.8 & 6.8 & 33,193 & 23,126 & 37.2 & 3,421 & 22,737 & 6.6 & 3,185 & 22,385 & 7.0 \\
\hline
\end{tabular}

1 U.S. totals include imputations for underreporting and nonreporting states. 2 Includes imputations for underreporting

3 Support staff underreported.

${ }^{4}$ Estimated by the National Center for Education Statistics.
SOURCE: U.S. Department of Education, National Center for Education Statistics, Common Core of Data survey; and unpublished estimates. (This table was prepared May 1998.) 
Table 88.-Principals in public and private elementary and secondary schools, by selected characteristics: 1993-94

\begin{tabular}{|c|c|c|c|c|c|c|c|c|c|c|c|}
\hline \multirow[b]{2}{*}{ Selected characteristics } & \multirow[b]{2}{*}{ Total $^{1}$} & \multicolumn{4}{|c|}{$\begin{array}{l}\text { Percent of principals, } \\
\text { by highest degree earned }{ }^{2}\end{array}$} & \multicolumn{2}{|c|}{$\begin{array}{l}\text { Average years of } \\
\text { experience }\end{array}$} & \multicolumn{4}{|c|}{$\begin{array}{l}\text { Average annual salary of principals, by } \\
\text { length of school year }{ }^{3}\end{array}$} \\
\hline & & $\begin{array}{l}\text { Bach- } \\
\text { elor's }\end{array}$ & Master's & $\begin{array}{l}\text { Education } \\
\text { specialist }\end{array}$ & $\begin{array}{l}\text { Doctor's } \\
\text { and first- } \\
\text { profes- } \\
\text { sional }\end{array}$ & $\begin{array}{c}\text { As a } \\
\text { principal }\end{array}$ & $\begin{array}{l}\text { Prior } \\
\text { teaching } \\
\text { experi- } \\
\text { ence }\end{array}$ & Total & $\begin{array}{l}10 \text { months } \\
\text { or less }\end{array}$ & $\begin{array}{c}11 \\
\text { months }\end{array}$ & $\begin{array}{c}12 \\
\text { months }\end{array}$ \\
\hline \multirow[t]{2}{*}{1} & 2 & 3 & 4 & 5 & 6 & 7 & 8 & 9 & 10 & 11 & 12 \\
\hline & \multicolumn{11}{|c|}{ Public schools } \\
\hline Total ................. & 79,618 & 1.4 & 63.4 & 25.8 & 9.3 & 8.7 & 11.0 & $\$ 54,858$ & $\$ 50,103$ & $\$ 53,117$ & $\$ 58,399$ \\
\hline $\begin{array}{l}\text { Men } \ldots \ldots \ldots \ldots \ldots \ldots \ldots \ldots \ldots \\
\text { Women } \ldots \ldots \ldots \ldots \ldots \ldots \ldots \ldots \ldots\end{array}$ & $\begin{array}{l}52,114 \\
27,505\end{array}$ & $\begin{array}{l}1.1 \\
2.0\end{array}$ & $\begin{array}{l}65.1 \\
60.2\end{array}$ & $\begin{array}{l}24.7 \\
27.9\end{array}$ & $\begin{array}{l}9.1 \\
9.8\end{array}$ & $\begin{array}{r}10.3 \\
5.6\end{array}$ & $\begin{array}{l}10.0 \\
13.0\end{array}$ & $\begin{array}{l}54,922 \\
54,736\end{array}$ & $\begin{array}{l}49,545 \\
50,908\end{array}$ & $\begin{array}{l}52,946 \\
53,439\end{array}$ & $\begin{array}{l}58,492 \\
58,195\end{array}$ \\
\hline \multicolumn{12}{|l|}{ Race/ethnicity } \\
\hline White, non-Hispanic ..... & 67,081 & 1.5 & 62.8 & 26.5 & 9.2 & 9.0 & 10.8 & 54,466 & 48,797 & 52,893 & 58,311 \\
\hline Black, non-Hispanic ..... & 8,018 & 0.0 & 64.3 & 23.7 & 11.9 & 7.1 & 12.7 & 57,669 & 58,346 & 54,061 & 58,836 \\
\hline 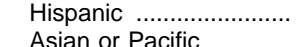 & 3,269 & 2.7 & 74.5 & 17.3 & 5.5 & 6.3 & 11.3 & 55,862 & 50,035 & 54,898 & 59,597 \\
\hline Islander ................ & 620 & 6.7 & 50.9 & 25.4 & 17.0 & 5.6 & 11.7 & 59,447 & 56,916 & $\left({ }^{4}\right)$ & $\left({ }^{4}\right)$ \\
\hline $\begin{array}{l}\text { American Indian or } \\
\text { Alaskan Native } \ldots . . . . . .\end{array}$ & 631 & 1.1 & 65.8 & 24.8 & 8.2 & 8.2 & 9.9 & 51,117 & 46,401 & 49,121 & 55,337 \\
\hline \multicolumn{12}{|l|}{ Age } \\
\hline Under 40 & 5,936 & 4.5 & 71.2 & 18.9 & 5.3 & 2.8 & 7.8 & 46,542 & 41,817 & 46,877 & 49,779 \\
\hline 40 to $44 \ldots$. & 14,571 & 1.6 & 65.4 & 26.2 & 6.7 & 5.0 & 10.3 & 52,038 & 48,033 & 49,581 & 55,443 \\
\hline 45 to $49 \ldots \ldots \ldots . .$. & 25,427 & 0.9 & 59.8 & 30.0 & 9.3 & 7.1 & 11.4 & 55,423 & 50,663 & 53,705 & 58,872 \\
\hline 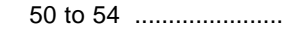 & 18,868 & 1.0 & 63.9 & 24.9 & 10.3 & 10.3 & 11.8 & 56,559 & 52,464 & 54,279 & 59,643 \\
\hline 55 or over...$\ldots \ldots \ldots \ldots \ldots \ldots$ & 14,817 & 1.4 & 63.8 & 22.4 & 12.4 & 15.1 & 11.6 & 57,826 & 52,414 & 56,355 & 62,148 \\
\hline \multicolumn{12}{|l|}{ Type of school } \\
\hline Elementary ....................... & 53,684 & 1.5 & 64.1 & 25.7 & 8.6 & 8.9 & 11.2 & 54,161 & 50,306 & 52,930 & 57,620 \\
\hline Secondary ..................... & 18,262 & 1.2 & 63.1 & 25.4 & 10.3 & 8.0 & 10.6 & 56,601 & 47,100 & 53,982 & 60,204 \\
\hline \multirow[t]{2}{*}{ 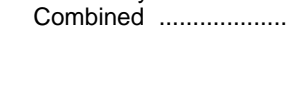 } & 2,747 & 2.6 & 60.2 & 27.8 & 9.4 & 7.5 & 10.9 & 52,825 & 50,729 & 51,879 & 54,040 \\
\hline & \multicolumn{11}{|c|}{ Private schools } \\
\hline Total .... & 25,015 & 25.9 & 51.6 & 8.2 & 5.9 & 8.8 & 9.4 & $\$ 32,075$ & $\$ 21,994$ & $\$ 32,215$ & $\$ 35,295$ \\
\hline Men & 11,606 & 23.1 & 49.6 & 6.8 & 9.2 & 9.0 & 7.6 & 35,597 & 21,144 & 41,663 & 38,350 \\
\hline Women .......................... & 13,410 & 28.3 & 53.3 & 9.4 & 3.0 & 8.6 & 11.1 & 29,185 & 22,537 & 27,818 & 32,231 \\
\hline \multicolumn{12}{|l|}{ Race/ethnicity } \\
\hline White, non-Hispanic ..... & 23,133 & 25.6 & 52.1 & 8.1 & 5.8 & 8.7 & 9.5 & 31,969 & 21,289 & 32,071 & 35,283 \\
\hline Black, non-Hispanic ..... & 1,060 & 26.5 & 43.6 & 11.0 & 4.6 & 8.3 & 7.4 & 34,383 & $(4)$ & $(4)$ & 35,801 \\
\hline Hispanic . .......................... & 524 & 34.5 & 44.0 & 9.2 & 12.1 & 10.1 & 12.1 & 31,350 & & & \\
\hline \multicolumn{12}{|l|}{ Age } \\
\hline 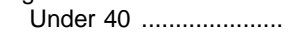 & 4,794 & 38.1 & 36.6 & 8.2 & 1.4 & 3.5 & 5.0 & 26,308 & 17,903 & 33,527 & 29,420 \\
\hline 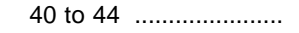 & 4,403 & 35.9 & 45.5 & 8.5 & 5.3 & 5.3 & 7.9 & 30,486 & 20,004 & 30,127 & 33,044 \\
\hline 45 to $49 \ldots \ldots \ldots \ldots \ldots \ldots \ldots \ldots$ & 5,144 & 22.2 & 59.0 & 8.1 & 5.5 & 8.3 & 9.9 & 34,641 & 23,945 & 31,812 & 38,932 \\
\hline 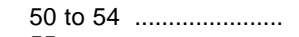 & 4,120 & 15.1 & 59.1 & 7.7 & 11.0 & 9.6 & 11.1 & 37,727 & 27,338 & 35,421 & 40,097 \\
\hline 55 or over $\ldots \ldots \ldots \ldots \ldots \ldots \ldots$ & 6,553 & 20.0 & 56.0 & 8.3 & 6.8 & 14.8 & 12.4 & 31,781 & 23,679 & 31,308 & 35,144 \\
\hline \multicolumn{12}{|l|}{ Type of school } \\
\hline Elementary ... & 13,354 & 26.1 & 54.2 & 8.0 & 4.7 & 9.4 & 10.4 & 28,779 & 23,427 & 30,050 & 30,687 \\
\hline Secondary ..................... & 2,304 & 6.0 & 67.4 & 14.0 & 12.4 & 7.8 & 10.5 & 43,683 & $(4)$ & 40,018 & 45,195 \\
\hline Combined $\ldots \ldots \ldots \ldots \ldots \ldots$ & 6,772 & 29.4 & 44.2 & 6.6 & 5.5 & 8.0 & 7.5 & 33,634 & 17,957 & 39,884 & 37,490 \\
\hline
\end{tabular}

1 Total differs from data appearing in other tables because of varying survey processing procedures and time period coverages.

2 Percentages for those with less than a bachelor's degree are not shown.

${ }^{3}$ Excludes principals reporting a salary of $\$ 0$. About 7.4 percent of private school principals had $\$ 0$ salary. If these principals are included in the average annual salary calculations, the average for all private school principals is $\$ 29,714$.
${ }^{4}$ Too few cases for reliable estimate.

NOTE.-Details may not add to 100.0 percent because of rounding and survey item nonresponse.

SOURCE: U.S. Department of Education, National Center for Education Statistics, "Schools and Staffing Survey, 1993-94." (This table was prepared November 1996.) 
Table 89.-Public elementary and secondary students, schools, pupil/teacher ratios, and finances, by type of locale: 1995 and 1996

\begin{tabular}{|c|c|c|c|c|c|c|c|c|}
\hline Characteristic & Total & $\begin{array}{c}\text { Large } \\
\text { central city }{ }^{1}\end{array}$ & $\begin{array}{c}\text { Mid-size } \\
\text { central city } 2\end{array}$ & $\begin{array}{l}\text { Urban } \\
\text { fringe of } \\
\text { large city }{ }^{3}\end{array}$ & $\begin{array}{l}\text { Urban } \\
\text { fringe of } \\
\text { mid-size } \\
\text { city }{ }^{4}\end{array}$ & $\begin{array}{l}\text { Large } \\
\text { town } 5\end{array}$ & $\begin{array}{l}\text { Small } \\
\text { town } 6\end{array}$ & Rural $^{7}$ \\
\hline \multirow[t]{2}{*}{1} & 2 & 3 & 4 & 5 & 6 & 7 & 8 & 9 \\
\hline & \multicolumn{8}{|c|}{ Schools, enrollment, and teachers, 1996-97 } \\
\hline 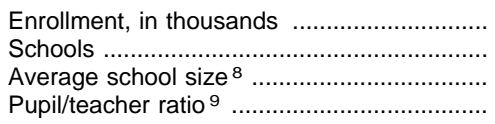 & $\begin{array}{r}45,705 \\
88,223 \\
527 \\
17.3\end{array}$ & $\begin{array}{r}8,300 \\
12,109 \\
729 \\
18.5\end{array}$ & $\begin{array}{r}7,597 \\
13,019 \\
590 \\
17.1\end{array}$ & $\begin{array}{r}13,588 \\
21,523 \\
635 \\
17.9\end{array}$ & $\begin{array}{r}4,330 \\
7,828 \\
560 \\
17.4\end{array}$ & $\begin{array}{r}803 \\
1,616 \\
506 \\
17.2\end{array}$ & $\begin{array}{r}5,279 \\
12,516 \\
430 \\
16.5\end{array}$ & $\begin{array}{r}5,808 \\
19,609 \\
299 \\
15.6\end{array}$ \\
\hline \multirow[t]{2}{*}{ 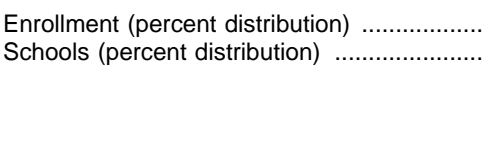 } & $\begin{array}{l}100.0 \\
100.0\end{array}$ & $\begin{array}{l}18.2 \\
13.7\end{array}$ & $\begin{array}{l}16.6 \\
14.8\end{array}$ & $\begin{array}{l}29.7 \\
24.4\end{array}$ & $\begin{array}{l}9.5 \\
8.9\end{array}$ & $\begin{array}{l}1.8 \\
1.8\end{array}$ & $\begin{array}{l}11.6 \\
14.2\end{array}$ & $\begin{array}{l}12.7 \\
22.2\end{array}$ \\
\hline & \multicolumn{8}{|c|}{ Revenues and expenditures, 1994-95 (in millions) } \\
\hline 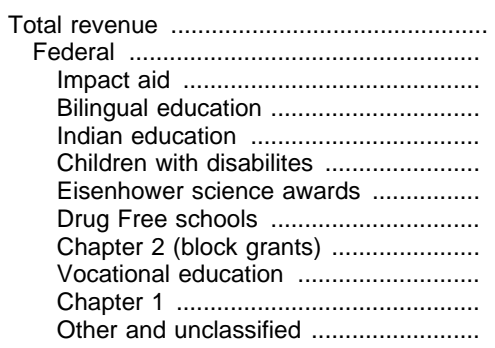 & $\begin{array}{r}\$ 267,361 \\
17,588 \\
679 \\
31 \\
47 \\
1,918 \\
158 \\
281 \\
323 \\
569 \\
6,347 \\
7,235\end{array}$ & $\begin{array}{r}\$ 51,109 \\
4,932 \\
61 \\
7 \\
3 \\
391 \\
45 \\
74 \\
86 \\
183 \\
1,984 \\
2,098\end{array}$ & $\begin{array}{r}\$ 43,649 \\
3,285 \\
88 \\
5 \\
4 \\
357 \\
30 \\
54 \\
59 \\
112 \\
1,217 \\
1,361\end{array}$ & $\begin{array}{r}\$ 83,883 \\
3,267 \\
143 \\
5 \\
4 \\
537 \\
36 \\
65 \\
71 \\
99 \\
971 \\
1,337\end{array}$ & $\begin{array}{r}\$ 23,728 \\
1,315 \\
53 \\
2 \\
1 \\
166 \\
12 \\
22 \\
24 \\
39 \\
440 \\
556\end{array}$ & $\begin{array}{r}\$ 4,076 \\
316 \\
14 \\
2 \\
2 \\
36 \\
3 \\
5 \\
6 \\
11 \\
113 \\
125\end{array}$ & $\begin{array}{r}\$ 27,654 \\
2,249 \\
129 \\
5 \\
15 \\
229 \\
17 \\
32 \\
39 \\
74 \\
823 \\
886\end{array}$ & $\begin{array}{r}\$ 33,263 \\
2,223 \\
191 \\
6 \\
19 \\
202 \\
15 \\
30 \\
39 \\
52 \\
798 \\
871\end{array}$ \\
\hline $\begin{array}{l}\text { State } \\
\text { State school lunch programs }\end{array}$ & $\begin{array}{r}126,688 \\
441\end{array}$ & $\begin{array}{r}23,667 \\
107\end{array}$ & $\begin{array}{r}21,973 \\
90\end{array}$ & $\begin{array}{r}34,031 \\
94\end{array}$ & $\begin{array}{r}11,719 \\
39\end{array}$ & $\begin{array}{r}2,258 \\
5\end{array}$ & $\begin{array}{r}15,182 \\
50\end{array}$ & $\begin{array}{r}17,858 \\
56\end{array}$ \\
\hline 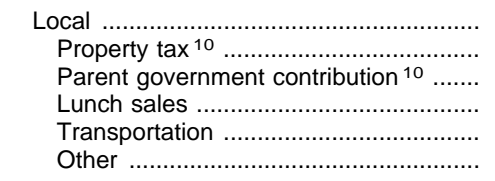 & $\begin{array}{r}123,085 \\
82,657 \\
22,271 \\
4,121 \\
35 \\
14,001\end{array}$ & $\begin{array}{r}22,510 \\
13,301 \\
5,839 \\
500 \\
3 \\
2,866\end{array}$ & $\begin{array}{r}18,391 \\
11,778 \\
3,693 \\
642 \\
5 \\
2,273\end{array}$ & $\begin{array}{r}46,585 \\
33,429 \\
7,761 \\
1,373 \\
16 \\
4,005\end{array}$ & $\begin{array}{r}10,693 \\
6,697 \\
2,210 \\
434 \\
3 \\
1,349\end{array}$ & $\begin{array}{r}1,501 \\
1,051 \\
162 \\
74 \\
1 \\
213\end{array}$ & $\begin{array}{r}10,222 \\
7,325 \\
889 \\
497 \\
4 \\
1,508\end{array}$ & $\begin{array}{r}13,183 \\
9,076 \\
1,717 \\
601 \\
3 \\
1,786\end{array}$ \\
\hline $\begin{array}{l}\text { Total revenue (percent distribution) } \\
\text { Federal } \\
\text { State } \\
\text { Local }\end{array}$ & $\begin{array}{r}100.0 \\
6.6 \\
47.4 \\
46.0\end{array}$ & $\begin{array}{r}100.0 \\
9.6 \\
46.3 \\
44.0\end{array}$ & $\begin{array}{r}100.0 \\
7.5 \\
50.3 \\
42.1\end{array}$ & $\begin{array}{r}100.0 \\
3.9 \\
40.6 \\
55.5\end{array}$ & $\begin{array}{r}100.0 \\
5.5 \\
49.4 \\
45.1\end{array}$ & $\begin{array}{r}100.0 \\
7.8 \\
55.4 \\
36.8\end{array}$ & $\begin{array}{r}100.0 \\
8.1 \\
54.9 \\
37.0\end{array}$ & $\begin{array}{r}100.0 \\
6.7 \\
53.7 \\
39.6\end{array}$ \\
\hline 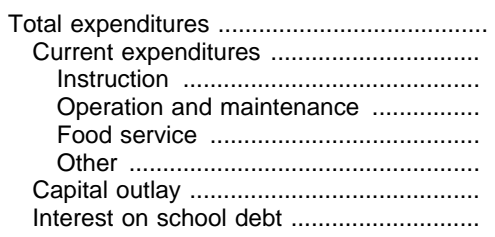 & $\begin{array}{r}\$ 264,336 \\
239,725 \\
147,620 \\
23,748 \\
10,024 \\
58,333 \\
19,433 \\
5,179\end{array}$ & $\begin{array}{r}\$ 51,145 \\
46,729 \\
28,884 \\
4,961 \\
1,959 \\
10,925 \\
3,521 \\
896\end{array}$ & $\begin{array}{r}\$ 43,349 \\
39,379 \\
24,081 \\
3,948 \\
1,712 \\
9,638 \\
3,167 \\
803\end{array}$ & $\begin{array}{r}\$ 83,108 \\
74,775 \\
45,792 \\
7,561 \\
2,509 \\
18,913 \\
6,531 \\
1,801\end{array}$ & $\begin{array}{r}\$ 23,287 \\
20,962 \\
13,201 \\
1,916 \\
921 \\
4,925 \\
1,814 \\
511\end{array}$ & $\begin{array}{r}\$ 4,048 \\
3,712 \\
2,298 \\
368 \\
175 \\
871 \\
262 \\
74\end{array}$ & $\begin{array}{r}\$ 27,147 \\
24,830 \\
15,369 \\
2,302 \\
1,308 \\
5,850 \\
1,857 \\
460\end{array}$ & $\begin{array}{r}\$ 32,252 \\
29,337 \\
17,995 \\
2,692 \\
1,440 \\
7,211 \\
2,280 \\
634\end{array}$ \\
\hline 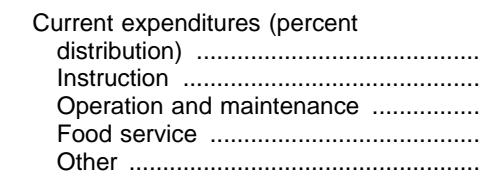 & $\begin{array}{r}100.0 \\
61.6 \\
9.9 \\
4.2 \\
24.3\end{array}$ & $\begin{array}{r}100.0 \\
61.8 \\
10.6 \\
4.2 \\
23.4\end{array}$ & $\begin{array}{r}100.0 \\
61.2 \\
10.0 \\
4.3 \\
24.5\end{array}$ & $\begin{array}{r}100.0 \\
61.2 \\
10.1 \\
3.4 \\
25.3\end{array}$ & $\begin{array}{r}100.0 \\
63.0 \\
9.1 \\
4.4 \\
23.5\end{array}$ & $\begin{array}{r}100.0 \\
61.9 \\
9.9 \\
4.7 \\
23.5\end{array}$ & $\begin{array}{r}100.0 \\
61.9 \\
9.3 \\
5.3 \\
23.6\end{array}$ & $\begin{array}{r}100.0 \\
61.3 \\
9.2 \\
4.9 \\
24.6\end{array}$ \\
\hline $\begin{array}{l}\text { Current expenditure per student ..................... } \\
\text { Instruction expenditure per student } \ldots \ldots \ldots \ldots \ldots . . .\end{array}$ & $\begin{array}{r}\$ 5,481 \\
3,375\end{array}$ & $\begin{array}{r}\$ 5,881 \\
3,635\end{array}$ & $\begin{array}{r}\$ 5,388 \\
3,295\end{array}$ & $\begin{array}{r}\$ 5,859 \\
3,588\end{array}$ & $\begin{array}{r}\$ 5,034 \\
3,170\end{array}$ & $\begin{array}{r}\$ 4,744 \\
2,937\end{array}$ & $\begin{array}{r}\$ 4,812 \\
2,979\end{array}$ & $\begin{array}{r}\$ 5,225 \\
3,205\end{array}$ \\
\hline
\end{tabular}

${ }^{1}$ Central city of metropolitan statistical area (MSA) with population of 400,000 or more or a population density of 6,000 or more persons per square mile.

${ }^{2}$ Central city of an MSA but not designated as a large central city.

${ }^{3}$ Place within the MSA of a large central city.

${ }^{4}$ Place within the MSA of a mid-size central city.

5 Place not within an MSA but with population of 25,000 or more and defined as urban.

${ }^{6}$ Place not within an MSA with a population of at least 2,500 but less than 25,000 .

7 Place with a population of less than 2,500.

${ }^{8}$ Average for schools reporting enrollment.

${ }^{9}$ Ratio for schools reporting both FTE teachers and fall enrollment data.
10 Property tax and parent government contributions are determined on the basis of independence or dependence of the local school system and are mutually exclusive.

NOTE.-Locale classification procedures not comparable with previous years. Enrollments by locale were used to distribute school district revenue and expenditure amounts by locale classification.

SOURCE: U.S. Department of Education, National Center for Education Statistics, Common Core of Data survey; and U.S. Department of Commerce, Bureau of the Census, Survey of Local Government Finances, unpublished data. (This table was prepared February 1999.) 
Table 90.-Public school districts and public and private elementary and secondary schools: 1929-30 to 1996-97

\begin{tabular}{|c|c|c|c|c|c|c|c|c|c|}
\hline \multirow{3}{*}{ School year } & \multirow{3}{*}{$\begin{array}{c}\text { Public } \\
\text { school } \\
\text { districts }{ }^{1}\end{array}$} & \multicolumn{5}{|c|}{ Public schools ${ }^{2}$} & \multicolumn{3}{|c|}{ Private schools 2,3} \\
\hline & & \multirow{2}{*}{$\begin{array}{l}\text { Total, all } \\
\text { schools }^{4}\end{array}$} & \multirow{2}{*}{$\begin{array}{l}\text { Total, } \\
\text { regular } \\
\text { schools }^{5}\end{array}$} & \multicolumn{2}{|c|}{$\begin{array}{l}\text { Schools with elementary } \\
\text { grades }\end{array}$} & \multirow{2}{*}{$\begin{array}{c}\text { Schools } \\
\text { with sec- } \\
\text { ondary } \\
\text { grades }\end{array}$} & \multirow{2}{*}{ Total 4} & \multirow{2}{*}{$\begin{array}{c}\text { Schools } \\
\text { with ele- } \\
\text { mentary } \\
\text { grades }\end{array}$} & \multirow{2}{*}{$\begin{array}{c}\text { Schools } \\
\text { with sec- } \\
\text { ondary } \\
\text { grades }\end{array}$} \\
\hline & & & & Total & One-teacher & & & & \\
\hline 1 & 2 & 3 & 4 & 5 & 6 & 7 & 8 & 9 & 10 \\
\hline 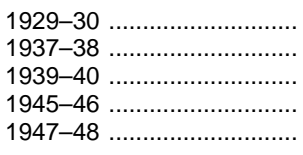 & $\begin{array}{r}- \\
119,001 \\
117,108 \\
101,382 \\
94,926\end{array}$ & $\begin{array}{l}- \\
- \\
-\end{array}$ & $\begin{array}{l}- \\
- \\
-\end{array}$ & $\begin{array}{r}238,306 \\
221,660 \\
- \\
160,227 \\
146,760\end{array}$ & $\begin{array}{r}149,282 \\
121,178 \\
113,600 \\
86,563 \\
75,096\end{array}$ & $\begin{array}{r}23,930 \\
25,467 \\
-24,314 \\
25,484\end{array}$ & $\begin{array}{l}- \\
- \\
-\end{array}$ & $\begin{array}{r}9,275 \\
9,992 \\
11,306 \\
9,863 \\
10,071\end{array}$ & $\begin{array}{l}3,258 \\
3,327 \\
3,568 \\
3,294 \\
3,292\end{array}$ \\
\hline 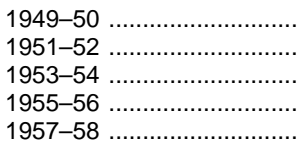 & $\begin{array}{l}83,718 \\
71,094 \\
63,057 \\
54,859 \\
47,594\end{array}$ & $\begin{array}{l}- \\
- \\
-\end{array}$ & $\begin{array}{l}- \\
- \\
-\end{array}$ & $\begin{array}{r}128,225 \\
123,763 \\
110,875 \\
104,427 \\
95,446\end{array}$ & $\begin{array}{l}59,652 \\
50,742 \\
42,865 \\
34,964 \\
25,341\end{array}$ & $\begin{array}{l}24,542 \\
23,746 \\
25,637 \\
26,046 \\
25,507\end{array}$ & $\begin{array}{l}- \\
- \\
-\end{array}$ & $\begin{array}{l}10,375 \\
10,666 \\
11,739 \\
12,372 \\
13,065\end{array}$ & $\begin{array}{l}3,331 \\
3,322 \\
3,913 \\
3,887 \\
3,994\end{array}$ \\
\hline 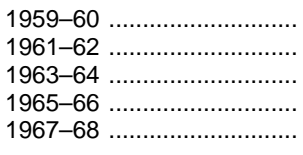 & $\begin{array}{l}40,520 \\
35,676 \\
31,705 \\
26,983 \\
22,010\end{array}$ & $\begin{array}{l}- \\
- \\
-\end{array}$ & $\frac{-}{-}$ & $\begin{array}{l}91,853 \\
81,910 \\
77,584 \\
73,216 \\
70,879\end{array}$ & $\begin{array}{r}20,213 \\
13,333 \\
9,895 \\
6,491 \\
4,146\end{array}$ & $\begin{array}{l}25,784 \\
25,350 \\
26,431 \\
26,597 \\
27,011\end{array}$ & $\begin{array}{r}- \\
17,849 \\
-\end{array}$ & $\begin{array}{r}13,574 \\
14,762 \\
- \\
15,340 \\
-\end{array}$ & $\begin{array}{r}4,061 \\
4,129 \\
4,451 \\
4,606 \\
\end{array}$ \\
\hline 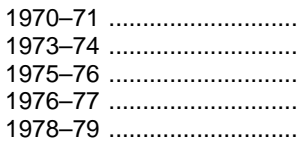 & $\begin{array}{l}17,995 \\
16,730 \\
16,376 \\
16,271 \\
16,014\end{array}$ & $\begin{array}{r}- \\
88,597 \\
-\end{array}$ & $\begin{array}{l}89,372 \\
88,655 \\
87,034 \\
86,501 \\
84,816\end{array}$ & $\begin{array}{l}65,800 \\
65,070 \\
63,242 \\
62,644 \\
61,982\end{array}$ & $\begin{array}{l}1,815 \\
1,365 \\
1,166 \\
1,111 \\
1,056\end{array}$ & $\begin{array}{l}25,352 \\
25,906 \\
25,330 \\
25,378 \\
24,504\end{array}$ & $\begin{array}{r}- \\
\frac{-}{19,910} \\
19,489\end{array}$ & $\begin{array}{r}14,372 \\
- \\
16,385 \\
16,097\end{array}$ & $\begin{array}{r}3,770 \\
- \\
5,904 \\
5,766\end{array}$ \\
\hline $\begin{array}{l}1980-81 \\
1982-83 \\
1983-84\end{array}$ & $\begin{array}{r}15,912 \\
15,824 \\
15,747 \\
- \\
-\end{array}$ & $\begin{array}{r}85,982 \\
84,740 \\
84,178 \\
84,007 \\
\end{array}$ & $\begin{array}{r}83,688 \\
82,039 \\
81,418 \\
81,147 \\
-\end{array}$ & $\begin{array}{r}61,069 \\
59,656 \\
59,082 \\
58,827 \\
\end{array}$ & $\begin{array}{r}921 \\
798 \\
838 \\
825 \\
-\end{array}$ & $\begin{array}{r}24,362 \\
23,988 \\
23,947 \\
23,916 \\
\end{array}$ & $\begin{array}{r}20,764 \\
627,694 \\
625,616\end{array}$ & $\begin{array}{r}16,792 \\
620,872 \\
620,252\end{array}$ & $\begin{array}{r}5,678 \\
67,862 \\
67,387\end{array}$ \\
\hline 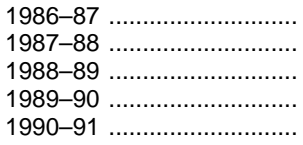 & $\begin{array}{l}715,713 \\
715,577 \\
715,376 \\
715,367 \\
715,358\end{array}$ & $\begin{array}{l}83,455 \\
83,248 \\
83,165 \\
83,425 \\
84,538\end{array}$ & $\begin{array}{l}82,190 \\
81,416 \\
81,579 \\
81,880 \\
82,475\end{array}$ & $\begin{array}{l}60,784 \\
59,754 \\
60,176 \\
60,699 \\
61,340\end{array}$ & $\begin{array}{l}763 \\
729 \\
583 \\
630 \\
617\end{array}$ & $\begin{array}{l}23,389 \\
23,841 \\
23,638 \\
23,461 \\
23,460\end{array}$ & $\begin{array}{r}{ }^{6} 26,807 \\
\frac{-}{-} \\
624,690\end{array}$ & $\begin{array}{r}{ }^{6} 22,959 \\
\frac{-}{-} \\
622,223\end{array}$ & ${ }^{6} 8,418$ \\
\hline 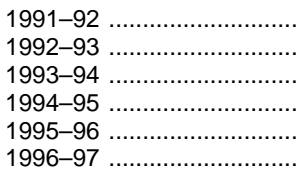 & $\begin{array}{l}715,173 \\
715,025 \\
714,881 \\
714,772 \\
714,766 \\
714,841\end{array}$ & $\begin{array}{l}84,578 \\
84,497 \\
85,393 \\
86,221 \\
87,125 \\
88,223\end{array}$ & $\begin{array}{l}82,506 \\
82,896 \\
83,431 \\
84,476 \\
84,958 \\
86,092\end{array}$ & $\begin{array}{l}61,739 \\
62,225 \\
62,726 \\
63,572 \\
63,961 \\
64,785\end{array}$ & $\begin{array}{l}569 \\
430 \\
442 \\
458 \\
474 \\
487\end{array}$ & $\begin{array}{l}23,248 \\
23,220 \\
23,379 \\
23,668 \\
23,793 \\
24,287\end{array}$ & $\begin{array}{r}625,998 \\
-6 \\
26,093 \\
- \\
27,686 \\
-\end{array}$ & $\begin{array}{r}623,523 \\
-\overline{6} \\
23,543 \\
- \\
25,153 \\
-\end{array}$ & $\begin{array}{r}69,282 \\
610,555 \\
10,942\end{array}$ \\
\hline
\end{tabular}

1 Includes operating and nonoperating districts.

2 Schools with both elementary and secondary programs are included under elementary schools and also under secondary schools.

${ }^{3}$ Data for most years are partly estimated.

${ }^{4}$ Includes regular schools and special schools not classified by grade span.

${ }^{5}$ Includes elementary, secondary, and combined elementary/secondary schools.

${ }^{6}$ These data are from sample surveys and should not be compared directly with the data for earlier years.
${ }^{7}$ Because of expanded survey coverage, data are not directly comparable with figures for earlier years.

-Data not available.

SOURCE: U.S. Department of Education, National Center for Education Statistics, Statistics of State School Systems; Statistics of Public Elementary and Secondary School Systems; Statistics of Nonpublic Elementary and Secondary Schools; Private Schools in American Education; and Common Core of Data surveys. (This table was prepared February 1999.)

Table 91.-Public school districts and enrollment, by size of district: 1988-89 to 1996-97

\begin{tabular}{|c|c|c|c|c|c|c|c|c|c|c|c|c|c|}
\hline \multirow[b]{2}{*}{ Enrollment size of district } & $1988-89$ & $1989-90$ & $1990-91$ & $1991-92$ & $1992-93$ & $1993-94$ & 1994-95 & \multicolumn{3}{|c|}{$1995-96$} & \multicolumn{3}{|c|}{$1996-97$} \\
\hline & $\begin{array}{l}\text { Number } \\
\text { of dis- } \\
\text { tricts }\end{array}$ & $\begin{array}{l}\text { Number } \\
\text { of dis- } \\
\text { tricts }\end{array}$ & $\begin{array}{l}\text { Number } \\
\text { of dis- } \\
\text { tricts }\end{array}$ & $\begin{array}{l}\text { Number } \\
\text { of dis- } \\
\text { tricts }\end{array}$ & $\begin{array}{l}\text { Number } \\
\text { of dis- } \\
\text { tricts }\end{array}$ & $\begin{array}{l}\text { Number } \\
\text { of dis- } \\
\text { tricts }\end{array}$ & $\begin{array}{l}\text { Number } \\
\text { of dis- } \\
\text { tricts }\end{array}$ & $\begin{array}{l}\text { Number } \\
\text { of dis- } \\
\text { tricts }\end{array}$ & $\begin{array}{l}\text { Percent } \\
\text { of dis- } \\
\text { tricts }\end{array}$ & $\begin{array}{l}\text { Percent } \\
\text { of stu- } \\
\text { dents }\end{array}$ & $\begin{array}{l}\text { Number } \\
\text { of dis- } \\
\text { tricts }\end{array}$ & $\begin{array}{l}\text { Percent } \\
\text { of dis- } \\
\text { tricts }\end{array}$ & $\begin{array}{l}\text { Percent } \\
\text { of stu- } \\
\text { dents }\end{array}$ \\
\hline 1 & 2 & 3 & 4 & 5 & 6 & 7 & 8 & 9 & 10 & 11 & 12 & 13 & 14 \\
\hline Total $\ldots \ldots \ldots \ldots \ldots \ldots$ & 15,376 & 15,367 & 15,358 & 15,173 & 15,025 & 14,881 & 14,772 & 14,766 & 100.0 & 100.0 & 14,841 & 100.0 & 100.0 \\
\hline $\begin{array}{l}25,000 \text { or more } \ldots \ldots \ldots \ldots \ldots . . \\
10,000 \text { to } 24,999 \ldots \ldots \ldots \ldots \ldots \\
5,000 \text { to } 9,999 \ldots \ldots \ldots \ldots \ldots \ldots \\
2,500 \text { to } 4,999 \ldots \ldots \ldots \ldots \ldots . . .\end{array}$ & $\begin{array}{r}177 \\
473 \\
924 \\
1,907\end{array}$ & $\begin{array}{r}179 \\
479 \\
913 \\
1,937\end{array}$ & $\begin{array}{r}190 \\
489 \\
937 \\
1,940\end{array}$ & $\begin{array}{r}195 \\
502 \\
941 \\
1,981\end{array}$ & $\begin{array}{r}202 \\
510 \\
955 \\
2,002\end{array}$ & $\begin{array}{r}206 \\
525 \\
973 \\
2,008\end{array}$ & $\begin{array}{r}207 \\
542 \\
996 \\
2,013\end{array}$ & $\begin{array}{r}216 \\
553 \\
1,013 \\
2,027\end{array}$ & $\begin{array}{r}1.5 \\
3.7 \\
6.9 \\
13.7\end{array}$ & $\begin{array}{l}30.5 \\
18.6 \\
15.7 \\
16.0\end{array}$ & $\begin{array}{r}226 \\
569 \\
1,024 \\
2,069\end{array}$ & $\begin{array}{r}1.5 \\
3.8 \\
6.9 \\
13.9\end{array}$ & $\begin{array}{l}31.1 \\
18.7 \\
15.5 \\
15.9\end{array}$ \\
\hline 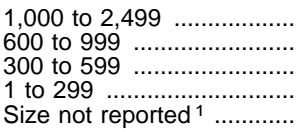 & $\begin{array}{r}3,529 \\
1,813 \\
2,266 \\
3,984 \\
303\end{array}$ & $\begin{array}{r}3,547 \\
1,801 \\
2,283 \\
3,910 \\
318\end{array}$ & $\begin{array}{r}3,542 \\
1,799 \\
2,275 \\
3,816 \\
370\end{array}$ & $\begin{array}{r}3,525 \\
1,793 \\
2,222 \\
3,648 \\
366\end{array}$ & $\begin{array}{r}3,530 \\
1,798 \\
2,200 \\
3,465 \\
363\end{array}$ & $\begin{array}{r}3,570 \\
1,785 \\
2,162 \\
3,294 \\
358\end{array}$ & $\begin{array}{r}3,579 \\
1,777 \\
2,113 \\
3,173 \\
372\end{array}$ & $\begin{array}{r}3,554 \\
1,777 \\
2,104 \\
3,123 \\
399\end{array}$ & $\begin{array}{r}24.1 \\
12.0 \\
14.2 \\
21.1 \\
2.7\end{array}$ & $\begin{array}{r}13.1 \\
3.2 \\
2.1 \\
1.0 \\
-\end{array}$ & $\begin{array}{r}3,536 \\
1,772 \\
2,066 \\
3,160 \\
419\end{array}$ & $\begin{array}{r}23.8 \\
11.9 \\
13.9 \\
21.3 \\
2.8\end{array}$ & $\begin{array}{r}12.7 \\
3.1 \\
2.0 \\
1.0 \\
\end{array}$ \\
\hline
\end{tabular}

1 Includes school districts reporting enrollment of 0 .

-Data not reported.
SOURCE: U.S. Department of Education, National Center for Education Statistics, Common Core of Data surveys. (This table was prepared October 1998.)

NOTE.-Because of rounding, details may not add to totals. 
Table 92.-Number and percentage of public elementary and secondary education agencies, by state and type of agency: 1995-96 and 1996-97

\begin{tabular}{|c|c|c|c|c|c|c|c|c|c|c|c|c|}
\hline \multirow{3}{*}{ State or other area } & \multicolumn{2}{|c|}{ Total agencies } & \multirow{2}{*}{\multicolumn{2}{|c|}{$\begin{array}{l}\text { Regular school dis- } \\
\text { tricts, including su- } \\
\text { pervisory union } \\
\text { components }\end{array}$}} & \multirow{2}{*}{\multicolumn{2}{|c|}{$\begin{array}{l}\text { Regional education } \\
\text { service agencies and } \\
\text { supervisory union ad- } \\
\text { ministrative centers }\end{array}$}} & \multicolumn{2}{|c|}{$\begin{array}{l}\text { State-operated } \\
\text { agencies }\end{array}$} & \multicolumn{2}{|c|}{$\begin{array}{c}\text { Federally operated } \\
\text { agencies }\end{array}$} & \multicolumn{2}{|c|}{ Other agencies } \\
\hline & \multirow{2}{*}{ 1995-96 } & \multirow{2}{*}{ 1996-97 } & & & & & \multirow{2}{*}{ 1995-96 } & \multirow{2}{*}{$1996-97$} & \multirow{2}{*}{ 1995-96 } & \multirow{2}{*}{ 1996-97 } & \multirow{2}{*}{ 1995-96 } & \multirow{2}{*}{ 1996-97 } \\
\hline & & & 1995-96 & 1996-97 & 1995-96 & 1996-97 & & & & & & \\
\hline 1 & 2 & 3 & 4 & 5 & 6 & 7 & 8 & 9 & 10 & 11 & 12 & 13 \\
\hline United States ............. & 16,265 & 16,359 & 14,766 & 14,841 & 1,164 & 1,165 & 194 & 194 & 44 & 44 & 97 & 115 \\
\hline 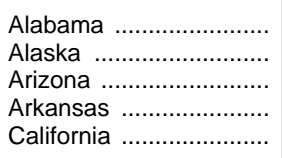 & $\begin{array}{r}131 \\
55 \\
242 \\
332 \\
1,060\end{array}$ & $\begin{array}{r}131 \\
55 \\
317 \\
331 \\
1,060\end{array}$ & $\begin{array}{r}127 \\
55 \\
227 \\
311 \\
999\end{array}$ & $\begin{array}{r}127 \\
53 \\
302 \\
311 \\
999\end{array}$ & $\begin{array}{r}0 \\
0 \\
5 \\
17 \\
58\end{array}$ & $\begin{array}{r}0 \\
0 \\
5 \\
16 \\
58\end{array}$ & $\begin{array}{l}1 \\
0 \\
1 \\
4 \\
3\end{array}$ & $\begin{array}{l}1 \\
2 \\
1 \\
4 \\
3\end{array}$ & $\begin{array}{l}3 \\
0 \\
8 \\
0 \\
0\end{array}$ & $\begin{array}{l}3 \\
0 \\
8 \\
0 \\
0\end{array}$ & $\begin{array}{l}0 \\
0 \\
1 \\
0 \\
0\end{array}$ & $\begin{array}{l}0 \\
0 \\
1 \\
0 \\
0\end{array}$ \\
\hline 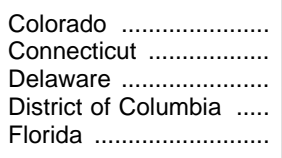 & $\begin{array}{r}194 \\
179 \\
22 \\
1 \\
74\end{array}$ & $\begin{array}{r}194 \\
179 \\
24 \\
1 \\
74\end{array}$ & $\begin{array}{r}176 \\
166 \\
19 \\
1 \\
67\end{array}$ & $\begin{array}{r}176 \\
166 \\
19 \\
1 \\
67\end{array}$ & $\begin{array}{r}18 \\
6 \\
0 \\
0 \\
0\end{array}$ & $\begin{array}{r}18 \\
6 \\
0 \\
0 \\
0\end{array}$ & $\begin{array}{l}0 \\
4 \\
3 \\
0 \\
1\end{array}$ & $\begin{array}{l}0 \\
4 \\
3 \\
0 \\
1\end{array}$ & $\begin{array}{l}0 \\
0 \\
0 \\
0 \\
0\end{array}$ & $\begin{array}{l}0 \\
0 \\
0 \\
0 \\
0\end{array}$ & $\begin{array}{l}0 \\
3 \\
0 \\
0 \\
6\end{array}$ & $\begin{array}{l}0 \\
3 \\
2 \\
0 \\
6\end{array}$ \\
\hline 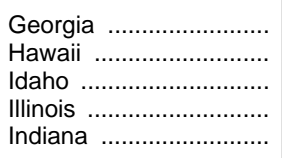 & $\begin{array}{r}180 \\
1 \\
113 \\
1,024 \\
327\end{array}$ & $\begin{array}{r}180 \\
1 \\
113 \\
1,040 \\
327\end{array}$ & $\begin{array}{r}180 \\
1 \\
112 \\
905 \\
295\end{array}$ & $\begin{array}{r}180 \\
1 \\
112 \\
924 \\
295\end{array}$ & $\begin{array}{r}0 \\
0 \\
0 \\
83 \\
28\end{array}$ & $\begin{array}{r}0 \\
0 \\
0 \\
81 \\
28\end{array}$ & $\begin{array}{l}0 \\
0 \\
1 \\
5 \\
3\end{array}$ & $\begin{array}{l}0 \\
0 \\
1 \\
5 \\
3\end{array}$ & $\begin{array}{l}0 \\
0 \\
0 \\
0 \\
0\end{array}$ & $\begin{array}{l}0 \\
0 \\
0 \\
0 \\
0\end{array}$ & $\begin{array}{r}0 \\
0 \\
0 \\
31 \\
1\end{array}$ & $\begin{array}{r}0 \\
0 \\
0 \\
30 \\
1\end{array}$ \\
\hline 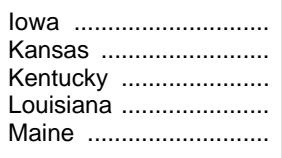 & $\begin{array}{r}415 \\
304 \\
258 \\
72 \\
326\end{array}$ & $\begin{array}{r}408 \\
304 \\
258 \\
72 \\
326\end{array}$ & $\begin{array}{r}384 \\
304 \\
176 \\
66 \\
284\end{array}$ & $\begin{array}{r}379 \\
304 \\
176 \\
66 \\
284\end{array}$ & $\begin{array}{r}15 \\
0 \\
0 \\
0 \\
40\end{array}$ & $\begin{array}{r}15 \\
0 \\
0 \\
0 \\
40\end{array}$ & $\begin{array}{r}15 \\
0 \\
80 \\
5 \\
1\end{array}$ & $\begin{array}{r}13 \\
0 \\
80 \\
5 \\
1\end{array}$ & $\begin{array}{l}1 \\
0 \\
2 \\
0 \\
0\end{array}$ & $\begin{array}{l}1 \\
0 \\
2 \\
0 \\
0\end{array}$ & $\begin{array}{l}0 \\
0 \\
0 \\
1 \\
1\end{array}$ & $\begin{array}{l}0 \\
0 \\
0 \\
1 \\
1\end{array}$ \\
\hline 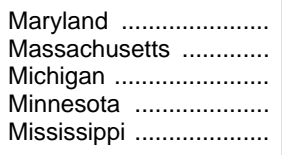 & $\begin{array}{r}24 \\
464 \\
693 \\
452 \\
164\end{array}$ & $\begin{array}{r}24 \\
465 \\
730 \\
453 \\
164\end{array}$ & $\begin{array}{r}24 \\
353 \\
631 \\
388 \\
153\end{array}$ & $\begin{array}{r}24 \\
353 \\
668 \\
382 \\
153\end{array}$ & $\begin{array}{r}0 \\
85 \\
57 \\
61 \\
0\end{array}$ & $\begin{array}{r}0 \\
85 \\
57 \\
68 \\
0\end{array}$ & $\begin{array}{r}0 \\
1 \\
4 \\
3 \\
10\end{array}$ & $\begin{array}{r}0 \\
1 \\
4 \\
3 \\
10\end{array}$ & $\begin{array}{l}0 \\
0 \\
0 \\
0 \\
1\end{array}$ & $\begin{array}{l}0 \\
0 \\
0 \\
0 \\
1\end{array}$ & $\begin{array}{r}0 \\
25 \\
1 \\
0 \\
0\end{array}$ & $\begin{array}{r}0 \\
26 \\
1 \\
0 \\
0\end{array}$ \\
\hline 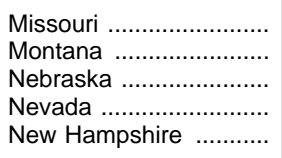 & $\begin{array}{r}537 \\
551 \\
786 \\
18 \\
246\end{array}$ & $\begin{array}{r}531 \\
551 \\
774 \\
18 \\
248\end{array}$ & $\begin{array}{r}531 \\
472 \\
668 \\
17 \\
178\end{array}$ & $\begin{array}{r}525 \\
472 \\
656 \\
17 \\
178\end{array}$ & $\begin{array}{r}0 \\
77 \\
112 \\
0 \\
68\end{array}$ & $\begin{array}{r}0 \\
77 \\
112 \\
0 \\
70\end{array}$ & $\begin{array}{l}2 \\
2 \\
6 \\
1 \\
0\end{array}$ & $\begin{array}{l}2 \\
2 \\
6 \\
1 \\
0\end{array}$ & $\begin{array}{l}0 \\
0 \\
0 \\
0 \\
0\end{array}$ & $\begin{array}{l}0 \\
0 \\
0 \\
0 \\
0\end{array}$ & $\begin{array}{l}4 \\
0 \\
0 \\
0 \\
0\end{array}$ & $\begin{array}{l}4 \\
0 \\
0 \\
0 \\
0\end{array}$ \\
\hline $\begin{array}{l}\text { New Jersey } \ldots \ldots . . . \ldots \ldots . . . . \\
\text { New Mexico } \\
\text { New York }\end{array}$ & $\begin{array}{r}620 \\
89 \\
753 \\
123 \\
284\end{array}$ & $\begin{array}{r}620 \\
89 \\
744 \\
123 \\
282\end{array}$ & $\begin{array}{r}608 \\
89 \\
715 \\
119 \\
238\end{array}$ & $\begin{array}{r}608 \\
89 \\
706 \\
119 \\
236\end{array}$ & $\begin{array}{r}12 \\
0 \\
38 \\
0 \\
38\end{array}$ & $\begin{array}{r}12 \\
0 \\
38 \\
0 \\
38\end{array}$ & $\begin{array}{l}0 \\
0 \\
0 \\
2 \\
3\end{array}$ & $\begin{array}{l}0 \\
0 \\
0 \\
2 \\
3\end{array}$ & $\begin{array}{l}0 \\
0 \\
0 \\
2 \\
5\end{array}$ & $\begin{array}{l}0 \\
0 \\
0 \\
2 \\
5\end{array}$ & $\begin{array}{l}0 \\
0 \\
0 \\
0 \\
0\end{array}$ & $\begin{array}{l}0 \\
0 \\
0 \\
0 \\
0\end{array}$ \\
\hline 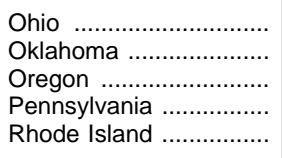 & $\begin{array}{r}781 \\
548 \\
243 \\
614 \\
37\end{array}$ & $\begin{array}{r}776 \\
549 \\
226 \\
614 \\
37\end{array}$ & $\begin{array}{r}661 \\
548 \\
234 \\
501 \\
36\end{array}$ & $\begin{array}{r}661 \\
549 \\
219 \\
501 \\
36\end{array}$ & $\begin{array}{r}94 \\
0 \\
6 \\
101 \\
0\end{array}$ & $\begin{array}{r}89 \\
0 \\
5 \\
100 \\
0\end{array}$ & $\begin{array}{r}3 \\
0 \\
2 \\
12 \\
1\end{array}$ & $\begin{array}{r}3 \\
0 \\
1 \\
13 \\
1\end{array}$ & $\begin{array}{l}0 \\
0 \\
1 \\
0 \\
0\end{array}$ & $\begin{array}{l}0 \\
0 \\
1 \\
0 \\
0\end{array}$ & $\begin{array}{r}23 \\
0 \\
0 \\
0 \\
0\end{array}$ & $\begin{array}{r}23 \\
0 \\
0 \\
0 \\
0\end{array}$ \\
\hline $\begin{array}{l}\text { South Carolina } \\
\text { South Dakota } \\
\text { Tennessee }\end{array}$ & $\begin{array}{r}106 \\
218 \\
140 \\
1,044 \\
47\end{array}$ & $\begin{array}{r}104 \\
218 \\
140 \\
1,059 \\
47\end{array}$ & $\begin{array}{r}95 \\
177 \\
140 \\
1,044 \\
40\end{array}$ & $\begin{array}{r}95 \\
177 \\
140 \\
1,043 \\
40\end{array}$ & $\begin{array}{r}11 \\
17 \\
0 \\
0 \\
5\end{array}$ & $\begin{array}{r}9 \\
17 \\
0 \\
0 \\
5\end{array}$ & $\begin{array}{l}0 \\
5 \\
0 \\
0 \\
2\end{array}$ & $\begin{array}{l}0 \\
5 \\
0 \\
0 \\
2\end{array}$ & $\begin{array}{r}0 \\
19 \\
0 \\
0 \\
0\end{array}$ & $\begin{array}{r}0 \\
19 \\
0 \\
0 \\
0\end{array}$ & $\begin{array}{l}0 \\
0 \\
0 \\
0 \\
0\end{array}$ & $\begin{array}{r}0 \\
0 \\
0 \\
16 \\
0\end{array}$ \\
\hline 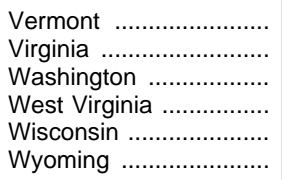 & $\begin{array}{r}344 \\
165 \\
305 \\
57 \\
444 \\
58\end{array}$ & $\begin{array}{r}346 \\
169 \\
305 \\
57 \\
444 \\
57\end{array}$ & $\begin{array}{r}284 \\
141 \\
296 \\
55 \\
426 \\
49\end{array}$ & $\begin{array}{r}285 \\
141 \\
296 \\
55 \\
426 \\
49\end{array}$ & $\begin{array}{r}60 \\
22 \\
9 \\
0 \\
16 \\
5\end{array}$ & $\begin{array}{r}60 \\
26 \\
9 \\
0 \\
16 \\
5\end{array}$ & $\begin{array}{l}0 \\
0 \\
0 \\
2 \\
2 \\
4\end{array}$ & $\begin{array}{l}1 \\
0 \\
0 \\
2 \\
2 \\
3\end{array}$ & $\begin{array}{l}0 \\
2 \\
0 \\
0 \\
0 \\
0\end{array}$ & $\begin{array}{l}0 \\
2 \\
0 \\
0 \\
0 \\
0\end{array}$ & $\begin{array}{l}0 \\
0 \\
0 \\
0 \\
0 \\
0\end{array}$ & $\begin{array}{l}0 \\
0 \\
0 \\
0 \\
0 \\
0\end{array}$ \\
\hline $\begin{array}{c}\text { Department of Defense } \\
\text { dependents schools } \\
\text { Outlying areas }\end{array}$ & 12 & 12 & 0 & 0 & 0 & 0 & 0 & 0 & 12 & 12 & 0 & 0 \\
\hline 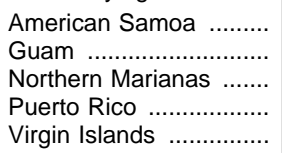 & $\begin{array}{l}1 \\
1 \\
1 \\
1 \\
1\end{array}$ & $\begin{array}{l}1 \\
1 \\
1 \\
1 \\
1\end{array}$ & $\begin{array}{l}1 \\
1 \\
1 \\
1 \\
1\end{array}$ & $\begin{array}{l}1 \\
1 \\
1 \\
1 \\
1\end{array}$ & $\begin{array}{l}0 \\
0 \\
0 \\
0 \\
0\end{array}$ & $\begin{array}{l}0 \\
0 \\
0 \\
0 \\
0\end{array}$ & $\begin{array}{l}0 \\
0 \\
0 \\
0 \\
0\end{array}$ & $\begin{array}{l}0 \\
0 \\
0 \\
0 \\
0\end{array}$ & $\begin{array}{l}0 \\
0 \\
0 \\
0 \\
0\end{array}$ & $\begin{array}{l}0 \\
0 \\
0 \\
0 \\
0\end{array}$ & $\begin{array}{l}0 \\
0 \\
0 \\
0 \\
0\end{array}$ & $\begin{array}{l}0 \\
0 \\
0 \\
0 \\
0\end{array}$ \\
\hline
\end{tabular}


Table 93.-Selected statistics on enrollment, teachers, graduates, and dropouts in public school districts enrolling more than 15,000 pupils, by state: 1989 and 1996

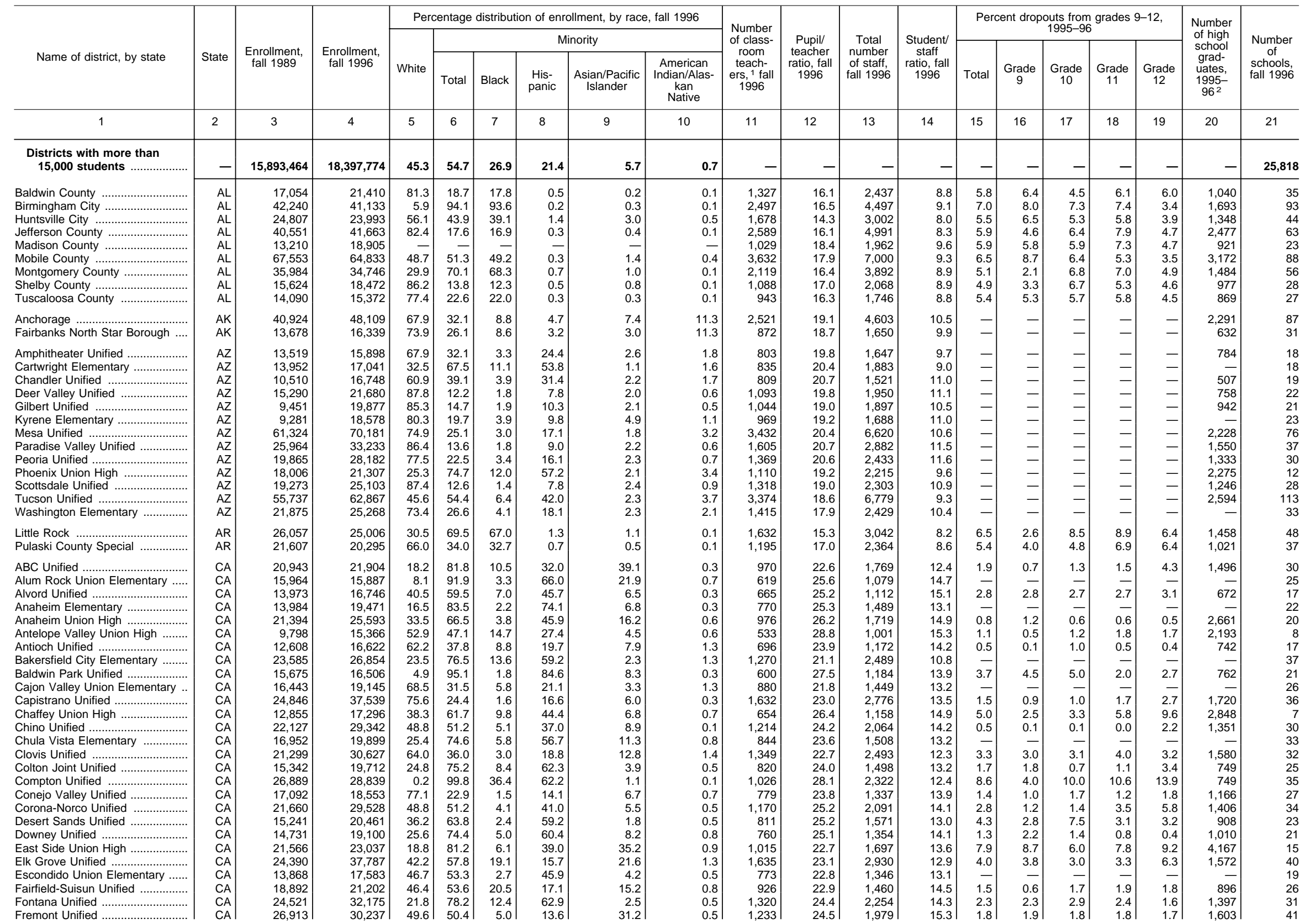


Table 93.-Selected statistics on enrollment, teachers, graduates, and dropouts in public school districts enrolling more than 15,000

pupils, by state: 1989 and 1996-Continued

\begin{tabular}{|c|c|c|c|c|c|c|c|c|c|c|c|c|c|c|c|c|c|c|c|c|}
\hline \multirow[b]{2}{*}{ Name of district, by state } & \multirow[b]{2}{*}{ State } & \multirow[b]{2}{*}{$\begin{array}{l}\text { Enrollment, } \\
\text { fall } 1989\end{array}$} & \multirow[b]{2}{*}{$\begin{array}{l}\text { Enrollment, } \\
\text { fall } 1996\end{array}$} & \multicolumn{6}{|c|}{ Percentage distribution of enrollment, by race, fall 1996} & \multirow{2}{*}{$\begin{array}{c}\text { Number } \\
\text { of class- } \\
\text { room } \\
\text { teach- } \\
\text { ers, t fall } \\
1996 \\
1996\end{array}$} & \multirow{2}{*}{$\begin{array}{c}\text { Pupil/ } \\
\text { teacher } \\
\text { ratio, fall } \\
1996\end{array}$} & \multirow{2}{*}{$\begin{array}{c}\text { Total } \\
\text { number } \\
\text { of staff, } \\
\text { fall 1996 }\end{array}$} & & Perc & cent dropo & $\begin{array}{l}\text { outs from } \\
1995-96\end{array}$ & grades 9 & $9-12$ & $\begin{array}{l}\text { Number } \\
\text { of high }\end{array}$ & \\
\hline & & & & White & Total & Black & $\begin{array}{c}\text { His- } \\
\text { panic }\end{array}$ & $\begin{array}{c}\text { Asian/Pacific } \\
\text { Islander }\end{array}$ & $\begin{array}{c}\text { American } \\
\text { Indian/Alas- } \\
\text { kan } \\
\text { Native }\end{array}$ & & & & \begin{tabular}{|c} 
staff \\
ratio, fall \\
1996
\end{tabular} & Total & $\underset{9}{\operatorname{Grade}}$ & $\begin{array}{c}\text { Grade } \\
10\end{array}$ & $\underset{11}{\text { Grade }}$ & $\begin{array}{c}\text { Grade } \\
12\end{array}$ & $\begin{array}{l}\text { School } \\
\text { grad- } \\
\text { uates, } \\
1995- \\
96^{2}\end{array}$ & $\begin{array}{l}\text { of } \\
\text { schools, } \\
\text { fall } 1996\end{array}$ \\
\hline 1 & 2 & 3 & 4 & 5 & 6 & 7 & 8 & 9 & 10 & 11 & 12 & 13 & 14 & 15 & 16 & 17 & 18 & 19 & 20 & 21 \\
\hline Fresno Unified & $\mathrm{CA}$ & 67,492 & 78,470 & 22.8 & 77.2 & 11.1 & 43.6 & 21.7 & 0.8 & 3,525 & 22.3 & 6,639 & 11.8 & 7.1 & 6.7 & 7.6 & 7.5 & 6.3 & 2,868 & 90 \\
\hline Garden Grove Unified. & $\mathrm{CA}$ & 36,725 & 44,661 & 24.4 & 75.6 & 1.3 & 42.8 & 31.0 & 0.3 & 1,810 & 24.7 & 3,514 & 12.7 & 1.6 & 1.5 & 1.7 & 1.3 & 2.0 & 2,203 & 63 \\
\hline Glend & $\mathrm{CA}$ & 24 & 30,164 & 58.8 & 41.2 & 1.1 & 6 & 16.3 & 0.2 & 1,131 & 26.7 & 2,336 & 12.9 & 0.4 & .0 & 0.2 & 0.6 & 0.9 & 1,785 & 29 \\
\hline Gross & $\mathrm{CA}$ & 18 & 22 & 69.9 & 30.1 & 5.9 & 3 & 5.4 & 4 & 885 & 25.1 & 1,736 & 12.8 & 4.0 & 4 & 4.3 & 4.2 & 2.7 & 3,663 & 13 \\
\hline Hacienda La Puer & $\mathrm{CA}$ & 22,779 & 22,345 & 10.9 & 89.1 & 2.6 & 66.9 & 19.2 & 0.4 & 892 & 25.1 & 1,744 & 12.8 & 2.9 & 2.6 & 2.2 & 2.8 & 4.2 & 1,241 & 35 \\
\hline Hayward Unified .. & $\mathrm{CA}$ & 18,608 & 21,693 & 24.5 & 75.5 & 19.7 & 36.2 & 18.8 & 0.7 & 977 & 22.2 & 1,619 & 13.4 & 6.5 & 7.4 & 6.7 & 6.5 & 4.5 & 830 & 33 \\
\hline Hemet Unified ..... & $\mathrm{CA}$ & 11,976 & 15,500 & 66.1 & 33.9 & 2.6 & 28.6 & 2.0 & 8 & 632 & 24.5 & 1,111 & 13.9 & 1.9 & .4 & 2.9 & 1.4 & 1.8 & 700 & 18 \\
\hline Hesperia Unified ... & $\mathrm{CA}$ & 11,814 & 15,327 & 61.4 & 38.6 & 5.2 & 31.2 & 1.5 & 0.6 & 618 & 24.8 & 1,186 & 12.9 & 6.5 & .5 & 5.7 & 8.2 & 8.2 & 622 & 16 \\
\hline Inglewood Unified ... & $\mathrm{CA}$ & 15,863 & 16,765 & 0.6 & 99.4 & 43.3 & 55.2 & 0.9 & 0.1 & 612 & 27.4 & 1,086 & 15.4 & 4.7 & 1.9 & 4.3 & 4.0 & 5.8 & 522 & 18 \\
\hline Irvine Unified .......... & $\mathrm{CA}$ & 20,303 & 22,563 & 63.3 & 36.7 & 3.2 & 7.3 & 25.8 & 0.4 & 996 & 22.7 & 1,735 & 13.0 & 0.5 & 0.8 & 0.3 & 0.1 & 0.8 & 1,530 & 31 \\
\hline Jurupa Unified. & $\mathrm{CA}$ & 14,571 & 17,686 & 41.2 & 58.8 & 5.2 & 51.4 & 2.1 & 0.2 & 717 & 24.7 & 1,285 & 13.8 & 3.0 & 3.9 & 2.4 & 2.7 & 2.8 & 777 & 23 \\
\hline Kern Union High . & $\mathrm{CA}$ & 19,391 & 25,919 & 48.7 & 51.3 & 7.3 & 40.1 & 3.0 & 0.9 & 962 & 26.9 & 1,969 & 13.2 & 4.2 & 1.7 & 2.4 & 4.0 & 12.2 & 4,514 & 23 \\
\hline Lodi Unified ........... & $\mathrm{CA}$ & 23,230 & 25,662 & 46.5 & 53.5 & 5.8 & 23.3 & 23.7 & 0.8 & 1,166 & 22.0 & 2,172 & 11.8 & 4.8 & 3.4 & 5.3 & 5.5 & 5.4 & 1,246 & 35 \\
\hline Long Beach Unified ... & $\mathrm{CA}$ & 68,292 & 83,038 & 19.9 & 80.1 & 20.7 & 39.0 & 20.0 & 0.4 & 3,613 & 23.0 & 7,322 & 11.3 & 10.2 & 6.2 & 7.5 & 11.7 & 17.1 & 3,178 & 84 \\
\hline Los Angeles Unified .. & $\mathrm{CA}$ & 609,746 & 667,305 & 11.0 & 89.0 & 14.0 & 68.0 & 6.7 & 0.3 & 28,492 & 23.4 & 53,221 & 12.5 & 8.9 & 8.5 & 10.2 & 9.4 & 6.6 & 24,646 & 642 \\
\hline Lynwood Unified ........ & $\mathrm{CA}$ & 14,612 & 16,206 & 0.4 & 99.6 & 13.0 & 85.8 & 0.8 & 0.1 & 599 & 27.1 & 1,069 & 15.2 & 4.5 & 4.3 & 6.4 & 4.8 & 1.8 & 590 & 12 \\
\hline Madera Unified ... & $\mathrm{CA}$ & $\begin{array}{l}13,046 \\
13,0\end{array}$ & 16,015 & 28.7 & 71.3 & $\begin{array}{r}3.7 \\
3.7\end{array}$ & $\begin{array}{l}00.0 \\
66.0\end{array}$ & $\begin{array}{l}.0 \\
1.3\end{array}$ & $\begin{array}{l}.1 \\
0.2\end{array}$ & 683 & 23.5 & 1,314 & 12.2 & $\begin{array}{l}4.9 \\
4.9\end{array}$ & $\begin{array}{l}4.0 \\
1.4\end{array}$ & $\begin{array}{l}. .4 \\
3.7\end{array}$ & $\begin{array}{l}4.0 \\
3.7\end{array}$ & 12.5 & 672 & 20 \\
\hline Mante & $\mathrm{CA}$ & 13,177 & 15,841 & 59.3 & 40.7 & 4.4 & & 6.8 & 1.4 & 650 & 24.4 & 1,138 & 13.9 & $\begin{array}{l}1.6 \\
1.6\end{array}$ & 2.0 & 2.0 & 1.1 & 0.8 & 676 & 19 \\
\hline ementary & $\mathrm{CA}$ & 16,609 & 18,157 & 40.7 & 59.3 & 4.6 & 41.5 & 12.4 & 0.8 & 750 & 24.2 & 1,337 & 13.6 & - & 2.0 & 2.0 & $\cdots$ & 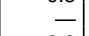 & 1 & 27 \\
\hline Monte & $\mathrm{CA}$ & 32,362 & 33,147 & 3.8 & 96.2 & 0.5 & & 5.5 & 0.1 & 1,184 & 28.0 & 2,323 & 14.3 & 3.4 & 4.0 & 3.3 & 2.0 & 3.9 & 1,440 & 28 \\
\hline Moren & $\mathrm{CA}$ & 26,6 & 31,303 & 36.9 & 63.1 & 22.7 & & 6.5 & 0.3 & 1,299 & 24.1 & 2,488 & 12.6 & 2.3 & 2.0 & 2.4 & 2.5 & 2.5 & 1,477 & 34 \\
\hline t. Di & $\mathrm{CA}$ & 32,5 & 35,834 & 67.8 & 32.2 & 4.7 & 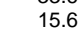 & 11.4 & 0. & 1,618 & 22.1 & 2,702 & 13.3 & ? & 2 & 1.7 & 3.3 & 3.2 & 1,897 & 54 \\
\hline (2 & $\mathrm{CA}$ & 12,9 & 15,704 & 68.7 & 31 & 17 & 5.0 & 3. & 1.1 & 719 & 21.8 & 1,250 & 12.6 & 7 & 0 & 0.5 & 0.6 & 1.6 & 776 & 30 \\
\hline Newpo & $\mathrm{CA}$ & 16,08 & 19,560 & 58.8 & 41.2 & 1.1 & 4 & 6.5 & 0.1 & 870 & 22. & 1,554 & 12.6 & 1.6 & 2. & 1.9 & 1.4 & 1.1 & 1706 & 27 \\
\hline Norwalk-La Mirada Unified . & $\mathrm{CA}$ & 18,557 & 21,600 & 24.5 & 75.5 & 5.0 & 1 & 8.2 & 0.3 & 843 & 25.6 & 1,929 & 11.2 & 3.7 & 1.4 & 1.2 & 6.0 & 7.7 & 981 & 26 \\
\hline Oakland Unified ... & $\mathrm{CA}$ & 50,741 & 53,462 & 6.2 & 93.8 & 51.7 & 1.7 & 19.9 & 0.5 & 2,508 & 21.3 & 4,618 & 11.6 & 9.1 & 8.9 & 10.4 & 8.9 & 7.1 & 1,710 & 93 \\
\hline Ocean & $\mathrm{CA}$ & 16,309 & 20,247 & 34.3 & 65.7 & 15.1 & .8 & 8.9 & 8 & 867 & 23.3 & 1,556 & 13.0 & 1.9 & 1.8 & 2.0 & 1.7 & 2.0 & 691 & 22 \\
\hline air Elementary . & $\mathrm{CA}$ & 20,356 & 24,196 & 17.2 & 82.8 & 7.9 & & 4.1 & 0.5 & 1,068 & 22.7 & 1,930 & 12.5 & - & & - & $\cdots$ & & & 31 \\
\hline Orange Unified. & $\mathrm{CA}$ & 24,618 & 28,294 & 48.8 & 51.2 & 2.1 & & 12.7 & 0.3 & 1,112 & 25.4 & 2,108 & 13.4 & 2.7 & 3.6 & 2.8 & 2.5 & 1.8 & 1,517 & 37 \\
\hline Pajaro Valley Joint Unified ........... & $\mathrm{CA}$ & 16 & 18,355 & 25.1 & 74.9 & 0.6 & 71.4 & 2.8 & 0.2 & 815 & 22.5 & 1,622 & 11.3 & 3.3 & 5.4 & 3.0 & 2.0 & 1.0 & 698 & 24 \\
\hline Palm $s$ & $\mathrm{CA}$ & 13,302 & 18,129 & 37.2 & 62.8 & 5.9 & & 3.6 & 1.1 & 749 & 24.2 & 1,442 & 12.6 & 2.6 & 3.1 & 1.9 & 1.8 & 3.7 & 618 & 21 \\
\hline Palmdale Elementary .. & $\mathrm{CA}$ & 11,548 & 18,631 & 40.9 & 59.1 & 15.4 & 4 & 4.2 & 1.0 & 659 & 28.3 & 1,106 & 16.8 & - & 0.1 & - & - & - & 4 & 18 \\
\hline Paramount Unified & $\mathrm{CA}$ & 12,7 & 15,843 & 5.5 & 94.5 & 15.3 & 8 & 4.0 & 0.4 & 647 & 24.5 & 1,236 & 12.8 & 7.8 & 9.6 & 8.6 & 6.4 & 5.2 & 534 & 15 \\
\hline Pasad & $\mathrm{CA}$ & 21,6 & 22,490 & 17.2 & 82.8 & 32.9 & 0 & 3.7 & 0.1 & 942 & 23.9 & 1,966 & 11.4 & 4.6 & 4.4 & 5.8 & 4.3 & 3.7 & & 30 \\
\hline Linda Unified . & $\mathrm{CA}$ & 21,2 & 24,381 & 63.5 & 36.5 & 2.1 & & 9.1 & $\begin{array}{l}0.1 \\
0.2\end{array}$ & 986 & 24.7 & 1,689 & 14.4 & $\begin{array}{l}1.0 \\
1.0\end{array}$ & 0. & $\begin{array}{l}1.0 \\
1.4\end{array}$ & 1.0 & $\begin{array}{l}.7 \\
1.0\end{array}$ & $\begin{array}{r}1,239 \\
\end{array}$ & 29 \\
\hline Pomon & $\mathrm{CA}$ & 25,9 & 31,214 & 9.8 & 90.2 & 11.5 & 70.7 & 7.9 & 0.1 & 1,199 & 26.0 & $\begin{array}{l}2,237 \\
2,230\end{array}$ & 14.0 & 5.0 & 4. & 5.5 & 4.6 & 4.8 & 1,039 & 37 \\
\hline Poway & $\mathrm{CA}$ & 23,402 & 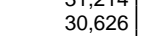 & $\begin{array}{r}3.0 \\
72.6\end{array}$ & 27.4 & $\begin{array}{r}1.3 \\
2.8\end{array}$ & 7.5 & 16.6 & 0.5 & 1,339 & 22.9 & 2,436 & 12.6 & 1. & 0. & 0.5 & $\begin{array}{l}4.0 \\
0.8\end{array}$ & $\begin{array}{l}4.0 \\
2.3\end{array}$ & $\begin{array}{l}1,812 \\
1,812\end{array}$ & 28 \\
\hline Redlar & $\mathrm{CA}$ & $\begin{array}{l}20,40< \\
15,247\end{array}$ & $\begin{array}{l}17,950 \\
10,020\end{array}$ & 50.7 & 49.3 & $\begin{array}{l}.0 . \\
7.8\end{array}$ & 30.3 & $\begin{array}{l}10.0 \\
10.3\end{array}$ & 0.9 & $\begin{array}{r}1,039 \\
726\end{array}$ & 24.7 & $\begin{array}{l}1,400 \\
1,226\end{array}$ & $\begin{array}{l}14.6 \\
14.6\end{array}$ & 2.8 & 0 & 0.2 & $\begin{array}{l}.0 \\
1.8\end{array}$ & $\begin{array}{l}0 \\
2 \\
\end{array}$ & | & 17 \\
\hline $\begin{array}{l}\text { Rialto } \\
\text { Rial }\end{array}$ & $\mathrm{CA}$ & $\begin{array}{l}18,2 \\
18,4\end{array}$ & 24,757 & 18.1 & $\begin{array}{r}4.3 \\
81.9\end{array}$ & $\begin{array}{r}1.0 \\
27.9\end{array}$ & 8 & $\begin{array}{r}0.3 \\
4.0\end{array}$ & $\begin{array}{l}0.9 \\
0.2\end{array}$ & 984 & $\begin{array}{l}25.1 \\
25.2\end{array}$ & $\begin{array}{l}1,220 \\
1,881\end{array}$ & 13 & 3 & 3 & $\begin{array}{l}3.2 \\
3.5\end{array}$ & $\begin{array}{l}.0 \\
3.5\end{array}$ & 3 & $\begin{array}{r}1,065 \\
\end{array}$ & 24 \\
\hline d. & CA & $\begin{array}{r}18,481 \\
30,258\end{array}$ & $\begin{array}{l}24,751 \\
35,407\end{array}$ & $\begin{array}{l}45.1 \\
45.1\end{array}$ & $\begin{array}{l}8.9 \\
54.9\end{array}$ & $\begin{array}{l}27.9 \\
10.1\end{array}$ & 4 & $\begin{array}{l}4.0 \\
4.8\end{array}$ & 0.6 & $\begin{array}{r}984 \\
1,502\end{array}$ & $\begin{array}{l}25.2 \\
23.6\end{array}$ & $\begin{array}{l}2,8810 \\
2,830\end{array}$ & 12 & 2 & 3 & $\begin{array}{l}3.5 \\
2.8\end{array}$ & $\begin{array}{l}3.5 \\
2.1\end{array}$ & .6 & $\begin{array}{l}1,060 \\
1,670\end{array}$ & $\begin{array}{l}24 \\
42\end{array}$ \\
\hline a.. & CA & $\begin{array}{l}30,258 \\
18,881\end{array}$ & $\begin{array}{l}35,401 \\
18,833\end{array}$ & $\begin{array}{l}45.1 \\
12.2\end{array}$ & $\begin{array}{l}54 \\
87\end{array}$ & 10.1 & & $\begin{array}{r}4.8 \\
26.5\end{array}$ & $\begin{array}{l}0.6 \\
0.2\end{array}$ & $\begin{array}{r}1,502 \\
770\end{array}$ & $\begin{array}{l}24.4 \\
24.6\end{array}$ & $\begin{array}{l}1,830 \\
1,450\end{array}$ & 13 & 2.9 & 4 & $\begin{array}{l}.8 \\
3.1\end{array}$ & 2.0 & 0 & 1 & $\begin{array}{l}42 \\
22\end{array}$ \\
\hline & $\mathrm{CA}$ & 48 & 5 & & 72 & 21 & & & 1. & 2,064 & & 4, & 12 & & & & 6 & & & 76 \\
\hline & c & & & & & & & $10>2>$ & & & & & & & & & & & & 35 \\
\hline & c & & & & & & & & & & & & 12 & & & & & & & 58 \\
\hline & c & 119 & 133 & & & & & 18 & & & & & 11 & & & & & & & 163 \\
\hline San & ( & 61 & & 1 & & 16 & & 4 & & 3, & 17 & 5, & 11 & 2 & 2 & 2.2 & 1.8 & 1. & & $\begin{array}{l}112 \\
112\end{array}$ \\
\hline $\mathrm{Sa}$ & $C_{0}$ & & & & & 3.4 & 48 & 14. & & 1,1 & & 2,6 & 12 & 1. & & 2.6 & 1.5 & 1.6 & & 49 \\
\hline & C & 46, & & & & 5.9 & 8.6 & 6.0 & 2.0 & 2,19 & 21.8 & 4,1 & 11 & 4. & 1. & 2.8 & 5.1 & 8.3 & 2,767 & 87 \\
\hline y Unified .. & $\mathrm{CA}$ & 15,8 & 18 & 81.7 & 18 & 1.7 & 4.3 & 11.7 & 0.6 & 813 & 23.3 & 1,387 & 13.7 & 1.2 & 0.2 & 0.3 & 0.9 & 3.5 & 1,208 & 25 \\
\hline Santa Ana Unified & $\mathrm{CA}$ & 42,785 & 52,107 & 3.6 & 96.4 & 1.2 & 89.9 & 5.3 & 0.0 & 2,082 & 25.0 & 4.147 & 12.6 & 7.6 & 8.1 & 8.5 & 7.0 & 5.8 & 1,781 & 45 \\
\hline Simi Valley Unified. & $\mathrm{CA}$ & 18,279 & 18,923 & 72.9 & 27.1 & 1.7 & 17.4 & 7.0 & 1.0 & 815 & 23.2 & 1.461 & 13.0 & 2.1 & 0.0 & 0.8 & 4.0 & 3.4 & 1,202 & 27 \\
\hline Stockton City Unified & $\mathrm{CA}$ & 31,849 & $\begin{array}{l}10,0<0 \\
35,154\end{array}$ & 16.6 & 83.4 & 13.0 & 41.3 & 27.4 & 1.6 & $\begin{array}{r}1,532 \\
\end{array}$ & 22.9 & $\begin{array}{l}3,401 \\
3,132\end{array}$ & 11.2 & 2.4 & 1.7 & $\begin{array}{l}.0 \\
1.5\end{array}$ & 2.9 & $\begin{array}{l}.4 .5 \\
4.5\end{array}$ & $\left.\begin{array}{l}1,202 \\
994\end{array}\right]$ & 41 \\
\hline & $\mathrm{CA}$ & $\begin{array}{l}31,049 \\
27,265\end{array}$ & $\begin{array}{l}30,754 \\
30,772\end{array}$ & $\begin{array}{r}10.0 \\
18.2\end{array}$ & $\begin{array}{l}\begin{array}{l}03.4 \\
81.8\end{array} \\
\end{array}$ & $\begin{array}{r}3.0 \\
4.9\end{array}$ & $\begin{array}{l}41.3 \\
63.4\end{array}$ & $\begin{array}{l}2.4 .9 \\
12.9\end{array}$ & & $\begin{array}{l}1,032 \\
1,303\end{array}$ & $\begin{array}{l}23.9 \\
23.6\end{array}$ & $\begin{array}{l}2,132 \\
2,376\end{array}$ & 12.2 & $\begin{array}{l}2.4 \\
4.4\end{array}$ & 5.1 & $\begin{array}{l}.5 \\
4.2\end{array}$ & $\begin{array}{l}2.9 \\
3.6\end{array}$ & $\begin{array}{l}4.0 \\
4.7\end{array}$ & $\begin{array}{r}9444 \\
3,341\end{array}$ & $\begin{array}{l}41 \\
19\end{array}$ \\
\hline & $\begin{array}{l}\mathrm{CA} \\
\mathrm{CA}\end{array}$ & $\begin{array}{l}2,26 \\
19,12\end{array}$ & 23, & $\begin{array}{l}18.2 \\
49.3\end{array}$ & $\begin{array}{l}81.8 .2 \\
50.2\end{array}$ & $\begin{array}{l}4.9 \\
4.2\end{array}$ & $\begin{array}{l}63.4 \\
15.0\end{array}$ & $\begin{array}{l}2.9 \\
30.9\end{array}$ & $\begin{array}{l}0.6 \\
0.6\end{array}$ & $\begin{array}{r}1,303 \\
978\end{array}$ & $\begin{array}{l}23.6 \\
23.8\end{array}$ & $\begin{array}{l}2,3 / 6 \\
1,713\end{array}$ & 13 & $\begin{array}{l}4.4 \\
0.4\end{array}$ & $\begin{array}{l}5.1 \\
0.2\end{array}$ & $\begin{array}{l}4.2 \\
0.7\end{array}$ & $\begin{array}{l}3.6 \\
0.4\end{array}$ & .5 & $\begin{array}{l}3,341 \\
1,521\end{array}$ & $\begin{array}{l}19 \\
30\end{array}$ \\
\hline & $\mathrm{CA}$ & 18 & 19 & 22.6 & 77. & 34.3 & & 27.5 & 0. & 759 & 25.7 & 1,437 & 13 & 3 & 0. & 7.5 & 3. & 2 & 879 & 25 \\
\hline Ventura Unif & $\mathrm{CA}$ & 15,3 & 16 & 61.2 & 38.8 & $\begin{array}{r}2.3 \\
\end{array}$ & 32.3 & 3.3 & 1.0 & 679 & 24.8 & 1,293 & 13 & 4.7 & 3. & 3.1 & 4.4 & 8.9 & 809 & 27 \\
\hline Visalia Unified & $\mathrm{CA}$ & 19,913 & 24,515 & 46.8 & 53.2 & 1.8 & 42.2 & 8.4 & 0.8 & 1,099 & 22.3 & 2,010 & 12.2 & $\begin{array}{l}3.1 \\
3.9\end{array}$ & 2.8 & 2.2 & 3.8 & $\begin{array}{l}\text { o.9 } \\
7.4\end{array}$ & 1,161 & 32 \\
\hline & & & & & & & & & & 1,052 & & & & & & & & & & \\
\hline
\end{tabular}


Table 93.-Selected statistics on enrollment, teachers, graduates, and dropouts in public school districts enrolling more than 15,000 pupils, by state: 1989 and 1996-Continued

\begin{tabular}{|c|c|c|c|c|c|c|c|c|c|c|c|c|c|c|c|c|c|c|c|c|}
\hline \multirow{3}{*}{ Name of district, by state } & \multirow{3}{*}{ State } & \multirow{3}{*}{$\begin{array}{l}\text { Enrollment, } \\
\text { fall } 1989\end{array}$} & \multirow{3}{*}{$\begin{array}{l}\text { Enrollment, } \\
\text { fall } 1996\end{array}$} & \multicolumn{6}{|c|}{ Percentage distribution of enrollment, by race, fall 1996} & \multirow{3}{*}{$\begin{array}{c}\text { Number } \\
\text { of class- } \\
\text { room } \\
\text { teach- } \\
\text { ers, } 1 \text { fall } \\
1996\end{array}$} & \multirow{3}{*}{$\begin{array}{c}\text { Pupil/ } \\
\text { teacher } \\
\text { ratio, fall } \\
1996\end{array}$} & \multirow{3}{*}{$\begin{array}{c}\text { Total } \\
\text { number } \\
\text { of staff, } \\
\text { fall } 1996\end{array}$} & \multirow{3}{*}{\begin{tabular}{|c|} 
Student/ \\
staff \\
ratio, fall \\
1996
\end{tabular}} & \multirow{2}{*}{\multicolumn{5}{|c|}{$\begin{array}{l}\text { Percent dropouts from grades 9-12, } \\
\text { 1995-96 }\end{array}$}} & & \\
\hline & & & & & & & & linority & & & & & & & & & & & or nign & Number \\
\hline & & & & White & Total & Black & $\begin{array}{l}\text { His- } \\
\text { panic }\end{array}$ & $\begin{array}{c}\text { Asian/Pacific } \\
\text { Islander }\end{array}$ & $\begin{array}{c}\text { American } \\
\text { Indian/Alas- } \\
\text { kan } \\
\text { Native }\end{array}$ & & & & & Total & $\underset{9}{\text { Grade }}$ & Grade & Grade & $\underset{12}{\text { Grade }}$ & $\begin{array}{c}\text { grad- } \\
\text { uates, } \\
1995- \\
96^{2}\end{array}$ & $\begin{array}{l}\text { schools, } \\
\text { fall } 1996\end{array}$ \\
\hline 1 & 2 & 3 & 4 & 5 & 6 & 7 & 8 & 9 & 10 & 11 & 12 & 13 & 14 & 15 & 16 & 17 & 18 & 19 & 20 & 21 \\
\hline West Contra Costa Unified. & $\mathrm{CA}$ & 31,102 & 32,284 & 22.5 & 77.5 & 35.0 & 23.7 & 18.5 & 0.3 & 1,412 & 22.9 & 2,596 & 12.4 & 2.9 & 3.0 & 2.9 & 3.2 & 2.1 & 1,600 & 57 \\
\hline Adams-Arapahoe ........... & $\mathrm{co}$ & 25,345 & 28,492 & 54.1 & 45.9 & 24.1 & 15.7 & 5.1 & 1.0 & 1,502 & 19.0 & 2,920 & 9.8 & - & - & - & - & - & 1,177 & 44 \\
\hline Boulder Valley ............. & $\mathrm{CO}$ & 21,013 & 25,648 & 82.9 & 17.1 & 1.7 & 10.0 & 4.5 & 0.9 & 1,373 & 18.7 & 2,603 & 9.9 & - & - & - & - & - & 1,361 & 52 \\
\hline Cherry Creek ................... & $\mathrm{co}$ & 28,027 & 37,128 & 82.6 & 17.4 & 7.0 & 5.1 & 4.9 & 0.4 & 2,018 & 18.4 & 4,001 & 9.3 & - & - & - & - & - & 2,101 & 45 \\
\hline Colorado Springs .......... & $\mathrm{co}$ & 29,931 & 33,175 & 73.3 & 26.7 & 9.5 & 13.9 & 2.3 & 1.1 & 1,696 & 19.6 & 3,162 & 10.5 & - & - & - & - & - & 1,648 & 61 \\
\hline Denver County .... & $\mathrm{co}$ & 58,299 & 66,331 & 26.1 & 73.9 & 21.3 & 47.5 & 3.7 & 1.4 & $\begin{array}{l}3,198 \\
3, \quad\end{array}$ & 20.7 & 7,117 & 9.3 & - & - & - & - & - & 2,363 & 118 \\
\hline Douglas County ....... & $\mathrm{co}$ & 12,001 & 24,495 & 92.9 & 7.1 & 0.9 & 3.5 & 2.2 & 0.5 & 1,330 & 18.4 & 2,491 & 9.8 & - & - & - & - & - & 1,055 & 39 \\
\hline Jeffers & $\mathrm{co}$ & 75,164 & 86,670 & 86.0 & 14.0 & 1.1 & 9.3 & 2.8 & 0.7 & 4,134 & 21.0 & 9,201 & 9.4 & - & - & - & - & - & 4,443 & 151 \\
\hline ttleto & $\mathrm{co}$ & 15,356 & 16,044 & 90.7 & 9.3 & 1.3 & 4.9 & 2.7 & 0.4 & $\begin{array}{r}4,104 \\
856\end{array}$ & 18.8 & $\begin{array}{l}1,615 \\
1,615\end{array}$ & $\begin{array}{l}.4 .9 \\
9.9\end{array}$ & - & - & - & - & - & $\begin{array}{r}r+4+0 \\
960\end{array}$ & 25 \\
\hline Mesa County Valley ........... & $\mathrm{co}$ & 16,286 & 19,049 & 85.9 & 14.1 & 0.7 & 11.7 & 0.9 & 0.8 & 1,039 & 18.3 & 1,880 & 10.1 & - & - & - & - & - & 1,140 & 37 \\
\hline Northglenn-Thornton ……............. & $\mathrm{co}$ & 20,692 & 25,604 & 75.2 & 24.8 & 1.9 & 18.4 & 3.3 & 1.2 & 1,291 & 19.8 & 2,414 & 10.6 & - & - & - & - & - & 1,237 & 40 \\
\hline Poudre .................................. & $\mathrm{co}$ & 17,965 & 21,922 & 84.8 & 15.2 & 1.2 & 10.4 & 2.6 & 1.0 & 1,101 & 19.9 & 2,080 & 10.5 & - & - & - & - & - & 1,139 & 44 \\
\hline 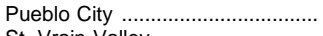 & $\mathrm{co}$ & 18,403 & 18,100 & 44.6 & 55.4 & 2.2 & 50.9 & 0.7 & 1.6 & 931 & 19.4 & 1,719 & 10.5 & - & - & - & - & - & 994 & 38 \\
\hline St. Vrain Valley .......................... & $\mathrm{co}$ & 14,929 & 17,459 & 79.3 & 20.7 & 0.4 & 17.5 & 1.8 & 1.0 & 885 & 19.7 & 1,673 & 10.4 & - & - & - & - & - & 879 & 33 \\
\hline $\begin{array}{l}\text { Bridgeport ........ } \\
\text { Hartford }\end{array}$ & $\begin{array}{l}\mathrm{CT} \\
\mathrm{CT}\end{array}$ & $\begin{array}{l}19,332 \\
24,682\end{array}$ & $\begin{array}{l}21,884 \\
23,429\end{array}$ & $\begin{array}{r}11.3 \\
4.6\end{array}$ & $\begin{array}{l}88.7 \\
95.4\end{array}$ & $\begin{array}{l}42.1 \\
42.1\end{array}$ & $\begin{array}{l}42.9 \\
50.7\end{array}$ & $\begin{array}{l}3.6 \\
2.6\end{array}$ & $\begin{array}{l}0.1 \\
0.1\end{array}$ & $\begin{array}{l}1,391 \\
1,712\end{array}$ & $\begin{array}{l}15.7 \\
13.7\end{array}$ & $\begin{array}{l}2,533 \\
2,911\end{array}$ & $\begin{array}{l}8.6 \\
8.0\end{array}$ & $\begin{array}{r}7.0 \\
23.8\end{array}$ & $\begin{array}{r}8.3 \\
33.8\end{array}$ & $\begin{array}{r}5.6 \\
18.0\end{array}$ & $\begin{array}{r}6.7 \\
16.6\end{array}$ & $\begin{array}{r}7.0 \\
15.6\end{array}$ & $\begin{array}{l}600 \\
787\end{array}$ & $\begin{array}{l}36 \\
36\end{array}$ \\
\hline $\begin{array}{l}\text { Hartford .............. } \\
\text { New Haven ......... }\end{array}$ & $\begin{array}{l}\mathrm{CT} \\
\mathrm{CT}\end{array}$ & $\begin{array}{l}24,682 \\
17,689\end{array}$ & $\begin{array}{l}23,429 \\
18,951\end{array}$ & $\begin{array}{r}4.6 \\
12.5\end{array}$ & $\begin{array}{l}95.4 \\
87.5\end{array}$ & $\begin{array}{l}42.1 \\
58.7\end{array}$ & $\begin{array}{l}50.7 \\
26.8\end{array}$ & $\begin{array}{l}2.6 \\
2.0\end{array}$ & $\begin{array}{l}0.1 \\
0.0\end{array}$ & $\begin{array}{l}1,712 \\
1,234\end{array}$ & $\begin{array}{l}13.7 \\
15.4\end{array}$ & $\begin{array}{l}2,911 \\
2,473\end{array}$ & $\begin{array}{l}8.0 \\
7.7\end{array}$ & $\begin{array}{l}23.8 \\
14.9\end{array}$ & $\begin{array}{l}33.8 \\
15.6\end{array}$ & $\begin{array}{l}18.0 \\
18.3\end{array}$ & $\begin{array}{l}16.6 \\
13.2\end{array}$ & $\begin{array}{l}15.6 \\
11.1\end{array}$ & $\begin{array}{l}787 \\
643\end{array}$ & $\begin{array}{l}36 \\
45\end{array}$ \\
\hline Christina & $\mathrm{DE}$ & 16,784 & 20,182 & 60.7 & 39.3 & 32.8 & 3.8 & 2.6 & 0.1 & 1,171 & 17.2 & 2,233 & 9.0 & 6.1 & 6.5 & 7.0 & 5.4 & 4.6 & 876 & 30 \\
\hline Red Clay Consolidated. & $\mathrm{DE}$ & 14,372 & 15,517 & 54.8 & 45.2 & 30.6 & 11.8 & 2.7 & 0.1 & 884 & 17.6 & 1,598 & 9.7 & 6.0 & 5.1 & 7.8 & 6.7 & 4.0 & 631 & 26 \\
\hline District of Columbia .... & DC & 81,301 & 78,648 & 3.9 & 96.1 & 87.3 & 7.2 & 1.4 & 0.1 & 5,288 & 14.9 & 9,318 & 8.4 & - & - & - & - & - & 2,696 & 184 \\
\hline Alachua County . & $\mathrm{FL}$ & 25,495 & 29,648 & 57.1 & 42.9 & 37.2 & 3.3 & 2.2 & 0.2 & 1,630 & 18.2 & 3,885 & 7.6 & - & - & - & - & - & 1,250 & 44 \\
\hline ay C & $\mathrm{FL}$ & 21,002 & 25,665 & 81.0 & 19.0 & 15.2 & $\begin{array}{l}.00 \\
1.4\end{array}$ & 2.1 & 0.3 & 1,447 & 17.7 & $\begin{array}{l}3,0012 \\
3,012\end{array}$ & $\begin{array}{l}8.5 \\
8.5\end{array}$ & - & - & - & - & - & 1,085 & 34 \\
\hline Brevard County .. & $\mathrm{FL}$ & 53,619 & 66,663 & 79.8 & 20.2 & 14.6 & 3.7 & 1.8 & 0.2 & 3,711 & 18.0 & 7,062 & 9.4 & - & - & - & - & - & 2,957 & 85 \\
\hline Broward County & $\mathrm{FL}$ & 148,739 & 218,608 & 47.4 & 52.6 & 35.3 & 14.4 & 26 & 0.3 & 10,341 & 21.1 & 20,338 & 10.7 & - & - & - & - & - & 8,623 & 193 \\
\hline Charlo & $\mathrm{FL}$ & 11,831 & 16,088 & 87.0 & 13.0 & 8 & 3.1 & 1. & 0.2 & & 19.5 & 1,8 & 8.6 & - & - & - & - & - & 810 & 24 \\
\hline Clay C & $\mathrm{FL}$ & 20,847 & 25,940 & 86.2 & 13.8 & 9.0 & 2.6 & 2.0 & 0.2 & 1,360 & 19.1 & 2,588 & 10.0 & - & - & - & - & - & 1,183 & 29 \\
\hline Collier County . & $\mathrm{FL}$ & 19,576 & 28,177 & 62.7 & 37.3 & 11.2 & 25.1 & 0.5 & 0.5 & 1,569 & 18.0 & 3,416 & 8.2 & - & - & - & - & - & 965 & 41 \\
\hline Dade County ................. & $\mathrm{FL}$ & 279,420 & 341,117 & 13.5 & 86.5 & 33.6 & 51.5 & 1.3 & 0.1 & 17,241 & 19.8 & 33,013 & 10.3 & - & - & - & - & - & 14,290 & 322 \\
\hline Duve & $\mathrm{FL}$ & 106,961 & 126,118 & 53.7 & 46.3 & 40.7 & 2.8 & 2.6 & 0.1 & 6,276 & 20.1 & 11,576 & 10.9 & - & - & - & - & - & 4,436 & 155 \\
\hline County .. & $\mathrm{FL}$ & 41,967 & 45,744 & 60.4 & 39.6 & 35.1 & 1.2 & 2.7 & 0.6 & 2,470 & 18.5 & 5,147 & 8.9 & - & - & - & - & - & 2,127 & 81 \\
\hline County . & $\mathrm{FL}$ & 11, & 15 & 86.5 & 13.5 & 7.7 & 4.9 & 0.8 & 0.1 & 816 & 19.4 & 1,946 & 8.1 & - & - & - & - & - & 734 & 19 \\
\hline County .. & $\mathrm{FL}$ & 119,810 & 147,826 & 56.0 & 44.0 & 24.1 & 17.6 & 2.0 & 0.3 & 8,735 & 16.9 & 17,652 & 8.4 & - & - & - & - & - & 5,874 & 164 \\
\hline Lake C & $\mathrm{FL}$ & 20,095 & 26,131 & 75.3 & 24.7 & 17.8 & 5.8 & 0.8 & 0.2 & 1,366 & 19.1 & 2.914 & $\begin{array}{l}9.4 \\
9.0\end{array}$ & - & - & - & - & - & 1,078 & 42 \\
\hline Lee C & $\mathrm{FL}$ & 40,569 & 52,317 & 71.1 & 28.9 & 15.9 & 11.7 & 10 & 0.2 & 2,883 & 18.1 & 5,760 & $\begin{array}{l}9.1 \\
9.1\end{array}$ & - & - & - & 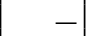 & - & 2,3 & 72 \\
\hline Leon County & $\mathrm{FL}$ & 26,211 & 31,560 & 58.2 & 41.8 & 38.6 & 1.6 & 1.5 & 0.1 & 1,810 & 17.4 & 4,219 & 7.5 & - & - & - & 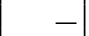 & - & 1,3 & 47 \\
\hline . & $\mathrm{FL}$ & 25,3 & 32,794 & & 30 & 18 & 11.4 & 0.8 & 0. & 1,7 & 18.4 & 3,957 & 8.3 & - & - & - & - & - & & 61 \\
\hline & $\mathrm{Fl}$ & & & & & & 5.5 & . & 0. & 2,0 & 17.7 & 4,456 & 8.1 & - & - & - & - & - & & 49 \\
\hline r & $\mathrm{Fl}$ & 25 & 30 & & 19 & 12 & 3.0 & 3.2 & 0.4 & 1,6 & 18.8 & 3,306 & 9.1 & - & - & - & - & - & 1,576 & 37 \\
\hline Ora & $\mathrm{FL}$ & 96,2 & 129 & 5 & 49 & 28 & 17.2 & 4 & & 7,0 & 18.3 & 15,397 & 8.4 & - & - & - & - & - & 6,0 & 160 \\
\hline unty .............. & $\mathrm{FL}$ & & & 5 & 41.1 & 5 & & & ? & 1,334 & 20.5 & 3,083 & 8.9 & - & - & - & - & - & & 32 \\
\hline County ......... & $\mathrm{FL}$ & & 13 & & 46.2 & 29.6 & 14.3 & 0 & $t$ & 7,258 & 19.0 & 14,873 & 9.3 & - & - & - & - & - & 5,7 & 135 \\
\hline nty .... & $\mathrm{FL}$ & 32 & & & 11.1 & 4.0 & 8 & 1 & 0.2 & 2,447 & 17.8 & 5,506 & 7.9 & - & - & - & - & - & 1,709 & 47 \\
\hline unty . & $\mathrm{FL}$ & 90,133 & 107, & 75.1 & 24.9 & 19.0 & 1 & 2.7 & 0.2 & 6,183 & 17.3 & 12,910 & 8.3 & - & - & - & - & - & 4,471 & 146 \\
\hline Polk County ............ & $\mathrm{FL}$ & 63,503 & 74,808 & 67.1 & 32.9 & 23.4 & 8.4 & 0.9 & 0.2 & 4,186 & 17.9 & 8,883 & 8.4 & - & - & - & - & - & 2,840 & 124 \\
\hline Santa Rosa County .......... & $\mathrm{FL}$ & 15,181 & 20,668 & 91.4 & 8.6 & 5.4 & 1.2 & 1.5 & 0.5 & 1,123 & 18.4 & 2,090 & 9.9 & - & - & - & - & - & 888 & 30 \\
\hline Sarasota County ................................... & $\mathrm{FL}$ & 27,541 & 31,950 & 83.3 & 16.7 & 10.8 & 4.5 & 1.2 & 0.1 & 1,825 & 17.5 & 4,008 & 8.0 & - & - & - & - & - & 1,397 & 39 \\
\hline Seminole County ................................... & $\mathrm{FL}$ & 46,505 & 55,972 & 71.8 & 28.2 & 14.6 & 10.6 & 2.8 & 0.2 & 2,829 & 19.8 & 5,381 & $\begin{array}{r}10.4 \\
\end{array}$ & - & - & - & - & - & 2,585 & 58 \\
\hline 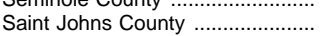 & $\mathrm{FL}$ & $\begin{array}{l}11,473 \\
11,00\end{array}$ & 16,374 & 85.6 & 14.4 & 11.7 & $\begin{array}{r}1.0 \\
1.8\end{array}$ & $\begin{array}{l}2.0 \\
0.8\end{array}$ & 0.2 & $\begin{array}{l}2,0<9 \\
1,012\end{array}$ & 16.2 & 1,942 & $\begin{array}{r}8.4 \\
8.4\end{array}$ & - & - & - & - & - & $\begin{array}{r}602 \\
662\end{array}$ & 26 \\
\hline 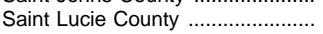 & & 20,653 & 27,672 & 60.0 & & & 7.8 & 1.0 & & 1,858 & 14.9 & 4,021 & & - & - & - & - & - & 1,026 & 35 \\
\hline Volusia County ......... & $\mathrm{FL}$ & 45,697 & 58,004 & 75.6 & 24.4 & $\begin{array}{l}01.0 \\
16.3\end{array}$ & $\begin{array}{l}1.0 \\
6.9\end{array}$ & 1.0 & 0.2 & 3,370 & 17.2 & 7,295 & 8.0 & - & - & - & - & - & 2,577 & 79 \\
\hline A & GA & 61,36 & 60,064 & 6.6 & 93.4 & 90.1 & 1.9 & 1.3 & 0.0 & 3,605 & 16.7 & 4,187 & 14.3 & 10.1 & 13.8 & 8.9 & 7.6 & 6.0 & 2,054 & 99 \\
\hline & GA & 24,033 & 24,840 & 31.7 & 68.3 & 67.1 & 0.5 & 0.4 & 0.2 & 1,469 & 16.9 & 1,712 & 14.5 & 12.6 & 4.8 & 25.9 & 11.7 & 12.9 & 912 & 41 \\
\hline Chatham County & GA & 33,399 & 36,382 & 34.7 & 65.3 & 62.4 & 1.2 & 1.5 & 0.2 & 2,224 & 16.4 & 2,450 & 14.9 & 8.2 & 10.1 & 7.9 & 7.0 & 5.2 & 1,511 & 43 \\
\hline Cherokee County ..... & $\mathrm{GA}$ & 15,354 & 22,189 & 94.9 & 5.1 & 2.3 & 2.0 & 0.6 & 0.1 & 1,287 & 17.2 & 1,463 & 15.2 & 6.3 & 0.9 & 2.6 & 6.1 & 20.0 & 939 & 30 \\
\hline
\end{tabular}


Table 93.-Selected statistics on enrollment, teachers, graduates, and dropouts in public school districts enrolling more than 15,000 pupils, by state: 1989 and 1996-Continued

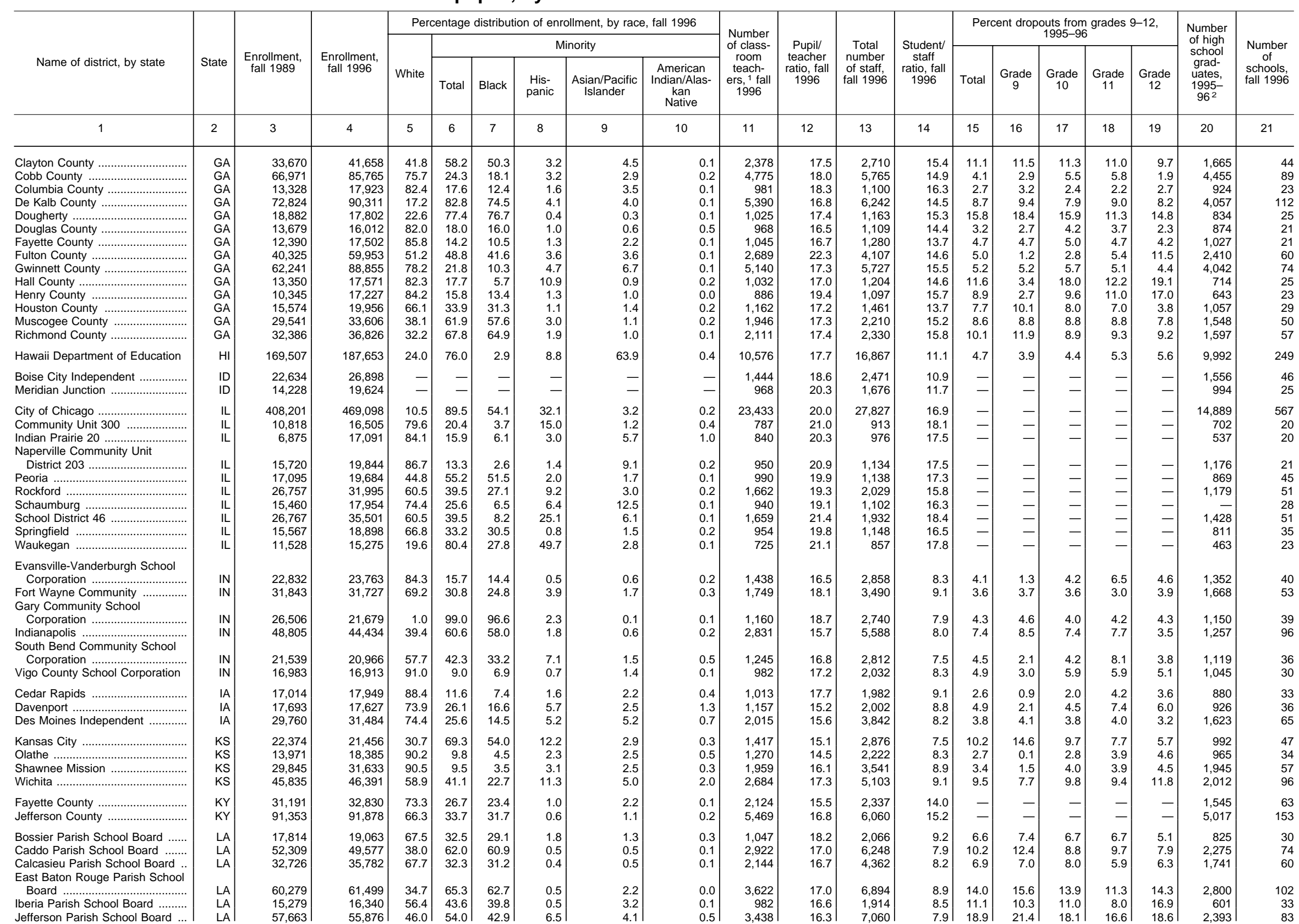


Table 93.-Selected statistics on enrollment, teachers, graduates, and dropouts in public school districts enrolling more than 15,000 pupils, by state: 1989 and 1996-Continued

\begin{tabular}{|c|c|c|c|c|c|c|c|c|c|c|c|c|c|c|c|c|c|c|c|c|}
\hline \multirow{3}{*}{ Name of district, by state } & \multirow{3}{*}{ State } & \multirow{3}{*}{$\begin{array}{l}\text { Enrollment, } \\
\text { fall } 1989\end{array}$} & \multirow{3}{*}{$\begin{array}{l}\text { Enrollment, } \\
\text { fall } 1996\end{array}$} & \multicolumn{6}{|c|}{ Percentage distribution of enrollment, by race, fall 1996} & \multirow{3}{*}{$\begin{array}{c}\text { Number } \\
\text { of class- } \\
\text { room } \\
\text { teach- } \\
\text { ers, } 1 \text { fall } \\
1996\end{array}$} & \multirow{3}{*}{$\begin{array}{c}\text { Pupil/ } \\
\text { teacher } \\
\text { ratio, fall } \\
1996\end{array}$} & \multirow{3}{*}{$\begin{array}{c}\text { Total } \\
\text { number } \\
\text { of staff, } \\
\text { fall } 1996\end{array}$} & \multirow{3}{*}{$\begin{array}{c}\text { Student/ } \\
\text { staff } \\
\text { ratio, fall } \\
1996\end{array}$} & \multirow{2}{*}{\multicolumn{5}{|c|}{$\begin{array}{l}\text { Percent dropouts from grades 9-12, } \\
1995-96\end{array}$}} & \multirow{3}{*}{$\begin{array}{c}\text { Number } \\
\text { of high } \\
\text { school } \\
\text { grad- } \\
\text { uates, } \\
1995- \\
96^{2}\end{array}$} & \multirow{3}{*}{$\begin{array}{l}\text { Number } \\
\text { of } \\
\text { schools, } \\
\text { fall } 1996\end{array}$} \\
\hline & & & & \multirow[b]{2}{*}{ White } & & & & linority & & & & & & & & & & & & \\
\hline & & & & & Total & Black & $\begin{array}{c}\text { His- } \\
\text { panic }\end{array}$ & $\begin{array}{c}\text { Asian/Pacific } \\
\text { Islander }\end{array}$ & $\begin{array}{c}\text { American } \\
\text { Indian/Alas- } \\
\text { kan } \\
\text { Native }\end{array}$ & & & & & Total & $\underset{9}{\text { Grade }}$ & $\underset{10}{\text { Grade }}$ & $\underset{11}{\text { Grade }}$ & $\underset{12}{\text { Grade }}$ & & \\
\hline 1 & 2 & 3 & 4 & 5 & 6 & 7 & 8 & 9 & 10 & 11 & 12 & 13 & 14 & 15 & 16 & 17 & 18 & 19 & 20 & 21 \\
\hline Lafayette Parish School Board .. & LA & 28,392 & 31,287 & 63.8 & 36.2 & 34.2 & 0.7 & 1.1 & 0.1 & 1,855 & 16.9 & 3,401 & 9.2 & 8.7 & 12.2 & 8.1 & 7.5 & 5.0 & 1,407 & 41 \\
\hline Lafourche $\mathrm{P}$ & LA & 16 & 17,100 & 73.5 & 26.5 & 21.2 & 0.6 & 1.2 & 3.4 & 1,148 & 14.9 & 2,043 & 8.4 & 6.9 & 6.4 & 8.0 & 6.4 & 6.7 & 802 & 28 \\
\hline Livingst & LA & 16 & 18 & 93.2 & 6.8 & 6.2 & 3 & .2 & 1 & 1,031 & 17.9 & 1,900 & 9.7 & 11.9 & 14.1 & 10.9 & 12.4 & 8.8 & 42 & 34 \\
\hline Orleans $\mathrm{Pa}$ & LA & 84,428 & 85,064 & 5.5 & 94.5 & 90.7 & 3 & .5 & .0 & 4,579 & 18.6 & 8,602 & 9.9 & 4.4 & 3 & 13.9 & 12.4 & 16.2 & 3,340 & 122 \\
\hline Ouachita Parish Sc & LA & 17,523 & 18,289 & 75.2 & 24.8 & 23.8 & 4 & 6 & 0.0 & 1,104 & 16.6 & 2,148 & 8.5 & 18.4 & 11.7 & 20.7 & 20.6 & 24.7 & 1,641 & 31 \\
\hline $\begin{array}{l}\text { Rapides Parish School Board ..... } \\
\text { Saint Landry Parish School }\end{array}$ & LA & 24,404 & 25,404 & 56.3 & 43.7 & 41.0 & 0.4 & 1.0 & 1.3 & 1,609 & 15.8 & 3,169 & 8.0 & 9.1 & 9.3 & 10.9 & 9.3 & 6.7 & 1,400 & 55 \\
\hline Board & LA & 17,379 & 18,552 & 45.0 & 55.0 & 54.5 & 0.2 & 0.1 & 0.1 & 1,086 & 17.1 & 2,219 & 8.4 & 6.7 & 9.3 & 7.5 & 5.3 & 3.3 & 787 & 37 \\
\hline $\begin{array}{l}\text { Saint Tammany Parish School } \\
\text { Board }\end{array}$ & & & & & & & & & & & & & & & & & & & & \\
\hline $\begin{array}{l}\text { Board ....... } \\
\text { Tangipah Parish School Board }\end{array}$ & LA & $\begin{array}{l}28,055 \\
117266\end{array}$ & $\begin{array}{l}33,100 \\
19,431\end{array}$ & $\begin{array}{l}83.7 \\
54.4\end{array}$ & 16.3 & 14.7 & 0.8 & 0.7 & 0.1 & 2,102 & 15.7 & 4,075 & 8.1 & 9.4 & 11.1 & 8.8 & 8.4 & 8.7 & 1,642 & 49 \\
\hline $\begin{array}{l}\text { Tangipahoa Parish School Board } \\
\text { Terrebonne Parish School Board }\end{array}$ & $\begin{array}{l}\text { LA } \\
\text { LA }\end{array}$ & $\begin{array}{l}1,266 \\
21,331\end{array}$ & $\begin{array}{l}19,431 \\
22,179\end{array}$ & $\begin{array}{l}54.4 \\
64.2\end{array}$ & $\begin{array}{l}45.6 \\
35.8\end{array}$ & $\begin{array}{l}44.4 \\
26.2\end{array}$ & 0.6 & 0.4 & 0.0 & 1,020 & 19.1 & 2,077 & 9.4 & 21.6 & 17.9 & 26.3 & 21.0 & 23.0 & 863 & 37 \\
\hline Anne Arundel County Public & & & & & & 20.2 & 0.6 & 1.1 & 7.9 & 1,233 & 18.0 & 2,282 & 9.7 & 11.7 & 13.4 & 12.4 & 11.2 & 8.3 & 911 & 43 \\
\hline $\begin{array}{l}\text { Schools ....................... } \\
\text { Baltimore City Public Schoo }\end{array}$ & MD & 64,104 & 72,322 & 77.9 & 22.1 & 18.1 & 1.6 & 2.2 & 0.2 & 4,064 & 17.8 & 7,094 & 10.2 & -1 & -1 & - & - & - & 3,569 & 111 \\
\hline 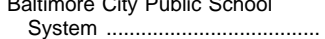 & $\mathrm{MD}$ & 107.782 & 108759 & & & & & & & & & & & & & & & & 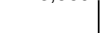 & \\
\hline Baltimore Coun & $\mathrm{MD}$ & 84,133 & $\begin{array}{l}108,159 \\
104,073\end{array}$ & $\begin{array}{l}13.4 \\
68.7\end{array}$ & $\begin{array}{l}86.6 \\
31.3\end{array}$ & $\begin{array}{l}85.1 \\
26.5\end{array}$ & $\begin{array}{l}0.4 \\
1.2\end{array}$ & $\begin{array}{l}0.6 \\
3.4\end{array}$ & $\begin{array}{l}0.5 \\
0.2\end{array}$ & $\begin{array}{l}6,259 \\
6,442\end{array}$ & $\begin{array}{l}17.4 \\
16.2\end{array}$ & $\begin{array}{l}10,020 \\
11,531\end{array}$ & $\begin{array}{r}10.9 \\
9.0\end{array}$ & - & 二 & 二 & - & - & $\begin{array}{l}3,827 \\
5,510\end{array}$ & $\begin{array}{l}179 \\
160\end{array}$ \\
\hline Carroll County & MD & 21,244 & 26,231 & 96.0 & 4.0 & 2.3 & 0.7 & 0.9 & 0.2 & 1,408 & 18.6 & 2,428 & 10.8 & - & - & - & - & - & $\begin{array}{l}1,421 \\
1\end{array}$ & 33 \\
\hline $\begin{array}{l}\text { Board of Education, Charles } \\
\text { County }\end{array}$ & & & & & & & & & & & & & & & & & & & & \\
\hline Frederick County Board of & MD & 18,299 & 21,159 & 68.8 & 31.2 & 26.9 & 1.3 & 1.9 & 1.1 & 1,161 & 18.2 & 1,939 & 10.9 & - & - & - & - & - & 1,235 & 32 \\
\hline Education & MD & 26,173 & 33,749 & 88.7 & 11.3 & 7.9 & 1.7 & 1.6 & 0.2 & 2,008 & 16.8 & 3,472 & 9.7 & - & - & - & - & - & 1,968 & 50 \\
\hline Harford County ...................... & MD & 30,217 & 37,709 & 83.3 & 16.7 & 12.7 & 1.7 & 1.8 & 0.5 & 2,244 & 16.8 & 3,896 & 9.7 & - & - & - & - & - & 1,813 & 52 \\
\hline $\begin{array}{l}\text { Howard County Public Schools } \\
\text { System }\end{array}$ & MD & 28,874 & 38,857 & 73.9 & 26.1 & 16.3 & 1.8 & 7.9 & 0.1 & 2,457 & 15.8 & 4.352 & 8.9 & - & - & - & - & -1 & 2,304 & 59 \\
\hline Montgomery County …….................. & $\mathrm{MD}$ & 100,261 & 122,505 & 54.7 & 45.3 & 19.8 & 12.5 & 12.6 & 0.4 & 7,208 & 17.0 & 13,765 & 8.9 & - & - & - & - & - & 6,765 & 182 \\
\hline Prince George's County Public & & & & & & & & & & & & & & & & & & & & \\
\hline $\begin{array}{l}\text { Schools ........... } \\
\text { Board of Educatio }\end{array}$ & MD & 106,974 & 125,198 & 16.7 & 83.3 & 73.4 & 5.7 & 3.8 & 0.4 & 6,996 & 17.9 & 13,472 & 9.3 & - & - & - & - & - & 6,751 & 179 \\
\hline County .................... & MD & 17,424 & 19,896 & 91.9 & 8.1 & 5.9 & 1.1 & 1.1 & 0.1 & 1,219 & 16.3 & 2,034 & 9.8 & - & - & - & - & - & 1,128 & 44 \\
\hline oston & MA & 59,597 & 63,239 & 16.9 & 83.1 & 48.4 & 25.2 & 9.2 & 0.4 & 4,076 & 15.5 & 8,444 & 7.5 & 7.2 & 7.1 & 7.6 & 8.1 & 5.7 & 3,001 & 124 \\
\hline & MA & 14,738 & 15,461 & 48.6 & 51.4 & 35.3 & & 3 & 0.5 & 961 & 16.1 & 1,800 & 8.6 & 7.3 & 5.2 & 11.5 & 7.2 & 3.3 & 549 & 24 \\
\hline & MA & 13,414 & 15,759 & 45.2 & 54.8 & 3.4 & 21.8 & 29.5 & 0.1 & 1,087 & 14.5 & 1,788 & 8.8 & 2.6 & 1.9 & 4.2 & 1.8 & 1.7 & 454 & 29 \\
\hline$s p r$ & MA & 23,614 & 24,422 & 28.1 & 71.9 & 30.3 & 39.5 & 2.0 & 0.1 & 2,038 & 12.0 & 3,786 & 6.5 & 2.9 & 3.4 & 3.4 & 2.1 & 1.6 & 805 & 46 \\
\hline Worcester ... & MA & 21,081 & 23,728 & 57.1 & 42.9 & 9.4 & 26.0 & 6.9 & 0.6 & 1,891 & 12.5 & 3,308 & 7.2 & 7.4 & 5.2 & 8.3 & 8.6 & 7.8 & 808 & 49 \\
\hline Ann Arbor ......... & Ml & 13,640 & 15,587 & 70.9 & 29.1 & 17.6 & 2.2 & 8.9 & 0.4 & 809 & 19.3 & 1,740 & 9.0 & - & - & - & - & - & 832 & 32 \\
\hline & MI & & & 95.5 & 5 & 1.3 & & & & $\begin{array}{r}918 \\
\end{array}$ & $\begin{array}{l}0 \\
0 \\
1\end{array}$ & & $\begin{array}{r}9.0 \\
8.0\end{array}$ & - & - & - & - & - & $\begin{array}{r}832 \\
\end{array}$ & $\begin{array}{r}29 \\
279\end{array}$ \\
\hline & $M$ & 175, & 182 & $\begin{array}{r}5.2 \\
55.0\end{array}$ & 94.8 & 9 & $\begin{array}{l}8 \\
0 \\
\end{array}$ & & 0 & 8,808 & $\begin{array}{l}7.1 \\
0 \\
\end{array}$ & 22,077 & $\begin{array}{r}8.3 \\
89 \\
\end{array}$ & - & - & - & - & - & 6,056 & 279 \\
\hline & $\mathrm{MI}$ & & & 25.0 & 75.0 & & & & & 1,404 & & & $\begin{array}{l}8.9 \\
8.7\end{array}$ & - & - & - & - & - & $\begin{array}{l}914 \\
781\end{array}$ & 48 \\
\hline Gra & MI & 26,063 & 28,282 & 40.8 & 59.2 & & 14.2 & ? & 1.3 & 1,392 & 24 & & 8. & - & - & - & - & - & 781 & 100 \\
\hline 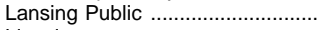 & $\mathrm{MI}$ & 21,407 & 19,413 & 47.0 & 53.0 & 34.0 & 12.6 & 5.2 & 1.2 & 1,066 & 18.2 & 2,440 & 8.0 & - & - & - & - & - & 691 & 45 \\
\hline nton Community & MI & 16,115 & 18,100 & 95.7 & 4.3 & 1.6 & 0.8 & 1.5 & 0.3 & 906 & 20.0 & 1,935 & 9.4 & - & - & - & - & - & 1,171 & 36 \\
\hline $\begin{array}{l}\text { Plymouth-Canton Community } \\
\text { Schools ................................... }\end{array}$ & MI & 14, & 15,800 & 91.2 & 8.8 & 2.6 & 0 & 4.7 & 0.5 & 739 & 21 & 1,6 & 9.8 & - & -1 & - & -1 & - & 935 & 22 \\
\hline Utica Comm & $\mathrm{MI}$ & 24,486 & 25,635 & 96.2 & 3.8 & 1.0 & 0.5 & 2.2 & 0.2 & 1,182 & 21.7 & 2,416 & 10.6 & - & - & - & - & - & 1,599 & 41 \\
\hline Wayne-Westland Community ....... & $\mathrm{Ml}$ & 16,600 & 15,151 & 84.7 & 15.3 & 11.9 & 1.5 & 0.9 & 1.0 & 693 & 21.9 & 1,394 & 10.9 & - & - & - & - & - & 674 & 26 \\
\hline Anoka-Hennepin & MN & 33,562 & 39,874 & 93.4 & 6.6 & 2.0 & & 2.4 & & 2,201 & 18.1 & 3,833 & 10.4 & 5.4 & 1.1 & 4.8 & 8.0 & 8.3 & 2,075 & 50 \\
\hline & $\mathrm{MN}$ & 6 & 7,978 & 35.0 & 65.0 & 41.2 & 5.0 & 12.6 & 6.3 & 3,080 & 15.6 & 5,515 & 8.7 & 18.2 & 18.0 & 17.1 & 18.1 & 19.9 & 1,617 & 144 \\
\hline & $\mathrm{MN}$ & 18,9 & 21,664 & 82.2 & 17. & 10.1 & 1.4 & 5.6 & 0.6 & 1,197 & 18 & 2,009 & 10.8 & 5.9 & 0.6 & 5.6 & 8.8 & 9. & 1,213 & 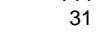 \\
\hline & $\mathrm{MN}$ & 13,2 & 15,544 & 85.2 & 14.8 & 4 & 2. & 8.2 & 0.3 & 848 & 18 & 1,547 & 10. & 4.6 & 1.6 & 5.3 & 7.1 & 4.3 & & 29 \\
\hline ipple Valley-Eagan & $\mathrm{MN}$ & 11,185 & 26,566 & 90.4 & 9.6 & 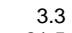 & 1.3 & 4.5 & 0.5 & 1,559 & $11 \%$ & 3,102 & 8.6 & 3.0 & 0.6 & 2.5 & 3.9 & 5.7 & & 36 \\
\hline 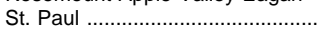 & $\mathrm{MN}$ & 31,852 & 43,766 & 42.9 & 57.1 & 21.5 & 7.2 & 26.7 & 1.7 & 2,203 & 19.9 & 3,471 & 12.6 & 12.5 & 5.2 & 11.5 & 16.2 & 18.6 & 1,596 & 139 \\
\hline 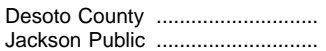 & $\begin{array}{l}\text { MS } \\
\text { MS }\end{array}$ & $\begin{array}{l}13,099 \\
33,330\end{array}$ & $\begin{array}{l}16,625 \\
32,636\end{array}$ & $\begin{array}{l}81.3 \\
11.1\end{array}$ & $\begin{array}{l}18.7 \\
88.9\end{array}$ & $\begin{array}{l}16.5 \\
88.3\end{array}$ & $\begin{array}{l}1.4 \\
0.2\end{array}$ & $\begin{array}{l}0.3 \\
0.4\end{array}$ & $\begin{array}{l}0.3 \\
0.1\end{array}$ & $\begin{array}{r}853 \\
1,808\end{array}$ & $\begin{array}{l}19.5 \\
18.0\end{array}$ & $\begin{array}{l}1,699 \\
4,215\end{array}$ & $\begin{array}{l}9.8 \\
7.7\end{array}$ & $\begin{array}{l}4.3 \\
8.6\end{array}$ & $\begin{array}{r}4.7 \\
11.2\end{array}$ & $\begin{array}{l}4.1 \\
8.1\end{array}$ & $\begin{array}{l}3.0 \\
7.2\end{array}$ & $\begin{array}{l}5.0 \\
5.1\end{array}$ & $\begin{array}{r}686 \\
1,330\end{array}$ & $\begin{array}{l}21 \\
58\end{array}$ \\
\hline Columbia ......... & MO & 12,539 & 15,605 & 77.9 | & 22.1 & 16.6 & 1.2 & 3.9 & 0.4 & 1,052 & 14.8 & $1,356 \mid$ & 11.5 & 9.21 & 2.1 & 15.1 & 9.6 & 8.6 & & 30 \\
\hline
\end{tabular}


Table 93.-Selected statistics on enrollment, teachers, graduates, and dropouts in public school districts enrolling more than 15,000 pupils, by state: 1989 and 1996-Continued

\begin{tabular}{|c|c|c|c|c|c|c|c|c|c|c|c|c|c|c|c|c|c|c|c|c|}
\hline \multirow[b]{2}{*}{ Name of district, by state } & \multirow[b]{2}{*}{ State } & \multirow[b]{2}{*}{$\begin{array}{l}\text { Enrollment, } \\
\text { fall } 1989\end{array}$} & \multirow[b]{2}{*}{$\begin{array}{l}\text { Enrollment, } \\
\text { fall } 1996\end{array}$} & \multicolumn{6}{|c|}{ Percentage distribution of enrollment, by race, fall 1996} & \multirow{2}{*}{$\begin{array}{l}\text { Number } \\
\text { of class- } \\
\text { room } \\
\text { teach- } \\
\text { ers, } 1 \text { fall } \\
1996\end{array}$} & \multirow{2}{*}{$\begin{array}{c}\text { Pupil/ } \\
\text { teacher } \\
\text { ratio, fall } \\
1966\end{array}$} & \multirow{2}{*}{$\begin{array}{c}\text { Total } \\
\text { number } \\
\text { of staff, } \\
\text { fall } 1996\end{array}$} & \multirow{2}{*}{$\begin{array}{l}\text { Student/ } \\
\text { staff } \\
\text { ratio, fall } \\
1996\end{array}$} & \multicolumn{5}{|c|}{$\begin{array}{l}\text { Percent dropouts from grades 9-12, } \\
1995-96\end{array}$} & \multirow{2}{*}{$\begin{array}{c}\text { Number } \\
\text { of high } \\
\text { school } \\
\text { grad- } \\
\text { uates, } \\
1995- \\
96^{2}\end{array}$} & \multirow{2}{*}{$\begin{array}{l}\text { Number } \\
\text { of } \\
\text { schools, } \\
\text { fall } 1996\end{array}$} \\
\hline & & & & White & Total & Black & $\begin{array}{c}\text { His- } \\
\text { panic }\end{array}$ & $\begin{array}{c}\text { Asian/Pacific } \\
\text { Islander }\end{array}$ & $\begin{array}{c}\text { American } \\
\text { Indian/Alas- } \\
\text { kan } \\
\text { Native }\end{array}$ & & & & & Total & $\underset{9}{\operatorname{Grade}}$ & $\underset{10}{\text { Grade }}$ & $\underset{11}{G}$ & $\begin{array}{c}\text { Grade } \\
12\end{array}$ & & \\
\hline 1 & 2 & 3 & 4 & 5 & 6 & 7 & 8 & 9 & 10 & 11 & 12 & 13 & 14 & 15 & 16 & 17 & 18 & 19 & 20 & 21 \\
\hline 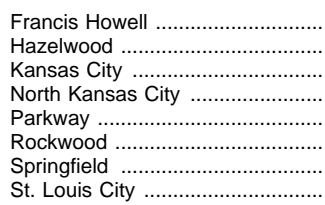 & $\begin{array}{l}\text { MO } \\
\text { MO } \\
\text { MO } \\
\text { MO } \\
\text { MO } \\
\text { MO } \\
\text { MO } \\
\text { MO }\end{array}$ & $\begin{array}{l}12,836 \\
17,175 \\
34,640 \\
15,617 \\
22,379 \\
14,657 \\
23,248 \\
44,056\end{array}$ & $\begin{array}{l}18,106 \\
18,511 \\
38,521 \\
16,941 \\
21,483 \\
19,871 \\
25,207 \\
44,620\end{array}$ & $\begin{array}{l}93.8 \\
60.7 \\
20.1 \\
92.1 \\
74.7 \\
83.3 \\
92.0 \\
18.0\end{array}$ & $\begin{array}{r}6.2 \\
39.3 \\
79.9 \\
7.9 \\
25.3 \\
16.7 \\
8.0 \\
82.0\end{array}$ & $\begin{array}{r}5.0 \\
37.4 \\
71.5 \\
3.5 \\
18.1 \\
14.3 \\
4.1 \\
79.7\end{array}$ & $\begin{array}{l}0.4 \\
0.7 \\
6.0 \\
2.5 \\
0.9 \\
0.5 \\
1.6 \\
0.7\end{array}$ & $\begin{array}{l}0.6 \\
1.1 \\
2.0 \\
1.6 \\
6.1 \\
1.8 \\
1.7 \\
1.6\end{array}$ & $\begin{array}{l}0.2 \\
0.1 \\
0.3 \\
0.4 \\
0.1 \\
0.1 \\
0.6 \\
0.1\end{array}$ & $\begin{array}{l}1,097 \\
1,034 \\
2,645 \\
1,072 \\
1,248 \\
1,109 \\
1,483 \\
3,205\end{array}$ & $\begin{array}{l}16.5 \\
17.9 \\
14.6 \\
15.8 \\
17.2 \\
17.9 \\
17.0 \\
13.9\end{array}$ & $\begin{array}{l}1,390 \\
1,281 \\
3,488 \\
1,305 \\
1,592 \\
1,403 \\
2,057 \\
4,471\end{array}$ & $\begin{array}{l}13.0 \\
14.5 \\
11.0 \\
13.0 \\
13.5 \\
14.2 \\
12.3 \\
10.0\end{array}$ & $\begin{array}{r}6.0 \\
4.3 \\
11.2 \\
7.5 \\
2.1 \\
3.7 \\
8.1 \\
22.4\end{array}$ & $\begin{array}{r}5.8 \\
3.4 \\
12.3 \\
5.5 \\
1.7 \\
2.9 \\
5.1 \\
27.0\end{array}$ & $\begin{array}{r}7.1 \\
5.0 \\
12.7 \\
5.2 \\
2.4 \\
4.0 \\
8.4 \\
24.1\end{array}$ & $\begin{array}{r}6.4 \\
4.6 \\
11.0 \\
9.8 \\
2.7 \\
4.7 \\
10.3 \\
17.5\end{array}$ & $\begin{array}{r}4.4 \\
4.1 \\
6.6 \\
10.0 \\
1.5 \\
3.6 \\
9.1 \\
11.5\end{array}$ & $\begin{array}{r}965 \\
1,122 \\
1,132 \\
920 \\
1,530 \\
1,131 \\
1,434 \\
1,084\end{array}$ & $\begin{array}{r}15 \\
25 \\
83 \\
29 \\
28 \\
26 \\
57 \\
111\end{array}$ \\
\hline $\begin{array}{l}\text { Lincoln } \\
\text { Millard } \\
\text { Omaha }\end{array}$ & $\begin{array}{l}\mathrm{NE} \\
\mathrm{NE} \\
\mathrm{NE}\end{array}$ & $\begin{array}{l}27,356 \\
16,244 \\
41,251\end{array}$ & $\begin{array}{l}30,691 \\
18,647 \\
44,761\end{array}$ & $\begin{array}{l}87.7 \\
95.7 \\
59.6\end{array}$ & $\begin{array}{r}12.3 \\
4.3 \\
40.4\end{array}$ & $\begin{array}{r}5.2 \\
1.1 \\
29.8\end{array}$ & $\begin{array}{l}2.6 \\
1.3 \\
7.7\end{array}$ & $\begin{array}{l}3.3 \\
1.7 \\
1.3\end{array}$ & $\begin{array}{l}1.2 \\
0.3 \\
1.5\end{array}$ & $\begin{array}{l}2,124 \\
1,090 \\
2,853\end{array}$ & $\begin{array}{l}14.5 \\
17.1 \\
15.7\end{array}$ & $\begin{array}{l}4,223 \\
1,962 \\
5,512\end{array}$ & $\begin{array}{l}7.3 \\
9.5 \\
8.1\end{array}$ & $\begin{array}{r}7.0 \\
2.1 \\
10.9\end{array}$ & $\begin{array}{l}1.2 \\
0.4 \\
8.8\end{array}$ & $\begin{array}{r}4.6 \\
1.1 \\
15.4\end{array}$ & $\begin{array}{r}10.1 \\
2.3 \\
11.1\end{array}$ & $\begin{array}{r}13.1 \\
4.9 \\
6.5\end{array}$ & $\begin{array}{l}1,699 \\
1,114 \\
2,131\end{array}$ & $\begin{array}{l}53 \\
29 \\
82\end{array}$ \\
\hline 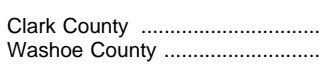 & $\begin{array}{l}\text { NV } \\
\text { NV }\end{array}$ & $\begin{array}{r}111,460 \\
36,662\end{array}$ & $\begin{array}{r}179,106 \\
49,671\end{array}$ & $\begin{array}{l}58.4 \\
72.7\end{array}$ & $\begin{array}{l}41.6 \\
27.3\end{array}$ & $\begin{array}{r}13.8 \\
3.5\end{array}$ & $\begin{array}{l}21.4 \\
16.4\end{array}$ & $\begin{array}{l}5.5 \\
4.8\end{array}$ & $\begin{array}{l}0.9 \\
2.6\end{array}$ & $\begin{array}{l}8,875 \\
2,842\end{array}$ & $\begin{array}{l}20.2 \\
17.5\end{array}$ & $\begin{array}{r}14,752 \\
4,962\end{array}$ & $\begin{array}{l}12.1 \\
10.0\end{array}$ & $\begin{array}{r}11.1 \\
8.2\end{array}$ & $\begin{array}{l}4.2 \\
2.4\end{array}$ & $\begin{array}{l}6.8 \\
5.2\end{array}$ & $\begin{array}{l}12.7 \\
10.6\end{array}$ & $\begin{array}{l}24.6 \\
17.8\end{array}$ & $\begin{array}{l}7,063 \\
2,032\end{array}$ & $\begin{array}{r}211 \\
83\end{array}$ \\
\hline Manchester ............. & $\mathrm{NH}$ & 13,912 & 16,265 & 91.1 & 8.9 & 2.4 & 4.0 & 1.9 & 0.5 & 851 & 19.1 & 1,367 & 11.9 & - & - & - & - & - & 1,304 & 23 \\
\hline 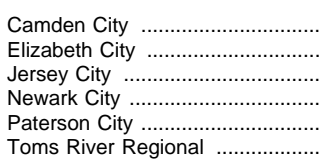 & $\begin{array}{l}\mathrm{NJ} \\
\mathrm{NJ} \\
\mathrm{NJ} \\
\mathrm{NJ} \\
\mathrm{NJ} \\
\mathrm{NJ}\end{array}$ & $\begin{array}{l}18,999 \\
14,955 \\
27,788 \\
48,573 \\
21,671 \\
16,055\end{array}$ & $\begin{array}{l}19,841 \\
17,056 \\
31,666 \\
45,805 \\
23,408 \\
16,854\end{array}$ & $\begin{array}{r}3.1 \\
16.6 \\
9.2 \\
8.6 \\
6.6 \\
94.1\end{array}$ & $\begin{array}{r}96.9 \\
83.4 \\
90.8 \\
91.4 \\
93.4 \\
5.9\end{array}$ & $\begin{array}{r}57.8 \\
28.7 \\
42.3 \\
63.4 \\
41.3 \\
2.1\end{array}$ & $\begin{array}{r}36.7 \\
51.9 \\
37.3 \\
27.2 \\
50.1 \\
2.2\end{array}$ & $\begin{array}{r}2.3 \\
2.7 \\
10.5 \\
0.8 \\
2.0 \\
1.5\end{array}$ & $\begin{array}{l}0.1 \\
0.1 \\
0.6 \\
0.0 \\
0.0 \\
0.1\end{array}$ & $\begin{array}{l}1,512 \\
1,247 \\
2,133 \\
3,538 \\
1,666 \\
1,058\end{array}$ & $\begin{array}{l}13.1 \\
13.7 \\
14.8 \\
12.9 \\
14.1 \\
15.9\end{array}$ & $\begin{array}{l}3,584 \\
2,472 \\
4,169 \\
7,689 \\
3,239 \\
2,007\end{array}$ & $\begin{array}{l}5.5 \\
6.9 \\
7.6 \\
6.0 \\
7.2 \\
8.4\end{array}$ & $\begin{array}{l}- \\
- \\
- \\
- \\
-\end{array}$ & $\begin{array}{l}- \\
= \\
= \\
=\end{array}$ & $\begin{array}{l}- \\
- \\
- \\
- \\
-\end{array}$ & $\begin{array}{l}- \\
- \\
= \\
-\end{array}$ & $\begin{array}{l}- \\
= \\
= \\
=\end{array}$ & $\begin{array}{r}688 \\
725 \\
1,047 \\
1,413 \\
632 \\
1,069\end{array}$ & $\begin{array}{l}33 \\
25 \\
37 \\
80 \\
35 \\
16\end{array}$ \\
\hline 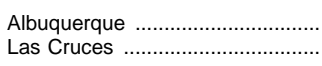 & $\begin{array}{l}\text { NM } \\
\text { NM }\end{array}$ & $\begin{array}{l}86,370 \\
18,688\end{array}$ & $\begin{array}{l}89,092 \\
22,523\end{array}$ & $\begin{array}{l}44.2 \\
34.3\end{array}$ & $\begin{array}{l}55.8 \\
65.7\end{array}$ & $\begin{array}{l}3.6 \\
2.3\end{array}$ & $\begin{array}{l}46.2 \\
60.6\end{array}$ & $\begin{array}{l}1.8 \\
1.1\end{array}$ & $\begin{array}{l}4.1 \\
1.7\end{array}$ & $\begin{array}{l}5,631 \\
1,396\end{array}$ & $\begin{array}{l}15.8 \\
16.1\end{array}$ & $\begin{array}{r}10,545 \\
2,675\end{array}$ & $\begin{array}{l}8.4 \\
8.4\end{array}$ & $\overline{-}$ & $\overline{-}$ & $\overline{-}$ & $\overline{-}$ & $\overline{-}$ & $\begin{array}{l}4,358 \\
1,049\end{array}$ & $\begin{array}{r}124 \\
34\end{array}$ \\
\hline 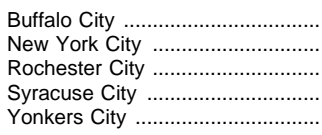 & $\begin{array}{l}\text { NY } \\
\text { NY } \\
\text { NY } \\
\text { NY } \\
\text { NY }\end{array}$ & $\begin{array}{r}46,689 \\
930,440 \\
31,930 \\
21,811 \\
17,992\end{array}$ & $\begin{array}{r}47,845 \\
1,063,561 \\
37,912 \\
23,760 \\
23,655\end{array}$ & $\begin{array}{l}33.1 \\
16.1 \\
19.6 \\
49.6 \\
24.2\end{array}$ & $\begin{array}{l}66.9 \\
83.9 \\
80.4 \\
50.4 \\
75.8\end{array}$ & $\begin{array}{l}54.0 \\
36.1 \\
60.2 \\
42.7 \\
30.1\end{array}$ & \begin{tabular}{r|}
10.4 \\
37.3 \\
17.7 \\
4.9 \\
41.2
\end{tabular} & $\begin{array}{r}1.3 \\
10.0 \\
2.2 \\
1.7 \\
4.5\end{array}$ & $\begin{array}{l}1.2 \\
0.5 \\
0.3 \\
1.2 \\
0.1\end{array}$ & $\begin{array}{r}3,200 \\
57,338 \\
2,584 \\
1,682 \\
1,471\end{array}$ & $\begin{array}{l}14.9 \\
18.5 \\
14.7 \\
14.1 \\
16.1\end{array}$ & $\begin{array}{r}5,831 \\
110,709 \\
4,337 \\
3,917 \\
2,823\end{array}$ & $\begin{array}{l}8.2 \\
9.6 \\
8.7 \\
6.1 \\
8.4\end{array}$ & $\begin{array}{l}6.4 \\
5.7 \\
7.1 \\
5.4 \\
3.7\end{array}$ & $\begin{array}{l}4.6 \\
2.9 \\
5.5 \\
4.1 \\
3.3\end{array}$ & $\begin{array}{l}7.5 \\
6.2 \\
8.7 \\
7.1 \\
3.4\end{array}$ & \begin{tabular}{r|r}
8.0 & 11.1 \\
10.3 \\
7.3 \\
5.2
\end{tabular} & $\begin{array}{l}6.0 \\
2.5 \\
4.2 \\
3.4 \\
3.5\end{array}$ & $\begin{array}{r}1,905 \\
38,075 \\
935 \\
806 \\
811\end{array}$ & $\begin{array}{r}73 \\
1,120 \\
58 \\
36 \\
36\end{array}$ \\
\hline $\begin{array}{l}\text { Alamance-Burlington . } \\
\text { Buncombe County }\end{array}$ & $\begin{array}{l}\mathrm{NC} \\
\mathrm{NC} \\
\mathrm{NC}\end{array}$ & $\begin{array}{l}10,330 \\
21,821\end{array}$ & $\begin{array}{l}18,943 \\
24,547 \\
16,497\end{array}$ & $\begin{array}{l}68.4 \\
91.7 \\
83.5\end{array}$ & $\begin{array}{r}31.6 \\
8.3 \\
16.5\end{array}$ & $\begin{array}{r}26.7 \\
5.8 \\
135\end{array}$ & $\begin{array}{l}3.7 \\
1.2 \\
2.2\end{array}$ & $\begin{array}{l}1.0 \\
0.8 \\
0.6\end{array}$ & $\begin{array}{l}0.2 \\
0.5 \\
0.3\end{array}$ & $\begin{array}{l}1,135 \\
1,429 \\
1100\end{array}$ & $\begin{array}{l}16.7 \\
17.2 \\
16.4\end{array}$ & $\begin{array}{l}2,157 \\
2,801 \\
1811\end{array}$ & $\begin{array}{l}8.8 \\
8.8 \\
91\end{array}$ & $\begin{array}{l}- \\
-\end{array}$ & $\begin{array}{l}- \\
-\end{array}$ & $\begin{array}{l}- \\
-\end{array}$ & $\begin{array}{l}- \\
-\end{array}$ & $\begin{array}{l}- \\
-\end{array}$ & $\begin{array}{r}895 \\
1,232 \\
777\end{array}$ & $\begin{array}{l}31 \\
36 \\
20\end{array}$ \\
\hline cklenburg. & $\begin{array}{l}\mathrm{NC} \\
\mathrm{NC}\end{array}$ & $\begin{array}{l}12,4 \\
75,9\end{array}$ & $\begin{array}{l}16 \\
93\end{array}$ & $\begin{array}{l}83.5 \\
52.2\end{array}$ & $\begin{array}{l}16.5 \\
47.8\end{array}$ & $\begin{array}{l}13.5 \\
41.2\end{array}$ & .4 & $\begin{array}{l}0.6 \\
3.7\end{array}$ & $\begin{array}{l}0.3 \\
0.5\end{array}$ & $\begin{array}{l}1,005 \\
5,523\end{array}$ & $\begin{array}{l}16.4 \\
16.9\end{array}$ & $\begin{array}{r}1,811 \\
10,602\end{array}$ & $\begin{array}{l}9.1 \\
8.8\end{array}$ & - & - & - & - & - & 4,156 & 130 \\
\hline & NC & 44, & & & 53.9 & 45.8 & 4 & & & 2,9 & 17.5 & 5,5 & 9.1 & - & - & - & - & - & 2,481 & 72 \\
\hline County ………………..... & $\begin{array}{l}\text { NC } \\
\text { NC }\end{array}$ & $\begin{array}{l}16 \\
18\end{array}$ & $\begin{array}{l}18, \\
29\end{array}$ & $\begin{array}{l}96.6 \\
37.9\end{array}$ & $\begin{array}{r}3.4 \\
62.1\end{array}$ & $\begin{array}{r}2.2 \\
57.4\end{array}$ & 2 & $\begin{array}{l}0.5 \\
2.0\end{array}$ & $\begin{array}{l}0.3 \\
0.3\end{array}$ & $\begin{array}{l}1,025 \\
1,972\end{array}$ & $\begin{array}{l}17.7 \\
14.7\end{array}$ & $\begin{array}{l}1,927 \\
4,056\end{array}$ & $\begin{array}{l}9.4 \\
7.2\end{array}$ & $\overline{-}$ & $\bar{z}$ & $\overline{-}$ & 二 & $\overline{-}$ & $\begin{array}{r}925 \\
1.334\end{array}$ & $\begin{array}{l}26 \\
44\end{array}$ \\
\hline bunty ....……………........ & & & & & 4 & & & & 0. & & 15 & & 9.2 & - & - & - & - & - & & 58 \\
\hline ........ & & 30,0 & & & & & & 1.4 & 0 & & 16 & & 9.4 & - & - & - & - & - & & 3 \\
\hline y... & & 30 & & 55.8 & 44.2 & 39.0 & 1.5 & 3.0 & 0. & 3,656 & 16 & 7,025 & 8. & - & - & - & - & - & 2,887 & \\
\hline & & & & 72.1 & 27.9 & 22 & | & . & . & , & 15 & 21 & & 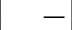 & . & & & & & 7 \\
\hline & N & & & & & 5 & & & 0 & & & & & - & - & & & & & 7 \\
\hline $\mathrm{Ne}$ & NC & 18, & & & & & & & 0 & & & & & - & - & - & & & 1,144 & 30 \\
\hline & NC & 17 & & & 32 & 2 & & & 0 & 1, & & & 9 & - & - & - & - & - & 935 & 29 \\
\hline & & & & & & & & & & 1,2 & & & & - & - & - & - & - & & 30 \\
\hline 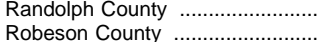 & & $\begin{array}{l}13, \\
23,\end{array}$ & & & 8 & $3 c^{5}$ & & & $\begin{array}{r}0.4 \\
44.4\end{array}$ & $\begin{array}{r}917 \\
1503\end{array}$ & 17 & $1, \frac{5}{2}$ & $\begin{array}{r}8 \\
8\end{array}$ & - & - & 二 & - & 二 & 704 & $\begin{array}{l}23 \\
41\end{array}$ \\
\hline ……..... & & & & & & & & & & & & & 8 & - & - & - & - & - & 939 & 28 \\
\hline ……..... & & & & & & & & & & & & & 8 & - & - & - & - & - & & 30 \\
\hline Wake Count & NC & 62,474 & 85,7 & 67. & 32 & 26.6 & 2. & 3.1 & 0.2 & 5,166 & & & 9.2 & - & - & - & - & - & 3,870 & 102 \\
\hline Wayne County ………………............... & NC & 13,407 & 19,279 & 52.0 & 48.0 & 44.1 & 2.9 & 0.9 & 0.1 & 1,124 & 17.2 & 2,239 & 8.6 & - & - & - & - & - & 971 & 27 \\
\hline Akron City & $\mathrm{OH}$ & $\begin{array}{l}33,230 \\
50842\end{array}$ & $\begin{array}{l}31,992 \\
50,396\end{array}$ & $\begin{array}{l}51.5 \\
30.1\end{array}$ & $\begin{array}{l}48.5 \\
69.9\end{array}$ & 45.9 & 0.5 & 2.0 & 0.1 & $\begin{array}{l}2,308 \\
2,878\end{array}$ & 13.9 & $\begin{array}{l}5,023 \\
4,948\end{array}$ & $\begin{array}{r}6.4 \\
10 ?\end{array}$ & - & - & - & - & $=$ & $\begin{array}{l}1,466 \\
1246\end{array}$ & $\begin{array}{l}62 \\
82\end{array}$ \\
\hline Cleve & $\mathrm{OH}$ & $\begin{array}{l}69,7 \\
69,7\end{array}$ & 74,0 & 20.6 & 79.4 & $\begin{array}{l}70.0 \\
70.4\end{array}$ & 7.7 & $\begin{array}{l}0.0 \\
1.0\end{array}$ & 0. & $\begin{array}{l}2,010 \\
4,196\end{array}$ & $\begin{array}{l}17.5 \\
17.6\end{array}$ & $\begin{array}{r}\quad 7,940 \\
7,634\end{array}$ & 9 & - & - & - & - & - & $\begin{array}{l}1,46 \\
1,665\end{array}$ & 122 \\
\hline 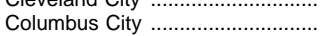 & $\mathrm{OH}$ & 63, & & 2 & 57.9 & 5 & & 1. & 0. & & & 1,004 & & 6.6 & $4 . \overline{8}$ & 6.1 & 6.0 & 11.6 & & 146 \\
\hline Cist & & 27,662 & 26,762 & & & 67.8 & 0.5 & 0.5 & 0.1 & 1,699 & 15.8 & 3,154 & 8.5 & & & & & & & 50 \\
\hline
\end{tabular}


Table 93.-Selected statistics on enrollment, teachers, graduates, and dropouts in public school districts enrolling more than 15,000 pupils, by state: 1989 and 1996-Continued

\begin{tabular}{|c|c|c|c|c|c|c|c|c|c|c|c|c|c|c|c|c|c|c|c|c|}
\hline \multirow{3}{*}{ Name of district, by state } & \multirow{3}{*}{ State } & \multirow{3}{*}{$\begin{array}{l}\text { Enrollment, } \\
\text { fall } 1989\end{array}$} & \multirow{3}{*}{$\begin{array}{l}\text { Enrollment, } \\
\text { fall } 1996\end{array}$} & \multicolumn{6}{|c|}{ Percentage distribution of enrollment, by race, fall 1996} & \multirow{3}{*}{$\begin{array}{c}\text { Number } \\
\text { of class- } \\
\text { room } \\
\text { teach- } \\
\text { ers, } 1 \text { fall } \\
1996\end{array}$} & \multirow{3}{*}{$\begin{array}{c}\text { Pupil/ } \\
\text { teacher } \\
\text { ratio, fall } \\
1996\end{array}$} & \multirow{3}{*}{$\begin{array}{c}\text { Total } \\
\text { number } \\
\text { of staff, } \\
\text { fall } 1996\end{array}$} & \multirow{3}{*}{$\begin{array}{c}\text { Student/ } \\
\text { staff } \\
\text { ratio, fall } \\
1996\end{array}$} & \multirow{2}{*}{\multicolumn{5}{|c|}{$\begin{array}{c}\text { Percent dropouts from grades 9-12, } \\
1995-96\end{array}$}} & \multirow{3}{*}{\begin{tabular}{|l} 
Number \\
of high \\
school \\
grad- \\
uates, \\
$1995-$ \\
$96^{2}$
\end{tabular}} & \multirow{3}{*}{$\begin{array}{l}\text { Number } \\
\text { of } \\
\text { schools, } \\
\text { fall } 1996\end{array}$} \\
\hline & & & & \multirow[b]{2}{*}{ White } & \multicolumn{5}{|c|}{ Minority } & & & & & & & & & & & \\
\hline & & & & & Total & Black & $\begin{array}{c}\text { His- } \\
\text { panic }\end{array}$ & $\begin{array}{c}\text { Asian/Pacific } \\
\text { Islander }\end{array}$ & $\begin{array}{c}\text { American } \\
\text { Indian/Alas- } \\
\text { kan } \\
\text { Native }\end{array}$ & & & & & Total & $\underset{9}{\text { Grade }}$ & $\underset{10}{\text { Grade }}$ & Grade & $\underset{12}{\text { Grade }}$ & & \\
\hline 1 & 2 & 3 & 4 & 5 & 6 & 7 & 8 & 9 & 10 & 11 & 12 & 13 & 14 & 15 & 16 & 17 & 18 & 19 & 20 & 21 \\
\hline 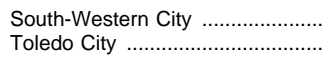 & $\begin{array}{l}\mathrm{OH} \\
\mathrm{OH}\end{array}$ & $\begin{array}{l}16,441 \\
40,617\end{array}$ & $\begin{array}{l}19,000 \\
39,712\end{array}$ & $\begin{array}{l}90.9 \\
49.3\end{array}$ & $\begin{array}{r}9.1 \\
50.7\end{array}$ & $\begin{array}{r}7.0 \\
43.7\end{array}$ & $\begin{array}{l}0.7 \\
6.2\end{array}$ & $\begin{array}{l}1.3 \\
0.8\end{array}$ & $\begin{array}{l}0.1 \\
0.1\end{array}$ & $\begin{array}{l}1,072 \\
2,534\end{array}$ & $\begin{array}{l}17.7 \\
15.7\end{array}$ & $\begin{array}{l}1,891 \\
4,613\end{array}$ & $\begin{array}{r}10.0 \\
8.6\end{array}$ & - & $=$ & $\overline{-}$ & $=$ & $=$ & $\begin{array}{l}1,005 \\
1,735\end{array}$ & $\begin{array}{l}29 \\
66\end{array}$ \\
\hline 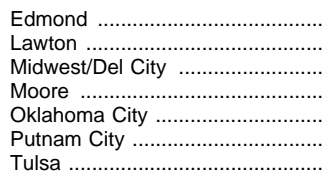 & $\begin{array}{l}\text { OK } \\
\text { OK } \\
\text { OK } \\
\text { OK } \\
\text { OK } \\
\text { OK } \\
\text { OK }\end{array}$ & $\begin{array}{l}12,519 \\
17,798 \\
15,744 \\
16,320 \\
38,092 \\
17,716 \\
40,919\end{array}$ & $\begin{array}{l}16,182 \\
18,501 \\
15,675 \\
18,243 \\
39,827 \\
19,079 \\
41,644\end{array}$ & $\begin{array}{l}87.4 \\
54.2 \\
67.0 \\
77.2 \\
36.3 \\
76.4 \\
51.2\end{array}$ & $\begin{array}{l}12.6 \\
45.8 \\
33.0 \\
22.8 \\
63.7 \\
23.6 \\
48.8\end{array}$ & $\begin{array}{r}5.2 \\
29.9 \\
22.0 \\
3.9 \\
39.7 \\
12.4 \\
34.3 \\
\end{array}$ & $\begin{array}{r}1.9 \\
8.0 \\
2.9 \\
3.8 \\
16.0 \\
4.3 \\
5.1\end{array}$ & $\begin{array}{l}2.2 \\
2.6 \\
2.2 \\
3.4 \\
2.8 \\
3.6 \\
1.3\end{array}$ & $\begin{array}{r}3.3 \\
5.3 \\
5.8 \\
11.7 \\
5.3 \\
3.3 \\
8.2\end{array}$ & $\begin{array}{r}917 \\
1,046 \\
882 \\
1,114 \\
2,238 \\
1,097 \\
2,461\end{array}$ & $\begin{array}{l}17.7 \\
17.7 \\
17.8 \\
16.4 \\
17.8 \\
17.4 \\
16.9\end{array}$ & $\begin{array}{l}1,628 \\
2,389 \\
1,652 \\
2,073 \\
5,149 \\
1,791 \\
5,400\end{array}$ & \begin{tabular}{r|}
9.9 \\
7.7 \\
9.5 \\
8.8 \\
7.7 \\
10.7 \\
7.7
\end{tabular} & $\begin{array}{l}- \\
\overline{-} \\
- \\
- \\
-\end{array}$ & $\begin{array}{l}= \\
\overline{-} \\
\overline{-} \\
\overline{-}\end{array}$ & $\begin{array}{l}- \\
z \\
- \\
- \\
-\end{array}$ & $\begin{array}{l}- \\
= \\
= \\
= \\
-\end{array}$ & $\begin{array}{l}- \\
- \\
- \\
- \\
-\end{array}$ & $\begin{array}{r}824 \\
954 \\
1,005 \\
1,131 \\
1,128 \\
1,016 \\
1,702\end{array}$ & $\begin{array}{l}21 \\
42 \\
26 \\
27 \\
86 \\
27 \\
80\end{array}$ \\
\hline 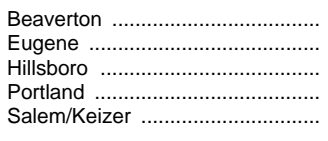 & $\begin{array}{l}\text { OR } \\
\text { OR } \\
\text { OR } \\
\text { OR } \\
\text { OR }\end{array}$ & $\begin{array}{l}23,443 \\
17,368 \\
51,825 \\
26,930\end{array}$ & $\begin{array}{l}30,027 \\
18,717 \\
15,963 \\
56,856 \\
32,491\end{array}$ & $\begin{array}{l}80.4 \\
88.2 \\
78.7 \\
68.6 \\
82.7\end{array}$ & $\begin{array}{l}19.6 \\
11.8 \\
21.3 \\
31.4 \\
17.3\end{array}$ & \begin{tabular}{r|}
2.1 \\
2.1 \\
1.1 \\
15.2 \\
1.3
\end{tabular} & $\begin{array}{r}6.5 \\
3.7 \\
15.2 \\
5.5 \\
12.0\end{array}$ & $\begin{array}{r}10.2 \\
3.9 \\
4.4 \\
8.4 \\
2.6\end{array}$ & $\begin{array}{l}0.8 \\
2.0 \\
0.5 \\
2.3 \\
1.4\end{array}$ & $\begin{array}{r}1,370 \\
829 \\
756 \\
2,910 \\
1,430\end{array}$ & $\begin{array}{l}21.9 \\
22.6 \\
21.1 \\
19.5 \\
22.7\end{array}$ & $\begin{array}{l}2,520 \\
1,677 \\
1,762 \\
5,429 \\
2,854\end{array}$ & \begin{tabular}{r|}
11.9 \\
11.2 \\
9.1 \\
10.5 \\
11.4
\end{tabular} & $\begin{array}{r}8.0 \\
7.3 \\
-1 \\
10.3 \\
9.0\end{array}$ & $\begin{array}{l}2.4 \\
5.1 \\
-1.2 \\
4.9\end{array}$ & $\begin{array}{r}5.8 \\
7.6 \\
- \\
8.4 \\
7.3\end{array}$ & $\begin{array}{r}10.1 \\
8.1 \\
- \\
10.3 \\
8.4\end{array}$ & $\begin{array}{r}14.8 \\
8.8 \\
- \\
15.5 \\
16.7\end{array}$ & $\begin{array}{r}1,557 \\
1,139 \\
777 \\
2,795 \\
1,635\end{array}$ & $\begin{array}{r}42 \\
46 \\
27 \\
101 \\
53\end{array}$ \\
\hline 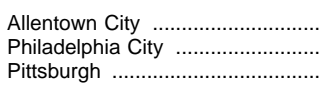 & $\begin{array}{l}\text { PA } \\
\text { PA } \\
\text { PA }\end{array}$ & $\begin{array}{r}13,396 \\
189,451 \\
39,559\end{array}$ & $\begin{array}{r}15,491 \\
212,150 \\
39,955\end{array}$ & $\begin{array}{l}47.3 \\
19.8 \\
42.6\end{array}$ & $\begin{array}{l}52.7 \\
80.2 \\
57.4\end{array}$ & $\begin{array}{l}12.6 \\
63.8 \\
55.6\end{array}$ & $\begin{array}{r}37.6 \\
11.6 \\
0.4\end{array}$ & $\begin{array}{l}2.4 \\
4.7 \\
1.4\end{array}$ & $\begin{array}{l}0.1 \\
0.2 \\
0.1\end{array}$ & $\begin{array}{r}753 \\
11,144 \\
2,687\end{array}$ & $\begin{array}{l}20.6 \\
19.0 \\
14.9\end{array}$ & $\begin{array}{r}1,466 \\
23,216 \\
5,441\end{array}$ & $\begin{array}{r}10.6 \\
9.1 \\
7.3\end{array}$ & $\begin{array}{r}7.4 \\
11.7 \\
6.7\end{array}$ & $\begin{array}{r}3.1 \\
10.7 \\
5.2\end{array}$ & $\begin{array}{r}7.3 \\
12.7 \\
7.8\end{array}$ & $\begin{array}{r}9.4 \\
12.9 \\
7.2\end{array}$ & $\begin{array}{r}11.4 \\
11.2 \\
7.3\end{array}$ & $\begin{array}{r}708 \\
9,009 \\
2,140\end{array}$ & $\begin{array}{r}23 \\
259 \\
89\end{array}$ \\
\hline Providence ….............. & $\mathrm{RI}$ & 20,429 & 24,535 & 24.1 & 75.9 & 23.1 & 41.2 & 11.0 & 0.6 & 1,482 & 16.6 & 2,340 & 10.5 & 6.7 & 6.7 & 8.6 & 5.3 & 5.1 & 829 & 45 \\
\hline 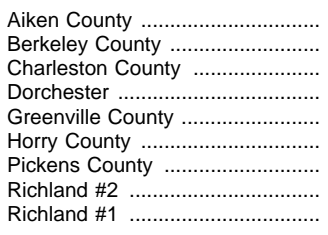 & $\begin{array}{l}\text { SC } \\
\text { SC } \\
\text { SC } \\
\text { SC } \\
\text { SC } \\
\text { SC } \\
\text { SC } \\
\text { SC } \\
\text { SC }\end{array}$ & $\begin{array}{l}23,300 \\
27,080 \\
42,893 \\
13,267 \\
50,876 \\
23,713 \\
14,449 \\
12,362 \\
26,966\end{array}$ & $\begin{array}{l}24,588 \\
26,106 \\
43,457 \\
15,367 \\
55,893 \\
26,14 \\
15,417 \\
15,313 \\
27,102 \\
\end{array}$ & $\begin{array}{l}64.5 \\
63.4 \\
39.2 \\
73.0 \\
71.1 \\
69.8 \\
89.7 \\
21.5 \\
49.6\end{array}$ & $\begin{array}{l}35.5 \\
36.6 \\
60.8 \\
27.0 \\
28.9 \\
30.2 \\
10.3 \\
78.5 \\
50.4\end{array}$ & $\begin{array}{r}33.9 \\
33.1 \\
58.6 \\
24.9 \\
26.5 \\
28.5 \\
8.9 \\
76.8 \\
45.1\end{array}$ & $\begin{array}{l}0.9 \\
1.3 \\
1.0 \\
0.8 \\
1.2 \\
0.7 \\
0.5 \\
1.0 \\
2.7\end{array}$ & $\begin{array}{l}0.5 \\
1.8 \\
1.0 \\
1.0 \\
1.1 \\
0.8 \\
0.8 \\
0.7 \\
2.4\end{array}$ & $\begin{array}{l}0.1 \\
0.4 \\
0.1 \\
0.4 \\
0.1 \\
0.3 \\
0.1 \\
0.1 \\
0.2\end{array}$ & $\begin{array}{r}1,320 \\
1,465 \\
2,798 \\
878 \\
3,456 \\
1,729 \\
923 \\
987 \\
2,022\end{array}$ & $\begin{array}{l}18.6 \\
17.8 \\
15.5 \\
17.5 \\
16.2 \\
15.1 \\
16.7 \\
15.5 \\
13.4\end{array}$ & $\begin{array}{r}1,516 \\
1,674 \\
3,139 \\
972 \\
3,902 \\
1,950 \\
1,048 \\
1,096 \\
2,287\end{array}$ & $\begin{array}{l}16.2 \\
15.6 \\
13.8 \\
15.8 \\
14.3 \\
13.4 \\
14.7 \\
14.0 \\
11.9\end{array}$ & $\begin{array}{l}4.4 \\
2.3 \\
1.9 \\
2.3 \\
1.2 \\
2.7 \\
3.7 \\
2.1 \\
2.6\end{array}$ & $\begin{array}{l}6.0 \\
2.0 \\
1.6 \\
2.1 \\
1.2 \\
2.9 \\
3.4 \\
1.7 \\
3.2\end{array}$ & $\begin{array}{l}4.3 \\
2.7 \\
2.9 \\
2.1 \\
1.3 \\
2.8 \\
3.5 \\
2.1 \\
2.5\end{array}$ & $\begin{array}{l}4.2 \\
2.4 \\
1.5 \\
2.5 \\
1.6 \\
2.6 \\
5.6 \\
1.9 \\
2.4\end{array}$ & $\begin{array}{l}2.1 \\
2.4 \\
1.3 \\
2.7 \\
0.8 \\
2.1 \\
2.1 \\
2.8 \\
1.9\end{array}$ & $\begin{array}{r}1,242 \\
1,238 \\
1,692 \\
825 \\
2,860 \\
1,281 \\
735 \\
867 \\
1,296\end{array}$ & $\begin{array}{l}37 \\
35 \\
72 \\
15 \\
92 \\
38 \\
25 \\
17 \\
51\end{array}$ \\
\hline Sioux Falls .................................... & SD & 15,455 & 18,175 & 90.6 & 9.4 & 3.2 & 1.2 & 2.0 & 3.0 & 1,089 & 16.7 & 1,954 & 9.3 & - & - & - & - & - & 922 & 37 \\
\hline $\begin{array}{l}\text { Chattanooga City } \\
\text { Hamilton County .................................................. }\end{array}$ & $\begin{array}{l}\text { TN } \\
\text { TN }\end{array}$ & $\begin{array}{l}21,385 \\
22,654\end{array}$ & $\begin{array}{l}19,938 \\
23,589\end{array}$ & $\begin{array}{l}34.5 \\
93.9\end{array}$ & $\begin{array}{r}65.5 \\
6.1\end{array}$ & $\begin{array}{r}63.2 \\
4.2\end{array}$ & $\begin{array}{l}0.5 \\
0.7\end{array}$ & $\begin{array}{l}1.7 \\
1.1\end{array}$ & $\begin{array}{l}0.0 \\
0.1\end{array}$ & $\begin{array}{l}1,257 \\
1,413\end{array}$ & $\begin{array}{l}15.9 \\
16.7\end{array}$ & $\begin{array}{l}2,432 \\
2,230\end{array}$ & $\begin{array}{r}8.2 \\
10.6\end{array}$ & 二 & 二 & $\overline{-}$ & - & $\overline{-}$ & $\begin{array}{r}922 \\
1,289\end{array}$ & $\begin{array}{l}37 \\
43\end{array}$ \\
\hline & TN & 50,087 & 51,224 & 84.5 & 15.5 & 13.3 & 0.7 & 1.4 & 0.1 & 3,404 & 15.0 & 6,204 & 8.3 & - & - & - & - & - & 2,816 & 84 \\
\hline & TN & 105,604 & 111,156 & 14.4 & 85.6 & 82.5 & 0.6 & 1.3 & 1.2 & 6,351 & 17.5 & 11,367 & 9.8 & - & - & - & - & - & 4,598 & 164 \\
\hline SOUn & TN & 16,066 & 22,280 & 69.0 & 31.0 & 25.1 & 3.6 & 2.0 & 0. & 1,283 & 17.4 & 2,343 & 9.5 & - & - & - & - & - & 990 & 26 \\
\hline & & & & & & 42 & & & 0 & & & & & - & - & & & t & & 12 \\
\hline $\mathrm{Ru}$ & & & & & & & & & & & & & 11 & - & - & & & & & 77 \\
\hline .. & $\mathrm{v}$ & & & & 24 & 20 & & & & & & & 10 & - & - & - & - & - & & 44 \\
\hline Sumn & TN & 19, & & 92 & 7 & 6 & 0 & 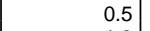 & 0.2 & 1,33 & 16 & 2,4 & 8.8 & - & - & - & - & - & 1,372 & 34 \\
\hline Williamson County ………............... & $\mathrm{TN}$ & 11,144 & 16,471 & 93.3 & 6.7 & 4.4 & 0.9 & 1.3 & 0.1 & 947 & 17.4 & 1,674 & 9.8 & - & - & - & - & - & 1,039 & 25 \\
\hline $\begin{array}{l}\text { Abile } \\
\text { Aldin }\end{array}$ & TX & 18,69 & $\begin{array}{l}19,562 \\
47,242\end{array}$ & 60.6 & & 11.0 & 26.6 & $\begin{array}{l}1.5 \\
37\end{array}$ & 0.3 & 1,464 & 13.4 & 2,518 & 7.8 & - & - & - & - & - & 812 & 42 \\
\hline & $\begin{array}{l}\text { TX } \\
\text { TX }\end{array}$ & $\begin{array}{l}39,133 \\
28,408\end{array}$ & $\begin{array}{l}47,242 \\
38,383\end{array}$ & $\begin{array}{l}17.5 \\
17.9\end{array}$ & $\begin{array}{l}82.5 \\
82.1\end{array}$ & $\begin{array}{l}36.0 \\
34.2\end{array}$ & $\begin{array}{l}42.7 \\
29.1\end{array}$ & $\begin{array}{r}3.7 \\
18.8\end{array}$ & $\begin{array}{l}0.1 \\
0.1\end{array}$ & $\begin{array}{l}3,048 \\
2,344\end{array}$ & $\begin{array}{l}15.5 \\
16.4\end{array}$ & $\begin{array}{l}5,741 \\
4,148\end{array}$ & $\begin{array}{l}8.2 \\
9.3\end{array}$ & - & $\bar{z}$ & $\overline{-}$ & 二 & $\overline{-}$ & $\begin{array}{l}1,627 \\
1,251\end{array}$ & $\begin{array}{l}49 \\
34\end{array}$ \\
\hline Amari & TX & 26,983 & 29,566 & & 41.6 & & & & 0.3 & 1,865 & & 3,216 & 9.2 & - & - & - & - & - & 1,350 & 50 \\
\hline & $1 \hat{v}$ & 42,352 & 53,343 & 58 & 41.1 & $\begin{array}{r}1.5 \\
16.9\end{array}$ & 17.1 & 6. & 0.7 & 3,225 & 16.5 & 5,270 & $\begin{array}{r}.< \\
10.1\end{array}$ & - & - & - & - & - & 2,334 & 63 \\
\hline & & & & 37 & 62 & 18.0 & 41.7 & 2.2 & 0.3 & 4,645 & 16.4 & 7,880 & 9.7 & - & - & - & - & - & 2,865 & 100 \\
\hline & & & & & & 65 & & & & & & & & & & & & & & 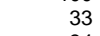 \\
\hline & $\mathrm{T}$ & & & & & & & & & & & & 9 & - & -1 & - & & - & & 34 \\
\hline & 1 & & & & & 0.1 & & & & & & & 7.4 & - & - & - & - & - & & 1 \\
\hline ers Branc & & & & & & 8.5 & & 11. & & & & & 9 & - & - & - & - & - & 3 & 30 \\
\hline ) & TX & & & & 26 & 6.6 & & 8.3 & 0.3 & 1,5 & 17 & & 10.5 & - & - & - & - & - & 1,354 & 29 \\
\hline & $T X$ & 22,234 & 29,5 & 78.7 & 21.3 & 5.7 & 13.9 & 1.5 & 0.2 & 2,003 & 14.8 & 3,6 & 8.2 & - & - & - & - & - & 1,576 & 39 \\
\hline isti ISD ……….......... & TX & 41,277 & 41,606 & 25.1 & 74.9 & 6.0 & 67.7 & 0.9 & 0. & 2,465 & 16.9 & 4,471 & 9.3 & - & - & - & - & - & 1,814 & 63 \\
\hline Cypress-Fairbanks ISD ………......... & TX & 38,920 & 52,930 & 65.8 & 34.2 & 8.9 & 17.8 & 7.3 & 0. & 3,185 & 16.6 & 5,613 & 9.4 & - & - & - & - & - & 2,426 & 49 \\
\hline 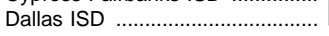 & $\mathrm{TX}$ & 132,256 & 154,847 & 11.0 & 89.0 & 41.5 & 45.5 & 1.7 & 0.4 & 9,202 & 16.8 & 15,717 & 9.9 & & -1 & - & -1 & & 4,910 & 211 \\
\hline
\end{tabular}


Table 93.-Selected statistics on enrollment, teachers, graduates, and dropouts in public school districts enrolling more than 15,000 pupils, by state: 1989 and 1996-Continued

\begin{tabular}{|c|c|c|c|c|c|c|c|c|c|c|c|c|c|c|c|c|c|c|c|c|}
\hline \multirow[b]{2}{*}{ Name of district, by state } & \multirow[b]{2}{*}{ State } & \multirow[b]{2}{*}{$\begin{array}{l}\text { Enrollment, } \\
\text { fall } 1989\end{array}$} & \multirow[b]{2}{*}{$\begin{array}{l}\text { Enrollment, } \\
\text { fall } 1996\end{array}$} & \multicolumn{6}{|c|}{ Percentage distribution of enrollment, by race, fall 1996} & \multirow{2}{*}{$\begin{array}{c}\text { Number } \\
\text { of class- } \\
\text { room } \\
\text { teach- } \\
\text { ers, t fall } \\
1996 \\
1996\end{array}$} & \multirow{2}{*}{$\begin{array}{c}\text { Pupil/ } \\
\text { teacher } \\
\text { ratio, fall } \\
1996\end{array}$} & \multirow{2}{*}{$\begin{array}{c}\text { Total } \\
\text { number } \\
\text { of staff, } \\
\text { fall 1996 }\end{array}$} & \multirow{2}{*}{$\begin{array}{c}\text { Student/ } \\
\text { staff } \\
\text { ratio, fall } \\
1996\end{array}$} & Perc & cent drop & $\begin{array}{l}\text { outs from } \\
1995-96\end{array}$ & ${ }_{6}^{n}$ grades & $9-12$ & $\begin{array}{l}\text { Number } \\
\text { of high }\end{array}$ & \\
\hline & & & & White & Total & Black & $\begin{array}{l}\text { His- } \\
\text { panic }\end{array}$ & $\begin{array}{c}\text { Asian/Pacific } \\
\text { Islander }\end{array}$ & $\begin{array}{c}\text { American } \\
\text { Indian/Alas- } \\
\text { kan } \\
\text { Native }\end{array}$ & & & & & Total & $\underset{9}{\text { Grade }}$ & $\begin{array}{c}\text { Grade } \\
10\end{array}$ & $\underset{11}{\text { Grade }}$ & $\begin{array}{c}\text { Grade } \\
12\end{array}$ & $\begin{array}{l}\text { School } \\
\text { grad- } \\
\text { uates, } \\
1995- \\
96^{2}\end{array}$ & $\begin{array}{l}\text { of } \\
\text { schools, } \\
\text { fall } 1996\end{array}$ \\
\hline 1 & 2 & 3 & 4 & 5 & 6 & 7 & 8 & 9 & 10 & 11 & 12 & 13 & 14 & 15 & 16 & 17 & 18 & 19 & 20 & 21 \\
\hline ctor County ISD & & 26,366 & 28,709 & 43.7 & 56.3 & & & & 0.4 & 1,724 & & & & - & - & & & - & & \\
\hline Edinburg ISD ........... & $\mathrm{TX}$ & 15,089 & 19,153 & 4.1 & 95.9 & 0.1 & 95.5 & 0.2 & 0.1 & 1,203 & 15.9 & 2,477 & 7.7 & - & - & - & - & - & 807 & 27 \\
\hline El Pas & TX & 64 & 64 & 18.0 & 82.0 & 4.5 & 76.2 & 1.1 & 0.1 & 4,044 & 15.9 & 7,378 & 8.7 & - & - & - & - & - & 2,811 & 81 \\
\hline Fort Bend IS & TX & 33 & 46 & 43.2 & 56.8 & 27.5 & 15.8 & 13.3 & 0.1 & 2,573 & 18.2 & 4,629 & 10.1 & - & - & - & - & - & 2,300 & 45 \\
\hline Fort Worth I & $T X$ & 69,3 & 75,813 & 25.9 & 74.1 & 33.2 & 38.4 & 2.3 & .2 & 4,277 & 17.7 & 7,769 & 9.8 & - & - & - & - & - & 2,262 & 130 \\
\hline Galena Park ISD & $T X$ & 15,2 & 17,610 & 25.0 & 75.0 & 20.5 & 52.1 & 2.3 & 1 & 1,017 & 17.3 & 1,718 & 10.2 & - & - & - & - & - & 820 & 20 \\
\hline Garland ISD ............ & $T X$ & 36,158 & 44,869 & 58.0 & 42.0 & 14.5 & 21.4 & 5.4 & 6 & 2,628 & 17.1 & 4,469 & 10.0 & - & - & - & - & - & 1,904 & 62 \\
\hline Goose Creek ISD ........ & $T X$ & 17,150 & 17,921 & 46.2 & 53.8 & 17.2 & 35.6 & 0.8 & 1 & 1,098 & 16.3 & 1,956 & 9.2 & - & - & - & - & - & 89 & 25 \\
\hline Grand Prairie ISD ................. & $T X$ & 16,464 & 18,383 & 42.5 & 57.5 & 12.7 & 40.2 & 3.8 & 0.8 & 1,116 & 16.5 & 1,807 & 10.2 & - & - & - & - & - & 750 & 28 \\
\hline Harlandale ISD .................. & $T X$ & 15,039 & 15,148 & 6.8 & 93.2 & 0.5 & 92.4 & 0.2 & 0.1 & 963 & 15.7 & 1,862 & 8.1 & - & - & - & - & - & 561 & 25 \\
\hline Harlingen Cons ISD . & $\mathrm{TX}$ & 14,498 & 16,156 & 14.1 & 85.9 & 0.8 & 84.4 & 0.6 & 0.0 & 977 & 16.5 & 1,916 & 8.4 & - & - & - & - & - & 697 & 22 \\
\hline Houston ISD .............. & $\mathrm{TX}$ & 191,282 & 209,375 & 11.1 & 88.9 & 34.3 & 51.8 & 2.8 & 0.1 & 11,853 & 17.7 & 20,741 & 10.1 & - & - & - & - & - & 6,311 & 286 \\
\hline Humble ISD ... & $\mathrm{TX}$ & 18,835 & 22,650 & 79.2 & 20.8 & 8.3 & 9.8 & 2.6 & 0.1 & 1,503 & 15.1 & 2,703 & 8.4 & - & - & - & - & - & 1,309 & 30 \\
\hline Hurst-Euless-Bedford ISD ... & $\mathrm{TX}$ & 17,542 & 19,204 & 76.7 & 23.3 & 6.2 & 9.8 & 6.5 & 0.8 & 1,196 & 16.1 & 2,046 & 9.4 & - & - & . & - & - & 1,052 & 28 \\
\hline Irving ISD ... & $\mathrm{TX}$ & 22,639 & 26,714 & 43.4 & 56.6 & 13.9 & 36.0 & 6.0 & 0.7 & 1,673 & 16.0 & 2,751 & $\begin{array}{l}9.4 \\
9.7\end{array}$ & - & - & -1 & - & - & 1,052 & 33 \\
\hline Judson & $\mathrm{TX}$ & $\begin{array}{l}22,005 \\
12,883\end{array}$ & 15,460 & $\begin{array}{l}44.1 \\
44.1\end{array}$ & 55.9 & 22.4 & 30.3 & $\begin{array}{l}2.0 \\
2.9\end{array}$ & 0.2 & 1,021 & 15.1 & 1,856 & $\begin{array}{l}.1 \\
8.3\end{array}$ & - & - & - & - & - & $\begin{array}{r}7,020 \\
740\end{array}$ & 20 \\
\hline Katy IS & $\mathrm{TX}$ & 18,385 & 26,597 & 78.7 & 21.3 & 4.7 & 12.4 & 4.1 & 0.1 & 1,579 & 16.8 & 2,768 & 9.6 & - & - & - & - & - & 1,231 & 26 \\
\hline Killeen & $\mathrm{TX}$ & 22,854 & 28,414 & 41.1 & 58.9 & 37.8 & 16.1 & 4.4 & 0.5 & 1,856 & 15.3 & 3,543 & 8.0 & - & - & - & - & - & 1,064 & 39 \\
\hline Klein I & $\mathrm{TX}$ & 25,088 & 29,892 & 67.6 & 32.4 & 11.7 & 13.6 & 6.8 & 0.3 & 1,841 & 16.2 & 3,465 & 8.6 & - & - & - & - & - & $\begin{array}{l}1,619 \\
1,619\end{array}$ & 27 \\
\hline Laredo & $\mathrm{TX}$ & $\begin{array}{l}23,161 \\
23\end{array}$ & 22,987 & 1.6 & 98.4 & 0.1 & 98.2 & $\begin{array}{l}0.1 \\
0.1\end{array}$ & 0.0 & 1,403 & 16.4 & $\begin{array}{l}3,197 \\
3,197\end{array}$ & $\begin{array}{l}0.0 \\
7.2\end{array}$ & - & - & - & - & - & 1,237 & 29 \\
\hline wis & $\mathrm{TX}$ & 19,554 & 30,243 & 82.4 & 17.6 & 5.4 & 9.2 & .5 & 0.4 & 2,019 & 15.0 & 2,969 & 10.2 & - & - & - & - & - & 1,419 & 39 \\
\hline (1) & $\mathrm{TX}$ & 30 & 30,081 & 44.4 & 55.6 & 14.1 & 40.2 & & 0.2 & 2,066 & 14.6 & 3,328 & 9.0 & - & - & - & - & - & 1,672 & 59 \\
\hline Alle & $\mathrm{TX}$ & 21,1 & 21,704 & 11.4 & 88.6 & 0.3 & & 1. & . & 1,427 & 15.2 & 2,747 & 7.9 & - & - & - & - & - & 1,233 & 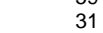 \\
\hline …............ & $\mathrm{TX}$ & 24,649 & 29,971 & 70.6 & 29.4 & 11.8 & .5 & .7 & 0.4 & 1,674 & 17.9 & 2,884 & 10.4 & - & - & - & - & 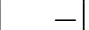 & 1,394 & 38 \\
\hline Midland ISD & $T X$ & 20,276 & 23,284 & 51.9 & 48.1 & 10.2 & & .9 & 0.3 & 1,378 & 16.9 & 2,471 & 9.4 & - & - & - & - & - & 992 & 35 \\
\hline North East ISD & $T X$ & 39,622 & 45,184 & 54.2 & 45.8 & 8.9 & & 2.4 & & 2,949 & 15.3 & 5,435 & 8.3 & - & - & - & - & - & 2,502 & 55 \\
\hline Norths & $T X$ & 49,447 & 59, & 40.6 & 59.4 & 6.8 & & 2.1 & 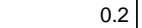 & 3,789 & 15.6 & 6,814 & 8.7 & - & - & - & - & - & 3,142 & 77 \\
\hline Pasad & $T\rangle$ & 36 & 40 & 36.7 & & 5.3 & & 6 & 3 & 2,342 & 17.3 & 4,137 & 9.8 & - & - & - & - & - & 1,680 & 52 \\
\hline Juan-Alamo ISD .... & $T X$ & 18, & & 1.7 & 98.3 & 0.1 & 98.1 & .1 & 0.0 & 1,274 & 16.0 & 2,778 & 7.3 & - & - & 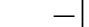 & - & - & 5 & 29 \\
\hline Plano & $\mathrm{TX}$ & 29 & 40, & 77.2 & 22.8 & 5.7 & 7.3 & 9.6 & 2 & 2,611 & 15.7 & 4,056 & 10.1 & - & - & - & - & - & 2,085 & 49 \\
\hline on ISD .. & $\mathrm{TX}$ & 32 & 34, & 57.0 & 43.0 & 19.7 & 14.2 & 8.8 & 0.3 & 2,187 & 15.6 & 3,531 & 9.7 & - & - & - & - & - & 1,842 & 52 \\
\hline Round Rock ISD & $\mathrm{TX}$ & 18, & & 73.3 & 26.7 & 6.3 & 15.2 & 4.9 & 0.3 & 1,752 & 15.0 & 2,887 & 9.1 & - & - & - & - & - & 1,358 & 33 \\
\hline lo ISD . & $\mathrm{TX}$ & 16 & & 50.2 & 49.8 & 6.0 & & 1.0 & 0. & 1,098 & 15.8 & 1,847 & 9.4 & - & - & - & - & - & 806 & 29 \\
\hline io ISD .... & $\mathrm{TX}$ & 61,1 & 61,361 & 5.2 & 94.8 & 10.8 & & 0.2 & 0. & 3,692 & 16.6 & 6,854 & $\begin{array}{l}9.4 \\
9.0\end{array}$ & - & - & - & - & - & 1,669 & 109 \\
\hline D............... & $\mathrm{TX}$ & 12,9 & 21,098 & 9.3 & 90.7 & $\begin{array}{r}1.2 \\
1.2\end{array}$ & & 0.4 & 0.1 & 1,302 & 16.2 & $\begin{array}{l}2,0352 \\
2,352\end{array}$ & $\begin{array}{l}9.0 \\
9.0\end{array}$ & - & - & - & 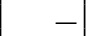 & - & $\begin{array}{r}, \quad 0054 \\
854\end{array}$ & 21 \\
\hline nch ISD .. & $\mathrm{TX}$ & 26,044 & 29,881 & $\begin{array}{r}40.8 \\
40.8\end{array}$ & 59.2 & 6.5 & 44.6 & 7.9 & 0.1 & 1,900 & 15.7 & 3,513 & 8.5 & - & - & - & 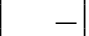 & - & $\begin{array}{r}1,269 \\
\end{array}$ & 37 \\
\hline Spring Is & $\mathrm{TX}$ & $\begin{array}{l}20,044 \\
17,917\end{array}$ & 21,044 & $\begin{array}{r}53.2 \\
53.2\end{array}$ & 46.8 & $\begin{array}{r}0.0 \\
21.2\end{array}$ & $\begin{array}{r}19.4 \\
19.4\end{array}$ & 5.8 & $\begin{array}{l}.1 \\
0.3\end{array}$ & 1,337 & 15.7 & 2,415 & $\begin{array}{l}8.0 \\
8.7\end{array}$ & - & - & - & - & - & $\begin{array}{r}, \quad 209 \\
894\end{array}$ & 23 \\
\hline Tyler is & $\mathrm{TX}$ & 16,069 & $\begin{array}{l}21,044 \\
16,511\end{array}$ & 42.6 & $\begin{array}{l}4.0 \\
57.4\end{array}$ & $\begin{array}{l}31.2 \\
36.2\end{array}$ & $\begin{array}{l}20.2 \\
20\end{array}$ & $\begin{array}{l}.0 \\
0.9\end{array}$ & 0.1 & 1,081 & 15.3 & 1,965 & $\begin{array}{l}8.1 \\
8.4\end{array}$ & - & - & - & - & - & $\begin{array}{l}534 \\
769\end{array}$ & 29 \\
\hline United & $\mathrm{TX}$ & 11,478 & 21,387 & 4.4 & 95.6 & 0.1 & 8 & 0.6 & 0.1 & 1,289 & 16.6 & 2,529 & 8.5 & - & - & - & - & - & 853 & 31 \\
\hline Waco & $\mathrm{TX}$ & 14 & 16,170 & 23.7 & 76.3 & 40.2 & 35.6 & 0.5 & 0.1 & 1,062 & 15.2 & 1,713 & 9.4 & - & - & - & - & - & - & 30 \\
\hline Ills ISD ... & TX & 14, & 15 & 63.9 & 36.1 & 16.1 & & 2.5 & 5 & 1,121 & 13.9 & & 8.9 & - & - & - & - & - & 779 & 30 \\
\hline Ysleta ISD. & $\mathrm{TX}$ & 50,009 & 47,366 & 11.1 & 88.9 & $\begin{array}{r}10.1 \\
2.6\end{array}$ & 85.4 & 0.5 & 0.4 & 2,991 & 15.8 & 5,172 & $\begin{array}{l}0.9 \\
9.2\end{array}$ & - & - & - & - & - & 2,620 & 66 \\
\hline Alpine & UT & 38,246 & 43,719 & 94.3 & 5.7 & 0.3 & 3.1 & 1.5 & 0.6 & 1,712 & 25.5 & 2,574 & 17.0 & 2.4 & 0.5 & 1.6 & 3.6 & 4.1 & 2,672 & 51 \\
\hline & 4 & & & & & & & & & & & & 13 & .5 & 0 & 1.7 & 1.9 & 1.2 & & 78 \\
\hline ....... & 4 & & & & 15.2 & 1. & 8 & 1 & 1.0 & 3,0 & & 6 & 11 & 9.3 & .4 & 10.2 & 11.0 & 7.4 & & 96 \\
\hline $\mathrm{J}$ & 10 & & & & 6.2 & 0.3 & 7 & 7 & & 2,8 & & 5, & 14 & 3.0 & 0.0 & 2.4 & 4.5 & 5.6 & & 72 \\
\hline & UT & 16, & 19, & 95.9 & 4.1 & 0.1 & 0 & 0.7 & 0.3 & 732 & 26.3 & 1,294 & 14.9 & 0.3 & 0.3 & 0.3 & 0.1 & 0.6 & 1,191 & 27 \\
\hline City & UT & 24,5 & 25,8 & 65.1 & 34.9 & 2.9 & 20.8 & 8.6 & 2.6 & 1,155 & 22.4 & 2,412 & 10.7 & 13.6 & 8.4 & 11.6 & 15.5 & 20.6 & 1,140 & 40 \\
\hline Washington .... & UT & 12,647 & 18,078 & 93.9 & 6.1 & 0.3 & 3.0 & 1.0 & 1.8 & 689 & 26.3 & 1,218 & 14.8 & 2.2 & 0.1 & 1.7 & 2.4 & 5.4 & 1,003 & 27 \\
\hline Weber. & UT & 25,275 & 28,139 & 93.2 & 6.8 & 1.0 & 4.0 & 1.4 & 0.5 & 1,080 & 26.1 & 1,891 & 14.9 & 3.3 & 0.1 & 3.0 & 4.0 & 7.0 & 1,761 & 39 \\
\hline Arling & VA & 14,290 & 17,546 & 42.1 & 57.9 & 17.1 & 30.7 & 9.9 & 0.1 & - & - & - & - & - & - & - & - & - & 788 & 30 \\
\hline Cne & VA & 28,32 & 35,593 & 63.5 & 36. & 33.7 & 1.0 & 1.6 & 0. & - & - & - & - & - & - & - & - & - & 1,936 & 42 \\
\hline & $\mathrm{VA}$ & 42,86 & 49,781 & 76.3 & 23. & 19.5 & 1.4 & 2.7 & 0.2 & - & - & - & - & - & - & - & - & - & 2,816 & \\
\hline & $\mathrm{VA}$ & 126,7 & 143,266 & 64 & 35 & 11 & 9 & 14.0 & 0. & - & - & - & - & - & - & - & - & - & 8,789 & 212 \\
\hline Clty & $\mathrm{VA}$ & 20,788 & 23 & 41.8 & 58.2 & 54.4 & 1.7 & 1.8 & 0.2 & - & - & - & - & - & - & . & - & - & 1,214 & 212 \\
\hline Henrico County & $\mathrm{VA}$ & 31,963 & 38,1 & 63.7 & 36.3 & 31.7 & 1.2 & 3.3 & 0.1 & - & - & - & - & - & - & - & - & - & 1,940 & 58 \\
\hline Loudoun County & VA & & & & & & & & & & & & & & & & & & & \\
\hline
\end{tabular}


Table 93.-Selected statistics on enrollment, teachers, graduates, and dropouts in public school districts enrolling more than 15,000 pupils, by state: 1989 and 1996-Continued

\begin{tabular}{|c|c|c|c|c|c|c|c|c|c|c|c|c|c|c|c|c|c|c|c|c|}
\hline \multirow{3}{*}{ Name of district, by state } & \multirow{3}{*}{ State } & \multirow{3}{*}{$\begin{array}{l}\text { Enrollment, } \\
\text { fall } 1989\end{array}$} & \multirow{3}{*}{$\begin{array}{l}\text { Enrollment, } \\
\text { fall } 1996\end{array}$} & \multicolumn{6}{|c|}{ Percentage distribution of enrollment, by race, fall 1996} & \multirow{3}{*}{$\begin{array}{c}\text { Number } \\
\text { of class- } \\
\text { room } \\
\text { teach- } \\
\text { ers, } 1 \text { fall } \\
1996 \\
1996\end{array}$} & \multirow{3}{*}{$\begin{array}{c}\text { Pupil/ } \\
\text { teacher } \\
\text { ratio, fall } \\
1996\end{array}$} & \multirow{3}{*}{$\begin{array}{c}\text { Total } \\
\text { number } \\
\text { of staff, } \\
\text { fall } 1996\end{array}$} & \multirow{3}{*}{$\begin{array}{c}\text { Student/ } \\
\text { staff } \\
\text { ratio, fall } \\
1996\end{array}$} & \multirow{2}{*}{\multicolumn{5}{|c|}{$\begin{array}{l}\text { Percent dropouts from grades 9-12, } \\
1995-96\end{array}$}} & \multirow{3}{*}{$\begin{array}{c}\text { Number } \\
\text { of high } \\
\text { school } \\
\text { grad- } \\
\text { uates, } \\
1995- \\
96^{2}\end{array}$} & \multirow{3}{*}{$\begin{array}{l}\text { Number } \\
\text { of } \\
\text { schools, } \\
\text { fall } 1996\end{array}$} \\
\hline & & & & \multirow[b]{2}{*}{ White } & \multicolumn{5}{|c|}{ Minority } & & & & & & & & & & & \\
\hline & & & & & Total & Black & $\begin{array}{c}\text { His- } \\
\text { panic }\end{array}$ & $\begin{array}{c}\text { Asian/Pacific } \\
\text { Islander }\end{array}$ & $\begin{array}{c}\text { American } \\
\text { Indian/Alas- } \\
\text { kan } \\
\text { Native }\end{array}$ & & & & & Total & $\underset{9}{\operatorname{Grade}}$ & $\underset{10}{\text { Grade }}$ & $\underset{11}{\text { Grade }}$ & $\underset{12}{\text { Grade }}$ & & \\
\hline 1 & 2 & 3 & 4 & 5 & 6 & 7 & 8 & 9 & 10 & 11 & 12 & 13 & 14 & 15 & 16 & 17 & 18 & 19 & 20 & 21 \\
\hline ewport News City & $\mathrm{VA}$ & 27,225 & 32,791 & 42.0 & 58.0 & 51.5 & 3.4 & 2.3 & 0.8 & - & - & - & - & - & - & - & - & - & 1,398 & \\
\hline Norfolk $\mathrm{Ci}$ & VA & & & 30.6 & 69.4 & 65.3 & 1.7 & 2.2 & 0.2 & - & - & - & - & - & - & - & - & - & 1,238 & 60 \\
\hline Portsmouth City .... & VA & 18,523 & 17,845 & 30.7 & 69.3 & 67.7 & 0.7 & 0.7 & 0.1 & - & - & - & - & - & - & - & - & - & 734 & 29 \\
\hline Prince William County. & VA & 40,991 & 48,333 & 67.4 & 32.6 & 21.9 & 6.6 & 3.6 & 0.5 & - & - & - & - & - & - & - & - & - & 2,640 & 66 \\
\hline Richmond City ............. & VA & 26,736 & 27,872 & 7.9 & 92.1 & 90.6 & 0.7 & 0.7 & 0.1 & - & - & - & - & - & - & - & - & - & 935 & 61 \\
\hline a County & $\mathrm{VA}$ & 11,527 & 16,036 & 83.4 & 16.6 & 13.4 & 1.9 & 1.1 & 0.3 & - & - & - & - & - & - & - & - & - & 794 & 23 \\
\hline Stafford & $\mathrm{VA}$ & $\begin{array}{l}11,994 \\
\end{array}$ & 17,378 & 84.6 & 15.4 & 1 & 2.0 & 1.6 & 0. & - & - & - & - & - & - & - & - & - & 953 & 19 \\
\hline Virginia Beach City & VA & 68,348 & 76,677 & 67.5 & 32.5 & 24.2 & 2.9 & 5.4 & 0.1 & - & - & - & - & - & - & - & - & - & 3,674 & 82 \\
\hline Bellevue . & WA & 14,971 & 15,533 & 71.4 & 28.6 & 4.0 & 5.4 & 18.8 & 0.4 & 756 & 20.5 & 1,481 & 10.5 & - & - & - & - & - & 1,065 & 32 \\
\hline amo & WA & 18 & & 80.6 & & & & & 1.9 & 1,027 & 20.9 & 2,012 & 10.7 & - & - & - & - & - & 961 & 41 \\
\hline Everet & WA & 14,8 & 17,553 & 83 & 16.3 & 3.0 & 3.8 & 7.5 & 1.9 & 828 & 21.2 & 1,548 & 11.3 & - & - & - & - & - & 700 & 29 \\
\hline Evergreen (Clark) & WA & 14,163 & 18,366 & 87.0 & 13.0 & 2.8 & 3.1 & 6.2 & 1.0 & 947 & 19.4 & 1,632 & 11.3 & - & - & - & - & - & 839 & 29 \\
\hline Feder & WA & 17,2 & 20,8 & 71.3 & 28.7 & 10.4 & 4.9 & 12.0 & 1. & 1,014 & 20.6 & 1,821 & 11.5 & - & - & - & - & - & 969 & 36 \\
\hline Highlin & WA & 15, & 18 & 62.1 & 37.9 & 9.5 & 8.2 & 17.1 & 3. & 871 & 21.1 & 1,722 & 10.7 & - & - & - & - & - & 1,265 & 39 \\
\hline nt & WA & 20 & 24,8 & 78.7 & 21.3 & 6.9 & 1 & 9.1 & 1.2 & 1,214 & 20.4 & 2,228 & 11.1 & - & - & - & - & - & 1,413 & 40 \\
\hline ke Washington. & WA & 22 & 24,852 & 84.7 & 15.3 & 1 & 4 & 9.3 & 0.5 & $\begin{array}{l}1,148 \\
\end{array}$ & 21.6 & 2,091 & 11.9 & - & - & - & - & - & 1,456 & 48 \\
\hline $\begin{array}{l}\text { Norths } \\
\text { Nort }\end{array}$ & WA & $\begin{array}{l}17,032 \\
17,03\end{array}$ & $\begin{array}{l}19,457 \\
19,0\end{array}$ & 87.8 & $\begin{array}{l}12.2 \\
\end{array}$ & 5 & 8 & $\begin{array}{l}7.0 \\
7.0\end{array}$ & 0.9 & $\begin{array}{l}954 \\
954\end{array}$ & 20.4 & 1,698 & 11.5 & - & - & - & - & - & $\begin{array}{l}1,068 \\
1,068\end{array}$ & 32 \\
\hline Puyall & WA & 14,325 & $\begin{array}{l}18,545 \\
\end{array}$ & 83.8 & 16.2 & 2.2 & $\begin{array}{l}3.0 \\
3.2\end{array}$ & 4.7 & 6.1 & 886 & 20.9 & $\begin{array}{l}1,612 \\
\end{array}$ & 11.5 & - & - & - & - & - & $\begin{array}{r}, \quad 800 \\
862\end{array}$ & 36 \\
\hline & WA & $40,7 \varepsilon$ & 47,629 & 40 & 59. & 23.0 & 8.5 & 24.8 & 3.1 & 2,450 & 19.4 & & 10.3 & - & - & t & - & - & 2,430 & 116 \\
\hline & WA & 27,9 & 32,041 & 86 & 13 & & 2.3 & 2.9 & 4. & & 19. & 2,9 & 10. & - & - & - & - & - & & 67 \\
\hline Tacon & WA & 29,343 & 31,844 & 60.0 & 40.0 & 19.6 & 5.0 & 13.6 & 1.8 & 1,712 & 18. & 3,1 & 10.3 & - & - & - & - & - & 1,3 & 71 \\
\hline Vancouver & WA & 15,707 & 20,657 & 84.5 & 15.5 & 3.6 & 5.1 & 4.7 & 2.1 & 982 & 21.0 & 1,884 & 11.0 & - & - & - & - & - & 1,090 & 37 \\
\hline Kanawha County ... & wV & 35,005 & 31,491 & 88.9 & 11.1 & 9.8 & 0.9 & 0.3 & 0.1 & 2,177 & 14.5 & 3,888 & 8.1 & 5.0 & 3.7 & 5.8 & 6.5 & 4.3 & 2,102 & 89 \\
\hline & WI & 17,491 & 19,722 & 81.3 & 18.7 & 1.9 & 3.5 & 9.1 & 4.1 & 1,263 & 15.6 & 2,236 & 8.8 & - & - & - & - & - & 1,046 & 35 \\
\hline ......... & WI & 15,742 & 19,048 & 76.7 & 23.3 & 12.4 & 9.3 & $\begin{array}{l}.1 .2 \\
1.25\end{array}$ & 0.4 & 1,122 & 17.0 & 2,028 & 9.4 & - & - & - & - & - & 804 & 33 \\
\hline Madis & WI & 22,137 & 25,158 & 70.0 & 30.0 & 17.2 & 4.2 & 8.0 & 0.6 & 1,911 & 13.2 & 3,465 & 7.3 & - & - & - & - & - & 1,367 & 51 \\
\hline & WI & 91,819 & 101,007 & 22. & 77 & 60 & 12 & 8 & 1.0 & 5,754 & 17.6 & 11,21 & 9.0 & - & - & - & - & - & & 202 \\
\hline Racine & WI & 21,741 & 22,114 & 63.8 & 36.2 & 24.2 & 10.8 & 0.9 & 0.3 & 1,418 & 15.6 & 2,496 & 8.9 & - & - & - & - & - & 1,078 & 37 \\
\hline
\end{tabular}

1 Data exclude teachers reported as working in school district offices rather than in schools. ${ }^{2}$ Includes all categories of high school completers such as GEDs.

-Data not available or not applicable.

$-I S D=$ Independent school district.

SOURCE: U.S. Department of Education, National Center for Education Statistics, Common Core of Data survey. (This table was prepared February 1999.) 
Table 94.-Revenues and expenditures of public school districts enrolling more than 15,000 pupils, by state: 1994-95

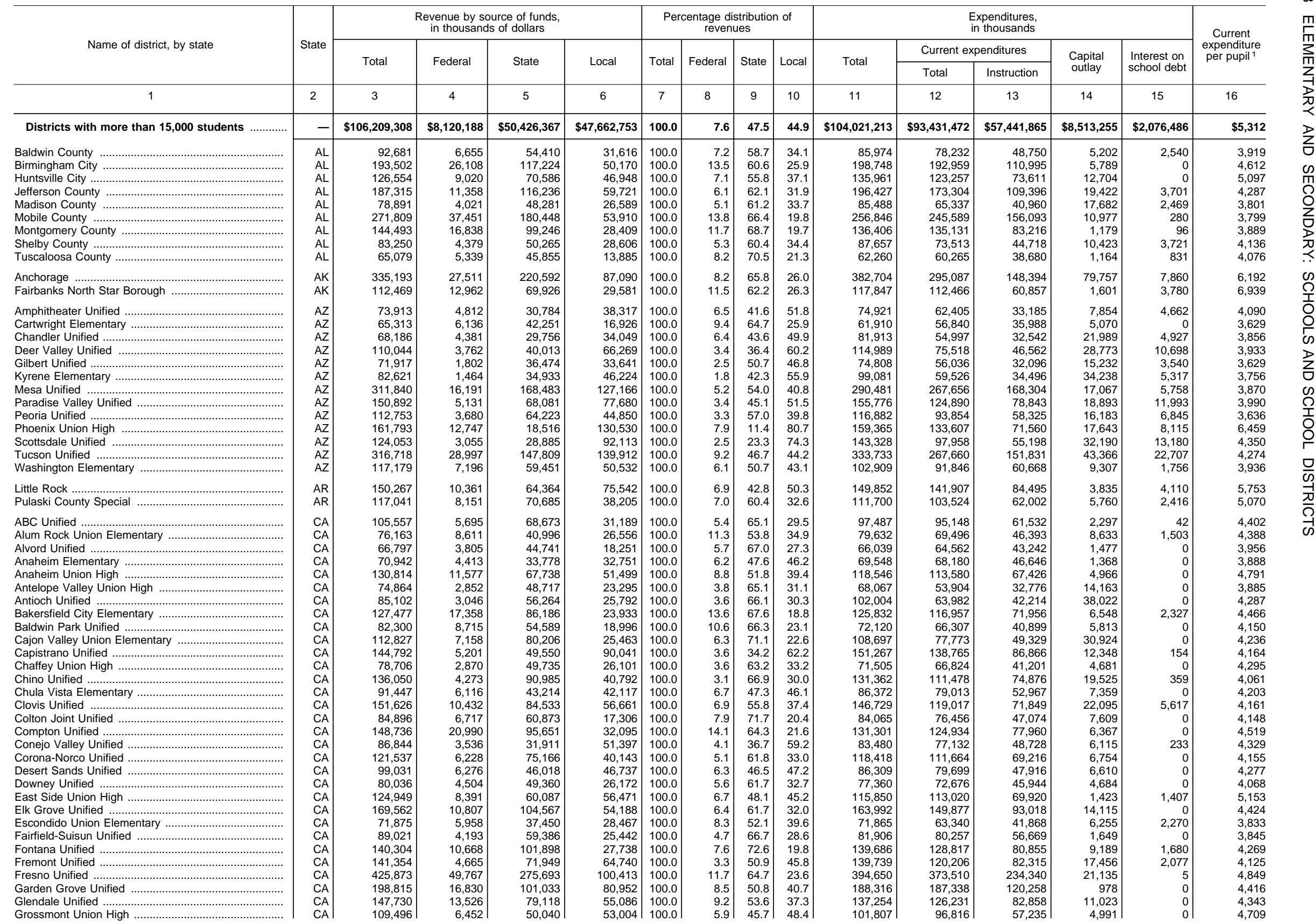


Table 94.-Revenues and expenditures of public school districts enrolling more than 15,000 pupils, by state: 1994-95-Continued

\begin{tabular}{|c|c|c|c|c|c|c|c|c|c|c|c|c|c|c|c|}
\hline \multirow{3}{*}{ Name of district, by state } & \multirow{3}{*}{ State } & \multicolumn{4}{|c|}{$\begin{array}{l}\text { Revenue by source of funds, } \\
\text { in thousands of dollars }\end{array}$} & \multicolumn{4}{|c|}{$\begin{array}{l}\text { Percentage distribution of } \\
\text { revenues }\end{array}$} & \multicolumn{5}{|c|}{$\begin{array}{l}\text { Expenditures, } \\
\text { in thousands }\end{array}$} & \multirow{3}{*}{$\begin{array}{c}\text { Current } \\
\text { expenditure } \\
\text { per pupil1 } 1\end{array}$} \\
\hline & & \multirow{2}{*}{ Total } & \multirow{2}{*}{ Federal } & \multirow{2}{*}{ State } & 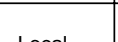 & Totol & Fodonat & Stato t & tonge & 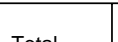 & Current exp & enditures & Capital & terest on & \\
\hline & & & & & Local & lotal & | Federal & State & | Local & Iotal & Total & Instruction & outlay & debt & \\
\hline 1 & 2 & 3 & 4 & 5 & 6 & 7 & 8 & 9 & 10 & 11 & 12 & 13 & 14 & 15 & 16 \\
\hline Hacienda La Puente Unified . & $\mathrm{CA}$ & 134,981 & 11,258 & 86,810 & 36,913 & 100.0 & 8.3 & 64.3 & 27.3 & 96,171 & 93,494 & 55,890 & 2.677 & 0 & 4,294 \\
\hline Hayward Unified ................. & $\begin{array}{l}\mathrm{CA} \\
\mathrm{CA}\end{array}$ & $\begin{array}{l}134,981 \\
104,468\end{array}$ & $\begin{array}{r}r, 258 \\
8,745\end{array}$ & $\begin{array}{l}80,810 \\
56,473\end{array}$ & $\begin{array}{l}36,213 \\
39,250\end{array}$ & 100.0 & $\begin{array}{l}8.3 \\
8.4\end{array}-1$ & $\begin{array}{l}64.3 \\
54.1\end{array}$ & $\begin{array}{l}27.3 \\
37.6\end{array}$ & 89,340 & $\begin{array}{l}93,494 \\
86,053\end{array}$ & $\begin{array}{l}53,590 \\
53,539\end{array}$ & $\begin{array}{l}3,617 \\
3,287\end{array}$ & 0 & $\begin{array}{l}4,294 \\
4,316\end{array}$ \\
\hline Hemet Unified ..... & $\mathrm{CA}$ & 82,295 & 5,745 & 56,015 & 20,535 & 100.0 & 7.0 & 68.1 & 25.0 & 76,529 & 60,402 & 39,258 & 16,127 & 0 & 4,151 \\
\hline Hesperia Unified. & $\mathrm{CA}$ & 73,589 & 4,196 & 54,409 & 14,984 & 100.0 & 5.7 & 73.9 & 20.4 & 74,331 & 60,148 & 37,530 & 14,183 & 0 & 4,148 \\
\hline Inglewood Unified. & $\mathrm{CA}$ & 93,201 & 9,037 & 60,526 & 23,638 & 100.0 & 9.7 & 64.9 & 25.4 & 82,016 & 71,489 & 43,945 & 10,527 & 0 & 4,395 \\
\hline Irvine Unified ...………………………………….... & $\mathrm{CA}$ & 103,601 & 4,492 & 36,540 & 62,569 & 100.0 & 4.3 & 35.3 & 60.4 & 101,080 & 98,924 & 63,980 & 1,123 & 1,033 & 4,508 \\
\hline Jurupa Unified. & $\mathrm{CA}$ & 82,427 & 4,474 & 58,945 & 19,008 & 100.0 & 5.4 & 71.5 & 23.1 & 75,855 & 69,330 & 45,969 & 6,525 & 0 & 4,107 \\
\hline Kern Union High & $\mathrm{CA}$ & 146,049 & 10,479 & 69,339 & 66,231 & 100.0 & 7.2 & 47.5 & 45.3 & 136,595 & 120,905 & 64,398 & 11,994 & 3,696 & 5,073 \\
\hline Lodi Unified .......... & $\mathrm{CA}$ & 119,928 & 10,075 & 72,216 & 37,637 & 100.0 & 8.4 & 60.2 & 31.4 & 112,147 & 109,040 & 69,041 & 3,008 & 99 & 4,337 \\
\hline Long Beach Unified .............. & $\mathrm{CA}$ & 452,033 & 54,825 & 288,497 & 108,711 & 100.0 & 12.1 & 63.8 & 24.0 & 390,742 & 370,907 & 238,171 & 19,835 & $\begin{array}{r}0 \\
0\end{array}$ & 4,747 \\
\hline Los Angeles Unified ................. & $\mathrm{CA}$ & $3,771,981$ & 465,823 & $2,251,218$ & $1,054,940$ & 100.0 & 12.3 & 59.7 & 28.0 & $3,395,358$ & $3,276,287$ & $2,146,781$ & 119,071 & 0 & 5,176 \\
\hline Lynwood Unified ........ & $\mathrm{CA}$ & 108,167 & 7,253 & 84,364 & 16,550 & 100.0 & 6.7 & 78.0 & 15.3 & 72,587 & 59,338 & 40,334 & 13,249 & 0 & 3,900 \\
\hline Madera Unified . & $\mathrm{CA}$ & 72,415 & 6,186 & 45,755 & 20,474 & 100.0 & 8.5 & 63.2 & 28.3 & 71,472 & 63,774 & 36,871 & 7,698 & 0 & 4,200 \\
\hline Manteca Unified & $\mathrm{CA}$ & 64,717 & 3,301 & 41,725 & 19,691 & 100.0 & 5.1 & 64.5 & 30.4 & 61,475 & 59,294 & 37,520 & 2,181 & 0 & 4,050 \\
\hline Modesto City Elementary .. & $\mathrm{CA}$ & 149,631 & 15,188 & 81,998 & 52,445 & 100.0 & 10.2 & 54.8 & 35.0 & 143,059 & 136,536 & 85,141 & 3,058 & 3,465 & 4,274 \\
\hline Montebello Unified .............. & $\mathrm{CA}$ & 157,246 & 15,955 & 97,062 & 44,229 & 100.0 & 10.1 & 61.7 & 28.1 & 156,294 & 135,214 & 85,997 & 21,080 & 0 & 4,223 \\
\hline Moreno Valley Unified . & $\mathrm{CA}$ & 141,047 & 10,091 & 102,070 & 28,886 & 100.0 & 7.2 & 72.4 & 20.5 & 137,736 & 135,372 & 84,476 & 2,260 & 104 & 4,282 \\
\hline Mt. Diablo Unified ....... & $\mathrm{CA}$ & 167,077 & 7,837 & 72,186 & 87,054 & 100.0 & 4.7 & 43.2 & 52.1 & 156,562 & 152,915 & 95,580 & 3,647 & 0 & 4,444 \\
\hline Napa Valley Unified. & $\mathrm{CA}$ & 70,544 & 3,918 & 22,975 & 43,651 & 100.0 & 5.6 & 32.6 & 61.9 & 65,476 & 62,381 & 39,416 & 3,087 & 8 & 4,153 \\
\hline Newport-Mesa Unified. & $\mathrm{CA}$ & 98,375 & 4.474 & 20,121 & 73,780 & 100.0 & $\begin{array}{l}3.6 \\
4.5\end{array}$ & $\begin{array}{l}32.6 \\
20.5\end{array}$ & $\begin{array}{l}6.9 \\
75.0\end{array}$ & $\begin{array}{l}65,476 \\
84,778\end{array}$ & $\begin{array}{l}62,381 \\
82,827\end{array}$ & $\begin{array}{l}39,410 \\
49,253\end{array}$ & $\begin{array}{l}3,081 \\
1,914\end{array}$ & $\begin{array}{r}8 \\
37\end{array}$ & $\begin{array}{l}4,153 \\
4,648\end{array}$ \\
\hline Norwalk-La Mirada Unified & $\mathrm{CA}$ & 113,207 & 8,291 & 65,830 & 39,086 & 100.0 & $\begin{array}{l}4.5 \\
7.3\end{array}$ & 58.2 & 34.5 & $\begin{array}{l}84,710 \\
94,859\end{array}$ & $\begin{array}{l}0<, 0<1 \\
90,679\end{array}$ & $\begin{array}{l}49,260 \\
54,260\end{array}$ & $\begin{array}{r}4,180 \\
4,180\end{array}$ & $\begin{array}{r}3 \\
0\end{array}$ & $\begin{array}{l}4,648 \\
4,458\end{array}$ \\
\hline Oakland Unified & $\mathrm{CA}$ & 299,426 & $\begin{array}{r}3,262 \\
32,262\end{array}$ & 181,601 & 85,563 & 100.0 & 10.8 & $\begin{array}{l}58.2 \\
60.6\end{array}$ & $\begin{array}{l}34.5 \\
28.6\end{array}$ & $\begin{array}{r}4,859 \\
282,097\end{array}$ & $\begin{array}{r}279,180 \\
279\end{array}$ & $\begin{array}{r}54,260 \\
165,632\end{array}$ & $\begin{array}{l}4,180 \\
2,258\end{array}$ & 659 & 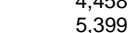 \\
\hline 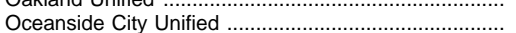 & $\mathrm{CA}$ & $\begin{array}{r}84,233 \\
84,200\end{array}$ & $\begin{array}{r}3,202 \\
7,919\end{array}$ & $\begin{array}{r}1 \\
47,377\end{array}$ & $\begin{array}{l}28,937 \\
28,00\end{array}$ & 100.0 & 9.4 & 56.2 & $\begin{array}{l}20.0 \\
34.4\end{array}$ & $\begin{array}{r}20,091 \\
82,567\end{array}$ & 81,413 & $\left.\begin{array}{r}105,032 \\
52,221\end{array}\right]$ & $\begin{array}{l}2,200 \\
1,154\end{array}$ & 0 & 4,298 \\
\hline Ontario-Montclair Elementary & $\mathrm{CA}$ & $\begin{array}{r}114,032 \\
114,030\end{array}$ & 10,557 & 80,198 & $\begin{array}{l}20,277 \\
23,277\end{array}$ & 100.0 & $\begin{array}{l}.44 \\
9.3\end{array}-1$ & 70.3 & $\begin{array}{l}20.4 \\
20.4\end{array}$ & $\begin{array}{l}0 ., 007 \\
108,316\end{array}$ & $\begin{array}{l}01,410 \\
95,421\end{array}$ & 64,093 & $\begin{array}{r}1,894 \\
12,895\end{array}$ & 0 & 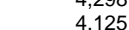 \\
\hline Orange Unified & $\begin{array}{ll}A A \\
C A\end{array}$ & 122878 & $\begin{array}{r}1,501 \\
6812\end{array}$ & 44.411 & 71,655 & 100.0 & 5.5 & 36.1 & $\begin{array}{l}2.4 \\
58.3\end{array}$ & $\begin{array}{r}10,310 \\
107793\end{array}$ & $\begin{array}{r}9,4<1 \\
106,350\end{array}$ & $\begin{array}{l}-64,390 \\
64,323\end{array}$ & $\begin{array}{r}12,095 \\
1,443\end{array}$ & 0 & $\begin{array}{l}4,1<5 \\
3,982\end{array}$ \\
\hline Pajaro Valley Joint Unified. & $\begin{array}{l}\mathrm{AA} \\
\mathrm{CA}\end{array}$ & $\begin{array}{r}12,818 \\
96,509\end{array}$ & $\begin{array}{r}0,812 \\
11,162\end{array}$ & $\begin{array}{l}44,411 \\
51,579\end{array}$ & $\begin{array}{l}\quad 1,1,550 \\
33,768\end{array}$ & 100.0 & 11.6 & 53.4 & $\begin{array}{r}5.3 \\
35.0\end{array}$ & 89,359 & 79,175 & $\begin{array}{l}64,323 \\
50,112\end{array}$ & $\begin{array}{r}1,443 \\
10,184\end{array}$ & 0 & $\begin{array}{l}3,982 \\
4,554\end{array}$ \\
\hline 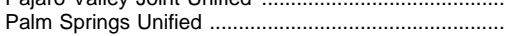 & $\mathrm{CA}$ & 80,548 & 5,481 & 42,679 & $\begin{array}{l}32,388 \\
32,1\end{array}$ & 100.0 & 6.8 & 53.0 & 40.2 & $\begin{array}{l}89,108 \\
89,1\end{array}$ & 69,871 & 42,414 & 18,270 & 967 & 4,173 \\
\hline Palmdale Elementary & $\mathrm{CA}$ & 74,934 & 6,469 & 47,263 & $\begin{array}{l}20,802 \\
20,00 \\
\end{array}$ & 100.0 & $\begin{array}{l}0.0 \\
9.2\end{array}$ & 63.1 & 27.8 & 71,640 & 66,758 & $\begin{array}{l}4<, 247 \\
41,247\end{array}$ & $\begin{array}{r}1,270 \\
4,882\end{array}$ & $\begin{array}{r}501 \\
0\end{array}$ & 3,896 \\
\hline Paramount Unified . & $\mathrm{CA}$ & 66,190 & 6,531 & 42,177 & 17,482 & 100.0 & 9.9 & 63.7 & 26.4 & 62,142 & $\begin{array}{l}60,000 \\
61,029\end{array}$ & $\begin{array}{l}41,247 \\
37,189\end{array}$ & 1,113 & 0 & $\begin{array}{l}\quad, 090 \\
4,252\end{array}$ \\
\hline Pasadena Unified .. & $\mathrm{CA}$ & 115,788 & 13,387 & 59,785 & 42,616 & 100.0 & 11.6 & 51.6 & 36.8 & 115,219 & 114,094 & 68,572 & 1,125 & 0 & 5,180 \\
\hline Placentia-Yorba Linda Unified ......... & $\mathrm{CA}$ & 111,474 & 3,837 & 50,556 & 57,081 & 100.0 & 3.4 & $\begin{array}{llll}45.4 & & l & \\
\end{array}$ & 51.2 & 105,566 & 101,785 & 64,658 & 3,702 & 79 & 4,386 \\
\hline Pomona Unified ............................... & $\mathrm{CA}$ & 165,857 & 22,634 & 103,740 & 39,483 & 100.0 & 13.6 & 62.5 & 23.8 & 151,113 & 140,909 & 86,359 & 7,550 & 2,654 & 4,690 \\
\hline Poway Unified ... & $\mathrm{CA}$ & 134,038 & 3,777 & 64,473 & 65,788 & 100.0 & 2.8 & 48.1 & 49.1 & 131,433 & 126,354 & 78,977 & 5,079 & 0 & 4,334 \\
\hline Redlands Unified & $\mathrm{CA}$ & 84,364 & 3,999 & 54,664 & 25,701 & 100.0 & 4.7 & 64.8 & 30.5 & 80,738 & 72,278 & 46,057 & 5,858 & 2,602 & 4,121 \\
\hline Rialto Unified . & $\mathrm{CA}$ & 101,550 & 6,908 & 73,703 & 20,939 & 100.0 & 6.8 & 72.6 & 20.6 & 105,222 & 96,874 & 57,856 & 8,318 & 30 & 4,199 \\
\hline Riverside Unified ………………… & $\mathrm{CA}$ & 168,852 & 12,234 & 111,061 & 45,557 & 100.0 & 7.2 & 65.8 & 27.0 & 163,649 & 150,089 & 91,687 & 13,557 & 3 & 4,330 \\
\hline Rowland Unified ……………........ & $\mathrm{CA}$ & 85,581 & 5,256 & 53,972 & 26,353 & 100.0 & 6.1 & 63.1 & 30.8 & $\begin{array}{r}79,604 \\
79,604\end{array}$ & $\begin{array}{r}77,898 \\
\end{array}$ & $\begin{array}{l}51,401 \\
46,415\end{array}$ & 1,706 & $\begin{array}{l}0 \\
0\end{array}$ & 4,251 \\
\hline Sacramento City Unified & $\mathrm{CA}$ & 252,085 & 29,287 & 154,406 & 68,392 & 100.0 & 11.6 & 61.3 & $\begin{array}{l}30.0 \\
27.1\end{array}$ & 234,058 & $\begin{array}{r}230,635 \\
230\end{array}$ & $\begin{array}{r}48,410 \\
147,049\end{array}$ & 2,725 & 698 & 4,680 \\
\hline Saddleback Valley Unified & $\mathrm{CA}$ & 124,350 & 3,548 & 47,039 & 73,763 & 100.0 & 2.9 & 37.8 & 59.3 & 118,585 & 116,774 & 76,957 & 1,457 & 354 & 4,042 \\
\hline San Bernardino City Unified. & $\mathrm{CA}$ & 226,021 & $\begin{array}{r}3,040 \\
22,724\end{array}$ & $\begin{array}{r}4 \\
158,219\end{array}$ & $\begin{array}{l}45,078 \\
45,103\end{array}$ & 100.0 & 10.1 & $\begin{array}{l}3.0 \\
70.0\end{array}$ & 19.9 & 222,291 & 206,591 & $\begin{array}{r}117,989 \\
117,951\end{array}$ & $\begin{array}{r}1,451 \\
15,700\end{array}$ & $\begin{array}{r}534 \\
0\end{array}$ & $\begin{array}{l}4,042 \\
4,669\end{array}$ \\
\hline San Diego City Unified .......... & $\begin{array}{l}\mathrm{AA} \\
\mathrm{CA}\end{array}$ & $\begin{array}{l}220,021 \\
740,952\end{array}$ & $\begin{array}{l}22,, 24 \\
62,022\end{array}$ & $\begin{array}{l}158,219 \\
309,152\end{array}$ & $\begin{array}{r}469,078 \\
369,778\end{array}$ & 100.0 & $\begin{array}{r}10.1 \\
8.4\end{array}$ & 41.7 & $\begin{array}{r}19.9 \\
49.9\end{array}$ & $\begin{array}{l}22,291 \\
675,573\end{array}$ & $\begin{array}{l}2044,531 \\
64,4\end{array}$ & 377,380 & $\begin{array}{l}15,00 \\
31,094\end{array}$ & 42 & $\begin{array}{l}4,609 \\
5,013\end{array}$ \\
\hline San Francisco Unified ... & $\begin{array}{l}\mathrm{CA} \\
\mathrm{CA}\end{array}$ & $\begin{array}{l}74,952 \\
391,880\end{array}$ & $\begin{array}{l}62,022 \\
32,622\end{array}$ & $\begin{array}{l}318,748 \\
118,75\end{array}$ & $\begin{array}{l}36, / 718 \\
240,510\end{array}$ & $\begin{array}{l}10.0 \\
100.0\end{array}$ & $\begin{array}{l}8.4 \\
8.3\end{array}-3$ & $\begin{array}{l}4.1 \\
30.3\end{array}$ & $\begin{array}{l}4.9 \\
61.4\end{array}$ & $\begin{array}{l}6 / 5,5 / 3 \\
339,365\end{array}$ & $\begin{array}{l}64,437 \\
311,503\end{array}$ & $\begin{array}{l}37,380 \\
204,393\end{array}$ & $\begin{array}{l}31,094 \\
27,862\end{array}$ & - $\begin{array}{r}42 \\
0\end{array}$ & $\begin{array}{l}5,013 \\
5,078\end{array}$ \\
\hline $\begin{array}{l}\text { San Francisco Unired . } \\
\text { San Jose Unified .......... }\end{array}$ & $\begin{array}{l}\mathrm{CA} \\
\mathrm{CA}\end{array}$ & $\begin{array}{l}391,880 \\
181,898\end{array}$ & $\begin{array}{l}32,622 \\
13,490\end{array}$ & $\begin{array}{r}118, / 48 \\
75,954\end{array}$ & $\begin{array}{r}24,510 \\
92,454\end{array}$ & $\begin{array}{l}10.0 \\
100.0\end{array}$ & $\begin{array}{l}8.3 \\
7.4\end{array}$ & $\begin{array}{l}3.3 \\
41.8\end{array}$ & $\begin{array}{l}6.4 \\
50.8\end{array} \mid$ & $\begin{array}{l}33,36,365 \\
176,665\end{array}$ & $\begin{array}{l}31,503 \\
167,218\end{array}$ & $\begin{array}{r}20,393 \\
97,134\end{array}$ & $\begin{array}{r}27,862 \\
9,439\end{array}$ & $\begin{array}{l}0 \\
8\end{array}$ & $\begin{array}{l}5,0 / 8 \\
5,377\end{array}$ \\
\hline $\begin{array}{l}\text { San Jose Unifred } \\
\text { San Juan Unified }\end{array}$ & $\begin{array}{l}\mathrm{CA} \\
\mathrm{CA}\end{array}$ & $\begin{array}{l}181,898 \\
240,937\end{array}$ & $\begin{array}{l}13,490 \\
18,163\end{array}$ & $\begin{array}{r}15,954 \\
145,992\end{array}$ & $\begin{array}{l}92,454 \\
76,782\end{array}$ & $\begin{array}{l}100.0 \\
100.0\end{array}$ & 7.5 & $\begin{array}{l}41.8 \\
60.6\end{array}$ & $\begin{array}{l}5.8 \\
31.9\end{array}$ & $\begin{array}{l}1 / 6,665 \\
229,166\end{array}$ & $\begin{array}{l}16,218 \\
216,558\end{array}$ & $\begin{array}{r}9,134 \\
135,958\end{array}$ & $\begin{array}{r}9,439 \\
12,608\end{array}$ & $\begin{array}{l}8 \\
0\end{array}$ & $\begin{array}{l}5,3 / 7 \\
4,600\end{array}$ \\
\hline San Ramon Valley Unified & $\begin{array}{l}\mathrm{CA} \\
\mathrm{CA}\end{array}$ & $\begin{array}{r}240,937 \\
88,707\end{array}$ & $\begin{array}{r}18,163 \\
1,124\end{array}$ & $\begin{array}{r}14,992 \\
20,874\end{array}$ & $\begin{array}{l}76,82 \\
66,709\end{array}$ & $\begin{array}{l}10.0 \\
100.0\end{array}$ & $\begin{array}{l}1.5 \\
1.3\end{array}$ & $\begin{array}{l}60.6 \\
23.5\end{array}$ & $\begin{array}{l}31.9 \\
75.2\end{array}$ & $\begin{array}{r}22,166 \\
81,937\end{array}$ & $\begin{array}{r}217,558 \\
72,906\end{array}$ & $\begin{array}{r}133,958 \\
48,809\end{array}$ & $\begin{array}{r}12,608 \\
8,732\end{array}$ & 299 & $\begin{array}{l}4,600 \\
4,070\end{array}$ \\
\hline $\begin{array}{l}\text { San Ramon Valley Unirle } \\
\text { Santa Ana Unified ......... }\end{array}$ & $\begin{array}{l}\mathrm{CA} \\
\mathrm{CA}\end{array}$ & $\begin{array}{r}88,707 \\
238,133\end{array}$ & $\begin{array}{r}1,124 \\
21,499\end{array}$ & $\begin{array}{r}20,8 / 4 \\
126,217\end{array}$ & $\begin{array}{l}66,09 \\
90,417\end{array}$ & $\begin{array}{l}100.0 \\
100.0\end{array}$ & $\begin{array}{l}1.3 \\
9.0\end{array}-2$ & $\begin{array}{l}23.5 \\
53.0\end{array}$ & $\begin{array}{r}15.2 \\
38.0\end{array}$ & $\begin{array}{r}8,937 \\
225,088\end{array}$ & $\begin{array}{r}7,906 \\
204,940\end{array}$ & $\begin{array}{r}48,809 \\
132,778\end{array}$ & $\begin{array}{r}8,32 \\
19,900\end{array}$ & $\begin{array}{l}299 \\
248\end{array}$ & $\begin{array}{l}4,070 \\
4,194\end{array}$ \\
\hline Simi Valley Unifie & $\mathrm{CA}$ & $\begin{array}{r}92,918 \\
\end{array}$ & $\begin{array}{r}5,240 \\
5,400\end{array}$ & 50,630 & 37,048 & 100.0 & 5.6 & 54.5 & $\begin{array}{l}38.0 \\
39.9\end{array}$ & 84,467 & 78,619 & 48,687 & 3,925 & 1,923 & 4,300 \\
\hline Stockto & $\mathrm{CA}$ & $\begin{array}{r}178,846 \\
172\end{array}$ & 24,24 & $\begin{array}{r}110,400 \\
\end{array}$ & $\begin{array}{l}34,197 \\
44,0\end{array}$ & 100.0 & $\begin{array}{r}5.0 \\
13.6\end{array}$ & 61.7 & 24.7 & $\begin{array}{r}04,401 \\
167,571\end{array}$ & $\begin{array}{r}16,02,838 \\
162,\end{array}$ & $\begin{array}{r}40,001 \\
100,798\end{array}$ & 4,697 & $\begin{array}{r}r, 5<0 \\
36\end{array}$ & 4,787 \\
\hline Sw & $\mathrm{CA}$ & $\begin{array}{l}155,130 \\
150,0\end{array}$ & 11,5 & 103 & 40,319 & 100.0 & 7.4 & 66.6 & 26.0 & 140,525 & $\begin{array}{r}138,000 \\
138,102\end{array}$ & 80 & $\begin{array}{l}4,097 \\
2,423\end{array}$ & . & 4,784 \\
\hline Torrance Unifie & $\mathrm{CA}$ & 104 & 3. & & $\begin{array}{l}40,099 \\
47,099\end{array}$ & 100.0 & $\begin{array}{l}1.4 \\
3.0\end{array}$ & $\begin{array}{l}52.1 \\
52.0\end{array}$ & $\begin{array}{l}20.0 \\
44.9\end{array}$ & & & & 4,0 & 0 & $\begin{array}{l}4,104 \\
4,090\end{array}$ \\
\hline Vallejo City L & $\mathrm{CA}$ & 94 & 6, & 6 & 26,897 & 100.0 & 7.4 & 64.0 & 28.6 & 92 & 88 & & 4,155 & 0 & 4, \\
\hline ㄴ. & $\mathrm{CA}$ & 82 & 4,4 & 35,8 & 42,519 & 100.0 & 5.4 & 43.3 & 51.3 & 70,110 & 65,776 & 38,182 & 4,334 & 0 & 4,130 \\
\hline Visalia Unified .. & $\mathrm{CA}$ & 115,509 & 11,173 & 73,778 & 30,558 & 100.0 & 9.7 & 63.9 & 26.5 & 102,271 & 99,551 & 66,075 & 2,421 & 299 & 4,216 \\
\hline Vista Unified & $\mathrm{CA}$ & 108,374 & 6,215 & 61,577 & 40,582 & 100.0 & 5.7 & 56.8 & 37.4 & 101,867 & 98,296 & 63,471 & 3,571 & 0 & 4,240 \\
\hline West Contra Costa Unified ......................................... & $\mathrm{CA}$ & 167,611 & 13,072 & 89,256 & 65,283 & 100.0 & 7.8 & 53.3 & $\begin{array}{l}38.9 \\
38.9\end{array}$ & 154,399 & 142,947 & 93,335 & $\begin{array}{r}31,452 \\
\end{array}$ & 0 & 4,527 \\
\hline Adams-Arapahoe ... & $\mathrm{col}$ & 160,760 & 8,215 & 86,808 & 65,737 & 100.0 & 5.1 & 54.0 & 40.9 & 151,054 & 140,453 & 85,022 & 5,418 & 5,183 & 5,122 \\
\hline ㄱ. & $\mathrm{co}$ & 148,462 & 5,077 & $\begin{array}{l}00,000 \\
28,123\end{array}$ & $\begin{array}{r}05,151 \\
115,262\end{array}$ & 100.0 & 3.4 & $\begin{array}{l}5.0 \\
18.9\end{array}$ & 77.6 & 138,545 & $\begin{array}{r}127,430 \\
127,430\end{array}$ & $\begin{array}{l}05,022 \\
78,779\end{array}$ & $\begin{array}{l}5,410 \\
5,360\end{array}$ & 5,755 & 5,168 \\
\hline Cherry C & $\mathrm{cO}$ & 225,825 & 3,702 & 73,223 & 148,900 & 100.0 & 1.6 & 32.4 & 65.9 & 208,072 & 191,811 & 116,584 & 4,954 & 11,307 & 5,525 \\
\hline Colo & $\mathrm{co}$ & 156,159 & 8,15 & 80,709 & 67,295 & 100.0 & 5.2 & 51.7 & 43 & 151 & 68 & 88 & 4,964 & & 4, \\
\hline Denver County & $\mathrm{co}$ & 391,829 & 32,72 & 109,666 & 249,439 & 100.0 & 8.4 & 28.0 & 63 & 393,742 & 351,373 & 190,168 & 32,270 & 10,099 & 5,598 \\
\hline Douglas County & $\mathrm{col}$ & 155,302 & 2,169 & 44,086 & 109,047 & 100.0 & 1.4 & 28.4 & 70.2 & 116,581 & 96,160 & 53,401 & 15,426 & 4,995 & 4,798 \\
\hline
\end{tabular}




\begin{tabular}{|c|c|c|c|c|c|c|c|c|c|c|c|c|c|c|c|}
\hline \multirow{3}{*}{ Name of district, by state } & \multirow{3}{*}{ State } & \multicolumn{4}{|c|}{$\begin{array}{l}\text { Revenue by source of funds, } \\
\text { in thousands of dollars }\end{array}$} & \multicolumn{4}{|c|}{$\begin{array}{l}\text { Percentage distribution of } \\
\text { revenues }\end{array}$} & \multicolumn{5}{|c|}{$\begin{array}{l}\text { Expenditures, } \\
\text { in thousands }\end{array}$} & \multirow{3}{*}{$\begin{array}{l}\text { Current } \\
\text { expenditure } \\
\text { per pupil } 1\end{array}$} \\
\hline & & \multirow{2}{*}{ Total } & \multirow{2}{*}{ Federal } & \multirow{2}{*}{ State } & \multirow{2}{*}{ Local } & \multirow{2}{*}{ Total } & \multirow{2}{*}{ Federal } & \multirow{2}{*}{ State } & \multirow{2}{*}{ Local } & \multirow{2}{*}{ Total } & \multicolumn{2}{|c|}{ Current expenditures } & ( & on & \\
\hline & & & & & & & & & & & Total & Instruction & outlay & ebt & \\
\hline 1 & 2 & 3 & 4 & 5 & 6 & 7 & 8 & 9 & 10 & 11 & 12 & 13 & 14 & 15 & 16 \\
\hline 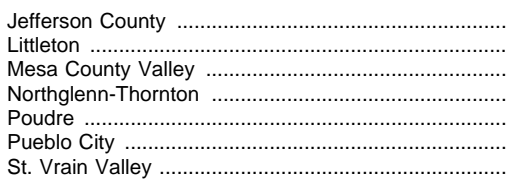 & $\begin{array}{l}\mathrm{CO} \\
\mathrm{CO} \\
\mathrm{CO} \\
\mathrm{CO} \\
\mathrm{CO} \\
\mathrm{cO} \\
\mathrm{CO}\end{array}$ & $\begin{array}{r}541,438 \\
86,566 \\
88,868 \\
144,125 \\
112,296 \\
92,114 \\
88,787\end{array}$ & $\begin{array}{r}13,947 \\
2,261 \\
5,650 \\
4,336 \\
5,218 \\
8,712 \\
3,405\end{array}$ & $\begin{array}{r}211,108 \\
40,073 \\
52,824 \\
72,802 \\
43,037 \\
53,959 \\
39,604\end{array}$ & $\begin{array}{r}316,383 \\
44,232 \\
30,394 \\
66,987 \\
64,041 \\
29,443 \\
45,778\end{array}$ & $\begin{array}{l}100.0 \\
100.0 \\
100.0 \\
100.0 \\
100.0 \\
100.0 \\
100.0\end{array}$ & $\begin{array}{l}2.6 \\
2.6 \\
6.4 \\
3.0 \\
4.6 \\
9.5 \\
3.8\end{array}$ & $\begin{array}{l}39.0 \\
46.3 \\
59.4 \\
50.5 \\
38.3 \\
58.6 \\
44.6\end{array}$ & $\begin{array}{l}58.4 \\
51.1 \\
34.2 \\
46.5 \\
57.0 \\
32.0 \\
51.6\end{array}$ & $\begin{array}{r}631,698 \\
82,354 \\
84,031 \\
119,845 \\
140,709 \\
90,738 \\
84,056\end{array}$ & $\begin{array}{r}466,601 \\
76,176 \\
80,328 \\
108,994 \\
93,805 \\
86,489 \\
78,209\end{array}$ & $\begin{array}{r}238,919 \\
47,053 \\
49,844 \\
66,517 \\
58,763 \\
54,670 \\
44,395\end{array}$ & $\begin{array}{r}139,759 \\
3,915 \\
2,561 \\
5,224 \\
38,159 \\
4,249 \\
2,794\end{array}$ & $\begin{array}{r}25,338 \\
2,263 \\
1,142 \\
5,627 \\
8,745 \\
0 \\
3,053\end{array}$ & $\begin{array}{l}5,554 \\
4,836 \\
4,370 \\
4,663 \\
4,428 \\
4,805 \\
4,745\end{array}$ \\
\hline 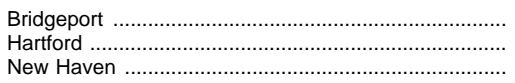 & $\begin{array}{l}\mathrm{CT} \\
\mathrm{CT} \\
\mathrm{CT}\end{array}$ & $\begin{array}{l}177,404 \\
251,702 \\
177,746\end{array}$ & $\begin{array}{l}17,810 \\
19,806 \\
18,214\end{array}$ & $\begin{array}{l}122,637 \\
165,618 \\
114,561\end{array}$ & $\begin{array}{l}36,957 \\
66,278 \\
44,971\end{array}$ & $\begin{array}{l}100.0 \\
100.0 \\
100.0\end{array}$ & $\begin{array}{r}10.0 \\
7.9 \\
10.2\end{array}$ & $\begin{array}{l}69.1 \\
65.8 \\
64.5\end{array}$ & $\begin{array}{l}20.8 \\
26.3 \\
25.3\end{array}$ & $\begin{array}{l}173,724 \\
244,790 \\
170,558\end{array}$ & $\begin{array}{l}164,925 \\
241,442 \\
166,123\end{array}$ & $\begin{array}{l}110,648 \\
164,855 \\
117,115\end{array}$ & $\begin{array}{r}5,954 \\
236 \\
1,944\end{array}$ & $\begin{array}{l}2,845 \\
3,112 \\
2,491\end{array}$ & $\begin{array}{r}7,899 \\
10,017 \\
8,988\end{array}$ \\
\hline $\begin{array}{l}\text { Christina .............................. } \\
\text { Red Clay Consolidated ....... }\end{array}$ & $\begin{array}{l}\mathrm{DE} \\
\mathrm{DE}\end{array}$ & $\begin{array}{l}143,416 \\
106,583\end{array}$ & $\begin{array}{l}7,725 \\
6,518\end{array}$ & $\begin{array}{l}86,077 \\
60,410\end{array}$ & $\begin{array}{l}49,614 \\
39,655\end{array}$ & $\begin{array}{l}100.0 \\
100.0\end{array}$ & $\begin{array}{l}5.4 \\
6.1\end{array}$ & $\begin{array}{l}60.0 \\
56.7\end{array}$ & $\begin{array}{l}34.6 \\
37.2\end{array}$ & $\begin{array}{l}133,380 \\
103,918\end{array}$ & $\begin{array}{l}129,147 \\
102,323\end{array}$ & $\begin{array}{l}81,394 \\
64,650\end{array}$ & $\begin{array}{l}3,534 \\
1,595\end{array}$ & $\begin{array}{r}699 \\
0\end{array}$ & $\begin{array}{l}6,651 \\
6,859\end{array}$ \\
\hline District of Columbia ... & DC & 700,111 & 65,527 & - & 634,584 & 100.0 & 9.4 & - & 90.6 & 686,586 & 666,938 & 336,543 & 19,648 & 0 & 8,290 \\
\hline 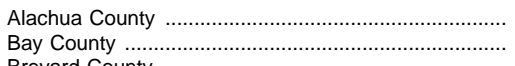 & $\begin{array}{l}\mathrm{FL} \\
\mathrm{FL}\end{array}$ & $\begin{array}{r}170,870 \\
142,139\end{array}$ & $\begin{array}{r}16,223 \\
10,450\end{array}$ & $\begin{array}{r}96,432 \\
85,264 \\
\end{array}$ & $\begin{array}{r}58,215 \\
46,425 \\
\end{array}$ & $\begin{array}{l}100.0 \\
100.0\end{array}$ & $\begin{array}{l}9.5 \\
7.4 \\
7.4\end{array}$ & $\begin{array}{l}56.4 \\
60.0 \\
52 .\end{array}$ & $\begin{array}{l}34.1 \\
32.7 \\
3.2\end{array}$ & $\begin{array}{l}164,887 \\
134,417\end{array}$ & $\begin{array}{l}136,647 \\
119,751\end{array}$ & $\begin{array}{r}72,785 \\
73,379\end{array}$ & $\begin{array}{l}22,287 \\
12,836\end{array}$ & $\begin{array}{l}5,953 \\
1,830 \\
5\end{array}$ & $\begin{array}{l}4,743 \\
4,828\end{array}$ \\
\hline $\begin{array}{l}\text { Brevard County } \\
\text { Broward County }\end{array}$ & $\mathrm{FL}$ & $\begin{array}{r}347,200 \\
\end{array}$ & 21,232 & 182,448 & 143,520 & 100.0 & 6.1 & 52.5 & 41.3 & 361,735 & 299,696 & 179,799 & 56,527 & 5,512 & 4,640 \\
\hline $\begin{array}{l}\text { Broward County .......... } \\
\text { Charlotte County .... }\end{array}$ & $\begin{array}{ll}\mathrm{FL} \\
\mathrm{FL}\end{array}$ & $\begin{array}{r}1,317,698 \\
95,539\end{array}$ & $\begin{array}{r}77,867 \\
4880\end{array}$ & 661,136 & 578,695 & 100.0 & 5.9 & 50.2 & 43.9 & $1,248,289$ & $1,024,098$ & 570,890 & 191,569 & 32,622 & 5,140 \\
\hline & $\mathrm{FL}$ & $\begin{array}{r}95,539 \\
118,889\end{array}$ & $\begin{array}{l}4,880 \\
6,154\end{array}$ & $\begin{array}{l}2,113 \\
79,180\end{array}$ & $\begin{array}{l}63,566 \\
33,555\end{array}$ & $\begin{array}{l}100.0 \\
100.0\end{array}$ & $\begin{array}{l}5.1 \\
5.2\end{array}$ & $\begin{array}{l}28.4 \\
66.6\end{array}$ & $\begin{array}{l}66.5 \\
28.2\end{array}$ & $\begin{array}{r}86,600 \\
108,297\end{array}$ & $\begin{array}{l}77,411 \\
99,554\end{array} \mid$ & $\begin{array}{l}43,030 \\
56,136\end{array}$ & $\begin{array}{l}7,401 \\
8,318\end{array}$ & $\begin{array}{r}1,948 \\
425\end{array}$ & $\begin{array}{l}5,129 \\
4,176\end{array}$ \\
\hline Collier County ... & $\mathrm{FL}$ & 194,726 & 14,195 & 31,042 & 149,489 & 100.0 & 7.3 & 15.9 & 76.8 & 218,170 & 149,122 & 88,135 & 63,536 & 5,512 & 5,928 \\
\hline Dade County ................. & $\mathrm{FL}$ & $2,183,071$ & 182,832 & 1,159, & 841,089 & 100.0 & 8.4 & 53.1 & 38.5 & $2,209,145$ & $1,844,088$ & $1,085,450$ & 321,454 & 43,603 & 5,734 \\
\hline Duval County .......................................... & $\mathrm{FL}$ & 670,683 & 49,826 & 377,064 & 243,793 & 100.0 & 7.4 & 56.2 & 36.3 & 605,002 & 560,115 & 320,032 & 34,220 & 10,667 & 4,615 \\
\hline Escambia County ......... & $\mathrm{FL}$ & 253,872 & 23,786 & 163,740 & 66,346 & 100.0 & 9.4 & 64.5 & 26.1 & 248,818 & 219,741 & 121,197 & 25,360 & 3,717 & 4,909 \\
\hline Hernando County ........ & $\mathrm{FL}$ & 85,365 & 5,240 & 40,667 & 39,458 & 100.0 & 6.1 & 47.6 & 46.2 & 81,510 & 68,469 & 36,597 & 8,065 & 4,976 & 4,613 \\
\hline Hillsborough County ....... & $\mathrm{FL}$ & 886,056 & 80,868 & 496,803 & 308,385 & 100.0 & 9.1 & 56.1 & 34.8 & 873,555 & 747,392 & 424,198 & 111,626 & 14,537 & 5,393 \\
\hline Lake County ............... & $\mathrm{FL}$ & 128,117 & 9,404 & 69,481 & 49,232 & 100.0 & 7.3 & 54.2 & 38.4 & 117,065 & 103,787 & 56,929 & 11,488 & 1,790 & 4,395 \\
\hline Lee County ...... & $\mathrm{FL}$ & 321,370 & 19,260 & 96,896 & 205,214 & 100.0 & 6.0 & 30.2 & 63.9 & 329,814 & 263,842 & 137,470 & 53,651 & 12,321 & 5,340 \\
\hline Leon County ... & $\mathrm{FL}$ & 193,931 & 12,542 & 109,524 & 71,865 & 100.0 & 6.5 & 56.5 & 37.1 & 183,451 & 153,838 & 84,285 & 24,656 & 4,957 & 5,045 \\
\hline Manatee County ...... & $\mathrm{FL}$ & 202,089 & 12,913 & 83,750 & 105,426 & 100.0 & 6.4 & 41.4 & 52.2 & 164,081 & 150,071 & 86,722 & 13,722 & 288 & 4,862 \\
\hline Marion County .............. & $\mathrm{FL}$ & 190,458 & 15,635 & 112,605 & 62,218 & 100.0 & 8.2 & 59.1 & 32.7 & 184,184 & 161,565 & 92,587 & 18,227 & 4,392 & 4,749 \\
\hline Okaloosa County & 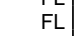 & 151,343 & $\begin{array}{l}12,135 \\
\end{array}$ & 91,373 & 47,835 & 100.0 & 8.0 & 60.4 & 31.6 & 135,481 & 125,243 & 73,261 & 8,821 & 1,417 & 4,314 \\
\hline Oran & & 745,6 & 48,3 & 318 & 379,242 & 100.0 & 6.5 & 42.7 & 50.9 & 632,182 & 580,058 & 302,649 & 36,171 & 15,953 & 4,888 \\
\hline Osc & $\mathrm{FL}$ & 143,6 & 6,5 & & 63,643 & 100. & 4.6 & 51.1 & 44.3 & 133,435 & 109,225 & 58,647 & 19,748 & 4,462 & 4,508 \\
\hline County & $\mathrm{FL}$ & 926,7 & 52,541 & 268 & 605,876 & 100 & 5.7 & 29.0 & 65 & 866 & 691 & 437,330 & 155,562 & 19,482 & 5,420 \\
\hline Pasco County .............. & $\mathrm{FL}$ & 240,850 & 17,100 & 138,700 & 85,050 & 100.0 & 7.1 & 57.6 & 35.3 & 231,555 & 196,456 & 105,875 & 28,327 & 6,772 & 4,897 \\
\hline Pinellas County & $\mathrm{FL}$ & 658,123 & 39,781 & 301,2 & 317,126 & 100.0 & 6.0 & 45.8 & 48.2 & 608,432 & 525 & 309 & 82,038 & 452 & 5,148 \\
\hline 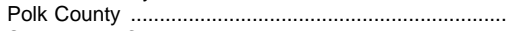 & $\mathrm{FL}$ & 379,653 & 33,100 & 225,0 & 121,538 & 100.0 & 8.7 & 59.3 & 32.0 & 373,047 & 331,874 & 185,461 & 36,710 & 4,463 & 4,655 \\
\hline Santa Rosa County ................... & $\mathrm{FL}$ & 99,827 & 7,428 & 64,277 & 28,122 & 100.0 & 7.4 & 64.4 & 28.2 & 93,111 & 83,693 & 48,963 & 8,324 & 1,094 & 4,411 \\
\hline Sarasota County .... & $\mathrm{FL}$ & 251,644 & 9,253 & 50,994 & 191,397 & 100.0 & 3.7 & 20.3 & 76.1 & 207,146 & 178,513 & 97,210 & 22,845 & 5,788 & 5,866 \\
\hline Seminole County . & $\mathrm{FL}$ & 286,340 & 11,020 & 148,641 & 126,679 & 100.0 & 3.8 & 51.9 & 44.2 & 299,111 & 227,657 & 135,457 & 58,600 & 12,854 & 4,266 \\
\hline Saint Johns County .. & $\mathrm{FL}$ & 102,124 & 4,471 & 44,545 & 53,108 & 100.0 & 4.4 & 43.6 & 52.0 & 88,657 & 72,290 & 38,739 & 12,951 & 3,416 & 4,965 \\
\hline Saint Lucie County ... & $\mathrm{FL}$ & 159,712 & 12,542 & 73,043 & 74,127 & 100.0 & 7.9 & 45.7 & 46.4 & 159,862 & 132,888 & 73,437 & 21,224 & 5,750 & 5,069 \\
\hline Volusia County & $\mathrm{FL}$ & 324,580 & 17,954 & 155,752 & 150,874 & 100.0 & 5.5 & 48.0 & 46.5 & 300,156 & 269,017 & 153,585 & 19,898 & 11,241 & 4,845 \\
\hline Atlanta City .... & GA & 499,845 & 37,661 & 139,998 & 322,186 & 100.0 & 7.5 & 28.0 & 64.5 & 480,586 & 416,105 & 232,222 & 64,481 & 0 & 6,986 \\
\hline & G & & & & 45 & 100.0 & 9.7 & & & & & & & 1,924 & \\
\hline County . & GA & 213 & 15,729 & 92,911 & 104,807 & 100.0 & 7.4 & 43.5 & 49.1 & 255 & 194 & 119,947 & 55,395 & 5,758 & 5,480 \\
\hline County ... & GA & & 3,0 & 56 & 42, & 100.0 & 3.0 & 55.4 & 41.6 & & & & 25,959 & 4,181 & 4,469 \\
\hline County ...………… & GA & $202, \varepsilon$ & 10,655 & 104, & 88,153 & 100.0 & 5.3 & 51.3 & 43.5 & 195 & 186,317 & 109,341 & 7,352 & 1,873 & 4,759 \\
\hline Dunty .. & GA & 401,695 & 6,787 & 191,879 & 203,029 & 100.0 & 1.7 & 47.8 & 50.5 & 401,902 & 379,596 & 246,974 & 11,394 & 10,912 & 4,717 \\
\hline Columbia County .. & GA & 79,932 & 2,714 & 45,616 & 31,602 & 100.0 & 3.4 & 57.1 & 39.5 & 81,139 & 67,878 & 43,486 & 9,990 & 3,271 & 4,010 \\
\hline De Kalb County .. & $\mathrm{GA}$ & 513,712 & 23,582 & 206,064 & 284,066 & 100.0 & 4.6 & 40.1 & 55.3 & 523,449 & 482,571 & 320,799 & 35,033 & 5,845 & 5,764 \\
\hline Dougherty .......... & $\mathrm{GA}$ & 105,016 & 13,979 & 62,127 & 28,910 & 100.0 & 13.3 & 59.2 & 27.5 & 98,242 & 92,068 & 53,228 & 5,906 & 268 & 5,091 \\
\hline Douglas County. & $\mathrm{GA}$ & 77,816 & $\begin{array}{l}3,203 \\
\end{array}$ & 43,766 & 30,847 & 100.0 & 4.1 & 56.2 & 39.6 & 74,718 & 68,119 & 41,626 & 3,653 & 2,946 & 4,538 \\
\hline Fayet & GA & 91,162 & 1,678 & 42,048 & 47,436 & 100.0 & 1.8 & 46.1 & 52.0 & 91,024 & 70,905 & 47,570 & 14,387 & 5,732 & 4,427 \\
\hline ounty & GA & 372,06 & 13,316 & 108,443 & 250,309 & 100.0 & 3.6 & 29.1 & 67.3 & 412,831 & 315,635 & 176,768 & 80,215 & 16,981 & 5,939 \\
\hline punt & GA & 442,880 & 9,362 & 195,744 & 237,774 & 100.0 & 2.1 & 44.2 & 53.7 & 464,003 & 371,929 & 240,091 & 72,717 & 19,357 & 4,636 \\
\hline II County. & $\mathrm{GA}$ & 77,198 & 4,709 & 45,446 & 27,043 & 100.0 & 6.1 & 58.9 & 35.0 & 77,159 & 68,888 & 43,572 & 5,597 & 2,674 & 4,288 \\
\hline Henry County & GA & 75,695 & 2,196 & 38,477 & 35,022 & 100.0 & $2.9 \mid$ & 50.8 & 46.3 & 83,222 & 62,589 & 39,027 & 16,171 & 4,462 & 4,375 \\
\hline
\end{tabular}


Table 94.-Revenues and expenditures of public school districts enrolling more than 15,000 pupils, by state: 1994-95-Continued

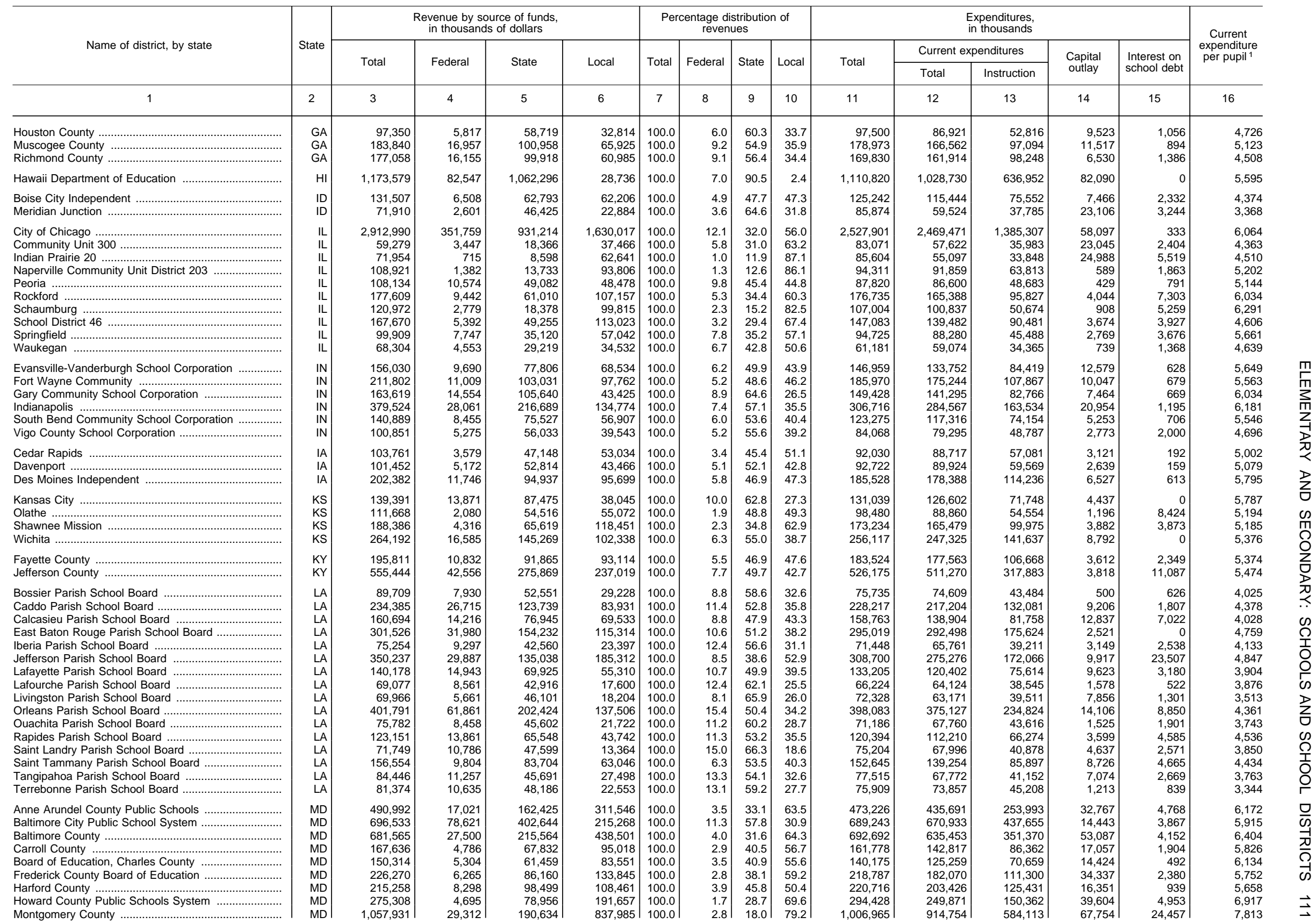




\begin{tabular}{|c|c|c|c|c|c|c|c|c|c|c|c|c|c|c|c|}
\hline \multirow{3}{*}{ Name of district, by state } & \multirow{3}{*}{ State } & \multicolumn{4}{|c|}{$\begin{array}{l}\text { Revenue by source of funds, } \\
\text { in thousands of dollars }\end{array}$} & \multicolumn{4}{|c|}{$\begin{array}{l}\text { Percentage distribution of } \\
\text { revenues }\end{array}$} & \multicolumn{5}{|c|}{$\begin{array}{l}\text { Expenditures, } \\
\text { in thousands }\end{array}$} & \multirow{3}{*}{$\begin{array}{l}\text { Current } \\
\text { expenditure } \\
\text { per pupil } 1\end{array}$} \\
\hline & & \multirow{2}{*}{ Total } & \multirow{2}{*}{ Federal } & \multirow{2}{*}{ State } & \multirow{2}{*}{ Local } & \multirow{2}{*}{ Total } & \multirow{2}{*}{ Federal } & \multirow{2}{*}{ State } & \multirow{2}{*}{ Local } & \multirow{2}{*}{ Total } & \multicolumn{2}{|c|}{ Current expenditures } & \multirow{2}{*}{$\begin{array}{l}\text { Capital } \\
\text { outlay }\end{array}$} & on & \\
\hline & & & & & & & & & & & Total & Instruction & & debt & \\
\hline 1 & 2 & 3 & 4 & 5 & 6 & 7 & 8 & 9 & 10 & 11 & 12 & 13 & 14 & 15 & 16 \\
\hline $\begin{array}{l}\text { Prince George's County Public Schools } \\
\text { Board of Education, Washington County ............................................ }\end{array}$ & $\begin{array}{l}M D \\
M D\end{array}$ & $\begin{array}{l}816,911 \\
127,603\end{array}$ & $\begin{array}{r}40,610 \\
7,674\end{array}$ & $\begin{array}{r}341,338 \\
59,258\end{array}$ & $\begin{array}{r}434,963 \\
60,671\end{array}$ & $\begin{array}{l}100.0 \\
100.0\end{array}$ & $\begin{array}{l}5.0 \\
6.0\end{array}$ & $\begin{array}{l}41.8 \\
46.4\end{array}$ & $\begin{array}{l}53.2 \\
47.5\end{array}$ & $\begin{array}{l}819,704 \\
124,872\end{array}$ & $\begin{array}{l}776,806 \\
113,388\end{array}$ & $\begin{array}{r}453,918 \\
69,816\end{array}$ & $\begin{array}{r}42,778 \\
9,855\end{array}$ & $\begin{array}{r}120 \\
1,629\end{array}$ & $\begin{array}{l}6,557 \\
5,812\end{array}$ \\
\hline 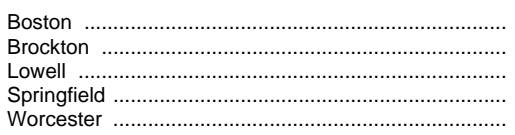 & $\begin{array}{l}\text { MA } \\
\text { MA } \\
\text { MA } \\
\text { MA } \\
\text { MA }\end{array}$ & $\begin{array}{r}598,771 \\
91,169 \\
112,989 \\
193,135 \\
180,901\end{array}$ & $\begin{array}{r}40,715 \\
5,807 \\
10,079 \\
13,702 \\
13,891\end{array}$ & $\begin{array}{r}165,841 \\
8,258 \\
59,106 \\
101,713 \\
93,917\end{array}$ & $\begin{array}{r}392,215 \\
77,104 \\
43,804 \\
77,720 \\
73,093\end{array}$ & $\begin{array}{l}100.0 \\
100.0 \\
100.0 \\
100.0 \\
100.0\end{array}$ & $\begin{array}{l}6.8 \\
6.4 \\
8.9 \\
7.1 \\
7.7\end{array}$ & $\begin{array}{r}27.7 \\
9.1 \\
52.3 \\
52.7 \\
51.9\end{array}$ & $\begin{array}{l}65.5 \\
84.6 \\
38.8 \\
40.2 \\
40.4\end{array}$ & $\begin{array}{r}528,728 \\
85,485 \\
104,577 \\
177,357 \\
158,814\end{array}$ & $\begin{array}{r}505,728 \\
85,317 \\
90,579 \\
173,688 \\
146,281\end{array}$ & $\begin{array}{r}312,037 \\
54,500 \\
60,023 \\
113,405 \\
98,235\end{array}$ & $\begin{array}{r}13,729 \\
0 \\
7,554 \\
0 \\
9,716\end{array}$ & $\begin{array}{r}9,271 \\
168 \\
6,444 \\
3,669 \\
2,817\end{array}$ & $\begin{array}{l}8,225 \\
5,947 \\
6,165 \\
7,227 \\
6,483\end{array}$ \\
\hline 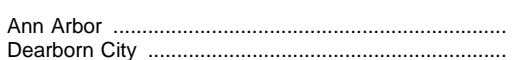 & $\begin{array}{l}\mathrm{Ml} \\
\mathrm{MI}\end{array}$ & $\begin{array}{l}141,849 \\
121,794\end{array}$ & $\begin{array}{l}2,517 \\
4,089\end{array}$ & $\begin{array}{l}65,829 \\
57,086\end{array}$ & $\begin{array}{l}73,503 \\
60,619\end{array}$ & $\begin{array}{l}100.0 \\
100.0\end{array}$ & $\begin{array}{l}1.8 \\
3.4\end{array}$ & $\begin{array}{l}46.4 \\
46.9\end{array}$ & $\begin{array}{l}51.8 \\
49.8\end{array}$ & $\begin{array}{l}126,442 \\
129,266\end{array}$ & $\begin{array}{l}119,516 \\
103,125\end{array}$ & $\begin{array}{l}67,878 \\
60,470\end{array}$ & $\begin{array}{r}3,533 \\
21,323\end{array}$ & $\begin{array}{l}3,393 \\
4,818\end{array}$ & $\begin{array}{l}7,920 \\
7,119\end{array}$ \\
\hline Detroit City …………ㄴ. & $\mathrm{Ml}$ & $1,261,256$ & 107,607 & 997,451 & 156,198 & 100.0 & 8.5 & 79.1 & 12.4 & $1,224,334$ & $1,187,944$ & 794,609 & 17,561 & 18,829 & 6,953 \\
\hline Flint City & $\mathrm{MI}$ & 216,573 & 25,315 & 148,790 & 42,468 & 100.0 & 11.7 & 68.7 & 19.6 & 204,734 & 202,539 & 101,890 & 2,195 & 0 & 7,688 \\
\hline Grand Rapids City ............... & $\mathrm{MI}$ & 223,398 & 18,899 & 145,261 & 59,238 & 100.0 & 8.5 & 65.0 & 26.5 & 216,014 & 194,063 & 106,522 & 15,245 & 6,706 & 7,201 \\
\hline Lansing Public ........ & $\mathrm{MI}$ & 169,403 & 12,067 & 110,752 & 46,584 & 100.0 & 7.1 & 65.4 & 27.5 & 151,947 & 149,656 & 79,049 & 752 & 1,539 & 7,439 \\
\hline Livonia .......... & $\mathrm{MI}$ & 140,386 & 2,447 & 90,889 & 47,050 & 100.0 & 1.7 & 64.7 & 33.5 & 150,460 & 125,176 & 69,935 & 16,688 & 8,596 & 7,140 \\
\hline 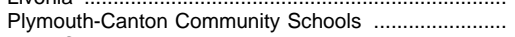 & $\mathrm{MI}$ & 100,245 & 2,192 & 71,060 & 26,993 & 100.0 & 2.2 & 70.9 & 26.9 & 105,356 & 90,133 & 50,866 & 10,743 & 4,480 & 6,024 \\
\hline Utica Community & $\mathrm{MI}$ & 169,908 & 2,534 & 123,696 & 43,678 & 100.0 & 1.5 & 72.8 & 25.7 & 154,689 & 148,188 & 90,040 & 3,027 & 3,474 & 6,058 \\
\hline Wayne-Westland Community ... & MI & 111,114 & 3,324 & 78,101 & 29,689 & 100.0 & 3.0 & 70.3 & 26.7 & 104,415 & 102,766 & 60,265 & 142 & 1,507 & 6,739 \\
\hline Anoka-Hennepin ... & $\mathrm{MN}$ & 243,092 & 6,304 & 146,374 & 90,414 & 100.0 & 2.6 & 60.2 & 37.2 & 232,424 & 211,656 & 129,998 & 15,480 & 5,288 & 5,520 \\
\hline Minneapolis & MN & 409,984 & 28,774 & 166,954 & 214,256 & 100.0 & 7.0 & 40.7 & 52.3 & 391,039 & 355,526 & 211,950 & 28,039 & 7,474 & 7,868 \\
\hline Osseo .......... & $\mathrm{MN}$ & 143,353 & 3,208 & 77,908 & 62,237 & 100.0 & 2.2 & 54.3 & 43.4 & 163,229 & 117,304 & 76,235 & 36,086 & 9,839 & 5,529 \\
\hline Rochester. & $\mathrm{MN}$ & 104,363 & $\begin{array}{l}3,379 \\
3,379\end{array}$ & $\begin{array}{l}46,936 \\
46,1\end{array}$ & 54,048 & 100.0 & 3.2 & 45.0 & 51.8 & $\begin{array}{r}92,067 \\
92,0\end{array}$ & $\begin{array}{r}86,563 \\
\end{array}$ & 55,512 & $\begin{array}{r}r 0,000 \\
3,333\end{array}$ & 2,171 & 5,723 \\
\hline Rosemount-Apple Valley-Eagan . & MN & 146,651 & 3,038 & 80,270 & 63,343 & & 2.1 & 54.7 & 43.2 & 148,831 & 116,621 & 79,277 & 20,765 & 11,445 & 4,679 \\
\hline St. Paul ................................... & MN & 307,347 & 25,883 & 162,369 & 119,095 & 100.0 & 8.4 & 52.8 & 38.7 & 316,202 & 269,584 & 161,167 & 40,338 & 6,280 & 6,618 \\
\hline $\begin{array}{l}\text { Desoto County } \\
\text { Jackson Public }\end{array}$ & $\begin{array}{l}\text { MS } \\
\text { MS }\end{array}$ & $\begin{array}{r}58,646 \\
164,446\end{array}$ & $\begin{array}{r}4,070 \\
19,712\end{array}$ & $\begin{array}{l}34,039 \\
70,044\end{array}$ & $\begin{array}{l}20,537 \\
74,690\end{array}$ & $\begin{array}{l}100.0 \\
100.0\end{array}$ & $\begin{array}{r}6.9 \\
12.0\end{array}$ & $\begin{array}{l}58.0 \\
42.6\end{array}$ & $\begin{array}{l}35.0 \\
45.4\end{array}$ & $\begin{array}{r}62,936 \\
155,358\end{array}$ & $\begin{array}{r}47,175 \\
143,178\end{array}$ & $\begin{array}{l}28,963 \\
85,362\end{array}$ & $\begin{array}{r}13,401 \\
7,565\end{array}$ & $\begin{array}{l}2,360 \\
4615\end{array}$ & $\begin{array}{l}3,085 \\
4,374\end{array}$ \\
\hline $\begin{array}{l}\text { Jackson Public } \\
\text { Columbia }\end{array}$ & mo & 80,361 & 4,603 & $\begin{array}{r}0,044 \\
25,328\end{array}$ & $\begin{array}{l}74,690 \\
50,430\end{array}$ & 100.0 & 5.7 & $\begin{array}{l}42.6 \\
31.5\end{array}$ & $\begin{array}{l}45.4 \\
62.8\end{array}$ & $\begin{array}{r}155,358 \\
86,254\end{array}$ & $\begin{array}{r}143,178 \\
70,788\end{array}$ & $\begin{array}{l}85,362 \\
43,917\end{array}$ & $\begin{array}{r}1,565 \\
11,254\end{array}$ & $\begin{array}{l}4,615 \\
4,212\end{array}$ & $\begin{array}{l}4,374 \\
4,831\end{array}$ \\
\hline Francis Howell. & MO & 80,355 & 1,632 & $\begin{array}{r}20,000 \\
28,413\end{array}$ & $\begin{array}{l}50,430 \\
50,310\end{array}$ & 100.0 & $\begin{array}{l}.1 \\
2.0\end{array}$ & $\begin{array}{l}31.5 \\
35.4\end{array}$ & $\begin{array}{l}62.8 \\
62.6\end{array}$ & $\begin{array}{l}80,254 \\
82,905\end{array}$ & $\begin{array}{l}0,0,88 \\
72,545\end{array}$ & $\begin{array}{l}43,911 \\
47,664\end{array}$ & $\begin{array}{r}11,254 \\
5,775\end{array}$ & $\begin{array}{l}4,212 \\
4,585\end{array}$ & $\begin{array}{l}4,831 \\
4,410\end{array}$ \\
\hline Hazelwood & MO & 94,152 & 1,580 & 20,270 & 72,302 & 100.0 & 1.7 & 21.5 & 76.8 & 97,330 & 89,256 & 53,893 & 6,919 & 1,155 & 4,945 \\
\hline Kansas City & MO & 412,489 & 29,439 & 211,342 & 171,708 & 100.0 & 7.1 & 51.2 & 41.6 & 416,102 & 345,322 & 160,432 & 70,780 & 0 & 9,436 \\
\hline 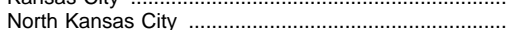 & MO & 86,088 & 2,932 & 20,815 & 62,341 & 100.0 & 3.4 & 24.2 & 72.4 & 81,559 & 77,455 & $\begin{array}{r}50,612 \\
\end{array}$ & 2,740 & 1,364 & 4,721 \\
\hline Parkway _a & MO & 139,235 & 1,985 & 28,838 & 108,412 & 100.0 & $\begin{array}{l}.4 .4 \\
1.4\end{array}$ & 20.7 & 77.9 & 162,158 & 127,653 & 81,480 & 31,314 & $\begin{array}{l}3,004 \\
3,191\end{array}$ & 5,760 \\
\hline Rockwood... & MO & 113,883 & 5,678 & $\begin{array}{l}20,000 \\
25,023\end{array}$ & 83,182 & 100.0 & $\begin{array}{l}5.0 \\
5.0\end{array}$ & 22.0 & 73.0 & 100,804 & 91,234 & 54,801 & $\begin{array}{r}1,327 \\
4,327\end{array}$ & 5,243 & 477 \\
\hline Springfield. & MO & 113,271 & $\begin{array}{l}0,064 \\
7,064\end{array}$ & $\begin{array}{l}25,0<0 \\
34,550\end{array}$ & $\begin{array}{l}00,102 \\
71,657\end{array}$ & 100.0 & $\begin{array}{l}3.0 \\
6.2\end{array}$ & 30.5 & 63.3 & 110,686 & $\begin{array}{r}r,<04 \\
104,700\end{array}$ & 64,145 & $\begin{array}{l}4,3<7 \\
1,797\end{array}$ & 4,189 & 4,227 \\
\hline 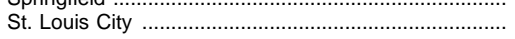 & MO & 377,166 & & 164,446 & $\begin{array}{r}172,131 \\
172,1\end{array}$ & 100.0 & 10.8 & 43.6 & 45.6 & 389,548 & 309,688 & 159,873 & 67,240 & 12,620 & 7,543 \\
\hline Lincoln ………................. & NE & 203,946 & 11,797 & 54,335 & 137,814 & 100.0 & 5.8 & 26.6 & 67.6 & 203,735 & 169,457 & 113,898 & 30,567 & 3,711 & 5,583 \\
\hline Millard . & $\mathrm{NE}$ & 100,077 & 2,243 & 39,727 & 58,107 & 100.0 & 2.2 & 39.7 & 58.1 & 122,140 & 83,271 & 57,403 & 34,370 & 4,499 & 4,658 \\
\hline 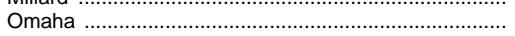 & $\mathrm{NE}$ & 276,352 & 20,477 & 91,626 & 164,249 & 100.0 & 7.4 & 33.2 & 59.4 & 241,536 & 226,764 & 131,630 & 11,808 & 2,964 & 5,204 \\
\hline 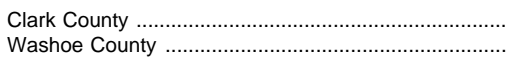 & $\begin{array}{l}\text { NV } \\
\text { NV }\end{array}$ & $\begin{array}{l}834,032 \\
230,344\end{array}$ & $\begin{array}{r}41,500 \\
9,859\end{array}$ & $\begin{array}{r}235,544 \\
44,262\end{array}$ & $\begin{array}{l}556,988 \\
176,223\end{array}$ & $\begin{array}{l}100.0 \\
100.0\end{array}$ & $\begin{array}{l}5.0 \\
4.3\end{array}$ & $\begin{array}{l}28.2 \\
19.2\end{array}$ & $\begin{array}{l}66.8 \\
76.5\end{array}$ & $\begin{array}{l}787,854 \\
275,407\end{array}$ & $\begin{array}{l}716,702 \\
207,036\end{array}$ & $\begin{array}{l}419,790 \\
128,760\end{array}$ & $\begin{array}{r}35,660 \\
53,462\end{array}$ & $\begin{array}{l}35,492 \\
14,909\end{array}$ & $\begin{array}{l}4,584 \\
4,525\end{array}$ \\
\hline Manchester ……......................... & $\mathrm{NH}$ & 80,010 & 4,050 & 3,311 & 72,649 & 100.0 & 5.1 & 4.1 & 90.8 & 74,329 & 72,257 & 47,592 & 229 & 1,843 & 4,603 \\
\hline Camden City ............................ & $\mathrm{NJ}$ & 212,244 & 17,898 & 179,0 & 15,321 & 100.0 & 8.4 & 84.3 & 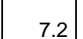 & 207,375 & 196,329 & 107,738 & 9,800 & 1,246 & 9,997 \\
\hline Elizabeth City ………………...... & NJ & 155,212 & $\begin{array}{r}9,761 \\
\end{array}$ & 101,077 & 44,374 & 100.0 & $\begin{array}{l}0.4 \\
6.3\end{array}$ & 65.1 & 28.6 & 146,988 & 137,656 & $\begin{array}{r}77,043 \\
\end{array}$ & 8,559 & 773 & 8,354 \\
\hline Jersey City ..... & NJ & 287,108 & 21,069 & 176,669 & 89,370 & 100.0 & 7.3 & 61.5 & 31.1 & 279,356 & 262,611 & 157,878 & 16,745 & 0 & 8,446 \\
\hline N Newark City …………………………………………........ & NJ & 544,710 & 31,188 & 419,106 & 94,416 & 100.0 & 5.7 & 76.9 & 17.3 & 547,700 & 508,477 & 274,748 & 33,246 & 5,977 & 10,925 \\
\hline Paterson City ........................... & NJ & 240,597 & 18,809 & 176,305 & 45,483 & 100.0 & 7.8 & 73.3 & 18.9 & 215,712 & 210,711 & 130,905 & 5,001 & 0 & 9,199 \\
\hline 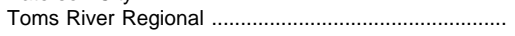 & NJ & 143,895 & 2,842 & 62,770 & 78,283 & 100.0 & 2.0 & 43.6 & 54.4 & 131,252 & 125,030 & 73,936 & 5,663 & 559 & 7,456 \\
\hline $\begin{array}{l}\text { Albuquerque } \\
\text { Las Cruces }\end{array}$ & $\begin{array}{l}\text { NM } \\
\text { NM }\end{array}$ & $\begin{array}{l}445,156 \\
106,670\end{array}$ & $\begin{array}{l}31,788 \\
11,631\end{array}$ & $\begin{array}{r}342,518 \\
80,848\end{array}$ & $\begin{array}{l}70,850 \\
14,191\end{array}$ & $\begin{array}{l}100.0 \\
100.0\end{array}$ & $\begin{array}{r}7.1 \\
10.9\end{array}$ & $\begin{array}{l}76.9 \\
75.8\end{array}$ & $\begin{array}{l}15.9 \\
13.3\end{array}$ & $\begin{array}{r}421,522 \\
95,192\end{array}$ & $\begin{array}{r}373,790 \\
87,419\end{array}$ & $\begin{array}{r}227,673 \\
50,197\end{array}$ & $\begin{array}{r}46,663 \\
5,050\end{array}$ & $\begin{array}{l}1,069 \\
2,723\end{array}$ & $\begin{array}{l}4,200 \\
4,009\end{array}$ \\
\hline $\begin{array}{l}\text { Las Cruces ........ } \\
\text { Buffalo City ........ }\end{array}$ & $N Y$ & $\begin{array}{l}106,670 \\
135,857\end{array}$ & $\begin{array}{l}11,631 \\
37,257\end{array}$ & $\begin{array}{r}80,848 \\
311549\end{array}$ & $\begin{array}{l}14,191 \\
87,051\end{array}$ & 100.0 & $\begin{array}{r}10.9 \\
8.5\end{array}$ & 15.8 & 13.3 & $\begin{array}{r}95,192 \\
920,833\end{array}$ & $\begin{array}{r}87,419 \\
399729\end{array}$ & $\begin{array}{r}50,197 \\
264,282\end{array}$ & $\begin{array}{r}5,050 \\
18300\end{array}$ & 2,723 & 4,009 \\
\hline $\begin{array}{l}\text { Buffalo City ...... } \\
\text { New York City }\end{array}$ & NY & $\begin{array}{r}435,851 \\
8,025,686\end{array}$ & $\begin{array}{r}3,251 \\
846,971\end{array}$ & $\begin{array}{r}311,2599 \\
3,275,295\end{array}$ & $\begin{array}{r}80,031 \\
3,903,420\end{array}$ & $\begin{array}{l}1000.0 \\
100 .\end{array}$ & $\begin{array}{r}8.5 \\
10.6\end{array}$ & $\begin{array}{l}11.5 \\
40.8\end{array}$ & $\begin{array}{ll}20.0 \\
48.6\end{array}$ & $\begin{array}{r}42,2,823 \\
8.938,067\end{array}$ & $\begin{array}{r}39,2,59 \\
7.788,536\end{array}$ & $\begin{array}{r}264,282 \\
5,545,767\end{array}$ & $\begin{array}{r}18,300 \\
884,940\end{array}$ & $\begin{array}{r}4,794 \\
264.591\end{array}$ & $\begin{array}{l}8,399 \\
7,617\end{array}$ \\
\hline $\begin{array}{l}\text { New York City } \\
\text { Rochester City }\end{array}$ & $\begin{array}{l}\text { NY } \\
\text { NY }\end{array}$ & $\begin{array}{r}8,025,686 \\
378,465\end{array}$ & $\begin{array}{r}846,9 / 1 \\
32,854\end{array}$ & $\begin{array}{r}3,2 / 5,295 \\
203,885\end{array}$ & $\begin{array}{l}3,930,420 \\
141,726\end{array}$ & $\begin{array}{l}100.0 \\
100.0\end{array}$ & $\begin{array}{r}10.6 \\
8.7\end{array}$ & $\begin{array}{l}40.8 \\
53.9\end{array}$ & $\begin{array}{l}48.6 \\
37.4\end{array}$ & $\begin{array}{r}8,398,067 \\
363,642\end{array}$ & $\begin{array}{r}, / 88,536 \\
319,446\end{array}$ & $\begin{array}{r}5,545,, 67 \\
202,468\end{array}$ & $\begin{array}{r}884,940 \\
39,975\end{array}$ & $\begin{array}{r}264,591 \\
4,221\end{array}$ & $\begin{array}{l}8,611 \\
8,854\end{array}$ \\
\hline Syracuse City. & NY & 218,334 & 20,330 & 131,851 & 66,153 & 100.0 & 9.3 & 60.4 & 30.3 & 218,493 & 192,722 & 128,866 & 20,765 & 5,006 & 8,203 \\
\hline Yonkers City. & NY & 238,949 & 11,879 & 84,440 & 142,630 & 100.0 & 5.0 & 35.3 & 59.7 & 226,115 & 217,693 & 141,683 & 5,125 & 3,297 & 9,972 \\
\hline Alamance-Burlington & NC & 55,347 & 3,543 & 35,745 & 16,059 & 100.0 & 6.4 & 64.6 & 29.0 & 56,565 & 49,760 & 30,900 & 5,261 & 1,544 & 4,384 \\
\hline
\end{tabular}


Table 94.-Revenues and expenditures of public school districts enrolling more than 15,000 pupils, by state: 1994-95-Continued

\begin{tabular}{|c|c|c|c|c|c|c|c|c|c|c|c|c|c|c|c|}
\hline \multirow{3}{*}{ Name of district, by state } & \multirow{3}{*}{ State } & \multicolumn{4}{|c|}{$\begin{array}{l}\text { Revenue by source of funds, } \\
\text { in thousands of dollars }\end{array}$} & \multicolumn{4}{|c|}{$\begin{array}{l}\text { Percentage distribution of } \\
\text { revenues }\end{array}$} & \multicolumn{5}{|c|}{$\begin{array}{l}\text { Expenditures, } \\
\text { in thousands }\end{array}$} & \multirow{3}{*}{$\begin{array}{c}\text { Current } \\
\text { expenditure } \\
\text { per pupil }{ }^{1}\end{array}$} \\
\hline & & \multirow{2}{*}{ Total } & \multirow{2}{*}{ Federal } & \multirow{2}{*}{ State } & \multirow{2}{*}{ Local } & \multirow{2}{*}{ Total } & Fodout & Stat & | & & Current exp & enditures & Capital & terest on & \\
\hline & & & & & & & Federal & State & | Local & Iotal & Total & Instruction & outlay & debt & \\
\hline 1 & 2 & 3 & 4 & 5 & 6 & 7 & 8 & 9 & 10 & 11 & 12 & 13 & 14 & 15 & 16 \\
\hline Buncombe County ......... & $\mathrm{NC}$ & 128,848 & 6,650 & 79,124 & 43,074 & 100.0 & 5.2 & 61.4 & 33.4 & 132,374 & 115,005 & 71,395 & 13,551 & 3,818 & 4,803 \\
\hline Cabarrus County ............ & NC & 74,030 & 3,942 & 47,755 & 22,333 & 100.0 & 5.3 & 64.5 & 30.2 & 69,084 & 66,761 & 43,584 & 552 & $\begin{array}{l}3,010 \\
1,771\end{array}$ & 4,412 \\
\hline Charlotte-Mecklenburg & $\mathrm{NC}$ & 452,326 & 30,524 & 270,263 & 151,539 & 100.0 & 6.7 & 59.7 & 33.5 & 530,059 & 445,564 & 273,901 & 66,804 & 17,691 & 5,180 \\
\hline Cumberland County . & NC & 230,211 & 27,162 & 151,465 & 51,584 & 100.0 & 11.8 & 65.8 & 22.4 & 247,491 & 219,673 & 136,977 & 25,376 & 2,442 & 4,394 \\
\hline Davidson County ....................... & NC & 72,408 & 3,750 & 54,181 & 14,477 & 100.0 & 5.2 & 74.8 & 20.0 & 82,743 & 72,389 & 46,198 & 9,405 & 949 & 4,186 \\
\hline 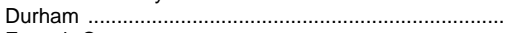 & NC & 158,208 & 8,778 & 87,315 & 62,115 & 100.0 & 5.5 & 55.2 & 39.3 & 191,321 & 155,746 & 91,615 & 26,187 & 9,388 & 5,589 \\
\hline Forsyth County & NC & 211,325 & 10,991 & 125,321 & 75,013 & 100.0 & 5.2 & 59.3 & 35.5 & 218,031 & 205,687 & 129,289 & 7,769 & 4,575 & 5,200 \\
\hline Gaston County & $\mathrm{NC}$ & 133,834 & 8,714 & 94,428 & 30,692 & 100.0 & 6.5 & 70.6 & 22.9 & 150,840 & 128,783 & 84,157 & 21,565 & 492 & 4,408 \\
\hline Guilford County & $\mathrm{NC}$ & 314,444 & 17,262 & 182,642 & 114,540 & 100.0 & 5.5 & 58.1 & 36.4 & 308,367 & 297,907 & 182,088 & 9,367 & 1,093 & 5,350 \\
\hline Johnston County ...................... & NC & 82,818 & 4,631 & 55,874 & 22,313 & 100.0 & 5.6 & 67.5 & 26.9 & 80,921 & 72,642 & 45,063 & 7,886 & 393 & 4,517 \\
\hline Nash-Rocky Mount ..................... & NC & 97,759 & 8,246 & 54,968 & 34,545 & 100.0 & 8.4 & 56.2 & 35.3 & 85,487 & 80,623 & 50,735 & 4,864 & 0 & 4,569 \\
\hline New Hanover County .......... & $\mathrm{NC}$ & 107,412 & 7,395 & 65,499 & 34,518 & 100.0 & 6.9 & 61.0 & 32.1 & 105,459 & 98,121 & 60,904 & 6,711 & 627 & 4,709 \\
\hline Onslow County ........... & $\mathrm{NC}$ & 83,810 & 7,592 & 60,862 & 15,356 & 100.0 & 9.1 & 72.6 & 18.3 & $\begin{array}{r}84,616 \\
\end{array}$ & 80,014 & 49,970 & 3,994 & 608 & 3,957 \\
\hline Pitt County ........ & $\mathrm{NC}$ & 90,695 & 8,205 & 60,993 & 21,497 & 100.0 & 9.0 & 67.3 & 23.7 & 89,390 & 86,808 & 54,105 & 985 & 1,597 & 4,536 \\
\hline Randolph County ....... & $\mathrm{NC}$ & 68,328 & 3,746 & 46,840 & 17,742 & 100.0 & 5.5 & 68.6 & 26.0 & 68,143 & $\begin{array}{l}61,572 \\
6\end{array}$ & 39,046 & 4,497 & 2,074 & 4,147 \\
\hline Robeson County ......... & NC & 108,671 & $\begin{array}{r}14,722 \\
\end{array}$ & 77,135 & $\begin{array}{l}16,814 \\
\end{array}$ & 100.0 & 13.5 & 71.0 & 15.5 & $\begin{array}{r}08,935 \\
\end{array}$ & 105,600 & 66,354 & 2,964 & 371 & 4,498 \\
\hline Rowan-Salisbury ........ & NC & 83,336 & $\begin{array}{r}5,508 \\
5,502\end{array}$ & 59,631 & $\begin{array}{l}18,0,197 \\
18,197\end{array}$ & 100.0 & $\begin{array}{r}0.5 \\
6.6\end{array}$ & 71.6 & 21.8 & 99,789 & 82,103 & $\begin{array}{l}50,459 \\
52,459\end{array}$ & $\begin{array}{r}2,304 \\
16,490\end{array}$ & $\begin{array}{r}5,196 \\
1,1\end{array}$ & $\begin{array}{l}4,490 \\
4,499\end{array}$ \\
\hline Union County ....... & NC & $\begin{array}{l}03,030 \\
85,981\end{array}$ & 4,607 & $\begin{array}{l}55,998 \\
55,931\end{array}$ & 25,376 & 100.0 & $\begin{array}{l}0.0 \\
5.4\end{array}$ & 65.1 & 29.5 & $\begin{array}{l}25,109 \\
83,678\end{array}$ & $\begin{array}{l}0<, 103 \\
78,755\end{array}$ & $\begin{array}{l}5<, 459 \\
49,368\end{array}$ & $\begin{array}{r}10,490 \\
2,450\end{array}$ & 2,473 & $\begin{array}{l}4,499 \\
4,477\end{array}$ \\
\hline Wake County ... & $\mathrm{NC}$ & 476,673 & 17,395 & 236,611 & 222,667 & 100.0 & 3.6 & 49.6 & 46.7 & 442,750 & 357,563 & 221,495 & 68,198 & 16,989 & 4,648 \\
\hline Wayne County. & $\mathrm{NC}$ & 85,612 & 9,813 & 60,068 & 15,731 & 100.0 & 11.5 & 70.2 & 18.4 & 86,710 & 82,786 & 52,435 & 2,825 & 1,099 & 4,471 \\
\hline Akron City . & $\mathrm{OH}$ & 193,978 & 26,074 & 86,476 & 81,428 & 100.0 & 13.4 & 44.6 & 42.0 & 191,126 & 184,315 & 108,958 & 5,607 & 1,204 & 5,503 \\
\hline Cincinnati City …………….......... & $\mathrm{OH}$ & 360,756 & 45,784 & 122,397 & 192,575 & 100.0 & 12.7 & 33.9 & 53.4 & 356,031 & 337,158 & 207,355 & 17,852 & 1,021 & 6,379 \\
\hline Cleveland City ............................ & $\mathrm{OH}$ & 512,249 & 68,679 & 275,610 & 167,960 & 100.0 & 13.4 & 53.8 & 32.8 & 503,318 & 480,505 & 281,352 & 9,056 & 13,757 & 6,511 \\
\hline Columbus City ........... & $\mathrm{OH}$ & 439,538 & 40,923 & 151,251 & 247,364 & 100.0 & 9.3 & 34.4 & 56.3 & 420,856 & 407,461 & 217,904 & 8,214 & 5,181 & 6,192 \\
\hline Dayton City ...... & $\mathrm{OH}$ & 201,866 & 27,099 & 84,055 & 90,712 & 100.0 & 13.4 & 41.6 & 44.9 & 190,075 & 185,996 & 103,954 & 4,059 & 20 & 6,587 \\
\hline South-Western City & $\mathrm{OH}$ & 106,923 & 5,738 & 36,172 & 65,013 & 100.0 & 5.4 & 33.8 & 60.8 & 109,694 & 91,384 & 52,214 & 15,767 & 2,543 & 5,156 \\
\hline Toledo City & $\mathrm{OH}$ & 255,509 & 26,038 & 114,503 & 114,968 & 100.0 & 10.2 & 44.8 & 45.0 & 236,539 & 234,168 & 133,511 & 2,037 & 334 & 6,001 \\
\hline Edmond …….......................... & OK & 68,106 & 1,937 & 35,250 & 30,919 & 100.0 & 2.8 & 51.8 & 45.4 & 70,653 & 57,865 & 35,287 & 9,992 & 2,796 & 3,811 \\
\hline Lawton ……................... & OK & 82,080 & $\begin{array}{r}9,448 \\
5579\end{array}$ & 54,500 & 18,132 & 100.0 & $\begin{array}{r}11.5 \\
17.5\end{array}$ & 66.4 & 22.1 & 82,179 & 81,428 & 46,624 & 751 & 0 & 4,344 \\
\hline Midwest/Del City . & $\begin{array}{l}\text { OK } \\
O K\end{array}$ & $\begin{array}{r}74,741 \\
76\end{array}$ & $\begin{array}{r}5,579 \\
362\end{array}$ & $\begin{array}{r}45,908 \\
501\end{array}$ & 23,254 & $\mid 100.0$ & $\begin{array}{r}7.5 \\
4.4\end{array}$ & 61.4 & 31.1 & $\begin{array}{r}71,990 \\
80325\end{array}$ & 66,442 & 42,120 & 4,336 & 1,212 & 4,217 \\
\hline Moore .............. & OK & 76,546 & 3,362 & 50,514 & 22,670 & $\mid 100.0$ & 4.4 & 66.0 & 29.6 & 80,335 & 71,710 & 44,824 & 7,310 & 1,315 & 3,995 \\
\hline Oklahoma City & OK & 202,182 & 24,792 & 106,339 & 71,051 & $\mid 100.0$ & 12.3 & 52.6 & 35.1 & 238,924 & 181,466 & 105,288 & 51,506 & 5,952 & 4,647 \\
\hline Putnam City ................. & OK & 85,008 & 4,147 & 45,727 & 35,134 & 100. & 4.9 & 53.8 & 41.3 & 81,610 & 74,983 & 45,613 & 3,973 & 2,654 & 3,973 \\
\hline 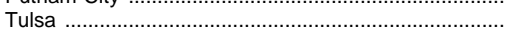 & $\mathrm{OK}$ & 210,285 & 18,705 & 103,750 & 87,830 & 100.0 & 8.9 & 49.3 & 41.8 & 199,579 & 191,705 & 103,379 & 5,212 & 2,662 & 4,699 \\
\hline Beaverton & OR & 144,538 & 4,416 & 54,219 & 85,903 & 100.0 & 3.1 & 37.5 & 59.4 & 142,809 & 133,172 & 80,903 & 4,366 & 5,271 & 4,750 \\
\hline 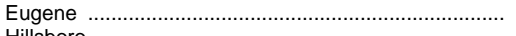 & OR & 109,092 & 7,854 & 45,079 & 56,159 & 100.0 & 7.2 & 41.3 & 51.5 & 123,295 & 97,618 & 61,777 & 22,664 & 3,013 & 5,293 \\
\hline 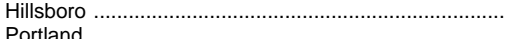 & $\begin{array}{l}O R \\
O R\end{array}$ & & 29,766 & 154.505 & 182548 & 1000 & 8.1 & 121 & 498 & 353.739 & 344,151 & 211968 & 1060 & 8.528 & 6275 \\
\hline $\begin{array}{l}\text { Portland ......... } \\
\text { Salem/Keizer . }\end{array}$ & $\begin{array}{l}\text { OR } \\
\text { OR }\end{array}$ & $\begin{array}{l}366,819 \\
183,787\end{array}$ & $\begin{array}{l}29,766 \\
10,028\end{array}$ & $\begin{array}{r}154,505 \\
94,815\end{array}$ & $\begin{array}{r}182,548 \\
78,944\end{array}$ & \begin{tabular}{|l|}
100.0 \\
100.0
\end{tabular} & $\begin{array}{l}8.1 \\
5.5\end{array}$ & $\begin{array}{l}42.1 \\
51.6\end{array}$ & $\begin{array}{l}49.8 \\
43.0\end{array}$ & $\begin{array}{l}353, / 39 \\
199,530\end{array}$ & $\begin{array}{l}344,151 \\
158,802\end{array}$ & $\begin{array}{r}211,968 \\
98,049\end{array}$ & $\begin{array}{r}1,060 \\
34,654\end{array}$ & $\begin{array}{l}8,528 \\
6,074\end{array}$ & $\begin{array}{l}6,2 / 5 \\
5,502\end{array}$ \\
\hline Allentown City . & $\mathrm{PA}$ & 102,836 & 6,114 & 33,565 & 63,157 & 100.0 & 5.9 & 32.6 & 61.4 & 89,014 & 87,510 & 61,010 & 380 & 1,124 & 5,958 \\
\hline Philadelphia City ... & $\mathrm{PA}$ & $1,389,214$ & 163,445 & 684,446 & 541,323 & 100.0 & 11.8 & 49.3 & 39.0 & $1,102,589$ & $1,065,286$ & 657,215 & 5,446 & 31,857 & 5,104 \\
\hline 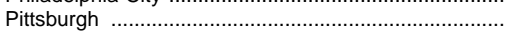 & $\mathrm{PA}$ & 386,767 & 28,389 & 143,356 & 215,022 & 100.0 & 7.3 & 37.1 & 55.6 & 341,392 & 324,832 & 182,073 & 12,340 & 4,220 & 8,179 \\
\hline 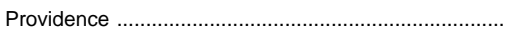 & $\mathrm{RI}$ & 182,183 & 18,714 & 98,340 & 65,129 & 100.0 & 10.3 & 54.0 & 35.7 & 173,748 & 162,140 & 104,040 & 7,732 & 3,876 & 6,873 \\
\hline Aiken County …………………......... & $\mathrm{sc}$ & 114,991 & 9,169 & 57,693 & 48,129 & 100.0 & 8.0 & 50.2 & 41.9 & 111,949 & 97,720 & 59,640 & 12,948 & 1,281 & 3,959 \\
\hline Jounty .... & $\mathrm{sc}$ & & 13,1 & 67 & 38,070 & 100.0 & 11.0 & 57.0 & 31.9 & 110 & 106,871 & 60,914 & 2,392 & 1,145 & 3,899 \\
\hline County & $\mathrm{sc}$ & 230 , & 23,705 & 95,809 & 111,327 & 100.0 & 10.3 & 41.5 & 48.2 & 208,343 & 196,759 & 117,719 & 6,423 & 5,161 & 4,405 \\
\hline & $\mathrm{sc}$ & & & & 26, & 100.0 & 5.7 & 54.9 & 39.5 & & 58,716 & & 1,592 & 2,732 & 3,897 \\
\hline Greenville County ........ & $\mathrm{sc}$ & 270 , & 16,883 & 118, & 134,593 & 100.0 & 6.3 & 43.9 & 49.8 & 257,636 & 232,604 & 137,748 & 20,323 & 4,709 & 4,302 \\
\hline 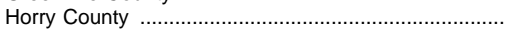 & sc & 143,102 & 11,278 & 48,816 & 83,008 & 100.0 & 7.9 & 34.1 & 58.0 & 133,305 & 122,782 & 73,180 & 6,195 & 4,328 & 4,862 \\
\hline 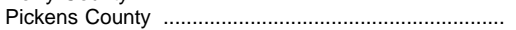 & sc & 69,797 & 4,090 & 34,457 & 31,250 & 100.0 & 5.9 & 49.4 & 44.8 & 68,223 & 62,001 & 40,612 & 4,726 & 1,496 & 4,094 \\
\hline Richland \#2 ............ & $\mathrm{sc}$ & 79,934 & 4,327 & 33,677 & 41,930 & 100.0 & 5.4 & 42.1 & 52.5 & 82,194 & 68,571 & 41,993 & 10,835 & 2,788 & 4,795 \\
\hline Richland \#1 .. & $\mathrm{sc}$ & 161,203 & 15,170 & 58,895 & 87,138 & 100.0 & 9.4 & 36.5 & 54.1 & 156,553 & 145,535 & 83,671 & 8,961 & 2,057 & 5,368 \\
\hline Sioux Falls ......... & SD & 95,462 & 5,056 & 14,918 & 75,488 & 100.0 & 5.3 & 15.6 & 79.1 & 88,337 & 83,759 & 52,246 & 1,247 & 3,331 & 4,637 \\
\hline Chatta! & $\mathrm{TN}$ & 102,890 & 11,761 & 38,928 & 52,201 & $\mid 100.0$ & 11.4 & 37.8 & 50 & 104,905 & 92,641 & 57,815 & 10,375 & 1,889 & 4,576 \\
\hline Hamilton County . & $\mathrm{TN}$ & 105,596 & 5,153 & 44,709 & 55,734 & \begin{tabular}{|l|}
100.0 \\
\end{tabular} & 4.9 & 42.3 & 52.8 & 100,129 & 95,954 & 64,831 & 1,852 & $\begin{array}{l}2,003 \\
2,323\end{array}$ & 3,978 \\
\hline Knox County ........ & TN & 243,518 & 10,158 & 97,433 & 135,927 & 100.0 & 4.2 & 40.0 & 55.8 & 235,564 & 208,616 & 138,982 & 23,162 & 3,786 & 3,990 \\
\hline Memphis City & TN $\mid$ & 529,532 & 60,884 & 221,208 & 247,440 & $|100.0|$ & 11.5 & 41.8 & 46.7 & 504,492 & 480,269 & 299,223 & 23,151 & 1,072 & 4,421 \\
\hline
\end{tabular}


Table 94.-Revenues and expenditures of public school districts enrolling more than 15,000 pupils, by state: 1994-95-Continued

\begin{tabular}{|c|c|c|c|c|c|c|c|c|c|c|c|c|c|c|c|}
\hline \multirow{3}{*}{ Name of district, by state } & \multirow{3}{*}{ State } & \multicolumn{4}{|c|}{$\begin{array}{l}\text { Revenue by source of funds, } \\
\text { in thousands of dollars }\end{array}$} & \multicolumn{4}{|c|}{$\begin{array}{l}\text { Percentage distribution of } \\
\text { revenues }\end{array}$} & \multicolumn{5}{|c|}{$\begin{array}{l}\text { Expenditures, } \\
\text { in thousands }\end{array}$} & \multirow{3}{*}{$\begin{array}{c}\text { Current } \\
\text { expenditure } \\
\text { per pupil }{ }^{1}\end{array}$} \\
\hline & & \multirow{2}{*}{ Total } & \multirow{2}{*}{ Federal } & \multirow{2}{*}{ State } & Local & Total & Federal & State & L L & Total & Current exp & enditures & al & & \\
\hline & & & & & Lucal & Tulal & rederal & Siale & Lucal & Tovil & Total & Instruction & ou & & \\
\hline 1 & 2 & 3 & 4 & 5 & 6 & 7 & 8 & 9 & 10 & 11 & 12 & 13 & 14 & 15 & 16 \\
\hline Montgomery County & $\mathrm{TN}$ & 78,536 & 6,799 & 41,507 & 30,230 & 100.0 & 8.7 & 52.9 & 38.5 & 82,910 & 70,824 & 45,535 & 8,778 & 3,308 & 3,445 \\
\hline 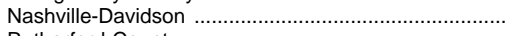 & TN & 361,966 & 27,621 & 131,194 & 203,151 & 100.0 & 7.6 & 36.2 & 56.1 & 386,593 & $\begin{array}{r}342,535 \\
\end{array}$ & 216,349 & 38,508 & 5,550 & 4,786 \\
\hline Rutherford County ................. & TN & 86,260 & 4,215 & 43,764 & 38,281 & 100.0 & 4.9 & 50.7 & 44.4 & 83,199 & 78,974 & 52,116 & 2,129 & 2,096 & 3,784 \\
\hline Shelby County. & TN & 172,784 & 6,516 & 83,192 & 83,076 & 100.0 & 3.8 & 48.1 & 48.1 & 185,529 & 151,409 & 100,799 & 30,021 & 4,099 & 3,453 \\
\hline Sumner County & TN & 84,743 & 4,835 & 44,598 & 35,310 & 100.0 & 5.7 & 52.6 & 41.7 & 81,337 & 77,428 & 50,296 & 1,251 & 2,658 & 3,682 \\
\hline Williamson County ........................... & $\mathrm{TN}$ & 61,167 & 2,100 & 29,084 & 29,983 & 100.0 & 3.4 & 47.5 & 49.0 & 86,856 & 59,228 & 38,147 & 19,600 & 8,028 & 3,955 \\
\hline Abilene ISD & $T X$ & 106,991 & 8,287 & 64,746 & 33,958 & 100.0 & 7.7 & 60.5 & 31.7 & 100,318 & 95,359 & 63,368 & 2,904 & 2,055 & 4,836 \\
\hline Aldine ISD .. & $\mathrm{TX}$ & 228,143 & 11,186 & 121,122 & 95,835 & 100.0 & 4.9 & 53.1 & 42.0 & 245,785 & 216,905 & 138,930 & 24,270 & 4,610 & 4,950 \\
\hline Alief ISD ..... & $\mathrm{TX}$ & 189,274 & 9,208 & 88,191 & 91,875 & 100.0 & 4.9 & 46.6 & 48.5 & 184,406 & 156,234 & 98,161 & 14,809 & 13,363 & 4,505 \\
\hline Amarillo ISD & $\mathrm{TX}$ & 139,324 & 11,133 & 70,403 & 57,788 & 100.0 & 8.0 & 50.5 & 41.5 & 132,911 & 125,944 & 79,264 & 3,707 & 3,260 & 4,255 \\
\hline Arlington ISD & TX & 221,517 & 5,641 & 59,043 & 156,833 & 100.0 & 2.5 & 26.7 & 70.8 & 213,847 & 188,725 & 120,879 & 14,967 & 10,155 & 3,753 \\
\hline Austin ISD .... & TX & 407,812 & 26,922 & 79,683 & 301,207 & 100.0 & 6.6 & 19.5 & 73.9 & 376,081 & 354,093 & 212,369 & 8,425 & 13,563 & 4,838 \\
\hline Beaumont ISD .. & TX & 113,461 & 12,556 & 25,690 & 75,215 & 100.0 & 11.1 & 22.6 & 66.3 & 109,236 & 103,122 & 61,528 & 5,144 & 970 & 5,141 \\
\hline Birdville ISD ........... & TX & 107,040 & 6,584 & 41,966 & 58,490 & 100.0 & 6.2 & 39.2 & 54.6 & 104,035 & 88,434 & 58,530 & 12,942 & 2,659 & 4,481 \\
\hline Brownsville ISD & $\mathrm{TX}$ & 231,566 & 33,644 & 166,619 & 31,303 & 100.0 & 14.5 & 72.0 & 13.5 & 219,567 & 206,936 & 134,825 & 11,057 & 1,574 & 5,159 \\
\hline Carrollton-Farmers Branch is & $\mathrm{TX}$ & 136,249 & $\begin{array}{r}3,744 \\
\end{array}$ & 16,312 & 116,193 & 100.0 & 2.7 & 12.0 & 85.3 & 107,734 & 90,210 & 54,568 & 13,482 & 4,042 & 4,576 \\
\hline Clear Creek ISD .... & $\mathrm{TX}$ & 142,167 & 3,862 & 20,902 & 117,403 & 100.0 & 2.7 & 14.7 & 82.6 & 144,590 & 113,060 & 69,404 & 24,312 & 7,218 & 4,468 \\
\hline Conroe ISD ........ & $\mathrm{TX}$ & 153,520 & 5,164 & 63.405 & 84,951 & 100.0 & 3.4 & 41.3 & 55.3 & 208,652 & 146,651 & 82,612 & 51,409 & 10,592 & 5,326 \\
\hline Corpus Christi ISD & $\mathrm{TX}$ & 219,113 & 20,396 & 110,942 & 87,775 & 100.0 & 9.3 & 50.6 & 40.1 & 209,586 & 194,092 & 119,739 & $\begin{array}{r}9,264 \\
9,404\end{array}$ & 6,230 & 4,632 \\
\hline Cypress-Fairbanks ISD & $\mathrm{TX}$ & 271,586 & 7,499 & 90,200 & 173,887 & 100.0 & 2.8 & 33.2 & 64.0 & 270,286 & 234,004 & 139,008 & 22,832 & 13,450 & 4,740 \\
\hline Dallas ISD & $\mathrm{TX}$ & 773,795 & 74,611 & 174,794 & 524,390 & 100.0 & 9.6 & 22.6 & 67.8 & 17,273 & 744,392 & 441,327 & 55,369 & 17,512 & 5,133 \\
\hline Ector County ISD & $T X$ & 133,114 & 12,430 & 57,780 & 62,904 & 100.0 & 9.3 & 43.4 & 47.3 & 137,035 & 117,614 & 70,312 & 16,005 & 3,416 & 4,176 \\
\hline Edinburg ISD .......... & TX & 103,227 & 12,928 & 65,355 & 24,944 & 100.0 & 12.5 & 63.3 & 24.2 & 112,797 & 91,434 & 56,340 & 18,578 & 2,785 & 5,007 \\
\hline El Paso ISD ......................... & TX & 329,652 & 36,119 & 168,112 & 125,421 & 100.0 & 11.0 & 51.0 & 38.0 & 333,861 & 295,785 & 184,492 & 26,941 & 11,135 & 4,559 \\
\hline Fort Bend ISD ........ & $T X$ & 223,946 & 6,413 & 97,440 & 120,093 & 100.0 & 2.9 & 43.5 & 53.6 & 216,126 & 178,582 & 108,338 & 28,417 & 9,127 & 4,142 \\
\hline Fort Worth ISD & $T X$ & 383,210 & 34,941 & 165,132 & 183,137 & $\mid 100.0$ & 9.1 & 43.1 & 47.8 & 354,771 & 344,092 & 195,813 & 4,598 & 6,081 & 4,756 \\
\hline Galena Park ISD & $\mathrm{TX}$ & 65,164 & 5,892 & 18,023 & 41,249 & $\mid 100.0$ & 9.0 & 27.7 & 63.3 & 80,245 & 72,930 & 41,060 & 5,767 & 1,548 & 4,292 \\
\hline Garland ISD .. & $\mathrm{TX}$ & 203,679 & 8,265 & 91,562 & 103,852 & $\mid 100.0$ & 4.1 & 45.0 & 51.0 & 209,170 & 168,972 & 104,477 & 28,856 & 11,342 & 3,982 \\
\hline Goose Creek ISD .. & $\mathrm{TX}$ & 106,966 & 6,532 & 17,878 & 82,556 & $\mid 100.0$ & 6.1 & 16.7 & 77.2 & 98,046 & 87,689 & 51,664 & 5,506 & 4,851 & 4,916 \\
\hline Grand Prairie ISD ......... & $\mathrm{TX}$ & 88,615 & 5,993 & 46,032 & 36,590 & 100.0 & 6.8 & 51.9 & 41.3 & 80,730 & 74,709 & 45,763 & 3,154 & 2,867 & 4,252 \\
\hline Harlandale ISD .. & $\mathrm{TX}$ & 93,714 & 10,287 & 66,821 & 16,606 & \begin{tabular}{|l|}
100.0 \\
\end{tabular} & 11.0 & 71.3 & 17.7 & 84,297 & 81,704 & 49,263 & 1,547 & 1,046 & 5,546 \\
\hline Harlingen Cons ISD & $\mathrm{TX}$ & 83,022 & 9,749 & 51,683 & 21,590 & \begin{tabular}{|l|}
100.0 \\
\end{tabular} & 11.7 & 62.3 & 26.0 & 74,934 & 70,225 & 45,391 & 3,471 & 1,238 & 4,418 \\
\hline Houston ISD ...... & $\mathrm{TX}$ & $1,043,913$ & 114,850 & 269,808 & 659,255 & \begin{tabular}{|l|} 
\\
100.0
\end{tabular} & 11.0 & 25.8 & 63.2 & $1,050,508$ & 967,353 & 560,358 & 62,643 & 20,512 & 4,785 \\
\hline Humble ISD ....................... & TX & 121,481 & 3,215 & 46,778 & 71,488 & 100.0 & 2.6 & 38.5 & 58.8 & 130,515 & 98,046 & 57,732 & 23,370 & 9,099 & 4,534 \\
\hline Hurst-Euless-Bedford ISD .. & $\mathrm{TX}$ & 98,086 & 3,733 & $\begin{array}{l}40,110 \\
19,848\end{array}$ & $\begin{array}{l}74,500 \\
74,505\end{array}$ & \begin{tabular}{|l|}
1000.0 \\
100
\end{tabular} & 3.8 & 20.2 & 76.0 & 103,954 & $\begin{array}{l}50,210 \\
84,210\end{array}$ & $\begin{array}{l}54,740 \\
54,1\end{array}$ & $\begin{array}{l}20,010 \\
15,558\end{array}$ & 4,186 & $\begin{array}{l}4,393 \\
4,393\end{array}$ \\
\hline Irving ISD & $\mathrm{TX}$ & $\begin{array}{r}130,000 \\
133,688\end{array}$ & $\begin{array}{l}-1,1063 \\
6,663\end{array}$ & $\begin{array}{r}\quad 3,040 \\
33,402\end{array}$ & $\begin{array}{l}93,623 \\
93,023\end{array}$ & \begin{tabular}{|l|}
1000.0 \\
100
\end{tabular} & $\begin{array}{l}.00 \\
5.0\end{array}$ & 25.0 & 70.0 & 129,653 & 113,814 & 71,673 & $\begin{array}{r}9,408 \\
9,498\end{array}$ & 6,341 & 4,409 \\
\hline Judso & $\begin{array}{l}\mathrm{TX} \\
\mathrm{TX}\end{array}$ & $\begin{array}{r}75,000 \\
75,803\end{array}$ & $\begin{array}{l}0,003 \\
4,450\end{array}$ & 40,227 & $\begin{array}{l}93,003 \\
31,126\end{array}$ & \begin{tabular}{|l|}
1000.0 \\
100
\end{tabular} & 5.9 & 53.1 & 41.1 & $\begin{array}{r}74,180 \\
74,180\end{array}$ & $\begin{array}{r}6,014 \\
62,910\end{array}$ & $\begin{array}{l}39,531 \\
39,1\end{array}$ & $\begin{array}{r}\quad, 490 \\
8,098\end{array}$ & $\begin{array}{l}0,041 \\
3,172\end{array}$ & $\begin{array}{l}4,409 \\
4,366\end{array}$ \\
\hline Katy IS & $\mathrm{TX}$ & 128,410 & 3,3 & 40,689 & 84,370 & 100.0 & 2.6 & 31.7 & 65.7 & 135,790 & 103,210 & 64,037 & 24,842 & 7,738 & 4,347 \\
\hline Killeen & $\mathrm{TX}$ & 133,125 & 22,4 & 82, & 28,076 & 100.0 & 16.8 & 62.1 & 21.1 & 149,460 & 113,758 & 67,785 & 33,004 & 2,698 & 4,153 \\
\hline & $\mathrm{TX}$ & & 4,7 & 71 , & 78,722 & \begin{tabular}{|l|} 
\\
100.0
\end{tabular} & 1 & 46.0 & 50.9 & & & & & 9,082 & 4,745 \\
\hline 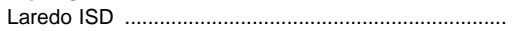 & $\mathrm{TX}$ & 107, & 12,1 & 6 & 25,972 & 10 & 11.3 & 64.6 & & & & 71 & 8,050 & 1,026 & 5,052 \\
\hline Lewis & TX & 13 & & 44, & 83,604 & 10 & 2.7 & 33. & 63.5 & 8 & 57 & 71 & 24,020 & 9,061 & 4,198 \\
\hline & $\mathrm{TX}$ & 16 & 14,98 & 78, & 73,727 & & 9.0 & 46 & & & & 91 & & 3,377 & 4,871 \\
\hline McA & $\mathrm{TX}$ & & 13,6 & 82 & 40,544 & 10 & 10.0 & 60.4 & 29.6 & 11 & & & & 1, & 5,094 \\
\hline …………... & $\mathrm{TX}$ & & 5,1 & 70, & 62,541 & 10 & 3.7 & 51.1 & 45.2 & & & 67,771 & 18,738 & 9,516 & 3,891 \\
\hline 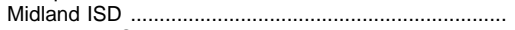 & $T X$ & 110,418 & 9,7 & 49,6 & 50,969 & 10 & 8.8 & 45.0 & 46.2 & 105,947 & 100,389 & 61,395 & 3,628 & 1,930 & 4,351 \\
\hline North East ISD & $T X$ & 240,064 & 11,303 & 75,287 & 153,474 & 100.0 & 4.7 & 31.4 & 63.9 & 216,244 & 205,729 & 128,361 & 6,931 & 3,584 & 4,731 \\
\hline Northside IS & $T X$ & 303,540 & 18,000 & 141,571 & 143,969 & 100.0 & 5.9 & 46.6 & 47.4 & 265,086 & 245,652 & 156,303 & 7,864 & 11,570 & 4,377 \\
\hline Pasadena ISD & $\mathrm{TX}$ & 171,618 & 12,620 & 68,925 & 90,073 & 100.0 & 7.4 & 40.2 & 52.5 & 188,008 & 180,429 & 108,246 & 4,531 & 3,048 & 4,604 \\
\hline Pharr-San Juan-Alamo ISD ........ & $\mathrm{TX}$ & 118,811 & 17,962 & 83,497 & 17,352 & 100.0 & 15.1 & 70.3 & 14.6 & 105,082 & 100,321 & 62,697 & 3,768 & 993 & 5,018 \\
\hline 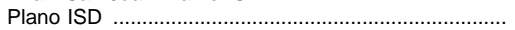 & $\mathrm{TX}$ & 241,482 & 5,311 & 25,438 & 210,733 & 100.0 & 2.2 & 10.5 & 87.3 & 253,618 & 183,955 & 115,077 & 58,753 & 10,910 & 5,050 \\
\hline Richardson ISD & $\mathrm{TX}$ & 198,471 & 5,770 & 25,481 & 167,220 & 100.0 & 2.9 & 12.8 & 84.3 & 183,970 & 162,655 & 98,182 & 14,779 & 6,536 & 4,834 \\
\hline Round Rock ISD & TX & 139,534 & 4,018 & 56,213 & 79,303 & 100.0 & 2.9 & 40.3 & 56.8 & 129,324 & 113,199 & 72,547 & 9,939 & 6,186 & 4.728 \\
\hline San Angelo ISD .... & TX & 72,900 & 6,905 & 36,412 & 29,583 & 100.0 & 9.5 & 49.9 & 40.6 & 76,703 & 72,318 & 46,197 & 4,170 & 215 & 4,163 \\
\hline San Antonio ISD .... & $T \hat{T X}$ & 357,965 & $\begin{array}{r}0,3007 \\
45,367\end{array}$ & 209,616 & $\begin{array}{r}2,000 \\
102,982\end{array}$ & \begin{tabular}{|l|}
1000.0 \\
100
\end{tabular} & 12.7 & 58.6 & 28.8 & 345,142 & 330,576 & 205,264 & 12,217 & 2,349 & 5,471 \\
\hline & $\mathrm{TX}$ & 101,652 & 8,766 & 70,880 & 22,006 & 100.0 & 8.6 & 69.7 & 21.6 & 102,338 & 89,640 & 54,143 & 8,642 & 4,056 & 4,763 \\
\hline nch ISD & $\mathrm{TX}$ & 194 & 12,4 & 2 & 153,900 & 100.0 & 6.4 & 14.3 & 79.3 & 179 & 153,147 & 91 & 19,976 & 6,192 & 5,385 \\
\hline Spr & $\mathrm{TX}$ & $10 €$ & 3,7 & 4 & 60,980 & 10 & 3.6 & 39.1 & 57.4 & 104 & 5 & & 7,880 & 2,062 & 4,788 \\
\hline Tyler ISD & TX & 82, & 7,0 & 29, & 45 , & 100.0 & 8.6 & 35.8 & 55.6 & 78 & 76 & & 623 & 1,600 & 4,594 \\
\hline United ISD ……………………… & $\mathrm{TX}$ & 104,928 & 8,397 & 51,281 & 45,250 & 100.0 & 8.0 & 48.9 & 43.1 & 121,355 & 86,522 & 50,325 & 29,870 & 4,963 & 4,670 \\
\hline Waco ISD ……………....... & $T X \mid$ & 77,426 & 5,460 & 43,836 & 28,130 & $|100.0|$ & 7.1 & 56.6 & 36.3 & 81,931 & 78,640 & 46,129 & 1,819 & 1,472 & 5,053 \\
\hline
\end{tabular}


Table 94.-Revenues and expenditures of public school districts enrolling more than 15,000 pupils, by state: 1994-95-Continued

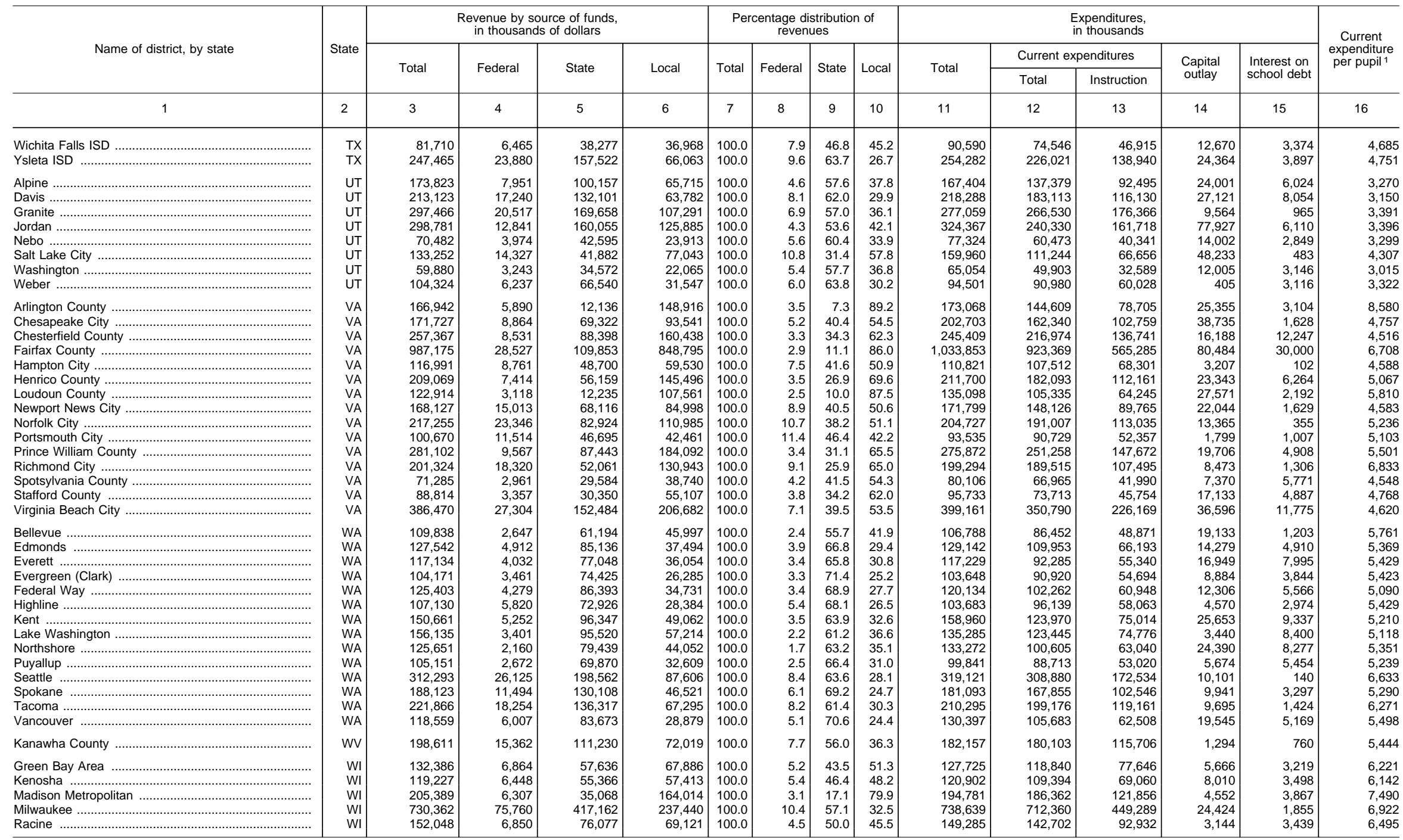

${ }^{1}$ Current expenditure per pupil based on fall enrollment collected by the Bureau of the Census. - $\mathrm{SD}=$ Independent school district.
SOURCE: U.S. Department of Education, National Center for Education Statistics, Common Core of Data survey; and U.S. Department of Commerce, "Survey of Local Government Finances." (This table was prepared December 
Table 95.-Enrollment of the 130 largest public school districts: Fall 1996

\begin{tabular}{|c|c|c|c|c|c|c|c|}
\hline Name of school district & State & $\begin{array}{c}\text { Rank } \\
\text { order }^{1}\end{array}$ & $\begin{array}{l}\text { Enrollment, } \\
\text { fall } 1996\end{array}$ & Name of school district & State & $\begin{array}{c}\text { Rank } \\
\text { order }^{1}\end{array}$ & $\begin{array}{l}\text { Enrollment, } \\
\text { fall } 1996\end{array}$ \\
\hline 1 & 2 & 3 & 4 & 1 & 2 & 3 & 4 \\
\hline $\begin{array}{l}\text { New York City } \\
\text { Los Angeles Unified } \ldots \ldots \ldots \ldots \ldots \ldots \ldots \ldots \ldots \ldots \\
\text { City of Chicago } \\
\text { Dade County } \\
\text { Broward County }\end{array}$ & $\begin{array}{l}\text { NY } \\
\text { CA } \\
\text { IL } \\
\text { FL } \\
\text { FL }\end{array}$ & $\begin{array}{l}1 \\
2 \\
3 \\
4 \\
5\end{array}$ & $\begin{array}{r}1,063,561 \\
667,305 \\
469,098 \\
341,117 \\
218,608\end{array}$ & 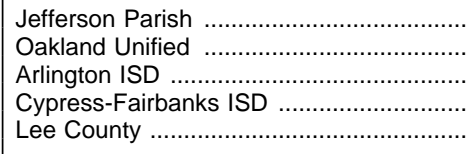 & $\begin{array}{l}\text { LA } \\
\text { CA } \\
\text { TX } \\
\text { TX } \\
\text { FL }\end{array}$ & $\begin{array}{l}66 \\
67 \\
68 \\
69 \\
70\end{array}$ & $\begin{array}{l}55,876 \\
53,462 \\
53,343 \\
52,930 \\
52,317\end{array}$ \\
\hline 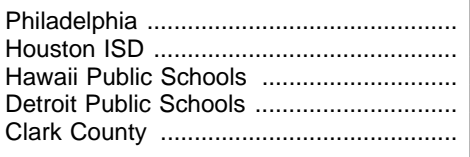 & $\begin{array}{l}\text { PA } \\
\text { TX } \\
\text { HI } \\
\text { MI } \\
\text { NV }\end{array}$ & $\begin{array}{r}6 \\
7 \\
8 \\
9 \\
10\end{array}$ & $\begin{array}{l}212,150 \\
209,375 \\
187,653 \\
182,316 \\
179,106\end{array}$ & 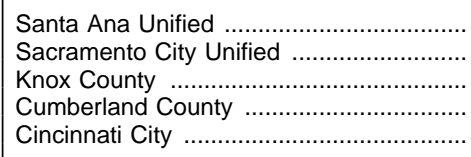 & $\begin{array}{l}\text { CA } \\
\text { CA } \\
\text { TN } \\
\mathrm{NC} \\
\mathrm{OH}\end{array}$ & $\begin{array}{l}71 \\
72 \\
73 \\
74 \\
75\end{array}$ & $\begin{array}{l}52,107 \\
51,240 \\
51,224 \\
51,035 \\
50,396\end{array}$ \\
\hline 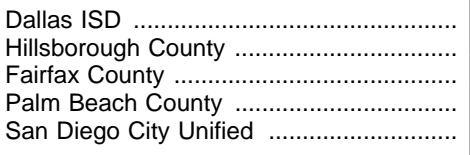 & $\begin{array}{l}\text { TX } \\
\text { FL } \\
\text { VA } \\
\text { FL } \\
\text { CA }\end{array}$ & $\begin{array}{l}11 \\
12 \\
13 \\
14 \\
15\end{array}$ & $\begin{array}{l}154,847 \\
147,826 \\
143,266 \\
137,585 \\
133,687\end{array}$ & 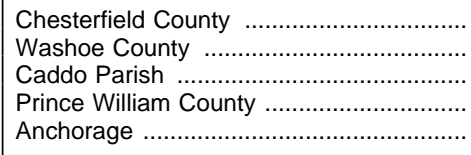 & $\begin{array}{l}\text { VA } \\
\text { NV } \\
\text { LA } \\
\text { VA } \\
\text { AK }\end{array}$ & $\begin{array}{l}76 \\
77 \\
78 \\
79 \\
80\end{array}$ & $\begin{array}{l}49,781 \\
49,671 \\
49,577 \\
48,333 \\
48,109\end{array}$ \\
\hline $\begin{array}{l}\text { Orange County School Board } \ldots \ldots \ldots \ldots \ldots \ldots \\
\text { Duval County } \ldots \ldots \ldots \ldots \ldots \ldots \ldots \ldots \ldots \ldots \ldots \ldots \ldots \\
\text { Prince George's County } \ldots \ldots \ldots \ldots \ldots \ldots \ldots \ldots \ldots \ldots \\
\text { Montgomery County } \\
\text { Memphis City }\end{array}$ & $\begin{array}{l}\text { FL } \\
\text { FL } \\
\text { MD } \\
\text { MD } \\
\text { TN }\end{array}$ & $\begin{array}{l}16 \\
17 \\
18 \\
19 \\
20\end{array}$ & $\begin{array}{l}129,143 \\
126,118 \\
125,198 \\
122,505 \\
111,156\end{array}$ & 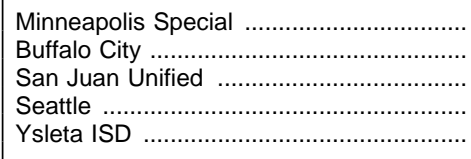 & $\begin{array}{l}\text { MN } \\
\text { NY } \\
\text { CA } \\
\text { WA } \\
\text { TX }\end{array}$ & $\begin{array}{l}81 \\
82 \\
83 \\
84 \\
85\end{array}$ & $\begin{array}{l}47,978 \\
47,845 \\
47,819 \\
47,629 \\
47,366\end{array}$ \\
\hline 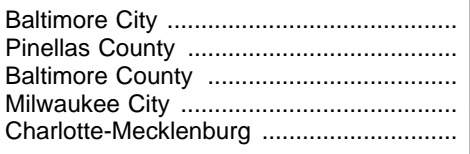 & $\begin{array}{l}\text { MD } \\
\text { FL } \\
\text { MD } \\
\text { WI } \\
\text { NC }\end{array}$ & $\begin{array}{l}21 \\
22 \\
23 \\
24 \\
25\end{array}$ & $\begin{array}{r}108,759 \\
107,060 \\
104,073 \\
101,007 \\
93,533\end{array}$ & Aldine ISD & $\begin{array}{l}\text { TX } \\
\text { TX } \\
\text { TN } \\
\text { KS } \\
\text { CA }\end{array}$ & $\begin{array}{l}86 \\
87 \\
88 \\
89 \\
90\end{array}$ & $\begin{array}{l}47,242 \\
46,881 \\
46,454 \\
46,391 \\
46,309\end{array}$ \\
\hline 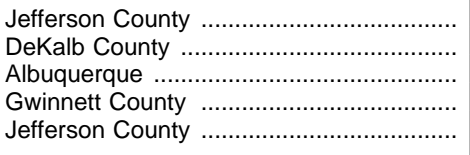 & $\begin{array}{l}\text { KY } \\
\text { GA } \\
\text { NM } \\
\text { GA } \\
\text { CO }\end{array}$ & $\begin{array}{l}26 \\
27 \\
28 \\
29 \\
30\end{array}$ & $\begin{array}{l}91,878 \\
90,311 \\
89,092 \\
88,855 \\
86,670\end{array}$ & 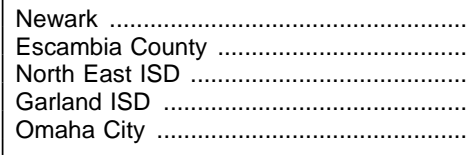 & $\begin{array}{l}\text { NJ } \\
\text { FL } \\
\text { TX } \\
\text { TX } \\
\text { NE }\end{array}$ & $\begin{array}{l}91 \\
92 \\
93 \\
94 \\
95\end{array}$ & $\begin{array}{l}45,805 \\
45,744 \\
45,184 \\
44,869 \\
44,761\end{array}$ \\
\hline 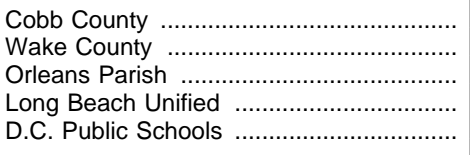 & $\begin{array}{l}\text { GA } \\
\text { NC } \\
\text { LA } \\
\text { CA } \\
\text { DC }\end{array}$ & $\begin{array}{l}31 \\
32 \\
33 \\
34 \\
35\end{array}$ & $\begin{array}{l}85,765 \\
85,735 \\
85,064 \\
83,038 \\
78,648\end{array}$ & 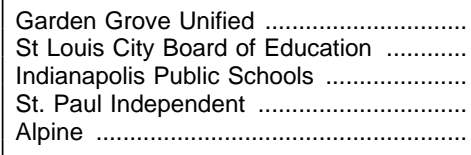 & $\begin{array}{l}\text { CA } \\
\text { MO } \\
\text { IN } \\
\text { MN } \\
\text { UT }\end{array}$ & $\begin{array}{r}96 \\
97 \\
98 \\
99 \\
100\end{array}$ & $\begin{array}{l}44,661 \\
44,620 \\
44,434 \\
43,766 \\
43,719\end{array}$ \\
\hline 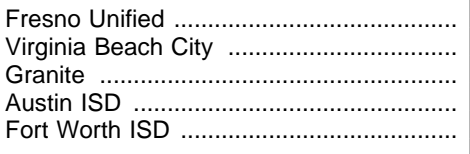 & $\begin{array}{l}\text { CA } \\
\text { VA } \\
\text { UT } \\
\text { TX } \\
\text { TX }\end{array}$ & $\begin{array}{l}36 \\
37 \\
38 \\
39 \\
40\end{array}$ & $\begin{array}{l}78,470 \\
76,677 \\
76,456 \\
76,054 \\
75,813\end{array}$ & $\begin{array}{l}\text { Pasco County School Board } \ldots \ldots \ldots \ldots \ldots \ldots \\
\text { Charleston County } \ldots \ldots \ldots \ldots \ldots \ldots \ldots \ldots \ldots \ldots \\
\text { Forsyth County-Winston-Salem } \ldots \ldots \ldots \ldots \ldots \ldots \\
\text { Jefferson County } \\
\text { Clayton County }\end{array}$ & $\begin{array}{l}F L \\
S C \\
N C \\
\text { AL } \\
\text { GA }\end{array}$ & $\begin{array}{l}101 \\
102 \\
103 \\
104 \\
105\end{array}$ & $\begin{array}{l}43,461 \\
43,457 \\
41,851 \\
41,663 \\
41,658\end{array}$ \\
\hline 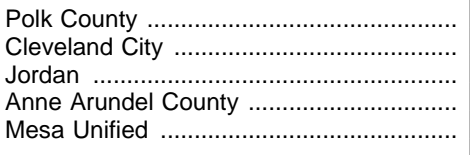 & $\begin{array}{l}\text { FL } \\
\text { OH } \\
\text { UT } \\
\text { MD } \\
\text { AZ }\end{array}$ & $\begin{array}{l}41 \\
42 \\
43 \\
44 \\
45\end{array}$ & $\begin{array}{l}74,808 \\
74,026 \\
72,748 \\
72,322 \\
70,181\end{array}$ & 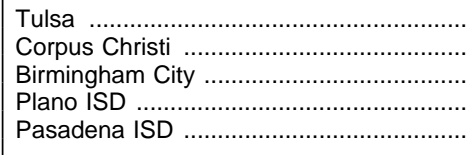 & $\begin{array}{l}\text { OK } \\
\text { TX } \\
\text { AL } \\
\text { TX } \\
\text { TX }\end{array}$ & $\begin{array}{l}106 \\
107 \\
108 \\
109 \\
110\end{array}$ & $\begin{array}{l}41,644 \\
41,606 \\
41,133 \\
40,864 \\
40,512\end{array}$ \\
\hline 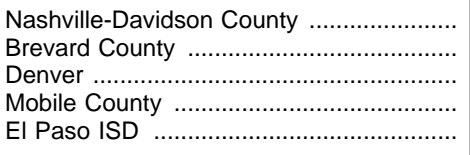 & $\begin{array}{l}\text { TN } \\
\text { FL } \\
\text { CO } \\
\text { AL } \\
\text { TX }\end{array}$ & $\begin{array}{l}46 \\
47 \\
48 \\
49 \\
50\end{array}$ & $\begin{array}{l}69,888 \\
66,663 \\
66,331 \\
64,833 \\
64,444\end{array}$ & 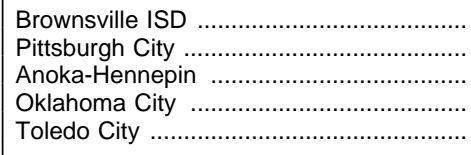 & $\begin{array}{l}\text { TX } \\
\text { PA } \\
\text { MN } \\
\text { OK } \\
\text { OH }\end{array}$ & $\begin{array}{l}111 \\
112 \\
113 \\
114 \\
115\end{array}$ & $\begin{array}{l}40,494 \\
39,955 \\
39,874 \\
39,827 \\
39,712\end{array}$ \\
\hline 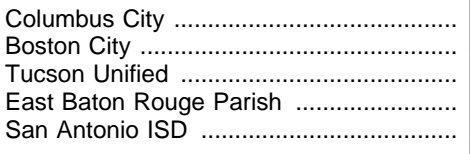 & $\begin{array}{l}\text { OH } \\
\text { MA } \\
\text { AZ } \\
\text { LA } \\
\text { TX }\end{array}$ & $\begin{array}{l}51 \\
52 \\
53 \\
54 \\
55\end{array}$ & $\begin{array}{l}63,894 \\
63,239 \\
62,867 \\
61,499 \\
61,361\end{array}$ & 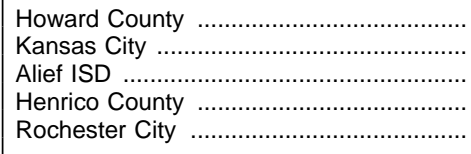 & $\begin{array}{l}\text { MD } \\
\text { MO } \\
\text { TX } \\
\text { VA } \\
\text { NY }\end{array}$ & $\begin{array}{l}116 \\
117 \\
118 \\
119 \\
120\end{array}$ & $\begin{array}{l}38,857 \\
38,521 \\
38,383 \\
38,102 \\
37,912\end{array}$ \\
\hline 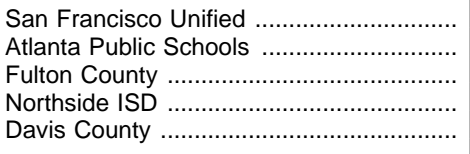 & $\begin{array}{l}\text { CA } \\
\text { GA } \\
\text { GA } \\
\text { TX } \\
\text { UT }\end{array}$ & $\begin{array}{l}56 \\
57 \\
58 \\
59 \\
60\end{array}$ & $\begin{array}{l}61,174 \\
60,064 \\
59,953 \\
59,284 \\
59,220\end{array}$ & 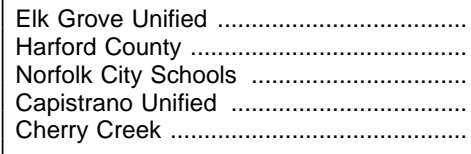 & $\begin{array}{l}\text { CA } \\
\text { MD } \\
\text { VA } \\
\text { CA } \\
\text { CO }\end{array}$ & $\begin{array}{l}121 \\
122 \\
123 \\
124 \\
125\end{array}$ & $\begin{array}{l}37,787 \\
37,709 \\
37,672 \\
37,539 \\
37,128\end{array}$ \\
\hline 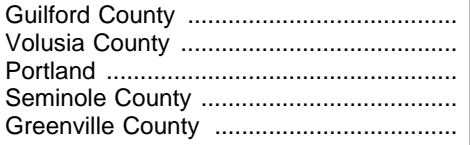 & $\begin{array}{l}\text { NC } \\
\text { FL } \\
\text { OR } \\
\text { FL } \\
\text { SC }\end{array}$ & $\begin{array}{l}61 \\
62 \\
63 \\
64 \\
65\end{array}$ & $\begin{array}{l}58,736 \\
58,004 \\
56,856 \\
55,972 \\
55,893\end{array}$ & 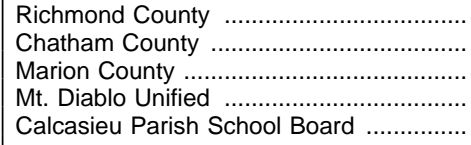 & $\begin{array}{l}\text { GA } \\
\text { GA } \\
\text { FL } \\
\text { CA } \\
\text { LA }\end{array}$ & $\begin{array}{l}126 \\
127 \\
128 \\
129 \\
130\end{array}$ & $\begin{array}{l}36,826 \\
36,382 \\
36,242 \\
35,834 \\
35,782\end{array}$ \\
\hline
\end{tabular}


Table 96.-Public elementary and secondary schools, by type of school: 1967-68 to 1996-97

\begin{tabular}{|c|c|c|c|c|c|c|c|c|c|c|c|c|c|}
\hline \multirow{3}{*}{ Year } & \multirow{3}{*}{$\begin{array}{l}\text { Total, } \\
\text { all } \\
\text { public } \\
\text { schools }\end{array}$} & \multicolumn{11}{|c|}{ Schools with reported grade spans } & \multirow{3}{*}{$\begin{array}{l}\text { Other } \\
\text { schools }\end{array}$} \\
\hline & & \multirow[b]{2}{*}{ Total $^{1}$} & \multicolumn{4}{|c|}{ Elementary schools } & \multicolumn{5}{|c|}{ Secondary schools } & \multirow[b]{2}{*}{$\begin{array}{l}\text { Combined } \\
\text { elementary/ } \\
\text { secondary } \\
\text { schools }^{6}\end{array}$} & \\
\hline & & & Total $^{2}$ & $\begin{array}{l}\text { Middle } \\
\text { schools }^{3}\end{array}$ & $\begin{array}{l}\text { One- } \\
\text { teacher } \\
\text { schools }\end{array}$ & $\begin{array}{l}\text { Other } \\
\text { elementary } \\
\text { schools }\end{array}$ & Total $^{4}$ & $\begin{array}{l}\text { Junior } \\
\text { high } 5\end{array}$ & $\begin{array}{l}\text { 3-year or } \\
\text { 4-year } \\
\text { high } \\
\text { schools }\end{array}$ & $\begin{array}{l}\text { 5-year or } \\
\text { 6-year } \\
\text { high } \\
\text { schools }\end{array}$ & $\begin{array}{l}\text { Other } \\
\text { sec- } \\
\text { ondary } \\
\text { schools }\end{array}$ & & \\
\hline 1 & 2 & 3 & 4 & 5 & 6 & 7 & 8 & 9 & 10 & 11 & 12 & 13 & 14 \\
\hline $\begin{array}{rrr}1967-68 & \ldots \ldots \ldots \ldots \\
1970-71 & \ldots \ldots \ldots \ldots . . . \\
1972-73 & \ldots \ldots \ldots \ldots . . \\
1974-75 & \ldots \ldots \ldots \ldots . . . \\
1975-76 & \ldots \ldots \ldots \ldots . . .\end{array}$ & $\begin{array}{r}- \\
\frac{-}{-} \\
88,597\end{array}$ & $\begin{array}{l}94,197 \\
89,372 \\
88,864 \\
87,456 \\
87,034\end{array}$ & $\begin{array}{l}67,186 \\
64,020 \\
62,942 \\
61,759 \\
61,704\end{array}$ & $\begin{array}{l}-\overline{2} \\
2,080 \\
2,308 \\
3,224 \\
3,916\end{array}$ & $\begin{array}{l}4,146 \\
1,815 \\
1,475 \\
1,247 \\
1,166\end{array}$ & $\begin{array}{l}63,040 \\
60,125 \\
59,159 \\
57,288 \\
56,622\end{array}$ & $\begin{array}{l}23,318 \\
23,572 \\
23,919 \\
23,837 \\
23,792\end{array}$ & $\begin{array}{l}7,437 \\
7,750 \\
7,878 \\
7,690 \\
7,521\end{array}$ & $\begin{array}{l}10,751 \\
11,265 \\
11,550 \\
11,480 \\
11,572\end{array}$ & $\begin{array}{l}4,650 \\
3,887 \\
3,962 \\
4,122 \\
4,113\end{array}$ & $\begin{array}{l}480 \\
670 \\
529 \\
545 \\
586\end{array}$ & $\begin{array}{l}3,693 \\
1,780 \\
2,003 \\
1,860 \\
1,538\end{array}$ & $\begin{array}{r}- \\
- \\
1,563\end{array}$ \\
\hline $\begin{array}{ll}1976-77 & \ldots \ldots \ldots \ldots \\
1978-79 & \ldots \ldots \ldots \ldots . . . \\
1980-81 & \ldots \ldots \ldots \ldots . . \\
1982-83 & \ldots \ldots \ldots \ldots . . . \\
1983-84 & \ldots \ldots \ldots \ldots . . .\end{array}$ & $\begin{array}{r}- \\
85,982 \\
84,740 \\
84,178\end{array}$ & $\begin{array}{l}86,501 \\
84,816 \\
83,688 \\
82,039 \\
81,418\end{array}$ & $\begin{array}{l}61,123 \\
60,312 \\
59,326 \\
58,051 \\
57,471\end{array}$ & $\begin{array}{l}4,180 \\
5,879 \\
6,003 \\
6,875 \\
6,885\end{array}$ & $\begin{array}{r}1,111 \\
1,056 \\
921 \\
798 \\
838\end{array}$ & $\begin{array}{l}55,832 \\
53,377 \\
52,402 \\
50,378 \\
49,748\end{array}$ & $\begin{array}{l}23,857 \\
22,834 \\
22,619 \\
22,383 \\
22,336\end{array}$ & $\begin{array}{l}7,434 \\
6,282 \\
5,890 \\
5,948 \\
5,936\end{array}$ & $\begin{array}{l}11,658 \\
11,410 \\
10,758 \\
11,678 \\
11,670\end{array}$ & $\begin{array}{l}4,130 \\
4,429 \\
4,193 \\
4,067 \\
4,046\end{array}$ & $\begin{array}{r}635 \\
713 \\
1,778 \\
690 \\
684\end{array}$ & $\begin{array}{l}1,521 \\
1,670 \\
1,743 \\
1,605 \\
1,611\end{array}$ & $\begin{array}{r}- \\
2,294 \\
2,701 \\
2,760\end{array}$ \\
\hline $\begin{array}{ll}1984-85 & \ldots \ldots \ldots \ldots \\
1986-87 & \ldots \ldots \ldots \ldots \\
1987-88 & \ldots \ldots \ldots \ldots . . . \\
1988-89 & \ldots \ldots \ldots \ldots \ldots \\
1989-90 & \ldots \ldots \ldots \ldots \ldots\end{array}$ & $\begin{array}{l}84,007 \\
83,455 \\
83,248 \\
83,165 \\
83,425\end{array}$ & $\begin{array}{l}81,147 \\
82,190 \\
81,416 \\
81,579 \\
81,880\end{array}$ & $\begin{array}{l}57,231 \\
58,801 \\
57,575 \\
57,941 \\
58,419\end{array}$ & $\begin{array}{l}6,893 \\
7,452 \\
7,641 \\
7,957 \\
8,272\end{array}$ & $\begin{array}{l}825 \\
763 \\
729 \\
583 \\
630\end{array}$ & $\begin{array}{l}49,513 \\
50,586 \\
49,205 \\
49,401 \\
49,517\end{array}$ & $\begin{array}{l}22,320 \\
21,406 \\
21,662 \\
21,403 \\
21,181\end{array}$ & $\begin{array}{l}5,916 \\
5,142 \\
4,900 \\
4,687 \\
4,512\end{array}$ & $\begin{array}{l}11,671 \\
11,453 \\
11,279 \\
11,350 \\
11,492\end{array}$ & $\begin{array}{l}4,021 \\
4,197 \\
4,048 \\
3,994 \\
3,812\end{array}$ & $\begin{array}{r}712 \\
614 \\
1,435 \\
1,372 \\
1,365\end{array}$ & $\begin{array}{l}1,596 \\
1,983 \\
2,179 \\
2,235 \\
2,280\end{array}$ & $\begin{array}{l}2,860 \\
81,265 \\
81,832 \\
81,586 \\
81,545\end{array}$ \\
\hline $\begin{array}{ll}1990-91 & \ldots \ldots \ldots \ldots \\
1991-92 & \ldots \ldots \ldots \ldots . . \\
1992-93 & \ldots \ldots \ldots \ldots \\
1993-94 & \ldots \ldots \ldots \ldots . . \\
1994-95 & \ldots \ldots \ldots \ldots \ldots\end{array}$ & $\begin{array}{l}84,538 \\
84,578 \\
84,497 \\
85,393 \\
86,221\end{array}$ & $\begin{array}{l}82,475 \\
82,506 \\
82,896 \\
83,431 \\
84,476\end{array}$ & $\begin{array}{l}59,015 \\
59,258 \\
59,676 \\
60,052 \\
60,808\end{array}$ & $\begin{array}{l}8,545 \\
8,829 \\
9,152 \\
9,573 \\
9,954\end{array}$ & $\begin{array}{l}617 \\
569 \\
430 \\
442 \\
458\end{array}$ & $\begin{array}{l}49,853 \\
49,860 \\
50,094 \\
50,037 \\
50,396\end{array}$ & $\begin{array}{l}21,135 \\
20,767 \\
20,671 \\
20,705 \\
20,904\end{array}$ & $\begin{array}{l}4,561 \\
4,298 \\
4,115 \\
3,970 \\
3,859\end{array}$ & $\begin{array}{l}11,537 \\
11,528 \\
11,651 \\
11,858 \\
12,058\end{array}$ & $\begin{array}{l}3,723 \\
3,699 \\
3,613 \\
3,595 \\
3,628\end{array}$ & $\begin{array}{l}1,314 \\
1,242 \\
1,292 \\
1,282 \\
1,359\end{array}$ & $\begin{array}{l}2,325 \\
2,481 \\
2,549 \\
2,674 \\
2,764\end{array}$ & $\begin{array}{l}2,063 \\
2,072 \\
1,601 \\
1,962 \\
1,745\end{array}$ \\
\hline $\begin{array}{l}1995-96 \\
1996-97\end{array}$ & $\begin{array}{l}87,125 \\
88,223\end{array}$ & $\begin{array}{l}84,958 \\
86,092\end{array}$ & $\begin{array}{l}61,165 \\
61,805\end{array}$ & $\begin{array}{l}10,205 \\
10,499\end{array}$ & $\begin{array}{l}474 \\
487\end{array}$ & $\begin{array}{l}50,486 \\
50,819\end{array}$ & $\begin{array}{l}20,997 \\
21,307\end{array}$ & $\begin{array}{l}3,743 \\
3,707\end{array}$ & $\begin{array}{l}12,168 \\
12,424\end{array}$ & $\begin{array}{l}3,621 \\
3,614\end{array}$ & $\begin{array}{l}1,465 \\
1,562\end{array}$ & $\begin{array}{l}2,796 \\
2,980\end{array}$ & $\begin{array}{l}2,167 \\
2,131\end{array}$ \\
\hline
\end{tabular}

1 Excludes special education, alternative, and other schools not classified by grade span.

2 Includes schools beginning with grade 6 or below and with no grade higher than 8 .

3 Includes schools with grade spans beginning with 4,5 , or 6 and ending with grade 6,7 , or 8 .

${ }^{4}$ Includes schools with no grade lower than 7.

${ }^{5}$ Includes schools with grades 7 and 8 or grades 7 through 9 .

${ }^{6}$ Includes schools beginning with grade 6 or lower and ending with grade 9 or above. ${ }^{7}$ Includes special education, alternative, and other schools not classified by grade span.
${ }^{8}$ Because of revision in data collection procedures, figures not comparable to data for other years.

-Data not available.

NOTE.-Some data revised from previously published figures.

SOURCE: U.S. Department of Education, National Center for Education Statistics, Statistics of State School Systems; and Common Core of Data surveys. (This table was prepared August 1998.)

Table 97.-Public elementary and secondary schools, by type and size of school: 1996-97

\begin{tabular}{|c|c|c|c|c|c|c|c|c|c|c|c|c|}
\hline \multirow{3}{*}{ Enrollment size of school } & \multicolumn{6}{|c|}{ Number of schools, by type } & \multicolumn{6}{|c|}{ Enrollment, by type of school ${ }^{1}$} \\
\hline & \multirow{2}{*}{ Total $^{2}$} & \multirow{2}{*}{$\begin{array}{c}\text { Elemen- } \\
\text { tary }^{3}\end{array}$} & \multicolumn{2}{|c|}{ Secondary ${ }^{4}$} & \multirow{2}{*}{$\begin{array}{l}\text { Com- } \\
\text { bined } \\
\text { elemen- } \\
\text { tary/sec- } \\
\text { ondary } 5\end{array}$} & \multirow{2}{*}{ Other ${ }^{2}$} & \multirow{2}{*}{ Total $^{2}$} & \multirow{2}{*}{$\begin{array}{l}\text { Elemen- } \\
\text { tary }^{3}\end{array}$} & \multicolumn{2}{|c|}{ Secondary ${ }^{4}$} & \multirow{2}{*}{$\begin{array}{l}\text { Com- } \\
\text { bined } \\
\text { elemen- } \\
\text { tary/sec- } \\
\text { ondary } 5\end{array}$} & \multirow{2}{*}{ Other ${ }^{2}$} \\
\hline & & & $\begin{array}{c}\text { All } \\
\text { schools }\end{array}$ & $\begin{array}{l}\text { Regular } \\
\text { schools }^{6}\end{array}$ & & & & & All schools & $\begin{array}{l}\text { Regular } \\
\text { schools }^{6}\end{array}$ & & \\
\hline 1 & 2 & 3 & 4 & 5 & 6 & 7 & 8 & 9 & 10 & 11 & 12 & 13 \\
\hline 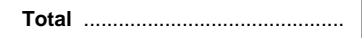 & 88,223 & 61,805 & 21,307 & 18,207 & 2,980 & 2,131 & $45,364,791$ & $29,572,370$ & $14,564,205$ & $14,138,959$ & $1,151,966$ & 76,250 \\
\hline Percent $^{7}$ & 100.00 & 100.00 & 100.00 & 100.00 & 100.00 & 100.00 & 100.00 & 100.00 & 100.00 & 100.00 & 100.00 & 100.00 \\
\hline $\begin{array}{l}\text { Under } 100 \\
100 \text { to } 199 \\
200 \text { to } 299 \\
300 \text { to } 399 \\
400 \text { to } 499\end{array}$ & $\begin{array}{r}9.22 \\
9.43 \\
11.27 \\
13.20 \\
13.24\end{array}$ & $\begin{array}{r}5.98 \\
8.70 \\
12.21 \\
15.38 \\
15.79\end{array}$ & $\begin{array}{r}14.26 \\
10.54 \\
8.61 \\
7.66 \\
6.90\end{array}$ & $\begin{array}{l}8.03 \\
9.66 \\
8.66 \\
8.07 \\
7.52\end{array}$ & $\begin{array}{r}31.54 \\
15.23 \\
10.27 \\
7.79 \\
6.51\end{array}$ & $\begin{array}{r}60.04 \\
18.65 \\
10.83 \\
6.04 \\
1.95\end{array}$ & $\begin{array}{r}0.82 \\
2.68 \\
5.39 \\
8.75 \\
11.27\end{array}$ & $\begin{array}{r}0.60 \\
2.75 \\
6.47 \\
11.24 \\
14.81\end{array}$ & $\begin{array}{l}0.96 \\
2.20 \\
3.04 \\
3.80 \\
4.40\end{array}$ & $\begin{array}{l}0.59 \\
1.84 \\
2.78 \\
3.63 \\
4.34\end{array}$ & $\begin{array}{l}3.59 \\
5.68 \\
6.44 \\
7.02 \\
7.53\end{array}$ & $\begin{array}{r}19.40 \\
19.33 \\
19.31 \\
15.12 \\
6.34\end{array}$ \\
\hline 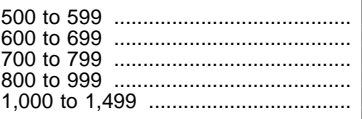 & $\begin{array}{r}11.77 \\
8.78 \\
6.15 \\
7.41 \\
6.22\end{array}$ & $\begin{array}{r}13.83 \\
9.87 \\
6.64 \\
7.13 \\
3.96\end{array}$ & $\begin{array}{r}6.66 \\
6.24 \\
5.21 \\
8.76 \\
13.30\end{array}$ & $\begin{array}{r}7.29 \\
6.88 \\
5.79 \\
9.85 \\
14.92\end{array}$ & $\begin{array}{l}6.51 \\
5.57 \\
3.46 \\
5.23 \\
4.87\end{array}$ & $\begin{array}{l}0.53 \\
0.00 \\
0.36 \\
0.53 \\
0.71\end{array}$ & $\begin{array}{r}12.23 \\
10.78 \\
8.71 \\
12.47 \\
14.08\end{array}$ & $\begin{array}{r}15.83 \\
13.33 \\
10.36 \\
13.16 \\
9.60\end{array}$ & $\begin{array}{r}5.20 \\
5.76 \\
5.55 \\
11.15 \\
23.13\end{array}$ & $\begin{array}{r}5.16 \\
5.74 \\
5.59 \\
11.35 \\
23.50\end{array}$ & $\begin{array}{r}9.20 \\
9.33 \\
6.72 \\
12.14 \\
15.15\end{array}$ & $\begin{array}{l}2.07 \\
0.00 \\
1.98 \\
3.38 \\
6.49\end{array}$ \\
\hline 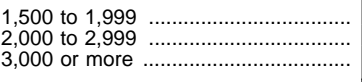 & $\begin{array}{l}2.00 \\
1.11 \\
0.20 \\
\end{array}$ & $\begin{array}{l}0.41 \\
0.08 \\
0.00\end{array}$ & $\begin{array}{l}6.82 \\
4.26 \\
0.76 \\
\end{array}$ & $\begin{array}{l}7.66 \\
4.81 \\
0.86 \\
\end{array}$ & $\begin{array}{l}1.88 \\
0.84 \\
0.30 \\
\end{array}$ & $\begin{array}{l}0.18 \\
0.00 \\
0.18 \\
\end{array}$ & $\begin{array}{l}6.51 \\
4.96 \\
1.36 \\
\end{array}$ & $\begin{array}{l}1.42 \\
0.39 \\
0.04 \\
\end{array}$ & $\begin{array}{r}16.71 \\
14.27 \\
3.84 \\
\end{array}$ & $\begin{array}{r}16.99 \\
14.57 \\
3.94 \\
\end{array}$ & $\begin{array}{l}8.35 \\
5.11 \\
3.75 \\
\end{array}$ & $\begin{array}{l}2.05 \\
0.00 \\
4.51 \\
\end{array}$ \\
\hline Average enrollment ${ }^{7} \ldots \ldots \ldots \ldots \ldots \ldots \ldots \ldots$ & 527 & 478 & 703 & 777 & 387 & 135 & 527 & 478 & 703 & 777 & 387 & $\overline{135}$ \\
\hline
\end{tabular}

${ }^{1}$ These enrollment data should be regarded as approximations only. Totals differ from those reported in other tables because this table represents data reported by schools rather than by states or school districts. Percent distribution and average enrollment calculations exclude data for schools not reporting enrollment.

2 Includes special education, alternative, and other schools not classified by grade span.

3 Includes schools beginning with grade 6 or below and with no grade higher than 8 . ${ }^{4}$ Includes schools with no grade lower than 7 .
5 Includes schools beginning with grade 6 or below and ending with grade 9 or above. ${ }^{6}$ Excludes special education schools, vocational schools, and alternative schools. 7 Data are for schools reporting their enrollment size. NOTE.-Because of rounding, details may not add to totals.

SOURCE: U.S. Department of Education, National Center for Education Statistics, Common Core of Data survey. (This table was prepared August 1998.) 
Table 98.-Public elementary and secondary schools, by type and state: 1990-91 to 1996-97

\begin{tabular}{|c|c|c|c|c|c|c|c|c|c|c|c|c|c|}
\hline \multirow[b]{3}{*}{ State or other area } & \multirow[b]{3}{*}{$\begin{array}{l}\text { Total, all } \\
\text { schools, } \\
1990-91\end{array}$} & \multirow[b]{3}{*}{$\begin{array}{l}\text { Total, all } \\
\text { schools, } \\
\text { 1994-95 }\end{array}$} & \multirow[b]{3}{*}{$\begin{array}{l}\text { Total, all } \\
\text { schools, } \\
1995-96\end{array}$} & \multicolumn{10}{|c|}{ Number of schools, 1996-97 } \\
\hline & & & & \multirow[b]{2}{*}{ Total } & \multirow[b]{2}{*}{$\begin{array}{l}\text { Elemen- } \\
\text { tary }^{1}\end{array}$} & \multirow[b]{2}{*}{$\begin{array}{l}\text { Second- } \\
\text { ary }^{2}\end{array}$} & \multicolumn{4}{|c|}{ Combined elementary/secondary ${ }^{3}$} & \multirow[b]{2}{*}{ Other ${ }^{4}$} & \multirow[b]{2}{*}{$\begin{array}{c}\text { Alter- } \\
\text { native }{ }^{5}\end{array}$} & \multirow[b]{2}{*}{$\begin{array}{l}\text { Special } \\
\text { edu- } \\
\text { cation } 5\end{array}$} \\
\hline & & & & & & & Total & $\begin{array}{c}\text { pre- } \\
\text { kindergar- } \\
\text { ten, kin- } \\
\text { dergar- } \\
\text { ten, or } \\
\text { 1st grade } \\
\text { to grade } \\
12\end{array}$ & $\begin{array}{c}\text { Other } \\
\text { schools } \\
\text { ending } \\
\text { with grade } \\
12\end{array}$ & $\begin{array}{c}\text { Other } \\
\text { combined } \\
\text { schools }\end{array}$ & & & \\
\hline 1 & 2 & 3 & 4 & 5 & 6 & 7 & 8 & 9 & 10 & 11 & 12 & 13 & 14 \\
\hline United States & 84,538 & 86,221 & 87,125 & 88,223 & 61,805 & 21,307 & 2,980 & 1,568 & 773 & 639 & 2,131 & 3,428 & 2,058 \\
\hline 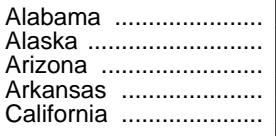 & $\begin{array}{r}1,297 \\
498 \\
1,049 \\
1,098 \\
7,913\end{array}$ & $\begin{array}{r}1,309 \\
498 \\
1,136 \\
1,073 \\
7,821\end{array}$ & $\begin{array}{r}1,319 \\
495 \\
1,133 \\
1,098 \\
7,876\end{array}$ & $\begin{array}{r}1,345 \\
497 \\
1,340 \\
1,104 \\
7,984\end{array}$ & $\begin{array}{r}874 \\
191 \\
934 \\
680 \\
5,835\end{array}$ & $\begin{array}{r}304 \\
89 \\
299 \\
415 \\
1,886\end{array}$ & $\begin{array}{r}162 \\
205 \\
32 \\
9 \\
191\end{array}$ & $\begin{array}{r}126 \\
153 \\
15 \\
7 \\
123\end{array}$ & \begin{tabular}{r|}
18 \\
7 \\
7 \\
1 \\
56
\end{tabular} & $\begin{array}{r}18 \\
45 \\
10 \\
1 \\
12\end{array}$ & $\begin{array}{r}5 \\
12 \\
75 \\
0 \\
72\end{array}$ & $\begin{array}{r}21 \\
35 \\
63 \\
0 \\
777\end{array}$ & $\begin{array}{r}19 \\
3 \\
16 \\
0 \\
127\end{array}$ \\
\hline 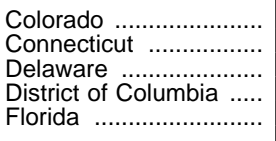 & $\begin{array}{r}1,344 \\
985 \\
173 \\
181 \\
2,516\end{array}$ & $\begin{array}{r}1,460 \\
1,045 \\
182 \\
175 \\
2,733\end{array}$ & $\begin{array}{r}1,486 \\
1,045 \\
181 \\
186 \\
2,760\end{array}$ & $\begin{array}{r}1,531 \\
1,027 \\
183 \\
184 \\
2,801\end{array}$ & $\begin{array}{r}1,079 \\
782 \\
120 \\
129 \\
1,969\end{array}$ & $\begin{array}{r}354 \\
201 \\
44 \\
39 \\
466\end{array}$ & $\begin{array}{r}30 \\
37 \\
19 \\
3 \\
357\end{array}$ & $\begin{array}{r}9 \\
15 \\
13 \\
0 \\
190\end{array}$ & $\begin{array}{r}11 \\
4 \\
2 \\
0 \\
83\end{array}$ & $\begin{array}{r}10 \\
18 \\
4 \\
3 \\
84\end{array}$ & $\begin{array}{r}68 \\
7 \\
0 \\
13 \\
9\end{array}$ & $\begin{array}{r}105 \\
35 \\
3 \\
8 \\
278\end{array}$ & $\begin{array}{r}13 \\
23 \\
28 \\
10 \\
102\end{array}$ \\
\hline 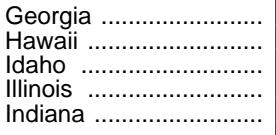 & $\begin{array}{r}1,734 \\
235 \\
582 \\
4,239 \\
1,915\end{array}$ & $\begin{array}{r}1,767 \\
242 \\
608 \\
4,195 \\
1,912\end{array}$ & $\begin{array}{r}1,763 \\
246 \\
618 \\
4,142 \\
1,924\end{array}$ & $\begin{array}{r}1,798 \\
249 \\
629 \\
4,185 \\
1,929\end{array}$ & $\begin{array}{r}1,420 \\
189 \\
393 \\
3,076 \\
1,410\end{array}$ & $\begin{array}{r}308 \\
47 \\
208 \\
983 \\
451\end{array}$ & $\begin{array}{r}70 \\
13 \\
23 \\
112 \\
32\end{array}$ & $\begin{array}{r}19 \\
6 \\
15 \\
58 \\
14\end{array}$ & $\begin{array}{r}42 \\
3 \\
4 \\
30 \\
15\end{array}$ & $\begin{array}{r}9 \\
4 \\
4 \\
24 \\
3\end{array}$ & $\begin{array}{r}0 \\
0 \\
5 \\
14 \\
36\end{array}$ & $\begin{array}{r}0 \\
1 \\
50 \\
74 \\
40\end{array}$ & $\begin{array}{r}0 \\
4 \\
17 \\
247 \\
42\end{array}$ \\
\hline 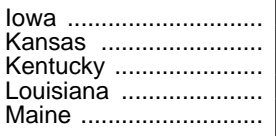 & $\begin{array}{r}1,588 \\
1,477 \\
1,400 \\
1,533 \\
747\end{array}$ & $\begin{array}{r}1,554 \\
1,491 \\
1,374 \\
1,459 \\
733\end{array}$ & $\begin{array}{r}1,556 \\
1,487 \\
1,402 \\
1,470 \\
726\end{array}$ & $\begin{array}{r}1,552 \\
1,464 \\
1,407 \\
1,477 \\
721\end{array}$ & $\begin{array}{r}1,071 \\
1,028 \\
974 \\
1,007 \\
546\end{array}$ & $\begin{array}{l}444 \\
425 \\
361 \\
319 \\
159\end{array}$ & $\begin{array}{r}29 \\
8 \\
7 \\
124 \\
12\end{array}$ & $\begin{array}{r}4 \\
2 \\
0 \\
88 \\
10\end{array}$ & \begin{tabular}{r|r}
22 \\
3 \\
1 \\
17 \\
1
\end{tabular} & $\begin{array}{r}3 \\
3 \\
6 \\
19 \\
1\end{array}$ & $\begin{array}{r}8 \\
3 \\
65 \\
27 \\
4\end{array}$ & $\begin{array}{r}33 \\
17 \\
54 \\
58 \\
0\end{array}$ & $\begin{array}{r}14 \\
1 \\
8 \\
39 \\
1\end{array}$ \\
\hline 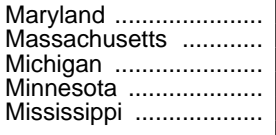 & $\begin{array}{r}1,220 \\
1,842 \\
3,313 \\
1,590 \\
972\end{array}$ & $\begin{array}{l}1,263 \\
1,831 \\
3,432 \\
2,100 \\
1,018\end{array}$ & $\begin{array}{l}1,276 \\
1,850 \\
3,748 \\
2,157 \\
1,011\end{array}$ & $\begin{array}{l}1,286 \\
1,856 \\
3,853 \\
2,116 \\
1,007\end{array}$ & $\begin{array}{r}1,043 \\
1,471 \\
2,530 \\
1,100 \\
569\end{array}$ & $\begin{array}{l}217 \\
335 \\
821 \\
624 \\
307\end{array}$ & $\begin{array}{r}19 \\
30 \\
102 \\
72 \\
74\end{array}$ & $\begin{array}{l}12 \\
17 \\
43 \\
14 \\
61\end{array}$ & $\begin{array}{r}3 \\
8 \\
39 \\
30 \\
10\end{array}$ & $\begin{array}{r}4 \\
5 \\
20 \\
28 \\
3\end{array}$ & $\begin{array}{r}7 \\
20 \\
400 \\
320 \\
57\end{array}$ & $\begin{array}{r}30 \\
30 \\
135 \\
508 \\
40\end{array}$ & $\begin{array}{r}48 \\
7 \\
203 \\
111 \\
0\end{array}$ \\
\hline $\begin{array}{l}\text { Missouri } \\
\text { Montana ............................ } \\
\text { Nebraska ...................... } \\
\text { Nevada ................ } \\
\text { New Hampshire ............ }\end{array}$ & $\begin{array}{r}2,199 \\
900 \\
1,506 \\
354 \\
439\end{array}$ & $\begin{array}{r}2,234 \\
899 \\
1,419 \\
421 \\
458\end{array}$ & $\begin{array}{r}2,256 \\
894 \\
1,411 \\
423 \\
460\end{array}$ & $\begin{array}{r}2,291 \\
892 \\
1,396 \\
442 \\
512\end{array}$ & $\begin{array}{r}1,494 \\
526 \\
999 \\
327 \\
411\end{array}$ & $\begin{array}{l}629 \\
366 \\
360 \\
100 \\
100\end{array}$ & $\begin{array}{r}33 \\
0 \\
20 \\
8 \\
1\end{array}$ & $\begin{array}{l}7 \\
0 \\
8 \\
2 \\
0\end{array}$ & $\begin{array}{r}18 \\
0 \\
6 \\
5 \\
0\end{array}$ & $\begin{array}{l}8 \\
0 \\
6 \\
1 \\
1\end{array}$ & $\begin{array}{r}135 \\
0 \\
17 \\
7 \\
0\end{array}$ & $\begin{array}{r}60 \\
3 \\
0 \\
23 \\
0\end{array}$ & $\begin{array}{r}67 \\
2 \\
63 \\
13 \\
0\end{array}$ \\
\hline 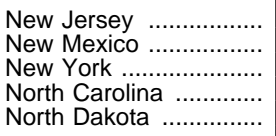 & $\begin{array}{r}2,272 \\
681 \\
4,010 \\
1,955 \\
663\end{array}$ & $\begin{array}{r}2,295 \\
715 \\
4,130 \\
1,968 \\
623\end{array}$ & $\begin{array}{r}2,279 \\
721 \\
4,149 \\
1,985 \\
613\end{array}$ & $\begin{array}{r}2,279 \\
732 \\
4,172 \\
2,005 \\
609\end{array}$ & $\begin{array}{r}1,770 \\
541 \\
3,004 \\
1,544 \\
349\end{array}$ & $\begin{array}{l}427 \\
181 \\
919 \\
399 \\
222\end{array}$ & $\begin{array}{r}7 \\
3 \\
148 \\
59 \\
5\end{array}$ & $\begin{array}{r}1 \\
0 \\
82 \\
32 \\
2\end{array}$ & $\begin{array}{r}4 \\
1 \\
47 \\
14 \\
2\end{array}$ & \begin{tabular}{r|}
2 \\
2 \\
19 \\
13 \\
1
\end{tabular} & $\begin{array}{r}75 \\
7 \\
101 \\
3 \\
33\end{array}$ & $\begin{array}{r}0 \\
27 \\
71 \\
51 \\
0\end{array}$ & $\begin{array}{l}79 \\
17 \\
88 \\
25 \\
31\end{array}$ \\
\hline 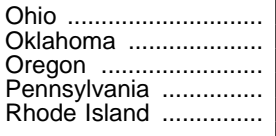 & $\begin{array}{r}3,731 \\
1,880 \\
1,199 \\
3,260 \\
309\end{array}$ & $\begin{array}{r}3,812 \\
1,824 \\
1,213 \\
3,190 \\
308\end{array}$ & $\begin{array}{r}3,865 \\
1,830 \\
1,216 \\
3,182 \\
310\end{array}$ & $\begin{array}{r}3,876 \\
1,828 \\
1,222 \\
3,178 \\
316\end{array}$ & $\begin{array}{r}2,718 \\
1,220 \\
913 \\
2,344 \\
255\end{array}$ & $\begin{array}{r}958 \\
598 \\
257 \\
791 \\
57\end{array}$ & $\begin{array}{r}115 \\
0 \\
48 \\
29 \\
2\end{array}$ & $\begin{array}{r}44 \\
0 \\
34 \\
7 \\
2\end{array}$ & \begin{tabular}{r|}
17 \\
0 \\
10 \\
12 \\
0
\end{tabular} & $\begin{array}{r}54 \\
0 \\
4 \\
10 \\
0\end{array}$ & $\begin{array}{r}85 \\
10 \\
4 \\
14 \\
2\end{array}$ & $\begin{array}{r}19 \\
0 \\
42 \\
11 \\
3\end{array}$ & $\begin{array}{r}37 \\
15 \\
15 \\
11 \\
4\end{array}$ \\
\hline 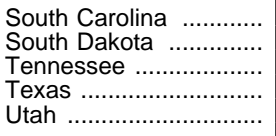 & $\begin{array}{r}1,097 \\
802 \\
1,543 \\
5,991 \\
714\end{array}$ & $\begin{array}{r}1,094 \\
827 \\
1,554 \\
6,465 \\
728\end{array}$ & $\begin{array}{r}1,095 \\
824 \\
1,563 \\
6,638 \\
735\end{array}$ & $\begin{array}{r}1,088 \\
832 \\
1,565 \\
6,875 \\
742\end{array}$ & $\begin{array}{r}796 \\
508 \\
1,127 \\
4,654 \\
479\end{array}$ & $\begin{array}{r}277 \\
309 \\
350 \\
1,790 \\
234\end{array}$ & $\begin{array}{r}15 \\
0 \\
53 \\
431 \\
16\end{array}$ & $\begin{array}{r}5 \\
0 \\
35 \\
203 \\
5\end{array}$ & $\begin{array}{r}10 \\
0 \\
8 \\
120 \\
7\end{array}$ & $\begin{array}{r}0 \\
0 \\
10 \\
108 \\
4\end{array}$ & $\begin{array}{r}0 \\
15 \\
35 \\
0 \\
13\end{array}$ & $\begin{array}{r}15 \\
11 \\
12 \\
389 \\
42\end{array}$ & $\begin{array}{r}10 \\
13 \\
19 \\
224 \\
23\end{array}$ \\
\hline 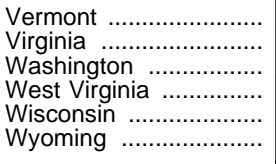 & $\begin{array}{r}397 \\
1,811 \\
1,936 \\
1,015 \\
2,018 \\
415\end{array}$ & $\begin{array}{r}394 \\
1,851 \\
2,064 \\
883 \\
2,030 \\
411 \\
\end{array}$ & $\begin{array}{r}384 \\
1,889 \\
2,124 \\
877 \\
2,037 \\
410\end{array}$ & $\begin{array}{r}395 \\
1,895 \\
2,180 \\
869 \\
2,096 \\
411\end{array}$ & $\begin{array}{r}270 \\
1,395 \\
1,324 \\
622 \\
1,508 \\
287\end{array}$ & $\begin{array}{r}69 \\
393 \\
542 \\
208 \\
547 \\
118 \\
\end{array}$ & $\begin{array}{r}22 \\
22 \\
110 \\
22 \\
37 \\
2\end{array}$ & $\begin{array}{r}16 \\
3 \\
47 \\
11 \\
8 \\
0 \\
\end{array}$ & $\begin{array}{r}6 \\
13 \\
33 \\
1 \\
20 \\
2\end{array}$ & $\begin{array}{r}0 \\
6 \\
30 \\
10 \\
9 \\
0 \\
\end{array}$ & $\begin{array}{r}34 \\
85 \\
204 \\
17 \\
4 \\
4 \\
\end{array}$ & $\begin{array}{r}1 \\
63 \\
132 \\
14 \\
36 \\
8 \\
\end{array}$ & $\begin{array}{r}60 \\
57 \\
71 \\
12 \\
14 \\
5 \\
\end{array}$ \\
\hline $\begin{array}{l}\text { Department of Defense } \\
\text { dependents schools. }\end{array}$ & - & - & 171 & 165 & 109 & 41 & 15 & 11 & 3 & 1 & 0 & 0 & 0 \\
\hline $\begin{array}{l}\text { Outlying areas } \\
\text { American Samoa ......... } \\
\text { Guam ..................... } \\
\text { Northern Marianas } \\
\text { Puerto Rico ................. } \\
\text { Virgin Islands .............. } \\
\end{array}$ & $\begin{array}{r}30 \\
35 \\
26 \\
1,619 \\
33 \\
\end{array}$ & $\begin{array}{r}31 \\
35 \\
25 \\
1,566 \\
32 \\
\end{array}$ & $\begin{array}{r}31 \\
35 \\
24 \\
1,561 \\
34 \\
\end{array}$ & $\begin{array}{r}31 \\
35 \\
26 \\
1,555 \\
35 \\
\end{array}$ & $\begin{array}{r}24 \\
30 \\
22 \\
960 \\
23 \\
\end{array}$ & $\begin{array}{r}6 \\
5 \\
4 \\
365 \\
11 \\
\end{array}$ & $\begin{array}{r}0 \\
0 \\
0 \\
196 \\
1 \\
\end{array}$ & $\begin{array}{l}0 \\
0 \\
0 \\
1 \\
0 \\
\end{array}$ & \begin{tabular}{l|l}
0 \\
0 \\
0 \\
1 \\
0 \\
\end{tabular} & $\begin{array}{r}0 \\
0 \\
0 \\
194 \\
1 \\
\end{array}$ & $\begin{array}{r}1 \\
0 \\
0 \\
34 \\
0\end{array}$ & $\begin{array}{l}0 \\
0 \\
0 \\
9 \\
1\end{array}$ & $\begin{array}{r}1 \\
0 \\
0 \\
22 \\
0 \\
\end{array}$ \\
\hline
\end{tabular}

${ }^{1}$ Includes schools beginning with grade 6 or below and with no grade higher than 8 . 2 Includes schools with no grade lower than 7.

${ }^{3}$ Includes schools beginning with grade 6 or below and ending with grade 9 or above. ${ }^{4}$ Includes special education, alternative, and other schools not classified by grade span.
${ }^{5}$ Schools are also included under elementary, secondary, combined, or other as appropriate.

-Data not available.

SOURCE: U.S. Department of Education, National Center for Education Statistics, Common Core of Data survey. (This table was prepared August 1998.) 
Table 99.-Public elementary schools, by grade span and average school size, by state: 1996-97

\begin{tabular}{|c|c|c|c|c|c|c|c|c|c|c|}
\hline \multirow[b]{2}{*}{ State or other area } & \multirow[b]{2}{*}{$\begin{array}{l}\text { Total, all } \\
\text { elementary } \\
\text { schools }\end{array}$} & \multirow[b]{2}{*}{$\begin{array}{l}\text { Total, all } \\
\text { regular } \\
\text { elementary } \\
\text { schools }^{1}\end{array}$} & \multicolumn{6}{|c|}{ Schools, by grade span } & \multicolumn{2}{|c|}{$\begin{array}{l}\text { Average number of } \\
\text { students per school } 2\end{array}$} \\
\hline & & & $\begin{array}{c}\text { Prekinder- } \\
\text { garten, } \\
\text { kindergarten, } \\
\text { or 1st grade } \\
\text { to grades } 3 \\
\text { or } 4\end{array}$ & $\begin{array}{l}\text { Prekinder- } \\
\text { garten, } \\
\text { kindergarten, } \\
\text { or } 1 \text { st grade } \\
\text { to grade } 5\end{array}$ & $\begin{array}{l}\text { Prekinder- } \\
\text { garten, } \\
\text { kindergarten, } \\
\text { or } 1 \text { st grade } \\
\text { to grade } 6\end{array}$ & $\begin{array}{l}\text { Prekinder- } \\
\text { garten, kin- } \\
\text { dergarten, or } \\
\text { 1st grade to } \\
\text { grade } 8\end{array}$ & $\begin{array}{l}\text { Grades } 4,5, \\
\text { or } 6 \text { to } 6,7 \text {, } \\
\quad \text { or } 8\end{array}$ & $\begin{array}{l}\text { Other grade } \\
\text { spans }\end{array}$ & $\begin{array}{l}\text { All } \\
\text { elementary } \\
\text { schools }\end{array}$ & $\begin{array}{l}\text { Regular } \\
\text { elementary } \\
\text { schools }{ }^{1}\end{array}$ \\
\hline 1 & 2 & 3 & 4 & 5 & 6 & 7 & 8 & 9 & 10 & 11 \\
\hline United States ......... & 61,805 & 60,912 & 4,910 & 20,570 & 15,578 & 4,543 & 10,499 & 5,705 & 478 & 483 \\
\hline 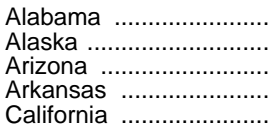 & $\begin{array}{r}874 \\
191 \\
934 \\
680 \\
5,835\end{array}$ & $\begin{array}{r}862 \\
190 \\
912 \\
680 \\
5,787\end{array}$ & $\begin{array}{r}87 \\
5 \\
53 \\
93 \\
175\end{array}$ & $\begin{array}{r}251 \\
27 \\
204 \\
68 \\
1,872\end{array}$ & $\begin{array}{r}194 \\
108 \\
291 \\
352 \\
2,240\end{array}$ & $\begin{array}{r}79 \\
20 \\
172 \\
7 \\
569\end{array}$ & $\begin{array}{r}177 \\
16 \\
128 \\
95 \\
741\end{array}$ & $\begin{array}{r}86 \\
15 \\
86 \\
65 \\
238\end{array}$ & $\begin{array}{l}489 \\
357 \\
560 \\
394 \\
629\end{array}$ & $\begin{array}{l}495 \\
358 \\
568 \\
394 \\
633\end{array}$ \\
\hline 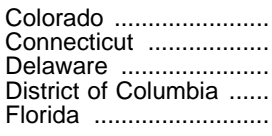 & $\begin{array}{r}1,079 \\
782 \\
120 \\
129 \\
1,969\end{array}$ & $\begin{array}{r}1,077 \\
775 \\
112 \\
128 \\
1,911\end{array}$ & $\begin{array}{r}35 \\
81 \\
39 \\
8 \\
26\end{array}$ & $\begin{array}{r}504 \\
306 \\
15 \\
13 \\
1,233\end{array}$ & $\begin{array}{r}231 \\
142 \\
10 \\
87 \\
191\end{array}$ & $\begin{array}{r}19 \\
40 \\
3 \\
4 \\
33\end{array}$ & $\begin{array}{r}209 \\
142 \\
29 \\
12 \\
384\end{array}$ & $\begin{array}{r}81 \\
71 \\
24 \\
5 \\
102\end{array}$ & $\begin{array}{l}422 \\
465 \\
567 \\
413 \\
783\end{array}$ & $\begin{array}{l}422 \\
468 \\
601 \\
415 \\
801\end{array}$ \\
\hline 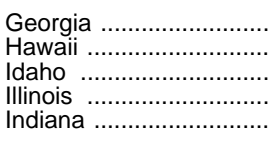 & $\begin{array}{r}1,420 \\
189 \\
393 \\
3,076 \\
1,410\end{array}$ & $\begin{array}{r}1,420 \\
188 \\
387 \\
2,978 \\
1,392\end{array}$ & $\begin{array}{r}30 \\
0 \\
32 \\
325 \\
65\end{array}$ & $\begin{array}{r}757 \\
34 \\
86 \\
551 \\
578\end{array}$ & $\begin{array}{l}129 \\
126 \\
166 \\
648 \\
421\end{array}$ & $\begin{array}{r}22 \\
7 \\
15 \\
725 \\
29\end{array}$ & $\begin{array}{r}297 \\
17 \\
56 \\
466 \\
233\end{array}$ & $\begin{array}{r}185 \\
5 \\
38 \\
361 \\
84\end{array}$ & $\begin{array}{l}661 \\
623 \\
365 \\
427 \\
445\end{array}$ & $\begin{array}{l}661 \\
627 \\
370 \\
438 \\
450\end{array}$ \\
\hline 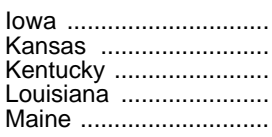 & $\begin{array}{r}1,071 \\
1,028 \\
974 \\
1,007 \\
546\end{array}$ & $\begin{array}{r}1,062 \\
1,022 \\
963 \\
984 \\
545\end{array}$ & $\begin{array}{r}123 \\
74 \\
57 \\
112 \\
78\end{array}$ & $\begin{array}{r}316 \\
299 \\
400 \\
287 \\
84\end{array}$ & $\begin{array}{r}263 \\
265 \\
225 \\
211 \\
88\end{array}$ & $\begin{array}{r}20 \\
129 \\
92 \\
75 \\
110\end{array}$ & $\begin{array}{r}209 \\
168 \\
175 \\
209 \\
92\end{array}$ & $\begin{array}{r}140 \\
93 \\
25 \\
113 \\
94\end{array}$ & $\begin{array}{l}288 \\
290 \\
423 \\
494 \\
262\end{array}$ & $\begin{array}{l}290 \\
291 \\
427 \\
497 \\
262\end{array}$ \\
\hline 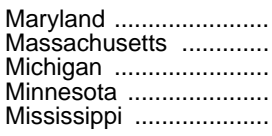 & $\begin{array}{r}1,043 \\
1,471 \\
2,530 \\
1,100 \\
569\end{array}$ & $\begin{array}{r}1,002 \\
1,462 \\
2,492 \\
972 \\
569\end{array}$ & $\begin{array}{r}17 \\
211 \\
208 \\
137 \\
82\end{array}$ & $\begin{array}{r}591 \\
478 \\
984 \\
222 \\
92\end{array}$ & $\begin{array}{l}165 \\
258 \\
556 \\
434 \\
136\end{array}$ & $\begin{array}{l}21 \\
78 \\
71 \\
33 \\
51\end{array}$ & $\begin{array}{l}193 \\
246 \\
453 \\
142 \\
113\end{array}$ & $\begin{array}{r}56 \\
200 \\
258 \\
132 \\
95\end{array}$ & $\begin{array}{l}551 \\
437 \\
433 \\
434 \\
522\end{array}$ & $\begin{array}{l}566 \\
437 \\
435 \\
478 \\
522\end{array}$ \\
\hline 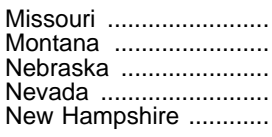 & $\begin{array}{r}1,494 \\
526 \\
999 \\
327 \\
411\end{array}$ & $\begin{array}{r}1,481 \\
525 \\
961 \\
319 \\
411\end{array}$ & $\begin{array}{r}104 \\
33 \\
55 \\
13 \\
49\end{array}$ & $\begin{array}{r}488 \\
79 \\
124 \\
140 \\
82\end{array}$ & $\begin{array}{r}370 \\
244 \\
465 \\
89 \\
79\end{array}$ & $\begin{array}{r}106 \\
66 \\
156 \\
15 \\
48\end{array}$ & $\begin{array}{r}268 \\
41 \\
63 \\
43 \\
65\end{array}$ & $\begin{array}{r}158 \\
63 \\
136 \\
27 \\
88\end{array}$ & $\begin{array}{l}392 \\
187 \\
172 \\
595 \\
329\end{array}$ & $\begin{array}{l}395 \\
187 \\
178 \\
608 \\
329\end{array}$ \\
\hline 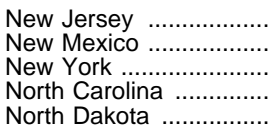 & $\begin{array}{r}1,770 \\
541 \\
3,004 \\
1,544 \\
349\end{array}$ & $\begin{array}{r}1,764 \\
530 \\
3,001 \\
1,534 \\
349\end{array}$ & $\begin{array}{r}270 \\
30 \\
277 \\
83 \\
13\end{array}$ & $\begin{array}{r}432 \\
193 \\
984 \\
721 \\
26\end{array}$ & $\begin{array}{l}297 \\
157 \\
739 \\
190 \\
227\end{array}$ & $\begin{array}{r}261 \\
4 \\
81 \\
112 \\
44\end{array}$ & $\begin{array}{r}306 \\
100 \\
540 \\
331 \\
17\end{array}$ & $\begin{array}{r}204 \\
57 \\
383 \\
107 \\
22\end{array}$ & $\begin{array}{l}456 \\
399 \\
614 \\
548 \\
190\end{array}$ & $\begin{array}{l}457 \\
404 \\
614 \\
550 \\
190\end{array}$ \\
\hline 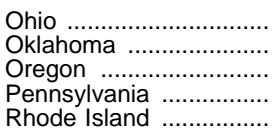 & $\begin{array}{r}2,718 \\
1,220 \\
913 \\
2,344 \\
255\end{array}$ & $\begin{array}{r}2,701 \\
1,210 \\
891 \\
2,343 \\
254\end{array}$ & $\begin{array}{r}329 \\
52 \\
59 \\
292 \\
36\end{array}$ & $\begin{array}{r}809 \\
357 \\
390 \\
823 \\
78\end{array}$ & $\begin{array}{r}776 \\
199 \\
179 \\
620 \\
67\end{array}$ & $\begin{array}{r}81 \\
295 \\
78 \\
61 \\
4\end{array}$ & $\begin{array}{r}483 \\
212 \\
162 \\
395 \\
38\end{array}$ & $\begin{array}{r}240 \\
105 \\
45 \\
153 \\
32\end{array}$ & $\begin{array}{l}425 \\
340 \\
382 \\
488 \\
399\end{array}$ & $\begin{array}{l}427 \\
341 \\
389 \\
488 \\
399\end{array}$ \\
\hline 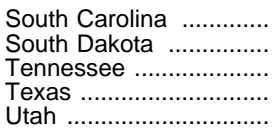 & $\begin{array}{r}796 \\
508 \\
1,127 \\
4,654 \\
479\end{array}$ & $\begin{array}{r}792 \\
505 \\
1,124 \\
4,550 \\
475\end{array}$ & $\begin{array}{r}90 \\
25 \\
119 \\
475 \\
10\end{array}$ & $\begin{array}{r}334 \\
105 \\
314 \\
1,733 \\
100\end{array}$ & $\begin{array}{r}91 \\
138 \\
221 \\
764 \\
311\end{array}$ & $\begin{array}{r}20 \\
98 \\
220 \\
92 \\
4\end{array}$ & $\begin{array}{r}198 \\
77 \\
183 \\
1,039 \\
36\end{array}$ & $\begin{array}{r}63 \\
65 \\
70 \\
551 \\
18\end{array}$ & $\begin{array}{l}544 \\
178 \\
515 \\
547 \\
548\end{array}$ & $\begin{array}{l}546 \\
179 \\
515 \\
556 \\
550\end{array}$ \\
\hline 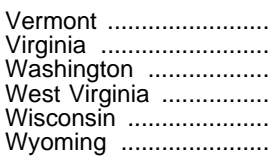 & $\begin{array}{r}270 \\
1,395 \\
1,324 \\
622 \\
1,508 \\
287\end{array}$ & $\begin{array}{r}248 \\
1,389 \\
1,286 \\
618 \\
1,493 \\
286\end{array}$ & $\begin{array}{l}18 \\
80 \\
72 \\
57 \\
97 \\
19\end{array}$ & $\begin{array}{r}20 \\
713 \\
450 \\
186 \\
568 \\
69\end{array}$ & $\begin{array}{l}119 \\
163 \\
454 \\
228 \\
334 \\
120\end{array}$ & $\begin{array}{r}63 \\
7 \\
56 \\
37 \\
103 \\
7\end{array}$ & $\begin{array}{r}16 \\
282 \\
196 \\
87 \\
272 \\
47\end{array}$ & $\begin{array}{r}34 \\
150 \\
96 \\
27 \\
134 \\
25\end{array}$ & $\begin{array}{l}237 \\
533 \\
452 \\
296 \\
371 \\
201\end{array}$ & $\begin{array}{l}254 \\
535 \\
462 \\
298 \\
374 \\
201\end{array}$ \\
\hline $\begin{array}{c}\text { Department of Defense } \\
\text { dependents schools .. } \\
\text { Outlying areas }\end{array}$ & 109 & 109 & 7 & 25 & 53 & 10 & 14 & 0 & 503 & 503 \\
\hline $\begin{array}{l}\text { American Samoa } \\
\text { Guam .................................. } \\
\text { Northern Marianas ........ } \\
\text { Puerto Rico .................. } \\
\text { Virgin Islands .................... }\end{array}$ & $\begin{array}{r}24 \\
30 \\
22 \\
960 \\
23\end{array}$ & $\begin{array}{r}24 \\
30 \\
22 \\
959 \\
23\end{array}$ & $\begin{array}{r}1 \\
0 \\
0 \\
96 \\
0\end{array}$ & $\begin{array}{r}0 \\
21 \\
0 \\
24 \\
0\end{array}$ & $\begin{array}{r}0 \\
0 \\
10 \\
759 \\
23\end{array}$ & $\begin{array}{r}21 \\
0 \\
0 \\
4 \\
0\end{array}$ & $\begin{array}{r}1 \\
6 \\
0 \\
35 \\
0\end{array}$ & $\begin{array}{r}1 \\
3 \\
12 \\
42 \\
0\end{array}$ & $\begin{array}{l}473 \\
839 \\
266 \\
306 \\
512\end{array}$ & $\begin{array}{l}473 \\
839 \\
266 \\
306 \\
512\end{array}$ \\
\hline
\end{tabular}

1 Excludes special education and alternative schools.

${ }^{2}$ Average for schools reporting enrollment data.

NOTE_-Includes schools beginning with grade 6 or below and with no grade highe than 8 . Excludes schools not reported by grade level, such as some special education schools for the disabled.
SOURCE: U.S. Department of Education, National Center for Education Statistics, Common Core of Data survey. (This table was prepared August 1998.) 
Table 100.-Public secondary schools, by grade span and average school size, by state: 1996-97

\begin{tabular}{|c|c|c|c|c|c|c|c|c|c|c|c|c|}
\hline \multirow[b]{2}{*}{ State or other area } & \multirow[b]{2}{*}{$\begin{array}{l}\text { Total, all } \\
\text { secondary } \\
\text { schools }\end{array}$} & \multirow[b]{2}{*}{$\begin{array}{l}\text { Total, all } \\
\text { regular } \\
\text { secondary } \\
\text { schools }^{1}\end{array}$} & \multicolumn{7}{|c|}{ Schools, by grade span } & \multirow[b]{2}{*}{$\begin{array}{l}\text { Vocational } \\
\text { schools }^{2}\end{array}$} & \multicolumn{2}{|c|}{$\begin{array}{l}\text { Average number of stu- } \\
\text { dents per school }{ }^{3}\end{array}$} \\
\hline & & & $\begin{array}{c}\text { Grades } 7 \\
\text { to } 8 \text { and } 7 \\
\text { to } 9\end{array}$ & $\begin{array}{c}\text { Grades } 7 \\
\text { to } 12\end{array}$ & $\begin{array}{c}\text { Grades } 8 \\
\text { to } 12\end{array}$ & $\begin{array}{l}\text { Grades } 9 \\
\text { to } 12\end{array}$ & $\begin{array}{c}\text { Grades } 10 \\
\text { to } 12\end{array}$ & \begin{tabular}{|c|} 
Other \\
spans \\
ending with \\
grade 12
\end{tabular} & $\begin{array}{l}\text { Other } \\
\text { grade } \\
\text { spans }\end{array}$ & & $\begin{array}{l}\text { All second- } \\
\text { ary schools }\end{array}$ & $\begin{array}{l}\text { Regular } \\
\text { secondary } \\
\text { schools }^{1}\end{array}$ \\
\hline 1 & 2 & 3 & 4 & 5 & 6 & 7 & 8 & 9 & 10 & 11 & 12 & 13 \\
\hline United States .......... & 21,307 & 18,207 & 3,707 & 3,123 & 491 & 11,619 & 805 & 183 & 1,379 & 905 & 703 & 777 \\
\hline $\begin{array}{l}\text { Alabama } \ldots \ldots \ldots \ldots \ldots \ldots \\
\text { Alaska } \ldots \ldots \ldots \ldots \ldots \ldots \ldots \ldots \\
\text { Arizona } \ldots \ldots \ldots \ldots \ldots \ldots \ldots \ldots \ldots \\
\text { Arkansas } \ldots \ldots \ldots \ldots \ldots \ldots \ldots \ldots \\
\text { California } \ldots \ldots \ldots \ldots \ldots \ldots \ldots \ldots\end{array}$ & $\begin{array}{r}304 \\
89 \\
299 \\
415 \\
1,886\end{array}$ & $\begin{array}{r}288 \\
71 \\
265 \\
414 \\
1,268\end{array}$ & $\begin{array}{r}37 \\
17 \\
78 \\
75 \\
416\end{array}$ & $\begin{array}{r}71 \\
21 \\
20 \\
205 \\
95\end{array}$ & $\begin{array}{r}11 \\
3 \\
3 \\
4 \\
43\end{array}$ & $\begin{array}{r}164 \\
41 \\
172 \\
51 \\
1,148\end{array}$ & $\begin{array}{r}10 \\
0 \\
7 \\
60 \\
96\end{array}$ & $\begin{array}{r}1 \\
0 \\
1 \\
0 \\
15\end{array}$ & $\begin{array}{r}10 \\
7 \\
18 \\
20 \\
73\end{array}$ & $\begin{array}{l}3 \\
6 \\
6 \\
1 \\
0\end{array}$ & $\begin{array}{l}688 \\
481 \\
887 \\
448 \\
972\end{array}$ & $\begin{array}{r}722 \\
565 \\
960 \\
444 \\
1,373\end{array}$ \\
\hline $\begin{array}{l}\text { Colorado ...................... } \\
\text { Connecticut .................. } \\
\text { Delaware .................. } \\
\text { District of Columbia ...... } \\
\text { Florida .......................... }\end{array}$ & $\begin{array}{r}354 \\
201 \\
44 \\
39 \\
466\end{array}$ & $\begin{array}{r}301 \\
170 \\
35 \\
35 \\
318\end{array}$ & $\begin{array}{l}49 \\
30 \\
10 \\
14 \\
25\end{array}$ & $\begin{array}{r}63 \\
11 \\
3 \\
0 \\
49\end{array}$ & \begin{tabular}{r|}
2 \\
2 \\
0 \\
0 \\
19
\end{tabular} & $\begin{array}{r}212 \\
157 \\
30 \\
19 \\
273\end{array}$ & $\begin{array}{r}11 \\
1 \\
0 \\
3 \\
18\end{array}$ & $\begin{array}{r}2 \\
0 \\
0 \\
0 \\
15\end{array}$ & $\begin{array}{r}15 \\
0 \\
1 \\
3 \\
67\end{array}$ & $\begin{array}{r}6 \\
17 \\
5 \\
0 \\
32\end{array}$ & $\begin{array}{r}595 \\
772 \\
916 \\
551 \\
1,121\end{array}$ & $\begin{array}{r}672 \\
849 \\
990 \\
603 \\
1,612\end{array}$ \\
\hline 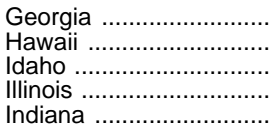 & $\begin{array}{r}308 \\
47 \\
208 \\
983 \\
451\end{array}$ & $\begin{array}{r}308 \\
44 \\
161 \\
824 \\
410\end{array}$ & $\begin{array}{r}24 \\
12 \\
44 \\
209 \\
73\end{array}$ & $\begin{array}{r}12 \\
9 \\
40 \\
52 \\
104\end{array}$ & $\begin{array}{r}22 \\
1 \\
2 \\
27 \\
1\end{array}$ & $\begin{array}{r}245 \\
23 \\
90 \\
606 \\
234\end{array}$ & $\begin{array}{r}2 \\
0 \\
23 \\
14 \\
6\end{array}$ & $\begin{array}{r}0 \\
0 \\
1 \\
30 \\
1\end{array}$ & $\begin{array}{r}3 \\
2 \\
8 \\
45 \\
32\end{array}$ & $\begin{array}{r}0 \\
0 \\
0 \\
26 \\
27\end{array}$ & $\begin{array}{r}1,154 \\
1,339 \\
474 \\
652 \\
808\end{array}$ & $\begin{array}{r}1,154 \\
1,426 \\
593 \\
737 \\
833\end{array}$ \\
\hline 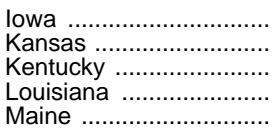 & $\begin{array}{l}444 \\
425 \\
361 \\
319 \\
159\end{array}$ & $\begin{array}{l}415 \\
417 \\
314 \\
284 \\
132\end{array}$ & $\begin{array}{l}66 \\
65 \\
41 \\
62 \\
22\end{array}$ & $\begin{array}{r}107 \\
70 \\
59 \\
52 \\
13\end{array}$ & $\begin{array}{r}1 \\
4 \\
9 \\
10 \\
2\end{array}$ & $\begin{array}{r}254 \\
268 \\
211 \\
184 \\
93\end{array}$ & $\begin{array}{r}11 \\
11 \\
5 \\
5 \\
1\end{array}$ & $\begin{array}{l}2 \\
5 \\
1 \\
2 \\
0\end{array}$ & $\begin{array}{r}3 \\
2 \\
35 \\
4 \\
28\end{array}$ & $\begin{array}{r}0 \\
0 \\
11 \\
10 \\
27\end{array}$ & $\begin{array}{l}403 \\
388 \\
613 \\
765 \\
509\end{array}$ & $\begin{array}{l}423 \\
394 \\
681 \\
819 \\
509\end{array}$ \\
\hline 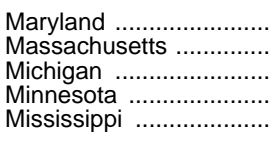 & $\begin{array}{l}217 \\
335 \\
821 \\
624 \\
307\end{array}$ & $\begin{array}{l}185 \\
276 \\
707 \\
416 \\
220\end{array}$ & $\begin{array}{r}28 \\
41 \\
120 \\
72 \\
37\end{array}$ & $\begin{array}{r}7 \\
42 \\
104 \\
224 \\
46\end{array}$ & $\begin{array}{r}1 \\
15 \\
27 \\
38 \\
7\end{array}$ & $\begin{array}{l}169 \\
223 \\
472 \\
182 \\
110\end{array}$ & $\begin{array}{r}2 \\
5 \\
20 \\
47 \\
13\end{array}$ & $\begin{array}{r}2 \\
3 \\
6 \\
18 \\
1\end{array}$ & $\begin{array}{r}8 \\
6 \\
72 \\
43 \\
93\end{array}$ & $\begin{array}{l}11 \\
45 \\
59 \\
12 \\
87\end{array}$ & $\begin{array}{r}1,081 \\
797 \\
677 \\
490 \\
693\end{array}$ & $\begin{array}{r}1,198 \\
843 \\
730 \\
697 \\
693\end{array}$ \\
\hline $\begin{array}{l}\text { Missouri ........................ } \\
\text { Montana ..................... } \\
\text { Nebraska ..................... } \\
\text { Nevada ..................... } \\
\text { New Hampshire ............ }\end{array}$ & $\begin{array}{l}629 \\
366 \\
360 \\
100 \\
100\end{array}$ & $\begin{array}{r}560 \\
362 \\
354 \\
79 \\
100\end{array}$ & $\begin{array}{r}58 \\
190 \\
42 \\
16 \\
23\end{array}$ & $\begin{array}{r}197 \\
0 \\
214 \\
18 \\
0\end{array}$ & $\begin{array}{l}5 \\
0 \\
5 \\
4 \\
0\end{array}$ & $\begin{array}{r}275 \\
174 \\
85 \\
53 \\
75\end{array}$ & $\begin{array}{r}18 \\
1 \\
11 \\
2 \\
2\end{array}$ & $\begin{array}{l}2 \\
0 \\
1 \\
2 \\
0\end{array}$ & $\begin{array}{r}74 \\
1 \\
2 \\
5 \\
0\end{array}$ & $\begin{array}{r}61 \\
0 \\
0 \\
3 \\
0\end{array}$ & $\begin{array}{l}526 \\
181 \\
331 \\
871 \\
626\end{array}$ & $\begin{array}{r}534 \\
182 \\
336 \\
1,030 \\
626\end{array}$ \\
\hline $\begin{array}{l}\text { New Jersey } \ldots \ldots \ldots \ldots \ldots \ldots \\
\text { New Mexico .................... } \\
\text { New York ..................... } \\
\text { North Carolina .............. } \\
\text { North Dakota ................ }\end{array}$ & $\begin{array}{l}427 \\
181 \\
919 \\
399 \\
222\end{array}$ & $\begin{array}{l}382 \\
158 \\
834 \\
361 \\
215\end{array}$ & $\begin{array}{r}70 \\
41 \\
124 \\
54 \\
20\end{array}$ & $\begin{array}{r}37 \\
27 \\
179 \\
23 \\
148\end{array}$ & $\begin{array}{r}10 \\
3 \\
15 \\
7 \\
4\end{array}$ & $\begin{array}{r}254 \\
94 \\
528 \\
288 \\
34\end{array}$ & $\begin{array}{r}3 \\
8 \\
26 \\
13 \\
6\end{array}$ & $\begin{array}{l}2 \\
0 \\
2 \\
1 \\
1\end{array}$ & $\begin{array}{r}51 \\
8 \\
45 \\
13 \\
9\end{array}$ & $\begin{array}{r}44 \\
0 \\
24 \\
8 \\
7\end{array}$ & $\begin{array}{l}887 \\
630 \\
964 \\
883 \\
246\end{array}$ & $\begin{array}{l}936 \\
704 \\
990 \\
956 \\
246\end{array}$ \\
\hline 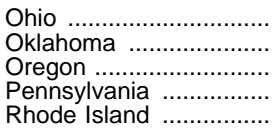 & $\begin{array}{r}958 \\
598 \\
257 \\
791 \\
57\end{array}$ & $\begin{array}{r}864 \\
597 \\
240 \\
705 \\
51\end{array}$ & $\begin{array}{r}183 \\
116 \\
43 \\
112 \\
13\end{array}$ & $\begin{array}{r}134 \\
0 \\
23 \\
177 \\
3\end{array}$ & $\begin{array}{r}32 \\
0 \\
7 \\
17 \\
0\end{array}$ & $\begin{array}{r}509 \\
383 \\
177 \\
354 \\
38\end{array}$ & $\begin{array}{r}17 \\
76 \\
4 \\
44 \\
1\end{array}$ & $\begin{array}{l}2 \\
4 \\
0 \\
7 \\
0\end{array}$ & $\begin{array}{r}81 \\
19 \\
3 \\
80 \\
2\end{array}$ & $\begin{array}{r}81 \\
0 \\
0 \\
82 \\
3\end{array}$ & $\begin{array}{l}723 \\
340 \\
684 \\
866 \\
863\end{array}$ & $\begin{array}{l}738 \\
341 \\
725 \\
872 \\
938\end{array}$ \\
\hline 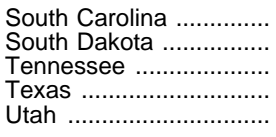 & $\begin{array}{r}277 \\
309 \\
350 \\
1,790 \\
234\end{array}$ & $\begin{array}{r}224 \\
296 \\
312 \\
1,440 \\
193\end{array}$ & $\begin{array}{r}36 \\
113 \\
54 \\
312 \\
80\end{array}$ & $\begin{array}{r}21 \\
2 \\
42 \\
196 \\
30\end{array}$ & $\begin{array}{r}7 \\
0 \\
4 \\
45 \\
11\end{array}$ & $\begin{array}{r}158 \\
187 \\
208 \\
1,030 \\
45\end{array}$ & $\begin{array}{r}4 \\
0 \\
12 \\
37 \\
53\end{array}$ & $\begin{array}{r}0 \\
2 \\
4 \\
28 \\
3\end{array}$ & $\begin{array}{r}51 \\
5 \\
26 \\
142 \\
12\end{array}$ & $\begin{array}{r}41 \\
4 \\
27 \\
23 \\
2\end{array}$ & $\begin{array}{l}868 \\
173 \\
835 \\
672 \\
906\end{array}$ & $\begin{array}{r}912 \\
175 \\
866 \\
815 \\
1,070\end{array}$ \\
\hline 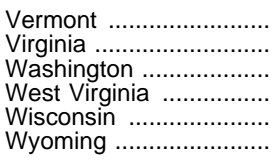 & $\begin{array}{r}69 \\
393 \\
542 \\
208 \\
547 \\
118\end{array}$ & $\begin{array}{r}53 \\
322 \\
427 \\
171 \\
519 \\
110\end{array}$ & $\begin{array}{r}6 \\
38 \\
122 \\
49 \\
85 \\
40\end{array}$ & $\begin{array}{r}24 \\
9 \\
52 \\
24 \\
63 \\
1\end{array}$ & $\begin{array}{r}0 \\
42 \\
14 \\
1 \\
3 \\
1\end{array}$ & $\begin{array}{r}25 \\
236 \\
269 \\
81 \\
363 \\
65\end{array}$ & $\begin{array}{r}0 \\
8 \\
43 \\
18 \\
18 \\
9\end{array}$ & $\begin{array}{r}0 \\
0 \\
10 \\
1 \\
5 \\
0\end{array}$ & $\begin{array}{r}14 \\
60 \\
32 \\
34 \\
10 \\
2\end{array}$ & $\begin{array}{r}14 \\
49 \\
8 \\
32 \\
0 \\
1\end{array}$ & $\begin{array}{l}621 \\
993 \\
651 \\
615 \\
559 \\
349\end{array}$ & $\begin{array}{r}644 \\
1,050 \\
795 \\
636 \\
584 \\
367\end{array}$ \\
\hline $\begin{array}{c}\text { Department of Defense } \\
\text { dependents schools .. } \\
\text { Outlying areas }\end{array}$ & 41 & 41 & 3 & 26 & 0 & 12 & 0 & 0 & 0 & 0 & 465 & 465 \\
\hline $\begin{array}{l}\text { American Samoa ........... } \\
\text { Guam ......................... } \\
\text { Northern Marianas ........ } \\
\text { Puerto Rico .................. } \\
\text { Virgin Islands ............... }\end{array}$ & $\begin{array}{r}6 \\
5 \\
4 \\
365 \\
11\end{array}$ & $\begin{array}{r}5 \\
5 \\
4 \\
338 \\
9\end{array}$ & $\begin{array}{r}0 \\
0 \\
1 \\
172 \\
6\end{array}$ & $\begin{array}{r}0 \\
0 \\
2 \\
32 \\
0\end{array}$ & $\begin{array}{l}0 \\
0 \\
0 \\
0 \\
0\end{array}$ & $\begin{array}{l}6 \\
5 \\
1 \\
2 \\
4\end{array}$ & $\begin{array}{r}0 \\
0 \\
0 \\
135 \\
0\end{array}$ & $\begin{array}{l}0 \\
0 \\
0 \\
0 \\
0\end{array}$ & $\begin{array}{r}0 \\
0 \\
0 \\
24 \\
1\end{array}$ & $\begin{array}{r}1 \\
0 \\
0 \\
26 \\
1\end{array}$ & $\begin{array}{r}558 \\
1,635 \\
799 \\
633 \\
1,012\end{array}$ & $\begin{array}{r}613 \\
1,635 \\
799 \\
636 \\
1,118\end{array}$ \\
\hline
\end{tabular}

1 Excludes vocational, special education, and alternative schools.

${ }^{2}$ Vocational schools are also included under appropriate grade span.

${ }^{3}$ Average for schools reporting enrollment data.
NOTE.- Includes schools with no grade lower than 7. Excludes schools not reported by level, such as special education schools for the disabled.

SOURCE: U.S. Department of Education, National Center for Education Statistics, Common Core of Data survey. (This table was prepared August 1998.) 
Table 101.-High school graduates compared with population 17 years of age, by sex and control of school: $1869-70$ to $1997-98$

[Numbers in thousands]

\begin{tabular}{|c|c|c|c|c|c|c|c|}
\hline \multirow{3}{*}{ School year } & \multirow{3}{*}{$\begin{array}{l}\text { Population } 17 \\
\text { years old }{ }^{1}\end{array}$} & \multicolumn{5}{|c|}{ High school graduates } & \multirow{3}{*}{$\begin{array}{l}\text { Graduates as a } \\
\text { percent of } \\
17 \text {-year-old } \\
\text { population }\end{array}$} \\
\hline & & \multirow{2}{*}{ Total $^{2}$} & \multicolumn{2}{|c|}{ Sex } & \multicolumn{2}{|c|}{ Control } & \\
\hline & & & Male & Female & Public ${ }^{3}$ & Private 4 & \\
\hline 1 & 2 & 3 & 4 & 5 & 6 & 7 & 8 \\
\hline $\begin{array}{l}1869-70 \\
1879-80 \\
1889-90 \\
1899-1900 \\
1909-10\end{array}$ & $\begin{array}{r}815 \\
946 \\
1,259 \\
1,489 \\
1,786\end{array}$ & $\begin{array}{r}16 \\
24 \\
44 \\
95 \\
156\end{array}$ & $\begin{array}{r}7 \\
11 \\
19 \\
38 \\
64\end{array}$ & $\begin{array}{r}9 \\
13 \\
25 \\
57 \\
93\end{array}$ & $\begin{array}{r}\overline{-} \\
22 \\
62 \\
111\end{array}$ & $\begin{array}{l}- \\
\overline{22} \\
33 \\
45\end{array}$ & $\begin{array}{l}2.0 \\
2.5 \\
3.5 \\
6.4 \\
8.8\end{array}$ \\
\hline $\begin{array}{l}1919-20 \\
1929-30 \\
1939-40 \\
1947-48 \\
1949-50\end{array}$ & $\begin{array}{l}1,855 \\
2,296 \\
2,403 \\
2,261 \\
2,034\end{array}$ & $\begin{array}{r}311 \\
667 \\
1,221 \\
1,190 \\
1,200\end{array}$ & $\begin{array}{l}124 \\
300 \\
579 \\
563 \\
571\end{array}$ & $\begin{array}{l}188 \\
367 \\
643 \\
627 \\
629\end{array}$ & $\begin{array}{r}231 \\
592 \\
1,143 \\
1,073 \\
1,063\end{array}$ & $\begin{array}{r}80 \\
75 \\
78 \\
117 \\
136\end{array}$ & $\begin{array}{l}16.8 \\
29.0 \\
50.8 \\
52.6 \\
59.0\end{array}$ \\
\hline $\begin{array}{l}1951-52 \\
1953-54 \\
1955-56 \\
1956-57 \\
1957-58\end{array}$ & $\begin{array}{l}2,086 \\
2,135 \\
2,242 \\
2,272 \\
2,325\end{array}$ & $\begin{array}{l}1,197 \\
1,276 \\
1,415 \\
1,434 \\
1,506\end{array}$ & $\begin{array}{l}569 \\
613 \\
680 \\
690 \\
725\end{array}$ & $\begin{array}{l}627 \\
664 \\
735 \\
744 \\
781\end{array}$ & $\begin{array}{l}1,056 \\
1,129 \\
1,252 \\
1,270 \\
1,332\end{array}$ & $\begin{array}{l}141 \\
147 \\
163 \\
164 \\
174\end{array}$ & $\begin{array}{l}57.4 \\
59.8 \\
63.1 \\
63.1 \\
64.8\end{array}$ \\
\hline $\begin{array}{l}1958-59 \\
1959-60 \\
1960-61 \\
1961-62 \\
1962-63\end{array}$ & $\begin{array}{l}2,458 \\
2,672 \\
2,892 \\
2,768 \\
2,740\end{array}$ & $\begin{array}{l}1,627 \\
1,858 \\
1,964 \\
1,918 \\
1,943\end{array}$ & $\begin{array}{l}784 \\
895 \\
955 \\
938 \\
956\end{array}$ & $\begin{array}{r}843 \\
963 \\
1,009 \\
980 \\
987\end{array}$ & $\begin{array}{l}1,435 \\
1,627 \\
1,725 \\
1,678 \\
1,710\end{array}$ & $\begin{array}{l}192 \\
231 \\
239 \\
240 \\
233\end{array}$ & $\begin{array}{l}66.2 \\
69.5 \\
67.9 \\
69.3 \\
70.9\end{array}$ \\
\hline $\begin{array}{l}1963-64 \\
1964-65 \\
1965-66 \\
1966-67\end{array}$ & $\begin{array}{l}2,978 \\
3,684 \\
3,489 \\
3,500 \\
3,532\end{array}$ & $\begin{array}{l}2,283 \\
2,658 \\
2,665 \\
2,672 \\
2,695\end{array}$ & $\begin{array}{l}1,120 \\
1,311 \\
1,323 \\
1,328 \\
1,338\end{array}$ & $\begin{array}{l}1,163 \\
1,347 \\
1,342 \\
1,344 \\
1,357\end{array}$ & $\begin{array}{l}2,008 \\
2,360 \\
2,367 \\
2,374 \\
2,395\end{array}$ & $\begin{array}{l}275 \\
298 \\
298 \\
298 \\
300\end{array}$ & $\begin{array}{l}76.7 \\
72.1 \\
76.4 \\
76.3 \\
76.3\end{array}$ \\
\hline $\begin{array}{l}1968-69 \\
1969-70 \\
1970-71 \\
1971-72 \\
1972-73\end{array}$ & $\begin{array}{l}3,659 \\
3,757 \\
3,872 \\
3,973 \\
4,049\end{array}$ & $\begin{array}{l}2,822 \\
2,889 \\
2,938 \\
3,002 \\
3,035\end{array}$ & $\begin{array}{l}1,399 \\
1,430 \\
1,454 \\
1,487 \\
1,500\end{array}$ & $\begin{array}{l}1,423 \\
1,459 \\
1,484 \\
1,515 \\
1,535\end{array}$ & $\begin{array}{l}2,522 \\
2,589 \\
2,638 \\
2,700 \\
2,729\end{array}$ & $\begin{array}{l}300 \\
300 \\
300 \\
302 \\
306\end{array}$ & $\begin{array}{l}77.1 \\
76.9 \\
75.9 \\
75.6 \\
75.0\end{array}$ \\
\hline $\begin{array}{l}1973-74 \\
1974-75 \\
1975-76 \\
1976-77 \\
1977-78\end{array}$ & $\begin{array}{l}4,132 \\
4,256 \\
4,272 \\
4,272 \\
4,286\end{array}$ & $\begin{array}{l}3,073 \\
3,133 \\
3,148 \\
3,152 \\
3,127\end{array}$ & $\begin{array}{l}1,512 \\
1,542 \\
1,552 \\
1,548 \\
1,531\end{array}$ & $\begin{array}{l}1,561 \\
1,591 \\
1,596 \\
1,604 \\
1,596\end{array}$ & $\begin{array}{l}2,763 \\
2,823 \\
2,837 \\
2,837 \\
2,825\end{array}$ & $\begin{array}{l}310 \\
310 \\
311 \\
315 \\
302\end{array}$ & $\begin{array}{l}74.4 \\
73.6 \\
73.7 \\
73.8 \\
73.0\end{array}$ \\
\hline $\begin{array}{l}1978-79 \\
1979-80 \\
1980-81 \\
1981-82 \\
1982-83\end{array}$ & $\begin{array}{l}4,327 \\
4,262 \\
4,212 \\
4,134 \\
3,962\end{array}$ & $\begin{array}{l}3,101 \\
3,043 \\
3,020 \\
2,995 \\
2,888\end{array}$ & $\begin{array}{l}1,517 \\
1,491 \\
1,483 \\
1,471 \\
1,437\end{array}$ & $\begin{array}{l}1,584 \\
1,552 \\
1,537 \\
1,524 \\
1,451\end{array}$ & $\begin{array}{l}2,801 \\
2,748 \\
2,725 \\
2,705 \\
2,598\end{array}$ & $\begin{array}{l}300 \\
295 \\
295 \\
290 \\
290\end{array}$ & $\begin{array}{l}71.7 \\
71.4 \\
71.7 \\
72.4 \\
72.9\end{array}$ \\
\hline $\begin{array}{l}1983-84 \\
1984-85 \\
1985-86 \\
1986-87 \\
1987-88 \ldots \ldots \ldots \ldots \ldots \ldots . . .\end{array}$ & $\begin{array}{l}3,784 \\
3,699 \\
3,670 \\
3,754 \\
3,849\end{array}$ & $\begin{array}{l}2,767 \\
2,677 \\
2,643 \\
2,694 \\
2,773\end{array}$ & $\begin{array}{l}- \\
- \\
- \\
-\end{array}$ & $\begin{array}{l}- \\
- \\
-\end{array}$ & $\begin{array}{l}2,495 \\
2,414 \\
2,383 \\
2,429 \\
2,500\end{array}$ & $\begin{array}{l}272 \\
263 \\
260 \\
265 \\
273\end{array}$ & $\begin{array}{l}73.1 \\
72.4 \\
72.0 \\
71.8 \\
72.1\end{array}$ \\
\hline $\begin{array}{l}1988-89 \\
1989-90 \\
1990-91 \\
1991-92 \\
1992-93\end{array}$ & $\begin{array}{l}3,842 \\
3,505 \\
3,421 \\
3,391 \\
3,447\end{array}$ & $\begin{array}{l}2,727 \\
2,586 \\
2,503 \\
2,482 \\
2,490\end{array}$ & $\begin{array}{l}- \\
- \\
- \\
-\end{array}$ & $\begin{array}{l}- \\
- \\
-\end{array}$ & $\begin{array}{l}2,459 \\
2,320 \\
2,235 \\
2,226 \\
2,233\end{array}$ & $\begin{array}{l}268 \\
266 \\
268 \\
256 \\
257\end{array}$ & $\begin{array}{l}71.0 \\
73.8 \\
73.2 \\
73.2 \\
72.2\end{array}$ \\
\hline $\begin{array}{l}1993-94 \\
1994-95 \\
1995-96 \\
1996-975 \\
1997-985\end{array}$ & $\begin{array}{l}3,459 \\
3,588 \\
3,641 \\
3,773 \\
3,923\end{array}$ & $\begin{array}{l}2,479 \\
2,538 \\
2,548 \\
2,623 \\
2,708\end{array}$ & $\begin{array}{l}- \\
- \\
- \\
-\end{array}$ & $\begin{array}{l}- \\
- \\
-\end{array}$ & $\begin{array}{l}2,221 \\
2,274 \\
2,281 \\
2,360 \\
2,433\end{array}$ & $\begin{array}{l}258 \\
264 \\
267 \\
267 \\
275\end{array}$ & $\begin{array}{l}71.7 \\
70.7 \\
70.0 \\
69.6 \\
69.0\end{array}$ \\
\hline
\end{tabular}

${ }^{1}$ Derived from Current Population Reports, Series P-25. 17-year-old population adjusted to reflect October 17-year-old population.

2 Includes graduates of public and private schools.

${ }^{3}$ Data for 1929-30 and preceding years are from Statistics of Public High Schools and exclude graduates of high schools which failed to report to the Office of Education.

${ }^{4}$ For most years, private school data have been estimated based on periodic private school surveys. For years through 1957-58, private includes data for subcollegiate de partments of institutions of higher education and residential schools for exceptional children.

${ }^{5}$ Public high school graduates based on state estimates.

-Data not available.
NOTE.-Includes graduates of regular day school programs. Excludes graduates of other programs, when separately reported, and recipients of high school equivalency certificates. Some data have been revised from previously published figures. Because of rounding, details may not add to totals.

SOURCE: U.S. Department of Education, National Center for Education Statistics, Statistics of Public High Schools; Biennial Survey of Education in the United States; Statistics of State School Systems; Statistics of Nonpublic Elementary and Secondary Schools; Projections of Education Statistics; Common Core of Data surveys; and U.S. Department of Commerce, Bureau of the Census, Current Population Reports, Series P25. (This table was prepared June 1998.) 
Table 102.-Public high school graduates, by state: $1969-70$ to $1997-98$

\begin{tabular}{|c|c|c|c|c|c|c|c|c|c|c|c|}
\hline State & 1969-70 & 1979-80 & $1980-81$ & 1985-86 & $1990-91$ & 1993-94 & 1994-95 & 1995-96 & $\begin{array}{l}\text { Estimated } \\
\text { 1996-971 }\end{array}$ & $\begin{array}{c}\text { Estimated } \\
1997-98\end{array}$ & $\begin{array}{c}\text { Percent } \\
\text { change, } \\
1990-91 \\
\text { to } \\
1997-98\end{array}$ \\
\hline 1 & 2 & 3 & 4 & 5 & 6 & 7 & 8 & 9 & 10 & 11 & 12 \\
\hline United States ................ & $2,588,639$ & $2,747,678$ & $2,725,285$ & $2,382,616$ & $2,234,893$ & $2,220,849$ & $2,273,541$ & $22,281,317$ & $22,359,572$ & $22,433,373$ & 8.9 \\
\hline Alabama & 45,286 & 45,190 & 44,894 & 39,620 & 39,042 & 34,447 & 36,268 & 35,043 & 334,726 & 35,264 & -9.7 \\
\hline Alaska & 3,297 & 5,223 & 5,343 & 5,464 & 5,458 & 5,747 & 5,765 & 5,945 & 5,984 & 6,092 & 11.6 \\
\hline Arizona & 22,040 & 28,633 & 28,416 & 27,533 & 31,282 & 31,799 & 30,989 & 30,008 & 432,886 & ${ }^{4} 36,128$ & 15.5 \\
\hline 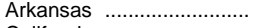 & 26,068 & 29,052 & 29,577 & 26,227 & 25,668 & 24,990 & 24,636 & 25,094 & 25,069 & ${ }^{4} 25,853$ & 0.7 \\
\hline California ............................. & 260,908 & 249,217 & 242,172 & 229,026 & 234,164 & 253,083 & 255,200 & 259,071 & 269,294 & 282,678 & 20.7 \\
\hline Colorado & 30,312 & 36,804 & 35,897 & 32,621 & 31,293 & 31,867 & 32,409 & 32,608 & 3 34,221 & 34,688 & 10.8 \\
\hline Connecticut ...... & 34,755 & 37,683 & 38,369 & 33,571 & 27,290 & 26,330 & 26,445 & 26,319 & 26,850 & 28,814 & 5.6 \\
\hline 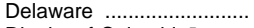 & 6,985 & 7,582 & 7,349 & 5,791 & 5,223 & 5,230 & 5,234 & 5,609 & ${ }^{3} 5,623$ & 5,879 & 12.6 \\
\hline District of Columbia $^{5} \ldots \ldots .$. & 4,980 & 4,959 & 4,848 & 3,875 & 3,369 & 3,207 & 2,974 & 2,696 & ${ }^{4} 2,709$ & ${ }^{4} 2,729$ & -19.0 \\
\hline Florida & 70,478 & 87,324 & 88,755 & 83,029 & 87,419 & 88,032 & 89,827 & 89,242 & ${ }^{3} 92,267$ & 95,397 & 9.1 \\
\hline Georgia . & 56,859 & 61,621 & 62,963 & 59,082 & 60,088 & 56,356 & 56,660 & 56,271 & 61,004 & 62,956 & 4.8 \\
\hline 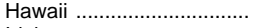 & 10,407 & 11,493 & 11,472 & 9,958 & 8,974 & 9,369 & 9,407 & 9,387 & 49,595 & 9,779 & 9.0 \\
\hline Idaho & 12,296 & 13,187 & 12,679 & 12,059 & 11,961 & 13,281 & 14,198 & 14,667 & 14,900 & 15,100 & 26.2 \\
\hline Illinois & 126,864 & 135,579 & 136,795 & 114,319 & 103,329 & 102,126 & 105,164 & 110,486 & 3 110,186 & 113,860 & 10.2 \\
\hline 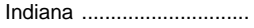 & 69,984 & 73,143 & 73,381 & 59,817 & 57,892 & 54,650 & 56,058 & 56,368 & 56,569 & 58,187 & 0.5 \\
\hline lowa & 44,063 & 43,445 & 42,635 & 34,279 & 28,593 & 30,247 & 31,268 & 31,689 & 32,735 & 33,816 & 18.3 \\
\hline Kansas & 33,394 & 30,890 & 29,397 & 25,587 & 24,414 & 25,319 & 26,125 & 25,786 & 26,726 & 27,755 & 13.7 \\
\hline 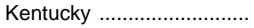 & 37,473 & 41,203 & 41,714 & 37,288 & 35,835 & 38,454 & 37,626 & 36,641 & 437,146 & 437,009 & 3.3 \\
\hline Louisiana .......................... & 43,641 & 46,297 & 46,199 & 39,965 & 33,489 & 34,822 & 36,480 & 36,467 & 336,727 & 436,943 & 10.3 \\
\hline Maine ……............................. & 14,003 & 15,445 & 15,554 & 13,006 & 13,151 & 11,384 & 11,501 & 11,795 & 312,405 & 12,587 & -4.3 \\
\hline 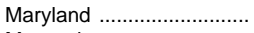 & 46,462 & 54,270 & 54,050 & 46,700 & 39,014 & 39,091 & 41,387 & 41,785 & 343,365 & 43,863 & 12.4 \\
\hline Massachusetts …............... & 63,865 & 73,802 & 74,831 & 60,360 & 50,216 & 47,453 & 47,679 & 47,993 & 48,933 & 49,911 & -0.6 \\
\hline 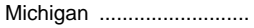 & 121,000 & 124,316 & 124,372 & 101,042 & 88,234 & 83,385 & 84,628 & 85,530 & 88,000 & 93,700 & 6.2 \\
\hline Minnesota .......................... & 60,480 & 64,908 & 64,166 & 51,988 & 46,474 & 47,514 & 49,354 & 50,481 & 52,340 & 54,940 & 18.2 \\
\hline Mississippi .......................... & 29,653 & 27,586 & 28,083 & 25,134 & 23,665 & 23,379 & 23,837 & 23,032 & 23,255 & 24,233 & 2.4 \\
\hline 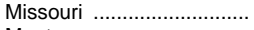 & 55,315 & 62,265 & 60,359 & 49,204 & 46,928 & 46,566 & 48,862 & 48,870 & 350,223 & 51,920 & 10.6 \\
\hline Montana …............................ & 11,520 & 12,135 & 11,634 & 9,761 & 9,013 & 9,601 & 10,134 & 10,139 & 10,320 & 10,637 & 18.0 \\
\hline 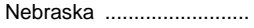 & 21,280 & 22,410 & 21,411 & 17,845 & 16,500 & 17,072 & 17,969 & 18,014 & 19,183 & 20,263 & 22.8 \\
\hline Nevada & 5,449 & 8,473 & 9,069 & 8,784 & 9,370 & 9,485 & 10,038 & 10,374 & 3 11,299 & 11,610 & 23.9 \\
\hline New Hampshire .................. & 8,516 & 11,722 & 11,552 & 10,648 & 10,059 & 9,933 & 10,145 & 10,094 & 9,398 & 9,320 & -7.3 \\
\hline 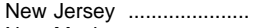 & 86,498 & 94,564 & 93,168 & 78,781 & 67,003 & 66,125 & 67,403 & ${ }^{4} 67,516$ & ${ }^{4} 69,715$ & 472,247 & 7.8 \\
\hline New Mexico ......................... & 16,060 & 18,424 & 17,915 & 15,468 & 15,157 & 14,892 & 14,928 & 15,402 & 15,700 & 15,400 & 1.6 \\
\hline 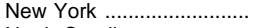 & 190,000 & 204,064 & 198,465 & 162,165 & 133,562 & 132,708 & 132,401 & 135,569 & 137,600 & 140,500 & 5.2 \\
\hline North Carolina ..................... & 68,886 & 70,862 & 69,395 & 65,865 & 62,792 & 57,738 & 59,540 & 57,014 & 3 57,886 & 59,438 & -5.3 \\
\hline North Dakota .......................... & 11,150 & 9,928 & 9,924 & 7,610 & 7,573 & 7,522 & 7,817 & 8,027 & ${ }^{3} 7,990$ & 8,145 & 7.6 \\
\hline Ohio & 142,248 & 144,169 & 143,503 & 119,561 & 107,484 & 107,700 & 109,418 & 103,435 & 106,924 & 109,000 & 1.4 \\
\hline Oklahoma ................................ & 36,293 & 39,305 & 38,875 & 34,452 & 33,007 & 31,872 & 33,319 & 33,060 & 33,224 & 33,577 & 1.7 \\
\hline Oregon & 32,236 & 29,939 & 28,729 & 26,286 & 24,597 & 26,338 & 26,713 & 26,570 & 3 27,799 & 27,700 & 12.6 \\
\hline 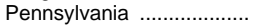 & 151,014 & 146,458 & 144,645 & 122,871 & 104,770 & 101,958 & 104,146 & 105,981 & 109,160 & 111,350 & 6.3 \\
\hline Rhode Island ....................... & 10,146 & 10,864 & 10,719 & 8,908 & 7,744 & 7,450 & 7,826 & 7,689 & 7,734 & 7,001 & -9.6 \\
\hline South Carolina ..................... & 34,940 & 38,697 & 38,347 & 34,500 & 32,999 & 30,603 & 30,680 & 30,313 & 32,800 & 34,000 & 3.0 \\
\hline South Dakota ...................... & 11,757 & 10,689 & 10,385 & 7,870 & 7,127 & 8,442 & 8,355 & 8,532 & 9,108 & 12,034 & 68.9 \\
\hline Tennessee ............................. & 49,000 & 49,845 & 50,648 & 43,263 & 44,847 & 40,643 & 43,556 & 43,792 & 3 45,962 & 45,980 & 2.5 \\
\hline 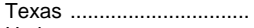 & 139,046 & 171,449 & 171,665 & 161,150 & 174,306 & 163,191 & 170,322 & 171,844 & 180,369 & 185,050 & 6.2 \\
\hline Utah ..................................... & 18,395 & 20,035 & 19,886 & 19,774 & 22,219 & 26,407 & 27,670 & 26,293 & ${ }^{3} 31,032$ & 32,000 & 44.0 \\
\hline ………....... & 6,095 & 6,733 & 6,424 & 5,794 & 5,212 & 5,414 & 5,871 & 5,870 & ${ }^{3} 6,102$ & ${ }^{3} 6,209$ & 19.1 \\
\hline Virginia ……………........ & 58,562 & 66,621 & 67,126 & 63,113 & 58,441 & 56,140 & 58,260 & 58,166 & ${ }^{3} 62,258$ & 64,383 & 10.2 \\
\hline 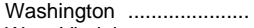 & 50,425 & 50,402 & 50,046 & 45,805 & 42,514 & 47,235 & 49,294 & 49,862 & 52,900 & 55,021 & 29.4 \\
\hline West Virginia ...................... & 26,139 & 23,369 & 23,580 & 21,870 & 21,064 & 19,884 & 20,131 & 20,335 & 3 19,547 & 20,052 & -4.8 \\
\hline Wisconsin .............................. & 66,753 & 69,332 & 67,743 & 58,340 & 49,340 & 48,371 & 51,735 & 52,651 & 55,500 & 56,300 & 14.1 \\
\hline 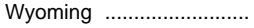 & 5,363 & 6,072 & 6,161 & 5,587 & 5,728 & 5,997 & 5,889 & 5,892 & ${ }^{3} 6,324$ & 6,075 & 6.1 \\
\hline \multicolumn{12}{|l|}{ Outlying areas } \\
\hline American Samoa .................. & 6367 & - & - & 608 & 597 & 738 & 695 & 719 & 3705 & 677 & 13.4 \\
\hline Guam & 972 & - & - & 840 & 1,014 & 985 & 987 & - & 31,076 & 1,146 & 13.0 \\
\hline Northern Marianas ........... & - & - & - & - & 273 & 328 & 319 & 325 & ${ }^{3} 310$ & 424 & 55.3 \\
\hline Puerto Rico ............................. & 24,917 & - & - & 31,597 & 29,329 & 27,718 & 29,747 & 29,499 & 28,740 & 28,829 & -1.7 \\
\hline Virgin Islands ........................ & 6432 & - & - & 1,044 & 981 & 886 & 995 & 937 & 3 912 & 998 & 1.7 \\
\hline
\end{tabular}

${ }^{1}$ Revised from previously published data.

2 National total includes estimates for nonreporting states.

${ }^{3}$ Actual count.

${ }^{4}$ Data imputed by the National Center for Education Statistics based on previous year's data.

${ }^{5}$ Beginning in 1985-86, graduates from adult programs are excluded.

${ }^{6}$ Data are for $1970-71$.

-Data not reported.
NOTE.-Data include graduates of regular day school programs, but exclude graduates of other programs and persons receiving high school equivalency certificates. They also exclude graduates of subcollegiate departments of institutions of higher education, federal schools for American Indians and on federal installations, and residential schools for disabled children. Some data have been revised from previously published figures. All 1996-97 and 1997-98 data are state estimates unless otherwise indicated.

SOURCE: U.S. Department of Education, National Center for Education Statistics, Common Core of Data surveys. (This table was prepared May 1998.) 
Table 103.-High school graduates and dropouts in public elementary and secondary schools, by race/ethnicity and state: 1995-96

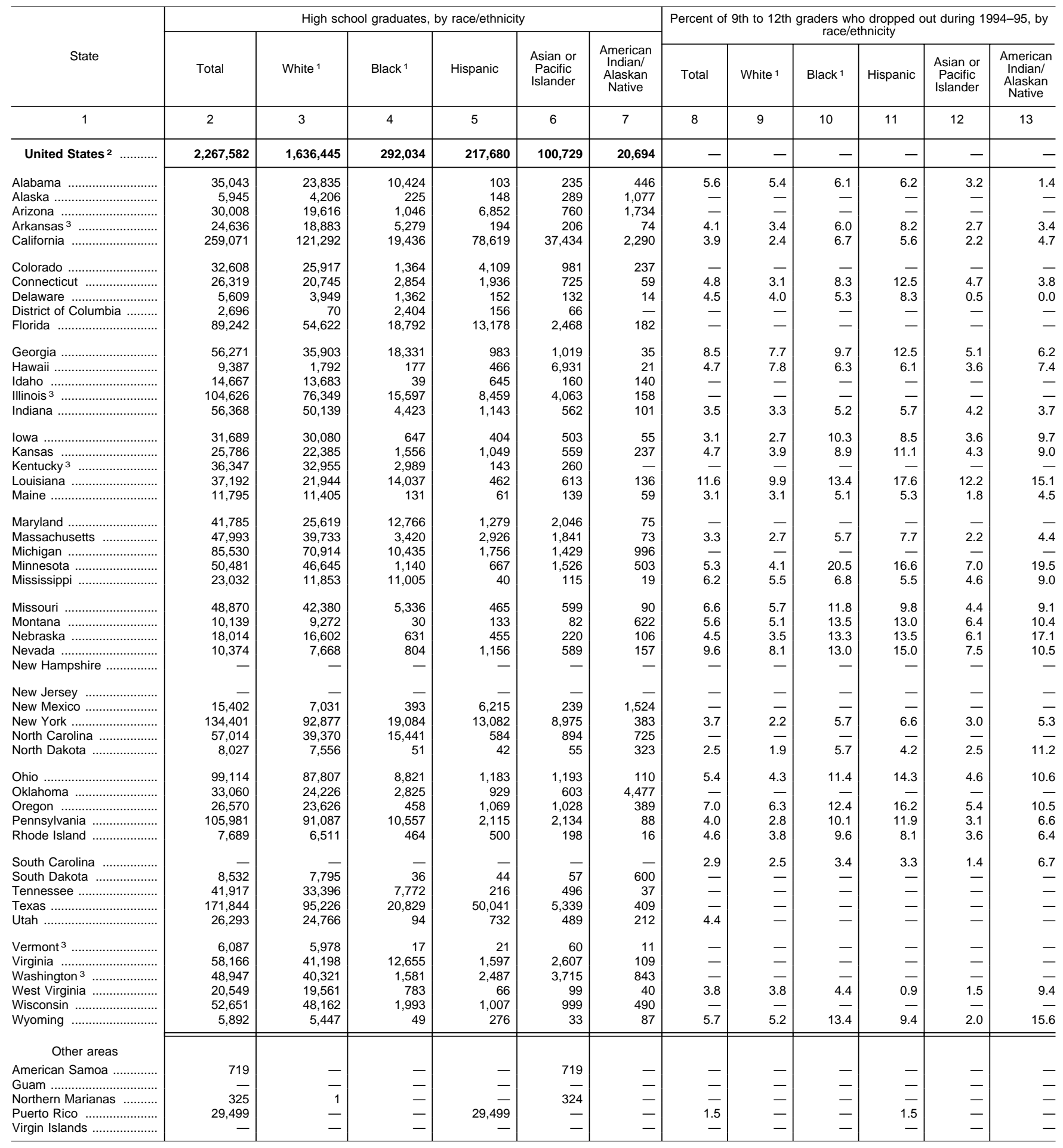

1 Excludes persons of Hispanic origin.

${ }^{2}$ U.S. total includes estimates for nonreporting states, based on 199612 th grade racial/ethnic distribution reported by state.

${ }^{3}$ Estimates provided by state education agencies.

${ }^{4}$ Racial/ethnic distribution estimated by NCES based on 1996 12th grade racial/ethnic distribution reported by state.

-Data not available.
NOTE.-Because data for some graduates are not available by race, totals differ from figures reported on other tables.

SOURCE: U.S. Department of Education, National Center for Education Statistics, Common Core of Data survey; and unpublished data. (This table was prepared March 1999.) 
Table 104.-General Educational Development (GED) credentials issued, and number and age of test takers: United States and outlying areas, 1971 to 1996

\begin{tabular}{|c|c|c|c|c|c|c|c|c|}
\hline \multirow{2}{*}{ Year } & \multirow{2}{*}{$\begin{array}{l}\text { Number of cre- } \\
\text { dentials issued, } \\
\text { in thousands }{ }^{1}\end{array}$} & \multirow{2}{*}{$\begin{array}{l}\text { Number com- } \\
\text { pleting test } \\
\text { battery, in } \\
\text { thousands }^{2}\end{array}$} & \multirow{2}{*}{$\begin{array}{l}\text { Number of test } \\
\text { takers, in } \\
\text { thousands }{ }^{3}\end{array}$} & \multicolumn{5}{|c|}{ Percentage distribution of test takers, by age } \\
\hline & & & & $\begin{array}{c}19 \text { years old or } \\
\text { less }\end{array}$ & $\begin{array}{l}20 \text { - to } 24 \text {-year- } \\
\text { olds }\end{array}$ & $\begin{array}{l}25 \text { - to } 29 \text {-year- } \\
\text { olds }\end{array}$ & $\begin{array}{l}\text { 30- to } 34 \text {-year- } \\
\text { olds }\end{array}$ & $\begin{array}{c}35 \text { years old or } \\
\text { over }\end{array}$ \\
\hline 1 & 2 & 3 & 4 & 5 & 6 & 7 & 8 & 9 \\
\hline 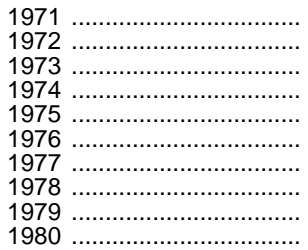 & $\begin{array}{l}227 \\
245 \\
249 \\
295 \\
342 \\
337 \\
331 \\
381 \\
435 \\
488\end{array}$ & $\begin{array}{l}- \\
\overline{-} \\
412 \\
507 \\
507 \\
488 \\
467 \\
583 \\
708\end{array}$ & $\begin{array}{l}377 \\
419 \\
423 \\
540 \\
652 \\
656 \\
680 \\
641 \\
744 \\
779\end{array}$ & $\begin{array}{l}- \\
\\
35 \\
33 \\
31 \\
40 \\
31 \\
35 \\
37\end{array}$ & $\begin{array}{l}- \\
- \\
27 \\
26 \\
28 \\
24 \\
27 \\
27 \\
27\end{array}$ & $\begin{array}{l}- \\
\overline{-} \\
\overline{13} \\
14 \\
14 \\
13 \\
13 \\
13 \\
13\end{array}$ & $\begin{array}{r}- \\
- \\
9 \\
9 \\
10 \\
9 \\
10 \\
8 \\
8\end{array}$ & $\begin{array}{l}- \\
- \\
1 \\
1 \\
1 \\
1 \\
1 \\
1 \\
1 \\
1\end{array}$ \\
\hline 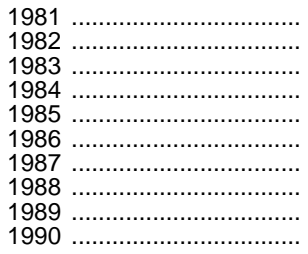 & $\begin{array}{l}500 \\
494 \\
477 \\
437 \\
427 \\
439 \\
458 \\
421 \\
364 \\
419\end{array}$ & $\begin{array}{l}701 \\
692 \\
678 \\
613 \\
622 \\
648 \\
662 \\
617 \\
554 \\
628\end{array}$ & $\begin{array}{l}770 \\
756 \\
740 \\
676 \\
685 \\
713 \\
729 \\
701 \\
645 \\
727\end{array}$ & $\begin{array}{l}37 \\
37 \\
34 \\
32 \\
33 \\
33 \\
33 \\
36 \\
36 \\
35\end{array}$ & $\begin{array}{l}27 \\
28 \\
29 \\
28 \\
26 \\
26 \\
24 \\
23 \\
24 \\
25\end{array}$ & $\begin{array}{l}13 \\
13 \\
14 \\
15 \\
15 \\
15 \\
15 \\
14 \\
13 \\
14\end{array}$ & $\begin{array}{r}8 \\
8 \\
9 \\
9 \\
10 \\
10 \\
10 \\
10 \\
10 \\
10\end{array}$ & $\begin{array}{l}1 \\
1 \\
1 \\
1 \\
1 \\
1 \\
1 \\
1\end{array}$ \\
\hline 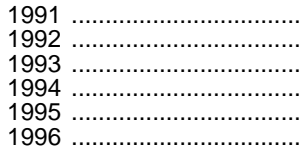 & $\begin{array}{l}471 \\
465 \\
476 \\
499 \\
513 \\
514\end{array}$ & $\begin{array}{l}672 \\
653 \\
652 \\
684 \\
698 \\
733\end{array}$ & $\begin{array}{l}770 \\
754 \\
757 \\
793 \\
803 \\
842\end{array}$ & $\begin{array}{l}33 \\
32 \\
33 \\
34 \\
37 \\
40\end{array}$ & $\begin{array}{l}27 \\
28 \\
27 \\
26 \\
25 \\
25\end{array}$ & $\begin{array}{l}14 \\
13 \\
14 \\
13 \\
13 \\
13\end{array}$ & $\begin{array}{r}10 \\
11 \\
11 \\
10 \\
10 \\
9\end{array}$ & $\begin{array}{l}1 \\
1 \\
1\end{array}$ \\
\hline
\end{tabular}

${ }^{1}$ Number of people receiving high school equivalency credentials based on the GED tests.

${ }^{2}$ Number of people completing the entire GED battery of five tests.

${ }^{3}$ Number of people taking the GED tests (one or more subtests).

-Data not available.

NOTE.-Because of rounding, percentages may not add to 100. Some data have been revised from previously published figures.

SOURCE: American Council on Education, General Educational Development Testing Service. (This table was prepared August 1998.)

Table 105.-Percent of high school dropouts (status dropouts) among persons 16 to 24 years old, by sex and race/ethnicity: April 1960 to October 1997

\begin{tabular}{|c|c|c|c|c|c|c|c|c|c|c|c|c|}
\hline \multirow[b]{2}{*}{ Year } & \multicolumn{4}{|c|}{ Total } & \multicolumn{4}{|c|}{ Men } & \multicolumn{4}{|c|}{ Women } \\
\hline & All races & $\begin{array}{l}\text { White, non- } \\
\text { Hispanic }\end{array}$ & $\begin{array}{l}\text { Black, non- } \\
\text { Hispanic }\end{array}$ & $\begin{array}{c}\text { Hispanic } \\
\text { origin }\end{array}$ & All races & $\begin{array}{l}\text { White, non- } \\
\text { Hispanic }\end{array}$ & $\begin{array}{l}\text { Black, non- } \\
\text { Hispanic }\end{array}$ & $\begin{array}{l}\text { Hispanic } \\
\text { origin }\end{array}$ & All races & $\begin{array}{l}\text { White, non- } \\
\text { Hispanic }\end{array}$ & $\begin{array}{l}\text { Black, non- } \\
\text { Hispanic }\end{array}$ & $\begin{array}{c}\text { Hispanic } \\
\text { origin }\end{array}$ \\
\hline 1 & 2 & 3 & 4 & 5 & 6 & 7 & 8 & 9 & 10 & 11 & 12 & 13 \\
\hline $\begin{array}{l}1960^{1} \ldots \ldots . . \\
19672 \quad \ldots \ldots \ldots \\
19682 \\
1969^{2} \\
1970^{2}\end{array}$ & $\begin{array}{l}27.2- \\
17.0= \\
16.2= \\
15.2= \\
15.0-\end{array}$ & $\begin{array}{l}15.4= \\
14.7= \\
13.6= \\
13.2-\end{array}$ & $\begin{array}{l}28.6- \\
27.4- \\
26.7- \\
27.9-\end{array}$ & $\begin{array}{l}-二 \\
-二 \\
-二 \\
--\end{array}$ & $\begin{array}{l}27.8- \\
16.5- \\
15.8= \\
14.3= \\
14.2-\end{array}$ & $\begin{array}{l}14.7= \\
14.4= \\
12.6- \\
12.2-\end{array}$ & $\begin{array}{l}30 . \overline{6}- \\
27.1- \\
26.9- \\
29.4-\end{array}$ & $\begin{array}{l}-ニ \\
-z \\
-z \\
--\end{array}$ & $\begin{array}{l}26.7- \\
17.3= \\
16.5= \\
16.0= \\
15.7-\end{array}$ & $\begin{array}{l}16.1= \\
15.0= \\
14.6= \\
14.1-\end{array}$ & $\begin{array}{l}26.9= \\
27.6- \\
26.7= \\
26.6-\end{array}$ & $\begin{array}{l}-- \\
-二 \\
-z \\
--\end{array}$ \\
\hline $\begin{array}{l}19712 \ldots \ldots . . \\
1972 \ldots \ldots \ldots . . \\
1973 \ldots \ldots \ldots . . \\
1974 \ldots \ldots \ldots . . \\
1975 \ldots \ldots \ldots . .\end{array}$ & $\begin{array}{r}14.7- \\
14.6(0.3) \\
14.1(0.3) \\
14.3(0.3) \\
13.9(0.3)\end{array}$ & $\begin{array}{r}13.4-\overline{1} \\
12.3(0.3) \\
11.6(0.3) \\
11.9(0.3) \\
11.4(0.3)\end{array}$ & $\begin{array}{r}23.7- \\
21.3(1.1) \\
22.2(1.1) \\
21.2(1.0) \\
22.9(1.1)\end{array}$ & $\begin{array}{l}34.3(2.2) \\
33.5(2.2) \\
33.0(2.1) \\
29.2(2.0)\end{array}$ & $\begin{array}{r}14.2- \\
14.1(0.4) \\
13.7(0.4) \\
14.2(0.4) \\
13.3(0.4)\end{array}$ & $\begin{array}{r}12.6- \\
11.6(0.4) \\
11.5(0.4) \\
12.0(0.4) \\
11.0(0.4)\end{array}$ & $\begin{array}{r}25.5- \\
22.3(1.6) \\
21.5(1.5) \\
20.1(1.5) \\
23.0(1.6)\end{array}$ & $\begin{array}{l}33.7(3.2) \\
30.4(3.2) \\
33.8(3.0) \\
26.7(2.8)\end{array}$ & $\begin{array}{r}15.2- \\
15.1(0.4) \\
14.5(0.4) \\
14.3(0.4) \\
14.5(0.4)\end{array}$ & $\begin{array}{r}14.2-\overline{1} \\
12.8(0.4) \\
11.8(0.4) \\
11.8(0.4) \\
11.8(0.4)\end{array}$ & $\begin{array}{r}22.1-\overline{1} \\
20.5(1.4) \\
22.8(1.5) \\
22.1(1.5) \\
22.9(1.4)\end{array}$ & $\begin{array}{l}34.8(3.1) \\
36.4(3.2) \\
32.2(2.9) \\
31.6(2.9)\end{array}$ \\
\hline 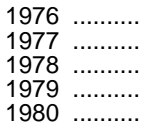 & $\begin{array}{l}14.1(0.3) \\
14.1(0.3) \\
14.2(0.3) \\
14.6(0.3) \\
14.1(0.3)\end{array}$ & $\begin{array}{l}12.0(0.3) \\
11.9(0.3) \\
11.9(0.3) \\
12.0(0.3) \\
11.4(0.3)\end{array}$ & $\begin{array}{l}20.5(1.0) \\
19.8(1.0) \\
20.2(1.0) \\
21.1(1.0) \\
19.1(1.0)\end{array}$ & $\begin{array}{l}31.4(2.0) \\
33.0(2.0) \\
33.3(2.0) \\
33.8(2.0) \\
35.2(1.9)\end{array}$ & $\begin{array}{l}14.1(0.4) \\
14.5(0.4) \\
14.6(0.4) \\
15.0(0.4) \\
15.1(0.4)\end{array}$ & $\begin{array}{l}12.1(0.4) \\
12.6(0.4) \\
12.2(0.4) \\
12.6(0.4) \\
12.3(0.4)\end{array}$ & $\begin{array}{l}21.2(1.5) \\
19.5(1.5) \\
22.5(1.5) \\
22.4(1.5) \\
20.8(1.5)\end{array}$ & $\begin{array}{l}30.3(2.9) \\
31.6(2.9) \\
33.6(2.9) \\
33.0(2.8) \\
37.2(2.7)\end{array}$ & $\begin{array}{l}14.2(0.4) \\
13.8(0.4) \\
13.9(0.4) \\
14.2(0.4) \\
13.1(0.4)\end{array}$ & $\begin{array}{l}11.8(0.4) \\
11.2(0.4) \\
11.6(0.4) \\
11.5(0.4) \\
10.5(0.4)\end{array}$ & $\begin{array}{l}19.9(1.4) \\
20.0(1.4) \\
18.3(1.3) \\
20.0(1.3) \\
17.7(1.3)\end{array}$ & $\begin{array}{l}32.3(2.8) \\
34.3(2.8) \\
33.1(2.8) \\
34.5(2.8) \\
33.2(2.6)\end{array}$ \\
\hline $\begin{array}{ll}1981 & \ldots \ldots \ldots \ldots \\
1982 & \ldots \ldots \ldots \ldots \\
1983 & \ldots \ldots \ldots \ldots \\
1984 & \ldots \ldots \ldots \ldots \\
1985 & \ldots \ldots \ldots \ldots\end{array}$ & $\begin{array}{l}13.9(0.3) \\
13.9(0.3) \\
13.7(0.3) \\
13.1(0.3) \\
12.6(0.3)\end{array}$ & $\begin{array}{l}11.3(0.3) \\
11.4(0.3) \\
11.1(0.3) \\
11.0(0.3) \\
10.4(0.3)\end{array}$ & $\begin{array}{l}18.4(0.9) \\
18.4(1.0) \\
18.0(1.0) \\
15.5(0.9) \\
15.2(0.9)\end{array}$ & $\begin{array}{l}33.2(1.8) \\
31.7(1.9) \\
31.6(1.9) \\
29.8(1.9) \\
27.6(1.9)\end{array}$ & $\begin{array}{l}15.1(0.4) \\
14.5(0.4) \\
14.9(0.4) \\
14.0(0.4) \\
13.4(0.4)\end{array}$ & $\begin{array}{l}12.5(0.4) \\
12.0(0.4) \\
12.2(0.4) \\
11.9(0.4) \\
11.1(0.4)\end{array}$ & $\begin{array}{l}19.9(1.4) \\
21.2(1.5) \\
19.9(1.5) \\
16.8(1.4) \\
16.1(1.4)\end{array}$ & $\begin{array}{l}36.0(2.6) \\
30.5(2.7) \\
34.3(2.8) \\
30.6(2.8) \\
29.9(2.8)\end{array}$ & $\begin{array}{l}12.8(0.4) \\
13.3(0.4) \\
12.5(0.4) \\
12.3(0.4) \\
11.8(0.4)\end{array}$ & $\begin{array}{r}10.2(0.4) \\
10.8(0.4) \\
10.1(0.4) \\
10.1(0.4) \\
9.8(0.4)\end{array}$ & $\begin{array}{l}17.1(1.2) \\
15.9(1.3) \\
16.2(1.3) \\
14.3(1.2) \\
14.3(1.2)\end{array}$ & $\begin{array}{l}30.4(2.5) \\
32.8(2.7) \\
29.1(2.6) \\
29.0(2.6) \\
25.2(2.7)\end{array}$ \\
\hline 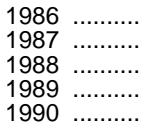 & $\begin{array}{l}12.2(0.3) \\
12.6(0.3) \\
12.9(0.3) \\
12.6(0.3) \\
12.1(0.3)\end{array}$ & $\begin{array}{r}9.7(0.3) \\
10.4(0.3) \\
9.6(0.3) \\
9.4(0.3) \\
9.0(0.3)\end{array}$ & $\begin{array}{l}14.2(0.9) \\
14.1(0.9) \\
14.5(1.0) \\
13.9(1.0) \\
13.2(0.9)\end{array}$ & $\begin{array}{l}30.1(1.9) \\
28.6(1.8) \\
35.8(2.3) \\
33.0(2.2) \\
32.4(1.9)\end{array}$ & $\begin{array}{l}13.1(0.4) \\
13.2(0.4) \\
13.5(0.4) \\
13.6(0.5) \\
12.3(0.4)\end{array}$ & $\begin{array}{r}10.3(0.4) \\
10.8(0.4) \\
10.3(0.5) \\
10.3(0.5) \\
9.3(0.4)\end{array}$ & $\begin{array}{l}15.0(1.3) \\
15.0(1.3) \\
15.0(1.5) \\
14.9(1.5) \\
11.9(1.3)\end{array}$ & $\begin{array}{l}32.8(2.7) \\
29.1(2.6) \\
36.0(3.2) \\
34.4(3.1) \\
34.3(2.7)\end{array}$ & $\begin{array}{l}11.4(0.4) \\
12.1(0.4) \\
12.2(0.4) \\
11.7(0.4) \\
11.8(0.4)\end{array}$ & $\begin{array}{r}9.1(0.4) \\
10.0(0.4) \\
8.9(0.4) \\
8.5(0.4) \\
8.7(0.4)\end{array}$ & $\begin{array}{l}13.5(1.2) \\
13.3(1.2) \\
14.0(1.4) \\
13.0(1.3) \\
14.4(1.3)\end{array}$ & $\begin{array}{l}27.2(2.6) \\
28.1(2.6) \\
35.4(3.3) \\
31.6(3.1) \\
30.3(2.7)\end{array}$ \\
\hline $\begin{array}{l}1991 \ldots \ldots \ldots \\
1993^{3} \ldots \ldots \ldots . \\
1993^{3} \ldots \ldots \ldots \\
19944^{3} \ldots \ldots \ldots . \\
1995^{3} \ldots \ldots \ldots . .\end{array}$ & $\begin{array}{l}12.5(0.3) \\
11.0(0.3) \\
11.0(0.3) \\
11.4(0.3) \\
12.0(0.3)\end{array}$ & $\begin{array}{l}8.9(0.3) \\
7.7(0.3) \\
7.9(0.3) \\
7.7(0.3) \\
8.6(0.3)\end{array}$ & $\begin{array}{l}13.6(0.9) \\
13.7(0.9) \\
13.6(0.9) \\
12.6(0.8) \\
12.1(0.7)\end{array}$ & $\begin{array}{l}35.3(1.9) \\
29.4(1.9) \\
27.5(1.8) \\
30.0(1.2) \\
30.0(1.1)\end{array}$ & $\begin{array}{l}13.0(0.4) \\
11.3(0.4) \\
11.2(0.4) \\
12.3(0.4) \\
12.2(0.4)\end{array}$ & $\begin{array}{l}8.9(0.4) \\
8.0(0.4) \\
8.2(0.4) \\
8.0(0.4) \\
9.0(0.4)\end{array}$ & $\begin{array}{l}13.5(1.4) \\
12.5(1.3) \\
12.6(1.3) \\
14.1(1.1) \\
11.1(1.0)\end{array}$ & $\begin{array}{l}39.2(2.7) \\
32.1(2.7) \\
28.1(2.5) \\
31.6(1.6) \\
30.0(1.6)\end{array}$ & $\begin{array}{l}11.9(0.4) \\
10.7(0.4) \\
10.9(0.4) \\
10.6(0.4) \\
11.7(0.4)\end{array}$ & $\begin{array}{l}8.9(0.4) \\
7.4(0.4) \\
7.6(0.4) \\
7.5(0.4) \\
8.2(0.4)\end{array}$ & $\begin{array}{l}13.7(1.3) \\
14.8(1.4) \\
14.4(1.3) \\
11.3(1.0) \\
12.9(1.1)\end{array}$ & $\begin{array}{l}31.1(2.7) \\
26.6(2.6) \\
26.9(2.5) \\
28.1(1.7) \\
30.0(1.7)\end{array}$ \\
\hline $\begin{array}{l}1996^{3} \ldots \ldots . . \\
1997^{3} \ldots \ldots \ldots\end{array}$ & $\begin{array}{l}11.1(0.3) \\
11.0(0.3)\end{array}$ & $\begin{array}{l}7.3(0.3) \\
7.6(0.3)\end{array}$ & $\begin{array}{l}13.0(0.8) \\
13.4(0.8)\end{array}$ & $\begin{array}{l}29.4(1.2) \\
25.3(1.1)\end{array}$ & $\begin{array}{l}11.4(0.4) \\
11.9(0.4)\end{array}$ & $\begin{array}{l}7.3(0.4) \\
8.5(0.4)\end{array}$ & $\begin{array}{l}13.5(1.2) \\
13.3(1.2)\end{array}$ & $\begin{array}{l}30.3(1.7) \\
27.0(1.6)\end{array}$ & $\begin{array}{l}10.9(0.4) \\
10.1(0.4)\end{array}$ & $\begin{array}{l}7.3(0.4) \\
6.7(0.4)\end{array}$ & $\begin{array}{l}12.5(1.1) \\
13.5(1.1)\end{array}$ & $\begin{array}{l}28.3(1.7) \\
23.4(1.6)\end{array}$ \\
\hline
\end{tabular}

1 Based on the April 1960 decennial census.

${ }^{2}$ White and black include persons of Hispanic origin

${ }^{3}$ Because of changes in data collection procedures, data may not be comparable with figures for earlier years.

-Data not available.

NOTE.- "Status" dropouts are 16- to 24-year-olds who are not enrolled in school and who have not completed a high school program, regardless of when they left school. People who have received GED credentials are counted as high school completers. All data except for 1960 are based on October counts. Data are based upon sample surveys of the civilian noninstitutional population. Standard errors appear in parentheses.

SOURCE: U.S. Department of Commerce, Bureau of the Census, Current Population Survey, unpublished tabulations; and U.S. Department of Education, National Center for Education Statistics, Dropout Rates in the United States. (This table was prepared December 1998.) 
Table 106.-Percent of high school dropouts (status dropouts) among persons 16 to 34 years old, by age, sex, and race/ethnicity: October 1970 to October 1997

\begin{tabular}{|c|c|c|c|c|c|c|}
\hline Year, race/ethnicity, and sex & $\begin{array}{c}16 \text { and } 17 \\
\text { years }\end{array}$ & $\begin{array}{c}18 \text { and } 19 \\
\text { years }\end{array}$ & $\begin{array}{c}20 \text { and } 21 \\
\text { years }\end{array}$ & $\begin{array}{l}22 \text { to } 24 \\
\text { years }\end{array}$ & $\begin{array}{l}25 \text { to } 29 \\
\text { years }\end{array}$ & $\begin{array}{c}30 \text { to } 34 \\
\text { years }\end{array}$ \\
\hline 1 & 2 & 3 & 4 & 5 & 6 & 7 \\
\hline 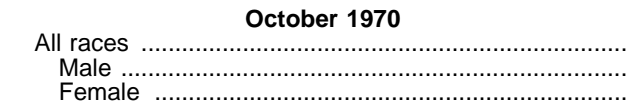 & $\begin{array}{l}8.0 \\
7.1 \\
8.9\end{array}$ & $\begin{array}{l}16.2 \\
16.0 \\
16.3\end{array}$ & $\begin{array}{l}16.6 \\
16.1 \\
16.9\end{array}$ & $\begin{array}{l}18.7 \\
17.9 \\
19.4\end{array}$ & $\begin{array}{l}22.5 \\
21.4 \\
23.6\end{array}$ & $\begin{array}{l}26.5 \\
26.2 \\
26.8\end{array}$ \\
\hline $\begin{array}{l}\text { White } \\
\quad \text { Male } \\
\text { Female }\end{array}$ & $\begin{array}{l}7.3 \\
6.3 \\
8.4\end{array}$ & $\begin{array}{l}14.1 \\
13.3 \\
14.8\end{array}$ & $\begin{array}{l}14.6 \\
14.1 \\
15.1\end{array}$ & $\begin{array}{l}16.3 \\
15.3 \\
17.2\end{array}$ & $\begin{array}{l}19.9 \\
19.0 \\
20.7\end{array}$ & $\begin{array}{l}24.6 \\
24.2 \\
24.9\end{array}$ \\
\hline Black 1 (ale & $\begin{array}{l}12.8 \\
13.3 \\
12.4\end{array}$ & $\begin{array}{l}31.2 \\
36.4 \\
26.6\end{array}$ & $\begin{array}{l}29.6 \\
29.6 \\
29.6\end{array}$ & $\begin{array}{l}37.8 \\
39.5 \\
36.4\end{array}$ & $\begin{array}{l}44.4 \\
43.1 \\
45.6\end{array}$ & $\begin{array}{l}43.5 \\
45.9 \\
41.5\end{array}$ \\
\hline 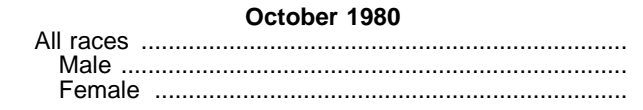 & $\begin{array}{l}8.9 \\
8.9 \\
8.8\end{array}$ & $\begin{array}{l}15.7 \\
16.9 \\
14.7\end{array}$ & $\begin{array}{l}16.0 \\
17.8 \\
14.3\end{array}$ & $\begin{array}{l}15.2 \\
16.4 \\
14.0\end{array}$ & $\begin{array}{l}13.9 \\
13.8 \\
14.0\end{array}$ & $\begin{array}{l}14.6 \\
14.0 \\
15.2\end{array}$ \\
\hline $\begin{array}{l}\text { White, non-Hispanic } \\
\text { Male } \\
\text { Female }\end{array}$ & $\begin{array}{l}8.6 \\
8.5 \\
8.6\end{array}$ & $\begin{array}{l}12.7 \\
13.6 \\
11.9\end{array}$ & $\begin{array}{l}12.1 \\
13.5 \\
10.9\end{array}$ & $\begin{array}{l}11.8 \\
13.2 \\
10.4\end{array}$ & $\begin{array}{l}10.4 \\
10.6 \\
10.3\end{array}$ & $\begin{array}{l}11.0 \\
10.7 \\
11.3\end{array}$ \\
\hline $\begin{array}{l}\text { Black, non-Hispanic } \\
\quad \text { Male } \\
\text { Female }\end{array}$ & $\begin{array}{l}7.0 \\
7.2 \\
6.8\end{array}$ & $\begin{array}{l}21.0 \\
22.2 \\
19.8\end{array}$ & $\begin{array}{l}24.6 \\
30.8 \\
19.6\end{array}$ & $\begin{array}{l}23.6 \\
24.6 \\
22.8\end{array}$ & $\begin{array}{l}22.4 \\
22.2 \\
22.6\end{array}$ & $\begin{array}{l}23.1 \\
21.9 \\
24.0\end{array}$ \\
\hline 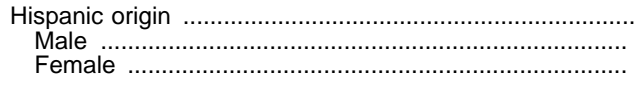 & $\begin{array}{l}16.5 \\
18.1 \\
15.0\end{array}$ & $\begin{array}{l}39.0 \\
43.1 \\
34.6\end{array}$ & $\begin{array}{l}41.6 \\
41.4 \\
41.9\end{array}$ & $\begin{array}{l}40.6 \\
42.9 \\
38.6\end{array}$ & $\begin{array}{l}40.9 \\
40.1 \\
41.7\end{array}$ & $\begin{array}{l}45.4 \\
43.9 \\
47.0\end{array}$ \\
\hline 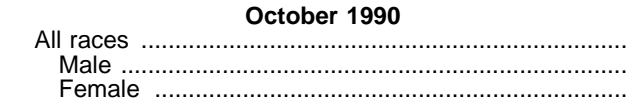 & $\begin{array}{l}6.3 \\
6.6 \\
6.1\end{array}$ & $\begin{array}{l}14.2 \\
14.6 \\
13.8\end{array}$ & $\begin{array}{l}12.8 \\
13.2 \\
12.4\end{array}$ & $\begin{array}{l}13.8 \\
14.0 \\
13.6\end{array}$ & $\begin{array}{l}13.9 \\
14.5 \\
13.4\end{array}$ & $\begin{array}{l}12.9 \\
13.3 \\
12.5\end{array}$ \\
\hline $\begin{array}{c}\text { White, non-Hispanic } \\
\text { Male } \\
\text { Female }\end{array}$ & $\begin{array}{l}5.4 \\
5.9 \\
5.0\end{array}$ & $\begin{array}{l}11.1 \\
11.4 \\
10.8\end{array}$ & $\begin{array}{l}9.4 \\
9.6 \\
9.1\end{array}$ & $\begin{array}{l}9.5 \\
9.8 \\
9.1\end{array}$ & $\begin{array}{l}9.2 \\
9.8 \\
8.5\end{array}$ & $\begin{array}{l}8.7 \\
9.4 \\
8.0\end{array}$ \\
\hline 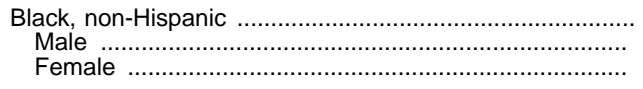 & $\begin{array}{l}6.9 \\
6.3 \\
7.5\end{array}$ & $\begin{array}{l}16.6 \\
15.5 \\
17.6\end{array}$ & $\begin{array}{l}15.6 \\
12.4 \\
18.6\end{array}$ & $\begin{array}{l}13.6 \\
13.2 \\
13.9\end{array}$ & $\begin{array}{l}19.3 \\
18.9 \\
19.6\end{array}$ & $\begin{array}{l}16.7 \\
16.4 \\
16.9\end{array}$ \\
\hline Hispanic origin & $\begin{array}{l}12.9 \\
13.1 \\
12.5\end{array}$ & $\begin{array}{l}34.2 \\
39.4 \\
29.4\end{array}$ & $\begin{array}{l}31.6 \\
37.9 \\
25.0\end{array}$ & $\begin{array}{l}42.8 \\
41.4 \\
44.4\end{array}$ & $\begin{array}{l}41.7 \\
42.6 \\
40.7\end{array}$ & $\begin{array}{l}42.4 \\
41.4 \\
43.5\end{array}$ \\
\hline 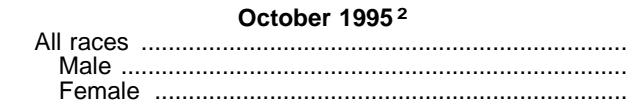 & $\begin{array}{l}5.4 \\
4.8 \\
6.1\end{array}$ & $\begin{array}{l}14.6 \\
14.7 \\
14.5\end{array}$ & $\begin{array}{l}13.8 \\
13.6 \\
13.9\end{array}$ & $\begin{array}{l}13.6 \\
14.9 \\
12.3\end{array}$ & $\begin{array}{l}12.4 \\
13.9 \\
10.9\end{array}$ & $\begin{array}{l}11.7 \\
12.0 \\
11.4\end{array}$ \\
\hline 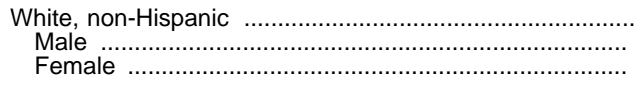 & $\begin{array}{l}4.7 \\
4.2 \\
5.2\end{array}$ & $\begin{array}{l}11.4 \\
11.7 \\
11.0\end{array}$ & $\begin{array}{l}9.4 \\
9.3 \\
9.5\end{array}$ & $\begin{array}{r}8.9 \\
10.4 \\
7.4\end{array}$ & $\begin{array}{l}7.8 \\
9.0 \\
6.7\end{array}$ & $\begin{array}{l}7.7 \\
7.9 \\
7.5\end{array}$ \\
\hline $\begin{array}{l}\text { Black, non-Hispanic } \\
\text { Male } \\
\text { Female }\end{array}$ & $\begin{array}{l}5.6 \\
4.1 \\
7.3\end{array}$ & $\begin{array}{l}15.7 \\
18.1 \\
13.7\end{array}$ & $\begin{array}{l}15.1 \\
16.2 \\
14.2\end{array}$ & $\begin{array}{r}12.6 \\
9.4 \\
15.4\end{array}$ & $\begin{array}{l}11.6 \\
11.3 \\
11.8\end{array}$ & $\begin{array}{l}11.6 \\
12.1 \\
11.1\end{array}$ \\
\hline $\begin{array}{l}\text { Hispanic origin } \\
\text { Male } \\
\text { Female }\end{array}$ & $\begin{array}{l}10.7 \\
11.2 \\
10.2\end{array}$ & $\begin{array}{l}30.8 \\
27.0 \\
35.0\end{array}$ & $\begin{array}{l}34.4 \\
33.4 \\
35.4\end{array}$ & $\begin{array}{l}37.4 \\
39.0 \\
35.3\end{array}$ & $\begin{array}{l}39.0 \\
42.1 \\
35.6\end{array}$ & $\begin{array}{l}36.6 \\
35.5 \\
37.8\end{array}$ \\
\hline 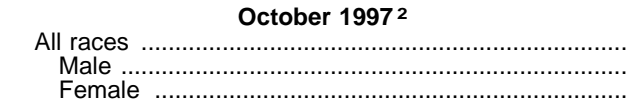 & $\begin{array}{l}4.8 \\
5.0 \\
4.7\end{array}$ & $\begin{array}{l}13.8 \\
15.3 \\
12.3\end{array}$ & $\begin{array}{l}12.7 \\
13.9 \\
11.4\end{array}$ & $\begin{array}{l}12.5 \\
13.3 \\
11.8\end{array}$ & $\begin{array}{l}12.0 \\
13.3 \\
10.8\end{array}$ & $\begin{array}{l}11.8 \\
13.0 \\
10.7\end{array}$ \\
\hline 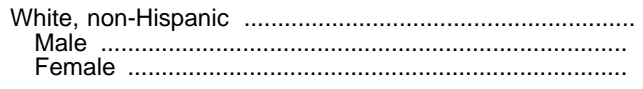 & $\begin{array}{l}4.3 \\
5.1 \\
3.4\end{array}$ & $\begin{array}{r}11.2 \\
12.8 \\
9.6\end{array}$ & $\begin{array}{l}8.5 \\
9.4 \\
7.6\end{array}$ & $\begin{array}{l}6.9 \\
7.3 \\
6.4\end{array}$ & $\begin{array}{l}6.6 \\
7.7 \\
5.5\end{array}$ & $\begin{array}{l}6.5 \\
7.1 \\
6.0\end{array}$ \\
\hline $\begin{array}{l}\text { Black, non-Hispanic } \\
\text { Male } \\
\text { Female }\end{array}$ & $\begin{array}{l}5.5 \\
4.5 \\
6.4\end{array}$ & $\begin{array}{l}14.9 \\
16.0 \\
13.9\end{array}$ & $\begin{array}{l}17.9 \\
19.6 \\
16.5\end{array}$ & $\begin{array}{l}16.2 \\
15.6 \\
16.7\end{array}$ & $\begin{array}{r}11.7 \\
9.5 \\
13.4\end{array}$ & $\begin{array}{l}12.7 \\
15.4 \\
10.4\end{array}$ \\
\hline $\begin{array}{l}\text { Hispanic origin } \\
\quad \text { Male } \\
\text { Female }\end{array}$ & $\begin{array}{l}7.3 \\
5.1 \\
9.6\end{array}$ & $\begin{array}{l}25.2 \\
28.0 \\
22.1\end{array}$ & $\begin{array}{l}29.2 \\
32.2 \\
25.7\end{array}$ & $\begin{array}{l}35.3 \\
37.5 \\
32.7\end{array}$ & $\begin{array}{l}37.6 \\
39.9 \\
34.9\end{array}$ & $\begin{array}{l}39.5 \\
40.1 \\
38.7\end{array}$ \\
\hline
\end{tabular}

1 Includes persons of Hispanic origin.

${ }^{2}$ Because of changes in data collection procedures, data may not be comparable with figures for earlier years.

NOTE.- "Status" dropouts are persons who are 16- to 24-year-olds who are not enrolled in school and who have not completed a high school program, regardless of when they left school. People who have received GED credentials are counted as high school completers. Data are based upon sample surveys of the civilian noninstitutional population.

SOURCE: U.S. Department of Commerce, Bureau of the Census, Current Population Survey, unpublished data. (This table was prepared September 1998.) 
Table 107.-Students with disabilities exiting the educational system, by age, type of disability, and basis of exit: United States and outlying areas, 1993-94 and 1994-95

\begin{tabular}{|c|c|c|c|c|c|c|c|c|c|c|c|c|}
\hline \multirow{3}{*}{ Student characteristics } & \multicolumn{6}{|c|}{ Number } & \multicolumn{6}{|c|}{ Percent } \\
\hline & \multicolumn{2}{|c|}{$\begin{array}{l}\text { Graduated with } \\
\text { diploma }\end{array}$} & \multicolumn{2}{|c|}{$\begin{array}{l}\text { Graduated with } \\
\text { certificate }\end{array}$} & \multicolumn{2}{|c|}{$\begin{array}{l}\text { Reached maximum } \\
\text { age }^{1}\end{array}$} & \multicolumn{2}{|c|}{$\begin{array}{l}\text { Graduated with } \\
\text { diploma }\end{array}$} & \multicolumn{2}{|c|}{$\begin{array}{l}\text { Graduated with } \\
\text { certificate }\end{array}$} & \multicolumn{2}{|c|}{$\begin{array}{l}\text { Reached maximum } \\
\text { age }^{1}\end{array}$} \\
\hline & $1993-94^{2}$ & 1994-95 & $1993-94^{2}$ & 1994-95 & $1993-94^{2}$ & 1994-95 & $1993-94^{2}$ & 1994-95 & $1993-94^{2}$ & 1994-95 & $1993-94^{2}$ & 1994-95 \\
\hline 1 & 2 & 3 & 4 & 5 & 6 & 7 & 8 & 9 & 10 & 11 & 12 & 13 \\
\hline Age group & & & & & & & & & & & & \\
\hline 14 to 21 (and over) & $\begin{array}{r}113,910 \\
91 \\
169 \\
532 \\
15,417 \\
47,847 \\
35,730 \\
9,361 \\
4,763\end{array}$ & $\begin{array}{r}118,471 \\
62 \\
106 \\
545 \\
16,455 \\
49,988 \\
37,154 \\
9,254 \\
4,907\end{array}$ & $\begin{array}{r}23,983 \\
130 \\
71 \\
178 \\
2,016 \\
7,766 \\
7,001 \\
3,408 \\
3,413\end{array}$ & $\begin{array}{r}25,106 \\
73 \\
68 \\
154 \\
2,373 \\
9,017 \\
7,308 \\
3,083 \\
3,030\end{array}$ & $\begin{array}{r}4,594 \\
7 \\
9 \\
39 \\
106 \\
110 \\
91 \\
525 \\
3,707\end{array}$ & $\begin{array}{r}3,954 \\
4 \\
7 \\
26 \\
37 \\
110 \\
79 \\
383 \\
3,308\end{array}$ & $\begin{array}{r}28.1 \\
0.2 \\
0.4 \\
1.0 \\
22.7 \\
51.9 \\
59.7 \\
48.0 \\
30.9\end{array}$ & $\begin{array}{r}26.8 \\
0.1 \\
0.2 \\
0.9 \\
21.7 \\
50.3 \\
59.9 \\
48.5 \\
33.3\end{array}$ & $\begin{array}{r}5.9 \\
0.3 \\
0.1 \\
0.3 \\
3.0 \\
8.4 \\
11.7 \\
17.5 \\
22.1\end{array}$ & $\begin{array}{r}5.7 \\
0.1 \\
0.1 \\
0.2 \\
3.1 \\
9.1 \\
11.8 \\
16.1 \\
20.5\end{array}$ & $\begin{array}{r}1.1 \\
0.0 \\
0.0 \\
0.1 \\
0.2 \\
0.1 \\
0.2 \\
2.7 \\
24.0\end{array}$ & $\begin{array}{r}0.9 \\
0.0 \\
0.0 \\
0.0 \\
0.0 \\
0.1 \\
0.1 \\
2.0 \\
22.4\end{array}$ \\
\hline \multicolumn{13}{|l|}{ Type of disability } \\
\hline $\begin{array}{l}\text { All disabilities, } 14 \text { to } 21 \text { and over ....... } \\
\text { Specific learning disabilities ......... } \\
\text { Mental retardation .................... } \\
\text { Serious emotional disturbance ...... } \\
\text { Speech or language impairments } \\
\text { Multiple disabilities ...................... } \\
\text { Other health impairments ............ } \\
\text { Hearing impairments }\end{array}$ & $\begin{array}{r}113,945 \\
76,735 \\
13,900 \\
11,251 \\
3,423 \\
1,254 \\
2,250 \\
2,209 \\
1,557 \\
931 \\
169 \\
34 \\
232\end{array}$ & $\begin{array}{r}118,471 \\
80,666 \\
13,817 \\
11,611 \\
3,492 \\
1,416 \\
2,222 \\
2,110 \\
1,619 \\
960 \\
211 \\
33 \\
314\end{array}$ & $\begin{array}{r}23,948 \\
10,871 \\
9,117 \\
1,649 \\
473 \\
675 \\
191 \\
391 \\
285 \\
105 \\
120 \\
26 \\
45\end{array}$ & $\begin{array}{r}25,106 \\
11,716 \\
9,045 \\
1,693 \\
485 \\
788 \\
260 \\
454 \\
339 \\
114 \\
115 \\
34 \\
63\end{array}$ & $\begin{array}{r}4,594 \\
891 \\
2,307 \\
331 \\
121 \\
553 \\
44 \\
48 \\
133 \\
53 \\
80 \\
8 \\
25\end{array}$ & $\begin{array}{r}3,954 \\
631 \\
2,101 \\
292 \\
70 \\
515 \\
40 \\
33 \\
107 \\
47 \\
88 \\
9 \\
21\end{array}$ & $\begin{array}{l}28.1 \\
32.5 \\
26.3 \\
16.1 \\
18.3 \\
25.1 \\
21.7 \\
44.1 \\
33.5 \\
46.3 \\
24.1 \\
23.9 \\
35.4\end{array}$ & $\begin{array}{l}26.8 \\
31.2 \\
25.5 \\
15.0 \\
17.6 \\
22.5 \\
20.1 \\
40.5 \\
31.2 \\
46.0 \\
25.5 \\
20.5 \\
36.9\end{array}$ & $\begin{array}{r}5.9 \\
4.6 \\
17.2 \\
2.4 \\
2.5 \\
13.5 \\
1.8 \\
7.8 \\
6.1 \\
5.2 \\
17.1 \\
18.3 \\
6.9\end{array}$ & $\begin{array}{r}5.7 \\
4.5 \\
16.7 \\
2.2 \\
2.4 \\
12.5 \\
2.3 \\
8.7 \\
6.5 \\
5.5 \\
13.9 \\
21.1 \\
7.4\end{array}$ & $\begin{array}{r}1.1 \\
0.4 \\
4.4 \\
0.5 \\
0.6 \\
11.1 \\
0.4 \\
1.0 \\
2.9 \\
2.6 \\
11.4 \\
5.6 \\
3.8\end{array}$ & $\begin{array}{r}0.9 \\
0.2 \\
3.9 \\
0.4 \\
0.4 \\
8.2 \\
0.4 \\
0.6 \\
2.1 \\
2.3 \\
10.6 \\
5.6 \\
2.5\end{array}$ \\
\hline
\end{tabular}

1 These figures reflect an estimate of those who were actually known to have dropped out and do not include youth who simply stopped coming to school or whose status was unknown.

2 Upper age limits for service eligibility vary by state.
SOURCE: U.S. Department of Education, Office of Special Education and Rehabilitative Services, Sixteenth, Seventeenth, and Nineteenth Annual Reports to Congress on the Implementation of The Individuals with Disabilities Education Act, 1995 and 1996. (This table was prepared November 1998.)

Table 108.-Postsecondary education and employment status, wages earned, and living arrangements of special education students out of secondary school up to 3 years, by type of disability: 1990

\begin{tabular}{|c|c|c|c|c|c|}
\hline \multirow{2}{*}{ Type of disability } & \multicolumn{2}{|c|}{ Percent in postsecondary education } & \multirow{2}{*}{$\begin{array}{l}\text { Percent currently com- } \\
\text { petitively employed }\end{array}$} & \multirow{2}{*}{$\begin{array}{l}\text { Average annual total } \\
\text { compensation }\end{array}$} & \multirow{2}{*}{$\begin{array}{l}\text { Percent living } \\
\text { independently } 1\end{array}$} \\
\hline & Academic & Vocational & & & \\
\hline 1 & 2 & 3 & 4 & 5 & 6 \\
\hline All disabilities ${ }^{2} \ldots \ldots \ldots \ldots \ldots \ldots$ & 16.5 & 14.7 & 55.0 & $\$ 5,524$ & 27.8 \\
\hline Learning disabled ..................... & 18.7 & 17.8 & 63.1 & 6,932 & 33.9 \\
\hline Serious emotional disturbance & 15.3 & 13.3 & 52.0 & 5,310 & 21.1 \\
\hline Speech/language impairments & 37.0 & 17.9 & 58.5 & 4,389 & 36.4 \\
\hline Mental retardation ....................... & 2.5 & 5.7 & 40.8 & 3,078 & 14.8 \\
\hline Visual impairment & 53.9 & 14.9 & 30.3 & 2,027 & 39.3 \\
\hline Hard of hearing $\ldots \ldots \ldots \ldots \ldots \ldots \ldots \ldots \ldots$ & 35.0 & 20.0 & 43.6 & 2,773 & 25.9 \\
\hline Deaf & 28.3 & 19.9 & 24.8 & 1,689 & 32.3 \\
\hline Orthopedic impairments ............. & 30.9 & 13.4 & 26.4 & 1,636 & 16.6 \\
\hline Other health impairments ................ & 35.1 & 23.5 & 47.5 & 4,388 & 17.2 \\
\hline Multiple disabilities ..................... & 8.0 & 4.0 & 15.8 & 778 & 8.0 \\
\hline
\end{tabular}

${ }^{1}$ Living independently includes living alone, with a spouse or roommate, in a college dormitory, or in military housing not as a dependent.

${ }^{2}$ All conditions includes youth in each of the 11 Federal special education disability categories. Percentages are reported separately only for categories with at least 25 youth in the sample.

NOTE.-Data based on students who had been out of school up to three years and had attended special and regular schools in the 1985-86 or 1986-87 school years.
SOURCE: U.S. Department of Education, Office of Special Education and Rehabilitative Services, The Seventeenth Annual Report to Congress on the Implementation of The Individuals with Disabilities Education Act, The National Longitudinal Transition Study, 1995. (This table was prepared April 1996.) 
Table 109.-Average student proficiency in reading, by age and selected characteristics of students: 1971 to 1996

\begin{tabular}{|c|c|c|c|c|c|c|c|c|c|}
\hline Selected characteristics of students & 1971 & 1975 & 1980 & 1984 & 1988 & 1990 & 1992 & 1994 & 1996 \\
\hline 1 & 2 & 3 & 4 & 5 & 6 & 7 & 8 & 9 & 10 \\
\hline & \multicolumn{9}{|c|}{9 -year-olds ${ }^{1}$} \\
\hline Total ....... & $207.6(1.0)$ & $210.0(0.7)$ & $215.0(1.0)$ & $210.9(0.7)$ & $211.8(1.1)$ & $209.2(1.2)$ & $210.5(0.9)$ & $211.0(1.2)$ & $212.4(1.0)$ \\
\hline 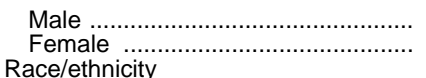 & $\begin{array}{l}201.2(1.1) \\
213.9(1.0)\end{array}$ & $\begin{array}{l}204.3(0.8) \\
215.8(0.8)\end{array}$ & $\begin{array}{l}210.0(1.1) \\
220.1(1.1)\end{array}$ & $\begin{array}{l}207.5(0.8) \\
214.2(0.8)\end{array}$ & $\begin{array}{l}207.5(1.4) \\
216.3(1.3)\end{array}$ & $\begin{array}{l}204.0(1.7) \\
214.5(1.2)\end{array}$ & $\begin{array}{l}205.9(1.3) \\
215.4(0.9)\end{array}$ & $\begin{array}{l}207.3(1.3) \\
214.7(1.4)\end{array}$ & $\begin{array}{l}206.8(1.5) \\
218.0(1.2)\end{array}$ \\
\hline 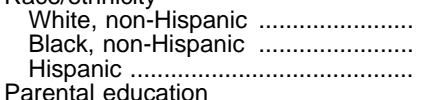 & $\begin{array}{r}214.00 .9 \\
170.1(1.7) \\
(2)\end{array}$ & $\begin{array}{l}216.6(0.7) \\
181.2(1.2) \\
182.7(2.2)\end{array}$ & $\begin{array}{l}221.3(0.8) \\
189.3(1.8) \\
190.2(2.3)\end{array}$ & $\begin{array}{l}218.2(0.8) \\
185.7(1.1) \\
187.2(2.1)\end{array}$ & $\begin{array}{l}217.7(1.4) \\
188.5(2.4) \\
193.7(3.5)\end{array}$ & $\begin{array}{l}217.0(1.3) \\
181.8(2.9) \\
189.4(2.3)\end{array}$ & $\begin{array}{l}217.9(1.0) \\
184.5(2.2) \\
191.7(3.1)\end{array}$ & $\begin{array}{l}218.0(1.3) \\
185.4(2.3) \\
185.9(3.9)\end{array}$ & $\begin{array}{l}219.9(1.2) \\
190.0(2.7) \\
194.1(3.5)\end{array}$ \\
\hline 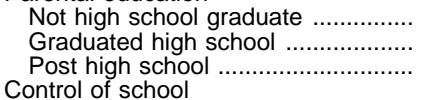 & $\begin{array}{l}188.6(1.5) \\
207.8(1.2) \\
223.9(1.1)\end{array}$ & $\begin{array}{l}189.9(1.3) \\
211.3(0.9) \\
221.5(0.9)\end{array}$ & $\begin{array}{l}194.3(1.6) \\
213.0(1.3) \\
226.0(1.1)\end{array}$ & $\begin{array}{l}195.1(1.4) \\
208.9(1.0) \\
222.9(0.9)\end{array}$ & $\begin{array}{l}192.5(4.9) \\
210.8(2.2) \\
220.0(1.7)\end{array}$ & $\begin{array}{l}192.6(3.2) \\
209.1(1.8) \\
217.7(2.0)\end{array}$ & $\begin{array}{l}194.9(4.5) \\
207.4(1.5) \\
219.5(1.4)\end{array}$ & $\begin{array}{l}189.1(4.0) \\
207.1(2.6) \\
221.0(1.3)\end{array}$ & $\begin{array}{l}197.0(3.6) \\
207.0(2.1) \\
220.0(1.4)\end{array}$ \\
\hline 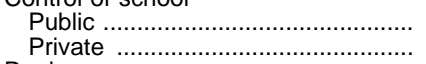 & -二 & -二 & $\begin{array}{l}213.5(1.1) \\
227.0(1.8)\end{array}$ & $\begin{array}{l}209.4(0.8) \\
222.8(1.6)\end{array}$ & $\begin{array}{l}210.2(1.2) \\
223.4(3.0)\end{array}$ & $\begin{array}{l}207.5(1.4) \\
228.3(3.3)\end{array}$ & $\begin{array}{l}208.6(1.0) \\
224.7(2.3)\end{array}$ & $\begin{array}{l}209.4(1.4) \\
225.0(2.7)\end{array}$ & $\begin{array}{l}210.0(1.1) \\
227.0(3.1)\end{array}$ \\
\hline 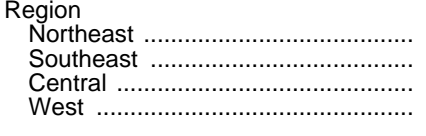 & $\begin{array}{l}213.0(1.7) \\
193.9(2.9) \\
214.9(1.2) \\
205.0(2.0)\end{array}$ & $\begin{array}{l}214.8(1.3) \\
201.1(1.2) \\
215.5(1.2) \\
207.0(2.0)\end{array}$ & $\begin{array}{l}221.1(2.1) \\
210.3(2.3) \\
216.7(1.4) \\
212.8(1.8)\end{array}$ & $\begin{array}{l}215.7(1.7) \\
204.3(1.6) \\
215.3(1.5) \\
207.8(1.5)\end{array}$ & $\begin{array}{l}215.2(2.6) \\
207.2(2.1) \\
218.2(2.2) \\
207.9(2.6)\end{array}$ & $\begin{array}{l}217.4(2.2) \\
197.4(3.2) \\
212.7(2.0) \\
209.6(2.8)\end{array}$ & $\begin{array}{l}217.6(2.6) \\
199.3(2.0) \\
215.8(1.6) \\
209.3(2.3)\end{array}$ & $\begin{array}{l}217.4(2.9) \\
208.4(3.0) \\
214.3(2.3) \\
205.1(2.8)\end{array}$ & $\begin{array}{l}220.0(1.9) \\
206.0(2.9) \\
215.0(2.7) \\
210.0(2.0)\end{array}$ \\
\hline 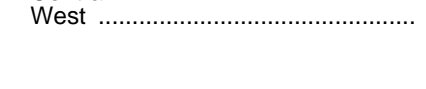 & \multicolumn{9}{|c|}{ 13-year-olds 1} \\
\hline Total & $255.2(0.9)$ & $255.9(0.8)$ & $258.5(0.9)$ & $257.1(0.5)$ & $257.5(1.0)$ & $256.8(0.8)$ & $259.8(1.2)$ & $257.9(0.9)$ & $259.1(0.9)$ \\
\hline 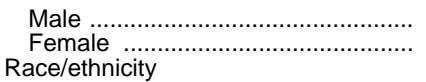 & $\begin{array}{l}249.6(1.0) \\
260.8(0.9)\end{array}$ & $\begin{array}{l}249.6(0.8) \\
262.3(0.9)\end{array}$ & $\begin{array}{l}254.3(1.1) \\
262.6(0.9)\end{array}$ & $\begin{array}{l}252.6(0.6) \\
261.7(0.6)\end{array}$ & $\begin{array}{l}251.8(1.3) \\
263.0(1.0)\end{array}$ & $\begin{array}{l}250.5(1.1) \\
263.1(1.1)\end{array}$ & $\begin{array}{l}254.1(1.7) \\
265.3(1.2)\end{array}$ & $\begin{array}{l}250.6(1.2) \\
265.7(1.2)\end{array}$ & $\begin{array}{l}252.5(1.2) \\
265.4(1.2)\end{array}$ \\
\hline 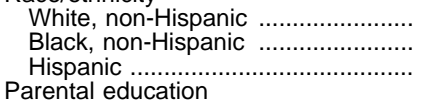 & $\begin{array}{r}260.9(0.7) \\
222.4(1.2) \\
(2)\end{array}$ & $\begin{array}{l}262.1(0.7) \\
225.7(1.2) \\
232.5(3.0)\end{array}$ & $\begin{array}{l}264.4(0.7) \\
232.8(1.5) \\
237.2(2.0)\end{array}$ & $\begin{array}{l}262.6(0.6) \\
236.3(1.0) \\
239.6(1.7)\end{array}$ & $\begin{array}{l}261.3(1.1) \\
242.9(2.4) \\
240.1(3.5)\end{array}$ & $\begin{array}{l}262.3(0.9) \\
241.5(2.2) \\
237.8(2.3)\end{array}$ & $\begin{array}{l}266.4(1.2) \\
237.6(2.3) \\
239.2(3.5)\end{array}$ & $\begin{array}{l}265.1(1.1) \\
234.3(2.4) \\
235.1(1.9)\end{array}$ & $\begin{array}{l}267.0(1.0) \\
235.6(2.6) \\
239.9(2.9)\end{array}$ \\
\hline $\begin{array}{l}\text { Not high school graduate } \ldots \ldots \ldots \ldots \ldots . . . \\
\text { Graduated high school .................... } \\
\text { Post high school ........................... }\end{array}$ & $\begin{array}{l}238.4(1.3) \\
255.5(0.8) \\
270.2(0.8)\end{array}$ & $\begin{array}{l}238.7(1.2) \\
254.6(0.7) \\
269.8(0.8)\end{array}$ & $\begin{array}{l}238.5(1.1) \\
253.5(0.9) \\
270.9(0.8)\end{array}$ & $\begin{array}{l}240.0(0.9) \\
253.4(0.7) \\
267.6(0.7)\end{array}$ & $\begin{array}{l}246.5(2.1) \\
252.7(1.2) \\
265.3(1.4)\end{array}$ & $\begin{array}{l}240.8(1.8) \\
251.4(0.9) \\
266.9(1.0)\end{array}$ & $\begin{array}{l}239.2(2.6) \\
252.1(1.7) \\
269.9(1.4)\end{array}$ & $\begin{array}{l}236.7(2.4) \\
251.4(1.4) \\
268.5(1.2)\end{array}$ & $\begin{array}{l}241.0(2.7) \\
252.0(1.4) \\
270.0(1.2)\end{array}$ \\
\hline 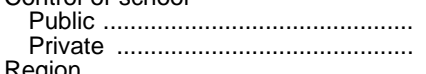 & -- & -二 & $\begin{array}{l}256.9(1.1) \\
270.6(1.5)\end{array}$ & $\begin{array}{l}255.2(0.6) \\
271.2(1.7)\end{array}$ & $\begin{array}{l}256.1(1.0) \\
268.3(2.8)\end{array}$ & $\begin{array}{l}255.0(0.8) \\
269.7(2.9)\end{array}$ & $\begin{array}{l}257.2(1.3) \\
276.3(2.6)\end{array}$ & $\begin{array}{l}255.6(1.0) \\
275.8(3.4)\end{array}$ & $\begin{array}{l}257.0(1.1) \\
274.0(3.3)\end{array}$ \\
\hline 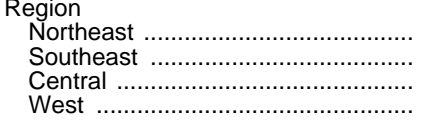 & $\begin{array}{l}261.1(2.0) \\
244.7(1.7) \\
260.1(1.8) \\
253.6(1.3)\end{array}$ & $\begin{array}{l}258.5(1.8) \\
249.3(1.5) \\
261.5(1.4) \\
253.2(1.7)\end{array}$ & $\begin{array}{l}260.0(1.8) \\
252.6(1.6) \\
264.5(1.4) \\
256.4(2.0)\end{array}$ & $\begin{array}{l}260.4(0.6) \\
256.4(1.5) \\
258.8(1.0) \\
253.8(0.9)\end{array}$ & $\begin{array}{l}258.6(2.4) \\
257.6(2.2) \\
255.9(2.0) \\
257.9(2.1)\end{array}$ & $\begin{array}{l}258.9(1.8) \\
255.5(2.2) \\
257.4(1.5) \\
255.6(1.6)\end{array}$ & $\begin{array}{l}264.6(3.2) \\
253.8(2.5) \\
263.5(3.0) \\
257.5(1.6)\end{array}$ & $\begin{array}{l}269.0(2.0) \\
252.7(2.5) \\
259.3(3.3) \\
252.9(2.1)\end{array}$ & $\begin{array}{l}261.0(2.5) \\
252.0(3.2) \\
268.0(1.8) \\
258.0(1.7)\end{array}$ \\
\hline 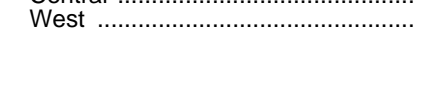 & \multicolumn{9}{|c|}{17 -year-olds 1} \\
\hline Total & $285.2(1.2)$ & $285.6(0.8)$ & $285.5(1.2)$ & $288.8(0.6)$ & $290.1(1.0)$ & $290.2(1.1)$ & $289.7(1.1)$ & $288.1(1.3)$ & $286.9(1.1)$ \\
\hline 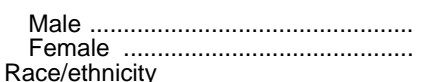 & $\begin{array}{l}278.9(1.2) \\
291.3(1.3)\end{array}$ & $\begin{array}{l}279.7(1.0) \\
291.2(1.0)\end{array}$ & $\begin{array}{l}281.8(1.3) \\
289.2(1.2)\end{array}$ & $\begin{array}{l}283.8(0.6) \\
293.9(0.8)\end{array}$ & $\begin{array}{l}286.0(1.5) \\
293.8(1.5)\end{array}$ & $\begin{array}{l}284.0(1.6) \\
296.5(1.2)\end{array}$ & $\begin{array}{l}284.2(1.6) \\
295.7(1.1)\end{array}$ & $\begin{array}{l}281.7(2.2) \\
294.7(1.5)\end{array}$ & $\begin{array}{l}279.9(1.3) \\
294.4(1.2)\end{array}$ \\
\hline 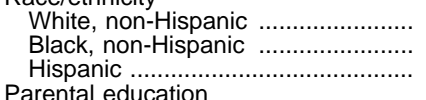 & $\begin{array}{r}291.4(1.0) \\
238.7(1.7) \\
\left({ }^{2}\right)-\end{array}$ & $\begin{array}{l}293.0(0.6) \\
240.6(2.0) \\
252.4(3.6)\end{array}$ & $\begin{array}{l}292.8(0.9) \\
243.1(1.8) \\
261.4(2.7)\end{array}$ & $\begin{array}{l}295.2(0.7) \\
264.3(1.0) \\
268.1(2.2)\end{array}$ & $\begin{array}{l}294.7(1.2) \\
274.4(2.4) \\
270.8(4.3)\end{array}$ & $\begin{array}{l}296.6(1.2) \\
267.3(2.3) \\
274.8(3.6)\end{array}$ & $\begin{array}{l}297.4(1.4) \\
260.6(2.1) \\
271.2(3.7)\end{array}$ & $\begin{array}{l}295.7(1.5) \\
266.2(3.9) \\
263.2(4.9)\end{array}$ & $\begin{array}{l}294.4(1.2) \\
265.4(2.7) \\
264.7(4.1)\end{array}$ \\
\hline 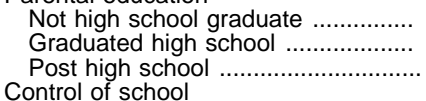 & $\begin{array}{l}261.3(1.5) \\
283.0(1.2) \\
302.2(1.0)\end{array}$ & $\begin{array}{l}262.5(1.3) \\
281.4(1.1) \\
300.6(0.7)\end{array}$ & $\begin{array}{l}262.1(1.5) \\
277.5(1.0) \\
298.9(1.0)\end{array}$ & $\begin{array}{l}269.4(1.1) \\
281.2(0.7) \\
301.2(0.7)\end{array}$ & $\begin{array}{l}267.4(2.0) \\
282.0(1.3) \\
299.5(1.3)\end{array}$ & $\begin{array}{l}269.7(2.8) \\
282.9(1.4) \\
299.9(1.1)\end{array}$ & $\begin{array}{l}270.8(3.9) \\
280.5(1.6) \\
298.6(1.4)\end{array}$ & $\begin{array}{l}267.9(2.7) \\
276.1(1.9) \\
298.5(1.4)\end{array}$ & $\begin{array}{l}267.0(3.2) \\
273.0(1.7) \\
297.0(1.2)\end{array}$ \\
\hline 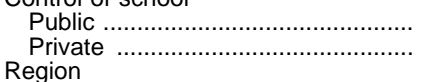 & $-\frac{}{-}$ & -二 & $\begin{array}{l}284.4(1.2) \\
298.4(2.7)\end{array}$ & $\begin{array}{l}287.2(0.6) \\
303.0(2.0)\end{array}$ & $\begin{array}{l}288.7(1.0) \\
299.6(3.8)\end{array}$ & $\begin{array}{l}288.6(1.1) \\
311.0(4.2)\end{array}$ & $\begin{array}{l}287.8(1.0) \\
309.6(4.2)\end{array}$ & $\begin{array}{l}286.0(1.5) \\
306.1(5.8)\end{array}$ & $\begin{array}{l}286.0(1.1) \\
294.0(5.7)\end{array}$ \\
\hline 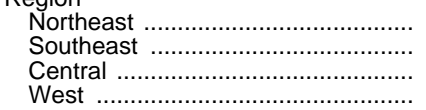 & $\begin{array}{l}291.3(2.8) \\
270.5(2.4) \\
290.7(2.1) \\
283.7(1.8)\end{array}$ & $\begin{array}{l}289.1(1.7) \\
276.5(1.4) \\
291.8(1.4) \\
281.6(1.9)\end{array}$ & $\begin{array}{l}285.9(2.4) \\
280.1(2.2) \\
287.4(2.2) \\
287.3(2.1)\end{array}$ & $\begin{array}{l}292.2(1.9) \\
284.7(1.6) \\
290.0(1.4) \\
288.4(1.1)\end{array}$ & $\begin{array}{l}294.8(2.9) \\
285.5(2.1) \\
291.2(1.9) \\
289.0(1.8)\end{array}$ & $\begin{array}{l}295.7(1.8) \\
285.1(2.5) \\
293.5(2.4) \\
286.8(2.6)\end{array}$ & $\begin{array}{l}297.3(3.2) \\
278.4(2.9) \\
293.8(2.1) \\
290.4(2.3)\end{array}$ & $\begin{array}{l}296.8(4.2) \\
283.5(2.8) \\
285.7(3.7) \\
287.8(2.8)\end{array}$ & $\begin{array}{l}291.0(2.8) \\
279.0(2.6) \\
292.0(2.1) \\
286.0(2.4)\end{array}$ \\
\hline
\end{tabular}

1 Excludes persons not enrolled in school.

${ }^{2}$ Test scores of Hispanics were not tabulated separately.

NOTE.-These test scores are from the National Assessment of Educational Progress (NAEP). The NAEP scores have been evaluated at certain performance levels. A score of 300 implies an ability to find, understand, summarize, and explain relatively complicated literary and informational material. A score of 250 implies an ability to search for specific information, interrelate ideas, and make generalizations about literature, science, and social studies materials. A score of 200 implies an ability to understand, combine ideas, and make inferences based on short uncomplicated passages about specific or sequentially related information. A score of 150 implies an ability to follow brief written directions and carry out simple, discrete reading tasks. Scale ranges from 0 to 500 . Standard errors appear in parentheses.

SOURCE: U.S. Department of Education, National Center for Education Statistics, National Assessment of Educational Progress, NAEP 1996 Trends in Academic Progress, by Educational Testing Service. (This table was prepared October 1998.) 
Table 110.-Student proficiency in reading, by percentile and age: 1971 to 1996

\begin{tabular}{|c|c|c|c|c|c|c|c|c|c|}
\hline Percentile & 1971 & 1975 & 1980 & 1984 & 1988 & 1990 & 1992 & 1994 & 1996 \\
\hline 1 & 2 & 3 & 4 & 5 & 6 & 7 & 8 & 9 & 10 \\
\hline \multirow{4}{*}{$\begin{array}{l}\text { Average } \\
\text { Standard deviation } \\
\text { Percentiles } \\
\text { 5th } \\
\text { 10th } \\
25 \text { th } \\
50 \text { th } \\
75 \text { th }\end{array}$} & \multicolumn{9}{|c|}{ 9-year-olds ${ }^{1}$} \\
\hline & $\begin{array}{r}207.6 \\
42.1\end{array}$ & $\begin{array}{r}210.0 \\
38.6\end{array}$ & $\begin{array}{r}215.0 \\
37.9\end{array}$ & $\begin{array}{r}210.9 \\
41.1\end{array}$ & $\begin{array}{r}211.8 \\
41.2\end{array}$ & $\begin{array}{r}209.2 \\
44.7\end{array}$ & $\begin{array}{r}210.5 \\
40.3\end{array}$ & $\begin{array}{r}211.0 \\
40.5\end{array}$ & $\begin{array}{r}212.4 \\
40.5\end{array}$ \\
\hline & $\begin{array}{l}134.8 \\
151.6 \\
180.0 \\
209.3 \\
236.7 \\
260.5 \\
274.1\end{array}$ & $\begin{array}{l}143.2 \\
159.2 \\
185.2 \\
211.9 \\
236.9 \\
258.1 \\
270.6\end{array}$ & $\begin{array}{l}148.5 \\
165.1 \\
191.1 \\
217.2 \\
241.3 \\
261.7 \\
273.3\end{array}$ & $\begin{array}{l}140.5 \\
156.7 \\
183.7 \\
212.6 \\
239.6 \\
262.8 \\
276.5\end{array}$ & $\begin{array}{l}141.9 \\
156.7 \\
184.3 \\
213.7 \\
240.1 \\
263.0 \\
277.5\end{array}$ & $\begin{array}{l}134.8 \\
150.1 \\
178.7 \\
210.3 \\
240.3 \\
265.7 \\
280.4\end{array}$ & $\begin{array}{l}140.7 \\
156.0 \\
183.1 \\
213.6 \\
239.3 \\
259.9 \\
272.1\end{array}$ & $\begin{array}{l}140.1 \\
155.6 \\
184.1 \\
214.8 \\
240.0 \\
260.1 \\
271.7\end{array}$ & $\begin{array}{l}141.8 \\
157.6 \\
185.0 \\
215.5 \\
241.4 \\
261.5 \\
274.1\end{array}$ \\
\hline & \multicolumn{9}{|c|}{ 13-year-olds ${ }^{1}$} \\
\hline $\begin{array}{l}\text { Average } \\
\text { Standard deviation }\end{array}$ & $\begin{array}{r}255.2 \\
35.7\end{array}$ & $\begin{array}{r}255.9 \\
35.8\end{array}$ & $\begin{array}{r}258.5 \\
34.9\end{array}$ & $\begin{array}{r}257.1 \\
35.5\end{array}$ & $\begin{array}{r}257.5 \\
34.7\end{array}$ & $\begin{array}{r}256.8 \\
36.0\end{array}$ & $\begin{array}{r}259.8 \\
39.4\end{array}$ & $\begin{array}{r}257.9 \\
39.8\end{array}$ & $\begin{array}{r}259.1 \\
38.4\end{array}$ \\
\hline \multirow[t]{2}{*}{$\begin{array}{l}\text { Percentiles } \\
\text { 5th } \\
\text { 10th } \\
25 \text { th } \\
\text { 50th } \\
\text { 75th } \\
90 \text { 9th } \\
\text { 95th }\end{array}$} & $\begin{array}{l}192.8 \\
207.8 \\
232.3 \\
257.0 \\
279.9 \\
299.6 \\
310.8\end{array}$ & $\begin{array}{l}193.5 \\
208.7 \\
232.9 \\
257.7 \\
280.6 \\
300.5 \\
311.8\end{array}$ & $\begin{array}{l}199.1 \\
212.8 \\
235.3 \\
259.6 \\
282.8 \\
302.3 \\
313.9\end{array}$ & $\begin{array}{l}196.7 \\
210.2 \\
233.9 \\
258.2 \\
281.6 \\
301.7 \\
313.7\end{array}$ & $\begin{array}{l}199.5 \\
212.9 \\
234.2 \\
257.9 \\
281.4 \\
301.6 \\
313.7\end{array}$ & $\begin{array}{l}195.7 \\
209.8 \\
233.2 \\
257.3 \\
281.5 \\
302.0 \\
314.4\end{array}$ & $\begin{array}{l}190.9 \\
207.9 \\
234.7 \\
261.6 \\
287.0 \\
309.2 \\
321.9\end{array}$ & $\begin{array}{l}188.2 \\
205.1 \\
232.5 \\
260.1 \\
285.2 \\
307.4 \\
320.3\end{array}$ & $\begin{array}{l}191.5 \\
208.5 \\
234.8 \\
261.2 \\
285.5 \\
306.5 \\
319.4\end{array}$ \\
\hline & \multicolumn{9}{|c|}{17 -year-olds ${ }^{1}$} \\
\hline $\begin{array}{l}\text { Average } \\
\text { Standard deviation }\end{array}$ & $\begin{array}{r}285.2 \\
45.8\end{array}$ & $\begin{array}{r}285.6 \\
44.0\end{array}$ & $\begin{array}{r}285.5 \\
41.8\end{array}$ & $\begin{array}{r}288.8 \\
40.3\end{array}$ & $\begin{array}{r}290.1 \\
37.1\end{array}$ & $\begin{array}{r}290.2 \\
41.3\end{array}$ & $\begin{array}{r}289.7 \\
43.0\end{array}$ & $\begin{array}{r}288.1 \\
44.4\end{array}$ & $\begin{array}{r}286.9 \\
42.3\end{array}$ \\
\hline $\begin{array}{l}\text { Percentiles } \\
5 \text { th } \\
\text { 10th } \\
25 \text { th } \\
\text { 50th } \\
\text { 75th } \\
90 \text { th } \\
\text { 95th }\end{array}$ & $\begin{array}{l}206.1 \\
225.3 \\
255.9 \\
287.7 \\
316.7 \\
341.7 \\
356.5\end{array}$ & $\begin{array}{l}209.3 \\
228.4 \\
257.8 \\
287.9 \\
315.7 \\
340.0 \\
354.3\end{array}$ & $\begin{array}{l}213.0 \\
230.6 \\
258.7 \\
287.5 \\
314.6 \\
337.5 \\
350.9\end{array}$ & $\begin{array}{l}219.9 \\
236.0 \\
262.5 \\
290.3 \\
316.8 \\
339.6 \\
352.6\end{array}$ & $\begin{array}{l}226.1 \\
241.5 \\
265.7 \\
291.1 \\
316.0 \\
336.9 \\
348.7\end{array}$ & $\begin{array}{l}220.0 \\
236.9 \\
263.5 \\
291.1 \\
318.6 \\
342.7 \\
356.0\end{array}$ & $\begin{array}{l}214.3 \\
232.7 \\
262.6 \\
293.0 \\
319.4 \\
342.7 \\
355.8\end{array}$ & $\begin{array}{l}210.8 \\
230.0 \\
259.8 \\
289.9 \\
318.7 \\
343.0 \\
357.7\end{array}$ & $\begin{array}{l}213.2 \\
231.4 \\
259.1 \\
288.2 \\
315.8 \\
340.4 \\
354.4\end{array}$ \\
\hline
\end{tabular}

1 Excludes persons not enrolled in school.

NOTE.-These test scores are from the National Assessment of Educational Progress (NAEP). The NAEP scores have been evaluated at certain performance levels. A score of 300 implies an ability to find, understand, summarize, and explain relatively complicated literary and informational material. A score of 250 implies an ability to search for specific information, interrelate ideas, and make generalizations about literature, science, and social studies materials. A score of 200 implies an ability to understand, combine ideas, and make inferences based on short uncomplicated passages about specific or sequentially related information. A score of 150 implies an ability to follow brief written directions and carry out simple, discrete reading tasks. Scale ranges from 0 to 500 .

SOURCE: U.S. Department of Education, National Center for Education Statistics, National Assessment of Educational Progress, NAEP 1996 Trends in Academic Progress, by Educational Testing Service. (This table was prepared September 1997.) 
Table 111.-Student proficiency in reading, by age, amount of time spent on homework, and reading habits: 1984, 1994, and 1996

\begin{tabular}{|c|c|c|c|c|c|c|c|c|c|}
\hline \multirow{2}{*}{$\begin{array}{c}\text { Time spent on homework and reading } \\
\text { habits }\end{array}$} & \multicolumn{3}{|c|}{ 9-year-olds ${ }^{1}$} & \multicolumn{3}{|c|}{13 -year-olds ${ }^{1}$} & \multicolumn{3}{|c|}{17 -year-olds ${ }^{1}$} \\
\hline & 1984 & 1994 & 1996 & 1984 & 1994 & 1996 & 1984 & 1994 & 1996 \\
\hline \multirow[t]{2}{*}{1} & 2 & 3 & 4 & 5 & 6 & 7 & 8 & 9 & 10 \\
\hline & \multicolumn{9}{|c|}{ Average proficiency } \\
\hline 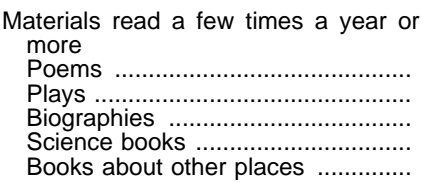 & $\begin{array}{l}211 \\
211 \\
213 \\
212 \\
211\end{array}$ & $\begin{array}{l}210 \\
207 \\
210 \\
211 \\
211\end{array}$ & $\begin{array}{l}\text { 二 } \\
\text { - }\end{array}$ & $\begin{array}{l}260 \\
260 \\
261 \\
259 \\
259\end{array}$ & $\begin{array}{l}261 \\
263 \\
261 \\
260 \\
260\end{array}$ & $\begin{array}{l}\text { 二 } \\
\text { 二 }\end{array}$ & $\begin{array}{l}290 \\
290 \\
292 \\
289 \\
289\end{array}$ & $\begin{array}{l}293 \\
294 \\
293 \\
293 \\
293\end{array}$ & $\begin{array}{l}- \\
- \\
-\end{array}$ \\
\hline 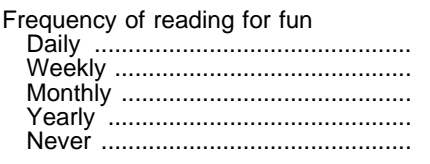 & $\begin{array}{l}214 \\
212 \\
204 \\
197 \\
198\end{array}$ & $\begin{array}{l}215 \\
214 \\
213 \\
193\end{array}$ & $\begin{array}{l}213 \\
212 \\
210 \\
199\end{array}$ & $\begin{array}{l}264 \\
255 \\
255 \\
252 \\
239\end{array}$ & $\begin{array}{l}272 \\
255 \\
255 \\
252 \\
237\end{array}$ & $\begin{array}{r}270 \\
259 \\
260 \\
238\end{array}$ & $\begin{array}{l}297 \\
290 \\
290 \\
280 \\
269\end{array}$ & $\begin{array}{l}302 \\
286 \\
286 \\
281 \\
258\end{array}$ & $\begin{array}{l}301 \\
292 \\
290 \\
285 \\
269\end{array}$ \\
\hline \multirow[t]{2}{*}{ 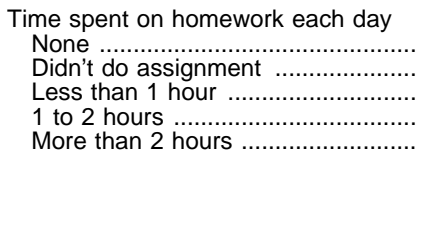 } & $\begin{array}{l}213 \\
199 \\
218 \\
216 \\
201\end{array}$ & $\begin{array}{l}213 \\
200 \\
212 \\
214 \\
193\end{array}$ & $\begin{array}{l}210 \\
195 \\
215 \\
220 \\
198\end{array}$ & $\begin{array}{l}254 \\
247 \\
261 \\
266 \\
265\end{array}$ & $\begin{array}{l}250 \\
243 \\
261 \\
268 \\
270\end{array}$ & $\begin{array}{l}256 \\
251 \\
259 \\
267 \\
269\end{array}$ & $\begin{array}{l}276 \\
287 \\
290 \\
296 \\
303\end{array}$ & $\begin{array}{l}273 \\
285 \\
288 \\
297 \\
306\end{array}$ & $\begin{array}{l}273 \\
281 \\
288 \\
295 \\
307\end{array}$ \\
\hline & \multicolumn{9}{|c|}{ Percent } \\
\hline 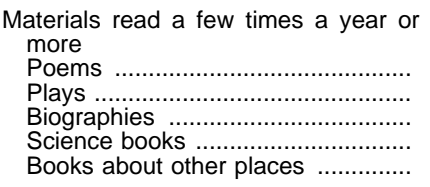 & $\begin{array}{l}70 \\
56 \\
45 \\
84 \\
79\end{array}$ & $\begin{array}{l}62 \\
45 \\
47 \\
87 \\
79\end{array}$ & $\begin{array}{l}60 \\
42 \\
46 \\
83 \\
78\end{array}$ & $\begin{array}{l}68 \\
59 \\
62 \\
90 \\
83\end{array}$ & $\begin{array}{l}79 \\
63 \\
68 \\
92 \\
83\end{array}$ & $\begin{array}{l}80 \\
67 \\
65 \\
90 \\
84\end{array}$ & $\begin{array}{l}76 \\
63 \\
59 \\
70 \\
81\end{array}$ & $\begin{array}{l}85 \\
70 \\
69 \\
84 \\
82\end{array}$ & $\begin{array}{l}80 \\
67 \\
66 \\
82 \\
81\end{array}$ \\
\hline 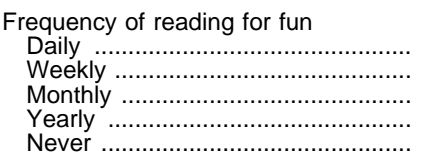 & $\begin{array}{r}53 \\
28 \\
7 \\
3 \\
9\end{array}$ & $\begin{array}{r}58 \\
25 \\
5 \\
3 \\
9\end{array}$ & $\begin{array}{r}54 \\
27 \\
8 \\
3 \\
8\end{array}$ & $\begin{array}{r}35 \\
35 \\
14 \\
7 \\
9\end{array}$ & $\begin{array}{l}32 \\
32 \\
14 \\
10 \\
12\end{array}$ & $\begin{array}{r}32 \\
31 \\
15 \\
9 \\
13\end{array}$ & $\begin{array}{r}31 \\
34 \\
17 \\
10 \\
9\end{array}$ & $\begin{array}{l}30 \\
31 \\
15 \\
12 \\
12\end{array}$ & $\begin{array}{l}23 \\
32 \\
17 \\
12 \\
16\end{array}$ \\
\hline 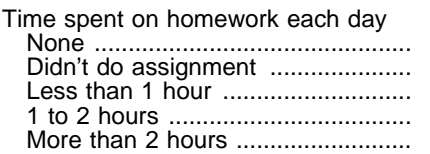 & $\begin{array}{r}36 \\
4 \\
42 \\
13 \\
6\end{array}$ & $\begin{array}{r}32 \\
5 \\
48 \\
12 \\
4\end{array}$ & $\begin{array}{r}26 \\
4 \\
53 \\
13 \\
4\end{array}$ & $\begin{array}{r}23 \\
4 \\
36 \\
29 \\
9\end{array}$ & $\begin{array}{r}23 \\
6 \\
34 \\
28 \\
9\end{array}$ & $\begin{array}{r}22 \\
5 \\
37 \\
27 \\
8\end{array}$ & $\begin{array}{l}22 \\
11 \\
26 \\
27 \\
13\end{array}$ & $\begin{array}{l}23 \\
11 \\
27 \\
26 \\
13\end{array}$ & $\begin{array}{l}23 \\
13 \\
28 \\
24 \\
11\end{array}$ \\
\hline
\end{tabular}

${ }^{1}$ Excludes persons not enrolled in school. -Data not available.

NOTE.-These test scores are from the National Assessment of Educational Progress (NAEP). The NAEP scores have been evaluated at certain performance levels. A score of 300 implies an ability to find, understand, summarize and explain relatively complicated literary and informational material. A score of 250 implies an ability to search for specific information, interrelate ideas, and make generalizations about literature, science, and social studies materials. A score of 200 implies an ability to understand, combine ideas, and make inferences based on short uncomplicated passages about specific or sequentially related information. A score of 150 implies an ability to follow brief written directions and carry out simple, discrete reading tasks. Scale ranges from 0 to 500 .

SOURCE: U.S. Department of Education, National Center for Education Statistics, National Assessment of Educational Progress, NAEP 1996 Trends in Academic Progress, by Educational Testing Service. (This table was prepared September 1997.) 
Table 112.-Percent of students at or above selected reading proficiency levels, ${ }^{1}$ by sex, race/ethnicity, and age: 1971 to 1996

\begin{tabular}{|c|c|c|c|c|c|c|c|c|c|}
\hline Sex, race/ethnicity, and level & 1971 & 1975 & 1980 & 1984 & 1988 & 1990 & 1992 & 1994 & 1996 \\
\hline 1 & 2 & 3 & 4 & 5 & 6 & 7 & 8 & 9 & 10 \\
\hline & \multicolumn{9}{|c|}{9 -year-olds ${ }^{2}$} \\
\hline \multicolumn{8}{|l|}{ Total } & & \\
\hline 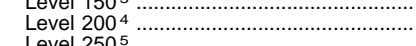 & 58.7 & 62.1 & 67.7 & 61.5 & 62.6 & $\begin{array}{l}9.1 \\
58.9\end{array}$ & 62.0 & $\begin{array}{l}9.1 \\
63.3\end{array}$ & $\begin{array}{l}9.7 \\
63.7\end{array}$ \\
\hline \multicolumn{9}{|l|}{ 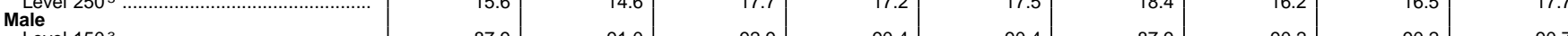 } & \\
\hline $\begin{array}{l}\text { Male } \\
\text { Level } 150^{3}\end{array}$ & 87.9 & 91.0 & 92.9 & 90.4 & 90.4 & 87.9 & 90.2 & 90.2 & 90.7 \\
\hline $\begin{array}{l}\text { Level } 200^{4} \\
\text { Level }\end{array} 250^{5}$ & 52.7 & 56.2 & 62.7 & 58.0 & 58.4 & 53.8 & 56.9 & 59.2 & 57.8 \\
\hline \multicolumn{10}{|l|}{ Female } \\
\hline 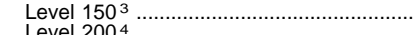 & 93.2 & 95.3 & 96.4 & 94.2 & 94.9 & 92.4 & 94.4 & 94.0 & 94.6 \\
\hline $\begin{array}{l}\text { Level } 200^{4} \\
\text { Level } 2505\end{array}$ & $\begin{array}{ll}64.6 \\
192\end{array}$ & 68.1 & 72.7 & 65.2 & 66.9 & 64.2 & 67.3 & 67.3 & 69.5 \\
\hline \multicolumn{10}{|l|}{ White 6} \\
\hline Level $150^{3} \ldots \ldots \ldots$ & 94.0 & 96.0 & 97.1 & 95.4 & 95.1 & 93.5 & 95.8 & 95.7 & 95.9 \\
\hline 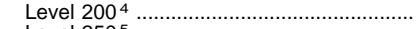 & 65.0 & 69.0 & 74.2 & 68.6 & 68.4 & 66.0 & 69.3 & 70.1 & 70.9 \\
\hline \multirow{2}{*}{\multicolumn{10}{|c|}{ Black ${ }^{6}$}} \\
\hline & & & & & & & & & 831 \\
\hline Level $200^{4}$ & 22.0 & 31.6 & 41.3 & $\begin{array}{l}01.5 \\
36.6\end{array}$ & $\begin{array}{l}0.4 .4 \\
39.4\end{array}$ & 33.9 & 36.6 & 38.3 & 41.3 \\
\hline 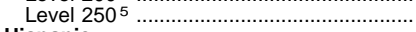 & 1.6 & 2.0 & 4.1 & 4.5 & 5.6 & 5.2 & 4.6 & 4.4 & 6.6 \\
\hline \multirow{4}{*}{ 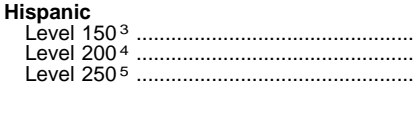 } & .... & & & & & & & & \\
\hline & 二 & $\begin{array}{l}8.8 \\
34.6\end{array}$ & $\begin{array}{l}84.5 \\
41.6\end{array}-1250$ & $\begin{array}{l}82.0 \\
39.6\end{array}$ & $\begin{array}{ll}85.6 \\
45.9\end{array}$ & 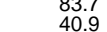 & 83.4 & $\begin{array}{l}80.4 \\
371\end{array}$ & 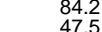 \\
\hline & - & $\begin{array}{r}3.0 \\
2.6\end{array}$ & $\begin{array}{r}4.0 \\
5.0\end{array}$ & 4.3 & 8.6 & $\begin{array}{r}4.9 \\
5.8\end{array}$ & 7.2 & 6.4 & 7.5 \\
\hline & & & & & -year-olds ${ }^{2}$ & & & & \\
\hline Total & & & & & & & & & \\
\hline Level $150^{3}$............................................ & 99.8 & 99.7 & 99.9 & 99.8 & 99.9 & 99.8 & 99.5 & 99.3 & 99.6 \\
\hline Level $200^{4}$ & 57.8 & 58.6 & 60.7 & 59.0 & 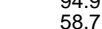 & 58.7 & 61.6 & 60.4 & $\begin{array}{l}9.8 \\
61.3\end{array}$ \\
\hline Level $300^{7}$ & 9.8 & 10.2 & 11.3 & 11.0 & 10.9 & 11.0 & 15.3 & 14.1 & 13.8 \\
\hline Male & & & & & & & & & \\
\hline 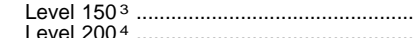 & 99.6 & 99.6 & 99.8 & 99.7 & 99.7 & 99.7 & 99.2 & 99.1 & 99.5 \\
\hline 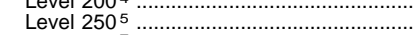 & $\begin{array}{l}9.7 \\
51.6\end{array}$ & $\begin{array}{l}90.9 \\
51.7\end{array}$ & $\begin{array}{l}93.4 \\
55.9\end{array}-120$ & $\begin{array}{l}92.2 \\
54.0\end{array}-10-100$ & $\begin{array}{l}92.8 \\
52.3\end{array}$ & $\begin{array}{l}91.4 \\
52.4\end{array}$ & $\begin{array}{l}90.4 \\
55.5\end{array}$ & $\begin{array}{l}88.8 \\
53.3\end{array}$ & $\begin{array}{l}90.1 \\
54.8\end{array}$ \\
\hline Level $300^{7}$ & 7.3 & 7.0 & 9.1 & 9.0 & 8.6 & 7.6 & 12.8 & 10.1 & 10.3 \\
\hline Female & & & & & & & & & \\
\hline 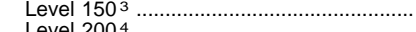 & 99.9 & 99.9 & 99.9 & 99.9 & 100.0 & 99.9 & 99.8 & 99.6 & 99.8 \\
\hline $\begin{array}{l}\text { Level } 200^{4} \\
\text { Level } 250^{5}\end{array}$ & $\begin{array}{cc}95.2 \\
640\end{array}$ & $\begin{array}{l}95.5 \\
65.5\end{array}$ & $\begin{array}{l}96.1 \\
65.4\end{array}$ & 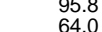 & 96.9 & 96.3 & 95.0 & 94.9 & 95.3 \\
\hline 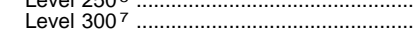 & $\begin{array}{ll}04.0 \\
12.3\end{array}$ & $\begin{array}{l}65.5 \\
13.5\end{array}$ & $\begin{array}{l}65.4 \\
13.5\end{array}$ & $\begin{array}{l}64.0 \\
13.2\end{array}$ & $\begin{array}{l}6.0 \\
13.2\end{array}$ & $\begin{array}{l}65.0 \\
145\end{array}$ & 67.5 & $\begin{array}{l}67.9 \\
184\end{array}$ & 67.5 \\
\hline White ${ }^{6}$ & & t & 10.0 & 10.2 & 10.2 & 14.0 & & & \\
\hline Level $150^{3} \ldots \ldots \ldots \ldots$ & 99.9 & 99.9 & 100.0 & 99.9 & 99.9 & 99.9 & 99.8 & 99.6 & 99.8 \\
\hline Level $200^{4} \ldots \ldots \ldots \ldots \ldots \ldots \ldots \ldots \ldots \ldots \ldots \ldots \ldots \ldots . . . \cdots \cdots \cdots$ & 96.2 & 96.4 & 97.1 & 96.2 & 96.0 & 96.0 & 95.9 & 95.0 & 95.9 \\
\hline $\begin{array}{l}\text { Leve } 250^{5} \\
\text { Level } 300^{7}\end{array}$ & 64.2 & & 67.8 & 65.3 & 63.7 & 64.8 & 68.5 & 68.1 & 70.1 \\
\hline Black ${ }^{6}$ [oo & 11.3 & 12.1 & 13.6 & 13.1 & 12.4 & 13.3 & 18.1 & 17.2 & 17.2 \\
\hline 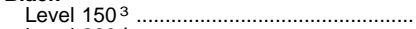 & 98.6 & 98.4 & 99.3 & 99.4 & 99.8 & 99.4 & 98.7 & 98.6 & 99.4 \\
\hline 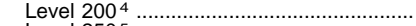 & 74.2 & 76.9 & 84.1 & 85.5 & 91.3 & 87.7 & 82.0 & 80.6 & 82.7 \\
\hline Level $250^{5}$ & 21.1 & 24.8 & 30.1 & 34.6 & 40.2 & 41.7 & 38.4 & 35.6 & 35.1 \\
\hline Level $300^{7}$............................................. & 0.8 & 1.5 & 1.8 & 2.8 & 4.6 & 4.6 & 5.7 & 3.9 & 3.1 \\
\hline $\begin{array}{l}\text { Hispanic } \\
\text { Level } 150^{3}, \ldots \ldots . . .\end{array}$ & -1 & 99.6 & 99.7 & 99.5 & 99.2 & 99.1 & 98.1 & 98.7 & 98.7. \\
\hline Level $200^{4}$ & - & 81.3 & 86.8 & 86.7 & 87.4 & 85.8 & 83.4 & 82.4 & 86.1 \\
\hline Level 2505 ...................................................... & -1 & 32.0 & 35.4 & 39.0 & 38.0 & 37.2 & 40.9 & 33.9 & \\
\hline Level $300^{7}$ & - & 2.2 & 2.3 & 4.1 & 4.4 & 3.9 & 6.0 & 4.3 & 5.5 \\
\hline & & & & & -year-olds ${ }^{2}$ & & & & \\
\hline Total & & & & & & & & & \\
\hline Level $150^{3} \ldots \ldots \ldots \ldots \ldots \ldots \ldots \ldots \ldots \ldots \ldots \ldots \ldots \ldots$ & & 99.7 & & & & 99.9 & 99.8 & & \\
\hline 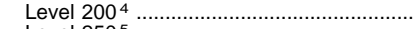 & 96.0 & 96.4 & 97.2 & 98.3 & 98.9 & 98.1 & 97.1 & 96.8 & 97.4 \\
\hline 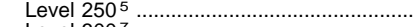 & 78.6 & 80.1 & 80.7 & & 85.7 & 84.1 & 82.5 & 80.8 & 81.4 \\
\hline 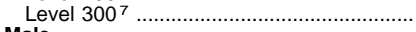 & 39.0 & 38.7 & 37.8 & 40.3 & 40.9 & 41.4 & 43.2 & 41.0 & 38.6 \\
\hline Male & & & & & & & & & \\
\hline 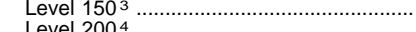 & 99.4 & 99.5 & 99.8 & 99.9 & 100.0 & 99.8 & 99.7 & 99.7 & 99.9 \\
\hline Level $200^{4} \ldots \ldots \ldots \ldots \ldots \ldots \ldots \ldots \ldots \ldots \ldots \ldots \ldots \ldots$ & $\begin{array}{ll}94.7 \\
74.4\end{array}$ & 95.3 & 96.3 & 97.6 & 98.5 & 97.0 & 96.3 & 95.5 & 96.3 \\
\hline Level $300^{7}$ & $\begin{array}{l}74.4 \\
33.9\end{array}$ & $\begin{array}{r}15.6 \\
33.7\end{array}$ & 35.0 & 35.6 & 37.9 & 36.1 & 38.4 & $\begin{array}{l}10.2 \\
35.6\end{array}$ & $\begin{array}{l}76.7 \\
32.8\end{array}$ \\
\hline Female & & & & & & & & & \\
\hline 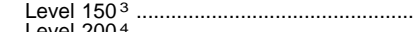 & 99.8 & 99.8 & 99.9 & 99.9 & 100.0 & 100.0 & 99.9 & 99.9 & 100.0 \\
\hline 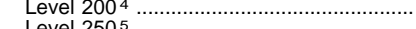 & 97.3 & & 98.1 & 99.0 & 99.3 & 99.2 & 97.9 & 98.0 & 98.6 \\
\hline Level 2505 ................................... & 82.6 & 84.3 & 83.6 & 86.8 & 88.2 & 88.6 & 86.8 & 85.6 & 86.4 \\
\hline White ${ }^{6} 300 \ldots$ & 44.0 & 43.6 & 40.7 & 45.0 & 44.4 & 46.8 & 48.5 & 46.5 & 44.7 \\
\hline Level $150^{3} \ldots \ldots \ldots \ldots \ldots \ldots \ldots \ldots \ldots \ldots \ldots \ldots \ldots$ & 99.9 & 99.9 & 100.0 & 100.0 & 100.0 & 100.0 & 99.9 & 100.0 & 100.0 \\
\hline Level $200^{4}$ & 97.9 & 98.6 & 99.1 & 99.0 & 99.3 & 98.8 & 98.6 & 98.1 & 98.5 \\
\hline Level $250^{5}$ & 83.7 & 86.2 & 86.9 & 88.0 & 88.7 & 88.3 & 88.0 & 86.2 & 86.8 \\
\hline 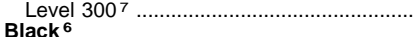 & 43.2 & 43.9 & 43.3 & 46.3 & 45.4 & 47.5 & 50.1 & 47.7 & 45.1 \\
\hline $\begin{array}{l}\text { Diack } \\
\text { Level } 150^{3} \ldots . . . .\end{array}$ & 97.6 & 97.7 & 99.0 & 99.9 & 100.0 & 99.6 & 99.1 & 99.5 & 998.8 \\
\hline Level 2004 & 81.9 & 82.0 & 85.6 & 95.9 & 98.0 & 95.7 & 91.6 & 93.4 & 94.8 \\
\hline Level $250^{5}$ & 40.1 & 43.0 & 44.0 & 65.7 & 75.8 & 69.1 & 61.4 & 65.7 & 672 \\
\hline Level $300^{7}$ & 7.7 & 8.1 & 7.1 & 16.2 & 24.9 & 19.7 & 16.9 & 21.5 & 18.0 \\
\hline Hispanic & & & & & & & & & \\
\hline Level $150^{3}$............................................ & $=$ & 99.3 & 99.8 & 99.8 & 99.9 & 99.7 & 99.8 & 99.0 & 99.9 \\
\hline Level $200^{4}=\ldots$ & 二 & $\begin{array}{l}88.7 \\
529\end{array}$ & $\begin{array}{r}93.3 \\
62.2\end{array}$ & $\begin{array}{l}95.6 \\
68.3\end{array}$ & $\begin{array}{l}96.3 \\
71.5\end{array}$ & $\begin{array}{r}95.99 \\
752\end{array}$ & 93.4 & 91.1 & $\begin{aligned} 94.0 \\
64.2\end{aligned}$ \\
\hline Level $300^{7}$ & - & 12.6 & 16.5 & 21.2 & 23.3 & 27.1 & 27.3 & 20.1 & 20.0 \\
\hline
\end{tabular}

${ }^{1}$ As measured by the National Assessment of Educational Progress (NAEP). ${ }^{2}$ Excludes persons not enrolled in school.

${ }^{3}$ Able to follow brief written directions and carry out simple, discrete reading tasks.

${ }^{4}$ Able to understand, combine ideas, and make inferences based on short uncomplicated passages about specific or sequentially related information.

${ }^{5}$ Able to search for specific information, interrelate ideas, and make generalizations about literature, science, and social studies materials.
7 Able to find, understand, summarize, and explain relatively complicated literary and informational material.

-Data not available.

SOURCE: U.S. Department of Education, National Center for Education Statistics, National Assessment of Educational Progress, NAEP 1996 Trends in Academic Progress, by Educational Testing Service. (This table was prepared September 1997.) 
Table 113.-Average proficiency in reading for 4 th-graders in public schools, ${ }^{1}$ by selected characteristics, region, and state: 1994

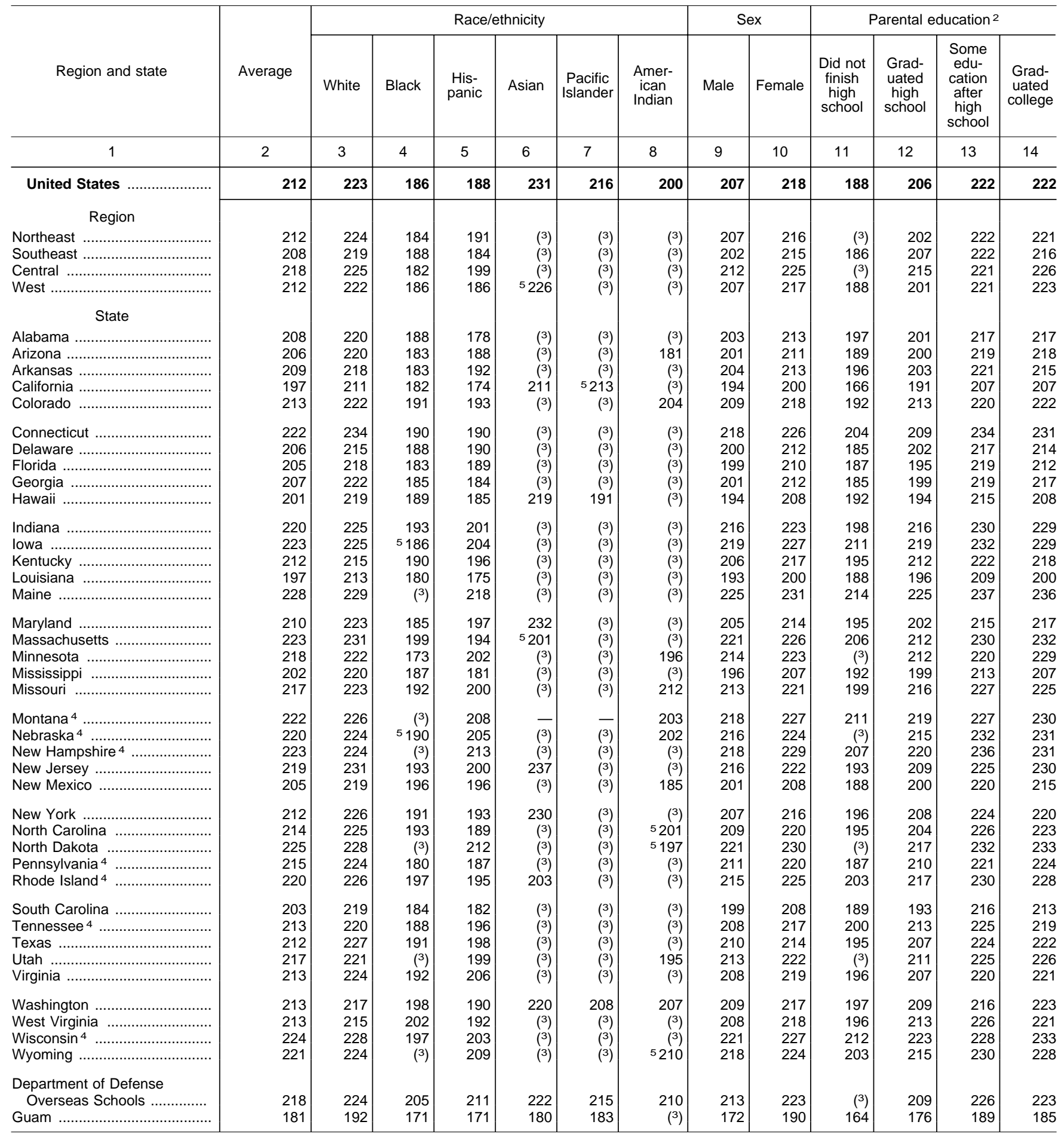

1 As measured by the National Assessment of Educational Progress (NAEP). Fortyone states and Guam participated in the test, but the sample size in two states was insufficient to permit a reliable estimate.

2 Parents' highest level of education. Data not shown for students who did not know parents' level of education.

${ }^{3}$ Sample size is insufficient to permit a reliable estimate.

${ }^{4}$ Did not satisfy one or more of the guidelines for school sample participation rates. Data are subject to appreciable nonresponse bias.

5 The nature of the sample does not allow accurate determination of the variability of this value.

-Data not available.

NOTE.-These test scores are from the National Assessment of Educational Progress (NAEP). The NAEP scores have been evaluated at certain performance levels. A score of 300 implies an ability to find, understand, summarize, and explain relatively complicated literary and informational material. A score of 250 implies an ability to search for specific information, interrelate ideas, and make generalizations about literature, science, and social studies materials. A score of 200 implies an ability to understand, combine ideas, and make inferences based on short uncomplicated passages about specific or sequentially related information A short uncomplicated passages about brief written directions and carry out simple, discrete reading tasks. Scale ranges from 0 to 500 . Excludes states not participating in the survey. Some data have been revised from previously published figures.

SOURCE: U.S. Department of Education, National Center for Education Statistics, National Assessment of Educational Progress, 1994 NAEP Reading, Revised Edition: A First Look, prepared by Educational Testing Service. (This table was prepared November 1995.) 
Table 114.-Percentage distribution of 4th-graders in public schools, by time spent on homework and television viewing each day: 1992 and 1996

\begin{tabular}{|c|c|c|c|c|c|c|c|c|c|}
\hline \multirow[b]{2}{*}{ Selected characteristics of students } & \multicolumn{5}{|c|}{ Time spent on homework each day } & \multicolumn{4}{|c|}{ Amount of television watched each day } \\
\hline & Don't have & Don't do & $\begin{array}{l}\text { Half hour } \\
\text { or less }\end{array}$ & One hour & $\begin{array}{c}\text { More than } \\
\text { one hour }\end{array}$ & $\begin{array}{l}\text { Six hours } \\
\text { or more }\end{array}$ & $\begin{array}{l}\text { Four to } \\
\text { five hours }\end{array}$ & $\begin{array}{l}\text { Two to } \\
\text { three } \\
\text { hours }\end{array}$ & $\begin{array}{l}\text { One hour } \\
\text { or less }\end{array}$ \\
\hline \multirow[t]{2}{*}{1} & 2 & 3 & 4 & 5 & 6 & 7 & 8 & 9 & 10 \\
\hline & \multicolumn{9}{|c|}{1992} \\
\hline All students & $15.1(1.2)$ & $3.0(0.3)$ & $39.4(1.3)$ & $26.7(0.9)$ & $15.8(0.7)$ & $21.2(0.7)$ & $21.6(0.7)$ & $35.9(0.7)$ & $21.3(0.7)$ \\
\hline Male. & $16.6(1.5)$ & $4.6(0.4)$ & $38.8(1.4)$ & $25.0(1.1)$ & $15.0(0.9)$ & $25.3(1.1)$ & $21.8(0.9)$ & $34.3(1.2)$ & $18.5(0.9)$ \\
\hline Female & $13.5(1.1)$ & $1.4(0.3)$ & $40.1(1.5)$ & $28.4(1.0)$ & $16.6(0.8)$ & $17.1(0.8)$ & $21.3(0.9)$ & $37.4(1.0)$ & $24.1(0.9)$ \\
\hline \multicolumn{10}{|l|}{ Race/ethnicity } \\
\hline White .............. & $16.9(1.4)$ & $2.4(0.3)$ & $38.9(1.6)$ & $27.7(1.1)$ & $14.1(0.7)$ & $15.1(0.8)$ & $22.3(0.9)$ & $39.8(0.8)$ & $22.9(0.9)$ \\
\hline Black . & $9.5(1.4)$ & $5.3(0.9)$ & $42.7(1.5)$ & $22.2(1.4)$ & $20.2(1.3)$ & $44.0(2.0)$ & $18.8(1.5)$ & $22.6(1.6)$ & $14.5(1.0)$ \\
\hline Hispanic . & $11.6(1.5)$ & $3.6(0.7)$ & $38.3(1.8)$ & $27.1(1.4)$ & $19.4(1.6)$ & $28.6(1.6)$ & $20.7(1.2)$ & $31.4(1.7)$ & $19.2(1.6)$ \\
\hline Asian/Pacific Islander & $8.9(2.6)$ & $2.2(1.1)$ & $35.2(2.9)$ & $34.1(3.4)$ & $19.5(2.7)$ & $19.2(2.4)$ & $21.7(2.9)$ & $33.4(3.5)$ & $25.7(3.0)$ \\
\hline 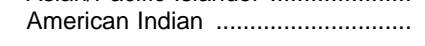 & $16.4(3.1)$ & $1.8(0.9)$ & $43.8(4.3)$ & $15.8(2.7)$ & $22.1(3.4)$ & $28.1(3.7)$ & $23.4(3.9)$ & $25.1(3.5)$ & $23.3(3.0)$ \\
\hline \multicolumn{10}{|l|}{ Parents' highest level of education } \\
\hline 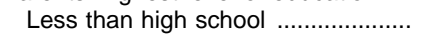 & $17.6(3.1)$ & $5.1(1.6)$ & $37.6(2.8)$ & $24.2(2.3)$ & $15.4(2.1)$ & $28.2(3.9)$ & $20.8(2.1)$ & $32.3(4.1)$ & $18.8(3.4)$ \\
\hline Graduated high school ................... & $14.3(2.0)$ & $3.2(0.6)$ & $39.9(2.6)$ & $23.2(1.9)$ & $19.4(1.6)$ & $24.5(1.9)$ & $25.2(2.4)$ & $36.1(1.7)$ & $14.3(1.2)$ \\
\hline Some education after high school & $16.9(2.4)$ & $2.8(0.8)$ & $40.9(2.3)$ & $25.8(2.3)$ & $13.6(1.7)$ & $20.8(1.8)$ & $24.9(1.9)$ & $35.9(2.2)$ & $18.4(1.7)$ \\
\hline Graduated college ............................. & $14.4(1.5)$ & $2.2(0.3)$ & $40.0(1.5)$ & $28.7(1.3)$ & $14.7(0.9)$ & $17.5(1.1)$ & $19.4(0.9)$ & $37.0(1.1)$ & $26.2(1.2)$ \\
\hline \multicolumn{10}{|l|}{ Region } \\
\hline Northeast & $2.9(0.4)$ & $2.4(0.5)$ & $42.8(1.7)$ & $33.6(1.6)$ & $18.2(1.3)$ & $21.9(2.4)$ & $21.5(2.2)$ & $36.6(1.6)$ & $20.0(1.8)$ \\
\hline Southeast & $11.4(1.5)$ & $4.8(0.7)$ & $38.0(1.9)$ & $27.4(1.7)$ & $18.5(1.2)$ & $27.0(1.7)$ & $18.3(1.0)$ & $35.0(1.4)$ & $19.7(1.5)$ \\
\hline Central ........................ & $27.0(3.4)$ & $2.0(0.5)$ & $34.6(2.8)$ & $22.7(1.6)$ & $13.7(1.1)$ & $17.8(1.2)$ & $24.7(0.9)$ & $38.2(1.3)$ & $19.2(1.0)$ \\
\hline West $\ldots \ldots \ldots \ldots \ldots \ldots \ldots \ldots$ & $15.9(2.5)$ & $2.8(0.3)$ & $42.7(3.1)$ & $24.8(1.9)$ & $13.8(1.6)$ & $19.0(1.4)$ & $21.4(1.5)$ & $33.9(1.5)$ & $25.7(1.3)$ \\
\hline \multicolumn{10}{|l|}{ Type of location } \\
\hline Central city .... & $13.1(2.5)$ & $4.2(0.6)$ & $43.2(2.4)$ & $23.7(1.7)$ & $15.7(1.3)$ & $26.8(1.5)$ & $21.2(0.6)$ & $30.8(1.1)$ & $21.2(1.3)$ \\
\hline Urban fringe/large town ...... & $16.0(1.9)$ & $2.4(0.3)$ & $41.2(2.1)$ & $27.1(1.3)$ & $13.4(1.1)$ & $17.2(1.1)$ & $21.0(1.4)$ & $38.5(1.3)$ & $23.3(1.3)$ \\
\hline \multirow[t]{2}{*}{ 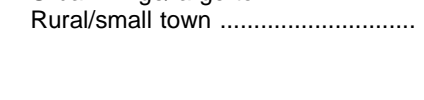 } & $18.2(2.8)$ & $3.4(0.6)$ & $35.7(2.5)$ & $27.0(2.3)$ & $15.8(1.3)$ & $20.4(1.5)$ & $23.2(1.2)$ & $38.3(1.5)$ & $18.1(1.2)$ \\
\hline & \multicolumn{9}{|c|}{1996} \\
\hline All students & $11.0(1.0)$ & $3.0(0.3)$ & $40.3(1.1)$ & $29.3(0.8)$ & $16.4(0.6)$ & $19.0(0.7)$ & $19.5(0.7)$ & $36.4(0.7)$ & $25.1(1.1)$ \\
\hline 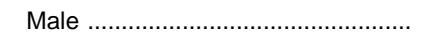 & $11.8(1.1)$ & $4.4(0.5)$ & $40.0(1.4)$ & $27.7(1.0)$ & $16.1(0.7)$ & $22.4(0.9)$ & $21.4(1.0)$ & $34.8(1.0)$ & $21.4(1.3)$ \\
\hline Female & $10.2(1.1)$ & $1.6(0.2)$ & $40.7(1.3)$ & $30.9(1.2)$ & $16.6(1.0)$ & $15.5(0.9)$ & $17.6(1.0)$ & $38.0(0.8)$ & $28.9(1.2)$ \\
\hline \multicolumn{10}{|l|}{ Race/ethnicity } \\
\hline White ............. & $12.6(1.4)$ & $2.5(0.4)$ & $39.0(1.3)$ & $30.7(1.0)$ & $15.1(0.8)$ & $13.3(0.7)$ & $19.9(0.9)$ & $40.5(0.8)$ & $26.3(1.3)$ \\
\hline Black ............. & $7.4(1.6)$ & $5.2(0.7)$ & $43.5(1.7)$ & $24.5(1.6)$ & $19.4(1.5)$ & $42.1(2.0)$ & $19.0(1.4)$ & $22.1(1.5)$ & $16.8(1.6)$ \\
\hline 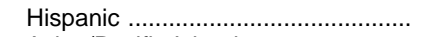 & $7.8(1.2)$ & $3.8(0.8)$ & $42.3(2.1)$ & $28.1(2.0)$ & $18.1(1.7)$ & $21.5(1.8)$ & $18.2(1.2)$ & $33.8(1.7)$ & $26.6(1.8)$ \\
\hline Asian/Pacific Islander ..................... & $4.8(1.8)$ & $1.7(0.9)$ & $41.5(4.3)$ & $28.8(2.5)$ & $23.1(3.4)$ & $18.9(3.1)$ & $18.8(3.3)$ & $29.2(3.8)$ & $33.1(5.2)$ \\
\hline American Indian $\ldots \ldots \ldots \ldots \ldots \ldots \ldots \ldots \ldots \ldots$ & $14.4(3.2)$ & $3.0(1.6)$ & $44.7(3.7)$ & $24.2(4.2)$ & $13.6(2.8)$ & $25.1(4.2)$ & $16.2(3.3)$ & $29.1(4.1)$ & $29.6(4.7)$ \\
\hline \multicolumn{10}{|l|}{ Parents' highest level of education } \\
\hline Less than high school. & $6.8(2.1)$ & $6.4(1.7)$ & $42.1(4.6)$ & $21.7(3.4)$ & $23.0(3.8)$ & $27.3(3.6)$ & $24.9(3.0)$ & $24.4(3.3)$ & $23.4(2.8)$ \\
\hline Graduated high school ................... & $12.2(2.0)$ & $3.5(0.8)$ & $42.7(2.1)$ & $26.8(1.9)$ & $14.8(1.3)$ & $22.1(1.8)$ & $19.8(1.5)$ & $38.6(1.8)$ & $19.6(1.9)$ \\
\hline Some education after high school & $11.0(2.4)$ & $1.9(0.7)$ & $39.7(2.7)$ & $35.5(2.7)$ & $11.9(1.6)$ & $15.8(2.1)$ & $24.5(2.3)$ & $39.6(2.2)$ & $20.1(2.1)$ \\
\hline Graduated college ......................... & $10.5(1.2)$ & $1.9(0.3)$ & $39.5(1.6)$ & $31.5(1.2)$ & $16.6(0.9)$ & $16.8(1.1)$ & $17.3(1.2)$ & $38.9(1.1)$ & $27.0(1.7)$ \\
\hline \multicolumn{10}{|l|}{ Region } \\
\hline 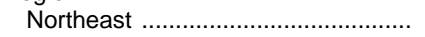 & $2.5(0.8)$ & $2.9(0.5)$ & $39.2(2.8)$ & $36.3(1.6)$ & $19.1(1.4)$ & $17.2(1.7)$ & $21.7(1.2)$ & $36.2(1.8)$ & $24.9(1.9)$ \\
\hline 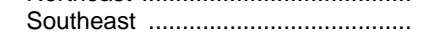 & $4.8(1.0)$ & $3.4(0.5)$ & $44.2(1.9)$ & $29.5(0.8)$ & $18.1(1.4)$ & $27.8(1.9)$ & $18.8(1.8)$ & $31.9(1.5)$ & $21.5(1.6)$ \\
\hline 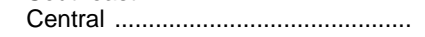 & $23.2(3.1)$ & $3.0(0.6)$ & $35.2(1.6)$ & $24.6(1.6)$ & $13.9(1.2)$ & $16.4(1.4)$ & $20.0(1.6)$ & $40.0(0.8)$ & $23.6(2.2)$ \\
\hline 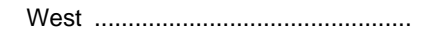 & $11.5(1.9)$ & $2.8(0.5)$ & $42.6(2.1)$ & $27.8(1.8)$ & $15.3(1.2)$ & $16.4(1.3)$ & $18.1(1.2)$ & $36.7(1.4)$ & $28.8(2.3)$ \\
\hline \multicolumn{10}{|l|}{ Type of location } \\
\hline 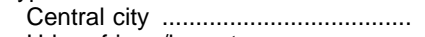 & $9.1(1.7)$ & $4.0(0.6)$ & $42.7(1.6)$ & $26.9(1.5)$ & $17.3(1.3)$ & $23.9(1.2)$ & $18.6(1.0)$ & $34.5(1.0)$ & $23.1(1.3)$ \\
\hline Urban fringe/large town ................... & $9.4(1.5)$ & $2.6(0.3)$ & $42.2(1.6)$ & $30.8(1.2)$ & $15.0(1.1)$ & $15.1(1.1)$ & $19.6(1.1)$ & $38.8(1.0)$ & $26.5(1.6)$ \\
\hline Rural/small town ........................... & $18.2(2.8)$ & $3.7(0.7)$ & $38.8(2.4)$ & $24.7(2.5)$ & $14.7(1.5)$ & $20.4(1.3)$ & $20.6(1.4)$ & $34.2(1.6)$ & $24.9(2.1)$ \\
\hline
\end{tabular}

NOTE.-Standard errors appear in parentheses.

SOURCE: U.S. Department of Education, National Center for Education Statistics, $\mathrm{Na}$ tional Assessment of Educational Progress, National Mathematics Results, 1992 and 1996. (This table was prepared September 1997.) 
Table 115.-Average writing performance of 4th-, 8th-, and 11th-graders, by selected characteristics of students: 1984 to 1996

\begin{tabular}{|c|c|c|c|c|c|c|}
\hline Selected characteristics of students & 1984 & 1988 & 1990 & 1992 & 1994 & 1996 \\
\hline \multirow[t]{2}{*}{1} & 2 & 3 & 4 & 5 & 6 & 7 \\
\hline & \multicolumn{6}{|c|}{4 th graders } \\
\hline Total . & $204(1.5)$ & $206(1.6)$ & $202(1.5)$ & $207(1.5)$ & $205(1.6)$ & $207(1.2)$ \\
\hline 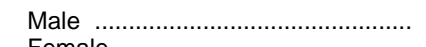 & $201(2.8)$ & $199(2.3)$ & $195(1.9)$ & $198(1.7)$ & $196(1.7)$ & $200(1.8)$ \\
\hline 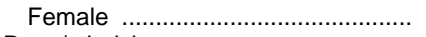 & $208(3.1)$ & $213(2.0)$ & $209(2.2)$ & $216(1.7)$ & $214(2.2)$ & $214(1.9)$ \\
\hline \multicolumn{7}{|l|}{ Race/ethnicity } \\
\hline White ............... & $211(1.9)$ & $215(1.9)$ & $211(2.0)$ & $217(1.7)$ & $214(1.5)$ & $216(1.6)$ \\
\hline Black ............................ & $182(5.0)$ & $173(4.7)$ & $171(5.4)$ & $175(3.8)$ & $173(3.2)$ & $182(2.3)$ \\
\hline Hispanic ................................... & $189(5.8)$ & $190(3.5)$ & $184(4.1)$ & $189(3.6)$ & $189(3.1)$ & $191(3.2)$ \\
\hline \multicolumn{7}{|l|}{ Parental education } \\
\hline Not high school graduate .................. & $179(4.6)$ & $194(5.4)$ & $186(3.9)$ & $191(3.2)$ & $188(7.8)$ & $190(5.5)$ \\
\hline 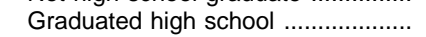 & $192(3.4)$ & $199(3.0)$ & $197(3.0)$ & $202(3.2)$ & $202(2.3)$ & $203(2.3)$ \\
\hline 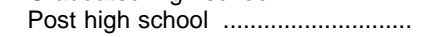 & $208(6.5)$ & $211(6.3)$ & $214(4.0)$ & $201(4.5)$ & $212(4.0)$ & $205(5.2)$ \\
\hline Graduated college ........................... & $218(3.0)$ & $212(2.2)$ & $209(1.6)$ & $214(1.4)$ & $212(2.1)$ & $214(1.7)$ \\
\hline \multicolumn{7}{|l|}{ Control of school } \\
\hline Public ................ & $202(1.8)$ & $204(2.0)$ & $200(1.4)$ & $205(1.6)$ & $204(1.8)$ & $206(1.5)$ \\
\hline Private & $215(4.6)$ & $216(4.1)$ & $216(5.7)$ & $222(3.3)$ & $213(4.3)$ & $218(3.2)$ \\
\hline \multicolumn{7}{|l|}{ Region } \\
\hline Northeast ........................................... & $212(4.0)$ & $204(4.9)$ & $211(3.6)$ & $216(4.0)$ & $210(4.0)$ & $213(2.8)$ \\
\hline 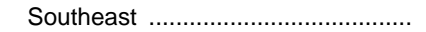 & $204(3.3)$ & $200(2.3)$ & $192(4.0)$ & $193(2.4)$ & $198(3.4)$ & $200(3.4)$ \\
\hline Central & $201(2.6)$ & $212(3.0)$ & $203(3.1)$ & $214(3.1)$ & 209 (3.3) & $212(3.1)$ \\
\hline \multirow[t]{2}{*}{ 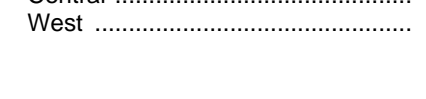 } & $201(4.9)$ & $207(3.4)$ & $201(2.7)$ & $206(2.2)$ & $203(2.7)$ & $205(2.5)$ \\
\hline & \multicolumn{6}{|c|}{ 8th graders } \\
\hline Total & $267(2.0)$ & $264(1.3)$ & $257(1.2)$ & $274(1.3)$ & $265(1.3)$ & $264(1.0)$ \\
\hline Male & $258(2.3)$ & $254(1.5)$ & $246(1.5)$ & $264(1.9)$ & $254(1.8)$ & $251(1.1)$ \\
\hline Female ........ & $276(2.4)$ & $274(1.7)$ & $268(1.3)$ & $285(1.3)$ & $278(1.4)$ & $276(1.2)$ \\
\hline \multicolumn{7}{|l|}{ Race/ethnicity } \\
\hline 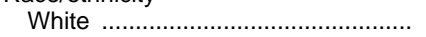 & $272(2.1)$ & $269(1.3)$ & $262(1.6)$ & $279(1.3)$ & $272(1.4)$ & $271(1.0)$ \\
\hline Black & $247(5.7)$ & $246(3.5)$ & $239(2.3)$ & $258(4.0)$ & $245(3.4)$ & $242(2.6)$ \\
\hline Hispanic ....................................... & $247(6.4)$ & $250(2.5)$ & $246(2.8)$ & $265(2.2)$ & $252(3.3)$ & $246(2.3)$ \\
\hline \multicolumn{7}{|l|}{ Parental education } \\
\hline Not high school graduate ................... & $258(4.8)$ & $254(3.9)$ & $246(3.7)$ & $258(5.3)$ & $250(4.1)$ & $245(4.5)$ \\
\hline Graduated high school .................... & $261(1.6)$ & $258(2.1)$ & $253(1.4)$ & $268(1.6)$ & $259(2.2)$ & $258(1.9)$ \\
\hline Post high school & $271(3.9)$ & $275(3.3)$ & $267(3.0)$ & $280(2.2)$ & $270(3.1)$ & $270(2.4)$ \\
\hline 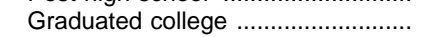 & $278(1.8)$ & $271(1.8)$ & $265(1.8)$ & $284(1.9)$ & $275(1.3)$ & $274(1.3)$ \\
\hline \multicolumn{7}{|l|}{ Control of school } \\
\hline 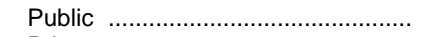 & $264(2.0)$ & $262(1.5)$ & $254(1.2)$ & $272(1.3)$ & $264(1.6)$ & $263(1.2)$ \\
\hline 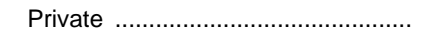 & $282(5.5)$ & $276(3.0)$ & $277(4.4)$ & $288(3.2)$ & $279(3.8)$ & $272(3.3)$ \\
\hline \multicolumn{7}{|l|}{ Region } \\
\hline 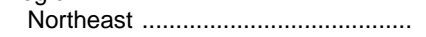 & $273(3.6)$ & $265(2.7)$ & $261(3.3)$ & $285(3.3)$ & $277(2.2)$ & $264(2.4)$ \\
\hline Southeast & $267(3.6)$ & $268(2.3)$ & $252(2.8)$ & $266(2.2)$ & $259(2.1)$ & $260(3.5)$ \\
\hline Central ........................................... & $264(2.3)$ & $258(2.2)$ & $259(3.9)$ & $277(2.0)$ & $270(4.1)$ & $268(2.3)$ \\
\hline \multirow[t]{2}{*}{ West } & $264(3.0)$ & $264(2.1)$ & $255(2.6)$ & $271(2.3)$ & $259(1.6)$ & $263(1.3)$ \\
\hline & & & 11th $\mathrm{g}$ & & & \\
\hline Total $\ldots$ & $290(1.6)$ & $291(1.3)$ & $287(1.0)$ & $287(1.4)$ & $285(1.2)$ & 283 (1.2) \\
\hline Male & $281(1.4)$ & $282(2.0)$ & $276(1.6)$ & $279(1.2)$ & $276(1.5)$ & $275(1.4)$ \\
\hline Female & $299(2.5)$ & $299(1.2)$ & $298(1.5)$ & $296(2.0)$ & $293(1.5)$ & $292(1.4)$ \\
\hline Race/ethnicity & & & & & & \\
\hline White ................ & $297(1.8)$ & $296(1.3)$ & $293(1.2)$ & $294(1.2)$ & $291(1.4)$ & $289(1.5)$ \\
\hline 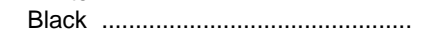 & $270(3.6)$ & $275(2.9)$ & $268(2.3)$ & $263(3.2)$ & $267(2.2)$ & $267(3.0)$ \\
\hline 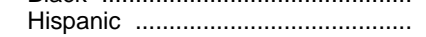 & $259(6.6)$ & $274(4.4)$ & $277(2.6)$ & $274(3.8)$ & $271(4.0)$ & $269(2.5)$ \\
\hline Parental education & & & & & & \\
\hline Not high school graduate ................ & $274(5.2)$ & $276(3.5)$ & $268(4.0)$ & $271(3.7)$ & $269(4.7)$ & $260(3.0)$ \\
\hline Graduated high school ................... & $284(3.0)$ & $285(2.2)$ & $278(1.9)$ & $278(2.2)$ & $279(1.7)$ & $275(1.6)$ \\
\hline 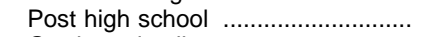 & $298(2.5)$ & $296(2.6)$ & $292(2.7)$ & $292(2.0)$ & $286(1.7)$ & $287(2.1)$ \\
\hline 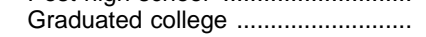 & $300(2.4)$ & $299(2.0)$ & $298(2.0)$ & $296(1.4)$ & $293(1.5)$ & $291(1.9)$ \\
\hline Control of school & & & & & & \\
\hline 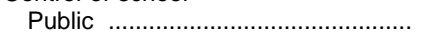 & $288(1.6)$ & $290(1.2)$ & $286(1.1)$ & $287(1.6)$ & $284(1.4)$ & $283(1.4)$ \\
\hline 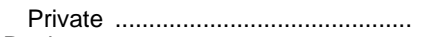 & $305(3.7)$ & $300(3.6)$ & $306(5.2)$ & $295(4.4)$ & $291(3.8)$ & $287(6.6)$ \\
\hline Region & & & & & & \\
\hline 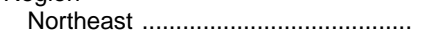 & $291(3.0)$ & $295(2.8)$ & $295(2.5)$ & $290(2.3)$ & $291(2.4)$ & $290(2.2)$ \\
\hline 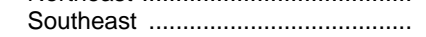 & $287(4.9)$ & $289(2.2)$ & $280(2.3)$ & $278(3.3)$ & $277(2.5)$ & $273(2.2)$ \\
\hline 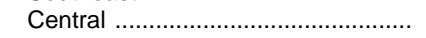 & $291(2.7)$ & $292(4.0)$ & $289(2.7)$ & $291(2.2)$ & $284(2.3)$ & $285(2.5)$ \\
\hline 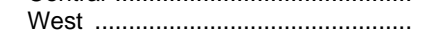 & $289(3.7)$ & $289(2.3)$ & $285(2.1)$ & $289(2.1)$ & $287(2.7)$ & $284(2.2)$ \\
\hline
\end{tabular}

NOTE.-These test scores are from the National Assessment of Educational Progress (NAEP). The writing scale score ranges from 0 to 500 and is defined as the average of a respondent's estimated scores on specific writing tasks. The average response method is used to estimate average writing achievement for each participant as if each had performed all 11 writing tasks. Standard errors appear in parentheses.
SOURCE: U.S. Department of Education, National Center for Education Statistics, National Assessment of Educational Progress, NAEP 1996 Trends in Academic Progress, by Educational Testing Service. (This table was prepared September 1997.) 
Table 116.-Student values and attitudes toward writing, by grade level: 1984, 1990, 1992, and 1994

\begin{tabular}{|c|c|c|c|c|c|c|c|c|c|c|c|c|}
\hline \multirow{3}{*}{ Statements about writing } & \multicolumn{12}{|c|}{$\begin{array}{c}\text { Percent of students reporting the statement is true more than half the time, by grade } \\
\text { level }\end{array}$} \\
\hline & \multicolumn{4}{|c|}{ Grade 4} & \multicolumn{4}{|c|}{ Grade 8} & \multicolumn{4}{|c|}{ Grade 11} \\
\hline & 1984 & 1990 & 1992 & 1994 & 1984 & 1990 & 1992 & 1994 & 1984 & 1990 & 1992 & 1994 \\
\hline 1 & 2 & 3 & 4 & 5 & 6 & 7 & 8 & 9 & 10 & 11 & 12 & 13 \\
\hline Writing helps me think more clearly ...... & - & - & - & - & 44 & 46 & 42 & 42 & 52 & 47 & 50 & 54 \\
\hline 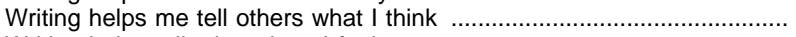 & - & - & - & - & 52 & 56 & 52 & 54 & 55 & 58 & 57 & 58 \\
\hline 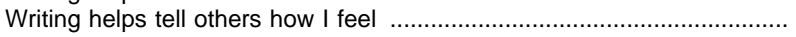 & - & - & - & - & 50 & 56 & 52 & 52 & 55 & 60 & 60 & 60 \\
\hline Writing helps me understand my own feelings ........................................ & - & - & - & - & 40 & 47 & 44 & 45 & 47 & 50 & 49 & 54 \\
\hline People who write well have a better chance of getting good jobs ............ & 一 & - & - & 一 & 47 & 53 & 51 & 51 & 54 & 58 & 59 & 58 \\
\hline 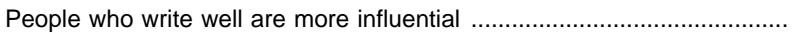 & - & - & - & - & 49 & 55 & 52 & 51 & 54 & 60 & 60 & 57 \\
\hline I like to write & 56 & 57 & 54 & 56 & 39 & 42 & 43 & 42 & 40 & 39 & 43 & 42 \\
\hline I am a good writer $\ldots \ldots \ldots \ldots \ldots \ldots \ldots \ldots \ldots \ldots \ldots \ldots \ldots$ & 60 & 62 & 63 & 64 & 42 & 44 & 44 & 49 & 39 & 44 & 49 & 46 \\
\hline People like what I write & 53 & 56 & 55 & 58 & 38 & 39 & 44 & 44 & 36 & 42 & 46 & 44 \\
\hline 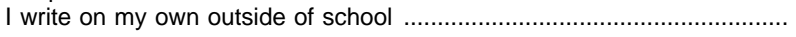 & 48 & 42 & 46 & 45 & 36 & 35 & 37 & 36 & 31 & 28 & 33 & 32 \\
\hline I don't like to write things that will be graded & 38 & 33 & 32 & 33 & 31 & 36 & 37 & 38 & 27 & 30 & 30 & 33 \\
\hline If I didn't have to write for school, I wouldn't write anything ....................... & 33 & 27 & 28 & 27 & 17 & 19 & 18 & 21 & 15 & 16 & 17 & 17 \\
\hline
\end{tabular}

-Data not available.

SOURCE: U.S. Department of Education, National Center for Education Statistics, NAEP 1994 Trends in Academic Progress, by Educational Testing Service. (This table was prepared March 1997.)

Table 117.-Percent of students at or above selected history proficiency levels, by selected characteristics and grade level: 1994

\begin{tabular}{|c|c|c|c|c|c|c|c|c|c|c|c|c|}
\hline \multirow[b]{2}{*}{ Selected characteristics of students } & \multicolumn{4}{|c|}{ Percentage of 4 th graders } & \multicolumn{4}{|c|}{ Percentage of 8th graders } & \multicolumn{4}{|c|}{ Percentage of 12 th graders } \\
\hline & $\begin{array}{l}\text { Below } \\
\text { basic }\end{array}$ & $\begin{array}{l}\text { At or } \\
\text { above } \\
\text { basic }\end{array}$ & $\begin{array}{l}\text { At or } \\
\text { above } \\
\text { pro- } \\
\text { ficient }\end{array}$ & $\begin{array}{c}\text { At or } \\
\text { above } \\
\text { advanced }\end{array}$ & $\begin{array}{l}\text { Below } \\
\text { basic }\end{array}$ & $\begin{array}{l}\text { At or } \\
\text { above } \\
\text { basic }\end{array}$ & $\begin{array}{l}\text { At or } \\
\text { above } \\
\text { pro- } \\
\text { ficient }\end{array}$ & $\begin{array}{l}\text { At or } \\
\text { above } \\
\text { advanced }\end{array}$ & $\begin{array}{l}\text { Below } \\
\text { basic }\end{array}$ & $\begin{array}{l}\text { At or } \\
\text { above } \\
\text { basic }\end{array}$ & $\begin{array}{l}\text { At or } \\
\text { above } \\
\text { pro- } \\
\text { ficient }\end{array}$ & $\begin{array}{c}\text { At or } \\
\text { above } \\
\text { advanced }\end{array}$ \\
\hline 1 & 2 & 3 & 4 & 5 & 6 & 7 & 8 & 9 & 10 & 11 & 12 & 13 \\
\hline 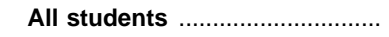 & 36 & 64 & 17 & 2 & 39 & 61 & 14 & 1 & 57 & 43 & 11 & 1 \\
\hline 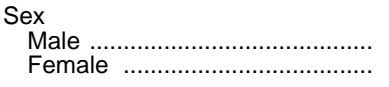 & $\begin{array}{l}38 \\
35\end{array}$ & $\begin{array}{l}62 \\
65\end{array}$ & $\begin{array}{l}18 \\
16\end{array}$ & $\begin{array}{l}2 \\
2\end{array}$ & $\begin{array}{l}39 \\
39\end{array}$ & $\begin{array}{l}61 \\
61\end{array}$ & $\begin{array}{l}15 \\
13\end{array}$ & $\begin{array}{l}1 \\
1\end{array}$ & $\begin{array}{l}55 \\
60\end{array}$ & $\begin{array}{l}45 \\
40\end{array}$ & $\begin{array}{r}12 \\
9\end{array}$ & $\begin{array}{l}1 \\
1\end{array}$ \\
\hline 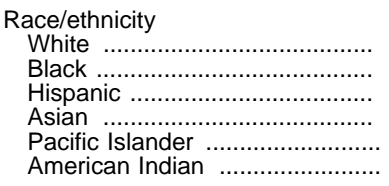 & $\begin{array}{l}26 \\
64 \\
59 \\
36 \\
41 \\
49\end{array}$ & $\begin{array}{l}74 \\
36 \\
41 \\
64 \\
59 \\
51\end{array}$ & $\begin{array}{r}22 \\
4 \\
6 \\
22 \\
16 \\
9\end{array}$ & $\begin{array}{l}3 \\
0 \\
1 \\
4 \\
3 \\
0\end{array}$ & $\begin{array}{l}29 \\
67 \\
59 \\
28 \\
48 \\
58\end{array}$ & $\begin{array}{l}71 \\
33 \\
41 \\
72 \\
52 \\
42\end{array}$ & $\begin{array}{r}17 \\
4 \\
5 \\
23 \\
11 \\
5\end{array}$ & $\begin{array}{l}1 \\
0 \\
0 \\
2 \\
1 \\
0\end{array}$ & $\begin{array}{l}50 \\
83 \\
78 \\
54 \\
67 \\
70\end{array}$ & $\begin{array}{l}50 \\
17 \\
22 \\
46 \\
33 \\
30\end{array}$ & $\begin{array}{r}13 \\
2 \\
4 \\
16 \\
7 \\
5\end{array}$ & $\begin{array}{l}1 \\
0 \\
0 \\
2 \\
1 \\
0\end{array}$ \\
\hline 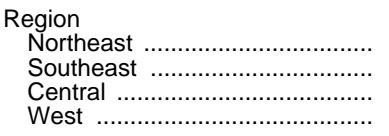 & $\begin{array}{l}37 \\
39 \\
29 \\
39\end{array}$ & $\begin{array}{l}63 \\
61 \\
71 \\
61\end{array}$ & $\begin{array}{l}18 \\
15 \\
20 \\
16\end{array}$ & $\begin{array}{l}3 \\
2 \\
3 \\
1\end{array}$ & $\begin{array}{l}31 \\
49 \\
31 \\
42\end{array}$ & $\begin{array}{l}69 \\
51 \\
69 \\
58\end{array}$ & $\begin{array}{r}19 \\
9 \\
17 \\
11\end{array}$ & $\begin{array}{l}1 \\
0 \\
1 \\
1\end{array}$ & $\begin{array}{l}54 \\
63 \\
55 \\
57\end{array}$ & $\begin{array}{l}46 \\
37 \\
45 \\
43\end{array}$ & $\begin{array}{r}13 \\
8 \\
11 \\
10\end{array}$ & $\begin{array}{l}1 \\
0 \\
1 \\
1\end{array}$ \\
\hline $\begin{array}{l}\text { Parents' level of education } \\
\text { Not high school graduate } \ldots \ldots \ldots . . . \\
\text { Graduated high school ............. } \\
\text { Some college ........................... } \\
\text { Graduated college }\end{array}$ & $\begin{array}{l}63 \\
43 \\
26 \\
26\end{array}$ & $\begin{array}{l}37 \\
57 \\
74 \\
74\end{array}$ & $\begin{array}{r}2 \\
10 \\
21 \\
25\end{array}$ & $\begin{array}{l}0 \\
1 \\
3 \\
4\end{array}$ & $\begin{array}{l}63 \\
50 \\
32 \\
26\end{array}$ & $\begin{array}{l}37 \\
50 \\
68 \\
74\end{array}$ & $\begin{array}{r}3 \\
7 \\
14 \\
22\end{array}$ & $\begin{array}{l}0 \\
0 \\
0 \\
1\end{array}$ & $\begin{array}{l}85 \\
71 \\
58 \\
44\end{array}$ & $\begin{array}{l}15 \\
29 \\
42 \\
56\end{array}$ & $\begin{array}{r}1 \\
4 \\
8 \\
17\end{array}$ & $\begin{array}{l}0 \\
0 \\
1 \\
1\end{array}$ \\
\hline
\end{tabular}

SOURCE: U.S. Department of Education, National Center for Education Statistics, National Assessment of Educational Progress, NAEP 1994 U.S. History Report Card. (This table was prepared November 1995.) 
Table 118.-Average student proficiency in geography and U.S. history, by student characteristics: 1994

\begin{tabular}{|c|c|c|c|c|c|c|c|c|c|c|c|c|c|c|c|}
\hline \multirow[b]{2}{*}{ Characteristic } & \multirow{2}{*}{$\begin{array}{c}\text { Per- } \\
\text { cent- } \\
\text { age } \\
\text { dis- } \\
\text { tribu- } \\
\text { tion of } \\
12 \text { th } \\
\text { grad- } \\
\text { ers in } \\
\text { geog- } \\
\text { raphy }\end{array}$} & \multicolumn{3}{|c|}{ Geography scores } & \multicolumn{3}{|c|}{ History scores } & \multirow[b]{2}{*}{ Characteristic } & \multirow{2}{*}{$\begin{array}{l}\text { Per- } \\
\text { cent- } \\
\text { age } \\
\text { dis- } \\
\text { tribu- } \\
\text { tion of } \\
12 \text { th } \\
\text { grad- } \\
\text { ers in } \\
\text { geog- } \\
\text { raphy }\end{array}$} & \multicolumn{3}{|c|}{ Geography scores } & \multicolumn{3}{|c|}{ History scores } \\
\hline & & $\begin{array}{l}\text { 4th } \\
\text { grad- } \\
\text { ers }\end{array}$ & $\begin{array}{l}\text { 8th } \\
\text { grad- } \\
\text { ers }\end{array}$ & $\begin{array}{l}12 \text { th } \\
\text { grad- } \\
\text { ers }\end{array}$ & $\begin{array}{l}\text { 4th } \\
\text { grad- } \\
\text { ers }\end{array}$ & $\begin{array}{l}\text { 8th } \\
\text { grad- } \\
\text { ers }\end{array}$ & $\begin{array}{l}12 \text { th } \\
\text { grad- } \\
\text { ers }\end{array}$ & & & $\begin{array}{l}\text { 4th } \\
\text { grad- } \\
\text { ers }\end{array}$ & $\begin{array}{l}\text { 8th } \\
\text { grad- } \\
\text { ers }\end{array}$ & $\begin{array}{l}\text { 12th } \\
\text { grad- } \\
\text { ers }\end{array}$ & $\begin{array}{l}\text { 4th } \\
\text { grad- } \\
\text { ers }\end{array}$ & $\begin{array}{l}\text { 8th } \\
\text { grad- } \\
\text { ers }\end{array}$ & $\begin{array}{l}12 \text { th } \\
\text { grad- } \\
\text { ers }\end{array}$ \\
\hline 1 & 2 & 3 & 4 & 5 & 6 & 7 & 8 & 1 & 2 & 3 & 4 & 5 & 6 & 7 & 8 \\
\hline United States .. & 100 & 206 & 260 & 285 & 205 & 259 & 286 & & & & & & & & \\
\hline $\begin{array}{l}\text { Sex } \\
\quad \text { Male ....................... }\end{array}$ & 50 & 208 & 262 & 288 & 203 & 259 & 288 & Type of school & & & & & & & \\
\hline $\begin{array}{l}\text { Female .............. } \\
\text { Race }\end{array}$ & 50 & 203 & 258 & 281 & 206 & 259 & 285 & $\begin{array}{r}\text { Public } \\
\text { Nonpublic schools } \\
\text { Catholic schools }\end{array}$ & $\begin{array}{r}89 \\
11 \\
6\end{array}$ & $\begin{array}{l}204 \\
221 \\
222\end{array}$ & $\begin{array}{l}258 \\
276 \\
276\end{array}$ & $\begin{array}{l}283 \\
294 \\
291\end{array}$ & $\begin{array}{l}203 \\
222 \\
221\end{array}$ & $\begin{array}{l}257 \\
278 \\
279\end{array}$ & $\begin{array}{l}284 \\
299 \\
298\end{array}$ \\
\hline White …............. & 74 & 218 & 270 & 291 & 215 & 267 & 292 & Other nonpublic ................. & 4 & 220 & 276 & 298 & 224 & 277 & 299 \\
\hline Black ................ & 12 & 168 & 229 & 258 & 177 & 239 & 265 & & & & & & & & \\
\hline Hispanic ........... & 8 & 183 & 239 & 268 & 180 & 243 & 267 & & & & & & & & \\
\hline $\begin{array}{l}\text { Region } \\
\text { Northeast }\end{array}$ & 21 & 203 & 266 & 284 & 204 & 266 & 289 & Parents' level of education & 7 & 186 & 238 & 263 & 177 & 241 & 263 \\
\hline Southeast .......... & 23 & 200 & 252 & 278 & 201 & 251 & 282 & Graduated high school ....... & 22 & 197 & 250 & 274 & 197 & 251 & 276 \\
\hline Central ............... & 28 & 215 & 268 & 289 & 212 & 266 & 288 & Some college ......................... & 25 & 216 & 265 & 286 & 214 & 264 & 287 \\
\hline West .................. & 29 & 205 & 255 & 286 & 202 & 256 & 286 & Graduated college ................ & 44 & 216 & 272 & 294 & 216 & 270 & 296 \\
\hline
\end{tabular}

NOTE.-These test scores are from the National Assessment of Educational Progress (NAEP). As with the NAEP reading scale, these scales range from 0 to 500 . However, the distribution of scores varies by subject. Therefore, direct score comparisons among

the subjects should be avoided.
SOURCE: U.S. Department of Education, National Center for Education Statistics, National Assessment of Educational Progress, NAEP 1994 U.S. History Report Card, and The Geography Report Card, prepared by Educational Testing Service. (This table was prepared November 1995.)

Table 119.--Percent of students at or above selected geography proficiency levels, by selected characteristics and grade level: 1994

\begin{tabular}{|c|c|c|c|c|c|c|c|c|c|c|c|c|}
\hline \multirow[b]{2}{*}{ Selected characteristics of students } & \multicolumn{4}{|c|}{ Percentage of 4 th graders } & \multicolumn{4}{|c|}{ Percentage of 8th graders } & \multicolumn{4}{|c|}{ Percentage of 12 th graders } \\
\hline & $\begin{array}{l}\text { Below } \\
\text { basic }\end{array}$ & $\begin{array}{l}\text { At or } \\
\text { above } \\
\text { basic }\end{array}$ & $\begin{array}{c}\text { At or } \\
\text { above } \\
\text { pro- } \\
\text { ficient }\end{array}$ & $\begin{array}{c}\text { At or } \\
\text { above } \\
\text { advanced }\end{array}$ & $\begin{array}{l}\text { Below } \\
\text { basic }\end{array}$ & $\begin{array}{l}\text { At or } \\
\text { above } \\
\text { basic }\end{array}$ & $\begin{array}{c}\text { At or } \\
\text { above } \\
\text { pro- } \\
\text { ficient }\end{array}$ & $\begin{array}{c}\text { At or } \\
\text { above } \\
\text { advanced }\end{array}$ & $\begin{array}{l}\text { Below } \\
\text { basic }\end{array}$ & $\begin{array}{l}\text { At or } \\
\text { above } \\
\text { basic }\end{array}$ & $\begin{array}{l}\text { At or } \\
\text { above } \\
\text { pro- } \\
\text { ficient }\end{array}$ & $\begin{array}{c}\text { At or } \\
\text { above } \\
\text { advanced }\end{array}$ \\
\hline 1 & 2 & 3 & 4 & 5 & 6 & 7 & 8 & 9 & 10 & 11 & 12 & 13 \\
\hline All students ..... & 30 & 70 & 22 & 3 & 29 & 71 & 28 & 4 & 30 & 70 & 27 & 2 \\
\hline 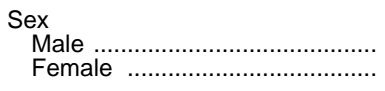 & $\begin{array}{l}29 \\
32\end{array}$ & $\begin{array}{l}71 \\
68\end{array}$ & $\begin{array}{l}26 \\
19\end{array}$ & $\begin{array}{l}4 \\
2\end{array}$ & $\begin{array}{l}28 \\
31\end{array}$ & $\begin{array}{l}72 \\
69\end{array}$ & $\begin{array}{l}30 \\
25\end{array}$ & $\begin{array}{l}5 \\
3\end{array}$ & $\begin{array}{l}27 \\
33\end{array}$ & $\begin{array}{l}73 \\
67\end{array}$ & $\begin{array}{l}32 \\
22\end{array}$ & $\begin{array}{l}2 \\
1\end{array}$ \\
\hline 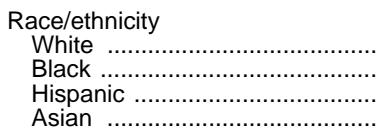 & $\begin{array}{l}19 \\
66 \\
51 \\
21\end{array}$ & $\begin{array}{l}81 \\
34 \\
49 \\
79\end{array}$ & $\begin{array}{r}29 \\
3 \\
10 \\
32\end{array}$ & $\begin{array}{l}4 \\
0 \\
1 \\
5\end{array}$ & $\begin{array}{l}18 \\
66 \\
50 \\
21\end{array}$ & $\begin{array}{l}82 \\
34 \\
50 \\
79\end{array}$ & $\begin{array}{r}36 \\
5 \\
10 \\
40\end{array}$ & $\begin{array}{l}5 \\
0 \\
1 \\
8\end{array}$ & $\begin{array}{l}22 \\
68 \\
52 \\
31\end{array}$ & $\begin{array}{l}78 \\
32 \\
48 \\
69\end{array}$ & $\begin{array}{r}33 \\
5 \\
10 \\
32\end{array}$ & $\begin{array}{l}2 \\
0 \\
0 \\
3\end{array}$ \\
\hline 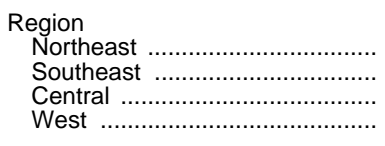 & $\begin{array}{l}33 \\
36 \\
22 \\
30\end{array}$ & $\begin{array}{l}67 \\
64 \\
78 \\
70\end{array}$ & $\begin{array}{l}22 \\
17 \\
28 \\
21\end{array}$ & $\begin{array}{l}3 \\
2 \\
4 \\
3\end{array}$ & $\begin{array}{l}24 \\
38 \\
20 \\
33\end{array}$ & $\begin{array}{l}76 \\
62 \\
80 \\
67\end{array}$ & $\begin{array}{l}33 \\
21 \\
36 \\
23\end{array}$ & $\begin{array}{l}6 \\
3 \\
6 \\
3\end{array}$ & $\begin{array}{l}31 \\
40 \\
25 \\
28\end{array}$ & $\begin{array}{l}69 \\
60 \\
75 \\
72\end{array}$ & $\begin{array}{l}25 \\
20 \\
32 \\
29\end{array}$ & $\begin{array}{l}2 \\
1 \\
2 \\
2\end{array}$ \\
\hline $\begin{array}{l}\text { Parents' level of education } \\
\text { Not high school graduate ......... } \\
\text { Graduated high school ............. } \\
\text { Some college .......................... } \\
\text { Graduated college .................. }\end{array}$ & $\begin{array}{l}48 \\
37 \\
20 \\
22\end{array}$ & $\begin{array}{l}52 \\
63 \\
80 \\
78\end{array}$ & $\begin{array}{r}8 \\
15 \\
30 \\
31\end{array}$ & $\begin{array}{l}0 \\
1 \\
3 \\
5\end{array}$ & $\begin{array}{l}53 \\
38 \\
21 \\
18\end{array}$ & $\begin{array}{l}47 \\
62 \\
79 \\
82\end{array}$ & $\begin{array}{r}8 \\
15 \\
29 \\
41\end{array}$ & $\begin{array}{l}1 \\
1 \\
3 \\
7\end{array}$ & $\begin{array}{l}59 \\
44 \\
25 \\
19\end{array}$ & $\begin{array}{l}41 \\
56 \\
75 \\
81\end{array}$ & $\begin{array}{r}7 \\
14 \\
24 \\
40\end{array}$ & $\begin{array}{l}0 \\
0 \\
1 \\
3\end{array}$ \\
\hline
\end{tabular}

SOURCE: U.S. Department of Education, National Center for Education Statistics, National Assessment of Educational Progress, NAEP 1994 Geography Report Card. (This table was prepared November 1995.) 
Table 120.-Average mathematics proficiency, by age and by selected characteristics of students: 1973 to 1996

\begin{tabular}{|c|c|c|c|c|c|c|c|c|}
\hline Selected characteristics of students & 1973 & 1978 & 1982 & 1986 & 1990 & 1992 & 1994 & 1996 \\
\hline \multirow[t]{2}{*}{1} & 2 & 3 & 4 & 5 & 6 & 7 & 8 & 9 \\
\hline & \multicolumn{8}{|c|}{9 -year-olds ${ }^{1}$} \\
\hline Total ............. & $219(0.8)$ & $219(0.8)$ & $219(1.1)$ & $222(1.0)$ & $230(0.8)$ & $230(0.8)$ & $231(0.8)$ & $231(0.8)$ \\
\hline Male & $218(0.7)$ & $217(0.7)$ & $217(1.2)$ & $222(1.1)$ & $229(0.9)$ & $231(1.0)$ & $232(1.0)$ & $233(1.2)$ \\
\hline Female & $220(1.1)$ & $220(1.0)$ & $221(1.2)$ & $222(1.2)$ & $230(1.1)$ & $228(1.0)$ & $230(0.9)$ & $229(0.7)$ \\
\hline \multicolumn{9}{|l|}{ Race/ethnicity } \\
\hline White ........... & $225(1.0)$ & $224(0.9)$ & $224(1.1)$ & $227(1.1)$ & $235(0.8)$ & $235(0.8)$ & $237(1.0)$ & $237(1.0)$ \\
\hline Black ........ & $190(1.8)$ & $192(1.1)$ & $195(1.6)$ & $202(1.6)$ & $208(2.2)$ & $208(2.0)$ & $212(1.6)$ & $212(1.4)$ \\
\hline Hispanic ............... & $202(2.4)$ & $203(2.2)$ & $204(1.3)$ & $205(2.1)$ & $214(2.1)$ & $212(2.3)$ & $210(2.3)$ & $215(1.7)$ \\
\hline \multicolumn{9}{|l|}{ Parental education } \\
\hline Not high school graduate ................. & -- & $200(1.5)$ & $199(1.7)$ & $201(2.5)$ & $210(2.3)$ & $217(2.2)$ & $210(3.0)$ & $220(3.3)$ \\
\hline Graduated high school .................... & -- & $219(1.1)$ & $218(1.1)$ & $218(1.6)$ & $226(1.2)$ & $222(1.5)$ & $225(1.3)$ & $221(1.7)$ \\
\hline Some education after high school & -- & $230(1.7)$ & $225(2.1)$ & $229(2.1)$ & $236(2.0)$ & $237(1.9)$ & $239(2.1)$ & $238(2.5)$ \\
\hline Graduated college & -- & $231(1.1)$ & $229(1.5)$ & $231(1.1)$ & $238(1.3)$ & $236(1.0)$ & $238(0.8)$ & $240(1.4)$ \\
\hline \multicolumn{9}{|l|}{ Control of school } \\
\hline Public ................. & -- & $217(0.8)$ & $217(1.1)$ & $220(1.2)$ & $229(0.9)$ & $228(0.9)$ & $229(0.9)$ & $230(0.8)$ \\
\hline Private & -- & $231(1.7)$ & $232(2.1)$ & $230(2.5)$ & $238(2.3)$ & $242(1.7)$ & $245(2.3)$ & $239(2.1)$ \\
\hline \multicolumn{9}{|l|}{ Region } \\
\hline Northeast ............................................ & $227(1.9)$ & $227(1.9)$ & $226(1.8)$ & $226(2.7)$ & $236(2.1)$ & $235(1.9)$ & $238(2.2)$ & $236(2.0)$ \\
\hline Southeast .......................................... & $208(1.3)$ & $209(1.2)$ & $210(2.5)$ & $218(2.5)$ & $224(2.4)$ & $221(1.7)$ & $229(1.4)$ & $227(2.0)$ \\
\hline Central & $224(1.5)$ & $224(1.5)$ & $221(2.7)$ & $226(2.3)$ & $231(1.3)$ & $234(1.6)$ & $233(1.8)$ & $233(2.3)$ \\
\hline \multirow[t]{2}{*}{ West } & $216(2.2)$ & $214(1.3)$ & $219(1.8)$ & $217(2.4)$ & $229(1.8)$ & $229(2.3)$ & $226(1.6)$ & $229(1.3)$ \\
\hline & \multicolumn{8}{|c|}{13 -year-olds ${ }^{1}$} \\
\hline Total & $266(1.1)$ & $264(1.1)$ & $269(1.1)$ & $269(1.2)$ & $270(0.9)$ & $273(0.9)$ & $274(1.0)$ & $274(0.8)$ \\
\hline Male ......... & $265(1.3)$ & $264(1.3)$ & $269(1.4)$ & $270(1.1)$ & $271(1.2)$ & $274(1.1)$ & $276(1.3)$ & $276(0.9)$ \\
\hline Female ……........................ & $267(1.1)$ & $265(1.1)$ & $268(1.1)$ & $268(1.5)$ & $270(0.9)$ & $272(1.0)$ & $273(1.0)$ & $272(1.0)$ \\
\hline \multicolumn{9}{|l|}{ Race/ethnicity } \\
\hline White ............ & $274(0.9)$ & $272(0.8)$ & $274(1.0)$ & $274(1.3)$ & $276(1.1)$ & $279(0.9)$ & $281(0.9)$ & $281(0.9)$ \\
\hline Black ......................... & $228(1.9)$ & $230(1.9)$ & $240(1.6)$ & $249(2.3)$ & $249(2.3)$ & $250(1.9)$ & $252(3.5)$ & $252(1.3)$ \\
\hline Hispanic ............... & $239(2.2)$ & $238(2.0)$ & $252(1.7)$ & $254(2.9)$ & $255(1.8)$ & $259(1.8)$ & 256 (1.9) & $256(1.6)$ \\
\hline \multicolumn{9}{|l|}{ Parental education } \\
\hline Not high school graduate & -- & $245(1.2)$ & $251(1.4)$ & $252(2.3)$ & $253(1.8)$ & $256(1.0)$ & $255(2.1)$ & $254(2.4)$ \\
\hline Graduated high school ............................ & -- & $263(1.0)$ & $263(0.8)$ & $263(1.2)$ & $263(1.2)$ & $263(1.2)$ & $266(1.1)$ & $267(1.1)$ \\
\hline Some education after high school & -- & $273(1.2)$ & $275(0.9)$ & $274(0.8)$ & $277(1.0)$ & $278(1.0)$ & $277(1.6)$ & $278(1.4)$ \\
\hline 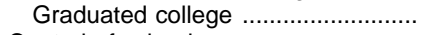 & -- & $284(1.2)$ & $282(1.5)$ & $280(1.4)$ & $280(1.0)$ & $283(1.0)$ & $285(1.2)$ & $283(1.2)$ \\
\hline \multicolumn{9}{|l|}{ Control of school } \\
\hline 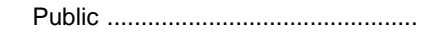 & -- & $263(1.2)$ & $267(1.3)$ & $269(1.2)$ & $269(1.0)$ & $272(1.0)$ & $273(1.1)$ & $273(0.9)$ \\
\hline 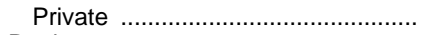 & -- & $279(1.4)$ & $281(2.1)$ & 276 (4.9) & $280(1.7)$ & $283(2.5)$ & $285(2.4)$ & $286(3.6)$ \\
\hline \multicolumn{9}{|l|}{ Region } \\
\hline Northeast .................... & $275(2.4)$ & $273(2.4)$ & $277(2.0)$ & $277(2.2)$ & $275(2.3)$ & $274(2.2)$ & $284(1.5)$ & $275(2.1)$ \\
\hline Southeast ..................... & $255(3.2)$ & $253(3.3)$ & $258(2.2)$ & $264(1.4)$ & $266(1.9)$ & $271(2.5)$ & $269(2.0)$ & $270(1.8)$ \\
\hline 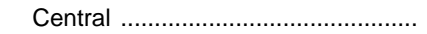 & $271(1.8)$ & $269(1.8)$ & $273(2.1)$ & $266(4.5)$ & $272(2.4)$ & $275(1.5)$ & $275(3.4)$ & $280(1.3)$ \\
\hline 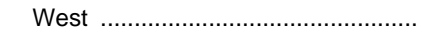 & $262(1.9)$ & $260(1.9)$ & $266(2.4)$ & $270(2.1)$ & $269(1.6)$ & $272(1.4)$ & $272(1.7)$ & $273(1.9)$ \\
\hline & & & & $17-y \epsilon$ & & & & \\
\hline Total & $304(1.1)$ & $300(1.0)$ & $299(0.9)$ & $302(0.9)$ & $305(0.9)$ & $307(0.9)$ & $306(1.0)$ & 307 (1.2) \\
\hline Male & $309(1.2)$ & $304(1.0)$ & $302(1.0)$ & $305(1.2)$ & $306(1.1)$ & $309(1.1)$ & $309(1.4)$ & $310(1.3)$ \\
\hline …………..... & $301(1.1)$ & $297(1.0)$ & $296(1.0)$ & $299(1.0)$ & $303(1.1)$ & $305(1.1)$ & $304(1.1)$ & $305(1.4)$ \\
\hline Race/ethnicity & & & & & & & & \\
\hline 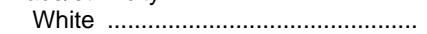 & $310(1.1)$ & $306(0.9)$ & $304(0.9)$ & $308(1.0)$ & $310(1.0)$ & $312(0.8)$ & $312(1.1)$ & $313(1.4)$ \\
\hline Black & $270(1.3)$ & $268(1.3)$ & $272(1.2)$ & $279(2.1)$ & $289(2.8)$ & $286(2.2)$ & $286(1.8)$ & $286(1.7)$ \\
\hline Hispanic .. & $277(2.2)$ & $276(2.3)$ & $277(1.8)$ & $283(2.9)$ & $284(2.9)$ & $292(2.6)$ & $291(3.7)$ & $292(2.1)$ \\
\hline Parental education & & & & & & & & \\
\hline Not high school graduate .................. & -- & $280(1.2)$ & $279(1.0)$ & $279(2.3)$ & $285(2.2)$ & $286(2.3)$ & $284(2.4)$ & $281(2.4)$ \\
\hline Graduated high school ............................ & -- & $294(0.8)$ & $293(0.8)$ & $293(1.0)$ & $294(0.9)$ & $298(1.7)$ & $295(1.1)$ & $297(2.4)$ \\
\hline Some education after high school & -- & $305(0.9)$ & $304(0.9)$ & $305(1.2)$ & $308(1.0)$ & $308(1.1)$ & $305(1.3)$ & $307(1.5)$ \\
\hline Graduated college .............................. & -- & $317(1.0)$ & $312(1.0)$ & $314(1.4)$ & $316(1.3)$ & $316(1.0)$ & $318(1.4)$ & $317(1.3)$ \\
\hline Control of school & & & & & & & & \\
\hline Public ................. & -- & $300(1.0)$ & $297(0.9)$ & $301(1.0)$ & $304(0.8)$ & $305(0.9)$ & $304(0.9)$ & $306(1.1)$ \\
\hline 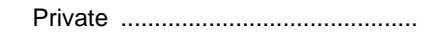 & -- & $314(3.2)$ & $311(1.7)$ & $320(9.8)$ & $318(6.6)$ & $320(3.0)$ & $319(4.0)$ & $316(4.5)$ \\
\hline Region & & & & & & & & \\
\hline 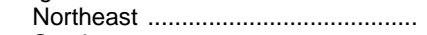 & $312(1.8)$ & $307(1.8)$ & $304(2.0)$ & $307(1.9)$ & $304(2.1)$ & $311(2.0)$ & $313(2.9)$ & $309(3.0)$ \\
\hline 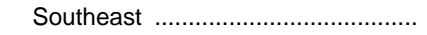 & $296(1.8)$ & $292(1.7)$ & $292(2.1)$ & 297 (1.4) & $301(2.3)$ & $301(1.9)$ & $301(1.6)$ & $303(2.1)$ \\
\hline Central & $306(1.8)$ & $305(1.9)$ & $302(1.4)$ & $304(1.9)$ & $311(2.1)$ & $312(2.0)$ & $307(2.2)$ & $314(2.0)$ \\
\hline West & $303(2.0)$ & $296(1.8)$ & $294(1.9)$ & $299(2.7)$ & $302(1.5)$ & $303(1.5)$ & $305(2.4)$ & $304(2.3)$ \\
\hline
\end{tabular}

1 Excludes persons not enrolled in school. -Data not available.

NOTE.-These test scores are from the National Assessment of Educational Progress (NAEP). Performers at the 150 level know some basic addition and subtraction facts, and most can add two-digit numbers without regrouping. They recognize simple situations in which addition and subtraction apply. Performers at the 200 level have considerable understanding of two-digit numbers and know some basic multiplication and division facts. Performers at the 250 level have an initial understanding of the four basic operations. They can also compare information from graphs and charts, and are developing an ability to analyze simple logical relations. Performers at the 300 level can compute decimals, simple fractions and percents. They can identify geometric figures, measure lengths and angles, and calculate areas of rectangles. They are developing the skills to operate with signed numbers, exponents, and square roots. Performers at the 350 level can apply a range of reasoning skills to solve multi-step problems. They can solve routine problems involving fractions and percents, recognize properties of basic geometric figures, and work with exponents and square roots. Scale ranges from 0 to 500 . Standard errors appear in parentheses.

SOURCE: U.S. Department of Education, National Center for Education Statistics, National Assessment of Educational Progress, NAEP 1996 Trends in Academic Progress, prepared by Educational Testing Service. (This table was prepared August 1997. 
Table 121.-Percent of students at or above selected mathematics proficiency levels, ${ }^{1}$ by sex, race/ethnicity, control of school, and age: 1978 to 1996

\begin{tabular}{|c|c|c|c|c|c|c|c|c|c|c|c|c|}
\hline \multirow[b]{2}{*}{$\begin{array}{l}\text { Sex, race/ethnicity, } \\
\text { control, and year }\end{array}$} & \multicolumn{4}{|c|}{ 9-year-olds ${ }^{2}$} & \multicolumn{4}{|c|}{ 13-year-olds ${ }^{3}$} & \multicolumn{4}{|c|}{ 17-year-olds ${ }^{3}$} \\
\hline & $\begin{array}{l}\text { Simple } \\
\text { arithmetic } \\
\text { facts }^{4}\end{array}$ & $\begin{array}{l}\text { Beginning } \\
\text { skills and } \\
\text { under- } \\
\text { standing }{ }^{5}\end{array}$ & $\begin{array}{c}\text { Numerical } \\
\text { operations } \\
\text { and } \\
\text { beginning } \\
\text { problem } \\
\text { solving }\end{array}$ & $\begin{array}{c}\text { Moderately } \\
\text { complex } \\
\text { procedures } \\
\text { and } \\
\text { reasoning } 7\end{array}$ & $\begin{array}{l}\text { Beginning } \\
\text { skills and } \\
\text { under- } \\
\text { standing }{ }^{5}\end{array}$ & $\begin{array}{c}\text { Numerical } \\
\text { operations } \\
\text { and } \\
\text { beginning } \\
\text { problem } \\
\text { solving } 6\end{array}$ & $\begin{array}{l}\text { Moderately } \\
\text { complex } \\
\text { procedures } \\
\text { and } \\
\text { reasoning } 7\end{array}$ & $\begin{array}{l}\text { Multi-step } \\
\text { problem } \\
\text { solving and } \\
\text { algebra }^{8}\end{array}$ & $\begin{array}{l}\text { Beginning } \\
\text { skills and } \\
\text { under- } \\
\text { standing }{ }^{5}\end{array}$ & $\begin{array}{c}\text { Numerical } \\
\text { operations } \\
\text { and } \\
\text { beginning } \\
\text { problem } \\
\text { solving } 6\end{array}$ & $\begin{array}{c}\text { Moderately } \\
\text { complex } \\
\text { procedures } \\
\text { and } \\
\text { reasoning } 7\end{array}$ & $\begin{array}{c}\text { Multi-step } \\
\text { problem } \\
\text { solving and } \\
\text { algebra }^{8}\end{array}$ \\
\hline 1 & 2 & 3 & 4 & 5 & 6 & 7 & 8 & 9 & 10 & 11 & 12 & 13 \\
\hline \multicolumn{13}{|l|}{ Total } \\
\hline 1978 & $96.7(0.3)$ & $70.4(0.9)$ & $19.6(0.7)$ & $0.8(0.1)$ & $94.6(0.5)$ & $64.9(1.2)$ & $18.0(0.7)$ & $1.0(0.2)$ & $99.8(0.1)$ & $92.0(0.5)$ & $51.5(1.1)$ & $7.3(0.4)$ \\
\hline 1982 & $97.1(0.3)$ & $71.4(1.2)$ & $18.8(1.0)$ & $0.6(0.1)$ & $97.7(0.4)$ & $71.4(1.2)$ & $17.4(0.9)$ & $0.5(0.1)$ & $99.9(0.0)$ & $93.0(0.5)$ & $48.5(1.3)$ & $5.5(0.4)$ \\
\hline $1986 \ldots .$. & $97.9(0.3)$ & $74.1(1.2)$ & $20.7(0.9)$ & $0.6(0.2)$ & $98.6(0.2)$ & $73.3(1.6)$ & $15.8(1.0)$ & $0.4(0.1)$ & $99.9-$ & $95.6(0.5)$ & $51.7(1.4)$ & $6.5(0.5)$ \\
\hline 1990 & $99.1(0.2)$ & $81.5(1.0)$ & $27.7(0.9)$ & $1.2(0.3)$ & $98.5(0.2)$ & $74.7(1.0)$ & $17.3(1.0)$ & $0.4(0.1)$ & $100.0-$ & $96.0(0.5)$ & $56.1(1.4)$ & $7.2(0.6)$ \\
\hline 1992 & $99.0(0.2)$ & $81.4(0.8)$ & $27.8(0.9)$ & $1.2(0.3)$ & $98.7(0.3)$ & $77.9(1.1)$ & $18.9(1.0)$ & $0.4(0.2)$ & $100.0-$ & $96.6(0.5)$ & $59.1(1.3)$ & $7.2(0.6)$ \\
\hline $1994 \ldots . .$. & $99.0(0.2)$ & $82.0(0.7)$ & $29.9(1.1)$ & $1.3(0.4)$ & $98.5(0.3)$ & 78.1 (1.1) & $21.3(1.4)$ & $0.6(0.2)$ & $100.0-$ & $96.5(0.5)$ & $58.6(1.4)$ & $7.4(0.8)$ \\
\hline 1996 & $99.1(0.2)$ & $81.5(0.8)$ & $29.7(1.0)$ & $1.6(0.3)$ & $98.8(0.2)$ & $78.6(0.9)$ & $20.6(1.2)$ & $0.6(0.1)$ & $100.0-$ & $96.8(0.4)$ & $60.1(1.7)$ & $7.4(0.8)$ \\
\hline \multicolumn{13}{|l|}{ Male } \\
\hline $1978 \ldots$ & $96.2(0.5)$ & $68.9(1.0)$ & $19.2(0.6)$ & $0.7(0.2)$ & $93.9(0.5)$ & $63.9(1.3)$ & $18.4(0.9)$ & $1.1(0.2)$ & $99.9(0.1)$ & $93.0(0.5)$ & $55.1(1.2)$ & $9.5(0.6)$ \\
\hline 1982 & $96.5(0.5)$ & $68.8(1.3)$ & $18.1(1.1)$ & $0.6(0.1)$ & $97.5(0.6)$ & $71.3(1.4)$ & $18.9(1.2)$ & $0.7(0.2)$ & $100.0-$ & $93.9(0.6)$ & $51.9(1.5)$ & $6.9(0.7)$ \\
\hline 1986 & $98.0(0.5)$ & $74.0(1.4)$ & $20.9(1.1)$ & $0.7(0.3)$ & $98.5(0.3)$ & $73.8(1.8)$ & $17.6(1.1)$ & $0.5(0.2)$ & $99.9-$ & $96.1(0.6)$ & $54.6(1.8)$ & $8.4(0.9)$ \\
\hline 1990 & $99.0(0.3)$ & $80.6(1.0)$ & $27.5(1.0)$ & $1.3(0.4)$ & $98.2(0.3)$ & $75.1(1.8)$ & $19.0(1.2)$ & $0.5(0.2)$ & $99.9-$ & $95.8(0.8)$ & $57.6(1.4)$ & $8.8(0.8)$ \\
\hline 1992. & $99.0(0.3)$ & $81.9(1.0)$ & $29.4(1.2)$ & $1.4(0.3)$ & $98.8(0.4)$ & $78.1(1.6)$ & $20.7(1.1)$ & $0.5(0.2)$ & $100.0-$ & $96.9(0.6)$ & $60.5(1.8)$ & $9.1(0.7)$ \\
\hline 1994 & $99.1(0.3)$ & $82.3(0.9)$ & $31.5(1.6)$ & $1.4(0.4)$ & $98.3(0.4)$ & $78.9(1.5)$ & $23.9(1.6)$ & $0.8(0.3)$ & $100.0-$ & $97.3(0.6)$ & $60.2(2.1)$ & $9.3(1.0)$ \\
\hline 1996 ..................................... & $99.1(0.2)$ & $82.5(1.1)$ & $32.7(1.7)$ & $2.0(0.5)$ & $98.7(0.3)$ & $79.8(1.4)$ & $23.0(1.6)$ & $0.8(0.2)$ & $100.0-$ & $97.0(0.7)$ & $62.7(1.8)$ & $9.5(1.3)$ \\
\hline \multicolumn{13}{|l|}{ Female } \\
\hline 1978 & $97.2(0.3)$ & $72.0(1.1)$ & $19.9(1.0)$ & $0.8(0.2)$ & $95.2(0.5)$ & $65.9(1.2)$ & $17.5(0.7)$ & $0.9(0.2)$ & $99.7(0.1)$ & $91.0(0.6)$ & $48.2(1.3)$ & $5.2(0.7)$ \\
\hline 198 & $97.6(0.3)$ & $74.0(1.3)$ & $19.6(1.1)$ & $0.5(0.1)$ & $98.0(0.3)$ & $71.4(1.3)$ & $15.9(1.0)$ & $0.4(0.2)$ & $99.9(0.0)$ & $92.1(0.6)$ & $45.3(1.4)$ & $4.1(0.4)$ \\
\hline 1986 & $97.8(0.4)$ & $74.3(1.3)$ & $20.6(1.3)$ & $0.6(0.3)$ & $98.6(0.3)$ & $72.7(1.9)$ & $14.1(1.3)$ & $0.3(0.1)$ & $100.0-$ & $95.1(0.7)$ & $48.9(1.7)$ & $4.7(0.6)$ \\
\hline 1990 & $99.1(0.3)$ & $82.3(1.3)$ & $27.9(1.3)$ & $1.0(0.3)$ & $98.9(0.2)$ & $74.4(1.3)$ & $15.7(1.0)$ & $0.2(0.1)$ & $100.0-$ & $96.2(0.8)$ & $54.7(1.8)$ & $5.6(0.8)$ \\
\hline 1992 & $99.0(0.3)$ & $80.9(1.1)$ & $26.3(1.5)$ & $1.0(0.4)$ & $98.6(0.2)$ & $77.7(1.1)$ & $17.2(1.4)$ & $0.3-$ & $100.0-$ & $96.3(0.8)$ & $57.7(1.6)$ & $5.2(0.8)$ \\
\hline 1994 & $98.9(0.3)$ & $81.7(0.9)$ & $28.3(1.3)$ & $1.1(0.4)$ & $98.7(0.3)$ & $77.3(1.0)$ & $18.7(1.4)$ & $0.5(0.3)$ & $100.0-$ & $96.0(0.6)$ & $57.2(1.4)$ & $5.5(0.9)$ \\
\hline 1996 & $99.1(0.4)$ & $80.7(0.9)$ & $26.7(1.1)$ & $1.2(0.4)$ & $98.8(0.3)$ & $77.4(1.1)$ & $18.4(1.5)$ & $0.5(0.2)$ & $100.0-$ & $96.7(0.6)$ & $57.6(2.2)$ & $5.3(0.8)$ \\
\hline \multicolumn{13}{|l|}{ White, non-Hispanic } \\
\hline 1978 & $98.3(0.2)$ & $76.3(1.0)$ & $22.9(0.9)$ & $0.9(0.2)$ & $97.6(0.3)$ & $72.9(0.9)$ & $21.4(0.7)$ & $1.2(0.2)$ & $100.0-$ & $95.6(0.3)$ & $57.6(1.1)$ & $8.5(0.5)$ \\
\hline 1982 & $98.5(0.3)$ & $76.8(1.2)$ & $21.8(1.1)$ & $0.6(0.1)$ & $99.1(0.1)$ & $78.3(0.9)$ & $20.5(1.0)$ & $0.6(0.1)$ & $100.0-$ & $96.2(0.3)$ & $54.7(1.4)$ & $6.4(0.5)$ \\
\hline … & $98.8(0.2)$ & $79.6(1.3)$ & $24.6(1.0)$ & $0.8(0.3)$ & $99.3(0.3)$ & $78.9(1.7)$ & $18.6(1.2)$ & $0.4(0.1)$ & $100.0-$ & $98.0(0.4)$ & $59.1(1.7)$ & $7.9(0.7)$ \\
\hline 1990 & $99.6(0.2)$ & $86.9(0.9)$ & $32.7(1.0)$ & $1.5(0.4)$ & $99.4(0.1)$ & $82.0(1.0)$ & $21.0(1.2)$ & $0.4(0.2)$ & $100.0-$ & $97.6(0.3)$ & $63.2(1.6)$ & $8.3(0.7)$ \\
\hline$x_{10}$ & $99.6(0.1)$ & $86.9(0.7)$ & $32.4(1.0)$ & $1.4(0.3)$ & $99.6(0.2)$ & $84.9(1.1)$ & $22.8(1.3)$ & $0.4(0.2)$ & $100.0-$ & $98.3(0.4)$ & $66.4(1.4)$ & $8.7(0.9)$ \\
\hline ㄴ. & $99.6(0.2)$ & $87.0(0.8)$ & $35.3(1.3)$ & $1.5(0.4)$ & $99.3(0.2)$ & $85.5(0.9)$ & $25.6(1.6)$ & $0.7(0.3)$ & $100.0-$ & $98.4(0.4)$ & $67.0(1.4)$ & $9.4(1.1)$ \\
\hline 1996 .................................... & $99.6(0.1)$ & $86.6(0.8)$ & $35.7(1.4)$ & $2.0(0.4)$ & $99.6(0.2)$ & $86.4(1.0)$ & $25.4(1.5)$ & $0.8(0.2)$ & $100.0-$ & $98.7(0.4)$ & $68.7(2.2)$ & $9.2(1.0)$ \\
\hline \multicolumn{13}{|l|}{ Black, non-Hispanic } \\
\hline 1978 & $88.4(1.0)$ & $42.0(1.4)$ & $4.1(0.6)$ & $0.0-$ & $79.7(1.5)$ & $28.7(2.1)$ & $2.3(0.5)$ & $0.0-$ & $98.8(0.3)$ & $70.7(1.7)$ & $16.8(1.6)$ & $0.5(0.2)$ \\
\hline 1982 & $90.2(1.0)$ & $46.1(2.4)$ & $4.4(0.8)$ & $0.0-$ & $90.2(1.6)$ & $37.9(2.5)$ & $2.9(1.0)$ & $0.0-$ & $99.7(0.2)$ & $76.4(1.5)$ & $17.1(1.5)$ & $0.5(0.3)$ \\
\hline 1986 & $93.9(1.4)$ & $53.4(2.5)$ & $5.6(0.9)$ & $0.1-$ & $95.4(0.9)$ & $49.0(3.7)$ & $4.0(1.4)$ & $0.1-$ & $100.0-$ & $85.6(2.5)$ & $20.8(2.8)$ & $0.2-$ \\
\hline 1990 & $96.9(0.9)$ & $60.0(2.8)$ & $9.4(1.7)$ & $0.1-$ & $95.4(1.1)$ & 48.7 (3.6) & $3.9(1.6)$ & $0.1-$ & $99.9-$ & $92.4(2.2)$ & $32.8(4.5)$ & $2.0(1.0)$ \\
\hline 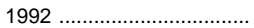 & $96.6(1.1)$ & $59.8(2.8)$ & $9.6(1.4)$ & $0.1-$ & $95.0(1.4)$ & $51.0(2.7)$ & $4.0(0.7)$ & $0.1-$ & $100.0-$ & $89.6(2.5)$ & $29.8(3.9)$ & $0.9-$ \\
\hline 1994 & $97.4(1.0)$ & $65.9(2.6)$ & $11.1(1.7)$ & $0.0-$ & $95.6(1.6)$ & $51.0(3.9)$ & $6.4(2.4)$ & $0.3-$ & $100.0-$ & $90.6(1.8)$ & $29.8(3.4)$ & $0.4-$ \\
\hline 1996 & $97.3(0.8)$ & $65.3(2.4)$ & $10.0(1.2)$ & $0.1-$ & $96.2(1.3)$ & $53.7(2.6)$ & $4.8(1.1)$ & $0.1-$ & $100.0-$ & $90.6(1.3)$ & $31.2(2.5)$ & $0.9-$ \\
\hline Hispanic & & & & & & & & & & & & \\
\hline 1978 & $93.0(1.2)$ & $54.2(2.8)$ & $9.2(2.5)$ & $0.2-$ & $86.4(0.9)$ & $36.0(2.9)$ & $4.0(1.0)$ & $0.1-$ & $99.3(0.4)$ & $78.3(2.3)$ & $23.4(2.7)$ & $1.4(0.6)$ \\
\hline 1982 & $94.3(1.2)$ & $55.7(2.3)$ & $7.8(1.7)$ & $0.0-$ & $95.9(0.9)$ & $52.2(2.5)$ & $6.3(1.0)$ & $0.0-$ & $99.8-$ & $81.4(1.9)$ & $21.6(2.2)$ & $0.7(0.4)$ \\
\hline 1986 & $96.4(1.3)$ & $57.6(2.9)$ & $7.3(2.8)$ & $0.1-$ & $96.9(1.4)$ & $56.0(5.0)$ & $5.5(1.1)$ & $0.2-$ & $99.4-$ & $89.3(2.5)$ & $26.5(4.5)$ & $1.1-$ \\
\hline ㄴ. & $98.0(0.8)$ & $68.4(3.0)$ & $11.3(3.5)$ & $0.2-$ & $96.8(1.1)$ & $56.7(3.3)$ & $6.4(1.7)$ & $0.1-$ & $99.6-$ & $85.8(4.2)$ & $30.1(3.1)$ & $1.9(0.8)$ \\
\hline 1992 & $97.2(1.3)$ & $65.0(2.9)$ & $11.7(2.5)$ & $0.1-$ & $98.1(0.7)$ & $63.3(2.7)$ & $7.0(1.2)$ & $0.0-$ & $100.0-$ & $94.1(2.2)$ & $39.2(4.9)$ & $1.2-$ \\
\hline (2) & $97.2(1.2)$ & $63.5(3.1)$ & $9.7(1.8)$ & $0.0-$ & $97.1(1.3)$ & $59.2(2.2)$ & $6.4(1.8)$ & $0.0-$ & $100.0-$ & $91.8(3.6)$ & $38.3(5.5)$ & $1.4-$ \\
\hline 1996 & $98.1(0.7)$ & $67.1(2.1)$ & $13.8(2.3)$ & $0.2-$ & $96.2(0.8)$ & $58.3(2.3)$ & $6.7(1.2)$ & $0.0-$ & $99.9-$ & $92.2(2.2)$ & $40.1(3.5)$ & $1.8-$ \\
\hline Public & & & & & & & & & & & & \\
\hline 197 & $96.4(0.3)$ & $68.8(0.9)$ & $18.5(0.7)$ & $0.7(0.2)$ & $94.1(0.5)$ & $63.3(1.2)$ & $17.0(0.8)$ & $0.9(0.2)$ & $99.8(0.1)$ & $91.7(0.5)$ & $50.6(1.2)$ & $7.0(0.4)$ \\
\hline (1) & $96.8(0.4)$ & $69.4(1.2)$ & $17.3(0.9)$ & $0.5(0.1)$ & $97.5(0.4)$ & $69.7(1.3)$ & $16.4(1.0)$ & $0.5(0.1)$ & $99.9(0.0)$ & $92.5(0.6)$ & $46.9(1.3)$ & $5.2(0.4)$ \\
\hline 1986 & $97.7(0.3)$ & $72.7(1.4)$ & $19.1(1.1)$ & $0.6(0.2)$ & $98.5(0.3)$ & $72.9(1.7)$ & $15.6(1.0)$ & $0.4(0.1)$ & $99.9-$ & $95.5(0.5)$ & $50.7(1.6)$ & $6.1(0.5)$ \\
\hline 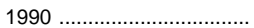 & $99.0(0.2)$ & $80.5(1.1)$ & $26.8(1.0)$ & $1.1(0.3)$ & $98.4(0.2)$ & $73.3(1.2)$ & $16.7(1.1)$ & $0.3(0.1)$ & $100.0-$ & $95.8(0.6)$ & $55.0(1.3)$ & $6.5(0.5)$ \\
\hline (2) & $98.8(0.3)$ & $79.7(0.9)$ & $26.1(0.9)$ & $1.1(0.3)$ & $98.5(0.3)$ & $76.3(1.2)$ & $18.0(1.0)$ & $0.3(0.2)$ & $100.0-$ & $96.3(0.6)$ & $56.9(1.2)$ & $6.7(0.7)$ \\
\hline$\ldots$ & $98.9(0.3)$ & $80.6(0.8)$ & $27.9(1.2)$ & $1.1(0.4)$ & $98.5(0.3)$ & $76.7(1.2)$ & $20.0(1.4)$ & $0.6(0.2)$ & $100.0-$ & $96.2(0.5)$ & $56.2(1.3)$ & $6.4(0.7)$ \\
\hline 1996 & $99.0(0.2)$ & $80.7(0.8)$ & $28.3(1.1)$ & $1.5(0.3)$ & $98.6(0.2)$ & $77.2(0.9)$ & $19.2(1.3)$ & $0.6(0.1)$ & $100.0-$ & $96.7(0.5)$ & $59.0(1.8)$ & $7.1(0.7)$ \\
\hline & & & & & & & & & & & & \\
\hline 1978 & $99.0-$ & $83.3(1.9)$ & $28.4(2.0)$ & $1.2(0.4)$ & $99.0(0.4)$ & $80.8(1.7)$ & $26.9(1.8)$ & $1.4(0.4)$ & $100.0-$ & $97.1(0.6)$ & $67.7(3.3)$ & $12.9(2.7)$ \\
\hline 1982 & $99.0(0.4)$ & $84.3(2.1)$ & $28.6(2.6)$ & $1.0(0.6)$ & $99.5(0.3)$ & $85.1(1.6)$ & $26.3(3.1)$ & $1.0(0.3)$ & $100.0-$ & $98.1(0.5)$ & $66.3(2.4)$ & $8.2(1.4)$ \\
\hline ㄴ.1. & $98.7(0.8)$ & $81.8(2.3)$ & $28.9(2.7)$ & $1.1(0.6)$ & $98.9(0.6)$ & $81.9(3.3)$ & $22.0(6.8)$ & $0.1-$ & $100.0-$ & $99.4-$ & $75.1(10.6)$ & $16.3(9.1)$ \\
\hline 1990 & $99.7-$ & $89.3(1.8)$ & $35.2(3.3)$ & $1.8(1.2)$ & $99.7-$ & $87.0(2.0)$ & $23.2(2.5)$ & $0.7(0.4)$ & $100.0-$ & $98.2(1.2)$ & $71.0(7.9)$ & $15.7(5.3)$ \\
\hline 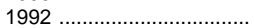 & $99.8(0.1)$ & $92.2(1.2)$ & $38.6(2.7)$ & $1.9(0.7)$ & $99.9-$ & $89.7(2.1)$ & 25.9 & $0.7(0.4)$ & $100.0-$ & $99.5-$ & $79.5(3.7)$ & $12.2(2.7)$ \\
\hline - & $99.8-$ & $92.3(1.3)$ & $44.4(4.0)$ & $2.2(0.8)$ & $98.7-$ & $88.5(2.6)$ & 30.7 (3.7) & $1.0-$ & $100.0-$ & $98.8(0.6)$ & 75.7 (4.3) & $14.5(3.5)$ \\
\hline 1996 & $99.6-$ & $87.1(1.5)$ & $38.7(3.0)$ & $2.1(1.1)$ & $99.6-$ & $89.3(3.5)$ & $31.6(4.8)$ & $1.0(0.6)$ & $100.0-$ & $98.5(0.8)$ & $71.5(6.4)$ & $10.4(1.0)$ \\
\hline
\end{tabular}

${ }^{1}$ As measured by the National Assessment of Educational Progress (NAEP).

2 Virtually no students were able to perform multi-step problems and algebra.

${ }^{3}$ Virtually all students knew simple arithmetic facts. Data are only for students enrolled in school.

${ }^{4}$ Scale score of 150 or above.

${ }^{5}$ Scale score of 200 or above.

${ }^{6}$ Scale score of 250 or above.

${ }^{7}$ Scale score of 300 or above.
8 Scale score of 350 or above.

-Data not available or not applicable.

NOTE.-Standard errors appear in parentheses.

SOURCE: U.S. Department of Education, National Assessment of Educational Progress, NAEP 1996 Trends in Academic Progress, prepared by Educational Testing Service. (This table was prepared September 1997.) 
Table 122.-Mathematics attainment for 8th-graders in public schools, by region and state: 1996

\begin{tabular}{|c|c|c|c|c|c|c|c|c|c|}
\hline \multirow[b]{2}{*}{ Region and state } & \multirow[b]{2}{*}{$\begin{array}{l}\text { Average } \\
\text { proficiency }\end{array}$} & \multicolumn{4}{|c|}{ Percent attaining mathematics achievement levels ${ }^{1}$} & \multicolumn{4}{|c|}{$\begin{array}{c}\text { Percent of students by highest level of education } \\
\text { attained by parents }{ }^{2}\end{array}$} \\
\hline & & $\begin{array}{l}\text { Below } \\
\text { basic }\end{array}$ & $\begin{array}{l}\text { Basic or } \\
\text { above }^{3}\end{array}$ & $\begin{array}{l}\text { Proficient } \\
\text { or above } 4\end{array}$ & $\begin{array}{l}\text { Advanced } \\
\text { or above } 5\end{array}$ & $\begin{array}{l}\text { Did not } \\
\text { finish high } \\
\text { school }\end{array}$ & $\begin{array}{l}\text { Graduated } \\
\text { high school }\end{array}$ & $\begin{array}{l}\text { Some } \\
\text { education } \\
\text { after high } \\
\text { school }\end{array}$ & $\begin{array}{l}\text { Graduated } \\
\text { college }\end{array}$ \\
\hline 1 & 2 & 3 & 4 & 5 & 6 & 7 & 8 & 9 & 10 \\
\hline United States & $271(1.1)$ & $38(1.1)$ & $62(1.1)$ & $24(1.1)$ & $4(0.5)$ & $8(0.5)$ & $23(0.8)$ & $19(0.8)$ & $39(1.4)$ \\
\hline $\begin{array}{l}\quad \text { Region } \\
\text { Northeast } \\
\text { Southeast } \ldots \ldots \ldots \ldots \ldots \ldots \ldots \ldots \ldots \ldots \ldots \ldots \ldots \\
\text { Central } \\
\text { West }\end{array}$ & $\begin{array}{l}277(3.1) \\
266(2.6) \\
277(3.1) \\
269(2.2)\end{array}$ & $\begin{array}{l}33(3.1) \\
44(3.2) \\
31(3.4) \\
41(2.2)\end{array}$ & $\begin{array}{l}67(3.1) \\
56(3.2) \\
69(3.4) \\
59(2.2)\end{array}$ & $\begin{array}{l}27(3.7) \\
18(1.8) \\
29(2.5) \\
22(1.9)\end{array}$ & $\begin{array}{l}5(1.9) \\
3(0.6) \\
5(1.0) \\
3(0.6)\end{array}$ & $\begin{array}{l}- \\
- \\
-\end{array}$ & $\begin{array}{l}- \\
- \\
-\end{array}$ & $\begin{array}{l}- \\
- \\
-\end{array}$ & $\begin{array}{l}- \\
- \\
-\end{array}$ \\
\hline 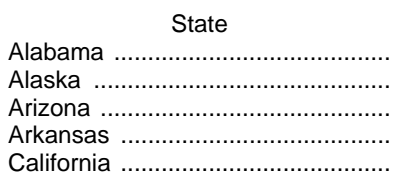 & $\begin{array}{l}257(2.1) \\
278(1.8) \\
268(1.6) \\
262(1.5) \\
263(1.9)\end{array}$ & $\begin{array}{l}55(2.6) \\
32(2.3) \\
43(1.9) \\
48(1.8) \\
49(2.1)\end{array}$ & $\begin{array}{l}45(2.6) \\
68(2.3) \\
57(1.9) \\
52(1.8) \\
51(2.1)\end{array}$ & $\begin{array}{l}12(1.8) \\
30(1.6) \\
18(1.2) \\
13(1.0) \\
17(1.5)\end{array}$ & $\begin{array}{l}1(0.4) \\
7(1.1) \\
2(0.3) \\
2(0.4) \\
3(0.5)\end{array}$ & $\begin{aligned} & 10(0.8) \\
& 4(0.7) \\
& 9(0.9) \\
& 10(0.8) \\
& 10(0.8)\end{aligned}$ & $\begin{array}{l}30(1.5) \\
19(1.1) \\
18(1.1) \\
30(1.6) \\
17(0.8)\end{array}$ & $\begin{array}{l}15(0.8) \\
20(1.1) \\
21(1.0) \\
19(1.0) \\
16(1.0)\end{array}$ & $\begin{array}{l}37(2.1) \\
43(1.5) \\
38(1.8) \\
30(1.4) \\
38(1.7)\end{array}$ \\
\hline $\begin{array}{l}\text { Colorado } \\
\text { Connecticut } \\
\text { Delaware } \\
\text { District of Columbia } \\
\text { Florida }\end{array}$ & $\begin{array}{l}276(1.1) \\
280(1.1) \\
267(0.9) \\
233(1.3) \\
264(1.8)\end{array}$ & $\begin{array}{l}33(1.3) \\
30(1.4) \\
45(1.3) \\
80(1.2) \\
46(2.1)\end{array}$ & $\begin{array}{l}67(1.3) \\
70(1.4) \\
55(1.3) \\
20(1.2) \\
54(2.1)\end{array}$ & $\begin{aligned} & 25(1.3) \\
& 31(1.5) \\
& 19(1.0) \\
& 5(0.8) \\
& 17(1.3)\end{aligned}$ & $\begin{array}{l}3(0.5) \\
5(0.6) \\
3(0.6) \\
1(0.3) \\
2(0.4)\end{array}$ & $\begin{array}{l}6(0.6) \\
5(0.6) \\
5(0.5) \\
7(0.6) \\
8(0.7)\end{array}$ & $\begin{array}{l}19(0.9) \\
19(0.9) \\
27(1.2) \\
28(1.1) \\
23(1.1)\end{array}$ & $\begin{array}{l}20(0.8) \\
17(0.8) \\
19(0.9) \\
18(0.9) \\
18(0.9)\end{array}$ & $\begin{array}{l}45(1.5) \\
51(1.3) \\
38(1.2) \\
33(1.3) \\
40(1.6)\end{array}$ \\
\hline $\begin{array}{l}\text { Georgia } \\
\text { Hawaii } \\
\text { Indiana } \\
\text { lowa } \\
\text { Kentucky }\end{array}$ & $\begin{array}{l}262(1.6) \\
262(1.0) \\
276(1.4) \\
284(1.3) \\
267(1.1)\end{array}$ & $\begin{array}{l}49(2.0) \\
49(1.5) \\
32(2.0) \\
22(1.4) \\
44(1.6)\end{array}$ & $\begin{array}{l}51(2.0) \\
51(1.5) \\
68(2.0) \\
78(1.4) \\
56(1.6)\end{array}$ & $\begin{array}{l}16(1.8) \\
16(0.9) \\
24(1.7) \\
31(1.8) \\
16(1.2)\end{array}$ & $\begin{array}{l}2(0.5) \\
2(0.4) \\
3(0.5) \\
4(0.6) \\
1(0.3)\end{array}$ & $\begin{aligned} & 8(0.7) \\
& 4(0.5) \\
& 7(0.7) \\
& 5(0.5) \\
& 13(0.8)\end{aligned}$ & $\begin{array}{l}27(1.4) \\
26(1.1) \\
30(1.2) \\
24(1.6) \\
31(0.9)\end{array}$ & $\begin{array}{l}18(1.0) \\
16(0.8) \\
21(1.1) \\
19(0.9) \\
17(0.8)\end{array}$ & $\begin{array}{l}39(2.0) \\
38(1.0) \\
36(1.4) \\
46(1.7) \\
30(1.3)\end{array}$ \\
\hline 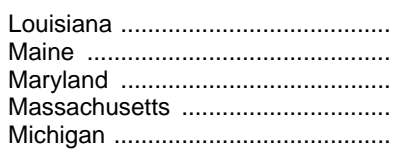 & $\begin{array}{l}252(1.6) \\
284(1.3) \\
270(2.1) \\
278(1.7) \\
277(1.8)\end{array}$ & $\begin{array}{l}62(2.0) \\
23(1.5) \\
43(2.2) \\
32(2.3) \\
33(2.1)\end{array}$ & & $\begin{aligned} & 7(1.1) \\
& 31(1.7) \\
& 24(2.3) \\
& 28(1.8) \\
& 28(1.8)\end{aligned}$ & $\begin{array}{l}0(0.2) \\
6(0.7) \\
5(1.0) \\
5(0.8) \\
4(0.8)\end{array}$ & $\begin{array}{l}9(0.7) \\
5(0.5) \\
5(0.6) \\
6(0.6) \\
5(0.5)\end{array}$ & $\begin{array}{l}33(1.0) \\
23(0.9) \\
24(1.3) \\
18(1.0) \\
22(1.5)\end{array}$ & $\begin{array}{l}19(0.8) \\
21(1.1) \\
17(1.0) \\
15(0.8) \\
21(0.9)\end{array}$ & $\begin{array}{l}30(1.3) \\
44(1.6) \\
45(1.6) \\
51(1.7) \\
42(1.6)\end{array}$ \\
\hline $\begin{array}{l}\text { Minnesota } \\
\text { Mississippi } \\
\text { Missouri } \\
\text { Montana } \\
\text { Nebraska }\end{array}$ & $\begin{array}{l}284(1.3) \\
250(1.2) \\
273(1.4) \\
283(1.3) \\
283(1.0)\end{array}$ & $\begin{array}{l}25(1.5) \\
64(1.3) \\
36(2.0) \\
25(1.7) \\
24(1.1)\end{array}$ & $\begin{array}{l}75(1.5) \\
36(1.3) \\
64(2.0) \\
75(1.7) \\
76(1.1)\end{array}$ & $\begin{aligned} & 34(1.8) \\
& 7(0.8) \\
& 22(1.4) \\
& 32(1.5) \\
& 31(1.5)\end{aligned}$ & $\begin{array}{l}6(0.8) \\
0(0.2) \\
2(0.5) \\
5(0.5) \\
5(0.7)\end{array}$ & $\begin{aligned} 3 & (0.3) \\
11 & (0.6) \\
8 & (0.6) \\
6 & (0.8) \\
6 & (0.7)\end{aligned}$ & $\begin{array}{l}21(1.1) \\
29(1.1) \\
27(1.0) \\
21(1.1) \\
19(1.5)\end{array}$ & $\begin{array}{l}19(1.1) \\
15(0.7) \\
19(0.9) \\
20(1.2) \\
18(1.2)\end{array}$ & $\begin{array}{l}50(1.6) \\
36(1.2) \\
37(1.6) \\
48(1.5) \\
49(2.4)\end{array}$ \\
\hline $\begin{array}{l}\text { New Mexico } \\
\text { New York } \\
\text { North Carolina } \\
\text { North Dakota } \\
\text { Oregon }\end{array}$ & $\begin{array}{l}262(1.2) \\
270(1.7) \\
268(1.4) \\
284(0.9) \\
276(1.5)\end{array}$ & $\begin{array}{l}49(1.6) \\
39(2.0) \\
44(1.8) \\
23(1.2) \\
33(1.7)\end{array}$ & $\begin{array}{l}51(1.6) \\
61(2.0) \\
56(1.8) \\
77(1.2) \\
67(1.7)\end{array}$ & $\begin{array}{l}14(1.1) \\
22(1.5) \\
20(1.3) \\
33(1.5) \\
26(1.6)\end{array}$ & $\begin{array}{l}2(0.3) \\
3(0.5) \\
3(0.6) \\
4(0.7) \\
4(0.7)\end{array}$ & $\begin{aligned} & 11(0.9) \\
& 6(0.6) \\
& 7(0.5) \\
& 3(0.4) \\
& 7(0.6)\end{aligned}$ & $\begin{array}{l}25(1.1) \\
20(1.1) \\
24(1.1) \\
19(1.0) \\
18(0.9)\end{array}$ & $\begin{array}{l}19(1.0) \\
17(1.0) \\
20(0.9) \\
16(0.7) \\
20(1.0)\end{array}$ & $\begin{array}{l}34(1.3) \\
45(1.5) \\
40(1.5) \\
55(1.2) \\
44(1.7)\end{array}$ \\
\hline $\begin{array}{l}\text { Rhode Island } \\
\text { South Carolina } \\
\text { Tennessee } \\
\text { Texas }\end{array}$ & $\begin{array}{l}269(0.9) \\
261(1.5) \\
263(1.4) \\
270(1.4) \\
277(1.0)\end{array}$ & $\begin{array}{l}40(1.6) \\
52(1.7) \\
47(1.8) \\
41(1.8) \\
30(1.5)\end{array}$ & $\begin{array}{l}60(1.6) \\
48(1.7) \\
53(1.8) \\
59(1.8) \\
70(1.5)\end{array}$ & $\begin{array}{l}20(1.3) \\
14(1.2) \\
15(1.3) \\
21(1.5) \\
24(1.3)\end{array}$ & $\begin{array}{l}3(0.4) \\
2(0.4) \\
2(0.3) \\
3(0.4) \\
3(0.4)\end{array}$ & $\begin{aligned} 8(0.5) \\
9(0.7) \\
10(0.7) \\
13(1.1) \\
3(0.4)\end{aligned}$ & $\begin{array}{l}22(0.9) \\
28(1.1) \\
32(1.4) \\
21(1.0) \\
17(0.8)\end{array}$ & $\begin{array}{l}17(0.7) \\
17(0.9) \\
19(0.8) \\
15(1.0) \\
18(0.8)\end{array}$ & $\begin{array}{l}40(0.9) \\
37(1.4) \\
31(1.6) \\
38(2.0) \\
53(1.3)\end{array}$ \\
\hline $\begin{array}{l}\text { Vermont } \\
\text { Virginia } \\
\text { Washington } \\
\text { West Virginia } \\
\text { Wisconsin } \\
\text { Wyoming }\end{array}$ & $\begin{array}{l}279(1.0) \\
270(1.6) \\
276(1.3) \\
265(1.0) \\
283(1.5) \\
275(0.9)\end{array}$ & $\begin{array}{l}28(1.7) \\
42(2.0) \\
33(1.6) \\
46(1.6) \\
25(2.0) \\
32(1.2)\end{array}$ & $\begin{array}{l}72(1.7) \\
58(2.0) \\
67(1.6) \\
54(1.6) \\
75(2.0) \\
68(1.2)\end{array}$ & $\begin{array}{l}27(1.4) \\
21(1.2) \\
26(1.2) \\
14(0.9) \\
32(2.0) \\
22(1.0)\end{array}$ & $\begin{array}{l}4(0.6) \\
3(0.4) \\
4(0.7) \\
1(0.4) \\
5(0.8) \\
2(0.6)\end{array}$ & $\begin{aligned} & 5(0.5) \\
& 8(0.8) \\
& 6(0.6) \\
& 11(0.8) \\
& 5(0.7) \\
& 5(0.5)\end{aligned}$ & $\begin{array}{l}25(1.1) \\
26(1.1) \\
16(0.9) \\
33(0.9) \\
26(1.1) \\
21(0.9)\end{array}$ & $\begin{array}{l}16(0.9) \\
16(0.9) \\
21(0.8) \\
19(0.8) \\
21(0.9) \\
20(0.8)\end{array}$ & $\begin{array}{l}49(1.4) \\
42(1.7) \\
46(1.4) \\
30(1.1) \\
40(1.6) \\
44(1.2)\end{array}$ \\
\hline $\begin{array}{c}\text { Outlying area } \\
\text { Guam }\end{array}$ & 239 (1.7) & $71(1.6)$ & $29(1.6)$ & $6(0.8)$ & $0-$ & $2(0.6)$ & $21(1.5)$ & $22(1.7)$ & $43(2.1)$ \\
\hline
\end{tabular}

1 Achievement levels are in developmental status.

2 Excludes students who responded "I don't know" to the question about education level of parents.

3 This level denotes partial mastery of prerequisite knowledge and skills that are fundamental for proficient work at the 8th grade.

4 This level represents solid academic performance for 8th graders. Students reaching this level have demonstrated competency over challenging subject matter, including subject-matter knowledge, application of such knowledge to real-world situations, and analytical skills appropriate to the subject matter.

5 This level signifies superior performance.

-Data not available.
NOTE.-These test scores are from the National Assessment of Educational Progress (NAEP). Forty-four states, the District of Columbia, and one outlying area participated in the 1996 Trial State Assessment of 8th graders. Scale ranges from 0 to 500 . Results are not shown for states with a school participation rate of less than 70 percent. Standard errors appear in parentheses.

SOURCE: U.S. Department of Education, National Center for Education Statistics, National Assessment of Educational Progress, NAEP 1996 Mathematics Report Card for the Nation and the States, prepared by Educational Testing Service. (This table was prepared August 1997.) 
Table 123.-Mathematics attainment for 4th-graders in public schools, by region and state: 1996

\begin{tabular}{|c|c|c|c|c|c|c|c|c|c|}
\hline \multirow[b]{2}{*}{ Region and state } & \multirow[b]{2}{*}{$\begin{array}{l}\text { Average } \\
\text { proficiency }\end{array}$} & \multicolumn{4}{|c|}{ Percent attaining mathematics achievement levels ${ }^{1}$} & \multicolumn{4}{|c|}{$\begin{array}{c}\text { Percent of students by highest level of education } \\
\text { attained by parents }{ }^{2}\end{array}$} \\
\hline & & $\begin{array}{l}\text { Below } \\
\text { basic }\end{array}$ & $\begin{array}{l}\text { Basic or } \\
\text { above }^{3}\end{array}$ & $\begin{array}{l}\text { Proficient } \\
\text { or above }{ }^{4}\end{array}$ & $\begin{array}{l}\text { Advanced } \\
\text { or above }^{5}\end{array}$ & $\begin{array}{l}\text { Did not } \\
\text { finish high } \\
\text { school }\end{array}$ & $\begin{array}{l}\text { Graduated } \\
\text { high school }\end{array}$ & $\begin{array}{l}\text { Some } \\
\text { education } \\
\text { after high } \\
\text { school }\end{array}$ & $\begin{array}{l}\text { Graduated } \\
\text { college }\end{array}$ \\
\hline 1 & 2 & 3 & 4 & 5 & 6 & 7 & 8 & 9 & 10 \\
\hline 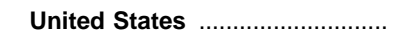 & $224(1.0)$ & $36(1.4)$ & $64(1.4)$ & $21(1.0)$ & $2(0.3)$ & $4(0.4)$ & $13(0.7)$ & $7(0.4)$ & $37(1.3)$ \\
\hline 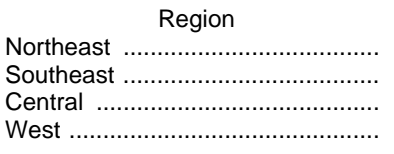 & $\begin{array}{l}228(2.0) \\
218(1.9) \\
231(2.9) \\
220(1.7)\end{array}$ & $\begin{array}{l}30(2.9) \\
45(2.9) \\
25(2.6) \\
42(2.8)\end{array}$ & $\begin{array}{l}70(2.9) \\
55(2.9) \\
75(2.6) \\
58(2.8)\end{array}$ & $\begin{array}{l}26(1.6) \\
16(2.4) \\
27(2.1) \\
18(1.7)\end{array}$ & $\begin{array}{l}3(0.9) \\
2(0.8) \\
2(0.6) \\
2(0.5)\end{array}$ & $\begin{array}{l}- \\
- \\
-\end{array}$ & $\begin{array}{l}- \\
- \\
-\end{array}$ & $\begin{array}{l}- \\
- \\
-\end{array}$ & $\begin{array}{l}- \\
- \\
-\end{array}$ \\
\hline 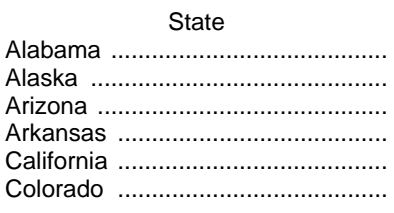 & $\begin{array}{l}212(1.2) \\
224(1.3) \\
218(1.7) \\
216(1.5) \\
209(1.8) \\
226(1.0)\end{array}$ & $\begin{array}{l}52(2.0) \\
35(2.0) \\
43(2.4) \\
46(2.2) \\
54(2.4) \\
33(1.6)\end{array}$ & $\begin{array}{l}48(2.0) \\
65(2.0) \\
57(2.4) \\
54(2.2) \\
46(2.4) \\
67(1.6)\end{array}$ & $\begin{array}{l}11(1.1) \\
21(1.2) \\
15(1.6) \\
13(1.4) \\
11(1.5) \\
22(1.3)\end{array}$ & $\begin{array}{ll}1 & (0.2) \\
2 & (0.5) \\
1 & (0.4) \\
1 & (0.3) \\
1 & (0.4) \\
2 & (0.3)\end{array}$ & $\begin{array}{l}7(0.8) \\
3(0.5) \\
5(0.5) \\
6(0.6) \\
4(0.6) \\
3(0.4)\end{array}$ & $\begin{array}{r}19(1.0) \\
10(0.9) \\
11(0.9) \\
20(1.0) \\
9(0.7) \\
10(0.7)\end{array}$ & $\begin{array}{r}9(0.7) \\
8(0.7) \\
9(0.6) \\
9(0.7) \\
7(0.6) \\
10(0.6)\end{array}$ & $\begin{array}{l}35(1.6) \\
34(1.5) \\
34(1.7) \\
31(1.3) \\
32(1.4) \\
42(1.6)\end{array}$ \\
\hline $\begin{array}{l}\text { Connecticut } \\
\text { Delaware } \\
\text { District of Columbia } \\
\text { Florida } \\
\text { Georgia }\end{array}$ & $\begin{array}{l}232(1.1) \\
215(0.6) \\
187(1.1) \\
216(1.2) \\
215(1.5)\end{array}$ & $\begin{array}{l}25(1.5) \\
46(1.1) \\
80(0.8) \\
45(1.7) \\
47(2.1)\end{array}$ & $\begin{array}{l}75(1.5) \\
54(1.1) \\
20(0.8) \\
55(1.7) \\
53(2.1)\end{array}$ & $\begin{array}{r}31(1.7) \\
16(1.2) \\
5(0.5) \\
15(1.1) \\
13(1.3)\end{array}$ & $\begin{array}{ll}3 & (0.5) \\
1 & (0.4) \\
1 & (0.4) \\
1 & (0.2) \\
1 & (0.3)\end{array}$ & $\begin{array}{l}3(0.4) \\
3(0.4) \\
4(0.4) \\
4(0.6) \\
6(0.6)\end{array}$ & $\begin{array}{r}9(0.6) \\
13(0.8) \\
15(0.6) \\
12(1.0) \\
17(0.9)\end{array}$ & $\begin{array}{l}8(0.6) \\
8(0.7) \\
6(0.4) \\
7(0.6) \\
7(0.6)\end{array}$ & $\begin{array}{l}47(1.3) \\
37(1.0) \\
42(1.0) \\
38(1.5) \\
36(1.6)\end{array}$ \\
\hline $\begin{array}{l}\text { Hawaii } \\
\text { Indiana } \\
\text { lowa } \\
\text { Kentucky } \\
\text { Louisiana }\end{array}$ & $\begin{array}{l}215(1.5) \\
229(1.0) \\
229(1.1) \\
220(1.1) \\
209(1.1)\end{array}$ & $\begin{array}{l}47(1.6) \\
28(1.7) \\
26(1.4) \\
40(1.8) \\
56(1.8)\end{array}$ & $\begin{array}{l}53(1.6) \\
72(1.7) \\
74(1.4) \\
60(1.8) \\
44(1.8)\end{array}$ & $\begin{array}{r}16(1.1) \\
24(1.6) \\
22(1.4) \\
16(1.1) \\
8(0.9)\end{array}$ & $\begin{array}{l}2(0.4) \\
2(0.5) \\
1(0.4) \\
1(0.3) \\
0(0.2)\end{array}$ & $\begin{array}{l}2(0.3) \\
4(0.4) \\
3(0.4) \\
9(0.9) \\
6(0.6)\end{array}$ & $\begin{array}{l}12(0.7) \\
19(1.0) \\
16(0.9) \\
19(1.1) \\
19(1.1)\end{array}$ & $\begin{array}{l}6(0.5) \\
9(0.9) \\
9(0.7) \\
8(0.7) \\
9(0.7)\end{array}$ & $\begin{array}{l}39(1.2) \\
37(1.8) \\
36(1.7) \\
31(1.2) \\
35(1.4)\end{array}$ \\
\hline 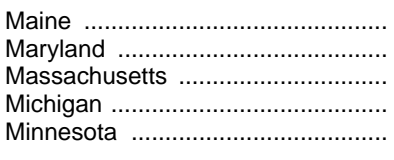 & $\begin{array}{l}232(1.0) \\
221(1.6) \\
229(1.4) \\
226(1.3) \\
232(1.1)\end{array}$ & $\begin{array}{l}25(1.4) \\
41(1.8) \\
29(1.8) \\
32(1.8) \\
24(1.5)\end{array}$ & $\begin{array}{l}75(1.4) \\
59(1.8) \\
71(1.8) \\
68(1.8) \\
76(1.5)\end{array}$ & $\begin{array}{l}27(1.4) \\
22(1.7) \\
24(1.9) \\
23(1.5) \\
29(1.5)\end{array}$ & $\begin{array}{l}3(0.6) \\
3(0.7) \\
2(0.5) \\
2(0.5) \\
3(0.5)\end{array}$ & $\begin{array}{l}3(0.4) \\
3(0.4) \\
2(0.3) \\
4(0.5) \\
2(0.3)\end{array}$ & $\begin{array}{l}13(0.9) \\
13(0.9) \\
10(0.7) \\
14(1.0) \\
11(0.8)\end{array}$ & $\begin{array}{l}9(0.6) \\
7(0.6) \\
8(0.6) \\
8(0.7) \\
7(0.6)\end{array}$ & $\begin{array}{l}39(1.8) \\
45(1.6) \\
48(1.9) \\
38(1.5) \\
42(1.5)\end{array}$ \\
\hline 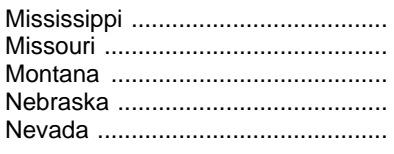 & $\begin{array}{l}208(1.2) \\
225(1.1) \\
228(1.2) \\
228(1.2) \\
218(1.3)\end{array}$ & $\begin{array}{l}58(1.9) \\
34(1.7) \\
29(1.9) \\
30(1.6) \\
43(1.8)\end{array}$ & $\begin{array}{l}42(1.9) \\
66(1.7) \\
71(1.9) \\
70(1.6) \\
57(1.8)\end{array}$ & $\begin{array}{r}8(0.9) \\
20(1.3) \\
22(1.6) \\
24(1.4) \\
14(1.2)\end{array}$ & $\begin{array}{l}0(0.2) \\
1(0.3) \\
1(0.4) \\
2(0.3) \\
1(0.3)\end{array}$ & $\begin{array}{l}7(0.6) \\
4(0.5) \\
3(0.4) \\
3(0.4) \\
4(0.6)\end{array}$ & $\begin{array}{l}19(1.0) \\
16(0.9) \\
11(0.8) \\
13(0.9) \\
12(0.7)\end{array}$ & $\begin{array}{r}7(0.5) \\
9(0.7) \\
11(0.8) \\
9(0.7) \\
8(0.6)\end{array}$ & $\begin{array}{l}35(1.3) \\
36(1.6) \\
40(1.5) \\
41(1.2) \\
34(1.2)\end{array}$ \\
\hline 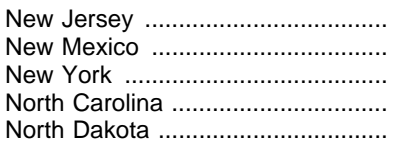 & $\begin{array}{l}227(1.5) \\
214(1.8) \\
223(1.2) \\
224(1.2) \\
231(1.2)\end{array}$ & $\begin{array}{l}32(2.1) \\
49(2.4) \\
36(1.8) \\
36(1.6) \\
25(1.9)\end{array}$ & $\begin{array}{l}68(2.1) \\
51(2.4) \\
64(1.8) \\
64(1.6) \\
75(1.9)\end{array}$ & $\begin{array}{l}25(1.7) \\
13(1.2) \\
20(1.2) \\
21(1.3) \\
24(1.3)\end{array}$ & $\begin{array}{l}3(0.7) \\
1(0.3) \\
2(0.4) \\
2(0.4) \\
2(0.5)\end{array}$ & $\begin{array}{l}3(0.5) \\
6(0.6) \\
4(0.4) \\
5(0.6) \\
2(0.3)\end{array}$ & $\begin{array}{l}12(1.1) \\
15(0.8) \\
10(0.8) \\
12(0.8) \\
11(0.7)\end{array}$ & $\begin{array}{r}7(0.6) \\
11(0.9) \\
6(0.6) \\
7(0.6) \\
8(0.8)\end{array}$ & $\begin{array}{l}46(2.0) \\
35(1.3) \\
43(1.6) \\
42(1.7) \\
47(1.4)\end{array}$ \\
\hline 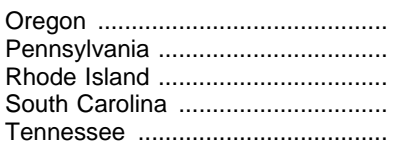 & $\begin{array}{l}223(1.4) \\
226(1.2) \\
220(1.4) \\
213(1.3) \\
219(1.4)\end{array}$ & $\begin{array}{l}35(2.2) \\
32(1.8) \\
39(2.0) \\
52(2.0) \\
42(2.0)\end{array}$ & $\begin{array}{l}65(2.2) \\
68(1.8) \\
61(2.0) \\
48(2.0) \\
58(2.0)\end{array}$ & $\begin{array}{l}21(1.3) \\
20(1.5) \\
17(1.3) \\
12(1.3) \\
17(1.5)\end{array}$ & $\begin{array}{ll}2 & (0.5) \\
1 & (0.3) \\
1 & (0.3) \\
1 & (0.3) \\
1 & (0.3)\end{array}$ & $\begin{array}{l}4(0.5) \\
5(0.4) \\
5(0.5) \\
6(0.6)\end{array}$ & $\begin{array}{l}11(0.8) \\
12(0.9) \\
16(1.0) \\
19(0.9)\end{array}$ & $\begin{array}{l}7(0.5) \\
7(0.5) \\
7(0.8) \\
8(0.6)\end{array}$ & $\begin{array}{l}38(1.5) \\
40(1.3) \\
38(1.2) \\
36(1.5)\end{array}$ \\
\hline 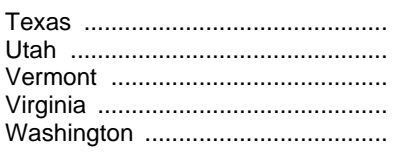 & $\begin{array}{l}229(1.4) \\
227(1.2) \\
225(1.2) \\
223(1.4) \\
225(1.2)\end{array}$ & $\begin{array}{l}31(1.9) \\
31(1.6) \\
33(2.1) \\
38(2.2) \\
33(1.8)\end{array}$ & $\begin{array}{l}69(1.9) \\
69(1.6) \\
67(2.1) \\
62(2.2) \\
67(1.8)\end{array}$ & $\begin{array}{l}25(1.5) \\
23(1.3) \\
23(1.1) \\
19(1.5) \\
21(1.2)\end{array}$ & $\begin{array}{l}3(0.5) \\
2(0.4) \\
3(0.5) \\
2(0.5) \\
1(0.2)\end{array}$ & $\begin{array}{l}6(0.5) \\
2(0.3) \\
3(0.4) \\
5(0.7) \\
2(0.3)\end{array}$ & $\begin{array}{l}11(0.8) \\
10(0.7) \\
12(0.9) \\
15(1.0) \\
9(0.7)\end{array}$ & $\begin{array}{l}7(0.5) \\
8(0.6) \\
7(0.7) \\
7(0.7) \\
8(0.6)\end{array}$ & $\begin{array}{l}38(1.6) \\
41(1.7) \\
44(1.4) \\
41(1.8) \\
38(1.5)\end{array}$ \\
\hline 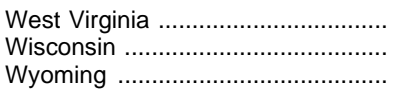 & $\begin{array}{l}223(1.0) \\
231(1.0) \\
223(1.4)\end{array}$ & $\begin{array}{l}37(1.6) \\
26(1.2) \\
36(1.7)\end{array}$ & $\begin{array}{l}63(1.6) \\
74(1.2) \\
64(1.7)\end{array}$ & $\begin{array}{l}19(1.2) \\
27(1.3) \\
19(1.2)\end{array}$ & $\begin{array}{l}2(0.5) \\
3(0.6) \\
1(0.3)\end{array}$ & $\begin{array}{l}7(0.7) \\
2(0.5) \\
4(0.5)\end{array}$ & $\begin{array}{l}21(0.9) \\
13(1.0) \\
12(0.7)\end{array}$ & $\begin{array}{l}9(0.7) \\
8(0.8) \\
8(0.5)\end{array}$ & $\begin{array}{l}35(1.4) \\
38(1.6) \\
38(1.2)\end{array}$ \\
\hline 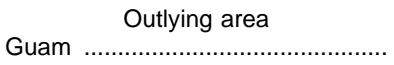 & $188(1.3)$ & 77 (1.4) & $23(1.4)$ & $3(0.5)$ & $0-$ & $5(0.7)$ & $14(1.0)$ & $5(0.6)$ & $36(1.4)$ \\
\hline
\end{tabular}

${ }^{1}$ Achievement levels are in developmental status.

2Excludes students who responded "I don't know" to the question about educational level of parents.

${ }^{3}$ This level denotes partial mastery of prerequisite knowledge and skills that are fundamental for proficient work at the 4th grade.

4 This level represents solid academic mastery for 4 th graders. Students reaching this level have demnostrated competency over challenging subject matter, including subjectmatter knowledge, application of such knowledge to real-world situations, and analytical skills appropriate to the subject matter.

5 This level signifies superior performance.
-Data not available.

NOTE.-These test scores are from the National Assessment of Educational Progress (NAEP). Forty-seven states, the District of Columbia, and Guam participated in the 1996 Trial State Assessment of 4th graders. Scale ranges from 0 to 500. Results are not shown for states with a school participation rate of less than 70 percent. Standard errors appear in parentheses.

SOURCE: U.S. Department of Education, National Center for Education Statistics, National Assessment of Educational Progress, NAEP 1996 Mathematics Report Card for the Nation and the States, prepared by Educational Testing Service. (This table was prepared August 1997.) 
Table 124.-Selected characteristics of 8 th-grade students in public schools, by region and state: 19921

\begin{tabular}{|c|c|c|c|c|c|c|c|c|c|c|c|c|}
\hline \multirow[b]{2}{*}{ Region and state } & \multirow[b]{2}{*}{$\begin{array}{l}\text { Math } \\
\text { units } \\
\text { required } \\
\text { for } \\
\text { graduation }\end{array}$} & \multirow[b]{2}{*}{$\begin{array}{l}\text { Year of } \\
\text { revision of } \\
\text { state guides } \\
\text { with NCTM } \\
\text { standards }^{2}\end{array}$} & \multicolumn{2}{|c|}{$\begin{array}{l}\text { Length of } \\
\text { school year }\end{array}$} & \multirow[b]{2}{*}{$\begin{array}{l}\text { Passing } \\
\text { test in } \\
\text { math } \\
\text { required } \\
\text { for } \\
\text { graduation } \\
\text { in } 1993\end{array}$} & \multirow[b]{2}{*}{$\begin{array}{l}\text { Percent of } \\
\text { students } \\
\text { with } 4 \text { or } \\
\text { more } \\
\text { hours of } \\
\text { math } \\
\text { instruction } \\
\text { each week }\end{array}$} & \multicolumn{6}{|c|}{ Percent of students reporting } \\
\hline & & & 1989 & 1992 & & & $\begin{array}{l}\text { Spending } \\
30 \\
\text { minutes or } \\
\text { more on } \\
\text { math } \\
\text { homework } \\
\text { each day }\end{array}$ & $\begin{array}{l}\text { Spending } \\
1 \text { or } 2 \\
\text { hours } \\
\text { on all } \\
\text { homework } \\
\text { each day }\end{array}$ & $\begin{array}{l}\text { Spending } \\
\text { more than } \\
2 \text { hours } \\
\text { on all } \\
\text { homework } \\
\text { each day }\end{array}$ & $\begin{array}{c}\text { Positive } \\
\text { attitudes } \\
\text { towards } \\
\text { math }^{3}\end{array}$ & $\begin{array}{l}\text { Both } \\
\text { parents } \\
\text { living } \\
\text { at home }\end{array}$ & $\begin{array}{c}\text { Watching } \\
6 \text { or more } \\
\text { hours of } \\
\text { television } \\
\text { each day }\end{array}$ \\
\hline 1 & 2 & 3 & 4 & 5 & 6 & 7 & 8 & 9 & 10 & 11 & 12 & 13 \\
\hline United States ........ & - & - & - & - & - & 32 & 64 & 59 & 8 & 59 & 75 & 13 \\
\hline 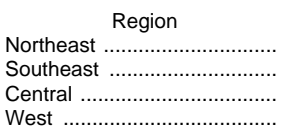 & $\begin{array}{l}- \\
- \\
-\end{array}$ & $\begin{array}{l}- \\
- \\
-\end{array}$ & $\begin{array}{l}- \\
- \\
-\end{array}$ & $\begin{array}{l}- \\
- \\
-\end{array}$ & $\begin{array}{l}- \\
- \\
-\end{array}$ & $\begin{array}{l}35 \\
37 \\
24 \\
30\end{array}$ & $\begin{array}{l}59 \\
65 \\
63 \\
68\end{array}$ & $\begin{array}{l}62 \\
56 \\
65 \\
56\end{array}$ & $\begin{array}{r}8 \\
7 \\
6 \\
10\end{array}$ & $\begin{array}{l}56 \\
59 \\
63 \\
56\end{array}$ & $\begin{array}{l}75 \\
71 \\
79 \\
75\end{array}$ & $\begin{array}{l}14 \\
17 \\
11 \\
12\end{array}$ \\
\hline 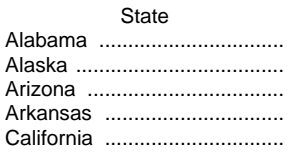 & $\begin{array}{l}2 \\
2 \\
2 \\
3 \\
2\end{array}$ & $\begin{array}{r}1989 \\
\text { Devel., } 1994 \\
1992 \\
1993 \\
1991\end{array}$ & $\begin{array}{r}175 \\
175 \\
178 \\
180\end{array}$ & $\begin{array}{l}175 \\
180 \\
175 \\
178 \\
180\end{array}$ & $\begin{array}{l}\text { Yes } \\
\text { No } \\
\text { No } \\
\text { No } \\
\text { No }\end{array}$ & $\begin{array}{l}60 \\
34 \\
42 \\
43\end{array}$ & $\begin{array}{l}\frac{65}{65} \\
61 \\
67\end{array}$ & $\begin{array}{l}59 \\
56 \\
56 \\
63\end{array}$ & $\begin{array}{r}7 \\
5 \\
7 \\
10\end{array}$ & $\begin{array}{l}\frac{62}{54} \\
60 \\
56\end{array}$ & $\begin{array}{l}72 \\
76 \\
75 \\
74\end{array}$ & $\begin{array}{r}20 \\
9 \\
20 \\
10\end{array}$ \\
\hline $\begin{array}{l}\text { Colorado } \\
\text { Connecticut } \\
\text { Delaware } \\
\text { District of Columbia } \\
\text { Florida }\end{array}$ & $\begin{array}{r}(4) \\
3 \\
2 \\
3 \\
3\end{array}$ & $\begin{array}{r}1994 \\
\text { Devel.,1995 } \\
\text { Devel.,1994 } \\
1993 \\
\text { Devel.,1994 }\end{array}$ & $\begin{array}{l}180 \\
180 \\
180 \\
190 \\
180\end{array}$ & $\begin{array}{r}(5) \\
180 \\
180 \\
180 \\
180\end{array}$ & $\begin{array}{l}\text { No } \\
\text { No } \\
\text { No } \\
\text { No } \\
\text { Yes }\end{array}$ & $\begin{array}{l}27 \\
21 \\
30 \\
52 \\
40\end{array}$ & $\begin{array}{l}65 \\
61 \\
57 \\
63 \\
62\end{array}$ & $\begin{array}{l}61 \\
70 \\
62 \\
63 \\
57\end{array}$ & $\begin{array}{r}7 \\
9 \\
5 \\
10 \\
7\end{array}$ & $\begin{array}{l}58 \\
59 \\
63 \\
73 \\
61\end{array}$ & $\begin{array}{l}77 \\
79 \\
73 \\
45 \\
71\end{array}$ & $\begin{array}{r}7 \\
11 \\
17 \\
31 \\
15\end{array}$ \\
\hline $\begin{array}{l}\text { Georgia } \\
\text { Hawaii } \\
\text { Idaho } \\
\text { Illinois } \\
\text { Indiana }\end{array}$ & $\begin{array}{l}3 \\
3 \\
2 \\
2 \\
2\end{array}$ & $\begin{array}{r}1992 \\
\text { Devel., } 1994 \\
1994 \\
\text { Devel.,1994 } \\
1991\end{array}$ & $\begin{array}{l}180 \\
183 \\
180 \\
180 \\
180\end{array}$ & $\begin{array}{l}180 \\
180 \\
180 \\
180 \\
180\end{array}$ & $\begin{array}{r}\text { Yes } \\
\text { Yes } \\
\text { No } \\
\text { No } \\
\text { No }\end{array}$ & $\begin{array}{l}56 \\
34 \\
28 \\
32\end{array}$ & $\begin{array}{l}65 \\
68 \\
63 \\
\frac{62}{62}\end{array}$ & $\begin{array}{l}59 \\
55 \\
57 \\
\frac{60}{60}\end{array}$ & $\begin{array}{r}7 \\
11 \\
5 \\
\frac{6}{6}\end{array}$ & $\begin{array}{l}66 \\
54 \\
56 \\
-61\end{array}$ & $\begin{array}{l}71 \\
75 \\
83 \\
78\end{array}$ & $\begin{array}{r}18 \\
22 \\
7 \\
9\end{array}$ \\
\hline 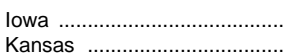 & $\begin{array}{r}(4) \\
2\end{array}$ & $\begin{array}{l}1987 \\
1991\end{array}$ & 180 & $\begin{array}{l}180 \\
180\end{array}$ & $\begin{array}{l}\text { No } \\
\text { No }\end{array}$ & 20 & 61 & 63 & $\underline{4}$ & 63 & 83 & $\underline{7}$ \\
\hline 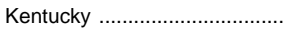 & 3 & 1993 & 175 & 175 & No & 47 & 61 & 54 & 6 & 57 & 78 & 13 \\
\hline 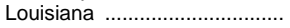 & 3 & Devel.,1994 & 180 & 180 & Yes & 54 & 62 & 61 & 10 & 63 & 71 & 20 \\
\hline Maine & 2 & Devel.,1994 & - & 175 & No & 12 & 66 & 70 & 8 & 61 & 81 & 8 \\
\hline 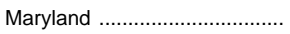 & 3 & 1985 & 180 & 180 & Yes & 45 & 60 & 65 & 7 & 61 & 73 & 17 \\
\hline Massachusetts …....................... & $\left({ }^{4}\right)$ & 1994 & - & 180 & No & 28 & 67 & 70 & 9 & 57 & 77 & 8 \\
\hline 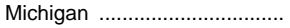 & 3 & Devel.,1994 & 180 & 180 & Yes & 39 & 67 & 61 & 7 & 60 & 75 & 13 \\
\hline 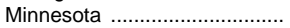 & 1 & Devel.,1994 & 175 & 175 & No & 41 & 64 & 59 & 5 & 57 & 85 & 5 \\
\hline 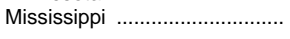 & 2 & 1993 & - & 180 & Yes & 60 & 68 & 60 & 8 & 67 & 70 & 21 \\
\hline 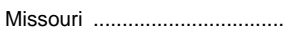 & 2 & 1990 & - & 174 & No & 44 & 66 & 60 & 6 & 60 & 77 & 12 \\
\hline 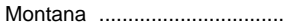 & 2 & Devel.,1995 & 180 & 180 & No & - & - & - & - & - & - & - \\
\hline 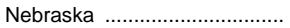 & $(4)$ & Devel.,1994 & $(5)$ & $(5)$ & No & 25 & 69 & 61 & 5 & 60 & 81 & 8 \\
\hline Nevada & 2 & 1993 & - & 180 & Yes & - & - & - & - & - & - & - \\
\hline New Hampshire ........................... & 2 & 1993 & 180 & 180 & No & 38 & 62 & 68 & 9 & 58 & 81 & 7 \\
\hline New Jersey . ............................. & 3 & 1993 & 180 & 180 & Yes & 28 & 62 & 68 & 10 & 62 & 78 & 13 \\
\hline New Mexico ……..................... & 3 & 1992 & 180 & 180 & Yes & 26 & 65 & 56 & 7 & 56 & 75 & 11 \\
\hline New York & 2 & Devel., 1994 & 180 & 180 & Yes & 20 & 54 & 66 & 9 & 62 & 75 & 15 \\
\hline North Carolina ............................ & 2 & 1992 & 180 & 180 & Yes & 52 & 64 & 64 & 7 & 65 & 73 & 16 \\
\hline 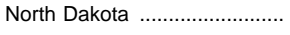 & 2 & 1993 & 180 & 180 & No & 44 & 70 & 63 & 6 & 55 & 85 & 5 \\
\hline Ohio & 2 & 1990 & 182 & 182 & Yes & 26 & 62 & 62 & 6 & 62 & 74 & 12 \\
\hline 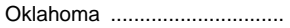 & 2 & 1993 & 175 & 175 & No & 37 & 69 & 59 & 7 & 58 & 78 & 11 \\
\hline 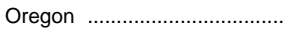 & 2 & Devel.,1994 & 175 & $(5)$ & No & - & - & - & - & - & - & - \\
\hline 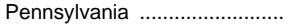 & 3 & none & 180 & 180 & No & 24 & 58 & 63 & 4 & 59 & 79 & 9 \\
\hline Rhode Island ............................ & 2 & Devel., 1994 & 180 & 180 & No & 43 & 62 & 67 & 7 & 56 & 78 & 9 \\
\hline South Carolina ......................... & 3 & 1993 & - & 180 & Yes & 59 & 61 & 61 & 7 & 70 & 73 & 17 \\
\hline South Dakota ............................ & 2 & Devel.,1995 & - & 175 & No & - & - & - & - & - & - & - \\
\hline 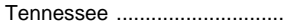 & 2 & 1991 & - & 180 & Yes & 60 & 67 & 62 & 6 & 58 & 73 & 14 \\
\hline 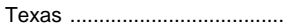 & 3 & 1991 & 175 & 175 & Yes & 38 & 67 & 57 & 8 & 61 & 75 & 12 \\
\hline 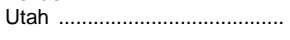 & 2 & 1993 & - & 180 & No & 28 & 62 & 56 & 5 & 55 & 85 & 5 \\
\hline Vermont & (6) & Devel.,1994 & - & 175 & No & - & - & - & - & - & - & - \\
\hline Virginia & 2 & 1988 & 180 & 180 & Yes & 38 & 65 & 63 & 7 & 63 & 77 & 15 \\
\hline Washington ……....................... & 2 & Devel.,1994 & - & 180 & No & - & - & - & - & - & - & - \\
\hline West Virginia ............................. & 2 & 1992 & 180 & 180 & Yes & 40 & 57 & 55 & 5 & 58 & 78 & 13 \\
\hline Wisconsin & 2 & Devel.,1995 & 180 & 180 & No & 32 & 59 & 61 & 5 & 59 & 80 & 8 \\
\hline 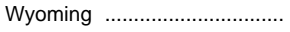 & $\left({ }^{4}\right)$ & 1990 & 175 & 175 & No & 24 & 60 & 55 & 5 & 58 & 81 & 8 \\
\hline Outlying areas & & & & & & & & & & & & \\
\hline 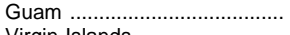 & - & 一 & - & - & 一 & 28 & 68 & 47 & 12 & 50 & 79 & 20 \\
\hline 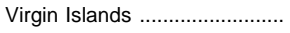 & - & - & - & 180 & - & 31 & 61 & 47 & 11 & 75 & 56 & 32 \\
\hline
\end{tabular}

1 Data are for 1992 unless otherwise specified.

2 Standards recommended by the National Council of Teachers of Mathematics.

${ }^{3}$ Percent of students agreeing or strongly agreeing with positive statements about mathematics.

${ }^{4}$ Local board determines.

${ }^{5}$ No statewide policy.

65 units of math and science combined.
—Data not available or not applicable.

SOURCE: U.S. Department of Education, National Center for Education Statistics, National Assessment of Educational Progress, The State of Mathematics Achievement, by Educational Testing Service; and Council of Chief State School Officers, State Education Indicators. (This table was prepared June 1994.) 
Table 125.- Mathematics proficiency of 17-year-olds, by highest mathematics course taken, sex, and race/ethnicity: 1978 to 1996

\begin{tabular}{|c|c|c|c|c|c|c|c|c|c|c|c|}
\hline \multirow[b]{2}{*}{ Year, sex, and race/ethnicity } & \multirow[b]{2}{*}{$\begin{array}{l}\text { Percent } \\
\text { of } \\
\text { stu- } \\
\text { dents }\end{array}$} & \multicolumn{6}{|c|}{ Average proficiency by highest mathematics course taken } & \multicolumn{4}{|c|}{ Percent of students at or above } \\
\hline & & $\begin{array}{c}\text { All } \\
\text { areas }\end{array}$ & $\begin{array}{c}\text { Prealgebra } \\
\text { or general } \\
\text { mathematics }\end{array}$ & Algebra & $\begin{array}{l}\text { Geom- } \\
\text { etry }\end{array}$ & $\underset{\text { II }}{\text { Algebra }}$ & $\begin{array}{l}\text { Precalculus } \\
\text { or calculus }\end{array}$ & $200^{1}$ & $250^{2}$ & $300^{3}$ & $350^{4}$ \\
\hline 1 & 2 & 3 & 4 & 5 & 6 & 7 & 8 & 9 & 10 & 11 & 12 \\
\hline 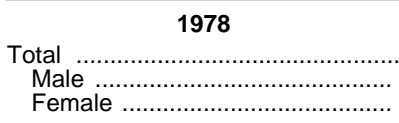 & $\begin{array}{r}100.0 \\
48.7 \\
51.3\end{array}$ & $\begin{array}{l}300.4 \\
303.8 \\
297.1\end{array}$ & $\begin{array}{l}267 \\
269 \\
265\end{array}$ & $\begin{array}{l}286 \\
289 \\
284\end{array}$ & $\begin{array}{l}307 \\
310 \\
304\end{array}$ & $\begin{array}{l}321 \\
325 \\
318\end{array}$ & $\begin{array}{l}334 \\
337 \\
329\end{array}$ & $\begin{array}{l}99.8 \\
99.9 \\
99.7\end{array}$ & $\begin{array}{l}92.0 \\
93.0 \\
91.0\end{array}$ & $\begin{array}{l}51.5 \\
55.1 \\
48.2\end{array}$ & $\begin{array}{l}7.3 \\
9.5 \\
5.2\end{array}$ \\
\hline 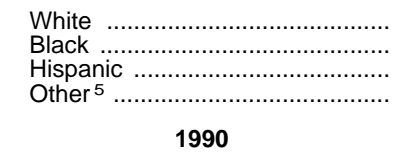 & $\begin{array}{r}83.1 \\
11.8 \\
4.0 \\
1.1\end{array}$ & $\begin{array}{l}305.9 \\
268.4 \\
276.3 \\
312.9\end{array}$ & $\begin{array}{l}272 \\
247 \\
256 \\
-\end{array}$ & $\begin{array}{r}291 \\
264 \\
273 \\
-\end{array}$ & $\begin{array}{r}310 \\
281 \\
294 \\
\end{array}$ & $\begin{array}{r}325 \\
292 \\
303 \\
-\end{array}$ & $\begin{array}{r}338 \\
297 \\
306 \\
\end{array}$ & $\begin{array}{r}100.0 \\
98.8 \\
99.3 \\
100.0\end{array}$ & $\begin{array}{l}95.6 \\
70.7 \\
78.3 \\
94.5\end{array}$ & $\begin{array}{l}57.6 \\
16.8 \\
23.4 \\
64.7\end{array}$ & $\begin{array}{r}8.5 \\
0.5 \\
1.4 \\
15.4\end{array}$ \\
\hline 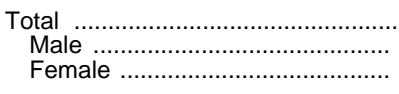 & $\begin{array}{r}100.0 \\
48.6 \\
51.4\end{array}$ & $\begin{array}{l}304.6 \\
306.3 \\
302.9\end{array}$ & $\begin{array}{l}273 \\
274 \\
271\end{array}$ & $\begin{array}{l}288 \\
291 \\
285\end{array}$ & $\begin{array}{l}299 \\
302 \\
296\end{array}$ & $\begin{array}{l}319 \\
323 \\
316\end{array}$ & $\begin{array}{l}344 \\
347 \\
341\end{array}$ & $\begin{array}{r}100.0 \\
99.9 \\
100.0\end{array}$ & $\begin{array}{l}96.0 \\
95.8 \\
96.2\end{array}$ & $\begin{array}{l}56.1 \\
57.6 \\
54.7\end{array}$ & $\begin{array}{l}7.2 \\
8.8 \\
5.6\end{array}$ \\
\hline 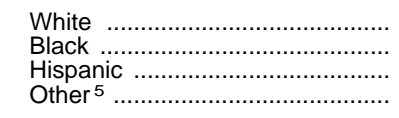 & $\begin{array}{r}73.3 \\
15.6 \\
6.9 \\
4.2\end{array}$ & $\begin{array}{l}309.5 \\
288.5 \\
283.5 \\
312.5\end{array}$ & $\begin{array}{l}277 \\
264 \\
259 \\
-\end{array}$ & $\begin{array}{r}292 \\
278 \\
278 \\
-\end{array}$ & $\begin{array}{r}304 \\
285 \\
286 \\
-\end{array}$ & $\begin{array}{r}323 \\
302 \\
306 \\
-\end{array}$ & $\begin{array}{r}347 \\
329 \\
323 \\
\end{array}$ & $\begin{array}{r}100.0 \\
99.9 \\
99.6 \\
100.0\end{array}$ & $\begin{array}{l}97.6 \\
92.4 \\
85.8 \\
97.9\end{array}$ & $\begin{array}{l}63.2 \\
32.8 \\
30.1 \\
61.6\end{array}$ & $\begin{array}{r}8.3 \\
2.0 \\
1.9 \\
15.9\end{array}$ \\
\hline 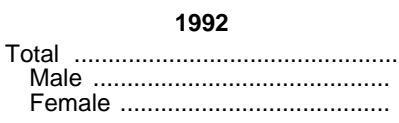 & $\begin{array}{r}100.0 \\
50.7 \\
49.3\end{array}$ & $\begin{array}{l}306.7 \\
308.9 \\
304.5\end{array}$ & $\begin{array}{l}271 \\
275 \\
267\end{array}$ & $\begin{array}{l}289 \\
291 \\
287\end{array}$ & $\begin{array}{l}302 \\
306 \\
297\end{array}$ & $\begin{array}{l}320 \\
323 \\
317\end{array}$ & $\begin{array}{l}343 \\
344 \\
341\end{array}$ & $\begin{array}{l}100.0 \\
100.0 \\
100.0\end{array}$ & $\begin{array}{l}96.6 \\
96.9 \\
96.3\end{array}$ & $\begin{array}{l}59.1 \\
60.5 \\
57.7\end{array}$ & $\begin{array}{l}7.2 \\
9.1 \\
5.2\end{array}$ \\
\hline 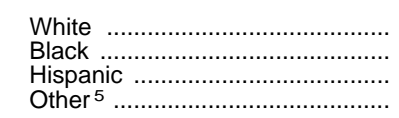 & $\begin{array}{r}74.7 \\
14.8 \\
7.4 \\
3.1\end{array}$ & $\begin{array}{l}311.9 \\
285.8 \\
292.2 \\
317.1\end{array}$ & $\begin{array}{r}276 \\
256 \\
269 \\
-\end{array}$ & $\begin{array}{r}293 \\
279 \\
285 \\
-\end{array}$ & $\begin{array}{r}306 \\
283 \\
297 \\
-\end{array}$ & $\begin{array}{r}323 \\
301 \\
312 \\
-\end{array}$ & $\begin{array}{r}347 \\
313 \\
320 \\
\end{array}$ & $\begin{array}{l}100.0 \\
100.0 \\
100.0 \\
100.0\end{array}$ & $\begin{array}{l}98.3 \\
89.6 \\
94.1 \\
96.5\end{array}$ & $\begin{array}{l}66.4 \\
29.8 \\
39.2 \\
69.8\end{array}$ & $\begin{array}{r}8.7 \\
0.9 \\
1.2 \\
16.9\end{array}$ \\
\hline 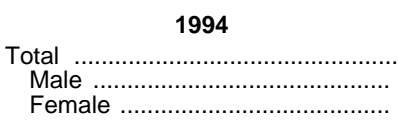 & $\begin{array}{r}100.0 \\
49.5 \\
50.5\end{array}$ & $\begin{array}{l}306.2 \\
308.5 \\
304.1\end{array}$ & $\begin{array}{l}272 \\
274 \\
268\end{array}$ & $\begin{array}{l}288 \\
289 \\
286\end{array}$ & $\begin{array}{l}297 \\
301 \\
293\end{array}$ & $\begin{array}{l}316 \\
320 \\
313\end{array}$ & $\begin{array}{l}340 \\
343 \\
337\end{array}$ & $\begin{array}{l}100.0 \\
100.0 \\
100.0\end{array}$ & $\begin{array}{l}96.5 \\
97.3 \\
96.0\end{array}$ & $\begin{array}{l}58.6 \\
60.2 \\
57.2\end{array}$ & $\begin{array}{l}7.4 \\
9.3 \\
5.5\end{array}$ \\
\hline 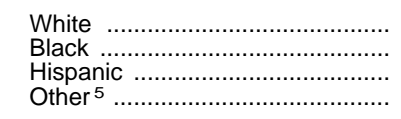 & $\begin{array}{r}72.5 \\
15.5 \\
8.8 \\
3.2\end{array}$ & $\begin{array}{l}312.3 \\
285.5 \\
290.8 \\
312.7\end{array}$ & $\begin{array}{l}275 \\
- \\
-\end{array}$ & $\begin{array}{r}292 \\
275 \\
- \\
-\end{array}$ & $\begin{array}{r}301 \\
283 \\
- \\
-\end{array}$ & $\begin{array}{r}320 \\
297 \\
304 \\
-\end{array}$ & $\frac{344}{-}$ & $\begin{array}{l}100.0 \\
100.0 \\
100.0 \\
100.0\end{array}$ & $\begin{array}{l}98.4 \\
90.6 \\
91.8 \\
97.0\end{array}$ & $\begin{array}{l}67.0 \\
29.8 \\
38.3 \\
66.4\end{array}$ & $\begin{array}{r}9.4 \\
0.4 \\
1.4 \\
12.1\end{array}$ \\
\hline 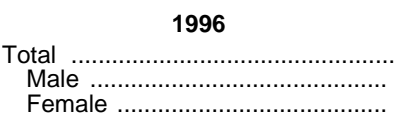 & $\begin{array}{r}100.0 \\
49.5 \\
50.5\end{array}$ & $\begin{array}{l}307.2 \\
309.5 \\
304.9\end{array}$ & $\begin{array}{l}269 \\
272 \\
265\end{array}$ & $\begin{array}{l}283 \\
287 \\
278\end{array}$ & $\begin{array}{l}298 \\
302 \\
294\end{array}$ & $\begin{array}{l}316 \\
320 \\
313\end{array}$ & $\begin{array}{l}339 \\
342 \\
335\end{array}$ & $\begin{array}{l}100.0 \\
100.0 \\
100.0\end{array}$ & $\begin{array}{l}96.8 \\
97.0 \\
96.7\end{array}$ & $\begin{array}{l}60.4 \\
62.7 \\
57.6\end{array}$ & $\begin{array}{l}7.4 \\
9.5 \\
5.3\end{array}$ \\
\hline 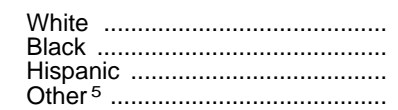 & $\begin{array}{r}71.0 \\
15.0 \\
9.0 \\
5.0\end{array}$ & $\begin{array}{r}313.4 \\
286.4 \\
292.0 \\
\end{array}$ & $\begin{array}{c}273 \\
- \\
-\end{array}$ & $\begin{array}{r}287 \\
273 \\
-\end{array}$ & $\begin{array}{r}304 \\
280 \\
-\end{array}$ & $\begin{array}{r}320 \\
299 \\
306 \\
-\end{array}$ & $\begin{array}{r}342 \\
- \\
-\end{array}$ & $\begin{array}{r}100.0 \\
100.0 \\
99.9 \\
100.0\end{array}$ & $\begin{array}{l}98.7 \\
90.6 \\
92.2 \\
97.4\end{array}$ & $\begin{array}{l}68.7 \\
31.2 \\
40.1 \\
63.5\end{array}$ & $\begin{array}{r}9.2 \\
0.9 \\
1.8 \\
13.7\end{array}$ \\
\hline
\end{tabular}

1 Indicates ability to perform simple additive reasoning and problem solving. ${ }^{2}$ Indicates ability to perform simple multiplicative reasoning and 2-step problem solving.

${ }^{3}$ Indicates ability to perform reasoning and problem solving involving fractions, decimals, percents, elementary geometry, and simple algebra.

${ }^{4}$ Indicates ability to perform reasoning and problem solving involving geometry, algebra, and beginning statistics and probability.

5 Includes Asian/Pacific Islanders and American Indians/Alaskan Natives.

—Data not available.

NOTE.-These test scores are from the National Assessment of Educational Progress (NAEP). Scale ranges from 0 to 500 .

SOURCE: U.S. Department of Education, National Center for Education Statistics, National Assessment of Educational Progress, NAEP 1996 Trends in Academic Progress, prepared by Educational Testing Service. (This table was prepared September 1997.) 
Table 126.-Percent of students at or above selected science proficiency levels, ${ }^{1}$ by sex, race/ethnicity, control of school, and age: 1977 to 1996

\begin{tabular}{|c|c|c|c|c|c|c|c|c|c|c|c|c|}
\hline \multirow[b]{2}{*}{$\begin{array}{l}\text { Sex, race/ethnicity, } \\
\text { control, and year }\end{array}$} & \multicolumn{4}{|c|}{9 -year-olds ${ }^{2}$} & \multicolumn{4}{|c|}{13 -year-olds ${ }^{3}$} & \multicolumn{4}{|c|}{17 -year-olds ${ }^{3}$} \\
\hline & $\begin{array}{l}\text { Know } \\
\text { everyday } \\
\text { science } \\
\text { facts }^{4}\end{array}$ & $\begin{array}{l}\text { Understand } \\
\text { simple } \\
\text { scientific } \\
\text { principles }^{5}\end{array}$ & $\begin{array}{l}\text { Apply } \\
\text { general } \\
\text { scientific } \\
\text { informa- } \\
\text { tion }^{6}\end{array}$ & $\begin{array}{c}\text { Analyze } \\
\text { scientific } \\
\text { procedures } \\
\text { and data }^{7}\end{array}$ & $\begin{array}{l}\text { Understand } \\
\text { simple } \\
\text { scientific } \\
\text { principles }^{5}\end{array}$ & $\begin{array}{l}\text { Apply } \\
\text { general } \\
\text { scientific } \\
\text { informa- } \\
\text { tion } 6\end{array}$ & \begin{tabular}{|c|} 
Analyze \\
scientific \\
procedures \\
and data $^{7}$
\end{tabular} & $\begin{array}{c}\text { Integrate } \\
\text { specialized } \\
\text { scientific } \\
\text { informa- } \\
\text { tion }^{8}\end{array}$ & $\begin{array}{l}\text { Understand } \\
\text { simple } \\
\text { scientific } \\
\text { principles }^{5}\end{array}$ & $\begin{array}{l}\text { Apply } \\
\text { general } \\
\text { scientific } \\
\text { informa- } \\
\text { tion }^{6}\end{array}$ & $\begin{array}{c}\text { Analyze } \\
\text { scientific } \\
\text { procedures } \\
\text { and data }{ }^{7}\end{array}$ & $\begin{array}{c}\text { Integrate } \\
\text { specialized } \\
\text { scientific } \\
\text { informa- } \\
\text { tion }^{8}\end{array}$ \\
\hline 1 & 2 & 3 & 4 & 5 & 6 & 7 & 8 & 9 & 10 & 11 & 12 & 13 \\
\hline \multicolumn{13}{|l|}{ Total } \\
\hline 1977 & $93.5(0.6)$ & $68.0(1.1)$ & $25.7(0.7)$ & $3.2(0.3)$ & $86.0(0.7)$ & $48.8(1.1)$ & $11.1(0.5)$ & $0.7(0.1)$ & $97.1(0.2)$ & $81.6(0.7)$ & $41.7(0.9)$ & $8.5(0.4)$ \\
\hline 1982. & $95.2(0.7)$ & 70.7 (1.9) & $24.3(1.8)$ & $2.3(0.7)$ & $89.8(0.8)$ & $50.9(1.6)$ & $9.6(0.7)$ & $0.4(0.1)$ & $95.7(0.5)$ & $76.6(1.0)$ & $37.3(0.9)$ & $7.1(0.4)$ \\
\hline 1986 & $96.2(0.3)$ & $72.0(1.1)$ & 27.5 & $3.0(0.5)$ & $91.6(1.0)$ & $52.5(1.6)$ & $9.1(0.9)$ & $0.2(0.1)$ & $97.1(0.5)$ & $80.7(1.3)$ & $41.3(1.4)$ & $7.9(0.7)$ \\
\hline 1990 & $97.0(0.3)$ & $76.4(0.9)$ & $31.1(0.8)$ & $3.1(0.3)$ & $92.3(0.7)$ & $56.5(1.0)$ & $11.2(0.6)$ & $0.4(0.1)$ & $96.7(0.3)$ & $81.2(0.9)$ & $43.3(1.3)$ & $9.2(0.5)$ \\
\hline 1992. & $97.4(0.3)$ & $78.0(1.2)$ & $32.8(1.0)$ & $3.4(0.3)$ & $93.1(0.5)$ & $61.3(1.1)$ & $12.0(0.8)$ & $0.2(0.1)$ & $97.8(0.5)$ & $83.3(1.2)$ & $46.6(1.5)$ & $10.1(0.7)$ \\
\hline 1994 & $97.2(0.4)$ & $77.4(1.0)$ & $33.7(1.2)$ & $3.8(0.4)$ & $92.4(0.6)$ & $59.5(1.1)$ & $11.8(0.9)$ & $0.2(0.1)$ & $97.1(0.7)$ & $83.1(1.2)$ & 47.5 (1.3) & $10.0(0.8)$ \\
\hline $1996 \ldots$ & $96.8(0.4)$ & $76.1(1.2)$ & $32.2(1.3)$ & $4.4(0.4)$ & $92.0(0.8)$ & $57.6(1.1)$ & $12.3(0.7)$ & $0.4(0.2)$ & $97.8(0.3)$ & $83.8(0.9)$ & 48.4 (1.3) & $10.8(1.0)$ \\
\hline \multicolumn{13}{|l|}{ Male } \\
\hline 1977 & $94.3(0.5)$ & $69.5(1.2)$ & $27.4(0.9)$ & $3.7(0.3)$ & $87.2(0.8)$ & $52.3(1.3)$ & $13.1(0.6)$ & $0.9(0.2)$ & $97.8(0.2)$ & $85.2(0.7)$ & $48.8(1.1)$ & $11.8(0.6)$ \\
\hline 1982 & $95.0(1.0)$ & $69.7(2.0)$ & $25.6(2.6)$ & $2.5(1.0)$ & $91.9(0.8)$ & $56.2(1.8)$ & $12.6(1.1)$ & $0.5(0.2)$ & $96.8(0.5)$ & $81.2(1.2)$ & $45.2(1.2)$ & $10.4(0.8)$ \\
\hline 1986 & $96.8(0.5)$ & 74.1 (1.4) & $29.9(2.0)$ & $3.8(0.6)$ & $92.9(1.0)$ & $57.3(2.1)$ & $11.9(1.3)$ & $0.3(0.2)$ & $97.4(0.7)$ & $82.4(1.4)$ & $48.8(2.1)$ & $11.4(1.3)$ \\
\hline 1990 & $96.8(0.5)$ & $76.3(1.2)$ & $33.1(1.1)$ & $4.2(0.6)$ & $92.7(0.8)$ & $59.8(1.3)$ & $14.0(0.9)$ & $0.6(0.2)$ & $96.8(0.5)$ & $82.5(1.2)$ & $48.2(1.6)$ & $13.0(0.8)$ \\
\hline 1992 & $97.7(0.3)$ & $80.4(1.4)$ & $37.2(1.7)$ & $4.6(0.6)$ & $93.1(0.8)$ & $62.9(1.4)$ & $14.2(1.1)$ & $0.3(0.1)$ & $98.0(0.6)$ & $85.0(1.4)$ & $50.9(2.0)$ & $13.6(1.0)$ \\
\hline 1994 & $97.1(0.4)$ & $77.6(0.9)$ & $35.3(1.4)$ & $4.5(0.7)$ & $92.2(0.8)$ & $62.0(1.3)$ & $14.8(1.1)$ & $0.3(0.2)$ & $97.1(0.6)$ & $84.9(1.3)$ & $52.9(1.8)$ & $13.8(1.2)$ \\
\hline 1996. & $96.9(0.5)$ & $76.8(1.8)$ & 33.9 (1.9) & $5.2(0.7)$ & $93.2(0.9)$ & $61.7(1.4)$ & $15.5(0.9)$ & $0.7(0.2)$ & $97.5(0.5)$ & $83.8(1.1)$ & $53.1(1.5)$ & $14.2(1.4)$ \\
\hline \multicolumn{13}{|l|}{ Female } \\
\hline 1977 & $92.8(0.7)$ & $66.5(1.1)$ & $24.0(0.9)$ & $2.6(0.3)$ & $84.7(0.8)$ & $45.4(1.2)$ & $9.0(0.5)$ & $0.4(0.1)$ & $96.4(0.3)$ & $78.0(1.0)$ & $34.8(1.0)$ & $5.3(0.4)$ \\
\hline 1982 & 95.5 (1.2) & $71.8(2.2)$ & $23.0(2.0)$ & $2.1(0.6)$ & $87.9(1.0)$ & $46.0(1.6)$ & $6.9(0.7)$ & $0.2(0.1)$ & $94.6(0.8)$ & $72.2(1.3)$ & $29.9(1.2)$ & $3.9(0.4)$ \\
\hline 1986 & $95.6(0.6)$ & $70.0(1.3)$ & $25.1(1.4)$ & $2.2(0.5)$ & $90.3(1.2)$ & $47.7(1.7)$ & $6.3(1.1)$ & $0.1(0.1)$ & $96.9(0.5)$ & $79.1(1.7)$ & $34.1(1.5)$ & $4.5(0.8)$ \\
\hline 1990 & $97.1(0.4)$ & $76.4(1.1)$ & $29.1(1.0)$ & $2.0(0.3)$ & $92.0(0.8)$ & $53.3(1.4)$ & $8.5(0.6)$ & $0.2-$ & $96.6(0.6)$ & $79.9(1.4)$ & $38.7(1.7)$ & $5.5(0.5)$ \\
\hline 1992 & $97.1(0.5)$ & 75.7 (1.2) & 28.6 & $2.2(0.3)$ & $93.1(0.7)$ & $59.6(1.4)$ & $9.9(0.8)$ & $0.2-$ & $97.5(0.7)$ & $81.6(1.4)$ & $42.0(1.7)$ & $6.6(1.0)$ \\
\hline 1994 & $97.3(0.5)$ & $77.2(1.4)$ & $32.2(1.5)$ & $3.2(0.4)$ & $92.6(0.6)$ & $57.1(1.4)$ & $8.8(1.0)$ & $0.1-$ & $97.2(1.0)$ & $81.6(1.6)$ & $42.4(1.8)$ & $6.4(0.6)$ \\
\hline 1996 & $96.6(0.6)$ & $75.5(1.0)$ & 30.7 (1.9) & $3.6(0.6)$ & $90.9(1.2)$ & $53.8(1.5)$ & $9.2(0.8)$ & $0.2-$ & $98.1(0.4)$ & $83.7(1.1)$ & 43.9 (1.7) & $7.4(1.0)$ \\
\hline \multicolumn{13}{|l|}{ White, non-Hispanic } \\
\hline $1977 \ldots \ldots$ & $97.7(0.3)$ & $76.8(0.7)$ & $30.8(0.7)$ & $3.9(0.3)$ & $92.2(0.5)$ & $56.5(0.9)$ & $13.4(0.5)$ & $0.8(0.1)$ & $(0.1)$ & $88.2(0.4)$ & $47.5(0.7)$ & $10.0(0.4)$ \\
\hline 1982 & $98.3(0.4)$ & $78.4(2.0)$ & $29.4(2.1)$ & $2.9(0.9)$ & $94.4(0.6)$ & $58.3(1.4)$ & $11.5(0.8)$ & $0.4(0.1)$ & $98.6(0.2)$ & $84.9(0.9)$ & $43.9(1.1)$ & $8.6(0.6)$ \\
\hline 1986 & $98.2(0.3)$ & $78.9(1.0)$ & $32.7(1.5)$ & $3.8(0.6)$ & $96.1(0.8)$ & $61.0(1.7)$ & $11.3(1.2)$ & $0.3(0.1)$ & $98.8(0.3)$ & $87.8(1.4)$ & $48.7(1.7)$ & $9.6(0.9)$ \\
\hline 1990 & $99.2(0.2)$ & $84.4(0.7)$ & $37.5(1.1)$ & $3.9(0.4)$ & $96.9(0.4)$ & $66.5(1.2)$ & $14.2(0.8)$ & $0.5(0.1)$ & $99.0(0.2)$ & $89.6(0.8)$ & $51.2(1.5)$ & $11.4(0.7)$ \\
\hline 1992 & $99.2(0.1)$ & $85.5(0.9)$ & $39.4(1.1)$ & $4.3(0.4)$ & $97.9(0.4)$ & $71.1(1.3)$ & $15.0(1.0)$ & $0.3(0.1)$ & $99.3(0.3)$ & $90.5(1.0)$ & $55.4(1.7)$ & $12.8(0.9)$ \\
\hline 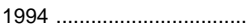 & $99.1(0.3)$ & $85.6(1.0)$ & $40.8(1.5)$ & $4.9(0.6)$ & $97.6(0.4)$ & $70.5(1.1)$ & $14.8(1.0)$ & $0.3(0.1)$ & $99.3(0.3)$ & $91.5(0.9)$ & 57.5 (1.6) & $13.2(1.1)$ \\
\hline ……................ & $98.6(0.3)$ & $83.8(1.2)$ & $39.6(1.5)$ & $5.9(0.5)$ & $97.0(0.5)$ & $68.5(1.2)$ & $15.9(0.8)$ & $0.6(0.2)$ & $99.3(0.3)$ & $91.2(0.7)$ & $58.5(1.6)$ & $13.8(1.4)$ \\
\hline \multicolumn{13}{|l|}{ Black, non-Hispanic } \\
\hline 1977. & $72.4(1.8)$ & $27.2(1.5)$ & $3.5(0.6)$ & $0.2-$ & $57.3(2.4)$ & $14.9(1.7)$ & $1.2(0.4)$ & $0.0-$ & $83.6(1.3)$ & $40.5(1.5)$ & $7.7(1.0)$ & $0.4(0.2)$ \\
\hline 1982 & $82.1(3.0)$ & $38.9(2.7)$ & $3.9(1.3)$ & $0.1-$ & $68.6(2.4)$ & $17.1(1.9)$ & $0.8(0.3)$ & $0.0-$ & $79.7(1.9)$ & $35.0(2.1)$ & $6.5(1.1)$ & $0.2(0.2)$ \\
\hline 1986 & $88.6(1.4)$ & $46.2(2.3)$ & $8.3(1.5)$ & $0.3-$ & $73.6(3.0)$ & $19.6(2.8)$ & $1.1(0.4)$ & $0.0-$ & $90.9(2.1)$ & $52.2(3.2)$ & $12.5(2.2)$ & $0.9(0.6)$ \\
\hline 1990 & $88.0(1.3)$ & $46.4(3.1)$ & $8.5(1.1)$ & $0.1-$ & $77.6(3.6)$ & $24.3(3.3)$ & $1.5(0.5)$ & $0.1-$ & $88.3(1.9)$ & $51.4(3.7)$ & $15.7(4.0)$ & $1.5(0.8)$ \\
\hline 1992 & $90.7(1.8)$ & $51.3(3.5)$ & $9.2(1.4)$ & $0.3-$ & $73.8(2.8)$ & $26.2(2.8)$ & $1.8(0.8)$ & $0.0-$ & $92.1(1.8)$ & $55.7(3.7)$ & $14.1(2.5)$ & $0.8-$ \\
\hline 1994 & 91.0 (1.5) & $51.6(2.3)$ & $11.1(1.4)$ & $0.2-$ & $73.5(3.2)$ & $22.4(4.3)$ & $2.2-$ & $0.0-$ & $91.1(1.9)$ & $58.1(3.7)$ & $15.4(2.3)$ & $0.5(0.3)$ \\
\hline 1996 & $91.0(1.6)$ & $52.2(3.4)$ & $10.6(2.0)$ & $0.3-$ & $75.9(2.7)$ & $25.5(2.2)$ & $1.9(0.9)$ & $0.0-$ & $93.0(1.2)$ & $59.8(3.2)$ & $17.7(2.7)$ & $0.8(0.5)$ \\
\hline Hispanic & & & & & & & & & & & & \\
\hline 1977 & $84.6(1.8)$ & $42.0(3.1)$ & $8.8(1.7)$ & $0.3-$ & $62.2(2.4)$ & $18.1(1.8)$ & $1.8(0.8)$ & $0.0-$ & $93.1(1.7)$ & $61.5(1.7)$ & $18.5(2.1)$ & $1.8(0.6)$ \\
\hline 1982 & $85.1(3.1)$ & $40.2(6.1)$ & $4.2(2.7)$ & $0.0-$ & 75.5 (3.3) & $24.1(5.1)$ & $2.4(0.9)$ & $0.0-$ & $86.9(2.9)$ & $48.0(2.7)$ & $11.1(2.0)$ & $1.4(0.9)$ \\
\hline 1986 & $89.6(2.4)$ & 50.1 (3.7) & $10.7(2.4)$ & $0.2-$ & $76.7(3.2)$ & 24.9 (4.3) & $1.5(0.7)$ & $0.0-$ & $93.3(2.4)$ & $60.0(7.2)$ & $14.8(2.9)$ & $1.1(0.7)$ \\
\hline 1990 & $93.6(1.5)$ & $56.3(3.7)$ & $11.6(2.1)$ & $0.4-$ & $80.2(2.9)$ & $30.0(2.8)$ & $3.3(0.8)$ & $0.1-$ & $91.9(2.2)$ & $59.9(5.0)$ & $21.1(3.3)$ & $2.1-$ \\
\hline 1992 & $92.4(1.7)$ & $55.5(4.3)$ & $11.7(1.8)$ & $0.4-$ & $86.2(2.6)$ & $36.5(2.9)$ & $3.3(1.3)$ & $0.0-$ & $94.6(2.6)$ & $68.3(6.6)$ & $23.0(3.8)$ & $2.5(1.2)$ \\
\hline 1994 & $91.1(2.3)$ & $49.9(3.1)$ & $10.8(2.5)$ & $0.7(0.5)$ & $81.2(2.5)$ & $31.6(3.3)$ & $2.4(0.9)$ & $0.0-$ & 89.9 (3.3) & $58.6(7.4)$ & $21.7(4.1)$ & $1.5(0.7)$ \\
\hline $1996 \ldots \ldots \ldots . .$. & $92.6(1.9)$ & $57.8(3.1)$ & $13.1(3.1)$ & $0.4-$ & $81.0(2.8)$ & $30.9(3.3)$ & $3.2(1.0)$ & $0.0-$ & $94.1(1.6)$ & $67.6(4.5)$ & $23.9(2.5)$ & $3.0(1.4)$ \\
\hline & & & & & & & & & & & & \\
\hline 197 & $93.0(0.7)$ & $66.4(1.3)$ & $24.5(0.9)$ & $2.9(0.3)$ & $84.9(0.8)$ & $46.7(1.2)$ & $10.2(0.5)$ & $0.6(0.1)$ & $97.0(0.2)$ & $80.8(0.7)$ & $40.5(0.8)$ & $8.1(0.4)$ \\
\hline 1982 & $94.9(0.8)$ & $69.5(2.1)$ & $23.9(2.1)$ & $2.3(0.7)$ & $89.2(0.9)$ & $49.2(1.8)$ & $8.9(0.8)$ & $0.3(0.1)$ & $95.4(0.6)$ & $75.8(1.0)$ & $36.6(0.9)$ & $6.9(0.4)$ \\
\hline 1986 & $95.8(0.4)$ & 70.5 (1.3) & $26.3(1.5)$ & $2.8(0.6)$ & $91.3(1.0)$ & $51.9(1.7)$ & $8.9(0.9)$ & $0.2(0.1)$ & $97.0(0.5)$ & $80.1(1.4)$ & $39.9(1.5)$ & $7.2(0.7)$ \\
\hline 1990 & $96.7(0.4)$ & $75.5(1.0)$ & $30.3(0.8)$ & $3.0(0.4)$ & $91.6(0.8)$ & $54.7(1.2)$ & $10.7(0.7)$ & $0.4(0.1)$ & $96.5(0.4)$ & $80.4(0.9)$ & 42.0 (1.3) & $8.7(0.5)$ \\
\hline 1992 & $97.1(0.4)$ & $76.7(1.3)$ & $31.5(1.0)$ & $3.2(0.3)$ & $92.7(0.5)$ & $60.2(1.2)$ & $11.9(0.9)$ & $0.3(0.1)$ & $97.5(0.5)$ & $82.0(1.2)$ & $44.8(1.5)$ & $9.6(0.8)$ \\
\hline 1994 & $96.9(0.4)$ & 76.1 (1.2) & 32.5 & $3.6(0.5)$ & $91.9(0.6)$ & $57.8(1.2)$ & $11.3(0.9)$ & $0.2(0.1)$ & $96.8(0.7)$ & $81.7(1.3)$ & $45.3(1.1)$ & $9.4(0.5)$ \\
\hline 1996. & $96.7(0.5)$ & $75.3(1.3)$ & $30.9(1.4)$ & $4.1(0.3)$ & $91.5(0.8)$ & $56.0(1.3)$ & $11.5(0.8)$ & $0.4(0.2)$ & $97.7(0.4)$ & $83.2(1.0)$ & 47.7 (1.3) & $10.5(1.0)$ \\
\hline ate & & & & & & & & & & & & \\
\hline 1977 & $98.1(0.6)$ & $80.3(1.7)$ & $35.6(1.9)$ & $5.1(1.1)$ & $95.7(1.0)$ & $68.8(2.6)$ & $19.6(1.9)$ & $1.6(0.3)$ & $99.5(0.2)$ & $92.9(1.2)$ & $58.9(2.8)$ & $14.8(1.9)$ \\
\hline 1982 & $98.9-$ & $82.6(3.5)$ & $28.2(5.6)$ & $2.1(1.2)$ & $95.0(1.5)$ & $65.8(4.1)$ & $16.0(2.4)$ & $0.8(0.5)$ & $97.9(0.7)$ & $83.5(2.8)$ & $44.2(2.6)$ & $8.5(2.3)$ \\
\hline ………… & $98.2(0.7)$ & $79.7(2.3)$ & $33.8(2.8)$ & $4.0(0.7)$ & $97.3(1.8)$ & $66.8(8.2)$ & $12.8(3.6)$ & $0.3-$ & $99.8-$ & $96.5(2.2)$ & $74.6(10.9)$ & 23.1 (7.7) \\
\hline 1990 & $98.7-$ & $83.6(2.4)$ & $37.2(3.0)$ & $3.9(1.0)$ & $98.4(0.8)$ & $72.0(2.6)$ & $16.2(1.5)$ & $0.5-$ & $99.5-$ & $90.6(4.1)$ & $59.8(6.7)$ & 15.8 (3.2) \\
\hline $1992 .$. & $99.2-$ & $86.2(2.0)$ & $40.6(3.4)$ & $4.6(1.3)$ & $96.4(1.1)$ & $68.9(3.1)$ & $13.2(2.0)$ & $0.1-$ & $100.0-$ & $95.5(2.0)$ & $63.1(5.3)$ & $14.1(2.7)$ \\
\hline (1) & $99.3(0.4)$ & $87.1(2.4)$ & $42.7(2.8)$ & $5.6(1.0)$ & $96.5(1.4)$ & $72.7(3.2)$ & $15.5(2.6)$ & $0.1-$ & $99.3(0.4)$ & $93.1(2.3)$ & $62.7(5.2)$ & $14.8(4.0)$ \\
\hline 1996. & $97.2(1.2)$ & $81.6(3.2)$ & 41.1 (3.7) & $6.5(2.2)$ & $96.0(2.1)$ & $70.6(5.4)$ & $18.2(3.0)$ & $1.0-$ & $99.0-$ & $90.1(3.0)$ & $56.3(7.0)$ & $13.0(3.1)$ \\
\hline
\end{tabular}

1 As measured by the National Assessment of Educational Progress (NAEP).

2 Virtually no students were able to integrate specialized scientific information.

3 Virtually all students knew everyday science facts. Data exclude persons not enrolled in school.

${ }^{4}$ Scale score of 150 or above.

${ }^{5}$ Scale score of 200 or above.

${ }^{6}$ Scale score of 250 or above.

7 Scale score of 300 or above.
8 Scale score of 350 or above.

—Data not available or not applicable.

NOTE.-Standard errors appear in parentheses.

SOURCE: U.S. Department of Education, National Assessment of Educational Progress, NAEP 1996 Trends in Academic Progress, prepared by Educational Testing Service. (This table was prepared September 1998.) 
Table 127.-Average proficiency in science for 8th-graders in public schools, by selected characteristics and state: 1996

\begin{tabular}{|c|c|c|c|c|c|c|c|c|c|c|c|c|}
\hline \multirow[b]{2}{*}{ State } & \multirow[b]{2}{*}{ Average } & \multicolumn{5}{|c|}{ Race/ethnicity } & \multicolumn{2}{|c|}{ Sex } & \multicolumn{4}{|c|}{ Parental education ${ }^{1}$} \\
\hline & & White & Black & Hispanic & Asian & $\begin{array}{l}\text { Amer- } \\
\text { ican In- } \\
\text { dian }\end{array}$ & Male & Female & $\begin{array}{l}\text { Did not } \\
\text { finish } \\
\text { high } \\
\text { school }\end{array}$ & $\begin{array}{l}\text { Grad- } \\
\text { uated } \\
\text { high } \\
\text { school }\end{array}$ & $\begin{array}{l}\text { Some } \\
\text { edu- } \\
\text { cation } \\
\text { after } \\
\text { high } \\
\text { school }\end{array}$ & $\begin{array}{l}\text { Grad- } \\
\text { uated } \\
\text { college }\end{array}$ \\
\hline 1 & 2 & 3 & 4 & 5 & 6 & 7 & 8 & 9 & 10 & 11 & 12 & 13 \\
\hline United States & 148 & 159 & 120 & 127 & 150 & 148 & 149 & 148 & 131 & 140 & 155 & 157 \\
\hline $\begin{array}{l}\text { Alabama } \\
\text { Alaska }^{3} \\
\text { Arizona }^{2} \\
\text { Arkansas }^{3} \\
\text { California }\end{array}$ & $\begin{array}{l}139 \\
153 \\
145 \\
144 \\
138\end{array}$ & $\begin{array}{l}151 \\
162 \\
157 \\
154 \\
156\end{array}$ & $\begin{array}{r}117 \\
\left({ }^{2}\right) \\
124 \\
116 \\
121\end{array}$ & $\begin{array}{l}107 \\
137 \\
129 \\
122 \\
121\end{array}$ & $\begin{array}{r}(2) \\
152 \\
(2) \\
(2) \\
148\end{array}$ & $\begin{array}{r}(2) \\
129 \\
121 \\
(2) \\
(2)\end{array}$ & $\begin{array}{l}138 \\
155 \\
147 \\
147 \\
140\end{array}$ & $\begin{array}{l}139 \\
150 \\
143 \\
142 \\
136\end{array}$ & $\begin{array}{r}130 \\
(2) \\
121 \\
129 \\
118\end{array}$ & $\begin{array}{l}129 \\
141 \\
136 \\
136 \\
129\end{array}$ & $\begin{array}{l}145 \\
155 \\
151 \\
150 \\
144\end{array}$ & $\begin{array}{l}147 \\
163 \\
158 \\
154 \\
153\end{array}$ \\
\hline 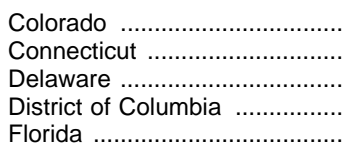 & $\begin{array}{l}155 \\
155 \\
142 \\
113 \\
142\end{array}$ & $\begin{array}{r}162 \\
165 \\
152 \\
(2) \\
155\end{array}$ & $\begin{array}{l}142 \\
121 \\
122 \\
112 \\
119\end{array}$ & $\begin{array}{r}135 \\
122 \\
116 \\
98 \\
129\end{array}$ & $\begin{array}{r}155 \\
163 \\
(2) \\
(2) \\
(2)\end{array}$ & $\begin{array}{r}142 \\
(2) \\
(2) \\
(2) \\
(2)\end{array}$ & $\begin{array}{l}156 \\
156 \\
143 \\
113 \\
144\end{array}$ & $\begin{array}{l}153 \\
155 \\
140 \\
113 \\
140\end{array}$ & $\begin{array}{l}133 \\
129 \\
121 \\
106 \\
127\end{array}$ & $\begin{array}{l}142 \\
140 \\
135 \\
107 \\
132\end{array}$ & $\begin{array}{l}157 \\
155 \\
146 \\
120 \\
148\end{array}$ & $\begin{array}{l}163 \\
167 \\
151 \\
121 \\
150\end{array}$ \\
\hline $\begin{array}{l}\text { Georgia } \\
\text { Hawaii } \\
\text { Indiana } \\
\text { lowa }^{3} \\
\text { Kentucky }\end{array}$ & $\begin{array}{l}142 \\
135 \\
153 \\
158 \\
147\end{array}$ & $\begin{array}{l}155 \\
146 \\
158 \\
160 \\
151\end{array}$ & $\begin{array}{l}122 \\
128 \\
125 \\
131 \\
127\end{array}$ & $\begin{array}{l}128 \\
121 \\
139 \\
140 \\
113\end{array}$ & $\begin{array}{r}(2) \\
138 \\
(2) \\
(2) \\
(2)\end{array}$ & $\begin{array}{l}(2) \\
(2) \\
(2) \\
(2) \\
(2)\end{array}$ & $\begin{array}{l}144 \\
135 \\
154 \\
159 \\
148\end{array}$ & $\begin{array}{l}139 \\
135 \\
152 \\
157 \\
147\end{array}$ & $\begin{array}{l}127 \\
119 \\
139 \\
141 \\
130\end{array}$ & $\begin{array}{l}129 \\
120 \\
144 \\
150 \\
143\end{array}$ & $\begin{array}{l}145 \\
139 \\
156 \\
160 \\
151\end{array}$ & $\begin{array}{l}153 \\
147 \\
162 \\
165 \\
158\end{array}$ \\
\hline $\begin{array}{l}\text { Louisiana } \\
\text { Maine } \\
\text { Maryland }^{3} \text {. } \\
\text { Massachusetts } \\
\text { Michigan }\end{array}$ & $\begin{array}{l}132 \\
163 \\
145 \\
157 \\
153\end{array}$ & $\begin{array}{l}148 \\
164 \\
160 \\
163 \\
161\end{array}$ & $\begin{array}{r}113 \\
(2) \\
124 \\
126 \\
122\end{array}$ & $\begin{array}{l}104 \\
141 \\
121 \\
126 \\
134\end{array}$ & $\begin{array}{r}(2) \\
(2) \\
161 \\
152 \\
(2)\end{array}$ & $\begin{array}{l}(2) \\
(2) \\
(2) \\
(2) \\
(2)\end{array}$ & $\begin{array}{l}136 \\
165 \\
146 \\
159 \\
156\end{array}$ & $\begin{array}{l}129 \\
161 \\
145 \\
154 \\
150\end{array}$ & $\begin{array}{l}123 \\
141 \\
126 \\
134 \\
137\end{array}$ & $\begin{array}{l}128 \\
153 \\
136 \\
145 \\
144\end{array}$ & $\begin{array}{l}141 \\
164 \\
147 \\
156 \\
156\end{array}$ & $\begin{array}{l}136 \\
171 \\
153 \\
166 \\
161\end{array}$ \\
\hline $\begin{array}{l}\text { Minnesota } \\
\text { Mississippi } \\
\text { Missouri } \\
\text { Montana } \\
\text { Nebraska }\end{array}$ & $\begin{array}{l}159 \\
133 \\
151 \\
162 \\
157\end{array}$ & $\begin{array}{l}162 \\
149 \\
158 \\
166 \\
161\end{array}$ & $\begin{array}{r}130 \\
119 \\
120 \\
(2) \\
130\end{array}$ & $\begin{array}{l}134 \\
105 \\
130 \\
147 \\
134\end{array}$ & $\begin{array}{r}152 \\
(2) \\
(2) \\
(2) \\
(2)\end{array}$ & $\begin{array}{r}(2) \\
(2) \\
(2) \\
139 \\
(2)\end{array}$ & $\begin{array}{l}161 \\
134 \\
152 \\
164 \\
160\end{array}$ & $\begin{array}{l}157 \\
132 \\
150 \\
160 \\
155\end{array}$ & $\begin{array}{l}137 \\
125 \\
136 \\
139 \\
133\end{array}$ & $\begin{array}{l}151 \\
126 \\
144 \\
155 \\
148\end{array}$ & $\begin{array}{l}161 \\
142 \\
156 \\
164 \\
161\end{array}$ & $\begin{array}{l}165 \\
138 \\
159 \\
168 \\
165\end{array}$ \\
\hline $\begin{array}{l}\text { New Mexico } \\
\text { New York }{ }^{3} \\
\text { North Carolina } \\
\text { North Dakota } \\
\text { Oregon }\end{array}$ & $\begin{array}{l}141 \\
146 \\
147 \\
162 \\
155\end{array}$ & $\begin{array}{l}159 \\
161 \\
157 \\
164 \\
158\end{array}$ & $\begin{array}{r}\left({ }^{2}\right) \\
120 \\
126 \\
(2) \\
(2)\end{array}$ & $\begin{array}{l}130 \\
116 \\
123 \\
137 \\
133\end{array}$ & $\begin{array}{r}(2) \\
155 \\
(2) \\
(2) \\
157\end{array}$ & $\begin{array}{r}126 \\
(2) \\
136 \\
137 \\
142\end{array}$ & $\begin{array}{l}143 \\
148 \\
149 \\
163 \\
157\end{array}$ & $\begin{array}{l}139 \\
143 \\
145 \\
161 \\
153\end{array}$ & $\begin{array}{l}119 \\
123 \\
126 \\
148 \\
137\end{array}$ & $\begin{array}{l}131 \\
138 \\
134 \\
157 \\
143\end{array}$ & $\begin{array}{l}147 \\
147 \\
150 \\
160 \\
157\end{array}$ & $\begin{array}{l}154 \\
157 \\
158 \\
167 \\
164\end{array}$ \\
\hline $\begin{array}{l}\text { Rhode Island } \\
\text { South Carolina }{ }^{3} \\
\text { Tennessee } \\
\text { Texas }\end{array}$ & $\begin{array}{l}149 \\
139 \\
143 \\
145 \\
156\end{array}$ & $\begin{array}{l}155 \\
153 \\
151 \\
161 \\
159\end{array}$ & $\begin{array}{r}130 \\
122 \\
117 \\
127 \\
\left.{ }^{2}\right)\end{array}$ & $\begin{array}{l}118 \\
122 \\
104 \\
129 \\
133\end{array}$ & $\begin{array}{r}142 \\
(2) \\
(2) \\
157 \\
143\end{array}$ & $\begin{array}{l}(2) \\
(2) \\
(2) \\
(2) \\
(2)\end{array}$ & $\begin{array}{l}150 \\
141 \\
144 \\
147 \\
159\end{array}$ & $\begin{array}{l}148 \\
136 \\
142 \\
143 \\
154\end{array}$ & $\begin{array}{l}123 \\
125 \\
127 \\
128 \\
129\end{array}$ & $\begin{array}{l}141 \\
127 \\
135 \\
137 \\
147\end{array}$ & $\begin{array}{l}154 \\
145 \\
149 \\
152 \\
156\end{array}$ & $\begin{array}{l}160 \\
148 \\
154 \\
157 \\
162\end{array}$ \\
\hline 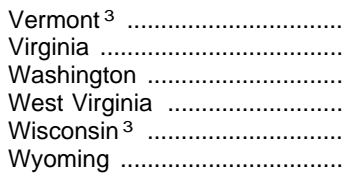 & $\begin{array}{l}157 \\
149 \\
150 \\
147 \\
160 \\
158\end{array}$ & $\begin{array}{l}159 \\
158 \\
156 \\
149 \\
165 \\
161\end{array}$ & $\begin{array}{r}(2) \\
126 \\
127 \\
127 \\
115 \\
(2)\end{array}$ & $\begin{array}{l}136 \\
132 \\
125 \\
122 \\
141 \\
140\end{array}$ & $\begin{array}{r}(2) \\
165 \\
149 \\
(2) \\
(2) \\
(2)\end{array}$ & $\begin{array}{r}(2) \\
(2) \\
130 \\
(2) \\
(2) \\
138\end{array}$ & $\begin{array}{l}158 \\
150 \\
152 \\
148 \\
161 \\
159\end{array}$ & $\begin{array}{l}156 \\
148 \\
147 \\
147 \\
158 \\
156\end{array}$ & $\begin{array}{l}132 \\
127 \\
128 \\
130 \\
140 \\
139\end{array}$ & $\begin{array}{l}146 \\
136 \\
141 \\
142 \\
155 \\
150\end{array}$ & $\begin{array}{l}157 \\
152 \\
154 \\
152 \\
161 \\
159\end{array}$ & $\begin{array}{l}167 \\
161 \\
158 \\
156 \\
169 \\
165\end{array}$ \\
\hline $\begin{array}{l}\text { Department of Defense } \\
\text { Overseas Schools } \\
\text { Guam }\end{array}$ & $\begin{array}{l}155 \\
120\end{array}$ & $\begin{array}{l}164 \\
138\end{array}$ & $\begin{array}{r}140 \\
\left.{ }^{2}\right)\end{array}$ & $\begin{array}{l}146 \\
106\end{array}$ & $\begin{array}{l}156 \\
122\end{array}$ & $\begin{array}{l}(2) \\
(2)\end{array}$ & $\begin{array}{l}157 \\
120\end{array}$ & $\begin{array}{l}154 \\
120\end{array}$ & $\begin{array}{r}\left({ }^{2}\right) \\
106\end{array}$ & $\begin{array}{l}144 \\
113\end{array}$ & $\begin{array}{l}159 \\
130\end{array}$ & $\begin{array}{l}158 \\
128\end{array}$ \\
\hline
\end{tabular}

1 Parents' highest level of education. Data not shown for students who did not know parents' level of education.

${ }^{3}$ Did not satisfy one or more of the guidelines for school sample participation rates. Data are subject to appreciable nonresponse bias.

NOTE.-These test scores are from the National Assessment of Educational Progress (NAEP). The NAEP scores have been evaluated at certain performance levels. Scale ranges from 0 to 300 . Excludes states not participating in the survey. Some data have been revised from previously published figures.

SOURCE: U.S. Department of Education, National Center for Education Statistics, National Assessment of Educational Progress, NAEP 1996 Science Report Card for the $\mathrm{Na}$ tion and the States, prepared by Educational Testing Service. (This table was prepared June 1997.) 
Table 128.-Average science proficiency, by age and by selected characteristics of students: 1970 to 1996

\begin{tabular}{|c|c|c|c|c|c|c|c|c|c|}
\hline Selected characteristics of students & 1970 & 1973 & 1977 & 1982 & 1986 & 1990 & 1992 & 1994 & 1996 \\
\hline \multirow[t]{2}{*}{1} & 2 & 3 & 4 & 5 & 6 & 7 & 8 & 9 & 10 \\
\hline & \multicolumn{9}{|c|}{9 -year-olds ${ }^{1}$} \\
\hline Total & $225(1.2)$ & $220(1.2)$ & $220(1.2)$ & $221(1.8)$ & $224(1.2)$ & $229(0.8)$ & $231(1.0)$ & $231(1.2)$ & $230(1.2)$ \\
\hline Male . & $228(1.3)$ & $223(1.3)$ & $222(1.3)$ & $221(2.3)$ & $227(1.4)$ & $230(1.1)$ & $235(1.2)$ & $232(1.3)$ & $231(1.7)$ \\
\hline \multirow{2}{*}{\multicolumn{6}{|c|}{ Race/ethnicity }} & $227(1.0)$ & $227(1.0)$ & $230(1.4)$ & $228(1.5)$ \\
\hline & & & & $229(1.9)$ & $232(1.2)$ & $238(0.8)$ & $239(1.0)$ & $240(1.3)$ & $239(1.4)$ \\
\hline Black, non-Hispanic & $179(1.9)$ & $177(1.9)$ & $175(1.8)$ & $187(3.0)$ & $196(1.9)$ & $196(2.0)$ & $200(2.7)$ & $201(1.7)$ & $202(3.0)$ \\
\hline Hispanic ........................ & -- & -- & $192(2.7)$ & $189(4.2)$ & $199(3.1)$ & $206(2.2)$ & $205(2.8)$ & $201(2.7)$ & $207(2.8)$ \\
\hline \multicolumn{10}{|l|}{ Parental education } \\
\hline & -- & -- & $199(2.2)$ & $198(6.0)$ & $204(2.9)$ & $210(2.7)$ & $217(2.6)$ & $211(3.4)$ & $210(2.9)$ \\
\hline $\begin{array}{l}\text { Graduated high school .................................. } \\
\text { Some college }\end{array}$ & -- & -- & $223(1.4)$ & $218(3.3)$ & $\begin{array}{l}220(1.5) \\
236(2.6)\end{array}$ & $226(1.7)$ & $222(1.9)$ & $225(1.4)$ & $\begin{array}{l}222(2.3) \\
242(29)\end{array}$ \\
\hline & -- & -- & $237(1.5)$ & 229 (3.2) & $236(2.6)$ & $238(2.1)$ & $237(2.4)$ & $239(2.8)$ & $242(2.9)$ \\
\hline & $239(1.4)$ & \\
\hline Public ………………… & -- & -- & $218(1.4)$ & $220(2.0)$ & $223(1.4)$ & $228(0.9)$ & $229(1.0)$ & $230(1.4)$ & $228(1.3)$ \\
\hline \multirow{2}{*}{\multicolumn{10}{|c|}{ Region }} \\
\hline & & & & & & & & & \\
\hline Northeast .... & $230(2.9)$ & $222(2.9)$ & $224(1.6)$ & $222(2.9)$ & $228(3.5)$ & $231(2.4)$ & $234(2.8)$ & $235(2.5)$ & $234(2.6)$ \\
\hline Southeast ... & $206(1.6)$ & $207(1.6)$ & $205(2.9)$ & $214(3.6)$ & $219(3.1)$ & $220(1.9)$ & $223(1.7)$ & $227(2.2)$ & $224(3.4)$ \\
\hline Central & $233(3.0)$ & $228(3.0)$ & $225(2.2)$ & 226 (3.5) & $228(2.2)$ & $234(1.7)$ & $238(1.8)$ & $236(2.7)$ & $234(2.4)$ \\
\hline \multirow[t]{2}{*}{ 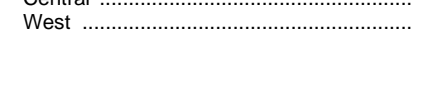 } & $226(2.2)$ & $221(2.2)$ & $221(2.2)$ & $220(4.1)$ & $222(3.2)$ & $230(1.8)$ & $227(2.2)$ & $226(2.7)$ & $228(1.9)$ \\
\hline & \multicolumn{9}{|c|}{ 13-year-olds 1} \\
\hline Total . & $255(1.1)$ & $250(1.1)$ & 247 (1.1) & $250(1.3)$ & $251(1.4)$ & $255(0.9)$ & $258(0.8)$ & $257(1.0)$ & $256(1.0)$ \\
\hline Male & $257(1.3)$ & $252(1.3)$ & $251(1.3)$ & $256(1.5)$ & $256(1.6)$ & $259(1.1)$ & $260(1.2)$ & $259(1.2)$ & $260(1.0)$ \\
\hline \multirow{2}{*}{\multicolumn{10}{|c|}{ Race/ethnicity }} \\
\hline & & & & & & & & & \\
\hline White, non-Hispanic & $263(0.8)$ & $259(0.8)$ & $256(0.8)$ & $257(1.1)$ & $259(1.4)$ & $264(0.9)$ & $267(1.0)$ & $267(1.0)$ & $266(1.1)$ \\
\hline Black, non-Hispanic . & $215(2.4)$ & $205(2.4)$ & $208(2.4)$ & 217 (1.3) & $222(2.5)$ & $226(3.1)$ & $224(2.7)$ & $224(4.2)$ & $226(2.1)$ \\
\hline Hispanic .. & -- & -- & $213(1.9)$ & $226(3.9)$ & $226(3.1)$ & $232(2.6)$ & $238(2.6)$ & $232(2.4)$ & $232(2.5)$ \\
\hline \multicolumn{10}{|l|}{ Parental education } \\
\hline Not high school graduate & -- & -- & $224(1.3)$ & $225(1.9)$ & $229(2.7)$ & $233(2.1)$ & $234(2.9)$ & $234(2.5)$ & $230(3.1)$ \\
\hline Graduated high school ... & -- & -- & $245(1.1)$ & $243(1.3)$ & $245(1.4)$ & $247(1.3)$ & $246(1.4)$ & $247(1.2)$ & $248(1.7)$ \\
\hline Some college ..................... & $-\overline{-}$ & $-\overline{-}$ & $260(1.3)$ & $259(1.5)$ & $258(1.4)$ & $\begin{array}{l}263(1.2) \\
263(1 .)\end{array}$ & $266(1.1)$ & $260(2.0)$ & $261(1.4)$ \\
\hline Graduated college ......... & -- & -- & $266(1.0)$ & $264(1.5)$ & $264(1.9)$ & $268(1.1)$ & $269(1.0)$ & $269(1.3)$ & $266(1.2)$ \\
\hline \multicolumn{10}{|l|}{ Type of school } \\
\hline 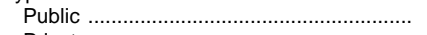 & -- & -- & $245(1.2)$ & $249(1.4)$ & $251(1.4)$ & $254(1.1)$ & $257(1.0)$ & $255(1.1)$ & $254(1.1)$ \\
\hline Private …………………. & -- & -- & $268(2.1)$ & $264(3.2)$ & $263(6.4)$ & $269(1.8)$ & $265(2.4)$ & $268(2.6)$ & $268(5.0)$ \\
\hline \multicolumn{10}{|l|}{ Region } \\
\hline Northeast .... & $261(2.2)$ & $256(2.2)$ & $255(2.3)$ & $254(2.1)$ & $258(3.1)$ & $257(2.7)$ & $257(2.2)$ & $263(1.7)$ & $255(3.0)$ \\
\hline Southeast ........ & $239(2.4)$ & $237(2.4)$ & $235(1.8)$ & $239(2.3)$ & $247(2.2)$ & $251(1.9)$ & & & $251(2.7)$ \\
\hline \multirow{3}{*}{ 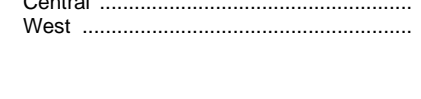 } & $262(1.8)$ & $256(1.8)$ & $254(1.8)$ & $254(2.6)$ & $249(5.3)$ & $260(2.8)$ & $263(2.1)$ & $261(3.5)$ & $266(1.8)$ \\
\hline & $255(1.8)$ & $248(1.8)$ & $243(2.3)$ & $252(2.8)$ & $252(2.7)$ & $253(2.1)$ & $258(1.6)$ & $252(2.1)$ & $254(1.8)$ \\
\hline & & & & & -year-olds 1 & & & & \\
\hline Total & $305(1.0)$ & $296(1.0)$ & $290(1.0)$ & $283(1.2)$ & $289(1.4)$ & $290(1.1)$ & $294(1.3)$ & $294(1.6)$ & $296(1.2)$ \\
\hline Male & $314(1.2)$ & $304(1.2)$ & $297(1.2)$ & $292(1.4)$ & $295(1.9)$ & $296(1.3)$ & $299(1.7)$ & $300(2.0)$ & $300(1.6)$ \\
\hline Female & $297(1.1)$ & $288(1.1)$ & $282(1.1)$ & $275(1.3)$ & $282(1.5)$ & $285(1.6)$ & $289(1.5)$ & $289(1.7)$ & $292(1.4)$ \\
\hline Race/t & & & & & & & & & \\
\hline Hispanic .. & $312(0.8)$ & $304(0.8)$ & $298(0.7)$ & $293(1.0)$ & 298 & 301 & $304(1.3)$ & $306(1.5)$ & $307(1.2)$ \\
\hline -Hispanic ... & $258(1.5)$ & $250(1.5)$ & $240(1.5)$ & $235(1.7)$ & $253(2.9)$ & $253(4.5)$ & $256(3.2)$ & $257(3.1)$ & $260(2.4)$ \\
\hline Hispanic & -- & -- & $262(2.2)$ & $249(2.3)$ & $259(3.8)$ & $262(4.4)$ & $270(5.6)$ & $261(6.7)$ & $269(3.3)$ \\
\hline Parental education & & & & & & & & & \\
\hline Not high school graduate. & -- & -- & 265 (1.3) & $259(2.4)$ & $258(3.1)$ & $261(2.8)$ & $262(3.8)$ & $256(4.2)$ & $259(4.0)$ \\
\hline igh school. & -- & -- & $284(0.8)$ & 275 (1.6) & $277(2.0)$ & $276(1.4)$ & & $279(1.7)$ & $282(2.5)$ \\
\hline & -- & -- & 296 & $290(1.7)$ & $295(2.5)$ & $297(1.6)$ & & $295(1.9)$ & $297(1.9)$ \\
\hline Graduated college .................. & -- & -- & $309(1.0)$ & $300(1.7)$ & $304(2.1)$ & $306(1.7)$ & $308(1.3)$ & $311(1.6)$ & $308(1.5)$ \\
\hline Type of school & & & & & & & & & \\
\hline Public ... & -- & -- & $288(1.0)$ & $282(1.1)$ & $287(1.6)$ & $289(1.1)$ & $292(1.3)$ & $292(1.5)$ & $295(1.2)$ \\
\hline Private . & 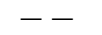 & -- & $308(2.4)$ & $292(2.9)$ & $321(10.1)$ & $308(6.6)$ & $312(3.7)$ & $310(4.8)$ & $304(5.5)$ \\
\hline Regio & & & & & & & & & \\
\hline east & $308(2.5)$ & $298(2.5)$ & $296(2.2)$ & $284(2.0)$ & $292(4.3)$ & $293(3.2)$ & $300(2.4)$ & $299(4.2)$ & $296(3.3)$ \\
\hline 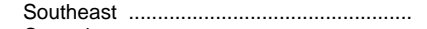 & $287(2.3)$ & $283(2.3)$ & 276 (1.9) & $276(2.7)$ & $284(2.0)$ & $284(2.4)$ & $283(2.5)$ & $288(2.8)$ & $288(3.1)$ \\
\hline 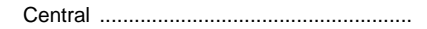 & $308(1.9)$ & $300(1.9)$ & $294(1.5)$ & $289(2.6)$ & $294(2.3)$ & $300(3.0)$ & $304(2.7)$ & $298(3.7)$ & $307(2.6)$ \\
\hline West ... & $308(1.7)$ & $295(1.7)$ & $287(1.5)$ & $281(2.7)$ & $283(3.8)$ & $286(2.3)$ & $290(3.8)$ & $292(4.1)$ & $292(2.4)$ \\
\hline
\end{tabular}

${ }^{1}$ Excludes persons not enrolled in school.

-Data not available.

NOTE.-These test scores are from the National Assessment of Educational Progress (NAEP). Performers at the 150 level know some general scientific facts of the type that could be learned from everyday experiences. Performers at the 200 level are developing some understanding of simple scientific principles, particularly in the life sciences. Performers at the 250 level can interpret data from simple tables and make inferences about the outcomes of experimental procedures. They exhibit knowledge and understanding of the outcomes of experimental procedures. They exhibit knowledge and understanding of physical sciences. Performers at the 300 level can evaluate the appropriateness of the design of an experiment and have the skill to apply their scientific knowledge in interpret- ing information from text and graphs. These students also exhibit a growing understanding of principles from the physical sciences. Performers at the 350 level can infer relationships and draw conclusions using detailed scientific knowledge from the physical sciences, particularly chemistry. They also can apply basic principles of genetics and interpret the societal implications of research in this field. Scale ranges from 0 to 500 . Standard errors appear in parentheses.

SOURCE: U.S. Department of Education, National Center for Education Statistics, National Assessment of Educational Progress, NAEP 1996 Trends in Academic Progress (addendum), prepared by Educational Testing Service. (This table was prepared September 1998.) 
Table 129.-Twelfth graders' achievement on history, mathematics, reading, and science tests: 1992

\begin{tabular}{|c|c|c|c|c|c|c|c|c|c|c|c|c|c|c|}
\hline \multirow[b]{2}{*}{ Achievement test } & \multirow[b]{2}{*}{ Total } & \multicolumn{2}{|c|}{ Sex } & \multicolumn{5}{|c|}{ Race/ethnicity } & \multicolumn{3}{|c|}{ Socioeconomic status ${ }^{1}$} & \multicolumn{3}{|c|}{ Control of school } \\
\hline & & Male & Female & White & Black & Hispanic & Asian & $\begin{array}{c}\text { American } \\
\text { Indian }\end{array}$ & Low & Middle & High & Public & Catholic & $\begin{array}{c}\text { Other } \\
\text { private }\end{array}$ \\
\hline 1 & 2 & 3 & 4 & 5 & 6 & 7 & 8 & 9 & 10 & 11 & 12 & 13 & 14 & 15 \\
\hline \multirow{3}{*}{$\begin{array}{l}\text { History } \\
\text { Mathematics } \\
\text { Reading } \\
\text { Science }\end{array}$} & \multicolumn{14}{|c|}{ Twelfth graders' achievement, standardized score ${ }^{2}$} \\
\hline & $\begin{array}{l}51.2 \\
51.4 \\
51.0 \\
51.1\end{array}$ & $\begin{array}{l}51.9 \\
51.8 \\
49.9 \\
52.4\end{array}$ & $\begin{array}{l}50.5 \\
51.0 \\
52.2 \\
49.7\end{array}$ & $\begin{array}{l}52.5 \\
52.9 \\
52.4 \\
52.9\end{array}$ & $\begin{array}{l}45.9 \\
44.8 \\
45.5 \\
43.3\end{array}$ & $\begin{array}{l}47.4 \\
47.3 \\
47.2 \\
46.5\end{array}$ & $\begin{array}{l}52.1 \\
54.3 \\
51.4 \\
51.8\end{array}$ & $\begin{array}{l}44.5 \\
45.2 \\
45.2 \\
44.8\end{array}$ & $\begin{array}{l}45.8 \\
45.5 \\
45.9 \\
45.4\end{array}$ & $\begin{array}{l}50.5 \\
50.6 \\
50.4 \\
50.5\end{array}$ & $\begin{array}{l}55.9 \\
56.7 \\
55.5 \\
55.9\end{array}$ & $\begin{array}{l}50.8 \\
50.9 \\
50.6 \\
50.7\end{array}$ & $\begin{array}{l}55.1 \\
55.1 \\
54.7 \\
53.9\end{array}$ & $\begin{array}{l}54.9 \\
56.1 \\
55.0 \\
55.0\end{array}$ \\
\hline & \multicolumn{14}{|c|}{ Distribution of twelfth graders' achievement, by score quartile ${ }^{3}$} \\
\hline $\begin{array}{l}\text { History } \\
\text { Lower quartile } \\
\text { Lower middle quartile }\end{array}$ Upper middle quartile & $\begin{array}{r}100.0 \\
20.2 \\
24.6 \\
26.9 \\
28.3\end{array}$ & $\begin{array}{r}100.0 \\
19.6 \\
21.5 \\
26.3 \\
32.5\end{array}$ & $\begin{array}{r}100.0 \\
20.9 \\
27.9 \\
27.4 \\
23.8\end{array}$ & $\begin{array}{r}100.0 \\
15.5 \\
23.4 \\
28.4 \\
32.7\end{array}$ & $\begin{array}{r}100.0 \\
39.6 \\
28.1 \\
21.5 \\
10.8\end{array}$ & $\begin{array}{r}100.0 \\
32.4 \\
28.9 \\
23.5 \\
15.3\end{array}$ & $\begin{array}{r}100.0 \\
16.8 \\
25.6 \\
25.5 \\
32.2\end{array}$ & $\begin{array}{r}100.0 \\
41.1 \\
32.5 \\
13.6 \\
12.7\end{array}$ & $\begin{array}{r}100.0 \\
37.6 \\
30.9 \\
21.1 \\
10.3\end{array}$ & $\begin{array}{r}100.0 \\
20.5 \\
26.9 \\
27.7 \\
24.8\end{array}$ & $\begin{array}{r}100.0 \\
7.9 \\
16.5 \\
29.2 \\
46.5\end{array}$ & $\begin{array}{r}100.0 \\
21.4 \\
25.2 \\
26.8 \\
26.6\end{array}$ & $\begin{array}{r}100.0 \\
7.1 \\
21.0 \\
31.2 \\
40.7\end{array}$ & $\begin{array}{r}100.0 \\
13.8 \\
17.2 \\
22.1 \\
46.9\end{array}$ \\
\hline 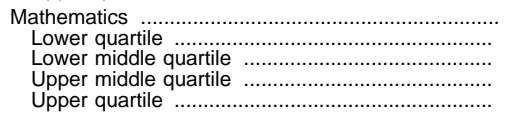 & $\begin{array}{r}100.0 \\
19.7 \\
24.2 \\
27.6 \\
28.5\end{array}$ & $\begin{array}{r}100.0 \\
20.1 \\
22.4 \\
26.9 \\
30.6\end{array}$ & $\begin{array}{r}100.0 \\
19.2 \\
26.0 \\
28.4 \\
26.3\end{array}$ & $\begin{array}{r}100.0 \\
14.8 \\
22.5 \\
29.5 \\
33.2\end{array}$ & $\begin{array}{r}100.0 \\
41.2 \\
30.0 \\
20.3 \\
8.5\end{array}$ & $\begin{array}{r}100.0 \\
31.6 \\
30.6 \\
22.9 \\
14.9\end{array}$ & $\begin{array}{r}100.0 \\
11.9 \\
21.1 \\
28.4 \\
38.7\end{array}$ & $\begin{array}{r}100.0 \\
42.8 \\
29.8 \\
18.5 \\
8.9\end{array}$ & $\begin{array}{r}100.0 \\
37.0 \\
32.4 \\
22.4 \\
8.3\end{array}$ & $\begin{array}{r}100.0 \\
20.4 \\
26.3 \\
29.3 \\
23.9\end{array}$ & $\begin{array}{r}100.0 \\
6.5 \\
15.2 \\
28.4 \\
50.0\end{array}$ & $\begin{array}{r}100.0 \\
20.9 \\
24.9 \\
27.2 \\
27.0\end{array}$ & $\begin{array}{r}100.0 \\
8.2 \\
17.0 \\
34.3 \\
40.5\end{array}$ & $\begin{array}{r}100.0 \\
7.6 \\
17.3 \\
28.5 \\
46.6\end{array}$ \\
\hline 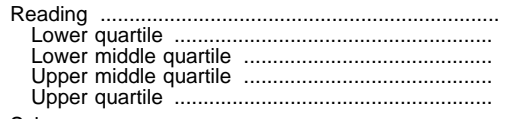 & $\begin{array}{r}100.0 \\
21.1 \\
24.6 \\
26.4 \\
27.8\end{array}$ & $\begin{array}{r}100.0 \\
25.6 \\
24.5 \\
25.0 \\
24.9\end{array}$ & $\begin{array}{r}100.0 \\
16.4 \\
24.7 \\
27.9 \\
30.9\end{array}$ & $\begin{array}{r}100.0 \\
16.6 \\
22.6 \\
28.3 \\
32.5\end{array}$ & $\begin{array}{r}100.0 \\
38.2 \\
31.3 \\
20.7 \\
9.8\end{array}$ & $\begin{array}{r}100.0 \\
31.6 \\
32.9 \\
21.2 \\
14.3\end{array}$ & $\begin{array}{r}100.0 \\
23.2 \\
20.0 \\
24.9 \\
31.9\end{array}$ & $\begin{array}{r}100.0 \\
41.2 \\
31.1 \\
15.5 \\
12.2\end{array}$ & $\begin{array}{r}100.0 \\
36.3 \\
32.4 \\
20.8 \\
10.5\end{array}$ & $\begin{array}{r}100.0 \\
21.6 \\
26.8 \\
27.4 \\
24.3\end{array}$ & $\begin{array}{r}100.0 \\
9.8 \\
15.8 \\
28.6 \\
45.9\end{array}$ & $\begin{array}{r}100.0 \\
22.3 \\
25.5 \\
25.8 \\
26.4\end{array}$ & $\begin{array}{r}100.0 \\
8.1 \\
18.1 \\
36.3 \\
37.5\end{array}$ & $\begin{array}{r}100.0 \\
14.0 \\
13.6 \\
25.2 \\
47.2\end{array}$ \\
\hline 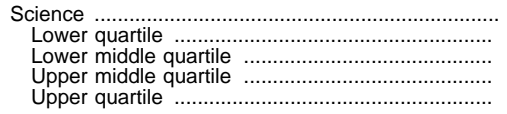 & $\begin{array}{r}100.0 \\
20.9 \\
24.5 \\
26.3 \\
28.3\end{array}$ & $\begin{array}{r}100.0 \\
18.2 \\
21.1 \\
27.1 \\
33.6\end{array}$ & $\begin{array}{r}100.0 \\
23.6 \\
28.1 \\
25.5 \\
22.7\end{array}$ & $\begin{array}{r}100.0 \\
14.0 \\
23.0 \\
29.0 \\
33.9\end{array}$ & $\begin{array}{r}100.0 \\
52.6 \\
25.2 \\
16.0 \\
6.2\end{array}$ & $\begin{array}{r}100.0 \\
34.3 \\
33.8 \\
18.9 \\
13.1\end{array}$ & $\begin{array}{r}100.0 \\
17.7 \\
25.2 \\
26.5 \\
30.5\end{array}$ & $\begin{array}{r}100.0 \\
37.6 \\
35.8 \\
20.9 \\
5.7\end{array}$ & $\begin{array}{r}100.0 \\
39.0 \\
31.9 \\
19.8 \\
9.3\end{array}$ & $\begin{array}{r}100.0 \\
20.9 \\
26.8 \\
28.3 \\
24.1\end{array}$ & $\begin{array}{r}100.0 \\
8.4 \\
16.0 \\
27.4 \\
48.3\end{array}$ & $\begin{array}{r}100.0 \\
21.9 \\
25.0 \\
26.3 \\
26.8\end{array}$ & $\begin{array}{r}100.0 \\
11.7 \\
22.0 \\
27.3 \\
39.0\end{array}$ & $\begin{array}{r}100.0 \\
10.5 \\
17.4 \\
26.1 \\
46.0\end{array}$ \\
\hline
\end{tabular}

${ }^{1}$ Socioeconomic status was measured by a composite score on parental education and occupations, and family income. The "Low" SES group is the lowest quartile; the "Middle" SES group is the middle two quartiles; and the "High" SES group is the upper quartile.

2 In the full data file, the standardized scores have a mean of 50 and a standard deviation of 10. Because dropouts and students who were retained in grades between 8 and 11 were excluded from this tabulation, the scores are slightly higher.
${ }^{3}$ In the full data file, twenty-five percent of all students fall into each one of the quartile groupings. Because dropouts and students who were retained in grades between 8 and 11 were excluded from this tabulation, the scores are slightly higher.

NOTE.-Because of rounding, details may not add to totals.

SOURCE: U.S. Department of Education, National Center for Education Statistics, "National Education Longitudinal Study of 1988, Second Followup" survey. (This table was prepared July 1995.)

Table 130.-Performance of 8th-grade students in music, theatre, and visual arts, by selected characteristics of students: 1997

\begin{tabular}{|c|c|c|c|c|c|c|c|}
\hline \multirow[b]{2}{*}{ Selected characteristics of students } & \multicolumn{3}{|c|}{ Music } & \multicolumn{2}{|c|}{ Visual arts } & \multicolumn{2}{|c|}{ Theatre } \\
\hline & $\begin{array}{l}\text { Average creating } \\
\text { score (0 to } 100 \\
\text { percent) }\end{array}$ & $\begin{array}{l}\text { Average perform- } \\
\text { ing score }(0 \text { to } \\
100 \text { percent })\end{array}$ & $\begin{array}{l}\text { Average respond- } \\
\text { ing scale score } \\
(0-300)\end{array}$ & $\begin{array}{l}\text { Average creating } \\
\text { score (0 to } 100 \\
\text { percent) }\end{array}$ & $\begin{array}{l}\text { Average respond- } \\
\text { ing scale score } \\
(0-300)\end{array}$ & $\begin{array}{l}\text { Average creating/ } \\
\text { performing ( } 0 \text { to } \\
100 \text { percent) }\end{array}$ & $\begin{array}{l}\text { Average responding } \\
\text { scale score }(0-300)\end{array}$ \\
\hline 1 & 2 & 3 & 4 & 5 & 6 & 7 & 8 \\
\hline All students ................... & $34(1.1)$ & $34(1.2)$ & $150(1.3)$ & $43(0.7)$ & $150(1.1)$ & $49(2.0)$ & $150(5.7)$ \\
\hline 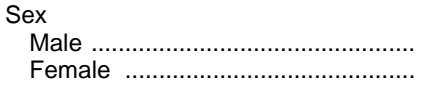 & $\begin{array}{ll}32 & (1.0) \\
37 & (1.6)\end{array}$ & $\begin{array}{ll}27 & (1.4) \\
40 & (1.5)\end{array}$ & $\begin{array}{ll}140(1.5) \\
160(1.6)\end{array}$ & $\begin{array}{ll}42 & (0.7) \\
45 & (0.9)\end{array}$ & $\begin{array}{ll}146 & (1.5) \\
154 & (1.4)\end{array}$ & $\begin{array}{ll}46 & (2.2) \\
52 & (2.1)\end{array}$ & $\begin{array}{l}140(6.6) \\
158(5.6)\end{array}$ \\
\hline 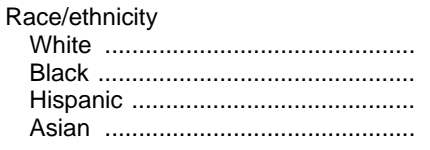 & $\begin{array}{ll}36 & (1.2) \\
34 & (3.6) \\
29 & (2.7) \\
31 & (3.8)\end{array}$ & $\begin{array}{l}36(1.4) \\
30(1.9) \\
24(3.7) \\
--\end{array}$ & $\begin{array}{ll}158 & (1.4) \\
130 & (2.3) \\
127 & (3.5) \\
152 & (6.2)\end{array}$ & $\begin{array}{ll}46 & (0.9) \\
37 & (1.8) \\
38 & (1.3) \\
45 & (1.6)\end{array}$ & $\begin{array}{ll}159(1.3) \\
124 \\
128 \\
12.0) \\
153(6.4)\end{array}$ & $\begin{array}{l}52(1.9) \\
39(2.2) \\
44(2.5) \\
--\end{array}$ & $\begin{array}{ll}159 & (4.4) \\
120 & (10.1) \\
139 & (6.2) \\
- & -\end{array}$ \\
\hline 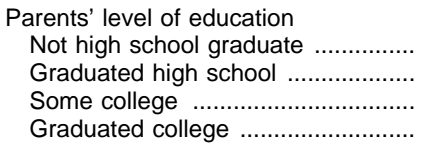 & $\begin{array}{ll}24 & (2.5) \\
29 & (2.0) \\
35 & (1.3) \\
39 & (1.3)\end{array}$ & $\begin{array}{ll}21 & (2.4) \\
29 & (2.4) \\
34 & (2.4) \\
39 & (1.5)\end{array}$ & $\begin{array}{l}129(3.5) \\
139(1.3) \\
150(1.8) \\
159(1.7)\end{array}$ & $\begin{array}{ll}36 & (1.4) \\
41 & (1.1) \\
44 & (0.8) \\
46 & (0.7)\end{array}$ & $\begin{array}{l}125(2.4) \\
138(1.8) \\
153(1.8) \\
158(1.4)\end{array}$ & $\begin{array}{ll}42 & (2.1) \\
42 & (1.9) \\
49 & (1.8) \\
52 & (2.2)\end{array}$ & $\begin{array}{ll}131 & (4.4) \\
130 & (8.5) \\
153 & (5.1) \\
157 & (5.6)\end{array}$ \\
\hline 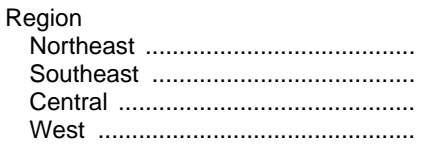 & $\begin{array}{ll}39 & (2.0) \\
30 & (2.7) \\
36 & (1.4) \\
33 & (2.3)\end{array}$ & $\begin{array}{ll}34 & (2.6) \\
33 & (2.4) \\
33 & (2.1) \\
35 & (2.9)\end{array}$ & $\begin{array}{ll}153 & (4.0) \\
139 & (2.7) \\
157 & (3.0) \\
152 & (3.0)\end{array}$ & $\begin{array}{ll}45 & (1.5) \\
42 & (1.0) \\
45 & (1.8) \\
43 & (1.3)\end{array}$ & $\begin{array}{ll}152 & (4.0) \\
143 & (3.3) \\
157 & (3.5) \\
149 & (2.6)\end{array}$ & $\begin{array}{l}-- \\
-\overline{51}-\end{array}$ & $\begin{array}{c}-- \\
\overline{-}- \\
157\end{array}$ \\
\hline
\end{tabular}

-Sample size insufficient to permit a reliable estimate.

NOTE.-Creating refers to expressing ideas and feelings in the form of an original work of art, for example,a dance, a piece of music, a dramatic improvisation, or a sculpture. Performing refers to performing an existing work, a process that calls upon the in- terpretive or re-creative skills of the student. Responding refers to observing, describing, analyzing, and evaluating works of art. Standard errors appear in parentheses.

SOURCE: U.S. Department of Education, National Center for Education Statistics, National Assessment of Educational Progress, The NAEP 1997 Arts Report Card. (This table was prepared November 1998.) 
Table 131.-Scholastic Assessment Test ${ }^{1}$ score averages, by race/ethnicity: 1987, 1996, and 1997

\begin{tabular}{|c|c|c|c|c|c|}
\hline Racial/ethnic background & 1987 & 1996 & 1997 & $\begin{array}{c}\text { Percent } \\
\text { change, } \\
1987 \text { to } \\
1997\end{array}$ & $\begin{array}{c}\text { Percent } \\
\text { change, } \\
1996 \text { to } \\
1997\end{array}$ \\
\hline 1 & 2 & 3 & 4 & 5 & 6 \\
\hline SAT-Verbal & 507 & 505 & 505 & -2 & 0 \\
\hline 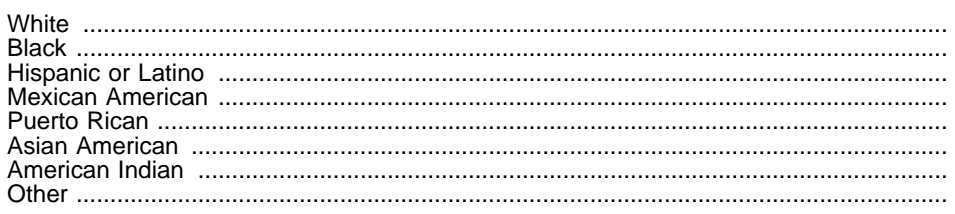 & $\begin{array}{l}524 \\
428 \\
464 \\
457 \\
436 \\
479 \\
471 \\
480\end{array}$ & $\begin{array}{l}526 \\
434 \\
465 \\
455 \\
452 \\
496 \\
483 \\
511\end{array}$ & \begin{tabular}{l|}
526 \\
434 \\
466 \\
451 \\
454 \\
496 \\
475 \\
512
\end{tabular} & \begin{tabular}{r|r}
2 \\
6 \\
2 \\
-6 \\
18 \\
17 \\
4 \\
32
\end{tabular} & $\begin{array}{r}0 \\
0 \\
1 \\
-4 \\
2 \\
0 \\
-8 \\
1\end{array}$ \\
\hline SAT-Mathematical & 501 & 508 & 511 & 10 & 3 \\
\hline 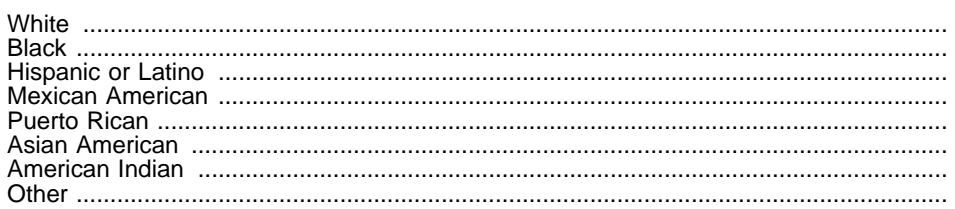 & $\begin{array}{l}514 \\
411 \\
462 \\
455 \\
432 \\
541 \\
463 \\
482\end{array}$ & $\begin{array}{l}523 \\
422 \\
466 \\
459 \\
445 \\
558 \\
477 \\
512\end{array}$ & $\begin{array}{l}526 \\
423 \\
468 \\
458 \\
447 \\
560 \\
475 \\
514\end{array}$ & $\begin{array}{r}12 \\
12 \\
6 \\
3 \\
15 \\
19 \\
12 \\
32\end{array}$ & $\begin{array}{r}3 \\
1 \\
2 \\
-1 \\
2 \\
2 \\
-2 \\
2\end{array}$ \\
\hline
\end{tabular}

${ }^{1}$ Formerly known as the Scholastic Aptitude Test.

NOTE.-Possible scores on each part of the SAT range from 200 to 800 .
SOURCE: College Entrance Examination Board, National Report on College-Bound Seniors, 1997. (Copyright (0) 1997 by the College Entrance Examination Board. All rights reserved.) (This table was prepared September 1998.)

Table 132.-Scholastic Assessment Test ${ }^{1}$ score averages for college-bound high school seniors, by sex: $1966-67$ to $1997-98$

\begin{tabular}{|c|c|c|c|c|c|c|c|c|c|c|c|c|}
\hline \multirow{3}{*}{ School year } & \multicolumn{6}{|c|}{$\begin{array}{c}\text { Scholastic Assessment Test I } \\
\text { (recentered scale })^{2}\end{array}$} & \multicolumn{6}{|c|}{$\begin{array}{l}\text { Scholastic Aptitude Test } \\
\text { (old scale) }\end{array}$} \\
\hline & \multicolumn{3}{|c|}{ Verbal score } & \multicolumn{3}{|c|}{ Mathematical score } & \multicolumn{3}{|c|}{ Verbal score } & \multicolumn{3}{|c|}{ Mathematical score } \\
\hline & Total & Male & Female & Total & Male & Female & Total & Male & Female & Total & Male & Female \\
\hline 1 & 2 & 3 & 4 & 5 & 6 & 7 & 8 & 9 & 10 & 11 & 12 & 13 \\
\hline 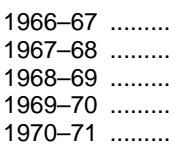 & $\begin{array}{l}- \\
- \\
- \\
-\end{array}$ & $\begin{array}{l}- \\
- \\
- \\
-\end{array}$ & $\begin{array}{l}- \\
- \\
- \\
-\end{array}$ & $\begin{array}{l}- \\
- \\
- \\
-\end{array}$ & $\begin{array}{l}- \\
- \\
- \\
-\end{array}$ & $\begin{array}{l}- \\
- \\
-\end{array}$ & $\begin{array}{l}466 \\
466 \\
463 \\
460 \\
455\end{array}$ & $\begin{array}{l}463 \\
464 \\
459 \\
459 \\
454\end{array}$ & $\begin{array}{l}468 \\
466 \\
466 \\
461 \\
457\end{array}$ & $\begin{array}{l}492 \\
492 \\
493 \\
488 \\
488\end{array}$ & $\begin{array}{l}514 \\
512 \\
513 \\
509 \\
507\end{array}$ & $\begin{array}{l}467 \\
470 \\
470 \\
465 \\
466\end{array}$ \\
\hline $\begin{array}{l}1971-72 \ldots \ldots . . \\
1972-73 \ldots \ldots \ldots \\
1973-74 \ldots \ldots \ldots . \\
1974-75 \\
1975-76\end{array}$ & $\begin{array}{l}530 \\
523 \\
521 \\
512 \\
509\end{array}$ & $\begin{array}{l}531 \\
523 \\
524 \\
515 \\
511\end{array}$ & $\begin{array}{l}529 \\
521 \\
520 \\
509 \\
508\end{array}$ & $\begin{array}{l}509 \\
506 \\
505 \\
498 \\
497\end{array}$ & $\begin{array}{l}527 \\
525 \\
524 \\
518 \\
520\end{array}$ & $\begin{array}{l}489 \\
489 \\
488 \\
479 \\
475\end{array}$ & $\begin{array}{l}453 \\
445 \\
444 \\
434 \\
431\end{array}$ & $\begin{array}{l}454 \\
446 \\
447 \\
437 \\
433\end{array}$ & $\begin{array}{l}452 \\
443 \\
442 \\
431 \\
430\end{array}$ & $\begin{array}{l}484 \\
481 \\
480 \\
472 \\
472\end{array}$ & $\begin{array}{l}505 \\
502 \\
501 \\
495 \\
497\end{array}$ & $\begin{array}{l}461 \\
460 \\
459 \\
449 \\
446\end{array}$ \\
\hline $\begin{aligned} 1976-77 & \ldots \ldots \ldots . . \\
1977-78 & \ldots \ldots \ldots . . \\
1978-79 & \ldots \ldots \ldots . . \\
1979-80 & \ldots \ldots \ldots . \\
1980-81 & \ldots \ldots \ldots . .\end{aligned}$ & $\begin{array}{l}507 \\
507 \\
505 \\
502 \\
502\end{array}$ & $\begin{array}{l}509 \\
511 \\
509 \\
506 \\
508\end{array}$ & $\begin{array}{l}505 \\
503 \\
501 \\
498 \\
496\end{array}$ & $\begin{array}{l}496 \\
494 \\
493 \\
492 \\
492\end{array}$ & $\begin{array}{l}520 \\
517 \\
516 \\
515 \\
516\end{array}$ & $\begin{array}{l}474 \\
474 \\
473 \\
473 \\
473\end{array}$ & $\begin{array}{l}429 \\
429 \\
427 \\
424 \\
424\end{array}$ & $\begin{array}{l}431 \\
433 \\
431 \\
428 \\
430\end{array}$ & $\begin{array}{l}427 \\
425 \\
423 \\
420 \\
418\end{array}$ & $\begin{array}{l}470 \\
468 \\
467 \\
466 \\
466\end{array}$ & $\begin{array}{l}497 \\
494 \\
493 \\
491 \\
492\end{array}$ & $\begin{array}{l}445 \\
444 \\
443 \\
443 \\
443\end{array}$ \\
\hline $\begin{array}{ll}1981-82 & \ldots \ldots \ldots . . \\
1982-83 & \ldots \ldots \ldots . . \\
1983-84 & \ldots \ldots \ldots . . \\
1984-85 & \ldots \ldots \ldots . \\
1985-86 & \ldots \ldots \ldots . .\end{array}$ & $\begin{array}{l}504 \\
503 \\
504 \\
509 \\
509\end{array}$ & $\begin{array}{l}509 \\
508 \\
511 \\
514 \\
515\end{array}$ & $\begin{array}{l}499 \\
498 \\
498 \\
503 \\
504\end{array}$ & $\begin{array}{l}493 \\
494 \\
497 \\
500 \\
500\end{array}$ & $\begin{array}{l}516 \\
516 \\
518 \\
522 \\
523\end{array}$ & $\begin{array}{l}473 \\
474 \\
478 \\
480 \\
479\end{array}$ & $\begin{array}{l}426 \\
425 \\
426 \\
431 \\
431\end{array}$ & $\begin{array}{l}431 \\
430 \\
433 \\
437 \\
437\end{array}$ & $\begin{array}{l}421 \\
420 \\
420 \\
425 \\
426\end{array}$ & $\begin{array}{l}467 \\
468 \\
471 \\
475 \\
475\end{array}$ & $\begin{array}{l}493 \\
493 \\
495 \\
499 \\
501\end{array}$ & $\begin{array}{l}443 \\
445 \\
449 \\
452 \\
451\end{array}$ \\
\hline $\begin{aligned} 1986-87 & \ldots \ldots \ldots . . \\
1987-88 & \ldots \ldots \ldots . . \\
1988-89 & \ldots \ldots \ldots . . \\
1989-90 & \ldots \ldots \ldots . \\
1990-91 & \ldots \ldots \ldots . .\end{aligned}$ & $\begin{array}{l}507 \\
505 \\
504 \\
500 \\
499\end{array}$ & $\begin{array}{l}512 \\
512 \\
510 \\
505 \\
503\end{array}$ & $\begin{array}{l}502 \\
499 \\
498 \\
496 \\
495\end{array}$ & $\begin{array}{l}501 \\
501 \\
502 \\
501 \\
500\end{array}$ & $\begin{array}{l}523 \\
521 \\
523 \\
521 \\
520\end{array}$ & $\begin{array}{l}481 \\
483 \\
482 \\
483 \\
482\end{array}$ & $\begin{array}{l}430 \\
428 \\
427 \\
424 \\
422\end{array}$ & $\begin{array}{l}435 \\
435 \\
434 \\
429 \\
426\end{array}$ & $\begin{array}{l}425 \\
422 \\
421 \\
419 \\
418\end{array}$ & $\begin{array}{l}476 \\
476 \\
476 \\
476 \\
474\end{array}$ & $\begin{array}{l}500 \\
498 \\
500 \\
499 \\
497\end{array}$ & $\begin{array}{l}453 \\
455 \\
454 \\
455 \\
453\end{array}$ \\
\hline 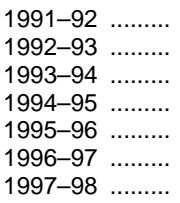 & $\begin{array}{l}500 \\
500 \\
499 \\
504 \\
505 \\
505 \\
505\end{array}$ & $\begin{array}{l}504 \\
504 \\
501 \\
505 \\
507 \\
507 \\
509\end{array}$ & $\begin{array}{l}496 \\
497 \\
497 \\
502 \\
503 \\
503 \\
502\end{array}$ & $\begin{array}{l}501 \\
503 \\
504 \\
506 \\
508 \\
511 \\
512\end{array}$ & $\begin{array}{l}521 \\
524 \\
523 \\
525 \\
527 \\
530 \\
531\end{array}$ & $\begin{array}{l}484 \\
484 \\
487 \\
490 \\
492 \\
494 \\
496\end{array}$ & $\begin{array}{l}423 \\
424 \\
423 \\
428 \\
- \\
- \\
-\end{array}$ & $\begin{array}{l}428 \\
428 \\
425 \\
429 \\
- \\
- \\
-\end{array}$ & $\begin{array}{l}419 \\
420 \\
421 \\
426 \\
- \\
- \\
-\end{array}$ & $\begin{array}{l}476 \\
478 \\
479 \\
482 \\
- \\
-\end{array}$ & $\begin{array}{l}499 \\
502 \\
501 \\
503 \\
- \\
- \\
-\end{array}$ & $\begin{array}{r}456 \\
457 \\
460 \\
463 \\
- \\
- \\
-\end{array}$ \\
\hline
\end{tabular}

1 Formerly known as the Scholastic Aptitude Test.

2 Data for 1972 to 1986 were converted to the recentered scale by using a formula applied to the original mean and standard deviation. For 1987 to 1995 , individual student scores were converted to the recentered scale and recomputed. For 1996 and 1997, most students received scores on the recentered scale score. Any score on the origina scale was converted to the recentered scale prior to recomputing the mean.

-Data not available.
NOTE.-Possible scores on each part of the SAT range from 200 to 800 . Data for the years 1966-67 through 1970-71 are estimates derived from the test scores of all participants.

SOURCE: College Entrance Examination Board, National Report on College-Bound Seniors, various years. (Copyright (C) 1997 by the College Entrance Examination Board. All rights reserved.) (This table was prepared September 1998.) 
Table 133.-Scholastic Assessment Test ${ }^{1}$ score averages, by selected student characteristics: 1996 and 1997

\begin{tabular}{|c|c|c|c|c|c|c|}
\hline \multirow[b]{2}{*}{ Selected characteristics } & \multicolumn{3}{|c|}{1996} & \multicolumn{3}{|c|}{1997} \\
\hline & Verbal score & $\begin{array}{l}\text { Mathematics } \\
\text { score }\end{array}$ & $\begin{array}{c}\text { Percent } \\
\text { distribution }\end{array}$ & Verbal score & $\begin{array}{l}\text { Mathematics } \\
\text { score }\end{array}$ & $\begin{array}{c}\text { Percent } \\
\text { distribution }\end{array}$ \\
\hline 1 & 2 & 3 & 4 & 5 & 6 & 7 \\
\hline All students & 505 & 508 & 100 & 505 & 511 & 100 \\
\hline $\begin{array}{l}\text { High school rank } \\
\text { Top tenth } \\
\text { Second tenth } \\
\text { Second fifth } \\
\text { Third fifth } \\
\text { Fourth fifth } \\
\text { Lowest fifth }\end{array}$ & $\begin{array}{l}591 \\
530 \\
494 \\
455 \\
429 \\
411\end{array}$ & $\begin{array}{l}606 \\
539 \\
496 \\
448 \\
418 \\
401\end{array}$ & \begin{tabular}{r|}
22 \\
22 \\
28 \\
24 \\
4 \\
1
\end{tabular} & $\begin{array}{l}589 \\
529 \\
494 \\
455 \\
428 \\
411\end{array}$ & $\begin{array}{l}606 \\
541 \\
498 \\
451 \\
420 \\
404\end{array}$ & $\begin{array}{r}22 \\
23 \\
27 \\
23 \\
4 \\
1\end{array}$ \\
\hline $\begin{array}{l}\text { High school grade point average } \\
\text { A+ (97-100) } \\
\text { A (93-96) } \\
\text { A- }(90-92) \\
\text { B (80-89) } \\
\text { C (70-79) } \\
\text { D, E, or F }\end{array}$ & $\begin{array}{l}617 \\
573 \\
545 \\
486 \\
432 \\
414\end{array}$ & $\begin{array}{l}632 \\
583 \\
554 \\
485 \\
426 \\
408\end{array}$ & \begin{tabular}{r|}
6 \\
14 \\
15 \\
49 \\
15 \\
0
\end{tabular} & $\begin{array}{l}613 \\
570 \\
542 \\
485 \\
432 \\
411\end{array}$ & $\begin{array}{l}630 \\
583 \\
553 \\
486 \\
428 \\
409\end{array}$ & $\begin{array}{r}6 \\
15 \\
16 \\
49 \\
14 \\
0\end{array}$ \\
\hline 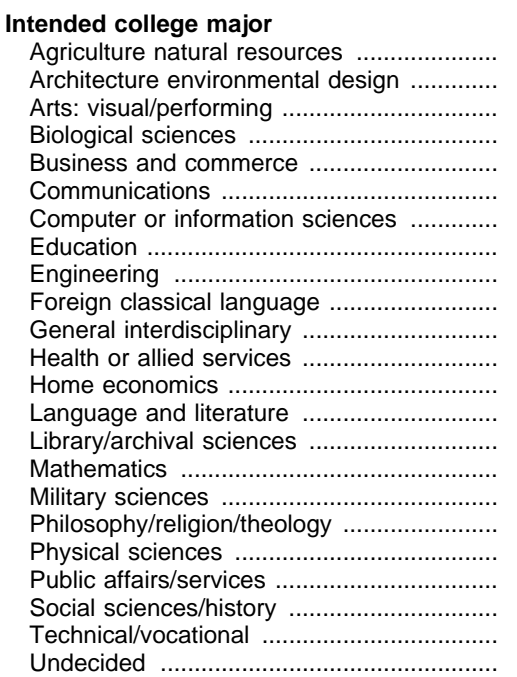 & $\begin{array}{l}491 \\
492 \\
520 \\
546 \\
483 \\
527 \\
497 \\
487 \\
525 \\
556 \\
576 \\
500 \\
458 \\
605 \\
554 \\
552 \\
503 \\
560 \\
575 \\
458 \\
532 \\
435 \\
500\end{array}$ & $\begin{array}{l}484 \\
519 \\
497 \\
545 \\
500 \\
497 \\
522 \\
477 \\
569 \\
534 \\
553 \\
505 \\
452 \\
545 \\
512 \\
628 \\
505 \\
536 \\
595 \\
448 \\
509 \\
441 \\
507\end{array}$ & $\begin{array}{r}2 \\
3 \\
6 \\
6 \\
13 \\
4 \\
3 \\
8 \\
8 \\
-7 \\
19 \\
1 \\
-1 \\
1 \\
- \\
1 \\
3 \\
11 \\
1 \\
7\end{array}$ & $\begin{array}{l}492 \\
492 \\
522 \\
545 \\
482 \\
523 \\
498 \\
485 \\
523 \\
554 \\
567 \\
499 \\
459 \\
609 \\
561 \\
549 \\
505 \\
558 \\
572 \\
457 \\
531 \\
437 \\
504\end{array}$ & $\begin{array}{l}486 \\
523 \\
501 \\
546 \\
504 \\
498 \\
526 \\
479 \\
570 \\
535 \\
548 \\
507 \\
456 \\
546 \\
522 \\
623 \\
507 \\
538 \\
593 \\
450 \\
510 \\
447 \\
514\end{array}$ & $\begin{array}{r}2 \\
2 \\
7 \\
6 \\
13 \\
4 \\
4 \\
9 \\
8 \\
0 \\
0 \\
19 \\
0 \\
1 \\
0 \\
1 \\
0 \\
1 \\
1 \\
1 \\
3 \\
11 \\
1 \\
7\end{array}$ \\
\hline 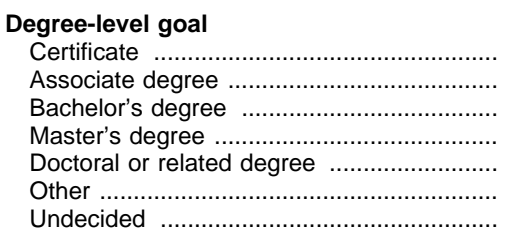 & $\begin{array}{l}434 \\
422 \\
476 \\
514 \\
548 \\
430 \\
502\end{array}$ & $\begin{array}{l}439 \\
415 \\
476 \\
518 \\
552 \\
438 \\
503\end{array}$ & \begin{tabular}{r|r}
1 \\
2 \\
23 \\
29 \\
24 \\
1 \\
20
\end{tabular} & $\begin{array}{l}435 \\
422 \\
475 \\
513 \\
547 \\
432 \\
504\end{array}$ & $\begin{array}{l}444 \\
418 \\
478 \\
520 \\
552 \\
444 \\
508\end{array}$ & $\begin{array}{r}1 \\
2 \\
23 \\
30 \\
24 \\
1 \\
20\end{array}$ \\
\hline 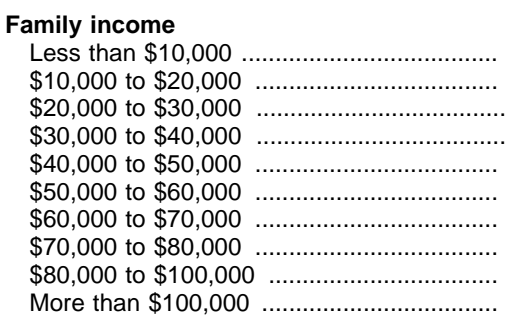 & $\begin{array}{l}429 \\
456 \\
482 \\
497 \\
509 \\
517 \\
524 \\
531 \\
541 \\
560\end{array}$ & $\begin{array}{l}444 \\
464 \\
482 \\
495 \\
507 \\
517 \\
525 \\
533 \\
544 \\
569\end{array}$ & \begin{tabular}{r|}
4 \\
8 \\
10 \\
12 \\
10 \\
9 \\
7 \\
6 \\
7 \\
9
\end{tabular} & $\begin{array}{l}428 \\
454 \\
480 \\
496 \\
507 \\
515 \\
522 \\
529 \\
540 \\
559\end{array}$ & $\begin{array}{l}445 \\
464 \\
482 \\
497 \\
508 \\
518 \\
526 \\
533 \\
544 \\
571\end{array}$ & $\begin{array}{r}5 \\
9 \\
12 \\
14 \\
12 \\
11 \\
9 \\
7 \\
9 \\
12\end{array}$ \\
\hline 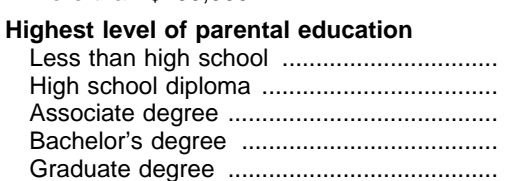 & $\begin{array}{l}414 \\
475 \\
489 \\
525 \\
556\end{array}$ & $\begin{array}{l}439 \\
474 \\
487 \\
529 \\
558\end{array}$ & $\begin{array}{r}4 \\
31 \\
7 \\
25 \\
23\end{array}$ & $\begin{array}{l}412 \\
474 \\
488 \\
524 \\
556\end{array}$ & $\begin{array}{l}441 \\
476 \\
489 \\
530 \\
560\end{array}$ & $\begin{array}{r}4 \\
34 \\
8 \\
28 \\
25\end{array}$ \\
\hline
\end{tabular}

${ }^{1}$ Fomerly known as the Scholastic Aptitude Test. -Data not available.

NOTE.-Possible scores on each part of the SAT range from 200 to 800
SOURCE: College Entrance Examination Board, National Report on College Bound Seniors, various years. (Copyright (C) 1997 by the College Entrance Examination Board. All rights reserved). (This table was prepared September 1998). 
Table 134.-Scholastic Assessment Test ${ }^{1}$ score averages, by state: 1987 to 1997

\begin{tabular}{|c|c|c|c|c|c|c|c|c|c|c|c|}
\hline \multirow[b]{2}{*}{ State } & \multicolumn{2}{|c|}{1987} & \multicolumn{2}{|c|}{1994} & \multicolumn{2}{|c|}{1995} & \multicolumn{2}{|c|}{1996} & \multicolumn{2}{|c|}{1997} & \multirow{2}{*}{$\begin{array}{c}\text { Percentage } \\
\text { of } \\
\text { graduates } \\
\text { taking SAT, } \\
1997^{2}\end{array}$} \\
\hline & Verbal & $\begin{array}{l}\text { Mathe- } \\
\text { matical }\end{array}$ & Verbal & $\begin{array}{l}\text { Mathe- } \\
\text { matical }\end{array}$ & Verbal & $\begin{array}{l}\text { Mathe- } \\
\text { matical }\end{array}$ & Verbal & $\begin{array}{l}\text { Mathe- } \\
\text { matical }\end{array}$ & Verbal & $\begin{array}{l}\text { Mathe- } \\
\text { matical }\end{array}$ & \\
\hline 1 & 2 & 3 & 4 & 5 & 6 & 7 & 8 & 9 & 10 & 11 & 12 \\
\hline United States ........ & 507 & 501 & 499 & 504 & 504 & 506 & 505 & 508 & 505 & 511 & 42 \\
\hline Alabama & 553 & 535 & 556 & 547 & 565 & 555 & 565 & 558 & 561 & 555 & 8 \\
\hline Alaska & 521 & 504 & 510 & 502 & 521 & 513 & 521 & 513 & 520 & 517 & 48 \\
\hline 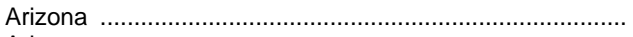 & 539 & 526 & 519 & 519 & 524 & 520 & 525 & 521 & 523 & 522 & 29 \\
\hline Arkansas ............................ & 556 & 540 & 552 & 537 & 556 & 542 & 566 & 550 & 567 & 558 & 6 \\
\hline California...$\ldots \ldots \ldots \ldots \ldots \ldots \ldots$ & 500 & 507 & 489 & 506 & 492 & 509 & 495 & 511 & 496 & 514 & 45 \\
\hline Colorado & 542 & 535 & 532 & 534 & 538 & 538 & 536 & 538 & 536 & 539 & 30 \\
\hline Connecticut & 515 & 499 & 502 & 497 & 507 & 502 & 507 & 504 & 509 & 507 & 79 \\
\hline Delaware .................. & 517 & 496 & 505 & 491 & 505 & 494 & 508 & 495 & 505 & 498 & 65 \\
\hline District of Columbia & 482 & 462 & 479 & 468 & 485 & 471 & 489 & 473 & 490 & 475 & 60 \\
\hline Florida & 501 & 497 & 490 & 492 & 497 & 496 & 498 & 496 & 499 & 499 & 50 \\
\hline Georgia .... & 478 & 470 & 474 & 474 & 483 & 477 & 484 & 477 & 486 & 481 & 63 \\
\hline Hawaii ................................ & 481 & 502 & 477 & 504 & 483 & 507 & 485 & 510 & 483 & 512 & 54 \\
\hline Idaho .................................. & 548 & 524 & 537 & 529 & 544 & 532 & 543 & 536 & 544 & 539 & 15 \\
\hline 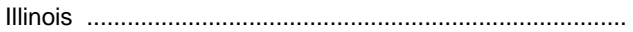 & 539 & 540 & 553 & 562 & 563 & 574 & 564 & 575 & 562 & 578 & 14 \\
\hline Indiana & 492 & 487 & 488 & 493 & 492 & 494 & 494 & 494 & 494 & 497 & 57 \\
\hline lowa ......... & 588 & 586 & 580 & 586 & 589 & 595 & 590 & 600 & 589 & 601 & 5 \\
\hline Kansas ...... & 572 & 562 & 568 & 565 & 576 & 571 & 579 & 571 & 578 & 575 & 9 \\
\hline 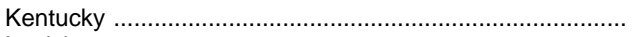 & 554 & 538 & 549 & 543 & 552 & 542 & 549 & 544 & 548 & 546 & 12 \\
\hline 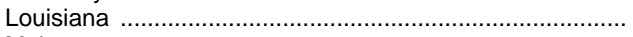 & 548 & 530 & 556 & 549 & 560 & 552 & 559 & 550 & 560 & 553 & 10 \\
\hline Maine $\ldots \ldots \ldots \ldots \ldots \ldots \ldots \ldots \ldots$ & 510 & 493 & 497 & 490 & 504 & 497 & 504 & 498 & 507 & 504 & 67 \\
\hline Maryland & 513 & 502 & 505 & 503 & 506 & 503 & 507 & 504 & 507 & 507 & 64 \\
\hline Massachusetts & 511 & 500 & 502 & 500 & 505 & 502 & 507 & 504 & 508 & 508 & 80 \\
\hline 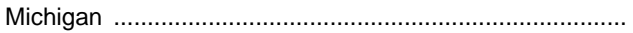 & 534 & 533 & 547 & 554 & 559 & 565 & 557 & 565 & 557 & 566 & 11 \\
\hline 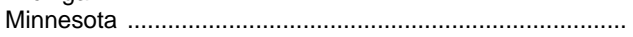 & 548 & 549 & 569 & 576 & 580 & 591 & 582 & 593 & 582 & 592 & 9 \\
\hline 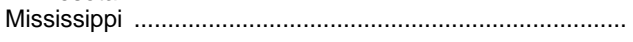 & 561 & 540 & 559 & 546 & 572 & 557 & 569 & 557 & 567 & 551 & 4 \\
\hline Missouri .......................... & 549 & 538 & 560 & 554 & 569 & 566 & 570 & 569 & 567 & 568 & 9 \\
\hline Montana & 555 & 548 & 540 & 542 & 549 & 553 & 546 & 547 & 545 & 548 & 22 \\
\hline Nebraska ............................ & 563 & 562 & 557 & 559 & 568 & 570 & 567 & 568 & 562 & 564 & 9 \\
\hline Nevada $\ldots \ldots \ldots \ldots \ldots \ldots \ldots \ldots$ & 516 & 508 & 506 & 508 & 511 & 508 & 508 & 507 & 508 & 509 & 32 \\
\hline New Hampshire ................ & 527 & 512 & 515 & 510 & 520 & 515 & 520 & 514 & 521 & 518 & 70 \\
\hline New Jersey ..... & 502 & 493 & 494 & 500 & 496 & 503 & 498 & 505 & 497 & 508 & 69 \\
\hline 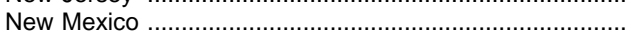 & 559 & 544 & 550 & 546 & 559 & 549 & 554 & 548 & 554 & 545 & 12 \\
\hline New York ............................ & 501 & 495 & 492 & 497 & 495 & 498 & 497 & 499 & 495 & 502 & 74 \\
\hline North Carolina ................. & 477 & 468 & 482 & 482 & 488 & 482 & 490 & 486 & 490 & 488 & 59 \\
\hline North Dakota ................... & 583 & 573 & 570 & 573 & 587 & 602 & 596 & 599 & 588 & 595 & 5 \\
\hline Ohio & 532 & 521 & 533 & 531 & 536 & 535 & 536 & 535 & 535 & 536 & 25 \\
\hline Oklahoma ..................... & 560 & 539 & 557 & 554 & 565 & 553 & 566 & 557 & 568 & 560 & 8 \\
\hline Oregon & 521 & 509 & 513 & 515 & 525 & 522 & 523 & 521 & 525 & 524 & 50 \\
\hline 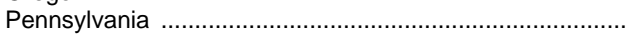 & 505 & 491 & 494 & 489 & 496 & 489 & 498 & 492 & 498 & 495 & 72 \\
\hline 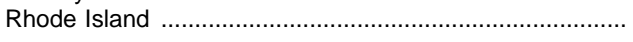 & 509 & 492 & 496 & 488 & 502 & 490 & 501 & 491 & 499 & 493 & 70 \\
\hline South Carolina ............. & 474 & 466 & 473 & 473 & 478 & 473 & 480 & 474 & 479 & 474 & 56 \\
\hline South Dakota & 587 & 577 & 558 & 563 & 579 & 576 & 574 & 566 & 574 & 570 & 4 \\
\hline Tennessee $\ldots \ldots \ldots \ldots \ldots \ldots \ldots \ldots \ldots$ & 563 & 543 & 562 & 553 & 571 & 560 & 563 & 552 & 564 & 556 & 13 \\
\hline Texas ................................... & 493 & 486 & 489 & 500 & 495 & 501 & 495 & 500 & 494 & 501 & 49 \\
\hline Utah & 577 & 557 & 582 & 573 & 585 & 576 & 583 & 575 & 576 & 570 & 4 \\
\hline Vermont & 518 & 500 & 504 & 498 & 506 & 499 & 506 & 500 & 508 & 502 & 69 \\
\hline Virginia & 511 & 499 & 501 & 495 & 504 & 494 & 507 & 496 & 506 & 497 & 69 \\
\hline Washington & 532 & 519 & 511 & 512 & 519 & 517 & 519 & 519 & 523 & 523 & 46 \\
\hline West Virginia .................... & 534 & 519 & 516 & 507 & 525 & 509 & 526 & 506 & 524 & 508 & 18 \\
\hline 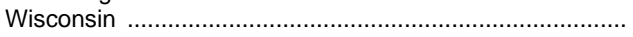 & 550 & 551 & 562 & 575 & 574 & 585 & 577 & 586 & 579 & 590 & 7 \\
\hline Wyoming & 557 & 551 & 535 & 541 & 551 & 544 & 544 & 544 & 543 & 543 & 12 \\
\hline
\end{tabular}

${ }^{1}$ Formerly known as the Scholastic Aptitude Test.

${ }^{2}$ Based on the number of high school graduates in 1997 as projected by the Western Interstate Commission for Higher Education and the number of 1997 seniors who took the SAT I.
NOTE.-Possible scores on each part of the SAT range from 200 to 800 . Rankings of states based on SAT scores alone are invalid because of the varying proportions of students in each state taking the tests.

SOURCE: College Entrance Examination Board, "College-Bound Seniors: 1997 Profile of SAT Program Test Takers," Copyright 1997 by the College Entrance Examination Board. All rights reserved.) (This table was prepared September 1998.) 
Table 135.-American College Testing (ACT) score ${ }^{1}$ averages, by sex: 1970 to 1997

\begin{tabular}{|c|c|c|c|c|c|c|c|c|c|c|c|c|c|c|c|c|c|c|}
\hline Type of test & 1970 & 1975 & 1980 & 1983 & 1984 & 1985 & 1986 & 1987 & 1988 & 1989 & 1990 & 1991 & 1992 & 1993 & 1994 & 1995 & 1996 & 1997 \\
\hline 1 & 2 & 3 & 4 & 5 & 6 & 7 & 8 & 9 & 10 & 11 & 12 & 13 & 14 & 15 & 16 & 17 & 18 & 19 \\
\hline \multirow[t]{2}{*}{$\begin{array}{l}\text { Participants: }{ }^{2} \\
\quad \text { Total (in thousands) } \ldots \ldots \ldots \ldots \ldots \ldots \ldots \ldots \ldots \ldots \ldots \ldots \ldots \ldots \ldots\end{array}$} & 714 & 822 & 836 & 835 & 849 & 739 & 730 & 777 & 842 & 855 & 817 & 796 & 832 & 876 & 892 & 945 & 924 & 959 \\
\hline & \multicolumn{18}{|c|}{ Test scores ${ }^{3}$} \\
\hline $\begin{array}{l}\text { Composite, total } \\
\text { Male } \\
\text { Female }\end{array}$ & $\begin{array}{l}18.6 \\
19.5 \\
17.8\end{array}$ & $\begin{array}{l}18.5 \\
19.3 \\
17.9\end{array}$ & $\begin{array}{l}18.5 \\
19.3 \\
17.8\end{array}$ & $\begin{array}{l}18.3 \\
19.1 \\
17.6\end{array}$ & $\begin{array}{l}18.5 \\
19.3 \\
17.9\end{array}$ & $\begin{array}{l}18.6 \\
19.4 \\
17.9\end{array}$ & $\begin{array}{l}18.8 \\
19.6 \\
18.1\end{array}$ & $\begin{array}{l}18.7 \\
19.5 \\
18.1\end{array}$ & $\begin{array}{l}18.8 \\
19.6 \\
18.1\end{array}$ & $\begin{array}{l}18.6 \\
19.3 \\
18.0\end{array}$ & $\begin{array}{l}20.6 \\
21.0 \\
20.3\end{array}$ & $\begin{array}{l}20.6 \\
20.9 \\
20.4\end{array}$ & $\begin{array}{l}20.6 \\
20.9 \\
20.5\end{array}$ & $\begin{array}{l}20.7 \\
21.0 \\
20.5\end{array}$ & $\begin{array}{l}20.8 \\
20.9 \\
20.7\end{array}$ & $\begin{array}{l}20.8 \\
21.0 \\
20.7\end{array}$ & $\begin{array}{l}20.9 \\
21.0 \\
20.8\end{array}$ & $\begin{array}{l}21.0 \\
21.1 \\
20.8\end{array}$ \\
\hline $\begin{array}{l}\text { English, total } \\
\text { Male } \\
\text { Female }\end{array}$ & $\begin{array}{l}17.7 \\
17.1 \\
18.3\end{array}$ & $\begin{array}{l}17.9 \\
17.3 \\
18.3\end{array}$ & $\begin{array}{l}17.8 \\
17.3 \\
18.2\end{array}$ & $\begin{array}{l}17.8 \\
17.3 \\
18.2\end{array}$ & $\begin{array}{l}18.1 \\
17.5 \\
18.6\end{array}$ & $\begin{array}{l}18.1 \\
17.6 \\
18.6\end{array}$ & $\begin{array}{l}18.5 \\
17.9 \\
18.9\end{array}$ & $\begin{array}{l}18.4 \\
17.9 \\
18.9\end{array}$ & $\begin{array}{l}18.5 \\
18.0 \\
19.0\end{array}$ & $\begin{array}{l}18.4 \\
17.8 \\
18.9\end{array}$ & $\begin{array}{l}20.5 \\
20.1 \\
20.9\end{array}$ & $\begin{array}{l}20.3 \\
19.8 \\
20.7\end{array}$ & $\begin{array}{l}20.2 \\
19.8 \\
20.6\end{array}$ & $\begin{array}{l}20.3 \\
19.8 \\
20.6\end{array}$ & $\begin{array}{l}20.3 \\
19.8 \\
20.7\end{array}$ & $\begin{array}{l}20.2 \\
19.8 \\
20.6\end{array}$ & $\begin{array}{l}20.3 \\
19.8 \\
20.7\end{array}$ & $\begin{array}{l}20.3 \\
19.9 \\
20.7\end{array}$ \\
\hline $\begin{array}{l}\text { Math, total } \\
\text { Male } \\
\text { Female }\end{array}$ & $\begin{array}{l}17.6 \\
19.3 \\
16.2\end{array}$ & $\begin{array}{l}17.4 \\
18.9 \\
16.2\end{array}$ & $\begin{array}{l}17.3 \\
18.9 \\
16.0\end{array}$ & $\begin{array}{l}16.9 \\
18.4 \\
15.7\end{array}$ & $\begin{array}{l}17.3 \\
18.6 \\
16.1\end{array}$ & $\begin{array}{l}17.2 \\
18.6 \\
16.0\end{array}$ & $\begin{array}{l}17.3 \\
18.8 \\
16.0\end{array}$ & $\begin{array}{l}17.2 \\
18.6 \\
16.1\end{array}$ & $\begin{array}{l}17.2 \\
18.4 \\
16.1\end{array}$ & $\begin{array}{l}17.1 \\
18.3 \\
16.1\end{array}$ & $\begin{array}{l}19.9 \\
20.7 \\
19.3\end{array}$ & $\begin{array}{l}20.0 \\
20.6 \\
19.4\end{array}$ & $\begin{array}{l}20.0 \\
20.7 \\
19.5\end{array}$ & $\begin{array}{l}20.1 \\
20.8 \\
19.6\end{array}$ & $\begin{array}{l}20.2 \\
20.8 \\
19.6\end{array}$ & $\begin{array}{l}20.2 \\
20.9 \\
19.7\end{array}$ & $\begin{array}{l}20.2 \\
20.9 \\
19.7\end{array}$ & $\begin{array}{l}20.6 \\
21.3 \\
20.1\end{array}$ \\
\hline $\begin{array}{l}\text { Social studies, total }{ }^{4} \\
\text { Male }\end{array}$ & $\begin{array}{l}17.4 \\
18.7 \\
16.4\end{array}$ & $\begin{array}{l}17.2 \\
18.2 \\
16.4\end{array}$ & $\begin{array}{l}17.2 \\
18.3 \\
16.4\end{array}$ & $\begin{array}{l}17.1 \\
18.0 \\
16.4\end{array}$ & $\begin{array}{l}17.3 \\
18.1 \\
16.5\end{array}$ & $\begin{array}{l}17.4 \\
18.3 \\
16.6\end{array}$ & $\begin{array}{l}17.6 \\
18.6 \\
16.9\end{array}$ & $\begin{array}{l}17.5 \\
18.4 \\
16.7\end{array}$ & $\begin{array}{l}17.4 \\
18.4 \\
16.6\end{array}$ & $\begin{array}{l}17.2 \\
18.1 \\
16.4\end{array}$ & $\begin{array}{l}- \\
-\end{array}$ & $\begin{array}{l}21.2 \\
21.3 \\
21.1\end{array}$ & $\begin{array}{l}21.1 \\
21.1 \\
21.1\end{array}$ & $\begin{array}{l}21.2 \\
21.2 \\
21.2\end{array}$ & $\begin{array}{l}21.2 \\
21.1 \\
21.4\end{array}$ & $\begin{array}{l}21.3 \\
21.1 \\
21.4\end{array}$ & $\begin{array}{l}21.3 \\
21.0 \\
21.6\end{array}$ & $\begin{array}{l}21.3 \\
21.2 \\
21.5\end{array}$ \\
\hline $\begin{array}{l}\text { Natural science, total } 5 \\
\quad \text { Male }\end{array}$ & $\begin{array}{l}21.1 \\
22.4 \\
20.0\end{array}$ & $\begin{array}{l}21.1 \\
22.4 \\
20.0\end{array}$ & $\begin{array}{l}21.0 \\
22.3 \\
20.0\end{array}$ & $\begin{array}{l}20.9 \\
22.4 \\
19.6\end{array}$ & $\begin{array}{l}21.0 \\
22.4 \\
19.9\end{array}$ & $\begin{array}{l}21.2 \\
22.6 \\
20.0\end{array}$ & $\begin{array}{l}21.4 \\
22.7 \\
20.2\end{array}$ & $\begin{array}{l}21.4 \\
22.8 \\
20.1\end{array}$ & $\begin{array}{l}21.4 \\
22.8 \\
20.2\end{array}$ & $\begin{array}{l}21.2 \\
22.6 \\
20.0\end{array}$ & $\begin{array}{l}- \\
- \\
-\end{array}$ & $\begin{array}{l}20.7 \\
21.3 \\
20.1\end{array}$ & $\begin{array}{l}20.7 \\
21.4 \\
20.1\end{array}$ & $\begin{array}{l}20.8 \\
21.5 \\
20.3\end{array}$ & $\begin{array}{l}20.9 \\
21.6 \\
20.4\end{array}$ & $\begin{array}{l}21.0 \\
21.6 \\
20.5\end{array}$ & $\begin{array}{l}21.1 \\
21.7 \\
20.5\end{array}$ & $\begin{array}{l}21.1 \\
21.7 \\
20.6\end{array}$ \\
\hline Female & \multicolumn{18}{|c|}{ Percent } \\
\hline $\begin{array}{l}\text { Obtaining composite scores of- } \\
28 \text { or above } \\
17 \text { or below }\end{array}$ & - & - & - & - & - & - & - & 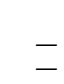 & - & - & - & - & - & $\overline{-}$ & 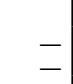 & - & - & $\begin{array}{l}10 \\
26\end{array}$ \\
\hline $\begin{array}{l}\text { Planned major field of study } \\
\text { Business } 6\end{array}$ & 21 & 20 & 19 & 18 & 19 & 21 & 22 & 23 & 23 & 22 & 20 & 18 & 15 & 13 & 12 & 12 & 12 & 13 \\
\hline Engineering ${ }^{7}$ & 6 & 8 & 10 & 10 & 9 & 9 & 9 & 8 & 9 & 9 & 9 & 10 & 10 & 9 & 9 & 8 & 8 & 9 \\
\hline Social science ${ }^{8}$ & 9 & 6 & 6 & 6 & 7 & 7 & 8 & 9 & 10 & 11 & 10 & 10 & 10 & 9 & 9 & 8 & 8 & 9 \\
\hline Education ${ }^{9}$ & 12 & 9 & 7 & 6 & 6 & 6 & 7 & 8 & 8 & 8 & 8 & 10 & 5 & 8 & 8 & 8 & 9 & 11 \\
\hline
\end{tabular}

1 Test scores for 1990 and later data are not comparable with previous years because a new version of the ACT was introduced. Estimated average composite scores for the new version for prior years were: 1989, 20.6; 1988, 1987, and 1986, 20.8; and 1982, 20.3 .

${ }^{2}$ Beginning in 1985, data are for seniors who graduated in year shown and had taken the ACT in their junior or senior years.

3 Minimum score, 1 ; maximum score, 36 .

${ }^{4}$ Beginning in 1990 , the test was changed to "reading."

5 Beginning in 1990, the test was changed to "science reasoning."
6 Includes political and persuasive (e.g., sales) fields through 1975; thereafter, business and commerce.

7 Beginning in 1993, includes engineering and engineering related technologies.

8 Includes religion through 1975.

9 Includes education and teacher education.

-Data not available.

SOURCE: The American College Testing program, High School Profile Report, annual. (This table was prepared July 1998.) 
Table 136.-Average number of Carnegie units earned by public high school graduates in various subject fields, by student characteristics: 1982 to 1994

\begin{tabular}{|c|c|c|c|c|c|c|c|c|c|c|c|c|c|c|c|c|}
\hline \multirow[b]{2}{*}{$\begin{array}{c}\text { Student } \\
\text { characteristics }\end{array}$} & \multirow[b]{2}{*}{ Total } & \multirow[b]{2}{*}{ English } & \multirow{2}{*}{$\begin{array}{c}\text { His- } \\
\text { tory/so- } \\
\text { cial } \\
\text { studies }\end{array}$} & \multicolumn{3}{|c|}{ Mathematics } & \multicolumn{5}{|c|}{ Science } & \multirow{2}{*}{$\begin{array}{l}\text { For- } \\
\text { eign } \\
\text { lan- } \\
\text { guages }\end{array}$} & \multirow[b]{2}{*}{ Arts } & \multirow{2}{*}{$\begin{array}{l}\text { Voca- } \\
\text { tional } \\
\text { edu- } \\
\text { ca- } \\
\text { tion } 1\end{array}$} & \multirow[b]{2}{*}{$\begin{array}{l}\text { Per- } \\
\text { sonal } \\
\text { use }^{2}\end{array}$} & \multirow[b]{2}{*}{$\begin{array}{c}\text { Com- } \\
\text { puter } \\
\text { science }^{3}\end{array}$} \\
\hline & & & & Total & $\begin{array}{l}\text { Less } \\
\text { than } \\
\text { algebra }\end{array}$ & $\begin{array}{l}\text { Alge- } \\
\text { bra or } \\
\text { higher }\end{array}$ & Total & $\begin{array}{c}\text { Gen- } \\
\text { eral } \\
\text { science }\end{array}$ & Biology & $\begin{array}{c}\text { Chem- } \\
\text { istry }\end{array}$ & $\begin{array}{l}\text { Phys- } \\
\text { ics }\end{array}$ & & & & & \\
\hline 1 & 2 & 3 & 4 & 5 & 6 & 7 & 8 & 9 & 10 & 11 & 12 & 13 & 14 & 15 & 16 & 17 \\
\hline 1982 graduates. & 21.64 & 3.90 & 3.19 & 2.57 & 0.92 & 1.65 & 2.17 & 0.74 & 0.93 & 0.34 & 0.17 & 0.97 & 1.46 & 4.68 & 2.69 & 0.14 \\
\hline $\begin{array}{l}\text { Male } \\
\text { Female }\end{array}$ & $\begin{array}{l}21.44 \\
21.82\end{array}$ & $\begin{array}{l}3.86 \\
3.93\end{array}$ & $\begin{array}{l}3.19 \\
3.20\end{array}$ & $\begin{array}{l}2.65 \\
2.49\end{array}$ & $\begin{array}{l}0.99 \\
0.85\end{array}$ & $\begin{array}{l}1.66 \\
1.64\end{array}$ & $\begin{array}{l}2.24 \\
2.11\end{array}$ & $\begin{array}{l}0.77 \\
0.71\end{array}$ & $\begin{array}{l}0.89 \\
0.97\end{array}$ & $\begin{array}{l}0.35 \\
0.32\end{array}$ & $\begin{array}{l}0.22 \\
0.12\end{array}$ & $\begin{array}{l}0.78 \\
1.14\end{array}$ & $\begin{array}{l}1.29 \\
1.63\end{array}$ & $\begin{array}{l}4.63 \\
4.72\end{array}$ & $\begin{array}{l}2.80 \\
2.60\end{array}$ & $\begin{array}{l}0.16 \\
0.13\end{array}$ \\
\hline \multicolumn{17}{|l|}{ Race/ethnicity } \\
\hline White ............... & 21.75 & 3.88 & 3.23 & 2.61 & 0.79 & 1.82 & 2.25 & 0.73 & 0.96 & 0.37 & 0.19 & 1.03 & 1.52 & 4.58 & 2.63 & 0.15 \\
\hline 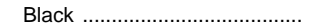 & 21.25 & 4.06 & 3.11 & 2.55 & 1.39 & 1.16 & 2.04 & 0.81 & 0.89 & 0.25 & 0.09 & 0.71 & 1.25 & 4.84 & 2.68 & 0.16 \\
\hline Hispanic .............................. & 21.30 & 3.89 & 3.03 & 2.26 & 1.23 & 1.03 & 1.78 & 0.77 & 0.79 & 0.16 & 0.06 & 0.76 & 1.31 & 5.26 & 3.02 & 0.09 \\
\hline Asian ......... & 22.43 & 3.82 & 3.18 & 3.16 & 0.71 & 2.44 & 2.59 & 0.50 & 1.09 & 0.60 & 0.40 & 1.96 & 1.31 & 3.23 & 3.17 & 0.23 \\
\hline American Indian .......................... & 21.51 & 3.94 & 3.25 & 2.12 & 1.12 & 1.00 & 2.00 & 0.71 & 0.80 & 0.38 & 0.11 & 0.48 & 1.69 & 5.09 & 2.96 & 0.09 \\
\hline Academic track & & & & & & & & & & & & & & & & \\
\hline Academic ${ }^{4} \ldots$ & 22.41 & 4.25 & 3.53 & 3.34 & 0.77 & 2.57 & 2.98 & 0.77 & 1.21 & 0.66 & 0.34 & 1.62 & 1.51 & 2.54 & 2.66 & 0.15 \\
\hline Vocational 5 & 20.99 & 3.52 & 2.79 & 1.81 & 1.03 & 0.78 & 1.44 & 0.71 & 0.63 & 0.07 & 0.03 & 0.35 & 1.02 & 7.55 & 2.48 & 0.16 \\
\hline Both 6 ............. & 24.21 & 4.34 & 3.75 & 3.04 & 1.16 & 1.88 & 2.53 & 0.92 & 1.04 & 0.39 & 0.19 & 0.57 & 0.88 & 6.47 & 2.61 & 0.22 \\
\hline Neither ${ }^{7}$.. & 20.21 & 3.60 & 2.89 & 1.98 & 0.94 & 1.05 & 1.57 & 0.66 & 0.77 & 0.11 & 0.03 & 0.75 & 2.02 & 4.39 & 2.98 & 0.09 \\
\hline 1987 graduates & 23.06 & 4.06 & 3.37 & 3.05 & 0.95 & 2.10 & 2.53 & 0.75 & 1.09 & 0.48 & 0.21 & 1.38 & 1.43 & 4.48 & 2.94 & 0.49 \\
\hline Male & 22.92 & 4.03 & 3.35 & 3.10 & 1.01 & 2.09 & 2.58 & 0.78 & 1.05 & 0.49 & 0.26 & 1.18 & 1.23 & 4.58 & 3.13 & 0.49 \\
\hline 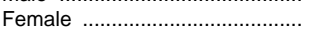 & 23.18 & 4.09 & 3.39 & 3.00 & 0.89 & 2.11 & 2.49 & 0.73 & 1.13 & 0.47 & 0.16 & 1.57 & 1.63 & 4.38 & 2.75 & 0.49 \\
\hline Race/ethnicity & & & & & & & & & & & & & & & & \\
\hline White ............... & 23.14 & 4.06 & 3.33 & 3.06 & 0.84 & 2.22 & 2.59 & 0.74 & 1.12 & 0.51 & 0.23 & 1.38 & 1.49 & 4.55 & 2.86 & 0.50 \\
\hline 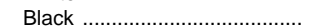 & 22.43 & 4.17 & 3.37 & 2.97 & 1.45 & 1.52 & 2.29 & 0.87 & 1.02 & 0.30 & 0.10 & 1.07 & 1.17 & 4.64 & 3.08 & 0.41 \\
\hline Hispanic ............................................ & 23.00 & 4.03 & 3.30 & 2.91 & 1.40 & 1.50 & 2.31 & 0.82 & 1.06 & 0.32 & 0.11 & 1.61 & 1.36 & 4.20 & 3.49 & 0.45 \\
\hline 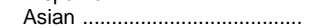 & 24.77 & 4.01 & 3.75 & 3.89 & 0.64 & 3.24 & 3.20 & 0.59 & 1.17 & 0.92 & 0.53 & 2.48 & 1.09 & 2.95 & 3.45 & 0.63 \\
\hline 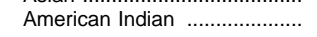 & 23.26 & 4.22 & 3.22 & 3.05 & 1.53 & 1.52 & 2.48 & 0.83 & 1.25 & 0.30 & 0.10 & 0.73 & 1.60 & 4.82 & 3.43 & 0.44 \\
\hline Academic track & & & & & & & & & & & & & & & & \\
\hline Academic ${ }^{4}$. & 23.65 & 4.28 & 3.67 & 3.56 & 0.72 & 2.84 & 3.07 & 0.73 & 1.26 & 0.74 & 0.34 & 1.92 & 1.61 & 2.77 & 2.88 & 0.50 \\
\hline Vocational $^{5}$ & 21.95 & 3.64 & 2.76 & 2.07 & 1.23 & 0.85 & 1.60 & 0.75 & 0.77 & 0.07 & 0.02 & 0.48 & 0.96 & 7.86 & 2.86 & 0.47 \\
\hline Both 6 ................ & 23.92 & 4.20 & 3.50 & 3.17 & 1.19 & 1.98 & 2.50 & 0.88 & 1.11 & 0.38 & 0.14 & 0.89 & 0.83 & 6.38 & 2.65 & 0.64 \\
\hline Neither ${ }^{7} \ldots \ldots$ & 21.16 & 3.62 & 2.86 & 2.19 & 1.22 & 0.97 & 1.71 & 0.71 & 0.86 & 0.12 & 0.02 & 1.03 & 2.11 & 4.42 & 3.61 & 0.31 \\
\hline 1990 graduates & 23.54 & 4.09 & 3.50 & 3.20 & 0.99 & 2.21 & 2.75 & 0.84 & 1.14 & 0.54 & 0.23 & 1.59 & 1.55 & 4.10 & 2.95 & 0.55 \\
\hline Male & 23.36 & 4.04 & 3.47 & 3.22 & 1.06 & 2.16 & 2.78 & 0.87 & 1.11 & 0.53 & 0.28 & 1.39 & 1.31 & 4.23 & 3.17 & 0.52 \\
\hline Female ................. & 23.70 & 4.13 & 3.52 & 3.18 & 0.93 & 2.25 & 2.72 & 0.82 & 1.17 & 0.54 & 0.19 & 1.78 & 1.77 & 3.99 & 2.74 & 0.57 \\
\hline Race/ethnicity & & & & & & & & & & & & & & & & \\
\hline 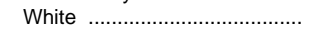 & 23.55 & 4.08 & 3.48 & 3.17 & 0.89 & 2.28 & 2.79 & 0.83 & 1.15 & 0.56 & 0.25 & 1.58 & 1.61 & 4.13 & 2.87 & 0.53 \\
\hline Black & 23.41 & 4.25 & 3.51 & 3.25 & 1.33 & 1.92 & 2.68 & 0.97 & 1.11 & 0.44 & 0.16 & 1.23 & 1.34 & 4.39 & 3.02 & 0.61 \\
\hline Hispanic ........................................ & 23.85 & 4.05 & 3.46 & 3.22 & 1.41 & 1.81 & 2.49 & 0.83 & 1.11 & 0.42 & 0.14 & 1.99 & 1.48 & 3.99 & 3.43 & 0.59 \\
\hline 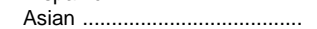 & 24.08 & 4.02 & 3.70 & 3.64 & 0.83 & 2.81 & 2.97 & 0.68 & 1.12 & 0.74 & 0.42 & 2.52 & 1.30 & 2.89 & 3.12 & 0.55 \\
\hline 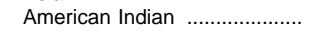 & 22.64 & 4.01 & 3.36 & 3.17 & 1.25 & 1.93 & 2.48 & 0.83 & 1.09 & 0.42 & 0.15 & 1.15 & 1.11 & 4.43 & 3.14 & 0.60 \\
\hline Academic track & & & & & & & & & & & & & & & & \\
\hline Academic $^{4}$ & 23.84 & 4.26 & 3.72 & 3.54 & 0.78 & 2.76 & 3.12 & 0.82 & 1.25 & 0.73 & 0.33 & 2.02 & 1.74 & 2.64 & 2.92 & 0.53 \\
\hline Vocational 5. & 22.53 & 3.58 & 2.75 & 2.18 & 1.46 & 0.72 & 1.77 & 0.88 & 0.80 & 0.07 & 0.02 & 0.55 & 1.01 & 8.15 & 2.93 & 0.53 \\
\hline Both 6 & 24.29 & 4.16 & 3.50 & 3.18 & 1.30 & 1.88 & 2.58 & 0.96 & 1.12 & 0.37 & 0.13 & 0.99 & 0.93 & 6.47 & 2.70 & 0.70 \\
\hline Neither ${ }^{7}$ & 21.45 & 3.51 & 2.97 & 2.25 & 1.24 & 1.01 & 1.85 & 0.77 & 0.88 & 0.16 & 0.05 & 1.19 & 2.08 & 4.39 & 3.55 & 0.41 \\
\hline 1994 graduates & 24.16 & 4.20 & 3.57 & 3.37 & 0.85 & 2.53 & 3.04 & 0.87 & 1.26 & 0.62 & 0.28 & 1.76 & 1.66 & 3.87 & 2.92 & 0.65 \\
\hline Male & 23.98 & 4.16 & 3.54 & 3.36 & 0.93 & 2.44 & 3.02 & 0.90 & 1.20 & 0.60 & 0.32 & 1.54 & 1.43 & 4.07 & 3.18 & 0.65 \\
\hline 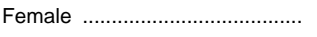 & 24.33 & 4.23 & 3.61 & 3.38 & 0.77 & 2.62 & 3.05 & 0.85 & 1.31 & 0.65 & 0.25 & 1.97 & 1.87 & 3.69 & 2.68 & 0.65 \\
\hline Race/ethnicity & & & & & & & & & & & & & & & & \\
\hline$\ldots$ & 24.31 & 4.19 & 3.58 & 3.39 & 0.78 & 2.62 & 3.12 & 0.88 & 1.29 & 0.66 & 0.30 & 1.75 & 1.74 & 3.87 & 2.87 & 0.64 \\
\hline Black & 23.60 & 4.31 & 3.54 & 3.26 & 1.15 & 2.12 & 2.80 & 0.91 & 1.21 & 0.50 & 0.18 & 1.37 & 1.36 & 4.24 & 3.00 & 0.65 \\
\hline 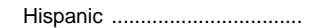 & 24.07 & 4.22 & 3.49 & 3.39 & 1.09 & 2.30 & 2.69 & 0.83 & 1.19 & 0.50 & 0.18 & 2.10 & 1.51 & 3.70 & 3.36 & 0.76 \\
\hline 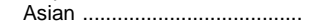 & 24.50 & 4.04 & 3.68 & 3.76 & 0.81 & 2.95 & 3.35 & 0.79 & 1.22 & 0.82 & 0.52 & 2.62 & 1.31 & 2.88 & 2.92 & 0.73 \\
\hline American Indian ....................... & 24.25 & 4.22 & 3.79 & 3.15 & 1.05 & 2.10 & 2.82 & 0.92 & 1.29 & 0.46 & 0.14 & 1.26 & 1.96 & 4.06 & 3.19 & 0.74 \\
\hline Academi & & & & & & & & & & & & & & & & \\
\hline 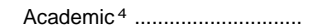 & 24.30 & 4.30 & 3.75 & 3.62 & 0.69 & 2.93 & 3.33 & 0.84 & 1.34 & 0.78 & 0.37 & 2.11 & 1.88 & 2.56 & 2.89 & 0.61 \\
\hline 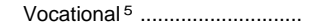 & 22.77 & 3.67 & 2.77 & 2.19 & 1.38 & 0.81 & 1.87 & 0.87 & 0.91 & 0.06 & 0.02 & 0.54 & 0.97 & 8.33 & 2.97 & 0.65 \\
\hline Both 6 . & 24.95 & 4.22 & 3.50 & 3.27 & 1.07 & 2.20 & 2.80 & 1.00 & 1.20 & 0.45 & 0.16 & 1.16 & 1.08 & 6.49 & 2.67 & 0.84 \\
\hline 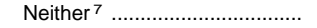 & 21.52 & 3.53 & 2.84 & 2.35 & 1.26 & 1.09 & 1.92 & 0.79 & 0.93 & 0.15 & 0.05 & 1.23 & 1.89 & 4.54 & 4.18 & 0.45 \\
\hline
\end{tabular}

1 Includes nonoccupational vocational education, vocational general introduction, agriculture, business, marketing, health, occupational home economics, trade and industry, and technical courses.

${ }^{2}$ Includes personal and social courses, religion and theology, and courses not included in the other subject fields.

3 Computer courses are included in mathematics and vocational categories.

${ }^{4}$ Includes students who complete at least 12 Carnegie units in academic courses, but less than 3 Carnegie units in any specific labor market preparation field.

${ }^{5}$ Includes students who complete at least 3 Carnegie units in a specific labor market preparation field, but less than 12 Carnegie units in academic courses.

${ }^{6}$ Includes students who complete at least 12 Carnegie units in academic courses and at least 3 Carnegie units in a specific labor market preparation field.
7 Includes students who complete less than 12 Carnegie units in academic courses and less than 3 Carnegie units in a specific labor market preparation field.

NOTE.-The Carnegie unit is a standard of measurement that represents one credit for the completion of a 1-year course.

SOURCE: U.S. Department of Education, National Center for Education Statistics, "High School and Beyond," First Followup survey; "1990 High School Transcript Study," "National Education Longitudinal Study of 1988," Second Followup survey, and the "1994 High School Transcript Study." (This table was prepared June 1997.) 
Table 137.-Average number of Carnegie units earned by public school graduates in vocational education courses, by student characteristics: 1982 to 1994

\begin{tabular}{|c|c|c|c|c|c|c|c|c|c|c|c|c|}
\hline \multirow[b]{2}{*}{$\begin{array}{c}\text { Student characteris- } \\
\text { tics }\end{array}$} & \multirow[b]{2}{*}{ Total } & \multirow{2}{*}{$\begin{array}{l}\text { General } \\
\text { labor } \\
\text { market } \\
\text { prepara- } \\
\text { tion }\end{array}$} & \multirow{2}{*}{$\begin{array}{c}\text { Consumer } \\
\text { and } \\
\text { home- } \\
\text { making } \\
\text { education }\end{array}$} & \multicolumn{9}{|c|}{ Specific labor market preparation } \\
\hline & & & & Total & $\begin{array}{l}\text { Agri- } \\
\text { culture }\end{array}$ & Business & Marketing & Health & $\begin{array}{c}\text { Occupa- } \\
\text { tional home } \\
\text { economics }\end{array}$ & $\begin{array}{l}\text { Trade and } \\
\text { industrial }\end{array}$ & $\begin{array}{c}\text { Tech- } \\
\text { nical/ } \\
\text { commu- } \\
\text { nications }\end{array}$ & Other \\
\hline 1 & 2 & 3 & 4 & 5 & 6 & 7 & 8 & 9 & 10 & 11 & 12 & 13 \\
\hline 1982 graduates ...... & 4.68 & 1.08 & 0.69 & 2.91 & 0.22 & 1.05 & 0.16 & 0.05 & 0.18 & 1.06 & 0.12 & 0.09 \\
\hline $\begin{array}{l}\text { Male } \\
\text { Female .................... } \\
\text { Race/ethnicity }\end{array}$ & $\begin{array}{l}4.63 \\
4.72\end{array}$ & $\begin{array}{l}1.03 \\
1.12\end{array}$ & $\begin{array}{l}0.31 \\
1.05\end{array}$ & $\begin{array}{l}3.29 \\
2.55\end{array}$ & $\begin{array}{l}0.37 \\
0.08\end{array}$ & $\begin{array}{l}0.49 \\
1.57\end{array}$ & $\begin{array}{l}0.14 \\
0.17\end{array}$ & $\begin{array}{l}0.02 \\
0.08\end{array}$ & $\begin{array}{l}0.05 \\
0.29\end{array}$ & $\begin{array}{l}1.97 \\
0.20\end{array}$ & $\begin{array}{l}0.14 \\
0.09\end{array}$ & $\begin{array}{l}0.11 \\
0.07\end{array}$ \\
\hline White ................. & 4.58 & 1.05 & 0.64 & 2.88 & 0.24 & 1.08 & 0.15 & 0.04 & 0.17 & 1.01 & 0.12 & 0.08 \\
\hline Black ............... & 4.84 & 1.10 & 0.90 & 2.84 & 0.09 & 0.98 & 0.22 & 0.13 & 0.23 & 0.97 & 0.11 & 0.10 \\
\hline Hispanic ......... & 5.26 & 1.21 & 0.86 & 3.19 & 0.24 & 1.00 & 0.15 & 0.07 & 0.20 & 1.34 & 0.07 & 0.12 \\
\hline $\begin{array}{l}\text { Asian .............. } \\
\text { American }\end{array}$ & 3.23 & 1.06 & 0.29 & 1.89 & 0.05 & 0.59 & 0.04 & 0.03 & 0.05 & 0.88 & 0.17 & 0.08 \\
\hline Indian ............ & 5.09 & 1.22 & 0.52 & 3.35 & 0.27 & 0.74 & 0.14 & 0.07 & 0.10 & 1.86 & 0.05 & 0.12 \\
\hline $\begin{array}{l}\text { Academic track } \\
\text { Academic }^{1} \ldots . . .\end{array}$ & 2.54 & 0.87 & 0.48 & 1.19 & 0.06 & 0.51 & 0.05 & 0.03 & 0.05 & 0.36 & 0.12 & \\
\hline Vocational $^{2} \ldots$. & 7.55 & 1.11 & 0.64 & 5.80 & 0.51 & 1.85 & 0.29 & 0.09 & 0.35 & 2.40 & 0.11 & 0.20 \\
\hline Both ${ }^{3} \ldots \ldots \ldots \ldots$ & 6.47 & 0.94 & 0.56 & 4.97 & 0.43 & 1.66 & 0.26 & 0.10 & 0.28 & 1.97 & 0.14 & 0.11 \\
\hline Neither 4 .......... & 4.39 & 1.38 & 1.10 & 1.91 & 0.10 & 0.84 & 0.14 & 0.04 & 0.15 & 0.46 & 0.10 & 0.07 \\
\hline 1987 graduates ..... & 4.48 & 0.92 & 0.59 & 2.96 & 0.21 & 0.98 & 0.17 & 0.07 & 0.19 & 0.98 & 0.24 & 0.12 \\
\hline Male & 4.58 & 0.89 & 0.32 & 3.37 & 0.35 & 0.58 & 0.13 & 0.02 & 0.08 & 1.78 & 0.30 & 0.13 \\
\hline $\begin{array}{l}\text { Female ............... } \\
\text { Race/ethnicity }\end{array}$ & 4.38 & 0.94 & 0.86 & 2.58 & 0.07 & 1.37 & 0.20 & 0.11 & 0.30 & 0.23 & 0.19 & 0.11 \\
\hline White ............... & 4.55 & 0.93 & 0.59 & 3.03 & 0.25 & 0.99 & 0.16 & 0.06 & 0.18 & 1.02 & 0.26 & 0.10 \\
\hline Black .............. & 4.64 & 1.01 & 0.74 & 2.89 & 0.10 & 1.00 & 0.18 & 0.12 & 0.29 & 0.80 & 0.18 & 0.21 \\
\hline Hispanic ..... & 4.20 & 0.93 & 0.55 & 2.72 & 0.07 & 0.92 & 0.17 & 0.06 & 0.17 & 1.05 & 0.14 & 0.14 \\
\hline Asian ................. & 2.95 & 0.62 & 0.31 & 2.02 & 0.13 & 0.68 & 0.10 & 0.04 & 0.09 & 0.50 & 0.37 & 0.10 \\
\hline $\begin{array}{c}\text { American } \\
\text { Indian ........... } \\
\text { Academic track }\end{array}$ & 4.82 & 0.89 & 0.66 & 3.27 & 0.21 & 1.11 & 0.09 & 0.08 & 0.09 & 1.39 & 0.19 & 0.11 \\
\hline Academic ${ }^{1} \ldots$ & 2.77 & 0.81 & 0.49 & 1.46 & 0.05 & 0.61 & 0.06 & 0.03 & 0.06 & 0.33 & 0.27 & 0.04 \\
\hline Vocational $^{2} \ldots$. & 7.86 & 1.07 & 0.66 & 6.14 & 0.52 & 1.68 & 0.39 & 0.15 & 0.52 & 2.45 & 0.17 & 0.26 \\
\hline Both $^{3} \ldots \ldots \ldots . . .$. & 6.38 & 0.90 & 0.47 & 5.02 & 0.47 & 1.60 & 0.25 & 0.12 & 0.27 & 1.86 & 0.27 & 0.18 \\
\hline Neither 4 ......... & 4.42 & 1.19 & 1.06 & 2.17 & 0.10 & 0.79 & 0.18 & 0.05 & 0.19 & 0.54 & 0.17 & 0.15 \\
\hline 1990 graduates $\ldots . .$. & 4.10 & 0.83 & 0.57 & 2.70 & 0.20 & 0.90 & 0.16 & 0.04 & 0.17 & 0.87 & 0.22 & 0.14 \\
\hline Male ...................... & 4.23 & 0.78 & 0.33 & 3.12 & 0.32 & 0.58 & 0.13 & 0.02 & 0.06 & 1.58 & 0.27 & 0.15 \\
\hline $\begin{array}{l}\text { Female ............... } \\
\text { Race/ethnicity }\end{array}$ & 3.99 & 0.87 & 0.79 & 2.32 & 0.09 & 1.19 & 0.18 & 0.06 & 0.27 & 0.22 & 0.18 & 0.12 \\
\hline White ............... & 4.13 & 0.80 & 0.55 & 2.78 & 0.24 & 0.87 & 0.16 & 0.04 & 0.15 & 0.94 & 0.22 & 0.15 \\
\hline Black ................. & 4.39 & 0.96 & 0.81 & 2.62 & 0.06 & 1.08 & 0.17 & 0.04 & 0.28 & 0.64 & 0.23 & 0.11 \\
\hline Hispanic ......... & 3.99 & 0.85 & 0.54 & 2.61 & 0.15 & 0.95 & 0.19 & 0.02 & 0.27 & 0.75 & 0.17 & 0.10 \\
\hline $\begin{array}{l}\text { Asian ................ } \\
\text { American }\end{array}$ & 2.89 & 0.73 & 0.32 & 1.85 & 0.04 & 0.66 & 0.05 & 0.01 & 0.05 & 0.73 & 0.26 & 0.05 \\
\hline Indian & 4.43 & 0.84 & 0.72 & 2.87 & 0.36 & 0.96 & 0.15 & 0.02 & 0.08 & 0.95 & 0.16 & 0.19 \\
\hline $\begin{array}{l}\text { Academic track } \\
\text { Academic }^{1}\end{array}$ & & & & & & & & & & & & \\
\hline Academic $^{1} \ldots .$. & 2.64 & 0.73 & 0.52 & 1.39 & 0.05 & 0.60 & 0.07 & 0.02 & 0.07 & 0.32 & 0.24 & 0.04 \\
\hline Vocational 2 .... & 8.15 & 1.02 & 0.62 & 6.50 & 0.69 & 1.60 & 0.32 & 0.11 & 0.51 & 2.73 & 0.16 & 0.37 \\
\hline Both $^{3}$............ & 6.47 & 0.81 & 0.50 & 5.16 & 0.44 & 1.60 & 0.38 & 0.09 & 0.33 & 1.81 & 0.22 & 0.29 \\
\hline Neither ${ }^{4} \ldots \ldots . .$. & 4.39 & 1.24 & 0.99 & 2.16 & 0.13 & 0.77 & 0.17 & 0.04 & 0.14 & 0.56 & 0.17 & 0.19 \\
\hline 1994 graduates ..... & 3.87 & 0.70 & 0.53 & 2.65 & 0.24 & 0.89 & 0.18 & 0.08 & 0.19 & 0.70 & 0.22 & 0.15 \\
\hline Male ................... & 4.07 & 0.74 & 0.35 & 2.99 & 0.38 & 0.67 & 0.14 & 0.03 & 0.08 & 1.25 & 0.28 & 0.16 \\
\hline $\begin{array}{l}\text { Female ................ } \\
\text { Race/ethnicity }\end{array}$ & 3.69 & 0.66 & 0.70 & 2.33 & 0.11 & 1.10 & 0.22 & 0.12 & 0.30 & 0.17 & 0.16 & 0.14 \\
\hline White ........... & 3.87 & 0.69 & 0.52 & 2.66 & 0.28 & 0.88 & 0.19 & 0.08 & 0.16 & 0.72 & 0.22 & 0.15 \\
\hline Black & 4.24 & 0.77 & 0.62 & 2.84 & 0.13 & 1.02 & 0.20 & 0.11 & 0.38 & 0.60 & 0.21 & 0.19 \\
\hline Hispanic ......... & 3.70 & 0.67 & 0.48 & 2.55 & 0.13 & 0.94 & 0.15 & 0.07 & 0.26 & 0.65 & 0.20 & 0.16 \\
\hline Asian ................. & 2.88 & 0.56 & 0.37 & 1.96 & 0.14 & 0.71 & 0.11 & 0.06 & 0.12 & 0.50 & 0.28 & 0.05 \\
\hline American & & & & & & & & & & & & \\
\hline Indian ............. & 4.06 & 0.81 & 0.62 & 2.63 & 0.36 & 0.92 & 0.05 & 0.15 & 0.13 & 0.57 & 0.26 & 0.19 \\
\hline Academic track & & & & & & & & & & & & \\
\hline Academic $^{1} \ldots .$. & 2.56 & 0.60 & 0.48 & 1.48 & 0.08 & 0.65 & 0.09 & 0.05 & 0.08 & 0.29 & 0.21 & 0.04 \\
\hline Vocational $^{2} \ldots$. & 8.33 & 1.01 & 0.70 & 6.62 & 0.80 & 1.44 & 0.37 & 0.17 & 0.55 & 2.46 & 0.25 & 0.59 \\
\hline Both $^{3} \ldots \ldots \ldots \ldots$ & 6.49 & 0.72 & 0.50 & 5.28 & 0.63 & 1.54 & 0.42 & 0.17 & 0.42 & 1.50 & 0.26 & 0.34 \\
\hline Neither ${ }^{4} \ldots \ldots . .$. & 4.54 & 1.35 & 0.94 & 2.25 & 0.18 & 0.73 & 0.20 & 0.06 & 0.20 & 0.53 & 0.16 & 0.18 \\
\hline
\end{tabular}

1 Includes students who complete at least 12 Carnegie units in academic courses, but less than 3 Carnegie units in any specific labor market preparation field.

2 Includes students who complete at least 3 Carnegie units in a specific labor market preparation field, but less than 12 Carnegie units in academic courses.

3 Includes students who complete at least 12 Carnegie units in academic courses and at least 3 Carnegie units in a specific labor market preparation field.

${ }^{4}$ Includes students who complete less than 12 Carnegie units in academic courses and less than 3 Carnegie units in a specific labor market preparation field.
NOTE.-The Carnegie unit is a standard of measurement that represents one credit for the completion of a 1-year course.

SOURCE: U.S. Department of Education, National Center for Education Statistics, "High School and Beyond," First Followup survey; "1990 High School Transcript Study," "National Education Longitudinal Study of 1988," Second Followup survey, and the "1994 High School Transcript Study." (This table was prepared June 1997.) 
Table 138.-Percentage of high school graduates taking selected mathematics and science courses in high school, by sex and race/ethnicity: 1982 to 1994

\begin{tabular}{|c|c|c|c|c|c|c|c|c|c|c|c|}
\hline \multirow{4}{*}{ Courses (credits) } & \multirow{4}{*}{1982} & \multirow{4}{*}{1987} & \multirow{4}{*}{1990} & \multicolumn{8}{|c|}{1994} \\
\hline & & & & \multirow{3}{*}{ Total } & \multirow{2}{*}{\multicolumn{2}{|c|}{ Sex }} & \multicolumn{5}{|c|}{ Race/ethnicity } \\
\hline & & & & & & & \multirow{2}{*}{ White } & \multirow{2}{*}{ Black } & \multirow{2}{*}{$\begin{array}{l}\text { His- } \\
\text { panic }\end{array}$} & \multirow{2}{*}{$\begin{array}{c}\text { Asian/ } \\
\text { Pacific } \\
\text { Islander }\end{array}$} & \multirow{2}{*}{$\begin{array}{c}\text { American } \\
\text { Indian/ } \\
\text { Alaskan } \\
\text { Native }\end{array}$} \\
\hline & & & & & Men & Women & & & & & \\
\hline 1 & 2 & 3 & 4 & 5 & 6 & 7 & 8 & 9 & 10 & 11 & 12 \\
\hline \multicolumn{12}{|l|}{ Mathematics ${ }^{1}$} \\
\hline Any mathematics $(1.0)$ & 98.5 & 98.9 & 99.6 & 99.6 & 99.5 & 99.6 & 99.6 & 99.3 & 99.2 & 100.0 & 98.9 \\
\hline Algebra I (1.0) & 53.9 & 64.0 & 64.2 & 66.4 & 64.7 & 68.1 & 67.5 & 65.0 & 70.7 & 61.7 & 58.7 \\
\hline 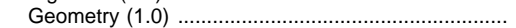 & 45.5 & 59.7 & 63.4 & 70.4 & 68.3 & 72.4 & 72.7 & 58.1 & 69.4 & 75.8 & 60.0 \\
\hline 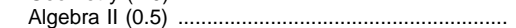 & 32.2 & 48.6 & 51.7 & 58.6 & 55.4 & 61.6 & 61.6 & 43.7 & 51.0 & 66.6 & 39.2 \\
\hline Trigonometry (0.5) …1-1. & 12.1 & 18.6 & 18.2 & 17.2 & 16.6 & 17.8 & 18.6 & 13.6 & 9.8 & 25.3 & 6.7 \\
\hline Analysis/pre-calculus (0.5) . & 5.9 & 12.6 & 13.4 & 17.3 & 16.3 & 18.2 & 18.2 & 9.8 & 13.9 & 33.9 & 8.7 \\
\hline 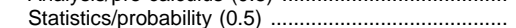 & 1.0 & 1.3 & 1.0 & 2.0 & 2.0 & 2.1 & 2.3 & 1.7 & 1.0 & 1.1 & 1.2 \\
\hline Calculus (1.0) & 4.6 & 6.0 & 6.5 & 9.2 & 9.4 & 9.1 & 9.6 & 3.8 & 6.0 & 23.4 & 3.8 \\
\hline AP calculus $(1.0)$ & 1.5 & 3.2 & 4.1 & 7.0 & 7.2 & 6.8 & 7.3 & 2.0 & 4.6 & 21.0 & 2.2 \\
\hline \multicolumn{12}{|l|}{ Science } \\
\hline Any science $(1.0)$ & 96.6 & 98.7 & 99.4 & 99.5 & 99.3 & 99.8 & 99.7 & 99.5 & 99.3 & 99.3 & 99.7 \\
\hline Biology (1.0) ................................ & 76.4 & 87.8 & 91.3 & 93.5 & 92.3 & 94.7 & 94.4 & 91.3 & 94.0 & 90.9 & 91.2 \\
\hline AP/honors biology (1.0) ……… & 6.6 & 2.7 & 4.9 & 4.6 & 4.0 & 5.1 & 4.6 & 2.7 & 3.3 & 8.3 & 1.7 \\
\hline Chemistry (1.0) & 30.9 & 43.7 & 49.0 & 56.0 & 53.2 & 58.7 & 58.5 & 43.8 & 46.5 & 69.3 & 41.3 \\
\hline AP/honors chemistry $(1.0)$ & 2.9 & 3.3 & 3.5 & 3.9 & 4.1 & 3.7 & 4.3 & 2.1 & 2.5 & 7.7 & 0.6 \\
\hline Physics (1.0) …ㄴ) & 14.2 & 19.2 & 21.5 & 24.4 & 26.9 & 22.0 & 26.1 & 14.7 & 16.0 & 42.3 & 10.3 \\
\hline 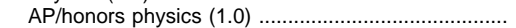 & 1.0 & 1.6 & 2.0 & 2.4 & 3.0 & 1.8 & 2.5 & 1.4 & 1.8 & 6.0 & 0.3 \\
\hline 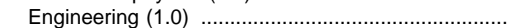 & 0.1 & 0.1 & 0.1 & 0.3 & 0.4 & 0.2 & 0.2 & 0.4 & 0.1 & 1.0 & - \\
\hline 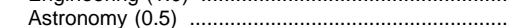 & 1.1 & 1.0 & 1.2 & 1.7 & 2.0 & 1.5 & 2.0 & 0.6 & 0.4 & 0.8 & 2.2 \\
\hline Geology/earth science $(0.5)$ & 13.2 & 14.5 & 24.8 & 23.0 & 22.8 & 23.2 & 23.8 & 23.3 & 15.3 & 16.7 & 23.2 \\
\hline Biology and chemistry $(2.0)$ & 28.1 & 42.1 & 47.6 & 53.8 & 50.9 & 56.6 & 56.4 & 42.2 & 45.1 & 64.8 & 39.6 \\
\hline Biology, chemistry, and physics $(3.0)$ & 10.6 & 16.4 & 18.8 & 21.3 & 23.1 & 19.6 & 22.7 & 13.0 & 13.4 & 37.2 & 8.0 \\
\hline
\end{tabular}

1 These data only report the percentage of students who earned credit in each mathematics course while in high school and does not count those students who took these courses prior to entering high school. In 1992, approximately 93 percent of graduates had taken algebra I before or during high school, and 70 percent had taken geometry.

- Less than 0.05 percent.
SOURCE: U.S. Department of Education, National Center for Education Statistics, National Assessment of Educational Progress, The 1994 High School Transcript Study Tabulations: Comparative Data on Credits Earned and Demographics for 1994, 1990, 1987, and 1982 High School Graduates, 1996. (This table was prepared September 1996.)

\section{Table 139.-Percent of high school graduates earning minimum credits in selected combinations of academic} courses, by sex and race/ethnicity: 1982 to 1994

\begin{tabular}{|c|c|c|c|c|c|c|c|c|}
\hline \multirow[b]{2}{*}{ Year of graduation and course combinations taken 1} & \multirow[b]{2}{*}{$\begin{array}{c}\text { All } \\
\text { students }\end{array}$} & \multicolumn{2}{|c|}{ Sex } & \multicolumn{5}{|c|}{ Race/ethnicity } \\
\hline & & Male & Female & White & Black & Hispanic & Asian & $\begin{array}{c}\text { American } \\
\text { Indian/ } \\
\text { Alaskan } \\
\text { Native }\end{array}$ \\
\hline 1 & 2 & 3 & 4 & 5 & 6 & 7 & 8 & 9 \\
\hline 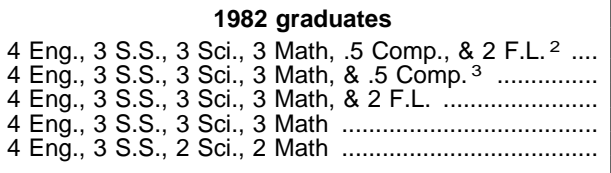 & $\begin{array}{r}2.0 \\
2.9 \\
9.2 \\
14.0 \\
31.5\end{array}$ & $\begin{array}{r}2.2 \\
3.6 \\
8.8 \\
14.8 \\
31.6\end{array}$ & $\begin{array}{r}1.8 \\
2.3 \\
9.6 \\
13.3 \\
31.5\end{array}$ & $\begin{array}{r}2.4 \\
3.4 \\
10.5 \\
15.5 \\
32.5\end{array}$ & $\begin{array}{r}0.9 \\
1.3 \\
5.3 \\
11.6 \\
31.7\end{array}$ & $\begin{array}{r}0.6 \\
0.9 \\
3.7 \\
6.5 \\
25.2\end{array}$ & $\begin{array}{r}5.6 \\
6.6 \\
17.1 \\
21.3 \\
34.3\end{array}$ & $\begin{array}{r}0.1 \\
0.1 \\
5.7 \\
6.5 \\
35.7\end{array}$ \\
\hline 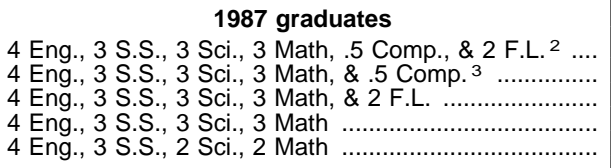 & $\begin{array}{l}12.1 \\
16.6 \\
20.6 \\
27.9 \\
54.0\end{array}$ & $\begin{array}{l}13.0 \\
18.1 \\
20.2 \\
28.8 \\
53.5\end{array}$ & $\begin{array}{l}11.4 \\
15.1 \\
20.9 \\
27.1 \\
54.7\end{array}$ & $\begin{array}{l}12.8 \\
17.6 \\
21.4 \\
29.2 \\
53.4\end{array}$ & $\begin{array}{r}7.8 \\
11.3 \\
15.0 \\
22.0 \\
56.0\end{array}$ & $\begin{array}{r}6.4 \\
9.0 \\
12.9 \\
17.6 \\
51.6\end{array}$ & $\begin{array}{l}25.6 \\
28.8 \\
42.6 \\
48.8 \\
68.9\end{array}$ & $\begin{array}{r}2.8 \\
15.2 \\
5.8 \\
26.6 \\
66.7\end{array}$ \\
\hline 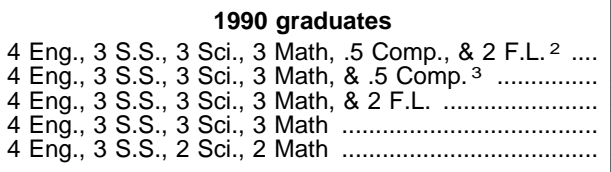 & $\begin{array}{l}18.3 \\
23.3 \\
30.3 \\
38.8 \\
66.5\end{array}$ & $\begin{array}{l}18.1 \\
23.9 \\
29.2 \\
39.2 \\
65.9\end{array}$ & $\begin{array}{l}18.4 \\
22.8 \\
31.3 \\
38.4 \\
67.1\end{array}$ & $\begin{array}{l}18.9 \\
23.5 \\
32.0 \\
39.8 \\
65.8\end{array}$ & $\begin{array}{l}15.5 \\
25.3 \\
23.3 \\
39.5 \\
73.3\end{array}$ & $\begin{array}{l}18.2 \\
20.5 \\
25.8 \\
30.3 \\
64.6\end{array}$ & $\begin{array}{l}23.9 \\
27.2 \\
43.7 \\
48.8 \\
70.6\end{array}$ & $\begin{array}{r}7.8 \\
14.6 \\
9.9 \\
20.9 \\
47.9\end{array}$ \\
\hline 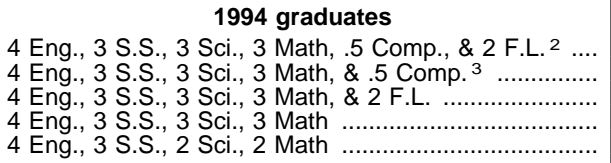 & $\begin{array}{l}25.3 \\
32.0 \\
39.1 \\
49.8 \\
74.6\end{array}$ & $\begin{array}{l}23.5 \\
31.1 \\
35.1 \\
47.5 \\
72.2\end{array}$ & $\begin{array}{l}26.9 \\
32.9 \\
42.9 \\
51.9 \\
76.9\end{array}$ & $\begin{array}{l}26.5 \\
33.5 \\
41.6 \\
52.7 \\
75.5\end{array}$ & $\begin{array}{l}19.5 \\
28.2 \\
30.2 \\
45.0 \\
76.7\end{array}$ & $\begin{array}{l}27.7 \\
31.1 \\
36.3 \\
41.2 \\
77.5\end{array}$ & $\begin{array}{l}36.3 \\
40.2 \\
51.2 \\
56.1 \\
73.1\end{array}$ & $\begin{array}{l}12.9 \\
25.5 \\
22.5 \\
46.0 \\
77.0\end{array}$ \\
\hline
\end{tabular}

${ }^{1}$ Eng. $=$ English; S.S. $=$ social studies; Sci. = science; Comp. = computer science; and F.L. = foreign language.

2 The National Commission on Excellence in Education recommended that all college bound high school students take these courses as a minimum.

${ }^{3}$ The National Commission on Excellence in Education recommended that all high school students take these courses as a minimum.
SOURCE: U.S. Department of Education, National Center for Education Statistics, The 1994 High School Transcript Study Tabulations: Comparative Data on Credits Earned and Demographics for 1994, 1990, 1987, and 1982 High School Graduates, 1996. (This table was prepared October 1996.) 
Table 140.-Reasons given by 12th-graders for taking current mathematics and science classes, by selected student and school characteristics: 1992

\begin{tabular}{|c|c|c|c|c|c|c|c|c|c|c|c|c|c|c|c|}
\hline \multirow{4}{*}{ Class subject and opinion } & \multicolumn{15}{|c|}{ Percent of 12th graders who answered, "somewhat important" or "very important" } \\
\hline & \multirow{3}{*}{$\begin{array}{l}\text { All 12th } \\
\text { graders }\end{array}$} & \multirow{2}{*}{\multicolumn{2}{|c|}{ Sex }} & \multicolumn{5}{|c|}{ Race/ethnicity } & \multirow{2}{*}{\multicolumn{4}{|c|}{ Socioeconomic status quartile 1}} & \multirow{2}{*}{\multicolumn{3}{|c|}{ Control of school attended }} \\
\hline & & & & \multirow{2}{*}{ White } & \multirow{2}{*}{ Black } & \multirow{2}{*}{$\begin{array}{l}\text { His- } \\
\text { panic }\end{array}$} & \multirow{2}{*}{ Asian } & \multirow{2}{*}{$\begin{array}{l}\text { Amer- } \\
\text { ican In- } \\
\text { dian }\end{array}$} & & & & & & & \\
\hline & & Male & Female & & & & & & Lowest & Second & Third & Highest & Public & Catholic & $\begin{array}{l}\text { Other } \\
\text { private }\end{array}$ \\
\hline 1 & 2 & 3 & 4 & 5 & 6 & 7 & 8 & 9 & 10 & 11 & 12 & 13 & 14 & 15 & 16 \\
\hline $\begin{array}{c}\text { Mathematics class } \\
\text { I am interested in mathe- } \\
\text { matics ......................... } \\
\text { I do well in mathematics .... } \\
\text { I need it for college or trade }\end{array}$ & $\begin{array}{l}74.5 \\
77.1\end{array}$ & $\begin{array}{l}77.4 \\
80.2\end{array}$ & $\begin{array}{l}71.3 \\
73.7\end{array}$ & $\begin{array}{l}72.9 \\
76.4\end{array}$ & $\begin{array}{l}74.6 \\
76.1\end{array}$ & $\begin{array}{l}80.4 \\
79.7\end{array}$ & $\begin{array}{l}81.9 \\
83.6\end{array}$ & $\begin{array}{l}87.7 \\
76.8\end{array}$ & $\begin{array}{l}78.0 \\
79.5\end{array}$ & $\begin{array}{l}74.6 \\
77.8\end{array}$ & $\begin{array}{l}73.1 \\
76.3\end{array}$ & $\begin{array}{l}74.2 \\
76.1\end{array}$ & $\begin{array}{l}73.8 \\
76.7\end{array}$ & $\begin{array}{l}78.4 \\
78.4\end{array}$ & $\begin{array}{l}81.7 \\
82.1\end{array}$ \\
\hline $\begin{array}{l}\text { school ...................... } \\
\text { I need it for a job after high }\end{array}$ & 87.2 & 86.6 & 87.8 & 86.5 & 89.8 & 86.5 & 90.8 & 90.5 & 83.3 & 85.4 & 88.9 & 88.6 & 87.1 & 87.9 & 87.5 \\
\hline $\begin{array}{l}\text { school ........................... } \\
\text { I need it for advanced }\end{array}$ & 64.7 & 65.9 & 63.4 & 62.5 & 69.7 & 70.9 & 66.3 & 83.9 & 71.2 & 68.5 & 65.5 & 57.8 & 65.9 & 58.1 & 51.9 \\
\hline $\begin{array}{l}\text { placement } \\
\text { Advised to take class by: }\end{array}$ & 53.6 & 53.3 & 54.0 & 49.6 & 58.4 & 62.5 & 72.6 & 56.9 & 59.8 & 46.7 & 52.2 & 55.7 & 54.1 & 47.2 & 53.9 \\
\hline 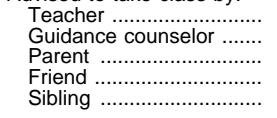 & $\begin{array}{l}65.9 \\
64.8 \\
71.6 \\
42.2 \\
30.9\end{array}$ & $\begin{array}{l}63.3 \\
62.9 \\
69.1 \\
41.4 \\
29.5\end{array}$ & $\begin{array}{l}68.8 \\
66.8 \\
74.2 \\
43.2 \\
32.5\end{array}$ & $\begin{array}{l}63.6 \\
60.7 \\
70.5 \\
39.8 \\
26.3\end{array}$ & $\begin{array}{l}74.8 \\
77.8 \\
74.6 \\
51.2 \\
37.2\end{array}$ & $\begin{array}{l}71.1 \\
76.2 \\
74.4 \\
43.7 \\
43.1\end{array}$ & $\begin{array}{l}66.7 \\
64.2 \\
73.3 \\
50.8 \\
46.2\end{array}$ & $\begin{array}{l}70.6 \\
83.0 \\
79.8 \\
56.2 \\
51.5\end{array}$ & $\begin{array}{l}69.2 \\
76.4 \\
66.3 \\
46.1 \\
40.4\end{array}$ & $\begin{array}{l}65.1 \\
67.5 \\
67.2 \\
43.2 \\
29.7\end{array}$ & $\begin{array}{l}66.3 \\
62.6 \\
70.3 \\
41.7 \\
27.7\end{array}$ & $\begin{array}{l}64.7 \\
58.6 \\
76.6 \\
40.7 \\
29.4\end{array}$ & $\begin{array}{l}65.7 \\
65.8 \\
71.8 \\
42.5 \\
31.8\end{array}$ & $\begin{array}{l}66.2 \\
55.1 \\
68.4 \\
40.6 \\
21.9\end{array}$ & $\begin{array}{l}70.0 \\
59.6 \\
71.4 \\
39.1 \\
28.9\end{array}$ \\
\hline Science class & & & & & & & & & & & & & & & \\
\hline $\begin{array}{l}\text { I am interested in science ... } \\
\text { I do well in science ............ } \\
\text { I need it for college or trade }\end{array}$ & $\begin{array}{l}78.8 \\
80.6\end{array}$ & $\begin{array}{l}82.7 \\
83.9\end{array}$ & $\begin{array}{l}74.4 \\
77.0\end{array}$ & $\begin{array}{l}78.5 \\
80.1\end{array}$ & $\begin{array}{l}77.4 \\
76.7\end{array}$ & $\begin{array}{l}78.9 \\
86.1\end{array}$ & $\begin{array}{l}83.6 \\
84.2\end{array}$ & $\begin{array}{l}74.9 \\
86.6\end{array}$ & $\begin{array}{l}74.5 \\
78.1\end{array}$ & $\begin{array}{l}76.7 \\
80.1\end{array}$ & $\begin{array}{l}76.9 \\
77.1\end{array}$ & $\begin{array}{l}82.7 \\
84.0\end{array}$ & $\begin{array}{l}77.9 \\
80.1\end{array}$ & $\begin{array}{l}81.1 \\
79.8\end{array}$ & $\begin{array}{l}89.9 \\
90.2\end{array}$ \\
\hline $\begin{array}{l}\text { school .................. } \\
\text { I need it for a job after high }\end{array}$ & 83.3 & 81.7 & 85.0 & 82.4 & 86.4 & 83.5 & 88.4 & 88.8 & 78.5 & 81.9 & 84.6 & 84.8 & 83.3 & 85.3 & 80.7 \\
\hline $\begin{array}{l}\text { school ........................... } \\
\text { I need it for advanced }\end{array}$ & 47.0 & 47.9 & 45.9 & 44.5 & 53.2 & 57.6 & 51.3 & 55.9 & 53.4 & 47.6 & 50.4 & 41.6 & 47.8 & 45.7 & 35.7 \\
\hline $\begin{array}{l}\text { placement ....................... } \\
\text { Advised to take class by: }\end{array}$ & 50.2 & 49.7 & 50.9 & 47.1 & 51.6 & 59.0 & 66.8 & 59.6 & 48.9 & 47.9 & 46.8 & 53.9 & 49.2 & 53.5 & 60.3 \\
\hline 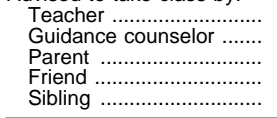 & $\begin{array}{l}58.9 \\
59.4 \\
66.3 \\
43.5 \\
28.7\end{array}$ & $\begin{array}{l}56.2 \\
57.8 \\
63.4 \\
43.4 \\
26.8\end{array}$ & $\begin{array}{l}61.9 \\
61.2 \\
69.4 \\
43.6 \\
31.0\end{array}$ & $\begin{array}{l}57.6 \\
56.2 \\
65.7 \\
42.9 \\
25.3\end{array}$ & $\begin{array}{l}61.7 \\
71.4 \\
69.1 \\
40.9 \\
35.0\end{array}$ & $\begin{array}{l}63.7 \\
70.9 \\
70.5 \\
44.6 \\
35.5\end{array}$ & $\begin{array}{l}61.0 \\
59.7 \\
64.1 \\
49.7 \\
44.3\end{array}$ & $\begin{array}{l}67.2 \\
57.9 \\
73.8 \\
62.9 \\
57.6\end{array}$ & $\begin{array}{l}61.3 \\
74.0 \\
61.9 \\
45.6 \\
36.1\end{array}$ & $\begin{array}{l}57.7 \\
59.5 \\
59.9 \\
41.6 \\
25.2\end{array}$ & $\begin{array}{l}58.3 \\
55.8 \\
66.4 \\
41.0 \\
25.2\end{array}$ & $\begin{array}{l}59.0 \\
55.5 \\
70.6 \\
45.0 \\
29.6\end{array}$ & $\begin{array}{l}57.8 \\
60.3 \\
67.0 \\
43.6 \\
29.4\end{array}$ & $\begin{array}{l}60.3 \\
44.1 \\
58.7 \\
36.6 \\
21.0\end{array}$ & $\begin{array}{l}74.1 \\
67.3 \\
67.4 \\
52.5 \\
30.5\end{array}$ \\
\hline
\end{tabular}

${ }^{1}$ Socioeconomic status was measured by a composite score on parental education and occupations, and family income.

SOURCE: U.S. Department of Education, National Center for Education Statistics, "National Education Longitudinal Study of 1988," Second Followup survey. (This table was prepared February 1994.)

Table 141.-Expected occupations of 8th-, 10th-, and 12th-graders at age 30, by selected student and school characteristics: 1988, 1990, and 1992

[Percentage distribution]

\begin{tabular}{|c|c|c|c|c|c|c|c|c|c|c|c|c|c|c|c|c|}
\hline \multirow{4}{*}{$\begin{array}{l}\text { Expected } \\
\text { occupation } \\
\text { at age } 30\end{array}$} & \multirow{4}{*}{$\begin{array}{c}\text { 8th } \\
\text { graders } \\
\text { in } 1988\end{array}$} & \multirow{4}{*}{$\begin{array}{c}\text { 10th } \\
\text { graders } \\
\text { in } 1990\end{array}$} & \multicolumn{14}{|c|}{ 12th graders in 1992} \\
\hline & & & \multirow{3}{*}{ Total } & \multirow{2}{*}{\multicolumn{2}{|c|}{ Sex }} & \multicolumn{5}{|c|}{ Race/ethnicity } & \multirow{2}{*}{\multicolumn{3}{|c|}{ Socioeconomic status ${ }^{1}$}} & \multirow{2}{*}{\multicolumn{3}{|c|}{$\begin{array}{c}\text { Control of school } \\
\text { attended }\end{array}$}} \\
\hline & & & & & & \multirow{2}{*}{ White } & \multirow{2}{*}{ Black } & \multirow{2}{*}{$\begin{array}{l}\text { His- } \\
\text { panic }\end{array}$} & \multirow{2}{*}{ Asian } & \multirow{2}{*}{$\begin{array}{c}\text { Amer- } \\
\text { ican } \\
\text { Indian }\end{array}$} & & & & & & \\
\hline & & & & Male & Female & & & & & & Low & Middle & High & Public & Catholic & $\begin{array}{l}\text { Other } \\
\text { private }\end{array}$ \\
\hline 1 & 2 & 3 & 4 & 5 & 6 & 7 & 8 & 9 & 10 & 11 & 12 & 13 & 14 & 15 & 16 & 17 \\
\hline …….............. & 100.0 & 100.0 & 100.0 & 100.0 & 100.0 & 100.0 & 100.0 & 100.0 & 100.0 & 100.0 & 100.0 & 100.0 & 100.0 & 100.0 & 100.0 & 100.0 \\
\hline $\begin{array}{l}\text { Craftsperson or operator .......... } \\
\text { Farmer or farm manager .......... } \\
\text { Housewife/homemaker ............ } \\
\text { Laborer or farm worker ........... } \\
\text { Military, police, or }\end{array}$ & $\begin{array}{l}4.2 \\
1.0 \\
2.3 \\
0.6\end{array}$ & \begin{tabular}{l|}
5.6 \\
1.1 \\
2.0 \\
0.8
\end{tabular} & $\begin{array}{l}3.5 \\
0.9 \\
1.0 \\
0.7\end{array}$ & $\begin{array}{l}6.6 \\
1.4 \\
0.1 \\
1.3\end{array}$ & \begin{tabular}{l|}
0.5 \\
0.3 \\
2.0 \\
0.1
\end{tabular} & $\begin{array}{l}3.7 \\
1.0 \\
1.2 \\
0.7\end{array}$ & $\begin{array}{l}3.4 \\
0.6 \\
0.4 \\
0.3\end{array}$ & $\begin{array}{l}2.7 \\
0.7 \\
0.7 \\
0.6\end{array}$ & $\begin{array}{l}2.4 \\
0.1 \\
0.8 \\
1.2\end{array}$ & $\begin{array}{r}2.7 \\
(2) \\
(2) \\
1.9\end{array}$ & $\begin{array}{l}6.8 \\
1.4 \\
0.9 \\
1.2\end{array}$ & $\begin{array}{l}3.9 \\
1.0 \\
1.1 \\
0.8\end{array}$ & $\begin{array}{l}0.7 \\
0.5 \\
1.2 \\
0.2\end{array}$ & $\begin{array}{l}3.9 \\
0.9 \\
1.1 \\
0.7\end{array}$ & $\begin{array}{l}0.9 \\
0.6 \\
0.7 \\
0.4\end{array}$ & $\begin{array}{l}0.3 \\
0.6 \\
1.5 \\
0.8\end{array}$ \\
\hline $\begin{array}{l}\text { security officer } \\
\text { Professional, business, or }\end{array}$ & 9.6 & 5.7 & 6.6 & 11.2 & 2.0 & 6.4 & 7.7 & 7.4 & 5.1 & 10.0 & 9.3 & 7.4 & 3.6 & 7.0 & 3.3 & 1.7 \\
\hline 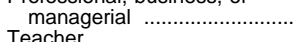 & $\begin{array}{r}34.5 \\
(3)\end{array}$ & $\begin{array}{r}45.7 \\
4.1\end{array}$ & $\begin{array}{r}50.8 \\
75\end{array}$ & $\begin{array}{r}45.9 \\
4.1\end{array}$ & $\begin{array}{l}55.7 \\
10.8\end{array}$ & $\begin{array}{r}50.0 \\
8.4\end{array}$ & $\begin{array}{r}55.1 \\
3.7\end{array}$ & $\begin{array}{r}47.1 \\
6.7\end{array}$ & $\begin{array}{r}61.3 \\
3.4\end{array}$ & $\begin{array}{r}43.3 \\
48\end{array}$ & $\begin{aligned} 38.7 \\
6.7\end{aligned}$ & 48.1 & 63.0 & 49.4 & 66.3 & 59.2 \\
\hline Business owner ....... & 6.2 & $\begin{array}{l}4.1 \\
5.3\end{array}$ & $\begin{array}{l}7.5 \\
6.0\end{array}$ & $\begin{array}{l}4.1 \\
7.8\end{array}$ & $\begin{array}{r}10.8 \\
4.3\end{array}$ & $\begin{array}{l}8.4 \\
5.6\end{array}$ & $\begin{array}{l}3.1 \\
6.8\end{array}$ & $\begin{array}{l}6.7 \\
7.7\end{array}$ & $\begin{array}{l}3.4 \\
7.0\end{array}$ & $\begin{array}{l}4.8 \\
6.4\end{array}$ & $\begin{array}{l}0.2 \\
6.7\end{array}$ & $\begin{array}{l}7.6 \\
6.4\end{array}$ & $\begin{array}{l}8.2 \\
4.9\end{array}$ & $\begin{array}{l}7.3 \\
6.3\end{array}$ & $\begin{array}{l}8.1 \\
3.8\end{array}$ & $\begin{array}{r}11.1 \\
3.3\end{array}$ \\
\hline $\begin{array}{l}\text { Technical ........................... } \\
\text { Salesperson clerical, or }\end{array}$ & 6.2 & 4.7 & 5.4 & 7.5 & 3.4 & 5.0 & 5.5 & 7.5 & 6.0 & 8.2 & 7.1 & 5.9 & 3.5 & 5.7 & $\begin{array}{l}0.0 \\
2.4\end{array}$ & 3.6 \\
\hline office worker .... & 2.8 & 4.9 & 4.8 & 3.1 & 6.5 & 4.6 & 5.3 & 6.4 & 4.1 & 5.2 & 8.0 & 4.7 & 3.1 & 4.9 & 2.6 & 5.8 \\
\hline Service worker ...... & 4.9 & 1.8 & 2.4 & 0.5 & 4.2 & 2.3 & 3.1 & 2.5 & 0.6 & 5.8 & 4.6 & 2.3 & 0.9 & 2.5 & 1.5 & 0.8 \\
\hline Other employment ........... & 17.0 & 7.7 & 10.2 & 10.3 & 10.2 & 10.8 & 8.0 & 9.6 & 8.0 & 10.6 & 8.8 & 10.8 & 10.2 & 10.3 & 9.6 & 11.3 \\
\hline Don't know or no plans ................. & 10.5 & 10.5 & 0.2 & 0.2 & 0.2 & 0.2 & 0.2 & 0.5 & 0.2 & 1.0 & 0.4 & 0.2 & 0.1 & 0.2 & (2) & 0.1 \\
\hline
\end{tabular}

1 Socioeconomic status was measured by a composite score on parental education and occupations, and family income. The "Low" SES group is the lowest quartile; the "Middle" SES group is the middle two quartiles; and the "High" SES group is the upper quartile.

${ }^{2}$ Less than .05 percent.
3 Included under "Professional, business, or managerial."

SOURCE: U.S. Department of Education, National Center for Education Statistics, "National Education Longitudinal Study of 1988," First and Second Followup surveys. (This table was prepared March 1994.) 
Table 142.-Eighth-, 10th-, and 12th-graders' attitudes about school climate, by student and school characteristics: 1988, 1990, and 1992

\begin{tabular}{|c|c|c|c|c|c|c|c|c|c|c|c|c|c|c|c|c|c|}
\hline \multirow{4}{*}{ Statements about school climate } & \multicolumn{17}{|c|}{ Percent who strongly agree or agree with statement } \\
\hline & \multirow{3}{*}{\begin{tabular}{|l} 
Eighth \\
graders \\
in 1988
\end{tabular}} & \multirow{3}{*}{$\begin{array}{c}\text { Tenth } \\
\text { graders } \\
\text { in } 1990\end{array}$} & \multicolumn{15}{|c|}{ Twelfth graders in 1992} \\
\hline & & & \multirow[b]{2}{*}{ Total } & \multicolumn{2}{|c|}{ Sex } & \multicolumn{5}{|c|}{ Race/ethnicity } & \multicolumn{4}{|c|}{ Socioeconomic status quartile 1} & \multicolumn{3}{|c|}{$\begin{array}{l}\text { Control of school } \\
\text { attended }\end{array}$} \\
\hline & & & & Male & $\begin{array}{c}\mathrm{Fe}- \\
\text { male }\end{array}$ & White & Black & $\begin{array}{l}\text { His- } \\
\text { panic }\end{array}$ & Asian & $\begin{array}{l}\text { Amer- } \\
\text { ican } \\
\text { Indian }\end{array}$ & $\begin{array}{l}\text { Low- } \\
\text { est }\end{array}$ & $\begin{array}{l}\text { Sec- } \\
\text { ond }\end{array}$ & Third & $\begin{array}{c}\text { High- } \\
\text { est }\end{array}$ & Public & Catholic & $\begin{array}{c}\text { Other } \\
\text { private }\end{array}$ \\
\hline 1 & 2 & 3 & 4 & 5 & 6 & 7 & 8 & 9 & 10 & 11 & 12 & 13 & 14 & 15 & 16 & 17 & 18 \\
\hline $\begin{array}{l}\text { There is real school spirit .............. } \\
\text { Discipline is fair .......................... } \\
\text { Teaching is good .................... } \\
\text { Teachers are interested in }\end{array}$ & $\begin{array}{l}68.6 \\
69.1 \\
80.2 \\
752\end{array}$ & $\begin{array}{l}70.4 \\
70.2 \\
81.9 \\
76.0\end{array}$ & $\begin{array}{l}71.4 \\
68.0 \\
85.4 \\
81.6\end{array}$ & $\begin{array}{l}72.9 \\
67.0 \\
84.8 \\
81.5\end{array}$ & $\begin{array}{l}69.8 \\
69.0 \\
86.0 \\
81 .\end{array}$ & $\begin{array}{l}72.1 \\
68.0 \\
85.1 \\
81.9\end{array}$ & $\begin{array}{l}67.4 \\
58.6 \\
84.1 \\
78.4\end{array}$ & $\begin{array}{l}71.0 \\
74.7 \\
88.5 \\
83.7\end{array}$ & $\begin{array}{l}70.7 \\
75.6 \\
85.5 \\
80.1\end{array}$ & $\begin{array}{l}62.0 \\
73.0 \\
88.3 \\
83.0\end{array}$ & $\begin{array}{l}73.4 \\
66.3 \\
85.6 \\
80.3\end{array}$ & $\begin{array}{l}71.3 \\
66.2 \\
84.2 \\
80.5\end{array}$ & $\begin{array}{l}72.0 \\
68.1 \\
84.3 \\
80.1\end{array}$ & $\begin{array}{l}69.5 \\
69.7 \\
87.2 \\
84.8\end{array}$ & $\begin{array}{l}70.4 \\
67.3 \\
84.7 \\
80.4\end{array}$ & $\begin{array}{l}82.2 \\
69.9 \\
90.4 \\
911\end{array}$ & $\begin{array}{l}76.0 \\
77.0 \\
93.7 \\
95.4\end{array}$ \\
\hline $\begin{array}{l}\text { students } \\
\text { I don't feel safe at this } \\
\text { school }\end{array}$ & $\begin{array}{l}75.2 \\
11.8\end{array}$ & $\begin{array}{r}76.0 \\
8.0\end{array}$ & $\begin{array}{l}81.6 \\
10.4\end{array}$ & $\begin{array}{l}81.5 \\
10.8\end{array}$ & $\begin{array}{l}81.8 \\
10.1\end{array}$ & $\begin{array}{r}81.9 \\
8.6\end{array}$ & $\begin{array}{l}78.4 \\
16.1\end{array}$ & $\begin{array}{l}83.7 \\
14.7\end{array}$ & $\begin{array}{l}80.1 \\
15.8\end{array}$ & $\begin{array}{l}83.0 \\
13.0\end{array}$ & $\begin{array}{l}80.3 \\
13.1\end{array}$ & $\begin{array}{l}80.5 \\
11.2\end{array}$ & $\begin{array}{l}80.1 \\
10.5\end{array}$ & $\begin{array}{r}84.8 \\
7.5\end{array}$ & $\begin{array}{l}80.4 \\
11.1\end{array}$ & $\begin{array}{r}91.1 \\
4.9\end{array}$ & $\begin{array}{r}95.4 \\
3.5\end{array}$ \\
\hline $\begin{array}{l}\text { Disruptions by other students } \\
\text { interfere with my learning } \\
\text { Fights often occur between }\end{array}$ & 39.6 & 39.9 & 33.1 & 31.6 & 34.7 & 30.8 & 38.1 & 39.8 & 41.4 & 40.5 & 37.0 & 35.9 & 34.6 & 26.3 & 34.2 & 25.4 & 21.8 \\
\hline $\begin{array}{l}\text { different racial/ethnic groups } \\
\text { There are many gangs in school } \\
\text { Students are graded fairly ............ }\end{array}$ & 二 & $\overline{-}$ & $\begin{array}{l}22.7 \\
16.3 \\
78.3\end{array}$ & $\begin{array}{l}22.2 \\
16.4 \\
78.6\end{array}$ & $\begin{array}{l}23.2 \\
16.2 \\
78.0\end{array}$ & $\begin{array}{l}20.9 \\
12.5 \\
79.5\end{array}$ & $\begin{array}{l}22.2 \\
17.5 \\
71.6\end{array}$ & $\begin{array}{l}31.9 \\
36.4 \\
77.6\end{array}$ & $\begin{array}{l}30.5 \\
27.2 \\
77.3\end{array}$ & $\begin{array}{l}29.9 \\
23.2 \\
74.7\end{array}$ & $\begin{array}{l}25.1 \\
21.9 \\
74.8\end{array}$ & $\begin{array}{l}23.9 \\
15.8 \\
76.3\end{array}$ & $\begin{array}{l}23.5 \\
16.7 \\
78.3\end{array}$ & $\begin{array}{l}18.6 \\
12.1 \\
82.4\end{array}$ & $\begin{array}{l}24.5 \\
17.7 \\
77.3\end{array}$ & $\begin{array}{r}8.3 \\
4.5 \\
84.1\end{array}$ & $\begin{array}{r}3.0 \\
1.5 \\
91.8\end{array}$ \\
\hline $\begin{array}{l}\text { There is a lot of cheating } \\
\text { on tests and assignments .... } \\
\text { Some teachers ignore cheating }\end{array}$ & - & - & 58.8 & 56.0 & 61.7 & 59.7 & 57.1 & 53.8 & 63.5 & 59.8 & 55.8 & 59.1 & 61.8 & 58.6 & 60.2 & 56.9 & 32.6 \\
\hline when they see it ...................... & - & - & 30.9 & 29.3 & 32.6 & 32.7 & 25.4 & 26.0 & 30.7 & 24.8 & 26.9 & 31.4 & 32.7 & 31.9 & 31.9 & 26.5 & 16.9 \\
\hline
\end{tabular}

${ }^{1}$ Socioeconomic status was measured by a composite score on parental education and occupations, and family income.

SOURCE: U.S. Department of Education, National Center for Education Statistics, "National Education Longitudinal Study of 1988," Base Year and First and Second Fol-Data not available.

Table 143.-Percentage of 3- to 5-year-olds who were read to every day in the last week by a family member: 1993, 1995, and 1996

\begin{tabular}{|c|c|c|c|}
\hline Characteristic & 1993 & 1995 & 1996 \\
\hline 1 & 2 & 3 & 4 \\
\hline Percent of all 3- to 5-year-olds & 53 & 58 & 57 \\
\hline 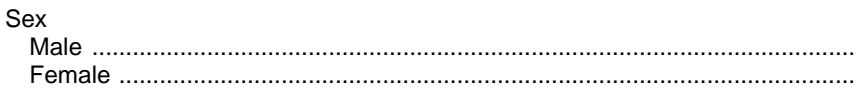 & $\begin{array}{l}51 \\
54\end{array}$ & $\begin{array}{l}57 \\
59\end{array}$ & $\begin{array}{l}56 \\
57\end{array}$ \\
\hline 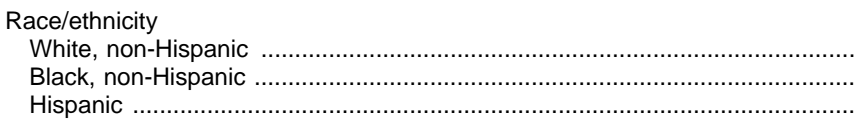 & $\begin{array}{l}59 \\
39 \\
37\end{array}$ & $\begin{array}{l}65 \\
43 \\
38\end{array}$ & $\begin{array}{l}64 \\
44 \\
39\end{array}$ \\
\hline 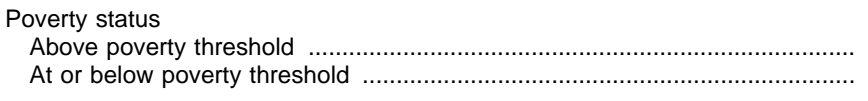 & $\begin{array}{l}56 \\
44\end{array}$ & $\begin{array}{l}62 \\
48\end{array}$ & $\begin{array}{l}61 \\
46\end{array}$ \\
\hline 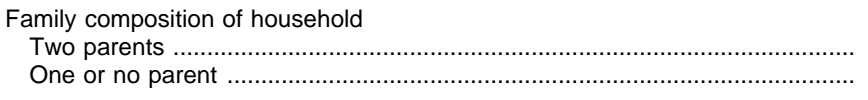 & $\begin{array}{l}55 \\
46\end{array}$ & $\begin{array}{l}61 \\
49\end{array}$ & $\begin{array}{l}61 \\
46\end{array}$ \\
\hline 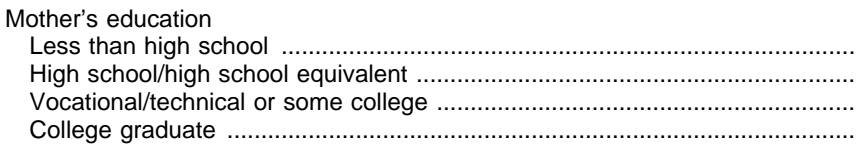 & $\begin{array}{l}37 \\
48 \\
57 \\
71\end{array}$ & $\begin{array}{l}40 \\
48 \\
64 \\
76\end{array}$ & $\begin{array}{l}37 \\
49 \\
62 \\
77\end{array}$ \\
\hline 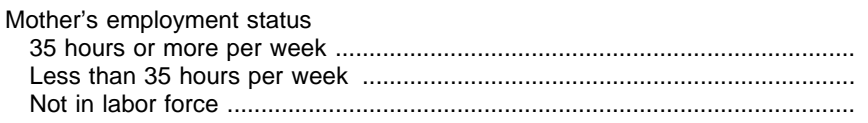 & $\begin{array}{l}52 \\
56 \\
55\end{array}$ & $\begin{array}{l}55 \\
63 \\
60\end{array}$ & $\begin{array}{l}54 \\
59 \\
59\end{array}$ \\
\hline
\end{tabular}

SOURCE: U.S. Department of Education, National Center for Education Statistics, $\mathrm{Na}$ tional Household Education Survey, 1993, 1995, and 1996. (This table was prepared July 1997). 
Table 144.-Participation of 10th- and 12th-graders in extracurricular activities, by selected student characteristics: 1990 and 1992

\begin{tabular}{|c|c|c|c|c|c|c|c|c|c|c|c|c|c|c|c|}
\hline \multirow{4}{*}{ Extracurricular activities } & \multicolumn{15}{|c|}{ Percent who participated in school activities } \\
\hline & \multirow{3}{*}{$\begin{array}{c}\text { Total } \\
1990 \\
10 \text { th } \\
\text { grad- } \\
\text { ers }\end{array}$} & \multicolumn{14}{|c|}{1992 12th graders } \\
\hline & & \multirow{2}{*}{ Total } & \multicolumn{2}{|c|}{ Sex } & \multicolumn{5}{|c|}{ Race/ethnicity } & \multicolumn{3}{|c|}{$\begin{array}{l}\text { Socioeconomic } \\
\text { status }{ }^{1}\end{array}$} & \multicolumn{3}{|c|}{$\begin{array}{l}\text { Control of school } \\
\text { attended }\end{array}$} \\
\hline & & & Male & $\begin{array}{c}\mathrm{Fe}- \\
\text { male }\end{array}$ & White & Black & Hispanic & Asian & $\begin{array}{c}\text { American } \\
\text { Indian }\end{array}$ & Low & Middle & High & Public & Catholic & $\begin{array}{l}\text { Other } \\
\text { private }\end{array}$ \\
\hline 1 & 2 & 3 & 4 & 5 & 6 & 7 & 8 & 9 & 10 & 11 & 12 & 13 & 14 & 15 & 16 \\
\hline Athletics & & & & & & & & & & & & & & & \\
\hline $\begin{array}{l}\text { Interscholastic team sport } \\
\text { Interscholastic individual }\end{array}$ & - & 30.4 & 41.2 & 19.7 & 30.8 & 32.3 & 25.8 & 28.3 & 30.4 & 25.3 & 30.1 & 34.4 & 29.6 & 31.2 & 48.9 \\
\hline & - & 20.3 & 26.8 & 13.9 & 20.9 & 21.2 & 14.9 & 21.6 & 20.7 & 13.6 & 18.7 & 27.7 & 20.0 & 24.6 & 21.8 \\
\hline Intramural team & - & 22.7 & 31.8 & 13.8 & 22.3 & 25.8 & 20.8 & 24.9 & 27.9 & 20.4 & 22.9 & 24.1 & 22.0 & 29.7 & 29.6 \\
\hline Intramural individual sport & - & 13.3 & 16.7 & 10.0 & 12.5 & 16.7 & 14.0 & 14.7 & 18.2 & 10.8 & 12.5 & 15.9 & 13.5 & 13.3 & 10.7 \\
\hline \multicolumn{16}{|l|}{ Performing arts } \\
\hline Cheerleading & 5.9 & 7.6 & 2.0 & 13.0 & 7.4 & 10.6 & 6.7 & 5.1 & 11.9 & 6.5 & 7.9 & 7.8 & 7.6 & 8.3 & 5.9 \\
\hline School band or orchestra & 20.9 & 19.8 & 15.1 & 24.5 & 19.6 & 24.4 & 16.9 & 17.7 & 16.8 & 17.6 & 19.6 & 22.0 & 19.8 & 12.0 & 31.3 \\
\hline School play or musical ....... & 11.0 & 15.4 & 14.1 & 16.7 & 16.1 & 15.9 & 10.6 & 13.7 & 14.0 & 11.4 & 14.8 & 19.4 & 15.0 & 14.2 & 26.2 \\
\hline \multicolumn{16}{|l|}{ School government/clubs } \\
\hline Student government ........... & 7.3 & 15.4 & 13.1 & 17.7 & 15.4 & 16.7 & 14.7 & 14.6 & 14.3 & 11.0 & 14.7 & 19.8 & 15.0 & 14.5 & 27.9 \\
\hline Academic honor society .... & 7.7 & 18.5 & 14.4 & 22.7 & 19.6 & 14.0 & 12.5 & 27.2 & 13.6 & 9.6 & 15.9 & 29.5 & 17.7 & 28.0 & 22.9 \\
\hline paper & 8.8 & 18.8 & 14.0 & 23.5 & 19.7 & 14.3 & 16.8 & 18.9 & 21.2 & 14.3 & 16.9 & 25.1 & 17.0 & 28.0 & 46.7 \\
\hline School service clubs .......... & 11.5 & 13.9 & 10.3 & 17.4 & 13.6 & 13.6 & 14.4 & 19.3 & 11.6 & 8.4 & 12.5 & 19.6 & 13.6 & 17.3 & 15.4 \\
\hline School academic clubs ....... & 30.7 & 25.1 & 22.9 & 27.4 & 25.8 & 20.7 & 22.6 & 32.3 & 17.7 & 18.8 & 24.1 & 31.1 & 25.1 & 26.4 & 24.5 \\
\hline School hobby clubs ............. & 7.3 & 7.7 & 8.1 & 7.4 & 7.4 & 6.6 & 9.1 & 11.3 & 10.8 & 6.7 & 7.0 & 9.3 & 7.4 & 9.8 & 11.0 \\
\hline $\begin{array}{l}\text { School FTA, FHA, and } \\
\text { FFA }\end{array}$ & 117 & 177 & 147 & 207 & 176 & 225 & 164 & 88 & 221 & 248 & 197 & 9.9 & & 24 & \\
\hline & 11.7 & 17.7 & 14.7 & 20.7 & 17.6 & 22.5 & 16.4 & 8.8 & 22.1 & 24.8 & 19.7 & 9.9 & 19.4 & 2.4 & 2.9 \\
\hline
\end{tabular}

1 Socioeconomic status was measured by a composite score on parental education and occupations, and family income. The "Low" SES group is the lowest quartile; the "Middle" SES group is the middle two quartiles; and the "High" SES group is the upper quartile.

-Data not available.
SOURCE: U.S. Department of Education, National Center for Education Statistics, "National Education Longitudinal Study of 1988," First and Second Followup surveys. (This table was prepared March 1994.)

Table 145.-Percent of high school seniors who plan to go to college after graduation, by student characteristics: 1982 and 1992

\begin{tabular}{|c|c|c|c|c|c|c|c|c|c|c|}
\hline \multirow{2}{*}{ Student characteristics } & \multicolumn{2}{|c|}{ No college } & \multicolumn{2}{|c|}{ Right after high school } & \multicolumn{2}{|c|}{ After a year } & \multicolumn{2}{|c|}{ After more than a year } & \multicolumn{2}{|c|}{ Don't know } \\
\hline & 1982 & 1992 & 1982 & 1992 & 1982 & 1992 & 1982 & 1992 & 1982 & 1992 \\
\hline 1 & 2 & 3 & 4 & 5 & 6 & 7 & 8 & 9 & 10 & 11 \\
\hline $\begin{array}{l}\text { All seniors } \\
\text { Male } \\
\text { Female }\end{array}$ & $\begin{array}{l}\mathbf{1 8 . 3} \\
22.8 \\
14.0\end{array}$ & $\begin{array}{l}4.0 \\
5.7 \\
2.3\end{array}$ & $\begin{array}{l}58.3 \\
53.4 \\
63.0\end{array}$ & $\begin{array}{l}76.6 \\
73.0 \\
80.1\end{array}$ & $\begin{array}{l}7.1 \\
6.6 \\
7.6\end{array}$ & $\begin{array}{l}10.7 \\
10.2 \\
11.1\end{array}$ & $\begin{array}{l}3.9 \\
4.0 \\
3.8\end{array}$ & $\begin{array}{l}4.1 \\
5.6 \\
2.7\end{array}$ & $\begin{array}{l}\mathbf{1 2 . 3} \\
13.1 \\
11.6\end{array}$ & $\begin{array}{l}4.6 \\
5.5 \\
3.8\end{array}$ \\
\hline 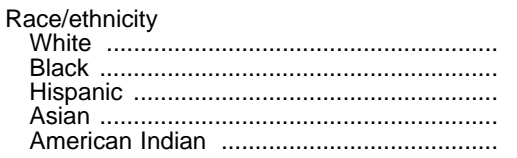 & $\begin{array}{r}18.2 \\
14.6 \\
24.1 \\
5.6 \\
22.2\end{array}$ & $\begin{array}{l}3.9 \\
5.4 \\
3.5 \\
2.6 \\
5.8\end{array}$ & $\begin{array}{l}60.2 \\
57.5 \\
45.6 \\
81.7 \\
48.5\end{array}$ & $\begin{array}{l}76.6 \\
75.2 \\
75.4 \\
83.4 \\
65.7\end{array}$ & $\begin{array}{l}7.0 \\
8.2 \\
7.5 \\
5.6 \\
9.0\end{array}$ & $\begin{array}{r}10.6 \\
11.2 \\
11.6 \\
8.6 \\
15.5\end{array}$ & $\begin{array}{l}3.4 \\
5.7 \\
5.8 \\
2.1 \\
3.3\end{array}$ & $\begin{array}{l}4.4 \\
3.2 \\
3.6 \\
2.4 \\
5.3\end{array}$ & $\begin{array}{r}11.3 \\
14.1 \\
17.0 \\
5.1 \\
17.1\end{array}$ & $\begin{array}{l}4.5 \\
5.2 \\
5.9 \\
3.1 \\
7.7\end{array}$ \\
\hline 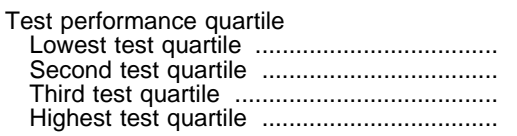 & $\begin{array}{r}32.3 \\
26.5 \\
15.6 \\
3.8\end{array}$ & $\begin{array}{r}11.4 \\
3.9 \\
2.0 \\
0.6\end{array}$ & $\begin{array}{l}32.8 \\
45.2 \\
61.9 \\
85.4\end{array}$ & $\begin{array}{l}59.3 \\
71.2 \\
81.2 \\
90.9\end{array}$ & $\begin{array}{l}9.1 \\
7.8 \\
7.9 \\
4.7\end{array}$ & $\begin{array}{r}15.1 \\
14.3 \\
9.9 \\
4.8\end{array}$ & $\begin{array}{l}4.5 \\
4.8 \\
3.8 \\
2.4\end{array}$ & $\begin{array}{l}3.4 \\
4.4 \\
4.1 \\
2.6\end{array}$ & $\begin{array}{r}21.3 \\
15.8 \\
10.8 \\
3.8\end{array}$ & $\begin{array}{r}10.9 \\
6.3 \\
2.8 \\
1.2\end{array}$ \\
\hline 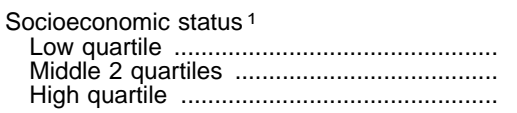 & $\begin{array}{r}29.1 \\
18.3 \\
6.6\end{array}$ & $\begin{array}{l}8.1 \\
4.1 \\
1.1\end{array}$ & $\begin{array}{l}38.3 \\
56.6 \\
82.8\end{array}$ & $\begin{array}{l}60.3 \\
74.6 \\
91.1\end{array}$ & $\begin{array}{l}7.6 \\
8.1 \\
5.0\end{array}$ & $\begin{array}{r}16.5 \\
11.8 \\
4.6\end{array}$ & $\begin{array}{l}5.8 \\
4.1 \\
1.5\end{array}$ & $\begin{array}{l}5.8 \\
4.7 \\
1.7\end{array}$ & $\begin{array}{r}19.2 \\
12.9 \\
4.1\end{array}$ & $\begin{array}{l}9.4 \\
4.8 \\
1.5\end{array}$ \\
\hline 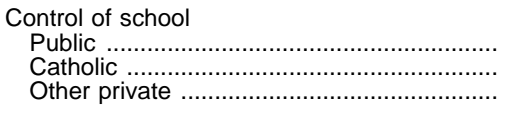 & $\begin{array}{r}19.4 \\
8.2 \\
9.9\end{array}$ & $\begin{array}{l}4.4 \\
0.5 \\
0.7\end{array}$ & $\begin{array}{l}56.0 \\
80.0 \\
77.3\end{array}$ & $\begin{array}{l}74.8 \\
93.0 \\
92.0\end{array}$ & $\begin{array}{l}7.3 \\
5.1 \\
6.4\end{array}$ & $\begin{array}{r}11.4 \\
4.3 \\
3.0\end{array}$ & $\begin{array}{l}4.1 \\
1.4 \\
2.5\end{array}$ & $\begin{array}{l}4.5 \\
0.7 \\
0.6\end{array}$ & $\begin{array}{r}13.1 \\
5.4 \\
3.9\end{array}$ & $\begin{array}{l}4.9 \\
1.6 \\
3.7\end{array}$ \\
\hline $\begin{array}{l}\text { Location of school } \\
\text { Urban } \\
\text { Suburban } \\
\text { Rural/nonmetropolitan area }\end{array}$ & $\begin{array}{l}16.6 \\
15.5 \\
24.0\end{array}$ & $\begin{array}{l}3.0 \\
3.3 \\
5.9\end{array}$ & $\begin{array}{l}59.3 \\
62.3 \\
51.4\end{array}$ & $\begin{array}{l}79.5 \\
78.6 \\
71.2\end{array}$ & $\begin{array}{l}8.2 \\
6.8 \\
6.9\end{array}$ & $\begin{array}{r}10.1 \\
9.7 \\
12.3\end{array}$ & $\begin{array}{l}4.0 \\
4.1 \\
3.6\end{array}$ & $\begin{array}{l}3.0 \\
4.4 \\
4.9\end{array}$ & $\begin{array}{l}11.8 \\
11.3 \\
14.2\end{array}$ & $\begin{array}{l}4.4 \\
4.0 \\
5.8\end{array}$ \\
\hline
\end{tabular}

${ }^{1}$ Socioeconomic status was measured by a composite score on parental education and occupations, and family income. The "Low" SES group is the lowest quartile; the "Middle" SES group is the middle two quartiles; and the "High" SES group is the upper quartile.
SOURCE: U.S. Department of Education, National Center for Education Statistics "High School and Beyond," First Followup survey; and "National Education Longitudina Study of 1988," Second Followup Student survey. (This table was prepared April 1995.) 
Table 146.-Percent of high school seniors who say they engage in various activities, by student characteristics: 1982 and 1992

\begin{tabular}{|c|c|c|c|c|c|c|c|c|c|c|c|c|c|c|}
\hline \multirow[b]{2}{*}{ Activity } & \multirow[b]{2}{*}{ Total } & \multicolumn{2}{|c|}{ Sex } & \multicolumn{5}{|c|}{ Race/ethncity } & \multicolumn{3}{|c|}{ Socioeconomic status ${ }^{1}$} & \multicolumn{3}{|c|}{ Control of school attended } \\
\hline & & Male & Female & White & Black & Hispanic & Asian & $\begin{array}{c}\text { American } \\
\text { Indian }\end{array}$ & Low & Middle & High & Public & Catholic & $\begin{array}{l}\text { Other } \\
\text { private }\end{array}$ \\
\hline 1 & 2 & 3 & 4 & 5 & 6 & 7 & 8 & 9 & 10 & 11 & 12 & 13 & 14 & 15 \\
\hline & \multicolumn{14}{|c|}{ Percent of 12th graders, 1982} \\
\hline $\begin{array}{l}\text { At least once a week } \\
\text { Talking with friends ................ } \\
\text { Reading for pleasure ............. } \\
\text { Going on dates .................... } \\
\text { Driving or riding around .......... } \\
\text { Thinking or daydreaming ......... } \\
\text { Talking with parents .............. } \\
\text { Reading front page of }\end{array}$ & $\begin{array}{l}92.7 \\
50.4 \\
61.3 \\
62.4 \\
68.5 \\
83.9\end{array}$ & $\begin{array}{l}92.5 \\
43.4 \\
60.6 \\
65.9 \\
61.8 \\
79.9\end{array}$ & $\begin{array}{l}93.0 \\
57.1 \\
62.0 \\
59.1 \\
74.8 \\
87.6\end{array}$ & $\begin{array}{l}94.2 \\
51.0 \\
63.9 \\
65.2 \\
71.1 \\
85.6\end{array}$ & $\begin{array}{l}89.1 \\
53.9 \\
51.9 \\
48.9 \\
64.6 \\
80.1\end{array}$ & $\begin{array}{l}88.9 \\
43.1 \\
58.1 \\
60.7 \\
58.0 \\
78.0\end{array}$ & $\begin{array}{l}86.7 \\
56.4 \\
40.3 \\
42.4 \\
62.4 \\
79.8\end{array}$ & $\begin{array}{l}91.3 \\
50.3 \\
54.5 \\
62.3 \\
53.9 \\
76.0\end{array}$ & $\begin{array}{l}88.6 \\
45.2 \\
55.8 \\
56.2 \\
63.3 \\
78.5\end{array}$ & $\begin{array}{l}93.7 \\
50.1 \\
63.4 \\
65.0 \\
67.5 \\
84.7\end{array}$ & $\begin{array}{l}95.6 \\
56.8 \\
62.8 \\
65.1 \\
75.9 \\
87.8\end{array}$ & $\begin{array}{l}92.3 \\
50.1 \\
61.4 \\
62.6 \\
67.7 \\
83.4\end{array}$ & $\begin{array}{l}96.4 \\
51.4 \\
60.7 \\
64.6 \\
75.2 \\
87.7\end{array}$ & $\begin{array}{l}97.2 \\
56.2 \\
60.7 \\
55.0 \\
76.5 \\
87.9\end{array}$ \\
\hline 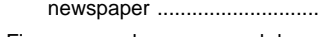 & 69.1 & 70.8 & 67.5 & 69.7 & 71.9 & 63.3 & 73.5 & 61.8 & 61.5 & 69.1 & 77.0 & 68.5 & 75.7 & 72.0 \\
\hline \multirow[t]{2}{*}{$\begin{array}{l}\text { Five or more hours on weekdays } \\
\text { Watches television }\end{array}$} & 11.5 & 11.9 & 11.2 & 9.4 & 22.2 & 13.8 & 8.1 & 20.9 & 16.5 & 11.5 & 6.4 & 12.1 & 8.0 & 3.9 \\
\hline & \multicolumn{14}{|c|}{ Percent of 12 th graders, 1992} \\
\hline $\begin{array}{l}\text { At least once a week } \\
\text { Use personal computer ........... } \\
\text { Work on hobbies ................ } \\
\text { Attend religious activities ........ } \\
\text { Attend youth groups ............. } \\
\text { Perform community service ..... } \\
\text { Driving or riding around .......... } \\
\text { Do things with friends ............ } \\
\text { Do things with parent ............. } \\
\text { Talk with other adult ............. } \\
\text { Take music, art, or dance }\end{array}$ & $\begin{array}{l}23.7 \\
40.9 \\
31.0 \\
22.4 \\
11.3 \\
73.3 \\
88.1 \\
66.7 \\
47.7\end{array}$ & $\begin{array}{l}28.1 \\
44.4 \\
28.1 \\
24.6 \\
10.7 \\
74.3 \\
88.2 \\
61.2 \\
45.4\end{array}$ & $\begin{array}{l}19.3 \\
37.4 \\
33.8 \\
20.1 \\
11.9 \\
72.3 \\
88.0 \\
72.1 \\
49.9\end{array}$ & $\begin{array}{l}23.9 \\
42.0 \\
31.4 \\
22.5 \\
11.1 \\
75.7 \\
90.7 \\
68.2 \\
48.8\end{array}$ & $\begin{array}{l}23.6 \\
34.8 \\
33.7 \\
23.3 \\
12.1 \\
67.8 \\
79.8 \\
62.0 \\
44.3\end{array}$ & $\begin{array}{l}20.9 \\
39.9 \\
26.9 \\
18.5 \\
10.9 \\
66.2 \\
82.4 \\
63.8 \\
46.2\end{array}$ & $\begin{array}{l}27.0 \\
37.8 \\
30.4 \\
26.4 \\
14.0 \\
66.7 \\
85.9 \\
63.4 \\
43.0\end{array}$ & $\begin{array}{r}23.8 \\
49.8 \\
14.6 \\
22.1 \\
9.2 \\
71.0 \\
77.2 \\
61.2 \\
44.0\end{array}$ & $\begin{array}{r}18.9 \\
36.3 \\
22.2 \\
16.6 \\
7.7 \\
69.6 \\
80.8 \\
59.6 \\
47.6\end{array}$ & $\begin{array}{r}23.3 \\
41.1 \\
29.4 \\
21.3 \\
9.5 \\
75.3 \\
88.1 \\
66.3 \\
49.0\end{array}$ & $\begin{array}{l}27.7 \\
43.5 \\
39.9 \\
28.1 \\
16.7 \\
72.4 \\
93.2 \\
71.7 \\
45.0\end{array}$ & $\begin{array}{r}23.4 \\
40.6 \\
29.4 \\
21.8 \\
9.7 \\
73.4 \\
87.5 \\
66.0 \\
47.3\end{array}$ & $\begin{array}{l}25.2 \\
43.4 \\
38.8 \\
22.9 \\
22.3 \\
77.8 \\
94.5 \\
73.6 \\
46.4\end{array}$ & $\begin{array}{l}28.0 \\
43.2 \\
54.9 \\
33.3 \\
31.2 \\
63.0 \\
91.9 \\
72.8 \\
58.8\end{array}$ \\
\hline 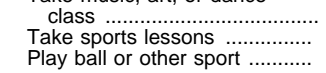 & $\begin{array}{r}10.1 \\
7.3 \\
26.3\end{array}$ & $\begin{array}{r}7.9 \\
9.7 \\
38.8\end{array}$ & $\begin{array}{r}12.2 \\
5.0 \\
14.0\end{array}$ & $\begin{array}{r}9.9 \\
7.0 \\
27.1\end{array}$ & $\begin{array}{r}9.7 \\
7.4 \\
22.9\end{array}$ & $\begin{array}{r}9.8 \\
8.2 \\
23.6\end{array}$ & $\begin{array}{r}14.0 \\
9.4 \\
28.7\end{array}$ & $\begin{array}{l}10.6 \\
11.6 \\
29.4\end{array}$ & $\begin{array}{r}7.1 \\
5.6 \\
20.7\end{array}$ & $\begin{array}{r}8.8 \\
6.6 \\
24.5\end{array}$ & $\begin{array}{r}14.0 \\
9.5 \\
33.1\end{array}$ & $\begin{array}{r}9.7 \\
7.1 \\
25.6\end{array}$ & $\begin{array}{l}13.4 \\
11.1 \\
34.0\end{array}$ & $\begin{array}{r}12.4 \\
7.8 \\
31.4\end{array}$ \\
\hline 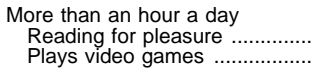 & $\begin{array}{l}55.4 \\
13.0\end{array}$ & $\begin{array}{l}53.1 \\
19.2\end{array}$ & $\begin{array}{r}57.7 \\
6.8\end{array}$ & $\begin{array}{l}56.3 \\
11.7\end{array}$ & $\begin{array}{l}51.0 \\
19.9\end{array}$ & $\begin{array}{l}53.5 \\
13.0\end{array}$ & $\begin{array}{l}54.4 \\
13.5\end{array}$ & $\begin{array}{l}59.3 \\
21.1\end{array}$ & $\begin{array}{l}51.6 \\
16.9\end{array}$ & $\begin{array}{l}55.0 \\
13.7\end{array}$ & $\begin{array}{r}58.6 \\
9.4\end{array}$ & $\begin{array}{l}55.0 \\
13.3\end{array}$ & $\begin{array}{l}56.0 \\
10.4\end{array}$ & $\begin{array}{r}62.9 \\
8.9\end{array}$ \\
\hline $\begin{array}{l}\text { Five or more hours on weekdays } \\
\text { Watches television }\end{array}$ & 8.4 & 8.5 & 8.4 & 6.4 & 21.3 & 9.3 & 6.4 & 12.7 & 12.0 & 9.4 & 4.1 & 8.7 & 7.9 & 4.1 \\
\hline
\end{tabular}

1 Socioeconomic status was measured by a composite score on parental education and occupations, and family income. The "Low" SES group is the lowest quartile; the "Middle" SES group is the middle two quartiles; and the "High" SES group is the upper quartile.
SOURCE: U.S. Department of Education, National Center for Education Statistics, "National Education Longitudinal Study of 1988," Second Followup survey, and "High School and Beyond," First Followup survey. (This table was prepared March 1994.)

Table 147.-Percent of high school seniors who participate in selected school-sponsored extracurricular activities, by student characteristics: 1980 and 1992

\begin{tabular}{|c|c|c|c|c|c|c|c|c|c|c|c|c|}
\hline \multirow{2}{*}{ Student characteristics } & \multicolumn{2}{|c|}{ Academic clubs } & \multicolumn{2}{|c|}{ Athletics } & \multicolumn{2}{|c|}{$\begin{array}{l}\text { Cheerleading and } \\
\text { drill team }\end{array}$} & \multicolumn{2}{|c|}{$\begin{array}{l}\text { Newspaper or } \\
\text { yearbook }\end{array}$} & \multicolumn{2}{|c|}{$\begin{array}{l}\text { Music, drama, } \\
\text { debate }\end{array}$} & \multicolumn{2}{|c|}{ Vocational clubs } \\
\hline & 1980 & 1992 & 1980 & 1992 & 1980 & 1992 & 1980 & 1992 & 1980 & 1992 & 1980 & 1992 \\
\hline 1 & 2 & 3 & 4 & 5 & 6 & 7 & 8 & 9 & 10 & 11 & 12 & 13 \\
\hline $\begin{array}{l}\text { All seniors } \\
\quad \text { Male } \\
\text { Female }\end{array}$ & $\begin{array}{l}25.6 \\
20.3 \\
30.9\end{array}$ & $\begin{array}{l}25.1 \\
22.8 \\
27.4\end{array}$ & $\begin{array}{l}51.8 \\
64.0 \\
40.6\end{array}$ & $\begin{array}{l}42.9 \\
55.3 \\
30.3\end{array}$ & $\begin{array}{r}15.1 \\
4.5 \\
24.8\end{array}$ & $\begin{array}{r}7.5 \\
2.0 \\
13.0\end{array}$ & $\begin{array}{l}\mathbf{1 9 . 9} \\
15.4 \\
24.0\end{array}$ & $\begin{array}{l}\mathbf{1 8 . 8} \\
14.0 \\
23.5\end{array}$ & $\begin{array}{l}36.5 \\
28.4 \\
44.0\end{array}$ & $\begin{array}{l}27.9 \\
23.0 \\
32.7\end{array}$ & $\begin{array}{l}23.1 \\
19.1 \\
26.7\end{array}$ & $\begin{array}{l}\mathbf{1 7 . 7} \\
14.7 \\
20.6\end{array}$ \\
\hline $\begin{array}{c}\text { Race/ethnicity } \\
\text { White } \\
\text { Black } \\
\text { Hispanic } \\
\text { Asian }\end{array}$ & $\begin{array}{l}25.0 \\
33.1 \\
24.2 \\
26.6\end{array}$ & $\begin{array}{l}25.8 \\
20.6 \\
22.6 \\
32.3\end{array}$ & $\begin{array}{l}51.6 \\
54.4 \\
49.4 \\
48.8\end{array}$ & $\begin{array}{l}44.1 \\
41.4 \\
35.3 \\
45.2\end{array}$ & $\begin{array}{l}14.9 \\
17.6 \\
12.3 \\
14.6\end{array}$ & $\begin{array}{r}7.4 \\
10.6 \\
6.6 \\
5.1\end{array}$ & $\begin{array}{l}20.1 \\
17.8 \\
15.8 \\
21.4\end{array}$ & $\begin{array}{l}19.7 \\
14.3 \\
16.8 \\
18.9\end{array}$ & $\begin{array}{l}35.8 \\
43.2 \\
31.1 \\
36.6\end{array}$ & $\begin{array}{l}28.1 \\
32.2 \\
22.3 \\
25.8\end{array}$ & $\begin{array}{r}22.3 \\
30.1 \\
27.3 \\
9.6\end{array}$ & $\begin{array}{r}17.6 \\
22.5 \\
16.4 \\
8.8\end{array}$ \\
\hline $\begin{array}{l}\text { Test performance quartile } \\
\text { Lowest test quartile .............. } \\
\text { Middle } 2 \text { test quartiles ........ } \\
\text { Highest test quartile ............. }\end{array}$ & $\begin{array}{l}24.6 \\
24.3 \\
29.0\end{array}$ & $\begin{array}{l}18.1 \\
23.3 \\
37.1\end{array}$ & $\begin{array}{l}46.3 \\
49.4 \\
54.0\end{array}$ & $\begin{array}{l}40.3 \\
42.3 \\
49.0\end{array}$ & $\begin{array}{l}15.0 \\
16.0 \\
13.5\end{array}$ & $\begin{array}{l}8.5 \\
7.6 \\
7.9\end{array}$ & $\begin{array}{l}14.6 \\
18.7 \\
27.1\end{array}$ & $\begin{array}{l}12.0 \\
17.1 \\
27.9\end{array}$ & $\begin{array}{l}31.8 \\
35.6 \\
43.4\end{array}$ & $\begin{array}{l}23.3 \\
26.5 \\
35.2\end{array}$ & $\begin{array}{l}33.0 \\
24.2 \\
12.4\end{array}$ & $\begin{array}{l}25.0 \\
20.0 \\
11.4\end{array}$ \\
\hline 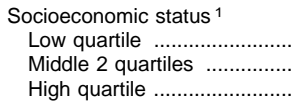 & $\begin{array}{l}24.6 \\
24.3 \\
29.0\end{array}$ & $\begin{array}{l}19.4 \\
24.5 \\
31.7\end{array}$ & $\begin{array}{l}43.2 \\
52.1 \\
61.7\end{array}$ & $\begin{array}{l}33.9 \\
41.7 \\
53.9\end{array}$ & $\begin{array}{l}13.0 \\
15.9 \\
15.6\end{array}$ & $\begin{array}{l}6.7 \\
8.0 \\
7.7\end{array}$ & $\begin{array}{l}15.7 \\
19.2 \\
25.3\end{array}$ & $\begin{array}{l}14.2 \\
17.5 \\
25.5\end{array}$ & $\begin{array}{l}31.0 \\
35.8 \\
43.8\end{array}$ & $\begin{array}{l}24.1 \\
27.8 \\
31.6\end{array}$ & $\begin{array}{l}30.6 \\
24.1 \\
13.4\end{array}$ & $\begin{array}{r}24.8 \\
18.5 \\
9.3\end{array}$ \\
\hline $\begin{array}{l}\text { Region } \\
\text { Northwest } \\
\text { Midwest } \\
\text { South } \\
\text { West }\end{array}$ & $\begin{array}{l}19.6 \\
21.4 \\
30.8 \\
21.9\end{array}$ & $\begin{array}{l}23.1 \\
25.4 \\
28.2 \\
21.6\end{array}$ & $\begin{array}{l}54.5 \\
52.8 \\
48.2 \\
52.9\end{array}$ & $\begin{array}{l}48.6 \\
45.8 \\
38.8 \\
40.6\end{array}$ & $\begin{array}{l}11.5 \\
15.3 \\
18.0 \\
14.0\end{array}$ & $\begin{array}{l}6.9 \\
8.0 \\
8.5 \\
6.0\end{array}$ & $\begin{array}{l}24.6 \\
18.4 \\
18.8 \\
16.8\end{array}$ & $\begin{array}{l}28.3 \\
18.2 \\
15.0 \\
16.5\end{array}$ & $\begin{array}{l}34.5 \\
37.1 \\
37.9 \\
35.2\end{array}$ & $\begin{array}{l}28.4 \\
32.0 \\
25.6 \\
25.6\end{array}$ & $\begin{array}{l}10.6 \\
20.0 \\
40.0 \\
15.8\end{array}$ & $\begin{array}{r}8.1 \\
18.4 \\
27.2 \\
10.0\end{array}$ \\
\hline 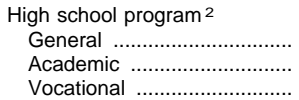 & $\begin{array}{l}19.6 \\
28.7 \\
23.1\end{array}$ & $\begin{array}{l}18.3 \\
34.2 \\
14.7\end{array}$ & $\begin{array}{l}49.9 \\
60.1 \\
42.4\end{array}$ & $\begin{array}{l}37.8 \\
50.8 \\
30.1\end{array}$ & $\begin{array}{l}14.0 \\
17.2 \\
13.3\end{array}$ & $\begin{array}{l}7.1 \\
8.8 \\
4.9\end{array}$ & $\begin{array}{l}16.7 \\
26.9 \\
13.2\end{array}$ & $\begin{array}{l}14.6 \\
24.9 \\
11.2\end{array}$ & $\begin{array}{l}34.5 \\
44.1 \\
27.7\end{array}$ & $\begin{array}{l}26.3 \\
32.8 \\
16.2\end{array}$ & $\begin{array}{l}22.6 \\
13.1 \\
39.3\end{array}$ & $\begin{array}{l}16.7 \\
12.6 \\
41.2\end{array}$ \\
\hline
\end{tabular}

${ }^{1}$ Socioeconomic status was measured by a composite score on parental education and occupations, and family income. The "low" SES group is the lowest quartile; the middle SES group is the middle two quartiles; and the "high" SES group is the upper quartile.

${ }^{2}$ Program as reported by student.
SOURCE: U.S. Department of Education, National Center for Education Statistics, "High School and Beyond," Senior Cohort; and "National Education Longitudinal Study of 1988," Second Followup survey. (This table was prepared February 1996.) 
Table 148.-Percentage of students in grades 9 through 12 who reported experience with drugs and violence on school property, by race/ethnicity, grade, and sex: 1995 and 1997

\begin{tabular}{|c|c|c|c|c|c|c|c|c|c|}
\hline \multirow{3}{*}{ Type of violence or drug-related behavior } & \multirow{3}{*}{1995} & \multicolumn{8}{|c|}{1997} \\
\hline & & \multirow{2}{*}{ Total } & \multicolumn{3}{|c|}{ Race/ethnicity } & \multicolumn{4}{|c|}{ Grade } \\
\hline & & & White & Black & Hispanic & 9 & 10 & 11 & 12 \\
\hline 1 & 2 & 3 & 4 & 5 & 6 & 7 & 8 & 9 & 10 \\
\hline 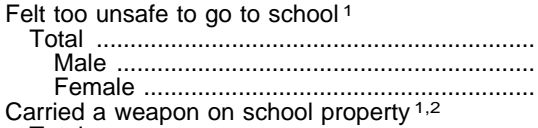 & $\begin{array}{l}4.5 \\
4.7 \\
4.3\end{array}$ & $\begin{array}{l}4.0 \\
4.1 \\
3.9\end{array}$ & $\begin{array}{l}2.4 \\
2.3 \\
2.5\end{array}$ & $\begin{array}{l}6.8 \\
7.5 \\
6.1\end{array}$ & $\begin{array}{l}7.2 \\
6.8 \\
7.7\end{array}$ & $\begin{array}{l}5.5 \\
5.2 \\
5.8\end{array}$ & $\begin{array}{l}4.0 \\
4.0 \\
3.9\end{array}$ & $\begin{array}{l}4.2 \\
5.0 \\
3.2\end{array}$ & $\begin{array}{l}2.6 \\
2.3 \\
3.0\end{array}$ \\
\hline 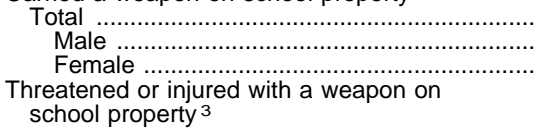 & $\begin{array}{r}9.8 \\
14.3 \\
4.9\end{array}$ & $\begin{array}{r}8.5 \\
12.5 \\
3.7\end{array}$ & $\begin{array}{r}7.8 \\
12.3 \\
2.1\end{array}$ & $\begin{array}{r}9.2 \\
10.7 \\
7.8\end{array}$ & $\begin{array}{r}10.4 \\
15.6 \\
4.3\end{array}$ & $\begin{array}{r}10.2 \\
14.5 \\
5.4\end{array}$ & $\begin{array}{r}7.7 \\
11.1 \\
3.5\end{array}$ & $\begin{array}{r}9.4 \\
14.6 \\
3.1\end{array}$ & $\begin{array}{r}7.0 \\
10.1 \\
3.0\end{array}$ \\
\hline 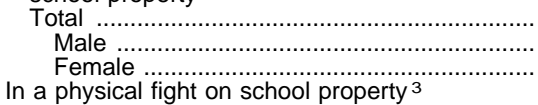 & $\begin{array}{r}8.4 \\
10.9 \\
5.8\end{array}$ & $\begin{array}{r}7.4 \\
10.2 \\
4.0\end{array}$ & $\begin{array}{l}6.2 \\
8.2 \\
3.7\end{array}$ & $\begin{array}{r}9.9 \\
14.0 \\
5.8\end{array}$ & $\begin{array}{r}9.0 \\
12.7 \\
4.6\end{array}$ & $\begin{array}{r}10.1 \\
13.7 \\
6.1\end{array}$ & $\begin{array}{r}7.9 \\
10.1 \\
5.2\end{array}$ & $\begin{array}{l}5.9 \\
9.0 \\
2.3\end{array}$ & $\begin{array}{l}5.8 \\
8.4 \\
2.5\end{array}$ \\
\hline $\begin{array}{l}\text { Male } \\
\text { Female } \\
\text { Property stolen or deliberately damaged on } \\
\text { school property }\end{array}$ & $\begin{array}{r}15.5 \\
21.0 \\
9.6\end{array}$ & $\begin{array}{r}14.8 \\
20.0 \\
8.6\end{array}$ & $\begin{array}{r}13.3 \\
19.1 \\
5.9\end{array}$ & $\begin{array}{l}20.7 \\
24.6 \\
17.0\end{array}$ & $\begin{array}{l}19.0 \\
24.7 \\
12.3\end{array}$ & $\begin{array}{l}21.3 \\
29.3 \\
12.4\end{array}$ & $\begin{array}{l}17.0 \\
21.6 \\
11.3\end{array}$ & $\begin{array}{r}12.5 \\
17.8 \\
6.2\end{array}$ & $\begin{array}{r}9.5 \\
13.1 \\
4.9\end{array}$ \\
\hline 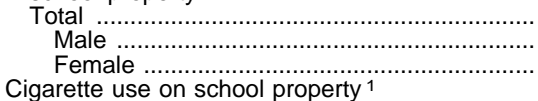 & $\begin{array}{l}34.9 \\
41.4 \\
28.0\end{array}$ & $\begin{array}{l}32.9 \\
36.1 \\
29.0\end{array}$ & $\begin{array}{l}32.6 \\
35.7 \\
28.6\end{array}$ & $\begin{array}{l}34.0 \\
37.5 \\
30.6\end{array}$ & $\begin{array}{l}32.1 \\
33.4 \\
30.6\end{array}$ & $\begin{array}{l}36.9 \\
39.8 \\
33.7\end{array}$ & $\begin{array}{l}35.4 \\
39.7 \\
30.0\end{array}$ & $\begin{array}{l}32.3 \\
36.2 \\
27.5\end{array}$ & $\begin{array}{l}27.9 \\
30.0 \\
25.4\end{array}$ \\
\hline 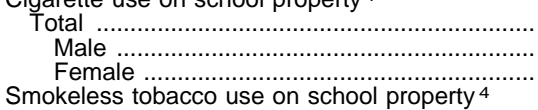 & $\begin{array}{l}16.0 \\
16.8 \\
15.1\end{array}$ & $\begin{array}{l}14.6 \\
15.9 \\
13.0\end{array}$ & $\begin{array}{l}15.8 \\
16.5 \\
14.9\end{array}$ & $\begin{array}{r}8.8 \\
12.4 \\
5.5\end{array}$ & $\begin{array}{r}11.9 \\
15.3 \\
7.7\end{array}$ & $\begin{array}{l}14.0 \\
15.9 \\
11.8\end{array}$ & $\begin{array}{l}14.4 \\
15.5 \\
13.2\end{array}$ & $\begin{array}{l}15.8 \\
16.2 \\
15.2\end{array}$ & $\begin{array}{l}14.1 \\
16.1 \\
11.6\end{array}$ \\
\hline 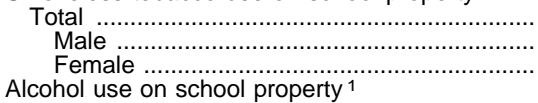 & $\begin{array}{r}6.3 \\
11.2 \\
0.9\end{array}$ & $\begin{array}{l}5.1 \\
9.0 \\
0.4\end{array}$ & $\begin{array}{r}6.5 \\
11.3 \\
0.4\end{array}$ & $\begin{array}{l}1.4 \\
2.5 \\
0.4\end{array}$ & $\begin{array}{l}3.3 \\
5.8 \\
0.3\end{array}$ & $\begin{array}{l}5.2 \\
9.5 \\
0.4\end{array}$ & $\begin{array}{l}3.2 \\
5.7 \\
0.1\end{array}$ & $\begin{array}{l}5.6 \\
9.8 \\
0.6\end{array}$ & $\begin{array}{r}6.0 \\
10.6 \\
0.1\end{array}$ \\
\hline 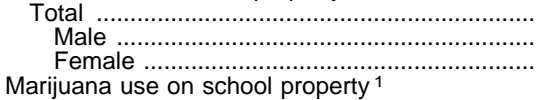 & $\begin{array}{l}6.3 \\
7.2 \\
5.3\end{array}$ & $\begin{array}{l}5.6 \\
7.2 \\
3.6\end{array}$ & $\begin{array}{l}4.8 \\
6.3 \\
2.9\end{array}$ & $\begin{array}{l}5.6 \\
7.3 \\
4.0\end{array}$ & $\begin{array}{l}8.2 \\
8.7 \\
7.6\end{array}$ & $\begin{array}{l}5.9 \\
6.3 \\
5.3\end{array}$ & $\begin{array}{l}4.6 \\
5.6 \\
3.2\end{array}$ & $\begin{array}{l}6.0 \\
7.9 \\
3.8\end{array}$ & $\begin{array}{l}5.9 \\
8.8 \\
2.2\end{array}$ \\
\hline $\begin{array}{l}\text { Total } \\
\text { Memale } \\
\text { Offered, sold, or given an illegal } \\
\text { drug on school property }{ }^{3}\end{array}$ & $\begin{array}{r}8.8 \\
11.9 \\
5.5\end{array}$ & $\begin{array}{l}7.0 \\
9.0 \\
4.6\end{array}$ & $\begin{array}{l}5.8 \\
7.3 \\
3.9\end{array}$ & $\begin{array}{r}9.1 \\
13.0 \\
5.4\end{array}$ & $\begin{array}{r}10.4 \\
14.1 \\
5.9\end{array}$ & $\begin{array}{l}8.1 \\
9.6 \\
6.5\end{array}$ & $\begin{array}{l}6.4 \\
8.2 \\
4.2\end{array}$ & $\begin{array}{r}7.9 \\
10.2 \\
5.2\end{array}$ & $\begin{array}{l}5.7 \\
8.2 \\
2.6\end{array}$ \\
\hline 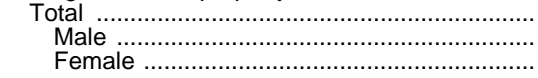 & $\begin{array}{l}32.1 \\
38.8 \\
24.8\end{array}$ & $\begin{array}{l}31.7 \\
37.4 \\
24.7\end{array}$ & $\begin{array}{l}31.0 \\
36.1 \\
24.5\end{array}$ & $\begin{array}{l}25.4 \\
34.6 \\
16.7\end{array}$ & $\begin{array}{l}41.1 \\
46.8 \\
34.4\end{array}$ & $\begin{array}{l}31.4 \\
34.5 \\
28.0\end{array}$ & $\begin{array}{l}33.4 \\
40.0 \\
25.3\end{array}$ & $\begin{array}{l}33.2 \\
38.8 \\
26.4\end{array}$ & $\begin{array}{l}29.0 \\
36.4 \\
19.6\end{array}$ \\
\hline
\end{tabular}

1 On one or more of the 30 days preceding the survey.

2 Such as a gun, knife, or club.

${ }^{3}$ One or more times during the 12 months preceding the survey.

SOURCE: U.S. Department of Health and Human Services, Centers for Disease Control and Prevention, CDC Surveillance Summaries, August 14, 1998, MMWR 1998; 47

(No. SS-3). (This table was prepared October 1998.)

4 Used chewing tobacco or snuff during 1 of the 30 days preceding the survey.

Table 149.-Percent of 12- to 17-year-olds reporting drug use during the past 30 days and the past year: 1982 to 1996

\begin{tabular}{|c|c|c|c|c|c|c|c|c|c|c|}
\hline Type of drug and frequency use & 1982 & 1985 & 1988 & 1990 & 1991 & 1992 & 1993 & 1994 & 1995 & 1996 \\
\hline 1 & 2 & 3 & 4 & 5 & 6 & 7 & 8 & 9 & 10 & 11 \\
\hline & \multicolumn{10}{|c|}{ Percent reporting drug use during past 30 days } \\
\hline Any illicit use $\quad$ Marijuana & 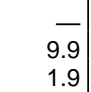 & $\begin{array}{r}13.2 \\
10.2 \\
1.5\end{array}$ & $\begin{array}{l}8.1 \\
5.4 \\
1.2\end{array}$ & $\begin{array}{l}7.1 \\
4.4 \\
0.6\end{array}$ & $\begin{array}{l}5.8 \\
3.6 \\
0.4\end{array}$ & $\begin{array}{l}5.3 \\
3.4 \\
0.3\end{array}$ & $\begin{array}{l}5.7 \\
4.0 \\
0.4\end{array}$ & $\begin{array}{l}8.2 \\
6.0 \\
0.3\end{array}$ & $\begin{array}{r}10.9 \\
8.2 \\
0.8\end{array}$ & $\begin{array}{l}9.0 \\
7.1 \\
0.6\end{array}$ \\
\hline Alcohol & $\begin{array}{r}34.9 \\
-\end{array}$ & $\begin{array}{l}41.2 \\
29.4\end{array}$ & $\begin{array}{l}33.4 \\
22.7\end{array}$ & $\begin{array}{l}32.5 \\
22.4\end{array}$ & $\begin{array}{l}27.0 \\
20.9\end{array}$ & $\begin{array}{l}20.9 \\
18.4\end{array}$ & $\begin{array}{l}23.9 \\
18.5\end{array}$ & $\begin{array}{l}21.6 \\
18.9\end{array}$ & $\begin{array}{l}21.1 \\
20.2\end{array}$ & $\begin{array}{l}18.8 \\
18.3\end{array}$ \\
\hline & \multicolumn{10}{|c|}{ Percent reporting drug use during past year } \\
\hline 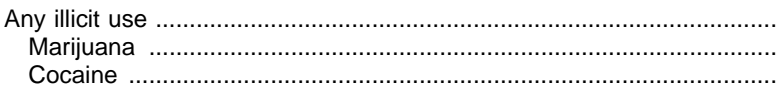 & $\begin{array}{r}-\overline{17.7} \\
3.7\end{array}$ & $\begin{array}{r}20.7 \\
16.7 \\
3.4\end{array}$ & $\begin{array}{r}14.9 \\
10.7 \\
2.5\end{array}$ & $\begin{array}{r}14.1 \\
9.6 \\
1.9\end{array}$ & $\begin{array}{r}13.1 \\
8.5 \\
1.3\end{array}$ & $\begin{array}{r}10.4 \\
6.9 \\
1.0\end{array}$ & $\begin{array}{r}11.9 \\
8.5 \\
0.7\end{array}$ & $\begin{array}{r}15.5 \\
11.4 \\
1.1\end{array}$ & $\begin{array}{r}18.0 \\
14.2 \\
1.7\end{array}$ & $\begin{array}{r}16.7 \\
13.0 \\
1.4\end{array}$ \\
\hline $\begin{array}{l}\text { Alcohol } \ldots \ldots \ldots \ldots \ldots \ldots \\
\text { Cigarettes } \ldots \ldots \ldots \ldots \ldots . . . \ldots\end{array}$ & $\begin{array}{r}46.1 \\
-\end{array}$ & $\begin{array}{l}52.7 \\
29.9\end{array}$ & $\begin{array}{l}45.5 \\
26.8\end{array}$ & $\begin{array}{l}41.8 \\
26.2\end{array}$ & $\begin{array}{l}41.2 \\
23.7\end{array}$ & $\begin{array}{l}33.3 \\
21.4\end{array}$ & $\begin{array}{l}35.9 \\
22.5\end{array}$ & $\begin{array}{l}36.2 \\
24.5\end{array}$ & $\begin{array}{l}35.1 \\
26.6\end{array}$ & $\begin{array}{l}32.7 \\
24.2\end{array}$ \\
\hline
\end{tabular}

-Data not available, or low precision; no estimate reported.

NOTE.-Due to changes in the survey instrument and administration and to improve comparability with new data, estimates for 1982 through 1993 have been adjusted and may differ from those reported in previous years.
SOURCE: U.S. Department of Health and Human Services, Substance Abuse and Mental Health Services Administration, "Preliminary Estimates from the 1996 National Household Survey on Drug Abuse," 1997. (This table was prepared July 1998.) 
Table 150.-Percent of high school seniors reporting drug use, by type of drug and frequency of use: 1975 to 1997

\begin{tabular}{|c|c|c|c|c|c|c|c|c|c|c|c|c|c|c|c|c|c|c|}
\hline $\begin{array}{l}\text { Type of drug and } \\
\text { frequency of use }\end{array}$ & $\begin{array}{l}\text { Class } \\
\text { of } \\
1975\end{array}$ & $\begin{array}{c}\text { Class } \\
\text { of } \\
1980\end{array}$ & $\begin{array}{c}\text { Class } \\
\text { of } \\
1982\end{array}$ & $\begin{array}{l}\text { Class } \\
\text { of } \\
1983\end{array}$ & $\begin{array}{c}\text { Class } \\
\text { of } \\
1984\end{array}$ & $\begin{array}{l}\text { Class } \\
\text { of } \\
1985\end{array}$ & $\begin{array}{l}\text { Class } \\
\text { of } \\
1986\end{array}$ & $\begin{array}{l}\text { Class } \\
\text { of } \\
1987\end{array}$ & $\begin{array}{l}\text { Class } \\
\text { of } \\
1988\end{array}$ & $\begin{array}{l}\text { Class } \\
\text { of } \\
1989\end{array}$ & $\begin{array}{c}\text { Class } \\
\text { of } \\
1990\end{array}$ & $\begin{array}{l}\text { Class } \\
\text { of } \\
1991\end{array}$ & $\begin{array}{c}\text { Class } \\
\text { of } \\
1992\end{array}$ & $\begin{array}{l}\text { Class } \\
\text { of } \\
1993\end{array}$ & $\begin{array}{l}\text { Class } \\
\text { of } \\
1994\end{array}$ & $\begin{array}{l}\text { Class } \\
\text { of } \\
1995\end{array}$ & $\begin{array}{l}\text { Class } \\
\text { of } \\
1996\end{array}$ & $\begin{array}{c}\text { Class } \\
\text { of } \\
1997\end{array}$ \\
\hline 1 & 2 & 3 & 4 & 5 & 6 & 7 & 8 & 9 & 10 & 11 & 12 & 13 & 14 & 15 & 16 & 17 & 18 & 19 \\
\hline & \multicolumn{18}{|c|}{ Percent reporting having ever used drugs } \\
\hline Alcohol ${ }^{1}$ & 90.4 & 93.2 & 92.8 & 92.6 & 92.6 & 92.2 & 91.3 & 92.2 & 92.0 & 90.7 & 89.5 & 88.0 & 87.5 & 80.0 & 80.4 & 80.7 & 79.2 & 81.7 \\
\hline Any illicit drug & 55.2 & 65.4 & 64.4 & 62.9 & 61.6 & 60.6 & 57.6 & 56.6 & 53.9 & 50.9 & 47.9 & 44.1 & 40.7 & 42.9 & 45.6 & 48.4 & 50.8 & - \\
\hline \multirow{2}{*}{$\begin{array}{l}\text { Marijuana only } \\
\text { Any illicit drug other than } \\
\text { marijuana }{ }^{2}\end{array}$} & 19.0 & 26.7 & 23.3 & 22.5 & 21.3 & 20.9 & 19.9 & 20.8 & 21.4 & 19.5 & 18.5 & 17.2 & 15.6 & 16.2 & 18.0 & 20.3 & 22.3 & - \\
\hline & 36.2 & 38.7 & 41.1 & 40.4 & 40.3 & 39.7 & 37.7 & 35.8 & 32.5 & 31.4 & 29.4 & 26.9 & 25.1 & 26.7 & 27.6 & 28.1 & 28.5 & - \\
\hline \multirow{6}{*}{ 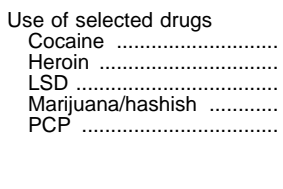 } & & & & & & & & & & & & & & & & & & \\
\hline & 9.0 & 15.7 & 16.0 & 16.2 & 16.1 & 17.3 & 16.9 & 15.2 & 12.1 & 10.3 & 9.4 & 7.8 & 6.1 & 6.1 & 5.9 & 6.0 & 7.1 & 8.7 \\
\hline & $\begin{array}{r}2.2 \\
11.3\end{array}$ & $\begin{array}{l}1.1 \\
9.3\end{array}$ & $\begin{array}{l}1.2 \\
9.6\end{array}$ & $\begin{array}{l}1.2 \\
8.9\end{array}$ & $\begin{array}{l}1.3 \\
8.0\end{array}$ & $\begin{array}{l}1.2 \\
7.5\end{array}$ & $\begin{array}{l}1.1 \\
7.2\end{array}$ & $\begin{array}{l}1.2 \\
8.4\end{array}$ & $\begin{array}{l}1.1 \\
7.7\end{array}$ & $\begin{array}{l}1.3 \\
8.3\end{array}$ & $\begin{array}{l}1.3 \\
8.7\end{array}$ & $\begin{array}{l}0.9 \\
8.8\end{array}$ & $\begin{array}{l}1.2 \\
8.6\end{array}$ & $\begin{array}{r}1.1 \\
103\end{array}$ & $\begin{array}{r}1.2 \\
10.5\end{array}$ & $\begin{array}{r}1.6 \\
11.7\end{array}$ & $\begin{array}{r}1.8 \\
126\end{array}$ & $\begin{array}{r}2.1 \\
13.6\end{array}$ \\
\hline & 47.3 & 60.3 & 58.7 & 57.0 & 54.9 & 54.2 & 50.9 & 50.2 & 47.2 & 43.7 & 40.7 & 36.7 & 32.6 & 35.3 & 38.2 & 41.7 & 44.9 & 49.6 \\
\hline & & 9.6 & 6.0 & 5.6 & 5.0 & 4.9 & 4.8 & 3.0 & 2.9 & 3.9 & 2.8 & 2.9 & 2.4 & 2.9 & 2.8 & 2.7 & 4.0 & \\
\hline & \multicolumn{18}{|c|}{ Percent reporting use of drugs in the past 12 months } \\
\hline Alcohol ${ }^{1}$ & 84.8 & 87.9 & 86.8 & 87.3 & 86.0 & 85.6 & 84.5 & 85.7 & 85.3 & 82.7 & 80.6 & 77.7 & 76.8 & 72.7 & 73.0 & 73.7 & 72.5 & 74.8 \\
\hline Any illicit drug & 45.0 & 53.1 & 49.4 & 47.4 & 45.8 & 46.3 & 44.3 & 41.7 & 38.5 & 35.4 & 32.5 & 29.4 & 27.1 & 31.0 & 35.8 & 39.0 & 40.2 & - \\
\hline \multirow{2}{*}{$\begin{array}{l}\text { Marijuana only } \\
\text { Any illicit drug other than } \\
\text { marijuana }{ }^{2}\end{array}$} & 18.8 & 22.7 & 19.3 & 19.0 & 17.8 & 18.9 & 18.4 & 17.6 & 17.4 & 15.4 & 14.6 & 13.2 & 12.2 & 13.9 & 17.8 & 19.6 & 20.4 & - \\
\hline & 26.2 & 30.4 & 30.1 & 28.4 & 28.0 & 27.4 & 25.9 & 24.1 & 21.1 & 20.0 & 17.9 & 16.2 & 14.9 & 17.1 & 18.0 & 19.4 & 19.8 & 20.7 \\
\hline \multirow{6}{*}{$\begin{array}{l}\text { Use of selected drugs } \\
\text { Cocaine ........................... } \\
\text { Heroin ......................... } \\
\text { LSD .......................... } \\
\text { Marijuana/hashish }\end{array}$} & & & & & & & & & & & & & & & & & & \\
\hline & 5.6 & 12.3 & 11.5 & 11.4 & 11.6 & 13.1 & 12.7 & 10.3 & 7.9 & 6.5 & 5.3 & 3.5 & 3.1 & 3.3 & 3.6 & 4.0 & 4.9 & 5.5 \\
\hline & 1.0 & 0.5 & 0.6 & 0.6 & 0.5 & 0.6 & 0.5 & 0.5 & 0.5 & 0.6 & 0.5 & 0.4 & 0.6 & 0.5 & 0.6 & 1.1 & 1.0 & 1.2 \\
\hline & 7.2 & 6.5 & 6.1 & 5.4 & 4.7 & 4.4 & $\begin{array}{r}4.5 \\
38\end{array}$ & 5.2 & 4.8 & 4.9 & 5.4 & 5.2 & 5.6 & 6.8 & $\begin{array}{r}6.9 \\
20.9\end{array}$ & 8.4 & 8.8 & 8.4 \\
\hline & & $\begin{array}{r}48.8 \\
4.4\end{array}$ & $\begin{array}{r}44.3 \\
2.2\end{array}$ & $\begin{array}{r}42.3 \\
2.6\end{array}$ & $\begin{array}{r}40.0 \\
2.3\end{array}$ & $\begin{array}{r}40.6 \\
2.9\end{array}$ & $\begin{array}{r}38.8 \\
2.4\end{array}$ & $\begin{array}{r}36.3 \\
1.3\end{array}$ & $\begin{array}{r}33.1 \\
1.2\end{array}$ & $\begin{array}{r}29.6 \\
2.4\end{array}$ & $\begin{array}{r}27.0 \\
1.2\end{array}$ & $\begin{array}{r}23.9 \\
1.4\end{array}$ & $\begin{array}{r}21.9 \\
1.4\end{array}$ & $\begin{array}{r}26.0 \\
1.4\end{array}$ & $\begin{array}{r}30.1 \\
1.6\end{array}$ & $\begin{array}{r}34.7 \\
1.8\end{array}$ & $\begin{array}{r}35.8 \\
2.6\end{array}$ & 38.5 \\
\hline & \multicolumn{18}{|c|}{ Percent reporting use of drugs in the past 30 days } \\
\hline Alcohol ${ }^{1}$ & 68.2 & 72.0 & 69.7 & 69.4 & 67.2 & 65.9 & 65.3 & 66.4 & 63.9 & 60.0 & 57.1 & 54.0 & 51.3 & 48.6 & 50.1 & 51.3 & 50.8 & 52.7 \\
\hline Any illicit d & 30.7 & 37.2 & 32.5 & 30.5 & 29.2 & 29.7 & 27.1 & 24.7 & 21.3 & 19.7 & 17.2 & 16.4 & 14.4 & 18.3 & 21.9 & 23.8 & 24.6 & - \\
\hline $\begin{array}{l}\text { Marijuana only ...................... } \\
\text { Any illicit drug other than }\end{array}$ & 15.3 & 18.8 & 15.5 & 15.1 & 14.1 & 14.8 & 13.9 & 13.1 & 11.3 & 10.6 & 9.2 & 9.3 & 8.1 & 10.4 & 13.1 & 13.8 & 15.1 & - \\
\hline $\begin{array}{l}\text { Any illicit drug other than } \\
\text { marijuana }^{2}\end{array}$ & 15.4 & 18.4 & 17.0 & 15.4 & 15.1 & 14.9 & 13.2 & 11.6 & 10.0 & 9.1 & 8.0 & 7.1 & 6.3 & 7.9 & 8.8 & 10.0 & 9.5 & - \\
\hline \multicolumn{19}{|l|}{ Use of selected drugs } \\
\hline Cocaine ...... & 1.9 & 5.2 & 5.0 & 4.9 & 5.8 & 6.7 & 6.2 & 4.3 & 3.4 & 2.8 & 1.9 & 1.4 & 1.3 & 1.3 & 1.5 & 1.8 & 2.0 & 2.3 \\
\hline 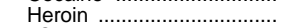 & 0.4 & 0.2 & 0.2 & 0.2 & 0.3 & 0.3 & 0.2 & 0.2 & 0.2 & 0.3 & 0.2 & 0.2 & 0.3 & 0.2 & 0.3 & 0.6 & 0.5 & 0.5 \\
\hline LSD ...................... & 2.3 & 2.3 & 2.4 & 1.9 & 1.5 & 1.6 & 1.7 & 1.8 & 1.8 & 1.8 & 1.9 & 1.9 & 2.0 & 2.4 & 2.6 & 4.0 & 2.5 & 3.1 \\
\hline Marijuar & 27.1 & 33.7 & 28.5 & 27.0 & 25.2 & 25.7 & 23.4 & 21.0 & 18.0 & 16.7 & 14.0 & 13.8 & 11.9 & 15.5 & 19.0 & 21.2 & 21.9 & 23.7 \\
\hline PCP. & & 1.4 & 1.0 & 1.3 & 1.0 & 1.6 & 1.3 & 0.6 & 0.3 & 1.4 & 0.4 & 0.5 & 0.6 & 1.0 & 0.7 & 0.6 & 1.3 & - \\
\hline
\end{tabular}

${ }^{1}$ Survey question changed in 1993; data are not comparable to figures for earlier years.

2Other illicit drugs include any use of hallucinogens, cocaine, and heroin, or any use of other opiates, stimulants, sedatives, or tranquilizers not under a doctor's orders. -Data not available.

NOTE.-A revised questionnaire was used in 1982 and later years to reduce the inap propriate reporting of nonprescription stimulants. This slightly reduced the positive responses for some types of drug abuse.
SOURCE: U.S. Department of Health and Human Services, Alcohol, Drug Abuse, and Mental Health Administration, Drug Use Among American High School Students and Other Young Adults, National Trends Through 1988; and press releases dated January 1992, April 1993, and January 1994; and University of Michigan, Institute for Social Research, Monitoring the Future, unpublished data. (This table was prepared February 1999.)

Table 151.-Percent of students (grades 7 to 12) who feel that certain problems are very serious: 1996

\begin{tabular}{|c|c|c|c|c|c|c|}
\hline Student characteristics & $\begin{array}{l}\text { Tight groups of } \\
\text { friends that do } \\
\text { not talk to one } \\
\text { another }\end{array}$ & $\begin{array}{l}\text { Hostile or threat- } \\
\text { ening remarks } \\
\text { between groups } \\
\text { of students }\end{array}$ & $\begin{array}{l}\text { Threats or de- } \\
\text { structive acts, } \\
\text { other than } \\
\text { physical fights }\end{array}$ & $\begin{array}{l}\text { Turf battles be- } \\
\text { tween different } \\
\text { groups of } \\
\text { students }\end{array}$ & $\begin{array}{l}\text { Physical fights } \\
\text { between mem- } \\
\text { bers of different } \\
\text { groups of friends }\end{array}$ & Gang violence \\
\hline 1 & 2 & 3 & 4 & 5 & 6 & 7 \\
\hline All students & 10 & 25 & 24 & 21 & 26 & 26 \\
\hline 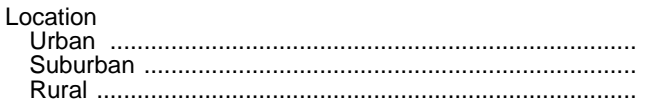 & $\begin{array}{r}11 \\
11 \\
8\end{array}$ & $\begin{array}{l}32 \\
22 \\
20\end{array}$ & $\begin{array}{l}33 \\
20 \\
19\end{array}$ & $\begin{array}{l}30 \\
18 \\
13\end{array}$ & $\begin{array}{l}33 \\
24 \\
20\end{array}$ & $\begin{array}{l}36 \\
21 \\
17\end{array}$ \\
\hline 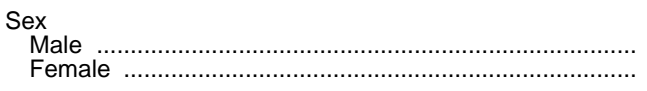 & $\begin{array}{l}10 \\
10\end{array}$ & $\begin{array}{l}24 \\
27\end{array}$ & $\begin{array}{l}23 \\
26\end{array}$ & $\begin{array}{l}21 \\
21\end{array}$ & $\begin{array}{l}26 \\
27\end{array}$ & $\begin{array}{l}25 \\
26\end{array}$ \\
\hline 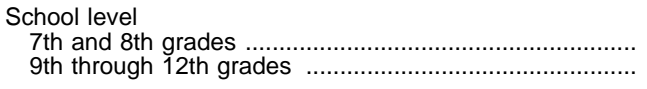 & $\begin{array}{r}9 \\
11\end{array}$ & $\begin{array}{l}32 \\
22\end{array}$ & $\begin{array}{l}28 \\
22\end{array}$ & $\begin{array}{l}24 \\
20\end{array}$ & $\begin{array}{l}32 \\
23\end{array}$ & $\begin{array}{l}31 \\
23\end{array}$ \\
\hline 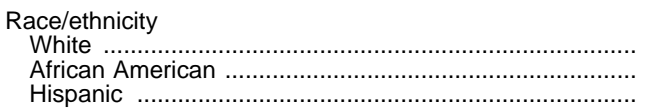 & $\begin{array}{r}9 \\
12 \\
13\end{array}$ & $\begin{array}{l}22 \\
36 \\
33\end{array}$ & $\begin{array}{l}21 \\
33 \\
32\end{array}$ & $\begin{array}{l}16 \\
32 \\
33\end{array}$ & $\begin{array}{l}22 \\
37 \\
34\end{array}$ & $\begin{array}{l}19 \\
40 \\
41\end{array}$ \\
\hline
\end{tabular}

SOURCE: Metropolitan Life/Louis Harris Associates, Inc., The Metropolitan Life Survey of The American Teacher, 1996. Part I. "Students Voice Their Opinions On: Violence, Social Tension and Equality Among Teens." (This table was prepared July 1997.) 
Table 152.-Ages for compulsory school attendance, special education services for students, policies for kindergarten programs, and year-round schools, by state: 1997 and 1995

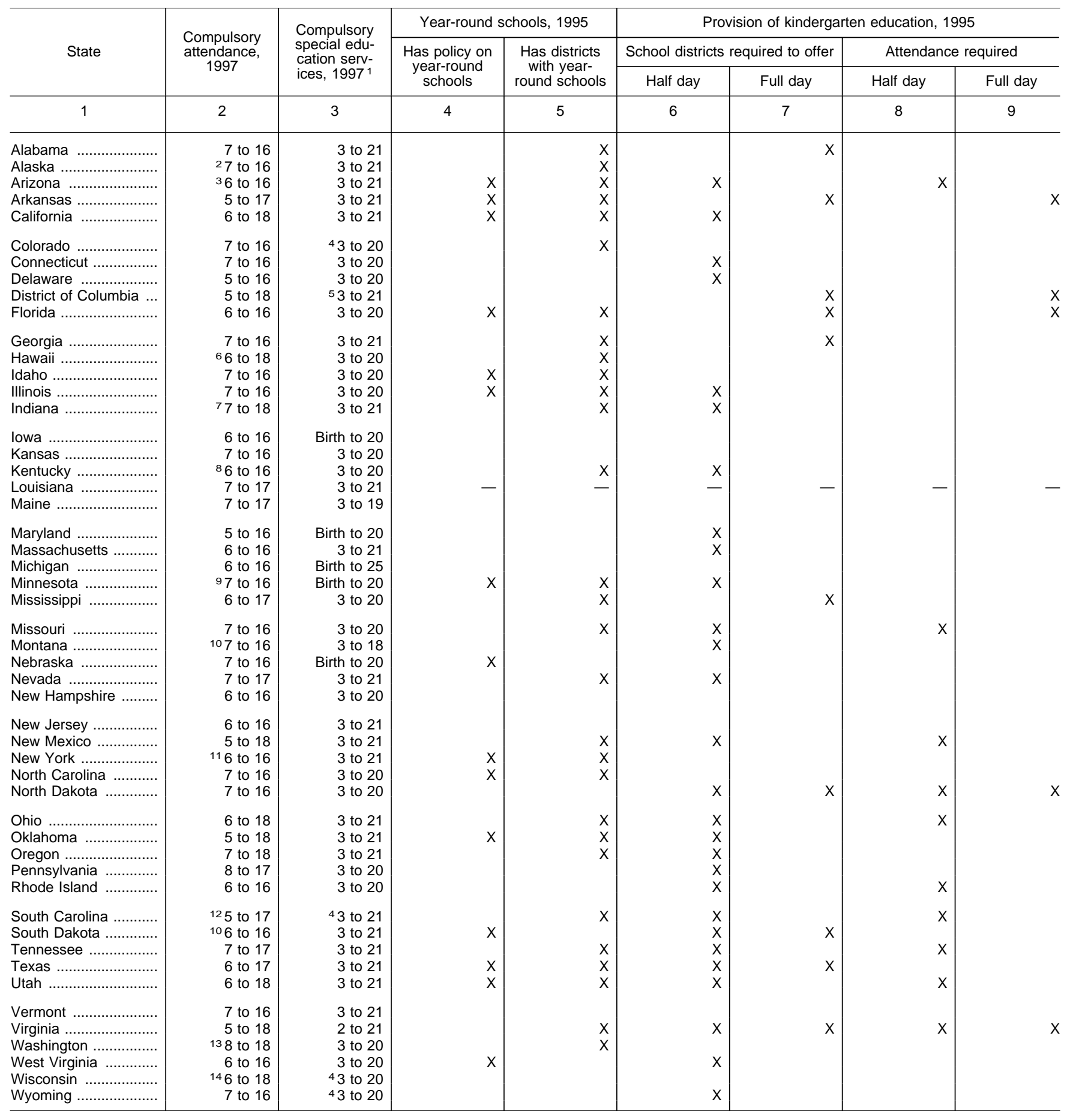

Most states have an upper age limit whereby education is provided up to a certain age or completion of secondary school, whichever comes first.

${ }^{2}$ Ages 7 to 16 or high school graduation.

${ }^{3}$ Ages 6 to 16 or tenth grade completion.

Upper age limit for eligibility has been updated for 1997.

5 State has established two points in the program year by which children must be 3 years of age to be eligible for services.

${ }^{6}$ Students over the age of 16 may withdraw with the approval of a principal and student's guardians, and if an alternative education program exists.

${ }^{7}$ From age 7 until student (1) graduates; (2) between age 16 to 18 and meets requirements for exit interview before graduation; or (3) reaches 18 . Withdrawal before 18 requires parent/guardian and principal written permission.

${ }^{8}$ Must have parental signature for leaving school between ages 16 to 18

${ }^{9}$ Age 18 takes effect in 2000 .

${ }_{10}$ Age 16 or completion of eighth grade.

11 Ages 6 to 17 for New York City and Buffalo.

12 Permits parental waiver of kindergarten at age 5.

${ }^{13} \mathrm{Or}$ can exit if age 16 or older, has a useful occupation, has met graduation requirements or has a certificate of education competency.

${ }^{14}$ Ages 6 to 18 or high school graduation.
NOTE.-The Education of the Handicapped Act (EHA) Amendments of 1986 make it mandatory for all states receiving EHA funds to serve all 3- to 18-year-old disabled children.

SOURCE: U.S. Department of Education, Office of Special Education and Rehabilitative Services, The Eighteenth Annual Report to Congress on the Implementation of The Individuals with Disabilities Education Act, 1996; National Association of State Directors of Special Education, Inc., unpublished data; Education Commission of the States, "Clearinghouse Notes," March 1997; and Council of Chief State School Officers, State Education Policies on Student Attendance and Use of Time: 1995. (This table was prepared May 1997.) 
Table 153.-Tenth- and 12th-graders' attendance patterns, by selected student and school characteristics: 1990 and 1992

\begin{tabular}{|c|c|c|c|c|c|c|c|c|c|c|c|c|c|c|}
\hline \multirow{3}{*}{ Attendance pattern } & \multirow{3}{*}{$\begin{array}{c}\text { All } \\
\text { stu- } \\
\text { dents }\end{array}$} & \multicolumn{2}{|c|}{ Sex } & \multicolumn{5}{|c|}{ Race/ethnicity } & \multicolumn{3}{|c|}{ Socioeconomic status ${ }^{1}$} & \multirow{2}{*}{\multicolumn{3}{|c|}{$\begin{array}{l}\text { Control of school } \\
\text { attended }\end{array}$}} \\
\hline & & & & & & & & & & & & & & \\
\hline & & Male & $\begin{array}{l}\text { Fe- } \\
\text { male }\end{array}$ & White & Black & Hispanic & Asian & $\begin{array}{c}\text { American } \\
\text { Indian }\end{array}$ & Low & Middle & High & Public & $\begin{array}{l}\text { Catho- } \\
\text { lic }\end{array}$ & $\begin{array}{l}\text { Other } \\
\text { private }\end{array}$ \\
\hline \multirow[t]{2}{*}{1} & 2 & 3 & 4 & 5 & 6 & 7 & 8 & 9 & 10 & 11 & 12 & 13 & 14 & 15 \\
\hline & \multicolumn{14}{|c|}{ Percent of 10 th graders in 1990} \\
\hline \multicolumn{15}{|l|}{$\begin{array}{l}\text { Number of days missed first } \\
\text { half of current school year }\end{array}$} \\
\hline None & 14.3 & 17.1 & 11.6 & 13.0 & 21.2 & 12.5 & 23.1 & 12.0 & 13.1 & 15.0 & 14.9 & 14.0 & 18.3 & 15.1 \\
\hline 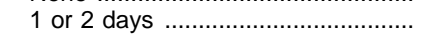 & 23.2 & 24.9 & 21.5 & 22.8 & 27.2 & 20.6 & 28.6 & 12.5 & 20.0 & 23.0 & 26.6 & 22.6 & 26.4 & 33.6 \\
\hline 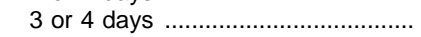 & 27.7 & 27.1 & 28.3 & 28.8 & 24.5 & 25.0 & 23.9 & 33.7 & 25.3 & 27.6 & 29.5 & 27.9 & 26.6 & 27.7 \\
\hline 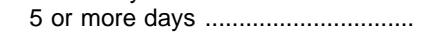 & 34.8 & 30.9 & 38.7 & 35.4 & 27.1 & 41.9 & 24.4 & 41.9 & 41.6 & 34.3 & 29.0 & 35.4 & 28.8 & 23.5 \\
\hline \multicolumn{15}{|l|}{$\begin{array}{l}\text { Number of times late first } \\
\text { half of current school year }\end{array}$} \\
\hline 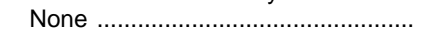 & 25.2 & 25.4 & 24.9 & 27.8 & 17.8 & 17.8 & 22.0 & 18.6 & 23.9 & 25.7 & 26.6 & 25.3 & 27.7 & 17.9 \\
\hline 1 or 2 days & 38.2 & 38.1 & 38.3 & 38.0 & 41.1 & 36.7 & 39.7 & 31.3 & 37.4 & 38.6 & 38.2 & 37.8 & 39.8 & 44.6 \\
\hline 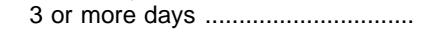 & 36.7 & 36.6 & 36.8 & 34.2 & 41.1 & 45.5 & 38.3 & 50.1 & 38.7 & 35.7 & 35.2 & 36.9 & 32.4 & 37.5 \\
\hline \multicolumn{15}{|l|}{ Cut classes } \\
\hline 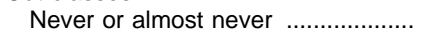 & 84.8 & 83.5 & 86.2 & 85.8 & 86.5 & 75.8 & 87.1 & 81.4 & 82.3 & 84.5 & 89.0 & 84.0 & 95.2 & 90.9 \\
\hline \multirow[t]{2}{*}{ At least sometimes } & 15.2 & 16.5 & 13.8 & 14.2 & 13.5 & 24.2 & 12.9 & 18.6 & 17.7 & 15.5 & 11.0 & 16.0 & 4.8 & 9.1 \\
\hline & \multicolumn{14}{|c|}{ Percent of 12th graders in 1992} \\
\hline \multicolumn{15}{|l|}{$\begin{array}{l}\text { Number of days missed first } \\
\text { half of current school year }\end{array}$} \\
\hline 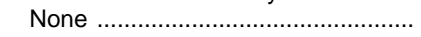 & 8.7 & 10.5 & 6.9 & 7.4 & 15.8 & 6.9 & 15.6 & 11.3 & 8.7 & 8.6 & 8.8 & 8.6 & 10.2 & 9.1 \\
\hline 1 or 2 days & 30.3 & 30.8 & 29.9 & 29.9 & 31.0 & 31.6 & 34.3 & 22.4 & 27.5 & 30.8 & 31.7 & 30.2 & 31.2 & 32.7 \\
\hline 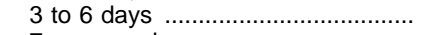 & 35.0 & 35.0 & 35.1 & 36.2 & 31.2 & 34.4 & 27.4 & 37.8 & 34.0 & 34.0 & 37.7 & 34.8 & 37.5 & 37.8 \\
\hline 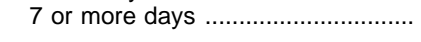 & 25.9 & 23.7 & 28.2 & 26.5 & 22.1 & 27.1 & 22.7 & 28.6 & 29.8 & 26.6 & 21.8 & 26.4 & 21.1 & 20.5 \\
\hline \multicolumn{15}{|l|}{$\begin{array}{l}\text { Number of times late first } \\
\text { half of current school year }\end{array}$} \\
\hline None & 19.0 & 17.7 & 20.3 & 20.6 & 14.0 & 14.7 & 16.2 & 19.1 & 19.7 & 19.0 & 18.7 & 19.2 & 19.5 & 12.3 \\
\hline 1 or 2 days $\ldots \ldots \ldots \ldots \ldots \ldots \ldots \ldots$ & 33.5 & 32.4 & 34.5 & 34.4 & 32.1 & 28.7 & 33.8 & 25.3 & 32.8 & 34.2 & 33.1 & 33.0 & 36.4 & 37.6 \\
\hline 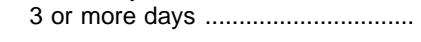 & 47.6 & 49.9 & 45.2 & 45.0 & 53.9 & 56.6 & 50.0 & 55.6 & 47.5 & 46.8 & 48.2 & 47.8 & 44.1 & 50.1 \\
\hline \multicolumn{15}{|l|}{ Cut classes } \\
\hline 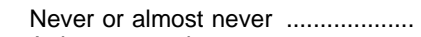 & 75.6 & 72.8 & 78.4 & 76.5 & 77.7 & 67.9 & 72.7 & 73.7 & 76.2 & 75.6 & 75.4 & 74.3 & 87.1 & 86.3 \\
\hline At least sometimes .......................... & 24.4 & 27.2 & 21.6 & 23.5 & 22.3 & 32.1 & 27.3 & 26.3 & 23.8 & 24.4 & 24.6 & 25.7 & 12.9 & 13.7 \\
\hline
\end{tabular}

${ }^{1}$ Socioeconomic status was measured by a composite score on parental education and occupations, and family income. The "Low" SES group is the lowest quartile; the "Middle" SES group is the middle two quartiles; and the "High" SES group is the upper

SOURCE: U.S. Department of Education, National Center for Education Statistics, "National Education Longitudinal Study of 1988," First and Second Followup surveys. (This table was prepared March 1994.) 
Table 154.-State requirements for high school graduation, in Carnegie units: 1993 and 1996

\begin{tabular}{|c|c|c|c|c|c|c|c|c|c|c|c|}
\hline \multirow{3}{*}{ State } & \multirow{3}{*}{\begin{tabular}{|c|}
1993 \\
$\begin{array}{c}\text { All } \\
\text { courses }\end{array}$ \\
\end{tabular}} & \multicolumn{8}{|c|}{1996} & \multirow{3}{*}{\begin{tabular}{|c|} 
First \\
graduating \\
class to \\
which these \\
requirements \\
apply
\end{tabular}} & \multirow{3}{*}{ Notes } \\
\hline & & \multirow[b]{2}{*}{$\begin{array}{c}\text { All } \\
\text { courses }\end{array}$} & \multicolumn{7}{|c|}{ Subject areas } & & \\
\hline & & & \begin{tabular}{|c|} 
English/ \\
language \\
arts
\end{tabular} & $\begin{array}{c}\text { Social } \\
\text { studies }\end{array}$ & $\begin{array}{l}\text { Mathe- } \\
\text { matics }\end{array}$ & Science & $\begin{array}{l}\begin{array}{c}\text { Physical } \\
\text { education/ } \\
\text { health }\end{array} \\
\end{array}$ & Electives & Other courses & & \\
\hline 1 & 2 & 3 & 4 & 5 & 6 & 7 & 8 & 9 & 10 & 11 & 12 \\
\hline 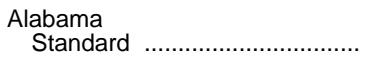 & 22 & 24 & 4 & 4 & 4 & 4 & 1.5 & 5.5 & $\begin{array}{l}1 \text { (.5 fine arts; } .5 \text { computer appli- } \\
\text { cations). }\end{array}$ & 2000 & $\begin{array}{l}\text { Students must become computer literate through re- } \\
\text { lated coursework. }\end{array}$ \\
\hline Alaska & 21 & 21 & 4 & 3 & 2 & 2 & 1 & 9 & & - & \\
\hline 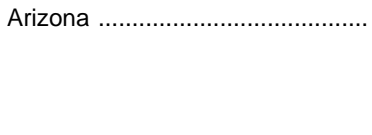 & 20 & 20 & 4 & 2.5 & 2 & 2 & 0 & 8 & $\begin{array}{l}1.5 \text { (.5 free enterprise, } 1 \text { fine } \\
\text { arts). }\end{array}$ & 1996 & $\begin{array}{l}\text { State board is required to adopt competency tests for } \\
\text { graduation in reading, writing and mathematics } \\
\text { (1996). Social studies requirement includes } 1 \text { unit } \\
\text { in world history and geography; } 1.5 \text { units in U.S. } \\
\text { and Arizona Constitutions and Arizona history. } 1\end{array}$ \\
\hline $\begin{array}{l}\text { Arkansas } \\
\text { Technical postsecondary }\end{array}$ & & & & & & & & & & & \\
\hline preparatory ……………....... & 20 & 21 & 4 & 2 & 3 & 3 & 1 & 3 & $\begin{array}{l}5 \text { (.5 oral communications; } 1 \text { vo- } \\
\text { cational/technical; } .5 \text { fine arts; } \\
\text { seniors take at least } 3 \text { aca- } \\
\text { demic courses). }\end{array}$ & 1997 & $\begin{array}{l}\text { Science requirements include } 1 \text { unit in life science } \\
\text { and } 1 \text { unit in physical science. Physical education } \\
\text { requirement includes } .5 \text { unit in health and safety } \\
\text { and } .5 \text { unit in physical education. Physical edu- } \\
\text { cation cannot exceed } 1 \text { unit. }{ }^{2}\end{array}$ \\
\hline College preparatory ……............ & - & 21 & 4 & 3 & 3 & 3 & 1 & 3 & $\begin{array}{l}4 \text { (.5 oral communication; } .5 \text { fine } \\
\text { arts; seniors take at least } 3 \\
\text { academic courses). }\end{array}$ & 1988 & $\begin{array}{l}\text { Science requirements include } 1 \text { unit in life science } \\
\text { and } 1 \text { unit in physical science. Physical education } \\
\text { requirement includes } 5 \text { unit in health and safety } \\
\text { and } 5 \text { unit in physical education. Physical edu- } \\
\text { cation cannot exceed } 1 \text { unit. }{ }^{1,2}\end{array}$ \\
\hline 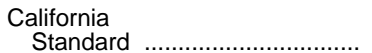 & & & & & & & & & & & \\
\hline Colorado & - & (1) & (1) & (1) & (1) & (1) & (1) & (1) & $\begin{array}{l}1 \text { (includes foreign language or } \\
\text { American Sign Language or } \\
\text { visual and performing arts). }\end{array}$ & 1989 & 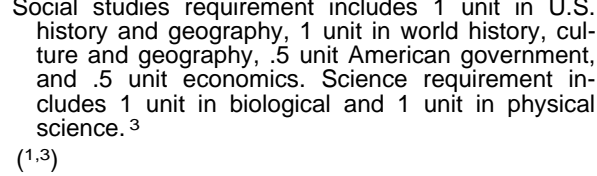 \\
\hline Connecticut ..................................... & 20 & 20 & 4 & 3 & 3 & 2 & 1 & 1 & 6 & 1988 & Electives could be in arts or vocational education. \\
\hline $\begin{array}{l}\text { Delaware } \\
\text { Standard }(1997,1998) \ldots \ldots \ldots \ldots . . .\end{array}$ & 19 & 19 & 4 & 3 & 2 & 2 & 1.5 & 6.5 & - & 1997 & $\begin{array}{l}\text { Physical education requirement includes } .5 \text { unit in } \\
\text { health and } 1 \text { unit in physical education. }\end{array}$ \\
\hline Standard (1999) ........ & - & 20 & 4 & 3 & 2 & 2 & 1.5 & 6.5 & $\begin{array}{l}1 \text { (computer literacy); students } \\
\text { must become computer literate } \\
\text { through formal class or related } \\
\text { coursework. }\end{array}$ & 1999 & $\begin{array}{l}\text { Physical education requirement includes } .5 \text { unit in } \\
\text { health and } 1 \text { unit in physical education. }\end{array}$ \\
\hline Standard $(2000) \ldots \ldots . .$. & - & 22 & 4 & 3 & 3 & 3 & 1.5 & - & $\begin{array}{l}7.5 \text { ( } 1 \text { computer literacy; students } \\
\text { must become computer literate } \\
\text { through formal class or related } \\
\text { coursework; } 3 \text { Career Path- } \\
\text { way } 4 \text {; } 3.5 \text { additional academic } \\
\text { coursework). }\end{array}$ & 2000 & $\begin{array}{l}\text { Physical education requirement includes } .5 \text { unit in } \\
\text { health and } 1 \text { unit in physical education. }\end{array}$ \\
\hline District of Columbia ........ & 23.5 & 23.5 & 4 & 3.5 & 3 & 3 & 1.5 & 3.5 & $\begin{array}{l}5 \text { (2 foreign language; } 1 \text { life } \\
\text { skills; } 1 \text { career/vocational; } .5 \\
\text { fine arts; } .5 \text { music). }\end{array}$ & 1996 & $\begin{array}{l}\text { D.C. requires } 100 \text { hours of community service with- } \\
\text { out credit. }\end{array}$ \\
\hline Florida & 24 & 24 & 4 & 2.5 & 3 & 3 & 1 & 9 & $\begin{array}{l}1.5 \text { (.5 economics; } 1 \text { practical } \\
\text { arts or exploratory career edu- } \\
\text { cation). }\end{array}$ & - & $\begin{array}{l}\text { Social studies requirement includes } 1 \text { unit in Amer- } \\
\text { ican history, } 1 \text { unit in world history and .5 unit in } \\
\text { American government. Two science units must } \\
\text { have a laboratory component. The physical edu- } \\
\text { cation requirement includes. } 5 \text { unit in life manage- } \\
\text { ment skills and } .5 \text { units in physical education. }{ }^{1,2}\end{array}$ \\
\hline $\begin{array}{l}\text { Georgia } \\
\text { Standard }\end{array}$ & 21 & 21 & 4 & 3 & 3 & 3 & 1 & 6 & $\begin{array}{l}1 \text { (computer technology and/or } \\
\text { fine arts and/or vocational edu- } \\
\text { cation and/or junior ROTC). }\end{array}$ & 1997 & $\begin{array}{l}\text { Students who completed } 4 \text { units of vocational edu- } \\
\text { cation in addition to requirements receive a state } \\
\text { seal of endorsement. Mathematics requirement in- } \\
\text { cludes } 1 \text { unit in algebra. } 1,2\end{array}$ \\
\hline
\end{tabular}


Table 154.-State requirements for high school graduation, in Carnegie units: 1993 and 1996-Continued

\begin{tabular}{|c|c|c|c|c|c|c|c|c|c|c|c|}
\hline \multirow{3}{*}{ State } & \multirow{3}{*}{\begin{tabular}{|c|}
1993 \\
$\begin{array}{c}\text { All } \\
\text { courses }\end{array}$ \\
\end{tabular}} & \multicolumn{8}{|c|}{1996} & \multirow{3}{*}{$\begin{array}{l}\text { First } \\
\text { graduating } \\
\text { class to } \\
\text { which these } \\
\text { requirements } \\
\text { apply }\end{array}$} & \multirow{3}{*}{ Notes } \\
\hline & & \multirow[b]{2}{*}{$\begin{array}{c}\text { All } \\
\text { courses }\end{array}$} & \multicolumn{7}{|c|}{ Subject areas } & & \\
\hline & & & $\begin{array}{c}\text { English/ } \\
\text { language } \\
\text { arts }\end{array}$ & $\begin{array}{l}\text { Social } \\
\text { studies }\end{array}$ & $\begin{array}{l}\text { Mathe- } \\
\text { matics }\end{array}$ & Science & $\begin{array}{c}\text { Physical } \\
\text { education/ } \\
\text { health }\end{array}$ & Electives & Other courses & & \\
\hline 1 & 2 & 3 & 4 & 5 & 6 & 7 & 8 & 9 & 10 & 11 & 12 \\
\hline Advanced ……… & 21 & 21 & 4 & 3 & 3 & 3 & 1 & 4 & $\begin{array}{l}3 \text { (2 foreign language; } 1 \text { fine arts, } \\
\text { vocational education, computer } \\
\text { technology, or ROTC). }\end{array}$ & - & $(1,2)$ \\
\hline Hawaii & & & & & & & & & & & \\
\hline Standard ………… & 22 & 22 & 4 & 4 & 3 & 3 & 2 & 6 & - & 1997 & $\begin{array}{l}\text { Physical education includes } 1 \text { unit in health and guid- } \\
\text { ance and } 1 \text { unit in physical education. } 10 \text { th grade } \\
\text { students take the Hawaii State Test of Essential } \\
\text { Competencies (HSTEC). }\end{array}$ \\
\hline Recognition diploma ................ & - & 24 & 4 & 4 & 3 & 3 & 2 & 6 & $\begin{array}{l}2 \text { (foreign language, performing/ } \\
\text { fine arts, or vocational edu- } \\
\text { cation). }\end{array}$ & 1997 & $\begin{array}{l}\text { Physical education requirement includes } 1 \text { unit in } \\
\text { health and guidance and } 1 \text { unit in physical edu- } \\
\text { cation. 10th grade students take Hawaii State of } \\
\text { Essential Competencies (HSTEC). }\end{array}$ \\
\hline Idaho ……......................... & 21 & 21 & 4 & 2 & 2 & 2 & 1.5 & 6 & $\begin{array}{l}3.5 \text { (.5 reading; } .5 \text { speech; } .5 \\
\text { consumer education; } 2 \text { human- } \\
\text { ities. Practical arts may sub- } \\
\text { stitute for } 1 \text { of the } 2 \text { units in } \\
\text { the humanities). }\end{array}$ & 1997 & $\begin{array}{l}\text { State requires a C average, demonstrated com- } \\
\text { petency in core curriculum on a junior class com- } \\
\text { petency test or adherence to a local district's } \\
\text { achievement plan for graduation. History require- } \\
\text { ment includes } 1 \text { unit in U.S. history and } 1 \text { unit in } \\
\text { American government. Both science units must in- } \\
\text { clude a laboratory component. The physical edu- } \\
\text { cation requirement includes .5 unit in health and } 1 \\
\text { unit in physical education. }\end{array}$ \\
\hline Illinois & 16 & 16 & 3 & 2 & 2 & 1 & 4.5 & 2.25 & $\begin{array}{l}1.25 \text { ( } 1 \text { from music, art, foreign } \\
\text { language which includes } \\
\text { American Sign Language, or } \\
\text { vocational education; . } 25 \text { from } \\
\text { consumer education). }\end{array}$ & 1995 & $\begin{array}{l}1 \text { year of mathematics may be computer technology. } \\
\text { Social studies requirement includes } 1 \text { unit in U.S. } \\
\text { history or } .5 \text { unit in U.S. history and } .5 \text { unit in } \\
\text { American government. Physical education require- } \\
\text { ment includes } .5 \text { unit in health education. }{ }^{2}\end{array}$ \\
\hline $\begin{array}{l}\text { Indiana } \\
\text { Standard }\end{array}$ & & & & & & & & & & & \\
\hline Standard & 19.5 & 19.5 & 4 & 2 & 2 & 2 & 1.5 & 8 & - & 1989 & $\begin{array}{l}\text { State does not use standard Carnegie units. Tenth } \\
\text { grade exit exam begins with the class of 1999- } \\
2000.1\end{array}$ \\
\hline Academic honors ........................ & 24 & 24 & 4 & 3 & 4 & 4 & 1 & 4 or 5 & $\begin{array}{l}3 \text { or } 4 \text { in foreign language }(3 \\
\text { years of } 1 \text { language or } 2 \text { years } \\
\text { in } 2 \text { languages })\end{array}$ & 1990 & $\begin{array}{l}\text { State does not use standard Carnegie units. Tenth } \\
\text { grade exit exam begins with the class of 1999- } \\
\text { 2000. }{ }^{1}\end{array}$ \\
\hline lowa & - & - & - & 1.5 & - & - & - & - & - & - & $\begin{array}{l}\text { All students must participate in physical education } \\
\text { unless they qualify under certain exceptions. Social } \\
\text { studies requirement includes } 1 \text { unit in U.S. history } \\
\text { and } .5 \text { unit in American government. 1,3 }\end{array}$ \\
\hline Kansas ........................ & 21 & 21 & 4 & 3 & 2 & 2 & 1 & 9 & - & - & $\begin{array}{l}\text { Students are required to take a course in Kansas } \\
\text { history or government (consisting of a minimum of } \\
9 \text { weeks and } 1,800 \text { minutes) in grades } 7-12 \text {. Eng- } \\
\text { lish/language arts requirement includes } 3 \text { units in } \\
\text { English. Social studies requirement includes } 1 \text { unit } \\
\text { in American history and } .5 \text { unit in American gov- } \\
\text { ernment. } 1\end{array}$ \\
\hline $\begin{array}{l}\text { Kentucky } \\
\text { Standard ......... }\end{array}$ & 20 & 20 & 4 & 2 & 3 & 2 & 1 & 8 & - & 1987 & $\begin{array}{l}\text { Social studies requirement includes } 1 \text { unit in U.S. } \\
\text { history. The physical education requirement in- } \\
\text { cludes } .5 \text { unit in health and } .5 \text { unit in physical edu- } \\
\text { cation. }\end{array}$ \\
\hline Commonwealth ........................ & 22 & 22 & 5 & 2 & 3 & 2 & 1 & 8 & $\begin{array}{l}1 \text { foreign language in advanced } \\
\text { placement. }\end{array}$ & 1993 & $\begin{array}{l}\text { Completion of } 1 \text { exam in at least } 3 \text { of the advanced } \\
\text { placement classes (science or mathematics, for- } \\
\text { eign language and English) is required. Physical } \\
\text { education requirement includes } .5 \text { unit in health } \\
\text { and } .5 \text { unit in physical education. }\end{array}$ \\
\hline
\end{tabular}


Table 154.-State requirements for high school graduation, in Carnegie units: 1993 and 1996-Continued

\begin{tabular}{|c|c|c|c|c|c|c|c|c|c|c|c|}
\hline \multirow{3}{*}{ State } & \multirow{3}{*}{\begin{tabular}{|c|}
1993 \\
$\begin{array}{c}\text { All } \\
\text { courses }\end{array}$ \\
\end{tabular}} & \multicolumn{8}{|c|}{1996} & \multirow{3}{*}{\begin{tabular}{|c|} 
First \\
graduating \\
class to \\
which these \\
requirements \\
apply
\end{tabular}} & \multirow{3}{*}{ Notes } \\
\hline & & \multirow[b]{2}{*}{$\begin{array}{c}\text { All } \\
\text { courses }\end{array}$} & \multicolumn{7}{|c|}{ Subject areas } & & \\
\hline & & & \begin{tabular}{|c|} 
English/ \\
language \\
arts
\end{tabular} & $\begin{array}{c}\text { Social } \\
\text { studies }\end{array}$ & $\begin{array}{l}\text { Mathe- } \\
\text { matics }\end{array}$ & Science & \begin{tabular}{|c|}
$\begin{array}{c}\text { Physical } \\
\text { education// } \\
\text { health }\end{array}$
\end{tabular} & Electives & Other courses & & \\
\hline 1 & 2 & 3 & 4 & 5 & 6 & 7 & 8 & 9 & 10 & 11 & 12 \\
\hline $\begin{array}{l}\text { Louisiana } \\
\text { Standard }\end{array}$ & 23 & 23 & 4 & 3 & 3 & 3 & 2 & 7.5 & .5 computer literacy & 1987 & $\begin{array}{l}\text { With an ACT score of } 29 \text { or above, } 3.5 \text { GPA or } \\
\text { above with no semester grade lower than a B, and } \\
\text { no unexcused absences or suspensions, students } \\
\text { may receive a Scholar Program Seal on their di- } \\
\text { ploma. }{ }^{1,2}\end{array}$ \\
\hline Regents program ….................. & 24 & 24 & 4 & 3.5 & 3 & 3 & 2 & 4.5 & $\begin{array}{l}4 \underset{(3}{3} \text { foreign language; } 1 \text { fine } \\
\text { arts). }\end{array}$ & 1983 & \\
\hline 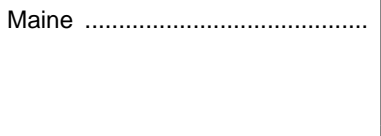 & 16 & 16 & 4 & 2 & 2 & 2 & 1.5 & 3.5 & 1 fine arts & 1989 & $\begin{array}{l}\text { Social studies requirement includes } 1 \text { unit in Amer- } \\
\text { ican history and } 1 \text { unit in American government. } \\
\text { One science unit must include a laboratory compo- } \\
\text { nent. Students must pass computer proficiency } \\
\text { standards. }{ }^{\text {s. }}\end{array}$ \\
\hline 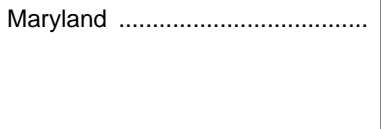 & 21 & 21 & 4 & 3 & 3 & 2 & 1 & 5 & $\begin{array}{l}3 \text { (1 fine arts; } 1 \text { industrial arts/ } \\
\text { technology education, home } \\
\text { economics, vocational edu- } \\
\text { cation, or computer studies; } \\
\text { and 1 community service). }\end{array}$ & 1997 & $\left({ }^{2}\right)$ \\
\hline 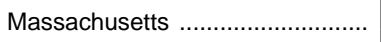 & - & - & - & 1 & - & - & 4 & 一 & - & - & American history is required. $1,2,3$ \\
\hline 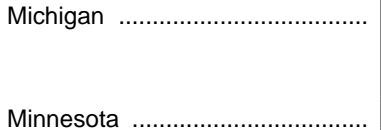 & - & - & - & - & - & - & - & - & - & 1993 & $\begin{array}{l}\text { A competency exam is optional for students wanting } \\
\text { an endorsed diploma. Students must receive in- } \\
\text { struction on U.S. and Michigan history and take a } \\
\text { semester of civics. }{ }^{3} \\
(1,2)\end{array}$ \\
\hline 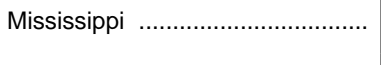 & 18 & 18 & 4 & 2 & 2 & 2 & - & 8 & - & 1989 & $\begin{array}{l}\text { One science unit must include a laboratory compo- } \\
\text { nent. }^{2}\end{array}$ \\
\hline $\begin{array}{l}\text { Missouri } \\
\text { Standard }\end{array}$ & 22 & 22 & 3 & 2 & 2 & 2 & 1 & 10 & 2 (1 practical arts 1 fine arts) & 1988 & Local districts may add to the requirements. \\
\hline College preparatory certificate & 24 & 24 & 4 & 3 & 3 & 2 & 1 & 9 & 2 (1 practical arts; 1 fine arts). & 1988 & $\begin{array}{l}\text { Social studies requirement includes } 1 \text { unit in Amer- } \\
\text { ican history. One science unit must include a lab- } \\
\text { oratory component. Of the } 9 \text { elective units, } 3 \text { core } \\
\text { electives are selected from foreign language, Eng- } \\
\text { lish, social studies, mathematics, science or fine } \\
\text { arts. A GPA of } 3.0 \text { and SAT of } 1014 \text { or enhanced } \\
\text { ACT of } 21 \text { is required. }\end{array}$ \\
\hline 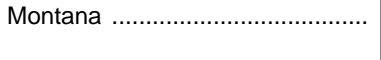 & 20 & 20 & 4 & 2 & 2 & 2 & 1 & 7 & $\begin{array}{l}2 \text { (1 fine arts; } 1 \text { vocational/prac- } \\
\text { tical arts). }\end{array}$ & 1989 & \\
\hline 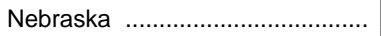 & - & - & - & - & - & - & - & - & - & 1991 & The state does not use standard Carnegie units. ${ }^{3}$ \\
\hline 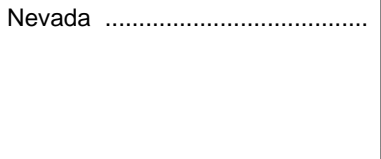 & 22.5 & 22.5 & 4 & 2 & 2 & 2 & 2.5 & 8.5 & $\begin{array}{l}1.5 \text { ( } 1 \text { arts and humanities; .5 } \\
\text { computer literacy). }\end{array}$ & 1992 & $\begin{array}{l}\text { Computer literacy course requirement may be waived } \\
\text { by demonstration of competency. Social studies re- } \\
\text { quirement includes } 1 \text { unit in American government } \\
\text { and } 1 \text { unit American history. Physical education re- } \\
\text { quirement includes } .5 \text { unit in health and } 2 \text { units in } \\
\text { physical education. } 1,2\end{array}$ \\
\hline New Hampshire ........................... & 19.75 & 19.75 & 4 & 2 & 2 & 2 & 1.25 & 7 & $\begin{array}{l}1.5 \text { (.5 arts; } .5 \text { computer edu- } \\
\text { cation; } .5 \text { basic business and } \\
\text { economics). }\end{array}$ & 1989 & $\begin{array}{l}\text { The social studies requirement includes } 1 \text { unit in U.S. } \\
\text { and New Hampshire history and } 1 \text { elective unit. } \\
\text { Science requirement includes } 1 \text { unit in physical } \\
\text { and } 1 \text { unit in biological science. Physical education } \\
\text { requirement includes . } 25 \text { unit in health and } 1 \text { unit } \\
\text { in physical education. }\end{array}$ \\
\hline 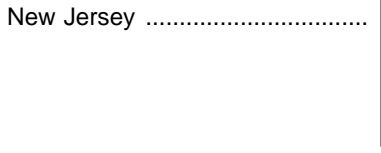 & 21.5 & 21.5 & 4 & 3 & 3 & 2 & 4 & 4 & $\begin{array}{l}1.5 \text { ( } 1 \text { fine, practical, or perform- } \\
\text { ing arts; .5 career education). }\end{array}$ & 1990 & $\begin{array}{l}110 \text { credit hours are required for graduation. (The (The } \\
\text { state does not use standard Carnegie units.) So- So } \\
\text { cial studies requirement includes } 2 \text { units in U.S. } \\
\text { history and } 1 \text { unit in world history/cultures. Science } \\
\text { unit may be either natural or physical science. The } \\
\text { state allows credit for college coursework. }{ }^{1,2}\end{array}$ \\
\hline
\end{tabular}


Table 154.- State requirements for high school graduation, in Carnegie units: 1993 and 1996—Continued

\begin{tabular}{|c|c|c|c|c|c|c|c|c|c|c|c|}
\hline \multirow{3}{*}{ State } & \multirow{3}{*}{\begin{tabular}{|c|}
1993 \\
$\begin{array}{c}\text { All } \\
\text { courses }\end{array}$ \\
\end{tabular}} & \multicolumn{8}{|c|}{1996} & \multirow{3}{*}{$\begin{array}{c}\text { First } \\
\text { graduating } \\
\text { class to } \\
\text { which these } \\
\text { requirements } \\
\text { apply }\end{array}$} & \multirow{3}{*}{ Notes } \\
\hline & & \multirow[b]{2}{*}{$\begin{array}{c}\text { All } \\
\text { courses }\end{array}$} & \multicolumn{7}{|c|}{ Subject areas } & & \\
\hline & & & $\begin{array}{c}\text { English/ } \\
\text { language } \\
\text { arts }\end{array}$ & $\begin{array}{c}\text { Social } \\
\text { studies }\end{array}$ & $\begin{array}{l}\text { Mathe- } \\
\text { matics }\end{array}$ & Science & \begin{tabular}{|c|} 
Physical \\
education/ \\
health
\end{tabular} & Electives & Other courses & & \\
\hline 1 & 2 & 3 & 4 & 5 & 6 & 7 & 8 & 9 & 10 & 11 & 12 \\
\hline 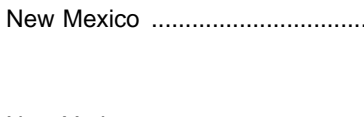 & 23 & 23 & 4 & 3 & 3 & 2 & 1 & 9 & 1 communication skills & 1990 & $\begin{array}{l}\text { One science unit must have a laboratory component. } \\
\text { Social studies requirement includes government } \\
\text { and economics, world history and geography, and } \\
\text { U.S. history and geography. }{ }^{2}\end{array}$ \\
\hline $\begin{array}{l}\text { New York } \\
\quad \text { Standard }\end{array}$ & 18.5 & 20.5 & - & 4 & - & - & 2.5 & 2 & $\begin{array}{l}4 \text { (1 art and/or music; } 3 \text { second } \\
\text { language). }\end{array}$ & 1989 & $\begin{array}{l}\text { Social studies requirement includes U.S. history and } \\
\text { government. }{ }^{2}\end{array}$ \\
\hline Regents diploma …….................. & 18.5 & 18.5 & 4 & 4 & 2 & 2 & 2.5 & 3 to 5 & $\begin{array}{l}1 \text { (foreign language, art and/or } \\
\text { music, occupational, technical } \\
\text { or home economics edu- } \\
\text { cation). }\end{array}$ & 2000 & $\begin{array}{l}\text { Physical education requirement includes } .5 \text { unit in } \\
\text { health and } 2 \text { physical education. Physical edu- } \\
\text { cation courses may not be included toward the } \\
18.5 \text { units required for graduation. One science } \\
\text { credit must include a laboratory component. The } 3 \\
\text { to } 5 \text { elective units are chosen from a specified se- } \\
\text { quence of courses. }{ }^{2}\end{array}$ \\
\hline North Carolina & & & & & & & & & & & \\
\hline 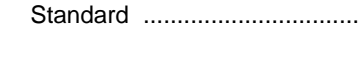 & 20 & 20 & 4 & 2 & 2 & 2 & 1 & 9 & - & 1987 & $\begin{array}{l}\text { One science class must include a laboratory compo- } \\
\text { nent. }{ }^{2}\end{array}$ \\
\hline Scholars program ……............... & 22 & 22 & 4 & 3 & 3 & 3 & 1 & 4 & $\begin{array}{l}4 \text { (2 foreign language; } 2 \text { addi- } \\
\text { tional credits from English, } \\
\text { mathematics, science, social } \\
\text { science, or foreign language). }\end{array}$ & 1994 & $\begin{array}{l}\text { One science class must include a laboratory compo- } \\
\text { nent. }{ }^{2}\end{array}$ \\
\hline North Dakota & 17 & 17 & 4 & 3 & 2 & 2 & 1 & 5 & - & 1994 & $\begin{array}{l}\text { The social studies requirement includes } 1 \text { unit in } \\
\text { world history and geography and } 1 \text { unit in } U \text {.S. his- } \\
\text { tory and geography. A unit of higher level foreign } \\
\text { language may be substituted for the fourth unit of } \\
\text { English. }{ }^{3}\end{array}$ \\
\hline Ohio & 18 & 18 & 3 & 2 & 2 & 1 & 1 & 9 & $\begin{array}{l}3 \text { (total units in a subject area } \\
\text { other than language arts/Eng- } \\
\text { lish must be taken to complete } \\
\text { a "minor"). }\end{array}$ & 1988 & $(1,2)$ \\
\hline Oklahoma & & & & & & & & & & & \\
\hline Standard ................. & 20 & 21 & 4 & 2 & 3 & 2 & 0 & 8 & $\begin{array}{l}2 \text { (1 fine/performing arts; } 1 \text { citi- } \\
\text { zenship skills). }\end{array}$ & 2000 & ( 1 ) \\
\hline College preparatory .................... & 15 & 15 & 4 & 2 & 3 & 2 & 0 & - & $\begin{array}{l}4 \text { (3 units chosen from foreign } \\
\text { language, computer science, } \\
\text { English, mathematics, history, } \\
\text { sociology, science, speech, or } \\
\text { psychology; } 1 \text { unit from eco- } \\
\text { nomics, geography, govern- } \\
\text { ment or non-Western culture. }\end{array}$ & 1996 & $(1)$ \\
\hline Oregon & 22 & 22 & 3 & 3.5 & 2 & 2 & 2 & 8 & $\begin{array}{l}1.5 \text { (.5 career development; } 1 \\
\text { applied arts, or foreign lan- } \\
\text { guage). }\end{array}$ & 1988 & $\begin{array}{l}\text { Students receive an honors diploma for a GPA of } 3.5 \\
\text { or higher. }\end{array}$ \\
\hline Pennsylvania & 21 & 21 & 4 & 3 & 3 & 3 & 1 & 5 & $\begin{array}{l}2 \text { credits in arts, humanities or } \\
\text { computer science }\end{array}$ & 1989 & $\begin{array}{l}\text { Students must achieve } 52 \text { state academic perform } \\
\text { ances and locally developed outcomes. }\end{array}$ \\
\hline $\begin{array}{l}\text { Rhode Island } \\
\text { Standard }\end{array}$ & 16 & 16 & 4 & 2 & 2 & 2 & -1 & 6 & - & 1989 & \\
\hline College preparatory .................. & 18 & 18 & 4 & 2 & 3 & 2 & - & 4 & $\begin{array}{l}3 \text { ( } 2 \text { credits in foreign language; } \\
.5 \text { computer, } .5 \text { arts). }\end{array}$ & - & \\
\hline
\end{tabular}


Table 154.-State requirements for high school graduation, in Carnegie units: 1993 and 1996-Continued

\begin{tabular}{|c|c|c|c|c|c|c|c|c|c|c|c|}
\hline \multirow{3}{*}{ State } & \multirow{3}{*}{\begin{tabular}{|c|}
1993 \\
$\begin{array}{c}\text { All } \\
\text { courses }\end{array}$ \\
\end{tabular}} & \multicolumn{8}{|c|}{1996} & \multirow{3}{*}{\begin{tabular}{|c|} 
First \\
graduating \\
class to \\
which these \\
requirements \\
apply
\end{tabular}} & \multirow{3}{*}{ Notes } \\
\hline & & \multirow[b]{2}{*}{$\begin{array}{c}\text { All } \\
\text { courses }\end{array}$} & \multicolumn{7}{|c|}{ Subject areas } & & \\
\hline & & & \begin{tabular}{|c|} 
English/ \\
language \\
arts
\end{tabular} & $\begin{array}{l}\text { Social } \\
\text { studies }\end{array}$ & \begin{tabular}{c|} 
Mathe- \\
matics
\end{tabular} & Science & $\begin{array}{c}\text { Physical } \\
\text { education/ } \\
\text { health }\end{array}$ & Electives & Other courses & & \\
\hline 1 & 2 & 3 & 4 & 5 & 6 & 7 & 8 & 9 & 10 & 11 & 12 \\
\hline $\begin{array}{l}\text { South Carolina } \\
\text { Technical preparatory ............. }\end{array}$ & 20 & 24 & 4 & 3 & 4 & 3 & 1 & 3 & $\begin{array}{l}6 \text { ( } 4 \text { credits in occupational spe- } \\
\text { cialty; } 2 \text { in foreign language). }\end{array}$ & 2000 & 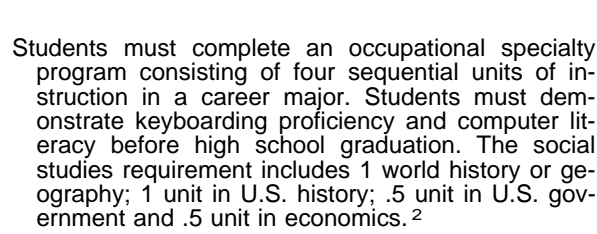 \\
\hline 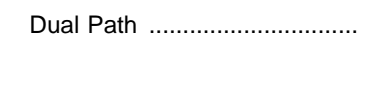 & 22 & 24 & 4 & 4 & 4 & 4 & 1 & 1 & $\begin{array}{l}6 \text { (4 occupational specialty; } 2 \text { for- } \\
\text { eign language). }\end{array}$ & 2000 & $\begin{array}{l}\text { Social studies requirement includes } 1 \text { unit in world } \\
\text { history; } 1 \text { unit in world geography; } 1 \text { unit in U.S. } \\
\text { history; } .5 \text { unit in U.S. government; and } .5 \text { unit in } \\
\text { economics. }\end{array}$ \\
\hline College preparatory ……......... & - & 24 & 4 & 4 & 4 & 4 & 1 & 4 & 3 credits in foreign language & - & $\begin{array}{l}\text { Proficiency in computer keyboarding/computer lit- } \\
\text { eracy is required for graduation. Social studies re- } \\
\text { quirement includes } 1 \text { unit in world history; } 1 \text { unit in } \\
\text { world geography; } 1 \text { unit in U.S. history; } 5 \text { unit in } \\
\text { U.S. government; and } .5 \text { unit in economics. }\end{array}$ \\
\hline South Dakota & 20 & 20 & 4 & 3 & 2 & 2 & - & 8 & $\begin{array}{l}1 \text { (.5 computer studies; } .5 \text { fine } \\
\text { arts). }\end{array}$ & 1989 & $\begin{array}{l}\text { Language arts/English requirement includes } 1.5 \text { units } \\
\text { in writing, } .5 \text { unit in American literature, } .5 \text { unit in } \\
\text { literature and } .5 \text { unit in speech. Social studies re- } \\
\text { quirement includes } 1 \text { unit in U.S. history, } .5 \text { unit in } \\
\text { U.S. government and } .5 \text { unit in geography. Both } \\
\text { science units must include a laboratory. }\end{array}$ \\
\hline Tennessee & & & & & & & & & & & \\
\hline Technical preparatory .............. & 20 & 20 & 4 & 3 & 3 & 3 & 1 & 2 & $\begin{array}{l}4 \text { (program of study focusing on } \\
\text { a particular technical area). }\end{array}$ & 1989 & $\begin{array}{l}\text { Exit exam with no passing standards is required be- } \\
\text { fore graduation; it is used to assess readiness for } \\
\text { workplace or higher education. }\end{array}$ \\
\hline University preparatory .............. & 20.5 & 20 & 4 & 3 & 3 & 3 & 1 & 3 & $\begin{array}{l}3 \text { (2 in foreign language; } 1 \text { fine } \\
\text { art) }\end{array}$ & 1989 & $\begin{array}{l}\text { Exit exam with no passing standards is required be- } \\
\text { fore graduation; it is used to assess readiness for } \\
\text { workplace or higher education. }\end{array}$ \\
\hline Texas & & & & & & & & & & & \\
\hline Standard (1998) ....................... & 21 & 22 & 4 & 2 & 3 & 2 & 2 & 7 & $\begin{array}{l}2 \text { (.5 economics/free enterprise; } \\
.5 \text { speech; } 1 \text { technology appli- } \\
\text { cation). }\end{array}$ & 1998 & $\begin{array}{l}\text { Physical education requirement includes } .5 \text { unit in } \\
\text { health and } 1.5 \text { units in physical education. }{ }^{2}\end{array}$ \\
\hline Standard (2000) ........................ & 22 & 24 & 4 & 4 & 3 & 3 & 2 & 3 & $\begin{array}{l}5 \text { (3 foreign language; } 1 \text { tech- } \\
\text { nology application; } 1 \text { fine arts). }\end{array}$ & 2000 & $\begin{array}{l}\text { Students must choose one of the three-credit addi- } \\
\text { tional options for electives. College Board ad- } \\
\text { vanced placement and International Baccalaureate } \\
\text { courses may be substituted for requirements in ap- } \\
\text { propriate proficiency areas to receive dual credits } \\
\text { for college coursework. Physical education require- } \\
\text { ment includes .5 unit in health and } 1.5 \text { units in } \\
\text { physical education. Social studies requirement in- } \\
\text { cludes economics. }\end{array}$ \\
\hline Utah & 24 & 24 & 3 & 3 & 2 & 2 & 2 & 9.5 & $\begin{array}{l}2.5 \text { (1.5 arts; } 1 \text { applied technical } \\
\text { education or occupational } \\
\text { preparation). }\end{array}$ & 1988 & $\begin{array}{l}\text { Students may accumulate credits more quickly than } \\
\text { peers and be eligible to receive a Centennial } \\
\text { Scholarship for Early Graduation to be applied to } \\
\text { college tuition. }{ }^{1,3}\end{array}$ \\
\hline Vermont & 14.5 & 14.5 & 4 & 3 & 0 to 5 & 0 to 5 & 1.5 & - & 1 arts & 1989 & $\begin{array}{l}\text { A total of } 5 \text { credits are required in mathematics and } \\
\text { science. }\end{array}$ \\
\hline $\begin{array}{l}\text { Virginia } \\
\text { Standard }\end{array}$ & 21 & 21 & 4 & 3 & 2 & 2 & 2 & 6 & $\begin{array}{l}2 \text { (1 additional mathematics or } \\
\text { science; } 1 \text { fine or practical } \\
\text { arts). }\end{array}$ & 1989 & (2) \\
\hline Advanced studies ..................... & 23 & 23 & 4 & 3 & 3 & 3 & 2 & 4 & $\begin{array}{l}4 \text { (3 foreign language; } 1 \text { fine or } \\
\text { practical arts). }\end{array}$ & - & $\left({ }^{2}\right)$ \\
\hline
\end{tabular}


Table 154.-State requirements for high school graduation, in Carnegie units: 1993 and 1996-Continued

\begin{tabular}{|c|c|c|c|c|c|c|c|c|c|c|c|}
\hline \multirow{3}{*}{ State } & \multirow{3}{*}{\begin{tabular}{|c|}
1993 \\
$\begin{array}{c}\text { All } \\
\text { courses }\end{array}$ \\
\end{tabular}} & \multicolumn{8}{|c|}{1996} & \multirow{3}{*}{$\begin{array}{c}\text { First } \\
\text { graduating } \\
\text { class to } \\
\text { which these } \\
\text { requirements } \\
\text { apply }\end{array}$} & \multirow{3}{*}{ Notes } \\
\hline & & \multirow[b]{2}{*}{$\begin{array}{c}\text { All } \\
\text { courses }\end{array}$} & \multicolumn{7}{|c|}{ Subject areas } & & \\
\hline & & & $\begin{array}{l}\text { English/ } \\
\text { language } \\
\text { arts }\end{array}$ & $\begin{array}{l}\text { Social } \\
\text { studies }\end{array}$ & $\begin{array}{l}\text { Mathe- } \\
\text { matics }\end{array}$ & Science & $\begin{array}{c}\begin{array}{c}\text { Physical } \\
\text { education// } \\
\text { health }\end{array} \\
\end{array}$ & Electives & Other courses & & \\
\hline 1 & 2 & 3 & 4 & 5 & 6 & 7 & 8 & 9 & 10 & 11 & 12 \\
\hline 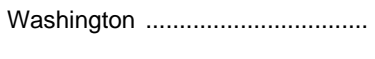 & 19 & 19 & 3 & 2.5 & 2 & 2 & 2 & 5.5 & $\begin{array}{l}2 \text { (1 occupational education; } 1 \\
\text { fine/visual or performing arts). }\end{array}$ & 1991 & $(1)$ \\
\hline 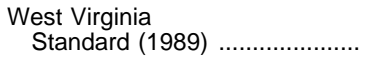 & 21 & 21 & 4 & 3 & 2 & 2 & 2 & 8 & - & 1989 & $\begin{array}{l}\text { Electives must be from applied arts, fine or perform- } \\
\text { ing arts, or a foreign lanquage. }\end{array}$ \\
\hline Standard (2002) ......................... & 21 & 21 & 4 & 3 & 2 & 2 & 2 & 7 & 1 art, music, theater or dance & 2002 & \\
\hline Wisconsin & 13 & 21.5 & 4 & 3 & 2 & 2 & 2 & - & - & 1989 & $\begin{array}{l}\text { Grades } 9-12 \text { need } 1.5 \text { units of physical education } \\
\text { and grades } 7-12 \text { need } .5 \text { unit of health. } 1,3\end{array}$ \\
\hline Wyoming & 18 & 18 & 4 & 3 & 2 & 2 & - & 5 & - & 1997 & $\left({ }^{3}\right)$ \\
\hline
\end{tabular}

1 State allows dual credit for college coursework.

2 Minimum competency test is required.

${ }_{3}^{3}$ Local boards determine at least some requirements.

${ }^{4} \mathrm{~A}$ Career Pathway is a planned program of sequenced or specialized courses designed to develop knowledge and skills in a particular career area. Students may use the Additional Academic Coursework (visual and performing arts,

foreign language and/or vocational technical education coursework, including Junior ROTC) as an option, to pursue individual academic interests. The credits in these two categories will eventually replace the elective credits. -Data not available or not applicable.

NOTE.-Local school districts frequently have other graduation requirements in addition to state requirements.

SOURCE: Education Commission of the States, Clearinghouse Notes, "Minimum High School Graduation Requirements" November 1996. (This table was prepared July 1997.) 
Table 155.-States using minimum-competency testing, by government level setting standards, grade levels assessed, and expected uses of standards: 1995-96

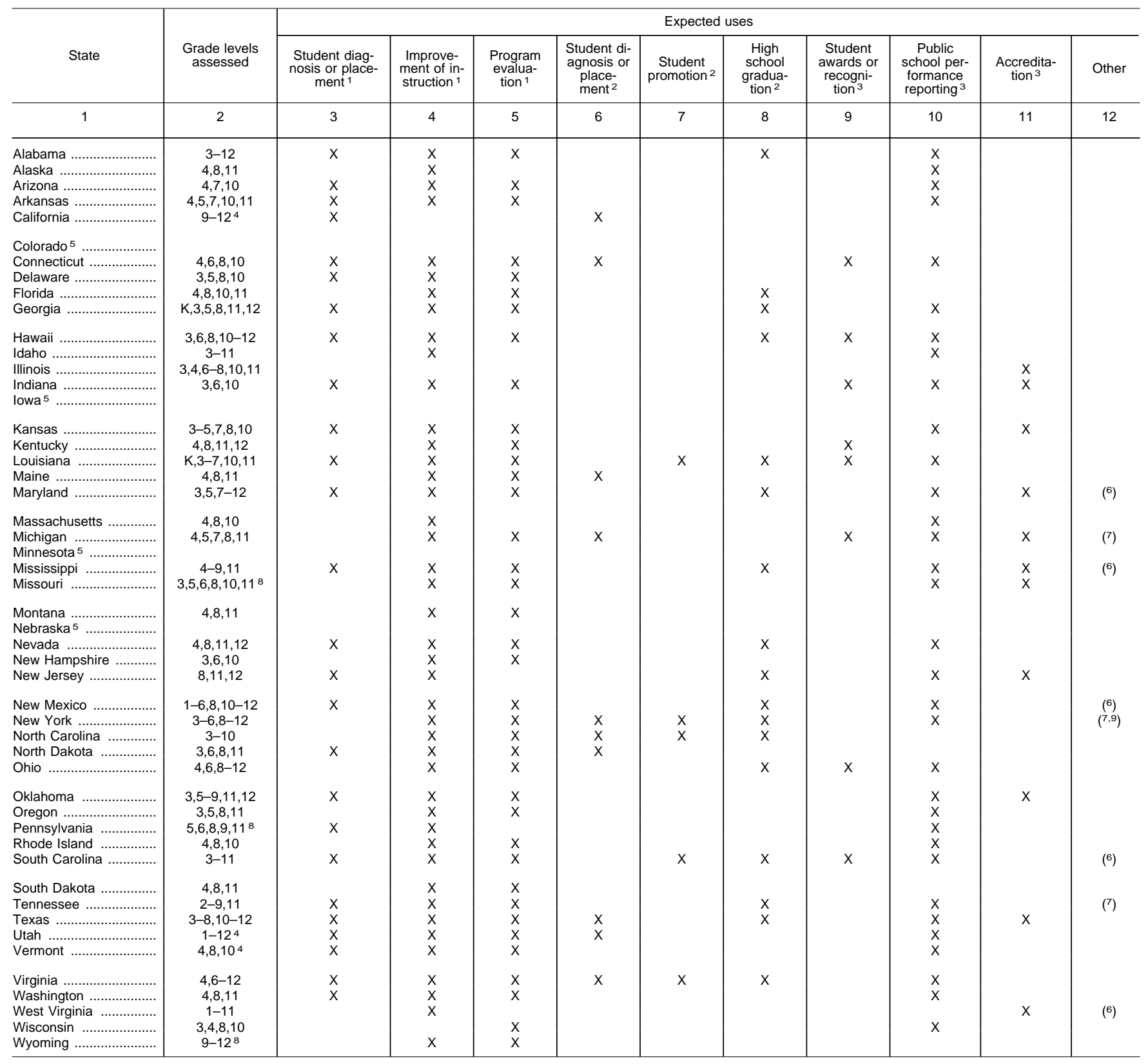

1 Testing program is for instructional purposes.

2 Testing program is for the purpose of student accountability.

${ }^{3}$ Testing program is for school accountability.

4 Inclusion is voluntary for students, schools or school districts for one or more grades. 5 States did not administer any statewide assessments for the 1995-96 school year. ${ }^{6}$ High school skills guarantee.

7 Endorsed diploma.
${ }^{8} \mathrm{~A}$ sample of students is tested for one or more grades 9 Honors diploma.

SOURCE: Council of Chief State School Officers, North Central Regional Educational Laboratory, "Annual Survey of State Student Assessment Programs, Fall 1996." (This table was prepared July 1997. 
Table 156.-States requiring testing for initial certification of teachers, by authorization, year enacted, year effective, and test used: 1990 and 1998

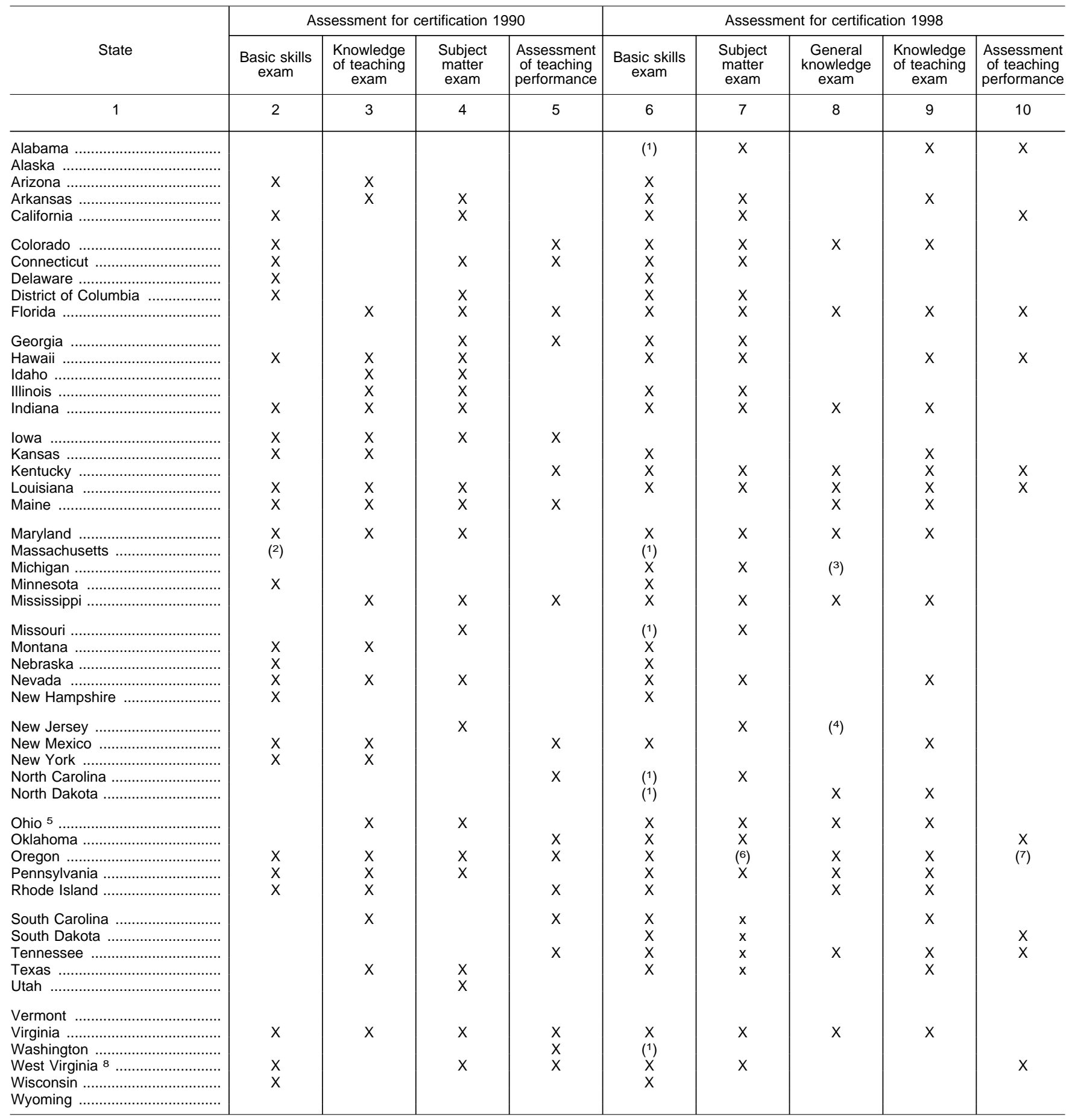

1 For admission to program.

2 Test required for foreign language, bilingual, and English as a Second Language.

${ }^{3}$ Elementary certificate exam (subject-area exam).

${ }^{4}$ For elementary education.

${ }^{5}$ Test requirements set by local school districts.

${ }^{6}$ Specialty area exams.

${ }^{7}$ For Oregon graduates.
${ }^{8}$ Required for individuals entering West Virginia-approved education programs as of fall 1985.

SOURCE: Council of Chief State School Officers, "State Education Indicators, 1990," and National Association of State Directors of Teacher Education and Certification, "The NASDTEC Manual, 1996-1997 and 1998-1999: Manual on Certification \& Preparation of Educational Personnel in the United States \& Canada." (This table was prepared November 1998.) 
Table 157.-Revenues for public elementary and secondary schools, by source of funds: 1919-20 to 1995-96

\begin{tabular}{|c|c|c|c|c|c|c|c|c|}
\hline \multirow[b]{2}{*}{ School year } & \multicolumn{4}{|c|}{ In thousands } & \multicolumn{4}{|c|}{ Percentage distribution } \\
\hline & Total & Federal & State & $\begin{array}{l}\text { Local (including } \\
\text { intermediate) }{ }^{1}\end{array}$ & Total & Federal & State & $\begin{array}{l}\text { Local (including } \\
\text { intermediate) }{ }^{1}\end{array}$ \\
\hline 1 & 2 & 3 & 4 & 5 & 6 & 7 & 8 & 9 \\
\hline 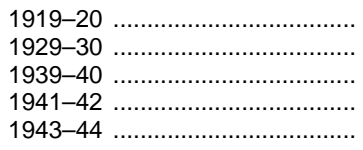 & $\begin{array}{r}\$ 970,121 \\
2,088,557 \\
2,260,527 \\
2,416,580 \\
2,604,322\end{array}$ & $\begin{array}{r}\$ 2,475 \\
7,334 \\
39,810 \\
34,305 \\
35,886\end{array}$ & $\begin{array}{r}\$ 160,085 \\
353,670 \\
684,354 \\
759,993 \\
859,183\end{array}$ & $\begin{array}{r}\$ 807,561 \\
1,727,553 \\
1,536,363 \\
1,622,281 \\
1,709,253\end{array}$ & $\begin{array}{l}100.0 \\
100.0 \\
100.0 \\
100.0 \\
100.0\end{array}$ & $\begin{array}{l}0.3 \\
0.4 \\
1.8 \\
1.4 \\
1.4\end{array}$ & $\begin{array}{l}16.5 \\
16.9 \\
30.3 \\
31.4 \\
33.0\end{array}$ & $\begin{array}{l}83.2 \\
82.7 \\
68.0 \\
67.1 \\
65.6\end{array}$ \\
\hline 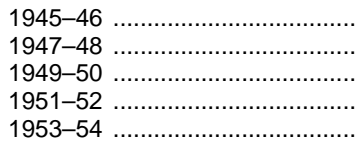 & $\begin{array}{l}3,059,845 \\
4,311,534 \\
5,437,044 \\
6,423,816 \\
7,866,852\end{array}$ & $\begin{array}{r}41,378 \\
120,270 \\
155,848 \\
227,711 \\
355,237\end{array}$ & $\begin{array}{l}1,062,057 \\
1,676,362 \\
2,165,689 \\
2,478,596 \\
2,944,103\end{array}$ & $\begin{array}{l}1,956,409 \\
2,514,902 \\
3,115,507 \\
3,717,507 \\
4,567,512\end{array}$ & $\begin{array}{l}100.0 \\
100.0 \\
100.0 \\
100.0 \\
100.0\end{array}$ & $\begin{array}{l}1.4 \\
2.8 \\
2.9 \\
3.5 \\
4.5\end{array}$ & $\begin{array}{l}34.7 \\
38.9 \\
39.8 \\
38.6 \\
37.4\end{array}$ & $\begin{array}{l}63.9 \\
58.3 \\
57.3 \\
57.9 \\
58.1\end{array}$ \\
\hline 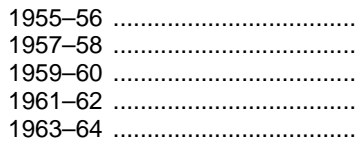 & $\begin{array}{r}9,686,677 \\
12,181,513 \\
14,746,618 \\
17,527,707 \\
20,544,182\end{array}$ & $\begin{array}{l}441,442 \\
486,484 \\
651,639 \\
760,975 \\
896,956\end{array}$ & $\begin{array}{l}3,828,886 \\
4,800,368 \\
5,768,047 \\
6,789,190 \\
8,078,014\end{array}$ & $\begin{array}{r}5,416,350 \\
6,894,661 \\
8,326,932 \\
9,977,542 \\
11,569,213\end{array}$ & $\begin{array}{l}100.0 \\
100.0 \\
100.0 \\
100.0 \\
100.0\end{array}$ & $\begin{array}{l}4.6 \\
4.0 \\
4.4 \\
4.3 \\
4.4\end{array}$ & $\begin{array}{l}39.5 \\
39.4 \\
39.1 \\
38.7 \\
39.3\end{array}$ & $\begin{array}{l}55.9 \\
56.6 \\
56.5 \\
56.9 \\
56.3\end{array}$ \\
\hline $\begin{array}{l}1965-66 \\
1967-68 \\
1969-70 \\
1970-71 \\
1971-72\end{array}$ & $\begin{array}{l}25,356,858 \\
31,903,064 \\
40,266,923 \\
44,511,292 \\
50,003,645\end{array}$ & $\begin{array}{l}1,996,954 \\
2,806,469 \\
3,219,557 \\
3,753,461 \\
4,467,969\end{array}$ & $\begin{array}{r}9,920,219 \\
12,275,536 \\
16,062,776 \\
17,409,086 \\
19,133,256\end{array}$ & $\begin{array}{l}13,439,686 \\
16,821,063 \\
20,984,589 \\
23,348,745 \\
26,402,420\end{array}$ & $\begin{array}{l}100.0 \\
100.0 \\
100.0 \\
100.0 \\
100.0\end{array}$ & $\begin{array}{l}7.9 \\
8.8 \\
8.0 \\
8.4 \\
8.9\end{array}$ & $\begin{array}{l}39.1 \\
38.5 \\
39.9 \\
39.1 \\
38.3\end{array}$ & $\begin{array}{l}53.0 \\
52.7 \\
52.1 \\
52.5 \\
52.8\end{array}$ \\
\hline 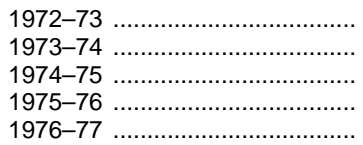 & $\begin{array}{l}52,117,930 \\
58,230,892 \\
64,445,239 \\
71,206,073 \\
75,322,532\end{array}$ & $\begin{array}{l}4,525,000 \\
4,930,351 \\
5,811,595 \\
6,318,345 \\
6,629,498\end{array}$ & $\begin{array}{l}20,699,752 \\
24,113,409 \\
27,060,563 \\
31,602,885 \\
32,526,018\end{array}$ & $\begin{array}{l}26,893,180 \\
29,187,132 \\
31,573,079 \\
33,284,840 \\
36,137,018\end{array}$ & $\begin{array}{l}100.0 \\
100.0 \\
100.0 \\
100.0 \\
100.0\end{array}$ & $\begin{array}{l}8.7 \\
8.5 \\
9.0 \\
8.9 \\
8.8\end{array}$ & $\begin{array}{l}39.7 \\
41.4 \\
42.0 \\
44.4 \\
43.2\end{array}$ & $\begin{array}{l}51.6 \\
50.1 \\
49.0 \\
46.7 \\
48.0\end{array}$ \\
\hline $\begin{array}{l}1977-78 \\
1978-79 \\
1979-80 \\
1980-81 \\
1981-82\end{array}$ & $\begin{array}{r}81,443,160 \\
87,994,143 \\
96,881,165 \\
105,949,087 \\
110,191,257\end{array}$ & $\begin{array}{l}7,694,194 \\
8,600,116 \\
9,503,537 \\
9,768,262 \\
8,186,466\end{array}$ & $\begin{array}{l}35,013,266 \\
40,132,136 \\
45,348,814 \\
50,182,659 \\
52,436,435\end{array}$ & $\begin{array}{l}38,735,700 \\
39,261,891 \\
42,028,813 \\
45,998,166 \\
49,568,356\end{array}$ & $\begin{array}{l}100.0 \\
100.0 \\
100.0 \\
100.0 \\
100.0\end{array}$ & $\begin{array}{l}9.4 \\
9.8 \\
9.8 \\
9.2 \\
7.4\end{array}$ & $\begin{array}{l}43.0 \\
45.6 \\
46.8 \\
47.4 \\
47.6\end{array}$ & $\begin{array}{l}47.6 \\
44.6 \\
43.4 \\
43.4 \\
45.0\end{array}$ \\
\hline 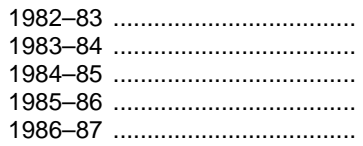 & $\begin{array}{l}117,497,502 \\
126,055,419 \\
137,294,678 \\
149,127,779 \\
158,523,693\end{array}$ & $\begin{array}{r}8,339,990 \\
8,576,547 \\
9,105,569 \\
9,975,622 \\
10,146,013\end{array}$ & $\begin{array}{l}56,282,157 \\
60,232,981 \\
67,168,684 \\
73,619,575 \\
78,830,437\end{array}$ & $\begin{array}{l}52,875,354 \\
57,245,892 \\
61,020,425 \\
65,532,582 \\
69,547,243\end{array}$ & $\begin{array}{l}100.0 \\
100.0 \\
100.0 \\
100.0 \\
100.0\end{array}$ & $\begin{array}{l}7.1 \\
6.8 \\
6.6 \\
6.7 \\
6.4\end{array}$ & $\begin{array}{l}47.9 \\
47.8 \\
48.9 \\
49.4 \\
49.7\end{array}$ & $\begin{array}{l}45.0 \\
45.4 \\
44.4 \\
43.9 \\
43.9\end{array}$ \\
\hline $\begin{array}{l}1987-88 \\
1988-89 \\
1989-90 \\
1990-91 \\
1991-92\end{array}$ & \begin{tabular}{|l}
$169,561,974$ \\
$192,016,374$ \\
$208,547,573$ \\
$223,340,537$ \\
$234,581,384$
\end{tabular} & $\begin{array}{l}10,716,687 \\
11,902,001 \\
12,700,784 \\
13,776,066 \\
15,493,330\end{array}$ & $\begin{array}{r}84,004,415 \\
91,768,911 \\
98,238,633 \\
105,324,533 \\
108,783,449\end{array}$ & $\begin{array}{r}74,840,873 \\
88,345,462 \\
97,608,157 \\
104,239,939 \\
110,304,605\end{array}$ & $\begin{array}{l}100.0 \\
100.0 \\
100.0 \\
100.0 \\
100.0\end{array}$ & $\begin{array}{l}6.3 \\
6.2 \\
6.1 \\
6.2 \\
6.6\end{array}$ & $\begin{array}{l}49.5 \\
47.8 \\
47.1 \\
47.2 \\
46.4\end{array}$ & $\begin{array}{l}44.1 \\
46.0 \\
46.8 \\
46.7 \\
47.0\end{array}$ \\
\hline $\begin{array}{l}1992-93 \\
1993-94 \ldots \ldots \ldots \ldots \ldots \\
1994-952 \\
1995-96\end{array}$ & \begin{tabular}{|l|}
$247,626,168$ \\
$260,159,468$ \\
$273,149,449$ \\
$287,702,844$
\end{tabular} & $\begin{array}{l}17,261,252 \\
18,341,483 \\
18,582,157 \\
19,104,019\end{array}$ & $\begin{array}{l}113,403,436 \\
117,474,209 \\
127,729,576 \\
136,670,754\end{array}$ & $\begin{array}{l}116,961,481 \\
124,343,776 \\
126,837,717 \\
131,928,071\end{array}$ & $\begin{array}{l}100.0 \\
100.0 \\
100.0 \\
100.0\end{array}$ & $\begin{array}{l}7.0 \\
7.1 \\
6.8 \\
6.6\end{array}$ & $\begin{array}{l}45.8 \\
45.2 \\
46.8 \\
47.5\end{array}$ & $\begin{array}{l}47.2 \\
47.8 \\
46.4 \\
45.9\end{array}$ \\
\hline
\end{tabular}

1 Includes a relatively small amount from nongovernmental private sources (gifts and tuition and transportation fees from patrons). These sources accounted for 2.6 percent of total revenues in 1995-96.

${ }^{2}$ Revised from previously published figures.

NOTE.-Beginning in 1980-81, revenues for state education agencies are excluded. Beginning in 1988-89, data reflect new survey collection procedures and may not be en tirely comparable with figures for earlier years. Because of rounding, details may not add to totals.

SOURCE: U.S. Department of Education, National Center for Education Statistics, Statistics of State School Systems; Revenues and Expenditures for Public Elementary and Secondary Education; and Common Core of Data surveys. (This table was prepared June 1998.) 
Table 158.-Revenues for public elementary and secondary schools, by source and state: 1995-96

[Amounts in thousands of dollars]

\begin{tabular}{|c|c|c|c|c|c|c|c|c|c|}
\hline \multirow[b]{2}{*}{ State or other area } & \multirow[b]{2}{*}{ Total } & \multicolumn{2}{|c|}{ Federal } & \multicolumn{2}{|l|}{ State } & \multicolumn{2}{|c|}{ Local and intermediate } & \multicolumn{2}{|c|}{ Private $^{1}$} \\
\hline & & Amount & $\begin{array}{l}\text { Percent } \\
\text { of total }\end{array}$ & Amount & $\begin{array}{l}\text { Percent } \\
\text { of total }\end{array}$ & Amount & $\begin{array}{l}\text { Percent } \\
\text { of total }\end{array}$ & Amount & $\begin{array}{l}\text { Percent } \\
\text { of total }\end{array}$ \\
\hline 1 & 2 & 3 & 4 & 5 & 6 & 7 & 8 & 9 & 10 \\
\hline United States & $\$ 287,702,844$ & $\$ 19,104,019$ & 6.6 & $\$ 136,670,754$ & 47.5 & $\$ 124,308,202$ & 43.2 & $\$ 7,619,869$ & 2.6 \\
\hline $\begin{array}{l}\text { Alabama } \\
\text { Alaska } \\
\text { Arizona } \\
\text { Arkansas } \\
\text { California }\end{array}$ & $\begin{array}{r}3,771,940 \\
1,183,127 \\
4,151,421 \\
2,204,845 \\
30,858,564\end{array}$ & $\begin{array}{r}348,717 \\
130,903 \\
375,299 \\
188,064 \\
2,742,893\end{array}$ & $\begin{array}{r}9.2 \\
11.1 \\
9.0 \\
8.5 \\
8.9\end{array}$ & $\begin{array}{r}2,310,952 \\
782,559 \\
1,829,488 \\
1,322,273 \\
17,207,011\end{array}$ & $\begin{array}{l}61.3 \\
66.1 \\
44.1 \\
60.0 \\
55.8\end{array}$ & $\begin{array}{r}790,919 \\
239,553 \\
1,850,818 \\
580,387 \\
10,546,059\end{array}$ & $\begin{array}{l}21.0 \\
20.2 \\
44.6 \\
26.3 \\
34.2\end{array}$ & $\begin{array}{r}321,353 \\
30,112 \\
95,817 \\
114,121 \\
362,602\end{array}$ & $\begin{array}{l}8.5 \\
2.5 \\
2.3 \\
5.2 \\
1.2\end{array}$ \\
\hline 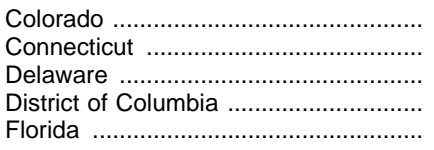 & $\begin{array}{r}3,804,992 \\
4,786,247 \\
822,226 \\
675,409 \\
13,214,948\end{array}$ & $\begin{array}{r}200,537 \\
177,394 \\
54,837 \\
54,405 \\
972,473\end{array}$ & $\begin{array}{l}5.3 \\
3.7 \\
6.7 \\
8.1 \\
7.4\end{array}$ & $\begin{array}{r}1,665,138 \\
1,819,099 \\
547,837 \\
- \\
6,422,329\end{array}$ & $\begin{array}{r}43.8 \\
38.0 \\
66.6 \\
- \\
48.6\end{array}$ & $\begin{array}{r}1,811,053 \\
2,656,280 \\
207,183 \\
617,760 \\
5,317,562\end{array}$ & $\begin{array}{l}47.6 \\
55.5 \\
25.2 \\
91.5 \\
40.2\end{array}$ & $\begin{array}{r}128,263 \\
133,474 \\
12,369 \\
3,244 \\
502,583\end{array}$ & $\begin{array}{l}3.4 \\
2.8 \\
1.5 \\
0.5 \\
3.8\end{array}$ \\
\hline $\begin{array}{l}\text { Georgia } \\
\text { Hawaii } \\
\text { Idaho } \\
\text { Illinois } \\
\text { Indiana }\end{array}$ & $\begin{array}{r}7,627,823 \\
1,201,888 \\
1,179,927 \\
12,290,140 \\
6,191,534\end{array}$ & $\begin{array}{r}520,690 \\
94,261 \\
83,787 \\
745,113 \\
319,237\end{array}$ & $\begin{array}{l}6.8 \\
7.8 \\
7.1 \\
6.1 \\
5.2\end{array}$ & $\begin{array}{r}3,956,281 \\
1,079,096 \\
758,538 \\
3,359,525 \\
3,362,035\end{array}$ & $\begin{array}{l}51.9 \\
89.8 \\
64.3 \\
27.3 \\
54.3\end{array}$ & $\begin{array}{r}3,005,940 \\
5,294 \\
316,851 \\
7,898,466 \\
2,312,251\end{array}$ & $\begin{array}{r}39.4 \\
0.4 \\
26.9 \\
64.3 \\
37.3\end{array}$ & $\begin{array}{r}144,911 \\
23,238 \\
20,750 \\
287,036 \\
198,012\end{array}$ & $\begin{array}{l}1.9 \\
1.9 \\
1.8 \\
2.3 \\
3.2\end{array}$ \\
\hline $\begin{array}{l}\text { lowa } \\
\text { Kansas } \\
\text { Kentucky } \\
\text { Louisiana } \\
\text { Maine }\end{array}$ & $\begin{array}{l}3,033,687 \\
2,948,036 \\
3,492,890 \\
3,934,998 \\
1,451,987\end{array}$ & $\begin{array}{r}154,638 \\
160,308 \\
290,625 \\
477,761 \\
80,876\end{array}$ & $\begin{array}{r}5.1 \\
5.4 \\
8.3 \\
12.1 \\
5.6\end{array}$ & $\begin{array}{r}1,486,472 \\
1,690,101 \\
2,280,140 \\
1,978,050 \\
681,853\end{array}$ & $\begin{array}{l}49.0 \\
57.3 \\
65.3 \\
50.3 \\
47.0\end{array}$ & $\begin{array}{r}1,231,268 \\
1,022,587 \\
895,219 \\
1,374,937 \\
673,602\end{array}$ & $\begin{array}{l}40.6 \\
34.7 \\
25.6 \\
34.9 \\
46.4\end{array}$ & $\begin{array}{r}161,308 \\
75,040 \\
26,906 \\
104,250 \\
15,656\end{array}$ & $\begin{array}{l}5.3 \\
2.5 \\
0.8 \\
2.6 \\
1.1\end{array}$ \\
\hline 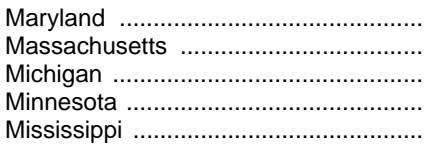 & $\begin{array}{r}5,695,850 \\
6,772,855 \\
12,698,697 \\
5,939,765 \\
2,225,798\end{array}$ & $\begin{array}{l}281,709 \\
318,591 \\
777,325 \\
253,845 \\
304,024\end{array}$ & $\begin{array}{r}4.9 \\
4.7 \\
6.1 \\
4.3 \\
13.7\end{array}$ & $\begin{array}{l}2,175,948 \\
2,593,935 \\
8,483,312 \\
3,458,503 \\
1,285,426\end{array}$ & $\begin{array}{l}38.2 \\
38.3 \\
66.8 \\
58.2 \\
57.8\end{array}$ & $\begin{array}{r}3,058,142 \\
3,749,747 \\
3,184,072 \\
2,000,762 \\
560,821\end{array}$ & $\begin{array}{l}53.7 \\
55.4 \\
25.1 \\
33.7 \\
25.2\end{array}$ & $\begin{array}{r}180,051 \\
110,582 \\
253,987 \\
226,655 \\
75,527\end{array}$ & $\begin{array}{l}3.2 \\
1.6 \\
2.0 \\
3.8 \\
3.4\end{array}$ \\
\hline 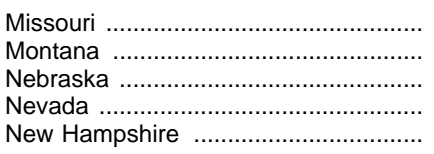 & $\begin{array}{r}5,263,003 \\
941,538 \\
1,876,494 \\
1,554,888 \\
1,217,104\end{array}$ & $\begin{array}{r}317,991 \\
92,802 \\
104,388 \\
69,857 \\
40,623\end{array}$ & $\begin{array}{l}6.0 \\
9.9 \\
5.6 \\
4.5 \\
3.3\end{array}$ & $\begin{array}{r}2,113,958 \\
457,958 \\
593,662 \\
497,744 \\
84,764\end{array}$ & $\begin{array}{r}40.2 \\
48.6 \\
31.6 \\
32.0 \\
7.0\end{array}$ & $\begin{array}{r}2,618,966 \\
350,452 \\
1,067,218 \\
930,476 \\
1,060,083\end{array}$ & $\begin{array}{l}49.8 \\
37.2 \\
56.9 \\
59.8 \\
87.1\end{array}$ & $\begin{array}{r}212,088 \\
40,326 \\
111,226 \\
56,810 \\
31,633\end{array}$ & $\begin{array}{l}4.0 \\
4.3 \\
5.9 \\
3.7 \\
2.6\end{array}$ \\
\hline 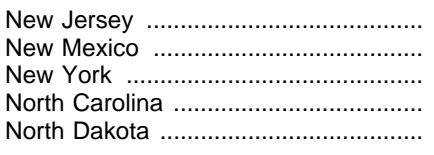 & $\begin{array}{r}11,882,657 \\
1,783,804 \\
25,849,431 \\
6,154,971 \\
618,322\end{array}$ & $\begin{array}{r}402,135 \\
216,810 \\
1,507,150 \\
443,121 \\
71,300\end{array}$ & $\begin{array}{r}3.4 \\
12.2 \\
5.8 \\
7.2 \\
11.5\end{array}$ & $\begin{array}{r}4,582,794 \\
1,318,739 \\
10,261,383 \\
3,971,825 \\
260,260\end{array}$ & $\begin{array}{l}38.6 \\
73.9 \\
39.7 \\
64.5 \\
42.1\end{array}$ & $\begin{array}{r}6,615,530 \\
209,699 \\
13,840,857 \\
1,565,289 \\
253,276\end{array}$ & $\begin{array}{l}55.7 \\
11.8 \\
53.5 \\
25.4 \\
41.0\end{array}$ & $\begin{array}{r}282,198 \\
38,556 \\
240,040 \\
174,735 \\
33,486\end{array}$ & $\begin{array}{l}2.4 \\
2.2 \\
0.9 \\
2.8 \\
5.4\end{array}$ \\
\hline $\begin{array}{l}\text { Ohio } \\
\text { Oklahoma } \\
\text { Oregon } \\
\text { Pennsylvania } \\
\text { Rhode Island }\end{array}$ & $\begin{array}{r}11,794,089 \\
2,856,688 \\
3,366,831 \\
14,047,905 \\
1,138,171\end{array}$ & $\begin{array}{r}738,880 \\
266,970 \\
218,785 \\
776,499 \\
57,906\end{array}$ & $\begin{array}{l}6.3 \\
9.3 \\
6.5 \\
5.5 \\
5.1\end{array}$ & $\begin{array}{r}4,797,764 \\
1,694,433 \\
1,821,888 \\
5,589,707 \\
472,134\end{array}$ & $\begin{array}{l}40.7 \\
59.3 \\
54.1 \\
39.8 \\
41.5\end{array}$ & $\begin{array}{r}5,775,786 \\
738,270 \\
1,203,913 \\
7,425,427 \\
593,824\end{array}$ & $\begin{array}{l}49.0 \\
25.8 \\
35.8 \\
52.9 \\
52.2\end{array}$ & $\begin{array}{r}481,659 \\
157,016 \\
122,245 \\
256,273 \\
14,308\end{array}$ & $\begin{array}{l}4.1 \\
5.5 \\
3.6 \\
1.8 \\
1.3\end{array}$ \\
\hline $\begin{array}{l}\text { South Carolina } \\
\text { South Dakota } \\
\text { Tennessee } \\
\text { Texas }\end{array}$ & $\begin{array}{r}3,697,232 \\
717,005 \\
4,142,148 \\
21,689,792 \\
2,066,218\end{array}$ & $\begin{array}{r}308,082 \\
70,519 \\
358,035 \\
1,557,597 \\
137,707\end{array}$ & $\begin{array}{l}8.3 \\
9.8 \\
8.6 \\
7.2 \\
6.7\end{array}$ & $\begin{array}{r}1,955,378 \\
213,290 \\
1,985,414 \\
9,312,159 \\
1,209,925\end{array}$ & $\begin{array}{l}52.9 \\
29.7 \\
47.9 \\
42.9 \\
58.6\end{array}$ & $\begin{array}{r}1,271,210 \\
410,705 \\
1,530,085 \\
10,246,162 \\
612,311\end{array}$ & $\begin{array}{l}34.4 \\
57.3 \\
36.9 \\
47.2 \\
29.6\end{array}$ & $\begin{array}{r}162,561 \\
22,491 \\
268,614 \\
573,876 \\
106,275\end{array}$ & $\begin{array}{l}4.4 \\
3.1 \\
6.5 \\
2.6 \\
5.1\end{array}$ \\
\hline $\begin{array}{l}\text { Vermont } \\
\text { Virginia } \\
\text { Washington } \\
\text { West Virginia } \\
\text { Wisconsin } \\
\text { Wyoming }\end{array}$ & $\begin{array}{r}773,448 \\
6,826,448 \\
6,327,993 \\
1,990,094 \\
6,304,318 \\
662,660\end{array}$ & $\begin{array}{r}36,481 \\
361,752 \\
365,988 \\
160,084 \\
273,225 \\
41,022\end{array}$ & $\begin{array}{l}4.7 \\
5.3 \\
5.8 \\
8.0 \\
4.3 \\
6.2\end{array}$ & $\begin{array}{r}215,275 \\
2,123,203 \\
4,302,300 \\
1,253,995 \\
2,705,278 \\
339,624\end{array}$ & $\begin{array}{l}27.8 \\
31.1 \\
68.0 \\
63.0 \\
42.9 \\
51.3\end{array}$ & $\begin{array}{r}501,925 \\
4,106,568 \\
1,464,556 \\
544,803 \\
3,192,597 \\
270,684\end{array}$ & $\begin{array}{l}64.9 \\
60.2 \\
23.1 \\
27.4 \\
50.6 \\
40.8\end{array}$ & $\begin{array}{r}19,767 \\
234,925 \\
195,150 \\
31,213 \\
133,219 \\
11,331\end{array}$ & $\begin{array}{l}2.6 \\
3.4 \\
3.1 \\
1.6 \\
2.1 \\
1.7\end{array}$ \\
\hline Outlying areas & & & & & & & & & \\
\hline American Samoa .................................... & $\begin{array}{r}45,087 \\
171,464\end{array}$ & $\begin{array}{l}34,218 \\
19524\end{array}$ & $\begin{array}{l}75.9 \\
11.4\end{array}$ & 10,801 & 24.0 & $\begin{array}{r}0 \\
150.544\end{array}$ & $-\overline{8}$ & $\begin{array}{r}68 \\
\end{array}$ & 0.2 \\
\hline Northern Marianas & 44,418 & 11,785 & 26.5 & 32,504 & 73.2 & 70 & 0.2 & 58 & 0.1 \\
\hline 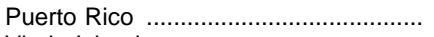 & $1,821,858$ & 536,899 & 29.5 & $1,284,218$ & 70.5 & 256 & $\left({ }^{2}\right)$ & 484 & $\left({ }^{2}\right)$ \\
\hline Virgin Islands & 142,016 & 24,495 & 17.2 & 0 & - & 117,434 & 82.7 & 87 & 0.1 \\
\hline
\end{tabular}

1 Includes revenues from gifts, and tuition and fees from patrons. 2 Less than .05 percent.

-Data not available or not applicable.
NOTE.-Excludes revenues for state education agencies. Because of rounding, details may not add to totals.

SOURCE: U.S. Department of Education, National Center for Education Statistics, Common Core of Data survey. (This table was prepared February 1998.) 
Table 159.--Revenues for public elementary and secondary schools, by source and state: 1994-95

[Amounts in thousands of dollars]

\begin{tabular}{|c|c|c|c|c|c|c|c|c|c|}
\hline \multirow{2}{*}{ State or other area } & \multirow[b]{2}{*}{ Total } & \multicolumn{2}{|c|}{ Federal } & \multicolumn{2}{|l|}{ State } & \multicolumn{2}{|c|}{ Local and intermediate } & \multicolumn{2}{|c|}{ Private $^{1}$} \\
\hline & & Amount & $\begin{array}{l}\text { Percent } \\
\text { of total }\end{array}$ & Amount & $\begin{array}{l}\text { Percent } \\
\text { of total }\end{array}$ & Amount & $\begin{array}{l}\text { Percent } \\
\text { of total }\end{array}$ & Amount & $\begin{array}{l}\text { Percent } \\
\text { of total }\end{array}$ \\
\hline 1 & 2 & 3 & 4 & 5 & 6 & 7 & 8 & 9 & 10 \\
\hline United States ..... & $\$ 273,149,449$ & $\$ 18,582,157$ & 6.8 & $\$ 127,729,576$ & 46.8 & $\$ 119,538,294$ & 43.8 & $\$ 7,299,422$ & 2.7 \\
\hline $\begin{array}{l}\text { Alabama } \\
\text { Alaska } \\
\text { Arizona } \\
\text { Arkansas } \\
\text { California }\end{array}$ & $\begin{array}{r}3,541,876 \\
1,207,000 \\
3,783,285 \\
2,175,109 \\
28,891,301\end{array}$ & $\begin{array}{r}343,927 \\
129,911 \\
354,242 \\
199,163 \\
2,751,519\end{array}$ & $\begin{array}{r}9.7 \\
10.8 \\
9.4 \\
9.2 \\
9.5\end{array}$ & $\begin{array}{r}2,161,685 \\
815,286 \\
1,664,966 \\
1,266,778 \\
15,670,329\end{array}$ & $\begin{array}{l}61.0 \\
67.5 \\
44.0 \\
58.2 \\
54.2\end{array}$ & $\begin{array}{r}766,020 \\
234,263 \\
1,673,192 \\
605,499 \\
10,127,054\end{array}$ & $\begin{array}{l}21.6 \\
19.4 \\
44.2 \\
27.8 \\
35.1\end{array}$ & $\begin{array}{r}270,244 \\
27,541 \\
90,886 \\
103,669 \\
342,399\end{array}$ & $\begin{array}{l}7.6 \\
2.3 \\
2.4 \\
4.8 \\
1.2\end{array}$ \\
\hline 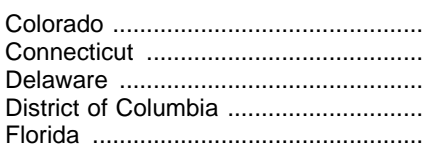 & \begin{tabular}{r|}
$3,679,162$ \\
$4,431,603$ \\
745,036 \\
701,300 \\
$12,805,853$
\end{tabular} & $\begin{array}{r}193,865 \\
177,446 \\
53,885 \\
66,716 \\
971,277\end{array}$ & $\begin{array}{l}5.3 \\
4.0 \\
7.2 \\
9.5 \\
7.6\end{array}$ & $\begin{array}{r}1,578,428 \\
1,748,802 \\
479,319 \\
- \\
6,286,323\end{array}$ & $\begin{array}{r}42.9 \\
39.5 \\
64.3 \\
-\overline{49.1}\end{array}$ & $\begin{array}{r}1,788,285 \\
2,375,694 \\
199,689 \\
631,028 \\
5,067,892\end{array}$ & $\begin{array}{l}48.6 \\
53.6 \\
26.8 \\
90.0 \\
39.6\end{array}$ & $\begin{array}{r}118,585 \\
129,661 \\
12,143 \\
3,556 \\
480,362\end{array}$ & $\begin{array}{l}3.2 \\
2.9 \\
1.6 \\
0.5 \\
3.8\end{array}$ \\
\hline $\begin{array}{l}\text { Georgia } \\
\text { Hawaii } \\
\text { Idaho } \\
\text { Illinois } \\
\text { Indiana }\end{array}$ & $\begin{array}{r}6,965,472 \\
1,177,915 \\
1,088,596 \\
12,016,320 \\
6,362,528\end{array}$ & $\begin{array}{r}512,456 \\
86,882 \\
84,012 \\
780,212 \\
306,971\end{array}$ & $\begin{array}{l}7.4 \\
7.4 \\
7.7 \\
6.5 \\
4.8\end{array}$ & $\begin{array}{r}3,530,615 \\
1,062,296 \\
666,387 \\
3,361,268 \\
3,391,558\end{array}$ & $\begin{array}{l}50.7 \\
90.2 \\
61.2 \\
28.0 \\
53.3\end{array}$ & $\begin{array}{r}2,785,137 \\
6,307 \\
318,671 \\
7,605,409 \\
2,472,119\end{array}$ & $\begin{array}{r}40.0 \\
0.5 \\
29.3 \\
63.3 \\
38.9\end{array}$ & $\begin{array}{r}137,265 \\
22,429 \\
19,527 \\
269,431 \\
191,880\end{array}$ & $\begin{array}{l}2.0 \\
1.9 \\
1.8 \\
2.2 \\
3.0\end{array}$ \\
\hline 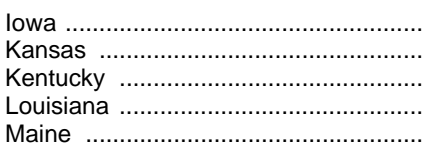 & $\begin{array}{l}2,881,176 \\
2,883,345 \\
3,240,926 \\
3,837,863 \\
1,400,439\end{array}$ & $\begin{array}{r}151,225 \\
152,757 \\
301,243 \\
458,344 \\
79,403\end{array}$ & $\begin{array}{r}5.2 \\
5.3 \\
9.3 \\
11.9 \\
5.7\end{array}$ & $\begin{array}{r}1,381,238 \\
1,655,905 \\
2,132,169 \\
1,999,368 \\
670,517\end{array}$ & $\begin{array}{l}47.9 \\
57.4 \\
65.8 \\
52.1 \\
47.9\end{array}$ & $\begin{array}{r}1,182,483 \\
1,002,034 \\
782,230 \\
1,281,012 \\
635,247\end{array}$ & $\begin{array}{l}41.0 \\
34.8 \\
24.1 \\
33.4 \\
45.4\end{array}$ & $\begin{array}{r}166,230 \\
72,648 \\
25,283 \\
99,139 \\
15,272\end{array}$ & $\begin{array}{l}5.8 \\
2.5 \\
0.8 \\
2.6 \\
1.1\end{array}$ \\
\hline 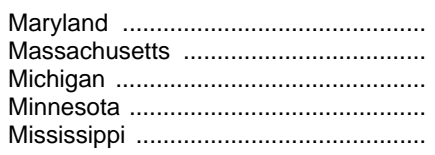 & $\begin{array}{r}5,559,604 \\
6,549,468 \\
11,925,311 \\
5,606,567 \\
2,099,795\end{array}$ & $\begin{array}{l}279,464 \\
352,760 \\
734,290 \\
247,964 \\
310,249\end{array}$ & $\begin{array}{r}5.0 \\
5.4 \\
6.2 \\
4.4 \\
14.8\end{array}$ & $\begin{array}{l}2,059,241 \\
2,376,538 \\
8,023,133 \\
2,939,545 \\
1,185,185\end{array}$ & $\begin{array}{l}37.0 \\
36.3 \\
67.3 \\
52.4 \\
56.4\end{array}$ & $\begin{array}{r}3,049,831 \\
3,668,716 \\
2,937,025 \\
2,210,175 \\
532,021\end{array}$ & $\begin{array}{l}54.9 \\
56.0 \\
24.6 \\
39.4 \\
25.3\end{array}$ & $\begin{array}{r}171,068 \\
151,453 \\
230,863 \\
208,884 \\
72,340\end{array}$ & $\begin{array}{l}3.1 \\
2.3 \\
1.9 \\
3.7 \\
3.4\end{array}$ \\
\hline 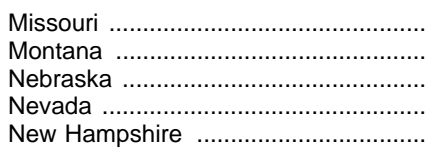 & $\begin{array}{r}4,891,384 \\
915,392 \\
1,797,785 \\
1,370,529 \\
1,149,673\end{array}$ & $\begin{array}{r}317,002 \\
91,912 \\
104,608 \\
67,369 \\
35,169\end{array}$ & $\begin{array}{r}6.5 \\
10.0 \\
5.8 \\
4.9 \\
3.1\end{array}$ & $\begin{array}{r}1,892,112 \\
453,778 \\
582,430 \\
412,904 \\
83,611\end{array}$ & $\begin{array}{r}38.7 \\
49.6 \\
32.4 \\
30.1 \\
7.3\end{array}$ & $\begin{array}{r}2,481,121 \\
331,846 \\
1,002,900 \\
837,374 \\
1,004,110\end{array}$ & $\begin{array}{l}50.7 \\
36.3 \\
55.8 \\
61.1 \\
87.3\end{array}$ & $\begin{array}{r}201,149 \\
37,857 \\
107,847 \\
52,883 \\
26,782\end{array}$ & $\begin{array}{l}4.1 \\
4.1 \\
6.0 \\
3.9 \\
2.3\end{array}$ \\
\hline 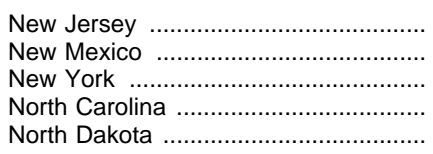 & $\begin{array}{r}11,485,382 \\
1,695,358 \\
24,889,904 \\
5,940,519 \\
592,329\end{array}$ & $\begin{array}{r}383,016 \\
199,231 \\
1,196,994 \\
443,701 \\
73,249\end{array}$ & $\begin{array}{r}3.3 \\
11.8 \\
4.8 \\
7.5 \\
12.4\end{array}$ & $\begin{array}{r}4,361,977 \\
1,261,807 \\
10,127,462 \\
3,867,413 \\
249,273\end{array}$ & $\begin{array}{l}38.0 \\
74.4 \\
40.7 \\
65.1 \\
42.1\end{array}$ & $\begin{array}{r}6,433,765 \\
196,841 \\
13,330,601 \\
1,463,703 \\
238,440\end{array}$ & $\begin{array}{l}56.0 \\
11.6 \\
53.6 \\
24.6 \\
40.3\end{array}$ & $\begin{array}{r}306,623 \\
37,480 \\
234,847 \\
165,702 \\
31,367\end{array}$ & $\begin{array}{l}2.7 \\
2.2 \\
0.9 \\
2.8 \\
5.3\end{array}$ \\
\hline 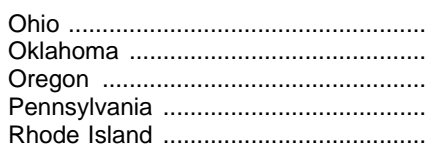 & $\begin{array}{r}11,024,539 \\
2,767,709 \\
3,294,014 \\
13,271,164 \\
1,091,960\end{array}$ & $\begin{array}{r}714,840 \\
260,760 \\
224,139 \\
746,601 \\
60,256\end{array}$ & $\begin{array}{l}6.5 \\
9.4 \\
6.8 \\
5.6 \\
5.5\end{array}$ & $\begin{array}{r}4,410,699 \\
1,644,176 \\
1,521,760 \\
5,325,072 \\
447,397\end{array}$ & $\begin{array}{l}40.0 \\
59.4 \\
46.2 \\
40.1 \\
41.0\end{array}$ & $\begin{array}{r}5,433,715 \\
715,199 \\
1,442,103 \\
6,943,281 \\
571,750\end{array}$ & $\begin{array}{l}49.3 \\
25.8 \\
43.8 \\
52.3 \\
52.4\end{array}$ & $\begin{array}{r}465,286 \\
147,575 \\
106,011 \\
256,210 \\
12,557\end{array}$ & $\begin{array}{l}4.2 \\
5.3 \\
3.2 \\
1.9 \\
1.1\end{array}$ \\
\hline $\begin{array}{l}\text { South Carolina } \\
\text { South Dakota } \\
\text { Tennessee } \\
\text { Texas }\end{array}$ & $\begin{array}{r}3,450,203 \\
691,685 \\
3,908,306 \\
19,678,883 \\
1,940,247\end{array}$ & $\begin{array}{r}299,232 \\
69,162 \\
348,729 \\
1,511,000 \\
133,543\end{array}$ & $\begin{array}{r}8.7 \\
10.0 \\
8.9 \\
7.7 \\
6.9\end{array}$ & $\begin{array}{r}1,598,971 \\
183,552 \\
1,855,784 \\
7,908,524 \\
1,054,222\end{array}$ & $\begin{array}{l}46.3 \\
26.5 \\
47.5 \\
40.2 \\
54.3\end{array}$ & $\begin{array}{r}1,399,989 \\
418,328 \\
1,443,757 \\
9,712,168 \\
645,245\end{array}$ & $\begin{array}{l}40.6 \\
60.5 \\
36.9 \\
49.4 \\
33.3\end{array}$ & $\begin{array}{r}152,010 \\
20,643 \\
260,036 \\
547,191 \\
107,237\end{array}$ & $\begin{array}{l}4.4 \\
3.0 \\
6.7 \\
2.8 \\
5.5\end{array}$ \\
\hline 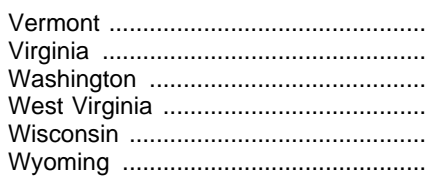 & $\begin{array}{r}753,905 \\
6,456,381 \\
5,976,441 \\
1,940,425 \\
5,985,761 \\
632,720\end{array}$ & $\begin{array}{r}34,424 \\
368,102 \\
357,615 \\
156,555 \\
262,315 \\
42,453\end{array}$ & \begin{tabular}{l|l}
4.6 \\
5.7 \\
6.0 \\
8.1 \\
4.4 \\
6.7
\end{tabular} & $\begin{array}{r}224,941 \\
2,052,415 \\
4,103,287 \\
1,234,701 \\
2,460,520 \\
303,908\end{array}$ & \begin{tabular}{l|l}
29.8 \\
31.8 \\
68.7 \\
63.6 \\
41.1 \\
48.0
\end{tabular} & $\begin{array}{r}476,096 \\
3,813,487 \\
1,330,433 \\
520,036 \\
3,139,562 \\
275,412\end{array}$ & $\begin{array}{l}63.2 \\
59.1 \\
22.3 \\
26.8 \\
52.5 \\
43.5\end{array}$ & $\begin{array}{r}18,445 \\
222,377 \\
185,106 \\
29,134 \\
123,364 \\
10,947\end{array}$ & $\begin{array}{l}2.4 \\
3.4 \\
3.1 \\
1.5 \\
2.1 \\
1.7\end{array}$ \\
\hline Outlying areas & & & & & & & & & \\
\hline 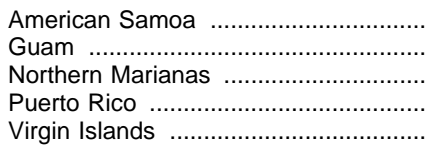 & $\begin{array}{r}45,151 \\
171,866 \\
44,122 \\
1,641,580 \\
142,961\end{array}$ & $\begin{array}{r}37,858 \\
17,132 \\
11,663 \\
474,419 \\
25,435\end{array}$ & $\begin{array}{l}83.8 \\
10.0 \\
26.4 \\
28.9 \\
17.8\end{array}$ & \begin{tabular}{r|}
6,987 \\
0 \\
32,321 \\
$1,166,632$ \\
0
\end{tabular} & $\begin{array}{r}15.5 \\
73.3 \\
71.1 \\
-\end{array}$ & $\begin{array}{r}190 \\
153,269 \\
54 \\
218 \\
117,441\end{array}$ & $\begin{array}{r}0.4 \\
89.2 \\
0.1 \\
(2) \\
82.1\end{array}$ & $\begin{array}{r}116 \\
1,465 \\
85 \\
311 \\
85\end{array}$ & $\begin{array}{r}0.3 \\
0.9 \\
0.2 \\
(2) \\
0.1\end{array}$ \\
\hline
\end{tabular}

1 Includes revenues from gifts, and tuition and fees from patrons. 2 Less than .05 percent.

-Data not available or not applicable.
NOTE.-Excludes revenues for state education agencies. Because of rounding, details may not add to totals. Some data revised from previously published figures.

SOURCE: U.S. Department of Education, National Center for Education Statistics, Common Core of Data survey. (This table was prepared July 1998.) 
Table 160.-Funds and staff for state education agencies, ${ }^{1}$ by source of funding and state: $1992-93$

\begin{tabular}{|c|c|c|c|c|c|c|c|c|c|}
\hline \multirow[b]{2}{*}{ State } & \multicolumn{4}{|c|}{$\begin{array}{l}\text { Funds retained for state administration, by source, } \\
\text { in thousands }\end{array}$} & \multirow{2}{*}{$\begin{array}{l}\text { Total state } \\
\text { administra- } \\
\text { tion funds } \\
\text { per } \\
\text { student }\end{array}$} & \multicolumn{3}{|c|}{$\begin{array}{l}\text { State education agency (FTE) staff, } \\
\text { by source of funds for position }\end{array}$} & \multirow{2}{*}{$\begin{array}{l}\text { Students } \\
\text { per state } \\
\text { FTE staff }\end{array}$} \\
\hline & Total & $\begin{array}{l}\text { Federal } \\
\text { (core ac- } \\
\text { tivities) }{ }^{2}\end{array}$ & $\begin{array}{l}\text { Percent } \\
\text { federal }\end{array}$ & $\begin{array}{l}\text { State and } \\
\text { local }\end{array}$ & & $\begin{array}{c}\text { Total FTE } \\
\text { staff }\end{array}$ & $\begin{array}{l}\text { Federally } \\
\text { supported } \\
\text { (core ac- } \\
\text { tivities) }{ }^{2}\end{array}$ & $\begin{array}{l}\text { State and } \\
\text { local sup- } \\
\text { ported }\end{array}$ & \\
\hline 1 & 2 & 3 & 4 & 5 & 6 & 7 & 8 & 9 & 10 \\
\hline 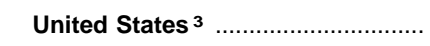 & $\$ 1,966,453$ & $\$ 526,847$ & 26.8 & $\$ 1,439,606$ & $\$ 46$ & 28,626 & 7,054 & 21,572 & 1,496 \\
\hline $\begin{array}{l}\text { Alabama } \\
\text { Alaska } \\
\text { Arizona } \\
\text { Arkansas } \\
\text { California }\end{array}$ & $\begin{array}{r}52,111 \\
38,461 \\
19,315 \\
17,561 \\
148,989\end{array}$ & $\begin{array}{r}13,007 \\
5,046 \\
7,460 \\
4,204 \\
52,316\end{array}$ & $\begin{array}{l}25.0 \\
13.1 \\
38.6 \\
23.9 \\
35.1\end{array}$ & $\begin{array}{l}39,103 \\
33,414 \\
11,856 \\
13,356 \\
96,673\end{array}$ & $\begin{array}{r}71 \\
314 \\
29 \\
40 \\
28\end{array}$ & $\begin{array}{r}1,006 \\
503 \\
362 \\
290 \\
1,898\end{array}$ & $\begin{array}{r}127 \\
44 \\
175 \\
74 \\
419\end{array}$ & $\begin{array}{r}879 \\
460 \\
187 \\
216 \\
1,479\end{array}$ & $\begin{array}{r}727 \\
244 \\
1,862 \\
1,522 \\
2,768\end{array}$ \\
\hline 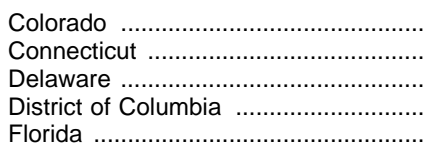 & $\begin{array}{r}21,361 \\
139,733 \\
10,949 \\
56,310\end{array}$ & $\begin{array}{r}5,991 \\
11,433 \\
2,578 \\
-25,470\end{array}$ & $\begin{array}{r}28.0 \\
8.2 \\
23.5 \\
-\overline{45.2}\end{array}$ & $\begin{array}{r}15,370 \\
128,300 \\
8,371 \\
- \\
30,840\end{array}$ & $\begin{array}{r}35 \\
286 \\
105 \\
- \\
28\end{array}$ & $\begin{array}{r}223 \\
2,005 \\
128 \\
-688\end{array}$ & $\begin{array}{r}90 \\
196 \\
44 \\
- \\
323\end{array}$ & $\begin{array}{r}133 \\
1,809 \\
84 \\
- \\
366\end{array}$ & $\begin{array}{r}2,750 \\
244 \\
817 \\
2,878\end{array}$ \\
\hline $\begin{array}{l}\text { Georgia } \\
\text { Hawaii } \\
\text { Idaho } \\
\text { Illinois } \\
\text { Indiana }\end{array}$ & $\begin{array}{r}58,632 \\
7,346 \\
42,854 \\
29,220\end{array}$ & $\begin{array}{r}9,918 \\
- \\
2,938 \\
22,092 \\
7,339\end{array}$ & $\begin{array}{r}16.9 \\
40.0 \\
51.6 \\
25.1\end{array}$ & $\begin{array}{r}48,714 \\
4,408 \\
20,762 \\
21,880\end{array}$ & $\begin{array}{l}49 \\
32 \\
23 \\
30\end{array}$ & $\begin{array}{r}935 \\
104 \\
746 \\
309\end{array}$ & $\begin{array}{r}147 \\
45 \\
317 \\
132\end{array}$ & $\begin{array}{r}788 \\
- \\
59 \\
429 \\
177\end{array}$ & $\begin{array}{r}1,291 \\
2,224 \\
2,511 \\
3,109\end{array}$ \\
\hline $\begin{array}{l}\text { lowa } \\
\text { Kansas } \\
\text { Kentucky } \\
\text { Louisiana } \\
\text { Maine }{ }^{4}\end{array}$ & $\begin{array}{l}20,589 \\
12,701 \\
49,745 \\
35,978 \\
17,356\end{array}$ & $\begin{array}{r}9,582 \\
5,422 \\
6,202 \\
13,015 \\
4,248\end{array}$ & $\begin{array}{l}46.5 \\
42.7 \\
12.5 \\
36.2 \\
24.5\end{array}$ & $\begin{array}{r}11,007 \\
7,279 \\
43,542 \\
22,963 \\
13,109\end{array}$ & $\begin{array}{l}42 \\
28 \\
76 \\
45 \\
80\end{array}$ & $\begin{array}{l}226 \\
199 \\
859 \\
573 \\
207\end{array}$ & $\begin{array}{r}106 \\
83 \\
105 \\
254 \\
90\end{array}$ & $\begin{array}{l}120 \\
116 \\
754 \\
320 \\
117\end{array}$ & $\begin{array}{r}2,192 \\
2,269 \\
763 \\
1,393 \\
1,046\end{array}$ \\
\hline 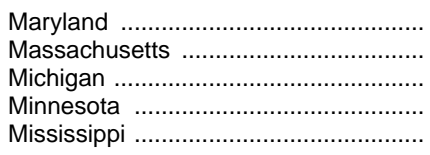 & $\begin{array}{l}42,343 \\
30,191 \\
53,743 \\
23,730 \\
40,892\end{array}$ & $\begin{array}{r}8,737 \\
13,557 \\
15,656 \\
9,072 \\
5,703\end{array}$ & $\begin{array}{l}20.6 \\
44.9 \\
29.1 \\
38.2 \\
13.9\end{array}$ & $\begin{array}{l}33,606 \\
16,633 \\
38,088 \\
14,658 \\
35,190\end{array}$ & $\begin{array}{l}56 \\
35 \\
34 \\
30 \\
81\end{array}$ & $\begin{array}{l}556 \\
368 \\
844 \\
416 \\
724\end{array}$ & $\begin{array}{l}126 \\
173 \\
256 \\
129 \\
144\end{array}$ & $\begin{array}{l}430 \\
195 \\
588 \\
287 \\
580\end{array}$ & $\begin{array}{r}1,351 \\
2,337 \\
1,899 \\
1,908 \\
700\end{array}$ \\
\hline 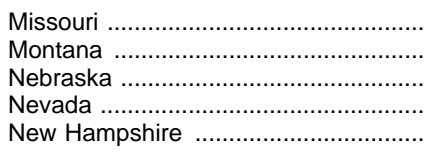 & $\begin{array}{r}42,860 \\
8,070 \\
20,624 \\
5,305 \\
7,889\end{array}$ & $\begin{array}{l}8,708 \\
3,490 \\
5,018 \\
2,643 \\
2,662\end{array}$ & $\begin{array}{l}20.3 \\
43.2 \\
24.3 \\
49.8 \\
33.7\end{array}$ & $\begin{array}{r}34,152 \\
4,581 \\
15,607 \\
2,662 \\
5,226\end{array}$ & $\begin{array}{l}50 \\
50 \\
73 \\
24 \\
44\end{array}$ & $\begin{array}{r}1,448 \\
137 \\
398 \\
90 \\
157\end{array}$ & $\begin{array}{r}132 \\
52 \\
75 \\
47 \\
60\end{array}$ & $\begin{array}{r}1,317 \\
85 \\
323 \\
42 \\
97\end{array}$ & $\begin{array}{r}593 \\
1,168 \\
710 \\
2,491 \\
1,154\end{array}$ \\
\hline 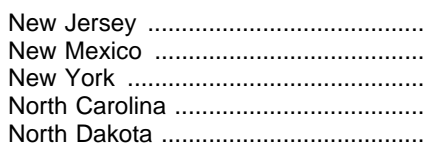 & $\begin{array}{r}65,111 \\
10,398 \\
181,649 \\
49,298 \\
5,683\end{array}$ & $\begin{array}{r}25,857 \\
3,753 \\
47,866 \\
13,990 \\
3,187\end{array}$ & $\begin{array}{l}39.7 \\
36.1 \\
26.4 \\
28.4 \\
56.1\end{array}$ & $\begin{array}{r}39,254 \\
6,645 \\
133,783 \\
35,308 \\
2,496\end{array}$ & $\begin{array}{l}58 \\
33 \\
68 \\
44 \\
48\end{array}$ & $\begin{array}{r}1,001 \\
216 \\
2,565 \\
796 \\
93\end{array}$ & $\begin{array}{r}326 \\
67 \\
567 \\
144 \\
52\end{array}$ & $\begin{array}{r}675 \\
149 \\
1,998 \\
652 \\
41\end{array}$ & $\begin{array}{l}1,129 \\
1,461 \\
1,049 \\
1,399 \\
1,277\end{array}$ \\
\hline 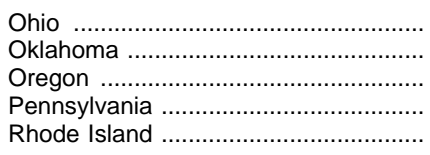 & $\begin{array}{l}32,879 \\
32,178 \\
61,178 \\
72,979 \\
13,705\end{array}$ & $\begin{array}{r}14,741 \\
8,347 \\
15,822 \\
19,746 \\
4,347\end{array}$ & $\begin{array}{l}44.8 \\
25.9 \\
25.9 \\
27.1 \\
31.7\end{array}$ & $\begin{array}{r}18,139 \\
23,831 \\
45,357 \\
53,233 \\
9,358\end{array}$ & $\begin{array}{r}18 \\
54 \\
120 \\
42 \\
95\end{array}$ & $\begin{array}{r}511 \\
499 \\
418 \\
1,134 \\
152\end{array}$ & $\begin{array}{r}242 \\
98 \\
58 \\
237 \\
59\end{array}$ & $\begin{array}{r}269 \\
401 \\
360 \\
897 \\
93\end{array}$ & $\begin{array}{r}3,513 \\
1,196 \\
1,221 \\
1,515 \\
948\end{array}$ \\
\hline 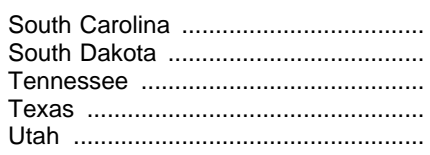 & $\begin{array}{r}87,109 \\
7,419 \\
36,778 \\
59,560 \\
25,763\end{array}$ & $\begin{array}{r}9,130 \\
3,988 \\
10,525 \\
18,321 \\
6,092\end{array}$ & $\begin{array}{l}10.5 \\
53.8 \\
28.6 \\
30.8 \\
23.6\end{array}$ & $\begin{array}{r}77,979 \\
3,430 \\
26,253 \\
41,238 \\
19,671\end{array}$ & $\begin{array}{r}136 \\
55 \\
43 \\
17 \\
56\end{array}$ & $\begin{array}{r}946 \\
102 \\
456 \\
1,013 \\
364\end{array}$ & $\begin{array}{r}105 \\
42 \\
100 \\
358 \\
62\end{array}$ & $\begin{array}{r}841 \\
60 \\
356 \\
654 \\
302\end{array}$ & $\begin{array}{r}677 \\
1,324 \\
1,876 \\
3,498 \\
1,273\end{array}$ \\
\hline 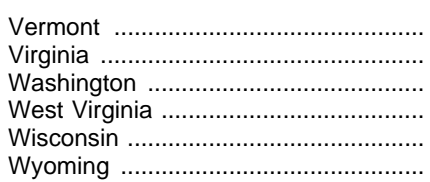 & $\begin{array}{r}7,348 \\
29,236 \\
19,472 \\
21,188 \\
87,883 \\
4,782\end{array}$ & $\begin{array}{r}2,672 \\
9,830 \\
6,843 \\
5,069 \\
11,377 \\
1,837\end{array}$ & $\begin{array}{l}36.4 \\
33.6 \\
35.1 \\
23.9 \\
12.9 \\
38.4\end{array}$ & $\begin{array}{r}4,675 \\
19,406 \\
12,629 \\
16,119 \\
76,506 \\
2,945\end{array}$ & $\begin{array}{r}75 \\
28 \\
22 \\
67 \\
106 \\
48\end{array}$ & $\begin{array}{l}143 \\
371 \\
253 \\
403 \\
692 \\
100\end{array}$ & $\begin{array}{r}65 \\
102 \\
88 \\
113 \\
179 \\
25\end{array}$ & $\begin{array}{r}78 \\
270 \\
165 \\
289 \\
512 \\
75\end{array}$ & $\begin{array}{r}689 \\
2,781 \\
3,542 \\
790 \\
1,199 \\
1,003\end{array}$ \\
\hline
\end{tabular}

1 Excludes funds for schools and school districts.

${ }^{2}$ Core education activities include: Chapter 1; Chapter 2; Special Education; Child Nutrition; Vocational Education; Adult Education; AIDS Education; Civil Rights Act; and Homeless Education Programs.

${ }^{3}$ Excludes District of Columbia and Hawaii.

${ }^{4}$ Excludes State Teacher Retirement Program.

-Data not available.
FTE=full-time equivalent.

NOTE.-Because of rounding, details may not add to totals.

SOURCE: U.S. General Accounting Office, Education Finance, Extent of Federal Funding in State Education Agencies, and U.S. Department of Education, National Center for Education Statistics, Common Core of Data survey. (This table was prepared September 1996.) 
Table 161.-Summary of expenditures for public elementary and secondary education, by purpose: 1919-20 to 1995-96

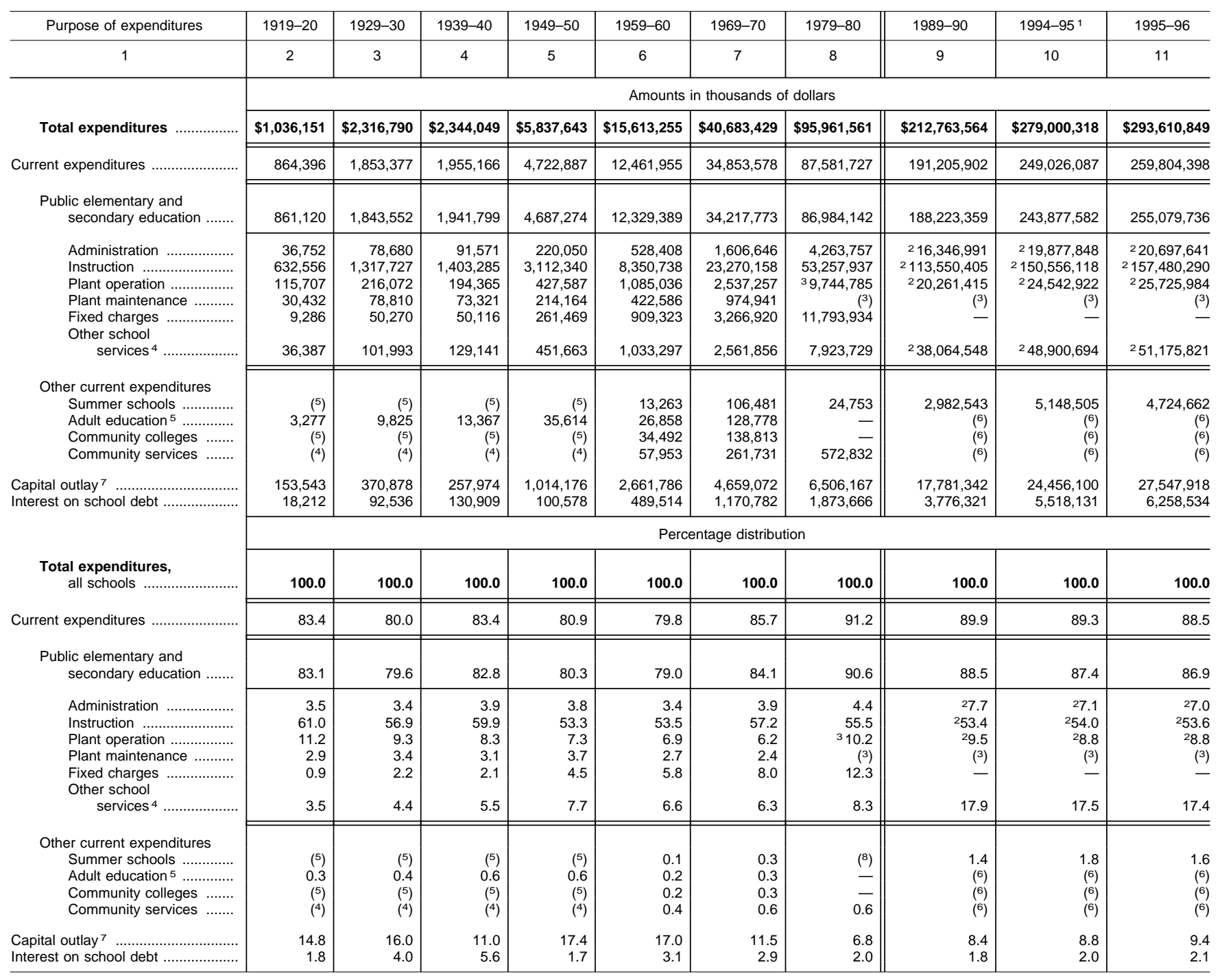

${ }^{1}$ Revised from previously published data.

2 Data not comparable to figures prior to $1989-90$

3 Plant operation also includes plant maintenance.

4 Prior to 1959-60, items included under "other school services" were listed under "auxiliary services," a more comprehensive classification that also included community services.

${ }^{5}$ Prior to 1959-60, data shown for adult education represent combined expenditures for adult education, summer schools, and community colleges.

${ }^{6}$ Included under summer schools.

7 Prior to $1969-70$, excludes capital outlay by state and local schoolhousing authori-
${ }^{8}$ Less than 0.05 percent.

-Data not available.

NOTE.-Beginning in 1959-60, includes Alaska and Hawaii. Beginning in 1980-81, state administration expenditures were excluded from both "total" and "current" expenditures. Beginning in 1988-89, extensive changes were made in the data collection procedures. Because of rounding, details may not add to totals.

SOURCE: U.S. Department of Education, National Center for Education Statistics, Statistics of State School Systems; and Common Core of Data surveys. (This table was prepared June 1998.) 
Table 162.-Total expenditures for public elementary and secondary education, by function and subfunction: 1990-91 to 1995-96

\begin{tabular}{|c|c|c|c|c|c|c|c|c|c|c|c|c|}
\hline \multirow[b]{2}{*}{ Items } & \multicolumn{6}{|c|}{ Expenditures (in thousands) } & \multicolumn{6}{|c|}{ Percentage distribution } \\
\hline & $1990-91$ & $1991-92$ & $1992-93$ & 1993-94 & 1994-95 & $1995-96$ & $\begin{array}{c}1990- \\
91\end{array}$ & $\begin{array}{c}1991- \\
92\end{array}$ & $\begin{array}{c}1992- \\
93\end{array}$ & $\begin{array}{c}1993- \\
94\end{array}$ & $\begin{array}{c}1994- \\
95\end{array}$ & $\begin{array}{c}1995- \\
96\end{array}$ \\
\hline 1 & 2 & 3 & 4 & 5 & 6 & 7 & 8 & 9 & 10 & 11 & 12 & 13 \\
\hline Total expenditures & $\$ 229,429,715$ & $\$ 241,054,784$ & $\$ 252,934,872$ & $\$ 265,306,634$ & $\$ 279,000,318$ & $\$ 293,610,849$ & - & 一 & - & - & - & 一 \\
\hline Current expenditures ...................... & $202,037,752$ & $211,210,190$ & $220,948,052$ & $231,542,764$ & $243,877,582$ & $255,079,736$ & 100.00 & 100.00 & 100.00 & 100.00 & 100.00 & 100.00 \\
\hline 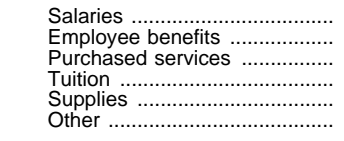 & 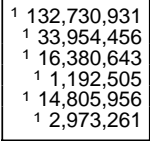 & $\begin{array}{r}138,279,377 \\
36,062,813 \\
17,790,523 \\
939,322 \\
14,944,495 \\
3,193,661 \\
\end{array}$ & $\begin{array}{r}144,276,674 \\
39,267,087 \\
17,933,497 \\
967,884 \\
16,370,100 \\
2,132,810\end{array}$ & $\begin{array}{r}150,545,401 \\
41,181,982 \\
19,232,698 \\
1,231,076 \\
17,249,817 \\
2,101,790\end{array}$ & $\begin{array}{r}158,914,976 \\
43,107,541 \\
20,643,153 \\
1,476,697 \\
17,362,430 \\
2,372,785 \\
\end{array}$ & $\begin{array}{r}165,777,514 \\
44,788,283 \\
21,580,618 \\
1,590,326 \\
18,756,757 \\
2,586,237\end{array}$ & $\begin{array}{r}65.70 \\
16.81 \\
8.11 \\
0.59 \\
7.33 \\
1.47\end{array}$ & $\begin{array}{r}65.47 \\
17.07 \\
8.42 \\
0.44 \\
7.08 \\
1.51\end{array}$ & $\begin{array}{r}65.30 \\
17.77 \\
8.12 \\
0.44 \\
7.41 \\
0.97\end{array}$ & $\begin{array}{r}65.02 \\
17.79 \\
8.31 \\
0.53 \\
7.45 \\
0.91\end{array}$ & $\begin{array}{r}65.16 \\
17.68 \\
8.46 \\
0.61 \\
7.12 \\
0.97\end{array}$ & $\begin{array}{r}64.99 \\
17.56 \\
8.46 \\
0.62 \\
7.35 \\
1.01\end{array}$ \\
\hline $\begin{array}{l}\text { Instruction } \\
\text { Salaries ............................... } \\
\text { Employee benefits ............ } \\
\text { Purchased services ............ } \\
\text { Tuition ……................... } \\
\text { Supplies }\end{array}$ & $\begin{array}{r}122,223,362 \\
90,742,284 \\
22,347,524 \\
2,722,639 \\
1,192,505 \\
4,584,754 \\
633,656\end{array}$ & $\begin{array}{r}128,475,859 \\
95,018,405 \\
23,683,606 \\
3,348,142 \\
939,322 \\
4,703,762 \\
782,620\end{array}$ & $\begin{array}{r}134,971,088 \\
99,089,718 \\
26,075,723 \\
3,357,323 \\
967,884 \\
5,052,972 \\
427,468\end{array}$ & $\begin{array}{r}141,620,474 \\
103,506,419 \\
27,456,084 \\
3,421,355 \\
1,231,076 \\
5,507,720 \\
497,820\end{array}$ & $\begin{array}{r}150,556,118 \\
109,702,815 \\
29,190,486 \\
3,823,789 \\
1,476,697 \\
5,764,061 \\
598,269\end{array}$ & $\begin{array}{r}157,480,290 \\
114,585,415 \\
30,300,667 \\
3,825,604 \\
1,590,326 \\
6,513,874 \\
664,404\end{array}$ & $\begin{array}{r}60.50 \\
44.91 \\
11.06 \\
1.35 \\
0.59 \\
2.27 \\
0.31\end{array}$ & $\begin{array}{r}60.83 \\
44.99 \\
11.21 \\
1.59 \\
0.44 \\
2.23 \\
0.37\end{array}$ & $\begin{array}{r}61.09 \\
44.85 \\
11.80 \\
1.52 \\
0.44 \\
2.29 \\
0.19\end{array}$ & $\begin{array}{r}61.16 \\
44.70 \\
11.86 \\
1.48 \\
0.53 \\
2.38 \\
0.22\end{array}$ & $\begin{array}{r}61.73 \\
44.98 \\
11.97 \\
1.57 \\
0.61 \\
2.36 \\
0.25\end{array}$ & $\begin{array}{r}61.74 \\
44.92 \\
11.88 \\
1.50 \\
0.62 \\
2.55 \\
0.26\end{array}$ \\
\hline 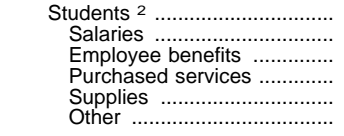 & $\begin{array}{r}8,926,010 \\
6,565,965 \\
1,660,082 \\
455,996 \\
191,482 \\
52,485\end{array}$ & $\begin{array}{r}9,226,247 \\
6,791,228 \\
1,751,537 \\
441,946 \\
181,261 \\
60,275\end{array}$ & $\begin{array}{r}9,760,087 \\
7,134,434 \\
1,904,341 \\
489,215 \\
195,240 \\
36,857\end{array}$ & $\begin{array}{r}10,946,191 \\
7,998,204 \\
2,110,012 \\
593,522 \\
206,352 \\
38,101\end{array}$ & $\begin{array}{r}11,679,127 \\
8,519,771 \\
2,212,775 \\
657,236 \\
238,876 \\
50,469\end{array}$ & $\begin{array}{r}12,243,641 \\
8,863,163 \\
2,307,501 \\
687,320 \\
247,270 \\
138,387\end{array}$ & $\begin{array}{l}4.42 \\
3.25 \\
0.82 \\
0.23 \\
0.09 \\
0.03\end{array}$ & $\begin{array}{l}4.37 \\
3.22 \\
0.83 \\
0.21 \\
0.09 \\
0.03\end{array}$ & $\begin{array}{l}4.42 \\
3.23 \\
0.86 \\
0.22 \\
0.09 \\
0.02\end{array}$ & $\begin{array}{l}4.73 \\
3.45 \\
0.91 \\
0.26 \\
0.09 \\
0.02\end{array}$ & $\begin{array}{l}4.79 \\
3.49 \\
0.91 \\
0.27 \\
0.10 \\
0.02\end{array}$ & $\begin{array}{l}4.80 \\
3.47 \\
0.90 \\
0.27 \\
0.10 \\
0.05\end{array}$ \\
\hline 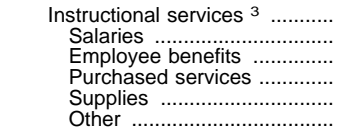 & $\begin{array}{r}8,467,142 \\
5,560,129 \\
1,408,217 \\
622,487 \\
776,863 \\
99,445\end{array}$ & $\begin{array}{r}8,827,800 \\
5,808,305 \\
1,463,736 \\
685,654 \\
772,096 \\
98,009\end{array}$ & $\begin{array}{r}9,241,929 \\
6,014,671 \\
1,601,713 \\
741,983 \\
820,919 \\
62,644\end{array}$ & $\begin{array}{r}9,236,588 \\
5,933,810 \\
1,583,597 \\
785,841 \\
860,224 \\
73,116\end{array}$ & $\begin{array}{r}9,654,676 \\
6,162,669 \\
1,638,271 \\
898,500 \\
872,394 \\
82,842\end{array}$ & $\begin{array}{r}10,071,302 \\
6,419,144 \\
1,719,563 \\
925,581 \\
918,261 \\
88,753\end{array}$ & $\begin{array}{l}4.19 \\
2.75 \\
0.70 \\
0.31 \\
0.38 \\
0.05\end{array}$ & $\begin{array}{l}4.18 \\
2.75 \\
0.69 \\
0.32 \\
0.37 \\
0.05\end{array}$ & $\begin{array}{l}4.18 \\
2.72 \\
0.72 \\
0.34 \\
0.37 \\
0.03\end{array}$ & $\begin{array}{l}3.99 \\
2.56 \\
0.68 \\
0.34 \\
0.37 \\
0.03\end{array}$ & $\begin{array}{l}3.96 \\
2.53 \\
0.67 \\
0.37 \\
0.36 \\
0.03\end{array}$ & $\begin{array}{l}3.95 \\
2.52 \\
0.67 \\
0.36 \\
0.36 \\
0.03\end{array}$ \\
\hline 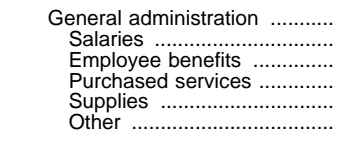 & $\begin{array}{r}5,791,253 \\
2,603,562 \\
777,381 \\
1,482,427 \\
172,898 \\
754,985\end{array}$ & $\begin{array}{r}6,039,397 \\
2,688,515 \\
815,581 \\
1,540,476 \\
158,193 \\
836,633\end{array}$ & $\begin{array}{r}5,851,983 \\
2,787,145 \\
846,638 \\
1,592,937 \\
211,727 \\
413,535\end{array}$ & $\begin{array}{r}5,909,692 \\
2,688,481 \\
888,209 \\
1,856,065 \\
168,785 \\
308,151\end{array}$ & $\begin{array}{r}5,731,420 \\
2,808,090 \\
844,267 \\
1,563,558 \\
177,448 \\
338,056\end{array}$ & $\begin{array}{r}5,866,480 \\
2,889,160 \\
828,483 \\
1,626,177 \\
185,831 \\
336,828\end{array}$ & $\begin{array}{l}2.87 \\
1.29 \\
0.38 \\
0.73 \\
0.09 \\
0.37\end{array}$ & $\begin{array}{l}2.86 \\
1.27 \\
0.39 \\
0.73 \\
0.07 \\
0.40\end{array}$ & $\begin{array}{l}2.65 \\
1.26 \\
0.38 \\
0.72 \\
0.10 \\
0.19\end{array}$ & $\begin{array}{l}2.55 \\
1.16 \\
0.38 \\
0.80 \\
0.07 \\
0.13\end{array}$ & $\begin{array}{l}2.35 \\
1.15 \\
0.35 \\
0.64 \\
0.07 \\
0.14\end{array}$ & $\begin{array}{l}2.30 \\
1.13 \\
0.32 \\
0.64 \\
0.07 \\
0.13\end{array}$ \\
\hline 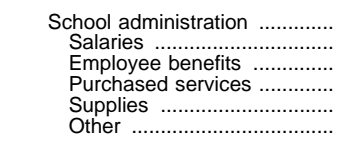 & $\begin{array}{r}11,695,344 \\
8,935,903 \\
2,257,783 \\
247,750 \\
189,711 \\
64,197\end{array}$ & $\begin{array}{r}12,280,680 \\
9,293,958 \\
2,410,404 \\
277,904 \\
196,485 \\
101,929\end{array}$ & $\begin{array}{r}12,777,815 \\
9,593,613 \\
2,615,351 \\
300,288 \\
207,078 \\
61,485\end{array}$ & $\begin{array}{r}13,492,502 \\
10,144,727 \\
2,738,216 \\
320,442 \\
223,794 \\
65,323\end{array}$ & $\begin{array}{r}14,146,428 \\
10,680,024 \\
2,796,440 \\
358,651 \\
243,681 \\
67,632\end{array}$ & $\begin{array}{r}14,831,161 \\
11,156,461 \\
2,963,991 \\
384,909 \\
256,857 \\
68,943\end{array}$ & $\begin{array}{l}5.79 \\
4.42 \\
1.12 \\
0.12 \\
0.09 \\
0.03\end{array}$ & $\begin{array}{l}5.81 \\
4.40 \\
1.14 \\
0.13 \\
0.09 \\
0.05\end{array}$ & $\begin{array}{l}5.78 \\
4.34 \\
1.18 \\
0.14 \\
0.09 \\
0.03\end{array}$ & $\begin{array}{l}5.83 \\
4.38 \\
1.18 \\
0.14 \\
0.10 \\
0.03\end{array}$ & $\begin{array}{l}5.80 \\
4.38 \\
1.15 \\
0.15 \\
0.10 \\
0.03\end{array}$ & $\begin{array}{l}5.81 \\
4.37 \\
1.16 \\
0.15 \\
0.10 \\
0.03\end{array}$ \\
\hline 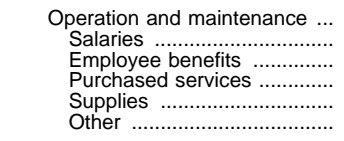 & $\begin{array}{r}21,290,655 \\
8,849,559 \\
2,633,075 \\
5,721,125 \\
3,761,738 \\
325,157\end{array}$ & $\begin{array}{r}21,889,514 \\
9,143,832 \\
2,788,592 \\
5,830,363 \\
3,807,024 \\
319,703\end{array}$ & $\begin{array}{r}22,823,758 \\
9,384,209 \\
2,970,466 \\
6,013,075 \\
4,262,006 \\
194,002\end{array}$ & $\begin{array}{r}23,875,871 \\
9,768,777 \\
3,048,615 \\
6,451,727 \\
4,399,064 \\
207,688\end{array}$ & $\begin{array}{r}24,542,922 \\
10,117,056 \\
3,027,306 \\
7,261,776 \\
3,927,664 \\
209,120\end{array}$ & $\begin{array}{r}25,725,984 \\
10,456,710 \\
3,130,162 \\
7,699,472 \\
4,214,399 \\
225,240\end{array}$ & $\begin{array}{r}10.54 \\
4.38 \\
1.30 \\
2.83 \\
1.86 \\
0.16\end{array}$ & $\begin{array}{r}10.36 \\
4.33 \\
1.32 \\
2.76 \\
1.80 \\
0.15\end{array}$ & $\begin{array}{r}10.33 \\
4.25 \\
1.34 \\
2.72 \\
1.93 \\
0.09\end{array}$ & $\begin{array}{r}10.31 \\
4.22 \\
1.32 \\
2.79 \\
1.90 \\
0.09\end{array}$ & $\begin{array}{r}10.06 \\
4.15 \\
1.24 \\
2.98 \\
1.61 \\
0.09\end{array}$ & $\begin{array}{r}10.09 \\
4.10 \\
1.23 \\
3.02 \\
1.65 \\
0.09\end{array}$ \\
\hline 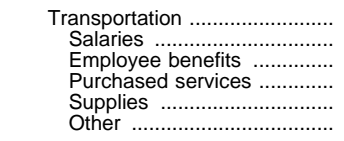 & $\begin{array}{r}8,678,954 \\
3,285,127 \\
892,985 \\
3,345,232 \\
961,447 \\
194,163\end{array}$ & $\begin{array}{r}8,769,754 \\
3,268,689 \\
965,731 \\
3,548,716 \\
811,781 \\
174,837\end{array}$ & $\begin{array}{r}9,252,300 \\
3,407,602 \\
1,063,064 \\
3,758,313 \\
877,077 \\
146,243\end{array}$ & $\begin{array}{r}9,627,155 \\
3,567,556 \\
1,107,878 \\
3,946,935 \\
854,940 \\
149,847\end{array}$ & $\begin{array}{r}9,889,034 \\
3,775,214 \\
1,138,485 \\
4,016,400 \\
800,344 \\
158,590\end{array}$ & $\begin{array}{r}10,394,695 \\
3,932,980 \\
1,207,762 \\
4,257,289 \\
836,366 \\
160,299\end{array}$ & $\begin{array}{l}4.30 \\
1.63 \\
0.44 \\
1.66 \\
0.48 \\
0.10\end{array}$ & $\begin{array}{l}4.15 \\
1.55 \\
0.46 \\
1.68 \\
0.38 \\
0.08\end{array}$ & $\begin{array}{l}4.19 \\
1.54 \\
0.48 \\
1.70 \\
0.40 \\
0.07\end{array}$ & $\begin{array}{l}4.16 \\
1.54 \\
0.48 \\
1.70 \\
0.37 \\
0.06\end{array}$ & $\begin{array}{l}4.05 \\
1.55 \\
0.47 \\
1.65 \\
0.33 \\
0.07\end{array}$ & $\begin{array}{l}4.08 \\
1.54 \\
0.47 \\
1.67 \\
0.33 \\
0.06\end{array}$ \\
\hline 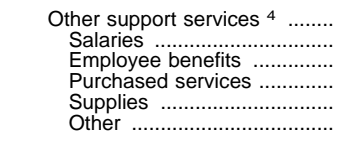 & $\begin{array}{r}5,587,837 \\
2,900,394 \\
980,859 \\
798,922 \\
294,527 \\
613,135\end{array}$ & $\begin{array}{r}6,088,305 \\
2,890,746 \\
1,153,683 \\
1,149,930 \\
306,701 \\
587,245\end{array}$ & $\begin{array}{r}6,207,775 \\
3,192,790 \\
1,088,011 \\
1,045,655 \\
327,377 \\
553,942\end{array}$ & $\begin{array}{r}6,318,312 \\
3,164,490 \\
1,109,764 \\
1,141,643 \\
362,838 \\
539,576\end{array}$ & $\begin{array}{r}6,708,262 \\
3,286,071 \\
1,136,286 \\
1,262,449 \\
372,852 \\
650,604\end{array}$ & $\begin{array}{r}7,039,392 \\
3,450,829 \\
1,182,181 \\
1,363,079 \\
398,544 \\
644,758\end{array}$ & $\begin{array}{l}2.77 \\
1.44 \\
0.49 \\
0.40 \\
0.15 \\
0.30\end{array}$ & $\begin{array}{l}2.88 \\
1.37 \\
0.55 \\
0.54 \\
0.15 \\
0.28\end{array}$ & $\begin{array}{l}2.81 \\
1.45 \\
0.49 \\
0.47 \\
0.15 \\
0.25\end{array}$ & $\begin{array}{l}2.73 \\
1.37 \\
0.48 \\
0.49 \\
0.16 \\
0.23\end{array}$ & $\begin{array}{l}2.75 \\
1.35 \\
0.47 \\
0.52 \\
0.15 \\
0.27\end{array}$ & $\begin{array}{l}2.76 \\
1.35 \\
0.46 \\
0.53 \\
0.16 \\
0.25\end{array}$ \\
\hline 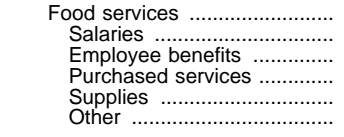 & $\begin{array}{r}8,430,490 \\
- \\
- \\
-\end{array}$ & $\begin{array}{r}8,821,308 \\
3,118,637 \\
979,089 \\
720,018 \\
3,829,025 \\
174,539\end{array}$ & $\begin{array}{r}9,263,181 \\
3,398,599 \\
1,042,743 \\
497,100 \\
4,186,945 \\
137,793\end{array}$ & $\begin{array}{r}9,774,315 \\
3,532,183 \\
1,095,686 \\
556,251 \\
4,445,897 \\
144,298\end{array}$ & $\begin{array}{r}10,268,542 \\
3,697,705 \\
1,081,221 \\
629,266 \\
4,718,569 \\
141,782\end{array}$ & $\begin{array}{r}10,648,854 \\
3,844,290 \\
1,103,427 \\
627,900 \\
4,916,307 \\
156,929\end{array}$ & $\begin{array}{r}4.17 \\
= \\
= \\
-\end{array}$ & $\begin{array}{l}4.18 \\
1.48 \\
0.46 \\
0.34 \\
1.81 \\
0.08\end{array}$ & $\begin{array}{l}4.19 \\
1.54 \\
0.47 \\
0.22 \\
1.89 \\
0.06\end{array}$ & $\begin{array}{l}4.22 \\
1.53 \\
0.47 \\
0.24 \\
1.92 \\
0.06\end{array}$ & $\begin{array}{l}4.21 \\
1.52 \\
0.44 \\
0.26 \\
1.93 \\
0.06\end{array}$ & $\begin{array}{l}4.17 \\
1.51 \\
0.43 \\
0.25 \\
1.93 \\
0.06\end{array}$ \\
\hline 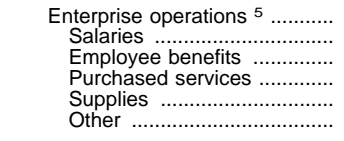 & $\begin{array}{r}946,705 \\
- \\
- \\
-\end{array}$ & $\begin{array}{r}791,326 \\
257,063 \\
50,854 \\
247,373 \\
178,166 \\
57,869 \\
\end{array}$ & $\begin{array}{r}798,136 \\
273,893 \\
59,038 \\
137,608 \\
228,758 \\
98,840 \\
\end{array}$ & $\begin{array}{r}741,665 \\
240,754 \\
43,921 \\
158,917 \\
220,203 \\
77,870 \\
\end{array}$ & $\begin{array}{r}701,053 \\
165,562 \\
42,003 \\
171,526 \\
246,541 \\
75,420 \\
\end{array}$ & $\begin{array}{r}777,936 \\
179,362 \\
44,546 \\
183,287 \\
269,047 \\
101,694 \\
\end{array}$ & $\begin{array}{r}0.47 \\
- \\
- \\
-\end{array}$ & $\begin{array}{l}0.37 \\
0.12 \\
0.02 \\
0.12 \\
0.08 \\
0.03\end{array}$ & $\begin{array}{l}0.36 \\
0.12 \\
0.03 \\
0.06 \\
0.10 \\
0.04\end{array}$ & $\begin{array}{l}0.32 \\
0.10 \\
0.02 \\
0.07 \\
0.10 \\
0.03\end{array}$ & $\begin{array}{l}0.29 \\
0.07 \\
0.02 \\
0.07 \\
0.10 \\
0.03\end{array}$ & $\begin{array}{l}0.30 \\
0.07 \\
0.02 \\
0.07 \\
0.11 \\
0.04 \\
\end{array}$ \\
\hline 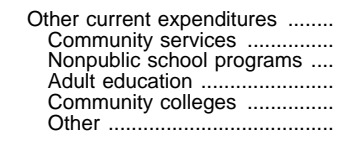 & $\begin{array}{r}3,295,717 \\
964,370 \\
527,609 \\
1,365,523 \\
5,356 \\
432,858\end{array}$ & $\begin{array}{r}4,393,698 \\
1,177,742 \\
652,403 \\
1,498,962 \\
5,136 \\
1,059,455\end{array}$ & $\begin{array}{r}4,378,506 \\
1,331,004 \\
644,150 \\
1,484,057 \\
5,454 \\
913,841\end{array}$ & $\begin{array}{r}4,681,798 \\
1,485,670 \\
689,888 \\
1,489,405 \\
7,432 \\
1,009,402\end{array}$ & $\begin{array}{r}5,148,505 \\
1,933,565 \\
569,851 \\
1,460,149 \\
83,573 \\
1,101,367\end{array}$ & $\begin{array}{r}4,724,662 \\
1,728,672 \\
781,148 \\
1,500,438 \\
7,746 \\
706,657\end{array}$ & $\begin{array}{l}- \\
- \\
- \\
-\end{array}$ & $\begin{array}{l}\text { 二 } \\
\text { 二 } \\
\text { 二 }\end{array}$ & $\begin{array}{l}- \\
- \\
- \\
-\end{array}$ & $\begin{array}{l}- \\
- \\
- \\
-\end{array}$ & $\begin{array}{l}- \\
- \\
- \\
-\end{array}$ & $\begin{array}{l}\text { 二 } \\
\text { 二 } \\
\text { 二 }\end{array}$ \\
\hline $\begin{array}{l}\text { Capital outlay }{ }^{6} \\
\text { Interest on school debt }\end{array}$ & $\begin{array}{r}19,771,478 \\
4,324,768\end{array}$ & $\begin{array}{r}20,286,977 \\
5,163,919\end{array}$ & $\begin{array}{r}22,171,768 \\
5,436,547\end{array}$ & $\begin{array}{r}23,747,021 \\
5,335,050\end{array}$ & $\begin{array}{r}24,456,100 \\
5,518,131\end{array}$ & $\begin{array}{r}27,547,918 \\
6,258,534\end{array}$ & $\overline{-}$ & 二 & - & 二 & - & - \\
\hline
\end{tabular}

${ }^{1}$ Includes estimated data for subfunctions of food services and enterprise operations. 2 Includes expenditures for guidance, health, attendance, and speech pathology services.

${ }^{3}$ Includes expenditures for curriculum development, staff training, libraries, and media and computer centers.

${ }^{4}$ Includes business support services concerned with paying, transporting, exchanging and maintaining goods and services for local education agencies; central support services, including planning, research, evaluation, information, staff, and data processing services; and other support services.

5 Includes expenditures for operations funded by sales of products or services (e.g. school bookstore or computer time).
${ }^{6}$ Includes expenditures for property, and for buildings and alterations completed by school district staff or contractors.

-Data not available or not applicable.

NOTE.-Excludes expenditures for state education agencies. Some data have been revised from previously published figures. Because of rounding, details may not add to totals.

SOURCE: U.S. Department of Education, National Center for Education Statistics, Common Core of Data survey. (This table was prepared July 1998.) 
Table 163.-Expenditures for instruction in public elementary and secondary schools, by subfunction and state: 1994-95 and 1995-96

[In thousands of dollars]

\begin{tabular}{|c|c|c|c|c|c|c|c|c|c|c|c|c|}
\hline \multirow[b]{2}{*}{ State or other area } & \multicolumn{6}{|c|}{$1994-95$} & \multicolumn{6}{|c|}{$1995-96$} \\
\hline & Total & Salaries & $\begin{array}{l}\text { Employee } \\
\text { benefits }\end{array}$ & $\begin{array}{l}\text { Purchased } \\
\text { services } 1\end{array}$ & Supplies & $\begin{array}{c}\text { Tuition and } \\
\text { other }\end{array}$ & Total & Salaries & $\begin{array}{l}\text { Employee } \\
\text { benefits }\end{array}$ & $\begin{array}{l}\text { Purchased } \\
\text { services }^{2}\end{array}$ & Supplies & $\begin{array}{l}\text { Tuition and } \\
\text { other }\end{array}$ \\
\hline 1 & 2 & 3 & 4 & 5 & 6 & 7 & 8 & 9 & 10 & 11 & 12 & 13 \\
\hline United States & $\$ 150,556,118$ & $\$ 109,702,815$ & $\$ 29,190,486$ & $\$ 3,823,789$ & $\$ 5,764,061$ & $\$ 2,074,966$ & $\$ 157,480,290$ & $\$ 114,585,415$ & $\$ 30,300,667$ & $\$ 3,825,604$ & $\$ 6,513,874$ & $\$ 2,254,731$ \\
\hline 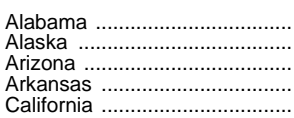 & $\begin{array}{r}1,906,471 \\
574,242 \\
1,811,167 \\
1,144,389 \\
15,549,692\end{array}$ & $\begin{array}{r}1,446,029 \\
413,383 \\
1,500,416 \\
868,482 \\
11,038,093\end{array}$ & \begin{tabular}{r|}
335,738 \\
100,487 \\
238,820 \\
206,954 \\
$3,262,337$
\end{tabular} & $\begin{array}{r}5,645 \\
18,237 \\
16,547 \\
23,230 \\
424,379\end{array}$ & $\begin{array}{r}99,824 \\
21,514 \\
31,128 \\
35,930 \\
536,517\end{array}$ & $\begin{array}{r}19,236 \\
20,622 \\
24,256 \\
9,793 \\
288,366\end{array}$ & \begin{tabular}{r|}
$2,032,706$ \\
591,338 \\
$1,921,658$ \\
$1,244,145$ \\
$16,333,392$
\end{tabular} & $\begin{array}{r}1,489,955 \\
425,755 \\
1,588,625 \\
937,990 \\
11,551,320\end{array}$ & \begin{tabular}{r|}
390,938 \\
105,093 \\
250,336 \\
218,738 \\
$3,354,696$ \\
\end{tabular} & $\begin{array}{r}6,424 \\
20,086 \\
17,716 \\
21,679 \\
468,228 \\
\end{array}$ & $\begin{array}{r}116,054 \\
24,152 \\
34,043 \\
56,789 \\
630,791\end{array}$ & $\begin{array}{r}29,335 \\
16,252 \\
30,938 \\
8,948 \\
328,357\end{array}$ \\
\hline 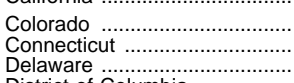 & $\begin{array}{r}1,970,908 \\
2,721,552 \\
431,618\end{array}$ & $\begin{array}{r}1,508,701 \\
2,004,391 \\
297,607\end{array}$ & $\begin{array}{r}306,238 \\
463,152 \\
103,254\end{array}$ & $\begin{array}{r}67,936 \\
50,246 \\
7,194 \\
7,25\end{array}$ & $\begin{array}{l}80,563 \\
64,845 \\
15,843\end{array}$ & $\begin{array}{r}7,470 \\
138,919 \\
7,719 \\
7,719\end{array}$ & $\begin{array}{r}2,069,222 \\
2,780,996 \\
474,549\end{array}$ & $\begin{array}{r}1,593,451 \\
2,057,312 \\
312,457 \\
22,45\end{array}$ & $\begin{array}{r}318,375 \\
460,386 \\
101,520 \\
77,487\end{array}$ & $\begin{array}{r}64,306 \\
52,467 \\
8,094 \\
7,175\end{array}$ & $\begin{array}{l}85,769 \\
71,058 \\
17,805 \\
659\end{array}$ & $\begin{array}{r}7,321 \\
139,774 \\
7,673 \\
11,778\end{array}$ \\
\hline $\begin{array}{l}\text { District of Columbia } \\
\text { Florida }\end{array}$ & $\begin{array}{r}336,543 \\
6,395,934\end{array}$ & $\begin{array}{r}239,594 \\
4,283,275\end{array}$ & $\begin{array}{r}65,979 \\
1,422,087\end{array}$ & $\begin{array}{r}5,251 \\
408,034\end{array}$ & $\begin{array}{r}3,556 \\
209,508\end{array}$ & $\begin{array}{l}22,163 \\
73,030\end{array}$ & $\begin{array}{r}334,893 \\
6,675,272\end{array}$ & $\begin{array}{r}231,862 \\
4,434,224\end{array}$ & $\begin{array}{r}77,487 \\
1,490,753\end{array}$ & $\begin{array}{r}7,175 \\
445,203\end{array}$ & $\begin{array}{r}6,592 \\
234,639\end{array}$ & $\begin{array}{l}11,778 \\
70,453\end{array}$ \\
\hline 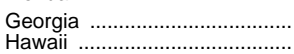 & $\begin{array}{r}3,779,713 \\
636,952\end{array}$ & $\begin{array}{l}2,799,934 \\
457,861\end{array}$ & $\begin{array}{l}770,839 \\
127,015\end{array}$ & $\begin{array}{l}39,991 \\
18,255\end{array}$ & $\begin{array}{r}164,184 \\
32,471\end{array}$ & $\begin{array}{l}4,763 \\
1,352\end{array}$ & $\begin{array}{r}4,116,129 \\
651,832\end{array}$ & $\begin{array}{l}3,048,284 \\
455,415\end{array}$ & $\begin{array}{l}836,598 \\
144,410\end{array}$ & $\begin{array}{l}39,620 \\
16,395\end{array}$ & $\begin{array}{r}185,668 \\
34,274\end{array}$ & $\begin{array}{l}5,959 \\
1,339\end{array}$ \\
\hline 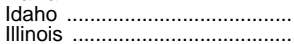 & $\begin{array}{r}602,232 \\
6,367,082\end{array}$ & $\begin{array}{r}430,919 \\
4,797,408\end{array}$ & $\begin{array}{r}130,741 \\
1,061,451\end{array}$ & $\begin{array}{r}11,204 \\
120,542\end{array}$ & $\begin{array}{r}28,940 \\
265,284\end{array}$ & $\begin{array}{r}428 \\
122,397\end{array}$ & $\begin{array}{r}643,243 \\
6.461,142\end{array}$ & $\begin{array}{r}455,405 \\
4,932,198\end{array}$ & $\begin{array}{r}136,112 \\
1,043,497\end{array}$ & $\begin{array}{r}12,915 \\
111,831\end{array}$ & $\begin{array}{r}38,329 \\
248,470\end{array}$ & $\begin{array}{r}483 \\
125.146\end{array}$ \\
\hline Indiana ................ & $\begin{array}{l}-1,06,2023 \\
3,262,523\end{array}$ & $2,417,230$ & 697,094 & 35,344 & 107,345 & 5,510 & $3,412,502$ & 2,483,959 & - 780,886 & 36,571 & $\begin{array}{l}105,978 \\
105\end{array}$ & 5,108 \\
\hline lowa $\ldots$ & $\begin{array}{l}1,623,942 \\
1,387198\end{array}$ & $1,160,673$ & 277,271 & 56,959 & 116,398 & $\begin{array}{r}12,641 \\
5,807\end{array}$ & $\begin{array}{l}1,691,945 \\
1,41 \\
1439\end{array}$ & $\begin{array}{l}1,213,673 \\
1146,381\end{array}$ & 289,250 & 56,097 & 115,160 & $\begin{array}{r}17,765 \\
5,356\end{array}$ \\
\hline Kentucky. & $1,787,693$ & $\begin{array}{l}1,423,656 \\
1,408\end{array}$ & 291,715 & $\begin{array}{r}12,294 \\
94\end{array}$ & 72,209 & $\begin{array}{r}0,001 \\
19\end{array}$ & $1,942,324$ & $\begin{array}{l}1,1,511,577 \\
1,48\end{array}$ & 327,707 & $\begin{array}{l}16,6,6 \\
11,324\end{array}$ & $\begin{array}{l}87,945 \\
87,96\end{array}$ & 3,770 \\
\hline Louisiana & $2,071,476$ & $1,544,288$ & 415,405 & 19,349 & 87,321 & 5,113 & $2,099,916$ & $1,549,599$ & 433,815 & 24,462 & 86,620 & 5,420 \\
\hline $\begin{array}{l}\text { Maine ....... } \\
\text { Maryland. }\end{array}$ & $\begin{array}{r}859,560 \\
3,127,996\end{array}$ & $\begin{array}{r}570,803 \\
2,130,372\end{array}$ & $\begin{array}{l}190,981 \\
729,842\end{array}$ & $\begin{array}{l}24,493 \\
86,737\end{array}$ & $\begin{array}{l}27,895 \\
88,971\end{array}$ & $\begin{array}{l}45,388 \\
92,074\end{array}$ & $\begin{array}{r}882,302 \\
3,263,165\end{array}$ & $\begin{array}{r}588,364 \\
2,205,823\end{array}$ & $\begin{array}{l}194,717 \\
773,588\end{array}$ & $\begin{array}{l}25,816 \\
86,416\end{array}$ & $\begin{array}{l}28,448 \\
91,857\end{array}$ & $\begin{array}{r}44,957 \\
105,482\end{array}$ \\
\hline Massachusetts. & $3,994,523$ & $2,691,297$ & $\begin{array}{r}728,275 \\
\end{array}$ & 254,433 & 111,466 & $\begin{array}{l}209,053 \\
35,495\end{array}$ & $4,475,924$ & 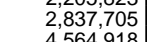 & $\begin{array}{r}779,970 \\
\end{array}$ & $\begin{array}{l}316,877 \\
3164,366\end{array}$ & $\begin{array}{r}121,764 \\
121,764\end{array}$ & 219,608 \\
\hline $\begin{array}{l}\text { Mlchigan .......... } \\
\text { Minnesota ........ }\end{array}$ & $\begin{array}{l}6,222,315 \\
2,946,240\end{array}$ & $\begin{array}{l}4,328,190 \\
2,160,089\end{array}$ & $\begin{array}{r}1,569,832 \\
579,243\end{array}$ & $\begin{array}{l}8,022 \\
78,764\end{array}$ & $\begin{array}{l}210,, / 6 \\
105,214\end{array}$ & $\begin{array}{r}33,495 \\
22,929\end{array}$ & $\begin{array}{l}6,533,062 \\
3,095,995\end{array}$ & $\begin{array}{l}4,54,4918 \\
2,265,431\end{array}$ & $\begin{array}{r}1,609,270 \\
612,068\end{array}$ & $\begin{array}{r}104,366 \\
83,094\end{array}$ & $\begin{array}{l}259,957 \\
111,419\end{array}$ & $\begin{array}{l}44,551 \\
23,984\end{array}$ \\
\hline Mississippi & $1,197,868$ & 891,328 & 216,101 & 18,628 & 65,880 & 5,931 & $1,246,654$ & 925,578 & 219,691 & 19,743 & 75,940 & 5,702 \\
\hline Missouri ……….............. & $\begin{array}{l}2,597,027 \\
55667\end{array}$ & $\begin{array}{r}1,969,708 \\
379161\end{array}$ & $\begin{array}{l}355,700 \\
101,394\end{array}$ & $\begin{array}{l}53,202 \\
11080\end{array}$ & $\begin{array}{r}207,753 \\
31900\end{array}$ & $\begin{array}{r}10,663 \\
2082\end{array}$ & $2,770,426$ & $2,097,350$ & $\begin{array}{l}379,417 \\
104,118\end{array}$ & $\begin{array}{l}57,015 \\
12,261\end{array}$ & 224,149 & $\begin{array}{r}12,496 \\
3,347\end{array}$ \\
\hline Nebraska ........... & 997,581 & 732,361 & 178,023 & $\begin{array}{l}11,370 \\
24,0\end{array}$ & 40,341 & 22,484 & $1,027,617$ & $\begin{array}{l}766,556 \\
76\end{array}$ & 173,626 & 21,174 & 41,219 & 25,042 \\
\hline $\begin{array}{l}\text { Nevada .............. } \\
\text { New Hampshire. }\end{array}$ & $\begin{array}{l}706,132 \\
679,079\end{array}$ & $\begin{array}{l}528,908 \\
498,773\end{array}$ & $\begin{array}{r}144,432 \\
97,472\end{array}$ & $\begin{array}{r}4,552 \\
16,606\end{array}$ & $\begin{array}{l}27,143 \\
21,773\end{array}$ & $\begin{array}{r}1,097 \\
44,455\end{array}$ & $\begin{array}{l}768,352 \\
725,558\end{array}$ & $\begin{array}{l}574,313 \\
527,208\end{array}$ & $\begin{array}{l}157,016 \\
106,297\end{array}$ & $\begin{array}{r}5,916 \\
19,404\end{array}$ & $\begin{array}{l}30,288 \\
21,944\end{array}$ & $\begin{array}{r}819 \\
50,706\end{array}$ \\
\hline New Jersey ............. & $6,467,203$ & $4,715,340$ & $1,128,758$ & 51,960 & 232,132 & 339,014 & $6,775,687$ & $4,944,632$ & $1,154,848$ & $\begin{array}{r}62,732 \\
62,704\end{array}$ & 244,773 & 368,702 \\
\hline $\begin{array}{l}\text { New Mexico ......... } \\
\text { New York } \\
\text { North Carolina } \\
\text { North Dakota }\end{array}$ & $\begin{array}{r}837,029 \\
15,636,396 \\
3,387,680 \\
328,461\end{array}$ & $\begin{array}{r}618,787 \\
11,525,744 \\
2,556,856 \\
240,567\end{array}$ & $\begin{array}{r}158,931 \\
3,387,241 \\
623,633 \\
60,009\end{array}$ & $\begin{array}{r}8,022 \\
358,939 \\
48,461 \\
8896\end{array}$ & $\begin{array}{r}45,294 \\
361,933 \\
155,787 \\
16,378\end{array}$ & $\begin{array}{r}5,995 \\
2,559 \\
2,942 \\
2,610\end{array}$ & $\begin{array}{r}872,133 \\
15,948,326 \\
3,479,891 \\
339,950\end{array}$ & $\begin{array}{r}646,516 \\
11,761,851 \\
2,606,682 \\
248,414\end{array}$ & $\begin{array}{r}163,749 \\
3,449,781 \\
632,459 \\
61,567\end{array}$ & $\begin{array}{r}7,055 \\
368,152 \\
52,824 \\
9,122\end{array}$ & $\begin{array}{r}48,267 \\
365,990 \\
183,853 \\
17,684\end{array}$ & $\begin{array}{l}6,546 \\
2,551 \\
4,073 \\
3,163\end{array}$ \\
\hline Ohio ………….............. & $5,960,083$ & $4,362,651$ & $1,182,673$ & 103,167 & 235,248 & 76,343 & $6,200,538$ & $4,526,538$ & $1,219,614$ & 112,421 & 251,327 & 90,637 \\
\hline Oklahoma ........ & $\begin{array}{l}1,662,373 \\
1,761,4\end{array}$ & $1,266,325$ & $\begin{array}{l}261,121 \\
412583\end{array}$ & $\begin{array}{l}26,166 \\
59993\end{array}$ & $\begin{array}{r}97,571 \\
99\end{array}$ & $\begin{array}{l}11,190 \\
10441\end{array}$ & 1,680, & $1,270,992$ & 52 & 7 & 102,017 & 12,207 \\
\hline $\begin{array}{l}\text { Pennsy } \\
\text { Pennsy }\end{array}$ & $\begin{array}{l}1,776,1148 \\
7,460,973\end{array}$ & $\begin{array}{l}1,193,420 \\
5,049,611\end{array}$ & $\begin{array}{r}412,583 \\
1,591,109\end{array}$ & 512,608 & $\begin{array}{r}994,712 \\
224,403\end{array}$ & $\begin{array}{l}10,441 \\
83,241\end{array}$ & $\begin{array}{l}1,8,82,333 \\
7,922,896\end{array}$ & $\begin{array}{l}1,252,352 \\
5,600,394\end{array}$ & $\begin{array}{r}412,07 \\
1,747,009\end{array}$ & $\begin{array}{r}5,5,774 \\
243,952\end{array}$ & $\begin{array}{l}113,959 \\
242,227\end{array}$ & $\begin{array}{l}13,541 \\
89,314\end{array}$ \\
\hline Rhode Islane & 703,185 & 492,096 & 156,125 & 16,358 & 15,919 & 22,687 & 728,417 & 513,600 & 156,649 & 17,361 & 17,090 & 23,716 \\
\hline South Carolina & $1,727,214$ & $1,298,160$ & 320,509 & 27,097 & 80,175 & 1,274 & $1,821,432$ & $1,359,201$ & 337,297 & 26,578 & 78,897 & 19,459 \\
\hline & $\begin{array}{l}376,116 \\
2\end{array}$ & 272 & $\begin{array}{r}59,785 \\
395994\end{array}$ & $\begin{array}{r}11,243 \\
38,23\end{array}$ & $\begin{array}{r}22,634 \\
104\end{array}$ & 9,811 & & 271,138 & & & 20,677 & 9,127 \\
\hline Ten & $\begin{array}{r}2,285,884 \\
10753,150\end{array}$ & $\begin{array}{l}1,740,065 \\
8,517,213\end{array}$ & $\begin{array}{r}395,947 \\
1,268,868\end{array}$ & $\begin{array}{r}38,603 \\
294 \\
213\end{array}$ & $\begin{array}{l}104,857 \\
606\end{array}$ & $\begin{array}{r}6,413 \\
66202\end{array}$ & $\begin{array}{r}2,378,112 \\
11,540336\end{array}$ & $\begin{array}{l}1,83 \\
897\end{array}$ & $\begin{array}{r}419,574 \\
1229\end{array}$ & $\begin{array}{r}38,707 \\
318,852\end{array}$ & 83,313 & 5,145 \\
\hline $\begin{array}{l}\text { Texas } \\
\text { Utah }\end{array}$ & $1,089,195$ & $\begin{array}{r}8,517,213 \\
706,401\end{array}$ & $\begin{array}{r}1,200,000 \\
250,913\end{array}$ & $\begin{array}{r}24,413 \\
16,429\end{array}$ & $\begin{array}{r}00,032 \\
46,339\end{array}$ & $\begin{array}{l}00,025 \\
69,112\end{array}$ & $\begin{array}{r}1,152,136 \\
1,150\end{array}$ & $8,949,589$ & $\begin{array}{l}1,229,981 \\
261,557\end{array}$ & $\begin{array}{r}r 18,8522 \\
18,922\end{array}$ & $\begin{array}{r}943,745 \\
56,205\end{array}$ & $\begin{array}{l}75,014 \\
65,863\end{array}$ \\
\hline Vermont & 434,933 & 306,881 & $\begin{array}{r}77,637 \\
671,729\end{array}$ & 15,984 & $\begin{array}{r}13,596 \\
118\end{array}$ & 20,835 & 444,162 & 316,808 & $\begin{array}{r}74,167 \\
\end{array}$ & 18,071 & 14,343 & 20,774 \\
\hline $\begin{array}{l}\text { Virginia .... } \\
\text { Washingto }\end{array}$ & $\begin{array}{l}3,483,576 \\
3,075,781\end{array}$ & $\begin{array}{l}2,640,491 \\
2,156,923\end{array}$ & $\begin{array}{l}671,729 \\
670,680\end{array}$ & $\begin{array}{r}48,638 \\
101,440\end{array}$ & $\begin{array}{l}118,633 \\
124,646\end{array}$ & $\begin{array}{r}4,085 \\
22,091\end{array}$ & $\begin{array}{l}3,601,235 \\
3,225,122\end{array}$ & $\begin{array}{l}2,732,602 \\
2,286,424\end{array}$ & $\begin{array}{l}699,087 \\
683,795\end{array}$ & $\begin{array}{r}52,615 \\
107,381\end{array}$ & $\begin{array}{l}122,251 \\
122,769\end{array}$ & $\begin{array}{r}3,681 \\
24,753\end{array}$ \\
\hline West Virgin & $1,090,056$ & 766,359 & 280,057 & 11,134 & 32,343 & 163 & $1,122,084$ & 774,557 & 294,333 & 11,786 & 40,989 & 418 \\
\hline Wisconsin & $3,441,286$ & $2,400,781$ & 800,389 & 55,545 & 129,411 & 55,160 & $3,591,487$ & $2,499,757$ & 842,192 & 59,404 & 133,468 & 56,667 \\
\hline Wyoming & 358,131 & 253,841 & 70,846 & 11,073 & 20,630 & 1,741 & 360,771 & 255,926 & 71,141 & 12,326 & 19,864 & 1,513 \\
\hline Outlying areas & & & & & & & & & & & & \\
\hline American Samoa & $\begin{array}{l}11,796 \\
7096\end{array}$ & $\begin{array}{r}8,900 \\
65432\end{array}$ & $\begin{array}{r}1,386 \\
13237\end{array}$ & $\begin{array}{l}236 \\
83\end{array}$ & $\begin{array}{r}1,065 \\
424\end{array}$ & $\begin{array}{c}211 \\
161\end{array}$ & $\begin{array}{l}12,456 \\
87773\end{array}$ & 9,101 & $\begin{array}{r}1,759 \\
15206\end{array}$ & $\begin{array}{r}323 \\
190\end{array}$ & 1,042 & 230 \\
\hline & $\begin{array}{l}79,336 \\
35,613\end{array}$ & $\begin{array}{l}65,432 \\
21,718\end{array}$ & $\begin{array}{r}13,237 \\
6,259\end{array}$ & $\begin{array}{r}83 \\
3.678\end{array}$ & $\begin{array}{r}424 \\
3.551\end{array}$ & $\begin{array}{l}161 \\
407\end{array}$ & $\begin{array}{l}87,773 \\
35,357\end{array}$ & $\begin{array}{l}67,167 \\
22.495\end{array}$ & 15,226 & 1 & 5,190 & \\
\hline $\begin{array}{l}\text { Northeern Ma } \\
\text { Puerto Rico }\end{array}$ & $1,093,038$ & 903,531 & 127,031 & 11,148 & 20,234 & 31,094 & $1,198,197$ & 979,626 & 134,208 & 12,024 & 28,201 & 44,138 \\
\hline Virgin Islands & 69,349 & 55,563 & 11,042 & 572 & 652 & 1,520 & 69,478 & 55,629 & 11,283 & 540 & 611 & 1,415 \\
\hline
\end{tabular}

1 Includes purchased professional services of teachers or others who provide instruction for students and travel for instructional staff. Some 1994-95 data have been revised from previously published figures.

SOURCE: U.S. Department of Education, National Center for Education Statistics, Common Core of Data surveys. (This table was prepared July 1998.) 
Table 164.-Current expenditures for public elementary and secondary education, by state: 1969-70 to 1997-98

[In thousands of dollars]

\begin{tabular}{|c|c|c|c|c|c|c|c|c|}
\hline State or other area & $1969-70$ & $1979-80$ & $1980-81$ & $1985-86$ & $1986-87$ & $1987-88$ & $1988-89$ & $1989-90$ \\
\hline 1 & 2 & 3 & 4 & 5 & 6 & 7 & 8 & 9 \\
\hline United States & $34,217,773$ & $\$ 86,984,142$ & $\$ 94,321,093$ & $\$ 137,164,965$ & $146,364,922$ & $\$ 157,097,951$ & $\$ 173,098,906$ & $\$ 188,229,359$ \\
\hline $\begin{array}{l}\text { Alabama } \\
\text { Alaska } \\
\text { Arizona } \\
\text { Arkansas } \\
\text { California }\end{array}$ & $\begin{array}{r}422,730 \\
81,374 \\
281,941 \\
235,083 \\
3,831,595\end{array}$ & $\begin{array}{r}1,146,713 \\
377,947 \\
949,753 \\
666,949 \\
9,172,158\end{array}$ & $\begin{array}{r}1,393,137 \\
476,368 \\
1,075,362 \\
709,394 \\
9,936,642\end{array}$ & $\begin{array}{r}1,761,154 \\
818,219 \\
1,649,832 \\
1,085,943 \\
15,040,898\end{array}$ & $\begin{array}{r}1,775,997 \\
769,015 \\
1,836,908 \\
1,118,904 \\
16,512,668\end{array}$ & $\begin{array}{r}1,873,390 \\
756,577 \\
2,002,395 \\
1,211,156 \\
17,402,063\end{array}$ & $\begin{array}{r}2,188,020 \\
739,020 \\
2,143,148 \\
1,319,370 \\
19,417,178\end{array}$ & $\begin{array}{r}2,275,233 \\
828,051 \\
2,258,660 \\
1,404,545 \\
21,485,782\end{array}$ \\
\hline 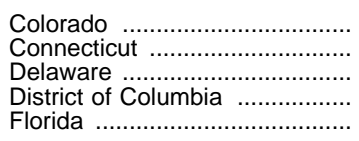 & $\begin{array}{l}369,218 \\
588,710 \\
108,747 \\
141,138 \\
961,273\end{array}$ & $\begin{array}{r}1,243,049 \\
1,227,892 \\
269,108 \\
298,448 \\
2,766,468\end{array}$ & $\begin{array}{r}1,369,883 \\
1,440,881 \\
270,439 \\
295,155 \\
3,336,657\end{array}$ & $\begin{array}{r}2,018,579 \\
2,144,094 \\
391,558 \\
406,910 \\
5,092,668\end{array}$ & $\begin{array}{r}2,129,964 \\
2,414,708 \\
418,116 \\
441,135 \\
5,650,083\end{array}$ & $\begin{array}{r}2,172,563 \\
2,748,567 \\
440,631 \\
489,357 \\
6,288,977\end{array}$ & $\begin{array}{r}2,324,625 \\
2,984,542 \\
479,327 \\
584,035 \\
7,245,515\end{array}$ & $\begin{array}{r}2,451,833 \\
3,444,520 \\
520,953 \\
639,983 \\
8,228,531\end{array}$ \\
\hline 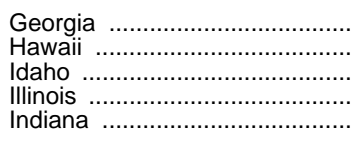 & $\begin{array}{r}599,371 \\
141,324 \\
103,107 \\
1,896,067 \\
809,105\end{array}$ & $\begin{array}{r}1,608,028 \\
351,889 \\
313,927 \\
4,579,355 \\
1,851,292\end{array}$ & $\begin{array}{r}1,688,714 \\
395,038 \\
352,912 \\
4,773,179 \\
1,898,194\end{array}$ & $\begin{array}{r}2,979,980 \\
575,456 \\
492,092 \\
6,066,390 \\
2,851,080\end{array}$ & $\begin{array}{r}3,254,786 \\
576,749 \\
513,011 \\
6,463,564 \\
3,106,616\end{array}$ & $\begin{array}{r}3,549,038 \\
608,264 \\
532,274 \\
6,923,298 \\
3,330,525\end{array}$ & $\begin{array}{r}4,006,069 \\
643,319 \\
570,013 \\
7,655,153 \\
3,779,468\end{array}$ & $\begin{array}{r}4,505,962 \\
700,012 \\
627,794 \\
8,125,493 \\
4,074,578\end{array}$ \\
\hline 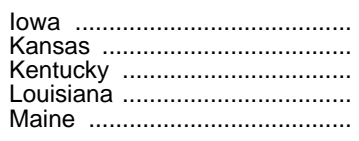 & $\begin{array}{l}527,086 \\
362,593 \\
353,265 \\
503,217 \\
155,907\end{array}$ & $\begin{array}{r}1,186,659 \\
830,133 \\
1,054,459 \\
1,303,902 \\
385,492\end{array}$ & $\begin{array}{r}1,337,504 \\
958,281 \\
1,096,472 \\
1,767,692 \\
401,355\end{array}$ & $\begin{array}{r}1,644,359 \\
1,423,225 \\
1,434,962 \\
2,333,748 \\
688,673\end{array}$ & $\begin{array}{r}1,708,440 \\
1,486,814 \\
1,583,158 \\
2,260,393 \\
760,446\end{array}$ & $\begin{array}{r}1,859,173 \\
1,568,041 \\
1,741,799 \\
2,289,241 \\
839,860\end{array}$ & $\begin{array}{r}1,925,623 \\
1,712,260 \\
1,918,741 \\
2,468,307 \\
921,931\end{array}$ & $\begin{array}{l}2,004,742 \\
1,848,302 \\
2,134,011 \\
2,838,283 \\
1,048,195\end{array}$ \\
\hline 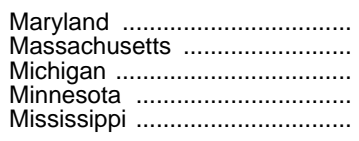 & $\begin{array}{r}721,794 \\
907,341 \\
1,799,945 \\
781,243 \\
262,760\end{array}$ & $\begin{array}{r}1,783,056 \\
2,638,734 \\
4,642,847 \\
1,786,768 \\
756,018\end{array}$ & $\begin{array}{r}1,937,159 \\
2,794,762 \\
5,196,249 \\
1,900,322 \\
716,878\end{array}$ & & & & & $\begin{array}{l}3,894,644 \\
4,760,390 \\
8,025,621 \\
3,474,398 \\
1,472,710\end{array}$ \\
\hline 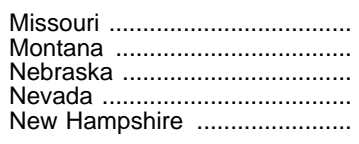 & $\begin{array}{r}642,030 \\
127,176 \\
231,612 \\
87,273 \\
101,370\end{array}$ & $\begin{array}{r}1,504,988 \\
358,118 \\
581,615 \\
281,901 \\
295,400\end{array}$ & $\begin{array}{r}1,643,258 \\
380,092 \\
629,017 \\
287,752 \\
340,518\end{array}$ & $\begin{array}{r}2,277,576 \\
567,901 \\
911,983 \\
495,147 \\
522,604\end{array}$ & $\begin{array}{r}2,515,846 \\
583,861 \\
948,149 \\
513,014 \\
589,850\end{array}$ & $\begin{array}{r}2,747,234 \\
590,226 \\
995,235 \\
555,272 \\
677,507\end{array}$ & $\begin{array}{r}3,096,666 \\
592,454 \\
1,105,009 \\
628,657 \\
733,240\end{array}$ & $\begin{array}{r}3,288,738 \\
641,345 \\
1,233,431 \\
712,898 \\
821,671\end{array}$ \\
\hline $\begin{array}{l}\text { New Jersey } \\
\text { New Mexico } \\
\text { New York } \\
\text { North Ca.................................... } \\
\text { North Dakota ............................... } \\
.\end{array}$ & $\begin{array}{r}1,343,564 \\
183,736 \\
4,111,839 \\
676,193 \\
97,895\end{array}$ & $\begin{array}{r}3,638,533 \\
515,451 \\
8,760,500 \\
1,880,862 \\
228,483\end{array}$ & $\begin{array}{r}3,648,914 \\
560,213 \\
9,259,948 \\
2,112,417 \\
254,197\end{array}$ & $\begin{array}{r}5,735,895 \\
808,036 \\
13,686,039 \\
2,991,747 \\
379,470\end{array}$ & $\begin{array}{r}6,099,473 \\
865,789 \\
14,724,687 \\
3,193,337 \\
374,941\end{array}$ & $\begin{array}{r}6,621,860 \\
916,305 \\
16,073,392 \\
3,424,194 \\
385,427\end{array}$ & $\begin{array}{r}7,309,147 \\
975,552 \\
17,127,596 \\
3,892,971 \\
431,814\end{array}$ & $\begin{array}{r}8,119,336 \\
1,020,148 \\
18,090,978 \\
4,342,826 \\
459,391\end{array}$ \\
\hline 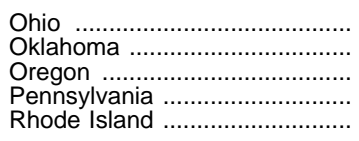 & $\begin{array}{r}1,639,805 \\
339,105 \\
403,844 \\
1,912,644 \\
145,443\end{array}$ & $\begin{array}{r}3,836,576 \\
1,055,844 \\
1,126,812 \\
4,584,320 \\
362,046\end{array}$ & $\begin{array}{r}4,149,858 \\
1,193,373 \\
1,292,624 \\
4,955,115 \\
395,389\end{array}$ & $\begin{array}{r}5,856,999 \\
1,740,981 \\
1,662,372 \\
6,750,520 \\
569,935\end{array}$ & $\begin{array}{r}6,114,426 \\
1,707,396 \\
1,747,125 \\
7,176,886 \\
608,318\end{array}$ & & $\begin{array}{r}7,484,434 \\
1,833,743 \\
2,123,241 \\
8,579,546 \\
747,852\end{array}$ & $\begin{array}{r}7,994,379 \\
1,905,332 \\
2,297,944 \\
9,496,788 \\
801,908\end{array}$ \\
\hline $\begin{array}{l}\text { South Carolina } \\
\text { South Dakota .......................... } \\
\text { Tennessee } \\
\text { Texas }\end{array}$ & $\begin{array}{r}367,689 \\
109,375 \\
473,226 \\
1,518,181 \\
179,981\end{array}$ & $\begin{array}{r}997,984 \\
238,332 \\
1,319,303 \\
4,997,689 \\
518,251\end{array}$ & $\begin{array}{r}1,006,088 \\
242,215 \\
1,429,938 \\
5,310,181 \\
587,648\end{array}$ & & $\begin{array}{r}1,814,160 \\
368,266 \\
2,167,026 \\
10,152,521 \\
932,740\end{array}$ & $\begin{array}{r}1,932,502 \\
389,436 \\
2,352,183 \\
10,791,854 \\
974,666\end{array}$ & $\begin{array}{r}2,118,732 \\
428,014 \\
2,668,341 \\
11,761,447 \\
1,043,759\end{array}$ & $\begin{array}{r}2,322,618 \\
447,074 \\
2,790,808 \\
12,763,954 \\
1,130,135\end{array}$ \\
\hline 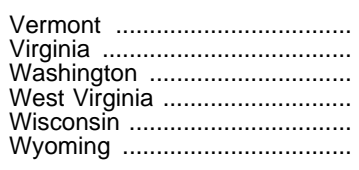 & $\begin{array}{r}78,921 \\
704,677 \\
699,984 \\
249,404 \\
777,288 \\
69,584\end{array}$ & $\begin{array}{r}189,811 \\
1,881,519 \\
1,825,782 \\
678,386 \\
1,908,523 \\
226,067\end{array}$ & $\begin{array}{r}224,901 \\
2,045,412 \\
1,791,477 \\
754,889 \\
2,035,879 \\
271,153 \\
\end{array}$ & $\begin{array}{r}346,164 \\
3,183,707 \\
2,702,652 \\
1,164,882 \\
2,893,797 \\
488,616 \\
\end{array}$ & $\begin{array}{r}378,264 \\
3,444,952 \\
2,808,636 \\
1,229,069 \\
3,086,878 \\
489,825 \\
\end{array}$ & $\begin{array}{r}456,992 \\
3,793,475 \\
3,005,980 \\
1,231,966 \\
3,318,247 \\
466,921 \\
\end{array}$ & $\begin{array}{r}485,226 \\
4,151,050 \\
3,209,992 \\
1,202,486 \\
3,688,311 \\
491,930 \\
\end{array}$ & $\begin{array}{r}546,901 \\
4,621,071 \\
3,550,819 \\
1,316,637 \\
3,929,920 \\
509,084\end{array}$ \\
\hline 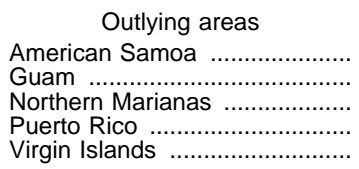 & $\begin{array}{r}16,652 \\
\text { 二 } \\
\text { - }\end{array}$ & $\begin{array}{l}- \\
-\end{array}$ & $\begin{array}{r}713,000 \\
-\end{array}$ & $\begin{array}{r}14,997 \\
78,545 \\
12,556 \\
842,827 \\
76,751\end{array}$ & $\begin{array}{r}19,497 \\
78,278 \\
15,714 \\
872,050 \\
97,585\end{array}$ & $\begin{array}{r}20,186 \\
76,359 \\
19,694 \\
935,392 \\
89,217\end{array}$ & $\begin{array}{r}22,314 \\
94,368 \\
16,118 \\
1,030,387 \\
111,750\end{array}$ & $\begin{array}{r}21,838 \\
101,130 \\
20,476 \\
1,045,407 \\
128,065\end{array}$ \\
\hline
\end{tabular}


Table 164.-Current expenditures for public elementary and secondary education, by state: 1969-70 to 1997-98-Continued

[In thousands of dollars]

\begin{tabular}{|c|c|c|c|c|c|c|c|c|}
\hline State or other area & 1990-91 & $1991-92$ & 1992-93 & 1993-94 & $1994-95^{1}$ & 1995-96 & $\begin{array}{l}\text { Estimated } \\
1996-97^{2}\end{array}$ & $\begin{array}{l}\text { Estimated } \\
1997-98^{2}\end{array}$ \\
\hline 1 & 10 & 11 & 12 & 13 & 14 & 15 & 16 & 17 \\
\hline United States & $\$ 202,037,752$ & $\$ 211,210,190$ & $\$ 220,948,052$ & $\$ 231,542,764$ & $\$ 243,877,582$ & $\$ 255,079,736$ & $3 \$ 269,507,252$ & $3 \$ 281,729,089$ \\
\hline 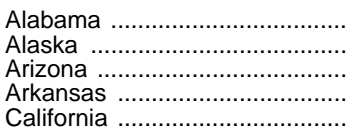 & $\begin{array}{r}2,475,216 \\
854,499 \\
2,469,543 \\
1,510,092 \\
22,748,218\end{array}$ & $\begin{array}{r}2,465,523 \\
931,869 \\
2,599,586 \\
1,656,201 \\
23,696,863\end{array}$ & $\begin{array}{r}2,610,514 \\
967,765 \\
2,753,504 \\
1,703,621 \\
24,219,792\end{array}$ & $\begin{array}{r}2,809,713 \\
1,002,515 \\
2,911,304 \\
1,782,645 \\
25,140,639\end{array}$ & $\begin{array}{r}3,026,287 \\
1,020,675 \\
3,144,540 \\
1,873,595 \\
25,949,033\end{array}$ & $\begin{array}{r}3,240,364 \\
1,045,022 \\
3,327,969 \\
1,994,748 \\
27,334,639\end{array}$ & $\begin{array}{r}43,258,021 \\
1,086,444 \\
43,683,833 \\
51,877,336 \\
30,408,173\end{array}$ & $\begin{array}{r}43,322,496 \\
1,119,037 \\
43,933,742 \\
41,881,863 \\
32,653,391\end{array}$ \\
\hline 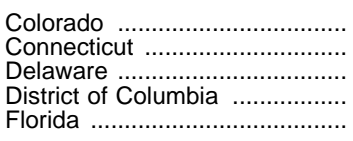 & $\begin{array}{r}2,642,850 \\
3,540,411 \\
543,933 \\
647,901 \\
9,045,710\end{array}$ & $\begin{array}{r}2,754,087 \\
3,665,505 \\
572,152 \\
677,422 \\
9,314,079\end{array}$ & $\begin{array}{r}2,919,916 \\
3,739,497 \\
600,161 \\
670,677 \\
9,661,012\end{array}$ & $\begin{array}{r}2,954,793 \\
3,943,891 \\
643,915 \\
713,427 \\
10,331,896\end{array}$ & $\begin{array}{r}3,232,976 \\
4,247,328 \\
694,473 \\
666,938 \\
11,019,735\end{array}$ & $\begin{array}{r}3,360,529 \\
4,366,123 \\
726,241 \\
679,106 \\
11,480,359\end{array}$ & $\begin{array}{r}3,280,342 \\
4,423,000 \\
817,749 \\
4690,673 \\
12,028,408\end{array}$ & $\begin{array}{r}3,404,995 \\
4,665,000 \\
877,779 \\
4676,222 \\
12,566,484\end{array}$ \\
\hline 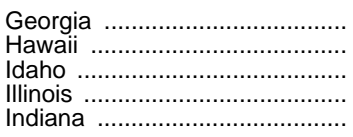 & $\begin{array}{r}4,804,225 \\
827,579 \\
708,045 \\
8,932,538 \\
4,379,142\end{array}$ & $\begin{array}{r}4,856,583 \\
884,591 \\
760,440 \\
9,244,655 \\
4,544,829\end{array}$ & $\begin{array}{r}5,273,143 \\
946,074 \\
804,231 \\
9,942,737 \\
4,797,946\end{array}$ & $\begin{array}{r}5,643,843 \\
998,143 \\
859,088 \\
10,076,889 \\
5,064,685\end{array}$ & $\begin{array}{r}6,136,689 \\
1,028,729 \\
951,350 \\
10,640,279 \\
5,243,761\end{array}$ & $\begin{array}{r}6,629,646 \\
1,040,682 \\
1,019,594 \\
10,727,091 \\
5,493,653\end{array}$ & $\begin{array}{r}6,583,572 \\
1,008,025 \\
1,361,500 \\
12,517,068 \\
5,758,000\end{array}$ & $\begin{array}{r}6,807,414 \\
1,019,113 \\
1,493,400 \\
12,923,480 \\
6,046,000\end{array}$ \\
\hline 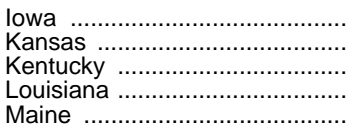 & $\begin{array}{l}2,136,561 \\
1,938,012 \\
2,480,363 \\
3,023,690 \\
1,070,965\end{array}$ & $\begin{array}{l}2,356,196 \\
2,028,440 \\
2,709,623 \\
3,188,024 \\
1,121,360\end{array}$ & $\begin{array}{l}2,459,141 \\
2,224,080 \\
2,823,134 \\
3,199,919 \\
1,217,418\end{array}$ & $\begin{array}{l}2,527,434 \\
2,325,247 \\
2,952,119 \\
3,309,018 \\
1,208,411\end{array}$ & $\begin{array}{l}2,622,510 \\
2,406,580 \\
2,988,892 \\
3,475,926 \\
1,281,706\end{array}$ & $\begin{array}{l}2,753,425 \\
2,488,077 \\
3,171,495 \\
3,545,832 \\
1,313,759\end{array}$ & $\begin{array}{r}2,885,589 \\
2,562,719 \\
43,247,568 \\
43,580,283 \\
1,319,479\end{array}$ & $\begin{array}{r}3,015,440 \\
2,662,665 \\
2,840,922 \\
43,500,590 \\
1,373,578\end{array}$ \\
\hline 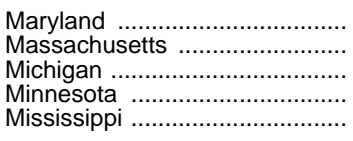 & $\begin{array}{l}4,240,862 \\
4,906,828 \\
8,545,805 \\
3,740,820 \\
1,510,552\end{array}$ & $\begin{array}{l}4,362,679 \\
5,035,973 \\
9,156,501 \\
3,936,695 \\
1,536,295\end{array}$ & $\begin{array}{l}4,556,266 \\
5,281,067 \\
9,532,994 \\
4,135,284 \\
1,600,752\end{array}$ & $\begin{array}{l}4,783,023 \\
5,637,337 \\
9,816,830 \\
4,328,093 \\
1,725,386\end{array}$ & $\begin{array}{r}5,083,380 \\
6,062,303 \\
10,440,206 \\
4,622,930 \\
1,921,480\end{array}$ & $\begin{array}{r}5,311,207 \\
6,435,458 \\
11,137,877 \\
4,844,879 \\
2,000,321\end{array}$ & $\begin{array}{r}4,709,060 \\
6,789,408 \\
11,441,941 \\
5,077,433 \\
52,034,791\end{array}$ & $\begin{array}{r}5,018,597 \\
7,162,825 \\
11,754,306 \\
5,321,150 \\
2,136,530\end{array}$ \\
\hline 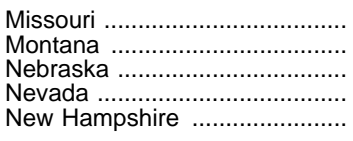 & $\begin{array}{r}3,487,786 \\
719,963 \\
1,297,643 \\
864,379 \\
890,116\end{array}$ & $\begin{array}{r}3,611,613 \\
751,710 \\
1,381,290 \\
962,800 \\
927,625\end{array}$ & $\begin{array}{r}3,710,426 \\
785,159 \\
1,430,039 \\
1,035,623 \\
972,963\end{array}$ & $\begin{array}{r}3,981,614 \\
822,015 \\
1,513,971 \\
1,099,685 \\
1,007,129\end{array}$ & $\begin{array}{r}4,275,217 \\
844,257 \\
1,594,928 \\
1,186,132 \\
1,053,966\end{array}$ & $\begin{array}{r}4,531,192 \\
868,892 \\
1,648,104 \\
1,296,629 \\
1,114,540\end{array}$ & $\begin{array}{r}4,416,746 \\
959,000 \\
1,748,474 \\
1,440,442 \\
1,234,945\end{array}$ & $\begin{array}{r}4,619,725 \\
983,000 \\
41,741,256 \\
1,754,908 \\
1,287,577\end{array}$ \\
\hline 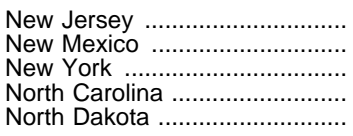 & $\begin{array}{r}8,897,612 \\
1,134,156 \\
19,514,583 \\
4,605,384 \\
460,581\end{array}$ & $\begin{array}{r}9,660,899 \\
1,212,189 \\
19,781,384 \\
4,660,027 \\
491,293\end{array}$ & $\begin{array}{r}9,915,482 \\
1,240,310 \\
20,898,267 \\
4,930,823 \\
511,095\end{array}$ & $\begin{array}{r}10,448,096 \\
1,323,459 \\
22,059,949 \\
5,145,416 \\
522,377\end{array}$ & $\begin{array}{r}10,776,982 \\
1,441,078 \\
22,989,629 \\
5,440,426 \\
534,632\end{array}$ & $\begin{array}{r}11,208,558 \\
1,517,517 \\
23,522,461 \\
5,582,994 \\
557,043\end{array}$ & $\begin{array}{r}411,703,897 \\
51,559,825 \\
24,345,747 \\
5,935,075 \\
5582,784\end{array}$ & $\begin{array}{r}411,789,530 \\
51,737,846 \\
25,197,850 \\
6,110,753 \\
609,009\end{array}$ \\
\hline 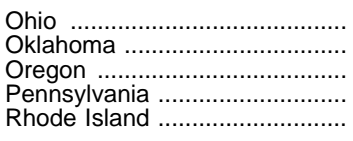 & $\begin{array}{r}8,407,428 \\
2,107,513 \\
2,453,934 \\
10,087,322 \\
823,655\end{array}$ & $\begin{array}{r}9,124,731 \\
2,268,958 \\
2,626,803 \\
10,371,796 \\
865,898\end{array}$ & $\begin{array}{r}9,173,393 \\
2,442,320 \\
2,849,009 \\
10,944,392 \\
934,815\end{array}$ & $\begin{array}{r}9,612,678 \\
2,680,113 \\
2,852,723 \\
11,236,417 \\
990,094\end{array}$ & $\begin{array}{r}10,030,956 \\
2,763,721 \\
2,948,539 \\
11,587,027 \\
1,050,969\end{array}$ & $\begin{array}{r}10,408,022 \\
2,804,088 \\
3,056,801 \\
12,374,073 \\
1,094,185\end{array}$ & $\begin{array}{r}10,782,926 \\
3,047,410 \\
3,247,000 \\
13,117,000 \\
1,079,175\end{array}$ & $\begin{array}{r}11,106,000 \\
3,169,306 \\
3,479,000 \\
13,904,000 \\
1,119,104\end{array}$ \\
\hline 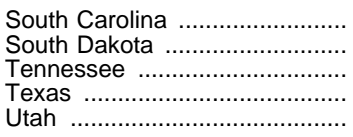 & $\begin{array}{r}2,494,254 \\
481,304 \\
2,903,209 \\
13,695,327 \\
1,235,916\end{array}$ & $\begin{array}{r}2,564,949 \\
518,156 \\
2,859,755 \\
14,709,628 \\
1,296,723\end{array}$ & $\begin{array}{r}2,690,009 \\
553,005 \\
3,139,223 \\
15,121,655 \\
1,376,319\end{array}$ & $\begin{array}{r}2,790,878 \\
584,894 \\
3,305,579 \\
16,193,722 \\
1,511,205\end{array}$ & $\begin{array}{r}2,920,230 \\
612,825 \\
3,540,682 \\
17,572,269 \\
1,618,047\end{array}$ & $\begin{array}{r}3,085,495 \\
610,640 \\
3,728,486 \\
18,801,462 \\
1,719,782\end{array}$ & $\begin{array}{r}3,208,915 \\
639,543 \\
43,885,590 \\
21,254,691 \\
1,833,122\end{array}$ & $\begin{array}{r}3,369,361 \\
647,720 \\
43,914,976 \\
22,850,684 \\
1,888,115\end{array}$ \\
\hline 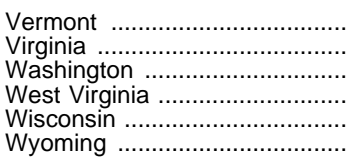 & $\begin{array}{r}599,018 \\
4,958,213 \\
3,906,471 \\
1,473,640 \\
4,292,434 \\
521,549\end{array}$ & $\begin{array}{r}606,410 \\
4,993,480 \\
4,259,048 \\
1,503,980 \\
4,597,004 \\
545,870\end{array}$ & $\begin{array}{r}616,212 \\
5,228,326 \\
4,679,698 \\
1,626,005 \\
4,954,900 \\
547,938\end{array}$ & $\begin{array}{r}643,828 \\
5,441,384 \\
4,892,690 \\
1,663,868 \\
5,170,343 \\
558,353\end{array}$ & $\begin{array}{r}665,559 \\
5,750,318 \\
5,138,928 \\
1,758,557 \\
5,422,264 \\
577,144\end{array}$ & $\begin{array}{r}684,864 \\
5,969,608 \\
5,367,559 \\
1,806,004 \\
5,670,826 \\
581,817\end{array}$ & $\begin{array}{r}5684,862 \\
46,474,880 \\
5,480,787 \\
1,847,874 \\
5,968,287 \\
597,842\end{array}$ & $\begin{array}{r}4676,187 \\
46,188,603 \\
6,604,200 \\
1,907,006 \\
6,281,352 \\
615,000\end{array}$ \\
\hline $\begin{array}{l}\text { Outlying areas } \\
\text { American Samoa } \\
\text { Guam ................................................. } \\
\text { Northern Marianas } \\
\text { Puerto Rico ................................... } \\
\text { Virgin Islands } \ldots \ldots \ldots \ldots \ldots \ldots \ldots \ldots \ldots \ldots\end{array}$ & $\begin{array}{r}24,946 \\
116,406 \\
26,822 \\
1,142,863 \\
119,950\end{array}$ & $\begin{array}{r}26,972 \\
132,494 \\
32,498 \\
1,207,235 \\
121,660\end{array}$ & $\begin{array}{r}23,636 \\
161,477 \\
38,784 \\
1,295,452 \\
120,510\end{array}$ & $\begin{array}{r}25,161 \\
160,797 \\
32,824 \\
1,360,762 \\
120,556\end{array}$ & $\begin{array}{r}28,643 \\
161,434 \\
45,008 \\
1,501,485 \\
122,094\end{array}$ & $\begin{array}{r}30,382 \\
158,303 \\
44,037 \\
1,667,640 \\
122,286\end{array}$ & $\begin{array}{r}36,498 \\
5145,623 \\
553,366 \\
51,800,000 \\
5127,754\end{array}$ & $\begin{array}{r}437,373 \\
181,000 \\
53,200 \\
1,921,000 \\
4123,112\end{array}$ \\
\hline
\end{tabular}

1 Data revised from previously published figures.

Data estimated by state education agencies unless otherwise indicated.

U.S. total includes National Center for Education Statistics estimates for nonreporting states.

${ }^{4}$ Estimated by the National Center for Education Statistics.

${ }^{5}$ Actual preliminary count.

-Data not available or not applicable.
NOTE.-Beginning in 1980-81, expenditures for state administration are excluded. Because of rounding, details may not add to totals.

SOURCE: U.S. Department of Education, National Center for Education Statistics, Statistics of State School Systems; and Common Core of Data surveys. (This table was prepared July 1998.) 
Table 165.-Total expenditures for public elementary and secondary education, by function and state: 1995-96

[In thousands]

\begin{tabular}{|c|c|c|c|c|c|c|c|c|}
\hline \multirow{4}{*}{ State or other area } & \multicolumn{8}{|c|}{ Total expenditures } \\
\hline & \multirow{3}{*}{ Total } & \multicolumn{7}{|c|}{ Current expenditures for elementary and secondary programs } \\
\hline & & \multirow{2}{*}{$\begin{array}{c}\text { Current } \\
\text { expenditures } \\
\text { for } \\
\text { public schools }\end{array}$} & \multirow{2}{*}{ Instruction } & \multicolumn{5}{|c|}{ Student services } \\
\hline & & & & Total & Students $^{3}$ & Instructional ${ }^{4}$ & $\begin{array}{c}\text { General } \\
\text { administration }\end{array}$ & $\begin{array}{c}\text { School } \\
\text { administration }\end{array}$ \\
\hline 1 & 2 & 3 & 4 & 5 & 6 & 7 & 8 & 9 \\
\hline United States ......... & $\$ 293,610,849$ & $\$ 255,079,736$ & $\$ 157,480,290$ & $\$ 86,172,655$ & $\$ 12,243,641$ & $\$ 10,071,302$ & $\$ 5,866,480$ & $\$ 14,831,161$ \\
\hline 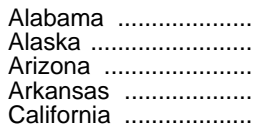 & $\begin{array}{r}3,633,168 \\
1,251,355 \\
4,393,822 \\
2,248,059 \\
30,406,167\end{array}$ & $\begin{array}{r}3,240,364 \\
1,045,022 \\
3,327,969 \\
1,994,748 \\
27,334,639\end{array}$ & $\begin{array}{r}2,032,706 \\
591,338 \\
1,921,658 \\
1,244,145 \\
16,333,392\end{array}$ & $\begin{array}{r}970,024 \\
420,151 \\
1,192,286 \\
613,193 \\
9,829,490\end{array}$ & $\begin{array}{r}108,627 \\
52,586 \\
145,080 \\
81,449 \\
1,452,162\end{array}$ & $\begin{array}{r}106,993 \\
58,700 \\
105,672 \\
75,532 \\
1,253,659\end{array}$ & $\begin{array}{r}71,865 \\
60,212 \\
134,589 \\
68,403 \\
168,029\end{array}$ & $\begin{array}{r}191,236 \\
63,392 \\
181,920 \\
111,804 \\
2,089,532\end{array}$ \\
\hline $\begin{array}{l}\text { Colorado ................... } \\
\text { Connecticut .............. } \\
\text { Delaware ................ } \\
\text { District of Columbia .... } \\
\text { Florida }\end{array}$ & $\begin{array}{r}4,138,328 \\
4,656,518 \\
823,067 \\
711,929 \\
14,231,901\end{array}$ & $\begin{array}{r}3,360,529 \\
4,366,123 \\
726,241 \\
679,106 \\
11,480,359\end{array}$ & $\begin{array}{r}2,069,222 \\
2,780,996 \\
447,549 \\
334,893 \\
6,675,272\end{array}$ & $\begin{array}{r}1,156,615 \\
1,363,960 \\
244,095 \\
312,944 \\
4,238,643\end{array}$ & $\begin{array}{r}142,866 \\
227,587 \\
35,038 \\
85,684 \\
518,152\end{array}$ & $\begin{array}{r}124,223 \\
126,630 \\
10,375 \\
34,518 \\
642,321\end{array}$ & $\begin{array}{r}94,664 \\
87,172 \\
7,963 \\
19,903 \\
125,889\end{array}$ & $\begin{array}{r}224,970 \\
242,156 \\
40,913 \\
37,519 \\
771,572\end{array}$ \\
\hline 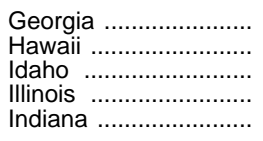 & $\begin{array}{r}8,051,720 \\
1,262,385 \\
1,204,717 \\
12,262,164 \\
6,568,240\end{array}$ & $\begin{array}{r}6,629,646 \\
1,040,682 \\
1,019,594 \\
10,727,091 \\
5,493,653\end{array}$ & $\begin{array}{r}4,116,129 \\
651,832 \\
643,243 \\
6,461,142 \\
3,412,502\end{array}$ & $\begin{array}{r}2,109,944 \\
322,254 \\
330,614 \\
3,892,546 \\
1,836,980\end{array}$ & $\begin{array}{r}267,862 \\
64,740 \\
53,541 \\
540,225 \\
233,153\end{array}$ & $\begin{array}{r}324,776 \\
39,115 \\
31,225 \\
401,100 \\
154,438\end{array}$ & $\begin{array}{r}94,189 \\
7,734 \\
25,765 \\
321,916 \\
100,287\end{array}$ & $\begin{array}{r}416,759 \\
65,454 \\
62,332 \\
590,324 \\
308,242\end{array}$ \\
\hline 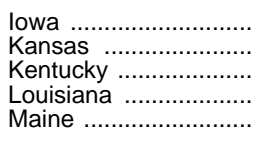 & $\begin{array}{l}3,048,566 \\
2,732,391 \\
3,447,820 \\
3,878,876 \\
1,422,526\end{array}$ & $\begin{array}{l}2,753,425 \\
2,488,077 \\
3,171,495 \\
3,545,832 \\
1,313,759\end{array}$ & $\begin{array}{r}1,691,945 \\
1,441,539 \\
1,942,324 \\
2,099,916 \\
882,302\end{array}$ & $\begin{array}{r}926,348 \\
923,743 \\
1,081,739 \\
1,130,311 \\
383,560\end{array}$ & $\begin{array}{r}170,366 \\
122,982 \\
124,475 \\
134,689 \\
38,651\end{array}$ & $\begin{array}{r}124,464 \\
102,164 \\
85,394 \\
141,633 \\
36,857\end{array}$ & $\begin{array}{r}81,817 \\
96,897 \\
126,085 \\
81,098 \\
25,370\end{array}$ & $\begin{array}{r}143,571 \\
167,840 \\
194,448 \\
195,971 \\
74,519\end{array}$ \\
\hline $\begin{array}{l}\text { Maryland ................. } \\
\text { Massachusetts .......... } \\
\text { Michigan ................... } \\
\text { Minnesota ................. } \\
\text { Mississippi ................. }\end{array}$ & $\begin{array}{r}5,839,898 \\
6,680,053 \\
12,742,147 \\
6,184,218 \\
2,286,758\end{array}$ & $\begin{array}{r}5,311,207 \\
6,435,458 \\
11,137,877 \\
4,844,879 \\
2,000,321\end{array}$ & $\begin{array}{l}3,263,165 \\
4,275,924 \\
6,583,062 \\
3,095,995 \\
1,246,654\end{array}$ & $\begin{array}{r}1,796,246 \\
1,947,224 \\
4,229,411 \\
1,553,894 \\
603,502\end{array}$ & $\begin{array}{r}219,149 \\
298,248 \\
703,337 \\
152,927 \\
72,944\end{array}$ & $\begin{array}{r}216,968 \\
203,651 \\
478,208 \\
264,047 \\
76,766\end{array}$ & $\begin{array}{r}28,931 \\
144,036 \\
226,291 \\
115,247 \\
60,174\end{array}$ & $\begin{array}{l}437,906 \\
302,442 \\
681,482 \\
209,100 \\
110,001\end{array}$ \\
\hline $\begin{array}{l}\text { Missouri ................... } \\
\text { Montana .................. } \\
\text { Nebraska ................. } \\
\text { Nevada ................... } \\
\text { New Hampshire ......... }\end{array}$ & $\begin{array}{r}5,319,015 \\
946,567 \\
1,907,419 \\
1,611,165 \\
1,244,321\end{array}$ & $\begin{array}{r}4,531,192 \\
868,892 \\
1,648,104 \\
1,296,629 \\
1,114,540\end{array}$ & $\begin{array}{r}2,770,426 \\
541,473 \\
1,027,617 \\
768,352 \\
725,558\end{array}$ & $\begin{array}{r}1,565,327 \\
291,170 \\
487,949 \\
483,971 \\
349,699\end{array}$ & $\begin{array}{r}193,113 \\
38,937 \\
65,446 \\
49,234 \\
60,948\end{array}$ & $\begin{array}{r}177,747 \\
29,562 \\
56,991 \\
35,803 \\
30,362\end{array}$ & $\begin{array}{r}143,728 \\
27,864 \\
60,530 \\
25,315 \\
38,858\end{array}$ & $\begin{array}{r}268,686 \\
46,206 \\
84,875 \\
94,642 \\
63,061\end{array}$ \\
\hline $\begin{array}{l}\text { New Jersey } \ldots \ldots \ldots \ldots \ldots . . \\
\text { New Mexico ............... } \\
\text { New York ................. } \\
\text { North Carolina ........... } \\
\text { North Dakota .............. }\end{array}$ & $\begin{array}{r}12,231,660 \\
1,796,491 \\
26,907,652 \\
6,490,339 \\
620,394\end{array}$ & $\begin{array}{r}11,208,558 \\
1,517,517 \\
23,522,461 \\
5,582,994 \\
557,043\end{array}$ & $\begin{array}{r}6,775,687 \\
872,133 \\
15,948,326 \\
3,479,891 \\
339,950\end{array}$ & $\begin{array}{r}4,061,688 \\
558,257 \\
6,943,853 \\
1,740,685 \\
168,142\end{array}$ & $\begin{array}{r}747,150 \\
119,802 \\
941,911 \\
277,597 \\
16,563\end{array}$ & $\begin{array}{r}344,067 \\
69,280 \\
530,265 \\
201,268 \\
12,415\end{array}$ & $\begin{array}{r}330,090 \\
40,968 \\
556,860 \\
107,979 \\
28,442\end{array}$ & $\begin{array}{r}628,605 \\
74,953 \\
984,540 \\
366,907 \\
25,975\end{array}$ \\
\hline $\begin{array}{l}\text { Ohio ...................... } \\
\text { Oklahoma ................. } \\
\text { Oregon .................... } \\
\text { Pennsylvania ............. } \\
\text { Rhode Island ............. }\end{array}$ & $\begin{array}{r}11,874,454 \\
3,111,652 \\
3,436,859 \\
14,337,270 \\
1,145,773\end{array}$ & $\begin{array}{r}10,408,022 \\
2,804,088 \\
3,056,801 \\
12,374,073 \\
1,094,185\end{array}$ & $\begin{array}{r}6,200,538 \\
1,680,375 \\
1,852,333 \\
7,922,896 \\
728,417\end{array}$ & $\begin{array}{r}3,819,921 \\
949,350 \\
1,095,768 \\
4,003,738 \\
336,288\end{array}$ & $\begin{array}{r}517,122 \\
152,299 \\
147,570 \\
572,386 \\
67,987\end{array}$ & $\begin{array}{r}512,259 \\
80,474 \\
141,742 \\
386,905 \\
35,315\end{array}$ & $\begin{array}{r}264,166 \\
116,722 \\
66,483 \\
359,263 \\
24,511\end{array}$ & $\begin{array}{r}620,053 \\
154,505 \\
203,347 \\
559,187 \\
53,354\end{array}$ \\
\hline 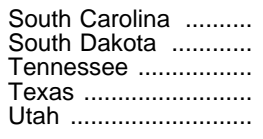 & $\begin{array}{r}3,683,763 \\
686,104 \\
4,295,064 \\
22,217,305 \\
2,159,133\end{array}$ & $\begin{array}{r}3,085,495 \\
610,640 \\
3,728,486 \\
18,801,462 \\
1,719,782\end{array}$ & $\begin{array}{r}1,821,432 \\
370,593 \\
2,378,112 \\
11,540,336 \\
1,152,136\end{array}$ & $\begin{array}{r}1,064,316 \\
205,012 \\
1,151,816 \\
6,179,630 \\
465,935\end{array}$ & $\begin{array}{r}202,810 \\
25,120 \\
119,988 \\
861,085 \\
51,345\end{array}$ & $\begin{array}{r}175,636 \\
21,076 \\
194,847 \\
815,973 \\
63,991\end{array}$ & $\begin{array}{r}43,376 \\
17,874 \\
84,329 \\
692,991 \\
17,324\end{array}$ & $\begin{array}{r}195,675 \\
35,547 \\
205,363 \\
1,035,280 \\
98,351\end{array}$ \\
\hline 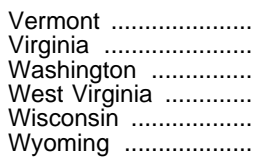 & $\begin{array}{r}769,049 \\
6,986,861 \\
6,544,096 \\
1,965,472 \\
6,544,688 \\
671,489\end{array}$ & $\begin{array}{r}684,864 \\
5,969,608 \\
5,367,559 \\
1,806,004 \\
5,670,826 \\
581,817\end{array}$ & $\begin{array}{r}444,162 \\
3,601,235 \\
3,225,122 \\
1,122,084 \\
3,591,487 \\
360,771\end{array}$ & $\begin{array}{r}219,761 \\
2,045,379 \\
1,890,496 \\
578,586 \\
1,905,973 \\
200,226\end{array}$ & $\begin{array}{r}40,718 \\
286,321 \\
315,886 \\
57,382 \\
235,633 \\
32,768\end{array}$ & $\begin{array}{r}20,734 \\
323,547 \\
260,129 \\
47,184 \\
266,345 \\
17,955\end{array}$ & $\begin{array}{r}20,392 \\
63,245 \\
145,262 \\
47,320 \\
155,267 \\
12,799\end{array}$ & $\begin{array}{r}45,469 \\
359,684 \\
271,935 \\
104,923 \\
299,474 \\
35,159\end{array}$ \\
\hline $\begin{array}{l}\text { Outlying areas } \\
\text { American Samoa ........ } \\
\text { Guam ...................... } \\
\text { Northern Marianas .... } \\
\text { Puerto Rico ............... } \\
\text { Virgin Islands ............. }\end{array}$ & $\begin{array}{r}35,490 \\
158,445 \\
47,578 \\
1,722,788 \\
127,754\end{array}$ & $\begin{array}{r}30,382 \\
158,303 \\
44,037 \\
1,667,640 \\
122,286\end{array}$ & $\begin{array}{r}12,456 \\
87,773 \\
35,357 \\
1,198,197 \\
69,478\end{array}$ & $\begin{array}{r}10,874 \\
61,187 \\
5,698 \\
250,596 \\
46,012\end{array}$ & $\begin{array}{r}3,570 \\
17,077 \\
152 \\
51,554 \\
6,182\end{array}$ & $\begin{array}{r}1,545 \\
3,512 \\
182 \\
0 \\
7,700\end{array}$ & $\begin{array}{r}501 \\
1,416 \\
4,643 \\
98,089 \\
9,303\end{array}$ & $\begin{array}{r}1,626 \\
7,763 \\
0 \\
19,035 \\
6,803\end{array}$ \\
\hline
\end{tabular}



Table 165.-Total expenditures for public elementary and secondary education, by function and state:
1995-96-Continued

[In thousands]

\begin{tabular}{|c|c|c|c|c|c|c|c|c|}
\hline \multirow{4}{*}{ State or other area } & \multicolumn{8}{|c|}{ Total expenditures } \\
\hline & \multicolumn{5}{|c|}{ Current expenditures for elementary and secondary programs } & \multirow{3}{*}{$\begin{array}{l}\text { Other current } \\
\text { expenditures }{ }^{1}\end{array}$} & \multirow{3}{*}{$\begin{array}{l}\text { Capital } \\
\text { outlay }^{2}\end{array}$} & \multirow{3}{*}{$\begin{array}{l}\text { Interest on } \\
\text { school debt }\end{array}$} \\
\hline & \multicolumn{3}{|c|}{ Student services } & \multirow{2}{*}{ Food services } & \multirow{2}{*}{$\begin{array}{l}\text { Enterprise } \\
\text { operations }{ }^{5}\end{array}$} & & & \\
\hline & $\begin{array}{l}\text { Operation and } \\
\text { maintenance }\end{array}$ & $\begin{array}{l}\text { Student } \\
\text { transportation }\end{array}$ & $\begin{array}{l}\text { Other support } \\
\text { services }\end{array}$ & & & & & \\
\hline 1 & 10 & 11 & 12 & 13 & 14 & 15 & 16 & 17 \\
\hline United States ...... & $\$ 25,725,984$ & $\$ 10,394,695$ & $\$ 7,039,392$ & $\$ 10,648,854$ & $\$ 777,936$ & $\$ 4,724,662$ & $\$ 27,547,918$ & $\$ 6,258,534$ \\
\hline 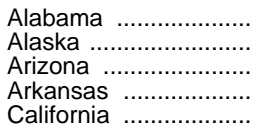 & $\begin{array}{r}289,843 \\
147,093 \\
378,922 \\
171,166 \\
2,863,245\end{array}$ & $\begin{array}{r}131,883 \\
35,820 \\
134,032 \\
75,532 \\
768,783\end{array}$ & $\begin{array}{r}69,576 \\
2,347 \\
112,071 \\
29,308 \\
1,234,080\end{array}$ & $\begin{array}{r}237,634 \\
29,009 \\
172,221 \\
119,701 \\
1,166,119\end{array}$ & $\begin{array}{r}0 \\
4,524 \\
41,803 \\
17,710 \\
5,638\end{array}$ & $\begin{array}{r}56,173 \\
5,402 \\
29,293 \\
11,659 \\
531,838\end{array}$ & $\begin{array}{r}292,706 \\
178,915 \\
812,131 \\
196,003 \\
2,417,780\end{array}$ & $\begin{array}{r}43,925 \\
22,016 \\
224,430 \\
45,650 \\
121,909\end{array}$ \\
\hline 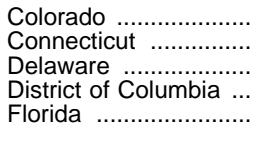 & $\begin{array}{r}299,420 \\
408,419 \\
71,852 \\
98,172 \\
1,335,948\end{array}$ & $\begin{array}{r}98,258 \\
189,983 \\
42,045 \\
14,754 \\
491,354\end{array}$ & $\begin{array}{r}172,215 \\
82,014 \\
35,909 \\
22,394 \\
353,408\end{array}$ & $\begin{array}{r}121,450 \\
119,894 \\
34,596 \\
29,179 \\
566,444\end{array}$ & $\begin{array}{r}13,242 \\
101,273 \\
0 \\
2,091 \\
0\end{array}$ & $\begin{array}{r}8,676 \\
81,637 \\
13,367 \\
8,721 \\
411,670\end{array}$ & $\begin{array}{r}617,785 \\
106,111 \\
74,700 \\
21,467 \\
2,048,092\end{array}$ & $\begin{array}{r}151,338 \\
102,647 \\
8,759 \\
2,635 \\
291,780\end{array}$ \\
\hline 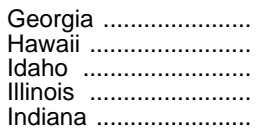 & $\begin{array}{r}574,027 \\
105,042 \\
94,954 \\
1,192,303 \\
601,872\end{array}$ & $\begin{array}{r}254,766 \\
19,298 \\
47,268 \\
506,262 \\
312,061\end{array}$ & $\begin{array}{r}177,565 \\
20,873 \\
15,530 \\
340,417 \\
126,928\end{array}$ & $\begin{array}{r}397,944 \\
66,595 \\
45,736 \\
373,402 \\
244,171\end{array}$ & $\begin{array}{r}5,630 \\
0 \\
0 \\
0 \\
0\end{array}$ & $\begin{array}{r}254,738 \\
31,309 \\
2,122 \\
90,228 \\
41,861\end{array}$ & $\begin{array}{r}1,045,456 \\
159,558 \\
157,597 \\
1,173,420 \\
624,306\end{array}$ & $\begin{array}{r}121,880 \\
30,837 \\
25,405 \\
271,426 \\
408,420\end{array}$ \\
\hline 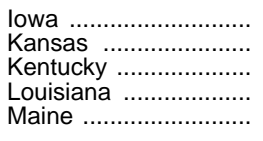 & $\begin{array}{l}242,507 \\
281,318 \\
320,285 \\
319,344 \\
124,832\end{array}$ & $\begin{array}{r}86,381 \\
103,062 \\
184,915 \\
198,277 \\
61,177\end{array}$ & $\begin{array}{l}77,242 \\
49,480 \\
46,136 \\
59,299 \\
22,153\end{array}$ & $\begin{array}{r}122,983 \\
122,794 \\
147,432 \\
264,211 \\
47,824\end{array}$ & $\begin{array}{r}12,148 \\
0 \\
0 \\
51,393 \\
73\end{array}$ & $\begin{array}{r}17,177 \\
3,029 \\
21,541 \\
23,370 \\
15,648\end{array}$ & $\begin{array}{r}242,068 \\
186,590 \\
185,609 \\
236,608 \\
60,078\end{array}$ & $\begin{array}{l}35,896 \\
54,696 \\
69,175 \\
73,067 \\
33,042\end{array}$ \\
\hline $\begin{array}{l}\text { Maryland ................ } \\
\text { Massachusetts .......... } \\
\text { Michigan ................... } \\
\text { Minnesota …............. } \\
\text { Mississippi ................ }\end{array}$ & $\begin{array}{r}527,925 \\
598,964 \\
1,204,619 \\
409,419 \\
173,345\end{array}$ & $\begin{array}{r}266,100 \\
286,248 \\
475,639 \\
259,091 \\
81,208\end{array}$ & $\begin{array}{r}99,267 \\
113,634 \\
459,835 \\
144,063 \\
29,063\end{array}$ & $\begin{array}{l}166,649 \\
212,310 \\
325,403 \\
194,990 \\
149,666\end{array}$ & $\begin{array}{r}85,148 \\
0 \\
0 \\
0 \\
499\end{array}$ & $\begin{array}{r}18,192 \\
59,591 \\
356,592 \\
218,463 \\
13,499\end{array}$ & $\begin{array}{r}452,471 \\
66,818 \\
952,539 \\
927,467 \\
232,798\end{array}$ & $\begin{array}{r}58,027 \\
118,187 \\
295,139 \\
193,409 \\
40,140\end{array}$ \\
\hline $\begin{array}{l}\text { Missouri ....................... } \\
\text { Montana .................. } \\
\text { Nebraska ................. } \\
\text { Nevada .................... } \\
\text { New Hampshire ......... }\end{array}$ & $\begin{array}{r}441,455 \\
90,804 \\
144,439 \\
131,000 \\
98,111\end{array}$ & $\begin{array}{r}255,492 \\
38,308 \\
47,312 \\
57,157 \\
49,447\end{array}$ & $\begin{array}{r}85,106 \\
19,489 \\
28,354 \\
90,819 \\
8,912\end{array}$ & $\begin{array}{r}195,439 \\
35,778 \\
62,840 \\
44,305 \\
39,284\end{array}$ & $\begin{array}{r}0 \\
470 \\
69,698 \\
0 \\
0\end{array}$ & $\begin{array}{r}85,301 \\
5,747 \\
2,060 \\
9,069 \\
4,276\end{array}$ & $\begin{array}{r}575,759 \\
61,361 \\
229,681 \\
230,269 \\
97,162\end{array}$ & $\begin{array}{r}126,763 \\
10,567 \\
27,574 \\
75,199 \\
28,342\end{array}$ \\
\hline $\begin{array}{l}\text { New Jersey } \ldots \ldots \ldots \ldots \ldots . . \\
\text { New Mexico ................ } \\
\text { New York ................. } \\
\text { North Carolina ........... } \\
\text { North Dakota ............ }\end{array}$ & $\begin{array}{r}1,230,498 \\
157,011 \\
2,183,189 \\
474,144 \\
49,878\end{array}$ & $\begin{array}{r}558,986 \\
74,787 \\
1,172,615 \\
209,247 \\
24,733\end{array}$ & $\begin{array}{r}222,293 \\
21,456 \\
574,474 \\
103,544 \\
10,137\end{array}$ & $\begin{array}{r}330,898 \\
77,732 \\
630,281 \\
362,417 \\
28,314\end{array}$ & $\begin{array}{r}40,284 \\
9,396 \\
0 \\
0 \\
20,637\end{array}$ & $\begin{array}{r}141,304 \\
7,952 \\
912,651 \\
39,864 \\
4,253\end{array}$ & $\begin{array}{r}727,284 \\
246,961 \\
1,918,134 \\
727,293 \\
52,052\end{array}$ & $\begin{array}{r}154,515 \\
24,061 \\
554,406 \\
140,188 \\
7,046\end{array}$ \\
\hline $\begin{array}{l}\text { Ohio ....................... } \\
\text { Oklahoma ................. } \\
\text { Oregon .................... } \\
\text { Pennsylvania .............. } \\
\text { Rhode Island ............. }\end{array}$ & $\begin{array}{r}1,005,165 \\
292,724 \\
280,413 \\
1,258,224 \\
98,914\end{array}$ & $\begin{array}{r}273,774 \\
91,566 \\
124,502 \\
543,990 \\
44,336\end{array}$ & $\begin{array}{r}627,382 \\
61,060 \\
131,712 \\
323,783 \\
11,870\end{array}$ & $\begin{array}{r}384,139 \\
149,468 \\
104,771 \\
435,188 \\
29,480\end{array}$ & $\begin{array}{r}3,425 \\
24,896 \\
3,929 \\
12,250 \\
0\end{array}$ & $\begin{array}{r}352,284 \\
11,672 \\
11,450 \\
315,558 \\
9,322\end{array}$ & $\begin{array}{r}819,258 \\
273,257 \\
288,229 \\
1,234,924 \\
22,106\end{array}$ & $\begin{array}{r}294,890 \\
22,634 \\
80,380 \\
412,716 \\
20,160\end{array}$ \\
\hline $\begin{array}{l}\text { South Carolina } \\
\text { South Dakota ............. } \\
\text { Tennessee .................. } \\
\text { Texas ......................... } \\
\text { Utah ........................ }\end{array}$ & $\begin{array}{r}286,155 \\
61,045 \\
357,936 \\
2,084,036 \\
155,632\end{array}$ & $\begin{array}{r}93,456 \\
24,593 \\
135,300 \\
522,233 \\
48,483\end{array}$ & $\begin{array}{r}67,209 \\
19,756 \\
54,053 \\
168,033 \\
30,809\end{array}$ & $\begin{array}{r}181,207 \\
32,571 \\
198,558 \\
1,029,383 \\
94,445\end{array}$ & $\begin{array}{r}18,539 \\
2,464 \\
0 \\
52,114 \\
7,265\end{array}$ & $\begin{array}{r}55,275 \\
1,013 \\
17,641 \\
96,344 \\
51,870\end{array}$ & $\begin{array}{r}453,207 \\
62,693 \\
463,845 \\
2,710,954 \\
338,271\end{array}$ & $\begin{array}{r}89,786 \\
11,759 \\
85,092 \\
608,545 \\
49,211\end{array}$ \\
\hline 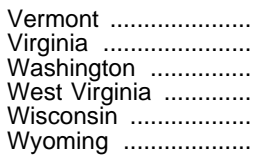 & $\begin{array}{r}56,197 \\
628,660 \\
555,847 \\
180,967 \\
524,527 \\
64,176\end{array}$ & $\begin{array}{r}22,869 \\
265,821 \\
213,329 \\
116,280 \\
239,221 \\
22,663\end{array}$ & $\begin{array}{r}13,382 \\
118,101 \\
128,108 \\
24,530 \\
185,506 \\
14,706\end{array}$ & $\begin{array}{r}20,242 \\
230,510 \\
173,880 \\
105,181 \\
173,366 \\
20,820\end{array}$ & $\begin{array}{r}699 \\
92,484 \\
78,061 \\
154 \\
0 \\
0\end{array}$ & $\begin{array}{r}2,050 \\
113,349 \\
27,709 \\
29,007 \\
90,754 \\
1,092\end{array}$ & $\begin{array}{r}69,409 \\
752,071 \\
898,786 \\
113,988 \\
633,453 \\
78,443\end{array}$ & $\begin{array}{r}12,726 \\
151,833 \\
250,041 \\
16,473 \\
149,655 \\
10,136\end{array}$ \\
\hline $\begin{array}{l}\text { Outlying areas } \\
\text { American Samoa ........ } \\
\text { Guam ....................... } \\
\text { Northern Marianas .... } \\
\text { Puerto Rico ............... } \\
\text { Virgin Islands ............. }\end{array}$ & $\begin{array}{r}1,834 \\
15,190 \\
192 \\
43,435 \\
7,023\end{array}$ & $\begin{array}{r}587 \\
10,594 \\
406 \\
36,370 \\
3,218\end{array}$ & $\begin{array}{r}1,210 \\
5,635 \\
123 \\
2,114 \\
5,783\end{array}$ & $\begin{array}{r}7,052 \\
9,343 \\
2,982 \\
218,847 \\
6,730\end{array}$ & $\begin{array}{r}0 \\
0 \\
0 \\
0 \\
65\end{array}$ & $\begin{array}{r}2,480 \\
142 \\
1,906 \\
22,299 \\
1,425\end{array}$ & $\begin{array}{r}2,628 \\
0 \\
1,635 \\
32,305 \\
4,043\end{array}$ & $\begin{array}{r}0 \\
0 \\
0 \\
543 \\
0\end{array}$ \\
\hline
\end{tabular}

1 Includes expenditures for adult education, community colleges, private school programs funded by local and state education agencies, and community services.

${ }^{2}$ Includes expenditures for property and for building and alterations completed by school district staff or contractors.

${ }^{3}$ Includes expenditures for health, attendance, and speech pathology services.

${ }^{4}$ Includes expenditures for curriculum development, staff training, libraries, and media and computer centers.
5 Includes expenditures for operations funded by sales of products or services (e.g., school bookstore or computer time).

NOTE.-Excludes expenditures for state education agencies. Because of rounding, details may not add to totals.

SOURCE: U.S. Department of Education, National Center for Education Statistics, Common Core of Data survey. (This table was prepared June 1998.) 
Table 166.-Total expenditures for public elementary and secondary education, by function and state: 1994-95

[In thousands]

\begin{tabular}{|c|c|c|c|c|c|c|c|c|}
\hline \multirow{4}{*}{ State or other area } & \multicolumn{8}{|c|}{ Total expenditures } \\
\hline & \multirow{3}{*}{ Total } & \multicolumn{7}{|c|}{ Current expenditures for elementary and secondary programs } \\
\hline & & \multirow{2}{*}{$\begin{array}{c}\text { Current } \\
\text { expenditures } \\
\text { for }\end{array}$} & \multirow[b]{2}{*}{ Instruction } & \multicolumn{5}{|c|}{ Student services } \\
\hline & & & & Total & Students ${ }^{3}$ & Instructional 4 & $\begin{array}{c}\text { General } \\
\text { administration }\end{array}$ & $\begin{array}{c}\text { School } \\
\text { administration }\end{array}$ \\
\hline 1 & 2 & 3 & 4 & 5 & 6 & 7 & 8 & 9 \\
\hline United States ........ & $\$ 279,000,318$ & $\$ 243,877,582$ & $\$ 150,556,118$ & $\$ 82,351,869$ & $\$ 11,679,127$ & $\$ 9,654,676$ & $\$ 5,731,420$ & $\$ 14,146,428$ \\
\hline 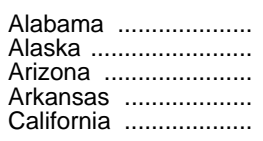 & $\begin{array}{r}3,372,114 \\
1,208,525 \\
4,071,643 \\
2,094,833 \\
29,070,435\end{array}$ & $\begin{array}{r}3,026,287 \\
1,020,675 \\
3,144,540 \\
1,873,595 \\
25,949,033\end{array}$ & $\begin{array}{r}1,906,471 \\
574,242 \\
1,811,167 \\
1,144,389 \\
15,549,692\end{array}$ & $\begin{array}{r}887,965 \\
414,526 \\
1,122,380 \\
601,518 \\
9,299,207\end{array}$ & $\begin{array}{r}95,915 \\
46,037 \\
136,799 \\
80,417 \\
1,389,412\end{array}$ & $\begin{array}{r}101,461 \\
59,776 \\
101,272 \\
81,129 \\
1,184,061\end{array}$ & $\begin{array}{r}67,361 \\
59,146 \\
127,853 \\
69,890 \\
157,603\end{array}$ & $\begin{array}{r}178,661 \\
62,651 \\
172,363 \\
108,937 \\
1,988,240\end{array}$ \\
\hline $\begin{array}{l}\text { Colorado .................... } \\
\text { Connecticut ............... } \\
\text { Delaware ............... } \\
\text { District of Columbia ... } \\
\text { Florida ........................ }\end{array}$ & $\begin{array}{r}3,867,788 \\
4,501,537 \\
776,034 \\
706,715 \\
13,756,867\end{array}$ & $\begin{array}{r}3,232,976 \\
4,247,328 \\
694,473 \\
666,938 \\
11,019,735\end{array}$ & $\begin{array}{r}1,970,908 \\
2,721,552 \\
431,618 \\
336,543 \\
6,395,934\end{array}$ & $\begin{array}{r}1,138,810 \\
1,308,873 \\
234,509 \\
301,372 \\
4,085,932\end{array}$ & $\begin{array}{r}134,882 \\
205,801 \\
35,208 \\
68,249 \\
493,124\end{array}$ & $\begin{array}{r}105,180 \\
125,781 \\
10,054 \\
35,583 \\
621,024\end{array}$ & $\begin{array}{r}95,407 \\
85,815 \\
8,607 \\
24,128 \\
124,221\end{array}$ & $\begin{array}{r}212,746 \\
230,445 \\
39,851 \\
35,772 \\
751,327\end{array}$ \\
\hline 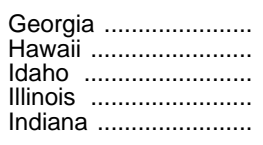 & $\begin{array}{r}7,394,767 \\
1,185,571 \\
1,110,948 \\
12,102,804 \\
6,297,458\end{array}$ & $\begin{array}{r}6,136,689 \\
1,028,729 \\
951,350 \\
10,640,279 \\
5,243,761\end{array}$ & $\begin{array}{r}3,779,713 \\
636,952 \\
602,232 \\
6,367,082 \\
3,262,523\end{array}$ & $\begin{array}{r}1,980,428 \\
328,578 \\
304,596 \\
3,913,546 \\
1,746,052\end{array}$ & $\begin{array}{r}243,585 \\
56,477 \\
47,883 \\
598,430 \\
220,704\end{array}$ & $\begin{array}{r}308,258 \\
47,903 \\
27,869 \\
414,320 \\
150,548\end{array}$ & $\begin{array}{r}92,699 \\
8,317 \\
22,736 \\
346,332 \\
97,521\end{array}$ & $\begin{array}{r}390,256 \\
61,235 \\
57,616 \\
567,303 \\
286,489\end{array}$ \\
\hline 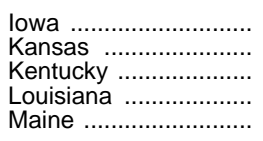 & $\begin{array}{l}2,876,604 \\
2,651,153 \\
3,228,465 \\
3,811,767 \\
1,402,024\end{array}$ & $\begin{array}{l}2,622,510 \\
2,406,580 \\
2,988,892 \\
3,475,926 \\
1,281,706\end{array}$ & $\begin{array}{r}1,623,942 \\
1,387,198 \\
1,787,693 \\
2,071,476 \\
859,560\end{array}$ & $\begin{array}{r}869,366 \\
901,603 \\
1,048,757 \\
1,092,851 \\
375,712\end{array}$ & $\begin{array}{r}151,650 \\
122,448 \\
114,995 \\
129,617 \\
37,206\end{array}$ & $\begin{array}{r}111,906 \\
96,919 \\
94,131 \\
134,672 \\
35,897\end{array}$ & $\begin{array}{r}93,466 \\
97,200 \\
116,323 \\
79,512 \\
25,281\end{array}$ & $\begin{array}{r}136,484 \\
163,849 \\
192,765 \\
191,691 \\
71,727\end{array}$ \\
\hline $\begin{array}{l}\text { Maryland .................. } \\
\text { Massachusetts .......... } \\
\text { Michigan .................... } \\
\text { Minnesota ................ } \\
\text { Mississippi ................ }\end{array}$ & $\begin{array}{r}5,616,288 \\
6,255,672 \\
11,864,469 \\
5,829,727 \\
2,158,879\end{array}$ & $\begin{array}{r}5,083,380 \\
6,062,303 \\
10,440,206 \\
4,622,930 \\
1,921,480\end{array}$ & $\begin{array}{l}3,127,996 \\
3,994,523 \\
6,228,315 \\
2,946,240 \\
1,197,868\end{array}$ & $\begin{array}{r}1,714,032 \\
1,867,028 \\
3,905,033 \\
1,490,265 \\
573,685\end{array}$ & $\begin{array}{r}204,542 \\
280,004 \\
646,546 \\
150,969 \\
67,952\end{array}$ & $\begin{array}{r}205,561 \\
193,981 \\
440,927 \\
244,948 \\
75,608\end{array}$ & $\begin{array}{r}28,724 \\
154,586 \\
216,139 \\
120,037 \\
57,872\end{array}$ & $\begin{array}{l}407,145 \\
262,665 \\
621,034 \\
211,671 \\
104,056\end{array}$ \\
\hline $\begin{array}{l}\text { Missouri . .................... } \\
\text { Montana ................. } \\
\text { Nebraska .................. } \\
\text { Nevada ................. } \\
\text { New Hampshire ......... }\end{array}$ & $\begin{array}{r}4,970,915 \\
917,118 \\
1,858,791 \\
1,382,856 \\
1,165,596\end{array}$ & $\begin{array}{r}4,275,217 \\
844,257 \\
1,594,928 \\
1,186,132 \\
1,053,966\end{array}$ & $\begin{array}{r}2,597,027 \\
525,617 \\
997,581 \\
706,132 \\
679,079\end{array}$ & $\begin{array}{r}1,491,719 \\
283,019 \\
464,411 \\
439,092 \\
337,425\end{array}$ & $\begin{array}{r}177,983 \\
38,085 \\
61,438 \\
44,003 \\
57,176\end{array}$ & $\begin{array}{r}172,595 \\
28,041 \\
52,704 \\
34,017 \\
29,368\end{array}$ & $\begin{array}{r}135,644 \\
28,878 \\
59,617 \\
19,791 \\
37,333\end{array}$ & $\begin{array}{r}250,535 \\
44,106 \\
80,733 \\
85,859 \\
59,965\end{array}$ \\
\hline $\begin{array}{l}\text { New Jersey } \ldots \ldots \ldots \ldots \ldots . . \\
\text { New Mexico ............... } \\
\text { New York ................. } \\
\text { North Carolina ........... } \\
\text { North Dakota .............. }\end{array}$ & $\begin{array}{r}11,785,829 \\
1,672,973 \\
26,273,275 \\
6,206,406 \\
587,279\end{array}$ & $\begin{array}{r}10,776,982 \\
1,441,078 \\
22,989,629 \\
5,440,426 \\
534,632\end{array}$ & $\begin{array}{r}6,467,203 \\
837,029 \\
15,636,396 \\
3,387,680 \\
328,461\end{array}$ & $\begin{array}{r}3,962,515 \\
524,885 \\
6,716,673 \\
1,700,284 \\
158,320\end{array}$ & $\begin{array}{r}711,455 \\
109,502 \\
920,036 \\
275,299 \\
15,055\end{array}$ & $\begin{array}{r}343,400 \\
62,194 \\
515,478 \\
203,004 \\
11,342\end{array}$ & $\begin{array}{r}333,877 \\
38,770 \\
532,921 \\
109,618 \\
26,664\end{array}$ & $\begin{array}{r}616,362 \\
70,822 \\
967,188 \\
360,519 \\
24,667\end{array}$ \\
\hline $\begin{array}{l}\text { Ohio ....................... } \\
\text { Oklahoma ................. } \\
\text { Oregon .................... } \\
\text { Pennsylvania ............. } \\
\text { Rhode Island ............. }\end{array}$ & $\begin{array}{r}11,711,711 \\
3,064,964 \\
3,327,032 \\
13,135,222 \\
1,094,983\end{array}$ & $\begin{array}{r}10,030,956 \\
2,763,721 \\
2,948,539 \\
11,587,027 \\
1,050,969\end{array}$ & $\begin{array}{r}5,960,083 \\
1,662,373 \\
1,776,148 \\
7,460,973 \\
703,185\end{array}$ & $\begin{array}{r}3,696,226 \\
932,702 \\
1,071,438 \\
3,674,151 \\
318,828\end{array}$ & $\begin{array}{r}494,237 \\
146,932 \\
144,181 \\
520,141 \\
63,190\end{array}$ & $\begin{array}{r}491,446 \\
80,318 \\
140,178 \\
360,427 \\
35,484\end{array}$ & $\begin{array}{r}256,871 \\
111,885 \\
64,919 \\
323,749 \\
23,089\end{array}$ & $\begin{array}{r}600,742 \\
153,770 \\
186,509 \\
531,342 \\
51,318\end{array}$ \\
\hline $\begin{array}{l}\text { South Carolina } \\
\text { South Dakota } \ldots \ldots \ldots \ldots . . . \\
\text { Tennessee .................. } \\
\text { Texas .......................... } \\
\text { Utah …..................... }\end{array}$ & $\begin{array}{r}3,353,682 \\
695,692 \\
4,027,607 \\
20,352,717 \\
2,050,021\end{array}$ & $\begin{array}{r}2,920,230 \\
612,825 \\
3,540,682 \\
17,572,269 \\
1,618,047\end{array}$ & $\begin{array}{r}1,727,214 \\
376,116 \\
2,285,884 \\
10,753,150 \\
1,089,195\end{array}$ & $\begin{array}{r}1,007,017 \\
203,434 \\
1,063,138 \\
5,793,863 \\
433,062\end{array}$ & $\begin{array}{r}188,416 \\
25,030 \\
107,096 \\
818,794 \\
46,035\end{array}$ & $\begin{array}{r}164,710 \\
20,853 \\
184,306 \\
756,747 \\
59,045\end{array}$ & $\begin{array}{r}50,323 \\
18,149 \\
77,382 \\
657,189 \\
16,309\end{array}$ & $\begin{array}{r}185,744 \\
34,923 \\
193,446 \\
983,347 \\
91,455\end{array}$ \\
\hline 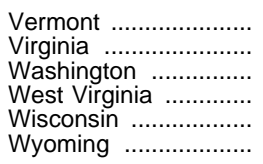 & $\begin{array}{r}727,870 \\
6,637,551 \\
6,172,346 \\
1,945,379 \\
6,030,769 \\
638,647\end{array}$ & $\begin{array}{r}665,559 \\
5,750,318 \\
5,138,928 \\
1,758,557 \\
5,422,264 \\
577,144\end{array}$ & $\begin{array}{r}434,933 \\
3,483,576 \\
3,075,781 \\
1,090,056 \\
3,441,286 \\
358,131\end{array}$ & $\begin{array}{r}209,344 \\
1,959,196 \\
1,824,722 \\
564,738 \\
1,816,370 \\
198,676\end{array}$ & $\begin{array}{r}39,133 \\
276,456 \\
324,236 \\
56,646 \\
227,651 \\
32,069\end{array}$ & $\begin{array}{r}20,037 \\
310,885 \\
248,340 \\
47,696 \\
255,756 \\
17,539\end{array}$ & $\begin{array}{r}19,726 \\
63,440 \\
137,716 \\
45,205 \\
152,683 \\
12,896\end{array}$ & $\begin{array}{r}43,535 \\
343,478 \\
258,070 \\
103,189 \\
282,766 \\
35,055\end{array}$ \\
\hline $\begin{array}{l}\text { Outlying areas } \\
\text { American Samoa ........ } \\
\text { Guam ...................... } \\
\text { Northern Marianas .... } \\
\text { Puerto Rico ............... } \\
\text { Virgin Islands ............. }\end{array}$ & $\begin{array}{r}34,511 \\
161,823 \\
48,127 \\
1,551,369 \\
137,020\end{array}$ & $\begin{array}{r}28,643 \\
161,434 \\
45,008 \\
1,501,485 \\
122,094\end{array}$ & $\begin{array}{r}11,796 \\
79,336 \\
35,613 \\
1,093,038 \\
69,349\end{array}$ & $\begin{array}{r}11,453 \\
68,478 \\
6,581 \\
219,007 \\
45,951\end{array}$ & $\begin{array}{r}3,314 \\
19,120 \\
6,581 \\
34,985 \\
6,171\end{array}$ & $\begin{array}{r}2,397 \\
4,585 \\
0 \\
0 \\
7,677\end{array}$ & $\begin{array}{r}471 \\
2,207 \\
0 \\
94,633 \\
9,289\end{array}$ & $\begin{array}{r}1,568 \\
9,681 \\
0 \\
15,904 \\
6,801\end{array}$ \\
\hline
\end{tabular}


Table 166.-Total expenditures for public elementary and secondary education, by function and state: 1994-95-Continued

[In thousands]

\begin{tabular}{|c|c|c|c|c|c|c|c|c|}
\hline \multirow{4}{*}{ State or other area } & \multicolumn{8}{|c|}{ Total expenditures } \\
\hline & \multicolumn{5}{|c|}{ Current expenditures for elementary and secondary programs } & \multirow{3}{*}{$\begin{array}{l}\text { Other current } \\
\text { expenditures }{ }^{1}\end{array}$} & \multirow{3}{*}{$\begin{array}{l}\text { Capital } \\
\text { outlay }^{2}\end{array}$} & \multirow{3}{*}{$\begin{array}{l}\text { Interest on } \\
\text { school debt }\end{array}$} \\
\hline & \multicolumn{3}{|c|}{ Student services } & \multirow{2}{*}{ Food services } & \multirow{2}{*}{$\begin{array}{l}\text { Enterprise } \\
\text { operations }{ }^{5}\end{array}$} & & & \\
\hline & $\begin{array}{l}\text { Operation and } \\
\text { maintenance }\end{array}$ & $\begin{array}{c}\text { Student } \\
\text { transportation }\end{array}$ & $\begin{array}{l}\text { Other support } \\
\text { services }\end{array}$ & & & & & \\
\hline 1 & 10 & 11 & 12 & 13 & 14 & 15 & 16 & 17 \\
\hline United States ......... & $\$ 24,542,922$ & $\$ 9,889,034$ & $\$ 6,708,262$ & $\$ 10,268,542$ & $\$ 701,053$ & $\$ 5,148,505$ & $\$ 24,456,100$ & $\$ 5,518,131$ \\
\hline 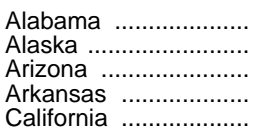 & $\begin{array}{r}257,876 \\
149,321 \\
355,125 \\
160,194 \\
2,703,051\end{array}$ & $\begin{array}{r}125,387 \\
35,338 \\
121,198 \\
71,079 \\
728,475\end{array}$ & $\begin{array}{r}61,304 \\
2,258 \\
107,769 \\
29,872 \\
1,148,364\end{array}$ & $\begin{array}{r}231,851 \\
27,454 \\
169,981 \\
112,852 \\
1,096,200\end{array}$ & $\begin{array}{r}0 \\
4,453 \\
41,012 \\
14,837 \\
3,934\end{array}$ & $\begin{array}{r}55,454 \\
5,636 \\
26,014 \\
11,060 \\
493,215\end{array}$ & $\begin{array}{r}247,086 \\
157,651 \\
725,588 \\
165,941 \\
2,529,013\end{array}$ & $\begin{array}{r}43,287 \\
24,563 \\
175,501 \\
44,237 \\
99,174\end{array}$ \\
\hline 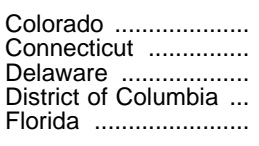 & $\begin{array}{r}288,364 \\
390,086 \\
66,400 \\
100,787 \\
1,284,882\end{array}$ & $\begin{array}{r}91,328 \\
180,164 \\
40,603 \\
14,673 \\
461,045\end{array}$ & $\begin{array}{r}210,903 \\
90,782 \\
33,785 \\
22,179 \\
350,308\end{array}$ & $\begin{array}{r}112,961 \\
124,397 \\
28,347 \\
26,953 \\
537,869\end{array}$ & $\begin{array}{r}10,297 \\
92,506 \\
0 \\
2,071 \\
0\end{array}$ & $\begin{array}{r}8,237 \\
66,132 \\
20,661 \\
9,183 \\
398,246\end{array}$ & $\begin{array}{r}458,354 \\
86,860 \\
52,594 \\
27,400 \\
2,077,463\end{array}$ & $\begin{array}{r}168,220 \\
101,217 \\
8,306 \\
3,194 \\
261,424\end{array}$ \\
\hline 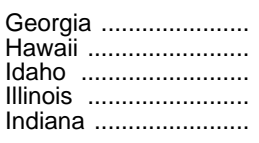 & $\begin{array}{r}541,410 \\
109,945 \\
88,963 \\
1,176,403 \\
571,228\end{array}$ & $\begin{array}{r}236,703 \\
20,932 \\
44,129 \\
488,953 \\
296,455\end{array}$ & $\begin{array}{r}167,517 \\
23,769 \\
15,399 \\
321,805 \\
123,106\end{array}$ & $\begin{array}{r}372,965 \\
63,199 \\
44,522 \\
359,650 \\
235,186\end{array}$ & $\begin{array}{r}3,583 \\
0 \\
0 \\
0 \\
0\end{array}$ & $\begin{array}{r}245,749 \\
33,858 \\
1,699 \\
387,113 \\
40,278\end{array}$ & $\begin{array}{r}899,069 \\
94,706 \\
134,626 \\
835,313 \\
644,345\end{array}$ & $\begin{array}{r}113,260 \\
28,277 \\
23,273 \\
240,099 \\
369,075\end{array}$ \\
\hline 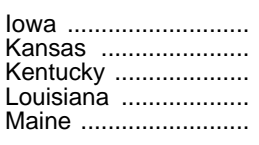 & $\begin{array}{l}230,119 \\
267,158 \\
310,055 \\
301,605 \\
124,030\end{array}$ & $\begin{array}{r}83,499 \\
99,645 \\
178,019 \\
198,378 \\
59,747\end{array}$ & $\begin{array}{l}62,242 \\
54,384 \\
42,470 \\
57,375 \\
21,824\end{array}$ & $\begin{array}{r}118,903 \\
117,778 \\
152,442 \\
262,485 \\
46,432\end{array}$ & $\begin{array}{r}10,299 \\
0 \\
0 \\
49,115 \\
3\end{array}$ & $\begin{array}{r}15,714 \\
3,238 \\
7,540 \\
22,939 \\
15,461\end{array}$ & $\begin{array}{r}209,806 \\
186,381 \\
167,857 \\
219,307 \\
69,977\end{array}$ & $\begin{array}{l}28,574 \\
54,954 \\
64,176 \\
93,594 \\
34,880\end{array}$ \\
\hline $\begin{array}{l}\text { Maryland ................ } \\
\text { Massachusetts .......... } \\
\text { Michigan .................. } \\
\text { Minnesota ................. } \\
\text { Mississippi ................. }\end{array}$ & $\begin{array}{r}508,935 \\
607,195 \\
1,106,729 \\
374,231 \\
161,563\end{array}$ & $\begin{array}{r}258,942 \\
260,916 \\
443,303 \\
246,818 \\
79,374\end{array}$ & $\begin{array}{r}100,184 \\
107,680 \\
430,355 \\
141,593 \\
27,260\end{array}$ & $\begin{array}{l}161,657 \\
200,752 \\
306,858 \\
186,425 \\
149,321\end{array}$ & $\begin{array}{r}79,695 \\
0 \\
0 \\
0 \\
606\end{array}$ & $\begin{array}{r}20,811 \\
22,046 \\
396,602 \\
206,489 \\
12,975\end{array}$ & $\begin{array}{r}458,718 \\
56,327 \\
779,103 \\
832,894 \\
189,219\end{array}$ & $\begin{array}{r}53,379 \\
114,995 \\
248,558 \\
167,414 \\
35,206\end{array}$ \\
\hline $\begin{array}{l}\text { Missouri } \\
\text { Montana ......................... } \\
\text { Nebraska .................... } \\
\text { Nevada .................. } \\
\text { New Hampshire .......... }\end{array}$ & $\begin{array}{r}414,091 \\
88,928 \\
137,977 \\
124,105 \\
95,538\end{array}$ & $\begin{array}{r}252,573 \\
36,971 \\
45,967 \\
52,440 \\
47,865\end{array}$ & $\begin{array}{l}88,297 \\
18,010 \\
25,975 \\
78,878 \\
10,179\end{array}$ & $\begin{array}{r}186,472 \\
35,335 \\
61,069 \\
40,907 \\
37,462\end{array}$ & $\begin{array}{r}0 \\
286 \\
71,867 \\
0 \\
0\end{array}$ & $\begin{array}{r}72,886 \\
3,446 \\
1,895 \\
7,831 \\
3,853\end{array}$ & $\begin{array}{r}527,098 \\
58,245 \\
234,277 \\
126,517 \\
80,403\end{array}$ & $\begin{array}{l}95,714 \\
11,170 \\
27,691 \\
62,377 \\
27,374\end{array}$ \\
\hline 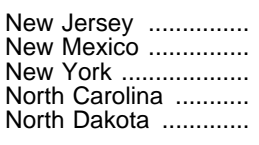 & $\begin{array}{r}1,187,881 \\
151,975 \\
2,112,752 \\
452,060 \\
47,023\end{array}$ & $\begin{array}{r}542,987 \\
72,478 \\
1,135,476 \\
202,679 \\
24,086\end{array}$ & $\begin{array}{r}226,552 \\
19,144 \\
532,822 \\
97,104 \\
9,483\end{array}$ & $\begin{array}{r}305,128 \\
69,589 \\
636,560 \\
352,461 \\
28,392\end{array}$ & $\begin{array}{r}42,136 \\
9,575 \\
0 \\
0 \\
19,459\end{array}$ & $\begin{array}{r}155,678 \\
9,795 \\
891,267 \\
34,895 \\
4,271\end{array}$ & $\begin{array}{r}713,451 \\
199,753 \\
1,911,244 \\
602,044 \\
41,158\end{array}$ & $\begin{array}{r}139,717 \\
22,348 \\
481,135 \\
129,041 \\
7,218\end{array}$ \\
\hline $\begin{array}{l}\text { Ohio ....................... } \\
\text { Oklahoma ................. } \\
\text { Oregon .................... } \\
\text { Pennsylvania ............. } \\
\text { Rhode Island . ............. }\end{array}$ & $\begin{array}{r}976,449 \\
281,658 \\
283,418 \\
1,191,240 \\
86,845\end{array}$ & $\begin{array}{r}267,937 \\
89,730 \\
117,678 \\
464,772 \\
46,942\end{array}$ & $\begin{array}{r}608,545 \\
68,410 \\
134,554 \\
282,480 \\
11,961\end{array}$ & $\begin{array}{r}372,258 \\
146,101 \\
98,931 \\
442,456 \\
28,956\end{array}$ & $\begin{array}{r}2,390 \\
22,545 \\
2,023 \\
9,448 \\
0\end{array}$ & $\begin{array}{r}693,248 \\
10,678 \\
9,784 \\
284,200 \\
6,645\end{array}$ & $\begin{array}{r}709,604 \\
271,306 \\
304,585 \\
994,217 \\
20,229\end{array}$ & $\begin{array}{r}277,903 \\
19,259 \\
64,124 \\
269,779 \\
17,140\end{array}$ \\
\hline $\begin{array}{l}\text { South Carolina } \\
\text { South Dakota } \ldots \ldots \ldots \ldots . . . . . \\
\text { Tennessee .................. } \\
\text { Texas ........................ } \\
\text { Utah ........................ }\end{array}$ & $\begin{array}{r}265,137 \\
59,110 \\
326,088 \\
1,956,723 \\
147,363\end{array}$ & $\begin{array}{r}91,002 \\
24,625 \\
128,713 \\
485,709 \\
45,359\end{array}$ & $\begin{array}{r}61,685 \\
20,743 \\
46,107 \\
135,354 \\
27,497\end{array}$ & $\begin{array}{r}175,774 \\
31,867 \\
191,660 \\
993,076 \\
91,662\end{array}$ & $\begin{array}{r}10,225 \\
1,408 \\
0 \\
32,180 \\
4,128\end{array}$ & $\begin{array}{r}61,754 \\
1,194 \\
16,785 \\
87,311 \\
48,035\end{array}$ & $\begin{array}{r}293,549 \\
69,492 \\
395,526 \\
2,148,179 \\
337,844\end{array}$ & $\begin{array}{r}78,150 \\
12,181 \\
74,614 \\
544,958 \\
46,095\end{array}$ \\
\hline 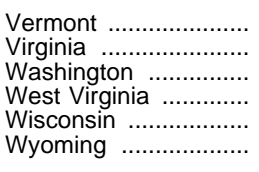 & $\begin{array}{r}53,494 \\
604,534 \\
530,680 \\
174,973 \\
493,584 \\
63,640 \\
\end{array}$ & $\begin{array}{r}22,184 \\
253,327 \\
206,454 \\
113,597 \\
229,896 \\
22,485 \\
\end{array}$ & $\begin{array}{r}11,236 \\
107,077 \\
119,226 \\
23,432 \\
174,034 \\
14,992 \\
\end{array}$ & $\begin{array}{r}19,129 \\
221,934 \\
165,327 \\
103,652 \\
164,608 \\
20,336 \\
\end{array}$ & $\begin{array}{r}2,154 \\
85,612 \\
73,098 \\
111 \\
0 \\
0 \\
\end{array}$ & $\begin{array}{r}3,502 \\
110,016 \\
24,984 \\
28,917 \\
47,641 \\
1,643 \\
\end{array}$ & $\begin{array}{r}49,269 \\
631,622 \\
785,663 \\
141,023 \\
455,293 \\
48,913 \\
\end{array}$ & $\begin{array}{r}9,540 \\
145,594 \\
222,772 \\
16,882 \\
105,571 \\
10,947 \\
\end{array}$ \\
\hline $\begin{array}{l}\text { Outlying areas } \\
\text { American Samoa ........ } \\
\text { Guam ...................... } \\
\text { Northern Marianas .... } \\
\text { Puerto Rico ............... } \\
\text { Virgin Islands .............. }\end{array}$ & $\begin{array}{r}1,614 \\
16,199 \\
0 \\
38,081 \\
7,020\end{array}$ & $\begin{array}{r}834 \\
10,608 \\
0 \\
34,259 \\
3,214\end{array}$ & $\begin{array}{r}1,254 \\
6,078 \\
0 \\
1,144 \\
5,780\end{array}$ & $\begin{array}{r}5,394 \\
10,099 \\
2,814 \\
189,440 \\
6,731\end{array}$ & $\begin{array}{r}0 \\
3,520 \\
0 \\
0 \\
64\end{array}$ & $\begin{array}{r}2,901 \\
169 \\
261 \\
20,351 \\
1,485\end{array}$ & $\begin{array}{r}2,967 \\
219 \\
2,858 \\
28,709 \\
13,441\end{array}$ & $\begin{array}{r}0 \\
0 \\
0 \\
824 \\
0\end{array}$ \\
\hline
\end{tabular}

1 Includes expenditures for adult education, community colleges, private school programs funded by local and state education agencies, and community services.

${ }^{2}$ Includes expenditures for property and for building and alterations completed by school district staff or contractors.

${ }^{3}$ Includes expenditures for health, attendance, and speech pathology services.

${ }^{4}$ Includes expenditures for curriculum development, staff training, libraries, and media and computer centers.
5 Includes expenditures for operations funded by sales of products or services (e.g., school bookstore or computer time).

NOTE.-Excludes expenditures for state education agencies. Some data have been revised from previously published figures. Because of rounding, details may not add to totals.

SOURCE: U.S. Department of Education, National Center for Education Statistics, Common Core of Data survey. (This table was prepared July 1998.) 
Table 167.-Current expenditure per pupil in average daily attendance in public elementary and secondary schools, by state: $1959-60$ to $1995-96$

\begin{tabular}{|c|c|c|c|c|c|c|c|c|c|c|c|c|c|c|}
\hline \multirow{2}{*}{ State or other area } & \multicolumn{14}{|c|}{ Unadjusted dollars } \\
\hline & $1959-60$ & $1969-70$ & $1979-80$ & $1980-81$ & $1985-86$ & $1987-88$ & 1988-89 & $1989-90$ & $1990-91$ & 1991-92 & $1992-93$ & $1993-94$ & 1994-95 & $1995-96$ \\
\hline 1 & 2 & 3 & 4 & 5 & 6 & 7 & 8 & 9 & 10 & 11 & 12 & 13 & 14 & 15 \\
\hline United States .............. & $\$ 375$ & $\$ 816$ & $\$ 2,272$ & $\$ 2,502$ & $\$ 3,756$ & $\$ 4,240$ & $\$ 4,645$ & $\$ 4,980$ & $\$ 5,258$ & $\$ 5,421$ & $\$ 5,584$ & $\$ 5,767$ & $\$ 5,989$ & $\$ 6,146$ \\
\hline 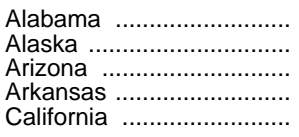 & $\begin{array}{r}241 \\
546 \\
404 \\
225 \\
2424\end{array}$ & $\begin{array}{r}544 \\
1,123 \\
720 \\
568 \\
867\end{array}$ & $\begin{array}{l}1,612 \\
4,728 \\
1,971 \\
1,574 \\
2,268\end{array}$ & $\begin{array}{l}1,985 \\
5,688 \\
2,258 \\
1,701 \\
2,475\end{array}$ & $\begin{array}{l}2,565 \\
8,304 \\
3,336 \\
2,658 \\
3,543\end{array}$ & $\begin{array}{l}2,718 \\
7,971 \\
3,744 \\
2,989 \\
3,840\end{array}$ & $\begin{array}{l}3,197 \\
7,716 \\
3,902 \\
3,273 \\
4,135\end{array}$ & $\begin{array}{l}3,327 \\
8,431 \\
4,053 \\
3,485 \\
4,391\end{array}$ & $\begin{array}{l}3,627 \\
8,330 \\
4,309 \\
3,700 \\
4,491\end{array}$ & $\begin{array}{l}3,616 \\
8,450 \\
4,381 \\
4,031 \\
4,746\end{array}$ & $\begin{array}{l}3,761 \\
8,735 \\
4,510 \\
4,124 \\
4,780\end{array}$ & $\begin{array}{l}4,037 \\
8,882 \\
4,611 \\
4,280 \\
4,921\end{array}$ & $\begin{array}{l}4,405 \\
8,963 \\
4,778 \\
4,459 \\
4,992\end{array}$ & $\begin{array}{l}4,716 \\
9,012 \\
4,860 \\
4,710 \\
5,108\end{array}$ \\
\hline $\begin{array}{l}\text { Colorado } \\
\text { Connecticut .......................... } \\
\text { Delaware ..................... } \\
\text { District of Columbia ......... } \\
\text { Florida .............................. }\end{array}$ & $\begin{array}{l}396 \\
436 \\
456 \\
431 \\
318\end{array}$ & $\begin{array}{r}738 \\
951 \\
900 \\
1,018 \\
732\end{array}$ & $\begin{array}{l}2,421 \\
2,420 \\
2,861 \\
3,259 \\
1,889\end{array}$ & $\begin{array}{l}2,693 \\
2,876 \\
3,018 \\
3,441 \\
2,401\end{array}$ & $\begin{array}{l}3,975 \\
4,743 \\
4,610 \\
5,337 \\
3,529\end{array}$ & $\begin{array}{l}4,220 \\
6,230 \\
5,017 \\
6,132 \\
4,092\end{array}$ & $\begin{array}{l}4,521 \\
6,857 \\
5,422 \\
7,850 \\
4,563\end{array}$ & $\begin{array}{l}4,720 \\
7,837 \\
5,799 \\
8,955 \\
4,997\end{array}$ & $\begin{array}{l}5,064 \\
7,853 \\
5,974 \\
9,377 \\
5,276\end{array}$ & $\begin{array}{l}5,172 \\
8,012 \\
6,093 \\
9,549 \\
5,243\end{array}$ & $\begin{array}{l}5,139 \\
7,973 \\
6,274 \\
9,419 \\
5,314\end{array}$ & $\begin{array}{r}5,097 \\
8,473 \\
6,621 \\
10,180 \\
5,516\end{array}$ & $\begin{array}{l}5,443 \\
8,817 \\
7,030 \\
9,335 \\
5,718\end{array}$ & $\begin{array}{l}5,521 \\
8,817 \\
7,267 \\
9,565 \\
5,894\end{array}$ \\
\hline 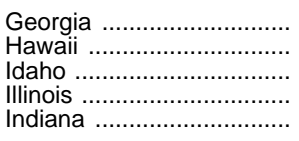 & $\begin{array}{l}253 \\
325 \\
290 \\
438 \\
369\end{array}$ & $\begin{array}{l}588 \\
841 \\
603 \\
909 \\
728\end{array}$ & $\begin{array}{l}1,625 \\
2,322 \\
1,659 \\
2,587 \\
1,882\end{array}$ & $\begin{array}{l}1,708 \\
2,604 \\
1,856 \\
2,704 \\
2,010\end{array}$ & $\begin{array}{l}2,966 \\
3,807 \\
2,484 \\
3,781 \\
3,275\end{array}$ & $\begin{array}{l}3,434 \\
3,919 \\
2,667 \\
4,369 \\
3,794\end{array}$ & $\begin{array}{l}3,852 \\
4,121 \\
2,833 \\
4,906 \\
4,284\end{array}$ & $\begin{array}{l}4,275 \\
4,448 \\
3,078 \\
5,118 \\
4,606\end{array}$ & $\begin{array}{l}4,466 \\
5,166 \\
3,386 \\
5,520 \\
4,930\end{array}$ & $\begin{array}{l}4,419 \\
5,420 \\
3,556 \\
5,670 \\
5,074\end{array}$ & $\begin{array}{l}4,686 \\
5,704 \\
3,690 \\
5,898 \\
5,344\end{array}$ & $\begin{array}{l}4,915 \\
5,879 \\
3,844 \\
5,893 \\
5,630\end{array}$ & $\begin{array}{l}5,193 \\
6,078 \\
4,210 \\
6,136 \\
5,826\end{array}$ & $\begin{array}{l}5,377 \\
6,051 \\
4,465 \\
6,128 \\
6,040\end{array}$ \\
\hline 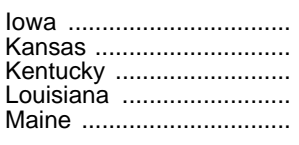 & $\begin{array}{l}368 \\
348 \\
233 \\
372 \\
283\end{array}$ & $\begin{array}{l}844 \\
771 \\
545 \\
648 \\
692\end{array}$ & $\begin{array}{l}2,326 \\
2,173 \\
1,701 \\
1,792 \\
1,824\end{array}$ & $\begin{array}{l}2,668 \\
2,559 \\
1,784 \\
2,469 \\
1,934\end{array}$ & $\begin{array}{l}3,619 \\
3,829 \\
2,486 \\
3,187 \\
3,472\end{array}$ & $\begin{array}{l}4,124 \\
4,076 \\
3,011 \\
3,138 \\
4,258\end{array}$ & $\begin{array}{l}4,285 \\
4,443 \\
3,347 \\
3,317 \\
4,744\end{array}$ & $\begin{array}{l}4,453 \\
4,752 \\
3,745 \\
3,903 \\
5,373\end{array}$ & $\begin{array}{l}4,679 \\
4,874 \\
4,354 \\
4,196 \\
5,458\end{array}$ & $\begin{array}{l}5,096 \\
5,007 \\
4,719 \\
4,352 \\
5,652\end{array}$ & $\begin{array}{l}5,257 \\
5,442 \\
4,872 \\
4,428 \\
6,073\end{array}$ & $\begin{array}{l}5,288 \\
5,659 \\
5,107 \\
4,519 \\
6,069\end{array}$ & $\begin{array}{l}5,483 \\
5,817 \\
5,217 \\
4,761 \\
6,428\end{array}$ & $\begin{array}{l}5,772 \\
5,971 \\
5,545 \\
4,988 \\
6,546\end{array}$ \\
\hline 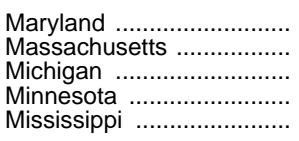 & $\begin{array}{l}393 \\
409 \\
415 \\
425 \\
206\end{array}$ & $\begin{array}{l}918 \\
859 \\
904 \\
904 \\
501\end{array}$ & $\begin{array}{l}2,598 \\
2,819 \\
2,640 \\
2,387 \\
1,664\end{array}$ & $\begin{array}{l}2,914 \\
2,940 \\
3,037 \\
2,673 \\
1,605\end{array}$ & $\begin{array}{l}4,447 \\
4,562 \\
4,176 \\
3,941 \\
2,362\end{array}$ & $\begin{array}{l}5,201 \\
5,471 \\
4,692 \\
4,386 \\
2,548\end{array}$ & $\begin{array}{l}5,758 \\
5,972 \\
5,150 \\
4,755 \\
2,861\end{array}$ & $\begin{array}{l}6,275 \\
6,237 \\
5,546 \\
4,971 \\
3,094\end{array}$ & $\begin{array}{l}6,654 \\
6,366 \\
5,883 \\
5,239 \\
3,187\end{array}$ & $\begin{array}{l}6,679 \\
6,408 \\
6,268 \\
5,409 \\
3,245\end{array}$ & $\begin{array}{l}6,813 \\
6,627 \\
6,494 \\
5,554 \\
3,382\end{array}$ & $\begin{array}{l}6,958 \\
6,959 \\
6,658 \\
5,720 \\
3,660\end{array}$ & $\begin{array}{l}7,245 \\
7,287 \\
6,994 \\
6,000 \\
4,080\end{array}$ & $\begin{array}{l}7,382 \\
7,613 \\
7,166 \\
6,162 \\
4,250\end{array}$ \\
\hline $\begin{array}{l}\text { Missouri } \\
\text { Montana ............................... } \\
\text { Nebraska ......................... } \\
\text { Nevada ...................... } \\
\text { New Hampshire ............... }\end{array}$ & $\begin{array}{l}344 \\
411 \\
337 \\
430 \\
347\end{array}$ & $\begin{array}{l}709 \\
782 \\
736 \\
769 \\
723\end{array}$ & $\begin{array}{l}1,936 \\
2,476 \\
2,150 \\
2,088 \\
1,916\end{array}$ & $\begin{array}{l}2,172 \\
2,683 \\
2,384 \\
2,078 \\
2,265\end{array}$ & $\begin{array}{l}3,189 \\
4,091 \\
3,634 \\
3,440 \\
3,542\end{array}$ & $\begin{array}{l}3,786 \\
4,246 \\
3,943 \\
3,623 \\
4,457\end{array}$ & $\begin{array}{l}4,263 \\
4,293 \\
4,360 \\
3,871 \\
4,807\end{array}$ & $\begin{array}{l}4,507 \\
4,736 \\
4,842 \\
4,117 \\
5,304\end{array}$ & $\begin{array}{l}4,754 \\
5,204 \\
5,038 \\
4,653 \\
5,685\end{array}$ & $\begin{array}{l}4,830 \\
5,319 \\
5,263 \\
4,926 \\
5,790\end{array}$ & $\begin{array}{l}4,885 \\
5,425 \\
5,336 \\
5,066 \\
5,644\end{array}$ & $\begin{array}{l}5,114 \\
5,598 \\
5,651 \\
5,052 \\
5,723\end{array}$ & $\begin{array}{l}5,383 \\
5,692 \\
5,935 \\
5,160 \\
5,859\end{array}$ & $\begin{array}{l}5,626 \\
5,847 \\
6,083 \\
5,320 \\
5,958\end{array}$ \\
\hline $\begin{array}{l}\text { New Jersey } \ldots \ldots \ldots \ldots \ldots \ldots \ldots \\
\text { New Mexico ...................... } \\
\text { New York ...................... } \\
\text { North Carolina ................ } \\
\text { North Dakota ................... }\end{array}$ & $\begin{array}{l}388 \\
363 \\
562 \\
237 \\
367\end{array}$ & $\begin{array}{r}1,016 \\
707 \\
1,327 \\
612 \\
690\end{array}$ & $\begin{array}{l}3,191 \\
2,034 \\
3,462 \\
1,754 \\
1,920\end{array}$ & $\begin{array}{l}3,254 \\
2,329 \\
3,741 \\
2,001 \\
2,275\end{array}$ & $\begin{array}{l}5,570 \\
3,195 \\
6,011 \\
2,948 \\
3,483\end{array}$ & $\begin{array}{l}6,564 \\
3,691 \\
7,151 \\
3,368 \\
3,519\end{array}$ & $\begin{array}{l}7,549 \\
3,473 \\
7,663 \\
3,874 \\
3,952\end{array}$ & $\begin{array}{l}8,139 \\
3,515 \\
8,062 \\
4,290 \\
4,189\end{array}$ & $\begin{array}{l}8,756 \\
3,895 \\
8,565 \\
4,548 \\
4,199\end{array}$ & $\begin{array}{l}9,317 \\
3,765 \\
8,527 \\
4,554 \\
4,441\end{array}$ & $\begin{array}{l}9,415 \\
4,071 \\
8,902 \\
4,763 \\
4,597\end{array}$ & $\begin{array}{l}9,677 \\
4,261 \\
9,175 \\
4,894 \\
4,674\end{array}$ & $\begin{array}{l}9,774 \\
4,577 \\
9,623 \\
5,077 \\
4,795\end{array}$ & $\begin{array}{l}9,955 \\
4,587 \\
9,549 \\
5,090 \\
4,979\end{array}$ \\
\hline 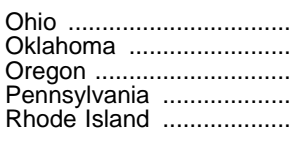 & $\begin{array}{l}365 \\
311 \\
448 \\
409 \\
413\end{array}$ & $\begin{array}{l}730 \\
604 \\
925 \\
882 \\
891\end{array}$ & $\begin{array}{l}2,075 \\
1,926 \\
2,692 \\
2,535 \\
2,601\end{array}$ & $\begin{array}{l}2,303 \\
2,199 \\
3,100 \\
2,824 \\
2,927\end{array}$ & $\begin{array}{l}3,527 \\
3,146 \\
4,141 \\
4,325 \\
4,667\end{array}$ & $\begin{array}{l}3,998 \\
3,093 \\
4,789 \\
4,989 \\
5,329\end{array}$ & $\begin{array}{l}4,686 \\
3,379 \\
5,182 \\
5,597 \\
6,064\end{array}$ & $\begin{array}{l}5,045 \\
3,508 \\
5,474 \\
6,228 \\
6,368\end{array}$ & $\begin{array}{l}5,245 \\
3,843 \\
5,683 \\
6,541 \\
6,343\end{array}$ & $\begin{array}{l}5,694 \\
4,076 \\
5,913 \\
6,613 \\
6,546\end{array}$ & $\begin{array}{l}5,754 \\
4,355 \\
6,296 \\
6,890 \\
6,938\end{array}$ & $\begin{array}{l}5,971 \\
4,734 \\
6,263 \\
6,983 \\
7,333\end{array}$ & $\begin{array}{l}6,162 \\
4,845 \\
6,436 \\
7,109 \\
7,715\end{array}$ & $\begin{array}{l}6,266 \\
4,881 \\
6,615 \\
7,492 \\
7,936\end{array}$ \\
\hline 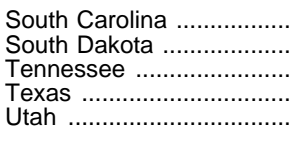 & $\begin{array}{l}220 \\
347 \\
238 \\
332 \\
322\end{array}$ & $\begin{array}{l}613 \\
690 \\
566 \\
624 \\
626\end{array}$ & $\begin{array}{l}1,752 \\
1,908 \\
1,635 \\
1,916 \\
1,657\end{array}$ & $\begin{array}{l}1,734 \\
1,991 \\
1,794 \\
2,006 \\
1,819\end{array}$ & $\begin{array}{l}3,058 \\
3,051 \\
2,612 \\
3,298 \\
2,390\end{array}$ & $\begin{array}{l}3,408 \\
3,249 \\
3,068 \\
3,608 \\
2,454\end{array}$ & $\begin{array}{l}3,736 \\
3,585 \\
3,491 \\
3,877 \\
2,588\end{array}$ & $\begin{array}{l}4,082 \\
3,731 \\
3,664 \\
4,150 \\
2,764\end{array}$ & $\begin{array}{l}4,352 \\
3,965 \\
3,782 \\
4,438 \\
2,960\end{array}$ & $\begin{array}{l}4,436 \\
4,173 \\
3,692 \\
4,632 \\
3,040\end{array}$ & $\begin{array}{l}4,624 \\
4,357 \\
3,993 \\
4,670 \\
3,180\end{array}$ & $\begin{array}{l}4,761 \\
4,586 \\
4,149 \\
4,898 \\
3,439\end{array}$ & $\begin{array}{l}4,797 \\
4,775 \\
4,388 \\
5,222 \\
3,656\end{array}$ & $\begin{array}{l}5,096 \\
4,780 \\
4,548 \\
5,473 \\
3,867\end{array}$ \\
\hline 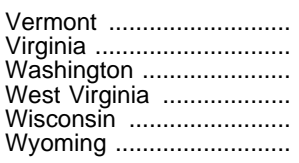 & $\begin{array}{l}344 \\
274 \\
420 \\
258 \\
413 \\
450\end{array}$ & $\begin{array}{l}807 \\
708 \\
915 \\
670 \\
883 \\
856\end{array}$ & $\begin{array}{l}1,997 \\
1,970 \\
2,568 \\
1,920 \\
2,477 \\
2,527\end{array}$ & $\begin{array}{l}2,475 \\
2,179 \\
2,542 \\
2,146 \\
2,738 \\
2,967\end{array}$ & $\begin{array}{l}4,031 \\
3,520 \\
3,881 \\
3,528 \\
4,168 \\
5,114\end{array}$ & $\begin{array}{l}5,207 \\
4,149 \\
4,164 \\
3,858 \\
4,747 \\
5,051\end{array}$ & $\begin{array}{l}5,481 \\
4,539 \\
4,359 \\
3,883 \\
5,266 \\
5,375\end{array}$ & $\begin{array}{l}6,227 \\
4,672 \\
4,702 \\
4,360 \\
5,524 \\
5,577\end{array}$ & $\begin{array}{l}6,738 \\
4,902 \\
5,000 \\
4,911 \\
5,871 \\
5,638\end{array}$ & $\begin{array}{l}6,671 \\
4,878 \\
5,271 \\
5,078 \\
6,139 \\
5,812\end{array}$ & $\begin{array}{l}6,411 \\
4,980 \\
5,614 \\
5,527 \\
6,475 \\
5,822\end{array}$ & $\begin{array}{l}6,600 \\
5,109 \\
5,751 \\
5,713 \\
6,717 \\
5,899\end{array}$ & $\begin{array}{l}6,750 \\
5,327 \\
5,906 \\
6,107 \\
6,930 \\
6,160\end{array}$ & $\begin{array}{l}6,837 \\
5,433 \\
6,044 \\
6,325 \\
7,094 \\
6,243\end{array}$ \\
\hline $\begin{array}{l}\text { Outlying areas } \\
\text { American Samoa } \ldots \ldots \ldots \ldots . . . \\
\text { Guam .......................... } \\
\text { Northern Marianas .......... } \\
\text { Puerto Rico ..................... } \\
\text { Virgin Islands ................. }\end{array}$ & $\begin{array}{l}106 \\
271\end{array}$ & $\begin{array}{r}\overline{-} \\
- \\
-\end{array}$ & $\begin{array}{l}- \\
- \\
-\end{array}$ & $\begin{array}{l}- \\
- \\
-\end{array}$ & $\begin{array}{l}1,387 \\
3,383 \\
2,552 \\
1,325 \\
3,223\end{array}$ & $\begin{array}{l}1,908 \\
3,295 \\
3,366 \\
1,504 \\
4,036\end{array}$ & $\begin{array}{l}1,988 \\
4,067 \\
2,414 \\
1,692 \\
5,281\end{array}$ & $\begin{array}{l}1,908 \\
4,234 \\
3,007 \\
1,750 \\
6,767\end{array}$ & $\begin{array}{l}2,033 \\
4,596 \\
4,425 \\
1,913 \\
6,002\end{array}$ & $\begin{array}{l}2,085 \\
5,231 \\
5,247 \\
2,162 \\
5,935\end{array}$ & $\begin{array}{l}1,670 \\
5,309 \\
5,288 \\
2,364 \\
5,843\end{array}$ & $\begin{array}{l}1,785 \\
5,071 \\
4,510 \\
2,312 \\
5,915\end{array}$ & $\begin{array}{l}2,046 \\
5,080 \\
6,123 \\
2,742 \\
6,003\end{array}$ & $\begin{array}{l}2,159 \\
4,947 \\
5,863 \\
3,039 \\
6,155\end{array}$ \\
\hline
\end{tabular}


Table 167.-Current expenditure per pupil in average daily attendance in public elementary and secondary schools, by state: 1959-60 to 1995-96-Continued

\begin{tabular}{|c|c|c|c|c|c|c|c|c|c|c|c|c|c|c|}
\hline \multirow{2}{*}{ State or other area } & \multicolumn{14}{|c|}{ Constant $1995-96$ dollars $^{1}$} \\
\hline & $1959-60$ & 1969-70 & $1979-80$ & $1980-81$ & $1985-86$ & $1987-88$ & 1988-89 & $1989-90$ & $1990-91$ & 1991-92 & 1992-93 & 1993-94 & 1994-95 & $1995-96$ \\
\hline 1 & 16 & 17 & 18 & 19 & 20 & 21 & 22 & 23 & 24 & 25 & 26 & 27 & 28 & 29 \\
\hline United States ............... & $\$ 1,973$ & $\$ 3,337$ & $\$ 4,521$ & $\$ 4,462$ & $\$ 5,332$ & $\$ 5,655$ & $\$ 5,921$ & $\$ 6,059$ & $\$ 6,066$ & $\$ 6,060$ & $\$ 6,053$ & $\$ 6,094$ & $\$ 6,152$ & $\$ 6,146$ \\
\hline 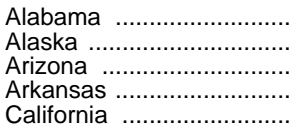 & $\begin{array}{r}1,268 \\
2,873 \\
2,122 \\
1,184 \\
22,229\end{array}$ & $\begin{array}{l}2,225 \\
4,591 \\
2,945 \\
2,322 \\
3,547\end{array}$ & $\begin{array}{l}3,208 \\
9,409 \\
3,922 \\
3,133 \\
4,513\end{array}$ & $\begin{array}{r}3,540 \\
10,145 \\
4,028 \\
3,034 \\
4,414\end{array}$ & $\begin{array}{r}3,641 \\
11,790 \\
4,737 \\
3,773 \\
5,031\end{array}$ & $\begin{array}{r}3,625 \\
10,631 \\
4,994 \\
3,987 \\
5,122\end{array}$ & $\begin{array}{l}4,075 \\
9,837 \\
4,975 \\
4,173 \\
5,271\end{array}$ & $\begin{array}{r}4,048 \\
10,259 \\
4,932 \\
4,240 \\
5,343\end{array}$ & $\begin{array}{l}4,184 \\
9,610 \\
4,971 \\
4,269 \\
5,181\end{array}$ & $\begin{array}{l}4,042 \\
9,446 \\
4,897 \\
4,506 \\
5,305\end{array}$ & $\begin{array}{l}4,077 \\
9,468 \\
4,889 \\
4,471 \\
5,182\end{array}$ & $\begin{array}{l}4,265 \\
9,385 \\
4,872 \\
4,523 \\
5,200\end{array}$ & $\begin{array}{l}4,525 \\
9,207 \\
4,908 \\
4,580 \\
5,128\end{array}$ & $\begin{array}{l}4,716 \\
9,012 \\
4,860 \\
4,710 \\
5,108\end{array}$ \\
\hline $\begin{array}{l}\text { Colorado } \\
\text { Connecticut ........................ } \\
\text { Delaware ..................... } \\
\text { District of Columbia ......... } \\
\text { Florida ........................... }\end{array}$ & $\begin{array}{l}2,083 \\
2,293 \\
2,396 \\
2,267 \\
1,670\end{array}$ & $\begin{array}{l}3,018 \\
3,891 \\
3,681 \\
4,165 \\
2,995\end{array}$ & $\begin{array}{l}4,818 \\
4,816 \\
5,694 \\
6,486 \\
3,759\end{array}$ & $\begin{array}{l}4,802 \\
5,129 \\
5,383 \\
6,137 \\
4,283\end{array}$ & $\begin{array}{l}5,643 \\
6,734 \\
6,545 \\
7,578 \\
5,011\end{array}$ & $\begin{array}{l}5,628 \\
8,310 \\
6,692 \\
8,179 \\
5,458\end{array}$ & $\begin{array}{r}5,763 \\
8,742 \\
6,913 \\
10,008 \\
5,817\end{array}$ & $\begin{array}{r}5,744 \\
9,536 \\
7,056 \\
10,896 \\
6,081\end{array}$ & $\begin{array}{r}5,842 \\
9,061 \\
6,892 \\
10,819 \\
6,087\end{array}$ & $\begin{array}{r}5,781 \\
8,957 \\
6,811 \\
10,675 \\
5,861\end{array}$ & $\begin{array}{r}5,571 \\
8,643 \\
6,801 \\
10,211 \\
5,761\end{array}$ & $\begin{array}{r}5,386 \\
8,953 \\
6,997 \\
10,757 \\
5,828\end{array}$ & $\begin{array}{l}5,591 \\
9,056 \\
7,221 \\
9,589 \\
5,874\end{array}$ & $\begin{array}{l}5,521 \\
8,817 \\
7,267 \\
9,565 \\
5,894\end{array}$ \\
\hline 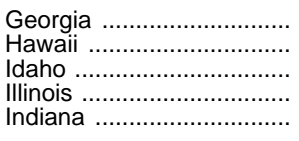 & $\begin{array}{l}1,333 \\
1,707 \\
1,523 \\
2,305 \\
1,939\end{array}$ & $\begin{array}{l}2,405 \\
3,438 \\
2,467 \\
3,720 \\
2,978\end{array}$ & $\begin{array}{l}3,234 \\
4,621 \\
3,302 \\
5,148 \\
3,746\end{array}$ & $\begin{array}{l}3,047 \\
4,644 \\
3,310 \\
4,822 \\
3,585\end{array}$ & $\begin{array}{l}4,211 \\
5,405 \\
3,526 \\
5,369 \\
4,650\end{array}$ & $\begin{array}{l}4,580 \\
5,226 \\
3,557 \\
5,827 \\
5,060\end{array}$ & $\begin{array}{l}4,911 \\
5,253 \\
3,611 \\
6,254 \\
5,462\end{array}$ & $\begin{array}{l}5,201 \\
5,413 \\
3,745 \\
6,227 \\
5,605\end{array}$ & $\begin{array}{l}5,152 \\
5,960 \\
3,907 \\
6,369 \\
5,688\end{array}$ & $\begin{array}{l}4,940 \\
6,059 \\
3,975 \\
6,338 \\
5,672\end{array}$ & $\begin{array}{l}5,079 \\
6,184 \\
4,000 \\
6,394 \\
5,793\end{array}$ & $\begin{array}{l}5,193 \\
6,212 \\
4,062 \\
6,227 \\
5,949\end{array}$ & $\begin{array}{l}5,334 \\
6,243 \\
4,324 \\
6,303 \\
5,985\end{array}$ & $\begin{array}{l}5,377 \\
6,051 \\
4,465 \\
6,128 \\
6,040\end{array}$ \\
\hline 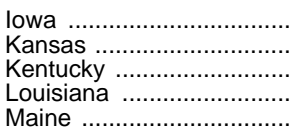 & $\begin{array}{l}1,933 \\
1,828 \\
1,226 \\
1,956 \\
1,487\end{array}$ & $\begin{array}{l}3,453 \\
3,153 \\
2,230 \\
2,650 \\
2,832\end{array}$ & $\begin{array}{l}4,630 \\
4,325 \\
3,385 \\
3,566 \\
3,629\end{array}$ & $\begin{array}{l}4,758 \\
4,564 \\
3,182 \\
4,404 \\
3,449\end{array}$ & $\begin{array}{l}5,139 \\
5,437 \\
3,530 \\
4,525 \\
4,929\end{array}$ & $\begin{array}{l}5,500 \\
5,437 \\
4,015 \\
4,185 \\
5,679\end{array}$ & $\begin{array}{l}5,462 \\
5,664 \\
4,267 \\
4,229 \\
6,047\end{array}$ & $\begin{array}{l}5,418 \\
5,782 \\
4,557 \\
4,750 \\
6,538\end{array}$ & $\begin{array}{l}5,398 \\
5,623 \\
5,023 \\
4,841 \\
6,297\end{array}$ & $\begin{array}{l}5,697 \\
5,598 \\
5,275 \\
4,865 \\
6,318\end{array}$ & $\begin{array}{l}5,699 \\
5,899 \\
5,281 \\
4,800 \\
6,583\end{array}$ & $\begin{array}{l}5,588 \\
5,980 \\
5,397 \\
4,775 \\
6,412\end{array}$ & $\begin{array}{l}5,632 \\
5,975 \\
5,359 \\
4,890 \\
6,603\end{array}$ & $\begin{array}{l}5,772 \\
5,971 \\
5,545 \\
4,988 \\
6,546\end{array}$ \\
\hline 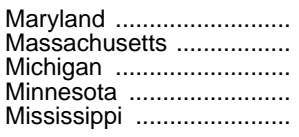 & $\begin{array}{l}2,065 \\
2,150 \\
2,183 \\
2,236 \\
1,083\end{array}$ & $\begin{array}{l}3,756 \\
3,514 \\
3,697 \\
3,696 \\
2,048\end{array}$ & $\begin{array}{l}5,170 \\
5,611 \\
5,255 \\
4,750 \\
3,311\end{array}$ & $\begin{array}{l}5,197 \\
5,243 \\
5,416 \\
4,768 \\
2,863\end{array}$ & $\begin{array}{l}6,314 \\
6,478 \\
5,929 \\
5,595 \\
3,353\end{array}$ & $\begin{array}{l}6,937 \\
7,297 \\
6,257 \\
5,850 \\
3,398\end{array}$ & $\begin{array}{l}7,341 \\
7,613 \\
6,565 \\
6,062 \\
3,647\end{array}$ & $\begin{array}{l}7,636 \\
7,589 \\
6,749 \\
6,048 \\
3,764\end{array}$ & $\begin{array}{l}7,676 \\
7,344 \\
6,787 \\
6,044 \\
3,676\end{array}$ & $\begin{array}{l}7,466 \\
7,164 \\
7,007 \\
6,046 \\
3,628\end{array}$ & $\begin{array}{l}7,385 \\
7,184 \\
7,040 \\
6,021 \\
3,667\end{array}$ & $\begin{array}{l}7,352 \\
7,354 \\
7,035 \\
6,044 \\
3,868\end{array}$ & $\begin{array}{l}7,443 \\
7,485 \\
7,185 \\
6,163 \\
4,191\end{array}$ & $\begin{array}{l}7,382 \\
7,613 \\
7,166 \\
6,162 \\
4,250\end{array}$ \\
\hline $\begin{array}{l}\text { Missouri ............................. } \\
\text { Montana ........................ } \\
\text { Nebraska ...................... } \\
\text { Nevada ......................... } \\
\text { New Hampshire ............... }\end{array}$ & $\begin{array}{l}1,809 \\
2,160 \\
1,772 \\
2,263 \\
1,826\end{array}$ & $\begin{array}{l}2,898 \\
3,198 \\
3,012 \\
3,147 \\
2,957\end{array}$ & $\begin{array}{l}3,853 \\
4,929 \\
4,279 \\
4,156 \\
3,813\end{array}$ & $\begin{array}{l}3,874 \\
4,786 \\
4,253 \\
3,706 \\
4,040\end{array}$ & $\begin{array}{l}4,528 \\
5,808 \\
5,159 \\
4,884 \\
5,028\end{array}$ & $\begin{array}{l}5,049 \\
5,663 \\
5,259 \\
4,832 \\
5,945\end{array}$ & $\begin{array}{l}5,434 \\
5,472 \\
5,559 \\
4,934 \\
6,128\end{array}$ & $\begin{array}{l}5,484 \\
5,763 \\
5,891 \\
5,010 \\
6,454\end{array}$ & $\begin{array}{l}5,484 \\
6,004 \\
5,812 \\
5,369 \\
6,559\end{array}$ & $\begin{array}{l}5,399 \\
5,946 \\
5,884 \\
5,506 \\
6,473\end{array}$ & $\begin{array}{l}5,296 \\
5,881 \\
5,785 \\
5,491 \\
6,119\end{array}$ & $\begin{array}{l}5,403 \\
5,915 \\
5,971 \\
5,338 \\
6,048\end{array}$ & $\begin{array}{l}5,530 \\
5,847 \\
6,096 \\
5,301 \\
6,018\end{array}$ & $\begin{array}{l}5,626 \\
5,847 \\
6,083 \\
5,320 \\
5,958\end{array}$ \\
\hline $\begin{array}{l}\text { New Jersey } \ldots \ldots \ldots \ldots \ldots \ldots \ldots \\
\text { New Mexico ...................... } \\
\text { New York ....................... } \\
\text { North Carolina ................ } \\
\text { North Dakota ................... }\end{array}$ & $\begin{array}{l}2,038 \\
1,907 \\
2,953 \\
1,247 \\
1,928\end{array}$ & $\begin{array}{l}4,156 \\
2,892 \\
5,426 \\
2,504 \\
2,820\end{array}$ & $\begin{array}{l}6,351 \\
4,047 \\
6,890 \\
3,491 \\
3,822\end{array}$ & $\begin{array}{l}5,804 \\
4,155 \\
6,673 \\
3,569 \\
4,057\end{array}$ & $\begin{array}{l}7,908 \\
4,537 \\
8,534 \\
4,186 \\
4,945\end{array}$ & $\begin{array}{l}8,755 \\
4,923 \\
9,538 \\
4,492 \\
4,694\end{array}$ & $\begin{array}{l}9,624 \\
4,427 \\
9,770 \\
4,939 \\
5,038\end{array}$ & $\begin{array}{l}9,904 \\
4,277 \\
9,809 \\
5,220 \\
5,097\end{array}$ & $\begin{array}{r}10,102 \\
4,493 \\
9,881 \\
5,247 \\
4,844\end{array}$ & $\begin{array}{r}10,416 \\
4,209 \\
9,533 \\
5,091 \\
4,964\end{array}$ & $\begin{array}{r}10,206 \\
4,413 \\
9,650 \\
5,163 \\
4,984\end{array}$ & $\begin{array}{r}10,225 \\
4,502 \\
9,694 \\
5,172 \\
4,938\end{array}$ & $\begin{array}{r}10,040 \\
4,702 \\
9,885 \\
5,215 \\
4,925\end{array}$ & $\begin{array}{l}9,955 \\
4,587 \\
9,549 \\
5,090 \\
4,979\end{array}$ \\
\hline 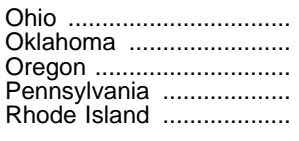 & $\begin{array}{l}1,919 \\
1,637 \\
2,357 \\
2,153 \\
2,174\end{array}$ & $\begin{array}{l}2,986 \\
2,472 \\
3,782 \\
3,606 \\
3,645\end{array}$ & $\begin{array}{l}4,129 \\
3,834 \\
5,357 \\
5,044 \\
5,176\end{array}$ & $\begin{array}{l}4,108 \\
3,921 \\
5,529 \\
5,036 \\
5,220\end{array}$ & $\begin{array}{l}5,007 \\
4,467 \\
5,879 \\
6,141 \\
6,627\end{array}$ & $\begin{array}{l}5,332 \\
4,125 \\
6,387 \\
6,654 \\
7,108\end{array}$ & $\begin{array}{l}5,974 \\
4,308 \\
6,606 \\
7,136 \\
7,731\end{array}$ & $\begin{array}{l}6,138 \\
4,268 \\
6,661 \\
7,578 \\
7,748\end{array}$ & $\begin{array}{l}6,051 \\
4,434 \\
6,556 \\
7,547 \\
7,318\end{array}$ & $\begin{array}{l}6,366 \\
4,557 \\
6,610 \\
7,393 \\
7,318\end{array}$ & $\begin{array}{l}6,238 \\
4,721 \\
6,825 \\
7,469 \\
7,521\end{array}$ & $\begin{array}{l}6,309 \\
5,002 \\
6,618 \\
7,379 \\
7,749\end{array}$ & $\begin{array}{l}6,329 \\
4,977 \\
6,611 \\
7,303 \\
7,925\end{array}$ & $\begin{array}{l}6,266 \\
4,881 \\
6,615 \\
7,492 \\
7,936\end{array}$ \\
\hline 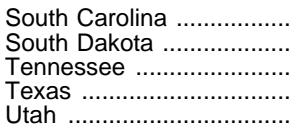 & $\begin{array}{l}1,157 \\
1,824 \\
1,252 \\
1,747 \\
1,695\end{array}$ & $\begin{array}{l}2,505 \\
2,822 \\
2,315 \\
2,553 \\
2,561\end{array}$ & $\begin{array}{l}3,487 \\
3,797 \\
3,255 \\
3,812 \\
3,297\end{array}$ & $\begin{array}{l}3,093 \\
3,551 \\
3,199 \\
3,578 \\
3,244\end{array}$ & $\begin{array}{l}4,342 \\
4,332 \\
3,708 \\
4,683 \\
3,394\end{array}$ & $\begin{array}{l}4,545 \\
4,333 \\
4,092 \\
4,812 \\
3,273\end{array}$ & $\begin{array}{l}4,763 \\
4,570 \\
4,450 \\
4,942 \\
3,299\end{array}$ & $\begin{array}{l}4,967 \\
4,540 \\
4,458 \\
5,050 \\
3,363\end{array}$ & $\begin{array}{l}5,021 \\
4,574 \\
4,363 \\
5,121 \\
3,414\end{array}$ & $\begin{array}{l}4,959 \\
4,665 \\
4,127 \\
5,178 \\
3,399\end{array}$ & $\begin{array}{l}5,012 \\
4,723 \\
4,329 \\
5,063 \\
3,447\end{array}$ & $\begin{array}{l}5,031 \\
4,845 \\
4,384 \\
5,175 \\
3,633\end{array}$ & $\begin{array}{l}4,928 \\
4,905 \\
4,507 \\
5,364 \\
3,755\end{array}$ & $\begin{array}{l}5,096 \\
4,780 \\
4,548 \\
5,473 \\
3,867\end{array}$ \\
\hline 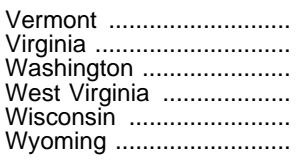 & $\begin{array}{l}1,808 \\
1,442 \\
2,211 \\
1,359 \\
2,172 \\
2,368\end{array}$ & $\begin{array}{l}3,301 \\
2,895 \\
3,744 \\
2,740 \\
3,610 \\
3,501\end{array}$ & $\begin{array}{l}3,974 \\
3,920 \\
5,111 \\
3,822 \\
4,929 \\
5,028\end{array}$ & $\begin{array}{l}4,414 \\
3,886 \\
4,534 \\
3,827 \\
4,884 \\
5,292\end{array}$ & $\begin{array}{l}5,723 \\
4,998 \\
5,510 \\
5,010 \\
5,917 \\
7,261\end{array}$ & $\begin{array}{l}6,945 \\
5,533 \\
5,553 \\
5,145 \\
6,332 \\
6,737\end{array}$ & $\begin{array}{l}6,987 \\
5,787 \\
5,557 \\
4,950 \\
6,713 \\
6,853\end{array}$ & $\begin{array}{l}7,576 \\
5,684 \\
5,722 \\
5,306 \\
6,721 \\
6,786\end{array}$ & $\begin{array}{l}7,774 \\
5,655 \\
5,768 \\
5,666 \\
6,774 \\
6,505\end{array}$ & $\begin{array}{l}7,457 \\
5,453 \\
5,892 \\
5,676 \\
6,863 \\
6,497\end{array}$ & $\begin{array}{l}6,949 \\
5,398 \\
6,085 \\
5,991 \\
7,020 \\
6,312\end{array}$ & $\begin{array}{l}6,974 \\
5,398 \\
6,076 \\
6,037 \\
7,098 \\
6,233\end{array}$ & $\begin{array}{l}6,933 \\
5,472 \\
6,066 \\
6,274 \\
7,119 \\
6,328\end{array}$ & $\begin{array}{l}6,837 \\
5,433 \\
6,044 \\
6,325 \\
7,094 \\
6,243\end{array}$ \\
\hline $\begin{array}{l}\text { Outlying areas } \\
\text { American Samoa } \ldots \ldots \ldots \ldots \ldots \\
\text { Guam ............................. } \\
\text { Northern Marianas .......... } \\
\text { Puerto Rico .................... } \\
\text { Virgin Islands ................. }\end{array}$ & $\begin{array}{r}1,243 \\
\overline{558} \\
1,423\end{array}$ & $\begin{array}{r}\begin{array}{r}3,353 \\
- \\
-\end{array} \\
-\end{array}$ & $\begin{array}{l}- \\
- \\
-\end{array}$ & $\begin{array}{l}- \\
- \\
-\end{array}$ & $\begin{array}{l}1,969 \\
4,803 \\
3,623 \\
1,881 \\
4,577\end{array}$ & $\begin{array}{l}2,545 \\
4,395 \\
4,489 \\
2,007 \\
5,383\end{array}$ & $\begin{array}{l}2,535 \\
5,185 \\
3,077 \\
2,157 \\
6,733\end{array}$ & $\begin{array}{l}2,321 \\
5,152 \\
3,659 \\
2,129 \\
8,234\end{array}$ & $\begin{array}{l}2,345 \\
5,302 \\
5,105 \\
2,207 \\
6,925\end{array}$ & $\begin{array}{l}2,331 \\
5,847 \\
5,865 \\
2,416 \\
6,635\end{array}$ & $\begin{array}{l}1,811 \\
5,755 \\
5,733 \\
2,562 \\
6,334\end{array}$ & $\begin{array}{l}1,886 \\
5,358 \\
4,766 \\
2,443 \\
6,250\end{array}$ & $\begin{array}{l}2,102 \\
5,218 \\
6,289 \\
2,817 \\
6,166\end{array}$ & $\begin{array}{l}2,159 \\
4,947 \\
5,863 \\
3,039 \\
6,155\end{array}$ \\
\hline
\end{tabular}

${ }^{1}$ Based on the Consumer Price Index, prepared by the Bureau of Labor Statistics, U.S. Department of Labor, adjusted to a school-year basis. These data do not reflect differences in inflation rates from state to state.

2 Estimated by the National Center for Education Statistics.

-Data not available or not applicable.

NOTE.-Beginning in 1980-81, state administration expenditures are excluded. Beginning in 1988-89, extensive changes were made in the data collection procedures. There are discrepancies in average daily attendance reporting practices from state to state. Some data have been revised from previously published figures.

SOURCE: U.S. Department of Education, National Center for Education Statistics, Statistics of State School Systems; and Common Core of Data surveys. (This table was prepared July 1998.) 
Table 168.-Current expenditure per pupil in fall enrollment in public elementary and secondary schools, by state: $1969-70$ to $1995-96$

\begin{tabular}{|c|c|c|c|c|c|c|c|c|c|c|c|c|c|c|}
\hline \multirow{2}{*}{ State or other area } & \multicolumn{14}{|c|}{ Unadjusted dollars } \\
\hline & $1969-70$ & $1979-80$ & $1980-81$ & $1985-86$ & $1986-87$ & 1987-88 & 1988-89 & 1989-90 & $1990-91$ & 1991-92 & 1992-93 & 1993-94 & 1994-95 & 1995-96 \\
\hline 1 & 2 & 3 & 4 & 5 & 6 & 7 & 8 & 9 & 10 & 11 & 12 & 13 & 14 & 15 \\
\hline United States .............. & $\$ 751$ & $\$ 2,088$ & $\$ 2,307$ & $\$ 3,479$ & $\$ 3,682$ & $\$ 3,927$ & $\$ 4,307$ & $\$ 4,643$ & $\$ 4,902$ & $\$ 5,023$ & $\$ 5,160$ & $\$ 5,327$ & $\$ 5,529$ & $\$ 5,689$ \\
\hline 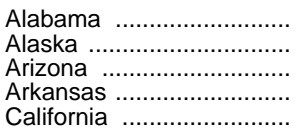 & $\begin{array}{r}512 \\
1,059 \\
674 \\
511 \\
833\end{array}$ & $\begin{array}{l}1,520 \\
4,267 \\
1,865 \\
1,472 \\
2,227\end{array}$ & $\begin{array}{l}1,836 \\
5,506 \\
2,093 \\
1,585 \\
2,438\end{array}$ & $\begin{array}{l}2,411 \\
7,622 \\
3,009 \\
2,506 \\
3,534\end{array}$ & $\begin{array}{l}2,420 \\
7,131 \\
3,436 \\
2,558 \\
3,772\end{array}$ & $\begin{array}{l}2,569 \\
7,079 \\
3,498 \\
2,771 \\
3,877\end{array}$ & $\begin{array}{l}3,019 \\
6,940 \\
3,728 \\
3,023 \\
4,205\end{array}$ & $\begin{array}{l}3,144 \\
7,577 \\
3,717 \\
3,229 \\
4,502\end{array}$ & $\begin{array}{l}3,429 \\
7,502 \\
3,860 \\
3,461 \\
4,595\end{array}$ & $\begin{array}{l}3,415 \\
7,852 \\
3,957 \\
3,777 \\
4,640\end{array}$ & $\begin{array}{l}3,568 \\
7,901 \\
4,088 \\
3,859 \\
4,609\end{array}$ & $\begin{array}{l}3,826 \\
7,960 \\
4,104 \\
4,013 \\
4,719\end{array}$ & $\begin{array}{l}4,109 \\
8,033 \\
4,264 \\
4,186 \\
4,799\end{array}$ & $\begin{array}{l}4,343 \\
8,189 \\
4,476 \\
4,401 \\
4,937\end{array}$ \\
\hline $\begin{array}{l}\text { Colorado } \\
\text { Connecticut ........................ } \\
\text { Delaware ..................... } \\
\text { District of Columbia ......... } \\
\text { Florida ........................... }\end{array}$ & $\begin{array}{l}686 \\
911 \\
833 \\
947 \\
683\end{array}$ & $\begin{array}{l}2,258 \\
2,167 \\
2,587 \\
2,811 \\
1,834\end{array}$ & $\begin{array}{l}2,509 \\
2,711 \\
2,721 \\
2,950 \\
2,209\end{array}$ & $\begin{array}{l}3,666 \\
4,641 \\
4,215 \\
4,672 \\
3,260\end{array}$ & $\begin{array}{l}3,814 \\
5,150 \\
4,429 \\
5,153 \\
3,515\end{array}$ & $\begin{array}{l}3,878 \\
5,905 \\
4,606 \\
5,662 \\
3,778\end{array}$ & $\begin{array}{l}4,151 \\
6,479 \\
4,958 \\
6,888 \\
4,210\end{array}$ & $\begin{array}{l}4,357 \\
7,463 \\
5,326 \\
7,872 \\
4,597\end{array}$ & $\begin{array}{l}4,603 \\
7,547 \\
5,458 \\
8,029 \\
4,859\end{array}$ & $\begin{array}{l}4,644 \\
7,620 \\
5,599 \\
8,403 \\
4,821\end{array}$ & $\begin{array}{l}4,766 \\
7,655 \\
5,753 \\
8,286 \\
4,876\end{array}$ & $\begin{array}{l}4,727 \\
7,947 \\
6,101 \\
8,843 \\
5,063\end{array}$ & $\begin{array}{l}5,047 \\
8,380 \\
6,502 \\
8,290 \\
5,220\end{array}$ & $\begin{array}{l}5,121 \\
8,430 \\
6,696 \\
8,510 \\
5,275\end{array}$ \\
\hline 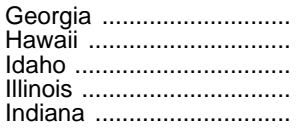 & $\begin{array}{l}539 \\
792 \\
573 \\
816 \\
661\end{array}$ & $\begin{array}{l}1,491 \\
2,086 \\
1,548 \\
2,241 \\
1,708\end{array}$ & $\begin{array}{l}1,580 \\
2,393 \\
1,736 \\
2,406 \\
1,798\end{array}$ & $\begin{array}{l}2,760 \\
3,505 \\
2,358 \\
3,321 \\
2,951\end{array}$ & $\begin{array}{l}2,969 \\
3,503 \\
2,462 \\
3,541 \\
3,213\end{array}$ & $\begin{array}{l}3,195 \\
3,661 \\
2,505 \\
3,822 \\
3,454\end{array}$ & $\begin{array}{l}3,616 \\
3,841 \\
2,656 \\
4,265 \\
3,933\end{array}$ & $\begin{array}{l}4,000 \\
4,130 \\
2,921 \\
4,521 \\
4,270\end{array}$ & $\begin{array}{l}4,171 \\
4,820 \\
3,206 \\
4,904 \\
4,588\end{array}$ & $\begin{array}{l}4,124 \\
5,062 \\
3,370 \\
5,002 \\
4,749\end{array}$ & $\begin{array}{l}4,368 \\
5,332 \\
3,471 \\
5,307 \\
4,995\end{array}$ & $\begin{array}{l}4,569 \\
5,533 \\
3,628 \\
5,323 \\
5,245\end{array}$ & $\begin{array}{l}4,828 \\
5,597 \\
3,957 \\
5,553 \\
5,411\end{array}$ & $\begin{array}{l}5,056 \\
5,560 \\
4,194 \\
5,519 \\
5,621\end{array}$ \\
\hline 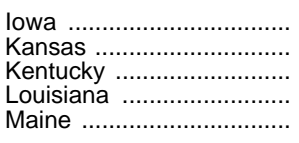 & $\begin{array}{l}798 \\
699 \\
502 \\
589 \\
649\end{array}$ & $\begin{array}{l}2,164 \\
1,963 \\
1,557 \\
1,629 \\
1,692\end{array}$ & $\begin{array}{l}2,505 \\
2,307 \\
1,637 \\
2,273 \\
1,804\end{array}$ & $\begin{array}{l}3,388 \\
3,469 \\
2,229 \\
2,960 \\
3,341\end{array}$ & $\begin{array}{l}3,550 \\
3,573 \\
2,463 \\
2,843 \\
3,591\end{array}$ & $\begin{array}{l}3,867 \\
3,724 \\
2,710 \\
2,886 \\
3,965\end{array}$ & $\begin{array}{l}4,027 \\
4,014 \\
3,009 \\
3,138 \\
4,330\end{array}$ & $\begin{array}{l}4,190 \\
4,290 \\
3,384 \\
3,625 \\
4,903\end{array}$ & $\begin{array}{l}4,418 \\
4,434 \\
3,897 \\
3,853 \\
4,978\end{array}$ & $\begin{array}{l}4,795 \\
4,554 \\
4,194 \\
4,014 \\
5,182\end{array}$ & $\begin{array}{l}4,970 \\
4,926 \\
4,310 \\
4,010 \\
5,624\end{array}$ & $\begin{array}{l}5,070 \\
5,081 \\
4,505 \\
4,133 \\
5,569\end{array}$ & $\begin{array}{l}5,240 \\
5,222 \\
4,545 \\
4,356 \\
6,029\end{array}$ & $\begin{array}{l}5,481 \\
5,374 \\
4,807 \\
4,447 \\
6,151\end{array}$ \\
\hline 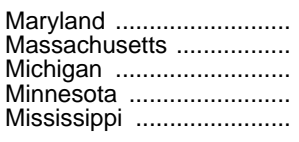 & $\begin{array}{l}809 \\
791 \\
841 \\
855 \\
457\end{array}$ & $\begin{array}{l}2,293 \\
2,548 \\
2,495 \\
2,296 \\
1,568\end{array}$ & $\begin{array}{l}2,581 \\
2,735 \\
2,892 \\
2,519 \\
1,503\end{array}$ & $\begin{array}{l}3,923 \\
4,031 \\
3,859 \\
3,741 \\
2,246\end{array}$ & $\begin{array}{l}4,211 \\
4,490 \\
4,024 \\
3,963 \\
2,231\end{array}$ & $\begin{array}{l}4,575 \\
4,965 \\
4,350 \\
4,132 \\
2,416\end{array}$ & $\begin{array}{l}5,088 \\
5,485 \\
4,734 \\
4,515 \\
2,714\end{array}$ & $\begin{array}{l}5,573 \\
5,766 \\
5,090 \\
4,698 \\
2,934\end{array}$ & $\begin{array}{l}5,930 \\
5,881 \\
5,394 \\
4,946 \\
3,007\end{array}$ & $\begin{array}{l}5,926 \\
5,952 \\
5,746 \\
5,089 \\
3,047\end{array}$ & $\begin{array}{l}6,060 \\
6,141 \\
5,945 \\
5,210 \\
3,159\end{array}$ & $\begin{array}{l}6,191 \\
6,423 \\
6,138 \\
5,342 \\
3,410\end{array}$ & $\begin{array}{l}6,427 \\
6,783 \\
6,465 \\
5,626 \\
3,798\end{array}$ & $\begin{array}{l}6,593 \\
7,033 \\
6,785 \\
5,801 \\
3,951\end{array}$ \\
\hline $\begin{array}{l}\text { Missouri ............................ } \\
\text { Montana ........................ } \\
\text { Nebraska ...................... } \\
\text { Nevada ........................ } \\
\text { New Hampshire ............... }\end{array}$ & $\begin{array}{l}596 \\
728 \\
700 \\
706 \\
666\end{array}$ & $\begin{array}{l}1,724 \\
2,264 \\
2,025 \\
1,908 \\
1,732\end{array}$ & $\begin{array}{l}1,945 \\
2,449 \\
2,243 \\
1,925 \\
2,036\end{array}$ & $\begin{array}{l}2,864 \\
3,691 \\
3,431 \\
3,196 \\
3,247\end{array}$ & $\begin{array}{l}3,142 \\
3,808 \\
3,549 \\
3,182 \\
3,603\end{array}$ & $\begin{array}{l}3,425 \\
3,878 \\
3,712 \\
3,298 \\
4,080\end{array}$ & $\begin{array}{l}3,839 \\
3,893 \\
4,101 \\
3,562 \\
4,328\end{array}$ & $\begin{array}{l}4,071 \\
4,240 \\
4,553 \\
3,816 \\
4,786\end{array}$ & $\begin{array}{l}4,271 \\
4,706 \\
4,735 \\
4,294 \\
5,152\end{array}$ & $\begin{array}{l}4,284 \\
4,825 \\
4,941 \\
4,546 \\
5,237\end{array}$ & $\begin{array}{l}4,318 \\
4,907 \\
5,064 \\
4,645 \\
5,368\end{array}$ & $\begin{array}{l}4,596 \\
5,043 \\
5,310 \\
4,664 \\
5,433\end{array}$ & $\begin{array}{l}4,866 \\
5,137 \\
5,555 \\
4,730 \\
5,567\end{array}$ & $\begin{array}{l}5,092 \\
5,249 \\
5,688 \\
4,892 \\
5,740\end{array}$ \\
\hline $\begin{array}{l}\text { New Jersey ....................... } \\
\text { New Mexico .................... } \\
\text { New York ...................... } \\
\text { North Carolina ................. } \\
\text { North Dakota ................. }\end{array}$ & $\begin{array}{r}924 \\
665 \\
1,194 \\
570 \\
662\end{array}$ & $\begin{array}{l}2,825 \\
1,870 \\
2,950 \\
1,635 \\
1,941\end{array}$ & $\begin{array}{l}2,928 \\
2,066 \\
3,225 \\
1,870 \\
2,175\end{array}$ & $\begin{array}{l}5,139 \\
2,911 \\
5,221 \\
2,754 \\
3,200\end{array}$ & $\begin{array}{l}5,508 \\
3,071 \\
5,647 \\
2,942 \\
3,159\end{array}$ & $\begin{array}{l}6,059 \\
3,190 \\
6,196 \\
3,153 \\
3,239\end{array}$ & $\begin{array}{l}6,762 \\
3,336 \\
6,655 \\
3,594 \\
3,635\end{array}$ & $\begin{array}{l}7,546 \\
3,446 \\
7,051 \\
4,018 \\
3,899\end{array}$ & $\begin{array}{l}8,166 \\
3,757 \\
7,510 \\
4,237 \\
3,909\end{array}$ & $\begin{array}{l}8,705 \\
3,927 \\
7,482 \\
4,246 \\
4,150\end{array}$ & $\begin{array}{l}8,770 \\
3,929 \\
7,770 \\
4,426 \\
4,305\end{array}$ & $\begin{array}{l}9,075 \\
4,106 \\
8,069 \\
4,540 \\
4,385\end{array}$ & $\begin{array}{l}9,178 \\
4,404 \\
8,311 \\
4,703 \\
4,482\end{array}$ & $\begin{array}{l}9,361 \\
4,604 \\
8,361 \\
4,719 \\
4,677\end{array}$ \\
\hline 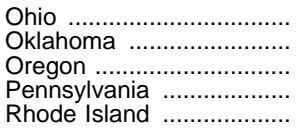 & $\begin{array}{l}677 \\
554 \\
843 \\
815 \\
807\end{array}$ & $\begin{array}{l}1,894 \\
1,810 \\
2,412 \\
2,328 \\
2,340\end{array}$ & $\begin{array}{l}2,120 \\
2,065 \\
2,782 \\
2,595 \\
2,654\end{array}$ & $\begin{array}{l}3,265 \\
2,939 \\
3,715 \\
4,010 \\
4,255\end{array}$ & $\begin{array}{l}3,409 \\
2,878 \\
3,888 \\
4,287 \\
4,516\end{array}$ & $\begin{array}{l}3,595 \\
2,897 \\
4,266 \\
4,603 \\
4,924\end{array}$ & $\begin{array}{l}4,208 \\
3,159 \\
4,598 \\
5,169 \\
5,598\end{array}$ & $\begin{array}{l}4,531 \\
3,293 \\
4,864 \\
5,737 \\
5,908\end{array}$ & $\begin{array}{l}4,747 \\
3,639 \\
5,195 \\
6,048 \\
5,934\end{array}$ & $\begin{array}{l}5,115 \\
3,857 \\
5,268 \\
6,127 \\
6,092\end{array}$ & $\begin{array}{l}5,110 \\
4,090 \\
5,585 \\
6,372 \\
6,501\end{array}$ & $\begin{array}{l}5,319 \\
4,437 \\
5,522 \\
6,443 \\
6,797\end{array}$ & $\begin{array}{l}5,529 \\
4,533 \\
5,649 \\
6,565 \\
7,126\end{array}$ & $\begin{array}{l}5,669 \\
4,549 \\
5,790 \\
6,922 \\
7,304\end{array}$ \\
\hline 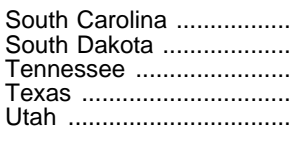 & $\begin{array}{l}567 \\
656 \\
531 \\
551 \\
595\end{array}$ & $\begin{array}{l}1,597 \\
1,781 \\
1,523 \\
1,740 \\
1,556\end{array}$ & $\begin{array}{l}1,625 \\
1,885 \\
1,675 \\
1,831 \\
1,710\end{array}$ & $\begin{array}{l}2,816 \\
2,903 \\
2,447 \\
3,079 \\
2,248\end{array}$ & $\begin{array}{l}2,966 \\
2,935 \\
2,649 \\
3,163 \\
2,242\end{array}$ & $\begin{array}{l}3,143 \\
3,071 \\
2,855 \\
3,334 \\
2,302\end{array}$ & $\begin{array}{l}3,441 \\
3,373 \\
3,248 \\
3,582 \\
2,421\end{array}$ & $\begin{array}{l}3,769 \\
3,511 \\
3,405 \\
3,835 \\
2,577\end{array}$ & $\begin{array}{l}4,009 \\
3,726 \\
3,521 \\
4,048 \\
2,767\end{array}$ & $\begin{array}{l}4,088 \\
3,938 \\
3,430 \\
4,246 \\
2,841\end{array}$ & $\begin{array}{l}4,200 \\
4,109 \\
3,671 \\
4,270 \\
2,967\end{array}$ & $\begin{array}{l}4,336 \\
4,095 \\
3,815 \\
4,488 \\
3,206\end{array}$ & $\begin{array}{l}4,501 \\
4,271 \\
4,017 \\
4,779 \\
3,409\end{array}$ & $\begin{array}{l}4,779 \\
4,220 \\
4,172 \\
5,016 \\
3,604\end{array}$ \\
\hline 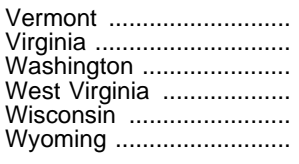 & $\begin{array}{l}790 \\
654 \\
853 \\
621 \\
793 \\
805\end{array}$ & $\begin{array}{l}1,930 \\
1,824 \\
2,387 \\
1,749 \\
2,225 \\
2,369\end{array}$ & $\begin{array}{l}2,347 \\
2,024 \\
2,365 \\
1,968 \\
2,452 \\
2,758\end{array}$ & $\begin{array}{l}3,840 \\
3,289 \\
3,605 \\
3,255 \\
3,767 \\
4,754\end{array}$ & $\begin{array}{l}4,107 \\
3,533 \\
3,689 \\
3,493 \\
4,020 \\
4,852\end{array}$ & $\begin{array}{l}4,927 \\
3,873 \\
3,875 \\
3,579 \\
4,296 \\
4,742\end{array}$ & $\begin{array}{l}5,196 \\
4,225 \\
4,059 \\
3,580 \\
4,760 \\
5,030\end{array}$ & $\begin{array}{l}5,770 \\
4,690 \\
4,382 \\
4,020 \\
5,020 \\
5,239 \\
\end{array}$ & $\begin{array}{l}6,255 \\
4,965 \\
4,652 \\
4,571 \\
5,382 \\
5,310 \\
\end{array}$ & $\begin{array}{l}6,243 \\
4,914 \\
4,899 \\
4,696 \\
5,643 \\
5,348\end{array}$ & $\begin{array}{l}6,252 \\
5,067 \\
5,220 \\
5,108 \\
5,974 \\
5,462\end{array}$ & $\begin{array}{l}6,266 \\
5,205 \\
5,342 \\
5,292 \\
6,126 \\
5,534\end{array}$ & $\begin{array}{l}6,367 \\
5,421 \\
5,477 \\
5,663 \\
6,301 \\
5,753\end{array}$ & $\begin{array}{l}6,488 \\
5,528 \\
5,611 \\
5,881 \\
6,517 \\
5,826\end{array}$ \\
\hline $\begin{array}{l}\text { Outlying areas } \\
\text { American Samoa ............. } \\
\text { Guam ........................ } \\
\text { Northern Marianas .......... } \\
\text { Puerto Rico ................... } \\
\text { Trust Territories .............. } \\
\text { Virgin Islands ................. }\end{array}$ & $\begin{array}{c}\overline{766} \\
- \\
- \\
-\end{array}$ & $\begin{array}{l}- \\
- \\
- \\
-\end{array}$ & $\begin{array}{r}\bar{Z} \\
1,000 \\
-\end{array}$ & $\begin{array}{r}3, \overline{16} \\
1,2 \overline{27} \\
3,0 \overline{16}\end{array}$ & $\begin{array}{r}1,764 \\
3,049 \\
1,283 \\
3,994\end{array}$ & $\begin{array}{r}1,795 \\
2,944 \\
3,384 \\
1,390 \\
3,714\end{array}$ & $\begin{array}{r}1,897 \\
3,624 \\
2,651 \\
1,557 \\
4,757\end{array}$ & $\begin{array}{r}1,781 \\
3,817 \\
3,356 \\
1,605 \\
6,043\end{array}$ & $\begin{array}{r}2,002 \\
4,411 \\
4,159 \\
1,773 \\
5,515\end{array}$ & $\begin{array}{r}2,018 \\
4,676 \\
4,580 \\
1,879 \\
5,444\end{array}$ & $\begin{array}{r}1,689 \\
5,369 \\
4,796 \\
2,034 \\
5,265\end{array}$ & $\begin{array}{r}1,737 \\
5,200 \\
4,009 \\
2,155 \\
5,299\end{array}$ & $\begin{array}{r}1,983 \\
5,016 \\
5,340 \\
2,417 \\
5,280\end{array}$ & $\begin{array}{r}2,084 \\
4,803 \\
4,999 \\
2,657 \\
5,378\end{array}$ \\
\hline
\end{tabular}


Table 168.-Current expenditure per pupil in fall enrollment in public elementary and secondary schools, by state: 1969-70 to 1995-96-Continued

\begin{tabular}{|c|c|c|c|c|c|c|c|c|c|c|c|c|c|c|}
\hline \multirow{2}{*}{ State or other area } & \multicolumn{14}{|c|}{ Constant $1995-96$ dollars ${ }^{1}$} \\
\hline & 1969-70 & $1979-80$ & $1980-81$ & $1985-86$ & $1986-87$ & $1987-88$ & 1988-89 & $1989-90$ & $1990-91$ & 1991-92 & 1992-93 & 1993-94 & 1994-95 & 1995-96 \\
\hline 1 & 16 & 17 & 18 & 19 & 20 & 21 & 22 & 23 & 24 & 25 & 26 & 27 & 28 & 29 \\
\hline United States .............. & $\$ 3,072$ & $\$ 4,156$ & $\$ 4,115$ & $\$ 4,940$ & $\$ 5,114$ & $\$ 5,237$ & $\$ 5,491$ & $\$ 5,649$ & $\$ 5,655$ & $\$ 5,615$ & $\$ 5,593$ & $\$ 5,629$ & $\$ 5,679$ & $\$ 5,689$ \\
\hline 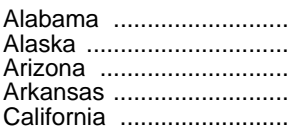 & $\begin{array}{l}2,093 \\
4,332 \\
2,758 \\
2,090 \\
3,408\end{array}$ & $\begin{array}{l}3,026 \\
8,492 \\
3,712 \\
2,929 \\
4,431\end{array}$ & $\begin{array}{l}3,275 \\
9,821 \\
3,733 \\
2,826 \\
4,348\end{array}$ & $\begin{array}{r}3,423 \\
10,822 \\
4,273 \\
3,557 \\
5,018\end{array}$ & $\begin{array}{l}3,362 \\
9,904 \\
4,773 \\
3,553 \\
5,239\end{array}$ & $\begin{array}{l}3,426 \\
9,442 \\
4,665 \\
3,696 \\
5,171\end{array}$ & $\begin{array}{l}3,849 \\
8,848 \\
4,752 \\
3,854 \\
5,360\end{array}$ & $\begin{array}{l}3,825 \\
9,220 \\
4,523 \\
3,929 \\
5,479\end{array}$ & $\begin{array}{l}3,956 \\
8,655 \\
4,453 \\
3,993 \\
5,301\end{array}$ & $\begin{array}{l}3,817 \\
8,778 \\
4,423 \\
4,222 \\
5,187\end{array}$ & $\begin{array}{l}3,868 \\
8,565 \\
4,432 \\
4,183 \\
4,996\end{array}$ & $\begin{array}{l}4,043 \\
8,411 \\
4,336 \\
4,240 \\
4,987\end{array}$ & $\begin{array}{l}4,221 \\
8,252 \\
4,380 \\
4,300 \\
4,929\end{array}$ & $\begin{array}{l}4,343 \\
8,189 \\
4,476 \\
4,401 \\
4,937\end{array}$ \\
\hline 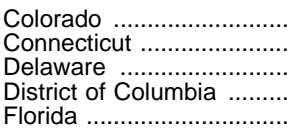 & $\begin{array}{l}2,806 \\
3,725 \\
3,409 \\
3,873 \\
2,792\end{array}$ & $\begin{array}{l}4,494 \\
4,313 \\
5,148 \\
5,595 \\
3,650\end{array}$ & $\begin{array}{l}4,475 \\
4,836 \\
4,852 \\
5,262 \\
3,941\end{array}$ & $\begin{array}{l}5,205 \\
6,589 \\
5,984 \\
6,634 \\
4,628\end{array}$ & $\begin{array}{l}5,298 \\
7,154 \\
6,151 \\
7,157 \\
4,883\end{array}$ & $\begin{array}{l}5,172 \\
7,876 \\
6,143 \\
7,551 \\
5,038\end{array}$ & $\begin{array}{l}5,291 \\
8,260 \\
6,321 \\
8,781 \\
5,367\end{array}$ & $\begin{array}{l}5,301 \\
9,081 \\
6,481 \\
9,578 \\
5,594\end{array}$ & $\begin{array}{l}5,310 \\
8,707 \\
6,297 \\
9,263 \\
5,606\end{array}$ & $\begin{array}{l}5,192 \\
8,518 \\
6,259 \\
9,393 \\
5,389\end{array}$ & $\begin{array}{l}5,167 \\
8,299 \\
6,236 \\
8,983 \\
5,286\end{array}$ & $\begin{array}{l}4,995 \\
8,397 \\
6,446 \\
9,344 \\
5,350\end{array}$ & $\begin{array}{l}5,185 \\
8,608 \\
6,679 \\
8,516 \\
5,362\end{array}$ & $\begin{array}{l}5,121 \\
8,430 \\
6,696 \\
8,510 \\
5,275\end{array}$ \\
\hline 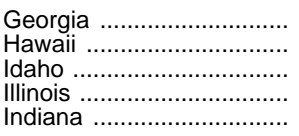 & $\begin{array}{l}2,204 \\
3,239 \\
2,344 \\
3,336 \\
2,704\end{array}$ & $\begin{array}{l}2,967 \\
4,152 \\
3,081 \\
4,460 \\
3,399\end{array}$ & $\begin{array}{l}2,818 \\
4,268 \\
3,097 \\
4,292 \\
3,207\end{array}$ & $\begin{array}{l}3,919 \\
4,977 \\
3,348 \\
4,716 \\
4,190\end{array}$ & $\begin{array}{l}4,123 \\
4,866 \\
3,419 \\
4,919 \\
4,463\end{array}$ & $\begin{array}{l}4,261 \\
4,882 \\
3,342 \\
5,097 \\
4,607\end{array}$ & $\begin{array}{l}4,609 \\
4,897 \\
3,386 \\
5,437 \\
5,014\end{array}$ & $\begin{array}{l}4,867 \\
5,025 \\
3,554 \\
5,501 \\
5,196\end{array}$ & $\begin{array}{l}4,813 \\
5,560 \\
3,699 \\
5,658 \\
5,293\end{array}$ & $\begin{array}{l}4,610 \\
5,659 \\
3,767 \\
5,592 \\
5,309\end{array}$ & $\begin{array}{l}4,735 \\
5,780 \\
3,763 \\
5,753 \\
5,414\end{array}$ & $\begin{array}{l}4,828 \\
5,846 \\
3,834 \\
5,625 \\
5,542\end{array}$ & $\begin{array}{l}4,960 \\
5,749 \\
4,064 \\
5,704 \\
5,559\end{array}$ & $\begin{array}{l}5,056 \\
5,560 \\
4,194 \\
5,519 \\
5,621\end{array}$ \\
\hline 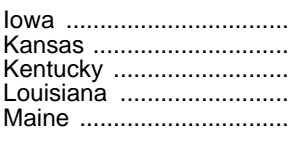 & $\begin{array}{l}3,264 \\
2,858 \\
2,053 \\
2,411 \\
2,655\end{array}$ & $\begin{array}{l}4,307 \\
3,906 \\
3,099 \\
3,242 \\
3,367\end{array}$ & $\begin{array}{l}4,468 \\
4,116 \\
2,920 \\
4,055 \\
3,217\end{array}$ & $\begin{array}{l}4,810 \\
4,926 \\
3,164 \\
4,203 \\
4,744\end{array}$ & $\begin{array}{l}4,931 \\
4,963 \\
3,421 \\
3,948 \\
4,988\end{array}$ & $\begin{array}{l}5,157 \\
4,966 \\
3,615 \\
3,850 \\
5,288\end{array}$ & $\begin{array}{l}5,134 \\
5,117 \\
3,836 \\
4,000 \\
5,520\end{array}$ & $\begin{array}{l}5,098 \\
5,220 \\
4,117 \\
4,411 \\
5,966\end{array}$ & $\begin{array}{l}5,097 \\
5,116 \\
4,497 \\
4,445 \\
5,743\end{array}$ & $\begin{array}{l}5,360 \\
5,091 \\
4,689 \\
4,488 \\
5,793\end{array}$ & $\begin{array}{l}5,387 \\
5,339 \\
4,672 \\
4,347 \\
6,097\end{array}$ & $\begin{array}{l}5,357 \\
5,369 \\
4,760 \\
4,368 \\
5,884\end{array}$ & $\begin{array}{l}5,383 \\
5,364 \\
4,669 \\
4,475 \\
6,193\end{array}$ & $\begin{array}{l}5,481 \\
5,374 \\
4,807 \\
4,447 \\
6,151\end{array}$ \\
\hline 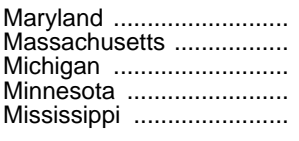 & $\begin{array}{l}3,310 \\
3,234 \\
3,442 \\
3,496 \\
1,868\end{array}$ & $\begin{array}{l}4,563 \\
5,070 \\
4,966 \\
4,570 \\
3,121\end{array}$ & $\begin{array}{l}4,603 \\
4,878 \\
5,157 \\
4,493 \\
2,680\end{array}$ & $\begin{array}{l}5,569 \\
5,723 \\
5,479 \\
5,311 \\
3,189\end{array}$ & $\begin{array}{l}5,849 \\
6,236 \\
5,590 \\
5,505 \\
3,099\end{array}$ & $\begin{array}{l}6,101 \\
6,622 \\
5,802 \\
5,511 \\
3,223\end{array}$ & $\begin{array}{l}6,486 \\
6,993 \\
6,035 \\
5,756 \\
3,459\end{array}$ & $\begin{array}{l}6,781 \\
7,016 \\
6,193 \\
5,716 \\
3,569\end{array}$ & $\begin{array}{l}6,841 \\
6,785 \\
6,223 \\
5,706 \\
3,469\end{array}$ & $\begin{array}{l}6,624 \\
6,653 \\
6,423 \\
5,689 \\
3,407\end{array}$ & $\begin{array}{l}6,569 \\
6,657 \\
6,444 \\
5,648 \\
3,425\end{array}$ & $\begin{array}{l}6,541 \\
6,786 \\
6,486 \\
5,644 \\
3,604\end{array}$ & $\begin{array}{l}6,602 \\
6,968 \\
6,641 \\
5,779 \\
3,901\end{array}$ & $\begin{array}{l}6,593 \\
7,033 \\
6,785 \\
5,801 \\
3,951\end{array}$ \\
\hline 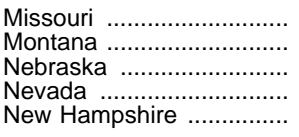 & $\begin{array}{l}2,438 \\
2,976 \\
2,862 \\
2,886 \\
2,724\end{array}$ & $\begin{array}{l}3,431 \\
4,505 \\
4,029 \\
3,798 \\
3,447\end{array}$ & $\begin{array}{l}3,470 \\
4,368 \\
4,001 \\
3,433 \\
3,632\end{array}$ & $\begin{array}{l}4,067 \\
5,240 \\
4,871 \\
4,537 \\
4,609\end{array}$ & $\begin{array}{l}4,365 \\
5,289 \\
4,930 \\
4,419 \\
5,004\end{array}$ & $\begin{array}{l}4,568 \\
5,172 \\
4,951 \\
4,399 \\
5,442\end{array}$ & $\begin{array}{l}4,894 \\
4,963 \\
5,228 \\
4,541 \\
5,518\end{array}$ & $\begin{array}{l}4,953 \\
5,159 \\
5,540 \\
4,643 \\
5,823\end{array}$ & $\begin{array}{l}4,928 \\
5,430 \\
5,462 \\
4,954 \\
5,943\end{array}$ & $\begin{array}{l}4,789 \\
5,394 \\
5,524 \\
5,081 \\
5,854\end{array}$ & $\begin{array}{l}4,680 \\
5,319 \\
5,489 \\
5,035 \\
5,819\end{array}$ & $\begin{array}{l}4,856 \\
5,328 \\
5,611 \\
4,928 \\
5,741\end{array}$ & $\begin{array}{l}4,999 \\
5,277 \\
5,706 \\
4,859 \\
5,719\end{array}$ & $\begin{array}{l}5,092 \\
5,249 \\
5,688 \\
4,892 \\
5,740\end{array}$ \\
\hline $\begin{array}{l}\text { New Jersey } \\
\text { New Mexico ........................ } \\
\text { New York ....................... } \\
\text { North Carolina ................ } \\
\text { North Dakota } . . . \ldots \ldots \ldots \ldots \ldots \ldots . . .\end{array}$ & $\begin{array}{l}3,778 \\
2,720 \\
4,885 \\
2,333 \\
2,709\end{array}$ & $\begin{array}{l}5,623 \\
3,722 \\
5,872 \\
3,255 \\
3,864\end{array}$ & $\begin{array}{l}5,223 \\
3,684 \\
5,751 \\
3,336 \\
3,879\end{array}$ & $\begin{array}{l}7,296 \\
4,134 \\
7,413 \\
3,911 \\
4,544\end{array}$ & $\begin{array}{l}7,650 \\
4,265 \\
7,843 \\
4,087 \\
4,387\end{array}$ & $\begin{array}{l}8,080 \\
4,255 \\
8,264 \\
4,205 \\
4,320\end{array}$ & $\begin{array}{l}8,621 \\
4,253 \\
8,484 \\
4,582 \\
4,633\end{array}$ & $\begin{array}{l}9,182 \\
4,193 \\
8,579 \\
4,889 \\
4,744\end{array}$ & $\begin{array}{l}9,421 \\
4,334 \\
8,665 \\
4,889 \\
4,510\end{array}$ & $\begin{array}{l}9,731 \\
4,390 \\
8,364 \\
4,746 \\
4,640\end{array}$ & $\begin{array}{l}9,507 \\
4,259 \\
8,423 \\
4,798 \\
4,666\end{array}$ & $\begin{array}{l}9,589 \\
4,339 \\
8,526 \\
4,798 \\
4,633\end{array}$ & $\begin{array}{l}9,428 \\
4,523 \\
8,537 \\
4,831 \\
4,604\end{array}$ & $\begin{array}{l}9,361 \\
4,604 \\
8,361 \\
4,719 \\
4,677\end{array}$ \\
\hline 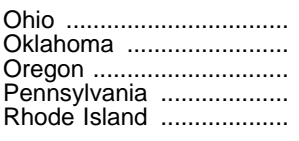 & $\begin{array}{l}2,767 \\
2,265 \\
3,449 \\
3,334 \\
3,300\end{array}$ & $\begin{array}{l}3,770 \\
3,601 \\
4,801 \\
4,634 \\
4,658\end{array}$ & $\begin{array}{l}3,781 \\
3,684 \\
4,962 \\
4,629 \\
4,734\end{array}$ & $\begin{array}{l}4,635 \\
4,173 \\
5,274 \\
5,694 \\
6,041\end{array}$ & $\begin{array}{l}4,735 \\
3,998 \\
5,401 \\
5,954 \\
6,273\end{array}$ & $\begin{array}{l}4,794 \\
3,863 \\
5,689 \\
6,139 \\
6,568\end{array}$ & $\begin{array}{l}5,365 \\
4,028 \\
5,862 \\
6,590 \\
7,137\end{array}$ & $\begin{array}{l}5,513 \\
4,007 \\
5,919 \\
6,981 \\
7,189\end{array}$ & $\begin{array}{l}5,477 \\
4,199 \\
5,993 \\
6,978 \\
6,846\end{array}$ & $\begin{array}{l}5,718 \\
4,312 \\
5,889 \\
6,849 \\
6,810\end{array}$ & $\begin{array}{l}5,539 \\
4,434 \\
6,054 \\
6,907 \\
7,047\end{array}$ & $\begin{array}{l}5,620 \\
4,688 \\
5,835 \\
6,808 \\
7,182\end{array}$ & $\begin{array}{l}5,679 \\
4,656 \\
5,803 \\
6,744 \\
7,320\end{array}$ & $\begin{array}{l}5,669 \\
4,549 \\
5,790 \\
6,922 \\
7,304\end{array}$ \\
\hline 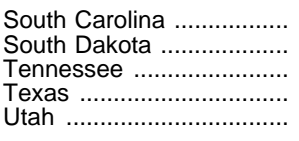 & $\begin{array}{l}2,320 \\
2,684 \\
2,171 \\
2,254 \\
2,434\end{array}$ & $\begin{array}{l}3,179 \\
3,544 \\
3,031 \\
3,462 \\
3,097\end{array}$ & $\begin{array}{l}2,898 \\
3,362 \\
2,988 \\
3,266 \\
3,050\end{array}$ & $\begin{array}{l}3,999 \\
4,122 \\
3,474 \\
4,372 \\
3,191\end{array}$ & $\begin{array}{l}4,120 \\
4,077 \\
3,679 \\
4,394 \\
3,114\end{array}$ & $\begin{array}{l}4,191 \\
4,096 \\
3,808 \\
4,447 \\
3,070\end{array}$ & $\begin{array}{l}4,386 \\
4,299 \\
4,140 \\
4,566 \\
3,086\end{array}$ & $\begin{array}{l}4,587 \\
4,272 \\
4,143 \\
4,666 \\
3,136\end{array}$ & $\begin{array}{l}4,626 \\
4,299 \\
4,062 \\
4,671 \\
3,192\end{array}$ & $\begin{array}{l}4,570 \\
4,402 \\
3,835 \\
4,746 \\
3,176\end{array}$ & $\begin{array}{l}4,553 \\
4,455 \\
3,979 \\
4,628 \\
3,216\end{array}$ & $\begin{array}{l}4,581 \\
4,327 \\
4,031 \\
4,742 \\
3,388\end{array}$ & $\begin{array}{l}4,624 \\
4,387 \\
4,126 \\
4,909 \\
3,501\end{array}$ & $\begin{array}{l}4,779 \\
4,220 \\
4,172 \\
5,016 \\
3,604\end{array}$ \\
\hline 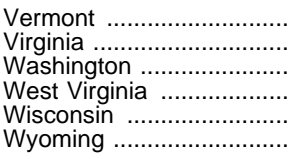 & $\begin{array}{l}3,229 \\
2,677 \\
3,489 \\
2,541 \\
3,244 \\
3,292\end{array}$ & $\begin{array}{l}3,841 \\
3,630 \\
4,750 \\
3,480 \\
4,428 \\
4,715\end{array}$ & $\begin{array}{l}4,186 \\
3,611 \\
4,217 \\
3,511 \\
4,374 \\
4,920\end{array}$ & $\begin{array}{l}5,451 \\
4,669 \\
5,118 \\
4,621 \\
5,348 \\
6,750\end{array}$ & $\begin{array}{l}5,704 \\
4,907 \\
5,123 \\
4,852 \\
5,584 \\
6,739\end{array}$ & $\begin{array}{l}6,571 \\
5,166 \\
5,168 \\
4,773 \\
5,730 \\
6,325\end{array}$ & $\begin{array}{l}6,624 \\
5,387 \\
5,174 \\
4,564 \\
6,068 \\
6,413\end{array}$ & $\begin{array}{l}7,021 \\
5,706 \\
5,332 \\
4,891 \\
6,108 \\
6,375\end{array}$ & $\begin{array}{l}7,217 \\
5,728 \\
5,367 \\
5,274 \\
6,209 \\
6,126\end{array}$ & $\begin{array}{l}6,979 \\
5,493 \\
5,477 \\
5,250 \\
6,308 \\
5,978\end{array}$ & $\begin{array}{l}6,778 \\
5,492 \\
5,659 \\
5,538 \\
6,476 \\
5,921\end{array}$ & $\begin{array}{l}6,621 \\
5,500 \\
5,644 \\
5,592 \\
6,473 \\
5,847\end{array}$ & $\begin{array}{l}6,540 \\
5,568 \\
5,626 \\
5,818 \\
6,472 \\
5,910\end{array}$ & $\begin{array}{l}6,488 \\
5,528 \\
5,611 \\
5,881 \\
6,517 \\
5,826\end{array}$ \\
\hline $\begin{array}{l}\qquad \text { Outlying areas } \\
\text { American Samoa .............. } \\
\text { Guam .......................... } \\
\text { Northern Marianas ........... } \\
\text { Puerto Rico .................... } \\
\text { Trust Territories ............... } \\
\text { Virgin Islands .................. }\end{array}$ & $3,1 \overline{35}$ & $\begin{array}{l}- \\
- \\
- \\
-\end{array}$ & $\begin{array}{r}1,784 \\
-\end{array}$ & $\begin{array}{r}4, \overline{282} \\
1,7 \overline{42} \\
4,2 \overline{82}\end{array}$ & $\begin{array}{r}2,450 \\
4,235 \\
1,783 \\
5,5 \overline{47}\end{array}$ & $\begin{array}{r}2,394 \\
3,927 \\
4,514 \\
1,854 \\
4,954\end{array}$ & $\begin{array}{l}2,418 \\
4,620 \\
3,380 \\
1,985\end{array}$ & $\begin{array}{l}2,168 \\
4,645 \\
4,084 \\
1,953\end{array}$ & $\begin{array}{r}2,309 \\
5,089 \\
4,798 \\
2,045 \\
6,363\end{array}$ & $\begin{array}{l}2,256 \\
5,227 \\
5,120 \\
2,101\end{array}$ & $\begin{array}{l}1,831 \\
5,820 \\
5,199 \\
2,204 \\
5,708\end{array}$ & $\begin{array}{r}1,836 \\
5,495 \\
4,236 \\
2,277 \\
5,599\end{array}$ & $\begin{array}{r}2,037 \\
5,152 \\
5,485 \\
2,483 \\
5,423\end{array}$ & $\begin{array}{l}2,084 \\
4,803 \\
4,999 \\
2,657\end{array}$ \\
\hline
\end{tabular}

1 Based on the Consumer Price Index, prepared by the Bureau of Labor Statistics, U.S. Department of Labor, adjusted to a school year basis. These data do not reflect differences in inflation rates from state to state.

-Data not available or not applicable.

NOTE-Beginning in 1980-81, expenditures for state administration are excluded. Beginning in 1988-89, survey was expanded and coverage of state expenditures for public school districts was improved.
SOURCE: U.S. Department of Education, National Center for Education Statistics, Revenues and Expenditures for Public Elementary and Secondary Schools, various years; Statistics of State School Systems, various years; and Common Core of Data surveys. (This table was prepared February 1999.) 
Table 169.-Total and current expenditure per pupil in public elementary and secondary schools: 1919-20 to 1997-98

\begin{tabular}{|c|c|c|c|c|c|c|c|c|}
\hline \multirow{3}{*}{$\begin{array}{l}\text { School } \\
\text { year }\end{array}$} & \multicolumn{4}{|c|}{$\begin{array}{l}\text { Expenditure per pupil in } \\
\text { average daily attendance }\end{array}$} & \multicolumn{4}{|c|}{$\begin{array}{l}\text { Expenditure per pupil in } \\
\text { fall enrollment }{ }^{1}\end{array}$} \\
\hline & \multicolumn{2}{|c|}{ Unadjusted dollars } & \multicolumn{2}{|c|}{ Constant $1997-98^{2}$ dollars } & \multicolumn{2}{|c|}{ Unadjusted dollars } & \multicolumn{2}{|c|}{ Constant $1997-98$ dollars $^{2}$} \\
\hline & $\begin{array}{c}\text { Total } \\
\text { expenditure }\end{array}$ & $\begin{array}{c}\text { Current } \\
\text { expenditure }\end{array}$ & $\begin{array}{c}\text { Total } \\
\text { expenditure }\end{array}$ & $\begin{array}{c}\text { Current } \\
\text { expenditure }\end{array}$ & $\begin{array}{c}\text { Total } \\
\text { expenditure }\end{array}$ & $\begin{array}{c}\text { Current } \\
\text { expenditure }\end{array}$ & $\begin{array}{c}\text { Total } \\
\text { expenditure }\end{array}$ & $\begin{array}{l}\text { Current } \\
\text { expenditure }\end{array}$ \\
\hline 1 & 2 & 3 & 4 & 5 & 6 & 7 & 8 & 9 \\
\hline $\begin{array}{l}1919-20 \\
1929-30 \\
1931-32 \\
1933-34 \\
1935-36\end{array}$ & $\begin{array}{r}\$ 64 \\
108 \\
97 \\
76 \\
88\end{array}$ & $\begin{array}{r}\$ 53 \\
87 \\
81 \\
67 \\
74\end{array}$ & $\begin{array}{r}\$ 543 \\
1,025 \\
1,087 \\
931 \\
1,035\end{array}$ & $\begin{array}{r}\$ 453 \\
819 \\
910 \\
824 \\
874\end{array}$ & $\begin{array}{r}\$ 48 \\
90 \\
82 \\
65 \\
74\end{array}$ & $\begin{array}{r}\$ 40 \\
72 \\
69 \\
57 \\
63\end{array}$ & $\begin{array}{r}\$ 406 \\
849 \\
920 \\
791 \\
875\end{array}$ & $\begin{array}{r}\$ 339 \\
678 \\
770 \\
700 \\
740\end{array}$ \\
\hline $\begin{array}{l}1937-38 \\
1939-40 \\
1941-42 \\
1943-44 \\
1945-46\end{array}$ & $\begin{array}{l}100 \\
106 \\
110 \\
125 \\
146\end{array}$ & $\begin{array}{r}84 \\
88 \\
98 \\
117 \\
136\end{array}$ & $\begin{array}{l}1,126 \\
1,224 \\
1,141 \\
1,157 \\
1,293\end{array}$ & $\begin{array}{r}947 \\
1,020 \\
1,020 \\
1,086 \\
1,209\end{array}$ & $\begin{array}{r}86 \\
92 \\
94 \\
105 \\
124\end{array}$ & $\begin{array}{r}72 \\
76 \\
84 \\
99 \\
116\end{array}$ & $\begin{array}{r}966 \\
1,061 \\
977 \\
975 \\
1,102\end{array}$ & $\begin{array}{r}813 \\
884 \\
873 \\
915 \\
1,030\end{array}$ \\
\hline $\begin{array}{l}1947-48 \\
1949-50 \\
1951-52 \\
1953-54 \\
1955-56\end{array}$ & $\begin{array}{l}205 \\
260 \\
314 \\
351 \\
387\end{array}$ & $\begin{array}{l}181 \\
210 \\
246 \\
265 \\
294\end{array}$ & $\begin{array}{l}1,422 \\
1,778 \\
1,935 \\
2,111 \\
2,329\end{array}$ & $\begin{array}{l}1,260 \\
1,437 \\
1,514 \\
1,593 \\
1,770\end{array}$ & $\begin{array}{l}179 \\
231 \\
275 \\
312 \\
354\end{array}$ & $\begin{array}{l}158 \\
187 \\
215 \\
236 \\
269\end{array}$ & $\begin{array}{l}1,242 \\
1,578 \\
1,694 \\
1,877 \\
2,129\end{array}$ & $\begin{array}{l}1,100 \\
1,275 \\
1,326 \\
1,416 \\
1,618\end{array}$ \\
\hline $\begin{array}{l}1957-58 \\
1959-60 \\
1961-62\end{array}$ & $\begin{array}{l}447 \\
471 \\
517 \\
559 \\
654\end{array}$ & $\begin{array}{l}341 \\
375 \\
419 \\
460 \\
538\end{array}$ & $\begin{array}{l}2,534 \\
2,593 \\
2,783 \\
2,930 \\
3,314\end{array}$ & $\begin{array}{l}1,932 \\
2,065 \\
2,255 \\
2,414 \\
2,726\end{array}$ & $\begin{array}{l}408 \\
440 \\
485 \\
520 \\
607\end{array}$ & $\begin{array}{l}311 \\
350 \\
393 \\
428 \\
499\end{array}$ & $\begin{array}{l}2,311 \\
2,422 \\
2,611 \\
2,727 \\
3,077\end{array}$ & $\begin{array}{l}1,762 \\
1,929 \\
2,116 \\
2,247 \\
2,530\end{array}$ \\
\hline $\begin{array}{l}1967-68 \\
1969-70 \\
1970-71 \\
1971-72 \\
1972-73\end{array}$ & $\begin{array}{r}786 \\
955 \\
1,049 \\
1,128 \\
1,211\end{array}$ & $\begin{array}{r}658 \\
816 \\
911 \\
990 \\
1,077\end{array}$ & $\begin{array}{l}3,741 \\
4,089 \\
4,273 \\
4,433 \\
4,574\end{array}$ & $\begin{array}{l}3,131 \\
3,494 \\
3,710 \\
3,890 \\
4,069\end{array}$ & $\begin{array}{r}732 \\
879 \\
970 \\
1,034 \\
1,117\end{array}$ & $\begin{array}{l}612 \\
751 \\
842 \\
908 \\
993\end{array}$ & $\begin{array}{l}3,479 \\
3,764 \\
3,950 \\
4,066 \\
4,219\end{array}$ & $\begin{array}{l}2,912 \\
3,216 \\
3,430 \\
3,568 \\
3,753\end{array}$ \\
\hline $\begin{array}{l}1973-74 \\
1974-75 \\
1975-76 \\
1976-77 \\
1977-78\end{array}$ & $\begin{array}{l}1,364 \\
1,545 \\
1,697 \\
1,816 \\
2,002\end{array}$ & $\begin{array}{l}1,207 \\
1,365 \\
1,504 \\
1,638 \\
1,823\end{array}$ & $\begin{array}{l}4,731 \\
4,824 \\
4,950 \\
5,005 \\
5,171\end{array}$ & $\begin{array}{l}4,188 \\
4,261 \\
4,385 \\
4,513 \\
4,707\end{array}$ & $\begin{array}{l}1,244 \\
1,423 \\
1,563 \\
1,674 \\
1,842\end{array}$ & $\begin{array}{l}1,101 \\
1,257 \\
1,385 \\
1,509 \\
1,677\end{array}$ & $\begin{array}{l}4,314 \\
4,444 \\
4,558 \\
4,612 \\
4,756\end{array}$ & $\begin{array}{l}3,819 \\
3,926 \\
4,038 \\
4,158 \\
4,329\end{array}$ \\
\hline $\begin{array}{l}1978-79 \\
1979-80 \\
1980-81 \\
1981-82\end{array}$ & $\begin{array}{r}2,210 \\
2,491 \\
32,742 \\
32,973 \\
33,203\end{array}$ & $\begin{array}{l}2,020 \\
2,272 \\
2,502 \\
2,726 \\
2,955\end{array}$ & $\begin{array}{r}5,218 \\
5,189 \\
35,120 \\
35,110 \\
35,279\end{array}$ & $\begin{array}{l}4,771 \\
4,733 \\
4,671 \\
4,685 \\
4,870\end{array}$ & $\begin{array}{r}2,029 \\
2,290 \\
32,529 \\
32,754 \\
32,966\end{array}$ & $\begin{array}{l}1,855 \\
2,088 \\
2,307 \\
2,525 \\
2,736\end{array}$ & $\begin{array}{r}4,792 \\
4,770 \\
34,723 \\
34,734 \\
34,888\end{array}$ & $\begin{array}{l}4,381 \\
4,351 \\
4,308 \\
4,340 \\
4,509\end{array}$ \\
\hline $\begin{array}{l}1983-84 \\
1984-85 \\
1985-86\end{array}$ & $\begin{array}{l}33,471 \\
33,722 \\
34,020 \\
34,308 \\
34,654\end{array}$ & $\begin{array}{l}3,173 \\
3,470 \\
3,756 \\
3,970 \\
4,240\end{array}$ & $\begin{array}{l}35,516 \\
35,692 \\
35,975 \\
36,264 \\
{ }^{3} 6,498\end{array}$ & $\begin{array}{l}5,043 \\
5,307 \\
5,582 \\
5,773 \\
5,920\end{array}$ & $\begin{array}{l}33,216 \\
33,456 \\
33,724 \\
33,995 \\
34,310\end{array}$ & $\begin{array}{l}2,940 \\
3,222 \\
3,479 \\
3,682 \\
3,927\end{array}$ & $\begin{array}{l}35,110 \\
35,285 \\
35,536 \\
35,809 \\
36,018\end{array}$ & $\begin{array}{l}4,672 \\
4,928 \\
5,172 \\
5,354 \\
5,482\end{array}$ \\
\hline $\begin{array}{l}1988-89 \\
1989-90 \\
1990-91 \\
1991-92\end{array}$ & $\begin{array}{l}5,109 \\
5,550 \\
5,885 \\
6,074 \\
6,281\end{array}$ & $\begin{array}{l}4,645 \\
4,980 \\
5,258 \\
5,421 \\
5,584\end{array}$ & $\begin{array}{l}6,819 \\
7,070 \\
7,108 \\
7,109 \\
7,128\end{array}$ & $\begin{array}{l}6,199 \\
6,343 \\
6,350 \\
6,344 \\
6,337\end{array}$ & $\begin{array}{l}4,738 \\
5,174 \\
5,486 \\
5,629 \\
5,804\end{array}$ & $\begin{array}{l}4,307 \\
4,643 \\
4,902 \\
5,023 \\
5,160\end{array}$ & $\begin{array}{l}6,323 \\
6,591 \\
6,626 \\
6,587 \\
6,587\end{array}$ & $\begin{array}{l}5,748 \\
5,914 \\
5,920 \\
5,879 \\
5,855\end{array}$ \\
\hline 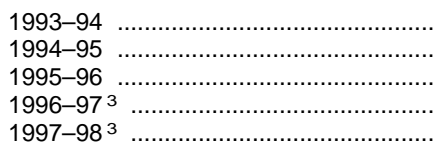 & $\begin{array}{l}6,492 \\
6,725 \\
6,961 \\
7,233 \\
7,502\end{array}$ & $\begin{array}{l}5,767 \\
5,989 \\
6,146 \\
6,387 \\
6,624\end{array}$ & $\begin{array}{l}7,181 \\
7,232 \\
7,287 \\
7,362 \\
7,502\end{array}$ & $\begin{array}{l}6,380 \\
6,440 \\
6,434 \\
6,501 \\
6,624\end{array}$ & $\begin{array}{l}5,996 \\
6,208 \\
6,443 \\
6,695 \\
6,943\end{array}$ & $\begin{array}{l}5,327 \\
5,529 \\
5,689 \\
5,911 \\
6,131\end{array}$ & $\begin{array}{l}6,633 \\
6,676 \\
6,745 \\
6,814 \\
6,943\end{array}$ & $\begin{array}{l}5,893 \\
5,945 \\
5,955 \\
6,017 \\
6,131\end{array}$ \\
\hline
\end{tabular}

1 Data for 1919-20 to 1953-54 are based on school-year enrollment.

2 Based on the Consumer Price Index, prepared by the Bureau of Labor Statistics, U.S. Department of Labor, adjusted to a school-year basis.

3 Estimated.

NOTE.-Beginning in 1980-81, state administration expenditures are excluded from both "total" and "current" expenditures. Beginning in 1988-89, extensive changes were made in the data collection procedures. Some data have been revised from previously published figures.

SOURCE: U.S. Department of Education, National Center for Education Statistics, Statistics of State School Systems; Revenues and Expenditures for Public Elementary and Secondary Education; and Common Core of Data surveys. (This table was prepared July 1998.) 


\section{CHAPTER 3}

\section{Postsecondary Education}

Postsecondary education includes an array of diverse educational experiences, including a wide range of programs offered by American colleges and universities. For example, a community college may offer vocational training or the first 2 years of training at the college level. A university typically offers a full undergraduate course of study leading to a bachelor's degree as well as first-professional and graduate programs leading to advanced degrees. Vocational and technical institutions offer training programs that are designed to prepare students for specific careers. Other types of educational opportunities for adults are provided by community groups, churches, libraries, and businesses.

This chapter provides an overview of the latest statistics on postsecondary education, which includes academic, vocational, and continuing professional education programs after high school. However, to maintain comparability over time, most of the data in the Digest are for higher education institutions, which include 2- and 4-year colleges and universities and exclude most vocational and continuing education programs. This chapter highlights historical data that enable the reader to observe long-range trends in American higher education.

Other chapters provide related information on postsecondary education. Data on price indexes and on the number of degrees held by the general population are in chapter 1 . Chapter 4 contains tabulations on federal funding for postsecondary education. Information on employment outcomes for college graduates is in chapter 5 . Chapter 7 contains data on college libraries and use of computers by young adults. Further information on survey methodologies is in the "Guide to Sources" in the appendix and in the publications cited in the source notes.

\section{Enrollment}

Higher education enrollment increased by 14 percent between 1976 and 1986. Between 1986 and 1996, enrollment increased at the same rate, from 12.5 million to 14.3 million. There was a slight decline in enrollment in the later part of the period from 1992 to 1995, but it was overshadowed by large increases in the late 1980s. Much of this growth was in female enrollment (table 172). Between 1986 and 1996, the number of men enrolled rose 8 percent, while the number of women increased by 20 percent. Part-time enrollment rose by 13 percent compared to an increase of 15 percent in full-time enrollment. In addition to the enrollment in accredited 2-year colleges, 4-year colleges, and universities, about 541,000 students attended non degree-granting postsecondary institutions in fall 1996 (table 170).

The number of older students has been growing more rapidly than the number of younger students, though this pattern is beginning to change. Between 1990 and 1996, the enrollment of students under age 25 increased by 2 percent. During the same period, enrollment of persons 25 and over rose by 6 percent. From 1996 to 2000, NCES projects a rise of 6 percent in enrollments of persons under 25 and an increase of 2 percent in the number 25 and over (table 174).

Enrollment trends have differed at the undergraduate, graduate, and first-professional levels. Undergraduate enrollment generally increased during the 1970s, but dipped between 1983 and 1985. From 1985 to 1992, undergraduate enrollment increased each year, rising 18 percent before declining slightly between 1993 and 1996. Graduate enrollment had been steady at about 1.3 million in the late 1970s and early 1980s, but rose about 26 percent between 1985 and 1996. After rising very rapidly during the 1970s, enrollment in first-professional programs stabilized in the 1980s. There was a 9 percent increase in first-professional enrollment between 1985 and 1996 (tables 187, 188, and 189).

Since 1984, the number of women in graduate schools has exceeded the number of men. Between 1986 and 1996, the number of male full-time graduate students increased by 22 percent, compared to 66 percent for full-time women. Among part-time graduate students, the number of men increased by 1 percent compared to a 17 percent increase for women (table 188).

The proportion of American college students who are minorities has been increasing. In 1976, 16 percent were minorities, compared with 26 percent in 1996. Much of the change can be attributed to rising numbers of Hispanic and Asian students. The proportion of Asian and Pacific Islander students rose from 2 percent to 6 percent, and the Hispanic proportion rose from 4 percent to 8 percent during that time 
period. The proportion of black students fluctuated during most of the early part of the period, before rising to 11 percent in 1996. These percentages exclude foreign students enrolled in U.S. colleges and universities (table 206).

Despite the sizable numbers of small degree-granting colleges, most students attend the larger colleges and universities. In fall 1996, 41 percent of institutions had fewer than 1,000 students; however, these campuses enrolled only 4 percent of college students. While 10 percent of the campuses enrolled 10,000 or more students, they accounted for 50 percent of total college enrollment (table 215).

\section{Faculty, Staff, and Salaries}

The student/staff ratio at colleges and universities dropped from 5.4 in 1976 to 4.9 in 1995. During the same time period, the student/faculty ratio dropped from 16.6 to 15.2. The proportion of administrative staff and other nonteaching professional staff rose from 15 percent in 1976 to 22 percent in 1995, while the proportion of nonprofessional staff declined from 42 percent to 34 percent (table 221).

Approximately 2.7 million people were employed in colleges and universities in the fall of 1995, including 1.7 million professional and .9 million nonprofessional staff. About 43 percent of the staff were faculty or teaching assistants, 6 percent were managerial, 17 percent were other nonteaching professionals, and 34 percent were nonprofessional staff (table 223).

Colleges differ in their practices of employing parttime and full-time staff. In fall 1995, 50 percent of the employees at public 2-year colleges were employed full-time compared with 71 percent at public 4-year colleges and 72 percent at private 4-year colleges. A higher proportion of the faculty at public 4-year colleges were employed full-time (76 percent) than at private 4-year colleges (60 percent) or public 2-year colleges (35 percent) (table 223).

Full-time and part-time faculty and instructional staff also differ by the number and types of students that they teach. In 1992, 67 percent of full-time faculty taught 50 students or more, while only 30 percent of part-time faculty taught that many students. Part-time faculty also taught fewer hours per week. About 46 percent of full-time faculty taught for 10 or more hours per week, compared to 18 percent of part-time faculty. Of the full-time faculty teaching only undergraduate students, 61 percent taught three or more classes, compared to 18 percent of part-time faculty (tables 227 and 228).

The proportion of time that full-time faculty spent teaching was 55 percent in 1992 . For the remaining faculty time, research and scholarship accounted for 18 percent of the time; professional growth, 5 percent; administration, 13 percent; outside consulting, 3 percent; service and nonteaching activities, 7 percent (table 227).

About 13 percent of U.S. faculty in colleges and universities were minorities in 1995 (based on a total excluding nonresident aliens and race unknown persons). Five percent of the faculty were black; 4 percent, Asian/Pacific Islanders; 3 percent, Hispanic; and .4 percent, American Indian/Alaskan Native. The majority of college faculty were white males. Fiftythree percent of faculty fell in this category, while 35 percent were white females. About 14 percent of executive, managerial, and administrative staff were minorities in 1995, compared to about 29 percent of the nonprofessional staff. The proportion of minority staff was about the same at public and private institutions, with both types of institutions having 20 percent minority staff (table 226).

The age distribution of full-time faculty was concentrated in the middle age brackets in 1992. Faculty under the age of 30 composed 1 percent of the total, but 36 percent were ages 30 to 44, and 36 percent were 45 to 54 years old. Thirteen percent were 55 to 59 ; 8 percent, 60 to 64 ; and 5 percent, 65 or older (table 230).

College faculty generally suffered losses in the purchasing power of their salaries from 1972-73 to 1980-81, when average salaries fell 17 percent after adjustment for inflation. During the 1980s, average salaries rose and recouped most of the losses. Between 1992-93 and 1996-97, there was a slight rise in average faculty salaries, but still remaining slightly below the value for 1972-73. Average salaries for men in 1996-97 $(\$ 54,465)$ were considerably higher than the average for women $(\$ 44,325)$, but women's salaries have increased at a slightly faster rate since 1990-91 (table 235).

The proportion of faculty with tenure has remained relatively stable in recent years. About 65 percent of full-time faculty had tenure in 1996-97, but a large difference existed between the proportion of men and women with tenure. Seventy-two percent of men compared with 52 percent of women had tenure in 1996-97. About 68 percent of the faculty at public institutions had tenure, compared with 58 percent of faculty at private institutions (table 240).

\section{Degrees}

During the 1996-97 academic year, 4,009 accredited institutions offered degrees at the associate degree level or above. This included 2,267 4-year colleges and 1,742 2-year colleges (table 242). Institutions awarding various higher education degrees in 1995-96 numbered 2,385 for associate degrees, 1,862 for bachelor's degrees, 1,369 for master's degrees, and 488 for doctor's degrees (tables 257).

More people are completing college. Between 1985-86 and 1995-96, the number of associate, 
bachelor's, master's, and doctor's degrees rose. Associate degrees increased 24 percent, bachelor's degrees increased 18 percent, master's degrees increased 41 percent, and doctor's degrees increased 33 percent during this period. The number of firstprofessional degrees was 4 percent higher in 199596 than it was in 1985-86. The number of first-professional degrees declined in the mid-1980s before increasing in the first half of the 1990s (table 244).

The total number of bachelor's degrees increased slowly during the early 1980 s and more rapidly towards the end of that decade, especially for women. Between 1985-86 and 1995-96, the number of bachelor's degrees awarded to men increased by 8 percent, while those awarded to women rose by 28 percent (table 244).

Of the 1,165,000 bachelor's degrees conferred in 1995-96, the largest numbers of degrees were conferred in the fields of business $(227,000)$, social sciences $(126,000)$, and education $(106,000)$. At the master's degree level, the largest fields were education $(106,000)$ and business $(94,000)$. The largest fields at the doctor's degree level were education $(6,700)$, engineering $(6,400)$, biological sciences $(4,800)$, and physical sciences $(4,600)$ (tables 250 , 251 , and 252).

The pattern of bachelor's degrees by field of study has shifted significantly in recent years. Declines are significant in some male majority fields such as engineering and computer and information sciences. Engineering and engineering technologies declined 18 percent between 1985-86 and 1990-91, and then posted a further 2 percent decline between 1990-91 and 1995-96. Computer and information sciences grew rapidly during the 1970 s and mid 1980s, but dropped 42 percent between 1985-86 and 1995-96 (table 250). Other technical fields have been driven upwards in recent years, in part, by increasing numbers of female graduates. For example, biological science degrees increased 3 percent between 198586 and 1990-91, and then rose 54 percent between 1990-91 and 1995-96. During the later period, the number of male graduates grew 49 percent, while the number of female graduates grew 60 percent (table 278). After declining by 29 percent overall between 1985-86 and 1990-91, the number of male graduates in the physical sciences rose 13 percent between 1990-91 and 1995-96. The number of fe- male graduates in the physical sciences fell by 13 percent in the first period and rose by 37 percent in the second half (table 291). Although the number of male graduates in agriculture and natural resources grew by 53 percent between 1990-91 and 1995-96, the number of female graduates grew 84 percent (table 276).

About half (53 percent) of the students who enrolled in a 4-year college in 1989-90 had completed their degree by spring 1994. About 7 percent of students had completed an associate degree or other certificate below the bachelor's degree, 15 percent of the students were still enrolled toward a bachelor's degree, and 24 percent were no longer working towards a bachelor's degree (table 309).

\section{Finances}

For the 1997-98 academic year, annual prices for undergraduate tuition, room, and board were estimated to be $\$ 6,788$ at public colleges and $\$ 18,745$ at private colleges. Between 1987-88 and 1997-98, prices at public colleges have risen by 20 percent, and prices at private colleges have increased by 28 percent, after adjustment for inflation (tables 38 and 311).

Trend data show increases in the expenditures per student at institutions of higher education through the late 1980s and further increases after 1992. After an adjustment for inflation at colleges and universities, current-fund expenditures per student rose about 5 percent between 1985-86 and 1990-91, and another 7 percent between 1990-91 and 1995-96 (table 335).

Scholarships and fellowships have been rising more rapidly than most other types of college expenditures in recent years. At public universities, between 1985-86 and 1995-96, inflation adjusted scholarships and fellowships expenditures per fulltime-equivalent student rose 84 percent compared with 9 percent for instruction expenditures per student. At private universities during the same period, scholarships and fellowships costs per student rose 67 percent, and the instruction costs rose by 32 percent (tables 342 and 345). Another rapidly rising expenditure for public colleges during the decade was research, which rose by 29 percent per student at public universities, and by 35 percent at other public 4-year colleges (tables 342 and 343). 


\section{Figure 13.-Enrollment, degrees conferred, and expenditures in institutions of higher education: $1960-61$ to $1997-98$}
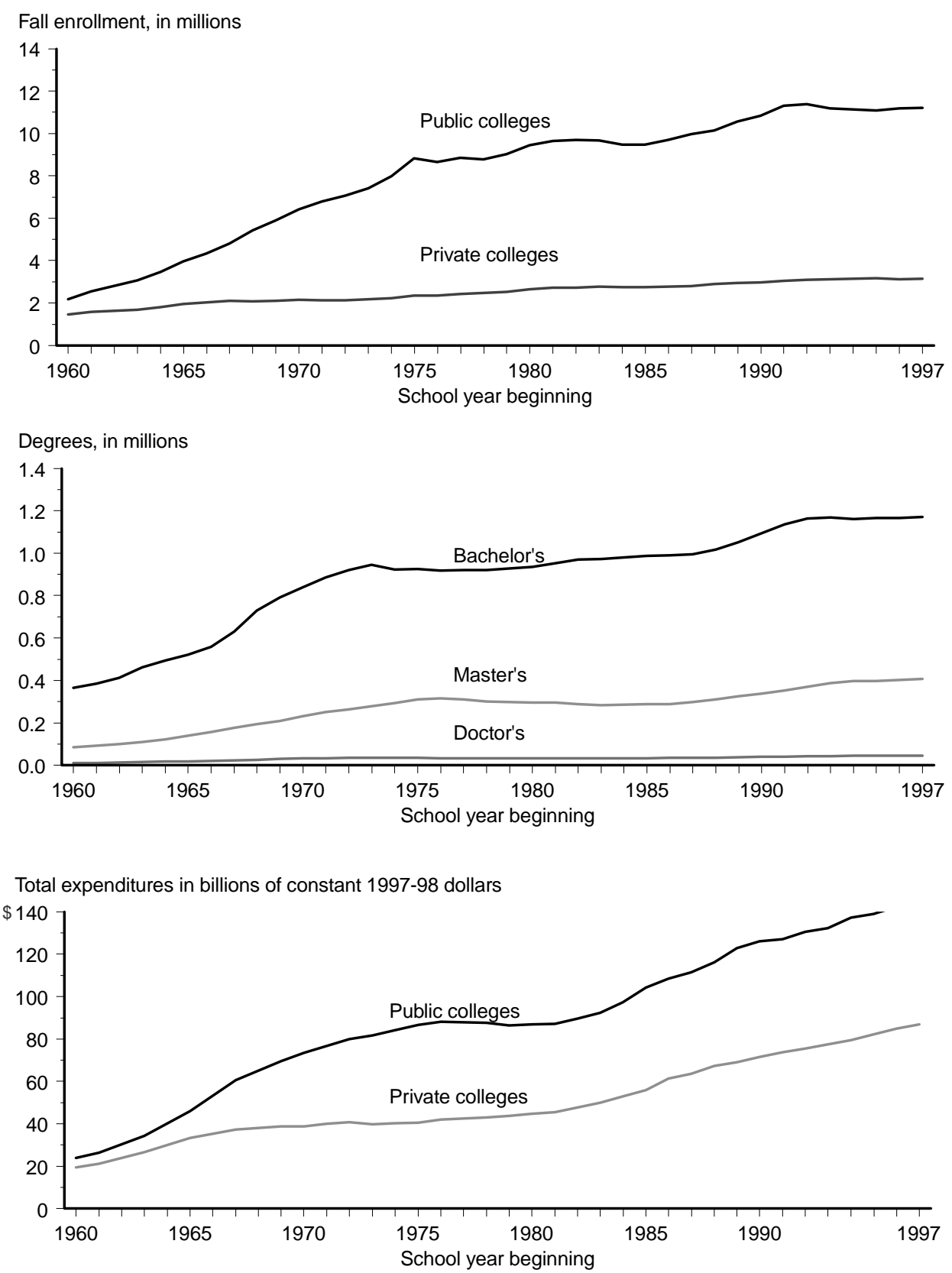

NOTE.-Degree and finance data for 1996-97 and 1997-98 and enrollment data for fall 1997 are estimated.

SOURCE: U.S. Department of Education, National Center for Education Statistics, Higher Education General Information Survey (HEGIS), "Fall Enrollment in Institutions of Higher Education," "Degrees and Other Formal Awards Conferred," and "Financial Statistics of Institutions of Higher Education" surveys; and Integrated Postsecondary Education Data System (IPEDS), "Fall Enrollment," "Completions," and "Finance" surveys. 
Figure 14.-Percentage change in total enrollment of institutions of higher education, by state: Fall 1990 to fall 1996

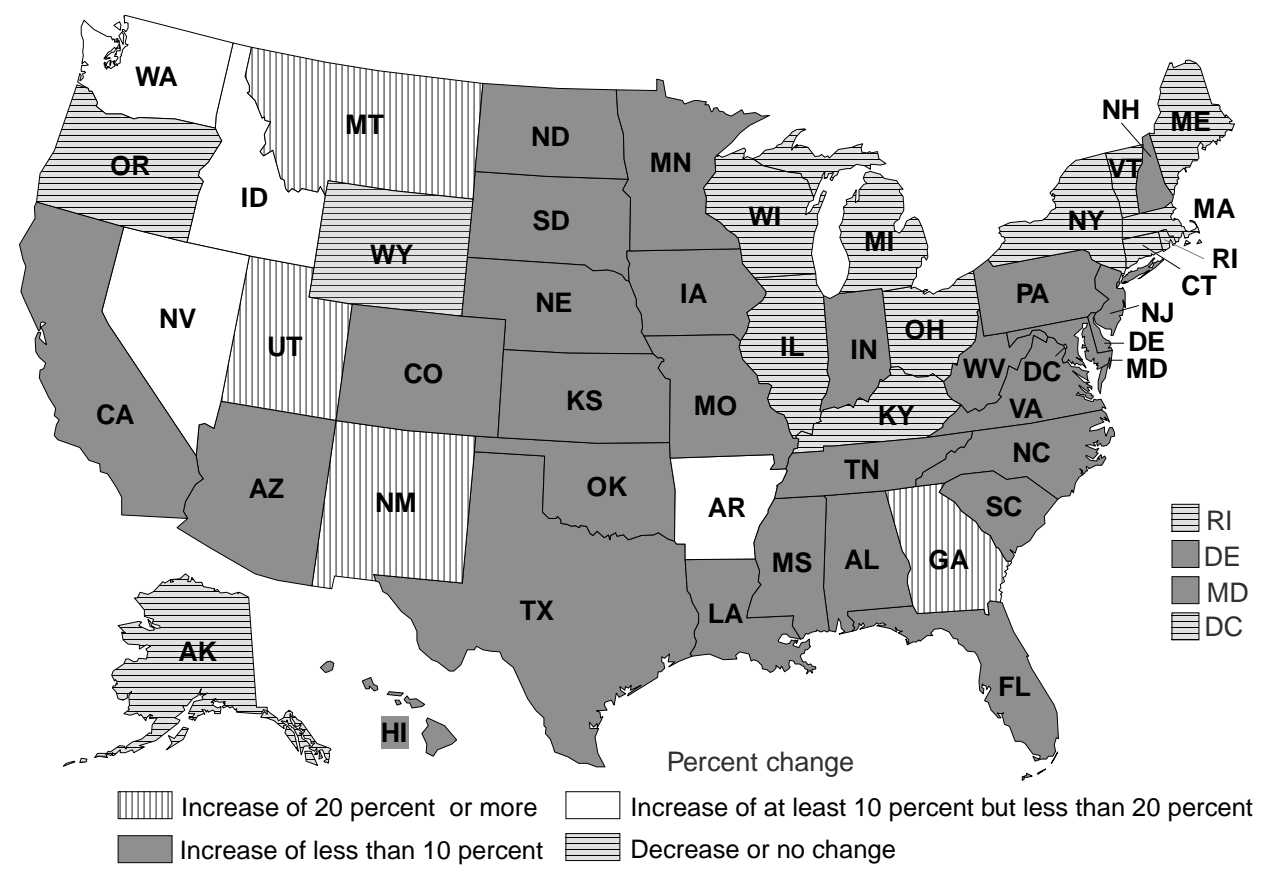

SOURCE: U.S. Department of Education, National Center for Education Statistics, Integrated Postsecondary Education Data System (IPEDS), "Fall Enrollment" surveys.

Figure 15.-Enrollment in institutions of higher education, by age: Fall 1970 to fall 2008

Enrollment in thousands

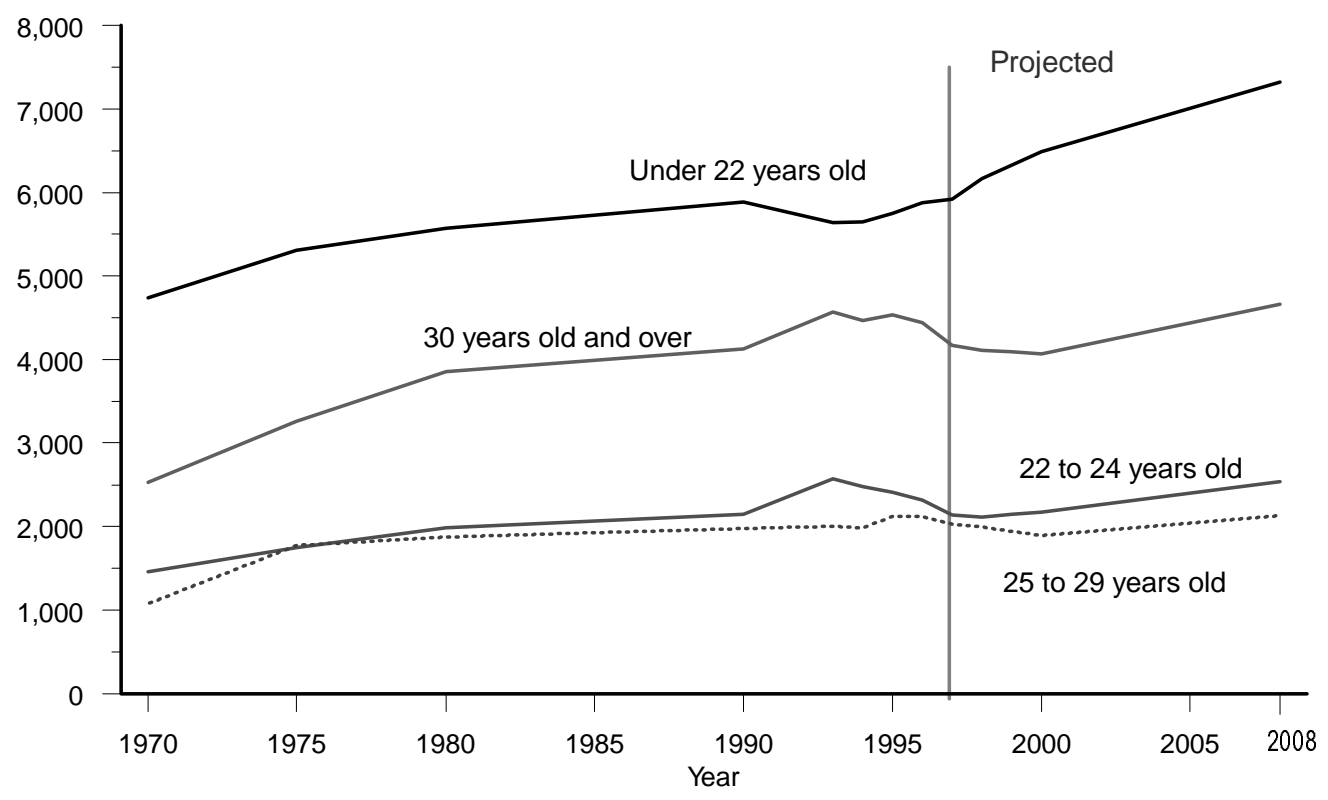

SOURCE: U.S. Department of Education, National Center for Education Statistics, Higher Education General Information Survey (HEGIS), "Fall Enrollment in Institutions of Higher Education" survey; Integrated Postsecondary Education Data System (IPEDS), "Fall Enrollment" surveys; Projections of Education Statistics to 2008; and U.S. Department of Commerce, Bureau of the Census, Current Population Reports, Series P-20, "Social and Economic Characteristics of Students," various years. 
Figure 16.-Full-time-equivalent students per staff member in public and private institutions of higher education: 1976 and 1995

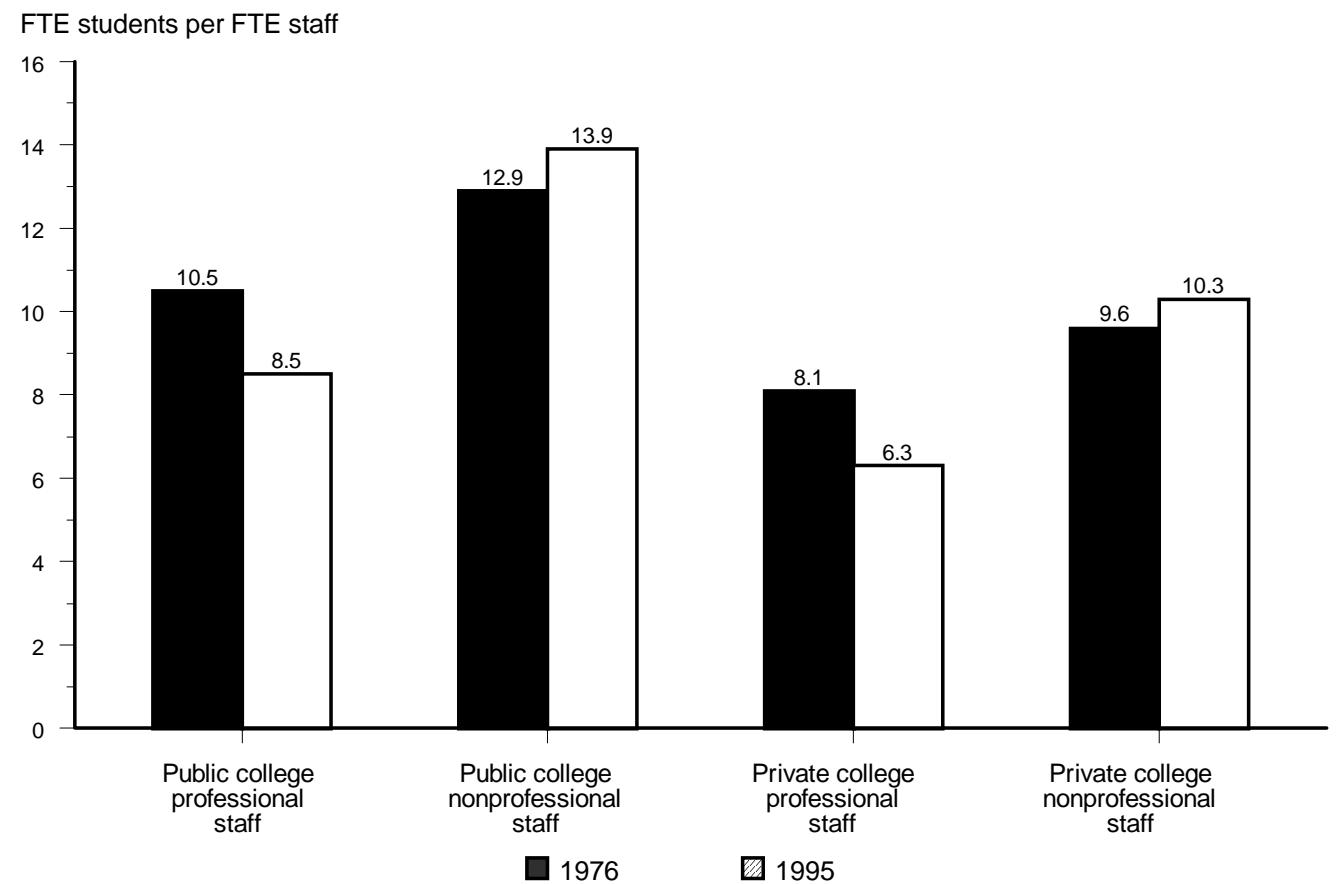

SOURCE: U.S. Department of Education, National Center for Education Statistics, Higher Education General Information Survey (HEGIS), "Staff" and "Fall Enrollment in Higher Education" surveys, and Integrated Postsecondary Education Data System (IPEDS), "Staff" and "Fall Enrollment" surveys.

Figure 17.-Trends in bachelor's degrees conferred in selected fields of study: 1985-86, 1990-91, and 1995-96

Fields of study

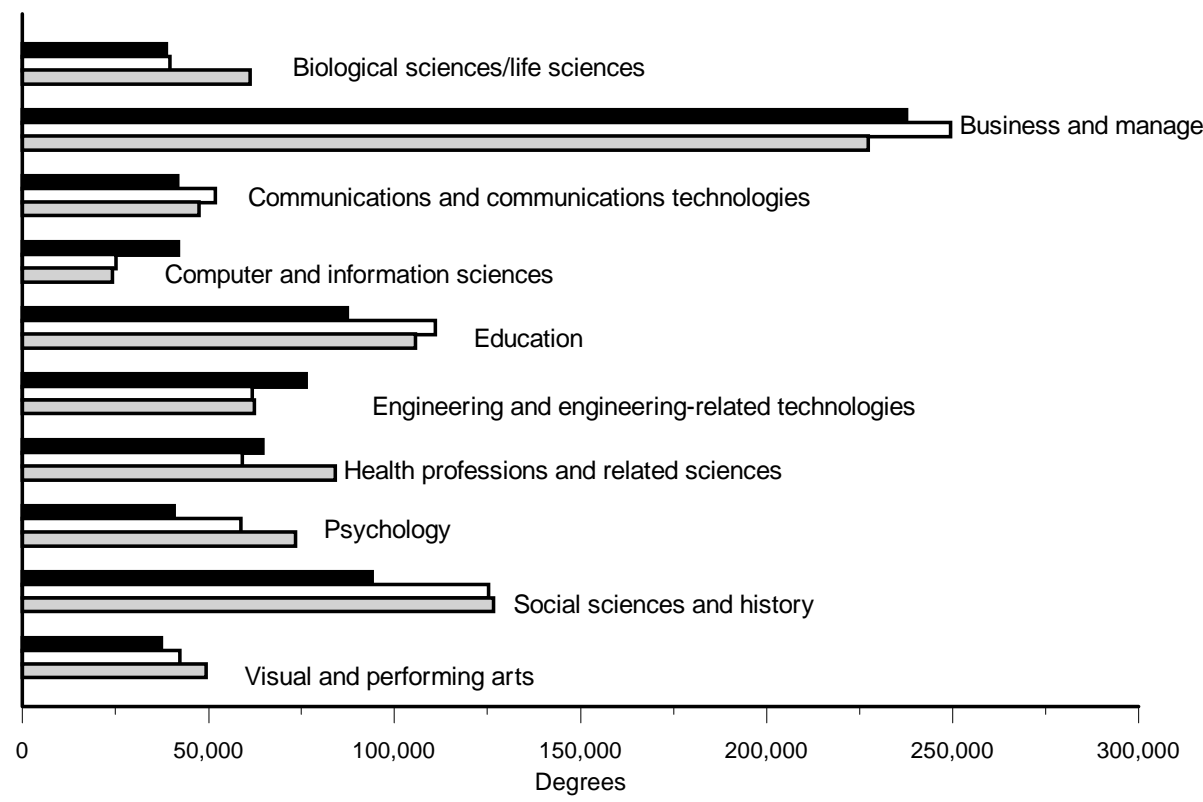

SOURCE: U.S. Department of Education, National Center for Education Statistics, Higher Education General Information Survey (HEGIS), "Degrees and Other Formal Awards Conferred" survey, and Integrated Postsecondary Education Data System (IPEDS), "Completions" surveys. 
Figure 18.-Sources of current-fund revenue for public institutions of higher education: 1995-96

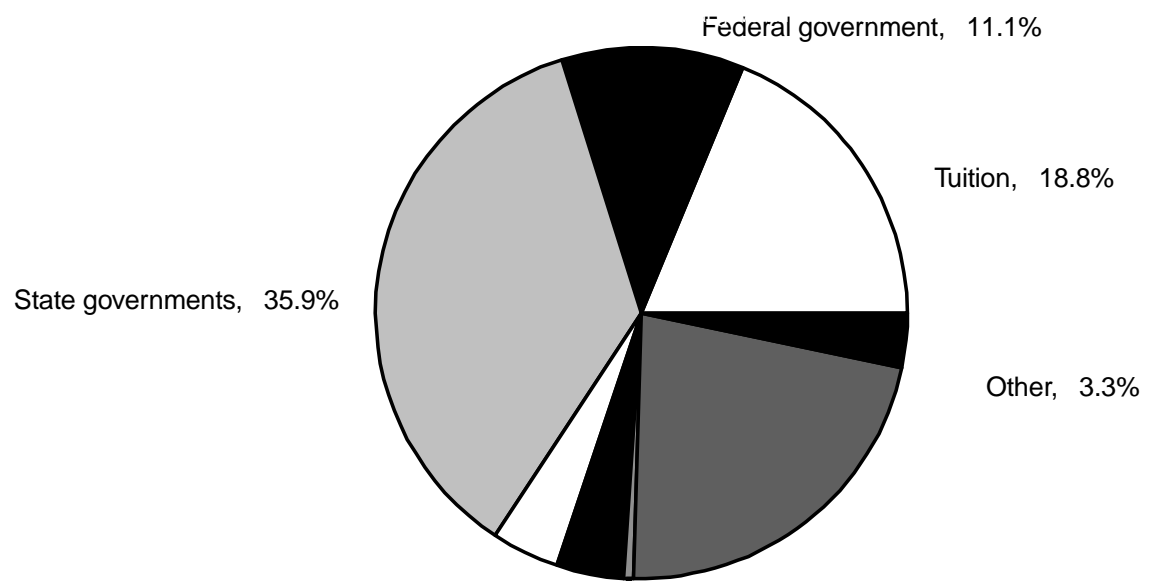

Local governments, $4.1 \%$

Sales and services, $22.2 \%$

Private sources, $4.1 \% \quad$ Endowment income, $0.6 \%$

Total revenues $=\$ 123.5$ billion

SOURCE: U.S. Department of Education, National Center for Education Statistics, Integrated Postsecondary Education Data System (IPEDS), "Finance FY96" survey.

Figure 19.-Sources of current-fund revenue for private institutions of higher education: 1995-96

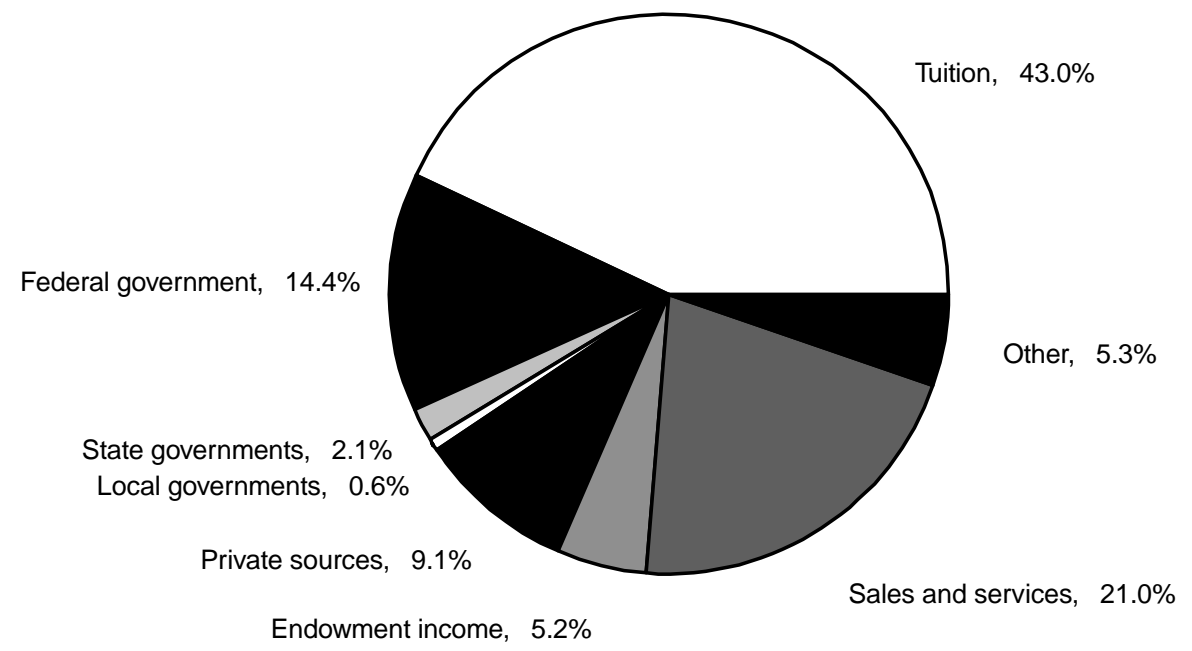

Total revenues $=\$ 74.5$ billion

SOURCE: U.S. Department of Education, National Center for Education Statistics, Integrated Postsecondary Education Data System (IPEDS), "Finance, FY96” survey. 
Table 170.-Enrollment and staff in, and degrees conferred by, degree-granting and nondegree-granting postsecondary institutions: 1995-96 and fall 1995 and 1996

\begin{tabular}{|c|c|c|c|c|c|c|c|c|c|c|c|}
\hline \multirow{3}{*}{$\begin{array}{l}\text { Level of institution, type of } \\
\text { degree, and sex of student }\end{array}$} & \multirow{3}{*}{$\begin{array}{c}\text { All post- } \\
\text { secondary }\end{array}$} & \multicolumn{5}{|c|}{ 2-year and 4-year degree-granting institutions ${ }^{2}$} & \multicolumn{5}{|c|}{ Non-degree-granting institutions ${ }^{3}$} \\
\hline & & \multirow[b]{2}{*}{ Total } & \multirow[b]{2}{*}{ Public } & \multicolumn{3}{|c|}{ Private } & \multirow[b]{2}{*}{ Total } & \multirow[b]{2}{*}{ Public } & \multicolumn{3}{|c|}{ Private } \\
\hline & & & & Total & Nonprofit & $\begin{array}{l}\text { Propri- } \\
\text { etary }\end{array}$ & & & Total & Nonprofit & $\begin{array}{l}\text { Propri- } \\
\text { etary }\end{array}$ \\
\hline \multirow[t]{2}{*}{1} & 2 & 3 & 4 & 5 & 6 & 7 & 8 & 9 & 10 & 11 & 12 \\
\hline & \multicolumn{11}{|c|}{ Enrollment, fall 1996} \\
\hline 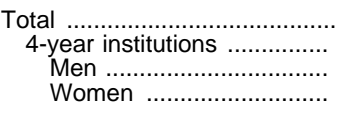 & $\begin{array}{r}14,908,352 \\
8,829,284 \\
4,009,278 \\
4,820,006\end{array}$ & $\begin{array}{r}14,367,520 \\
8,804,193 \\
3,993,911 \\
4,810,282\end{array}$ & $\begin{array}{r}11,120,499 \\
5,806,036 \\
2,646,337 \\
3,159,699\end{array}$ & $\begin{array}{l}3,247,021 \\
2,998,157 \\
1,347,574 \\
1,650,583\end{array}$ & \begin{tabular}{|l|}
$2,942,556$ \\
$2,867,181$ \\
$1,275,934$ \\
$1,591,247$
\end{tabular} & $\begin{array}{r}304,465 \\
130,976 \\
71,640 \\
59,336\end{array}$ & $\begin{array}{r}540,832 \\
25,091 \\
15,367 \\
9,724\end{array}$ & $\begin{array}{r}199,947 \\
1,278 \\
632 \\
646\end{array}$ & $\begin{array}{r}340,885 \\
23,813 \\
14,735 \\
9,078\end{array}$ & $\begin{array}{r}55,750 \\
19,544 \\
11,404 \\
8,140\end{array}$ & $\begin{array}{r}285,135 \\
4,269 \\
3,331 \\
938\end{array}$ \\
\hline $\begin{array}{l}\text { 2-year institutions .............. } \\
\text { Men ............................... } \\
\text { Women ........................ }\end{array}$ & $\begin{array}{l}5,745,842 \\
2,439,373 \\
3,306,469\end{array}$ & $\begin{array}{l}5,563,327 \\
2,358,914 \\
3,204,413\end{array}$ & $\begin{array}{l}5,314,463 \\
2,256,116 \\
3,058,347\end{array}$ & $\begin{array}{l}248,864 \\
102,798 \\
146,066\end{array}$ & $\begin{array}{l}75,375 \\
29,401 \\
45,974\end{array}$ & $\begin{array}{r}173,489 \\
73,397 \\
100,092\end{array}$ & $\begin{array}{r}182,515 \\
80,459 \\
102,056\end{array}$ & $\begin{array}{r}114,319 \\
56,484 \\
57,835\end{array}$ & $\begin{array}{l}68,196 \\
23,975 \\
44,221\end{array}$ & $\begin{array}{r}18,191 \\
4,713 \\
13,478\end{array}$ & $\begin{array}{l}50,005 \\
19,262 \\
30,743\end{array}$ \\
\hline $\begin{array}{l}\text { Less than } 2 \text {-year } \ldots \ldots \ldots \ldots \ldots \ldots \\
\quad \text { Men } \ldots \ldots \ldots \ldots \ldots \ldots \ldots \ldots \ldots \ldots \ldots \ldots \\
\text { Women } \ldots \ldots \ldots \ldots \ldots \ldots \ldots \ldots \ldots\end{array}$ & $\begin{array}{l}333,226 \\
127,947 \\
205,279\end{array}$ & - & - & - & $\begin{array}{l}- \\
-\end{array}$ & - & $\begin{array}{l}333,226 \\
127,947 \\
205,279\end{array}$ & $\begin{array}{l}84,350 \\
39,899 \\
44,451\end{array}$ & $\begin{array}{r}248,876 \\
88,048 \\
160,828\end{array}$ & $\begin{array}{r}18,015 \\
7,310 \\
10,705\end{array}$ & $\begin{array}{r}230,861 \\
80,738 \\
150,123 \\
\end{array}$ \\
\hline 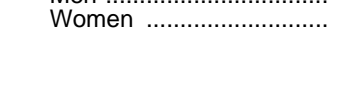 & \multicolumn{11}{|c|}{ Staff, fall $1995^{4}$} \\
\hline 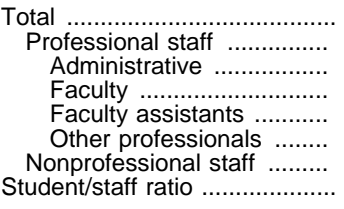 & $\begin{array}{r}2,770,704 \\
1,831,016 \\
163,314 \\
988,441 \\
219,218 \\
460,043 \\
939,688 \\
5.5\end{array}$ & $\begin{array}{r}2,662,075 \\
1,744,867 \\
147,445 \\
931,706 \\
215,909 \\
449,807 \\
917,208 \\
5.4\end{array}$ & $\begin{array}{r}1,865,930 \\
1,230,006 \\
82,396 \\
656,833 \\
181,743 \\
309,034 \\
635,924 \\
5.9\end{array}$ & $\begin{array}{r}796,145 \\
514,861 \\
65,049 \\
274,873 \\
34,166 \\
140,773 \\
281,284 \\
4.0\end{array}$ & $\begin{array}{r}769,698 \\
493,375 \\
62,541 \\
260,900 \\
33,129 \\
136,805 \\
276,323 \\
3.8\end{array}$ & $\begin{array}{r}26,447 \\
21,486 \\
2,508 \\
13,973 \\
1,037 \\
3,968 \\
4,961 \\
9.1\end{array}$ & $\begin{array}{r}108,629 \\
86,149 \\
15,869 \\
56,735 \\
3,309 \\
10,236 \\
22,480 \\
7.8\end{array}$ & $\begin{array}{r}31,327 \\
23,384 \\
2,320 \\
17,597 \\
1,394 \\
2,073 \\
7,943 \\
8.9\end{array}$ & $\begin{array}{r}77,302 \\
62,765 \\
13,549 \\
39,138 \\
1,915 \\
8,163 \\
14,537 \\
7.4\end{array}$ & $\begin{array}{r}24,941 \\
19,004 \\
3,385 \\
12,705 \\
494 \\
2,420 \\
5,937 \\
7.3\end{array}$ & $\begin{array}{r}52,361 \\
43,761 \\
10,164 \\
26,433 \\
1,421 \\
5,743 \\
8,600 \\
7.4\end{array}$ \\
\hline $\begin{array}{l}\text { Nonprofessional staff } \ldots \ldots \ldots . . . \\
\text { Student/staff ratio } \ldots \ldots \ldots \ldots \ldots \ldots \ldots . . . . . . . .\end{array}$ & \multicolumn{11}{|c|}{ Degrees conferred, 1995-96 } \\
\hline 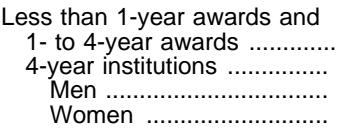 & $\begin{array}{r}620,669 \\
19,587 \\
9,105 \\
10,482\end{array}$ & $\begin{array}{r}240,576 \\
19,306 \\
9,039 \\
10,267\end{array}$ & $\begin{array}{r}181,340 \\
8,728 \\
4,542 \\
4,186\end{array}$ & $\begin{array}{r}59,236 \\
10,578 \\
4,497 \\
6,081\end{array}$ & $\begin{array}{r}13,428 \\
7,868 \\
3,049 \\
4,819\end{array}$ & $\begin{array}{r}45,808 \\
2,710 \\
1,448 \\
1,262\end{array}$ & $\begin{array}{r}380,093 \\
281 \\
66 \\
215\end{array}$ & $\begin{array}{r}126,018 \\
- \\
-\end{array}$ & $\begin{array}{r}254,075 \\
281 \\
66 \\
215\end{array}$ & $\begin{array}{r}20,831 \\
281 \\
66 \\
215\end{array}$ & $\begin{array}{r}233,244 \\
- \\
-\end{array}$ \\
\hline $\begin{array}{l}\text { 2-year institutions ............... } \\
\text { Men ................................. } \\
\text { Women ....................... }\end{array}$ & $\begin{array}{l}328,663 \\
137,379 \\
191,284\end{array}$ & $\begin{array}{r}221,270 \\
94,197 \\
127,073\end{array}$ & $\begin{array}{r}172,612 \\
75,546 \\
97,066\end{array}$ & $\begin{array}{l}48,658 \\
18,651 \\
30,007\end{array}$ & $\begin{array}{l}5,560 \\
2,523 \\
3,037\end{array}$ & $\begin{array}{l}43,098 \\
16,128 \\
26,970\end{array}$ & $\begin{array}{r}107,393 \\
43,182 \\
64,211\end{array}$ & $\begin{array}{l}73,433 \\
33,110 \\
40,323\end{array}$ & $\begin{array}{l}33,960 \\
10,072 \\
23,888\end{array}$ & $\begin{array}{l}7,618 \\
1,897 \\
5,721\end{array}$ & $\begin{array}{r}26,342 \\
8,175 \\
18,167\end{array}$ \\
\hline 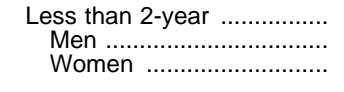 & $\begin{array}{r}272,419 \\
92,541 \\
179,878\end{array}$ & - & $\overline{-}$ & - & - & - & $\begin{array}{r}272,419 \\
92,541 \\
179,878\end{array}$ & $\begin{array}{l}52,585 \\
23,259 \\
29,326\end{array}$ & $\begin{array}{r}219,834 \\
69,282 \\
150,552\end{array}$ & $\begin{array}{r}12,932 \\
5,675 \\
7,257\end{array}$ & $\begin{array}{r}206,902 \\
63,607 \\
143,295\end{array}$ \\
\hline 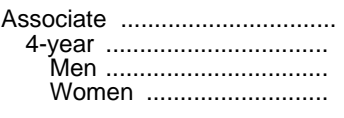 & $\begin{array}{r}557,858 \\
80,347 \\
34,172 \\
46,175\end{array}$ & $\begin{array}{r}555,216 \\
79,863 \\
34,003 \\
45,860\end{array}$ & $\begin{array}{r}454,291 \\
36,170 \\
14,438 \\
21,732\end{array}$ & $\begin{array}{r}100,925 \\
43,693 \\
19,565 \\
24,128\end{array}$ & $\begin{array}{l}50,678 \\
31,857 \\
12,046 \\
19,811\end{array}$ & $\begin{array}{r}50,247 \\
11,836 \\
7,519 \\
4,317\end{array}$ & $\begin{array}{r}2,642 \\
484 \\
169 \\
315\end{array}$ & $\begin{array}{r}161 \\
55 \\
23 \\
32\end{array}$ & $\begin{array}{r}2,481 \\
429 \\
146 \\
283\end{array}$ & $\begin{array}{r}571 \\
253 \\
92 \\
161\end{array}$ & $\begin{array}{r}1,910 \\
176 \\
54 \\
122\end{array}$ \\
\hline 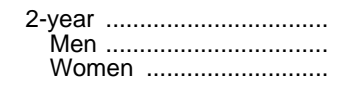 & $\begin{array}{l}477,454 \\
186,321 \\
291,133\end{array}$ & $\begin{array}{l}475,353 \\
185,511 \\
289,842\end{array}$ & $\begin{array}{l}418,121 \\
162,573 \\
255,548\end{array}$ & $\begin{array}{l}57,232 \\
22,938 \\
34,294\end{array}$ & $\begin{array}{r}18,821 \\
7,270 \\
11,551\end{array}$ & $\begin{array}{l}38,411 \\
15,668 \\
22,743\end{array}$ & $\begin{array}{r}2,101 \\
810 \\
1,291\end{array}$ & $\begin{array}{l}88 \\
51 \\
37\end{array}$ & $\begin{array}{r}2,013 \\
759 \\
1,254\end{array}$ & $\begin{array}{l}318 \\
194 \\
124\end{array}$ & $\begin{array}{r}1,695 \\
565 \\
1,130\end{array}$ \\
\hline $\begin{array}{l}\text { Less than } 2 \text {-year } \ldots \ldots \ldots \ldots \ldots \ldots \\
\quad \text { Men ................................ } \\
\text { Women …................... }\end{array}$ & $\begin{array}{l}57 \\
23 \\
34\end{array}$ & - & - & - & - & $\begin{array}{l}- \\
-\end{array}$ & $\begin{array}{l}57 \\
23 \\
34\end{array}$ & $\begin{array}{r}18 \\
17 \\
1\end{array}$ & $\begin{array}{r}39 \\
6 \\
33\end{array}$ & $\begin{array}{l}- \\
-\end{array}$ & $\begin{array}{r}39 \\
6 \\
33\end{array}$ \\
\hline 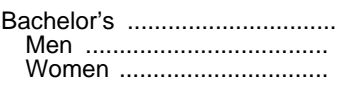 & $\begin{array}{r}1,166,963 \\
523,652 \\
643,311\end{array}$ & $\begin{array}{r}1,164,792 \\
522,454 \\
642,338\end{array}$ & $\begin{array}{l}774,070 \\
350,446 \\
423,624\end{array}$ & $\begin{array}{l}390,722 \\
172,008 \\
218,714\end{array}$ & $\begin{array}{l}379,916 \\
165,859 \\
214,057\end{array}$ & $\begin{array}{r}10,806 \\
6,149 \\
4,657\end{array}$ & $\begin{array}{r}2,171 \\
1,198 \\
973\end{array}$ & $\begin{array}{r}194 \\
97 \\
97\end{array}$ & $\begin{array}{r}1,977 \\
1,101 \\
876\end{array}$ & $\begin{array}{r}1,855 \\
1,017 \\
838\end{array}$ & $\begin{array}{r}122 \\
84 \\
38\end{array}$ \\
\hline 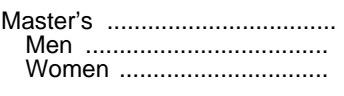 & $\begin{array}{l}407,778 \\
180,120 \\
227,658\end{array}$ & $\begin{array}{l}406,301 \\
179,081 \\
227,220\end{array}$ & $\begin{array}{r}227,179 \\
96,624 \\
130,555\end{array}$ & $\begin{array}{r}179,122 \\
82,457 \\
96,665\end{array}$ & $\begin{array}{r}175,263 \\
80,397 \\
94,866\end{array}$ & $\begin{array}{l}3,859 \\
2,060 \\
1,799\end{array}$ & $\begin{array}{r}1,477 \\
1,039 \\
438\end{array}$ & - & $\begin{array}{r}1,477 \\
1,039 \\
438\end{array}$ & $\begin{array}{r}1,435 \\
1,006 \\
429\end{array}$ & $\begin{array}{r}42 \\
33 \\
9\end{array}$ \\
\hline 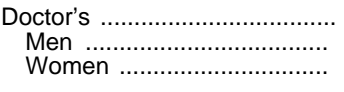 & $\begin{array}{l}44,730 \\
26,903 \\
17,827\end{array}$ & $\begin{array}{l}44,652 \\
26,841 \\
17,811\end{array}$ & $\begin{array}{l}29,516 \\
17,738 \\
11,778\end{array}$ & $\begin{array}{r}15,136 \\
9,103 \\
6,033\end{array}$ & $\begin{array}{r}14,853 \\
8,970 \\
5,883\end{array}$ & $\begin{array}{l}283 \\
133 \\
150\end{array}$ & $\begin{array}{l}78 \\
62 \\
16\end{array}$ & - & $\begin{array}{l}78 \\
62 \\
16\end{array}$ & $\begin{array}{r}55 \\
47 \\
8\end{array}$ & $\begin{array}{r}23 \\
15 \\
8\end{array}$ \\
\hline 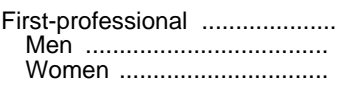 & $\begin{array}{l}76,998 \\
44,979 \\
32,019\end{array}$ & $\begin{array}{l}76,734 \\
44,748 \\
31,986\end{array}$ & $\begin{array}{l}29,882 \\
16,586 \\
13,296\end{array}$ & $\begin{array}{l}46,852 \\
28,162 \\
18,690\end{array}$ & $\begin{array}{l}46,532 \\
27,981 \\
18,551\end{array}$ & $\begin{array}{l}320 \\
181 \\
139\end{array}$ & $\begin{array}{r}264 \\
231 \\
33\end{array}$ & - & $\begin{array}{r}264 \\
231 \\
33\end{array}$ & $\begin{array}{r}264 \\
231 \\
33\end{array}$ & - \\
\hline
\end{tabular}

1 Includes non-degree-granting institutions with non-accredited degree programs.

2 Preliminary data are for 4-year and 2-year degree-granting institutions that were eligible to participate in Title IV federal financial aid programs.

${ }^{3}$ Preliminary data are for institutions that did not offer accredited 4-year or 2-year degree programs or were not eligible to participate in Title IV federal financial aid programs. Includes some schools with non-accredited degree programs.

${ }^{4}$ Staff data under degree-granting institutions are for institutions of higher education. Staff data under non-degree granting institutions are for noncollegiate institutions. -Not available or not applicable.

SOURCE: U.S. Department of Education, National Center for Education Statistics, Integrated Postsecondary Education Data System (IPEDS), "Fall Enrollment," "Staff," and "Completions" surveys. (This table was prepared December 1998.) 
Table 171.-Historical summary of faculty, students, degrees, and finances in institutions of higher education: 1869-70 to 1995-96

\begin{tabular}{|c|c|c|c|c|c|c|c|c|c|c|c|c|c|c|c|}
\hline Item & $1869-70$ & $1879-80$ & $\mid 1889-90$ & 1899-1900 & $1909-10$ & $1919-20$ & $1929-30$ & $1939-40$ & $1949-50$ & $1959-60$ & $1969-70$ & $1979-80$ & $1989-90$ & $1994-95$ & $1995-96$ \\
\hline 1 & 2 & 3 & 4 & 5 & 6 & 7 & 8 & 9 & 10 & 11 & 12 & 13 & 14 & 15 & 16 \\
\hline Total institutions 1 ....... & 563 & 811 & 998 & 977 & 951 & 041 & 1,409 & 1,708 & 1,851 & 2,004 & 2,525 & 3,152 & 3,53 & 3,688 & 3,706 \\
\hline 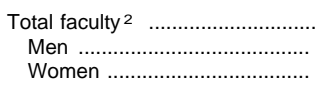 & $\begin{array}{r}35,553 \\
34,887 \\
{ }^{3} 666\end{array}$ & $\begin{array}{r}311,522 \\
37,328 \\
34,194\end{array}$ & $\begin{array}{r}315,809 \\
312,704 \\
33,105\end{array}$ & & & $\begin{array}{l}48,615 \\
35,807 \\
12,808\end{array}$ & $\begin{array}{l}82,386 \\
60,017 \\
22,369\end{array}$ & $\begin{array}{r}146,929 \\
106,328 \\
40,601\end{array}$ & $\begin{array}{r}246,722 \\
186,189 \\
60,533\end{array}$ & $\begin{array}{r}380,554 \\
296,773 \\
83,781\end{array}$ & $\begin{array}{l}4450,000 \\
4346,000 \\
4104,000\end{array}$ & $\begin{array}{l}4675,000 \\
4479,000 \\
4196,000\end{array}$ & $\begin{array}{l}5824,220 \\
5577,298 \\
5246,922\end{array}$ & $\begin{array}{r}3,5923,000 \\
-\end{array}$ & $\begin{array}{r}5931,706 \\
562,893 \\
368,813\end{array}$ \\
\hline 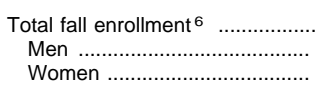 & \begin{tabular}{|l|}
352,286 \\
341,160 \\
311,126 \\
\end{tabular} & $\begin{array}{r}3115,817 \\
377,972 \\
337,845\end{array}$ & \begin{tabular}{|r|}
3156,756 \\
3100,453 \\
356,303
\end{tabular} & $\begin{array}{r}237,592 \\
152,254 \\
85,338\end{array}$ & $\begin{array}{l}355,213 \\
3214,648 \\
3140,565\end{array}$ & $\begin{array}{l}597,880 \\
314,938 \\
282,942\end{array}$ & $\begin{array}{r}1,100,737 \\
619,935 \\
480,802\end{array}$ & $\begin{array}{r}1,494,203 \\
893,250 \\
600,953\end{array}$ & \begin{tabular}{r|}
$2,659,021$ \\
$1,853,006$ \\
805,953
\end{tabular} & $\begin{array}{l}3,639,847 \\
2,332,617 \\
1,307,230\end{array}$ & $\begin{array}{l}8,004,660 \\
4,746,201 \\
3,258,459\end{array}$ & $\begin{array}{r}11,569,899 \\
5,682,877 \\
5,887,022\end{array}$ & $\begin{array}{r}13,538,560 \\
6,190,015 \\
7,348,545\end{array}$ & $\begin{array}{r}14,278,790 \\
6,371,898 \\
7,906,892\end{array}$ & $\begin{array}{r}14,261,781 \\
6,342,539 \\
7,919,242\end{array}$ \\
\hline 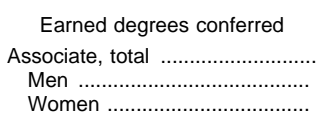 & $\begin{array}{l}- \\
-\end{array}$ & $\begin{array}{l}\overline{-} \\
-\end{array}$ & $\begin{array}{l}- \\
-\end{array}$ & $\begin{array}{l}- \\
-\end{array}$ & $\begin{array}{l}- \\
\overline{-}\end{array}$ & $\begin{array}{l}- \\
-\end{array}$ & $\begin{array}{l}- \\
- \\
-\end{array}$ & $\begin{array}{l}- \\
- \\
-\end{array}$ & $\begin{array}{l}- \\
-\end{array}$ & $\begin{array}{l}\overline{-} \\
\overline{-}\end{array}$ & $\begin{array}{r}206,023 \\
117,432 \\
88,591\end{array}$ & $\begin{array}{l}400,910 \\
183,737 \\
217,173\end{array}$ & $\begin{array}{l}455,102 \\
191,195 \\
263,907\end{array}$ & $\begin{array}{l}539,691 \\
218,352 \\
321,339\end{array}$ & $\begin{array}{l}7555,216 \\
7219,514 \\
7335,702\end{array}$ \\
\hline 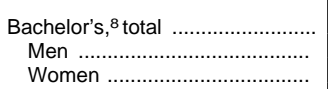 & $\begin{array}{l}9,371 \\
7,993 \\
1,378\end{array}$ & $\begin{array}{r}12,896 \\
10,411 \\
2,485\end{array}$ & $\begin{array}{r}15,539 \\
12,857 \\
2,682\end{array}$ & $\begin{array}{r}27,410 \\
22,173 \\
5,237\end{array}$ & $\begin{array}{r}37,199 \\
28,762 \\
8,437\end{array}$ & $\begin{array}{l}48,622 \\
31,980 \\
16,642\end{array}$ & $\begin{array}{r}122,484 \\
73,615 \\
48,869\end{array}$ & $\begin{array}{r}186,500 \\
109,546 \\
76,954\end{array}$ & $\begin{array}{l}432,058 \\
328,841 \\
103,217\end{array}$ & $\begin{array}{l}392,440 \\
254,063 \\
138,377\end{array}$ & $\begin{array}{l}792,316 \\
451,097 \\
341,219\end{array}$ & $\begin{array}{l}929,417 \\
473,611 \\
455,806\end{array}$ & $\begin{array}{r}1,051,344 \\
491,696 \\
559,648\end{array}$ & $\begin{array}{r}1,160,134 \\
526,131 \\
634,003\end{array}$ & $\begin{array}{r}71,164,792 \\
7522,454 \\
7642,338\end{array}$ \\
\hline 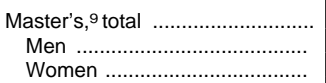 & $\begin{array}{l}0 \\
0 \\
0\end{array}$ & $\begin{array}{r}879 \\
868 \\
11\end{array}$ & $\begin{array}{r}1,015 \\
821 \\
194\end{array}$ & $\begin{array}{r}1,583 \\
1,280 \\
303\end{array}$ & $\begin{array}{r}2,113 \\
1,555 \\
558\end{array}$ & $\begin{array}{l}4,279 \\
2,985 \\
1,294\end{array}$ & $\begin{array}{r}14,969 \\
8,925 \\
6,044\end{array}$ & $\begin{array}{l}26,731 \\
16,508 \\
10,223\end{array}$ & $\begin{array}{l}58,183 \\
41,220 \\
16,963\end{array}$ & $\begin{array}{l}74,435 \\
50,898 \\
23,537\end{array}$ & $\begin{array}{r}208,291 \\
125,624 \\
82,667\end{array}$ & $\begin{array}{l}298,081 \\
150,749 \\
147,332\end{array}$ & & $\begin{array}{l}397,629 \\
178,598 \\
219,031\end{array}$ & $\begin{array}{l}7406,301 \\
7179,081 \\
7227,220\end{array}$ \\
\hline $\begin{array}{l}\text { First-professional, }{ }^{8} \text { total } \\
\text { Men } \ldots . . . . . . . . . . \\
\text { Women }\end{array}$ & $\begin{array}{l}(8) \\
(8) \\
(8)\end{array}$ & $\begin{array}{l}(8) \\
(8) \\
(8)\end{array}$ & $\left.\begin{array}{l}(8) \\
(8) \\
(8)\end{array}\right]$ & $\begin{array}{l}(8) \\
(8) \\
(8)\end{array}$ & $\begin{array}{l}(8) \\
(8) \\
(8)\end{array}$ & $\begin{array}{l}(8) \\
(8) \\
(8)\end{array}$ & $\begin{array}{l}(8) \\
(8) \\
(8)\end{array}$ & $\begin{array}{l}(8) \\
(8) \\
(8)\end{array}$ & $\begin{array}{l}(8) \\
(8) \\
(8)\end{array}$ & $\begin{array}{l}(8) \\
(8) \\
(8)\end{array}$ & $\begin{array}{r}34,918 \\
33,077 \\
1,841\end{array}$ & $\begin{array}{l}70,131 \\
52,716 \\
17,415\end{array}$ & $\begin{array}{l}70,988 \\
43,961 \\
27,027\end{array}$ & $\begin{array}{l}75,800 \\
44,853 \\
30,947\end{array}$ & $\begin{array}{l}776,734 \\
744,748 \\
731,986\end{array}$ \\
\hline $\begin{array}{l}\text { Doctor's, total } \\
\text { Men } \ldots \ldots \\
\text { Women }\end{array}$ & $\begin{array}{l}1 \\
1 \\
0\end{array}$ & $\begin{array}{r}54 \\
51 \\
3\end{array}$ & $\begin{array}{r}149 \\
147 \\
2\end{array}$ & $\begin{array}{r}382 \\
359 \\
23\end{array}$ & $\begin{array}{r}443 \\
399 \\
44\end{array}$ & $\begin{array}{r}615 \\
522 \\
93\end{array}$ & $\begin{array}{r}2,299 \\
1,946 \\
353\end{array}$ & $\begin{array}{r}3,290 \\
2,861 \\
429\end{array}$ & $\begin{array}{r}6,420 \\
5,804 \\
616\end{array}$ & $\begin{array}{l}9,829 \\
8,801 \\
1,028\end{array}$ & $\begin{array}{r}29,866 \\
25,890 \\
3,976\end{array}$ & $\begin{array}{r}32,615 \\
22,943 \\
9,672\end{array}$ & $\begin{array}{l}38,371 \\
24,401 \\
13,970\end{array}$ & $\begin{array}{l}44,446 \\
26,916 \\
17,530\end{array}$ & $\begin{array}{l}744,652 \\
726,841 \\
717,811\end{array}$ \\
\hline $\begin{array}{l}\text { Finances, in thousands } \\
\text { Current-fund revenue ................ } \\
\text { Educational and general in- }\end{array}$ & - & - & - & - & $\$ 76,883$ & $\$ 199,922$ & $\$ 554,511$ & $\$ 715,211$ & $\$ 2,374,645$ & $\$ 5,785,537$ & $\$ 21,515,242$ & $\$ 58,519,982$ & $\$ 139,635,477$ & $\$ 189,120,570$ & $7 \$ 197,973,236$ \\
\hline $\begin{array}{l}\text { come .... } \\
\text { Current-fund } \\
\text { Educationa }\end{array}$ & - & - & $\$ 21,464$ & $\$ 35,084$ & 67,917 & 172,929 & $\begin{array}{l}483,065 \\
507,142\end{array}$ & $\begin{array}{l}571,288 \\
674,688\end{array}$ & $\begin{array}{l}1,833,845 \\
2,245,661\end{array}$ & $\begin{array}{l}4,688,352 \\
5,601,376\end{array}$ & $\begin{array}{l}16,486,177 \\
21,043,113\end{array}$ & $56,913,588$ & $134,655,571$ & $182,968,610$ & $7190,476,163$ \\
\hline $\begin{array}{r}\text { Edu } \\
\text { pe } \\
\text { Value }\end{array}$ & - & - & $95, \overline{-}$ & 253,599 & 457,594 & 747,333 & $\begin{array}{r}377,903 \\
2,065,049\end{array}$ & $\begin{array}{r}521,990 \\
102,753,780\end{array}$ & $\begin{array}{l}1,706,444 \\
4,799,964\end{array}$ & $\begin{array}{r}4,685,258 \\
13,548,548\end{array}$ & $\begin{array}{l}16,845,212 \\
42,093,580\end{array}$ & $\begin{array}{l}44,542,843 \\
83,733,387\end{array}$ & $\begin{array}{l}105,585,076 \\
164,635,000\end{array}$ & $\begin{array}{l}144,158,002 \\
212,201,113\end{array}$ & $\begin{array}{l}7151,445,605 \\
7220,400,104\end{array}$ \\
\hline $\begin{array}{l}\text { Market value of endowment } \\
\text { funds }\end{array}$ & - & - & 1178,788 & 11194,998 & 11323,661 & 11569,071 & $111,372,068$ & $111,686,283$ & $112,601,223$ & $115,322,080$ & $11,206,632$ & $20,743,045$ & $67,978,726$ & $109,706,704$ & $7128,837,030$ \\
\hline
\end{tabular}

1 Prior to $1979-80$, excludes branch campuses

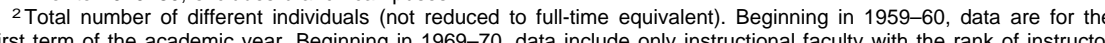
1969-70, data include only instructional faculty with the rank of instructor or above.

${ }^{4}$ Estimated number of senior instructional staff. Excludes graduate assistants.

Because of revised survey procedures, data may not be drectly comparable with figures prior to 1989-90.

Enrolled at any time during the academic year.

inancial aid programs.

8 From 1869-70 to 1959-60, first-professional degrees included under bachelor's degrees.
${ }^{9}$ Figures for years prior to $1969-70$ are not precisely comparable with later data.

11 cludes unexpended plant funds.

nonexpendable funds.

SOURCE: U.S. Department of Education, National Center for Education Statistics, Biennial Survey of Education in the United States; Education Directory, Colleges and Universities; Faculty and Other Professional Staft in Institutions of Higher Education; Fall Enrolment in Colleges and Universiles, Eamed Degrees Conferred; Financial Statistics of tions of Higher Education" "Degrees and Other Formal Awards Conferred," and "Financial Statistics of Institutions of Higher Education" surveys; and Integrated Postsecondary Education Data System (IPEDS), "Fall Enrollment," "Completions," and "Finance" surveys. (This table was prepared November 1998.) 
Table 172.-Total fall enrollment in institutions of higher education, by attendance status, sex of student, and control of institution: 1947 to 1996

\begin{tabular}{|c|c|c|c|c|c|c|c|c|c|}
\hline \multirow{3}{*}{ Year } & \multirow{3}{*}{$\begin{array}{c}\text { Total } \\
\text { enrollment }\end{array}$} & \multicolumn{2}{|c|}{ Attendance status } & \multicolumn{2}{|c|}{ Sex of student } & \multicolumn{4}{|c|}{ Control of institution } \\
\hline & & \multirow{2}{*}{ Full-time } & \multirow{2}{*}{ Part-time } & \multirow{2}{*}{ Men } & \multirow{2}{*}{ Women } & \multirow{2}{*}{ Public } & \multicolumn{3}{|c|}{ Private } \\
\hline & & & & & & & Total & Nonprofit & Proprietary \\
\hline \multirow[t]{2}{*}{1} & 2 & 3 & 4 & 5 & 6 & 7 & 8 & 9 & 10 \\
\hline & \multicolumn{9}{|c|}{ Institutions of higher education } \\
\hline $\begin{array}{l}1947^{1} \ldots \ldots \ldots \ldots . . \\
19481 \\
19499^{1} \ldots \ldots \ldots \ldots \ldots . . . \\
1950^{1} \ldots \ldots \ldots \ldots . . . \\
1951^{1} \ldots \ldots \ldots \ldots \ldots . .\end{array}$ & \begin{tabular}{l|}
$2,338,226$ \\
$2,403,396$ \\
$2,444,900$ \\
$2,281,298$ \\
$2,101,962$
\end{tabular} & $\begin{array}{l}- \\
- \\
- \\
-\end{array}$ & $\begin{array}{l}- \\
- \\
- \\
-\end{array}$ & $\begin{array}{l}1,659,249 \\
1,709,367 \\
1,721,572 \\
1,560,392 \\
1,390,740\end{array}$ & $\begin{array}{l}678,977 \\
694,029 \\
723,328 \\
720,906 \\
711,222\end{array}$ & $\begin{array}{l}1,152,377 \\
1,185,588 \\
1,207,151 \\
1,139,699 \\
1,037,938\end{array}$ & $\begin{array}{l}1,185,849 \\
1,217,808 \\
1,237,749 \\
1,141,599 \\
1,064,024\end{array}$ & $\begin{array}{l}- \\
\overline{-} \\
-\end{array}$ & $\begin{array}{l}- \\
- \\
-\end{array}$ \\
\hline 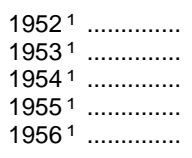 & $\begin{array}{l}2,134,242 \\
2,231,054 \\
2,446,693 \\
2,653,034 \\
2,918,212\end{array}$ & $\begin{array}{l}- \\
- \\
- \\
-\end{array}$ & $\begin{array}{l}- \\
- \\
- \\
-\end{array}$ & $\begin{array}{l}1,380,357 \\
1,422,598 \\
1,563,382 \\
1,733,184 \\
1,911,458\end{array}$ & $\begin{array}{r}753,885 \\
808,456 \\
883,311 \\
919,850 \\
1,006,754\end{array}$ & $\begin{array}{l}1,101,240 \\
1,185,876 \\
1,353,531 \\
1,476,282 \\
1,656,402\end{array}$ & $\begin{array}{l}1,033,002 \\
1,045,178 \\
1,093,162 \\
1,176,752 \\
1,261,810\end{array}$ & $\begin{array}{l}- \\
\overline{-} \\
-\end{array}$ & $\begin{array}{l}- \\
- \\
-\end{array}$ \\
\hline $\begin{array}{l}1957 \\
1959 \\
1961 \\
1963 \ldots \ldots \ldots \ldots \ldots \ldots . . . \\
1964\end{array}$ & $\begin{array}{l}3,323,783 \\
3,639,847 \\
4,145,065 \\
4,779,609 \\
5,280,020\end{array}$ & $\begin{array}{l}-\overline{ } \\
2,421,016 \\
2,785,133 \\
3,183,833 \\
3,573,238\end{array}$ & $\begin{array}{l}21,218,831 \\
21,359,932 \\
21,595,776 \\
21,706,782\end{array}$ & $\begin{array}{l}2,170,765 \\
2,332,617 \\
2,585,821 \\
2,961,540 \\
3,248,713\end{array}$ & $\begin{array}{l}1,153,018 \\
1,307,230 \\
1,559,244 \\
1,818,069 \\
2,031,307\end{array}$ & $\begin{array}{l}1,972,673 \\
2,180,982 \\
2,561,447 \\
3,081,279 \\
3,467,708\end{array}$ & $\begin{array}{l}1,351,110 \\
1,458,865 \\
1,583,618 \\
1,698,330 \\
1,812,312\end{array}$ & $\begin{array}{l}- \\
\overline{-} \\
-\end{array}$ & $\begin{array}{l}- \\
z \\
-\end{array}$ \\
\hline 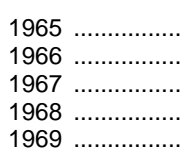 & $\begin{array}{l}5,920,864 \\
6,389,872 \\
6,911,748 \\
7,513,091 \\
8,004,660\end{array}$ & $\begin{array}{l}4,095,728 \\
4,438,606 \\
4,793,128 \\
5,210,155 \\
5,498,883\end{array}$ & $\begin{array}{r}21,825,136 \\
21,951,266 \\
22,118,620 \\
2,302,936 \\
2,505,777\end{array}$ & $\begin{array}{l}3,630,020 \\
3,856,216 \\
4,132,800 \\
4,477,649 \\
4,746,201\end{array}$ & $\begin{array}{l}2,290,844 \\
2,533,656 \\
2,778,948 \\
3,035,442 \\
3,258,459\end{array}$ & $\begin{array}{l}3,969,596 \\
4,348,917 \\
4,816,028 \\
5,430,652 \\
5,896,868\end{array}$ & $\begin{array}{l}1,951,268 \\
2,040,955 \\
2,095,720 \\
2,082,439 \\
2,107,792\end{array}$ & $\begin{array}{l}- \\
\overline{-} \\
-\end{array}$ & $\begin{array}{l}- \\
\overline{-} \\
-\end{array}$ \\
\hline $\begin{array}{l}1970 \\
1971 \ldots \ldots \ldots \ldots \ldots . . \\
1972 \ldots \ldots \ldots \ldots \ldots . . \\
1973 \ldots \ldots \ldots \ldots . . . \\
1974 \ldots \ldots \ldots \ldots . . .\end{array}$ & $\begin{array}{r}8,580,887 \\
8,948,644 \\
9,214,820 \\
9,602,123 \\
10,223,729\end{array}$ & $\begin{array}{l}5,816,290 \\
6,077,232 \\
6,072,389 \\
6,189,493 \\
6,370,273\end{array}$ & $\begin{array}{l}2,764,597 \\
2,871,412 \\
3,142,471 \\
3,412,630 \\
3,853,456\end{array}$ & $\begin{array}{l}5,043,642 \\
5,207,004 \\
5,238,757 \\
5,371,052 \\
5,622,429\end{array}$ & $\begin{array}{l}3,537,245 \\
3,741,640 \\
3,976,103 \\
4,231,071 \\
4,601,300\end{array}$ & $\begin{array}{l}6,428,134 \\
6,804,309 \\
7,070,635 \\
7,419,516 \\
7,988,500\end{array}$ & $\begin{array}{l}2,152,753 \\
2,144,335 \\
2,144,185 \\
2,182,607 \\
2,235,229\end{array}$ & $\begin{array}{l}- \\
\overline{-} \\
-\end{array}$ & $\begin{array}{l}- \\
\overline{-} \\
-\end{array}$ \\
\hline $\begin{array}{l}1975 \\
1976 \ldots \ldots \ldots \ldots \ldots . . \\
1977 \ldots \ldots \ldots \ldots \ldots . . \\
1978 \ldots \ldots \ldots \ldots \ldots . . \\
1979\end{array}$ & $\begin{array}{l}11,184,859 \\
11,012,137 \\
11,285,787 \\
11,260,092 \\
11,569,899\end{array}$ & $\begin{array}{l}6,841,334 \\
6,717,058 \\
6,792,925 \\
6,667,657 \\
6,794,039\end{array}$ & $\begin{array}{l}4,343,525 \\
4,295,079 \\
4,492,862 \\
4,592,435 \\
4,775,860\end{array}$ & $\begin{array}{l}6,148,997 \\
5,810,828 \\
5,789,016 \\
5,640,998 \\
5,682,877\end{array}$ & $\begin{array}{l}5,035,862 \\
5,201,309 \\
5,496,771 \\
5,619,094 \\
5,887,022\end{array}$ & $\begin{array}{l}8,834,508 \\
8,653,477 \\
8,846,993 \\
8,785,893 \\
9,036,822\end{array}$ & $\begin{array}{l}2,350,351 \\
2,358,660 \\
2,438,794 \\
2,474,199 \\
2,533,077\end{array}$ & $\begin{array}{l}\quad-\overline{2} \\
2,314,298 \\
2,386,652 \\
2,408,331 \\
2,461,773\end{array}$ & $\begin{array}{l}-\overline{-} \\
44,362 \\
52,142 \\
65,868 \\
71,304\end{array}$ \\
\hline $\begin{array}{l}1980 \\
1981 \\
1982 \\
1983 \ldots \ldots \ldots \ldots \ldots \ldots \ldots . . . \\
1984\end{array}$ & $\begin{array}{l}12,096,895 \\
12,371,672 \\
12,425,780 \\
12,464,661 \\
12,241,940\end{array}$ & $\begin{array}{l}7,097,958 \\
7,181,250 \\
7,220,618 \\
7,261,050 \\
7,098,388\end{array}$ & $\begin{array}{l}4,998,937 \\
5,190,422 \\
5,205,162 \\
5,203,611 \\
5,143,552\end{array}$ & $\begin{array}{l}5,874,374 \\
5,975,056 \\
6,031,384 \\
6,023,725 \\
5,863,574\end{array}$ & $\begin{array}{l}6,222,521 \\
6,396,616 \\
6,394,396 \\
6,440,936 \\
6,378,366\end{array}$ & $\begin{array}{l}9,457,394 \\
9,647,032 \\
9,696,087 \\
9,682,734 \\
9,477,370\end{array}$ & $\begin{array}{l}2,639,501 \\
2,724,640 \\
2,729,693 \\
2,781,927 \\
2,764,570\end{array}$ & $\begin{array}{l}2,527,787 \\
2,572,405 \\
2,552,739 \\
2,589,187 \\
2,574,419\end{array}$ & $\begin{array}{r}3111,714 \\
3152,235 \\
3176,954 \\
192,740 \\
190,151\end{array}$ \\
\hline 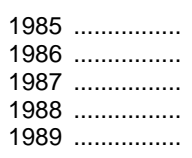 & $\begin{array}{l}12,247,055 \\
12,503,511 \\
12,766,642 \\
13,055,337 \\
13,538,560\end{array}$ & $\begin{array}{l}7,075,221 \\
7,119,550 \\
7,231,085 \\
7,436,768 \\
7,660,950\end{array}$ & $\begin{array}{l}5,171,834 \\
5,383,961 \\
5,535,557 \\
5,618,569 \\
5,877,610\end{array}$ & $\begin{array}{l}5,818,450 \\
5,884,515 \\
5,932,056 \\
6,001,896 \\
6,190,015\end{array}$ & $\begin{array}{l}6,428,605 \\
6,618,996 \\
6,834,586 \\
7,053,441 \\
7,348,545\end{array}$ & $\begin{array}{r}9,479,273 \\
9,713,893 \\
9,973,254 \\
10,161,388 \\
10,577,963\end{array}$ & $\begin{array}{l}2,767,782 \\
2,789,618 \\
2,793,388 \\
2,893,949 \\
2,960,597\end{array}$ & $\begin{array}{l}2,571,791 \\
2,572,479 \\
2,602,350 \\
2,673,567 \\
2,731,174\end{array}$ & $\begin{array}{r}195,991 \\
4217,139 \\
4191,038 \\
220,382 \\
229,423\end{array}$ \\
\hline $\begin{array}{l}1990 \\
1991 \\
1992\end{array}$ & $\begin{array}{l}13,818,637 \\
14,358,953 \\
14,487,359 \\
14,304,803 \\
14,278,790 \\
14,261,781 \\
14,300,255\end{array}$ & \begin{tabular}{l|}
$7,820,985$ \\
$8,115,329$ \\
$8,162,118$ \\
$8,127,618$ \\
$8,137,776$ \\
$8,128,802$ \\
$8,213,490$
\end{tabular} & $\begin{array}{l}5,997,652 \\
6,243,624 \\
6,325,241 \\
6,177,185 \\
6,141,014 \\
6,132,979 \\
6,086,765\end{array}$ & $\begin{array}{l}6,283,909 \\
6,501,844 \\
6,523,989 \\
6,427,450 \\
6,371,898 \\
6,342,539 \\
6,343,992\end{array}$ & $\begin{array}{l}7,534,728 \\
7,857,109 \\
7,963,370 \\
7,877,353 \\
7,906,892 \\
7,919,242 \\
7,956,263\end{array}$ & $\begin{array}{l}10,844,717 \\
11,309,563 \\
11,384,567 \\
11,189,088 \\
11,133,680 \\
11,092,374 \\
11,090,171\end{array}$ & $\begin{array}{l}2,973,920 \\
3,049,390 \\
3,102,792 \\
3,115,715 \\
3,145,110 \\
3,169,407 \\
3,210,084\end{array}$ & $\begin{array}{l}2,760,227 \\
2,819,041 \\
2,872,523 \\
2,888,897 \\
2,910,107 \\
2,929,044 \\
2,940,557\end{array}$ & $\begin{array}{l}213,693 \\
230,349 \\
230,269 \\
226,818 \\
235,003 \\
240,363 \\
269,527\end{array}$ \\
\hline
\end{tabular}

Degree-granting institutions ${ }^{6}$

\begin{tabular}{r|r|r|r|r|r|r|r|r|r}
\cline { 2 - 8 } 19965 .............. & $14,367,520$ & $8,302,953$ & $6,064,567$ & $6,352,825$ & $8,014,695$ & $11,120,499$ & $3,247,021$ & $2,942,556$ & 304,465 \\
\hline
\end{tabular}

${ }^{1}$ Degree-credit enrollment only.

${ }^{2}$ Includes part-time resident students and all extension students.

${ }^{3}$ Large increases are due to the addition of schools accredited by the Accrediting Commission of Career Schools and Colleges of Technology.

${ }^{4}$ Because of imputation techniques, data are not consistent with figures for other years.

5 Preliminary data.

${ }^{6}$ Data are for 4-year and 2-year degree-granting higher education institutions that were eligible to participate in Title IV federal financial aid programs.

-Data not available.
NOTE.-Trend tabulations of institutions of higher education data are based on institutions that were accredited by an agency or association that was recognized by the U.S Department of Education. The Department of Education no longer distinguishes between those institutions and other institutions that are eligible to participate in Title IV programs. The new degree-granting classification is very similar to the earlier higher education classification, except that it includes some additional, primarily 2-year colleges, and excludes a few higher education institutions that did not award degrees.

SOURCE: U.S. Department of Education, National Center for Education Statistics, Higher Education General Information Survey (HEGIS), "Fall Enrollment in Colleges and Universities" surveys; and Integrated Postsecondary Education Data System (IPEDS), "Fall Enrollment" surveys. (This table was prepared April 1998.) 
Table 173.-Total fall enrollment in institutions of higher education and degree-granting institutions, by control and type of institution: 1965 to 1996

\begin{tabular}{|c|c|c|c|c|c|c|c|c|c|c|c|c|c|c|c|}
\hline \multirow{3}{*}{ Year } & \multicolumn{5}{|c|}{ All institutions } & \multicolumn{5}{|c|}{ Public institutions } & \multicolumn{5}{|c|}{ Private institutions } \\
\hline & \multirow[b]{2}{*}{ Total } & \multicolumn{3}{|c|}{ 4-year } & \multirow[b]{2}{*}{ 2-year } & \multirow[b]{2}{*}{ Total } & \multicolumn{3}{|c|}{ 4-year } & \multirow[b]{2}{*}{ 2-year } & \multirow[b]{2}{*}{ Total } & \multicolumn{3}{|c|}{ 4-year } & \multirow[b]{2}{*}{ 2-year } \\
\hline & & Total & University & $\begin{array}{l}\text { Other } \\
\text { 4-year }\end{array}$ & & & Total & University & $\begin{array}{l}\text { Other } \\
\text { 4-year }\end{array}$ & & & Total & University & $\begin{array}{l}\text { Other } \\
\text { 4-year }\end{array}$ & \\
\hline \multirow[t]{2}{*}{1} & 2 & 3 & 4 & 5 & 6 & 7 & 8 & 9 & 10 & 11 & 12 & 13 & 14 & 15 & 16 \\
\hline & \multicolumn{15}{|c|}{ Institutions of higher education } \\
\hline 1965 & $5,920,864$ & $4,747,912$ & - & - & $1,172,952$ & $3,969,596$ & $2,928,332$ & - & - & $1,041,264$ & $1,951,268$ & $1,819,580$ & - & - & 131,68 \\
\hline . & 372 & 063,902 & - & - & $1,325,970$ & 917 & $3,159,748$ & - & - & $1,189,169$ & $2,040,955$ & $1,904,154$ & - & - & 136, \\
\hline 1 & 11,748 & $5,398,986$ & - & - & $1,512,762$ & 816,028 & $3,443,975$ & - & - & $1,372,053$ & $2,095,720$ & $1,955,011$ & - & - & 140,7 \\
\hline 681 & $7,513,091$ & $5,720,795$ & - & - & $1,792,296$ & 430,652 & $3,784,178$ & - & - & $1,646,474$ & $2,082,439$ & $1,936,617$ & - & - & 145,8 \\
\hline $1969 \ldots \ldots . . . .$. & $8,004,660$ & $5,937,127$ & - & - & $2,067,533$ & $5,896,868$ & $3,962,522$ & - & - & $1,934,346$ & $2,107,792$ & $1,974,605$ & - & - & 133,18 \\
\hline 970 & $8,580,887$ & $6,261,502$ & - & - & $2,319,385$ & $6,428,134$ & $4,232,722$ & - & - & $2,195,412$ & $2,152,753$ & $2,028,780$ & - & - & 123,973 \\
\hline 71 & & $6,36 \mathrm{~s}$ & - & - & $2,579,289$ & & $4,346,990$ & - & - & & & & - & - & \\
\hline $1972 \ldots \ldots \ldots \ldots$ & 320 & 6,45 & - & - & 2,75 & 35 & 4,4 & - & - & $2,640,939$ & $2,144,185$ & 2,02 & - & - & 115,247 \\
\hline 1973 & & $6,590,023$ & - & - & $3,012,100$ & 419,516 & $4,529,895$ & - & - & $2,889,621$ & $2,182,607$ & $2,060,128$ & - & - & 122,4 \\
\hline 1974 & $10,223,729$ & $6,819,735$ & - & - & $3,403,994$ & $7,988,500$ & $4,703,018$ & - & - & $3,285,482$ & $2,235,229$ & $2,116,717$ & - & - & 118,512 \\
\hline 1975 & 1 & 740 & $2,838,266$ & 376,474 & 9 & 8 & 42 & $2,124,221$ & $2,873,921$ & 6 & 2 , & 98 & 714,045 & $1,502,553$ & 133 \\
\hline 76 & & 7 & $2,780,289$ & 4,34 & & & 4,96 & 929 & $2,821,762$ & & & 125 & 360 & $1,526,765$ & 15 \\
\hline 1977 & 87 & $7,242,845$ & $2,793,418$ & $4,449,427$ & 4,04 & 93 & $4,945,224$ & $2,070,032$ & $2,875,192$ & $3,901,769$ & $2,438,794$ & $2,297,621$ & 723,386 & $1,574,235$ & 141,173 \\
\hline 1978 & 092 & $7,231,625$ & $2,780,729$ & $4,451,222$ & 467 & 393 & $4,912,203$ & $2,062,295$ & $2,849,908$ & $3,873,690$ & $2,474,199$ & $2,319,422$ & 718,434 & $1,601,314$ & 154 \\
\hline 1979 & $11,569,899$ & $7,353,233$ & $2,839,582$ & $4,513,651$ & $4,216,666$ & $9,036,822$ & $4,980,012$ & $2,099,525$ & $2,880,487$ & $4,056,810$ & $2,533,077$ & $2,373,221$ & 740,057 & $1,633,164$ & 159,856 \\
\hline 1980 & 12 & $7,570,608$ & $2,902,014$ & $4,668,594$ & 4,526 & 945 & 128,612 & 2,15 & $2,974,329$ & 32 & 2,6 & 2,4 & 31 & $1,694,265$ & 05 \\
\hline 1981 & & & 2,90 & 7 & & & 24 & 474 & & & & & 870 & ,267 & 2235, \\
\hline 1982. & & 7,65 & 2,88 & & & & & $2,152,547$ & $3,023,887$ & & & & 188 & 1,7 & 2 \\
\hline 1983. & $12,464,661$ & $7,741,195$ & $2,888,813$ & $4,852,382$ & $4,723,466$ & $9,682,734$ & $5,223,404$ & $2,154,790$ & $3,068,614$ & $4,459,330$ & $2,781,927$ & $2,517,791$ & 734,023 & $1,783,768$ & 264,136 \\
\hline 1984. & $12,241,940$ & $7,711,167$ & $2,870,329$ & $4,840,838$ & $4,530,773$ & $9,477,370$ & $5,198,273$ & $2,138,621$ & $3,059,652$ & $4,279,097$ & $2,764,570$ & $2,512,894$ & 731,708 & $1,781,186$ & 251,67 \\
\hline 35 & 12,2 & $7,715,978$ & $2,870,692$ & $4,845,286$ & 4,531 & 9,47 & $5,209,540$ & $2,141,112$ & $3,068,428$ & $4,269,733$ & $2,767,782$ & $2,506,438$ & 729,580 & $1,776,858$ & 26 \\
\hline 1986 & & & $2,897,207$ & $4,926,756$ & & & $5,300,202$ & $2,160,646$ & $3,139,556$ & & & 2,52 & 736,561 & $1,787,200$ & 3265,857 \\
\hline 1987. & & 7,9 & $2,929,327$ & $5,061,093$ & & & & & $3,244,192$ & & & & & $1,816,901$ & ${ }^{3} 235,16$ \\
\hline 1988 & 37 & $8,180,182$ & $2,978,593$ & $5,201,589$ & 4 & & $5,545,901$ & $2,229,868$ & $3,316,033$ & & & 2,6 & 748,725 & $1,885,556$ & 259,6 \\
\hline 1989 & $13,538,560$ & $8,387,671$ & $3,019,115$ & $5,368,556$ & $5,150,889$ & $10,577,963$ & $5,694,303$ & $2,266,056$ & $3,428,247$ & $4,883,660$ & $2,960,597$ & $2,693,368$ & 753,059 & $1,940,309$ & 267,2 \\
\hline 1990 & 13 & 8 , & 670 & 5,53 & 5 & $10,844,717$ & 2 & 464 & 778 & 75 & 2,9 & 2,7 & 206 & 106 & 08 \\
\hline & & 8, & 429 & 5,64 & & & 748 & $2,301,222$ & 3,526 & & & & 207 & 098 & \\
\hline 1992. & $14,487,359$ & $8,764,969$ & $3,050,345$ & $5,714,624$ & 5,722 & 4,567 & $5,900,012$ & $2,283,834$ & $3,616,178$ & 5,4 & 792 & $2,864,957$ & 766,511 & $2,098,446$ & 237,83 \\
\hline 1993. & & & 728 & 5,71 & & & & $2,259,692$ & $3,592,068$ & & & $2,887,176$ & 763,036 & $2,124,140$ & \\
\hline 1994 & $14,278,790$ & $8,749,080$ & $3,009,072$ & $5,740,008$ & $5,529,710$ & $11,133,680$ & $5,825,213$ & $2,244,636$ & $3,580,577$ & $5,308,467$ & $3,145,110$ & $2,923,867$ & 764,436 & $2,159,431$ & 221,243 \\
\hline \multirow{4}{*}{$\begin{array}{l}1995 \\
19964\end{array}$} & 14,26 & $8,769,252$ & $2,999,641$ & $5,769,611$ & 5,49 & 11,0 & 5,814 & $2,235,939$ & $3,578,606$ & 5,27 & 3,16 & 2,95 & 763,702 & $2,191,005$ & 214,700 \\
\hline & 14,30 & $8,802,835$ & $2,984,965$ & $5,817,870$ & $5,497,420$ & 11,0 & $5,806,904$ & $2,226,529$ & $3,580,375$ & $5,283,267$ & $3,210,084$ & 2,99 & 758,436 & $2,237,495$ & 214,1 \\
\hline & \multicolumn{15}{|c|}{ Degree-granting institutions 5} \\
\hline & $14,367,520$ & $8,804,193$ & $2,984,965$ & $5,819,228$ & $5,563,327$ & 120,499 & $5,806,036$ & ר? 50 & 257050 & $21116 ?$ & & 000157 & & 202070 & 248,86 \\
\hline
\end{tabular}

1 Data for 2-year branch campuses of 4-year institutions are included with the 4-year institutions.

${ }^{2}$ Large increases are due to the addition of schools accredited by the Accrediting Commission of Career Schools and Colleges of Technology.

Because of imputation techniques, data are not consistent with figures for other years.

${ }^{5}$ Data are for 4-year and 2-year degree-granting higher education institutions that were eligible to participate in Title IV federal financial aid programs.

-Data not available.

NOTE.-Trend tabulations of institutions of higher education data are based on institutions that were accredited by an agency or association that was recognized by the U.S. Department of Education. The Department of Education no longer distinguishes between those institutions and other institutions that are eligible to participate in Title IV programs. The new degree-granting clasification is very similar to the earlier higher education classification, except tha includes some additional institutions, primarily 2-year colleges, and excludes a few higher education institutions tha did not award degrees.

SOURCE: U.S. Department of Education, National Center for Education Statistics, Higher Education General Information Survey (HEGIS), "Fall Enrollment in Colleges and Universities" surveys; and Integrated Postsecondary Education Data System (IPEDS), "Fall Enrollment" surveys. (This table was prepared April 1998.) 
Table 174.-Total fall enrollment in institutions of higher education, by attendance status, sex, and age: 1970 to 2008

[In thousands]

\begin{tabular}{|c|c|c|c|c|c|c|c|c|c|c|c|c|c|}
\hline \multirow{2}{*}{ Sex and age } & \multirow{2}{*}{1970} & \multirow{2}{*}{1975} & \multirow{2}{*}{1980} & \multirow{2}{*}{1990} & 1002 & 1004 & 1005 & 1006 & & & rojected & & \\
\hline & & & & & 1993 & 1994 & 1995 & 1990 & 1997 & 1998 & 1999 & 2000 & 2008 \\
\hline 1 & 2 & 3 & 4 & 5 & 6 & 7 & 8 & 9 & 10 & 11 & 12 & 13 & 14 \\
\hline Men and women, total ......... & 8,581 & 11,185 & 12,097 & 13,819 & 14,305 & 14,279 & 14,262 & 14,300 & 14,350 & 14,590 & 14,758 & 14,889 & 16,083 \\
\hline 14 to 17 years old $\ldots \ldots \ldots \ldots . . .$. & 259 & 278 & 247 & 177 & 127 & 138 & 148 & 229 & 187 & 201 & 202 & 209 & 252 \\
\hline 18 and 19 years old ........... & 2,600 & 2,786 & 2,901 & 2,950 & 2,840 & 2,787 & 2,894 & 3,004 & 3,089 & 3,247 & 3,347 & 3,390 & 3,842 \\
\hline 20 and 21 years old ........... & 1,880 & 2,243 & 2,424 & 2,761 & 2,674 & 2,724 & 2,705 & 2,643 & 2,644 & 2,720 & 2,778 & 2,890 & 3,228 \\
\hline 22 to 24 years old ............. & 1,457 & 1,753 & 1,989 & 2,144 & 2,570 & 2,482 & 2,411 & 2,316 & 2,138 & 2,115 & 2,150 & 2,171 & 2,535 \\
\hline 25 to 29 years old ............... & 1,074 & 1,774 & 1,871 & 1,982 & 2,002 & 1,985 & 2,120 & 2,124 & 2,028 & 1,994 & 1,946 & 1,895 & 2,130 \\
\hline 30 to 34 years old $\ldots \ldots \ldots \ldots \ldots$ & 487 & 967 & 1,243 & 1,322 & 1,345 & 1,414 & 1,236 & 1,194 & 1,249 & 1,247 & 1,242 & 1,245 & 1,236 \\
\hline 35 years old and over ....... & 823 & 1,383 & 1,421 & 2,484 & 2,747 & 2,750 & 2,747 & 2,790 & 3,014 & 3,066 & 3,091 & 3,089 & 2,861 \\
\hline Men & 5,044 & 6,149 & 5,874 & 6,284 & 6,427 & 6,372 & 6,343 & 6,344 & 6,239 & 6,324 & 6,383 & 6,442 & 6,906 \\
\hline 14 to 17 years old ........... & 130 & 126 & 99 & 87 & 54 & 62 & 61 & 92 & 88 & 98 & 94 & 99 & 110 \\
\hline 18 and 19 years old ...... & 1,349 & 1,397 & 1,375 & 1,421 & 1,288 & 1,302 & 1,338 & 1,342 & 1,374 & 1,434 & 1,474 & 1,492 & 1,667 \\
\hline 20 and 21 years old ....... & 1,095 & 1,245 & 1,259 & 1,368 & 1,284 & 1,264 & 1,282 & 1,224 & 1,215 & 1,246 & 1,271 & 1,323 & 1,456 \\
\hline 22 to 24 years old .......... & 964 & 1,047 & 1,064 & 1,107 & 1,344 & 1,238 & 1,153 & 1,175 & 1,038 & 1,030 & 1,050 & 1,063 & 1,227 \\
\hline 25 to 29 years old .......... & 783 & 1,122 & 993 & 940 & 903 & 936 & 962 & 993 & 954 & 942 & 922 & 899 & 1,001 \\
\hline 30 to 34 years old ........... & 308 & 557 & 576 & 537 & 584 & 601 & 561 & 480 & 561 & 555 & 550 & 548 & 523 \\
\hline 35 years old and over ... & 415 & 654 & 507 & 824 & 970 & 969 & 986 & 1,039 & 1,009 & 1,019 & 1,022 & 1,019 & 922 \\
\hline 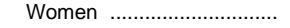 & 3,537 & 5,036 & 6,223 & 7,535 & 7,877 & 7,907 & 7,919 & 7,956 & 8,111 & 8,266 & 8,375 & 8,447 & 9,177 \\
\hline 14 to 17 years old & 129 & 152 & 148 & 90 & 73 & 75 & 87 & 137 & 99 & 103 & 108 & 110 & 142 \\
\hline 18 and 19 years old ....... & 1,250 & 1,389 & 1,526 & 1,529 & 1,552 & 1,485 & 1,557 & 1,662 & 1,715 & 1,813 & 1,872 & 1,898 & 2,176 \\
\hline 20 and 21 years old ....... & 786 & 998 & 1,165 & 1,392 & 1,391 & 1,461 & 1,424 & 1,419 & 1,429 & 1,474 & 1,507 & 1,567 & 1,772 \\
\hline 22 to 24 years old ........... & 493 & 706 & 925 & 1,037 & 1,226 & 1,243 & 1,258 & 1,141 & 1,101 & 1,085 & 1,101 & 1,108 & 1,307 \\
\hline 25 to 29 years old .......... & 291 & 652 & 878 & 1,043 & 1,098 & 1,049 & 1,159 & 1,131 & 1,075 & 1,052 & 1,025 & 996 & 1,128 \\
\hline 30 to 34 years old .......... & 179 & 410 & 667 & 784 & 761 & 812 & 675 & 714 & 688 & 692 & 693 & 697 & 712 \\
\hline 35 years old and over ... & 409 & 729 & 914 & 1,659 & 1,777 & 1,781 & 1,760 & 1,752 & 2,004 & 2,047 & 2,069 & 2,070 & 1,939 \\
\hline Full-time & 5,816 & 6,841 & 7,098 & 7,821 & 8,128 & 8,138 & 8,129 & 8,213 & 8,091 & 8,280 & 8,426 & 8,543 & 9,562 \\
\hline 14 to 17 years old ........... & 242 & 253 & 223 & 144 & 92 & 118 & 123 & 164 & 160 & 166 & 173 & 176 & 216 \\
\hline 18 and 19 years old ....... & 2,406 & 2,619 & 2,669 & 2,548 & 2,370 & 2,321 & 2,387 & 2,516 & 2,649 & 2,799 & 2,892 & 2,933 & 3,341 \\
\hline 20 and 21 years old ....... & 1,647 & 1,910 & 2,075 & 2,151 & 2,148 & 2,178 & 2,109 & 2,098 & 2,112 & 2,185 & 2,239 & 2,334 & 2,625 \\
\hline 22 to 24 years old ........... & 881 & 924 & 1,121 & 1,350 & 1,612 & 1,551 & 1,517 & 1,586 & 1,344 & 1,329 & 1,351 & 1,363 & 1,599 \\
\hline 25 to 29 years old ........... & 407 & 630 & 577 & 770 & 839 & 869 & 908 & 902 & 827 & 803 & 777 & 751 & 845 \\
\hline 30 to 34 years old .......... & 100 & 264 & 251 & 387 & 424 & 440 & 430 & 379 & 404 & 399 & 393 & 389 & 375 \\
\hline 35 years old and over ... & 134 & 241 & 182 & 471 & 643 & 660 & 653 & 568 & 595 & 600 & 601 & 597 & 561 \\
\hline Men & 3,505 & 3,927 & 3,689 & 3,808 & 3,891 & 3,855 & 3,807 & 3,816 & 3,667 & 3,718 & 3,768 & 3,816 & 4,182 \\
\hline 14 to 17 years old $\ldots . .$. & 124 & 114 & 87 & 71 & 37 & 51 & 54 & 71 & 77 & 78 & 80 & 80 & 91 \\
\hline 18 and 19 years old ... & 1,265 & 1,329 & 1,270 & 1,230 & 1,079 & 1,081 & 1,091 & 1,111 & 1,167 & 1,223 & 1,260 & 1,277 & 1,427 \\
\hline 20 and 21 years old .. & 990 & 1,074 & 1,109 & 1,055 & 1,003 & 1,029 & 999 & 961 & 956 & 984 & 1,006 & 1,049 & 1,155 \\
\hline 22 to 24 years old ...... & 650 & 633 & 665 & 742 & 896 & 811 & 789 & 853 & 679 & 670 & 680 & 687 & 790 \\
\hline 25 to 29 years old ...... & 327 & 445 & 360 & 401 & 443 & 457 & 454 & 440 & 414 & 401 & 387 & 375 & 411 \\
\hline 30 to 34 years old ...... & 72 & 181 & 124 & 156 & 180 & 193 & 183 & 143 & 171 & 166 & 163 & 161 & 149 \\
\hline 35 years old and over & 75 & 149 & 74 & 152 & 253 & 232 & 238 & 237 & 205 & 197 & 191 & 186 & 159 \\
\hline Women ……........................ & 2,311 & 2,915 & 3,409 & 4,013 & 4,237 & 4,283 & 4,321 & 4,398 & 4,424 & 4,562 & 4,658 & 4,727 & 5,380 \\
\hline 14 to 17 years old $\ldots . .$. & 117 & 138 & 136 & 73 & 55 & 67 & 69 & 93 & 84 & 88 & 93 & 95 & 125 \\
\hline 18 and 19 years old & 1,140 & 1,290 & 1,399 & 1,318 & 1,291 & 1,240 & 1,296 & 1,405 & 1,482 & 1,576 & 1,632 & 1,657 & 1,914 \\
\hline 20 and 21 years old .. & 657 & 835 & 966 & 1,096 & 1,145 & 1,149 & 1,111 & 1,137 & 1,156 & 1,201 & 1,233 & 1,285 & 1,469 \\
\hline 22 to 24 years old ...... & 231 & 291 & 456 & 608 & 716 & 740 & 729 & 734 & 665 & 660 & 671 & 675 & 810 \\
\hline 25 to 29 years old ...... & 80 & 185 & 217 & 369 & 396 & 412 & 455 & 462 & 413 & 402 & 389 & 376 & 434 \\
\hline 30 to 34 years old ...... & 28 & 83 & 127 & 231 & 244 & 247 & 247 & 236 & 234 & 232 & 230 & 228 & 226 \\
\hline 35 years old and over & 59 & 92 & 108 & 319 & 390 & 428 & 415 & 331 & 390 & 403 & 410 & 411 & 402 \\
\hline Part-time & 2,765 & 4,344 & 4,998 & 5,998 & 6,177 & 6,141 & 6,133 & 6,087 & 6,259 & 6,310 & 6,332 & 6,346 & 6,520 \\
\hline 14 to 17 years old ........... & 17 & 42 & 38 & 32 & 35 & 19 & 25 & 65 & 27 & 35 & 29 & 33 & 36 \\
\hline 18 and 19 years old ....... & 194 & 340 & 418 & 402 & 470 & 466 & 507 & 488 & 440 & 448 & 454 & 456 & 501 \\
\hline 20 and 21 years old ....... & 233 & 447 & 441 & 610 & 526 & 546 & 596 & 544 & 533 & 535 & 539 & 557 & 603 \\
\hline 22 to 24 years old ........... & 576 & 717 & 844 & 794 & 958 & 930 & 894 & 729 & 794 & 786 & 799 & 808 & 935 \\
\hline 25 to 29 years old ........... & 668 & 1,032 & 1,209 & 1,213 & 1,163 & 1,116 & 1,212 & 1,222 & 1,201 & 1,191 & 1,170 & 1,144 & 1,285 \\
\hline 30 to 34 years old .......... & 388 & 670 & 905 & 935 & 921 & 973 & 805 & 815 & 845 & 849 & 850 & 856 & 860 \\
\hline 35 years old and over ... & 689 & 1,098 & 1,145 & 2,012 & 2,104 & 2,091 & 2,093 & 2,222 & 2,419 & 2,466 & 2,490 & 2,491 & 2,300 \\
\hline Men …............................ & 1,540 & 2,222 & 2,185 & 2,476 & 2,537 & 2,517 & 2,535 & 2,528 & 2,572 & 2,606 & 2,615 & 2,626 & 2,724 \\
\hline 14 to 17 years old ...... & 5 & 18 & 17 & 16 & 17 & 11 & 7 & 21 & 12 & 20 & 14 & 18 & 19 \\
\hline 18 and 19 years old ... & 84 & 153 & 202 & 191 & 210 & 220 & 246 & 231 & 207 & 211 & 214 & 215 & 239 \\
\hline 20 and 21 years old .. & 105 & 219 & 201 & 313 & 281 & 235 & 283 & 263 & 260 & 263 & 265 & 274 & 300 \\
\hline 22 to 24 years old ...... & 314 & 358 & 392 & 365 & 448 & 427 & 365 & 323 & 359 & 360 & 370 & 375 & 438 \\
\hline 25 to 29 years old ...... & 456 & 631 & 594 & 539 & 460 & 479 & 508 & 553 & 540 & 541 & 534 & 524 & 590 \\
\hline 30 to 34 years old ...... & 236 & 361 & 397 & 381 & 404 & 408 & 378 & 337 & 390 & 389 & 387 & 387 & 374 \\
\hline 35 years old and over & 340 & 486 & 382 & 672 & 717 & 737 & 748 & 801 & 805 & 822 & 831 & 833 & 763 \\
\hline Women …........................... & 1,225 & 2,121 & 2,814 & 3,521 & 3,640 & 3,624 & 3,598 & 3,558 & 3,687 & 3,704 & 3,717 & 3,720 & 3,797 \\
\hline 14 to 17 years old $\ldots . .$. & 12 & 24 & 20 & 17 & 18 & 8 & 18 & 45 & 15 & 15 & 15 & 15 & 17 \\
\hline 18 and 19 years old ... & 110 & 188 & 215 & 211 & 261 & 245 & 261 & 257 & 233 & 237 & 240 & 241 & 262 \\
\hline 20 and 21 years old .. & 128 & 228 & 240 & 297 & 245 & 311 & 313 & 282 & 273 & 273 & 274 & 283 & 303 \\
\hline 22 to 24 years old ..... & 262 & 359 & 452 & 429 & 510 & 504 & 529 & 407 & 436 & 425 & 430 & 433 & 497 \\
\hline 25 to 29 years old ...... & 212 & 401 & 616 & 674 & 702 & 637 & 704 & 669 & 661 & 650 & 636 & 620 & 695 \\
\hline 30 to 34 years old ...... & 151 & 309 & 507 & 554 & 517 & 565 & 427 & 478 & 455 & 460 & 463 & 469 & 487 \\
\hline 35 years old and over & 349 & 612 & 762 & 1,340 & 1,386 & 1,354 & 1,345 & 1,421 & 1,614 & 1,644 & 1,659 & 1,659 & 1,537 \\
\hline
\end{tabular}

NOTE.-Distributions by age are estimates based on samples of the civilian noninstitutional population. Because of rounding, details may not add to totals. Historical numbers may differ from those in previous editions.

SOURCE: U.S. Department of Education, National Center for Education Statistics, Fall Enrollment in Institutions of Higher Education; Integrated Postsecondary Education Data System (IPEDS), "Fall Enrollment" surveys; Projections of Education Statistics to 2008; and U.S. Department of Commerce, Bureau of the Census, Current Population Reports, "Social and Economic Characteristics of Students," various years. (This table was prepared September 1998.) 
Table 175.-Total fall enrollment in institutions of higher education, by level, sex, age, and attendance status of student: 1995

\begin{tabular}{|c|c|c|c|c|c|c|c|c|c|c|c|c|}
\hline \multirow{2}{*}{$\begin{array}{l}\text { Attendance status and age of } \\
\text { student }\end{array}$} & \multicolumn{3}{|c|}{ All levels } & \multicolumn{3}{|c|}{ Undergraduate } & \multicolumn{3}{|c|}{ First-professional } & \multicolumn{3}{|c|}{ Graduate } \\
\hline & Total & Men & Women & Total & Men & Women & Total & Men & Women & Total & Men & Women \\
\hline 1 & 2 & 3 & 4 & 5 & 6 & 7 & 8 & 9 & 10 & 11 & 12 & 13 \\
\hline All students & $14,261,781$ & $6,342,539$ & $7,919,242$ & $12,231,719$ & $5,401,130$ & $6,830,589$ & 297,592 & 173,897 & 123,695 & $1,732,470$ & 767,512 & 964,958 \\
\hline 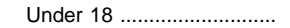 & 285,383 & 114,735 & 170,648 & 284,759 & 114,456 & 170,303 & 77 & 40 & 37 & 547 & 239 & 308 \\
\hline 18 and 19 & $2,796,149$ & $1,256,770$ & $1,539,379$ & $2,794,635$ & $1,256,001$ & $1,538,634$ & 352 & 179 & 173 & 1,162 & 590 & 572 \\
\hline 20 and 21 & $2,617,440$ & $1,220,653$ & $1,396,787$ & $2,597,107$ & $1,211,777$ & $1,385,330$ & 7,366 & 3,249 & 4,117 & 12,967 & 5,627 & 7,340 \\
\hline 22 to 24 & $2,356,678$ & $1,157,227$ & $1,199,451$ & $1,991,784$ & 991,364 & $1,000,420$ & 107,149 & 58,389 & 48,760 & 257,745 & 107,474 & 150,271 \\
\hline 25 to 29 & $2,113,799$ & $1,008,579$ & $1,105,220$ & $1,484,742$ & 690,986 & 793,756 & 110,853 & 68,846 & 42,007 & 518,204 & 248,747 & 269,457 \\
\hline 30 to 34 & $1,295,176$ & 561,110 & 734,066 & 954,866 & 380,067 & 574,799 & 33,729 & 21,577 & 12,152 & 306,581 & 159,466 & 147,115 \\
\hline 35 to 39 & 980,171 & 376,083 & 604,088 & 757,416 & 272,998 & 484,418 & 16,661 & 10,089 & 6,572 & 206,094 & 92,996 & 113,098 \\
\hline 40 to 49 & $1,234,660$ & 427,681 & 806,979 & 910,307 & 309,117 & 601,190 & 15,529 & 8,496 & 7,033 & 308,824 & 110,068 & 198,756 \\
\hline 50 to 64 & 356,036 & 123,342 & 232,694 & 269,524 & 94,144 & 175,380 & 3,408 & 1,696 & 1,712 & 83,104 & 27,502 & 55,602 \\
\hline 65 and over .............................. & 80,950 & 33,454 & 47,496 & 75,125 & 30,799 & 44,326 & 336 & 192 & 144 & 5,489 & 2,463 & 3,026 \\
\hline Age unknown .... & 145,339 & 62,905 & 82,434 & 111,454 & 49,421 & 62,033 & 2,132 & 1,144 & 988 & 31,753 & 12,340 & 19,413 \\
\hline Full-time ........ & $8,128,802$ & $3,807,392$ & $4,321,410$ & $7,145,268$ & $3,296,610$ & $3,848,658$ & 266,414 & 155,056 & 111,358 & 717,120 & 355,726 & 361,394 \\
\hline Under $18 \ldots \ldots \ldots$ & 115,479 & 45,123 & 70,356 & 115,193 & 44,988 & 70,205 & 61 & 30 & 31 & 225 & 105 & 120 \\
\hline 18 and 19 & $2,395,257$ & $1,072,206$ & $1,323,051$ & $2,394,042$ & $1,071,549$ & $1,322,493$ & 345 & 176 & 169 & 870 & 481 & 389 \\
\hline 20 and 21 & $2,088,263$ & 977,094 & $1,111,169$ & $2,070,547$ & 969,175 & $1,101,372$ & 7,260 & 3,199 & 4,061 & 10,456 & 4,720 & 5,736 \\
\hline 22 to 24 & $1,501,692$ & 771,189 & 730,503 & $1,224,186$ & 637,463 & 586,723 & 104,110 & 56,754 & 47,356 & 173,396 & 76,972 & 96,424 \\
\hline 25 to 29 & 951,825 & 493,254 & 458,571 & 597,685 & 295,896 & 301,789 & 101,168 & 62,741 & 38,427 & 252,972 & 134,617 & 118,355 \\
\hline 30 to 34 & 423,324 & 191,737 & 231,587 & 280,133 & 108,369 & 171,764 & 27,121 & 17,307 & 9,814 & 116,070 & 66,061 & 50,009 \\
\hline 35 to 39 & 265,514 & 104,568 & 160,946 & 191,114 & 66,111 & 125,003 & 12,180 & 7,296 & 4,884 & 62,220 & 31,161 & 31,059 \\
\hline 40 to 49 & 279,755 & 106,129 & 173,626 & 194,854 & 70,101 & 124,753 & 10,284 & 5,580 & 4,704 & 74,617 & 30,448 & 44,169 \\
\hline 50 to 64 & 57,402 & 22,360 & 35,042 & 38,184 & 14,816 & 23,368 & 2,068 & 1,025 & 1,043 & 17,150 & 6,519 & 10,631 \\
\hline 65 and over ............................ & 6,615 & 3,282 & 3,333 & 5,481 & 2,679 & 2,802 & 236 & 139 & 97 & 898 & 464 & 434 \\
\hline Age unknown ........................... & 43,676 & 20,450 & 23,226 & 33,849 & 15,463 & 18,386 & 1,581 & 809 & 772 & 8,246 & 4,178 & 4,068 \\
\hline Part-time & $6,132,979$ & $2,535,147$ & $3,597,832$ & $5,086,451$ & $2,104,520$ & $2,981,931$ & 31,178 & 18,841 & 12,337 & $1,015,350$ & 411,786 & 603,564 \\
\hline Under 18 & 169,904 & 69,612 & 100,292 & 169,566 & 69,468 & 100,098 & 16 & 10 & 6 & 322 & 134 & 188 \\
\hline 18 and 19 & 400,892 & 184,564 & 216,328 & 400,593 & 184,452 & 216,141 & 7 & 3 & 4 & 292 & 109 & 183 \\
\hline 20 and 21 & 529,177 & 243,559 & 285,618 & 526,560 & 242,602 & 283,958 & 106 & 50 & 56 & 2,511 & 907 & 1,604 \\
\hline 22 to 24 & 854,986 & 386,038 & 468,948 & 767,598 & 353,901 & 413,697 & 3,039 & 1,635 & 1,404 & 84,349 & 30,502 & 53,847 \\
\hline 25 to 29 & $1,161,974$ & 515,325 & 646,649 & 887,057 & 395,090 & 491,967 & 9,685 & 6,105 & 3,580 & 265,232 & 114,130 & 151,102 \\
\hline 30 to 34 & 871,852 & 369,373 & 502,479 & 674,733 & 271,698 & 403,035 & 6,608 & 4,270 & 2,338 & 190,511 & 93,405 & 97,106 \\
\hline 35 to 39 & 714,657 & 271,515 & 443,142 & 566,302 & 206,887 & 359,415 & 4,481 & 2,793 & 1,688 & 143,874 & 61,835 & 82,039 \\
\hline 40 to 49 & 954,905 & 321,552 & 633,353 & 715,453 & 239,016 & 476,437 & 5,245 & 2,916 & 2,329 & 234,207 & 79,620 & 154,587 \\
\hline 50 to 64 & 298,634 & 100,982 & 197,652 & 231,340 & 79,328 & 152,012 & 1,340 & 671 & 669 & 65,954 & 20,983 & 44,971 \\
\hline 65 and over .......................... & 74,335 & 30,172 & 44,163 & 69,644 & 28,120 & 41,524 & 100 & 53 & 47 & 4,591 & 1,999 & 2,592 \\
\hline Age unknown ........................... & 101,663 & 42,455 & 59,208 & 77,605 & 33,958 & 43,647 & 551 & 335 & 216 & 23,507 & 8,162 & 15,345 \\
\hline & & & & & Perc & ntage distrib & tion & & & & & \\
\hline All students . & 100.0 & 100.0 & 100.0 & 100.0 & 100.0 & 100.0 & 100.0 & 100.0 & 100.0 & 100.0 & 100.0 & 100.0 \\
\hline 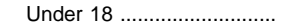 & 2.0 & 1.8 & 2.2 & 2.3 & 2.1 & 2.5 & (1) & (1) & (1) & (1) & (1) & $\left({ }^{1}\right)$ \\
\hline 18 and 19 & 19.6 & 19.8 & 19.4 & 22.8 & 23.3 & 22.5 & 0.1 & 0.1 & 0.1 & 0.1 & 0.1 & 0.1 \\
\hline 20 and 21 & 18.4 & 19.2 & 17.6 & 21.2 & 22.4 & 20.3 & 2.5 & 1.9 & 3.3 & 0.7 & 0.7 & 0.8 \\
\hline 22 to 24 & 16.5 & 18.2 & 15.1 & 16.3 & 18.4 & 14.6 & 36.0 & 33.6 & 39.4 & 14.9 & 14.0 & 15.6 \\
\hline 25 to 29 & 14.8 & 15.9 & 14.0 & 12.1 & 12.8 & 11.6 & 37.2 & 39.6 & 34.0 & 29.9 & 32.4 & 27.9 \\
\hline 30 to 34 & 9.1 & 8.8 & 9.3 & 7.8 & 7.0 & 8.4 & 11.3 & 12.4 & 9.8 & 17.7 & 20.8 & 15.2 \\
\hline 35 to 39 & 6.9 & 5.9 & 7.6 & 6.2 & 5.1 & 7.1 & 5.6 & 5.8 & 5.3 & 11.9 & 12.1 & 11.7 \\
\hline 40 to 49 & 8.7 & 6.7 & 10.2 & 7.4 & 5.7 & 8.8 & 5.2 & 4.9 & 5.7 & 17.8 & 14.3 & 20.6 \\
\hline 50 to 64 & 2.5 & 1.9 & 2.9 & 2.2 & 1.7 & 2.6 & 1.1 & 1.0 & 1.4 & 4.8 & 3.6 & 5.8 \\
\hline 65 and over .............................. & 0.6 & 0.5 & 0.6 & 0.6 & 0.6 & 0.6 & 0.1 & 0.1 & 0.1 & 0.3 & 0.3 & 0.3 \\
\hline Age unknown ...................... & 1.0 & 1.0 & 1.0 & 0.9 & 0.9 & 0.9 & 0.7 & 0.7 & 0.8 & 1.8 & 1.6 & 2.0 \\
\hline 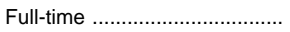 & 100.0 & 100.0 & 100.0 & 100.0 & 100.0 & 100.0 & 100.0 & 100.0 & 100.0 & 100.0 & 100.0 & 100.0 \\
\hline Under 18 & 1.4 & 1.2 & 1.6 & 1.6 & 1.4 & 1.8 & $\left({ }^{1}\right)$ & (1) & (1) & (1) & $\left({ }^{1}\right)$ & $\left({ }^{1}\right)$ \\
\hline 18 and 19 & 29.5 & 28.2 & 30.6 & 33.5 & 32.5 & 34.4 & 0.1 & 0.1 & 0.2 & 0.1 & 0.1 & 0.1 \\
\hline 20 and 21 & 25.7 & 25.7 & 25.7 & 29.0 & 29.4 & 28.6 & 2.7 & 2.1 & 3.6 & 1.5 & 1.3 & 1.6 \\
\hline 22 to 24 & 18.5 & 20.3 & 16.9 & 17.1 & 19.3 & 15.2 & 39.1 & 36.6 & 42.5 & 24.2 & 21.6 & 26.7 \\
\hline 25 to 29 & 11.7 & 13.0 & 10.6 & 8.4 & 9.0 & 7.8 & 38.0 & 40.5 & 34.5 & 35.3 & 37.8 & 32.7 \\
\hline 30 to 34 & 5.2 & 5.0 & 5.4 & 3.9 & 3.3 & 4.5 & 10.2 & 11.2 & 8.8 & 16.2 & 18.6 & 13.8 \\
\hline 35 to 39 & 3.3 & 2.7 & 3.7 & 2.7 & 2.0 & 3.2 & 4.6 & 4.7 & 4.4 & 8.7 & 8.8 & 8.6 \\
\hline 40 to 49 & 3.4 & 2.8 & 4.0 & 2.7 & 2.1 & 3.2 & 3.9 & 3.6 & 4.2 & 10.4 & 8.6 & 12.2 \\
\hline 50 to 64 & 0.7 & 0.6 & 0.8 & 0.5 & 0.4 & 0.6 & 0.8 & 0.7 & 0.9 & 2.4 & 1.8 & 2.9 \\
\hline 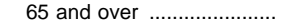 & 0.1 & 0.1 & 0.1 & 0.1 & 0.1 & 0.1 & 0.1 & 0.1 & 0.1 & 0.1 & 0.1 & 0.1 \\
\hline Age unknown .......................... & 0.5 & 0.5 & 0.5 & 0.5 & 0.5 & 0.5 & 0.6 & 0.5 & 0.7 & 1.1 & 1.2 & 1.1 \\
\hline Part-time & 100.0 & 100.0 & 100.0 & 100.0 & 100.0 & 100.0 & 100.0 & 100.0 & 100.0 & 100.0 & 100.0 & 100.0 \\
\hline Under 18 & 2.8 & 2.7 & 2.8 & 3.3 & 3.3 & 3.4 & 0.1 & 0.1 & (1) & (1) & (1) & (1) \\
\hline 18 and 19 & 6.5 & 7.3 & 6.0 & 7.9 & 8.8 & 7.2 & (1) & $\left({ }^{1}\right)$ & (1) & (1) & (1) & $\left({ }^{1}\right)$ \\
\hline 20 and 21 & 8.6 & 9.6 & 7.9 & 10.4 & 11.5 & 9.5 & 0.3 & 0.3 & 0.5 & 0.2 & 0.2 & 0.3 \\
\hline 22 to 24 & 13.9 & 15.2 & 13.0 & 15.1 & 16.8 & 13.9 & 9.7 & 8.7 & 11.4 & 8.3 & 7.4 & 8.9 \\
\hline 25 to 29 & 18.9 & 20.3 & 18.0 & 17.4 & 18.8 & 16.5 & 31.1 & 32.4 & 29.0 & 26.1 & 27.7 & 25.0 \\
\hline 30 to 34 & 14.2 & 14.6 & 14.0 & 13.3 & 12.9 & 13.5 & 21.2 & 22.7 & 19.0 & 18.8 & 22.7 & 16.1 \\
\hline 35 to 39 & 11.7 & 10.7 & 12.3 & 11.1 & 9.8 & 12.1 & 14.4 & 14.8 & 13.7 & 14.2 & 15.0 & 13.6 \\
\hline 40 to 49 & 15.6 & 12.7 & 17.6 & 14.1 & 11.4 & 16.0 & 16.8 & 15.5 & 18.9 & 23.1 & 19.3 & 25.6 \\
\hline 50 to 64 & 4.9 & 4.0 & 5.5 & 4.5 & 3.8 & 5.1 & 4.3 & 3.6 & 5.4 & 6.5 & 5.1 & 7.5 \\
\hline 65 and over ........................... & 1.2 & 1.2 & 1.2 & 1.4 & 1.3 & 1.4 & 0.3 & 0.3 & 0.4 & 0.5 & 0.5 & 0.4 \\
\hline Age unknown .......................... & 1.7 & 1.7 & 1.6 & 1.5 & 1.6 & 1.5 & 1.8 & 1.8 & 1.8 & 2.3 & 2.0 & 2.5 \\
\hline
\end{tabular}

1 Less than 0.05 percent.

NOTE.-Because of rounding, details may not add to 100.0 percent.
SOURCE: US. Department of Education, National Center for Education Statistics, In tegrated Postsecondary Education Data System, "Fall Enrollment, 1995" survey. (This table was prepared January 1997 .) 
Table 176.-Total fall enrollment in institutions of higher education, by type and control of institution, and age and attendance status of student: 1995

\begin{tabular}{|c|c|c|c|c|c|c|c|c|c|}
\hline \multirow{2}{*}{ Attendance status and age of student } & \multicolumn{3}{|c|}{ All institutions } & \multicolumn{3}{|c|}{ Public institutions } & \multicolumn{3}{|c|}{ Private institutions } \\
\hline & Total & 4-year & 2-year & Total & 4-year & 2-year & Total & 4-year & 2-year \\
\hline 1 & 2 & 3 & 4 & 5 & 6 & 7 & 8 & 9 & 10 \\
\hline All students & $14,261,781$ & $8,769,252$ & $5,492,529$ & $11,092,374$ & $5,814,545$ & $5,277,829$ & $3,169,407$ & $2,954,707$ & 214,700 \\
\hline Under $18 \ldots$ & 285,383 & 120,128 & 165,255 & 232,944 & 71,696 & 161,248 & 52,439 & 48,432 & 4,007 \\
\hline 18 and 19 & $2,796,149$ & $1,771,315$ & $1,024,834$ & $2,149,691$ & $1,171,170$ & 978,521 & 646,458 & 600,145 & 46,313 \\
\hline 20 and 21 & $2,617,440$ & $1,803,281$ & 814,159 & $2,006,878$ & $1,225,544$ & 781,334 & 610,562 & 577,737 & 32,825 \\
\hline 22 to 24 & $2,356,678$ & $1,619,883$ & 736,795 & $1,888,417$ & $1,183,191$ & 705,226 & 468,261 & 436,692 & 31,569 \\
\hline 25 to 29 & $2,113,799$ & $1,323,542$ & 790,257 & $1,629,437$ & 872,668 & 756,769 & 484,362 & 450,874 & 33,488 \\
\hline 30 to 34 & $1,295,176$ & 710,029 & 585,147 & $1,009,461$ & 446,471 & 562,990 & 285,715 & 263,558 & 22,157 \\
\hline 35 to 39 & 980,171 & 500,210 & 479,961 & 769,045 & 306,134 & 462,911 & 211,126 & 194,076 & 17,050 \\
\hline 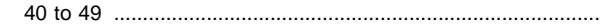 & $1,234,660$ & 650,510 & 584,150 & 967,950 & 401,321 & 566,629 & 266,710 & 249,189 & 17,521 \\
\hline 50 to 64 & 356,036 & 159,542 & 196,494 & 286,672 & 94,425 & 192,247 & 69,364 & 65,117 & 4,247 \\
\hline 65 and over ……… & 80,950 & 19,877 & 61,073 & 74,103 & 13,424 & 60,679 & 6,847 & 6,453 & 394 \\
\hline 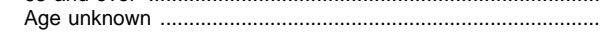 & 145,339 & 90,935 & 54,404 & 77,776 & 28,501 & 49,275 & 67,563 & 62,434 & 5,129 \\
\hline Full-time . & $8,128,802$ & $6,151,755$ & $1,977,047$ & $5,925,301$ & $4,084,711$ & $1,840,590$ & $2,203,501$ & $2,067,044$ & 136,457 \\
\hline Under 18 & 115,479 & 74,749 & 40,730 & 80,738 & 42,529 & 38,209 & 34,741 & 32,220 & 2,521 \\
\hline 18 and 19 & $2,395,257$ & $1,697,545$ & 697,712 & $1,766,874$ & $1,111,423$ & 655,451 & 628,383 & 586,122 & 42,261 \\
\hline 20 and 21 & $2,088,263$ & $1,665,857$ & 422,406 & $1,512,500$ & $1,115,658$ & 396,842 & 575,763 & 550,199 & 25,564 \\
\hline 22 to 24 & $1,501,692$ & $1,243,540$ & 258,152 & $1,136,955$ & 899,614 & 237,341 & 364,737 & 343,926 & 20,811 \\
\hline 25 to 29 & 951,825 & 741,706 & 210,119 & 675,068 & 483,407 & 191,661 & 276,757 & 258,299 & 18,458 \\
\hline 30 to 34 & 423,324 & 296,556 & 126,768 & 303,791 & 187,311 & 116,480 & 119,533 & 109,245 & 10,288 \\
\hline 35 to 39 & 265,514 & 174,137 & 91,377 & 189,805 & 105,424 & 84,381 & 75,709 & 68,713 & 6,996 \\
\hline 40 to 49 & 279,755 & 185,797 & 93,958 & 196,730 & 109,114 & 87,616 & 83,025 & 76,683 & 6,342 \\
\hline 50 to 64 & 57,402 & 36,010 & 21,392 & 38,404 & 18,391 & 20,013 & 18,998 & 17,619 & 1,379 \\
\hline 65 and over & 6,615 & 3,115 & 3,500 & 4,637 & 1,238 & 3,399 & 1,978 & 1,877 & 101 \\
\hline Age unknown ... & 43,676 & 32,743 & 10,933 & 19,799 & 10,602 & 9,197 & 23,877 & 22,141 & 1,736 \\
\hline Part-time & $6,132,979$ & $2,617,497$ & $3,515,482$ & $5,167,073$ & $1,729,834$ & $3,437,239$ & 965,906 & 887,663 & 78,243 \\
\hline Under 18 & 169,904 & 45,379 & 124,525 & 152,206 & 29,167 & 123,039 & 17,698 & 16,212 & 1,486 \\
\hline 18 and 19 & 400,892 & 73,770 & 327,122 & 382,817 & 59,747 & 323,070 & 18,075 & 14,023 & 4,052 \\
\hline 20 and 21 & 529,177 & 137,424 & 391,753 & 494,378 & 109,886 & 384,492 & 34,799 & 27,538 & 7,261 \\
\hline 22 to 24 & 854,986 & 376,343 & 478,643 & 751,462 & 283,577 & 467,885 & 103,524 & 92,766 & 10,758 \\
\hline 25 to 29 & $1,161,974$ & 581,836 & 580,138 & 954,369 & 389,261 & 565,108 & 207,605 & 192,575 & 15,030 \\
\hline 30 to 34 & 871,852 & 413,473 & 458,379 & 705,670 & 259,160 & 446,510 & 166,182 & 154,313 & 11,869 \\
\hline 35 to 39 & 714,657 & 326,073 & 388,584 & 579,240 & 200,710 & 378,530 & 135,417 & 125,363 & 10,054 \\
\hline 40 to 49 & 954,905 & 464,713 & 490,192 & 771,220 & 292,207 & 479,013 & 183,685 & 172,506 & 11,179 \\
\hline 50 to 64 & 298,634 & 123,532 & 175,102 & 248,268 & 76,034 & 172,234 & 50,366 & 47,498 & 2,868 \\
\hline 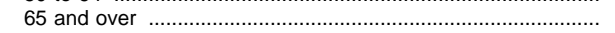 & 74,335 & 16,762 & 57,573 & 69,466 & 12,186 & 57,280 & 4,869 & 4,576 & 293 \\
\hline \multirow[t]{2}{*}{ 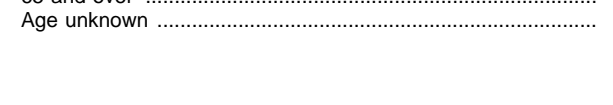 } & 101,663 & 58,192 & 43,471 & 57,977 & 17,899 & 40,078 & 43,686 & 40,293 & 3,393 \\
\hline & \multicolumn{9}{|c|}{ Percentage distribution } \\
\hline All students & 100.0 & 100.0 & 100.0 & 100.0 & 100.0 & 100.0 & 100.0 & 100.0 & 100.0 \\
\hline Under $18 \ldots$ & 2.0 & 1.4 & 3.0 & 2.1 & 1.2 & 3.1 & 1.7 & 1.6 & 1.9 \\
\hline 18 and 19 & 19.6 & 20.2 & 18.7 & 19.4 & 20.1 & 18.5 & 20.4 & 20.3 & 21.6 \\
\hline 20 and 21 & 18.4 & 20.6 & 14.8 & 18.1 & 21.1 & 14.8 & 19.3 & 19.6 & 15.3 \\
\hline 22 to 24 & 16.5 & 18.5 & 13.4 & 17.0 & 20.3 & 13.4 & 14.8 & 14.8 & 14.7 \\
\hline 25 to 29 & 14.8 & 15.1 & 14.4 & 14.7 & 15.0 & 14.3 & 15.3 & 15.3 & 15.6 \\
\hline 30 to 34 & 9.1 & 8.1 & 10.7 & 9.1 & 7.7 & 10.7 & 9.0 & 8.9 & 10.3 \\
\hline 35 to 39 & 6.9 & 5.7 & 8.7 & 6.9 & 5.3 & 8.8 & 6.7 & 6.6 & 7.9 \\
\hline 40 to 49 & 8.7 & 7.4 & 10.6 & 8.7 & 6.9 & 10.7 & 8.4 & 8.4 & 8.2 \\
\hline 50 to 64 & 2.5 & 1.8 & 3.6 & 2.6 & 1.6 & 3.6 & 2.2 & 2.2 & 2.0 \\
\hline 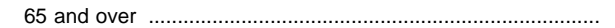 & 0.6 & 0.2 & 1.1 & 0.7 & 0.2 & 1.1 & 0.2 & 0.2 & 0.2 \\
\hline Age unknown & 1.0 & 1.0 & 1.0 & 0.7 & 0.5 & 0.9 & 2.1 & 2.1 & 2.4 \\
\hline Full-time . & 100.0 & 100.0 & 100.0 & 100.0 & 100.0 & 100.0 & 100.0 & 100.0 & 100.0 \\
\hline 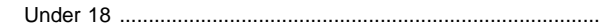 & 1.4 & 1.2 & 2.1 & 1.4 & 1.0 & 2.1 & 1.6 & 1.6 & 1.8 \\
\hline 18 and 19 & 29.5 & 27.6 & 35.3 & 29.8 & 27.2 & 35.6 & 28.5 & 28.4 & 31.0 \\
\hline 20 and 21 & 25.7 & 27.1 & 21.4 & 25.5 & 27.3 & 21.6 & 26.1 & 26.6 & 18.7 \\
\hline 22 to 24 & 18.5 & 20.2 & 13.1 & 19.2 & 22.0 & 12.9 & 16.6 & 16.6 & 15.3 \\
\hline 25 to 29 & 11.7 & 12.1 & 10.6 & 11.4 & 11.8 & 10.4 & 12.6 & 12.5 & 13.5 \\
\hline 30 to 34 & 5.2 & 4.8 & 6.4 & 5.1 & 4.6 & 6.3 & 5.4 & 5.3 & 7.5 \\
\hline 35 to 39 & 3.3 & 2.8 & 4.6 & 3.2 & 2.6 & 4.6 & 3.4 & 3.3 & 5.1 \\
\hline 40 to 49 & 3.4 & 3.0 & 4.8 & 3.3 & 2.7 & 4.8 & 3.8 & 3.7 & 4.6 \\
\hline 50 to 64 & 0.7 & 0.6 & 1.1 & 0.6 & 0.5 & 1.1 & 0.9 & 0.9 & 1.0 \\
\hline 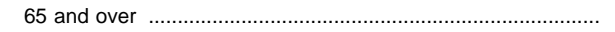 & 0.1 & 0.1 & 0.2 & 0.1 & 0.0 & 0.2 & 0.1 & 0.1 & 0.2 \\
\hline 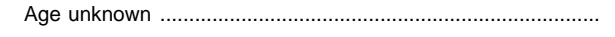 & 0.5 & 0.5 & 0.6 & 0.3 & 0.3 & 0.5 & 1.1 & 1.1 & 1.3 \\
\hline Part-time & 100.0 & 100.0 & 100.0 & 100.0 & 100.0 & 100.0 & 100.0 & 100.0 & 100.0 \\
\hline 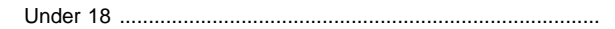 & 2.8 & 1.7 & 3.5 & 2.9 & 1.7 & 3.6 & 1.8 & 1.8 & 1.9 \\
\hline 18 and 19 & 6.5 & 2.8 & 9.3 & 7.4 & 3.5 & 9.4 & 1.9 & 1.6 & 5.2 \\
\hline 20 and 21 & 8.6 & 5.3 & 11.1 & 9.6 & 6.4 & 11.2 & 3.6 & 3.1 & 9.3 \\
\hline 22 to 24 & 13.9 & 14.4 & 13.6 & 14.5 & 16.4 & 13.6 & 10.7 & 10.5 & 13.7 \\
\hline 25 to 29 & 18.9 & 22.2 & 16.5 & 18.5 & 22.5 & 16.4 & 21.5 & 21.7 & 19.2 \\
\hline 30 to 34 & 14.2 & 15.8 & 13.0 & 13.7 & 15.0 & 13.0 & 17.2 & 17.4 & 15.2 \\
\hline 35 to 39 & 11.7 & 12.5 & 11.1 & 11.2 & 11.6 & 11.0 & 14.0 & 14.1 & 12.8 \\
\hline (2) & 15.6 & 17.8 & 13.9 & 14.9 & 16.9 & 13.9 & 19.0 & 19.4 & 14.3 \\
\hline 50 to 64 & 4.9 & 4.7 & 5.0 & 4.8 & 4.4 & 5.0 & 5.2 & 5.4 & 3.7 \\
\hline 65 and over & 1.2 & 0.6 & 1.6 & 1.3 & 0.7 & 1.7 & 0.5 & 0.5 & 0.4 \\
\hline Age unknown & 1.7 & 2.2 & 1.2 & 1.1 & 1.0 & 1.2 & 4.5 & 4.5 & 4.3 \\
\hline
\end{tabular}

NOTE.-Because of rounding, details may not add to 100.0 percent.

SOURCE: U.S. Department of Education, National Center for Education Statistics, Integrated Postsecondary Education Data System, "Fall Enrollment, 1995" survey. (This table was prepared January 1997.) 
Table 177.-Total fall enrollment in institutions of higher education and degree-granting institutions, by level of enrollment, sex, attendance status, and type and control of institution: 19961

\begin{tabular}{|c|c|c|c|c|c|c|c|c|c|c|c|c|}
\hline \multirow{2}{*}{$\begin{array}{l}\text { Attendance status, and type and } \\
\text { control of institution }\end{array}$} & \multicolumn{3}{|c|}{ Total } & \multicolumn{3}{|c|}{ Undergraduate } & \multicolumn{3}{|c|}{ First-professional } & \multicolumn{3}{|c|}{ Graduate } \\
\hline & Total & Men & Women & Total & Men & Women & Total & Men & Women & Total & Men & Women \\
\hline \multirow[t]{2}{*}{1} & 2 & 3 & 4 & 5 & 6 & 7 & 8 & 9 & 10 & 11 & 12 & 13 \\
\hline & \multicolumn{12}{|c|}{ Higher education institutions } \\
\hline Total . & $14,300,255$ & $6,343,992$ & $7,956,263$ & $12,259,417$ & $5,411,058$ & $6,848,359$ & 297,739 & 172,462 & 125,277 & $1,743,099$ & 760,472 & 982,627 \\
\hline $\begin{array}{l}\text { Full-time ...... } \\
\text { Part-time .... }\end{array}$ & $\begin{array}{l}8,213,490 \\
6,086,765\end{array}$ & $\begin{array}{l}3,815,519 \\
2,528,473\end{array}$ & $\begin{array}{l}4,397,971 \\
3,558,292\end{array}$ & $\begin{array}{l}7,210,698 \\
5,048,719\end{array}$ & $\begin{array}{l}3,303,961 \\
2,107,097\end{array}$ & $\begin{array}{l}3,906,737 \\
2,941,622\end{array}$ & $\begin{array}{r}266,812 \\
30,927\end{array}$ & $\begin{array}{r}153,983 \\
18,479\end{array}$ & $\begin{array}{r}112,829 \\
12,448\end{array}$ & $\begin{array}{r}735,980 \\
1,007,119\end{array}$ & $\begin{array}{l}357,575 \\
402,897\end{array}$ & $\begin{array}{l}378,405 \\
604,222\end{array}$ \\
\hline Total 4-year & $8,802,835$ & $3,995,901$ & $4,806,934$ & $6,762,544$ & $3,063,089$ & $3,699,455$ & 297,739 & 172,462 & 125,277 & $1,742,552$ & 760,350 & 982,202 \\
\hline Full-time ... & $6,226,868$ & $2,933,912$ & $3,292,956$ & $5,224,166$ & $2,422,374$ & $2,801,792$ & 266,812 & 153,983 & 112,829 & 735,890 & 357,555 & 378,335 \\
\hline Part-time . & $2,575,967$ & $1,061,989$ & $1,513,978$ & $1,538,378$ & 640,715 & 897,663 & 30,927 & 18,479 & 12,448 & $1,006,662$ & 402,795 & 603,867 \\
\hline Total 2-year & $5,497,420$ & $2,348,091$ & $3,149,329$ & $5,496,873$ & $2,347,969$ & $3,148,904$ & - & - & - & 547 & 122 & 425 \\
\hline Full-time .. & $1,986,622$ & 881,607 & $1,105,015$ & $1,986,532$ & 881,587 & $1,104,945$ & - & - & - & 90 & 20 & 70 \\
\hline 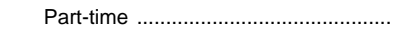 & $3,510,798$ & $1,466,484$ & $2,044,314$ & $3,510,341$ & $1,466,382$ & $2,043,959$ & - & - & - & 457 & 102 & 355 \\
\hline Public, total & $11,090,171$ & $4,887,537$ & $6,202,634$ & $9,905,339$ & $4,368,021$ & $5,537,318$ & 116,385 & 63,608 & 52,777 & $1,068,447$ & 455,908 & 612,539 \\
\hline Full-time & $5,964,174$ & $2,767,918$ & $3,196,256$ & $5,410,564$ & $2,490,931$ & $2,919,633$ & 111,395 & 60,951 & 50,444 & 442,215 & 216,036 & 226,179 \\
\hline Part-time & $5,125,997$ & $2,119,619$ & $3,006,378$ & $4,494,775$ & $1,877,090$ & $2,617,685$ & 4,990 & 2,657 & 2,333 & 626,232 & 239,872 & 386,360 \\
\hline 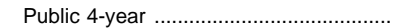 & $5,806,904$ & $2,646,777$ & $3,160,127$ & $4,622,497$ & $2,127,360$ & $2,495,137$ & 116,385 & 63,608 & 52,777 & $1,068,022$ & 455,809 & 612,213 \\
\hline 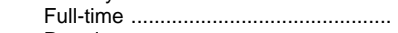 & $4,106,094$ & $1,943,086$ & $2,163,008$ & $3,552,484$ & $1,666,099$ & $1,886,385$ & 111,395 & 60,951 & 50,444 & 442,215 & 216,036 & 226,179 \\
\hline 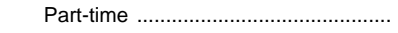 & $1,700,810$ & 703,691 & 997,119 & $1,070,013$ & 461,261 & 608,752 & 4,990 & 2,657 & 2,333 & 625,807 & 239,773 & 386,034 \\
\hline Public 2-year & $5,283,267$ & $2,240,760$ & $3,042,507$ & $5,282,842$ & $2,240,661$ & $3,042,181$ & - & - & - & 425 & 99 & 326 \\
\hline 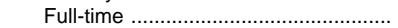 & $1,858,080$ & 824,832 & $1,033,248$ & $1,858,080$ & 824,832 & $1,033,248$ & - & - & - & - & - & - \\
\hline 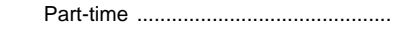 & $3,425,187$ & $1,415,928$ & $2,009,259$ & $3,424,762$ & $1,415,829$ & $2,008,933$ & - & - & - & 425 & 99 & 326 \\
\hline Private, total & $3,210,084$ & $1,456,455$ & $1,753,629$ & $2,354,078$ & $1,043,037$ & $1,311,041$ & 181,354 & 108,854 & 72,500 & 674,652 & 304,564 & 370,088 \\
\hline Full-time .... & $2,249,316$ & $1,047,601$ & $1,201,715$ & $1,800,134$ & 813,030 & 987,104 & 155,417 & 93,032 & 62,385 & 293,765 & 141,539 & 152,226 \\
\hline Part-time & 960,768 & 408,854 & 551,914 & 553,944 & 230,007 & 323,937 & 25,937 & 15,822 & 10,115 & 380,887 & 163,025 & 217,862 \\
\hline Private 4-year ............ & $2,995,931$ & $1,349,124$ & $1,646,807$ & $2,140,047$ & 935,729 & $1,204,318$ & 181,354 & 108,854 & 72,500 & 674,530 & 304,541 & 369,989 \\
\hline Full-time . & $2,120,774$ & 990,826 & $1,129,948$ & $1,671,682$ & 756,275 & 915,407 & 155,417 & 93,032 & 62,385 & 293,675 & 141,519 & 152,156 \\
\hline Part-time …....................................... & 875,157 & 358,298 & 516,859 & 468,365 & 179,454 & 288,911 & 25,937 & 15,822 & 10,115 & 380,855 & 163,022 & 217,833 \\
\hline Private 2-year & 214,153 & 107,331 & 106,822 & 214,031 & 107,308 & 106,723 & - & - & - & 122 & 23 & 99 \\
\hline Full-time & 128,542 & 56,775 & 71,767 & 128,452 & 56,755 & 71,697 & - & - & - & 90 & 20 & 70 \\
\hline \multirow[t]{2}{*}{ 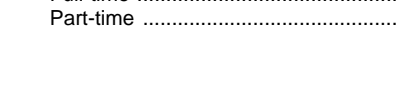 } & 85,611 & 50,556 & 35,055 & 85,579 & 50,553 & 35,026 & - & - & - & 32 & 3 & 29 \\
\hline & \multicolumn{12}{|c|}{ Degree-granting institutions ${ }^{2}$} \\
\hline Total & $14,367,520$ & $6,352,825$ & $8,014,695$ & $12,326,948$ & $5,420,672$ & 6,906,276 & 298,312 & 172,742 & 125,570 & $1,742,260$ & 759,411 & 982,849 \\
\hline Full-time & $8,302,953$ & $3,851,208$ & $4,451,745$ & $7,298,839$ & $3,339,108$ & $3,959,731$ & 267,209 & 154,107 & 113,102 & 736,905 & 357,993 & 378,912 \\
\hline Part-time & $6,064,567$ & $2,501,617$ & $3,562,950$ & $5,028,109$ & $2,081,564$ & $2,946,545$ & 31,103 & 18,635 & 12,468 & $1,005,355$ & 401,418 & 603,937 \\
\hline Total 4-year ........................ & $8,804,193$ & $3,993,911$ & $4,810,282$ & $6,764,168$ & $3,061,880$ & $3,702,288$ & 298,312 & 172,742 & 125,570 & $1,741,713$ & 759,289 & 982,424 \\
\hline Full-time .................. & $6,230,648$ & $2,934,736$ & $3,295,912$ & $5,226,624$ & $2,422,656$ & $2,803,968$ & 267,209 & 154,107 & 113,102 & 736,815 & 357,973 & 378,842 \\
\hline Part-time . & $2,573,545$ & $1,059,175$ & $1,514,370$ & $1,537,544$ & 639,224 & 898,320 & 31,103 & 18,635 & 12,468 & $1,004,898$ & 401,316 & 603,582 \\
\hline Total 2 & $5,563,327$ & $2,358,914$ & ,413 & 780 & $2,358,792$ & 3 & - & - & - & 547 & 122 & 425 \\
\hline 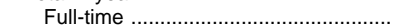 & $2,072,305$ & 916,472 & $1,155,833$ & $2,072,215$ & 916,452 & $1,155,763$ & - & - & - & 90 & 20 & 70 \\
\hline 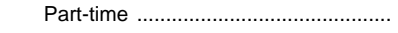 & $3,491,022$ & $1,442,442$ & $2,048,580$ & $3,490,565$ & $1,442,340$ & $2,048,225$ & - & - & - & 457 & 102 & 355 \\
\hline Public, total & $11,120,499$ & $4,902,453$ & 3,046 & ,283 & 2,751 &, 532 & 116,665 & 63,742 & 52,923 & $1,068,551$ & 455,960 & 612,591 \\
\hline Full-time $\ldots \ldots \ldots \ldots \ldots \ldots \ldots$ & $5,978,467$ & $2,776,098$ & $3,202,369$ & $5,424,498$ & $2,498,938$ & $2,925,560$ & 111,650 & 61,072 & 50,578 & 442,319 & 216,088 & 226,231 \\
\hline Part-time & $5,142,032$ & $2,126,355$ & $3,015,677$ & $4,510,785$ & $1,883,813$ & $2,626,972$ & 5,015 & 2,670 & 2,345 & 626,232 & 239,872 & 386,360 \\
\hline Public 4-year & 036 & 2,6 & 99 & 245 & 734 & 2,4 & 116,665 & 63,742 & 52,923 & $1,068,126$ & 455,861 & 612,265 \\
\hline Full-time ................ & $4,106,453$ & $1,943,259$ & $2,163,194$ & $3,552,484$ & $1,666,099$ & $1,886,385$ & 111,650 & 61,072 & 50,578 & 442,319 & 216,088 & 226,231 \\
\hline 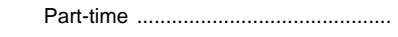 & $1,699,583$ & 703,078 & 996,505 & $1,068,761$ & 460,635 & 608,126 & 5,015 & 2,670 & 2,345 & 625,807 & 239,773 & 386,034 \\
\hline Public 2-year & $5,314,463$ & $2,256,116$ & 347 & 38 & $2,256,017$ & & - & - & - & 425 & 99 & 326 \\
\hline 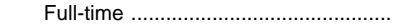 & $1,872,014$ & 832,839 & $1,039,175$ & $1,872,014$ & 832,839 & $1,039,175$ & - & - & - & - & - & - \\
\hline 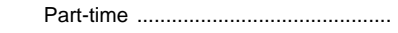 & $3,442,449$ & $1,423,277$ & $2,019,172$ & $3,442,024$ & $1,423,178$ & $2,018,846$ & - & - & - & 425 & 99 & 326 \\
\hline Private & $3,247,021$ & $1,450,372$ & $1,7 \varsigma$ & 665 & 1,03 & 1,3 & 181,647 & 109,000 & 72,647 & 709 & ,451 & 258 \\
\hline 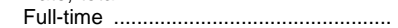 & $2,324,486$ & $1,075,110$ & $1,249,376$ & $1,874,341$ & 840,170 & $1,034,171$ & 155,559 & 93,035 & 62,524 & 294,586 & 141,905 & 152,681 \\
\hline Part-time & 922,535 & 375,262 & 547,273 & 517,324 & 197,751 & 319,573 & 26,088 & 15,965 & 10,123 & 379,123 & 161,546 & 217,577 \\
\hline Private 4-year & $2,998,157$ & $1,347,574$ & $1,650,583$ & $2,142,923$ & 935,146 & $1,207,777$ & 181,647 & 109,000 & 72,647 & 673,587 & 303,428 & 370,159 \\
\hline 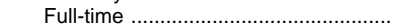 & $2,124,195$ & 991,477 & $1,132,718$ & $1,674,140$ & 756,557 & 917,583 & 155,559 & 93,035 & 62,524 & 294,496 & 141,885 & 152,611 \\
\hline Part-time …….............................. & 873,962 & 356,097 & 517,865 & 468,783 & 178,589 & 290,194 & 26,088 & 15,965 & 10,123 & 379,091 & 161,543 & 217,548 \\
\hline Priva & 864 & 102,798 & 66 & 42 & 775 & 14 & - & - & - & 122 & 23 & 99 \\
\hline Full-time ........ & 200,291 & 83,633 & 116,658 & 200,201 & 83,613 & 116,588 & - & - & - & 90 & 20 & 70 \\
\hline 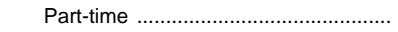 & 48,573 & 19,165 & 29,408 & 48,541 & 19,162 & 29,379 & - & - & - & 32 & 3 & 29 \\
\hline
\end{tabular}

1 Preliminary data.

2 Data are for 4-year and 2-year degree-granting higher education institutions that were eligible to participate in Title IV federal financial aid programs.

-Not applicable.

NOTE.- Institutions of higher education data are based on institutions that were ac credited by an agency or association that was recognized by the U.S. Department of Education. The Department of Education no longer distinguishes between those institu- tions and other institutions that are eligible to participate in Title IV programs. The new degree-granting classification is very similar to the earlier higher education classification, except that it includes some additional institutions, primarily 2-year colleges, and excludes a few higher education institutions that did not award degrees.

SOURCE: U.S. Department of Education, National Center for Education Statistics, Integrated Postsecondary Education Data System (IPEDS), "Fall Enrollment" surveys. (This table was prepared May 1998.) 
Table 178.-Total fall enrollment in institutions of higher education and degree-granting institutions, by type and control of institution, attendance status, and sex of student: 1970 to 1996

\begin{tabular}{|c|c|c|c|c|c|c|c|c|c|c|c|c|}
\hline \multirow{2}{*}{$\begin{array}{l}\text { Type and control of } \\
\text { institution, sex and } \\
\text { attendance status of } \\
\text { student }\end{array}$} & \multicolumn{11}{|c|}{ Institutions of higher education } & \multirow{2}{*}{$\begin{array}{l}\text { Degree } \\
\text { granting } \\
\text { institutions, } \\
\text { fall } 1996^{2}\end{array}$} \\
\hline & 1970 & 1975 & 1980 & 1985 & 1990 & 1991 & 1992 & 1993 & 1994 & 1995 & $1996^{1}$ & \\
\hline 1 & 2 & 3 & 4 & 5 & 6 & 7 & 8 & 9 & 10 & 11 & 12 & 13 \\
\hline Total & $8,580,887$ & $11,184,859$ & $12,096,895$ & $12,247,055$ & $13,818,637$ & $14,358,953$ & $14,487,359$ & $14,304,803$ & $14,278,790$ & $14,261,781$ & $14,300,255$ & $14,367,520$ \\
\hline Full-time ...... & $5,816,290$ & $6,841,334$ & $7,097,958$ & $7,075,221$ & $7,820,985$ & $8,115,329$ & $8,162,118$ & $8,127,618$ & $8,137,776$ & $8,128,802$ & $8,213,490$ & $8,302,953$ \\
\hline Men ............ & $3,504,095$ & $3,926,753$ & $3,689,244$ & $3,607,720$ & $3,807,752$ & $3,929,375$ & $3,926,905$ & $3,890,571$ & $3,855,183$ & $3,807,392$ & $3,815,519$ & $3,851,208$ \\
\hline Women & $2,312,195$ & $2,914,581$ & $3,408,714$ & $3,467,501$ & $4,013,233$ & $4,185,954$ & $4,235,213$ & $4,237,047$ & $4,282,593$ & $4,321,410$ & $4,397,971$ & $4,451,745$ \\
\hline Part-time ……................. & $2,764,597$ & $4,343,525$ & $4,998,937$ & $5,171,834$ & $5,997,652$ & $6,243,624$ & $6,325,241$ & $6,177,185$ & $6,141,014$ & $6,132,979$ & $6,086,765$ & $6,064,567$ \\
\hline Men ……................... & $1,539,547$ & $2,222,244$ & $2,185,130$ & $2,210,730$ & $2,476,157$ & $2,572,469$ & $2,597,084$ & $2,536,879$ & $2,516,715$ & $2,535,147$ & $2,528,473$ & $2,501,617$ \\
\hline Women .... & $1,225,050$ & $2,121,281$ & $2,813,807$ & $2,961,104$ & $3,521,495$ & $3,671,155$ & $3,728,157$ & $3,640,306$ & $3,624,299$ & $3,597,832$ & $3,558,292$ & $3,562,950$ \\
\hline 4-year, total. & $6,261,502$ & $7,214,740$ & $7,570,608$ & $7,715,978$ & $8,578,554$ & $8,707,053$ & $8,764,969$ & $8,738,936$ & $8,749,080$ & $8,769,252$ & $8,802,835$ & $8,804,193$ \\
\hline Full-time ................... & $4,587,379$ & $5,080,256$ & $5,344,163$ & $5,384,614$ & $5,937,023$ & $6,040,799$ & $6,082,112$ & $6,084,299$ & $6,106,062$ & $6,151,755$ & $6,226,868$ & $6,230,648$ \\
\hline Men ……................. & $2,732,796$ & $2,891,192$ & $2,809,528$ & $2,781,412$ & $2,926,360$ & $2,967,978$ & $2,975,089$ & $2,962,355$ & $2,943,593$ & $2,929,177$ & $2,933,912$ & $2,934,736$ \\
\hline Women & $1,854,583$ & $2,189,064$ & $2,534,635$ & $2,603,202$ & $3,010,663$ & $3,072,821$ & $3,107,023$ & $3,121,944$ & $3,162,469$ & $3,222,578$ & $3,292,956$ & $3,295,912$ \\
\hline Part-time .................... & $1,674,123$ & $2,134,484$ & $2,226,445$ & $2,331,364$ & $2,641,531$ & $2,666,254$ & $2,682,857$ & $2,654,637$ & $2,643,018$ & $2,617,497$ & $2,575,967$ & $2,573,545$ \\
\hline Men ...................... & 936,189 & $1,092,461$ & $1,017,813$ & $1,034,804$ & $1,124,780$ & $1,131,956$ & $1,135,624$ & $1,119,636$ & $1,105,102$ & $1,084,753$ & $1,061,989$ & $1,059,175$ \\
\hline Women …........... & 737,934 & $1,042,023$ & $1,208,632$ & $1,296,560$ & $1,516,751$ & $1,534,298$ & $1,547,233$ & $1,535,001$ & $1,537,916$ & $1,532,744$ & $1,513,978$ & $1,514,370$ \\
\hline Public 4-year ....... & $4,232,722$ & $4,998,142$ & $5,128,612$ & $5,209,540$ & $5,848,242$ & $5,904,748$ & $5,900,012$ & $5,851,760$ & $5,825,213$ & $5,814,545$ & $5,806,904$ & $5,806,036$ \\
\hline Full-time & $3,086,491$ & $3,469,821$ & $3,592,193$ & $3,623,341$ & $4,033,654$ & $4,088,970$ & $4,095,310$ & $4,074,055$ & $4,065,067$ & $4,084,711$ & $4,106,094$ & $4,106,453$ \\
\hline Men …............. & $1,813,584$ & $1,947,823$ & $1,873,397$ & $1,863,689$ & $1,982,369$ & $2,005,941$ & $2,005,043$ & $1,989,410$ & $1,965,524$ & $1,951,140$ & $1,943,086$ & $1,943,259$ \\
\hline Women .......... & $1,272,907$ & $1,521,998$ & $1,718,796$ & $1,759,652$ & $2,051,285$ & $2,083,029$ & $2,090,267$ & $2,084,645$ & $2,099,543$ & $2,133,571$ & $2,163,008$ & $2,163,194$ \\
\hline Part-time ............. & $1,146,231$ & $1,528,321$ & $1,536,419$ & $1,586,199$ & $1,814,588$ & $1,815,778$ & $1,804,702$ & $1,777,705$ & $1,760,146$ & $1,729,834$ & $1,700,810$ & $1,699,583$ \\
\hline Men ...... & 609,422 & 760,469 & 685,051 & 693,115 & 764,248 & 764,969 & 760,186 & 750,409 & 737,891 & 720,402 & 703,691 & 703,078 \\
\hline Women ........... & 536,809 & 767,852 & 851,368 & 893,084 & $1,050,340$ & $1,050,809$ & $1,044,516$ & $1,027,296$ & $1,022,255$ & $1,009,432$ & 997,119 & 996,505 \\
\hline Private 4-year ..... & $2,028,780$ & $2,216,598$ & $2,441,996$ & $2,506,438$ & $2,730,312$ & $2,802,305$ & $2,864,957$ & $2,887,176$ & $2,923,867$ & $2,954,707$ & $2,995,931$ & $2,998,157$ \\
\hline Full-time ............ & $1,500,888$ & $1,610,435$ & $1,751,970$ & $1,761,273$ & $1,903,369$ & $1,951,829$ & $1,986,802$ & $2,010,244$ & $2,040,995$ & $2,067,044$ & $2,120,774$ & $2,124,195$ \\
\hline Men ..................... & 919,212 & 943,369 & 936,131 & 917,723 & 943,991 & 962,037 & 970,046 & 972,945 & 978,069 & 978,037 & 990,826 & 991,477 \\
\hline Women ............ & 581,676 & 667,066 & 815,839 & 843,550 & 959,378 & 989,792 & $1,016,756$ & $1,037,299$ & $1,062,926$ & $1,089,007$ & $1,129,948$ & $1,132,718$ \\
\hline Part-time ........... & 527,892 & 606,163 & 690,026 & 745,165 & 826,943 & 850,476 & 878,155 & 876,932 & 882,872 & 887,663 & 875,157 & 873,962 \\
\hline Men ................... & 326,767 & 331,992 & 332,762 & 341,689 & 360,532 & 366,987 & 375,438 & 369,227 & 367,211 & 364,351 & 358,298 & 356,097 \\
\hline Women ........... & 201,125 & 274,171 & 357,264 & 403,476 & 466,411 & 483,489 & 502,717 & 507,705 & 515,661 & 523,312 & 516,859 & 517,865 \\
\hline \multicolumn{13}{|l|}{ Nonprofit } \\
\hline 4-year & - & - & $2,413,693$ & $2,463,000$ & $2,671,069$ & $2,729,752$ & $2,789,235$ & $2,802,540$ & $2,824,500$ & $2,853,890$ & $2,871,693$ & $2,867,181$ \\
\hline Full-time ....... & - & - & $1,733,014$ & $1,727,707$ & $1,859,124$ & $1,896,454$ & $1,930,460$ & $1,946,349$ & $1,962,751$ & $1,989,457$ & $2,024,856$ & $2,021,570$ \\
\hline Men ............. & - & - & 921,253 & 894,080 & 915,100 & 926,799 & 934,651 & 934,792 & 931,600 & 931,956 & 937,078 & 934,474 \\
\hline Women ..... & - & - & 811,761 & 833,627 & 944,024 & 969,655 & 995,809 & $1,011,557$ & $1,031,151$ & $1,057,501$ & $1,087,778$ & $1,087,096$ \\
\hline Part-time ........ & - & - & 680,679 & 735,293 & 811,945 & 833,298 & 858,775 & 856,191 & 861,749 & 864,433 & 846,837 & 845,611 \\
\hline Men ............. & - & - & 327,986 & 336,168 & 352,106 & 357,431 & 364,442 & 357,705 & 355,538 & 351,874 & 342,826 & 341,460 \\
\hline Women .... & - & - & 352,693 & 399,125 & 459,839 & 475,867 & 494,333 & 498,486 & 506,211 & 512,559 & 504,011 & 504,151 \\
\hline 2-year, total ............... & $2,319,385$ & $3,970,119$ & $4,526,287$ & $4,531,077$ & $5,240,083$ & $5,651,900$ & $5,722,390$ & $5,565,867$ & $5,529,710$ & $5,492,529$ & $5,497,420$ & $5,563,327$ \\
\hline Full-time ... & $1,228,911$ & $1,761,078$ & $1,753,795$ & $1,690,607$ & $1,883,962$ & $2,074,530$ & $2,080,006$ & $2,043,319$ & $2,031,714$ & $1,977,047$ & $1,986,622$ & $2,072,305$ \\
\hline Men ......... & 771,299 & $1,035,561$ & 879,716 & 826,308 & 881,392 & 961,397 & 951,816 & 928,216 & 911,590 & 878,215 & 881,607 & 916,472 \\
\hline Women & 457,612 & 725,517 & 874,079 & 864,299 & $1,002,570$ & $1,113,133$ & $1,128,190$ & $1,115,103$ & $1,120,124$ & $1,098,832$ & $1,105,015$ & $1,155,833$ \\
\hline Part-time .... & $1,090,474$ & $2,209,041$ & $2,772,492$ & $2,840,470$ & $3,356,121$ & $3,577,370$ & $3,642,384$ & $3,522,548$ & $3,497,996$ & $3,515,482$ & 0,798 & $3,491,022$ \\
\hline Men ............... & 603,358 & $1,129,783$ & $1,167,317$ & $1,175,926$ & $1,351,377$ & $1,440,513$ & $1,461,460$ & $1,417,243$ & $1,411,613$ & $1,450,394$ & $1,466,484$ & $1,442,442$ \\
\hline Women ................ & 487,116 & $1,079,258$ & $1,605,175$ & $1,664,544$ & $2,004,744$ & $2,136,857$ & $2,180,924$ & $2,105,305$ & $2,086,383$ & $2,065,088$ & $2,044,314$ & $2,048,580$ \\
\hline Public 2-year ....... & $2,195,412$ & $3,836,366$ & $4,328,782$ &, 733 & 475 & 15 & 5,4 & 328 & 5,308, & 829 & 267 & 463 \\
\hline Full-time ............ & $1,129,165$ & $1,662,621$ & $1,595,493$ & $1,496,905$ & $1,716,843$ & $1,885,607$ & $1,915,565$ & $1,888,507$ & $1,885,753$ & $1,840,590$ & $1,858,080$ & $1,872,014$ \\
\hline Men ……............ & 720,440 & 988,701 & 811,871 & 742,673 & 810,664 & 881,576 & 878,076 & 858,600 & 847,702 & 818,605 & 824,832 & 832,839 \\
\hline Women .......... & 408,725 & 673,920 & 783,622 & 754,232 & 906,179 & $1,004,031$ & $1,037,489$ & $1,029,907$ & $1,038,051$ & $1,021,985$ & $1,033,248$ & $1,039,175$ \\
\hline Part-time ........... & $1,066,247$ & $2,173,745$ & $2,733,289$ & $2,772,828$ & $3,279,632$ & $3,519,208$ & $3,568,990$ & $3,448,821$ & $3,422,714$ & $3,437,239$ & $3,425,187$ & $3,442,449$ \\
\hline Men ........................ & 589,439 & $1,107,680$ & $1,152,268$ & $1,138,011$ & $1,317,730$ & $1,413,870$ & $1,431,091$ & $1,386,092$ & $1,378,951$ & $1,417,488$ & $1,415,928$ & $1,423,277$ \\
\hline 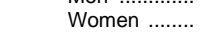 & 476,808 & $1,066,065$ & $1,581,021$ & $1,634,817$ & $1,961,902$ & $2,105,338$ & $2,137,899$ & $2,062,729$ & $2,043,763$ & $2,019,751$ & $2,009,259$ & $2,019,172$ \\
\hline Private 2 & 123,973 & 133,753 & 97,505 & ,344 & 608 & 247,085 & 237,835 & 539 & 221,243 & 214,700 & 214,153 & 248,864 \\
\hline Full-time ........... & 99,746 & 98,457 & 3158,302 & 193,702 & 167,119 & 188,923 & 164,441 & 154,812 & 145,961 & 136,457 & 128,542 & 200,291 \\
\hline Men & 50,859 & 46,860 & 367,845 & 83,635 & 70,728 & 79,821 & 73,740 & 69,616 & 63,888 & 59,610 & 56,775 & 83,633 \\
\hline Women & 48,887 & 51,597 & 390,457 & 110,067 & 96,391 & 109,102 & 90,701 & 85,196 & 82,073 & 76,847 & 71,767 & 116,658 \\
\hline Part-time …......... & 24,227 & 35,296 & $\begin{array}{l}3 \\
3\end{array} 9,203$ & 67,642 & 76,489 & 58,162 & 73,394 & 73,727 & 75,282 & 78,243 & 85,611 & 48,573 \\
\hline 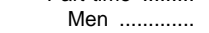 & 13,919 & 22,103 & 315,049 & 37,915 & 33,647 & 26,643 & 30,369 & 31,151 & 32,662 & 32,906 & 50,556 & 19,165 \\
\hline Women .......... & 10,308 & 13,193 & ${ }^{3} 24,154$ & 29,727 & 42,842 & 31,519 & 43,025 & 42,576 & 42,620 & 45,337 & 35,055 & 29,408 \\
\hline \multicolumn{13}{|l|}{ Nonprofit } \\
\hline 2-year & - & - & 114,094 & 108,791 & 89,158 & 89,289 & 83,288 & 86,357 & 85,607 & 75,154 & 68,864 & 75,375 \\
\hline Full-time & - & - & 83,009 & 76,547 & 62,003 & 61,521 & 55,691 & 60,005 & 59,021 & 54,033 & 50,202 & 56,434 \\
\hline Men ................. & - & - & 34,968 & 30,878 & 25,946 & 25,572 & 23,272 & 26,185 & 25,048 & 23,265 & 21,386 & 24,064 \\
\hline Women ..... & - & - & 48,041 & 45,669 & 36,057 & 35,949 & 32,419 & 33,820 & 33,973 & 30,768 & 28,816 & 32,370 \\
\hline Part-time ....... & - & - & 31,085 & 32,244 & 27,155 & 27,768 & 27,597 & 26,352 & 26,586 & 21,121 & 18,662 & 18,941 \\
\hline Men ................ & - & - & 11,445 & 10,786 & 7,970 & 7,689 & 7,738 & 7,649 & 7,530 & 6,080 & 5,227 & 5,337 \\
\hline Women .... & - & - & 19,640 & 21,458 & 19,185 & 20,079 & 19,859 & 18,703 & 19,056 & 15,041 & 13,435 & 13,604 \\
\hline
\end{tabular}

1 Preliminary data.

2 Preliminary data are for 4-year and 2-year degree-granting institutions that were eligible to participate in Title IV federal financial aid programs.

${ }^{3}$ Large increase is due to the addition of schools accredited by the Accrediting Commission of Career Schools and Colleges of Technology.

-Data not available.

NOTE.-Trend tabulations of institutions of higher education data are based on institutions that were accredited by an agency or association that was recognized by the U.S Department of Education. The Department of Education no longer distinguishes between those institutions and other institutions that are eligible to participate in Title IV programs. The new degree-granting classification is very similar to the earlier higher education classification, except that it includes some additional institutions, primarily 2-year colleges, and excludes a few higher education institutions that did not award degrees.

SOURCE: U.S. Department of Education, National Center for Education Statistics, Higher Education General Information Survey (HEGIS), "Fall Enrollment in Colleges and Universities" surveys; and Integrated Postsecondary Education Data Systems (IPEDS), "Fall Enrollment" surveys. (This table was prepared May 1998.) 
Table 179.-Fall enrollment and number of institutions of higher education, by affiliation ${ }^{1}$ of institution: 1980 to 1996

\begin{tabular}{|c|c|c|c|c|c|c|c|c|c|c|c|c|c|}
\hline \multirow{4}{*}{ Affiliation } & \multicolumn{9}{|c|}{ Enrollment } & \multicolumn{4}{|c|}{ Number of institutions ${ }^{2}$} \\
\hline & \multirow{3}{*}{$\begin{array}{l}\text { Total, } \\
\text { fall } 1980\end{array}$} & \multirow{3}{*}{$\begin{array}{l}\text { Total, } \\
\text { fall } 1990\end{array}$} & \multirow{3}{*}{$\begin{array}{l}\text { Total, fall } \\
1994\end{array}$} & \multirow{3}{*}{$\begin{array}{c}\text { Total, fall } \\
1995\end{array}$} & \multicolumn{5}{|c|}{ Fall $1996^{3}$} & \multirow{3}{*}{$\begin{array}{l}\text { Fall } \\
1980\end{array}$} & \multirow{3}{*}{$\begin{array}{l}\text { Fall } \\
1990\end{array}$} & \multirow{3}{*}{$\begin{array}{c}\text { Fall } \\
1995\end{array}$} & \multirow{3}{*}{$\begin{array}{l}\text { Fall } \\
1996\end{array}$} \\
\hline & & & & & \multirow{2}{*}{ Total } & \multicolumn{2}{|c|}{ Full-time } & \multicolumn{2}{|c|}{ Part-time } & & & & \\
\hline & & & & & & Men & Women & Men & Women & & & & \\
\hline 1 & 2 & 3 & 4 & 5 & 6 & 7 & 8 & 9 & 10 & 11 & 12 & 13 & 14 \\
\hline 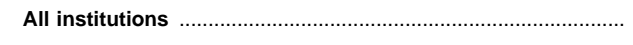 & $12,096,895$ & $13,818,637$ & $14,278,790$ & $14,261,781$ & $14,300,255$ & $3,815,519$ & $4,397,971$ & $2,528,473$ & $3,558,292$ & 3,226 & 3,501 & 3,545 & 3,534 \\
\hline Public institutions .... & $9,457,394$ & $10,844,717$ & $11,133,680$ & $11,092,374$ & $11,090,171$ & $2,767,918$ & $3,196,256$ & $2,119,619$ & $3,006,378$ & 1,493 & 1,548 & 1,603 & 1,595 \\
\hline $\begin{array}{l}\text { Federal ................... } \\
\text { State }\end{array}$ & 50,989 & $\begin{array}{r}50,669 \\
7181,880\end{array}$ & $\begin{array}{r}53,548 \\
7\end{array}$ & 90,046 & $\begin{array}{r}83,230 \\
\end{array}$ & $\begin{array}{r}17,180 \\
270\end{array}$ & 3,441 & $\begin{array}{r}52,375 \\
\end{array}$ & 10,234 & 12 & 17 & 14 & 14 \\
\hline $\begin{array}{l}\text { State .. } \\
\text { Local . }\end{array}$ & $\left(\begin{array}{l}4 \\
(4)\end{array}\right]$ & $\begin{array}{r}7,181,380 \\
3\end{array}$ & $\begin{array}{l}7,869,965 \\
3,064\end{array}$ & $\begin{array}{l}7,842,782 \\
3023\end{array}$ & $\begin{array}{r}7,905,241 \\
2,08020\end{array}$ & $2,279,593$ & $2,611,138$ & $1,228,344$ & $1,786,166$ & $\left(\begin{array}{l}(4) \\
(4)\end{array}\right]$ & $\begin{array}{r}978 \\
920\end{array}$ & 1,123 & 1,133 \\
\hline & $9,406,405$ & $\begin{array}{r}3,508,941 \\
103,727\end{array}$ & $\begin{array}{r}3,064,925 \\
145,242\end{array}$ & $\begin{array}{r}3,023,723 \\
135,823\end{array}$ & $\begin{array}{r}2,980,820 \\
120,880\end{array}$ & $\begin{array}{r}442,188 \\
28,957\end{array}$ & $\begin{array}{r}547,291 \\
34,386\end{array}$ & $\begin{array}{r}816,500 \\
22,400\end{array}$ & $\begin{array}{r}1,174,841 \\
35,137\end{array}$ & $\begin{array}{r}(4) \\
1,481\end{array}$ & $\begin{array}{r}523 \\
30\end{array}$ & $\begin{array}{r}429 \\
37\end{array}$ & $\begin{array}{r}410 \\
38\end{array}$ \\
\hline Private institutions & $2,639,501$ & $2,973,920$ & $3,145,110$ & $3,169,407$ & $3,210,084$ & $1,047,601$ & $1,201,715$ & 408,854 & 551,914 & 1,733 & 1,953 & 1,942 & 1,939 \\
\hline Independent nonprofit ...................................................................... & $\begin{array}{r}1,521,614 \\
111714\end{array}$ & $\begin{array}{r}1,474,818 \\
213,693\end{array}$ & $\begin{array}{r}1,506,994 \\
235003\end{array}$ & $1,511,151$ & $1,515,330$ & 513,017 & $\begin{array}{r}552,813 \\
85121\end{array}$ & $\begin{array}{r}191,779 \\
60801\end{array}$ & 257,721 & 795 & 709 & $\begin{array}{r}716 \\
700\end{array}$ & 708 \\
\hline 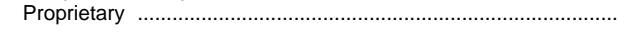 & 111,714 & 213,693 & 235,003 & 240,363 & 269,527 & 89,137 & 85,121 & 60,801 & 34,468 & 164 & 322 & 298 & 303 \\
\hline Religiously affiliated ............ & $1,006,173$ & $1,285,409$ & $1,403,113$ & $1,417,893$ & $1,425,227$ & 445,447 & 563,781 & 156,274 & 259,725 & 774 & 922 & 928 & 928 \\
\hline Advent Christian Church & 143 & -1 & - & - & - & - & - & - & - & 1 & - & - & - \\
\hline African Methodist Episcopal Zion Church ......................... & 1,091 & 88 & - & - & - & - & - & - & - & 3 & 1 & - & - \\
\hline 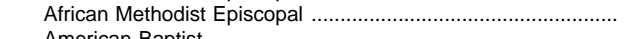 & 4,541 & $\begin{array}{r}3,220 \\
10,800\end{array}$ & $\begin{array}{r}3,799 \\
1,201\end{array}$ & $\begin{array}{r}3,503 \\
11,304\end{array}$ & $\begin{array}{r}5,180 \\
11530\end{array}$ & 2,152 & 2,746 & $\begin{array}{r}113 \\
1555\end{array}$ & $\begin{array}{r}169 \\
3207\end{array}$ & $\begin{array}{r}6 \\
6\end{array}$ & $\begin{array}{r}5 \\
5\end{array}$ & 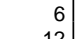 & 7 \\
\hline $\begin{array}{l}\text { American Baptist .............................. } \\
\text { American Evangelical Lutheran Church }\end{array}$ & 6,131 & 10,800 & 12,221 & 11,394 & 11,532 & 2,906 & 3,864 & 1,555 & 3,207 & 11 & 15 & 12 & 12 \\
\hline American Evangelical Lutheran Church . & - & - & 814 & 779 & 822 & 407 & 285 & 55 & 75 & - & - & 1 & 1 \\
\hline American Lutheran and Lutheran Church in America. & 3,092 & - & 1,335 & 1,304 & 1,234 & 347 & 531 & 155 & 201 & 3 & - & 1 & 1 \\
\hline American Lutheran ......................... & 21,608 & - & 10,163 & 10,459 & 10,153 & 3,817 & 4,668 & 412 & 1,256 & 13 & - & 9 & 9 \\
\hline Assemblies of God Church & 7,814 & 8,307 & 9,493 & 9,652 & 9,860 & 4,194 & 4,476 & 569 & 621 & 10 & 11 & 13 & 13 \\
\hline 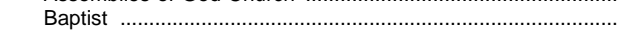 & 38,231 & 99,510 & 100,991 & 105,802 & 105,251 & 37,459 & 45,758 & 9,317 & 12,717 & 33 & 69 & 64 & 64 \\
\hline Brethren Church ......... & 3,925 & 958 & 1,447 & 1,456 & 1,414 & 589 & 620 & 101 & 104 & 3 & 3 & 3 & 3 \\
\hline Brethren in Christ Church .............. & 1,301 & 2,239 & 2,344 & 2,416 & 2,517 & 961 & 1,465 & 27 & 64 & 1 & 1 & 1 & 1 \\
\hline Christian and Missionary Alliance Church .. & 1,705 & 2,519 & 3,386 & 3,723 & 3,953 & 1,465 & 1,851 & 272 & 365 & 3 & 4 & 4 & 4 \\
\hline Christian Church (Disciples of Christ) .... & 14,913 & 30,397 & 32,629 & 33,029 & 33,492 & 6,856 & 10,283 & 6,619 & 9,734 & 12 & 18 & 16 & 16 \\
\hline Christian Churches and Churches of Christ ....... & 1,342 & 2,263 & 3,394 & 3,494 & 4,616 & 1,872 & 1,839 & 560 & 345 & 7 & 8 & 11 & 13 \\
\hline Christian Methodist Episcopal ...................................... & 2,486 & 2,174 & 2,456 & 2,598 & 1,881 & 848 & 949 & 36 & 48 & 4 & 4 & 3 & 2 \\
\hline Christian Reformed Church . & 5,408 & 4,488 & 4,075 & 4,205 & 4,308 & 1,793 & 2,106 & 213 & 196 & 3 & 2 & 2 & 2 \\
\hline Church of Christ (Scientist) ... & 2,773 & 2,557 & 4,222 & 4,320 & 4,407 & 1,729 & 1,997 & 438 & 243 & 6 & 8 & 5 & 5 \\
\hline Church of God of Prophecy . & & 249 & & & & & & & & - & 1 & - & - \\
\hline Church of God ....... & 6,082 & 5,627 & 4,534 & 4,410 & 6,913 & 2,738 & 3,240 & 470 & 465 & 9 & 9 & 7 & 8 \\
\hline Church of New Jerusalem & 170 & & & 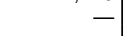 & & & & & & 1 & - & - & - \\
\hline Church of the Brethren. & 8,482 & 4,463 & 2,870 & 2,812 & 2,856 & 1,025 & 1,551 & 112 & 168 & 6 & 5 & 3 & 3 \\
\hline Church of the Nazarene ... & 11,716 & 10,779 & 14,450 & 14,466 & 14,502 & 5,136 & 6,764 & 1,018 & 1,584 & 10 & 9 & 10 & 10 \\
\hline Churches of Christ ............ & 9,343 & 14,611 & 22,495 & 22,807 & 23,035 & 7,828 & 8,696 & 3,081 & 3,430 & 9 & 19 & 15 & 15 \\
\hline Cumberland Presbyterian ...................... & 594 & 746 & 715 & 799 & 823 & 377 & 259 & 72 & 115 & 2 & 2 & 2 & 2 \\
\hline 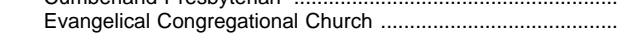 & 80 & 88 & 95 & 65 & 95 & 11 & 1 & 63 & 20 & 1 & 1 & 1 & 1 \\
\hline Evangelical Convent Church of America . & 1,401 & 1,035 & 1,650 & 1,745 & 1,815 & 526 & 667 & 198 & 424 & 1 & 1 & 1 & 1 \\
\hline Evangelical Free Church of America & 833 & 2,355 & 3,840 & 3,778 & 3,937 & 1,364 & 1,128 & 1,001 & 444 & 1 & 2 & 4 & 3 \\
\hline Evangelical Lutheran Chı & 743 & 49,210 & 38,218 & 39,089 & 38,666 & 13,912 & 19,023 & 2,143 & 3,588 & 3 & 33 & 26 & 26 \\
\hline Free Methodis & 5,543 & 5,902 & 8,375 & 8,696 & 8,713 & 2,855 & 4,211 & 631 & 1,016 & 5 & 3 & 5 & 5 \\
\hline 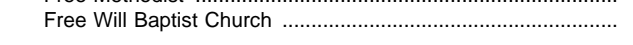 & 1,132 & 1,177 & 1,312 & 1,467 & 1,681 & 566 & 597 & 274 & 244 & 4 & 3 & 2 & 2 \\
\hline Friends United Meetin & 1,109 & - & - & - & - & - & - & - & - & 1 & - & - & - \\
\hline Frien & 5,157 & 5,844 & 6,586 & 6,600 & 9,711 & 3,653 & 4,742 & 520 & 796 & 5 & 6 & 6 & 7 \\
\hline General Conference Mennonite Church & 820 & 1,243 & 899 & 1,046 & 1,095 & 504 & 466 & 39 & 86 & 2 & 2 & 1 & 1 \\
\hline Greek Orthodox ........ & 204 & 148 & 197 & $\begin{array}{r}168 \\
5671\end{array}$ & 179 & $\begin{array}{r}137 \\
560\end{array}$ & 28 & 10 & 4 & 1 & 1 & 1 & 1 \\
\hline 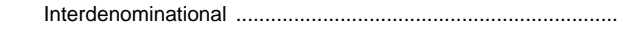 & 1,254 & 11,103 & 6,342 & 5,571 & 5,510 & 2,568 & 2,133 & 542 & 267 & 4 & 17 & 10 & 8 \\
\hline Jewi & 5,738 & 12,217 & 13,038 & 11,481 & 12,273 & 10,328 & 805 & 742 & 398 & 24 & 63 & 58 & 62 \\
\hline Latter-Day Saints & 39,172 & 42,274 & 40,296 & 40,086 & 42,371 & 18,040 & 20,774 & 1,685 & 1,872 & 4 & 4 & 3 & 4 \\
\hline Lutheran Church - Missouri Synod ……………………….... & 11,727 & 13,827 & 10,614 & 11,315 & 12,145 & 4,111 & 5,420 & 957 & 1,657 & 15 & 14 & 8 & 9 \\
\hline Lutheran Church in America & 23,877 & 5,796 & 4,338 & 4,321 & 4,291 & 1,560 & 2,233 & 139 & 359 & 20 & 5 & 3 & 3 \\
\hline 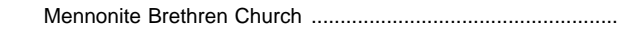 & 1,344 & 1,864 & 2,161 & 2,269 & 2,225 & 540 & 754 & 302 & $629 \mid$ & $3 \mid$ & $3 \mid$ & 3 | & 3 \\
\hline
\end{tabular}




\begin{tabular}{|c|c|c|c|c|c|c|c|c|c|c|c|c|c|}
\hline \multirow{4}{*}{ Affiliation } & \multicolumn{9}{|c|}{ Enrollment } & \multicolumn{4}{|c|}{ Number of institutions ${ }^{2}$} \\
\hline & \multirow{3}{*}{$\begin{array}{l}\text { Total, } \\
\text { fall } 1980\end{array}$} & \multirow{3}{*}{$\begin{array}{l}\text { Total, } \\
\text { fall } 1990\end{array}$} & \multirow{3}{*}{$\begin{array}{l}\text { Total, fall } \\
1994\end{array}$} & \multirow{3}{*}{$\begin{array}{c}\text { Total, fall } \\
1995\end{array}$} & \multicolumn{5}{|c|}{ Fall $1996^{3}$} & \multirow{3}{*}{$\begin{array}{r}\text { Fall } \\
1980\end{array}$} & \multirow{3}{*}{$\begin{array}{l}\text { Fall } \\
1990\end{array}$} & \multirow{3}{*}{$\begin{array}{l}\text { Fall } \\
1995\end{array}$} & \multirow{3}{*}{$\begin{array}{l}\text { Fall } \\
1996\end{array}$} \\
\hline & & & & & \multirow{2}{*}{ Total } & \multicolumn{2}{|c|}{ Full-time } & \multicolumn{2}{|c|}{ Part-time } & & & & \\
\hline & & & & & & Men & Women & Men & Women & & & & \\
\hline 1 & 2 & 3 & 4 & 5 & 6 & 7 & 8 & 9 & 10 & 11 & 12 & 13 & 14 \\
\hline Mennonite Church .. & 4,008 & 2,859 & 3,462 & 3,502 & 3,427 & 1,226 & 1,661 & 215 & 325 & 6 & 5 & 5 & 5 \\
\hline Missionary Church Inc. ……………........ & 487 & $\begin{array}{r}699 \\
2511\end{array}$ & 1,201 & 1,352 & 1,467 & 350 & 553 & 175 & 389 & 1 & 1 & 1 & 1 \\
\hline Moravian Church ............................... & 2,434 & 2,511 & 2,741 & 2,804 & 2,861 & 640 & 1,291 & 283 & 647 & 2 & 2 & 2 & 2 \\
\hline $\begin{array}{l}\text { Multiple Protestant Denominations } \\
\text { North American Baptist }\end{array}$ & $\begin{array}{r}5,526 \\
155\end{array}$ & 211 & $\begin{array}{l}167 \\
170\end{array}$ & $\begin{array}{l}164 \\
186\end{array}$ & $\begin{array}{r}7,580 \\
179\end{array}$ & $\begin{array}{r}2,095 \\
75\end{array}$ & $\begin{array}{r}3,221 \\
40\end{array}$ & $\begin{array}{r}1,181 \\
39\end{array}$ & $\begin{array}{r}1,083 \\
25\end{array}$ & 8 & 1 & 1 & $\begin{array}{l}8 \\
1\end{array}$ \\
\hline Pentecostal Holiness Church ............ & 767 & 566 & 968 & 1,002 & 1,237 & 464 & 484 & 124 & 165 & 3 & 3 & 3 & \\
\hline Presbyterian U.S. and United Presbyterian & 47,144 & 77,700 & 69,790 & 70,357 & 71,034 & 27,258 & 33,311 & 4,038 & 6,427 & 57 & 70 & 65 & 64 \\
\hline Presbyterian Church in America ................... & - & 1,877 & 3,745 & 3,809 & 2,183 & 881 & 804 & 333 & 165 & - & 1 & 3 & 3 \\
\hline Protestant Episcopal .. & 5,396 & 4,559 & 4,514 & 4,603 & 4,593 & 1,862 & 2,327 & 170 & 234 & 12 & 9 & 11 & 11 \\
\hline Protestant, other ....... & 4,072 & 38,136 & 59,870 & 60,386 & 54,427 & 18,227 & 22,588 & 5,427 & 8,185 & 11 & 44 & 67 & 61 \\
\hline Reformed Church in America .... & 2,713 & 5,525 & 5,419 & 5,582 & 5,327 & 2,156 & 2,860 & 128 & 183 & 4 & 4 & 4 & 4 \\
\hline $\begin{array}{l}\text { Reformed Episcopal Church ....... } \\
\text { Reformed Presbyterian Church . }\end{array}$ & 2,014 & 1,556 & 1,767 & 1,771 & 1,819 & 704 & 758 & 173 & 184 & $\begin{array}{l}1 \\
4\end{array}$ & $\overline{2}$ & $\overline{2}$ & 2 \\
\hline Reorganized Latter-Day Saints Church & 4,274 & 4,793 & 10,508 & 11,063 & 11,746 & 2,517 & 2,469 & 2,356 & 4,404 & 2 & 1 & 2 & 2 \\
\hline Roman Catholic ........................................................... & 422,842 & 530,585 & 592,119 & 594,464 & 594,537 & 152,823 & 213,789 & 77,754 & 150,171 & 229 & 239 & 249 & 248 \\
\hline Russian Orthodox . & 47 & 38 & 24 & 32 & 36 & 34 & 0 & 2 & 0 & 1 & 1 & 1 & 1 \\
\hline Seventh-Day Adventists ... & 19,168 & 15,771 & 17,110 & 17,519 & 17,744 & 6,426 & 7,550 & 1,355 & 2,413 & 11 & 11 & 11 & 11 \\
\hline Southern Baptist .................................... & 85,281 & 49,493 & 45,165 & 46,042 & 47,704 & 14,425 & 16,109 & 8,750 & 8,420 & 54 & 29 & 30 & 30 \\
\hline Undenominational .................................... & - & 6,758 & 17,330 & 18,729 & 15,166 & 4,768 & 5,885 & 2,194 & 2,319 & - & 14 & 17 & 12 \\
\hline Unitarian Universalist . & 87 & 82 & 106 & 126 & 131 & 37 & 73 & 10 & 11 & 2 & 2 & 2 & 2 \\
\hline United Brethren Church ……………...... & 545 & 601 & 635 & 721 & 740 & 297 & 345 & 64 & 34 & 1 & 1 & 1 & 1 \\
\hline United Church of Christ ....…………....... & 14,169 & 20,175 & 24,305 & 24,013 & 22,612 & 6,357 & 9,443 & 2,213 & 4,599 & 16 & 18 & 21 & 20 \\
\hline 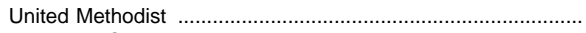 & 127,099 & 148,851 & 146,935 & 148,091 & 148,926 & 50,579 & 63,992 & 13,523 & 20,832 & 91 & 96 & 90 & 91 \\
\hline Wesleyan Church .................................... & 3,583 & 5,311 & 7,497 & 7,734 & 8,336 & 2,898 & 4,635 & 305 & 498 & 5 & 4 & 3 & 3 \\
\hline Wisconsin Evangelical Lutheran Synod. & 808 & 931 & 1,142 & 1,165 & 1,218 & 567 & 601 & 19 & 31 & 1 & 3 & 2 & 2 \\
\hline Other religiously affiliated & 462 & 5,743 & 10,629 & 11,551 & 6,741 & 2,607 & 2,062 & 1,002 & 1,070 & 1 & 9 & 14 & 12 \\
\hline
\end{tabular}

1 Religious affiliation as reported by institutions of higher education. 2Because data are derived from the "Fall Enrollment" survey, counts of institutions may differ from counts in other tables.

3 Preliminary data.

NOTE.-Some data have been revised from previously published figures.

SOURCE: U.S. Department of Education, National Center for Education Statistics, Higher Education General Information Survey (HEGIS), "Fall Enrollment in Institutions of Higher Education" and "Institutional Characteristics" surveys veys. (This table was prepared June 1998). 
Table 180.-Total fall enrollment in institutions of higher education and degree-granting institutions, by type and control of institution, and attendance status, sex, and level of student: 1994 to 1996

\begin{tabular}{|c|c|c|c|c|c|c|c|c|c|c|c|c|}
\hline \multirow[b]{2}{*}{ Level of student and enrollment status } & \multirow{2}{*}{$\begin{array}{c}\text { Total, } \\
\text { fall } \\
1994\end{array}$} & \multirow{2}{*}{$\begin{array}{c}\text { Total, } \\
\text { fall } \\
1995\end{array}$} & \multicolumn{5}{|c|}{$1996^{1}$} & \multicolumn{5}{|c|}{ Degree-granting institutions, fall $1996^{2}$} \\
\hline & & & Total & $\begin{array}{l}\text { Public } \\
\text { 4-year }\end{array}$ & $\begin{array}{l}\text { Private } \\
\text { 4-year }\end{array}$ & $\begin{array}{l}\text { Public } \\
2 \text {-year }\end{array}$ & $\begin{array}{l}\text { Private } \\
2 \text {-year }\end{array}$ & Total & $\begin{array}{l}\text { Public } \\
\text { 4-year }\end{array}$ & $\begin{array}{l}\text { Private } \\
\text { 4-year }\end{array}$ & $\begin{array}{l}\text { Public } \\
2 \text {-year }\end{array}$ & $\begin{array}{l}\text { Private } \\
\text { 2-year }\end{array}$ \\
\hline 1 & 2 & 3 & 4 & 5 & 6 & 7 & 8 & 9 & 10 & 11 & 12 & 13 \\
\hline All students & $14,278,790$ & $14,261,781$ & $14,300,255$ & $5,806,904$ & $2,995,931$ & $5,283,267$ & 214,153 & $14,367,520$ & $5,806,036$ & $2,998,157$ & $5,314,463$ & 248,864 \\
\hline Undergraduate, full-time and part-time & $12,262,608$ & $12,231,719$ & $12,259,417$ & $4,622,497$ & $2,140,047$ & $5,282,842$ & 214,031 & $12,326,948$ & $4,621,245$ & $2,142,923$ & $5,314,038$ & 248,742 \\
\hline Degree seeking …………..................... & $10,728,256$ & $10,621,283$ & $10,608,815$ & $4,413,530$ & $2,042,309$ & $3,997,617$ & 155,359 & $10,720,738$ & $4,412,278$ & $2,045,246$ & $4,027,863$ & 235,351 \\
\hline 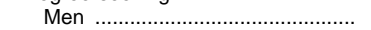 & $4,767,756$ & $4,708,420$ & $4,684,930$ & $2,037,470$ & 896,301 & $1,685,688$ & 65,471 & $4,727,637$ & $2,036,844$ & 895,819 & $1,700,685$ & 94,289 \\
\hline Women . & $5,960,500$ & $5,912,863$ & $5,923,885$ & $2,376,060$ & $1,146,008$ & $2,311,929$ & 89,888 & $5,993,101$ & $2,375,434$ & $1,149,427$ & $2,327,178$ & 141,062 \\
\hline First-time freshmen ............................ & $2,133,205$ & $2,168,831$ & $2,193,429$ & 741,164 & 425,959 & 967,971 & 58,335 & $2,274,319$ & 741,164 & 427,442 & 989,536 & 116,177 \\
\hline Men ............................. & 984,558 & $1,001,052$ & $1,013,616$ & 340,810 & 194,823 & 450,816 & 27,167 & $1,046,662$ & 340,810 & 195,302 & 461,549 & 49,001 \\
\hline 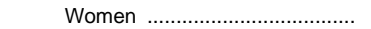 & $1,148,647$ & $1,167,779$ & $1,179,813$ & 400,354 & 231,136 & 517,155 & 31,168 & $1,227,657$ & 400,354 & 232,140 & 527,987 & 67,176 \\
\hline Other first-year .................................. & $2,501,937$ & $2,433,434$ & $2,421,277$ & 496,603 & 199,410 & $1,683,824$ & 41,440 & $2,416,098$ & 496,603 & 198,757 & $1,677,072$ & 43,666 \\
\hline Men ..... & $1,070,025$ & $1,046,475$ & $1,047,280$ & 233,141 & 90,265 & 706,940 & 16,934 & $1,044,926$ & 233,141 & 89,334 & 704,467 & 17,984 \\
\hline Women . & $1,431,912$ & $1,386,959$ & $1,373,997$ & 263,462 & 109,145 & 976,884 & 24,506 & $1,371,172$ & 263,462 & 109,423 & 972,605 & 25,682 \\
\hline Second year & $2,807,591$ & $2,767,344$ & $2,719,130$ & 876,918 & 442,251 & $1,344,384$ & 55,577 & $2,755,714$ & 876,918 & 443,482 & $\mid 1,359,817$ & 75,497 \\
\hline Men ............... & $1,196,982$ & $1,174,985$ & $1,143,568$ & 401,714 & 193,035 & 527,453 & 21,366 & $1,156,512$ & 401,714 & 193,306 & 534,190 & 27,302 \\
\hline 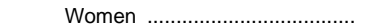 & $1,610,609$ & $1,592,359$ & $1,575,562$ & 475,204 & 249,216 & 816,931 & 34,211 & $1,599,202$ & 475,204 & 250,176 & 825,627 & 48,195 \\
\hline Third year ........................................... & $1,410,544$ & $1,394,845$ & $1,397,921$ & 974,210 & 423,000 & 704 & 7 & $1,398,336$ & 974,210 & 423,411 & 704 & 11 \\
\hline Men ........... & 645,805 & 631,360 & 626,737 & 444,118 & 182,372 & 243 & 4 & 626,649 & 444,118 & 182,286 & 243 & 2 \\
\hline Women . & 764,739 & 763,485 & 771,184 & 530,092 & 240,628 & 461 & 3 & 771,687 & 530,092 & 241,125 & 461 & 9 \\
\hline Fourth year and beyond & $1,722,393$ & $1,714,665$ & $1,728,819$ & $1,260,108$ & 468,082 & 629 & - & $1,729,076$ & $1,260,108$ & 468,339 & 629 & - \\
\hline Men ……......................... & 806,598 & 795,243 & 792,455 & 588,953 & 203,309 & 193 & - & 792,331 & 588,953 & 203,185 & 193 & - \\
\hline Women & 915,795 & 919,422 & 936,364 & 671,155 & 264,773 & 436 & - & 936,745 & 671,155 & 265,154 & 436 & - \\
\hline Unclassified by level ...... & 152,586 & 142,164 & 148,239 & 64,527 & 83,607 & 105 & - & 147,195 & 63,275 & 83,815 & 105 & - \\
\hline 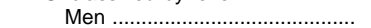 & 63,788 & 59,305 & 61,274 & 28,734 & 32,497 & 43 & - & 60,557 & 28,108 & 32,406 & 43 & - \\
\hline Women & 88,798 & 82,859 & 86,965 & 35,793 & 51,110 & 62 & - & 86,638 & 35,167 & 51,409 & 62 & - \\
\hline Others in credit courses ..... & $1,534,352$ & $1,610,436$ & $1,650,602$ & 208,967 & 97,738 & $1,285,225$ & 58,672 & $1,606,210$ & 208,967 & 97,677 & $1,286,175$ & 13,391 \\
\hline Men ……… & 654,357 & 692,710 & 726,128 & 89,890 & 39,428 & 554,973 & 41,837 & 693,035 & 89,890 & 39,327 & 555,332 & 8,486 \\
\hline Women . & 879,995 & 917,726 & 924,474 & 119,077 & 58,310 & 730,252 & 16,835 & 913,175 & 119,077 & 58,350 & 730,843 & 4,905 \\
\hline Full-time & $7,168,706$ & $7,145,268$ & $7,210,698$ & $3,552,484$ & $1,671,682$ & $1,858,080$ & 128,452 & $7,298,839$ & $3,552,484$ & $1,674,140$ & $1,872,014$ & 200,201 \\
\hline Degree seeking & $6,903,775$ & $6,883,159$ & $6,949,391$ & $3,520,918$ & $1,655,072$ & $1,649,710$ & 123,691 & $7,036,393$ & $3,520,918$ & $1,657,702$ & $1,663,403$ & 194,370 \\
\hline First-time freshmen & $1,603,106$ & $1,646,812$ & $1,674,178$ & 694,390 & 400,397 & 528,297 & 51,094 & $1,739,852$ & 694,390 & 401,408 & 539,359 & 104,695 \\
\hline Other first-year & $1,165,709$ & $1,136,399$ & $1,151,651$ & 377,242 & 136,651 & 607,164 & 30,594 & $1,150,715$ & 377,242 & 136,735 & 604,014 & 32,724 \\
\hline Second year ................................. & $1,695,721$ & $1,688,726$ & $1,681,757$ & 740,635 & 385,144 & 513,980 & 41,998 & $1,703,436$ & 740,635 & 386,091 & 519,761 & 56,949 \\
\hline Third $y$ & $1,138,336$ & $1,126,949$ & $1,136,190$ & 783,225 & 352,773 & 187 & 5 & $1,136,388$ & 783,225 & 352,974 & 187 & 2 \\
\hline nd beyond & $1,267,625$ & $1,259,327$ & $1,276,595$ & 914,667 & 361,851 & 77 & - & $1,276,754$ & 914,667 & 362,010 & 77 & - \\
\hline Unclassified by level ...................... & 33,278 & 24,946 & 29,020 & 10,759 & 18,256 & 5 & - & 29,248 & 10,759 & 18,484 & 5 & - \\
\hline Others in credit courses $\ldots . . \ldots \ldots \ldots . . . . .$. & 264,931 & 262,109 & 261,307 & 31,566 & 16,610 & 208,370 & 4,761 & 262,446 & 31,566 & 16,438 & 208,611 & 5,831 \\
\hline Part-t & $5,093,902$ & $5,086,451$ & $5,048,719$ & $1,070,013$ & 468,365 & $3,424,762$ & 85,579 & $5,028,109$ & $1,068,761$ & 468,783 & $3,442,024$ & 48,541 \\
\hline Degree & $3,824,481$ & $3,738,124$ & $3,659,424$ & 892,612 & 387,237 & $2,347,907$ & 31,668 & $3,684,345$ & 891,360 & 387,544 & $2,364,460$ & 40,981 \\
\hline 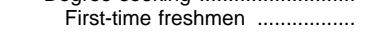 & 530,099 & 522,019 & 519,251 & 46,774 & 25,562 & 439,674 & 7,241 & 534,467 & 46,774 & 26,034 & 450,177 & 11,482 \\
\hline Other first-year .............................. & $1,336,228$ & $1,297,035$ & $1,269,626$ & 119,361 & 62,759 & $1,076,660$ & 10,846 & $1,265,383$ & 119,361 & 62,022 & $1,073,058$ & 10,942 \\
\hline year ……........................ & $1,111,870$ & $1,078,618$ & $1,037,373$ & 136,283 & 57,107 & 830,404 & 13,579 & $1,052,278$ & 136,283 & 57,391 & 840,056 & 18,548 \\
\hline Third year & 272,208 & 267,896 & 261,731 & 190,985 & 70,227 & 517 & 2 & 261,948 & 190,985 & 70,437 & 517 & 9 \\
\hline Fourth year and beyond ........... & 454,768 & 455,338 & 452,224 & 345,441 & 106,231 & 552 & - & 452,322 & 345,441 & 106,329 & 552 & - \\
\hline Unclassified by level ........ & 119,308 & 117,218 & 119,219 & 53,768 & 65,351 & 100 & - & 117,947 & 52,516 & 65,331 & 100 & - \\
\hline Others in credit courses $. . . \ldots \ldots \ldots . . . . .$. & $1,269,421$ & $1,348,327$ & $1,389,295$ & 177,401 & 81,128 & $1,076,855$ & 53,911 & $1,343,764$ & 177,401 & 81,239 & $1,077,564$ & 7,560 \\
\hline Postbaccalaureate & $2,016,182$ & $2,030,062$ & $2,040,838$ & $1,184,407$ & 855,884 & 425 & 122 & $2,040,572$ & $1,184,791$ & 855,234 & 425 & 122 \\
\hline First-professional & 294,713 & 297,592 & 297,739 & 385 & 181,354 & - & - & 298,312 & 116,665 & 181,647 & - & - \\
\hline Full-time & 263,311 & 266,414 & 266,812 & 111,395 & 155,417 & - & - & 267,209 & 111,650 & 155,559 & - & - \\
\hline First-time . & 80,286 & 78,890 & 77,581 & 30,590 & 46,991 & - & - & 77,695 & 30,696 & 46,999 & - & - \\
\hline Other & 183,025 & 187,524 & 189,231 & 80,805 & 108,426 & - & - & 189,514 & 80,954 & 108,560 & - & - \\
\hline 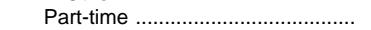 & 31,402 & 31,178 & 30,927 & 4,990 & 25,937 & - & - & 31,103 & 5,015 & 26,088 & - & - \\
\hline First-time .. & 9,872 & 10,760 & 9,429 & 820 & 8,609 & - & - & 9,533 & 845 & 8,688 & - & - \\
\hline 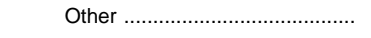 & 21,530 & 20,418 & 21,498 & 4,170 & 17,328 & - & - & 21,570 & 4,170 & 17,400 & - & - \\
\hline Graduate & $1,721,469$ & $1,732,470$ & $1,743,099$ & $1,068,022$ & 530 & 425 & 122 & $1,742,260$ & 1,06 & 587 & 425 & 122 \\
\hline Full-time ................. & 705,759 & 717,120 & 735,980 & 442,215 & 293,675 & - & 90 & 736,905 & 442,319 & 294,496 & - & 90 \\
\hline Degree seeking ... & 665,966 & 670,222 & 688,493 & 403,791 & 284,612 & - & 90 & 689,883 & 403,895 & 285,898 & - & 90 \\
\hline First-time …w........................ & 224,412 & 222,196 & 231,084 & 126,191 & 104,863 & - & 30 & 232,330 & 126,247 & 106,053 & - & 30 \\
\hline Other degree seeking ............ & 441,554 & 448,026 & 457,409 & 277,600 & 179,749 & - & 60 & 457,553 & 277,648 & 179,845 & - & 60 \\
\hline Others in credit courses ........... & 39,793 & 46,898 & 47,487 & 38,424 & 9,063 & - & - & 47,022 & 38,424 & 8,598 & - & - \\
\hline 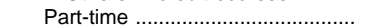 & $1,015,710$ & $1,015,350$ & $1,007,119$ & 625,807 & 380,855 & 425 & 32 & $1,005,355$ & 625,807 & 379,091 & 425 & 32 \\
\hline Degree $s$ & 774,962 & 775,811 & 773,707 & 450,850 & 322,688 & 137 & 32 & 772,760 & 450,850 & 321,741 & 137 & 32 \\
\hline First-time ……........................ & 147,236 & 148,220 & 148,773 & 76,837 & 71,927 & 9 & - & 147,614 & 76,837 & 70,768 & 9 & - \\
\hline Other degree seeking ............ & 627,726 & 627,591 & 624,934 & 374,013 & 250,761 & 128 & 32 & 625,146 & 374,013 & 250,973 & 128 & 32 \\
\hline Others in credit courses ............ & 240,748 & 239,539 & 233,412 & 174,957 & 58,167 & 288 & - & 232,595 & 174,957 & 57,350 & 288 & - \\
\hline
\end{tabular}

1 Preliminary data.

${ }^{2}$ Preliminary data are for 4-year and 2-year degree-granting institutions that were eligible to participate in Title IV federal financial aid programs.

-Data not available or not applicable.

NOTE.-Trend tabulations of institutions of higher education data are based on institutions that were accredited by an agency or association that was recognized by the U.S Department of Education. The Department of Education no longer distinguishes between those institutions and other institutions that are eligible to participate in Title IV programs. The new degree-granting classification is very similar to the earlier higher education classification, except that it includes some additional institutions, primarily 2-year colleges, and excludes a few higher education institutions that did not award degrees.

SOURCE: U.S. Department of Education, National Center for Education Statistics, Integrated Postsecondary Education Data System, "Fall Enrollment" surveys. (This table was prepared May 1998.) 
Table 181.-Total first-time freshmen enrolled in institutions of higher education and degree-granting institutions, by sex of student, attendance status, and type and control of institution: Fall 1955 to fall 1996

[In thousands]

\begin{tabular}{|c|c|c|c|c|c|c|c|c|c|c|c|c|c|}
\hline \multirow{3}{*}{ Year } & \multirow{3}{*}{$\begin{array}{c}\text { Total, all } \\
\text { freshmen }\end{array}$} & \multirow{3}{*}{ Full-time } & \multirow{3}{*}{ Part-time } & \multicolumn{3}{|c|}{ Men } & \multicolumn{3}{|c|}{ Women } & \multicolumn{4}{|c|}{ Type of institution, by control } \\
\hline & & & & \multirow{2}{*}{ Total } & \multirow{2}{*}{ Full-time } & \multirow{2}{*}{ Part-time } & \multirow{2}{*}{ Total } & \multirow{2}{*}{ Full-time } & \multirow{2}{*}{ Part-time } & \multicolumn{2}{|c|}{ 4-year } & \multicolumn{2}{|c|}{ 2-year } \\
\hline & & & & & & & & & & Public & Private & Public & Private \\
\hline \multirow[t]{2}{*}{1} & 2 & 3 & 4 & 5 & 6 & 7 & 8 & 9 & 10 & 11 & 12 & 13 & 14 \\
\hline & \multicolumn{13}{|c|}{ Institutions of higher education } \\
\hline $1955^{1}$ & 670 & - & - & 416 & - & - & 254 & - & - & 2283 & 2247 & 2117 & 223 \\
\hline $1956^{1}$. & 718 & - & - & 443 & - & - & 275 & - & - & 2293 & ${ }^{2} 262$ & 2137 & ${ }^{2} 25$ \\
\hline $1957^{1}$ & 724 & - & - & 442 & - & - & 282 & - & - & 2294 & 2263 & 2141 & 227 \\
\hline $1958^{1}$. & 775 & - & - & 465 & - & - & 310 & - & - & 2328 & 2272 & 2146 & 229 \\
\hline $1959{ }^{1} \ldots \ldots \ldots \ldots \ldots \ldots \ldots$ & 822 & - & - & 488 & - & - & 334 & - & - & 2348 & 2292 & 2153 & 228 \\
\hline $1960^{1} \ldots \ldots$ & 923 & - & - & 540 & - & - & 384 & - & - & 2396 & 2313 & 2182 & 232 \\
\hline $1961^{1} \ldots$ & 1,018 & - & - & 592 & - & - & 426 & - & - & 2438 & 2336 & 2210 & 234 \\
\hline $19621 \ldots \ldots \ldots \ldots \ldots$ & 1,031 & - & - & 598 & - & - & 432 & - & - & 2445 & 2325 & 2225 & 236 \\
\hline $1963{ }^{1} \ldots \ldots \ldots \ldots \ldots \ldots \ldots$ & 1,046 & - & - & 604 & - & - & 442 & - & - & - & - & - & - \\
\hline $1964^{1} \ldots \ldots \ldots \ldots \ldots \ldots \ldots$ & 1,225 & - & - & 702 & - & - & 523 & - & - & 2539 & 2363 & 2275 & 247 \\
\hline $1965^{1} \ldots$ & 1,442 & - & - & 829 & - & - & 613 & - & - & ${ }^{2} 642$ & 2399 & 2348 & 253 \\
\hline $1966 \ldots \ldots$ & 1,554 & - & - & 890 & - & - & 665 & - & - & 2626 & 2383 & 2478 & 267 \\
\hline $1967 \ldots . .$. & 1,641 & 1,336 & 305 & 931 & 761 & 170 & 710 & 574 & 136 & 2645 & 2368 & 2561 & 267 \\
\hline $1968 \ldots \ldots . .$. & 1,893 & 1,471 & 422 & 1,082 & 847 & 235 & 810 & 624 & 187 & 2725 & 2378 & 2718 & 272 \\
\hline $1969 \ldots \ldots$. & 1,967 & 1,525 & 442 & 1,118 & 876 & 242 & 849 & 649 & 200 & 2737 & 2393 & 2776 & 261 \\
\hline 1970 & 2,063 & 1,587 & 476 & 1,152 & 896 & 256 & 911 & 691 & 221 & 2754 & 2397 & 2854 & 258 \\
\hline $1 \ldots \ldots .$. & 2,119 & 06 & 513 & 1 & 896 & 275 & 949 & 710 & 238 & 2738 & 2386 & 2937 & 258 \\
\hline 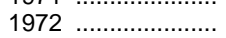 & 2,153 & 1,574 & 579 & 1,158 & 858 & 299 & 995 & 716 & 279 & 680 & 381 & 1,037 & 55 \\
\hline 1973 & 2,226 & 1,607 & 619 & 1,182 & 867 & 315 & 1,044 & 740 & 304 & 699 & 379 & 1,089 & 59 \\
\hline $1974 \ldots \ldots \ldots \ldots \ldots \ldots$ & 2,366 & 1,673 & 692 & 1,244 & 896 & 348 & 1,122 & 777 & 345 & 746 & 386 & 1,176 & 58 \\
\hline 1975 & 2,515 & 1,763 & 752 & 1,328 & 942 & 386 & 1,187 & 821 & 366 & 772 & 395 & 1,284 & 64 \\
\hline 1976 & 2,347 & 1,662 & 685 & 1,170 & 855 & 316 & 1,177 & 808 & 369 & 717 & 414 & 1,153 & 63 \\
\hline $1977 \ldots \ldots \ldots$ & 2,394 & 1,681 & 714 & 1,156 & 840 & 316 & 1,239 & 841 & 398 & 737 & 405 & 1,186 & 67 \\
\hline $1978 \ldots \ldots \ldots$ & 2,390 & 1,651 & 739 & 1,142 & 817 & 324 & 1,248 & 834 & 414 & 737 & 407 & 1,174 & 73 \\
\hline 1979 & 2,503 & 1,707 & 796 & 1,180 & 840 & 340 & 1,323 & 866 & 457 & 760 & 415 & 1,254 & 74 \\
\hline 1980 & 2,588 & 1,750 & 838 & 1,219 & 862 & 357 & 1,369 & 887 & 481 & 765 & 418 & 1,314 & 91 \\
\hline 1981 & 2,595 & 1,738 & 858 & 1,218 & 852 & 366 & 1,378 & 886 & 492 & 754 & 419 & 1,318 & 104 \\
\hline 1982 & 2,505 & 1, & 817 & 1,199 & 837 & 362 & 1,306 & 851 & 455 & 731 & 404 & 1,254 & 116 \\
\hline ․․…….......... & 2,444 & 1,678 & 766 & 1,159 & 825 & 334 & 1,285 & 853 & 431 & 728 & 404 & 1,190 & 122 \\
\hline 1984 & 2,357 & 1,613 & 744 & 1,112 & 786 & 326 & 1,245 & 827 & 418 & 714 & 403 & 1,130 & 110 \\
\hline 1985 & 2,292 & 1,602 & 690 & 1,076 & 775 & 301 & 1,216 & 827 & 389 & 717 & 399 & 1,060 & 116 \\
\hline 1986 & 2,219 & 9 & 630 & 1,0 & 769 & 278 & 1,173 & 821 & 352 & 720 & 392 & 991 & 3 117 \\
\hline 1987 & 2,246 & 1,627 & 620 & 1,047 & 779 & 267 & 1,200 & 847 & 352 & 758 & 405 & 980 & 104 \\
\hline 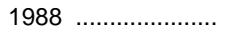 & 2,379 & 1,699 & 680 & 1,100 & 807 & 293 & 1,279 & 892 & 387 & 783 & 426 & 1,049 & 121 \\
\hline 1989 & 2,341 & 1,657 & 684 & 1,095 & 791 & 303 & 1,246 & 865 & 381 & 762 & 414 & 1,049 & 3116 \\
\hline $1990 \ldots \ldots$ & 2,257 & 1,617 & 640 & 1,04 & 771 & 274 & 1,211 & 846 & 366 & 727 & 400 & 1,041 & 488 \\
\hline $1991 \ldots$ & 2,278 & 1,653 & 625 & 1,068 & 798 & 270 & 1,209 & 855 & 355 & 718 & 393 & 1,070 & 497 \\
\hline $1992 \ldots \ldots \ldots \ldots \ldots \ldots \ldots$ & 2,184 & 1,604 & 580 & 1,013 & 760 & 253 & 1,171 & 843 & 328 & 697 & 408 & 993 & 485 \\
\hline $1993 \ldots . .$. & 2,161 & 1,608 & 552 & 1,008 & 762 & 245 & 1,153 & 846 & 307 & 702 & 411 & 974 & 474 \\
\hline $1994 \ldots . .$. & 2,133 & 1,603 & 530 & 985 & 751 & 233 & 1,149 & 852 & 297 & 709 & 406 & 952 & 466 \\
\hline & 2,169 & 1,647 & 522 & 1,001 & 767 & 234 & 1,168 & 880 & 288 & 732 & 419 & 955 & 463 \\
\hline \multirow[t]{2}{*}{19965} & 2,193 & 1,674 & 519 & 1,014 & 779 & 234 & 1,180 & 895 & 285 & 741 & 426 & 968 & ${ }^{4} 58$ \\
\hline & & & & & & gre & ing $i$ & ons ${ }^{6}$ & & & & & \\
\hline 19965 & 2,274 & 1,740 & 534 & 1,047 & 806 & 241 & 1,228 & 934 & 294 & 741 & 427 & 990 & 4116 \\
\hline
\end{tabular}

${ }^{1}$ Excludes first-time freshmen in occupational programs not creditable towards a bachelor's degree.

${ }^{2}$ Data for 2-year branches of 4-year college systems are aggregated with the 4-year institutions.

${ }^{3}$ Because of imputation techniques, data are not consistent with figures for other years.

${ }^{4}$ Data not comparable with pre-1990 figures because of a change in reporting procedures.

5 Preliminary data.

${ }^{6}$ Data are for 4-year and 2-year degree-granting institutions that were eligible to participate in Title IV federal financial aid programs.

-Data not available.
NOTE.-Trend tabulations of institutions of higher education data are based on institutions that were accredited by an agency or association that was recognized by the U.S. Department of Education. The Department of Education no longer distinguishes between those institutions and other institutions that are eligible to participate in Title IV programs. The new degree-granting clasification is very similar to the earlier higher education classification, except that it includes some additional institutions, primarily 2-year colleges, and excludes a few higher education institutions that did not award degrees. Alaska and Hawaii are included in all years. Because of rounding, details may not add to totals.

SOURCE: U.S. Department of Education, National Center for Education Statistics, Fall Enrollment in Higher Education, various years; "Fall Enrollment in Colleges and Universities" survey; and Integrated Postsecondary Education Data System (IPEDS), "Fall Enrollment" surveys. (This table was prepared May 1998.) 
Table 182.-Total first-time freshmen enrolled in institutions of higher education, by attendance status, sex, control of institution, and state: Fall 1992 to fall 1996

\begin{tabular}{|c|c|c|c|c|c|c|c|c|c|c|c|c|c|}
\hline \multirow{3}{*}{ State or other area } & \multirow{3}{*}{ Fall 1992} & \multirow{3}{*}{ Fall 1993} & \multirow{3}{*}{ Fall 1994} & \multirow{3}{*}{ Fall 1995} & \multicolumn{9}{|c|}{ Fall $1996^{1}$} \\
\hline & & & & & \multirow{2}{*}{ Total } & \multicolumn{3}{|c|}{ Full-time } & \multicolumn{3}{|c|}{ Part-time } & Public & Priv \\
\hline & & & & & & Total & Men & Women & Total & Men & Women & institutions & ins \\
\hline 1 & 2 & 3 & 4 & 5 & 6 & 7 & 8 & 9 & 10 & 11 & 12 & 13 & 14 \\
\hline United States ........ & $2,184,113$ & $2,160,710$ & $2,133,205$ & $2,168,831$ & $2,193,429$ & $1,674,178$ & 779,438 & 894,740 & 519,251 & 234,178 & 285,073 & $1,709,135$ & 484,294 \\
\hline Alabama & 42,604 & 41,812 & 41,542 & 37,166 & 36,672 & 31,759 & 13,890 & 17,869 & 4,913 & 2,215 & 2,698 & 32,246 & 4,426 \\
\hline Alaska & 2,584 & 2,700 & 1,835 & 1,880 & 1,953 & 1,651 & 779 & 872 & 302 & 102 & 200 & 1,744 & 209 \\
\hline Arizona & 31,358 & 36,671 & 32,753 & 37,049 & 34,408 & 23,183 & 11,424 & 11,759 & 11,225 & 5,034 & 6,191 & 30,851 & 3,557 \\
\hline 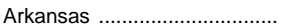 & 18,680 & 17,406 & 16,378 & 16,924 & 16,976 & 15,173 & 6,713 & 8,460 & 1,803 & 762 & 1,041 & 14,172 & 2,804 \\
\hline 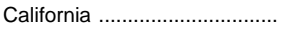 & 252,762 & 250,810 & 258,687 & 272,715 & 277,656 & 154,068 & 72,897 & 81,171 & 123,588 & 58,572 & 65,016 & 247,425 & 30,231 \\
\hline Colorado & 33,359 & 31,353 & 31,001 & 32,775 & 31,775 & 23,755 & 11,730 & 12,025 & 8,020 & 3,712 & 4,308 & 27,813 & 3,962 \\
\hline Connecticut & 22,490 & 21,489 & 21,259 & 21,268 & 21,169 & 16,781 & 7,930 & 8,851 & 4,388 & 1,740 & 2,648 & 12,502 & 8,667 \\
\hline Delaware .............. & 7,227 & 7,361 & 6,921 & 8,092 & 7,854 & 6,036 & 2,544 & 3,492 & 1,818 & 704 & 1,114 & 6,577 & 1,277 \\
\hline District of Columbia .................. & 8,427 & 8,954 & 9,706 & 9,077 & 8,645 & 7,073 & 2,802 & 4,271 & 1,572 & 619 & 953 & 1,492 & 7,153 \\
\hline 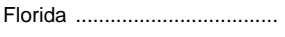 & 72,311 & 71,351 & 71,318 & 72,722 & 74,048 & 54,540 & 25,065 & 29,475 & 19,508 & 8,459 & 11,049 & 58,192 & 15,856 \\
\hline Georgia & 56,389 & 59,784 & 58,991 & 59,829 & 59,732 & 46,509 & 20,315 & 26,194 & 13,223 & 5,190 & 8,033 & 46,706 & 13,026 \\
\hline Hawaii ....... & 9,461 & 9,752 & 10,309 & 9,524 & 9,079 & 6,259 & 2,832 & 3,427 & 2,820 & 1,353 & 1,467 & 6,863 & 2,216 \\
\hline Idaho ............................ & 10,960 & 11,069 & 10,646 & 10,103 & 10,664 & 8,877 & 4,207 & 4,670 & 1,787 & 725 & 1,062 & 7,972 & 2,692 \\
\hline Illinois ........ & 116,967 & 112,542 & 111,309 & 109,483 & 106,440 & 73,357 & 35,147 & 38,210 & 33,083 & 14,904 & 18,179 & 82,875 & 23,565 \\
\hline 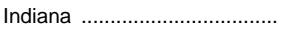 & 50,147 & 49,111 & 48,059 & 51,071 & 51,108 & 43,620 & 21,239 & 22,381 & 7,488 & 3,109 & 4,379 & 37,057 & 14,051 \\
\hline lowa & 36,730 & 35,922 & 35,229 & 35,097 & 39,469 & 30,166 & 14,796 & 15,370 & 9,303 & 3,651 & 5,652 & 31,312 & 8,157 \\
\hline Kansas .. & 25,453 & 25,304 & 24,641 & 29,083 & 27,231 & 20,022 & 10,013 & 10,009 & 7,209 & 3,082 & 4,127 & 24,818 & 2,413 \\
\hline 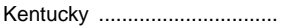 & 29,738 & 31,334 & 28,983 & 29,024 & 28,524 & 25,192 & 10,959 & 14,233 & 3,332 & 1,434 & 1,898 & 22,434 & 6,090 \\
\hline 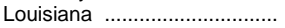 & 31,810 & 30,160 & 30,951 & 31,412 & 31,710 & 28,794 & 12,377 & 16,417 & 2,916 & 1,206 & 1,710 & 27,319 & 4,391 \\
\hline Maine …................................ & 8,765 & 8,751 & 8,149 & 8,273 & 8,349 & 7,410 & 3,524 & 3,886 & 939 & 352 & 587 & 5,391 & 2,958 \\
\hline Maryland & 32,133 & 31,675 & 31,647 & 32,993 & 33,198 & 24,494 & 11,013 & 13,481 & 8,704 & 3,447 & 5,257 & 28,191 & 5,007 \\
\hline 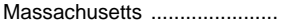 & 64,751 & 68,316 & 65,768 & 64,892 & 62,259 & 54,299 & 24,669 & 29,630 & 7,960 & 2,900 & 5,060 & 27,666 & 34,593 \\
\hline 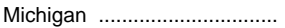 & 88,744 & 87,025 & 83,697 & 76,360 & 76,216 & 56,876 & 25,923 & 30,953 & 19,340 & 8,396 & 10,944 & 61,444 & 14,772 \\
\hline Minnesota ............................ & 50,869 & 43,794 & 43,783 & 46,794 & 51,388 & 41,481 & 20,119 & 21,362 & 9,907 & 4,208 & 5,699 & 41,083 & 10,305 \\
\hline Mississippi ................................ & 25,960 & 26,223 & 25,862 & 26,602 & 27,669 & 24,038 & 11,000 & 13,038 & 3,631 & 1,331 & 2,300 & 25,878 & 1,791 \\
\hline Missouri & 39,886 & 40,868 & 38,544 & 39,610 & 39,105 & 32,599 & 14,982 & 17,617 & 6,506 & 2,633 & 3,873 & 26,439 & 12,666 \\
\hline Montana . & 6,413 & 6,950 & 6,819 & 7,473 & 7,876 & 6,637 & 3,254 & 3,383 & 1,239 & 476 & 763 & 7,030 & 846 \\
\hline 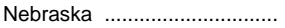 & 17,362 & 15,943 & 16,616 & 16,147 & 17,136 & 14,420 & 6,910 & 7,510 & 2,716 & 1,215 & 1,501 & 13,921 & 3,215 \\
\hline Nevada & 4,620 & 5,367 & 6,939 & 6,799 & 7,254 & 3,781 & 1,763 & 2,018 & 3,473 & 1,552 & 1,921 & 6,986 & 268 \\
\hline New Hampshire .......................... & 11,316 & 11,659 & 11,373 & 11,789 & 10,894 & 9,530 & 4,375 & 5,155 & 1,364 & 483 & 881 & 6,126 & 4,768 \\
\hline New Jersey & 44,932 & 44,971 & 43,063 & 45,308 & 45,907 & 38,708 & 18,077 & 20,631 & 7,199 & 3,124 & 4,075 & 36,491 & 9,416 \\
\hline New Mexico ............................ & 11,818 & 13,358 & 13,864 & 12,104 & 12,445 & 7,530 & 3,607 & 3,923 & 4,915 & 2,151 & 2,764 & 11,791 & 654 \\
\hline 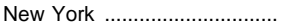 & 158,380 & 157,350 & 155,922 & 151,682 & 152,071 & 136,786 & 62,340 & 74,446 & 15,285 & 6,701 & 8,584 & 90,131 & 61,940 \\
\hline North Carolina & 55,075 & 52,857 & 51,346 & 51,706 & 53,792 & 46,438 & 20,661 & 25,777 & 7,354 & 3,548 & 3,806 & 40,180 & 13,612 \\
\hline North Dakota ............................... & 8,813 & 8,322 & 8,122 & 8,386 & 8,495 & 7,677 & 4,016 & 3,661 & 818 & 354 & 464 & 7,546 & 949 \\
\hline Ohio & 92,902 & 90,190 & 88,585 & 89,510 & 91,001 & 72,854 & 33,924 & 38,930 & 18,147 & 8,586 & 9,561 & 66,431 & 24,570 \\
\hline Oklahoma & 30,296 & 30,252 & 29,627 & 28,474 & 28,866 & 20,399 & 9,970 & 10,429 & 8,467 & 3,543 & 4,924 & 25,832 & 3,034 \\
\hline Oregon ………..................... & 22,930 & 23,293 & 23,321 & 20,562 & 22,028 & 16,806 & 8,095 & 8,711 & 5,222 & 2,519 & 2,703 & 18,304 & 3,724 \\
\hline Pennsylvania ……..................... & 113,070 & 100,372 & 98,488 & 101,053 & 102,950 & 87,395 & 41,056 & 46,339 & 15,555 & 6,270 & 9,285 & 61,792 & 41,158 \\
\hline Rhode Island .............................. & 12,813 & 13,106 & 12,645 & 12,745 & 12,643 & 10,912 & 5,155 & 5,757 & 1,731 & 713 & 1,018 & 5,637 & 7,006 \\
\hline South Carolina & 30,185 & 30,070 & 28,577 & 29,036 & 30,719 & 26,018 & 11,481 & 14,537 & 4,701 & 1,947 & 2,754 & 24,334 & 6,385 \\
\hline South Dakota ................. & 6,513 & 6,691 & 6,607 & 6,378 & 5,769 & 5,232 & 2,398 & 2,834 & 537 & 212 & 325 & 4,507 & 1,262 \\
\hline Tennessee ……......................... & 35,721 & 35,341 & 34,180 & 36,628 & 36,779 & 32,800 & 14,917 & 17,883 & 3,979 & 1,627 & 2,352 & 26,218 & 10,561 \\
\hline 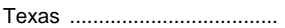 & 127,584 & 129,921 & 127,586 & 131,905 & 137,475 & 100,061 & 47,113 & 52,948 & 37,414 & 17,048 & 20,366 & 118,709 & 18,766 \\
\hline 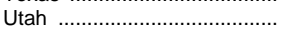 & 23,536 & 24,465 & 24,383 & 24,041 & 26,075 & 18,665 & 8,535 & 10,130 & 7,410 & 3,830 & 3,580 & 20,356 & 5,719 \\
\hline Vermont & 6,274 & 6,347 & 6,132 & 6,506 & 6,265 & 5,688 & 2,773 & 2,915 & 577 & 202 & 375 & 3,596 & 2,669 \\
\hline Virgini & 45,011 & 43,820 & 45,272 & 46,533 & 46,922 & 40,774 & 18,350 & 22,424 & 6,148 & 2,634 & 3,514 & 36,213 & 10,709 \\
\hline Washington ………….................... & 68,649 & 70,476 & 68,613 & 73,255 & 75,842 & 45,405 & 21,545 & 23,860 & 30,437 & 14,622 & 15,815 & 70,427 & 5,415 \\
\hline West Virginia & 17,029 & 15,727 & 15,928 & 15,880 & 15,655 & 13,696 & 6,439 & 7,257 & 1,959 & 776 & 1,183 & 13,016 & 2,639 \\
\hline Wisconsin ............................. & 47,271 & 47,351 & 46,479 & 49,201 & 50,172 & 40,102 & 18,560 & 21,542 & 10,070 & 4,429 & 5,641 & 42,232 & 7,940 \\
\hline 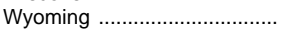 & 4,686 & 4,858 & 4,814 & 4,626 & 4,458 & 3,762 & 1,832 & 1,930 & 696 & 267 & 429 & 4,224 & 234 \\
\hline U.S. Service Schools .............. & 10,349 & 10,116 & 9,936 & 11,286 & 10,643 & 4,090 & 3,403 & 687 & 6,553 & 5,509 & 1,044 & 10,643 & - \\
\hline Outlying areas ..................... & 35,409 & 41,759 & 30,573 & 38,714 & 36,928 & 34,035 & 13,786 & 20,249 & 2,893 & 1,358 & 1,535 & 16,998 & 19,930 \\
\hline American Samoa ...................... & 989 & 967 & 948 & 943 & 954 & 716 & 368 & 348 & 238 & 133 & 105 & 954 & - \\
\hline $\begin{array}{l}\text { Federated States of Microne- } \\
\text { sia }\end{array}$ & 409 & 235 & 410 & 354 & 417 & 317 & 142 & 175 & 100 & 51 & 49 & 417 & - \\
\hline Guam. & 709 & 1,490 & 956 & 478 & 484 & 360 & 144 & 216 & 124 & 62 & 62 & $\begin{array}{l}417 \\
484\end{array}$ & - \\
\hline Marshall Islands . & 139 & 166 & 22 & 22 & 121 & 68 & 32 & 36 & 53 & 28 & 25 & 121 & - \\
\hline Northern Marianas ……............. & 173 & 455 & 440 & 153 & 113 & 72 & 30 & 42 & 41 & 19 & 22 & 113 & - \\
\hline 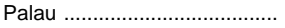 & 24 & 24 & 13 & 14 & 109 & 103 & 70 & 33 & 6 & 4 & 2 & 109 & - \\
\hline 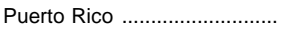 & 32,664 & 38,057 & 27,408 & 36,343 & 34,397 & 32,104 & 12,922 & 19,182 & 2,293 & 1,050 & 1,243 & 14,467 & 19,930 \\
\hline Virgin Islands ... & 302 & 365 & 376 & 407 & 333 & 295 & 78 & 217 & 38 & 11 & 27 & 333 & - \\
\hline
\end{tabular}

1 Preliminary data.

-Data not available or not applicable.
SOURCE: U.S. Department of Education, National Center for Education Statistics, Integrated Postsecondary Education Data System, "Fall Enrollment" surveys. (This table was prepared June 1998.) 
Table 183.-College enrollment rates of high school graduates, by race/ethnicity: 1960 to 1997

[Numbers in thousands]

\begin{tabular}{|c|c|c|c|c|c|c|c|c|c|c|c|c|c|c|}
\hline \multirow{5}{*}{\multicolumn{2}{|c|}{ Year }} & \multicolumn{4}{|c|}{ High school graduates ${ }^{1}$} & \multicolumn{9}{|c|}{ Enrolled in college ${ }^{2}$} \\
\hline & & \multirow{4}{*}{ Total } & \multirow{4}{*}{ White ${ }^{3}$} & \multirow{4}{*}{ Black 3,4} & \multirow{4}{*}{$\begin{array}{c}\text { His- } \\
\text { panic }{ }^{4}\end{array}$} & \multirow{3}{*}{\multicolumn{2}{|c|}{ Total }} & \multirow{3}{*}{\multicolumn{2}{|c|}{ White ${ }^{3}$}} & \multirow{3}{*}{\multicolumn{2}{|c|}{ Black $^{3,4}$}} & \multicolumn{3}{|c|}{ Hispanic ${ }^{4}$} \\
\hline & & & & & & & & & & & & \multirow{3}{*}{ Number } & \multicolumn{2}{|c|}{ Percent } \\
\hline & & & & & & & & & & & & & \multirow{2}{*}{ Annual } & \multirow{2}{*}{$\begin{array}{l}\text { 3-year } \\
\text { moving } \\
\text { average }\end{array}$} \\
\hline & & & & & & Number & Percent & Number & Percent & Number & Percent & & & \\
\hline & 1 & 2 & 3 & 4 & 5 & 6 & 7 & 8 & 9 & 10 & 11 & 12 & 13 & 14 \\
\hline 1960 & $\cdots \cdot x_{2}>$ & 1,679 & 1,565 & - & - & 758 & 45.1 & 717 & 45.8 & - & - & - & - & - \\
\hline 1961 & $\ldots .$. & 1,763 & 1,612 & - & - & 847 & 48.0 & 798 & 49.5 & - & - & - & - & - \\
\hline 1962 & & 1,838 & 1,660 & - & - & 900 & 49.0 & 840 & 50.6 & - & - & - & - & - \\
\hline 1963 & 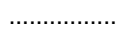 & 1,741 & 1,615 & - & - & 784 & 45.0 & 736 & 45.6 & - & - & - & - & - \\
\hline 1964 & & 2,145 & 1,964 & - & - & 1,037 & 48.3 & 967 & 49.2 & - & - & - & - & - \\
\hline 1965 & & 2,659 & 2,417 & - & - & 1,354 & 50.9 & 1,249 & 51.7 & - & - & - & - & - \\
\hline 1966 & $\ldots .$. & 2,612 & 2,403 & - & - & 1,309 & 50.1 & 1,243 & 51.7 & - & - & - & - & - \\
\hline 1967 & & 2,525 & 2,267 & - & - & 1,311 & 51.9 & 1,202 & 53.0 & - & - & - & - & - \\
\hline 1968 & & 2,606 & 2,303 & - & - & 1,444 & 55.4 & 1,304 & 56.6 & - & - & - & - & - \\
\hline 1969 & & 2,842 & 2,538 & - & - & 1,516 & 53.3 & 1,402 & 55.2 & - & - & - & - & - \\
\hline 1970 & . & 2,757 & 2,461 & - & - & 1,427 & 51.8 & 1,280 & 52.0 & - & - & - & - & - \\
\hline 1971 & ....... & 2,872 & 2,596 & - & - & 1,535 & 53.4 & 1,402 & 54.0 & - & - & - & - & - \\
\hline 1972 & & 2,961 & 2,614 & - & - & 1,457 & 49.2 & 1,292 & 49.4 & - & - & - & - & - \\
\hline 1973 & & 3,059 & 2,707 & - & - & 1,425 & 46.6 & 1,302 & 48.1 & - & - & - & - & - \\
\hline 1974 & $\ldots \ldots$ & 3,101 & 2,736 & - & - & 1,474 & 47.5 & 1,288 & 47.1 & - & - & - & - & - \\
\hline 1975 & & 3,186 & 2,825 & - & - & 1,615 & 50.7 & 1,446 & 51.2 & - & - & - & - & - \\
\hline 1976 & $\ldots .$. & 2,987 & 2,640 & 320 & 152 & 1,458 & 48.8 & 1,291 & 48.9 & 134 & 41.9 & 80 & 52.6 & - \\
\hline 1977 & & 3,140 & 2,768 & 335 & 156 & 1,590 & 50.6 & 1,403 & 50.7 & 166 & 49.6 & 80 & 51.3 & 48.9 \\
\hline 1978 & & 3,161 & 2,750 & 352 & 133 & 1,584 & 50.1 & 1,378 & 50.1 & 161 & 45.7 & 57 & 42.9 & 46.3 \\
\hline 1979 & & 3,160 & 2,776 & 324 & 154 & 1,559 & 49.3 & 1,376 & 49.6 & 147 & 45.4 & 69 & 44.8 & 46.8 \\
\hline 1980 & & 3,089 & 2,682 & 361 & 129 & 1,524 & 49.3 & 1,339 & 49.9 & 151 & 41.8 & 68 & 52.7 & 49.9 \\
\hline 1981 & ..... & 3,053 & 2,626 & 359 & 146 & 1,646 & 53.9 & 1,434 & 54.6 & 154 & 42.9 & 76 & 52.1 & 49.3 \\
\hline 1982 & $\ldots \ldots$ & 3,100 & 2,644 & 384 & 174 & 1,568 & 50.6 & 1,376 & 52.0 & 140 & 36.5 & 75 & 43.1 & 49.8 \\
\hline 1983 & $\ldots \ldots .$. & 2,964 & 2,496 & 392 & 138 & 1,562 & 52.7 & 1,372 & 55.0 & 151 & 38.5 & 75 & 54.3 & 47.3 \\
\hline 1984 & 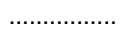 & 3,012 & 2,514 & 438 & 185 & 1,662 & 55.2 & 1,455 & 57.9 & 176 & 40.2 & 82 & 44.3 & 49.9 \\
\hline 1985 & 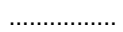 & 2,666 & 2,241 & 333 & 141 & 1,539 & 57.7 & 1,332 & 59.4 & 141 & 42.3 & 72 & 51.1 & 46.6 \\
\hline 1986 & ……… & 2,786 & 2,307 & 386 & 169 & 1,499 & 53.8 & 1,292 & 56.0 & 141 & 36.5 & 75 & 44.4 & 43.0 \\
\hline 1987 & & 2,647 & 2,207 & 337 & 176 & 1,503 & 56.8 & 1,249 & 56.6 & 175 & 51.9 & 59 & 33.5 & 45.0 \\
\hline 1988 & $\ldots \ldots$. & 2,673 & 2,187 & 382 & 179 & 1,575 & 58.9 & 1,328 & 60.7 & 172 & 45.0 & 102 & 57.0 & 48.6 \\
\hline 1989 & & 2,454 & 2,051 & 337 & 168 & 1,463 & 59.6 & 1,238 & 60.4 & 178 & 52.8 & 93 & 55.4 & 53.2 \\
\hline 1990 & & 2,355 & 1,921 & 341 & 112 & 1,410 & 59.9 & 1,182 & 61.5 & 158 & 46.3 & 53 & 47.3 & 53.3 \\
\hline 1991 & .............. & 2,276 & 1,867 & 320 & 154 & 1,420 & 62.4 & 1,207 & 64.6 & 146 & 45.6 & 88 & 57.1 & 53.1 \\
\hline 1992 & $\ldots \ldots$ & 2,398 & 1,900 & 353 & 199 & 1,479 & 61.7 & 1,204 & 63.4 & 169 & 47.9 & 109 & 54.8 & 58.1 \\
\hline 1993 & ................. & 2,338 & 1,910 & 302 & 200 & 1,464 & 62.6 & 1,200 & 62.8 & 168 & 55.6 & 125 & 62.5 & 55.4 \\
\hline 1994 & …............. & 2,517 & 2,065 & 318 & 178 & 1,559 & 61.9 & 1,313 & 63.6 & 162 & 50.9 & 87 & 48.9 & 55.1 \\
\hline 1995 & N........ & 2,599 & 2,088 & 356 & 288 & 1,610 & 61.9 & 1,308 & 62.6 & 183 & 51.4 & 155 & 53.8 & 51.1 \\
\hline 1996 & $\ldots$ & 2,660 & 2,092 & 416 & 227 & 1,729 & 65.0 & 1,377 & 65.8 & 230 & 55.3 & 115 & 50.7 & 55.0 \\
\hline 1997 & .................. & 2,769 & 2,228 & 394 & 336 & 1,856 & 67.0 & 1,504 & 67.5 & 235 & 59.6 & 220 & 65.5 & - \\
\hline
\end{tabular}

${ }^{1}$ Individuals age 16 to 24 who graduated from high school during the preceding 12 months.

${ }^{2}$ Enrollment in college as of October of each year for individuals age 16 to 24 who graduated from high school during the preceding 12 months.

${ }^{3}$ Includes persons of Hispanic origin.

${ }^{4}$ Due to the small sample size, data are subject to relatively large sampling errors.

-Data not available.
NOTE.-Data are based upon sample surveys of the civilian population. High schoo graduate data in this table differ from figures appearing in other tables because of varying survey procedures and coverage. High school graduates include GED recipients.

SOURCE: American College Testing Program, unpublished tabulations, 1987, derived from statistics collected by the U.S. Bureau of the Census; and U.S. Department of Labor, College Enrollment of High School Graduates, various years. (This table was prepared June 1998.) 
Table 184.-College enrollment rates of high school graduates, by sex: 1960 to 1997

[Numbers in thousands]

\begin{tabular}{|c|c|c|c|c|c|c|c|c|c|}
\hline \multirow{3}{*}{ Year } & \multicolumn{3}{|c|}{ Total high school graduates ${ }^{1}$} & \multicolumn{6}{|c|}{ Enrolled in college ${ }^{2}$} \\
\hline & \multirow{2}{*}{ Total } & \multirow{2}{*}{ Males } & \multirow{2}{*}{ Females } & \multicolumn{2}{|c|}{ Total } & \multicolumn{2}{|c|}{ Males } & \multicolumn{2}{|c|}{ Females } \\
\hline & & & & Number & Percent & Number & Percent & Number & Percent \\
\hline 1 & 2 & 3 & 4 & 5 & 6 & 7 & 8 & 9 & 10 \\
\hline $\begin{array}{l}1960 \\
1961 \\
1962 \\
1963 \\
1964\end{array}$ & $\begin{array}{l}1,679 \\
1,763 \\
1,838 \\
1,741 \\
2,145\end{array}$ & $\begin{array}{l}756 \\
790 \\
872 \\
794 \\
997\end{array}$ & $\begin{array}{r}923 \\
973 \\
966 \\
947 \\
1,148\end{array}$ & $\begin{array}{r}758 \\
847 \\
900 \\
784 \\
1,037\end{array}$ & $\begin{array}{l}45.1 \\
48.0 \\
49.0 \\
45.0 \\
48.3\end{array}$ & $\begin{array}{l}408 \\
445 \\
480 \\
415 \\
570\end{array}$ & $\begin{array}{l}54.0 \\
56.3 \\
55.0 \\
52.3 \\
57.2\end{array}$ & $\begin{array}{l}350 \\
402 \\
420 \\
369 \\
467\end{array}$ & $\begin{array}{l}37.9 \\
41.3 \\
43.5 \\
39.0 \\
40.7\end{array}$ \\
\hline 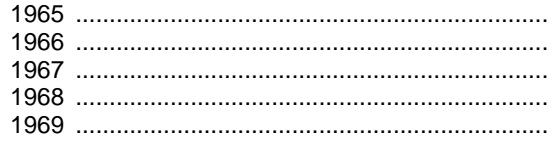 & $\begin{array}{l}2,659 \\
2,612 \\
2,525 \\
2,606 \\
2,842\end{array}$ & $\begin{array}{l}1,254 \\
1,207 \\
1,142 \\
1,184 \\
1,352\end{array}$ & $\begin{array}{l}1,405 \\
1,405 \\
1,383 \\
1,422 \\
1,490\end{array}$ & $\begin{array}{l}1,354 \\
1,309 \\
1,311 \\
1,444 \\
1,516\end{array}$ & $\begin{array}{l}50.9 \\
50.1 \\
51.9 \\
55.4 \\
53.3\end{array}$ & $\begin{array}{l}718 \\
709 \\
658 \\
748 \\
812\end{array}$ & $\begin{array}{l}57.3 \\
58.7 \\
57.6 \\
63.2 \\
60.1\end{array}$ & $\begin{array}{l}636 \\
600 \\
653 \\
696 \\
704\end{array}$ & $\begin{array}{l}45.3 \\
42.7 \\
47.2 \\
48.9 \\
47.2\end{array}$ \\
\hline 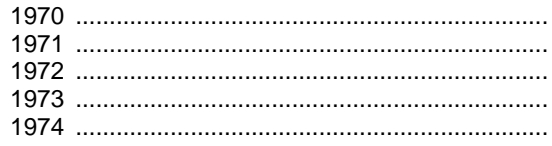 & $\begin{array}{l}2,757 \\
2,872 \\
2,961 \\
3,059 \\
3,101\end{array}$ & $\begin{array}{l}1,343 \\
1,369 \\
1,420 \\
1,458 \\
1,491\end{array}$ & $\begin{array}{l}1,414 \\
1,503 \\
1,541 \\
1,601 \\
1,610\end{array}$ & $\begin{array}{l}1,427 \\
1,535 \\
1,457 \\
1,425 \\
1,474\end{array}$ & $\begin{array}{l}51.8 \\
53.4 \\
49.2 \\
46.6 \\
47.5\end{array}$ & $\begin{array}{l}741 \\
788 \\
749 \\
730 \\
736\end{array}$ & $\begin{array}{l}55.2 \\
57.6 \\
52.7 \\
50.1 \\
49.4\end{array}$ & $\begin{array}{l}686 \\
747 \\
708 \\
695 \\
738\end{array}$ & $\begin{array}{l}48.5 \\
49.7 \\
45.9 \\
43.4 \\
45.8\end{array}$ \\
\hline 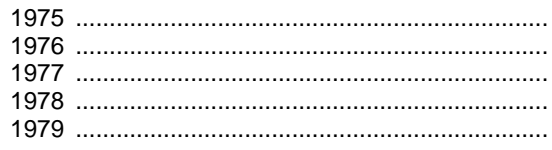 & $\begin{array}{l}3,186 \\
2,987 \\
3,140 \\
3,161 \\
3,160\end{array}$ & $\begin{array}{l}1,513 \\
1,450 \\
1,482 \\
1,485 \\
1,474\end{array}$ & $\begin{array}{l}1,673 \\
1,537 \\
1,658 \\
1,676 \\
1,686\end{array}$ & $\begin{array}{l}1,615 \\
1,458 \\
1,590 \\
1,584 \\
1,559\end{array}$ & $\begin{array}{l}50.7 \\
48.8 \\
50.6 \\
50.1 \\
49.3\end{array}$ & $\begin{array}{l}796 \\
685 \\
773 \\
758 \\
743\end{array}$ & $\begin{array}{l}52.6 \\
47.2 \\
52.2 \\
51.0 \\
50.4\end{array}$ & $\begin{array}{l}819 \\
773 \\
817 \\
826 \\
816\end{array}$ & $\begin{array}{l}49.0 \\
50.3 \\
49.3 \\
49.3 \\
48.4\end{array}$ \\
\hline $\begin{array}{l}1980 \\
1981 \\
1982 \\
1983 \\
1984\end{array}$ & $\begin{array}{l}3,089 \\
3,053 \\
3,100 \\
2,964 \\
3,012\end{array}$ & $\begin{array}{l}1,500 \\
1,490 \\
1,508 \\
1,390 \\
1,429\end{array}$ & $\begin{array}{l}1,589 \\
1,563 \\
1,592 \\
1,574 \\
1,583\end{array}$ & $\begin{array}{l}1,524 \\
1,646 \\
1,568 \\
1,562 \\
1,662\end{array}$ & $\begin{array}{l}49.3 \\
53.9 \\
50.6 \\
52.7 \\
55.2\end{array}$ & $\begin{array}{l}701 \\
816 \\
739 \\
721 \\
800\end{array}$ & $\begin{array}{l}46.7 \\
54.8 \\
49.0 \\
51.9 \\
56.0\end{array}$ & $\begin{array}{l}823 \\
830 \\
829 \\
841 \\
862\end{array}$ & $\begin{array}{l}51.8 \\
53.1 \\
52.1 \\
53.4 \\
54.5\end{array}$ \\
\hline $\begin{array}{l}1985 \\
1986 \\
1987 \\
1988 \\
1989\end{array}$ & $\begin{array}{l}2,666 \\
2,786 \\
2,647 \\
2,673 \\
2,454\end{array}$ & $\begin{array}{l}1,286 \\
1,331 \\
1,278 \\
1,334 \\
1,208\end{array}$ & $\begin{array}{l}1,380 \\
1,455 \\
1,369 \\
1,339 \\
1,245\end{array}$ & $\begin{array}{l}1,539 \\
1,499 \\
1,503 \\
1,575 \\
1,463\end{array}$ & $\begin{array}{l}57.7 \\
53.8 \\
56.8 \\
58.9 \\
59.6\end{array}$ & $\begin{array}{l}754 \\
744 \\
746 \\
761 \\
696\end{array}$ & $\begin{array}{l}58.6 \\
55.9 \\
58.4 \\
57.0 \\
57.6\end{array}$ & $\begin{array}{l}785 \\
755 \\
757 \\
814 \\
767\end{array}$ & $\begin{array}{l}56.9 \\
51.9 \\
55.3 \\
60.8 \\
61.6\end{array}$ \\
\hline $\begin{array}{l}1990 \\
1991 \\
1992 \\
1993 \\
1994 \\
1995\end{array}$ & $\begin{array}{l}2,355 \\
2,276 \\
2,398 \\
2,338 \\
2,517 \\
2,599 \\
2,660 \\
2,769\end{array}$ & $\begin{array}{l}1,169 \\
1,139 \\
1,216 \\
1,118 \\
1,244 \\
1,238 \\
1,297 \\
1,354\end{array}$ & $\begin{array}{l}1,185 \\
1,137 \\
1,182 \\
1,219 \\
1,273 \\
1,361 \\
1,363 \\
1,415\end{array}$ & $\begin{array}{l}1,410 \\
1,420 \\
1,479 \\
1,464 \\
1,559 \\
1,610 \\
1,729 \\
1,856\end{array}$ & $\begin{array}{l}59.9 \\
62.4 \\
61.7 \\
62.6 \\
61.9 \\
61.9 \\
65.0 \\
67.0\end{array}$ & $\begin{array}{l}676 \\
656 \\
725 \\
668 \\
754 \\
775 \\
779 \\
860\end{array}$ & $\begin{array}{l}57.8 \\
57.6 \\
59.6 \\
59.7 \\
60.6 \\
62.6 \\
60.1 \\
63.5\end{array}$ & $\begin{array}{l}735 \\
763 \\
754 \\
797 \\
805 \\
835 \\
950 \\
995\end{array}$ & $\begin{array}{l}62.0 \\
67.1 \\
63.8 \\
65.4 \\
63.2 \\
61.4 \\
69.7 \\
70.3\end{array}$ \\
\hline
\end{tabular}

${ }^{1}$ Individuals age 16 to 24 who graduated from high school during the preceding 12 months.

${ }^{2}$ Enrollment in college as of October of each year for individuals age 16 to 24 who graduated from high school during the preceding 12 months.

NOTE.-Data are based upon sample surveys of the civilian population. High schoo graduate data in this table differ from figures appearing in other tables because of varying survey procedures and coverage. High school graduates include GED recipients.
SOURCE: American College Testing Program, unpublished tabulations, 1987, derived from statistics collected by the U.S. Bureau of the Census; and U.S. Department of Labor, College Enrollment of High School Graduates, various years. (This table was prepared June 1998.)

Table 185.-Graduation, college preparation, and college application rates of high school students, by selected school characteristics: 1993-94

\begin{tabular}{|c|c|c|c|c|c|c|}
\hline \multirow[b]{2}{*}{ Selected school characteristics } & \multicolumn{3}{|c|}{ Public schools } & \multicolumn{3}{|c|}{ Private schools } \\
\hline & $\begin{array}{l}\text { Number of } \\
\text { schools with } \\
\text { 12th graders }\end{array}$ & $\begin{array}{l}1993 \\
\text { graduation } \\
\text { rate of fall } \\
199212 \text { th } \\
\text { graders }\end{array}$ & $\begin{array}{l}\text { Average } \\
\text { college } \\
\text { application } \\
\text { rate of } 12 \text { th } \\
\text { graders }\end{array}$ & $\begin{array}{l}\text { Number of } \\
\text { schools with } \\
\text { 12th graders }\end{array}$ & $\begin{array}{c}1993 \\
\text { graduation } \\
\text { rate of fall } \\
199212 \text { th } \\
\text { graders }\end{array}$ & $\begin{array}{l}\text { Average } \\
\text { college } \\
\text { application } \\
\text { rate of } 12 \text { th } \\
\text { graders }\end{array}$ \\
\hline 1 & 2 & 3 & 4 & 5 & 6 & 7 \\
\hline Total & 17,838 & 92.6 & 57.4 & 7,875 & 98.2 & 87.5 \\
\hline Percent minority students & & & & & & \\
\hline Less than $5 \%$ & 6,843 & 94.1 & 56.4 & 2,926 & 98.9 & 84.8 \\
\hline $5 \%$ to $19 \%$ & 3,784 & 93.7 & 60.2 & 2,735 & 98.5 & 90.0 \\
\hline $20 \%$ to $49 \%$ & 3,850 & 92.1 & 58.5 & 1,439 & 97.7 & 90.2 \\
\hline $50 \%$ or more & 3,360 & 90.1 & 54.2 & 775 & 96.5 & 79.9 \\
\hline Community type & & & & & & \\
\hline 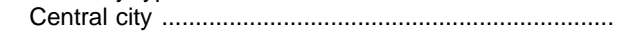 & 2,949 & 89.7 & 56.5 & 2,808 & 98.3 & 89.0 \\
\hline 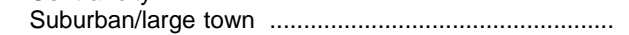 & 3,798 & 92.5 & 61.6 & 2,486 & 98.4 & 88.1 \\
\hline 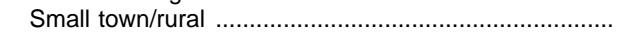 & 11,091 & 94.6 & 54.3 & 2,581 & 97.6 & 81.5 \\
\hline
\end{tabular}

NOTE.-Data are based upon a sample survey and may not be strictly comparable with data reported elsewhere. Only includes schools with students enrolled in 12th grade. Some data have been revised from previously published figures. Because of rounding, details may not add to totals.
SOURCE: U.S. Department of Education, National Center for Education Statistics, "Schools and Staffing Survey, 1993-94." (This table was prepared September 1996.) 
Table 186.-Enrollment rates of 18- to 24-year-olds in institutions of higher education, by race/ethnicity: 1967 to 1997

\begin{tabular}{|c|c|c|c|c|c|c|c|c|}
\hline \multirow[b]{2}{*}{ Year } & \multicolumn{2}{|c|}{ Total } & \multicolumn{2}{|c|}{ White, non-Hispanic } & \multicolumn{2}{|c|}{ Black, non-Hispanic } & \multicolumn{2}{|c|}{ Hispanic origin } \\
\hline & $\begin{array}{l}\text { Enrollment as a } \\
\text { percent of } 18 \text { - to } \\
24 \text {-year-olds }\end{array}$ & $\begin{array}{l}\text { Enrollment as } \\
\text { a percent of } \\
\text { high school } \\
\text { graduates }^{1}\end{array}$ & $\begin{array}{l}\text { Enrollment as a } \\
\text { percent of } 18 \text { - to } \\
24 \text {-year-olds }\end{array}$ & $\begin{array}{l}\text { Enrollment as } \\
\text { a percent of } \\
\text { high school } \\
\text { graduates }{ }^{1}\end{array}$ & $\begin{array}{l}\text { Enrollment as a } \\
\text { percent of } 18-\text { to } \\
24 \text {-year-olds }\end{array}$ & $\begin{array}{l}\text { Enrollment as } \\
\text { a percent of } \\
\text { high school } \\
\text { graduates }{ }^{1}\end{array}$ & $\begin{array}{l}\text { Enrollment as a } \\
\text { percent of } 18 \text { - to } \\
24 \text {-year-olds }\end{array}$ & $\begin{array}{l}\text { Enrollment as } \\
\text { a percent of } \\
\text { high school } \\
\text { graduates }^{1}\end{array}$ \\
\hline 1 & 2 & 3 & 4 & 5 & 6 & 7 & 8 & 9 \\
\hline $\begin{array}{l}1967^{2} \ldots \ldots \ldots \\
1968^{2} \ldots \ldots \ldots \\
1969^{2} \ldots \ldots \ldots \\
1970^{2} \ldots \ldots \ldots \\
1971^{2} \ldots \ldots \ldots\end{array}$ & $\begin{array}{l}25.5 \\
26.0 \\
27.3 \\
25.7 \\
26.2\end{array}$ & $\begin{array}{l}33.7 \\
34.2 \\
35.0 \\
32.7 \\
33.2\end{array}$ & $\begin{array}{l}26.9 \\
27.5 \\
28.7 \\
27.1 \\
27.2\end{array}$ & $\begin{array}{l}34.5 \\
34.9 \\
35.6 \\
33.2 \\
33.5\end{array}$ & $\begin{array}{l}13.0 \\
14.5 \\
16.0 \\
15.5 \\
18.2\end{array}$ & $\begin{array}{l}23.3 \\
25.2 \\
27.2 \\
26.0 \\
29.2\end{array}$ & $\begin{array}{l}- \\
- \\
-\end{array}$ & $\begin{array}{l}- \\
- \\
-\end{array}$ \\
\hline $\begin{array}{l}1972 \ldots \ldots \ldots . \\
1973 \ldots \ldots \ldots . \\
1974 \ldots \ldots \ldots . \\
1975 \ldots \ldots \ldots . \\
1976 \ldots \ldots \ldots . .\end{array}$ & $\begin{array}{l}25.5 \\
24.0 \\
24.6 \\
26.3 \\
26.7\end{array}$ & $\begin{array}{l}31.1 \\
28.9 \\
29.8 \\
31.4 \\
32.3\end{array}$ & $\begin{array}{l}27.2 \\
25.5 \\
25.8 \\
27.4 \\
27.6\end{array}$ & $\begin{array}{l}31.9 \\
29.5 \\
29.9 \\
31.3 \\
32.1\end{array}$ & $\begin{array}{l}18.3 \\
15.9 \\
17.6 \\
20.4 \\
22.5\end{array}$ & $\begin{array}{l}25.2 \\
22.5 \\
24.6 \\
30.1 \\
32.1\end{array}$ & $\begin{array}{l}13.4 \\
16.1 \\
18.0 \\
20.4 \\
20.0\end{array}$ & $\begin{array}{l}24.1 \\
27.6 \\
30.7 \\
33.0 \\
34.7\end{array}$ \\
\hline $\begin{array}{l}1977 \ldots \ldots \ldots \\
1978 \ldots \ldots \ldots \\
1979 \ldots \ldots \ldots \\
1980 \ldots \ldots \ldots . . \\
1981 \ldots \ldots \ldots\end{array}$ & $\begin{array}{l}26.1 \\
25.3 \\
25.0 \\
25.7 \\
26.2\end{array}$ & $\begin{array}{l}31.4 \\
30.0 \\
29.9 \\
30.5 \\
31.3\end{array}$ & $\begin{array}{l}27.2 \\
26.5 \\
26.3 \\
27.3 \\
27.7\end{array}$ & $\begin{array}{l}31.3 \\
30.1 \\
30.2 \\
31.0 \\
31.6\end{array}$ & $\begin{array}{l}21.1 \\
20.1 \\
19.8 \\
19.4 \\
19.9\end{array}$ & $\begin{array}{l}29.1 \\
27.9 \\
27.5 \\
26.0 \\
26.6\end{array}$ & $\begin{array}{l}17.2 \\
15.2 \\
16.7 \\
16.1 \\
16.6\end{array}$ & $\begin{array}{l}30.5 \\
25.9 \\
27.8 \\
27.6 \\
28.5\end{array}$ \\
\hline $\begin{array}{l}1982 \ldots \ldots \ldots \\
1983 \ldots \ldots \ldots \\
1984 \ldots \ldots \ldots \\
1985 \ldots \ldots \ldots \\
1986 \ldots \ldots \ldots\end{array}$ & $\begin{array}{l}26.6 \\
26.2 \\
27.1 \\
27.8 \\
27.9\end{array}$ & $\begin{array}{l}31.6 \\
31.3 \\
31.8 \\
32.5 \\
32.7\end{array}$ & $\begin{array}{l}28.1 \\
28.0 \\
28.9 \\
30.0 \\
29.7\end{array}$ & $\begin{array}{l}32.0 \\
31.8 \\
32.6 \\
33.9 \\
33.3\end{array}$ & $\begin{array}{l}19.9 \\
19.2 \\
20.3 \\
19.6 \\
21.9\end{array}$ & $\begin{array}{l}26.5 \\
25.3 \\
25.6 \\
24.5 \\
26.9\end{array}$ & $\begin{array}{l}16.8 \\
17.3 \\
17.9 \\
16.9 \\
17.6\end{array}$ & $\begin{array}{l}27.6 \\
29.9 \\
28.8 \\
25.0 \\
28.3\end{array}$ \\
\hline $\begin{array}{l}1987 \quad \ldots \ldots \ldots . . \\
1988 \ldots \ldots \ldots . \\
1989 \ldots \ldots \ldots . . \\
1990 \\
1991\end{array}$ & $\begin{array}{l}29.7 \\
30.2 \\
30.9 \\
32.1 \\
33.3\end{array}$ & $\begin{array}{l}35.4 \\
36.0 \\
36.5 \\
37.7 \\
39.3\end{array}$ & $\begin{array}{l}31.9 \\
33.1 \\
34.2 \\
35.2 \\
36.8\end{array}$ & $\begin{array}{l}36.6 \\
37.4 \\
38.3 \\
39.2 \\
41.0\end{array}$ & $\begin{array}{l}23.0 \\
21.1 \\
23.4 \\
25.3 \\
23.4\end{array}$ & $\begin{array}{l}28.2 \\
26.8 \\
28.5 \\
30.4 \\
28.2\end{array}$ & $\begin{array}{l}17.7 \\
17.1 \\
16.0 \\
16.2 \\
17.8\end{array}$ & $\begin{array}{l}26.6 \\
29.1 \\
26.6 \\
26.8 \\
31.4\end{array}$ \\
\hline 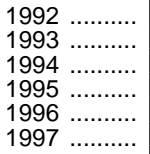 & $\begin{array}{l}34.4 \\
34.0 \\
34.6 \\
34.3 \\
35.5 \\
36.2\end{array}$ & $\begin{array}{l}42.0 \\
41.6 \\
42.3 \\
42.3 \\
43.4 \\
44.6\end{array}$ & $\begin{array}{l}37.3 \\
36.8 \\
38.1 \\
37.9 \\
39.5 \\
40.6\end{array}$ & $\begin{array}{l}42.8 \\
42.6 \\
43.7 \\
44.0 \\
45.1 \\
46.8\end{array}$ & $\begin{array}{l}25.2 \\
24.5 \\
27.7 \\
27.5 \\
27.4 \\
29.8\end{array}$ & $\begin{array}{l}33.9 \\
32.8 \\
35.6 \\
35.4 \\
35.9 \\
39.6\end{array}$ & $\begin{array}{l}21.3 \\
21.7 \\
18.8 \\
20.7 \\
20.1 \\
22.4\end{array}$ & $\begin{array}{l}37.5 \\
36.1 \\
33.1 \\
35.2 \\
34.5 \\
36.1\end{array}$ \\
\hline
\end{tabular}

${ }^{1}$ Includes students who were enrolled in college, but did not report high school completion.

${ }^{2}$ Data for white and black enrollment include persons of Hispanic origin.

-Data not available.

NOTE.-Data are based upon sample surveys of the civilian noninstitutional population. Percents based on 18- to 24-year-old high school graduates for 1992 and late years, use a slightly different definition of graduation and may not be directly comparable with figures for other years. All college students are counted as high school graduates.

SOURCE: U.S. Department of Commerce, Bureau of the Census, Current Population Survey, unpublished data. (This table was prepared September 1998.)

Table 187.-Total undergraduate fall enrollment ${ }^{1}$ in institutions of higher education, by sex of student, attendance status, and control of institution: 1969 to 1996

[In thousands]

\begin{tabular}{|c|c|c|c|c|c|c|c|c|c|c|c|c|c|}
\hline \multirow{2}{*}{ Year } & \multirow{2}{*}{ Total } & \multirow{2}{*}{ Full-time } & \multirow{2}{*}{ Part-time } & \multirow{2}{*}{ Men } & \multirow{2}{*}{ Women } & \multicolumn{2}{|c|}{ Men } & \multicolumn{2}{|c|}{ Women } & \multicolumn{2}{|c|}{ Men } & \multicolumn{2}{|c|}{ Women } \\
\hline & & & & & & Full-time & Part-time & Full-time & Part-time & Public & Private & Public & Private \\
\hline 1 & 2 & 3 & 4 & 5 & 6 & 7 & 8 & 9 & 10 & 11 & 12 & 13 & 14 \\
\hline $\begin{array}{l}1969 \\
1970 \ldots \ldots \ldots \ldots . \cdots \cdots \\
1971 \\
1972 \\
1973\end{array}$ & $\begin{array}{l}6,884 \\
7,376 \\
7,743 \\
7,941 \\
8,261\end{array}$ & $\begin{array}{l}4,991 \\
5,280 \\
5,512 \\
5,488 \\
5,580\end{array}$ & $\begin{array}{l}1,893 \\
2,096 \\
2,231 \\
2,453 \\
2,681\end{array}$ & $\begin{array}{l}4,008 \\
4,254 \\
4,418 \\
4,429 \\
4,538\end{array}$ & $\begin{array}{l}2,876 \\
3,122 \\
3,325 \\
3,512 \\
3,723\end{array}$ & $\begin{array}{l}2,952 \\
3,097 \\
3,201 \\
3,121 \\
3,135\end{array}$ & $\begin{array}{l}056 \\
, 157 \\
, 217 \\
, 308 \\
403\end{array}$ & $\begin{array}{l}2,039 \\
2,183 \\
2,311 \\
2,367 \\
2,445\end{array}$ & $\begin{array}{r}837 \\
939 \\
1,014 \\
1,145 \\
1,278\end{array}$ & $\begin{array}{l}2,997 \\
3,241 \\
3,427 \\
3,467 \\
3,579\end{array}$ & $\begin{array}{r}1,011 \\
1,013 \\
991 \\
962 \\
959\end{array}$ & $\begin{array}{l}2,162 \\
2,387 \\
2,580 \\
2,756 \\
2,943\end{array}$ & $\begin{array}{l}714 \\
735 \\
745 \\
756 \\
780\end{array}$ \\
\hline 1974 & 8,798 & 5,726 & 3,072 & 4,765 & 4,033 & 191 &, 574 & 2,535 & 1,498 & 3,799 & 966 & & 801 \\
\hline 5 & & & & & 4 & & & 0 & & & & & 841 \\
\hline 976 & 9 & 6 & . & 2 & 4,5 & 3, & & 2 & & & & & 859 \\
\hline $977 .$. & 9 & 6,0 & & & 4,8 & 3, & & 2, & & & & & 9 \\
\hline ….......... & & & & & & & & & & & & & 9 \\
\hline $1979 \ldots \ldots$ & 9,99 & 6 , & 3, & 4,8 & 5,178 & 3,0 & 1,7 & 2,9 & 2 & 3,8 & & 4, & 995 \\
\hline $1980 \ldots$ & 10,4 & & & 50 & 5,4 & & & 3,1 & & 4,014 & & & 1,048 \\
\hline $981 \ldots$ & & & & 5 & 5 & 3,2 & 1, & 3 & & 4, & 1,0 & & 1,088 \\
\hline $82 \ldots$ & 1 & 6 & & & & & & 3 & & & & & 1, \\
\hline 33. & & & & & & 3,3 & & 3, & & & & & \\
\hline 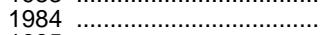 & & & & & 5 , & & & 3, & & & & & 1,1 \\
\hline $1985 \ldots$. & & & 4 & $4, \mathrm{~g}$ & & 3 & 1 , & 3 & 2 & 3, & 1, & & 1,110 \\
\hline $1986 \ldots$ & & & & & & & & & & & & & 1,122 \\
\hline 987 & & & & & & & & & & & & & 1,1 \\
\hline 1988 & & & 4,6 & & 6,1 & & & 3, & & & & & 1,1 \\
\hline 1000 & & & & & & & & & & & & & \\
\hline$\ldots .$. & & & & & & & & & & & & & \\
\hline 19 & & & & & 6 , & & & 3 & & 4, & 1, & & 1,251 \\
\hline 199 & & 7,2 & & & & & & 3,8 & & & & & 1,275 \\
\hline 199 & & 7 & 5,1 & & & & & 3,7 & & 4 & & & 1,276 \\
\hline 199 & 12 & 7,1 & 5,0 & & & 3 & & 3,8 & & 4, & & & 1,290 \\
\hline 100 & & 7. & & & & 3, & & 3, & & 4,380 & & & 1,307 \\
\hline & 12 & 7,21 & 5,049 & 5,411 & 6,848 & 3,304 & 2,107 & 3,90 & 2,942 & 4,368 & 1,043 & 5,537 & 1,311 \\
\hline
\end{tabular}

1 Includes unclassified undergraduate students.

2 Preliminary data.

NOTE.-Because of rounding, details may not add to totals.
SOURCE: U.S. Department of Education, National Center for Education Statistics, Higher Education General Information Survey (HEGIS), "Fall Enrollment in Colleges and Universities" surveys; and Integrated Postsecondary Education Data System, "Fall Enrollment" surveys. (This table was prepared May 1998.) 
Table 188.-Total graduate fall enrollment ${ }^{1}$ in institutions of higher education, by attendance status, sex of student, and control of institution: 1969 to 1996

[In thousands]

\begin{tabular}{|c|c|c|c|c|c|c|c|c|c|c|c|c|c|}
\hline \multirow{2}{*}{ Year } & \multirow{2}{*}{ Total } & \multirow{2}{*}{ Full-time } & \multirow{2}{*}{ Part-time } & \multirow{2}{*}{ Men } & \multirow{2}{*}{ Women } & \multicolumn{2}{|c|}{ Men } & \multicolumn{2}{|c|}{ Women } & \multicolumn{2}{|c|}{ Men } & \multicolumn{2}{|c|}{ Women } \\
\hline & & & & & & Full-time & Part-time & Full-time & Part-time & Public & Private & Public & Private \\
\hline 1 & 2 & 3 & 4 & 5 & 6 & 7 & 8 & 9 & 10 & 11 & 12 & 13 & 14 \\
\hline 1969 & 955 & 363 & 593 & 590 & 366 & 252 & 338 & 111 & 255 & 393 & 197 & 273 & 93 \\
\hline 1970 & 1,031 & 379 & 651 & 630 & 400 & 264 & 366 & 115 & 285 & 423 & 207 & 301 & 99 \\
\hline $1971 \ldots \ldots \ldots \ldots \ldots \ldots \ldots$ & 1,012 & 388 & 621 & 615 & 394 & 269 & 346 & 119 & 275 & 415 & 200 & 296 & 100 \\
\hline $1972 \ldots \ldots \ldots \ldots$ & 1,066 & 394 & 671 & 626 & 439 & 268 & 358 & 126 & 313 & 427 & 199 & 330 & 109 \\
\hline $1973 \ldots \ldots$ & 1,123 & 410 & 715 & 648 & 477 & 273 & 375 & 137 & 340 & 442 & 206 & 358 & 119 \\
\hline $1974 \ldots$. & 1,190 & 427 & 762 & 663 & 526 & 276 & 387 & 151 & 375 & 454 & 209 & 398 & 128 \\
\hline $1975 \ldots$. & 1,263 & 453 & 810 & 700 & 563 & 290 & 410 & 163 & 400 & 481 & 219 & 425 & 138 \\
\hline $1976 \ldots \ldots$ & 1,333 & 463 & 870 & 714 & 619 & 287 & 427 & 176 & 443 & 477 & 237 & 454 & 165 \\
\hline 1977 & 1,319 & 473 & 845 & 700 & 617 & 289 & 411 & 184 & 434 & 458 & 243 & 443 & 174 \\
\hline $1978 \ldots \ldots$ & 1,312 & 468 & 844 & 682 & 630 & 280 & 402 & 188 & 442 & 441 & 241 & 453 & 177 \\
\hline 1979 & 1,309 & 476 & 833 & 669 & 640 & 280 & 389 & 196 & 444 & 427 & 242 & 457 & 182 \\
\hline 1980 & 1,343 & 485 & 860 & 675 & 670 & 281 & 394 & 204 & 466 & 426 & 247 & 474 & 195 \\
\hline 1981 & 1,343 & 484 & 859 & 674 & 669 & 277 & 397 & 207 & 462 & 419 & 255 & 468 & 201 \\
\hline $1982 \ldots$ & 1,322 & 485 & 838 & 670 & 653 & 280 & 390 & 205 & 447 & 417 & 253 & 453 & 200 \\
\hline $1983 \ldots \ldots \ldots \ldots \ldots \ldots \ldots \ldots$ & 1,340 & 497 & 843 & 677 & 663 & 286 & 391 & 211 & 452 & 418 & 259 & 454 & 209 \\
\hline 1984 & 1,345 & 501 & 844 & 672 & 673 & 286 & 386 & 215 & 459 & 411 & 261 & 459 & 215 \\
\hline $1985 \ldots$ & 1,376 & 509 & 867 & 677 & 700 & 289 & 388 & 220 & 479 & 414 & 263 & 477 & 223 \\
\hline 1986 & 1,435 & 522 & 913 & 693 & 742 & 294 & 399 & 228 & 514 & 433 & 260 & 508 & 234 \\
\hline 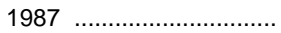 & 1,452 & 527 & 925 & 693 & 759 & 294 & 400 & 233 & 525 & 429 & 264 & 516 & 243 \\
\hline $1988 \ldots .$. & 1,472 & 553 & 919 & 697 & 774 & 304 & 393 & 249 & 526 & 429 & 268 & 520 & 254 \\
\hline $1989 \ldots \ldots$ & 1,522 & 572 & 949 & 710 & 811 & 309 & 401 & 263 & 548 & 437 & 273 & 541 & 271 \\
\hline 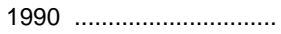 & 1,586 & 599 & 987 & 737 & 849 & 321 & 416 & 278 & 571 & 456 & 281 & 567 & 282 \\
\hline $1991 \ldots \ldots$. & 1,639 & 642 & 997 & 761 & 878 & 341 & 419 & 300 & 578 & 471 & 290 & 580 & 299 \\
\hline $1992 \ldots \ldots$ & 1,669 & 666 & 1,003 & 772 & 896 & 351 & 421 & 314 & 582 & 474 & 298 & 584 & 313 \\
\hline $1993 \ldots$ & 1,688 & 688 & 1,000 & 771 & 917 & 355 & 416 & 334 & 584 & 473 & 298 & 590 & 327 \\
\hline $1994 \ldots$ & 1,721 & 706 & 1,016 & 776 & 946 & 359 & 417 & 347 & 598 & 472 & 304 & 603 & 343 \\
\hline $1995 \ldots .$. & 1,732 & 717 & 1,015 & 768 & 965 & 356 & 412 & 361 & 604 & 464 & 304 & 610 & 355 \\
\hline 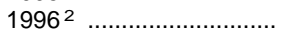 & 1,743 & 736 & 1,007 & 760 & 983 & 358 & 403 & 378 & 604 & 456 & 305 & 613 & 370 \\
\hline
\end{tabular}

1 Includes unclassified postbaccalaureate students. 2 Preliminary data.

NOTE.-Because of rounding, details may not add to totals.

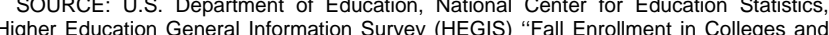
Universities" surveys; and Integrated Postsecondary Education Data System (IPEDS), "Fall Enrollment" surveys. (This table was prepared May 1998.)

Table 189.-Total first-professional fall enrollment in institutions of higher education, by attendance status, sex of student, and control of institution: 1969 to 1996

\begin{tabular}{|c|c|c|c|c|c|c|c|c|c|c|c|c|c|c|}
\hline \multirow{2}{*}{\multicolumn{2}{|c|}{ Year }} & \multirow[b]{2}{*}{ Total } & \multirow[b]{2}{*}{ Full-time } & \multirow{2}{*}{$\begin{array}{l}\text { Part- } \\
\text { time }\end{array}$} & \multirow[b]{2}{*}{ Men } & \multirow[b]{2}{*}{ Women } & \multicolumn{2}{|c|}{ Men } & \multicolumn{2}{|c|}{ Women } & \multicolumn{2}{|c|}{ Men } & \multicolumn{2}{|c|}{ Women } \\
\hline & & & & & & & Full-time & $\begin{array}{l}\text { Part- } \\
\text { time }\end{array}$ & Full-time & $\begin{array}{l}\text { Part- } \\
\text { time }\end{array}$ & Public & Private & Public & Private \\
\hline & 1 & 2 & 3 & 4 & 5 & 6 & 7 & 8 & 9 & 10 & 11 & 12 & 13 & 14 \\
\hline 1969 & & 164,737 & 143,081 & 21,656 & 148,926 & 15,811 & 131,368 & 17,558 & 11,713 & 4,098 & 64,241 & 84,685 & 8,354 & 7,457 \\
\hline 1970 & & 173,411 & 157,384 & 16,027 & 158,649 & 14,762 & 144,270 & 14,379 & 13,114 & 1,648 & 68,956 & 89,693 & 6,501 & 8,261 \\
\hline 1971 & & 192,668 & 176,224 & 16,444 & 174,058 & 18,610 & 159,386 & 14,672 & 16,838 & 1,772 & 98,233 & 75,825 & 9,430 & 9,180 \\
\hline 1972 & & 206,659 & 190,039 & 16,620 & 183,443 & 23,216 & 168,990 & 14,453 & 21,049 & 2,167 & 79,723 & 103,720 & 10,842 & 12,374 \\
\hline 1973 & & 218,990 & 201,663 & 17,327 & 186,297 & 32,693 & 171,731 & 14,566 & 29,932 & 2,761 & 81,811 & 104,486 & 16,138 & 16,555 \\
\hline 1974 & & 235,452 & 216,329 & 19,123 & 194,079 & 41,373 & 178,926 & 15,153 & 37,403 & 3,970 & 84,271 & 109,808 & 20,085 & 21,288 \\
\hline 1975 & & 242,267 & 219,886 & 22,381 & 192,100 & 50,167 & 177,117 & 14,983 & 42,769 & 7,398 & 79,240 & 112,860 & 23,557 & 26,610 \\
\hline 1976 & . & 244,292 & 220,124 & 24,168 & 189,810 & 54,482 & 171,967 & 17,843 & 48,157 & 6,325 & 77,873 & 111,937 & 23,468 & 31,014 \\
\hline 1977 & & 251,357 & 226,318 & 25,039 & 191,451 & 59,906 & 173,165 & 18,286 & 53,153 & 6,753 & 78,189 & 113,262 & 24,901 & 35,005 \\
\hline 1978 & & 256,904 & 232,540 & 24,364 & 192,221 & 64,683 & 174,906 & 17,315 & 57,634 & 7,049 & 77,748 & 114,473 & 26,839 & 37,844 \\
\hline 1979 & & 263,404 & 238,949 & 24,455 & 193,363 & 70,041 & 176,394 & 16,969 & 62,555 & 7,486 & 77,122 & 116,241 & 29,026 & 41,015 \\
\hline 1980 & & 277,767 & 251,359 & 26,408 & 199,344 & 78,423 & 181,448 & 17,896 & 69,911 & 8,512 & 81,022 & 118,322 & 33,415 & 45,008 \\
\hline 1981 & & 274,595 & 248,328 & 26,267 & 192,936 & 81,659 & 175,414 & 17,522 & 72,914 & 8,745 & 77,562 & 115,374 & 34,177 & 47,482 \\
\hline 1982 & & 278,425 & 252,108 & 26,317 & 191,200 & 87,225 & 173,941 & 17,259 & 78,167 & 9,058 & 76,273 & 114,927 & 37,183 & 50,042 \\
\hline 1983 & & 278,529 & 249,636 & 28,893 & 188,096 & 90,433 & 169,071 & 19,025 & 80,565 & 9,868 & 74,938 & 113,158 & 38,484 & 51,949 \\
\hline 1984 & & 278,598 & 249,708 & 28,890 & 184,949 & 93,649 & 166,286 & 18,663 & 83,422 & 10,227 & 73,722 & 111,227 & 40,186 & 53,463 \\
\hline 1985 & & 274,200 & 246,619 & 27,581 & 179,792 & 94,408 & 162,368 & 17,424 & 84,251 & 10,157 & 71,373 & 108,419 & 40,435 & 53,973 \\
\hline 1986 & & 270,401 & 245,647 & 24,754 & 173,851 & 96,550 & 158,557 & 15,294 & 87,090 & 9,460 & 70,326 & 103,525 & 41,699 & 54,851 \\
\hline 1987 & $\ldots \ldots \ldots \ldots \ldots \ldots$ & 268,332 & 241,807 & 26,525 & 170,129 & 98,203 & 153,668 & 16,461 & 88,139 & 10,064 & 68,089 & 102,040 & 41,947 & 56,256 \\
\hline 1988 & & 267,109 & 241,228 & 25,881 & 166,912 & 100,197 & 151,045 & 15,867 & 90,183 & 10,014 & 66,196 & 100,716 & 42,743 & 57,454 \\
\hline 1989 & 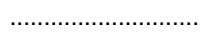 & 274,451 & 247,812 & 26,639 & 168,773 & 105,678 & 152,511 & 16,262 & 95,301 & 10,377 & 67,548 & 101,225 & 45,090 & 60,588 \\
\hline 1990 & 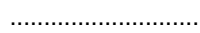 & 273,366 & 245,854 & 27,512 & 166,798 & 106,568 & 149,805 & 16,993 & 96,049 & 10,519 & 66,071 & 100,727 & 45,674 & 60,894 \\
\hline 1991 & & 280,531 & 252,012 & 28,519 & 169,875 & 110,656 & 152,356 & 17,519 & 99,656 & 11,000 & 64,821 & 105,054 & 46,661 & 63,995 \\
\hline 1992 & $\ldots \ldots \ldots \ldots \ldots$ & 280,922 & 252,138 & 28,784 & 168,620 & 112,302 & 151,025 & 17,595 & 101,113 & 11,189 & 63,511 & 105,109 & 47,178 & 65,124 \\
\hline 1993 & 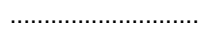 & 292,431 & 259,764 & 32,667 & 172,788 & 119,643 & 153,873 & 18,915 & 105,891 & 13,752 & 63,973 & 108,815 & 49,681 & 69,962 \\
\hline 1994 & $\ldots$ & 294,713 & 263,311 & 31,402 & 173,956 & 120,757 & 155,018 & 18,938 & 108,293 & 12,464 & 63,844 & 110,112 & 50,153 & 70,604 \\
\hline 1995 & $\ldots \ldots \ldots \ldots \ldots$ & 297,592 & 266,414 & 31,178 & 173,897 & 123,695 & 155,056 & 18,841 & 111,358 & 12,337 & 63,594 & 110,303 & 51,478 & 72,217 \\
\hline 1996 & 1 . & 297,739 & 266,812 & 30,927 & 172,462 & 125,277 & 153,983 & 18,479 & 112,829 & 12,448 & 63,608 & 108,854 & 52,777 & 72,500 \\
\hline
\end{tabular}


Table 190.-Total fall enrollment in institutions of higher education and degree-granting institutions, by state: 1970 to 1996

\begin{tabular}{|c|c|c|c|c|c|c|c|c|c|c|c|}
\hline \multirow[b]{2}{*}{ State or other area } & \multicolumn{10}{|c|}{ Institutions of higher education } & \multirow[b]{2}{*}{$\begin{array}{c}\text { Degree- } \\
\text { granting in- } \\
\text { stitutions, } \\
\text { fall } 1996\end{array}$} \\
\hline & Fall 1970 & Fall 1975 & Fall 1980 & Fall 1985 & Fall 1990 & Fall 1993 & Fall 1994 & Fall 1995 & Fall $1996{ }^{1}$ & $\begin{array}{c}\text { Percent } \\
\text { change, } \\
1990 \text { to } \\
1996\end{array}$ & \\
\hline 1 & 2 & 3 & 4 & 5 & 6 & 7 & 8 & 9 & 10 & 11 & 12 \\
\hline United States ...... & $8,580,887$ & $11,184,859$ & $12,096,895$ & $12,247,055$ & $13,818,637$ & $14,304,803$ & $14,278,790$ & $14,261,781$ & $14,300,255$ & 3.5 & $14,367,520$ \\
\hline 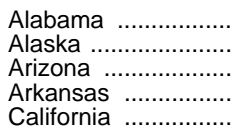 & $\begin{array}{r}103,936 \\
9,471 \\
109,619 \\
52,039 \\
1,257,245\end{array}$ & $\begin{array}{r}164,700 \\
13,998 \\
173,542 \\
65,547 \\
1,787,932\end{array}$ & $\begin{array}{r}164,306 \\
21,296 \\
202,716 \\
77,607 \\
1,790,993\end{array}$ & $\begin{array}{r}179,343 \\
27,479 \\
216,854 \\
77,958 \\
1,650,439\end{array}$ & $\begin{array}{r}218,589 \\
29,833 \\
264,148 \\
90,425 \\
1,808,740\end{array}$ & $\begin{array}{r}233,525 \\
30,638 \\
272,300 \\
99,262 \\
1,836,349\end{array}$ & $\begin{array}{r}229,511 \\
28,798 \\
274,932 \\
96,294 \\
1,835,791\end{array}$ & $\begin{array}{r}225,612 \\
29,348 \\
273,981 \\
98,180 \\
1,817,042\end{array}$ & $\begin{array}{r}219,499 \\
28,846 \\
276,832 \\
100,688 \\
1,882,634\end{array}$ & \begin{tabular}{r||}
0.4 \\
-3.3 \\
4.8 \\
11.3 \\
4.1
\end{tabular} & $\begin{array}{r}220,711 \\
28,806 \\
288,036 \\
108,636 \\
1,900,099\end{array}$ \\
\hline $\begin{array}{l}\text { Colorado } \\
\text { Connecticut ....................... } \\
\text { Delaware .............. } \\
\text { District of Columbia } \\
\text { Florida }\end{array}$ & $\begin{array}{r}123,395 \\
124,700 \\
25,260 \\
77,158 \\
235,525\end{array}$ & $\begin{array}{r}149,814 \\
148,491 \\
32,389 \\
84,190 \\
344,267\end{array}$ & $\begin{array}{r}162,916 \\
159,632 \\
32,939 \\
86,675 \\
411,891\end{array}$ & $\begin{array}{r}161,314 \\
159,348 \\
31,883 \\
78,201 \\
451,392\end{array}$ & $\begin{array}{r}227,131 \\
168,604 \\
42,004 \\
79,551 \\
588,086\end{array}$ & $\begin{array}{r}239,805 \\
162,300 \\
43,528 \\
81,565 \\
623,403\end{array}$ & $\begin{array}{r}241,295 \\
159,990 \\
44,197 \\
77,256 \\
634,237\end{array}$ & $\begin{array}{r}242,739 \\
157,695 \\
44,307 \\
77,277 \\
637,303\end{array}$ & $\begin{array}{r}242,949 \\
155,361 \\
44,838 \\
74,239 \\
641,173\end{array}$ & $\begin{array}{r}7.0 \\
-7.9 \\
6.7 \\
-6.7 \\
9.0\end{array}$ & $\begin{array}{r}245,112 \\
154,139 \\
44,838 \\
74,460 \\
645,832\end{array}$ \\
\hline 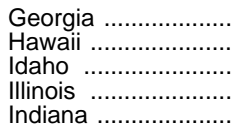 & $\begin{array}{r}126,511 \\
36,562 \\
34,567 \\
452,146 \\
192,668\end{array}$ & $\begin{array}{r}173,585 \\
46,671 \\
39,075 \\
584,089 \\
213,820\end{array}$ & $\begin{array}{r}184,159 \\
47,181 \\
43,018 \\
644,245 \\
247,253\end{array}$ & $\begin{array}{r}196,826 \\
49,937 \\
42,668 \\
678,689 \\
250,567\end{array}$ & $\begin{array}{r}251,786 \\
56,436 \\
51,881 \\
729,246 \\
284,832\end{array}$ & $\begin{array}{r}302,844 \\
62,871 \\
58,768 \\
734,089 \\
294,685\end{array}$ & $\begin{array}{r}308,587 \\
64,322 \\
60,393 \\
731,420 \\
292,276\end{array}$ & $\begin{array}{r}314,712 \\
63,198 \\
59,566 \\
717,854 \\
289,615\end{array}$ & $\begin{array}{r}317,999 \\
61,383 \\
59,904 \\
720,987 \\
286,326\end{array}$ & \begin{tabular}{r|}
26.3 \\
8.8 \\
15.5 \\
-1.1 \\
0.5
\end{tabular} & $\begin{array}{r}300,795 \\
62,844 \\
60,411 \\
721,133 \\
290,184\end{array}$ \\
\hline 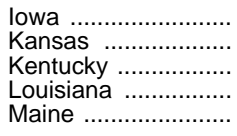 & $\begin{array}{r}108,902 \\
102,485 \\
98,591 \\
120,728 \\
34,134\end{array}$ & $\begin{array}{r}121,678 \\
120,833 \\
125,253 \\
153,213 \\
40,443\end{array}$ & & $\begin{array}{r}152,897 \\
141,359 \\
141,724 \\
177,176 \\
52,201\end{array}$ & & $\begin{array}{r}172,797 \\
170,135 \\
187,332 \\
201,987 \\
56,294\end{array}$ & $\begin{array}{r}172,450 \\
170,603 \\
182,577 \\
203,567 \\
56,724\end{array}$ & & & \begin{tabular}{r||}
3.8 \\
5.3 \\
-0.1 \\
8.9 \\
-2.7
\end{tabular} & $\begin{array}{r}178,860 \\
173,865 \\
178,904 \\
213,993 \\
56,017\end{array}$ \\
\hline $\begin{array}{l}\text { Maryland ............... } \\
\text { Massachusetts ....... } \\
\text { Michigan ................ } \\
\text { Minnesota ............. } \\
\text { Mississippi ............. }\end{array}$ & $\begin{array}{r}149,607 \\
303,809 \\
392,726 \\
160,788 \\
73,967\end{array}$ & $\begin{array}{r}205,570 \\
384,485 \\
496,405 \\
184,756 \\
99,962\end{array}$ & $\begin{array}{l}225,526 \\
418,415 \\
520,131 \\
206,691 \\
102,364\end{array}$ & $\begin{array}{l}231,649 \\
421,175 \\
507,293 \\
221,162 \\
101,180\end{array}$ & $\begin{array}{l}00 \\
33 \\
03 \\
89 \\
83\end{array}$ & $\begin{array}{l}05 \\
27 \\
10 \\
18 \\
08\end{array}$ & $\begin{array}{l}14 \\
05 \\
07 \\
00 \\
84\end{array}$ & & & \begin{tabular}{r||}
0.4 \\
-1.8 \\
-4.0 \\
8.5 \\
2.7
\end{tabular} & $\begin{array}{l}757 \\
676 \\
629 \\
964\end{array}$ \\
\hline $\begin{array}{l}\text { Missouri ................... } \\
\text { Montana ............... } \\
\text { Nebraska ............... } \\
\text { Nevada ............... } \\
\text { New Hampshire ...... }\end{array}$ & $\begin{array}{r}183,930 \\
30,062 \\
66,915 \\
13,669 \\
29,400\end{array}$ & $\begin{array}{r}223,115 \\
30,843 \\
74,705 \\
30,187 \\
41,030\end{array}$ & $\begin{array}{r}234,421 \\
35,177 \\
89,488 \\
40,455 \\
46,794\end{array}$ & $\begin{array}{r}241,146 \\
35,958 \\
97,769 \\
43,656 \\
52,283\end{array}$ & $\begin{array}{r}289, \\
35, \\
112, \\
61, \\
59,\end{array}$ & $\begin{array}{r}297,062 \\
39,557 \\
115,523 \\
63,947 \\
64,043\end{array}$ & $\begin{array}{r}293,810 \\
40,095 \\
116,000 \\
64,085 \\
62,847\end{array}$ & $\begin{array}{r}291,536 \\
42,674 \\
115,718 \\
67,826 \\
64,327\end{array}$ & & \begin{tabular}{r||}
0.2 \\
20.3 \\
5.7 \\
19.0 \\
8.3
\end{tabular} & $\begin{array}{r}293,584 \\
43,550 \\
120,689 \\
73,970 \\
64,396\end{array}$ \\
\hline $\begin{array}{l}\text { New Jersey } \\
\text { New Mexico ................. } \\
\text { New York ................ } \\
\text { North Carolina ........ } \\
\text { North Dakota .......... }\end{array}$ & $\begin{array}{r}216,121 \\
44,461 \\
806,479 \\
171,925 \\
31,495\end{array}$ & $\begin{array}{r}297,114 \\
51,944 \\
1,005,063 \\
251,786 \\
29,743\end{array}$ & $\begin{array}{r}321,610 \\
58,283 \\
992,237 \\
287,537 \\
34,069\end{array}$ & $\begin{array}{r}297,658 \\
68,295 \\
1,000,098 \\
327,288 \\
37,939\end{array}$ & $\begin{array}{r}324,286 \\
85,500 \\
1,048,286 \\
352,138 \\
37,878\end{array}$ & $\begin{array}{r}343,029 \\
101,460 \\
1,062,924 \\
371,280 \\
40,316\end{array}$ & $\begin{array}{r}335,480 \\
101,881 \\
1,057,841 \\
369,386 \\
40,184\end{array}$ & $\begin{array}{r}333,831 \\
102,405 \\
1,041,566 \\
372,030 \\
40,399\end{array}$ & $\begin{array}{r}328,188 \\
103,546 \\
1,027,870 \\
373,168 \\
40,554\end{array}$ & \begin{tabular}{r||}
1.2 \\
21.1 \\
-1.9 \\
6.0 \\
7.1
\end{tabular} & $\begin{array}{r}328,143 \\
106,662 \\
1,028,351 \\
372,993 \\
41,142\end{array}$ \\
\hline $\begin{array}{l}\text { Ohio } \\
\text { Oklahoma ................ } \\
\text { Oregon .................. } \\
\text { Pennsylvania .......... } \\
\text { Rhode Island .......... }\end{array}$ & $\begin{array}{r}376,267 \\
110,155 \\
122,177 \\
411,044 \\
45,898\end{array}$ & $\begin{array}{r}436,052 \\
146,613 \\
145,281 \\
470,536 \\
64,479\end{array}$ & & & & & & & & \begin{tabular}{r||}
-3.6 \\
2.3 \\
-0.3 \\
3.0 \\
-7.5
\end{tabular} & \\
\hline $\begin{array}{l}\text { South Carolina } \\
\text { South Dakota } \\
\text { Tennes........ } \\
\text { Texas }\end{array}$ & $\begin{array}{r}69,518 \\
30,639 \\
135,103 \\
442,225 \\
81,687\end{array}$ & $\begin{array}{r}133,023 \\
30,260 \\
181,435 \\
624,390 \\
87,323\end{array}$ & $\begin{array}{r}132,476 \\
32,761 \\
204,581 \\
701,391 \\
93,987\end{array}$ & $\begin{array}{r}131,902 \\
32,772 \\
194,845 \\
769,692 \\
103,994\end{array}$ & $\begin{array}{r}159,302 \\
34,208 \\
226,238 \\
901,437 \\
121,303\end{array}$ & $\begin{array}{r}174,302 \\
38,166 \\
244,936 \\
942,178 \\
138,139\end{array}$ & $\begin{array}{r}173,070 \\
37,764 \\
242,966 \\
954,495 \\
146,196\end{array}$ & & & \begin{tabular}{r|}
9.4 \\
3.4 \\
9.2 \\
6.0 \\
25.0
\end{tabular} & $\begin{array}{r}174,303 \\
39,820 \\
247,637 \\
959,698 \\
152,262\end{array}$ \\
\hline 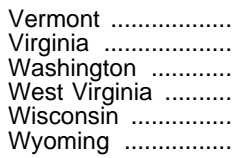 & $\begin{array}{r}22,209 \\
151,915 \\
183,544 \\
63,153 \\
202,058 \\
15,220\end{array}$ & $\begin{array}{r}29,095 \\
244,671 \\
227,168 \\
78,619 \\
240,701 \\
18,078\end{array}$ & $\begin{array}{r}30,628 \\
280,504 \\
303,603 \\
81,973 \\
269,086 \\
21,147\end{array}$ & $\begin{array}{r}31,416 \\
292,416 \\
231,553 \\
76,659 \\
275,069 \\
24,204\end{array}$ & $\begin{array}{r}36,398 \\
353,442 \\
263,384 \\
84,790 \\
299,774 \\
31,326\end{array}$ & $\begin{array}{r}36,415 \\
348,535 \\
279,845 \\
88,852 \\
309,036 \\
30,702\end{array}$ & $\begin{array}{r}35,409 \\
354,149 \\
284,662 \\
87,741 \\
303,861 \\
30,682\end{array}$ & & & $\begin{array}{r}-3.6 \\
0.1 \\
10.9 \\
1.1 \\
-0.2 \\
-1.7\end{array}$ & $\begin{array}{r}355,190 \\
303,450 \\
87,099 \\
299,522 \\
30,805\end{array}$ \\
\hline $\begin{array}{l}\text { U.S. Service } \\
\text { Schools .... }\end{array}$ & 17,079 & 36,897 & 49,808 & 54,719 & 48,692 & 52,998 & 51,939 & 88,451 & 81,669 & 67.7 & 81,669 \\
\hline Outly & 37 & 270 & 749 & 4,890 & 84,618 & 172,989 & 170,686 & 83,657 & $181,66 c$ & 10.4 & 182,536 \\
\hline $\begin{array}{l}\text { American Samoa .... } \\
\text { Federated States of }\end{array}$ & - & 689 & 976 & 758 & 19 & 1,264 & 1,249 & 1,232 & 1,239 & 1.6 & 1, \\
\hline & 719 & 000 & 3 & 4,601 & 4,7 & & & & & $\begin{array}{l}43 . \\
12 .\end{array}$ & $\begin{array}{r}1,396 \\
5,335 \\
431\end{array}$ \\
\hline $\begin{array}{l}\mathrm{P} \\
\mathrm{N}\end{array}$ & - & & 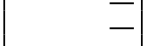 & 318 & & & & & & & \\
\hline & 63,073 & 97,517 & 131,184 & 155,917 & 154,065 & 159,709 & 156,439 & 170,337 & 168,933 & 9.7 & 169,809 \\
\hline 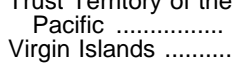 & 1,445 & $\begin{array}{r}185 \\
2,079\end{array}$ & $\begin{array}{r}224 \\
2,148\end{array}$ & $\begin{array}{r}724 \\
2,572\end{array}$ & 2,466 & 2,942 & 3,095 & 3,054 & 2,898 & 17.5 & 2,898 \\
\hline
\end{tabular}

1 Preliminary data.

${ }^{2}$ Preliminary data are for 4-year and 2-year degree-granting higher education institutions that were eligible to participate in Title IV federal financial aid programs.

-Data not reported or not applicable.

SOURCE: U.S. Department of Education, National Center for Education Statistics, Higher Education General Information Survey (HEGIS), "Fall Enrollment in Colleges and
Universities" surveys; and Integrated Postsecondary Education Data System (IPEDS), "Fall Enrollment" surveys. (This table was prepared October 1998.) 
Table 191.-Total fall enrollment in public institutions of higher education and degree-granting institutions, by state: 1970 to 1996

\begin{tabular}{|c|c|c|c|c|c|c|c|c|c|c|c|}
\hline \multirow[b]{2}{*}{ State or other area } & \multicolumn{10}{|c|}{ Institutions of higher education } & \multirow[b]{2}{*}{$\begin{array}{l}\text { Degree- } \\
\text { granting in- } \\
\text { stitutions, } 2 \\
\text { fall } 1996\end{array}$} \\
\hline & Fall 1970 & Fall 1975 & Fall 1980 & Fall 1985 & Fall 1990 & Fall 1993 & Fall 1994 & Fall 1995 & Fall 19961 & \begin{tabular}{|c|} 
Percent \\
change, \\
1990 to \\
1996
\end{tabular} & \\
\hline 1 & 2 & 3 & 4 & 5 & 6 & 7 & 8 & 9 & 10 & 11 & 12 \\
\hline United States & $6,428,134$ & $8,834,508$ & $9,457,394$ & $9,479,273$ & $10,844,717$ & $11,189,088$ & $11,133,680$ & $11,092,374$ & $11,090,171$ & 2.3 & $11,120,499$ \\
\hline 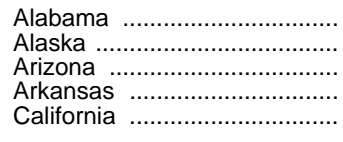 & $\begin{array}{r}87,884 \\
8,563 \\
107,315 \\
43,599 \\
1,123,529\end{array}$ & $\begin{array}{r}145,698 \\
13,218 \\
168,666 \\
56,127 \\
1,617,558\end{array}$ & $\begin{array}{r}143,674 \\
20,561 \\
194,034 \\
66,068 \\
1,599,838\end{array}$ & $\begin{array}{r}158,688 \\
26,510 \\
202,036 \\
66,123 \\
1,444,207\end{array}$ & $\begin{array}{r}195,939 \\
27,792 \\
248,213 \\
78,645 \\
1,594,710\end{array}$ & $\begin{array}{r}210,094 \\
28,708 \\
246,754 \\
87,942 \\
1,604,158\end{array}$ & $\begin{array}{r}206,546 \\
27,631 \\
252,184 \\
85,601 \\
1,582,837\end{array}$ & $\begin{array}{r}203,165 \\
28,368 \\
254,530 \\
87,067 \\
1,564,230\end{array}$ & $\begin{array}{r}196,531 \\
27,828 \\
253,469 \\
89,457 \\
1,624,907\end{array}$ & \begin{tabular}{r||}
0.3 \\
0.1 \\
2.1 \\
13.7 \\
1.9
\end{tabular} & $\begin{array}{r}196,531 \\
27,828 \\
259,163 \\
97,405 \\
1,625,021\end{array}$ \\
\hline 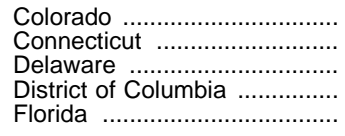 & $\begin{array}{r}108,562 \\
73,391 \\
21,151 \\
12,194 \\
189,450\end{array}$ & $\begin{array}{r}136,370 \\
93,567 \\
27,082 \\
15,159 \\
287,745\end{array}$ & $\begin{array}{r}145,598 \\
97,788 \\
28,325 \\
13,900 \\
334,349\end{array}$ & $\begin{array}{r}142,031 \\
98,616 \\
27,933 \\
12,080 \\
362,241\end{array}$ & $\begin{array}{r}200,653 \\
109,556 \\
34,252 \\
11,990 \\
489,081\end{array}$ & $\begin{array}{r}209,932 \\
105,446 \\
35,771 \\
10,608 \\
518,480\end{array}$ & $\begin{array}{r}209,717 \\
102,450 \\
36,322 \\
10,599 \\
528,024\end{array}$ & $\begin{array}{r}210,312 \\
100,539 \\
36,204 \\
9,663 \\
530,607\end{array}$ & $\begin{array}{r}209,183 \\
97,588 \\
36,579 \\
7,456 \\
531,030\end{array}$ & $\begin{array}{r}4.3 \\
-10.9 \\
6.8 \\
-37.8 \\
8.6\end{array}$ & $\begin{array}{r}209,183 \\
96,336 \\
36,579 \\
7,736 \\
529,422\end{array}$ \\
\hline 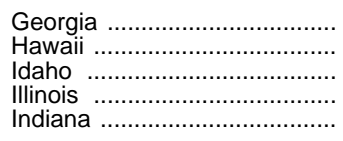 & $\begin{array}{r}101,900 \\
32,963 \\
27,072 \\
315,634 \\
136,739\end{array}$ & $\begin{array}{r}142,593 \\
43,278 \\
31,298 \\
444,458 \\
159,453\end{array}$ & $\begin{array}{r}140,158 \\
43,269 \\
34,491 \\
491,274 \\
189,224\end{array}$ & $\begin{array}{r}148,956 \\
43,246 \\
33,666 \\
520,224 \\
193,833\end{array}$ & $\begin{array}{r}196,413 \\
45,728 \\
41,315 \\
551,333 \\
223,953\end{array}$ & $\begin{array}{r}239,755 \\
50,618 \\
47,524 \\
549,745 \\
231,259\end{array}$ & $\begin{array}{r}243,855 \\
51,646 \\
48,994 \\
545,958 \\
228,270\end{array}$ & $\begin{array}{r}248,682 \\
50,198 \\
48,986 \\
530,248 \\
224,795\end{array}$ & $\begin{array}{r}249,284 \\
47,370 \\
49,392 \\
532,470 \\
220,967\end{array}$ & \begin{tabular}{r||}
26.9 \\
3.6 \\
19.5 \\
-3.4 \\
-1.3
\end{tabular} & $\begin{array}{r}230,204 \\
47,370 \\
49,806 \\
532,470 \\
220,967\end{array}$ \\
\hline 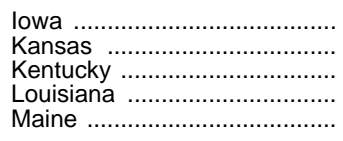 & $\begin{array}{r}68,390 \\
88,215 \\
77,240 \\
101,127 \\
25,405\end{array}$ & $\begin{array}{r}83,572 \\
107,761 \\
105,265 \\
132,054 \\
31,092\end{array}$ & $\begin{array}{r}97,454 \\
121,987 \\
114,884 \\
136,703 \\
31,878\end{array}$ & $\begin{array}{r}109,765 \\
127,220 \\
110,836 \\
153,173 \\
33,188\end{array}$ & & & & & & \begin{tabular}{r||}
6.9 \\
4.2 \\
0.2 \\
10.3 \\
-8.7
\end{tabular} & $\begin{array}{r}125,923 \\
156,446 \\
147,423 \\
185,223 \\
38,260\end{array}$ \\
\hline 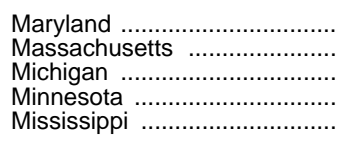 & $\begin{array}{r}118,988 \\
116,127 \\
339,625 \\
130,567 \\
64,968\end{array}$ & $\begin{array}{r}176,544 \\
173,564 \\
436,655 \\
148,630 \\
89,919\end{array}$ & $\begin{array}{r}195,051 \\
183,765 \\
454,147 \\
162,379 \\
90,661\end{array}$ & & & & & & & $\begin{array}{r}-1.6 \\
-6.8 \\
-5.8 \\
4.7 \\
5.4\end{array}$ & $\begin{array}{l}217,277 \\
173,854 \\
458,989 \\
213,284 \\
114,905\end{array}$ \\
\hline 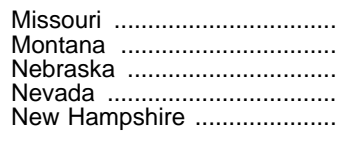 & $\begin{array}{r}132,540 \\
27,287 \\
51,454 \\
13,576 \\
15,979\end{array}$ & $\begin{array}{r}158,196 \\
27,798 \\
61,240 \\
30,010 \\
24,205\end{array}$ & $\begin{array}{r}165,179 \\
31,178 \\
73,509 \\
40,280 \\
24,119\end{array}$ & $\begin{array}{r}168,829 \\
32,032 \\
81,202 \\
43,368 \\
26,669\end{array}$ & $\begin{array}{r}200,093 \\
31,865 \\
94,614 \\
61,242 \\
32,163\end{array}$ & $\begin{array}{r}197,821 \\
34,326 \\
95,782 \\
63,229 \\
35,571\end{array}$ & $\begin{array}{r}191,859 \\
34,927 \\
95,877 \\
63,271 \\
34,988\end{array}$ & $\begin{array}{r}189,993 \\
37,435 \\
95,599 \\
66,683 \\
36,069\end{array}$ & $\begin{array}{r}189,269 \\
38,000 \\
99,717 \\
71,925 \\
36,365\end{array}$ & \begin{tabular}{r||}
-5.4 \\
19.3 \\
5.4 \\
17.4 \\
13.1
\end{tabular} & $\begin{array}{r}189,851 \\
38,000 \\
99,717 \\
71,925 \\
36,365\end{array}$ \\
\hline $\begin{array}{l}\text { New Jersey } \\
\text { New Mexico …......................... } \\
\text { New York } 21 \ldots \ldots \ldots \ldots \ldots \ldots \ldots \ldots \ldots \ldots \\
\text { North Carolina ........................ } \\
\text { North Dakota ..................... }\end{array}$ & $\begin{array}{r}145,373 \\
40,795 \\
449,437 \\
123,761 \\
30,192\end{array}$ & $\begin{array}{r}227,764 \\
47,605 \\
613,842 \\
201,288 \\
27,954\end{array}$ & $\begin{array}{r}247,028 \\
55,077 \\
563,251 \\
228,154 \\
31,709\end{array}$ & $\begin{array}{r}237,297 \\
66,059 \\
563,251 \\
267,044 \\
34,802\end{array}$ & & & & & & \begin{tabular}{r||}
1.1 \\
17.1 \\
-7.2 \\
6.1 \\
6.0
\end{tabular} & $\begin{array}{r}264,596 \\
99,918 \\
572,482 \\
302,939 \\
36,765\end{array}$ \\
\hline 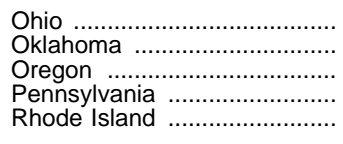 & $\begin{array}{r}281,099 \\
91,438 \\
108,483 \\
232,982 \\
25,527\end{array}$ & $\begin{array}{r}336,931 \\
124,372 \\
129,785 \\
287,436 \\
32,311\end{array}$ & $\begin{array}{r}381,765 \\
137,188 \\
140,102 \\
292,499 \\
35,052\end{array}$ & & & & & & & \begin{tabular}{r||}
-5.2 \\
2.2 \\
-2.1 \\
-2.4 \\
-11.5
\end{tabular} & $\begin{array}{r}407,108 \\
154,381 \\
141,429 \\
335,181 \\
37,487\end{array}$ \\
\hline $\begin{array}{l}\text { South Carolina } \\
\text { South Dakota } \\
\text { Tennessee }\end{array}$ & $\begin{array}{r}47,101 \\
23,936 \\
98,897 \\
365,522 \\
49,588\end{array}$ & $\begin{array}{r}107,690 \\
21,925 \\
139,526 \\
542,212 \\
56,536\end{array}$ & $\begin{array}{r}107,683 \\
24,328 \\
156,835 \\
613,552 \\
59,598\end{array}$ & $\begin{array}{r}105,854 \\
23,339 \\
147,951 \\
677,192 \\
69,426\end{array}$ & & & & & & \begin{tabular}{r||}
13.1 \\
7.4 \\
10.9 \\
4.5 \\
32.6
\end{tabular} & $\begin{array}{r}148,363 \\
32,861 \\
194,138 \\
838,943 \\
113,696\end{array}$ \\
\hline 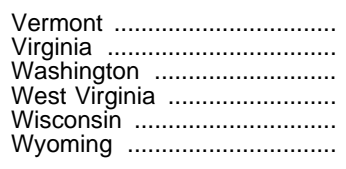 & $\begin{array}{r}12,536 \\
123,279 \\
162,718 \\
51,363 \\
170,374 \\
15,220\end{array}$ & $\begin{array}{r}17,145 \\
215,253 \\
202,531 \\
68,117 \\
210,535 \\
18,078\end{array}$ & $\begin{array}{r}17,984 \\
246,500 \\
276,028 \\
71,228 \\
235,179 \\
21,121\end{array}$ & $\begin{array}{r}18,844 \\
250,754 \\
201,532 \\
66,531 \\
238,735 \\
24,204\end{array}$ & $\begin{array}{r}20,910 \\
291,286 \\
227,632 \\
74,108 \\
253,529 \\
30,623\end{array}$ & $\begin{array}{r}21,001 \\
293,810 \\
241,813 \\
77,500 \\
256,669 \\
30,002\end{array}$ & $\begin{array}{r}20,505 \\
293,165 \\
244,772 \\
76,120 \\
250,246 \\
30,015\end{array}$ & $\begin{array}{r}20,470 \\
293,127 \\
246,635 \\
74,857 \\
245,770 \\
29,420\end{array}$ & $\begin{array}{r}20,139 \\
292,412 \\
251,869 \\
74,755 \\
244,628 \\
29,994\end{array}$ & \begin{tabular}{r||}
-3.7 \\
0.4 \\
10.6 \\
0.9 \\
-3.5 \\
-2.1
\end{tabular} & $\begin{array}{r}20,139 \\
292,412 \\
262,359 \\
75,116 \\
245,060 \\
29,994\end{array}$ \\
\hline U.S. Service Schools & 17,079 & 36,897 & 49,808 & 54,719 & 48,692 & 52,998 & 51,939 & 88,451 & 81,669 & 67.7 & 81,669 \\
\hline Outlying areas ........................ & 46,680 & 59,923 & 60,692 & 65,411 & 66,244 & 69,115 & 70,917 & 77,050 & 79,861 & 20.6 & 79,083 \\
\hline $\begin{array}{l}\text { Amer } \\
\text { Feder }\end{array}$ & - & 689 & 976 & 8 & 9 & 4 & 9 & 32 & 39 & 1 & 39 \\
\hline $\mathrm{Gu}$ & $\underline{719}$ & 800 & ,217 & 4,601 & $\begin{array}{r}975 \\
4,741 \\
\end{array}$ & $\begin{array}{l}1, \\
5, \xi\end{array}$ & $\begin{array}{r}1,374 \\
6,449 \\
424\end{array}$ & $\begin{array}{r}1,296 \\
6,010 \\
418\end{array}$ & $\begin{array}{r}1,396 \\
5,335 \\
4331\end{array}$ & $\begin{array}{r}43.2 \\
12.5 \\
\end{array}$ & $\begin{array}{l}1,396 \\
5,335 \\
431\end{array}$ \\
\hline 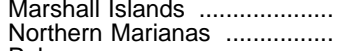 & - & - & 二 & 318 & & 1,261 & $\begin{array}{r}424 \\
1,253\end{array}$ & $\begin{array}{l}418 \\
959\end{array}$ & $\begin{array}{r}431 \\
1,096\end{array}$ & 65.8 & $\begin{array}{r}431 \\
1,096\end{array}$ \\
\hline co .................. & 42,516 & 53,170 & 54,127 & 56,438 & & & & & & $\begin{array}{r}-32.4 \\
20.5\end{array}$ & $\begin{array}{r}332 \\
66,356\end{array}$ \\
\hline ry of the & & & & & & & & & & & \\
\hline Virgin & 1,445 & & 2,148 & 2,572 & 2,466 & 2,942 & 3,095 & 3,054 & 2,898 & 17.5 & 2,898 \\
\hline
\end{tabular}

1 Preliminary data.

2 Preliminary data are for 4-year and 2-year degree-granting higher education institutions that were eligible to participate in Title IV federal financial aid programs.

-Data not reported or not applicable.
SOURCE: US. Department of Education, National Center for Education Statistics, Higher Education General Information Survey (HEGIS), "Fall Enrollment in Colleges and Universities" surveys; and Integrated Postsecondary Education Data System (IPEDS), "Fall Enrollment" surveys. (This table was prepared October 1998). 
Table 192.-Total fall enrollment in private institutions of higher education and degree-granting institutions, by state: 1970 to 1996

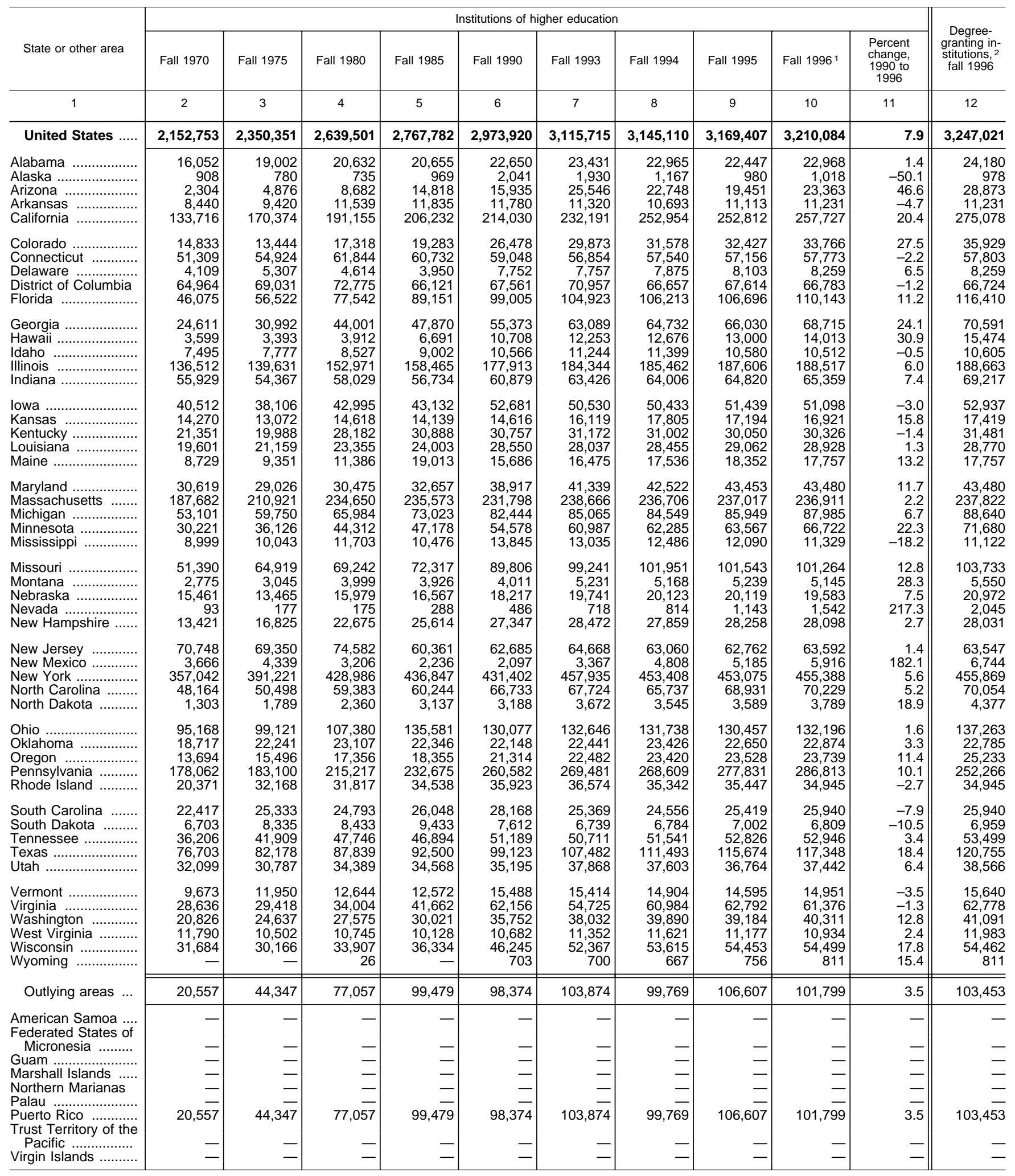

1 Preliminary data.

2Preliminary data are for 4-year and 2-year institutions of higher education that were eligible to participate in Title IV federal financial aid programs.

-Data not reported or not applicable.
SOURCE: US. Department of Education, National Center for Education Statistics, Higher Education General Information Survey (HEGIS), "Fall Enrollment in Colleges and Universities" surveys; and Integrated Postsecondary Education Data System (IPEDS), "Fall Enrollment" surveys. (This table was prepared October 1998.) 
Table 193.-Total fall enrollment in all institutions of higher education, by attendance status, sex, and state: 1995 and 1996

\begin{tabular}{|c|c|c|c|c|c|c|c|c|c|c|}
\hline \multirow{3}{*}{ State or other area } & \multicolumn{5}{|c|}{ Fall 1995} & \multicolumn{5}{|c|}{ Fall 19961} \\
\hline & \multirow{2}{*}{ Total } & \multicolumn{2}{|c|}{ Full-time } & \multicolumn{2}{|c|}{ Part-time } & \multirow{2}{*}{ Total } & \multicolumn{2}{|c|}{ Full-time } & \multicolumn{2}{|c|}{ Part-time } \\
\hline & & Men & Women & Men & Women & & Men & Women & Men & Women \\
\hline 1 & 2 & 3 & 4 & 5 & 6 & 7 & 8 & 9 & 10 & 11 \\
\hline 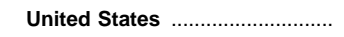 & $14,261,781$ & $3,807,392$ & $4,321,410$ & $2,535,147$ & $3,597,832$ & $14,300,255$ & $3,815,519$ & $4,397,971$ & $2,528,473$ & $3,558,292$ \\
\hline Alabama & 225,612 & 68,713 & 83,031 & 31,064 & 42,804 & 219,499 & 66,707 & 83,614 & 28,979 & 40,199 \\
\hline Alaska ............................ & 29,348 & 5,424 & 6,559 & 6,444 & 10,921 & 28,846 & 5,351 & 6,533 & 6,225 & 10,737 \\
\hline Arizona ……..... & 273,981 & 61,685 & 64,369 & 61,226 & 86,701 & 276,832 & 63,773 & 67,366 & 60,962 & 84,731 \\
\hline 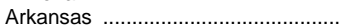 & 98,180 & 30,077 & 37,101 & 11,626 & 19,376 & 100,688 & 30,053 & 37,662 & 12,488 & 20,485 \\
\hline 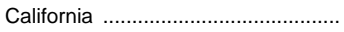 & $1,817,042$ & 408,376 & 458,540 & 410,267 & 539,859 & $1,882,634$ & 413,893 & 473,499 & 427,409 & 567,833 \\
\hline Colorado & 242,739 & 62,892 & 65,994 & 48,117 & 65,736 & 242,949 & 63,329 & 67,736 & 47,205 & 64,679 \\
\hline 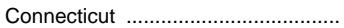 & 157,695 & 38,877 & 43,222 & 29,623 & 45,973 & 155,361 & 39,208 & 43,696 & 28,384 & 44,073 \\
\hline 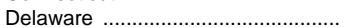 & 44,307 & 11,287 & 14,252 & 7,576 & 11,192 & 44,838 & 11,408 & 14,786 & 7,280 & 11,364 \\
\hline District of Columbia & 77,277 & 22,706 & 27,643 & 11,807 & 15,121 & 74,239 & 22,069 & 27,283 & 10,962 & 13,925 \\
\hline Florida & 637,303 & 142,368 & 162,172 & 135,424 & 197,339 & 641,173 & 142,163 & 166,896 & 134,800 & 197,314 \\
\hline Georgia & 314,712 & 93,962 & 115,663 & 40,920 & 64,167 & 317,999 & 94,993 & 118,973 & 40,338 & 63,695 \\
\hline Hawaii & 63,198 & 16,175 & 19,166 & 12,030 & 15,827 & 61,383 & 15,992 & 19,333 & 11,442 & 14,616 \\
\hline Idaho & 59,566 & 19,013 & 21,136 & 7,706 & 11,711 & 59,904 & 19,184 & 21,650 & 7,573 & 11,497 \\
\hline |llinois …….................................. & 717,854 & 174,969 & 193,430 & 141,323 & 208,132 & 720,987 & 174,844 & 196,071 & 141,225 & 208,847 \\
\hline 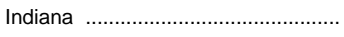 & 289,615 & 90,941 & 98,818 & 41,298 & 58,558 & 286,326 & 91,790 & 99,690 & 39,365 & 55,481 \\
\hline lowa & 173,835 & 58,553 & 62,170 & 19,478 & 33,634 & 177,021 & 59,127 & 62,731 & 21,540 & 33,623 \\
\hline 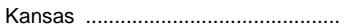 & 177,643 & 47,394 & 50,144 & 31,446 & 48,659 & 172,350 & 46,418 & 49,261 & 31,038 & 45,633 \\
\hline Kentucky & 178,858 & 52,229 & 65,429 & 22,025 & 39,175 & 177,749 & 52,055 & 65,876 & 21,789 & 38,029 \\
\hline Louisiana & 203,935 & 64,292 & 79,971 & 21,820 & 37,852 & 203,517 & 63,769 & 81,027 & 21,828 & 36,893 \\
\hline 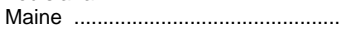 & 56,547 & 14,632 & 16,920 & 7,978 & 17,017 & 55,645 & 14,605 & 17,146 & 7,706 & 16,188 \\
\hline Maryland & 266,310 & 57,822 & 68,689 & 54,075 & 85,724 & 260,757 & 57,867 & 70,351 & 50,585 & 81,954 \\
\hline 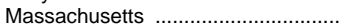 & 413,794 & 121,670 & 140,343 & 59,062 & 92,719 & 410,327 & 120,605 & 140,736 & 58,624 & 90,362 \\
\hline 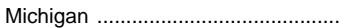 & 548,339 & 127,404 & 146,846 & 113,756 & 160,333 & 546,974 & 127,877 & 150,454 & 111,420 & 157,223 \\
\hline 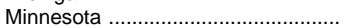 & 280,816 & 74,919 & 83,181 & 51,380 & 71,336 & 275,262 & 76,703 & 87,543 & 44,836 & 66,180 \\
\hline 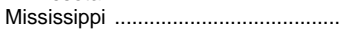 & 122,690 & 41,390 & 50,577 & 11,219 & 19,504 & 126,234 & 41,641 & 51,825 & 12,254 & 20,514 \\
\hline Missouri & 291,536 & 77,858 & 88,270 & 49,402 & 76,006 & 290,533 & 79,313 & 90,361 & 47,352 & 73,507 \\
\hline Montana .......................... & 42,674 & 15,967 & 16,789 & 3,991 & 5,927 & 43,145 & 15,930 & 17,013 & 4,080 & 6,122 \\
\hline 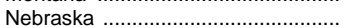 & 115,718 & 32,125 & 34,529 & 20,327 & 28,737 & 119,300 & 32,538 & 35,779 & 21,170 & 29,813 \\
\hline Nevada & 67,826 & 10,196 & 11,524 & 19,787 & 26,319 & 73,467 & 11,247 & 12,587 & 21,412 & 28,221 \\
\hline 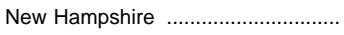 & 64,327 & 18,307 & 21,598 & 9,070 & 15,352 & 64,463 & 18,120 & 21,344 & 9,218 & 15,781 \\
\hline New Jersey & 333,831 & 81,944 & 92,990 & 63,695 & 95,202 & 328,188 & 82,413 & 94,564 & 60,101 & 91,110 \\
\hline New Mexico ………………… & 102,405 & 23,306 & 28,210 & 19,900 & 30,989 & 103,546 & 23,094 & 28,326 & 20,278 & 31,848 \\
\hline 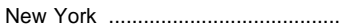 & $1,041,566$ & 301,712 & 363,252 & 142,426 & 234,176 & $1,027,870$ & 298,983 & 366,160 & 137,537 & 225,190 \\
\hline North Carolina ............................... & 372,030 & 105,756 & 132,332 & 54,248 & 79,694 & 373,168 & 105,922 & 134,926 & 54,042 & 78,278 \\
\hline 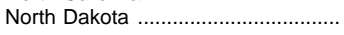 & 40,399 & 16,462 & 15,756 & 3,480 & 4,701 & 40,554 & 16,454 & 15,851 & 3,602 & 4,647 \\
\hline Ohio & 540,275 & 157,392 & 180,152 & 84,648 & 118,083 & 537,535 & 156,466 & 180,961 & 83,615 & 116,493 \\
\hline Oklahoma & 180,676 & 51,848 & 56,218 & 30,422 & 42,188 & 177,255 & 51,655 & 55,709 & 29,185 & 40,706 \\
\hline 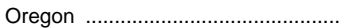 & 167,145 & 43,214 & 46,067 & 33,792 & 44,072 & 165,168 & 43,838 & 47,835 & 32,052 & 41,443 \\
\hline Pennsylvania & 617,759 & 186,435 & 201,884 & 91,493 & 137,947 & 621,994 & 186,469 & 204,540 & 106,383 & 124,602 \\
\hline 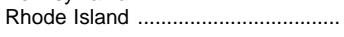 & 74,100 & 22,522 & 24,308 & 10,642 & 16,628 & 72,432 & 22,163 & 24,208 & 10,170 & 15,891 \\
\hline 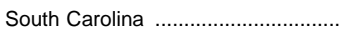 & 174,125 & 48,980 & 60,159 & 23,666 & 41,320 & 174,303 & 49,412 & 61,860 & 22,680 & 40,351 \\
\hline South Dakota ……................................ & 36,695 & 12,586 & 14,021 & 3,610 & 6,478 & 35,373 & 12,093 & 13,668 & 3,503 & 6,109 \\
\hline Tennessee ……… & 245,962 & 73,010 & 86,590 & 35,318 & 51,044 & 247,043 & 72,959 & 88,939 & 35,083 & 50,062 \\
\hline 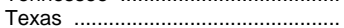 & 952,525 & 248,597 & 267,274 & 189,578 & 247,076 & 955,439 & 248,690 & 272,788 & 188,072 & 245,889 \\
\hline 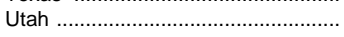 & 147,324 & 49,018 & 48,685 & 24,854 & 24,767 & 151,637 & 47,838 & 48,294 & 27,761 & 27,744 \\
\hline Vermont...$\cdots \ldots \ldots \ldots \ldots \ldots \ldots$ & 35,065 & 11,238 & 12,739 & 3,599 & 7,489 & 35,090 & 11,288 & 12,883 & 3,494 & 7,425 \\
\hline Virginia & 355,919 & 91,570 & 108,894 & 63,394 & 92,061 & 353,788 & 92,305 & 109,925 & 61,464 & 90,094 \\
\hline 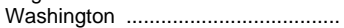 & 285,819 & 81,914 & 93,836 & 44,585 & 65,484 & 292,180 & 82,719 & 96,880 & 45,816 & 66,765 \\
\hline West Virginia ………............................. & 86,034 & 28,848 & 30,935 & 9,191 & 17,060 & 85,689 & 28,555 & 31,103 & 9,382 & 16,649 \\
\hline Wisconsin ……………… & 300,223 & 84,279 & 97,288 & 48,088 & 70,568 & 299,127 & 84,542 & 97,724 & 47,855 & 69,006 \\
\hline 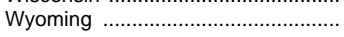 & 30,176 & 8,532 & 9,068 & 4,543 & 8,033 & 30,805 & 8,440 & 9,123 & 4,690 & 8,552 \\
\hline U.S. Service Schools & 88,451 & 16,006 & 2,676 & 58,708 & 11,061 & 81,669 & 16,649 & 2,882 & 52,219 & 9,919 \\
\hline 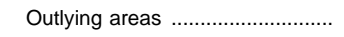 & 183,657 & 53,526 & 83,879 & 18,544 & 27,708 & 181,660 & 52,805 & 85,257 & 17,930 & 25,668 \\
\hline American Samoa & 1,232 & 428 & 436 & 217 & 151 & 1,239 & 435 & 442 & 215 & 147 \\
\hline Federated States of Micronesia ...... & 1,296 & 518 & 447 & 150 & 181 & 1,396 & 471 & 476 & 184 & 265 \\
\hline Guam & 6,010 & 989 & 1,597 & 1,567 & 1,857 & 5,335 & 944 & 1,549 & 1,270 & 1,572 \\
\hline Marshall Islands & 418 & 89 & 75 & 146 & 108 & 431 & 125 & 109 & 115 & 82 \\
\hline Northern Marianas ….............................. & 959 & 203 & 253 & 188 & 315 & 1,096 & 223 & 267 & 221 & 385 \\
\hline Palau & 351 & 143 & 125 & 31 & 52 & 332 & 143 & 112 & 28 & 49 \\
\hline 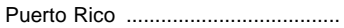 & 170,337 & 50,834 & 79,876 & 15,798 & 23,829 & 168,933 & 50,148 & 81,289 & 15,514 & 21,982 \\
\hline Virgin Islands ….................................... & 3,054 & 322 & 1,070 & 447 & 1,215 & 2,898 & 316 & 1,013 & 383 & 1,186 \\
\hline
\end{tabular}


Table 194.-Total fall enrollment in public institutions of higher education, by attendance status, sex, and state: 1995 and 1996

\begin{tabular}{|c|c|c|c|c|c|c|c|c|c|c|}
\hline \multirow{3}{*}{ State or other area } & \multicolumn{5}{|c|}{ Fall 1995} & \multicolumn{5}{|c|}{ Fall $1996^{1}$} \\
\hline & \multirow{2}{*}{ Total } & \multicolumn{2}{|c|}{ Full-time } & \multicolumn{2}{|c|}{ Part-time } & \multirow{2}{*}{ Total } & \multicolumn{2}{|c|}{ Full-time } & \multicolumn{2}{|c|}{ Part-time } \\
\hline & & Men & Women & Men & Women & & Men & Women & Men & Women \\
\hline 1 & 2 & 3 & 4 & 5 & 6 & 7 & 8 & 9 & 10 & 11 \\
\hline United States & $11,092,374$ & $2,769,745$ & $3,155,556$ & $2,137,890$ & $3,029,183$ & $11,090,171$ & $2,767,918$ & $3,196,256$ & $2,119,619$ & $3,006,378$ \\
\hline 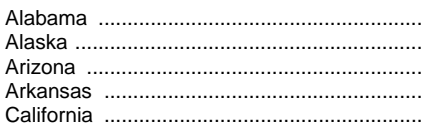 & $\begin{array}{r}203,165 \\
28,368 \\
254,530 \\
87,067 \\
1,564,230\end{array}$ & $\begin{array}{r}60,666 \\
5,171 \\
52,572 \\
25,493 \\
319,499\end{array}$ & $\begin{array}{r}72,704 \\
6,201 \\
57,142 \\
31,866 \\
362,281\end{array}$ & $\begin{array}{r}29,366 \\
6,290 \\
59,849 \\
11,145 \\
378,663\end{array}$ & $\begin{array}{r}40,429 \\
10,706 \\
84,967 \\
18,563 \\
503,787\end{array}$ & $\begin{array}{r}196,531 \\
27,828 \\
253,469 \\
89,457 \\
1,624,907\end{array}$ & $\begin{array}{r}58,741 \\
5,069 \\
53,035 \\
25,448 \\
323,279\end{array}$ & $\begin{array}{r}72,625 \\
6,114 \\
58,398 \\
32,168 \\
373,860\end{array}$ & $\begin{array}{r}27,430 \\
6,105 \\
59,357 \\
12,043 \\
396,407\end{array}$ & $\begin{array}{r}37,735 \\
10,540 \\
82,679 \\
19,798 \\
531,361\end{array}$ \\
\hline 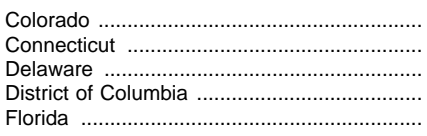 & $\begin{array}{r}210,312 \\
100,539 \\
36,204 \\
9,663 \\
530,607\end{array}$ & $\begin{array}{r}52,690 \\
21,063 \\
9,713 \\
1,444 \\
105,794\end{array}$ & $\begin{array}{r}55,717 \\
23,818 \\
12,429 \\
2,015 \\
126,880\end{array}$ & $\begin{array}{r}42,163 \\
21,226 \\
5,897 \\
2,482 \\
118,165\end{array}$ & $\begin{array}{r}59,742 \\
34,432 \\
8,165 \\
3,722 \\
179,768\end{array}$ & $\begin{array}{r}209,183 \\
97,588 \\
36,579 \\
7,456 \\
531,030\end{array}$ & $\begin{array}{r}52,670 \\
20,828 \\
9,902 \\
1,111 \\
105,225\end{array}$ & $\begin{array}{r}56,526 \\
23,509 \\
12,914 \\
1,502 \\
129,429\end{array}$ & $\begin{array}{r}41,417 \\
20,369 \\
5,642 \\
2,021 \\
117,791\end{array}$ & $\begin{array}{r}58,570 \\
32,882 \\
8,121 \\
2,822 \\
178,585\end{array}$ \\
\hline 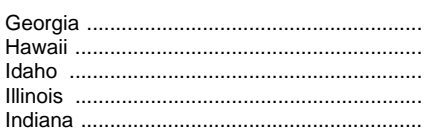 & $\begin{array}{r}248,682 \\
50,198 \\
48,986 \\
530,248 \\
224,795\end{array}$ & $\begin{array}{r}68,441 \\
12,419 \\
14,759 \\
116,061 \\
65,085\end{array}$ & $\begin{array}{r}86,296 \\
14,997 \\
15,562 \\
128,965 \\
71,868\end{array}$ & $\begin{array}{r}36,366 \\
9,392 \\
7,443 \\
114,352 \\
37,579\end{array}$ & $\begin{array}{r}57,579 \\
13,390 \\
11,222 \\
170,870 \\
50,263\end{array}$ & $\begin{array}{r}249,284 \\
47,370 \\
49,392 \\
532,470 \\
220,967\end{array}$ & $\begin{array}{r}68,799 \\
11,830 \\
14,959 \\
115,679 \\
65,790\end{array}$ & $\begin{array}{r}87,760 \\
14,261 \\
16,152 \\
130,360 \\
72,309\end{array}$ & $\begin{array}{r}35,959 \\
8,973 \\
7,319 \\
114,651 \\
35,575\end{array}$ & $\begin{array}{r}56,766 \\
12,306 \\
10,962 \\
171,780 \\
47,293\end{array}$ \\
\hline 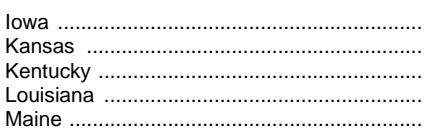 & $\begin{array}{r}122,396 \\
160,449 \\
148,808 \\
174,873 \\
38,195\end{array}$ & $\begin{array}{l}41,636 \\
41,551 \\
42,192 \\
54,727 \\
10,024\end{array}$ & $\begin{array}{l}42,672 \\
43,254 \\
53,218 \\
68,616 \\
10,288\end{array}$ & $\begin{array}{r}14,870 \\
29,814 \\
19,316 \\
18,188 \\
6,646\end{array}$ & $\begin{array}{l}23,218 \\
45,830 \\
34,082 \\
33,342 \\
11,237\end{array}$ & $\begin{array}{r}125,923 \\
155,429 \\
147,423 \\
174,589 \\
37,888\end{array}$ & $\begin{array}{r}42,482 \\
40,718 \\
41,903 \\
54,723 \\
9,866\end{array}$ & $\begin{array}{l}43,120 \\
42,407 \\
53,328 \\
69,386 \\
10,377\end{array}$ & $\begin{array}{r}16,122 \\
29,448 \\
19,031 \\
17,690 \\
6,439\end{array}$ & $\begin{array}{l}24,199 \\
42,856 \\
33,161 \\
32,790 \\
11,206\end{array}$ \\
\hline 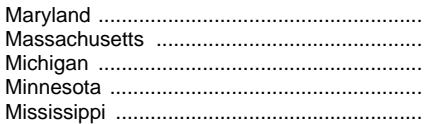 & $\begin{array}{l}222,857 \\
176,777 \\
462,390 \\
217,249 \\
110,600\end{array}$ & $\begin{array}{r}46,869 \\
43,528 \\
106,872 \\
55,886 \\
37,592\end{array}$ & $\begin{array}{r}56,092 \\
50,097 \\
119,925 \\
58,199 \\
45,524\end{array}$ & $\begin{array}{r}46,512 \\
32,004 \\
98,467 \\
43,815 \\
9,988\end{array}$ & $\begin{array}{r}73,384 \\
51,148 \\
137,126 \\
59,349 \\
17,496\end{array}$ & $\begin{array}{l}217,277 \\
173,416 \\
458,989 \\
208,540 \\
114,905\end{array}$ & $\begin{array}{r}46,829 \\
42,568 \\
106,972 \\
57,308 \\
38,142\end{array}$ & $\begin{array}{r}57,343 \\
49,371 \\
121,283 \\
61,630 \\
47,113\end{array}$ & $\begin{array}{l}43,239 \\
31,656 \\
96,597 \\
37,618 \\
11,122\end{array}$ & $\begin{array}{r}69,866 \\
49,821 \\
134,137 \\
51,984 \\
18,528\end{array}$ \\
\hline 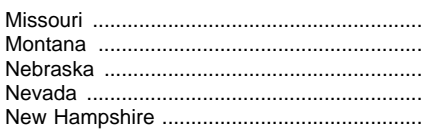 & $\begin{array}{r}189,993 \\
37,435 \\
95,599 \\
66,683 \\
36,069\end{array}$ & $\begin{array}{r}48,618 \\
14,596 \\
25,462 \\
9,790 \\
10,016\end{array}$ & $\begin{array}{l}56,455 \\
14,638 \\
26,147 \\
11,031 \\
11,947\end{array}$ & $\begin{array}{r}31,883 \\
3,320 \\
18,694 \\
19,698 \\
5,461\end{array}$ & $\begin{array}{r}53,037 \\
4,881 \\
25,296 \\
26,164 \\
8,645\end{array}$ & $\begin{array}{r}189,269 \\
38,000 \\
99,717 \\
71,925 \\
36,365\end{array}$ & $\begin{array}{r}48,602 \\
14,585 \\
25,969 \\
10,695 \\
9,852\end{array}$ & $\begin{array}{l}56,982 \\
14,835 \\
27,281 \\
11,944 \\
11,757\end{array}$ & $\begin{array}{r}31,333 \\
3,440 \\
19,711 \\
21,299 \\
5,625\end{array}$ & $\begin{array}{r}52,352 \\
5,140 \\
26,756 \\
27,987 \\
9,131\end{array}$ \\
\hline 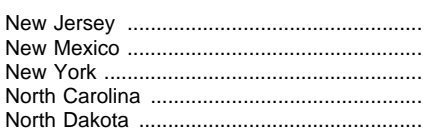 & $\begin{array}{r}271,069 \\
97,220 \\
588,491 \\
303,099 \\
36,810\end{array}$ & $\begin{array}{r}63,116 \\
21,459 \\
158,869 \\
79,417 \\
15,101\end{array}$ & $\begin{array}{r}73,508 \\
25,789 \\
197,894 \\
101,777 \\
13,936\end{array}$ & $\begin{array}{r}53,991 \\
19,638 \\
87,647 \\
49,422 \\
3,371\end{array}$ & $\begin{array}{r}80,454 \\
30,334 \\
144,081 \\
72,483 \\
4,402\end{array}$ & $\begin{array}{r}264,596 \\
97,630 \\
572,482 \\
302,939 \\
36,765\end{array}$ & $\begin{array}{r}62,969 \\
21,005 \\
156,287 \\
79,171 \\
15,056\end{array}$ & $\begin{array}{r}74,721 \\
25,536 \\
196,219 \\
103,283 \\
13,913\end{array}$ & $\begin{array}{r}50,532 \\
19,975 \\
83,524 \\
49,258 \\
3,468\end{array}$ & $\begin{array}{r}76,374 \\
31,114 \\
136,452 \\
71,227 \\
4,328\end{array}$ \\
\hline 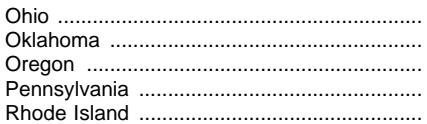 & $\begin{array}{r}409,818 \\
158,026 \\
143,617 \\
339,928 \\
38,653\end{array}$ & $\begin{array}{r}115,135 \\
42,828 \\
34,837 \\
104,724 \\
8,123\end{array}$ & $\begin{array}{r}133,907 \\
47,622 \\
36,319 \\
113,496 \\
11,040\end{array}$ & $\begin{array}{r}65,403 \\
27,747 \\
31,503 \\
47,661 \\
6,919\end{array}$ & $\begin{array}{l}95,373 \\
39,829 \\
40,958 \\
74,047 \\
12,571\end{array}$ & $\begin{array}{r}405,339 \\
154,381 \\
141,429 \\
335,181 \\
37,487\end{array}$ & $\begin{array}{r}113,072 \\
42,636 \\
35,501 \\
104,176 \\
7,922\end{array}$ & $\begin{array}{r}133,729 \\
47,018 \\
37,787 \\
114,027 \\
10,883\end{array}$ & $\begin{array}{r}64,332 \\
26,458 \\
29,666 \\
45,999 \\
6,660\end{array}$ & $\begin{array}{l}94,206 \\
38,269 \\
38,475 \\
70,979 \\
12,022\end{array}$ \\
\hline 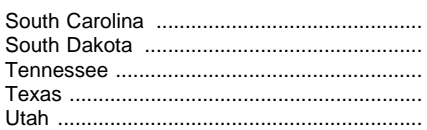 & $\begin{array}{r}148,706 \\
29,693 \\
193,136 \\
836,851 \\
110,560\end{array}$ & $\begin{array}{r}39,600 \\
10,710 \\
51,586 \\
205,744 \\
32,939\end{array}$ & $\begin{array}{r}48,272 \\
11,159 \\
63,275 \\
22,376 \\
32,010\end{array}$ & $\begin{array}{r}22,148 \\
2,858 \\
32,233 \\
174,241 \\
22,957\end{array}$ & $\begin{array}{r}38,686 \\
4,966 \\
46,042 \\
231,490 \\
22,654\end{array}$ & $\begin{array}{r}148,363 \\
28,564 \\
194,097 \\
838,091 \\
114,195\end{array}$ & $\begin{array}{r}39,825 \\
10,209 \\
51,535 \\
206,177 \\
31,794\end{array}$ & $\begin{array}{r}49,454 \\
10,784 \\
64,945 \\
229,838 \\
31,476\end{array}$ & $\begin{array}{r}21,248 \\
2,845 \\
32,008 \\
172,222 \\
25,349\end{array}$ & $\begin{array}{r}37,836 \\
4,726 \\
45,609 \\
229,854 \\
25,576\end{array}$ \\
\hline 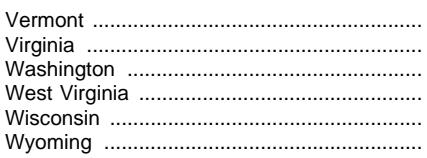 & $\begin{array}{r}20,470 \\
293,127 \\
246,635 \\
74,857 \\
245,770 \\
29,420\end{array}$ & $\begin{array}{r}6,094 \\
73,170 \\
69,018 \\
25,009 \\
68,248 \\
7,783\end{array}$ & $\begin{array}{r}6,749 \\
83,865 \\
78,010 \\
25,724 \\
77,247 \\
9,061\end{array}$ & $\begin{array}{r}2,464 \\
55,091 \\
40,335 \\
8,542 \\
41,414 \\
4,543\end{array}$ & $\begin{array}{r}5,163 \\
81,001 \\
59,272 \\
15,582 \\
58,861 \\
8,033\end{array}$ & $\begin{array}{r}20,139 \\
292,412 \\
251,869 \\
74,755 \\
244,628 \\
29,994\end{array}$ & $\begin{array}{r}6,177 \\
73,540 \\
69,556 \\
24,858 \\
68,582 \\
7,642\end{array}$ & $\begin{array}{r}6,738 \\
84,570 \\
79,870 \\
25,898 \\
77,531 \\
9,110\end{array}$ & $\begin{array}{r}2,359 \\
54,098 \\
41,608 \\
8,742 \\
40,930 \\
4,690\end{array}$ & $\begin{array}{r}4,865 \\
80,204 \\
60,835 \\
15,257 \\
57,585 \\
8,552\end{array}$ \\
\hline U.S. Service Schools & 88,451 & 16,006 & 2,676 & 58,708 & 11,061 & 81,669 & 16,649 & 2,882 & 52,219 & 9,919 \\
\hline Outlying areas & 77,050 & 22,397 & 36,464 & 6,978 & 11,211 & 79,861 & 23,347 & 39,099 & 6,616 & 10,799 \\
\hline 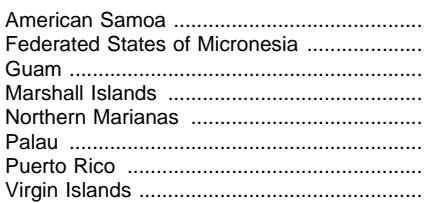 & $\begin{array}{r}1,232 \\
1,296 \\
6,010 \\
418 \\
959 \\
351 \\
63,730 \\
3,054\end{array}$ & $\begin{array}{r}428 \\
518 \\
989 \\
89 \\
203 \\
143 \\
19,705 \\
322\end{array}$ & $\begin{array}{r}436 \\
447 \\
1,597 \\
75 \\
253 \\
125 \\
32,461 \\
1,070\end{array}$ & $\begin{array}{r}217 \\
150 \\
1,567 \\
146 \\
188 \\
31 \\
4,232 \\
447\end{array}$ & $\begin{array}{r}151 \\
181 \\
1,857 \\
108 \\
315 \\
52 \\
7,332 \\
1,215\end{array}$ & $\begin{array}{r}1,239 \\
1,396 \\
5,335 \\
431 \\
1,096 \\
332 \\
67,134 \\
2,898\end{array}$ & $\begin{array}{r}435 \\
471 \\
944 \\
125 \\
223 \\
143 \\
20,690 \\
316\end{array}$ & $\begin{array}{r}442 \\
476 \\
1,549 \\
109 \\
267 \\
112 \\
35,131 \\
1,013\end{array}$ & $\begin{array}{r}215 \\
184 \\
1,270 \\
115 \\
221 \\
28 \\
4,200 \\
383\end{array}$ & $\begin{array}{r}147 \\
265 \\
1,572 \\
82 \\
385 \\
49 \\
7,113 \\
1,186\end{array}$ \\
\hline
\end{tabular}

\footnotetext{
1 Preliminary data.
}

SOURCE: U.S. Department of Education, National Center for Education Statistics, In(This 
Table 195.-Total fall enrollment in private institutions of higher education, by attendance status, sex, and state: 1995 and 1996

\begin{tabular}{|c|c|c|c|c|c|c|c|c|c|c|}
\hline \multirow{3}{*}{ State or other area } & \multicolumn{5}{|c|}{ Fall 1995} & \multicolumn{5}{|c|}{ Fall 19961} \\
\hline & \multirow{2}{*}{ Total } & \multicolumn{2}{|c|}{ Full-time } & \multicolumn{2}{|c|}{ Part-time } & \multirow{2}{*}{ Total } & \multicolumn{2}{|c|}{ Full-time } & \multicolumn{2}{|c|}{ Part-time } \\
\hline & & Men & Women & Men & Women & & Men & Women & Men & Women \\
\hline 1 & 2 & 3 & 4 & 5 & 6 & 7 & 8 & 9 & 10 & 11 \\
\hline United States & $3,169,407$ & $1,037,647$ & $1,165,854$ & 397,257 & 568,649 & $3,210,084$ & $1,047,601$ & $1,201,715$ & 408,854 & 551,914 \\
\hline Alabama & 22,447 & 8,047 & 10,327 & 1,698 & 2,375 & 22,968 & 7,966 & 10,989 & 1,549 & 2,464 \\
\hline Alaska ........ & 980 & 253 & 358 & 154 & 215 & 1,018 & 282 & 419 & 120 & 197 \\
\hline 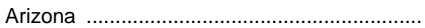 & 19,451 & 9,113 & 7,227 & 1,377 & 1,734 & 23,363 & 10,738 & 8,968 & 1,605 & 2,052 \\
\hline Arkansas & 11,113 & 4,584 & 5,235 & 481 & 813 & 11,231 & 4,605 & 5,494 & 445 & 687 \\
\hline 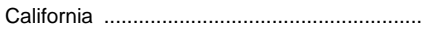 & 252,812 & 88,877 & 96,259 & 31,604 & 36,072 & 257,727 & 90,614 & 99,639 & 31,002 & 36,472 \\
\hline Colorado & 32,427 & 10,202 & 10,277 & 5,954 & 5,994 & 33,766 & 10,659 & 11,210 & 5,788 & 6,109 \\
\hline 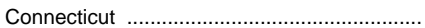 & 57,156 & 17,814 & 19,404 & 8,397 & 11,541 & 57,773 & 18,380 & 20,187 & 8,015 & 11,191 \\
\hline Delaware ………............. & 8,103 & 1,574 & 1,823 & 1,679 & 3,027 & 8,259 & 1,506 & 1,872 & 1,638 & 3,243 \\
\hline District of Columbia & 67,614 & 21,262 & 25,628 & 9,325 & 11,399 & 66,783 & 20,958 & 25,781 & 8,941 & 11,103 \\
\hline 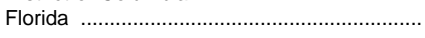 & 106,696 & 36,574 & 35,292 & 17,259 & 17,571 & 110,143 & 36,938 & 37,467 & 17,009 & 18,729 \\
\hline Georgia & 66,030 & 25,521 & 29,367 & 4,554 & 6,588 & 68,715 & 26,194 & 31,213 & 4,379 & 6,929 \\
\hline Hawaii . & 13,000 & 3,756 & 4,169 & 2,638 & 2,437 & 14,013 & 4,162 & 5,072 & 2,469 & 2,310 \\
\hline 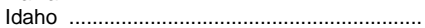 & 10,580 & 4,254 & 5,574 & 263 & 489 & 10,512 & 4,225 & 5,498 & 254 & 535 \\
\hline 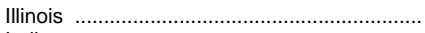 & 187,606 & 58,908 & 64,465 & 26,971 & 37,262 & 188,517 & 59,165 & 65,711 & 26,574 & 37,067 \\
\hline Indiana & 64,820 & 25,856 & 26,950 & 3,719 & 8,295 & 65,359 & 26,000 & 27,381 & 3,790 & 8,188 \\
\hline lowa . & 51,439 & 16,917 & 19,498 & 4,608 & 10,416 & 51,098 & 16,645 & 19,611 & 5,418 & 9,424 \\
\hline 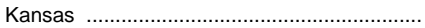 & 17,194 & 5,843 & 6,890 & 1,632 & 2,829 & 16,921 & 5,700 & 6,854 & 1,590 & 2,777 \\
\hline Kentucky & 30,050 & 10,037 & 12,211 & 2,709 & 5,093 & 30,326 & 10,152 & 12,548 & 2,758 & 4,868 \\
\hline Louisiana & 29,062 & 9,565 & 11,355 & 3,632 & 4,510 & 28,928 & 9,046 & 11,641 & 4,138 & 4,103 \\
\hline 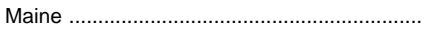 & 18,352 & 4,608 & 6,632 & 1,332 & 5,780 & 17,757 & 4,739 & 6,769 & 1,267 & 4,982 \\
\hline Maryland ... & 43,453 & 10,953 & 12,597 & 7,563 & 12,340 & 43,480 & 11,038 & 13,008 & 7,346 & 12,088 \\
\hline 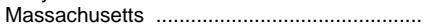 & 237,017 & 78,142 & 90,246 & 27,058 & 41,571 & 236,911 & 78,037 & 91,365 & 26,968 & 40,541 \\
\hline 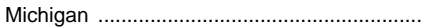 & 85,949 & 20,532 & 26,921 & 15,289 & 23,207 & 87,985 & 20,905 & 29,171 & 14,823 & 23,086 \\
\hline Minnesota & 63,567 & 19,033 & 24,982 & 7,565 & 11,987 & 66,722 & 19,395 & 25,913 & 7,218 & 14,196 \\
\hline 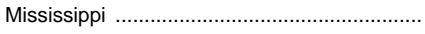 & 12,090 & 3,798 & 5,053 & 1,231 & 2,008 & 11,329 & 3,499 & 4,712 & 1,132 & 1,986 \\
\hline Missouri & 101,543 & 29,240 & 31,815 & 17,519 & 22,969 & 101,264 & 30,711 & 33,379 & 16,019 & 21,155 \\
\hline 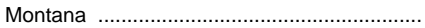 & 5,239 & 1,371 & 2,151 & 671 & 1,046 & 5,145 & 1,345 & 2,178 & 640 & 982 \\
\hline 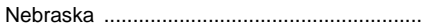 & 20,119 & 6,663 & 8,382 & 1,633 & 3,441 & 19,583 & 6,569 & 8,498 & 1,459 & 3,057 \\
\hline 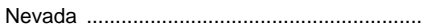 & 1,143 & 406 & 493 & 89 & 155 & 1,542 & 552 & 643 & 113 & 234 \\
\hline 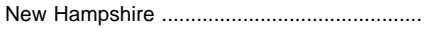 & 28,258 & 8,291 & 9,651 & 3,609 & 6,707 & 28,098 & 8,268 & 9,587 & 3,593 & 6,650 \\
\hline New Jersey & 62,762 & 18,828 & 19,482 & 9,704 & 14,748 & 63,592 & 19,444 & 19,843 & 9,569 & 14,736 \\
\hline 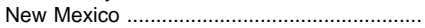 & 5,185 & 1,847 & 2,421 & 262 & 655 & 5,916 & 2,089 & 2,790 & 303 & 734 \\
\hline New York & 453,075 & 142,843 & 165,358 & 54,779 & 90,095 & 455,388 & 142,696 & 169,941 & 54,013 & 88,738 \\
\hline 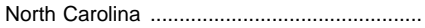 & 68,931 & 26,339 & 30,555 & 4,826 & 7,211 & 70,229 & 26,751 & 31,643 & 4,784 & 7,051 \\
\hline 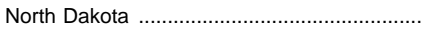 & 3,589 & 1,361 & 1,820 & 109 & 299 & 3,789 & 1,398 & 1,938 & 134 & 319 \\
\hline Ohio ........... & 130,457 & 42,257 & 46,245 & 19,245 & 22,710 & 132,196 & 43,394 & 47,232 & 19,283 & 22,287 \\
\hline 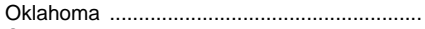 & 22,650 & 9,020 & 8,596 & 2,675 & 2,359 & 22,874 & 9,019 & 8,691 & 2,727 & 2,437 \\
\hline 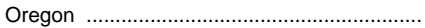 & 23,528 & 8,377 & 9,748 & 2,289 & 3,114 & 23,739 & 8,337 & 10,048 & 2,386 & 2,968 \\
\hline 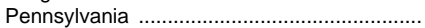 & 277,831 & 81,711 & 88,388 & 43,832 & 63,900 & 286,813 & 82,293 & 90,513 & 60,384 & 53,623 \\
\hline 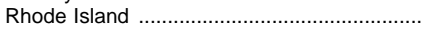 & 35,447 & 14,399 & 13,268 & 3,723 & 4,057 & 34,945 & 14,241 & 13,325 & 3,510 & 3,869 \\
\hline South Carolina & 25,419 & 9,380 & 11,887 & 1,518 & 2,634 & 25,940 & 9,587 & 12,406 & 1,432 & 2,515 \\
\hline South Dakota & 7,002 & 1,876 & 2,862 & 752 & 1,512 & 6,809 & 1,884 & 2,884 & 658 & 1,383 \\
\hline 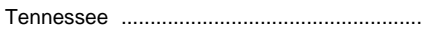 & 52,826 & 21,424 & 23,315 & 3,085 & 5,002 & 52,946 & 21,424 & 23,994 & 3,075 & 4,453 \\
\hline Texas & 115,674 & 42,853 & 41,898 & 15,337 & 15,586 & 117,348 & 42,513 & 42,950 & 15,850 & 16,035 \\
\hline 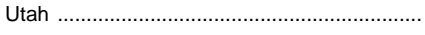 & 36,764 & 16,079 & 16,675 & 1,897 & 2,113 & 37,442 & 16,044 & 16,818 & 2,412 & 2,168 \\
\hline Vermont & 14,595 & 5,144 & 5,990 & 1,135 & 2,326 & 14,951 & 5,111 & 6,145 & 1,135 & 2,560 \\
\hline Virginia & 62,792 & 18,400 & 25,029 & 8,303 & 11,060 & 61,376 & 18,765 & 25,355 & 7,366 & 9,890 \\
\hline 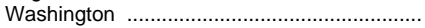 & 39,184 & 12,896 & 15,826 & 4,250 & 6,212 & 40,311 & 13,163 & 17,010 & 4,208 & 5,930 \\
\hline 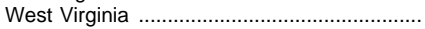 & 11,177 & 3,839 & 5,211 & 649 & 1,478 & 10,934 & 3,697 & 5,205 & 640 & 1,392 \\
\hline Wisconsin & 54,453 & 16,031 & 20,041 & 6,674 & 11,707 & 54,499 & 15,960 & 20,193 & 6,925 & 11,421 \\
\hline Wyoming & 756 & 749 & 7 & - & - & 811 & 798 & 13 & - & - \\
\hline Outlying areas & 106,607 & 31,129 & 47,415 & 11,566 & 16,497 & 101,799 & 29,458 & 46,158 & 11,314 & 14,869 \\
\hline American Samoa & - & - & - & - & - & - & - & - & - & - \\
\hline 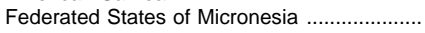 & - & - & - & 一 & - & - & - & - & - & - \\
\hline Guam & - & - & - & - & - & - & - & - & - & - \\
\hline Marshall Islands & - & - & - & - & - & - & - & - & - & - \\
\hline Northern Marianas & - & - & - & - & - & - & - & - & - & - \\
\hline Palau & - & - & - & - & - & - & - & - & - & - \\
\hline Puerto Rico & 106,607 & 31,129 & 47,415 & 11,566 & 16,497 & 101,799 & 29,458 & 46,158 & 11,314 & 14,869 \\
\hline Virgin Islands & - & - & - & - & - & - & - & - & - & 一 \\
\hline
\end{tabular}

1 Preliminary data.

—Data not reported or not applicable.
SOURCE: U.S. Department of Education, National Center for Education Statistics, Integrated Postsecondary Education Data System (IPEDS), "Fall Enrollment" surveys. (This table was prepared May 1998). 
Table 196.-Total fall enrollment in institutions of higher education, by control, type of institution, and state: 1995 and 1996

\begin{tabular}{|c|c|c|c|c|c|c|c|c|c|c|c|c|}
\hline \multirow{3}{*}{ State or other area } & \multicolumn{6}{|c|}{ Fall 1995} & \multicolumn{6}{|c|}{ Fall 19961} \\
\hline & \multirow{2}{*}{$\begin{array}{l}\text { Public } \\
4 \text {-year }\end{array}$} & \multirow{2}{*}{$\begin{array}{l}\text { Public } \\
2 \text {-year }\end{array}$} & \multicolumn{2}{|c|}{$\begin{array}{l}\text { Private } \\
4 \text {-year }\end{array}$} & \multicolumn{2}{|c|}{$\begin{array}{l}\text { Private } \\
2 \text {-year }\end{array}$} & \multirow{2}{*}{$\begin{array}{l}\text { Public } \\
\text { 4-year }\end{array}$} & \multirow{2}{*}{$\begin{array}{l}\text { Public } \\
2 \text {-year }\end{array}$} & \multicolumn{2}{|c|}{$\begin{array}{l}\text { Private } \\
\text { 4-year }\end{array}$} & $\begin{array}{l}\text { Priv } \\
2-y\end{array}$ & \\
\hline & & & Total & Nonprofit & Total & Nonprofit & & & Total & Nonprofit & Total & Nonprofit \\
\hline 1 & 2 & 3 & 4 & 5 & 6 & 7 & 8 & 9 & 10 & 11 & 12 & 13 \\
\hline United States .................... & $5,814,545$ & $5,277,829$ & $2,954,707$ & $2,853,890$ & 214,700 & 75,154 & $5,806,904$ & $5,283,267$ & $2,995,931$ & $2,871,693$ & 214,153 & 68,864 \\
\hline Alabama & 126,508 & 76,657 & 21,949 & 21,949 & 498 & 223 & 122,796 & 73,735 & 21,869 & 21,869 & 1,099 & 169 \\
\hline Alaska ... & 27,556 & 812 & 776 & 776 & 204 & - & 27,077 & 751 & 692 & 692 & 326 & - \\
\hline 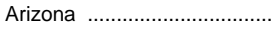 & 101,718 & 152,812 & 18,562 & 7,579 & 889 & - & 102,501 & 150,968 & 22,402 & 8,691 & 961 & - \\
\hline Arkansas & 62,809 & 24,258 & 10,667 & 10,667 & 446 & 446 & 62,094 & 27,363 & 10,825 & 10,825 & 406 & 406 \\
\hline California & 490,231 & $1,073,999$ & 238,755 & 217,702 & 14,057 & 7,853 & 504,803 & $1,120,104$ & 243,468 & 217,372 & 14,259 & 9,125 \\
\hline Colorado ………… & 132,616 & 77,696 & 28,804 & 22,644 & 3,623 & 39 & 132,293 & 76,890 & 32,205 & 23,049 & 1,561 & 40 \\
\hline Connecticut ............................. & 57,711 & 42,828 & 55,594 & 55,344 & 1,562 & 1,021 & 56,548 & 41,040 & 56,217 & 55,963 & 1,556 & 983 \\
\hline Delaware & 24,540 & 11,664 & 8,103 & 8,103 & - & - & 24,708 & 11,871 & 8,259 & 8,259 & - & - \\
\hline District of Columbia ................ & 9,663 & - & 67,614 & 65,481 & - & - & 7,456 & - & 66,783 & 64,306 & - & - \\
\hline 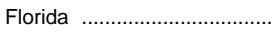 & 206,961 & 323,646 & 101,265 & 92,456 & 5,431 & 1,094 & 211,159 & 319,871 & 104,308 & 94,287 & 5,835 & - \\
\hline Georgia & 160,425 & 88,257 & 61,480 & 55,870 & 4,550 & 3,127 & 159,013 & 90,271 & 64,257 & 57,592 & 4,458 & 3,251 \\
\hline Hawaii & 23,345 & 26,853 & 13,000 & 12,900 & - & - & 21,691 & 25,679 & 14,013 & 13,338 & - & - \\
\hline Idaho & 41,449 & 7,537 & 2,308 & 2,308 & 8,272 & 7,956 & 41,344 & 8,048 & 2,390 & 2,390 & 8,122 & 7,755 \\
\hline Illinois & 192,532 & 337,716 & 183,336 & 172,421 & 4,270 & 3,564 & 192,319 & 340,151 & 184,393 & 172,466 & 4,124 & 3,443 \\
\hline 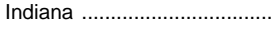 & 184,184 & 40,611 & 61,331 & 59,622 & 3,489 & 2,118 & 182,946 & 38,021 & 61,849 & 60,064 & 3,510 & 2,190 \\
\hline lowa & 65,841 & 56,555 & 50,324 & 50,020 & 1,115 & 1,115 & 66,539 & 59,384 & 50,044 & 49,757 & 1,054 & 1,054 \\
\hline Kansas & 86,770 & 73,679 & 16,316 & 16,316 & 878 & 878 & 85,934 & 69,495 & 16,048 & 16,048 & 873 & 873 \\
\hline 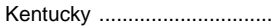 & 105,529 & 43,279 & 27,382 & 25,235 & 2,668 & 937 & 104,317 & 43,106 & 27,717 & 25,425 & 2,609 & 346 \\
\hline 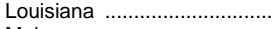 & 147,920 & 26,953 & 27,884 & 27,393 & 1,178 & 768 & 147,238 & 27,351 & 27,507 & 25,930 & 1,421 & 1,421 \\
\hline 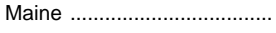 & 31,275 & 6,920 & 16,437 & 16,437 & 1,915 & 85 & 30,979 & 6,909 & 15,946 & 15,946 & 1,811 & 88 \\
\hline 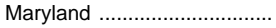 & 113,738 & 109,119 & 42,267 & 42,267 & 1,186 & 669 & 113,159 & 104,118 & 42,299 & 42,299 & 1,181 & 660 \\
\hline Massachusetts …….................. & 101,814 & 74,963 & 228,964 & 228,897 & 8,053 & 7,382 & 101,824 & 71,592 & 229,983 & 229,922 & 6,928 & 6,195 \\
\hline 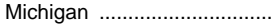 & 258,996 & 203,394 & 83,304 & 83,304 & 2,645 & 2,645 & 259,414 & 199,575 & 86,298 & 85,688 & 1,687 & 1,687 \\
\hline 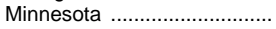 & 117,188 & 100,061 & 59,410 & 58,318 & 4,157 & 1,905 & 117,831 & 90,709 & 61,954 & 60,278 & 4,768 & 2,029 \\
\hline 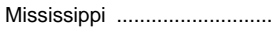 & 58,847 & 51,753 & 11,278 & 11,278 & 812 & 812 & 60,560 & 54,345 & 10,614 & 10,614 & 715 & 715 \\
\hline Missouri ......................... & 117,871 & 72,122 & 96,946 & 93,909 & 4,597 & 2,629 & 117,213 & 72,056 & 96,973 & 93,677 & 4,291 & 2,437 \\
\hline 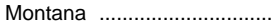 & 31,412 & 6,023 & 4,319 & 4,319 & 920 & 920 & 31,697 & 6,303 & 4,314 & 4,314 & 831 & 831 \\
\hline 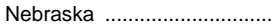 & 58,081 & 37,518 & 19,575 & 19,575 & 544 & - & 57,266 & 42,451 & 19,583 & 19,583 & - & - \\
\hline 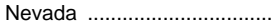 & 30,831 & 35,852 & 1,116 & 466 & 27 & 27 & 30,988 & 40,937 & 1,518 & 583 & 24 & 24 \\
\hline New Hampshire ......................... & 26,497 & 9,572 & 24,227 & 24,227 & 4,031 & 491 & 26,547 & 9,818 & 24,229 & 24,229 & 3,869 & 392 \\
\hline New Jersey ..... & 137,829 & 133,240 & 58,045 & 58,045 & 4,717 & 167 & 137,493 & 127,103 & 58,402 & 58,402 & 5,190 & 131 \\
\hline New Mexico ……..................... & 49,819 & 47,401 & 4,231 & 2,598 & 954 & - & 48,818 & 48,812 & 4,865 & 2,819 & 1,051 & - \\
\hline 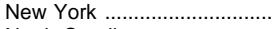 & 335,728 & 252,763 & 425,065 & 419,181 & 28,010 & 6,446 & 328,666 & 243,816 & 431,012 & 421,722 & 24,376 & 6,077 \\
\hline North Carolina & 157,414 & 145,685 & 67,448 & 67,448 & 1,483 & 1,339 & 156,539 & 146,400 & 69,220 & 69,220 & 1,009 & 893 \\
\hline North Dakota ........................... & 28,396 & 8,414 & 3,334 & 3,334 & 255 & 255 & 28,052 & 8,713 & 3,514 & 3,514 & 275 & 275 \\
\hline Ohio & 262,036 & 147,782 & 117,115 & 114,199 & 13,342 & 3,043 & 258,417 & 146,922 & 118,757 & 115,767 & 13,439 & 3,109 \\
\hline 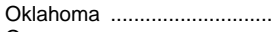 & 95,387 & 62,639 & 20,621 & 20,621 & 2,029 & 719 & 93,778 & 60,603 & 20,837 & 20,837 & 2,037 & 755 \\
\hline Oregon & 63,056 & 80,561 & 23,359 & 22,748 & 169 & - & 64,413 & 77,016 & 23,739 & 23,092 & - & - \\
\hline 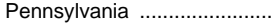 & 233,433 & 106,495 & 220,269 & 220,134 & 57,562 & 6,708 & 232,223 & 102,958 & 219,848 & 219,734 & 66,965 & 7,420 \\
\hline Rhode Island ............................. & 22,764 & 15,889 & 33,021 & 33,021 & 2,426 & 2,426 & 22,251 & 15,236 & 34,945 & 34,945 & & 一 \\
\hline South Carolina & 87,813 & 60,893 & 24,124 & 24,124 & 1,295 & 804 & 87,344 & 61,019 & 24,626 & 24,626 & 1,314 & 765 \\
\hline South Dakota & 29,484 & 209 & 6,769 & 4,968 & 233 & 233 & 28,367 & 197 & 6,605 & 4,906 & 204 & 204 \\
\hline 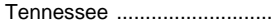 & 115,042 & 78,094 & 50,388 & 50,001 & 2,438 & 1,098 & 115,467 & 78,630 & 51,065 & 50,257 & 1,881 & 621 \\
\hline Texas & 417,431 & 419,420 & 109,724 & 107,409 & 5,950 & 763 & 414,021 & 424,070 & 111,166 & 108,747 & 6,182 & 796 \\
\hline 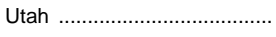 & 80,088 & 30,472 & 35,505 & 33,287 & 1,259 & 830 & 81,313 & 32,882 & 36,186 & 33,313 & 1,256 & 801 \\
\hline Vermont & 15,835 & 4,635 & 14,394 & 14,394 & 201 & 201 & 15,578 & 4,561 & 14,717 & 14,717 & 234 & 234 \\
\hline 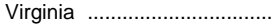 & 164,782 & 128,345 & 57,917 & 51,461 & 4,875 & 1,266 & 167,809 & 124,603 & 56,762 & 49,774 & 4,614 & 539 \\
\hline Washington & 86,080 & 160,555 & 36,950 & 36,400 & 2,234 & 16 & 87,304 & 164,565 & 37,785 & 37,299 & 2,526 & 16 \\
\hline West Virginia ............................ & 67,877 & 6,980 & 10,391 & 10,391 & 786 & - & 68,036 & 6,719 & 10,187 & 10,187 & 747 & - \\
\hline 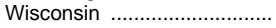 & 139,192 & 106,578 & 52,744 & 52,343 & 1,709 & 136 & 140,964 & 103,664 & 52,736 & 52,359 & 1,763 & 114 \\
\hline Wyoming & 11,361 & 18,059 & - & & 756 & - & 11,251 & 18,743 & - & & 811 & - \\
\hline U.S. Service Schools ............ & 18,840 & 69,611 & 一 & - & - & - & 18,546 & 63,123 & 一 & - & 一 & 一 \\
\hline Outlying areas ……............ & 62,568 & 14,482 & 97,712 & 95,142 & 8,895 & 1,363 & 67,569 & 12,292 & 92,849 & 89,815 & 8,950 & 1,074 \\
\hline American Samoa & - & 1,232 & - & - & - & - & - & 1,239 & - & - & - & - \\
\hline $\begin{array}{l}\text { Federated States of Micro- } \\
\text { nesia }\end{array}$ & - & 1,296 & - & - & - & - & - & 1,396 & - & - & - & - \\
\hline Guam & 3,654 & 2,356 & - & - & - & - & 3,383 & 1,952 & - & - & - & - \\
\hline Marshall Islands ....................... & - & 418 & - & - & - & - & - & 431 & - & - & - & - \\
\hline Northern Marianas ................ & - & 959 & - & - & - & - & - & 1,096 & - & 一 & - & 一 \\
\hline . & - & 351 & - & - & - & - & - & 332 & - & - & - & - \\
\hline 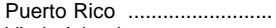 & 55,860 & 7,870 & 97,712 & 95,142 & 8,895 & 1,363 & 61,288 & 5,846 & 92,849 & 89,815 & 8,950 & 1,074 \\
\hline 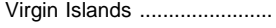 & 3,054 & - & - & - & - & - & 2,898 & - & - & - & - & - \\
\hline
\end{tabular}

1 Preliminary data.

-Data not reported or not applicable.
SOURCE: U.S. Department of Education, National Center for Education Statistics, Integrated Postsecondary Education Data System (IPEDS), "Fall Enrollment" surveys. (This table was prepared January 1999.) 
Table 197.-Total fall enrollment in institutions of higher education, by level of enrollment and state: 1994 to 1996

\begin{tabular}{|c|c|c|c|c|c|c|c|c|c|c|c|}
\hline \multirow[b]{2}{*}{ State or other area } & \multicolumn{4}{|c|}{ Fall 1994} & \multicolumn{3}{|c|}{ Fall 1995} & \multicolumn{4}{|c|}{ Fall $1996^{1}$} \\
\hline & Total & $\begin{array}{l}\text { Under- } \\
\text { graduate }\end{array}$ & $\begin{array}{l}\text { First-pro- } \\
\text { fessional }\end{array}$ & Graduate & $\begin{array}{l}\text { Under- } \\
\text { graduate }\end{array}$ & $\begin{array}{c}\text { First-profes- } \\
\text { sional }\end{array}$ & Graduate & Total & $\begin{array}{l}\text { Under- } \\
\text { graduate }\end{array}$ & $\begin{array}{l}\text { First-profes- } \\
\text { sional }\end{array}$ & Graduate \\
\hline 1 & 2 & 3 & 4 & 5 & 6 & 7 & 8 & 9 & 10 & 11 & 12 \\
\hline United States. & $14,278,790$ & $12,262,608$ & 294,713 & $1,721,469$ & $12,231,719$ & 297,592 & $1,732,470$ & $14,300,255$ & $12,259,417$ & 297,739 & $1,743,099$ \\
\hline Alabama & 229,511 & 202,408 & 3,834 & 23,269 & 198,050 & 4,139 & 23,423 & 219,499 & 192,979 & 4,141 & 22,379 \\
\hline Alaska ........ & 28,798 & 27,189 & - & 1,609 & 27,657 & & 1,691 & 28,846 & 27,291 & - & 1,555 \\
\hline Arizona …….................. & 274,932 & 241,290 & 1,549 & 32,093 & 242,113 & 1,561 & 30,307 & 276,832 & 243,247 & 1,553 & 32,032 \\
\hline Arkansas . & 96,294 & 87,197 & 1,705 & 7,392 & 88,460 & 1,702 & 8,018 & 100,688 & 90,840 & 1,667 & 8,181 \\
\hline 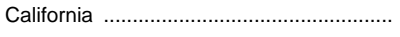 & $1,835,791$ & $1,624,924$ & 35,340 & 175,527 & $1,605,825$ & 35,547 & 175,670 & $1,882,634$ & $1,666,592$ & 33,404 & 182,638 \\
\hline Colorado ....... & 241,295 & 201,110 & 3,206 & 36,979 & 201,005 & 3,130 & 38,604 & 242,949 & 202,559 & 3,173 & 37,217 \\
\hline Connecticut & 159,990 & 125,939 & 3,394 & 30,657 & 124,063 & 3,416 & 30,216 & 155,361 & 121,831 & 3,407 & 30,123 \\
\hline Delaware ..... & 44,197 & 38,296 & 1,333 & 4,568 & 38,177 & 1,289 & 4,841 & 44,838 & 38,624 & 1,272 & 4,942 \\
\hline District of Columbia ..................................... & 77,256 & 43,623 & 8,819 & 24,814 & 43,365 & 9,068 & 24,844 & 74,239 & 41,004 & 8,956 & 24,279 \\
\hline 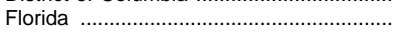 & 634,237 & 562,961 & 8,653 & 62,623 & 564,635 & 9,284 & 63,384 & 641,173 & 566,243 & 9,870 & 65,060 \\
\hline Georgia & 308,587 & 263,604 & 9,595 & 35,388 & 267,900 & 10,060 & 36,752 & 317,999 & 270,167 & 10,222 & 37,610 \\
\hline Hawaii .. & 64,322 & 55,850 & 495 & 7,977 & 54,901 & 498 & 7,799 & 61,383 & 53,438 & 467 & 7,478 \\
\hline 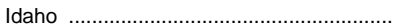 & 60,393 & 51,783 & 559 & 8,051 & 51,978 & 529 & 7,059 & 59,904 & 52,594 & 546 & 6,764 \\
\hline Illinois ........ & 731,420 & 617,549 & 17,173 & 96,698 & 601,745 & 17,368 & 98,741 & 720,987 & 604,941 & 17,208 & 98,838 \\
\hline 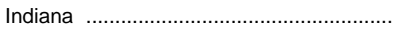 & 292,276 & 252,801 & 5,513 & 33,962 & 249,847 & 5,339 & 34,429 & 286,326 & 246,852 & 5,432 & 34,042 \\
\hline lowa ........... & 172,450 & 149,331 & 6,650 & 16,469 & 151,082 & 6,568 & 16,185 & 177,021 & 154,081 & 6,463 & 16,477 \\
\hline 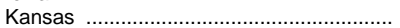 & 170,603 & 148,046 & 2,075 & 20,482 & 155,852 & 2,074 & 19,717 & 172,350 & 150,015 & 2,101 & 20,234 \\
\hline Kentucky . & 182,577 & 158,177 & 4,512 & 19,888 & 153,840 & 4,647 & 20,371 & 177,749 & 152,535 & 4,783 & 20,431 \\
\hline 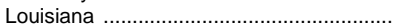 & 203,567 & 172,561 & 6,102 & 24,904 & 171,941 & 6,129 & 25,865 & 203,517 & 172,017 & 6,058 & 25,442 \\
\hline 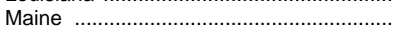 & 56,724 & 50,274 & 667 & 5,783 & 49,730 & 681 & 6,136 & 55,645 & 49,109 & 713 & 5,823 \\
\hline Maryland & 266,214 & 220,535 & 4,173 & 41,506 & 218,536 & 4,410 & 43,364 & 260,757 & 213,735 & 4,305 & 42,717 \\
\hline 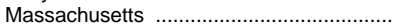 & 416,505 & 323,868 & 13,283 & 79,354 & 319,541 & 13,450 & 80,803 & 410,327 & 315,321 & 13,494 & 81,512 \\
\hline Michigan & 551,307 & 474,357 & 10,681 & 66,269 & 470,493 & 10,719 & 67,127 & 546,974 & 467,576 & 10,445 & 68,953 \\
\hline 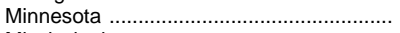 & 289,300 & 251,649 & 5,838 & 31,813 & 242,048 & 6,085 & 32,683 & 275,262 & 234,087 & 6,223 & 34,952 \\
\hline Mississippi & 120,884 & 108,003 & 1,895 & 10,986 & 109,298 & 1,759 & 11,633 & 126,234 & 112,430 & 1,867 & 11,937 \\
\hline Missouri . & 293,810 & 247,484 & 10,208 & 36,118 & 242,876 & 9,370 & 39,290 & 290,533 & 240,430 & 9,665 & 40,438 \\
\hline Montana & 40,095 & 36,414 & 235 & 3,446 & 39,113 & 236 & 3,325 & 43,145 & 39,628 & 227 & 3,290 \\
\hline 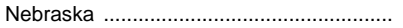 & 116,000 & 100,482 & 3,219 & 12,299 & 100,107 & 3,165 & 12,446 & 119,300 & 103,799 & 3,116 & 12,385 \\
\hline 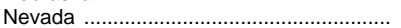 & 64,085 & 57,103 & 218 & 6,764 & 60,398 & 211 & 7,217 & 73,467 & 65,835 & 205 & 7,427 \\
\hline New Hampshire ............................................. & 62,847 & 53,154 & 724 & 8,969 & 54,114 & 702 & 9,511 & 64,463 & 54,428 & 710 & 9,325 \\
\hline New Jersey ..... & 335,480 & 286,020 & 6,588 & 42,872 & 284,552 & 6,611 & 42,668 & 328,188 & 279,431 & 6,586 & 42,171 \\
\hline New Mexico …………… & 101,881 & 88,643 & 625 & 12,613 & 88,793 & 635 & 12,977 & 103,546 & 89,360 & 871 & 13,315 \\
\hline 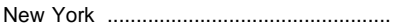 & $1,057,841$ & 856,719 & 27,707 & 173,415 & 841,352 & 27,783 & 172,431 & $1,027,870$ & 829,446 & 27,422 & 171,002 \\
\hline 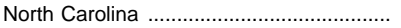 & 369,386 & 327,812 & 6,525 & 35,049 & 329,893 & 6,663 & 35,474 & 373,168 & 330,738 & 7,169 & 35,261 \\
\hline North Dakota .................................................... & 40,184 & 37,016 & 483 & 2,685 & 37,183 & 447 & 2,769 & 40,554 & 37,374 & 438 & 2,742 \\
\hline Ohio ……...................... & 549,304 & 471,266 & 12,321 & 65,717 & 461,524 & 12,500 & 66,251 & 537,535 & 458,748 & 12,425 & 66,362 \\
\hline 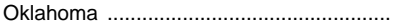 & 185,174 & 159,288 & 3,582 & 22,304 & 154,949 & 3,481 & 22,246 & 177,255 & 152,668 & 3,101 & 21,486 \\
\hline Oregon ............. & 164,447 & 144,583 & 3,559 & 16,305 & 147,444 & 3,653 & 16,048 & 165,168 & 144,434 & 3,807 & 16,927 \\
\hline 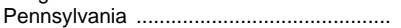 & 611,174 & 513,257 & 15,462 & 82,455 & 520,371 & 15,626 & 81,762 & 621,994 & 525,882 & 15,605 & 80,507 \\
\hline 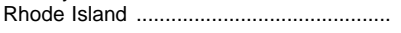 & 74,718 & 64,743 & 655 & 9,320 & 64,072 & 820 & 9,208 & 72,432 & 62,259 & 869 & 9,304 \\
\hline South Carolina & 173,070 & 148,120 & 2,369 & 22,581 & 148,808 & 2,423 & 22,894 & 174,303 & 149,508 & 2,738 & 22,057 \\
\hline South Dakota & 37,764 & 33,281 & 512 & 3,971 & 32,160 & 637 & 3,898 & 35,373 & 30,909 & 672 & 3,792 \\
\hline 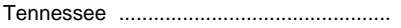 & 242,966 & 211,374 & 5,766 & 25,826 & 213,842 & 5,619 & 26,501 & 247,043 & 214,286 & 5,690 & 27,067 \\
\hline Texas nownon. & 954,495 & 832,145 & 19,194 & 103,156 & 830,381 & 19,463 & 102,681 & 955,439 & 833,031 & 19,890 & 102,518 \\
\hline Utah …… & 146,196 & 132,211 & 1,250 & 12,735 & 134,319 & 1,253 & 11,752 & 151,637 & 138,119 & 1,254 & 12,264 \\
\hline Vermont & 35,409 & 30,459 & 898 & 4,052 & 30,488 & 890 & 3,687 & 35,090 & 30,285 & 896 & 3,909 \\
\hline Virginia & 354,149 & 300,598 & 6,419 & 47,132 & 300,612 & 6,461 & 48,846 & 353,788 & 298,491 & 6,900 & 48,397 \\
\hline 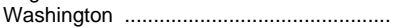 & 284,662 & 257,746 & 3,307 & 23,609 & 259,928 & 3,596 & 22,295 & 292,180 & 265,685 & 3,758 & 22,737 \\
\hline 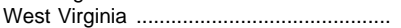 & 87,741 & 74,844 & 1,384 & 11,513 & 73,845 & 1,397 & 10,792 & 85,689 & 73,279 & 1,420 & 10,990 \\
\hline Wisconsin . & 303,861 & 269,548 & 3,568 & 30,745 & 267,273 & 3,605 & 29,345 & 299,127 & 265,835 & 3,653 & 29,639 \\
\hline 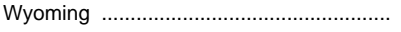 & 30,682 & 27,771 & 232 & 2,679 & 27,620 & 225 & 2,331 & 30,805 & 28,374 & 209 & 2,222 \\
\hline U.S. Service Schools . & 51,939 & 47,202 & 659 & 4,078 & 83,620 & 668 & 4,163 & 81,669 & 77,047 & 673 & 3,949 \\
\hline Outlying areas & 170,686 & 155,093 & 2,691 & 12,902 & 168,107 & 2,890 & 12,660 & 181,660 & 165,153 & 3,132 & 13,375 \\
\hline American Samoa & 1,249 & 1,249 & - & - & 1,232 & - & - & 1,239 & 1,239 & - & - \\
\hline Federated States of Micronesia . & 1,374 & 1,374 & - & - & 1,296 & - & - & 1,396 & 1,396 & - & - \\
\hline 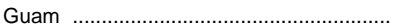 & 6,449 & 6,052 & - & 397 & 5,644 & - & 366 & 5,335 & 4,986 & - & 349 \\
\hline 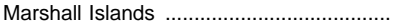 & 424 & 424 & - & - & 418 & - & - & 431 & 431 & - & - \\
\hline 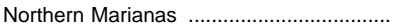 & 1,253 & 1,253 & - & - & 959 & - & - & 1,096 & 1,096 & - & - \\
\hline Palau & 403 & 403 & - & - & 351 & - & - & 332 & 332 & - & - \\
\hline Puerto Rico & 156,439 & 141,543 & 2,691 & 12,205 & 155,430 & 2,890 & 12,017 & 168,933 & 153,007 & 3,132 & 12,794 \\
\hline Virgin Islands & 3,095 & 2,795 & - & 300 & 2,777 & - & 277 & 2,898 & 2,666 & - & 232 \\
\hline
\end{tabular}

1 Preliminary data.

-Data not reported or not applicable.
SOURCE: U.S. Department of Education, National Center for Education Statistics, Integrated Postsecondary Education Data System (IPEDS), "Fall Enrollment" survey. (This table was prepared May 1998.) 
Table 198.-Total fall enrollment in institutions of higher education, by control, level of enrollment, and state: $1996{ }^{1}$

\begin{tabular}{|c|c|c|c|c|c|c|c|c|c|c|}
\hline \multirow{3}{*}{ State or other area } & \multicolumn{5}{|c|}{ Public } & \multicolumn{5}{|c|}{ Private } \\
\hline & \multicolumn{3}{|c|}{ Undergraduate } & \multirow{2}{*}{$\begin{array}{l}\text { First-pro- } \\
\text { fessional }\end{array}$} & \multirow{2}{*}{ Graduate } & \multicolumn{3}{|c|}{ Undergraduate } & \multirow{2}{*}{$\begin{array}{l}\text { First-pro- } \\
\text { fessional }\end{array}$} & \multirow{2}{*}{ Graduate } \\
\hline & Total & 4-year & 2-year & & & Total & 4-year & 2-year & & \\
\hline 1 & 2 & 3 & 4 & 5 & 6 & 7 & 8 & 9 & 10 & 11 \\
\hline United States & $9,905,339$ & $4,622,497$ & $5,282,842$ & 116,385 & $1,068,447$ & $2,354,078$ & $2,140,047$ & 214,031 & 181,354 & 674,652 \\
\hline Alabama .......................... & 173,387 & 99,652 & 73,735 & 2,236 & 20,908 & 19,592 & 18,493 & 1,099 & 1,905 & 1,471 \\
\hline 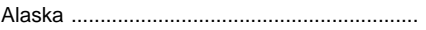 & 26,462 & 25,711 & 751 & - & 1,366 & 829 & 503 & 326 & - & 189 \\
\hline Arizona & 227,432 & 76,464 & 150,968 & 1,553 & 24,484 & 15,815 & 14,854 & 961 & - & 7,548 \\
\hline Arkansas & 79,878 & 52,515 & 27,363 & 1,667 & 7,912 & 10,962 & 10,556 & 406 & - & 269 \\
\hline 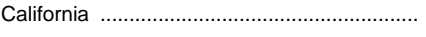 & $1,518,803$ & 398,699 & $1,120,104$ & 7,910 & 98,194 & 147,789 & 133,530 & 14,259 & 25,494 & 84,444 \\
\hline Colorado ............... & 180,235 & 103,345 & 76,890 & 1,811 & 27,137 & 22,324 & 20,763 & 1,561 & 1,362 & 10,080 \\
\hline Connecticut ........ & 82,015 & 40,975 & 41,040 & 1,143 & 14,430 & 39,816 & 38,260 & 1,556 & 2,264 & 15,693 \\
\hline 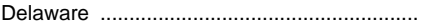 & 32,995 & 21,124 & 11,871 & - & 3,584 & 5,629 & 5,629 & - & 1,272 & 1,358 \\
\hline District of Columbia & 7,105 & 7,105 & - & - & 351 & 33,899 & 33,899 & - & 8,956 & 23,928 \\
\hline 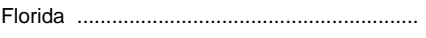 & 486,171 & 166,300 & 319,871 & 3,654 & 41,205 & 80,072 & 74,237 & 5,835 & 6,216 & 23,855 \\
\hline Georgia .... & 218,359 & 128,088 & 90,271 & 3,070 & 27,855 & 51,808 & 47,350 & 4,458 & 7,152 & 9,755 \\
\hline Hawaii & 41,436 & 15,757 & 25,679 & 456 & 5,478 & 12,002 & 12,002 & - & 11 & 2,000 \\
\hline Idaho & 42,531 & 34,483 & 8,048 & 546 & 6,315 & 10,063 & 1,941 & 8,122 & - & 449 \\
\hline Illinois & 482,623 & 142,472 & 340,151 & 4,368 & 45,479 & 122,318 & 118,194 & 4,124 & 12,840 & 53,359 \\
\hline Indiana & 190,190 & 152,169 & 38,021 & 3,706 & 27,071 & 56,662 & 53,152 & 3,510 & 1,726 & 6,971 \\
\hline lowa .......... & 110,374 & 50,990 & 59,384 & 2,830 & 12,719 & 43,707 & 42,653 & 1,054 & 3,633 & 3,758 \\
\hline Kansas & 134,934 & 65,439 & 69,495 & 2,020 & 18,475 & 15,081 & 14,208 & 873 & 81 & 1,759 \\
\hline Kentucky & 126,995 & 83,889 & 43,106 & 3,113 & 17,315 & 25,540 & 22,931 & 2,609 & 1,670 & 3,116 \\
\hline 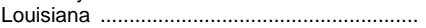 & 151,275 & 123,924 & 27,351 & 2,629 & 20,685 & 20,742 & 19,321 & 1,421 & 3,429 & 4,757 \\
\hline 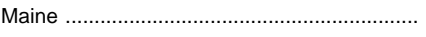 & 33,888 & 26,979 & 6,909 & 296 & 3,704 & 15,221 & 13,410 & 1,811 & 417 & 2,119 \\
\hline 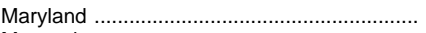 & 189,637 & 85,519 & 104,118 & 3,564 & 24,076 & 24,098 & 22,917 & 1,181 & 741 & 18,641 \\
\hline Massachusetts & 153,625 & 82,033 & 71,592 & 433 & 19,358 & 161,696 & 154,768 & 6,928 & 13,061 & 62,154 \\
\hline 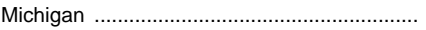 & 393,974 & 194,399 & 199,575 & 6,479 & 58,536 & 73,602 & 71,915 & 1,687 & 3,966 & 10,417 \\
\hline 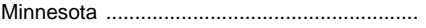 & 189,171 & 98,462 & 90,709 & 2,696 & 16,673 & 44,916 & 40,270 & 4,646 & 3,527 & 18,279 \\
\hline Mississippi ................. & 103,170 & 48,825 & 54,345 & 1,282 & 10,453 & 9,260 & 8,545 & 715 & 585 & 1,484 \\
\hline Missouri & 168,890 & 96,834 & 72,056 & 2,503 & 17,876 & 71,540 & 67,249 & 4,291 & 7,162 & 22,562 \\
\hline 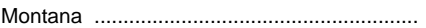 & 34,627 & 28,324 & 6,303 & 227 & 3,146 & 5,001 & 4,170 & 831 & - & 144 \\
\hline 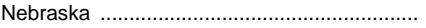 & 87,688 & 45,237 & 42,451 & 1,304 & 10,725 & 16,111 & 16,111 & - & 1,812 & 1,660 \\
\hline Nevada & 64,848 & 23,911 & 40,937 & 205 & 6,872 & 987 & 963 & 24 & - & 555 \\
\hline New Hampshire ............................................. & 32,514 & 22,696 & 9,818 & - & 3,851 & 21,914 & 18,045 & 3,869 & 710 & 5,474 \\
\hline New Jersey & 234,198 & 107,095 & 127,103 & 3,615 & 26,783 & 45,233 & 40,043 & 5,190 & 2,971 & 15,388 \\
\hline 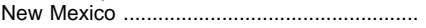 & 84,667 & 35,855 & 48,812 & 717 & 12,246 & 4,693 & 3,642 & 1,051 & 154 & 1,069 \\
\hline 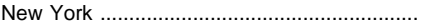 & 509,053 & 265,237 & 243,816 & 4,679 & 58,750 & 320,393 & 296,017 & 24,376 & 22,743 & 112,252 \\
\hline 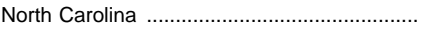 & 272,790 & 126,390 & 146,400 & 2,878 & 27,271 & 57,948 & 56,939 & 1,009 & 4,291 & 7,990 \\
\hline 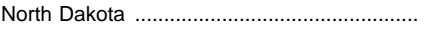 & 33,734 & 25,021 & 8,713 & 438 & 2,593 & 3,640 & 3,365 & 275 & - & 149 \\
\hline Ohio ......................... & 352,088 & 205,591 & 146,497 & 7,656 & 45,595 & 106,660 & 93,221 & 13,439 & 4,769 & 20,767 \\
\hline Oklahoma & 134,805 & 74,202 & 60,603 & 1,853 & 17,723 & 17,863 & 15,826 & 2,037 & 1,248 & 3,763 \\
\hline Oregon & 127,098 & 50,082 & 77,016 & 1,262 & 13,069 & 17,336 & 17,336 & - & 2,545 & 3,858 \\
\hline Pennsylvania & 293,891 & 190,933 & 102,958 & 4,449 & 36,841 & 231,991 & 165,026 & 66,965 & 11,156 & 43,666 \\
\hline 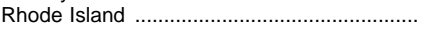 & 32,487 & 17,251 & 15,236 & 34 & 4,966 & 29,772 & 29,772 & - & 835 & 4,338 \\
\hline 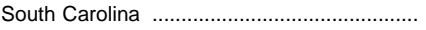 & 126,001 & 64,982 & 61,019 & 1,923 & 20,439 & 23,507 & 22,193 & 1,314 & 815 & 1,618 \\
\hline 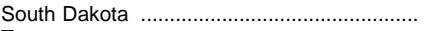 & 24,583 & 24,386 & 197 & 566 & 3,415 & 6,326 & 6,122 & 204 & 106 & 377 \\
\hline 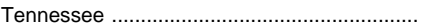 & 171,244 & 92,614 & 78,630 & 2,766 & 20,087 & 43,042 & 41,161 & 1,881 & 2,924 & 6,980 \\
\hline Texas & 746,237 & 322,167 & 424,070 & 10,067 & 81,787 & 86,794 & 80,612 & 6,182 & 9,823 & 20,731 \\
\hline 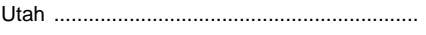 & 104,747 & 71,865 & 32,882 & 775 & 8,673 & 33,372 & 32,116 & 1,256 & 479 & 3,591 \\
\hline Vermont & 18,255 & 13,694 & 4,561 & 373 & 1,511 & 12,030 & 11,796 & 234 & 523 & 2,398 \\
\hline 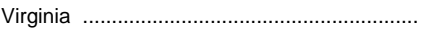 & 247,646 & 123,043 & 124,603 & 4,499 & 40,267 & 50,845 & 46,231 & 4,614 & 2,401 & 8,130 \\
\hline Washington & 237,095 & 72,530 & 164,565 & 1,993 & 12,781 & 28,590 & 26,064 & 2,526 & 1,765 & 9,956 \\
\hline West Virginia & 62,826 & 56,107 & 6,719 & 1,420 & 10,509 & 10,453 & 9,706 & 747 & - & 481 \\
\hline Wisconsin & 222,052 & 118,388 & 103,664 & 1,839 & 20,737 & 43,783 & 42,020 & 1,763 & 1,814 & 8,902 \\
\hline 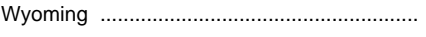 & 27,563 & 8,820 & 18,743 & 209 & 2,222 & 811 & - & 811 & - & - \\
\hline U.S. Service Schools & 77,047 & 13,924 & 63,123 & 673 & 3,949 & - & - & - & - & - \\
\hline 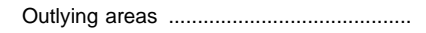 & 73,509 & 61,217 & 12,292 & 1,272 & 5,080 & 91,644 & 82,694 & 8,950 & 1,860 & 8,295 \\
\hline 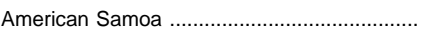 & 1,239 & - & 1,239 & - & - & - & - & - & - & - \\
\hline Federated States of Micronesia ......................... & 1,396 & - & 1,396 & - & - & - & - & - & - & - \\
\hline Guam & 4,986 & 3,034 & 1,952 & - & 349 & - & - & - & - & - \\
\hline 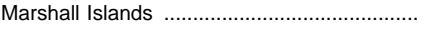 & 431 & - & 431 & - & - & - & - & - & - & - \\
\hline Northern Marianas ……..................................... & 1,096 & - & 1,096 & - & - & - & - & - & - & - \\
\hline Palau & 332 & - & 332 & - & - & - & - & - & - & - \\
\hline 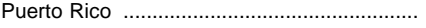 & 61,363 & 55,517 & 5,846 & 1,272 & 4,499 & 91,644 & 82,694 & 8,950 & 1,860 & 8,295 \\
\hline 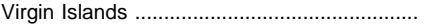 & 2,666 & 2,666 & - & - & 232 & - & - & - & - & - \\
\hline
\end{tabular}

1 Preliminary data.

-Data not reported or not applicable.
SOURCE: U.S. Department of Education, National Center for Education Statistics, In tegrated Postsecondary Education Data System (IPEDS), "Fall Enrollment, 1996" survey. (This table was prepared May 1998.) 
HIGHER EDUCATION: ENROLLMENT 221

Table 199.-Total fall enrollment in institutions of higher education, by control, level of enrollment, and state: 1995

\begin{tabular}{|c|c|c|c|c|c|c|c|c|c|c|}
\hline \multirow{3}{*}{ State or other area } & \multicolumn{5}{|c|}{ Public } & \multicolumn{5}{|c|}{ Private } \\
\hline & \multicolumn{3}{|c|}{ Undergraduate } & \multirow{2}{*}{$\begin{array}{l}\text { First-pro- } \\
\text { fessional }\end{array}$} & \multirow{2}{*}{ Graduate } & \multicolumn{3}{|c|}{ Undergraduate } & \multirow{2}{*}{$\begin{array}{l}\text { First-pro- } \\
\text { fessional }\end{array}$} & \multirow{2}{*}{ Graduate } \\
\hline & Total & 4-year & 2-year & & & Total & 4-year & 2-year & & \\
\hline 1 & 2 & 3 & 4 & 5 & 6 & 7 & 8 & 9 & 10 & 11 \\
\hline United States & $9,903,626$ & $4,626,228$ & $5,277,398$ & 115,072 & $1,073,676$ & $2,328,093$ & $2,113,393$ & 214,700 & 182,520 & 658,794 \\
\hline Alabama .. & 179,073 & 102,416 & 76,657 & 2,282 & 21,810 & 18,977 & 18,479 & 498 & 1,857 & 1,613 \\
\hline Alaska ........ & 26,878 & 26,066 & 812 & & 1,490 & 779 & 575 & 204 & & 201 \\
\hline 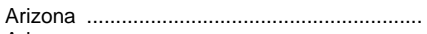 & 228,108 & 75,296 & 152,812 & 1,561 & 24,861 & 14,005 & 13,116 & 889 & - & 5,446 \\
\hline 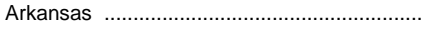 & 77,654 & 53,396 & 24,258 & 1,702 & 7,711 & 10,806 & 10,360 & 446 & & 307 \\
\hline 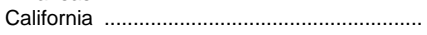 & $1,461,528$ & 387,529 & $1,073,999$ & 7,866 & 94,836 & 144,297 & 130,240 & 14,057 & 27,681 & 80,834 \\
\hline Colorado . & 179,961 & 102,265 & 77,696 & 1,784 & 28,567 & 21,044 & 17,421 & 3,623 & 1,346 & 10,037 \\
\hline Connecticut & 84,780 & 41,952 & 42,828 & 1,161 & 14,598 & 39,283 & 37,721 & 1,562 & 2,255 & 15,618 \\
\hline Delaware ……............ & 32,707 & 21,043 & 11,664 & - & 3,497 & 5,470 & 5,470 & - & 1,289 & 1,344 \\
\hline District of Columbia ... & 9,179 & 9,179 & & 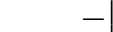 & 484 & 34,186 & 34,186 & & 9,068 & 24,360 \\
\hline 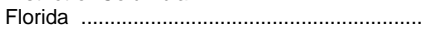 & 486,639 & 162,993 & 323,646 & 3,411 & 40,557 & 77,996 & 72,565 & 5,431 & 5,873 & 22,827 \\
\hline Georgia . & 217,773 & 129,516 & 88,257 & 3,076 & 27,833 & 50,127 & 45,577 & 4,550 & 6,984 & 8,919 \\
\hline Hawaii ....................................... & 43,651 & 16,798 & 26,853 & 453 & 6,094 & 11,250 & 11,250 & - & 45 & 1,705 \\
\hline 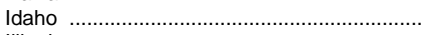 & 41,777 & 34,240 & 7,537 & 529 & 6,680 & 10,201 & 1,929 & 8,272 & & 379 \\
\hline Illinois ... & 479,731 & 142,015 & 337,716 & 4,397 & 46,120 & 122,014 & 117,744 & 4,270 & 12,971 & 52,621 \\
\hline 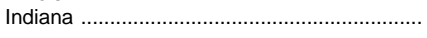 & 193,364 & 152,753 & 40,611 & 3,529 & 27,902 & 56,483 & 52,994 & 3,489 & 1,810 & 6,527 \\
\hline lowa ........ & 106,854 & 50,299 & 56,555 & 2,811 & 12,731 & 44,228 & 43,113 & 1,115 & 3,757 & 3,454 \\
\hline 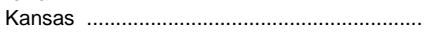 & 140,376 & 66,697 & 73,679 & 2,005 & 18,068 & 15,476 & 14,598 & 878 & 69 & 1,649 \\
\hline Kentucky ….............................. & 128,633 & 85,354 & 43,279 & 2,990 & 17,185 & 25,207 & 22,539 & 2,668 & 1,657 & 3,186 \\
\hline Louisiana ………………..... & 151,350 & 124,397 & 26,953 & 2,631 & 20,892 & 20,591 & 19,413 & 1,178 & 3,498 & 4,973 \\
\hline Maine ………………………... & 34,057 & 27,137 & 6,920 & 286 & 3,852 & 15,673 & 13,758 & 1,915 & 395 & 2,284 \\
\hline Maryland .... & 194,618 & 85,499 & 109,119 & 3,593 & 24,646 & 23,918 & 22,732 & 1,186 & 817 & 18,718 \\
\hline Massachusetts. & 157,775 & 82,812 & 74,963 & 423 & 18,579 & 161,766 & 153,713 & 8,053 & 13,027 & 62,224 \\
\hline 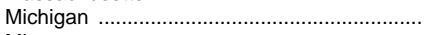 & 397,593 & 194,199 & 203,394 & 6,615 & 58,182 & 72,900 & 70,255 & 2,645 & 4,104 & 8,945 \\
\hline 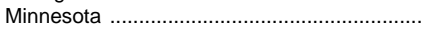 & 198,113 & 98,052 & 100,061 & 2,612 & 16,524 & 43,935 & 39,778 & 4,157 & 3,473 & 16,159 \\
\hline 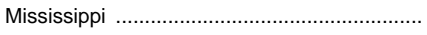 & 99,430 & 47,677 & 51,753 & 1,212 & 9,958 & 9,868 & 9,056 & 812 & 547 & 1,675 \\
\hline Missouri ....... & 169,460 & 97,338 & 72,122 & 2,441 & 18,092 & 73,416 & 68,819 & 4,597 & 6,929 & 21,198 \\
\hline Montana .. & 34,020 & 27,997 & 6,023 & 236 & 3,179 & 5,093 & 4,173 & 920 & & 146 \\
\hline 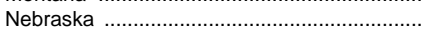 & 83,346 & 45,828 & 37,518 & 1,345 & 10,908 & 16,761 & 16,217 & 544 & 1,820 & 1,538 \\
\hline 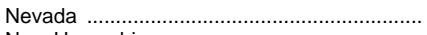 & 59,581 & 23,729 & 35,852 & 211 & 6,891 & 817 & 790 & 27 & & 326 \\
\hline New Hampshire ........................................ & 32,122 & 22,550 & 9,572 & & 3,947 & 21,992 & 17,961 & 4,031 & 702 & 5,564 \\
\hline New Jerse & 240,280 & 107,040 & 133,240 & 3,593 & 96 & 44 & 3 & 4,717 & 3,018 & 15,472 \\
\hline 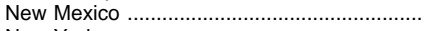 & 84,537 & 37,136 & 47,401 & 635 & 12,048 & 4,256 & 3,302 & 954 & & 929 \\
\hline New York & 523,666 & 270,903 & 252,763 & 4,760 & 60,065 & 317,686 & 289,676 & 28,010 & 23,023 & 112,366 \\
\hline North Carolina . & 272,390 & 126,705 & 145,685 & 2,604 & 28,105 & 57,503 & 56,020 & 1,483 & 4,059 & 7,369 \\
\hline North Dakota ... & 33,726 & 25,312 & 8,414 & 447 & 2,637 & 3,457 & 3,202 & 255 & & 132 \\
\hline Ohio & 355,683 & 208,332 & 147,351 & 7,722 & 46,413 & 105,841 & 92,499 & 13,342 & 4,778 & 19,838 \\
\hline Oklahoma ………………………….......... & 137,601 & 74,962 & 62,639 & 2,045 & 18,380 & 17,348 & 15,319 & 2,029 & 1,436 & 3,866 \\
\hline Orego & 130,049 & 49,488 & 80,561 & 1,200 & 12,368 & 17,395 & 17,226 & 169 & 2,453 & 3,680 \\
\hline 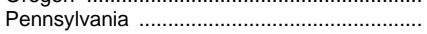 & 297,548 & 191,053 & 106,495 & 4,416 & 37,964 & 222,823 & 165,261 & 57,562 & 11,210 & 43,798 \\
\hline Rhode Island ……… & 33,619 & 17,730 & 15,889 & 15 & 5,019 & 30,453 & 28,027 & 2,426 & 805 & 4,189 \\
\hline South Carolina . & 125,825 & 64,932 & 60,893 & 1,876 & 21,005 & 22,983 & 21,688 & 1,295 & 547 & 1,889 \\
\hline South & 25,660 & 25,451 & 209 & 533 & 3,500 & 6,500 & 6,267 & 233 & 104 & 398 \\
\hline Tennessee & 170,622 & 92,528 & 78,094 & 2,749 & 19,765 & 43,220 & 40,782 & 2,438 & 2,870 & 6,736 \\
\hline ……………...... & 744,492 & 325,072 & 419,420 & 9,829 & 82,530 & 85,889 & 79,939 & 5,950 & 9,634 & 20,151 \\
\hline 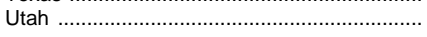 & 101,576 & 71,104 & 30,472 & 785 & 8,199 & 32,743 & 31,484 & 1,259 & 468 & 3,553 \\
\hline Vermont ................. & 18,559 & 13,924 & 4,635 & 377 & 1,534 & 9 & 11, & 201 & 513 & 2,153 \\
\hline & 248,866 & 120,521 & 128,3 & 4,376 & 39,885 & 51,746 & 46,871 & 4,875 & 2,085 & 8,961 \\
\hline 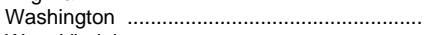 & 231,917 & 71,362 & 160 & 1,831 & 12,887 & 28,011 & 25,777 & 2,234 & 1,765 & 9,408 \\
\hline 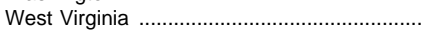 & 63,108 & 56,128 & 6,980 & 1,397 & 10,352 & 10,737 & 9,951 & 786 & & 440 \\
\hline Wisconsin ........................ & 223,287 & 116,709 & 106,578 & 1,827 & 20,656 & 43,986 & 42,277 & 1,709 & 1,778 & 8,689 \\
\hline Wyoming & 26,864 & 8,805 & 18,059 & 225 & 2,331 & 756 & - & 756 & - & 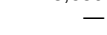 \\
\hline U.S. Service Schools & 83,620 & 14,009 & 69,611 & 668 & 4,163 & - & - & - & - & - \\
\hline Outlying areas & 70,515 & 56,033 & 14,482 & 1,114 & 5,421 & 97,592 & 88,697 & 8,895 & 1,776 & 7,239 \\
\hline American Samoz & 1,232 & - & 1,232 & - & -1 & - & - & - & - & - \\
\hline Federated States of Micronesia . & 1,296 & - & 1,296 & 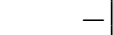 & - & - & - & - & - & - \\
\hline Guam & 5,644 & 3,288 & 2,356 & - & 366 & - & - & - & - & - \\
\hline Marshall Islands ........... & 418 & - & 418 & - & - & - & - & - & - & - \\
\hline Northern Marianas ………………………...... & 959 & - & 959 & - & - & - & - & - & - & - \\
\hline Palau ................................ & 351 & - & 351 & - & - & - & - & - & - & - \\
\hline ………......... & 57,838 & 49,968 & 7,870 & 1,114 & 4,778 & 97,592 & 88,697 & 8,895 & 1,776 & 7,239 \\
\hline 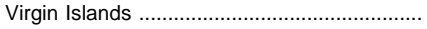 & 2,777 & 2,777 & & & 277 & & -1 & & & \\
\hline
\end{tabular}

—Data not reported or not applicable.

SOURCE: U.S. Department of Education, National Center for Education Statistics, Integrated Postsecondary Education Data System (IPEDS), "Fall Enrollment, 1995" survey. (This table was prepared May 1998.) 
Table 200.-Full-time-equivalent fall enrollment in institutions of higher education and degree-granting institutions, by control and type of institution: 1969 to 1996

\begin{tabular}{|c|c|c|c|c|c|c|c|c|c|}
\hline \multirow{2}{*}{ Year } & \multicolumn{3}{|c|}{ All institutions } & \multicolumn{3}{|c|}{ Public institutions } & \multicolumn{3}{|c|}{ Private institutions } \\
\hline & Total & 4-year & 2-year & Total & 4-year & 2-year & Total & 4-year & 2-year \\
\hline \multirow[t]{2}{*}{1} & 2 & 3 & 4 & 5 & 6 & 7 & 8 & 9 & 10 \\
\hline & \multicolumn{9}{|c|}{ Institutions of higher education } \\
\hline $\begin{array}{l}1969 \\
1970 \\
1971 \\
1972 \\
1973 \ldots \ldots \ldots \ldots \ldots \ldots \ldots \ldots \ldots \ldots \ldots \ldots \ldots \ldots . . . \\
1974\end{array}$ & $\begin{array}{l}6,334,139 \\
6,737,817 \\
7,148,575 \\
7,253,712 \\
7,453,467 \\
7,805,454\end{array}$ & $\begin{array}{l}4,899,526 \\
5,145,410 \\
5,357,708 \\
5,406,792 \\
5,439,226 \\
5,606,248\end{array}$ & $\begin{array}{l}1,434,612 \\
1,592,404 \\
1,790,867 \\
1,846,921 \\
2,014,241 \\
2,199,206\end{array}$ & $\begin{array}{l}4,577,985 \\
4,953,149 \\
5,344,356 \\
5,452,851 \\
5,629,568 \\
5,944,799\end{array}$ & $\begin{array}{l}3,259,676 \\
3,468,572 \\
3,660,624 \\
3,706,238 \\
3,721,035 \\
3,847,542\end{array}$ & $\begin{array}{l}1,318,309 \\
1,484,577 \\
1,683,732 \\
1,746,613 \\
1,908,533 \\
2,097,257\end{array}$ & $\begin{array}{l}1,756,153 \\
1,784,665 \\
1,804,219 \\
1,800,862 \\
1,823,899 \\
1,860,655\end{array}$ & $\begin{array}{l}1,639,850 \\
1,676,838 \\
1,697,084 \\
1,700,554 \\
1,718,191 \\
1,758,706\end{array}$ & $\begin{array}{l}116,303 \\
107,827 \\
107,135 \\
100,308 \\
105,708 \\
101,949\end{array}$ \\
\hline $\begin{array}{l}1975 \\
1976 \\
1977 \\
1978 \\
1979\end{array}$ & $\begin{array}{l}8,479,688 \\
8,312,502 \\
8,415,339 \\
8,348,482 \\
8,487,317\end{array}$ & $\begin{array}{l}5,900,403 \\
5,848,001 \\
5,935,076 \\
5,932,357 \\
6,016,072\end{array}$ & $\begin{array}{l}2,579,285 \\
2,464,501 \\
2,480,263 \\
2,416,125 \\
2,471,245\end{array}$ & $\begin{array}{l}6,522,310 \\
6,349,903 \\
6,396,476 \\
6,279,199 \\
6,392,617\end{array}$ & $\begin{array}{l}4,056,500 \\
3,998,450 \\
4,039,071 \\
3,996,126 \\
4,059,304\end{array}$ & $\begin{array}{l}2,465,810 \\
2,351,453 \\
2,357,405 \\
2,283,073 \\
2,333,313\end{array}$ & $\begin{array}{l}1,957,378 \\
1,962,599 \\
2,018,863 \\
2,069,283 \\
2,094,700\end{array}$ & $\begin{array}{l}1,843,903 \\
1,849,551 \\
1,896,005 \\
1,936,231 \\
1,956,768\end{array}$ & $\begin{array}{l}113,475 \\
113,048 \\
122,858 \\
133,052 \\
137,932\end{array}$ \\
\hline $\begin{array}{l}1980 \\
1981 \\
1982 \\
1983 \\
1984\end{array}$ & $\begin{array}{l}8,819,013 \\
9,014,521 \\
9,091,648 \\
9,166,398 \\
8,951,695\end{array}$ & $\begin{array}{l}6,161,372 \\
6,249,847 \\
6,248,923 \\
6,325,222 \\
6,292,711\end{array}$ & $\begin{array}{l}2,657,641 \\
2,764,674 \\
2,842,725 \\
2,841,176 \\
2,658,984\end{array}$ & $\begin{array}{l}6,642,294 \\
6,781,300 \\
6,850,589 \\
6,881,479 \\
6,684,664\end{array}$ & $\begin{array}{l}4,158,267 \\
4,208,506 \\
4,220,648 \\
4,265,807 \\
4,237,895\end{array}$ & $\begin{array}{l}2,484,027 \\
2,572,794 \\
2,629,941 \\
2,615,672 \\
2,446,769\end{array}$ & $\begin{array}{l}2,176,719 \\
2,233,221 \\
2,241,059 \\
2,284,919 \\
2,267,031\end{array}$ & $\begin{array}{l}2,003,105 \\
2,041,341 \\
2,028,275 \\
2,059,415 \\
2,054,816\end{array}$ & $\begin{array}{r}1173,614 \\
1191,880 \\
212,784 \\
225,504 \\
212,215\end{array}$ \\
\hline $\begin{array}{l}1985 \\
1986 \\
1987 \\
1988 \\
1989\end{array}$ & $\begin{array}{l}8,943,433 \\
9,064,165 \\
9,229,736 \\
9,464,271 \\
9,780,881\end{array}$ & $\begin{array}{l}6,294,339 \\
6,360,325 \\
6,486,504 \\
6,664,146 \\
6,813,602\end{array}$ & $\begin{array}{l}2,649,094 \\
2,703,842 \\
2,743,230 \\
2,800,125 \\
2,967,279\end{array}$ & $\begin{array}{l}6,667,781 \\
6,778,045 \\
6,937,690 \\
7,096,905 \\
7,371,590\end{array}$ & $\begin{array}{l}4,239,622 \\
4,295,494 \\
4,395,728 \\
4,505,774 \\
4,619,828\end{array}$ & $\begin{array}{l}2,428,159 \\
2,482,551 \\
2,541,961 \\
2,591,131 \\
2,751,762\end{array}$ & $\begin{array}{l}2,275,652 \\
2,286,122 \\
2,292,045 \\
2,367,366 \\
2,409,291\end{array}$ & $\begin{array}{l}2,054,717 \\
2,064,831 \\
2,090,776 \\
2,158,372 \\
2,193,774\end{array}$ & $\begin{array}{r}220,935 \\
2221,291 \\
201,269 \\
208,994 \\
215,517\end{array}$ \\
\hline $\begin{array}{l}1990 \\
1991 \\
1992 \\
1993 \\
1994\end{array}$ & $\begin{array}{r}9,983,436 \\
10,360,606 \\
10,436,776 \\
10,351,415 \\
10,348,072\end{array}$ & $\begin{array}{l}6,968,008 \\
7,081,454 \\
7,129,379 \\
7,120,921 \\
7,137,341\end{array}$ & $\begin{array}{l}3,015,428 \\
3,279,152 \\
3,307,397 \\
3,230,494 \\
3,210,731\end{array}$ & $\begin{array}{l}7,557,982 \\
7,862,845 \\
7,911,701 \\
7,812,394 \\
7,784,396\end{array}$ & $\begin{array}{l}4,740,049 \\
4,795,704 \\
4,797,884 \\
4,765,983 \\
4,749,524\end{array}$ & $\begin{array}{l}2,817,933 \\
3,067,141 \\
3,113,817 \\
3,046,411 \\
3,034,872\end{array}$ & $\begin{array}{l}2,425,454 \\
2,497,761 \\
2,525,075 \\
2,539,021 \\
2,563,676\end{array}$ & $\begin{array}{l}2,227,959 \\
2,285,750 \\
2,331,495 \\
2,354,938 \\
2,387,817\end{array}$ & $\begin{array}{l}197,495 \\
212,011 \\
193,580 \\
184,083 \\
175,859\end{array}$ \\
\hline \multirow[t]{2}{*}{1995} & $\begin{array}{l}10,334,956 \\
10,402,260\end{array}$ & $\begin{array}{l}7,172,844 \\
7,231,680\end{array}$ & $\begin{array}{l}3,162,112 \\
3,170,580\end{array}$ & $\begin{array}{l}7,751,815 \\
7,775,298\end{array}$ & $\begin{array}{l}4,757,223 \\
4,767,248\end{array}$ & $\begin{array}{l}2,994,592 \\
3,008,050\end{array}$ & $\begin{array}{l}2,583,141 \\
2,626,962\end{array}$ & $\begin{array}{l}2,415,621 \\
2,464,432\end{array}$ & $\begin{array}{l}167,520 \\
162,530\end{array}$ \\
\hline & \multicolumn{9}{|c|}{ Degree-granting institutions ${ }^{4}$} \\
\hline $1996^{3}$ & $10,481,886$ & $7,234,541$ & $3,247,345$ & $7,794,895$ & $4,767,117$ & $3,027,778$ & $2,686,991$ & $2,467,424$ & 219,567 \\
\hline
\end{tabular}

${ }^{1}$ Large increases are due to the addition of schools accredited by the Accrediting Commission of Career Schools and Colleges of Technology in 1980 and 1981.

${ }^{2}$ Because of imputation techniques, data are not consistent with figures for other years.

3 Preliminary data.

${ }^{4}$ Data are for 4-year and 2-year degree-granting higher education institutions that were eligible to participate in Title IV federal financial aid programs.

NOTE.-Trend tabulations of institutions of higher education data are based on institutions that were accredited by an agency or association that was recognized by the U.S.
Department of Education. The Department of Education no longer distinguishes between those institutions and other institutions that are eligible to participate in Title IV programs. The new degree-granting classification is very similar to the earlier higher education classification, except that it includes some additional institutions, primarily 2-year colleges, and excludes a few higher education institutions that did not award degrees.

SOURCE: U.S. Department of Education, National Center for Education Statistics Higher Education General Information Survey (HEGIS), "Fall Enrollment in Colleges and Universities" surveys; and Integrated Postsecondary Education Data System (IPEDS), "Fall Enrollment" surveys. (This table was prepared June 1998.) 
Table 201.-Full-time-equivalent fall enrollment in institutions of higher education, by control, type of institution, and state: 1994 to 1996

\begin{tabular}{|c|c|c|c|c|c|c|c|c|c|c|c|c|}
\hline \multirow{2}{*}{ State or other area } & \multicolumn{3}{|c|}{ Public 4-year } & \multicolumn{3}{|c|}{ Public 2-year } & \multicolumn{3}{|c|}{ Private 4-year } & \multicolumn{3}{|c|}{ Private 2-year } \\
\hline & 1994 & 1995 & $1996^{1}$ & 1994 & 1995 & $1996^{1}$ & 1994 & 1995 & $1996^{1}$ & 1994 & 1995 & $1996^{1}$ \\
\hline United States …................................. & $4,749,524$ & $4,757,223$ & $4,767,248$ & $3,034,872$ & $2,994,592$ & $3,008,050$ & $2,387,817$ & $2,415,621$ & $2,464,432$ & 175,859 & 167,520 & 162,530 \\
\hline Alabama & 103,200 & 104,189 & 101,864 & 56,255 & 54,564 & 53,207 & 19,485 & 19,533 & 19,655 & 1,231 & 450 & 883 \\
\hline Alaska & 17,810 & 17,823 & 17,508 & 244 & 326 & 322 & 622 & 588 & 555 & 303 & 167 & 270 \\
\hline Arizona & 82,558 & 83,010 & 84,062 & 76,262 & 76,822 & 76,541 & 19,129 & 16,658 & 20,174 & 929 & 889 & 948 \\
\hline 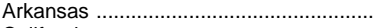 & 54,540 & 53,057 & 52,468 & 13,281 & 15,177 & 16,713 & 9,666 & 9,975 & 10,167 & 346 & 349 & 376 \\
\hline California & 413,527 & 421,100 & 434,560 & 575,613 & 563,047 & 580,225 & 199,213 & 199,346 & 203,916 & 12,344 & 12,886 & 13,246 \\
\hline Colorado & 104,474 & 104,521 & 104,977 & 40,104 & 40,332 & 39,996 & 21,477 & 21,702 & 24,957 & 3,121 & 3,442 & 1,554 \\
\hline Connecticut & 43,582 & 43,441 & 42,967 & 22,303 & 21,322 & 20,374 & 43,398 & 43,831 & 44,901 & 1,188 & 1,157 & 1,160 \\
\hline Delaware ................. & 20,982 & 20,533 & 20,821 & 6,529 & 6,705 & 6,975 & 5,232 & 5,298 & 5,351 & - & - & - \\
\hline District of Columbia & 6,495 & 5,950 & 4,559 & - & - & - & 53,802 & 55,068 & 54,654 & - & - & - \\
\hline 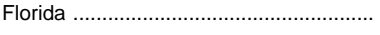 & 155,232 & 160,046 & 163,504 & 179,177 & 176,817 & 174,897 & 80,234 & 80,301 & 82,796 & 4,884 & 5,123 & 5,524 \\
\hline Georgia & 128,563 & 132,111 & 131,676 & 55,739 & 56,843 & 58,585 & 52,189 & 55,179 & 57,817 & 5,319 & 4,132 & 4,105 \\
\hline 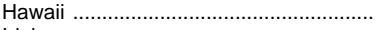 & 19,437 & 19,158 & 17,680 & 16,692 & 16,222 & 15,859 & 9,485 & 9,916 & 11,101 & - & - & - \\
\hline 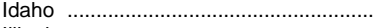 & 32,237 & 32,161 & 32,375 & 5,218 & 5,265 & 5,693 & 2,252 & 1,998 & 2,042 & 8,280 & 8,122 & 7,986 \\
\hline Illinois & 161,500 & 159,900 & 159,822 & 190,946 & 183,337 & 184,823 & 141,160 & 144,744 & 146,132 & 5,421 & 3,784 & 3,684 \\
\hline 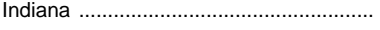 & 147,844 & 146,709 & 147,182 & 24,279 & 23,310 & 22,165 & 53,673 & 54,658 & 55,213 & 2,997 & 2,866 & 2,878 \\
\hline 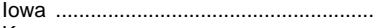 & 57,556 & 57,870 & 58,444 & 39,735 & 39,829 & 41,310 & 40,905 & 41,377 & 41,185 & 1,212 & 926 & 890 \\
\hline Kansas ...... & 71,257 & 71,592 & 70,500 & 37,568 & 39,813 & 38,116 & 14,166 & 13,756 & 13,545 & 784 & 735 & 721 \\
\hline Kentucky & 87,211 & 86,774 & 86,022 & 29,039 & 28,227 & 28,346 & 22,331 & 22,965 & 23,316 & 4,153 & 2,361 & 2,403 \\
\hline 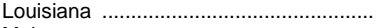 & 124,883 & 125,563 & 125,650 & 17,595 & 17,057 & 17,320 & 23,195 & 23,442 & 23,060 & 985 & 754 & 943 \\
\hline Maine ......... & 23,461 & 22,812 & 22,656 & 4,549 & 4,369 & 4,361 & 11,945 & 12,364 & 12,357 & 1,602 & 1,655 & 1,594 \\
\hline Maryland & 86,578 & 87,997 & 88,440 & 58,471 & 57,419 & 55,837 & 29,393 & 30,193 & 30,537 & 937 & 1,032 & 1,005 \\
\hline 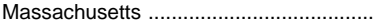 & 78,686 & 78,616 & 78,570 & 47,035 & 44,938 & 42,703 & 184,199 & 189,336 & 190,839 & 9,506 & 5,997 & 5,093 \\
\hline 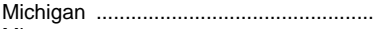 & 205,800 & 206,495 & 207,628 & 108,182 & 103,720 & 102,348 & 61,100 & 61,116 & 64,277 & 1,614 & 1,728 & 945 \\
\hline Minnesota & 89,990 & 88,696 & 89,123 & 67,471 & 62,765 & 62,673 & 47,395 & 48,406 & 49,981 & 3,521 & 3,263 & 3,706 \\
\hline 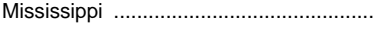 & 50,417 & 51,561 & 52,907 & 40,669 & 41,384 & 42,928 & 9,425 & 9,400 & 8,795 & 960 & 722 & 643 \\
\hline Missc & 95,401 & 94,930 & 94,552 & 41,935 & 40,677 & 41,119 & 71,773 & 73,005 & 74,840 & 4,934 & 3,939 & 3,818 \\
\hline Montana & 26,857 & 27,724 & 27,942 & 3,294 & 4,607 & 4,708 & 3,652 & 3,597 & 3,606 & 529 & 600 & 556 \\
\hline 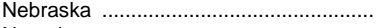 & 47,248 & 47,537 & 47,036 & 20,129 & 19,711 & 22,656 & 16,682 & 16,627 & 16,833 & 338 & 403 & - \\
\hline Nevada & 21,963 & 21,806 & 22,382 & 13,855 & 15,191 & 17,544 & 598 & 967 & 1,305 & 27 & 27 & 24 \\
\hline 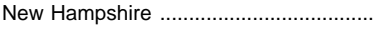 & 21,962 & 21,960 & 21,763 & 5,025 & 5,136 & 5,214 & 18,603 & 18,845 & 18,952 & 2,952 & 3,122 & 2,904 \\
\hline New Jersey . & 102,204 & 103,590 & 104,618 & 81,903 & 81,176 & 78,580 & 44,368 & 44,052 & 44,668 & 3,295 & 3,851 & 4,154 \\
\hline 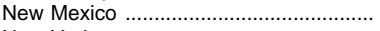 & 39,973 & 39,186 & 38,147 & 25,126 & 25,717 & 26,415 & 3,550 & 3,671 & 4,230 & 651 & 954 & 1,051 \\
\hline New York ......................... & 272,066 & 265,171 & 261,193 & 180,543 & 175,517 & 171,022 & 339,369 & 339,528 & 346,514 & 26,016 & 25,311 & 21,917 \\
\hline North Carolina ...................................... & 132,091 & 132,949 & 132,690 & 91,727 & 91,106 & 92,126 & 56,789 & 60,326 & 62,219 & 2,241 & 1,327 & 852 \\
\hline 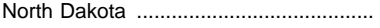 & 25,055 & 25,147 & 24,827 & 6,642 & 6,792 & 7,053 & 3,038 & 3,091 & 3,257 & 242 & 249 & 256 \\
\hline Ohio & 223,580 & 219,518 & 216,875 & 88,888 & 87,324 & 86,890 & 95,994 & 96,059 & 98,040 & 9,586 & 8,909 & 8,891 \\
\hline Oklahoma & 78,501 & 77,450 & 76,320 & 38,063 & 37,142 & 36,486 & 18,138 & 17,675 & 17,852 & 2,459 & 1,909 & 1,900 \\
\hline Oregon & 52,916 & 53,445 & 54,255 & 44,748 & 42,866 & 42,781 & 19,949 & 20,115 & 20,519 & 163 & 158 & - \\
\hline 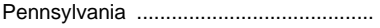 & 198,056 & 200,590 & 200,854 & 64,045 & 61,233 & 59,234 & 179,269 & 179,812 & 181,249 & 28,926 & 32,634 & 36,386 \\
\hline Rhode Island .................................... & 18,015 & 17,634 & 17,143 & 8,524 & 8,490 & 8,348 & 28,720 & 28,583 & 30,478 & 1,930 & 2,149 & 一 \\
\hline South Carolina & 71,132 & 71,984 & 72,543 & 37,571 & 37,475 & 37,651 & 20,849 & 21,694 & 22,336 & 1,343 & 1,200 & 1,225 \\
\hline 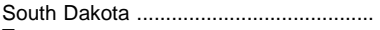 & 25,822 & 24,753 & 23,799 & 158 & 172 & 152 & 5,384 & 5,487 & 5,454 & 143 & 143 & 116 \\
\hline 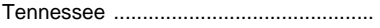 & 93,976 & 95,789 & 96,234 & 46,958 & 46,996 & 47,938 & 44,083 & 45,903 & 46,748 & 2,425 & 2,018 & 1,644 \\
\hline Texas & 339,801 & 337,321 & 336,716 & 237,787 & 237,117 & 241,061 & 87,907 & 91,399 & 92,304 & 5,987 & 5,641 & 5,815 \\
\hline 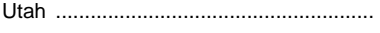 & 61,636 & 62,683 & 62,014 & 18,453 & 19,369 & 20,344 & 33,661 & 33,170 & 33,512 & 1,079 & 1,146 & 1,136 \\
\hline Ver & 13,765 & 13,715 & 13,588 & 1,834 & 1,885 & 1,937 & 12,390 & 12,301 & 12,504 & 163 & 178 & 188 \\
\hline Virginia & 136,115 & 138,030 & 140,484 & 67,688 & 66,674 & 64,728 & 46,742 & 46,992 & 47,157 & 3,744 & 4,016 & 3,723 \\
\hline Washington & 77,461 & 78,111 & 78,855 & 101,499 & 103,132 & 105,787 & 30,620 & 30,744 & 31,818 & 1,938 & 2,063 & 2,325 \\
\hline 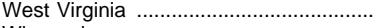 & 55,841 & 55,159 & 55,322 & 4,930 & 4,792 & 4,603 & 9,349 & 9,104 & 8,966 & 846 & 776 & 731 \\
\hline Wisconsin & 122,297 & 121,755 & 123,130 & 59,860 & 58,958 & 57,638 & 41,269 & 41,724 & 41,748 & 1,598 & 1,501 & 1,550 \\
\hline 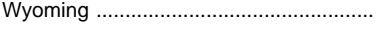 & 10,116 & 9,752 & 9,635 & 11,318 & 11,430 & 11,684 & - & & & 667 & 756 & 811 \\
\hline U.S. Service Schools & 17,854 & 17,849 & 18,366 & 19,413 & 24,297 & 22,034 & - & - & - & - & - & - \\
\hline Outlying areas ….................................... & 49,518 & 54,519 & 59,787 & 9,886 & 11,238 & 9,287 & 73,595 & 81,801 & 77,884 & 10,161 & 7,806 & 8,040 \\
\hline American Samoa . & - & - & - & 998 & 988 & 999 & - & - & - & - & - & - \\
\hline Federated States of Micronesia .............. & - & - & - & 1,040 & 1,076 & 1,098 & - & - & 一 & - & 一 & - \\
\hline 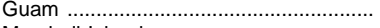 & 3,159 & 2,787 & 2,610 & 1,049 & 1,032 & 912 & - & - & - & - & - & - \\
\hline Marshall Islands & - & - & - & 254 & 249 & 300 & - & - & - & - & 一 & - \\
\hline 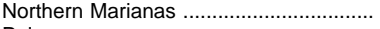 & - & - & - & 653 & 625 & 693 & - & - & - & - & - & - \\
\hline 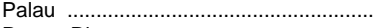 & - & - & - & 357 & 296 & 281 & - & - & - & - & - & - \\
\hline Puerto Rico & 44,321 & 49,679 & 55,224 & 5,535 & 6,972 & 5,004 & 73,595 & 81,801 & 77,884 & 10,161 & 7,806 & 8,040 \\
\hline 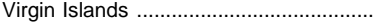 & 2,038 & 2,053 & 1,953 & - & - & - & - & - & - & - & - & - \\
\hline
\end{tabular}

1 Preliminary data.

-Data not reported or not applicable.
SOURCE: U.S. Department of Education, National Center for Education Statistics, Integrated Postsecondary Education Data System (IPEDS), "Fall Enrollment" surveys. (This table was prepared June 1998.) 
Table 202.-Full-time-equivalent fall enrollment in institutions of higher education, by control and state: 1980 to 1996

\begin{tabular}{|c|c|c|c|c|c|c|c|c|c|c|c|}
\hline \multirow{2}{*}{ State or other area } & \multicolumn{5}{|c|}{ Total } & \multicolumn{3}{|c|}{ Public } & \multicolumn{3}{|c|}{ Private } \\
\hline & 1980 & 1985 & 1990 & 1995 & $1996^{1}$ & 1990 & 1995 & $1996^{1}$ & 1990 & 1995 & $1996^{1}$ \\
\hline 1 & 2 & 3 & 4 & 5 & 6 & 7 & 8 & 9 & 10 & 11 & 12 \\
\hline United States .... & $8,819,013$ & $8,943,433$ & $9,983,436$ & $10,334,956$ & $10,402,260$ & $7,557,982$ & $7,751,815$ & $7,775,298$ & $2,425,454$ & $2,583,141$ & $2,626,962$ \\
\hline 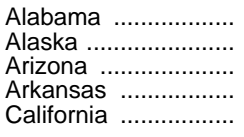 & $\begin{array}{r}138,910 \\
10,073 \\
127,114 \\
64,307 \\
1,099,559\end{array}$ & $\begin{array}{r}149,895 \\
14,098 \\
134,954 \\
63,230 \\
1,062,439\end{array}$ & $\begin{array}{r}174,610 \\
18,496 \\
167,617 \\
74,449 \\
1,156,288\end{array}$ & $\begin{array}{r}178,736 \\
18,904 \\
177,379 \\
78,558 \\
1,196,379\end{array}$ & $\begin{array}{r}175,609 \\
18,655 \\
181,725 \\
79,724 \\
1,231,947\end{array}$ & $\begin{array}{r}154,343 \\
17,087 \\
153,500 \\
63,472 \\
979,663\end{array}$ & $\begin{array}{r}158,753 \\
18,149 \\
159,832 \\
68,234 \\
984,147\end{array}$ & $\begin{array}{r}155,071 \\
17,830 \\
160,603 \\
69,181 \\
1,014,785\end{array}$ & $\begin{array}{r}20,267 \\
1,409 \\
14,117 \\
10,977 \\
176,625\end{array}$ & $\begin{array}{r}19,983 \\
755 \\
17,547 \\
10,324 \\
212,232\end{array}$ & $\begin{array}{r}20,538 \\
825 \\
21,122 \\
10,543 \\
217,162\end{array}$ \\
\hline $\begin{array}{l}\text { Colorado .................. } \\
\text { Connecticut .............. } \\
\text { Delaware ............... } \\
\text { District of Columbia } \\
\text { Florida ........................ }\end{array}$ & $\begin{array}{r}123,589 \\
112,612 \\
26,284 \\
62,126 \\
290,647\end{array}$ & $\begin{array}{r}121,804 \\
107,803 \\
25,750 \\
58,945 \\
308,315\end{array}$ & $\begin{array}{r}159,032 \\
115,791 \\
31,612 \\
61,549 \\
383,385\end{array}$ & $\begin{array}{r}169,997 \\
109,751 \\
32,536 \\
61,018 \\
422,287\end{array}$ & $\begin{array}{r}171,484 \\
109,402 \\
33,147 \\
59,213 \\
426,721\end{array}$ & $\begin{array}{r}138,350 \\
70,870 \\
26,059 \\
7,294 \\
302,579\end{array}$ & $\begin{array}{r}144,853 \\
64,763 \\
27,238 \\
5,950 \\
336,863\end{array}$ & $\begin{array}{r}144,973 \\
63,341 \\
27,796 \\
4,559 \\
338,401\end{array}$ & $\begin{array}{r}20,682 \\
44,921 \\
5,553 \\
54,255 \\
80,806\end{array}$ & $\begin{array}{r}25,144 \\
44,988 \\
5,298 \\
55,068 \\
85,424\end{array}$ & $\begin{array}{r}26,511 \\
46,061 \\
5,351 \\
54,654 \\
88,320\end{array}$ \\
\hline 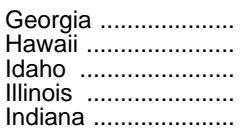 & $\begin{array}{r}152,369 \\
35,859 \\
33,938 \\
432,365 \\
193,445\end{array}$ & $\begin{array}{r}161,952 \\
36,986 \\
32,649 \\
450,504 \\
195,630\end{array}$ & $\begin{array}{r}198,549 \\
41,097 \\
41,275 \\
493,364 \\
222,835\end{array}$ & $\begin{array}{r}248,265 \\
45,296 \\
47,546 \\
491,765 \\
227,543\end{array}$ & $\begin{array}{r}252,183 \\
44,640 \\
48,096 \\
494,461 \\
227,438\end{array}$ & $\begin{array}{r}149,115 \\
32,496 \\
31,408 \\
353,247 \\
168,984\end{array}$ & $\begin{array}{r}188,954 \\
35,380 \\
37,426 \\
343,237 \\
170,019\end{array}$ & $\begin{array}{r}190,261 \\
33,539 \\
38,068 \\
344,645 \\
169,347\end{array}$ & $\begin{array}{r}49,434 \\
8,601 \\
9,867 \\
140,117 \\
53,851\end{array}$ & $\begin{array}{r}59,311 \\
9,916 \\
10,120 \\
148,528 \\
57,524\end{array}$ & $\begin{array}{r}61,922 \\
11,101 \\
10,028 \\
149,816 \\
58,091\end{array}$ \\
\hline 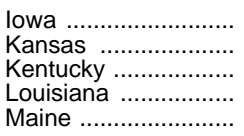 & $\begin{array}{r}120,083 \\
101,147 \\
113,709 \\
132,780 \\
34,471\end{array}$ & $\begin{array}{r}128,492 \\
100,807 \\
110,539 \\
148,983 \\
37,993\end{array}$ & $\begin{array}{r}138,565 \\
118,969 \\
137,651 \\
154,132 \\
42,021\end{array}$ & $\begin{array}{r}140,002 \\
125,896 \\
140,327 \\
166,816 \\
41,200\end{array}$ & $\begin{array}{r}141,829 \\
122,882 \\
140,087 \\
166,973 \\
40,968\end{array}$ & $\begin{array}{r}95,772 \\
106,570 \\
111,858 \\
129,357 \\
29,876\end{array}$ & $\begin{array}{r}97,699 \\
111,405 \\
115,001 \\
142,620 \\
27,181\end{array}$ & $\begin{array}{r}99,754 \\
108,616 \\
114,368 \\
142,970 \\
27,017\end{array}$ & $\begin{array}{l}42,793 \\
12,399 \\
25,793 \\
24,775 \\
12,145\end{array}$ & $\begin{array}{l}42,303 \\
14,491 \\
25,326 \\
24,196 \\
14,019\end{array}$ & $\begin{array}{l}42,075 \\
14,266 \\
25,719 \\
24,003 \\
13,951\end{array}$ \\
\hline $\begin{array}{l}\text { Maryland ................. } \\
\text { Massachusetts ........ } \\
\text { Michigan .................. } \\
\text { Minnesota .............. } \\
\text { Mississippi ............... }\end{array}$ & $\begin{array}{r}149,202 \\
315,937 \\
366,058 \\
162,559 \\
85,621\end{array}$ & $\begin{array}{r}148,091 \\
321,022 \\
354,690 \\
170,958 \\
86,846\end{array}$ & $\begin{array}{l}169,972 \\
320,299 \\
389,814 \\
190,608 \\
103,957\end{array}$ & $\begin{array}{l}176,641 \\
318,887 \\
373,059 \\
203,130 \\
103,067\end{array}$ & $\begin{array}{l}175,819 \\
317,205 \\
375,198 \\
205,483 \\
105,273\end{array}$ & $\begin{array}{r}141,950 \\
130,962 \\
326,952 \\
143,424 \\
92,269\end{array}$ & $\begin{array}{r}145,416 \\
123,554 \\
310,215 \\
151,461 \\
92,945\end{array}$ & $\begin{array}{r}144,277 \\
121,273 \\
309,976 \\
151,796 \\
95,835\end{array}$ & $\begin{array}{r}28,022 \\
189,337 \\
62,862 \\
47,184 \\
11,688\end{array}$ & $\begin{array}{r}31,225 \\
195,333 \\
62,844 \\
51,669 \\
10,122\end{array}$ & $\begin{array}{r}31,542 \\
195,932 \\
65,222 \\
53,687 \\
9,438\end{array}$ \\
\hline $\begin{array}{l}\text { Missouri ................... } \\
\text { Montana ................ } \\
\text { Nebraska .................. } \\
\text { Nevada ................. } \\
\text { New Hampshire ........ }\end{array}$ & $\begin{array}{r}180,156 \\
29,428 \\
68,505 \\
22,467 \\
39,456\end{array}$ & $\begin{array}{r}178,090 \\
29,992 \\
70,778 \\
23,093 \\
41,733\end{array}$ & $\begin{array}{r}210,104 \\
29,905 \\
80,989 \\
33,814 \\
45,762\end{array}$ & $\begin{array}{r}212,551 \\
36,528 \\
84,278 \\
37,991 \\
49,063\end{array}$ & $\begin{array}{r}214,329 \\
36,812 \\
86,525 \\
41,255 \\
48,833\end{array}$ & $\begin{array}{r}142,953 \\
26,835 \\
65,739 \\
33,392 \\
24,948\end{array}$ & $\begin{array}{r}135,607 \\
32,331 \\
67,248 \\
36,997 \\
27,096\end{array}$ & $\begin{array}{r}135,671 \\
32,650 \\
69,692 \\
39,926 \\
26,977\end{array}$ & $\begin{array}{r}67,151 \\
3,070 \\
15,250 \\
422 \\
20,814\end{array}$ & $\begin{array}{r}76,944 \\
4,197 \\
17,030 \\
994 \\
21,967\end{array}$ & $\begin{array}{r}78,658 \\
4,162 \\
16,833 \\
1,329 \\
21,856\end{array}$ \\
\hline $\begin{array}{l}\text { New Jersey } . . . . . . . . . . . \\
\text { New Mexico ............ } \\
\text { New York ............... } \\
\text { North Carolina ......... } \\
\text { North Dakota ........... }\end{array}$ & $\begin{array}{r}218,838 \\
43,722 \\
760,305 \\
235,266 \\
30,188\end{array}$ & $\begin{array}{r}201,270 \\
47,169 \\
763,596 \\
249,901 \\
32,456\end{array}$ & $\begin{array}{r}221,468 \\
59,517 \\
798,696 \\
269,025 \\
33,118\end{array}$ & $\begin{array}{r}232,669 \\
69,528 \\
805,527 \\
285,708 \\
35,279\end{array}$ & $\begin{array}{r}232,020 \\
69,843 \\
800,646 \\
287,887 \\
35,393\end{array}$ & $\begin{array}{r}174,324 \\
57,870 \\
446,379 \\
208,321 \\
30,276\end{array}$ & $\begin{array}{r}184,766 \\
64,903 \\
440,688 \\
224,055 \\
31,939\end{array}$ & $\begin{array}{r}183,198 \\
64,562 \\
432,215 \\
224,816 \\
31,880\end{array}$ & $\begin{array}{r}47,144 \\
1,647 \\
352,317 \\
60,704 \\
2,842\end{array}$ & $\begin{array}{r}47,903 \\
4,625 \\
364,839 \\
61,653 \\
3,340\end{array}$ & $\begin{array}{r}48,822 \\
5,281 \\
368,431 \\
63,071 \\
3,513\end{array}$ \\
\hline $\begin{array}{l}\text { Ohio ..................... } \\
\text { Oklahoma ................ } \\
\text { Oregon .................. } \\
\text { Pennsylvania ........... } \\
\text { Rhode Island ........... }\end{array}$ & $\begin{array}{r}369,342 \\
115,701 \\
110,649 \\
404,192 \\
50,628\end{array}$ & $\begin{array}{r}383,898 \\
126,691 \\
102,247 \\
422,349 \\
53,016\end{array}$ & $\begin{array}{r}420,499 \\
128,203 \\
120,176 \\
464,179 \\
60,168\end{array}$ & $\begin{array}{r}411,810 \\
134,176 \\
116,584 \\
474,269 \\
56,856\end{array}$ & $\begin{array}{r}410,696 \\
132,558 \\
117,555 \\
477,723 \\
55,969\end{array}$ & $\begin{array}{r}317,837 \\
108,933 \\
101,424 \\
261,305 \\
28,804\end{array}$ & $\begin{array}{r}306,842 \\
114,592 \\
96,311 \\
261,823 \\
26,124\end{array}$ & $\begin{array}{r}303,765 \\
112,806 \\
97,036 \\
260,088 \\
25,491\end{array}$ & $\begin{array}{r}102,662 \\
19,270 \\
18,752 \\
202,874 \\
31,364\end{array}$ & $\begin{array}{r}104,968 \\
19,584 \\
20,273 \\
212,446 \\
30,732\end{array}$ & $\begin{array}{r}106,931 \\
19,752 \\
20,519 \\
217,635 \\
30,478\end{array}$ \\
\hline 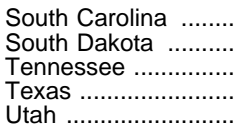 & $\begin{array}{r}109,346 \\
27,873 \\
161,058 \\
527,724 \\
78,199\end{array}$ & $\begin{array}{r}109,303 \\
26,988 \\
152,967 \\
566,736 \\
84,095\end{array}$ & $\begin{array}{r}127,225 \\
28,256 \\
175,961 \\
637,742 \\
94,012\end{array}$ & $\begin{array}{r}132,353 \\
30,555 \\
190,706 \\
671,478 \\
116,368\end{array}$ & $\begin{array}{r}133,755 \\
29,521 \\
192,564 \\
675,896 \\
117,006\end{array}$ & $\begin{array}{r}101,918 \\
22,128 \\
130,184 \\
553,436 \\
63,495\end{array}$ & $\begin{array}{r}109,459 \\
24,925 \\
142,785 \\
574,438 \\
82,052\end{array}$ & $\begin{array}{r}110,194 \\
23,951 \\
144,172 \\
577,777 \\
82,358\end{array}$ & $\begin{array}{r}25,307 \\
6,128 \\
45,777 \\
84,306 \\
30,517\end{array}$ & $\begin{array}{r}22,894 \\
5,630 \\
47,921 \\
97,040 \\
34,316\end{array}$ & $\begin{array}{r}23,561 \\
5,570 \\
48,392 \\
98,119 \\
34,648\end{array}$ \\
\hline $\begin{array}{l}\text { Vermont .................. } \\
\text { Virginia ................... } \\
\text { Washington ............. } \\
\text { West Virginia ............ } \\
\text { Wisconsin ................. } \\
\text { Wyoming ................ }\end{array}$ & $\begin{array}{r}25,572 \\
199,549 \\
194,440 \\
60,394 \\
206,790 \\
14,725\end{array}$ & $\begin{array}{r}25,649 \\
204,928 \\
171,668 \\
58,438 \\
211,749 \\
17,037\end{array}$ & $\begin{array}{r}29,072 \\
251,708 \\
189,521 \\
68,235 \\
229,975 \\
21,888\end{array}$ & $\begin{array}{r}28,079 \\
255,712 \\
214,050 \\
69,831 \\
223,938 \\
21,938\end{array}$ & $\begin{array}{r}28,217 \\
256,092 \\
218,785 \\
69,622 \\
224,066 \\
22,130\end{array}$ & $\begin{array}{r}16,048 \\
202,285 \\
160,889 \\
59,229 \\
192,107 \\
21,185\end{array}$ & $\begin{array}{r}15,600 \\
204,704 \\
181,243 \\
59,951 \\
180,713 \\
21,182\end{array}$ & $\begin{array}{r}15,525 \\
205,212 \\
184,642 \\
59,925 \\
180,768 \\
21,319\end{array}$ & $\begin{array}{r}13,024 \\
49,423 \\
28,632 \\
9,006 \\
37,868 \\
703\end{array}$ & $\begin{array}{r}12,479 \\
51,008 \\
32,807 \\
9,880 \\
43,225 \\
756\end{array}$ & $\begin{array}{r}12,692 \\
50,880 \\
34,143 \\
9,697 \\
43,298 \\
811\end{array}$ \\
\hline $\begin{array}{l}\text { U.S. Service } \\
\text { Schools ...... }\end{array}$ & 49,736 & 54,221 & 48,281 & 42,146 & 40,400 & 48,281 & 42,146 & 40,400 & - & 一 & - \\
\hline Outlying areas .... & 117,637 & 145,530 & 140,954 & 155,364 & 154,998 & 55,908 & 65,757 & 69,074 & 85,046 & 89,607 & 85,924 \\
\hline $\begin{array}{l}\text { American Samoa ..... } \\
\text { Federated States of }\end{array}$ & 824 & 497 & 952 & 988 & 999 & 952 & 988 & 999 & - & - & - \\
\hline 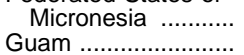 & 2,115 & $3,0 \overline{49}$ & $\begin{array}{r}549 \\
2,956\end{array}$ & $\begin{array}{l}1,076 \\
3,819\end{array}$ & $\begin{array}{l}1,098 \\
3,522\end{array}$ & $\begin{array}{r}549 \\
2,956\end{array}$ & $\begin{array}{l}1,076 \\
3,819\end{array}$ & $\begin{array}{l}1,098 \\
3,522\end{array}$ & - & - & 二 \\
\hline Marshall Islands ...... & & $\overline{100}$ & & 249 & 300 & & 249 & 300 & - & - & - \\
\hline $\begin{array}{l}\text { Northern Marianas .. } \\
\text { Palau }\end{array}$ & & $\underline{183}$ & $\begin{array}{l}376 \\
423\end{array}$ & $\begin{array}{l}625 \\
296\end{array}$ & $\begin{array}{l}693 \\
281\end{array}$ & $\begin{array}{l}376 \\
423\end{array}$ & $\begin{array}{l}625 \\
296\end{array}$ & $\begin{array}{l}693 \\
281\end{array}$ & - & - & 二 \\
\hline Puerto Rico ............................... & 113,285 & 139,627 & 134,193 & 146,258 & 146,152 & 49,147 & 56,651 & 60,228 & 85,046 & 89,607 & 85,924 \\
\hline $\begin{array}{l}\text { Pacific ...................................... } \\
\text { Virgin Islands }\end{array}$ & $\begin{array}{r}195 \\
1,218\end{array}$ & $\begin{array}{r}680 \\
1,494\end{array}$ & $1, \overline{05}$ & 2,053 & 1,953 & $1,5 \overline{05}$ & $2, \overline{53}$ & 1,953 & - & - & - \\
\hline
\end{tabular}

1 Preliminary data.

-Data not reported or not applicable.
SOURCE: U.S. Department of Education, National Center for Education Statistics, Integrated Postsecondary Education Data System (IPEDS), "Fall Enrollment" surveys. (This table was prepared June 1998.) 
HIGHER EDUCATION: ENROLLMENT 225

Table 203.--Residence and migration of all freshmen students ${ }^{1}$ in degree-granting institutions, by state: Fall 1996

\begin{tabular}{|c|c|c|c|c|c|c|c|c|}
\hline \multirow[b]{2}{*}{ State or other area } & \multirow{2}{*}{$\begin{array}{l}\text { Students } \\
\text { enrolled in } \\
\text { institutions } \\
\text { located in } \\
\text { the juris- } \\
\text { diction }{ }^{2}\end{array}$} & \multicolumn{2}{|c|}{$\begin{array}{c}\text { Student residents of } \\
\text { state }\end{array}$} & \multicolumn{2}{|c|}{$\begin{array}{l}\text { Ratio of students } \\
\text { remaining to- }\end{array}$} & \multicolumn{3}{|c|}{ Migration of students } \\
\hline & & $\begin{array}{l}\text { Attending } \\
\text { college in } \\
\text { any juris- } \\
\text { diction }^{3}\end{array}$ & $\begin{array}{l}\text { Attending } \\
\text { college in } \\
\text { home juris- } \\
\text { diction } 4\end{array}$ & $\begin{array}{c}\text { Students } \\
\text { enrolled } \\
\text { (col.4/col.2) }\end{array}$ & $\begin{array}{c}\text { Student } \\
\text { residents } \\
\text { (col.4/col.3) }\end{array}$ & $\begin{array}{c}\text { Out of } \\
\text { (col. 3-col. 4) }\end{array}$ & $\begin{array}{l}\text { Into } \\
\text { (col. } 2-\text { col. } 4)\end{array}$ & $\begin{array}{c}\text { Net } \\
\text { (col. 8-col. 7) }\end{array}$ \\
\hline 1 & 2 & 3 & 4 & 5 & 6 & 7 & 8 & 9 \\
\hline United States ….......................... & $2,188,131$ & $2,151,310$ & $1,808,647$ & 0.83 & 0.84 & 342,663 & 379,484 & 536,821 \\
\hline $\begin{array}{l}\text { Alabama } \\
\text { Alaska } \\
\text { Arizona } \\
\text { Arkansas } \\
\text { California }\end{array}$ & $\begin{array}{r}36,881 \\
1,946 \\
34,421 \\
18,388 \\
277,399\end{array}$ & $\begin{array}{r}33,053 \\
3,387 \\
29,933 \\
17,838 \\
277,373\end{array}$ & $\begin{array}{r}30,178 \\
1,682 \\
27,187 \\
15,659 \\
259,696\end{array}$ & $\begin{array}{l}0.82 \\
0.86 \\
0.79 \\
0.85 \\
0.94\end{array}$ & $\begin{array}{l}0.91 \\
0.50 \\
0.91 \\
0.88 \\
0.94\end{array}$ & $\begin{array}{r}2,875 \\
1,705 \\
2,746 \\
2,179 \\
17,677\end{array}$ & $\begin{array}{r}6,703 \\
264 \\
7,234 \\
2,729 \\
17,703\end{array}$ & $\begin{array}{r}3,828 \\
-1,441 \\
4,488 \\
550 \\
26\end{array}$ \\
\hline 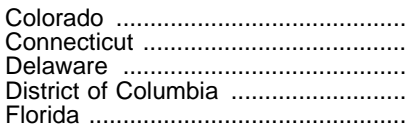 & $\begin{array}{r}31,816 \\
21,169 \\
7,854 \\
8,645 \\
72,465\end{array}$ & $\begin{array}{r}29,815 \\
25,336 \\
6,224 \\
2,898 \\
68,530\end{array}$ & $\begin{array}{r}24,560 \\
14,088 \\
4,667 \\
1,298 \\
58,096\end{array}$ & $\begin{array}{l}0.77 \\
0.67 \\
0.59 \\
0.15 \\
0.80\end{array}$ & $\begin{array}{l}0.82 \\
0.56 \\
0.75 \\
0.45 \\
0.85\end{array}$ & $\begin{array}{r}5,255 \\
11,248 \\
1,557 \\
1,600 \\
10,434\end{array}$ & $\begin{array}{r}7,256 \\
7,081 \\
3,187 \\
7,347 \\
14,369\end{array}$ & $\begin{array}{r}2,001 \\
-4,167 \\
1,630 \\
5,747 \\
3,935\end{array}$ \\
\hline 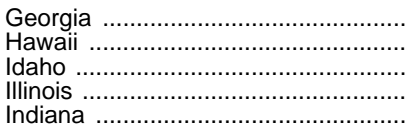 & $\begin{array}{r}53,393 \\
9,519 \\
10,664 \\
106,362 \\
51,108\end{array}$ & $\begin{array}{r}50,602 \\
9,936 \\
10,393 \\
115,198 \\
45,746\end{array}$ & $\begin{array}{r}43,575 \\
7,611 \\
8,052 \\
97,158 \\
40,309\end{array}$ & $\begin{array}{l}0.82 \\
0.80 \\
0.76 \\
0.91 \\
0.79\end{array}$ & $\begin{array}{l}0.86 \\
0.77 \\
0.77 \\
0.84 \\
0.88\end{array}$ & $\begin{array}{r}7,027 \\
2,325 \\
2,341 \\
18,040 \\
5,437\end{array}$ & $\begin{array}{r}9,818 \\
1,908 \\
2,612 \\
9,204 \\
10,799\end{array}$ & $\begin{array}{r}2,791 \\
-417 \\
271 \\
-8,836 \\
5,362\end{array}$ \\
\hline 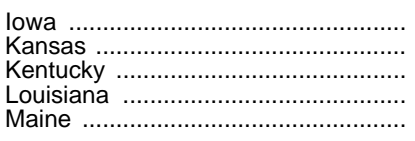 & $\begin{array}{r}39,449 \\
27,581 \\
28,546 \\
31,710 \\
8,349\end{array}$ & $\begin{array}{r}34,939 \\
26,049 \\
27,554 \\
30,869 \\
9,682\end{array}$ & $\begin{array}{r}31,469 \\
23,443 \\
24,043 \\
26,884 \\
5,935\end{array}$ & $\begin{array}{l}0.80 \\
0.85 \\
0.84 \\
0.85 \\
0.71\end{array}$ & $\begin{array}{l}0.90 \\
0.90 \\
0.87 \\
0.87 \\
0.61\end{array}$ & $\begin{array}{l}3,470 \\
2,606 \\
3,511 \\
3,985 \\
3,747\end{array}$ & $\begin{array}{l}7,980 \\
4,138 \\
4,503 \\
4,826 \\
2,414\end{array}$ & $\begin{array}{r}4,510 \\
1,532 \\
992 \\
841 \\
-1,333\end{array}$ \\
\hline 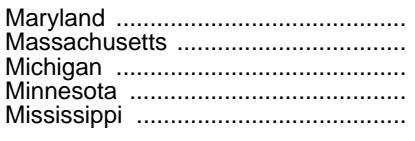 & $\begin{array}{l}33,198 \\
62,356 \\
76,216 \\
51,137 \\
27,669\end{array}$ & $\begin{array}{l}37,453 \\
53,067 \\
75,980 \\
50,751 \\
25,615\end{array}$ & $\begin{array}{l}26,115 \\
39,240 \\
68,959 \\
41,458 \\
23,828\end{array}$ & $\begin{array}{l}0.79 \\
0.63 \\
0.90 \\
0.81 \\
0.86\end{array}$ & $\begin{array}{l}0.70 \\
0.74 \\
0.91 \\
0.82 \\
0.93\end{array}$ & $\begin{array}{r}11,338 \\
13,827 \\
7,021 \\
9,293 \\
1,787\end{array}$ & $\begin{array}{r}7,083 \\
23,116 \\
7,257 \\
9,679 \\
3,841\end{array}$ & $\begin{array}{r}-4,255 \\
9,289 \\
236 \\
386 \\
2,054\end{array}$ \\
\hline 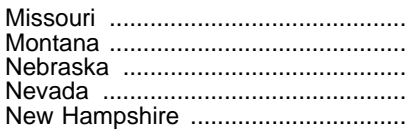 & $\begin{array}{r}38,484 \\
7,872 \\
17,136 \\
7,254 \\
10,872\end{array}$ & $\begin{array}{r}36,102 \\
8,259 \\
16,600 \\
6,891 \\
9,199\end{array}$ & $\begin{array}{r}30,174 \\
6,227 \\
14,051 \\
5,040 \\
5,301\end{array}$ & $\begin{array}{l}0.78 \\
0.79 \\
0.82 \\
0.69 \\
0.49\end{array}$ & $\begin{array}{l}0.84 \\
0.75 \\
0.85 \\
0.73 \\
0.58\end{array}$ & $\begin{array}{l}5,928 \\
2,032 \\
2,549 \\
1,851 \\
3,898\end{array}$ & $\begin{array}{l}8,310 \\
1,645 \\
3,085 \\
2,214 \\
5,571\end{array}$ & $\begin{array}{r}2,382 \\
-387 \\
536 \\
363 \\
1,673\end{array}$ \\
\hline 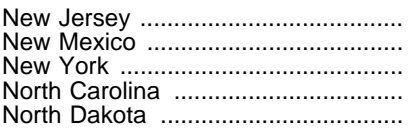 & $\begin{array}{r}45,899 \\
12,464 \\
151,388 \\
53,751 \\
8,495\end{array}$ & $\begin{array}{r}65,904 \\
12,997 \\
154,632 \\
45,918 \\
7,358\end{array}$ & $\begin{array}{r}41,465 \\
10,209 \\
127,503 \\
42,056 \\
5,711\end{array}$ & $\begin{array}{l}0.90 \\
0.82 \\
0.84 \\
0.78 \\
0.67\end{array}$ & $\begin{array}{l}0.63 \\
0.79 \\
0.82 \\
0.92 \\
0.78\end{array}$ & $\begin{array}{r}24,439 \\
2,788 \\
27,129 \\
3,862 \\
1,647\end{array}$ & $\begin{array}{r}4,434 \\
2,255 \\
23,885 \\
11,695 \\
2,784\end{array}$ & $\begin{array}{r}-20,005 \\
-533 \\
-3,244 \\
7,833 \\
1,137\end{array}$ \\
\hline 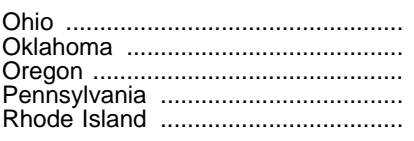 & $\begin{array}{r}90,806 \\
28,654 \\
22,126 \\
102,447 \\
12,643\end{array}$ & $\begin{array}{r}88,056 \\
27,847 \\
21,101 \\
94,108 \\
8,203\end{array}$ & $\begin{array}{r}77,345 \\
25,068 \\
17,308 \\
78,863 \\
5,514\end{array}$ & $\begin{array}{l}0.85 \\
0.87 \\
0.78 \\
0.77 \\
0.44\end{array}$ & $\begin{array}{l}0.88 \\
0.90 \\
0.82 \\
0.84 \\
0.67\end{array}$ & $\begin{array}{r}10,711 \\
2,779 \\
3,793 \\
15,245 \\
2,689\end{array}$ & $\begin{array}{r}13,461 \\
3,586 \\
4,818 \\
23,584 \\
7,129\end{array}$ & $\begin{array}{r}2,750 \\
807 \\
1,025 \\
8,339 \\
4,440\end{array}$ \\
\hline 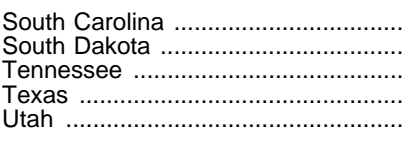 & $\begin{array}{r}30,719 \\
5,769 \\
36,516 \\
137,610 \\
25,732\end{array}$ & $\begin{array}{r}27,991 \\
6,004 \\
33,853 \\
137,449 \\
19,681\end{array}$ & $\begin{array}{r}24,795 \\
4,196 \\
28,805 \\
126,346 \\
18,408\end{array}$ & $\begin{array}{l}0.81 \\
0.73 \\
0.79 \\
0.92 \\
0.72\end{array}$ & $\begin{array}{l}0.89 \\
0.70 \\
0.85 \\
0.92 \\
0.94\end{array}$ & $\begin{array}{r}3,196 \\
1,808 \\
5,048 \\
11,103 \\
1,273\end{array}$ & $\begin{array}{r}5,924 \\
1,573 \\
7,711 \\
11,264 \\
7,324\end{array}$ & $\begin{array}{r}2,728 \\
-235 \\
2,663 \\
161 \\
6,051\end{array}$ \\
\hline 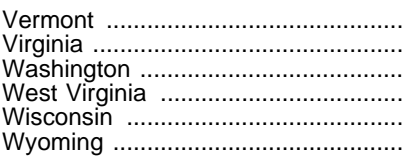 & $\begin{array}{r}6,551 \\
46,961 \\
85,536 \\
15,655 \\
50,136 \\
4,458\end{array}$ & $\begin{array}{r}4,632 \\
42,418 \\
80,368 \\
14,049 \\
49,646 \\
4,446\end{array}$ & $\begin{array}{r}2,597 \\
34,023 \\
74,719 \\
11,785 \\
42,350 \\
3,296\end{array}$ & $\begin{array}{l}0.40 \\
0.72 \\
0.87 \\
0.75 \\
0.84 \\
0.74\end{array}$ & $\begin{array}{l}0.56 \\
0.80 \\
0.93 \\
0.84 \\
0.85 \\
0.74\end{array}$ & $\begin{array}{l}2,035 \\
8,395 \\
5,649 \\
2,264 \\
7,296 \\
1,150\end{array}$ & $\begin{array}{r}3,954 \\
12,938 \\
10,817 \\
3,870 \\
7,786 \\
1,162\end{array}$ & $\begin{array}{r}1,919 \\
4,543 \\
5,168 \\
1,606 \\
490 \\
12\end{array}$ \\
\hline 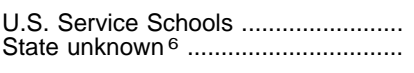 & $\underline{3,956}$ & $29, \overline{777}$ & $\underline{302}$ & - & - & $\begin{array}{r}-302 \\
29,377 \\
\end{array}$ & $\stackrel{3,654}{-}$ & $\begin{array}{r}3,956 \\
-29,377 \\
\end{array}$ \\
\hline 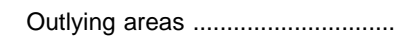 & 35,633 & 39,197 & 35,485 & 1.00 & 0.91 & 3,712 & 148 & $-3,564$ \\
\hline 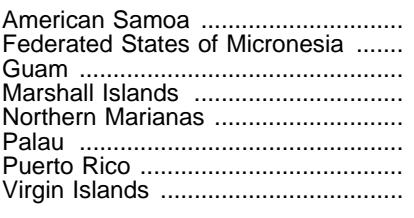 & $\begin{array}{r}3 \overline{359} \\
484 \\
121 \\
113 \\
109 \\
34,114 \\
333 \\
\end{array}$ & $\begin{array}{r}51 \\
2,504 \\
608 \\
127 \\
125 \\
137 \\
34,911 \\
734 \\
\end{array}$ & $\begin{array}{r}359 \\
442 \\
115 \\
105 \\
70 \\
34,084 \\
310\end{array}$ & $\begin{array}{l}1 . \overline{00} \\
0.91 \\
0.95 \\
0.93 \\
0.64 \\
1.00 \\
0.93\end{array}$ & $\begin{array}{l}0 . \overline{14} \\
0.73 \\
0.91 \\
0.84 \\
0.51 \\
0.98 \\
0.42\end{array}$ & $\begin{array}{r}51 \\
2,145 \\
166 \\
12 \\
20 \\
67 \\
827 \\
424 \\
\end{array}$ & $\begin{array}{r}0 \\
0 \\
42 \\
6 \\
8 \\
39 \\
30 \\
23\end{array}$ & $\begin{array}{r}-51 \\
-2,145 \\
-124 \\
-6 \\
-12 \\
-28 \\
-797 \\
-401\end{array}$ \\
\hline Foreign countries...$\ldots \ldots \ldots \ldots \ldots \ldots \ldots \ldots \ldots$ & - & 33,257 & - & - & - & 33,257 & - & $-33,257$ \\
\hline
\end{tabular}

${ }^{1}$ Students who are enrolled at the reporting institution for the first time.

${ }^{2}$ All of the new students reported by the institutions in that state; i.e., all in-migrants and "remaining" students.

${ }^{3}$ All students living in a particular state when admitted to an institution in any state. Students may be enrolled in any state.

${ }^{4}$ Students who attend institutions in their home state.

5 Includes students coming to U.S. colleges from foreign countries and the outlying areas.

${ }^{6}$ Students are reported in "state unknown" when an institution is unable to determine the student's home state.
-Data not available or not applicable.

NOTE.-Data are for 4-year and 2-year degree-granting higher education institutions that were eligible to participate in Title IV federal financial aid programs in the 199697 academic year.

SOURCE: U.S. Department of Education, National Center for Education Statistics, Integrated Postsecondary Education Data System (IPEDS), "Residence of First-Time Students" survey, 1996. (This table was prepared January 1998.) 
Table 204.-Residence and migration of all freshmen students ${ }^{1}$ in degree-granting institutions graduating from high school in the past 12 months, by state: Fall 1996

\begin{tabular}{|c|c|c|c|c|c|c|c|c|}
\hline \multirow[b]{2}{*}{ State or other area } & \multirow{2}{*}{$\begin{array}{l}\text { Students } \\
\text { enrolled in } \\
\text { institutions } \\
\text { located in } \\
\text { the juris- } \\
\text { diction }^{2}\end{array}$} & \multicolumn{2}{|c|}{$\begin{array}{l}\text { Student residents of } \\
\text { state }\end{array}$} & \multicolumn{2}{|c|}{$\begin{array}{l}\text { Ratio of students } \\
\text { remaining to- }\end{array}$} & \multicolumn{3}{|c|}{ Migration of students } \\
\hline & & $\begin{array}{l}\text { Attending } \\
\text { college in } \\
\text { any juris- } \\
\text { diction }^{3}\end{array}$ & $\begin{array}{l}\text { Attending } \\
\text { college in } \\
\text { home juris- } \\
\text { diction }{ }^{4}\end{array}$ & $\begin{array}{l}\text { Students en- } \\
\text { rolled (col. 4/ } \\
\text { col. 2) }\end{array}$ & $\begin{array}{l}\text { Student resi- } \\
\text { dents (col. 4/ } \\
\text { col. 3) }\end{array}$ & $\begin{array}{l}\text { Out of } \\
\text { (col. 3- } \\
\text { col. 4) }\end{array}$ & $\begin{array}{l}\text { Into } \\
\text { (col. 2- } \\
\text { col. 4) }\end{array}$ & $\begin{array}{c}\text { Net } \\
\text { (column 8- } \\
\text { column 7) }\end{array}$ \\
\hline 1 & 2 & 3 & 4 & 5 & 6 & 7 & 8 & 9 \\
\hline 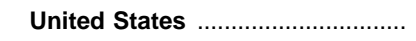 & $1,513,122$ & $1,491,441$ & $1,209,015$ & 0.80 & 0.81 & 282,426 & 304,107 & 521,681 \\
\hline 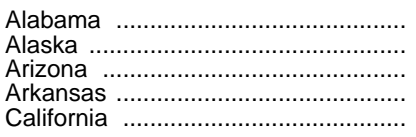 & $\begin{array}{r}26,841 \\
1,241 \\
18,414 \\
14,173 \\
186,894\end{array}$ & $\begin{array}{r}23,512 \\
2,494 \\
15,559 \\
13,476 \\
188,822\end{array}$ & $\begin{array}{r}21,115 \\
1,050 \\
13,280 \\
11,723 \\
173,860\end{array}$ & $\begin{array}{l}0.79 \\
0.85 \\
0.72 \\
0.83 \\
0.93\end{array}$ & $\begin{array}{l}0.90 \\
0.42 \\
0.85 \\
0.87 \\
0.92\end{array}$ & $\begin{array}{r}2,397 \\
1,444 \\
2,279 \\
1,753 \\
14,962\end{array}$ & $\begin{array}{r}5,726 \\
191 \\
5,134 \\
2,450 \\
13,034\end{array}$ & $\begin{array}{r}3,329 \\
-1,253 \\
2,855 \\
697 \\
-1,928\end{array}$ \\
\hline 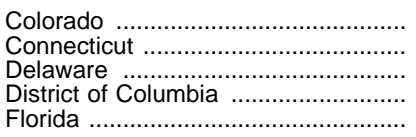 & $\begin{array}{r}18,840 \\
15,754 \\
6,333 \\
7,707 \\
51,221\end{array}$ & $\begin{array}{r}18,188 \\
19,577 \\
4,719 \\
2,277 \\
49,999\end{array}$ & $\begin{array}{r}13,656 \\
9,202 \\
3,356 \\
973 \\
41,265\end{array}$ & $\begin{array}{l}0.72 \\
0.58 \\
0.53 \\
0.13 \\
0.81\end{array}$ & $\begin{array}{l}0.75 \\
0.47 \\
0.71 \\
0.43 \\
0.83\end{array}$ & $\begin{array}{r}4,532 \\
10,375 \\
1,363 \\
1,304 \\
8,734\end{array}$ & $\begin{array}{l}5,184 \\
6,552 \\
2,977 \\
6,734 \\
9,956\end{array}$ & $\begin{array}{r}652 \\
-3,823 \\
1,614 \\
5,430 \\
1,222\end{array}$ \\
\hline 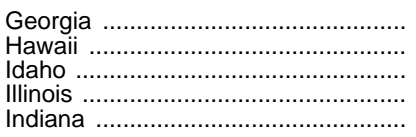 & $\begin{array}{r}35,508 \\
6,062 \\
7,171 \\
68,351 \\
40,481\end{array}$ & $\begin{array}{r}34,508 \\
7,020 \\
6,933 \\
76,889 \\
35,079\end{array}$ & $\begin{array}{r}28,305 \\
4,951 \\
5,034 \\
60,941 \\
30,605\end{array}$ & $\begin{array}{l}0.80 \\
0.82 \\
0.70 \\
0.89 \\
0.76\end{array}$ & $\begin{array}{l}0.82 \\
0.71 \\
0.73 \\
0.79 \\
0.87\end{array}$ & $\begin{array}{r}6,203 \\
2,069 \\
1,899 \\
15,948 \\
4,474\end{array}$ & $\begin{array}{l}7,203 \\
1,111 \\
2,137 \\
7,410 \\
9,876\end{array}$ & $\begin{array}{r}1,000 \\
-958 \\
238 \\
-8,538 \\
5,402\end{array}$ \\
\hline 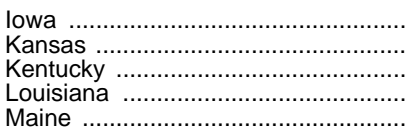 & $\begin{array}{r}25,222 \\
18,334 \\
21,902 \\
25,332 \\
6,391\end{array}$ & $\begin{array}{r}21,852 \\
16,937 \\
20,979 \\
24,118 \\
7,422\end{array}$ & $\begin{array}{r}18,828 \\
14,812 \\
18,210 \\
20,941 \\
4,136\end{array}$ & $\begin{array}{l}0.75 \\
0.81 \\
0.83 \\
0.83 \\
0.65\end{array}$ & $\begin{array}{l}0.86 \\
0.87 \\
0.87 \\
0.87 \\
0.56\end{array}$ & $\begin{array}{l}3,024 \\
2,125 \\
2,769 \\
3,177 \\
3,286\end{array}$ & $\begin{array}{l}6,394 \\
3,522 \\
3,692 \\
4,391 \\
2,255\end{array}$ & $\begin{array}{r}3,370 \\
1,397 \\
923 \\
1,214 \\
-1,031\end{array}$ \\
\hline 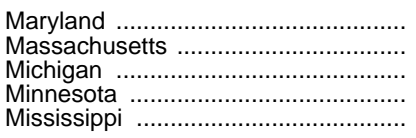 & $\begin{array}{l}23,969 \\
49,793 \\
55,718 \\
27,799 \\
18,937\end{array}$ & $\begin{array}{l}27,699 \\
41,485 \\
55,476 \\
29,104 \\
17,157\end{array}$ & $\begin{array}{l}17,711 \\
29,054 \\
49,673 \\
21,251 \\
15,680\end{array}$ & $\begin{array}{l}0.74 \\
0.58 \\
0.89 \\
0.76 \\
0.83\end{array}$ & $\begin{array}{l}0.64 \\
0.70 \\
0.90 \\
0.73 \\
0.91\end{array}$ & $\begin{array}{r}9,988 \\
12,431 \\
5,803 \\
7,853 \\
1,477\end{array}$ & $\begin{array}{r}6,258 \\
20,739 \\
6,045 \\
6,548 \\
3,257\end{array}$ & $\begin{array}{r}-3,730 \\
8,308 \\
242 \\
-1,305 \\
1,780\end{array}$ \\
\hline 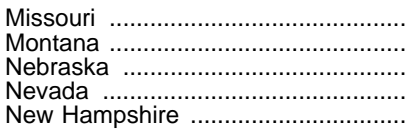 & $\begin{array}{r}29,136 \\
5,501 \\
12,653 \\
3,750 \\
8,347\end{array}$ & $\begin{array}{r}27,554 \\
5,834 \\
12,329 \\
4,275 \\
6,814\end{array}$ & $\begin{array}{r}22,433 \\
4,112 \\
10,180 \\
2,696 \\
3,420\end{array}$ & $\begin{array}{l}0.77 \\
0.75 \\
0.80 \\
0.72 \\
0.41\end{array}$ & $\begin{array}{l}0.81 \\
0.70 \\
0.83 \\
0.63 \\
0.50\end{array}$ & $\begin{array}{l}5,121 \\
1,722 \\
2,149 \\
1,579 \\
3,394\end{array}$ & $\begin{array}{l}6,703 \\
1,389 \\
2,473 \\
1,054 \\
4,927\end{array}$ & $\begin{array}{r}1,582 \\
-333 \\
324 \\
-525 \\
1,533\end{array}$ \\
\hline 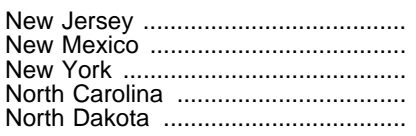 & $\begin{array}{r}32,767 \\
8,382 \\
110,563 \\
39,722 \\
7,284\end{array}$ & $\begin{array}{r}51,483 \\
9,169 \\
114,907 \\
32,303 \\
5,939\end{array}$ & $\begin{array}{r}29,265 \\
6,822 \\
90,527 \\
29,259 \\
4,757\end{array}$ & $\begin{array}{l}0.89 \\
0.81 \\
0.82 \\
0.74 \\
0.65\end{array}$ & $\begin{array}{l}0.57 \\
0.74 \\
0.79 \\
0.91 \\
0.80\end{array}$ & $\begin{array}{r}22,218 \\
2,347 \\
24,380 \\
3,044 \\
1,182\end{array}$ & $\begin{array}{r}3,502 \\
1,560 \\
20,036 \\
10,463 \\
2,527\end{array}$ & $\begin{array}{r}-18,716 \\
-787 \\
-4,344 \\
7,419 \\
1,345\end{array}$ \\
\hline 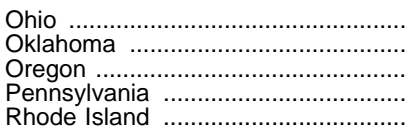 & $\begin{array}{r}64,521 \\
16,475 \\
15,394 \\
77,081 \\
9,781\end{array}$ & $\begin{array}{r}63,371 \\
16,481 \\
14,898 \\
70,898 \\
5,944\end{array}$ & $\begin{array}{r}54,089 \\
14,107 \\
11,527 \\
57,231 \\
3,536\end{array}$ & $\begin{array}{l}0.84 \\
0.86 \\
0.75 \\
0.74 \\
0.36\end{array}$ & $\begin{array}{l}0.85 \\
0.86 \\
0.77 \\
0.81 \\
0.59\end{array}$ & $\begin{array}{r}9,282 \\
2,374 \\
3,371 \\
13,667 \\
2,408\end{array}$ & $\begin{array}{r}10,432 \\
2,368 \\
3,867 \\
19,850 \\
6,245\end{array}$ & $\begin{array}{r}1,150 \\
-6 \\
496 \\
6,183 \\
3,837\end{array}$ \\
\hline 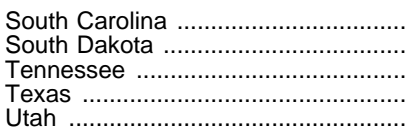 & $\begin{array}{r}21,789 \\
4,393 \\
28,857 \\
95,793 \\
18,328\end{array}$ & $\begin{array}{r}19,357 \\
4,568 \\
26,308 \\
97,688 \\
13,657\end{array}$ & $\begin{array}{r}16,656 \\
3,054 \\
21,941 \\
88,127 \\
12,612\end{array}$ & $\begin{array}{l}0.76 \\
0.70 \\
0.76 \\
0.92 \\
0.69\end{array}$ & $\begin{array}{l}0.86 \\
0.67 \\
0.83 \\
0.90 \\
0.92\end{array}$ & $\begin{array}{l}2,701 \\
1,514 \\
4,367 \\
9,561 \\
1,045\end{array}$ & $\begin{array}{l}5,133 \\
1,339 \\
6,916 \\
7,666 \\
5,716\end{array}$ & $\begin{array}{r}2,432 \\
-175 \\
2,549 \\
-1,895 \\
4,671\end{array}$ \\
\hline 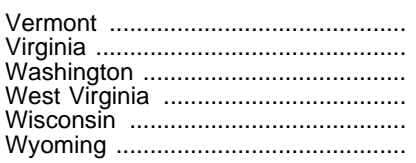 & $\begin{array}{r}4,983 \\
38,287 \\
30,060 \\
12,248 \\
32,447 \\
3,147\end{array}$ & $\begin{array}{r}3,313 \\
34,248 \\
30,551 \\
10,535 \\
33,445 \\
3,127\end{array}$ & $\begin{array}{r}1,532 \\
27,005 \\
25,819 \\
8,837 \\
27,426 \\
2,202\end{array}$ & $\begin{array}{l}0.31 \\
0.71 \\
0.86 \\
0.72 \\
0.85 \\
0.70\end{array}$ & $\begin{array}{l}0.46 \\
0.79 \\
0.85 \\
0.84 \\
0.82 \\
0.70\end{array}$ & $\begin{array}{r}1,781 \\
7,243 \\
4,732 \\
1,698 \\
6,019 \\
925\end{array}$ & $\begin{array}{r}3,451 \\
11,282 \\
4,241 \\
3,411 \\
5,021 \\
945\end{array}$ & $\begin{array}{r}1,670 \\
4,039 \\
-491 \\
1,713 \\
-998 \\
20\end{array}$ \\
\hline 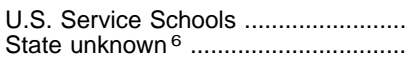 & $\stackrel{3,045}{-}$ & $11, \overline{64}$ & 231 & $\underline{0.08}$ & 二 & $\begin{array}{r}-231 \\
11,164\end{array}$ & $\stackrel{2,814}{-}$ & $\begin{array}{r}3,045 \\
-11,164\end{array}$ \\
\hline 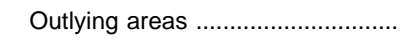 & 32,634 & 34,534 & 32,533 & 1.00 & 0.94 & 2,001 & 101 & $-1,900$ \\
\hline 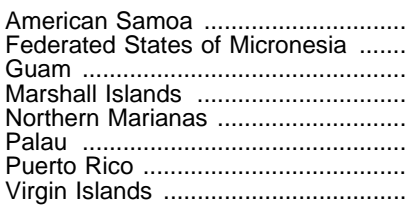 & $\begin{array}{r}320 \\
309 \\
113 \\
100 \\
109 \\
31,489 \\
194\end{array}$ & $\begin{array}{r}37 \\
1,078 \\
426 \\
115 \\
109 \\
114 \\
32,141 \\
514\end{array}$ & $\begin{array}{r}3 \overline{320} \\
285 \\
107 \\
95 \\
70 \\
31,467 \\
189\end{array}$ & $\begin{array}{l}1 . \overline{0} \\
0.92 \\
0.95 \\
0.95 \\
0.64 \\
1.00 \\
0.97\end{array}$ & $\begin{array}{l}0 . \overline{30} \\
0.67 \\
0.93 \\
0.87 \\
0.61 \\
0.98 \\
0.37\end{array}$ & $\begin{array}{r}37 \\
758 \\
141 \\
8 \\
14 \\
44 \\
674 \\
325\end{array}$ & $\begin{array}{r}- \\
24 \\
6 \\
5 \\
39 \\
22 \\
5\end{array}$ & $\begin{array}{r}-37 \\
-758 \\
-117 \\
-2 \\
-9 \\
-5 \\
-652 \\
-320\end{array}$ \\
\hline Foreign countries $\ldots \ldots \ldots \ldots \ldots \ldots \ldots \ldots \ldots$ & - & 19,781 & - & - & - & 19,781 & - & $-19,781$ \\
\hline
\end{tabular}

${ }^{1}$ Students who are enrolled at the reporting institution for the first time ever enrolled anywhere.

${ }^{2}$ All of the new students reported by the institutions in that state; i.e., all in-migrants and "remaining" students.

${ }^{3}$ All students living in a particular state when admitted to an institution in any state. Students may be enrolled in any state.

${ }^{4}$ Students who attend institutions in their home state.

5 Includes students coming to U.S. colleges from foreign countries and the outlying areas.

${ }^{6}$ Students are reported in "state unknown" when an institution is unable to determine the student's home state.
-Data not available or not applicable.

NOTE.-Data are for 4-year and 2-year degree-granting higher education institutions that were eligible to participate in Title IV federal financial aid programs in the 199697 academic year.

SOURCE: U.S. Department of Education, National Center for Education Statistics, Integrated Postsecondary Education Data System (IPEDS), "Residence of First-Time Students" survey, 1996. (This table was prepared January 1998.) 
Table 205.-Residence and migration of all freshmen students ${ }^{1}$ in 4-year colleges graduating from high school in the past 12 months, by state: Fall 1996

\begin{tabular}{|c|c|c|c|c|c|c|c|c|}
\hline \multirow[b]{2}{*}{ State or other area } & \multirow{2}{*}{$\begin{array}{l}\text { Students } \\
\text { enrolled in } \\
\text { institutions } \\
\text { located in } \\
\text { the juris- } \\
\text { diction }^{2}\end{array}$} & \multicolumn{2}{|c|}{$\begin{array}{c}\text { Student residents of } \\
\text { state }\end{array}$} & \multicolumn{2}{|c|}{$\begin{array}{l}\text { Ratio of students } \\
\text { remaining to- }\end{array}$} & \multicolumn{3}{|c|}{ Migration of students } \\
\hline & & $\begin{array}{l}\text { Attending } \\
\text { college in } \\
\text { any juris- } \\
\text { diction }^{3}\end{array}$ & $\begin{array}{l}\text { Attending } \\
\text { college in } \\
\text { home juris- } \\
\text { diction } 4\end{array}$ & $\begin{array}{l}\text { Students } \\
\text { enrolled } \\
\text { (col.4/col.2) }\end{array}$ & $\begin{array}{l}\text { Student } \\
\text { residents } \\
\text { (col.4/col.3) }\end{array}$ & $\begin{array}{c}\text { Out of } \\
\text { (col. 3-col. 4) }\end{array}$ & 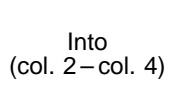 & $\begin{array}{c}\text { Net } \\
\text { (col. 8-col. 7) }\end{array}$ \\
\hline 1 & 2 & 3 & 4 & 5 & 6 & 7 & 8 & 9 \\
\hline 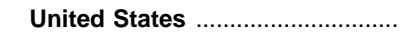 & $1,015,534$ & 996,330 & 737,654 & 0.73 & 0.74 & 258,676 & 277,880 & 519,204 \\
\hline 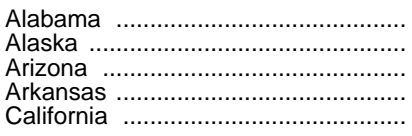 & $\begin{array}{r}16,164 \\
1,207 \\
11,614 \\
10,732 \\
72,130\end{array}$ & $\begin{array}{r}13,174 \\
2,333 \\
9,055 \\
9,770 \\
77,482\end{array}$ & $\begin{array}{r}10,960 \\
1,016 \\
6,979 \\
8,507 \\
63,264\end{array}$ & $\begin{array}{l}0.68 \\
0.84 \\
0.60 \\
0.79 \\
0.88\end{array}$ & $\begin{array}{l}0.83 \\
0.44 \\
0.77 \\
0.87 \\
0.82\end{array}$ & $\begin{array}{r}2,214 \\
1,317 \\
2,076 \\
1,263 \\
14,218\end{array}$ & $\begin{array}{r}5,204 \\
191 \\
4,635 \\
2,225 \\
8,866\end{array}$ & $\begin{array}{r}2,990 \\
-1,126 \\
2,559 \\
962 \\
-5,352\end{array}$ \\
\hline 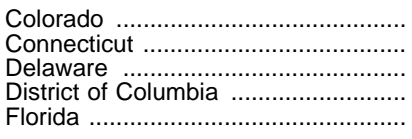 & $\begin{array}{r}15,653 \\
13,024 \\
5,145 \\
7,707 \\
29,148\end{array}$ & $\begin{array}{r}14,910 \\
16,772 \\
3,551 \\
2,198 \\
28,947\end{array}$ & $\begin{array}{r}10,761 \\
6,644 \\
2,239 \\
973 \\
20,721\end{array}$ & $\begin{array}{l}0.69 \\
0.51 \\
0.44 \\
0.13 \\
0.71\end{array}$ & $\begin{array}{l}0.72 \\
0.40 \\
0.63 \\
0.44 \\
0.72\end{array}$ & $\begin{array}{r}4,149 \\
10,128 \\
1,312 \\
1,225 \\
8,226\end{array}$ & $\begin{array}{l}4,892 \\
6,380 \\
2,906 \\
6,734 \\
8,427\end{array}$ & $\begin{array}{r}743 \\
-3,748 \\
1,594 \\
5,509 \\
201\end{array}$ \\
\hline 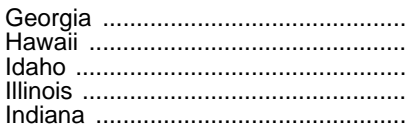 & $\begin{array}{r}26,849 \\
3,037 \\
4,177 \\
38,478 \\
35,639\end{array}$ & $\begin{array}{r}26,094 \\
3,929 \\
5,029 \\
46,615 \\
30,033\end{array}$ & $\begin{array}{r}20,329 \\
1,978 \\
3,403 \\
31,459 \\
26,067\end{array}$ & $\begin{array}{l}0.76 \\
0.65 \\
0.81 \\
0.82 \\
0.73\end{array}$ & $\begin{array}{l}0.78 \\
0.50 \\
0.68 \\
0.67 \\
0.87\end{array}$ & $\begin{array}{r}5,765 \\
1,951 \\
1,626 \\
15,156 \\
3,966\end{array}$ & $\begin{array}{r}6,520 \\
1,059 \\
774 \\
7,019 \\
9,572\end{array}$ & $\begin{array}{r}755 \\
-892 \\
-852 \\
-8,137 \\
5,606\end{array}$ \\
\hline 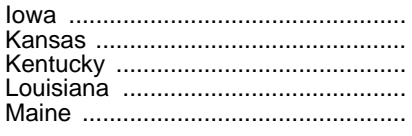 & $\begin{array}{r}16,157 \\
11,791 \\
16,085 \\
22,654 \\
5,489\end{array}$ & $\begin{array}{r}13,355 \\
11,019 \\
15,127 \\
21,110 \\
6,435\end{array}$ & $\begin{array}{r}10,499 \\
9,018 \\
12,619 \\
18,300 \\
3,288\end{array}$ & $\begin{array}{l}0.65 \\
0.76 \\
0.78 \\
0.81 \\
0.60\end{array}$ & $\begin{array}{l}0.79 \\
0.82 \\
0.83 \\
0.87 \\
0.51\end{array}$ & $\begin{array}{l}2,856 \\
2,001 \\
2,508 \\
2,810 \\
3,147\end{array}$ & $\begin{array}{l}5,658 \\
2,773 \\
3,466 \\
4,354 \\
2,201\end{array}$ & $\begin{array}{r}2,802 \\
772 \\
958 \\
1,544 \\
-946\end{array}$ \\
\hline 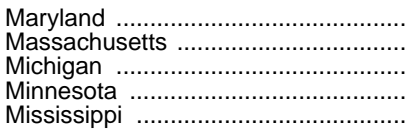 & $\begin{array}{r}14,573 \\
39,697 \\
40,761 \\
19,390 \\
8,452\end{array}$ & $\begin{array}{r}18,546 \\
31,538 \\
40,385 \\
21,108 \\
6,979\end{array}$ & $\begin{array}{r}8,805 \\
19,542 \\
34,945 \\
13,634 \\
5,632\end{array}$ & $\begin{array}{l}0.60 \\
0.49 \\
0.86 \\
0.70 \\
0.67\end{array}$ & $\begin{array}{l}0.47 \\
0.62 \\
0.87 \\
0.65 \\
0.81\end{array}$ & $\begin{array}{r}9,741 \\
11,996 \\
5,440 \\
7,474 \\
1,347\end{array}$ & $\begin{array}{r}5,768 \\
20,155 \\
5,816 \\
5,756 \\
2,820\end{array}$ & $\begin{array}{r}-3,973 \\
8,159 \\
376 \\
-1,718 \\
1,473\end{array}$ \\
\hline 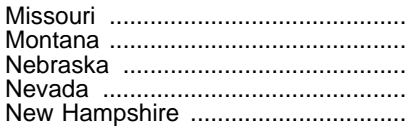 & $\begin{array}{r}22,791 \\
4,734 \\
9,847 \\
2,822 \\
7,120\end{array}$ & $\begin{array}{r}21,253 \\
4,706 \\
9,405 \\
3,281 \\
5,661\end{array}$ & $\begin{array}{r}16,684 \\
3,370 \\
7,524 \\
1,994 \\
2,527\end{array}$ & $\begin{array}{l}0.73 \\
0.71 \\
0.76 \\
0.71 \\
0.35\end{array}$ & $\begin{array}{l}0.79 \\
0.72 \\
0.80 \\
0.61 \\
0.45\end{array}$ & $\begin{array}{l}4,569 \\
1,336 \\
1,881 \\
1,287 \\
3,134\end{array}$ & $\begin{array}{r}6,107 \\
1,364 \\
2,323 \\
828 \\
4,593\end{array}$ & $\begin{array}{r}1,538 \\
28 \\
442 \\
-459 \\
1,459\end{array}$ \\
\hline 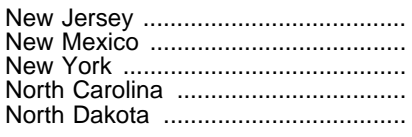 & $\begin{array}{r}19,259 \\
4,356 \\
78,835 \\
32,526 \\
4,865\end{array}$ & $\begin{array}{r}38,080 \\
5,431 \\
83,484 \\
25,111 \\
3,788\end{array}$ & $\begin{array}{r}16,286 \\
3,362 \\
59,748 \\
22,309 \\
2,784\end{array}$ & $\begin{array}{l}0.85 \\
0.77 \\
0.76 \\
0.69 \\
0.57\end{array}$ & $\begin{array}{l}0.43 \\
0.62 \\
0.72 \\
0.89 \\
0.73\end{array}$ & $\begin{array}{r}21,794 \\
2,069 \\
23,736 \\
2,802 \\
1,004\end{array}$ & $\begin{array}{r}2,973 \\
994 \\
19,087 \\
10,217 \\
2,081\end{array}$ & $\begin{array}{r}-18,821 \\
-1,075 \\
-4,649 \\
7,415 \\
1,077\end{array}$ \\
\hline 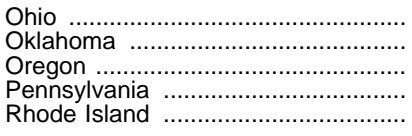 & $\begin{array}{r}49,413 \\
10,571 \\
9,698 \\
62,583 \\
8,291\end{array}$ & $\begin{array}{r}48,326 \\
10,509 \\
9,420 \\
57,256 \\
4,458\end{array}$ & $\begin{array}{r}39,542 \\
8,551 \\
6,301 \\
44,230 \\
2,160\end{array}$ & $\begin{array}{l}0.80 \\
0.81 \\
0.65 \\
0.71 \\
0.26\end{array}$ & $\begin{array}{l}0.82 \\
0.81 \\
0.67 \\
0.77 \\
0.48\end{array}$ & $\begin{array}{r}8,784 \\
1,958 \\
3,119 \\
13,026 \\
2,298\end{array}$ & $\begin{array}{r}9,871 \\
2,020 \\
3,397 \\
18,353 \\
6,131\end{array}$ & $\begin{array}{r}1,087 \\
62 \\
278 \\
5,327 \\
3,833\end{array}$ \\
\hline 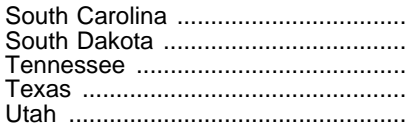 & $\begin{array}{r}16,152 \\
4,360 \\
21,110 \\
57,103 \\
13,342\end{array}$ & $\begin{array}{r}13,732 \\
4,259 \\
18,475 \\
60,083 \\
8,696\end{array}$ & $\begin{array}{r}11,185 \\
3,024 \\
14,414 \\
51,040 \\
8,069\end{array}$ & $\begin{array}{l}0.69 \\
0.69 \\
0.68 \\
0.89 \\
0.60\end{array}$ & $\begin{array}{l}0.81 \\
0.71 \\
0.78 \\
0.85 \\
0.93\end{array}$ & $\begin{array}{r}2,547 \\
1,235 \\
4,061 \\
9,043 \\
627\end{array}$ & $\begin{array}{l}4,967 \\
1,336 \\
6,696 \\
6,063 \\
5,273\end{array}$ & $\begin{array}{r}2,420 \\
101 \\
2,635 \\
-2,980 \\
4,646\end{array}$ \\
\hline 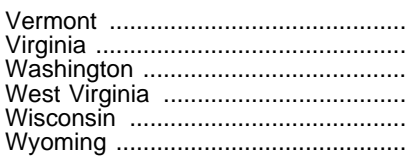 & $\begin{array}{r}4,897 \\
30,941 \\
14,268 \\
11,188 \\
24,516 \\
1,148\end{array}$ & $\begin{array}{r}3,105 \\
26,928 \\
15,107 \\
9,370 \\
25,136 \\
1,532\end{array}$ & $\begin{array}{r}1,465 \\
20,002 \\
10,883 \\
7,951 \\
19,695 \\
741\end{array}$ & $\begin{array}{l}0.30 \\
0.65 \\
0.76 \\
0.71 \\
0.80 \\
0.65\end{array}$ & $\begin{array}{l}0.47 \\
0.74 \\
0.72 \\
0.85 \\
0.78 \\
0.48\end{array}$ & $\begin{array}{r}1,640 \\
6,926 \\
4,224 \\
1,419 \\
5,441 \\
791\end{array}$ & $\begin{array}{r}3,432 \\
10,939 \\
3,385 \\
3,237 \\
4,821 \\
407\end{array}$ & $\begin{array}{l}1,792 \\
4,013 \\
-839 \\
1,818 \\
-620 \\
-384\end{array}$ \\
\hline $\begin{array}{l}\text { U.S. Service schools } \ldots \ldots \ldots \ldots \ldots \ldots \ldots \ldots \\
\text { State unknown }{ }^{6} \ldots \ldots \ldots \ldots \ldots \ldots \ldots \ldots \ldots \ldots \ldots \ldots \ldots \ldots \ldots \ldots \ldots \ldots \ldots \ldots \ldots\end{array}$ & $\begin{array}{r}3,045 \\
0 \\
\end{array}$ & $\begin{array}{r}0 \\
4,244\end{array}$ & $\begin{array}{r}231 \\
0\end{array}$ & - & - & $\begin{array}{l}-231 \\
4,244\end{array}$ & $\stackrel{2,814}{-}$ & $\begin{array}{r}3,045 \\
-4,244\end{array}$ \\
\hline 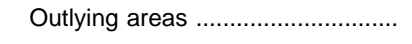 & 28,358 & 29,614 & 28,308 & 1.00 & 0.96 & 1,306 & 50 & $-1,256$ \\
\hline 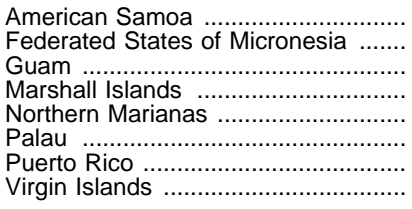 & $\begin{array}{r}\overline{-} \\
306 \\
- \\
27,858 \\
194\end{array}$ & $\begin{array}{r}36 \\
165 \\
406 \\
4 \\
11 \\
39 \\
28,448 \\
505\end{array}$ & $\begin{array}{r}\overline{-} \\
283 \\
- \\
\overline{-} \\
27,836 \\
189\end{array}$ & $\begin{array}{l}- \\
- \\
\overline{-} \\
1 . \overline{0} \\
0.97\end{array}$ & $\begin{array}{l}- \\
\bar{Z} \\
\overline{-} \\
0 . \overline{98} \\
0.37\end{array}$ & $\begin{array}{r}36 \\
165 \\
123 \\
4 \\
11 \\
39 \\
612 \\
316\end{array}$ & $\begin{array}{l}\overline{-} \\
\overline{23} \\
\overline{-} \\
\overline{22} \\
5\end{array}$ & $\begin{array}{r}-36 \\
-165 \\
-100 \\
-4 \\
-11 \\
-39 \\
-590 \\
-311\end{array}$ \\
\hline Foreign countries & - & 17,948 & 一 & - & - & 17,948 & - & $-17,948$ \\
\hline
\end{tabular}

1 Students who are enrolled at the reporting institution for the first time.

${ }^{2}$ All of the new students reported by the institutions in that state; i.e., all in-migrants and "remaining" students.

${ }^{3}$ All students living in a particular state when first admitted to an institution in any state. Students may be enrolled in any state.

${ }^{4}$ Students who attend institutions in their home state.

5 Includes students coming to U.S. colleges from foreign countries and the outlying areas.

${ }^{6}$ Students are reported in "state unknown" when an institution is unable to determine the student's home state.
-Data not available or not applicable.

NOTE.-Data are for 4-year and 2-year degree-granting higher education institutions that were eligible to participate in Title IV federal financial aid programs in the 199697 academic year.

SOURCE: U.S. Department of Education, National Center for Education Statistics, Integrated Postsecondary Education Data System (IPEDS), "Residence of First-Time Students" survey, 1996. (This table was prepared January 1998.) 
Table 206.-Total fall enrollment in institutions of higher education and degree-granting institutions, by type and control of institution and race/ethnicity of student: 1976 to 1996

\begin{tabular}{|c|c|c|c|c|c|c|c|c|c|c|c|c|c|c|c|}
\hline \multirow{3}{*}{$\begin{array}{l}\text { Type and control of institution and } \\
\text { race/ethnicity of student }\end{array}$} & \multicolumn{7}{|c|}{ Institutions of higher education, in thousands, $1996^{3}$} & \multirow{3}{*}{$\begin{array}{l}\text { Degree- } \\
\text { granting } \\
\text { institu- } \\
\text { tions, in } \\
\text { thou- } \\
\text { sands, } \\
1996^{3}\end{array}$} & \multicolumn{7}{|c|}{ Percentage distribution by type and control 1} \\
\hline & \multirow{2}{*}{1976} & \multirow{2}{*}{1980} & \multirow{2}{*}{1990} & \multirow{2}{*}{1993} & \multirow{2}{*}{1994} & \multirow{2}{*}{1995} & \multirow{2}{*}{$996^{2}$} & & \multicolumn{6}{|c|}{ ns of higher educatio } & \multirow{2}{*}{\begin{tabular}{||c} 
Degree \\
grant- \\
ing in- \\
stitu- \\
tions, \\
$1996^{3}$
\end{tabular}} \\
\hline & & & & & & & & & 1976 & 980 & 1990 & 1994 & 1995 & $1996^{2}$ & \\
\hline 1 & 2 & 3 & 4 & 5 & 6 & 7 & 8 & 9 & 10 & 11 & 12 & 13 & 14 & 15 & 16 \\
\hline 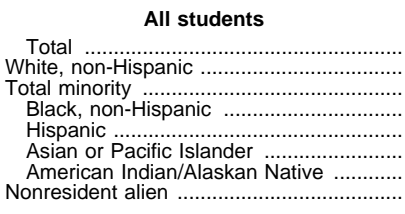 & $\begin{array}{r}10,985.6 \\
9,076.1 \\
1,69.8 \\
1,033.0 \\
383.8 \\
197.9 \\
76.1 \\
218.7 \\
\end{array}$ & $\begin{array}{r}12,086.8 \\
9,833.0 \\
1,948.8 \\
1,106.8 \\
471.7 \\
286.4 \\
83.9 \\
305.0\end{array}$ & \begin{tabular}{|r}
$13,818.6$ \\
$10,722.5$ \\
$2,704.7$ \\
$1,247.0$ \\
782.4 \\
572.4 \\
102.8 \\
391.5 \\
\end{tabular} & \begin{tabular}{|r|}
$14,304.8$ \\
$10,600.0$ \\
$3,247.7$ \\
$1,412.8$ \\
988.8 \\
724.4 \\
121.7 \\
457.1 \\
\end{tabular} & $\begin{array}{r}14,278.8 \\
10,427.0 \\
3,395.9 \\
1,448.6 \\
1,04.6 \\
774.3 \\
127.4 \\
455.9 \\
\end{array}$ & $\begin{aligned} 14,261.8 \\
10,311.2 \\
3,496.2 \\
1,473.7 \\
1,09.8 \\
797.4 \\
131.3 \\
454.4 \\
\end{aligned}$ & $\begin{array}{r}14,300.3 \\
10,226.0 \\
3,609.3 \\
1,499.4 \\
1,152.2 \\
823.6 \\
134.0 \\
464.9 \\
\end{array}$ & $\begin{array}{r}14,367.5 \\
10,263.9 \\
3,637.4 \\
1,505.6 \\
1,166.1 \\
828.2 \\
137.6 \\
466.3\end{array}$ & $\begin{aligned} r 00.0 \\
84.3 \\
15.7 \\
9.6 \\
3.6 \\
1.8 \\
0.7\end{aligned}$ & $\begin{array}{r}100.0 \\
83.5 \\
16.5 \\
9.4 \\
4.0 \\
2.4 \\
0.7\end{array}$ & $\begin{array}{r}100.0 \\
79.9 \\
20.1 \\
9.3 \\
5.8 \\
4.3 \\
0.8\end{array}$ & $\begin{array}{r}100.0 \\
75.4 \\
24.6 \\
10.5 \\
7.6 \\
5.6 \\
0.9\end{array}$ & $\begin{array}{r}100.0 \\
74.7 \\
25.3 \\
10.7 \\
7.9 \\
5.8 \\
1.0\end{array}$ & $\begin{array}{r}100.0 \\
73.9 \\
26.1 \\
10.8 \\
8.3 \\
6.0 \\
1.0\end{array}$ & $\begin{array}{l}100.0 \\
73.8 \\
26.2 \\
10.8 \\
8.4 \\
6.0 \\
1.0\end{array}$ \\
\hline 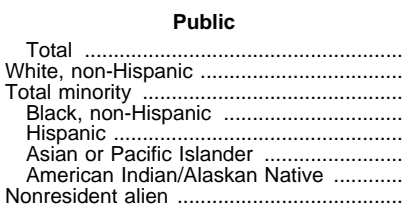 & $\begin{array}{r}8,641.0 \\
7,094.5 \\
1,401.2 \\
831.2 \\
336.8 \\
165.7 \\
67.5 \\
145.3\end{array}$ & $\begin{aligned} 9,456.4 \\
7,656.1 \\
1,596.2 \\
876.1 \\
406.2 \\
239.7 \\
74.2 \\
204.2\end{aligned}$ & \begin{tabular}{|r}
$10,844.7$ \\
$8,385.4$ \\
$2,199.2$ \\
976.4 \\
671.4 \\
461.0 \\
90.4 \\
260.0
\end{tabular} & \begin{tabular}{|r|}
$11,189.1$ \\
$8,226.6$ \\
$2,658.1$ \\
$1,114.3$ \\
851.3 \\
586.2 \\
106.4 \\
304.4
\end{tabular} & $\begin{array}{r}11,133.7 \\
8,056.4 \\
2,776.1 \\
1,144.5 \\
898.7 \\
622.1 \\
110.8 \\
301.3\end{array}$ & $\begin{array}{r}11,092.4 \\
7,945.4 \\
2,849.5 \\
1,160.6 \\
937.1 \\
638.0 \\
113.8 \\
297.5\end{array}$ & $\begin{aligned} 11,090.2 \\
7,848.3 \\
2,938.2 \\
1,177.3 \\
987.6 \\
657.1 \\
11.3 \\
303.7\end{aligned}$ & $\begin{array}{r}11,120.5 \\
7,871.9 \\
2,944.8 \\
1,177.4 \\
990.7 \\
657.9 \\
118.8 \\
303.8\end{array}$ & $\begin{array}{r}100.0 \\
83.5 \\
16.5 \\
9.8 \\
4.0 \\
2.0 \\
0.8\end{array}$ & $\begin{array}{r}100.0 \\
82.7 \\
17.3 \\
9.5 \\
4.4 \\
2.6 \\
0.8\end{array}$ & $\begin{array}{r}100.0 \\
79.2 \\
20.8 \\
9.2 \\
6.3 \\
4.4 \\
0.9\end{array}$ & $\begin{array}{r}100.0 \\
75.6 \\
24.4 \\
10.2 \\
7.8 \\
5.4 \\
1.0\end{array}$ & $\begin{array}{r}100.0 \\
74.4 \\
25.6 \\
10.6 \\
8.3 \\
5.7 \\
1.0\end{array}$ & $\begin{array}{r}100.0 \\
73.6 \\
26.4 \\
10.8 \\
8.7 \\
5.9 \\
1.1\end{array}$ & $\begin{array}{r}100.0 \\
72.8 \\
27.2 \\
10.9 \\
9.2 \\
6.1 \\
1.1\end{array}$ \\
\hline 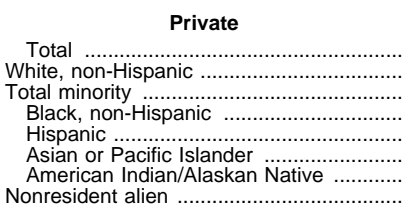 & $\begin{array}{r}2,344.6 \\
1,981.6 \\
289.6 \\
201.8 \\
47.0 \\
32.2 \\
8.6 \\
73.4\end{array}$ & $\begin{array}{r}2,176.9 \\
352.7 \\
230.7 \\
65.6 \\
46.7 \\
9.7 \\
100.8\end{array}$ & $\begin{array}{r}2,973.9 \\
2,337.0 \\
505.5 \\
270.6 \\
111.0 \\
111.5 \\
12.4 \\
131.4\end{array}$ & $\begin{array}{r}3,115.7 \\
2,373.5 \\
589.5 \\
298.5 \\
137.5 \\
138.2 \\
15.3 \\
152.7\end{array}$ & $\begin{array}{r}3,145.1 \\
2,370.6 \\
619.8 \\
304.1 \\
146.9 \\
152.2 \\
16.6 \\
154.7\end{array}$ & $\begin{array}{r}3,169.4 \\
2,365.9 \\
646.6 \\
313.0 \\
156.8 \\
159.4 \\
17.5 \\
156.9\end{array}$ & $\begin{array}{r}3,210.1 \\
2,377.7 \\
671.1 \\
322.2 \\
164.7 \\
166.5 \\
17.7 \\
161.3\end{array}$ & $\begin{array}{r}3,247.0 \\
2,392.0 \\
692.6 \\
328.1 \\
175.4 \\
170.3 \\
18.8 \\
162.5\end{array}$ & $\begin{aligned} 100.0 \\
87.3 \\
12.7 \\
8.9 \\
2.1 \\
1.4 \\
0.4 \\
-\end{aligned}$ & $\begin{array}{r}100.0 \\
86.1 \\
13.9 \\
9.1 \\
2.6 \\
1.8 \\
0.4\end{array}$ & $\begin{array}{r}100.0 \\
82.2 \\
17.8 \\
9.5 \\
3.9 \\
3.9 \\
0.4 \\
-\end{array}$ & $\begin{array}{r}100.0 \\
80.1 \\
19.9 \\
10.1 \\
4.6 \\
4.7 \\
0.5 \\
-\end{array}$ & $\begin{array}{r}100.0 \\
79.3 \\
20.7 \\
10.2 \\
4.9 \\
5.1 \\
0.6 \\
-\end{array}$ & $\begin{array}{r}r 00.0 \\
78.5 \\
21.5 \\
10.4 \\
5.2 \\
5.3 \\
0.6\end{array}$ & $\begin{aligned} 100.0 \\
78.0 \\
22.0 \\
10.6 \\
5.4 \\
5.5 \\
0.6\end{aligned}$ \\
\hline $\begin{array}{l}\text { Black, non-Hispan } \\
\text { Hispanic ........ } \\
\text { Asian or Pacific is } \\
\text { American Indian/A } \\
\text { Nonresident alien .. }\end{array}$ & $\begin{array}{r}7,106.5 \\
5,999.0 \\
931.0 \\
603.7 \\
173.6 \\
118.7 \\
35.0 \\
176.5\end{array}$ & $\begin{array}{r}7,565.4 \\
6,274.5 \\
1,049.9 \\
634.3 \\
216.6 \\
162.1 \\
36.9 \\
240.9\end{array}$ & $\begin{array}{r}8,578.6 \\
6,768.1 \\
1,486.1 \\
722.8 \\
358.2 \\
357.2 \\
47.9 \\
324.3\end{array}$ & $\begin{array}{r}8,738.9 \\
6,639.5 \\
1,733.6 \\
813.7 \\
432.0 \\
429.4 \\
58.5 \\
365.9\end{array}$ & $\begin{array}{r}8,749.1 \\
6,565.3 \\
1,819.2 \\
833.6 \\
462.7 \\
461.8 \\
61.2 \\
364.5\end{array}$ & $\begin{array}{r}8,769.3 \\
6,517.2 \\
1,885.8 \\
852.2 \\
485.5 \\
482.4 \\
65.7 \\
366.2\end{array}$ & $\begin{array}{l}870.2 \\
508.1 \\
500.7 \\
67.2 \\
373.5\end{array}$ & $\begin{array}{r}8,804.2 \\
6,483.1 \\
1,946.8 \\
869.6 \\
508.8 \\
501.1 \\
67.3 \\
374.3\end{array}$ & $\begin{array}{r}00.0 \\
86.6 \\
13.4 \\
8.7 \\
2.5 \\
1.7 \\
0.5\end{array}$ & $\begin{array}{r}100.0 \\
85.7 \\
14.3 \\
8.7 \\
3.0 \\
2.2 \\
0.5\end{array}$ & $\begin{array}{r}100.0 \\
82.0 \\
18.0 \\
8.8 \\
4.3 \\
4.3 \\
0.6\end{array}$ & $\begin{array}{r}100.0 \\
78.3 \\
21.7 \\
9.9 \\
5.5 \\
5.5 \\
0.7\end{array}$ & $\begin{array}{r}100.0 \\
77.6 \\
22.4 \\
10.1 \\
5.8 \\
5.7 \\
0.8\end{array}$ & $\begin{array}{r}100.0 \\
76.9 \\
23.1 \\
10.3 \\
6.0 \\
5.9 \\
0.8\end{array}$ & $\begin{array}{r}00.0 \\
76.9 \\
23.1 \\
10.3 \\
6.0 \\
5.9 \\
0.8\end{array}$ \\
\hline 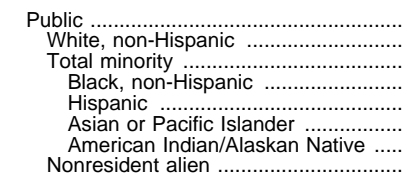 & $\begin{array}{r}4,892.9 \\
4,120.2 \\
666.7 \\
421.8 \\
129.3 \\
87.5 \\
28.2 \\
106.0\end{array}$ & $\begin{aligned} 5,127.6 \\
4,243.0 \\
740.8 \\
438.2 \\
156.4 \\
117.2 \\
29.0 \\
143.8\end{aligned}$ & $\begin{array}{r}5,848.2 \\
4,605.6 \\
1,046.2 \\
495.1 \\
262.5 \\
250.6 \\
38.0 \\
196.4\end{array}$ & $\begin{array}{r}5,851.8 \\
4,432.9 \\
1,202.1 \\
548.2 \\
311.5 \\
296.6 \\
45.9 \\
216.7\end{array}$ & $\begin{array}{r}5,825.2 \\
4,355.0 \\
1,256.7 \\
561.4 \\
332.6 \\
315.3 \\
47.5 \\
213.4\end{array}$ & $\begin{array}{r}5,814.5 \\
4,303.3 \\
1,299.3 \\
572.5 \\
346.8 \\
329.3 \\
50.8 \\
211.9\end{array}$ & $\begin{array}{r}1,302.0 \\
580.0 \\
359.8 \\
340.5 \\
52.0 \\
215.0\end{array}$ & $\begin{array}{r}5,806.0 \\
4,258.7 \\
1,332.3 \\
580.1 \\
359.8 \\
340.5 \\
52.0 \\
215.0\end{array}$ & $\begin{array}{r}100.0 \\
86.1 \\
13.9 \\
8.8 \\
2.7 \\
1.8 \\
0.6\end{array}$ & $\begin{array}{r}100.0 \\
85.1 \\
14.9 \\
8.8 \\
3.1 \\
2.4 \\
0.6\end{array}$ & $\begin{array}{r}100.0 \\
81.5 \\
18.5 \\
8.8 \\
4.6 \\
4.4 \\
0.7\end{array}$ & $\begin{array}{r}100.0 \\
77.6 \\
22.4 \\
10.0 \\
5.9 \\
5.6 \\
0.8\end{array}$ & $\begin{array}{r}100.0 \\
76.8 \\
23.2 \\
10.2 \\
6.2 \\
5.9 \\
0.9\end{array}$ & $\begin{array}{r}100.0 \\
76.2 \\
23.8 \\
10.4 \\
6.4 \\
6.1 \\
0.9\end{array}$ & $\begin{array}{r}100.0 \\
76.2 \\
23.8 \\
10.4 \\
6.4 \\
6.1 \\
0.9\end{array}$ \\
\hline 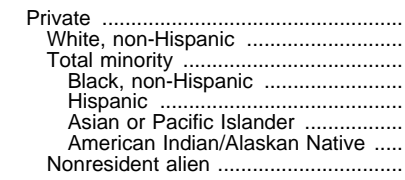 & $\begin{array}{r}2,213.6 \\
1,878.8 \\
264.3 \\
182.0 \\
44.3 \\
31.2 \\
6.8 \\
70.5\end{array}$ & $\begin{array}{r}2,437.8 \\
2,031.5 \\
309.2 \\
196.1 \\
60.2 \\
44.9 \\
7.9 \\
97.1\end{array}$ & $\begin{array}{r}2,730.3 \\
2,162.5 \\
439.8 \\
227.7 \\
95.7 \\
106.6 \\
9.9 \\
127.9\end{array}$ & $\begin{array}{r}2,887.2 \\
2,206.6 \\
531.5 \\
265.6 \\
120.4 \\
132.8 \\
12.6 \\
149.1\end{array}$ & $\begin{array}{r}2,923.9 \\
2,210.3 \\
562.5 \\
272.2 \\
130.1 \\
146.5 \\
13.6 \\
151.1\end{array}$ & $\begin{array}{r}2,954.7 \\
2,213.9 \\
586.5 \\
279.7 \\
138.7 \\
153.2 \\
14.9 \\
154.3\end{array}$ & $\begin{array}{r}2,995.9 \\
2,223.6 \\
613.9 \\
290.2 \\
148.3 \\
160.2 \\
15.2 \\
158.4\end{array}$ & $\begin{array}{r}2,998.2 \\
2,224.4 \\
614.5 \\
289.5 \\
149.0 \\
160.7 \\
15.3 \\
159.3\end{array}$ & $\begin{array}{r}100.0 \\
87.7 \\
12.3 \\
8.5 \\
2.1 \\
1.5 \\
0.3\end{array}$ & $\begin{array}{r}100.0 \\
86.8 \\
13.2 \\
8.4 \\
2.6\end{array}$ & $\begin{array}{r}100.0 \\
83.1 \\
16.9 \\
8.7 \\
3.7 \\
4.1 \\
0.4\end{array}$ & $\begin{array}{r}100.0 \\
79.7 \\
20.3 \\
9.8 \\
4.7 \\
5.3 \\
0.5\end{array}$ & $\begin{array}{r}100.0 \\
79.1 \\
20.9 \\
10.0 \\
5.0 \\
5.5 \\
0.5\end{array}$ & $\begin{array}{r}100.0 \\
78.4 \\
21.6 \\
10.2 \\
5.2 \\
5.6 \\
0.5\end{array}$ & $\begin{array}{r}100.0 \\
78.4 \\
21.6 \\
10.2 \\
5.2 \\
5.7 \\
0.5\end{array}$ \\
\hline $\begin{array}{l}\text { Total minority } \\
\text { Black, non } \\
\text { Hispanic } \\
\text { Asian or } \ddot{P} \\
\text { American I } \\
\text { Nonresident }\end{array}$ & $\begin{array}{r}3,879.1 \\
3,077.1 \\
759.8 \\
429.3 \\
210.2 \\
79.2 \\
41.2 \\
42.2\end{array}$ & $\begin{array}{r}4,521.4 \\
3,558.5 \\
898.9 \\
472.5 \\
255.1 \\
124.3 \\
47.0 \\
64.1\end{array}$ & $\begin{array}{r}5,240.1 \\
3,954.3 \\
1,218.6 \\
524.3 \\
424.2 \\
215.2 \\
54.9 \\
67.1\end{array}$ & $\begin{array}{r}5,565.9 \\
3,960.6 \\
1,514.1 \\
599.0 \\
556.8 \\
295.0 \\
63.2 \\
91.2\end{array}$ & $\begin{array}{r}5,52 \\
3,86 \\
1,5 \\
6 \\
58 \\
3 \\
6\end{array}$ & $\begin{array}{r}5,492.5 \\
3,794.0 \\
1,610.4 \\
621.5 \\
608.4 \\
314.9 \\
65.6 \\
88.1\end{array}$ & $\begin{array}{r}1,66 \\
62 \\
64 \\
32 \\
6\end{array}$ & $\begin{array}{r}5,563.3 \\
3,780.8 \\
1,690.6 \\
636.0 \\
657.3 \\
327.0 \\
70.2 \\
92.0\end{array}$ & $\begin{array}{r}r 00.0 \\
80.2 \\
19.8 \\
11.2 \\
5.5 \\
2.1 \\
1.1\end{array}$ & $\begin{array}{r}100.0 \\
79.8 \\
20.2 \\
10.6 \\
5.7 \\
2.8\end{array}$ & $\begin{array}{r}r 00.0 \\
76.4 \\
23.6 \\
10.1 \\
8.2 \\
4.2 \\
1.1\end{array}$ & $\begin{array}{r}100.0 \\
71.0 \\
29.0 \\
11.3 \\
10.7 \\
5.7 \\
1.2\end{array}$ & $\begin{array}{r}100.0 \\
70.2 \\
29.8 \\
11.5 \\
11.3 \\
5.8 \\
1.2\end{array}$ & $\begin{array}{r}100.0 \\
69.2 \\
30.8 \\
11.6 \\
11.9 \\
6.0\end{array}$ & $\begin{array}{r}100.0 \\
69.1 \\
30.9 \\
11.6 \\
12.0 \\
6.0 \\
1.3\end{array}$ \\
\hline $\begin{array}{r}\text { Public ..... } \\
\text { White, } \\
\text { Total } m \\
\text { Black } \\
\text { Hispa } \\
\text { Asian } \\
\text { Amer } \\
\text { Nonres }\end{array}$ & $\begin{array}{r}3,748.1 \\
2,974.3 \\
734.5 \\
409.5 \\
207.5 \\
78.2 \\
39.3 \\
39.2\end{array}$ & $\begin{array}{r}4,328.8 \\
3,413.1 \\
855.4 \\
437.9 \\
249.8 \\
122.5 \\
45.2 \\
60.3\end{array}$ & $\begin{array}{r}4,996.5 \\
3,779.8 \\
1,153.0 \\
481.4 \\
408.9 \\
210.3 \\
52.4 \\
63.6\end{array}$ & $\begin{array}{r}5,337.3 \\
3,793.7 \\
1,456.0 \\
566.1 \\
539.8 \\
289.7 \\
60.5 \\
87.6\end{array}$ & $\begin{array}{r}5,308.5 \\
3,701.3 \\
1,519.3 \\
583.2 \\
566.1 \\
20.8\end{array}$ & $\begin{array}{r}588.2 \\
590.3 \\
308.7 \\
63.0 \\
85.6\end{array}$ & $\begin{array}{r}59 \\
62 \\
31 \\
6\end{array}$ & $\begin{array}{r}5,314.5 \\
3,613.2 \\
1,612.5 \\
597.4 \\
631.0 \\
317.5 \\
66.7 \\
88.8\end{array}$ & $\begin{array}{r}100.0 \\
80.2 \\
19.8 \\
11.0 \\
5.6 \\
2.1 \\
1.1\end{array}$ & $\begin{array}{r}100.0 \\
80.0 \\
20.0 \\
10.3 \\
5.9\end{array}$ & $\begin{array}{r}100.0 \\
76.6 \\
23.4 \\
9.8 \\
8.3 \\
4.3 \\
1.1\end{array}$ & $\begin{array}{r}100.0 \\
70.9 \\
29.1 \\
11.2 \\
10.8 \\
5.9 \\
1.2\end{array}$ & $\begin{array}{r}100.0 \\
70.1 \\
29.9 \\
11.3 \\
11.4 \\
5.9 \\
1.2\end{array}$ & $\begin{array}{r}100.0 \\
69.1 \\
30.9 \\
11.5 \\
12.1 \\
6.1\end{array}$ & $\begin{array}{r}100.0 \\
69.1 \\
30.9 \\
11.4 \\
12.1 \\
6.1\end{array}$ \\
\hline $\begin{array}{l}\text { Private } \\
\text { White, non-Hispanic } \\
\text { Total minority } \\
\text { Black, non-Hispan } \\
\text { Hispanic - } \\
\text { Asian or Pacifici Is } \\
\text { American Indian/A } \\
\text { Nonresident alien ... }\end{array}$ & $\begin{array}{r}131.0 \\
102.8 \\
25.3 \\
19.8 \\
2.6 \\
0.9 \\
1.8 \\
3.0\end{array}$ & $\begin{array}{r}192.6 \\
145.4 \\
43.5 \\
34.6 \\
5.3 \\
1.8 \\
1.8 \\
3.7\end{array}$ & $\begin{array}{r}243.6 \\
174.5 \\
65.6 \\
42.9 \\
15.3 \\
4.9 \\
2.5 \\
3.5\end{array}$ & $\begin{array}{r}228.5 \\
166.9 \\
58.1 \\
32.9 \\
17.1 \\
5.4 \\
2.7 \\
3.6\end{array}$ & $\begin{array}{r}221.2 \\
160.3 \\
57.3 \\
31.9 \\
16.7 \\
5.7\end{array}$ & $\begin{array}{r}214.7 \\
152.0 \\
60.2 \\
3.3 \\
18.1 \\
6.2 \\
2.6 \\
2.6\end{array}$ & $\begin{array}{r}154 . \\
57.2 \\
32 . \\
16 . \\
6.5 \\
2 . \\
2.8\end{array}$ & $\begin{array}{r}248.9 \\
167.6 \\
78.1 \\
38.6 \\
26.4 \\
9.6 \\
3.5 \\
3.2\end{array}$ & $\begin{array}{r}00.0 \\
80.3 \\
19.7 \\
15.5 \\
2.1 \\
0.7 \\
1.4 \\
\end{array}$ & $\begin{array}{r}100.0 \\
77.0 \\
23.0 \\
18.3 \\
2.8\end{array}$ & $\begin{array}{r}100.0 \\
72.7 \\
27.3 \\
17.9 \\
6.4 \\
2.0 \\
1.1\end{array}$ & $\begin{array}{r}100.0 \\
73.7 \\
26.3 \\
14.6 \\
77.7 \\
2.6 \\
1.4\end{array}$ & $\begin{array}{r}r 00.0 \\
71.6 \\
28.4 \\
15.7 \\
8.5\end{array}$ & $\begin{array}{r}73.0 \\
27.0 \\
15.1 \\
7.7 \\
3.0 \\
1.2\end{array}$ & $\begin{array}{r}100.0 \\
68.2 \\
31.8 \\
15.7 \\
10.7 \\
3.9 \\
1.4\end{array}$ \\
\hline
\end{tabular}

1 Distribution for U.S. citizens only.

2 Preliminary data.

3 Preliminary data are for 4-year and 2-year degree-granting institutions that were eligible to participate in Title IV federal financial aid programs.

-Not applicable.

NOTE.-Because of underreporting and nonreporting of racial/ethnic data, some figures are slightly lower than corresponding data in other tables. Trend tabulations of institutions of higher education data are based on institutions that were accredited by an agency or association that was recognized by the U.S. Department of Education. The Department of Education no longer distinguishes between those institutions and other in stitutions that are eligible to participate in Title IV programs. The new degree-granting classification is very similar to the earlier higher education classification, except that it includes some additional institutions, primarily 2-year colleges, and excludes a few higher education institutions that did not award degrees. Because of rounding, details may not add to totals.

SOURCE: U.S. Department of Education, National Center for Education Statistics, Higher Education General Information Survey (HEGIS), "Fall Enrollment in Colleges and Universities" surveys; and Integrated Postsecondary Education Data System (IPEDS), "Fall Enrollment" surveys. (This table was prepared May 1998.) 
Table 207.-Total fall enrollment in institutions of higher education and degree-granting institutions, by level of study, sex, and race/ethnicity of student: 1976 to 1996

\begin{tabular}{|c|c|c|c|c|c|c|c|c|c|c|c|c|c|c|c|}
\hline \multirow{3}{*}{$\begin{array}{c}\text { Level of study, sex, and race/ethnicity of } \\
\text { student }\end{array}$} & \multicolumn{7}{|c|}{ Institutions of higher education, in thousands } & \multirow{3}{*}{$\begin{array}{c}\text { Degree- } \\
\text { granting } \\
\text { institu- } \\
\text { tions, in } \\
\text { thou- } \\
\text { sands, } \\
1996^{3}\end{array}$} & \multicolumn{7}{|c|}{ Percentage distribution by type and control 1} \\
\hline & \multirow{2}{*}{1976} & \multirow{2}{*}{1980} & \multirow{2}{*}{1990} & \multirow{2}{*}{1993} & \multirow{2}{*}{1994} & \multirow{2}{*}{1995} & \multirow{2}{*}{$1996^{2}$} & & \multicolumn{6}{|c|}{ Institutions of higher education } & \multirow{2}{*}{$\begin{array}{c}\text { Degree } \\
\text { grant- } \\
\text { ing in- } \\
\text { stitu- } \\
\text { tions, } \\
1996^{3}\end{array}$} \\
\hline & & & & & & & & & 1976 & 1980 & 1990 & 1994 & 1995 & $1996^{2}$ & \\
\hline 1 & 2 & 3 & 4 & 5 & 6 & 7 & 8 & 9 & 10 & 11 & 12 & 13 & 14 & 15 & 16 \\
\hline 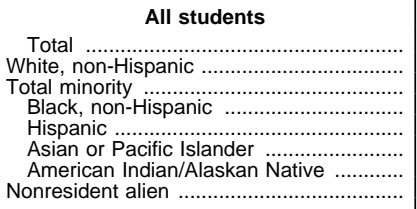 & $\begin{array}{r}10,985.6 \\
9,076.1 \\
1,690.8 \\
1,033.0 \\
383.8 \\
197.9 \\
76.1 \\
218.7\end{array}$ & \begin{tabular}{|r|}
$12,086.8$ \\
$9,833.0$ \\
$1,948.8$ \\
$1,106.8$ \\
471.7 \\
286.4 \\
83.9 \\
305.0
\end{tabular} & \begin{tabular}{|r|}
$13,818.6$ \\
$10,722.5$ \\
$2,704.7$ \\
$1,247.0$ \\
782.4 \\
572.4 \\
102.8 \\
391.5
\end{tabular} & \begin{tabular}{|r}
$14,304.8$ \\
$10,600.0$ \\
$3,247.7$ \\
$1,412.8$ \\
988.8 \\
724.4 \\
121.7 \\
457.1
\end{tabular} & $\begin{array}{r}14,278.8 \\
10,427.0 \\
3,395.9 \\
1,448.6 \\
1,045.6 \\
774.3 \\
127.4 \\
455.9\end{array}$ & $\begin{array}{r}14,261.8 \\
10,311.2 \\
3,496.2 \\
1,473.7 \\
1,093.8 \\
797.4 \\
131.3 \\
454.4\end{array}$ & \begin{tabular}{|r|}
$14,300.3$ \\
$10,226.0$ \\
$3,609.3$ \\
$1,499.4$ \\
$1,152.2$ \\
823.6 \\
134.0 \\
464.9
\end{tabular} & \begin{tabular}{|r|}
$14,367.5$ \\
$10,263.9$ \\
$3,637.4$ \\
$1,505.6$ \\
$1,166.1$ \\
828.2 \\
137.6 \\
466.3
\end{tabular} & $\begin{array}{r}100.0 \\
84.3 \\
15.7 \\
9.6 \\
3.6 \\
1.8 \\
0.7 \\
-\end{array}$ & $\begin{array}{r}100.0 \\
83.5 \\
16.5 \\
9.4 \\
4.0 \\
2.4 \\
0.7 \\
-\end{array}$ & $\begin{array}{r}100.0 \\
79.9 \\
20.1 \\
9.3 \\
5.8 \\
4.3 \\
0.8 \\
-\end{array}$ & $\begin{array}{r}100.0 \\
75.4 \\
24.6 \\
10.5 \\
7.6 \\
5.6 \\
0.9 \\
-\end{array}$ & $\begin{array}{r}100.0 \\
74.7 \\
25.3 \\
10.7 \\
7.9 \\
5.8 \\
1.0 \\
-\end{array}$ & $\begin{array}{r}100.0 \\
73.9 \\
26.1 \\
10.8 \\
8.3 \\
6.0 \\
1.0 \\
\end{array}$ & $\begin{array}{r}100.0 \\
73.8 \\
26.2 \\
10.8 \\
8.4 \\
6.0 \\
1.0\end{array}$ \\
\hline 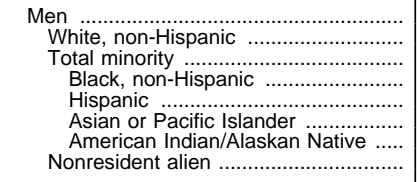 & $\begin{array}{r}5,794.4 \\
4,813.7 \\
826.6 \\
469.9 \\
209.7 \\
108.4 \\
38.5 \\
154.1\end{array}$ & $\begin{array}{r}5,868.1 \\
4,772.9 \\
884.4 \\
463.7 \\
231.6 \\
151.3 \\
37.8 \\
210.8\end{array}$ & $\begin{array}{r}6,283.9 \\
4,861.0 \\
1,176.6 \\
484.7 \\
353.9 \\
294.9 \\
43.1 \\
246.3\end{array}$ & $\begin{array}{r}6,427.5 \\
4,755.0 \\
1,399.1 \\
543.7 \\
441.2 \\
363.1 \\
51.2 \\
273.4\end{array}$ & $\begin{array}{r}6,371.9 \\
4,650.7 \\
1,451.7 \\
549.7 \\
464.0 \\
385.0 \\
53.0 \\
269.5\end{array}$ & $\begin{array}{r}6,342.5 \\
4,594.1 \\
1,484.2 \\
555.9 \\
480.2 \\
393.3 \\
54.8 \\
264.3\end{array}$ & $\begin{array}{r}6,344.0 \\
4,553.0 \\
1,524.3 \\
563.6 \\
501.3 \\
403.6 \\
55.7 \\
266.7\end{array}$ & $\begin{array}{r}6,352.8 \\
4,552.2 \\
1,533.4 \\
564.1 \\
506.6 \\
405.5 \\
57.2 \\
267.2\end{array}$ & $\begin{array}{r}100.0 \\
85.3 \\
14.7 \\
8.3 \\
3.7 \\
1.9 \\
0.7 \\
-\end{array}$ & $\begin{array}{r}100.0 \\
84.4 \\
15.6 \\
8.2 \\
4.1 \\
2.7 \\
0.7 \\
\end{array}$ & $\begin{array}{r}100.0 \\
80.5 \\
19.5 \\
8.0 \\
5.9 \\
4.9 \\
0.7 \\
-\end{array}$ & \begin{tabular}{|r|}
100.0 \\
76.2 \\
23.8 \\
9.0 \\
7.6 \\
6.3 \\
0.9
\end{tabular} & \begin{tabular}{|r|}
100.0 \\
75.6 \\
24.4 \\
9.1 \\
7.9 \\
6.5 \\
0.9
\end{tabular} & $\begin{array}{r}100.0 \\
74.9 \\
25.1 \\
9.3 \\
8.2 \\
6.6 \\
0.9\end{array}$ & $\begin{array}{r}100.0 \\
74.8 \\
25.2 \\
9.3 \\
8.3 \\
6.7 \\
0.9\end{array}$ \\
\hline 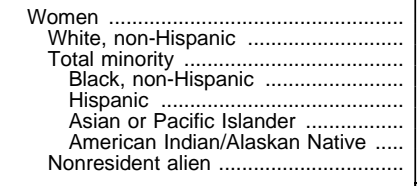 & $\begin{array}{r}5,191.2 \\
4,262.4 \\
864.2 \\
563.1 \\
174.1 \\
89.4 \\
37.6 \\
64.6 \\
\end{array}$ & $\begin{array}{r}6,218.7 \\
5,060.1 \\
1,064.4 \\
643.0 \\
240.1 \\
135.2 \\
46.1 \\
94.2 \\
\end{array}$ & $\begin{array}{r}7,534.7 \\
5,861.5 \\
1,528.1 \\
762.3 \\
428.5 \\
277.5 \\
59.7 \\
145.2\end{array}$ & $\begin{array}{r}7,877.4 \\
5,845.1 \\
1,848.6 \\
869.1 \\
547.6 \\
361.3 \\
70.5 \\
183.7\end{array}$ & $\begin{array}{r}7,906.9 \\
5,776.3 \\
1,944.2 \\
898.9 \\
581.6 \\
389.3 \\
74.4 \\
186.4\end{array}$ & $\begin{array}{r}7,919.2 \\
5,717.2 \\
2,012.0 \\
917.8 \\
613.7 \\
404.1 \\
76.5 \\
190.1\end{array}$ & $\begin{array}{r}7,956.3 \\
5,673.1 \\
2,085.0 \\
935.8 \\
650.9 \\
420.0 \\
78.2 \\
198.2 \\
\end{array}$ & $\begin{array}{r}8,014.7 \\
5,711.7 \\
2,104.0 \\
941.4 \\
659.5 \\
422.6 \\
80.4 \\
199.0 \\
\end{array}$ & $\begin{array}{r}100.0 \\
83.1 \\
16.9 \\
11.0 \\
3.4 \\
1.7 \\
0.7 \\
\end{array}$ & $\begin{array}{r}100.0 \\
82.6 \\
17.4 \\
10.5 \\
3.9 \\
2.2 \\
0.8 \\
\end{array}$ & $\begin{array}{r}100.0 \\
79.3 \\
20.7 \\
10.3 \\
5.8 \\
3.8 \\
0.8 \\
-\end{array}$ & $\begin{array}{r}100.0 \\
74.8 \\
25.2 \\
11.6 \\
7.5 \\
5.0 \\
1.0 \\
-\end{array}$ & $\begin{array}{r}100.0 \\
74.0 \\
26.0 \\
11.9 \\
7.9 \\
5.2 \\
1.0 \\
-\end{array}$ & $\begin{array}{r}100.0 \\
73.1 \\
26.9 \\
12.1 \\
8.4 \\
5.4 \\
1.0 \\
-\end{array}$ & $\begin{array}{r}100.0 \\
73.1 \\
26.9 \\
12.0 \\
8.4 \\
5.4 \\
1.0 \\
\end{array}$ \\
\hline 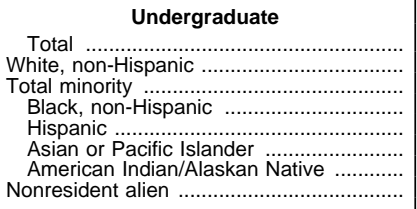 & $\begin{array}{r}9,419.0 \\
7,740.5 \\
1,535.3 \\
943.4 \\
352.9 \\
169.3 \\
69.7 \\
143.2\end{array}$ & \begin{tabular}{|r|}
$10,469.1$ \\
$8,480.7$ \\
$1,778.5$ \\
$1,018.8$ \\
433.1 \\
248.7 \\
77.9 \\
209.9
\end{tabular} & $\begin{array}{r}11,959.1 \\
9,272.6 \\
2,467.7 \\
1,147.2 \\
724.6 \\
500.5 \\
95.5 \\
218.7\end{array}$ & \begin{tabular}{r|r}
$12,324.0$ \\
$9,100.4$ \\
$2,955.4$ \\
$1,290.4$ \\
918.1 \\
634.2 \\
112.7 \\
268.2
\end{tabular} & \begin{tabular}{|r|}
$12,262.6$ \\
$8,916.0$ \\
$3,077.2$ \\
$1,317.3$ \\
968.3 \\
674.1 \\
117.4 \\
269.4
\end{tabular} & \begin{tabular}{|r|}
$12,231.7$ \\
$8,805.6$ \\
$3,158.5$ \\
$1,333.6$ \\
$1,012.0$ \\
692.2 \\
120.7 \\
267.6
\end{tabular} & \begin{tabular}{|r|}
$12,259.4$ \\
$8,730.9$ \\
$3,254.4$ \\
$1,352.6$ \\
$1,065.6$ \\
713.2 \\
122.9 \\
274.1
\end{tabular} & \begin{tabular}{|r|}
$12,326.9$ \\
$8,769.5$ \\
$3,282.1$ \\
$1,358.6$ \\
$1,079.4$ \\
717.6 \\
126.5 \\
275.3
\end{tabular} & $\begin{array}{r}100.0 \\
83.4 \\
16.6 \\
10.2 \\
3.8 \\
1.8 \\
0.8 \\
-\end{array}$ & $\begin{array}{r}100.0 \\
82.7 \\
17.3 \\
9.9 \\
4.2 \\
2.4 \\
0.8 \\
-\end{array}$ & $\begin{array}{r}100.0 \\
79.0 \\
21.0 \\
9.8 \\
6.2 \\
4.3 \\
0.8 \\
-\end{array}$ & \begin{tabular}{|r|}
100.0 \\
74.3 \\
25.7 \\
11.0 \\
8.1 \\
5.6 \\
1.0 \\
-
\end{tabular} & $\begin{array}{r}100.0 \\
73.6 \\
26.4 \\
11.1 \\
8.5 \\
5.8 \\
1.0 \\
-\end{array}$ & $\begin{array}{r}100.0 \\
72.8 \\
27.2 \\
11.3 \\
8.9 \\
6.0 \\
1.0\end{array}$ & $\begin{array}{r}100.0 \\
72.8 \\
27.2 \\
11.3 \\
9.0 \\
6.0 \\
1.0\end{array}$ \\
\hline 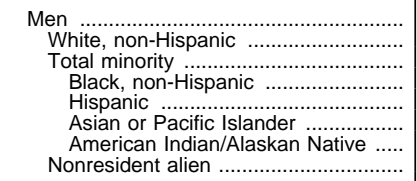 & \begin{tabular}{r|}
$4,896.8$ \\
$4,052.2$ \\
748.2 \\
430.7 \\
191.7 \\
91.1 \\
34.8 \\
96.4
\end{tabular} & $\begin{array}{r}4,997.4 \\
4,054.9 \\
802.7 \\
428.2 \\
211.2 \\
128.5 \\
34.8 \\
139.8\end{array}$ & $\begin{array}{r}5,379.8 \\
4,184.4 \\
1,069.3 \\
448.0 \\
326.9 \\
254.5 \\
39.9 \\
126.1\end{array}$ & $\begin{array}{r}5,483.7 \\
4,067.0 \\
1,270.1 \\
499.6 \\
409.2 \\
314.1 \\
47.2 \\
146.6\end{array}$ & $\begin{array}{r}5,422.1 \\
3,963.1 \\
1,312.4 \\
502.9 \\
429.4 \\
331.4 \\
48.6 \\
146.6\end{array}$ & $\begin{array}{r}5,401.1 \\
3,918.1 \\
1,339.3 \\
506.8 \\
444.2 \\
338.1 \\
50.2 \\
143.8\end{array}$ & $\begin{array}{r}5,411.1 \\
3,890.7 \\
1,375.0 \\
513.1 \\
464.0 \\
346.9 \\
51.0 \\
145.3\end{array}$ & $\begin{array}{r}5,420.7 \\
3,890.8 \\
1,384.1 \\
513.6 \\
469.2 \\
348.8 \\
52.4 \\
145.8\end{array}$ & $\begin{array}{r}100.0 \\
84.4 \\
15.6 \\
9.0 \\
4.0 \\
1.9 \\
0.7\end{array}$ & $\begin{array}{r}100.0 \\
83.5 \\
16.5 \\
8.8 \\
4.3 \\
2.6 \\
0.7\end{array}$ & $\begin{array}{r}100.0 \\
79.6 \\
20.4 \\
8.5 \\
6.2 \\
4.8 \\
0.8\end{array}$ & $\begin{array}{r}100.0 \\
75.1 \\
24.9 \\
9.5 \\
8.1 \\
6.3 \\
0.9\end{array}$ & $\begin{array}{r}100.0 \\
74.5 \\
25.5 \\
9.6 \\
8.4 \\
6.4 \\
1.0\end{array}$ & $\begin{array}{r}100.0 \\
73.9 \\
26.1 \\
9.7 \\
8.8 \\
6.6 \\
1.0\end{array}$ & $\begin{array}{r}100.0 \\
73.8 \\
26.2 \\
9.7 \\
8.9 \\
6.6 \\
1.0\end{array}$ \\
\hline 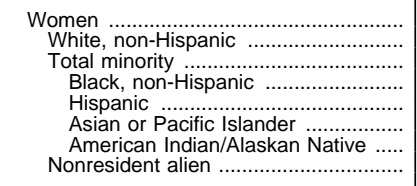 & $\begin{array}{r}4,522.1 \\
3,688.3 \\
787.0 \\
512.7 \\
161.2 \\
78.2 \\
34.9 \\
46.8\end{array}$ & $\begin{array}{r}5,471.7 \\
4,425.8 \\
975.8 \\
590.6 \\
221.8 \\
120.2 \\
43.1 \\
70.1\end{array}$ & $\begin{array}{r}6,579.3 \\
5,088.2 \\
1,398.5 \\
699.2 \\
397.6 \\
246.0 \\
55.5 \\
92.6\end{array}$ & $\begin{array}{r}6,840.3 \\
5,033.4 \\
1,685.2 \\
790.8 \\
508.9 \\
320.0 \\
65.5 \\
121.7\end{array}$ & $\begin{array}{r}6,840.5 \\
4,953.0 \\
1,764.8 \\
814.4 \\
538.9 \\
342.7 \\
68.8 \\
122.8\end{array}$ & $\begin{array}{r}6,830.6 \\
4,887.5 \\
1,819.2 \\
826.9 \\
567.8 \\
354.1 \\
70.5 \\
123.8\end{array}$ & $\begin{array}{r}6,848.4 \\
4,840.2 \\
1,879.3 \\
839.5 \\
601.6 \\
366.3 \\
71.9 \\
128.8\end{array}$ & $\begin{array}{r}6,906.3 \\
4,878.7 \\
1,898.1 \\
845.0 \\
610.1 \\
368.8 \\
74.1 \\
129.5\end{array}$ & $\begin{array}{r}100.0 \\
82.4 \\
17.6 \\
11.5 \\
3.6 \\
1.7 \\
0.8\end{array}$ & $\begin{array}{r}100.0 \\
81.9 \\
18.1 \\
10.9 \\
4.1 \\
2.2 \\
0.8 \\
\end{array}$ & $\begin{array}{r}100.0 \\
78.4 \\
21.6 \\
10.8 \\
6.1 \\
3.8 \\
0.9\end{array}$ & $\begin{array}{r}100.0 \\
73.7 \\
26.3 \\
12.1 \\
8.0 \\
5.1 \\
1.0\end{array}$ & $\begin{array}{r}100.0 \\
72.9 \\
27.1 \\
12.3 \\
8.5 \\
5.3 \\
1.1\end{array}$ & $\begin{array}{r}100.0 \\
72.0 \\
28.0 \\
12.5 \\
9.0 \\
5.5 \\
1.1\end{array}$ & $\begin{array}{r}100.0 \\
72.0 \\
28.0 \\
12.5 \\
9.0 \\
5.4 \\
1.1\end{array}$ \\
\hline Graduate & & & & & & & & & & & & & & & \\
\hline 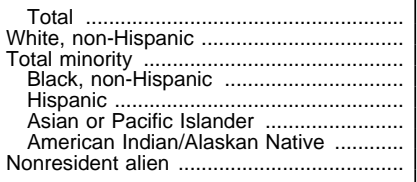 & $\begin{array}{r}1,322.5 \\
1,115.6 \\
134.5 \\
78.5 \\
26.4 \\
24.5 \\
5.1 \\
72.4\end{array}$ & $\begin{array}{r}1,340.9 \\
1,104.7 \\
144.0 \\
75.1 \\
32.1 \\
31.6 \\
5.2 \\
92.2\end{array}$ & $\begin{array}{r}1,586.2 \\
1228.4 \\
190.5 \\
83.9 \\
47.2 \\
53.2 \\
6.2 \\
167.3\end{array}$ & $\begin{array}{r}1,688.4 \\
1,273.8 \\
232.7 \\
102.2 \\
57.9 \\
65.2 \\
7.3 \\
182.0\end{array}$ & $\begin{array}{r}1,721.5 \\
1,286.8 \\
255.2 \\
110.6 \\
63.9 \\
72.6 \\
8.1 \\
179.5\end{array}$ & $\begin{array}{r}1,732.5 \\
1,282.3 \\
270.7 \\
118.6 \\
68.0 \\
75.6 \\
8.5 \\
179.5\end{array}$ & $\begin{array}{r}1,743.1 \\
1,273.9 \\
286.0 \\
125.5 \\
72.7 \\
79.0 \\
8.9 \\
183.2\end{array}$ & $\begin{array}{r}1,742.3 \\
1,272.6 \\
286.3 \\
125.5 \\
72.8 \\
79.1 \\
8.9 \\
183.3\end{array}$ & $\begin{array}{r}100.0 \\
89.2 \\
10.8 \\
6.3 \\
2.1 \\
2.0 \\
0.4 \\
-\end{array}$ & $\begin{array}{r}100.0 \\
88.5 \\
11.5 \\
6.0 \\
2.6 \\
2.5 \\
0.4 \\
-\end{array}$ & $\begin{array}{r}100.0 \\
86.6 \\
13.4 \\
5.9 \\
3.3 \\
3.8 \\
0.4 \\
\end{array}$ & $\begin{array}{r}100.0 \\
83.5 \\
16.5 \\
7.2 \\
4.1 \\
4.7 \\
0.5\end{array}$ & $\begin{array}{r}100.0 \\
82.6 \\
17.4 \\
7.6 \\
4.4 \\
4.9 \\
0.5\end{array}$ & $\begin{array}{r}100.0 \\
81.7 \\
18.3 \\
8.0 \\
4.7 \\
5.1 \\
0.6\end{array}$ & $\begin{array}{r}100.0 \\
81.6 \\
18.4 \\
8.0 \\
4.7 \\
5.1 \\
0.6\end{array}$ \\
\hline 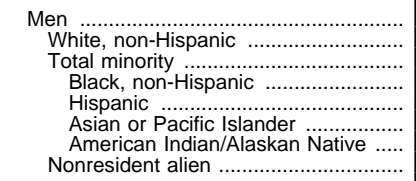 & $\begin{array}{r}707.9 \\
589.1 \\
63.7 \\
32.0 \\
14.6 \\
14.4 \\
2.7 \\
55.1\end{array}$ & $\begin{array}{r}672.2 \\
538.5 \\
65.0 \\
28.2 \\
15.7 \\
18.6 \\
2.5 \\
68.7\end{array}$ & $\begin{array}{r}737.4 \\
538.8 \\
82.1 \\
29.3 \\
20.6 \\
29.7 \\
2.6 \\
116.4\end{array}$ & $\begin{array}{r}771.0 \\
550.9 \\
98.1 \\
35.3 \\
24.8 \\
35.1 \\
3.0 \\
122.0\end{array}$ & $\begin{array}{r}775.8 \\
551.4 \\
106.3 \\
37.7 \\
27.0 \\
38.3 \\
3.3 \\
118.1\end{array}$ & $\begin{array}{r}767.5 \\
541.6 \\
110.4 \\
39.8 \\
28.2 \\
39.0 \\
3.4 \\
115.6\end{array}$ & $\begin{array}{r}760.5 \\
530.2 \\
113.9 \\
41.2 \\
29.5 \\
39.7 \\
3.6 \\
116.3\end{array}$ & $\begin{array}{r}759.4 \\
529.0 \\
114.0 \\
41.2 \\
29.6 \\
39.7 \\
3.6 \\
116.4\end{array}$ & $\begin{array}{r}100.0 \\
90.2 \\
9.8 \\
4.9 \\
2.2 \\
2.2 \\
0.4 \\
-\end{array}$ & $\begin{array}{r}100.0 \\
89.2 \\
10.8 \\
4.7 \\
2.6 \\
3.1 \\
0.4 \\
-\end{array}$ & $\begin{array}{r}100.0 \\
86.8 \\
13.2 \\
4.7 \\
3.3 \\
4.8 \\
0.4 \\
\end{array}$ & $\begin{array}{r}100.0 \\
83.8 \\
16.2 \\
5.7 \\
4.1 \\
5.8 \\
0.5\end{array}$ & $\begin{array}{r}100.0 \\
83.1 \\
16.9 \\
6.1 \\
4.3 \\
6.0 \\
0.5 \\
-\end{array}$ & $\begin{array}{r}100.0 \\
82.3 \\
17.7 \\
6.4 \\
4.6 \\
6.2 \\
0.6\end{array}$ & $\begin{array}{r}100.0 \\
82.3 \\
17.7 \\
6.4 \\
4.6 \\
6.2 \\
0.6\end{array}$ \\
\hline 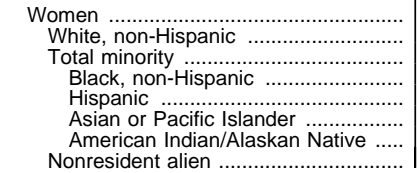 & $\begin{array}{r}614.6 \\
526.5 \\
70.8 \\
46.5 \\
11.8 \\
10.1 \\
2.4 \\
17.3\end{array}$ & $\begin{array}{r}668.7 \\
56.2 \\
79.0 \\
46.9 \\
16.4 \\
13.0 \\
2.7 \\
23.5\end{array}$ & $\begin{array}{r}848.8 \\
689.5 \\
108.3 \\
54.6 \\
26.6 \\
23.6 \\
3.6 \\
50.9\end{array}$ & $\begin{array}{r}917.4 \\
722.9 \\
134.6 \\
66.9 \\
33.1 \\
30.2 \\
4.3 \\
59.9\end{array}$ & $\begin{array}{r}945.6 \\
735.4 \\
148.9 \\
72.9 \\
36.9 \\
34.3 \\
4.8 \\
61.4\end{array}$ & $\begin{array}{r}965.0 \\
740.7 \\
160.3 \\
78.8 \\
39.9 \\
36.6 \\
5.0 \\
63.9\end{array}$ & $\begin{array}{r}982.6 \\
743.7 \\
172.1 \\
84.3 \\
43.1 \\
39.3 \\
5.3 \\
66.9\end{array}$ & $\begin{array}{r}982.8 \\
743.6 \\
172.3 \\
84.3 \\
43.2 \\
39.4 \\
5.3 \\
66.9\end{array}$ & $\begin{array}{r}100.0 \\
88.1 \\
11.9 \\
7.8 \\
2.0 \\
1.7 \\
0.4 \\
-\end{array}$ & $\begin{array}{r}100.0 \\
87.8 \\
12.2 \\
7.3 \\
2.5 \\
2.0 \\
0.4 \\
\end{array}$ & $\begin{array}{r}100.0 \\
86.4 \\
13.6 \\
6.8 \\
3.3 \\
3.0 \\
0.5 \\
\end{array}$ & $\begin{array}{r}100.0 \\
83.2 \\
16.8 \\
8.2 \\
4.2 \\
3.9 \\
0.5\end{array}$ & $\begin{array}{r}100.0 \\
82.2 \\
17.8 \\
8.7 \\
4.4 \\
4.1 \\
0.6\end{array}$ & $\begin{array}{r}100.0 \\
81.2 \\
18.8 \\
9.2 \\
4.7 \\
4.3 \\
0.6\end{array}$ & $\begin{array}{r}100.0 \\
81.2 \\
18.8 \\
9.2 \\
4.7 \\
4.3 \\
0.6\end{array}$ \\
\hline
\end{tabular}


Table 207.-Total fall enrollment in institutions of higher education and degree-granting institutions, by level of study, sex, and race/ethnicity of student: 1976 to 1996 -Continued

\begin{tabular}{|c|c|c|c|c|c|c|c|c|c|c|c|c|c|c|c|}
\hline \multirow{3}{*}{$\begin{array}{l}\text { Level of study, sex, and race/ethnicity of } \\
\text { student }\end{array}$} & \multicolumn{7}{|c|}{ Institutions of higher education, in thousands } & \multirow{3}{*}{$\begin{array}{c}\text { Degree- } \\
\text { granting } \\
\text { institu- } \\
\text { tions, in } \\
\text { thou- } \\
\text { sands, } \\
1996^{3}\end{array}$} & \multicolumn{7}{|c|}{ Percentage distribution by type and control 1} \\
\hline & \multirow{2}{*}{1976} & \multirow{2}{*}{1980} & \multirow{2}{*}{1990} & \multirow{2}{*}{1993} & \multirow{2}{*}{1994} & \multirow{2}{*}{1995} & \multirow{2}{*}{$1996^{2}$} & & \multicolumn{6}{|c|}{ Institutions of higher education } & \multirow{2}{*}{$\begin{array}{c}\text { Degree } \\
\text { grant- } \\
\text { ing in- } \\
\text { stitu- } \\
\text { tions, } \\
1996^{3}\end{array}$} \\
\hline & & & & & & & & & 1976 & 1980 & 1990 & 1994 & 1995 & $1996^{2}$ & \\
\hline 1 & 2 & 3 & 4 & 5 & 6 & 7 & 8 & 9 & 10 & 11 & 12 & 13 & 14 & 15 & 16 \\
\hline 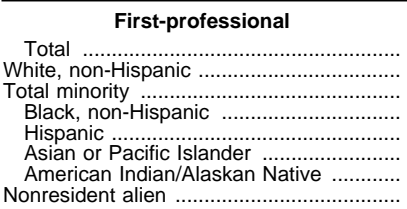 & $\begin{array}{r}244.1 \\
220.0 \\
21.1 \\
11.2 \\
4.5 \\
4.1 \\
1.3 \\
3.1\end{array}$ & $\begin{array}{r}276.8 \\
247.7 \\
26.3 \\
12.8 \\
6.5 \\
6.1 \\
0.8 \\
2.9\end{array}$ & \begin{tabular}{r|r|r}
273.4 \\
221.5 \\
46.5 \\
15.9 \\
10.7 \\
18.7 \\
1.1 \\
5.4
\end{tabular} & $\begin{array}{r}292.4 \\
225.9 \\
59.6 \\
20.2 \\
12.8 \\
25.0 \\
1.7 \\
6.9\end{array}$ & $\begin{array}{r}294.7 \\
224.2 \\
63.5 \\
20.7 \\
13.4 \\
27.6 \\
1.8 \\
7.0\end{array}$ & $\begin{array}{r}297.6 \\
223.3 \\
67.0 \\
21.4 \\
13.8 \\
29.6 \\
2.1 \\
7.3\end{array}$ & $\begin{array}{r}297.7 \\
221.2 \\
68.9 \\
21.4 \\
14.0 \\
31.4 \\
2.2 \\
7.7\end{array}$ & $\begin{array}{r}298.3 \\
221.7 \\
69.0 \\
21.5 \\
13.9 \\
31.4 \\
2.2 \\
7.6\end{array}$ & $\begin{array}{r}100.0 \\
91.3 \\
8.7 \\
4.6 \\
1.9 \\
1.7 \\
0.5 \\
-\end{array}$ & $\begin{array}{r}100.0 \\
90.4 \\
9.6 \\
4.7 \\
2.4 \\
2.2 \\
0.3 \\
-\end{array}$ & $\begin{array}{r}100.0 \\
82.6 \\
17.4 \\
5.9 \\
4.0 \\
7.0 \\
0.4 \\
-\end{array}$ & $\begin{array}{r}100.0 \\
77.9 \\
22.1 \\
7.2 \\
4.7 \\
9.6 \\
0.6 \\
-\end{array}$ & \begin{tabular}{|r|}
100.0 \\
76.9 \\
23.1 \\
7.4 \\
4.8 \\
10.2 \\
0.7 \\
-
\end{tabular} & $\begin{array}{r}100.0 \\
76.2 \\
23.8 \\
7.4 \\
4.8 \\
10.8 \\
0.7 \\
-\end{array}$ & $\begin{array}{r}100.0 \\
76.3 \\
23.7 \\
7.4 \\
4.8 \\
10.8 \\
0.7 \\
\end{array}$ \\
\hline 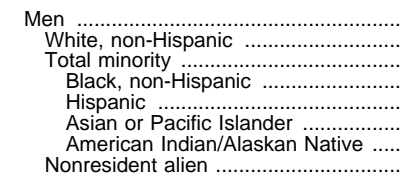 & $\begin{array}{r}189.6 \\
172.4 \\
14.7 \\
7.2 \\
3.5 \\
2.9 \\
1.0 \\
2.5\end{array}$ & $\begin{array}{r}198.5 \\
179.5 \\
16.7 \\
7.4 \\
4.6 \\
4.1 \\
0.5 \\
2.3\end{array}$ & $\begin{array}{r}166.8 \\
137.8 \\
25.3 \\
7.4 \\
6.4 \\
10.8 \\
0.6 \\
3.8\end{array}$ & $\begin{array}{r}172.8 \\
137.2 \\
30.9 \\
8.8 \\
7.2 \\
13.9 \\
0.9 \\
4.8\end{array}$ & $\begin{array}{r}174.0 \\
136.2 \\
33.0 \\
9.1 \\
7.5 \\
15.3 \\
1.0 \\
4.8\end{array}$ & $\begin{array}{r}173.9 \\
134.4 \\
34.6 \\
9.4 \\
7.8 \\
16.2 \\
1.2 \\
4.9\end{array}$ & $\begin{array}{r}172.5 \\
132.0 \\
35.3 \\
9.4 \\
7.8 \\
17.0 \\
1.2 \\
5.1\end{array}$ & $\begin{array}{r}172.7 \\
132.3 \\
35.4 \\
9.4 \\
7.7 \\
17.1 \\
1.2 \\
5.1\end{array}$ & $\begin{array}{r}100.0 \\
92.1 \\
7.9 \\
3.9 \\
1.9 \\
1.6 \\
0.6 \\
-\end{array}$ & $\begin{array}{r}100.0 \\
91.5 \\
8.5 \\
3.8 \\
2.4 \\
2.1 \\
0.3 \\
-\end{array}$ & $\begin{array}{r}100.0 \\
84.5 \\
15.5 \\
4.5 \\
3.9 \\
6.6 \\
0.4 \\
-\end{array}$ & $\begin{array}{r}100.0 \\
80.5 \\
19.5 \\
5.4 \\
4.5 \\
9.0 \\
0.6 \\
\end{array}$ & $\begin{array}{r}100.0 \\
79.5 \\
20.5 \\
5.5 \\
4.6 \\
9.6 \\
0.7 \\
-\end{array}$ & $\begin{array}{r}100.0 \\
78.9 \\
21.1 \\
5.6 \\
4.6 \\
10.2 \\
0.7 \\
\end{array}$ & $\begin{array}{r}100.0 \\
78.9 \\
21.1 \\
5.6 \\
4.6 \\
10.2 \\
0.7\end{array}$ \\
\hline 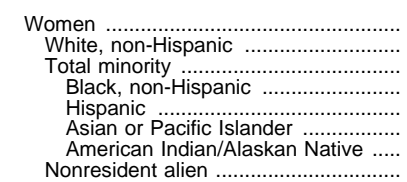 & $\begin{array}{r}54.5 \\
47.6 \\
6.4 \\
3.9 \\
1.0 \\
1.1 \\
0.2 \\
0.5\end{array}$ & $\begin{array}{r}78.4 \\
68.1 \\
9.6 \\
5.5 \\
1.9 \\
2.0 \\
0.3 \\
0.6\end{array}$ & $\begin{array}{r}106.6 \\
83.7 \\
21.3 \\
8.5 \\
4.3 \\
7.9 \\
0.5 \\
1.6\end{array}$ & $\begin{array}{r}119.6 \\
88.8 \\
28.8 \\
11.4 \\
5.5 \\
11.1 \\
0.7 \\
2.1\end{array}$ & $\begin{array}{r}120.8 \\
88.0 \\
30.5 \\
11.5 \\
5.9 \\
12.3 \\
0.8 \\
2.3\end{array}$ & $\begin{array}{r}123.7 \\
88.9 \\
32.4 \\
12.1 \\
6.0 \\
13.4 \\
0.9 \\
2.4\end{array}$ & $\begin{array}{r}125.3 \\
89.1 \\
33.6 \\
12.0 \\
6.2 \\
14.4 \\
1.0 \\
2.6\end{array}$ & $\begin{array}{r}125.6 \\
89.4 \\
33.6 \\
12.1 \\
6.2 \\
14.4 \\
1.0 \\
2.6\end{array}$ & $\begin{array}{r}100.0 \\
88.2 \\
11.8 \\
7.3 \\
1.9 \\
2.1 \\
0.4 \\
-\end{array}$ & $\begin{array}{r}100.0 \\
87.6 \\
12.4 \\
7.0 \\
2.4 \\
2.6 \\
0.3 \\
\end{array}$ & $\begin{array}{r}100.0 \\
79.7 \\
20.3 \\
8.1 \\
4.1 \\
7.6 \\
0.5 \\
-\end{array}$ & $\begin{array}{r}100.0 \\
74.2 \\
25.8 \\
9.7 \\
5.0 \\
10.4 \\
0.7 \\
-\end{array}$ & $\begin{array}{r}100.0 \\
73.3 \\
26.7 \\
10.0 \\
5.0 \\
11.0 \\
0.8 \\
-\end{array}$ & $\begin{array}{r}100.0 \\
72.6 \\
27.4 \\
9.8 \\
5.1 \\
11.7 \\
0.8 \\
\end{array}$ & $\begin{array}{r}100.0 \\
72.7 \\
27.3 \\
9.8 \\
5.0 \\
11.7 \\
0.8 \\
\end{array}$ \\
\hline
\end{tabular}

1 Distribution for U.S. citizens only.

2 Preliminary data.

${ }^{3}$ Preliminary data are for 4-year and 2-year degree-granting institutions that were eligible to participate in Title IV federal financial aid programs.

-Not applicable.

NOTE.-Because of underreporting and nonreporting of racial/ethnic data, some figures are slightly lower than corresponding data in other tables. Trend tabulations of institutions of higher education data are based on institutions that were accredited by an agency or association that was recognized by the U.S. Department of Education. The Department of Education no longer distinguishes between those institutions and other in- stitutions that are eligible to participate in Title IV programs. The new degree-granting classification is very similar to the earlier higher education classification, except that it includes some additional institutions, primarily 2-year colleges, and excludes a few higher education institutions that did not award degrees. Because of rounding, details may not add to totals.

SOURCE: U.S. Department of Education, National Center for Education Statistics, Higher Education General Information Survey (HEGIS), "Fall Enrollment in Colleges and Universities" surveys; and Integrated Postsecondary Education Data System (IPEDS), "Fall Enrollment" surveys. (This table was prepared May 1998.) 
Table 208.-Total fall enrollment in institutions of higher education and degree-granting institutions, by level, attendance status, sex, and race/ethnicity of student: 1995 and 1996

\begin{tabular}{|c|c|c|c|c|c|c|c|c|c|c|c|c|}
\hline \multirow{4}{*}{ Level and enrollment status } & \multicolumn{11}{|c|}{$1996^{1}$} & \multirow{4}{*}{$\begin{array}{c}\text { Percent } \\
\text { minority, } \\
\text { fall 19952 }\end{array}$} \\
\hline & \multirow{3}{*}{ Total } & \multirow{2}{*}{\multicolumn{2}{|c|}{ Enrollment, by sex }} & \multicolumn{7}{|c|}{ Enrollment, by race/ethnicity } & & \\
\hline & & & & & & & & & & & $\begin{array}{l}\text { Non- } \\
\text { resident }\end{array}$ & \\
\hline & & Male & Female & & & & & & lan & $\begin{array}{l}\text { Alaskan } \\
\text { Native }\end{array}$ & & \\
\hline 1 & 2 & 3 & 4 & 5 & 6 & 7 & 8 & 9 & 10 & 11 & 12 & 13 \\
\hline & & & & & Higher & education & institutions & & & & & \\
\hline All students ........ & $14,300,255$ & $6,343,992$ & $7,956,263$ & $10,226,034$ & $3,609,273$ & 26.1 & $1,499,439$ & $1,152,229$ & 823,633 & 133,972 & 464,948 & 25.3 \\
\hline Undergraduate, full-time and part-time ..... & $12,259,417$ & $5,411,058$ & $6,848,359$ & $8,730,928$ & $3,254,357$ & 27.2 & $1,352,578$ & $1,065,613$ & 713,230 & 122,936 & 274,132 & 26.4 \\
\hline 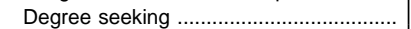 & $10,608,815$ & $4,684,930$ & $5,923,885$ & $7,528,654$ & $2,837,897$ & 27.4 & $1,202,467$ & 914,182 & 616,815 & 104,433 & 242,264 & 26.6 \\
\hline First-time freshmen & $2,193,429$ & $1,013,616$ & $1,179,813$ & $1,548,032$ & 603,353 & 28.0 & 260,169 & 197,407 & 121,881 & 23,896 & 42,044 & 27.6 \\
\hline Other first-year ........ & $2,421,277$ & $1,047,280$ & $1,373,997$ & $1,573,706$ & 796,654 & 33.6 & 334,554 & 286,756 & 147,175 & 28,169 & 50,917 & 32.8 \\
\hline Second year .............. & $2,719,130$ & $1,143,568$ & $1,575,562$ & $1,963,468$ & 700,419 & 26.3 & 301,138 & 227,215 & 145,127 & 26,939 & 55,243 & 25.4 \\
\hline Third year ........................................... & $1,397,921$ & 626,737 & 771,184 & $1,033,826$ & 325,568 & 23.9 & 136,274 & 91,305 & 87,047 & 10,942 & 38,527 & 23.2 \\
\hline Fourth year and beyond. & $1,728,819$ & 792,455 & 936,364 & $1,291,028$ & 387,162 & 23.1 & 156,849 & 106,641 & 110,368 & 13,304 & 50,629 & 22.1 \\
\hline Unclassified by level ........ & 148,239 & 61,274 & 86,965 & 118,594 & 24,741 & 17.3 & 13,483 & 4,858 & 5,217 & 1,183 & 4,904 & 17.6 \\
\hline Others in credit courses .......................... & $1,650,602$ & 726,128 & 924,474 & $1,202,274$ & 416,460 & 25.7 & 150,111 & 151,431 & 96,415 & 18,503 & 31,868 & 25.0 \\
\hline Full-time . & $7,210,698$ & $3,303,961$ & $3,906,737$ & $5,173,494$ & $1,831,836$ & 26.1 & 794,241 & 534,021 & 434,398 & 69,176 & 205,368 & 25.6 \\
\hline Degree seeking & $6,949,391$ & $3,180,500$ & $3,768,891$ & $5,001,893$ & $1,755,133$ & 26.0 & 764,854 & 507,105 & 417,188 & 65,986 & 192,365 & 25.5 \\
\hline First-time freshmen ….................... & $1,674,178$ & 779,438 & 894,740 & $1,208,086$ & 432,234 & 26.4 & 196,658 & 127,329 & 91,776 & 16,471 & 33,858 & 26.0 \\
\hline Other first-year .............................. & $1,151,651$ & 526,760 & 624,891 & 751,201 & 366,772 & 32.8 & 169,781 & 117,123 & 65,740 & 14,128 & 33,678 & 32.5 \\
\hline 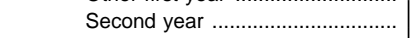 & $1,681,757$ & 746,251 & 935,506 & $1,226,912$ & 410,190 & 25.1 & 177,459 & 118,499 & 97,732 & 16,500 & 44,655 & 24.5 \\
\hline Third year ..................................... & $1,136,190$ & 524,208 & 611,982 & 842,502 & 258,105 & 23.5 & 105,444 & 68,966 & 74,885 & 8,810 & 35,583 & 22.8 \\
\hline Fourth year and beyond .............. & $1,276,595$ & 591,714 & 684,881 & 953,295 & 281,351 & 22.8 & 111,576 & 73,854 & 86,040 & 9,881 & 41,949 & 22.0 \\
\hline Unclassified by level ....... & 29,020 & 12,129 & 16,891 & 19,897 & 6,481 & 24.6 & 3,936 & 1,334 & 1,015 & 196 & 2,642 & 25.1 \\
\hline Others in credit courses .................. & 261,307 & 123,461 & 137,846 & 171,601 & 76,703 & 30.9 & 29,387 & 26,916 & 17,210 & 3,190 & 13,003 & 30.6 \\
\hline Part-time & $5,048,719$ & $2,107,097$ & $2,941,622$ & $3,557,434$ & $1,422,521$ & 28.6 & 558,337 & 531,592 & 278,832 & 53,760 & 68,764 & 27.5 \\
\hline Degree seeking & $3,659,424$ & $1,504,430$ & $2,154,994$ & $2,526,761$ & $1,082,764$ & 30.0 & 437,613 & 407,077 & 199,627 & 38,447 & 49,899 & 28.7 \\
\hline First-time freshmen & 519,251 & 234,178 & 285,073 & 339,946 & 171,119 & 33.5 & 63,511 & 70,078 & 30,105 & 7,425 & 8,186 & 32.5 \\
\hline Other first-year .............................. & $1,269,626$ & 520,520 & 749,106 & 822,505 & 429,882 & 34.3 & 164,773 & 169,633 & 81,435 & 14,041 & 17,239 & 33.0 \\
\hline 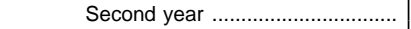 & $1,037,373$ & 397,317 & 640,056 & 736,556 & 290,229 & 28.3 & 123,679 & 108,716 & 47,395 & 10,439 & 10,588 & 26.8 \\
\hline 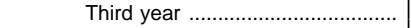 & 261,731 & 102,529 & 159,202 & 191,324 & 67,463 & 26.1 & 30,830 & 22,339 & 12,162 & 2,132 & 2,944 & 24.8 \\
\hline Fourth year and beyond .............. & 452,224 & 200,741 & 251,483 & 337,733 & 105,811 & 23.9 & 45,273 & 32,787 & 24,328 & 3,423 & 8,680 & 22.5 \\
\hline Unclassified by level ...................... & 119,219 & 49,145 & 70,074 & 98,697 & 18,260 & 15.6 & 9,547 & 3,524 & 4,202 & 987 & 2,262 & 16.1 \\
\hline Others in credit courses ...................... & $1,389,295$ & 602,667 & 786,628 & $1,030,673$ & 339,757 & 24.8 & 120,724 & 124,515 & 79,205 & 15,313 & 18,865 & 23.9 \\
\hline Postbaccalaureate ........... & $2,040,838$ & 932,934 & $1,107,904$ & $1,495,106$ & 354,916 & 19.2 & 146,861 & 86,616 & 110,403 & 11,036 & 190,816 & 18.3 \\
\hline First-professional & 297,739 & 172,462 & 125,277 & 221,157 & 68,918 & 23.8 & 21,398 & 13,966 & 31,398 & 2,156 & 7,664 & 23.1 \\
\hline Full-time .............. & 266,812 & 153,983 & 112,829 & 197,155 & 62,500 & 24.1 & 18,369 & 12,628 & 29,560 & 1,943 & 7,157 & 23.4 \\
\hline 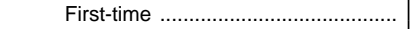 & 77,581 & 44,079 & 33,502 & 56,953 & 18,384 & 24.4 & 5,273 & 4,056 & 8,469 & 586 & 2,244 & 25.0 \\
\hline Other ……............... & 189,231 & 109,904 & 79,327 & 140,202 & 44,116 & 23.9 & 13,096 & 8,572 & 21,091 & 1,357 & 4,913 & 22.7 \\
\hline Part-time & 30,927 & 18,479 & 12,448 & 24,002 & 6,418 & 21.1 & 3,029 & 1,338 & 1,838 & 213 & 507 & 20.5 \\
\hline First-time $\ldots \ldots \ldots \ldots . . . . .$. & 9,429 & 5,529 & 3,900 & 7,175 & 2,105 & 22.7 & 942 & 475 & 617 & 71 & 149 & 22.0 \\
\hline Other & 21,498 & 12,950 & 8,548 & 16,827 & 4,313 & 20.4 & 2,087 & 863 & 1,221 & 142 & 358 & 19.7 \\
\hline Graduate students & $1,743,099$ & 760,472 & 982,627 & $1,273,949$ & 285,998 & 18.3 & 125,463 & 72,650 & 79,005 & 8,880 & 183,152 & 17.4 \\
\hline Full-time ............... & 735,980 & 357,575 & 378,405 & 476,879 & 122,879 & 20.5 & 48,436 & 30,432 & 39,970 & 4,041 & 136,222 & 19.5 \\
\hline Degree seeking ............................... & 688,493 & 337,286 & 351,207 & 444,906 & 111,270 & 20.0 & 45,052 & 26,837 & 35,688 & 3,693 & 132,317 & 19.0 \\
\hline First-time …….............................. & 231,084 & 110,740 & 120,344 & 148,703 & 39,350 & 20.9 & 15,709 & 9,507 & 12,926 & 1,208 & 43,031 & 19.4 \\
\hline Other degree seeking ...................... & 457,409 & 226,546 & 230,863 & 296,203 & 71,920 & 19.5 & 29,343 & 17,330 & 22,762 & 2,485 & 89,286 & 18.8 \\
\hline Others in credit courses ................... & 47,487 & 20,289 & 27,198 & 31,973 & 11,609 & 26.6 & 3,384 & 3,595 & 4,282 & 348 & 3,905 & 25.8 \\
\hline 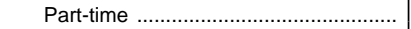 & $1,007,119$ & 402,897 & 604,222 & 797,070 & 163,119 & 17.0 & 77,027 & 42,218 & 39,035 & 4,839 & 46,930 & 16.2 \\
\hline Degree seeking ………................... & 773,707 & 324,380 & 449,327 & 609,048 & 122,174 & 16.7 & 57,482 & 30,478 & 30,584 & 3,630 & 42,485 & 16.0 \\
\hline (2) & 148,773 & 59,886 & 88,887 & 114,812 & 26,943 & 19.0 & 13,205 & 6,740 & 6,272 & 726 & 7,018 & 18.3 \\
\hline Other degree seeking ..................... & 624,934 & 264,494 & 360,440 & 494,236 & 95,231 & 16.2 & 44,277 & 23,738 & 24,312 & 2,904 & 35,467 & 15.4 \\
\hline Others in credit courses .................. & 233,412 & 78,517 & 154,895 & 188,022 & 40,945 & 17.9 & 19,545 & 11,740 & 8,451 & 1,209 & 4,445 & 16.8 \\
\hline & & & & & Degr & antin & titutions ${ }^{3}$ & & & & & \\
\hline All students & $14,367,520$ & $6,352,825$ & $8,014,695$ & $10,263,865$ & $3,637,396$ & 26.2 & $1,505,565$ & $1,166,108$ & 828,166 & 137,557 & 466,259 & - \\
\hline Undergraduate, full-time and part-time ..... & $12,326,948$ & $5,420,672$ & $6,906,276$ & $8,769,531$ & $3,282,107$ & 27.2 & $1,358,601$ & $1,079,350$ & 717,645 & 126,511 & 275,310 & - \\
\hline 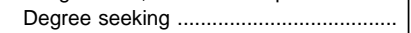 & $10,720,738$ & $4,727,637$ & $5,993,101$ & $7,605,537$ & $2,871,715$ & 27.4 & $1,213,324$ & 928,646 & 621,760 & 107,985 & 243,486 & - \\
\hline First-time freshmen & $2,274,319$ & $1,046,662$ & $1,227,657$ & $1,601,881$ & 629,743 & 28.2 & 270,687 & 208,018 & 125,141 & 25,897 & 42,695 & - \\
\hline 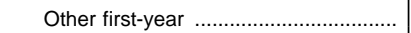 & $2,416,098$ & $1,044,926$ & $1,371,172$ & $1,569,553$ & 795,582 & 33.6 & 332,388 & 287,334 & 147,607 & 28,253 & 50,963 & - \\
\hline Second year & $2,755,714$ & $1,156,512$ & $1,599,202$ & $1,991,255$ & 708,855 & 26.3 & 303,770 & 230,338 & 146,347 & 28,400 & 55,604 & - \\
\hline Third year ......................................... & $1,398,336$ & 626,649 & 771,687 & $1,034,098$ & 325,589 & 23.9 & 136,213 & 91,348 & 87,077 & 10,951 & 38,649 & - \\
\hline Fourth year and beyond ........................ & $1,729,076$ & 792,331 & 936,745 & $1,291,245$ & 387,116 & 23.1 & 156,719 & 106,693 & 110,400 & 13,304 & 50,715 & - \\
\hline Unclassified by level ……….................. & 147,195 & 60,557 & 86,638 & 117,505 & 24,830 & 17.4 & 13,547 & 4,915 & 5,188 & 1,180 & 4,860 & - \\
\hline Others in credit courses ........................... & $1,606,210$ & 693,035 & 913,175 & $1,163,994$ & 410,392 & 26.1 & 145,277 & 150,704 & 95,885 & 18,526 & 31,824 & - \\
\hline Full-time & $7,298,839$ & $3,339,108$ & $3,959,731$ & $5,231,630$ & $1,860,801$ & 26.2 & 805,004 & 545,568 & 438,712 & 71,517 & 206,408 & - \\
\hline Degree seeking & $7,036,393$ & $3,215,162$ & $3,821,231$ & $5,059,616$ & $1,783,354$ & 26.1 & 775,143 & 518,471 & 421,434 & 68,306 & 193,423 & - \\
\hline First-time freshmen ......................... & $1,739,852$ & 805,982 & 933,870 & $1,250,257$ & 455,140 & 26.7 & 206,148 & 136,494 & 94,582 & 17,916 & 34,455 & - \\
\hline Other first-year ............................... & $1,150,715$ & 526,663 & 624,052 & 750,197 & 366,801 & 32.8 & 168,634 & 117,735 & 66,203 & 14,229 & 33,717 & - \\
\hline Second year ................................... & $1,703,436$ & 754,590 & 948,846 & $1,243,092$ & 415,390 & 25.0 & 179,420 & 120,024 & 98,683 & 17,263 & 44,954 & - \\
\hline Third year ..... & $1,136,388$ & 524,122 & 612,266 & 842,581 & 258,110 & 23.4 & 105,396 & 68,992 & 74,903 & 8,819 & 35,697 & - \\
\hline Fourth year and beyond ................ & $1,276,754$ & 591,620 & 685,134 & 953,419 & 281,326 & 22.8 & 111,483 & 73,897 & 86,062 & 9,884 & 42,009 & - \\
\hline Unclassified by level ...................... & 29,248 & 12,185 & 17,063 & 20,070 & 6,587 & 24.7 & 4,062 & 1,329 & 1,001 & 195 & 2,591 & - \\
\hline Others in credit courses & 262,446 & 123,946 & 138,500 & 172,014 & 77,447 & 31.0 & 9,861 & 27,097 & 17,278 & 3,211 & 12,985 & - \\
\hline
\end{tabular}


Table 208.-Total fall enrollment in institutions of higher education and degree-granting institutions, by level, attendance status, sex, and race/ethnicity of student: 1995 and 1996-Continued

\begin{tabular}{|c|c|c|c|c|c|c|c|c|c|c|c|c|}
\hline \multirow{4}{*}{ Level and enrollment status } & \multicolumn{11}{|c|}{$1996^{1}$} & \multirow{4}{*}{$\begin{array}{r}\text { Percent } \\
\text { minority, } \\
\text { fall } 1995^{2}\end{array}$} \\
\hline & \multirow{3}{*}{ Total } & \multirow{2}{*}{\multicolumn{2}{|c|}{ Enrollment, by sex }} & \multicolumn{7}{|c|}{ Enrollment, by race/ethnicity } & \multirow{3}{*}{$\begin{array}{l}\text { Non- } \\
\text { resident } \\
\text { alien }\end{array}$} & \\
\hline & & & & \multirow{2}{*}{ White } & \multirow{2}{*}{$\begin{array}{l}\text { Total, mi- } \\
\text { nority }\end{array}$} & \multirow{2}{*}{$\begin{array}{c}\text { Percent } \\
\text { minor- } \\
\text { ity }{ }^{2}\end{array}$} & \multirow{2}{*}{$\begin{array}{l}\text { Black, } \\
\text { non-His- } \\
\text { panic }\end{array}$} & \multirow{2}{*}{ Hispanic } & \multirow{2}{*}{$\begin{array}{c}\text { Asian/Pa- } \\
\text { cific Is- } \\
\text { lander }\end{array}$} & \multirow{2}{*}{$\begin{array}{c}\text { American } \\
\text { Indian/ } \\
\text { Alaskan } \\
\text { Native }\end{array}$} & & \\
\hline & & Male & Female & & & & & & & & & \\
\hline 1 & 2 & 3 & 4 & 5 & 6 & 7 & 8 & 9 & 10 & 11 & 12 & 13 \\
\hline Part-time . & $5,028,109$ & $2,081,564$ & $2,946,545$ & $3,537,901$ & $1,421,306$ & 28.7 & 553,597 & 533,782 & 278,933 & 54,994 & 68,902 & - \\
\hline Degree seeking & $3,684,345$ & $1,512,475$ & $2,171,870$ & $2,545,921$ & $1,088,361$ & 29.9 & 438,181 & 410,175 & 200,326 & 39,679 & 50,063 & - \\
\hline First-time freshmen & 534,467 & 240,680 & 293,787 & 351,624 & 174,603 & 33.2 & 64,539 & 71,524 & 30,559 & 7,981 & 8,240 & - \\
\hline 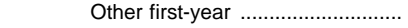 & $1,265,383$ & 518,263 & 747,120 & 819,356 & 428,781 & 34.4 & 163,754 & 169,599 & 81,404 & 14,024 & 17,246 & - \\
\hline Second year .................... & $1,052,278$ & 401,922 & 650,356 & 748,163 & 293,465 & 28.2 & 124,350 & 110,314 & 47,664 & 11,137 & 10,650 & - \\
\hline 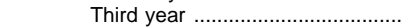 & 261,948 & 102,527 & 159,421 & 191,517 & 67,479 & 26.1 & 30,817 & 22,356 & 12,174 & 2,132 & 2,952 & - \\
\hline Fourth year and beyond & 452,322 & 200,711 & 251,611 & 337,826 & 105,790 & 23.8 & 45,236 & 32,796 & 24,338 & 3,420 & 8,706 & - \\
\hline Unclassified by level ....... & 117,947 & 48,372 & 69,575 & 97,435 & 18,243 & 15.8 & 9,485 & 3,586 & 4,187 & 985 & 2,269 & - \\
\hline Others in credit courses ..................... & $1,343,764$ & 569,089 & 774,675 & 991,980 & 332,945 & 25.1 & 115,416 & 123,607 & 78,607 & 15,315 & 18,839 & - \\
\hline Postbaccalaureate .... & $2,040,572$ & 932,153 & $1,108,419$ & $1,494,334$ & 355,289 & 19.2 & 146,964 & 86,758 & 110,521 & 11,046 & 190,949 & - \\
\hline First-professional & 298,312 & 172,742 & 125,570 & 221,688 & 69,001 & 23.7 & 21,477 & 13,939 & 31,425 & 2,160 & 7,623 & - \\
\hline Full-time ............. & 267,209 & 154,107 & 113,102 & 197,522 & 62,566 & 24.1 & 18,433 & 12,610 & 29,576 & 1,947 & 7,121 & - \\
\hline 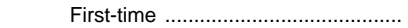 & 77,695 & 44,096 & 33,599 & 57,036 & 18,431 & 24.4 & 5,292 & 4,057 & 8,492 & 590 & 2,228 & - \\
\hline Other & 189,514 & 110,011 & 79,503 & 140,486 & 44,135 & 23.9 & 13,141 & 8,553 & 21,084 & 1,357 & 4,893 & - \\
\hline Part-time & 31,103 & 18,635 & 12,468 & 24,166 & 6,435 & 21.0 & 3,044 & 1,329 & 1,849 & 213 & 502 & - \\
\hline 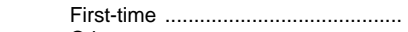 & 9,533 & 5,611 & 3,922 & 7,265 & 2,123 & 22.6 & 964 & 470 & 618 & 71 & 145 & - \\
\hline 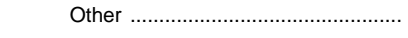 & 21,570 & 13,024 & 8,546 & 16,901 & 4,312 & 20.3 & 2,080 & 859 & 1,231 & 142 & 357 & - \\
\hline Graduate students & $1,742,260$ & 759,411 & 982,849 & $1,272,646$ & 286,288 & 18.4 & 125,487 & 72,819 & 79,096 & 8,886 & 183,326 & - \\
\hline Full-time ……..................... & 736,905 & 357,993 & 378,912 & 476,945 & 123,424 & 20.6 & 48,499 & 30,643 & 40,230 & 4,052 & 136,536 & - \\
\hline Degree seeking ………........................ & 689,883 & 337,782 & 352,101 & 445,357 & 111,856 & 20.1 & 45,135 & 27,056 & 35,960 & 3,705 & 132,670 & - \\
\hline 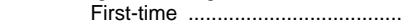 & 232,330 & 111,445 & 120,885 & 149,124 & 39,910 & 21.1 & 15,803 & 9,735 & 13,156 & 1,216 & 43,296 & - \\
\hline Other degree seeking …................. & 457,553 & 226,337 & 231,216 & 296,233 & 71,946 & 19.5 & 29,332 & 17,321 & 22,804 & 2,489 & 89,374 & - \\
\hline Others in credit courses ................... & 47,022 & 20,211 & 26,811 & 31,588 & 11,568 & 26.8 & 3,364 & 3,587 & 4,270 & 347 & 3,866 & - \\
\hline 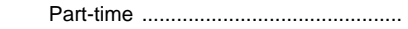 & $1,005,355$ & 401,418 & 603,937 & 795,701 & 162,864 & 17.0 & 76,988 & 42,176 & 38,866 & 4,834 & 46,790 & - \\
\hline Degree seeking …….......................... & 772,760 & 323,543 & 449,217 & 608,268 & 122,072 & 16.7 & 57,471 & 30,464 & 30,509 & 3,628 & 42,420 & - \\
\hline First-time & 147,614 & 58,927 & 88,687 & 113,867 & 26,803 & 19.1 & 13,188 & 6,721 & 6,175 & 719 & 6,944 & - \\
\hline Other degree seeking & 625,146 & 264,616 & 360,530 & 494,401 & 95,269 & 16.2 & 44,283 & 23,743 & 24,334 & 2,909 & 35,476 & - \\
\hline Others in credit courses ..................... & 232,595 & 77,875 & 154,720 & 187,433 & 40,792 & 17.9 & 19,517 & 11,712 & 8,357 & 1,206 & 4,370 & - \\
\hline
\end{tabular}

1 Preliminary data.

2 Percentage based on U.S. citizens only.

SOURCE: U.S. Department of Education, National Center for Education Statistics, In-

${ }^{3}$ Data are for 4-year and 2-year degree-granting higher education institutions that were egrated Postsecondary Education Data System (IPEDS), "Fall Enrollment" surveys. eligible to participate in Title IV federal financial aid programs. 
Table 209.-Total number of institutions and fall enrollment in institutions of higher education and degree-granting institutions, by percentage minority enrollment: 1996

\begin{tabular}{|c|c|c|c|c|c|c|c|c|c|c|c|c|c|c|c|}
\hline \multirow{4}{*}{$\begin{array}{c}\text { Minority percentage of U.S. citizen } \\
\text { enrollment }\end{array}$} & \multicolumn{4}{|c|}{ Degree-granting institutions ${ }^{2}$} & \multicolumn{11}{|c|}{ Institutions of higher education } \\
\hline & \multirow{3}{*}{$\begin{array}{c}\text { Total } \\
\text { enrollment }\end{array}$} & \multirow{3}{*}{$\begin{array}{l}\text { Public insti- } \\
\text { tutions }\end{array}$} & \multicolumn{2}{|c|}{ Private institutions } & \multirow{3}{*}{$\begin{array}{c}\text { Total } \\
\text { enrollment }\end{array}$} & \multicolumn{5}{|c|}{ Public institutions } & \multicolumn{5}{|c|}{ Private institutions } \\
\hline & & & \multirow[b]{2}{*}{ otal } & \multirow[b]{2}{*}{ Nonprofit } & & \multirow[b]{2}{*}{ Total } & \multicolumn{3}{|c|}{ 4-year institutions } & \multirow[b]{2}{*}{ 2-year } & \multirow[b]{2}{*}{ Total } & \multicolumn{3}{|c|}{ 4-year institutions } & \multirow[b]{2}{*}{ 2-year } \\
\hline & & & & & & & Total & University & $\begin{array}{l}\text { Other } \\
\text { 4-year }\end{array}$ & & & Total & $\begin{array}{l}\text { Univer- } \\
\text { sity }\end{array}$ & $\begin{array}{l}\text { Other } \\
\text { 4-year }\end{array}$ & \\
\hline 1 & 2 & 3 & 4 & 5 & 6 & 7 & 8 & 9 & 10 & 11 & 12 & 13 & 14 & 15 & 16 \\
\hline 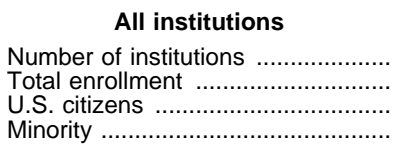 & $\begin{array}{r}3,842 \\
14,367,520 \\
13,901,261 \\
3,637,396\end{array}$ & \begin{tabular}{|r|}
1,645 \\
$11,120,499$ \\
$10,816,704$ \\
$2,944,838$
\end{tabular} & $\begin{array}{r}2,197 \\
3,247,021 \\
3,084,557 \\
692,558\end{array}$ & $\begin{array}{r}1,633 \\
2,942,556 \\
2,786,500 \\
592,567\end{array}$ & $\begin{array}{r}3,534 \\
14,300,255 \\
13,835,307 \\
3,609,273\end{array}$ & $\begin{array}{r}1,595 \\
11,090,171 \\
10,786,503 \\
2,938,218\end{array}$ & $\begin{array}{r}604 \\
5,806,904 \\
5,591,883 \\
1,332,254\end{array}$ & $\begin{array}{r}94 \\
2,226,529 \\
2,107,310 \\
385,711\end{array}$ & $\begin{array}{r}510 \\
3,580,375 \\
3,484,573 \\
946,543\end{array}$ & $\begin{array}{r}991 \\
5,283,267 \\
5,194,620 \\
1,605,964\end{array}$ & $\begin{array}{r}1,939 \\
3,210,084 \\
3,048,804 \\
671,055\end{array}$ & $\begin{array}{r}1,590 \\
2,995,931 \\
2,837,482 \\
613,903\end{array}$ & $\begin{array}{r}62 \\
758,436 \\
688,756 \\
173,409\end{array}$ & $\begin{array}{r}1,528 \\
2,237,495 \\
2,148,726 \\
440,494\end{array}$ & $\begin{array}{r}349 \\
214,153 \\
211,322 \\
57,152\end{array}$ \\
\hline $\begin{array}{l}\begin{array}{c}90.0 \text { percent or more } \\
\text { minority enrollment }\end{array} \\
\text { Number of institutions }\end{array}$ & $\begin{array}{r}126 \\
335,456 \\
326,126 \\
311,153\end{array}$ & $\begin{array}{r}54 \\
254,927 \\
248,230 \\
234,916\end{array}$ & $\begin{array}{r}72 \\
80,529 \\
77,896 \\
76,237\end{array}$ & $\begin{array}{r}65 \\
74,733 \\
72,213 \\
70,900\end{array}$ & $\begin{array}{r}119 \\
331,558 \\
322,296 \\
307,549\end{array}$ & $\begin{array}{r}51 \\
253,277 \\
246,586 \\
233,325\end{array}$ & $\begin{array}{r}27 \\
134,263 \\
131,077 \\
123,598\end{array}$ & $\begin{array}{l}0 \\
0 \\
0 \\
0\end{array}$ & $\begin{array}{r}27 \\
134,263 \\
131,077 \\
123,598\end{array}$ & $\begin{array}{r}24 \\
119,014 \\
115,509 \\
109,727\end{array}$ & $\begin{array}{r}68 \\
78,281 \\
75,710 \\
74,224\end{array}$ & $\begin{array}{r}60 \\
75,080 \\
72,565 \\
71,146\end{array}$ & $\begin{array}{r}1 \\
10,248 \\
9,230 \\
9,092\end{array}$ & $\begin{array}{r}59 \\
64,832 \\
63,335 \\
62,054\end{array}$ & $\begin{array}{r}8 \\
3,201 \\
3,145 \\
3,078\end{array}$ \\
\hline 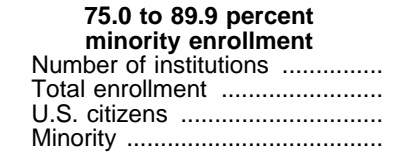 & $\begin{array}{r}107 \\
488,998 \\
470,459 \\
385,921\end{array}$ & $\begin{array}{r}62 \\
460,936 \\
443,183 \\
362,877\end{array}$ & $\begin{array}{r}45 \\
28,062 \\
27,276 \\
23,044\end{array}$ & $\begin{array}{r}18 \\
12,017 \\
11,588 \\
9,937\end{array}$ & $\begin{array}{r}94 \\
481,587 \\
462,804 \\
379,454\end{array}$ & $\begin{array}{r}60 \\
458,599 \\
440,862 \\
360,833\end{array}$ & $\begin{array}{r}19 \\
140,579 \\
134,116 \\
110,524\end{array}$ & $\begin{array}{r}1 \\
18,243 \\
16,700 \\
12,625\end{array}$ & $\begin{array}{r}18 \\
122,336 \\
117,416 \\
97,899\end{array}$ & $\begin{array}{r}41 \\
318,020 \\
306,746 \\
250,309\end{array}$ & $\begin{array}{r}34 \\
22,988 \\
21,942 \\
18,621\end{array}$ & $\begin{array}{r}16 \\
12,641 \\
11,806 \\
10,212\end{array}$ & $\begin{array}{l}0 \\
0 \\
0 \\
0\end{array}$ & $\begin{array}{r}16 \\
12,641 \\
11,806 \\
10,212\end{array}$ & $\begin{array}{r}18 \\
10,347 \\
10,136 \\
8,409\end{array}$ \\
\hline $\begin{array}{l}50.0 \text { to } 74.9 \text { percent } \\
\text { minority enrollment } \\
\text { Number of institutions } \\
\text { Total enrollment } \\
\text { U.S. citizens } \\
\text { Minority }\end{array}$ & $\begin{array}{r}246 \\
1,197,816 \\
1,154,525 \\
694,904\end{array}$ & $\begin{array}{r}120 \\
1,074,225 \\
1,034,620 \\
621,310\end{array}$ & $\begin{array}{r}126 \\
123,591 \\
119,905 \\
73,594\end{array}$ & $\begin{array}{r}58 \\
82,738 \\
79,760 \\
48,900\end{array}$ & $\begin{array}{r}210 \\
1,182,427 \\
1,139,156 \\
685,879\end{array}$ & $\begin{array}{r}114 \\
1,074,222 \\
1,034,618 \\
621,402\end{array}$ & $\begin{array}{r}32 \\
433,436 \\
414,550 \\
249,022\end{array}$ & $\begin{array}{l}2 \\
65,391 \\
61,568 \\
35,567\end{array}$ & $\begin{array}{r}30 \\
368,045 \\
352,982 \\
213,455\end{array}$ & $\begin{array}{r}82 \\
640,786 \\
620,068 \\
372,380\end{array}$ & $\begin{array}{r}96 \\
108,205 \\
104,538 \\
64,477\end{array}$ & $\begin{array}{r}44 \\
85,018 \\
81,856 \\
50,149\end{array}$ & $\begin{array}{l}0 \\
0 \\
0 \\
0\end{array}$ & $\begin{array}{r}44 \\
85,018 \\
81,856 \\
50,149\end{array}$ & $\begin{array}{r}52 \\
23,187 \\
22,682 \\
14,328\end{array}$ \\
\hline $\begin{array}{l}25.0 \text { to } 49.9 \text { percent } \\
\text { minority enrollment } \\
\text { Number of institutions } \\
\text { Total enrollment } \\
\text { U.S. citizens }\end{array}$ & $\begin{array}{r}757 \\
3,442,962 \\
3,304,936 \\
1,132,602\end{array}$ & $\begin{array}{r}341 \\
2,634,608 \\
2,560,069 \\
879,263\end{array}$ & $\begin{array}{r}416 \\
808,354 \\
744,867 \\
253,339\end{array}$ & $\begin{array}{r}243 \\
697,903 \\
637,355 \\
214,251\end{array}$ & $\begin{array}{r}674 \\
3,415,624 \\
3,279,085 \\
1,123,922\end{array}$ & $\begin{array}{r}331 \\
2,631,482 \\
2,556,985 \\
878,760\end{array}$ & $\begin{array}{r}100 \\
1,105,144 \\
1,061,769 \\
356,416\end{array}$ & $\begin{array}{r}12 \\
345,688 \\
325,616 \\
106,104\end{array}$ & $\begin{array}{r}88 \\
759,456 \\
736,153 \\
250,312\end{array}$ & $\begin{array}{r}231 \\
1,526,338 \\
1,495,216 \\
522,344\end{array}$ & $\begin{array}{r}343 \\
784,142 \\
722,100 \\
245,162\end{array}$ & $\begin{array}{r}257 \\
737,160 \\
675,781 \\
229,427\end{array}$ & $\begin{array}{r}24 \\
326,898 \\
291,724 \\
96,858\end{array}$ & $\begin{array}{r}233 \\
410,262 \\
384,057 \\
132,569\end{array}$ & $\begin{array}{r}86 \\
46,982 \\
46,319 \\
15,735\end{array}$ \\
\hline $\begin{array}{l}\quad \begin{array}{l}10.0 \text { to } 24.9 \text { percent } \\
\text { minority enrollment } \\
\text { Number of institutions }\end{array} \\
\text { Total enrollment } \\
\text { U.S. chitizens }\end{array}$ & $\begin{array}{r}1,323 \\
5,774,973 \\
5,578,543 \\
926,868\end{array}$ & $\begin{array}{r}554 \\
4,412,930 \\
4,286,835 \\
710,039\end{array}$ & $\begin{array}{r}769 \\
1,362,043 \\
1,291,708 \\
216,829\end{array}$ & $\begin{array}{r}601 \\
1,267,839 \\
1,199,594 \\
201,092\end{array}$ & $\begin{array}{r}1,228 \\
5,790,321 \\
5,593,975 \\
928,093\end{array}$ & $\begin{array}{r}540 \\
4,405,394 \\
4,279,307 \\
708,377\end{array}$ & $\begin{array}{r}223 \\
2,639,722 \\
2,531,223 \\
409,707\end{array}$ & $\begin{array}{r}53 \\
1,343,594 \\
1,268,716 \\
201,337\end{array}$ & $\begin{array}{r}170 \\
1,296,128 \\
1,262,507 \\
208,370\end{array}$ & $\begin{array}{r}317 \\
1,765,672 \\
1,748,084 \\
298,670\end{array}$ & $\begin{array}{r}688 \\
1,384,927 \\
1,314,668 \\
219,716\end{array}$ & $\begin{array}{r}603 \\
1,298,966 \\
1,229,342 \\
206,534\end{array}$ & $\begin{array}{r}33 \\
364,945 \\
334,068 \\
63,859\end{array}$ & $\begin{array}{r}570 \\
934,021 \\
895,274 \\
142,675\end{array}$ & $\begin{array}{r}85 \\
85,961 \\
85,326 \\
13,182\end{array}$ \\
\hline 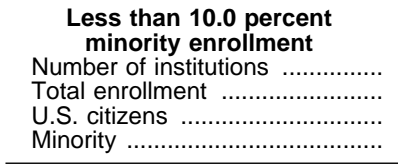 & $\begin{array}{r}1,283 \\
3,127,315 \\
3,066,072 \\
185,948 \\
\end{array}$ & $\begin{array}{r}514 \\
2,282,873 \\
2,243,767 \\
136,433 \\
\end{array}$ & $\begin{array}{r}769 \\
844,442 \\
822,905 \\
49,515\end{array}$ & $\begin{array}{r}648 \\
807,326 \\
785,990 \\
47,487 \\
\end{array}$ & $\begin{array}{r}1,209 \\
3,098,738 \\
3,037,991 \\
184,376\end{array}$ & $\begin{array}{r}499 \\
2,267,197 \\
2,228,145 \\
135,521\end{array}$ & $\begin{array}{r}203 \\
1,353,760 \\
1,319,148 \\
82,987\end{array}$ & $\begin{array}{r}26 \\
453,613 \\
434,710 \\
30,078\end{array}$ & $\begin{array}{r}177 \\
900,147 \\
884,438 \\
52,909\end{array}$ & $\begin{array}{r}296 \\
913,437 \\
908,997 \\
52,534\end{array}$ & $\begin{array}{r}710 \\
831,541 \\
809,846 \\
48,855\end{array}$ & $\begin{array}{r}610 \\
787,066 \\
766,132 \\
46,435\end{array}$ & $\begin{array}{r}4 \\
56,345 \\
53,734 \\
3,600\end{array}$ & $\begin{array}{r}606 \\
730,721 \\
712,398 \\
42,835\end{array}$ & $\begin{array}{r}100 \\
44,475 \\
43,714 \\
2,420 \\
\end{array}$ \\
\hline
\end{tabular}

1 Preliminary data. Minority includes black, Hispanic, Asian or Pacific Islander, and American Indian/Alaskan Native students.

IV federal financial aid programs.

NOTE - Some institutions do not report separate enrollment data for each branch campus. For this reason, counts of institutions in this table are somewhat lower than figures appearing in other tables. Tabulations of institutions of higher education data a the U.S. Department of Education. The Department of Education no longer distinguishes between those institutions and other institutions that are eligible to participate in Title IV programs. The new degree-granting classification is very similar to the earlier higher education classification, except that it includes some additional institutions, primarily 2-year colleges, and excludes a few higher education institutions that did not award degrees.

SOURCE: U.S. Department of Education, National Center for Education Statistics, Integrated Postsecondary Education Data System (IPEDS), "Fall Enrollment" survey. (This table was prepared January 1999.) 
Table 210.-Total fall enrollment in institutions of higher education, by race/ethnicity of student and by state: 1992 to 1996

\begin{tabular}{|c|c|c|c|c|c|c|c|c|c|c|c|c|c|}
\hline \multirow{3}{*}{ State or other area } & \multicolumn{8}{|c|}{19961} & \multicolumn{5}{|c|}{ Percent minority 2} \\
\hline & \multirow[b]{2}{*}{ Total } & \multirow[b]{2}{*}{$\begin{array}{l}\text { White, } \\
\text { non-His- } \\
\text { panic }\end{array}$} & \multicolumn{5}{|c|}{ Minority enrollment, by race/ethnicity } & \multirow[b]{2}{*}{$\begin{array}{l}\text { Non- } \\
\text { resident } \\
\text { alien }\end{array}$} & \multirow[b]{2}{*}{1992} & \multirow[b]{2}{*}{1993} & & & \\
\hline & & & Total & \begin{tabular}{|c|} 
Black, \\
non-His- \\
panic
\end{tabular} & Hispanic & $\begin{array}{l}\text { Asian/ } \\
\text { Pacific } \\
\text { Islander }\end{array}$ & \begin{tabular}{|c|} 
American \\
Indian/ \\
Alaskan \\
Native
\end{tabular} & & & & 1994 & 1995 & 1996 \\
\hline 1 & 2 & 3 & 4 & 5 & 6 & 7 & 8 & 9 & 10 & 11 & 12 & 13 & 14 \\
\hline United States & $14,300,255$ & $10,226,034$ & $3,609,273$ & $1,499,439$ & $1,152,229$ & 823,633 & 133,972 & 464,948 & 22.5 & 23.5 & 24.6 & 25.3 & 26.1 \\
\hline Alabama & 219,499 & 157,161 & 57.870 & 52,334 & 1,739 & 2,413 & 1,384 & 4.468 & 23.7 & 24.8 & 25.5 & 26.1 & 26.9 \\
\hline Alaska ............... & 28,846 & 22,369 & 5,397 & 1,058 & 713 & 754 & 2,872 & 1,080 & 18.3 & 18.6 & 18.7 & 19.3 & 19.4 \\
\hline Arizona ..................... & 276,832 & 200,429 & 68,701 & 9,243 & 40,063 & 8,807 & 10,588 & 7,702 & 22.2 & 23.8 & 24.0 & 25.0 & 25.5 \\
\hline Arkansas ................................ & 100,688 & 80,089 & 18,183 & 15,287 & 835 & 1,169 & 892 & 2,416 & 16.8 & 17.2 & 17.1 & 17.9 & 18.5 \\
\hline California & $1,882,634$ & 922,781 & 877,691 & 143,885 & 383,461 & 328,337 & 22,008 & 82,162 & 40.5 & 44.0 & 46.3 & 47.9 & 48.7 \\
\hline Colorado & 242,949 & 193,944 & 43,108 & 8,311 & 23,226 & 8,404 & 3,167 & 5,897 & 15.8 & 16.4 & 16.9 & 17.7 & 18.2 \\
\hline Connecticut & 155,361 & 123,344 & 26,203 & 11,864 & 8,020 & 5,783 & 536 & 5,814 & 14.2 & 15.1 & 16.3 & 16.9 & 17.5 \\
\hline Delaware ... & 44,838 & 35,287 & 8,476 & 6,357 & 901 & 1,025 & 193 & 1, & 16.0 & 16.9 & 18.0 & 18.6 & 19.4 \\
\hline District of Columbia .............................. & 74,239 & 35,897 & 30,192 & 22,420 & 2,978 & 4,548 & 246 & 8,150 & 44.0 & 44.0 & 45.4 & 45.8 & 45.7 \\
\hline Florida & 641,173 & 418,043 & 202,736 & 87,889 & 92,087 & 19,720 & 3,040 & 20,394 & 27.5 & 28.4 & 29.5 & 31.0 & 32.7 \\
\hline Georgia & 317,999 & 214,549 & 95,343 & 80,696 & 4,987 & 8,849 & 811 & 8,107 & 26.4 & 27.9 & 29.0 & 29.7 & 30.8 \\
\hline Hawaii ... & 61,383 & 16,394 & 39,319 & 1,285 & 1,342 & 36,443 & 249 & 5,670 & 69.6 & 69.9 & 70.6 & 70.8 & 70.6 \\
\hline Idaho ....... & 59,904 & 54,827 & 3,797 & 383 & 1,695 & 888 & 831 & 1,280 & 5.5 & 6.1 & 6.1 & 6.4 & 6.5 \\
\hline Illinois & 720,987 & 504,144 & 198,560 & 92,070 & 63,923 & 40,144 & 2,423 & 18,283 & 25.6 & 26.1 & 26.9 & 27.3 & 28.3 \\
\hline Indiana ………………………........... & 286,326 & 246,370 & 30,910 & 17,799 & 6,571 & 5,415 & 1,125 & 9,046 & 9.8 & 10.2 & 10.5 & 10.9 & 11.1 \\
\hline lowa & 177,021 & 156,705 & 13,018 & 4,996 & 906 & 4,343 & 773 & 7,2 & 6.2 & 6.6 & 7.2 & 7.4 & 7.7 \\
\hline Kansas & 172,350 & 145,757 & 21,011 & 8,155 & 6,233 & 4,012 & 2,611 & 5,582 & 10.7 & 11.0 & 11.5 & 12.8 & 12.6 \\
\hline Kentucky ………............................ & 177,749 & 158,077 & 16,502 & 12,416 & 1,196 & 2,145 & 745 & 3,170 & 8.2 & 8.6 & 8.9 & 9.1 & 9.5 \\
\hline 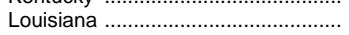 & 203,517 & 133,455 & 64,417 & 53,664 & 5,014 & 4,602 & 1,137 & 5,645 & 29.7 & 30.2 & 31.4 & 31.8 & 32.6 \\
\hline Maine ......... & 55,645 & 52,887 & 2,197 & 402 & 376 & 723 & 696 & 561 & 4.4 & 3.3 & 3.7 & 4.8 & 4.0 \\
\hline Maryland & 260,757 & 170,259 & 80,758 & 58,514 & 6,350 & 14,737 & 1,157 & 9,740 & 27.3 & 28.5 & 30.0 & 30.9 & 32.2 \\
\hline usetts. & 410,327 & 316,804 & 68,356 & 23,372 & 17,788 & 25,416 & 1,780 & 25 & 14.4 & 15.2 & 16.5 & 17.3 & 17.7 \\
\hline 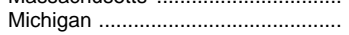 & 546,974 & 436,671 & 92,618 & 60,497 & 11,694 & 15,979 & 4,448 & 1 & 15.3 & 16.2 & 16.8 & 17.2 & 17.5 \\
\hline Minnesota & 275,262 & 243,962 & 23,971 & 7,624 & 3,756 & 9,682 & 2,909 & 7,329 & 6.8 & 7.5 & 8.0 & 8.9 & 8.9 \\
\hline 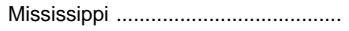 & 126,234 & 83,659 & 40,570 & 38,396 & 698 & 973 & 503 & 2,005 & 29.8 & 30.6 & 31.2 & 31.5 & 32.7 \\
\hline Missouri .... & 290,533 & 243,600 & 39,079 & 25,930 & 4,995 & 6,555 & 1,599 & 7,854 & 12.6 & 12.9 & 13.2 & 13.4 & 13.8 \\
\hline Monta & 43,145 & 37,389 & 4,711 & 144 & 504 & 354 & 3,709 & 1,0 & 12.9 & 11.5 & 11.5 & 11.4 & 11.2 \\
\hline Nebras & 119,300 & 107,274 & 9,257 & 3,458 & 2,393 & 2,284 & 1,122 & 2,769 & 7.2 & 7.0 & 7.4 & 7.8 & 7.9 \\
\hline ……............. & 73,467 & 55,008 & 16,404 & 4,396 & 6,236 & 4,585 & 1,187 & 2,055 & 18.7 & 18.0 & 19.5 & 21.1 & 23.0 \\
\hline New Hampshire ............................ & 64,463 & 60,068 & 3,135 & 915 & 864 & 1,057 & 299 & 1,260 & 5.4 & 4.9 & 4.6 & 5.2 & 5.0 \\
\hline New Jersey & 328,1 & 223,256 & 93,579 & 38,804 & . & 40 & 93 & 110 & $24 . \varepsilon$ & 25 & 27 & 28.6 & 9.5 \\
\hline New Mexico .......... & 103,546 & 57,323 & 4,525 & 2,568 & 2 & 1,869 & 6,856 & 1 , & 3 & 40.9 & 41.8 & 3.1 & 43.7 \\
\hline New York ................... & $1,027,870$ & 672,311 & 311,595 & 137,124 & 102,835 & 67,932 & 3,704 & 43, & 26.9 & 28.1 & 29.8 & 30.7 & 31.7 \\
\hline North Carolina .... & 373,168 & 275,630 & 91,076 & 74,808 & 4,965 & 7,547 & 3,756 & 6,462 & 22.6 & 23.2 & 24.1 & 24.2 & 24.8 \\
\hline North Dakota ......... & 40,554 & 35,916 & 3,187 & 339 & 286 & 310 & 2,252 & 1,451 & 7.3 & 7.5 & 7.8 & 7.6 & 8.2 \\
\hline Ohio & 537,535 & 448,218 & 72,892 & 51,225 & 8,1 & 11,371 & 2 , & 16,4 & 12. & 12.7 & 13.2 & 13.6 & 14.0 \\
\hline 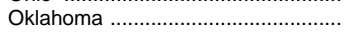 & & 13 & 35,409 & 12,848 & 4,280 & 4,440 & 13, & & & & & 20.4 & 21.0 \\
\hline$\ldots \ldots \ldots \ldots .$. & 165,168 & 138,104 & 20,660 & 2,784 & 5,764 & 9,525 & 2,587 & 6,404 & 10.6 & 11.6 & 12.2 & 13.4 & 13.0 \\
\hline Penns & 621,994 & 518,526 & 86,119 & 52,118 & 11,734 & 20,867 & 1,400 & 17,3 & 12.5 & 12.5 & 13.2 & 14.0 & 14.2 \\
\hline Rhode Island ......................... & 72,432 & 60,722 & 9,069 & 3,185 & 2,970 & 2,641 & 273 & 2,641 & 10.2 & 11.0 & 11.4 & 12.3 & 13.0 \\
\hline South & 174,303 & 126,593 & 44,786 & 40,371 & 1,639 & 2,263 & 513 & 2,924 & 23.7 & 23.8 & 24.7 & 25.3 & 26.1 \\
\hline & 35,373 & 31,431 & 3,019 & 288 & 1 & 259 & 2,2 & 9 & 7.5 & 6.8 & 8.6 & 8.9 & 8.8 \\
\hline 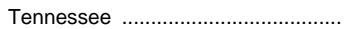 & 247,043 & 198,139 & 44,039 & 36,841 & 2,595 & 3,789 & 814 & 4,865 & 17.1 & 17.3 & 17.7 & 17.8 & 18.2 \\
\hline & 955,439 & 582,317 & 346,514 & 94,758 & 202,451 & 44,125 & 5,180 & 26,608 & 32.4 & 33.4 & 35.1 & 36.3 & 37.3 \\
\hline Utah & 151,637 & 136,543 & 9,902 & 912 & 4,130 & 3,309 & 1,551 & 5,192 & 5.9 & 6.6 & 6.5 & 6.6 & 6.8 \\
\hline Vermor & 35,090 & 32,762 & 1,528 & 366 & 490 & 494 & 178 & 800 & 4.0 & 3.9 & 4.8 & 5.9 & 4.5 \\
\hline & 3 & 26 & 85 & 58,191 & 8,447 & 17,660 & 1,5 & 7,868 & & 22.4 & & 24.0 & 24.8 \\
\hline & 292,180 & 231,505 & 51,229 & 10,735 & 11,410 & 23,401 & 5,683 & 9,446 & 14.8 & 15.7 & 16.9 & 17.5 & 18.1 \\
\hline & 85,689 & 78,727 & 5,215 & 3,572 & 517 & 899 & 227 & 1,747 & 5.4 & 5.6 & 5.9 & 5.9 & 6.2 \\
\hline ……...... & 299,127 & 264,203 & 28,055 & 12,863 & 6,307 & 6,562 & 2,323 & 6,869 & 8.7 & 9.1 & 9.4 & 9.5 & 9.6 \\
\hline Wyoming & 30,805 & 27,976 & 2,435 & 276 & 1,384 & 257 & 518 & 394 & 7.3 & 6.7 & 6.9 & 7.4 & 8.0 \\
\hline U.S. Service Schools & 81,669 & 65,036 & 16,107 & 10,703 & 2,929 & 2,107 & 368 & 526 & 21.1 & 21.6 & 22.0 & 19.8 & 19.9 \\
\hline Outlying areas ................................ & 181,660 & 698 & 180,300 & 2,527 & 168,985 & 8,780 & 8 & 662 & 99.5 & 99.4 & 99.5 & 99.6 & 99.6 \\
\hline $\mathrm{Al}^{2}$ & 1 & 0 & 1,2 & 0 & 0 & 1,2 & 0 & 0 & $T$ & 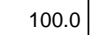 & 100 & 10 & 100.0 \\
\hline of Micronesia & 1,3 & 0 & 1, & 0 & 0 & 1,3 & 0 & 0 & 10 & 100.0 & 100.0 & 10 & 100.0 \\
\hline & 5,3 & 454 & 4,556 & 28 & 36 & 4,488 & 4 & 325 & 89.5 & 89.3 & 90.0 & 90.4 & 90.9 \\
\hline & 431 & 0 & 431 & 0 & 0 & 431 & 0 & 0 & 100.0 & 99.7 & 100.0 & 100.0 & 100.0 \\
\hline Northern Marianas & 1,096 & 73 & 860 & 0 & 7 & 853 & 0 & 163 & 89.5 & 92.1 & 92.3 & 92.1 & 92.2 \\
\hline & 332 & 0 & 332 & 0 & 0 & 332 & 0 & 0 & 100.0 & 100.0 & 100.0 & 100.0 & 100.0 \\
\hline & 68,933 & 37 & 168,846 & 5 & 8,831 & 9 & 1 & 50 & 100.0 & 99.9 & 100.0 & 100.0 & 100.0 \\
\hline Virgin Islands & 2,898 & 134 & 2,640 & 2,494 & 111 & 32 & 3 & 124 & 91.3 & 91.7 & 92.5 & 94.5 & 95.2 \\
\hline
\end{tabular}

1 Preliminary data.

${ }^{2}$ Percent minority based on U.S. citizen enrollment (total enrollment less enrollment of nonresident aliens).

NOTE.-Because of adjustments to underreported and nonreported racial/ethnic data figures are slightly different from corresponding data in other tables.
SOURCE: U.S. Department of Education, National Center for Education Statistics, Integrated Postsecondary Education Data System (IPEDS), "Fall Enrollment" surveys. (This table was prepared January 1998.) 
Table 211.-Number and percent of students enrolled in postsecondary institutions, by disability status and selected student characteristics: 1995-96

\begin{tabular}{|c|c|c|c|c|c|c|}
\hline \multirow{2}{*}{ Selected student characteristics } & \multicolumn{3}{|c|}{ Undergraduate } & \multicolumn{3}{|c|}{ Graduate and first-professional ${ }^{1}$} \\
\hline & All students & $\begin{array}{c}\text { Disabled } \\
\text { students }^{2}\end{array}$ & $\begin{array}{l}\text { Nondisabled } \\
\text { students }\end{array}$ & All students & $\begin{array}{c}\text { Disabled } \\
\text { students }^{2}\end{array}$ & $\begin{array}{l}\text { Nondisabled } \\
\text { students }\end{array}$ \\
\hline 1 & 2 & 3 & 4 & 5 & 6 & 7 \\
\hline Total (in thousands) & 16,678 & 892 & 15,786 & 2,784 & 89 & 2,695 \\
\hline 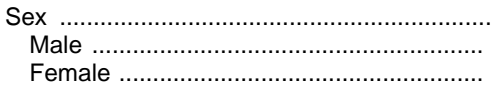 & $\begin{array}{r}100.0 \\
44.1 \\
55.9\end{array}$ & $\begin{array}{r}100.0 \\
50.0 \\
50.0\end{array}$ & $\begin{array}{r}100.0 \\
43.8 \\
56.2\end{array}$ & $\begin{array}{r}100.0 \\
45.7 \\
54.3\end{array}$ & $\begin{array}{r}100.0 \\
31.3 \\
68.7\end{array}$ & $\begin{array}{r}100.0 \\
46.2 \\
53.8\end{array}$ \\
\hline 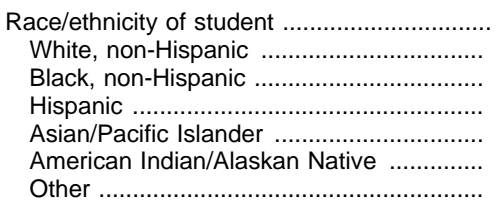 & $\begin{array}{r}100.0 \\
71.4 \\
11.6 \\
10.3 \\
5.3 \\
0.9 \\
0.5\end{array}$ & $\begin{array}{r}100.0 \\
80.9 \\
7.1 \\
7.7 \\
1.8 \\
2.1 \\
0.4\end{array}$ & $\begin{array}{r}100.0 \\
70.8 \\
11.9 \\
10.5 \\
5.5 \\
0.8 \\
0.5\end{array}$ & $\begin{array}{r}100.0 \\
80.6 \\
6.4 \\
4.9 \\
8.1 \\
- \\
\end{array}$ & $\begin{array}{r}100.0 \\
73.9 \\
10.7 \\
9.8 \\
5.6 \\
- \\
\end{array}$ & $\begin{array}{r}100.0 \\
80.9 \\
6.2 \\
4.7 \\
8.2 \\
- \\
\end{array}$ \\
\hline 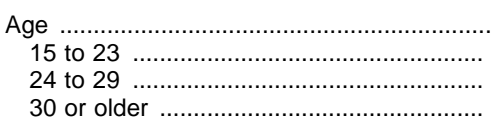 & $\begin{array}{r}100.0 \\
54.9 \\
17.9 \\
27.2\end{array}$ & $\begin{array}{r}100.0 \\
46.0 \\
13.6 \\
40.4\end{array}$ & $\begin{array}{r}100.0 \\
55.5 \\
18.1 \\
26.4\end{array}$ & $\begin{array}{r}100.0 \\
9.2 \\
42.7 \\
48.1\end{array}$ & $\begin{array}{r}100.0 \\
7.6 \\
32.3 \\
60.0\end{array}$ & $\begin{array}{r}100.0 \\
9.3 \\
43.0 \\
47.7\end{array}$ \\
\hline $\begin{array}{l}\text { Attendance status } \\
\quad \text { Full time } \\
\quad \text { Part time }\end{array}$ & $\begin{array}{r}100.0 \\
40.5 \\
59.5\end{array}$ & $\begin{array}{r}100.0 \\
38.7 \\
61.3\end{array}$ & $\begin{array}{r}100.0 \\
40.6 \\
59.4\end{array}$ & $\begin{array}{r}100.0 \\
32.5 \\
67.5\end{array}$ & $\begin{array}{r}100.0 \\
34.2 \\
65.8\end{array}$ & $\begin{array}{r}100.0 \\
32.5 \\
67.5\end{array}$ \\
\hline 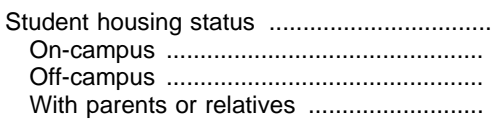 & $\begin{array}{r}100.0 \\
14.6 \\
58.0 \\
27.4\end{array}$ & $\begin{array}{r}100.0 \\
12.0 \\
62.7 \\
25.3\end{array}$ & $\begin{array}{r}100.0 \\
14.8 \\
57.7 \\
27.5\end{array}$ & $\begin{array}{r}100.0 \\
6.5 \\
86.9 \\
6.6\end{array}$ & $\begin{array}{r}100.0 \\
6.6 \\
82.3 \\
11.1\end{array}$ & $\begin{array}{r}100.0 \\
6.5 \\
87.1 \\
6.4\end{array}$ \\
\hline 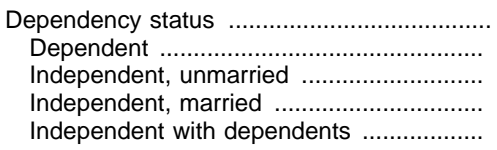 & $\begin{array}{r}100.0 \\
49.3 \\
16.7 \\
9.8 \\
24.2\end{array}$ & $\begin{array}{r}100.0 \\
40.7 \\
21.5 \\
8.0 \\
29.8\end{array}$ & $\begin{array}{r}100.0 \\
49.8 \\
16.4 \\
9.9 \\
23.9\end{array}$ & $\begin{array}{r}100.0 \\
50.5 \\
20.7 \\
28.8 \\
-\end{array}$ & $\begin{array}{r}100.0 \\
48.8 \\
21.5 \\
29.7 \\
\end{array}$ & $\begin{array}{r}100.0 \\
50.5 \\
20.7 \\
28.8 \\
\end{array}$ \\
\hline 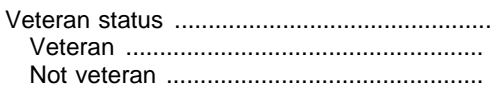 & $\begin{array}{r}100.0 \\
5.2 \\
94.8\end{array}$ & $\begin{array}{r}100.0 \\
9.7 \\
90.3\end{array}$ & $\begin{array}{r}100.0 \\
5.0 \\
95.0\end{array}$ & $\begin{array}{r}100.0 \\
5.2 \\
94.8\end{array}$ & $\begin{array}{r}100.0 \\
10.6 \\
89.4\end{array}$ & $\begin{array}{r}100.0 \\
5.0 \\
95.0\end{array}$ \\
\hline 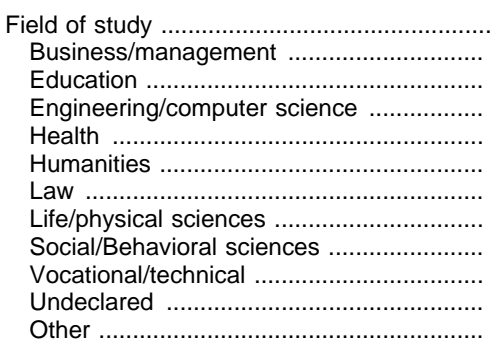 & $\begin{array}{r}100.0 \\
15.7 \\
6.8 \\
9.6 \\
10.1 \\
11.6 \\
0.0 \\
5.3 \\
7.6 \\
2.1 \\
20.3 \\
10.8\end{array}$ & $\begin{array}{r}100.0 \\
13.8 \\
6.6 \\
10.9 \\
9.0 \\
13.9 \\
0.0 \\
3.2 \\
7.5 \\
3.0 \\
20.9 \\
11.3\end{array}$ & $\begin{array}{r}100.0 \\
15.8 \\
6.8 \\
9.6 \\
10.2 \\
11.5 \\
0.0 \\
5.4 \\
7.6 \\
2.1 \\
20.3 \\
10.7\end{array}$ & $\begin{array}{r}100.0 \\
17.1 \\
26.1 \\
8.3 \\
13.0 \\
9.7 \\
5.2 \\
6.3 \\
7.8 \\
0.0 \\
3.5 \\
2.9\end{array}$ & $\begin{array}{r}100.0 \\
14.8 \\
23.8 \\
3.7 \\
28.6 \\
6.2 \\
4.1 \\
2.1 \\
5.8 \\
0.0 \\
7.1 \\
3.8\end{array}$ & $\begin{array}{r}100.0 \\
17.1 \\
26.2 \\
8.4 \\
12.5 \\
9.8 \\
5.2 \\
6.5 \\
7.9 \\
0.0 \\
3.4 \\
2.9\end{array}$ \\
\hline
\end{tabular}

1 Includes chiropractic medicine, medicine, dentistry, optometry, osteopathic medicine, pharmacy, podiatry, and veterinary medicine.

2 Disabled students are those who reported that they had one or more of the following conditions: a specific learning disability, a visual handicap, hard of hearing, deafness, a speech disability, an orthopedic handicap, or a health impairment.

-Sample size too small for a reliable estimate.
NOTE.-Because of rounding and survey item nonresponse, details may not add to totals

SOURCE: U.S. Department of Education, National Center for Education Statistics, "The 1995-96 National Postsecondary Student Aid Study." (This table was prepared October 1997). 
Table 212.-Enrollment of persons 14 to 34 years of age 1 in institutions of higher education, by race/ethnicity, sex, and year of college: October 1965 to October 1997

\begin{tabular}{|c|c|c|c|c|c|c|c|c|c|c|c|c|c|c|c|c|}
\hline Characteristic & 1965 & 1970 & 1975 & 1980 & $1985^{2}$ & 1987 & 1988 & 1989 & 1990 & 1991 & 1992 & 1993 & $1994^{3}$ & 1995 & 1996 & 1997 \\
\hline 1 & 2 & 3 & 4 & 5 & 6 & 7 & 8 & 9 & 10 & 11 & 12 & 13 & 14 & 15 & 16 & 17 \\
\hline & \multicolumn{16}{|c|}{ Numbers in thousands } \\
\hline All students & 5,675 & 7,413 & 9,697 & 10,181 & 10,863 & 10,915 & 10,937 & 11,066 & 11,303 & 11,589 & 11,671 & 11,409 & 12,298 & 12,046 & 12,448 & 12,640 \\
\hline \multicolumn{17}{|l|}{$\begin{array}{l}\text { White, non-His- } \\
\text { panic }^{4}\end{array}$} \\
\hline Total ................... & $\begin{array}{l}5,317 \\
3,326\end{array}$ & $\begin{array}{l}6,759 \\
4066\end{array}$ & $\begin{array}{l}8,141 \\
4566\end{array}$ & $\begin{array}{l}8,453 \\
4,25\end{array}$ & $\begin{array}{l}8,781 \\
4361\end{array}$ & $\begin{array}{l}8,519 \\
4 ? 21\end{array}$ & $\begin{array}{l}8,616 \\
4155\end{array}$ & $\begin{array}{l}8,786 \\
4 ? 20\end{array}$ & $\begin{array}{l}8,892 \\
4298\end{array}$ & $\begin{array}{l}8,916 \\
4,323\end{array}$ & $\begin{array}{l}8,883 \\
4207\end{array}$ & $\begin{array}{l}8,592 \\
4168\end{array}$ & $\begin{array}{l}9,076 \\
4,313\end{array}$ & $\begin{array}{l}8,973 \\
4319\end{array}$ & $\begin{array}{l}8,943 \\
4 ? 2 ?\end{array}$ & $\begin{array}{l}9,087 \\
4353\end{array}$ \\
\hline 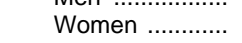 & $\begin{array}{l}0,0<0 \\
1,991\end{array}$ & $\begin{array}{l}4,066 \\
2,693\end{array}$ & $\begin{array}{l}4,566 \\
3,576\end{array}$ & 4,228 & 4,420 & 4,299 & 4,461 & 4,565 & 4,594 & 4,594 & 4,676 & 4,424 & 4,764 & 4,654 & 4,721 & 4,734 \\
\hline \multicolumn{17}{|l|}{ Black, non-Hispanic ${ }^{4}$} \\
\hline Total & 274 & 522 & 927 & 996 & 1,036 & 1,162 & 1,096 & 1,116 & 1,167 & 1,190 & 1,205 & 1,227 & 1,469 & 1,415 & 1,513 & 1,500 \\
\hline Men & 126 & 253 & 433 & 431 & 458 & 505 & 423 & 425 & 508 & 523 & 467 & 515 & 641 & 579 & 633 & 595 \\
\hline Women . & 148 & 269 & 494 & 565 & 578 & 657 & 674 & 690 & 659 & 667 & 738 & 713 & 828 & 837 & 879 & 904 \\
\hline \multicolumn{17}{|l|}{ Hispanic origin } \\
\hline Total & - & - & 411 & 443 & 579 & 667 & 654 & 640 & 617 & 721 & 816 & 867 & 982 & 1,014 & 1,039 & 1,109 \\
\hline Men & - & - & 219 & 222 & 280 & 369 & 313 & 311 & 297 & 310 & 349 & 391 & 443 & 495 & 440 & 495 \\
\hline Women . & - & - & 192 & 221 & 299 & 298 & 341 & 330 & 321 & 411 & 468 & 475 & 539 & 519 & 599 & 614 \\
\hline \multicolumn{17}{|l|}{ Year of college } \\
\hline & 1,861 & 2,212 & 2,886 & 2,958 & 2,956 & 2,915 & 3,131 & 2,983 & 3,109 & 2,995 & 3,274 & 3,139 & 3,357 & 3,236 & 3,295 & 3,637 \\
\hline Second & 1,256 & 1,739 & 2,376 & 2,411 & 2,585 & 2,745 & 2,598 & 2,680 & 2,798 & 2,959 & 3,002 & 2,964 & 3,075 & 3,068 & 3,060 & 2,764 \\
\hline Third & 896 & 1,248 & 1,491 & 1,716 & 1,931 & 2,011 & 1,979 & 2,017 & 1,958 & 2,009 & 2,136 & 2,080 & 2,244 & 2,239 & 2,235 & 2,280 \\
\hline Fourth & 803 & 1,074 & 1,354 & 1,403 & 1,642 & 1,556 & 1,631 & 1,676 & 1,817 & 1,877 & 1,681 & 1,692 & 1,902 & 1,772 & 2,033 & 2,010 \\
\hline \multirow[t]{2}{*}{ Fifth or higher .. } & 859 & 1,140 & 1,590 & 1,692 & 1,749 & 1,690 & 1,598 & 1,711 & 1,620 & 1,749 & 1,578 & 1,535 & 1,719 & 1,731 & 1,823 & 1,948 \\
\hline & \multicolumn{16}{|c|}{ Percentage distribution } \\
\hline All students ......... & 100.0 & 100.0 & 100.0 & 100.0 & 100.0 & 100.0 & 100.0 & 100.0 & 100.0 & 100.0 & 100.0 & 100.0 & 100.0 & 100.0 & 100.0 & 100.0 \\
\hline \multicolumn{17}{|l|}{$\begin{array}{l}\text { White, non-His- } \\
\text { panic }{ }^{4}\end{array}$} \\
\hline Total & 93.7 & 91.2 & 84.0 & 83.0 & 80.8 & 78.1 & 78.8 & 79.4 & 78.7 & 76.9 & 76.1 & 75.3 & 73.8 & 74.5 & 71.8 & 71.9 \\
\hline & 58.6 & 54.8 & 47.1 & 41.5 & 40.1 & 38.7 & 38.0 & 38.1 & 38.0 & 37.3 & 36.0 & 36.5 & 35.1 & 35.9 & 33.9 & 34.4 \\
\hline Women .............. & 35.1 & 36.3 & 36.9 & 41.5 & 40.7 & 39.4 & 40.8 & 41.3 & 40.6 & 39.6 & 40.1 & 38.8 & 38.7 & 38.6 & 37.9 & 37.5 \\
\hline \multicolumn{17}{|l|}{ Black, non-Hispanic ${ }^{4}$} \\
\hline Totá & 4.8 & 7.0 & 9.6 & 9.8 & 9.5 & 10.6 & 10.0 & 10.1 & 10.3 & 10.3 & 10.3 & 10.8 & 11.9 & 11.7 & 12.2 & 11.9 \\
\hline & 2.2 & 3.4 & 4.5 & 4.2 & 4.2 & 4.6 & 3.9 & 3.8 & 4.5 & 4.5 & 4.0 & 4.5 & 5.2 & 4.8 & 5.1 & 4.7 \\
\hline Women ... & 2.6 & 3.6 & 5.1 & 5.5 & 5.3 & 6.0 & 6.2 & 6.2 & 5.8 & 5.8 & 6.3 & 6.2 & 6.7 & 6.9 & 7.1 & 7.2 \\
\hline \multicolumn{17}{|l|}{ Hispanic origin } \\
\hline Total ................... & - & - & 4.2 & 4.4 & 5.3 & 6.1 & 6.0 & 5.8 & 5.5 & 6.2 & 7.0 & 7.6 & 8.0 & 8.4 & 8.3 & 8.8 \\
\hline & - & - & 2.3 & 2.2 & 2.6 & 3.4 & 2.9 & 2.8 & 2.6 & 2.7 & 3.0 & 3.4 & 3.6 & 4.1 & 3.5 & 3.9 \\
\hline Women ................ & - & - & 2.0 & 2.2 & 2.8 & 2.7 & 3.1 & 3.0 & 2.8 & 3.5 & 4.0 & 4.2 & 4.4 & 4.3 & 4.8 & 4.9 \\
\hline \multicolumn{17}{|l|}{ Year of } \\
\hline & 32.8 & 29.8 & 29.8 & 29.1 & 27.2 & 26.7 & 28.6 & 27.0 & 27.5 & 25.8 & 28.1 & 27.5 & 27.3 & 26.9 & 26.5 & 28.8 \\
\hline $\mathrm{S}$ & 22.1 & 23.5 & 24.5 & 23.7 & 23.8 & 25.1 & 23.8 & 24.2 & 24.8 & 25.5 & 25.7 & 26.0 & 25.0 & 25.5 & 24.6 & 21.9 \\
\hline Thir & 15.8 & 16.8 & 15.4 & 16.9 & 17.8 & 18.4 & 18.1 & 18.2 & 17.3 & 17.3 & 18.3 & 18.2 & 18.3 & 18.6 & 18.0 & 18.0 \\
\hline Fourth & 14.1 & 14.5 & 14.0 & 13.8 & 15.1 & 14.3 & 14.9 & 15.1 & 16.1 & 16.2 & 14.4 & 14.8 & 15.5 & 14.7 & 16.3 & 15.9 \\
\hline Fifth or higher. & 15.1 & 15.4 & 16.4 & 16.6 & 16.1 & 15.5 & 14.6 & 15.5 & 14.3 & 15.1 & 13.5 & 13.5 & 14.0 & 14.4 & 14.6 & 15.4 \\
\hline
\end{tabular}

1 Totals differ from those shown in other tables. This table presents data collected in sample surveys of households rather than surveys of institutions. Excludes persons age 35 and over.

2Data for 1985 to 1993 are controlled to 1980 census base.

${ }^{3}$ Data are controlled to 1990 census base. Large increase in 1994 is partly due to the change in census base and change in survey form administration procedures.

4 Data for 1965 and 1970 include persons of Hispanic origin.
-Data not available.

NOTE.-Data are based upon sample surveys of the civilian noninstitutional population. Because of rounding, details may not add to totals.

SOURCE: U.S. Department of Commerce, Bureau of the Census, Current Population Reports, Series P-20, No. 403, and unpublished data. (This table was prepared September 1998.) 
Table 213.-Enrollment in postsecondary education, by major field of study, age, and level of student: 1995-96

\begin{tabular}{|c|c|c|c|c|c|c|c|c|c|c|c|c|c|c|c|c|}
\hline \multirow{4}{*}{ Field of study } & \multicolumn{4}{|c|}{ All students } & \multicolumn{8}{|c|}{ Undergraduate } & \multicolumn{4}{|c|}{ Graduate and first-professional } \\
\hline & \multirow{3}{*}{$\begin{array}{c}\text { Total, in } \\
\text { thousands }\end{array}$} & \multicolumn{3}{|c|}{ Percentage distribution, by age } & \multicolumn{4}{|c|}{2 -year institutions ${ }^{1}$} & \multicolumn{4}{|c|}{ 4-year institutions } & \multirow{3}{*}{$\begin{array}{l}\text { Total, in } \\
\text { thousands }\end{array}$} & \multicolumn{3}{|c|}{ Percentage distribution, by age } \\
\hline & & \multirow{2}{*}{ Under 25} & \multirow{2}{*}{25 to 34} & \multirow{2}{*}{ Over 35} & \multirow{2}{*}{\begin{tabular}{|c|}
$\begin{array}{c}\text { Total, in } \\
\text { thousands }\end{array}$
\end{tabular}} & \multicolumn{3}{|c|}{ Percentage distribution, by age } & \multirow{2}{*}{$\begin{array}{c}\text { Total, in } \\
\text { thousands }\end{array}$} & \multicolumn{3}{|c|}{ Percentage distribution, by age } & & \multirow{2}{*}{ Under 25} & \multirow{2}{*}{25 to 34} & \multirow{2}{*}{ Over 35} \\
\hline & & & & & & Under 25 & 25 to 34 & Over 35 & & Under 25 & 25 to 34 & Over 35 & & & & \\
\hline 1 & 2 & 3 & 4 & 5 & 6 & 7 & 8 & 9 & 10 & 11 & 12 & 13 & 14 & 15 & 16 & 17 \\
\hline Total ........... & 19,444 & 53.0 & 26.3 & 20.7 & 8,887 & 48.1 & 27.0 & 24.9 & 7,791 & 71.4 & 17.1 & 11.5 & 2,767 & 17.4 & 49.5 & 33.1 \\
\hline $\begin{array}{l}\text { Agriculture } \\
\text { Architecture/city plan- }\end{array}$ & 204 & 65.8 & 21.1 & 13.1 & 71 & 60.5 & 21.0 & 18.5 & 109 & 80.5 & 12.0 & 7.5 & 24 & 13.7 & 63.8 & 22.5 \\
\hline 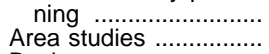 & 82 & 62.8 & 32.5 & 4.6 & 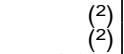 & $\left.\begin{array}{l}(2) \\
(2)\end{array}\right]$ & 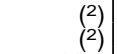 & $\begin{array}{l}(2) \\
(2)\end{array}$ & $\begin{array}{l}50 \\
24\end{array}$ & $\begin{array}{l}89.0 \\
76.2\end{array}$ & $\begin{array}{r}8.8 \\
11.5\end{array}$ & $\begin{array}{r}2.2 \\
12.3\end{array}$ & $\begin{array}{l}22 \\
(2)\end{array}$ & $\begin{array}{r}16.3 \\
(2)\end{array}$ & $\begin{array}{r}73.5 \\
(2)\end{array}$ & $\begin{array}{r}10.2 \\
(2)\end{array}$ \\
\hline $\begin{array}{l}\text { Business ........ } \\
\text { Communicatio }\end{array}$ & 2,949 & 48.7 & 29.7 & 21.6 & 1,295 & 45.2 & 29.0 & 25.8 & 1,233 & 64.2 & 20.8 & 15.0 & 420 & 13.9 & 58.0 & 28.1 \\
\hline 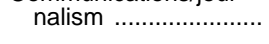 & 335 & 71.5 & 17.5 & 11.0 & 89 & 57.3 & 23.1 & 19.6 & 224 & 82.0 & 11.8 & 6.2 & 22 & 21.3 & 52.9 & 25.8 \\
\hline 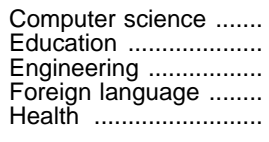 & $\begin{array}{r}554 \\
1,590 \\
1,002 \\
2,157\end{array}$ & $\begin{array}{r}42.7 \\
45.0 \\
58.6 \\
47.4\end{array}$ & $\begin{array}{l}31.6 \\
27.0 \\
28.9 \\
31.4\end{array}$ & $\begin{array}{l}25.7 \\
28.0 \\
12.5 \\
21.2\end{array}$ & $\begin{array}{r}275 \\
337 \\
403 \\
(2) \\
1,273\end{array}$ & $\begin{array}{r}34.4 \\
63.0 \\
48.2 \\
(2) \\
42.7\end{array}$ & $\begin{array}{r}31.1 \\
22.2 \\
30.4 \\
(2) \\
34.4\end{array}$ & $\begin{array}{r}34.5 \\
14.8 \\
21.5 \\
(2) \\
22.9\end{array}$ & $\begin{array}{r}219 \\
649 \\
477 \\
55 \\
637\end{array}$ & $\begin{array}{l}62.4 \\
67.0 \\
77.6 \\
78.2 \\
65.9\end{array}$ & $\begin{array}{l}23.4 \\
17.5 \\
18.5 \\
16.1 \\
19.8\end{array}$ & $\begin{array}{r}14.2 \\
15.5 \\
3.8 \\
5.7 \\
14.3\end{array}$ & $\begin{array}{r}60 \\
604 \\
122 \\
(2) \\
247\end{array}$ & $\begin{array}{r}9.2 \\
11.3 \\
18.7 \\
(2) \\
23.6\end{array}$ & $\begin{array}{r}63.3 \\
39.9 \\
64.4 \\
(2) \\
46.1\end{array}$ & $\begin{array}{r}27.6 \\
48.9 \\
16.9 \\
(2) \\
30.3\end{array}$ \\
\hline $\begin{array}{l}\text { Medicine/dentistry ........ } \\
\text { Home economics ....... } \\
\text { Industrial arts ............. } \\
\text { Interdisciplinary }\end{array}$ & $\begin{array}{r}83 \\
473 \\
210\end{array}$ & $\begin{array}{l}43.3 \\
55.8 \\
53.2\end{array}$ & $\begin{array}{l}49.9 \\
27.7 \\
30.0\end{array}$ & $\begin{array}{r}6.8 \\
16.5 \\
16.8\end{array}$ & $\begin{array}{l}\left({ }^{(2)}\right. \\
375 \\
181\end{array}$ & $\begin{array}{r}\left({ }^{2}\right) \\
53.0 \\
41.9\end{array}$ & $\begin{array}{r}\left({ }^{2}\right) \\
30.5 \\
33.5\end{array}$ & $\begin{array}{r}\left({ }^{2}\right) \\
16.6 \\
24.7\end{array}$ & $\begin{array}{l}(2) \\
81 \\
28\end{array}$ & $\begin{array}{r}\left({ }^{2}\right) \\
77.8 \\
81.9\end{array}$ & $\begin{array}{r}(2) \\
13.0 \\
11.0\end{array}$ & $\begin{array}{l}(2) \\
9.2 \\
7.1\end{array}$ & $\begin{array}{l}83 \\
17 \\
(2)\end{array}$ & $\begin{array}{r}43.3 \\
15.0 \\
(2)\end{array}$ & $\begin{array}{r}49.9 \\
36.1 \\
(2)\end{array}$ & $\begin{array}{r}6.8 \\
48.9 \\
(2)\end{array}$ \\
\hline Law & $\begin{array}{l}153 \\
636\end{array}$ & $\begin{array}{l}62.8 \\
53.2\end{array}$ & $\begin{array}{l}22.4 \\
30.0\end{array}$ & $\begin{array}{l}14.9 \\
16.8\end{array}$ & $\begin{array}{r}37 \\
352\end{array}$ & $\begin{array}{l}73.8 \\
52.2\end{array}$ & $\begin{array}{l}11.7 \\
27.1\end{array}$ & $\begin{array}{l}14.6 \\
20.6\end{array}$ & $\begin{array}{r}89 \\
142\end{array}$ & $\begin{array}{l}72.8 \\
69.0\end{array}$ & $\begin{array}{l}17.0 \\
21.0\end{array}$ & $\begin{array}{l}10.2 \\
10.0\end{array}$ & $\begin{array}{r}27 \\
142\end{array}$ & $\begin{array}{l}14.0 \\
39.6\end{array}$ & $\begin{array}{l}55.1 \\
46.3\end{array}$ & $\begin{array}{l}30.9 \\
14.1\end{array}$ \\
\hline $\begin{array}{l}\text { Letters/liberal studies .. } \\
\text { Library science ........... } \\
\text { Life sciences ............... } \\
\text { Mathematics ............. }\end{array}$ & $\begin{array}{r}1,340 \\
24 \\
558 \\
113\end{array}$ & $\begin{array}{r}60.6 \\
5.8 \\
77.2 \\
56.7\end{array}$ & $\begin{array}{l}21.9 \\
57.6 \\
19.1 \\
28.8\end{array}$ & $\begin{array}{r}17.5 \\
36.6 \\
3.7 \\
14.5\end{array}$ & $\begin{array}{r}908 \\
(2) \\
118 \\
(2)\end{array}$ & $\begin{array}{r}59.1 \\
(2) \\
72.0 \\
(2)\end{array}$ & $\begin{array}{r}22.3 \\
(2) \\
23.2 \\
(2)\end{array}$ & $\begin{array}{r}18.6 \\
(2) \\
4.8 \\
(2)\end{array}$ & $\begin{array}{r}383 \\
(2) \\
380 \\
63\end{array}$ & $\begin{array}{r}69.9 \\
\left({ }^{2}\right) \\
87.4 \\
76.5\end{array}$ & $\begin{array}{r}17.4 \\
(2) \\
10.3 \\
17.6\end{array}$ & $\begin{array}{r}12.7 \\
(2) \\
2.3 \\
6.0\end{array}$ & $\begin{array}{l}48 \\
24 \\
60 \\
25\end{array}$ & $\begin{array}{r}15.8 \\
5.8 \\
22.5 \\
20.6\end{array}$ & $\begin{array}{l}50.9 \\
57.6 \\
67.1 \\
61.1\end{array}$ & $\begin{array}{l}33.3 \\
36.6 \\
10.4 \\
18.4\end{array}$ \\
\hline $\begin{array}{c}\text { Mechanics/transpor- } \\
\text { tation }\end{array}$ & 230 & 39.4 & 29.3 & 31.3 & 208 & 34.8 & 30.9 & 34.3 & 22 & 82.1 & 15.0 & 3.0 & (2) & $\left({ }^{2}\right)$ & $\left({ }^{2}\right)$ & $\left({ }^{2}\right)$ \\
\hline $\begin{array}{l}\text { Philosophy and religion } \\
\text { Physical science ......... } \\
\text { Psychology } \\
\text { Public administration/ }\end{array}$ & $\begin{array}{r}90 \\
178 \\
495\end{array}$ & $\begin{array}{l}44.6 \\
63.4 \\
67.4\end{array}$ & $\begin{array}{l}33.9 \\
29.1 \\
21.1\end{array}$ & $\begin{array}{r}21.5 \\
7.5 \\
11.5\end{array}$ & $\begin{array}{l}(2) \\
(2) \\
84\end{array}$ & $\begin{array}{r}(2) \\
(2) \\
69.8\end{array}$ & $\begin{array}{r}(2) \\
(2) \\
20.8\end{array}$ & $\begin{array}{r}(2) \\
(2) \\
9.4\end{array}$ & $\begin{array}{r}46 \\
106 \\
347\end{array}$ & $\begin{array}{l}71.5 \\
81.4 \\
75.3\end{array}$ & $\begin{array}{l}15.0 \\
17.0 \\
15.7\end{array}$ & $\begin{array}{r}13.5 \\
1.6 \\
9.1\end{array}$ & $\begin{array}{l}42 \\
44 \\
65\end{array}$ & $\begin{array}{l}12.5 \\
20.9 \\
21.9\end{array}$ & $\begin{array}{l}56.1 \\
59.5 \\
50.8\end{array}$ & $\begin{array}{l}31.4 \\
19.6 \\
27.3\end{array}$ \\
\hline $\begin{array}{l}\text { social work ................... } \\
\text { Social sciences .......... }\end{array}$ & $\begin{array}{l}241 \\
713\end{array}$ & $\begin{array}{l}38.7 \\
67.3\end{array}$ & $\begin{array}{l}34.5 \\
21.4\end{array}$ & $\begin{array}{l}26.8 \\
11.3\end{array}$ & $\begin{array}{r}59 \\
122\end{array}$ & $\begin{array}{l}39.1 \\
65.2\end{array}$ & $\begin{array}{l}33.5 \\
22.0\end{array}$ & $\begin{array}{l}27.4 \\
12.8\end{array}$ & $\begin{array}{r}90 \\
492\end{array}$ & $\begin{array}{l}55.0 \\
76.9\end{array}$ & $\begin{array}{l}20.7 \\
15.0\end{array}$ & $\begin{array}{r}24.2 \\
8.2\end{array}$ & $\begin{array}{l}93 \\
99\end{array}$ & $\begin{array}{l}22.7 \\
22.7\end{array}$ & $\begin{array}{l}48.4 \\
52.4\end{array}$ & $\begin{array}{l}29.0 \\
24.9\end{array}$ \\
\hline $\begin{array}{l}\text { Visual and performing } \\
\text { arts } \\
\text { Other }{ }^{3}\end{array}$ & $\begin{array}{r}603 \\
181 \\
\end{array}$ & $\begin{array}{l}66.0 \\
53.0\end{array}$ & $\begin{array}{l}20.7 \\
23.4\end{array}$ & $\begin{array}{l}13.3 \\
23.5\end{array}$ & $\begin{array}{r}169 \\
27 \\
\end{array}$ & $\begin{array}{l}57.1 \\
35.1\end{array}$ & $\begin{array}{l}19.4 \\
27.0\end{array}$ & $\begin{array}{l}23.5 \\
37.9 \\
0.1\end{array}$ & $\begin{array}{r}357 \\
115 \\
\end{array}$ & $\begin{array}{l}79.4 \\
71.3 \\
71.7\end{array}$ & $\begin{array}{l}14.7 \\
16.2\end{array}$ & $\begin{array}{r}5.9 \\
12.6\end{array}$ & $\begin{array}{l}78 \\
38 \\
70\end{array}$ & $\begin{array}{l}23.6 \\
10.3\end{array}$ & $\begin{array}{l}51.2 \\
43.1\end{array}$ & $\begin{array}{l}25.2 \\
46.5\end{array}$ \\
\hline Undeclared .................... & 3,523 & 54.0 & 21.2 & 24.9 & 2,196 & 45.5 & 23.4 & 31.1 & 1,248 & 71.7 & 15.5 & 12.8 & 78 & 9.8 & 49.0 & 41.2 \\
\hline
\end{tabular}

1 Includes less-than-2-year schools.

NOTE.-Because of different survey editing and processing procedures, enrollment data in this table may differ from those appearing in other tables. Because of rounding, details may not add to totals. Includes students who enrolled
at any time during the 1995-96 academic year.

Includes students wh
-Data not available.

SOURCE: U.S. Department of Education, National Center for Education Statistics, "The 1995-96 National Postsecondary Student Aid Study," unpublished data. (This table was prepared November 1997). 
Table 214.-Graduate enrollment in science and engineering programs in institutions of higher education, by field of study: United States and outlying areas, fall 1985 to fall 1996

\begin{tabular}{|c|c|c|c|c|c|c|c|c|c|c|c|c|c|}
\hline Field of engineering or science & 19851 & $1986^{1}$ & 19871 & 1988 & 1989 & 1990 & 1991 & 1992 & 1993 & 1994 & 1995 & 1996 & $\begin{array}{c}\text { Percent } \\
\text { change, } \\
1990 \text { to } \\
1996 \\
\end{array}$ \\
\hline 1 & 2 & 3 & 4 & 5 & 6 & 7 & 8 & 9 & 10 & 11 & 12 & 13 & 14 \\
\hline Total, all sciences and engineering . & 404,088 & 15,557 & 421,526 & 424,671 & 434,567 & 452,178 & 471,262 & 493,632 & 504,449 & 504,542 & 499,702 & 194,526 & 9.4 \\
\hline ngineering, total & 95,991 & 101,874 & 103,953 & 102,829 & 104,043 & 107,625 & 113,576 & 118,035 & 116,858 & 113,023 & 107,199 & 103,223 & -4.1 \\
\hline Aero & 2,538 & 2,804 & 3,015 & 3223 & 3,524 & 3,934 & 4,120 & 4,036 & 3,940 & 3,715 & 3,343 & 3,208 & -18.5 \\
\hline Agricu & 948 & 1, & 1,080 & 1052 & 1,043 & 946 & 983 & 1,008 & 1,018 & 1,061 & 1,037 & 1,012 & 7.0 \\
\hline Biomedical .. & 1,370 & 1,534 & 1,674 & 1752 & 1,916 & 2,136 & 2,239 & 2,537 & 2,675 & 2,750 & 2,732 & 2,732 & 27.9 \\
\hline Chemical. & 7,150 & 7,012 & 7,111 & 6618 & 6,460 & 6,735 & 7,127 & 7,397 & 7,516 & 7,608 & 7,424 & 7,373 & 9.5 \\
\hline & 14,902 & 14,976 & 14,682 & 14811 & 14,909 & 15,542 & 17,398 & 19,572 & 10 & 19, & & & \\
\hline $\mathrm{E}$ & 28 & 9 & 31,399 & 32035 & 3,257 & 33,722 & 35,182 & 36,460 & 4 & 33, & 47 & 29,736 & -11.8 \\
\hline E & 2,098 & 2 & 2,343 & 2386 & 2,077 & 2,020 & 2,154 & 2,218 & 2,180 & 2,089 & 1,955 & 1,751 & -13.3 \\
\hline $\ln$ & 10,499 & 11, & 12,220 & 11393 & 11,094 & 11,248 & 12,676 & 13,525 & 13, & 13,661 & 13,143 & 12,399 & 10.2 \\
\hline Mech & 14,157 & 15,713 & 16,366 & 16151 & 16,265 & 16,879 & 17,730 & 18,637 & 18,477 & 17,761 & 16,363 & 15,509 & -8.1 \\
\hline & 3,943 & 4,208 & 4,366 & 4337 & 4,594 & 4,941 & 5,160 & 5,512 & 5,363 & & 4,920 & 4,713 & -4.6 \\
\hline & 489 & 512 & 513 & 489 & 418 & 437 & 489 & 437 & 427 & 24 & & & -15.1 \\
\hline & 1,220 & 1,2 & 1,2 & 1303 & 1,323 & 1,278 & 1,282 & 1,286 & 1,306 & 1,246 & 1,154 & 980 & 3.3 \\
\hline Petrol & 782 & 747 & 818 & 42 & 35 & 670 & 705 & 737 & 725 & 24 & 10 & 562 & 6.1 \\
\hline Other engineering & 7,692 & 8,172 & 7,087 & 6537 & 6,498 & 7,137 & 6,331 & 4,673 & 4,738 & 3,918 & 4,180 & 4,349 & -39.1 \\
\hline sci & 308,097 & 3,683 & 317,573 & 21,842 & 0,524 & 4,553 & 357,686 & 75,597 & 37,591 & 31,519 & 92,503 & 91,303 & 13.6 \\
\hline $\mathrm{Ph}$ & 30,981 & 246 & 32,727 & 962 & 3,616 &, 075 & 10 & 5,348 & 18 & 49 & 17 & 42 & -5.1 \\
\hline & 671 & 689 & 719 & 731 & 789 & 810 & 829 & 869 & 880 & 973 & 912 & 874 & 7.9 \\
\hline & 18,305 &, 744 & 3827 & 8579 & 3,828 & 9,118 & 19,407 & 9,929 & 31 & & & & 1.2 \\
\hline & $\begin{array}{r}11,672 \\
333\end{array}$ & 376 & 12,807 & 08 & 3,657 & 3,813 & & & & & & & -15.1 \\
\hline Other physical sciences & 333 & & 374 & 344 & 342 & 334 & 393 & 428 & 466 & 517 & 486 & 395 & 18.3 \\
\hline Earth, atmospheric, and ocean sciences & 15,420 & 15,066 & 14,371 & 13,867 & 3,643 & 13,984 & 14,480 & 15,347 & 805 & 16 & 15,805 & 274 & 9.2 \\
\hline nces & & & & & & & & & & & & & 16.3 \\
\hline & 10,294 & & & 8463 & & 7,692 & 7,567 & 7,744 & & & & & -4.8 \\
\hline & 2,081 & & & $2 C$ & 2,207 & 33 & & 2,530 & & & & & 11.4 \\
\hline nental science & 2,081 & 2,158 & 2,294 & 2431 & 2,472 & 3,030 & 3,559 & 3,984 & 7 & 1 & 4, & ,273 & 41.0 \\
\hline Mathe & 17,563 & 17,949 & 18,508 & 19,077 & 19,247 & 19,774 & 19,952 & 20,355 & 20,000 & 19,579 & 18,509 & & -8.9 \\
\hline ppied mán & 7 & & & & & 6 & 66 & & & & & & \\
\hline . & 6 & 2,334 & & 7 & 2, & 2,678 & 2,746 & 2, & 3,055 & 16 & 99 & 45 & 3.7 \\
\hline sciences, total & 29,769 & 31,349 & 32,051 & 32,227 & 32,482 & 34,257 & 34,610 & 36,293 & 36,189 & 34,128 & 33,432 & 34,592 & 1.0 \\
\hline es, total & 103,635 & 105,661 & 106,036 & 108,084 & 111,862 & 116,348 & 121,849 & 128,992 & 136,929 & 143,633 & 148,250 & 148,997 & 28.1 \\
\hline Agricultural sciences, total $\ldots \ldots \ldots \ldots \ldots \ldots$ & 11,561 & 11,458 & 11,118 & 11,135 & 11,190 & 11,316 & 11,506 & 11,827 & 11,914 & 12,199 & 12,367 & 11,914 & 5.3 \\
\hline Biologic & 46,112 & 46,765 & 46,747 & & 48,852 & 989 & 5 & & & & & & \\
\hline & & & & & & & & & & & & & \\
\hline & 4,654 & & & & & & & & & & & & 4.5 \\
\hline & 12,710 & 12,6 & 12 & 123 & 12, & 7 & & $13, \varepsilon$ & 14 & & 14, & & 2.3 \\
\hline & 1,360 & & & 16 & & & & & & & & & \\
\hline & & & , & & , & , & & {$[, 0$} & & & & & \\
\hline & & & & & & & & & & & & & \\
\hline & & & & & & & & & & & & & \\
\hline & & & & & & & & & & & & & \\
\hline tol & & & & & & & & & & & & & 2 \\
\hline & & & & & & & & & & & & & 2.8 \\
\hline & & & & & & & & & & & & & .8 \\
\hline & & & & & & & & & & & & & \\
\hline & & & & & & & & & & & & & \\
\hline & & & & & & & & & & & & & 12.7 \\
\hline & & & & & & & & & & & & & 3 \\
\hline & & & & & & & & & & & & & -9.2 \\
\hline Other biosciences ......... & 1,446 & 1,505 & 1,608 & 1792 & 1,948 & 2,313 & 2,635 & 3,294 & 3,449 & 3,609 & 4,003 & 3,887 | & 68.1 \\
\hline tal & 45,962 & 47,438 & 48,171 & 49,384 & 51,820 & 55,043 & 58,565 & 62,988 & 68,563 & 73,291 & 77,177 & 8,956 & 43.4 \\
\hline 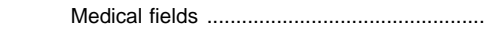 & 221 & 9,244 & 9809 & 10 & 10,232 & 10,950 & 707 & 594 & 4,184 & ,027 & 5,521 & & \\
\hline 0 & 36,741 & 4 & & & & 44,0 & & & & & & & \\
\hline & & & & & & & & & & & & & \\
\hline & 17 & & & & & 21, & & & & & & & 3.6 \\
\hline & & & & & 2,7 & 2,8 & & 2,804 & & & & & 3.0 \\
\hline 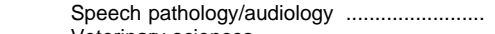 & 7,761 & 7,774 & & & 7,9 & 0 & & 9,7 & & & & & 5.3 \\
\hline & & & & & & 0 & & & & & & & \\
\hline & 7,028 & 7 & 8, & 8 & 66 & 9,800 & 3 & 12,523 & 5 & 14, & 16,031 & 63 & 3 \\
\hline & 40 & 1. $-2+3$ & $4 z^{2}-2$ & & & & & & & & & & \\
\hline & & & & & & & & & & & & & \\
\hline & & 40,3 & & & & & & & & & & & \\
\hline & & 2 & & & 16,822 & 3 & & & & & & 75 & 30.5 \\
\hline & & & & & & & & & & & & & \\
\hline & & & & & & & & & & & & & \\
\hline & & & & & & & & & & & & & \\
\hline$E$ & 12 & 12 & 11, & 120 & 12,139 & 12,326 & 12, & 13,252 & 13 & 12 & 12, & 12 & -2.0 \\
\hline & & & & & & 3,530 & & & & & & & \\
\hline & & & & & & & & & & & & & \\
\hline & & & & & & & & & & & & & -7.3 \\
\hline & 26, & 27, & 27,4 & 277 & 29,194 & 30,5 & 31,707 & 33, & $35, \mathrm{C}$ & 34, & 34,298 & 33, & 9.0 \\
\hline & 6,637 & 6,565 & 7,026 & 71 & 7,405 & 7,801 & 8,393 & 9,011 & 9,425 & $9,4 \mathrm{~S}$ & 9,564 & 9,428 & 20.9 \\
\hline So & 983 & 988 & 942 & 960 & 988 & 1,164 & 899 & 979 & 935 & 987 & 941 & 923 & -20.7 \\
\hline & 9,175 & 8,941 & 9,036 & 8883 & 8,947 & 10,058 & 10,419 & 1,355 & 2,299 & 13,297 & 13,976 & 15,177 & 50.9 \\
\hline
\end{tabular}

1 Includes estimates for master's degree granting institutions which were surveyed on a sample basis from 1985 through 1987.

NOTE.-Some data have been revised from previously published figures. Because of rounding, details may not add to totals.
SOURCE: National Science Foundation, Division of Science Resources Studies, Survey of Graduate Students and Postdoctorates in Science and Engineering, 1996. (This table was prepared July 1998.) 
Table 215.-Degree-granting 2-year and 4-year institutions, by type, control, and size of enrollment: Fall 1996 1

\begin{tabular}{|c|c|c|c|c|c|c|c|c|}
\hline \multirow{2}{*}{$\begin{array}{c}\text { Control of institution and size of total } \\
\text { enrollment }\end{array}$} & \multicolumn{2}{|c|}{ All institutions } & \multicolumn{2}{|c|}{ Universities } & \multicolumn{2}{|c|}{ All other 4-year institutions } & \multicolumn{2}{|c|}{ 2-year institutions } \\
\hline & Number ${ }^{2}$ & Enrollment & Number ${ }^{2}$ & Enrollment & Number ${ }^{2}$ & Enrollment & Number 2 & Enrollment \\
\hline 1 & 2 & 3 & 4 & 5 & 6 & 7 & 8 & 9 \\
\hline Total $\ldots \ldots \ldots \ldots \ldots \ldots \ldots \ldots$ & 3,842 & $14,367,520$ & 156 & $2,984,965$ & 2,044 & $5,819,228$ & 1,642 & $5,563,327$ \\
\hline 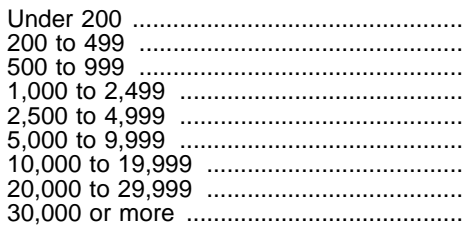 & $\begin{array}{r}474 \\
563 \\
523 \\
866 \\
563 \\
459 \\
272 \\
94 \\
28\end{array}$ & $\begin{array}{r}54,775 \\
188,906 \\
384,035 \\
1,445,889 \\
1,946,596 \\
3,228,457 \\
3,751,871 \\
2,273,919 \\
1,093,072\end{array}$ & $\begin{array}{r}0 \\
0 \\
0 \\
0 \\
5 \\
28 \\
55 \\
45 \\
23\end{array}$ & $\begin{array}{r}0 \\
0 \\
0 \\
0 \\
20,988 \\
219,382 \\
774,630 \\
1,098,907 \\
871,058\end{array}$ & $\begin{array}{r}249 \\
247 \\
346 \\
571 \\
285 \\
213 \\
112 \\
20 \\
1\end{array}$ & $\begin{array}{r}27,519 \\
84,757 \\
257,487 \\
929,358 \\
973,753 \\
1,464,502 \\
1,543,842 \\
501,744 \\
36,266\end{array}$ & $\begin{array}{r}225 \\
316 \\
177 \\
295 \\
273 \\
218 \\
105 \\
29 \\
4\end{array}$ & $\begin{array}{r}27,256 \\
104,149 \\
126,548 \\
516,531 \\
951,855 \\
1,544,573 \\
1,433,399 \\
673,268 \\
185,748\end{array}$ \\
\hline Public institutions ... & 1,645 & $11,120,499$ & 94 & $2,226,529$ & 514 & $3,579,507$ & 1,037 & $5,314,463$ \\
\hline 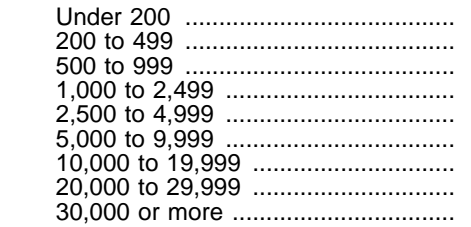 & $\begin{array}{r}28 \\
55 \\
115 \\
348 \\
381 \\
368 \\
235 \\
89 \\
26\end{array}$ & $\begin{array}{r}3,519 \\
19,630 \\
88,222 \\
618,430 \\
1,342,602 \\
2,613,085 \\
3,263,388 \\
2,146,275 \\
1,025,348\end{array}$ & $\begin{array}{r}0 \\
0 \\
0 \\
0 \\
0 \\
6 \\
27 \\
40 \\
21\end{array}$ & $\begin{array}{r}0 \\
0 \\
0 \\
0 \\
0 \\
53,094 \\
398,838 \\
971,263 \\
803,334\end{array}$ & $\begin{array}{r}5 \\
9 \\
31 \\
87 \\
112 \\
146 \\
103 \\
20 \\
1\end{array}$ & $\begin{array}{r}281 \\
3,200 \\
24,246 \\
150,946 \\
402,761 \\
1,028,912 \\
1,431,151 \\
501,744 \\
36,266\end{array}$ & $\begin{array}{r}23 \\
46 \\
84 \\
261 \\
269 \\
216 \\
105 \\
29 \\
4\end{array}$ & $\begin{array}{r}3,238 \\
16,430 \\
63,976 \\
467,484 \\
939,841 \\
1,531,079 \\
1,433,399 \\
673,268 \\
185,748\end{array}$ \\
\hline Private institutions & 2,197 & $3,247,021$ & 62 & 758,436 & 1,530 & $2,239,721$ & 605 & 248,864 \\
\hline 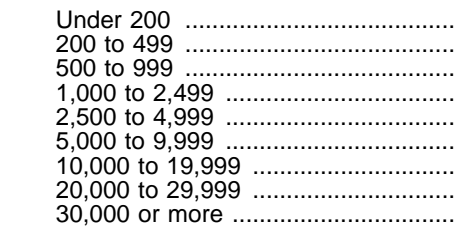 & $\begin{array}{r}446 \\
508 \\
408 \\
518 \\
182 \\
91 \\
37 \\
5 \\
2\end{array}$ & $\begin{array}{r}51,256 \\
169,276 \\
295,813 \\
827,459 \\
603,994 \\
615,372 \\
488,483 \\
127,644 \\
67,724\end{array}$ & $\begin{array}{r}0 \\
0 \\
0 \\
0 \\
5 \\
22 \\
28 \\
5 \\
2\end{array}$ & $\begin{array}{r}0 \\
0 \\
0 \\
0 \\
20,988 \\
166,288 \\
375,792 \\
127,644 \\
67,724\end{array}$ & $\begin{array}{r}244 \\
238 \\
315 \\
484 \\
173 \\
67 \\
9 \\
0 \\
0\end{array}$ & $\begin{array}{r}27,238 \\
81,557 \\
233,241 \\
778,412 \\
570,992 \\
435,590 \\
112,691 \\
0 \\
0\end{array}$ & $\begin{array}{r}202 \\
270 \\
93 \\
34 \\
4 \\
2 \\
0 \\
0 \\
0\end{array}$ & $\begin{array}{r}24,018 \\
87,719 \\
62,572 \\
49,047 \\
12,014 \\
13,494 \\
0 \\
0 \\
0\end{array}$ \\
\hline Nonprofit institutions & 1,633 & $2,942,556$ & 62 & 758,436 & 1,397 & $2,108,745$ & 174 & 75,375 \\
\hline 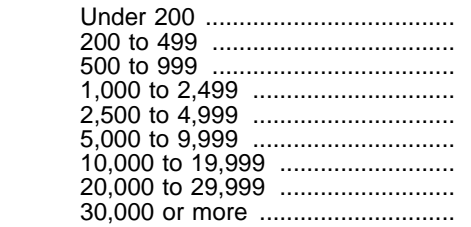 & $\begin{array}{r}292 \\
257 \\
315 \\
470 \\
168 \\
87 \\
37 \\
5 \\
2\end{array}$ & $\begin{array}{r}32,125 \\
87,446 \\
232,625 \\
755,555 \\
558,903 \\
592,051 \\
488,483 \\
127,644 \\
67,724\end{array}$ & $\begin{array}{r}0 \\
0 \\
0 \\
0 \\
5 \\
22 \\
28 \\
5 \\
2\end{array}$ & $\begin{array}{r}0 \\
0 \\
0 \\
0 \\
20,988 \\
166,288 \\
375,792 \\
127,644 \\
67,724\end{array}$ & $\begin{array}{r}226 \\
195 \\
279 \\
462 \\
162 \\
64 \\
9 \\
0 \\
0\end{array}$ & $\begin{array}{r}25,188 \\
66,755 \\
207,810 \\
743,319 \\
534,974 \\
418,008 \\
112,691 \\
0 \\
0\end{array}$ & $\begin{array}{r}66 \\
62 \\
36 \\
8 \\
1 \\
1 \\
0 \\
0 \\
0\end{array}$ & $\begin{array}{r}6,937 \\
20,691 \\
24,815 \\
12,236 \\
2,941 \\
7,755 \\
0 \\
0 \\
0\end{array}$ \\
\hline Proprietary institutions .................. & 564 & 304,465 & 0 & 0 & 133 & 130,976 & 431 & 173,489 \\
\hline 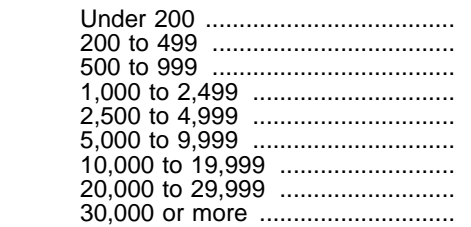 & $\begin{array}{r}154 \\
251 \\
93 \\
48 \\
14 \\
4 \\
0 \\
0 \\
0\end{array}$ & $\begin{array}{r}19,131 \\
81,830 \\
63,188 \\
71,904 \\
45,091 \\
23,321 \\
0 \\
0 \\
0\end{array}$ & $\begin{array}{l}0 \\
0 \\
0 \\
0 \\
0 \\
0 \\
0 \\
0 \\
0\end{array}$ & $\begin{array}{l}0 \\
0 \\
0 \\
0 \\
0 \\
0 \\
0 \\
0 \\
0\end{array}$ & $\begin{array}{r}18 \\
43 \\
36 \\
22 \\
11 \\
3 \\
0 \\
0 \\
0\end{array}$ & $\begin{array}{r}2,050 \\
14,802 \\
25,431 \\
35,093 \\
36,018 \\
17,582 \\
0 \\
0 \\
0\end{array}$ & $\begin{array}{r}136 \\
208 \\
57 \\
26 \\
3 \\
1 \\
0 \\
0 \\
0\end{array}$ & $\begin{array}{r}17,081 \\
67,028 \\
37,757 \\
36,811 \\
9,073 \\
5,739 \\
0 \\
0 \\
0\end{array}$ \\
\hline
\end{tabular}

${ }^{1}$ These preliminary data represent the branch campuses and enrollments reported in the "Fall Enrollment" survey. Includes 4-year and 2-year degree-granting institutions that were eligible to participate in Title IV federal financial aid programs.

${ }^{2}$ Some institutions do not report separate enrollment data for each branch campus. For this reason, counts of institutions in this table are somewhat lower than figures appearing in other tables.
SOURCE: U.S. Department of Education, National Center for Education Statistics, Integrated Postsecondary Education Data System (IPEDS), "Fall Enrollment, 1996" survey. (This table was prepared August 1998.) 
Table 216.-Selected statistics for college and university campuses enrolling more than 14,600 students in 1996

\begin{tabular}{|c|c|c|c|c|c|c|c|c|c|c|c|c|}
\hline \multirow{2}{*}{$\begin{array}{l}\text { Line } \\
\text { no. }\end{array}$} & \multirow{2}{*}{ Institution } & \multirow[t]{2}{*}{ State } & \multirow{2}{*}{$\begin{array}{l}\text { Con- } \\
\text { trol }^{1}\end{array}$} & Type 2 & $\begin{array}{c}\text { Total } \\
\text { enrollment, }\end{array}$ & $\begin{array}{c}\text { Total } \\
\text { enrollment, }\end{array}$ & \begin{tabular}{c|} 
Total \\
enrollment
\end{tabular} & $\begin{array}{c}\text { Total } \\
\text { enrollment. }\end{array}$ & $\begin{array}{l}\text { Enrollmer } \\
\text { fall }\end{array}$ & $\begin{array}{l}\text { nt, by sex, } \\
1996\end{array}$ & $\begin{array}{l}\text { Enrollm } \\
\text { attendan } \\
\text { fall }\end{array}$ & $\begin{array}{l}\text { ent, by } \\
\text { ce status, } \\
1996\end{array}$ \\
\hline & & & & & & & & & Men & Women & Full-time & Part-time \\
\hline 1 & 2 & 3 & 4 & 5 & 6 & 7 & 8 & 9 & 10 & 11 & 12 & 13 \\
\hline- & United States, all institutions . & - & - & - & $13,818,637$ & $14,261,781$ & $14,300,255$ & - & $6,343,992$ & $7,956,263$ & $8,213,490$ & $6,086,765$ \\
\hline- & Colleges with enrollment over 14,600 & - & - & - & $5,058,120$ & $5,097,869$ & $5,118,100$ & 一 & $2,403,032$ & $2,715,068$ & $2,998,186$ & $2,119,914$ \\
\hline 1 & Auburn University, Main Campus & Ala. & 1 & 1 & 21,537 & 22,122 & 21,778 & 21,505 & 11,457 & 10,321 & 18,675 & 3,103 \\
\hline 2 & The University of Alabama ............ & Ala. & 1 & 1 & 19,794 & 18,985 & 17,953 & 18,324 & 8,531 & 9,422 & 14,792 & 3,161 \\
\hline 3 & University of Alabama at Birmingham ......... & Ala. & 1 & 1 & 15,356 & 15,502 & 15,274 & 14,933 & 6,739 & 8,535 & 9,931 & 5,343 \\
\hline 4 & 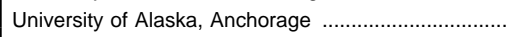 & Alaska & 1 & 1 & 17,490 & 16,206 & 16,041 & 14,765 & 6,298 & 9,743 & 6,113 & 9,928 \\
\hline 5 & Arizona State University, Main Campus ........................ & Ariz. & 1 & 1 & 42,936 & 42,040 & 42,463 & - & 20,831 & 21,632 & 29,949 & 12,514 \\
\hline 6 & 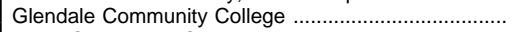 & Ariz. & 1 & 2 & 18,512 & 17,699 & 17,348 & 17,369 & 7,469 & 9,879 & 5,323 & 12,025 \\
\hline 7 & Mesa Community College ...... & Ariz. & 1 & 2 & 19,818 & 21,244 & 21,761 & 21,814 & 10,356 & 11,405 & 7,109 & 14,652 \\
\hline 8 & Northern Arizona University ..... & Ariz. & 1 & 1 & 16,992 & 20,131 & 19,605 & - & 7,937 & 11,668 & 13,521 & 6,084 \\
\hline 9 & Pima Community College ......... & Ariz. & 1 & 2 & 28,766 & 27,866 & 27,177 & 27,761 & 12,102 & 15,075 & 6,961 & 20,216 \\
\hline 10 & University of Arizona & Ariz. & 1 & 1 & 35,729 & 34,777 & 34,777 & - & 17,161 & 17,616 & 27,004 & 7,773 \\
\hline 11 & American River College & Calif. & 1 & 2 & 18,716 & 20,170 & 19,786 & - & 8,605 & 11,181 & 4,907 & 14,879 \\
\hline 12 & Cal. Polytechnic State U., San Luis Obispo ..................... & Calif. & 1 & 1 & 17,751 & 16,023 & 17,000 & 16,735 & 9,627 & 7,373 & 15,370 & 1,630 \\
\hline 13 & California State Polytechnic U., Pomona ......................... & Calif. & 1 & 1 & 19,468 & 16,605 & 16,803 & 17,246 & 9,447 & 7,356 & 11,930 & 4,873 \\
\hline 14 & California State University, Fresno ……........................... & Calif. & 1 & 1 & 19,960 & 17,461 & 17,213 & 18,113 & 7,703 & 9,510 & 13,600 & 3,613 \\
\hline 15 & California State University, Fullerton ........ & Calif. & 1 & 1 & 25,592 & 22,604 & 24,040 & 24,906 & 10,201 & 13,839 & 15,005 & 9,035 \\
\hline 16 & California State University, Long Beach ................ & Calif. & 1 & 1 & 33,987 & 26,403 & 27,431 & 27,809 & 12,108 & 15,323 & 17,900 & 9,531 \\
\hline 17 & California State University, Los Angeles .... & Calif. & 1 & 1 & 21,597 & 18,385 & 18,849 & 19,160 & 7,586 & 11,263 & 11,094 & 7,755 \\
\hline 18 & 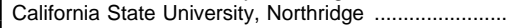 & Calif. & 1 & 1 & 31,167 & 25,015 & 27,189 & 27,653 & 11,555 & 15,634 & 17,472 & 9,717 \\
\hline 19 & California State University, Sacramento $\ldots \ldots \ldots \ldots \ldots$ & Calif. & 1 & 1 & 26,336 & 22,796 & 23,420 & 23,478 & 10,192 & 13,228 & 16,030 & 7,390 \\
\hline 20 & Cerritos College ..................................... & Calif. & 1 & 2 & 15,886 & 19,981 & 19,622 & - & 8,604 & 11,018 & 4,286 & 15,336 \\
\hline 21 & City College of San Francisco .... & Calif. & 1 & 2 & 24,408 & 26,019 & 26,933 & - & 12,034 & 14,899 & 6,687 & 20,246 \\
\hline 22 & De Anza College ............................. & Calif. & 1 & 2 & 21,948 & 22,545 & 23,697 & - & 11,028 & 12,669 & 7,581 & 16,116 \\
\hline 23 & 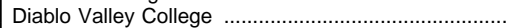 & Calif. & 1 & 2 & 20,255 & 18,192 & 18,687 & - & 8,492 & 10,195 & 6,207 & 12,480 \\
\hline 24 & East Los Angeles College & Calif. & 1 & 2 & 12,447 & 15,289 & 15,376 & - & 6,283 & 9,093 & 4,200 & 11,176 \\
\hline 25 & 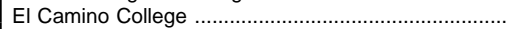 & Calif. & 1 & 2 & 25,789 & 21,540 & 22,657 & - & 10,183 & 12,474 & 6,023 & 16,634 \\
\hline 26 & 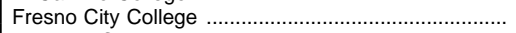 & Calif. & 1 & 2 & 14,710 & 16,287 & 16,819 & 一 & 7,722 & 9,097 & 5,066 & 11,753 \\
\hline 27 & Fullerton College & Calif. & 1 & 2 & 17,548 & 17,748 & 17,971 & - & 8,563 & 9,408 & 5,288 & 12,683 \\
\hline 28 & Grossmont College . & Calif. & 1 & 2 & 15,357 & 14,560 & 14,730 & - & 6,365 & 8,365 & 5,137 & 9,593 \\
\hline 29 & Long Beach City College ....... & Calif. & 1 & 2 & 18,378 & 18,137 & 17,509 & - & 7,601 & 9,908 & 4,060 & 13,449 \\
\hline 30 & Los Angeles Valley College ..... & Calif. & 1 & 2 & 16,457 & 15,362 & 15,537 & - & 6,536 & 9,001 & 3,856 & 11,681 \\
\hline 31 & 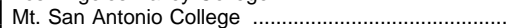 & Calif. & 1 & 2 & 20,563 & 22,202 & 22,960 & - & 10,660 & 12,300 & 6,956 & 16,004 \\
\hline 32 & 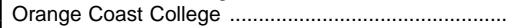 & Calif. & 1 & 2 & 22,365 & 21,135 & 21,405 & - & 10,433 & 10,972 & 6,034 & 15,371 \\
\hline 33 & Palomar College ................ & Calif. & 1 & 2 & 16,707 & 18,894 & 20,509 & - & 9,499 & 11,010 & 5,155 & 15,354 \\
\hline 34 & Pasadena City College .................... & Calif. & 1 & 2 & 19,581 & 21,101 & 21,680 & - & 9,619 & 12,061 & 6,576 & 15,104 \\
\hline 35 & Rancho Santiago College ........................ & Calif. & 1 & 2 & 20,532 & 20,392 & 24,611 & - & 14,102 & 10,509 & 5,464 & 19,147 \\
\hline 36 & Riverside Community College ...................................... & Calif. & 1 & 2 & 15,683 & 18,633 & 19,971 & - & 8,052 & 11,919 & 5,294 & 14,677 \\
\hline 37 & Sacramento City College. & Calif. & 1 & 2 & 14,474 & 16,098 & 16,583 & - & 6,904 & 9,679 & 5,227 & 11,356 \\
\hline 38 & 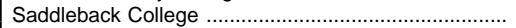 & Calif. & 1 & 2 & 14,527 & 14,093 & 17,242 & - & 7,205 & 10,037 & 4,156 & 13,086 \\
\hline 39 & 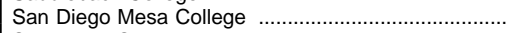 & Calif. & 1 & 2 & 23,410 & 19,904 & 20,055 & - & 9,513 & 10,542 & 5,163 & 14,892 \\
\hline 40 & San Diego State University ……............................... & Calif. & 1 & 1 & 35,493 & 29,350 & 29,981 & 30,593 & 13,295 & 16,686 & 21,479 & 8,502 \\
\hline 41 & San Francisco State University ......................................... & Calif. & 1 & 1 & 29,343 & 26,791 & 27,420 & 26,982 & 11,108 & 16,312 & 18,061 & 9,359 \\
\hline 42 & San Joaquin Delta College & Calif. & 1 & 2 & 14,792 & 14,640 & 15,608 & - & 6,525 & 9,083 & 5,200 & 10,408 \\
\hline 43 & San Jose State University ........................ & Calif. & 1 & 1 & 30,334 & 25,997 & 25,874 & 26,897 & 12,122 & 13,752 & 16,642 & 9,232 \\
\hline 44 & 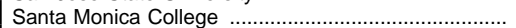 & Calif. & 1 & 2 & 18,108 & 20,392 & 22,068 & - & 9,559 & 12,509 & 6,660 & 15,408 \\
\hline 45 & Santa Rosa Junior College ....................... & Calif. & 1 & 2 & 20,475 & 20,102 & 22,663 & - & 9,464 & 13,199 & 5,976 & 16,687 \\
\hline 46 & Southwestern College ......... & Calif. & 1 & 2 & 13,010 & 15,037 & 15,517 & - & 6,975 & 8,542 & 5,003 & 10,514 \\
\hline 47 & Stanford University ....... & Calif. & 2 & 1 & 14,724 & 16,003 & 15,754 & - & 9,187 & 6,567 & 12,288 & 3,466 \\
\hline 48 & 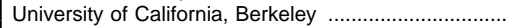 & Calif. & 1 & 1 & 30,634 & 29,630 & 29,797 & 30,290 & 15,730 & 14,067 & 27,007 & 2,790 \\
\hline 49 & 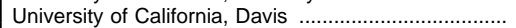 & Calif. & 1 & 1 & 23,890 & 23,091 & 23,931 & 24,551 & 11,628 & 12,303 & 21,664 & 2,267 \\
\hline 50 & University of California, Irvine & Calif. & 1 & 1 & 16,808 & 17,256 & 17,885 & 17,803 & 8,985 & 8,900 & 16,765 & 1,120 \\
\hline 51 & 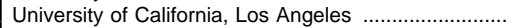 & Calif. & 1 & 1 & 36,420 & 34,713 & 35,594 & 35,558 & 17,894 & 17,700 & 33,622 & 1,972 \\
\hline 52 & 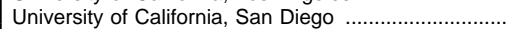 & Calif. & 1 & 1 & 17,790 & 18,315 & 18,110 & 18,657 & 9,449 & 8,661 & 17,328 & 782 \\
\hline 53 & 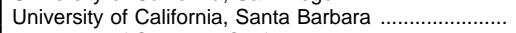 & Calif. & 1 & 1 & 18,385 & 18,224 & 18,531 & 18,940 & 8,897 & 9,634 & 17,770 & 761 \\
\hline 54 & University of Southern California ................................... & Calif. & 2 & 1 & 28,374 & 27,971 & 28,081 & - & 15,064 & 13,017 & 21,443 & 6,638 \\
\hline 55 & 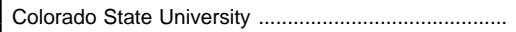 & Colo. & 1 & 1 & 26,828 & 26,340 & 25,865 & 26,365 & 12,472 & 13,393 & 19,483 & 6,382 \\
\hline 56 & Metropolitan State College of Denver & Colo. & 1 & 1 & 17,400 & 16,932 & 17,343 & 17,657 & 7,586 & 9,757 & 9,356 & 7,987 \\
\hline 57 & 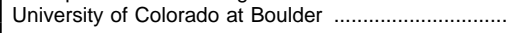 & Colo. & 1 & 1 & 28,600 & 27,624 & 27,546 & 28,209 & 14,665 & 12,881 & 21,137 & 6,409 \\
\hline 58 & University of Connecticut & Conn. & 1 & 1 & 25,497 & 22,471 & 21,805 & 21,249 & 10,571 & 11,234 & 15,892 & 5,913 \\
\hline 59 & University of Delaware .................. & Del. & 1 & 1 & 20,818 & 21,365 & 21,380 & 21,166 & 9,467 & 11,913 & 15,818 & 5,562 \\
\hline 60 & George Washington University & D.C. & 2 & 1 & 19,103 & 19,670 & 18,986 & 19,356 & 9,516 & 9,470 & 11,507 & 7,479 \\
\hline 61 & Broward Community College ... & Fla. & 1 & 2 & 24,365 & 25,738 & 26,435 & 26,472 & 10,304 & 16,131 & 7,720 & 18,715 \\
\hline 62 & 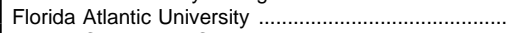 & Fla. & 1 & 1 & 12,767 & 17,704 & 18,111 & 18,823 & 7,349 & 10,762 & 8,319 & 9,792 \\
\hline 63 & Florida Community College at Jacksonville ..................... & Fla. & 1 & 2 & 20,974 & 21,237 & 20,944 & 20,530 & 8,558 & 12,386 & 5,551 & 15,393 \\
\hline 64 & Florida International University ……................... & Fla. & 1 & 1 & 22,466 & 28,171 & 29,720 & 30,012 & 12,663 & 17,057 & 13,591 & 16,129 \\
\hline 65 & Florida State University . & Fla. & 1 & 1 & 28,170 & 30,155 & 30,154 & 30,401 & 13,523 & 16,631 & 23,811 & 6,343 \\
\hline 66 & 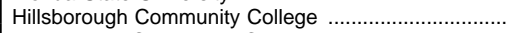 & Fla. & 1 & 2 & 19,134 & 20,311 & 18,518 & 17,936 & 7,669 & 10,849 & 3,918 & 14,600 \\
\hline 67 & Miami-Dade Community College & Fla. & 1 & 2 & 50,078 & 47,060 & 48,795 & 48,449 & 20,096 & 28,699 & 15,584 & 33,211 \\
\hline 68 & 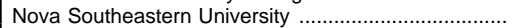 & Fla. & 2 & 1 & 9,562 & 13,941 & 14,951 & 15,782 & 5,706 & 9,245 & 6,899 & 8,052 \\
\hline 69 & Palm Beach Community College & Fla. & 1 & 2 & 18,392 & 18,310 & 18,032 & 18,410 & 6,890 & 11,142 & 5,101 & 12,931 \\
\hline 70 & 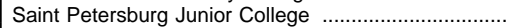 & Fla. & 1 & 2 & 20,012 & 21,176 & 20,174 & 20,696 & 7,759 & 12,415 & 5,878 & 14,296 \\
\hline 71 & University of Central Florida & Fla. & 1 & 1 & 21,541 & 26,556 & 27,684 & 28,685 & 12,686 & 14,998 & 16,265 & 11,419 \\
\hline 72 & University of Florida .. & Fla. I & 1 & 1 & 35,477 & 39,412 & 39,863 & - & 20,748 & 19,115 & 33,838 & 6,025 \\
\hline
\end{tabular}


Table 216.-Selected statistics for college and university campuses enrolling more than 14,600 students in 1996-Continued

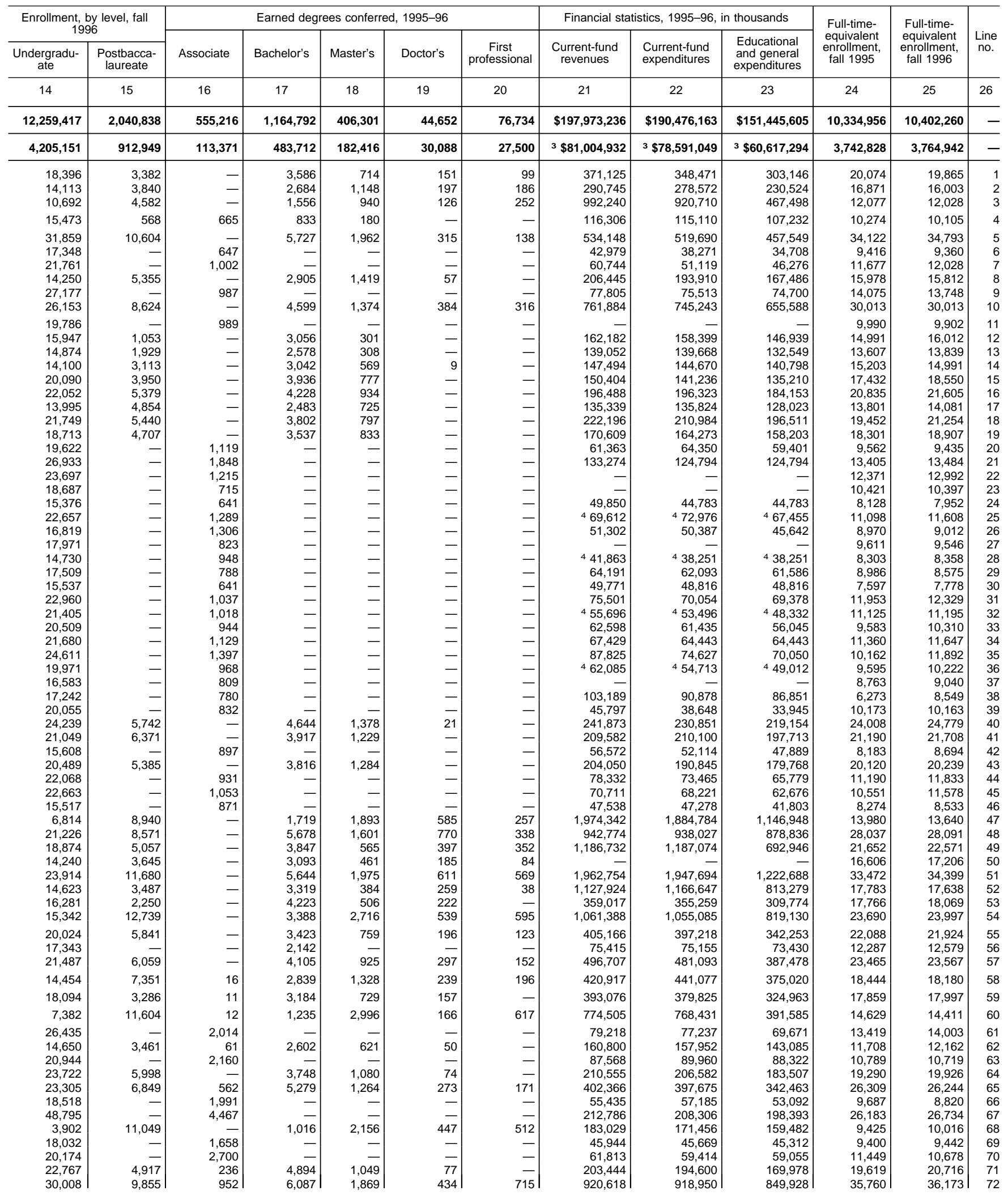


Table 216.-Selected statistics for college and university campuses enrolling more than 14,600 students in 1996-Continued

\begin{tabular}{|c|c|c|c|c|c|c|c|c|c|c|c|c|}
\hline \multirow{2}{*}{$\begin{array}{l}\text { Line } \\
\text { no. }\end{array}$} & \multirow{2}{*}{ Institution } & \multirow{2}{*}{ State } & \multirow{2}{*}{$\begin{array}{l}\text { Con- } \\
\text { trol }^{1}\end{array}$} & \multirow{2}{*}{ Type $^{2}$} & $\begin{array}{c}\text { Total } \\
\text { enrollment, }\end{array}$ & $\begin{array}{c}\text { Total } \\
\text { enrollment, }\end{array}$ & $\begin{array}{c}\text { Total } \\
\text { enrollment, }\end{array}$ & $\begin{array}{c}\text { Total } \\
\text { enrollment, }\end{array}$ & $\begin{array}{r}\text { Enrollmen } \\
\text { fall } 1\end{array}$ & by sex, & $\begin{array}{r}\text { Enrollm } \\
\text { attendanc } \\
\text { fall } 1\end{array}$ & $\begin{array}{l}\text { ent, by } \\
\text { e status, } \\
996\end{array}$ \\
\hline & & & & & & & & & Men & Women & Full-time & Part-time \\
\hline 1 & 2 & 3 & 4 & 5 & 6 & 7 & 8 & 9 & 10 & 11 & 12 & 13 \\
\hline $\begin{array}{l}73 \\
74\end{array}$ & $\begin{array}{l}\text { University of South Florida ...... } \\
\text { Valencia Community College }\end{array}$ & $\begin{array}{l}\text { Fla. } \\
\text { Fla. }\end{array}$ & $\begin{array}{l}1 \\
1\end{array}$ & $\begin{array}{l}1 \\
2\end{array}$ & $\begin{array}{l}32,326 \\
18,438\end{array}$ & $\begin{array}{l}36,142 \\
23,569\end{array}$ & $\begin{array}{l}36,266 \\
23,901\end{array}$ & $\begin{array}{l}34,036 \\
24,470\end{array}$ & $\begin{array}{l}15,133 \\
10,132\end{array}$ & $\begin{array}{l}21,133 \\
13,769\end{array}$ & $\begin{array}{r}18,747 \\
8,423\end{array}$ & $\begin{array}{l}17,519 \\
15,478\end{array}$ \\
\hline $\begin{array}{l}75 \\
76 \\
77\end{array}$ & $\begin{array}{l}\text { DeKalb College } \\
\text { Georgia State University } \\
\text { University of Georgia }\end{array}$ & $\begin{array}{l}\text { Ga. } \\
\text { Ga. } \\
\text { Ga. }\end{array}$ & $\begin{array}{l}1 \\
1 \\
1\end{array}$ & $\begin{array}{l}2 \\
1 \\
1\end{array}$ & $\begin{array}{l}13,944 \\
23,336 \\
28,395\end{array}$ & $\begin{array}{l}16,073 \\
24,274 \\
30,149\end{array}$ & $\begin{array}{l}15,689 \\
23,410 \\
29,404\end{array}$ & $\begin{array}{l}15,468 \\
24,276 \\
29,693\end{array}$ & $\begin{array}{r}6,118 \\
9,498 \\
13,446\end{array}$ & $\begin{array}{r}9,571 \\
13,912 \\
15,958\end{array}$ & $\begin{array}{r}5,999 \\
12,755 \\
25,320\end{array}$ & $\begin{array}{r}9,690 \\
10,655 \\
4,084\end{array}$ \\
\hline 78 & University of Hawaii at Manoa & $\mathrm{Hi}$. & 1 & 1 & 18,799 & 19,769 & 18,243 & 17,356 & 8,339 & 9,904 & 12,884 & 5,359 \\
\hline 79 & Boise State University & Idaho & 1 & 1 & 13,367 & 14,543 & 15,079 & 15,433 & 6,419 & 8,660 & 8,236 & 6,843 \\
\hline 80 & City Colleges of Chicago, Truman College ........ & III. & 1 & 2 & 16,460 & 14,883 & 15,644 & 16,009 & 7,076 & 8,568 & 3,784 & 11,860 \\
\hline 81 & College of Du Page & III. & 1 & 2 & 29,185 & 29,888 & 29,698 & 28,989 & 12,716 & 16,982 & 8,413 & 21,285 \\
\hline 82 & Depaul University ..... & III. & 2 & 1 & 15,711 & 17,133 & 17,294 & 17,804 & 7,780 & 9,514 & 9,819 & 7,475 \\
\hline 83 & Illinois State University & III. & 1 & 1 & 22,662 & 19,756 & 19,722 & 20,331 & 8,477 & 11,245 & 16,227 & 3,495 \\
\hline 84 & 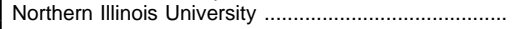 & III. & 1 & 1 & 24,509 & 22,218 & 21,609 & 22,082 & 9,640 & 11,969 & 15,507 & 6,102 \\
\hline 85 & Northwestern University .... & III. & 2 & 1 & 17,041 & 17,780 & 17,623 & 17,478 & 9,130 & 8,493 & 13,973 & 3,650 \\
\hline 86 & Southern Illinois University, Carbondale .......................... & III. & 1 & 1 & 24,078 & 22,418 & 21,863 & 21,908 & 12,371 & 9,492 & 17,959 & 3,904 \\
\hline 87 & Triton College & III. & 1 & 2 & 16,759 & 15,362 & 17,576 & 16,799 & 8,142 & 9,434 & 3,804 & 13,772 \\
\hline 88 & 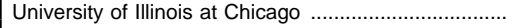 & III. & 1 & 1 & 24,959 & 24,870 & 24,931 & - & 11,515 & 13,416 & 18,953 & 5,978 \\
\hline 89 & 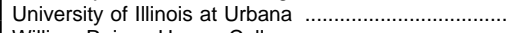 & III. & 1 & 1 & 38,163 & 38,420 & 38,841 & 38,070 & 20,942 & 17,899 & 33,571 & 5,270 \\
\hline 90 & William Rainey Harper College .................................... & III. & 1 & 2 & 16,509 & 15,106 & 15,041 & 15,690 & 6,367 & 8,674 & 4,610 & 10,431 \\
\hline 91 & Ball State University ..................... & Ind. & 1 & $\begin{array}{l}1 \\
1\end{array}$ & 20,343 & 20,014 & 19,431 & 19,419 & 9,098 & 10,333 & 15,976 & 3,455 \\
\hline 92 & 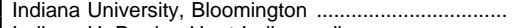 & Ind. & 1 & 1 & 35,451 & 35,063 & 34,700 & 34,937 & 16,184 & 18,516 & 29,103 & 5,597 \\
\hline 93 & 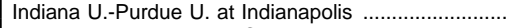 & Ind. & 1 & 1 & 27,517 & 26,939 & 27,011 & 27,036 & 11,286 & 15,725 & 13,492 & 13,519 \\
\hline 94 & Purdue University, Main Campus ..... & Ind. & 1 & 1 & 37,588 & 36,427 & 36,893 & 37,447 & 21,550 & 15,343 & 31,290 & 5,603 \\
\hline $\begin{array}{l}95 \\
96\end{array}$ & $\begin{array}{l}\text { lowa State University } \\
\text { University of lowa }\end{array}$ & $\begin{array}{l}\text { lowa } \\
\text { lowa }\end{array}$ & $\begin{array}{l}1 \\
1\end{array}$ & $\begin{array}{l}1 \\
1\end{array}$ & $\begin{array}{l}25,737 \\
28,785\end{array}$ & $\begin{array}{l}24,673 \\
28,052\end{array}$ & $\begin{array}{l}24,899 \\
28,447\end{array}$ & $\begin{array}{l}25,384 \\
28,409\end{array}$ & $\begin{array}{l}14,234 \\
13,626\end{array}$ & $\begin{array}{l}10,665 \\
14,821\end{array}$ & $\begin{array}{l}21,073 \\
21,586\end{array}$ & $\begin{array}{l}3,826 \\
6,861\end{array}$ \\
\hline 97 & Johnson County Community College ............................. & Kans. & 1 & 2 & 13,740 & 15,477 & 15,073 & 15,271 & 6,788 & 8,285 & 4,528 & 10,545 \\
\hline 98 & Kansas State $\mathrm{U}$. of Ag. and App. Science ............ & Kans. & 1 & 1 & 21,137 & 19,681 & 19,558 & 20,306 & 10,190 & 9,368 & 15,514 & 4,044 \\
\hline 99 & 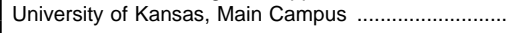 & Kans. & 1 & 1 & 26,434 & 25,036 & 24,874 & 25,108 & 12,133 & 12,741 & 19,120 & 5,754 \\
\hline 100 & Eastern Kentucky University ............ & Ky. & 1 & 1 & 15,290 & 15,703 & 15,137 & 15,388 & 6,338 & 8,799 & 11,105 & 4,032 \\
\hline 101 & University of Kentucky & Ky. & 1 & 1 & 22,538 & 23,794 & 23,431 & 23,540 & 11,368 & 12,063 & 18,477 & 4,954 \\
\hline 102 & University of Louisville & Ky. & 1 & 1 & 22,979 & 20,559 & 20,374 & 20,283 & 9,430 & 10,944 & 12,705 & 7,669 \\
\hline 103 & Western Kentucky University & Ky. & 1 & 1 & 15,170 & 14,675 & 14,613 & 14,543 & 5,839 & 8,774 & 10,308 & 4,305 \\
\hline 104 & Louisiana St. U. \& A\&M \& Hebert Laws Center & La. & 1 & 1 & 26,112 & 26,573 & 27,505 & 28,686 & 13,604 & 13,901 & 22,049 & 5,456 \\
\hline 105 & University of New Orleans & La. & 1 & 1 & 15,322 & 15,483 & 15,665 & 15,833 & 6,808 & 8,857 & 9,347 & 6,318 \\
\hline 106 & University of Southwestern Louisiana .............................. & La. & 1 & 1 & 15,764 & 16,902 & 16,740 & 17,020 & 7,196 & 9,544 & 12,658 & 4,082 \\
\hline 107 & Johns Hopkins University & Md. & 2 & 1 & 13,363 & 15,765 & 15,716 & - & 8,198 & 7,518 & 7,581 & 8,135 \\
\hline 108 & Towson State University .. & Md. & 1 & 1 & 15,035 & 14,643 & 15,105 & 15,524 & 5,808 & 9,297 & 10,556 & 4,549 \\
\hline 109 & University of Maryland College Park Campus ............. & Md. & 1 & 1 & 34,829 & 32,908 & 33,006 & 32,711 & 17,119 & 15,887 & 25,398 & 7,608 \\
\hline 110 & Boston College & Mass. & 2 & 1 & 14,502 & 14,729 & 14,863 & 14,705 & 6,708 & 8,155 & 11,528 & 3,335 \\
\hline 111 & 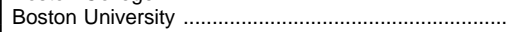 & Mass. & 2 & 1 & 27,996 & 29,132 & 28,706 & 29,387 & 13,034 & 15,672 & 23,112 & 5,594 \\
\hline 112 & Harvard University & Mass. & 2 & 1 & 22,851 & 24,687 & 24,409 & 24,328 & 12,806 & 11,603 & 18,166 & 6,243 \\
\hline 113 & Northeastern University & Mass. & 2 & 1 & 30,510 & 24,605 & 24,579 & 24,325 & 12,399 & 12,180 & 14,135 & 10,444 \\
\hline 114 & University of Massachusetts, Amherst .......................... & Mass. & 1 & 1 & 26,025 & 25,267 & 25,422 & 24,884 & 12,925 & 12,497 & 19,870 & 5,552 \\
\hline 115 & 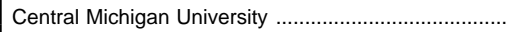 & Mich. & 1 & 1 & 18,286 & 23,575 & 24,249 & 24,747 & 10,393 & 13,856 & 15,583 & 8,666 \\
\hline 116 & Eastern Michigan University & Mich. & 1 & 1 & 25,011 & 23,142 & 22,541 & 22,730 & 8,937 & 13,604 & 12,813 & 9,728 \\
\hline 117 & 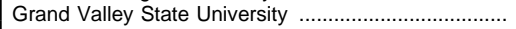 & Mich. & 1 & 1 & 11,725 & 13,887 & 14,662 & 15,676 & 5,800 & 8,862 & 9,633 & 5,029 \\
\hline 118 & Lansing Community College & Mich. & 1 & 2 & 22,343 & 16,404 & 16,136 & 15,690 & 6,890 & 9,246 & 4,147 & 11,989 \\
\hline 119 & 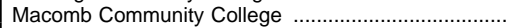 & Mich. & 1 & 2 & 31,538 & 25,176 & 24,400 & 23,574 & 12,062 & 12,338 & 5,517 & 18,883 \\
\hline 120 & 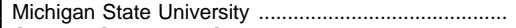 & Mich. & 1 & 1 & 44,307 & 40,647 & 41,545 & 42,603 & 19,670 & 21,875 & 33,271 & 8,274 \\
\hline 121 & Oakland Community College ....... & Mich. & 1 & 2 & 28,069 & 25,913 & 24,732 & 24,223 & 9,943 & 14,789 & 5,006 & 19,726 \\
\hline 122 & 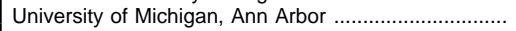 & Mich. & 1 & 1 & 36,391 & 36,687 & 36,525 & 36,995 & 19,376 & 17,149 & 33,057 & 3,468 \\
\hline 123 & 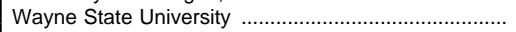 & Mich. & 1 & 1 & 33,872 & 32,149 & 31,185 & 30,729 & 13,509 & 17,676 & 14,481 & 16,704 \\
\hline 124 & 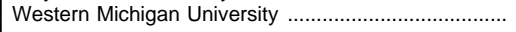 & Mich. & 1 & 1 & 26,989 & 26,537 & 25,699 & 26,132 & 11,476 & 14,223 & 16,598 & 9,101 \\
\hline 125 & University of Minnesota, Twin Cities & Minn. & 1 & 1 & 57,168 & 51,445 & 51,388 & 45,410 & 24,183 & 27,205 & 23,713 & 27,675 \\
\hline 126 & Mississippi State University ................... & Miss. & 1 & 1 & 14,391 & 14,330 & 14,831 & 15,628 & 8,321 & 6,510 & 11,906 & 2,925 \\
\hline 127 & Southwest Missouri State University & Mo. & 1 & 1 & 19,480 & 16,439 & 16,364 & 16,468 & 7,107 & 9,257 & 11,804 & 4,560 \\
\hline 128 & University of Missouri, Columbia ……........................ & Mo. & 1 & 1 & 25,058 & 22,356 & 22,519 & 22,552 & 10,807 & 11,712 & 18,773 & 3,746 \\
\hline 129 & 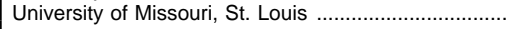 & Mo. & 1 & 1 & 15,393 & 15,972 & 16,094 & 15,576 & 5,963 & 10,131 & 5,577 & 10,517 \\
\hline 130 & Central Community College Area . & Nebr. & 1 & 2 & 10,915 & 11,869 & 14,903 & 6,743 & 6,006 & 8,897 & 2,699 & 12,204 \\
\hline 131 & University of Nebraska at Lincoln & Nebr. & 1 & 1 & 24,453 & 24,320 & 23,887 & 22,827 & 12,676 & 11,211 & 18,989 & 4,898 \\
\hline 132 & Community College of Southern Nevada & Nev. & 1 & 2 & 14,161 & 20,417 & 24,678 & 24,728 & 11,103 & 13,575 & 3,368 & 21,310 \\
\hline 133 & 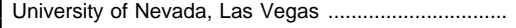 & Nev. & 1 & 1 & 17,937 & 18,842 & 18,709 & 19,249 & 8,540 & 10,169 & 9,703 & 9,006 \\
\hline 134 & University of New Hampshire, Main Campus. & N.H. & 1 & 1 & 13,260 & 15,466 & 15,429 & 15,146 & 6,481 & 8,948 & 11,527 & 3,902 \\
\hline 135 & Rutgers University, New Brunswick ................................. & N.J. & 1 & 1 & 33,016 & 33,773 & 33,862 & 34,420 & 15,251 & 18,611 & 25,222 & 8,640 \\
\hline 136 & Albuquerque Technical-Vocational Institute & N.Mex. & 1 & 2 & 9,739 & 15,225 & 15,549 & 16,069 & 6,581 & 8,968 & 4,171 & 11,378 \\
\hline 137 & New Mexico State University, Main Campus .................... & N.Mex. & 1 & 1 & 14,812 & 15,127 & 14,750 & 15,067 & 7,091 & 7,659 & 10,446 & 4,304 \\
\hline 138 & University of New Mexico, Main Campus ...................... & N.Mex. & 1 & 1 & 23,950 & 24,605 & 23,762 & 23,956 & 10,373 & 13,389 & 14,065 & 9,697 \\
\hline 139 & Columbia University in the City of New York ........ & N.Y. & 2 & 1 & 18,242 & 19,302 & 19,603 & 20,256 & 10,014 & 9,589 & 15,806 & 3,797 \\
\hline 140 & CUNY, Bernard M. Baruch College & N.Y. & 1 & 1 & 15,849 & 15,433 & 15,202 & - & 6,637 & 8,565 & 8,752 & \\
\hline 141 & CUNY, Borough of Manhattan Community College ... & N.Y. & 1 & 2 & 14,819 & 16,334 & 16,772 & - & 5,811 & 10,961 & 10,311 & 6,461 \\
\hline 142 & CUNY, Brooklyn College .. & N.Y. & 1 & 1 & 16,605 & 16,282 & 15,579 & - & 5,756 & 9,823 & 7,990 & 7,589 \\
\hline 143 & CUNY, Hunter College .... & N.Y. & 1 & 1 & 19,639 & 18,250 & 18,772 & - & 5,178 & 13,594 & 9,645 & 9,127 \\
\hline 144 & CUNY, Kingsborough Community College ................. & N.Y. & 1 & 2 & 13,809 & 14,553 & 14,758 & - & 5,598 & 9,160 & 7,247 & 7,511 \\
\hline 145 & Nassau Community College ............................. & N.Y. & 1 & 2 & 21,537 & 21,737 & 20,389 & 20,620 & 9,495 & 10,894 & 10,732 & 9,657 \\
\hline 146 & New York University & N.Y. & 2 & 1 & 32,813 & 35,835 & 36,305 & 36,679 & 15,564 & 20,741 & 24,047 & 12,258 \\
\hline 147 & Q Queens College & N.Y. & 1 & 1 & 18,072 & 17,522 & 16,633 & - & 6,151 & 10,482 & 8,542 & 8,091 \\
\hline 148 & Regents College, U. of the State of New York & N.Y. & 2 & 1 & 13,303 & 19,433 & 18,421 & 17,348 & 6,849 & 11,572 & -1 & 18,421 \\
\hline
\end{tabular}


Table 216.-Selected statistics for college and university campuses enrolling more than 14,600 students in 1996-Continued

\begin{tabular}{|c|c|c|c|c|c|c|c|c|c|c|c|c|}
\hline \multicolumn{2}{|c|}{$\begin{array}{c}\text { Enrollment, by level, fall } \\
1996\end{array}$} & \multicolumn{5}{|c|}{ Earned degrees conferred, 1995-96 } & \multicolumn{3}{|c|}{ Financial statistics, $1995-96$, in thousands } & \multirow{2}{*}{$\begin{array}{l}\text { Full-time- } \\
\text { equivalent } \\
\text { enrollment, } \\
\text { fall } 1995\end{array}$} & \multirow{2}{*}{$\begin{array}{l}\text { Full-time- } \\
\text { equivalent } \\
\text { enrollment, } \\
\text { fall } 1996\end{array}$} & \\
\hline $\begin{array}{l}\text { Undergradu- } \\
\text { ate }\end{array}$ & $\begin{array}{l}\text { Postbacca- } \\
\text { laureate }\end{array}$ & Associate & Bachelor's & Master's & Doctor's & $\begin{array}{c}\text { First } \\
\text { professional }\end{array}$ & $\begin{array}{l}\text { Current-fund } \\
\text { revenues }\end{array}$ & $\begin{array}{l}\text { Current-fund } \\
\text { expenditures }\end{array}$ & $\begin{array}{l}\text { Educational } \\
\text { and general } \\
\text { expenditures }\end{array}$ & & & $\begin{array}{l}\text { Line } \\
\text { no. }\end{array}$ \\
\hline 14 & 15 & 16 & 17 & 18 & 19 & 20 & 21 & 22 & 23 & 24 & 25 & 26 \\
\hline $\begin{array}{l}26,993 \\
23,901\end{array}$ & 9,273 & $\begin{array}{r}220 \\
2,573\end{array}$ & 5,496 & 1,782 & $\stackrel{140}{-}$ & $\underline{86}$ & $\begin{array}{r}446,045 \\
70,198\end{array}$ & $\begin{array}{r}443,812 \\
66,611\end{array}$ & $\begin{array}{r}385,384 \\
59,602\end{array}$ & $\begin{array}{l}25,136 \\
13,165\end{array}$ & $\begin{array}{l}25,554 \\
13,620\end{array}$ & $\begin{array}{l}73 \\
74\end{array}$ \\
\hline $\begin{array}{l}15,689 \\
16,320 \\
22,946\end{array}$ & $\begin{array}{r}7,090 \\
6,458\end{array}$ & $\begin{array}{r}822 \\
1 \\
1\end{array}$ & $\begin{array}{r}-\overline{1} \\
4,7433\end{array}$ & $\begin{array}{r}- \\
1,738 \\
1,195\end{array}$ & $\begin{array}{r}-\overline{128} \\
343\end{array}$ & $\begin{array}{r}\overline{146} \\
336\end{array}$ & $\begin{array}{r}61,051 \\
219,058 \\
696,537\end{array}$ & $\begin{array}{r}60,756 \\
216,033 \\
684,745\end{array}$ & $\begin{array}{r}56,597 \\
213,069 \\
628,933\end{array}$ & $\begin{array}{r}9,187 \\
17,112 \\
27,567\end{array}$ & $\begin{array}{r}9,252 \\
16,973 \\
26,909\end{array}$ & $\begin{array}{l}75 \\
76 \\
77\end{array}$ \\
\hline 12,524 & 5,719 & - & 2,782 & 1,053 & 186 & 122 & 392,402 & 442,547 & 395,190 & 16,300 & 14,917 & 78 \\
\hline 13,091 & 1,988 & 118 & 1,264 & 240 & - & - & 149,908 & 120,154 & 94,168 & 10,320 & 10,928 & 79 \\
\hline 15,644 & - & 515 & - & - & - & - & 45,246 & $\begin{array}{l}46,565 \\
86704\end{array}$ & 46,565 & $\begin{array}{r}7,381 \\
15642\end{array}$ & $\begin{array}{r}7,766 \\
15,559\end{array}$ & 80 \\
\hline $\begin{array}{l}29,698 \\
10,438\end{array}$ & $6, \overline{856}$ & 1,660 & $1, \overline{607}$ & $1, \overline{391}$ & $\overline{16}$ & $3 \overline{45}$ & $\begin{array}{r}93,699 \\
191,304\end{array}$ & $\begin{array}{r}86,104 \\
185,345\end{array}$ & $\begin{array}{r}8,300 \\
166,811\end{array}$ & $\begin{array}{l}15,642 \\
12,623\end{array}$ & $\begin{array}{l}15,559 \\
12,768\end{array}$ & $\begin{array}{l}81 \\
82\end{array}$ \\
\hline 16,773 & 2,949 & - & 3,609 & 600 & 62 & - & 211,358 & 210,201 & 171,173 & 17,477 & 17,561 & 83 \\
\hline 15,387 & 6,222 & - & 3,301 & 1,350 & 104 & 107 & 254,743 & 256,138 & 204,315 & 18,358 & 17,798 & 84 \\
\hline 9,654 & 7,969 & - & 1,955 & 2,297 & 359 & 474 & 804,277 & 765,321 & 720,326 & 15,463 & 15,388 & 85 \\
\hline 17,725 & 4,138 & 459 & 4,627 & 794 & 156 & 173 & 331,100 & 332,019 & 297,438 & 19,966 & 19,459 & 86 \\
\hline 17,576 & - & 805 & - & - & - & - & 50,414 & 47,506 & 43,332 & 7,748 & 8,428 & 87 \\
\hline 16,210 & 8,721 & - & 2,756 & 1,414 & 237 & 490 & 934,769 & 917,400 & 617,042 & 21,110 & 21,256 & 88 \\
\hline 28,540 & 10,301 & - & 6.050 & 2,449 & 698 & 271 & 913,480 & 893,739 & 781,997 & 35,455 & 35,599 & 89 \\
\hline 15,041 & - & 1,094 & - & - & - & - & 70,791 & 72,730 & 67,773 & 8,046 & $\begin{array}{r}8,112 \\
\end{array}$ & 90 \\
\hline 17,029 & 2,402 & 230 & 3,125 & 765 & 56 & - & 250,140 & 240,558 & 201,896 & 17,691 & 17,309 & 91 \\
\hline 26,788 & 7,912 & 66 & 5,007 & 1,771 & 374 & 276 & 700,262 & 700,002 & 507,609 & 31,520 & 31,257 & 92 \\
\hline 19,950 & 7,061 & 524 & 2,130 & 681 & 32 & 587 & 525,680 & 518,903 & 437,541 & 18,352 & 18,859 & 93 \\
\hline 30,213 & 6,680 & 677 & 5,122 & 1,254 & $\begin{array}{l}508 \\
508\end{array}$ & 92 & 709,611 & 679,842 & 582,951 & 32,887 & 33,465 & 94 \\
\hline 20,100 & 4,799 & - & 3,817 & 773 & 287 & 99 & 576,501 & 555,352 & 447,577 & 22,350 & 22,536 & 95 \\
\hline 19,188 & 9,259 & - & 3,237 & 1,317 & 377 & 484 & $1,139,777$ & $1,107,284$ & 576,018 & 23,946 & 24,203 & 96 \\
\hline 15,073 & - & 793 & - & - & - & - & 74,731 & 69,053 & 63,502 & 8,264 & 8,068 & 97 \\
\hline 16,168 & 3,390 & 35 & 2,895 & 666 & 181 & 89 & 278,120 & 273,626 & 254,595 & 17,466 & 17,076 & 98 \\
\hline 18,141 & 6,733 & - & 3,325 & 1,259 & 243 & 184 & 350,149 & 338,737 & 286,970 & 21,527 & 21,286 & 99 \\
\hline 13,151 & 1,986 & 254 & 1,714 & 398 & - & - & 129,029 & 128,070 & 112,544 & 13,131 & 12,667 & 100 \\
\hline 17,036 & 6,395 & - & 3,003 & 1,028 & 236 & 353 & 816,300 & 775,553 & 522,747 & 20,567 & 20,386 & 101 \\
\hline 14,773 & 5,601 & 101 & 1,818 & 948 & $\begin{array}{r}60 \\
69\end{array}$ & 304 & 404,343 & 355,666 & 314,197 & 15,726 & 15,697 & 102 \\
\hline 12,475 & 2,138 & 286 & 1,709 & 530 & - & - & 118,730 & 116,165 & 103,744 & 12,125 & 11,976 & 103 \\
\hline 21,413 & 6,092 & - & 3,005 & 1,030 & 238 & 259 & 463,839 & 454,169 & 378,017 & 23,035 & 24,174 & 104 \\
\hline 11,689 & 3,976 & - & 1,343 & 509 & $\begin{array}{r}200 \\
49\end{array}$ & - & 109,485 & 107,229 & 97,457 & 11,600 & $\begin{array}{l}24,784 \\
11,784\end{array}$ & 105 \\
\hline 15,148 & 1,592 & 71 & 1,603 & 283 & 32 & - & 115,303 & 112,511 & 95,565 & 14,364 & 14,267 & 106 \\
\hline 4,431 & 11,285 & 1 & 1,005 & 2,674 & 321 & 114 & $41,514,386$ & $41,494,071$ & $41,035,936$ & 10,602 & 10,695 & 107 \\
\hline 13,063 & 2,042 & - & 2,474 & 426 & $-0<1$ & - & 131,702 & 128,516 & 96,881 & 11,738 & 12,326 & 108 \\
\hline 24,529 & 8,477 & - & 4,691 & 1,550 & 466 & - & 666,723 & 634,044 & 547,997 & 28,116 & 28,291 & 109 \\
\hline 10,163 & 4,700 & - & 2,272 & 1,020 & 114 & 270 & 353,294 & 339,105 & 264,949 & 12,757 & 12,815 & 110 \\
\hline 18,319 & 10,387 & 6 & 3,445 & 3,057 & 309 & 594 & 884,453 & 848,376 & 757,880 & 25,458 & 25,279 & 111 \\
\hline 10,220 & 14,189 & 13 & 1,803 & 2,717 & 528 & 790 & $1,518,032$ & $1,520,306$ & $1,334,231$ & 20,764 & 20,590 & 112 \\
\hline 19,780 & $\begin{array}{r}4,799 \\
4,7\end{array}$ & 321 & 2,263 & 1,340 & $\begin{array}{r}780 \\
77\end{array}$ & 197 & 4309,584 & 4305,241 & 4288,655 & 18,037 & 18,215 & 113 \\
\hline 19,467 & 5,955 & 94 & 3,649 & 949 & 338 & - & 506,578 & 477,358 & 372,589 & 21,741 & 21,961 & 114 \\
\hline 16,224 & 8,025 & - & 2,824 & 1,978 & 6 & - & 231,383 & 216,447 & 181,892 & 18,144 & 18,825 & 115 \\
\hline 17,732 & 4,809 & - & 2,955 & 1,165 & 4 & - & 186,410 & 177,785 & 151,277 & $\begin{array}{l}10,144 \\
16,824\end{array}$ & $\begin{array}{l}10,0<0 \\
16,585\end{array}$ & 116 \\
\hline 11,734 & 2,928 & - & 1,847 & 409 & - & - & 110,309 & 106.957 & 93,071 & 10,889 & 11,560 & 117 \\
\hline 16,136 & - & 1,293 & - & - & - & - & 74,916 & 67,121 & 66,322 & 8,348 & 8,172 & 118 \\
\hline 24,400 & - & 2,386 & - & - & - & - & 85,566 & 77,105 & 70,550 & 12,114 & $\begin{array}{r}0,857 \\
11,857\end{array}$ & 119 \\
\hline 32,318 & 9,227 & $-2,000$ & 6,276 & 1,700 & 484 & 300 & 937,680 & 879,889 & 727,490 & 35,613 & 36,462 & 120 \\
\hline 24,732 & - & 1,814 & - & - & - & - & 116,302 & 91,025 & 85,250 & 12,100 & 11,629 & 121 \\
\hline 23,590 & 12,935 & - & 5,413 & 2,955 & 691 & $7 \overline{13}$ & $2,333,715$ & $2,102,593$ & $1,193,178$ & 34,548 & 34,377 & 122 \\
\hline 18,200 & 12,985 & - & 2,700 & 2,499 & 230 & 416 & 482,502 & 463,015 & 445,759 & 21,413 & 20,959 & 123 \\
\hline 19,803 & $\begin{array}{r}12,905 \\
5,896\end{array}$ & - & 3,844 & $\begin{array}{l}2,499 \\
1,380\end{array}$ & 55 & -4 & $\begin{array}{l}40<, 00< \\
270,288\end{array}$ & 256,042 & 198,562 & 20,447 & 20,072 & 124 \\
\hline 37,665 & 13,723 & 8 & 4,890 & 2,528 & 763 & 685 & $1,699,323$ & $1,654,829$ & $1,156,238$ & 34,376 & 34,595 & 125 \\
\hline 11,983 & 2,848 & - & 2,092 & 561 & 109 & 46 & 285,593 & 280,009 & 251,181 & 12,615 & 13,033 & 126 \\
\hline 14,309 & 2,055 & 2 & 2,189 & 392 & - & - & 132,091 & 128,413 & 109,601 & 13,710 & 13,579 & 127 \\
\hline 17,165 & 5,354 & - & 3,234 & 1,003 & 248 & 311 & 780,809 & 748,378 & 449,605 & 19,866 & 20,197 & 128 \\
\hline 13,230 & 2,864 & - & 1,587 & 596 & 25 & 41 & 108,943 & 103,682 & 94,370 & 9,648 & 9,722 & 129 \\
\hline 14,903 & - & 353 & - & - & - & - & 27,795 & 26,487 & 21,419 & 4,912 & 6,796 & 130 \\
\hline 18,954 & 4,933 & 14 & 2,834 & 781 & 261 & 147 & 427,170 & 412,160 & 324,188 & 21,097 & 20,866 & 131 \\
\hline 24,678 & - & 576 & - & - & - & - & 41,103 & 43,633 & 43,065 & 8,551 & 10,523 & 132 \\
\hline 14,931 & 3,778 & - & 2,051 & 574 & 20 & - & 162,846 & 167,431 & 147,708 & 12,844 & 13,211 & 133 \\
\hline 12,535 & 2,894 & 217 & 2,406 & 544 & 51 & - & 266,111 & 255,616 & 204,808 & 13,207 & 13,022 & 134 \\
\hline 25,939 & 7,923 & - & 5,040 & 1,422 & 416 & 24 & - & - & - & 28,172 & 28,498 & 135 \\
\hline 15,549 & - & 624 & - & - & - & - & 58,341 & 53,580 & 49,708 & 7,908 & 7,991 & 136 \\
\hline 11,874 & 2,876 & 111 & 1.947 & 655 & 82 & - & 253,537 & 240,769 & 207,773 & 12,413 & 12,125 & 137 \\
\hline 15,726 & 8,036 & 48 & 2,509 & 1,242 & 210 & 192 & 749,236 & 740,357 & 431,095 & 18,441 & 17,782 & 138 \\
\hline 7,008 & 12,595 & - & 1,385 & 3,484 & 404 & 567 & $1,216,311$ & $1,158,585$ & $1,111,711$ & 16,911 & 17,275 & 139 \\
\hline 12,833 & 2,369 & - & 1,873 & 703 & - & - & 113,407 & 109,758 & 109,196 & 11,734 & 11,289 & 140 \\
\hline 16,772 & - & 1,686 & - & - & - & - & 84,489 & 81,043 & 80,620 & 11,947 & 12,480 & 141 \\
\hline 10,940 & 4,639 & - & 1,450 & 774 & - & - & 115,627 & 112,254 & 111,049 & 11,295 & 10,874 & 142 \\
\hline 14,602 & 4,170 & - & 1,538 & 1,120 & - & - & 132,659 & 120,269 & 119,249 & 12,495 & 13,184 & 143 \\
\hline 14,758 & - & 1,439 & - & - & - & - & 72,503 & 70,170 & 69,416 & 9,682 & $\begin{array}{r}10,104 \\
9,769\end{array}$ & 144 \\
\hline 20,389 & - & 2,946 & - & - & - & - & 122,113 & 119,346 & 119,346 & $\begin{array}{r}14,677 \\
14,67\end{array}$ & 13,974 & 145 \\
\hline 17,060 & 19,245 & 420 & 3,233 & 4.936 & 356 & 792 & $1,630,825$ & $1,593,755$ & $1,050,225$ & 27,933 & 28,770 & 146 \\
\hline 13,002 & 3,631 & - & 2,025 & 892 & - & - & 123,392 & 117,412 & 113,361 & 12,394 & 11,668 & 147 \\
\hline 18,421 & - & 2,459 & 2,737 & - & - & - & 15,495 & $\begin{array}{r}14,650 \\
\end{array}$ & 14,650 & 7,634 & 7,237 & 148 \\
\hline
\end{tabular}


Table 216.-Selected statistics for college and university campuses enrolling more than 14,600 students in 1996-Continued

\begin{tabular}{|c|c|c|c|c|c|c|c|c|c|c|c|c|}
\hline \multirow{2}{*}{$\begin{array}{l}\text { Line } \\
\text { no. }\end{array}$} & \multirow{2}{*}{ Institution } & \multirow{2}{*}{ State } & Con- & Type $^{2}$ & $\begin{array}{c}\text { Total } \\
\text { enrollment }\end{array}$ & $\begin{array}{c}\text { Total } \\
\text { enrollment }\end{array}$ & $\begin{array}{c}\text { Total } \\
\text { enrollment }\end{array}$ & $\begin{array}{c}\text { Total } \\
\text { enrollment. }\end{array}$ & $\begin{array}{r}\text { Enrollmen } \\
\text { fall } 1\end{array}$ & $\begin{array}{l}\text {, by sex, } \\
996\end{array}$ & $\begin{array}{r}\text { Enrollm } \\
\text { attendanc } \\
\text { fall } 1\end{array}$ & $\begin{array}{l}\text { ent, by } \\
\text { status, } \\
996\end{array}$ \\
\hline & & & & & & & & & Men & Women & Full-time & Part-time \\
\hline 1 & 2 & 3 & 4 & 5 & 6 & 7 & 8 & 9 & 10 & 11 & 12 & 13 \\
\hline 149 & Saint Johns University, New York & N.Y. & 2 & 1 & 19,105 & 17,393 & 18,735 & 18,523 & 8,473 & 10,262 & 12,204 & 6,531 \\
\hline 150 & SUNY at Albany ............ & N.Y. & 1 & 1 & 17,400 & 15,996 & 15,973 & 16,050 & 7,714 & 8,259 & 11,663 & 4,310 \\
\hline 151 & SUNY at Buffalo & N.Y. & 1 & 1 & 27,638 & 24,493 & 23,577 & 23,429 & 12,571 & 11,006 & 17,866 & 5,711 \\
\hline 152 & SUNY at Stony Brook & N.Y. & 1 & 1 & 17,624 & 17,665 & 17,316 & 17,831 & 8,152 & 9,164 & 13,321 & 3,995 \\
\hline 153 & Syracuse University ... & N.Y. & 2 & 1 & 21,900 & 18,804 & 18,574 & 18,387 & 8,600 & 9,974 & 13,688 & 4,886 \\
\hline 154 & Central Piedmont Community College ........ & N.C. & 1 & 2 & 16,311 & 15,176 & 15,239 & 14,175 & 6,638 & 8,601 & 4,827 & 10,412 \\
\hline 155 & 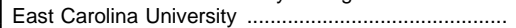 & N.C. & 1 & 1 & 17,564 & 17,923 & 17,583 & 18,271 & 7,226 & 10,357 & 14,179 & 3,404 \\
\hline 156 & North Carolina State University at Raleigh ......... & N.C. & 1 & 1 & 27,199 & 28,250 & 27,994 & 28,281 & 16,515 & 11,479 & 18,937 & 9,057 \\
\hline 157 & University of North Carolina at Chapel Hill & N.C. & 1 & 1 & 23,878 & 24,439 & 24,123 & 24,368 & 10,009 & 14,114 & 19,652 & 4,471 \\
\hline 158 & University of North Carolina at Charlotte ...................... & N.C. & 1 & 1 & 14,699 & 16,069 & 15,831 & 16,511 & 7,394 & 8,437 & 10,450 & 5,381 \\
\hline 159 & Bowling Green State University, Main Campus ........... & Ohio & 1 & 1 & 18,657 & 17,554 & 16,919 & 17,328 & 7,257 & 9,662 & 14,720 & 2,199 \\
\hline 160 & Cleveland State University & Ohio & 1 & 1 & 19,214 & 15,566 & 15,447 & 15,655 & 7,071 & 8,376 & 8,808 & 6,639 \\
\hline 161 & Columbus State Community College & Ohio & 1 & 2 & 13,290 & 16,013 & 16,330 & 16,340 & 6,686 & 9,644 & 5,687 & 10,643 \\
\hline 162 & Cuyahoga Community College District & Ohio & 1 & 2 & 23,157 & 22,785 & 21,051 & 20,164 & 7,529 & 13,522 & 7,064 & 13,987 \\
\hline 163 & Kent State University, Main Campus ........... & Ohio & 1 & 1 & 24,434 & 20,972 & 20,635 & 20,743 & 8,408 & 12,227 & 14,888 & 5,747 \\
\hline 164 & Miami University, Oxford ........................... & Ohio & 1 & 1 & 15,835 & 15,745 & 16,099 & 16,328 & 7,176 & 8,923 & 14,636 & 1,463 \\
\hline 165 & 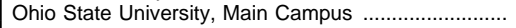 & Ohio & 1 & 1 & 54,087 & 48,676 & 48,352 & 48,278 & 24,803 & 23,549 & 39,054 & 9,298 \\
\hline 166 & Ohio University, Main Campus ................. & Ohio & 1 & 1 & 18,505 & 19,727 & 19,441 & 19,564 & 9,128 & 10,313 & 17,601 & 1,840 \\
\hline 167 & 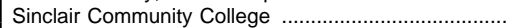 & Ohio & 1 & 2 & 16,367 & 17,344 & 17,221 & 17,239 & 6,578 & 10,643 & 5,941 & 11,280 \\
\hline 168 & 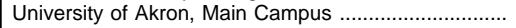 & Ohio & 1 & 1 & 28,801 & 23,640 & 22,732 & 22,153 & 10,537 & 12,195 & 13,005 & 9,727 \\
\hline 169 & 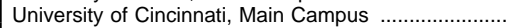 & Ohio & 1 & 1 & 31,013 & 28,373 & 28,995 & 28,161 & 14,975 & 14,020 & 20,175 & 8,820 \\
\hline 170 & University of Toledo & Ohio & 1 & 1 & 24,691 & 21,991 & 21,692 & 20,307 & 10,250 & 11,442 & 15,246 & 6,446 \\
\hline 171 & Wright State University, Main Campus ..... & Ohio & 1 & 1 & 16,393 & 15,710 & 14,863 & 14,994 & 6,693 & 8,170 & 9,899 & 4,964 \\
\hline 172 & Oklahoma State University, Main Campus & Okla. & 1 & 1 & 19,827 & 19,196 & 19,186 & 19,332 & 10,393 & 8,793 & 14,763 & 4,423 \\
\hline 173 & Tulsa Junior College …...................................... & Okla. & 1 & 2 & 17,955 & 18,632 & 17,569 & 17,331 & 7,083 & 10,486 & 4,636 & 12,933 \\
\hline 174 & University of Oklahoma, Norman Campus & Okla. & 1 & 1 & 20,774 & 22,299 & 22,359 & & 11,906 & 10,453 & 15,692 & 6,667 \\
\hline 175 & Portland Community College & Oreg. & 1 & 2 & 21,888 & 26,540 & 23,617 & 23,782 & 10,623 & 12,994 & 5,618 & 17,999 \\
\hline 176 & Portland State University & Oreg. & 1 & 1 & 16,921 & 15,600 & 16,660 & 16,997 & 7,362 & 9,298 & 8,266 & 8,394 \\
\hline 177 & 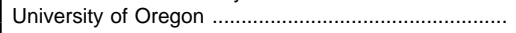 & Oreg. & 1 & 1 & 18,840 & 17,470 & 17,788 & 17,530 & 8,540 & 9,248 & 15,378 & 2,410 \\
\hline 178 & Community College of Allegheny County & $\mathrm{Pa}$. & 1 & 2 & 20,553 & 17,723 & 16,816 & 17,154 & 6,939 & 9,877 & 7,003 & 9,813 \\
\hline 179 & Community College of Philadelphia ........ & $\mathrm{Pa}$. & 1 & 2 & 15,151 & 17,865 & 17,233 & 16,539 & 5,829 & 11,404 & 5,190 & 12,043 \\
\hline 180 & International Correspondence Schools & Pa. & 3 & 3 & 20,727 & 32,560 & 40,077 & - & 29,367 & 10,710 & - & 40,077 \\
\hline 181 & Pennsylvania State University, Main Campus & $\mathrm{Pa}$. & 1 & 1 & 38,864 & 39,646 & 39,855 & 40,538 & 22,135 & 17,720 & 35,432 & 4,423 \\
\hline 182 & 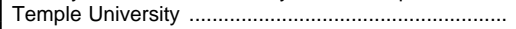 & Pa. & 1 & 1 & 29,714 & 29,028 & 27,979 & 27,652 & 12,552 & 15,427 & 18,030 & 9,949 \\
\hline 183 & University of Pennsylvania ...... & $\mathrm{Pa}$. & 2 & 1 & 21,868 & 22,148 & 21,869 & 21,643 & 11,000 & 10,869 & 18,064 & 3,805 \\
\hline 184 & University of Pittsburgh, Main Campus ........................ & $\mathrm{Pa}$ & 1 & 1 & 28,120 & 26,083 & 25,479 & 25,461 & 12,307 & 13,172 & 18,752 & 6,727 \\
\hline 185 & 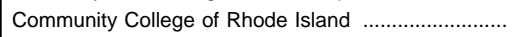 & R.I. & 1 & 2 & 16,620 & 15,889 & 15,236 & 15,220 & 5,725 & 9,511 & 4,866 & 10,370 \\
\hline 186 & 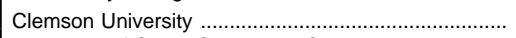 & S.C. & 1 & 1 & 15,714 & 16,318 & 16,526 & 16,396 & 8,859 & 7,667 & 13,832 & 2,694 \\
\hline 187 & University of South Carolina at Columbia . & S.C. & 1 & 1 & 25,613 & 26,346 & 25,489 & 25,447 & 10,869 & 14,620 & 17,309 & 8,180 \\
\hline 188 & Middle Tennessee State University . & Tenn. & 1 & 1 & 14,865 & 17,424 & 17,924 & 18,366 & 8,037 & 9,887 & 13,221 & 4,703 \\
\hline 189 & University of Memphis & Tenn. & 1 & 1 & 20,681 & 19,975 & 19,271 & 19,851 & 8,316 & 10,955 & 12,614 & 6,657 \\
\hline 190 & University of Tennessee, Knoxville ................................. & Tenn. & 1 & 1 & 26,055 & 25,723 & 25,517 & 25,401 & 12,564 & 12,953 & 20,006 & 5,511 \\
\hline 191 & Austin Community College ... & Tex. & 1 & 2 & 24,251 & 25,620 & 25,209 & 25,850 & 11,656 & 13,553 & 6,497 & 18,712 \\
\hline 192 & El Paso Community College .................... & Tex. & 1 & 2 & 17,081 & 21,856 & 21,340 & - & 8,493 & 12,847 & 6,839 & 14,501 \\
\hline 193 & Houston Community College System & Tex. & 1 & 2 & 36,437 & 39,541 & 38,493 & 38,463 & 16,861 & 21,632 & 10,062 & 28,431 \\
\hline 194 & North Harris-Montgomery Community College & Tex. & 1 & 2 & 15,653 & 19,251 & 19,959 & 21,044 & 7,913 & 12,046 & 7,010 & 12,949 \\
\hline 195 & 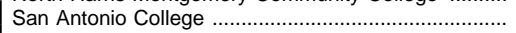 & Tex. & 1 & 2 & 20,083 & 19,319 & 19,358 & 19,594 & 8,095 & 11,263 & 7,188 & 12,170 \\
\hline 196 & Southwest Texas State University & Tex. & 1 & 1 & 20,940 & 20,917 & 20,776 & 20,652 & 9,324 & 11,452 & 14,749 & 6,027 \\
\hline 197 & 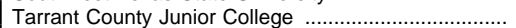 & Tex. & 1 & 2 & 28,161 & 25,953 & 25,273 & 25,856 & 10,873 & 14,400 & 7,653 & 17,620 \\
\hline 198 & 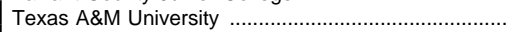 & Tex. & 1 & 1 & 41,171 & 41,790 & 41,892 & 41,461 & 23,157 & 18,735 & 37,563 & 4,329 \\
\hline 199 & Texas Tech University & Tex. & 1 & 1 & 25,363 & 24,185 & 24,716 & 25,022 & 13,389 & 11,327 & 20,852 & 3,864 \\
\hline 200 & The University of Texas at Arlington …….................. & Tex. & 1 & 1 & 24,782 & 22,121 & 20,544 & 19,286 & 10,250 & 10,294 & 11,403 & 9,141 \\
\hline 201 & The University of Texas at Austin ..... & Tex. & 1 & 1 & 49,617 & 47,905 & 48,008 & 48,857 & 24,826 & 23,182 & 42,029 & 5,979 \\
\hline 202 & The University of Texas at El Paso ............................... & Tex. & 1 & 1 & 16,524 & 16,275 & 15,389 & 15,176 & 7,089 & 8,300 & 9,329 & 6,060 \\
\hline 203 & 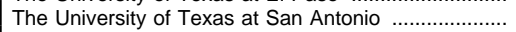 & Tex. & 1 & 1 & 15,489 & 17,389 & 17,547 & 17,494 & 8,143 & 9,404 & 10,095 & 7,452 \\
\hline 204 & University of Houston, University Park ...... & Tex. & 1 & 1 & 33,115 & 30,766 & 30,774 & 31,602 & 14,694 & 16,080 & 19,072 & 11,702 \\
\hline 205 & 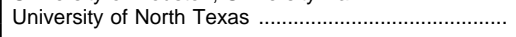 & Tex. & 1 & 1 & 27,160 & 25,114 & 24,964 & 25,013 & 11,702 & 13,262 & 16,365 & 8,599 \\
\hline 206 & Brigham Young University & Utah & 2 & 1 & 31,662 & 31,300 & 31,419 & 32,161 & 15,303 & 16,116 & 28,420 & 2,999 \\
\hline 207 & Salt Lake Community College... & Utah & 1 & 2 & 13,344 & 19,568 & 21,348 & 23,590 & 11,132 & 10,216 & 7,368 & 13,980 \\
\hline 208 & University of Utah & Utah & 1 & 1 & 24,922 & 27,137 & 26,358 & 25,889 & 13,894 & 12,464 & 17,609 & 8,749 \\
\hline 209 & 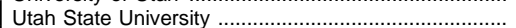 & Utah & 1 & 1 & 15,155 & 19,861 & 20,808 & 21,234 & 9,678 & 11,130 & 12,363 & 8,445 \\
\hline 210 & Utah Valley State College & Utah & 1 & 1 & 7,879 & 14,041 & 14,756 & 15,994 & 7,830 & 6,926 & 6,807 & 7,949 \\
\hline 211 & 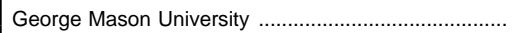 & Va. & 1 & 1 & 20,308 & 24,172 & 24,368 & 23,826 & 10,587 & 13,781 & 11,959 & 12,409 \\
\hline 212 & Northern Virginia Community College & Va. & 1 & 2 & 35,194 & 37,144 & 35,337 & 35,221 & 16,081 & 19,256 & 8,759 & 26,578 \\
\hline 213 & Old Dominion University .......................... & Va. & 1 & 1 & 16,729 & 17,077 & 17,800 & 18,557 & 7,914 & 9,886 & 9,809 & 7,991 \\
\hline 214 & Tidewater Community College & Va. & 1 & 2 & 17,726 & 16,780 & 16,199 & 17,907 & 6,844 & 9,355 & 4,530 & 11,669 \\
\hline 215 & 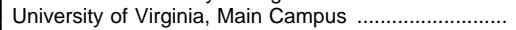 & Va. & 1 & 1 & 21,110 & 21,728 & 21,488 & 21,942 & 10,076 & 11,412 & 17,730 & 3,758 \\
\hline 216 & Virginia Commonwealth University ....................... & Va. & 1 & 1 & 21,764 & 21,349 & 21,681 & 22,702 & 8,668 & 13,013 & 13,959 & 7,722 \\
\hline 217 & 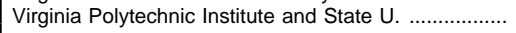 & Va. & 1 & 1 & 25,568 & 25,492 & 26,645 & 27,208 & 15,713 & 10,932 & 23,624 & 3,021 \\
\hline 218 & University of Washington & Wash. & 1 & 1 & 33,854 & 33,996 & 34,368 & 35,367 & 17,057 & 17,311 & 28,438 & 5,930 \\
\hline 219 & Washington State University & Wash. & 1 & 1 & 18,412 & 19,571 & 20,122 & 20,243 & 10,156 & 9,966 & 16,892 & 3,230 \\
\hline 220 & West Virginia University & W.Va. & 1 & 1 & 20,854 & 21,517 & 21,743 & 22,238 & 10,729 & 11,014 & 17,074 & 4,669 \\
\hline 221 & Milwaukee Area Technical College & Wisc. & 1 & 2 & 21,600 & 21,903 & 21,903 & 19,757 & 9,205 & 12,698 & 5,268 & 16,635 \\
\hline 222 & University of Wisconsin, Madison & Wisc. & 1 & 1 & 43,209 & 39,005 & 39,289 & - & 19,253 & 20,036 & 33,717 & 5,572 \\
\hline 223 & 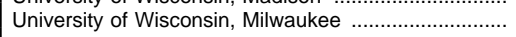 & Wisc. & 1 & 1 & 26,020 & 21,891 & 21,525 & - & 9,665 & 11,860 & 13,224 & 8,301 \\
\hline 224 & Community College of the Air Force ${ }^{4}$ & Ala. & 1 & 2 & 29,567 & 69,611 & 63,123 & - & 53,078 & 10,045 & 1,267 & 61,856 \\
\hline
\end{tabular}


Table 216.-Selected statistics for college and university campuses enrolling more than 14,600 students in 1996-Continued

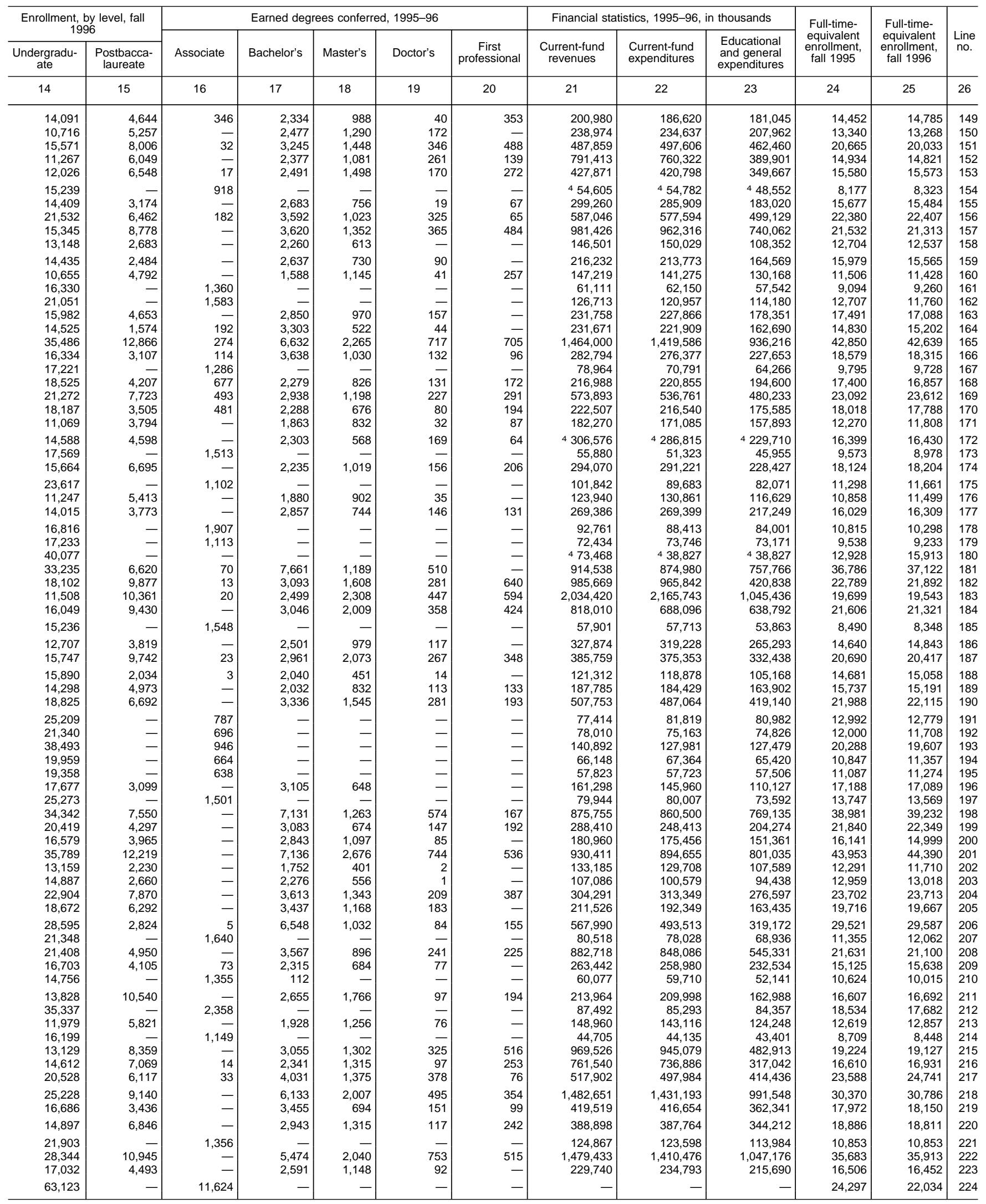

1 Publicly controlled institutions are identified by a "1;" private, nonprofit, by a "2;" and private, proprietary, by a "3."

2 The types of institutions are identified as follows: "1" for 4-year institutions; and "2" for 2-year institutions.

${ }^{3}$ Only includes institutions with reported or estimated values.

${ }^{4}$ Estimated.
—Data not available or not applicable.

SOURCE: U.S. Department of Education, National Center for Education Statistics, Integrated Postsecondary Education Data System (IPEDS), "Completions," "Finance," and "Fall Enrollment" surveys. (This table was prepared December 1998.) 
Table 217.-Enrollment of the 120 largest college and university campuses: Fall 1996

\begin{tabular}{|c|c|c|c|c|c|c|c|c|c|c|c|}
\hline Institution & State & Rank & $\begin{array}{l}\text { Con- } \\
\text { trol }^{1}\end{array}$ & Type $^{2}$ & \begin{tabular}{|c} 
Total \\
enroll- \\
ment, \\
fall \\
$1996^{3}$
\end{tabular} & Institution & State & Rank & $\begin{array}{l}\text { Con- } \\
\text { trol }{ }^{1}\end{array}$ & Type $^{2}$ & $\begin{array}{c}\text { Total } \\
\text { enroll- } \\
\text { ment, } \\
\text { fall } \\
1996^{3}\end{array}$ \\
\hline 1 & 2 & 3 & 4 & 5 & 6 & 1 & 2 & 3 & 4 & 5 & 6 \\
\hline Community College of the Air Force 4 & Ala. & 1 & 1 & 2 & 63,123 & Austin Community College & Tex. & 61 & 1 & 2 & 25,209 \\
\hline University of Minnesota, Twin Cities ... & Minn. & 2 & 1 & 1 & 51,388 & University of North Texas ... & Tex. & 62 & 1 & 1 & 24,964 \\
\hline 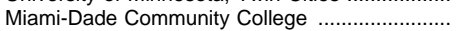 & Fla. & 3 & 1 & 2 & 48,795 & University of Illinois at Chicago . & III. & 63 & 1 & 1 & 24,931 \\
\hline Ohio State University, Main Campus ……........... & Ohio & 4 & 1 & 1 & 48,352 & lowa State University & lowa & 64 & 1 & 1 & 24,899 \\
\hline The University of Texas at Austin ........................ & Tex. & 5 & 1 & 1 & 48,008 & University of Kansas Main Campus ...................... & Kans. & 65 & 1 & 1 & 24,874 \\
\hline Arizona State University, Main Campus & Ariz. & 6 & 1 & 1 & 42,463 & Oakland Community College & Mich. & 66 & 1 & 2 & 24,732 \\
\hline 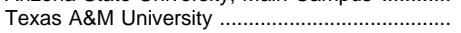 & Tex. & 7 & 1 & 1 & 41,892 & 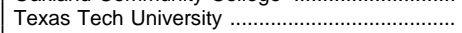 & Tex. & 67 & 1 & 1 & 24,716 \\
\hline Michigan State University & Mich. & 8 & 1 & 1 & 41,545 & Community College of Southern Nevada & Nev. & 68 & 1 & 2 & 24,678 \\
\hline International Correspondence Schools ................ & Pa. & 9 & 3 & 3 & 40,077 & Rancho Santiago College & Calif. & 69 & 1 & 2 & 24,611 \\
\hline 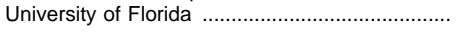 & Fla. & 10 & 1 & 1 & 39,863 & 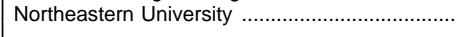 & Mass. & 70 & 2 & 1 & 24,579 \\
\hline Pennsylvania State University, Main Campus ... & Pa. & 11 & 1 & 1 & 39,855 & Harvard University . & Mass. & 71 & 2 & 1 & 24,409 \\
\hline University of Wisconsin, Madison ……................... & Wisc. & 12 & 1 & 1 & 39,289 & Macomb Community College & Mich. & 72 & 1 & 2 & 24,400 \\
\hline University of Illinois at Urbana ........ & III. & 13 & 1 & 1 & 38,841 & George Mason University . & Va. & 73 & 1 & 1 & 24,368 \\
\hline Houston Community College System & Tex. & 14 & 1 & 2 & 38,493 & Central Michigan University & Mich. & 74 & 1 & 1 & 24,249 \\
\hline Purdue University, Main Campus ......................... & Ind. & 15 & 1 & 1 & 36,893 & University of North Carolina at Chapel Hill .. & N.C. & 75 & 1 & 1 & 24,123 \\
\hline University of Michigan, Ann Arbor & Mich. & 16 & 1 & 1 & 36,525 & California State University, Fullerton & Calif. & 76 & 1 & 1 & 24,040 \\
\hline New York University .... & N.Y. & 17 & 2 & 1 & 36,305 & University of California, Davis . & Calif. & 77 & 1 & 1 & 23,931 \\
\hline University of South Florida & Fla. & 18 & 1 & 1 & 36,266 & Valencia Community College & Fla. & 78 & 1 & 2 & 23,901 \\
\hline University of California, Los Angeles ..................... & Calif. & 19 & 1 & 1 & 35,594 & 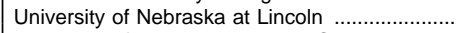 & Nebr. & 79 & 1 & 1 & 23,887 \\
\hline Northern Virginia Community College ................. & Va. & 20 & 1 & 2 & 35,337 & University of New Mexico, Main Campus ........... & N.Mex. & 80 & 1 & 1 & 23,762 \\
\hline University of Arizona & Ariz. & 21 & 1 & 1 & 34,777 & De Anza College & Calif. & 81 & 1 & 2 & 23,697 \\
\hline Indiana University, Bloomington & Ind. & 22 & 1 & 1 & 34,700 & Portland Community College & Oreg. & 82 & 1 & 2 & 23,617 \\
\hline 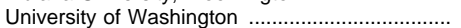 & Wash. & 23 & 1 & 1 & 34,368 & SUNY at Buffalo & N.Y. & 83 & 1 & 1 & 23,577 \\
\hline Rutgers University, New Brunswick . & N.J. & 24 & 1 & 1 & 33,862 & University of Kentucky & Ky. & 84 & 1 & 1 & 23,431 \\
\hline University of Maryland, College Park Campus .. & Md. & 25 & 1 & 1 & 33,006 & California State University, Sacramento .............. & Calif. & 85 & 1 & 1 & 23,420 \\
\hline Brigham Young University ....... & Utah & 26 & 2 & 1 & 31,419 & Georgia State University & Ga. & 86 & 1 & 1 & 23,410 \\
\hline Wayne State University .... & Mich. & 27 & 1 & 1 & 31,185 & Mt. San Antonio College . & Calif. & 87 & 1 & 2 & 22,960 \\
\hline University of Houston, University Park & Tex. & 28 & 1 & 1 & 30,774 & University of Akron Main Campus & Ohio & 88 & 1 & 1 & 22,732 \\
\hline Florida State University .................................... & Fla. & 29 & 1 & 1 & 30,154 & Santa Rosa Junior College & Calif. & 89 & 1 & 2 & 22,663 \\
\hline San Diego State University ................................... & Calif. & 30 & 1 & 1 & 29,981 & 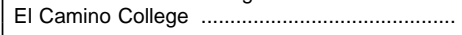 & Calif. & 90 & 1 & 2 & 22,657 \\
\hline University of California, Berkeley & Calif. & 31 & 1 & 1 & 29,797 & Michigan Univer & Mich. & 91 & 1 & 1 & 22,541 \\
\hline Florida International University .... & Fla. & 32 & 1 & 1 & 29,720 & University of Missouri, Columbia . & Mo. & 92 & 1 & 1 & 22,519 \\
\hline College of Du Page & III. & 33 & 1 & 2 & 29,698 & University of Oklahoma, Norman Campus ........ & Okla. & 93 & 1 & 1 & 22,359 \\
\hline University of Georgia & Ga. & 34 & 1 & 1 & 29,404 & Santa Monica College & Calif. & 94 & 1 & 2 & 22,068 \\
\hline University of Cincinnati, Main Campus ............... & Ohio & 35 & 1 & 1 & 28,995 & Milwaukee Area Technical College ..................... & Wisc. & 95 & 1 & 2 & 21,903 \\
\hline Boston University & Mass. & 36 & 2 & 1 & 28,706 & University of Pennsylvania & $\mathrm{Pa}$. & 96 & 2 & 1 & 21,869 \\
\hline University of lowa & lowa & 37 & 1 & 1 & 28,447 & Southern Illinois University, Carbondale . & III. & 97 & 1 & 1 & 21,863 \\
\hline University of Southern California & Calif. & 38 & 2 & 1 & 28,081 & University of Connecticut & Conn. & 98 & 1 & 1 & 21,805 \\
\hline North Carolina State University at Raleigh ......... & N.C. & 39 & 1 & 1 & 27,994 & Auburn University, Main Campus & Ala. & 99 & 1 & 1 & 21,778 \\
\hline 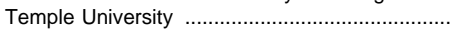 & Pa. & 40 & 1 & 1 & 27,979 & Mesa Community College .............. & Ariz. & 100 & 1 & 2 & 21,761 \\
\hline University of Central Florida & Fla. & 41 & 1 & 1 & 27,684 & West Virginia University & W.Va. & 101 & 1 & 1 & 21,743 \\
\hline University of Colorado at Boulder . & Colo. & 42 & 1 & 1 & 27,546 & University of Toledo & Ohio & 102 & 1 & 1 & 21,692 \\
\hline Louisiana St. U. \& A\&M \& Hebert Laws Center & La. & 43 & 1 & 1 & 27,505 & Virginia Commonwealth University & Va. & 103 & 1 & 1 & 21,681 \\
\hline California State University, Long Beach ........ & Calif. & 44 & 1 & 1 & 27,431 & Pasadena City College & Calif. & 104 & 1 & 2 & 21,680 \\
\hline 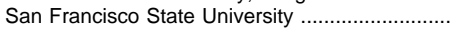 & Calif. & 45 & 1 & 1 & 27,420 & Northern Illinois University ......... & III. & 105 & 1 & 1 & 21,609 \\
\hline , Northridge & Calif. & 46 & 1 & 1 & 27,189 & Milwaukee .................... & Wisc. & 106 & 1 & 1 & 21,525 \\
\hline Pima Community College ............. & Ariz. & 47 & 1 & 2 & 27,177 & 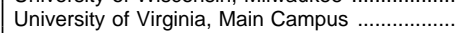 & Va. & 107 & 1 & 1 & 21,488 \\
\hline Indiana U.-Purdue U. at Indianapolis & Ind. & 48 & 1 & 1 & 27,011 & Orange Coast College & Calif. & 108 & 1 & 2 & 21,405 \\
\hline City College of San Francisco .............................. & Calif. & 49 & 1 & 2 & 26,933 & University of Delaware. & Del. & 109 & 1 & 1 & 21,380 \\
\hline Virginia Polytechnic Institute and State U. ......... & Va. & 50 & 1 & 1 & 26,645 & 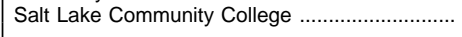 & Utah & 110 & 1 & 2 & 21,348 \\
\hline Broward Community College & Fla. & 51 & 1 & 2 & 26,435 & El Paso Community College & Tex. & 111 & 1 & 2 & 21,340 \\
\hline University of Utah & Utah & 52 & 1 & 1 & 26,358 & a Community College District & Ohio & 112 & 1 & 2 & 21,051 \\
\hline San Jose State University & Calif. & 53 & 1 & 1 & 25,874 & Florida Community College at Jacksonville & Fla. & 113 & 1 & 2 & 20,944 \\
\hline Colorado State University & Colo. & 54 & 1 & 1 & 25,865 & Utah State University & Utah & 114 & 1 & 1 & 20,808 \\
\hline 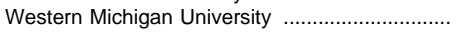 & Mich. & 55 & 1 & 1 & 25,699 & Southwest Texas State University ……................. & Tex. & 115 & 1 & 1 & 20,776 \\
\hline University of Tennesse & Tenn. & 56 & 1 & 1 & 25,517 & Kent State & Ohio & 116 & 1 & 1 & 20,635 \\
\hline University of South Carolina at Columbia ........... & S.C. & 57 & 1 & 1 & 25,489 & The University of Texas at Arlington ...................... & Tex. & 117 & 1 & 1 & 20,544 \\
\hline University of Pittsburgh, Main Campus …............ & $\mathrm{Pa}$. & 58 & 1 & 1 & 25,479 & Palomar College. & Calif. & 118 & 1 & 2 & 20,509 \\
\hline University of Massachusetts, Amherst ................. & Mass. & 59 & 1 & 1 & 25,422 & 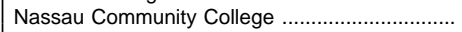 & N.Y. & 119 & 1 & 2 & 20,389 \\
\hline Tarrant County Junior College .............. & Tex. & 60 & 1 & 2 & 25,273 & University of Louisville ... & Ky. & 120 & 1 & 1 & 20,374 \\
\hline
\end{tabular}

${ }^{1}$ Publicly controlled institutions are identified by a "1," private, nonprofit, by a "2," and private, proprietary, by a "3."

2 The types of institutions are identified as follows: "1" for 4-year institutions; and " 2 " for 2-year institutions.

${ }^{3}$ College and university campuses ranked by fall 1996 preliminary enrollment data.
${ }^{4}$ Estimated.

SOURCE: U.S. Department of Education, National Center for Education Statistics, Integrated Postsecondary Education Data System (IPEDS), "Fall Enrollment, 1996" survey. (This table was prepared July 1998.) 
Table 218.-Selected statistics on historically black colleges and universities:1 1980, 1990 , and 1996

\begin{tabular}{|c|c|c|c|c|c|}
\hline \multirow{2}{*}{ Item } & \multirow{2}{*}{ Total } & \multicolumn{2}{|c|}{ Public } & \multicolumn{2}{|c|}{ Private } \\
\hline & & 4-year & 2-year & 4-year & 2-year \\
\hline 1 & 2 & 3 & 4 & 5 & 6 \\
\hline Number of institutions, fall 1996 & 104 & 40 & 10 & 51 & 3 \\
\hline 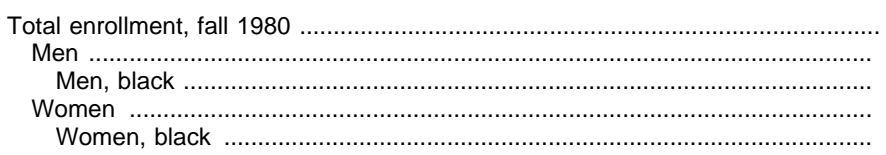 & $\begin{array}{r}233,557 \\
106,387 \\
81,818 \\
127,170 \\
109,171\end{array}$ & $\begin{array}{r}155,085 \\
70,236 \\
53,654 \\
84,849 \\
70,582\end{array}$ & $\begin{array}{r}13,132 \\
6,758 \\
2,781 \\
6,374 \\
4,644\end{array}$ & $\begin{array}{l}62,924 \\
28,352 \\
24,412 \\
34,572 \\
32,589\end{array}$ & $\begin{array}{r}2,416 \\
1,041 \\
971 \\
1,375 \\
1,356\end{array}$ \\
\hline 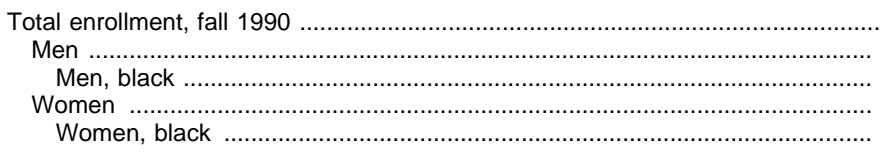 & $\begin{array}{r}257,152 \\
105,157 \\
82,897 \\
151,995 \\
125,785\end{array}$ & $\begin{array}{r}171,969 \\
70,220 \\
54,041 \\
101,749 \\
80,883\end{array}$ & $\begin{array}{r}15,077 \\
6,321 \\
3,214 \\
8,756 \\
6,066\end{array}$ & $\begin{array}{l}68,528 \\
28,054 \\
25,198 \\
40,474 \\
38,115\end{array}$ & $\begin{array}{r}1,578 \\
562 \\
444 \\
1,016 \\
721\end{array}$ \\
\hline 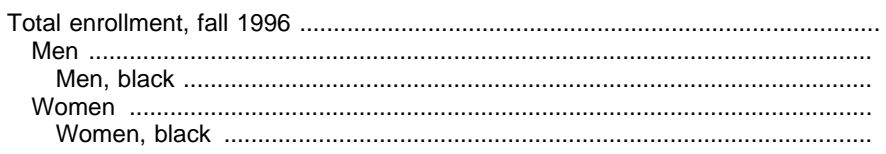 & $\begin{array}{r}273,931 \\
110,056 \\
88,257 \\
163,875 \\
135,241\end{array}$ & $\begin{array}{r}182,063 \\
72,929 \\
57,845 \\
109,134 \\
87,659\end{array}$ & $\begin{array}{r}18,506 \\
7,763 \\
3,657 \\
10,743 \\
6,381\end{array}$ & $\begin{array}{l}72,383 \\
28,900 \\
26,348 \\
43,483 \\
40,696\end{array}$ & $\begin{array}{l}979 \\
464 \\
407 \\
515 \\
505\end{array}$ \\
\hline 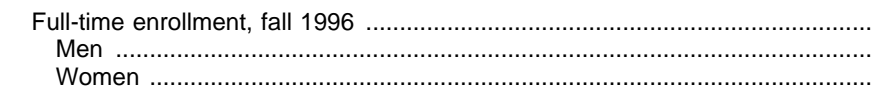 & $\begin{array}{r}211,940 \\
87,042 \\
124,898\end{array}$ & $\begin{array}{r}136,341 \\
56,756 \\
79,585\end{array}$ & $\begin{array}{l}9,927 \\
4,016 \\
5,911\end{array}$ & $\begin{array}{l}64,959 \\
25,959 \\
39,000\end{array}$ & $\begin{array}{l}713 \\
311 \\
402\end{array}$ \\
\hline 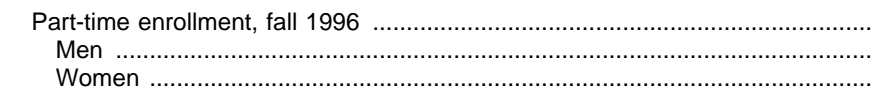 & $\begin{array}{l}61,991 \\
23,014 \\
38,977\end{array}$ & $\begin{array}{l}45,722 \\
16,173 \\
29,549\end{array}$ & $\begin{array}{l}8,579 \\
3,747 \\
4,832\end{array}$ & $\begin{array}{l}7,424 \\
2,941 \\
4,483\end{array}$ & $\begin{array}{l}266 \\
153 \\
113\end{array}$ \\
\hline Earned degrees conferred, 1995-96 & & & & & \\
\hline $\begin{array}{l}\text { Associate } \\
\text { Men } \\
\text { Men, black } \\
\text { Women, black }\end{array}$ & $\begin{array}{r}3,053 \\
1,111 \\
474 \\
1,942 \\
1,052\end{array}$ & $\begin{array}{r}1,285 \\
481 \\
199 \\
804 \\
313\end{array}$ & $\begin{array}{r}1,496 \\
535 \\
220 \\
961 \\
588\end{array}$ & $\begin{array}{r}137 \\
43 \\
29 \\
94 \\
76\end{array}$ & $\begin{array}{r}135 \\
52 \\
26 \\
83 \\
75\end{array}$ \\
\hline $\begin{array}{l}\text { Bachelor's } \\
\text { Men } \\
\text { Wenen black } \\
\text { Women, black }\end{array}$ & $\begin{array}{r}29,728 \\
10,884 \\
9,087 \\
18,844 \\
16,305\end{array}$ & $\begin{array}{r}20,187 \\
7,584 \\
6,007 \\
12,603 \\
10,335\end{array}$ & $\begin{array}{l}- \\
- \\
-\end{array}$ & $\begin{array}{l}9,541 \\
3,300 \\
3,080 \\
6,241 \\
5,970\end{array}$ & $\begin{array}{l}- \\
- \\
-\end{array}$ \\
\hline $\begin{array}{l}\text { Master's } \\
\text { Men } \\
\text { Men, black } \\
\text { Women }\end{array}$ & $\begin{array}{l}5,848 \\
1,881 \\
1,088 \\
3,967 \\
2,718\end{array}$ & $\begin{array}{r}4,777 \\
1,545 \\
850 \\
3,232 \\
2,111\end{array}$ & $\begin{array}{l}- \\
- \\
-\end{array}$ & $\begin{array}{r}1,071 \\
336 \\
238 \\
735 \\
607\end{array}$ & $\begin{array}{l}- \\
- \\
-\end{array}$ \\
\hline $\begin{array}{l}\text { Doctor's } \\
\text { Men } \\
\text { Men, black } \\
\text { Women, black }\end{array}$ & $\begin{array}{r}236 \\
127 \\
83 \\
109 \\
83\end{array}$ & $\begin{array}{r}105 \\
50 \\
26 \\
55 \\
38\end{array}$ & $\begin{array}{l}- \\
- \\
-\end{array}$ & $\begin{array}{r}131 \\
77 \\
57 \\
54 \\
45\end{array}$ & $\begin{array}{l}- \\
- \\
-\end{array}$ \\
\hline $\begin{array}{l}\text { First-professional } \\
\text { Men } \\
\text { Men, black } \\
\text { Women } \ldots \ldots \ldots \ldots\end{array}$ & $\begin{array}{r}1,178 \\
526 \\
344 \\
652 \\
497\end{array}$ & $\begin{array}{l}442 \\
212 \\
105 \\
230 \\
162\end{array}$ & $\begin{array}{l}- \\
- \\
-\end{array}$ & $\begin{array}{l}736 \\
314 \\
239 \\
422 \\
335\end{array}$ & $\begin{array}{l}- \\
- \\
-\end{array}$ \\
\hline $\begin{array}{c}\text { Financial statistics, 1995-96, } \\
\text { in thousands of dollars }\end{array}$ & & & & & \\
\hline $\begin{array}{l}\text { Current-fund revenues } \\
\text { Tuition and fees } \\
\text { Federal government }{ }^{2} \\
\text { State governments }{ }^{2} \\
\text { Local governments }{ }^{2} \\
\text { Private gifts, grants, and contracts } \\
\text { Endowment income and services } \\
\text { Other sources }\end{array}$ & $\begin{array}{r}\$ 3,855,794 \\
942,423 \\
816,612 \\
942,577 \\
96,157 \\
240,160 \\
37,014 \\
688,975 \\
91,876\end{array}$ & $\begin{array}{r}\$ 2,037,292 \\
419,116 \\
322,323 \\
844,659 \\
80,093 \\
36,703 \\
2,616 \\
284,649 \\
47,134\end{array}$ & $\begin{array}{r}\$ 96,108 \\
18,198 \\
16,992 \\
49,045 \\
6,793 \\
170 \\
3 \\
3,651 \\
1,255\end{array}$ & $\begin{array}{r}\$ 1,712,458 \\
501,837 \\
474,154 \\
48,406 \\
9,064 \\
202,049 \\
34,385 \\
399,285 \\
43,276\end{array}$ & $\begin{array}{r}\$ 9,936 \\
3,272 \\
3,142 \\
466 \\
207 \\
1,237 \\
10 \\
1,391 \\
211\end{array}$ \\
\hline $\begin{array}{l}\text { Current-fund expenditures } \\
\text { Educational and general expenditures } \\
\text { Auxiliary enterprises } \\
\text { Hospitals } \\
\text { Independent operations }\end{array}$ & $\begin{array}{r}3,744,816 \\
3,112,805 \\
388,753 \\
233,460 \\
9,798\end{array}$ & $\begin{array}{r}2,003,637 \\
1,738,574 \\
265,063 \\
0 \\
0\end{array}$ & $\begin{array}{r}95,818 \\
92,034 \\
3,785 \\
0 \\
0\end{array}$ & $\begin{array}{r}1,634,808 \\
1,271,960 \\
119,590 \\
233,460 \\
9,798\end{array}$ & $\begin{array}{r}10,554 \\
10,238 \\
316 \\
0 \\
0\end{array}$ \\
\hline
\end{tabular}

${ }^{1}$ Historically black colleges and universities are accredited institutions of higher education established prior to 1964 with the principal mission of educating black Americans Federal regulations, 20 U.S. Code, Section 1061 (2), allow for certain exceptions to the founding date. Most institutions are in the southern and border states and were established prior to 1954

2 Includes appropriations, grants, contracts, and independent operations.

-Not applicable.
NOTE.-Because of rounding, details may not add to totals.

SOURCE: U.S. Department of Education, National Center for Education Statistics, Higher Education General Information Survey (HEGIS), "Fall Enrollment in Institutions of Higher Education;" and Integrated Postsecondary Education Data System (IPEDS), "Fal Enrollment," "Completions," and "Finance" surveys. (This table was prepared November 1998.) 
Table 219.-Fall enrollment, degrees conferred, and expenditures in historically black colleges and universities, by institution: 1996

\begin{tabular}{|c|c|c|c|c|c|c|c|c|c|c|}
\hline \multirow[b]{2}{*}{ Institution } & \multirow{2}{*}{$\begin{array}{l}\text { Type } \\
\text { and } \\
\text { con- } \\
\text { trol }^{1}\end{array}$} & \multicolumn{2}{|c|}{ Enrollment, 1996} & \multicolumn{5}{|c|}{ Degrees conferred, 1995-96 } & \multicolumn{2}{|c|}{$\begin{array}{l}\text { Expenditures, } 1995-96 \\
\quad \text { (In thousands) }\end{array}$} \\
\hline & & Total & Black & $\begin{array}{l}\text { Associ- } \\
\text { ate }\end{array}$ & $\begin{array}{l}\text { Bach- } \\
\text { elor's }\end{array}$ & Master's & Doctor's & $\begin{array}{c}\text { First- } \\
\text { profes- } \\
\text { sional }\end{array}$ & $\begin{array}{l}\text { Current-fund } \\
\text { expenditures }\end{array}$ & $\begin{array}{l}\text { Educational } \\
\text { and general } \\
\text { expenditures }\end{array}$ \\
\hline 1 & 2 & 3 & 4 & 5 & 6 & 7 & 8 & 9 & 10 & 11 \\
\hline Total & - & 273,931 & 223,498 & 3,053 & 29,728 & 5,848 & 236 & 1,178 & $\$ 3,744,816$ & $\$ 3,112,805$ \\
\hline **Alabama A\&M University, AL & 1 & 5,263 & 4,137 & - & 589 & 382 & 8 & - & 63,407 & 56,728 \\
\hline Alabama State University, AL ………............... & 1 & 5,552 & 4,952 & 1 & 419 & 123 & - & - & 56,228 & 47,697 \\
\hline Bishop State Community College, AL .................. & 2 & 3,661 & 1,945 & 435 & - & - & - & - & 21,972 & 20,562 \\
\hline C. A. Fredd State Technical College, $\mathrm{AL}^{2} \ldots \ldots \ldots$ & 2 & 149 & 87 & 4 & - & - & - & - & - & - \\
\hline Concordia College, AL & 3 & 473 & 454 & 38 & 17 & - & - & - & 2,942 & 2,407 \\
\hline J.F. Drake Technical College, AL ............................ & 2 & 678 & 335 & 20 & - & - & - & - & 4,693 & 4,549 \\
\hline Lawson State Community College, AL .............. & 2 & 1,701 & 1,650 & 168 & - & - & - & - & 11,303 & 10,620 \\
\hline Miles College, AL ................................... & 3 & 1,202 & 1,199 & - & 140 & - & - & - & 9,950 & 8,808 \\
\hline Oakwood College, AL & 3 & 1,666 & 1,351 & 42 & 212 & - & - & - & 23,276 & 18,593 \\
\hline Selma University, $\mathrm{AL}^{3}$ & 3 & 66 & 62 & 1 & 31 & - & - & - & 5,036 & 4,661 \\
\hline Stillman College, AL ....... & 3 & 1,014 & 973 & - & 138 & - & - & - & 12,497 & 10,646 \\
\hline 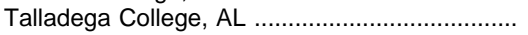 & 3 & 633 & 631 & - & 131 & - & - & - & 12,671 & 11,464 \\
\hline Trenholm State Technical College, AL .............. & 2 & 695 & 537 & 55 & - & - & - & - & 7,293 & 7,124 \\
\hline 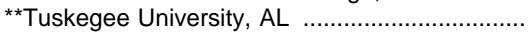 & 3 & 3,175 & 2,887 & - & 526 & 49 & - & 44 & 70,736 & 62,487 \\
\hline Arkansas Baptist College, AR & 3 & 225 & 224 & 3 & 22 & - & - & - & 2,061 & 1,959 \\
\hline Philander Smith College, AR & 3 & 925 & 874 & - & 118 & - & - & - & 6,656 & 6,200 \\
\hline Shorter College, AR & 4 & 252 & 205 & 30 & - & - & - & - & 1,524 & 1,498 \\
\hline${ }^{*}$ University of Arkansas, Pine Bluff, AR ............... & 1 & 3,078 & 2,794 & - & 362 & 11 & - & - & 37,250 & 33,067 \\
\hline${ }^{\star \star}$ Delaware State College, DE & 1 & 3,328 & 2,271 & - & 326 & 125 & - & - & 45,652 & 38,872 \\
\hline Howard University, DC & 3 & 10,248 & 8,780 & - & 1,333 & 456 & 84 & 322 & 553,976 & 297,794 \\
\hline${ }^{*}$ University of the District of Columbia, DC ....... & 1 & 7,456 & 5,398 & 280 & 586 & 132 & - & - & 98,632 & 97,399 \\
\hline Bethune-Cookman College, $\mathrm{F}$ & 3 & 2,335 & 2,168 & - & 230 & - & - & - & 33,555 & 29,098 \\
\hline Edward Waters College, FL & 3 & 429 & 377 & - & 78 & - & - & - & 6,276 & 5,987 \\
\hline${ }^{* *}$ Florida A\&M University, FL . & 1 & 10,667 & 9,527 & 45 & 1,463 & 223 & 3 & 30 & 141,996 & 129,052 \\
\hline Florida Memorial College, FL ................................ & 3 & 1,564 & 1,406 & - & 235 & - & - & - & 16,402 & 15,111 \\
\hline Albany State College, GA & 1 & 3,144 & 2,809 & - & 321 & 72 & - & - & 31,345 & 26,639 \\
\hline Clark Atlanta University, G & 3 & 5,798 & 5,569 & - & 525 & 294 & 26 & - & 122,416 & 116,080 \\
\hline${ }^{* *}$ Fort Valley State Co & 1 & 3,024 & 2,785 & 8 & 304 & 82 & - & - & 34,196 & 30,163 \\
\hline Interdenominational Theological Center, GA & 3 & 394 & 365 & - & - & 22 & 6 & 83 & 6,462 & 6,414 \\
\hline Morehouse College, GA . & 3 & 2,926 & 2,897 & - & 508 & - & - & - & 51,068 & 43,304 \\
\hline Morehouse School of Medicine, GA & 3 & 176 & 149 & - & - & - & - & 31 & 56,179 & 56,179 \\
\hline wn College, GA & 3 & 1,980 & 1,883 & - & 279 & - & - & - & 25,661 & 22,414 \\
\hline 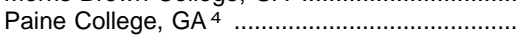 & 3 & 829 & 794 & - & 54 & - & - & - & 9,602 & 8,341 \\
\hline Savannah State College, GA …….......................... & 1 & 2,822 & 2,576 & - & 357 & 3 & - & - & 29,299 & 24,315 \\
\hline 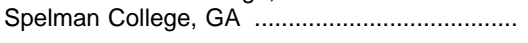 & 3 & 1,897 & 1,802 & - & 469 & - & 一 & - & 42,709 & 35,654 \\
\hline${ }^{* * K e n t u c k y ~ S t a t e ~ U n i v e r s i t y, ~ K Y ~}$ & 1 & 2,356 & 1,239 & 67 & 192 & 23 & - & - & 36,561 & 33,374 \\
\hline Dillard University, LA & 3 & 1,543 & 1,537 & - & 236 & - & - & - & 19,322 & 17,779 \\
\hline Grambling State University, LA ................ & 1 & 6,701 & 6,384 & 58 & 855 & 208 & 8 & - & 65,548 & 47,796 \\
\hline${ }^{* *}$ Southern University and A\&M College, & & & & & & & & & & \\
\hline Baton Rouge, LA & 1 & 10,259 & 9,635 & 30 & 955 & 199 & - & 89 & 95,447 & 83,120 \\
\hline $\begin{array}{l}\text { Southern University, New Orleans, LA ............... } \\
\text { Southern University, Shreveport-Bossier }\end{array}$ & 1 & 4,280 & 3,923 & 16 & 472 & 140 & - & - & 21,808 & 20,629 \\
\hline City Campus, LA. & 2 & 1,270 & 1,153 & 103 & - & - & - & - & 7,392 & 7,303 \\
\hline Xavier University of Louisiana, LA ........................ & 3 & 3,526 & 3,093 & - & 444 & 89 & - & 89 & 53,337 & 49,293 \\
\hline Bowie State Universit & 1 & 5,067 & 3,838 & - & 510 & 500 & - & - & 37,734 & 32,283 \\
\hline Coppin State College, MD ..... & 1 & 3,643 & 3,418 & - & 247 & 111 & - & - & 26,297 & 23,701 \\
\hline Morgan State University, MD & 1 & 5,888 & 5,524 & - & 705 & 90 & 3 & - & 77,314 & 65,668 \\
\hline${ }^{*}$ University of Maryland, Eastern Shore, MD .... & 1 & 3,166 & 2,237 & - & 346 & 54 & 3 & - & 39,790 & 32,672 \\
\hline Lewis College of Business, MI. & 4 & 223 & 221 & 26 & - & - & 一 & - & 2,020 & 2,016 \\
\hline **Alcorn State University, MS & 1 & 3,073 & 2,930 & 29 & 419 & 66 & - & - & 40,535 & 36,265 \\
\hline Coahoma Community College, MS ... & 2 & 905 & 869 & 94 & - & - & - & - & 8,518 & 7,923 \\
\hline Hinds Community College, Utica Campus, & & & & & & & & & & \\
\hline MS 5 & 2 & 1,351 & 1,102 & 58 & - & - & - & - & - & $\overline{0}$ \\
\hline Jackson State University, MS & 1 & 6,218 & 5,874 & - & 644 & 166 & 11 & - & 78,054 & 66,642 \\
\hline Mary Holmes College, MS ${ }^{4}$ & 4 & 383 & 368 & 48 & - & - & - & - & 7,010 & 6,724 \\
\hline Mississippi Valley State University, MS . & 1 & 2,228 & 2,191 & - & 169 & 1 & - & - & 25,537 & 21,444 \\
\hline Rust College, MS . & 3 & 937 & 871 & 7 & 148 & - & - & - & 11,833 & 10,306 \\
\hline Tougaloo College, MS & 3 & 981 & 979 & 2 & 163 & - & - & - & 14,109 & 13,425 \\
\hline College, MO ............................ & 1 & 1,723 & 1,277 & - & 136 & - & - & - & 12,157 & 12,157 \\
\hline${ }^{* * \text { Lincoln Univers }}$ & 1 & 2,980 & 684 & 101 & 280 & 85 & - & -1 & 29,020 & 27,039 \\
\hline
\end{tabular}


Table 219.-Fall enrollment, degrees conferred, and expenditures in historically black colleges and universities, by institution: 1996-Continued

\begin{tabular}{|c|c|c|c|c|c|c|c|c|c|c|}
\hline \multirow[b]{2}{*}{ Institution } & \multirow{2}{*}{$\begin{array}{l}\text { Type } \\
\text { and } \\
\text { con- } \\
\text { trol }^{1}\end{array}$} & \multicolumn{2}{|c|}{ Enrollment, 1996} & \multicolumn{5}{|c|}{ Degrees conferred, 1995-96 } & \multicolumn{2}{|c|}{$\begin{array}{l}\text { Expenditures, 1995-96 } \\
\text { (In thousands) }\end{array}$} \\
\hline & & Total & Black & $\begin{array}{l}\text { Associ- } \\
\text { ate }\end{array}$ & $\begin{array}{l}\text { Bach- } \\
\text { elor's }\end{array}$ & Master's & Doctor's & $\begin{array}{l}\text { First- } \\
\text { profes- } \\
\text { sional }\end{array}$ & $\begin{array}{l}\text { Current-fund } \\
\text { expenditures }\end{array}$ & $\begin{array}{l}\text { Educational } \\
\text { and general } \\
\text { expenditures }\end{array}$ \\
\hline 1 & 2 & 3 & 4 & 5 & 6 & 7 & 8 & 9 & 10 & 11 \\
\hline Barber-Scotia College, NC . & 3 & 440 & 432 & - & 51 & - & - & - & 4,851 & 4,385 \\
\hline Bennett College, NC ........... & 3 & 550 & 541 & - & 100 & - & - & - & 12,055 & 11,035 \\
\hline Elizabeth City State University, NC . & 1 & 1,931 & 1,435 & - & 352 & - & - & - & 31,790 & 26,966 \\
\hline 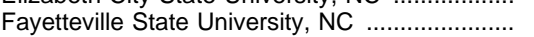 & 1 & 4,609 & 2,929 & 42 & 583 & 133 & - & - & 40,071 & 34,630 \\
\hline Johnson C. Smith University, NC ...................... & 3 & 1,438 & 1,435 & - & 169 & - & - & - & 24,847 & 22,012 \\
\hline Livingstone College, NC ................................. & 3 & 727 & 707 & - & 89 & 2 & - & 13 & 12,134 & 10,817 \\
\hline **North Carolina Agricultural and Technical & & & & & & & & & & \\
\hline State University, NC ................................ & 1 & 7,673 & 6,676 & - & 1,068 & 253 & - & - & 108,827 & 93,633 \\
\hline North Carolina Central University, NC ................ & 1 & 5,557 & 4,563 & - & 669 & 227 & - & 94 & 63,836 & 52,968 \\
\hline 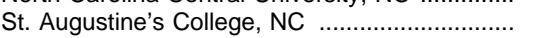 & 3 & 1,584 & 1,425 & - & 212 & - & - & - & 27,021 & 23,463 \\
\hline 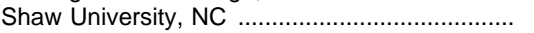 & 3 & 2,262 & 2,171 & 13 & 360 & - & - & - & 26,277 & 23,758 \\
\hline Winston-Salem State University, NC ................... & 1 & 2,889 & 2,201 & - & 509 & - & - & - & 34,652 & 28,451 \\
\hline Central State University, $\mathrm{OH} \ldots \ldots \ldots \ldots \ldots$ & 1 & 1,976 & 1,837 & - & 396 & 6 & - & - & 37,644 & 35,405 \\
\hline 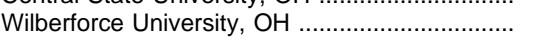 & 3 & 897 & 862 & - & 44 & - & - & - & 14,410 & 11,593 \\
\hline 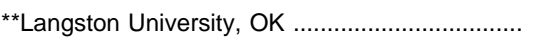 & 1 & 3,349 & 1,919 & - & 535 & 13 & - & - & 25,169 & 21,522 \\
\hline Cheyney University of Pennsylvania, PA & 1 & 1,360 & 1,262 & - & 127 & 88 & - & - & 25,528 & 22,603 \\
\hline Lincoln University, PA .............................. & 1 & 1,825 & 1,688 & - & 240 & 70 & - & - & 27,494 & 23,825 \\
\hline Allen University, SC ... & 3 & 242 & 242 & - & 17 & - & - & - & 3,008 & 2,749 \\
\hline Benedict College, SC ........ & 3 & 2,138 & 2,133 & - & 178 & - & - & - & 21,983 & 19,315 \\
\hline 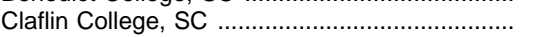 & 3 & 978 & 963 & - & 103 & - & - & - & 12,635 & 11,141 \\
\hline Clinton Junior College, $\mathrm{SC}^{3,4} \ldots \ldots \ldots$ & 4 & 121 & 118 & 31 & - & - & - & - & - & \\
\hline Denmark Technical College, SC . & 2 & 915 & 853 & 111 & - & - & - & - & 6,610 & 5,992 \\
\hline Morris College, SC ........................ & 3 & 911 & 911 & - & 110 & - & - & - & 10,803 & 9,513 \\
\hline${ }^{\star *}$ South Carolina State College, SC .. & 1 & 4,899 & 4,568 & - & 699 & 107 & 15 & - & 54,599 & 42,937 \\
\hline 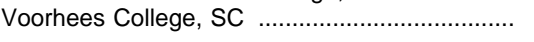 & 3 & 806 & 778 & - & 101 & - & - & - & 9,369 & 7,859 \\
\hline Fisk University, TN ........ & 3 & 812 & 806 & - & 150 & 16 & - & - & 15,784 & 13,713 \\
\hline Knoxville College, $\mathrm{TN}^{3}$ & 3 & 433 & 433 & 4 & 51 & - & - & - & 8,295 & 7,259 \\
\hline Lane College, TN 4 ..................... & 3 & 679 & 678 & - & 73 & - & - & - & 8,693 & 6,815 \\
\hline Le Moyne-Owen College, TN ................. & 3 & 983 & 950 & - & 176 & 12 & - & - & 14,614 & 14,438 \\
\hline Meharry Medical College, TN ............................. & 3 & 733 & 595 & - & - & 23 & 7 & 109 & 72,541 & 67,346 \\
\hline **Tennessee State University, TN ....................... & 1 & 8,643 & 5,852 & 150 & 794 & 262 & 33 & - & 84,191 & 77,365 \\
\hline Huston-Tillotson College, TX ........................... & 3 & 701 & 544 & - & 65 & - & - & - & 8,716 & 7,816 \\
\hline 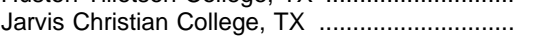 & 3 & 557 & 540 & - & 74 & - & - & - & 10,414 & 9,260 \\
\hline 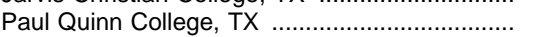 & 3 & 653 & 579 & - & 84 & - & - & - & 11,231 & 10,801 \\
\hline${ }^{\star *}$ Prairie View A\&M University, TX .................... & 1 & 6,167 & 5,267 & - & 640 & 313 & - & - & 73,293 & 60,085 \\
\hline 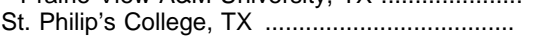 & 2 & 7,181 & 1,507 & 448 & - & - & - & - & 28,038 & 27,960 \\
\hline Southwestern Christian College, TX . & 3 & 199 & 174 & 26 & 5 & - & - & - & 3,574 & 3,230 \\
\hline Texas College, $\mathrm{TX}^{3}$ & 3 & 293 & 290 & 1 & 31 & - & - & - & 5,755 & 5,262 \\
\hline 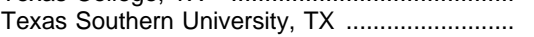 & 1 & 8,116 & 6,303 & - & 581 & 171 & 19 & 229 & 76,078 & 70,748 \\
\hline Wiley College, TX .......................... & 3 & 647 & 560 & - & 108 & - & - & - & 8,384 & 7,707 \\
\hline 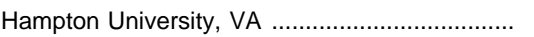 & 3 & 5,552 & 4,810 & - & 841 & 108 & - & - & 88,680 & 79,334 \\
\hline 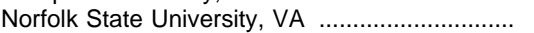 & 1 & 8,351 & 6,933 & 64 & 1,002 & 208 & 2 & - & 72,619 & 56,872 \\
\hline St. Paul's College, VA & 3 & 675 & 639 & - & 156 & - & - & - & 10,752 & 9,625 \\
\hline${ }^{* *}$ Virginia State University, VA ....... & 1 & 4,006 & 3,588 & - & 517 & 97 & - & - & 49,075 & 38,279 \\
\hline Virginia Union University, VA ..... & 3 & 1,551 & 1,521 & - & 156 & - & 8 & 45 & 19,250 & 17,309 \\
\hline Bluefield State College, WV .......... & 1 & 2,521 & 152 & 216 & 226 & - & - & - & 13,322 & 12,285 \\
\hline West Virginia State College, WV ... & 1 & 4,545 & 603 & 147 & 426 & - & - & - & 25,892 & 21,258 \\
\hline $\begin{array}{l}\text { **University of the Virgin Islands, } \\
\text { St. Thomas Campus, VI .............. }\end{array}$ & 1 & 1,730 & 1,325 & 31 & 166 & 33 & - & - & 35,750 & 32,024 \\
\hline
\end{tabular}

1 =public 4-year; 2=public 2-year; 3=private 4-year; and 4=private 2-year. 2 School merged with Sheldon State Community College. Enrollment is for C.A. Fredd State Technical College only. School reported data.

${ }^{3}$ School lost accreditation.

${ }^{4}$ School did not report. Data imputed.

5 School reported data.

** Land-grant institution.
-Data not reported or not applicable.

SOURCE: U.S. Department of Education, National Center for Education Statistics, Integrated Postsecondary Education Data System (IPEDS), "Fall Enrollment, 1996," "Completions, 1995-96," and "Finance, 1995-96" surveys. (This table was prepared November 1998.) 
Table 220.-Fall enrollment in historically black colleges and universities, by type and control of institution: 1976 to 1996

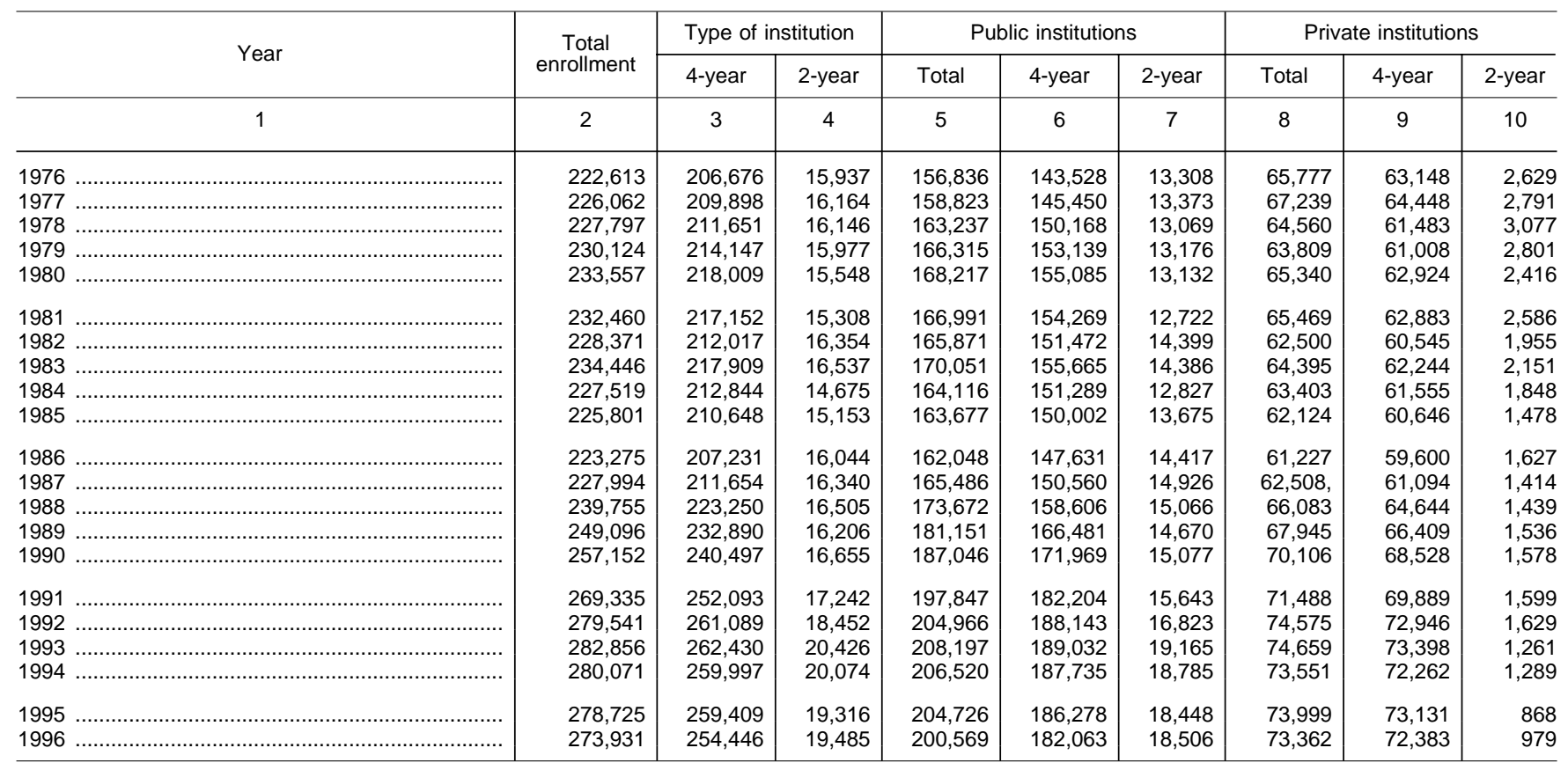

SOURCE: U.S. Department of Education, National Center for Education Statistics, Higher Education General Information Survey (HEGIS), "Fall Enrollment in Colleges and
Universities" surveys; and Integrated Postsecondary Education Data System (IPEDS), "Fall Enrollment" survey. (This table was prepared May 1998.)

Table 221.-Employees in institutions of higher education, by primary occupation, employment status, and control of institution: Fall 1976, fall 1991, and fall 1995

\begin{tabular}{|c|c|c|c|c|c|c|c|c|c|c|c|c|c|}
\hline \multirow{4}{*}{ Primary occupation and control of institution } & \multicolumn{5}{|c|}{ Fall 1976} & \multicolumn{4}{|c|}{ Fall 1991} & \multicolumn{4}{|c|}{ Fall 1995} \\
\hline & \multirow{2}{*}{\multicolumn{3}{|c|}{ Total staff }} & \multicolumn{2}{|c|}{$\begin{array}{c}\text { Full-time } \\
\text { equivalent staff }\end{array}$} & \multirow{2}{*}{\multicolumn{2}{|c|}{ Total staff }} & \multicolumn{2}{|c|}{$\begin{array}{c}\text { Full-time } \\
\text { equivalent staff }\end{array}$} & \multirow{2}{*}{\multicolumn{2}{|c|}{ Total staff }} & \multicolumn{2}{|c|}{$\begin{array}{c}\text { Full-time } \\
\text { equivalent staff }\end{array}$} \\
\hline & & & & \multirow{2}{*}{ Total } & \multirow{2}{*}{$\begin{array}{c}\text { FTE } \\
\text { stu- } \\
\text { dents } \\
\text { per } \\
\text { FTE } \\
\text { staff }\end{array}$} & & & \multirow{2}{*}{ Total } & \multirow{2}{*}{$\begin{array}{c}\text { FTE } \\
\text { stu- } \\
\text { dents } \\
\text { per } \\
\text { FTE } \\
\text { staff }\end{array}$} & & & \multirow{2}{*}{ Total } & \multirow{2}{*}{$\begin{array}{l}\text { FTE } \\
\text { stu- } \\
\text { dents } \\
\text { per } \\
\text { FTE } \\
\text { staff }\end{array}$} \\
\hline & Number & $\begin{array}{l}\text { Per- } \\
\text { cent }\end{array}$ & Full-time & & & Number & $\begin{array}{l}\text { Per- } \\
\text { cent }\end{array}$ & & & Number & $\begin{array}{l}\text { Per- } \\
\text { cent }\end{array}$ & & \\
\hline 1 & 2 & 3 & 4 & 5 & 6 & 7 & 8 & 9 & 10 & 11 & 12 & 13 & 14 \\
\hline Total, all institutions & $1,863,790$ & 100.0 & $1,339,911$ & $1,541,339$ & 5.4 & $2,545,235$ & 100.0 & $2,094,628$ & 4.9 & $2,662,075$ & 100.0 & $2,129,260$ & 4.9 \\
\hline Professional staff ... & $1,073,119$ & 57.6 & 709,400 & 845,456 & 9.8 & $1,595,460$ & 62.7 & $1,244,588$ & 8.3 & $1,744,867$ & 65.5 & $1,319,947$ & 7.8 \\
\hline Executive/administrative/managerial . & 101,263 & 5.4 & 97,003 & 98,972 & 84.0 & 144,755 & 5.7 & 141,718 & 73.1 & 147,445 & 5.5 & 143,965 & 71.8 \\
\hline Faculty (instruction and research) & 633,210 & 34.0 & 434,071 & 500,533 & 16.6 & 826,252 & 32.5 & 632,565 & 16.4 & 931,706 & 35.0 & 677,736 & 15.2 \\
\hline Instruction and research assistants & 160,086 & 8.6 & 28,007 & 82,684 & 100.5 & 197,751 & 7.8 & 81,467 & 127.2 & 215,909 & 8.1 & 89,238 & 115.8 \\
\hline Non-faculty professionals & 178,560 & 9.6 & 150,319 & 163,267 & 50.9 & 426,702 & 16.8 & 388,838 & 26.6 & 449,807 & 16.9 & 409,008 & 25.3 \\
\hline 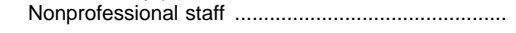 & 790,671 & 42.4 & 630,511 & 695,883 & 11.9 & 949,775 & 37.3 & 850,040 & 12.2 & 917,208 & 34.5 & 809,313 & 12.8 \\
\hline Public, total . & $1,329,122$ & 100.0 & 946,354 & $1,092,558$ & 5.8 & $1,783,328$ & 100.0 & $1,449,398$ & 5.4 & $1,865,930$ & 100.0 & $1,469,140$ & 5.3 \\
\hline Professional staff & 769,836 & 57.9 & 502,325 & 601,942 & 10.5 & $1,133,264$ & 63.5 & 868,112 & 9.1 & $1,230,006$ & 65.9 & 910,408 & 8.5 \\
\hline Executive/administrative/managerial & 60,733 & 4.6 & 58,649 & 59,579 & 106.6 & 84,446 & 4.7 & 82,835 & 94.9 & 82,396 & 4.4 & 80,504 & 96.3 \\
\hline Faculty (instruction and research) ... & 448,733 & 33.8 & 313,367 & 357,761 & 17.7 & 580,908 & 32.6 & 446,113 & 17.6 & 656,833 & 35.2 & 475,208 & 16.3 \\
\hline Instruction and research assistants & 127,925 & 9.6 & 19,076 & 63,420 & 100.1 & 173,560 & 9.7 & 70,707 & 111.2 & 181,743 & 9.7 & 74,040 & 104.7 \\
\hline Non-faculty professionals. & 132,445 & 10.0 & 111,233 & 121,182 & 52.4 & 294,350 & 16.5 & 268,458 & 29.3 & 309,034 & 16.6 & 280,655 & 27.6 \\
\hline Nonprofessional staff & 559,286 & 42.1 & 444,029 & 490,616 & 12.9 & 650,064 & 36.5 & 581,286 & 13.5 & 635,924 & 34.1 & 558,732 & 13.9 \\
\hline Private, total . & 534,668 & 100.0 & 393,557 & 448,781 & 4.4 & 761,907 & 100.0 & 645,231 & 3.9 & 796,145 & 100.0 & 660,119 & 3.9 \\
\hline Professional staff & 303,283 & 56.7 & 207,075 & 243,514 & 8.1 & 462,196 & 60.7 & 376,476 & 6.6 & 514,861 & 64.7 & 409,539 & 6.3 \\
\hline Executive/administrative/managerial . & 40,530 & 7.6 & 38,354 & 39,393 & 49.8 & 60,309 & 7.9 & 58,883 & 42.4 & 65,049 & 8.2 & 63,461 & 40.7 \\
\hline Faculty (instruction and research) & 184,477 & 34.5 & 120,704 & 142,772 & 13.7 & 245,344 & 32.2 & 186,452 & 13.4 & 274,873 & 34.5 & 202,527 & 12.8 \\
\hline Instruction and research assistants ....................... & 32,161 & 6.0 & 8,931 & 19,264 & 101.9 & 24,191 & 3.2 & 10,760 & 232.1 & 34,166 & 4.3 & 15,197 & 170.0 \\
\hline Non-faculty professionals & 46,115 & 8.6 & 39,086 & 42,085 & 46.6 & 132,352 & 17.4 & 120,380 & 20.7 & 140,773 & 17.7 & 128,353 & 20.1 \\
\hline 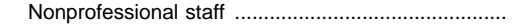 & 231,385 & 43.3 & 186,482 & 205,267 & 9.6 & 299,711 & 39.3 & 268,755 & 9.3 & 281,284 & 35.3 & 250,580 & 10.3 \\
\hline
\end{tabular}

NOTE.-Because of rounding, details may not add to totals.

SOURCE: U.S. Department of Education, National Center for Education Statistics, Higher Education General Information Survey (HEGIS), "Staff, 1976" survey; and Integrated Postsecondary Education Data System (IPEDS), "Fall Staff" surveys. (This table was prepared January 1998.) 
Table 222.-Employees in institutions of higher education, by race/ethnicity, primary occupation, employment status and type and control of institution: Fall 1995

\begin{tabular}{|c|c|c|c|c|c|c|c|c|}
\hline $\begin{array}{l}\text { Primary occupation, sex, employment status, } \\
\text { and type and control of institution }\end{array}$ & Total & $\begin{array}{c}\text { White, } \\
\text { non-- } \\
\text { Hispanic }\end{array}$ & $\begin{array}{c}\text { Black, } \\
\text { non-- } \\
\text { Hispanic }\end{array}$ & Hispanic & $\begin{array}{l}\text { Asian/ } \\
\text { Pacific } \\
\text { Islander }\end{array}$ & $\begin{array}{c}\text { American } \\
\text { Indian/ } \\
\text { Alaskan } \\
\text { Native }\end{array}$ & $\begin{array}{l}\text { Non- } \\
\text { resident } \\
\text { alien }\end{array}$ & $\begin{array}{c}\text { Race/ } \\
\text { ethnicity } \\
\text { unknown }\end{array}$ \\
\hline 1 & 2 & 3 & 4 & 5 & 6 & 7 & 8 & 9 \\
\hline Total, all institutions & $2,662,075$ & $2,043,257$ & 273,450 & 109,972 & 101,818 & 13,491 & 77,758 & 42,329 \\
\hline Professional staff .......... & $1,744,867$ & $1,400,072$ & 107,025 & 48,795 & 75,226 & 7,354 & 71,268 & 35,127 \\
\hline Executive/administrative/managerial & 147,445 & 125,569 & 13,268 & 3,991 & 2,649 & 732 & 642 & 594 \\
\hline Faculty (instruction and research) & 931,706 & 781,960 & 46,002 & 24,187 & 38,278 & 3,654 & 15,224 & 22,401 \\
\hline 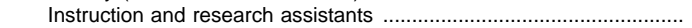 & 215,909 & 135,837 & 7,988 & 6,049 & 13,762 & 806 & 43,580 & 7,887 \\
\hline Non-faculty professionals & 449,807 & 356,706 & 39,767 & 14,568 & 20,537 & 2,162 & 11,822 & 4,245 \\
\hline 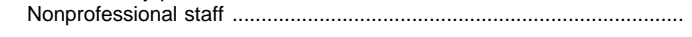 & 917,208 & 643,185 & 166,425 & 61,177 & 26,592 & 6,137 & 6,490 & 7,202 \\
\hline Men, total .. & $1,274,676$ & 980,448 & 105,860 & 50,641 & 55,078 & 6,128 & 51,861 & 24,660 \\
\hline Professional staff .... & 946,134 & 757,657 & 45,498 & 24,784 & 44,737 & 3,690 & 48,732 & 21,036 \\
\hline 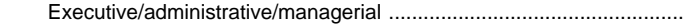 & 82,127 & 71,373 & 6,123 & 2,062 & 1,456 & 376 & 392 & 345 \\
\hline Faculty (instruction and research). & 562,893 & 472,998 & 23,050 & 13,904 & 26,340 & 2,037 & 11,003 & 13,561 \\
\hline Instruction and research assistants & 123,962 & 74,129 & 3,491 & 3,108 & 8,269 & 407 & 29,932 & 4,626 \\
\hline Non-faculty professionals .................. & 177,152 & 139,157 & 12,834 & 5,710 & 8,672 & 870 & 7,405 & 2,504 \\
\hline 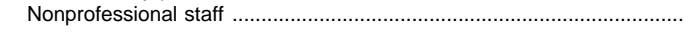 & 328,542 & 222,791 & 60,362 & 25,857 & 10,341 & 2,438 & 3,129 & 3,624 \\
\hline Women, total & $1,387,399$ & $1,062,809$ & 167,590 & 59,331 & 46,740 & 7,363 & 25,897 & 17,669 \\
\hline 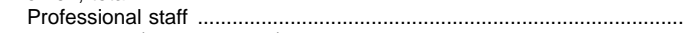 & 798,733 & 642,415 & 61,527 & 24,011 & 30,489 & 3,664 & 22,536 & 14,091 \\
\hline Executive/administrative/managerial & 65,318 & 54,196 & 7,145 & 1,929 & 1,193 & 356 & 250 & 249 \\
\hline 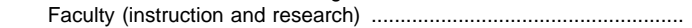 & 368,813 & 308,962 & 22,952 & 10,283 & 11,938 & 1,617 & 4,221 & 8,840 \\
\hline 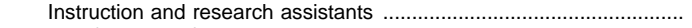 & 91,947 & 61,708 & 4,497 & 2,941 & 5,493 & 399 & 13,648 & 3,261 \\
\hline Non-faculty professionals ................... & 272,655 & 217,549 & 26,933 & 8,858 & 11,865 & 1,292 & 4,417 & 1,741 \\
\hline Nonprofessional staff ............. & 588,666 & 420,394 & 106,063 & 35,320 & 16,251 & 3,699 & 3,361 & 3,578 \\
\hline Full-time, total & $1,801,371$ & $1,397,482$ & 216,762 & 78,632 & 67,882 & 9,812 & 24,815 & 5,986 \\
\hline Professional staff & $1,066,510$ & 885,234 & 74,410 & 29,282 & 47,737 & 4,735 & 21,337 & 3,775 \\
\hline Executive/administrative/managerial . & 140,990 & 120,242 & 12,657 & 3,795 & 2,511 & 709 & 616 & 460 \\
\hline 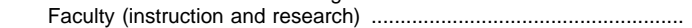 & 550,822 & 468,518 & 26,835 & 12,942 & 27,572 & 2,156 & 10,853 & 1,946 \\
\hline Non-faculty professionals & 374,698 & 296,474 & 34,918 & 12,545 & 17,654 & 1,870 & 9,868 & 1,369 \\
\hline 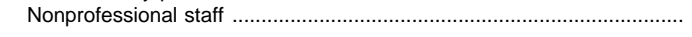 & 734,861 & 512,248 & 142,352 & 49,350 & 20,145 & 5,077 & 3,478 & 2,211 \\
\hline Part-time, total & 860,704 & 645,775 & 56,688 & 31,340 & 33,936 & 3,679 & 52,943 & 36,343 \\
\hline Professional staff & 678,357 & 514,838 & 32,615 & 19,513 & 27,489 & 2,619 & 49,931 & 31,352 \\
\hline 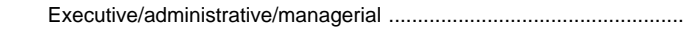 & 6,455 & 5,327 & 611 & 196 & 138 & 23 & 26 & 134 \\
\hline 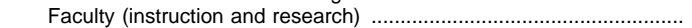 & 380,884 & 313,442 & 19,167 & 11,245 & 10,706 & 1,498 & 4,371 & 20,455 \\
\hline 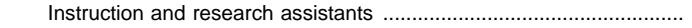 & 215,909 & 135,837 & 7,988 & 6,049 & 13,762 & 806 & 43,580 & 7,887 \\
\hline 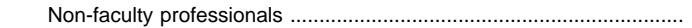 & 75,109 & 60,232 & 4,849 & 2,023 & 2,883 & 292 & 1,954 & 2,876 \\
\hline 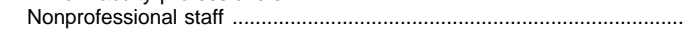 & 182,347 & 130,937 & 24,073 & 11,827 & 6,447 & 1,060 & 3,012 & 4,991 \\
\hline Public 4-year & $1,383,476$ & $1,042,710$ & 144,149 & 53,894 & 58,927 & 7,815 & 58,593 & 17,388 \\
\hline Professional staff & 893,345 & 697,570 & 52,721 & 24,200 & 45,376 & 3,998 & 55,591 & 13,889 \\
\hline Executive/administrative/managerial .. & 60,590 & 51,714 & 5,771 & 1,442 & 1,011 & 307 & 141 & 204 \\
\hline 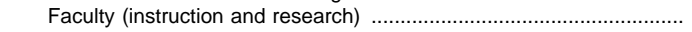 & 384,399 & 318,839 & 18,035 & 9,124 & 20,768 & 1,518 & 10,647 & 5,468 \\
\hline 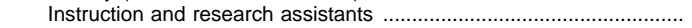 & 178,342 & 112,691 & 6,200 & 5,094 & 11,298 & 727 & 37,370 & 4,962 \\
\hline 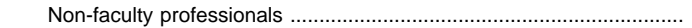 & 270,014 & 214,326 & 22,715 & 8,540 & 12,299 & 1,446 & 7,433 & 3,255 \\
\hline 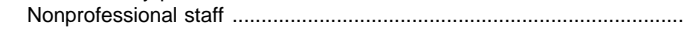 & 490,131 & 345,140 & 91,428 & 29,694 & 13,551 & 3,817 & 3,002 & 3,499 \\
\hline Private 4-year & 770,004 & 591,777 & 83,314 & 28,828 & 31,191 & 1,882 & 18,011 & 15,001 \\
\hline 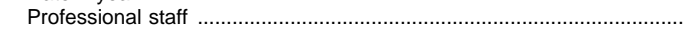 & 495,383 & 402,305 & 30,203 & 11,285 & 22,132 & 990 & 15,012 & 13,456 \\
\hline 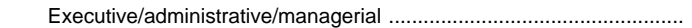 & 62,314 & 53,431 & 5,231 & 1,556 & 1,248 & 145 & 492 & 211 \\
\hline Faculty (instruction and research) & 262,660 & 220,660 & 11,357 & 5,136 & 11,216 & 452 & 4,076 & 9,763 \\
\hline 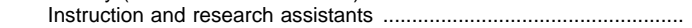 & 33,853 & 20,065 & 1,496 & 850 & 2,414 & 67 & 6,205 & 2,756 \\
\hline 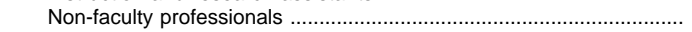 & 136,556 & 108,149 & 12,119 & 3,743 & 7,254 & 326 & 4,239 & 726 \\
\hline 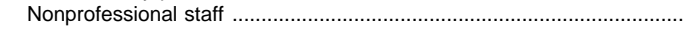 & 274,621 & 189,472 & 53,111 & 17,543 & 9,059 & 892 & 2,999 & 1,545 \\
\hline Public 2-year & 482,454 & 386,804 & 44,133 & 26,141 & 11,258 & 3,539 & 1,095 & 9,484 \\
\hline 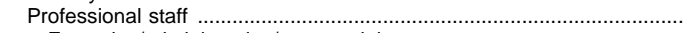 & 336,661 & 283,455 & 22,885 & 12,701 & 7,383 & 2,219 & 617 & 7,401 \\
\hline 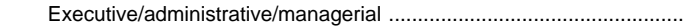 & 21,806 & 18,049 & 2,109 & 918 & 357 & 239 & 5 & 129 \\
\hline 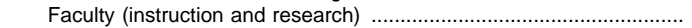 & 272,434 & 231,818 & 15,936 & 9,598 & 6,071 & 1,625 & 476 & 6,910 \\
\hline 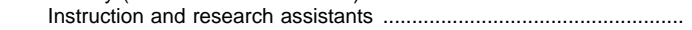 & 3,401 & 2,840 & 267 & 95 & 38 & 11 & 5 & 145 \\
\hline Non-faculty professionals & 39,020 & 30,748 & 4,573 & 2,090 & 917 & 344 & 131 & 217 \\
\hline 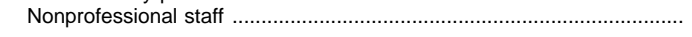 & 145,793 & 103,349 & 21,248 & 13,440 & 3,875 & 1,320 & 478 & 2,083 \\
\hline Private 2-year & 26,141 & 21,966 & 1,854 & 1,109 & 442 & 255 & 59 & 456 \\
\hline Professional staff & 19,478 & 16,742 & 1,216 & 609 & 335 & 147 & 48 & 381 \\
\hline 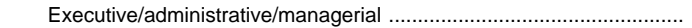 & 2,735 & 2,375 & 157 & 75 & 33 & 41 & 4 & 50 \\
\hline 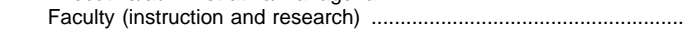 & 12,213 & 10,643 & 674 & 329 & 223 & 59 & 25 & 260 \\
\hline 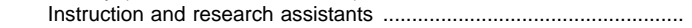 & 313 & 241 & 25 & 10 & 12 & 1 & 0 & 24 \\
\hline 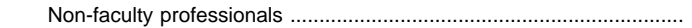 & 4,217 & 3,483 & 360 & 195 & 67 & 46 & 19 & 47 \\
\hline 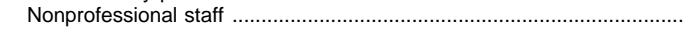 & 6,663 & 5,224 & 638 & 500 & 107 & 108 & 11 & 75 \\
\hline
\end{tabular}

SOURCE: U.S. Department of Education, National Center for Education Statistics, Integrated Postsecondary Education Data System (IPEDS), "Fall Staff" survey. (This table was prepared January 1998.) 
Table 223.-Employees in institutions of higher education, by primary occupation, sex, employment status, and by type and control of institution: Fall 1995

\begin{tabular}{|c|c|c|c|c|c|c|c|c|c|c|c|c|}
\hline \multirow{4}{*}{$\begin{array}{l}\text { Primary occupation and type and control of } \\
\text { institution }\end{array}$} & \multicolumn{5}{|c|}{ Full-time and part-time } & \multicolumn{4}{|c|}{ Full-time } & \multicolumn{3}{|c|}{ Part-time } \\
\hline & \multirow{2}{*}{\multicolumn{2}{|c|}{ Total }} & \multirow{3}{*}{ Men } & \multicolumn{2}{|c|}{ Women } & \multicolumn{2}{|c|}{ Total } & \multirow{3}{*}{ Men } & \multirow{3}{*}{ Women } & \multirow{3}{*}{ Total } & \multirow{3}{*}{ Men } & \multirow{3}{*}{ Women } \\
\hline & & & & & Per- & & & & & & & \\
\hline & Number & $\begin{array}{l}\text { Per- } \\
\text { cent }\end{array}$ & & TUTIVE & $\begin{array}{l}\text { ploy- } \\
\text { ees }\end{array}$ & Tum & $\begin{array}{l}\text { ploy- } \\
\text { ees }\end{array}$ & & & & & \\
\hline 1 & 2 & 3 & 4 & 5 & 6 & 7 & 8 & 9 & 10 & 11 & 12 & 13 \\
\hline Total, all employees & $2,662,075$ & 100.0 & $1,274,676$ & $1,387,399$ & 52.1 & $1,801,371$ & 67.7 & 856,289 & 945,082 & 860,704 & 418,387 & 442,317 \\
\hline Professional staff ................. & $1,744,867$ & 65.5 & 946,134 & 798,733 & 45.8 & $1,066,510$ & 61.1 & 590,916 & 475,594 & 678,357 & 355,218 & 323,139 \\
\hline Executive/administrative/managerial & 147,445 & 5.5 & 82,127 & 65,318 & 44.3 & 140,990 & 95.6 & 79,232 & 61,758 & 6,455 & 2,895 & 3,560 \\
\hline Faculty (instruction and research) & 931,706 & 35.0 & 562,893 & 368,813 & 39.6 & 550,822 & 59.1 & 360,150 & 190,672 & 380,884 & 202,743 & 178,141 \\
\hline Instruction and research assistants & 215,909 & 8.1 & 123,962 & 91,947 & 42.6 & - & - & - & - & 215,909 & 123,962 & 91,947 \\
\hline Non-faculty professionals ...................................... & 449,807 & 16.9 & 177,152 & 272,655 & 60.6 & 374,698 & 83.3 & 151,534 & 223,164 & 75,109 & 25,618 & 49,491 \\
\hline Nonprofessional staff & 917,208 & 34.5 & 328,542 & 588,666 & 64.2 & 734,861 & 80.1 & 265,373 & 469,488 & 182,347 & 63,169 & 119,178 \\
\hline Technical and paraprofessionals & 187,900 & 7.1 & 75,996 & 111,904 & 59.6 & 141,677 & 75.4 & 59,212 & 82,465 & 46,223 & 16,784 & 29,439 \\
\hline Clerical and secretarial .................. & 441,196 & 16.6 & 54,706 & 386,490 & 87.6 & 348,948 & 79.1 & 32,962 & 315,986 & 92,248 & 21,744 & 70,504 \\
\hline Skilled crafts ....................... & 64,583 & 2.4 & 60,494 & 4,089 & 6.3 & 61,273 & 94.9 & 58,160 & 3,113 & 3,310 & 2,334 & 976 \\
\hline Service and maintenance .. & 223,529 & 8.4 & 137,346 & 86,183 & 38.6 & 182,963 & 81.9 & 115,039 & 67,924 & 40,566 & 22,307 & 18,259 \\
\hline Public 4-year, total & $1,383,476$ & 100.0 & 676,113 & 707,363 & 51.1 & 986,996 & 71.3 & 480,094 & 506,902 & 396,480 & 196,019 & 200,461 \\
\hline Professional staff & 893,345 & 64.6 & 497,227 & 396,118 & 44.3 & 576,361 & 64.5 & 328,613 & 247,748 & 316,984 & 168,614 & 148,370 \\
\hline Executive/administrative/managerial & 60,590 & 4.4 & 36,401 & 24,189 & 39.9 & 58,519 & 96.6 & 35,443 & 23,076 & 2,071 & 958 & 1,113 \\
\hline Faculty (instruction and research) .... & 384,399 & 27.8 & 250,584 & 133,815 & 34.8 & 291,049 & 75.7 & 199,881 & 91,168 & 93,350 & 50,703 & 42,647 \\
\hline 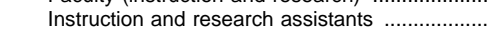 & 178,342 & 12.9 & 102,834 & 75,508 & 42.3 & - & - & - & - & 178,342 & 102,834 & 75,508 \\
\hline Non-faculty professionals .................... & 270,014 & 19.5 & 107,408 & 162,606 & 60.2 & 226,793 & 84.0 & 93,289 & 133,504 & 43,221 & 14,119 & 29,102 \\
\hline Nonprofessional staff & 490,131 & 35.4 & 178,886 & 311,245 & 63.5 & 410,635 & 83.8 & 151,481 & 259,154 & 79,496 & 27,405 & 52,091 \\
\hline Technical and paraprofessionals & 106,173 & 7.7 & 42,790 & 63,383 & 59.7 & 82,351 & 77.6 & 34,356 & 47,995 & 23,822 & 8,434 & 15,388 \\
\hline Clerical and secretarial & 221,378 & 16.0 & 26,119 & 195,259 & 88.2 & 185,179 & 83.6 & 17,489 & 167,690 & 36,199 & 8,630 & 27,569 \\
\hline Skilled crafts ........................ & 41,287 & 3.0 & 38,993 & 2,294 & 5.6 & 39,877 & 96.6 & 37,930 & 1,947 & 1,410 & 1,063 & 347 \\
\hline Service and maintenance & 121,293 & 8.8 & 70,984 & 50,309 & 41.5 & 103,228 & 85.1 & 61,706 & 41,522 & 18,065 & 9,278 & 8,787 \\
\hline Publi & 482,454 & 100.0 & 219,665 & 262,789 & 54.5 & 240,511 & 49.9 & 107,007 & 133,504 & 241,943 & 112,658 & 129,285 \\
\hline Professional staff & 336,661 & 69.8 & 169,416 & 167,245 & 49.7 & 144,782 & 43.0 & 73,989 & 70,793 & 191,879 & 95,427 & 96,452 \\
\hline Executive/administrative/managerial . & 21,806 & 4.5 & 12,274 & 9,532 & 43.7 & 20,461 & 93.8 & 11,643 & 8,818 & 1,345 & 631 & 714 \\
\hline Faculty (instruction and research) & 272,434 & 56.5 & 140,912 & 131,522 & 48.3 & 95,527 & 35.1 & 51,137 & 44,390 & 176,907 & 89,775 & 87,132 \\
\hline Instruction and research assistants ....................... & 3,401 & 0.7 & 1,457 & 1,944 & 57.2 & - & - & - & - & 3,401 & 1,457 & 1,944 \\
\hline 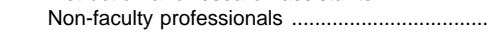 & 39,020 & 8.1 & 14,773 & 24,247 & 62.1 & 28,794 & 73.8 & 11,209 & 17,585 & 10,226 & 3,564 & 6,662 \\
\hline Nonprofessional staff & 145,793 & 30.2 & 50,249 & 95,544 & 65.5 & 95,729 & 65.7 & 33,018 & 62,711 & 50,064 & 17,231 & 32,833 \\
\hline Technical and paraprofessionals .... & 33,042 & 6.8 & 12,610 & 20,432 & 61.8 & 20,335 & 61.5 & 8,001 & 12,334 & 12,707 & 4,609 & 8,098 \\
\hline Clerical and secretarial & 76,464 & 15.8 & 10,415 & 66,049 & 86.4 & 47,484 & 62.1 & 3,004 & 44,480 & 28,980 & 7,411 & 21,569 \\
\hline Skilled crafts & 6,592 & 1.4 & 5,743 & 849 & 12.9 & 5,506 & 83.5 & 5,055 & 451 & 1,086 & 688 & 398 \\
\hline Service and maintenance & 29,695 & 6.2 & 21,481 & 8,214 & 27.7 & 22,404 & 75.4 & 16,958 & 5,446 & 7,291 & 4,523 & 2,768 \\
\hline Private 4-yea & 770,004 & 100.0 & 367,610 & 402,394 & 52.3 & 556,556 & 72.3 & 261,741 & 294,815 & 213,448 & 105,869 & 107,579 \\
\hline Professional staff & 495,383 & 64.3 & 270,326 & 225,057 & 45.4 & 332,837 & 67.2 & 182,356 & 150,481 & 162,546 & 87,970 & 74,576 \\
\hline 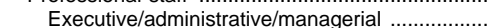 & 62,314 & 8.1 & 32,124 & 30,190 & 48.4 & 59,394 & 95.3 & 30,869 & 28,525 & 2,920 & 1,255 & 1,665 \\
\hline Faculty (instruction and research) & 262,660 & 34.1 & 165,113 & 97,547 & 37.1 & 157,958 & 60.1 & 105,689 & 52,269 & 104,702 & 59,424 & 45,278 \\
\hline 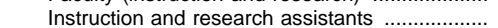 & 33,853 & 4.4 & 19,509 & 14,344 & 42.4 & - & - & - & - & 33,853 & 19,509 & 14,344 \\
\hline 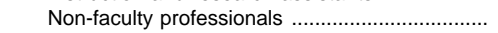 & 136,556 & 17.7 & 53,580 & 82,976 & 60.8 & 115,485 & 84.6 & 45,798 & 69,687 & 21,071 & 7,782 & 13,289 \\
\hline Nonprofessional staff & 274,621 & 35.7 & 97,284 & 177,337 & 64.6 & 223,719 & 81.5 & 79,385 & 144,334 & 50,902 & 17,899 & 33,003 \\
\hline Technical and paraprofessionals & 47,575 & 6.2 & 20,190 & 27,385 & 57.6 & 38,232 & 80.4 & 16,557 & 21,675 & 9,343 & 3,633 & 5,710 \\
\hline Clerical and secretarial & 139,888 & 18.2 & 17,884 & 122,004 & 87.2 & 113,708 & 81.3 & 12,303 & 101,405 & 26,180 & 5,581 & 20,599 \\
\hline Skilled crafts .................................. & 16,391 & 2.1 & 15,513 & 878 & 5.4 & 15,623 & 95.3 & 14,954 & 669 & 768 & 559 & 209 \\
\hline Service and maintenance & 70,767 & 9.2 & 43,697 & 27,070 & 38.3 & 56,156 & 79.4 & 35,571 & 20,585 & 14,611 & 8,126 & 6,485 \\
\hline Private 2-year, total & 26,141 & 100.0 & 11,288 & 14,853 & 56.8 & 17,308 & 66.2 & 7,447 & 9,861 & 8,833 & 3,841 & 4,992 \\
\hline Professional staff & 19,478 & 74.5 & 9,165 & 10,313 & 52.9 & 12,530 & 64.3 & 5,958 & 6,572 & 6,948 & 3,207 & 3,741 \\
\hline Executive/administrative/managerial & 2,735 & 10.5 & 1,328 & 1,407 & 51.4 & 2,616 & 95.6 & 1,277 & 1,339 & 119 & 51 & 68 \\
\hline Faculty (instruction and research) & 12,213 & 46.7 & 6,284 & 5,929 & 48.5 & 6,288 & 51.5 & 3,443 & 2,845 & 5,925 & 2,841 & 3,084 \\
\hline Instruction and research assistants ....................... & 313 & 1.2 & 162 & 151 & 48.2 & - & - & - & - & 313 & 162 & 151 \\
\hline Non-faculty professionals & 4,217 & 16.1 & 1,391 & 2,826 & 67.0 & 3,626 & 86.0 & 1,238 & 2,388 & 591 & 153 & 438 \\
\hline Nonprofessional staff & 6,663 & 25.5 & 2,123 & 4,540 & 68.1 & 4,778 & 71.7 & 1,489 & 3,289 & 1,885 & 634 & 1,251 \\
\hline 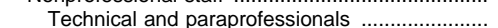 & 1,110 & 4.2 & 406 & 704 & 63.4 & 759 & 68.4 & 298 & 461 & 351 & 108 & 243 \\
\hline Clerical and secretarial & 3,466 & 13.3 & 288 & 3,178 & 91.7 & 2,577 & 74.4 & 166 & 2,411 & 889 & 122 & 767 \\
\hline Skilled crafts ...................... & 313 & 1.2 & 245 & 68 & 21.7 & 267 & 85.3 & 221 & 46 & 46 & 24 & 22 \\
\hline Service and maintenance & 1,774 & 6.8 & 1,184 & 590 & 33.3 & 1,175 & 66.2 & 804 & 371 & 599 & 380 & 219 \\
\hline
\end{tabular}

-Not applicable.

NOTE.-Because of rounding, details may not add to totals.
SOURCE: U.S. Department of Education, National Center for Education Statistics, Integrated Postsecondary Education Data System (IPEDS), "Fall Staff" survey. (This table was prepared January 1998.) 
Table 224.-Staff and student/staff ratios in institutions of higher education, by type and control of institution and by state: Fall 1995

\begin{tabular}{|c|c|c|c|c|c|c|c|c|c|c|c|c|c|c|c|c|c|c|c|c|}
\hline \multirow{4}{*}{ State or other area } & \multicolumn{4}{|c|}{ Full-time-equivalent staff } & \multicolumn{4}{|c|}{ Full-time-equivalent faculty } & \multirow{2}{*}{\multicolumn{4}{|c|}{$\begin{array}{l}\text { Full-time-equivalent } \\
\text { students per } \\
\text { FTE staff }\end{array}$}} & \multirow{2}{*}{\multicolumn{4}{|c|}{$\begin{array}{l}\text { Full-time-equivalent } \\
\text { students per } \\
\text { FTE faculty }\end{array}$}} & Ful & -time-e & quivale & ent \\
\hline & Pub & & Priv & & Put & & Priv & & & & & & & & & & & & staff & tit \\
\hline & & & & & & & & & & olic & Priv & /ate & Puk & blic & Priv & vate & $\mathrm{Pu}$ & blic & Priv & \\
\hline & 4-year & 2-year & 4-year & 2-year & 4-year & 2-year & 4-year & 2-year & $\begin{array}{c}4- \\
\text { year }\end{array}$ & $\begin{array}{c}2- \\
\text { year }\end{array}$ & $\begin{array}{c}4- \\
\text { year }\end{array}$ & $\begin{array}{c}2- \\
\text { year }\end{array}$ & \begin{tabular}{|c|}
$4-$ \\
year
\end{tabular} & $\begin{array}{c}2- \\
\text { year }\end{array}$ & $\begin{array}{c}4- \\
\text { year }\end{array}$ & $\begin{array}{c}2- \\
\text { year }\end{array}$ & $\begin{array}{c}4- \\
\text { year }\end{array}$ & $\begin{array}{c}2- \\
\text { year }\end{array}$ & $\begin{array}{c}4- \\
\text { year }\end{array}$ & $\begin{array}{c}2- \\
\text { year }\end{array}$ \\
\hline 1 & 2 & 3 & 4 & 5 & 6 & 7 & 8 & 9 & 10 & 11 & 12 & 13 & 14 & 15 & 16 & 17 & 18 & 19 & 20 & 21 \\
\hline United States .... & $1,143,594$ & 325,546 & 639,524 & 20,595 & 321,664 & 153,545 & 194,189 & 8,338 & 4.2 & 9.2 & 3.8 & 8.1 & 14.8 & 19.5 & 12.4 & 20.1 & 28.1 & 47.2 & 30.4 & 40.5 \\
\hline Alabama & 32,599 & 5,113 & 3,913 & 103 & 7,004 & 2,670 & 1,393 & 35 & 3.2 & 10.7 & 5.0 & 4.4 & 14.9 & 20.4 & 14.0 & 12.7 & 21.5 & 52.2 & 35.6 & 34.2 \\
\hline Alaska .......... & 3,116 & 29 & 169 & 47 & 1,016 & & 47 & 28 & 5.7 & 11.3 & 3.5 & 3.6 & 17.5 & 51.5 & 12.5 & 6.0 & 32.6 & 22.0 & 27.9 & 59.4 \\
\hline Arizona ....... & 19,732 & 6,654 & 1,802 & 101 & 4,742 & 2,939 & 791 & 32 & 4.2 & 11.5 & 9.2 & 8.8 & 17.5 & 26.1 & 21.1 & 27.7 & 24.0 & 44.2 & 43.9 & 31.7 \\
\hline Arkansas .. & 15,010 & 2,037 & 1,888 & 94 & 3,979 & 950 & 645 & 38 & 3.5 & 7.4 & 5.3 & 3.7 & 13.3 & $\mid 16.0$ & 15.5 & 9.2 & 26.5 & 46.6 & 34.1 & 40.6 \\
\hline California . & 92,969 & 42,432 & 45,518 & 1,605 & 29,354 & 20,832 & 14,391 & 605 & 4.5 & 13.3 & 4.4 & 8.0 & 14.3 & 27.0 & 13.9 & 21.3 & 31.6 & 49.1 & 31.6 & 37.7 \\
\hline Colorado & 21,434 & 4,672 & 4,362 & 410 & 7,956 & 2,090 & 1,302 & 193 & 4.9 & 8.6 & 5.0 & 8.4 & 13.1 & \begin{tabular}{|l|}
19.3 \\
\end{tabular} & 16.7 & 17.9 & 37.1 & 44.7 & 29.8 & 47.0 \\
\hline Connecticut & 10,341 & 2,586 & 15,072 & 238 & 2,987 & 1,283 & 5,091 & 90 & 4.2 & 8.2 & 2.9 & 4.9 & 14.5 & \begin{tabular}{|l|}
16.6 \\
\end{tabular} & 8.6 & 12.9 & 28.9 & 49.6 & 33.8 & 37.6 \\
\hline Delaware .... & 4,486 & 775 & 761 & - & 1,097 & 293 & 388 & - & 4.6 & 8.6 & 7.0 & - & 18.7 & 22.9 & 13.6 & - & 24.5 & 37.8 & 51.0 & - \\
\hline District of Columbia & 974 & - & 24,214 & - & 522 & - & 5,269 & - & 6.1 & - & 2.3 & - & 11.4 & - & 10.5 & - & 53.6 & - & 21.8 & - \\
\hline Florida & 32,694 & 21,272 & 18,977 & 784 & 9,456 & 8,983 & 5,953 & 289 & 4.9 & 8.3 & 4.2 & 6.5 & 16.9 & 19.7 & 13.5 & $\mid 17.7$ & 28.9 & 42.2 & 31.4 & 36.8 \\
\hline Georgia & 32,561 & 7,901 & 12,200 & 530 & 7,835 & 3,789 & 4,848 & 239 & 4.1 & 7.2 & 4.5 & 7.8 & 16.9 & 15.0 & 11.4 & 17.3 & 24.1 & 48.0 & 39.7 & 45.2 \\
\hline Hawaii ....... & 5,146 & 1,436 & 1,241 & - & 1,881 & 868 & 509 & - & 3.7 & 11.3 & 8.0 & - & \begin{tabular}{|l|}
10.2 \\
\end{tabular} & 18.7 & 19.5 & - & 36.6 & 60.4 & 41.0 & - \\
\hline Idaho .. & 5,591 & 679 & 363 & 845 & 2,000 & 297 & 165 & 358 & 5.8 & 7.8 & 5.5 & 9.6 & 16.1 & $\mid 17.7$ & 12.1 & 22.7 & 35.8 & 43.8 & 45.3 & 42.3 \\
\hline Illinois & 43,829 & 19,683 & 40,654 & 523 & 11,336 & 9,074 & 12,861 & 220 & 3.6 & 9.3 & 3.6 & 7.2 & 14.1 & 20.2 & 11.3 & 17.2 & 25.9 & 46.1 & 31.6 & 42.1 \\
\hline Indiana ........... & 32,658 & 3,329 & 11,968 & 268 & 8,955 & 1,473 & 3,684 & 112 & 4.5 & 7.0 & 4.6 & 10.7 & 16.4 & 15.8 & 14.8 & 25.5 & 27.4 & 44.2 & 30.8 & 41.9 \\
\hline lowa & 17,502 & 4,805 & 8,121 & 117 & 4,001 & 1,963 & 2,834 & 51 & 3.3 & 8.3 & 5.1 & 7.9 & 14.5 & 20.3 & 14.6 & 18.3 & 22.9 & 40.9 & 34.9 & 43.1 \\
\hline Kansa & 15,532 & 5,272 & 2,529 & 174 & 4,726 & 2,378 & 1,074 & 52 & 4.6 & 7.6 & 5.4 & 4.2 & 15.1 & $\mid 16.7$ & 12.8 & 14.2 & 30.4 & 15.1 & 42.5 & 29.8 \\
\hline Kentucky . & 21,006 & 2,702 & 4,258 & 283 & 6,001 & 1,535 & 1,455 & 118 & 4.1 & 10.4 & 5.4 & 8.3 & 14.5 & \begin{tabular}{|l|}
18.4 \\
\end{tabular} & 15.8 & 20.0 & 28.6 & 56.8 & 34.2 & 41.7 \\
\hline Louisiana ...................... & 25,612 & 1,448 & 6,190 & 94 & 7,847 & 692 & 2,037 & 48 & 4.9 & 11.8 & 3.8 & 8.0 & 16.0 & 24.6 & 11.5 & 15.7 & 30.6 & 47.8 & 32.9 & 51.2 \\
\hline Maine ……..................... & 4,960 & 643 & 2,949 & 137 & 1,498 & 308 & 882 & 60 & 4.6 & 6.8 & 4.2 & 12.1 & 15.2 & 14.2 & 14.0 & 27.6 & 30.2 & 47.8 & 29.9 & 43.8 \\
\hline IV & 20,655 & 8,437 & 13,466 & 158 & 6,936 & 3,790 & 3,723 & 44 & 4.3 & 6.8 & 2.2 & 6.5 & 12.7 & 15.1 & 8.1 & 23.6 & 33.6 & 44.9 & 27.6 & 27.6 \\
\hline Mass & 18,867 & 5,488 & 56,511 & 873 & 5,214 & 2,502 & 15,151 & 361 & 4.2 & 8.2 & 3.4 & 6.9 & 15.1 & 18.0 & 12.5 & 16.6 & 27.6 & 45.6 & 26.8 & 41.4 \\
\hline Michigan ……................. & 45,738 & 10,476 & 10,134 & 328 & 14,104 & 4,936 & 3,633 & 133 & 4.5 & 9.9 & 6.0 & 5.3 & 14.6 & 21.0 & 16.8 & 13.0 & 30.8 & 47.1 & 35.9 & 40.6 \\
\hline Minne & 22,480 & 6,050 & 8,752 & 440 & 5,317 & 3,242 & 3,231 & 204 & 3.9 & 10.4 & 5.5 & 7.4 & 16.7 & \begin{tabular}{|l|}
19.4 \\
\end{tabular} & 15.0 & 16.0 & 23.7 & 53.6 & 36.9 & 46.3 \\
\hline Mississippi .................. & 15,867 & 4,873 & 1,575 & 130 & 3,168 & 2,530 & 563 & 44 & 3.2 & 8.5 & 6.0 & 5.6 & 16.3 & 16.4 & 16.7 & 16.5 & 20.0 & 51.9 & 35.7 & 33.7 \\
\hline M & 23,276 & 4,983 & 17,752 & 743 & 7,711 & 2,150 & 5,819 & 308 & 4.1 & 8.2 & 4.1 & 5.3 & 12.3 & 18.9 & 12.5 & 12.8 & 33.1 & 43.1 & 32.8 & 41.4 \\
\hline Montana & 5,306 & 631 & 623 & 94 & 1,666 & 341 & 209 & 31 & 5.2 & 7.3 & 5.8 & 6.4 & 16.6 & 13.5 & 17.2 & \begin{tabular}{|l|}
19.1 \\
\end{tabular} & 31.4 & 54.0 & 33.5 & 33.5 \\
\hline Nebraska & 13,760 & 2,441 & 4,013 & 54 & 3,383 & 1,015 & 1,450 & 38 & 3.5 & 8.1 & 4.1 & 7.5 & 14.0 & \begin{tabular}{|l|}
19.4 \\
\end{tabular} & 11.5 & 10.6 & 24.6 & 41.6 & 36.1 & 70.4 \\
\hline Nevac & 4,544 & 1,654 & 137 & 14 & 1,628 & 821 & 68 & 5 & 4.8 & 9.2 & 7.1 & 1.9 & 13.4 & 18.5 & 14.2 & 5.4 & 35.8 & 49.6 & 49.7 & 36.1 \\
\hline New Hampshire. & 3,681 & 1,170 & 5,174 & 265 & 1,144 & 787 & 1,456 & 108 & 6.0 & 4.4 & 3.6 & 11.8 & 19.2 & 6.5 & 12.9 & 29.0 & 31.1 & 67.2 & 28.1 & 40.7 \\
\hline New & 26,971 & 8,008 & 11,708 & 397 & 6,835 & 3,208 & 3,291 & 159 & 3.8 & 10.1 & 3.8 & 9.7 & 15.2 & 25.3 & 13.4 & 24.2 & 25.3 & 40.1 & 28.1 & 40.0 \\
\hline New $M$ & 12,313 & 3,163 & 480 & 53 & 2,702 & 1,239 & 175 & 23 & 3.2 & 8.1 & 7.6 & 18.0 & 14.5 & 20.8 & 21.0 & 42.0 & 21.9 & 39.2 & 36.5 & 42.9 \\
\hline New & 52,989 & 22,351 & 104,750 & 2,644 & 16,916 & 10,428 & 30,515 & 1,144 & 5.0 & 7.9 & 3.2 & 9.6 & 15.7 & 16.8 & 11.1 & 22.1 & 31.9 & 46.7 & 29.1 & 43.3 \\
\hline North & 33,513 & 14,575 & 26,912 & 341 & 8,755 & 7,957 & 5,722 & 129 & 4.0 & 6.3 & 2.2 & 3.9 & 15.2 & \begin{tabular}{|l|}
11.4 \\
\end{tabular} & 10.5 & 10.3 & 26.1 & 54.6 & 21.3 & 37.9 \\
\hline North Dakota ............. & 5,332 & 926 & 404 & 170 & 1,831 & 383 & 173 & 34 & 4.7 & 7.3 & 7.7 & 1.5 & 13.7 & 17.7 & 17.8 & 7.3 & 34.3 & 41.4 & 43.0 & 20.1 \\
\hline Ohio & 50,420 & 9,426 & 20,436 & 837 & 13,807 & 4,528 & 7,153 & 373 & 4.4 & 9.3 & 4.7 & 10.7 & 15.9 & \begin{tabular}{|l|}
19.3 \\
\end{tabular} & 13.4 & 23.9 & 27.4 & 48.0 & 35.0 & 44.6 \\
\hline & 896 & 4,411 & 3,461 & 393 & 802 & 03 & 1,231 & 152 & 4. & 8.4 & 5.1 & 4.9 & 16.1 & 20.6 & 14.4 & 12.6 & 30.2 & 9 & 6 & 38.6 \\
\hline Ore & 15,723 & 6,733 & 3,990 & 17 & 5,471 & 2,955 & 1,585 & 11 & 3.4 & 6.4 & 5.0 & 9.0 & 9.8 & \begin{tabular}{|l|}
14.5 \\
\end{tabular} & 12.7 & \begin{tabular}{|l|}
14.3 \\
\end{tabular} & 34.8 & 43.9 & 39.7 & 63.4 \\
\hline Pennsylvania ................. & 52,022 & 7,414 & 50,477 & 3,361 & 16,146 & 4,091 & 16,094 & 1,174 & 3.9 & 8.3 & 3.6 & 9.7 & 12.4 & 15.0 & $\mid 11.2$ & 27.8 & 31.0 & 55.2 & 31.9 & 34.9 \\
\hline Rhode Island ............. & 3,327 & 673 & 7,174 & 212 & 1,013 & 287 & 1,796 & 109 & 5.3 & 12.6 & 4.0 & - & 17.4 & 29.6 & 15.9 & - & 30.4 & 42.6 & 25.0 & - \\
\hline ling & 15,904 & 4,821 & 4,100 & 228 & 5,028 & 2,173 & 1,353 & 85 & 4.5 & 7.8 & 5.3 & 5.3 & 14.3 & 17.2 & 16.0 & 14.2 & 31.6 & 45.1 & 33.0 & 37.1 \\
\hline So & 4,215 & & 1,070 & 35 & 1,485 & 34 & 414 & 5 & 5.9 & 3.1 & 5.1 & 4.1 & 16.7 & 5.1 & 13.2 & 28.4 & 35.2 & 0.2 & 38.7 & 14.5 \\
\hline Tennessee .................... & 27,278 & 5,021 & 17,161 & 304 & 6,929 & 2,240 & 4,427 & 150 & 3.5 & 9.4 & 2.7 & 6.6 & 13.8 & 21.0 & $\mid 10.4$ & 13.4 & 25.4 & 44.6 & 25.8 & 49.4 \\
\hline & 83,986 & 28,587 & 21,891 & 644 & 20,276 & 13,226 & 6,944 & 263 & 4.0 & 8.3 & 4.2 & 8.8 & 16.6 & 17.9 & 13.2 & 21.4 & 24.1 & 46.3 & 31.7 & 40.9 \\
\hline 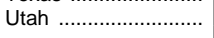 & 15,447 & 1,777 & 4,805 & 157 & 3,545 & 612 & 1,740 & 84 & 4.1 & 10.9 & 6.9 & 7.3 & 17.7 & 31.7 & 19.1 & 13.6 & 22.9 & 34.4 & 36.2 & 53.8 \\
\hline & 3,866 & 266 & 4 & 176 & 198 & 157 & 974 & 104 & 3. & 7.1 & 3.9 & 1.0 & 11.4 & 12.0 & 12.6 & 1.7 & 31.0 & & 30.5 & 59.1 \\
\hline & 37,812 & 4,688 & 10,216 & 585 & 9,250 & 1,999 & 3,379 & 261 & 3.7 & 14.2 & 4.6 & 6.9 & 14.9 & 33.4 & 13.9 & 15.4 & 24.5 & 42.6 & 33.1 & 44.6 \\
\hline Was & 24,840 & 9,934 & 5,735 & 228 & 6,299 & 4,940 & 2,338 & 100 & 3.1 & 10.4 & 5.4 & 9.0 & 12.4 & 20.9 & 13.2 & 20.7 & 25.4 & 49.7 & 40.8 & 43.6 \\
\hline$\therefore$ & 10,301 & 586 & 1,837 & 92 & 3,698 & 259 & 570 & 39 & 5. & 8.2 & 5.0 & 8.4 & 14.9 & 18.5 & 16.0 & \begin{tabular}{|l|}
19.9 \\
\end{tabular} & 35.9 & 44.2 & 31.1 & 42.4 \\
\hline Wisc & 29,113 & 10,809 & 14,440 & 127 & 7,634 & 5,795 & 3,396 & 57 & 4.2 & 5.5 & 2.9 & 11.8 & 15.9 & $\mid 10.2$ & 12.3 & 26.2 & 26.2 & 53.6 & 23.5 & 45.1 \\
\hline Wyoming .. & 2,826 & 1,563 & - & 141 & 848 & 697 & - & 39 & 3.5 & 7.3 & - & 5.4 & 11.5 & 16.4 & - & 19.5 & 30.0 & 44.6 & - & 27.5 \\
\hline U.S. Service Schools & 7,575 & 88 & - & - & 2,731 & - & - & - & 2.4 & - & - & - & 6.5 & - & - & - & 36.1 & - & - & - \\
\hline Outlying areas .... & 11,629 & 1,976 & 7,802 & 584 & 3,797 & 766 & 2,722 & 298 & 4.7 & 5.7 & 10.5 & 13.4 & 14.4 & 14.7 & 30.1 & 26.2 & 32.6 & 38.8 & 34.9 & 51.0 \\
\hline Amer & - & 182 & - & - & - & 98 & - & - & - & 5.4 & - & - & - & $\mid 10.1$ & - & - & - & 53.8 & - & - \\
\hline $\begin{array}{l}\text { Federated States of } \\
\text { Micronesia }\end{array}$ & & & & & & & & & -1 & & & & & & - & -1 & & & & \\
\hline & $\overline{573}$ & 240 & - & - & $\overline{212}$ & $\begin{array}{l}107 \\
135\end{array}$ & - & - & $\overline{49}$ & $\begin{array}{l}4.5 \\
36\end{array}$ & - & - & $\overline{131}$ & $\begin{array}{r}10.0 \\
76\end{array}$ & - & - & $37 \overline{1}$ & \begin{tabular}{|l|}
44.8 \\
46.9
\end{tabular} & - & - \\
\hline & - & $\begin{array}{r}288 \\
32\end{array}$ & - & - & - & 8 & - & - & - & $\begin{array}{l}3.0 \\
7.9\end{array}$ & - & - & - & 31.1 & - & - & - & 25.3 & - & - \\
\hline Northern Marianas .. & - & 206 & - & - & - & 49 & - & - & - & 3.0 & - & - & - & 12.8 & - & - & - & 23.8 & - & - \\
\hline ………… & - & 140 & - & - & - & 35 & - & - & - & 2.1 & - & - & - & 8.5 & - & - & - & 25.0 & - & - \\
\hline Puerto Rico ............... & 10,509 & 888 & 7,802 & 584 & 3,404 & 334 & 2,722 & 298 & 4.7 & 7.9 & 10.5 & 13.4 & 14.6 & 20.9 & 30.1 & 26.2 & 32.4 & 37.6 & 34.9 & 51.0 \\
\hline Virgin Islands ............. & 548 & - & - & - & 180 & - & - & - & 3.7 & - & - & - & 11.4 & - & - & - & 33.0 & - & - & - \\
\hline
\end{tabular}

—Data not reported or not applicable.

NOTE.-Data include imputations for nonrespondent institutions.
SOURCE: U.S. Department of Education, National Center for Education Statistics, Integrated Postsecondary Education Data System (IPEDS), "Fall Staff, 1995" and "Fall Enrollment" surveys. (This table was prepared January 1998.) 
Table 225.-Full-time and part-time senior instructional faculty $\mathbf{1}$ in institutions of higher education, by employment status, control, and type of institution: Fall 1970 to fall 1995

[In thousands]

\begin{tabular}{|c|c|c|c|c|c|c|c|c|c|}
\hline \multirow{3}{*}{ Year } & \multirow{3}{*}{ Total } & \multicolumn{2}{|c|}{ Employment status } & \multicolumn{4}{|c|}{ Control } & \multicolumn{2}{|c|}{ Type } \\
\hline & & \multirow{2}{*}{ Full-time } & \multirow{2}{*}{ Part-time } & \multirow{2}{*}{ Public } & \multicolumn{3}{|c|}{ Private } & \multirow{2}{*}{ 4-year } & \multirow{2}{*}{ 2-year } \\
\hline & & & & & Total & Nonprofit & Proprietary & & \\
\hline 1 & 2 & 3 & 4 & 5 & 6 & 7 & 8 & 9 & 10 \\
\hline 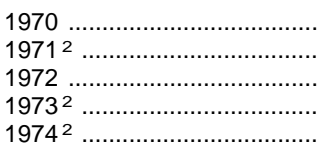 & $\begin{array}{l}474 \\
492 \\
500 \\
527 \\
567\end{array}$ & $\begin{array}{l}369 \\
379 \\
380 \\
389 \\
406\end{array}$ & $\begin{array}{l}104 \\
113 \\
120 \\
138 \\
161\end{array}$ & $\begin{array}{l}314 \\
333 \\
343 \\
365 \\
397\end{array}$ & $\begin{array}{l}160 \\
159 \\
157 \\
162 \\
170\end{array}$ & $\begin{array}{l}- \\
- \\
-\end{array}$ & $\begin{array}{l}- \\
- \\
-\end{array}$ & $\begin{array}{l}382 \\
387 \\
384 \\
401 \\
427\end{array}$ & $\begin{array}{r}92 \\
105 \\
116 \\
126 \\
140\end{array}$ \\
\hline 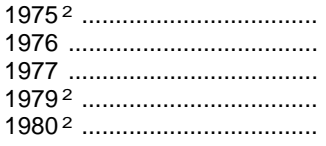 & $\begin{array}{l}628 \\
633 \\
678 \\
675 \\
686\end{array}$ & $\begin{array}{l}440 \\
434 \\
448 \\
445 \\
450\end{array}$ & $\begin{array}{l}188 \\
199 \\
230 \\
230 \\
236\end{array}$ & $\begin{array}{l}443 \\
449 \\
492 \\
488 \\
495\end{array}$ & $\begin{array}{l}185 \\
184 \\
186 \\
187 \\
191\end{array}$ & $\begin{array}{l}- \\
- \\
-\end{array}$ & $\begin{array}{l}- \\
- \\
-\end{array}$ & $\begin{array}{l}467 \\
467 \\
485 \\
494 \\
494\end{array}$ & $\begin{array}{l}161 \\
166 \\
193 \\
182 \\
192\end{array}$ \\
\hline 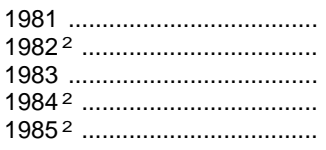 & $\begin{array}{l}705 \\
710 \\
724 \\
717 \\
715\end{array}$ & $\begin{array}{l}461 \\
462 \\
471 \\
462 \\
459\end{array}$ & $\begin{array}{l}244 \\
248 \\
254 \\
255 \\
256\end{array}$ & $\begin{array}{l}509 \\
506 \\
512 \\
505 \\
503\end{array}$ & $\begin{array}{l}196 \\
204 \\
212 \\
212 \\
212\end{array}$ & $\begin{array}{l}- \\
- \\
-\end{array}$ & $\begin{array}{l}- \\
- \\
-\end{array}$ & $\begin{array}{l}493 \\
493 \\
504 \\
504 \\
504\end{array}$ & $\begin{array}{l}212 \\
217 \\
220 \\
213 \\
211\end{array}$ \\
\hline 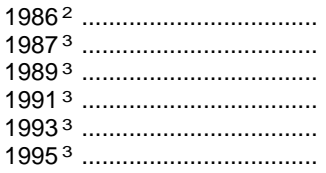 & $\begin{array}{l}722 \\
793 \\
824 \\
826 \\
915 \\
932\end{array}$ & $\begin{array}{l}459 \\
523 \\
524 \\
536 \\
546 \\
551\end{array}$ & $\begin{array}{l}263 \\
270 \\
300 \\
291 \\
370 \\
381\end{array}$ & $\begin{array}{l}510 \\
553 \\
577 \\
581 \\
650 \\
657\end{array}$ & $\begin{array}{l}212 \\
240 \\
247 \\
245 \\
265 \\
275\end{array}$ & $\begin{array}{l}- \\
- \\
\overline{-} \\
254 \\
261\end{array}$ & $\begin{array}{l}- \\
- \\
- \\
11 \\
14\end{array}$ & $\begin{array}{l}506 \\
548 \\
584 \\
591 \\
626 \\
647\end{array}$ & $\begin{array}{l}216 \\
246 \\
241 \\
235 \\
290 \\
285\end{array}$ \\
\hline
\end{tabular}

1 Includes faculty members with the title of professor, associate professor, assistant professor, instructor, lecturer, assisting professor, adjunct professor, or interim professor (or the equivalent). Excluded are graduate students with titles such as graduate or teaching fellow who assist senior faculty.

2 Estimated on the basis of enrollment.

${ }^{3}$ Because of revised survey methods, data are not directly comparable with figures for years prior to 1987.

-Data not available.
NOTE.-Data exclude faculty employed by system offices. For methodological details on estimates, see Projections of Education Statistics to 2000. Because of rounding, details may not add to totals.

SOURCE: U.S. Department of Education, National Center for Education Statistics, Employees in Institutions of Higher Education, various years; Projections of Education Statistics to 2000; Integrated Postsecondary Education Data System (IPEDS), "Fall Staff" survey; and U.S. Equal Employment Opportunity Commission, Higher Education Staff Information (EEO-6) Survey, 1977, 1981, and 1983. (This table was prepared January 1999.)

Table 226.-Full-time instructional faculty in institutions of higher education, by race/ethnicity, academic rank, and sex: Fall 1995

\begin{tabular}{|c|c|c|c|c|c|c|c|c|c|c|}
\hline \multirow{2}{*}{ Academic rank and sex } & \multirow{2}{*}{ Total } & \multirow{2}{*}{$\begin{array}{l}\text { White, } \\
\text { non- } \\
\text { Hispanic }\end{array}$} & \multicolumn{2}{|c|}{ Minority } & \multirow{2}{*}{$\begin{array}{l}\text { Black, } \\
\text { non- } \\
\text { Hispanic }\end{array}$} & \multirow{2}{*}{ Hispanic } & \multirow{2}{*}{$\begin{array}{l}\text { Asian or } \\
\text { Pacific } \\
\text { Islander }\end{array}$} & \multirow{2}{*}{$\begin{array}{c}\text { American } \\
\text { Indian/ } \\
\text { Alaskan } \\
\text { Native }\end{array}$} & \multirow{2}{*}{$\begin{array}{l}\text { Non- } \\
\text { resident } \\
\text { alien }\end{array}$} & \multirow{2}{*}{$\begin{array}{c}\text { Race/ } \\
\text { ethnicity } \\
\text { unknown }\end{array}$} \\
\hline & & & Number & Percent 1 & & & & & & \\
\hline 1 & 2 & 3 & 4 & 5 & 6 & 7 & 8 & 9 & 10 & 11 \\
\hline Men and women, all ranks ..... & 550,822 & 468,518 & 69,505 & 12.9 & 26,835 & 12,942 & 27,572 & 2,156 & 10,853 & 1,946 \\
\hline Professors & 159,333 & 142,819 & 15,254 & 9.6 & 4,768 & 2,470 & 7,643 & 373 & 975 & 285 \\
\hline Associate professors .............. & 125,082 & 108,953 & 14,710 & 11.9 & 5,634 & 2,607 & 6,119 & 350 & 1,179 & 240 \\
\hline 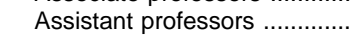 & 129,682 & 104,037 & 20,725 & 16.6 & 8,011 & 3,736 & 8,459 & 519 & 4,311 & 609 \\
\hline Instructors & 66,708 & 55,211 & 10,223 & 15.6 & 4,857 & 2,530 & 2,323 & 513 & 848 & 426 \\
\hline Lecturers . ............................... & 12,874 & 10,533 & 1,838 & 14.9 & 798 & 429 & 557 & 54 & 426 & 77 \\
\hline 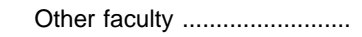 & 57,143 & 46,965 & 6,755 & 12.6 & 2,767 & 1,170 & 2,471 & 347 & 3,114 & 309 \\
\hline Men, all ranks .................. & 360,150 & 307,498 & 43,258 & 12.3 & 13,847 & 7,864 & 20,285 & 1,262 & 8,161 & 1,233 \\
\hline Professors & 130,940 & 117,844 & 11,987 & 9.2 & 3,085 & 1,912 & 6,691 & 299 & 879 & 230 \\
\hline 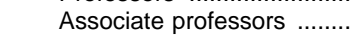 & 85,313 & 74,160 & 9,985 & 11.9 & 3,214 & 1,723 & 4,826 & 222 & 989 & 179 \\
\hline Assistant professors ................. & 73,141 & 57,580 & 11,952 & 17.2 & 3,897 & 2,068 & 5,734 & 253 & 3,225 & 384 \\
\hline Instructors & 33,067 & 27,239 & 5,037 & 15.6 & 2,154 & 1,345 & 1,244 & 294 & 551 & 240 \\
\hline Lecturers ............................. & 5,889 & 4,809 & 812 & 14.4 & 351 & 193 & 241 & 27 & 233 & 35 \\
\hline Other faculty ......................... & 31,800 & 25,866 & 3,485 & 11.9 & 1,146 & 623 & 1,549 & 167 & 2,284 & 165 \\
\hline Women, all ranks ............... & 190,672 & 161,020 & 26,247 & 14.0 & 12,988 & 5,078 & 7,287 & 894 & 2,692 & 713 \\
\hline Professors ........................... & 28,393 & 24,975 & 3,267 & 11.6 & 1,683 & 558 & 952 & 74 & 96 & 55 \\
\hline Associate professors .............. & 39,769 & 34,793 & 4,725 & 12.0 & 2,420 & 884 & 1,293 & 128 & 190 & 61 \\
\hline Assistant professors .................. & 56,541 & 46,457 & 8,773 & 15.9 & 4,114 & 1,668 & 2,725 & 266 & 1,086 & 225 \\
\hline Instructors & 33,641 & 27,972 & 5,186 & 15.6 & 2,703 & 1,185 & 1,079 & 219 & 297 & 186 \\
\hline Lecturers .................. & 6,985 & 5,724 & 1,026 & 15.2 & 447 & 236 & 316 & 27 & 193 & 42 \\
\hline 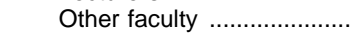 & 25,343 & 21,099 & 3,270 & 13.4 & 1,621 & 547 & 922 & 180 & 830 & 144 \\
\hline
\end{tabular}

1 Based on the number of U.S. citizen faculty with racial/ethnic data.

NOTE.-Data exclude faculty employed by system offices. Totals may differ from figures reported in other tables because of varying survey methodologies.
SOURCE: U.S. Department of Education, National Center for Education Statistics, Integrated Postsecondary Education Data System (IPEDS), "Fall Staff" survey. (This table was prepared June 1998. 
HIGHER EDUCATION: FACULTY 255

Table 227.-Full-time instructional faculty and staff in institutions of higher education, by instruction activities and type and control of institution: Fall 1992

\begin{tabular}{|c|c|c|c|c|c|c|c|c|c|c|}
\hline Instruction activities & $\begin{array}{c}\text { All } \\
\text { institutions }\end{array}$ & $\begin{array}{c}\text { Public } \\
\text { research }\end{array}$ & $\begin{array}{c}\text { Private } \\
\text { research }\end{array}$ & $\begin{array}{l}\text { Public } \\
\text { doctoral }\end{array}$ & $\begin{array}{c}\text { Private } \\
\text { doctoral }\end{array}$ & $\begin{array}{l}\text { Public } \\
\text { com- } \\
\text { prehen- } \\
\text { sive }\end{array}$ & $\begin{array}{l}\text { Private } \\
\text { com- } \\
\text { prehen- } \\
\text { sive }\end{array}$ & $\begin{array}{l}\text { Private } \\
\text { liberal } \\
\text { arts }\end{array}$ & $\begin{array}{l}\text { Public } \\
\text { 2-year }\end{array}$ & Other \\
\hline 1 & 2 & 3 & 4 & 5 & 6 & 7 & 8 & 9 & 10 & 11 \\
\hline $\begin{array}{l}\text { Number of full-time instructional faculty and staff } \\
\text { (in thousands) } \\
\text { Percentage distribution }\end{array}$ & $\begin{array}{r}528 \\
100.0\end{array}$ & $\begin{array}{r}107 \\
20.3\end{array}$ & $\begin{array}{r}32 \\
6.1\end{array}$ & $\begin{array}{r}53 \\
10.0\end{array}$ & $\begin{array}{r}29 \\
5.4\end{array}$ & $\begin{array}{r}94 \\
17.9\end{array}$ & $\begin{array}{r}39 \\
7.3\end{array}$ & $\begin{array}{r}38 \\
7.2\end{array}$ & $\begin{array}{r}110 \\
20.8\end{array}$ & $\begin{array}{r}26 \\
5.0\end{array}$ \\
\hline 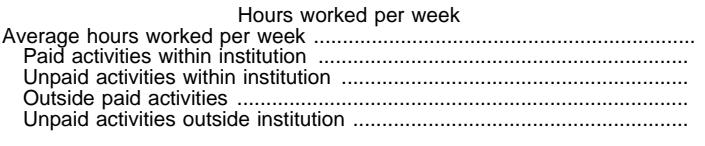 & $\begin{array}{r}52.5 \\
42.6 \\
5.1 \\
2.8 \\
2.0\end{array}$ & $\begin{array}{r}56.4 \\
48.0 \\
4.3 \\
2.4 \\
1.8\end{array}$ & $\begin{array}{r}57.6 \\
48.6 \\
4.1 \\
2.6 \\
2.2\end{array}$ & $\begin{array}{r}55.1 \\
46.2 \\
4.3 \\
2.5 \\
2.1\end{array}$ & \begin{tabular}{r|}
53.4 \\
44.6 \\
3.4 \\
3.6 \\
1.8
\end{tabular} & $\begin{array}{r}52.4 \\
41.3 \\
5.9 \\
2.8 \\
2.3\end{array}$ & $\begin{array}{r}51.8 \\
40.9 \\
5.8 \\
3.0 \\
2.1\end{array}$ & $\begin{array}{r}52.5 \\
42.4 \\
5.8 \\
2.6 \\
1.6\end{array}$ & $\begin{array}{r}46.9 \\
36.0 \\
6.0 \\
3.1 \\
1.9\end{array}$ & $\begin{array}{r}49.0 \\
39.5 \\
5.1 \\
2.8 \\
1.7\end{array}$ \\
\hline 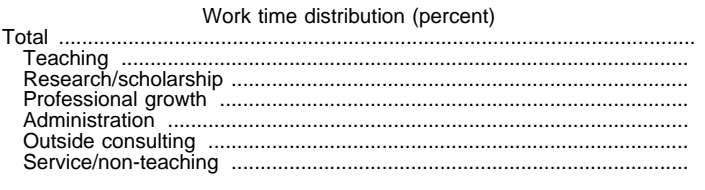 & $\begin{array}{r}100.0 \\
54.5 \\
17.7 \\
4.6 \\
13.0 \\
2.7 \\
7.4\end{array}$ & $\begin{array}{r}100.0 \\
40.4 \\
31.6 \\
3.7 \\
12.9 \\
2.5 \\
8.9\end{array}$ & $\begin{array}{r}100.0 \\
34.7 \\
35.5 \\
3.3 \\
12.9 \\
3.0 \\
10.6\end{array}$ & $\begin{array}{r}100.0 \\
46.9 \\
23.8 \\
4.1 \\
13.2 \\
2.5 \\
9.6\end{array}$ & $\begin{array}{r}100.0 \\
44.5 \\
21.7 \\
4.3 \\
15.7 \\
2.8 \\
11.0\end{array}$ & $\begin{array}{r}100.0 \\
60.3 \\
14.0 \\
5.0 \\
12.0 \\
2.7 \\
6.1\end{array}$ & $\begin{array}{r}100.0 \\
59.7 \\
11.8 \\
4.9 \\
14.6 \\
3.1 \\
5.9\end{array}$ & $\begin{array}{r}100.0 \\
63.7 \\
9.7 \\
4.7 \\
14.7 \\
2.3 \\
4.9\end{array}$ & $\begin{array}{r}100.0 \\
68.8 \\
4.5 \\
5.8 \\
12.0 \\
2.7 \\
6.1\end{array}$ & $\begin{array}{r}100.0 \\
60.8 \\
10.7 \\
5.1 \\
14.9 \\
2.8 \\
5.6\end{array}$ \\
\hline 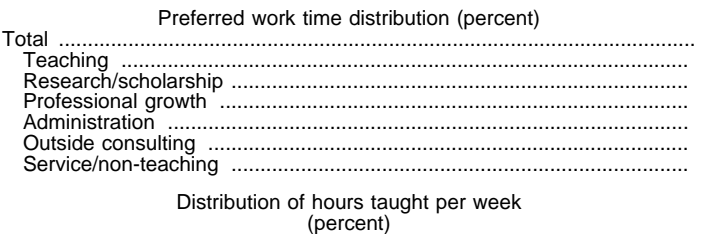 & $\begin{array}{r}100.0 \\
49.0 \\
24.7 \\
8.1 \\
8.2 \\
3.3 \\
6.6\end{array}$ & $\begin{array}{r}100.0 \\
36.6 \\
38.5 \\
6.5 \\
7.8 \\
3.1 \\
7.4\end{array}$ & $\begin{array}{r}100.0 \\
33.2 \\
41.7 \\
6.2 \\
7.1 \\
3.4 \\
8.4\end{array}$ & $\begin{array}{r}100.0 \\
41.8 \\
31.1 \\
7.2 \\
8.0 \\
3.3 \\
8.6\end{array}$ & $\begin{array}{r}100.0 \\
39.4 \\
30.1 \\
6.9 \\
10.2 \\
3.6 \\
9.9\end{array}$ & $\begin{array}{r}100.0 \\
52.4 \\
22.4 \\
8.5 \\
7.7 \\
3.5 \\
5.6\end{array}$ & $\begin{array}{r}100.0 \\
52.9 \\
19.8 \\
8.6 \\
9.2 \\
3.9 \\
5.7\end{array}$ & $\begin{array}{r}100.0 \\
56.1 \\
18.8 \\
8.8 \\
8.6 \\
2.9 \\
4.8\end{array}$ & $\begin{array}{r}100.0 \\
64.1 \\
9.2 \\
9.8 \\
8.1 \\
3.1 \\
5.7\end{array}$ & $\begin{array}{r}100.0 \\
54.1 \\
17.6 \\
9.3 \\
9.6 \\
3.7 \\
5.6\end{array}$ \\
\hline 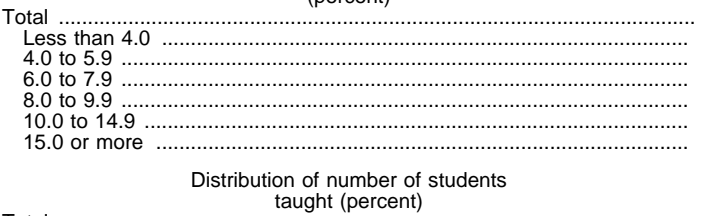 & $\begin{array}{r}100.0 \\
15.0 \\
8.0 \\
15.9 \\
14.6 \\
22.5 \\
23.9\end{array}$ & $\begin{array}{r}100.0 \\
30.4 \\
15.0 \\
26.5 \\
11.9 \\
8.9 \\
7.3\end{array}$ & $\begin{array}{r}100.0 \\
36.7 \\
18.9 \\
21.0 \\
7.0 \\
8.4 \\
8.1\end{array}$ & $\begin{array}{r}100.0 \\
18.9 \\
10.4 \\
21.2 \\
19.0 \\
16.9 \\
13.6\end{array}$ & $\begin{array}{r}100.0 \\
21.5 \\
9.1 \\
24.9 \\
18.9 \\
15.1 \\
10.6\end{array}$ & $\begin{array}{r}100.0 \\
8.2 \\
4.9 \\
12.6 \\
19.9 \\
36.5 \\
17.9\end{array}$ & $\begin{array}{r}100.0 \\
8.2 \\
5.2 \\
14.7 \\
21.9 \\
34.6 \\
15.4\end{array}$ & $\begin{array}{r}100.0 \\
6.3 \\
5.8 \\
13.1 \\
22.2 \\
34.1 \\
18.5\end{array}$ & $\begin{array}{r}100.0 \\
6.2 \\
3.3 \\
6.0 \\
6.5 \\
19.8 \\
58.2\end{array}$ & $\begin{array}{r}100.0 \\
10.5 \\
5.9 \\
14.6 \\
12.3 \\
28.6 \\
28.0\end{array}$ \\
\hline $\begin{array}{l}\text { Total } \\
\text { Less than } 25 \\
25 \text { to } 49 \\
50 \text { to } 74 \text {. } \\
75 \text { to } 99 \\
150 \text { to } 149\end{array}$ & $\begin{array}{r}100.0 \\
13.1 \\
19.9 \\
19.5 \\
15.8 \\
18.9 \\
12.8\end{array}$ & $\begin{array}{r}100.0 \\
21.7 \\
23.1 \\
18.7 \\
11.0 \\
10.9 \\
14.7\end{array}$ & $\begin{array}{r}100.0 \\
33.3 \\
24.3 \\
11.6 \\
8.9 \\
10.2 \\
11.7\end{array}$ & $\begin{array}{r}100.0 \\
15.9 \\
22.2 \\
16.7 \\
13.7 \\
15.5 \\
16.1\end{array}$ & $\begin{array}{r}100.0 \\
18.5 \\
22.4 \\
13.0 \\
11.1 \\
17.6 \\
17.5\end{array}$ & $\begin{array}{r}100.0 \\
7.3 \\
15.1 \\
20.2 \\
19.4 \\
25.1 \\
13.0\end{array}$ & $\begin{array}{r}100.0 \\
8.3 \\
20.4 \\
27.8 \\
21.2 \\
17.4 \\
5.0\end{array}$ & $\begin{array}{r}100.0 \\
11.7 \\
29.8 \\
26.7 \\
15.8 \\
12.0 \\
4.0\end{array}$ & $\begin{array}{r}100.0 \\
5.9 \\
14.3 \\
17.4 \\
18.8 \\
27.6 \\
16.0\end{array}$ & $\begin{array}{r}100.0 \\
13.2 \\
23.0 \\
24.7 \\
15.1 \\
16.3 \\
7.7\end{array}$ \\
\hline $\begin{array}{l}\text { Distribution of student classroom contact hours per week }{ }^{1} \text { (percent) } \\
\text { Total } \\
\text { Less than } 50 \\
50 \text { to } 99 \\
200 \text { to } 199\end{array}$ & $\begin{array}{r}100.0 \\
8.4 \\
10.6 \\
21.9 \\
27.6 \\
15.7 \\
15.8\end{array}$ & $\begin{array}{r}100.0 \\
16.6 \\
16.2 \\
25.8 \\
20.1 \\
8.3 \\
13.0\end{array}$ & $\begin{array}{r}100.0 \\
25.7 \\
18.2 \\
21.9 \\
18.4 \\
4.8 \\
11.0\end{array}$ & $\begin{array}{r}100.0 \\
10.3 \\
13.5 \\
22.5 \\
25.9 \\
11.3 \\
16.6\end{array}$ & $\begin{array}{r}100.0 \\
13.2 \\
12.7 \\
25.3 \\
18.1 \\
13.6 \\
17.1\end{array}$ & $\begin{array}{r}100.0 \\
3.3 \\
7.6 \\
20.0 \\
34.0 \\
20.4 \\
14.8\end{array}$ & $\begin{array}{r}100.0 \\
4.6 \\
9.9 \\
27.6 \\
38.4 \\
11.8 \\
7.8\end{array}$ & $\begin{array}{r}100.0 \\
6.1 \\
11.8 \\
34.8 \\
30.2 \\
10.4 \\
6.9\end{array}$ & $\begin{array}{r}100.0 \\
2.4 \\
4.6 \\
11.8 \\
28.2 \\
26.5 \\
26.6\end{array}$ & $\begin{array}{r}100.0 \\
6.6 \\
12.1 \\
25.7 \\
28.7 \\
14.8 \\
12.1\end{array}$ \\
\hline $\begin{array}{l}\text { Distribution of total classroom credit hours (percent) } \\
\text { Total } \\
\text { Less than } 4.0 \\
6.0 \text { to } 5.9 \\
8.0 \text { to } 9.9 \\
10.0 \text { to } 14.9\end{array}$ & $\begin{array}{r}100.0 \\
14.1 \\
8.6 \\
18.3 \\
18.6 \\
24.9 \\
15.5\end{array}$ & $\begin{array}{r}100.0 \\
26.2 \\
14.7 \\
31.0 \\
15.0 \\
9.5 \\
3.7\end{array}$ & $\begin{array}{r}100.0 \\
28.6 \\
14.8 \\
25.0 \\
16.1 \\
7.4 \\
8.0\end{array}$ & $\begin{array}{r}100.0 \\
15.4 \\
12.5 \\
26.0 \\
22.6 \\
17.9 \\
5.6\end{array}$ & $\begin{array}{r}100.0 \\
19.4 \\
10.8 \\
26.5 \\
18.8 \\
17.0 \\
7.5\end{array}$ & $\begin{array}{r}100.0 \\
8.0 \\
5.8 \\
15.0 \\
23.6 \\
37.3 \\
10.3\end{array}$ & $\begin{array}{r}100.0 \\
8.5 \\
6.0 \\
13.6 \\
28.2 \\
34.6 \\
9.2\end{array}$ & $\begin{array}{r}100.0 \\
11.8 \\
5.9 \\
13.2 \\
24.4 \\
34.9 \\
9.9\end{array}$ & $\begin{array}{r}100.0 \\
7.2 \\
4.2 \\
8.0 \\
10.7 \\
28.4 \\
41.5\end{array}$ & $\begin{array}{r}100.0 \\
12.1 \\
7.8 \\
15.3 \\
18.8 \\
29.1 \\
17.0\end{array}$ \\
\hline $\begin{array}{l}\text { Number of classes taught for credit } \\
\text { Faculty with undergraduate classes only (percent) }\end{array}$ & & & & & & & & & & \\
\hline Total & $\begin{array}{r}100.0 \\
16.0 \\
23.2 \\
23.6 \\
20.0 \\
17.2\end{array}$ & $\begin{array}{r}100.0 \\
34.4 \\
42.9 \\
14.5 \\
6.1 \\
2.1\end{array}$ & $\begin{array}{r}100.0 \\
40.9 \\
37.2 \\
7.9 \\
7.4 \\
6.5\end{array}$ & $\begin{array}{r}100.0 \\
20.6 \\
34.0 \\
27.6 \\
13.3 \\
4.5\end{array}$ & $\begin{array}{r}100.0 \\
22.1 \\
40.8 \\
25.0 \\
6.5 \\
5.5\end{array}$ & $\begin{array}{r}100.0 \\
11.5 \\
20.8 \\
31.9 \\
26.7 \\
9.2\end{array}$ & $\begin{array}{r}100.0 \\
11.3 \\
21.2 \\
31.2 \\
26.1 \\
10.2\end{array}$ & $\begin{array}{r}100.0 \\
9.9 \\
21.6 \\
35.0 \\
20.7 \\
12.9\end{array}$ & $\begin{array}{r}100.0 \\
12.3 \\
13.9 \\
15.3 \\
21.9 \\
36.6\end{array}$ & $\begin{array}{r}100.0 \\
13.1 \\
19.6 \\
27.1 \\
25.4 \\
14.8\end{array}$ \\
\hline Total $\quad$ Faculty with graduate classes only (percent) & $\begin{array}{r}100.0 \\
47.9 \\
33.4 \\
12.6 \\
4.1 \\
2.0\end{array}$ & $\begin{array}{r}100.0 \\
57.1 \\
33.7 \\
6.8 \\
1.9 \\
0.6\end{array}$ & $\begin{array}{r}100.0 \\
53.2 \\
38.4 \\
4.7 \\
1.6 \\
2.1\end{array}$ & $\begin{array}{r}100.0 \\
45.4 \\
35.0 \\
13.4 \\
3.5 \\
2.7\end{array}$ & $\begin{array}{r}100.0 \\
46.4 \\
31.3 \\
17.4 \\
3.5 \\
1.4\end{array}$ & $\begin{array}{r}100.0 \\
30.3 \\
23.0 \\
28.2 \\
13.3 \\
5.2\end{array}$ & $\begin{array}{r}100.0 \\
21.0 \\
36.3 \\
30.1 \\
9.9 \\
2.8\end{array}$ & $\begin{array}{l}- \\
- \\
- \\
-\end{array}$ & $\begin{array}{l}\bar{z} \\
\bar{z} \\
\overline{-}\end{array}$ & $\begin{array}{r}100.0 \\
32.6 \\
36.0 \\
18.1 \\
9.3 \\
4.1\end{array}$ \\
\hline $\begin{array}{c}\text { Faculty with both undergraduate and } \\
\text { graduate classes (percent) }\end{array}$ & & & & & & & & & & \\
\hline Total 2 & $\begin{array}{r}100.0 \\
42.3 \\
32.2 \\
16.1 \\
9.5\end{array}$ & $\begin{array}{r}100.0 \\
58.9 \\
29.9 \\
5.5 \\
5.7\end{array}$ & $\begin{array}{r}100.0 \\
67.6 \\
22.8 \\
7.4 \\
2.2\end{array}$ & $\begin{array}{r}100.0 \\
48.3 \\
31.3 \\
14.6 \\
5.8\end{array}$ & $\begin{array}{r}100.0 \\
40.5 \\
36.6 \\
12.1 \\
10.8\end{array}$ & $\begin{array}{r}100.0 \\
25.0 \\
34.0 \\
25.7 \\
15.3\end{array}$ & $\begin{array}{r}100.0 \\
17.6 \\
45.7 \\
27.6 \\
9.1\end{array}$ & $\begin{array}{r}100.0 \\
22.1 \\
21.7 \\
37.0 \\
19.3\end{array}$ & $\begin{array}{l}\bar{z} \\
\bar{z}\end{array}$ & $\begin{array}{l}\bar{z} \\
\overline{-} \\
-\end{array}$ \\
\hline
\end{tabular}

${ }^{1}$ Hours that faculty and instructional staff spend each week with students during classroom instruction multiplied by the number of students taught.

-Data not available or not applicable.

NOTE.-Because of rounding, details may not add to totals.
SOURCE: U.S. Department of Education, National Center for Education Statistics, National Study of Postsecondary Faculty (NSOPF), 1993. (This table was prepared September 1996.) 
Table 228.-Part-time instructional faculty and staff in institutions of higher education, by instruction activities and type and control of institution: Fall 1992

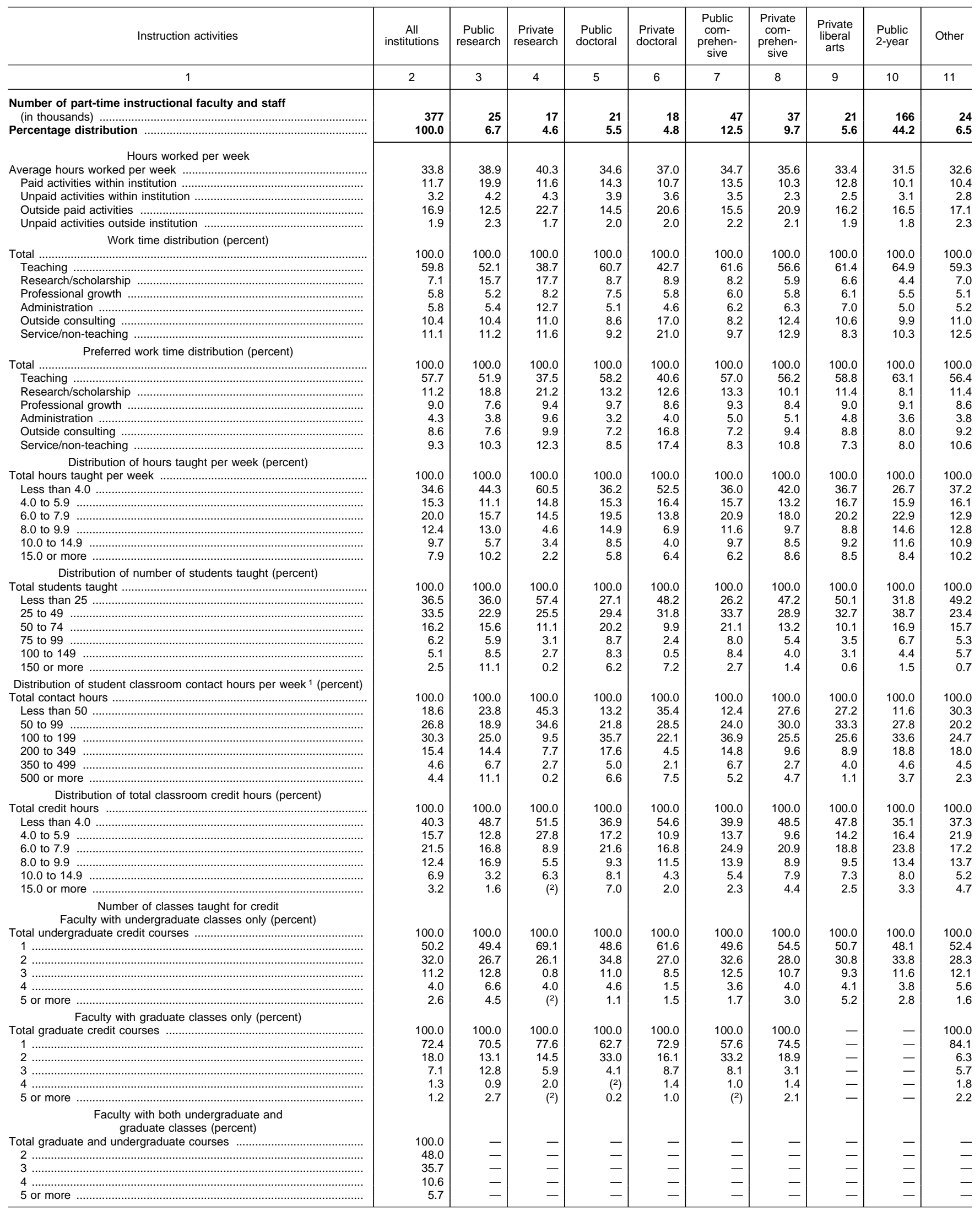

${ }^{1}$ Hours that faculty and instructional staff spend each week with students during classroom instruction multiplied by the number of students taught.

${ }^{2}$ Less than .05 percent.

-Data not available or not applicable.

NOTE.-Because of rounding, details may not add to totals.
SOURCE: U.S. Department of Education, National Center for Education Statistics, National Study of Postsecondary Faculty (NSOPF), 1993. (This table was prepared September 1996.) 
Table 229.-Percentage distribution of full-time and part-time instructional faculty and staff in institutions of higher education, by program area, race/ethnicity, and sex: Fall 1992

\begin{tabular}{|c|c|c|c|c|c|c|c|c|c|c|c|c|}
\hline \multirow{3}{*}{ Program area } & \multirow{3}{*}{ Number } & \multirow{3}{*}{ Percent } & \multicolumn{2}{|c|}{$\begin{array}{c}\text { White, } \\
\text { non-Hispanic }\end{array}$} & \multicolumn{2}{|c|}{$\begin{array}{c}\text { Black, } \\
\text { non-Hispanic }\end{array}$} & \multicolumn{2}{|c|}{ Hispanic } & \multicolumn{2}{|c|}{$\begin{array}{l}\text { Asian/Pacific } \\
\text { Islander }\end{array}$} & \multirow{2}{*}{\multicolumn{2}{|c|}{$\begin{array}{c}\text { American } \\
\text { Indian/Alaskan } \\
\text { Native }\end{array}$}} \\
\hline & & & & & & & Mal & Eomols & & & & \\
\hline & & & Male & Female & Male & Female & IVIale & remale & Male & Female & Male & $\overline{\text { Female }}$ \\
\hline 1 & 2 & 3 & 4 & 5 & 6 & 7 & 8 & 9 & 10 & 11 & 12 & 13 \\
\hline & & & & & Full-time & instruction & I faculty & and staff & & & & \\
\hline Total & 528,260 & 100.0 & 58.0 & 28.4 & 2.7 & 2.4 & 1.8 & 0.9 & 3.9 & 1.3 & 0.3 & 0.2 \\
\hline Agriculture and home economics & 11,366 & 100.0 & 70.4 & 20.3 & 2.3 & 1.6 & 1.6 & 0.2 & 1.0 & 1.9 & - & 0.7 \\
\hline Business ........................................... & 39,928 & 100.0 & 61.3 & 27.2 & 2.0 & 2.2 & 1.0 & 0.6 & 3.9 & 0.8 & 0.6 & 0.3 \\
\hline 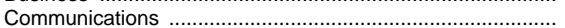 & 10,296 & 100.0 & 55.9 & 30.4 & 2.9 & 2.7 & 1.5 & - & 4.3 & 1.2 & 0.8 & 0.3 \\
\hline 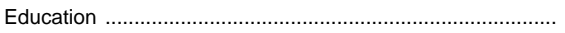 & 37,066 & 100.0 & 42.8 & 41.9 & 4.0 & 5.4 & 1.0 & 2.4 & 0.5 & 1.1 & 0.7 & 0.3 \\
\hline 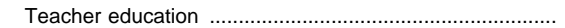 & 12,490 & 100.0 & 39.8 & 50.3 & 2.1 & 4.9 & 0.1 & 0.7 & 0.3 & 1.0 & 0.5 & 0.2 \\
\hline Other education ...... & 24,576 & 100.0 & 44.4 & 37.6 & 4.9 & 5.7 & 1.4 & 3.3 & 0.6 & 1.1 & 0.8 & 0.3 \\
\hline Engineering ....... & 24,431 & 100.0 & 72.7 & 3.9 & 2.1 & 0.7 & 2.9 & 0.2 & 15.5 & 1.3 & 0.7 & - \\
\hline Fine arts ................. & 31,659 & 100.0 & 59.6 & 29.0 & 3.8 & 1.9 & 2.1 & 0.3 & 1.2 & 1.5 & 0.3 & 0.2 \\
\hline Health sciences & 79,422 & 100.0 & 42.1 & 43.8 & 2.3 & 3.4 & 1.5 & 0.7 & 3.9 & 2.2 & 0.1 & 0.1 \\
\hline First-professional . & 36,867 & 100.0 & 63.3 & 19.0 & 3.6 & 1.0 & 2.8 & 0.9 & 7.2 & 2.1 & 0.2 & - \\
\hline Nursing & 21,776 & 100.0 & 0.9 & 87.5 & 0.5 & 7.1 & - & 0.9 & 0.1 & 2.9 & - & 0.2 \\
\hline 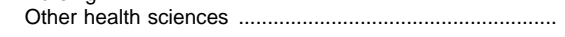 & 20,779 & 100.0 & 47.5 & 42.0 & 1.8 & 3.7 & 0.9 & 0.3 & 2.0 & 1.5 & 0.2 & 0.2 \\
\hline Humanities & 73,923 & 100.0 & 52.8 & 35.2 & 2.1 & 2.1 & 2.1 & 2.0 & 1.2 & 1.9 & 0.3 & 0.1 \\
\hline 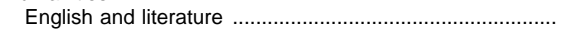 & 37,432 & 100.0 & 44.5 & 45.5 & 2.2 & 2.9 & 1.3 & 1.0 & 0.8 & 1.2 & 0.5 & 0.1 \\
\hline 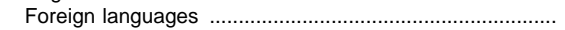 & 13,722 & 100.0 & 39.5 & 36.8 & 1.2 & 0.6 & 5.7 & 7.5 & 1.8 & 6.4 & - & 0.4 \\
\hline History ...................... & 14,574 & 100.0 & 70.2 & 20.2 & 3.0 & 2.3 & 1.3 & 0.4 & 1.7 & 0.4 & 0.3 & - \\
\hline 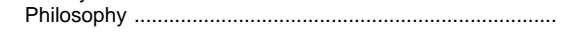 & 8,195 & 100.0 & 82.1 & 12.5 & 1.7 & 0.2 & 1.2 & 0.3 & 1.5 & 0.2 & 0.2 & - \\
\hline Law ……..................... & 8,524 & 100.0 & 57.6 & 30.1 & 5.4 & 3.0 & 1.2 & 1.0 & 0.2 & 1.4 & - & - \\
\hline Natural sciences .......... & 101,505 & 100.0 & 68.2 & 17.6 & 2.6 & 1.0 & 1.6 & 0.4 & 7.3 & 1.0 & 0.2 & 0.1 \\
\hline Biological sciences ... & 34,289 & 100.0 & 67.1 & 20.8 & 3.2 & 1.5 & 1.1 & 0.5 & 4.5 & 0.9 & 0.3 & 0.1 \\
\hline Physical sciences & 28,313 & 100.0 & 76.7 & 10.2 & 2.2 & 0.3 & 2.0 & 0.1 & 7.7 & 0.9 & - & - \\
\hline 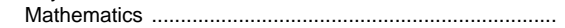 & 25,325 & 100.0 & 61.3 & 21.6 & 2.7 & 1.0 & 1.7 & 0.6 & 9.1 & 1.2 & 0.5 & 0.4 \\
\hline 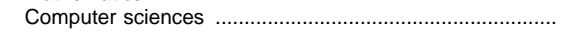 & 13,578 & 100.0 & 65.8 & 17.8 & 2.1 & 1.3 & 1.7 & 0.1 & 10.3 & 0.8 & - & - \\
\hline Social sciences ....... & 58,232 & 100.0 & 64.6 & 22.7 & 3.1 & 3.1 & 1.9 & 0.8 & 2.6 & 0.7 & 0.3 & 0.2 \\
\hline Economics ................... & 9,778 & 100.0 & 69.8 & 12.3 & 3.9 & 0.3 & 3.0 & 1.1 & 7.8 & 1.7 & - & - \\
\hline Political science & 9,324 & 100.0 & 75.0 & 14.8 & 3.6 & 1.9 & 2.7 & 0.5 & 1.1 & 0.2 & 0.1 & - \\
\hline Psychology ............ & 17,784 & 100.0 & 56.9 & 32.3 & 2.3 & 4.3 & 1.5 & 0.8 & 1.1 & 0.3 & 0.1 & 0.2 \\
\hline 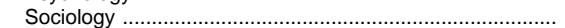 & 9,511 & 100.0 & 67.4 & 20.6 & 2.7 & 3.3 & 2.3 & 0.5 & 1.3 & 0.8 & 0.9 & - \\
\hline 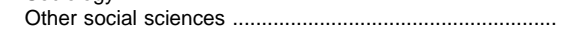 & 11,835 & 100.0 & 61.3 & 25.0 & 3.4 & 4.3 & 0.8 & 1.1 & 2.7 & 0.6 & 0.3 & 0.6 \\
\hline 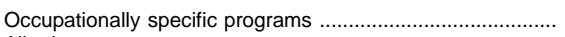 & 15,268 & 100.0 & 75.7 & 13.8 & 3.6 & 0.9 & 2.9 & 0.3 & 1.9 & 0.2 & 0.5 & 0.2 \\
\hline All other programs & 27,717 & 100.0 & 57.4 & 30.7 & 2.8 & 3.4 & 2.0 & 0.6 & 2.2 & 0.6 & - & 0.1 \\
\hline & & & & & Part-time & instruction & l faculty & and staff & & & & \\
\hline Total . & 376,675 & 100.0 & 48.6 & 39.8 & 2.7 & 2.1 & 1.8 & 1.1 & 1.9 & 1.4 & 0.4 & 0.2 \\
\hline 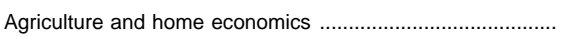 & 2,758 & 100.0 & 46.9 & 52.0 & - & - & 1.1 & - & - & - & - & - \\
\hline Business & 34,679 & 100.0 & 63.6 & 25.9 & 3.3 & 1.9 & 2.0 & 0.7 & 1.0 & 1.1 & 0.2 & 0.4 \\
\hline 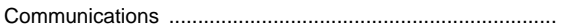 & 10,307 & 100.0 & 43.2 & 49.9 & 4.0 & 0.9 & - & 0.6 & 0.5 & 0.3 & 0.3 & 0.1 \\
\hline Education n... & 30,758 & 100.0 & 28.9 & 58.8 & 2.5 & 5.5 & 0.7 & 1.3 & 0.4 & 1.1 & 0.3 & 0.6 \\
\hline Teacher education & 12,390 & 100.0 & 20.0 & 68.5 & 2.3 & 6.6 & 0.6 & 0.8 & 0.5 & 0.8 & - & - \\
\hline 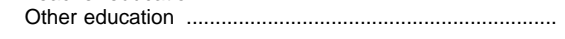 & 18,368 & 100.0 & 34.9 & 52.2 & 2.7 & 4.8 & 0.7 & 1.6 & 0.3 & 1.3 & 0.5 & 1.0 \\
\hline Engineering .................. & 11,632 & 100.0 & 79.3 & 7.2 & 1.9 & - & 2.0 & - & 6.8 & 0.8 & 1.9 & - \\
\hline Fine arts ........ & 32,814 & 100.0 & 46.2 & 43.1 & 3.4 & 1.8 & 1.3 & 1.3 & 0.4 & 1.9 & 0.5 & 0.2 \\
\hline Health sciences. & 44,763 & 100.0 & 36.8 & 51.4 & 3.0 & 2.6 & 1.0 & 0.7 & 2.3 & 1.7 & 0.4 & 0.1 \\
\hline 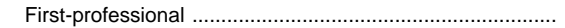 & 17,710 & 100.0 & 57.6 & 27.7 & 6.1 & 1.1 & 0.6 & 0.3 & 4.9 & 1.8 & - & - \\
\hline 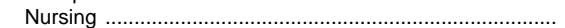 & 10,498 & 100.0 & 5.4 & 84.0 & - & 6.6 & - & 0.9 & - & 2.4 & - & 0.6 \\
\hline 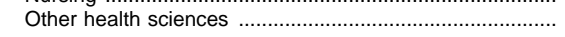 & 16,555 & 100.0 & 34.5 & 56.0 & 1.7 & 1.8 & 2.0 & 0.9 & 0.9 & 1.2 & 1.1 & - \\
\hline 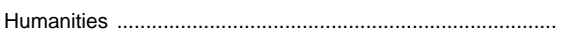 & 60,041 & 100.0 & 35.8 & 51.5 & 1.1 & 2.2 & 2.7 & 3.1 & 1.1 & 1.7 & 0.3 & 0.5 \\
\hline English and literature & 37,395 & 100.0 & 29.4 & 60.9 & 0.6 & 2.9 & 2.0 & 1.5 & 0.6 & 1.2 & 0.4 & 0.6 \\
\hline Foreign languages & 10,566 & 100.0 & 27.0 & 44.7 & 1.1 & 1.7 & 5.9 & 12.1 & 2.2 & 4.9 & - & 0.5 \\
\hline 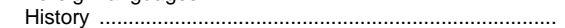 & 7,812 & 100.0 & 61.9 & 30.7 & 2.9 & 0.7 & 1.7 & 0.2 & 1.5 & - & 0.3 & - \\
\hline 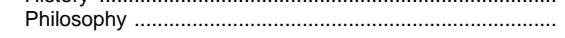 & 4,268 & 100.0 & 66.3 & 24.6 & 2.6 & 0.3 & 2.7 & - & 2.3 & 1.2 & - & - \\
\hline Law .............. & 13,552 & 100.0 & 68.2 & 23.6 & 3.7 & 2.7 & 0.3 & 0.2 & 1.3 & - & - & - \\
\hline Natural sciences .............. & 60,242 & 100.0 & 58.3 & 29.2 & 3.1 & 1.0 & 2.1 & 0.4 & 3.6 & 1.6 & 0.7 & (1) \\
\hline Biological sciences . & 11,747 & 100.0 & 50.3 & 37.4 & 3.2 & 1.1 & 2.1 & 0.6 & 1.8 & 3.5 & - & - \\
\hline 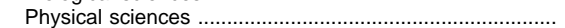 & 10,626 & 100.0 & 67.6 & 21.2 & 1.5 & 0.4 & 1.1 & 0.9 & 5.5 & 1.9 & - & - \\
\hline 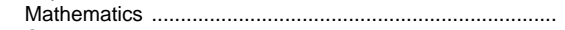 & 24,559 & 100.0 & 52.8 & 34.5 & 4.6 & 0.9 & 2.4 & 0.2 & 3.4 & 0.7 & 0.4 & 0.1 \\
\hline Computer sciences & 13,310 & 100.0 & 68.2 & 18.4 & 1.7 & 1.4 & 2.3 & 0.3 & 4.0 & 1.2 & 2.4 & - \\
\hline Social sciences . & 33,854 & 100.0 & 48.8 & 38.3 & 3.7 & 2.9 & 1.8 & 0.9 & 2.2 & 0.9 & 0.4 & 0.1 \\
\hline 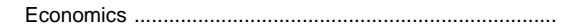 & 3,038 & 100.0 & 69.0 & 13.8 & 1.7 & 1.0 & 2.7 & - & 9.1 & 2.5 & - & - \\
\hline 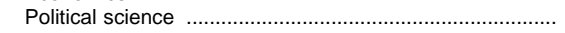 & 3,055 & 100.0 & 72.4 & 18.6 & 4.6 & 0.4 & 3.4 & 0.5 & - & - & - & - \\
\hline 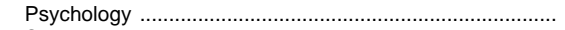 & 15,617 & 100.0 & 45.6 & 45.7 & 2.5 & 1.5 & 1.5 & 0.5 & 2.0 & 0.3 & 0.2 & 0.3 \\
\hline 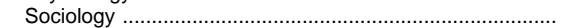 & 4,384 & 100.0 & 33.2 & 52.5 & 6.3 & 4.0 & 1.2 & 0.2 & 1.5 & 1.0 & - & - \\
\hline 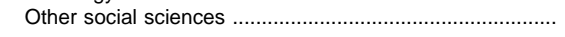 & 7,760 & 100.0 & 47.0 & 32.8 & 4.9 & 7.0 & 1.7 & 2.4 & 1.0 & 1.9 & 1.2 & - \\
\hline 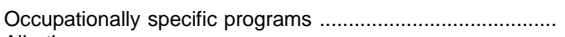 & 16,490 & 100.0 & 71.2 & 18.0 & 3.5 & 0.8 & 5.1 & - & 1.3 & - & 0.1 & - \\
\hline All other programs & 19,769 & 100.0 & 44.7 & 43.5 & 1.9 & 1.5 & 2.3 & 1.6 & 2.4 & 2.1 & - & - \\
\hline
\end{tabular}

${ }^{1}$ Less than 0.05 percent.

—Data not available or not applicable.

SOURCE: U.S. Department of Education, National Center for Education Statistics, National Study of Postsecondary Faculty (NSOPF), 1993. (This table was prepared September 1996.)

NOTE.-Because of rounding and nonresponse to program area question, details may not add to totals. 
Table 230.-Full-time and part-time instructional faculty and staff in institutions of higher education, by selected characteristics and type and control of institution: Fall 1992

\begin{tabular}{|c|c|c|c|c|c|c|c|c|c|c|c|}
\hline Selected characteristics & $\begin{array}{l}\text { Number in } \\
\text { thousands }\end{array}$ & $\begin{array}{c}\text { Percent } \\
\text { total }\end{array}$ & $\begin{array}{l}\text { Public } \\
\text { research }\end{array}$ & $\begin{array}{l}\text { Private } \\
\text { research }\end{array}$ & $\begin{array}{c}\text { Public } \\
\text { doctoral }\end{array}$ & $\begin{array}{l}\text { Private } \\
\text { doctoral }\end{array}$ & $\begin{array}{l}\text { Public } \\
\text { com- } \\
\text { prehen- } \\
\text { sive }\end{array}$ & $\begin{array}{l}\text { Private } \\
\text { com- } \\
\text { prehen- } \\
\text { sive }\end{array}$ & $\begin{array}{c}\text { Private } \\
\text { liberal } \\
\text { arts }\end{array}$ & $\begin{array}{l}\text { Public } \\
2 \text {-year }\end{array}$ & Other \\
\hline 1 & 2 & 3 & 4 & 5 & 6 & 7 & 8 & 9 & 10 & 11 & 12 \\
\hline & & \multicolumn{10}{|c|}{ Full-time instructional faculty } \\
\hline \multirow[t]{2}{*}{ Total (in thousands) } & \multirow[t]{2}{*}{528} & 100.0 & $\begin{array}{r}107 \\
20.3\end{array}$ & $\begin{array}{r}32 \\
6.1\end{array}$ & $\begin{array}{r}53 \\
10.0\end{array}$ & $\begin{array}{r}29 \\
5.4\end{array}$ & $\begin{array}{r}94 \\
17.9\end{array}$ & $\begin{array}{r}39 \\
7.3\end{array}$ & $\begin{array}{r}38 \\
7.2\end{array}$ & $\begin{array}{r}110 \\
20.8\end{array}$ & $\begin{array}{r}26 \\
5.0\end{array}$ \\
\hline & & \multicolumn{10}{|c|}{ Percentage distribution } \\
\hline Total & - & 100.0 & 100.0 & 100.0 & 100.0 & 100.0 & 100.0 & 100.0 & 100.0 & 100.0 & 100.0 \\
\hline \multicolumn{12}{|l|}{ Sex } \\
\hline Male ...... & 353 & 66.8 & 76.7 & 69.1 & 69.9 & 76.4 & 66.1 & 64.9 & 61.1 & 54.7 & 70.5 \\
\hline Female ........... & 176 & 33.2 & 23.3 & 30.9 & 30.1 & 23.6 & 33.9 & 35.2 & 38.9 & 45.3 & 29.5 \\
\hline \multicolumn{12}{|l|}{ Race } \\
\hline White, non-Hispanic .................... & 457 & 86.5 & 88.0 & 83.7 & 87.5 & 84.1 & 82.7 & 91.3 & 90.0 & 85.5 & 89.2 \\
\hline Black, non-Hispanic ..................... & 27 & 5.2 & 2.8 & 5.0 & 3.1 & 4.9 & 9.1 & 3.5 & 5.4 & 6.2 & 3.7 \\
\hline 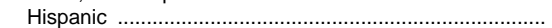 & 14 & 2.6 & 2.2 & 2.1 & 2.5 & 3.7 & 2.6 & 1.6 & 1.3 & 4.1 & 1.4 \\
\hline 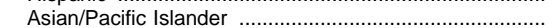 & 28 & 5.2 & 6.9 & 9.0 & 6.1 & 7.1 & 5.1 & 3.3 & 2.8 & 3.3 & 5.2 \\
\hline 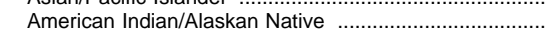 & 3 & 0.5 & 0.1 & 0.2 & 0.8 & 0.2 & 0.5 & 0.2 & 0.5 & 1.0 & 0.5 \\
\hline \multicolumn{12}{|l|}{ Age } \\
\hline 29 or younger & 8 & 1.4 & 1.0 & 1.8 & 1.2 & 0.6 & 1.5 & 1.4 & 2.1 & 1.7 & 2.0 \\
\hline 30 to 34 & 35 & 6.7 & 7.2 & 7.8 & 8.4 & 9.2 & 5.9 & 7.0 & 7.0 & 5.3 & 5.1 \\
\hline 35 to 39 & 67 & 12.6 & 14.3 & 20.4 & 14.4 & 15.4 & 10.6 & 10.4 & 13.9 & 9.8 & 10.8 \\
\hline 40 to 44 & 90 & 17.1 & 18.1 & 19.9 & 17.4 & 17.9 & 15.1 & 16.4 & 17.4 & 16.8 & 16.5 \\
\hline 45 to 49 & 98 & 18.5 & 17.0 & 15.3 & 16.8 & 19.7 & 18.8 & 18.9 & 19.7 & 20.8 & 17.8 \\
\hline 50 to 54 & 95 & 18.0 & 15.9 & 11.5 & 17.4 & 12.8 & 21.5 & 16.7 & 14.7 & 21.9 & 18.2 \\
\hline 55 to 59 & 67 & 12.7 & 12.8 & 9.1 & 11.7 & 10.0 & 14.4 & 12.8 & 11.9 & 13.5 & 14.4 \\
\hline 60 to 64 & 45 & 8.4 & 8.9 & 8.3 & 8.2 & 8.0 & 8.2 & 11.3 & 8.5 & 7.1 & 9.6 \\
\hline 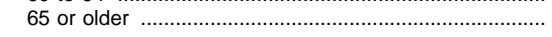 & 24 & 4.5 & 4.8 & 5.9 & 4.5 & 6.5 & 3.9 & 5.1 & 4.8 & 3.2 & 5.8 \\
\hline \multicolumn{12}{|l|}{ Highest degree } \\
\hline Doctoral ....... & 284 & 54.0 & 70.8 & 63.7 & 62.6 & 58.2 & 68.1 & 60.8 & 58.4 & 16.6 & 40.7 \\
\hline Professional ........... & 58 & 11.1 & 17.0 & 24.9 & 20.1 & 29.4 & 4.3 & 7.7 & 3.2 & 2.3 & 9.7 \\
\hline 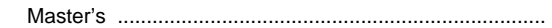 & 156 & 29.7 & 10.6 & 10.2 & 16.0 & 10.5 & 26.4 & 29.3 & 35.3 & 63.9 & 42.1 \\
\hline Bachelor's . & 21 & 4.0 & 1.6 & 1.1 & 1.3 & 1.9 & 1.1 & 2.1 & 3.1 & 11.9 & 6.6 \\
\hline 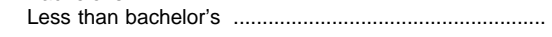 & 6 & 1.2 & 0.1 & 0.1 & $(1)$ & $(1)$ & 0.2 & 0.1 & $(1)$ & 5.4 & 0.9 \\
\hline \multicolumn{12}{|l|}{ Academic rank } \\
\hline Full professor ................................... & 161 & 30.4 & 39.8 & 33.3 & 31.3 & 30.5 & 34.3 & 26.8 & 28.7 & 19.1 & 27.8 \\
\hline Associate professor & 124 & 23.4 & 26.4 & 22.7 & 26.3 & 26.8 & 26.9 & 29.0 & 25.3 & 12.9 & 23.4 \\
\hline Assistant professor & 124 & 23.5 & 22.7 & 27.0 & 31.2 & 29.1 & 26.1 & 31.9 & 29.9 & 11.3 & 21.8 \\
\hline Instructor & 74 & 14.0 & 4.0 & 4.6 & 7.6 & 9.1 & 8.6 & 8.0 & 9.2 & 39.7 & 12.5 \\
\hline 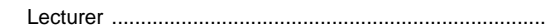 & 12 & 2.2 & 3.9 & 6.7 & 1.7 & 1.8 & 2.6 & 1.2 & 1.6 & 0.4 & 0.7 \\
\hline Other & 17 & 3.2 & 3.2 & 4.8 & 1.8 & 2.6 & 1.4 & 1.9 & 3.7 & 5.7 & 2.9 \\
\hline No rank .......... & 17 & 3.2 & 0.2 & 1.0 & 0.2 & 0.1 & 0.2 & 1.3 & 1.7 & 11.0 & 10.9 \\
\hline \multicolumn{12}{|l|}{ Base salary } \\
\hline Under $\$ 10,000$ & 14 & 2.6 & 2.0 & 3.0 & 2.1 & 2.7 & 2.1 & 2.7 & 2.5 & 3.5 & 3.6 \\
\hline$\$ 10,000$ to 24,999 & 29 & 5.6 & 3.6 & 5.1 & 4.7 & 2.8 & 5.5 & 5.3 & 10.0 & 6.2 & 10.7 \\
\hline 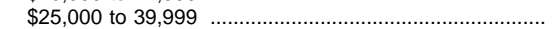 & 182 & 34.4 & 19.5 & 14.4 & 29.0 & 24.5 & 37.1 & 44.0 & 53.5 & 47.2 & 36.9 \\
\hline$\$ 40,000$ to 54,999 & 164 & 31.0 & 29.4 & 28.5 & 29.8 & 24.9 & 34.0 & 32.1 & 24.6 & 33.8 & 35.5 \\
\hline 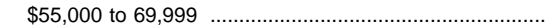 & 77 & 14.5 & 22.7 & 15.7 & 17.0 & 19.8 & 16.9 & 10.0 & 6.0 & 8.0 & 6.5 \\
\hline$\$ 70,000$ to 84,999 & 32 & 6.1 & 12.1 & 13.0 & 9.0 & 9.9 & 3.3 & 3.6 & 2.2 & 0.8 & 4.0 \\
\hline$\$ 85,000$ to 99,999 & 11 & 2.1 & 4.4 & 3.7 & 2.3 & 7.7 & 0.7 & 1.0 & 0.6 & 0.1 & 1.6 \\
\hline 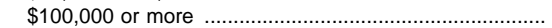 & 20 & 3.7 & 6.5 & 16.6 & 6.2 & 7.7 & 0.4 & 1.4 & 0.5 & 0.4 & 1.2 \\
\hline
\end{tabular}


Table 230.-Full-time and part-time instructional faculty and staff in institutions of higher education, by selected characteristics and type and control of institution: Fall 1992-Continued

\begin{tabular}{|c|c|c|c|c|c|c|c|c|c|c|c|}
\hline Selected characteristics & $\begin{array}{l}\text { Number in } \\
\text { thousands }\end{array}$ & $\begin{array}{l}\text { Percent } \\
\text { total }\end{array}$ & $\begin{array}{l}\text { Public } \\
\text { research }\end{array}$ & $\begin{array}{l}\text { Private } \\
\text { research }\end{array}$ & $\begin{array}{c}\text { Public } \\
\text { doctoral }\end{array}$ & $\begin{array}{l}\text { Private } \\
\text { doctoral }\end{array}$ & $\begin{array}{l}\text { Public } \\
\text { com- } \\
\text { prehen- } \\
\text { sive }\end{array}$ & $\begin{array}{l}\text { Private } \\
\text { com- } \\
\text { prehen- } \\
\text { sive }\end{array}$ & $\begin{array}{c}\text { Private } \\
\text { liberal } \\
\text { arts }\end{array}$ & $\begin{array}{l}\text { Public } \\
\text { 2-year }\end{array}$ & Other \\
\hline 1 & 2 & 3 & 4 & 5 & 6 & 7 & 8 & 9 & 10 & 11 & 12 \\
\hline \multirow{3}{*}{ Total (in thousands) } & \multirow{3}{*}{377} & \multicolumn{10}{|c|}{ Part-time instructional faculty } \\
\hline & & $10 \overline{0}$ & $\begin{array}{r}25 \\
6.7\end{array}$ & $\begin{array}{r}17 \\
4.6\end{array}$ & $\begin{array}{r}21 \\
5.5\end{array}$ & $\begin{array}{r}18 \\
4.8\end{array}$ & $\begin{array}{r}47 \\
12.5\end{array}$ & $\begin{array}{r}37 \\
9.7\end{array}$ & $\begin{array}{r}21 \\
5.6\end{array}$ & $\begin{array}{r}166 \\
44.2\end{array}$ & $\begin{array}{r}24 \\
6.5\end{array}$ \\
\hline & & \multicolumn{10}{|c|}{ Percentage distribution } \\
\hline Total & - & 100.0 & 100.0 & 100.0 & 100.0 & 100.0 & 100.0 & 100.0 & 100.0 & 100.0 & 100.0 \\
\hline \multicolumn{12}{|l|}{ Sex } \\
\hline Male & 209 & 55.4 & 56.8 & 58.7 & 55.4 & 63.1 & 49.1 & 56.4 & 46.6 & 56.6 & 56.1 \\
\hline 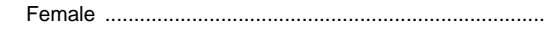 & 168 & 44.6 & 43.3 & 41.3 & 44.6 & 36.9 & 51.0 & 43.7 & 53.4 & 43.4 & 44.0 \\
\hline \multicolumn{12}{|l|}{ Race } \\
\hline White, non-Hispanic .................. & 333 & 88.3 & 87.8 & 89.5 & 91.4 & 87.7 & 85.0 & 90.8 & 89.6 & 87.9 & 90.8 \\
\hline 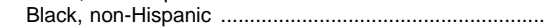 & 18 & 4.8 & 2.5 & 4.4 & 3.3 & 7.1 & 7.2 & 5.0 & 5.9 & 4.6 & 3.2 \\
\hline Hispanic & 11 & 3.0 & 3.2 & 2.7 & 1.6 & 1.5 & 3.0 & 1.1 & 2.9 & 4.0 & 1.1 \\
\hline Asian/Pacific Islander & 12 & 3.2 & 6.6 & 3.0 & 3.3 & 3.5 & 4.1 & 2.5 & 1.6 & 2.7 & 3.8 \\
\hline 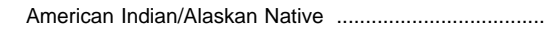 & 2 & 0.6 & $\left({ }^{1}\right)$ & 0.4 & 0.4 & 0.2 & 0.7 & 0.5 & 0.1 & 0.8 & 1.1 \\
\hline \multicolumn{12}{|l|}{ Age } \\
\hline 29 or younger & 20 & 5.4 & 4.0 & 2.7 & 8.3 & 1.9 & 7.7 & 4.0 & 2.7 & 6.1 & 5.0 \\
\hline 30 to 34 & 36 & 9.5 & 6.5 & 18.5 & 6.5 & 7.4 & 10.1 & 6.9 & 8.0 & 10.0 & 11.7 \\
\hline 35 to 39 & 59 & 15.6 & 15.7 & 13.8 & 16.8 & 27.3 & 15.0 & 14.6 & 19.3 & 14.6 & 14.5 \\
\hline 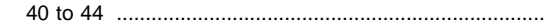 & 70 & 18.6 & 20.1 & 11.8 & 19.4 & 16.0 & 17.9 & 18.4 & 21.4 & 19.5 & 16.1 \\
\hline 45 to 49 & 68 & 18.0 & 19.0 & 19.0 & 17.1 & 18.9 & 16.1 & 20.9 & 21.8 & 17.5 & 16.7 \\
\hline 50 to 54 & 45 & 12.0 & 12.9 & 12.1 & 10.5 & 9.9 & 11.0 & 11.8 & 9.3 & 12.7 & 13.4 \\
\hline 55 to 59 & 29 & 7.6 & 8.1 & 11.1 & 6.2 & 3.8 & 10.0 & 9.3 & 6.1 & 7.2 & 6.3 \\
\hline 60 to 64 & 23 & 6.1 & 5.0 & 8.1 & 5.4 & 6.5 & 5.9 & 6.5 & 4.2 & 6.5 & 4.9 \\
\hline 65 or older & 27 & 7.1 & 8.9 & 2.8 & 10.0 & 8.4 & 6.4 & 7.6 & 7.2 & 6.1 & 11.6 \\
\hline \multicolumn{12}{|l|}{ Highest degree } \\
\hline Doctoral & 59 & 16.0 & 30.4 & 26.3 & 17.5 & 26.0 & 19.0 & 21.5 & 21.8 & 8.1 & 17.6 \\
\hline Professional & 40 & 10.7 & 18.5 & 23.7 & 29.2 & 34.4 & 5.2 & 10.5 & 3.2 & 5.1 & 15.0 \\
\hline Master's ......... & 190 & 51.6 & 39.1 & 43.2 & 41.4 & 31.5 & 61.1 & 58.4 & 58.7 & 53.0 & 50.3 \\
\hline Bachelor's & 63 & 17.0 & 12.1 & 6.8 & 11.7 & 7.9 & 14.0 & 9.3 & 15.7 & 24.0 & 13.3 \\
\hline 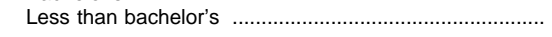 & 17 & 4.7 & $(1)$ & $(1)$ & 0.2 & 0.2 & 0.7 & 0.2 & 0.6 & 9.8 & 3.8 \\
\hline \multicolumn{12}{|l|}{ Academic rank } \\
\hline Full professor & 32 & 8.6 & 11.6 & 18.6 & 9.5 & 14.0 & 6.6 & 15.2 & 11.5 & 4.1 & 15.1 \\
\hline Associate professor & 23 & 6.0 & 17.3 & 15.5 & 13.5 & 11.6 & 3.2 & 6.4 & 4.7 & 2.4 & 7.0 \\
\hline Assistant professor & 24 & 6.4 & 14.2 & 12.6 & 11.6 & 19.9 & 4.1 & 7.5 & 11.3 & 2.4 & 5.8 \\
\hline Instructor & 215 & 57.2 & 24.7 & 27.8 & 40.1 & 27.4 & 51.3 & 43.5 & 53.6 & 76.4 & 52.7 \\
\hline 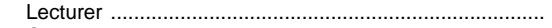 & 45 & 12.0 & 24.2 & 18.1 & 12.9 & 18.9 & 23.1 & 17.6 & 10.4 & 5.2 & 7.4 \\
\hline Other & 28 & 7.3 & 7.8 & 5.9 & 10.9 & 7.3 & 11.0 & 7.9 & 7.8 & 5.7 & 7.7 \\
\hline No rank & 9 & 2.5 & 0.3 & 1.6 & 1.4 & 0.8 & 0.8 & 1.9 & 0.7 & 3.8 & 4.3 \\
\hline \multicolumn{12}{|l|}{ Base salary } \\
\hline Under $\$ 10,000 \ldots \ldots$. & 281 & 74.5 & 51.8 & 70.9 & 65.1 & 66.3 & 69.2 & 79.4 & 70.0 & 81.7 & 72.2 \\
\hline$\$ 10,000$ to 24,999 & 68 & 18.1 & 30.8 & 19.3 & 21.8 & 23.3 & 23.0 & 16.4 & 23.1 & 13.2 & 19.3 \\
\hline$\$ 25,000$ to 39,999 & 16 & 4.2 & 8.8 & 5.0 & 8.1 & 4.2 & 5.1 & 2.9 & 4.4 & 2.9 & 4.7 \\
\hline$\$ 40,000$ to 54,999 & 5 & 1.4 & 2.6 & 1.9 & 2.8 & 2.2 & 1.0 & 0.7 & 1.1 & 1.1 & 2.1 \\
\hline$\$ 55,000$ to 69,999 & 2 & 0.6 & 3.5 & 0.9 & 0.5 & 0.5 & 0.3 & 0.5 & 0.1 & 0.3 & $(1)$ \\
\hline . & 1 & 0.3 & 0.2 & (1) & 0.6 & 1.4 & 0.2 & (1) & 0.1 & 0.2 & 0.9 \\
\hline$\$ 85,000$ to 99,999 & 1 & 0.3 & 1.7 & 1.6 & 0.1 & 0.2 & $\left({ }^{1}\right)$ & (1) & 0.1 & 0.1 & $\left({ }^{1}\right)$ \\
\hline$\$ 100,000$ or more & 3 & 0.7 & 0.6 & 0.4 & 1.0 & 1.9 & 1.1 & 0.1 & 1.1 & 0.5 & 0.9 \\
\hline
\end{tabular}

${ }^{1}$ Less than 0.05 percent.

-Data not applicable.

NOTE.-Data may not add to totals because of rounding or missing data
SOURCE: U.S. Department of Education, National Center for Education Statistics, National Study of Postsecondary Faculty (NSOPF), 1993. (This table was prepared September 1996.) 
Table 231.-Full-time and part-time instructional faculty and staff in institutions of higher education, by type and control, academic rank, age, salary, race/ethnicity, and sex: Fall 1992

\begin{tabular}{|c|c|c|c|c|c|c|c|c|c|c|c|c|}
\hline \multirow[t]{2}{*}{ Selected characteristics } & \multirow[t]{2}{*}{ Number } & \multirow[t]{2}{*}{ Percent } & \multicolumn{2}{|c|}{$\begin{array}{c}\text { White, } \\
\text { non-Hispanic }\end{array}$} & \multicolumn{2}{|c|}{$\begin{array}{c}\text { Black, } \\
\text { non-Hispanic }\end{array}$} & \multicolumn{2}{|c|}{ Hispanic } & \multicolumn{2}{|c|}{$\begin{array}{c}\text { Asian/Pacific } \\
\text { Islander }\end{array}$} & \multicolumn{2}{|c|}{$\begin{array}{c}\text { American } \\
\text { Indian/Alaskan } \\
\text { Native }\end{array}$} \\
\hline & & & Male & Female & Male & Female & Male & Female & Male & Female & Male & $\overline{\text { Female }}$ \\
\hline \multirow[t]{2}{*}{1} & 2 & 3 & 4 & 5 & 6 & 7 & 8 & 9 & 10 & 11 & 12 & 13 \\
\hline & & & & & Full-time & instruction & I faculty & and staff & & & & \\
\hline All institutions $\ldots \ldots \ldots \ldots \ldots \ldots \ldots \ldots \ldots \ldots \ldots$ & 528,260 & - & 306,477 & 150,265 & 14,457 & 12,941 & 9,289 & 4,564 & 20,858 & 6,851 & 1,638 & 920 \\
\hline Percentage distribution $. . . \ldots \ldots \ldots . . .$. & & 100.0 & 58.0 & 28.4 & 2.7 & & 1.8 & 0.9 & 3.9 & 1.3 & 0.3 & 0.2 \\
\hline Type and control & & & & & & & & & & & & \\
\hline 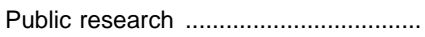 & 107,358 & 100.0 & 67.8 & 20.2 & 1.5 & 1.2 & 1.6 & 0.6 & 5.6 & 1.3 & 0.1 & 0.1 \\
\hline Private research ...................................... & 32,164 & 100.0 & 58.0 & 25.7 & 3.0 & 2.0 & 1.3 & 0.8 & 6.6 & 2.4 & 0.2 & - \\
\hline Public doctoral & 52,808 & 100.0 & 61.0 & 26.5 & 1.7 & 1.4 & 1.8 & 0.7 & 4.7 & 1.4 & 0.6 & 0.2 \\
\hline Private doctoral & 28,684 & 100.0 & 64.8 & 19.4 & 3.4 & 1.5 & 2.6 & 1.1 & 5.6 & 1.6 & 0.1 & 0.1 \\
\hline Public comprehensive . & 94,477 & 100.0 & 55.0 & 27.7 & 5.0 & 4.1 & 1.8 & 0.8 & 4.1 & 1.0 & 0.2 & 0.3 \\
\hline Private comprehensive ....................... & 38,561 & 100.0 & 59.7 & 31.6 & 1.7 & 1.9 & 1.0 & 0.6 & 2.5 & 0.9 & $(1)$ & 0.1 \\
\hline Private liberal arts ................................ & 38,052 & 100.0 & 54.4 & 35.6 & 3.7 & 1.7 & 0.8 & 0.5 & 1.9 & 0.9 & 0.3 & 0.2 \\
\hline 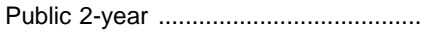 & 109,957 & 100.0 & 47.2 & 38.3 & 2.5 & 3.7 & 2.5 & 1.6 & 1.9 & 1.4 & 0.7 & 0.3 \\
\hline 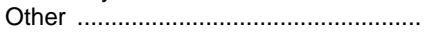 & 26,200 & 100.0 & 63.6 & 25.5 & 1.7 & 2.1 & 1.1 & 0.4 & 3.8 & 1.4 & 0.3 & 0.2 \\
\hline Academic rank & & & & & & & & & & & & \\
\hline 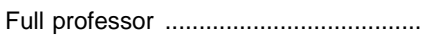 & 160,559 & 100.0 & 75.0 & 14.7 & 2.2 & 1.1 & 1.5 & 0.4 & 4.4 & 0.4 & 0.2 & 0.1 \\
\hline Associate professor ............. & 123,708 & 100.0 & 62.3 & 25.2 & 2.9 & 2.3 & 1.5 & 0.8 & 3.6 & 1.0 & 0.3 & 0.1 \\
\hline Assistant professor ............... & 124,293 & 100.0 & 46.8 & 36.3 & 2.9 & 3.2 & 2.1 & 1.2 & 4.9 & 2.2 & 0.2 & 0.2 \\
\hline Instructor ..................... & 73,897 & 100.0 & 43.2 & 41.3 & 3.2 & 4.0 & 2.2 & 1.1 & 2.4 & 1.8 & 0.6 & 0.3 \\
\hline Lecturer .................... & 11,869 & 100.0 & 28.7 & 54.5 & 2.6 & 3.7 & 2.0 & 1.2 & 3.8 & 2.5 & - & 1.1 \\
\hline Other ................................. & 17,072 & 100.0 & 40.3 & 40.6 & 4.2 & 4.8 & 2.2 & 1.8 & 4.1 & 1.7 & 0.2 & 0.1 \\
\hline 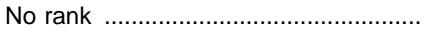 & 16,862 & 100.0 & 50.9 & 39.0 & 1.3 & 1.3 & 1.8 & 0.9 & 1.9 & 1.7 & 0.9 & 0.3 \\
\hline Age & & & & & & & & & & & & \\
\hline 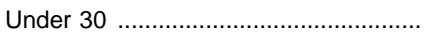 & 7,636 & 100.0 & 39.5 & 39.5 & 2.4 & 5.3 & 2.0 & 1.9 & 6.1 & 3.0 & 0.3 & 0.1 \\
\hline 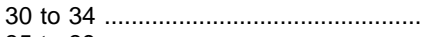 & 35,418 & 100.0 & 45.6 & 33.3 & 4.1 & 3.6 & 3.1 & 1.2 & 6.4 & 2.4 & 0.2 & - \\
\hline 35 to $39 \ldots$. & 66,757 & 100.0 & 49.9 & 33.9 & 2.7 & 2.5 & 1.8 & 1.0 & 5.5 & 2.1 & 0.4 & 0.2 \\
\hline 40 to $44 \ldots \ldots \ldots . .$. & 90,175 & 100.0 & 51.1 & 33.3 & 2.5 & 3.1 & 2.1 & 1.5 & 4.2 & 1.6 & 0.2 & 0.5 \\
\hline 45 to 49 . & 97,705 & 100.0 & 56.2 & 31.5 & 2.5 & 2.9 & 2.0 & 0.9 & 2.7 & 1.2 & 0.3 & 0.1 \\
\hline 50 to $54 \ldots \ldots$ & 94,852 & 100.0 & 63.3 & 26.2 & 2.5 & 1.9 & 1.3 & 0.6 & 3.1 & 0.8 & 0.3 & 0.2 \\
\hline 55 to 59 & 67,332 & 100.0 & 67.2 & 21.2 & 2.8 & 1.7 & 1.3 & 0.3 & 4.0 & 0.8 & 0.7 & 0.1 \\
\hline 60 to 64 & 44,609 & 100.0 & 70.2 & 18.2 & 2.8 & 1.8 & 1.3 & 0.5 & 4.2 & 0.8 & 0.2 & 0.1 \\
\hline 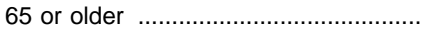 & 23,778 & 100.0 & 69.5 & 20.0 & 3.9 & 1.1 & 1.6 & 0.7 & 2.3 & 0.5 & 0.1 & 0.3 \\
\hline Base salary & & & & & & & & & & & & \\
\hline 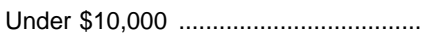 & 13,771 & 100.0 & 53.2 & 30.4 & 7.1 & 4.9 & 0.9 & 0.3 & 1.9 & 1.0 & 0.3 & 0.1 \\
\hline 10,000 to $24,999 \ldots$. & 29,384 & 100.0 & 35.7 & 50.6 & 1.8 & 3.9 & 1.3 & 1.3 & 2.5 & 2.3 & 0.1 & 0.6 \\
\hline 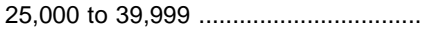 & 181,830 & 100.0 & 45.4 & 40.7 & 2.8 & 3.4 & 1.8 & 1.2 & 2.5 & 1.6 & 0.4 & 0.2 \\
\hline 40,000 to 54,999 ................. & 163,774 & 100.0 & 61.8 & 23.7 & 2.8 & 2.1 & 1.9 & 1.0 & 5.1 & 1.2 & 0.3 & 0.1 \\
\hline 55,000 to 69,999 ............... & 76,716 & 100.0 & 73.3 & 15.2 & 2.4 & 1.3 & 2.3 & 0.4 & 4.0 & 0.9 & 0.2 & 0.1 \\
\hline 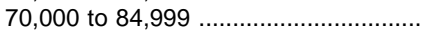 & 32,096 & 100.0 & 78.9 & 11.2 & 2.1 & 0.9 & 1.7 & $(1)$ & 4.5 & 0.6 & 0.2 & - \\
\hline 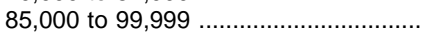 & 11,068 & 100.0 & 71.2 & 12.7 & 4.7 & 0.4 & 0.7 & - & 9.6 & 0.8 & - & - \\
\hline 100,000 or more & 19,622 & 100.0 & 78.5 & 9.4 & 1.4 & 0.6 & 0.7 & 0.1 & 7.1 & 1.5 & 0.6 & 0.2 \\
\hline Total income & & & & & & & & & & & & \\
\hline 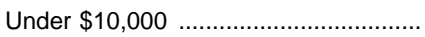 & 6,825 & 100.0 & 47.4 & 39.1 & 3.0 & 4.9 & 0.6 & 0.5 & 2.3 & 1.9 & - & 0.3 \\
\hline 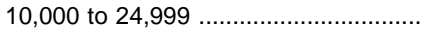 & 17,522 & 100.0 & 32.5 & 50.3 & 3.4 & 4.6 & 1.6 & 1.5 & 2.8 & 1.8 & 0.4 & 1.0 \\
\hline 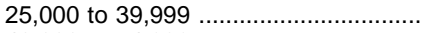 & 129,649 & 100.0 & 40.2 & 46.2 & 2.6 & 3.6 & 1.1 & 1.3 & 2.7 & 1.8 & 0.2 & 0.3 \\
\hline 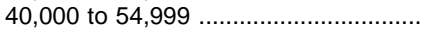 & 158,575 & 100.0 & 55.1 & 30.2 & 3.0 & 2.7 & 2.2 & 1.1 & 3.9 & 1.3 & 0.4 & 0.1 \\
\hline 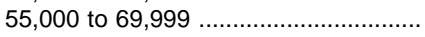 & 94,903 & 100.0 & 69.6 & 17.6 & 2.7 & 1.9 & 1.7 & 0.7 & 4.4 & 0.9 & 0.4 & 0.2 \\
\hline 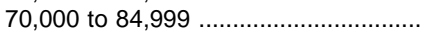 & 49,484 & 100.0 & 75.3 & 13.0 & 2.1 & 1.4 & 1.8 & 0.4 & 4.7 & 1.0 & 0.3 & $(1)$ \\
\hline 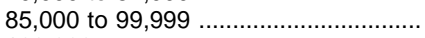 & 23,811 & 100.0 & 76.4 & 11.1 & 4.0 & 0.6 & 1.8 & 0.1 & 5.3 & 0.4 & 0.3 & - \\
\hline 100,000 or more & 47,490 & 100.0 & 77.1 & 10.9 & 1.9 & 0.7 & 2.3 & 0.1 & 5.8 & 1.0 & 0.2 & 0.1 \\
\hline
\end{tabular}


Table 231.-Full-time and part-time instructional faculty and staff in institutions of higher education, by type and control, academic rank, age, salary, race/ethnicity, and sex: Fall 1992—Continued

\begin{tabular}{|c|c|c|c|c|c|c|c|c|c|c|c|c|}
\hline Selected characteristics & Number & Percent & Male & Female & Male & Female & Male & Female & Male & Female & Male & Female \\
\hline \multirow[t]{2}{*}{1} & 2 & 3 & 4 & 5 & 6 & 7 & 8 & 9 & 10 & 11 & 12 & 13 \\
\hline & & & & & Part-time & instructior & faculty & and staff & & & & \\
\hline All institutions . & 376,675 & - & 182,976 & 149,814 & 10,274 & 7,987 & 6,965 & 4,232 & 7,016 & 5,135 & 1,478 & 797 \\
\hline Percentage distribution ............. & - & 100.0 & 48.6 & 39.8 & 2.7 & 2.1 & 1.8 & 1.1 & 1.9 & 1.4 & 0.4 & 0.2 \\
\hline Type and control & & & & & & & & & & & & \\
\hline 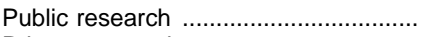 & 25,360 & 100.0 & 49.0 & 38.7 & 0.8 & 1.7 & 2.1 & 1.1 & 4.8 & 1.7 & - & - \\
\hline 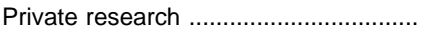 & 17,259 & 100.0 & 50.6 & 39.0 & 3.3 & 1.2 & 2.7 & - & 1.8 & 1.2 & 0.4 & 一 \\
\hline Public doctoral .. & 20,761 & 100.0 & 50.6 & 40.8 & 1.7 & 1.6 & 1.0 & 0.5 & 1.8 & 1.5 & 0.2 & 0.3 \\
\hline Private doctoral ....................................... & 18,014 & 100.0 & 54.6 & 33.1 & 6.0 & 1.2 & 1.3 & 0.2 & 1.0 & 2.5 & 0.2 & 一 \\
\hline Public comprehensive .............................. & 47,056 & 100.0 & 40.4 & 44.6 & 4.3 & 2.9 & 1.1 & 1.9 & 2.7 & 1.4 & 0.5 & 0.2 \\
\hline Private comprehensive $\ldots \ldots \ldots \ldots \ldots \ldots \ldots$ & 36,525 & 100.0 & 51.4 & 39.5 & 2.1 & 2.8 & 0.8 & 0.3 & 1.6 & 0.9 & 0.4 & 0.1 \\
\hline Private liberal arts .................................. & 20,909 & 100.0 & 40.5 & 49.1 & 3.9 & 2.0 & 1.4 & 1.5 & 0.8 & 0.8 & 0.1 & - \\
\hline 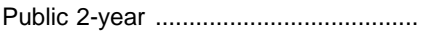 & 166,335 & 100.0 & 49.6 & 38.3 & 2.6 & 2.0 & 2.6 & 1.4 & 1.5 & 1.2 & 0.4 & 0.3 \\
\hline 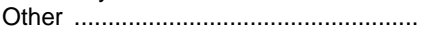 & 24,454 & 100.0 & 52.4 & 38.4 & 0.7 & 2.5 & 0.6 & 0.5 & 1.6 & 2.2 & 0.8 & 0.3 \\
\hline Academic rank & & & & & & & & & & & & \\
\hline Full professor & 32,269 & 100.0 & 63.2 & 25.0 & 3.5 & 1.7 & 1.7 & 0.4 & 2.9 & 0.7 & 0.8 & 0.2 \\
\hline Associate professor ... & 22,518 & 100.0 & 59.4 & 30.1 & 1.6 & 1.2 & 1.5 & 0.4 & 3.7 & 1.3 & 0.4 & 0.4 \\
\hline Assistant professor ............... & 24,237 & 100.0 & 49.1 & 37.4 & 5.7 & 2.5 & 0.6 & 0.4 & 2.4 & 1.9 & - & 0.1 \\
\hline 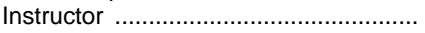 & 215,442 & 100.0 & 46.1 & 42.4 & 2.5 & 2.2 & 2.4 & 1.2 & 1.4 & 1.2 & 0.5 & 0.2 \\
\hline Lecturer & 45,328 & 100.0 & 48.5 & 39.8 & 2.1 & 2.0 & 1.3 & 1.6 & 2.5 & 1.8 & 0.2 & 0.2 \\
\hline Other & 27,553 & 100.0 & 43.7 & 44.8 & 3.6 & 2.3 & 0.8 & 1.2 & 1.2 & 2.0 & - & 0.5 \\
\hline No rank & 9,328 & 100.0 & 42.4 & 45.9 & 2.1 & 2.8 & - & 2.0 & 2.9 & 1.3 & 0.6 & - \\
\hline Age & & & & & & & & & & & & \\
\hline 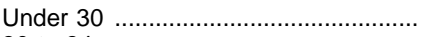 & 20,483 & 100.0 & 41.2 & 46.3 & 2.1 & 2.1 & 1.5 & 1.9 & 1.5 & 2.5 & 0.3 & 0.5 \\
\hline 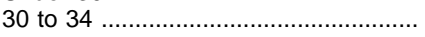 & 35,908 & 100.0 & 41.6 & 44.6 & 2.0 & 2.1 & 2.6 & 1.5 & 2.1 & 2.7 & 0.5 & 0.2 \\
\hline 35 to $39 \ldots \ldots$ & 58,923 & 100.0 & 42.8 & 43.8 & 4.1 & 2.2 & 2.1 & 1.0 & 2.0 & 1.1 & 0.6 & 0.2 \\
\hline 40 to $44 \ldots .$. & 70,025 & 100.0 & 47.5 & 41.8 & 2.2 & 1.9 & 1.8 & 1.4 & 1.6 & 1.5 & 0.2 & 0.2 \\
\hline 45 to $49 \ldots \ldots$ & 67,969 & 100.0 & 48.2 & 41.8 & 2.1 & 1.7 & 1.5 & 1.3 & 2.2 & 1.0 & $(1)$ & 0.3 \\
\hline 50 to $54 \ldots \ldots \ldots$ & 45,093 & 100.0 & 49.2 & 36.5 & 3.6 & 2.8 & 2.2 & 0.6 & 2.3 & 1.6 & 0.9 & 0.3 \\
\hline 55 to 59 ......................... & 28,764 & 100.0 & 55.3 & 34.6 & 3.3 & 1.6 & 1.4 & 0.6 & 2.0 & 1.0 & 0.2 & - \\
\hline 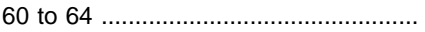 & 22,943 & 100.0 & 56.2 & 33.6 & 2.1 & 2.3 & 2.2 & 0.5 & 1.2 & 0.9 & 1.1 & 0.1 \\
\hline 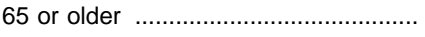 & 26,565 & 100.0 & 65.6 & 25.4 & 2.4 & 2.8 & 1.1 & 0.9 & 1.3 & 0.4 & - & 一 \\
\hline Base salary & & & & & & & & & & & & \\
\hline 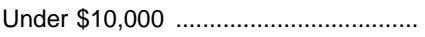 & 280,526 & 100.0 & 49.6 & 39.1 & 2.7 & 2.3 & 1.7 & 1.1 & 1.6 & 1.3 & 0.3 & 0.2 \\
\hline 10,000 to $24,999 \ldots$. & 68,117 & 100.0 & 43.1 & 44.9 & 2.2 & 1.4 & 2.8 & 1.3 & 2.5 & 1.5 & 0.3 & 0.2 \\
\hline 25,000 to $39,999 \ldots$. & 15,840 & 100.0 & 49.4 & 38.1 & 4.1 & 2.0 & 1.6 & 0.3 & 2.5 & 1.2 & 0.8 & - \\
\hline 40,000 to $54,999 \ldots \ldots .$. & 5,307 & 100.0 & 55.2 & 32.8 & 2.1 & 1.9 & 1.5 & 2.7 & 0.1 & 1.8 & 1.9 & 一 \\
\hline 55,000 to 69,999 .................. & 2,157 & - & - & - & 3.5 & - & 0.6 & - & 22.0 & 8.6 & - & - \\
\hline 70,000 to 84,999 ................... & 1,127 & - & - & - & 7.7 & 4.2 & - & - & 2.7 & - & 8.0 & - \\
\hline 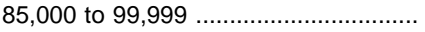 & 942 & - & - & - & - & - & - & - & - & - & - & - \\
\hline 100,000 or more $. . . \ldots \ldots \ldots . . . . .$. & 2,657 & 100.0 & 46.9 & 39.0 & 10.5 & 0.5 & 1.2 & - & - & 2.0 & - & 一 \\
\hline Total income & & & & & & & & & & & & \\
\hline 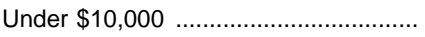 & 70,693 & 100.0 & 35.4 & 52.6 & 2.3 & 2.9 & 1.9 & 1.3 & 1.6 & 1.6 & $(1)$ & 0.4 \\
\hline 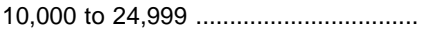 & 84,803 & 100.0 & 33.2 & 57.1 & 1.3 & 1.8 & 1.3 & 1.7 & 1.3 & 1.9 & 0.4 & 0.1 \\
\hline 25,000 to 39,999 ................... & 74,809 & 100.0 & 48.5 & 39.6 & 2.5 & 2.9 & 2.0 & 1.2 & 1.6 & 1.4 & 0.2 & 0.3 \\
\hline 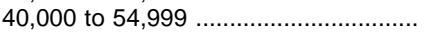 & 58,057 & 100.0 & 55.8 & 32.1 & 3.4 & 1.9 & 1.5 & 1.2 & 1.8 & 0.7 & 1.3 & 0.4 \\
\hline 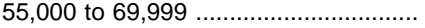 & 32,386 & 100.0 & 69.3 & 17.5 & 3.4 & 1.6 & 3.2 & 0.5 & 3.0 & 1.2 & 0.3 & - \\
\hline 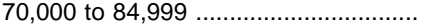 & 17,199 & 100.0 & 69.4 & 17.8 & 4.7 & 0.7 & 2.9 & 0.7 & 2.8 & 0.5 & 0.5 & - \\
\hline 85,000 to 99,999 & 8,231 & 100.0 & 70.2 & 18.1 & 4.7 & 0.8 & 4.7 & - & 1.4 & - & - & - \\
\hline 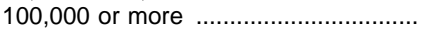 & 30,497 & 100.0 & 68.9 & 19.0 & 4.7 & 1.5 & 1.0 & - & 3.3 & 1.6 & 0.1 & - \\
\hline
\end{tabular}

${ }^{1}$ Less than 0.05 percent.

-Data not available or applicable.

NOTE.-Because of rounding, details may not add to totals.
SOURCE: U.S. Department of Education, National Center for Education Statistics, Na tional Study of Postsecondary Faculty (NSOPF), 1993. (This table was prepared September 1996.) 
Table 232.-Full-time and part-time instructional faculty and staff in institutions of higher education, by faculty characteristics and field: Fall 1992

\begin{tabular}{|c|c|c|c|c|c|c|c|c|c|c|c|c|}
\hline Faculty characteristics & $\begin{array}{l}\text { Number } \\
\text { in thou- } \\
\text { sands }\end{array}$ & All fields & $\begin{array}{l}\text { Agri- } \\
\text { culture } \\
\text { and } \\
\text { home } \\
\text { econom- } \\
\text { ics }\end{array}$ & Business & Education & $\begin{array}{l}\text { Engineer- } \\
\text { ing }\end{array}$ & Fine arts & Health & $\begin{array}{l}\text { Human- } \\
\text { ities }\end{array}$ & $\begin{array}{l}\text { Natural } \\
\text { sciences }\end{array}$ & $\begin{array}{c}\text { Social } \\
\text { sciences }\end{array}$ & $\begin{array}{l}\text { Other } \\
\text { and } \\
\text { not } \\
\text { reported }\end{array}$ \\
\hline 1 & 2 & 3 & 4 & 5 & 6 & 7 & 8 & 9 & 10 & 11 & 12 & 13 \\
\hline \multirow{3}{*}{$\begin{array}{l}\text { Full-time, in thousands } \ldots \ldots \ldots \ldots . . . \\
\text { Percent }\end{array}$} & & \multicolumn{11}{|c|}{ Full-time instructional faculty and staff } \\
\hline & $\begin{array}{r}528 \\
-\end{array}$ & $100 . \overline{0}$ & $\begin{array}{r}11 \\
2.2\end{array}$ & $\begin{array}{r}40 \\
7.7\end{array}$ & $\begin{array}{r}37 \\
7.1\end{array}$ & $\begin{array}{r}24 \\
4.7\end{array}$ & $\begin{array}{r}32 \\
6.1\end{array}$ & $\begin{array}{r}79 \\
15.3\end{array}$ & $\begin{array}{r}74 \\
14.2\end{array}$ & $\begin{array}{r}102 \\
19.5\end{array}$ & $\begin{array}{r}58 \\
11.2\end{array}$ & $\begin{array}{r}62 \\
11.9\end{array}$ \\
\hline & & \multicolumn{11}{|c|}{ Percentage distribution of full-time faculty } \\
\hline Total & 528 & 100.0 & 100.0 & 100.0 & 100.0 & 100.0 & 100.0 & 100.0 & 100.0 & 100.0 & 100.0 & 100.0 \\
\hline Sex & & & & & & & & & & & & \\
\hline Male & 353 & 66.8 & 75.3 & 68.9 & 48.9 & 93.9 & 67.0 & 49.9 & 58.6 & 79.9 & 72.5 & 69.6 \\
\hline Female $\ldots \ldots \ldots \ldots \ldots \ldots \ldots \ldots \ldots \ldots \ldots$ & 176 & 33.2 & 24.7 & 31.2 & 51.1 & 6.1 & 33.0 & 50.1 & 41.4 & 20.1 & 27.5 & 30.4 \\
\hline \multicolumn{13}{|l|}{ Race/ethnicity } \\
\hline 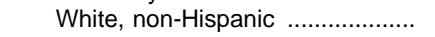 & 457 & 86.5 & 90.8 & 88.5 & 84.7 & 76.6 & 88.6 & 85.9 & 88.1 & 85.8 & 87.3 & 88.1 \\
\hline Black, non-Hispanic ..................... & 27 & 5.2 & 3.9 & 4.1 & 9.4 & 2.8 & 5.8 & 5.6 & 4.2 & 3.6 & 6.2 & 6.0 \\
\hline 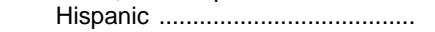 & 14 & 2.6 & 1.8 & 1.6 & 3.3 & 3.1 & 2.5 & 2.3 & 4.1 & 1.9 & 2.8 & 2.5 \\
\hline $\begin{array}{l}\text { Asian/Pacific Islander .................. } \\
\text { American Indian/ }\end{array}$ & 28 & 5.2 & 2.9 & 4.8 & 1.6 & 16.8 & 2.7 & 6.0 & 3.2 & 8.3 & 3.3 & 2.9 \\
\hline Alaskan Native ..................... & 3 & 0.5 & 0.7 & 1.0 & 1.0 & 0.7 & 0.5 & 0.2 & 0.5 & 0.3 & 0.5 & 0.4 \\
\hline \multicolumn{13}{|l|}{ Age } \\
\hline Under 30 & 8 & 1.4 & 0.4 & 1.2 & 1.1 & 1.3 & 1.3 & 1.1 & 1.7 & 1.5 & 0.8 & 2.4 \\
\hline 30 to 34. & 35 & 6.7 & 7.3 & 6.3 & 3.5 & 11.0 & 6.2 & 8.4 & 4.7 & 6.7 & 7.3 & 6.8 \\
\hline 35 to $39 \ldots \ldots \ldots . .$. & 67 & 12.6 & 9.1 & 13.5 & 7.7 & 13.1 & 13.1 & 16.2 & 9.6 & 13.9 & 13.0 & 12.3 \\
\hline 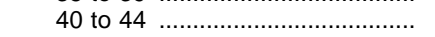 & 90 & 17.1 & 15.7 & 16.6 & 17.6 & 16.9 & 17.7 & 21.8 & 13.4 & 15.8 & 16.4 & 17.9 \\
\hline 45 to 49 & 98 & 18.5 & 17.7 & 20.9 & 19.7 & 14.8 & 18.5 & 19.2 & 19.9 & 17.2 & 17.9 & 17.7 \\
\hline 50 to 54 & 95 & 18.0 & 18.4 & 16.2 & 21.1 & 12.2 & 17.2 & 13.3 & 21.4 & 19.3 & 19.2 & 18.4 \\
\hline 55 to $59 \ldots$. & 67 & 12.7 & 14.4 & 11.7 & 14.1 & 15.0 & 14.1 & 9.6 & 14.7 & 13.5 & 12.2 & 12.4 \\
\hline 60 to 64 & 45 & 8.4 & 11.4 & 7.9 & 10.5 & 10.6 & 7.9 & 7.6 & 9.9 & 7.4 & 9.2 & 7.3 \\
\hline 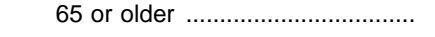 & 24 & 4.5 & 5.7 & 5.7 & 4.7 & 5.0 & 4.1 & 2.8 & 4.8 & 4.7 & 4.1 & 5.0 \\
\hline \multicolumn{13}{|l|}{ Degree } \\
\hline Less than bachelor's .................... & 6 & 1.2 & 0.2 & 0.5 & 0.3 & 2.0 & 0.7 & 1.2 & $(1)$ & 0.2 & 0.1 & 6.2 \\
\hline 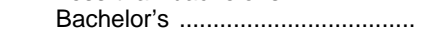 & 21 & 4.0 & 5.7 & 4.5 & 2.9 & 5.2 & 5.4 & 5.8 & 1.3 & 2.8 & 0.7 & 8.2 \\
\hline Master's ….................................. & 156 & 29.7 & 22.0 & 38.4 & 30.8 & 18.7 & 56.2 & 30.1 & 31.7 & 22.2 & 19.3 & 33.6 \\
\hline 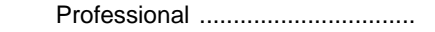 & 58 & 11.1 & 4.4 & 4.5 & 2.9 & 2.3 & 4.3 & 42.9 & 2.4 & 4.5 & 3.5 & 17.1 \\
\hline Doctoral …................................... & 284 & 54.0 & 67.8 & 52.0 & 63.2 & 71.8 & 33.4 & 20.0 & 64.6 & 70.3 & 76.4 & 35.0 \\
\hline \multicolumn{13}{|l|}{ Rank } \\
\hline Full professor & 161 & 30.4 & 41.4 & 24.7 & 24.3 & 36.8 & 32.0 & 21.2 & 33.1 & 37.0 & 36.8 & 26.9 \\
\hline Associate professor........ & 124 & 23.4 & 22.6 & 25.5 & 29.5 & 28.0 & 25.4 & 23.0 & 22.4 & 22.5 & 24.8 & 19.3 \\
\hline Assistant professor ........................ & 124 & 23.5 & 19.3 & 25.6 & 22.9 & 22.5 & 21.4 & 32.9 & 19.3 & 20.7 & 24.3 & 23.0 \\
\hline 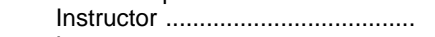 & 74 & 14.0 & 10.8 & 16.7 & 13.2 & 10.4 & 10.3 & 16.9 & 14.9 & 11.7 & 7.9 & 21.7 \\
\hline Lecturer …............................... & 12 & 2.2 & 1.0 & 1.3 & 2.5 & 0.9 & 2.8 & 2.3 & 3.9 & 1.7 & 1.7 & 2.7 \\
\hline 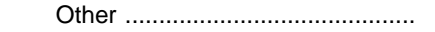 & 17 & 3.2 & 3.2 & 2.2 & 5.5 & 0.5 & 3.3 & 2.5 & 1.9 & 2.4 & 2.0 & 3.6 \\
\hline No rank ......................................... & 17 & 3.2 & 1.7 & 4.0 & 1.9 & 1.0 & 4.8 & 1.4 & 4.7 & 3.9 & 2.5 & 3.0 \\
\hline
\end{tabular}


Table 232.-Full-time and part-time instructional faculty and staff in institutions of higher education, by faculty characteristics and field: Fall 1992-Continued

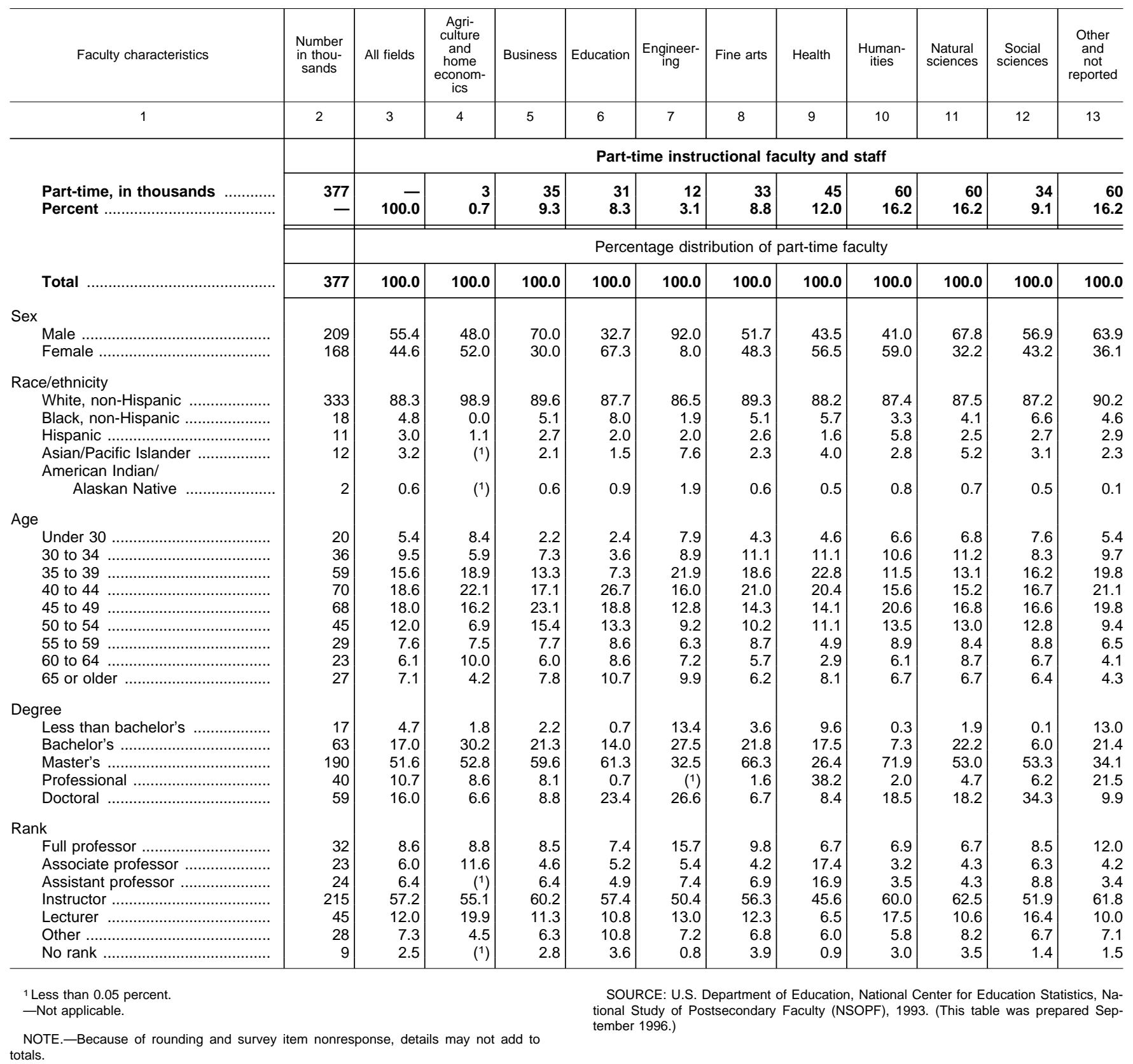


Table 233.-Average base salaries of full-time instructional faculty and staff in institutions of higher education, by type and control of institution and by field of instruction: 1987-88 and 1992-93

\begin{tabular}{|c|c|c|c|c|c|c|c|c|c|c|c|c|}
\hline Field of instruction & $\begin{array}{c}\text { All } \\
\text { institutions }\end{array}$ & $\begin{array}{l}\text { Total } \\
\text { public }\end{array}$ & $\begin{array}{c}\text { Total } \\
\text { private }\end{array}$ & $\begin{array}{l}\text { Public } \\
\text { research }\end{array}$ & $\begin{array}{l}\text { Private } \\
\text { research }\end{array}$ & $\begin{array}{l}\text { Public } \\
\text { doctoral }\end{array}$ & $\begin{array}{l}\text { Private } \\
\text { doctoral }\end{array}$ & $\begin{array}{c}\text { Public } \\
\text { comprehensive }\end{array}$ & $\begin{array}{c}\text { Private } \\
\text { comprehensive }\end{array}$ & $\begin{array}{l}\text { Private } \\
\text { liberal } \\
\text { arts }\end{array}$ & $\begin{array}{l}\text { Public } \\
\text { 2-year }\end{array}$ & Other \\
\hline 1 & 2 & 3 & 4 & 5 & 6 & 7 & 8 & 9 & 10 & 11 & 12 & 13 \\
\hline & \multicolumn{12}{|c|}{$1987-88$ salaries in $1992-93$ dollars } \\
\hline Instructional faculty, in thousands & 515 & 356 & 159 & 102 & 42 & 56 & 25 & 97 & 37 & 38 & 96 & 22 \\
\hline All fields & $\$ 48,381$ & $\$ 48,826$ & $\$ 47,386$ & $\$ 58,118$ & $\$ 63,669$ & $\$ 54,028$ & $\$ 57,215$ & $\$ 45,342$ & $\$ 39,564$ & $\$ 35,462$ & $\$ 39,847$ & $\$ 37,698$ \\
\hline Agriculture and home economics ... & 48,452 & 48,713 & - & 54,431 & - & 43,501 & - & 46,934 & - & - & - & - \\
\hline 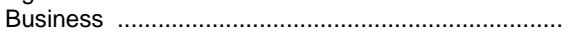 & 45,243 & 45,785 & 44,078 & 58,218 & - & 49,161 & - & 43,413 & 45,319 & - & 40,707 & 35,292 \\
\hline 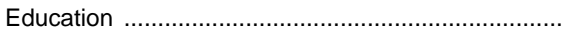 & 40,498 & 42,517 & 33,529 & 45,861 & - & 43,315 & - & 41,766 & 33,499 & 29,400 & 41,133 & - \\
\hline 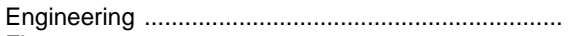 & 52,213 & 51,412 & 55,095 & 61,363 & - & 53,133 & - & 50,316 & 51,481 & & 36,794 & - \\
\hline Fine arts . & 37,840 & 39,547 & 34,368 & 40,297 & - & 38,155 & - & 39,367 & 33,170 & 34,484 & 40,216 & - \\
\hline Health & 64,860 & 64,447 & 65,689 & 73,454 & 77,144 & 71,065 & 67,278 & 57,124 & 47,683 & & 37,017 & 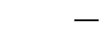 \\
\hline Humanities & 42,420 & 44,092 & 39,867 & 46,326 & 48,988 & 39,327 & 46,313 & 44,601 & 37,089 & 38,127 & 43,461 & 34,783 \\
\hline 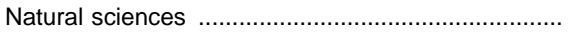 & 47,811 & 48,399 & 46,495 & 57,947 & 61,731 & 49,917 & 46,912 & 46,684 & 38,763 & 37,760 & 39,692 & 37,499 \\
\hline Social sciences & 46,234 & 46,506 & 45,730 & 52,842 & 61,043 & 47,938 & - & 44,933 & 38,613 & 35,728 & 41,052 & \\
\hline \multirow{2}{*}{ 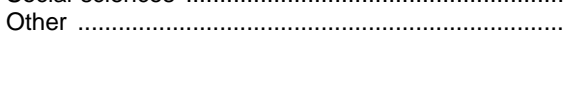 } & 44,712 & 44,239 & 45,834 & 52,646 & - & 45,427 & - & 41,853 & 35,733 & - & 37,762 & 44,331 \\
\hline & \multicolumn{12}{|c|}{$1992-93$} \\
\hline Instructional faculty, in thousands & 478 & 339 & 140 & 89 & 25 & 46 & 23 & 91 & 37 & 37 & 105 & 25 \\
\hline All fields & $\$ 46,833$ & $\$ 46,767$ & $\$ 46,993$ & $\$ 56,443$ & $\$ 63,967$ & $\$ 51,497$ & $\$ 56,011$ & $\$ 43,487$ & $\$ 43,255$ & $\$ 37,623$ & $\$ 39,351$ & $\$ 40,458$ \\
\hline Agriculture and home economics & 47,809 & 48,488 & - & 54,735 & - & 44,480 & - & 43,377 & 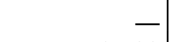 & - & 39,788 & - \\
\hline Business & 49,223 & 49,955 & 47,318 & 65,209 & - & 58,808 & 54,369 & 47,739 & 53,786 & 32,322 & 42,017 & 33,587 \\
\hline 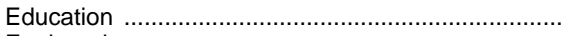 & 42,046 & 43,259 & 37,618 & 49,822 & - & 42,202 & 49,254 & 41,456 & 37,961 & 32,419 & 41,224 & - \\
\hline 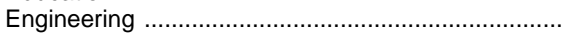 & 55,569 & 55,923 & 54,190 & 66,781 & 61,084 & 53,577 & 55,040 & 48,703 & 45,855 & & 38,648 & 56,036 \\
\hline 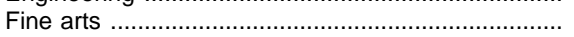 & 40,574 & 39,285 & 42,526 & 41,337 & 86,221 & 39,379 & 37,874 & 39,144 & 35,812 & 37,764 & 37,524 & 34,100 \\
\hline Health & 55,624 & 54,097 & 59,720 & 73,467 & 73,080 & 63,839 & 66,120 & 38,311 & 45,678 & 42,363 & 35,790 & 41,900 \\
\hline 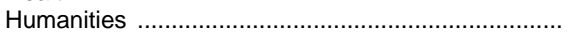 & 40,972 & 41,601 & 39,634 & 44,018 & 44,695 & 39,661 & 42,928 & 40,735 & 41,043 & 37,667 & 41,183 & 36,547 \\
\hline 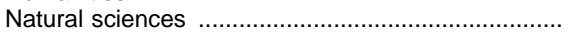 & 48,192 & 47,500 & 49,933 & 55,432 & 67,170 & 51,691 & 56,665 & 45,922 & 46,666 & 37,534 & 39,651 & 42,143 \\
\hline Social sciences & 45,960 & 46,103 & 45,667 & 53,139 & 59,296 & 48,709 & 49,505 & 43,686 & 39,838 & 40,492 & 40,312 & 44,389 \\
\hline Other & 44,594 & 43,431 & 47,030 & 51,007 & 65,685 & 43,777 & 61,854 & 45,357 & 41,722 & 36,436 & 37,668 & 39,199 \\
\hline
\end{tabular}

- Too few sample cases (fewer than 30) for a reliable estimate.

NOTE.-Data for 1992-93 differ from other tables because of adjustments to maintain consistency with the 198788 data. Because of rounding, details may not add to totals.
SOURCE: U.S. Department of Education, National Center for Education Statistics, National Study of Postsecondary Faculty (NSOPF), 1987-88 and 1992-93. (This table was prepared September 1996) 
Table 234.-Average salary of full-time instructional faculty on 9-month contracts in institutions of higher education, by academic rank, sex, and by type and control of institution: 1980-81, 1990-91, 1995-96, and 1996-97

\begin{tabular}{|c|c|c|c|c|c|c|c|c|c|}
\hline \multirow{2}{*}{$\begin{array}{c}\text { Academic year, control, } \\
\text { and } \\
\text { type of institution }\end{array}$} & \multirow[b]{2}{*}{ All faculty } & \multicolumn{6}{|c|}{ Academic rank } & \multicolumn{2}{|c|}{ Sex } \\
\hline & & Professor & $\begin{array}{l}\text { Associate } \\
\text { professor }\end{array}$ & $\begin{array}{l}\text { Assistant } \\
\text { professor }\end{array}$ & Instructor & Lecturer & $\begin{array}{c}\text { No } \\
\text { academic } \\
\text { rank }\end{array}$ & Men & Women \\
\hline 1 & 2 & 3 & 4 & 5 & 6 & 7 & 8 & 9 & 10 \\
\hline 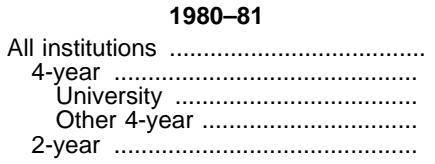 & $\begin{array}{r}\$ 23,302 \\
23,693 \\
25,949 \\
22,230 \\
21,898\end{array}$ & $\begin{array}{r}\$ 30,753 \\
31,016 \\
33,622 \\
28,798 \\
26,528\end{array}$ & $\begin{array}{r}\$ 23,214 \\
23,265 \\
24,392 \\
22,558 \\
22,750\end{array}$ & $\begin{array}{r}\$ 18,901 \\
18,867 \\
19,684 \\
18,398 \\
19,166\end{array}$ & $\begin{array}{r}\$ 15,178 \\
15,056 \\
15,530 \\
14,887 \\
15,621\end{array}$ & $\begin{array}{r}\$ 17,301 \\
17,375 \\
17,327 \\
17,425 \\
16,222\end{array}$ & $\begin{array}{r}\$ 22,334 \\
17,380 \\
17,856 \\
17,334 \\
22,615\end{array}$ & $\begin{array}{r}\$ 24,499 \\
24,909 \\
27,206 \\
23,271 \\
22,736\end{array}$ & $\begin{array}{r}\$ 19,996 \\
19,809 \\
20,736 \\
19,372 \\
20,434\end{array}$ \\
\hline 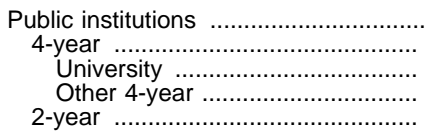 & $\begin{array}{l}23,745 \\
24,373 \\
25,571 \\
23,500 \\
22,177\end{array}$ & $\begin{array}{l}31,077 \\
31,442 \\
32,945 \\
30,097 \\
26,880\end{array}$ & $\begin{array}{l}23,772 \\
23,898 \\
24,268 \\
23,639 \\
22,947\end{array}$ & $\begin{array}{l}19,431 \\
19,442 \\
19,637 \\
19,315 \\
19,370\end{array}$ & $\begin{array}{l}15,613 \\
15,486 \\
15,305 \\
15,567 \\
15,928\end{array}$ & $\begin{array}{l}17,620 \\
17,712 \\
17,426 \\
17,997 \\
16,458\end{array}$ & $\begin{array}{l}22,820 \\
19,240 \\
17,358 \\
19,798 \\
22,875\end{array}$ & $\begin{array}{l}24,873 \\
25,509 \\
26,788 \\
24,499 \\
22,965\end{array}$ & $\begin{array}{l}20,673 \\
20,608 \\
20,564 \\
20,633 \\
20,778\end{array}$ \\
\hline 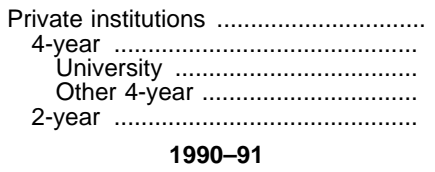 & $\begin{array}{l}22,093 \\
22,325 \\
26,897 \\
19,996 \\
15,065\end{array}$ & $\begin{array}{l}29,994 \\
30,089 \\
35,227 \\
26,173 \\
18,645\end{array}$ & $\begin{array}{l}21,833 \\
21,887 \\
24,730 \\
20,502 \\
17,685\end{array}$ & $\begin{array}{l}17,767 \\
17,816 \\
19,792 \\
16,939 \\
14,663\end{array}$ & $\begin{array}{l}14,192 \\
14,316 \\
16,197 \\
13,905 \\
12,155\end{array}$ & $\begin{array}{l}15,899 \\
15,971 \\
16,956 \\
14,741 \\
12,441\end{array}$ & $\begin{array}{l}15,946 \\
16,706 \\
18,933 \\
16,617 \\
14,993\end{array}$ & $\begin{array}{l}23,493 \\
23,669 \\
28,251 \\
21,040 \\
16,075\end{array}$ & $\begin{array}{l}18,073 \\
18,326 \\
21,176 \\
17,342 \\
13,892\end{array}$ \\
\hline 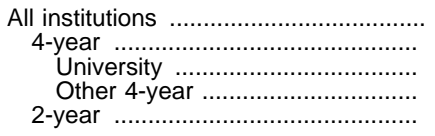 & $\begin{array}{l}42,165 \\
43,693 \\
49,430 \\
40,313 \\
36,642\end{array}$ & $\begin{array}{l}55,540 \\
56,485 \\
63,437 \\
51,467 \\
44,916\end{array}$ & $\begin{array}{l}41,414 \\
41,811 \\
44,877 \\
39,994 \\
37,650\end{array}$ & $\begin{array}{l}34,434 \\
34,657 \\
37,838 \\
33,020 \\
32,253\end{array}$ & $\begin{array}{l}26,332 \\
25,772 \\
27,105 \\
25,370 \\
27,933\end{array}$ & $\begin{array}{l}30,097 \\
30,209 \\
31,748 \\
29,009 \\
28,048\end{array}$ & $\begin{array}{l}36,395 \\
31,494 \\
31,533 \\
31,488 \\
36,752\end{array}$ & $\begin{array}{l}45,065 \\
46,519 \\
52,426 \\
42,660 \\
38,465\end{array}$ & $\begin{array}{l}35,881 \\
36,574 \\
39,788 \\
35,135 \\
34,224\end{array}$ \\
\hline 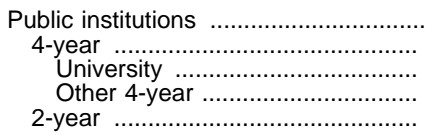 & $\begin{array}{l}42,317 \\
44,510 \\
47,499 \\
42,499 \\
37,055\end{array}$ & $\begin{array}{l}55,371 \\
56,668 \\
60,536 \\
53,704 \\
45,411\end{array}$ & $\begin{array}{l}42,101 \\
42,742 \\
43,851 \\
41,969 \\
38,051\end{array}$ & $\begin{array}{l}35,137 \\
35,520 \\
36,889 \\
34,680 \\
32,673\end{array}$ & $\begin{array}{l}26,907 \\
26,134 \\
25,647 \\
26,316 \\
28,389\end{array}$ & $\begin{array}{l}29,881 \\
29,956 \\
30,429 \\
29,664 \\
28,780\end{array}$ & $\begin{array}{l}36,990 \\
32,349 \\
30,412 \\
33,507 \\
37,096\end{array}$ & $\begin{array}{l}45,084 \\
47,168 \\
50,405 \\
44,804 \\
38,787\end{array}$ & $\begin{array}{l}36,459 \\
37,573 \\
38,363 \\
37,147 \\
34,720\end{array}$ \\
\hline 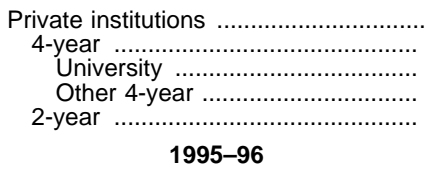 & $\begin{array}{l}41,788 \\
42,224 \\
53,875 \\
36,888 \\
24,088\end{array}$ & $\begin{array}{l}55,911 \\
56,127 \\
69,732 \\
47,405 \\
29,520\end{array}$ & $\begin{array}{l}39,983 \\
40,122 \\
47,405 \\
36,965 \\
26,353\end{array}$ & $\begin{array}{l}33,116 \\
33,235 \\
40,013 \\
30,688 \\
24,587\end{array}$ & $\begin{array}{l}24,928 \\
25,159 \\
31,239 \\
23,973 \\
20,911\end{array}$ & $\begin{array}{r}30,864 \\
31,053 \\
34,444 \\
25,416 \\
-\end{array}$ & $\begin{array}{l}28,523 \\
31,122 \\
36,211 \\
30,915 \\
23,187\end{array}$ & $\begin{array}{l}45,019 \\
45,319 \\
56,989 \\
39,162 \\
25,937\end{array}$ & $\begin{array}{l}34,359 \\
34,898 \\
43,273 \\
32,251 \\
22,585\end{array}$ \\
\hline 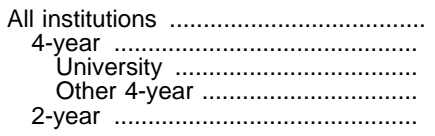 & $\begin{array}{l}49,309 \\
51,044 \\
58,173 \\
46,946 \\
43,009\end{array}$ & $\begin{array}{l}64,540 \\
65,866 \\
74,650 \\
59,599 \\
51,454\end{array}$ & $\begin{array}{l}47,966 \\
48,432 \\
51,993 \\
46,356 \\
43,107\end{array}$ & $\begin{array}{l}39,696 \\
39,991 \\
43,838 \\
38,179 \\
36,927\end{array}$ & $\begin{array}{l}30,344 \\
29,941 \\
30,689 \\
29,718 \\
31,421\end{array}$ & $\begin{array}{l}34,136 \\
34,082 \\
35,272 \\
33,140 \\
35,165\end{array}$ & $\begin{array}{l}42,996 \\
35,657 \\
36,818 \\
35,470 \\
43,537\end{array}$ & $\begin{array}{l}52,814 \\
54,520 \\
61,972 \\
49,726 \\
44,944\end{array}$ & $\begin{array}{l}42,871 \\
43,702 \\
48,011 \\
41,773 \\
40,791\end{array}$ \\
\hline 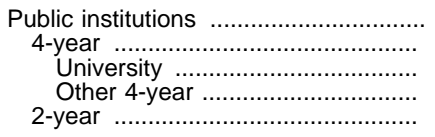 & $\begin{array}{l}48,837 \\
51,172 \\
55,068 \\
48,566 \\
43,295\end{array}$ & $\begin{array}{l}63,189 \\
64,946 \\
69,924 \\
61,076 \\
51,679\end{array}$ & $\begin{array}{l}48,122 \\
48,815 \\
50,186 \\
47,850 \\
43,389\end{array}$ & $\begin{array}{l}40,092 \\
40,562 \\
42,335 \\
39,544 \\
37,241\end{array}$ & $\begin{array}{l}30,581 \\
29,907 \\
29,186 \\
30,178 \\
31,805\end{array}$ & $\begin{array}{l}33,634 \\
33,525 \\
34,139 \\
33,134 \\
35,244\end{array}$ & $\begin{array}{l}43,590 \\
36,829 \\
35,532 \\
37,266 \\
43,754\end{array}$ & $\begin{array}{l}52,163 \\
54,448 \\
58,648 \\
51,375 \\
45,209\end{array}$ & $\begin{array}{l}42,871 \\
43,986 \\
45,676 \\
43,063 \\
41,086\end{array}$ \\
\hline 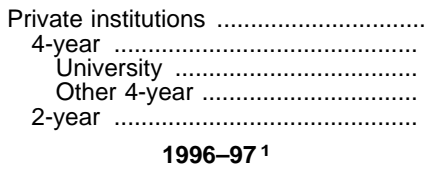 & $\begin{array}{l}50,466 \\
50,819 \\
65,405 \\
44,504 \\
31,915\end{array}$ & $\begin{array}{l}67,457 \\
67,598 \\
84,970 \\
57,089 \\
37,929\end{array}$ & $\begin{array}{l}47,654 \\
47,760 \\
56,517 \\
44,186 \\
33,283\end{array}$ & $\begin{array}{l}38,964 \\
39,071 \\
47,387 \\
36,325 \\
29,887\end{array}$ & $\begin{array}{l}29,701 \\
30,002 \\
35,782 \\
28,993 \\
23,895\end{array}$ & $\begin{array}{r}35,792 \\
35,810 \\
37,516 \\
33,170 \\
-\end{array}$ & $\begin{array}{l}34,599 \\
35,098 \\
38,649 \\
34,771 \\
33,410\end{array}$ & $\begin{array}{l}54,364 \\
54,649 \\
69,579 \\
47,126 \\
33,301\end{array}$ & $\begin{array}{l}42,871 \\
43,236 \\
53,717 \\
39,982 \\
30,671\end{array}$ \\
\hline 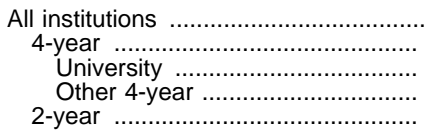 & $\begin{array}{l}50,829 \\
52,618 \\
60,199 \\
48,276 \\
44,314\end{array}$ & $\begin{array}{l}66,659 \\
68,152 \\
77,464 \\
61,478 \\
52,719\end{array}$ & $\begin{array}{l}49,307 \\
49,809 \\
53,552 \\
47,622 \\
44,092\end{array}$ & $\begin{array}{l}40,687 \\
40,987 \\
45,038 \\
39,126 \\
37,898\end{array}$ & $\begin{array}{l}31,193 \\
30,748 \\
31,304 \\
30,582 \\
32,462\end{array}$ & $\begin{array}{l}34,962 \\
34,948 \\
36,389 \\
33,791 \\
35,215\end{array}$ & $\begin{array}{l}44,200 \\
36,701 \\
38,265 \\
36,508 \\
44,796\end{array}$ & $\begin{array}{l}54,465 \\
56,266 \\
64,242 \\
51,140 \\
46,153\end{array}$ & $\begin{array}{l}44,325 \\
45,145 \\
49,703 \\
43,110 \\
42,236\end{array}$ \\
\hline 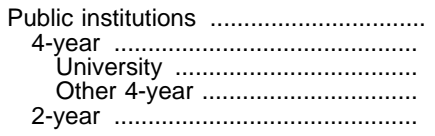 & $\begin{array}{l}50,303 \\
52,718 \\
57,047 \\
49,836 \\
44,584\end{array}$ & $\begin{array}{l}65,141 \\
67,121 \\
72,599 \\
62,846 \\
52,927\end{array}$ & $\begin{array}{l}49,470 \\
50,220 \\
51,835 \\
49,082 \\
44,371\end{array}$ & $\begin{array}{l}41,108 \\
41,590 \\
43,536 \\
40,500 \\
38,232\end{array}$ & $\begin{array}{l}31,452 \\
30,740 \\
30,000 \\
31,025 \\
32,822\end{array}$ & $\begin{array}{l}34,294 \\
34,229 \\
35,243 \\
33,607 \\
35,215\end{array}$ & $\begin{array}{l}44,803 \\
37,060 \\
35,099 \\
37,506 \\
44,998\end{array}$ & $\begin{array}{l}53,737 \\
56,162 \\
60,845 \\
52,744 \\
46,393\end{array}$ & $\begin{array}{l}44,306 \\
45,402 \\
47,389 \\
44,321 \\
42,531\end{array}$ \\
\hline 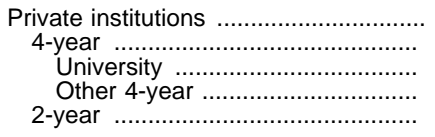 & $\begin{array}{l}52,112 \\
52,443 \\
67,457 \\
45,938 \\
32,628\end{array}$ & $\begin{array}{l}69,931 \\
70,071 \\
87,949 \\
59,174 \\
38,687\end{array}$ & $\begin{array}{l}48,984 \\
49,090 \\
57,812 \\
45,515 \\
33,998\end{array}$ & $\begin{array}{l}39,907 \\
40,021 \\
48,591 \\
37,259 \\
30,281\end{array}$ & $\begin{array}{l}30,502 \\
30,763 \\
35,960 \\
29,899 \\
24,189\end{array}$ & $\begin{array}{r}37,091 \\
37,091 \\
38,423 \\
34,735 \\
-\end{array}$ & $\begin{array}{l}35,915 \\
36,538 \\
41,779 \\
36,109 \\
34,079\end{array}$ & $\begin{array}{l}56,185 \\
56,453 \\
71,917 \\
48,626 \\
34,736\end{array}$ & $\begin{array}{l}44,374 \\
44,726 \\
55,306 \\
41,432 \\
30,661\end{array}$ \\
\hline
\end{tabular}

-Data not available.

1 Data are for degree-granting institutions. Survey coverage is slightly wider than data for higher education institutions tabulated for earlier years.

NOTE.-Data for 1990-91 through 1996-97 include imputations for nonrespondent institutions.
SOURCE: U.S. Department of Education, National Center for Education Statistics, Higher Education General Information Survey (HEGIS), Faculty Salaries, Tenure, and Fringe Benefits, 1980-81; and Integrated Postsecondary Education Data System (IPEDS), "Salaries, Tenure, and Fringe Benefits of Full-Time Instructional Faculty" surveys. (This table was prepared February 1998.) 
Table 235.-Average salary of full-time instructional faculty on 9-month contracts in institutions of higher education, by academic rank, sex, and control and type of institution: 1970-71 to 1996-97

\begin{tabular}{|c|c|c|c|c|c|c|c|c|c|c|c|c|c|}
\hline \multirow{2}{*}{ Academic year and sex } & \multirow{2}{*}{ All faculty } & \multicolumn{6}{|c|}{ Academic rank } & \multicolumn{3}{|c|}{ Public institutions } & \multicolumn{3}{|c|}{ Private institutions } \\
\hline & & Professor & $\begin{array}{l}\text { Associate } \\
\text { professor }\end{array}$ & $\begin{array}{l}\text { Assistant } \\
\text { professor }\end{array}$ & Instructor & Lecturer & No rank & Total & 4-year & 2-year & Total & 4-year & 2-year \\
\hline \multirow[t]{2}{*}{1} & 2 & 3 & 4 & 5 & 6 & 7 & 8 & 9 & 10 & 11 & 12 & 13 & 14 \\
\hline & \multicolumn{13}{|c|}{ Current dollars } \\
\hline 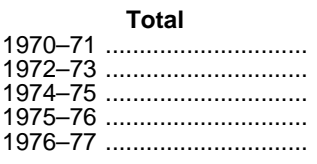 & $\begin{array}{r}\$ 12,710 \\
13,856 \\
15,622 \\
16,659 \\
17,560\end{array}$ & $\begin{array}{r}\$ 17,958 \\
19,191 \\
21,277 \\
22,649 \\
23,792\end{array}$ & $\begin{array}{r}\$ 13,563 \\
14,580 \\
16,146 \\
17,065 \\
17,905\end{array}$ & $\begin{array}{r}\$ 11,176 \\
12,032 \\
13,295 \\
13,986 \\
14,662\end{array}$ & $\begin{array}{l}\$ 9,360 \\
10,737 \\
12,691 \\
13,672 \\
11,835\end{array}$ & $\begin{array}{r}\$ 11,196 \\
11,637 \\
12,575 \\
12,906 \\
13,431\end{array}$ & $\begin{array}{r}\$ 12,333 \\
12,676 \\
13,532 \\
15,196 \\
16,634\end{array}$ & $\begin{array}{r}\$ 12,953 \\
14,016 \\
15,879 \\
16,942 \\
17,845\end{array}$ & $\begin{array}{r}\$ 13,121 \\
14,417 \\
16,271 \\
17,400 \\
18,313\end{array}$ & $\begin{array}{r}\$ 12,644 \\
12,919 \\
14,897 \\
15,820 \\
16,685\end{array}$ & $\begin{array}{r}\$ 11,619 \\
13,452 \\
14,912 \\
15,921 \\
16,787\end{array}$ & $\begin{array}{r}\$ 11,824 \\
13,622 \\
15,092 \\
16,116 \\
16,977\end{array}$ & $\begin{array}{r}\$ 8,664 \\
9,288 \\
10,242 \\
10,901 \\
11,637\end{array}$ \\
\hline 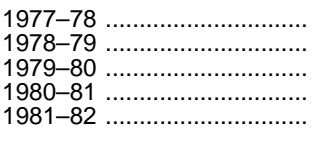 & $\begin{array}{l}18,709 \\
19,820 \\
21,348 \\
23,302 \\
25,449\end{array}$ & $\begin{array}{l}25,133 \\
26,470 \\
28,388 \\
30,753 \\
33,437\end{array}$ & $\begin{array}{l}18,987 \\
20,047 \\
21,451 \\
23,214 \\
25,278\end{array}$ & $\begin{array}{l}15,530 \\
16,374 \\
17,465 \\
18,901 \\
20,608\end{array}$ & $\begin{array}{l}12,504 \\
13,193 \\
14,023 \\
15,178 \\
16,450\end{array}$ & $\begin{array}{l}14,528 \\
15,281 \\
16,122 \\
17,301 \\
18,756\end{array}$ & $\begin{array}{l}17,831 \\
18,725 \\
20,262 \\
22,334 \\
24,331\end{array}$ & $\begin{array}{l}19,045 \\
20,179 \\
21,798 \\
23,745 \\
25,886\end{array}$ & $\begin{array}{l}19,517 \\
20,722 \\
22,349 \\
24,373 \\
26,591\end{array}$ & $\begin{array}{l}17,895 \\
18,844 \\
20,429 \\
22,177 \\
24,193\end{array}$ & $\begin{array}{l}17,773 \\
18,807 \\
20,105 \\
22,093 \\
24,255\end{array}$ & $\begin{array}{l}17,966 \\
19,010 \\
20,318 \\
22,325 \\
24,509\end{array}$ & $\begin{array}{l}12,191 \\
12,496 \\
13,250 \\
15,065 \\
15,926\end{array}$ \\
\hline $\begin{array}{l}1982-83 \quad \ldots \ldots \ldots \ldots \ldots \ldots \ldots \ldots \\
1984-85 \\
1985-86 \\
1987-88 \ldots \ldots \ldots \ldots \ldots \ldots \ldots \ldots \ldots \ldots \ldots \ldots \ldots \\
1989-90\end{array}$ & $\begin{array}{l}27,196 \\
30,447 \\
32,392 \\
35,897 \\
40,133\end{array}$ & $\begin{array}{l}35,540 \\
39,743 \\
42,268 \\
47,040 \\
52,810\end{array}$ & $\begin{array}{l}26,921 \\
29,945 \\
31,787 \\
35,231 \\
39,392\end{array}$ & $\begin{array}{l}22,056 \\
24,668 \\
26,277 \\
29,110 \\
32,689\end{array}$ & $\begin{array}{l}17,601 \\
20,230 \\
20,918 \\
22,728 \\
25,030\end{array}$ & $\begin{array}{l}20,072 \\
22,334 \\
23,770 \\
25,977 \\
28,990\end{array}$ & $\begin{array}{l}25,557 \\
27,683 \\
29,088 \\
31,532 \\
34,559\end{array}$ & $\begin{array}{l}27,488 \\
30,646 \\
32,750 \\
36,231 \\
40,416\end{array}$ & $\begin{array}{l}28,293 \\
31,764 \\
34,033 \\
37,840 \\
42,365\end{array}$ & $\begin{array}{l}25,567 \\
27,864 \\
29,590 \\
32,209 \\
35,516\end{array}$ & $\begin{array}{l}26,393 \\
29,910 \\
31,402 \\
35,049 \\
39,464\end{array}$ & $\begin{array}{l}26,691 \\
30,247 \\
31,732 \\
35,346 \\
39,817\end{array}$ & $\begin{array}{l}16,595 \\
18,510 \\
19,436 \\
21,867 \\
24,601\end{array}$ \\
\hline 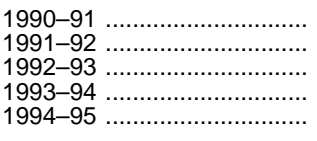 & $\begin{array}{l}42,165 \\
43,851 \\
44,714 \\
46,364 \\
47,811\end{array}$ & $\begin{array}{l}55,540 \\
57,433 \\
58,788 \\
60,649 \\
62,709\end{array}$ & $\begin{array}{l}41,414 \\
42,929 \\
43,945 \\
45,278 \\
46,713\end{array}$ & $\begin{array}{l}34,434 \\
35,745 \\
36,625 \\
37,630 \\
38,756\end{array}$ & $\begin{array}{l}26,332 \\
30,916 \\
28,499 \\
28,828 \\
29,665\end{array}$ & $\begin{array}{l}30,097 \\
30,456 \\
30,543 \\
32,729 \\
33,198\end{array}$ & $\begin{array}{l}36,395 \\
37,783 \\
37,771 \\
40,584 \\
41,227\end{array}$ & $\begin{array}{l}42,317 \\
43,641 \\
44,197 \\
45,920 \\
47,432\end{array}$ & $\begin{array}{l}44,510 \\
45,638 \\
46,515 \\
48,019 \\
49,738\end{array}$ & $\begin{array}{l}37,055 \\
38,959 \\
38,935 \\
41,040 \\
42,101\end{array}$ & $\begin{array}{l}41,788 \\
44,376 \\
45,985 \\
47,465 \\
48,741\end{array}$ & $\begin{array}{l}42,224 \\
44,793 \\
46,427 \\
47,880 \\
49,379\end{array}$ & $\begin{array}{l}24,088 \\
25,673 \\
26,105 \\
28,435 \\
25,613\end{array}$ \\
\hline 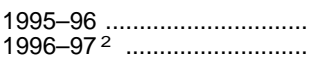 & $\begin{array}{l}49,309 \\
50,829\end{array}$ & $\begin{array}{l}64,540 \\
66,659\end{array}$ & $\begin{array}{l}47,966 \\
49,307\end{array}$ & $\begin{array}{l}39,696 \\
40,687\end{array}$ & $\begin{array}{l}30,344 \\
31,193\end{array}$ & $\begin{array}{l}34,136 \\
34,962\end{array}$ & $\begin{array}{l}42,996 \\
44,200\end{array}$ & $\begin{array}{l}48,837 \\
50,303\end{array}$ & $\begin{array}{l}51,172 \\
52,718\end{array}$ & $\begin{array}{l}43,295 \\
44,584\end{array}$ & $\begin{array}{l}50,466 \\
52,112\end{array}$ & $\begin{array}{l}50,819 \\
52,443\end{array}$ & $\begin{array}{l}31,915 \\
32,628\end{array}$ \\
\hline 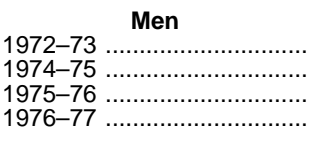 & $\begin{array}{l}14,422 \\
16,303 \\
17,414 \\
18,378\end{array}$ & $\begin{array}{l}19,414 \\
21,532 \\
22,902 \\
24,029\end{array}$ & $\begin{array}{l}14,723 \\
16,282 \\
17,209 \\
18,055\end{array}$ & $\begin{array}{l}12,193 \\
13,458 \\
14,174 \\
14,851\end{array}$ & $\begin{array}{l}11,147 \\
13,350 \\
14,430 \\
12,085\end{array}$ & $\begin{array}{l}12,106 \\
13,232 \\
13,579 \\
14,147\end{array}$ & $\begin{array}{l}13,047 \\
14,008 \\
15,761 \\
17,253\end{array}$ & $\begin{array}{l}14,545 \\
16,522 \\
17,661 \\
18,620\end{array}$ & $\begin{array}{l}14,944 \\
16,918 \\
18,121 \\
19,091\end{array}$ & $\begin{array}{l}13,268 \\
15,350 \\
16,339 \\
17,235\end{array}$ & $\begin{array}{l}14,116 \\
15,709 \\
16,784 \\
17,736\end{array}$ & $\begin{array}{l}14,253 \\
15,852 \\
16,946 \\
17,891\end{array}$ & $\begin{array}{r}9,571 \\
10,633 \\
11,378 \\
12,193\end{array}$ \\
\hline $\begin{array}{l}1977-78 \text { f. } \\
1978-79 \ldots \ldots \ldots \ldots \ldots \ldots \ldots \\
1979-80 \\
1980-81 \\
1981-82\end{array}$ & $\begin{array}{l}19,575 \\
20,777 \\
22,394 \\
24,499 \\
26,796\end{array}$ & $\begin{array}{l}25,370 \\
26,727 \\
28,672 \\
31,082 \\
33,799\end{array}$ & $\begin{array}{l}19,133 \\
20,221 \\
21,651 \\
23,451 \\
25,553\end{array}$ & $\begin{array}{l}15,726 \\
16,602 \\
17,720 \\
19,227 \\
21,025\end{array}$ & $\begin{array}{l}12,729 \\
13,441 \\
14,323 \\
15,545 \\
16,906\end{array}$ & $\begin{array}{l}15,181 \\
15,927 \\
16,932 \\
18,281 \\
19,721\end{array}$ & $\begin{array}{l}18,459 \\
19,400 \\
20,901 \\
23,170 \\
25,276\end{array}$ & $\begin{array}{l}19,867 \\
21,080 \\
22,789 \\
24,873 \\
27,149\end{array}$ & $\begin{array}{l}20,347 \\
21,628 \\
23,350 \\
25,509 \\
27,864\end{array}$ & $\begin{array}{l}18,479 \\
19,475 \\
21,131 \\
22,965 \\
25,085\end{array}$ & $\begin{array}{l}18,783 \\
19,935 \\
21,317 \\
23,493 \\
25,849\end{array}$ & $\begin{array}{l}18,935 \\
20,086 \\
21,472 \\
23,669 \\
26,037\end{array}$ & $\begin{array}{l}12,759 \\
13,048 \\
13,938 \\
16,075 \\
16,834\end{array}$ \\
\hline $\begin{array}{l}1982-83 \\
1984-85 \\
198 \ldots \ldots \ldots \ldots \ldots \ldots \ldots \ldots \ldots \\
1985-86 \\
1987-88 \ldots \ldots \ldots \ldots \ldots \ldots \ldots \ldots \ldots \ldots \\
1989-90\end{array}$ & $\begin{array}{l}28,664 \\
32,182 \\
34,294 \\
38,112 \\
42,763\end{array}$ & $\begin{array}{l}35,956 \\
40,269 \\
42,833 \\
47,735 \\
53,650\end{array}$ & $\begin{array}{l}27,262 \\
30,392 \\
32,273 \\
35,823 \\
40,131\end{array}$ & $\begin{array}{l}22,586 \\
25,330 \\
27,094 \\
30,086 \\
33,781\end{array}$ & $\begin{array}{l}18,160 \\
21,159 \\
21,693 \\
23,645 \\
25,933\end{array}$ & $\begin{array}{l}21,225 \\
23,557 \\
25,238 \\
27,652 \\
31,162\end{array}$ & $\begin{array}{l}26,541 \\
28,670 \\
30,267 \\
32,747 \\
35,980\end{array}$ & $\begin{array}{l}28,851 \\
32,240 \\
34,528 \\
38,314 \\
42,959\end{array}$ & $\begin{array}{l}29,661 \\
33,344 \\
35,786 \\
39,898 \\
44,834\end{array}$ & $\begin{array}{l}26,524 \\
28,891 \\
30,758 \\
33,477 \\
37,081\end{array}$ & $\begin{array}{l}28,159 \\
32,028 \\
33,656 \\
37,603 \\
42,312\end{array}$ & $\begin{array}{l}28,380 \\
32,278 \\
33,900 \\
37,817 \\
42,595\end{array}$ & $\begin{array}{l}17,346 \\
19,460 \\
20,412 \\
22,641 \\
25,218\end{array}$ \\
\hline $\begin{array}{l}1990-91 \\
1991-92 \\
1992-93 \\
19 \ldots \ldots \ldots \ldots \ldots \ldots \ldots \ldots \ldots \ldots \ldots \ldots \ldots \\
1993-94 \\
1994-95\end{array}$ & $\begin{array}{l}45,065 \\
46,848 \\
47,866 \\
49,579 \\
51,228\end{array}$ & $\begin{array}{l}56,549 \\
58,494 \\
59,972 \\
61,857 \\
64,046\end{array}$ & $\begin{array}{l}42,239 \\
43,814 \\
44,855 \\
46,229 \\
47,705\end{array}$ & $\begin{array}{l}35,636 \\
36,969 \\
37,842 \\
38,794 \\
39,923\end{array}$ & $\begin{array}{l}27,388 \\
33,359 \\
29,583 \\
29,815 \\
30,528\end{array}$ & $\begin{array}{l}32,398 \\
32,843 \\
32,512 \\
34,796 \\
35,082\end{array}$ & $\begin{array}{l}38,036 \\
39,422 \\
39,365 \\
42,251 \\
43,103\end{array}$ & $\begin{array}{l}45,084 \\
46,483 \\
47,175 \\
48,956 \\
50,629\end{array}$ & $\begin{array}{l}47,168 \\
48,401 \\
49,392 \\
50,989 \\
52,874\end{array}$ & $\begin{array}{l}38,787 \\
40,811 \\
40,725 \\
42,938 \\
44,020\end{array}$ & $\begin{array}{l}45,019 \\
47,733 \\
49,518 \\
51,076 \\
52,653\end{array}$ & $\begin{array}{l}45,319 \\
48,042 \\
49,837 \\
51,397 \\
53,036\end{array}$ & $\begin{array}{l}25,937 \\
26,825 \\
27,402 \\
30,783 \\
29,639\end{array}$ \\
\hline $\begin{array}{l}1995-96 \\
1996-972 \ldots \ldots \ldots \ldots \ldots \ldots \ldots \ldots \ldots \ldots \ldots \ldots \ldots \ldots\end{array}$ & $\begin{array}{l}52,814 \\
54,465\end{array}$ & $\begin{array}{l}65,949 \\
68,214\end{array}$ & $\begin{array}{l}49,037 \\
50,457\end{array}$ & $\begin{array}{l}40,858 \\
41,864\end{array}$ & $\begin{array}{l}30,940 \\
31,738\end{array}$ & $\begin{array}{l}36,135 \\
36,932\end{array}$ & $\begin{array}{l}44,624 \\
45,688\end{array}$ & $\begin{array}{l}52,163 \\
53,737\end{array}$ & $\begin{array}{l}54,448 \\
56,162\end{array}$ & $\begin{array}{l}45,209 \\
46,393\end{array}$ & $\begin{array}{l}54,364 \\
56,185\end{array}$ & $\begin{array}{l}54,649 \\
56,453\end{array}$ & $\begin{array}{l}33,301 \\
34,736\end{array}$ \\
\hline 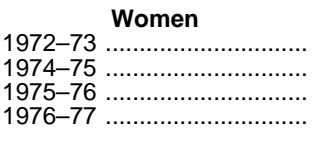 & $\begin{array}{l}11,925 \\
13,471 \\
14,308 \\
15,100\end{array}$ & $\begin{array}{l}17,123 \\
19,012 \\
20,308 \\
21,536\end{array}$ & $\begin{array}{l}13,827 \\
15,481 \\
16,364 \\
17,189\end{array}$ & $\begin{array}{l}11,510 \\
12,858 \\
13,522 \\
14,225\end{array}$ & $\begin{array}{l}10,098 \\
11,740 \\
12,572 \\
11,589\end{array}$ & $\begin{array}{l}10,775 \\
11,543 \\
11,901 \\
12,397\end{array}$ & $\begin{array}{l}11,913 \\
12,619 \\
14,094 \\
15,467\end{array}$ & $\begin{array}{l}12,250 \\
13,892 \\
14,762 \\
15,573\end{array}$ & $\begin{array}{l}12,300 \\
13,831 \\
14,758 \\
15,539\end{array}$ & $\begin{array}{l}12,165 \\
13,987 \\
14,769 \\
15,628\end{array}$ & $\begin{array}{l}11,044 \\
12,233 \\
13,030 \\
13,709\end{array}$ & $\begin{array}{l}11,219 \\
12,423 \\
13,231 \\
13,899\end{array}$ & $\begin{array}{r}8,888 \\
9,735 \\
10,201 \\
10,850\end{array}$ \\
\hline 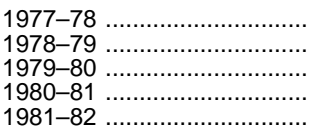 & $\begin{array}{l}16,159 \\
17,080 \\
18,396 \\
19,996 \\
21,802\end{array}$ & $\begin{array}{l}22,943 \\
24,143 \\
25,910 \\
27,959 \\
30,438\end{array}$ & $\begin{array}{l}18,325 \\
19,300 \\
20,642 \\
22,295 \\
24,271\end{array}$ & $\begin{array}{l}15,109 \\
15,914 \\
16,974 \\
18,302 \\
19,866\end{array}$ & $\begin{array}{l}12,288 \\
12,966 \\
13,750 \\
14,854 \\
16,054\end{array}$ & $\begin{array}{l}13,688 \\
14,465 \\
15,142 \\
16,168 \\
17,676\end{array}$ & $\begin{array}{l}16,637 \\
17,482 \\
19,069 \\
20,843 \\
22,672\end{array}$ & $\begin{array}{l}16,684 \\
17,646 \\
19,042 \\
20,673 \\
22,524\end{array}$ & $\begin{array}{l}16,619 \\
17,627 \\
18,985 \\
20,608 \\
22,454\end{array}$ & $\begin{array}{l}16,785 \\
17,676 \\
19,134 \\
20,778 \\
22,632\end{array}$ & $\begin{array}{l}14,597 \\
15,388 \\
16,539 \\
18,073 \\
19,743\end{array}$ & $\begin{array}{l}14,799 \\
15,611 \\
16,787 \\
18,326 \\
20,024\end{array}$ & $\begin{array}{l}11,470 \\
11,898 \\
12,541 \\
13,892 \\
14,984\end{array}$ \\
\hline 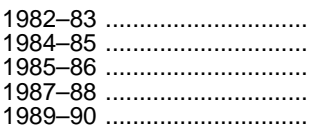 & $\begin{array}{l}23,261 \\
25,941 \\
27,576 \\
30,499 \\
34,183\end{array}$ & $\begin{array}{l}32,221 \\
35,824 \\
38,252 \\
42,371 \\
47,663\end{array}$ & $\begin{array}{l}25,738 \\
28,517 \\
30,300 \\
33,528 \\
37,469\end{array}$ & $\begin{array}{l}21,130 \\
23,575 \\
24,966 \\
27,600 \\
31,090\end{array}$ & $\begin{array}{l}17,102 \\
19,362 \\
20,237 \\
21,962 \\
24,320\end{array}$ & $\begin{array}{l}18,830 \\
21,004 \\
22,273 \\
24,370 \\
26,995\end{array}$ & $\begin{array}{l}23,855 \\
26,050 \\
27,171 \\
29,605 \\
32,528\end{array}$ & $\begin{array}{l}23,892 \\
26,566 \\
28,299 \\
31,215 \\
34,796\end{array}$ & $\begin{array}{l}23,876 \\
26,813 \\
28,680 \\
31,820 \\
35,704\end{array}$ & $\begin{array}{l}23,917 \\
26,172 \\
27,693 \\
30,228 \\
33,307\end{array}$ & $\begin{array}{l}21,451 \\
24,186 \\
25,523 \\
28,621 \\
32,650\end{array}$ & $\begin{array}{l}21,785 \\
24,560 \\
25,889 \\
28,946 \\
33,010\end{array}$ & $\begin{array}{l}15,845 \\
17,575 \\
18,504 \\
21,215 \\
24,002\end{array}$ \\
\hline 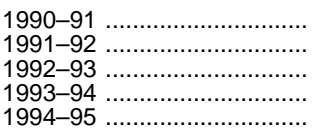 & $\begin{array}{l}35,881 \\
37,534 \\
38,385 \\
40,058 \\
41,369\end{array}$ & $\begin{array}{l}49,728 \\
51,621 \\
52,755 \\
54,746 \\
56,555\end{array}$ & $\begin{array}{l}39,329 \\
40,766 \\
41,861 \\
43,178 \\
44,626\end{array}$ & $\begin{array}{l}32,724 \\
34,063 \\
35,032 \\
36,169 \\
37,352\end{array}$ & $\begin{array}{l}25,534 \\
28,873 \\
27,700 \\
28,136 \\
29,072\end{array}$ & $\begin{array}{l}28,111 \\
28,550 \\
28,922 \\
31,048 \\
31,677\end{array}$ & $\begin{array}{l}34,179 \\
35,622 \\
35,792 \\
38,474 \\
38,967\end{array}$ & $\begin{array}{l}36,459 \\
37,800 \\
38,356 \\
40,118 \\
41,548\end{array}$ & $\begin{array}{l}37,573 \\
38,634 \\
39,470 \\
41,031 \\
42,663\end{array}$ & $\begin{array}{l}34,720 \\
36,517 \\
36,710 \\
38,707 \\
39,812\end{array}$ & $\begin{array}{l}34,359 \\
36,828 \\
38,460 \\
39,902 \\
40,908\end{array}$ & $\begin{array}{l}34,898 \\
37,309 \\
38,987 \\
40,378 \\
41,815\end{array}$ & $\begin{array}{l}22,585 \\
24,683 \\
25,068 \\
26,142 \\
22,851\end{array}$ \\
\hline $\begin{array}{l}1995-96 \\
1996-92^{2} \ldots \ldots \ldots \ldots \ldots \ldots \ldots \ldots \ldots \ldots \ldots \\
\end{array}$ & $\begin{array}{l}42,871 \\
44,325\end{array}$ & $\begin{array}{l}58,318 \\
60,160 \\
\end{array}$ & $\begin{array}{l}45,803 \\
47,101\end{array}$ & $\begin{array}{l}38,345 \\
39,350\end{array}$ & $\begin{array}{l}29,940 \\
30,819 \\
\end{array}$ & $\begin{array}{l}32,584 \\
33,415\end{array}$ & $\begin{array}{l}41,085 \\
42,474\end{array}$ & $\begin{array}{l}42,871 \\
44,306\end{array}$ & $\begin{array}{l}43,986 \\
45,402\end{array}$ & $\begin{array}{l}41,086 \\
42,531\end{array}$ & $\begin{array}{l}42,871 \\
44,374\end{array}$ & $\begin{array}{l}43,236 \\
44,726\end{array}$ & $\begin{array}{l}30,671 \\
30,661\end{array}$ \\
\hline
\end{tabular}


Table 235.-Average salary of full-time instructional faculty on 9-month contracts in institutions of higher education, by academic rank, sex, and control and type of institution: 1970-71 to 1996-97-Continued

\begin{tabular}{|c|c|c|c|c|c|c|c|c|c|c|c|c|c|}
\hline \multirow[b]{2}{*}{ Academic year and sex } & \multirow[b]{2}{*}{ All faculty } & \multicolumn{6}{|c|}{ Academic rank } & \multicolumn{3}{|c|}{ Public institutions } & \multicolumn{3}{|c|}{ Private institutions } \\
\hline & & Professor & & $\begin{array}{l}\text { sistant } \\
\text { ofessor }\end{array}$ & Instructor & Lecturer & No rank & Total & 4-year & 2-year & Total & 4-year & 2-year \\
\hline 1 & 2 & 3 & 4 & 5 & 6 & 7 & 8 & 9 & 10 & 11 & 12 & 13 & 14 \\
\hline & \multicolumn{13}{|c|}{ Constant $1996-97$ dollars 1} \\
\hline $\begin{array}{l}\text { Total } \\
1970-71 \\
1972-73 \\
1974-75 \\
1975-76 \ldots \ldots \ldots \ldots \ldots \ldots \\
1976-77\end{array}$ & $\begin{array}{l}50,841 \\
51,435 \\
47,931 \\
47,733 \\
47,545\end{array}$ & $\begin{array}{l}71,834 \\
71,238 \\
65,282 \\
64,898 \\
64,417\end{array}$ & $\begin{array}{l}54,256 \\
54,123 \\
49,540 \\
48,898 \\
48,477\end{array}$ & $\begin{array}{l}44,706 \\
44,663 \\
40,790 \\
40,076 \\
39,698\end{array}$ & $\begin{array}{l}37,441 \\
39,856 \\
38,937 \\
39,177 \\
32,043\end{array}$ & $\begin{array}{l}44,786 \\
43,196 \\
38,584 \\
36,980 \\
36,365\end{array}$ & $\begin{array}{l}49,335 \\
47,054 \\
41,519 \\
43,542 \\
45,036\end{array}$ & $\begin{array}{l}51,816 \\
52,028 \\
48,719 \\
48,545 \\
48,314\end{array}$ & $\begin{array}{l}52,489 \\
53,516 \\
49,924 \\
49,858 \\
49,583\end{array}$ & $\begin{array}{l}50,579 \\
47,955 \\
45,708 \\
45,329 \\
45,174\end{array}$ & $\begin{array}{l}46,476 \\
49,935 \\
45,751 \\
45,619 \\
45,450\end{array}$ & $\begin{array}{l}47,299 \\
50,565 \\
46,305 \\
46,180 \\
45,964\end{array}$ & $\begin{array}{l}34,658 \\
34,479 \\
31,424 \\
31,235 \\
31,507\end{array}$ \\
\hline $\begin{array}{l}1977-78 \\
1978-79 \\
1979-80 \\
1980-81 \\
1981-82\end{array}$ & $\begin{array}{l}47,466 \\
45,980 \\
43,698 \\
42,746 \\
42,972\end{array}$ & $\begin{array}{l}63,767 \\
61,407 \\
58,108 \\
56,414 \\
56,461\end{array}$ & $\begin{array}{l}48,173 \\
46,507 \\
43,908 \\
42,585 \\
42,684\end{array}$ & $\begin{array}{l}39,402 \\
37,986 \\
35,750 \\
34,673 \\
34,798\end{array}$ & $\begin{array}{l}31,723 \\
30,605 \\
28,703 \\
27,843 \\
27,777\end{array}$ & $\begin{array}{l}36,859 \\
35,449 \\
32,999 \\
31,738 \\
31,671\end{array}$ & $\begin{array}{l}45,240 \\
43,438 \\
41,474 \\
40,970 \\
41,085\end{array}$ & $\begin{array}{l}48,320 \\
46,812 \\
44,619 \\
43,559 \\
43,710\end{array}$ & $\begin{array}{l}49,518 \\
48,072 \\
45,746 \\
44,711 \\
44,901\end{array}$ & $\begin{array}{l}45,401 \\
43,714 \\
41,817 \\
40,682 \\
40,852\end{array}$ & & & $\begin{array}{l}30,929 \\
28,989 \\
27,122 \\
27,636 \\
26,892\end{array}$ \\
\hline $\begin{array}{l}1982-83 \\
1984-85 \\
1985-86 \\
1987-88\end{array}$ & $\begin{array}{l}44,031 \\
45,745 \\
47,303 \\
49,242 \\
50,226\end{array}$ & $\begin{array}{l}57,540 \\
59,711 \\
61,725 \\
64,528 \\
66,091\end{array}$ & $\begin{array}{l}43,586 \\
44,990 \\
46,419 \\
48,329 \\
49,299\end{array}$ & $\begin{array}{l}35,709 \\
37,062 \\
38,373 \\
39,932 \\
40,910\end{array}$ & $\begin{array}{l}28,497 \\
30,394 \\
30,547 \\
31,177 \\
31,325\end{array}$ & $\begin{array}{l}32,497 \\
33,555 \\
34,712 \\
35,634 \\
36,281\end{array}$ & $\begin{array}{l}41,378 \\
41,592 \\
42,478 \\
43,255 \\
43,250\end{array}$ & $\begin{array}{l}44,504 \\
46,044 \\
47,826 \\
49,700 \\
50,580\end{array}$ & $\begin{array}{l}45,807 \\
47,723 \\
49,699 \\
51,908 \\
53,019\end{array}$ & $\begin{array}{l}41,394 \\
41,864 \\
43,211 \\
44,183 \\
44,448\end{array}$ & & & $\begin{array}{l}26,868 \\
27,810 \\
28,383 \\
29,996 \\
30,788\end{array}$ \\
\hline $\begin{array}{l}\text { 1990-91 } \\
\text { 1991-92 } \\
1992-93 \\
1993-94 \ldots \ldots \ldots \ldots \ldots \ldots \ldots \ldots \ldots \ldots \ldots \ldots \ldots \ldots \ldots \ldots \ldots \ldots . . . \\
1994-95\end{array}$ & $\begin{array}{l}50,034 \\
50,419 \\
49,854 \\
50,389 \\
50,513\end{array}$ & $\begin{array}{l}65,905 \\
66,035 \\
65,545 \\
65,913 \\
66,252\end{array}$ & $\begin{array}{l}49,142 \\
49,358 \\
48,996 \\
49,207 \\
49,353\end{array}$ & $\begin{array}{l}40,860 \\
41,099 \\
40,835 \\
40,896 \\
40,946\end{array}$ & $\begin{array}{l}31,246 \\
35,546 \\
31,775 \\
31,330 \\
31,341\end{array}$ & $\begin{array}{l}35,714 \\
35,017 \\
34,054 \\
35,569 \\
35,074\end{array}$ & & & $\begin{array}{l}52,816 \\
52,473 \\
51,862 \\
52,187 \\
52,549\end{array}$ & $\begin{array}{l}43,970 \\
44,794 \\
43,410 \\
44,602 \\
44,480\end{array}$ & & & $\begin{array}{l}28,583 \\
29,518 \\
29,106 \\
30,903 \\
27,060\end{array}$ \\
\hline 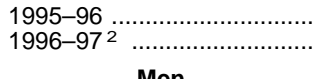 & $\begin{array}{l}50,716 \\
50,829\end{array}$ & $\begin{array}{l}66,382 \\
66,659\end{array}$ & $\begin{array}{l}49,334 \\
49,307\end{array}$ & & & $\begin{array}{l}35,110 \\
34,962\end{array}$ & & & & & & & $\begin{array}{l}32,826 \\
32,628\end{array}$ \\
\hline 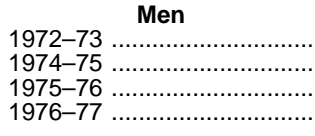 & $\begin{array}{l}53,536 \\
50,019 \\
49,897 \\
49,758\end{array}$ & $\begin{array}{l}72,068 \\
66,064 \\
65,622 \\
65,057\end{array}$ & $\begin{array}{l}54,654 \\
49,955 \\
49,309 \\
48,885\end{array}$ & $\begin{array}{l}45,262 \\
41,293 \\
40,615 \\
40,210\end{array}$ & $\begin{array}{l}41,380 \\
40,960 \\
41,347 \\
32,721\end{array}$ & $\begin{array}{l}44,937 \\
40,598 \\
38,909 \\
38,302\end{array}$ & $\begin{array}{l}48,432 \\
42,979 \\
45,161 \\
46,713\end{array}$ & & & & & & $\begin{array}{l}35,528 \\
32,624 \\
32,601 \\
33,013\end{array}$ \\
\hline $\begin{array}{l}1977-78 \\
1978-79 \\
1979-80 \\
1980-81 \\
1981-82\end{array}$ & $\begin{array}{l}49,665 \\
48,198 \\
45,838 \\
44,942 \\
45,247\end{array}$ & $\begin{array}{l}64,367 \\
62,003 \\
58,689 \\
57,018 \\
57,072\end{array}$ & & & & & & & & & & & $\begin{array}{l}28,531 \\
29,489 \\
28,425\end{array}$ \\
\hline 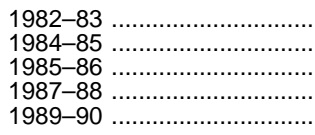 & $\begin{array}{l}46,408 \\
48,351 \\
50,080 \\
52,280 \\
53,518\end{array}$ & $\begin{array}{l}58,214 \\
60,502 \\
62,550 \\
65,481 \\
67,142\end{array}$ & $\begin{array}{l}44,138 \\
45,662 \\
47,129 \\
49,141 \\
50,223\end{array}$ & $\begin{array}{l}36,567 \\
38,057 \\
39,566 \\
41,271 \\
42,276\end{array}$ & & & & & & & & & $\begin{array}{l}28,084 \\
29,237 \\
29,808\end{array}$ \\
\hline 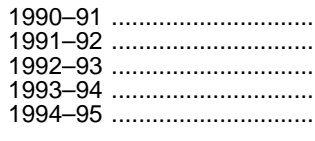 & $\begin{array}{l}53,475 \\
53,865 \\
53,368 \\
53,882 \\
54,123\end{array}$ & $\begin{array}{l}67,102 \\
67,254 \\
66,866 \\
67,226 \\
67,666\end{array}$ & $\begin{array}{l}50,121 \\
50,376 \\
50,012 \\
50,241 \\
50,401\end{array}$ & $\begin{array}{l}42,286 \\
42,505 \\
42,192 \\
42,161 \\
42,179\end{array}$ & $\begin{array}{l}32,500 \\
38,355 \\
32,984 \\
32,403 \\
32,253\end{array}$ & & & & & & & & \\
\hline 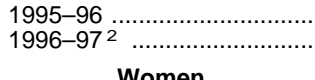 & $\begin{array}{l}54,321 \\
54,465\end{array}$ & 67,831 & $\begin{array}{l}50,437 \\
50,457\end{array}$ & $\begin{array}{l}42,024 \\
41,864\end{array}$ & 31,823 & $\begin{array}{l}37,166 \\
36,932\end{array}$ & & & & & & & \\
\hline 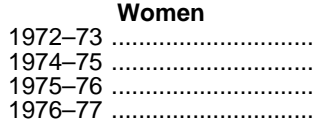 & $\begin{array}{l}44,266 \\
41,331 \\
40,997 \\
40,882\end{array}$ & $\begin{array}{l}63,561 \\
58,332 \\
58,190 \\
58,308\end{array}$ & $\begin{array}{l}51,326 \\
47,500 \\
46,889 \\
46,540\end{array}$ & & & & & & & & & & \\
\hline $\begin{array}{l}1977-78 \\
1978-79 \\
1979-80 \\
1980-81 \\
1981-82\end{array}$ & $\begin{array}{l}40,997 \\
39,623 \\
37,655 \\
36,681 \\
36,814\end{array}$ & $\begin{array}{l}58,209 \\
56,007 \\
53,037 \\
51,289 \\
51,397\end{array}$ & $\begin{array}{l}46,493 \\
44,773 \\
42,252 \\
40,899 \\
40,983\end{array}$ & $\begin{array}{l}38,334 \\
36,917 \\
34,744 \\
33,574 \\
33,545\end{array}$ & $\begin{array}{l}31,176 \\
30,079 \\
28,146 \\
27,249 \\
27,108\end{array}$ & & $\begin{array}{l}42,211 \\
40,556 \\
39,034 \\
38,235 \\
38,283\end{array}$ & & & & & & $\begin{array}{l}29,102 \\
27,600 \\
25,669 \\
25,484 \\
25,302\end{array}$ \\
\hline $\begin{array}{l}1982-83 \\
1984-85 \\
1985-86 \\
1987-88 \\
1989-90 \ldots \ldots \ldots \ldots \ldots \ldots \ldots \ldots \ldots \ldots \ldots \ldots \ldots \ldots \ldots . . .\end{array}$ & $\begin{array}{l}37,660 \\
38,975 \\
40,270 \\
41,838 \\
42,780\end{array}$ & $\begin{array}{l}52,167 \\
53,823 \\
55,860 \\
58,123 \\
59,649\end{array}$ & $\begin{array}{l}41,671 \\
42,845 \\
44,248 \\
45,993 \\
46,892\end{array}$ & $\begin{array}{l}34,210 \\
35,420 \\
36,458 \\
37,861 \\
38,908\end{array}$ & $\begin{array}{l}27,689 \\
29,090 \\
29,553 \\
30,126 \\
30,436\end{array}$ & $\begin{array}{l}30,486 \\
31,557 \\
32,526 \\
33,430 \\
33,784\end{array}$ & $\begin{array}{l}38,622 \\
39,138 \\
39,678 \\
40,611 \\
40,709\end{array}$ & & $\begin{array}{l}38,656 \\
40,285 \\
41,882 \\
43,650 \\
44,684\end{array}$ & & & & $\begin{array}{l}25,654 \\
26,405 \\
27,022 \\
29,102 \\
30,038\end{array}$ \\
\hline $\begin{array}{l}\text { 1990-91 } \\
1991-92 \\
1992-93 \\
1993-94 \\
1994-95\end{array}$ & $\begin{array}{l}42,576 \\
43,155 \\
42,797 \\
43,535 \\
43,707\end{array}$ & $\begin{array}{l}59,009 \\
59,352 \\
58,820 \\
59,498 \\
59,751\end{array}$ & $\begin{array}{l}46,669 \\
46,871 \\
46,672 \\
46,925 \\
47,148\end{array}$ & $\begin{array}{l}38,831 \\
39,165 \\
39,059 \\
39,308 \\
39,463\end{array}$ & $\begin{array}{l}30,299 \\
33,198 \\
30,885 \\
30,578 \\
30,715\end{array}$ & $\begin{array}{l}33,357 \\
32,826 \\
32,247 \\
33,743 \\
33,467\end{array}$ & & $\begin{array}{l}43,263 \\
43,462 \\
42,764 \\
43\end{array}$ & $\begin{array}{l}44,585 \\
44,420 \\
44,007 \\
44,592 \\
45,074\end{array}$ & & $\begin{array}{l}40,771 \\
42,344 \\
42,881 \\
43,366 \\
43,220\end{array}$ & $\begin{array}{l}41,410 \\
42,897 \\
43,468 \\
43,882 \\
44,178\end{array}$ & $\begin{array}{l}26,800 \\
28,380 \\
27,949 \\
28,411 \\
24,143\end{array}$ \\
\hline $\begin{array}{l}1995-96 \\
1996-972\end{array}$ & $\begin{array}{l}44,094 \\
44,325\end{array}$ & $\begin{array}{l}59,981 \\
60,160\end{array}$ & $\begin{array}{l}47,110 \\
47,101\end{array}$ & $\begin{array}{l}39,439 \\
39,350\end{array}$ & $\begin{array}{l}30,794 \\
30,819\end{array}$ & $\begin{array}{l}33,514 \\
33,415\end{array}$ & $\begin{array}{l}42,257 \\
42,474\end{array}$ & $\begin{array}{l}44,094 \\
44,306\end{array}$ & $\begin{array}{l}45,241 \\
45,402\end{array}$ & $\begin{array}{l}42,259 \\
42,531\end{array}$ & $\begin{array}{l}44,094 \\
44,374\end{array}$ & $\begin{array}{l}44,470 \\
44,726\end{array}$ & 30,661 \\
\hline
\end{tabular}

${ }^{1}$ Data adjusted by the Consumer Price Index prepared by the Bureau of Labor Statistics, averaged on an academic year time frame.

Data are for degree-granting institutions.

NOTE.-Data for 1987-88 and later years include imputations for nonrespondent institutions.
SOURCE: U.S. Department of Education, National Center for Education Statistics, Higher Education General Information Survey (HEGIS), Faculty Salaries, Tenure, and Fringe Benefits surveys; and Integrated Postsecondary Education Data System (IPEDS), "Salaries, Tenure, and Fringe Benefits of Full-Time Instructional Faculty" surveys. (This table was prepared July 1998 .) 
Table 236.-Average salary of full-time instructional faculty on 9-month contracts in degree-granting institutions, ${ }^{1}$ by type and control of institution and by state: 1996-97

\begin{tabular}{|c|c|c|c|c|c|c|c|c|c|c|c|}
\hline \multirow{3}{*}{ State or other area } & \multirow{3}{*}{$\begin{array}{c}\text { All } \\
\text { institutions }\end{array}$} & \multicolumn{5}{|c|}{ Public institutions } & \multicolumn{5}{|c|}{ Private institutions } \\
\hline & & \multirow[b]{2}{*}{ Total } & \multicolumn{3}{|c|}{ 4-year institutions } & \multirow[b]{2}{*}{ 2-year } & \multirow[b]{2}{*}{ Total } & \multicolumn{3}{|c|}{ 4-year institutions } & \multirow[b]{2}{*}{ 2-year } \\
\hline & & & Total & University & $\begin{array}{l}\text { Other } \\
\text { 4-year }\end{array}$ & & & Total & University & $\begin{array}{l}\text { Other } \\
\text { 4-year }\end{array}$ & \\
\hline 1 & 2 & 3 & 4 & 5 & 6 & 7 & 8 & 9 & 10 & 11 & 12 \\
\hline United States .................. & $\$ 50,829$ & $\$ 50,303$ & $\$ 52,718$ & $\$ 57,047$ & $\$ 49,836$ & $\$ 44,584$ & $\$ 52,112$ & $\$ 52,443$ & $\$ 67,457$ & $\$ 45,938$ & $\$ 32,628$ \\
\hline Alabama & 42,006 & 42,843 & 44,785 & 48,913 & 42,219 & 37,708 & 37,530 & 37,701 & - & 37,701 & 25,023 \\
\hline Alaska ........................... & 50,091 & 50,725 & 50,657 & 50,914 & 50,494 & 59,281 & 38,307 & 38,307 & - & 38,307 & - \\
\hline Arizona .......... & 52,605 & 52,681 & 54,206 & 57,275 & 45,889 & 49,601 & 50,636 & 50,636 & - & 50,636 & - \\
\hline 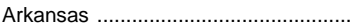 & 39,488 & 39,915 & 42,800 & 48,836 & 40,820 & 31,780 & 37,269 & 38,059 & - & 38,059 & 16,681 \\
\hline 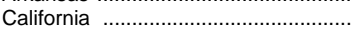 & 59,870 & 59,543 & 63,276 & 75,604 & 60,987 & 54,529 & 61,172 & 61,394 & 75,175 & 54,043 & 36,992 \\
\hline Colorado ....................... & 50,095 & 49,784 & 52,336 & 58,381 & 47,221 & 37,225 & 52,270 & 52,270 & 55,228 & 48,623 & - \\
\hline Connecticut . & 61,592 & 61,598 & 64,695 & 70,883 & 58,855 & 52,640 & 61,584 & 62,293 & 79,548 & 55,058 & 35,069 \\
\hline 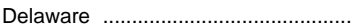 & 56,948 & 57,203 & 59,872 & 62,295 & 46,688 & 43,846 & 54,483 & 54,483 & - & 54,483 & - \\
\hline District of Columbia & 59,385 & - & - & - & - & - & 59,385 & 59,385 & 60,978 & 45,531 & - \\
\hline 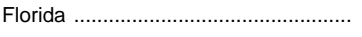 & 47,598 & 47,576 & 52,100 & 57,386 & 49,010 & 41,436 & 47,685 & 47,718 & 59,180 & 43,449 & 26,720 \\
\hline Georgia . & 47,193 & 47,721 & 49,929 & 55,990 & 48,444 & 37,663 & 45,767 & 46,227 & 69,677 & 39,794 & 30,492 \\
\hline 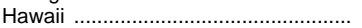 & 52,175 & 52,488 & 57,364 & 58,846 & 48,142 & 44,264 & 48,572 & 48,572 & - & 48,572 & - \\
\hline 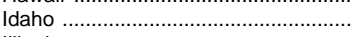 & 44,016 & 44,179 & 45,201 & 49,095 & 43,360 & 37,295 & 43,460 & 40,100 & - & 40,100 & 44,970 \\
\hline 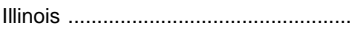 & 52,548 & 50,970 & 51,532 & 55,988 & 47,655 & 50,034 & 55,292 & 55,746 & 72,650 & 44,627 & 28,830 \\
\hline Indiana & 48,588 & 48,299 & 50,719 & 53,481 & 45,021 & 34,590 & 49,193 & 49,429 & 71,279 & 43,084 & 30,265 \\
\hline lowa & 47,191 & 51,033 & 57,503 & 60,581 & 49,273 & 36,710 & 40,880 & 40,897 & 51,200 & 39,593 & 29,025 \\
\hline 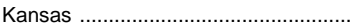 & 41,655 & 43,272 & 47,067 & 49,907 & 40,890 & 35,437 & 31,478 & 31,768 & - & 31,768 & 25,910 \\
\hline 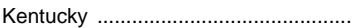 & 43,410 & 45,097 & 47,773 & 54,298 & 43,871 & 35,627 & 37,369 & 37,369 & - & 37,369 & - \\
\hline 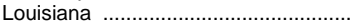 & 44,884 & 43,530 & 44,635 & 52,901 & 42,521 & 34,416 & 51,281 & 51,340 & 58,881 & 38,830 & 48,630 \\
\hline 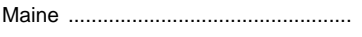 & 45,199 & 43,882 & 45,874 & 49,583 & 43,866 & 35,831 & 48,616 & 49,255 & - & 49,255 & 28,944 \\
\hline Maryland ........ & 50,802 & 49,781 & 52,144 & 59,221 & 48,566 & 45,594 & 54,379 & 54,441 & 71,669 & 45,791 & 25,000 \\
\hline 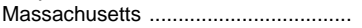 & 58,697 & 51,427 & 55,611 & 64,374 & 52,029 & 41,536 & 62,790 & 63,061 & 71,789 & 53,799 & 35,212 \\
\hline 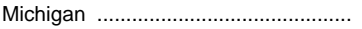 & 54,248 & 56,393 & 56,869 & 63,355 & 51,451 & 54,698 & 43,242 & 43,459 & 47,513 & 42,919 & 20,074 \\
\hline Minnesota & 48,877 & 50,390 & 53,763 & 64,476 & 48,163 & 45,176 & 45,347 & 45,591 & - & 45,591 & 36,638 \\
\hline 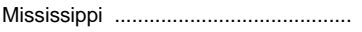 & 39,644 & 40,232 & 43,302 & 45,240 & 42,010 & 36,257 & 34,896 & 35,749 & - & 35,749 & 23,554 \\
\hline Missouri & 47,063 & 47,579 & 49,568 & 58,603 & 47,753 & 40,596 & 46,023 & 46,424 & 62,112 & 37,842 & 29,963 \\
\hline 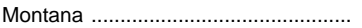 & 40,589 & 41,731 & 43,338 & 45,089 & 39,402 & 31,758 & 33,714 & 34,360 & - & 34,360 & 26,100 \\
\hline 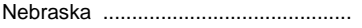 & 44,701 & 46,030 & 49,374 & 56,249 & 44,649 & 34,332 & 40,574 & 40,574 & 47,592 & 36,828 & - \\
\hline Nevada & 51,959 & 52,050 & 55,194 & 58,997 & 52,647 & 44,829 & 37,946 & 37,946 & - & 37,946 & - \\
\hline 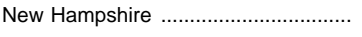 & 49,425 & 47,339 & 50,127 & 51,630 & 47,545 & 36,029 & 52,143 & 52,991 & - & 52,991 & 27,236 \\
\hline New Jersey & 61,538 & 61,419 & 64,359 & 71,997 & 61,765 & 54,694 & 61,850 & 61,989 & 75,071 & 51,694 & 25,845 \\
\hline 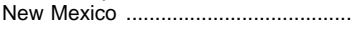 & 43,322 & 43,552 & 47,244 & 49,782 & 40,250 & 32,627 & 38,532 & 38,532 & - & 38,532 & - \\
\hline 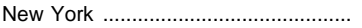 & 56,996 & 55,913 & 58,051 & 62,459 & 57,349 & 52,120 & 58,092 & 58,546 & 69,356 & 51,389 & 29,503 \\
\hline 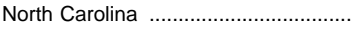 & 47,462 & 49,096 & 51,803 & 62,388 & 47,500 & 32,153 & 43,687 & 43,978 & 61,504 & 37,234 & 31,300 \\
\hline North Dakota ........................................... & 36,366 & 37,103 & 38,347 & 39,434 & 36,099 & 32,190 & 31,158 & 32,623 & - & 32,623 & 23,785 \\
\hline Ohio & 50,240 & 51,914 & 54,747 & 56,462 & 48,586 & 42,722 & 46,526 & 46,769 & 67,470 & 44,502 & 29,678 \\
\hline 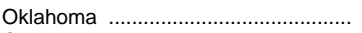 & 41,961 & 42,514 & 44,841 & 50,253 & 40,482 & 35,991 & 39,830 & 40,329 & 50,222 & 35,806 & 25,654 \\
\hline 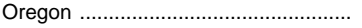 & 44,506 & 44,212 & 45,121 & 47,702 & 42,250 & 43,161 & 45,546 & 45,546 & - & 45,546 & - \\
\hline Pennsylvania & 55,132 & 56,029 & 57,330 & 62,407 & 54,469 & 48,938 & 54,040 & 54,457 & 73,122 & 48,846 & 31,440 \\
\hline 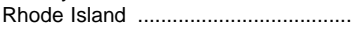 & 54,797 & 52,382 & 55,721 & 60,085 & 48,226 & 42,341 & 56,582 & 56,582 & - & 56,582 & - \\
\hline 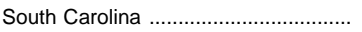 & 42,246 & 43,199 & 48,228 & 53,983 & 42,235 & 32,486 & 38,030 & 38,169 & - & 38,169 & 31,540 \\
\hline 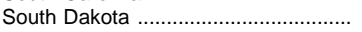 & 36,482 & 37,279 & 37,382 & 38,107 & 36,391 & 26,212 & 33,685 & 33,738 & - & 33,738 & 28,800 \\
\hline Tennessee & 45,532 & 45,994 & 49,315 & 56,243 & 46,955 & 35,625 & 44,488 & 44,636 & 67,787 & 35,955 & 23,582 \\
\hline 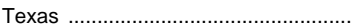 & 46,434 & 45,576 & 48,678 & 55,528 & 43,062 & 39,963 & 50,117 & 50,292 & 59,321 & 43,378 & 26,395 \\
\hline Utah & 46,735 & 45,037 & 47,232 & 51,683 & 39,984 & 36,352 & 50,704 & 50,859 & 51,750 & 39,229 & 37,370 \\
\hline Vermont & 44,722 & 46,461 & 46,461 & 49,695 & 38,167 & - & 43,140 & 44,403 & - & 44,403 & 20,261 \\
\hline 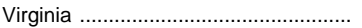 & 48,468 & 49,391 & 52,734 & 57,209 & 49,924 & 38,940 & 45,405 & 45,503 & - & 45,503 & 28,018 \\
\hline 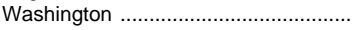 & 46,038 & 46,051 & 51,042 & 54,807 & 44,925 & 39,662 & 45,989 & 45,989 & - & 45,989 & - \\
\hline West Virginia & 40,929 & 41,942 & 42,570 & 49,056 & 39,510 & 33,520 & 35,534 & 35,534 & - & 35,534 & - \\
\hline Wisconsin & 49,325 & 50,747 & 52,106 & 63,364 & 48,066 & 48,694 & 43,320 & 43,320 & 54,490 & 40,117 & - \\
\hline 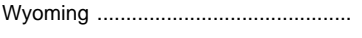 & 39,855 & 39,855 & 46,743 & 46,743 & & 33,007 & & & - & & - \\
\hline U.S. Service Schools ........................... & 61,536 & 61,536 & 61,536 & - & 61,536 & - & - & - & - & - & - \\
\hline Outlying areas & 33,163 & 34,652 & 34,840 & 36,820 & 33,761 & 33,380 & 21,412 & 21,412 & - & 21,412 & - \\
\hline American Samoa & 29,072 & 29,072 & - & - & - & 29,072 & - & - & - & - & - \\
\hline Federated States of Micronesia ......... & 17,695 & 17,695 & - & - & - & 17,695 & - & - & - & - & - \\
\hline Guam . & 47,679 & 47,679 & 51,109 & - & 51,109 & 43,155 & - & - & - & - & - \\
\hline 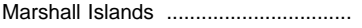 & - & - & - & - & - & - & - & - & - & - & - \\
\hline 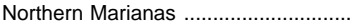 & 35,628 & 35,628 & - & - & - & 35,628 & - & - & - & - & - \\
\hline 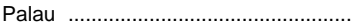 & 17,743 & 17,743 & - & - & - & 17,743 & - & - & - & - & - \\
\hline 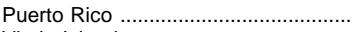 & 32,030 & 33,641 & 33,495 & 36,820 & 31,389 & 36,361 & 21,412 & 21,412 & - & 21,412 & - \\
\hline Virgin Islands ........ & 44,976 & 44,976 & 44,976 & - & 44,976 & - & - & - & - & - & - \\
\hline
\end{tabular}

1 Includes 2-year and 4-year degree-granting institutions that were eligible to participate in title IV federal financial aid programs.

-Data not reported or not applicable.

NOTE.-Data include imputations for nonrespondent institutions.
SOURCE: U.S. Department of Education, National Center for Education Statistics, Integrated Postsecondary Education Data System (IPEDS), "Salaries, Tenure, and Fringe Benefits of Full-Time Instructional Faculty, 1996-97" survey. (This table was prepared February 1998). 
Table 237.-Average salary of full-time instructional faculty on 9-month contracts in institutions of higher education, by type and control of institution and by state: 1995-96

\begin{tabular}{|c|c|c|c|c|c|c|c|c|c|c|c|}
\hline \multirow{3}{*}{ State or other area } & \multirow{3}{*}{$\begin{array}{c}\text { All } \\
\text { institutions }\end{array}$} & \multicolumn{5}{|c|}{ Public institutions } & \multicolumn{5}{|c|}{ Private institutions } \\
\hline & & \multirow[b]{2}{*}{ Total } & \multicolumn{3}{|c|}{ 4-year institutions } & \multirow[b]{2}{*}{ 2-year } & \multirow[b]{2}{*}{ Total } & \multicolumn{3}{|c|}{ 4-year institutions } & \multirow[b]{2}{*}{ 2-year } \\
\hline & & & Total & University & $\begin{array}{l}\text { Other } \\
\text { 4-year }\end{array}$ & & & Total & University & $\begin{array}{l}\text { Other } \\
\text { 4-year }\end{array}$ & \\
\hline 1 & 2 & 3 & 4 & 5 & 6 & 7 & 8 & 9 & 10 & 11 & 12 \\
\hline United States. & $\$ 49,309$ & $\$ 48,837$ & $\$ 51,172$ & $\$ 55,068$ & $\$ 48,566$ & $\$ 43,295$ & $\$ 50,466$ & $\$ 50,819$ & $\$ 65,405$ & $\$ 44,504$ & $\$ 31,915$ \\
\hline Alabama & 40,505 & 41,450 & 43,580 & 47,854 & 40,872 & 36,364 & 35,431 & 35,594 & - & 35,594 & 24,809 \\
\hline Alaska & 49,036 & 49,646 & 49,594 & 49,685 & 49,531 & 56,164 & 37,489 & 37,489 & - & 37,489 & - \\
\hline Arizona & 50,841 & 51,255 & 52,809 & 55,301 & 44,966 & 48,231 & 39,682 & 39,682 & - & 39,682 & - \\
\hline 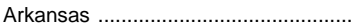 & 38,782 & 39,378 & 41,299 & 47,001 & 39,502 & 31,125 & 36,037 & 36,748 & - & 36,748 & 16,052 \\
\hline 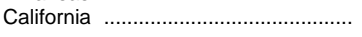 & 57,716 & 57,320 & 60,674 & 70,350 & 58,876 & 52,789 & 59,328 & 59,716 & 74,410 & 52,233 & 33,405 \\
\hline Colorado & 47,874 & 47,745 & 50,262 & 56,009 & 45,562 & 35,652 & 48,763 & 48,763 & 53,584 & 43,665 & - \\
\hline Connecticut & 59,253 & 59,018 & 61,635 & 67,363 & 56,188 & 51,143 & 59,524 & 60,090 & 77,086 & 53,141 & 33,576 \\
\hline Delaware .......................... & 55,148 & 55,378 & 57,693 & 59,944 & 45,399 & 42,950 & 53,092 & 53,092 & - & 53,092 & - \\
\hline District of Columbia ................................ & 56,994 & 51,610 & 51,610 & - & 51,610 & - & 57,758 & 57,758 & 59,352 & 44,266 & - \\
\hline Florida ......................... & 45,677 & 45,609 & 50,487 & 54,649 & 47,864 & 39,594 & 45,944 & 46,125 & 57,361 & 42,076 & 27,245 \\
\hline Georgia & 45,188 & 45,297 & 47,318 & 52,580 & 46,014 & 36,167 & 44,883 & 45,385 & 67,915 & 39,120 & 29,695 \\
\hline 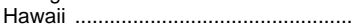 & 51,470 & 51,937 & 56,477 & 57,741 & 48,292 & 44,244 & 46,540 & 46,540 & - & 46,540 & - \\
\hline Idaho & 42,271 & 42,604 & 43,446 & 47,733 & 41,495 & 36,646 & 41,196 & 37,910 & - & 37,910 & 42,721 \\
\hline 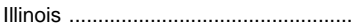 & 51,065 & 49,527 & 49,976 & 53,824 & 46,548 & 48,796 & 53,818 & 54,091 & 71,189 & 43,184 & 30,610 \\
\hline 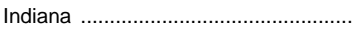 & 47,351 & 47,006 & 49,176 & 51,805 & 43,809 & 34,662 & 48,101 & 48,324 & 68,842 & 42,239 & 29,925 \\
\hline lowa .............. & 46,113 & 49,686 & 55,947 & 58,998 & 47,591 & 35,726 & 40,149 & 40,109 & 51,045 & 38,644 & 45,578 \\
\hline Kansas ................... & 41,497 & 43,372 & 46,436 & 48,886 & 41,003 & 35,716 & 30,603 & 31,003 & - & 31,003 & 24,510 \\
\hline 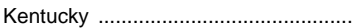 & 41,791 & 43,418 & 46,269 & 52,345 & 42,650 & 33,107 & 35,949 & 36,106 & - & 36,106 & 27,036 \\
\hline 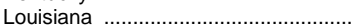 & 40,689 & 39,037 & 39,929 & 46,288 & 38,298 & 31,745 & 48,104 & 48,133 & 54,380 & 37,270 & 46,619 \\
\hline 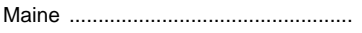 & 43,075 & 41,823 & 43,946 & 47,438 & 41,987 & 33,378 & 46,393 & 46,966 & - & 46,966 & 28,818 \\
\hline Maryland ............ & 49,835 & 48,994 & 51,395 & 57,592 & 48,264 & 44,772 & 52,861 & 52,923 & 68,457 & 45,004 & 24,267 \\
\hline Massachusetts …................................... & 56,498 & 48,720 & 52,530 & 60,364 & 49,430 & 39,963 & 60,944 & 61,270 & 69,753 & 52,094 & 35,083 \\
\hline 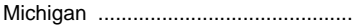 & 52,555 & 54,677 & 55,244 & 61,133 & 50,274 & 52,722 & 41,843 & 42,067 & 44,205 & 41,805 & 26,714 \\
\hline 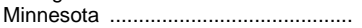 & 46,617 & 47,873 & 52,284 & 62,922 & 46,711 & 41,664 & 43,613 & 43,803 & - & 43,803 & 36,427 \\
\hline 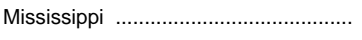 & 39,565 & 40,004 & 43,367 & 45,722 & 41,882 & 35,808 & 36,152 & 37,077 & - & 37,077 & 22,701 \\
\hline Missouri & 44,993 & 45,438 & 47,125 & 55,872 & 45,419 & 39,479 & 44,113 & 44,424 & 58,456 & 36,649 & 33,675 \\
\hline Montana & 38,784 & 39,737 & 41,120 & 42,742 & 37,603 & 30,952 & 32,029 & 31,834 & - & 31,834 & 34,981 \\
\hline 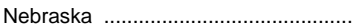 & 43,443 & 44,599 & 48,000 & 54,734 & 43,255 & 33,692 & 39,726 & 39,726 & 46,658 & 35,985 & - \\
\hline Nevada & 49,235 & 49,338 & 52,010 & 55,724 & 49,758 & 43,284 & 29,688 & 29,688 & - & 29,688 & - \\
\hline New Hampshire ....... & 48,438 & 46,856 & 49,817 & 52,205 & 45,604 & 34,956 & 50,547 & 51,242 & - & 51,242 & 24,508 \\
\hline New Jersey . & 60,408 & 60,796 & 64,539 & 73,263 & 61,394 & 52,283 & 59,408 & 59,540 & 71,701 & 49,817 & 39,947 \\
\hline 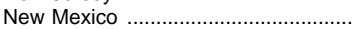 & 42,565 & 42,715 & 46,635 & 49,071 & 39,650 & 31,257 & 39,443 & 39,443 & - & 39,443 & - \\
\hline 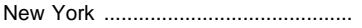 & 55,764 & 55,594 & 58,182 & 62,285 & 57,527 & 50,933 & 55,938 & 56,393 & 66,589 & 49,800 & 29,601 \\
\hline North Carolina & 45,065 & 46,299 & 48,732 & 56,948 & 45,296 & 30,638 & 42,206 & 42,516 & 60,020 & 35,977 & 32,711 \\
\hline 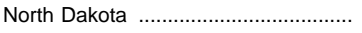 & 35,303 & 36,104 & 37,259 & 37,983 & 35,580 & 31,232 & 29,709 & 31,298 & - & 31,298 & 22,297 \\
\hline Ohio ........ & 48,468 & 50,008 & 52,784 & 54,168 & 47,857 & 40,886 & 45,025 & 45,134 & 64,920 & 42,989 & 24,138 \\
\hline Oklahoma & 40,798 & 41,046 & 42,958 & 48,109 & 38,836 & 35,038 & 39,807 & 40,286 & 51,464 & 35,457 & 25,039 \\
\hline Oregon & 44,272 & 44,002 & 45,646 & 47,983 & 42,832 & 42,091 & 45,278 & 45,278 & - & 45,278 & - \\
\hline Pennsylvania ……..................... & 53,987 & 55,481 & 56,830 & 60,944 & 54,526 & 48,206 & 52,196 & 52,742 & 69,693 & 47,251 & 28,934 \\
\hline Rhode Island & 52,805 & 50,493 & 53,509 & 57,683 & 46,702 & 41,379 & 54,585 & 54,585 & - & 54,585 & - \\
\hline 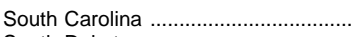 & 40,820 & 41,813 & 46,655 & 52,582 & 40,494 & 31,510 & 36,544 & 36,682 & - & 36,682 & 30,294 \\
\hline South Dakota ...................................... & 35,982 & 37,139 & 37,274 & 38,096 & 36,101 & 24,834 & 31,858 & 31,943 & - & 31,943 & 24,000 \\
\hline Tennessee & 44,431 & 44,940 & 48,112 & 54,072 & 46,011 & 34,743 & 43,278 & 43,586 & 66,150 & 35,055 & 27,747 \\
\hline Texas & 45,164 & 44,294 & 46,992 & 53,063 & 41,883 & 39,331 & 48,938 & 49,130 & 58,942 & 41,439 & 24,942 \\
\hline Utah & 45,437 & 43,796 & 45,919 & 50,097 & 39,301 & 35,147 & 49,268 & 49,540 & 50,420 & 38,275 & 33,089 \\
\hline Vermont & 43,171 & 45,068 & 45,068 & 48,168 & 37,379 & - & 41,430 & 42,640 & - & 42,640 & 20,024 \\
\hline 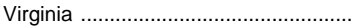 & 47,365 & 48,405 & 51,675 & 56,288 & 48,691 & 38,142 & 43,894 & 44,204 & - & 44,204 & 26,614 \\
\hline 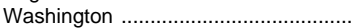 & 45,703 & 45,774 & 51,202 & 54,727 & 45,381 & 38,753 & 45,421 & 45,421 & - & 45,421 & - \\
\hline West Virginia & 39,793 & 40,667 & 41,323 & 47,507 & 38,401 & 31,816 & 35,038 & 35,038 & - & 35,038 & - \\
\hline 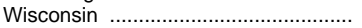 & 48,332 & 49,578 & 51,246 & 62,321 & 47,325 & 47,064 & 42,805 & 42,805 & 54,746 & 39,066 & - \\
\hline 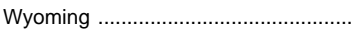 & 39,998 & 39,998 & 47,216 & 47,216 & - & 32,766 & - & - & - & - & - \\
\hline U.S. Service Schools & 61,758 & 61,758 & 61,758 & - & 61,758 & - & - & - & - & - & - \\
\hline Outlying areas & 31,663 & 33,248 & 33,796 & 34,217 & 33,495 & 31,026 & 19,633 & 19,633 & - & 19,633 & - \\
\hline American Samoa & 32,522 & 32,522 & - & - & - & 32,522 & - & - & - & - & - \\
\hline Federated States of Micronesia ......... & 26,884 & 26,884 & - & - & - & 26,884 & - & - & - & - & - \\
\hline Guam & 47,021 & 47,021 & 51,273 & - & 51,273 & 42,964 & - & - & - & - & - \\
\hline Marshall Islands & 14,722 & 14,722 & - & - & 14,722 & - & - & - & - & - & - \\
\hline Northern Marianas ……............................ & 32,321 & 32,321 & - & - & - & 32,321 & - & - & - & - & - \\
\hline Palau & 15,143 & 15,143 & - & - & - & 15,143 & - & - & - & - & - \\
\hline 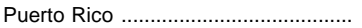 & 30,321 & 32,059 & 32,334 & 34,217 & 30,743 & 29,577 & 19,633 & 19,633 & - & 19,633 & - \\
\hline 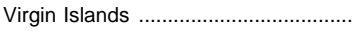 & 45,452 & 45,452 & 45,452 & - & 45,452 & - & - & - & - & - & - \\
\hline
\end{tabular}

-Data not reported or not applicable.

NOTE.-Data include imputations for nonrespondent institutions.
SOURCE: U.S. Department of Education, National Center for Education Statistics, Integrated Postsecondary Education Data System (IPEDS), "Salaries, Tenure, and Fringe Benefits of Full-Time Instructional Faculty, 1995-96" survey. (This table was prepared January 1997). 
Table 238.-Average salary of full-time instructional faculty on 9-month contracts in 4-year degree-granting institutions, ${ }^{1}$ by type and control of institution and rank of faculty and by state: 1996-97

\begin{tabular}{|c|c|c|c|c|c|c|c|c|c|c|c|c|}
\hline \multirow[b]{2}{*}{ State or other area } & \multicolumn{3}{|c|}{ Public university } & \multicolumn{3}{|c|}{ Public other 4-year } & \multicolumn{3}{|c|}{ Private university } & \multicolumn{3}{|c|}{ Private other 4-year } \\
\hline & Professor & $\begin{array}{l}\text { Associate } \\
\text { professor }\end{array}$ & $\begin{array}{l}\text { Assistant } \\
\text { professor }\end{array}$ & Professor & $\begin{array}{l}\text { Associate } \\
\text { professor }\end{array}$ & $\begin{array}{l}\text { Assistant } \\
\text { professor }\end{array}$ & Professor & $\begin{array}{l}\text { Associate } \\
\text { professor }\end{array}$ & $\begin{array}{l}\text { Assistant } \\
\text { professor }\end{array}$ & Professor & $\begin{array}{l}\text { Associate } \\
\text { professor }\end{array}$ & $\begin{array}{l}\text { Assistant } \\
\text { professor }\end{array}$ \\
\hline 1 & 2 & 3 & 4 & 5 & 6 & 7 & 8 & 9 & 10 & 11 & 12 & 13 \\
\hline 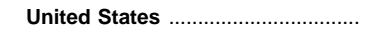 & $\$ 72,599$ & $\$ 51,835$ & $\$ 43,536$ & $\$ 62,846$ & $\$ 49,082$ & $\$ 40,500$ & $\$ 87,949$ & $\$ 57,812$ & $\$ 48,591$ & $\$ 59,174$ & $\$ 45,515$ & $\$ 37,259$ \\
\hline Alabama & 64,158 & 47,267 & 40,463 & 54,692 & 44,005 & 37,519 & - & - & - & 49,175 & 38,723 & 32,250 \\
\hline 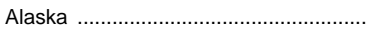 & 64,801 & 55,212 & 42,008 & 62,321 & 51,766 & 41,529 & - & - & - & 43,999 & 41,320 & 34,617 \\
\hline Arizona & 71,484 & 51,330 & 43,989 & 59,834 & 48,623 & 39,631 & - & - & - & 56,029 & 67,093 & 34,818 \\
\hline Arkansas ........................ & 63,795 & 48,624 & 42,159 & 52,574 & 42,669 & 36,859 & - & - & - & 45,366 & 38,097 & 32,426 \\
\hline 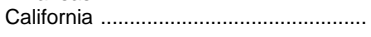 & 91,095 & 60,378 & 52,565 & 69,322 & 54,177 & 44,316 & 93,888 & 62,303 & 53,034 & 68,586 & 50,189 & 41,434 \\
\hline Colorado & 70,540 & 52,825 & 45,245 & 58,442 & 46,475 & 39,201 & 69,380 & 52,574 & 45,530 & 63,840 & 46,693 & 36,589 \\
\hline Connecticut ................ & 85,721 & 63,263 & 50,072 & 71,612 & 56,936 & 43,458 & 104,774 & 57,794 & 48,592 & 69,779 & 51,848 & 43,391 \\
\hline Delaware & 82,337 & 58,720 & 47,157 & 61,375 & 49,567 & 41,491 & - & - & - & 67,059 & 58,951 & 37,189 \\
\hline District of Columbia .......................... & - & - & - & - & - & - & 81,081 & 54,604 & 44,940 & 56,923 & 45,678 & 36,637 \\
\hline Florida ....................... & 68,784 & 49,539 & 44,692 & 62,840 & 48,490 & 41,613 & 78,969 & 54,050 & 44,169 & 56,367 & 42,454 & 35,984 \\
\hline Georgia & 73,791 & 52,015 & 44,752 & 63,385 & 50,058 & 41,113 & 92,931 & 58,662 & 49,729 & 51,171 & 41,681 & 34,420 \\
\hline 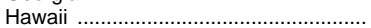 & 73,539 & 54,969 & 47,110 & 57,836 & 46,468 & 41,486 & - & - & - & 55,256 & 47,876 & 43,486 \\
\hline Idaho & 58,137 & 47,409 & 41,637 & 52,364 & 43,363 & 38,608 & - & - & - & 48,062 & 40,205 & 34,954 \\
\hline Illinois & 73,121 & 50,784 & 43,961 & 59,648 & 48,217 & 40,090 & 94,663 & 60,655 & 52,673 & 55,714 & 45,330 & 37,725 \\
\hline Indiana & 70,174 & 50,932 & 41,862 & 61,436 & 46,842 & 40,142 & 90,337 & 62,192 & 51,322 & 52,382 & 42,970 & 36,061 \\
\hline lowa & 75,140 & 53,768 & 45,220 & 64,145 & 50,027 & 42,735 & 63,918 & 48,366 & 40,124 & 50,397 & 39,711 & 33,578 \\
\hline Kansas .. & 62,199 & 45,949 & 40,166 & 52,362 & 41,630 & 35,848 & - & - & - & 37,858 & 33,034 & 28,391 \\
\hline Kentucky ... & 68,359 & 49,405 & 41,736 & 55,620 & 44,964 & 37,360 & - & - & - & 47,395 & 37,734 & 32,101 \\
\hline 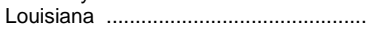 & 70,607 & 52,243 & 43,494 & 56,489 & 45,104 & 38,101 & 73,992 & 52,249 & 45,363 & 47,894 & 39,822 & 35,312 \\
\hline 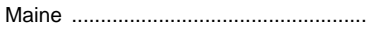 & 60,026 & 48,050 & 39,691 & 53,082 & 43,571 & 35,669 & - & - & - & 67,524 & 49,135 & 37,746 \\
\hline Maryland & 76,329 & 54,023 & 46,841 & 63,490 & 49,832 & 41,672 & 88,221 & 61,840 & 50,430 & 57,315 & 45,824 & 37,346 \\
\hline Massachusetts & 75,034 & 57,090 & 45,934 & 59,686 & 50,854 & 40,798 & 93,987 & 59,515 & 51,265 & 69,502 & 50,488 & 42,298 \\
\hline 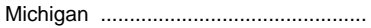 & 79,054 & 58,403 & 48,775 & 62,557 & 50,672 & 42,175 & 59,902 & 51,050 & 36,774 & 51,470 & 42,747 & 37,460 \\
\hline 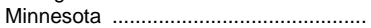 & 76,087 & 52,770 & 45,696 & 56,734 & 46,118 & 39,313 & - & - & - & 57,952 & 44,870 & 37,133 \\
\hline 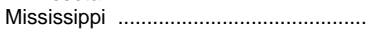 & 59,110 & 47,079 & 40,676 & 53,554 & 44,391 & 38,058 & - & - & - & 46,357 & 35,466 & 32,415 \\
\hline Missou & 72,974 & 54,586 & 46,778 & 60,511 & 48,307 & 39,465 & 80,705 & 54,912 & 48,918 & 47,096 & 39,280 & 33,745 \\
\hline Montana & 54,288 & 44,449 & 37,972 & 48,695 & 40,173 & 33,679 & - & - & - & 41,556 & 35,441 & 30,483 \\
\hline Nebraska …… & 73,016 & 50,605 & 43,566 & 55,717 & 46,709 & 37,794 & 70,712 & 48,884 & 36,563 & 44,919 & 37,278 & 32,694 \\
\hline 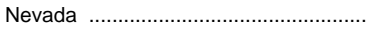 & 74,895 & 55,428 & 45,061 & 69,528 & 53,989 & 44,269 & - & - & - & 45,876 & 38,290 & 27,608 \\
\hline New Hampshire .................................... & 63,794 & 47,621 & 39,114 & 57,829 & 45,043 & 37,835 & - & - & - & 70,387 & 47,034 & 40,309 \\
\hline New Jersey & 91,007 & 64,184 & 48,461 & 78,477 & 61,261 & 47,259 & 100,970 & 59,109 & 47,448 & 63,953 & 51,853 & 40,535 \\
\hline New Mexico ……............................... & 63,004 & 48,162 & 39,877 & 51,953 & 40,870 & 34,920 & - & - & - & 42,072 & 33,046 & 31,735 \\
\hline 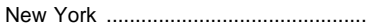 & 78,429 & 55,743 & 43,981 & 70,744 & 53,964 & 43,642 & 87,507 & 60,115 & 50,356 & 66,417 & 51,349 & 40,735 \\
\hline North Carolina ............ & 79,294 & 55,394 & 48,613 & 60,946 & 48,423 & 41,684 & 79,455 & 55,780 & 44,090 & 46,356 & 37,701 & 32,462 \\
\hline 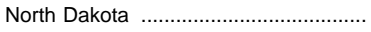 & 49,892 & 41,318 & 36,740 & 46,731 & 38,471 & 34,259 & - & - & - & 42,283 & 35,202 & 31,726 \\
\hline Ohio & 71,830 & 52,483 & 42,636 & 63,967 & 49,107 & 39,404 & 82,174 & 59,309 & 51,029 & 56,568 & 43,838 & 36,294 \\
\hline Oklahoma & 63,279 & 46,424 & 38,676 & 49,687 & 42,303 & 38,069 & 69,968 & 47,919 & 38,694 & 48,989 & 39,398 & 30,383 \\
\hline 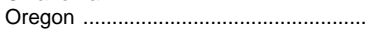 & 60,405 & 46,014 & 39,507 & 51,640 & 40,592 & 35,780 & - & - & - & 58,375 & 44,469 & 35,179 \\
\hline Pennsylvania & 81,139 & 57,502 & 45,187 & 71,306 & 56,029 & 44,408 & 92,520 & 61,022 & 51,974 & 62,730 & 48,707 & 39,715 \\
\hline Rhode Island & 68,840 & 51,631 & 44,032 & 54,238 & 47,880 & 39,535 & - & - & - & 71,982 & 51,771 & 45,032 \\
\hline South Carolina . & 68,422 & 50,207 & 42,245 & 52,509 & 43,677 & 36,923 & - & - & - & 49,045 & 37,662 & 32,153 \\
\hline South Dakota .................................... & 47,584 & 39,128 & 34,428 & 46,889 & 38,811 & 33,324 & - & - & - & 41,344 & 35,324 & 31,156 \\
\hline Tennessee & 65,579 & 51,299 & 43,418 & 58,146 & 45,503 & 38,092 & 89,305 & 59,212 & 46,166 & 45,412 & 36,144 & 32,393 \\
\hline Texas & 72,418 & 48,720 & 42,985 & 55,577 & 43,991 & 38,151 & 78,127 & 54,650 & 45,442 & 55,335 & 42,932 & 35,081 \\
\hline 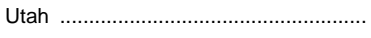 & 65,870 & 47,800 & 40,538 & 47,910 & 39,846 & 36,200 & 64,766 & 49,191 & 42,334 & 47,935 & 39,540 & 34,458 \\
\hline Vermont & 64,822 & 48,988 & 39,650 & 45,983 & 37,666 & 30,465 & - & - & - & 57,600 & 42,070 & 37,205 \\
\hline Virginia & 73,057 & 52,082 & 44,719 & 63,388 & 49,503 & 39,985 & - & - & - & 57,444 & 44,612 & 36,374 \\
\hline 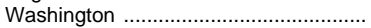 & 68,166 & 48,701 & 43,452 & 53,171 & 43,553 & 37,225 & - & - & - & 58,225 & 45,257 & 38,667 \\
\hline West Virginia & 60,938 & 47,969 & 39,976 & 47,335 & 39,052 & 33,268 & - & - & - & 42,916 & 37,659 & 31,378 \\
\hline Wisconsin ……… & 71,625 & 53,805 & 47,896 & 56,712 & 46,598 & 39,737 & 69,887 & 53,844 & 43,280 & 50,112 & 40,446 & 35,029 \\
\hline 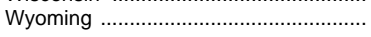 & 58,176 & 45,659 & 40,475 & - & - & - & - & - & - & - & - & - \\
\hline U.S. Service Schools & - & - & - & 74,021 & 57,949 & 48,942 & - & - & - & - & - & - \\
\hline 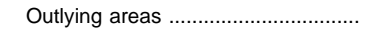 & 44,033 & 36,577 & 30,313 & 40,981 & 35,663 & 31,224 & - & - & - & 15,893 & 29,069 & 24,759 \\
\hline American Samoa & - & - & - & - & - & - & - & - & - & - & - & - \\
\hline Federated States of Micronesia ............ & - & - & - & - & - & - & - & - & - & - & - & - \\
\hline Guam & - & - & - & 70,312 & 54,690 & 43,942 & - & - & - & - & - & - \\
\hline 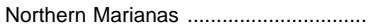 & - & - & - & - & - & - & - & - & - & - & - & - \\
\hline Palau & - & - & - & - & - & - & - & - & - & - & - & - \\
\hline 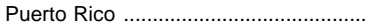 & 44,033 & 36,577 & 30,313 & 38,836 & 32,555 & 28,236 & - & - & - & 15,893 & 29,069 & 24,759 \\
\hline 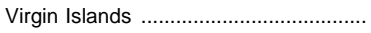 & - & - & 一 & 54,987 & 45,124 & 38,777 & - & - & - & - & - & - \\
\hline
\end{tabular}

1 Includes 4-year degree granting institutions that were eligible to participate in Title V federal financial aid programs.

-Data not reported or not applicable.

NOTE.-Data include imputations for nonrespondent institutions.
SOURCE: U.S. Department of Education, National Center for Education Statistics, Integrated Postsecondary Education Data System (IPEDS), "Salaries, Tenure, and Fringe Benefits of Full-Time Instructional Faculty, 1996-97" survey. (This table was prepared July 1998.) 
Table 239._Average salary of full-time instructional faculty on 9-month contracts in 4-year institutions of higher education, by type and control of institution and rank of faculty and by state: 1995-96

\begin{tabular}{|c|c|c|c|c|c|c|c|c|c|c|c|c|}
\hline \multirow[b]{2}{*}{ State or other area } & \multicolumn{3}{|c|}{ Public university } & \multicolumn{3}{|c|}{ Public other 4-year } & \multicolumn{3}{|c|}{ Private university } & \multicolumn{3}{|c|}{ Private other 4-year } \\
\hline & Professor & $\begin{array}{l}\text { Associate } \\
\text { professor }\end{array}$ & $\begin{array}{l}\text { Assistant } \\
\text { professor }\end{array}$ & Professor & $\begin{array}{l}\text { Associate } \\
\text { professor }\end{array}$ & $\begin{array}{l}\text { Assistant } \\
\text { professor }\end{array}$ & Professor & $\begin{array}{l}\text { Associate } \\
\text { professor }\end{array}$ & $\begin{array}{l}\text { Assistant } \\
\text { professor }\end{array}$ & Professor & $\begin{array}{l}\text { Associate } \\
\text { professor }\end{array}$ & $\begin{array}{l}\text { Assistant } \\
\text { professor }\end{array}$ \\
\hline 1 & 2 & 3 & 4 & 5 & 6 & 7 & 8 & 9 & 10 & 11 & 12 & 13 \\
\hline United States ................... & $\$ 69,924$ & $\$ 50,186$ & $\$ 42,335$ & $\$ 61,076$ & $\$ 47,850$ & $\$ 39,544$ & $\$ 84,970$ & $\$ 56,517$ & $\$ 47,387$ & $\$ 57,089$ & $\$ 44,186$ & $\$ 36,325$ \\
\hline Alabama & 62,390 & 46,175 & 39,248 & 53,010 & 42,698 & 36,375 & - & - & - & 45,566 & 37,175 & 31,028 \\
\hline 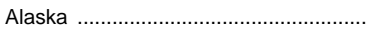 & 65,161 & 54,047 & 43,848 & 61,135 & 50,717 & 41,174 & - & - & - & 41,498 & 41,676 & 34,410 \\
\hline Arizona & 68,888 & 49,492 & 43,066 & 58,775 & 47,539 & 38,981 & - & - & - & 47,956 & 44,806 & 31,343 \\
\hline Arkansas ............................ & 61,336 & 47,575 & 41,002 & 50,980 & 41,391 & 35,689 & - & - & - & 43,878 & 37,204 & 31,116 \\
\hline 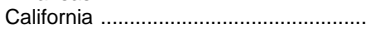 & 85,413 & 56,794 & 49,216 & 67,003 & 51,564 & 42,685 & 93,239 & 61,898 & 51,850 & 66,408 & 49,750 & 40,383 \\
\hline Colorado & 67,322 & 50,431 & 43,378 & 56,309 & 45,183 & 38,142 & 67,217 & 50,895 & 44,940 & 56,859 & 42,967 & 33,621 \\
\hline Connecticut. & 82,383 & 61,187 & 47,683 & 68,680 & 55,361 & 42,014 & 100,780 & 56,269 & 47,455 & 67,060 & 50,438 & 42,412 \\
\hline Delaware & 78,998 & 57,324 & 45,542 & 60,902 & 47,905 & 41,092 & - & - & - & 63,372 & 57,739 & 40,078 \\
\hline District of Columbia .......................... & - & - & - & 60,588 & 48,285 & 39,443 & 77,980 & 53,007 & 43,517 & 55,920 & 44,624 & 36,383 \\
\hline Florida ............................... & 65,827 & 46,252 & 42,734 & 60,336 & 46,483 & 40,759 & 75,661 & 53,277 & 43,032 & 54,865 & 41,324 & 35,065 \\
\hline Georgia & 69,549 & 49,500 & 41,710 & 59,802 & 47,848 & 39,414 & 88,656 & 57,909 & 48,878 & 49,438 & 40,894 & 33,869 \\
\hline 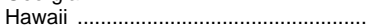 & 72,025 & 54,713 & 47,058 & 58,252 & 47,664 & 42,804 & - & - & - & 54,152 & 46,456 & 41,138 \\
\hline Idaho & 55,463 & 45,181 & 41,217 & 49,845 & 41,736 & 36,822 & - & - & - & 45,725 & 37,299 & 33,190 \\
\hline Illinois & 70,074 & 49,458 & 42,042 & 57,942 & 46,799 & 39,292 & 90,944 & 59,938 & 50,859 & 53,928 & 43,650 & 36,943 \\
\hline Indiana . & 67,151 & 48,838 & 40,835 & 59,107 & 45,465 & 39,201 & 86,818 & 60,580 & 49,998 & 51,722 & 42,292 & 35,328 \\
\hline lowa & 72,891 & 53,185 & 44,020 & 62,052 & 48,729 & 41,629 & 63,809 & 47,234 & 40,652 & 48,518 & 39,040 & 32,773 \\
\hline Kansas . & 61,279 & 45,374 & 39,387 & 51,778 & 41,733 & 35,815 & - & - & - & 36,583 & 32,111 & 28,159 \\
\hline Kentucky ... & 66,430 & 47,686 & 40,938 & 53,759 & 43,728 & 36,265 & - & - & - & 44,955 & 36,242 & 31,722 \\
\hline 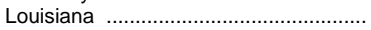 & 61,130 & 44,254 & 37,898 & 49,829 & 40,080 & 34,664 & 72,166 & 53,193 & 42,826 & 46,697 & 38,563 & 34,696 \\
\hline 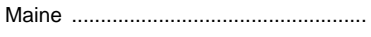 & 58,275 & 45,694 & 38,353 & 51,474 & 41,513 & 34,135 & - & - & - & 65,027 & 47,161 & 36,588 \\
\hline Maryland & 73,989 & 52,297 & 46,196 & 63,003 & 49,311 & 41,577 & 84,580 & 58,834 & 47,902 & 54,772 & 44,139 & 36,306 \\
\hline Massachusetts & 70,319 & 53,098 & 43,258 & 56,565 & 47,801 & 39,336 & 90,651 & 58,456 & 50,289 & 67,374 & 49,051 & 41,314 \\
\hline 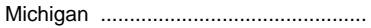 & 75,895 & 56,450 & 47,456 & 60,929 & 49,253 & 40,987 & 55,356 & 44,226 & 37,182 & 50,041 & 41,451 & 36,109 \\
\hline 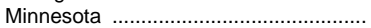 & 74,328 & 51,463 & 45,611 & 54,485 & 44,753 & 37,897 & - & - & - & 55,776 & 43,256 & 36,024 \\
\hline 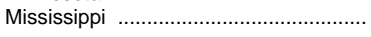 & 58,615 & 46,386 & 40,649 & 53,495 & 43,670 & 37,733 & - & - & - & 45,818 & 37,042 & 32,997 \\
\hline Missou & 68,773 & 51,557 & 45,108 & 57,140 & 46,356 & 38,212 & 76,800 & 52,602 & 45,574 & 45,663 & 37,430 & 32,730 \\
\hline Montana & 50,728 & 41,570 & 36,430 & 46,558 & 37,626 & 32,732 & - & - & - & 35,697 & 31,047 & 31,518 \\
\hline Nebraska …… & 71,391 & 49,411 & 42,735 & 53,718 & 44,698 & 37,161 & 69,771 & 48,644 & 35,633 & 43,626 & 36,600 & 32,035 \\
\hline Nevada & 70,672 & 52,609 & 42,054 & 65,586 & 51,336 & 42,708 & - & - & - & 43,691 & 29,914 & 13,273 \\
\hline New Hampshire .................................... & 64,240 & 48,104 & 40,127 & 55,694 & 44,153 & 37,049 & - & - & - & 68,903 & 45,483 & 38,183 \\
\hline New Jersey & 92,584 & 65,547 & 50,285 & 77,607 & 61,134 & 47,872 & 97,220 & 58,733 & 45,208 & 61,080 & 49,684 & 39,914 \\
\hline New Mexico ……............................... & 61,962 & 47,364 & 39,341 & 51,348 & 40,084 & 34,460 & - & - & - & 43,296 & 36,506 & 30,930 \\
\hline 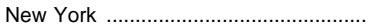 & 78,428 & 55,887 & 43,915 & 70,935 & 54,347 & 43,701 & 83,612 & 58,311 & 48,607 & 64,002 & 49,809 & 39,691 \\
\hline North Carolina ............ & 72,682 & 51,440 & 45,144 & 57,847 & 46,052 & 39,827 & 76,066 & 54,509 & 44,586 & 44,847 & 36,641 & 31,727 \\
\hline 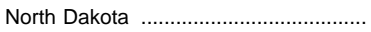 & 48,084 & 39,786 & 35,827 & 45,131 & 36,887 & 33,415 & - & - & - & 41,017 & 34,158 & 31,044 \\
\hline Ohio & 68,621 & 50,523 & 41,440 & 62,596 & 48,037 & 38,718 & 79,893 & 57,359 & 49,829 & 54,807 & 42,356 & 35,267 \\
\hline Oklahoma & 60,434 & 44,890 & 37,858 & 47,875 & 40,570 & 36,880 & 68,185 & 49,088 & 39,205 & 45,394 & 38,630 & 29,639 \\
\hline 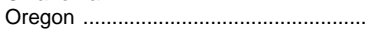 & 61,149 & 46,138 & 40,124 & 51,820 & 40,855 & 35,929 & - & - & - & 56,483 & 43,361 & 35,767 \\
\hline Pennsylvania & 79,229 & 56,381 & 44,953 & 71,512 & 55,784 & 44,542 & 89,077 & 59,000 & 49,988 & 60,123 & 47,137 & 38,447 \\
\hline 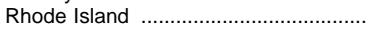 & 65,870 & 49,774 & 43,346 & 52,979 & 46,045 & 38,662 & - & 一 & - & 69,683 & 50,282 & 43,466 \\
\hline South Carolina & 65,998 & 48,591 & 41,654 & 49,727 & 42,142 & 35,537 & - & - & - & 47,102 & 36,172 & 31,038 \\
\hline South Dakota .................................... & 47,974 & 38,615 & 35,270 & 47,079 & 38,980 & 32,553 & - & - & - & 40,347 & 32,752 & 30,257 \\
\hline Tennessee & 63,839 & 49,636 & 42,613 & 56,843 & 45,508 & 37,704 & 86,111 & 57,222 & 45,353 & 44,141 & 35,691 & 31,378 \\
\hline Texas & 69,440 & 46,850 & 41,170 & 53,810 & 43,590 & 36,831 & 77,482 & 53,540 & 46,490 & 52,668 & 41,411 & 33,416 \\
\hline 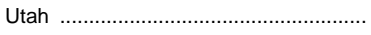 & 63,886 & 46,098 & 39,541 & 48,595 & 39,511 & 35,211 & 63,292 & 47,942 & 40,652 & 46,967 & 39,284 & 33,638 \\
\hline Vermont & 62,301 & 47,018 & 38,208 & 44,854 & 36,723 & 30,548 & - & - & - & 55,337 & 41,376 & 35,455 \\
\hline Virginia & 71,669 & 50,956 & 43,504 & 61,642 & 47,985 & 39,168 & - & - & - & 55,891 & 43,744 & 35,576 \\
\hline 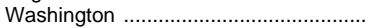 & 67,725 & 48,179 & 42,880 & 53,051 & 43,707 & 37,650 & - & - & - & 57,791 & 45,041 & 38,287 \\
\hline West Virginia & 58,545 & 46,249 & 38,084 & 46,150 & 38,404 & 32,697 & - & - & - & 42,483 & 36,147 & 30,821 \\
\hline Wisconsin ……… & 70,851 & 52,938 & 46,561 & 56,095 & 46,069 & 39,377 & 71,423 & 53,621 & 43,878 & 49,252 & 39,352 & 33,800 \\
\hline 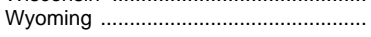 & 58,722 & 45,679 & 41,098 & - & - & - & - & - & - & - & - & - \\
\hline U.S. Service Schools & - & - & - & 73,712 & 57,491 & 52,214 & - & - & - & - & - & - \\
\hline 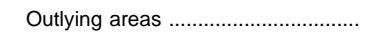 & 41,404 & 34,589 & 28,640 & 40,061 & 35,275 & 30,408 & - & - & - & 15,790 & 23,472 & 22,720 \\
\hline American Samoa & - & - & - & - & - & - & - & - & - & - & - & - \\
\hline Federated States of Micronesia ............ & - & - & - & - & - & - & - & - & - & - & - & - \\
\hline Guam & - & - & - & 70,692 & 57,425 & 44,197 & - & - & - & - & - & - \\
\hline 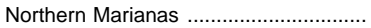 & - & - & - & - & - & - & - & - & - & - & - & - \\
\hline 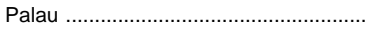 & - & - & - & - & - & - & - & - & - & - & - & - \\
\hline 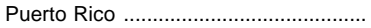 & 41,404 & 34,589 & 28,640 & 37,870 & 31,559 & 27,202 & - & - & - & 15,790 & 23,472 & 22,720 \\
\hline 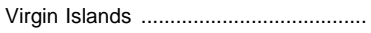 & - & - & 一 & 55,827 & 46,009 & 39,102 & - & - & - & - & - & - \\
\hline
\end{tabular}

—Data not reported or not applicable.

NOTE.-Data include imputations for nonrespondent institutions.
SOURCE: U.S. Department of Education, National Center for Education Statistics, Integrated Postsecondary Education Data System (IPEDS), "Salaries, Tenure, and Fringe Benefits of Full-Time Instructional Faculty, 1995-96" survey. (This table was prepared January 1997.) 
Table 240.-Full-time instructional faculty with tenure for institutions reporting tenure status, by academic rank, sex, and type and control of institution: 1980-81, 1990-91, 1995-96, and 1996-97

\begin{tabular}{|c|c|c|c|c|c|c|c|c|c|}
\hline \multirow{3}{*}{$\begin{array}{l}\text { Academic year, type, and } \\
\text { control of institution }\end{array}$} & \multicolumn{7}{|c|}{ Percent with tenure, by rank } & \multirow{2}{*}{\multicolumn{2}{|c|}{$\begin{array}{c}\text { Percent with tenure, by } \\
\text { sex }\end{array}$}} \\
\hline & \multirow[b]{2}{*}{ All ranks } & \multirow[b]{2}{*}{ Professor } & \multirow[b]{2}{*}{$\begin{array}{l}\text { Associate } \\
\text { professor }\end{array}$} & \multirow[b]{2}{*}{$\begin{array}{l}\text { Assistant } \\
\text { professor }\end{array}$} & \multirow[b]{2}{*}{ Instructor } & \multirow[b]{2}{*}{ Lecturer } & \multirow{2}{*}{$\begin{array}{l}\text { No } \\
\text { academic } \\
\text { rank }\end{array}$} & & \\
\hline & & & & & & & & Men & Women \\
\hline 1 & 2 & 3 & 4 & 5 & 6 & 7 & 8 & 9 & 10 \\
\hline $1980-81$ & & & & & & & & & \\
\hline All institutions ........... & 64.8 & 95.8 & 82.9 & 27.9 & 9.2 & 11.9 & 77.4 & 70.0 & 49.7 \\
\hline 4-year .......... & 62.7 & 95.8 & 82.2 & 24.1 & 6.6 & 10.7 & 24.7 & 68.3 & 44.0 \\
\hline University & 64.5 & 96.7 & 83.7 & 15.3 & 5.4 & 4.3 & 3.5 & 70.0 & 41.0 \\
\hline 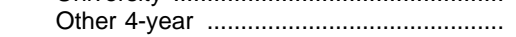 & 61.3 & 94.9 & 81.2 & 29.7 & 7.1 & 17.8 & 32.4 & 67.0 & 45.5 \\
\hline 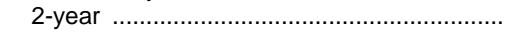 & 74.5 & 95.6 & 89.2 & 58.9 & 19.8 & 34.8 & 81.1 & 78.8 & 66.6 \\
\hline Public institutions & 68.0 & 96.6 & 85.9 & 32.5 & 11.8 & 14.3 & 79.4 & 72.8 & 54.0 \\
\hline 4-year ................. & 65.7 & 96.6 & 85.3 & 27.6 & 8.7 & 12.8 & 12.2 & 71.1 & 47.5 \\
\hline University ..... & 66.0 & 96.9 & 86.5 & 16.8 & 6.1 & 4.9 & 4.5 & 71.3 & 42.8 \\
\hline$\ldots \ldots \ldots \ldots \ldots \ldots \ldots \ldots \ldots \ldots \ldots \ldots$ & 65.5 & 96.3 & 84.4 & 35.5 & 10.0 & 21.4 & 17.2 & 70.9 & 50.2 \\
\hline 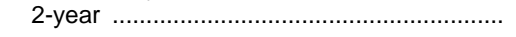 & 75.2 & 95.9 & 89.5 & 59.5 & 20.3 & 35.8 & 81.8 & 79.3 & 67.5 \\
\hline Private institutions & 55.9 & 93.8 & 75.2 & 17.5 & 3.0 & 1.5 & 43.4 & 62.2 & 37.2 \\
\hline 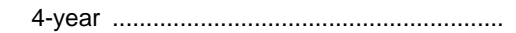 & 56.0 & 93.8 & 75.2 & 17.4 & 2.8 & 1.5 & 37.5 & 62.2 & 37.2 \\
\hline University ......................... & 60.4 & 96.3 & 75.8 & 11.5 & 3.5 & 1.8 & 0.6 & 66.3 & 36.5 \\
\hline 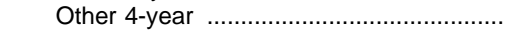 & 53.6 & 92.0 & 74.9 & 20.2 & 2.6 & 1.2 & 43.4 & 59.8 & 37.4 \\
\hline 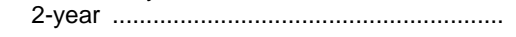 & 49.5 & 84.7 & 77.3 & 35.2 & 8.8 & - & 52.2 & 57.3 & 39.5 \\
\hline 1990-91 & & & & & & & & & \\
\hline All institutions ............ & 61.2 & 95.6 & 80.8 & 18.6 & 6.8 & 6.9 & 36.3 & 67.8 & 45.3 \\
\hline 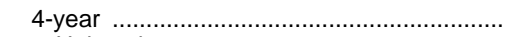 & 61.7 & 95.7 & 80.4 & 15.8 & 4.1 & 6.0 & 19.1 & 68.6 & 43.9 \\
\hline 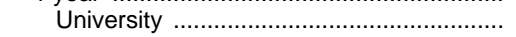 & 65.2 & 97.2 & 85.4 & 9.0 & 3.5 & 2.1 & 1.4 & 71.6 & 43.6 \\
\hline 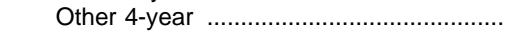 & 59.4 & 94.6 & 77.1 & 19.7 & 4.3 & 9.2 & 30.2 & 66.3 & 44.0 \\
\hline 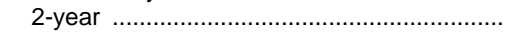 & 57.1 & 93.7 & 85.3 & 50.7 & 16.3 & 26.6 & 39.8 & 60.9 & 51.9 \\
\hline Public institutions & 62.9 & 96.3 & 83.7 & 21.7 & 8.6 & 8.4 & 36.6 & 69.4 & 47.4 \\
\hline 4-year ...................... & 64.0 & 96.5 & 83.5 & 18.0 & 5.3 & 7.3 & 11.3 & 70.8 & 45.9 \\
\hline 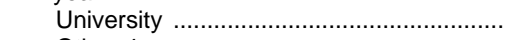 & 66.3 & 97.3 & 88.3 & 9.7 & 4.2 & 2.4 & 0.4 & 72.8 & 44.5 \\
\hline Other 4-year ..................................................... & 62.3 & 95.9 & 79.9 & 23.4 & 5.7 & 10.6 & 23.5 & 69.1 & 46.7 \\
\hline 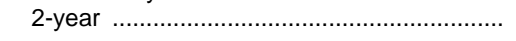 & 57.3 & 93.7 & 85.6 & 51.4 & 16.7 & 26.7 & 39.7 & 61.0 & 52.2 \\
\hline Private institutions . & 56.7 & 93.9 & 73.8 & 11.8 & 1.5 & 1.0 & 33.3 & 63.7 & 39.8 \\
\hline 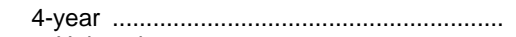 & 56.8 & 93.9 & 73.8 & 11.6 & 1.4 & 1.0 & 31.2 & 63.7 & 39.8 \\
\hline 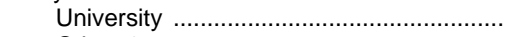 & 62.2 & 96.9 & 77.4 & 7.3 & 1.4 & 1.4 & 6.5 & 68.5 & 41.3 \\
\hline 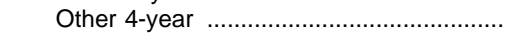 & 53.9 & 91.9 & 72.0 & 13.5 & 1.5 & 0.5 & 36.3 & 60.9 & 39.2 \\
\hline 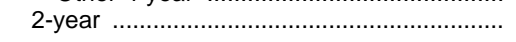 & 45.7 & 90.2 & 70.9 & 29.0 & 4.3 & - & 49.7 & 53.1 & 39.3 \\
\hline 1995-96 & & & & & & & & & \\
\hline All institutions & 64.8 & 96.1 & 83.3 & 16.7 & 7.1 & 1.3 & 75.1 & 71.8 & 51.0 \\
\hline 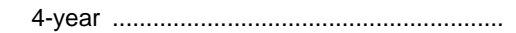 & 63.1 & 96.3 & 83.1 & 13.7 & 3.9 & 1.3 & 21.1 & 70.8 & 46.2 \\
\hline University & 66.9 & 97.4 & 87.9 & 6.7 & 2.5 & 1.0 & 5.5 & 74.3 & 46.3 \\
\hline 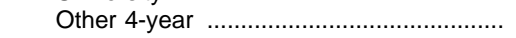 & 60.6 & 95.4 & 80.0 & 17.4 & 4.3 & 1.6 & 29.2 & 68.3 & 46.1 \\
\hline 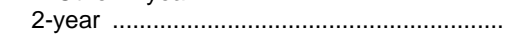 & 73.7 & 93.4 & 85.0 & 50.0 & 18.1 & - & 79.8 & 78.0 & 68.3 \\
\hline Public institutions & 67.7 & 97.3 & 87.1 & 19.8 & 9.1 & 1.4 & 76.6 & 74.6 & 54.3 \\
\hline 4-year ........................... & 65.9 & 97.7 & 87.3 & 15.5 & 5.2 & 1.5 & 12.5 & 73.8 & 48.2 \\
\hline University & 69.1 & 98.2 & 91.4 & 7.3 & 3.0 & 1.1 & 5.9 & 76.7 & 47.9 \\
\hline Other 4-year .................................................. & 63.5 & 97.3 & 84.1 & 20.6 & 6.1 & 1.7 & 16.2 & 71.3 & 48.3 \\
\hline 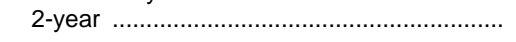 & 73.8 & 93.4 & 85.4 & 50.7 & 18.0 & - & 79.7 & 78.1 & 68.5 \\
\hline Private institutions & 57.8 & 93.4 & 75.2 & 10.7 & 1.4 & 0.9 & 51.1 & 65.2 & 42.9 \\
\hline 4-year ............ & 57.7 & 93.4 & 75.2 & 10.6 & 1.1 & 0.9 & 32.2 & 65.1 & 42.6 \\
\hline University & 61.5 & 95.5 & 78.8 & 5.5 & 1.1 & 0.9 & 5.1 & 68.5 & 42.7 \\
\hline 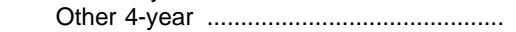 & 55.7 & 92.0 & 73.6 & 12.8 & 1.1 & 1.0 & 45.9 & 63.1 & 42.6 \\
\hline 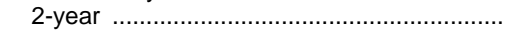 & 66.9 & 95.0 & 59.2 & 25.1 & - & - & 80.5 & 73.0 & 59.1 \\
\hline $1996-97$ & & & & & & & & & \\
\hline All institutions & 64.9 & 96.0 & 83.2 & 16.3 & 7.2 & 1.5 & 74.7 & 71.8 & 51.6 \\
\hline 4-year & 63.2 & 96.2 & 83.2 & 13.2 & 3.8 & 1.5 & 22.4 & 70.9 & 46.9 \\
\hline 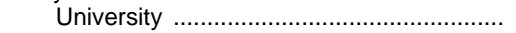 & 67.2 & 97.3 & 87.9 & 6.4 & 3.1 & 1.3 & 3.5 & 74.6 & 47.4 \\
\hline 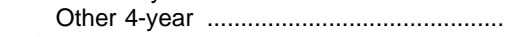 & 60.5 & 95.4 & 80.2 & 16.7 & 4.1 & 1.7 & 30.1 & 68.1 & 46.7 \\
\hline 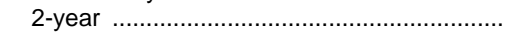 & 73.7 & 93.3 & 83.5 & 50.7 & 18.9 & - & 79.6 & 77.7 & 68.9 \\
\hline Public institutions & 67.6 & 97.2 & 87.0 & 19.1 & 9.2 & 1.4 & 76.4 & 74.4 & 54.8 \\
\hline 4-year & 65.8 & 97.7 & 87.3 & 14.7 & 4.9 & 1.5 & 14.3 & 73.6 & 48.8 \\
\hline 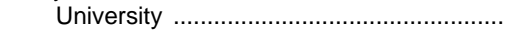 & 69.4 & 98.1 & 91.5 & 6.8 & 3.4 & 1.2 & 1.3 & 76.9 & 49.1 \\
\hline 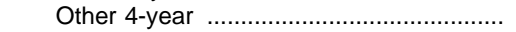 & 63.2 & 97.2 & 84.1 & 19.4 & 5.5 & 1.7 & 19.9 & 70.9 & 48.7 \\
\hline 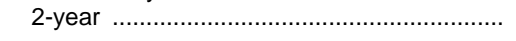 & 73.9 & 93.4 & 83.9 & 51.3 & 19.1 & - & 79.7 & 77.9 & 69.2 \\
\hline Private institutions $\ldots \ldots \ldots \ldots \ldots \ldots \ldots$ & 58.2 & 93.4 & 75.3 & 10.8 & 1.6 & 1.6 & 47.5 & 65.6 & 43.5 \\
\hline 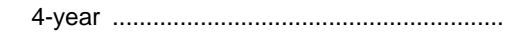 & 58.1 & 93.4 & 75.4 & 10.7 & 1.6 & 1.6 & 32.6 & 65.6 & 43.5 \\
\hline 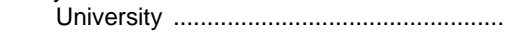 & 62.1 & 95.2 & 78.5 & 5.7 & 2.1 & 1.5 & 6.5 & 69.2 & 43.4 \\
\hline Other 4-year .............................................. & 56.1 & 92.2 & 73.9 & 12.8 & 1.4 & 1.7 & 42.3 & 63.4 & 43.5 \\
\hline 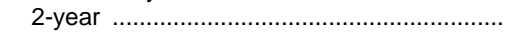 & 62.3 & 85.4 & 54.3 & 28.9 & 5.0 & - & 75.9 & 70.2 & 50.1 \\
\hline
\end{tabular}

—Data not available or not applicable.

SOURCE: U.S. Department of Education, National Center for Education Statistics, Higher Education General Information Survey (HEGIS), "Faculty Salaries, Tenure, and Fringe Benefits;" and Integrated Postsecondary Education Data System (IPEDS), "Sala- ries, Tenure, and Fringe Benefits of Full-Time Instructional Faculty" surveys. (This table was prepared July 1998.) 
Table 241.-Institutions of higher education, by control and type of institution: 1949-50 to 1995-96

\begin{tabular}{|c|c|c|c|c|c|c|c|c|c|c|}
\hline \multirow{2}{*}{\multicolumn{2}{|c|}{ Year }} & \multicolumn{3}{|c|}{ All institutions } & \multicolumn{3}{|c|}{ Public } & \multicolumn{3}{|c|}{ Private } \\
\hline & & Total & 4-year & 2-year & Total & 4-year & 2-year & Total & 4-year & 2-year \\
\hline & 1 & 2 & 3 & 4 & 5 & 6 & 7 & 8 & 9 & 10 \\
\hline $\begin{array}{l}1949-50 \\
1950-51 \\
1951-52 \\
1952-53 \\
1953-54\end{array}$ & Excluding branch campuses & $\begin{array}{l}1,851 \\
1,852 \\
1,832 \\
1,882 \\
1,863\end{array}$ & $\begin{array}{l}1,327 \\
1,312 \\
1,326 \\
1,355 \\
1,345\end{array}$ & $\begin{array}{l}524 \\
540 \\
506 \\
527 \\
518\end{array}$ & $\begin{array}{l}641 \\
636 \\
641 \\
639 \\
662\end{array}$ & $\begin{array}{l}344 \\
341 \\
350 \\
349 \\
369\end{array}$ & $\begin{array}{l}297 \\
295 \\
291 \\
290 \\
293\end{array}$ & $\begin{array}{l}1,210 \\
1,216 \\
1,191 \\
1,243 \\
1,201\end{array}$ & $\begin{array}{r}983 \\
971 \\
976 \\
1,006 \\
976\end{array}$ & $\begin{array}{l}227 \\
245 \\
215 \\
237 \\
225\end{array}$ \\
\hline $\begin{array}{l}1954-55 \\
1955-56 \\
1956-57 \\
1957-58 \\
1958-59\end{array}$ & , & $\begin{array}{l}1,849 \\
1,850 \\
1,878 \\
1,930 \\
1,947\end{array}$ & $\begin{array}{l}1,333 \\
1,347 \\
1,355 \\
1,390 \\
1,394\end{array}$ & $\begin{array}{l}516 \\
503 \\
523 \\
540 \\
553\end{array}$ & $\begin{array}{l}648 \\
650 \\
656 \\
666 \\
673\end{array}$ & $\begin{array}{l}353 \\
360 \\
359 \\
366 \\
366\end{array}$ & $\begin{array}{l}295 \\
290 \\
297 \\
300 \\
307\end{array}$ & $\begin{array}{l}1,201 \\
1,200 \\
1,222 \\
1,264 \\
1,274\end{array}$ & $\begin{array}{r}980 \\
987 \\
996 \\
1,024 \\
1,028\end{array}$ & $\begin{array}{l}221 \\
213 \\
226 \\
240 \\
246\end{array}$ \\
\hline $\begin{array}{l}1959-60 \\
1960-61 \\
1961-62 \\
1962-63 \\
1963-64\end{array}$ & , & $\begin{array}{l}2,004 \\
2,021 \\
2,033 \\
2,093 \\
2,132\end{array}$ & $\begin{array}{l}1,422 \\
1,431 \\
1,443 \\
1,468 \\
1,499\end{array}$ & $\begin{array}{l}582 \\
590 \\
590 \\
625 \\
633\end{array}$ & $\begin{array}{l}695 \\
700 \\
718 \\
740 \\
760\end{array}$ & $\begin{array}{l}367 \\
368 \\
374 \\
376 \\
386\end{array}$ & $\begin{array}{l}328 \\
332 \\
344 \\
364 \\
374\end{array}$ & $\begin{array}{l}1,309 \\
1,321 \\
1,315 \\
1,353 \\
1,372\end{array}$ & $\begin{array}{l}1,055 \\
1,063 \\
1,069 \\
1,092 \\
1,113\end{array}$ & $\begin{array}{l}254 \\
258 \\
246 \\
261 \\
259\end{array}$ \\
\hline $\begin{array}{l}1964-65 \\
1965-66 \\
1966-67 \\
1967-68 \\
1968-69\end{array}$ & (1) & $\begin{array}{l}2,175 \\
2,230 \\
2,329 \\
2,374 \\
2,483\end{array}$ & $\begin{array}{l}1,521 \\
1,551 \\
1,577 \\
1,588 \\
1,619\end{array}$ & $\begin{array}{l}654 \\
679 \\
752 \\
786 \\
864\end{array}$ & $\begin{array}{r}799 \\
821 \\
880 \\
934 \\
1,011\end{array}$ & $\begin{array}{l}393 \\
401 \\
403 \\
414 \\
417\end{array}$ & $\begin{array}{l}406 \\
420 \\
477 \\
520 \\
594\end{array}$ & $\begin{array}{l}1,376 \\
1,409 \\
1,449 \\
1,440 \\
1,472\end{array}$ & $\begin{array}{l}1,128 \\
1,150 \\
1,174 \\
1,174 \\
1,202\end{array}$ & $\begin{array}{l}248 \\
259 \\
275 \\
266 \\
270\end{array}$ \\
\hline $\begin{array}{l}1969-70 \\
1970-71 \\
1971-72 \\
1972-73 \\
1973-74\end{array}$ & , & $\begin{array}{l}2,525 \\
2,556 \\
2,606 \\
2,665 \\
2,720\end{array}$ & $\begin{array}{l}1,639 \\
1,665 \\
1,675 \\
1,701 \\
1,717\end{array}$ & $\begin{array}{r}886 \\
891 \\
931 \\
964 \\
1,003\end{array}$ & $\begin{array}{l}1,060 \\
1,089 \\
1,137 \\
1,182 \\
1,200\end{array}$ & $\begin{array}{l}426 \\
435 \\
440 \\
449 \\
440\end{array}$ & $\begin{array}{l}634 \\
654 \\
697 \\
733 \\
760\end{array}$ & $\begin{array}{l}1,465 \\
1,467 \\
1,469 \\
1,483 \\
1,520\end{array}$ & $\begin{array}{l}1,213 \\
1,230 \\
1,235 \\
1,252 \\
1,277\end{array}$ & $\begin{array}{l}252 \\
237 \\
234 \\
231 \\
243\end{array}$ \\
\hline $\begin{array}{l}1974-75 \\
1975-76 \\
1976-77 \\
1977-78 \\
1978-79\end{array}$ & (1) & $\begin{array}{l}2,747 \\
2,765 \\
2,785 \\
2,826 \\
2,954\end{array}$ & $\begin{array}{l}1,744 \\
1,767 \\
1,783 \\
1,808 \\
1,843\end{array}$ & $\begin{array}{r}1,003 \\
998 \\
1,002 \\
1,018 \\
1,111\end{array}$ & $\begin{array}{l}1,214 \\
1,219 \\
1,231 \\
1,241 \\
1,308\end{array}$ & $\begin{array}{l}447 \\
447 \\
452 \\
454 \\
463\end{array}$ & $\begin{array}{l}767 \\
772 \\
779 \\
787 \\
845\end{array}$ & $\begin{array}{l}1,533 \\
1,546 \\
1,554 \\
1,585 \\
1,646\end{array}$ & $\begin{array}{l}1,297 \\
1,320 \\
1,331 \\
1,354 \\
1,380\end{array}$ & $\begin{array}{l}236 \\
226 \\
223 \\
231 \\
266\end{array}$ \\
\hline $\begin{array}{l}1979-80 \\
1980-81 \\
1981-82 \\
1982-83 \\
1983-84\end{array}$ & (1) & $\begin{array}{l}2,975 \\
3,056 \\
3,083 \\
3,111 \\
3,117\end{array}$ & $\begin{array}{l}1,863 \\
1,861 \\
1,883 \\
1,887 \\
1,914\end{array}$ & $\begin{array}{l}1,112 \\
1,195 \\
1,200 \\
1,224 \\
1,203\end{array}$ & $\begin{array}{l}1,310 \\
1,334 \\
1,340 \\
1,336 \\
1,325\end{array}$ & $\begin{array}{l}464 \\
465 \\
471 \\
472 \\
474\end{array}$ & $\begin{array}{l}846 \\
869 \\
869 \\
864 \\
851\end{array}$ & $\begin{array}{l}1,665 \\
1,722 \\
1,743 \\
1,775 \\
1,792\end{array}$ & $\begin{array}{l}1,399 \\
1,396 \\
1,412 \\
1,415 \\
1,440\end{array}$ & $\begin{array}{r}266 \\
1326 \\
1331 \\
1360 \\
352\end{array}$ \\
\hline $\begin{array}{l}1984-85 \\
1985-86\end{array}$ & 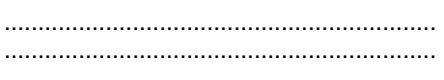 & $\begin{array}{l}3,146 \\
3,155\end{array}$ & $\begin{array}{l}1,911 \\
1,915\end{array}$ & $\begin{array}{l}1,235 \\
1,240\end{array}$ & $\begin{array}{l}1,329 \\
1,326\end{array}$ & $\begin{array}{l}461 \\
461\end{array}$ & $\begin{array}{l}868 \\
865\end{array}$ & $\begin{array}{l}1,817 \\
1,829\end{array}$ & $\begin{array}{l}1,450 \\
1,454\end{array}$ & $\begin{array}{l}367 \\
375\end{array}$ \\
\hline $\begin{array}{l}1974-75 \\
1975-76 \\
1976-77 \\
1977-78 \\
1978-79\end{array}$ & Including branch campuses & $\begin{array}{l}3,004 \\
3,026 \\
3,046 \\
3,095 \\
3,134\end{array}$ & $\begin{array}{l}1,866 \\
1,898 \\
1,913 \\
1,938 \\
1,941\end{array}$ & $\begin{array}{l}1,138 \\
1,128 \\
1,133 \\
1,157 \\
1,193\end{array}$ & $\begin{array}{l}1,433 \\
1,442 \\
1,455 \\
1,473 \\
1,474\end{array}$ & $\begin{array}{l}537 \\
545 \\
550 \\
552 \\
550\end{array}$ & $\begin{array}{l}896 \\
897 \\
905 \\
921 \\
924\end{array}$ & $\begin{array}{l}1,571 \\
1,584 \\
1,591 \\
1,622 \\
1,660\end{array}$ & $\begin{array}{l}1,329 \\
1,353 \\
1,363 \\
1,386 \\
1,391\end{array}$ & $\begin{array}{l}242 \\
231 \\
228 \\
236 \\
269\end{array}$ \\
\hline $\begin{array}{l}1979-80 \\
1980-81 \\
1981-82 \\
1982-83 \\
1983-84\end{array}$ & (1) & $\begin{array}{l}3,152 \\
3,231 \\
3,253 \\
3,280 \\
3,284\end{array}$ & $\begin{array}{l}1,957 \\
1,957 \\
1,979 \\
1,984 \\
2,013\end{array}$ & $\begin{array}{l}1,195 \\
1,274 \\
1,274 \\
1,296 \\
1,271\end{array}$ & $\begin{array}{l}1,475 \\
1,497 \\
1,498 \\
1,493 \\
1,481\end{array}$ & $\begin{array}{l}549 \\
552 \\
558 \\
560 \\
565\end{array}$ & $\begin{array}{l}926 \\
945 \\
940 \\
933 \\
916\end{array}$ & $\begin{array}{l}1,677 \\
1,734 \\
1,755 \\
1,787 \\
1,803\end{array}$ & $\begin{array}{l}1,408 \\
1,405 \\
1,421 \\
1,424 \\
1,448\end{array}$ & $\begin{array}{r}269 \\
1329 \\
1334 \\
1363 \\
355\end{array}$ \\
\hline $\begin{array}{l}1984-85 \\
1985-86 \\
1986-87^{2} \\
1987-88^{2} \\
1988-89^{2} \\
1989-90^{2}\end{array}$ & 2) & $\begin{array}{l}3,331 \\
3,340 \\
3,406 \\
3,587 \\
3,565 \\
3,535\end{array}$ & $\begin{array}{l}2,025 \\
2,029 \\
2,070 \\
2,135 \\
2,129 \\
2,127\end{array}$ & $\begin{array}{l}1,306 \\
1,311 \\
1,336 \\
1,452 \\
1,436 \\
1,408\end{array}$ & $\begin{array}{l}1,501 \\
1,498 \\
1,533 \\
1,591 \\
1,582 \\
1,563\end{array}$ & $\begin{array}{l}566 \\
566 \\
573 \\
599 \\
598 \\
595\end{array}$ & $\begin{array}{l}935 \\
932 \\
960 \\
992 \\
984 \\
968\end{array}$ & $\begin{array}{l}1,830 \\
1,842 \\
1,873 \\
1,996 \\
1,983 \\
1,972\end{array}$ & $\begin{array}{l}1,459 \\
1,463 \\
1,497 \\
1,536 \\
1,531 \\
1,532\end{array}$ & $\begin{array}{l}371 \\
379 \\
376 \\
460 \\
452 \\
440\end{array}$ \\
\hline $\begin{array}{l}1990-91^{2} \\
1991-92^{2} \\
1992-93^{2} \\
1993-94^{2} \\
1994-95^{2} \\
1995-96^{2}\end{array}$ & 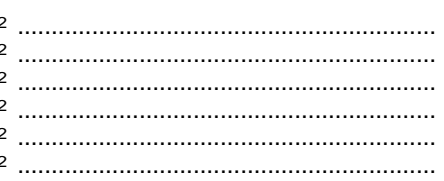 & $\begin{array}{l}3,559 \\
3,601 \\
3,638 \\
3,632 \\
3,688 \\
3,706\end{array}$ & $\begin{array}{l}2,141 \\
2,157 \\
2,169 \\
2,190 \\
2,215 \\
2,244\end{array}$ & $\begin{array}{l}1,418 \\
1,444 \\
1,469 \\
1,442 \\
1,473 \\
1,462\end{array}$ & $\begin{array}{l}1,567 \\
1,598 \\
1,624 \\
1,625 \\
1,641 \\
1,655\end{array}$ & $\begin{array}{l}595 \\
599 \\
600 \\
604 \\
605 \\
608\end{array}$ & $\begin{array}{r}972 \\
999 \\
1,024 \\
1,021 \\
1,036 \\
1,047\end{array}$ & $\begin{array}{l}1,992 \\
2,003 \\
2,014 \\
2,007 \\
2,047 \\
2,051\end{array}$ & $\begin{array}{l}1,546 \\
1,558 \\
1,569 \\
1,586 \\
1,610 \\
1,636\end{array}$ & $\begin{array}{l}446 \\
445 \\
445 \\
421 \\
437 \\
415\end{array}$ \\
\hline
\end{tabular}

${ }^{1}$ Large increases are due to the addition of schools accredited by the Accrediting Commission of Career Schools and Colleges of Technology.

2 Because of revised survey procedures, data are not entirely comparable with figures for earlier years. The number of branch campuses reporting separately has increased since 1986-87.

NOTE.-Includes those colleges designated as institutions of higher education by the Integrated Postsecondary Education Data System, even if they have a less than 2-yea program.
SOURCE: U.S. Department of Education, National Center for Education Statistics, Education Directory, Colleges and Universities; Higher Education General Information Survey (HEGIS), "Fall Enrollment in Higher Education" and "Institutional Characteristics of Colleges and Universities" surveys; and Integrated Postsecondary Education Data System (IPEDS), "Institutional Characteristics" surveys. (This table was prepared September 1996.) 
Table 242.-Degree-granting institutions of higher education and branches, by type, control of institution, and state: 1996-97

\begin{tabular}{|c|c|c|c|c|c|c|c|c|c|c|c|c|c|c|c|}
\hline \multirow[b]{2}{*}{ State or other area } & \multirow[b]{2}{*}{ Total } & \multicolumn{6}{|c|}{ Public, 4-year institutions } & \multirow[b]{2}{*}{$\begin{array}{l}\text { Public } \\
\text { 2-year }\end{array}$} & \multicolumn{6}{|c|}{ Private 4-year institutions } & \multirow[b]{2}{*}{$\begin{array}{l}\text { Private } \\
\text { 2-year }\end{array}$} \\
\hline & & Total & $\begin{array}{c}\text { Re- } \\
\text { search } 1\end{array}$ & $\begin{array}{l}\text { Doc- } \\
\text { toral }{ }^{2}\end{array}$ & $\begin{array}{c}\text { Mas- } \\
\text { ter }^{3}\end{array}$ & $\begin{array}{l}\text { Bacca- } \\
\text { laure- } \\
\text { ate }^{4}\end{array}$ & $\begin{array}{c}\text { Other } \\
4- \\
\text { year } 5\end{array}$ & & Total & $\begin{array}{c}\text { Re- } \\
\text { search } 1\end{array}$ & $\begin{array}{c}\text { Doc- } \\
\text { toral }{ }^{2}\end{array}$ & $\begin{array}{c}\text { Mas- } \\
\text { ter }^{3}\end{array}$ & $\begin{array}{l}\text { Bacca- } \\
\text { laure- } \\
\text { ate }^{4}\end{array}$ & $\begin{array}{c}\text { Other } \\
4- \\
\text { year } 5\end{array}$ & \\
\hline 1 & 2 & 3 & 4 & 5 & 6 & 7 & 8 & 9 & 10 & 11 & 12 & 13 & 14 & 15 & 16 \\
\hline United States & 4,009 & 614 & 85 & 66 & 278 & 113 & 72 & 1,088 & 1,653 & 40 & 49 & 291 & 659 & 614 & 654 \\
\hline 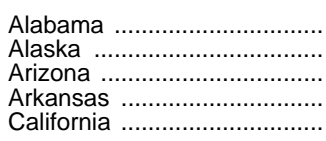 & $\begin{array}{r}82 \\
7 \\
67 \\
47 \\
383 \\
\end{array}$ & \begin{tabular}{r|}
18 \\
3 \\
5 \\
10 \\
32 \\
\end{tabular} & $\begin{array}{l}2 \\
0 \\
2 \\
1 \\
9\end{array}$ & \begin{tabular}{l|}
2 \\
1 \\
1 \\
0 \\
1
\end{tabular} & \begin{tabular}{r|}
13 \\
2 \\
1 \\
6 \\
19
\end{tabular} & \begin{tabular}{l|}
1 \\
0 \\
0 \\
2 \\
0
\end{tabular} & $\begin{array}{l}0 \\
0 \\
1 \\
1 \\
3\end{array}$ & $\begin{array}{r}34 \\
1 \\
20 \\
24 \\
108\end{array}$ & $\begin{array}{r}18 \\
2 \\
20 \\
10 \\
175\end{array}$ & $\begin{array}{l}0 \\
0 \\
0 \\
0 \\
3\end{array}$ & $\begin{array}{l}0 \\
0 \\
0 \\
0 \\
9\end{array}$ & \begin{tabular}{r|}
4 \\
1 \\
2 \\
1 \\
33
\end{tabular} & \begin{tabular}{r|}
10 \\
1 \\
8 \\
8 \\
33
\end{tabular} & \begin{tabular}{r|}
4 \\
0 \\
10 \\
1 \\
97
\end{tabular} & $\begin{array}{r}12 \\
1 \\
22 \\
3 \\
68\end{array}$ \\
\hline 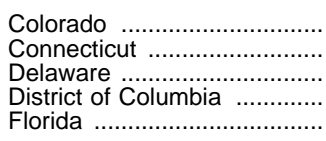 & $\begin{array}{r}69 \\
42 \\
9 \\
17 \\
134\end{array}$ & \begin{tabular}{r|}
14 \\
6 \\
2 \\
2 \\
10
\end{tabular} & $\begin{array}{l}2 \\
1 \\
1 \\
0 \\
3\end{array}$ & $\begin{array}{l}3 \\
0 \\
0 \\
0 \\
3\end{array}$ & \begin{tabular}{l|l}
2 \\
4 \\
1 \\
1 \\
3
\end{tabular} & $\begin{array}{l}5 \\
0 \\
0 \\
0 \\
0\end{array}$ & $\begin{array}{l}2 \\
1 \\
0 \\
1 \\
1\end{array}$ & $\begin{array}{r}15 \\
12 \\
3 \\
0 \\
28\end{array}$ & $\begin{array}{r}21 \\
19 \\
4 \\
15 \\
59\end{array}$ & \begin{tabular}{l|}
0 \\
1 \\
0 \\
3 \\
1
\end{tabular} & $\begin{array}{l}1 \\
0 \\
0 \\
2 \\
2\end{array}$ & $\begin{array}{r}3 \\
7 \\
2 \\
3 \\
11\end{array}$ & $\begin{array}{r}8 \\
6 \\
1 \\
1 \\
24\end{array}$ & $\begin{array}{r}9 \\
5 \\
1 \\
6 \\
21\end{array}$ & $\begin{array}{r}19 \\
5 \\
0 \\
0 \\
37\end{array}$ \\
\hline 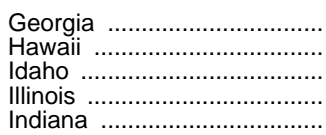 & $\begin{array}{r}102 \\
20 \\
14 \\
173 \\
96\end{array}$ & $\begin{array}{r}19 \\
3 \\
4 \\
12 \\
14\end{array}$ & $\begin{array}{l}2 \\
1 \\
1 \\
3 \\
2\end{array}$ & $\begin{array}{l}1 \\
0 \\
1 \\
2 \\
3\end{array}$ & \begin{tabular}{r|}
12 \\
0 \\
1 \\
7 \\
7
\end{tabular} & \begin{tabular}{l|}
1 \\
2 \\
1 \\
0 \\
2
\end{tabular} & $\begin{array}{l}3 \\
0 \\
0 \\
0 \\
0\end{array}$ & $\begin{array}{r}34 \\
7 \\
3 \\
49 \\
14\end{array}$ & $\begin{array}{r}40 \\
7 \\
4 \\
94 \\
40\end{array}$ & \begin{tabular}{l|}
1 \\
0 \\
0 \\
2 \\
1
\end{tabular} & $\begin{array}{l}2 \\
0 \\
0 \\
3 \\
0\end{array}$ & \begin{tabular}{r|}
2 \\
2 \\
0 \\
15 \\
6
\end{tabular} & $\begin{array}{r}21 \\
1 \\
3 \\
30 \\
22\end{array}$ & $\begin{array}{r}14 \\
4 \\
1 \\
44 \\
11\end{array}$ & $\begin{array}{r}9 \\
3 \\
3 \\
18 \\
28\end{array}$ \\
\hline 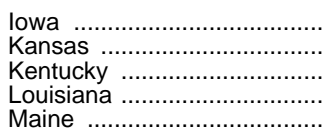 & $\begin{array}{l}64 \\
58 \\
65 \\
77 \\
34\end{array}$ & $\begin{array}{r}3 \\
10 \\
8 \\
14 \\
8\end{array}$ & $\begin{array}{l}2 \\
2 \\
1 \\
1 \\
0\end{array}$ & $\begin{array}{l}0 \\
1 \\
1 \\
3 \\
1\end{array}$ & $\begin{array}{l}1 \\
4 \\
6 \\
9 \\
1\end{array}$ & $\begin{array}{l}0 \\
1 \\
0 \\
0 \\
5\end{array}$ & $\begin{array}{l}0 \\
2 \\
0 \\
1 \\
1\end{array}$ & $\begin{array}{r}17 \\
23 \\
14 \\
43 \\
7\end{array}$ & $\begin{array}{l}37 \\
21 \\
28 \\
11 \\
13\end{array}$ & $\begin{array}{l}0 \\
0 \\
0 \\
1 \\
0\end{array}$ & $\begin{array}{l}0 \\
0 \\
0 \\
0 \\
1\end{array}$ & $\begin{array}{l}5 \\
5 \\
4 \\
3 \\
1\end{array}$ & \begin{tabular}{r|}
27 \\
13 \\
16 \\
3 \\
7
\end{tabular} & $\begin{array}{l}5 \\
3 \\
8 \\
4 \\
4\end{array}$ & $\begin{array}{r}7 \\
4 \\
15 \\
9 \\
6\end{array}$ \\
\hline 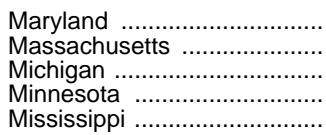 & $\begin{array}{r}56 \\
124 \\
110 \\
116 \\
44\end{array}$ & $\begin{array}{r}13 \\
15 \\
15 \\
12 \\
9\end{array}$ & $\begin{array}{l}1 \\
1 \\
3 \\
1 \\
2\end{array}$ & \begin{tabular}{l|}
1 \\
1 \\
2 \\
0 \\
1
\end{tabular} & $\begin{array}{r}9 \\
8 \\
10 \\
6 \\
3\end{array}$ & \begin{tabular}{l|}
1 \\
2 \\
0 \\
4 \\
2
\end{tabular} & $\begin{array}{l}1 \\
3 \\
0 \\
1 \\
1\end{array}$ & $\begin{array}{l}20 \\
18 \\
29 \\
46 \\
22\end{array}$ & $\begin{array}{l}20 \\
80 \\
59 \\
37 \\
11\end{array}$ & $\begin{array}{l}1 \\
6 \\
0 \\
0 \\
0\end{array}$ & $\begin{array}{l}0 \\
3 \\
2 \\
1 \\
0\end{array}$ & \begin{tabular}{r|}
4 \\
12 \\
6 \\
4 \\
2
\end{tabular} & $\begin{array}{r}6 \\
26 \\
21 \\
15 \\
5\end{array}$ & $\begin{array}{r}9 \\
33 \\
30 \\
17 \\
4\end{array}$ & $\begin{array}{r}3 \\
11 \\
7 \\
21 \\
2\end{array}$ \\
\hline 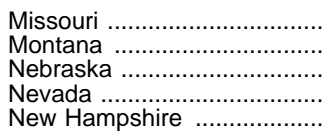 & $\begin{array}{r}109 \\
29 \\
37 \\
13 \\
29\end{array}$ & $\begin{array}{r}14 \\
6 \\
7 \\
2 \\
5\end{array}$ & \begin{tabular}{l|l}
1 \\
0 \\
1 \\
0 \\
0
\end{tabular} & $\begin{array}{l}3 \\
2 \\
0 \\
1 \\
1\end{array}$ & $\begin{array}{l}6 \\
3 \\
4 \\
1 \\
2\end{array}$ & \begin{tabular}{l|}
2 \\
1 \\
1 \\
0 \\
2
\end{tabular} & $\begin{array}{l}2 \\
0 \\
1 \\
0 \\
0\end{array}$ & $\begin{array}{r}18 \\
13 \\
9 \\
4 \\
7\end{array}$ & $\begin{array}{r}58 \\
5 \\
16 \\
3 \\
13\end{array}$ & $\begin{array}{l}2 \\
0 \\
0 \\
0 \\
0\end{array}$ & $\begin{array}{l}0 \\
0 \\
0 \\
0 \\
2\end{array}$ & $\begin{array}{l}9 \\
0 \\
2 \\
0 \\
2\end{array}$ & $\begin{array}{r}19 \\
4 \\
9 \\
1 \\
5\end{array}$ & $\begin{array}{r}28 \\
1 \\
5 \\
2 \\
4\end{array}$ & $\begin{array}{r}19 \\
5 \\
5 \\
4 \\
4\end{array}$ \\
\hline 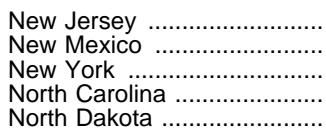 & $\begin{array}{r}58 \\
44 \\
310 \\
121 \\
23\end{array}$ & $\begin{array}{r}14 \\
6 \\
42 \\
16 \\
6\end{array}$ & \begin{tabular}{l|l}
1 \\
2 \\
3 \\
2 \\
0
\end{tabular} & $\begin{array}{l}2 \\
0 \\
3 \\
1 \\
2\end{array}$ & \begin{tabular}{r|}
7 \\
3 \\
19 \\
9 \\
1
\end{tabular} & $\begin{array}{l}3 \\
0 \\
8 \\
3 \\
3\end{array}$ & $\begin{array}{l}1 \\
1 \\
9 \\
1 \\
0\end{array}$ & $\begin{array}{r}19 \\
20 \\
47 \\
58 \\
9\end{array}$ & $\begin{array}{r}20 \\
13 \\
164 \\
42 \\
4\end{array}$ & $\begin{array}{l}1 \\
0 \\
8 \\
1 \\
0\end{array}$ & $\begin{array}{l}2 \\
0 \\
9 \\
1 \\
0\end{array}$ & $\begin{array}{r}5 \\
1 \\
29 \\
7 \\
1\end{array}$ & $\begin{array}{r}6 \\
6 \\
46 \\
28 \\
1\end{array}$ & $\begin{array}{r}6 \\
6 \\
72 \\
5 \\
2\end{array}$ & $\begin{array}{r}5 \\
5 \\
57 \\
5 \\
4\end{array}$ \\
\hline 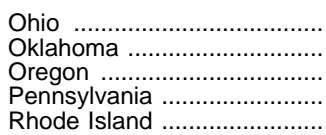 & $\begin{array}{r}178 \\
45 \\
51 \\
249 \\
12\end{array}$ & $\begin{array}{r}24 \\
14 \\
8 \\
45 \\
2\end{array}$ & $\begin{array}{l}4 \\
2 \\
2 \\
3 \\
1\end{array}$ & $\begin{array}{l}6 \\
0 \\
1 \\
2 \\
0\end{array}$ & \begin{tabular}{r|}
1 \\
6 \\
2 \\
16 \\
1
\end{tabular} & $\begin{array}{r}11 \\
4 \\
1 \\
21 \\
0\end{array}$ & $\begin{array}{l}2 \\
2 \\
2 \\
3 \\
0\end{array}$ & $\begin{array}{r}39 \\
15 \\
17 \\
20 \\
1\end{array}$ & $\begin{array}{r}67 \\
13 \\
25 \\
100 \\
9\end{array}$ & $\begin{array}{l}1 \\
0 \\
0 \\
3 \\
1\end{array}$ & $\begin{array}{l}1 \\
1 \\
0 \\
3 \\
0\end{array}$ & \begin{tabular}{r|}
11 \\
4 \\
4 \\
19 \\
1
\end{tabular} & $\begin{array}{r}32 \\
4 \\
10 \\
44 \\
3\end{array}$ & $\begin{array}{r}22 \\
4 \\
11 \\
31 \\
4\end{array}$ & $\begin{array}{r}48 \\
3 \\
1 \\
84 \\
0\end{array}$ \\
\hline 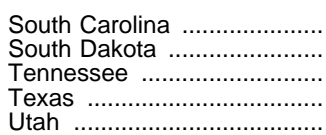 & $\begin{array}{r}60 \\
27 \\
83 \\
187 \\
21\end{array}$ & $\begin{array}{r}12 \\
8 \\
11 \\
40 \\
5\end{array}$ & $\begin{array}{l}2 \\
0 \\
1 \\
4 \\
2\end{array}$ & $\begin{array}{l}0 \\
1 \\
3 \\
6 \\
0\end{array}$ & $\begin{array}{r}6 \\
2 \\
5 \\
22 \\
1\end{array}$ & \begin{tabular}{l|}
3 \\
2 \\
0 \\
2 \\
2
\end{tabular} & $\begin{array}{l}1 \\
3 \\
2 \\
6 \\
0\end{array}$ & $\begin{array}{r}21 \\
6 \\
14 \\
67 \\
4\end{array}$ & $\begin{array}{r}22 \\
10 \\
43 \\
55 \\
4\end{array}$ & $\begin{array}{l}0 \\
0 \\
1 \\
1 \\
1\end{array}$ & $\begin{array}{l}0 \\
0 \\
0 \\
3 \\
0\end{array}$ & $\begin{array}{r}2 \\
0 \\
5 \\
14 \\
2\end{array}$ & $\begin{array}{r}17 \\
8 \\
25 \\
20 \\
1\end{array}$ & $\begin{array}{r}3 \\
2 \\
12 \\
17 \\
0\end{array}$ & $\begin{array}{r}5 \\
3 \\
15 \\
25 \\
8\end{array}$ \\
\hline 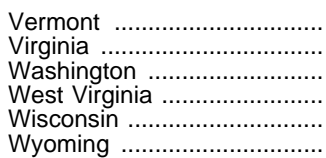 & $\begin{array}{r}25 \\
92 \\
72 \\
37 \\
66 \\
9\end{array}$ & $\begin{array}{r}5 \\
15 \\
8 \\
13 \\
13 \\
1\end{array}$ & $\begin{array}{l}1 \\
3 \\
2 \\
1 \\
2 \\
1\end{array}$ & $\begin{array}{l}0 \\
3 \\
0 \\
0 \\
0 \\
0\end{array}$ & $\begin{array}{r}2 \\
6 \\
5 \\
1 \\
11 \\
0\end{array}$ & $\begin{array}{l}2 \\
3 \\
1 \\
9 \\
0 \\
0\end{array}$ & $\begin{array}{l}0 \\
0 \\
0 \\
2 \\
0 \\
0\end{array}$ & $\begin{array}{r}1 \\
24 \\
32 \\
5 \\
19 \\
7\end{array}$ & $\begin{array}{r}15 \\
41 \\
26 \\
10 \\
30 \\
0\end{array}$ & $\begin{array}{l}0 \\
0 \\
0 \\
0 \\
0 \\
0\end{array}$ & $\begin{array}{l}0 \\
0 \\
0 \\
0 \\
1 \\
0\end{array}$ & \begin{tabular}{r|}
3 \\
13 \\
11 \\
3 \\
5 \\
0
\end{tabular} & $\begin{array}{r}10 \\
20 \\
3 \\
6 \\
15 \\
0\end{array}$ & $\begin{array}{r}2 \\
8 \\
12 \\
1 \\
9 \\
0\end{array}$ & $\begin{array}{r}4 \\
12 \\
6 \\
9 \\
4 \\
1\end{array}$ \\
\hline U.S. Service Schools ................ & 12 & 11 & 0 & 0 & 0 & 0 & 11 & 1 & 0 & 0 & 0 & 0 & 0 & 0 & 0 \\
\hline Outlying areas .................... & 79 & 14 & 0 & 1 & 4 & 5 & 4 & 12 & 37 & 0 & 0 & 6 & 19 & 12 & 16 \\
\hline 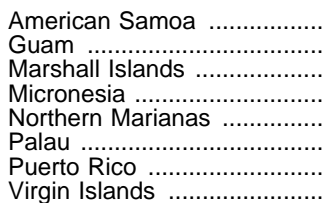 & $\begin{array}{r}1 \\
2 \\
1 \\
5 \\
1 \\
1 \\
66 \\
2\end{array}$ & $\begin{array}{r}0 \\
1 \\
0 \\
0 \\
0 \\
0 \\
11 \\
2\end{array}$ & $\begin{array}{l}0 \\
0 \\
0 \\
0 \\
0 \\
0 \\
0 \\
0\end{array}$ & \begin{tabular}{l|l}
0 \\
0 \\
0 \\
0 \\
0 \\
0 \\
1 \\
0
\end{tabular} & $\begin{array}{l}0 \\
1 \\
0 \\
0 \\
0 \\
0 \\
1 \\
2\end{array}$ & $\begin{array}{l}0 \\
0 \\
0 \\
0 \\
0 \\
0 \\
5 \\
0\end{array}$ & $\begin{array}{l}0 \\
0 \\
0 \\
0 \\
0 \\
0 \\
4 \\
0\end{array}$ & $\begin{array}{l}1 \\
1 \\
1 \\
5 \\
1 \\
1 \\
2 \\
0\end{array}$ & $\begin{array}{r}0 \\
0 \\
0 \\
0 \\
0 \\
0 \\
37 \\
0\end{array}$ & $\begin{array}{l}0 \\
0 \\
0 \\
0 \\
0 \\
0 \\
0 \\
0\end{array}$ & $\begin{array}{l}0 \\
0 \\
0 \\
0 \\
0 \\
0 \\
0 \\
0\end{array}$ & $\begin{array}{l}0 \\
0 \\
0 \\
0 \\
0 \\
0 \\
6 \\
0\end{array}$ & $\begin{array}{r}0 \\
0 \\
0 \\
0 \\
0 \\
0 \\
19 \\
0\end{array}$ & $\begin{array}{r}0 \\
0 \\
0 \\
0 \\
0 \\
0 \\
12 \\
0\end{array}$ & $\begin{array}{r}0 \\
0 \\
0 \\
0 \\
0 \\
0 \\
16 \\
0\end{array}$ \\
\hline
\end{tabular}

${ }^{1}$ Research institutions are commited to graduate education through the doctorate, give high priority to research and receive more than $\$ 15.5$ million in federal research funds annually.

2 Doctoral institutions offer a full range of baccalaureate programs and are committed to eduation through the doctorate. They award at least 40 doctoral degrees annually in 5 or more disciplines.

${ }^{3}$ Master's institutions offer a full range of baccalaureate programs and are committed to education through the master's degree. They award at least 20 master's degrees per year.

${ }^{4}$ Baccalaureate institutions primarily emphasize undergraduate education.

5 Other specialized 4-year institutions award degrees primarily in single fields of study, such as medicine, business, fine arts, theology and engineering. Also, includes some in- stitutions which have 4-year programs, but have not reported sufficient data to identify program category.

NOTE.-New institutions which do not have sufficient data to report by detailed level are included under "other 4-year" or 2-year depending on level reported by institution. Data are not comparable with preceding table.

SOURCE: U.S. Department of Education, National Center for Education Statistics, Integrated Postsecondary Education Data System (IPEDS), "Institutional Characteristics, 1996-97" survey. (This table was prepared December 1998.) 
Table 243.--Institutions of higher education that have closed their doors, by control and type of institution: 1960-61 to $1996-97$

\begin{tabular}{|c|c|c|c|c|c|c|c|c|c|}
\hline \multirow{2}{*}{ Year } & \multicolumn{3}{|c|}{ All institutions } & \multicolumn{3}{|c|}{ Public } & \multicolumn{3}{|c|}{ Private } \\
\hline & Total & 4-year & 2-year & Total & 4-year & 2-year & Total & 4-year & 2-year \\
\hline 1 & 2 & 3 & 4 & 5 & 6 & 7 & 8 & 9 & 10 \\
\hline $\begin{array}{l}\text { Excluding branch campuses: } \\
\text { Total, } 1960-61 \text { to } 1991-92 \ldots \ldots \ldots\end{array}$ & 343 & 179 & 164 & 38 & 1 & 37 & 305 & 178 & 127 \\
\hline 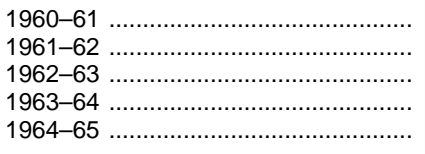 & $\begin{array}{r}8 \\
2 \\
7 \\
8\end{array}$ & $\begin{array}{r}1 \\
1 \\
1 \\
1\end{array}$ & $\begin{array}{r}7 \\
1 \\
6 \\
7\end{array}$ & $\begin{array}{r}1 \\
1 \\
4\end{array}$ & $\begin{array}{l}- \\
- \\
-\end{array}$ & $\begin{array}{r}1 \\
-1 \\
4\end{array}$ & $\begin{array}{r}7 \\
2 \\
6 \\
4\end{array}$ & $\begin{array}{r}1 \\
-1 \\
1\end{array}$ & $\begin{array}{l}6 \\
1 \\
5 \\
3\end{array}$ \\
\hline 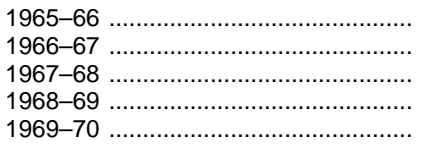 & $\begin{array}{r}8 \\
9 \\
14 \\
21 \\
18\end{array}$ & $\begin{array}{r}2 \\
2 \\
6 \\
11 \\
8\end{array}$ & $\begin{array}{r}6 \\
7 \\
8 \\
10 \\
10\end{array}$ & $\begin{array}{r}4 \\
3 \\
1 \\
3\end{array}$ & $\begin{array}{l}- \\
- \\
-\end{array}$ & $\begin{array}{r}4 \\
3 \\
1 \\
3\end{array}$ & $\begin{array}{r}4 \\
6 \\
14 \\
20 \\
15\end{array}$ & $\begin{array}{r}2 \\
2 \\
6 \\
11 \\
8\end{array}$ & $\begin{array}{l}2 \\
4 \\
8 \\
9 \\
7\end{array}$ \\
\hline 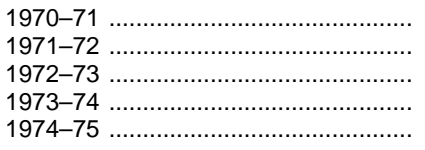 & $\begin{array}{l}32 \\
12 \\
19 \\
18 \\
17\end{array}$ & $\begin{array}{r}9 \\
3 \\
12 \\
11 \\
13\end{array}$ & $\begin{array}{r}23 \\
9 \\
7 \\
7 \\
4\end{array}$ & $\begin{array}{r}9 \\
3 \\
2 \\
3\end{array}$ & $\begin{array}{l}- \\
- \\
-\end{array}$ & $\begin{array}{r}9 \\
3 \\
2 \\
3\end{array}$ & $\begin{array}{r}23 \\
9 \\
17 \\
18 \\
14\end{array}$ & \begin{tabular}{r|}
9 \\
3 \\
12 \\
11 \\
13
\end{tabular} & $\begin{array}{r}14 \\
6 \\
5 \\
7 \\
1\end{array}$ \\
\hline 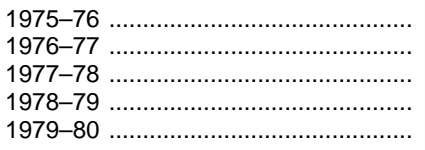 & $\begin{array}{r}8 \\
8 \\
12 \\
9 \\
6\end{array}$ & $\begin{array}{l}6 \\
5 \\
9 \\
4 \\
5\end{array}$ & $\begin{array}{l}2 \\
3 \\
3 \\
5 \\
1\end{array}$ & $\begin{array}{l}2 \\
- \\
-\end{array}$ & $\begin{array}{l}1 \\
- \\
-\end{array}$ & $\begin{array}{l}1 \\
- \\
-\end{array}$ & $\begin{array}{r}6 \\
8 \\
12 \\
9 \\
6\end{array}$ & $\begin{array}{l}5 \\
5 \\
9 \\
4 \\
5\end{array}$ & $\begin{array}{l}1 \\
3 \\
3 \\
5 \\
1\end{array}$ \\
\hline 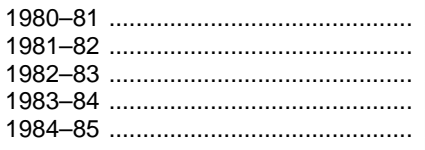 & $\begin{array}{l}4 \\
7 \\
7 \\
4 \\
4\end{array}$ & $\begin{array}{l}3 \\
6 \\
4 \\
4 \\
4\end{array}$ & $\begin{array}{r}1 \\
1 \\
3 \\
- \\
\end{array}$ & $\begin{array}{l}- \\
- \\
-\end{array}$ & $\begin{array}{l}- \\
- \\
-\end{array}$ & $\begin{array}{l}- \\
- \\
-\end{array}$ & $\begin{array}{l}4 \\
7 \\
7 \\
4 \\
4\end{array}$ & $\begin{array}{l}3 \\
6 \\
4 \\
4 \\
4\end{array}$ & $\begin{array}{l}1 \\
1 \\
3 \\
-\end{array}$ \\
\hline 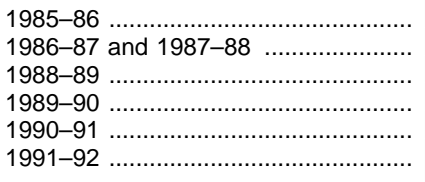 & $\begin{array}{l}10 \\
25 \\
14 \\
12 \\
10 \\
10\end{array}$ & $\begin{array}{r}6 \\
19 \\
6 \\
6 \\
4 \\
7\end{array}$ & $\begin{array}{l}4 \\
6 \\
8 \\
6 \\
6 \\
3\end{array}$ & $\begin{array}{r}1 \\
1 \\
- \\
- \\
-\end{array}$ & $\begin{array}{l}- \\
- \\
- \\
-\end{array}$ & $\begin{array}{r}1 \\
1 \\
- \\
- \\
-\end{array}$ & $\begin{array}{r}9 \\
24 \\
14 \\
12 \\
10 \\
10\end{array}$ & $\begin{array}{r}6 \\
19 \\
6 \\
6 \\
4 \\
7\end{array}$ & $\begin{array}{l}3 \\
5 \\
8 \\
6 \\
6 \\
3\end{array}$ \\
\hline $\begin{array}{l}\text { Including branch campuses: } \\
\text { Total, } 1969-70 \text { to } 1996-97 \ldots \ldots \ldots\end{array}$ & 448 & 212 & 236 & 39 & 5 & 34 & 409 & 207 & 202 \\
\hline 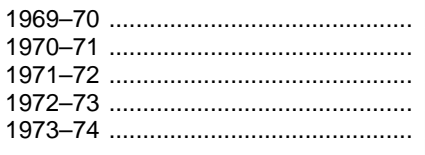 & $\begin{array}{l}24 \\
35 \\
14 \\
21 \\
20\end{array}$ & $\begin{array}{r}10 \\
10 \\
5 \\
12 \\
12\end{array}$ & $\begin{array}{r}14 \\
25 \\
9 \\
9 \\
8\end{array}$ & $\begin{array}{r}5 \\
11 \\
3 \\
4 \\
1\end{array}$ & $\begin{array}{l}1 \\
- \\
-\end{array}$ & $\begin{array}{r}4 \\
11 \\
3 \\
4 \\
1\end{array}$ & $\begin{array}{l}19 \\
24 \\
11 \\
17 \\
19\end{array}$ & $\begin{array}{r}9 \\
10 \\
5 \\
12 \\
12\end{array}$ & $\begin{array}{r}10 \\
14 \\
6 \\
5 \\
7\end{array}$ \\
\hline 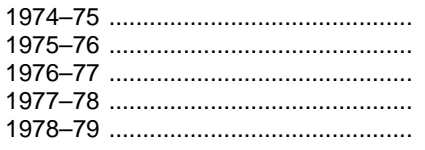 & $\begin{array}{r}18 \\
9 \\
9 \\
12 \\
9\end{array}$ & $\begin{array}{r}13 \\
7 \\
6 \\
9 \\
4\end{array}$ & $\begin{array}{l}5 \\
2 \\
3 \\
3 \\
5\end{array}$ & $\begin{array}{r}4 \\
2 \\
- \\
-\end{array}$ & $\begin{array}{l}- \\
- \\
-\end{array}$ & $\begin{array}{r}4 \\
1 \\
- \\
-\end{array}$ & $\begin{array}{r}14 \\
7 \\
9 \\
12 \\
9\end{array}$ & $\begin{array}{r}13 \\
6 \\
6 \\
9 \\
4\end{array}$ & $\begin{array}{l}1 \\
1 \\
3 \\
3 \\
5\end{array}$ \\
\hline 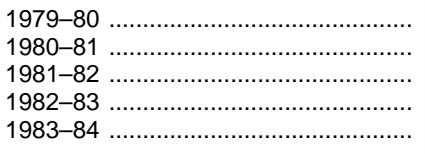 & $\begin{array}{l}6 \\
4 \\
7 \\
7 \\
5\end{array}$ & $\begin{array}{l}5 \\
3 \\
6 \\
4 \\
5\end{array}$ & $\begin{array}{r}1 \\
1 \\
1 \\
3 \\
-\end{array}$ & $\begin{array}{l}- \\
\frac{-}{1}\end{array}$ & $\frac{-}{-}$ & $\begin{array}{l}- \\
- \\
-\end{array}$ & $\begin{array}{l}6 \\
4 \\
7 \\
7 \\
4\end{array}$ & $\begin{array}{l}5 \\
3 \\
6 \\
4 \\
4\end{array}$ & $\begin{array}{l}1 \\
1 \\
1 \\
3 \\
\end{array}$ \\
\hline 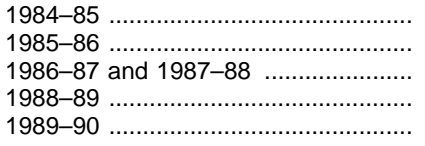 & $\begin{array}{r}4 \\
12 \\
26 \\
14 \\
19\end{array}$ & $\begin{array}{r}4 \\
8 \\
19 \\
6 \\
8\end{array}$ & $\begin{array}{r}-4 \\
7 \\
8 \\
11\end{array}$ & $\begin{array}{r}-1 \\
1 \\
-\end{array}$ & $\begin{array}{l}-1 \\
- \\
-\end{array}$ & $\begin{array}{l}- \\
- \\
-\end{array}$ & $\begin{array}{r}4 \\
11 \\
25 \\
14 \\
19\end{array}$ & $\begin{array}{r}4 \\
7 \\
19 \\
6 \\
8\end{array}$ & $\begin{array}{r}- \\
4 \\
6 \\
8 \\
11\end{array}$ \\
\hline 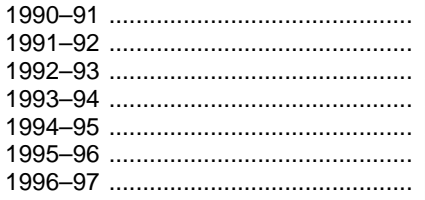 & $\begin{array}{l}18 \\
26 \\
24 \\
38 \\
15 \\
21 \\
31\end{array}$ & $\begin{array}{r}6 \\
8 \\
6 \\
10 \\
8 \\
8 \\
10\end{array}$ & $\begin{array}{r}12 \\
18 \\
18 \\
28 \\
7 \\
13 \\
21\end{array}$ & $\begin{array}{l}-1 \\
-1 \\
2 \\
1 \\
1\end{array}$ & $\begin{array}{l}- \\
- \\
- \\
-\end{array}$ & $\begin{array}{l}-1 \\
\frac{1}{2} \\
\frac{2}{1}\end{array}$ & $\begin{array}{l}18 \\
25 \\
24 \\
37 \\
13 \\
20 \\
30\end{array}$ & $\begin{array}{r}6 \\
8 \\
6 \\
10 \\
8 \\
7 \\
10\end{array}$ & $\begin{array}{r}12 \\
17 \\
18 \\
27 \\
5 \\
13 \\
20\end{array}$ \\
\hline
\end{tabular}

-Data not applicable or not available.

NOTE.-This table indicates the year in which the institution closed. Some data revised from previously published figures.
SOURCE: U.S. Department of Education, National Center for Education Statistics, Education Directory, Higher Education, 1960-61 to 1974-75; Education Directory, Colleges and Universities, 1975-76 to 1983-84; 1982-83 Supplement to the Education Directory, Colleges and Universities; and Integrated Postsecondary Education Data System, "Institutional Characteristics" surveys, unpublished data. (This table was prepared June 1998.) 
Table 244.-Earned degrees conferred by institutions of higher education, by level of degree and sex of student: 1869-70 to 2007-08

\begin{tabular}{|c|c|c|c|c|c|c|c|c|c|c|c|c|c|c|c|}
\hline \multirow{2}{*}{ Year } & \multicolumn{3}{|c|}{ Associate degrees } & \multicolumn{3}{|c|}{ Bachelor's degrees } & \multicolumn{3}{|c|}{ Master's degrees } & \multicolumn{3}{|c|}{ First-professional degrees } & \multicolumn{3}{|c|}{ Doctor's degrees } \\
\hline & Total & Men & Women & Total & Men & Women & Total & Men & Women & Total & Men & Women & Total & Men & Women \\
\hline 1 & 2 & 3 & 4 & 5 & 6 & 7 & 8 & 9 & 10 & 11 & 12 & 13 & 14 & 15 & 16 \\
\hline $1869-70$ & - & - & - & 19,371 & 17,993 & 11,378 & 0 & 0 & 0 & $(2)$ & $(2)$ & (2) & 1 & 1 & 0 \\
\hline $1879-80$ & - & - & - & 112,896 & 110,411 & 12,485 & 879 & 868 & 11 & (2) & (2) & (2) & 54 & 51 & 3 \\
\hline $1889-90$ & - & - & - & 115,539 & 112,857 & 12,682 & 1,015 & 821 & 194 & (2) & (2) & (2) & 149 & 147 & 2 \\
\hline 1899-1900 & - & - & - & 127,410 & 122,173 & 15,237 & 1,583 & 1,280 & 303 & (2) & (2) & (2) & 382 & 359 & 23 \\
\hline $1909-10$ & - & - & - & 137,199 & 128,762 & ${ }^{1} 8,437$ & 2,113 & 1,555 & 558 & (2) & $\left({ }^{2}\right)$ & $\left({ }^{2}\right)$ & 443 & 399 & 44 \\
\hline $1919-20$ & - & - & - & 148,622 & ${ }^{1} 31,980$ & 116,642 & 4,279 & 2,985 & 1,294 & (2) & ${ }^{(2)}$ & (2) & 615 & 522 & 93 \\
\hline $1929-30$ & - & - & - & 1122,484 & 173,615 & 148,869 & 14,969 & 8,925 & 6,044 & (2) & (2) & (2) & 2,299 & 1,946 & 353 \\
\hline $1939-40$ & - & - & - & 1186,500 & 1109,546 & 176,954 & 26,731 & 16,508 & 10,223 & (2) & (2) & (2) & 3,290 & 2,861 & 429 \\
\hline $1949-50$ & - & - & - & 1432,058 & 1328,841 & 1103,217 & 58,183 & 41,220 & 16,963 & (2) & ${ }^{(2)}$ & (2) & 6,420 & 5,804 & 616 \\
\hline $1959-60$ & - & - & - & 1392,440 & 1254,063 & 1138,377 & 74,435 & 50,898 & 23,537 & ( $\left.{ }^{2}\right)$ & $(2)$ & $\left({ }^{2}\right)$ & 9,829 & 8,801 & 1,028 \\
\hline $1960-61$ & - & - & - & 365,174 & 224,538 & 140,636 & 84,609 & 57,830 & 26,779 & 25,253 & 24,577 & 676 & 10,575 & 9,463 & 1,112 \\
\hline $1961-62$ & - & - & - & 383,961 & 230,456 & 153,505 & 91,418 & 62,603 & 28,815 & 25,607 & 24,836 & 771 & 11,622 & 10,377 & 1,245 \\
\hline $1962-6$ & - & - & - & 411,420 & 241,309 & 170,111 & 98,684 & 67,302 & 31,382 & 26,590 & 25,753 & 837 & 12,822 & 11,448 & 1,374 \\
\hline $1963-6$ & - & - & - & 461,266 & 265,349 & 195,917 & 109,183 & 73,850 & 35,333 & 27,209 & 26,357 & 852 & 14,490 & 12,955 & 1,535 \\
\hline $1964-65$ & & - & - & 493,757 & 282,173 & 211,584 & 121,167 & 81,319 & 39,848 & 28,290 & 27,283 & 1,007 & 16,467 & 14,692 & 1,775 \\
\hline $1965-66$ & 111,607 & 63,779 & 47,828 & 520,115 & 299,287 & 220,828 & 140,602 & 93,081 & 47,521 & 30,124 & 28,982 & 1,142 & 18,237 & 16,121 & 2,116 \\
\hline $1966-67$ & 139,183 & 78,356 & 60,827 & 558,534 & 322,711 & 235,823 & 157,726 & 103,109 & 54,617 & 31,695 & 30,401 & 1,294 & 20,617 & 18,163 & 2,454 \\
\hline $1967-68$ & 159,441 & 90,317 & 69,124 & 632,289 & 357,682 & 274,607 & 176,749 & 113,552 & 63,197 & 33,939 & 32,402 & 1,537 & 23,089 & 20,183 & 2,906 \\
\hline $1968-69$ & 183,279 & 105,661 & 77,618 & 728,845 & 410,595 & 318,250 & 193,756 & 121,531 & 72,225 & 35,114 & 33,595 & 1,519 & 26,158 & 22,722 & 3,436 \\
\hline $1969-70$. & 206,023 & 117,432 & 88,591 & 792,316 & 451,097 & 341,219 & 208,291 & 125,624 & 82,667 & 34,918 & 33,077 & 1,841 & 29,866 & 25,890 & 3,976 \\
\hline $1970-71$ & 252,311 & 144,144 & 108,167 & 839,730 & 475,594 & 364,136 & 230,509 & 38,146 & 2,363 & 37,946 & 35,544 & 2,402 & 32,107 & 27,530 & 4,577 \\
\hline $1971-72$ & 292,014 & 166,227 & 125,787 & 887,273 & 500,590 & 386,683 & 251,633 & 149,550 & 102,083 & 43,411 & 40,723 & 2,688 & 33,363 & 28,090 & 5,273 \\
\hline $1972-73$ & 316,174 & 175,413 & 140,761 & 922,362 & 518,191 & 404,171 & 263,371 & 154,468 & 108,903 & 50,018 & 46,489 & 3,529 & $\mid 34,777$ & 28,571 & 6,206 \\
\hline $1973-74$ & 343,924 & 188,591 & 155,333 & 945,776 & 527,313 & 418,463 & 277,033 & 157,842 & 119,191 & 53,816 & 48,530 & 5,286 & 33,816 & 27,365 & 6,451 \\
\hline $1974-75$ & 360,171 & 191,017 & 169,154 & 922,933 & 504,841 & 418,092 & 292,450 & 161,570 & 130,880 & 55,916 & 48,956 & 6,960 & 34,083 & 26,817 & 7,266 \\
\hline 1975 & 391,454 & 209,996 & 458 & 925,746 & & 821 & 1,771 & 167,248 & 523 & 62,649 & 2,892 & 9,757 & & & 7,797 \\
\hline $1976-77$ & 406,377 & 210,842 & 195,535 & 919,549 & 495,545 & 424,004 & 317,164 & 167,783 & 149,381 & 64,359 & 52,374 & 11,985 & 33,232 & 25,142 & 8,090 \\
\hline $1977-78$ & 412,246 & 204,718 & 207,528 & 921,204 & 487,347 & 433,857 & 311,620 & 161,212 & 150,408 & 66,581 & 52,270 & 14,311 & 32,131 & 23,658 & 8,473 \\
\hline $1978-79$ & 402,702 & 192,091 & 210,611 & 921,390 & 477,344 & 046 & 301,079 & 153,370 & 147,709 & 68,848 & 52,652 & 16,196 & 32,730 & 23,541 & 9,189 \\
\hline $1979-80$ & 400,910 & 183,737 & 217,173 & 929,417 & 473,611 & 455,806 & 298,081 & 150,749 & 147,332 & 70,131 & 52,716 & 17,415 & 32,615 & 22,943 & 9,672 \\
\hline 198 & 416,377 & 188,638 & 39 & 935 & & & & & 696 & 71,956 & 792 & & & & 247 \\
\hline $1981-82$ & 434,526 & 196,944 & 237,582 & 952,998 & 473,364 & 479,634 & 295,546 & 145,532 & 150,014 & 72,032 & 52,223 & 19,809 & 32,707 & 22,224 & 10,483 \\
\hline 198 & 449,620 & 203,991 & 245,629 & 969, & & & 289,921 & & 224 & 73,054 & 51,250 & 804 & 32 & & 10,873 \\
\hline $1983-84$ & 452,240 & 202,704 & 249,536 & 974,309 & 482,319 & 491,990 & 284,263 & 143,595 & 140,668 & 74,468 & 51,378 & 23,090 & 33,209 & 22,064 & 11,145 \\
\hline 1984-85 ……......................... & 454,712 & 202,932 & 251,780 & 979,477 & 482,528 & 496,949 & 286,251 & 143,390 & 142,861 & 75,063 & 50,455 & 24,608 & 32,943 & 21,700 & 11,243 \\
\hline 198 & 446,047 & 1 & 81 & 98 & 4 & 0 & 567 & 08 & 59 & 73,910 & 49,261 & 49 & 33 & 21 & 11,834 \\
\hline $1986-87$ & 436,304 & 190,839 & 245,465 & 991,264 & 480,782 & 482 & 289,349 & 269 & 3,080 & 71,617 & 46,523 & 25,094 & 34,041 & 22,061 & 11,980 \\
\hline .․․…….... & 435,085 & 190,047 & 038 & 9 & 4 & & 317 & 163 & 154 & 70,735 & 484 & 251 & 370 & 15 & 12,255 \\
\hline 1988-89 & 436,764 & 186,316 & 250,448 & $1,018,755$ & 483,346 & 535,409 & 310,621 & 149,354 & 161,267 & 70,856 & 45,046 & 25,810 & 35,720 & 22,648 & 13,072 \\
\hline 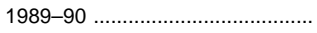 & 455,102 & 191,195 & 263,907 & $1,051,344$ & 491,696 & 559,648 & 324,301 & 153,653 & 170,648 & 70,988 & 43,961 & 27,027 & 38,371 & 24,401 & 13,970 \\
\hline 19 & 720 & 34 & 86 & $1,094,538$ & & & 68 & 82 & 686 & 71 & 46 & 102 & 94 & & 538 \\
\hline 199 & ,231 & 20 & 750 & 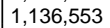 & & & 838 & & 996 & 74,146 & 071 & 075 & 59 & & 102 \\
\hline $1992-93$ & 514,756 & 211,964 & 302,792 & $1,165,178$ & 881 & 297 & 369,585 & 169,258 &, 327 & 75,387 & 45,153 & 30,234 & 42,132 & 26,073 & 16,059 \\
\hline 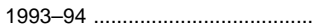 & 530,632 & 215,261 & 315,371 & $1,169,275$ & 422 & 5,853 & 387,070 & 176,085 & 210,985 & 75,418 & 44,707 & 30,711 & 43,185 & 26,552 & 16,633 \\
\hline 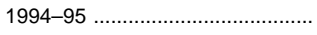 & 539,691 & 218,352 & 321,339 & $1,160,134$ & 526,131 & 634,003 & 397,629 & 178,598 & 219,031 & 75,800 & 44,853 & 30,947 & 44,446 & 26,916 & 17,530 \\
\hline & 216 & & & & & & & & 220 & 76 & 48 & & & & 311 \\
\hline 19 & 000 & 211,000 & 317,000 & 0 & 5 & & 000 & 000 & 000 & 79,700 & 46,000 & 700 & 44 & 27 & 17,600 \\
\hline $1997-98^{3}$ & 520,000 & 209,000 & 311,000 & $1,172,000$ & 523,000 & 649,000 & 406,000 & 183,000 & 223,000 & 78,400 & 46,100 & 32,300 & 45,200 & 27,200 & 18,000 \\
\hline & 528,000 & 209,000 & 319,000 & & & & 410,000 & 000 & 225,000 & 75,800 & 43,700 & 32,000 & 45,800 & 27,300 & 18,500 \\
\hline 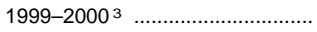 & 532,000 & 208,000 & 323,000 & $1,161,000$ & 502,000 & 659,000 & 414,000 & 187,000 & 227,000 & 74,000 & 42,000 & 32,000 & 46,400 & 27,400 & 19,000 \\
\hline 20 & 000 & & 00 & & & & & & & & & & & & 500 \\
\hline $2001-02^{3}$ & 550,000 & 211,000 & 339,000 & $1,195,000$ & 510,000 & 685,000 & 422,000 & 191,000 & 231,000 & 72,400 & 40,500 & 31,800 & 47,200 & 27,200 & 20,000 \\
\hline $2002-03^{3}$ & 555,000 & 212,000 & 343,000 & $1,214,000$ & 515,000 & 699,000 & 426,000 & 193,000 & 233,000 & 71,900 & 40,100 & 31,800 & 47,600 & 27,100 & 20,500 \\
\hline$-04^{3} \ldots \ldots \ldots \ldots \ldots$ & 559,000 & 213,000 & 346,000 & 1,227 & & & 430,000 & 195,000 & 000 & 71,800 & 39,800 & 32,000 & 47,900 & 27,000 & 20,900 \\
\hline $2004-05^{3}$..................................... & 560,000 & 213,000 & 347,000 & $1,235,000$ & 520,000 & 716,000 & 434,000 & 197,000 & 237,000 & 72,300 & 39,900 & 32,400 & 48,300 & 26,900 & 21,400 \\
\hline $6^{3}$ & 000 & 21 & 000 & 1 & & & 000 & & 000 & 73 & 40,100 & 00 & 700 & 300 & 21,900 \\
\hline $2006-07^{3}$ & 572,000 & 215,000 & 357,000 & $1,256,000$ & 527,000 & 729,000 & 442,000 & 201,000 & 241,000 & 74,100 & 40,500 & 33,600 & 49,100 & 26,700 & 22,400 \\
\hline $2007-08^{3}$ & 579,000 & 216,000 & 363,000 & $1,270,000$ & 530,000 & 739,000 & 446,000 & 203,000 & 243,000 & 75,000 & 40,800 & 34,200 & 49,500 & 26,600 & 22,900 \\
\hline
\end{tabular}

1 Includes first-professional degrees.

${ }^{2}$ First-professional degrees are included with bachelor's degrees.

${ }^{3}$ Projected.

-Data not available.

NOTE.-Some data have been revised from previously published figures. Because of rounding, details may not add to totals.
SOURCE: U.S. Department of Education, National Center for Education Statistics, Earned Degrees Conferred; Projections of Education Statistics to 2008; Higher Education General Information Survey (HEGIS), "Degrees and Other Formal Awards Conferred" surveys; and Integrated Postsecondary Education Data System (IPEDS), "Completions" surveys. (This table was prepared May 1998.) 
Table 245.-Degrees awarded by institutions of higher education, by control, level of degree, and state: 1995-96

\begin{tabular}{|c|c|c|c|c|c|c|c|c|c|c|}
\hline \multirow[b]{2}{*}{ State or other area } & \multicolumn{5}{|c|}{ Public } & \multicolumn{5}{|c|}{ Private } \\
\hline & $\begin{array}{l}\text { Associate } \\
\text { degrees }\end{array}$ & $\begin{array}{l}\text { Bachelor's } \\
\text { degrees }\end{array}$ & $\begin{array}{l}\text { First-pro- } \\
\text { fessional } \\
\text { degrees }{ }^{1}\end{array}$ & $\begin{array}{l}\text { Master's } \\
\text { degrees }\end{array}$ & $\begin{array}{l}\text { Doctor's } \\
\text { degrees } \\
\text { (Ph.D., } \\
\text { Ed.D., etc.) }\end{array}$ & $\begin{array}{l}\text { Associate } \\
\text { degrees }\end{array}$ & $\begin{array}{l}\text { Bachelor's } \\
\text { degrees }\end{array}$ & $\begin{array}{l}\text { First-pro- } \\
\text { fessional } \\
\text { degrees }{ }^{1}\end{array}$ & $\begin{array}{l}\text { Master's } \\
\text { degrees }\end{array}$ & $\begin{array}{l}\text { Doctor's } \\
\text { degrees } \\
\text { (Ph.D., } \\
\text { Ed.D., etc.) }\end{array}$ \\
\hline 1 & 2 & 3 & 4 & 5 & 6 & 7 & 8 & 9 & 10 & 11 \\
\hline United States ........... & 454,291 & 774,070 & 29,882 & 227,179 & 29,516 & 100,925 & 390,722 & 46,852 & 179,122 & 15,136 \\
\hline $\begin{array}{l}\text { Alabama } \\
\text { Alaska } \\
\text { Arizona } \\
\text { Arkansas } \\
\text { California }\end{array}$ & $\begin{array}{r}7,320 \\
890 \\
6,076 \\
2,869 \\
57,151\end{array}$ & $\begin{array}{r}16,758 \\
1,411 \\
14,049 \\
7,420 \\
82,540\end{array}$ & $\begin{array}{r}600 \\
0 \\
454 \\
499 \\
2,093\end{array}$ & $\begin{array}{r}6,023 \\
419 \\
4,860 \\
1,893 \\
18,217\end{array}$ & $\begin{array}{r}531 \\
28 \\
756 \\
148 \\
2,754\end{array}$ & $\begin{array}{r}940 \\
71 \\
2,070 \\
105 \\
7,831\end{array}$ & $\begin{array}{r}3,350 \\
82 \\
2,914 \\
1,679 \\
27,705\end{array}$ & $\begin{array}{r}435 \\
\overline{-} \\
6,562\end{array}$ & $\begin{array}{r}450 \\
55 \\
2,008 \\
80 \\
19,871\end{array}$ & $\begin{array}{r}\frac{2}{-} \\
2,356\end{array}$ \\
\hline $\begin{array}{l}\text { Colorado } \\
\text { Connecticut } \\
\text { Delaware } \\
\text { District of Columbia } \\
\text { Florida }\end{array}$ & $\begin{array}{r}5,361 \\
3,860 \\
987 \\
280 \\
35,984\end{array}$ & $\begin{array}{r}16,105 \\
6,788 \\
3,510 \\
586 \\
32,208\end{array}$ & $\begin{array}{r}436 \\
312 \\
0 \\
68 \\
1,002\end{array}$ & $\begin{array}{r}4,450 \\
2,529 \\
854 \\
132 \\
8,628\end{array}$ & $\begin{array}{r}709 \\
239 \\
157 \\
0 \\
1,058\end{array}$ & $\begin{array}{r}3,276 \\
790 \\
195 \\
109 \\
6,520\end{array}$ & $\begin{array}{r}3,334 \\
6,613 \\
874 \\
6,527 \\
14,103\end{array}$ & $\begin{array}{r}354 \\
609 \\
391 \\
2,427 \\
1,484\end{array}$ & $\begin{array}{r}2,403 \\
4,186 \\
396 \\
7,127 \\
6,684\end{array}$ & $\begin{array}{r}121 \\
437 \\
25 \\
526 \\
695\end{array}$ \\
\hline $\begin{array}{l}\text { Georgia } \\
\text { Hawaii } \\
\text { Idaho } \\
\text { Illinois } \\
\text { Indiana }\end{array}$ & $\begin{array}{r}7,476 \\
2,201 \\
1,275 \\
23,776 \\
7,469\end{array}$ & $\begin{array}{r}19,830 \\
3,395 \\
4,138 \\
29,079 \\
20,650\end{array}$ & $\begin{array}{r}723 \\
122 \\
157 \\
1,067 \\
955\end{array}$ & $\begin{array}{r}7,025 \\
1,053 \\
1,064 \\
10,026 \\
5,743\end{array}$ & $\begin{array}{r}740 \\
186 \\
94 \\
1,259 \\
997\end{array}$ & $\begin{array}{r}1,986 \\
487 \\
2,993 \\
3,063 \\
3,219\end{array}$ & $\begin{array}{r}7,616 \\
1,344 \\
351 \\
22,464 \\
9,921\end{array}$ & $\begin{array}{r}1,656 \\
- \\
3,568 \\
549\end{array}$ & $\begin{array}{r}2,215 \\
526 \\
39 \\
14,819 \\
1,829\end{array}$ & $\begin{array}{r}257 \\
10 \\
1,314 \\
179\end{array}$ \\
\hline $\begin{array}{l}\text { lowa } \\
\text { Kansas } \\
\text { Kentucky } \\
\text { Louisiana } \\
\text { Maine }\end{array}$ & $\begin{array}{l}7,546 \\
6,604 \\
4,926 \\
3,535 \\
1,555\end{array}$ & $\begin{array}{r}9,189 \\
11,520 \\
11,609 \\
14,868 \\
3,245\end{array}$ & $\begin{array}{r}583 \\
604 \\
785 \\
559 \\
88\end{array}$ & $\begin{array}{r}2,455 \\
3,950 \\
3,815 \\
3,908 \\
671\end{array}$ & $\begin{array}{r}676 \\
470 \\
305 \\
386 \\
47\end{array}$ & $\begin{array}{r}841 \\
677 \\
1,614 \\
723 \\
741\end{array}$ & $\begin{array}{l}8,491 \\
3,089 \\
3,071 \\
3,117 \\
2,374\end{array}$ & $\begin{array}{r}1,015 \\
8 \\
356 \\
969 \\
93\end{array}$ & $\begin{array}{r}929 \\
782 \\
678 \\
1,321 \\
234\end{array}$ & $\begin{array}{r}32 \\
96 \\
133 \\
-\end{array}$ \\
\hline $\begin{array}{l}\text { Maryland } \\
\text { Massachusetts } \\
\text { Michigan } \\
\text { Minnesota } \\
\text { Mississippi }\end{array}$ & $\begin{array}{r}8,129 \\
8,213 \\
18,449 \\
8,666 \\
5,804\end{array}$ & $\begin{array}{r}15,672 \\
12,312 \\
34,017 \\
15,074 \\
8,123\end{array}$ & $\begin{array}{r}706 \\
91 \\
1,464 \\
685 \\
328\end{array}$ & $\begin{array}{r}5,431 \\
3,076 \\
13,577 \\
3,896 \\
2,246\end{array}$ & $\begin{array}{r}578 \\
440 \\
1,526 \\
763 \\
352\end{array}$ & $\begin{array}{r}460 \\
4,469 \\
3,207 \\
2,847 \\
105\end{array}$ & $\begin{array}{r}4,270 \\
28,413 \\
10,355 \\
8,205 \\
1,860\end{array}$ & $\begin{array}{r}207 \\
3,577 \\
1,114 \\
812 \\
117\end{array}$ & $\begin{array}{r}4,376 \\
19,177 \\
2,107 \\
2,679 \\
464\end{array}$ & $\begin{array}{r}344 \\
1,936 \\
72 \\
274 \\
-\end{array}$ \\
\hline $\begin{array}{l}\text { Missouri } \\
\text { Montana } \\
\text { Nebraska } \\
\text { Nevada } \\
\text { New Hampshire }\end{array}$ & $\begin{array}{l}6,225 \\
1,027 \\
2,816 \\
1,274 \\
1,826\end{array}$ & $\begin{array}{r}15,069 \\
4,021 \\
6,641 \\
3,357 \\
3,862\end{array}$ & $\begin{array}{r}670 \\
75 \\
376 \\
55 \\
0\end{array}$ & $\begin{array}{r}4,121 \\
812 \\
1,878 \\
955 \\
748\end{array}$ & $\begin{array}{r}379 \\
61 \\
282 \\
76 \\
51\end{array}$ & $\begin{array}{r}3,859 \\
305 \\
380 \\
151 \\
1,401\end{array}$ & $\begin{array}{r}12,237 \\
764 \\
3,248 \\
64 \\
3,795\end{array}$ & $\frac{1,707}{4 \overline{40}}$ & $\begin{array}{r}6,714 \\
40 \\
495 \\
31 \\
1,702\end{array}$ & $\frac{406}{\frac{3}{59}}$ \\
\hline $\begin{array}{l}\text { New Jersey } \\
\text { New Mexico } \\
\text { New York } \\
\text { North Carolina } \\
\text { North Dakota }\end{array}$ & $\begin{array}{r}11,999 \\
3,172 \\
39,513 \\
13,032 \\
1,789\end{array}$ & $\begin{array}{r}18,035 \\
5,645 \\
41,950 \\
22,821 \\
3,910\end{array}$ & $\begin{array}{r}894 \\
192 \\
1,282 \\
710 \\
173\end{array}$ & $\begin{array}{r}4,840 \\
2,305 \\
13,640 \\
5,863 \\
661\end{array}$ & $\begin{array}{r}580 \\
305 \\
1,400 \\
789 \\
79\end{array}$ & $\begin{array}{r}1,006 \\
304 \\
13,696 \\
876 \\
238\end{array}$ & $\begin{array}{r}6,537 \\
572 \\
53,345 \\
9,940 \\
574\end{array}$ & $\begin{array}{r}800 \\
6,356 \\
1,031 \\
-\end{array}$ & $\begin{array}{r}3,580 \\
274 \\
30,535 \\
1,905 \\
44\end{array}$ & $\begin{array}{r}471 \\
2,365 \\
258 \\
-\end{array}$ \\
\hline $\begin{array}{l}\text { Ohio } \\
\text { Oklahoma } \\
\text { Oregon } \\
\text { Pennsylvania } \\
\text { Rhode Island }\end{array}$ & $\begin{array}{r}16,723 \\
5,974 \\
5,352 \\
12,204 \\
1,548\end{array}$ & $\begin{array}{r}32,089 \\
12,191 \\
9,359 \\
30,426 \\
3,208\end{array}$ & $\begin{array}{r}2,022 \\
501 \\
322 \\
1,175 \\
7\end{array}$ & $\begin{array}{r}10,548 \\
3,003 \\
2,767 \\
8,483 \\
888\end{array}$ & $\begin{array}{r}1,678 \\
333 \\
406 \\
1,223 \\
82\end{array}$ & $\begin{array}{r}3,902 \\
135 \\
362 \\
10,738 \\
2,391\end{array}$ & $\begin{array}{r}16,592 \\
2,231 \\
3,877 \\
31,327 \\
5,536\end{array}$ & $\begin{array}{r}1,267 \\
198 \\
635 \\
2,700 \\
173\end{array}$ & $\begin{array}{r}5,375 \\
853 \\
1,244 \\
11,024 \\
1,112\end{array}$ & $\begin{array}{r}532 \\
25 \\
70 \\
1,032 \\
219\end{array}$ \\
\hline $\begin{array}{l}\text { South Carolina } \\
\text { South Dakota } \\
\text { Tennessee } \\
\text { Texas } \\
\text { Utah }\end{array}$ & $\begin{array}{r}5,558 \\
1,606 \\
5,814 \\
22,605 \\
5,885\end{array}$ & $\begin{array}{r}11,504 \\
3,585 \\
13,491 \\
55,388 \\
8,337\end{array}$ & $\begin{array}{r}534 \\
126 \\
691 \\
2,615 \\
225\end{array}$ & $\begin{array}{r}4,041 \\
946 \\
4,296 \\
17,074 \\
1,675\end{array}$ & $\begin{array}{r}422 \\
89 \\
492 \\
2,443 \\
318\end{array}$ & $\begin{array}{r}817 \\
368 \\
1,246 \\
3,307 \\
552\end{array}$ & $\begin{array}{r}3,584 \\
854 \\
7,117 \\
15,316 \\
7,213\end{array}$ & $\begin{array}{r}171 \\
15 \\
647 \\
2,481 \\
155\end{array}$ & $\begin{array}{r}415 \\
116 \\
1,955 \\
5,514 \\
1,406\end{array}$ & $\begin{array}{r}13 \\
3 \\
210 \\
421 \\
84\end{array}$ \\
\hline 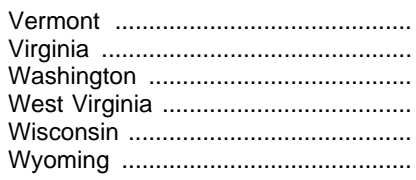 & $\begin{array}{r}689 \\
9,052 \\
18,349 \\
2,145 \\
8,330 \\
1,758\end{array}$ & $\begin{array}{r}2,396 \\
23,515 \\
17,395 \\
7,225 \\
19,713 \\
1,641\end{array}$ & $\begin{array}{r}94 \\
1,210 \\
453 \\
350 \\
515 \\
78\end{array}$ & $\begin{array}{r}425 \\
8,554 \\
3,868 \\
2,059 \\
5,055 \\
410\end{array}$ & $\begin{array}{r}57 \\
1,025 \\
646 \\
120 \\
845 \\
78\end{array}$ & $\begin{array}{r}781 \\
2,039 \\
1,000 \\
667 \\
835 \\
230\end{array}$ & $\begin{array}{r}2,099 \\
8,049 \\
5,149 \\
1,357 \\
7,223 \\
-\end{array}$ & $\begin{array}{r}- \\
667 \\
478 \\
- \\
434 \\
-\end{array}$ & $\begin{array}{r}866 \\
2,252 \\
4,466 \\
124 \\
1,645 \\
-\end{array}$ & $\begin{array}{r}4 \\
36 \\
44 \\
72 \\
\end{array}$ \\
\hline 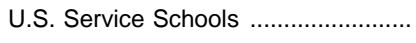 & 11,624 & 3,200 & 156 & 1,323 & 58 & - & - & 一 & - & - \\
\hline Outlying areas & 1,457 & 6,566 & 275 & 755 & 34 & 2,321 & 8,108 & 472 & 1,054 & 48 \\
\hline & & - & - & & - & & & - & - & - \\
\hline S of Micronesia & 15 & & $\overline{-}$ & & 二 & 二 & - & 二 & - & 二 \\
\hline 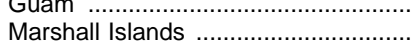 & 113 & 358 & - & 4 & - & 二 & - & 二 & $\overline{-}$ & - \\
\hline has ...................... & 107 & & - & 列 & - & - & - & - & - & - \\
\hline 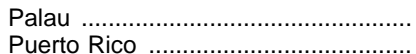 & 16 & & 275 & - & $\overline{34}$ & $\overline{321}$ & $\overline{108}$ & $\overline{472}$ & $\overline{54}$ & $\overline{48}$ \\
\hline Virgin Islands & $\begin{array}{r}9<5 \\
54\end{array}$ & 209 & - & 55 & - & - & - & - & - & - \\
\hline
\end{tabular}

${ }^{1}$ Includes degrees which require at least 6 years of college work for completion (including at least 2 years of preprofessional training). See Definitions for details.

-Data not available or not applicable.
SOURCE: U.S. Department of Education, National Center for Education Statistics, Integrated Postsecondary Education Data System (IPEDS), "Completions" survey. (This table was prepared May 1998.) 
Table 246.-Earned degrees conferred by institutions of higher education, by level of degree and by state: 1994-95 and 1995-96

\begin{tabular}{|c|c|c|c|c|c|c|c|c|c|c|}
\hline \multirow[b]{2}{*}{ State or other area } & \multicolumn{5}{|c|}{$1994-95$} & \multicolumn{5}{|c|}{$1995-96$} \\
\hline & $\begin{array}{l}\text { Associate } \\
\text { degrees }\end{array}$ & $\begin{array}{c}\text { Bachelor's } \\
\text { degrees }\end{array}$ & $\begin{array}{l}\text { First-pro- } \\
\text { fessional } \\
\text { degrees }{ }^{1}\end{array}$ & $\begin{array}{l}\text { Master's } \\
\text { degrees }\end{array}$ & \begin{tabular}{|c|} 
Doctor's \\
degrees \\
(Ph.D., \\
Ed.D., etc.)
\end{tabular} & $\begin{array}{l}\text { Associate } \\
\text { degrees }\end{array}$ & $\begin{array}{c}\text { Bachelor's } \\
\text { degrees }\end{array}$ & $\begin{array}{l}\text { First-pro- } \\
\text { fessional } \\
\text { degrees }{ }^{1}\end{array}$ & $\begin{array}{l}\text { Master's } \\
\text { degrees }\end{array}$ & $\begin{array}{c}\text { Doctor's } \\
\text { degrees } \\
\text { (Ph.D., } \\
\text { Ed.D., etc.) }\end{array}$ \\
\hline 1 & 2 & 3 & 4 & 5 & 6 & 7 & 8 & 9 & 10 & 11 \\
\hline United States & 539,691 & $1,160,134$ & 75,800 & 397,629 & 44,446 & 555,216 & $1,164,792$ & 76,734 & 406,301 & 44,652 \\
\hline $\begin{array}{l}\text { Alabama } \\
\text { Alaska } \\
\text { Arizona } \\
\text { Arkansas } \\
\text { California }\end{array}$ & $\begin{array}{r}7,835 \\
960 \\
6,809 \\
2,492 \\
60,503\end{array}$ & $\begin{array}{r}19,924 \\
1,526 \\
16,175 \\
8,623 \\
109,714\end{array}$ & $\begin{array}{r}963 \\
-445 \\
482 \\
8,783\end{array}$ & $\begin{array}{r}5,983 \\
463 \\
6,498 \\
2,041 \\
38,065\end{array}$ & $\begin{array}{r}438 \\
19 \\
787 \\
155 \\
5,367\end{array}$ & $\begin{array}{r}8,260 \\
961 \\
8,146 \\
2,974 \\
64,982\end{array}$ & $\begin{array}{r}20,108 \\
1,493 \\
16,963 \\
9,099 \\
110,245\end{array}$ & $\begin{array}{r}1,035 \\
0 \\
454 \\
499 \\
8,655\end{array}$ & $\begin{array}{r}6,473 \\
474 \\
6,868 \\
1,973 \\
38,088\end{array}$ & $\begin{array}{r}533 \\
28 \\
756 \\
148 \\
5,110\end{array}$ \\
\hline $\begin{array}{l}\text { Colorado } \\
\text { Connecticut } \\
\text { Delaware } \\
\text { District of Columbia } \\
\text { Florida }\end{array}$ & $\begin{array}{r}6,984 \\
4,800 \\
1,141 \\
205 \\
40,733\end{array}$ & $\begin{array}{r}19,929 \\
13,972 \\
4,466 \\
7,027 \\
44,924\end{array}$ & $\begin{array}{r}833 \\
920 \\
418 \\
2,467 \\
2,494\end{array}$ & $\begin{array}{r}7,111 \\
6,419 \\
1,102 \\
6,607 \\
14,793\end{array}$ & $\begin{array}{r}788 \\
707 \\
169 \\
474 \\
1,653\end{array}$ & $\begin{array}{r}8,637 \\
4,650 \\
1,182 \\
389 \\
42,504\end{array}$ & $\begin{array}{r}19,439 \\
13,401 \\
4,384 \\
7,113 \\
46,311\end{array}$ & $\begin{array}{r}790 \\
921 \\
391 \\
2,495 \\
2,486\end{array}$ & $\begin{array}{r}6,853 \\
6,715 \\
1,250 \\
7,259 \\
15,312\end{array}$ & $\begin{array}{r}830 \\
676 \\
182 \\
526 \\
1,753\end{array}$ \\
\hline $\begin{array}{l}\text { Georgia } \\
\text { Hawaii } \\
\text { Idaho } \\
\text { Illinois } \\
\text { Indiana }\end{array}$ & $\begin{array}{r}9,143 \\
2,387 \\
4,181 \\
27,126 \\
10,063\end{array}$ & $\begin{array}{r}26,312 \\
4,500 \\
4,235 \\
52,270 \\
30,253\end{array}$ & $\begin{array}{r}2,061 \\
160 \\
167 \\
4,360 \\
1,485\end{array}$ & $\begin{array}{r}8,644 \\
1,520 \\
1,077 \\
23,487 \\
7,597\end{array}$ & $\begin{array}{r}934 \\
166 \\
80 \\
2,850 \\
1,152\end{array}$ & $\begin{array}{r}9,462 \\
2,688 \\
4,268 \\
26,839 \\
10,688\end{array}$ & $\begin{array}{r}27,446 \\
4,739 \\
4,489 \\
51,543 \\
30,571\end{array}$ & $\begin{array}{r}2,379 \\
122 \\
157 \\
4,635 \\
1,504\end{array}$ & $\begin{array}{r}9,240 \\
1,579 \\
1,103 \\
24,845 \\
7,572\end{array}$ & $\begin{array}{r}997 \\
196 \\
94 \\
2,573 \\
1,176\end{array}$ \\
\hline $\begin{array}{l}\text { lowa } \\
\text { Kansas } \\
\text { Kentucky } \\
\text { Louisiana } \\
\text { Maine }\end{array}$ & $\begin{array}{l}8,191 \\
6,961 \\
6,446 \\
3,369 \\
2,445\end{array}$ & $\begin{array}{r}17,421 \\
14,594 \\
14,570 \\
17,920 \\
5,893\end{array}$ & $\begin{array}{r}1,535 \\
591 \\
1,127 \\
1,680 \\
180\end{array}$ & $\begin{array}{r}3,478 \\
4,350 \\
4,219 \\
5,346 \\
953\end{array}$ & $\begin{array}{r}686 \\
450 \\
397 \\
499 \\
42\end{array}$ & $\begin{array}{l}8,387 \\
7,281 \\
6,540 \\
4,258 \\
2,296\end{array}$ & $\begin{array}{r}17,680 \\
14,609 \\
14,680 \\
17,985 \\
5,619\end{array}$ & $\begin{array}{r}1,598 \\
612 \\
1,141 \\
1,528 \\
181\end{array}$ & $\begin{array}{r}3,384 \\
4,732 \\
4,493 \\
5,229 \\
905\end{array}$ & $\begin{array}{r}708 \\
470 \\
401 \\
519 \\
47\end{array}$ \\
\hline $\begin{array}{l}\text { Maryland } \\
\text { Massachusetts } \\
\text { Michigan } \\
\text { Minnesota } \\
\text { Mississippi }\end{array}$ & $\begin{array}{r}8,632 \\
12,808 \\
22,696 \\
12,216 \\
5,519\end{array}$ & $\begin{array}{l}19,908 \\
40,279 \\
44,317 \\
24,068 \\
10,335\end{array}$ & $\begin{array}{r}1,001 \\
3,656 \\
2,496 \\
1,538 \\
492\end{array}$ & $\begin{array}{r}8,991 \\
21,276 \\
15,460 \\
5,760 \\
2,621\end{array}$ & $\begin{array}{r}877 \\
2,283 \\
1,548 \\
889 \\
399\end{array}$ & $\begin{array}{r}8,589 \\
12,682 \\
21,656 \\
11,513 \\
5,909\end{array}$ & $\begin{array}{r}19,942 \\
40,725 \\
44,372 \\
23,279 \\
9,983\end{array}$ & $\begin{array}{r}913 \\
3,668 \\
2,578 \\
1,497 \\
445\end{array}$ & $\begin{array}{r}9,807 \\
22,253 \\
15,684 \\
6,575 \\
2,710\end{array}$ & $\begin{array}{r}922 \\
2,376 \\
1,598 \\
1,037 \\
352\end{array}$ \\
\hline $\begin{array}{l}\text { Missouri } \\
\text { Montana } \\
\text { Nebraska } \\
\text { Nevada } \\
\text { New Hampshire }\end{array}$ & $\begin{array}{l}8,928 \\
1,329 \\
3,365 \\
1,411 \\
3,530\end{array}$ & $\begin{array}{r}27,931 \\
4,354 \\
10,105 \\
3,371 \\
7,395\end{array}$ & $\begin{array}{r}2,296 \\
78 \\
825 \\
54 \\
193\end{array}$ & $\begin{array}{r}10,355 \\
857 \\
2,252 \\
897 \\
2,262\end{array}$ & $\begin{array}{r}719 \\
66 \\
255 \\
77 \\
112\end{array}$ & $\begin{array}{r}10,084 \\
1,332 \\
3,196 \\
1,425 \\
3,227\end{array}$ & $\begin{array}{r}27,306 \\
4,785 \\
9,889 \\
3,421 \\
7,657\end{array}$ & $\begin{array}{r}2,377 \\
75 \\
826 \\
55 \\
184\end{array}$ & $\begin{array}{r}10,835 \\
852 \\
2,373 \\
986 \\
2,450\end{array}$ & $\begin{array}{r}785 \\
61 \\
285 \\
76 \\
110\end{array}$ \\
\hline $\begin{array}{l}\text { New Jersey } \\
\text { New Mexico } \\
\text { New York } \\
\text { North Carolina } \\
\text { North Dakota }\end{array}$ & $\begin{array}{r}12,855 \\
3,277 \\
54,671 \\
14,107 \\
1,738\end{array}$ & $\begin{array}{r}24,627 \\
6,363 \\
93,549 \\
32,321 \\
4,440\end{array}$ & $\begin{array}{r}1,670 \\
172 \\
7,636 \\
1,696 \\
187\end{array}$ & $\begin{array}{r}8,261 \\
2,438 \\
44,726 \\
7,430 \\
628\end{array}$ & $\begin{array}{r}1,053 \\
285 \\
3,974 \\
1,022 \\
84\end{array}$ & $\begin{array}{r}13,005 \\
3,476 \\
53,209 \\
13,908 \\
2,027\end{array}$ & $\begin{array}{r}24,572 \\
6,217 \\
95,295 \\
32,761 \\
4,484\end{array}$ & $\begin{array}{r}1,694 \\
192 \\
7,638 \\
1,741 \\
173\end{array}$ & $\begin{array}{r}8,420 \\
2,579 \\
44,175 \\
7,768 \\
705\end{array}$ & $\begin{array}{r}1,051 \\
305 \\
3,765 \\
1,047 \\
79\end{array}$ \\
\hline $\begin{array}{l}\text { Ohio } \\
\text { Oklahoma } \\
\text { Oregon } \\
\text { Pennsylvania } \\
\text { Rhode Island }\end{array}$ & $\begin{array}{r}20,183 \\
7,011 \\
5,813 \\
20,569 \\
3,890\end{array}$ & $\begin{array}{r}49,588 \\
15,307 \\
12,917 \\
63,027 \\
8,978\end{array}$ & $\begin{array}{r}3,069 \\
955 \\
904 \\
3,942 \\
76\end{array}$ & $\begin{array}{r}15,387 \\
4,928 \\
3,914 \\
19,637 \\
2,041\end{array}$ & $\begin{array}{r}2,191 \\
414 \\
493 \\
2,402 \\
295\end{array}$ & $\begin{array}{r}20,625 \\
6,109 \\
5,714 \\
22,942 \\
3,939\end{array}$ & $\begin{array}{r}48,681 \\
14,422 \\
13,236 \\
61,753 \\
8,744\end{array}$ & $\begin{array}{r}3,289 \\
699 \\
957 \\
3,875 \\
180\end{array}$ & $\begin{array}{r}15,923 \\
3,856 \\
4,011 \\
19,507 \\
2,000\end{array}$ & $\begin{array}{r}2,210 \\
358 \\
476 \\
2,255 \\
301\end{array}$ \\
\hline $\begin{array}{l}\text { South Carolina } \\
\text { South Dakota } \\
\text { Tennessee } \\
\text { Texas }\end{array}$ & $\begin{array}{r}6,165 \\
834 \\
6,721 \\
25,800 \\
5,812\end{array}$ & $\begin{array}{r}15,176 \\
4,293 \\
20,463 \\
70,048 \\
14,541\end{array}$ & $\begin{array}{r}614 \\
137 \\
1,436 \\
4,775 \\
373\end{array}$ & $\begin{array}{r}4,525 \\
1,007 \\
6,193 \\
22,740 \\
3,045\end{array}$ & $\begin{array}{r}391 \\
63 \\
665 \\
2,727 \\
358\end{array}$ & $\begin{array}{r}6,375 \\
1,974 \\
7,060 \\
25,912 \\
6,437\end{array}$ & $\begin{array}{r}15,088 \\
4,439 \\
20,608 \\
70,704 \\
15,550\end{array}$ & $\begin{array}{r}705 \\
141 \\
1,338 \\
5,096 \\
380\end{array}$ & $\begin{array}{r}4,456 \\
1,062 \\
6,251 \\
22,588 \\
3,081\end{array}$ & $\begin{array}{r}435 \\
92 \\
702 \\
2,864 \\
402\end{array}$ \\
\hline $\begin{array}{l}\text { Vermont } \\
\text { Virginia } \\
\text { Washington } \\
\text { West Virginia } \\
\text { Wisconsin } \\
\text { Wyoming }\end{array}$ & $\begin{array}{r}1,311 \\
10,882 \\
19,102 \\
2,840 \\
9,262 \\
1,663\end{array}$ & $\begin{array}{r}4,591 \\
31,106 \\
21,828 \\
8,656 \\
26,943 \\
1,777\end{array}$ & $\begin{array}{r}90 \\
1,817 \\
909 \\
358 \\
977 \\
70\end{array}$ & $\begin{array}{r}1,091 \\
10,706 \\
7,947 \\
2,268 \\
6,446 \\
396\end{array}$ & $\begin{array}{r}54 \\
1,077 \\
687 \\
159 \\
907 \\
63\end{array}$ & $\begin{array}{r}1,470 \\
11,091 \\
19,349 \\
2,812 \\
9,165 \\
1,988\end{array}$ & $\begin{array}{r}4,495 \\
31,564 \\
22,544 \\
8,582 \\
26,936 \\
1,641\end{array}$ & $\begin{array}{r}94 \\
1,877 \\
931 \\
350 \\
949 \\
78\end{array}$ & $\begin{array}{r}1,291 \\
10,806 \\
8,334 \\
2,183 \\
6,700 \\
410\end{array}$ & $\begin{array}{r}61 \\
1,061 \\
690 \\
120 \\
917 \\
78\end{array}$ \\
\hline 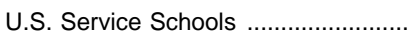 & 11,977 & 3,284 & 157 & 1,391 & 44 & 11,624 & 3,200 & 156 & 1,323 & 58 \\
\hline Outlying areas ........ & 4,403 & 14,302 & 657 & 1,799 & 67 & 3,778 & 14,674 & 747 & 1,809 & 82 \\
\hline & 419 & - & - & - & - & 42 & - & - & - & - \\
\hline $\begin{array}{l}\text { Federated States of Micronesia } \\
\text { Guam }\end{array}$ & $\begin{array}{r}163 \\
48\end{array}$ & $\overline{295}$ & $\overline{-}$ & $\overline{45}$ & - & $\begin{array}{r}156 \\
44\end{array}$ & $\overline{358}$ & - & $\overline{47}$ & - \\
\hline & 40 & - & - & - & - & 113 & - & - & - & - \\
\hline $\begin{array}{l}\text { Northern Marianas } \\
\text { Palau }\end{array}$ & 180 & 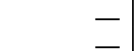 & 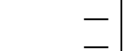 & 二 & - & 107 & - & 二 & 二 & 二 \\
\hline 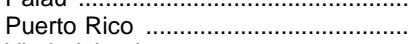 & 3,476 & 13,812 & 657 & 690 & 67 & 3,246 & 14,107 & $7 \overline{747}$ & 707 & 32 \\
\hline Virgin Islands & 56 & 195 & - & 64 & - & 54 & 209 & - & 55 & \\
\hline
\end{tabular}

${ }^{1}$ Includes degrees which require at least 6 years of college work for completion (including at least 2 years of preprofessional training). See Definitions for details.

-Data not available or not applicable.
SOURCE: U.S. Department of Education, National Center for Education Statistics, Integrated Postsecondary Education Data System (IPEDS), "Completions" survey. (This table was prepared May 1998.) 
HIGHER EDUCATION: DEGREES 279

Table 247.-Associate degrees conferred by institutions of higher education, by sex of student and field of study: $1989-90$ to $1993-94$

\begin{tabular}{|c|c|c|c|c|c|c|c|c|c|c|}
\hline \multirow{2}{*}{ Field of study } & \multicolumn{5}{|c|}{ Total } & \multicolumn{5}{|c|}{ Women } \\
\hline & $1989-90$ & $1990-91$ & 1991-92 & $1992-93$ & 1993-94 & $1989-90$ & $1990-91$ & 1991-92 & 1992-93 & 1993-94 \\
\hline 1 & 2 & 3 & 4 & 5 & 6 & 7 & 8 & 9 & 10 & 11 \\
\hline Total & 455,102 & 481,720 & 504,231 & 514,756 & 530,632 & 263,907 & 283,086 & 296,750 & 302,792 & 315,371 \\
\hline Agriculture and natural resources, total & 4,832 & 4,910 & 5,251 & 5,398 & 5,636 & 1,600 & 1,588 & 1,675 & 1,648 & 1,814 \\
\hline Agricultural business and production & 2,894 & 2,905 & 3,046 & 3,222 & 3,434 & 930 & 962 & 1,011 & 1,018 & 1,081 \\
\hline Agricultural sciences .......................... & 925 & 879 & 951 & 837 & 871 & 507 & 444 & 432 & 372 & 388 \\
\hline Conservation and renewable natural resources & 1,013 & 1,126 & 1,254 & 1,339 & 1,331 & 163 & 182 & 232 & 258 & 345 \\
\hline Architecture and related programs ............................ & 2,013 & 2,031 & 443 & 372 & 353 & 1,745 & 1,741 & 337 & 253 & 238 \\
\hline Area, ethnic, and cultural studies . & 68 & 19 & 29 & 33 & 75 & 56 & 13 & 20 & 23 & 50 \\
\hline Biological/life sciences ................. & 1,023 & 1,119 & 1,361 & 1,435 & 1,771 & 593 & 667 & 797 & 847 & 1,064 \\
\hline Business management and administrative services & 92,390 & 89,537 & 93,762 & 91,719 & 92,284 & 63,163 & 62,109 & 65,459 & 63,364 & 64,857 \\
\hline 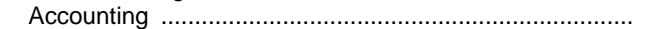 & 14,858 & 14,577 & 15,687 & 15,115 & 15,307 & 11,275 & 11,111 & 11,888 & 11,587 & 11,867 \\
\hline Business, general & 11,878 & 11,618 & 11,823 & 11,190 & 11,452 & 7,095 & 7,188 & 7,293 & 7,046 & 7,237 \\
\hline Business administration and management & 28,292 & 26,625 & 31,185 & 29,556 & 29,691 & 16,753 & 15,863 & 18,902 & 17,932 & 18,090 \\
\hline nd management, other …................. & 11,691 & 11,663 & 11,089 & 12,285 & 11,114 & 6,480 & 6,655 & 6,769 & 6,645 & 6,493 \\
\hline Business data processing & 8,532 & 8,182 & 6,394 & 6,405 & 6,883 & 4,733 & 4,775 & 3,679 & 3,693 & 3,853 \\
\hline Secretarial and related programs. & 17,139 & 16,872 & 17,584 & 17,168 & 17,837 & 16,827 & 16,517 & 16,928 & 16,461 & 17,317 \\
\hline Communications & 1,657 & 1,847 & 1,886 & 1,904 & 2,052 & 910 & 966 & 996 & 959 & 1,099 \\
\hline technologies & 2,027 & 2,032 & 1,794 & 1,828 & 2,469 & 678 & 681 & 649 & 632 & 834 \\
\hline rmation sciences & 7,574 & 7,677 & 9,290 & 9,196 & 9,301 & 3,768 & 3,770 & 4,725 & 4,655 & 4,677 \\
\hline Cons & 1,765 & 1,793 & 1,560 & 1,653 & 1,695 & 68 & 78 & 69 & 72 & 77 \\
\hline and personal services & 2,121 & 2,494 & 4,420 & 4,692 & 5,175 & 843 & 887 & 1,519 & 1,572 & 1,691 \\
\hline 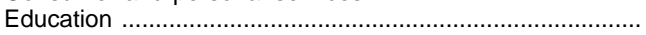 & 8,061 & 7,842 & 10,267 & 9,315 & 9,271 & 5,731 & 5,640 & 6,559 & 6,284 & 6,319 \\
\hline 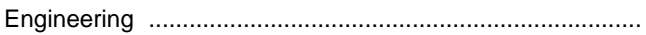 & 2,345 & 2,451 & 2,685 & 2,478 & 2,445 & 279 & 268 & 344 & 309 & 300 \\
\hline Engir & 40,033 & 37,890 & 35,861 & 36,321 & 35,618 & 4,006 & 3,724 & 3,757 & 3,690 & 3,799 \\
\hline nd literature/letters .............................. & 527 & 426 & 1,019 & 1,320 & 1,289 & 358 & 302 & 671 & 851 & 822 \\
\hline 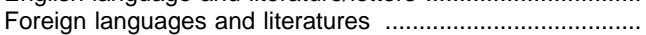 & 329 & 327 & 433 & 511 & 492 & 251 & 210 & 305 & 358 & 345 \\
\hline Health professions and related sciences ........................ & 64,113 & 70,833 & 79,453 & 86,237 & 94,601 & 6,125 & 1,495 & 8,648 & 73,266 & 79,449 \\
\hline Dental assisting & 3,697 & 3,810 & 4,013 & 4,165 & 4,259 & 3,502 & 3,612 & 3,822 & 3,929 & 3,977 \\
\hline Emergency medi & & & & & & & & & & \\
\hline & 332 & 371 & 378 & 442 & 510 & 100 & 116 & 114 & 139 & 155 \\
\hline Medic & 1,627 & 1,731 & 1,874 & 2,172 & 2,570 & 1,284 & 1,311 & 1,425 & 1,601 & 1,905 \\
\hline Medi & 1,404 & 1,496 & 1,960 & 2,130 & 2,785 & 1,375 & 1,451 & 1,741 & 1,907 & 2,672 \\
\hline Nursi & 0 & & 19 & 86 & & 0 & 4 & 13 & 70 & 5 \\
\hline 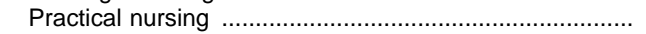 & 589 & 797 & 795 & 890 & 740 & 535 & 692 & 742 & 804 & 672 \\
\hline Nurs & 40,212 & 45,317 & 51,193 & 54,085 & 57,405 & 36,915 & 41,261 & 46,217 & 48,289 & 50,740 \\
\hline Healt & 16,252 & 17,306 & 19,221 & 22,267 & 26,326 & 12,414 & 13,048 & 14,574 & 16,527 & 19,323 \\
\hline vocational home economics & 7,798 & 8,067 & 6,436 & 6,914 & 7,463 & 6,080 & 6,243 & 49 & 6,259 & 6,821 \\
\hline Law & 4,552 & 5,484 & 7,053 & 8,028 & 8,681 & 3,967 & 4,892 & 6,146 & 7,069 & 7,652 \\
\hline sciences, general studies, and humanities & 133,466 & 142,722 & 154,594 & 158,040 & 165,106 & 78,768 & 84,977 & 91,777 & 94,173 & 99,025 \\
\hline Libr & 107 & 111 & 103 & 85 & 118 & 95 & 102 & 85 & 76 & 102 \\
\hline eting & 14,015 & 12,713 & 8,465 & 7,445 & 6,73 & 10,829 & 9,510 &, 494 & 5,646 & 5,049 \\
\hline ………....... & 756 & 670 & 744 & 743 & 70 & 270 & 264 & 280 & 315 & 309 \\
\hline & 7,704 & 7,640 & 10,264 & 10,966 & 11,3 & 431 & 445 & 71 & 686 & 738 \\
\hline ML & 8,176 & 7,454 & 7,841 & 8,486 & 8,4 & 4,156 & 3,998 & 4,059 & 4,411 & 4,382 \\
\hline studies & 485 & 425 & 620 & 717 & 75 & 200 & 177 & 251 & 288 & 301 \\
\hline W....... & 93 & 89 & 60 & 111 & 8 & 34 & 28 & 17 & 35 & 36 \\
\hline & 2,021 & 2,091 & 2,066 & 2,241 & 2 , & 811 & 901 & 861 & 945 & 1,069 \\
\hline $\mathrm{Ph}$ & 1,279 & 1,281 & 1,228 & 1,390 & 1,5 & 53 & 562 & 522 & 598 & 671 \\
\hline & 742 & 810 & 838 & 851 & 979 & 272 & 339 & 339 & 347 & 398 \\
\hline Precis & 8,616 & 9,093 & 9,005 & 9,204 & 9,357 & 1,898 & 1,975 & 1,872 & 1,811 & 1,846 \\
\hline & 12,855 & 13,564 & 15,117 & & & & & & & 5,131 \\
\hline orrections & 10,658 & 11,358 & 12,649 & 14,295 & 15,262 & 3,137 & 3,367 & 3,628 & 4,265 & 4,823 \\
\hline & 1,621 & 1,634 & 1,989 & 2,020 & 2,243 & 91 & 92 & 116 & 137 & 132 \\
\hline Prote & 576 & 572 & 479 & 519 & 694 & 174 & 140 & 132 & 143 & 176 \\
\hline & 1,115 & 997 & 1,209 & & & 829 & 740 & 871 & 955 & 1,040 \\
\hline rvices . & 2,613 & 2,779 & 3,162 & 3,301 & 3,696 & 2,076 & 2,243 & 523 & 2,653 & 2,938 \\
\hline hnologies .. & 129 & 85 & 172 & 52 & 265 & 15 & & 16 & & 20 \\
\hline & 2,872 & 2,505 & 3,160 & 3,930 & 3,936 & 1,611 & 1,494 & 1,760 & 2,252 & 2,400 \\
\hline & 653 & 578 & 496 & 508 & 641 & 264 & 243 & 216 & 227 & 299 \\
\hline ng workers & 2,619 & 2,609 & 2,418 & 2,210 & 1,922 & 395 & 469 & 440 & 360 & 320 \\
\hline Visua & 8,740 & 9,126 & 11,888 & 12,690 & 13,227 & 5,327 & 5,362 & 7,085 & 7,606 & 7,731 \\
\hline 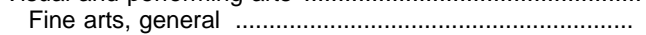 & 1,150 & 1,166 & 1,159 & 1,346 & 1,473 & 729 & 766 & 767 & 886 & 907 \\
\hline & 5,900 & 5,986 & 9,142 & 9,699 & 10,173 & 3,588 & 3,499 & 5,536 & 5,866 & 6,040 \\
\hline Visu & 1,690 & 1,974 & 1,587 & 1,645 & 1,5 & 1,010 & 1,097 & 782 & 854 & 784 \\
\hline 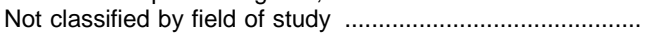 & 4,839 & 19,690 & 9,844 & 6,602 & 1,526 & 2,275 & 11,277 & 5,171 & 3,689 & 727 \\
\hline
\end{tabular}

SOURCE: U.S. Department of Education, National Center for Education Statistics, Integrated Postsecondary Education Data System (IPEDS), "Completions" surveys. (This table was prepared May 1998.) 
Table 248.-Associate degrees and other subbaccalaureate awards conferred by institutions of higher education, by length of curriculum, sex of student, and field of study: 1995-96

\begin{tabular}{|c|c|c|c|c|c|c|c|c|c|}
\hline \multirow{2}{*}{ Field of study } & \multicolumn{3}{|c|}{ Less than 1-year awards } & \multicolumn{3}{|c|}{ 1- to less than 4-year awards } & \multicolumn{3}{|c|}{ Associate degrees } \\
\hline & Total & Men & Women & Total & Men & Women & Total & Men & Women \\
\hline 1 & 2 & 3 & 4 & 5 & 6 & 7 & 8 & 9 & 10 \\
\hline Total & 100,888 & 47,358 & 53,530 & 139,688 & 55,878 & 83,810 & 555,216 & 219,514 & 335,702 \\
\hline Agriculture and natural resources, total & 1,749 & 1,327 & 422 & 1,874 & 1,325 & 549 & 6,182 & 4,218 & 1,964 \\
\hline Agricultural business and production & 1,471 & 1,151 & 320 & 1,677 & 1,186 & 491 & 3,846 & 2,574 & 1,272 \\
\hline Agricultural sciences $. . . \ldots \ldots \ldots \ldots \ldots \ldots \ldots . . . \ldots \ldots$ & 241 & 145 & 96 & 60 & 43 & 17 & 877 & 476 & 401 \\
\hline Conservation and renewable natural resources & 37 & 31 & 6 & 137 & 96 & 41 & 1,459 & 1,168 & 291 \\
\hline 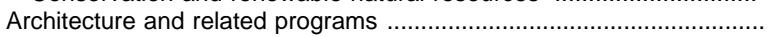 & 2 & 0 & 2 & 10 & 1 & 9 & 256 & 40 & 216 \\
\hline 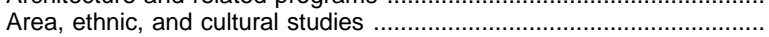 & 180 & 43 & 137 & 133 & 19 & 114 & 111 & 28 & 83 \\
\hline 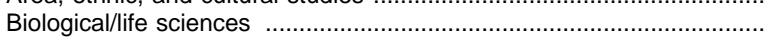 & 79 & 55 & 24 & 529 & 324 & 205 & 2,037 & 817 & 1,220 \\
\hline Business management and administrative services & 15,411 & 4,401 & 11,010 & 26,509 & 4,126 & 22,383 & 93,487 & 25,932 & 67,555 \\
\hline Accounting & 1,325 & 278 & 1,047 & 4,175 & 754 & 3,421 & 15,926 & 3,375 & 12,551 \\
\hline Business, general .......... & 580 & 301 & 279 & 998 & 321 & 677 & 11,397 & 4,105 & 7,292 \\
\hline Business administration and management & 1,535 & 620 & 915 & 2,724 & 976 & 1,748 & 28,901 & 10,695 & 18,206 \\
\hline Business and management, other $\ldots \ldots \ldots \ldots$ & 2,539 & 1,400 & 1,139 & 2,404 & 747 & 1,657 & 9,950 & 3,696 & 6,254 \\
\hline Business data processing $. . . \ldots \ldots \ldots . . . . .$. & 2,560 & 1,006 & 1,554 & 2,203 & 765 & 1,438 & 7,381 & 3,411 & 3,970 \\
\hline Secretarial and related programs .. & 6,872 & 796 & 6,076 & 14,005 & 563 & 13,442 & 19,932 & 650 & 19,282 \\
\hline Communications & 414 & 208 & 206 & 188 & 113 & 75 & 2,187 & 1,077 & 1,110 \\
\hline Communications technologies $\ldots \ldots \ldots \ldots . . . .$. & 91 & 54 & 37 & 369 & 204 & 165 & 1,757 & 1,169 & 588 \\
\hline Computer and information sciences & 4,349 & 2,309 & 2,040 & 3,570 & 1,702 & 1,868 & 9,658 & 4,954 & 4,704 \\
\hline Construction trades & 4,212 & 3,983 & 229 & 4,021 & 3,821 & 200 & 2,141 & 2,035 & 106 \\
\hline 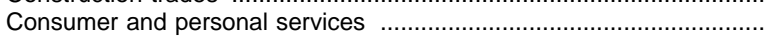 & 1,615 & 375 & 1,240 & 6,460 & 1,696 & 4,764 & 7,721 & 4,967 & 2,754 \\
\hline 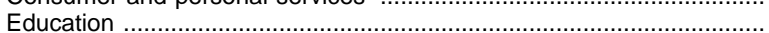 & 569 & 146 & 423 & 677 & 50 & 627 & 9,750 & 3,109 & 6,641 \\
\hline Engineering & 102 & 85 & 17 & 145 & 124 & 21 & 2,197 & 1,914 & 283 \\
\hline Engineering-related technolo.................... & 2,479 & 2,075 & 404 & 8,180 & 7,175 & 1,005 & 33,002 & 28,871 & 4,131 \\
\hline English language and literature/letters & 128 & 42 & 86 & 37 & 11 & 26 & 1,310 & 471 & 839 \\
\hline Foreign languages and literatures ....... & 419 & 155 & 264 & 29 & 7 & 22 & 607 & 163 & 444 \\
\hline Health professions and related sciences & 33,993 & 8,100 & 25,893 & 45,185 & 6,548 & 38,637 & 101,872 & 17,295 & 84,577 \\
\hline 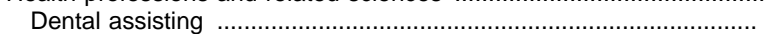 & 1,268 & 112 & 1,156 & 3,810 & 188 & 3,622 & 4,564 & 290 & 4,274 \\
\hline Emergency medical technician-ambulance and paramedic .... & 7,062 & 4,479 & 2,583 & 1,668 & 1,159 & 509 & 889 & 630 & 259 \\
\hline Medical lab technician & 103 & 19 & 84 & 96 & 22 & 74 & 2,982 & 776 & 2,206 \\
\hline Medical assisting ......... & 4,209 & 480 & 3,729 & 6,367 & 290 & 6,077 & 4,941 & 203 & 4,738 \\
\hline Nursing assisting & 10,529 & 1,059 & 9,470 & 280 & 26 & 254 & 7 & 0 & 7 \\
\hline 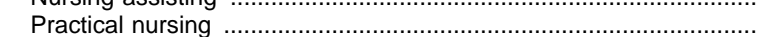 & 595 & 85 & 510 & 20,769 & 2,261 & 18,508 & 605 & 55 & 550 \\
\hline Nursing, R.N. and other ... & 2,536 & 260 & 2,276 & 2,248 & 265 & 1,983 & 56,562 & 7,307 & 49,255 \\
\hline Health sciences, other ........ & 7,691 & 1,606 & 6,085 & 9,947 & 2,337 & 7,610 & 31,322 & 8,034 & 23,288 \\
\hline 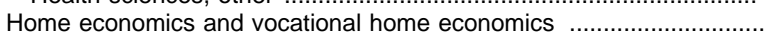 & 4,144 & 1,267 & 2,877 & 4,295 & 416 & 3,879 & 8,192 & 757 & 7,435 \\
\hline Law and legal studies & 850 & 143 & 707 & 2,006 & 287 & 1,719 & 9,106 & 1,119 & 7,987 \\
\hline 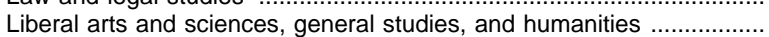 & 152 & 66 & 86 & 481 & 141 & 340 & 174,970 & 67,994 & 106,976 \\
\hline Library science & 117 & 10 & 107 & 57 & 8 & 49 & 94 & 13 & 81 \\
\hline Marketing operations/marketing and distribution & 2,388 & 754 & 1,634 & 1,624 & 407 & 1,217 & 5,960 & 1,424 & 4,536 \\
\hline Mathematics & 1 & 1 & 0 & 1 & 1 & 0 & 758 & 463 & 295 \\
\hline Mechanics and repairers ......... & 4,614 & 4,292 & 322 & 15,624 & 14,870 & 754 & 12,524 & 11,723 & 801 \\
\hline 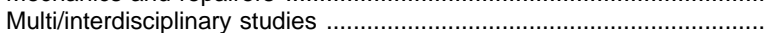 & 439 & 69 & 370 & 134 & 74 & 60 & 8,611 & 4,212 & 4,399 \\
\hline Parks, recreation, leisure, and fitness studies & 95 & 34 & 61 & 130 & 52 & 78 & 936 & 545 & 391 \\
\hline Philosophy and religion & 67 & 25 & 42 & 19 & 13 & 6 & 83 & 45 & 38 \\
\hline Physical sciences ................... & 86 & 39 & 47 & 81 & 51 & 30 & 2,612 & 1,458 & 1,154 \\
\hline Physical sciences, other & 26 & 11 & 15 & 17 & 13 & 4 & 1,749 & 961 & 788 \\
\hline Science technologies ......... & 60 & 28 & 32 & 64 & 38 & 26 & 863 & 497 & 366 \\
\hline Precision production trades..... & 4,009 & 3,285 & 724 & 8,104 & 6,711 & 1,393 & 10,217 & 8,119 & 2,098 \\
\hline Protective services .................. & 10,156 & 7,954 & 2,202 & 2,821 & 2,008 & 813 & 19,196 & 13,427 & 5,769 \\
\hline 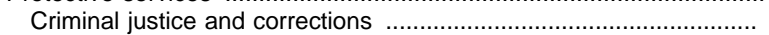 & 8,277 & 6,279 & 1,998 & 2,222 & 1,489 & 733 & 15,990 & 10,610 & 5,380 \\
\hline Fire control and safety .................. & 1,844 & 1,643 & 201 & 489 & 448 & 41 & 2,523 & 2,357 & 166 \\
\hline Protective services, other & 35 & 32 & 3 & 110 & 71 & 39 & 683 & 460 & 223 \\
\hline Psychology ... & 24 & 6 & 18 & 52 & 13 & 39 & 1,583 & 406 & 1,177 \\
\hline Public administration and services & 544 & 183 & 361 & 548 & 129 & 419 & 4,218 & 765 & 3,453 \\
\hline R.O.T.C. and military technologies & 0 & 0 & 0 & 0 & 0 & 0 & 556 & 514 & 42 \\
\hline (n) & 22 & 10 & 12 & 29 & 9 & 20 & 4,021 & 1,488 & 2,533 \\
\hline Theological studies/religious vocations & 82 & 35 & 47 & 542 & 293 & 249 & 608 & 314 & 294 \\
\hline 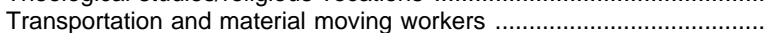 & 6,180 & 5,354 & 826 & 749 & 629 & 120 & 1,571 & 1,325 & 246 \\
\hline Visual and performing arts & 831 & 399 & 432 & 3,861 & 2,285 & 1,576 & 13,534 & 5,806 & 7,728 \\
\hline 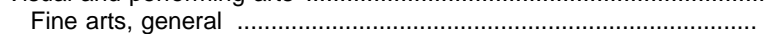 & 46 & 3 & 43 & 129 & 62 & 67 & 1,515 & 569 & 946 \\
\hline 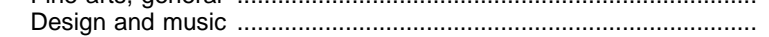 & 437 & 211 & 226 & 2,863 & 1,548 & 1,315 & 10,579 & 4,524 & 6,055 \\
\hline Visual and performing arts, other................... & 348 & 185 & 163 & 869 & 675 & 194 & 1,440 & 713 & 727 \\
\hline Not classified by field of study ......... & 295 & 74 & 221 & 614 & 235 & 379 & 1,591 & 537 & 1,054 \\
\hline
\end{tabular}

SOURCE: U.S. Department of Education, National Center for Education Statistics, Integrated Postsecondary Education Data System (IPEDS), "Completions" survey. (This table was prepared May 1998.) 
Table 249.-Associate degrees and other subbaccalaureate awards conferred by institutions of higher education, by length of curriculum, sex of student, and field of study: 1994-95

\begin{tabular}{|c|c|c|c|c|c|c|c|c|c|}
\hline \multirow{2}{*}{ Field of study } & \multicolumn{3}{|c|}{ Less than 1-year awards } & \multicolumn{3}{|c|}{ 1- to less than 4-year awards } & \multicolumn{3}{|c|}{ Associate degrees } \\
\hline & Total & Men & Women & Total & Men & Women & Total & Men & Women \\
\hline 1 & 2 & 3 & 4 & 5 & 6 & 7 & 8 & 9 & 10 \\
\hline Total & 85,195 & 42,636 & 42,559 & 152,037 & 62,646 & 89,391 & 539,691 & 218,352 & 321,339 \\
\hline Agriculture and natural resources, total & 1,705 & 1,320 & 385 & 4,067 & 2,242 & 1,825 & 5,730 & 4,001 & 1,729 \\
\hline Agricultural business and production & 1,311 & 997 & 314 & 1,344 & 913 & 431 & 3,564 & 2,458 & 1,106 \\
\hline Agricultural sciences ... & 334 & 274 & 60 & 1,548 & 427 & 1,121 & 829 & 465 & 364 \\
\hline Conservation and renewable natural resources & 60 & 49 & 11 & 1,175 & 902 & 273 & 1,337 & 1,078 & 259 \\
\hline Architecture and related programs ........................ & 15 & 4 & 11 & 10 & 2 & 8 & 277 & 70 & 207 \\
\hline Area, ethnic, and cultural studies & 118 & 28 & 90 & 136 & 10 & 126 & 68 & 17 & 51 \\
\hline Biological/life sciences ................ & 297 & 152 & 145 & 62 & 32 & 30 & 1,879 & 752 & 1,127 \\
\hline Business management and administrative services & 12,446 & 3,451 & 8,995 & 27,005 & 4,835 & 22,170 & 90,113 & 26,629 & 63,484 \\
\hline Accounting & 1,019 & 215 & 804 & 4,470 & 796 & 3,674 & 14,970 & 3,313 & 11,657 \\
\hline Business, general ..... & 447 & 209 & 238 & 906 & 318 & 588 & 11,622 & 4,368 & 7,254 \\
\hline Business administration and management & 1,687 & 674 & 1,013 & 2,367 & 834 & 1,533 & 28,968 & 11,076 & 17,892 \\
\hline Business and management, other $\ldots \ldots \ldots \ldots \ldots$ & 1,913 & 832 & 1,081 & 3,336 & 1,429 & 1,907 & 10,233 & 4,072 & 6,161 \\
\hline Business data processing ................ & 1,401 & 508 & 893 & 2,067 & 696 & 1,371 & 6,962 & 3,275 & 3,687 \\
\hline Secretarial and related programs. & 5,979 & 1,013 & 4,966 & 13,859 & 762 & 13,097 & 17,358 & 525 & 16,833 \\
\hline Communications & 1,712 & 1,182 & 530 & 348 & 134 & 214 & 3,160 & 1,624 & 1,536 \\
\hline Communications technologies ........ & 90 & 63 & 27 & 327 & 198 & 129 & 1,984 & 1,298 & 686 \\
\hline Computer and information sciences & 2,154 & 1,120 & 1,034 & 5,295 & 2,473 & 2,822 & 9,152 & 4,743 & 4,409 \\
\hline Construction trades & 2,310 & 2,133 & 177 & 4,582 & 4,328 & 254 & 1,728 & 1,598 & 130 \\
\hline Consumer and personal services .. & 1,518 & 425 & 1,093 & 6,120 & 1,371 & 4,749 & 5,626 & 3,747 & 1,879 \\
\hline Education . & 355 & 37 & 318 & 1,461 & 152 & 1,309 & 9,658 & 3,058 & 6,600 \\
\hline Engineering & 209 & 181 & 28 & 309 & 293 & 16 & 2,232 & 1,931 & 301 \\
\hline Engineering-related technologies & 2,050 & 1,618 & 432 & 7,491 & 6,638 & 853 & 34,732 & 30,820 & 3,912 \\
\hline English language and literature/letters & 98 & 28 & 70 & 50 & 14 & 36 & 1,548 & 505 & 1,043 \\
\hline Foreign languages and literatures & 248 & 86 & 162 & 196 & 118 & 78 & 616 & 177 & 439 \\
\hline 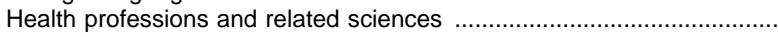 & 25,428 & 6,785 & 18,643 & 42,467 & 6,590 & 35,877 & 98,474 & 16,530 & 81,944 \\
\hline Dental assisting & 298 & 14 & 284 & 2,673 & 92 & 2,581 & 4,312 & 282 & 4,030 \\
\hline Emergency medical technician-ambulance and paramedic .............. & 6,215 & 4,022 & 2,193 & 1,619 & 1,149 & 470 & 771 & 536 & 235 \\
\hline Medical lab technician & 98 & 13 & 85 & 154 & 59 & 95 & 2,769 & 742 & 2,027 \\
\hline 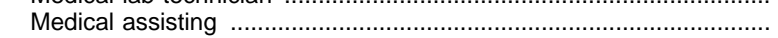 & 1,069 & 97 & 972 & 3,886 & 115 & 3,771 & 3,544 & 135 & 3,409 \\
\hline Nursing assisting ......... & 8,794 & 1,019 & 7,775 & 187 & 19 & 168 & 2 & 0 & 2 \\
\hline Practical nursing & 571 & 57 & 514 & 19,976 & 2,287 & 17,689 & 772 & 86 & 686 \\
\hline Nursing, R.N. and other & 2,156 & 251 & 1,905 & 2,897 & 364 & 2,533 & 57,456 & 7,142 & 50,314 \\
\hline Health sciences, other & 6,227 & 1,312 & 4,915 & 11,075 & 2,505 & 8,570 & 28,848 & 7,607 & 21,241 \\
\hline Home economics and vocational home economics & 5,218 & 2,129 & 3,089 & 8,582 & 1,638 & 6,944 & 7,821 & 815 & 7,006 \\
\hline Law and legal studies & 902 & 130 & 772 & 1,686 & 281 & 1,405 & 9,140 & 1,163 & 7,977 \\
\hline Liberal arts and sciences, general studies, and humanities & 334 & 249 & 85 & 1,273 & 423 & 850 & 170,817 & 67,834 & 102,983 \\
\hline Library science & 73 & 5 & 68 & 53 & 8 & 45 & 101 & 9 & 92 \\
\hline 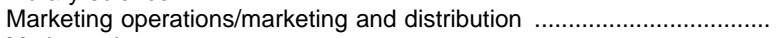 & 2,152 & 710 & 1,442 & 2,444 & 579 & 1,865 & 6,187 & 1,526 & 4,661 \\
\hline Mathematics & 5 & 4 & 1 & 1 & 0 & 1 & 782 & 438 & 344 \\
\hline Mechanics and repairers & 4,850 & 4,355 & 495 & 20,835 & 19,127 & 1,708 & 11,497 & 10,754 & 743 \\
\hline Multi/interdisciplinary studies & 181 & 17 & 164 & 130 & 56 & 74 & 8,692 & 4,228 & 4,464 \\
\hline Parks, recreation, leisure, and fitness studies. & 86 & 43 & 43 & 145 & 73 & 72 & 864 & 501 & 363 \\
\hline Philosophy and religion & 46 & 19 & 27 & 483 & 192 & 291 & 81 & 52 & 29 \\
\hline Physical sciences ................... & 32 & 16 & 16 & 79 & 47 & 32 & 2,456 & 1,424 & 1,032 \\
\hline Physical sciences, other & 16 & 8 & 8 & 29 & 21 & 8 & 1,645 & 921 & 724 \\
\hline Science technologies ....... & 16 & 8 & 8 & 50 & 26 & 24 & 811 & 503 & 308 \\
\hline Precision production trades & 2,956 & 2,424 & 532 & 7,179 & 5,845 & 1,334 & 9,344 & 7,453 & 1,891 \\
\hline Protective services & 8,678 & 6,796 & 1,882 & 3,536 & 2,628 & 908 & 19,709 & 14,202 & 5,507 \\
\hline Criminal justice and corrections & 7,499 & 5,737 & 1,762 & 2,943 & 2,108 & 835 & 16,584 & 11,408 & 5,176 \\
\hline 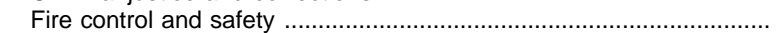 & 1,117 & 1,007 & 110 & 500 & 466 & 34 & 2,447 & 2,294 & 153 \\
\hline Protective services, other & 62 & 52 & 10 & 93 & 54 & 39 & 678 & 500 & 178 \\
\hline Psychology .................... & 33 & 9 & 24 & 69 & 19 & 50 & 1,600 & 446 & 1,154 \\
\hline Public administration and services & 608 & 235 & 373 & 732 & 230 & 502 & 3,882 & 783 & 3,099 \\
\hline R.O.T.C. and military technologies & 1 & 1 & 0 & 0 & 0 & 0 & 364 & 331 & 33 \\
\hline Social sciences and history .................... & 136 & 114 & 22 & 96 & 41 & 55 & 3,634 & 1,461 & 2,173 \\
\hline 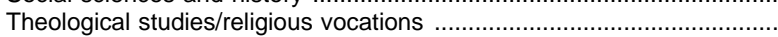 & 65 & 33 & 32 & 617 & 332 & 285 & 607 & 309 & 298 \\
\hline 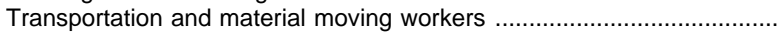 & 7,759 & 6,601 & 1,158 & 668 & 466 & 202 & 1,446 & 1,226 & 220 \\
\hline 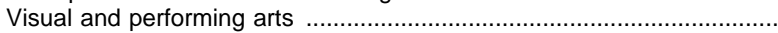 & 324 & 131 & 193 & 3,401 & 1,191 & 2,210 & 12,544 & 5,275 & 7,269 \\
\hline Fine arts, general ............... & 19 & 4 & 15 & 469 & 190 & 279 & 1,420 & 483 & 937 \\
\hline 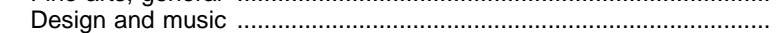 & 276 & 113 & 163 & 2,234 & 671 & 1,563 & 9,805 & 4,176 & 5,629 \\
\hline Visual and performing arts, other & 29 & 14 & 15 & 698 & 330 & 368 & 1,319 & 616 & 703 \\
\hline Not classified by field of study & 3 & 2 & 1 & 102 & 40 & 62 & 1,146 & 622 & 524 \\
\hline
\end{tabular}

SOURCE: U.S. Department of Education, National Center for Education Statistics, In tegrated Postsecondary Education Data System (IPEDS), "Completions" survey. (This table was prepared March 1997.) 


\begin{tabular}{|c|c|c|c|c|c|c|c|c|c|c|c|c|c|c|c|c|}
\hline Discipline division & $1970-71$ & $1975-76$ & $1980-81$ & $1983-84$ & $1984-85$ & $1985-86$ & $1986-87$ & $1987-88$ & $1988-89$ & 1989-90 & $1990-91$ & 1991-92 & 1992-93 & $1993-94$ & 1994-95 & 1995-96 \\
\hline 1 & 2 & 3 & 4 & 5 & 6 & 7 & 8 & 9 & 10 & 11 & 12 & 13 & 14 & 15 & 6 & 7 \\
\hline Total . & 39,730 & 5,746 & 35,140 & 4,309 & 9,477 & 987,823 & 1,264 & 4,829 & 18,755 & 551,344 & $1,094,538$ & 136,553 & $1,165,178$ & 169,275 & $1,160,134$ & 1,164 , \\
\hline 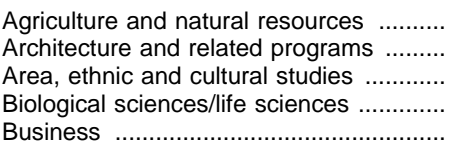 & $\begin{array}{r}12,672 \\
5,570 \\
2,582 \\
35,743 \\
114,729\end{array}$ & $\begin{array}{r}19,402 \\
9,146 \\
3,577 \\
54,275 \\
142,034\end{array}$ & $\begin{array}{r}21,886 \\
9,455 \\
2,887 \\
43,216 \\
198,983\end{array}$ & \begin{tabular}{|r|}
19,317 \\
9,186 \\
3,005 \\
38,640 \\
229,478
\end{tabular} & $\begin{array}{r}18,107 \\
9,325 \\
2,985 \\
38,445 \\
232,636\end{array}$ & $\begin{array}{r}16,823 \\
9,119 \\
3,178 \\
38,524 \\
237,319\end{array}$ & $\begin{array}{r}14,991 \\
8,950 \\
3,427 \\
38,121 \\
240,546\end{array}$ & $\begin{array}{r}14,222 \\
8,603 \\
3,601 \\
36,755 \\
243,021\end{array}$ & $\begin{array}{r}13,492 \\
9,150 \\
4,102 \\
36,059 \\
246,399\end{array}$ & $\begin{array}{r}12,900 \\
9,364 \\
4,613 \\
37,204 \\
248,698\end{array}$ & $\begin{array}{r}13,124 \\
9,781 \\
4,884 \\
39,530 \\
249,311\end{array}$ & $\begin{array}{r}15,124 \\
8,753 \\
5,342 \\
42,941 \\
256,603\end{array}$ & $\begin{array}{r}16,778 \\
9,167 \\
5,481 \\
47,038 \\
256,842\end{array}$ & & $\begin{array}{r}19,841 \\
8,756 \\
5,706 \\
55,984 \\
234,323\end{array}$ & $\begin{array}{r}21,431 \\
8,352 \\
5,786 \\
60,994 \\
227,102\end{array}$ \\
\hline 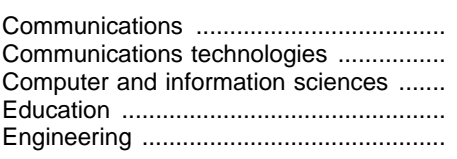 & $\begin{array}{r}10,324 \\
478 \\
2,388 \\
176,307 \\
44,898\end{array}$ & $\begin{array}{r}20,045 \\
1,237 \\
5,652 \\
154,437 \\
38,388\end{array}$ & $\begin{array}{r}29,428 \\
1,854 \\
15,121 \\
108,074 \\
63,287\end{array}$ & $\begin{array}{r}38,586 \\
1,527 \\
32,172 \\
92,299 \\
75,638\end{array}$ & $\begin{array}{l}, 358 \\
, 644 \\
, 878 \\
, 072 \\
, 066\end{array}$ & $\begin{array}{r}41,666 \\
1,410 \\
41,889 \\
87,114 \\
76,225\end{array}$ & $\begin{array}{l}3,953 \\
1,384 \\
, 589 \\
3,936 \\
3,747\end{array}$ & $\begin{array}{r}45,410 \\
1,239 \\
34,523 \\
91,112 \\
69,380\end{array}$ & $\begin{array}{r}47,405 \\
1,204 \\
30,454 \\
96,913 \\
66,099\end{array}$ & $\begin{array}{r}0,114 \\
1,194 \\
7,257 \\
5,112 \\
3,609\end{array}$ & $\begin{array}{r}51,650 \\
1,123 \\
25,083 \\
110,807 \\
61,531\end{array}$ & $\begin{array}{r}54,257 \\
720 \\
24,557 \\
108,006 \\
61,206\end{array}$ & $\begin{array}{r}53,874 \\
832 \\
24,200 \\
107,781 \\
61,973\end{array}$ & $\begin{array}{r}51,164 \\
663 \\
24,200 \\
107,600 \\
62,220\end{array}$ & $\begin{array}{r}48,104 \\
699 \\
24,404 \\
106,079 \\
62,342\end{array}$ & $\begin{array}{r}47,320 \\
683 \\
24,098 \\
105,509 \\
62,114\end{array}$ \\
\hline $\begin{array}{l}\ldots \ldots \ldots . \\
\text { tters .... } \\
\ldots \ldots \ldots . . \\
\text { iences } \\
\text { home }\end{array}$ & $\begin{array}{r}5,148 \\
64,342 \\
20,536 \\
25,226\end{array}$ & $\begin{array}{r}7,943 \\
42,006 \\
16,484 \\
53,958\end{array}$ & $\begin{array}{l}1,713 \\
2,254 \\
1,273 \\
3,649\end{array}$ & ,, 384 & $\begin{array}{l}62 \\
18 \\
27 \\
22\end{array}$ & $\begin{array}{r}, 4355 \\
,, 552 \\
, 984 \\
+, 396\end{array}$ & $\begin{array}{l}69 \\
84 \\
34 \\
03\end{array}$ & $\begin{array}{l}, 126 \\
, 661 \\
, 926 \\
, 644\end{array}$ & $\begin{array}{l}73 \\
70 \\
93 \\
5\end{array}$ & \begin{tabular}{l|}
13 \\
19 \\
86 \\
02
\end{tabular} & $\begin{array}{l}19 \\
41 \\
33 \\
70\end{array}$ & $\begin{array}{l}4,951 \\
3,903 \\
1,720\end{array}$ & $\begin{array}{l}78 \\
33 \\
87 \\
89\end{array}$ & $\begin{array}{r}05 \\
24 \\
78 \\
21\end{array}$ & $\begin{array}{l}12 \\
01 \\
75 \\
55\end{array}$ & $\begin{array}{l}0,698 \\
3,952 \\
4,036\end{array}$ \\
\hline & 545 & 531 & 776 & 1,272 & 157, & 1,197 & 1,178 & 1,303 & 1,976 & 1,592 & 1,758 & 2,14 & 2,056 & 2,171 & 2,032 & ,052 \\
\hline & $\begin{array}{l}7,481 \\
1,013\end{array}$ & $\begin{array}{r}18,855 \\
843\end{array}$ & $\begin{array}{r}1,643 \\
375\end{array}$ & $\begin{array}{l}, 479 \\
252\end{array}$ & $\begin{array}{r}818 \\
197\end{array}$ & \begin{tabular}{r|r}
, 336 \\
155
\end{tabular} & $\begin{array}{r}3,717 \\
136\end{array}$ & $\begin{array}{r}4,274 \\
119\end{array}$ & $\begin{array}{r}26,388 \\
121\end{array}$ & $\begin{array}{r}27,985 \\
77\end{array}$ & $\begin{array}{r}30,526 \\
90\end{array}$ & $\begin{array}{r}32,174 \\
97\end{array}$ & & & & $\begin{array}{r}3,997 \\
58\end{array}$ \\
\hline . & $\begin{array}{r}24,937 \\
6,286\end{array}$ & $\begin{array}{l}16,329 \\
13,588\end{array}$ & $\begin{array}{l}11,433 \\
12,848\end{array}$ & $\begin{array}{l}3,764 \\
3,940\end{array}$ & $\begin{array}{l}15,861 \\
12,978\end{array}$ & $\begin{array}{l}17,147 \\
13,489\end{array}$ & $\begin{array}{l}16,999 \\
13,933\end{array}$ & $\begin{array}{l}16,608 \\
14,723\end{array}$ & $\begin{array}{l}15,994 \\
15,168\end{array}$ & $\begin{array}{l}5,176 \\
6,267\end{array}$ & $\begin{array}{l}15,310 \\
17,561\end{array}$ & $\begin{array}{l}14,783 \\
20,647\end{array}$ & $\begin{array}{l}4,812 \\
3,955\end{array}$ & $\begin{array}{l}14,396 \\
25,167\end{array}$ & $\begin{array}{l}3,723 \\
,, 033\end{array}$ & $\begin{array}{l}3,143 \\
6,515\end{array}$ \\
\hline & $\begin{array}{l}1,621 \\
8,146\end{array}$ & 82 & 29 & 4850 & 25 & 620 & 264 & $\begin{array}{l}4,235 \\
5963\end{array}$ & 4,376 & 32 & 4,315 & ,446 & 59 & & 89 & 983 \\
\hline Protec & $\begin{array}{r}21,412 \\
2,045\end{array}$ & $\begin{array}{r}21,465 \\
- \\
12,507\end{array}$ & $\begin{array}{r}23,952 \\
- \\
13,707\end{array}$ & $\begin{array}{r}23,651 \\
371 \\
12,654\end{array}$ & $\begin{array}{r}23,704 \\
553 \\
12,510\end{array}$ & $\begin{array}{r}21,717 \\
400 \\
12,704\end{array}$ & $\begin{array}{r}20,070 \\
455 \\
12,930\end{array}$ & $\begin{array}{r}17,806 \\
481 \\
13,367\end{array}$ & $\begin{array}{r}17,186 \\
482 \\
14,698\end{array}$ & $\begin{array}{r}16,066 \\
528 \\
15,354\end{array}$ & $\begin{array}{r}16,344 \\
460 \\
16,806\end{array}$ & $\begin{array}{r}16,960 \\
378 \\
18,855\end{array}$ & $\begin{array}{r}17,545 \\
388 \\
20,902\end{array}$ & $\begin{array}{r}18,400 \\
420 \\
23,009\end{array}$ & $\begin{array}{r}19,177 \\
353 \\
24,157\end{array}$ & $\begin{array}{r}19,647 \\
401 \\
24,810\end{array}$ \\
\hline ;. & $\begin{array}{r}38,187 \\
5,466 \\
357 \\
155,324\end{array}$ & $\begin{array}{r}50,278 \\
15,440 \\
952 \\
126,396\end{array}$ & $\begin{array}{r}, 068 \\
, 707 \\
42 \\
, 513\end{array}$ & $\begin{array}{r}2,570 \\
195 \\
3,323\end{array}$ & $\begin{array}{l}, 900 \\
, 754 \\
299 \\
, 570\end{array}$ & \begin{tabular}{r|r}
, 628 \\
, 887 \\
256 \\
, 840 \\
\end{tabular} & $\begin{array}{l}994 \\
328 \\
384 \\
342 \\
\end{array}$ & $\begin{array}{r}385 \\
82 \\
460 \\
\end{array}$ & $\begin{array}{r}13,162 \\
198 \\
108,151\end{array}$ & $\begin{array}{r}53,952 \\
13,908 \\
196 \\
118,083\end{array}$ & $\begin{array}{r}3,655 \\
4,350 \\
183 \\
5,107\end{array}$ & $\begin{array}{l}, 987 \\
184 \\
, 974\end{array}$ & $\begin{array}{r}728 \\
775 \\
11 \\
703\end{array}$ & $\begin{array}{r}259 \\
815 \\
19 \\
680\end{array}$ & $\begin{array}{r}083 \\
, 086 \\
27 \\
154 \\
.\end{array}$ & $\begin{array}{r}3,291 \\
9,849 \\
7 \\
6,479\end{array}$ \\
\hline Transportation and material moving & 4 & 520 & 341 & 920 & 047 & 607 & 730 & 565 & 318 & 200 & 813 & 729 & 433 & 434 & 578 & 358 \\
\hline 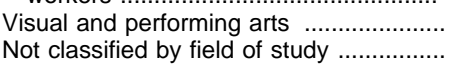 & $\begin{array}{r}30,394 \\
0\end{array}$ & $\begin{array}{r}42,138 \\
0\end{array}$ & $\begin{array}{r}0,479 \\
0\end{array}$ & $\begin{array}{r}40,131 \\
0\end{array}$ & $\begin{array}{r}3,140 \\
0\end{array}$ & $\begin{array}{r}37,241 \\
0\end{array}$ & $\begin{array}{r}15 \\
0\end{array}$ & 1,801 & 2,405 & $\begin{array}{r}39,934 \\
2,713\end{array}$ & $\begin{array}{l}42,186 \\
13,258\end{array}$ & $\begin{array}{r}46,522 \\
6,720\end{array}$ & $\begin{array}{r}47,761 \\
5,247\end{array}$ & $\begin{array}{r}49,053 \\
3,302\end{array}$ & $\begin{array}{r}r, 690 \\
1,346\end{array}$ & $\begin{array}{r}49,296 \\
1,756\end{array}$ \\
\hline
\end{tabular}

-Data not available or not applicable.

NOTE.-The new Classification of Instructional Programs was initiated in 1991-92. The figures for earlier years have been reclassified when necessary to make them conform to the new taxonomy. To facilitate trend comparisons, certain natural resources" includes Agricultural business and production, Agricultural sciences, and Conservation and renewable natural resources; "Business" includes Business management and administrative services, Marketing operations marketing and distribution, and Consumer and personal services; and "Engineering-related technologies" includes Engineering-related technologies, Mechanics and repairers, and Construction trades.

SOURCE: U.S. Department of Education, National Center for Education Statistics, Higher Education General Informavey (HEGIS), "Degrees and Other Formal Awards Conferred" surveys, and Integrated Postsecondary Education System (IPEDS), "Completions" surveys. (This table was prepared May 1998.) 
Table 251.-Master's degrees conferred by institutions of higher education, by discipline division: 1970-71 to 1995-96

\begin{tabular}{|c|c|c|c|c|c|c|c|c|c|c|c|c|c|c|c|c|}
\hline Discipline division & 970-71 & 1975-76 & 1980-81 & 1983-84 & 1984-85 & $1985-86$ & $\mid 1986-87$ & 1987-88 & $1988-89$ & $1989-90$ & 1990-91 & 1991-92 & 1992-93 & 1993-94 & 1994-95 & 1995-96 \\
\hline 1 & 2 & 3 & 4 & 5 & 6 & 7 & 8 & 9 & 10 & 11 & 12 & 13 & 14 & 15 & 16 & 17 \\
\hline Total . & 0,509 & 1,771 & 5,739 & 4,263 & 6,251 & 8,567 & 9,349 & 9,317 & 621 & 301 & 168 & 838 & 585 & 070 & 629 & ,30 \\
\hline $\begin{array}{l}\text { griculture and natural resources ............ } \\
\text { chitecture and related programs } \\
\text { ea, ethnic, and cultural studies } \\
\text { ological.......... } \\
\text { usiness sciences/life sciences .............. }\end{array}$ & $\begin{array}{r}2,457 \\
1,705 \\
1,032 \\
5,728 \\
25,977\end{array}$ & $\begin{array}{r}3,340 \\
3,215 \\
995 \\
6,582 \\
42,054\end{array}$ & $\begin{array}{r}4,003 \\
3,153 \\
804 \\
5,978 \\
57,391\end{array}$ & $\begin{array}{r}4,178 \\
3,223 \\
897 \\
5,406 \\
66,150\end{array}$ & $\begin{array}{r}3,928 \\
3,275 \\
904 \\
5,059 \\
66,996\end{array}$ & $\begin{array}{r}3,801 \\
3,260 \\
945 \\
5,013 \\
66,689\end{array}$ & $\begin{array}{r}3,522 \\
3,163 \\
864 \\
4,952 \\
67,093\end{array}$ & $\begin{array}{r}3,479 \\
3,159 \\
911 \\
4,784 \\
69,230\end{array}$ & $\begin{array}{r}3,245 \\
3,383 \\
1,016 \\
4,961 \\
73,065\end{array}$ & $\begin{array}{r}3,382 \\
3,499 \\
1,212 \\
4,869 \\
76,676\end{array}$ & $\begin{array}{r}3,295 \\
3,490 \\
1,263 \\
4,765 \\
78,255\end{array}$ & $\begin{array}{r}3,735 \\
3,640 \\
1,385 \\
4,785 \\
84,642\end{array}$ & $\begin{array}{r}3,965 \\
3,808 \\
1,523 \\
4,756 \\
89,615\end{array}$ & $\begin{array}{r}4,119 \\
3,943 \\
1,633 \\
5,196 \\
93,437\end{array}$ & $\begin{array}{r}4,252 \\
3,923 \\
1,639 \\
5,393 \\
93,809\end{array}$ & $\begin{array}{r}4,569 \\
3,993 \\
1,713 \\
6,157 \\
93,982\end{array}$ \\
\hline 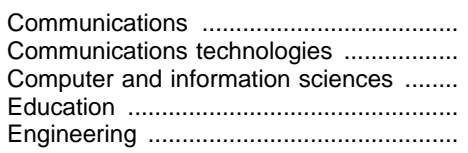 & $\begin{array}{r}1,770 \\
86 \\
1,588 \\
87,666 \\
16,309\end{array}$ & $\begin{array}{r}2,961 \\
165 \\
2,603 \\
126,061 \\
16,014\end{array}$ & $\begin{array}{r}2,896 \\
209 \\
4,218 \\
96,713 \\
16,386\end{array}$ & $\begin{array}{r}3,513 \\
143 \\
6,190 \\
75,664 \\
20,078\end{array}$ & $\begin{array}{r}3,460 \\
209 \\
7,101 \\
74,654 \\
20,905\end{array}$ & $\begin{array}{r}3,500 \\
323 \\
8,070 \\
74,801 \\
21,040\end{array}$ & $\begin{array}{r}3,622 \\
271 \\
8,481 \\
74,045 \\
22,015\end{array}$ & $\begin{array}{r}3,678 \\
247 \\
9,197 \\
76,566 \\
22,627\end{array}$ & $\begin{array}{r}3,940 \\
317 \\
9,414 \\
81,174 \\
23,740\end{array}$ & $\begin{array}{r}4,063 \\
299 \\
9,677 \\
84,881 \\
23,863\end{array}$ & $\begin{array}{r}4,123 \\
213 \\
9,324 \\
87,343 \\
23,962\end{array}$ & $\begin{array}{r}4,180 \\
284 \\
9,530 \\
92,668 \\
24,983\end{array}$ & $\begin{array}{r}4,754 \\
455 \\
10,163 \\
96,028 \\
27,626\end{array}$ & $\begin{array}{r}5,005 \\
414 \\
10,416 \\
98,938 \\
28,621\end{array}$ & $\begin{array}{r}5,142 \\
467 \\
10,326 \\
101,242 \\
28,553\end{array}$ & $\begin{array}{r}5,080 \\
524 \\
10,151 \\
106,253 \\
27,441\end{array}$ \\
\hline $\begin{array}{l}\ldots . . . \\
\ldots . . \\
\text { es } \\
\text { e }\end{array}$ & $\begin{array}{r}134 \\
10,686 \\
5,217 \\
5,749\end{array}$ & $\begin{array}{r}328 \\
8,809 \\
4,190 \\
12,556\end{array}$ & $\begin{array}{r}323 \\
5,929 \\
2,690 \\
16,515\end{array}$ & $\begin{array}{r}577 \\
5,010 \\
2,581 \\
17,411\end{array}$ & $\begin{array}{r}650 \\
5,187 \\
2,471 \\
17,385\end{array}$ & $\begin{array}{r}617 \\
5,518 \\
2,494 \\
18,573\end{array}$ & $\begin{array}{r}639 \\
5,483 \\
2,379 \\
18,394\end{array}$ & $\begin{array}{r}758 \\
5,562 \\
2,469 \\
18,657 \\
2,047\end{array}$ & $\begin{array}{r}828 \\
5,950 \\
2,595 \\
19,268\end{array}$ & $\begin{array}{r}909 \\
6,567 \\
2,760 \\
20,321 \\
2,100\end{array}$ & $\begin{array}{r}996 \\
7,026 \\
2,800 \\
21,200\end{array}$ & $\begin{array}{r}994 \\
7,450 \\
2,926 \\
23,065\end{array}$ & $\begin{array}{l}1,100 \\
7,790 \\
3,198 \\
25,718\end{array}$ & $\begin{array}{l}1,133 \\
7,885 \\
3,288 \\
8,025\end{array}$ & $\begin{array}{r}1,117 \\
7,845 \\
3,136 \\
1,243\end{array}$ & $\begin{array}{r}7,893 \\
3,124 \\
33,398\end{array}$ \\
\hline & 955 & 1,442 & 1,832 & 1,802 & 1,796 & 1,924 & 1,943 & 1,880 & 2,013 & 1,888 & 2,057 & 2,369 & 2,197 & 2,432 & 2,511 & 2,751 \\
\hline & $\begin{array}{r}885 \\
7,001 \\
5695\end{array}$ & $\begin{array}{l}2,633 \\
8,037 \\
4,315\end{array}$ & $\begin{array}{l}2,375 \\
4,859 \\
3074\end{array}$ & $\begin{array}{l}1,796 \\
3,782 \\
3,244\end{array}$ & $\begin{array}{l}1,696 \\
3,870 \\
3413\end{array}$ & $\begin{array}{l}1,586 \\
3,564 \\
3667\end{array}$ & $\begin{array}{l}1,581 \\
3,783 \\
3730\end{array}$ & $\begin{array}{l}1,814 \\
3,674 \\
3867\end{array}$ & $\begin{array}{l}1,850 \\
3,906 \\
3,903\end{array}$ & $\begin{array}{l}1,999 \\
4,341 \\
4,46\end{array}$ & $\begin{array}{l}2,213 \\
4,763 \\
4041\end{array}$ & $\begin{array}{l}2,394 \\
4,893 \\
4011\end{array}$ & & $\begin{array}{l}496 \\
116 \\
100\end{array}$ & $\begin{array}{l}665 \\
57 \\
81\end{array}$ & $\begin{array}{l}778 \\
099\end{array}$ \\
\hline ? & $\begin{array}{r}, 695 \\
821\end{array}$ & $\begin{array}{l}4,315 \\
1,158\end{array}$ & 2,144 & $\begin{array}{l}3,244 \\
2,431\end{array}$ & 2,583 & 2,625 & 2,482 & 2,575 & 2,762 & 2,834 & $\begin{array}{l}4,041 \\
1,796\end{array}$ & 2,126 & 498 & 2,464 & 2,457 & 2,347 \\
\hline s & $\begin{array}{r}218 \\
1,326\end{array}$ & $\begin{array}{r}571 \\
1,356\end{array}$ & $\begin{array}{r}643 \\
1,229\end{array}$ & $\begin{array}{r}603 \\
1,153\end{array}$ & $\begin{array}{r}596 \\
1,167\end{array}$ & $\begin{array}{r}570 \\
1,163\end{array}$ & $\begin{array}{r}560 \\
1,109\end{array}$ & $\begin{array}{r}544 \\
1,099\end{array}$ & $\begin{array}{r}535 \\
1,280\end{array}$ & $\begin{array}{r}529 \\
1,306\end{array}$ & $\begin{array}{r}483 \\
1,441\end{array}$ & $\begin{array}{l}1,358 \\
1,146\end{array}$ & $\begin{array}{l}1,434 \\
1,425\end{array}$ & $\begin{array}{l}1,625 \\
1,350\end{array}$ & $\begin{array}{l}1,755 \\
1,380\end{array}$ & $\begin{array}{l}1,751 \\
1,302\end{array}$ \\
\hline $\begin{array}{l}\text { technologies } \\
\text { Precision production trades } \\
\text { Protective services }\end{array}$ & $\frac{6,367}{194}$ & $\begin{array}{r}5,466 \\
1,197\end{array}$ & $\begin{array}{r}5,284 \\
1,538\end{array}$ & $\begin{array}{r}5,576 \\
0 \\
1,219\end{array}$ & $\begin{array}{r}5,796 \\
4 \\
1,235\end{array}$ & $\begin{array}{r}5,902 \\
0 \\
1,074\end{array}$ & $\begin{array}{r}5,629 \\
0 \\
1,019\end{array}$ & $\begin{array}{r}5,733 \\
4 \\
1,024\end{array}$ & $\begin{array}{r}5,723 \\
0 \\
1,047\end{array}$ & $\begin{array}{r}5,449 \\
3 \\
1,151\end{array}$ & $\begin{array}{r}5,309 \\
0 \\
1,108\end{array}$ & $\begin{array}{r}5,374 \\
0 \\
1,249\end{array}$ & $\begin{array}{r}5,366 \\
2 \\
1,357\end{array}$ & $\begin{array}{r}5,679 \\
2 \\
1,437\end{array}$ & $\begin{array}{r}5,753 \\
5 \\
1,706\end{array}$ & $\begin{array}{r}5,847 \\
8 \\
1,812\end{array}$ \\
\hline ... & $\begin{array}{r}5,717 \\
7,785 \\
2 \\
16,539\end{array}$ & $\begin{array}{r}10,167 \\
15,209 \\
0 \\
15,953\end{array}$ & $\begin{array}{r}10,223 \\
17,803 \\
43 \\
11,945\end{array}$ & $\begin{array}{r}9,525 \\
15,060 \\
127 \\
10,577\end{array}$ & $\begin{array}{r}9,891 \\
15,575 \\
119 \\
10,503\end{array}$ & $\begin{array}{r}9,845 \\
15,692 \\
83 \\
10,564\end{array}$ & $\begin{array}{r}9,562 \\
16,432 \\
119 \\
10,506 \\
4,966\end{array}$ & $\begin{array}{r}9,180 \\
16,424 \\
49 \\
10,412 \\
4,905\end{array}$ & $\begin{array}{r}9,940 \\
17,020 \\
0 \\
11,023 \\
4749\end{array}$ & $\begin{array}{r}10,730 \\
17,399 \\
0 \\
11,634 \\
4,959\end{array}$ & $\begin{array}{r}349 \\
05 \\
0 \\
333 \\
30\end{array}$ & $\begin{array}{r}10,215 \\
19,243 \\
0 \\
12,702 \\
5,185\end{array}$ & $\begin{array}{l}57 \\
34 \\
08 \\
71 \\
85\end{array}$ & $\begin{array}{r}12,181 \\
21,833 \\
124 \\
14,561\end{array}$ & $\begin{array}{r}13,921 \\
23,501 \\
124 \\
14,845\end{array}$ & $\begin{array}{r}13,792 \\
24,229 \\
136 \\
15,012\end{array}$ \\
\hline 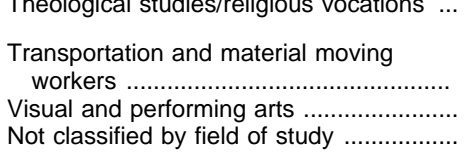 & $\begin{array}{r}63 \\
6,675 \\
0\end{array}$ & $\begin{array}{r}108 \\
8,817 \\
0\end{array}$ & $\begin{array}{r}120 \\
8,629 \\
0\end{array}$ & $\begin{array}{r}194 \\
8,526 \\
0\end{array}$ & $\begin{array}{r}295 \\
8,718 \\
0\end{array}$ & $\begin{array}{r}454 \\
8,420 \\
0\end{array}$ & $\begin{array}{r}433 \\
8,508 \\
0\end{array}$ & $\begin{array}{r}679 \\
7,939 \\
4,144\end{array}$ & $\begin{array}{r}692 \\
8,267 \\
851\end{array}$ & $\begin{array}{r}538 \\
8,481 \\
1,836\end{array}$ & $\begin{array}{r}406 \\
3,657 \\
3,523\end{array}$ & $\begin{array}{r}385 \\
9,353 \\
4,156\end{array}$ & $\begin{array}{r}495 \\
9,440 \\
884\end{array}$ & $\begin{array}{r}664 \\
9,925 \\
1,651\end{array}$ & $\begin{array}{r}823 \\
10,277 \\
577\end{array}$ & $\begin{array}{r}919 \\
10,280 \\
780\end{array}$ \\
\hline
\end{tabular}

-Data not available or not applicable.

marketing and distribution, and Consumer and personal services; and "Engineering-related technologies" includes Engineering-related technologies, Mechanics and repairers, and Construction trades.

SOURCE: U.S. Department of Education, National Center for Education Statistics, Higher Education General Informa-

(N) been reclassified when necessary to make them conform to the new taxonomy. "To facilitate trend comparisons, certain natural resources" includes Agricultural business and production, Agricultural sciences, and Conservation and renewable natural resources; "Business" includes Business management and administrative services, Marketing operations

Dystem (IPEDS), "Completions" surveys. (This table was prepared May 1998.) 


\begin{tabular}{|c|c|c|c|c|c|c|c|c|c|c|c|c|c|c|c|c|}
\hline Discipline division & 1970-71 & $1975-76$ & 1980-81 & 1983-84 & $1984-85$ & 1985-86 & $1986-87$ & 1987-88 & 1988-89 & 1989-90 & 1990-91 & 1991-92 & 1992-93 & 1993-94 & 1994-95 & $1995-96$ \\
\hline 1 & 2 & 3 & 4 & 5 & 6 & 7 & 8 & 9 & 10 & 11 & 12 & 13 & 14 & 15 & 16 & 17 \\
\hline Total & 32,107 &, 064 & 32,958 & 33,209 & 32,943 & 33,653 & 34,041 & 34,870 & 35,720 & 38,371 & 39,294 & 40,659 & 42,132 & 43,185 & 44,446 & 44,652 \\
\hline $\begin{array}{l}\text { Agriculture and natural resources } \ldots \ldots \ldots \ldots . . \\
\text { Architecture and related programs } \ldots \ldots \ldots \ldots . . \\
\text { Area, ethnic, and cultural studies } \ldots \ldots \ldots \ldots \ldots . \\
\text { Biological sciences/life sciences } \\
\text { Business }\end{array}$ & $\begin{array}{r}1,086 \\
36 \\
144 \\
3,645 \\
757\end{array}$ & $\begin{array}{r}928 \\
82 \\
188 \\
3,392 \\
900\end{array}$ & $\begin{array}{r}1,067 \\
93 \\
162 \\
3,718 \\
795\end{array}$ & $\begin{array}{r}1,172 \\
84 \\
141 \\
3,437 \\
929\end{array}$ & $\begin{array}{r}1,213 \\
89 \\
140 \\
3,432 \\
831\end{array}$ & $\begin{array}{r}1,158 \\
73 \\
159 \\
3,358 \\
934\end{array}$ & $\begin{array}{r}1,049 \\
92 \\
134 \\
3,419 \\
1,062\end{array}$ & $\begin{array}{r}1,142 \\
98 \\
142 \\
3,629 \\
1,063\end{array}$ & $\begin{array}{r}1,183 \\
86 \\
114 \\
3,520 \\
1,100\end{array}$ & $\begin{array}{r}1,295 \\
103 \\
131 \\
3,844 \\
1,093\end{array}$ & $\begin{array}{r}1,185 \\
135 \\
167 \\
4,093 \\
1,185\end{array}$ & $\begin{array}{r}1,214 \\
132 \\
155 \\
4,243 \\
1,242\end{array}$ & $\begin{array}{r}1,173 \\
148 \\
178 \\
4,435 \\
1,346\end{array}$ & $\begin{array}{r}1,278 \\
161 \\
155 \\
4,534 \\
1,364\end{array}$ & $\begin{array}{r}1,264 \\
141 \\
186 \\
4,645 \\
1,394\end{array}$ & $\begin{array}{r}1,271 \\
141 \\
184 \\
4,780 \\
1,368\end{array}$ \\
\hline $\begin{array}{l}\text { Communications } \\
\text { Communications technologies ............ } \\
\text { Computer and information sciences } \\
\text { Education } \\
\text { Engineering }\end{array}$ & $\begin{array}{r}145 \\
0 \\
128 \\
6,041 \\
3,637\end{array}$ & $\begin{array}{r}196 \\
8 \\
244 \\
7,202 \\
2,819\end{array}$ & $\begin{array}{r}171 \\
11 \\
252 \\
7,279 \\
2,551\end{array}$ & $\begin{array}{r}215 \\
4 \\
251 \\
6,911 \\
2,979\end{array}$ & $\begin{array}{r}228 \\
6 \\
248 \\
6,612 \\
3,221\end{array}$ & $\begin{array}{r}212 \\
11 \\
344 \\
6,605 \\
3,398\end{array}$ & $\begin{array}{r}273 \\
2 \\
374 \\
6,407 \\
3,801\end{array}$ & $\begin{array}{r}230 \\
4 \\
428 \\
6,060 \\
4,174\end{array}$ & $\begin{array}{r}247 \\
6 \\
551 \\
6,337 \\
4,506\end{array}$ & $\begin{array}{r}267 \\
6 \\
627 \\
6,502 \\
4,967\end{array}$ & $\begin{array}{r}259 \\
15 \\
676 \\
6,187 \\
5,258\end{array}$ & $\begin{array}{r}252 \\
3 \\
772 \\
6,864 \\
5,488\end{array}$ & $\begin{array}{r}293 \\
8 \\
805 \\
7,030 \\
5,823\end{array}$ & $\begin{array}{r}337 \\
8 \\
810 \\
6,908 \\
5,963\end{array}$ & $\begin{array}{r}320 \\
1 \\
884 \\
6,905 \\
6,110\end{array}$ & $\begin{array}{r}338 \\
7 \\
867 \\
6,676 \\
6,369\end{array}$ \\
\hline 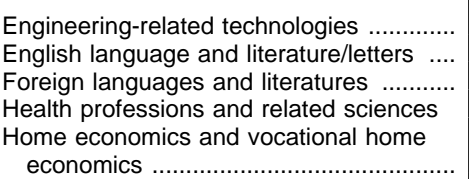 & $\begin{array}{r}1 \\
1,650 \\
988 \\
466 \\
123\end{array}$ & $\begin{array}{r}2 \\
1,672 \\
1,076 \\
577 \\
178\end{array}$ & $\begin{array}{r}10 \\
1,164 \\
804 \\
842 \\
247\end{array}$ & \begin{tabular}{r|r}
2 \\
1,018 \\
659 \\
1,164 \\
277
\end{tabular} & $\begin{array}{r}9 \\
1,041 \\
635 \\
1,199 \\
273\end{array}$ & $\begin{array}{r}12 \\
991 \\
672 \\
1,241 \\
311\end{array}$ & $\begin{array}{r}17 \\
961 \\
661 \\
1,213 \\
296\end{array}$ & $\begin{array}{r}17 \\
981 \\
602 \\
1,261 \\
307\end{array}$ & $\begin{array}{r}17 \\
1,022 \\
632 \\
1,437 \\
264\end{array}$ & $\begin{array}{r}14 \\
1,078 \\
724 \\
1,536 \\
301\end{array}$ & $\begin{array}{r}14 \\
1,184 \\
758 \\
1,613 \\
253\end{array}$ & $\begin{array}{r}11 \\
1,273 \\
850 \\
1,661 \\
293\end{array}$ & $\begin{array}{r}20 \\
1,341 \\
830 \\
1,767 \\
345\end{array}$ & $\begin{array}{r}16 \\
1,344 \\
886 \\
1,902 \\
365\end{array}$ & $\begin{array}{r}18 \\
1,561 \\
905 \\
2,069 \\
388\end{array}$ & $\begin{array}{r}11 \\
1,535 \\
876 \\
2,119\end{array}$ \\
\hline $\begin{array}{l}\text { Law and legal stl } \\
\text { Liberal arts and }\end{array}$ & 20 & 76 & 60 & 121 & 105 & 54 & 120 & 89 & 76 & 111 & 90 & 68 & 86 & 79 & 88 & 91 \\
\hline & $\begin{array}{l}32 \\
39\end{array}$ & $\begin{array}{r}162 \\
71\end{array}$ & $\begin{array}{r}121 \\
71\end{array}$ & $\begin{array}{r}173 \\
74\end{array}$ & $\begin{array}{r}112 \\
87\end{array}$ & $\begin{array}{l}90 \\
62\end{array}$ & $\begin{array}{l}56 \\
57\end{array}$ & $\begin{array}{l}66 \\
46\end{array}$ & $\begin{array}{l}72 \\
61\end{array}$ & $\begin{array}{l}63 \\
42\end{array}$ & $\begin{array}{l}70 \\
56\end{array}$ & $\begin{array}{l}67 \\
50\end{array}$ & $\begin{array}{l}81 \\
77\end{array}$ & $\begin{array}{l}80 \\
45\end{array}$ & $\begin{array}{l}90 \\
55\end{array}$ & $\begin{array}{l}75 \\
53\end{array}$ \\
\hline 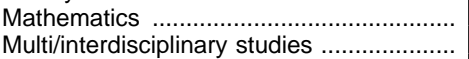 & $\begin{array}{r}1,249 \\
59\end{array}$ & $\begin{array}{l}909 \\
111\end{array}$ & $\begin{array}{l}775 \\
158\end{array}$ & $\begin{array}{l}743 \\
249\end{array}$ & $\begin{array}{l}734 \\
219\end{array}$ & $\begin{array}{l}777 \\
263\end{array}$ & $\begin{array}{l}759 \\
247\end{array}$ & $\begin{array}{l}796 \\
224\end{array}$ & $\begin{array}{l}915 \\
212\end{array}$ & $\begin{array}{l}966 \\
272\end{array}$ & $\begin{array}{r}1,036 \\
220\end{array}$ & $\begin{array}{r}1,082 \\
231\end{array}$ & $\begin{array}{r}1,189 \\
196\end{array}$ & $\begin{array}{r}1,157 \\
227\end{array}$ & $\begin{array}{r}1,226 \\
238\end{array}$ & $\begin{array}{r}1,209 \\
441\end{array}$ \\
\hline $\begin{array}{l}\text { Parks, } \\
\text { stud } \\
\text { Philos }\end{array}$ & $\begin{array}{r}2 \\
554\end{array}$ & $\begin{array}{r}15 \\
554\end{array}$ & $\begin{array}{r}42 \\
410\end{array}$ & $\begin{array}{r}27 \\
442\end{array}$ & $\begin{array}{r}36 \\
468\end{array}$ & $\begin{array}{r}39 \\
477\end{array}$ & $\begin{array}{r}32 \\
421\end{array}$ & $\begin{array}{r}29 \\
405\end{array}$ & $\begin{array}{r}35 \\
465\end{array}$ & $\begin{array}{r}35 \\
439\end{array}$ & $\begin{array}{r}28 \\
456\end{array}$ & $\begin{array}{r}61 \\
475\end{array}$ & $\begin{array}{l}108 \\
448\end{array}$ & $\begin{array}{l}116 \\
528\end{array}$ & $\begin{array}{l}149 \\
507\end{array}$ & $\begin{array}{l}104 \\
549\end{array}$ \\
\hline 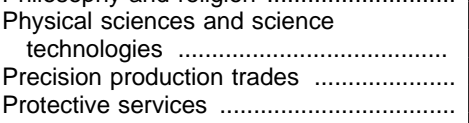 & $\frac{4,390}{-1}$ & $\frac{3,431}{9}$ & $\frac{3,141}{21}$ & $\begin{array}{r}3,306 \\
0 \\
31\end{array}$ & $\begin{array}{r}3,403 \\
0 \\
33\end{array}$ & $\begin{array}{r}3,551 \\
0 \\
21\end{array}$ & $\begin{array}{r}3,673 \\
0 \\
18\end{array}$ & $\begin{array}{r}3,809 \\
0 \\
32\end{array}$ & $\begin{array}{r}3,858 \\
0 \\
26\end{array}$ & $\begin{array}{r}4,164 \\
0 \\
38\end{array}$ & $\begin{array}{r}4,290 \\
0 \\
28\end{array}$ & $\begin{array}{r}4,391 \\
0 \\
24\end{array}$ & $\begin{array}{r}4,393 \\
0 \\
32\end{array}$ & $\begin{array}{r}4,650 \\
0 \\
25\end{array}$ & $\begin{array}{r}4,483 \\
0 \\
26\end{array}$ & $\begin{array}{r}4,571 \\
0 \\
38\end{array}$ \\
\hline $\begin{array}{l}\text { Public administration and servi } \\
\text { R.O.T.C. and military technolos } \\
\text { Social sciences and history .... } \\
\text { Theological studies/religious vo }\end{array}$ & $\begin{array}{r}2,144 \\
174 \\
0 \\
3,660 \\
312\end{array}$ & $\begin{array}{r}3,157 \\
292 \\
0 \\
4,157 \\
1,033\end{array}$ & $\begin{array}{r}3,576 \\
362 \\
0 \\
3,122 \\
1,276\end{array}$ & $\begin{array}{r}3,535 \\
420 \\
0 \\
2,911 \\
1,204\end{array}$ & $\begin{array}{r}3,447 \\
431 \\
0 \\
2,851 \\
1,144\end{array}$ & $\begin{array}{r}3,593 \\
382 \\
0 \\
2,955 \\
1,185\end{array}$ & $\begin{array}{r}3,560 \\
398 \\
0 \\
2,916 \\
1,230\end{array}$ & $\begin{array}{r}3,480 \\
470 \\
0 \\
2,781 \\
1,199\end{array}$ & $\begin{array}{r}3,685 \\
428 \\
0 \\
2,885 \\
1,166\end{array}$ & $\begin{array}{r}3,811 \\
508 \\
0 \\
3,010 \\
1,317\end{array}$ & $\begin{array}{r}3,932 \\
430 \\
0 \\
3,012 \\
1,079\end{array}$ & $\begin{array}{r}3,373 \\
432 \\
0 \\
3,218 \\
1,259\end{array}$ & $\begin{array}{r}3,651 \\
459 \\
0 \\
3,460 \\
1,417\end{array}$ & $\begin{array}{r}3,563 \\
519 \\
0 \\
3,627 \\
1,448\end{array}$ & $\begin{array}{r}3,822 \\
556 \\
0 \\
3,725 \\
1,591\end{array}$ & $\begin{array}{r}3,711 \\
499 \\
0 \\
3,760 \\
1,521\end{array}$ \\
\hline 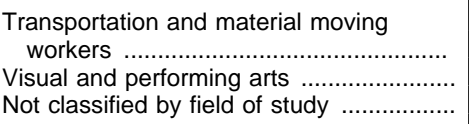 & $\begin{array}{r}621 \\
0\end{array}$ & $\begin{array}{r}620 \\
0\end{array}$ & $\begin{array}{r}654 \\
0\end{array}$ & $\begin{array}{r}730 \\
0\end{array}$ & $\begin{array}{r}0 \\
696 \\
0\end{array}$ & $\begin{array}{r}722 \\
0\end{array}$ & $\begin{array}{r}793 \\
0\end{array}$ & $\begin{array}{l}727 \\
579\end{array}$ & $\begin{array}{r}0 \\
753 \\
61\end{array}$ & $\begin{array}{l}849 \\
258\end{array}$ & $\begin{array}{l}838 \\
747\end{array}$ & $\begin{array}{r}0 \\
906 \\
569\end{array}$ & $\begin{array}{r}0 \\
882 \\
111\end{array}$ & $\begin{array}{r}0 \\
1,054 \\
36\end{array}$ & $\begin{array}{r}0 \\
1,080 \\
19\end{array}$ & $\begin{array}{r}0 \\
1,067 \\
7\end{array}$ \\
\hline
\end{tabular}

-Data not available or not applicable.

NOTE.-The new Classification of Instructional Programs was initiated in 1991-92. The figures for earlier years have been reclassified when necessary to make them conform to the new taxonomy. To facilitate trend comparisons, certain natural resources" includes Agricultural business and production, Agricultural sciences, and Conservation and renewable natural resources; "Business" includes Business management and administrative services, Marketing operations marketing and distribution, and Consumer and personal services; and "Engineering-related technologies" includes Engineering-related technologies, Mechanics and repairers, and Construction trades.

SOURCE: U.S. Department of Education, National Center for Education Statistics, Higher Education General InformaConferred" surveys, and Integrated Postsecondary Education (Dystem (IPEDS) "Completions" surveys. (This table was prepared May 1998.) 
HIGHER EDUCATION: DEGREES 285

Table 253.-Bachelor's, master's, and doctor's degrees conferred by institutions of higher education, by sex of student and field of study: 1995-96

\begin{tabular}{|c|c|c|c|c|c|c|c|c|c|}
\hline \multirow{2}{*}{ Field of study } & \multicolumn{3}{|c|}{$\begin{array}{c}\text { Bachelor's degrees requiring } \\
4 \text { or } 5 \text { years }\end{array}$} & \multicolumn{3}{|c|}{ Master's degrees } & \multicolumn{3}{|c|}{$\begin{array}{l}\text { Doctor's degrees } \\
\text { (Ph.D., Ed.D., etc.) }\end{array}$} \\
\hline & Total & Men & Women & Total & Men & Women & Total & Men & Women \\
\hline 1 & 2 & 3 & 4 & 5 & 6 & 7 & 8 & 9 & 10 \\
\hline All fields ... & $1,164,792$ & 522,454 & 642,338 & 406,301 & 179,081 & 227,220 & 44,652 & 26,841 & 17,811 \\
\hline Agriculture and natural resources, total & 21,431 & 13,535 & 7,896 & 4,569 & 2,650 & 1,919 & 1,271 & 935 & 336 \\
\hline Agricultural business and production, total & 4,848 & 3,506 & 1,342 & 648 & 411 & 237 & 236 & 182 & 54 \\
\hline Agricultural business and management, total & 3,279 & 2,379 & 900 & 501 & 313 & 188 & 193 & 151 & 42 \\
\hline Agricultural business and management, general . & 870 & 599 & 271 & 49 & 26 & 23 & 0 & 0 & 0 \\
\hline Agricultural business/agribusiness operations ........................... & 1,070 & 784 & 286 & 17 & 10 & 7 & 0 & 0 & 0 \\
\hline Agricultural economics ……............................... & 1,155 & 853 & 302 & 425 & 269 & 156 & 193 & 151 & 42 \\
\hline Agricultural business and management, other & 184 & 143 & 41 & 10 & 8 & 2 & 0 & 0 & 0 \\
\hline Agricultural mechanization ...................................... & 245 & 232 & 13 & 3 & 3 & 0 & 2 & 2 & 0 \\
\hline Agricultural production workers and managers & 129 & 98 & 31 & 64 & 52 & 12 & 8 & 7 & 1 \\
\hline Horticulture service operations and management & 544 & 396 & 148 & 31 & 17 & 14 & 19 & 11 & 8 \\
\hline International agriculture ……………………………… & 13 & 7 & 6 & 8 & 3 & 5 & 0 & 0 & 0 \\
\hline 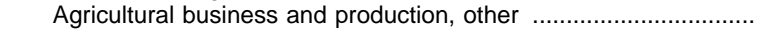 & 638 & 394 & 244 & 41 & 23 & 18 & 14 & 11 & 3 \\
\hline Agricultural sciences, total & 7,457 & 4,256 & 3,201 & 1,601 & 895 & 706 & 744 & 540 & 204 \\
\hline Agriculture/agricultural sciences, general & 1,085 & 765 & 320 & 180 & 115 & 65 & 2 & 2 & 0 \\
\hline Animal sciences, total ................ & 3,558 & 1,694 & 1,864 & 374 & 210 & 164 & 204 & 154 & 50 \\
\hline Animal sciences, general .......... & 2,980 & 1,372 & 1,608 & 286 & 157 & 129 & 155 & 116 & 39 \\
\hline 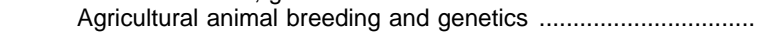 & 37 & 20 & 17 & 7 & 3 & 4 & 11 & 11 & 0 \\
\hline Agricultural animal health & 7 & 4 & 3 & 2 & 1 & 1 & 0 & 0 & 0 \\
\hline Agricultural animal nutrition & 0 & 0 & 0 & 10 & 6 & 4 & 8 & 6 & 2 \\
\hline 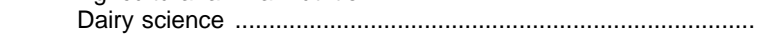 & 119 & 72 & 47 & 19 & 13 & 6 & 9 & 6 & 3 \\
\hline Poultry science & 154 & 117 & 37 & 23 & 15 & 8 & 11 & 9 & 2 \\
\hline iences, other & 261 & 109 & 152 & 27 & 15 & 12 & 10 & 6 & 4 \\
\hline Food sciences and technology & 513 & 201 & 312 & 308 & 112 & 196 & 144 & 76 & 68 \\
\hline Plant sciences, total ..................... & 1,897 & 1,356 & 541 & 603 & 380 & 223 & 314 & 248 & 66 \\
\hline Plant sciences, general & 327 & 218 & 109 & 76 & 51 & 25 & 37 & 21 & 16 \\
\hline Agronomy and crop science ... & 624 & 528 & 96 & 229 & 167 & 62 & 163 & 143 & 20 \\
\hline Horticulture science & 634 & 384 & 250 & 156 & 81 & 75 & 66 & 47 & 19 \\
\hline ding and genetics .... & 0 & 0 & 0 & 8 & 4 & 4 & 5 & 5 & 0 \\
\hline Agricultural plant pathology ........ & 6 & 4 & 2 & 8 & 4 & 4 & 4 & 3 & 1 \\
\hline ion (pest management) .. & 37 & 31 & 6 & 16 & 10 & 6 & 2 & 2 & 0 \\
\hline ience and management & 169 & 115 & 54 & 67 & 38 & 29 & 23 & 15 & 8 \\
\hline ices, other ....................... & 100 & 76 & 24 & 43 & 25 & 18 & 14 & 12 & -5 \\
\hline Soil sciences & 153 & 93 & 60 & 87 & 60 & 27 & 67 & 52 & 15 \\
\hline 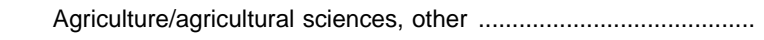 & 251 & 147 & 104 & 49 & 18 & 31 & 13 & 8 & 5 \\
\hline ources, total & 9,126 & 5,773 & 353 & 2,320 & 1,344 & 976 & 291 & 213 & 78 \\
\hline Nat & 5,113 & 2,923 & 2,190 & 1,256 & 661 & 595 & 80 & 56 & 24 \\
\hline anagement and policy. & 463 & 292 & 171 & 223 & 139 & 84 & 4 & 4 & 0 \\
\hline gement . & 237 & 176 & 61 & 80 & 56 & 24 & 28 & 23 & 5 \\
\hline Forest harvesting and production technology/technician & 281 & 194 & 87 & 11 & 10 & 1 & 15 & 12 & 3 \\
\hline & 1,389 & 1,098 & 291 & 517 & 329 & 188 & 138 & 102 & 36 \\
\hline wildlands management & 1,158 & 783 & 375 & 179 & 121 & 58 & 18 & 11 & 7 \\
\hline Conservation and renewable natural resources, other. & 485 & 307 & 178 & 54 & 28 & 26 & 8 & 5 & 3 \\
\hline Architecture and related programs, total & 8,352 & 5,340 & 3,012 & 3,993 & 2,361 & 1,632 & 141 & 96 & 45 \\
\hline $\mathrm{Ar}$ & 5,054 & 3,538 & 1,516 & 1,988 & 1,331 & 657 & 53 & 39 & 14 \\
\hline nning & 475 & 321 & 154 & 1,349 & 730 & 619 & 73 & 51 & 22 \\
\hline Architectural environmental design . & 614 & 402 & 212 & 63 & 29 & 34 & 2 & 1 & 1 \\
\hline Interic & 740 & 106 & 634 & 10 & 1 & 9 & 0 & 0 & 0 \\
\hline Lands & 894 & 615 & 279 & 367 & 163 & 204 & 6 & 3 & 0 \\
\hline Archit & 13 & 6 & 7 & 60 & 41 & 19 & 2 & 1 & 1 \\
\hline Architecture and related programs, other & 562 & 352 & 210 & 156 & 66 & 90 & 5 & 1 & 4 \\
\hline Area, ethnic, and cultural studies, total & 5,786 & 1,984 & 3,802 & 1,713 & 798 & 915 & 184 & 94 & 90 \\
\hline Are & 3,752 & 1,432 & 2,320 & 1,248 & 594 & 654 & 144 & 71 & 73 \\
\hline …ㅊ..… & 35 & 16 & 19 & 13 & 12 & 1 & 4 & 1 & 3 \\
\hline Idies/civilization . & 1,604 & 581 & 1,023 & 274 & 93 & 181 & 96 & 39 & 57 \\
\hline 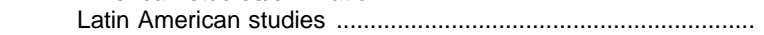 & 413 & 133 & 280 & 271 & 125 & 146 & 6 & 3 & 3 \\
\hline Middl & 84 & 41 & 43 & 90 & 48 & 42 & 18 & 14 & 4 \\
\hline Slavic studies & 159 & 61 & 98 & 97 & 50 & 47 & 1 & 1 & 0 \\
\hline & 836 & 392 & 444 & 294 & 155 & 139 & 15 & 10 & 5 \\
\hline Euror & 238 & 76 & 162 & 90 & 43 & 47 & 1 & 1 & 0 \\
\hline & 383 & 132 & 251 & 119 & 68 & 51 & 3 & 2 & 1 \\
\hline Ethnic and $\mathrm{c}$ & 1,574 & 343 & 1,231 & 189 & 46 & 143 & 29 & 13 & 16 \\
\hline Afro-American (black) studies .. & 606 & 213 & 393 & 68 & 23 & 45 & 11 & 4 & 7 \\
\hline Hispanic-American studies & 187 & 61 & 126 & 20 & 10 & 10 & 0 & 0 & 0 \\
\hline & 602 & 9 & 593 & 72 & 3 & 69 & 0 & 0 & 0 \\
\hline Ethnic studies, other . & 179 & 60 & 119 & 29 & 10 & 19 & 8 & 6 & 2 \\
\hline 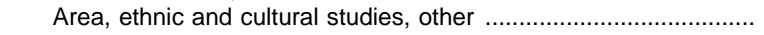 & 460 & 209 & 251 & 276 & 158 & 118 & 21 & 13 & 8 \\
\hline Biological sciences/life sciences, total & 60,994 & 28,849 & 32,145 & 6,157 & 2,902 & 3,255 & 4,780 & 2,773 & 2,007 \\
\hline Biology, general & 44,818 & 20,619 & 24,199 & 2,606 & 1,256 & 1,350 & 768 & 434 & 334 \\
\hline
\end{tabular}


Table 253.-Bachelor's, master's, and doctor's degrees conferred by institutions of higher education, by sex of student and field of study: 1995-96-Continued

\begin{tabular}{|c|c|c|c|c|c|c|c|c|c|}
\hline \multirow{2}{*}{ Field of study } & \multicolumn{3}{|c|}{$\begin{array}{c}\text { Bachelor's degrees requiring } \\
4 \text { or } 5 \text { years }\end{array}$} & \multicolumn{3}{|c|}{ Master's degrees } & \multicolumn{3}{|c|}{$\begin{array}{l}\text { Doctor's degrees } \\
\text { (Ph.D., Ed.D., etc.) }\end{array}$} \\
\hline & Total & Men & Women & Total & Men & Women & Total & Men & Women \\
\hline 1 & 2 & 3 & 4 & 5 & 6 & 7 & 8 & 9 & 10 \\
\hline Biochemistry and biophysics ... & 3,385 & 1,928 & 1,457 & 319 & 165 & 154 & 626 & 386 & 240 \\
\hline Botany, total $\ldots \ldots \ldots \ldots \ldots \ldots \ldots \ldots$ & 404 & 182 & 222 & 228 & 118 & 110 & 299 & 181 & 118 \\
\hline Botany, general & 370 & 167 & 203 & 145 & 68 & 77 & 144 & 77 & 67 \\
\hline Plant pathology . & 9 & 7 & 2 & 72 & 44 & 28 & 109 & 76 & 33 \\
\hline Botany, other .... & 25 & 8 & 17 & 11 & 6 & 5 & 46 & 28 & 18 \\
\hline Cell and molecular biology, total & 2,103 & 1,104 & 999 & 181 & 77 & 104 & 499 & 286 & 213 \\
\hline Cell biology & 234 & 131 & 103 & 40 & 16 & 24 & 152 & 95 & 57 \\
\hline Molecular biology & 680 & 347 & 333 & 83 & 41 & 42 & 247 & 136 & 111 \\
\hline Cell and molecular biology, other & 1,189 & 626 & 563 & 58 & 20 & 38 & 100 & 55 & 45 \\
\hline Microbiology/bacteriology ................................... & 2,130 & 1,067 & 1,063 & 324 & 143 & 181 & 477 & 260 & 217 \\
\hline Miscellaneous biological specializations, total .... & 2,981 & 1,382 & 1,599 & 1,507 & 587 & 920 & 1,083 & 605 & 478 \\
\hline Anatomy & 77 & 45 & 32 & 62 & 33 & 29 & 70 & 37 & 33 \\
\hline Ecology & 825 & 442 & 383 & 272 & 160 & 112 & 86 & 58 & 28 \\
\hline 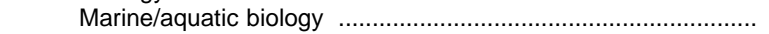 & 703 & 322 & 381 & 118 & 58 & 60 & 21 & 16 & 5 \\
\hline Neurosciences & 264 & 139 & 125 & 49 & 32 & 17 & 215 & 133 & 82 \\
\hline Nutritional sciences & 370 & 77 & 293 & 351 & 33 & 318 & 108 & 36 & 72 \\
\hline Toxicology & 54 & 25 & 29 & 82 & 28 & 54 & 87 & 47 & 40 \\
\hline Genetics, plant and animal & 257 & 121 & 136 & 130 & 45 & 85 & 230 & 129 & 101 \\
\hline Biometrics & 23 & 10 & 13 & 42 & 23 & 19 & 27 & 18 & 9 \\
\hline 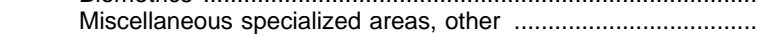 & 408 & 201 & 207 & 401 & 175 & 226 & 239 & 131 & 108 \\
\hline Zoology, total & 3,549 & 1,789 & 1,760 & 815 & 459 & 356 & 855 & 523 & 332 \\
\hline (1, & 2,903 & 1,444 & 1,459 & 236 & 128 & 108 & 150 & 102 & 48 \\
\hline 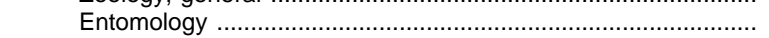 & 73 & 50 & 23 & 148 & 87 & 61 & 137 & 100 & 37 \\
\hline Pathology, human and animal & 14 & 2 & 12 & 60 & 31 & 29 & 103 & 58 & 45 \\
\hline 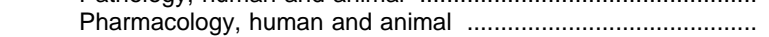 & 72 & 43 & 29 & 84 & 47 & 37 & 252 & 137 & 115 \\
\hline 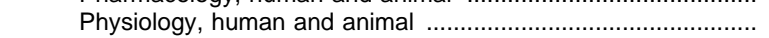 & 487 & 250 & 237 & 287 & 166 & 121 & 212 & 125 & 87 \\
\hline Zoology, other & 0 & 0 & 0 & 0 & 0 & 0 & 1 & 1 & 0 \\
\hline Biological sciences/life sciences, other & 1,624 & 778 & 846 & 177 & 97 & 80 & 173 & 98 & 75 \\
\hline Business management, administrative services and & & & & & & & & & \\
\hline marketing operations/marketing and distribution, total & 227,102 & 116,842 & 110,260 & 93,982 & 58,685 & 35,297 & 1,368 & 974 & 394 \\
\hline Business management and administrative services, total & 222,405 & 114,838 & 107,567 & 93,320 & 58,333 & 34,987 & 1,367 & 974 & 393 \\
\hline 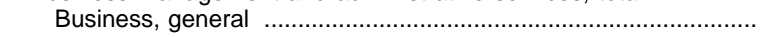 & 22,214 & 11,696 & 10,518 & 10,960 & 7,114 & 3,846 & 207 & 147 & 60 \\
\hline Business administration and management, total ......................... & 83,953 & 43,181 & 40,772 & 54,945 & 34,957 & 19,988 & 786 & 569 & 217 \\
\hline 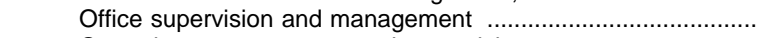 & 823 & 125 & 698 & 1 & 0 & 1 & 0 & 0 & 0 \\
\hline 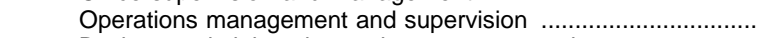 & 1,669 & 1,149 & 520 & 588 & 451 & 137 & 7 & 7 & 0 \\
\hline Business administration and management, other ..................... & 81,461 & 41,907 & 39,554 & 54,356 & 34,506 & 19,850 & 779 & 562 & 217 \\
\hline 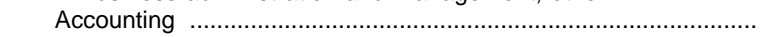 & 42,002 & 18,312 & 23,690 & 4,170 & 2,150 & 2,020 & 47 & 27 & 20 \\
\hline 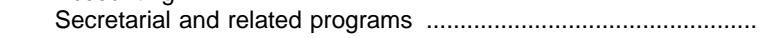 & 302 & 27 & 275 & 5 & 0 & 5 & 0 & 0 & 0 \\
\hline 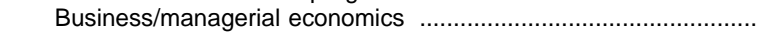 & 2,743 & 1,770 & 973 & 196 & 133 & 63 & 54 & 44 & 10 \\
\hline 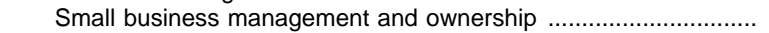 & 450 & 298 & 152 & 62 & 44 & 18 & 0 & 0 & 0 \\
\hline Finance, general and banking and financial support services ...... & 20,125 & 13,436 & 6,689 & 5,534 & 3,893 & 1,641 & 45 & 42 & 3 \\
\hline Actuarial sciences & 288 & 184 & 104 & 67 & 44 & 23 & 0 & 0 & 0 \\
\hline Insurance and risk management & 481 & 275 & 206 & 76 & 51 & 25 & 7 & 5 & 2 \\
\hline Investments and securities and financial planning ....................... & 312 & 191 & 121 & 326 & 224 & 102 & 0 & 0 & 0 \\
\hline 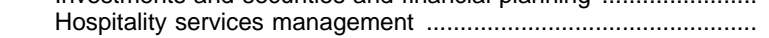 & 5,321 & 2,443 & 2,878 & 472 & 240 & 232 & 5 & 2 & 3 \\
\hline Human resources management .... & 5,715 & 2,236 & 3,479 & 1,787 & 700 & 1,087 & 38 & 16 & 22 \\
\hline 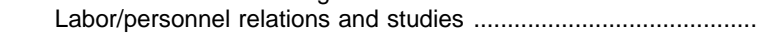 & 876 & 457 & 419 & 740 & 275 & 465 & 26 & 14 & 12 \\
\hline Organizational behavior studies & 1,164 & 513 & 651 & 270 & 98 & 172 & 22 & 15 & 7 \\
\hline International business & 3,034 & 1,460 & 1,574 & 3,038 & 1,880 & 1,158 & 12 & 7 & 5 \\
\hline 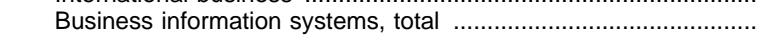 & 6,183 & 3,791 & 2,392 & 2,554 & 1,725 & 829 & 15 & 13 & 2 \\
\hline Management information systems and data processing, gen- & & & & & & & & & \\
\hline eral ... & 5,727 & 3,471 & 2,256 & 1,995 & 1,360 & 635 & 13 & 11 & 2 \\
\hline Business information systems, other ... & 456 & 320 & 136 & 559 & 365 & 194 & 2 & 2 & 0 \\
\hline Quantitative methods and management science, total & 1,714 & 999 & 715 & 825 & 553 & 272 & 28 & 22 & 6 \\
\hline statistics & 13 & 10 & 3 & 18 & 11 & 7 & 5 & 5 & 0 \\
\hline Managemen & 1,701 & 989 & 712 & 807 & 542 & 265 & 23 & 17 & 6 \\
\hline Marketing management and research .. & 20,909 & 11,107 & 9,802 & 2,048 & 1,141 & 907 & 39 & 25 & 14 \\
\hline Real estate ... & 400 & 279 & 121 & 252 & 196 & 56 & 1 & 1 & 0 \\
\hline 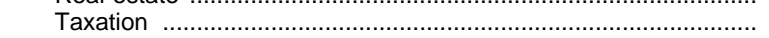 & 0 & 0 & 0 & 1,693 & 947 & 746 & 0 & 0 & 0 \\
\hline Consumer and personal services & 256 & 167 & 89 & 0 & 0 & 0 & 0 & 0 & 0 \\
\hline Business management and administrative services, other .. & 3,963 & 2,016 & 1,947 & 3,300 & 1,968 & 1,332 & 35 & 25 & 10 \\
\hline Marketing operations/marketing and distribution, total & 4,697 & 2,004 & 2,693 & 662 & 352 & 310 & 1 & 0 & 1 \\
\hline Apparel and accessories marketing operations .......... & 1,082 & 53 & 1,029 & 0 & 0 & 2 & 1 & 0 & 1 \\
\hline Business and personal services marketing operations .. & 344 & 193 & 151 & 15 & 5 & 10 & 0 & 0 & 0 \\
\hline General/retailing and wholesaling operations and skills ............... & 2,444 & 1,249 & 1,195 & 486 & 243 & 243 & 0 & 0 & 0 \\
\hline 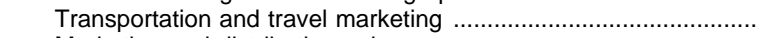 & 162 & 46 & 116 & 30 & 8 & 22 & 0 & 0 & 0 \\
\hline 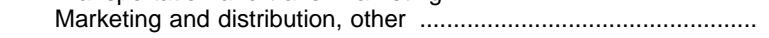 & 665 & 463 & 202 & 129 & 96 & 33 & 0 & 0 & 0 \\
\hline Communications and communications technologies, total . & 48,003 & 19,760 & 28,243 & 5,604 & 2,171 & 3,433 & 345 & 190 & 155 \\
\hline Comm & 47,320 & 19,391 & 27,929 & 5,080 & 1,900 & 3,180 & 338 & 184 & 154 \\
\hline Communications, general & 22,995 & 9,134 & 13,861 & 1,820 & 661 & 1,159 & 215 & 115 & 100 \\
\hline Advertising & 2,538 & 1,038 & 1,500 & 262 & 92 & 170 & 3 & 2 & 1 \\
\hline Journalism . & 9,097 & 3,250 & 5,847 & 1,393 & 505 & 888 & 31 & 15 & 16 \\
\hline Broadcast journalism & 586 & 255 & 331 & 14 & & & 0 & 0 & 0 \\
\hline
\end{tabular}


Table 253.-Bachelor's, master's, and doctor's degrees conferred by institutions of higher education, by sex of student and field of study: 1995-96-Continued

\begin{tabular}{|c|c|c|c|c|c|c|c|c|c|}
\hline \multirow[t]{2}{*}{ Field of study } & \multicolumn{3}{|c|}{$\begin{array}{c}\text { Bachelor's degrees requiring } \\
4 \text { or } 5 \text { years }\end{array}$} & \multicolumn{3}{|c|}{ Master's degrees } & \multicolumn{3}{|c|}{$\begin{array}{l}\text { Doctor's degrees } \\
\text { (Ph.D., Ed.D., etc.) }\end{array}$} \\
\hline & Total & Men & Women & Total & Men & Women & Total & Men & Women \\
\hline 1 & 2 & 3 & 4 & 5 & 6 & 7 & 8 & 9 & 10 \\
\hline Public relations and organizational communications & 2,215 & 668 & 1,547 & 284 & 74 & 210 & 0 & 0 & 0 \\
\hline Radio and television broadcasting & 5,125 & 2,843 & 2,282 & 318 & 158 & 160 & 17 & 11 & 6 \\
\hline Communications, other & 4,764 & 2,203 & 2,561 & 989 & 405 & 584 & 72 & 41 & 31 \\
\hline Communications technologies, total . & 683 & 369 & 314 & 524 & 271 & 253 & 7 & 6 & 1 \\
\hline Photographic technology & 15 & 5 & 10 & 0 & 0 & 0 & 0 & 0 & 0 \\
\hline Radio and television technology & 581 & 318 & 263 & 385 & 190 & 195 & 7 & 6 & 1 \\
\hline 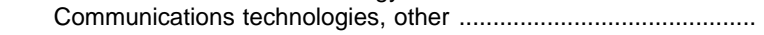 & 87 & 46 & 41 & 139 & 81 & 58 & 0 & 0 & 0 \\
\hline Computer and information sciences, total & 24,098 & 17,468 & 6,630 & 10,151 & 7,444 & 2,707 & 867 & 741 & 126 \\
\hline Computer and information sciences, general & 15,324 & 11,411 & 3,913 & 7,270 & 5,446 & 1,824 & 703 & 606 & 97 \\
\hline Computer programming . & 241 & 155 & 86 & 14 & 14 & & 0 & 0 & 0 \\
\hline Data processing technology/technician & 177 & 113 & 64 & 0 & 0 & 0 & 0 & 0 & 0 \\
\hline Information science and systems ......... & 4,142 & 2,603 & 1,539 & 1,386 & 881 & 505 & 29 & 19 & 10 \\
\hline Computer systems analysis ......... & 195 & 129 & 66 & 51 & 40 & 11 & 2 & 2 & 0 \\
\hline 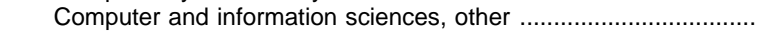 & 4,019 & 3,057 & 962 & 1,430 & 1,063 & 367 & 133 & 114 & 19 \\
\hline Education, total & 105,509 & 26,233 & 79,276 & 106,253 & 25,214 & 81,039 & 6,676 & 2,525 & 4,151 \\
\hline Education, general & 1,660 & 338 & 1,322 & 11,745 & 2,836 & 8,909 & 1,171 & 423 & 748 \\
\hline Bilingual/bicultural education & 89 & 5 & 84 & 356 & 63 & 293 & 25 & 10 & 15 \\
\hline Curriculum and instruction .... & 22 & 15 & 7 & 9,773 & 1,940 & 7,833 & 732 & 210 & 522 \\
\hline Education administration and supervision, total & 224 & 41 & 183 & 11,609 & 4,507 & 7,102 & 2,281 & 992 & 1,289 \\
\hline Education administration and supervision, general & 4 & 1 & 3 & 8,135 & 3,224 & 4,911 & 1,629 & 701 & 928 \\
\hline Administration of special education & 0 & 0 & 0 & 17 & 4 & 13 & & 3 & 6 \\
\hline Adult and continuing education administration & 2 & 1 & 1 & 240 & 66 & 174 & 66 & 27 & 39 \\
\hline Educational supervision .......... & 0 & 0 & 0 & 621 & 168 & 453 & 21 & 5 & 16 \\
\hline Elementary, middle, and secondary education administration & 218 & 39 & 179 & 1,507 & 634 & 873 & 85 & 33 & 52 \\
\hline 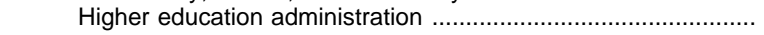 & 0 & 0 & 0 & 531 & 205 & 326 & 289 & 138 & 151 \\
\hline Community and junior college & 0 & 0 & 0 & 19 & 7 & 12 & 4 & 2 & 2 \\
\hline Education administration and & 0 & 0 & 0 & 539 & 199 & 340 & 152 & 72 & 80 \\
\hline Educational/instructional media design & 25 & 11 & 14 & 1,570 & 456 & 1,114 & 52 & 28 & 24 \\
\hline general & 31 & 5 & 26 & 40 & 19 & 21 & 25 & 12 & 13 \\
\hline 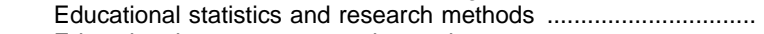 & 2 & 0 & 2 & 25 & 9 & 16 & 31 & 17 & 14 \\
\hline Educ & 0 & 0 & 0 & 81 & 10 & 71 & 29 & 12 & 17 \\
\hline Social and philosophical foundations of education ……................... & 5 & 1 & 4 & 213 & 59 & 154 & 101 & 36 & 65 \\
\hline 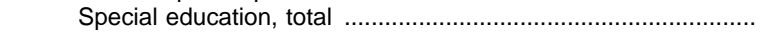 & 10,029 & 1,022 & 9,007 & 11,158 & 1,532 & 9,626 & 193 & 43 & 150 \\
\hline 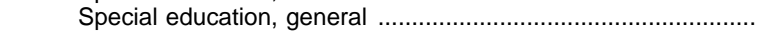 & 6,970 & 749 & 6,221 & 9,196 & 1,294 & 7,902 & 175 & 40 & 135 \\
\hline Educ & 266 & 16 & 250 & 165 & 22 & 143 & 0 & 0 & 0 \\
\hline Education of the gifted and talente & 6 & 0 & 6 & 146 & 13 & 133 & 0 & 0 & 0 \\
\hline 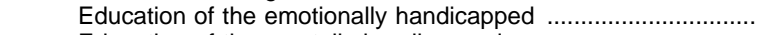 & 308 & 53 & 255 & 209 & 48 & 161 & 3 & 1 & 2 \\
\hline handicapped ..................................... & 528 & 56 & 472 & 80 & 7 & 73 & 0 & 0 & 0 \\
\hline …….............. & 147 & 13 & 134 & 216 & 20 & 196 & 4 & 0 & 4 \\
\hline Education of the $\mathrm{p}$ & 45 & 4 & 41 & 68 & 12 & 56 & 0 & 0 & 0 \\
\hline 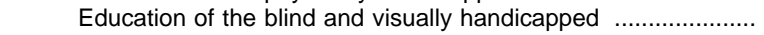 & 29 & 5 & 24 & 21 & 5 & 16 & 0 & 0 & 0 \\
\hline Education of the specific learning disabled $\ldots \ldots \ldots \ldots . . .$. & 635 & 49 & 586 & 548 & 64 & 484 & 2 & 0 & 2 \\
\hline impaired & 807 & 42 & 765 & 219 & 10 & 209 & 0 & 0 & 0 \\
\hline Specia & 288 & 35 & 253 & 290 & 37 & 253 & 9 & 2 & 7 \\
\hline services & 65 & 11 & 54 & 12,807 & 2,753 & 10,054 & 380 & 135 & 245 \\
\hline General teacher educat & 58,026 & 7,867 & 50,159 & 25,001 & 4,533 & 20,468 & 416 & 119 & 297 \\
\hline Adult and continuing education . & 43 & 19 & 24 & 885 & 242 & 643 & 167 & 58 & 109 \\
\hline Eleme & 45,578 & 5,430 & 40,148 & 13,682 & 1,637 & 12,045 & 82 & 7 & 75 \\
\hline ………....... & 1,410 & 359 & 1,051 & 706 & 132 & 574 & 0 & 0 & 0 \\
\hline rly childhood/kindergarten education & 6,422 & 227 & 6,195 & 2,105 & 54 & 2,051 & 28 & 5 & 23 \\
\hline Secon & 3,933 & 1,729 & 2,204 & 4,643 & 1,750 & 2,893 & 57 & 23 & 34 \\
\hline Teach & 640 & 103 & 537 & 2,980 & 718 & 2,262 & 82 & 26 & 56 \\
\hline nd vocational programs. & 34,012 & 16,338 & 17,674 & 16,287 & 5,333 & 10,954 & 677 & 322 & 355 \\
\hline education (vocational) ....... & 438 & 278 & 160 & 210 & 123 & 87 & 35 & 20 & 15 \\
\hline 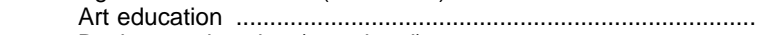 & 1,686 & 375 & 1,311 & 639 & 109 & 530 & 19 & 7 & 12 \\
\hline Busin & 1,088 & 304 & 784 & 425 & 132 & 293 & 8 & 4 & 4 \\
\hline 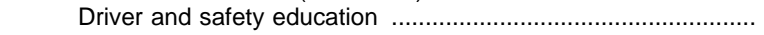 & 70 & 64 & & 28 & 16 & 12 & 1 & 1 & 0 \\
\hline Englis & 2,640 & 612 & 2,028 & 804 & 201 & 603 & 15 & 3 & 12 \\
\hline es education .. & 311 & 54 & 257 & 348 & 50 & 298 & 13 & 3 & 10 \\
\hline Health & 1,993 & 505 & 1,488 & 749 & 156 & 593 & 56 & 16 & 40 \\
\hline sation (vocational) . & 245 & & 241 & 70 & 2 & 68 & 6 & 0 & 6 \\
\hline Techno & 1,285 & 1,114 & 171 & 391 & 275 & 116 & 13 & 8 & 5 \\
\hline narketing and distribution education . & 71 & 36 & 35 & 7 & 2 & 5 & 0 & 0 & 0 \\
\hline education & 1,712 & 714 & 998 & 819 & 305 & 514 & 38 & 11 & 27 \\
\hline Music & 2,786 & 1,231 & 1,555 & 684 & 279 & 405 & 56 & 24 & 32 \\
\hline ation and coaching . & 12,139 & 7,141 & 4,998 & 3,109 & 1,699 & 1,410 & 181 & 108 & 73 \\
\hline ucation & 179 & 20 & 159 & 3,960 & 198 & 3,762 & 47 & 12 & 35 \\
\hline Scienc & 1,075 & 495 & 580 & 746 & 309 & 437 & 45 & 23 & 22 \\
\hline education & 794 & 429 & 365 & 98 & 53 & 45 & 1 & 1 & 0 \\
\hline Social studies education & 2,053 & 1,191 & 862 & 588 & 342 & 246 & 1 & 0 & 1 \\
\hline Technical education (vocational) & 178 & 114 & 64 & 398 & 146 & 252 & 30 & 18 & 12 \\
\hline Trade & 1,049 & 737 & 312 & 380 & 174 & 206 & 74 & 42 & 32 \\
\hline Teacher education, academic & 2,220 & 920 & 1,300 & 1,834 & 762 & 1,072 & 38 & 21 & 17 \\
\hline
\end{tabular}


Table 253.-Bachelor's, master's, and doctor's degrees conferred by institutions of higher education, by sex of student and field of study: 1995-96-Continued

\begin{tabular}{|c|c|c|c|c|c|c|c|c|c|}
\hline \multirow{2}{*}{ Field of study } & \multicolumn{3}{|c|}{$\begin{array}{l}\text { Bachelor's degrees requiring } \\
\qquad 4 \text { or } 5 \text { years }\end{array}$} & \multicolumn{3}{|c|}{ Master's degrees } & \multicolumn{3}{|c|}{$\begin{array}{l}\text { Doctor's degrees } \\
\text { (Ph.D., Ed.D., etc.) }\end{array}$} \\
\hline & Total & Men & Women & Total & Men & Women & Total & Men & Women \\
\hline 1 & 2 & 3 & 4 & 5 & 6 & 7 & 8 & 9 & 10 \\
\hline $\begin{array}{l}\text { Teaching English as a second language/foreign language } \\
\text { Education, other }\end{array}$ & $\begin{array}{r}52 \\
1,267\end{array}$ & $\begin{array}{r}12 \\
567\end{array}$ & $\begin{array}{r}40 \\
700\end{array}$ & $\begin{array}{l}1,662 \\
3,926\end{array}$ & $\begin{array}{l}334 \\
830\end{array}$ & $\begin{array}{l}1,328 \\
3,096\end{array}$ & $\begin{array}{r}13 \\
576\end{array}$ & $\begin{array}{r}8 \\
169\end{array}$ & $\begin{array}{r}5 \\
407\end{array}$ \\
\hline Engineering and engineering-related technologies, total ... & 77,437 & 64,956 & 12,481 & 28,566 & 23,641 & 4,925 & 6,380 & 5,580 & 800 \\
\hline Engineering, total & 62,114 & 51,069 & 11,045 & 27,441 & 22,735 & 4,706 & 6,369 & 5,570 & 799 \\
\hline Engineering, general . & 1,904 & 1,538 & 366 & 1,342 & 1,128 & 214 & 207 & 178 & 29 \\
\hline Aerospace, aeronautical, and astronautical engineering & 1,642 & 1,395 & 247 & 765 & 673 & 92 & 260 & 238 & 22 \\
\hline Agricultural engineering & 649 & 508 & 141 & 157 & 129 & 28 & 101 & 85 & 16 \\
\hline Architectural engineering ........................... & 489 & 397 & 92 & 51 & 39 & 12 & 7 & 7 & 0 \\
\hline 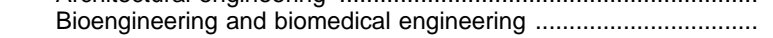 & 998 & 660 & 338 & 492 & 352 & 140 & 183 & 141 & 42 \\
\hline 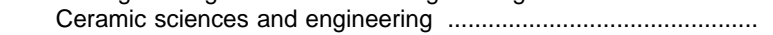 & 187 & 155 & 32 & 71 & 50 & 21 & 46 & 42 & 4 \\
\hline 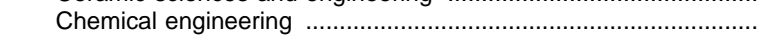 & 6,319 & 4,243 & 2,076 & 1,176 & 906 & 270 & 670 & 543 & 127 \\
\hline 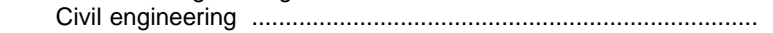 & 10,607 & 8,579 & 2,028 & 3,905 & 3,123 & 782 & 616 & 550 & 66 \\
\hline Computer engineering & 2,518 & 2,246 & 272 & 962 & 766 & 196 & 125 & 106 & 19 \\
\hline Electrical, electronics, and communications engineering ... & 13,900 & 12,246 & 1,654 & 7,103 & 6,110 & 993 & 1,591 & 1,431 & 160 \\
\hline 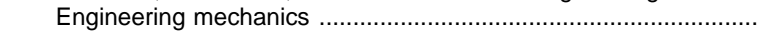 & 106 & 91 & 15 & 123 & 108 & 15 & 77 & 70 & 7 \\
\hline Engineering physics ....... & 263 & 227 & 36 & 58 & 51 & 7 & 41 & 36 & 5 \\
\hline Engineering science. & 312 & 254 & 58 & 336 & 274 & 62 & 54 & 49 & 5 \\
\hline Environmental/environmental health engineering & 745 & 478 & 267 & 1,038 & 768 & 270 & 72 & 54 & 18 \\
\hline Geological engineering & 179 & 131 & 48 & 39 & 36 & 3 & 14 & 12 & 2 \\
\hline Geophysical engineering & 21 & 13 & 8 & 12 & 12 & 0 & 2 & 2 & 0 \\
\hline Industrial/manufacturing engineering & 3,284 & 2,313 & 971 & 1,959 & 1,513 & 446 & 279 & 217 & 62 \\
\hline Material engineering & 473 & 368 & 105 & 457 & 354 & 103 & 361 & 314 & 47 \\
\hline Mechanical engineering ................. & 14,177 & 12,484 & 1,693 & 3,881 & 3,443 & 438 & 940 & 875 & 65 \\
\hline Metallurgical engineering & 255 & 190 & 65 & 137 & 102 & 35 & 74 & 57 & 17 \\
\hline Mining and mineral engineering & 126 & 114 & 12 & 40 & 39 & 1 & 26 & 23 & 3 \\
\hline Naval architecture and marine engineering ................................ & 329 & 303 & 26 & 29 & 22 & 7 & 7 & 6 & 1 \\
\hline 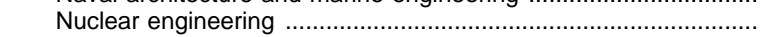 & 222 & 192 & 30 & 257 & 222 & 35 & 135 & 120 & 15 \\
\hline yineering ....... & 167 & 132 & 35 & 112 & 99 & 13 & 30 & 26 & 4 \\
\hline gineering & 240 & 209 & 31 & 145 & 132 & 13 & 49 & 47 & 2 \\
\hline 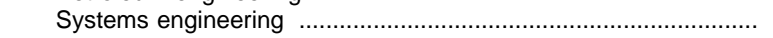 & 386 & 310 & 76 & 484 & 407 & 77 & 58 & 48 & 10 \\
\hline Textile sciences and engineering ............. & 72 & 50 & 22 & 32 & 17 & 15 & 3 & 3 & 0 \\
\hline 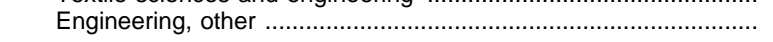 & 1,544 & 1,243 & 301 & 2,278 & 1,860 & 418 & 341 & 290 & 51 \\
\hline Engineering-related technologies, total & 15,323 & 13,887 & 1,436 & 1,125 & 906 & 219 & 11 & 10 & 1 \\
\hline Architectural engineering technologies & 517 & 463 & 54 & 0 & 0 & 0 & 0 & 0 & 0 \\
\hline 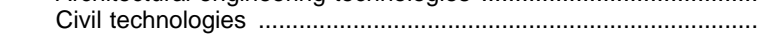 & 544 & 487 & 57 & 0 & 0 & 0 & 1 & 1 & 0 \\
\hline 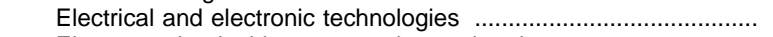 & 4,033 & 3,732 & 301 & 22 & 21 & 1 & 0 & 0 & 0 \\
\hline Electromechanical instrumentation and maintenance & & & & 1 & 1 & 0 & 0 & & 0 \\
\hline 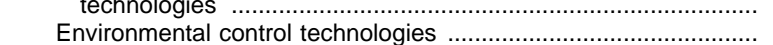 & $\begin{array}{l}434 \\
280\end{array}$ & $\begin{array}{l}412 \\
209\end{array}$ & $\begin{array}{l}22 \\
71\end{array}$ & $\begin{array}{r}1 \\
153\end{array}$ & $\begin{array}{r}1 \\
113\end{array}$ & $\begin{array}{r}0 \\
40\end{array}$ & $\begin{array}{l}0 \\
0\end{array}$ & $\begin{array}{l}0 \\
0\end{array}$ & $\begin{array}{l}0 \\
0\end{array}$ \\
\hline Industrial production technologies. & 3,848 & 3,412 & 436 & 231 & 186 & 45 & 4 & 4 & 0 \\
\hline trol and safety technologies..... & 498 & 396 & 102 & 373 & 296 & 77 & 0 & 0 & 0 \\
\hline Mechanical and related technologies & 1,668 & 1,555 & 113 & 0 & 0 & 0 & 0 & 0 & 0 \\
\hline Mining and petroleum technologies & 14 & 14 & 0 & 0 & 0 & 0 & 0 & 0 & 0 \\
\hline Surveying & 149 & 137 & 12 & 25 & 23 & 2 & 6 & 5 & 1 \\
\hline 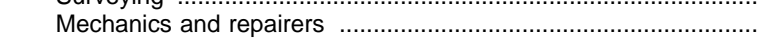 & 54 & 48 & 6 & 0 & 0 & 0 & 0 & 0 & 0 \\
\hline 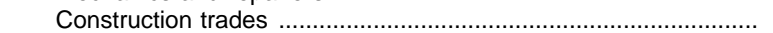 & 80 & 76 & 4 & 0 & 0 & 0 & 0 & 0 & 0 \\
\hline 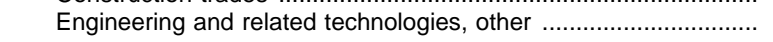 & 3,204 & 2,946 & 258 & 320 & 266 & 54 & 0 & 0 & 0 \\
\hline English language and literature/letters, total . & 50,698 & 17,253 & 33,445 & 7,893 & 2,814 & 5,079 & 1,535 & 590 & 945 \\
\hline English language and literature & 38,498 & 12,766 & 25,732 & 5,139 & 1,816 & 3,323 & 1,126 & 435 & 691 \\
\hline Comparative literature .... & 770 & 246 & 524 & 236 & 87 & 149 & 140 & 55 & 85 \\
\hline English composition & 262 & 100 & 162 & 24 & 5 & 19 & 5 & 1 & 4 \\
\hline English creative writing & 965 & 417 & 548 & 1,132 & 459 & 673 & 5 & 3 & 2 \\
\hline American literature (United States) & 42 & 16 & 26 & 6 & 1 & 5 & 15 & 6 & 9 \\
\hline English literature (British and Commonwealth) & 1,298 & 433 & 865 & 281 & 97 & 184 & 41 & 11 & 30 \\
\hline Speech and rhetorical studies & 7,634 & 2,877 & 4,757 & 752 & 250 & 502 & 143 & 58 & 85 \\
\hline English technical and business & 183 & 52 & 131 & 172 & 47 & 125 & 0 & 0 & 0 \\
\hline English language and literature/letters, other ......... & 1,046 & 346 & 700 & 151 & 52 & 99 & 60 & 21 & 39 \\
\hline Foreign languages and literatures, total & 13,952 & 4,219 & 9,733 & 3,124 & 1,017 & 2,107 & 876 & 387 & 489 \\
\hline Foreig & 1,498 & 452 & 1,046 & 894 & 299 & 595 & 249 & 127 & 122 \\
\hline 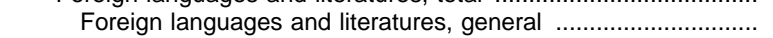 & 879 & 271 & 608 & 296 & 91 & 205 & 57 & 29 & 28 \\
\hline (n) & 619 & 181 & 438 & 598 & 208 & 390 & 192 & 98 & 94 \\
\hline East and Southeast Asian languages and literatures, total & 581 & 291 & 290 & 110 & 35 & 75 & 31 & 13 & 18 \\
\hline Chinese & 136 & 77 & 59 & 42 & 16 & 26 & 19 & 11 & 8 \\
\hline Japanese & 359 & 164 & 195 & 47 & 13 & 34 & 3 & 0 & 3 \\
\hline 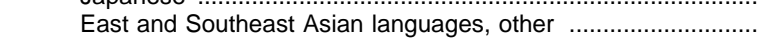 & 86 & 50 & 36 & 21 & 6 & 15 & 9 & 2 & 7 \\
\hline East European languages and literatures, total & 547 & 202 & 345 & 144 & 41 & 103 & 44 & 15 & 29 \\
\hline Russian languages & 494 & 182 & 312 & 58 & 15 & 43 & 7 & 2 & 5 \\
\hline 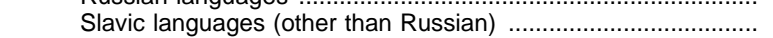 & 49 & 20 & 29 & 79 & 25 & 54 & 36 & 12 & 24 \\
\hline East European languages, other ...................... & 4 & 0 & 4 & 7 & 1 & 6 & 1 & 1 & 0 \\
\hline Germanic languages and literatures, total & 1,322 & 513 & 809 & 325 & 133 & 192 & 84 & 34 & 50 \\
\hline 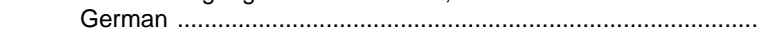 & 1,290 & 501 & 789 & 305 & 120 & 185 & 75 & 29 & 46 \\
\hline
\end{tabular}


Table 253.-Bachelor's, master's, and doctor's degrees conferred by institutions of higher education, by sex of student and field of study: 1995-96-Continued

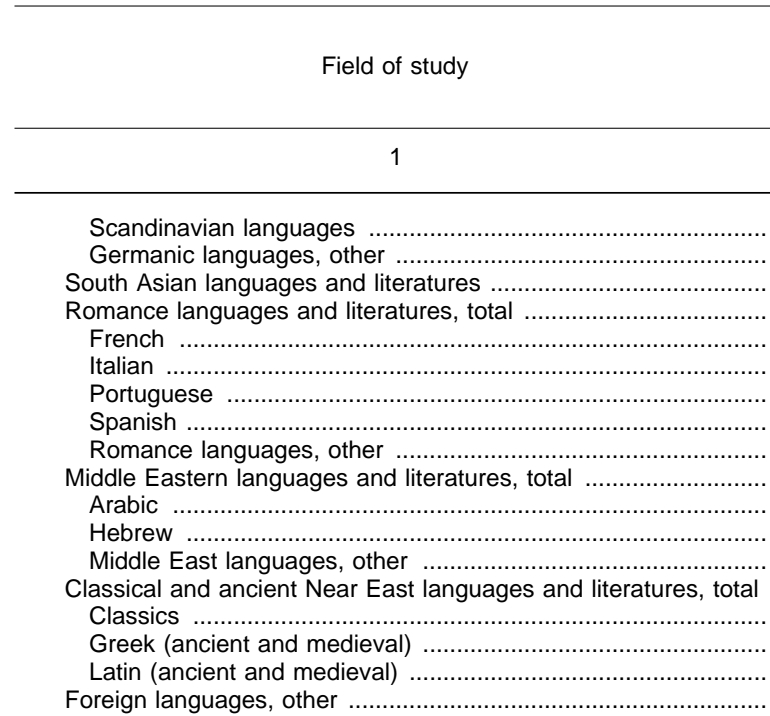

Health professions and related sciences, total

Communication disorders sciences and services

Community health liaison

Dentistry

Dental services

Epidemiology

Health services administration, total

Health services administration

Medical records administration

Medical records technology/technician

Health and medical administrative services, other

Health and medical assistants, total .........

Medical assistant

Physician assistant .

Health and medical assistants, other

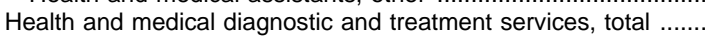

Respiratory therapy technology/technician

Health and medical diagnostic and treatment services, other

Medical laboratory technologies, total

Medical technology ......

Health and medical laboratory technologies/technicians, other

Pre-dentistry studies

Pre-medicine studies

Pre-pharmacy studies

Pre-veterinary studies

Medical basic sciences......

Mental health services, total

Alcohol/drug abuse counseling

Psychiatric/mental health services technician

Clinical and medical social work

Mental health services, other

Nursing

Optometry

Pharmacy

Rehabilitation/therapeutic services, total

Art therapy

Dance therapy

Music therapy

Occupational therapy

Orthotics/prosthetics

Physical therapy

Recreational therapy

Vocational rehabilitation counseling

Rehabilitative services, other

Veterinary medicine

Miscellaneous health professions

Health professions and related sciences, other

\begin{tabular}{|l|l|l} 
Bachelor's degrees requiring & Master's degrees & Doctor's degrees
\end{tabular}

\begin{tabular}{|}
\hline \\
\hline \\
\hline
\end{tabular}

ome economics and vocational home economics, total

Home economics, total

Home economics, general

Home economics business services

Family and community studies

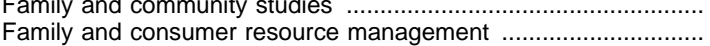

Food and nutrition studies

Housing studies

\begin{tabular}{|l|l|l} 
Bachelor's degrees requiring & Master's degrees & Doctor's degrees
\end{tabular}

\begin{tabular}{|c|c|c|c|c|c|c|c|c|}
\hline \multicolumn{3}{|c|}{4 or 5 years } & & & & \multicolumn{3}{|c|}{ (Ph.D., Ed.D., etc.) } \\
\hline Total & Men & Women & Total & Men & Women & Total & Men & Women \\
\hline 2 & 3 & 4 & 5 & 6 & 7 & 8 & 9 & 10 \\
\hline
\end{tabular}

\begin{tabular}{r|r}
20 & \\
12 & \\
8 & \\
8,988 & 2 \\
2,655 & \\
232 & \\
29 & \\
5,995 & 1 \\
77 & \\
76 & \\
8 & \\
45 & \\
23 & \\
735 & \\
619 & \\
26 & \\
90 & \\
197 &
\end{tabular}

6

84,036

6,120

4,247

4,247
2,298

709

1,238

1,440
0

1,271

169

1,595
385

1,210

2,972

2,543

429

138

667

266
384

384
621
109

109
97

117
298

44,544

133
6,288

6,288
8,069

75

185
3,217

26

3,225

160
233

943

421

4,384

15,803

15,328

2,620

122

229
1,022

1,022
3,648

3,648

489
5,724

6
6
5
2,270
558
53
18
1,623
18
24
4
10
10
390
340
12
38
72

15,432

370

170
5$$
\begin{array}{r}
5 \\
33 \\
0
\end{array}
$$

1,096

612

$\begin{array}{r}92 \\ 0 \\ \hline\end{array}$

392

636

588

48

614
165

449

913

752
161

75

355

83

145

128
41

22

4,838

72

2,331
1,923

, 923
3

0
26
474

21

1,078

28
47

446
0

183
1,461

1,461

1,68

1,682
193

193
14

24
293

293
518

$\begin{array}{r}53 \\ \hline 473\end{array}$

473

\begin{tabular}{r|}
14 \\
6 \\
3 \\
6,718 \\
2,097 \\
179 \\
11 \\
4,372 \\
59 \\
52 \\
4 \\
35 \\
13 \\
345 \\
279 \\
14 \\
52 \\
125 \\
\end{tabular}

68,604

5,750

$\begin{array}{r}644 \\ 4 \\ \hline\end{array}$

890

3,151

1,686
617

2
846

804

\begin{tabular}{r|r}
804 & 394 \\
0 & 0 \\
683 & 372
\end{tabular}

121

981
220

761

2,059

1,791

63

312

239

493
68

75

97

39,706

61
3,957
6,146

6,146

159

2,743

2,147

132

697

0
238
2,923

13,918

2,427

108

729

3,130

416
5,251

6
14

4
351

446

44
9
769

83

28

22
177

160

9
66

33,398

5,027

145
362

37
316

3,867

2,195

0
6
666

22
32

0
32

436

69
367

.$$
\begin{aligned}
& 0 \\
& 0 \\
& 2 \\
& 460
\end{aligned}
$$

446

380

39
50

74

217
0.510

14

298
5,615

198

18

31
1,030

0
3,343

0
623

372

140
884

4,493

2,917

2,885

300

4
55
70

597

13
1,745

4
9
1
374
104
15
3
226
26
24
2
13
9
95
90
2
3
15
021

,02

264

243

18
116

1,318

4

52

13

120

\begin{tabular}{r|r}
11 & 11 \\
23 & 9
\end{tabular}

0
23

163
19
144
0

0
0 $\quad 0$

0
215
56
6
8
13
29
733
7
157
1,431
12
0
10
101
0
1,055
0
165
88
67
478
1,562
496
494
24
0
12
11
69
1
360

2
231
324
33
42
61
188
9,777
7
141
4,184
186
18
21
929
0
2,288
0
458
284
73
406
2,931
2,421
2,391
276
4
43
59
528
12
1,385

1,385 
Table 253.-Bachelor's, master's, and doctor's degrees conferred by institutions of higher education, by sex of student and field of study: 1995-96-Continued

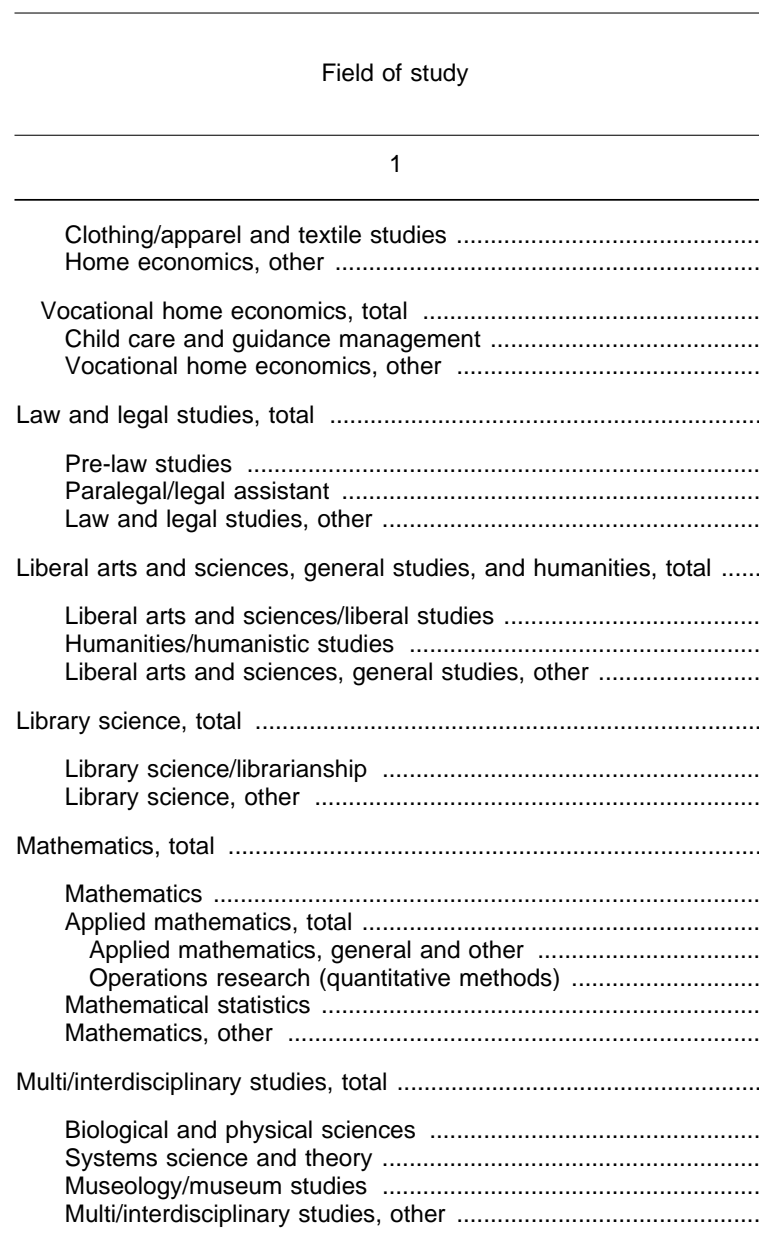

Parks, recreation, leisure, and fitness studies, total

Parks, recreation and leisure studies

Parks, recreation and leisure facilities management

Health and physical education/fitness

Parks, recreation, leisure and fitness studies, other

Philosophy and religion, total

Philosophy

Religion/religious studies

Philosophy and religion, other

Physical sciences and science technologies, total

Physical sciences, total

Physical sciences, general

Astronomy

Astrophysics

Atmospheric science and meteorology

Chemistry, total

Chemistry, general

Analytical chemistry

Inorganic chemistry

Organic chemistry

Medicinal/pharmaceutical chemistry

Chemistry, other

Geological and related sciences, total

Geology

Geochemistry

Geophysics and seismology

Geological and related sciences, othe

Miscellaneous physical sciences, total

Metallurgy ....

Oceanography

Earth and planetary sciences ..........1.

Miscellaneous physical sciences, other

Physics, total

Physics, general

Physics, other

Physical sciences, other

\section{Bachelor's degrees requiring $\quad$ Master's degrees $\quad$ Doctor's degrees}

4 or 5 years
 (Ph.D., Ed.D., etc.)

\begin{tabular}{c|c|c|c|c|c|c|c|c}
\hline Total & Men & Women & Total & Men & Women & Total & Men & Women \\
\hline 2 & 3 & 4 & 5 & 6 & 7 & 8 & 9 & 10 \\
\hline
\end{tabular}

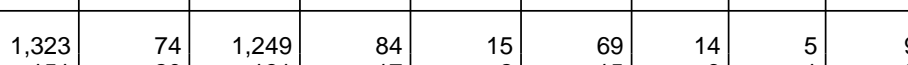

\begin{tabular}{rr|r|r|r|r|r|r|}
1,323 & 74 & 1,249 & 84 & 15 & 69 & 14 & 5 \\
151 & 20 & 131 & 17 & 2 & 15 & 9 & 1
\end{tabular}

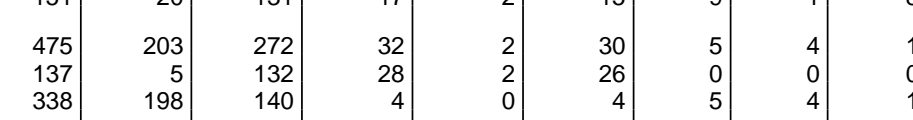

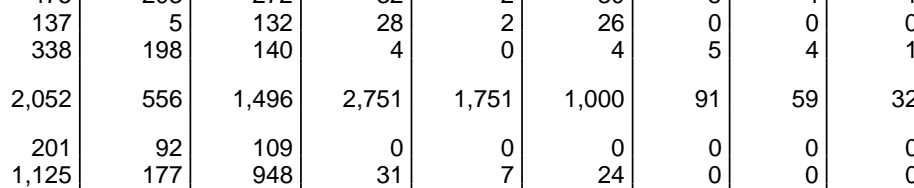

1,125
726

33,997

21,493

9,387

9,387

$$
56
$$

13,143$$
11,346
$$

1,094
664$$
430
$$$$
269
$$$$
26,515
$$$$
23,8
$$

\begin{tabular}{|c|c|c|c|c|}
\hline 2,574 & 1,318 & 1,256 & 243 & 128 \\
\hline 114 & 71 & 43 & 166 & 90 \\
\hline & 1 & 3 & 112 & 20 \\
\hline 23,823 & 7,896 & 15,927 & 1,826 & 844 \\
\hline 13,983 & 7,090 & 6,893 & 1,751 & 911 \\
\hline 2,146 & 979 & 1,167 & 208 & 90 \\
\hline 2,844 & 1,285 & 1,559 & 250 & 119 \\
\hline 8,756 & 4,679 & 4,077 & 1,270 & 693 \\
\hline 237 & 147 & 90 & 23 & 9 \\
\hline 7,388 & 4,859 & 2,529 & 1,302 & 845 \\
\hline 4,555 & 3,199 & 1,356 & 695 & 500 \\
\hline 2,543 & 1,477 & 1,066 & 540 & 321 \\
\hline 290 & 183 & 107 & 67 & 24 \\
\hline 19,647 & 12,578 & 7,069 & 5,847 & 3,966 \\
\hline 19,518 & 12,517 & 7,001 & 5,823 & 3,952 \\
\hline 392 & 238 & 154 & 71 & 58 \\
\hline 105 & 70 & 35 & 76 & 56 \\
\hline 43 & 23 & 20 & 39 & 32 \\
\hline 434 & 348 & 86 & 199 & 164 \\
\hline 10,415 & 5,970 & 4,445 & 2,254 & 1,269 \\
\hline 10,091 & 5,773 & 4,318 & 2,094 & 1,176 \\
\hline 0 & 0 & 0 & 16 & 13 \\
\hline 0 & 0 & 0 & 2 & 0 \\
\hline 14 & 8 & 6 & 19 & 10 \\
\hline 20 & 12 & 8 & 40 & 23 \\
\hline 290 & 177 & 113 & 83 & 47 \\
\hline 3,190 & 2,091 & 1,099 & 991 & 711 \\
\hline 2,922 & 1,927 & 995 & 816 & 581 \\
\hline 18 & 13 & 5 & 4 & 2 \\
\hline 60 & 45 & 15 & 76 & 58 \\
\hline 190 & 106 & 84 & 95 & 70 \\
\hline 904 & 575 & 329 & 405 & 233 \\
\hline 0 & 0 & 0 & 3 & 3 \\
\hline 185 & 120 & 65 & 142 & 88 \\
\hline 644 & 411 & 233 & 155 & 88 \\
\hline 75 & 44 & 31 & 105 & 54 \\
\hline 3,679 & 2,999 & 680 & 1,678 & 1,377 \\
\hline 3,548 & 2,899 & 649 & 1,546 & 1,274 \\
\hline 131 & 100 & 31 & 132 & 103 \\
\hline 356 & 203 & 153 & 110 & 52 \\
\hline
\end{tabular}

\begin{tabular}{|c|c|c|c|}
\hline 92 & 109 & 0 & 0 \\
\hline 177 & 948 & 31 & 7 \\
\hline 287 & 439 & 2,720 & 1,744 \\
\hline 3,379 & 20,618 & 2,778 & 961 \\
\hline 7,837 & 13,656 & 1,873 & 653 \\
\hline 1,099 & 2,018 & 488 & 190 \\
\hline 4,443 & 4,944 & 417 & 118 \\
\hline 8 & 50 & 5,099 & 1,071 \\
\hline 7 & 49 & 5,032 & 1,054 \\
\hline 1 & 1 & 67 & 17 \\
\hline 7,134 & 6,009 & 4,031 & 2,465 \\
\hline 6,029 & 5,317 & 2,381 & 1,407 \\
\hline 668 & 426 & 736 & 518 \\
\hline 381 & 283 & 356 & 231 \\
\hline 287 & 143 & 380 & 287 \\
\hline 257 & 177 & 819 & 481 \\
\hline 180 & 89 & 95 & 59 \\
\hline 9,286 & 17,229 & 2,347 & 1,082 \\
\hline 1,318 & 1,256 & 243 & 128 \\
\hline 71 & 43 & 166 & 90 \\
\hline & 3 & 112 & 20 \\
\hline 7,896 & 15,927 & 1,826 & 844 \\
\hline 7,090 & 6,893 & 1,751 & 911 \\
\hline 979 & 1,167 & 208 & 90 \\
\hline 1,285 & 1,559 & 250 & 119 \\
\hline 4,679 & 4,077 & 1,270 & 693 \\
\hline 147 & 90 & 23 & 9 \\
\hline 4,859 & 2,529 & 1,302 & 845 \\
\hline 3,199 & 1,356 & 695 & 500 \\
\hline 1,477 & 1,066 & 540 & 321 \\
\hline 183 & 107 & 67 & 24 \\
\hline & & & \\
\hline
\end{tabular}

1,881

\begin{tabular}{r|r|r|r}
1,871 & 4,563 & 3,508 & 1,055 \\
13 & 4 & 1 & 3 \\
20 & 97 & 74 & 23 \\
7 & 28 & 24 & 4 \\
35 & 97 & 80 & 17
\end{tabular}

\begin{tabular}{r|r|r|r}
35 & 97 & 80 & 17
\end{tabular}

\begin{tabular}{l|l|l|l}
985 & 2,287 & 1,598 & 689 \\
918 & 2,088 & 1,461 & 627
\end{tabular}

\begin{tabular}{r|r|r|r}
918 & 2,088 & 1,461 & 627 \\
3 & 14 & 11 & 3
\end{tabular}

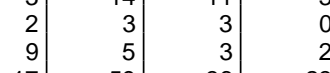

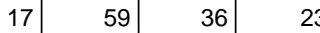

\begin{tabular}{lll|l}
36 & 118 & 84 & 34
\end{tabular}

\begin{tabular}{l|l|l|l}
280 & 372 & 298 & 74
\end{tabular}

\begin{tabular}{l|l|l|l}
235 & 279 & 215 & 64
\end{tabular}

\begin{tabular}{r|r|r|r}
2 & 4 & 4 & 0 \\
18 & 64 & 56 & 8 \\
25 & 25 & 23 & 2
\end{tabular}

$191-137$

\begin{tabular}{rr|r|r|r|r|}
0 & 1 & 1 & 0
\end{tabular}

\begin{tabular}{r|r|r|r}
54 & 105 & 72 & 33 \\
67 & 78 & 59 & 19
\end{tabular}

\begin{tabular}{rr|r|r}
51 & 78 & 59
\end{tabular}

\begin{tabular}{l|l|r|r}
301 & 1,462 & 1,276 & 186
\end{tabular}

\begin{tabular}{l|r|r|r}
272 & 1,379 & 1,204 & 175
\end{tabular}

\begin{tabular}{l|l|r|r}
29 & 83 & 72 & 11 \\
58 & 25 & 20 & 5
\end{tabular}


Table 253.-Bachelor's, master's, and doctor's degrees conferred by institutions of higher education, by sex of student and field of study: 1995-96-Continued

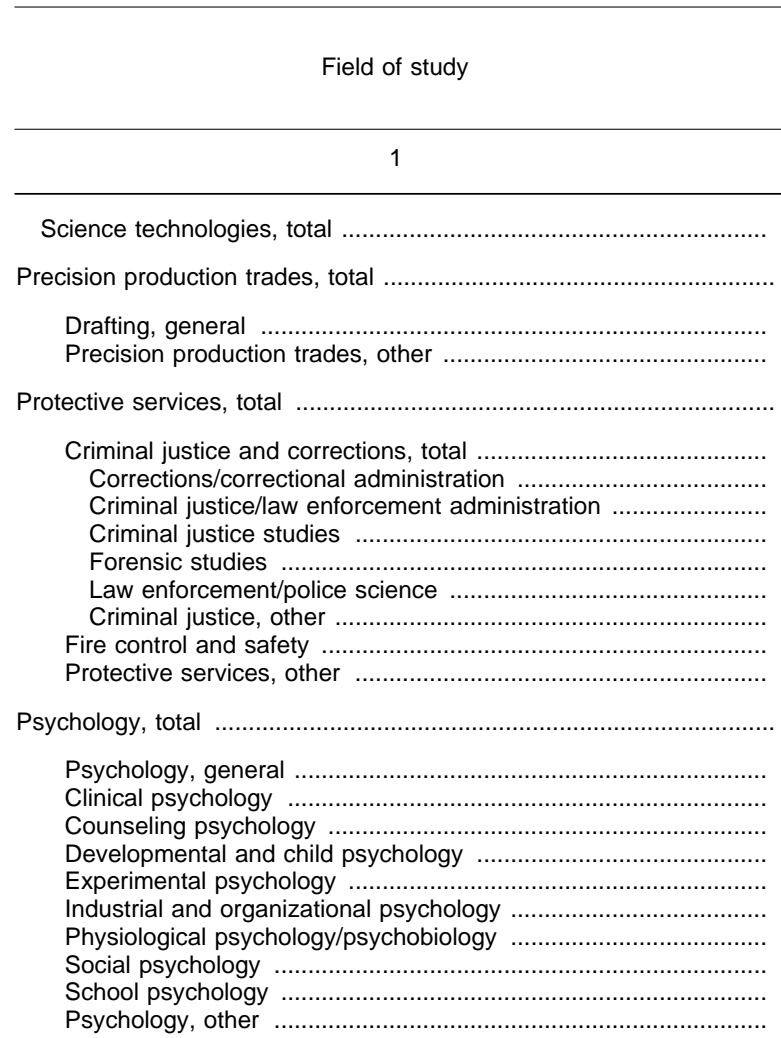

Public administration and services, total

Public administration

Community organization, resources and services

Public policy analysis

Social work ..................
Public affairs, other

R.O.T.C. and military technologies, total

Social sciences and history, total

Social sciences, general

Anthropology

Archeology

Criminology

Demography and population studies

Economics

Geography, total

Geography

Cartography

History

International relations and affairs

Political science and government, genera

Sociology

Urban affairs/studies

Social sciences and history, other

Theological studies/religious vocations, total

Biblical and other theological languages and literatures

Bible/biblical studies

Missions/missionary studies and misology

Religious education .......

Religious/sacred music

Theology/theological studies

Pastoral counseling and specialized ministries

Theological studies and religious vocations, other

Transportation and material moving workers, total

Air transportation workers ...

Water transportation workers

Transportation and material moving, other

Visual and performing arts, total

Visual and performing arts, general

Crafts, folk art, and artisanry

\begin{tabular}{|l|l|l}
\hline Bachelor's degrees requiring & Master's degrees & Doctor's degrees
\end{tabular}

\begin{tabular}{l|l|l}
4 or 5 years & \multicolumn{2}{|c|}{$\begin{array}{l}\text { Doctor's degrees } \\
\text { (Ph.D., Ed.D., etc.) }\end{array}$}
\end{tabular}

\begin{tabular}{c|c|c|c|c|c|c|c|c}
\hline Total & Men & Women & Total & Men & Women & Total & Men & Women \\
\hline 2 & 3 & 4 & 5 & 6 & 7 & 8 & 9 & 10 \\
\hline
\end{tabular}

129

.

24

24,396$$
\begin{array}{r}
8, \\
12, \\
1,
\end{array}
$$$$
\begin{array}{r}
1,734 \\
1,053 \\
304 \\
110
\end{array}
$$

$$
73,291
$$$$
69,04
$$

(1)


Table 253.-Bachelor's, master's, and doctor's degrees conferred by institutions of higher education, by sex of student and field of study: 1995-96-Continued

\begin{tabular}{|c|c|c|c|c|c|c|c|c|c|}
\hline \multirow{2}{*}{ Field of study } & \multicolumn{3}{|c|}{$\begin{array}{c}\text { Bachelor's degrees requiring } \\
4 \text { or } 5 \text { years }\end{array}$} & \multicolumn{3}{|c|}{ Master's degrees } & \multicolumn{3}{|c|}{$\begin{array}{l}\text { Doctor's degrees } \\
\text { (Ph.D., Ed.D., etc.) }\end{array}$} \\
\hline & Total & Men & Women & Total & Men & Women & Total & Men & Women \\
\hline 1 & 2 & 3 & 4 & 5 & 6 & 7 & 8 & 9 & 10 \\
\hline Dance & 925 & 94 & 831 & 191 & 29 & 162 & 10 & 1 & 9 \\
\hline 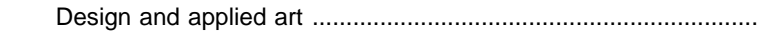 & 7,988 & 3,265 & 4,723 & 525 & 221 & 304 & 3 & 1 & 2 \\
\hline 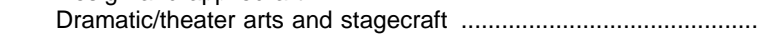 & 6,217 & 2,486 & 3,731 & 1,317 & 567 & 750 & 99 & 42 & 57 \\
\hline Film/video and photographic arts, total & 2,814 & 1,718 & 1,096 & 680 & 377 & 303 & 11 & 7 & 4 \\
\hline Film-video making/cinematography and production & 1,107 & 758 & 349 & 303 & 172 & 131 & 1 & 1 & 0 \\
\hline Photography & 939 & 481 & 458 & 157 & 72 & 85 & 5 & 5 & 0 \\
\hline Film arts, other & 768 & 479 & 289 & 220 & 133 & 87 & 5 & 1 & 4 \\
\hline Fine arts and art studies, total ....... & 20,585 & 7,413 & 13,172 & 3,354 & 1,201 & 2,153 & 183 & 51 & 132 \\
\hline 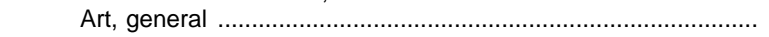 & 11,326 & 4,322 & 7,004 & 968 & 385 & 583 & 38 & 16 & 22 \\
\hline Art history, criticism and conservation ............ & 4,565 & 1,241 & 3,324 & 1,102 & 341 & 761 & 142 & 33 & 109 \\
\hline Arts management ............................. & 102 & 17 & 85 & 171 & 27 & 144 & 1 & 0 & 1 \\
\hline Painting ........................................ & 779 & 360 & 419 & 196 & 94 & 102 & 0 & 0 & 0 \\
\hline Ceramic arts and ceramics .......... & 191 & 62 & 129 & 65 & 32 & 33 & 0 & 0 & 0 \\
\hline 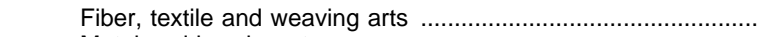 & 95 & 6 & 89 & 38 & 5 & 33 & 2 & 2 & 0 \\
\hline Metal and jewelry arts & 97 & 19 & 78 & 21 & 5 & 16 & 0 & 0 & 0 \\
\hline 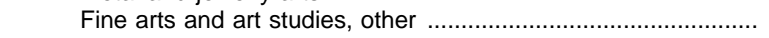 & 3,430 & 1,386 & 2,044 & 793 & 312 & 481 & 0 & 0 & 0 \\
\hline 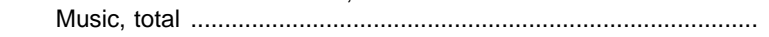 & 8,713 & 4,311 & 4,402 & 3,741 & 1,797 & 1,944 & 716 & 408 & 308 \\
\hline 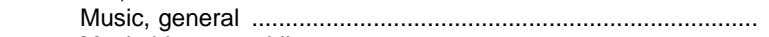 & 4,391 & 2,061 & 2,330 & 1,157 & 549 & 608 & 312 & 181 & 131 \\
\hline Music history and literature ......... & 57 & 23 & 34 & 69 & 34 & 35 & 24 & 14 & 10 \\
\hline Music, general performance .......... & 2,843 & 1,314 & 1,529 & 1,908 & 920 & 988 & 242 & 124 & 118 \\
\hline Music theory and composition ...... & 271 & 199 & 72 & 199 & 135 & 64 & 76 & 62 & 14 \\
\hline Music, other & 1,151 & 714 & 437 & 408 & 159 & 249 & 62 & 27 & 35 \\
\hline 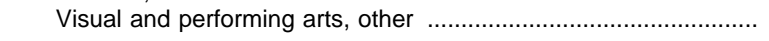 & 466 & 193 & 273 & 367 & 118 & 249 & 40 & 11 & 29 \\
\hline Not classified by field of study & 1,756 & 1,015 & 741 & 780 & 420 & 360 & 7 & 5 & 2 \\
\hline
\end{tabular}

NOTE.-Aggregations by field of study derived from the Classification of Instructional Programs developed by the National Center for Education Statistics.
SOURCE: U.S. Department of Education, National Center for Education Statistics, Integrated Postsecondary Education Data System (IPEDS), "Completions" survey. (This table was prepared April 1998.) 
Table 254.-Degrees conferred by institutions of higher education, by control of institution: $1969-70$ to $1995-96$

\begin{tabular}{|c|c|c|c|c|c|c|c|c|c|c|}
\hline \multirow[b]{2}{*}{ Year } & \multicolumn{5}{|c|}{ Public institutions } & \multicolumn{5}{|c|}{ Private institutions } \\
\hline & Associate & Bachelor's & Master's & Doctor's & $\begin{array}{l}\text { First- } \\
\text { profes- } \\
\text { sional }^{1}\end{array}$ & Associate & Bachelor's & Master's & Doctor's & $\begin{array}{c}\text { First- } \\
\text { profes- } \\
\text { sional }{ }^{1}\end{array}$ \\
\hline 1 & 2 & 3 & 4 & 5 & 6 & 7 & 8 & 9 & 10 & 11 \\
\hline $\begin{array}{l}1969-70 \\
1970-71 \\
1971-72 \\
1972-73 \\
1973-74 \\
1974-75 \\
1975-76 \\
1976-77 \\
1977-78 \\
1978-79 \\
1979-80 \\
1980-81 \\
1981-82 \\
1982-83 \\
1983-84 \\
1984-85 \\
1985-86 \\
1986-87 \\
1987-88 \\
1988-89 \\
1989-90 \\
1990-91 \\
1991-92 \\
1992-93 \\
1993-94 \ldots \ldots . . \\
1994-95 \\
1995-96\end{array}$ & $\begin{array}{r}170,966 \\
215,645 \\
255,218 \\
278,132 \\
303,188 \\
318,474 \\
345,006 \\
355,650 \\
358,874 \\
346,808 \\
344,536 \\
352,391 \\
2366,732 \\
377,817 \\
2379,249 \\
377,625 \\
369,052 \\
358,811 \\
354,180 \\
357,001 \\
375,635 \\
398,055 \\
420,265 \\
430,321 \\
3444,373 \\
451,539 \\
454,291\end{array}$ & $\begin{array}{l}519,550 \\
557,996 \\
599,615 \\
630,899 \\
651,544 \\
634,785 \\
635,161 \\
630,463 \\
627,903 \\
621,666 \\
624,084 \\
626,452 \\
636,475 \\
646,317 \\
646,013 \\
652,246 \\
658,586 \\
659,260 \\
658,491 \\
675,675 \\
700,015 \\
724,062 \\
759,475 \\
785,112 \\
789,148 \\
776,670 \\
774,070\end{array}$ & $\begin{array}{l}134,545 \\
151,603 \\
167,075 \\
174,405 \\
184,632 \\
193,804 \\
206,298 \\
208,901 \\
202,099 \\
192,016 \\
187,499 \\
184,384 \\
182,295 \\
176,246 \\
170,693 \\
170,000 \\
169,903 \\
167,797 \\
173,778 \\
179,109 \\
186,104 \\
193,057 \\
203,398 \\
213,843 \\
221,428 \\
224,152 \\
227,179\end{array}$ & $\begin{array}{l}19,183 \\
20,788 \\
21,776 \\
22,357 \\
21,810 \\
22,176 \\
21,751 \\
21,229 \\
20,456 \\
20,817 \\
20,608 \\
20,895 \\
20,889 \\
21,186 \\
21,141 \\
21,337 \\
21,433 \\
21,870 \\
22,488 \\
22,970 \\
24,641 \\
25,681 \\
26,820 \\
27,392 \\
28,524 \\
28,917 \\
29,516\end{array}$ & $\begin{array}{l}14,542 \\
16,139 \\
18,521 \\
21,872 \\
23,208 \\
23,612 \\
25,766 \\
26,344 \\
27,097 \\
27,785 \\
27,942 \\
29,128 \\
29,611 \\
29,757 \\
29,586 \\
30,152 \\
29,568 \\
29,346 \\
29,153 \\
28,993 \\
28,810 \\
29,554 \\
29,366 \\
29,628 \\
29,842 \\
29,871 \\
29,882\end{array}$ & $\begin{array}{r}35,057 \\
36,666 \\
36,796 \\
38,042 \\
40,736 \\
41,697 \\
46,448 \\
50,727 \\
53,372 \\
55,894 \\
56,374 \\
63,986 \\
267,794 \\
71,803 \\
272,991 \\
77,087 \\
76,995 \\
77,493 \\
80,905 \\
79,763 \\
79,467 \\
83,665 \\
83,966 \\
84,435 \\
86,259 \\
88,152 \\
100,925\end{array}$ & $\begin{array}{l}272,766 \\
281,734 \\
287,658 \\
291,463 \\
294,232 \\
288,148 \\
290,585 \\
289,086 \\
293,301 \\
299,724 \\
305,333 \\
308,688 \\
316,523 \\
323,193 \\
328,296 \\
327,231 \\
329,237 \\
332,004 \\
336,338 \\
343,080 \\
351,329 \\
370,476 \\
377,078 \\
380,066 \\
380,127 \\
383,464 \\
390,722\end{array}$ & $\begin{array}{r}73,746 \\
78,906 \\
84,558 \\
88,966 \\
92,401 \\
98,646 \\
105,473 \\
108,263 \\
109,521 \\
109,063 \\
110,582 \\
111,355 \\
113,251 \\
113,675 \\
113,570 \\
116,251 \\
118,664 \\
121,552 \\
125,539 \\
131,512 \\
138,197 \\
144,111 \\
149,440 \\
155,742 \\
165,642 \\
173,477 \\
179,122\end{array}$ & $\begin{array}{l}10,683 \\
11,319 \\
11,587 \\
12,420 \\
12,006 \\
11,907 \\
12,313 \\
12,003 \\
11,675 \\
11,913 \\
12,007 \\
12,063 \\
11,818 \\
11,589 \\
12,068 \\
11,606 \\
12,220 \\
12,171 \\
12,382 \\
12,750 \\
13,730 \\
13,613 \\
13,839 \\
14,740 \\
14,661 \\
15,529 \\
15,136\end{array}$ & $\begin{array}{l}20,376 \\
21,807 \\
24,890 \\
28,146 \\
30,608 \\
32,304 \\
36,883 \\
38,015 \\
39,484 \\
41,063 \\
42,189 \\
42,828 \\
42,421 \\
43,297 \\
44,882 \\
44,911 \\
44,342 \\
42,271 \\
41,582 \\
41,863 \\
42,178 \\
42,394 \\
44,780 \\
45,759 \\
45,576 \\
45,929 \\
46,852\end{array}$ \\
\hline
\end{tabular}

${ }^{1}$ Includes degrees which require at least 6 years of college work for completion (including at least 2 years of preprofessional training).

${ }^{2}$ Data are approximations.

${ }^{3}$ Revised from previously published figures.
SOURCE: U.S. Department of Education, National Center for Education Statistics, Higher Education General Information Survey (HEGIS), "Degrees and Other Formal Awards Conferred" surveys, and Integrated Postsecondary Education Data System (IPEDS), "Completions" surveys. (This table was prepared July 1998.)

Table 255.-Degrees conferred by institutions of higher education, by control of institution, level of degree, and discipline division: 1995-96

\begin{tabular}{|c|c|c|c|c|c|c|c|c|}
\hline \multirow[b]{2}{*}{ Discipline division } & \multicolumn{4}{|c|}{ Public institutions } & \multicolumn{4}{|c|}{ Private institutions } \\
\hline & $\begin{array}{l}\text { Associate } \\
\text { degrees }\end{array}$ & $\begin{array}{c}\text { Bachelor's } \\
\text { degrees }\end{array}$ & $\begin{array}{l}\text { Master's } \\
\text { degrees }\end{array}$ & $\begin{array}{l}\text { Doctor's } \\
\text { degrees }\end{array}$ & $\begin{array}{c}\text { Associate } \\
\text { degrees }\end{array}$ & $\begin{array}{c}\text { Bachelor's } \\
\text { degrees }\end{array}$ & $\begin{array}{l}\text { Master's } \\
\text { degrees }\end{array}$ & $\begin{array}{l}\text { Doctor's } \\
\text { degrees }\end{array}$ \\
\hline 1 & 2 & 3 & 4 & 5 & 6 & 7 & 8 & 9 \\
\hline Total $\ldots . .$. & 454,291 & 774,070 & 227,179 & 29,516 & 100,925 & 390,722 & 179,122 & 15,136 \\
\hline Agriculture and natural resources ${ }^{1}$ & 5,826 & 19,933 & 3,895 & 1,243 & 356 & 1,498 & 674 & 28 \\
\hline $\begin{array}{l}\text { Architecture and related programs } \\
\text { Area ethnic and cultural studies }\end{array}$ & $\begin{array}{r}248 \\
92\end{array}$ & $\begin{array}{l}6,191 \\
3,088\end{array}$ & $\begin{array}{r}2,776 \\
990\end{array}$ & $\begin{array}{l}96 \\
84\end{array}$ & & $\begin{array}{l}2,161 \\
2,698\end{array}$ & $\begin{array}{r}1,217 \\
723\end{array}$ & $\begin{array}{r}45 \\
100\end{array}$ \\
\hline Biological sciences/life sciences .... & 1,961 & 39,634 & 4,296 & 3,291 & 76 & 21,360 & 1,861 & 1,489 \\
\hline 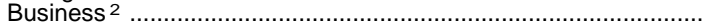 & 73,694 & 135,342 & 37,156 & 917 & 33,474 & 91,760 & 56,826 & 451 \\
\hline Communications ........... & 1,357 & 33,139 & 2,666 & 276 & 830 & 14,181 & 2,414 & 62 \\
\hline Communications technologies & 1,590 & 420 & 102 & 0 & 167 & 263 & 422 & 7 \\
\hline Computer and information sciences & 6,811 & 14,627 & 5,705 & 546 & 2,847 & 9,471 & 4,446 & 321 \\
\hline Construction trades & 1,562 & 24 & & 0 & 579 & 56 & & 0 \\
\hline Education & 8,593 & 78,471 & 67,562 & 5,082 & 1,157 & 27,038 & 38,691 & 1,594 \\
\hline Engineering .............................. & 1,756 & 47,068 & 18,610 & 4,531 & 441 & 15,046 & 8,831 & 1,838 \\
\hline 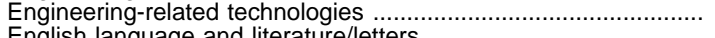 & 20,926 & & $\begin{array}{r}919 \\
5817\end{array}$ & 11 & $\begin{array}{r}12,076 \\
85\end{array}$ & $\begin{array}{r}4,283 \\
16675\end{array}$ & 206 & $\begin{array}{l}0 \\
3\end{array}$ \\
\hline & 1,225 & 34,023 & 5,817 & 1,172 & $\begin{array}{r}85 \\
227\end{array}$ & 16,675 & 2,076 & 363 \\
\hline $\begin{array}{l}\text { Foreign languages and literatures } \\
\text { Health professions and related sciences }\end{array}$ & $\begin{array}{r}380 \\
84.257\end{array}$ & $\begin{array}{r}9,070 \\
54.666\end{array}$ & $\begin{array}{r}2,356 \\
19,091\end{array}$ & $\begin{array}{r}524 \\
1568\end{array}$ & $\begin{array}{r}227 \\
17.615\end{array}$ & $\begin{array}{r}4,882 \\
29370\end{array}$ & $\begin{array}{r}768 \\
14307\end{array}$ & 352 \\
\hline 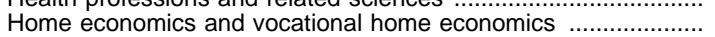 & $\begin{array}{r}04,862 \\
7,862\end{array}$ & 13,568 & 1,544 & 274 & 330 & 2,235 & $\begin{array}{r}14,301 \\
1,373\end{array}$ & 140 \\
\hline 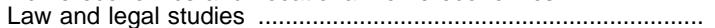 & 5,807 & 1,205 & 588 & 9 & 3,299 & 847 & 2,163 & 82 \\
\hline Liberal arts and sciences, general studies, and humanities ........ & 164,685 & 20,904 & 1,118 & 32 & 10,285 & 13,093 & 1,660 & 43 \\
\hline Library science & 92 & 46 & 4,208 & 50 & & & 891 & 3 \\
\hline 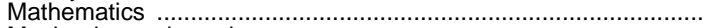 & 725 & 8,694 & 3,056 & 845 & 33 & 4,449 & 975 & 364 \\
\hline Mechanics and repairers & 10,164 & 43 & & 0 & 2,360 & & 0 & 0 \\
\hline Multi/interdisciplinary studies & 8,517 & 20,500 & 1,590 & 193 & 94 & 6, & 757 & 248 \\
\hline 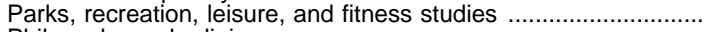 & 808 & 10,788 & 1,433 & 101 & 128 & 3 , & 318 & 3 \\
\hline Philosophy and religion & 34 & 3,025 & 504 & 218 & 49 & 4,363 & 798 & 331 \\
\hline Physical sciences and science technologies ... & 2,553 & 12,764 & 4,299 & 3,235 & 59 & 6,883 & 1,548 & 1,336 \\
\hline Précision production trades & 6,466 & 379 & & & 3,751 & & & \\
\hline Protective services ............. & 18,368 & 19,725 & 1,084 & 37 & 828 & 5 , & 728 & \\
\hline Psychology & 1,441 & $\begin{array}{l}48,612 \\
14288\end{array}$ & $\begin{array}{r}5,941 \\
14551\end{array}$ & $\begin{array}{l}1,881 \\
287\end{array}$ & 142 & 24, & 7,851 & 1,830 \\
\hline Public administration and services & $\begin{array}{r}3,847 \\
551\end{array}$ & & $\begin{array}{r}14,551 \\
136\end{array}$ & $\begin{aligned} 281 \\
0\end{aligned}$ & $\begin{array}{r}371 \\
5\end{array}$ & & $\begin{array}{r}9,678 \\
0\end{array}$ & $\begin{array}{r}12 \\
0\end{array}$ \\
\hline 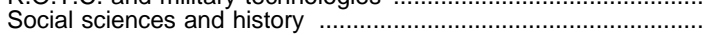 & 3,678 & 82,705 & 9,557 & 2,344 & 343 & 43,774 & 5,455 & 1,416 \\
\hline Theological studies/religious vocations & & & & & & & 5,107 & 1,521 \\
\hline Transportation and material moving workers & 1,255 & 1,677 & 106 & 0 & 316 & 1,884 & 813 & \\
\hline and performing arts & 6,726 & 28,542 & 5,523 & 669 & 6,808 & 20,754 & 4,757 & 398 \\
\hline Not classified by field of study & 434 & & & 0 & 1,15 & 1,756 & 780 & 7 \\
\hline
\end{tabular}

1 Includes "Agricultural business and production," "Agricultural sciences," and "Conservation and renewable natural resources."

2 Includes "Business management and administrative services," "Marketing operations/ marketing and distribution," and "Consumer and personal services."
SOURCE: U.S. Department of Education, National Center for Education Statistics, Integrated Postsecondary Education Data System, "Completions" survey, 1995-96 and "Consolidated" survey 1996. (This table was prepared May 1998.) 
Table 256.-Degrees conferred by institutions of higher education, by control of institution, level of degree, and discipline division: 1994-95

\begin{tabular}{|c|c|c|c|c|c|c|c|c|}
\hline \multirow[b]{2}{*}{ Discipline division } & \multicolumn{4}{|c|}{ Public institutions } & \multicolumn{4}{|c|}{ Private institutions } \\
\hline & $\begin{array}{c}\text { Associate } \\
\text { degrees }\end{array}$ & $\begin{array}{c}\text { Bachelor's } \\
\text { degrees }\end{array}$ & $\begin{array}{l}\text { Master's } \\
\text { degrees }\end{array}$ & $\begin{array}{l}\text { Doctor's } \\
\text { degrees }\end{array}$ & $\begin{array}{l}\text { Associate } \\
\text { degrees }\end{array}$ & $\begin{array}{c}\text { Bachelor's } \\
\text { degrees }\end{array}$ & $\begin{array}{l}\text { Master's } \\
\text { degrees }\end{array}$ & $\begin{array}{l}\text { Doctor's } \\
\text { degrees }\end{array}$ \\
\hline 1 & 2 & 3 & 4 & 5 & 6 & 7 & 8 & 9 \\
\hline 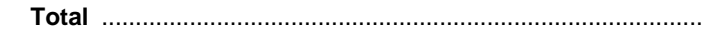 & 451,539 & 776,670 & 224,152 & 28,917 & 88,152 & 383,464 & 173,477 & 15,529 \\
\hline 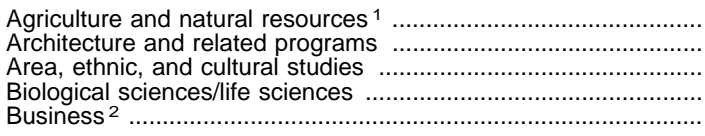 & $\begin{array}{r}5,418 \\
253 \\
52 \\
1,802 \\
75,415\end{array}$ & $\begin{array}{r}18,471 \\
6,532 \\
2,980 \\
36,640 \\
142,206\end{array}$ & $\begin{array}{r}3,778 \\
2,708 \\
963 \\
3,904 \\
37,114\end{array}$ & $\begin{array}{r}1,246 \\
81 \\
87 \\
3,274 \\
970\end{array}$ & $\begin{array}{r}312 \\
24 \\
16 \\
77 \\
26,511\end{array}$ & $\begin{array}{r}1,370 \\
2,224 \\
2,726 \\
19,344 \\
92,117\end{array}$ & $\begin{array}{r}474 \\
1,215 \\
676 \\
1,489 \\
56,695\end{array}$ & $\begin{array}{r}18 \\
60 \\
99 \\
1,371 \\
424\end{array}$ \\
\hline $\begin{array}{l}\text { Communications } \\
\text { Communications technologies } \\
\text { Computer and information sciences } \\
\text { Construction trades } \\
\text { Education }\end{array}$ & $\begin{array}{l}1,340 \\
1,659 \\
6,716 \\
1,345 \\
8,414\end{array}$ & $\begin{array}{r}33,847 \\
471 \\
14,793 \\
38 \\
79,536\end{array}$ & $\begin{array}{r}2,773 \\
82 \\
5,661 \\
0 \\
65,265\end{array}$ & $\begin{array}{r}266 \\
0 \\
594 \\
0 \\
5,139\end{array}$ & $\begin{array}{r}1,820 \\
325 \\
2,436 \\
383 \\
1,244\end{array}$ & $\begin{array}{r}14,257 \\
228 \\
9,611 \\
75 \\
26,543\end{array}$ & $\begin{array}{r}2,369 \\
385 \\
4,665 \\
7 \\
35,977\end{array}$ & $\begin{array}{r}54 \\
1 \\
290 \\
0 \\
1,766\end{array}$ \\
\hline 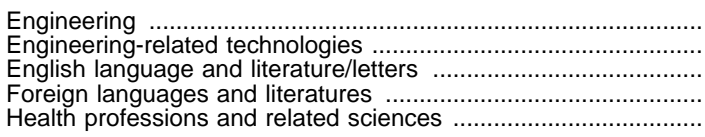 & $\begin{array}{r}1,908 \\
22,521 \\
1,491 \\
349 \\
84,962\end{array}$ & $\begin{array}{r}47,026 \\
11,550 \\
34,848 \\
8,896 \\
53,101\end{array}$ & $\begin{array}{r}19,314 \\
954 \\
5,900 \\
2,301 \\
18,049\end{array}$ & $\begin{array}{r}4,277 \\
18 \\
1,098 \\
563 \\
1,468\end{array}$ & $\begin{array}{r}324 \\
12,211 \\
57 \\
267 \\
13,512\end{array}$ & $\begin{array}{r}15,316 \\
4,083 \\
17,053 \\
4,879 \\
26,754\end{array}$ & $\begin{array}{r}9,239 \\
156 \\
1,945 \\
835 \\
13,194\end{array}$ & $\begin{array}{r}1,833 \\
0 \\
463 \\
342 \\
601\end{array}$ \\
\hline 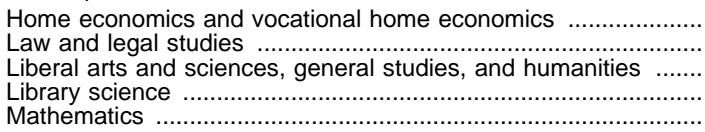 & $\begin{array}{r}7,476 \\
6,208 \\
159,722 \\
98 \\
748\end{array}$ & $\begin{array}{r}13,223 \\
1,242 \\
20,906 \\
45 \\
8,939\end{array}$ & $\begin{array}{r}1,586 \\
550 \\
1,096 \\
4,176 \\
3,190\end{array}$ & $\begin{array}{r}248 \\
10 \\
32 \\
49 \\
867\end{array}$ & $\begin{array}{r}345 \\
2,932 \\
11,095 \\
3 \\
34\end{array}$ & $\begin{array}{r}2,122 \\
790 \\
12,450 \\
5 \\
4,784\end{array}$ & $\begin{array}{r}1,278 \\
1,961 \\
1,469 \\
881 \\
991\end{array}$ & $\begin{array}{r}140 \\
78 \\
58 \\
6 \\
359\end{array}$ \\
\hline 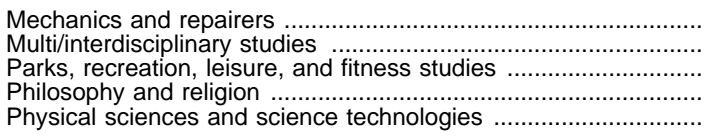 & $\begin{array}{r}9,880 \\
8,575 \\
730 \\
45 \\
2,397\end{array}$ & $\begin{array}{r}32 \\
20,157 \\
10,234 \\
2,931 \\
12,505\end{array}$ & $\begin{array}{r}0 \\
1,609 \\
1,375 \\
496 \\
4,251\end{array}$ & $\begin{array}{r}0 \\
171 \\
120 \\
203 \\
3,052\end{array}$ & $\begin{array}{r}1,617 \\
117 \\
134 \\
36 \\
59\end{array}$ & $\begin{array}{r}34 \\
5,876 \\
2,655 \\
4,345 \\
6,672\end{array}$ & $\begin{array}{r}0 \\
848 \\
380 \\
884 \\
1,502\end{array}$ & $\begin{array}{r}0 \\
67 \\
29 \\
304 \\
1,431\end{array}$ \\
\hline $\begin{array}{l}\text { Precision production trades } \\
\text { Protective services } \\
\text { Psychology } \\
\text { Public administration and services } \\
\text { R.O.T.C. and military technologies }\end{array}$ & $\begin{array}{r}6,413 \\
19,007 \\
1,437 \\
3,499 \\
349\end{array}$ & $\begin{array}{r}336 \\
19,347 \\
48,255 \\
13,349 \\
6\end{array}$ & $\begin{array}{r}0 \\
1,047 \\
5,985 \\
14,206 \\
124\end{array}$ & $\begin{array}{r}0 \\
26 \\
1,766 \\
291 \\
0\end{array}$ & $\begin{array}{r}2,931 \\
702 \\
163 \\
383 \\
15\end{array}$ & $\begin{array}{r}17 \\
4,810 \\
23,828 \\
5,237 \\
21\end{array}$ & $\begin{array}{r}5 \\
659 \\
7,936 \\
9,295 \\
0\end{array}$ & $\begin{array}{r}0 \\
0 \\
2,056 \\
265 \\
0\end{array}$ \\
\hline $\begin{array}{l}\text { Social sciences and history } \\
\text { Theological studies/religious vocations } \\
\text { Transportation and material moving workers } \\
\text { Visual and performing arts } \\
\text { Not classified by field of study }\end{array}$ & $\begin{array}{r}3,251 \\
35 \\
1,174 \\
6,402 \\
448\end{array}$ & $\begin{array}{r}84,021 \\
2 \\
1,693 \\
28,227 \\
285\end{array}$ & $\begin{array}{r}9,596 \\
2 \\
75 \\
5,664 \\
358\end{array}$ & $\begin{array}{r}2,303 \\
0 \\
0 \\
679 \\
19\end{array}$ & $\begin{array}{r}383 \\
572 \\
272 \\
6,142 \\
698\end{array}$ & $\begin{array}{r}44,133 \\
5,576 \\
2,005 \\
20,463 \\
1,061\end{array}$ & $\begin{array}{r}5,249 \\
5,238 \\
748 \\
4,613 \\
219\end{array}$ & $\begin{array}{r}1,422 \\
1,591 \\
0 \\
401 \\
0\end{array}$ \\
\hline
\end{tabular}

\footnotetext{
${ }^{1}$ Includes "Agricultural business and production," "Agricultural sciences," and "Conservation and renewable natural resources."

${ }^{2}$ Includes "Business management and administrative services," "Marketing operations/
} marketing and distribution" and "Consumer and personal services."

SOURCE: US. Department of Education, National Center for Education Statistics, Integrated Postsecondary Education Data System, "Completions" survey, 1994-95 and "Consolidated" survey 1995. (This table was prepared March 1997.) 
Table 257.-Number of institutions of higher education conferring degrees, by level of degree and discipline division: 1995-96

\begin{tabular}{|c|c|c|c|c|c|c|c|c|c|c|c|c|}
\hline \multirow{2}{*}{ Discipline division } & \multicolumn{4}{|c|}{$\begin{array}{l}\text { Total number of institutions } \\
\text { awarding degrees }\end{array}$} & \multicolumn{4}{|c|}{$\begin{array}{l}\text { Number of public institutions } \\
\text { awarding degrees }\end{array}$} & \multicolumn{4}{|c|}{$\begin{array}{l}\text { Number of private institutions } \\
\text { awarding degrees }\end{array}$} \\
\hline & $\begin{array}{l}\text { Associate } \\
\text { degrees }\end{array}$ & $\begin{array}{c}\text { Bachelor's } \\
\text { degrees }\end{array}$ & $\begin{array}{l}\text { Master's } \\
\text { degrees }\end{array}$ & $\begin{array}{l}\text { Doctor's } \\
\text { degrees }\end{array}$ & $\begin{array}{c}\text { Associate } \\
\text { degrees }\end{array}$ & $\begin{array}{l}\text { Bachelor's } \\
\text { degrees }\end{array}$ & $\begin{array}{l}\text { Master's } \\
\text { degrees }\end{array}$ & $\begin{array}{l}\text { Doctor's } \\
\text { degrees }\end{array}$ & $\begin{array}{l}\text { Associate } \\
\text { degrees }\end{array}$ & $\begin{array}{l}\text { Bachelor's } \\
\text { degrees }\end{array}$ & $\begin{array}{l}\text { Master's } \\
\text { degrees }\end{array}$ & $\begin{array}{l}\text { Doctor's } \\
\text { degrees }\end{array}$ \\
\hline 1 & 2 & 3 & 4 & 5 & 6 & 7 & 8 & 9 & 10 & 11 & 12 & 13 \\
\hline Total & 2,385 & 1,862 & 1,369 & 488 & 1,268 & 555 & 497 & 221 & 1,117 & 1,307 & 872 & 267 \\
\hline Agricultural business and production .. & 306 & 129 & 60 & 35 & 294 & 99 & 57 & 34 & 12 & 30 & 3 & 1 \\
\hline Agricultural sciences & 97 & 132 & 79 & 52 & 89 & 114 & 76 & 52 & 8 & 18 & 3 & 0 \\
\hline Architecture and related programs ..... & 36 & 169 & 116 & 26 & 33 & 109 & 88 & 19 & 3 & 60 & 28 & 7 \\
\hline Area, ethnic, and cultural studies ........ & 36 & 373 & 111 & 36 & 33 & 163 & 65 & 20 & 3 & 210 & 46 & 16 \\
\hline Biological sciences/life sciences .......... & 188 & 1,230 & 419 & 222 & 174 & 471 & 302 & 149 & 14 & 759 & 117 & 73 \\
\hline Business management and & & & & & & & & & & & & \\
\hline administrative services ... & 1,713 & 1,400 & 748 & 119 & 1,115 & 498 & 356 & 80 & 598 & 902 & 392 & 39 \\
\hline Communications ............... & 246 & 905 & 226 & 47 & 201 & 369 & 158 & 37 & 45 & 536 & 68 & 10 \\
\hline Communications technologies & 157 & 32 & 10 & 2 & 142 & 17 & 2 & 0 & 15 & 15 & 8 & 2 \\
\hline Computer and information sciences ... & 759 & 1,056 & 334 & 121 & 540 & 436 & 214 & 83 & 219 & 620 & 120 & 38 \\
\hline 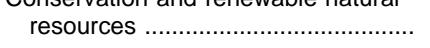 & 121 & 279 & 108 & 46 & 110 & 151 & 91 & 41 & 11 & 128 & 17 & 5 \\
\hline Consumer and personal services ........ & 238 & 12 & 0 & 0 & 198 & 6 & 0 & 0 & 40 & 6 & 0 & 0 \\
\hline Construction trades & 184 & 6 & 0 & 0 & 172 & 3 & 0 & 0 & 12 & 3 & 0 & 0 \\
\hline Education & 383 & 1,140 & 854 & 217 & 298 & 424 & 421 & 148 & 85 & 716 & 433 & 69 \\
\hline Engineering & 277 & 397 & 264 & 173 & 246 & 217 & 173 & 124 & 31 & 180 & 91 & 49 \\
\hline Engineering-related technologies ........ & 989 & 317 & 69 & 3 & 811 & 225 & 56 & 3 & 178 & 92 & 13 & 0 \\
\hline English language and & & & & & & & & & & & & \\
\hline 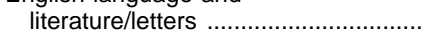 & 140 & 1,250 & 415 & 137 & 126 & 479 & 292 & 92 & 14 & 771 & 123 & 45 \\
\hline $\begin{array}{l}\text { Foreign languages and literatures ....... } \\
\text { Health professions and related }\end{array}$ & 76 & 826 & 200 & 84 & 71 & 371 & 143 & 52 & 5 & 455 & 57 & 32 \\
\hline sciences & 1,356 & 944 & 569 & 149 & 994 & 420 & 306 & 109 & 362 & 524 & 263 & 40 \\
\hline Home economics …............................... & 88 & 326 & 185 & 41 & 73 & 207 & 122 & 32 & 15 & 119 & 63 & 9 \\
\hline Law and legal studies ........................... & 482 & 128 & 66 & 15 & 313 & 47 & 26 & 4 & 169 & 81 & 40 & 11 \\
\hline $\begin{array}{l}\text { Liberal arts and sciences, general } \\
\text { studies, and humanities }\end{array}$ & 1,311 & 723 & 158 & 22 & 1,014 & 294 & 76 & 10 & 297 & 429 & 82 & 12 \\
\hline Library science & 31 & 13 & 70 & 13 & 29 & 11 & 58 & 12 & 2 & 2 & 12 & 1 \\
\hline $\begin{array}{l}\text { Marketing operations/marketing and } \\
\text { distribution }\end{array}$ & 476 & 172 & 18 & 1 & 365 & 65 & 4 & 1 & 111 & 107 & 14 & 0 \\
\hline 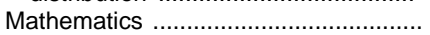 & 138 & 1,131 & 339 & 157 & 128 & 472 & 256 & 111 & 10 & 659 & $\begin{array}{l}14 \\
83\end{array}$ & 46 \\
\hline Mechanics and repairers ...................... & 549 & & 0 & 0 & 508 & 4 & 0 & 0 & 41 & 2 & 0 & 0 \\
\hline Multi/interdisciplinary studies .. & 176 & 633 & 189 & 60 & 160 & 263 & 132 & 43 & 16 & 370 & 57 & 17 \\
\hline Parks, recreation, leisure, and & & & & & & & & & & & & \\
\hline 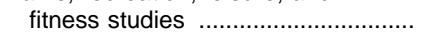 & 131 & 513 & 129 & 27 & 120 & 242 & 110 & 25 & 11 & 271 & 19 & 2 \\
\hline 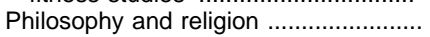 & 27 & 834 & 188 & 92 & 17 & 293 & 86 & 49 & 10 & 541 & 102 & 43 \\
\hline Physical sciences & 154 & 1,063 & 340 & 204 & 144 & 457 & 245 & 138 & 10 & 606 & 95 & 66 \\
\hline Precision production trades ....... & 668 & 30 & 2 & 0 & 565 & 24 & 0 & 0 & 103 & 6 & 2 & 0 \\
\hline 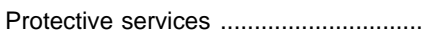 & 805 & 449 & 110 & 9 & 729 & 245 & 81 & 8 & 76 & 204 & 29 & 1 \\
\hline 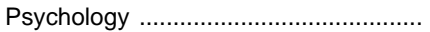 & 162 & 1,240 & 542 & 240 & 134 & 462 & 305 & 131 & 28 & 778 & 237 & 109 \\
\hline Public administration and services ..... & 258 & 640 & 345 & 77 & 222 & 299 & 234 & 46 & 36 & 341 & 111 & 31 \\
\hline R.O.T.C. and military technologies ..... & 4 & 3 & 1 & 0 & 3 & 2 & 1 & 0 & 1 & 1 & 0 & 0 \\
\hline Science technologies .......................... & 114 & 18 & 4 & 3 & 108 & 8 & 2 & 3 & 6 & 10 & 2 & 0 \\
\hline Social sciences and history . & 227 & 1,291 & 414 & 172 & 191 & 487 & 297 & 115 & 36 & 804 & 117 & 57 \\
\hline Theological studies/religious & & & & & & & & & & & & \\
\hline vocations & 85 & 323 & 252 & 106 & 0 & 0 & 0 & 0 & 85 & 323 & 252 & 106 \\
\hline $\begin{array}{l}\text { Transportation and material moving } \\
\text { workers }\end{array}$ & 105 & 70 & 7 & 0 & 89 & 35 & 4 & 0 & 16 & 35 & 3 & 0 \\
\hline 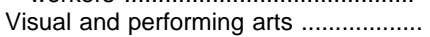 & 555 & 1,203 & 375 & 94 & 412 & 445 & 233 & 60 & 143 & 758 & 142 & 34 \\
\hline Vocational home economics ................ & 528 & 39 & 7 & 1 & 498 & 14 & 4 & 1 & 30 & 25 & 3 & 0 \\
\hline Not classified by field of study ............. & 15 & 16 & 15 & 4 & 3 & 0 & 0 & 0 & 12 & 16 & 15 & 4 \\
\hline
\end{tabular}


Table 258.-Number of institutions of higher education conferring degrees, by level of degree and discipline division: 1994-95

\begin{tabular}{|c|c|c|c|c|c|c|c|c|c|c|c|c|}
\hline \multirow{2}{*}{ Discipline division } & \multicolumn{4}{|c|}{$\begin{array}{l}\text { Total number of institutions } \\
\text { awarding degrees }\end{array}$} & \multicolumn{4}{|c|}{$\begin{array}{l}\text { Number of public institutions } \\
\text { awarding degrees }\end{array}$} & \multicolumn{4}{|c|}{$\begin{array}{l}\text { Number of private institutions } \\
\text { awarding degrees }\end{array}$} \\
\hline & $\begin{array}{c}\text { Associate } \\
\text { degrees }\end{array}$ & $\begin{array}{c}\text { Bachelor's } \\
\text { degrees }\end{array}$ & $\begin{array}{l}\text { Master's } \\
\text { degrees }\end{array}$ & \begin{tabular}{|l} 
Doctor's \\
degrees
\end{tabular} & $\begin{array}{c}\text { Associate } \\
\text { degrees }\end{array}$ & $\begin{array}{l}\text { Bachelor's } \\
\text { degrees }\end{array}$ & $\begin{array}{l}\text { Master's } \\
\text { degrees }\end{array}$ & $\begin{array}{l}\text { Doctor's } \\
\text { degrees }\end{array}$ & $\begin{array}{l}\text { Associate } \\
\text { degrees }\end{array}$ & $\begin{array}{c}\text { Bachelor's } \\
\text { degrees }\end{array}$ & $\begin{array}{l}\text { Master's } \\
\text { degrees }\end{array}$ & $\begin{array}{l}\text { Doctor's } \\
\text { degrees }\end{array}$ \\
\hline 1 & 2 & 3 & 4 & 5 & 6 & 7 & 8 & 9 & 10 & 11 & 12 & 13 \\
\hline Total & 2,184 & 1,855 & 1,351 & 482 & 1,252 & 557 & 488 & 217 & 932 & 1,298 & 863 & 265 \\
\hline Agricultural business and production .. & 306 & 129 & 60 & 32 & 292 & 98 & 57 & 31 & 14 & 31 & 3 & 1 \\
\hline Agricultural sciences $\ldots \ldots \ldots \ldots \ldots \ldots \ldots \ldots \ldots$ & 94 & 129 & 75 & 52 & 85 & 114 & 72 & 52 & 9 & 15 & 3 & 0 \\
\hline Architecture and related programs ..... & 44 & 171 & 119 & 26 & 36 & 107 & 92 & 18 & 8 & 64 & 27 & 8 \\
\hline Area, ethnic, and cultural studies ....... & 24 & 372 & 105 & 35 & 21 & 165 & 64 & 19 & 3 & 207 & 41 & 16 \\
\hline Biological sciences/life sciences .......... & 186 & 1,236 & 422 & 216 & 172 & 474 & 307 & 142 & 14 & 762 & 115 & 74 \\
\hline Business management and & & & & & & & & & & & & \\
\hline $\begin{array}{c}\text { administrative services } \ldots \ldots \ldots \ldots \ldots \ldots \ldots \\
\text { Communications } \ldots \ldots \ldots \ldots \ldots \ldots \ldots \ldots \ldots \ldots \ldots \ldots \ldots \ldots \ldots \ldots \ldots \ldots \ldots \ldots \ldots \ldots\end{array}$ & $\begin{array}{r}1,577 \\
227\end{array}$ & $\begin{array}{r}1,383 \\
900\end{array}$ & $\begin{array}{l}729 \\
226\end{array}$ & $\begin{array}{r}118 \\
46\end{array}$ & $\begin{array}{r}1,097 \\
187\end{array}$ & $\begin{array}{l}497 \\
369\end{array}$ & $\begin{array}{l}352 \\
156\end{array}$ & $\begin{array}{l}80 \\
36\end{array}$ & $\begin{array}{r}480 \\
40\end{array}$ & $\begin{array}{l}886 \\
531\end{array}$ & $\begin{array}{r}377 \\
70\end{array}$ & $\begin{array}{l}38 \\
10\end{array}$ \\
\hline 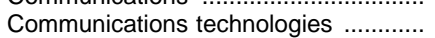 & 165 & 34 & $\begin{array}{r}220 \\
11\end{array}$ & $\begin{array}{r}40 \\
1\end{array}$ & 148 & 16 & $\begin{array}{r}150 \\
2\end{array}$ & $\begin{array}{r}30 \\
0\end{array}$ & $\begin{array}{l}40 \\
17\end{array}$ & $\begin{array}{r}531 \\
18\end{array}$ & $\begin{array}{r}70 \\
9\end{array}$ & 1 \\
\hline Computer and information sciences ... & 727 & 1,068 & 339 & 119 & 529 & 437 & 209 & 83 & 198 & 631 & 130 & 36 \\
\hline $\begin{array}{l}\text { Conservation and renewable natural } \\
\quad \text { resources }\end{array}$ & 116 & 257 & 100 & 45 & 108 & 141 & 85 & 42 & 8 & 116 & 15 & 3 \\
\hline Consumer and personal services ........ & 218 & 12 & 0 & 0 & 187 & 7 & 0 & 0 & 31 & 5 & 0 & 0 \\
\hline 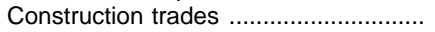 & 179 & 7 & 1 & 0 & 166 & 3 & 0 & 0 & 13 & 4 & 1 & 0 \\
\hline Education & 382 & 1,152 & 840 & 213 & 289 & 428 & 419 & 145 & 93 & 724 & 421 & 68 \\
\hline 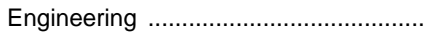 & 267 & 393 & 264 & 171 & 237 & 214 & 171 & 122 & 30 & 179 & 93 & 49 \\
\hline Engineering-related technologies $\ldots . . .$. & 969 & 315 & 70 & 3 & 801 & 224 & 55 & 3 & 168 & 91 & 15 & 0 \\
\hline English language and literature/letters & 139 & 1,248 & 417 & 133 & 128 & 477 & 294 & 88 & 11 & 771 & 123 & 45 \\
\hline $\begin{array}{l}\text { Foreign languages and literatures } \ldots . . . \\
\text { Health professions and related }\end{array}$ & 73 & 841 & 194 & 85 & 68 & 367 & 141 & 52 & 5 & 474 & 53 & 33 \\
\hline 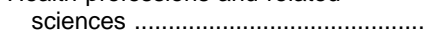 & 1,247 & 937 & 547 & 148 & 962 & 423 & 297 & 107 & 285 & 514 & 250 & 41 \\
\hline Home economics ............................... & 70 & 324 & 184 & 42 & 53 & 210 & 119 & 32 & 17 & 114 & 65 & 10 \\
\hline Law and legal studies ......................... & 434 & 132 & 62 & 14 & 295 & 45 & 26 & 3 & 139 & 87 & 36 & 11 \\
\hline $\begin{array}{l}\text { Liberal arts and sciences, general } \\
\text { studies, and humanities }\end{array}$ & 1,316 & 714 & 140 & 21 & 1,001 & 297 & 68 & 10 & 315 & 417 & 72 & 11 \\
\hline Library science & 30 & 11 & 69 & 16 & 28 & 10 & 58 & 13 & 2 & 1 & 11 & 3 \\
\hline $\begin{array}{l}\text { Marketing operations/marketing and } \\
\text { distribution }\end{array}$ & 502 & 177 & 23 & 3 & 393 & 66 & 4 & 2 & 109 & 111 & 19 & 1 \\
\hline Mathematics ….................................... & 139 & 1,145 & 343 & 157 & 129 & 472 & 256 & 108 & 10 & 673 & 87 & 49 \\
\hline Mechanics and repairers ...................... & 529 & & 0 & 0 & 495 & 4 & 0 & 0 & 34 & 5 & 0 & 0 \\
\hline Multi/interdisciplinary studies ............. & 176 & 612 & 180 & 59 & 156 & 257 & 123 & 40 & 20 & 355 & 57 & 19 \\
\hline $\begin{array}{l}\text { Parks, recreation, leisure, and fitness } \\
\text { studies }\end{array}$ & 131 & 500 & 121 & 24 & 118 & 243 & 102 & 22 & 13 & 257 & 19 & 2 \\
\hline Philosophy and religion ........................ & 29 & 839 & 187 & 90 & 20 & 286 & 86 & 49 & 9 & 553 & 101 & 41 \\
\hline 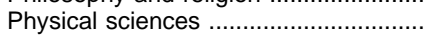 & 152 & 1,064 & 341 & 201 & 146 & 459 & 245 & 132 & 6 & 605 & 96 & 69 \\
\hline Precision production trades ....... & 631 & 26 & 1 & 0 & 554 & 21 & 0 & 0 & 77 & 5 & 1 & 0 \\
\hline Protective services …............................. & 788 & 439 & 103 & 6 & 720 & 243 & 76 & 6 & 68 & 196 & 27 & 0 \\
\hline Psychology .............. & 155 & 1,241 & 529 & 233 & 134 & 460 & 307 & 128 & 21 & 781 & 222 & 105 \\
\hline Public administration and services ...... & 260 & 635 & 349 & 79 & 224 & 293 & 230 & 45 & 36 & 342 & 119 & 34 \\
\hline R.O.T.C. and military technologies ..... & 4 & 4 & 1 & 0 & 3 & 3 & 1 & 0 & 1 & 1 & 0 & 0 \\
\hline Science technologies .......................... & 103 & 19 & 4 & 3 & 95 & 9 & 3 & 3 & 8 & 10 & 1 & 0 \\
\hline Social sciences and history .. & 216 & 1,290 & 418 & 174 & 178 & 486 & 297 & 114 & 38 & 804 & 121 & 60 \\
\hline Theological studies/religious vocations & 82 & 337 & 269 & 111 & 1 & 1 & 1 & 0 & 81 & 336 & 268 & 111 \\
\hline $\begin{array}{l}\text { Transportation and material moving } \\
\text { workers }\end{array}$ & 107 & 66 & 6 & 0 & 91 & 33 & 2 & 0 & 16 & 33 & 4 & 0 \\
\hline Visual and performing arts .................. & 540 & 1,207 & 377 & 97 & 410 & 443 & $23 \overline{6}$ & 62 & 130 & 764 & 141 & 35 \\
\hline Vocational home economics .................. & 505 & 42 & 9 & 2 & 479 & 21 & 6 & 1 & 26 & 21 & 3 & 1 \\
\hline Not classified by field of study ........... & 10 & 14 & 6 & 1 & 2 & 2 & 1 & 1 & 8 & 12 & 5 & 0 \\
\hline
\end{tabular}


Table 259.-First-professional degrees conferred by institutions of higher education in dentistry, medicine, and law, by sex, and number of institutions conferring degrees: 1949-50 to 1995-96

\begin{tabular}{|c|c|c|c|c|c|c|c|c|c|c|c|c|c|}
\hline \multirow{3}{*}{\multicolumn{2}{|c|}{ Year }} & \multicolumn{4}{|c|}{ Dentistry (D.D.S. or D.M.D.) } & \multicolumn{4}{|c|}{ Medicine (M.D.) } & \multicolumn{4}{|c|}{ Law (LL.B. or J.D.) } \\
\hline & & \multirow{2}{*}{$\begin{array}{c}\text { Number of } \\
\text { institutions } \\
\text { conferring } \\
\text { degrees }\end{array}$} & \multicolumn{3}{|c|}{ Degrees conferred } & \multirow{2}{*}{$\begin{array}{c}\text { Number of } \\
\text { institutions } \\
\text { conferring } \\
\text { degrees }\end{array}$} & \multicolumn{3}{|c|}{ Degrees conferred } & \multirow{2}{*}{$\begin{array}{c}\text { Number of } \\
\text { institutions } \\
\text { conferring } \\
\text { degrees }\end{array}$} & \multicolumn{3}{|c|}{ Degrees conferred } \\
\hline & & & Total & Men & Women & & Total & Men & Women & & Total & Men & Women \\
\hline & 1 & 2 & 3 & 4 & 5 & 6 & 7 & 8 & 9 & 10 & 11 & 12 & 13 \\
\hline $1949-50$ & . & 40 & 2,579 & 2,561 & 18 & 72 & 5,612 & 5,028 & 584 & $(1)$ & $(1)$ & $(1)$ & $(1)$ \\
\hline $1951-52$ & $\ldots \ldots$. & 41 & 2,918 & 2,895 & 23 & 72 & 6,201 & 5,871 & 330 & (1) & $(1)$ & $(1)$ & $(1)$ \\
\hline $1953-54$ & ........ & 42 & 3,102 & 3,063 & 39 & 73 & 6,712 & 6,377 & 335 & (1) & $(1)$ & $(1)$ & (1) \\
\hline $1955-56$ & $\ldots$ & 42 & 3,009 & 2,975 & 34 & 73 & 6,810 & 6,464 & 346 & 131 & 8,262 & 7,974 & 288 \\
\hline $1957-58$ & $\ldots \ldots$ & 43 & 3,065 & 3,031 & 34 & 75 & 6,816 & 6,469 & 347 & 131 & 9,394 & 9,122 & 272 \\
\hline 1959-60 & $\ldots$ & 45 & 3,247 & 3,221 & 26 & 79 & 7,032 & 6,645 & 387 & 134 & 9,240 & 9,010 & 230 \\
\hline $1961-62$ & $\ldots \ldots$ & 46 & 3,183 & 3,166 & 17 & 81 & 7,138 & 6,749 & 389 & 134 & 9,364 & 9,091 & 273 \\
\hline $1963-64$ & …................. & 46 & 3,180 & 3,168 & 12 & 82 & 7,303 & 6,878 & 425 & 133 & 10,679 & 10,372 & 307 \\
\hline 1965-66 & ….................. & 47 & 3,178 & 3,146 & 32 & 84 & 7,673 & 7,170 & 503 & 136 & 13,246 & 12,776 & 470 \\
\hline $1967-68$ & ....................... & 48 & 3,422 & 3,375 & 47 & 85 & 7,944 & 7,318 & 626 & 138 & 16,454 & 15,805 & 649 \\
\hline 1969-70 & $\ldots \ldots$ & 48 & 3,718 & 3,684 & 34 & 86 & 8,314 & 7,615 & 699 & 145 & 14,916 & 14,115 & 801 \\
\hline 1970-71 & ………............. & 48 & 3,745 & 3,703 & 42 & 89 & 8,919 & 8,110 & 809 & 147 & 17,421 & 16,181 & 1,240 \\
\hline $1971-72$ & 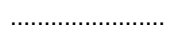 & 48 & 3,862 & 3,819 & 43 & 92 & 9,253 & 8,423 & 830 & 147 & 21,764 & 20,266 & 1,498 \\
\hline 1972-73 & ……............. & 51 & 4,047 & 3,992 & 55 & 97 & 10,307 & 9,388 & 919 & 152 & 27,205 & 25,037 & 2,168 \\
\hline $1973-74$ & ...................... & 52 & 4,440 & 4,355 & 85 & 99 & 11,356 & 10,093 & 1,263 & 151 & 29,326 & 25,986 & 3,340 \\
\hline $1974-75$ & ............. & 52 & 4,773 & 4,627 & 146 & 104 & 12,447 & 10,818 & 1,629 & 154 & 29,296 & 24,881 & 4,415 \\
\hline $1975-76$ & ......... & 56 & 5,425 & 5,187 & 238 & 107 & 13,426 & 11,252 & 2,174 & 166 & 32,293 & 26,085 & 6,208 \\
\hline $1976-77$ & . & 57 & 5,138 & 4,764 & 374 & 109 & 13,461 & 10,891 & 2,570 & 169 & 34,104 & 26,447 & 7,657 \\
\hline 1977-78 & $\ldots$. & 57 & 5,189 & 4,623 & 566 & 109 & 14,279 & 11,210 & 3,069 & 169 & 34,402 & 25,457 & 8,945 \\
\hline 1978-79 & 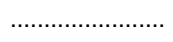 & 58 & 5,434 & 4,794 & 640 & 109 & 14,786 & 11,381 & 3,405 & 175 & 35,206 & 25,180 & 10,026 \\
\hline 1979-80 & ...... & 58 & 5,258 & 4,558 & 700 & 112 & 14,902 & 11,416 & 3,486 & 179 & 35,647 & 24,893 & 10,754 \\
\hline $1980-81$ & $\ldots \ldots$ & 58 & 5,460 & 4,672 & 788 & 116 & 15,505 & 11,672 & 3,833 & 176 & 36,331 & 24,563 & 11,768 \\
\hline 1981-82 & 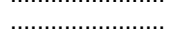 & 59 & 5,282 & 4,467 & 815 & 119 & 15,814 & 11,867 & 3,947 & 180 & 35,991 & 23,965 & 12,026 \\
\hline 1982-83 & ......................... & 59 & 5,585 & 4,631 & 954 & 118 & 15,484 & 11,350 & 4,134 & 177 & 36,853 & 23,550 & 13,303 \\
\hline 1983-84 & ....................... & 60 & 5,353 & 4,302 & 1,051 & 119 & 15,813 & 11,359 & 4,454 & 179 & 37,012 & 23,382 & 13,630 \\
\hline 1984-85 & 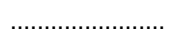 & 59 & 5,339 & 4,233 & 1,106 & 120 & 16,041 & 11,167 & 4,874 & 181 & 37,491 & 23,070 & 14,421 \\
\hline $1985-86$ & 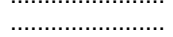 & 59 & 5,046 & 3,907 & 1,139 & 120 & 15,938 & 11,022 & 4,916 & 181 & 35,844 & 21,874 & 13,970 \\
\hline $1986-87$ & 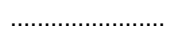 & 58 & 4,741 & 3,603 & 1,138 & 121 & 15,428 & 10,431 & 4,997 & 179 & 36,056 & 21,561 & 14,495 \\
\hline 1987-88 & 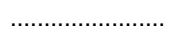 & 57 & 4,477 & 3,300 & 1,177 & 122 & 15,358 & 10,278 & 5,080 & 180 & 35,397 & 21,067 & 14,330 \\
\hline 1988-89 & ……................... & 58 & 4,265 & 3,124 & 1,141 & 124 & 15,460 & 10,310 & 5,150 & 182 & 35,634 & 21,069 & 14,565 \\
\hline 1989-90 & ..................... & 57 & 4,100 & 2,834 & 1,266 & 124 & 15,075 & 9,923 & 5,152 & 182 & 36,485 & 21,079 & 15,406 \\
\hline 1990-91 & . & 55 & 3,699 & 2,510 & 1,189 & 121 & 15,043 & 9,629 & 5,414 & 179 & 37,945 & 21,643 & 16,302 \\
\hline 1991-92 & .................. & 52 & 3,593 & 2,431 & 1,162 & 120 & 15,243 & 9,796 & 5,447 & 177 & 38,848 & 22,260 & 16,588 \\
\hline 1992-93 & … & 55 & 3,605 & 2,383 & 1,222 & 122 & 15,531 & 9,679 & 5,852 & 184 & 40,302 & 23,182 & 17,120 \\
\hline 1993-94 & 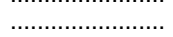 & 53 & 3,787 & 2,330 & 1,457 & 121 & 15,368 & 9,544 & 5,824 & 185 & 40,044 & 22,826 & 17,218 \\
\hline 1994-95 & (1) & 53 & 3,897 & 2,480 & 1,417 & 119 & 15,537 & 9,507 & 6,030 & 183 & 39,349 & 22,592 & 16,757 \\
\hline 1995-96 & ………… & 53 & 3,697 & 2,374 & 1,323 & 119 & 15,341 & 9,061 & 6,280 & 183 & 39,828 & 22,508 & 17,320 \\
\hline
\end{tabular}

\footnotetext{
1 Data prior to $1955-56$ are not shown because they lack comparability with the figures for subsequent years.
}

SOURCE: U.S. Department of Education, National Center for Education Statistics Higher Education General Information Survey (HEGIS), "Degrees and Other Formal Awards Conferred" surveys, and Integrated Postsecondary Education Data System (IPEDS), "Completions" surveys. (This table was prepared July 1998.) 
Table 260.-First-professional degrees ${ }^{1}$ conferred by institutions of higher education, by sex of student, control of institution, and field of study:

1984-85 to 1995-96

\begin{tabular}{|c|c|c|c|c|c|c|c|c|c|c|c|c|c|c|c|c|c|c|}
\hline Control of institution and field of study & $1984-85$ & $1985-86$ & $1986-87$ & $1987-88$ & $1988-89$ & $1989-90$ & $1990-91$ & 1991-92 & $1992-93$ & & 1993-94 & & & 1994-95 & & & 1995-96 & \\
\hline Total & Total & Total & Total & Total & Total & Total & Total & Total & Total & Total & Men & Women & Total & Men & Women & Total & Men & Women \\
\hline 1 & 2 & 3 & 4 & 5 & 6 & 7 & 8 & 9 & 10 & 11 & 12 & 13 & 14 & 15 & 16 & 17 & 18 & 19 \\
\hline Total, all institutions . & 063 & 910 & ,617 &, 735 & 856 & 0,988 & ,948 & 74,146 & ,387 & 75,418 &, 707 &, 711 & 5,800 & 4,853 &, 947 & 6,734 & 4,748 & 1,986 \\
\hline Dentistry (D.D.S. or $\mathrm{D}$ & 339 & 46 & 41 & 477 & 265 & 100 & 699 & 593 & 605 & 3,787 & 2,330 & 457 & 3,897 &, 480 & 417 & 3,697 & 2,374 & 1,323 \\
\hline & & & & & & & & 3 & & 15,368 & & 24 & 15,537 & & & 15,341 & & \\
\hline pto & 1,115 & 29 & 1,0 & 3 & 3 & 2 & 1,1 & & & 1,103 & & 19 & 1,185 & & 47 & 1,231 & & \\
\hline Oste & 1,4 & 1,547 & 1,6 & 1,5 & 1,6 & 1, & 1,4 & 1,326 & 1,6 & 1,7 & 1,1 & 63 & 1,854 & 1,2 & 6 & 1,895 & 1,232 & \\
\hline $\begin{array}{l}\text { Pharn } \\
\text { Podia }\end{array}$ & 1 & 903 & & 962 & 1,074 & 1,199 & 1,2 & 1,339 & 1,904 & 1,936 & 643 & 1,293 & 2,264 & 785 & 1,479 & 2,555 & 873 & 1,682 \\
\hline por & 82 & 612 & 59 & 645 & 636 & 675 & 589 & 504 & 476 & 465 & 330 & 135 & 545 & 370 & 175 & 650 & 453 & 197 \\
\hline Veter & 2,178 & 2,270 & 2,2 & 2,2 & 2,157 & 2,151 & 2,0 & 2,044 & 2,0 & 2,0 & 798 & 1,291 & 2,148 & & 1,386 & 2,109 & 5 & 1,394 \\
\hline Chiro & 2,661 & 3,395 & 2,493 & 2,628 & 2,890 & 2,581 & 2,640 & 2,694 & 2,799 & 2,806 & 2,010 & 796 & 2,968 & 2,094 & 874 & 3,379 & 2,470 & 909 \\
\hline $\begin{array}{l}\text { Law } \\
\text { Theo }\end{array}$ & 27101 & 35,844 & 36056 & 35,397 & 35,634 & 36,485 & 37,945 & 38,848 & 40,302 & 40,044 & 22,826 & 17,218 & 39,349 & 22,592 & o,757 & 39,828 & 22,508 & ,320 \\
\hline & 221 & 7,283 & 6,518 & 6,466 & 6,012 & 5,851 & 5,69 & 5,251 & 5,447 & 5,967 & 86 & 1,481 & 5,978 & 4,443 &, 535 & 5,879 & 4,400 & 1,479 \\
\hline Other ......... & 85 & 43 & & & & 244 & 487 & 2,072 & 491 & 55 & 21 & 34 & 75 & 33 & 42 & 170 & 94 & 76 \\
\hline Total, public institutions & 30,152 & 29,568 & 9,346 & 29,153 & 8,993 & 28,810 & 29,554 & 29,366 & 29,628 & 29,842 & 17,040 & 12,802 & 29,871 & 16,898 & 12,973 & 29,882 & 16,586 & 13,296 \\
\hline & & & & & & & & & & & & & 2,2 & & & & & 743 \\
\hline & & 1 & & & & & & 9,259 & & 9,5 & & 3,5 & 9,5 & & & 9,370 & & 3,800 \\
\hline O & 456 & 441 & 454 & 429 & 451 & 444 & 477 & 595 & 460 & 471 & 219 & 252 & 461 & 3 & 258 & 499 & 234 & 265 \\
\hline & 45 & 486 & 480 & 434 & 500 & 458 & 493 & 416 & 490 & 531 & 3 & 182 & 492 & & 170 & 528 & 337 & 191 \\
\hline & 416 & 473 & 475 & 615 & 679 & 727 & 808 & 852 & 1,171 & 1,185 & 390 & 795 & 1,344 & 489 & 855 & 1,557 & 553 & 1,004 \\
\hline Pod & & & & & & & & & & & & & & & & & & \\
\hline Vete & 963 & 1,931 & $\begin{array}{r}0 \\
2.003\end{array}$ & 2.014 & $\begin{array}{r}0 \\
1.943\end{array}$ & 1.943 & 1.814 & $\begin{array}{r}0 \\
1.831\end{array}$ & $\begin{array}{r}0 \\
1.840\end{array}$ & 1895 & 44 & 151 & 927 & 689 & 38 & 1,889 & 650 & $\begin{array}{r}0 \\
1.239\end{array}$ \\
\hline & & & & & & & & & & $\begin{array}{r}95 \\
0\end{array}$ & $\begin{array}{r}+4 \\
0\end{array}$ & $\begin{array}{r}51 \\
0\end{array}$ & $\begin{array}{r}27 \\
0\end{array}$ & $\begin{array}{r}009 \\
0\end{array}$ & $\begin{array}{r}0 \\
0\end{array}$ & & 0 & \\
\hline & 1 & 13,419 & 13,568 & 13,580 & 13,417 & 13,585 & 14,290 & 14,097 & 14,130 & 14,065 & 7,984 & 6,081 & 13,812 & 7,813 & 5,999 & 13,841 & 7,787 & 6,054 \\
\hline $\begin{array}{l}\text { Thec } \\
\text { or }\end{array}$ & & -1 & & & & & & 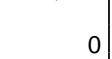 & & 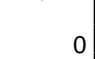 & & -1 & & & & & $x^{2}$ & \\
\hline Other ……… & 43 & 0 & 0 & 0 & 0 & 192 & 0 & 116 & 0 & 0 & 0 & 0 & 0 & & 1 & 0 & 0 & 0 \\
\hline Total, private institution & 1,911 & 44,342 & 2,271 &, 582 & ,863 & 42,178 & 2,394 & 44,780 & 5,759 & 45,576 & 27,667 & 17,909 & 45,929 & 27,955 & 17,974 & 46,852 & 28,162 & 18,690 \\
\hline & & & & & & & & 33 & & $1,5 \varsigma$ & & 645 & & & 658 & & & 30 \\
\hline & 70 &, 947 & 5,717 & & & 5,967 & 5,6 & 5,984 & 1 & 5,862 & 3,567 & 2,295 & 5,938 & 3,602 & 2,336 & 5,971 & 3,491 & 2,480 \\
\hline & & & & & & & & 637 & & & & 297 & & & & & & 398 \\
\hline & 1,034 & 1,061 & 138 & 1,110 & 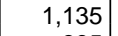 & 1,097 & & 910 & 1,137 & 1,267 & 8 & 451 & 1,362 & & 43 & 1,367 & 895 & 472 \\
\hline Pha & 445 & 430 & 386 & 347 & 395 & 472 & 436 & 487 & 733 & 751 & 253 & 498 & 920 & 296 & 624 & 998 & 320 & 678 \\
\hline & & & & & & & & & & & & & & & & & & \\
\hline & 58 & 612 & 590 & 64 & 636 & 675 & 589 & 504 & 47 & 465 & 330 & 135 & 545 & 370 & 175 & 650 & 453 & 197 \\
\hline (D.V.M.) & 5 & 339 & 22 & 2 & 214 & 208 & 21 & 213 & 2 & 194 & 54 & 140 & 21 & & 148 & 220 & & 155 \\
\hline & & 3,395 & 2,493 & 2,628 & 890 & 2,581 & 6 & 2,694 & 2,799 & 2,806 & 2,010 & 796 & 2,968 & 2,094 & 874 & 3,379 & 2,470 & 909 \\
\hline D & 23,796 & 22,425 & 22,488 & 21,817 & 22,217 & 22,900 & 23,655 & 24,751 & 26,172 & 25,979 & 14,842 & 11,137 & 25,537 & 14,779 & 10,758 & 25,987 & 14,721 & 11,266 \\
\hline $\begin{array}{l}\text { Theolo } \\
\text { or O }\end{array}$ & 219 & 7,283 & 6,518 & 6,466 & 12 & 51 & 5,6 & $b$ & $7 \mid$ & 5,967 & 86 & $1,481 \mid$ & 978 & +3 & 535 & 5,879 & 00 & 479 \\
\hline Other & 42 & 43 & & & & 52 & 487 & 1,956 & 491 & 55 & 21 & 34 & 75 & 33 & 42 & 170 & 94 & 76 \\
\hline
\end{tabular}

${ }^{1}$ Includes degrees which require at least 6 years of college work for completion (including at least 2 years of preprofessional training).
SOURCE: U.S. Department of Education, National Center for Education Statistics, Higher Education General Informaion Survey (HEGIS), "Degrees and Other Formal Awards Conferred" surveys, and Integrated Postsecondary Education (IPED), "Completions" surveys. (This table was prepared May 1998.) 
Table 261.-Associate degrees conferred by institutions of higher education, by racial/ethnic group and sex of student: $1976-77$ to $1995-96$

\begin{tabular}{|c|c|c|c|c|c|c|c|c|c|c|c|c|c|c|}
\hline \multirow[b]{2}{*}{ Year } & \multicolumn{7}{|c|}{ Number of degrees conferred } & \multicolumn{7}{|c|}{ Percentage distribution of degrees conferred } \\
\hline & Total & $\begin{array}{l}\text { White, } \\
\text { non-His- } \\
\text { panic }\end{array}$ & $\begin{array}{c}\text { Black, } \\
\text { non-His- } \\
\text { panic }\end{array}$ & Hispanic & $\begin{array}{l}\text { Asian/ } \\
\text { Pacific } \\
\text { Is- } \\
\text { lander }\end{array}$ & $\begin{array}{l}\text { Amer- } \\
\text { ican } \\
\text { Indian/ } \\
\text { Alas- } \\
\text { kan } \\
\text { Native }\end{array}$ & $\begin{array}{l}\text { Non- } \\
\text { resident } \\
\text { alien }\end{array}$ & Total & $\begin{array}{c}\text { White, } \\
\text { non- } \\
\text { His- } \\
\text { panic }\end{array}$ & $\begin{array}{c}\text { Black, } \\
\text { non- } \\
\text { His- } \\
\text { panic }\end{array}$ & $\begin{array}{l}\text { His- } \\
\text { panic }\end{array}$ & $\begin{array}{c}\text { Asian/ } \\
\text { Pacific } \\
\text { Is- } \\
\text { lander }\end{array}$ & $\begin{array}{c}\text { Amer- } \\
\text { ican } \\
\text { Indian/ } \\
\text { Alas- } \\
\text { kan } \\
\text { Native }\end{array}$ & $\begin{array}{l}\text { Non- } \\
\text { resi- } \\
\text { dent } \\
\text { alien }\end{array}$ \\
\hline \multirow[t]{2}{*}{1} & 2 & 3 & 4 & 5 & 6 & 7 & 8 & 9 & 10 & 11 & 12 & 13 & 14 & 15 \\
\hline & \multicolumn{7}{|c|}{ Total } & \multicolumn{7}{|c|}{ Total } \\
\hline $1976-77^{1} \ldots \ldots$ & 404,956 & 342,290 & 33,159 & 16,636 & 7,044 & 2,498 & 3,329 & 100.0 & 84.5 & 8.2 & 4.1 & 1.7 & 0.6 & 0.8 \\
\hline $1978-79^{2} \ldots \ldots \ldots$ & 396,745 & 331,092 & 34,979 & 16,269 & 7,518 & 2,336 & 4,551 & 100.0 & 83.5 & 8.8 & 4.1 & 1.9 & 0.6 & 1.1 \\
\hline $1980-81^{3} \ldots \ldots \ldots$ & 410,174 & 339,167 & 35,330 & 17,800 & 8,650 & 2,584 & 6,643 & 100.0 & 82.7 & 8.6 & 4.3 & 2.1 & 0.6 & 1.6 \\
\hline $1984-85^{4} \ldots \ldots .$. & 429,815 & 355,343 & 35,791 & 19,407 & 9,914 & 2,953 & 6,407 & 100.0 & 82.7 & 8.3 & 4.5 & 2.3 & 0.7 & 1.5 \\
\hline 1986-87 ............ & 436,304 & 361,861 & 35,447 & 19,334 & 11,779 & 3,195 & 4,688 & 100.0 & 82.9 & 8.1 & 4.4 & 2.7 & 0.7 & 1.1 \\
\hline $1988-89^{5,6} \ldots \ldots$ & 432,144 & 354,865 & 34,664 & 20,384 & 12,519 & 3,331 & 6,381 & 100.0 & 82.1 & 8.0 & 4.7 & 2.9 & 0.8 & 1.5 \\
\hline $1989-90^{5,7} \ldots \ldots$ & 450,263 & 369,580 & 35,327 & 22,195 & 13,482 & 3,530 & 6,149 & 100.0 & 82.1 & 7.8 & 4.9 & 3.0 & 0.8 & 1.4 \\
\hline $1990-91^{5,8} \ldots \ldots$ & 462,030 & 376,081 & 37,657 & 24,251 & 13,725 & 3,672 & 6,644 & 100.0 & 81.4 & 8.2 & 5.2 & 3.0 & 0.8 & 1.4 \\
\hline $1991-92^{5,9} \ldots \ldots$ & 494,387 & 400,530 & 39,411 & 26,905 & 15,596 & 4,008 & 7,937 & 100.0 & 81.0 & 8.0 & 5.4 & 3.2 & 0.8 & 1.6 \\
\hline $1992-93^{5,10}$ & 508,154 & 405,883 & 42,340 & 29,991 & 16,632 & 4,379 & 8,929 & 100.0 & 79.9 & 8.3 & 5.9 & 3.3 & 0.9 & 1.8 \\
\hline $1993-945,11$ & 529,106 & 418,301 & 45,461 & 32,074 & 18,433 & 4,871 & 9,966 & 100.0 & 79.1 & 8.6 & 6.1 & 3.5 & 0.9 & 1.9 \\
\hline $1994-95^{5,12} \ldots$ & 538,545 & 419,323 & 47,142 & 36,013 & 20,717 & 5,492 & 9,858 & 100.0 & 77.9 & 8.8 & 6.7 & 3.8 & 1.0 & 1.8 \\
\hline \multirow[t]{2}{*}{$1995-96^{5,13} \ldots$} & 553,625 & 425,028 & 51,672 & 38,163 & 23,091 & 5,556 & 10,115 & 100.0 & 76.8 & 9.3 & 6.9 & 4.2 & 1.0 & 1.8 \\
\hline & \multicolumn{7}{|c|}{ Men } & \multicolumn{7}{|c|}{ Men } \\
\hline $1976-77^{1}$ & 209,672 & 178,236 & 15,330 & 9,105 & 3,630 & 1,216 & 2,155 & 100.0 & 85.0 & 7.3 & 4.3 & 1.7 & 0.6 & 1.0 \\
\hline $1978-79^{2} \ldots \ldots$ & 187,284 & 156,671 & 14,425 & 8,135 & 4,058 & 1,069 & 2,926 & 100.0 & 83.7 & 7.7 & 4.3 & 2. & 0.6 & 1.6 \\
\hline $1980-81^{3} \ldots \ldots$ & 183,819 & 151,242 & 14,290 & 8,327 & 4,557 & 1,108 & 4,295 & 100.0 & 82.3 & 7.8 & 4.5 & 2.5 & 0.6 & 2.3 \\
\hline $1984-85^{4} \ldots \ldots \ldots$ & 190,409 & 157,278 & 14,184 & 8,561 & 5,492 & 1,198 & 3,696 & 100.0 & 82.6 & 7.4 & 4.5 & 2.9 & 0.6 & 1.9 \\
\hline $1986-87$ & 190,839 & 158,132 & 13,959 & 8,760 & 6,169 & 1,263 & 2,556 & 100.0 & 82.9 & 7.3 & 4.6 & 3.2 & 0.7 & 1.3 \\
\hline $1988-895,6$ & 183,963 & 150,978 & 12,884 & 9,217 & 6,366 & 1,323 & 3,195 & 100.0 & 82.1 & 7.0 & 5.0 & 3.5 & 0.7 & 1.7 \\
\hline $1989-905,7$ & 188,631 & 154,748 & 13,147 & 9,859 & 6,477 & 1,433 & 2,967 & 100.0 & 82.0 & 7.0 & 5.2 & 3.4 & 0.8 & 1.6 \\
\hline $1990-915,8$. & 190,221 & 155,330 & 13,718 & 10,210 & 6,440 & 1,373 & 3,150 & 100.0 & 81.7 & 7.2 & 5.4 & 3.4 & 0.7 & 1.7 \\
\hline $1991-92^{5,9}$ & 202,808 & 164,799 & 14,294 & 11,536 & 7,254 & 1,531 & 3,394 & 100.0 & 81.3 & 7.0 & 5.7 & 3.6 & 0.8 & 1.7 \\
\hline $1992-93^{5,10} \ldots$ & 209,051 & 167,312 & 15,497 & 12,924 & 7,877 & 1,663 & 3,778 & 100.0 & 80.0 & 7.4 & 6.2 & 3.8 & 0.8 & 1.8 \\
\hline $1993-945,11 \ldots$ & 214,462 & 170,137 & 16,917 & 13,204 & 8,288 & 1,836 & 4,080 & 100.0 & 79.3 & 7.9 & 6.2 & 3.9 & 0.9 & 1.9 \\
\hline $1994-95^{5,12}$ & 217,730 & 169,475 & 16,786 & 15,717 & 9,283 & 2,106 & 4,363 & 100.0 & 77.8 & 7.7 & 7.2 & 4.3 & 1.0 & 2.0 \\
\hline \multirow[t]{2}{*}{$1995-96^{5,13} \ldots}$. & 218,977 & 168,858 & 17,854 & 15,700 & 10,204 & 1,989 & 4,372 & 100.0 & 77.1 & 8.2 & 7.2 & 4.7 & 0.9 & 2.0 \\
\hline & \multicolumn{7}{|c|}{ Women } & \multicolumn{7}{|c|}{ Women } \\
\hline $1976-77^{1}$ & 195,284 & 164,054 & 17,829 & 7,531 & 3,414 & 1,282 & 1,174 & 100.0 & 84.0 & 9.1 & 3.9 & 1.7 & 0.7 & 0.6 \\
\hline $1978-79^{2}$ & 209,461 & 174,421 & 20,554 & 8,134 & 3,460 & 1,267 & 1,625 & 100.0 & 83.3 & 9.8 & 3.9 & 1.7 & 0.6 & 0.8 \\
\hline $1980-81^{3}$ & 226,355 & 187,925 & 21,040 & 9,473 & 4,093 & 1,476 & 2,348 & 100.0 & 83.0 & 9.3 & 4.2 & 1.8 & 0.7 & 1.0 \\
\hline $1984-85^{4} \ldots \ldots$ & 239,406 & 198,065 & 21,607 & 10,846 & 4,422 & 1,755 & 2,711 & 100.0 & 82.7 & 9.0 & 4.5 & 1.8 & 0.7 & 1.1 \\
\hline $1986-87 \ldots$ & 245,465 & 203,729 & 21,488 & 10,574 & 5,610 & 1,932 & 2,132 & 100.0 & 83.0 & 8.8 & 4.3 & 2.3 & 0.8 & 0.9 \\
\hline $1988-895,6$ & 248,181 & 203,887 & 21,780 & 11,167 & 6,153 & 2,008 & 3,186 & 100.0 & 82.2 & 8.8 & 4.5 & 2.5 & 0.8 & 1.3 \\
\hline $1989-90^{5,7}$ & 261,632 & 214,832 & 22,180 & 12,336 & 7,005 & 2,097 & 3,182 & 100.0 & 82.1 & 8.5 & 4.7 & 2.7 & 0.8 & 1.2 \\
\hline $1990-91^{5,8}$ & 271,809 & 220,751 & 23,939 & 14,041 & 7,285 & 2,299 & 3,494 & 100.0 & 81.2 & 8.8 & 5.2 & 2.7 & 0.8 & 1.3 \\
\hline $1991-92^{5,9}$ & 291,579 & 235,731 & 25,117 & 15,369 & 8,342 & 2,477 & 4,543 & 100.0 & 80.8 & 8.6 & 5.3 & 2.9 & 0.8 & 1.6 \\
\hline $1992-93^{5,10} \ldots$ & 299,103 & 238,571 & 26,843 & 17,067 & 8,755 & 2,716 & 5,151 & 100.0 & 79.8 & 9.0 & 5.7 & 2.9 & 0.9 & 1.7 \\
\hline $1993-945,11 \ldots$ & 314,644 & 248,164 & 28,544 & 18,870 & 10,145 & 3,035 & 5,886 & 100.0 & 78.9 & 9.1 & 6.0 & 3.2 & 1.0 & 1.9 \\
\hline $1994-95^{5,12} \ldots$ & 320,815 & 249,848 & 30,356 & 20,296 & 11,434 & 3,386 & 5,495 & 100.0 & 77.9 & 9.5 & 6.3 & 3.6 & 1.1 & 1.7 \\
\hline $1995-96^{5,13} \ldots$ & 334,648 & 256,170 & 33,818 & 22,463 & 12,887 & 3,567 & 5,743 & 100.0 & 76.5 & 10.1 & 6.7 & 3.9 & 1.1 & 1.7 \\
\hline
\end{tabular}

1 Excludes 1,170 men and 251 women whose racial/ethnic group was not available. 2 Excludes 4,807 men and 1,150 women whose racial/ethnic group was not available.

3 Excludes 4,819 men and 1,384 women whose raciallethnic group was not avilable.

Excludes 4,819 men and 1,150 women who This This tabulation excludes 11,490 men and 10,862 women whose racial/ethnic group could not be imputed. In addition, data for 1,033 men and 1,512 women were not available by field of study and were not imputed by race.

${ }^{5}$ Reported racial/ethnic distributions of students by level of degree, field of degree, and sex were used to estimate race/ethnicity for students whose race/ethnicity was not reported.

${ }^{6}$ Excludes 2,353 men and 2,267 women whose racial/ethnic group and field of study were not available.

7 Excludes 2,564 men and 2,275 women whose racial/ethnic group and field of study were not available.

${ }^{8}$ Excludes 8,413 men and 11,277 women whose racial/ethnic group and field of study were not available.

${ }^{9}$ Excludes 4,673 men and 5,171 women whose racial/ethnic group and field of study were not available.
10 Excludes 2,913 men and 3,689 women whose racial/ethnic group and field of study were not available.

11 Excludes 799 men and 727 women whose racial/ethnic group and field of study were not available.

12 Excludes 622 men and 524 women whose racial/ethnic group and field of study were not available.

${ }^{13}$ Excludes 537 men and 1,054 women whose racial/ethnic group and field of study were not available.

NOTE.-For years 1984-85 to 1995-96, reported racial/ethnic distributions of students by level of degree, field of degree, and sex were used to estimate race/ethnicity for students whose race/ethnicity was not reported. Because of rounding, percents may not add to 100.0 .

SOURCE: U.S. Department of Education, National Center for Education Statistics, Higher Education General Information Survey (HEGIS), "Degrees and Other Formal Awards Conferred" surveys, and Integrated Postsecondary Education Data System (IPEDS), "Completions" surveys. (This table was prepared June 1998.) 


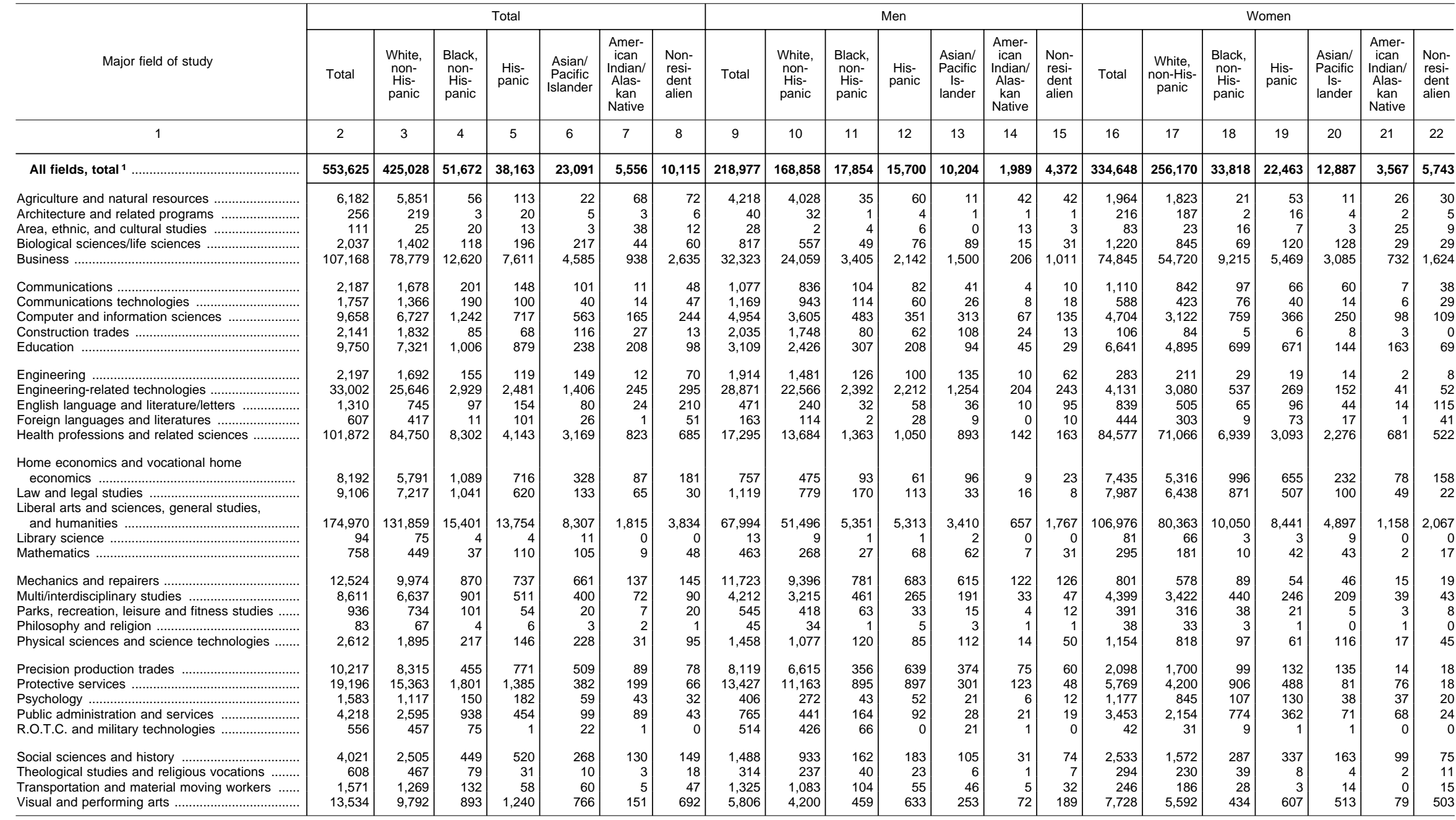

1 Reported racial/ethnic distributions of students by level of degree, field of degree, and sex were used to estimate ace/ethnicity for students whose race/ethnicity was not reported. Excludes 537 men and 1,054 women whose racial/

NOTE.- To facilitate trend comparisons, certain aggregations have been made of the degree fields as reported in
Agricultural sciences, and Conservation and renewable natural resources; and "Business" includes Business management and administrative services, Marketing operations/marketing and distribution, and Consumer and personal serv

SOURCE: U.S. Department of Education, National Center for Education Statistics, Integrated Postsecondary Education Data System (IPEDS), "Completions" survey. (This table was prepared June 1998.) 


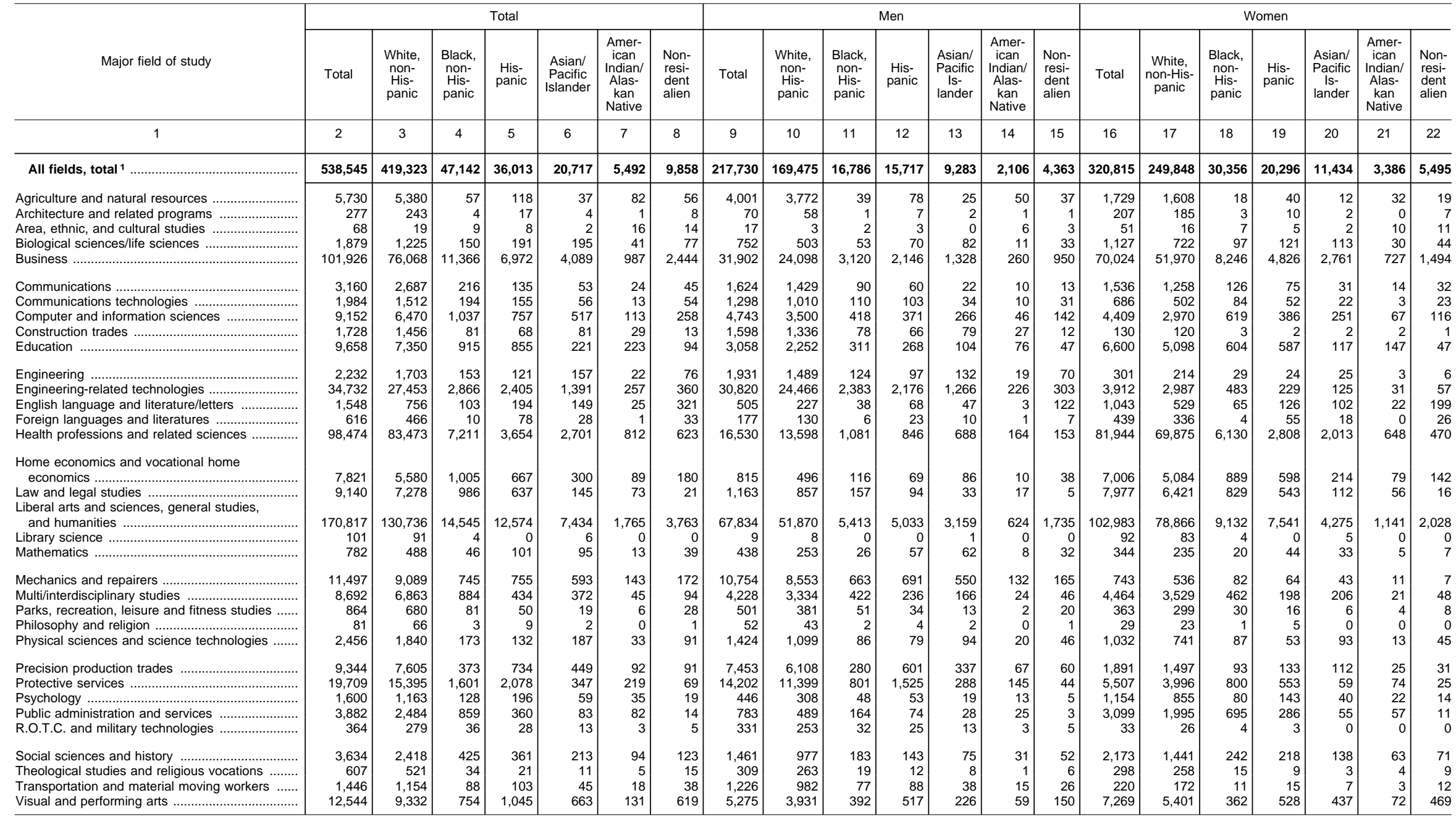

1Reported racial/ethnic distributions of students by level of degree, field of degree, and sex were used to estimate race/ethnicity for students whose race/ethnicity was not reported. Excludes 622 men and 524 women whose racial

NOTE.- To facilitate trend comparisons, certain aggregations have been made of the degree fields as reported in
Agricultural sciences, and Conservation and renewable natural resources; and "Business" includes Business management and administrative services, Marketing operations/marketing and distribution, and Consumer and personal serv-

SOURCE: U.S. Department of Education, National Center for Education Statistics, Integrated Postsecondary Education Data System (IPEDS), "Completions" survey. (This table was prepared April 1997.) 
Table 264.-Bachelor's degrees conferred by institutions of higher education, by racial/ethnic group and sex of student: $1976-77$ to $1995-96$

\begin{tabular}{|c|c|c|c|c|c|c|c|c|c|c|c|c|c|c|}
\hline \multirow[b]{2}{*}{ Year } & \multicolumn{7}{|c|}{ Number of degrees conferred } & \multicolumn{7}{|c|}{ Percentage distribution of degrees conferred } \\
\hline & Total & $\begin{array}{l}\text { White, } \\
\text { non-His- } \\
\text { panic }\end{array}$ & $\begin{array}{l}\text { Black, } \\
\text { non- } \\
\text { His- } \\
\text { panic }\end{array}$ & $\begin{array}{l}\text { His- } \\
\text { panic }\end{array}$ & $\begin{array}{l}\text { Asian/ } \\
\text { Pacific } \\
\text { Islander }\end{array}$ & $\begin{array}{c}\text { Amer- } \\
\text { ican In- } \\
\text { dian/ } \\
\text { Alaskan } \\
\text { Native }\end{array}$ & $\begin{array}{l}\text { Non- } \\
\text { resident } \\
\text { alien }\end{array}$ & Total & $\begin{array}{c}\text { White, } \\
\text { non- } \\
\text { His- } \\
\text { panic }\end{array}$ & $\begin{array}{c}\text { Black, } \\
\text { non- } \\
\text { His- } \\
\text { panic }\end{array}$ & $\begin{array}{c}\text { His- } \\
\text { panic }\end{array}$ & $\begin{array}{l}\text { Asian/ } \\
\text { Pacific } \\
\text { Is- } \\
\text { lander }\end{array}$ & $\begin{array}{l}\text { Amer- } \\
\text { ican } \\
\text { Indian/ } \\
\text { Alas- } \\
\text { kan } \\
\text { Native }\end{array}$ & $\begin{array}{l}\text { Non- } \\
\text { resi- } \\
\text { dent } \\
\text { alien }\end{array}$ \\
\hline \multirow[t]{2}{*}{1} & 2 & 3 & 4 & 5 & 6 & 7 & 8 & 9 & 10 & 11 & 12 & 13 & 14 & 15 \\
\hline & \multicolumn{7}{|c|}{ Total } & \multicolumn{7}{|c|}{ Total } \\
\hline 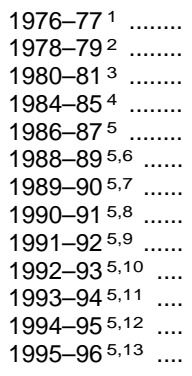 & $\begin{array}{r}917,900 \\
919,540 \\
934,800 \\
968,311 \\
991,264 \\
1,016,350 \\
1,048,631 \\
1,081,280 \\
1,129,833 \\
1,159,931 \\
1,165,973 \\
1,158,788 \\
1,163,036\end{array}$ & $\begin{array}{l}807,688 \\
802,542 \\
807,319 \\
826,106 \\
841,818 \\
859,703 \\
884,376 \\
904,062 \\
936,771 \\
947,309 \\
936,227 \\
913,377 \\
904,709\end{array}$ & $\begin{array}{l}58,636 \\
60,246 \\
60,673 \\
57,473 \\
56,560 \\
58,078 \\
61,063 \\
65,341 \\
72,326 \\
77,872 \\
83,576 \\
87,203 \\
91,166\end{array}$ & $\begin{array}{l}18,743 \\
20,096 \\
21,832 \\
25,874 \\
26,988 \\
29,918 \\
32,844 \\
36,612 \\
40,761 \\
45,376 \\
50,241 \\
54,201 \\
58,288\end{array}$ & $\begin{array}{l}13,793 \\
15,407 \\
18,794 \\
25,395 \\
32,624 \\
37,674 \\
39,248 \\
41,618 \\
46,720 \\
51,463 \\
55,660 \\
60,478 \\
64,359\end{array}$ & $\begin{array}{l}3,326 \\
3,410 \\
3,593 \\
4,246 \\
3,968 \\
3,951 \\
4,392 \\
4,513 \\
5,176 \\
5,671 \\
6,189 \\
6,606 \\
6,970\end{array}$ & $\begin{array}{l}15,714 \\
17,839 \\
22,589 \\
29,217 \\
29,306 \\
27,026 \\
26,708 \\
29,134 \\
28,079 \\
32,240 \\
34,080 \\
36,923 \\
37,544\end{array}$ & $\begin{array}{l}100.0 \\
100.0 \\
100.0 \\
100.0 \\
100.0 \\
100.0 \\
100.0 \\
100.0 \\
100.0 \\
100.0 \\
100.0 \\
100.0 \\
100.0\end{array}$ & $\begin{array}{l}88.0 \\
87.3 \\
86.4 \\
85.3 \\
84.9 \\
84.6 \\
84.3 \\
83.6 \\
82.9 \\
81.7 \\
80.3 \\
78.8 \\
77.8\end{array}$ & $\begin{array}{l}6.4 \\
6.6 \\
6.5 \\
5.9 \\
5.7 \\
5.7 \\
5.8 \\
6.0 \\
6.4 \\
6.7 \\
7.2 \\
7.5 \\
7.8\end{array}$ & $\begin{array}{l}2.0 \\
2.2 \\
2.3 \\
2.7 \\
2.7 \\
2.9 \\
3.1 \\
3.4 \\
3.6 \\
3.9 \\
4.3 \\
4.7 \\
5.0\end{array}$ & $\begin{array}{l}1.5 \\
1.7 \\
2.0 \\
2.6 \\
3.3 \\
3.7 \\
3.7 \\
3.8 \\
4.1 \\
4.4 \\
4.8 \\
5.2 \\
5.5\end{array}$ & $\begin{array}{l}0.4 \\
0.4 \\
0.4 \\
0.4 \\
0.4 \\
0.4 \\
0.4 \\
0.4 \\
0.5 \\
0.5 \\
0.5 \\
0.6 \\
0.6\end{array}$ & $\begin{array}{l}1.7 \\
1.9 \\
2.4 \\
3.0 \\
3.0 \\
2.7 \\
2.5 \\
2.7 \\
2.5 \\
2.8 \\
2.9 \\
3.2 \\
3.2\end{array}$ \\
\hline $1995-96^{5,13} \ldots$. & \multicolumn{7}{|c|}{ Men } & \multicolumn{7}{|c|}{ Men } \\
\hline 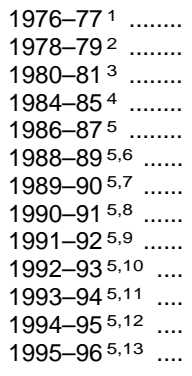 & $\begin{array}{l}494,424 \\
476,065 \\
469,625 \\
476,148 \\
480,782 \\
481,946 \\
490,317 \\
496,424 \\
516,976 \\
530,541 \\
530,804 \\
525,174 \\
521,439\end{array}$ & $\begin{array}{l}438,161 \\
418,215 \\
406,173 \\
405,085 \\
406,749 \\
407,154 \\
413,573 \\
415,505 \\
429,842 \\
435,084 \\
429,121 \\
417,006 \\
408,829\end{array}$ & $\begin{array}{l}25,147 \\
24,659 \\
24,511 \\
23,018 \\
22,501 \\
22,370 \\
23,262 \\
24,328 \\
26,956 \\
28,883 \\
30,648 \\
31,775 \\
32,852\end{array}$ & $\begin{array}{l}10,318 \\
10,418 \\
10,810 \\
12,402 \\
12,865 \\
13,950 \\
14,941 \\
16,158 \\
17,976 \\
19,865 \\
21,807 \\
23,600 \\
24,994\end{array}$ & $\begin{array}{r}7,638 \\
8,261 \\
10,107 \\
13,554 \\
17,253 \\
19,260 \\
19,721 \\
20,678 \\
23,248 \\
25,293 \\
26,938 \\
28,973 \\
30,630\end{array}$ & $\begin{array}{l}1,804 \\
1,736 \\
1,700 \\
1,998 \\
1,817 \\
1,730 \\
1,859 \\
1,901 \\
2,182 \\
2,449 \\
2,616 \\
2,736 \\
2,885\end{array}$ & $\begin{array}{l}11,356 \\
12,776 \\
16,324 \\
20,091 \\
19,597 \\
17,482 \\
16,961 \\
17,854 \\
16,772 \\
18,967 \\
19,674 \\
21,084 \\
21,249\end{array}$ & $\begin{array}{l}100.0 \\
100.0 \\
100.0 \\
100.0 \\
100.0 \\
100.0 \\
100.0 \\
100.0 \\
100.0 \\
100.0 \\
100.0 \\
100.0 \\
100.0\end{array}$ & $\begin{array}{l}88.6 \\
87.8 \\
86.5 \\
85.1 \\
84.6 \\
84.5 \\
84.3 \\
83.7 \\
83.1 \\
82.0 \\
80.8 \\
79.4 \\
78.4\end{array}$ & $\begin{array}{l}5.1 \\
5.2 \\
5.2 \\
4.8 \\
4.7 \\
4.6 \\
4.7 \\
4.9 \\
5.2 \\
5.4 \\
5.8 \\
6.1 \\
6.3\end{array}$ & $\begin{array}{l}2.1 \\
2.2 \\
2.3 \\
2.6 \\
2.7 \\
2.9 \\
3.0 \\
3.3 \\
3.5 \\
3.7 \\
4.1 \\
4.5 \\
4.8\end{array}$ & $\begin{array}{l}1.5 \\
1.7 \\
2.2 \\
2.8 \\
3.6 \\
4.0 \\
4.0 \\
4.2 \\
4.5 \\
4.8 \\
5.1 \\
5.5 \\
5.9\end{array}$ & $\begin{array}{l}0.4 \\
0.4 \\
0.4 \\
0.4 \\
0.4 \\
0.4 \\
0.4 \\
0.4 \\
0.4 \\
0.5 \\
0.5 \\
0.5 \\
0.6\end{array}$ & $\begin{array}{l}2.3 \\
2.7 \\
3.5 \\
4.2 \\
4.1 \\
3.6 \\
3.5 \\
3.6 \\
3.2 \\
3.6 \\
3.7 \\
4.0 \\
4.1\end{array}$ \\
\hline $1995-96^{5,13} \ldots$. & \multicolumn{7}{|c|}{ Women } & \multicolumn{7}{|c|}{ Women } \\
\hline 1976 & 3,476 &, 527 & 33,489 & 8,425 & 6,155 & 1,522 & 4,358 & 100.0 & 87.3 & 7.9 & 2.0 & 1.5 & 0.4 & 1.0 \\
\hline $1978-79^{2}$ & 443,475 & 384,327 & 35,587 & 9,678 & 7,146 & 1,674 & 5,063 & 100.0 & 86.7 & 8.0 & 2.2 & 1.6 & 0.4 & 1.1 \\
\hline $1980-81^{3}$ & 465,175 & 401,146 & 36,162 & 11,022 & 8,687 & 1,893 & 6,265 & 100.0 & 86.2 & 7.8 & 24 & 1.9 & & 1.3 \\
\hline $1984-85^{4} \ldots \ldots \ldots$ & 492,163 & 421,021 & 34,455 & 13,472 & 11,841 & 2,248 & 9,126 & 100.0 & 85.5 & 7.0 & 2.7 & 2.4 & 0.5 & 1.9 \\
\hline $1986-87^{5}$ & 510,482 & 435,069 & 34,059 & 14,123 & 15,371 & 2,151 & 9,709 & 100.0 & 85.2 & 6.7 & 2.8 & 3.0 & 0.4 & 1.9 \\
\hline $1988-89^{5,6} \ldots \ldots$ & 534,404 & 452,549 & 35,708 & 15,968 & 18,414 & 2,221 & 9,544 & 100.0 & 84.7 & 6.7 & 3.0 & 3.4 & 0.4 & 1.8 \\
\hline $1989-90^{5,7}$. & 558,314 & 470,803 & 37,801 & 17,903 & 19,527 & 2,533 & 9,747 & 100.0 & 84.3 & 6.8 & 3.2 & 3.5 & 0.5 & 1.7 \\
\hline $1990-91^{5,8}$ & 584,856 & 488,557 & 41,013 & 20,454 & 20,940 & 2,612 & 11,280 & 100.0 & 83.5 & 7.0 & 3.5 & 3.6 & 0.4 & 1.9 \\
\hline $1991-92^{5,9}$ & 612,857 & 506,929 & 45,370 & 22,785 & 23,472 & 2,994 & 11,307 & 100.0 & 82.7 & 7.4 & 3.7 & 3.8 & 0.5 & 1.8 \\
\hline $1992-93^{5,10} \ldots$ & 629,390 & 512,225 & 48,989 & 25,511 & 26,170 & 3,222 & 13,273 & 100.0 & 81.4 & 7.8 & 4.1 & 4.2 & 0.5 & 2.1 \\
\hline $1993-945,11$. & 635,169 & 507,106 & 52,928 & 28,434 & 28,722 & 3,573 & 14,406 & 100.0 & 79.8 & 8.3 & 4.5 & 4.5 & 0.6 & 2.3 \\
\hline $1994-95^{5,12} \ldots$ & 633,614 & 496,371 & 55,428 & 30,601 & 31,505 & 3,870 & 15,839 & 100.0 & 78.3 & 8.7 & 4.8 & 5.0 & 0.6 & 2.5 \\
\hline $1995-96^{5,13} \ldots$ & 641,597 & 495,880 & 58,314 & 33,294 & 33,729 & 4,085 & 16,295 & 100.0 & 77.3 & 9.1 & 5.2 & 5.3 & 0.6 & 2.5 \\
\hline
\end{tabular}

1 Excludes 1,121 men and 528 women whose racial/ethnic group was not available. 2Excludes 1,279 men and 571 women whose racial/ethnic group was not available. ${ }^{3}$ Excludes 258 men and 82 women whose racial/ethnic group was not available.

4 Excludes 6,380 men and 4,786 women whose racial/ethnic group was not available. ${ }^{5}$ Reported racial/ethnic distributions of students by level of degree, field of degree, and sex were used to estimate race/ethnicity for students whose race/ethnicity was not reported.

6 Excludes 1,400 men and 1,005 women whose racial/ethnic group and field of study were not available.

${ }^{7}$ Excludes 1,379 men and 1,334 women whose racial/ethnic group and field of study were not available.

${ }^{8}$ Excludes 7,621 men and 5,637 women whose racial/ethnic group and field of study were not available.

9 Excludes 3,835 men and 2,885 women whose racial/ethnic group and field of study were not available.

${ }^{10}$ Excludes 2,340 men and 2,907 women whose racial/ethnic group and field of study were not available.
${ }^{11}$ Excludes 1,618 men and 1,684 women whose racial/ethnic group and field of study were not available.

12 Excludes 957 men and 389 women whose racial/ethnic group and field of study were not available.

${ }^{13}$ Excludes 1,015 men and 741 women whose racial/ethnic group and field of study were not available.

NOTE.-For years 1984-85 to 1995-96, reported racial/ethnic distributions of students by level of degree, field of degree, and sex were used to estimate race/ethnicity for students whose race/ethnicity was not reported. Because of rounding, percents may not add to 100.0 .

SOURCE: U.S. Department of Education, National Center for Education Statistics, Higher Education General Information Survey (HEGIS), "Degrees and Other Forma Awards Conferred" surveys, and Integrated Postsecondary Education Data System (IPEDS), "Completions" surveys. (This table was prepared June 1998.) 


\begin{tabular}{|c|c|c|c|c|c|c|c|c|c|c|c|c|c|c|c|c|c|c|c|c|c|}
\hline \multirow[b]{2}{*}{ Major field of study } & \multicolumn{7}{|c|}{ Total } & \multicolumn{7}{|c|}{ Men } & \multicolumn{7}{|c|}{ Women } \\
\hline & Total & $\begin{array}{c}\text { White, } \\
\text { non- } \\
\text { His- } \\
\text { panic }\end{array}$ & \begin{tabular}{|c|} 
Black, \\
non- \\
His- \\
panic
\end{tabular} & $\begin{array}{c}\text { His- } \\
\text { panic }\end{array}$ & $\begin{array}{l}\text { Asian/ } \\
\text { Pacific } \\
\text { Islander }\end{array}$ & \begin{tabular}{|c|} 
Amer- \\
ican \\
Indian/ \\
Alas- \\
kan \\
Native
\end{tabular} & \begin{tabular}{|l|} 
Non- \\
resi- \\
dent \\
alien
\end{tabular} & Total & $\begin{array}{c}\text { White, } \\
\text { non- } \\
\text { His- } \\
\text { panic }\end{array}$ & $\begin{array}{l}\text { Black, } \\
\text { non- } \\
\text { His- } \\
\text { panic }\end{array}$ & \begin{tabular}{|c} 
His- \\
panic
\end{tabular} & $\begin{array}{l}\text { Asian/ } \\
\text { Pacific } \\
\text { Is- } \\
\text { lander }\end{array}$ & \begin{tabular}{|c|} 
Amer- \\
ican \\
Indian/ \\
Alas- \\
kan \\
Native \\
\end{tabular} & $\begin{array}{l}\text { Non- } \\
\text { resi- } \\
\text { dent } \\
\text { alien }\end{array}$ & Total & $\begin{array}{c}\text { White, } \\
\text { non-His- } \\
\text { panic }\end{array}$ & $\begin{array}{l}\text { Black, } \\
\text { non- } \\
\text { His- } \\
\text { panic }\end{array}$ & $\begin{array}{c}\text { His- } \\
\text { panic }\end{array}$ & \begin{tabular}{|c|} 
Asian/ \\
Pacific \\
Is- \\
Iander
\end{tabular} & \begin{tabular}{|c|} 
Amer- \\
ican \\
Indian/ \\
Alas- \\
kan \\
Native \\
\end{tabular} & $\begin{array}{l}\text { Non- } \\
\text { resi- } \\
\text { dent } \\
\text { alien }\end{array}$ \\
\hline 1 & 2 & 3 & 4 & 5 & 6 & 7 & 8 & 9 & 10 & 11 & 12 & 13 & 14 & 15 & 16 & 17 & 18 & 19 & 20 & 21 & 22 \\
\hline All fields, total 1 ....... & $1,163,036$ & 904,709 & 91,166 & 58,288 & 64,359 & 6,970 & \begin{tabular}{|l|}
37,544 \\
\end{tabular} & 521,439 & 408,829 & 32,852 & 24,994 & 30,630 & 2,885 & 21,249 & 641,597 & 495,880 & 58,314 & \begin{tabular}{|l|}
33,294 \\
\end{tabular} & 33,729 & 4,085 & 16,295 \\
\hline and natural resourc & 21,431 & 19,286 & 606 & 573 & 448 & 171 & 347 & 3,535 & 12,341 & 323 & 337 & 215 & 100 & 219 & 7,896 & 6.945 & 283 & 236 & 233 & 71 & 128 \\
\hline Archite & 8,352 & $\begin{array}{l}1,293 \\
6,293\end{array}$ & 317 & 576 & 706 & 33 & 427 & 5,340 & 4,088 & 207 & 369 & 392 & 23 & 261 & $\begin{array}{l}3,012 \\
3,012\end{array}$ & 2,205 & 110 & 207 & 314 & 10 & 166 \\
\hline Area, $€$ & 5,786 & 3,583 & 690 & 573 & 668 & 68 & 204 & 1,984 & 1,226 & 228 & 186 & 222 & 21 & 101 & 3,802 & 2,357 & 462 & 387 & 446 & 47 & 103 \\
\hline Biological s & ro,994 & 44,676 & 3,874 & 2,616 & 8,143 & $\begin{array}{r}324 \\
324\end{array}$ & 1,361 & $\begin{array}{r}1,204 \\
28,849\end{array}$ & $\begin{array}{r}1,2<0 \\
21,586\end{array}$ & 1,261 & $\begin{array}{r}1,269 \\
\end{array}$ & 3,976 & $\begin{array}{r}27 \\
147\end{array}$ & 610 & $\begin{array}{r}3,0<2 \\
32,145\end{array}$ & $\begin{array}{r}2,3031 \\
23,090\end{array}$ & 2,613 & 1,347 & $\begin{array}{r}4,167 \\
\end{array}$ & 177 & 751 \\
\hline Busines & 227,102 & 168,220 & 20,190 & 11,286 & 13,523 & 1,089 & 12,794 & 116,842 & 89,656 & 7,728 & 5,488 & 6,131 & 518 & 7,321 & 110,260 & 78,564 & \begin{tabular}{|l|}
12,462 \\
\end{tabular} & 5,798 & 7,392 & 571 & 5,473 \\
\hline Communication & 47,320 & 38,144 & 4,220 & 2,049 & 1,430 & 198 & 1,279 & 19,391 & 16,016 & 1,520 & 797 & 495 & 80 & 483 & 27,929 & 22,128 & 2,700 & 1,252 & 935 & 118 & 796 \\
\hline . &, $0<0$ & 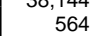 & $\begin{aligned} 74 \\
74\end{aligned}$ & 2,049 & $\begin{array}{r}1,400 \\
12\end{array}$ & $\begin{array}{r}150 \\
8\end{array}$ & 16 & 369 & $\begin{array}{r}10,010 \\
321\end{array}$ & 31 & $\begin{array}{r}4 \\
4\end{array}$ & 5 & $\begin{array}{r}0 \\
2\end{array}$ & $\begin{array}{r}400 \\
6\end{array}$ & 314 & $\begin{array}{r}r, 1<0 \\
243\end{array}$ & 2,100 & $\begin{array}{r}1,202 \\
5\end{array}$ & $\begin{array}{r}903 \\
7\end{array}$ & 6 & $\begin{array}{r}100 \\
10\end{array}$ \\
\hline Comp & 24,098 & 15,827 & 2,471 & 1,042 & 2,502 & 91 & 2,165 & 17,468 & 12,198 & 1,248 & 678 & 1,734 & 51 & 1,559 & 6,630 & 3,629 & 1,223 & 364 & 768 & 40 & 606 \\
\hline Const & 80 & 73 & 2 & 72 & 0 & (1) & 5 & 76 & 69 & 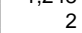 & 0 & 0 & 0 & 5 & & 4 & & 0 & 0 & 0 & 0 \\
\hline Education .............. & 105,509 & 91,259 & 7,149 & 3,792 & 1,517 & 886 & 906 & 26,233 & 22,539 & 1,863 & 889 & 415 & 234 & 293 & 79,276 & 68,720 & 5,286 & 2,903 & 1,102 & 652 & 613 \\
\hline $\operatorname{lgin}$ & 62,114 & 44,185 & 3,073 & 2,883 & 6,968 & 249 & 4,756 & 51,069 & 36,922 & 2,016 & 2,292 & 5,503 & 200 & 4,136 & 11,045 & 7,263 & 1,057 & 591 & 1,465 & 49 & 620 \\
\hline & & & & & 727 & 105 & 564 & & $\begin{array}{l}10,785 \\
10,752\end{array}$ & $\begin{array}{l}2,033 \\
1,033\end{array}$ & $\begin{array}{r}2,292 \\
678\end{array}$ & 661 & 86 & $\begin{array}{r}4,100 \\
520\end{array}$ & $\begin{array}{r}1,426 \\
1,45\end{array}$ & $\begin{array}{l}1,000 \\
934\end{array}$ & 293 & 70 & 66 & $\begin{array}{l}49 \\
19\end{array}$ & $\begin{array}{r}020 \\
44\end{array}$ \\
\hline & & 4 & 3,499 & 2, & 1,979 & 273 & 5 & 17 & 14 & 900 & & 62 & 110 & 197 & 33,445 & 27. & 2.599 & & 1,3 & 163 & 349 \\
\hline & & 46 & 年, & & (1) & 61 & & & & 1 & & 18 & 14 & 125 & & & & & , & 100 & 324 \\
\hline Health professions and related sciences ........ & 84,036 & 69,156 & 6,317 & 2,912 & 4,013 & 520 & 1,118 & 15,432 & 12,515 & 938 & 650 & 982 & 95 & 252 & 68,604 & 56,641 & 5,379 & 2,262 & 3,031 & 425 & 866 \\
\hline Home & & & & & & & & & & 159 & & & 17 & 38 & 13018 & 11820 & & 382 & & & \\
\hline Law & & $\begin{array}{r}13,351 \\
1,634\end{array}$ & $\begin{aligned} 1,101 \\
214\end{aligned}$ & $\begin{array}{l}448 \\
104\end{array}$ & $\begin{array}{r}522 \\
75\end{array}$ & $\begin{array}{l}98 \\
14\end{array}$ & $\begin{array}{r}253 \\
11\end{array}$ & $\begin{array}{r}1,885 \\
556\end{array}$ & $\begin{array}{r}1,531 \\
431\end{array}$ & $\begin{array}{r}159 \\
51\end{array}$ & $\begin{array}{l}60 \\
34\end{array}$ & 30 & $\begin{array}{r}17 \\
6 \\
\end{array}$ & $\begin{array}{r}38 \\
4\end{array}$ & $\begin{array}{r}13,918 \\
1,496\end{array}$ & $\begin{array}{l}1,200 \\
1,203\end{array}$ & $\begin{array}{c}942 \\
163\end{array}$ & $\begin{array}{r}382 \\
70\end{array}$ & $\begin{array}{r}4 / 8 \\
45\end{array}$ & $\begin{array}{r}81 \\
8\end{array}$ & 215 \\
\hline Libe & & & & & & & & & & & & & & & & & & & & & \\
\hline & 33,997 & 26,053 & 3,474 & 2,470 & 1,193 & 279 & 528 & 13,379 & 10,682 & 1,173 & 747 & 446 & 98 & 233 & 20,618 & 15,371 & 2,301 & 1,723 & 747 & 181 & 295 \\
\hline Librar & 58 & 52 & & 0 & 2 & 0 & 1 & 8 & 5 & 1 & 0 & 1 & 0 & 1 & 50 & 47 & 2 & 0 & 1 & 0 & 0 \\
\hline Mathemati & 13,143 & 10,033 & 986 & 558 & 955 & 54 & 557 & 7,134 & 5,366 & 465 & 334 & 552 & 31 & 386 & 6,009 & 4,667 & 521 & 224 & 403 & 23 & 171 \\
\hline lec & 54 & 39 & 3 & 2 & 2 & 4 & 4 & 48 & 36 & 2 & 1 & 1 & 4 & 4 & & & 1 & 1 & 1 & 0 & 0 \\
\hline & 26,5 & 2 & 2,111 & $2,1 \mathrm{~s}$ & 1,568 & 210 & 7 & 9,2 & 7,1 & 668 & 540 & 675 & 66 & 208 & 17,229 & 12, & 1,447 & 1,652 & 893 & 144 & 179 \\
\hline nd fitness & & & & 5 & 219 & 79 & & 7,0 & 6,0 & 457 & 3 & 113 & 46 & 10 & 6,8 & & 333 & 9 & 106 & 33 & 68 \\
\hline & 7 & 6,182 & 6 & & 375 & 20 & 158 & $\begin{array}{l}4,859 \\
\end{array}$ & 4,071 & 209 & 219 & 242 & $\begin{array}{l}40 \\
12\end{array}$ & 106 & 2,529 & 2,1 & 137 & 88 & 133 & $\begin{array}{r}5 \\
8\end{array}$ & 52 \\
\hline Physical sciences and science technologies & 19,647 & 15,551 & 1,130 & 566 & 1,605 & 108 & 687 & 12,578 & 10,277 & 497 & 355 & 934 & 77 & 438 & 7,069 & 5,274 & 633 & 211 & 671 & 31 & 249 \\
\hline Precisi & 401 & 315 & 20 & 12 & 7 & 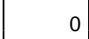 & 1 & 305 & 261 & 24 & 12 & 6 & 0 & 2 & 96 & 84 & & 1 & 1 & 0 & 2 \\
\hline & & $1 \varepsilon$ & & 1,9 & 447 & 222 & 127 & 15 , & 11,979 & 1,687 & 1,106 & 294 & 126 & 82 & 9,536 & & 2,023 & 812 & 153 & 96 & 45 \\
\hline & 73,2 & 57,254 & 6,157 & 4,640 & 3,744 & 482 & 1,014 & 19,817 & 15,582 & 1,455 & 1,218 & 1,151 & 136 & 275 & 53,474 & 41,672 & 4,702 & 3,422 & 2,593 & 346 & 739 \\
\hline ervices. & 19,849 & $\begin{array}{r}14,205 \\
7\end{array}$ & $\begin{array}{r}3,433 \\
0\end{array}$ & 1,290 & $\begin{array}{r}546 \\
0\end{array}$ & 194 & 181 & $\begin{array}{r}4,205 \\
7\end{array}$ & 2,942 & 747 & 286 & 147 & 33 & 50 & 15,644 & 11,263 & 2,686 & 1,004 & 399 & $\begin{array}{r}161 \\
0\end{array}$ & 131 \\
\hline K. & $6.42 \mathrm{c}$ & 8637 & 10 & 7,3 & 2 & 811 & 3,796 & 65,8 & 51. & 4.635 & 3,568 & 3,242 & 395 & 2.094 & 60, & 44,699 & 6342 & 3798 & 650 & 416 & 1.702 \\
\hline & & , & 10,8 & r,3 & $\begin{array}{r}0,092 \\
122\end{array}$ & 20 & $\begin{array}{r}3,700 \\
165\end{array}$ & ro, 4, & 3 & $\begin{array}{r}4,305 \\
139\end{array}$ & $\begin{array}{r}500 \\
74\end{array}$ & 74 & $\begin{array}{r}r 90 \\
17\end{array}$ & $\begin{array}{r}2,094 \\
110\end{array}$ & $\begin{array}{r}r, 314 \\
1,314\end{array}$ & $\begin{array}{r}44,659 \\
1,110\end{array}$ & $\begin{array}{r}542 \\
66\end{array}$ & $\begin{array}{l}30 \\
32\end{array}$ & 48 & $\begin{array}{r}10 \\
3\end{array}$ & 55 \\
\hline & 3,5 & 3,020 & 192 & 13 & 75 & 21 & 116 & 3,143 & 2,681 & 159 & 118 & 67 & 19 & 99 & 418 & 339 & 33 & 19 & 8 & 2 & 17 \\
\hline Visual & 49,296 & 39,743 & 2,002 & 2,176 & 2,649 & 278 & 2,448 & 20,126 & 16,142 & 914 & 977 & 1,043 & 121 & 929 & 29,170 & 23,601 & 1,088 & 1,199 & 1,606 & 157 & 1,519 \\
\hline
\end{tabular}

1 Reported racial/ethnic distributions of students by level of degree, field of degree, and sex were used to estimate race/ethnicity for students whose race/ethnicity was not reported. Excludes 1,015 men and 741 women whose racial

NOTE.- To facilitate trend comparisons, certain aggregations have been made of the degree fields as reported in
he
Agricultural sciences, and Conservation and renewable natural resources; and "Business" includes Business management and administrative services, Marketing operations/marketing and distribution, and Consumer and personal serv

SOURCE: U.S. Department of Education, National Center for Education Statistics, Integrated Postsecondary Education Data System (IPEDS), "Completions" survey. (This table was prepared June 1998.) 


\begin{tabular}{|c|c|c|c|c|c|c|c|c|c|c|c|c|c|c|c|c|c|c|c|c|c|}
\hline \multirow[b]{2}{*}{ Major field of study } & \multicolumn{7}{|c|}{ Total } & \multicolumn{7}{|c|}{ Men } & \multicolumn{7}{|c|}{ Women } \\
\hline & Total & $\begin{array}{c}\text { White, } \\
\text { non- } \\
\text { His- } \\
\text { panic }\end{array}$ & $\begin{array}{c}\text { Black, } \\
\text { non- } \\
\text { His- } \\
\text { panic }\end{array}$ & $\begin{array}{c}\text { His- } \\
\text { panic }\end{array}$ & $\begin{array}{l}\text { Asian/ } \\
\text { Pacific } \\
\text { Islander }\end{array}$ & \begin{tabular}{|l|} 
Amer- \\
ican \\
Indian// \\
Alas- \\
kan \\
Native
\end{tabular} & $\begin{array}{l}\text { Non- } \\
\text { resi- } \\
\text { dent } \\
\text { alien }\end{array}$ & Total & $\begin{array}{l}\text { White, } \\
\text { non- } \\
\text { His- } \\
\text { panic }\end{array}$ & $\begin{array}{c}\text { Black, } \\
\text { non- } \\
\text { His- } \\
\text { panic }\end{array}$ & \begin{tabular}{|c|} 
His- \\
panic
\end{tabular} & $\begin{array}{l}\text { Asian/ } \\
\text { Pacific } \\
\text { Is- } \\
\text { lander }\end{array}$ & \begin{tabular}{|c|} 
Amer- \\
ican \\
Indian/ \\
Alas- \\
kan \\
Native \\
\end{tabular} & $\begin{array}{l}\text { Non- } \\
\text { resi- } \\
\text { dent } \\
\text { alien }\end{array}$ & Total & $\begin{array}{l}\text { White, } \\
\text { non-His- } \\
\text { panic }\end{array}$ & $\begin{array}{c}\text { Black, } \\
\text { non- } \\
\text { His- } \\
\text { panic }\end{array}$ & $\begin{array}{c}\text { His- } \\
\text { panic }\end{array}$ & $\begin{array}{l}\text { Asian/ } \\
\text { Pacific } \\
\text { Is- } \\
\text { lander }\end{array}$ & \begin{tabular}{|c|} 
Amer- \\
ican \\
Indian/ \\
Alas- \\
kan \\
Native
\end{tabular} & $\begin{array}{l}\text { Non- } \\
\text { resi- } \\
\text { dent } \\
\text { alien }\end{array}$ \\
\hline 1 & 2 & 3 & 4 & 5 & 6 & 7 & 8 & 9 & 10 & 11 & 12 & 13 & 14 & 15 & 16 & 17 & 18 & 19 & 20 & 21 & 22 \\
\hline All fields, total 1 & $1,158,788$ & 913,377 & 87,203 & 54,201 & 60,478 & 6,606 & 36,923 & 525,174 & 417,006 & 31,775 & 23,600 & 28,973 & 2,736 & 21,084 & 633,614 & 496,371 & 55,428 & 30,601 & 31,505 & 3,870 & 15,839 \\
\hline $\begin{array}{l}\text { Agriculture and natural resources } \\
\text { Architecture and related programs } \\
\text { Area, ethnic, and cultural studies } \\
\text { Biological sciences/life sciences ... } \\
\text { Business ........................................... }\end{array}$ & $\begin{array}{r}19,841 \\
8,756 \\
5,706 \\
55,984 \\
234,323\end{array}$ & $\begin{array}{r}17,986 \\
6,716 \\
3,704 \\
41,573 \\
176,471\end{array}$ & $\begin{array}{r}472 \\
345 \\
650 \\
3,303 \\
20,286\end{array}$ & $\begin{array}{r}460 \\
544 \\
519 \\
2,331 \\
10,753\end{array}$ & $\begin{array}{r}424 \\
704 \\
558 \\
7,208 \\
13,174\end{array}$ & $\begin{array}{r}163 \\
28 \\
47 \\
291 \\
999\end{array}$ & $\begin{array}{r}336 \\
419 \\
228 \\
1,278 \\
12,640\end{array}$ & $\begin{array}{r}12,692 \\
5,741 \\
2,092 \\
26,687 \\
121,898\end{array}$ & $\begin{array}{r}11,645 \\
4,470 \\
1,321 \\
20,276 \\
95,039\end{array}$ & $\begin{array}{r}233 \\
213 \\
221 \\
1,004 \\
7,991\end{array}$ & $\begin{array}{r}280 \\
366 \\
189 \\
1,102 \\
5,258\end{array}$ & $\begin{array}{r}204 \\
404 \\
196 \\
3,553 \\
6,029\end{array}$ & $\begin{array}{r}99 \\
17 \\
25 \\
131 \\
478\end{array}$ & $\begin{array}{r}231 \\
271 \\
140 \\
621 \\
7,103\end{array}$ & $\begin{array}{r}7,149 \\
3,015 \\
3,614 \\
29,297 \\
112,425\end{array}$ & $\begin{array}{r}6,341 \\
2,246 \\
2,383 \\
21,297 \\
81,432\end{array}$ & $\begin{array}{r}239 \\
132 \\
429 \\
2,299 \\
12,295\end{array}$ & $\begin{array}{r}180 \\
178 \\
330 \\
1,229 \\
5,495\end{array}$ & $\begin{array}{r}220 \\
300 \\
362 \\
3,655 \\
7,145\end{array}$ & $\begin{array}{r}64 \\
11 \\
22 \\
160 \\
521\end{array}$ & $\begin{array}{r}105 \\
148 \\
88 \\
657 \\
5,537\end{array}$ \\
\hline 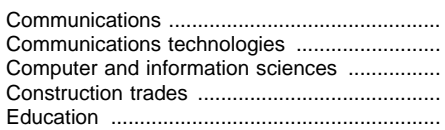 & $\begin{array}{r}48,104 \\
699 \\
24,404 \\
113 \\
106,079\end{array}$ & $\begin{array}{r}39,240 \\
553 \\
15,932 \\
95 \\
93,033\end{array}$ & $\begin{array}{r}4,036 \\
86 \\
2,563 \\
8 \\
6,658\end{array}$ & $\begin{array}{r}2,014 \\
14 \\
1,077 \\
0 \\
3,430\end{array}$ & $\begin{array}{r}1,378 \\
16 \\
2,425 \\
2 \\
1,381\end{array}$ & $\begin{array}{r}204 \\
2 \\
113 \\
1 \\
846\end{array}$ & $\begin{array}{r}1,232 \\
28 \\
2,294 \\
7 \\
731\end{array}$ & $\begin{array}{r}20,028 \\
376 \\
17,463 \\
91 \\
25,641\end{array}$ & $\begin{array}{r}16,808 \\
318 \\
12,095 \\
75 \\
22,347\end{array}$ & $\begin{array}{r}1,389 \\
30 \\
1,273 \\
6 \\
1,640\end{array}$ & $\begin{array}{r}773 \\
8 \\
730 \\
0 \\
823\end{array}$ & $\begin{array}{r}490 \\
8 \\
1,623 \\
2 \\
382\end{array}$ & $\begin{array}{r}79 \\
1 \\
75 \\
1 \\
214\end{array}$ & $\begin{array}{r}489 \\
11 \\
1,667 \\
7 \\
235\end{array}$ & $\begin{array}{r}28,076 \\
323 \\
6,941 \\
22 \\
80,438\end{array}$ & $\begin{array}{r}22,432 \\
235 \\
3,837 \\
20 \\
70,686\end{array}$ & $\begin{array}{r}2,647 \\
56 \\
1,290 \\
2 \\
5,018\end{array}$ & \begin{tabular}{r|r|r}
1,241 \\
6 \\
347 \\
0 \\
2,607
\end{tabular} & $\begin{array}{r}888 \\
8 \\
802 \\
0 \\
999\end{array}$ & \begin{tabular}{r|r}
125 \\
1 \\
38 \\
0 \\
632
\end{tabular} & $\begin{array}{r}743 \\
17 \\
627 \\
0 \\
496\end{array}$ \\
\hline $\begin{array}{l}\text { English language and literature/letters ............. } \\
\text { Foreign languages and literatures .............. } \\
\text { Health professions and related sciences ..... }\end{array}$ & $\begin{array}{l}62,342 \\
15,633 \\
51,901 \\
13,775 \\
79,855\end{array}$ & $\begin{array}{l}44,735 \\
12,332 \\
43,881 \\
10,251 \\
66,402\end{array}$ & $\begin{array}{r}2,908 \\
1,662 \\
3,303 \\
498 \\
5,806\end{array}$ & $\begin{array}{r}2,724 \\
688 \\
2,101 \\
1,903 \\
2,601\end{array}$ & $\begin{array}{r}6,939 \\
714 \\
1,755 \\
591 \\
3,563\end{array}$ & $\begin{array}{r}226 \\
115 \\
288 \\
55 \\
467\end{array}$ & $\begin{array}{r}4,810 \\
522 \\
573 \\
477 \\
1,016\end{array}$ & $\begin{array}{r}51,646 \\
14,133 \\
17,810 \\
4,243 \\
14,443\end{array}$ & $\begin{array}{r}37,662 \\
11,253 \\
15,495 \\
3,284 \\
11,757\end{array}$ & $\begin{array}{r}1,890 \\
1,035 \\
816 \\
134 \\
869\end{array}$ & $\begin{array}{r}2,203 \\
610 \\
686 \\
526 \\
543\end{array}$ & $\begin{array}{r}5,467 \\
639 \\
524 \\
154 \\
910\end{array}$ & $\begin{array}{r}180 \\
99 \\
99 \\
12 \\
95\end{array}$ & $\begin{array}{r}4,244 \\
497 \\
190 \\
133 \\
269\end{array}$ & $\begin{array}{r}10,696 \\
1,500 \\
34,091 \\
9,532 \\
65,412\end{array}$ & $\begin{array}{r}7,073 \\
1,079 \\
28,386 \\
6,967 \\
54,645\end{array}$ & $\begin{array}{r}1,018 \\
227 \\
2,487 \\
364 \\
4,937\end{array}$ & $\begin{array}{r}521 \\
78 \\
1,415 \\
1,377 \\
2,058\end{array}$ & $\begin{array}{r}1,472 \\
75 \\
1,231 \\
437 \\
2,653\end{array}$ & $\begin{array}{r}46 \\
16 \\
189 \\
43 \\
372\end{array}$ & $\begin{array}{r}566 \\
25 \\
383 \\
344 \\
747\end{array}$ \\
\hline $\begin{array}{l}\text { Home } \\
\text { econ } \\
\text { Law an }\end{array}$ & $\begin{array}{r}15,345 \\
2,032\end{array}$ & $\begin{array}{r}13,103 \\
1,646\end{array}$ & $\begin{array}{r}1,051 \\
211\end{array}$ & $\begin{array}{r}395 \\
88\end{array}$ & $\begin{array}{r}459 \\
66\end{array}$ & $\begin{array}{l}93 \\
14\end{array}$ & $\begin{array}{r}244 \\
7\end{array}$ & $\begin{array}{r}1,808 \\
595\end{array}$ & $\begin{array}{r}1,487 \\
467\end{array}$ & $\begin{array}{r}154 \\
67\end{array}$ & $\begin{array}{l}47 \\
26\end{array}$ & $\begin{array}{l}71 \\
28\end{array}$ & $\begin{array}{l}8 \\
5\end{array}$ & $\begin{array}{r}41 \\
2\end{array}$ & $\begin{array}{r}13,537 \\
1,437\end{array}$ & $\begin{array}{r}11,616 \\
1,179\end{array}$ & $\begin{array}{l}897 \\
144\end{array}$ & $\begin{array}{r}348 \\
62\end{array}$ & $\begin{array}{r}388 \\
38\end{array}$ & $\begin{array}{r}85 \\
9\end{array}$ & $\begin{array}{r}203 \\
5\end{array}$ \\
\hline ces, general studies, & $\begin{array}{r}33,356 \\
50\end{array}$ & $\begin{array}{r}25,842 \\
46\end{array}$ & $\begin{array}{r}3,155 \\
2\end{array}$ & $\begin{array}{r}2,413 \\
0\end{array}$ & $\begin{array}{r}1,091 \\
0\end{array}$ & $\begin{array}{r}298 \\
1\end{array}$ & $\begin{array}{r}557 \\
1\end{array}$ & $\begin{array}{r}13,157 \\
2 \\
\end{array}$ & $\begin{array}{r}10,557 \\
2\end{array}$ & $\begin{array}{r}1,077 \\
0\end{array}$ & $\begin{array}{r}791 \\
0\end{array}$ & $\begin{array}{r}380 \\
0\end{array}$ & $\begin{array}{r}100 \\
0\end{array}$ & $\begin{array}{r}252 \\
0\end{array}$ & $\begin{array}{r}2,701 \\
48\end{array}$ & $\begin{array}{r}15,285 \\
44\end{array}$ & $\begin{array}{r}2,078 \\
2\end{array}$ & $\begin{array}{r}1,622 \\
0\end{array}$ & $\begin{array}{r}711 \\
0\end{array}$ & $\begin{array}{r}198 \\
1\end{array}$ & $\begin{array}{r}305 \\
1\end{array}$ \\
\hline Mathem & 13,723 & 10,559 & 1,011 & 520 & 984 & 59 & 590 & 7,295 & 5,589 & 485 & 306 & 530 & 30 & 355 & 6,428 & 4,970 & 526 & 214 & 454 & 29 & 235 \\
\hline & $\begin{array}{r}66 \\
26,033\end{array}$ & $\begin{array}{r}57 \\
20,006\end{array}$ & $\begin{array}{r}2 \\
1,893\end{array}$ & $\begin{array}{r}0 \\
2,088\end{array}$ & $\begin{array}{r}2 \\
1,478\end{array}$ & $\begin{array}{r}0 \\
147\end{array}$ & $\begin{array}{r}5 \\
421\end{array}$ & $\begin{array}{r}63 \\
9,158\end{array}$ & $\begin{array}{r}56 \\
7,081\end{array}$ & $\begin{array}{r}2 \\
649\end{array}$ & $\begin{array}{r}0 \\
557\end{array}$ & $\begin{array}{r}1 \\
608\end{array}$ & $\begin{array}{r}0 \\
56\end{array}$ & $\begin{array}{r}4 \\
207\end{array}$ & & & $\begin{array}{r}0 \\
1,244\end{array}$ & $\begin{array}{r}0 \\
1,531\end{array}$ & $\begin{array}{r}1 \\
870\end{array}$ & $\begin{array}{r}0 \\
91\end{array}$ & $\begin{array}{r}1 \\
214\end{array}$ \\
\hline & 12, & 11,2 & 715 & 9 & 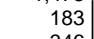 & 74 & 173 & & 5,7 & 439 & 31 & 87 & 34 & 85 & & & 27 & 189 & 96 & 40 & 88 \\
\hline & $\begin{array}{r}7,276 \\
19177\end{array}$ & $\begin{array}{r}6,102 \\
\quad\end{array}$ & 326 & 315 & $\begin{array}{r}346 \\
1.387\end{array}$ & 42 & $\begin{array}{r}145 \\
777\end{array}$ & $\begin{array}{r}4,670 \\
\end{array}$ & 3,911 & 194 & 238 & 199 & 24 & 104 & & & 13 & ] & 147 & 18 & 41 \\
\hline technologi & 19,177 & 15,398 & 1,056 & 507 & 1,387 & 102 & 727 & 12,497 & 10,319 & 505 & 320 & 809 & 69 & 475 & 6,680 & 5,079 & 551 & 187 & 578 & 33 & 252 \\
\hline Prect & $\begin{array}{r}353 \\
24,157\end{array}$ & $\begin{array}{r}281 \\
17,980\end{array}$ & $\begin{array}{r}43 \\
702\end{array}$ & $\begin{array}{r}11 \\
1,701\end{array}$ & $\begin{array}{r}12 \\
420\end{array}$ & $\begin{array}{r}1 \\
203\end{array}$ & $\begin{array}{r}5 \\
151\end{array}$ & $\begin{array}{r}247 \\
15,049\end{array}$ & $\begin{array}{r}200 \\
11,845\end{array}$ & $\begin{array}{r}29 \\
1,726\end{array}$ & $\begin{array}{r}8 \\
983\end{array}$ & $\begin{array}{r}7 \\
287\end{array}$ & $\begin{array}{r}1 \\
107\end{array}$ & $\begin{array}{r}2 \\
101\end{array}$ & $\begin{array}{r}106 \\
9,108\end{array}$ & $\begin{array}{r}81 \\
6,135\end{array}$ & $\begin{array}{r}14 \\
1,976\end{array}$ & $\begin{array}{r}3 \\
718\end{array}$ & $\begin{array}{r}5 \\
133\end{array}$ & \begin{tabular}{r|r}
0 \\
96
\end{tabular} & $\begin{array}{r}3 \\
50\end{array}$ \\
\hline & 72,083 & 57 & 5,878 & 4,149 & 3,404 & 417 & 938 & 19,548 & 15,653 & 1,439 & 1,111 & 990 & 123 & 232 & 52, & 41,644 & 4,439 & 3,038 & 2,414 & 294 & 706 \\
\hline 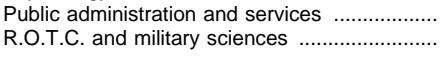 & $\begin{array}{r}18,586 \\
27\end{array}$ & $\begin{array}{r}13,533 \\
26\end{array}$ & $\begin{array}{r}3,026 \\
0\end{array}$ & $\begin{array}{r}1,170 \\
0\end{array}$ & 467 & $\begin{array}{r}205 \\
0\end{array}$ & $\begin{array}{r}185 \\
0\end{array}$ & $\begin{array}{r}3,935 \\
24\end{array}$ & $\begin{array}{r}2,833 \\
23\end{array}$ & $\begin{array}{r}640 \\
0\end{array}$ & $\begin{array}{r}253 \\
0\end{array}$ & 134 & $\begin{array}{r}36 \\
0\end{array}$ & $\begin{array}{r}39 \\
0\end{array}$ & $\begin{array}{r}14,651 \\
3\end{array}$ & $\begin{array}{r}10,700 \\
3\end{array}$ & $\begin{array}{r}2,386 \\
0\end{array}$ & $\begin{array}{r}917 \\
0\end{array}$ & $\begin{array}{r}333 \\
0\end{array}$ & $\begin{array}{r}169 \\
0\end{array}$ & 146 \\
\hline & 28,1 & 99 & 10,562 & 7,0 & 6,626 & 798 & 3,6 & 68, & 54,6 & 4,466 & 3,462 & 3,136 & 389 & 2,0 & 60 & 44, & 6,096 & 3,540 & 3,490 & 409 & 595 \\
\hline & 5, & $4, \xi$ & 243 & 136 & 151 & 24 & 194 & 4, & 3,707 & 160 & 99 & 96 & 16 & 123 & 1,377 & 1,123 & 83 & 37 & 5 & & 71 \\
\hline & $\begin{array}{r}3,698 \\
\end{array}$ & $\begin{array}{r}3,213 \\
39765\end{array}$ & $\begin{array}{r}168 \\
1975\end{array}$ & $\begin{array}{r}120 \\
1928\end{array}$ & $\begin{array}{r}101 \\
2468\end{array}$ & $\begin{array}{r}24 \\
259\end{array}$ & $\begin{array}{r}72 \\
\end{array}$ & $\begin{array}{r}3,297 \\
19781\end{array}$ & $\begin{array}{r}2,880 \\
16,123\end{array}$ & $\begin{array}{l}139 \\
860\end{array}$ & $\begin{array}{l}105 \\
887\end{array}$ & $\begin{array}{r}90 \\
934\end{array}$ & $\begin{array}{r}21 \\
112\end{array}$ & 62 & 401 & $\begin{array}{r}333 \\
3642\end{array}$ & 29 & $\begin{array}{r}15 \\
041\end{array}$ & $\begin{array}{r}11 \\
534\end{array}$ & $\begin{array}{r}3 \\
47\end{array}$ & 10 \\
\hline Vis & 48,690 & 39,765 & 1,975 & 1,928 & 2,468 & 259 & 2,295 & 19,781 & 16,123 & 860 & 887 & 934 & 112 & 865 & 28,909 & 23,642 & 1,115 & $1,041 \ldots$ & 1,534 & $147 \mid$ & 1,430 \\
\hline
\end{tabular}

1 Reported racial/ethnic distributions of students by level of degree, field of degree, and sex were used to estimate ace/ethnicity for students whose race/ethnicity was not reported. Excludes 957 men and 389 women whose racial

NOTE.- To facilitate trend comparisons, certain aggregations have been made of the degree fields as reported in
the IPEDS "Completions" survey: "Agriculture and natural resources" includes Agricultural business and production,
Agricultural sciences, and Conservation and renewable natural resources; and "Business" includes Business management and administrative services, Marketing operations/marketing and distribution, and Consumer and personal serv

SOURCE: U.S. Department of Education, National Center for Education Statistics, Integrated Postsecondary Education Data System (IPEDS), "Completions" survey. (This table was prepared April 1997.) 
HIGHER EDUCATION: DEGREES 305

Table 267.-Master's degrees conferred by institutions of higher education, by racial/ethnic group and sex of student: $1976-77$ to $1995-96$

\begin{tabular}{|c|c|c|c|c|c|c|c|c|c|c|c|c|c|c|}
\hline \multirow[b]{2}{*}{ Year } & \multicolumn{7}{|c|}{ Number of degrees conferred } & \multicolumn{7}{|c|}{ Percentage distribution of degrees conferred } \\
\hline & Total & $\begin{array}{l}\text { White, } \\
\text { non-His- } \\
\text { panic }\end{array}$ & $\begin{array}{c}\text { Black, } \\
\text { non-His- } \\
\text { panic }\end{array}$ & Hispanic & $\begin{array}{c}\text { Asian/ } \\
\text { Pacific } \\
\text { Islander }\end{array}$ & $\begin{array}{l}\text { Amer- } \\
\text { ican In- } \\
\text { dian/ } \\
\text { Alaskan } \\
\text { Native }\end{array}$ & $\begin{array}{l}\text { Non- } \\
\text { resi- } \\
\text { dent } \\
\text { alien }\end{array}$ & Total & $\begin{array}{c}\text { White, } \\
\text { non- } \\
\text { His- } \\
\text { panic }\end{array}$ & $\begin{array}{c}\text { Black, } \\
\text { non- } \\
\text { His- } \\
\text { panic }\end{array}$ & $\begin{array}{l}\text { His- } \\
\text { panic }\end{array}$ & $\begin{array}{l}\text { Asian/ } \\
\text { Pacific } \\
\text { Is- } \\
\text { lander }\end{array}$ & $\begin{array}{c}\text { Amer- } \\
\text { ican } \\
\text { Indian/ } \\
\text { Alas- } \\
\text { kan } \\
\text { Native }\end{array}$ & $\begin{array}{l}\text { Non- } \\
\text { resi- } \\
\text { dent } \\
\text { alien }\end{array}$ \\
\hline \multirow[t]{2}{*}{1} & 2 & 3 & 4 & 5 & 6 & 7 & 8 & 9 & 10 & 11 & 12 & 13 & 14 & 15 \\
\hline & \multicolumn{7}{|c|}{ Total } & \multicolumn{7}{|c|}{ Total } \\
\hline $1976-77^{1} \ldots \ldots$ & 316,602 & 266,061 & 21,037 & 6,071 & 5,122 & 967 & 17,344 & 100.0 & 84.0 & 6.6 & 1.9 & 1.6 & 0.3 & 5.5 \\
\hline $1978-79^{2}$ & 300,255 & 249,360 & 19,418 & 5,555 & 5,496 & 999 & 19,427 & 100.0 & 83.0 & 6.5 & 1.9 & 1.8 & 0.3 & 6.5 \\
\hline $1980-81^{3} \ldots \ldots \ldots$ & 294,183 & 241,216 & 17,133 & 6,461 & 6,282 & 1,034 & 22,057 & 100.0 & 82.0 & 5.8 & 2.2 & 2.1 & 0.4 & 7.5 \\
\hline $1984-85^{4} \ldots \ldots .$. & 280,421 & 223,628 & 13,939 & 6,864 & 7,782 & 1,256 & 26,952 & 100.0 & 79.7 & 5.0 & 2.4 & 2.8 & 0.4 & 9.6 \\
\hline $1986-87^{5} \ldots \ldots$ & 289,349 & 228,874 & 13,873 & 7,044 & 8,559 & 1,103 & 29,896 & 100.0 & 79.1 & 4.8 & 2.4 & 3.0 & 0.4 & 10.3 \\
\hline $1988-89^{5,6} \ldots \ldots$ & 309,770 & 242,764 & 14,095 & 7,277 & 10,335 & 1,086 & 34,213 & 100.0 & 78.4 & 4.6 & 2.3 & 3.3 & 0.4 & 11.0 \\
\hline $1989-90^{5,7} \ldots \ldots$ & 322,465 & 251,690 & 15,446 & 7,950 & 10,577 & 1,101 & 35,701 & 100.0 & 78.1 & 4.8 & 2.5 & 3.3 & 0.3 & 11.1 \\
\hline $1990-91^{5,8} \ldots \ldots$ & 328,645 & 255,281 & 16,139 & 8,386 & 11,180 & 1,136 & 36,523 & 100.0 & 77.7 & 4.9 & 2.6 & 3.4 & 0.3 & 11.1 \\
\hline $1991-92^{5,9} \ldots \ldots$ & 348,682 & 268,371 & 18,116 & 9,358 & 12,658 & 1,273 & 38,906 & 100.0 & 77.0 & 5.2 & 2.7 & 3.6 & 0.4 & 11.2 \\
\hline $1992-93^{5,10}$ & 368,701 & 278,829 & 19,780 & 10,665 & 13,866 & 1,407 & 44,154 & 100.0 & 75.6 & 5.4 & 2.9 & 3.8 & 0.4 & 12.0 \\
\hline $1993-945,11$ & 385,419 & 288,288 & 21,937 & 11,913 & 15,267 & 1,697 & 46,317 & 100.0 & 74.8 & 5.7 & 3.1 & 4.0 & 0.4 & 12.0 \\
\hline $1994-95^{5,12} \ldots$ & 397,052 & 292,784 & 24,171 & 12,907 & 16,842 & 1,621 & 48,727 & 100.0 & 73.7 & 6.1 & 3.3 & 4.2 & 0.4 & 12.3 \\
\hline \multirow{2}{*}{$1995-96^{5,13} \ldots$} & 405,521 & 297,558 & 25,801 & 14,412 & 18,161 & 1,778 & 47,811 & 100.0 & 73.4 & 6.4 & 3.6 & 4.5 & 0.4 & 11.8 \\
\hline & \multicolumn{7}{|c|}{ Men } & \multicolumn{7}{|c|}{ Men } \\
\hline $1976-77^{1}$ & 167,396 & 139,210 & 7,781 & 3,268 & 3,123 & 521 & 13,493 & 100.0 & 83.2 & 4.6 & 2.0 & 1.9 & 0.3 & 8.1 \\
\hline $1978-79^{2} \ldots \ldots \ldots$ & 152,637 & 124,058 & 7,070 & 2,786 & 3,325 & 495 & 14,903 & 100.0 & 81.3 & 4.6 & 1.8 & 2.2 & 0.3 & 9.8 \\
\hline $1980-81^{3}$ & 145,666 & 115,562 & 6,158 & 3,085 & 3,773 & 501 & 16,587 & 100.0 & 79.3 & 4.2 & 2.1 & 2.6 & 0.3 & 11.4 \\
\hline $1984-85^{4}$ & 139,417 & 106,059 & 5,200 & 3,059 & 4,842 & 583 & 19,674 & 100.0 & 76.1 & 3.7 & 2.2 & 3.5 & 0.4 & 14.1 \\
\hline $1986-87^{5}$ & 141,269 & 105,572 & 5,153 & 3,331 & 5,239 & 518 & 21,456 & 100.0 & 74.7 & 3.6 & 2.4 & 3.7 & 0.4 & 15.2 \\
\hline $1988-895,6$ & 148,872 & 109,715 & 5,175 & 3,325 & 6,048 & 476 & 24,133 & 100.0 & 73.7 & 3.5 & 2.2 & 4.1 & 0.3 & 16.2 \\
\hline $1989-905,7$ & 152,926 & 112,877 & 5,539 & 3,586 & 6,002 & 463 & 24,459 & 100.0 & 73.8 & 3.6 & 2.3 & 3.9 & 0.3 & 16.0 \\
\hline $1990-915,8$ & 151,796 & 111,224 & 5,709 & 3,670 & 6,319 & 459 & 24,415 & 100.0 & 73.3 & 3.8 & 2.4 & 4.2 & 0.3 & 16.1 \\
\hline $1991-92^{5,9}$ & 159,543 & 116,096 & 6,054 & 4,132 & 7,062 & 523 & 25,676 & 100.0 & 72.8 & 3.8 & 2.6 & 4.4 & 0.3 & 16.1 \\
\hline $1992-93^{5,10} \ldots$ & 168,754 & 120,225 & 6,821 & 4,735 & 7,544 & 586 & 28,843 & 100.0 & 71.2 & 4.0 & 2.8 & 4.5 & 0.3 & 17.1 \\
\hline $1993-945,11 \ldots$ & 175,355 & 123,854 & 7,413 & 5,113 & 8,225 & 691 & 30,059 & 100.0 & 70.6 & 4.2 & 2.9 & 4.7 & 0.4 & 17.1 \\
\hline $1994-95^{5,12}$ & 178,123 & 123,809 & 8,103 & 5,490 & 8,920 & 659 & 31,142 & 100.0 & 69.5 & 4.5 & 3.1 & 5.0 & 0.4 & 17.5 \\
\hline \multirow[t]{2}{*}{$1995-96^{5,13} \ldots}$. & 178,661 & 124,514 & 8,442 & 5,833 & 9,373 & 704 & 29,795 & 100.0 & 69.7 & 4.7 & 3.3 & 5.2 & 0.4 & 16.7 \\
\hline & \multicolumn{7}{|c|}{ Women } & \multicolumn{7}{|c|}{ Women } \\
\hline $1976-77^{1}$ & 49,206 & 126,851 & 13,256 & 2,803 & 1,999 & 44 & 3,851 & 100.0 & 85.0 & 8.9 & 1.9 & 1.3 & 0.3 & 2.6 \\
\hline $1978-79^{2}$ & 147,618 & 125,302 & 12,348 & 2,769 & 2,171 & 504 & 4,524 & 100.0 & 84.9 & 8.4 & 1.9 & 1.5 & 0.3 & 3.1 \\
\hline $1980-81^{3}$ & 148,517 & 125,654 & 10,975 & 3,376 & 2,509 & 533 & 5,470 & 100.0 & 84.6 & 7.4 & 2.3 & 1.7 & 0.4 & 3.7 \\
\hline $1984-85^{4}$ & 141,004 & 117,569 & 8,739 & 3,805 & 2,940 & 673 & 7,278 & 100.0 & 83.4 & 6.2 & 2.7 & 2.1 & 0.5 & 5.2 \\
\hline $1986-87^{5}$ & 148,080 & 123,302 & 8,720 & 3,713 & 3,320 & 585 & 8,440 & 100.0 & 83.3 & 5.9 & 2.5 & 2.2 & 0.4 & 5.7 \\
\hline $1988-895,6$ & 160,898 & 133,049 & 8,920 & 3,952 & 4,287 & 610 & 10,080 & 100.0 & 82.7 & 5.5 & 2.5 & 2.7 & 0.4 & 6.3 \\
\hline $1989-90^{5,7}$ & 169,539 & 138,813 & 9,907 & 4,364 & 4,575 & 638 & 11,242 & 100.0 & 81.9 & 5.8 & 2.6 & 2.7 & 0.4 & 6.6 \\
\hline $1990-91^{5,8}$ & 176,849 & 144,057 & 10,430 & 4,716 & 4,861 & 677 & 12,108 & 100.0 & 81.5 & 5.9 & 2.7 & 2.7 & 0.4 & 6.8 \\
\hline $1991-92^{5,9}$ & 189,139 & 152,275 & 12,062 & 5,226 & 5,596 & 750 & 13,230 & 100.0 & 80.5 & 6.4 & 2.8 & 3.0 & 0.4 & 7.0 \\
\hline $1992-93^{5,10} \ldots$ & 199,947 & 158,604 & 12,959 & 5,930 & 6,322 & 821 & 15,311 & 100.0 & 79.3 & 6.5 & 3.0 & 3.2 & 0.4 & 7.7 \\
\hline $1993-945,11 \ldots$ & 210,064 & 164,434 & 14,524 & 6,800 & 7,042 & 1,006 & 16,258 & 100.0 & 78.3 & 6.9 & 3.2 & 3.4 & 0.5 & 7.7 \\
\hline $1994-95^{5,12} \ldots$ & 218,929 & 168,975 & 16,068 & 7,417 & 7,922 & 962 & 17,585 & 100.0 & 77.2 & 7.3 & 3.4 & 3.6 & 0.4 & 8.0 \\
\hline $1995-96^{5,13} \ldots$ & 226,860 & 173,044 & 17,359 & 8,579 & 8,788 & 1,074 & 18,016 & 100.0 & 76.3 & 7.7 & 3.8 & 3.9 & 0.5 & 7.9 \\
\hline
\end{tabular}

1 Excludes 387 men and 175 women whose racial/ethnic group was not available. 2 Excludes 733 men and 91 women whose racial/ethnic group was not available.

${ }^{3}$ Excludes 1,377 men and 179 women whose racial/ethnic group was not available. ${ }^{4}$ Excludes 3,973 men and 1,857 women whose racial/ethnic group was not available. ${ }^{5}$ Reported racial/ethnic distributions of students by level of degree, field of degree, and sex were used to estimate race/ethnicity for students whose race/ethnicity was not reported.

${ }^{6}$ Excludes 482 men and 369 women whose racial/ethnic group and field of study were not available.

${ }^{7}$ Excludes 727 men and 1,109 women whose racial/ethnic group and field of study were not available.

${ }^{8}$ Excludes 4,686 men and 3,837 women whose racial/ethnic group and field of study were not available.

${ }^{9}$ Excludes 2,299 men and 1,857 women whose racial/ethnic group and field of study were not available.

${ }^{10}$ Excludes 504 men and 380 women whose racial/ethnic group and field of study were not available.
11 Excludes 730 men and 921 women whose racial/ethnic group and field of study were not available.

12 Excludes 475 men and 102 women whose racial/ethnic group and field of study were not available.

${ }^{13}$ Excludes 420 men and 360 women whose racial/ethnic group and field of study were not available.

NOTE.-For years 1984-85 to 1995-96, reported racial/ethnic distributions of students by level of degree, field of degree, and sex were used to estimate race/ethnicity for students whose race/ethnicity was not reported. Because of rounding, percents may not add to 100.0 .

SOURCE: U.S. Department of Education, National Center for Education Statistics, Higher Education General Information Survey (HEGIS), "Degrees and Other Forma Awards Conferred" surveys, and Integrated Postsecondary Education Data System (IPEDS), "Completions" surveys. (This table was prepared June 1998.) 


\begin{tabular}{|c|c|c|c|c|c|c|c|c|c|c|c|c|c|c|c|c|c|c|c|c|c|}
\hline \multirow[b]{2}{*}{ Major field of study } & \multicolumn{7}{|c|}{ Total } & \multicolumn{7}{|c|}{ Men } & \multicolumn{7}{|c|}{ Women } \\
\hline & Total & \begin{tabular}{|c} 
White, \\
non- \\
His- \\
panic
\end{tabular} & $\begin{array}{l}\text { Black, } \\
\text { non- } \\
\text { His- } \\
\text { panic }\end{array}$ & $\begin{array}{c}\text { His- } \\
\text { panic }\end{array}$ & $\begin{array}{l}\text { Asian/ } \\
\text { Pacific } \\
\text { Islander }\end{array}$ & $\begin{array}{l}\text { Amer- } \\
\text { ican } \\
\text { Indian/ } \\
\text { Alas- } \\
\text { kan } \\
\text { Native }\end{array}$ & $\begin{array}{l}\text { Non- } \\
\text { resi- } \\
\text { dent } \\
\text { alien }\end{array}$ & Total & $\begin{array}{l}\text { White, } \\
\text { non- } \\
\text { His- } \\
\text { panic }\end{array}$ & $\begin{array}{c}\text { Black, } \\
\text { non- } \\
\text { His- } \\
\text { panic }\end{array}$ & $\begin{array}{c}\text { His- } \\
\text { panic }\end{array}$ & $\begin{array}{l}\text { Asian/ } \\
\text { Pacific } \\
\text { Is- } \\
\text { lander }\end{array}$ & \begin{tabular}{|c|} 
Amer- \\
ican \\
Indian/ \\
Alas- \\
kan \\
Native \\
\end{tabular} & $\begin{array}{l}\text { Non- } \\
\text { resi- } \\
\text { dent } \\
\text { alien }\end{array}$ & Total & $\begin{array}{c}\text { White, } \\
\text { non-His- } \\
\text { panic }\end{array}$ & $\begin{array}{c}\text { Black, } \\
\text { non- } \\
\text { His- } \\
\text { panic }\end{array}$ & $\begin{array}{l}\text { His- } \\
\text { panic }\end{array}$ & $\begin{array}{l}\text { Asian/ } \\
\text { Pacific } \\
\text { Is- } \\
\text { lander }\end{array}$ & \begin{tabular}{|c|} 
Amer- \\
ican \\
Indian/ \\
Alas- \\
kan \\
Native
\end{tabular} & $\begin{array}{l}\text { Non- } \\
\text { resi- } \\
\text { dent } \\
\text { alien }\end{array}$ \\
\hline 1 & 2 & 3 & 4 & 5 & 6 & 7 & 8 & 9 & 10 & 11 & 12 & 13 & 14 & 15 & 16 & 17 & 18 & 19 & 20 & 21 & 22 \\
\hline All fields, total $1 \ldots$ & 405,521 & 297,558 & 25,801 & 14,412 & 18,161 & 1,778 & 47,811 & 178,661 & 124,514 & 8,442 & 5,833 & 9,373 & 704 & 29,795 & 226,860 & 173,044 & 17,359 & 8,579 & 8,788 & 1,074 & 18,016 \\
\hline 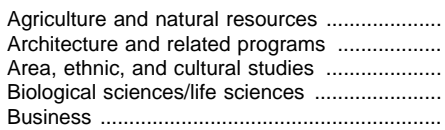 & $\begin{array}{r}4,569 \\
3,993 \\
1,713 \\
6,157 \\
93,982\end{array}$ & $\begin{array}{r}3,334 \\
2,664 \\
1,198 \\
4,262 \\
65,685\end{array}$ & $\begin{array}{r}116 \\
112 \\
115 \\
207 \\
5,753\end{array}$ & $\begin{array}{r}101 \\
187 \\
99 \\
161 \\
2,938\end{array}$ & $\begin{array}{r}124 \\
248 \\
98 \\
533 \\
5,417\end{array}$ & $\begin{array}{r}15 \\
11 \\
24 \\
17 \\
302\end{array}$ & $\begin{array}{r}879 \\
741 \\
179 \\
977 \\
13,887\end{array}$ & $\begin{array}{r}2,650 \\
2,361 \\
798 \\
2,902 \\
58,685\end{array}$ & $\begin{array}{r}1,922 \\
1,607 \\
558 \\
2,044 \\
41,964\end{array}$ & $\begin{array}{r}63 \\
73 \\
38 \\
79 \\
2,611\end{array}$ & $\begin{array}{r}59 \\
97 \\
60 \\
69 \\
1,800\end{array}$ & $\begin{array}{r}50 \\
136 \\
42 \\
246 \\
3,194\end{array}$ & $\begin{array}{r}6 \\
6 \\
9 \\
9 \\
184\end{array}$ & $\begin{array}{r}550 \\
442 \\
91 \\
455 \\
8,932\end{array}$ & $\begin{array}{r}1,919 \\
1,632 \\
915 \\
3,255 \\
35,297\end{array}$ & $\begin{array}{r}1,412 \\
1,057 \\
640 \\
2,218 \\
23,721\end{array}$ & $\begin{array}{r}53 \\
69 \\
77 \\
128 \\
3,142\end{array}$ & $\begin{array}{r}42 \\
90 \\
39 \\
92 \\
1,138\end{array}$ & $\begin{array}{r}74 \\
112 \\
56 \\
287 \\
2,223\end{array}$ & $\begin{array}{r}9 \\
5 \\
15 \\
8 \\
118\end{array}$ & $\begin{array}{r}329 \\
299 \\
88 \\
522 \\
4,955\end{array}$ \\
\hline 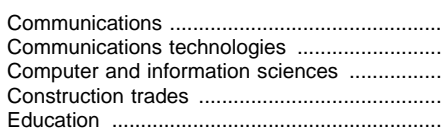 & $\begin{array}{r}5,080 \\
524 \\
10,151 \\
0 \\
106,253\end{array}$ & $\begin{array}{r}3,471 \\
297 \\
4,382 \\
0 \\
87,310\end{array}$ & $\begin{array}{r}406 \\
26 \\
406 \\
0 \\
8,557\end{array}$ & $\begin{array}{r}146 \\
15 \\
178 \\
0 \\
4,628\end{array}$ & $\begin{array}{r}170 \\
20 \\
1,321 \\
0 \\
1,833\end{array}$ & $\begin{array}{r}14 \\
4 \\
25 \\
0 \\
598\end{array}$ & $\begin{array}{r}873 \\
162 \\
3,839 \\
0 \\
3,327\end{array}$ & $\begin{array}{r}1,900 \\
271 \\
7,444 \\
0 \\
25,214\end{array}$ & $\begin{array}{r}1,326 \\
167 \\
3,384 \\
0 \\
20,376\end{array}$ & $\begin{array}{r}108 \\
12 \\
221 \\
0 \\
1,991\end{array}$ & $\begin{array}{r}60 \\
8 \\
129 \\
0 \\
1,110\end{array}$ & $\begin{array}{r}55 \\
7 \\
829 \\
0 \\
464\end{array}$ & \begin{tabular}{r|r}
7 \\
2 \\
18 \\
0 \\
159
\end{tabular} & $\begin{array}{r}344 \\
75 \\
2,863 \\
0 \\
1,114\end{array}$ & $\begin{array}{r}3,180 \\
253 \\
2,707 \\
0 \\
81,039\end{array}$ & $\begin{array}{r}2,145 \\
130 \\
998 \\
0 \\
66,934\end{array}$ & $\begin{array}{r}298 \\
14 \\
185 \\
0 \\
6,566\end{array}$ & $\begin{array}{r}86 \\
7 \\
49 \\
0 \\
3,518\end{array}$ & $\begin{array}{r}115 \\
13 \\
492 \\
0 \\
1,369\end{array}$ & $\begin{array}{r}7 \\
2 \\
7 \\
0 \\
439\end{array}$ & $\begin{array}{r}529 \\
87 \\
976 \\
0 \\
2,213\end{array}$ \\
\hline 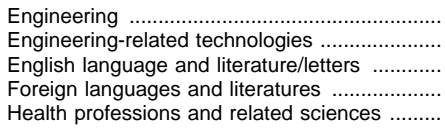 & $\begin{array}{r}27,441 \\
1,125 \\
7,893 \\
3,124 \\
33,398\end{array}$ & $\begin{array}{r}14,250 \\
843 \\
6,736 \\
2,054 \\
27,008\end{array}$ & $\begin{array}{r}704 \\
62 \\
292 \\
55 \\
1,875\end{array}$ & $\begin{array}{r}707 \\
36 \\
228 \\
322 \\
996\end{array}$ & $\begin{array}{r}2,755 \\
45 \\
223 \\
117 \\
1,832\end{array}$ & $\begin{array}{r}59 \\
3 \\
48 \\
12 \\
156\end{array}$ & $\begin{array}{r}8,966 \\
136 \\
366 \\
564 \\
1,531\end{array}$ & $\begin{array}{r}22,735 \\
906 \\
2,814 \\
1,017 \\
7,021\end{array}$ & $\begin{array}{r}11,972 \\
682 \\
2,410 \\
692 \\
5,122\end{array}$ & $\begin{array}{r}484 \\
44 \\
85 \\
23 \\
311\end{array}$ & $\begin{array}{r}546 \\
27 \\
95 \\
99 \\
235\end{array}$ & $\begin{array}{r}2,103 \\
37 \\
68 \\
31 \\
670\end{array}$ & $\begin{array}{r}54 \\
2 \\
20 \\
4 \\
41\end{array}$ & \begin{tabular}{r|r|}
7,576 \\
114 \\
136 \\
168 \\
642
\end{tabular} & $\begin{array}{r}4,706 \\
219 \\
5,079 \\
2,107 \\
26,377\end{array}$ & $\begin{array}{r}4,326 \\
1,362 \\
21,886\end{array}$ & $\begin{array}{r}220 \\
18 \\
207 \\
32 \\
1,564\end{array}$ & $\begin{array}{r}161 \\
9 \\
133 \\
223 \\
761\end{array}$ & $\begin{array}{r}652 \\
8 \\
155 \\
86 \\
1,162\end{array}$ & $\begin{array}{r}5 \\
1 \\
28 \\
8 \\
115\end{array}$ & $\begin{array}{r}1,390 \\
22 \\
230 \\
396 \\
889\end{array}$ \\
\hline Home e & $\begin{array}{l}2,917 \\
2,751\end{array}$ & $\begin{array}{l}2,293 \\
1,245\end{array}$ & $\begin{array}{l}192 \\
119\end{array}$ & $\begin{array}{l}94 \\
79\end{array}$ & $\begin{array}{r}74 \\
100\end{array}$ & $\begin{array}{l}24 \\
10\end{array}$ & $\begin{array}{r}240 \\
1,198\end{array}$ & $\begin{array}{r}496 \\
1,751\end{array}$ & $\begin{array}{l}374 \\
791\end{array}$ & $\begin{array}{l}38 \\
53\end{array}$ & $\begin{array}{l}15 \\
56\end{array}$ & 59 & $\begin{array}{l}6 \\
6\end{array}$ & $\begin{array}{r}54 \\
786\end{array}$ & $\begin{array}{l}2,421 \\
1,000\end{array}$ & 1,9 & $\begin{array}{r}154 \\
66\end{array}$ & $\begin{array}{l}79 \\
23\end{array}$ & $\begin{array}{l}65 \\
41\end{array}$ & $\begin{array}{r}18 \\
4\end{array}$ & $\begin{array}{l}186 \\
412\end{array}$ \\
\hline & & 1 & & & & 10 & 1,198 & $1, / 51$ & 191 & 53 & 50 & & & & & $15 t+25+2$ & & & & & \\
\hline & $\begin{array}{l}2, / 8 \\
5,099\end{array}$ & $\begin{array}{l}2,347 \\
4,411\end{array}$ & $\begin{array}{l}736 \\
211\end{array}$ & 116 & $\begin{array}{r}54 \\
146\end{array}$ & $\begin{array}{l}10 \\
15\end{array}$ & $\begin{array}{l}161 \\
200\end{array}$ & $\begin{array}{r}961 \\
1,071\end{array}$ & & $\begin{array}{l}46 \\
31\end{array}$ & $\begin{array}{l}24 \\
34\end{array}$ & $\begin{array}{l}21 \\
31\end{array}$ & $\begin{array}{l}4 \\
2\end{array}$ & $\begin{array}{l}15 \\
45\end{array}$ & $\begin{array}{l}1,817 \\
4,028\end{array}$ & & $\begin{array}{r}90 \\
180\end{array}$ & $\begin{array}{l}46 \\
82\end{array}$ & $\begin{array}{r}33 \\
115\end{array}$ & $\begin{array}{r}6 \\
13\end{array}$ & $\begin{array}{r}86 \\
155\end{array}$ \\
\hline 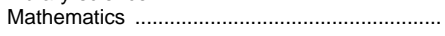 & 4,031 & 2,430 & 165 & 92 & 256 & 7 & 1,081 & 2,465 & 1,459 & 86 & 59 & 145 & 6 & 710 & 1,566 & 971 & 79 & 33 & 111 & 1 & 371 \\
\hline Mult & 2,347 & 1,86 & 119 & 73 & $\begin{array}{r}85 \\
17\end{array}$ & 11 & 194 & 1,08 & 848 & 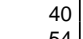 & $\begin{array}{r}38 \\
20\end{array}$ & 31 & 7 & 118 & 1,2 & 1,0 & 7 & 35 & 54 & 4 & 76 \\
\hline & & & & 3 & $\begin{array}{l}17 \\
34\end{array}$ & $\begin{array}{l}8 \\
2\end{array}$ & $\begin{array}{r}83 \\
123\end{array}$ & 9 & & 5 & $\begin{array}{l}22 \\
26\end{array}$ & 9 & 3 & 0 & 8 & & 70 & 14 & $\begin{array}{c}8 \\
0\end{array}$ & $\begin{array}{r}5 \\
2\end{array}$ & 33 \\
\hline $\begin{array}{l}\text { Physical sciences and science technologies. } \\
\text { Precision production trades }\end{array}$ & $\begin{array}{r}1,302 \\
5,847 \\
8\end{array}$ & $\begin{array}{r}1,067 \\
3,548 \\
6\end{array}$ & $\begin{array}{r}37 \\
123\end{array}$ & $\begin{array}{r}102 \\
0\end{array}$ & $\begin{array}{r}34 \\
327 \\
0\end{array}$ & $\begin{array}{r}2 \\
10 \\
0\end{array}$ & $\begin{array}{r}123 \\
1,737\end{array}$ & $\begin{array}{r}845 \\
3,966 \\
6\end{array}$ & $\begin{array}{r}2,459 \\
4\end{array}$ & $\begin{array}{r}21 \\
63 \\
1\end{array}$ & $\begin{array}{r}26 \\
69 \\
0\end{array}$ & $\begin{array}{r}26 \\
182 \\
0\end{array}$ & $\begin{array}{l}0 \\
6 \\
0\end{array}$ & $\begin{array}{r}90 \\
1,187 \\
1\end{array}$ & $\begin{array}{r}457 \\
1,881 \\
2\end{array}$ & $\begin{array}{r}385 \\
1,089 \\
2\end{array}$ & $\begin{array}{r}16 \\
60 \\
0\end{array}$ & $\begin{array}{r}13 \\
33 \\
0\end{array}$ & $\begin{array}{r}0 \\
145 \\
0\end{array}$ & $\begin{array}{l}2 \\
4 \\
0\end{array}$ & 550 \\
\hline & 812 & 1,437 & & 64 & 346 & t & st & 1151 & 3. & $?$ & 172 & ?2 & ? & 1015 & 9 & & 122 & 34 & 11 & 2 & 12 \\
\hline & & & & 1267 & $\begin{array}{l}346 \\
713\end{array}$ & $\begin{array}{r}84 \\
165\end{array}$ & $\begin{array}{r}439 \\
1112\end{array}-10$ & & $\begin{array}{r}3,157 \\
4989\end{array}$ & $\begin{array}{r}254 \\
753\end{array}$ & $\begin{array}{r}173 \\
378 \\
\end{array}$ & 82 & 49 & 124 & $\begin{array}{r}9,979 \\
17302\end{array}$ & & & & 264 & 61 & 315 \\
\hline $\begin{array}{l}\text { Pub } \\
\text { R.O }\end{array}$ & $\begin{array}{r}24,229 \\
136\end{array}$ & $\begin{array}{r}17,968 \\
127\end{array}$ & $\begin{array}{r}3,004 \\
5\end{array}$ & $\begin{array}{r}1,267 \\
0\end{array}$ & $\begin{array}{r}\begin{array}{r}13 \\
1\end{array} \\
\end{array}$ & $\begin{array}{r}r 65 \\
0\end{array}$ & $\begin{array}{r}1,112 \\
3\end{array}$ & $\begin{array}{l}6,927 \\
132\end{array}$ & $\begin{array}{r}4,989 \\
123\end{array}$ & $\begin{array}{r}753 \\
5\end{array}$ & $\begin{array}{r}378 \\
0\end{array}$ & $\begin{aligned} 227 \\
1\end{aligned}$ & $\begin{array}{r}49 \\
0\end{array}$ & $\begin{array}{r}531 \\
3\end{array}$ & r $\begin{array}{r}17,302 \\
4\end{array}$ & $\begin{array}{r}12,979 \\
4\end{array}$ & $\begin{array}{r}2,251 \\
0\end{array}$ & $\begin{array}{r}889 \\
0\end{array}$ & $\begin{array}{r}486 \\
0\end{array}$ & $\begin{array}{r}116 \\
0\end{array}$ & 581 \\
\hline Social sciences and history ……………….......... & 15,012 & 10,339 & 911 & 511 & 530 & 80 & 2,641 & 8,093 & 5,637 & 380 & 273 & 269 & 32 & 1,502 & 6,919 & 4,702 & 531 & 238 & 261 & 48 & 1,139 \\
\hline & $\begin{array}{c}5,107 \\
019\end{array}$ & 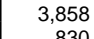 & $\begin{array}{r}298 \\
26\end{array}$ & 26 & $\begin{array}{r}242 \\
19\end{array}$ & 5 & $\begin{array}{r}605 \\
13\end{array}$ & $\begin{array}{r}3,056 \\
856\end{array}$ & $\begin{array}{r}2,314 \\
784\end{array}$ & $\begin{array}{r}159 \\
20\end{array}$ & $\begin{array}{l}50 \\
22\end{array}$ & $\begin{array}{r}136 \\
17\end{array}$ & 5 & 391 & 2,051 & 1,5 & $\begin{array}{r}139 \\
6\end{array}$ & $\begin{array}{r}45 \\
4\end{array}$ & $\begin{array}{r}106 \\
?\end{array}$ & 3 & 214 \\
\hline Visual and performing arts & 10,280 & $\begin{array}{r}830 \\
7.561\end{array}$ & $\begin{array}{r}26 \\
382\end{array}$ & $\begin{array}{r}26 \\
324\end{array}$ & $\begin{array}{r}19 \\
456\end{array}$ & 39 & 1,518 & $\begin{array}{r}856 \\
4.361\end{array}$ & $\begin{array}{r}3,218 \\
3,218\end{array}$ & 177 & $\begin{array}{r}22 \\
170\end{array}$ & $\begin{array}{r}1 / 1 \\
182\end{array}$ & 19 & $\begin{array}{r}8 \\
595\end{array}$ & $\begin{array}{r}63 \\
5,919\end{array}$ & $\begin{array}{r}46 \\
4,343\end{array}$ & 205 & $\begin{array}{r}4 \\
154\end{array}$ & 274 & 20 & 923 \\
\hline
\end{tabular}

${ }^{1}$ Reported racial/ethnic distributions of students by level of degree, field of degree, and sex were used to estimate race/ethnichy for students whose race/ethnicty was not reported. Excludes 420 men and 360 women whose racial ethnic group and field of study were not available.

NOTE.-To facilitate trend comparisons, certain aggregations have been made of the degree fields as reported in the IPEDS "Completions" survey: "Agriculture and natural resources" includes Agricultural business and production,
Agricultural sciences, and Conservation and renewable natural resources; and "Business" includes Business management and administrative services, Marketing operations/marketing and distribution, and Consumer and personal serv-

SOURCE: US. Department of Education, National Center for Education Statistics, Integrated Postsecondary Education Data System (IPEDS), "Completions" survey. (This table was prepared June 1998.) 


\begin{tabular}{|c|c|c|c|c|c|c|c|c|c|c|c|c|c|c|c|c|c|c|c|c|c|}
\hline \multirow[b]{2}{*}{ Major field of study } & \multicolumn{7}{|c|}{ Total } & \multicolumn{7}{|c|}{ Men } & \multicolumn{7}{|c|}{ Women } \\
\hline & Total & $\begin{array}{c}\text { White, } \\
\text { non- } \\
\text { His- } \\
\text { panic }\end{array}$ & $\begin{array}{c}\text { Black, } \\
\text { non- } \\
\text { His- } \\
\text { panic }\end{array}$ & $\begin{array}{c}\text { His- } \\
\text { panic }\end{array}$ & $\begin{array}{l}\text { Asian/ } \\
\text { Pacific } \\
\text { Islander }\end{array}$ & $\begin{array}{l}\text { Amer- } \\
\text { ican } \\
\text { Indian/ } \\
\text { Alas- } \\
\text { kan } \\
\text { Native }\end{array}$ & $\begin{array}{l}\text { Non- } \\
\text { resi- } \\
\text { dent } \\
\text { alien }\end{array}$ & Total & $\begin{array}{c}\text { White, } \\
\text { non- } \\
\text { His- } \\
\text { panic }\end{array}$ & $\begin{array}{c}\text { Black, } \\
\text { non- } \\
\text { His- } \\
\text { panic }\end{array}$ & $\begin{array}{c}\begin{array}{c}\text { His- } \\
\text { panic }\end{array} \\
\text {. }\end{array}$ & $\begin{array}{l}\text { Asian/ } \\
\text { Pacific } \\
\text { Is- } \\
\text { lander }\end{array}$ & \begin{tabular}{|c|} 
Amer- \\
ican \\
Indian/ \\
Alas- \\
kan \\
Native
\end{tabular} & $\begin{array}{l}\text { Non- } \\
\text { resi- } \\
\text { dent } \\
\text { alien }\end{array}$ & \begin{tabular}{l|r} 
Total \\
$\mathrm{r}$
\end{tabular} & $\begin{array}{l}\text { White, } \\
\text { non-His- } \\
\text { panic }\end{array}$ & $\begin{array}{c}\text { Black, } \\
\text { non- } \\
\text { His- } \\
\text { panic }\end{array}$ & $\begin{array}{c}\text { His- } \\
\text { panic }\end{array}$ & $\begin{array}{c}\text { Asian/ } \\
\text { Pacific } \\
\text { Is- } \\
\text { lander }\end{array}$ & \begin{tabular}{c|} 
Amer- \\
ican \\
Indian/ \\
Alas- \\
kan \\
Native
\end{tabular} & $\begin{array}{l}\text { Non- } \\
\text { resi- } \\
\text { dent } \\
\text { alien }\end{array}$ \\
\hline 1 & 2 & 3 & 4 & 5 & 6 & 7 & 8 & 9 & 10 & 11 & 12 & 13 & 14 & 15 & 16 & 17 & 18 & 19 & 20 & 21 & 22 \\
\hline All fields, total 1 . & 7,052 & 292,784 & 24,171 & 2,907 & 16,842 & 1,621 & ,727 & 178,123 & 123,809 & 8,103 & 5,490 & 8,920 & 659 & 31,142 & 218,929 & 168,975 & 16,068 & $\mathbf{7 , 4 1 7}$ & 7,922 & 962 & 17,585 \\
\hline 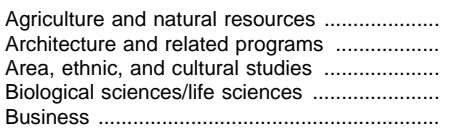 & $\begin{array}{r}4,252 \\
3,923 \\
1,639 \\
5,393 \\
93,809\end{array}$ & $\begin{array}{r}3,007 \\
2,628 \\
1,138 \\
3,741 \\
66,553\end{array}$ & $\begin{array}{r}116 \\
142 \\
121 \\
169 \\
5,165\end{array}$ & $\begin{array}{r}98 \\
155 \\
93 \\
154 \\
2,590\end{array}$ & $\begin{array}{r}129 \\
282 \\
86 \\
431 \\
4,924\end{array}$ & \begin{tabular}{r|r}
15 \\
9 \\
12 \\
21 \\
311
\end{tabular} & $\begin{array}{r}887 \\
707 \\
189 \\
877 \\
14,266\end{array}$ & $\begin{array}{r}2,551 \\
2,310 \\
765 \\
2,602 \\
59,109\end{array}$ & $\begin{array}{r}1,787 \\
1,557 \\
542 \\
1,805 \\
42,711\end{array}$ & \begin{tabular}{r|r}
57 \\
73 \\
47 \\
52 \\
2,427
\end{tabular} & $\begin{array}{r}54 \\
93 \\
49 \\
68 \\
1,621\end{array}$ & $\begin{array}{r}59 \\
134 \\
39 \\
215 \\
2,902\end{array}$ & \begin{tabular}{r|r}
11 \\
4 \\
4 \\
11 \\
199
\end{tabular} & $\begin{array}{r}583 \\
449 \\
84 \\
451 \\
9,249\end{array}$ & $\begin{array}{r}1,701 \\
1,613 \\
874 \\
2,791 \\
34,700\end{array}$ & $\begin{array}{r}1,220 \\
1,071 \\
596 \\
1,936 \\
23,842\end{array}$ & $\begin{array}{r}59 \\
69 \\
74 \\
117 \\
2,738\end{array}$ & $\begin{array}{r}44 \\
62 \\
44 \\
86 \\
969\end{array}$ & $\begin{array}{r}70 \\
148 \\
47 \\
216 \\
2,022\end{array}$ & $\begin{array}{r}4 \\
5 \\
8 \\
10 \\
112\end{array}$ & $\begin{array}{r}304 \\
258 \\
105 \\
426 \\
5,017\end{array}$ \\
\hline $\begin{array}{l}\text { Computer and information sciences } \\
\text { Construction trades } \\
\text { Education }\end{array}$ & $\begin{array}{r}5,142 \\
467 \\
10,326 \\
7 \\
101,242\end{array}$ & $\begin{array}{r}3,597 \\
259 \\
4,521 \\
0 \\
83,646\end{array}$ & $\begin{array}{r}376 \\
34 \\
372 \\
3 \\
8,163\end{array}$ & $\begin{array}{r}131 \\
12 \\
207 \\
1 \\
4,048\end{array}$ & $\begin{array}{r}171 \\
14 \\
1,329 \\
0 \\
1,706\end{array}$ & $\begin{array}{r}21 \\
0 \\
17 \\
0 \\
514\end{array}$ & $\begin{array}{r}846 \\
148 \\
3,880 \\
3 \\
3,165\end{array}$ & $\begin{array}{r}1,869 \\
239 \\
7,627 \\
4 \\
23,806\end{array}$ & $\begin{array}{r}1,358 \\
149 \\
3,488 \\
0 \\
19,303\end{array}$ & $\begin{array}{r}105 \\
16 \\
215 \\
1 \\
1,875\end{array}$ & $\begin{array}{r}45 \\
8 \\
160 \\
1 \\
1,032\end{array}$ & $\begin{array}{r}46 \\
5 \\
847 \\
0 \\
411\end{array}$ & \begin{tabular}{r|}
7 \\
0 \\
12 \\
0 \\
133
\end{tabular} & $\begin{array}{r}308 \\
61 \\
2,905 \\
2 \\
1,052\end{array}$ & $\begin{array}{r}3,273 \\
228 \\
2,699 \\
3 \\
77,436\end{array}$ & $\begin{array}{r}2,239 \\
110 \\
1,033 \\
0 \\
64,343\end{array}$ & $\begin{array}{r}271 \\
18 \\
157 \\
2 \\
6,288\end{array}$ & $\begin{array}{r}86 \\
4 \\
47 \\
0 \\
3,016\end{array}$ & $\begin{array}{r}125 \\
9 \\
482 \\
0 \\
1,295\end{array}$ & $\begin{array}{r}14 \\
0 \\
5 \\
0 \\
381\end{array}$ & $\begin{array}{r}538 \\
87 \\
975 \\
1 \\
113\end{array}$ \\
\hline $\begin{array}{l}\text { Foreign languages and literatures ............... } \\
\text { Health professions and related sciences .... }\end{array}$ & $\begin{array}{r}28,553 \\
1,110 \\
7,845 \\
3,136 \\
31,243\end{array}$ & $\begin{array}{r}14,686 \\
808 \\
6,758 \\
2,071 \\
25,244\end{array}$ & $\begin{array}{r}706 \\
58 \\
300 \\
75 \\
1,682\end{array}$ & $\begin{array}{r}688 \\
31 \\
198 \\
288 \\
849\end{array}$ & $\begin{array}{r}2,732 \\
46 \\
192 \\
112 \\
1,590\end{array}$ & $\begin{array}{r}45 \\
6 \\
38 \\
5 \\
131\end{array}$ & $\begin{array}{r}9,696 \\
161 \\
359 \\
585 \\
1,747\end{array}$ & $\begin{array}{r}23,935 \\
897 \\
2,764 \\
995 \\
6,754\end{array}$ & $\begin{array}{r}12,323 \\
649 \\
2,418 \\
690 \\
4,879\end{array}$ & $\begin{array}{r}494 \\
42 \\
74 \\
27 \\
293\end{array}$ & $\begin{array}{r}561 \\
27 \\
73 \\
83 \\
233\end{array}$ & $\begin{array}{r}2,153 \\
40 \\
63 \\
28 \\
606\end{array}$ & $\begin{array}{r}42 \\
4 \\
15 \\
3 \\
28\end{array}$ & $\begin{array}{r}8,362 \\
135 \\
121 \\
164 \\
715\end{array}$ & $\begin{array}{r}4,618 \\
213 \\
5,081 \\
2,141 \\
24,489\end{array}$ & $\begin{array}{r}2,363 \\
159 \\
4,340 \\
1,381 \\
20,365\end{array}$ & $\begin{array}{r}212 \\
16 \\
226 \\
48 \\
1,389\end{array}$ & $\begin{array}{r}127 \\
4 \\
125 \\
205 \\
616\end{array}$ & $\begin{array}{r}579 \\
6 \\
129 \\
84 \\
984\end{array}$ & $\begin{array}{r}3 \\
2 \\
23 \\
2 \\
103\end{array}$ & $\begin{array}{r}1,334 \\
26 \\
238 \\
421 \\
1,032\end{array}$ \\
\hline $\begin{aligned} \text { Home } & \\
\text { ecol } & \end{aligned}$ & & & $\begin{array}{r}238 \\
89\end{array}$ & $\begin{array}{l}92 \\
65\end{array}$ & $\begin{array}{l}76 \\
59\end{array}$ & $\begin{array}{r}12 \\
6\end{array}$ & $\begin{array}{r}270 \\
1064\end{array}$ & $\begin{array}{r}492 \\
1680\end{array}$ & $\begin{array}{l}359 \\
818\end{array}$ & $\begin{array}{l}26 \\
43\end{array}$ & $\begin{array}{l}25 \\
47\end{array}$ & $\begin{array}{l}13 \\
38\end{array}$ & $\begin{array}{l}3 \\
3\end{array}$ & $\begin{array}{r}66 \\
731\end{array}$ & 31 & $\begin{array}{l}817 \\
410\end{array}$ & $\begin{array}{r}212 \\
46\end{array}$ & $\begin{array}{l}67 \\
18\end{array}$ & \begin{tabular}{l|}
63 \\
21
\end{tabular} & $\begin{array}{l}9 \\
3\end{array}$ & 204 \\
\hline & & 8 & 89 & 65 & 59 & 6 & 1,064 & 1,680 & 818 & 43 & 47 & 38 & 3 & 731 & 31 & 410 & 46 & 18 & 21 & 3 & 333 \\
\hline & 2,565 & $\begin{array}{l}2,1 \\
4,3\end{array}$ & $\begin{array}{l}158 \\
227\end{array}$ & $\begin{array}{r}70 \\
114\end{array}$ & $\begin{array}{r}39 \\
146\end{array}$ & $\begin{array}{l}14 \\
12\end{array}$ & $\begin{array}{l}170 \\
174\end{array}$ & $\begin{array}{r}924 \\
1,054\end{array}$ & 747 & $\begin{array}{l}60 \\
30\end{array}$ & 24 & $\begin{array}{r}8 \\
26\end{array}$ & $\begin{array}{l}7 \\
3\end{array}$ & 78 & $\begin{array}{l}1,641 \\
4,003\end{array}$ & $\begin{array}{l}1,367 \\
3,459\end{array}$ & $\begin{array}{r}98 \\
197\end{array}$ & 46 & $\begin{array}{r}31 \\
120\end{array}$ & $\begin{array}{l}7 \\
9\end{array}$ & $\begin{array}{r}92 \\
131\end{array}$ \\
\hline TVlatnen & 4,181 & 2,523 & 162 & 72 & 257 & 11 & 1,156 & 2,543 & 1,485 & 70 & 52 & 147 & 5 & 784 & 1,638 & $\begin{array}{l}1,038 \\
1,03\end{array}$ & 92 & 20 & 110 & 6 & 372 \\
\hline & 2. & $\begin{array}{l}2,001 \\
1519\end{array}$ & $\begin{array}{r}131 \\
64\end{array}$ & $\begin{array}{l}65 \\
33\end{array}$ & $\begin{array}{l}75 \\
20\end{array}$ & $\begin{array}{r}13 \\
7\end{array}$ & 1 & 1,0 & $\begin{array}{l}86 \\
76\end{array}$ & $\begin{array}{l}54 \\
36\end{array}$ & $20 \mid$ & $\begin{array}{l}42 \\
10\end{array}$ & $\begin{array}{l}7 \\
4\end{array}$ & 10 & 1, & 1,14 & $\begin{array}{l}77 \\
28\end{array}$ & 37 & $\begin{array}{l}33 \\
10\end{array}$ & $\begin{array}{l}6 \\
3\end{array}$ & 59 \\
\hline & 1,3 & & $\begin{array}{l}64 \\
44\end{array}$ & $\begin{array}{l}33 \\
51\end{array}$ & $\begin{array}{l}20 \\
27\end{array}$ & $\begin{array}{l}7 \\
9\end{array}$ & $\begin{array}{l}112 \\
121\end{array}$ & $\begin{array}{l}2 \\
5 \\
5\end{array}$ & $\begin{array}{l}769 \\
704\end{array}$ & $\begin{array}{l}36 \\
31\end{array}$ & $\begin{array}{l}20 \\
28\end{array}$ & $\begin{array}{l}10 \\
18\end{array}$ & $\begin{array}{l}4 \\
4\end{array}$ & $\begin{array}{l}3 \\
0\end{array}$ & & $\begin{array}{l}750 \\
424\end{array}$ & $\begin{array}{l}28 \\
13\end{array}$ & $\begin{array}{l}13 \\
23\end{array}$ & \begin{tabular}{r|r}
$r 0$ \\
9
\end{tabular} & $\begin{array}{l}3 \\
5\end{array}$ & 31 \\
\hline $\begin{array}{l}\text { Physical sciences and science technologies } . . . \\
\text { Precision production trades }\end{array}$ & $\begin{array}{r}5,753 \\
5\end{array}$ & $\begin{array}{r}3,385 \\
5\end{array}$ & $\begin{array}{r}156 \\
0\end{array}$ & $\begin{array}{r}119 \\
0\end{array}$ & $\begin{array}{r}307 \\
0\end{array}$ & $\begin{array}{r}23 \\
0\end{array}$ & $\begin{array}{r}1,763 \\
0\end{array}$ & $\begin{array}{r}4,013 \\
4\end{array}$ & $\begin{array}{r}2,401 \\
4\end{array}$ & $\begin{array}{r}91 \\
0\end{array}$ & $\begin{array}{r}79 \\
0\end{array}$ & $\begin{array}{r}199 \\
0\end{array}$ & $\begin{array}{r}15 \\
0\end{array}$ & $\begin{array}{r}1,228 \\
0\end{array}$ & $\begin{array}{r}1,740 \\
1\end{array}$ & $\begin{array}{r}984 \\
1\end{array}$ & $\begin{array}{r}65 \\
0\end{array}$ & $\begin{array}{r}40 \\
0\end{array}$ & $\begin{array}{r}108 \\
0\end{array}$ & $\begin{array}{l}8 \\
0\end{array}$ & 535 \\
\hline & 1,706 & 1321 & 2 & 4 & 33 & 正 & 43 & 912 & 70 & 11 & . & 20 & 3 & 3 & & 6 & 135 & 20 & 13 & 0 & 10 \\
\hline & 13,921 & 11,562 & 898 & 579 & 310 & 88 & 484 & 3,893 & 3,240 & 228 & 164 & 82 & 31 & 148 & 10,028 & 8,322 & 670 & 415 & 228 & 57 & 336 \\
\hline & 23,501 & 18,056 & 2,702 & 1,128 & 593 & 137 & 885 & $\begin{array}{r}6,870 \\
117\end{array}$ & 5,030 & 739 & 357 & 205 & ${ }_{38}^{38}$ & 501 & 16,631 & 13,026 & 1,963 & 771 & 388 & 99 & 384 \\
\hline & & 11 & 7 & 4 & 7 & 1 & 0 & 117 & 99 & 6 & 4 & 5 & 1 & 0 & 7 & 6 & 1 & 0 & 0 & 0 & 0 \\
\hline Soc & 14,845 & 10,29 & 874 & 483 & 485 & 87 & 2,617 & 8,207 & 5,636 & 403 & 248 & 255 & 32 & 1,633 & 6,638 & 4,663 & 471 & 235 & 230 & 55 & 34 \\
\hline & & $\begin{array}{r}3,949 \\
741\end{array}$ & $\begin{array}{r}274 \\
30\end{array}$ & $\begin{array}{r}120 \\
19\end{array}$ & $\begin{array}{r}230 \\
18\end{array}$ & $\begin{array}{l}4 \\
6\end{array}$ & $\begin{array}{r}663 \\
9\end{array}$ & $\begin{array}{r}3,178 \\
775\end{array}$ & $\begin{array}{r}2,322 \\
703\end{array}$ & $\begin{array}{r}177 \\
26\end{array}$ & $\begin{array}{l}84 \\
18\end{array}$ & $\begin{array}{r}157 \\
16\end{array}$ & 4 & $\begin{array}{r}436 \\
8\end{array}$ & $\begin{array}{r}2,062 \\
48\end{array}$ & $\begin{array}{r}1,627 \\
38\end{array}$ & $\begin{array}{r}97 \\
4\end{array}$ & $\begin{array}{r}36 \\
16\end{array}$ & $\begin{array}{r}73 \\
2\end{array}$ & $\begin{array}{l}2 \\
2\end{array}$ & 1 \\
\hline Visual and performing arts. & 10,277 & 7,631 & 383 & 296 & 416 & 43 & 1,508 & 4,374 & $\begin{array}{l}3,343 \\
\end{array}$ & $\begin{array}{r}20 \\
168\end{array}$ & $\begin{array}{r}140 \\
143\end{array}$ & $\begin{array}{r}129 \\
129\end{array}$ & 24 & 567 & 5,903 & $\begin{array}{r}4,288 \\
\end{array}$ & 215 & 153 & 287 & 19 & 941 \\
\hline
\end{tabular}

${ }^{1}$ Reported racial/ethnic distributions of students by level of degree, field of degree, and sex were used to estimate race/ethnichy for students whose race/ethnicty was not reported. Excludes 475 men and 102 women whose racial ethnic group and field of study were not available.

NOTE.-To facilitate trend comparisons, certain aggregations have been made of the degree fields as reported in the IPEDS "Completions" survey: "Agriculture and natural resources" includes Agricultural business and production,
Agricultural sciences, and Conservation and renewable natural resources; and "Business" includes Business management and administrative services, Marketing operations/marketing and distribution, and Consumer and personal serv-

SOURCE: U.S. Department of Education, National Center for Education Statistics, Integrated Postsecondary Education Data System (IPEDS), "Completions" survey. (This table was prepared April 1997.) 
Table 270.-Doctor's degrees ${ }^{1}$ conferred by institutions of higher education, by racial/ethnic group and sex of student: 1976-77 to 1995-96

\begin{tabular}{|c|c|c|c|c|c|c|c|c|c|c|c|c|c|c|}
\hline \multirow[b]{2}{*}{ Year } & \multicolumn{7}{|c|}{ Number of degrees conferred } & \multicolumn{7}{|c|}{ Percentage distribution of degrees conferred } \\
\hline & Total & $\begin{array}{c}\text { White, } \\
\text { non- } \\
\text { His- } \\
\text { panic }\end{array}$ & $\begin{array}{c}\text { Black, } \\
\text { non- } \\
\text { His- } \\
\text { panic }\end{array}$ & $\begin{array}{l}\text { His- } \\
\text { panic }\end{array}$ & $\begin{array}{c}\text { Asian/ } \\
\text { Pacific } \\
\text { Is- } \\
\text { lander }\end{array}$ & $\begin{array}{c}\text { Amer- } \\
\text { ican In- } \\
\text { dian/ } \\
\text { Alas- } \\
\text { kan } \\
\text { Native }\end{array}$ & $\begin{array}{l}\text { Non- } \\
\text { resi- } \\
\text { dent } \\
\text { alien }\end{array}$ & Total & $\begin{array}{c}\text { White, } \\
\text { non- } \\
\text { His- } \\
\text { panic }\end{array}$ & $\begin{array}{c}\text { Black, } \\
\text { non- } \\
\text { His- } \\
\text { panic }\end{array}$ & $\begin{array}{l}\text { His- } \\
\text { panic }\end{array}$ & $\begin{array}{c}\text { Asian/ } \\
\text { Pacific } \\
\text { Is- } \\
\text { lander }\end{array}$ & $\begin{array}{c}\text { Amer- } \\
\text { ican In- } \\
\text { dian/ } \\
\text { Alas- } \\
\text { kan } \\
\text { Native }\end{array}$ & $\begin{array}{l}\text { Non- } \\
\text { resi- } \\
\text { dent } \\
\text { alien }\end{array}$ \\
\hline \multirow[t]{2}{*}{1} & 2 & 3 & 4 & 5 & 6 & 7 & 8 & 9 & 10 & 11 & 12 & 13 & 14 & 15 \\
\hline & \multicolumn{7}{|c|}{ Total } & \multicolumn{7}{|c|}{ Total } \\
\hline $\begin{array}{ll}1976-77^{2} & \ldots \ldots . . \\
1978-79^{3} & \ldots \ldots \ldots \\
1980-81^{4} & \ldots \ldots \ldots \\
1984-85^{5} & \ldots \ldots \ldots \\
1986-87^{6} & \ldots \ldots \ldots \\
1988-89^{6,7} & \ldots \ldots \\
1989-90^{6,8} & \ldots \ldots \\
1990-91^{6,9} & \ldots \ldots \\
1991-92^{6,10} & \ldots . \\
1992-93^{6,11} & \ldots . \\
1993-94^{6,12} & \ldots . \\
1994-95^{6,13} & \ldots . \\
1995-96^{6,14} & \ldots .\end{array}$ & $\begin{array}{l}33,126 \\
32,675 \\
32,839 \\
32,307 \\
34,041 \\
35,659 \\
38,113 \\
38,547 \\
40,090 \\
42,021 \\
43,149 \\
44,427 \\
44,645\end{array}$ & $\begin{array}{l}26,851 \\
26,138 \\
25,908 \\
23,934 \\
24,434 \\
24,884 \\
25,880 \\
25,328 \\
25,813 \\
26,700 \\
27,156 \\
27,826 \\
27,756\end{array}$ & $\begin{array}{l}1,253 \\
1,268 \\
1,265 \\
1,154 \\
1,057 \\
1,066 \\
1,153 \\
1,211 \\
1,223 \\
1,352 \\
1,393 \\
1,667 \\
1,636\end{array}$ & $\begin{array}{l}522 \\
439 \\
456 \\
677 \\
751 \\
629 \\
788 \\
732 \\
811 \\
827 \\
903 \\
984 \\
999\end{array}$ & \begin{tabular}{r|}
658 \\
811 \\
877 \\
1,106 \\
1,098 \\
1,323 \\
1,235 \\
1,459 \\
1,559 \\
1,582 \\
2,025 \\
2,690 \\
2,646
\end{tabular} & $\begin{array}{r}95 \\
104 \\
130 \\
119 \\
105 \\
85 \\
99 \\
102 \\
118 \\
106 \\
134 \\
130 \\
158\end{array}$ & $\begin{array}{r}3,747 \\
3,915 \\
4,203 \\
5,317 \\
6,596 \\
7,672 \\
8,958 \\
9,715 \\
10,566 \\
11,454 \\
11,538 \\
11,130 \\
11,450\end{array}$ & $\begin{array}{l}100.0 \\
100.0 \\
100.0 \\
100.0 \\
100.0 \\
100.0 \\
100.0 \\
100.0 \\
100.0 \\
100.0 \\
100.0 \\
100.0 \\
100.0\end{array}$ & $\begin{array}{l}81.1 \\
80.0 \\
78.9 \\
74.1 \\
71.8 \\
69.8 \\
67.9 \\
65.7 \\
64.4 \\
63.5 \\
62.9 \\
62.6 \\
62.2\end{array}$ & $\begin{array}{l}3.8 \\
3.9 \\
3.9 \\
3.6 \\
3.1 \\
3.0 \\
3.0 \\
3.1 \\
3.1 \\
3.2 \\
3.2 \\
3.8 \\
3.7\end{array}$ & $\begin{array}{l}1.6 \\
1.3 \\
1.4 \\
2.1 \\
2.2 \\
1.8 \\
2.1 \\
1.9 \\
2.0 \\
2.0 \\
2.1 \\
2.2 \\
2.2\end{array}$ & $\begin{array}{l}2.0 \\
2.5 \\
2.7 \\
3.4 \\
3.2 \\
3.7 \\
3.2 \\
3.8 \\
3.9 \\
3.8 \\
4.7 \\
6.1 \\
5.9\end{array}$ & $\begin{array}{l}0.3 \\
0.3 \\
0.4 \\
0.4 \\
0.3 \\
0.2 \\
0.3 \\
0.3 \\
0.3 \\
0.3 \\
0.3 \\
0.3 \\
0.4\end{array}$ & $\begin{array}{l}11.3 \\
12.0 \\
12.8 \\
16.5 \\
19.4 \\
21.5 \\
23.5 \\
25.2 \\
26.4 \\
27.3 \\
26.7 \\
25.1 \\
25.6\end{array}$ \\
\hline $1995-966,14 \ldots$ & \multicolumn{7}{|c|}{ Men } & \multicolumn{7}{|c|}{ Men } \\
\hline 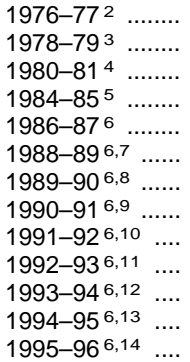 & $\begin{array}{l}25,036 \\
23,488 \\
22,595 \\
21,296 \\
22,061 \\
22,597 \\
24,248 \\
24,333 \\
25,168 \\
25,980 \\
26,531 \\
26,898 \\
26,836\end{array}$ & $\begin{array}{l}20,032 \\
18,433 \\
17,310 \\
15,017 \\
14,812 \\
14,541 \\
15,105 \\
14,565 \\
14,674 \\
14,902 \\
15,126 \\
15,354 \\
15,101\end{array}$ & $\begin{array}{l}766 \\
734 \\
694 \\
561 \\
485 \\
491 \\
533 \\
581 \\
576 \\
615 \\
631 \\
731 \\
730\end{array}$ & $\begin{array}{l}383 \\
294 \\
277 \\
431 \\
441 \\
350 \\
423 \\
387 \\
458 \\
439 \\
465 \\
488 \\
516\end{array}$ & $\begin{array}{r}540 \\
646 \\
655 \\
802 \\
794 \\
945 \\
871 \\
987 \\
1,062 \\
1,041 \\
1,373 \\
1,758 \\
1,693\end{array}$ & $\begin{array}{l}67 \\
69 \\
95 \\
64 \\
57 \\
50 \\
49 \\
58 \\
65 \\
51 \\
66 \\
58 \\
80\end{array}$ & $\begin{array}{l}3,248 \\
3,312 \\
3,564 \\
4,421 \\
5,472 \\
6,220 \\
7,267 \\
7,755 \\
8,333 \\
8,932 \\
8,870 \\
8,509 \\
8,716\end{array}$ & $\begin{array}{l}100.0 \\
100.0 \\
100.0 \\
100.0 \\
100.0 \\
100.0 \\
100.0 \\
100.0 \\
100.0 \\
100.0 \\
100.0 \\
100.0 \\
100.0\end{array}$ & $\begin{array}{l}80.0 \\
78.5 \\
76.6 \\
70.5 \\
67.1 \\
64.3 \\
62.3 \\
59.9 \\
58.3 \\
57.4 \\
57.0 \\
57.1 \\
56.3\end{array}$ & $\begin{array}{l}3.1 \\
3.1 \\
3.1 \\
2.6 \\
2.2 \\
2.2 \\
2.2 \\
2.4 \\
2.3 \\
2.4 \\
2.4 \\
2.7 \\
2.7\end{array}$ & $\begin{array}{l}1.5 \\
1.3 \\
1.2 \\
2.0 \\
2.0 \\
1.5 \\
1.7 \\
1.6 \\
1.8 \\
1.7 \\
1.8 \\
1.8 \\
1.9\end{array}$ & $\begin{array}{l}2.2 \\
2.8 \\
2.9 \\
3.8 \\
3.6 \\
4.2 \\
3.6 \\
4.1 \\
4.2 \\
4.0 \\
5.2 \\
6.5 \\
6.3\end{array}$ & $\begin{array}{l}0.3 \\
0.3 \\
0.4 \\
0.3 \\
0.3 \\
0.2 \\
0.2 \\
0.2 \\
0.3 \\
0.2 \\
0.2 \\
0.2 \\
0.3\end{array}$ & $\begin{array}{l}13.0 \\
14.1 \\
15.8 \\
20.8 \\
24.8 \\
27.5 \\
30.0 \\
31.9 \\
33.1 \\
34.4 \\
33.4 \\
31.6 \\
32.5\end{array}$ \\
\hline $1995-96^{6,14} \ldots$. & \multicolumn{7}{|c|}{ Women } & \multicolumn{7}{|c|}{ Women } \\
\hline $1976-77^{2} \ldots \ldots .$. & 8,090 & 6,819 & 487 & 139 & 118 & 28 & 499 & 100.0 & 84.3 & 6.0 & 1.7 & 1.5 & 0.3 & 6.2 \\
\hline $1978-79^{3} \ldots \ldots .$. & 9,187 & 7,705 & 534 & 145 & 165 & 35 & 603 & 100.0 & 83.9 & 5.8 & 1.6 & 1.8 & 0.4 & 6.6 \\
\hline $1980-81^{4} \ldots \ldots \ldots$ & 10,244 & 8,598 & 571 & 179 & 222 & 35 & 639 & 100.0 & 83.9 & 5.6 & 1.7 & 2.2 & 0.3 & 6.2 \\
\hline $1984-85^{5} \ldots \ldots .$. & 11,011 & 8,917 & 593 & 246 & 304 & 55 & 896 & 100.0 & 81.0 & 5.4 & 2.2 & 2.8 & 0.5 & 8.1 \\
\hline $1986-87^{6} \ldots \ldots .$. & 11,980 & 9,622 & 572 & 310 & 304 & 48 & 1,124 & 100.0 & 80.3 & 4.8 & 2.6 & 2.5 & 0.4 & 9.4 \\
\hline $1988-896,7 \ldots \ldots$ & 13,062 & 10,343 & 575 & 279 & 378 & 35 & 1,452 & 100.0 & 79.2 & 4.4 & 2.1 & 2.9 & 0.3 & 11.1 \\
\hline $1989-906,8 \ldots \ldots$ & 13,865 & 10,775 & 620 & 365 & 364 & 50 & 1,691 & 100.0 & 77.7 & 4.5 & 2.6 & 2.6 & 0.4 & 12.2 \\
\hline $1990-91^{6,9} \ldots \ldots$ & 14,214 & 10,763 & 630 & 345 & 472 & 44 & 1,960 & 100.0 & 75.7 & 4.4 & 2.4 & 3.3 & 0.3 & 13.8 \\
\hline $1991-92^{6,10} \ldots$ & 14,922 & 11,139 & 647 & 353 & 497 & 53 & 2,233 & 100.0 & 74.6 & 4.3 & 2.4 & 3.3 & 0.4 & 15.0 \\
\hline $1992-93^{6,11} \ldots$ & 16,041 & 11,798 & 737 & 388 & 541 & 55 & 2,522 & 100.0 & 73.5 & 4.6 & 2.4 & 3.4 & 0.3 & 15.7 \\
\hline $1993-946,12 \ldots$. & 16,618 & 12,030 & 762 & 438 & 652 & 68 & 2,668 & 100.0 & 72.4 & 4.6 & 2.6 & 3.9 & 0.4 & 16.1 \\
\hline $1994-95^{6,13} \ldots$ & 17,529 & 12,472 & 936 & 496 & 932 & 72 & 2,621 & 100.0 & 71.2 & 5.3 & 2.8 & 5.3 & 0.4 & 15.0 \\
\hline $1995-96^{6,14} \ldots$ & 17,809 & 12,655 & 906 & 483 & 953 & 78 & 2,734 & 100.0 & 71.1 & 5.1 & 2.7 & 5.4 & 0.4 & 15.4 \\
\hline
\end{tabular}

${ }^{1}$ Includes Ph.D., Ed.D, and comparable degrees at the doctoral level. Excludes firstprofessional degrees.

${ }^{2}$ Excludes 106 men whose racial/ethnic group was not available.

${ }^{3}$ Excludes 53 men and 2 women whose racial/ethnic group was not available.

${ }^{4}$ Excludes 116 men and 3 women whose racial/ethnic group was not available.

${ }^{5}$ Excludes 404 men and 232 women whose racial/ethnic group was not available.

${ }^{6}$ Reported racial/ethnic distributions of students by level of degree, field of degree, and sex were used to estimate race/ethnicity for students whose race/ethnicity was not reported.

${ }^{7}$ Excludes 51 men and 10 women whose racial/ethnic group and field of study were not available.

8 Excludes 153 men and 105 women whose racial/ethnic group and field of study were not available.

${ }^{9}$ Excludes 423 men and 324 women whose racial/ethnic group and field of study were not available.

${ }^{10}$ Excludes 389 men and 180 women whose racial/ethnic group and field of study were not available.
11 Excludes 93 men and 18 women whose racial/ethnic group and field of study were not available.

12 Excludes 21 men and 15 women whose racial/ethnic group and field of study were not available.

${ }^{13}$ Excludes 18 men and 1 woman whose racial/ethnic group and field of study were not available.

${ }^{14}$ Excludes 5 men and 2 women whose racial/ethnic group and field of study were not available.

NOTE.-For years 1984-85 to 1995-96, reported racial/ethnic distributions of students by level of degree, field of degree, and sex were used to estimate race/ethnicity for students whose race/ethnicity was not reported. Because of rounding, percents may not add to 100.0 .

SOURCE: U.S. Department of Education, National Center for Education Statistics, Higher Education General Information Survey (HEGIS), "Degrees and Other Formal Awards Conferred" surveys, and Integrated Postsecondary Education Data System (IPEDS), "Completions" surveys. (This table was prepared June 1998.) 


\begin{tabular}{|c|c|c|c|c|c|c|c|c|c|c|c|c|c|c|c|c|c|c|c|c|c|}
\hline \multirow[b]{2}{*}{ Major field of study } & \multicolumn{7}{|c|}{ Total } & \multicolumn{7}{|c|}{ Men } & \multicolumn{7}{|c|}{ Women } \\
\hline & Total & $\begin{array}{l}\text { White, } \\
\text { non- } \\
\text { His- } \\
\text { panic }\end{array}$ & $\begin{array}{c}\text { Black, } \\
\text { non- } \\
\text { His- } \\
\text { panic }\end{array}$ & $\begin{array}{c}\text { His- } \\
\text { panic }\end{array}$ & $\begin{array}{l}\text { Asian/ } \\
\text { Pacific } \\
\text { Islander }\end{array}$ & $\begin{array}{l}\text { Amer- } \\
\text { ican } \\
\text { Indian/ } \\
\text { Alas- } \\
\text { kan } \\
\text { Native }\end{array}$ & \begin{tabular}{|l} 
Non- \\
resi- \\
dent \\
alien
\end{tabular} & Total & $\begin{array}{l}\text { White, } \\
\text { non- } \\
\text { His- } \\
\text { panic }\end{array}$ & $\begin{array}{c}\text { Black, } \\
\text { non- } \\
\text { His- } \\
\text { panic }\end{array}$ & $\begin{array}{c}\text { His- } \\
\text { panic }\end{array}$ & $\begin{array}{l}\text { Asian/ } \\
\text { Pacific } \\
\text { Is- } \\
\text { lander }\end{array}$ & \begin{tabular}{|l|} 
Amer- \\
ican \\
Indian/ \\
Alas- \\
kan \\
Native
\end{tabular} & $\begin{array}{l}\text { Non- } \\
\text { resi- } \\
\text { dent } \\
\text { alien }\end{array}$ & Total & $\begin{array}{c}\text { White, } \\
\text { non-His- } \\
\text { panic }\end{array}$ & $\begin{array}{c}\text { Black, } \\
\text { non- } \\
\text { His- } \\
\text { panic }\end{array}$ & $\begin{array}{c}\text { His- } \\
\text { panic }\end{array}$ & $\begin{array}{l}\text { Asian/ } \\
\text { Pacific } \\
\text { Is- } \\
\text { lander }\end{array}$ & \begin{tabular}{|c|} 
Amer- \\
ican \\
Indian/ \\
Alas- \\
kan \\
Native
\end{tabular} & $\begin{array}{l}\text { Non- } \\
\text { resi- } \\
\text { dent } \\
\text { alien }\end{array}$ \\
\hline 1 & 2 & 3 & 4 & 5 & 6 & 7 & 8 & 9 & 10 & 11 & 12 & 13 & 14 & 15 & 16 & 17 & 18 & 19 & 20 & 21 & 22 \\
\hline All fields, total 1 ........ & 44,645 & 27,756 & 1,636 & 999 & 2,646 & 158 & 11,450 & 26,836 & 15,101 & 730 & 516 & 1,693 & 80 & 8,716 & 17,809 & 12,655 & 906 & 483 & 953 & 78 & 2,734 \\
\hline 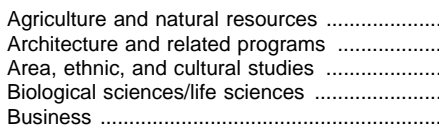 & $\begin{array}{r}1,271 \\
141 \\
184 \\
4,780 \\
1,368\end{array}$ & $\begin{array}{r}575 \\
67 \\
117 \\
2,838 \\
817\end{array}$ & $\begin{array}{r}23 \\
5 \\
22 \\
79 \\
45\end{array}$ & $\begin{array}{r}11 \\
0 \\
3 \\
101 \\
20\end{array}$ & $\begin{array}{r}72 \\
6 \\
13 \\
464 \\
77\end{array}$ & $\begin{array}{r}3 \\
0 \\
1 \\
14 \\
6\end{array}$ & $\begin{array}{r}587 \\
63 \\
28 \\
1,284 \\
403\end{array}$ & $\begin{array}{r}935 \\
96 \\
94 \\
2,773 \\
974\end{array}$ & $\begin{array}{r}403 \\
38 \\
55 \\
1,610 \\
529\end{array}$ & \begin{tabular}{r|r}
21 \\
3 \\
8 \\
43 \\
26
\end{tabular} & \begin{tabular}{r|}
8 \\
0 \\
2 \\
55 \\
14
\end{tabular} & $\begin{array}{r}51 \\
5 \\
7 \\
264 \\
58\end{array}$ & $\begin{array}{l}1 \\
0 \\
1 \\
6 \\
5\end{array}$ & $\begin{array}{r}451 \\
50 \\
21 \\
795 \\
342\end{array}$ & $\begin{array}{r}336 \\
45 \\
90 \\
2,007 \\
394\end{array}$ & $\begin{array}{r}172 \\
29 \\
62 \\
1,228 \\
288\end{array}$ & $\begin{array}{r}2 \\
2 \\
14 \\
36 \\
19\end{array}$ & $\begin{array}{r}3 \\
0 \\
1 \\
46 \\
6\end{array}$ & $\begin{array}{r}21 \\
1 \\
6 \\
200 \\
19\end{array}$ & $\begin{array}{l}2 \\
0 \\
0 \\
8 \\
1\end{array}$ & $\begin{array}{r}136 \\
13 \\
7 \\
489 \\
61\end{array}$ \\
\hline 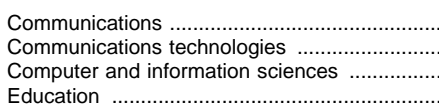 & $\begin{array}{r}338 \\
7 \\
867 \\
6,676\end{array}$ & $\begin{array}{r}232 \\
0 \\
367 \\
5,128\end{array}$ & $\begin{array}{r}19 \\
1 \\
10 \\
564\end{array}$ & $\begin{array}{r}5 \\
0 \\
9 \\
218\end{array}$ & $\begin{array}{r}12 \\
4 \\
84 \\
157\end{array}$ & $\begin{array}{r}0 \\
0 \\
2 \\
51\end{array}$ & $\begin{array}{r}70 \\
2 \\
395 \\
558\end{array}$ & $\begin{array}{r}184 \\
6 \\
741 \\
2,525\end{array}$ & $\begin{array}{r}124 \\
0 \\
302 \\
1,899\end{array}$ & $\begin{array}{r}10 \\
0 \\
10 \\
175\end{array}$ & $\begin{array}{r}4 \\
0 \\
8 \\
86\end{array}$ & $\begin{array}{r}6 \\
4 \\
72 \\
60\end{array}$ & $\begin{array}{r}0 \\
0 \\
2 \\
16\end{array}$ & $\begin{array}{r}40 \\
2 \\
347 \\
289\end{array}$ & $\begin{array}{r}154 \\
1 \\
126 \\
4,151\end{array}$ & $\begin{array}{r}108 \\
0 \\
65 \\
3,229\end{array}$ & $\begin{array}{r}9 \\
1 \\
0 \\
389\end{array}$ & $\begin{array}{r}1 \\
0 \\
1 \\
132\end{array}$ & $\begin{array}{r}6 \\
0 \\
12 \\
97\end{array}$ & $\begin{array}{r}0 \\
0 \\
0 \\
35\end{array}$ & $\begin{array}{r}30 \\
0 \\
48 \\
269\end{array}$ \\
\hline Engineering ……………….... & 6,369 & 2,507 & 74 & 89 & 570 & 12 & 3,117 & 5,570 & 2,125 & 55 & 72 & 482 & 10 & 2,826 & 799 & 382 & 19 & 17 & 88 & 2 & 291 \\
\hline Engineering-related techn & 11 & 3 & 0 & 0 & 1 & 0 & 7 & 10 & 3 & 0 & 0 & 1 & 0 & 6 & 1 & 0 & 0 & 0 & 0 & 0 & 1 \\
\hline English language and litera & 1,535 & $\begin{array}{l}1,240 \\
-499\end{array}$ & 50 & 32 & 46 & 5 & 162 & 590 & 460 & 16 & 12 & 17 & 3 & 82 & 945 & 780 & 34 & 20 & 29 & 2 & 80 \\
\hline $\begin{array}{l}\text { Foreign languages and literatures } \\
\text { Health professions and related sciences }\end{array}$ & $\begin{array}{r}876 \\
2,119\end{array}$ & $\begin{array}{r}499 \\
1,342\end{array}$ & $\begin{array}{r}8 \\
64\end{array}$ & $\begin{array}{l}64 \\
52\end{array}$ & $\begin{array}{r}45 \\
166\end{array}$ & $\begin{array}{l}1 \\
2\end{array}$ & $\begin{array}{l}259 \\
493\end{array}$ & $\begin{array}{l}387 \\
919\end{array}$ & $\begin{array}{l}209 \\
493\end{array}$ & $\begin{array}{r}3 \\
18\end{array}$ & $\begin{array}{l}28 \\
15\end{array}$ & $\begin{array}{l}18 \\
90\end{array}$ & $\begin{array}{l}0 \\
1\end{array}$ & $\begin{array}{l}129 \\
302\end{array}$ & $\begin{array}{r}489 \\
1,200\end{array}$ & $\begin{array}{l}290 \\
849\end{array}$ & $\begin{array}{r}5 \\
46\end{array}$ & $\begin{array}{l}36 \\
37\end{array}$ & $\begin{array}{l}27 \\
76\end{array}$ & $\begin{array}{l}1 \\
1\end{array}$ & $\begin{array}{l}130 \\
191\end{array}$ \\
\hline $\begin{array}{l}\text { Home economics and vocational home } \\
\text { economics }\end{array}$ & 414 & 289 & 33 & 9 & 8 & 0 & 75 & 117 & 83 & 8 & 5 & 3 & 0 & 18 & 297 & 206 & 25 & 4 & 5 & 0 & 57 \\
\hline $\begin{array}{l}\text { Law and legal studies ................................ } \\
\text { Liberal arts and sciences, general studies. }\end{array}$ & 91 & 40 & 2 & 3 & 5 & 0 & 41 & 59 & 24 & 1 & 1 & 2 & 0 & 31 & 32 & 16 & 1 & 2 & 3 & 0 & 10 \\
\hline & 75 & 61 & 6 & 1 & 2 & 0 & 5 & 33 & 28 & 3 & 1 & 0 & 0 & 1 & 42 & 33 & 3 & 0 & 2 & 0 & 4 \\
\hline $\begin{array}{l}\text { Library } \\
\text { Mathem }\end{array}$ & 53 & $\begin{array}{r}39 \\
547\end{array}$ & $\begin{array}{l}2 \\
9\end{array}$ & $\begin{array}{l}1 \\
9\end{array}$ & 68 & $\begin{array}{l}0 \\
1\end{array}$ & $\begin{array}{r}5 \\
545\end{array}$ & $\begin{array}{r}10 \\
962\end{array}$ & 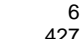 & $\begin{array}{c}0 \\
7\end{array}$ & $\begin{array}{r}1 \\
8 \\
\end{array}$ & 2 & 0 & 1 & 43 & 33 & $\begin{aligned} 2 \\
2\end{aligned}$ & $\begin{array}{l}0 \\
1\end{array}$ & $\begin{array}{r}4 \\
25\end{array}$ & 0 & 99 \\
\hline 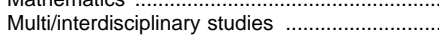 & 441 & 301 & 38 & 11 & 16 & 4 & 71 & 218 & 131 & 22 & 5 & 7 & 2 & 51 & 223 & 170 & $\begin{array}{r}16 \\
16\end{array}$ & 6 & $\begin{array}{r}2 \\
9\end{array}$ & 2 & 20 \\
\hline Parks, recreation, leisure and fitness studies. & 104 & $\begin{array}{r}71 \\
436\end{array}$ & $\begin{array}{r}7 \\
15\end{array}$ & 2 & 3 & $\begin{array}{l}0 \\
1\end{array}$ & 21 & $\begin{array}{r}65 \\
385\end{array}$ & 39 & 4 & 2 & 2 & 0 & 18 & $\begin{array}{r}39 \\
164\end{array}$ & $\begin{array}{r}32 \\
135\end{array}$ & $\begin{array}{l}3 \\
5 \\
\end{array}$ & $\begin{array}{l}0 \\
2\end{array}$ & $\begin{array}{l}1 \\
7\end{array}$ & 0 & 15 \\
\hline iences and science technologies & 4,571 & 2,446 & 56 & 68 & 389 & 11 & 1,601 & 3,515 & 1,864 & 39 & 58 & 267 & 1 & 1,280 & 1,056 & 582 & 17 & 10 & 122 & 4 & 321 \\
\hline Precis & 0 & 0 & 0 & 0 & 0 & 0 & 0 & 0 & 0 & 0 & 0 & 0 & 0 & 0 & 0 & 0 & 0 & 0 & 0 & 0 & 0 \\
\hline $\operatorname{Prc}$ & 38 & 32 & 2 & & 2 & 0 & 2 & 22 & 17 & 1 & 0 & & & 2 & 16 & 15 & & 0 & & 0 & 0 \\
\hline Psyc & 3,711 & 3,087 & 159 & 148 & 100 & 23 & 194 & 1,259 & 1,047 & 41 & 45 & 28 & 12 & 86 & 2,452 & 2,040 & 118 & 103 & 72 & 11 & 108 \\
\hline$P I$ & 499 & 3 & 4 & 4 & 11 & 1 & 9 & 2 & 142 & al & 5 & 6 & 0 & 58 & 279 & 198 & 35 & 9 & 5 & 1 & 31 \\
\hline $\mathrm{R}$. & & 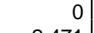 & 0 & 0 & 0 & 0 & 0 & & 0 & 0 & 0 & 0 & 0 & 0 & & & 0 & 0 & 0 & 0 & 0 \\
\hline Social sciences and history & 3,760 & 2,471 & 121 & 95 & 163 & 15 & 895 & 2,339 & 1,448 & 69 & 59 & 86 & 10 & 667 & 1,421 & 1,023 & 52 & 36 & 77 & 5 & 228 \\
\hline Theological studies and religious vocations .... & 1,521 & 1,062 & 147 & 10 & 63 & 4 & 235 & 1,304 & 903 & 112 & 9 & 57 & 2 & 221 & 217 & 159 & 35 & 1 & 6 & 2 & 14 \\
\hline oving workers. & 106 & $\begin{array}{r}0 \\
802\end{array}$ & 0 & 16 & $\begin{array}{r}0 \\
49\end{array}$ & $\begin{array}{l}0 \\
1\end{array}$ & $\begin{array}{r}0 \\
168\end{array}$ & 0 & 0 & 0 & $\begin{array}{l}0 \\
7\end{array}$ & 0 & 0 & 94 & 0 & 11 & 15 & 0 & $\begin{array}{r}0 \\
32\end{array}$ & $\begin{array}{l}0 \\
1\end{array}$ & 0 \\
\hline tal and performing & 1,067 & & & & & & & & & & & & & & & & & & & & \\
\hline
\end{tabular}

${ }^{1}$ Reported racial/ethnic distributions of students by level of degree, field of degree, and sex were used to estimate race/ethnicty for students whose race/ethnicity was not reported. Excludes 5 men and 2 women whose racial/ethnic group and field of study were not available.

NOTE.-To facilitate trend comparisons, certain aggregations have been made of the degree fields as reported in the IPEDS "Completions" survey: "Agriculture and natural resources" includes Agricultural business and production,
Agricultural sciences, and Conservation and renewable natural resources; and "Business" includes Business management and administrative services, Marketing operations/marketing and distribution, and Consumer and personal services.

SOURCE: U.S. Department of Education, National Center for Education Statistics, Integrated Postsecondary Education Data System (IPEDS), "Completions" survey. (This table was prepared June 1998.) 


\begin{tabular}{|c|c|c|c|c|c|c|c|c|c|c|c|c|c|c|c|c|c|c|c|c|c|}
\hline \multirow[b]{2}{*}{ Major field of study } & \multicolumn{7}{|c|}{ Total } & \multicolumn{7}{|c|}{ Men } & \multicolumn{7}{|c|}{ Women } \\
\hline & Total & $\begin{array}{c}\text { White, } \\
\text { non- } \\
\text { His- } \\
\text { panic }\end{array}$ & $\begin{array}{c}\text { Black, } \\
\text { non- } \\
\text { His- } \\
\text { panic }\end{array}$ & $\begin{array}{l}\text { His- } \\
\text { panic }\end{array}$ & $\begin{array}{c}\text { Asian/ } \\
\text { Pacific } \\
\text { Islander }\end{array}$ & \begin{tabular}{c|} 
Amer- \\
ican \\
Indian/ \\
Alas- \\
kan \\
Native
\end{tabular} & $\begin{array}{l}\text { Non- } \\
\text { resi- } \\
\text { dent } \\
\text { alien }\end{array}$ & Total & $\begin{array}{l}\text { White, } \\
\text { non- } \\
\text { His- } \\
\text { panic }\end{array}$ & $\begin{array}{c}\text { Black, } \\
\text { non- } \\
\text { His- } \\
\text { panic }\end{array}$ & $\begin{array}{c}\text { His- } \\
\text { panic }\end{array}$ & $\begin{array}{l}\text { Asian/ } \\
\text { Pacific } \\
\text { Is- } \\
\text { lander }\end{array}$ & \begin{tabular}{c|} 
Amer- \\
ican \\
Indian/ \\
Alas- \\
kan \\
Native
\end{tabular} & $\begin{array}{l}\text { Non- } \\
\text { resi- } \\
\text { dent } \\
\text { alien }\end{array}$ & Total & $\begin{array}{c}\text { White, } \\
\text { non-His- } \\
\text { panic }\end{array}$ & $\begin{array}{c}\text { Black, } \\
\text { non- } \\
\text { His- } \\
\text { panic }\end{array}$ & $\begin{array}{l}\text { His- } \\
\text { panic }\end{array}$ & $\begin{array}{l}\text { Asian/ } \\
\text { Pacific } \\
\text { Is- } \\
\text { lander }\end{array}$ & $\begin{array}{l}\text { Amer- } \\
\text { ican } \\
\text { Indian/ } \\
\text { Alas- } \\
\text { kan } \\
\text { Native }\end{array}$ & $\begin{array}{l}\text { Non- } \\
\text { resi- } \\
\text { dent } \\
\text { alien }\end{array}$ \\
\hline 1 & 2 & 3 & 4 & 5 & 6 & 7 & 8 & 9 & 10 & 11 & 12 & 13 & 14 & 15 & 16 & 17 & 18 & 19 & 20 & 21 & 22 \\
\hline All fields, total 1 ........ & 44,427 & 27,826 & 1,667 & 984 & 2,690 & 130 & 11,130 & 26,898 & 15,354 & 731 & 488 & 1,758 & 58 & 8,509 & 17,529 & 12,472 & 936 & 496 & 932 & 72 & 2,621 \\
\hline 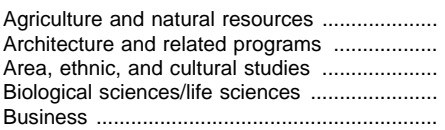 & $\begin{array}{r}1,264 \\
141 \\
186 \\
4,645 \\
1,394\end{array}$ & $\begin{array}{r}601 \\
69 \\
121 \\
2,883 \\
848\end{array}$ & $\begin{array}{r}13 \\
6 \\
22 \\
87 \\
41\end{array}$ & \begin{tabular}{r|}
19 \\
6 \\
6 \\
98 \\
16
\end{tabular} & \begin{tabular}{r|}
71 \\
4 \\
5 \\
407 \\
82
\end{tabular} & $\begin{array}{l}2 \\
0 \\
4 \\
4 \\
5\end{array}$ & $\begin{array}{r}558 \\
56 \\
28 \\
1,166 \\
402\end{array}$ & $\begin{array}{r}962 \\
95 \\
80 \\
2,771 \\
1,014\end{array}$ & $\begin{array}{r}446 \\
43 \\
53 \\
1,687 \\
568\end{array}$ & $\begin{array}{r}9 \\
4 \\
8 \\
52 \\
25\end{array}$ & $\begin{array}{r}12 \\
5 \\
1 \\
63 \\
11\end{array}$ & \begin{tabular}{r|r}
52 \\
3 \\
3 \\
228 \\
58
\end{tabular} & $\begin{array}{l}1 \\
0 \\
1 \\
0 \\
5\end{array}$ & $\begin{array}{r}442 \\
40 \\
14 \\
741 \\
347\end{array}$ & $\begin{array}{r}302 \\
46 \\
106 \\
1,874 \\
380\end{array}$ & $\begin{array}{r}155 \\
26 \\
68 \\
1,196 \\
280\end{array}$ & $\begin{array}{r}4 \\
2 \\
14 \\
35 \\
16\end{array}$ & \begin{tabular}{r|}
7 \\
1 \\
5 \\
35 \\
5
\end{tabular} & $\begin{array}{r}19 \\
1 \\
2 \\
179 \\
24\end{array}$ & $\begin{array}{l}1 \\
0 \\
3 \\
4 \\
0\end{array}$ & $\begin{array}{r}116 \\
16 \\
14 \\
425 \\
55\end{array}$ \\
\hline 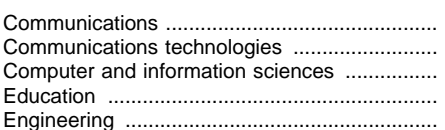 & $\begin{array}{r}320 \\
1 \\
884 \\
6,905 \\
6,110\end{array}$ & $\begin{array}{r}234 \\
1 \\
401 \\
5,205 \\
2,333\end{array}$ & \begin{tabular}{r|r}
14 \\
0 \\
9 \\
620 \\
76
\end{tabular} & $\begin{array}{r}6 \\
0 \\
6 \\
252 \\
60\end{array}$ & \begin{tabular}{r|}
15 \\
0 \\
92 \\
151 \\
635
\end{tabular} & $\begin{array}{r}0 \\
0 \\
0 \\
40 \\
5\end{array}$ & $\begin{array}{r}51 \\
0 \\
376 \\
637 \\
3,001\end{array}$ & $\begin{array}{r}162 \\
0 \\
723 \\
2,621 \\
5,383\end{array}$ & $\begin{array}{r}116 \\
0 \\
311 \\
1,964 \\
1,972\end{array}$ & $\begin{array}{r}3 \\
0 \\
8 \\
191 \\
59\end{array}$ & \begin{tabular}{r|}
3 \\
0 \\
2 \\
88 \\
51
\end{tabular} & \begin{tabular}{r|r}
7 \\
0 \\
73 \\
52 \\
525
\end{tabular} & $\begin{array}{r}0 \\
0 \\
0 \\
15 \\
3\end{array}$ & $\begin{array}{r}33 \\
0 \\
329 \\
311 \\
2,773\end{array}$ & $\begin{array}{r}158 \\
1 \\
161 \\
4,284 \\
727\end{array}$ & $\begin{array}{r}118 \\
1 \\
90 \\
3,241 \\
361\end{array}$ & $\begin{array}{r}11 \\
0 \\
1 \\
429 \\
17\end{array}$ & $\begin{array}{r}3 \\
0 \\
4 \\
164 \\
9\end{array}$ & $\begin{array}{r}8 \\
0 \\
19 \\
99 \\
110\end{array}$ & \begin{tabular}{r|r}
0 \\
0 \\
0 \\
25 \\
2
\end{tabular} & $\begin{array}{r}18 \\
0 \\
47 \\
326 \\
228\end{array}$ \\
\hline 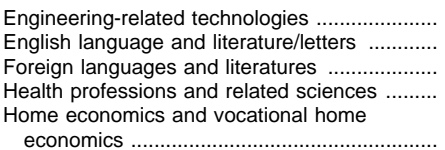 & $\begin{array}{r}18 \\
1,561 \\
905 \\
2,069\end{array}$ & $\begin{array}{r}7 \\
1,268 \\
536 \\
1,311\end{array}$ & $\begin{array}{r}0 \\
37 \\
8 \\
90 \\
28\end{array}$ & $\begin{array}{r}0 \\
26 \\
71 \\
38\end{array}$ & $\begin{array}{r}2 \\
35 \\
33 \\
153\end{array}$ & $\begin{array}{l}1 \\
7 \\
3 \\
9\end{array}$ & $\begin{array}{r}8 \\
188 \\
254 \\
468\end{array}$ & $\begin{array}{r}16 \\
665 \\
395 \\
867\end{array}$ & $\begin{array}{r}7 \\
525 \\
221 \\
444 \\
67\end{array}$ & $\begin{array}{r}0 \\
9 \\
5 \\
32\end{array}$ & $\begin{array}{r}0 \\
8 \\
27 \\
17\end{array}$ & $\begin{array}{r}2 \\
8 \\
13 \\
86\end{array}$ & $\begin{array}{l}1 \\
3 \\
3 \\
2\end{array}$ & $\begin{array}{r}6 \\
112 \\
126 \\
286\end{array}$ & $\begin{array}{r}2 \\
896 \\
510 \\
1,202 \\
289\end{array}$ & $\begin{array}{r}0 \\
743 \\
315 \\
867 \\
212\end{array}$ & $\begin{array}{r}0 \\
28 \\
3 \\
58 \\
22\end{array}$ & $\begin{array}{r}0 \\
18 \\
44 \\
21\end{array}$ & \begin{tabular}{r|}
0 \\
27 \\
20 \\
67 \\
7
\end{tabular} & $\begin{array}{l}0 \\
4 \\
0 \\
7\end{array}$ & $\begin{array}{r}2 \\
76 \\
128 \\
182 \\
42\end{array}$ \\
\hline $\begin{array}{l}\text { Law and legal studies ................................ } \\
\text { Liberal arts and sciences, general studies. }\end{array}$ & 88 & 32 & 1 & 0 & 1 & 0 & 54 & 62 & 20 & 1 & 0 & 0 & 0 & 41 & 26 & 12 & 0 & 0 & 1 & 0 & 13 \\
\hline $\begin{array}{l}\text { and } \mathrm{H} \\
\text { Library }\end{array}$ & $\begin{array}{l}90 \\
55\end{array}$ & $\begin{array}{l}71 \\
29\end{array}$ & $\begin{array}{l}8 \\
7\end{array}$ & $\begin{array}{l}0 \\
2\end{array}$ & $\begin{array}{l}2 \\
5\end{array}$ & $\begin{array}{l}0 \\
0\end{array}$ & \begin{tabular}{r|}
9 \\
12
\end{tabular} & $\begin{array}{l}41 \\
20\end{array}$ & $\begin{array}{l}31 \\
10\end{array}$ & $\begin{array}{l}1 \\
1\end{array}$ & $\begin{array}{l}0 \\
1\end{array}$ & $\begin{array}{l}2 \\
2\end{array}$ & $\begin{array}{l}0 \\
0\end{array}$ & $\begin{array}{l}7 \\
6\end{array}$ & $\begin{array}{l}49 \\
35\end{array}$ & $\begin{array}{l}40 \\
19\end{array}$ & $\begin{array}{l}7 \\
6\end{array}$ & $\begin{array}{l}0 \\
1\end{array}$ & $\begin{array}{l}0 \\
3\end{array}$ & $\begin{array}{l}0 \\
0\end{array}$ & 6 \\
\hline Mathen & 1,226 & 562 & 5 & 14 & 95 & 1 & 549 & 955 & 433 & 3 & 11 & 75 & 0 & 433 & 271 & 129 & 2 & 3 & 20 & 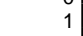 & 116 \\
\hline Multi/interdisciplinary studies & 238 & 155 & 13 & 8 & 14 & 2 & 46 & 129 & 79 & 5 & 4 & 8 & 0 & 33 & 109 & 76 & 8 & 4 & 6 & 2 & 13 \\
\hline $\begin{array}{l}\text { Parks, recreation, leisure and fitness studies } \\
\text { Philosophy and religion }\end{array}$ & $\begin{array}{l}149 \\
507\end{array}$ & $\begin{array}{l}110 \\
401\end{array}$ & \begin{tabular}{r|}
5 \\
14
\end{tabular} & $\begin{array}{l}7 \\
9\end{array}$ & $\begin{array}{r}6 \\
13\end{array}$ & $\begin{array}{l}0 \\
2\end{array}$ & $\begin{array}{l}21 \\
68\end{array}$ & $\begin{array}{r}87 \\
365\end{array}$ & $\begin{array}{r}61 \\
281\end{array}$ & $\begin{array}{r}4 \\
10\end{array}$ & $\begin{array}{l}4 \\
6\end{array}$ & $\begin{array}{l}2 \\
9\end{array}$ & $\begin{array}{l}0 \\
1\end{array}$ & $\begin{array}{l}16 \\
58\end{array}$ & $\begin{array}{r}62 \\
142\end{array}$ & $\begin{array}{r}49 \\
120\end{array}$ & $\begin{array}{l}1 \\
4\end{array}$ & $\begin{array}{l}3 \\
3\end{array}$ & $\begin{array}{l}4 \\
4\end{array}$ & $\begin{array}{l}0 \\
1\end{array}$ & 10 \\
\hline and science technologies & 4,483 & 2,455 & 45 & 62 & 438 & 9 & 1,474 & 3,428 & 1,865 & 30 & 45 & 312 & 5 & 1,171 & 1,055 & 590 & 15 & 17 & 126 & 4 & 303 \\
\hline $\begin{array}{l}\text { Precision production trad } \\
\text { Protective services }\end{array}$ & $\begin{array}{r}0 \\
26\end{array}$ & $\begin{array}{r}0 \\
17\end{array}$ & $\begin{array}{l}0 \\
4\end{array}$ & $\begin{array}{l}0 \\
0\end{array}$ & $\begin{array}{l}0 \\
3\end{array}$ & $\begin{array}{l}0 \\
0\end{array}$ & $\begin{array}{l}0 \\
2\end{array}$ & $\begin{array}{r}0 \\
14\end{array}$ & $\begin{array}{l}0 \\
8\end{array}$ & $\begin{array}{l}0 \\
3\end{array}$ & $\begin{array}{l}0 \\
0\end{array}$ & $\begin{array}{l}0 \\
2\end{array}$ & : & 0 & $\begin{array}{r}0 \\
12\end{array}$ & $\begin{array}{l}0 \\
9\end{array}$ & $\begin{array}{l}0 \\
1\end{array}$ & $\begin{array}{l}0 \\
0\end{array}$ & $\begin{array}{l}0 \\
1\end{array}$ & $\begin{array}{l}0 \\
0 \\
0\end{array}$ & 0 \\
\hline Psyche & 3822 & 3,231 & 15 & 12 & 104 & 18 & 186 & 1.431 & 1,213 & 35 & 44 & 41 & 5 & 93 & $2.39-2 \cdot r \cdot r$ & 2.018 & 119 & 85 & 63 & 13 & 93 \\
\hline & 556 & 31 & 9 & 3 & 6 & 2 & 5 & 274 & 172 & 23 & 7 & 12 & 1 & $-f_{0}$ & 282 & 209 & 36 & 6 & 4 & & 26 \\
\hline . & 0 & | & & 0 & 0 & 0 & 0 & 0 & 0 & I & 0 & 0 & t & 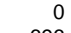 & 0 & 0 & 0 & 0 & 0 & 0 & 0 \\
\hline$\ldots$ & $\begin{array}{l}3,725 \\
1,591\end{array}$ & 2,360 & $\begin{array}{l}119 \\
150\end{array}$ & $\begin{array}{l}86 \\
30\end{array}$ & $\begin{array}{r}196 \\
51\end{array}$ & 10 & 954 & 2,319 & 1,378 & $\begin{array}{r}60 \\
-125\end{array}$ & 58 & 120 & 7 & $\begin{array}{l}696 \\
234\end{array}$ & 1,406 & 982 & $\begin{array}{r}59 \\
25\end{array}$ & $\begin{array}{r}28 \\
-18\end{array}$ & 76 & 3 & 258 \\
\hline Transpc & 1000 & 1 & 0 & \begin{tabular}{r|r}
0 \\
0
\end{tabular} & . & 0 & & -0 & 0 & 0 & 0 & 0 & 0 & & 0 & 20 & 舟 & 0 & 0 & 0 & 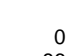 \\
\hline Visual and performing arts .......... & 1,080 & 817 & 32 & 13 & 52 & 2 & 64 & 545 & 424 & 19 & 7 & 16 & 1 & 78 & 535 & 393 & 13 & 6 & 36 & 1 & \\
\hline
\end{tabular}

${ }^{1}$ Reported racial/ethnic distributions of students by level of degree, field of degree, and sex were used to estimate race/ethnicity for students whose race/ethnicity was not reported. Excludes $18 \mathrm{men}$ and 1 woman whose racial/ethnic group and field of study were not available.

NOTE.-To facilitate trend comparisons, certain aggregations have been made of the degree fields as reported in the IPEDS "Completions" survey: "Agriculture and natural resources" includes Agricultural business and production,
Agricultural sciences, and Conservation and renewable natural resources; and "Business" includes Business management and administrative services, Marketing operations/marketing and distribution, and Consumer and personal services.

SOURCE: U.S. Department of Education, National Center for Education Statistics, Integrated Postsecondary Education Data System (IPEDS), "Completions" survey. (This table was prepared April 1997.) 
HIGHER EDUCATION: DEGREES 311

Table 273.-First-professional degrees conferred by institutions of higher education, by racial/ethnic group and sex of student: $1976-77$ to $1995-96$

\begin{tabular}{|c|c|c|c|c|c|c|c|c|c|c|c|c|c|c|}
\hline \multirow[b]{2}{*}{ Year } & \multicolumn{7}{|c|}{ Number of degrees conferred } & \multicolumn{7}{|c|}{ Percentage distribution of degrees conferred } \\
\hline & Total & $\begin{array}{c}\text { White, } \\
\text { non- } \\
\text { His- } \\
\text { panic }\end{array}$ & $\begin{array}{l}\text { Black, } \\
\text { non- } \\
\text { His- } \\
\text { panic }\end{array}$ & $\begin{array}{c}\text { His- } \\
\text { panic }\end{array}$ & $\begin{array}{c}\text { Asian/ } \\
\text { Pacific } \\
\text { Is- } \\
\text { lander }\end{array}$ & $\begin{array}{c}\text { Amer- } \\
\text { ican In- } \\
\text { dian/ } \\
\text { Alas- } \\
\text { kan } \\
\text { Native }\end{array}$ & $\begin{array}{l}\text { Non- } \\
\text { resi- } \\
\text { dent } \\
\text { alien }\end{array}$ & Total & $\begin{array}{c}\text { White, } \\
\text { non- } \\
\text { His- } \\
\text { panic }\end{array}$ & $\begin{array}{c}\text { Black, } \\
\text { non- } \\
\text { His- } \\
\text { panic }\end{array}$ & $\begin{array}{c}\text { His- } \\
\text { panic }\end{array}$ & $\begin{array}{l}\text { Asian/ } \\
\text { Pacific } \\
\text { Is- } \\
\text { lander }\end{array}$ & $\begin{array}{c}\text { Amer- } \\
\text { ican In- } \\
\text { dian/ } \\
\text { Alas- } \\
\text { kan } \\
\text { Native }\end{array}$ & $\begin{array}{l}\text { Non- } \\
\text { resi- } \\
\text { dent } \\
\text { alien }\end{array}$ \\
\hline \multirow[t]{2}{*}{1} & 2 & 3 & 4 & 5 & 6 & 7 & 8 & 9 & 10 & 11 & 12 & 13 & 14 & 15 \\
\hline & \multicolumn{7}{|c|}{ Total } & \multicolumn{7}{|c|}{ Total } \\
\hline 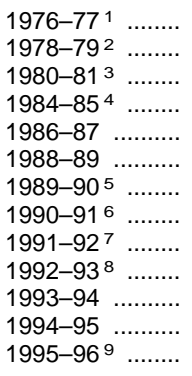 & $\begin{array}{l}63,953 \\
68,611 \\
71,340 \\
71,057 \\
71,617 \\
70,856 \\
70,744 \\
71,515 \\
72,129 \\
74,960 \\
75,418 \\
75,800 \\
76,641\end{array}$ & $\begin{array}{l}58,422 \\
62,430 \\
64,551 \\
63,219 \\
62,688 \\
61,214 \\
60,240 \\
60,327 \\
59,800 \\
60,830 \\
60,140 \\
59,402 \\
59,456\end{array}$ & $\begin{array}{l}2,537 \\
2,836 \\
2,931 \\
3,029 \\
3,420 \\
3,148 \\
3,410 \\
3,575 \\
3,560 \\
4,100 \\
4,444 \\
4,747 \\
5,016\end{array}$ & $\begin{array}{l}1,076 \\
1,283 \\
1,541 \\
1,884 \\
2,051 \\
2,269 \\
2,427 \\
2,527 \\
2,766 \\
2,984 \\
3,134 \\
3,231 \\
3,476\end{array}$ & $\begin{array}{l}1,021 \\
1,205 \\
1,456 \\
1,816 \\
2,270 \\
2,976 \\
3,362 \\
3,755 \\
4,455 \\
5,160 \\
5,892 \\
6,397 \\
6,617\end{array}$ & $\begin{array}{l}196 \\
216 \\
192 \\
248 \\
304 \\
264 \\
257 \\
261 \\
296 \\
368 \\
371 \\
412 \\
463\end{array}$ & $\begin{array}{r}701 \\
641 \\
669 \\
861 \\
884 \\
985 \\
1,048 \\
1,070 \\
1,252 \\
1,518 \\
1,437 \\
1,611 \\
1,613\end{array}$ & $\begin{array}{l}100.0 \\
100.0 \\
100.0 \\
100.0 \\
100.0 \\
100.0 \\
100.0 \\
100.0 \\
100.0 \\
100.0 \\
100.0 \\
100.0 \\
100.0\end{array}$ & $\begin{array}{l}91.4 \\
91.0 \\
90.5 \\
89.0 \\
87.5 \\
86.4 \\
85.2 \\
84.4 \\
82.9 \\
81.1 \\
79.7 \\
78.4 \\
77.6\end{array}$ & $\begin{array}{l}4.0 \\
4.1 \\
4.1 \\
4.3 \\
4.8 \\
4.4 \\
4.8 \\
5.0 \\
4.9 \\
5.5 \\
5.9 \\
6.3 \\
6.5\end{array}$ & $\begin{array}{l}1.7 \\
1.9 \\
2.2 \\
2.7 \\
2.9 \\
3.2 \\
3.4 \\
3.5 \\
3.8 \\
4.0 \\
4.2 \\
4.3 \\
4.5\end{array}$ & $\begin{array}{l}1.6 \\
1.8 \\
2.0 \\
2.6 \\
3.2 \\
4.2 \\
4.8 \\
5.3 \\
6.2 \\
6.9 \\
7.8 \\
8.4 \\
8.6\end{array}$ & $\begin{array}{l}0.3 \\
0.3 \\
0.3 \\
0.3 \\
0.4 \\
0.4 \\
0.4 \\
0.4 \\
0.4 \\
0.5 \\
0.5 \\
0.5 \\
0.6\end{array}$ & $\begin{array}{l}1.1 \\
0.9 \\
0.9 \\
1.2 \\
1.2 \\
1.4 \\
1.5 \\
1.5 \\
1.7 \\
2.0 \\
1.9 \\
2.1 \\
2.1\end{array}$ \\
\hline $1995-96^{9} \ldots \ldots . .$. & \multicolumn{7}{|c|}{ Men } & \multicolumn{7}{|c|}{ Men } \\
\hline 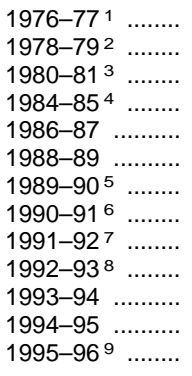 & $\begin{array}{l}51,980 \\
52,425 \\
52,194 \\
47,501 \\
46,523 \\
45,046 \\
43,778 \\
43,601 \\
43,812 \\
44,821 \\
44,707 \\
44,853 \\
44,679\end{array}$ & $\begin{array}{l}47,777 \\
48,123 \\
47,629 \\
42,630 \\
41,149 \\
39,399 \\
37,850 \\
37,348 \\
36,939 \\
37,157 \\
36,573 \\
36,146 \\
35,732\end{array}$ & $\begin{array}{l}1,761 \\
1,783 \\
1,772 \\
1,623 \\
1,835 \\
1,618 \\
1,672 \\
1,672 \\
1,603 \\
1,777 \\
1,902 \\
2,077 \\
2,107\end{array}$ & $\begin{array}{r}893 \\
989 \\
1,131 \\
1,239 \\
1,303 \\
1,374 \\
1,450 \\
1,506 \\
1,635 \\
1,762 \\
1,781 \\
1,836 \\
1,947\end{array}$ & $\begin{array}{r}776 \\
860 \\
991 \\
1,152 \\
1,420 \\
1,819 \\
1,963 \\
2,178 \\
2,593 \\
2,858 \\
3,214 \\
3,491 \\
3,533\end{array}$ & $\begin{array}{l}159 \\
150 \\
134 \\
176 \\
183 \\
148 \\
135 \\
144 \\
157 \\
190 \\
222 \\
222 \\
256\end{array}$ & $\begin{array}{r}614 \\
520 \\
537 \\
681 \\
633 \\
688 \\
708 \\
753 \\
885 \\
1,077 \\
1,015 \\
1,081 \\
1,104\end{array}$ & $\begin{array}{l}100.0 \\
100.0 \\
100.0 \\
100.0 \\
100.0 \\
100.0 \\
100.0 \\
100.0 \\
100.0 \\
100.0 \\
100.0 \\
100.0 \\
100.0\end{array}$ & $\begin{array}{l}91.9 \\
91.8 \\
91.3 \\
89.7 \\
88.4 \\
87.5 \\
86.5 \\
85.7 \\
84.3 \\
82.9 \\
81.8 \\
80.6 \\
80.0\end{array}$ & $\begin{array}{l}3.4 \\
3.4 \\
3.4 \\
3.4 \\
3.9 \\
3.6 \\
3.8 \\
3.8 \\
3.7 \\
4.0 \\
4.3 \\
4.6 \\
4.7\end{array}$ & $\begin{array}{l}1.7 \\
1.9 \\
2.2 \\
2.6 \\
2.8 \\
3.1 \\
3.3 \\
3.5 \\
3.7 \\
3.9 \\
4.0 \\
4.1 \\
4.4\end{array}$ & $\begin{array}{l}1.5 \\
1.6 \\
1.9 \\
2.4 \\
3.1 \\
4.0 \\
4.5 \\
5.0 \\
5.9 \\
6.4 \\
7.2 \\
7.8 \\
7.9\end{array}$ & $\begin{array}{l}0.3 \\
0.3 \\
0.3 \\
0.4 \\
0.4 \\
0.3 \\
0.3 \\
0.3 \\
0.4 \\
0.4 \\
0.5 \\
0.5 \\
0.6\end{array}$ & $\begin{array}{l}1.2 \\
1.0 \\
1.0 \\
1.4 \\
1.4 \\
1.5 \\
1.6 \\
1.7 \\
2.0 \\
2.4 \\
2.3 \\
2.4 \\
2.5\end{array}$ \\
\hline $1995-96^{9} \ldots \ldots \ldots$ & \multicolumn{7}{|c|}{ Women } & \multicolumn{7}{|c|}{ Women } \\
\hline $1976-77^{1} \ldots \ldots$. & 11,973 & 10,645 & 776 & 183 & 245 & 37 & 87 & 100.0 & 88.9 & 6.5 & 1.5 & 2.0 & 0.3 & 0.7 \\
\hline $1978-79^{2} \quad \ldots \ldots \ldots$ & 16,186 & 14,307 & 1,053 & 294 & 345 & 66 & 121 & 100.0 & 88.4 & 6.5 & 1.8 & 2.1 & 0.4 & 0.7 \\
\hline $1980-81^{3} \ldots \ldots .$. & 19,146 & 16,922 & 1,159 & 410 & 465 & 58 & 132 & 100.0 & 88.4 & 6.1 & 2.1 & 2.4 & 0.3 & 0.7 \\
\hline $1984-85^{4} \ldots \ldots .$. & 23,556 & 20,589 & 1,406 & 645 & 664 & 72 & 180 & 100.0 & 87.4 & 6.0 & 2.7 & 2.8 & 0.3 & 0.8 \\
\hline 1986-87 …........ & 25,094 & 21,539 & 1,585 & 748 & 850 & 121 & 251 & 100.0 & 85.8 & & 3.0 & 3.4 & 0.5 & 1.0 \\
\hline 1988-89 …........ & 25,810 & 21,815 & 1,530 & 895 & 1,157 & 116 & 297 & 100.0 & 84.5 & 5.9 & 3.5 & 4.5 & 0.4 & 1.2 \\
\hline $1989-90^{5} \ldots \ldots .$. & 26,966 & 22,390 & 1,738 & 977 & 1,399 & 122 & 340 & 100.0 & 83.0 & 6.4 & 3.6 & 5.2 & 0.5 & 1.3 \\
\hline $1990-91^{6} \ldots \ldots \ldots$ & 27,914 & 22,979 & 1,903 & 1,021 & 1,577 & 117 & 317 & 100.0 & 82.3 & 6.8 & 3.7 & 5.6 & 0.4 & 1.1 \\
\hline $1991-92^{7} \ldots \ldots \ldots$ & 28,317 & 22,861 & 1,957 & 1,131 & 1,862 & 139 & 367 & 100.0 & 80.7 & 6.9 & 4.0 & 6.6 & 0.5 & 1.3 \\
\hline $1992-93^{8} \ldots \ldots \ldots$ & 30,139 & 23,673 & 2,323 & 1,222 & 2,302 & 178 & 441 & 100.0 & 78.5 & 7.7 & 4.1 & 7.6 & 0.6 & 1.5 \\
\hline 1993-94 …....... & 30,711 & 23,567 & 2,542 & 1,353 & 2,678 & 149 & 422 & 100.0 & 76.7 & 8.3 & 4.4 & 8.7 & 0.5 & 1.4 \\
\hline 1994-95 …........ & 30,947 & 23,256 & 2,670 & 1,395 & 2,906 & 190 & 530 & 100.0 & 75.1 & 8.6 & 4.5 & 9.4 & 0.6 & 1.7 \\
\hline $1995-96^{9} \ldots \ldots .$. & 31,962 & 23,724 & 2,909 & 1,529 & 3,084 & 207 & 509 & 100.0 & 74.2 & 9.1 & 4.8 & 9.6 & 0.6 & 1.6 \\
\hline
\end{tabular}

1 Excludes 394 men and 12 women whose racial/ethnic group was not available. 2 Excludes 227 men and 10 women whose racial/ethnic group was not available.

${ }^{3}$ Excludes 598 men and 18 women whose racial/ethnic group was not available.

${ }^{4}$ Excludes 2,954 men and 1,052 women whose racial/ethnic group and field of study were not available.

${ }^{5}$ Excludes 183 men and 61 women whose racial/ethnic group and field of study were not available.

${ }^{6}$ Excludes 245 men and 188 women whose racial/ethnic group and field of study were not available.

${ }^{7}$ Excludes 1,259 men and 758 women whose racial/ethnic group and field of study were not available.

${ }^{8}$ Excludes 332 men and 95 women whose racial/ethnic group and field of study were not available.
9 Excludes 69 men and 24 women whose racial/ethnic group and field of study were not available.

NOTE.-For years 1984-85 to 1995-96, reported racial/ethnic distributions of students by level of degree, field of degree, and sex were used to estimate race/ethnicity for students whose race/ethnicity was not reported. Because of rounding, percents may not add to 100.0 .

SOURCE: US. Department of Education, National Center for Education Statistics, Higher Education General Information Survey (HEGIS), "Degrees and Other Formal Awards Conferred" surveys, and Integrated Postsecondary Education Data System (IPEDS), "Completions" surveys. (This table was prepared June 1998.) 
Table 274.-First-professional degrees conferred by institutions of higher education, by racial/ethnic group, major field of study, and sex of student: 1995-96

\begin{tabular}{|c|c|c|c|c|c|c|c|c|c|c|c|c|c|c|c|c|c|c|c|c|c|}
\hline \multirow[b]{2}{*}{ Major field of study } & \multicolumn{7}{|c|}{ Total } & \multicolumn{7}{|c|}{ Men } & \multicolumn{7}{|c|}{ Women } \\
\hline & Total & $\begin{array}{c}\text { White, } \\
\text { non- } \\
\text { His- } \\
\text { panic }\end{array}$ & $\begin{array}{c}\text { Black, } \\
\text { non- } \\
\text { His- } \\
\text { panic }\end{array}$ & $\begin{array}{c}\text { His- } \\
\text { panic }\end{array}$ & $\begin{array}{l}\text { Asian/ } \\
\text { Pacific } \\
\text { Is- } \\
\text { lander }\end{array}$ & \begin{tabular}{|c|} 
Amer- \\
ican \\
Indian/ \\
Alas- \\
kan \\
Native \\
\end{tabular} & \begin{tabular}{|l|} 
Non- \\
resi- \\
dent \\
alien \\
\end{tabular} & Total & \begin{tabular}{|c|} 
White, \\
non- \\
His- \\
panic
\end{tabular} & \begin{tabular}{|c} 
Black, \\
non- \\
His- \\
panic
\end{tabular} & $\begin{array}{c}\text { His- } \\
\text { panic }\end{array}$ & $\begin{array}{l}\text { Asian/ } \\
\text { Pacific } \\
\text { Is- } \\
\text { lander }\end{array}$ & \begin{tabular}{|c|} 
Amer- \\
ican \\
Indian/ \\
Alas- \\
kan \\
Native \\
\end{tabular} & $\begin{array}{l}\text { Non- } \\
\text { resi- } \\
\text { dent } \\
\text { alien }\end{array}$ & Total & $\begin{array}{c}\text { White, } \\
\text { non- } \\
\text { His- } \\
\text { panic }\end{array}$ & $\begin{array}{c}\text { Black, } \\
\text { non- } \\
\text { His- } \\
\text { panic }\end{array}$ & $\begin{array}{c}\begin{array}{c}\text { is- } \\
\text { panic }\end{array} \\
\text {. }\end{array}$ & $\begin{array}{l}\text { Asian/ } \\
\text { Pacific } \\
\text { Is- } \\
\text { lander }\end{array}$ & \begin{tabular}{|c|} 
Amer- \\
ican \\
Indian/ \\
Alas- \\
kan \\
Native \\
\end{tabular} & $\begin{array}{l}\text { Non- } \\
\text { resi- } \\
\text { dent } \\
\text { alien }\end{array}$ \\
\hline 1 & 2 & 3 & 4 & 5 & 6 & 7 & 8 & 9 & 10 & 11 & 12 & 13 & 14 & 15 & 16 & 17 & 18 & 19 & 20 & 21 & 22 \\
\hline All fields ${ }^{1}$ & 76,641 & 59,456 & 5,016 & 3,476 & 6,617 & 463 & $\mid 1,613$ & 44,679 & 35,732 & 2,107 & \begin{tabular}{|l|}
1,947 \\
\end{tabular} & 3,533 & 256 & 1,104 & 31,962 & 23,724 & 2,909 & 1,529 & 3,084 & 207 & 509 \\
\hline Dentistry (D.D.S. or D.M.D.) & 3,697 & 2,516 & 175 & 177 & 598 & 11 & 220 & 2,374 & 1,705 & 76 & 103 & 332 & 9 & 149 & 1,323 & 811 & 99 & 74 & 266 & 2 & 71 \\
\hline Medicine (M.D.) . & 15,341 & 10,956 & 988 & 702 & 2,406 & 93 & 196 & 9,061 & 6,661 & 387 & 397 & 1,435 & 54 & 127 & 6,280 & 4,295 & 601 & 305 & 971 & 39 & 69 \\
\hline Optometry (O.D.) & 1,231 & 911 & 35 & 47 & 169 & 2 & 67 & 568 & 442 & 9 & 17 & 60 & 1 & 39 & 663 & 469 & 26 & 30 & 109 & 1 & 28 \\
\hline Osteopathic medicine (D.O.) & 1,895 & 1,529 & 45 & 74 & 210 & 14 & 23 & 1,232 & 1,009 & 23 & 54 & 124 & 8 & 14 & 663 & 520 & 22 & 20 & 86 & 6 & 9 \\
\hline Pharmacy (Pharm.D.) & 2,555 & 1,570 & 275 & 80 & 526 & 8 & 96 & 873 & 572 & 78 & 33 & 148 & 3 & 39 & 1,682 & 998 & 197 & 47 & 378 & 5 & 57 \\
\hline Podiatry (Pod.D. or D.P.) or podiatric medic & 650 & 462 & 56 & 3 & 64 & 5 & 20 & 453 & 344 & 15 & 29 & 46 & 3 & 16 & 197 & 118 & 41 & 14 & 18 & 2 & 4 \\
\hline Veterina & 2,109 & 1,935 & 33 & 77 & 37 & 17 & 10 & 715 & 656 & 14 & 27 & 8 & 6 & 4 & 1,394 & 1,279 & 19 & 50 & 29 & 11 & 6 \\
\hline Chiropractic medicine (D.C. or D.C.M.) . & 3,379 & 2,777 & 65 & 113 & 134 & 18 & 272 & 2,470 & 2,051 & 29 & 75 & 103 & 11 & 201 & 909 & 726 & 36 & 38 & 31 & 7 & 71 \\
\hline Law (LL.B. or J.D.) & 39,828 & 32,085 & 2,842 & 2,052 & 2,182 & 280 & 387 & 22,508 & 18,794 & 1,162 & 1,115 & 1,031 & 153 & 253 & 17,320 & 13,291 & 1,680 & 937 & 1,151 & 127 & 134 \\
\hline Theology (M.Div., M.H.L., B.D., or Ord.) … & 5,879 & 4,657 & 501 & 111 & 289 & 15 & 306 & 4,400 & 3,478 & 313 & 97 & 244 & 8 & 260 & 1,479 & 1,179 & 188 & 14 & 45 & 7 & 46 \\
\hline Other & 77 & 58 & 1 & & 2 & 0 & 16 & 25 & 20 & 1 & 0 & 2 & 0 & 2 & 52 & 38 & 0 & 0 & 0 & 0 & 14 \\
\hline
\end{tabular}

1 Reported racial/ethnic distributions of students by level of degree, field of degree, and sex were used to estimate race/ethnicity for students whose race/ethnicity was not reported. Excludes 69 men and 24 women whose racial/ethnic

SOURCE: U.S. Department of Education, National Center for Education Statistics, Integrated Postsecondary Edugroup and field of study were not available. cation Data System (IPEDS), "Completions" survey. (This table was prepared June 1998.)

Table 275.-First-professional degrees conferred by institutions of higher education, by racial/ethnic group, major field of study, and sex of student: 1994-95

\begin{tabular}{|c|c|c|c|c|c|c|c|c|c|c|c|c|c|c|c|c|c|c|c|c|c|}
\hline \multirow[b]{2}{*}{ Major field of study } & \multicolumn{7}{|c|}{ Total } & \multicolumn{7}{|c|}{ Men } & \multicolumn{7}{|c|}{ Women } \\
\hline & Total & $\begin{array}{c}\text { White, } \\
\text { non- } \\
\text { His- } \\
\text { panic }\end{array}$ & $\begin{array}{c}\text { Black, } \\
\text { non- } \\
\text { His- } \\
\text { panic }\end{array}$ & $\left|\begin{array}{c}\text { His- } \\
\text { panic }\end{array}\right|$ & $\begin{array}{l}\text { Asian/ } \\
\text { Pacific } \\
\text { Is- } \\
\text { lander }\end{array}$ & \begin{tabular}{|c|} 
Amer- \\
ican \\
Indian/ \\
Alas- \\
kan \\
Native \\
\end{tabular} & \begin{tabular}{|l|} 
Non- \\
resi- \\
dent \\
alien
\end{tabular} & Total & $\begin{array}{c}\text { White, } \\
\text { non- } \\
\text { His- } \\
\text { panic }\end{array}$ & $\begin{array}{l}\text { Black, } \\
\text { non- } \\
\text { His- } \\
\text { panic }\end{array}$ & $\begin{array}{c}\text { His- } \\
\text { panic }\end{array}$ & $\begin{array}{c}\text { Asian/ } \\
\text { Pacific } \\
\text { Is- } \\
\text { lander }\end{array}$ & \begin{tabular}{|c|} 
Amer- \\
ican \\
Indian/ \\
Alas- \\
kan \\
Native \\
\end{tabular} & \begin{tabular}{|l|} 
Non- \\
resi- \\
dent \\
alien \\
\end{tabular} & Total & $\begin{array}{c}\text { White, } \\
\text { non- } \\
\text { His- } \\
\text { panic }\end{array}$ & \begin{tabular}{|c|} 
Black, \\
non- \\
His- \\
panic
\end{tabular} & $\begin{array}{c}\text { His- } \\
\text { panic }\end{array}$ & $\begin{array}{c}\text { Asian/ } \\
\text { Pacific } \\
\text { Is- } \\
\text { lander }\end{array}$ & \begin{tabular}{|c|} 
Amer- \\
ican \\
Indian/ \\
Alas- \\
kan \\
Native \\
\end{tabular} & $\begin{array}{l}\text { Non- } \\
\text { resi- } \\
\text { dent } \\
\text { alien }\end{array}$ \\
\hline 1 & 2 & 3 & 4 & 5 & 6 & 7 & 8 & 9 & 10 & 11 & 12 & 13 & 14 & 15 & 16 & 17 & 18 & 19 & 20 & 21 & 22 \\
\hline All fields ${ }^{1} \ldots$ & 75,800 & 59,402 & 4,747 & 3,231 & 6,397 & 412 & $\mid 1,611$ & 44,853 & 36,146 & 2,077 & 1,836 & 3,491 & 222 & 1,081 & 30,947 & 23,256 & 2,670 & 1,395 & 2,906 & 190 & 530 \\
\hline 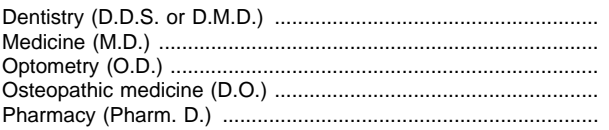 & $\begin{array}{r}3,897 \\
15,537 \\
1,185 \\
1,854 \\
2,264\end{array}$ & $\begin{array}{r}2,616 \\
11,215 \\
899 \\
1,524 \\
1,444\end{array}$ & \begin{tabular}{r|r}
180 \\
929 \\
27 \\
51 \\
233
\end{tabular} & $\begin{array}{r}233 \\
648 \\
36 \\
67 \\
50\end{array}$ & $\begin{array}{r}589 \\
2,485 \\
157 \\
185 \\
434\end{array}$ & $\begin{array}{r}12 \\
65 \\
5 \\
9 \\
7\end{array}$ & $\begin{array}{r}267 \\
195 \\
61 \\
18 \\
96\end{array}$ & $\begin{array}{r}2,480 \\
9,507 \\
538 \\
1,249 \\
785\end{array}$ & $\begin{array}{r}1,774 \\
7,058 \\
439 \\
1,040 \\
522\end{array}$ & $\begin{array}{r}83 \\
409 \\
5 \\
32 \\
66\end{array}$ & $\begin{array}{r}128 \\
399 \\
16 \\
49 \\
20\end{array}$ & $\begin{array}{r}313 \\
1,490 \\
48 \\
109 \\
134\end{array}$ & \begin{tabular}{r|r}
9 \\
28 \\
2 \\
6 \\
1
\end{tabular} & $\begin{array}{r}173 \\
123 \\
28 \\
13 \\
42\end{array}$ & $\begin{array}{r}1,417 \\
6,030 \\
647 \\
605 \\
1,479\end{array}$ & $\begin{array}{r}842 \\
4,157 \\
460 \\
484 \\
922\end{array}$ & \begin{tabular}{r|r}
97 & \\
520 & \\
22 & 19 \\
167 & 167
\end{tabular} & \begin{tabular}{r|}
105 \\
249 \\
20 \\
18 \\
30
\end{tabular} & \begin{tabular}{r|r}
276 \\
995 \\
109 \\
76 \\
300
\end{tabular} & $\begin{array}{r}3 \\
37 \\
3 \\
3 \\
6\end{array}$ & $\begin{array}{r}94 \\
72 \\
33 \\
5 \\
54\end{array}$ \\
\hline $\begin{array}{l}\text { Podiatry (Pod. D. or D.P.) or podiatric medicine (D.P.M.) } \\
\text { Veterinary medicine (D.V.M.) } \\
\text { Chiropractic medicine (D.C. or D.C.M.) } \\
\text { Law (LL.B. or J.D.) } \\
\text { Theology (M. Div., M.H.L., B.D., or Ord.) }\end{array}$ & \begin{tabular}{r|r}
545 \\
2,148 \\
2,968 \\
39,349 \\
5,978 \\
75
\end{tabular} & $\begin{array}{r}416 \\
1,983 \\
2,477 \\
32,126 \\
4,641 \\
61\end{array}$ & $\begin{array}{r}28 \\
52 \\
50 \\
2,699 \\
496 \\
2\end{array}$ & \begin{tabular}{|r|}
32 \\
53 \\
81 \\
1,897 \\
132 \\
2 \\
\end{tabular} & $\begin{array}{r}57 \\
37 \\
125 \\
2,011 \\
317 \\
0\end{array}$ & \begin{tabular}{r|}
1 \\
12 \\
14 \\
272 \\
15 \\
0
\end{tabular} & $\begin{array}{r}11 \\
11 \\
221 \\
344 \\
377 \\
10\end{array}$ & $\begin{array}{r}370 \\
762 \\
2,094 \\
22,592 \\
4,443 \\
33\end{array}$ & $\begin{array}{r}290 \\
694 \\
1,750 \\
19,108 \\
3,443 \\
28\end{array}$ & $\begin{array}{r}15 \\
22 \\
28 \\
1,118 \\
298 \\
1\end{array}$ & $\begin{array}{r}19 \\
27 \\
56 \\
1,016 \\
106 \\
0\end{array}$ & $\begin{array}{r}38 \\
9 \\
91 \\
987 \\
272 \\
0\end{array}$ & $\begin{array}{r}1 \\
5 \\
13 \\
146 \\
11 \\
0\end{array}$ & $\begin{array}{r}7 \\
5 \\
156 \\
217 \\
313 \\
4\end{array}$ & \begin{tabular}{|r|}
175 \\
1,386 \\
874 \\
16,757 \\
1,535 \\
42
\end{tabular} & $\begin{array}{r}126 \\
1,289 \\
727 \\
13,018 \\
1,198 \\
33\end{array}$ & $\begin{array}{r}13 \\
30 \\
22 \\
1,581 \\
198 \\
1\end{array}$ & $\begin{array}{r}13 \\
26 \\
25 \\
881 \\
26 \\
2\end{array}$ & $\begin{array}{r}19 \\
28 \\
34 \\
1,024 \\
45 \\
0\end{array}$ & $\begin{array}{r}0 \\
7 \\
1 \\
126 \\
4 \\
0\end{array}$ & $\begin{array}{r}4 \\
6 \\
65 \\
127 \\
64 \\
6\end{array}$ \\
\hline
\end{tabular}

${ }^{1}$ Reported racial/ethnic distributions of students by level of degree, field of degree, and sex were used to estimate race/ethnicity for students whose race/ethnicity was not reported.
SOURCE: U.S. Department of Education, National Center for Education Statistics, Integrated Postsecondary Education Data System (IPEDS), "Completions" survey. (This table was prepared April 1997.) 
Table 276.-Earned degrees in agriculture and natural resources ${ }^{1}$ conferred by institutions of higher education, by level of degree and sex of student: 1970-71 to 1995-96

\begin{tabular}{|c|c|c|c|c|c|c|c|c|c|c|}
\hline \multirow{2}{*}{\multicolumn{2}{|c|}{ Year }} & \multicolumn{3}{|c|}{ Bachelor's degrees } & \multicolumn{3}{|c|}{ Master's degrees } & \multicolumn{3}{|c|}{ Doctor's degrees } \\
\hline & & Total & Men & Women & Total & Men & Women & Total & Men & Women \\
\hline & 1 & 2 & 3 & 4 & 5 & 6 & 7 & 8 & 9 & 10 \\
\hline $1970-71$ & .......... & 12,672 & 12,136 & 536 & 2,457 & 2,313 & 144 & 1,086 & 1,055 & 31 \\
\hline 1971-72 & ......... & 13,516 & 12,779 & 737 & 2,680 & 2,490 & 190 & 971 & 945 & 26 \\
\hline 1972-73 & & 14,756 & 13,661 & 1,095 & 2,807 & 2,588 & 219 & 1,059 & 1,031 & 28 \\
\hline $1973-74$ & ...... & 16,253 & 14,684 & 1,569 & 2,928 & 2,640 & 288 & 930 & 897 & 33 \\
\hline 1974-75 & ............. & 17,528 & 15,061 & 2,467 & 3,067 & 2,703 & 364 & 991 & 958 & 33 \\
\hline $1975-76$ & ............ & 19,402 & 15,845 & 3,557 & 3,340 & 2,862 & 478 & 928 & 867 & 61 \\
\hline 1976-77 & & 21,467 & 16,690 & 4,777 & 3,724 & 3,177 & 547 & 893 & 831 & 62 \\
\hline 1977-78 & .......... & 22,650 & 17,069 & 5,581 & 4,023 & 3,268 & 755 & 971 & 909 & 62 \\
\hline 1978-79 & & 23,134 & 16,854 & 6,280 & 3,994 & 3,187 & 807 & 950 & 877 & 73 \\
\hline 1979-80 & $\ldots \ldots \ldots$. & 22,802 & 16,045 & 6,757 & 3,976 & 3,082 & 894 & 991 & 879 & 112 \\
\hline 1980-81 & ......... & 21,886 & 15,154 & 6,732 & 4,003 & 3,061 & 942 & 1,067 & 940 & 127 \\
\hline 1981-82 & $\ldots \ldots \ldots$ & 21,029 & 14,443 & 6,586 & 4,163 & 3,114 & 1,049 & 1,079 & 925 & 154 \\
\hline $1982-83$ & ......... & 20,909 & 14,085 & 6,824 & 4,254 & 3,129 & 1,125 & 1,149 & 1,004 & 145 \\
\hline 1983-84 & & 19,317 & 13,206 & 6,111 & 4,178 & 2,989 & 1,189 & 1,172 & 1,001 & 171 \\
\hline 1984-85 & & 18,107 & 12,477 & 5,630 & 3,928 & 2,846 & 1,082 & 1,213 & 1,036 & 177 \\
\hline 1985-86 & $\ldots .$. & 16,823 & 11,544 & 5,279 & 3,801 & 2,701 & 1,100 & 1,158 & 966 & 192 \\
\hline 1986-87 & & 14,991 & 10,314 & 4,677 & 3,522 & 2,460 & 1,062 & 1,049 & 871 & 178 \\
\hline 1987-88 & & 14,222 & 9,744 & 4,478 & 3,479 & 2,427 & 1,052 & 1,142 & 926 & 216 \\
\hline 1988-89 & & 13,492 & 9,298 & 4,194 & 3,245 & 2,231 & 1,014 & 1,183 & 950 & 233 \\
\hline 1989-90 & & 12,900 & 8,822 & 4,078 & 3,382 & 2,239 & 1,143 & 1,295 & 1,038 & 257 \\
\hline $1990-91$ & 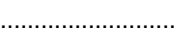 & 13,124 & 8,832 & 4,292 & 3,295 & 2,160 & 1,135 & 1,185 & 953 & 232 \\
\hline 1991-92 & & 15,124 & 9,869 & 5,255 & 3,735 & 2,413 & 1,322 & 1,214 & 963 & 251 \\
\hline 1992-93 & & 16,778 & 11,080 & 5,698 & 3,965 & 2,477 & 1,488 & 1,173 & 879 & 294 \\
\hline 1993-94 & 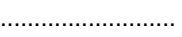 & 18,070 & 11,748 & 6,322 & 4,119 & 2,515 & 1,604 & 1,278 & 982 & 296 \\
\hline 1994-95 & & 19,841 & 12,692 & 7,149 & 4,252 & 2,551 & 1,701 & 1,264 & 962 & 302 \\
\hline 1995-96 & & 21,431 & 13,535 & 7,896 & 4,569 & 2,650 & 1,919 & 1,271 & 935 & 336 \\
\hline
\end{tabular}

${ }^{1}$ Includes degrees in agricultural business and production; agricultural sciences; and conservation and renewable natural resources.

SOURCE: U.S. Department of Education, National Center for Education Statistics, Higher Education General Information Survey (HEGIS), "Degrees and Other Formal Awards Conferred" surveys, and Integrated Postsecondary Education Data System (IPEDS), "Completions" surveys. (This table was prepared May 1998.)

Table 277.-Earned degrees in architecture and related programs ${ }^{1}$ conferred by institutions of higher education, by level of degree and sex of student: 1949-50 to 1995-96

\begin{tabular}{|c|c|c|c|c|c|c|c|c|c|c|}
\hline \multirow{2}{*}{\multicolumn{2}{|c|}{ Year }} & \multicolumn{3}{|c|}{ Bachelor's degrees } & \multicolumn{3}{|c|}{ Master's degrees } & \multicolumn{3}{|c|}{ Doctor's degrees } \\
\hline & & Total & Men & Women & Total & Men & Women & Total & Men & Women \\
\hline & 1 & 2 & 3 & 4 & 5 & 6 & 7 & 8 & 9 & 10 \\
\hline $1949-50$ & ................ & 2,563 & 2,441 & 122 & 166 & 159 & 7 & 1 & 1 & 0 \\
\hline $1959-60$ & … & 1,801 & 1,744 & 57 & 319 & 305 & 14 & 17 & 17 & 0 \\
\hline $1969-70$ & …… & 4,105 & 3,888 & 217 & 1,427 & 1,260 & 167 & 35 & 33 & 2 \\
\hline $1970-71$ & 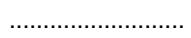 & 5,570 & 4,906 & 664 & 1,705 & 1,469 & 236 & 36 & 33 & 3 \\
\hline $1971-72$ & 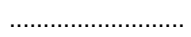 & 6,440 & 5,667 & 773 & 1,899 & 1,626 & 273 & 50 & 43 & 7 \\
\hline 1972-73 & ..................... & 6,962 & 6,042 & 920 & 2,307 & 1,943 & 364 & 58 & 54 & 4 \\
\hline $1973-74$ & ....................... & 7,822 & 6,665 & 1,157 & 2,702 & 2,208 & 494 & 69 & 65 & 4 \\
\hline $1974-75$ & ............... & 8,226 & 6,791 & 1,435 & 2,938 & 2,343 & 595 & 69 & 58 & 11 \\
\hline $1975-76$ & & 9,146 & 7,396 & 1,750 & 3,215 & 2,545 & 670 & 82 & 69 & 13 \\
\hline $1976-77$ & & 9,222 & 7,249 & 1,973 & 3,213 & 2,489 & 724 & 73 & 62 & 11 \\
\hline 1977-78 & & 9,250 & 7,054 & 2,196 & 3,115 & 2,304 & 811 & 73 & 57 & 16 \\
\hline 1978-79 & … & 9,273 & 6,876 & 2,397 & 3,113 & 2,226 & 887 & 96 & 74 & 22 \\
\hline $1979-80$ & 사 & 9,132 & 6,596 & 2,536 & 3,139 & 2,245 & 894 & 79 & 66 & 13 \\
\hline $1980-81$ & '……....... & 9,455 & 6,800 & 2,655 & 3,153 & 2,234 & 919 & 93 & 73 & 20 \\
\hline 1981-82 & . & 9,728 & 6,825 & 2,903 & 3,327 & 2,242 & 1,085 & 80 & 58 & 22 \\
\hline $1982-83$ & …… & 9,823 & 6,403 & 3,420 & 3,357 & 2,224 & 1,133 & 97 & 74 & 23 \\
\hline $1983-84$ & 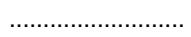 & 9,186 & 5,895 & 3,291 & 3,223 & 2,197 & 1,026 & 84 & 62 & 22 \\
\hline 1984-85 & 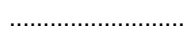 & 9,325 & 6,019 & 3,306 & 3,275 & 2,148 & 1,127 & 89 & 66 & 23 \\
\hline $1985-86$ & 사. & 9,119 & 5,824 & 3,295 & 3,260 & 2,129 & 1,131 & 73 & 56 & 17 \\
\hline $1986-87$ & 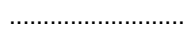 & 8,950 & 5,617 & 3,333 & 3,163 & 2,086 & 1,077 & 92 & 66 & 26 \\
\hline 1987-88 & .............. & 8,603 & 5,271 & 3,332 & 3,159 & 2,042 & 1,117 & 98 & 66 & 32 \\
\hline 1988-89 & $\ldots \ldots$ & 9,150 & 5,545 & 3,605 & 3,383 & 2,192 & 1,191 & 86 & 63 & 23 \\
\hline $1989-90$ & $\ldots \ldots \ldots$ & 9,364 & 5,703 & 3,661 & 3,499 & 2,228 & 1,271 & 103 & 73 & 30 \\
\hline $1990-91$ & & 9,781 & 5,788 & 3,993 & 3,490 & 2,244 & 1,246 & 135 & 101 & 34 \\
\hline 1991-92 & ....... & 8,753 & 5,805 & 2,948 & 3,640 & 2,271 & 1,369 & 132 & 93 & 39 \\
\hline $1992-93$ & 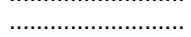 & 9,167 & 5,940 & 3,227 & 3,808 & 2,376 & 1,432 & 148 & 105 & 43 \\
\hline $1993-94$ & 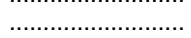 & 8,975 & 5,764 & 3,211 & 3,943 & 2,428 & 1,515 & 161 & 111 & 50 \\
\hline 1994-95 & 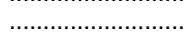 & 8,756 & 5,741 & 3,015 & 3,923 & 2,310 & 1,613 & 141 & 95 & 46 \\
\hline $1995-96$ & 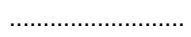 & 8,352 & 5,340 & 3,012 & 3,993 & 2,361 & 1,632 & 141 & 96 & 45 \\
\hline
\end{tabular}

1 Prior to $1969-70$, includes degrees in architecture. Beginning in 1969-70, includes degrees in architecture; city/urban, community, and regional planning; architectural environmental design; interior architecture; landscape architecture; architectural urban design and planning; and architecture and related programs, other.
SOURCE: U.S. Department of Education, National Center for Education Statistics, Higher Education General Information Survey (HEGIS), "Degrees and Other Formal Awards Conferred" surveys, and Integrated Postsecondary Education Data System (IPEDS), "Completions" surveys. (This table was prepared July 1998.) 
Table 278.-Earned degrees in the biological/life sciences ${ }^{1}$ conferred by institutions of higher education, by level of degree and sex of student: 1951-52 to 1995-96

\begin{tabular}{|c|c|c|c|c|c|c|c|c|c|c|}
\hline \multirow{2}{*}{\multicolumn{2}{|c|}{ Year }} & \multicolumn{3}{|c|}{ Bachelor's degrees } & \multicolumn{3}{|c|}{ Master's degrees } & \multicolumn{3}{|c|}{ Doctor's degrees } \\
\hline & & Total & Men & Women & Total & Men & Women & Total & Men & Women \\
\hline & 1 & 2 & 3 & 4 & 5 & 6 & 7 & 8 & 9 & 10 \\
\hline $1951-52$. & .............. & 11,094 & 8,212 & 2,882 & 2,307 & 1,908 & 399 & 764 & 680 & 84 \\
\hline $1955-56$. & ................ & 12,423 & 9,515 & 2,908 & 1,759 & 1,379 & 380 & 1,025 & 908 & 117 \\
\hline 1959-60. & ................. & 15,576 & 11,654 & 3,922 & 2,154 & 1,668 & 486 & 1,205 & 1,086 & 119 \\
\hline $1965-66$. & $\ldots \ldots \ldots \ldots \ldots$ & 26,916 & 19,368 & 7,548 & 4,232 & 3,085 & 1,147 & 2,097 & 1,792 & 305 \\
\hline 1969-70. & ............... & 34,034 & 23,919 & 10,115 & 5,800 & 3,975 & 1,825 & 3,289 & 2,820 & 469 \\
\hline 1970-71. & $\ldots \ldots \ldots \ldots \ldots$ & 35,743 & 25,333 & 10,410 & 5,728 & 3,805 & 1,923 & 3,645 & 3,050 & 595 \\
\hline 1971-72 & .................. & 37,293 & 26,323 & 10,970 & 6,101 & 4,087 & 2,014 & 3,653 & 3,031 & 622 \\
\hline $1972-73$ & ................. & 42,233 & 29,636 & 12,597 & 6,263 & 4,354 & 1,909 & 3,636 & 2,926 & 710 \\
\hline $1973-74$ & ……1..... & 48,340 & 33,245 & 15,095 & 6,552 & 4,555 & 1,997 & 3,439 & 2,740 & 699 \\
\hline 1974-75. & ................... & 51,741 & 34,612 & 17,129 & 6,550 & 4,587 & 1,963 & 3,384 & 2,641 & 743 \\
\hline $1975-76$ & $\ldots \ldots \ldots$ & 54,275 & 35,520 & 18,755 & 6,582 & 4,497 & 2,085 & 3,392 & 2,663 & 729 \\
\hline 1976-77. & & 53,605 & 34,218 & 19,387 & 7,114 & 4,718 & 2,396 & 3,397 & 2,671 & 726 \\
\hline 1977-78 . & & 51,502 & 31,705 & 19,797 & 6,806 & 4,400 & 2,406 & 3,309 & 2,511 & 798 \\
\hline 1978-79 . & & 48,846 & 29,191 & 19,655 & 6,831 & 4,265 & 2,566 & 3,542 & 2,636 & 906 \\
\hline 1979-80. & …............ & 46,370 & 26,828 & 19,542 & 6,510 & 4,098 & 2,412 & 3,636 & 2,690 & 946 \\
\hline 1980-81. & …….............. & 43,216 & 24,149 & 19,067 & 5,978 & 3,654 & 2,324 & 3,718 & 2,666 & 1,052 \\
\hline 1981-82 & 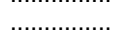 & 41,639 & 22,754 & 18,885 & 5,874 & 3,426 & 2,448 & 3,743 & 2,654 & 1,089 \\
\hline 1982-83 . & .............. & 39,982 & 21,564 & 18,418 & 5,696 & 3,214 & 2,482 & 3,341 & 2,266 & 1,075 \\
\hline 1983-84 & ................ & 38,640 & 20,558 & 18,082 & 5,406 & 2,996 & 2,410 & 3,437 & 2,381 & 1,056 \\
\hline 1984-85. & .................. & 38,445 & 20,064 & 18,381 & 5,059 & 2,647 & 2,412 & 3,432 & 2,307 & 1,125 \\
\hline 1985-86 & ……… & 38,524 & 19,993 & 18,531 & 5,013 & 2,616 & 2,397 & 3,358 & 2,229 & 1,129 \\
\hline 1986-87. & ……… & 38,121 & 19,657 & 18,464 & 4,952 & 2,538 & 2,414 & 3,419 & 2,225 & 1,194 \\
\hline 1987-88 & 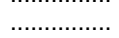 & 36,755 & 18,245 & 18,510 & 4,784 & 2,423 & 2,361 & 3,629 & 2,349 & 1,280 \\
\hline 1988-89. & .............. & 36,059 & 17,953 & 18,106 & 4,961 & 2,492 & 2,469 & 3,520 & 2,234 & 1,286 \\
\hline 1989-90. & ............... & 37,204 & 18,312 & 18,892 & 4,869 & 2,395 & 2,474 & 3,844 & 2,394 & 1,450 \\
\hline 1990-91. & …........... & 39,530 & 19,412 & 20,118 & 4,765 & 2,302 & 2,463 & 4,093 & 2,577 & 1,516 \\
\hline 1991-92 . & & 42,941 & 20,798 & 22,143 & 4,785 & 2,301 & 2,484 & 4,243 & 2,620 & 1,623 \\
\hline 1992-93. & .................. & 47,038 & 22,842 & 24,196 & 4,756 & 2,343 & 2,413 & 4,435 & 2,664 & 1,771 \\
\hline 1993-94. & …............ & 51,383 & 25,050 & 26,333 & 5,196 & 2,465 & 2,731 & 4,534 & 2,690 & 1,844 \\
\hline 1994-95. & ........... & 55,984 & 26,687 & 29,297 & 5,393 & 2,602 & 2,791 & 4,645 & 2,771 & 1,874 \\
\hline 1995-96. & ㄱ..' & 60,994 & 28,849 & 32,145 & 6,157 & 2,902 & 3,255 & 4,780 & 2,773 & 2,007 \\
\hline
\end{tabular}

1 Includes degrees in biology; biochemistry and biophysics; botany; cell and molecular biology; microbiology/bacteriology; zoology; and other biological sciences.
SOURCE: U.S. Department of Education, National Center for Education Statistics, Higher Education General Information Survey (HEGIS), "Degrees and Other Formal Awards Conferred" surveys, and Integrated Postsecondary Education Data System (IPEDS), "Completions" surveys. (This table was prepared July 1998.)

Table 279.-Earned degrees in biology, microbiology, and zoology conferred by institutions of higher education, by level of degree: $1970-71$ to $1995-96$

\begin{tabular}{|c|c|c|c|c|c|c|c|c|c|}
\hline \multirow{2}{*}{ Year } & \multicolumn{3}{|c|}{ Biology, general } & \multicolumn{3}{|c|}{ Microbiology 1} & \multicolumn{3}{|c|}{ Zoology 2} \\
\hline & Bachelor's & Master's & Doctor's & Bachelor's & Master's & Doctor's & Bachelor's & Master's & Doctor's \\
\hline 1 & 2 & 3 & 4 & 5 & 6 & 7 & 8 & 9 & 10 \\
\hline 1970-71 …............. & 26,294 & 2,665 & 536 & 1,475 & 456 & 365 & 5,722 & 1,167 & 1,107 \\
\hline $1971-72 \ldots$ & 27,473 & 2,943 & 580 & 1,548 & 470 & 351 & 5,522 & 1,189 & 1,094 \\
\hline $1972-73 \ldots$ & 31,185 & 2,959 & 627 & 1,940 & 517 & 344 & 5,770 & 1,191 & 1,008 \\
\hline $1973-74$ & 36,188 & 3,186 & 657 & 2,311 & 505 & 384 & 6,192 & 1,250 & 919 \\
\hline 1974-75 & 38,748 & 3,109 & 637 & 2,767 & 552 & 345 & 6,116 & 1,216 & 920 \\
\hline $1975-76 \ldots \ldots$ & 40,163 & 3,177 & 624 & 2,927 & 585 & 364 & 6,105 & 1,153 & 909 \\
\hline $1976-77 \ldots$ & 39,530 & 3,322 & 608 & 2,884 & 659 & 325 & 5,608 & 1,168 & 950 \\
\hline $1977-78 \ldots$ & 37,598 & 3,094 & 664 & 2,695 & 615 & 353 & 5,139 & 1,160 & 885 \\
\hline $1978-79 \ldots$ & 35,962 & 3,093 & 663 & 2,670 & 597 & 395 & 4,913 & 1,109 & 938 \\
\hline $1979-80 \ldots$ & 33,523 & 2,911 & 718 & 2,631 & 596 & 376 & 4,374 & 1,078 & 955 \\
\hline $1980-81 \ldots$ & 31,323 & 2,598 & 734 & 2,414 & 482 & 370 & 3,946 & 1,090 & 946 \\
\hline 1981-82 ............. & 29,651 & 2,579 & 678 & 2,377 & 470 & 350 & 3,664 & 1,028 & 936 \\
\hline $1982-83 \ldots \ldots$ & 28,022 & 2,354 & 521 & 2,306 & 446 & 331 & 3,453 & 918 & 809 \\
\hline 1983-84 ... & 27,379 & 2,313 & 617 & 2,329 & 447 & 360 & 3,294 & 867 & 826 \\
\hline 1984-85 ... & 27,593 & 2,130 & 658 & 2,180 & 413 & 302 & 3,128 & 778 & 802 \\
\hline $1985-86 \ldots$ & 27,618 & 2,173 & 574 & 2,217 & 353 & 336 & 2,940 & 723 & 844 \\
\hline $1986-87$ & 27,465 & 2,022 & 537 & 2,098 & 390 & 337 & 2,858 & 740 & 787 \\
\hline 1987-88 ... & 26,838 & 1,981 & 576 & 2,014 & 357 & 386 & 2,580 & 725 & 786 \\
\hline 1988-89 .... & 26,229 & 2,097 & 527 & 1,780 & 411 & 356 & 2,582 & 736 & 744 \\
\hline $1989-90 \ldots . .$. & 27,213 & 1,998 & 551 & 1,814 & 366 & 409 & 2,501 & 638 & 810 \\
\hline $1990-91 \ldots$ & 29,285 & 1,956 & 632 & 1,757 & 324 & 419 & 2,673 & 640 & 833 \\
\hline $1991-92 \ldots$ & 31,909 & 1,995 & 657 & 1,722 & 336 & 454 & 2,840 & 620 & 818 \\
\hline 1992-93. & 34,932 & 2,000 & 671 & 1,769 & 328 & 520 & 3,071 & 637 & 786 \\
\hline 1993-94 & 38,103 & 2,178 & 665 & 1,841 & 332 & 478 & 3,207 & 749 & 805 \\
\hline 1994-95 ......... & 41,658 & 2,350 & 729 & 1,908 & 295 & 443 & 3,206 & 689 & 767 \\
\hline 1995-96 ........ & 44,818 & 2,606 & 768 & 2,130 & 324 & 477 & 3,549 & 815 & 855 \\
\hline
\end{tabular}

1 Includes bacteriology.

${ }^{2}$ Includes general zoology; entomology; pathology; pharmacology; physiology; and zoology, other.
SOURCE: U.S. Department of Education, National Center for Education Statistics, Higher Education General Information Survey (HEGIS), "Degrees and Other Formal Awards Conferred" surveys, and Integrated Postsecondary Education Data System (IPEDS), "Completions" surveys. (This table was prepared July 1998.) 
Table 280.-Earned degrees in business ${ }^{1}$ conferred by institutions of higher education, by level of degree and sex of student: $1955-56$ to $1995-96$

\begin{tabular}{|c|c|c|c|c|c|c|c|c|c|c|}
\hline \multirow{2}{*}{\multicolumn{2}{|c|}{ Year }} & \multicolumn{3}{|c|}{ Bachelor's degrees } & \multicolumn{3}{|c|}{ Master's degrees } & \multicolumn{3}{|c|}{ Doctor's degrees } \\
\hline & & Total & Men & Women & Total & Men & Women & Total & Men & Women \\
\hline & 1 & 2 & 3 & 4 & 5 & 6 & 7 & 8 & 9 & 10 \\
\hline $1955-56$ & ........ & 42,813 & 38,706 & 4,107 & 3,280 & 3,118 & 162 & 129 & 127 & 2 \\
\hline $1959-60$ & (......................... & 51,076 & 47,262 & 3,814 & 4,643 & 4,476 & 167 & 135 & 133 & 2 \\
\hline $1965-66$ & (2) & 62,721 & 57,516 & 5,205 & 12,959 & 12,628 & 331 & 387 & 370 & 17 \\
\hline 1969-70 & $\ldots \ldots \ldots$ & 105,580 & 96,346 & 9,234 & 21,561 & 20,792 & 769 & 620 & 610 & 10 \\
\hline $1970-71$ & ......... & 114,729 & 104,275 & 10,454 & 25,977 & 24,967 & 1,010 & 757 & 736 & 21 \\
\hline $1971-72$ & & 121,266 & 109,688 & 11,578 & 30,028 & 28,845 & 1,183 & 859 & 840 & 19 \\
\hline 1972-73 & & 126,144 & 112,783 & 13,361 & 30,638 & 29,128 & 1,510 & 902 & 850 & 52 \\
\hline $1973-74$ & ....................... & 131,640 & 114,729 & 16,911 & 32,172 & 30,044 & 2,128 & 919 & 870 & 49 \\
\hline 1974-75 & ....................... & 132,731 & 111,144 & 21,587 & 35,758 & 32,732 & 3,026 & 936 & 897 & 39 \\
\hline $1975-76$ & …................... & 142,034 & 113,954 & 28,080 & 42,054 & 37,145 & 4,909 & 900 & 851 & 49 \\
\hline $1976-77$ & …...................... & 150,765 & 115,353 & 35,412 & 46,006 & 39,400 & 6,606 & 827 & 775 & 52 \\
\hline 1977-78 & ……… & 159,691 & 116,171 & 43,520 & 47,837 & 39,743 & 8,094 & 823 & 753 & 70 \\
\hline 1978-79 & 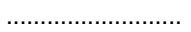 & 171,241 & 118,825 & 52,416 & 49,855 & 40,274 & 9,581 & 821 & 724 & 97 \\
\hline 1979-80 & 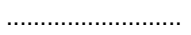 & 184,867 & 122,508 & 62,359 & 54,484 & 42,288 & 12,196 & 753 & 642 & 111 \\
\hline 1980-81. & 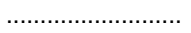 & 198,983 & 125,523 & 73,460 & 57,391 & 42,980 & 14,411 & 795 & 675 & 120 \\
\hline $1981-82$ & (...................... & 213,374 & 129,262 & 84,112 & 60,763 & 43,807 & 16,956 & 815 & 668 & 147 \\
\hline 1982-83 & 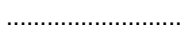 & 226,627 & 131,538 & 95,089 & 64,758 & 45,999 & 18,759 & 776 & 644 & 132 \\
\hline 1983-84 & .......... & 229,478 & 129,559 & 99,919 & 66,150 & 46,178 & 19,972 & 929 & 730 & 199 \\
\hline 1984-85 & . & 232,636 & 127,659 & 104,977 & 66,996 & 46,209 & 20,787 & 831 & 688 & 143 \\
\hline 1985-86 & $\ldots \ldots \ldots$ & 237,319 & 128,780 & 108,539 & 66,689 & 45,938 & 20,751 & 934 & 729 & 205 \\
\hline $1986-87$ & & 240,546 & 128,603 & 111,943 & 67,093 & 44,913 & 22,180 & 1,062 & 808 & 254 \\
\hline $1987-88$ & …................. & 243,021 & 129,552 & 113,469 & 69,230 & 45,980 & 23,250 & 1,063 & 810 & 253 \\
\hline 1988-89 & $\ldots \ldots \ldots \ldots \ldots \ldots \ldots$ & 246,399 & 131,157 & 115,242 & 73,065 & 48,540 & 24,525 & 1,100 & 800 & 300 \\
\hline 1989-90 . & (...................... & 248,698 & 132,329 & 116,369 & 76,676 & 50,585 & 26,091 & 1,093 & 818 & 275 \\
\hline 1990-91. & 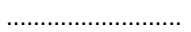 & 249,311 & 131,624 & 117,687 & 78,255 & 50,883 & 27,372 & 1,185 & 876 & 309 \\
\hline 1991-92 & 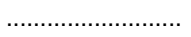 & 256,603 & 135,440 & 121,163 & 84,642 & 54,705 & 29,937 & 1,242 & 953 & 289 \\
\hline $1992-93$ & …..................... & 256,842 & 135,573 & 121,269 & 89,615 & 57,651 & 31,964 & 1,346 & 969 & 377 \\
\hline 1993-94 & 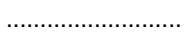 & 246,654 & 129,161 & 117,493 & 93,437 & 59,335 & 34,102 & 1,364 & 980 & 384 \\
\hline 1994-95 & …................... & 234,323 & 121,898 & 112,425 & 93,809 & 59,109 & 34,700 & 1,394 & 1,014 & 380 \\
\hline 1995-96 . & 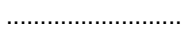 & 227,102 & 116,842 & 110,260 & 93,982 & 58,685 & 35,297 & 1,368 & 974 & 394 \\
\hline
\end{tabular}

${ }^{1}$ Includes degrees in business management/administrative services; marketing operations/marketing and distribution; and consumer and personal services.
SOURCE: U.S. Department of Education, National Center for Education Statistics, Higher Education General Information Survey (HEGIS), "Degrees and Other Formal Awards Conferred" surveys, and Integrated Postsecondary Education Data System (IPEDS), "Completions" surveys. (This table was prepared July 1998.)

Table 281.-Earned degrees in communications ${ }^{1}$ conferred by institutions of higher education, by level of degree and sex of student: 1970-71 to 1995-96

\begin{tabular}{|c|c|c|c|c|c|c|c|c|c|c|}
\hline \multirow{2}{*}{\multicolumn{2}{|c|}{ Year }} & \multicolumn{3}{|c|}{ Bachelor's degrees } & \multicolumn{3}{|c|}{ Master's degrees } & \multicolumn{3}{|c|}{ Doctor's degrees } \\
\hline & & Total & Men & Women & Total & Men & Women & Total & Men & Women \\
\hline & 1 & 2 & 3 & 4 & 5 & 6 & 7 & 8 & 9 & 10 \\
\hline $1970-71$ & ……................ & 10,802 & 6,989 & 3,813 & 1,856 & 1,214 & 642 & 145 & 126 & 19 \\
\hline 1971-72 & 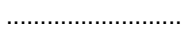 & 12,340 & 7,964 & 4,376 & 2,200 & 1,443 & 757 & 111 & 96 & 15 \\
\hline $1972-73$ & ….................... & 14,317 & 9,074 & 5,243 & 2,406 & 1,546 & 860 & 139 & 114 & 25 \\
\hline $1973-74$ & . & 17,096 & 10,536 & 6,560 & 2,640 & 1,668 & 972 & 175 & 146 & 29 \\
\hline $1974-75$ & (1) & 19,248 & 11,455 & 7,793 & 2,794 & 1,618 & 1,176 & 165 & 119 & 46 \\
\hline $1975-76$ & (2) & 21,282 & 12,458 & 8,824 & 3,126 & 1,818 & 1,308 & 204 & 154 & 50 \\
\hline $1976-77$ & .......... & 23,214 & 12,932 & 10,282 & 3,091 & 1,719 & 1,372 & 171 & 130 & 41 \\
\hline $1977-78$ & (2) & 25,400 & 13,480 & 11,920 & 3,296 & 1,673 & 1,623 & 191 & 138 & 53 \\
\hline 1978-79 & .......... & 26,457 & 13,266 & 13,191 & 2,882 & 1,483 & 1,399 & 192 & 138 & 54 \\
\hline $1979-80$ & ...... & 28,616 & 13,656 & 14,960 & 3,082 & 1,527 & 1,555 & 193 & 121 & 72 \\
\hline 1980-81 & ........ & 31,282 & 14,179 & 17,103 & 3,105 & 1,448 & 1,657 & 182 & 107 & 75 \\
\hline $1981-82$ & 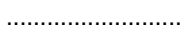 & 34,222 & 14,917 & 19,305 & 3,327 & 1,578 & 1,749 & 200 & 136 & 64 \\
\hline 1982-83 & ....................... & 38,567 & 16,161 & 22,406 & 3,604 & 1,661 & 1,943 & 214 & 126 & 88 \\
\hline 1983-84 & ......................... & 40,113 & 16,604 & 23,509 & 3,656 & 1,600 & 2,056 & 219 & 131 & 88 \\
\hline $1984-85$ & (2) & 42,002 & 17,175 & 24,827 & 3,669 & 1,576 & 2,093 & 234 & 143 & 91 \\
\hline $1985-86$ & (2) & 43,076 & 17,639 & 25,437 & 3,823 & 1,610 & 2,213 & 223 & 116 & 107 \\
\hline $1986-87$ & 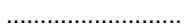 & 45,337 & 18,110 & 27,227 & 3,893 & 1,590 & 2,303 & 275 & 158 & 117 \\
\hline $1987-88$ & ......... & 46,649 & 18,527 & 28,122 & 3,925 & 1,568 & 2,357 & 234 & 134 & 100 \\
\hline 1988-89 & (2) & 48,609 & 19,215 & 29,394 & 4,257 & 1,737 & 2,520 & 253 & 138 & 115 \\
\hline $1989-90$ & 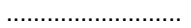 & 51,308 & 20,218 & 31,090 & 4,362 & 1,707 & 2,655 & 273 & 145 & 128 \\
\hline $1990-91$ & .......... & 52,773 & 20,645 & 32,128 & 4,336 & 1,711 & 2,625 & 274 & 151 & 123 \\
\hline $1991-92$ & (2) & 54,977 & 21,497 & 33,480 & 4,464 & 1,692 & 2,772 & 255 & 132 & 123 \\
\hline 1992-93 & ......... & 54,706 & 22,028 & 32,678 & 5,209 & 1,980 & 3,229 & 301 & 146 & 155 \\
\hline $1993-94$ & ……....... & 51,827 & 21,359 & 30,468 & 5,419 & 2,098 & 3,321 & 345 & 174 & 171 \\
\hline 1994-95 & $\ldots \ldots \ldots \ldots \ldots$ & 48,803 & 20,404 & 28,399 & 5,609 & 2,108 & 3,501 & 321 & 162 & 159 \\
\hline 1995-96 & ............... & 48,003 & 19,760 & 28,243 & 5,604 & 2,171 & 3,433 & 345 & 190 & 155 \\
\hline
\end{tabular}

${ }^{1}$ Includes degrees in communications, general; advertising; journalism; broadcast journalism; public relations and organizational communications; radio and television broadcasting; other communications; and communications technologies.
SOURCE: U.S. Department of Education, National Center for Education Statistics, Higher Education General Information Survey (HEGIS), "Degrees and Other Formal Awards Conferred" surveys, and Integrated Postsecondary Education Data System (IPEDS), "Completions" surveys. (This table was prepared July 1998.) 
Table 282.-Earned degrees in computer and information sciences ${ }^{1}$ conferred by institutions of higher education, by level of degree and sex of student: 1970-71 to 1995-96

\begin{tabular}{|c|c|c|c|c|c|c|c|c|c|c|}
\hline \multirow{2}{*}{\multicolumn{2}{|c|}{ Year }} & \multicolumn{3}{|c|}{ Bachelor's degrees } & \multicolumn{3}{|c|}{ Master's degrees } & \multicolumn{3}{|c|}{ Doctor's degrees } \\
\hline & & Total & Men & Women & Total & Men & Women & Total & Men & Women \\
\hline & 1 & 2 & 3 & 4 & 5 & 6 & 7 & 8 & 9 & 10 \\
\hline 1970-71 & ......... & 2,388 & 2,064 & 324 & 1,588 & 1,424 & 164 & 128 & 125 & 3 \\
\hline $1971-72$ & . & 3,402 & 2,941 & 461 & 1,977 & 1,752 & 225 & 167 & 155 & 12 \\
\hline $1972-73$ & 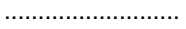 & 4,304 & 3,664 & 640 & 2,113 & 1,888 & 225 & 196 & 181 & 15 \\
\hline 1973-74 & …............ & 4,756 & 3,976 & 780 & 2,276 & 1,983 & 293 & 198 & 189 & 9 \\
\hline $1974-75$ & ......... & 5,033 & 4,080 & 953 & 2,299 & 1,961 & 338 & 213 & 199 & 14 \\
\hline $1975-76$ & ........ & 5,652 & 4,534 & 1,118 & 2,603 & 2,226 & 377 & 244 & 221 & 23 \\
\hline 1976-77 & & 6,407 & 4,876 & 1,531 & 2,798 & 2,332 & 466 & 216 & 197 & 19 \\
\hline 1977-78 & .......... & 7,201 & 5,349 & 1,852 & 3,038 & 2,471 & 567 & 196 & 181 & 15 \\
\hline 1978-79 & . & 8,719 & 6,272 & 2,447 & 3,055 & 2,480 & 575 & 236 & 206 & 30 \\
\hline $1979-80$ & . & 11,154 & 7,782 & 3,372 & 3,647 & 2,883 & 764 & 240 & 213 & 27 \\
\hline 1980-81 & (n....................... & 15,121 & 10,202 & 4,919 & 4,218 & 3,247 & 971 & 252 & 227 & 25 \\
\hline 1981-82 & . & 20,267 & 13,218 & 7,049 & 4,935 & 3,625 & 1,310 & 251 & 230 & 21 \\
\hline 1982-83 & ....................... & 24,510 & 15,606 & 8,904 & 5,321 & 3,813 & 1,508 & 262 & 228 & 34 \\
\hline 1983-84 & ......... & 32,172 & 20,246 & 11,926 & 6,190 & 4,379 & 1,811 & 251 & 225 & 26 \\
\hline 1984-85 & …1, & 38,878 & 24,579 & 14,299 & 7,101 & 5,064 & 2,037 & 248 & 223 & 25 \\
\hline 1985-86 & 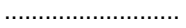 & 41,889 & 26,923 & 14,966 & 8,070 & 5,658 & 2,412 & 344 & 299 & 45 \\
\hline 1986-87 & & 39,589 & 25,865 & 13,724 & 8,481 & 5,985 & 2,496 & 374 & 322 & 52 \\
\hline 1987-88 & ....... & 34,523 & 23,331 & 11,192 & 9,197 & 6,726 & 2,471 & 428 & 380 & 48 \\
\hline 1988-89 & ...... & 30,454 & 21,087 & 9,367 & 9,414 & 6,775 & 2,639 & 551 & 466 & 85 \\
\hline 1989-90 & . & 27,257 & 19,117 & 8,140 & 9,677 & 6,960 & 2,717 & 627 & 534 & 93 \\
\hline $1990-91$ & . & 25,083 & 17,726 & 7,357 & 9,324 & 6,563 & 2,761 & 676 & 584 & 92 \\
\hline $1991-92$ & ..................... & 24,557 & 17,510 & 7,047 & 9,530 & 6,884 & 2,646 & 772 & 669 & 103 \\
\hline 1992-93 & . & 24,200 & 17,403 & 6,797 & 10,163 & 7,410 & 2,753 & 805 & 689 & 116 \\
\hline 1993-94 & . & 24,200 & 17,317 & 6,883 & 10,416 & 7,724 & 2,692 & 810 & 685 & 125 \\
\hline 1994-95 & 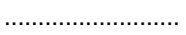 & 24,404 & 17,463 & 6,941 & 10,326 & 7,627 & 2,699 & 884 & 723 & 161 \\
\hline 1995-96 & . & 24,098 & 17,468 & 6,630 & 10,151 & 7,444 & 2,707 & 867 & 741 & 126 \\
\hline
\end{tabular}

1 Includes degrees in computer and information sciences, general; computer programming; data processing technology/technician; information science and systems; computer systems analysis; and other computer and information sciences.
SOURCE: U.S. Department of Education, National Center for Education Statistics, Higher Education General Information Survey (HEGIS), "Degrees and Other Forma Awards Conferred" surveys, and Integrated Postsecondary Education Data System (IPEDS), "Completions" surveys. (This table was prepared July 1998.)

Table 283.-Earned degrees in education conferred by institutions of higher education, by level of degree and sex of student: $1949-50$ to $1995-96$

\begin{tabular}{|c|c|c|c|c|c|c|c|c|c|c|}
\hline \multirow{2}{*}{\multicolumn{2}{|c|}{ Year }} & \multicolumn{3}{|c|}{ Bachelor's degrees } & \multicolumn{3}{|c|}{ Master's degrees } & \multicolumn{3}{|c|}{ Doctor's degrees } \\
\hline & & Total & Men & Women & Total & Men & Women & Total & Men & Women \\
\hline & 1 & 2 & 3 & 4 & 5 & 6 & 7 & 8 & 9 & 10 \\
\hline $1949-50$ & n............... & 61,472 & 31,398 & 30,074 & 20,069 & 12,025 & 8,044 & 953 & 797 & 156 \\
\hline $1959-60$ & .......... & 89,002 & 25,556 & 63,446 & 33,433 & 18,057 & 15,376 & 1,591 & 1,279 & 312 \\
\hline 1969-70 & $\ldots \ldots \ldots \ldots \ldots$ & 163,964 & 40,420 & 123,544 & 78,020 & 34,832 & 43,188 & 5,588 & 4,479 & 1,109 \\
\hline $1970-71$ & & 176,307 & 44,896 & 131,411 & 87,666 & 38,365 & 49,301 & 6,041 & 4,771 & 1,270 \\
\hline $1971-72$ & $\ldots \ldots \ldots$ & 190,880 & 49,344 & 141,536 & 96,668 & 41,141 & 55,527 & 6,648 & 5,104 & 1,544 \\
\hline $1972-73$ & ……… & 193,984 & 51,300 & 142,684 & 103,777 & 43,298 & 60,479 & 6,857 & 5,191 & 1,666 \\
\hline $1973-74$ & 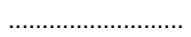 & 184,907 & 48,997 & 135,910 & 110,402 & 44,112 & 66,290 & 6,757 & 4,974 & 1,783 \\
\hline $1974-75$ & 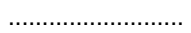 & 166,758 & 44,463 & 122,295 & 117,841 & 44,430 & 73,411 & 6,975 & 4,856 & 2,119 \\
\hline $1975-76$ & ......... & 154,437 & 42,004 & 112,433 & 126,061 & 44,831 & 81,230 & 7,202 & 4,826 & 2,376 \\
\hline $1976-77$ & & 143,234 & 39,867 & 103,367 & 124,267 & 42,308 & 81,959 & 7,338 & 4,832 & 2,506 \\
\hline 1977-78 & $\ldots$ & 135,821 & 37,410 & 98,411 & 116,916 & 37,662 & 79,254 & 7,018 & 4,281 & 2,737 \\
\hline $1978-79$ & $\ldots \ldots \ldots$ & 125,873 & 33,743 & 92,130 & 109,866 & 34,410 & 75,456 & 7,170 & 4,174 & 2,996 \\
\hline $1979-80$ & ….................. & 118,038 & 30,901 & 87,137 & 101,819 & 30,300 & 71,519 & 7,314 & 4,100 & 3,214 \\
\hline $1980-81$ & & 108,074 & 27,039 & 81,035 & 96,713 & 27,548 & 69,165 & 7,279 & 3,843 & 3,436 \\
\hline $1981-82$ & $\ldots \ldots$. & 100,932 & 24,380 & 76,552 & 91,601 & 25,339 & 66,262 & 6,999 & 3,612 & 3,387 \\
\hline 1982-83 & (n....... & 97,895 & 23,644 & 74,251 & 83,250 & 22,823 & 60,427 & 7,057 & 3,547 & 3,510 \\
\hline $1983-84$ & & 92,299 & 22,195 & 70,104 & 75,664 & 21,142 & 54,522 & 6,911 & 3,446 & 3,465 \\
\hline $1984-85$ & .................. & 88,072 & 21,252 & 66,820 & 74,654 & 20,537 & 54,117 & 6,612 & 3,172 & 3,440 \\
\hline $1985-86$ & 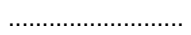 & 87,114 & 20,959 & 66,155 & 74,801 & 20,295 & 54,506 & 6,605 & 3,088 & 3,517 \\
\hline $1986-87$ & . & 86,936 & 20,729 & 66,207 & 74,045 & 19,293 & 54,752 & 6,407 & 2,931 & 3,476 \\
\hline 1987-88 & ............... & 91,112 & 20,988 & 70,124 & 76,566 & 19,108 & 57,458 & 6,060 & 2,739 & 3,321 \\
\hline 1988-89 & & 96,913 & 21,662 & 75,251 & 81,174 & 19,956 & 61,218 & 6,337 & 2,704 & 3,633 \\
\hline $1989-90$ & & 105,112 & 23,007 & 82,105 & 84,881 & 20,467 & 64,414 & 6,502 & 2,776 & 3,726 \\
\hline 1990-91 & & 110,807 & 23,417 & 87,390 & 87,343 & 20,448 & 66,895 & 6,187 & 2,613 & 3,574 \\
\hline 1991-92 & & 108,006 & 22,686 & 85,320 & 92,668 & 21,244 & 71,424 & 6,864 & 2,783 & 4,081 \\
\hline 1992-93 & …............... & 107,781 & 23,233 & 84,548 & 96,028 & 22,197 & 73,831 & 7,030 & 2,867 & 4,163 \\
\hline 1993-94 & & 107,600 & 24,450 & 83,150 & 98,938 & 23,008 & 75,930 & 6,908 & 2,706 & 4,202 \\
\hline 1994-95 & …................. & 106,079 & 25,641 & 80,438 & 101,242 & 23,806 & 77,436 & 6,905 & 2,621 & 4,284 \\
\hline 1995-96 & & 105,509 & 26,233 & 79,276 & 106,253 & 25,214 & 81,039 & 6,676 & 2,525 & 4,151 \\
\hline
\end{tabular}

SOURCE: U.S. Department of Education, National Center for Education Statistics, Higher Education General Information Survey (HEGIS), "Degrees and Other Formal
Awards Conferred" surveys, and Integrated Postsecondary Education Data System (IPEDS), "Completions" surveys. (This table was prepared July 1998.) 
Table 284.-Earned degrees in engineering ${ }^{1}$ conferred by institutions of higher education, by level of degree and sex of student: $1949-50$ to $1995-96$

\begin{tabular}{|c|c|c|c|c|c|c|c|c|c|c|}
\hline \multirow{2}{*}{\multicolumn{2}{|c|}{ Year }} & \multicolumn{3}{|c|}{ Bachelor's degrees } & \multicolumn{3}{|c|}{ Master's degrees } & \multicolumn{3}{|c|}{ Doctor's degrees } \\
\hline & & Total & Men & Women & Total & Men & Women & Total & Men & Women \\
\hline & 1 & 2 & 3 & 4 & 5 & 6 & 7 & 8 & 9 & 10 \\
\hline $1949-50$. & . & 52,246 & 52,071 & 175 & 4,496 & 4,481 & 15 & 417 & 416 & 1 \\
\hline $1959-60$. & 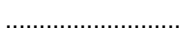 & 37,679 & 37,537 & 142 & 7,159 & 7,133 & 26 & 786 & 783 & 3 \\
\hline $1969-70$. & 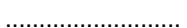 & 44,479 & 44,149 & 330 & 15,593 & 15,421 & 172 & 3,681 & 3,657 & 24 \\
\hline $1970-71$. & 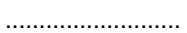 & 50,046 & 49,646 & 400 & 16,443 & 16,258 & 185 & 3,638 & 3,615 & 23 \\
\hline $1971-72$ & 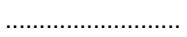 & 51,164 & 50,638 & 526 & 16,960 & 16,688 & 272 & 3,671 & 3,649 & 22 \\
\hline $1972-73$ & 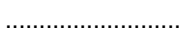 & 51,265 & 50,652 & 613 & 16,619 & 16,341 & 278 & 3,492 & 3,438 & 54 \\
\hline $1973-74$. & …............. & 50,286 & 49,490 & 796 & 15,379 & 15,023 & 356 & 3,312 & 3,257 & 55 \\
\hline $1974-75$. & 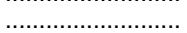 & 46,852 & 45,838 & 1,014 & 15,348 & 14,973 & 375 & 3,108 & 3,042 & 66 \\
\hline $1975-76$. & 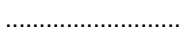 & 46,331 & 44,871 & 1,460 & 16,342 & 15,760 & 582 & 2,821 & 2,755 & 66 \\
\hline $1976-77$. & ........ & 49,283 & 47,065 & 2,218 & 16,245 & 15,525 & 720 & 2,586 & 2,513 & 73 \\
\hline $1977-78$. & ........ & 55,654 & 51,945 & 3,709 & 16,398 & 15,533 & 865 & 2,440 & 2,383 & 57 \\
\hline $1978-79$. & ...... & 62,375 & 57,201 & 5,174 & 15,495 & 14,544 & 951 & 2,506 & 2,423 & 83 \\
\hline $1979-80$. & & 68,893 & 62,488 & 6,405 & 16,243 & 15,101 & 1,142 & 2,507 & 2,412 & 95 \\
\hline 1980-81. & & 75,000 & 67,301 & 7,699 & 16,709 & 15,347 & 1,362 & 2,561 & 2,457 & 104 \\
\hline 1981-82. & (n)........... & 80,005 & 70,899 & 9,106 & 17,939 & 16,311 & 1,628 & 2,636 & 2,496 & 140 \\
\hline $1982-83$. & 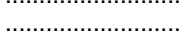 & 89,018 & 78,096 & 10,922 & 19,344 & 17,548 & 1,796 & 2,831 & 2,706 & 125 \\
\hline 1983-84. & 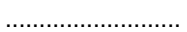 & 94,185 & 82,092 & 12,093 & 20,655 & 18,500 & 2,155 & 2,981 & 2,816 & 165 \\
\hline 1984-85. & 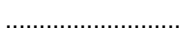 & 95,828 & 83,232 & 12,596 & 21,555 & 19,247 & 2,308 & 3,230 & 3,022 & 208 \\
\hline $1985-86$. & 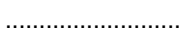 & 95,660 & 83,117 & 12,543 & 21,657 & 19,165 & 2,492 & 3,410 & 3,181 & 229 \\
\hline $1986-87$. & 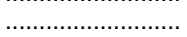 & 92,816 & 80,104 & 12,712 & 22,654 & 19,804 & 2,850 & 3,818 & 3,555 & 263 \\
\hline $1987-88$ & (...................... & 88,506 & 76,372 & 12,134 & 23,385 & 20,476 & 2,909 & 4,191 & 3,898 & 293 \\
\hline $1988-89$. & (1) & 85,002 & 73,436 & 11,566 & 24,568 & 21,374 & 3,194 & 4,523 & 4,123 & 400 \\
\hline $1989-90$. & …….................. & 81,322 & 70,071 & 11,251 & 24,772 & 21,357 & 3,415 & 4,981 & 4,536 & 445 \\
\hline 1990-91. & ........ & 78,650 & 67,738 & 10,912 & 24,958 & 21,430 & 3,528 & 5,272 & 4,787 & 485 \\
\hline 1991-92. & $\ldots \ldots$ & 77,541 & 66,716 & 10,825 & 25,977 & 22,143 & 3,834 & 5,499 & 4,972 & 527 \\
\hline 1992-93. & & 78,051 & 66,836 & 11,215 & 28,726 & 24,454 & 4,272 & 5,843 & 5,283 & 560 \\
\hline $1993-94$. & & 78,225 & 66,597 & 11,628 & 29,754 & 25,154 & 4,600 & 5,979 & 5,315 & 664 \\
\hline 1994-95. & ......... & 78,154 & 65,933 & 12,221 & 29,670 & 24,836 & 4,834 & 6,128 & 5,399 & 729 \\
\hline $1995-96$. & 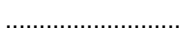 & 77,437 & 64,956 & 12,481 & 28,566 & 23,641 & 4,925 & 6,380 & 5,580 & 800 \\
\hline
\end{tabular}

1 Includes degrees in engineering, engineering-related technologies, construction trades, and mechanics and repairers from 1969-70 through 1995-96.
SOURCE: U.S. Department of Education, National Center for Education Statistics, Higher Education General Information Survey (HEGIS), "Degrees and Other Formal Awards Conferred" surveys, and Integrated Postsecondary Education Data System (IPEDS), "Completions" surveys. (This table was prepared July 1998.)

Table 285.-Earned degrees in chemical, civil, electrical, and mechanical engineering conferred by institutions of higher education, by level of degree: 1970-71 to 1995-96

\begin{tabular}{|c|c|c|c|c|c|c|c|c|c|c|c|c|}
\hline \multirow{3}{*}{ Year } & \multicolumn{3}{|c|}{ Chemical engineering } & \multicolumn{3}{|c|}{ Civil engineering ${ }^{1}$} & \multirow{2}{*}{\multicolumn{3}{|c|}{$\begin{array}{l}\text { Electrical, electronics, and com- } \\
\text { munications engineering }\end{array}$}} & \multicolumn{3}{|c|}{ Mechanical engineering } \\
\hline & \multirow{2}{*}{ Bachelor's } & \multirow{2}{*}{ Master's } & \multirow{2}{*}{ Doctor's } & \multirow{2}{*}{ Bachelor's } & \multirow{2}{*}{ Master's } & \multirow{2}{*}{ Doctor's } & & & & \multirow{2}{*}{ Bachelor's } & \multirow{2}{*}{ Master's } & \multirow{2}{*}{ Doctor's } \\
\hline & & & & & & & Bachelor's & Master's & Doctor's & & & \\
\hline 1 & 2 & 3 & 4 & 5 & 6 & 7 & 8 & 9 & 10 & 11 & 12 & 13 \\
\hline $1970-71$ & 3,579 & 1,100 & 406 & 6,526 & 2,425 & 446 & 12,198 & 4,282 & 879 & 8,858 & 2,237 & 438 \\
\hline 1971-72 …................. & 3,625 & 1,154 & 394 & 6,803 & 2,487 & 415 & 12,101 & 4,206 & 824 & 8,530 & 2,282 & 411 \\
\hline $1972-73 \quad \ldots \ldots \ldots \ldots$ & 3,578 & 1,051 & 397 & 7,390 & 2,627 & 397 & 12,313 & 3,895 & 791 & 8,523 & 2,141 & 370 \\
\hline 1973-74. & 3,399 & 1,044 & 400 & 8,017 & 2,652 & 368 & 11,316 & 3,499 & 705 & 7,677 & 1,843 & 385 \\
\hline $1974-75$ & 3,070 & 990 & 346 & 7,651 & 2,769 & 356 & 10,161 & 3,469 & 701 & 6,890 & 1,858 & 340 \\
\hline $1975-76$ & 3,140 & 1,031 & 308 & 7,923 & 2,999 & 370 & 9,791 & 3,774 & 649 & 6,800 & 1,907 & 305 \\
\hline 1976-77 & 3,524 & 1,086 & 291 & 8,228 & 2,964 & 309 & 9,936 & 3,788 & 566 & 7,703 & 1,952 & 283 \\
\hline 1977-78 & 4,569 & 1,235 & 259 & 9,135 & 2,685 & 277 & 11,133 & 3,740 & 503 & 8,875 & 1,942 & 279 \\
\hline $1978-79$ & 5,568 & 1,149 & 304 & 9,809 & 2,646 & 253 & 12,338 & 3,591 & 586 & 10,107 & 1,877 & 271 \\
\hline 1979-80 & 6,320 & 1,270 & 284 & 10,326 & 2,683 & 270 & 13,821 & 3,836 & 525 & 11,808 & 2,060 & 281 \\
\hline $1980-81$ & 6,527 & 1,267 & 300 & 10,678 & 2,891 & 325 & 14,938 & 3,901 & 535 & 13,329 & 2,291 & 276 \\
\hline $1981-82 \ldots \ldots \ldots \ldots$ & 6,740 & 1,285 & 311 & 10,524 & 2,995 & 329 & 16,455 & 4,462 & 526 & 13,922 & 2,399 & 333 \\
\hline $1982-83 \ldots \ldots \ldots \ldots$ & 7,185 & 1,368 & 319 & 9,989 & 3,074 & 340 & 18,049 & 4,531 & 550 & 15,675 & 2,511 & 299 \\
\hline $1983-84$ & 7,475 & 1,514 & 330 & 9,693 & 3,146 & 369 & 19,943 & 5,078 & 585 & 16,629 & 2,797 & 319 \\
\hline $1984-85 \ldots \ldots$ & 7,146 & 1,544 & 418 & 9,162 & 3,172 & 377 & 21,691 & 5,153 & 660 & 16,794 & 3,053 & 409 \\
\hline $1985-86 \ldots \ldots$ & 5,877 & 1,361 & 446 & 8,679 & 2,926 & 395 & 23,742 & 5,534 & 722 & 16,194 & 3,075 & 426 \\
\hline 1986-87 ..... & 4,991 & 1,184 & 497 & 8,147 & 2,901 & 451 & 24,547 & 6,183 & 724 & 15,450 & 3,198 & 528 \\
\hline $1987-88$ & 3,917 & 1,088 & 579 & 7,488 & 2,836 & 481 & 23,597 & 6,688 & 860 & 14,900 & 3,329 & 596 \\
\hline 1988-89 & 3,663 & 1,093 & 602 & 7,312 & 2,903 & 505 & 21,908 & 7,028 & 998 & 14,843 & 3,498 & 633 \\
\hline 1989-90 & 3,430 & 1,035 & 562 & 7,252 & 2,812 & 516 & 20,711 & 7,225 & 1,162 & 14,336 & 3,424 & 742 \\
\hline 1990-91 & 3,444 & 903 & 611 & 7,314 & 2,927 & 536 & 19,320 & 7,095 & 1,220 & 13,977 & 3,516 & 757 \\
\hline 1991-92 ........... & 3,754 & 956 & 590 & 8,034 & 3,113 & 540 & 17,958 & 7,360 & 1,282 & 14,067 & 3,653 & 851 \\
\hline 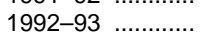 & 4,459 & 990 & 595 & 8,868 & 3,610 & 577 & 17,281 & 7,870 & 1,413 & 14,464 & 3,982 & 871 \\
\hline 1993-94 ................... & 5,163 & 1,032 & 604 & 9,479 & 3,873 & 651 & 15,823 & 7,791 & 1,470 & 15,030 & 4,099 & 887 \\
\hline 1994-95 ..... & 5,901 & 1,085 & 571 & 9,927 & 4,077 & 625 & 14,929 & 7,693 & 1,543 & 14,794 & 4,213 & 890 \\
\hline $1995-96 \ldots$ & 6,319 & 1,176 & 670 & 10,607 & 3,905 & 616 & 13,900 & 7,103 & 1,591 & 14,177 & 3,881 & 940 \\
\hline
\end{tabular}

1 From $1970-71$ to $1981-82$ includes "construction and transportation engineering." NOTE.-Degrees in engineering-related technologies are not included in this tabulation.
SOURCE: U.S. Department of Education, National Center for Education Statistics, Higher Education General Information Survey (HEGIS), "Degrees and Other Formal Awards Conferred" surveys, and Integrated Postsecondary Education Data System (IPEDS), "Completions" surveys. (This table was prepared July 1998.) 
Table 286.-Earned degrees in English language and literature/letters ${ }^{1}$ conferred by institutions of higher education, by level of degree and sex of student: 1949-50 to 1995-96

\begin{tabular}{|c|c|c|c|c|c|c|c|c|c|}
\hline \multirow{2}{*}{ Year } & \multicolumn{3}{|c|}{ Bachelor's degrees } & \multicolumn{3}{|c|}{ Master's degrees } & \multicolumn{3}{|c|}{ Doctor's degrees } \\
\hline & Total & Men & Women & Total & Men & Women & Total & Men & Women \\
\hline 1 & 2 & 3 & 4 & 5 & 6 & 7 & 8 & 9 & 10 \\
\hline $1949-50 \ldots$ & 17,240 & 8,221 & 9,019 & 2,259 & 1,320 & 939 & 230 & 181 & 49 \\
\hline 1959-60 .... & 20,128 & 7,580 & 12,548 & 2,931 & 1,458 & 1,473 & 397 & 314 & 83 \\
\hline 1969-70 ...... & 56,410 & 18,650 & 37,760 & 8,517 & 3,326 & 5,191 & 1,213 & 837 & 376 \\
\hline 1970-71 ............... & 64,342 & 22,155 & 42,187 & 10,686 & 4,211 & 6,475 & 1,650 & 1,175 & 475 \\
\hline 1971-72 ............... & 63,976 & 22,657 & 41,319 & 10,579 & 4,123 & 6,456 & 1,826 & 1,233 & 593 \\
\hline 1972-73 & 61,003 & 22,156 & 38,847 & 10,239 & 4,063 & 6,176 & 1,935 & 1,258 & 677 \\
\hline 1973-74 & 54,590 & 20,214 & 34,376 & 9,803 & 3,917 & 5,886 & 1,885 & 1,208 & 677 \\
\hline $1974-75$ & 47,619 & 17,880 & 29,739 & 9,444 & 3,569 & 5,875 & 1,711 & 1,025 & 686 \\
\hline $1975-76$ & 42,006 & 16,073 & 25,933 & 8,809 & 3,383 & 5,426 & 1,672 & 967 & 705 \\
\hline 1976-77 .............. & 37,794 & 14,295 & 23,499 & 8,016 & 2,985 & 5,031 & 1,508 & 841 & 667 \\
\hline 1977-78 .............. & 35,328 & 13,137 & 22,191 & 7,655 & 2,706 & 4,949 & 1,400 & 758 & 642 \\
\hline 1978-79 …............ & 33,561 & 12,198 & 21,363 & 6,684 & 2,369 & 4,315 & 1,314 & 708 & 606 \\
\hline 1979-80 ..... & 32,541 & 11,380 & 21,161 & 6,189 & 2,233 & 3,956 & 1,294 & 686 & 608 \\
\hline $1980-81 \ldots \ldots$ & 32,254 & 11,198 & 21,056 & 5,929 & 2,092 & 3,837 & 1,164 & 553 & 611 \\
\hline 1981-82 ............. & 33,419 & 11,414 & 22,005 & 5,772 & 1,983 & 3,789 & 1,101 & 511 & 590 \\
\hline 1982-83 ... & 31,829 & 10,859 & 20,970 & 5,048 & 1,710 & 3,338 & 991 & 471 & 520 \\
\hline $1983-84 \ldots$ & 32,834 & 11,170 & 21,664 & 5,010 & 1,736 & 3,274 & 1,018 & 459 & 559 \\
\hline 1984-85 ....... & 33,218 & 11,334 & 21,884 & 5,187 & 1,786 & 3,401 & 1,041 & 470 & 571 \\
\hline $1985-86$ & 34,552 & 11,819 & 22,733 & 5,518 & 1,881 & 3,637 & 991 & 428 & 563 \\
\hline $1986-87$ & 36,284 & 12,353 & 23,931 & 5,483 & 1,891 & 3,592 & 961 & 415 & 546 \\
\hline 1987-88 .... & 38,661 & 12,836 & 25,825 & 5,562 & 1,870 & 3,692 & 981 & 428 & 553 \\
\hline 1988-89 ...... & 42,470 & 13,927 & 28,543 & 5,950 & 2,002 & 3,948 & 1,022 & 458 & 564 \\
\hline 1989-90 .......... & 47,519 & 15,662 & 31,857 & 6,567 & 2,205 & 4,362 & 1,078 & 480 & 598 \\
\hline 1990-91 ................. & 51,841 & 17,146 & 34,695 & 7,026 & 2,296 & 4,730 & 1,184 & 517 & 667 \\
\hline 1991-92 ................ & 54,951 & 18,536 & 36,415 & 7,450 & 2,513 & 4,937 & 1,273 & 537 & 736 \\
\hline 1992-93 …........... & 56,133 & 19,247 & 36,886 & 7,790 & 2,667 & 5,123 & 1,341 & 550 & 791 \\
\hline 1993-94 ............... & 53,924 & 18,425 & 35,499 & 7,885 & 2,712 & 5,173 & 1,344 & 568 & 776 \\
\hline 1994-95 .......... & 51,901 & 17,810 & 34,091 & 7,845 & 2,764 & 5,081 & 1,561 & 665 & 896 \\
\hline $1995-96$ & 50,698 & 17,253 & 33,445 & 7,893 & 2,814 & 5,079 & 1,535 & 590 & 945 \\
\hline
\end{tabular}

1 Includes degrees conferred in English language and literature, general; comparative literature; English composition; English creative writing; American literature; English literature; speech and rhetorical studies; English technical and business writing; and English language and literature/letters, other
SOURCE: U.S. Department of Education, National Center for Education Statistics, Higher Education General Information Survey (HEGIS), "Degrees and Other Formal Awards Conferred" surveys, and Integrated Postsecondary Education Data System (IPEDS), "Completions" surveys. (This table was prepared July 1998.)

Table 287.-Earned degrees in modern foreign languages and literatures ${ }^{1}$ conferred by institutions of higher education, by level of degree and sex of student: 1949-50 to 1995-96

\begin{tabular}{|c|c|c|c|c|c|c|c|c|c|c|}
\hline \multirow{2}{*}{\multicolumn{2}{|c|}{ Year }} & \multicolumn{3}{|c|}{ Bachelor's degrees } & \multicolumn{3}{|c|}{ Master's degrees } & \multicolumn{3}{|c|}{ Doctor's degrees } \\
\hline & & Total & Men & Women & Total & Men & Women & Total & Men & Women \\
\hline & 1 & 2 & 3 & 4 & 5 & 6 & 7 & 8 & 9 & 10 \\
\hline $1949-50$. & . & 4,477 & 1,746 & 2,731 & 919 & 456 & 463 & 168 & 135 & 33 \\
\hline $1959-60$. & (n. & 4,527 & 1,548 & 2,979 & 832 & 392 & 440 & 150 & 100 & 50 \\
\hline 1969-70 . & & 19,457 & 4,921 & 14,536 & 4,154 & 1,476 & 2,678 & 590 & 369 & 221 \\
\hline 1970-71. & (n. & 19,055 & 4,734 & 14,321 & 4,407 & 1,492 & 2,915 & 703 & 425 & 278 \\
\hline 1971-72. & 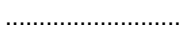 & 18,137 & 4,445 & 13,692 & 4,277 & 1,449 & 2,828 & 753 & 466 & 287 \\
\hline 1972-73 . & 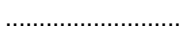 & 18,232 & 4,347 & 13,885 & 3,992 & 1,407 & 2,585 & 889 & 519 & 370 \\
\hline $1973-74$ & …................... & 18,252 & 4,276 & 13,976 & 3,793 & 1,252 & 2,541 & 875 & 487 & 388 \\
\hline 1974-75. & 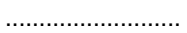 & 17,115 & 3,912 & 13,203 & 3,672 & 1,179 & 2,493 & 829 & 442 & 387 \\
\hline $1975-76$. & …........................ & 15,079 & 3,495 & 11,584 & 3,359 & 1,095 & 2,264 & 830 & 429 & 401 \\
\hline 1976-77 . & . & 13,626 & 3,225 & 10,401 & 2,986 & 886 & 2,100 & 728 & 347 & 381 \\
\hline 1977-78 . & $\ldots \ldots$ & 12,448 & 2,938 & 9,510 & 2,653 & 768 & 1,885 & 626 & 282 & 344 \\
\hline 1978-79. & ...... & 11,531 & 2,705 & 8,826 & 2,338 & 685 & 1,653 & 625 & 287 & 338 \\
\hline 1979-80. & $\ldots \ldots$ & 10,816 & 2,583 & 8,233 & 2,152 & 628 & 1,524 & 522 & 217 & 305 \\
\hline 1980-81. & ................ & 10,050 & 2,402 & 7,648 & 2,018 & 657 & 1,361 & 556 & 259 & 297 \\
\hline 1981-82. & 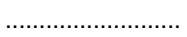 & 9,576 & 2,278 & 7,298 & 1,913 & 571 & 1,342 & 495 & 220 & 275 \\
\hline 1982-83. & ㅅ․ & 9,334 & 2,343 & 6,991 & 1,597 & 528 & 1,069 & 451 & 183 & 268 \\
\hline 1983-84 . & . & 9,152 & 2,399 & 6,753 & 1,640 & 512 & 1,128 & 424 & 191 & 233 \\
\hline 1984-85 . & & 9,675 & 2,529 & 7,146 & 1,611 & 503 & 1,108 & 387 & 156 & 231 \\
\hline 1985-86. & . & 9,808 & 2,685 & 7,123 & 1,655 & 482 & 1,173 & 426 & 173 & 253 \\
\hline $1986-87$. & 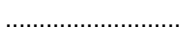 & 9,858 & 2,655 & 7,203 & 1,692 & 491 & 1,201 & 403 & 162 & 241 \\
\hline $1987-88$. & 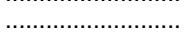 & 9,790 & 2,628 & 7,162 & 1,795 & 564 & 1,231 & 380 & 159 & 221 \\
\hline 1988-89 . & ...................... & 10,498 & 2,767 & 7,731 & 1,821 & 552 & 1,269 & 389 & 145 & 244 \\
\hline 1989-90. & ...... & 11,092 & 2,902 & 8,190 & 1,931 & 584 & 1,347 & 475 & 183 & 292 \\
\hline 1990-91. & $\ldots \ldots$ & 11,724 & 3,207 & 8,517 & 1,973 & 595 & 1,378 & 477 & 200 & 277 \\
\hline 1991-92. & $\ldots \ldots$ & 12,367 & 3,390 & 8,977 & 2,119 & 652 & 1,467 & 537 & 222 & 315 \\
\hline 1992-93. & ......... & 12,819 & 3,537 & 9,282 & 2,353 & 744 & 1,609 & 535 & 210 & 325 \\
\hline 1993-94. & ......... & 12,785 & 3,672 & 9,113 & 2,343 & 712 & 1,631 & 578 & 208 & 370 \\
\hline 1994-95. & ……................ & 12,309 & 3,666 & 8,643 & 2,306 & 688 & 1,618 & 626 & 250 & 376 \\
\hline $1995-96$. & 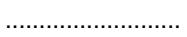 & 13,020 & 3,916 & 9,104 & 2,443 & 789 & 1,654 & 636 & 261 & 375 \\
\hline
\end{tabular}

${ }^{1}$ Includes degrees conferred in a single language or a combination of modern foreign languages. Excludes degrees in linguistics, Latin, classical Greek, and "other" foreign languages.
SOURCE: U.S. Department of Education, National Center for Education Statistics, Higher Education General Information Survey (HEGIS), "Degrees and Other Formal Awards Conferred" surveys, and Integrated Postsecondary Education Data System (IPEDS), "Completions" surveys. (This table was prepared July 1998.) 
Table 288.-Earned degrees in French, German, and Spanish conferred by institutions of higher education, by level of degree: $1949-50$ to $1995-96$

\begin{tabular}{|c|c|c|c|c|c|c|c|c|c|}
\hline \multirow{2}{*}{ Year } & \multicolumn{3}{|c|}{ French } & \multicolumn{3}{|c|}{ German } & \multicolumn{3}{|c|}{ Spanish } \\
\hline & Bachelor's & Master's & Doctor's & Bachelor's & Master's & Doctor's & Bachelor's & Master's & Doctor's \\
\hline 1 & 2 & 3 & 4 & 5 & 6 & 7 & 8 & 9 & 10 \\
\hline $1949-50 \ldots \ldots \ldots . .$. & 1,471 & 299 & 53 & 540 & 121 & 40 & 2,122 & 373 & 34 \\
\hline 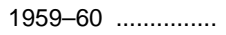 & 1,927 & 316 & 58 & 659 & 126 & 21 & 1,610 & 261 & 31 \\
\hline $1969-70 \quad \ldots \ldots \ldots \ldots \ldots . . . . .$. & 7,624 & 1,409 & 181 & 2,652 & 669 & 118 & 7,226 & 1,372 & 139 \\
\hline $1970-71$................. & 7,306 & 1,437 & 192 & 2,601 & 690 & 144 & 7,068 & 1,456 & 168 \\
\hline 1971-72 …….......... & 6,822 & 1,421 & 193 & 2,477 & 608 & 167 & 6,847 & 1,421 & 152 \\
\hline $1972-73 \quad \ldots \ldots \ldots \ldots \ldots$ & 6,705 & 1,277 & 203 & 2,520 & 598 & 176 & 7,209 & 1,298 & 206 \\
\hline $1973-74 \ldots \ldots \ldots \ldots$ & 6,263 & 1,195 & 213 & 2,425 & 550 & 149 & 7,250 & 1,217 & 203 \\
\hline $1974-75 \ldots \ldots \ldots \ldots \ldots .$. & 5,745 & 1,077 & 200 & 2,289 & 480 & 147 & 6,719 & 1,228 & 202 \\
\hline $1975-76 \ldots \ldots \ldots \ldots$ & 4,783 & 914 & 190 & 1,983 & 471 & 164 & 5,984 & 1,080 & 176 \\
\hline 1976-77 ……......... & 4,228 & 875 & 177 & 1,820 & 394 & 126 & 5,359 & 930 & 153 \\
\hline 1977-78 ……......... & 3,708 & 692 & 155 & 1,647 & 357 & 101 & 4,832 & 822 & 113 \\
\hline $1978-79 \quad \ldots \ldots \ldots \ldots \ldots \ldots$ & 3,558 & 576 & 143 & 1,524 & 344 & 106 & 4,563 & 720 & 118 \\
\hline 1979-80 ……......... & 3,285 & 513 & 128 & 1,466 & 309 & 94 & 4,331 & 685 & 103 \\
\hline $1980-81 \ldots \ldots \ldots \ldots \ldots$ & 3,178 & 460 & 115 & 1,286 & 294 & 79 & 3,870 & 592 & 131 \\
\hline 1981-82 …….......... & 3,054 & 485 & 92 & 1,327 & 324 & 76 & 3,633 & 568 & 140 \\
\hline $1982-83 \ldots \ldots \ldots \ldots \ldots$ & 2,871 & 360 & 106 & 1,367 & 281 & 68 & 3,349 & 506 & 129 \\
\hline 1983-84 …….......... & 2,876 & 418 & 86 & 1,292 & 241 & 63 & 3,254 & 537 & 102 \\
\hline 1984-85 ……....... & 2,991 & 385 & 74 & 1,411 & 240 & 58 & 3,415 & 505 & 115 \\
\hline $1985-86 \ldots \ldots \ldots \ldots \ldots$ & 3,015 & 409 & 86 & 1,396 & 249 & 73 & 3,385 & 521 & 95 \\
\hline 1986-87 ……........... & 3,062 & 421 & 85 & 1,366 & 234 & 70 & 3,450 & 504 & 104 \\
\hline 1987-88 …….......... & 3,082 & 437 & 89 & 1,350 & 244 & 71 & 3,416 & 553 & 93 \\
\hline 1988-89 ……........... & 3,297 & 444 & 83 & 1,428 & 263 & 59 & 3,748 & 552 & 101 \\
\hline $1989-90$................... & 3,259 & 478 & 115 & 1,437 & 253 & 67 & 4,176 & 573 & 108 \\
\hline $1990-91$.................. & 3,355 & 480 & 98 & 1,543 & 242 & 58 & 4,480 & 609 & 125 \\
\hline 1991-92 ……........... & 3,371 & 465 & 112 & 1,616 & 273 & 85 & 4,768 & 647 & 143 \\
\hline 1992-93 …….......... & 3,280 & 513 & 98 & 1,572 & 317 & 86 & 5,233 & 667 & 145 \\
\hline 1993-94 ……........... & 3,094 & 479 & 104 & 1,580 & 298 & 61 & 5,505 & 691 & 160 \\
\hline 1994-95 …............. & 2,764 & 470 & 118 & 1,352 & 278 & 83 & 5,602 & 709 & 161 \\
\hline 1995-96 ……......... & 2,655 & 446 & 113 & 1,290 & 305 & 75 & 5,995 & 769 & 151 \\
\hline
\end{tabular}

SOURCE: U.S. Department of Education, National Center for Education Statistics, Higher Education General Information Survey (HEGIS), "Degrees and Other Formal
Awards Conferred" surveys, and Integrated Postsecondary Education Data System (IPEDS), "Completions" surveys. (This table was prepared July 1998.)

Table 289.-Earned degrees in the health professions and related sciences ${ }^{1}$ conferred by institutions of higher education, by level of degree and sex of student: 1970-71 to 1995-96

\begin{tabular}{|c|c|c|c|c|c|c|c|c|c|}
\hline \multirow{2}{*}{ Year } & \multicolumn{3}{|c|}{ Bachelor's degrees } & \multicolumn{3}{|c|}{ Master's degrees } & \multicolumn{3}{|c|}{ Doctor's degrees } \\
\hline & Total & Men & Women & Total & Men & Women & Total & Men & Women \\
\hline 1 & 2 & 3 & 4 & 5 & 6 & 7 & 8 & 9 & 10 \\
\hline $1970-71$ & 25,226 & 5,788 & 19,438 & 5,749 & 2,567 & 3,182 & 466 & 389 & 77 \\
\hline $1971-72$ & 28,611 & 7,005 & 21,606 & 7,207 & 3,141 & 4,066 & 442 & 362 & 80 \\
\hline 1972-73 . & 33,564 & 7,754 & 25,810 & 8,362 & 3,567 & 4,795 & 646 & 485 & 161 \\
\hline 1973-74 „............... & 41,459 & 9,388 & 32,071 & 9,599 & 3,819 & 5,780 & 578 & 447 & 131 \\
\hline 1974-75 .............. & 49,090 & 10,930 & 38,160 & 10,692 & 4,092 & 6,600 & 618 & 441 & 177 \\
\hline $1975-76 \ldots \ldots$ & 53,958 & 11,456 & 42,502 & 12,556 & 4,217 & 8,339 & 577 & 411 & 166 \\
\hline $1976-77 \ldots \ldots$ & 57,328 & 11,947 & 45,381 & 12,951 & 4,163 & 8,788 & 538 & 366 & 172 \\
\hline $1977-78 \ldots \ldots$ & 59,434 & 11,593 & 47,841 & 14,325 & 4,265 & 10,060 & 654 & 402 & 252 \\
\hline $1978-79 \ldots$ & 62,085 & 11,205 & 50,880 & 15,485 & 4,494 & 10,991 & 718 & 454 & 264 \\
\hline $1979-80 \ldots$ & 63,920 & 11,391 & 52,529 & 15,704 & 4,357 & 11,347 & 786 & 435 & 351 \\
\hline $1980-81 \ldots$ & 63,649 & 10,519 & 53,130 & 16,515 & 4,316 & 12,199 & 842 & 475 & 367 \\
\hline 1981-82 ... & 63,653 & 10,105 & 53,548 & 16,503 & 4,006 & 12,497 & 925 & 503 & 422 \\
\hline $1982-83$. & 64,685 & 10,218 & 54,467 & 17,047 & 4,235 & 12,812 & 1,155 & 649 & 506 \\
\hline $1983-84 \ldots$ & 64,288 & 10,040 & 54,248 & 17,411 & 4,251 & 13,160 & 1,164 & 574 & 590 \\
\hline $1984-85 \ldots$ & 64,422 & 9,741 & 54,681 & 17,385 & 4,119 & 13,266 & 1,199 & 565 & 634 \\
\hline 1985-86 …................. & 64,396 & 9,630 & 54,766 & 18,573 & 4,428 & 14,145 & 1,241 & 604 & 637 \\
\hline $1986-87 \ldots \ldots$ & 63,103 & 9,134 & 53,969 & 18,394 & 3,874 & 14,520 & 1,213 & 564 & 649 \\
\hline 1987-88 ........... & 60,644 & 8,929 & 51,715 & 18,657 & 4,047 & 14,610 & 1,261 & 548 & 713 \\
\hline 1988-89 ............. & 59,005 & 8,872 & 50,133 & 19,268 & 4,226 & 15,042 & 1,437 & 609 & 828 \\
\hline $1989-90 \quad \ldots \ldots \ldots \ldots \ldots$ & 58,302 & 9,118 & 49,184 & 20,321 & 4,534 & 15,787 & 1,536 & 704 & 832 \\
\hline $1990-91 \ldots .$. & 59,070 & 9,596 & 49,474 & 21,200 & 4,444 & 16,756 & 1,613 & 694 & 919 \\
\hline 1991-92 ..... & 61,720 & 10,189 & 51,531 & 23,065 & 4,691 & 18,374 & 1,661 & 698 & 963 \\
\hline 1992-93 ...... & 67,089 & 11,347 & 55,742 & 25,718 & 5,227 & 20,491 & 1,767 & 753 & 1,014 \\
\hline 1993-94 ....... & 74,421 & 13,062 & 61,359 & 28,025 & 5,814 & 22,211 & 1,902 & 789 & 1,113 \\
\hline 1994-95 ....... & 79,855 & 14,443 & 65,412 & 31,243 & 6,754 & 24,489 & 2,069 & 867 & 1,202 \\
\hline 1995-96 .... & 84,036 & 15,432 & 68,604 & 33,398 & 7,021 & 26,377 & 2,119 & 919 & 1,200 \\
\hline
\end{tabular}

1 Includes degrees in chiropractic; communication disorders sciences; community health liaison; dentistry; dental services; health services administration; health and medical assistants; health and medical diagnostic and treatment services; medical laboratory technologies; predentistry; premedicine; prepharmacy; preveterinary; medical basic sciences; mental health services; nursing; optometry; pharmacy; epidemiology; rehabilitation and therapeutic services; veterinary medicine; and other health professions.
SOURCE: U.S. Department of Education, National Center for Education Statistics, Higher Education General Information Survey (HEGIS), "Degrees and Other Formal Awards Conferred" surveys, and Integrated Postsecondary Education Data System (IPEDS), "Completions" surveys. (This table was prepared July 1998.) 
Table 290.-Earned degrees in mathematics ${ }^{1}$ conferred by institutions of higher education, by level of degree and sex of student: 1949-50 to 1995-96

\begin{tabular}{|c|c|c|c|c|c|c|c|c|c|c|}
\hline \multirow{2}{*}{\multicolumn{2}{|c|}{ Year }} & \multicolumn{3}{|c|}{ Bachelor's degrees } & \multicolumn{3}{|c|}{ Master's degrees } & \multicolumn{3}{|c|}{ Doctor's degrees } \\
\hline & & Total & Men & Women & Total & Men & Women & Total & Men & Women \\
\hline & 1 & 2 & 3 & 4 & 5 & 6 & 7 & 8 & 9 & 10 \\
\hline 1949-50. & $\cdots \cdot$ & 6,382 & 4,942 & 1,440 & 974 & 784 & 190 & 160 & 151 & 9 \\
\hline 1959-60 . & ........ & 11,399 & 8,293 & 3,106 & 1,757 & 1,422 & 335 & 303 & 285 & 18 \\
\hline 1969-70. & & 27,442 & 17,177 & 10,265 & 5,636 & 3,966 & 1,670 & 1,236 & 1,140 & 96 \\
\hline 1970-71 . & ......... & 24,937 & 15,498 & 9,439 & 5,695 & 4,149 & 1,546 & 1,249 & 1,154 & 95 \\
\hline 1971-72 . & ....... & 23,807 & 14,542 & 9,265 & 5,537 & 3,976 & 1,561 & 1,165 & 1,075 & 90 \\
\hline 1972-73 . & & 23,186 & 13,910 & 9,276 & 5,397 & 3,878 & 1,519 & 1,089 & 987 & 102 \\
\hline 1973-74 . & & 21,761 & 12,912 & 8,849 & 5,306 & 3,784 & 1,522 & 1,093 & 992 & 101 \\
\hline 1974-75 . & & 18,460 & 10,853 & 7,607 & 4,816 & 3,358 & 1,458 & 1,048 & 936 & 112 \\
\hline 1975-76 . & ...... & 16,329 & 9,788 & 6,541 & 4,315 & 2,961 & 1,354 & 909 & 812 & 97 \\
\hline 1976-77. & & 14,395 & 8,476 & 5,919 & 4,109 & 2,762 & 1,347 & 859 & 748 & 111 \\
\hline 1977-78 . & .............. & 13,065 & 7,806 & 5,259 & 3,862 & 2,635 & 1,227 & 848 & 722 & 126 \\
\hline 1978-79. & $\ldots \ldots \ldots \ldots \ldots$ & 12,329 & 7,301 & 5,028 & 3,553 & 2,412 & 1,141 & 769 & 644 & 125 \\
\hline 1979-80 . & ..... & 11,872 & 6,951 & 4,921 & 3,382 & 2,262 & 1,120 & 763 & 659 & 104 \\
\hline 1980-81 . & ....... & 11,433 & 6,614 & 4,819 & 3,074 & 2,106 & 968 & 775 & 656 & 119 \\
\hline 1981-82 . & 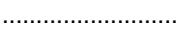 & 12,226 & 6,999 & 5,227 & 3,263 & 2,257 & 1,006 & 721 & 623 & 98 \\
\hline 1982-83 . & ...... & 12,719 & 7,175 & 5,544 & 3,398 & 2,316 & 1,082 & 731 & 611 & 120 \\
\hline 1983-84 . & ....... & 13,764 & 7,716 & 6,048 & 3,244 & 2,178 & 1,066 & 743 & 614 & 129 \\
\hline 1984-85 . & ........ & 15,861 & 8,537 & 7,324 & 3,413 & 2,289 & 1,124 & 734 & 620 & 114 \\
\hline 1985-86 . & ...... & 17,147 & 9,216 & 7,931 & 3,607 & 2,397 & 1,210 & 777 & 648 & 129 \\
\hline 1986-87 . & & 16,999 & 9,110 & 7,889 & 3,730 & 2,328 & 1,402 & 759 & 628 & 131 \\
\hline 1987-88 . & ... & 16,608 & 8,919 & 7,689 & 3,867 & 2,391 & 1,476 & 796 & 668 & 128 \\
\hline 1988-89 . & & 15,994 & 8,662 & 7,332 & 3,903 & 2,418 & 1,485 & 915 & 737 & 178 \\
\hline 1989-90 . & ........ & 15,176 & 8,236 & 6,940 & 4,146 & 2,568 & 1,578 & 966 & 794 & 172 \\
\hline 1990-91. & . & 15,310 & 8,178 & 7,132 & 4,041 & 2,446 & 1,595 & 1,036 & 837 & 199 \\
\hline 1991-92 . & . & 14,783 & 7,888 & 6,895 & 4,011 & 2,452 & 1,559 & 1,082 & 851 & 231 \\
\hline 1992-93 . & 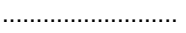 & 14,812 & 7,827 & 6,985 & 4,067 & 2,455 & 1,612 & 1,189 & 906 & 283 \\
\hline 1993-94 . & (2) & 14,396 & 7,735 & 6,661 & 4,100 & 2,536 & 1,564 & 1,157 & 904 & 253 \\
\hline 1994-95 . & . & 13,723 & 7,295 & 6,428 & 4,181 & 2,543 & 1,638 & 1,226 & 955 & 271 \\
\hline 1995-96 . & & 13,143 & 7,134 & 6,009 & 4,031 & 2,465 & 1,566 & 1,209 & 962 & 247 \\
\hline
\end{tabular}

1 Includes degrees conferred in statistics.

SOURCE: U.S. Department of Education, National Center for Education Statistics, Higher Education General Information Survey (HEGIS), "Degrees and Other Formal Awards Conferred" surveys, and Integrated Postsecondary Education Data System (IPEDS), "Completions" surveys. (This table was prepared July 1998.)

Table 291.-Earned degrees in the physical sciences ${ }^{1}$ conferred by institutions of higher education, by level of degree and sex of student: 1959-60 to 1995-96

\begin{tabular}{|c|c|c|c|c|c|c|c|c|c|c|}
\hline \multirow{2}{*}{\multicolumn{2}{|c|}{ Year }} & \multicolumn{3}{|c|}{ Bachelor's degrees } & \multicolumn{3}{|c|}{ Master's degrees } & \multicolumn{3}{|c|}{ Doctor's degrees } \\
\hline & & Total & Men & Women & Total & Men & Women & Total & Men & Women \\
\hline & 1 & 2 & 3 & 4 & 5 & 6 & 7 & 8 & 9 & 10 \\
\hline $1959-60$. & ....... & 16,007 & 14,013 & 1,994 & 3,376 & 3,049 & 327 & 1,838 & 1,776 & 62 \\
\hline $1969-70$. & . & 21,439 & 18,522 & 2,917 & 5,935 & 5,093 & 842 & 4,312 & 4,077 & 235 \\
\hline 1970-71. & ….................. & 21,412 & 18,459 & 2,953 & 6,367 & 5,521 & 846 & 4,390 & 4,144 & 246 \\
\hline 1971-72 . & . & 20,745 & 17,663 & 3,082 & 6,287 & 5,404 & 883 & 4,103 & 3,830 & 273 \\
\hline 1972-73 . & 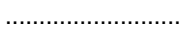 & 20,696 & 17,626 & 3,070 & 6,257 & 5,414 & 843 & 4,006 & 3,738 & 268 \\
\hline 1973-74 . & (................ & 21,178 & 17,674 & 3,504 & 6,062 & 5,186 & 876 & 3,626 & 3,373 & 253 \\
\hline 1974-75 . & 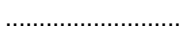 & 20,778 & 16,992 & 3,786 & 5,807 & 4,969 & 838 & 3,626 & 3,325 & 301 \\
\hline $1975-76$. & 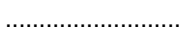 & 21,465 & 17,353 & 4,112 & 5,466 & 4,648 & 818 & 3,431 & 3,132 & 299 \\
\hline 1976-77 . & ....................... & 22,497 & 17,996 & 4,501 & 5,331 & 4,450 & 881 & 3,341 & 3,022 & 319 \\
\hline $1977-78$. & .......... & 22,986 & 18,090 & 4,896 & 5,561 & 4,620 & 941 & 3,133 & 2,821 & 312 \\
\hline 1978-79 . & & 23,207 & 17,985 & 5,222 & 5,451 & 4,461 & 990 & 3,102 & 2,752 & 350 \\
\hline 1979-80. & ...... & 23,410 & 17,864 & 5,546 & 5,219 & 4,248 & 971 & 3,089 & 2,705 & 384 \\
\hline 1980-81. & & 23,952 & 18,064 & 5,888 & 5,284 & 4,200 & 1,084 & 3,141 & 2,765 & 376 \\
\hline 1981-82 . & $\ldots \ldots$ & 24,052 & 17,866 & 6,186 & 5,514 & 4,318 & 1,196 & 3,286 & 2,835 & 451 \\
\hline 1982-83. & . & 23,381 & 16,993 & 6,388 & 5,290 & 4,157 & 1,133 & 3,269 & 2,811 & 458 \\
\hline $1983-84$. & 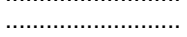 & 23,651 & 17,116 & 6,535 & 5,576 & 4,268 & 1,308 & 3,306 & 2,815 & 491 \\
\hline 1984-85 . & . & 23,704 & 17,069 & 6,635 & 5,796 & 4,452 & 1,344 & 3,403 & 2,851 & 552 \\
\hline 1985-86 . & . & 21,717 & 15,755 & 5,962 & 5,902 & 4,470 & 1,432 & 3,551 & 2,963 & 588 \\
\hline 1986-87 . & . & 20,070 & 14,372 & 5,698 & 5,629 & 4,219 & 1,410 & 3,673 & 3,039 & 634 \\
\hline $1987-88$ & …… & 17,806 & 12,389 & 5,417 & 5,733 & 4,324 & 1,409 & 3,809 & 3,123 & 686 \\
\hline 1988-89. & ……… & 17,186 & 12,077 & 5,109 & 5,723 & 4,199 & 1,524 & 3,858 & 3,088 & 770 \\
\hline 1989-90. & $\ldots \ldots \ldots \ldots \ldots \ldots \ldots \ldots$ & 16,066 & 11,031 & 5,035 & 5,449 & 4,010 & 1,439 & 4,164 & 3,356 & 808 \\
\hline 1990-91. & ...... & 16,344 & 11,176 & 5,168 & 5,309 & 3,837 & 1,472 & 4,290 & 3,447 & 843 \\
\hline 1991-92. & $\ldots \ldots$ & 16,960 & 11,431 & 5,529 & 5,374 & 3,909 & 1,465 & 4,391 & 3,429 & 962 \\
\hline 1992-93. & ..... & 17,545 & 11,825 & 5,720 & 5,366 & 3,808 & 1,558 & 4,393 & 3,432 & 961 \\
\hline 1993-94. & ...... & 18,400 & 12,223 & 6,177 & 5,679 & 4,018 & 1,661 & 4,650 & 3,642 & 1,008 \\
\hline 1994-95 . & ........ & 19,177 & 12,497 & 6,680 & 5,753 & 4,013 & 1,740 & 4,483 & 3,428 & 1,055 \\
\hline 1995-96. & ....................... & 19,647 & 12,578 & 7,069 & 5,847 & 3,966 & 1,881 & 4,571 & 3,515 & 1,056 \\
\hline
\end{tabular}

1 Includes degrees in physical sciences, general; astronomy; astrophysics; atmospheric science and meteorology; chemistry; geology; miscellaneous physical sciences; physics science technologies; and other physical sciences.
SOURCE: U.S. Department of Education, National Center for Education Statistics, Higher Education General Information Survey (HEGIS), "Degrees and Other Forma Awards Conferred" surveys, and Integrated Postsecondary Education Data System (IPEDS), "Completions" surveys. (This table was prepared July 1998.) 
Table 292.-Earned degrees in chemistry, geology, and physics conferred by institutions of higher education, by level of degree: $1970-71$ to $1995-96$

\begin{tabular}{|c|c|c|c|c|c|c|c|c|c|c|}
\hline \multirow{2}{*}{\multicolumn{2}{|c|}{ Year }} & \multicolumn{3}{|c|}{ Chemistry } & \multicolumn{3}{|c|}{ Geology ${ }^{1}$} & \multicolumn{3}{|c|}{ Physics } \\
\hline & & Bachelor's & Master's & Doctor's & Bachelor's & Master's & Doctor's & Bachelor's & Master's & Doctor's \\
\hline & 1 & 2 & 3 & 4 & 5 & 6 & 7 & 8 & 9 & 10 \\
\hline 1970-71. & .......... & 11,063 & 2,275 & 2,159 & 2,414 & 651 & 324 & 5,071 & 2,188 & 1,482 \\
\hline $1971-72$ & …................... & 10,590 & 2,248 & 1,971 & 2,573 & 841 & 310 & 4,634 & 2,033 & 1,344 \\
\hline $1972-73$ & (2) & 10,128 & 2,225 & 1,872 & 2,923 & 827 & 305 & 4,259 & 1,747 & 1,338 \\
\hline $1973-74$ & (........... & 10,438 & 2,125 & 1,823 & 3,253 & 938 & 315 & 3,952 & 1,655 & 1,115 \\
\hline 1974-75 & ......... & 10,549 & 1,986 & 1,822 & 3,319 & 932 & 292 & 3,706 & 1,574 & 1,080 \\
\hline $1975-76$ & & 11,022 & 1,783 & 1,621 & 3,358 & 1,003 & 313 & 3,544 & 1,451 & 997 \\
\hline $1976-77$ & & 11,215 & 1,767 & 1,568 & 3,879 & 1,047 & 325 & 3,420 & 1,319 & 945 \\
\hline 1977-78 & (n....................... & 11,315 & 1,886 & 1,521 & 4,342 & 1,239 & 268 & 3,330 & 1,294 & 873 \\
\hline 1978-79 & (...................... & 11,509 & 1,757 & 1,516 & 4,502 & 1,300 & 286 & 3,337 & 1,319 & 918 \\
\hline 1979-80 & …................... & 11,232 & 1,723 & 1,545 & 4,597 & 1,295 & 313 & 3,396 & 1,192 & 830 \\
\hline 1980-81 & …...................... & 11,347 & 1,654 & 1,622 & 5,202 & 1,396 & 294 & 3,441 & 1,294 & 866 \\
\hline $1981-82$ & ......................... & 11,062 & 1,751 & 1,722 & 5,538 & 1,540 & 282 & 3,472 & 1,284 & 873 \\
\hline $1982-83$ & ……… & 10,796 & 1,622 & 1,746 & 6,102 & 1,552 & 295 & 3,793 & 1,369 & 873 \\
\hline 1983-84 & . & 10,704 & 1,667 & 1,744 & 6,549 & 1,514 & 315 & 3,907 & 1,532 & 953 \\
\hline 1984-85 & 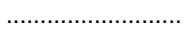 & 10,482 & 1,719 & 1,789 & 6,308 & 1,692 & 289 & 4,097 & 1,523 & 951 \\
\hline 1985-86 & (...................... & 10,116 & 1,754 & 1,908 & 4,974 & 1,767 & 271 & 4,180 & 1,501 & 1,010 \\
\hline 1986-87 & $\ldots \ldots \ldots \ldots \ldots \ldots \ldots$ & 9,670 & 1,738 & 1,976 & 3,665 & 1,603 & 280 & 4,318 & 1,543 & 1,074 \\
\hline 1987-88 & & 9,052 & 1,708 & 1,995 & 2,551 & 1,523 & 350 & 4,100 & 1,675 & 1,093 \\
\hline 1988-89 & & 8,625 & 1,774 & 2,037 & 2,252 & 1,404 & 358 & 4,352 & 1,736 & 1,112 \\
\hline 1989-90 & $\ldots \ldots$. & 8,132 & 1,682 & 2,183 & 1,767 & 1,200 & 414 & 4,155 & 1,831 & 1,192 \\
\hline 1990-91. & ..................... & 8,321 & 1,665 & 2,238 & 1,784 & 1,089 & 446 & 4,236 & 1,725 & 1,209 \\
\hline 1991-92 & ....................... & 8,641 & 1,780 & 2,280 & 2,078 & 990 & 413 & 4,098 & 1,834 & 1,337 \\
\hline 1992-93 & 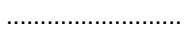 & 8,914 & 1,842 & 2,261 & 2,299 & 925 & 406 & 4,063 & 1,777 & 1,277 \\
\hline 1993-94 & . & 9,425 & 1,999 & 2,353 & 2,677 & 937 & 422 & 4,001 & 1,945 & 1,465 \\
\hline 1994-95 & (n....................... & 9,722 & 2,099 & 2,273 & 3,118 & 993 & 398 & 3,823 & 1,817 & 1,424 \\
\hline 1995-96 & $\ldots \ldots .$. & 10,415 & 2,254 & 2,287 & 3,190 & 991 & 372 & 3,679 & 1,678 & 1,462 \\
\hline
\end{tabular}

${ }^{1}$ Includes geology, geochemistry, and geophysics and seismology. Beginning in 1982 83 , also includes other geological sciences.
SOURCE: U.S. Department of Education, National Center for Education Statistics Higher Education General Information Survey (HEGIS), "Degrees and Other Forma Awards Conferred" surveys, and Integrated Postsecondary Education Data System (IPEDS), "Completions" surveys. (This table was prepared July 1998.)

Table 293.-Earned degrees in psychology conferred by institutions of higher education, by level of degree and by sex of student: 1949-50 to 1995-96

\begin{tabular}{|c|c|c|c|c|c|c|c|c|c|c|}
\hline \multirow{2}{*}{\multicolumn{2}{|c|}{ Year }} & \multicolumn{3}{|c|}{ Bachelor's degrees } & \multicolumn{3}{|c|}{ Master's degrees } & \multicolumn{3}{|c|}{ Doctor's degrees } \\
\hline & & Total & Men & Women & Total & Men & Women & Total & Men & Women \\
\hline & 1 & 2 & 3 & 4 & 5 & 6 & 7 & 8 & 9 & 10 \\
\hline $1949-50$ & . & 9,569 & 6,055 & 3,514 & 1,316 & 948 & 368 & 283 & 241 & 42 \\
\hline $1959-60$ & & 8,061 & 4,773 & 3,288 & 1,406 & 981 & 425 & 641 & 544 & 97 \\
\hline 1969-70 & 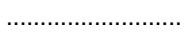 & 33,679 & 19,077 & 14,602 & 5,158 & 2,975 & 2,183 & 1,962 & 1,505 & 457 \\
\hline 1970-71. & 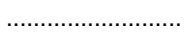 & 38,187 & 21,227 & 16,960 & 5,717 & 3,395 & 2,322 & 2,144 & 1,629 & 515 \\
\hline 1971-72 & (................ & 43,433 & 23,352 & 20,081 & 6,764 & 3,934 & 2,830 & 2,277 & 1,694 & 583 \\
\hline $1972-73$ & . & 47,940 & 25,117 & 22,823 & 7,619 & 4,325 & 3,294 & 2,550 & 1,797 & 753 \\
\hline $1973-74$ & 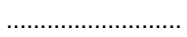 & 52,139 & 25,868 & 26,271 & 8,796 & 4,983 & 3,813 & 2,872 & 1,987 & 885 \\
\hline $1974-75$ & 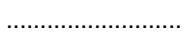 & 51,245 & 24,284 & 26,961 & 9,394 & 5,035 & 4,359 & 2,913 & 1,979 & 934 \\
\hline $1975-76$ & 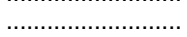 & 50,278 & 22,898 & 27,380 & 10,167 & 5,136 & 5,031 & 3,157 & 2,115 & 1,042 \\
\hline 1976-77 & $=0$ & 47,861 & 20,627 & 27,234 & 10,859 & 5,293 & 5,566 & 3,386 & 2,127 & 1,259 \\
\hline 1977-78 & ......... & 44,879 & 18,422 & 26,457 & 10,282 & 4,670 & 5,612 & 3,164 & 1,974 & 1,190 \\
\hline $1978-79$ & 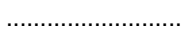 & 42,697 & 16,540 & 26,157 & 10,132 & 4,405 & 5,727 & 3,228 & 1,895 & 1,333 \\
\hline 1979-80 & $\ldots$ & 42,093 & 15,440 & 26,653 & 9,938 & 4,096 & 5,842 & 3,395 & 1,921 & 1,474 \\
\hline $1980-81$ & …................... & 41,068 & 14,332 & 26,736 & 10,223 & 4,066 & 6,157 & 3,576 & 2,002 & 1,574 \\
\hline $1981-82$ & 사. & 41,212 & 13,645 & 27,567 & 9,947 & 3,823 & 6,124 & 3,461 & 1,856 & 1,605 \\
\hline 1982-83 & . & 40,460 & 13,131 & 27,329 & 9,981 & 3,647 & 6,334 & 3,602 & 1,838 & 1,764 \\
\hline 1983-84 & . & 39,955 & 12,812 & 27,143 & 9,525 & 3,400 & 6,125 & 3,535 & 1,774 & 1,761 \\
\hline 1984-85 & ........................ & 39,900 & 12,706 & 27,194 & 9,891 & 3,452 & 6,439 & 3,447 & 1,739 & 1,708 \\
\hline $1985-86$ & 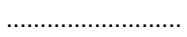 & 40,628 & 12,605 & 28,023 & 9,845 & 3,347 & 6,498 & 3,593 & 1,724 & 1,869 \\
\hline $1986-87$ & 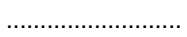 & 42,994 & 13,362 & 29,632 & 9,562 & 3,172 & 6,390 & 3,560 & 1,615 & 1,945 \\
\hline 1987-88 & 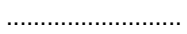 & 45,187 & 13,538 & 31,649 & 9,180 & 2,923 & 6,257 & 3,480 & 1,573 & 1,907 \\
\hline $1988-89$ & 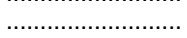 & 48,910 & 14,246 & 34,664 & 9,940 & 3,122 & 6,818 & 3,685 & 1,590 & 2,095 \\
\hline 1989-90 . & ......... & 53,952 & 15,336 & 38,616 & 10,730 & 3,377 & 7,353 & 3,811 & 1,566 & 2,245 \\
\hline 1990-91. & ........ & 58,655 & 16,067 & 42,588 & 11,349 & 3,329 & 8,020 & 3,932 & 1,520 & 2,412 \\
\hline $1991-92$ & $\ldots \ldots$ & 63,513 & 17,031 & 46,482 & 10,215 & 2,988 & 7,227 & 3,373 & 1,359 & 2,014 \\
\hline 1992-93 & ........... & 66,728 & 17,908 & 48,820 & 10,957 & 3,029 & 7,928 & 3,651 & 1,415 & 2,236 \\
\hline $1993-94$ & …...................... & 69,259 & 18,642 & 50,617 & 12,181 & 3,401 & 8,780 & 3,563 & 1,346 & 2,217 \\
\hline 1994-95 & 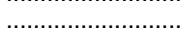 & 72,083 & 19,548 & 52,535 & 13,921 & 3,893 & 10,028 & 3,822 & 1,431 & 2,391 \\
\hline $1995-96$. & …….................... & 73,291 & 19,817 & 53,474 & 13,792 & 3,813 & 9,979 & 3,711 & 1,259 & 2,452 \\
\hline
\end{tabular}

SOURCE: U.S. Department of Education, National Center for Education Statistics, Higher Education General Information Survey (HEGIS), "Degrees and Other Formal
Awards Conferred" surveys, and Integrated Postsecondary Education Data System (IPEDS), "Completions" surveys. (This table was prepared July 1998.) 
Table 294.-Earned degrees in public administration and services ${ }^{1}$ conferred by institutions of higher education, by level of degree and sex of student: 1970-71 to 1995-96

\begin{tabular}{|c|c|c|c|c|c|c|c|c|c|}
\hline \multirow{2}{*}{ Year } & \multicolumn{3}{|c|}{ Bachelor's degrees } & \multicolumn{3}{|c|}{ Master's degrees } & \multicolumn{3}{|c|}{ Doctor's degrees } \\
\hline & Total & Men & Women & Total & Men & Women & Total & Men & Women \\
\hline 1 & 2 & 3 & 4 & 5 & 6 & 7 & 8 & 9 & 10 \\
\hline $\begin{array}{l}1970-71 \\
1971-72 \\
1972-73 \\
19 \ldots \ldots \ldots \ldots \ldots \\
1973-74 \quad \ldots \ldots \ldots \ldots \ldots \\
1974-75\end{array}$ & $\begin{array}{r}5,466 \\
7,508 \\
10,690 \\
11,966 \\
13,661\end{array}$ & $\begin{array}{l}1,726 \\
2,588 \\
3,998 \\
4,266 \\
4,630\end{array}$ & $\begin{array}{l}3,740 \\
4,920 \\
6,692 \\
7,700 \\
9,031\end{array}$ & $\begin{array}{r}7,785 \\
8,756 \\
10,068 \\
11,415 \\
13,617\end{array}$ & $\begin{array}{l}3,893 \\
4,537 \\
5,271 \\
6,028 \\
7,200\end{array}$ & $\begin{array}{l}3,892 \\
4,219 \\
4,797 \\
5,387 \\
6,417\end{array}$ & $\begin{array}{l}174 \\
193 \\
198 \\
201 \\
257\end{array}$ & $\begin{array}{l}132 \\
150 \\
160 \\
154 \\
192\end{array}$ & $\begin{array}{l}42 \\
43 \\
38 \\
47 \\
65\end{array}$ \\
\hline $\begin{array}{r}1975-76 \\
1976-77\end{array}$ & $\begin{array}{l}15,440 \\
16,136 \\
16,607 \\
17,328 \\
16,644\end{array}$ & $\begin{array}{l}5,706 \\
5,544 \\
5,096 \\
4,938 \\
4,451\end{array}$ & $\begin{array}{r}9,734 \\
10,592 \\
11,511 \\
12,390 \\
12,193\end{array}$ & $\begin{array}{l}15,209 \\
17,026 \\
17,337 \\
17,306 \\
17,560\end{array}$ & $\begin{array}{l}7,969 \\
8,810 \\
8,513 \\
8,051 \\
7,866\end{array}$ & $\begin{array}{l}7,240 \\
8,216 \\
8,824 \\
9,255 \\
9,694\end{array}$ & $\begin{array}{l}292 \\
292 \\
357 \\
315 \\
342\end{array}$ & $\begin{array}{l}192 \\
197 \\
237 \\
215 \\
216\end{array}$ & $\begin{array}{r}100 \\
95 \\
120 \\
100 \\
126\end{array}$ \\
\hline 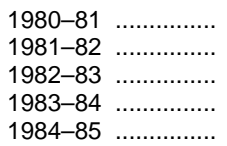 & $\begin{array}{l}16,707 \\
16,495 \\
14,414 \\
12,570 \\
11,754\end{array}$ & $\begin{array}{l}4,248 \\
4,176 \\
3,343 \\
2,998 \\
2,829\end{array}$ & $\begin{array}{r}12,459 \\
12,319 \\
11,071 \\
9,572 \\
8,925\end{array}$ & $\begin{array}{l}17,803 \\
17,416 \\
16,046 \\
15,060 \\
15,575\end{array}$ & $\begin{array}{l}7,460 \\
6,975 \\
5,961 \\
5,634 \\
5,573\end{array}$ & $\begin{array}{r}10,343 \\
10,441 \\
10,085 \\
9,426 \\
10,002\end{array}$ & $\begin{array}{l}362 \\
372 \\
347 \\
420 \\
431\end{array}$ & $\begin{array}{l}212 \\
205 \\
184 \\
230 \\
213\end{array}$ & $\begin{array}{l}150 \\
167 \\
163 \\
190 \\
218\end{array}$ \\
\hline 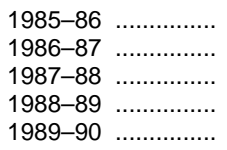 & $\begin{array}{l}11,887 \\
12,328 \\
12,385 \\
13,162 \\
13,908\end{array}$ & $\begin{array}{l}2,966 \\
2,993 \\
2,923 \\
3,214 \\
3,334\end{array}$ & $\begin{array}{r}8,921 \\
9,335 \\
9,462 \\
9,948 \\
10,574\end{array}$ & $\begin{array}{l}15,692 \\
16,432 \\
16,424 \\
17,020 \\
17,399\end{array}$ & $\begin{array}{l}5,594 \\
5,673 \\
5,631 \\
5,615 \\
5,634\end{array}$ & $\begin{array}{l}10,098 \\
10,759 \\
10,793 \\
11,405 \\
11,765\end{array}$ & $\begin{array}{l}382 \\
398 \\
470 \\
428 \\
508\end{array}$ & $\begin{array}{l}171 \\
216 \\
238 \\
210 \\
235\end{array}$ & $\begin{array}{l}211 \\
182 \\
232 \\
218 \\
273\end{array}$ \\
\hline $\begin{array}{l}1990-91 \\
1991-92\end{array}$ & $\begin{array}{l}14,350 \\
15,987 \\
16,775 \\
17,815 \\
18,586 \\
19,849\end{array}$ & $\begin{array}{l}3,215 \\
3,479 \\
3,801 \\
3,919 \\
3,935 \\
4,205\end{array}$ & $\begin{array}{l}11,135 \\
12,508 \\
12,974 \\
13,896 \\
14,651 \\
15,644\end{array}$ & $\begin{array}{l}17,905 \\
19,243 \\
20,634 \\
21,833 \\
23,501 \\
24,229\end{array}$ & $\begin{array}{l}5,679 \\
5,769 \\
6,105 \\
6,406 \\
6,870 \\
6,927\end{array}$ & $\begin{array}{l}12,226 \\
13,474 \\
14,529 \\
15,427 \\
16,631 \\
17,302\end{array}$ & $\begin{array}{l}430 \\
432 \\
459 \\
519 \\
556 \\
499\end{array}$ & $\begin{array}{l}190 \\
204 \\
215 \\
238 \\
274 \\
220\end{array}$ & $\begin{array}{l}240 \\
228 \\
244 \\
281 \\
282 \\
279\end{array}$ \\
\hline
\end{tabular}

1 Includes degrees in public administration; community organization, resources and services; public policy analysis; social work; and public affairs, other.
SOURCE: U.S. Department of Education, National Center for Education Statistics, Higher Education General Information Survey (HEGIS), "Degrees and Other Formal Awards Conferred" surveys, and Integrated Postsecondary Education Data System (IPEDS), "Completions" surveys. (This table was prepared July 1998.)

Table 295.-Earned degrees in the social sciences and history ${ }^{1}$ conferred by institutions of higher education, by level of degree and sex of student: 1970-71 to 1995-96

\begin{tabular}{|c|c|c|c|c|c|c|c|c|c|}
\hline \multirow{2}{*}{ Year } & \multicolumn{3}{|c|}{ Bachelor's degrees } & \multicolumn{3}{|c|}{ Master's degrees } & \multicolumn{3}{|c|}{ Doctor's degrees } \\
\hline & Total & Men & Women & Total & Men & Women & Total & Men & Women \\
\hline 1 & 2 & 3 & 4 & 5 & 6 & 7 & 8 & 9 & 10 \\
\hline $\begin{aligned} 1970-71 & \ldots \ldots \ldots \ldots \ldots . \\
1971-72 & \ldots \ldots \ldots \ldots \ldots . \\
1972-73 & \ldots \ldots \ldots \ldots \ldots . . \\
1973-74 & \ldots \ldots \ldots \ldots \ldots \ldots \\
1974-75 & \ldots \ldots \ldots \ldots \ldots \ldots\end{aligned}$ & $\begin{array}{l}155,324 \\
158,060 \\
155,970 \\
150,320 \\
135,190\end{array}$ & $\begin{array}{r}98,173 \\
100,895 \\
99,735 \\
95,650 \\
84,826\end{array}$ & $\begin{array}{l}57,151 \\
57,165 \\
56,235 \\
54,670 \\
50,364\end{array}$ & $\begin{array}{l}16,539 \\
17,445 \\
17,477 \\
17,293 \\
16,977\end{array}$ & $\begin{array}{l}11,833 \\
12,540 \\
12,605 \\
12,321 \\
11,875\end{array}$ & $\begin{array}{l}4,706 \\
4,905 \\
4,872 \\
4,972 \\
5,102\end{array}$ & $\begin{array}{l}3,660 \\
4,081 \\
4,234 \\
4,124 \\
4,212\end{array}$ & $\begin{array}{l}3,153 \\
3,483 \\
3,573 \\
3,383 \\
3,334\end{array}$ & $\begin{array}{l}507 \\
598 \\
661 \\
741 \\
878\end{array}$ \\
\hline $\begin{array}{rrr}1975-76 & \ldots \ldots \ldots \ldots \ldots \\
1976-77 & \ldots \ldots \ldots \ldots \ldots . . \\
1977-78 & \ldots \ldots \ldots \ldots \ldots . . \\
1978-79 & \ldots \ldots \ldots \ldots \ldots \ldots \\
1979-80 & \ldots \ldots \ldots \ldots \ldots \ldots\end{array}$ & $\begin{array}{l}126,396 \\
117,040 \\
112,952 \\
108,059 \\
103,662\end{array}$ & $\begin{array}{l}78,691 \\
71,128 \\
67,217 \\
62,852 \\
58,511\end{array}$ & $\begin{array}{l}47,705 \\
45,912 \\
45,735 \\
45,207 \\
45,151\end{array}$ & $\begin{array}{l}15,953 \\
15,533 \\
14,718 \\
12,963 \\
12,176\end{array}$ & $\begin{array}{r}10,918 \\
10,413 \\
9,845 \\
8,395 \\
7,794\end{array}$ & $\begin{array}{l}5,035 \\
5,120 \\
4,873 \\
4,568 \\
4,382\end{array}$ & $\begin{array}{l}4,157 \\
3,802 \\
3,594 \\
3,371 \\
3,230\end{array}$ & $\begin{array}{l}3,262 \\
2,957 \\
2,722 \\
2,501 \\
2,357\end{array}$ & $\begin{array}{l}895 \\
845 \\
872 \\
870 \\
873\end{array}$ \\
\hline $\begin{aligned} 1980-81 & \ldots \ldots \ldots \ldots \ldots . \\
1981-82 & \ldots \ldots \ldots \ldots \ldots . . \\
1982-83 & \ldots \ldots \ldots \ldots \ldots . . \\
1983-84 & \ldots \ldots \ldots \ldots \ldots . . \\
1984-85 & \ldots \ldots \ldots \ldots \ldots . .\end{aligned}$ & $\begin{array}{r}100,513 \\
99,705 \\
95,228 \\
93,323 \\
91,570\end{array}$ & $\begin{array}{l}56,131 \\
55,196 \\
52,771 \\
52,154 \\
51,226\end{array}$ & $\begin{array}{l}44,382 \\
44,509 \\
42,457 \\
41,169 \\
40,344\end{array}$ & $\begin{array}{l}11,945 \\
12,002 \\
11,205 \\
10,577 \\
10,503\end{array}$ & $\begin{array}{l}7,457 \\
7,468 \\
6,974 \\
6,551 \\
6,475\end{array}$ & $\begin{array}{l}4,488 \\
4,534 \\
4,231 \\
4,026 \\
4,028\end{array}$ & $\begin{array}{l}3,122 \\
3,061 \\
2,931 \\
2,911 \\
2,851\end{array}$ & $\begin{array}{l}2,274 \\
2,237 \\
2,042 \\
2,030 \\
1,933\end{array}$ & $\begin{array}{l}848 \\
824 \\
889 \\
881 \\
918\end{array}$ \\
\hline $\begin{array}{rrr}1985-86 & \ldots \ldots \ldots \ldots \ldots . . \\
1986-87 & \ldots \ldots \ldots \ldots \ldots . \\
1987-88 & \ldots \ldots \ldots \ldots \ldots . . \\
1988-89 & \ldots \ldots \ldots \ldots \ldots \ldots \\
1989-90 & \ldots \ldots \ldots \ldots \ldots \ldots . .\end{array}$ & $\begin{array}{r}93,840 \\
96,342 \\
100,460 \\
108,151 \\
118,083\end{array}$ & $\begin{array}{l}52,724 \\
53,949 \\
56,377 \\
60,121 \\
65,887\end{array}$ & $\begin{array}{l}41,116 \\
42,393 \\
44,083 \\
48,030 \\
52,196\end{array}$ & $\begin{array}{l}10,564 \\
10,506 \\
10,412 \\
11,023 \\
11,634\end{array}$ & $\begin{array}{l}6,419 \\
6,373 \\
6,310 \\
6,599 \\
6,898\end{array}$ & $\begin{array}{l}4,145 \\
4,133 \\
4,102 \\
4,424 \\
4,736\end{array}$ & $\begin{array}{l}2,955 \\
2,916 \\
2,781 \\
2,885 \\
3,010\end{array}$ & $\begin{array}{l}1,970 \\
2,026 \\
1,849 \\
1,949 \\
2,019\end{array}$ & $\begin{array}{l}985 \\
890 \\
932 \\
936 \\
991\end{array}$ \\
\hline $\begin{array}{l}1990-91 \\
1991-92\end{array}$ & $\begin{array}{l}125,107 \\
133,974 \\
135,703 \\
133,680 \\
128,154 \\
126,479\end{array}$ & $\begin{array}{l}68,701 \\
73,001 \\
73,589 \\
72,006 \\
68,139 \\
65,872\end{array}$ & $\begin{array}{l}56,406 \\
60,973 \\
62,114 \\
61,674 \\
60,015 \\
60,607\end{array}$ & $\begin{array}{l}12,233 \\
12,702 \\
13,471 \\
14,561 \\
14,845 \\
15,012\end{array}$ & $\begin{array}{l}7,016 \\
7,237 \\
7,671 \\
8,152 \\
8,207 \\
8,093\end{array}$ & $\begin{array}{l}5,217 \\
5,465 \\
5,800 \\
6,409 \\
6,638 \\
6,919\end{array}$ & $\begin{array}{l}3,012 \\
3,218 \\
3,460 \\
3,627 \\
3,725 \\
3,760\end{array}$ & $\begin{array}{l}1,956 \\
2,126 \\
2,203 \\
2,317 \\
2,319 \\
2,339\end{array}$ & $\begin{array}{l}1,056 \\
1,092 \\
1,257 \\
1,310 \\
1,406 \\
1,421\end{array}$ \\
\hline
\end{tabular}

${ }^{1}$ Includes degrees in social sciences, general; anthropology; archeology; criminology; demography and population studies; economics; geography; history; international relations and affairs; political science and government; sociology; urban affairs/studies; and social sciences and history, other.
SOURCE: U.S. Department of Education, National Center for Education Statistics, Higher Education General Information Survey (HEGIS), "Degrees and Other Forma Awards Conferred" surveys, and Integrated Postsecondary Education Data System (IPEDS), "Completions" surveys. (This table was prepared July 1998.) 
Table 296.-Earned degrees in economics, history, political science and government, and sociology conferred by institutions of higher education, by level of degree: 1949-50 to 1995-96

\begin{tabular}{|c|c|c|c|c|c|c|c|c|c|c|c|c|c|}
\hline \multirow{2}{*}{\multicolumn{2}{|c|}{ Year }} & \multicolumn{3}{|c|}{ Economics } & \multicolumn{3}{|c|}{ History } & \multicolumn{3}{|c|}{$\begin{array}{l}\text { Political science and } \\
\text { government } 1\end{array}$} & \multicolumn{3}{|c|}{ Sociology } \\
\hline & & $\begin{array}{l}\text { Bach- } \\
\text { elor's }\end{array}$ & Master's & Doctor's & $\begin{array}{l}\text { Bach- } \\
\text { elor's }\end{array}$ & Master's & Doctor's & $\begin{array}{l}\text { Bach- } \\
\text { elor's }\end{array}$ & Master's & Doctor's & $\begin{array}{l}\text { Bach- } \\
\text { elor's }\end{array}$ & Master's & Doctor's \\
\hline & 1 & 2 & 3 & 4 & 5 & 6 & 7 & 8 & 9 & 10 & 11 & 12 & 13 \\
\hline $\begin{array}{l}1949-50 \\
1955-56 \\
1959-60 \\
1961-62 \\
1963-64 \\
1965-66 \\
1967-68 \\
1969-70 \\
1970-71 \\
1971-72 \\
1972-73 \\
1973-74 \\
1974-75 \\
1975-76 \\
1976-77 \\
1977-78 \\
1978-79 \\
1979-80 \\
1980-81 \\
1981-82 \\
1982-83 \\
1983-84 \\
1984-85 \\
1985-86 \\
1986-87 \\
1987-88 \\
1988-89 \\
1989-90 \\
1990-91 \\
1991-92 \\
1992-93 \\
1993-94 \\
1994-95 \\
1995-96 \\
.\end{array}$ & , & $\begin{array}{r}14,568 \\
6,555 \\
7,453 \\
8,366 \\
10,583 \\
11,555 \\
15,193 \\
17,197 \\
15,758 \\
15,231 \\
14,770 \\
14,285 \\
14,046 \\
14,741 \\
15,296 \\
15,661 \\
16,409 \\
17,863 \\
18,753 \\
19,876 \\
20,517 \\
20,719 \\
20,711 \\
21,602 \\
22,378 \\
22,911 \\
23,454 \\
23,923 \\
23,488 \\
23,423 \\
21,321 \\
19,496 \\
17,673 \\
16,674\end{array}$ & $\begin{array}{r}921 \\
581 \\
708 \\
853 \\
1,104 \\
1,522 \\
1,916 \\
1,988 \\
1,995 \\
2,224 \\
2,225 \\
2,141 \\
2,127 \\
2,087 \\
2,158 \\
1,995 \\
1,955 \\
1,821 \\
1,911 \\
1,964 \\
1,972 \\
1,891 \\
1,992 \\
1,937 \\
1,855 \\
1,847 \\
1,886 \\
1,950 \\
1,951 \\
2,106 \\
2,292 \\
2,521 \\
2,400 \\
2,533\end{array}$ & $\begin{array}{l}200 \\
232 \\
237 \\
268 \\
385 \\
458 \\
600 \\
794 \\
721 \\
794 \\
845 \\
788 \\
815 \\
763 \\
758 \\
706 \\
712 \\
677 \\
727 \\
677 \\
734 \\
729 \\
749 \\
789 \\
750 \\
770 \\
827 \\
806 \\
802 \\
866 \\
879 \\
869 \\
910 \\
916\end{array}$ & $\begin{array}{l}13,542 \\
10,510 \\
14,737 \\
17,340 \\
23,668 \\
28,612 \\
35,291 \\
43,386 \\
44,663 \\
43,695 \\
40,943 \\
37,049 \\
31,470 \\
28,400 \\
25,433 \\
23,004 \\
21,019 \\
19,301 \\
18,301 \\
17,146 \\
16,467 \\
16,643 \\
16,049 \\
16,415 \\
16,997 \\
18,207 \\
20,159 \\
22,476 \\
24,541 \\
26,966 \\
27,774 \\
27,503 \\
26,598 \\
26,005\end{array}$ & $\begin{array}{l}1,801 \\
1,114 \\
1,794 \\
2,163 \\
2,705 \\
3,883 \\
4,845 \\
5,049 \\
5,157 \\
5,217 \\
5,030 \\
4,533 \\
4,226 \\
3,658 \\
3,393 \\
3,033 \\
2,536 \\
2,367 \\
2,237 \\
2,210 \\
2,041 \\
1,940 \\
1,921 \\
1,961 \\
2,021 \\
2,093 \\
2,121 \\
2,369 \\
2,591 \\
2,754 \\
2,952 \\
3,009 \\
3,091 \\
2,898\end{array}$ & $\begin{array}{r}275 \\
259 \\
342 \\
343 \\
507 \\
599 \\
688 \\
1,038 \\
991 \\
1,133 \\
1,140 \\
1,114 \\
1,117 \\
1,014 \\
921 \\
813 \\
756 \\
712 \\
643 \\
636 \\
575 \\
561 \\
468 \\
497 \\
534 \\
517 \\
487 \\
570 \\
606 \\
644 \\
690 \\
752 \\
816 \\
805\end{array}$ & $\begin{array}{r}6,336 \\
5,633 \\
6,596 \\
8,326 \\
12,126 \\
15,242 \\
20,387 \\
25,713 \\
27,482 \\
28,135 \\
30,100 \\
30,744 \\
29,126 \\
28,302 \\
26,411 \\
26,069 \\
25,628 \\
25,457 \\
24,977 \\
25,658 \\
25,791 \\
25,719 \\
25,834 \\
26,439 \\
26,817 \\
27,207 \\
30,450 \\
33,560 \\
35,737 \\
37,805 \\
37,931 \\
36,097 \\
33,013 \\
30,775\end{array}$ & $\begin{array}{r}710 \\
509 \\
722 \\
839 \\
1,163 \\
1,429 \\
1,937 \\
2,105 \\
2,318 \\
2,451 \\
2,398 \\
2,448 \\
2,333 \\
2,191 \\
2,222 \\
2,069 \\
2,037 \\
1,938 \\
1,875 \\
1,954 \\
1,829 \\
1,769 \\
1,500 \\
1,704 \\
1,618 \\
1,579 \\
1,598 \\
1,580 \\
1,772 \\
1,908 \\
1,943 \\
2,147 \\
2,019 \\
2,024\end{array}$ & $\begin{array}{l}127 \\
203 \\
201 \\
214 \\
263 \\
336 \\
457 \\
525 \\
700 \\
758 \\
747 \\
766 \\
680 \\
723 \\
641 \\
636 \\
563 \\
535 \\
484 \\
513 \\
435 \\
457 \\
441 \\
439 \\
435 \\
391 \\
452 \\
480 \\
468 \\
535 \\
529 \\
616 \\
637 \\
634\end{array}$ & $\begin{array}{r}7,870 \\
5,878 \\
7,147 \\
8,120 \\
10,943 \\
15,038 \\
21,710 \\
30,436 \\
33,263 \\
35,216 \\
35,436 \\
35,491 \\
31,488 \\
27,634 \\
24,713 \\
22,750 \\
20,285 \\
18,881 \\
17,272 \\
16,042 \\
14,105 \\
13,145 \\
11,968 \\
12,271 \\
12,239 \\
13,024 \\
14,435 \\
16,035 \\
17,550 \\
19,568 \\
20,896 \\
22,368 \\
22,886 \\
24,071\end{array}$ & $\begin{array}{r}552 \\
402 \\
440 \\
578 \\
646 \\
981 \\
1,193 \\
1,813 \\
1,808 \\
1,944 \\
1,923 \\
2,196 \\
2,112 \\
2,009 \\
1,830 \\
1,611 \\
1,415 \\
1,341 \\
1,240 \\
1,145 \\
1,112 \\
1,008 \\
1,022 \\
965 \\
950 \\
984 \\
1,135 \\
1,198 \\
1,260 \\
1,347 \\
1,521 \\
1,639 \\
1,748 \\
1,772\end{array}$ & $\begin{array}{r}98 \\
170 \\
161 \\
173 \\
198 \\
244 \\
367 \\
534 \\
574 \\
636 \\
583 \\
632 \\
693 \\
729 \\
714 \\
599 \\
612 \\
583 \\
610 \\
558 \\
522 \\
520 \\
480 \\
504 \\
451 \\
452 \\
451 \\
432 \\
465 \\
501 \\
536 \\
530 \\
546 \\
527\end{array}$ \\
\hline
\end{tabular}

1 Excludes degrees in public administration and international relations.

SOURCE: US. Department of Education, National Center for Education Statistics, Higher Education General Information Survey (HEGIS), "Degrees and Other Formal Awards Conferred" surveys, and Integrated Postsecondary Education Data System (IPEDS), "Completions" surveys. (This table was prepared July 1998.)

Table 297.-Earned degrees in visual and performing arts ${ }^{1}$ conferred by institutions of higher education, by level of degree and sex of student: 1970-71 to 1995-96

\begin{tabular}{|c|c|c|c|c|c|c|c|c|c|c|}
\hline \multirow{2}{*}{\multicolumn{2}{|c|}{ Year }} & \multicolumn{3}{|c|}{ Bachelor's degrees } & \multicolumn{3}{|c|}{ Master's degrees } & \multicolumn{3}{|c|}{ Doctor's degrees } \\
\hline & & Total & Men & Women & Total & Men & Women & Total & Men & Women \\
\hline & 1 & 2 & 3 & 4 & 5 & 6 & 7 & 8 & 9 & 10 \\
\hline $\begin{array}{l}1970-71 \\
1971-72 \\
1972-73 \\
1973-74 \\
1973 \\
1974-75 \\
1975-76 \\
1976-77 \\
1977-78 \\
1978-79 \\
1979-80 \\
1980-81 \\
1981-82 \\
1982-83 \\
1983-84 \\
1984-85 \\
1985-86 \\
1986-87 \\
1987-88 \\
1988-89 \\
1989-90 \\
1990-91 \\
1991-92 \\
1992-93 \\
1993-94 \\
1994-95 \\
1995-96\end{array}$ & (n) & $\begin{array}{l}30,394 \\
33,831 \\
36,017 \\
39,730 \\
40,782 \\
42,138 \\
41,793 \\
40,951 \\
40,969 \\
40,892 \\
40,479 \\
40,422 \\
39,794 \\
40,131 \\
38,140 \\
37,241 \\
36,615 \\
36,944 \\
38,227 \\
39,934 \\
42,186 \\
46,522 \\
47,761 \\
49,053 \\
48,690 \\
49,296\end{array}$ & $\begin{array}{l}12,256 \\
13,580 \\
14,267 \\
15,821 \\
15,532 \\
16,491 \\
16,166 \\
15,572 \\
15,380 \\
15,065 \\
14,798 \\
14,819 \\
14,690 \\
15,089 \\
14,462 \\
14,236 \\
13,751 \\
14,068 \\
14,539 \\
15,189 \\
15,761 \\
17,616 \\
18,610 \\
19,538 \\
19,781 \\
20,126\end{array}$ & $\begin{array}{l}18,138 \\
20,251 \\
21,750 \\
23,909 \\
25,250 \\
25,647 \\
25,627 \\
25,379 \\
25,589 \\
25,827 \\
25,681 \\
25,603 \\
25,104 \\
25,042 \\
23,678 \\
23,005 \\
22,864 \\
22,876 \\
23,688 \\
24,745 \\
26,425 \\
28,906 \\
29,151 \\
29,515 \\
28,909 \\
29,170\end{array}$ & $\begin{array}{r}6,675 \\
7,537 \\
7,254 \\
8,001 \\
8,362 \\
8,817 \\
8,636 \\
9,036 \\
8,524 \\
8,708 \\
8,629 \\
8,746 \\
8,763 \\
8,526 \\
8,718 \\
8,420 \\
8,508 \\
7,939 \\
8,267 \\
8,481 \\
8,657 \\
9,353 \\
9,440 \\
9,925 \\
10,277 \\
10,280\end{array}$ & $\begin{array}{l}3,510 \\
4,049 \\
4,005 \\
4,325 \\
4,448 \\
4,507 \\
4,211 \\
4,327 \\
3,933 \\
4,067 \\
4,056 \\
3,866 \\
4,013 \\
3,897 \\
3,894 \\
3,775 \\
3,756 \\
3,442 \\
3,611 \\
3,706 \\
3,830 \\
4,078 \\
4,099 \\
4,229 \\
4,374 \\
4,361\end{array}$ & $\begin{array}{l}3,165 \\
3,488 \\
3,249 \\
3,676 \\
3,914 \\
4,310 \\
4,425 \\
4,709 \\
4,591 \\
4,641 \\
4,573 \\
4,880 \\
4,750 \\
4,629 \\
4,824 \\
4,645 \\
4,752 \\
4,497 \\
4,656 \\
4,775 \\
4,827 \\
5,275 \\
5,341 \\
5,696 \\
5,903 \\
5,919\end{array}$ & $\begin{array}{r}621 \\
572 \\
616 \\
585 \\
649 \\
620 \\
662 \\
708 \\
700 \\
655 \\
654 \\
670 \\
692 \\
730 \\
696 \\
722 \\
793 \\
727 \\
753 \\
849 \\
838 \\
906 \\
882 \\
1,054 \\
1,080 \\
1,067\end{array}$ & $\begin{array}{l}483 \\
428 \\
449 \\
440 \\
446 \\
447 \\
447 \\
448 \\
454 \\
413 \\
396 \\
380 \\
404 \\
406 \\
407 \\
396 \\
447 \\
424 \\
446 \\
472 \\
466 \\
504 \\
478 \\
585 \\
545 \\
524\end{array}$ & $\begin{array}{l}138 \\
144 \\
167 \\
145 \\
203 \\
173 \\
215 \\
260 \\
246 \\
242 \\
258 \\
290 \\
288 \\
324 \\
289 \\
326 \\
346 \\
303 \\
307 \\
377 \\
372 \\
402 \\
404 \\
469 \\
535 \\
543\end{array}$ \\
\hline
\end{tabular}

1 Prior to 1982-83: Includes visual and performing arts, general; crafts, folk art, and artisanry; dance; design and applied art; theatre arts; film and photographic arts; fine arts; graphic arts technology; music; and precision production. From 1982-83: Includes visual and performing arts, general; crafts, folk art, and artisanry; dance; design and applied art; theatre arts and stagecraft; film/video and photographic arts; fine arts and art studies; music; and visual and performing arts, other.
SOURCE: U.S. Department of Education, National Center for Education Statistics, Higher Education General Information Survey (HEGIS), "Degrees and Other Formal Awards Conferred" surveys, and Integrated Postsecondary Education Data System (IPEDS), "Completions" surveys. (This table was prepared July 1998.) 
Table 298.-Statistical profile of persons receiving doctor's degrees, ${ }^{1}$ by field of study: $1995-96$

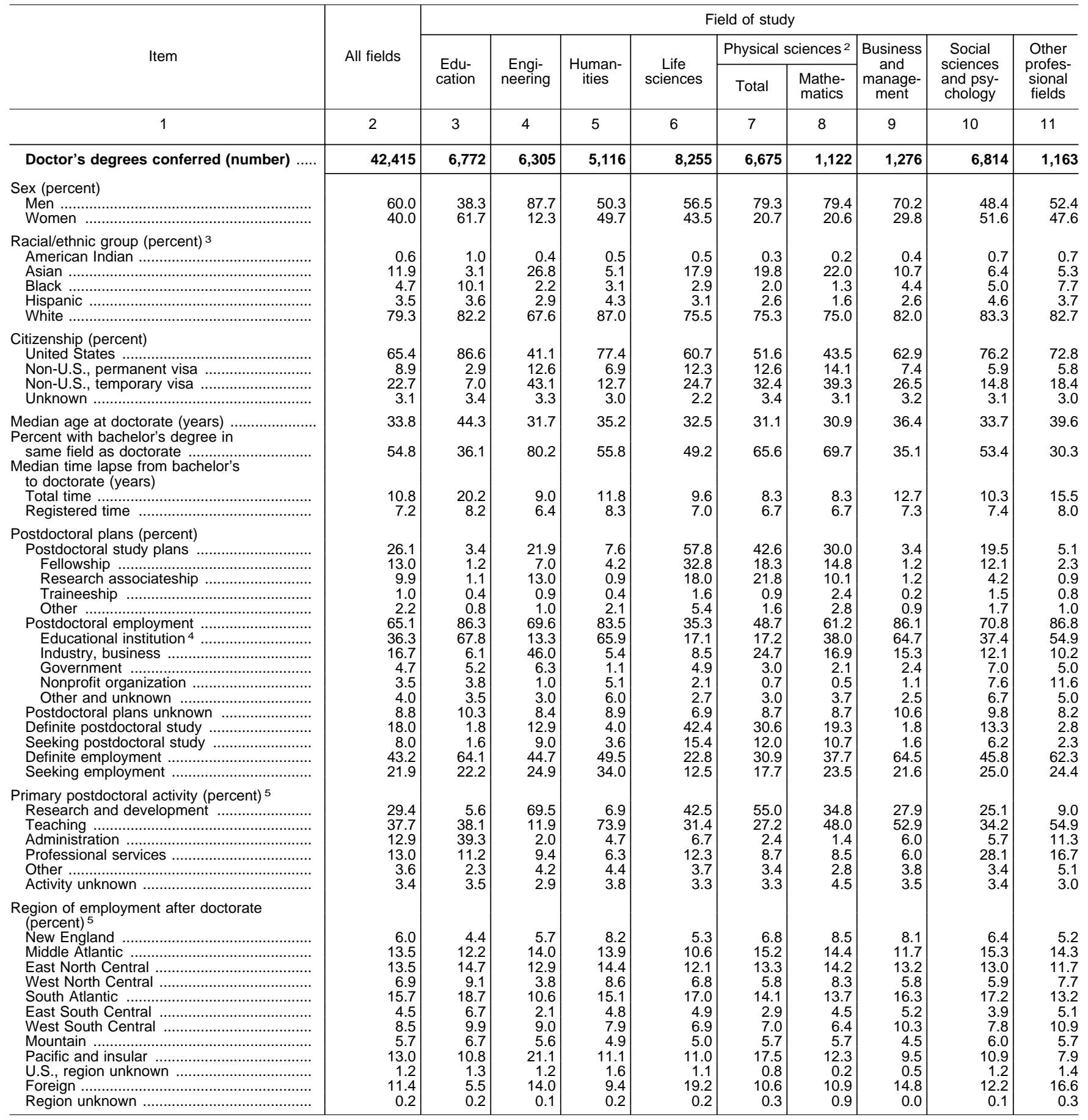

1 Includes Ph.D., Ed.D., and comparable degrees at the doctoral level. Excludes firstprofessional degrees, such as M.D., D.D.S., and D.V.M.

2 Includes mathematics, computer science, physics, astronomy, chemistry, and earth atmospheric, and marine sciences.

${ }^{3}$ Distribution by race/ethnicity based on U.S. citizens and those with permanent visas only.

4 Includes 2-year, 4-year, and foreign colleges and universities, medical schools, and elementary/secondary schools.

5 Includes only recipients with definite employment plans.

NOTE.-The above classification of degrees by field differs somewhat from that in most publications of the National Center for Education Statistics (NCES). The major dif- ferences are that history is included under humanities rather than social sciences and that psychology is included under social sciences. The number of degrees also differs slightly from that reported in the NCES "Completions" survey. The above tabulation excludes some non-research doctorate degrees such as doctor's degrees in theology. Total includes a small number of graduates not reported by field of study. Because of rounding, percents may not add to 100.0 .

SOURCE: National Academy of Sciences, National Research Council, Office of Scientific and Engineering Personnel, Summary Report 1996: Doctorate Recipients from United States Universities. (This table was prepared May 1998.) 
Table 299.-Statistical profile of persons receiving doctor's degrees in education: 1979-80 to 1995-96

\begin{tabular}{|c|c|c|c|c|c|c|c|c|c|c|c|c|c|c|c|}
\hline Item & $1979-80$ & $1980-81$ & 1983-84 & 1984-85 & $1985-86$ & $1986-87$ & $1987-88$ & $1988-89$ & $1989-90$ & 1990-91 & $1991-92$ & 1992-93 & 1993-94 & 1994-95 & 1995-96 \\
\hline 1 & 2 & 3 & 4 & 5 & 6 & 7 & 8 & 9 & 10 & 11 & 12 & 13 & 14 & 15 & 16 \\
\hline Number of doctorates & 7,576 & 7,489 & 6,780 & 6,717 & 6,649 & 6,454 & 6,362 & 6,281 & 6,510 & 6,454 & 6,677 & 6,689 & 6,708 & 6,649 & 6,772 \\
\hline \multicolumn{16}{|l|}{ Sex (percent) } \\
\hline Men & 55.5 & 52.8 & 49.0 & 48.2 & 45.6 & 44.9 & 44.8 & 42.5 & 42.4 & 41.9 & 40.5 & 41.3 & 39.1 & 38.4 & 38.3 \\
\hline Women .................... & 44.5 & 47.2 & 51.0 & 51.8 & 54.4 & 55.1 & 55.2 & 57.5 & 57.6 & 58.1 & 59.5 & 58.7 & 60.9 & 61.6 & 61.7 \\
\hline \multicolumn{16}{|l|}{$\begin{array}{l}\text { Racial/ethnic group } \\
\text { percent }{ }^{1}\end{array}$} \\
\hline American Indian ........... & 0.8 & 0.6 & 0.5 & 0.7 & 0.5 & 0.7 & 0.6 & 0.4 & 0.6 & 1.0 & 0.8 & 0.8 & 0.6 & 0.7 & 1.0 \\
\hline Asian .............................. & 1.3 & 1.9 & 1.5 & 1.7 & 1.6 & 1.7 & 2.4 & 1.9 & 1.8 & 2.2 & 2.4 & 2.4 & 2.9 & 3.0 & 3.1 \\
\hline Black ...................... & 9.1 & 9.1 & 8.7 & 8.7 & 8.1 & 7.4 & 7.6 & 8.1 & 8.2 & 7.9 & 8.4 & 9.4 & 8.6 & 10.4 & 10.1 \\
\hline Hispanic & 2.4 & 2.5 & 2.6 & 3.2 & 3.7 & 3.6 & 2.9 & 3.1 & 3.3 & 3.3 & 3.5 & 3.7 & 4.0 & 4.4 & 3.6 \\
\hline White ....... & 86.3 & 85.9 & 86.7 & 85.6 & 86.1 & 86.6 & 86.4 & 86.5 & 86.0 & 85.6 & 84.8 & 83.7 & 83.9 & 81.6 & 82.2 \\
\hline \multicolumn{16}{|l|}{ Citizenship (percent) } \\
\hline United States ............... & 88.7 & 87.7 & 86.8 & 85.5 & 84.7 & 84.9 & 83.1 & 82.9 & 84.4 & 84.8 & 86.8 & 86.4 & 87.4 & 86.8 & 86.6 \\
\hline Foreign $\ldots \ldots \ldots \ldots \ldots \ldots \ldots$ & 8.2 & 8.8 & 9.8 & 10.4 & 9.6 & 9.2 & 10.2 & 9.7 & 9.7 & 10.2 & 10.7 & 10.8 & 11.0 & 11.0 & 9.9 \\
\hline Unknown ........................ & 3.1 & 3.6 & 3.4 & 4.1 & 5.6 & 6.0 & 6.7 & 7.4 & 5.8 & 5.0 & 2.4 & 2.7 & 1.6 & 2.3 & 3.4 \\
\hline \multicolumn{16}{|l|}{ Median age at doctorate } \\
\hline (years) ................................. & 37.0 & 37.3 & 38.4 & 38.7 & 39.4 & 39.8 & 40.5 & 41.1 & 41.6 & 42.1 & 42.7 & 43.0 & 43.6 & 43.8 & 44.3 \\
\hline \multicolumn{16}{|l|}{$\begin{array}{l}\text { Percent with bachelor's } \\
\text { degree in same }\end{array}$} \\
\hline field as doctorate $\ldots . . .$. & 39.0 & 38.9 & 39.6 & 38.7 & 39.0 & 37.8 & 36.9 & 38.5 & 37.5 & 39.3 & 38.7 & 37.4 & 36.9 & 37.0 & 36.1 \\
\hline \multicolumn{16}{|l|}{$\begin{array}{l}\text { Median time lapse from } \\
\text { bachelor's to } \\
\text { doctorate (years) }\end{array}$} \\
\hline Total time ..................... & 13.1 & 13.5 & 14.6 & 15.1 & 15.7 & 16.2 & 16.9 & 17.3 & 17.9 & 18.4 & 18.9 & 19.2 & 19.7 & 19.9 & 20.2 \\
\hline Registered time ........... & 6.9 & 7.0 & 7.6 & 7.6 & 7.8 & 7.9 & 8.1 & 8.2 & 8.1 & 8.1 & 8.2 & 8.2 & 8.1 & 8.2 & 8.2 \\
\hline
\end{tabular}

${ }^{1}$ Longitudinal comparisons by race/ethnicity should be done with extreme care, due to periodic changes in the survey. Distribution by race/ethnicity based on U.S. citizens and those with permanent visas only.

NOTE.-The National Research Council's classification of degrees by field differs somewhat from that in most publications of the National Center for Education Statistics (NCES). The number of degrees also differs slightly from that reported in the NCES
"Completions" survey. Some data have been revised from previously published figures. Because of rounding, percents may not add to 100.0 .

SOURCE: National Academy of Sciences, National Research Council, Office of Scientific and Engineering Personnel, Doctorate Records File. (This table was prepared May 1998.)

Table 300.-Statistical profile of persons receiving doctor's degrees in engineering: 1979-80 to 1995-96

\begin{tabular}{|c|c|c|c|c|c|c|c|c|c|c|c|c|c|c|c|}
\hline Item & $1979-80$ & $1980-81$ & $1983-84$ & $1984-85$ & $1985-86$ & $1986-87$ & $1987-88$ & $1988-89$ & $\mid 1989-90$ & $\mid 1990-91$ & $1991-92$ & 1992-93 & $\mid 1993-94$ & 1994-95 & $1995-96$ \\
\hline 1 & 2 & 3 & 4 & 5 & 6 & 7 & 8 & 9 & 10 & 11 & 12 & 13 & 14 & 15 & 16 \\
\hline Number of doctorates & 2,479 & 2,528 & 2,915 & 3,165 & 3,376 & 3,712 & 4,187 & 4,543 & 4,894 & 5,214 & 5,438 & 5,698 & 5,822 & 6,008 & 6,305 \\
\hline Sex (percent) & & & & & & & & & & & & & & & \\
\hline Men & 96.4 & 96.1 & 94.8 & 93.7 & 93.3 & 93.5 & 93.2 & 91.8 & 91.5 & 91.3 & 90.7 & 90.9 & 89.1 & 88.4 & 87.7 \\
\hline Women ......... & 3.6 & 3.9 & 5.2 & 6.3 & 6.7 & 6.6 & 6.8 & 8.2 & 8.5 & 8.7 & 9.3 & 9.1 & 10.9 & 11.6 & 12.3 \\
\hline $\begin{array}{l}\text { Racial/ethnic group } \\
\text { (percent) }{ }^{1}\end{array}$ & & & & & & & & & & & & & & & \\
\hline Ämerican Indian ........ & 0.2 & 0.3 & 0.2 & 0.1 & 0.3 & 0.4 & 0.2 & 0.3 & 0.2 & 0.3 & 0.4 & 0.1 & 0.2 & 0.3 & 0.4 \\
\hline Asian & 18.9 & 20.0 & 17.1 & 18.4 & 15.6 & 17.7 & 16.0 & 16.6 & 15.3 & 17.4 & 18.2 & 19.7 & 28.8 & 31.5 & 26.8 \\
\hline Black & 1.2 & 1.4 & 1.0 & 2.2 & 1.4 & 1.3 & 1.4 & 1.4 & 1.8 & 2.4 & 1.9 & 1.9 & 1.8 & 2.2 & 2.2 \\
\hline Hispanic ......................... & 1.9 & 1.0 & 2.4 & 1.5 & 2.1 & 1.8 & 3.0 & 2.2 & 2.4 & 2.6 & 3.0 & 2.4 & 2.2 & 2.4 & 2.9 \\
\hline White & 77.8 & 77.3 & 79.3 & 77.8 & 80.6 & 78.8 & 79.4 & 79.5 & 80.4 & 77.4 & 76.5 & 75.9 & 67.0 & 63.7 & 67.6 \\
\hline Citizenship (percent) & & & & & & & & & & & & & & & \\
\hline Unitec & 50.6 & 46.2 & 42.5 & 40.4 & 40.8 & 41.8 & 42.4 & 40.9 & 39.4 & 37.9 & 38.7 & 39.1 & 38.0 & 39.7 & 41.1 \\
\hline Foreign ............. & 46.3 & 49.1 & 52.9 & 54.6 & 50.8 & 50.7 & 49.8 & 50.4 & 52.5 & 54.7 & 57.8 & 57.1 & 60.0 & 57.9 & 55.7 \\
\hline Unknown ......... & 3.1 & 4.7 & 4.6 & 5.0 & 8.4 & 7.4 & 7.7 & 8.8 & 8.1 & 7.3 & 3.5 & 3.9 & 2.1 & 2.5 & 3.3 \\
\hline Median age at doctorate & & & & & & & & & & & & & & & \\
\hline $\begin{array}{l}\text { (years) } \\
\text { Percent with bachelor's }\end{array}$ & 30.3 & 30.5 & 30.7 & 30.9 & 31.0 & 31.0 & 31.0 & 31.1 & 31.2 & 31.4 & 31.5 & 31.6 & 31.7 & 31.7 & 31.7 \\
\hline $\begin{array}{l}\text { degree in same } \\
\text { field as doctorate }\end{array}$ & & & & & & & & & & & & & & & \\
\hline $\begin{array}{l}\text { field as doctorate ........ } \\
\text { Median time lapse from }\end{array}$ & 15.2 & 14.1 & 14.3 & 14.2 & 13.0 & 15.2 & 16.4 & 10.2 & 76.9 & 79.0 & 81.8 & 80.1 & 80.4 & 79.1 & 80.2 \\
\hline $\begin{array}{l}\text { bachelor's to } \\
\text { doctorate (years) }\end{array}$ & & & & & & & & & & & & & & & \\
\hline Total ti & 7.6 & 7.9 & 8.0 & 8.1 & 8.1 & 8.1 & 8.1 & 8.1 & 8.2 & 8.5 & 8.7 & 8.8 & 9.0 & 9.1 & 9.0 \\
\hline Registered time & 5.6 & 5.6 & 5.8 & 5.8 & 5.9 & 5.9 & 5.9 & 6.0 & 6.0 & 6.1 & 6.2 & 6.3 & 6.4 & 6.4 & 6.4 \\
\hline
\end{tabular}

1 Longitudinal comparisons by race/ethnicity should be done with extreme care, due to periodic changes in the survey. Distribution by race/ethnicity based on U.S. citizens and those with permanent visas only.

NOTE.-The National Research Council's classification of degrees by field differs somewhat from that in most publications of the National Center for Education Statistics (NCES). The number of degrees also differs slightly from that reported in the NCES
"Completions" survey. Some data have been revised from previously published figures. Because of rounding, percents may not add to 100.0 .

SOURCE: National Academy of Sciences, National Research Council, Office of Scientific and Engineering Personnel, Doctorate Records File. (This table was prepared May 1998.) 
Table 301.-Statistical profile of persons receiving doctor's degrees in the humanities: 1 1979-80 to 1995-96

\begin{tabular}{|c|c|c|c|c|c|c|c|c|c|c|c|c|c|c|c|}
\hline Item & $1979-80$ & $1980-81$ & 1983-84 & 1984-85 & $1985-86$ & $1986-87$ & $1987-88$ & 1988-89 & $1989-90$ & $1990-91$ & 1991-92 & 1992-93 & 1993-94 & 1994-95 & $1995-96$ \\
\hline 1 & 2 & 3 & 4 & 5 & 6 & 7 & 8 & 9 & 10 & 11 & 12 & 13 & 14 & 15 & 16 \\
\hline Number of doctorates & 3,863 & 3,745 & 3,528 & 3,428 & 3,461 & 3,500 & 3,555 & 3,552 & 3,822 & 4,099 & 4,444 & 4,482 & 4,744 & 5,061 & 5,116 \\
\hline Sex (percent) & & & & & & & & & & & & & & & \\
\hline Men & 60.4 & 58.7 & 55.0 & 56.6 & 54.8 & 55.1 & 55.7 & 54.5 & 54.4 & 53.5 & 53.7 & 52.5 & 52.3 & 51.7 & 50.3 \\
\hline $\begin{array}{l}\text { Women ...................... } \\
\text { Racial/ethnic group } \\
\text { (percent) }{ }^{2}\end{array}$ & 39.6 & 41.3 & 45.0 & 43.4 & 45.2 & 44.9 & 44.3 & 45.5 & 45.6 & 46.5 & 46.3 & 47.5 & 47.7 & 48.3 & 49.7 \\
\hline Ämerican Indian ........... & 0.3 & 0.4 & 0.2 & 0.3 & 0.2 & 0.4 & 0.2 & 0.2 & 0.3 & 0.3 & 0.5 & 0.3 & 0.6 & 0.4 & 0.5 \\
\hline Asian .............. & 2.0 & 1.8 & 1.8 & 2.3 & 1.8 & 2.1 & 2.3 & 3.0 & 2.4 & 2.5 & 3.0 & 3.6 & 4.6 & 5.1 & 5.1 \\
\hline Black .................. & 3.0 & 2.9 & 3.4 & 2.6 & 2.9 & 2.9 & 3.0 & 2.9 & 2.3 & 3.0 & 2.7 & 3.0 & 2.9 & 2.9 & 3.1 \\
\hline Hispanic . & 3.0 & 3.2 & 3.7 & 3.8 & 3.5 & 4.3 & 3.9 & 3.8 & 4.2 & 4.3 & 3.9 & 4.2 & 4.4 & 3.8 & 4.3 \\
\hline White ......................... & 91.6 & 91.7 & 90.9 & 91.1 & 91.6 & 90.3 & 90.5 & 90.2 & 90.9 & 89.9 & 89.9 & 88.9 & 87.5 & 87.8 & 87.0 \\
\hline Citizenship (percent) & & & & & & & & & & & & & & & \\
\hline United States & 87.3 & 85.7 & 83.7 & 83.1 & 78.8 & 78.0 & 78.4 & 76.4 & 78.3 & 77.0 & 77.7 & 78.3 & 78.3 & 78.6 & 77.4 \\
\hline Foreic & 8.8 & 10.2 & 11.2 & 12.1 & 13.7 & 14.3 & 14.4 & 15.5 & 15.2 & 18.3 & 19.2 & 18.7 & 19.9 & 19.4 & 19.6 \\
\hline Unknown & 3.9 & 4.1 & 5.2 & 4.8 & 7.4 & 7.7 & 7.1 & 8.1 & 6.5 & 4.7 & 3.2 & 3.0 & 1.8 & 1.9 & 3.0 \\
\hline $\begin{array}{l}\text { Median age at doctorate } \\
\text { (years) }\end{array}$ & 33.4 & 33.5 & 34.5 & 34.7 & 35.0 & 35.0 & 35.4 & 35.7 & 35.7 & 35.8 & 35.6 & 35.6 & 35.7 & 35.4 & 35.2 \\
\hline $\begin{array}{l}\text { Percent with bachelor's } \\
\text { degree in same }\end{array}$ & 0.1 & 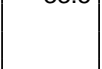 & . & 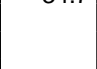 & 0.0 & 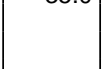 & & & & & & & & & \\
\hline field as doctorate .......... & 64.2 & 61.0 & 60.2 & 58.8 & 58.2 & 58.5 & 56.7 & 55.5 & 57.1 & 57.7 & 56.5 & 56.4 & 57.4 & 56.6 & 55.8 \\
\hline $\begin{array}{l}\text { Median time lapse from } \\
\text { bachelor's to } \\
\text { doctorate (years) }\end{array}$ & & & & & & & & & & & & & & & \\
\hline Total & 10.6 & 10.8 & 11.5 & 11.7 & 12.1 & 12.0 & 12.2 & 12.5 & 12.2 & 12.3 & 12.0 & 11.9 & 12.0 & 12.0 & 11.8 \\
\hline Registered time ......... & 7.7 & 7.7 & 8.2 & 8.3 & 8.2 & 8.4 & 8.5 & 8.4 & 8.3 & 8.4 & 8.3 & 8.3 & 8.5 & 8.4 & 8.3 \\
\hline
\end{tabular}

${ }^{1}$ Includes American studies, archeology, art history, classics, history, letters, literature, music, philosophy, religion, and theatre.

${ }^{2}$ Longitudinal comparisons by race/ethnicity should be done with extreme care, due to periodic changes in the survey. Distribution by race/ethnicity based on U.S. citizens and those with permanent visas only.

NOTE.-The National Research Council's classification of degrees by field differs somewhat from that in most publications of the National Center for Education Statistics (NCES). The major differences are that history is included under humanities rather than social sciences and that psychology is included under social sciences. The number of degrees also differs slightly from that reported in the NCES "Completions" survey. Some data have been revised from previously published figures. Because of rounding, percents may not add to 100.0 .

SOURCE: National Academy of Sciences, National Research Council, Office of Scientific and Engineering Personnel, Doctorate Records File. (This table was prepared May 1998.)

Table 302.-Statistical profile of persons receiving doctor's degrees in the life sciences: ${ }^{1} 1979-80$ to $1995-96$

\begin{tabular}{|c|c|c|c|c|c|c|c|c|c|c|c|c|c|c|c|}
\hline Item & $\mid 1979-80$ & $1980-81$ & 1983-84 & \begin{tabular}{|l|}
$1984-85$ \\
\end{tabular} & 1985-86 & \begin{tabular}{|l}
$1986-87$ \\
\end{tabular} & \begin{tabular}{|l|}
$1987-88$ \\
\end{tabular} & 1988-89 & 1989-90 & \begin{tabular}{|l|}
$1990-91$ \\
\end{tabular} & 1991-92 & \begin{tabular}{|l|}
$1992-93$ \\
\end{tabular} & \begin{tabular}{|l|}
$1993-94$ \\
\end{tabular} & 1994-95 & 1995-96 \\
\hline 1 & 2 & 3 & 4 & 5 & 6 & 7 & 8 & 9 & 10 & 11 & 12 & 13 & 14 & 15 & 16 \\
\hline Number of doctorates & 5,325 & 5,461 & 5,745 & 5,748 & 5,734 & 5,754 & 6,164 & 6,342 & 6,605 & 6,933 & 7,115 & 7,395 & 7,739 & 7,918 & 8,255 \\
\hline Sex (percent) & & & & & & & & & & & & & & & \\
\hline Men ................. & 74.8 & 73.6 & 68.9 & 67.7 & 66.0 & 64.8 & 63.2 & 61.8 & 62.6 & 61.4 & 60.7 & 58.3 & 58.4 & 57.9 & 56.5 \\
\hline Women ……………........ & 25.2 & 26.4 & 31.1 & 32.3 & 34.0 & 35.2 & 36.8 & 38.2 & 37.4 & 38.6 & 39.3 & 41.7 & 41.6 & 42.1 & 43.5 \\
\hline $\begin{array}{l}\text { Racial/ethnic group } \\
\text { (percent) }^{2}\end{array}$ & & & & & & & & & & & & & & & \\
\hline American Indian ............ & 0.2 & 0.2 & 0.3 & 0.4 & 0.5 & 0.4 & 0.4 & 0.3 & 0.2 & 0.4 & 0.4 & 0.3 & 0.4 & 0.5 & 0.5 \\
\hline 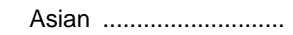 & 5.3 & 4.8 & 4.7 & 4.7 & 4.9 & 5.7 & 5.0 & 5.3 & 5.6 & 6.6 & 7.1 & 8.7 & 15.7 & 18.5 & 17.9 \\
\hline Black ......................... & 1.6 & 1.9 & 2.1 & 2.1 & 1.9 & 2.5 & 2.2 & 2.1 & 1.9 & 2.4 & 2.3 & 2.9 & 2.6 & 3.1 & 2.9 \\
\hline Hispanic ....... & 1.1 & 1.4 & 1.4 & 1.9 & 2.1 & 2.0 & 2.3 & 2.1 & 2.7 & 2.6 & 2.8 & 3.0 & 3.2 & 3.0 & 3.1 \\
\hline White & 91.8 & 91.7 & 91.5 & 90.8 & 90.5 & 89.4 & 90.0 & 90.1 & 89.6 & 88.0 & 87.3 & 85.1 & 78.2 & 74.9 & 75.5 \\
\hline Citizenship (percent) & & & & & & & & & & & & & & & \\
\hline United States ......... & 80.4 & 80.3 & 79.4 & 77.1 & 75.9 & 73.5 & 71.3 & 71.1 & 68.0 & 66.8 & 65.7 & 65.3 & 64.0 & 63.1 & 60.7 \\
\hline Foreig & 17.6 & 17.1 & 17.6 & 19.3 & 18.8 & 20.5 & 22.2 & 22.1 & 26.3 & 29.1 & 31.8 & 32.6 & 34.9 & 35.2 & 37.0 \\
\hline Unknown & 2.0 & 2.6 & 3.0 & 3.6 & 5.3 & 6.1 & 6.4 & 6.9 & 5.6 & 4.0 & 2.5 & 2.2 & 1.1 & 1.7 & 2.2 \\
\hline $\begin{array}{l}\text { Median age at doctorate } \\
\text { (years) }\end{array}$ & 30.0 & 30.1 & 310 & 31.3 & 31.6 & 317 & 319 & $32 ?$ & 323 & 324 & 327 & 325 & 327 & 324 & 325 \\
\hline $\begin{array}{l}\text { Percent with bachelor's } \\
\text { degree in same }\end{array}$ & & & & & & & & & & & & & 32.7 & 32.4 & 32.5 \\
\hline field as doctorate & 40.9 & 40.7 & 58.1 & 58.3 & 57.1 & 55.6 & 55.4 & 53.4 & 53.8 & 54.1 & 53.5 & 51.9 & 51.0 & 50.8 & 49.2 \\
\hline $\begin{array}{l}\text { Median time lapse from } \\
\text { bachelor's to } \\
\text { doctorate (years) }\end{array}$ & & & & & & & & & & & & & & & \\
\hline Total time ... & 7.3 & 7.3 & 8.2 & 8.4 & 8.7 & 8.7 & 8.9 & 9.1 & 9.1 & 9.1 & 9.4 & 9.4 & 9.5 & 9.5 & 9.6 \\
\hline Registered time ............ & 5.8 & 5.9 & 6.3 & 6.3 & 6.4 & 6.5 & 6.5 & 6.5 & 6.7 & 6.7 & 6.7 & 6.8 & 7.0 & 7.0 & 7.0 \\
\hline
\end{tabular}

1 Includes agricultural, biological, and health sciences.

2 Longitudinal comparisons by race/ethnicity should be done with extreme care, due to periodic changes in the survey. Distribution by race/ethnicity based on U.S. citizens and those with permanent visas only.

NOTE.-The National Research Council's classification of degrees by field differs somewhat from that in most publications of the National Center for Education Statistics
(NCES). The number of degrees also differs slightly from that reported in the NCES "Completions" survey. Some data have been revised from previously published figures. Because of rounding, percents may not add to 100.0 .

SOURCE: National Academy of Sciences, National Research Council, Office of Scientific and Engineering Personnel, Doctorate Records File. (This table was prepared May 1998.) 
Table 303.-Statistical profile of persons receiving doctor's degrees in the physical sciences: ${ }^{1} 1979-80$ to $1995-96$

\begin{tabular}{|c|c|c|c|c|c|c|c|c|c|c|c|c|c|c|c|}
\hline Item & $1979-80$ & $1980-81$ & 1983-84 & 1984-85 & $1985-86$ & $1986-87$ & $1987-88$ & $1988-89$ & $1989-90$ & 1990-91 & $1991-92$ & 1992-93 & 1993-94 & 1994-95 & 1995-96 \\
\hline 1 & 2 & 3 & 4 & 5 & 6 & 7 & 8 & 9 & 10 & 11 & 12 & 13 & 14 & 15 & 16 \\
\hline Number of doctorates & 3,151 & 3,208 & 3,459 & 3,531 & 3,679 & 3,840 & 4,045 & 3,984 & 4,262 & 4,441 & 4,575 & 4,470 & 4,801 & 4,621 & 4,632 \\
\hline \multicolumn{16}{|l|}{ Sex (percent) } \\
\hline Men & 87.7 & 88.7 & 85.4 & 83.7 & 83.6 & 83.3 & 82.6 & 80.9 & 81.2 & 81.0 & 79.1 & 78.9 & 79.0 & 77.3 & 78.1 \\
\hline Women .................... & 12.3 & 11.3 & 14.6 & 16.3 & 16.4 & 16.7 & 17.4 & 19.2 & 18.8 & 19.0 & 20.9 & 21.1 & 21.0 & 22.7 & 21.9 \\
\hline \multicolumn{16}{|l|}{$\begin{array}{l}\text { Racial/ethnic group } \\
\text { (percent) }{ }^{2}\end{array}$} \\
\hline American Indian ........... & 0.2 & 0.1 & 0.2 & 0.1 & 0.2 & 0.3 & 0.3 & 0.6 & 0.1 & 0.5 & 0.5 & 0.3 & 0.2 & 0.3 & 0.3 \\
\hline Asian .............................. & 7.7 & 6.9 & 6.6 & 6.9 & 7.1 & 7.0 & 5.7 & 6.7 & 6.6 & 6.6 & 8.9 & 10.2 & 20.8 & 25.3 & 18.9 \\
\hline Black ...................... & 1.0 & 1.3 & 1.3 & 1.2 & 1.0 & 1.0 & 1.3 & 1.3 & 1.0 & 1.2 & 1.1 & 1.6 & 1.6 & 1.4 & 2.1 \\
\hline Hispanic ...... & 1.1 & 1.3 & 2.0 & 1.7 & 2.1 & 2.4 & 2.6 & 2.6 & 3.1 & 2.9 & 3.2 & 3.4 & 2.6 & 2.5 & 2.8 \\
\hline White $\ldots \ldots \ldots \ldots \ldots$ & 90.0 & 90.5 & 89.9 & 90.1 & 89.5 & 89.3 & 90.1 & 88.8 & 89.3 & 88.8 & 86.4 & 84.5 & 74.8 & 70.6 & 76.0 \\
\hline \multicolumn{16}{|l|}{ Citizenship (percent) } \\
\hline United States ............... & 75.9 & 75.4 & 73.6 & 70.3 & 66.1 & 65.1 & 64.3 & 62.5 & 61.0 & 59.3 & 57.9 & 57.1 & 56.3 & 56.7 & 54.7 \\
\hline Foreign $\ldots \ldots \ldots \ldots \ldots \ldots \ldots$ & 21.6 & 21.3 & 23.5 & 25.5 & 27.8 & 28.5 & 28.8 & 29.8 & 32.4 & 35.9 & 39.6 & 39.7 & 41.7 & 41.7 & 41.8 \\
\hline Unknown ........................ & 2.4 & 3.3 & 2.9 & 4.1 & 6.1 & 6.4 & 6.9 & 7.8 & 6.7 & 4.8 & 2.5 & 3.2 & 2.1 & 1.8 & 3.5 \\
\hline \multicolumn{16}{|l|}{ Median age at doctorate } \\
\hline (years) ................................. & 29.1 & 29.0 & 29.5 & 29.5 & 29.9 & 29.8 & 30.1 & 30.0 & 30.7 & 30.2 & 30.3 & 30.6 & 30.7 & 30.7 & 31.6 \\
\hline \multicolumn{16}{|l|}{$\begin{array}{l}\text { Percent with bachelor's } \\
\text { degree in same }\end{array}$} \\
\hline field as doctorate $\ldots . . .$. & 76.5 & 76.6 & 77.7 & 75.0 & 73.4 & 72.6 & 72.6 & 72.6 & 80.0 & 76.9 & 74.5 & 72.9 & 73.0 & 70.8 & 69.6 \\
\hline \multicolumn{16}{|l|}{$\begin{array}{l}\text { Median time lapse from } \\
\text { bachelor's to } \\
\text { doctorate (years) }\end{array}$} \\
\hline Total time $. . . \ldots \ldots \ldots \ldots \ldots . . . . . . .$. & 6.8 & 6.7 & 7.0 & 7.1 & 7.1 & 7.1 & 7.2 & 7.2 & 7.8 & 7.5 & 7.8 & 8.0 & 8.2 & 8.1 & 8.9 \\
\hline Registered time ........... & 5.7 & 5.7 & 6.0 & 6.0 & 6.0 & 5.9 & 6.1 & 6.0 & 6.3 & 6.2 & 6.4 & 6.4 & 6.6 & 6.8 & 6.9 \\
\hline
\end{tabular}

${ }^{1}$ Includes physics, astronomy, chemistry, and earth, atmospheric, and marine sciences. Excludes mathematics and computer science.

2 Longitudinal comparisons by race/ethnicity should be done with extreme care, due to periodic changes in the survey. Distribution by race/ethnicity based on U.S. citizens and those with permanent visas only.

NOTE.-The National Research Council's classification of degrees by field differs somewhat from that in most publications of the National Center for Education Statistics
(NCES). The number of degrees also differs slightly from that reported in the NCES "Completions" survey. Some data have been revised from previously published figures. Because of rounding, percents may not add to 100.0 .

SOURCE: National Academy of Sciences, National Research Council, Office of Scientific and Engineering Personnel, Doctorate Records File. (This table was prepared May 1998.)

Table 304.-Statistical profile of persons receiving doctor's degrees in the social sciences: ${ }^{1} 1979-80$ to $1995-96$

\begin{tabular}{|c|c|c|c|c|c|c|c|c|c|c|c|c|c|c|c|}
\hline Item & 1979-80 & $1980-81$ & $1983-84$ & $1984-85$ & $1985-86$ & $1986-87$ & $1987-88$ & 1988-89 & $1989-90$ & $1990-91$ & 1991-92 & 1992-93 & $1993-94$ & 1994-95 & 1995-96 \\
\hline 1 & 2 & 3 & 4 & 5 & 6 & 7 & 8 & 9 & 10 & 11 & 12 & 13 & 14 & 15 & 16 \\
\hline Number of doctorates & 6,253 & 6,505 & 5,895 & 5,720 & 5,893 & 5,790 & 5,781 & 5,961 & 6,093 & 6,152 & 6,216 & 6,545 & 6,613 & 6,635 & 6,814 \\
\hline Sex (percent) & & & & & & & & & & & & & & & \\
\hline Men ............ & 65.4 & 64.4 & 59.2 & 58.9 & 57.6 & 57.2 & 55.0 & 54.8 & 53.7 & 50.6 & 52.6 & 50.7 & 50.6 & 49.2 & 48.4 \\
\hline Women ......................... & 34.6 & 35.6 & 40.8 & 41.1 & 42.4 & 42.8 & 45.0 & 45.2 & 46.3 & 49.4 & 47.4 & 49.3 & 49.4 & 50.8 & 51.6 \\
\hline $\begin{array}{l}\text { Racial/ethnic group } \\
\text { (percent) })^{2}\end{array}$ & & & & & & & & & & & & & & & \\
\hline American Indian . & 0.3 & 0.2 & 0.2 & 0.4 & 0.4 & 0.5 & 0.3 & 0.4 & 0.5 & 0.4 & 0.5 & 0.4 & 0.5 & 0.5 & 0.7 \\
\hline Asian ............................... & 2.8 & 2.5 & 2.5 & 2.6 & 2.6 & 3.2 & 3.3 & 3.1 & 3.0 & 3.3 & 3.6 & 4.0 & 6.1 & 7.3 & 6.4 \\
\hline Black ........................... & 4.2 & 4.0 & 4.6 & 4.4 & 4.1 & 3.8 & 4.4 & 4.4 & 4.4 & 4.9 & 4.5 & 4.7 & 4.7 & 5.2 & 5.0 \\
\hline Hispanic . ...................... & 2.0 & 2.3 & 2.8 & 2.9 & 3.3 & 3.6 & 3.3 & 3.3 & 3.9 & 4.2 & 3.8 & 4.1 & 3.6 & 4.2 & 4.6 \\
\hline 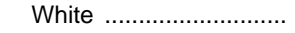 & 90.7 & 91.0 & 90.0 & 89.8 & 89.7 & 89.0 & 88.8 & 88.7 & 88.2 & 87.2 & 87.7 & 86.9 & 85.0 & 82.8 & 83.3 \\
\hline Citizenship (percent) & & & & & & & & & & & & & & & \\
\hline United States ......... & 84.7 & 84.0 & 80.6 & 79.3 & 77.9 & 76.1 & 74.8 & 70.4 & 73.8 & 73.4 & 74.3 & 75.5 & 75.5 & 76.0 & 76.2 \\
\hline Foreign ............................ & 11.6 & 11.9 & 14.1 & 15.3 & 15.3 & 15.7 & 16.1 & 17.3 & 18.0 & 19.8 & 21.2 & 21.3 & 21.7 & 21.4 & 20.7 \\
\hline Unknown ..................... & 3.7 & 4.2 & 5.4 & 5.4 & 6.9 & 8.3 & 9.1 & 12.2 & 8.2 & 6.8 & 4.4 & 3.1 & 2.8 & 2.6 & 3.1 \\
\hline Median age at doctorate & & & & & & & & & & & & & & & \\
\hline (years) ............................ & 31.6 & 32.0 & 32.7 & 33.0 & 33.4 & 33.5 & 34.1 & 33.9 & 34.2 & 34.1 & 34.3 & 34.3 & 34.1 & 34.1 & 33.7 \\
\hline $\begin{array}{l}\text { Percent with bachelor's } \\
\text { degree in same }\end{array}$ & & & & & & & & & & & & & & & \\
\hline field as doctorate ....... & 58.6 & 59.1 & 59.3 & 58.5 & 57.0 & 56.4 & 54.5 & 52.3 & 55.4 & 54.2 & 53.1 & 53.7 & 53.2 & 52.2 & 53.4 \\
\hline $\begin{array}{l}\text { Median time lapse from } \\
\text { bachelor's to } \\
\text { doctorate (years) }\end{array}$ & & & & & & & & & & & & & & & \\
\hline Total time ....................... & 8.7 & 9.0 & 9.7 & 9.9 & 10.0 & 10.3 & 10.5 & 10.3 & 10.6 & 10.5 & 10.6 & 10.4 & 10.5 & 10.5 & 10.3 \\
\hline Registered time ............ & 6.4 & 6.5 & 7.1 & 7.1 & 7.2 & 7.4 & 7.4 & 7.4 & 7.5 & 7.5 & 7.5 & 7.5 & 7.5 & 7.5 & 7.4 \\
\hline
\end{tabular}

${ }^{1}$ Includes anthropology, area studies, criminology, economics, geography, political science, public policy, psychology, and sociology.

2 Longitudinal comparisons by race/ethnicity should be done with extreme care, due to periodic changes in the survey. Distribution by race/ethnicity based on U.S. citizens and those with permanent visas only.

NOTE.-The National Research Council's classification of degrees by field differs somewhat from that in most publications of the National Center for Education Statistics (NCES). The major differences are that history is included under humanities rather than social sciences and that psychology is included under social sciences. The number of degrees also differs slightly from that reported in the NCES "Completions" survey. Some data have been revised from previously published figures. Because of rounding, percents may not add to 100.0 .

SOURCE: National Academy of Sciences, National Research Council, Office of Scientific and Engineering Personnel, Doctorate Records File. (This table was prepared May 1998.) 
Table 305.-Doctor's degrees ${ }^{1}$ conferred by 60 large institutions of higher education: $1986-87$ to $1995-961$

\begin{tabular}{|c|c|c|c|c|c|c|c|c|c|c|c|c|}
\hline Institution & $\begin{array}{c}\text { Rank } \\
\text { order }^{2}\end{array}$ & $\begin{array}{c}\text { Total, } \\
\text { 1986-87 } \\
\text { to } \\
1995-96\end{array}$ & 1986-87 & $1987-88$ & 1988-89 & 1989-90 & $1990-91$ & 1991-92 & 1992-93 & 1993-94 & 1994-95 & $1995-96$ \\
\hline 1 & 2 & 3 & 4 & 5 & 6 & 7 & 8 & 9 & 10 & 11 & 12 & 13 \\
\hline United States, all institutions ..... & 一 & 397,370 & 34,041 & 34,870 & 35,720 & 38,371 & 39,294 & 40,659 & 42,132 & 43,185 & 44,446 & 44,652 \\
\hline Total, 60 large institutions & - & 228,934 & 20,006 & 20,447 & 21,074 & 22,201 & 22,956 & 23,520 & 24,141 & 24,701 & 25,015 & 24,873 \\
\hline University of California, Berkeley & 1 & 8,009 & 727 & 742 & 838 & 800 & 800 & 798 & 810 & 896 & 828 & 770 \\
\hline 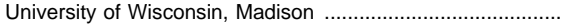 & 2 & 7,093 & 667 & 684 & 667 & 717 & 708 & 680 & 676 & 783 & 758 & 753 \\
\hline University of Illinois at Urbana .................. & 3 & 6,958 & 616 & 646 & 647 & 707 & 737 & 775 & 705 & 666 & 761 & 698 \\
\hline 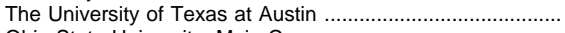 & 4 & 6,682 & 612 & 588 & 583 & 647 & 710 & 671 & 686 & 714 & 727 & 744 \\
\hline 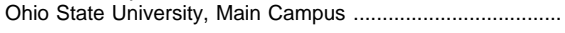 & 5 & 6,450 & 570 & 542 & 608 & 604 & 644 & 671 & 685 & 710 & 699 & 717 \\
\hline University of Minnesota Twin Cities . & 6 & 6,350 & 508 & 527 & 543 & 633 & 706 & 651 & 627 & 707 & 685 & 763 \\
\hline Columbia University in the City of New York ......................... & 7 & 6,325 & 593 & 567 & 615 & 723 & 802 & 630 & 687 & 644 & 660 & 404 \\
\hline University of Michigan, Ann Arbor & 8 & 6,308 & 589 & 564 & 527 & 583 & 661 & 676 & 654 & 649 & 714 & 691 \\
\hline 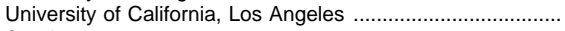 & 9 & 5,695 & 448 & 508 & 459 & 558 & 558 & 613 & 657 & 620 & 663 & 611 \\
\hline 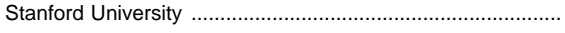 & 10 & 5,550 & 562 & 560 & 540 & 532 & 487 & 569 & 581 & 560 & 574 & 585 \\
\hline Cornell University ${ }^{3}$ & 11 & 5,160 & 445 & 454 & 481 & 555 & 531 & 540 & 520 & 593 & 525 & 516 \\
\hline 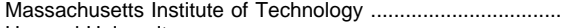 & 12 & 5,085 & 458 & 516 & 492 & 509 & 497 & 514 & 516 & 508 & 521 & 554 \\
\hline Harvard University & 13 & 5,033 & 434 & 465 & 461 & 505 & 505 & 501 & 540 & 538 & 556 & 528 \\
\hline 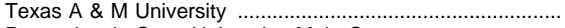 & 14 & 4,713 & 369 & 382 & 420 & 411 & 446 & 472 & 496 & 579 & 564 & 574 \\
\hline Pennsylvania State University, Main Campus ........................... & 15 & 4,636 & 341 & 379 & 417 & 420 & 463 & 541 & 495 & 507 & 563 & 510 \\
\hline Purdue University, Main Campus & 16 & 4,545 & 370 & 366 & 420 & 467 & 430 & 478 & 504 & 493 & 509 & 508 \\
\hline University of Maryland College Park Campus ............................ & 17 & 4,526 & 378 & 364 & 393 & 468 & 453 & 506 & 490 & 528 & 480 & 466 \\
\hline University of Pennsylvania & 18 & 4,454 & 307 & 319 & 414 & 462 & 495 & 477 & 506 & 488 & 539 & 447 \\
\hline University of Washington ... & 19 & 4,366 & 411 & 392 & 403 & 457 & 459 & 396 & 416 & 455 & 482 & 495 \\
\hline Michigan State University & 20 & 4,363 & 464 & 427 & 434 & 432 & 397 & 476 & 401 & 429 & 419 & 484 \\
\hline University of Southern California & 21 & 4,188 & 354 & 354 & 429 & 429 & 359 & 355 & 415 & 415 & 539 & 539 \\
\hline 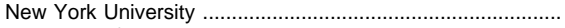 & 22 & 3,908 & 392 & 421 & 376 & 392 & 392 & 404 & 404 & 391 & 380 & 356 \\
\hline University of Florida & 23 & 3,718 & 313 & 315 & 342 & 366 & 370 & 364 & 372 & 442 & 400 & 434 \\
\hline Nova Southeastern University & 24 & 3,626 & 271 & 292 & 306 & 316 & 290 & 336 & 433 & 485 & 450 & 447 \\
\hline 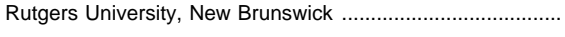 & 25 & 3,625 & 320 & 311 & 327 & 342 & 326 & 402 & 376 & 400 & 405 & 416 \\
\hline University of Arizona & 26 & 3,554 & 298 & 290 & 326 & 311 & 382 & 352 & 373 & 442 & 396 & 384 \\
\hline 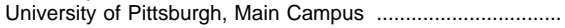 & 27 & 3,524 & 394 & 390 & 367 & 337 & 344 & 343 & 333 & 334 & 324 & 358 \\
\hline 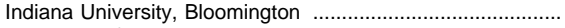 & 28 & 3,520 & 374 & 319 & 313 & 321 & 342 & 398 & 348 & 348 & 383 & 374 \\
\hline 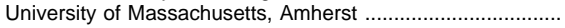 & 29 & 3,445 & 311 & 281 & 329 & 362 & 400 & 409 & 370 & 338 & 307 & 338 \\
\hline University of North Carolina at Chapel Hill ................................ & 30 & 3,417 & 311 & 301 & 299 & 337 & 336 & 338 & 388 & 373 & 369 & 365 \\
\hline Virginia Polytechnic Institute and State University ............... & 31 & 3,412 & 295 & 287 & 303 & 342 & 332 & 366 & 369 & 379 & 361 & 378 \\
\hline University of Chicago & 32 & 3,409 & 319 & 318 & 310 & 335 & 317 & 322 & 346 & 395 & 366 & 381 \\
\hline Northwestern University & 33 & 3,378 & 319 & 313 & 358 & 327 & 308 & 351 & 363 & 305 & 375 & 359 \\
\hline Yale University ............... & 34 & 3,365 & 305 & 290 & 317 & 312 & 344 & 347 & 369 & 348 & 366 & 367 \\
\hline University of lowa & 35 & 3,315 & 287 & 312 & 287 & 299 & 360 & 380 & 331 & 342 & 340 & 377 \\
\hline University of Georgia & 36 & 3,253 & 275 & 316 & 340 & 313 & 332 & 331 & 352 & 309 & 342 & 343 \\
\hline lowa State University & 37 & 2,952 & 296 & 309 & 257 & 282 & 297 & 277 & 322 & 307 & 318 & 287 \\
\hline State University of New York at Buffalo & 38 & 2,856 & 209 & 240 & 274 & 249 & 265 & 290 & 320 & 345 & 318 & 346 \\
\hline 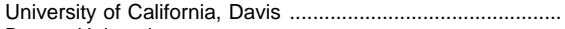 & 39 & 2,854 & 228 & 238 & 221 & 258 & 258 & 284 & 306 & 323 & 341 & 397 \\
\hline Boston University & 40 & 2,847 & 299 & 245 & 304 & 277 & 258 & 280 & 271 & 289 & 315 & 309 \\
\hline Temple University & 41 & 2,799 & 290 & 277 & 285 & 249 & 251 & 282 & 282 & 287 & 315 & 281 \\
\hline 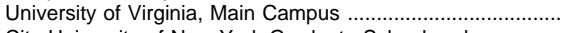 & 42 & 2,770 & 218 & 229 & 242 & 253 & 291 & 291 & 315 & 294 & 312 & 325 \\
\hline City University of New York Graduate School and & & & & & & & & & & & & \\
\hline 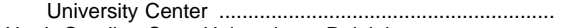 & 43 & 2,751 & 232 & 258 & 225 & 259 & 320 & 257 & 318 & 286 & 294 & 302 \\
\hline 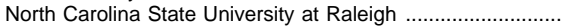 & 44 & 2,704 & 200 & 239 & 224 & 294 & 256 & 279 & 283 & 300 & 304 & 325 \\
\hline 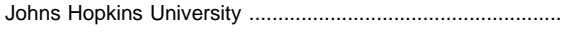 & 45 & 2,703 & 213 & 267 & 229 & 240 & 285 & 297 & 318 & 262 & 271 & 321 \\
\hline University of Colorado at Boulder & 46 & 2,642 & 229 & 231 & 221 & 248 & 263 & 249 & 299 & 306 & 299 & 297 \\
\hline Florida State University & 47 & 2,618 & 226 & 250 & 246 & 249 & 257 & 286 & 262 & 274 & 295 & 273 \\
\hline Princeton University & 48 & 2,555 & 218 & 269 & 227 & 240 & 244 & 255 & 249 & 267 & 300 & 286 \\
\hline 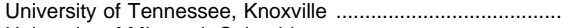 & 49 & 2,333 & 206 & 217 & 209 & 214 & 214 & 260 & 249 & 226 & 257 & 281 \\
\hline 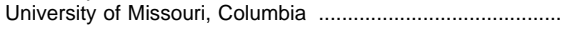 & 50 & 2,330 & 181 & 227 & 236 & 236 & 212 & 258 & 260 & 253 & 219 & 248 \\
\hline University of South Carolina at Columbia . & 51 & 2,307 & 169 & 191 & 169 & 215 & 248 & 242 & 281 & 288 & 237 & 267 \\
\hline Arizona State University, Main Campus ... & 52 & 2,286 & 146 & 158 & 194 & 191 & 227 & 222 & 270 & 258 & 305 & 315 \\
\hline 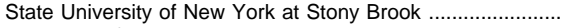 & 53 & 2,268 & 156 & 196 & 190 & 200 & 248 & 225 & 283 & 268 & 241 & 261 \\
\hline University of Nebraska at Lincoln & 54 & 2,241 & 203 & 233 & 236 & 217 & 202 & 212 & 221 & 227 & 229 & 261 \\
\hline 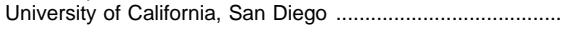 & 55 & 2,233 & 163 & 186 & 189 & 185 & 185 & 227 & 280 & 285 & 274 & 259 \\
\hline University of Cincinnati, Main Campus & 56 & 2,206 & 182 & 188 & 182 & 213 & 231 & 220 & 226 & 273 & 264 & 227 \\
\hline 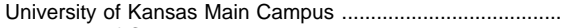 & 57 & 2,193 & 221 & 213 & 224 & 180 & 209 & 235 & 193 & 225 & 250 & 243 \\
\hline University of Connecticut & 58 & 2,188 & 193 & 180 & 198 & 217 & 228 & 206 & 216 & 246 & 265 & 239 \\
\hline University of Rochester & 59 & 2,185 & 198 & 167 & 208 & 226 & 194 & 231 & 224 & 236 & 242 & 259 \\
\hline Wayne State University & 60 & 2,155 & 123 & 137 & 193 & 178 & 290 & 222 & 299 & 263 & 220 & 230 \\
\hline
\end{tabular}

1 Includes Ph.D., Ed.D., and comparable degrees at the doctoral level. Excludes firstprofessional degrees (e.g., M.D., D.D.S., and D.V.M.).

2 Institutions are ranked by the total number of doctor's degrees conferred during the 10 -year period ending June 30, 1996.

3 Includes degrees conferred by the Endowed and Statutory Colleges.

-Not applicable.
SOURCE: U.S. Department of Education, National Center for Education Statistics, Higher Education General Information Survey (HEGIS), "Degrees and Other Formal Awards Conferred" surveys, and Integrated Postsecondary Education Data System (IPEDS), "Completions" surveys. (This table was prepared July 1998.) 
Table 306.-Percentage distribution of 1980 high school sophomores, by highest level of education completed through 1992, by selected student characteristics: 1980 to 1992

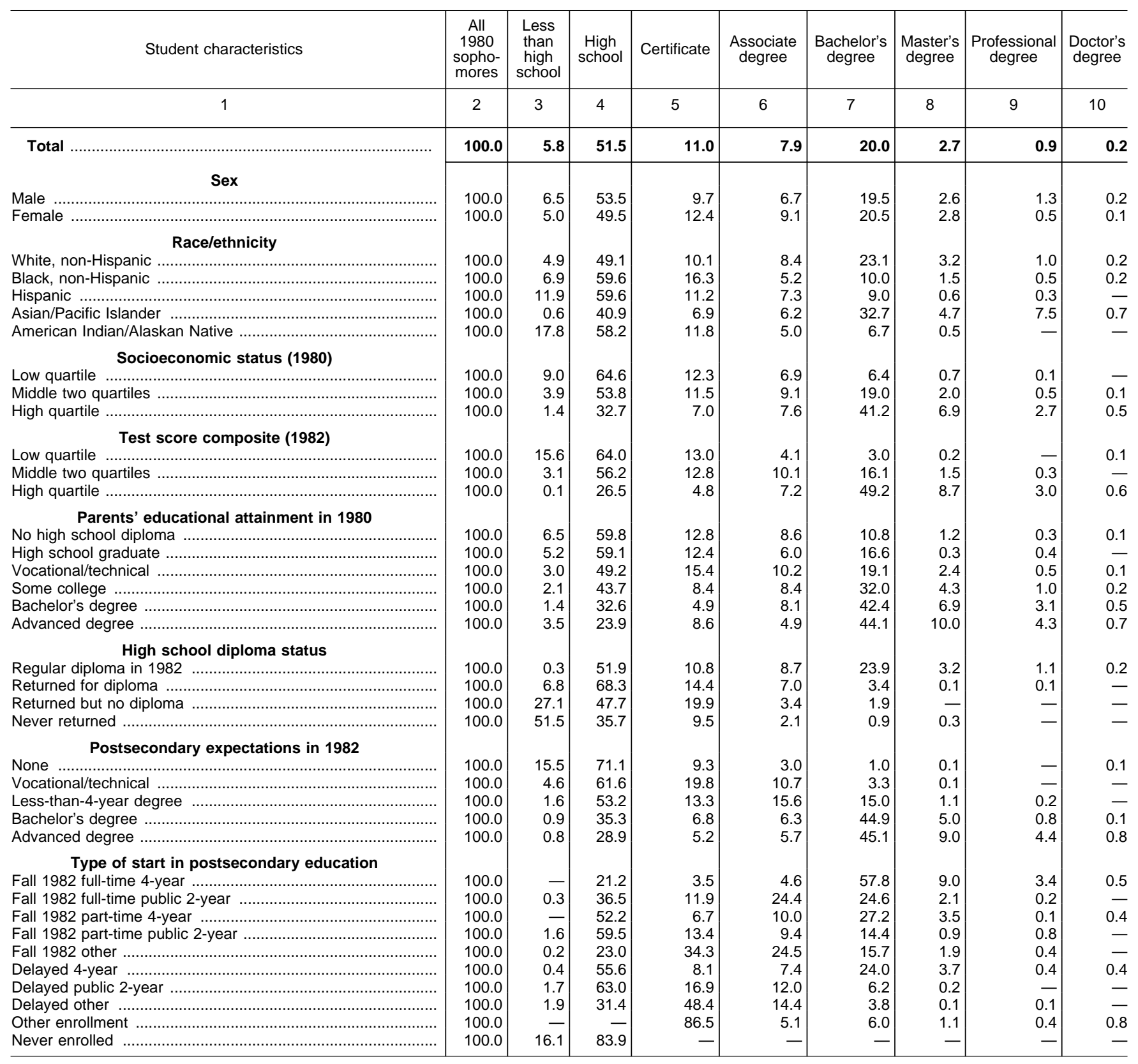

—Data not applicable or not available.

NOTE.-Because of rounding, details may not add to 100.0 percent.
SOURCE: National Center for Education Statistics, High School and Beyond, Educational Attainment of High School Sophomores by 1992. (This table was prepared May 1995.) 
Table 307.-Mean number of semester credits completed by bachelor's degree recipients, by major and course area: 1976, 1984, and 1992-93

\begin{tabular}{|c|c|c|c|c|c|c|c|c|c|c|}
\hline \multirow[b]{2}{*}{ Selected college majors } & \multicolumn{10}{|c|}{ Course areas } \\
\hline & Total & Business & $\begin{array}{l}\text { Computer } \\
\text { science }\end{array}$ & Education & Engineering & $\begin{array}{l}\text { Mathe- } \\
\text { matics }\end{array}$ & $\begin{array}{l}\text { Biological } \\
\text { sciences }\end{array}$ & $\begin{array}{l}\text { Physical } \\
\text { sciences }\end{array}$ & $\begin{array}{l}\text { Social } \\
\text { sciences } \\
\text { and psy- } \\
\text { chology }\end{array}$ & Other \\
\hline \multirow[t]{2}{*}{1} & 2 & 3 & 4 & 5 & 6 & 7 & 8 & 9 & 10 & 11 \\
\hline & \multicolumn{10}{|c|}{1972 high school seniors who completed bachelor's degrees by 1976} \\
\hline Mean, all majors ... & 124.0 & 7.8 & 1.0 & 9.7 & 2.3 & 7.4 & 7.6 & 9.0 & 30.3 & 48.8 \\
\hline Business and management .......... & 124.4 & 41.2 & 2.3 & 0.5 & 0.4 & 10.2 & 2.5 & 4.8 & 30.4 & 32.0 \\
\hline Computer science & 133.3 & 6.6 & 33.5 & 0.4 & 5.3 & 22.4 & 1.9 & 7.8 & 20.6 & 34.8 \\
\hline Education .............. & 126.4 & 0.9 & 0.3 & 40.2 & - & 5.0 & 5.5 & 4.3 & 23.9 & 46.4 \\
\hline Engineering .......... & 134.8 & 1.6 & 2.0 & 0.1 & 50.0 & 18.2 & 1.3 & 20.5 & 14.0 & 27.1 \\
\hline English .................. & 117.8 & 0.5 & 0.1 & 7.8 & 0.1 & 3.2 & 3.4 & 3.4 & 24.2 & 75.2 \\
\hline 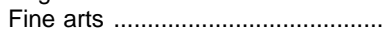 & 124.9 & 0.3 & 0.1 & 6.6 & - & 1.3 & 2.5 & 2.1 & 13.6 & 98.4 \\
\hline Life sciences & 122.2 & 0.4 & 0.8 & 1.7 & - & 8.4 & 35.6 & 26.2 & 17.8 & 31.3 \\
\hline Physical sciences & 122.7 & 0.8 & 1.4 & 0.9 & 1.9 & 16.2 & 9.6 & 49.5 & 13.1 & 29.2 \\
\hline 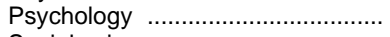 & 119.1 & 2.0 & 0.5 & 5.9 & 0.3 & 5.5 & 6.2 & 5.9 & 56.0 & 36.9 \\
\hline \multirow[t]{2}{*}{ 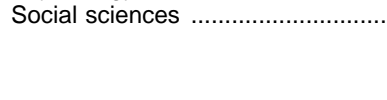 } & 120.6 & 3.4 & 0.4 & 3.3 & 0.4 & 5.3 & 3.2 & 4.3 & 60.3 & 40.1 \\
\hline & \multicolumn{10}{|c|}{1980 high school seniors who completed bachelor's degrees by 1984} \\
\hline Mean, all majors...$\ldots \ldots \ldots \ldots \ldots \ldots$ & 123.5 & 12.8 & 3.3 & 6.2 & 4.6 & 8.4 & 5.3 & 8.1 & 27.5 & 47.2 \\
\hline Business and management & 122.8 & 41.2 & 4.5 & 0.6 & 1.1 & 8.9 & 2.2 & 3.9 & 27.5 & 32.7 \\
\hline Computer science .......................... & 129.3 & 11.8 & 27.9 & 0.3 & 4.7 & 21.3 & 1.8 & 8.5 & 19.0 & 33.9 \\
\hline Education & 127.4 & 0.7 & 0.3 & 45.5 & 0.1 & 4.4 & 4.4 & 3.8 & 20.8 & 47.3 \\
\hline 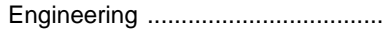 & 132.3 & 1.0 & 2.3 & 0.8 & 52.5 & 16.2 & 1.1 & 20.2 & 12.3 & 25.9 \\
\hline 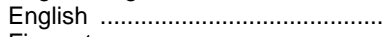 & 114.8 & 1.7 & 1.5 & 6.9 & - & 2.2 & 2.1 & 4.7 & 21.4 & 74.4 \\
\hline 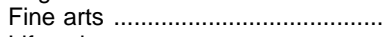 & 120.5 & 1.7 & 0.6 & 5.1 & - & 1.7 & 2.7 & 1.5 & 14.1 & 93.1 \\
\hline 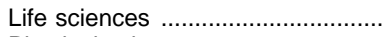 & 121.9 & 0.7 & 1.5 & 1.9 & 0.2 & 10.1 & 33.5 & 22.6 & 18.1 & 33.3 \\
\hline Physical sciences ............................. & 124.3 & 0.2 & 4.9 & 0.1 & 2.0 & 14.1 & 12.9 & 48.7 & 11.6 & 30.0 \\
\hline Psychology .................................... & 120.7 & 3.0 & 2.7 & 2.1 & - & 6.5 & 5.8 & 4.2 & 55.2 & 41.2 \\
\hline \multirow[t]{2}{*}{ Social sciences } & 119.2 & 6.0 & 1.4 & 1.0 & 0.5 & 5.4 & 4.4 & 5.1 & 52.0 & 43.3 \\
\hline & \multicolumn{10}{|c|}{ 1988-89 high school seniors who completed bachelor's degrees by 1993} \\
\hline Mean, all majors & 126.5 & 12.8 & 3.0 & 5.7 & 3.2 & 7.3 & 6.0 & 7.6 & 29.5 & 51.7 \\
\hline Business and management ........... & 123.9 & 44.4 & 3.9 & 0.9 & 0.1 & 7.6 & 2.6 & 3.3 & 23.1 & 37.9 \\
\hline 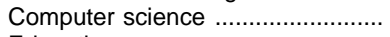 & 127.6 & 15.7 & 34.3 & 0.4 & 2.4 & 15.7 & 1.7 & 6.4 & 17.6 & 33.5 \\
\hline 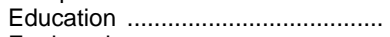 & 126.8 & 1.6 & 1.5 & 32.6 & - & 5.9 & 4.7 & 4.4 & 24.5 & 51.6 \\
\hline Engineering .................................... & 136.9 & 1.4 & 7.0 & 0.6 & 57.9 & 16.7 & 1.4 & 19.0 & 12.2 & 20.8 \\
\hline 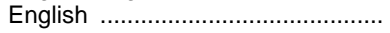 & 127.5 & 1.8 & 1.0 & 3.0 & 0.1 & 4.0 & 3.5 & 3.8 & 22.7 & 87.5 \\
\hline 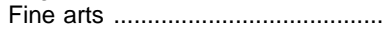 & 129.6 & 1.8 & 1.3 & 2.2 & 0.8 & 3.1 & 2.4 & 2.6 & 19.8 & 95.7 \\
\hline Life sciences ................. & 128.9 & 1.1 & 1.4 & 2.1 & 1.0 & 8.0 & 33.8 & 23.3 & 20.7 & 37.5 \\
\hline Physical sciences ....... & 129.1 & 1.1 & 2.7 & 1.1 & 2.3 & 15.0 & 7.5 & 49.3 & 16.9 & 33.2 \\
\hline Psychology ........... & 125.3 & 3.8 & 1.2 & 3.6 & 0.1 & 5.0 & 4.9 & 4.5 & 53.6 & 48.6 \\
\hline \multirow[t]{2}{*}{ 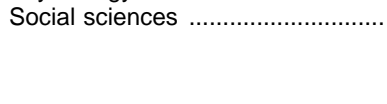 } & 125.5 & 6.2 & 1.2 & 1.8 & 0.1 & 4.8 & 2.9 & 5.1 & 55.7 & 47.6 \\
\hline & \multicolumn{10}{|c|}{ All bachelor's degree recipients of $1992-93$} \\
\hline Mean, all majors ...................... & 132.2 & 14.6 & 3.7 & 7.2 & 5.4 & 8.3 & 6.0 & 7.8 & 27.3 & 52.0 \\
\hline Business and management .......... & 129.5 & 46.8 & 4.7 & 0.9 & 0.7 & 8.8 & 2.8 & 3.6 & 23.6 & 37.6 \\
\hline Computer science & 137.0 & 17.4 & 37.1 & 0.4 & 5.0 & 16.7 & 2.5 & 7.5 & 17.3 & 33.0 \\
\hline Education ...................... & 135.9 & 2.2 & 1.5 & 40.1 & 0.3 & 6.3 & 5.4 & 5.0 & 24.7 & 50.5 \\
\hline Engineering ............... & 142.1 & 2.1 & 7.1 & 0.3 & 61.3 & 17.8 & 1.3 & 18.1 & 11.4 & 22.8 \\
\hline English .......................... & 128.8 & 2.9 & 1.4 & 4.6 & 0.1 & 4.3 & 3.5 & 4.2 & 23.2 & 84.5 \\
\hline 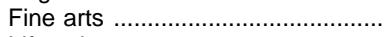 & 133.4 & 2.7 & 2.0 & 3.2 & 0.9 & 3.7 & 2.5 & 4.2 & 19.3 & 94.7 \\
\hline Life sciences ................................ & 132.5 & 1.7 & 1.6 & 2.9 & 0.9 & 8.7 & 34.8 & 22.3 & 21.3 & 38.2 \\
\hline Physical sciences .......................... & 137.8 & 2.6 & 2.9 & 1.9 & 4.0 & 15.5 & 8.2 & 50.6 & 18.2 & 33.9 \\
\hline Psychology ..................................... & 129.0 & 4.0 & 1.4 & 4.2 & 0.3 & 5.5 & 5.1 & 4.2 & 52.4 & 52.0 \\
\hline Social sciences …......................... & 127.9 & 6.2 & 1.4 & 2.3 & 0.3 & 5.6 & 3.3 & 5.4 & 54.8 & 48.6 \\
\hline
\end{tabular}

-Data not available.

NOTE.-All majors total includes fields not shown separately. Because of rounding, details may not add to totals.
SOURCE: U.S. Department of Education, National Center for Education Statistics, National Longitudinal Study of 1972; High School and Beyond; and Baccalaureate and Beyond survey. (This table was prepared January 1999.) 
Table 308.-Colleges and universities offering remedial services, by type and control of institution: 1987-88 to 1997-98

\begin{tabular}{|c|c|c|c|c|c|c|c|c|c|c|c|c|c|}
\hline \multirow{3}{*}{$\begin{array}{c}\text { Type and control of } \\
\text { institution }\end{array}$} & \multicolumn{11}{|c|}{ Percent of colleges offering remedial instruction or tutoring } & \multirow{2}{*}{\multicolumn{2}{|c|}{$\begin{array}{l}\text { Change in per- } \\
\text { centage points }\end{array}$}} \\
\hline & & & & & & & & & & & & & \\
\hline & $1987-88$ & $1988-89$ & $1989-90$ & $1990-91$ & $1991-92$ & $1992-93$ & $1993-94$ & 1994-95 & $1995-96$ & 1996-97 & $\begin{array}{c}1997- \\
98^{1}\end{array}$ & $\begin{array}{l}1987-88 \\
\text { to } \\
1996-97\end{array}$ & $\begin{array}{c}1990-91 \\
\text { to } \\
1997-98\end{array}$ \\
\hline 1 & 2 & 3 & 4 & 5 & 6 & 7 & 8 & 9 & 10 & 11 & 12 & 13 & 14 \\
\hline 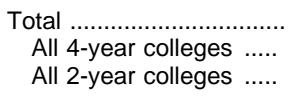 & $\begin{array}{l}72.7 \\
66.0 \\
82.7\end{array}$ & $\begin{array}{l}74.9 \\
68.2 \\
84.7\end{array}$ & $\begin{array}{l}76.6 \\
69.6 \\
87.2\end{array}$ & $\begin{array}{l}77.7 \\
70.6 \\
88.4\end{array}$ & $\begin{array}{l}78.6 \\
71.4 \\
89.2\end{array}$ & $\begin{array}{l}78.5 \\
71.5 \\
88.8\end{array}$ & $\begin{array}{l}79.0 \\
72.2 \\
89.5\end{array}$ & $\begin{array}{l}79.8 \\
73.6 \\
89.1\end{array}$ & $\begin{array}{l}79.5 \\
73.0 \\
89.4\end{array}$ & $\begin{array}{l}80.0 \\
73.1 \\
91.0\end{array}$ & $\begin{array}{l}76.7 \\
72.5 \\
82.2\end{array}$ & $\begin{array}{l}7.3 \\
7.1 \\
8.3\end{array}$ & - \\
\hline $\begin{array}{r}\text { Public institutions } . . . . . . \\
4-\text { year colleges } . . . . . . \\
2 \text {-year colleges ....... }\end{array}$ & $\begin{array}{l}90.4 \\
80.5 \\
96.4\end{array}$ & $\begin{array}{l}91.0 \\
81.8 \\
96.6\end{array}$ & $\begin{array}{l}92.4 \\
82.9 \\
98.2\end{array}$ & $\begin{array}{l}93.0 \\
83.5 \\
98.9\end{array}$ & $\begin{array}{l}93.9 \\
84.5 \\
99.6\end{array}$ & $\begin{array}{l}93.5 \\
84.5 \\
98.8\end{array}$ & $\begin{array}{l}93.5 \\
84.6 \\
98.7\end{array}$ & $\begin{array}{l}93.7 \\
85.3 \\
98.6\end{array}$ & $\begin{array}{l}93.7 \\
85.4 \\
98.6\end{array}$ & $\begin{array}{l}94.0 \\
85.1 \\
99.2\end{array}$ & $\begin{array}{l}93.8 \\
85.2 \\
98.7\end{array}$ & $\begin{array}{l}3.6 \\
4.6 \\
2.9\end{array}$ & $\begin{array}{l}0.8 \\
1.6 \\
0.2\end{array}$ \\
\hline $\begin{array}{r}\text { Private institutions } \ldots . . . \\
4 \text {-year colleges ....... } \\
2 \text {-year colleges ....... }\end{array}$ & $\begin{array}{l}58.6 \\
60.3 \\
53.0\end{array}$ & $\begin{array}{l}62.0 \\
63.0 \\
58.6\end{array}$ & $\begin{array}{l}64.1 \\
64.5 \\
63.0\end{array}$ & $\begin{array}{l}65.6 \\
65.6 \\
65.5\end{array}$ & $\begin{array}{l}66.3 \\
66.4 \\
65.8\end{array}$ & $\begin{array}{l}66.4 \\
66.5 \\
65.8\end{array}$ & $\begin{array}{l}67.4 \\
67.5 \\
67.0\end{array}$ & $\begin{array}{l}68.6 \\
69.2 \\
66.6\end{array}$ & $\begin{array}{l}68.0 \\
68.4 \\
66.3\end{array}$ & $\begin{array}{l}68.6 \\
68.6 \\
68.4\end{array}$ & $\begin{array}{l}64.2 \\
67.8 \\
55.1\end{array}$ & $\begin{array}{r}10.0 \\
8.3 \\
15.3\end{array}$ & - \\
\hline $\begin{array}{r}\text { Nonprofit .............. } \\
\text { 4-year colleges } \ldots \\
2 \text {-year colleges } \ldots\end{array}$ & $\begin{array}{l}- \\
-\end{array}$ & - & $\begin{array}{l}65.0 \\
64.2 \\
71.8\end{array}$ & $\begin{array}{l}65.6 \\
64.9 \\
71.3\end{array}$ & $\begin{array}{l}66.2 \\
65.8 \\
69.9\end{array}$ & $\begin{array}{l}66.7 \\
66.2 \\
71.5\end{array}$ & $\begin{array}{l}67.7 \\
67.0 \\
73.5\end{array}$ & $\begin{array}{l}69.3 \\
68.7 \\
74.0\end{array}$ & $\begin{array}{l}68.9 \\
68.3 \\
73.3\end{array}$ & $\begin{array}{l}69.2 \\
68.3 \\
77.3\end{array}$ & $\begin{array}{l}69.0 \\
68.3 \\
75.4\end{array}$ & - & $\begin{array}{l}3.5 \\
3.4 \\
4.2\end{array}$ \\
\hline $\begin{array}{r}\text { Proprietary .............. } \\
4 \text {-year colleges } \ldots \\
2 \text {-year colleges } \ldots\end{array}$ & $\begin{array}{l}- \\
-\end{array}$ & - & $\begin{array}{l}59.5 \\
71.7 \\
57.0\end{array}$ & $\begin{array}{l}65.6 \\
81.3 \\
62.0\end{array}$ & $\begin{array}{l}66.6 \\
79.2 \\
63.2\end{array}$ & $\begin{array}{l}64.6 \\
73.7 \\
62.0\end{array}$ & $\begin{array}{l}65.6 \\
76.3 \\
62.1\end{array}$ & $\begin{array}{l}65.2 \\
76.0 \\
60.8\end{array}$ & $\begin{array}{l}63.5 \\
69.2 \\
60.5\end{array}$ & $\begin{array}{l}65.2 \\
72.7 \\
60.8\end{array}$ & $\begin{array}{l}51.7 \\
63.9 \\
47.5\end{array}$ & - & - \\
\hline
\end{tabular}

1 Data are for 4-year and 2-year degree-granting institutions that were eligible to participate in Title IV federal finance aid programs.

-Data not available.
SOURCE: U.S. Department of Education, National Center for Education Statistics, Integrated Postsecondary Education Data System (IPEDS), "Institutional Characteristics" surveys. (This table was prepared January 1999.)

NOTE.-Some data have been revised from previously published figures. 
Table 309.-Percent distribution of enrollment and completion status of first-time postsecondary students starting during the 1989-90 academic year, by type of institution and other student characteristics: 1994

\begin{tabular}{|c|c|c|c|c|c|c|c|c|c|c|c|c|}
\hline \multirow{3}{*}{ Student and institution characteristics } & \multicolumn{6}{|c|}{ Students starting in 2-year institutions } & \multicolumn{6}{|c|}{ Students starting in 4-year institutions } \\
\hline & \multicolumn{4}{|c|}{ Highest degree attained } & \multirow{2}{*}{$\begin{array}{l}\text { No de- } \\
\text { gree, } \\
\text { still en- } \\
\text { rolled }\end{array}$} & \multirow{2}{*}{$\begin{array}{l}\text { No de- } \\
\text { gree, } \\
\text { not en- } \\
\text { rolled }\end{array}$} & \multicolumn{4}{|c|}{ Highest degree attained } & \multirow{2}{*}{$\begin{array}{l}\text { No de- } \\
\text { gree, } \\
\text { still en- } \\
\text { rolled }\end{array}$} & \multirow{2}{*}{$\begin{array}{l}\text { No de- } \\
\text { gree, } \\
\text { not en- } \\
\text { rolled }\end{array}$} \\
\hline & $\begin{array}{l}\text { Total, } \\
\text { any de- } \\
\text { gree }\end{array}$ & $\begin{array}{l}\text { Certifi- } \\
\text { cate }\end{array}$ & $\begin{array}{l}\text { Associ- } \\
\text { ate }\end{array}$ & $\begin{array}{l}\text { Bach- } \\
\text { elor's }\end{array}$ & & & $\begin{array}{l}\text { Total, } \\
\text { any de- } \\
\text { gree }\end{array}$ & $\begin{array}{l}\text { Certifi- } \\
\text { cate }\end{array}$ & $\begin{array}{l}\text { Associ- } \\
\text { ate }\end{array}$ & $\begin{array}{l}\text { Bach- } \\
\text { elor's }\end{array}$ & & \\
\hline 1 & 2 & 3 & 4 & 5 & 6 & 7 & 8 & 9 & 10 & 11 & 12 & 13 \\
\hline Total ....... & 38.4 & 13.8 & 18.6 & 6.1 & 13.6 & 48.0 & 60.4 & 2.9 & 4.2 & 53.3 & 15.2 & 24.4 \\
\hline Male & $\begin{array}{l}34.6 \\
41.9\end{array}$ & $\begin{array}{l}13.0 \\
14.4\end{array}$ & $\begin{array}{l}16.2 \\
20.9\end{array}$ & $\begin{array}{l}5.5 \\
6.6\end{array}$ & $\begin{array}{l}16.2 \\
11.2\end{array}$ & $\begin{array}{l}49.2 \\
46.8\end{array}$ & $\begin{array}{l}56.5 \\
63.9\end{array}$ & $\begin{array}{l}2.4 \\
3.3\end{array}$ & $\begin{array}{l}3.9 \\
4.4\end{array}$ & $\begin{array}{l}50.2 \\
56.2\end{array}$ & $\begin{array}{l}17.3 \\
13.4\end{array}$ & $\begin{array}{l}26.3 \\
22.7\end{array}$ \\
\hline 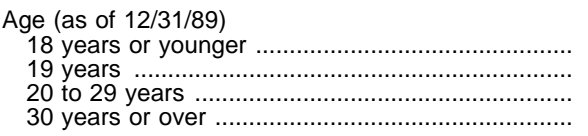 & $\begin{array}{l}46.8 \\
33.2 \\
31.2 \\
27.3\end{array}$ & $\begin{array}{r}9.9 \\
13.6 \\
18.8 \\
18.4\end{array}$ & $\begin{array}{r}25.8 \\
19.3 \\
9.9 \\
8.0\end{array}$ & $\begin{array}{r}11.0 \\
0.2 \\
2.5 \\
0.8\end{array}$ & $\begin{array}{r}14.7 \\
17.4 \\
12.0 \\
8.4\end{array}$ & $\begin{array}{l}38.5 \\
49.5 \\
56.8 \\
64.3\end{array}$ & $\begin{array}{l}64.4 \\
47.8 \\
34.8 \\
23.5\end{array}$ & $\begin{array}{l}2.4 \\
4.7 \\
5.3 \\
7.9\end{array}$ & $\begin{array}{l}4.0 \\
3.0 \\
6.9 \\
6.4\end{array}$ & $\begin{array}{r}58.0 \\
40.0 \\
22.5 \\
9.2\end{array}$ & $\begin{array}{l}15.3 \\
16.7 \\
12.7 \\
11.1\end{array}$ & $\begin{array}{l}20.3 \\
35.5 \\
52.5 \\
65.4\end{array}$ \\
\hline 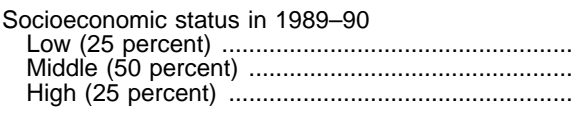 & $\begin{array}{l}31.9 \\
36.9 \\
45.4\end{array}$ & $\begin{array}{r}18.1 \\
14.9 \\
8.9\end{array}$ & $\begin{array}{l}11.8 \\
16.6 \\
26.6\end{array}$ & $\begin{array}{l}1.9 \\
5.4 \\
9.9\end{array}$ & $\begin{array}{r}9.6 \\
14.8 \\
13.9\end{array}$ & $\begin{array}{l}58.4 \\
48.3 \\
40.7\end{array}$ & $\begin{array}{l}33.5 \\
53.8 \\
67.3\end{array}$ & $\begin{array}{l}2.8 \\
3.7 \\
2.4\end{array}$ & $\begin{array}{l}4.9 \\
5.0 \\
3.5\end{array}$ & $\begin{array}{l}25.8 \\
45.1 \\
61.3\end{array}$ & $\begin{array}{l}17.4 \\
17.0 \\
13.8\end{array}$ & $\begin{array}{l}49.1 \\
29.2 \\
19.0\end{array}$ \\
\hline 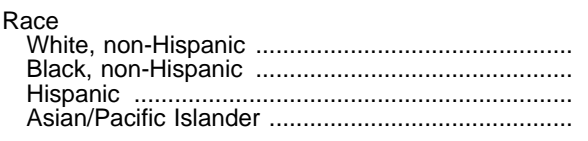 & $\begin{array}{l}39.0 \\
35.2 \\
38.2 \\
37.6\end{array}$ & $\begin{array}{l}13.1 \\
17.8 \\
15.3 \\
15.0\end{array}$ & $\begin{array}{l}19.6 \\
14.1 \\
16.4 \\
16.7\end{array}$ & $\begin{array}{l}6.4 \\
3.2 \\
6.6 \\
5.9\end{array}$ & $\begin{array}{l}12.2 \\
11.3 \\
20.5 \\
23.0\end{array}$ & $\begin{array}{l}48.8 \\
53.5 \\
41.3 \\
39.3\end{array}$ & $\begin{array}{l}61.4 \\
50.8 \\
50.6 \\
67.6\end{array}$ & $\begin{array}{l}2.7 \\
4.6 \\
1.3 \\
2.7\end{array}$ & $\begin{array}{l}4.4 \\
4.3 \\
2.1 \\
1.7\end{array}$ & $\begin{array}{l}54.3 \\
41.9 \\
47.2 \\
63.1\end{array}$ & $\begin{array}{l}14.1 \\
21.3 \\
21.3 \\
18.5\end{array}$ & $\begin{array}{l}24.4 \\
27.9 \\
28.1 \\
13.9\end{array}$ \\
\hline 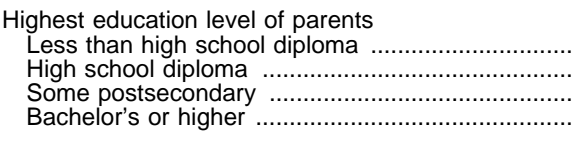 & $\begin{array}{l}30.3 \\
39.6 \\
39.0 \\
43.0\end{array}$ & $\begin{array}{r}19.2 \\
14.6 \\
11.4 \\
9.8\end{array}$ & $\begin{array}{r}9.1 \\
18.7 \\
20.9 \\
25.0\end{array}$ & $\begin{array}{l}2.0 \\
6.3 \\
6.8 \\
8.2\end{array}$ & $\begin{array}{r}10.2 \\
9.8 \\
16.3 \\
21.1\end{array}$ & $\begin{array}{l}59.5 \\
50.7 \\
44.7 \\
35.9\end{array}$ & $\begin{array}{l}55.8 \\
50.5 \\
58.1 \\
68.1\end{array}$ & $\begin{array}{l}7.1 \\
4.6 \\
2.1 \\
1.8\end{array}$ & $\begin{array}{l}6.6 \\
4.6 \\
4.9 \\
3.2\end{array}$ & $\begin{array}{l}42.0 \\
41.3 \\
51.2 \\
63.1\end{array}$ & $\begin{array}{l}14.7 \\
16.7 \\
14.9 \\
14.7\end{array}$ & $\begin{array}{l}29.6 \\
32.8 \\
26.9 \\
17.2\end{array}$ \\
\hline 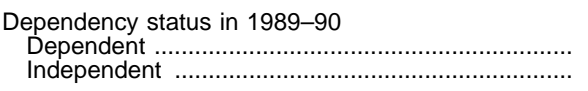 & $\begin{array}{l}43.5 \\
28.8\end{array}$ & $\begin{array}{l}11.7 \\
17.6\end{array}$ & $\begin{array}{r}23.5 \\
9.4\end{array}$ & $\begin{array}{l}8.4 \\
1.8\end{array}$ & $\begin{array}{l}14.6 \\
11.7\end{array}$ & $\begin{array}{l}41.8 \\
59.5\end{array}$ & $\begin{array}{l}62.9 \\
33.1\end{array}$ & $\begin{array}{l}2.6 \\
6.2\end{array}$ & $\begin{array}{l}4.0 \\
5.4\end{array}$ & $\begin{array}{l}56.3 \\
21.5\end{array}$ & $\begin{array}{l}15.3 \\
14.1\end{array}$ & $\begin{array}{l}21.8 \\
52.8\end{array}$ \\
\hline 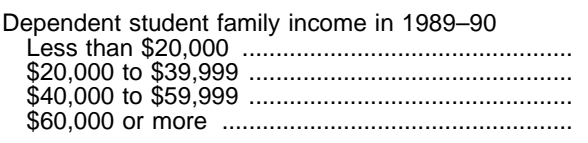 & $\begin{array}{l}40.6 \\
44.0 \\
44.5 \\
46.1\end{array}$ & $\begin{array}{r}12.7 \\
13.1 \\
12.1 \\
5.9\end{array}$ & $\begin{array}{l}22.3 \\
21.5 \\
23.3 \\
30.5\end{array}$ & $\begin{array}{l}5.6 \\
9.3 \\
9.1 \\
9.8\end{array}$ & $\begin{array}{l}14.4 \\
12.6 \\
12.5 \\
23.6\end{array}$ & $\begin{array}{l}45.1 \\
43.4 \\
43.0 \\
30.2\end{array}$ & $\begin{array}{l}52.5 \\
58.1 \\
64.8 \\
72.2\end{array}$ & $\begin{array}{l}3.0 \\
2.5 \\
3.3 \\
1.7\end{array}$ & $\begin{array}{l}4.9 \\
4.0 \\
4.1 \\
3.4\end{array}$ & $\begin{array}{l}44.5 \\
51.5 \\
57.4 \\
67.1\end{array}$ & $\begin{array}{l}18.2 \\
16.5 \\
15.5 \\
12.2\end{array}$ & $\begin{array}{l}29.3 \\
25.5 \\
19.6 \\
15.6\end{array}$ \\
\hline $\begin{array}{l}\text { Delayed postsecondary enrollment } \\
\quad \text { Did not delay }{ }^{1} \\
\text { Delayed entry }\end{array}$ & $\begin{array}{l}46.4 \\
28.4\end{array}$ & $\begin{array}{l}11.1 \\
17.1\end{array}$ & $\begin{array}{r}25.8 \\
9.6\end{array}$ & $\begin{array}{l}9.5 \\
1.7\end{array}$ & $\begin{array}{l}15.1 \\
11.6\end{array}$ & $\begin{array}{l}38.5 \\
60.0\end{array}$ & $\begin{array}{l}64.1 \\
32.6\end{array}$ & $\begin{array}{l}2.4 \\
6.4\end{array}$ & $\begin{array}{l}4.0 \\
5.4\end{array}$ & $\begin{array}{l}57.7 \\
20.8\end{array}$ & $\begin{array}{l}15.5 \\
12.7\end{array}$ & $\begin{array}{l}20.4 \\
54.7\end{array}$ \\
\hline $\begin{array}{c}\text { Attendance status when began at first institution } \\
\text { Full-time } \\
\text { Part-time }\end{array}$ & $\begin{array}{l}48.0 \\
27.3\end{array}$ & $\begin{array}{l}12.6 \\
15.0\end{array}$ & $\begin{array}{l}25.6 \\
10.6\end{array}$ & $\begin{array}{l}9.8 \\
1.8\end{array}$ & $\begin{array}{l}13.7 \\
14.4\end{array}$ & $\begin{array}{l}38.3 \\
58.2\end{array}$ & $\begin{array}{l}63.9 \\
33.3\end{array}$ & $\begin{array}{l}2.6 \\
6.4\end{array}$ & $\begin{array}{l}4.0 \\
8.2\end{array}$ & $\begin{array}{l}57.4 \\
18.7\end{array}$ & $\begin{array}{l}14.9 \\
14.9\end{array}$ & $\begin{array}{l}21.2 \\
51.9\end{array}$ \\
\hline $\begin{array}{l}\text { Intensity of enrollment through first degree } \\
\text { Exclusively part-time } \\
\text { Mixed full-time and part-time } \\
\text { Exclusively full-time }\end{array}$ & $\begin{array}{l}12.6 \\
46.5 \\
51.3\end{array}$ & $\begin{array}{l}10.9 \\
14.3 \\
15.7\end{array}$ & $\begin{array}{r}1.6 \\
24.7 \\
26.1\end{array}$ & $\begin{array}{l}0.2 \\
7.5 \\
9.6\end{array}$ & $\begin{array}{r}7.7 \\
22.3 \\
7.3\end{array}$ & $\begin{array}{l}79.8 \\
31.3 \\
41.4\end{array}$ & $\begin{array}{r}9.7 \\
59.4 \\
67.3\end{array}$ & $\begin{array}{l}5.5 \\
2.9 \\
2.5\end{array}$ & $\begin{array}{l}2.5 \\
4.1 \\
4.4\end{array}$ & $\begin{array}{r}1.7 \\
52.4 \\
60.3\end{array}$ & $\begin{array}{r}5.9 \\
19.8 \\
11.2\end{array}$ & $\begin{array}{l}84.4 \\
20.8 \\
21.6\end{array}$ \\
\hline 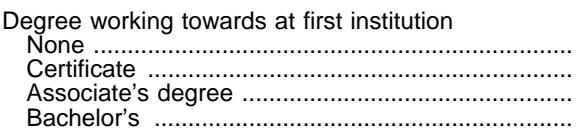 & $\begin{array}{l}13.0 \\
44.0 \\
42.6 \\
36.9\end{array}$ & $\begin{array}{r}6.0 \\
37.7 \\
11.4 \\
8.1\end{array}$ & $\begin{array}{r}3.6 \\
6.2 \\
23.7 \\
21.0\end{array}$ & $\begin{array}{l}3.4 \\
0.2 \\
7.5 \\
7.9\end{array}$ & $\begin{array}{r}13.8 \\
5.3 \\
12.1 \\
22.5\end{array}$ & $\begin{array}{l}73.3 \\
50.7 \\
45.2 \\
40.6\end{array}$ & $\begin{array}{l}30.5 \\
57.3 \\
44.0 \\
62.6\end{array}$ & $\begin{array}{r}5.3 \\
15.2 \\
5.8 \\
2.4\end{array}$ & $\begin{array}{r}4.4 \\
9.3 \\
16.7 \\
3.1\end{array}$ & $\begin{array}{l}20.8 \\
32.8 \\
21.5 \\
57.1\end{array}$ & $\begin{array}{r}12.4 \\
9.4 \\
13.1 \\
15.6\end{array}$ & $\begin{array}{l}57.1 \\
33.3 \\
43.0 \\
21.8\end{array}$ \\
\hline $\begin{array}{l}\text { Worked full time while enrolled when began at first } \\
\text { institution } \\
\text { Did not work full time } \\
\text { Worked full time }\end{array}$ & $\begin{array}{l}44.9 \\
26.6\end{array}$ & $\begin{array}{l}15.4 \\
11.6\end{array}$ & $\begin{array}{l}22.1 \\
12.2\end{array}$ & $\begin{array}{l}7.3 \\
2.8\end{array}$ & $\begin{array}{l}11.9 \\
16.7\end{array}$ & $\begin{array}{l}43.2 \\
56.7\end{array}$ & $\begin{array}{l}61.9 \\
55.5\end{array}$ & $\begin{array}{l}2.8 \\
3.5\end{array}$ & $\begin{array}{l}4.2 \\
4.4\end{array}$ & $\begin{array}{l}54.9 \\
47.6\end{array}$ & $\begin{array}{l}15.9 \\
12.5\end{array}$ & $\begin{array}{l}22.2 \\
32.1\end{array}$ \\
\hline 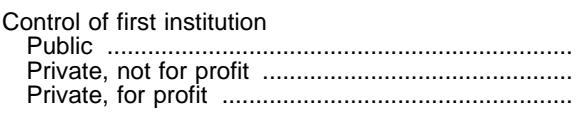 & $\begin{array}{l}36.7 \\
52.2 \\
52.0\end{array}$ & $\begin{array}{l}12.9 \\
14.5 \\
22.9\end{array}$ & $\begin{array}{l}17.5 \\
29.6 \\
26.8\end{array}$ & $\begin{array}{l}6.3 \\
8.1 \\
2.3\end{array}$ & $\begin{array}{r}14.7 \\
12.5 \\
1.5\end{array}$ & $\begin{array}{l}48.6 \\
35.3 \\
46.5\end{array}$ & $\begin{array}{r}54.8 \\
71.9 \\
-\end{array}$ & $\begin{array}{c}3.2 \\
2.3 \\
-\end{array}$ & $\begin{array}{c}4.7 \\
3.0 \\
-\end{array}$ & $\begin{array}{c}47.0 \\
66.6 \\
-\end{array}$ & $\begin{array}{r}18.4 \\
8.6 \\
-\end{array}$ & $\begin{array}{r}26.8 \\
19.5 \\
-\end{array}$ \\
\hline
\end{tabular}

${ }^{1}$ Students with a standard high school diploma who attended higher education in the same year as their graduation.

-Data not available or not applicable.

SOURCE: U.S. Department of Education, National Center for Education Statistics, Beginning Postsecondary Student Longitudinal Survey, 1994. (This table was prepared February 1999.)

NOTE.-Data reflect completion and enrollment status by spring 1994 of first-time postsecondary students starting academic year 1989-90. Some cells in this table have relatively large sampling errors. 
Table 310.-Scores on Graduate Record Examination (GRE) and subject matter tests: 1965 to 1997

\begin{tabular}{|c|c|c|c|c|c|c|c|c|c|c|c|c|c|c|c|c|c|c|c|c|}
\hline \multirow{3}{*}{ Academic year ending } & \multirow{3}{*}{$\begin{array}{c}\text { Number of GRE } \\
\text { takers }\end{array}$} & \multirow{3}{*}{$\begin{array}{c}\text { GRE takers } \\
\text { as a percent } \\
\text { of bachelor's } \\
\text { degrees }\end{array}$} & \multicolumn{2}{|c|}{ Verbal } & \multicolumn{2}{|c|}{ Quantitative } & \multicolumn{2}{|c|}{ Analytical } & \multicolumn{12}{|c|}{ Subject matter tests } \\
\hline & & & \multirow[b]{2}{*}{ Mean } & \multirow{2}{*}{$\begin{array}{l}\text { Standard } \\
\text { deviation }\end{array}$} & \multirow[b]{2}{*}{ Mean } & \multirow{2}{*}{$\begin{array}{l}\text { Standard } \\
\text { deviation }\end{array}$} & \multirow[b]{2}{*}{ Mean } & \multirow{2}{*}{$\begin{array}{l}\text { Standard } \\
\text { deviation }\end{array}$} & \multicolumn{2}{|c|}{ Biology } & \multicolumn{2}{|c|}{ Chemistry } & \multicolumn{2}{|c|}{ Education } & \multicolumn{2}{|c|}{ Engineering } & \multicolumn{2}{|c|}{ Literature } & \multicolumn{2}{|c|}{ Psychology } \\
\hline & & & & & & & & & Mean & $\begin{array}{l}\text { Standard } \\
\text { deviation }\end{array}$ & Mean & $\begin{array}{l}\text { Standard } \\
\text { deviation }\end{array}$ & Mean & $\begin{array}{l}\text { Standard } \\
\text { deviation }\end{array}$ & Mean & $\begin{array}{l}\text { Standard } \\
\text { deviation }\end{array}$ & Mean & \begin{tabular}{|l|} 
Standard \\
deviation
\end{tabular} & Mean & $\begin{array}{l}\text { Standard } \\
\text { deviation }\end{array}$ \\
\hline 1 & 2 & 3 & 4 & 5 & 6 & 7 & 8 & 9 & 10 & 11 & 12 & 13 & 14 & 15 & 16 & 17 & 18 & 19 & 20 & 21 \\
\hline $1965 \ldots . .$. & 93,792 & 18.7 & 530 & 124 & 533 & 137 & - & - & 617 & 117 & 628 & 114 & 481 & 86 & 618 & 108 & 591 & 95 & 556 & 91 \\
\hline (................. & & & & & & 133 & - & - & 610 & 115 & 618 & 110 & 474 & 87 & 609 & 106 & & 94 & 552 & 91 \\
\hline 7 ………….... & 151,134 & 27.0 & 519 & 125 & 528 & 134 & - & - & 613 & 114 & 615 & 104 & 476 & 90 & 603 & 104 & 582 & 91 & 553 & 93 \\
\hline 1968 & 182,432 & 28.8 & 520 & 124 & 527 & 135 & - & - & 614 & 114 & 617 & 104 & 478 & 87 & 601 & 105 & 572 & 91 & 547 & 93 \\
\hline 1969 & 206,113 & 28.3 & 515 & 124 & 524 & 132 & - & - & 613 & 112 & 613 & 104 & 477 & 88 & 591 & 103 & 569 & 89 & 543 & 89 \\
\hline 1970 . & 265,359 & 33.5 & 503 & 123 & 516 & 132 & - & - & 603 & 111 & 613 & 113 & 462 & 92 & 586 & 110 & 556 & 90 & 532 & 91 \\
\hline $1 .$. & 2 & 35 & 497 & 125 & 512 & 134 & - & - & 603 & 114 & 618 & 117 & 457 & 95 & 587 & 115 & 546 & 91 & 530 & 92 \\
\hline $1972 \ldots \ldots \ldots \ldots \ldots$ & 6 & 33.1 & 494 & 126 & 508 & 136 & - & - & 606 & 115 & 624 & 124 & 446 & 93 & 594 & 119 & 544 & 96 & 528 & 92 \\
\hline $3 \ldots \ldots \ldots \ldots$ & 290,104 & 31.5 & 497 & 125 & 512 & 135 & - & - & 619 & 110 & 630 & 114 & 459 & 96 & 593 & 114 & 545 & 96 & 529 & 92 \\
\hline 1974 & 301,070 & 31.8 & 492 & 126 & 509 & 137 & - & - & 624 & 110 & 634 & 115 & 452 & 93 & 591 & 121 & 547 & 99 & 530 & 95 \\
\hline $1975 \ldots$ & 298 & 32.3 & 493 & 125 & 50 & 137 & - & - & - & - & -1 & - & - & - & - & - & - & - & - & - \\
\hline 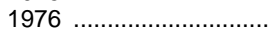 & 2 & 32. & 492 & 127 & 510 & 138 & - & - & 627 & 112 & 627 & 107 & 454 & 93 & 594 & 119 & 539 & 101 & 531 & 93 \\
\hline 1977. & 287,715 & 31.3 & 490 & 129 & 514 & 139 & - & - & 625 & 113 & 630 & 109 & 453 & 93 & 592 & 115 & 532 & 101 & 532 & 95 \\
\hline 1978. & 286,383 & 31.1 & 484 & 128 & 518 & 135 & - & - & 622 & 113 & 624 & 108 & 452 & 91 & 594 & 114 & 530 & 102 & 529 & 97 \\
\hline $1979 \ldots$. & 282,482 & 30.7 & 476 & 130 & 517 & 135 & - & - & 621 & 117 & 623 & 104 & 451 & 89 & 592 & 115 & 525 & 102 & 530 & 97 \\
\hline 1980 & 272,281 & 29.3 & 474 & 131 & 522 & 136 & - & - & 619 & 115 & 618 & 105 & 449 & 90 & 590 & 116 & 521 & 105 & 534 & 98 \\
\hline . & & 28 & 4 & 128 & 5 & 136 & - & - & 617 & 115 & 615 & 103 & 453 & 90 & 590 & 116 & 5 & 99 & 532 & 97 \\
\hline 15 & 2 & 26. & 4 & 130 & 5 & 137 & 498 & 126 & 616 & 114 & 616 & 105 & 456 & 89 & 593 & 115 & 5 & 100 & 532 & 97 \\
\hline 1983 & 263,674 & 27.2 & 473 & 131 & 541 & 138 & 504 & 128 & 623 & 115 & 620 & 105 & 459 & 90 & 599 & 114 & 527 & 98 & 542 & 95 \\
\hline $1984 \ldots \ldots \ldots \ldots \ldots$ & 265,221 & 27.2 & 475 & 130 & 541 & 139 & 512 & 129 & 622 & 115 & 619 & 102 & 461 & 90 & 604 & 114 & 530 & 97 & 543 & 96 \\
\hline $1985 \ldots$ & 271,972 & 27.8 & 474 & 126 & 545 & 140 & 516 & 129 & 61 & 114 & 621 & 10 & 45 & 89 & 615 & 12 & 53 & 95 & 541 & 95 \\
\hline $1986 \ldots$ & 279,428 & 28. & 47 & 126 & 5 & 140 & 520 & 129 & 612 & 114 & 628 & 106 & 464 & 87 & 616 & 119 & 527 & 96 & 542 & 97 \\
\hline 1987 & 293,560 & 29. & 477 & 126 & 550 & 140 & 521 & 128 & 616 & 116 & 629 & 104 & 465 & 86 & 619 & 119 & 526 & 95 & 536 & 95 \\
\hline 1988 & 303,703 & 30. & 483 & 123 & 557 & 140 & 528 & 128 & 615 & 114 & 631 & 108 & 467 & 85 & 622 & 120 & 525 & 94 & 537 & 94 \\
\hline 1989 & 326,096 & 32.0 & 484 & 125 & 560 & 142 & 530 & 129 & 612 & 114 & 642 & 117 & 465 & 87 & 626 & 116 & 528 & 91 & 538 & 95 \\
\hline $1990 \ldots$ & 344,572 & 32. & $4 \varepsilon$ & 123 & 56 & 143 & 534 & 128 & 61 & 114 & 662 & 123 & 46 & 84 & 617 & 111 & 523 & 92 & 537 & 95 \\
\hline & & 34.7 & 485 & 122 & 562 & 141 & 536 & 129 & 609 & 113 & 660 & 123 & 457 & 85 & 611 & 111 & 5 & 93 & 535 & 95 \\
\hline 1992. & 411,528 & 36.2 & 483 & 120 & 561 & 140 & 537 & 129 & 605 & 113 & 654 & 128 & 462 & 82 & 610 & 117 & 525 & 92 & 536 & 95 \\
\hline 199 & 400,2 & 34.4 & 481 & 117 & 557 & 140 & 541 & 129 & 606 & 114 & 662 & 133 & 462 & 80 & 602 & 115 & 516 & 94 & 536 & 97 \\
\hline 1994 & 1399,395 & 34.3 & 479 & 116 & 553 & 139 & 545 & 129 & 620 & 116 & 627 & 113 & 2493 & 104 & 601 & 115 & 517 & 95 & 538 & 96 \\
\hline 1995 & 1389,5 & 33. & 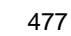 & 115 & 55 & 14 & 54 & 131 & 622 & 116 & 675 & 138 & 2488 & 102 & 596 & 113 & 513 & 96 & 544 & 98 \\
\hline 1996. & $137 €$ & 31.9 & 473 & 114 & 55 & 139 & 54 & 131 & 614 & 114 & 67 & 135 & 2489 & 104 & 604 & 119 & 51 & 97 & 547 & 99 \\
\hline 1997 & 1376,062 & 31.9 & 472 & 113 & 562 & 139 & 548 & 129 & 620 & 115 & 684 & 143 & 2487 & 103 & 602 & 114 & 525 & 100 & 554 & 99 \\
\hline
\end{tabular}

1 Total includes examinees who received no score on one or more General Test measures. 1994, 1995, 1996, and 1997 are from the revised education test.

ported or not applicable.

NOTE.-GRE scores for the verbal, quantitative, and analytical sections range from 200 to 800 . Subject matter test scores range from 200 to 990
SOURCE: Graduate Record Examination Board, Examinee and Score Trends for the GRE General Test, various years; and A Summary of Data Collected From Graduate Record Examinations Test-Takers During 1986-87; unpublished data; and U.S. Department of Education, National Center for for Education Statistics, Higher Education General Information Survey (HEGIS) "Degrees and Other Formal Awards Conferred" surveys, and Integrated Postsecondary Education Data System (IPEDS), "Completions" surveys. (This table was prepared November 1998.) 
Table 311.-Average undergraduate tuition and fees and room and board rates paid by full-time-equivalent students in institutions of higher education, by type and control of institution: 1964-65 to 1997-98

\begin{tabular}{|c|c|c|c|c|c|c|c|c|c|c|c|c|c|c|c|c|c|c|c|c|}
\hline \multirow{3}{*}{$\begin{array}{l}\text { Year and control of } \\
\text { institution }\end{array}$} & \multicolumn{5}{|c|}{ Total tuition, room, and board } & \multicolumn{5}{|c|}{ Tuition and required fees (in-state) } & \multicolumn{5}{|c|}{ Dormitory rooms } & \multicolumn{5}{|c|}{ Board (7-day basis) ${ }^{1}$} \\
\hline & \multirow{2}{*}{$\begin{array}{l}\text { All insti- } \\
\text { tutions }\end{array}$} & \multicolumn{3}{|c|}{ 4-year institutions } & \multirow[b]{2}{*}{ 2-year } & \multirow{2}{*}{$\begin{array}{l}\text { All insti- } \\
\text { tutions }\end{array}$} & & ear instituti & & & & & ear instituti & & & & & ear instituti & & \\
\hline & & $\begin{array}{c}\text { All } \\
\text { 4-year }\end{array}$ & $\begin{array}{l}\text { Univer- } \\
\text { sities }\end{array}$ & $\begin{array}{l}\text { Other } \\
4 \text {-year }\end{array}$ & & & $\begin{array}{c}\text { All } \\
4 \text {-year }\end{array}$ & $\begin{array}{l}\text { Univer- } \\
\text { sities }\end{array}$ & $\begin{array}{l}\text { Other } \\
4 \text {-year }\end{array}$ & 2-year & $\begin{array}{l}\text { lutions } \\
\text { tutions }\end{array}$ & $\begin{array}{c}\text { All } \\
\text { 4-year }\end{array}$ & $\begin{array}{l}\text { Univer- } \\
\text { sities }\end{array}$ & $\begin{array}{l}\text { Other } \\
4 \text {-year }\end{array}$ & 2-year & $\begin{array}{l}\text { tutions } \\
\text { tutions }\end{array}$ & $\begin{array}{c}\text { All } \\
\text { 4-year }\end{array}$ & $\begin{array}{l}\text { Univer- } \\
\text { sities }\end{array}$ & $\begin{array}{l}\text { Other } \\
\text { 4-year }\end{array}$ & 2-year \\
\hline 1 & 2 & 3 & 4 & 5 & 6 & 7 & 8 & 9 & 10 & 11 & 12 & 13 & 14 & 15 & 16 & 17 & 18 & 19 & 20 & 21 \\
\hline All institutions & & & & & & & & & & & & & & & & & & & & \\
\hline 976 & 2,275 & 2,577 & 2,647 & $\$ 2,527$ & $\$ 1,598$ & $\$ 924$ & $\$ 1,218$ & $\$ 1,210$ & $\$ 1,223$ & $\$ 346$ & $\$ 603$ & $\$ 611$ & $\$ 649$ & $\$ 584$ & $\$ 503$ & $\$ 748$ & $\$ 748$ & $\$ 788$ & $\$ 719$ & $\$ 750$ \\
\hline $1977-78 \ldots \ldots$. & 2,411 & 2,725 & 2,777 & 2,685 & 1,703 & 984 & 1,291 & 1,269 & 1,305 & 378 & 645 & 654 & 691 & 628 & 525 & 781 & 780 & 818 & 752 & 801 \\
\hline $1978-79 \ldots \ldots$. & 2,587 & 2,917 & 2,967 & 2,879 & 1,828 & 1,073 & 1,397 & 1,370 & 1,413 & 411 & 688 & 696 & 7 & 667 & 575 & 826 & 5 & 50 & 0 & 842 \\
\hline 1979 & 2,809 & 3,167 & 3,223 & 3,124 & 1,979 & 1,163 & 1,513 & 1,484 & 1,530 & 451 & 751 & 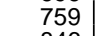 & 803 & 7 & 628 & 895 & 5 & 6 & 5 & 900 \\
\hline $1980-81$. & 3,101 & 3,499 & 3,535 & 3,469 & 2,230 & 1,289 & 1,679 & 1,634 & 1,705 & 526 & 836 & 846 & 881 & 821 & 705 & 976 & 975 & 1,020 & 943 & 1,000 \\
\hline $1981-8$ & 3,489 & 3,951 & 4,005 & 3,5 & 2,476 & 1,457 & 1,907 & 1,860 & 1,935 & 590 & 950 & 961 & 1,023 & 919 & 793 & 1,083 & 1,082 & 1,121 & 1,055 & 1,094 \\
\hline 198 & 3,877 & 4,406 & 4,4 & & 2,7 & 1,6 & 2,139 & 2,081 & & 6 & 1,064 & 1,078 & 1,150 & & 873 & & & & & 1,165 \\
\hline 1983-8 & 4,167 & 4,747 & 4,793 & 4,712 & 2,854 & 1,783 & 2,344 & 2,300 & 2,368 & 730 & 1,145 & 1,162 & 1,2 & 1,130 & 916 & & 1,2 & & & 1,208 \\
\hline $1984-85 \ldots$ & 4,563 & 5,160 & 5,236 & 5,107 & 3,179 & 1,985 & 2,567 & 2,539 & 2,583 & 821 & 1,267 & 1,282 & 1,343 & 1,242 & 1,058 & 1,310 & 1,311 & & & 1,301 \\
\hline $1985-86^{2} \ldots$ & 4,885 & 5,504 & 5,597 & 5,441 & 3,367 & 2,181 & 2,784 & 2,770 & 2,793 & 888 & 1,338 & 1,355 & 1,424 & 1,309 & 1,107 & 1,365 & 1,365 & 1,403 & 1,339 & 1,372 \\
\hline $1986-87^{3}$ & 5,206 & 5,964 & 6,124 & 5,857 & 3,295 & 2,312 & 3,042 & 3,042 & 3,042 & 897 & 1,405 & 1,427 & 1,501 & 1,376 & 1,034 & 1,489 & 1,495 & 1,581 & 1,439 & 1,364 \\
\hline 198 & 5,4 & 6,272 & 6,3 & 6,2 & 3,2 & 2,4 & 3,2 & 3,168 & & 809 & & & & & & & & & & 1,437 \\
\hline 198 & 5,869 & 6,725 & 6,801 & 6,67 & 3,573 & 2,658 & 3,472 & 3,422 & 3,499 & 979 & 1,575 & 1,609 & 1,6 & 1,5 & & & 1,6 & 1,7 & & 1,509 \\
\hline 198 & 6,207 & 7,212 & 7,347 & 7,1 & 3,705 & 2,839 & 3,800 & 3,765 & 3,819 & 97 & 1,6 & 1,6 & 1, & & & 1,730 & 1, & & & 1,622 \\
\hline $1990-91 \ldots \ldots$. & 6,562 & 7,602 & 7,709 & 7,5 & 3,930 & 3,016 & 4,009 & 3,958 & 4,036 & 1,087 & 1,743 & 1,782 & 1,848 & 1,740 & 1,182 & 1,802 & 1,811 & 1,903 & & 1,660 \\
\hline $1991-92 \ldots$ & 7,077 & 8,238 & 8,390 & 8,142 & 4,092 & 3,286 & 4,385 & 4,368 & 4,394 & 1,189 & 1,874 & 1,921 & 1,996 & 1,875 & 1,210 & 1,918 & 1,931 & 26 & 1,872 & 1,692 \\
\hline$-93 \ldots \ldots$. & & 8,75 & 8 & 8,6 & 4,2 & 3,5 & 4,7 & 4,665 & 4,7 & 1,2 & 1,0 & & 2, & 1, & 1,2 & $1, \mathrm{c}$ & & & & 1,692 \\
\hline 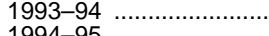 & 7,931 & $\begin{array}{l}9,296 \\
9,708\end{array}$ & 9,495 & 9,1 & 4,449 & 3,827 & 5,1 & 5,104 & 5,1 & 1,399 & 2,0 & 2,1 & 2,1 & & 1,3 & & & & & 1,718 \\
\hline 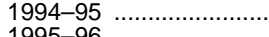 & 8,306 & $\begin{array}{r}9,728 \\
\end{array}$ & 9,863 & 9,6 & 4,6 & 4,044 & 5,3 & & 5,4 & 1,4 & 2,1 & 2,2 & & & & & & & & $\begin{array}{l}1,750 \\
1,730\end{array}$ \\
\hline 1995 & 8,800 & 10,330 & 10,560 & 10,1 & 4,7 & 4,3 & 5,7 & 5,7 & 5,8 & & & & & & & & & & & 1,730 \\
\hline 1996-97 ...... & 9,206 & 10,841 & 11,033 & & 4,895 & 4,564 & 6,11 & 6,055 & 6,150 & & & & & & & & & & & 1,830 \\
\hline 1997-98 4 ………..... & 9,536 & 11,227 & 11,388 & 11,129 & 5,075 & 4,726 & 6,329 & 6,229 & 6,378 & 1,582 & 2,463 & 2,525 & 2,613 & 2,477 & 1,587 & 2,347 & 2,372 & 2,546 & 2,274 & 1,907 \\
\hline Public institutions & & & & & & & & & & & & & & & & & & & & \\
\hline $1964-$ & 950 & - & 1,051 & 867 & 638 & 243 & - & 298 & 224 & 99 & 27 & - & 29 & 241 & 178 & 436 & - & 462 & 402 & 361 \\
\hline 100 & 983 & - & 1,1 & 90 & 670 & 257 & - & 200 & 2 & 109 & 2 & 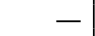 & 30 & 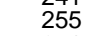 & 19 & 44 & - & & & 367 \\
\hline 19 & 1,026 & - & 1,1 & 9 & 710 & & - & 360 & 25 & 12 & 2 & - & & & & & - & & & 3 \\
\hline 15 & 1,064 & - & 1 & 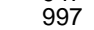 & 789 & 2 & - & 366 & 26 & 1 & 3 & - & & & & & - & & & $4 \mathrm{C}$ \\
\hline 1968 & 1,117 & - & 1,245 & 1,063 & 883 & 295 & - & 377 & 281 & 1 & 3 & $\ldots$ & & 318 & 278 & 4 & 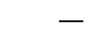 & & & 435 \\
\hline 1969 & 1,203 & - & 1,3 & & 951 & 323 & - & 427 & 306 & 178 & 369 & 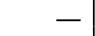 & 395 & 346 & 308 & 511 & - & 540 & 483 & 465 \\
\hline 19 & 1 & - & & & & & - & 478 & 3 & $1 \varepsilon$ & 4 & & 4 & & & & - & & & 473 \\
\hline .. & 1,357 & - & 1,5 & & 1,073 & 376 & - & 5 & 35 & 15 & 43 & - & 4 & 4 & 3 & 5 & - & & & 5 \\
\hline 19 & 1,458 & - & 1,6 & & 1,1 & & - & 5 & 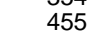 & ? & 47 & -1 & & & & & 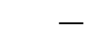 & & & 5 \\
\hline $1973-74 \ldots$ & 1,517 & - & 1,707 & 1,506 & 1,274 & 438 & - & 581 & 463 & 274 & 480 & - & 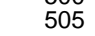 & & 409 & & - & 21 & & 591 \\
\hline $1974-75$. & 1,563 & - & 1,7 & & 1,339 & 432 & - & 599 & 448 & 277 & 506 & & 527 & 497 & 424 & 625 & - & 634 & 613 & 638 \\
\hline & 1 & . & & & & & 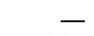 & & & & & & & & & & & & & 6 \\
\hline & 1,789 & 1,935 & 2, & & & 479 & 617 & 6 & 56 & $2 \varepsilon$ & 5 & 592 & & & 4 & 7 & 727 & & & 72 \\
\hline & 1888 & 2,038 & & & & & 6 & & 56 & & & 631 & & & & & 752 & & & 75 \\
\hline $1978-79 \ldots$ & 1,994 & 2,145 & 2,289 & 2,027 & 1,691 & 543 & 688 & 777 & 622 & & 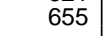 & 664 & & 041 & 527 & 196 & 793 & 20 & & 837 \\
\hline $1979-80 \ldots$ & $\begin{array}{l}2,165 \\
2,373\end{array}$ & $\begin{array}{l}2,327 \\
2,550\end{array}$ & & & & $\begin{array}{l}583 \\
635\end{array}$ & $\begin{array}{l}738 \\
804\end{array}$ & $\begin{array}{l}840 \\
915\end{array}$ & $\begin{array}{l}662 \\
722\end{array}$ & $\begin{array}{l}355 \\
391\end{array}$ & $\begin{array}{l}715 \\
799\end{array}$ & $\begin{array}{l}725 \\
811\end{array}$ & $\begin{array}{l}750 \\
827\end{array}$ & 703 & $\begin{array}{l}574 \\
642\end{array}$ & $\begin{array}{l}867 \\
940\end{array}$ & $\begin{array}{l}865 \\
936\end{array}$ & $\begin{array}{l}898 \\
969\end{array}$ & $\begin{array}{l}833 \\
904\end{array}$ & $\begin{array}{l}893 \\
994\end{array}$ \\
\hline $\begin{array}{l}-81 \ldots . \\
-82 \ldots\end{array}$ & $\begin{array}{l}2,373 \\
2,663\end{array}$ & $\begin{array}{l}2,550 \\
2,871\end{array}$ & 30 & & & $\begin{array}{l}635 \\
714\end{array}$ & $\begin{array}{l}804 \\
909\end{array}$ & $\begin{array}{r}915 \\
1,042\end{array}$ & $\begin{array}{l}73 \\
8\end{array}$ & 43 & 9 & 925 & $\begin{array}{l}82 \\
97\end{array}$ & 8 & 70 & 1.0 & $\begin{array}{r}936 \\
1.036\end{array}$ & & & $\begin{array}{r}994 \\
1.086\end{array}$ \\
\hline 1982-83 & 2,945 & $\begin{array}{l}3,196 \\
3,196\end{array}$ & & & & 75 & 1, & 1,1 & of & & & & & & & & & & & \\
\hline 1983-8 & 3,156 & 3,433 & 3,628 & & 2,534 & 891 & 1,148 & 1,284 & 1,052 & & 1,087 & 1,110 & 1,131 & 1,092 & 801 & 1,178 & 1,175 & 1,213 & 1,141 & 1,205 \\
\hline 1984-85 ... & 3,408 & & & & & 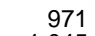 & & & & 5 & & & & & & & & & & \\
\hline & 3 & & & & & & & & & & & & & & & & & & & \\
\hline 15 & 3 & & & & & & & & & & & & & & & & & & & \\
\hline 19 & 4,0 & 4,4 & & & 3 & 1,2 & & & & 7 & & 10 & & & & & & & & 1, \\
\hline 1988-89 ...... & 4,274 & 4,678 & 4,905 & 4,526 & 3,183 & 1,285 & 1,646 & 1,846 & 1,515 & 730 & 1,457 & 1,496 & 1,483 & 1,506 & 965 & 1,533 & 1,536 & 1,576 & 1,504 & 1,488 \\
\hline $1989-90 \ldots$ & 4,504 & 4,975 & & 4,723 & & 1,3 & & & & 75 & & & & & & & & & & 1,581 \\
\hline & 4,7 & & & & & & & & & 8 & & & & & & & & & & \\
\hline & $\begin{array}{l}5,138 \\
5379\end{array}$ & $\begin{array}{l}5,693 \\
6020\end{array}$ & 6,0 & $\begin{array}{l}5,4 \\
57\end{array}$ & $\begin{array}{l}3,62 \\
376\end{array}$ & $\begin{array}{l}1,628 \\
1782\end{array}$ & 2,1 & 2,4 & $\begin{array}{l}1,931 \\
2,192\end{array}$ & 9 & 1,7 & $\begin{array}{l}1,785 \\
1,816\end{array}$ & 1,8 & 1,7 & & $\begin{array}{l}1,780 \\
1841\end{array}$ & $\begin{array}{l}1,792 \\
1,854\end{array}$ & 1, & & 1,612 \\
\hline $\begin{array}{l}1992-93 \ldots . \\
1993-94 \ldots .\end{array}$ & $\begin{array}{l}5,379 \\
5,694\end{array}$ & $\begin{array}{l}6,020 \\
6,365\end{array}$ & $\begin{array}{l}6,442 \\
6,710\end{array}$ & $\begin{array}{l}5,140 \\
6,146\end{array}$ & $\begin{array}{l}3,799 \\
3,996\end{array}$ & $\begin{array}{l}1,182 \\
1,942\end{array}$ & $\begin{array}{l}2,349 \\
2,537\end{array}$ & $\begin{array}{l}2,604 \\
2,820\end{array}$ & $\begin{array}{l}2,192 \\
2,360\end{array}$ & $\begin{array}{l}1,025 \\
1,125\end{array}$ & $\begin{array}{l}1, / 56 \\
1,873\end{array}$ & $\begin{array}{l}1,816 \\
1,934\end{array}$ & $\begin{array}{l}1,856 \\
1,897\end{array}$ & $\begin{array}{l}1,98 \\
1,958\end{array}$ & $\begin{array}{l}1,106 \\
1,190\end{array}$ & $\begin{array}{l}1,841 \\
1,880\end{array}$ & $\begin{array}{l}1,854 \\
1,895\end{array}$ & $\begin{array}{l}1,982 \\
1,993\end{array}$ & $\begin{array}{l}1,761 \\
1,828\end{array}$ & $\begin{array}{l}1,668 \\
1,681\end{array}$ \\
\hline 1994-95. & 5,96 & 6,6 & 7,0 & 6,4 & 4,1 & 2,0 & 2,6 & 2,9 & & 1,1 & & & & & & & & & & 1,712 \\
\hline & $=-1$ & 70 & & & 10 & 2,1 & & 3,1 & & 1,2 & & & & & & & & & & 1,681 \\
\hline & 530 & 34 & 792 & 035 & 404 & 2,271 & 987 &, 323 & מ & ,276 & $2,14 \varepsilon$ & & ,187 & & 30: & & 133 & 282 & 2,025 & 789 \\
\hline
\end{tabular}


Table 311.-Average undergraduate tuition and fees and room and board rates paid by full-time-equivalent students in institutions of higher education, by

type and control of institution: 1964-65 to 1997-98-Continued

\begin{tabular}{|c|c|c|c|c|c|c|c|c|c|c|c|c|c|c|c|c|c|c|c|c|}
\hline \multirow{3}{*}{$\begin{array}{l}\text { Year and control of } \\
\text { institution }\end{array}$} & \multicolumn{5}{|c|}{ Total tuition, room, and board } & \multicolumn{5}{|c|}{ Tuition and required fees (in-state) } & \multicolumn{5}{|c|}{ Dormitory rooms } & \multicolumn{5}{|c|}{ Board (7-day basis) ${ }^{1}$} \\
\hline & \multirow{2}{*}{$\begin{array}{l}\text { All insti- } \\
\text { tutions }\end{array}$} & \multicolumn{3}{|c|}{ 4-year institutions } & \multirow[b]{2}{*}{ 2-year } & \multirow{2}{*}{$\begin{array}{l}\text { All insti- } \\
\text { tutions }\end{array}$} & \multicolumn{3}{|c|}{ 4-year institutions } & \multirow[b]{2}{*}{ 2-year } & \multirow{2}{*}{$\begin{array}{l}\text { All insti- } \\
\text { tutions }\end{array}$} & \multicolumn{3}{|c|}{ 4-year institutions } & \multirow[b]{2}{*}{ 2-year } & \multirow{2}{*}{$\begin{array}{l}\text { All insti- } \\
\text { tutions }\end{array}$} & \multicolumn{3}{|c|}{ 4-year institutions } & \multirow[b]{2}{*}{ 2-year } \\
\hline & & $\begin{array}{c}\text { All } \\
\text { 4-year }\end{array}$ & $\begin{array}{l}\text { Univer- } \\
\text { sities }\end{array}$ & $\begin{array}{l}\text { Other } \\
\text { 4-year }\end{array}$ & & & $\begin{array}{c}\text { All } \\
4 \text {-year }\end{array}$ & $\begin{array}{l}\text { Univer- } \\
\text { sities }\end{array}$ & $\begin{array}{l}\text { Other } \\
\text { 4-year }\end{array}$ & & & $\begin{array}{c}\text { All } \\
4 \text {-year }\end{array}$ & $\begin{array}{l}\text { Univer- } \\
\text { sities }\end{array}$ & $\begin{array}{l}\text { Other } \\
\text { 4-year }\end{array}$ & & & $\begin{array}{c}\text { All } \\
\text { 4-year }\end{array}$ & $\begin{array}{c}\text { Univer- } \\
\text { sities }\end{array}$ & $\begin{array}{l}\text { Other } \\
\text { 4-year }\end{array}$ & \\
\hline 1 & 2 & 3 & 4 & 5 & 6 & 7 & 8 & 9 & 10 & 11 & 12 & 13 & 14 & 15 & 16 & 17 & 18 & 19 & 20 & 21 \\
\hline $\begin{array}{c}1997-98^{4} \ldots \ldots \ldots \ldots \ldots . . . \\
\text { Private institutions }\end{array}$ & 6,788 & 7,628 & 8,148 & 7,290 & 4,601 & 2,365 & 3,110 & 3,489 & 2,876 & 1,318 & 2,243 & 2,314 & 2,280 & 2,338 & 1,419 & 2,180 & 2,204 & 2,380 & 2,076 & 1,864 \\
\hline $\begin{array}{l}1964-65 \\
1965-66 \\
1966-67\end{array}$ & $\begin{array}{l}1,907 \\
2,005 \\
2,124 \\
2,205 \\
2,321\end{array}$ & $\begin{array}{l}- \\
\overline{-} \\
-\end{array}$ & $\begin{array}{l}2,202 \\
2,316 \\
2,456 \\
2,545 \\
2,673\end{array}$ & $\begin{array}{l}1,810 \\
1,899 \\
2,007 \\
2,104 \\
2,237\end{array}$ & $\begin{array}{l}1,455 \\
1,557 \\
1,679 \\
1,762 \\
1,876\end{array}$ & $\begin{array}{l}1,088 \\
1,154 \\
1,233 \\
1,297 \\
1,383\end{array}$ & $\begin{array}{l}- \\
\bar{z} \\
-\end{array}$ & $\begin{array}{l}1,297 \\
1,369 \\
1,456 \\
1,534 \\
1,638\end{array}$ & $\begin{array}{l}1,023 \\
1,086 \\
1,162 \\
1,237 \\
1,335\end{array}$ & $\begin{array}{l}702 \\
768 \\
845 \\
892 \\
956\end{array}$ & $\begin{array}{l}331 \\
356 \\
385 \\
392 \\
404\end{array}$ & $\begin{array}{l}- \\
= \\
=\end{array}$ & $\begin{array}{l}390 \\
418 \\
452 \\
455 \\
463\end{array}$ & $\begin{array}{l}308 \\
330 \\
355 \\
366 \\
382\end{array}$ & $\begin{array}{l}289 \\
316 \\
347 \\
366 \\
391\end{array}$ & $\begin{array}{l}488 \\
495 \\
506 \\
516 \\
534\end{array}$ & $\begin{array}{l}\bar{z} \\
\bar{z}\end{array}$ & $\begin{array}{l}515 \\
529 \\
548 \\
556 \\
572\end{array}$ & $\begin{array}{l}479 \\
483 \\
490 \\
501 \\
520\end{array}$ & $\begin{array}{l}464 \\
473 \\
487 \\
504 \\
529\end{array}$ \\
\hline 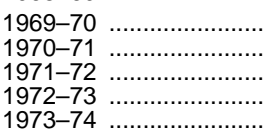 & $\begin{array}{l}2,530 \\
2,738 \\
2,917 \\
3,038 \\
3,164\end{array}$ & $\begin{array}{l}- \\
\bar{z} \\
\overline{-}\end{array}$ & $\begin{array}{l}2,920 \\
3,163 \\
3,375 \\
3,512 \\
3,717\end{array}$ & $\begin{array}{l}2,420 \\
2,599 \\
2,748 \\
2,934 \\
3,040\end{array}$ & $\begin{array}{l}1,993 \\
2,103 \\
2,186 \\
2,273 \\
2,410\end{array}$ & $\begin{array}{l}1,533 \\
1,684 \\
1,820 \\
1,898 \\
1,989\end{array}$ & $\begin{array}{l}- \\
\bar{z} \\
\bar{z}\end{array}$ & $\begin{array}{l}1,809 \\
1,980 \\
2,133 \\
2,226 \\
2,375\end{array}$ & $\begin{array}{l}1,468 \\
1,603 \\
1,721 \\
1,846 \\
1,925\end{array}$ & $\begin{array}{l}1,034 \\
1,109 \\
1,172 \\
1,221 \\
1,303\end{array}$ & $\begin{array}{l}436 \\
468 \\
494 \\
524 \\
533\end{array}$ & $\begin{array}{l}= \\
= \\
=\end{array}$ & $\begin{array}{l}503 \\
542 \\
576 \\
622 \\
622\end{array}$ & $\begin{array}{l}409 \\
434 \\
454 \\
490 \\
502\end{array}$ & $\begin{array}{l}413 \\
434 \\
449 \\
457 \\
483\end{array}$ & $\begin{array}{l}561 \\
586 \\
603 \\
616 \\
642\end{array}$ & $\begin{array}{l}\bar{z} \\
\bar{z}\end{array}$ & $\begin{array}{l}608 \\
641 \\
666 \\
664 \\
720\end{array}$ & $\begin{array}{l}543 \\
562 \\
573 \\
598 \\
613\end{array}$ & $\begin{array}{l}546 \\
560 \\
565 \\
595 \\
624\end{array}$ \\
\hline 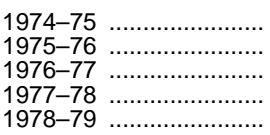 & $\begin{array}{l}3,403 \\
3,663 \\
3,906 \\
4,158 \\
4,514\end{array}$ & $\begin{array}{r}- \\
3,977 \\
4,240 \\
4,609\end{array}$ & $\begin{array}{l}4,076 \\
4,467 \\
4,715 \\
5,033 \\
5,403\end{array}$ & $\begin{array}{l}3,156 \\
3,385 \\
3,714 \\
3,967 \\
4,327\end{array}$ & $\begin{array}{l}2,591 \\
2,711 \\
2,971 \\
3,148 \\
3,389\end{array}$ & $\begin{array}{l}2,117 \\
2,272 \\
2,467 \\
2,624 \\
2,867\end{array}$ & $\begin{array}{l}\overline{-} \\
2,534 \\
2,700 \\
2,958\end{array}$ & $\begin{array}{l}2,614 \\
2,881 \\
3,051 \\
3,240 \\
3,487\end{array}$ & $\begin{array}{l}1,954 \\
2,084 \\
2,351 \\
2,520 \\
2,771\end{array}$ & & $\begin{array}{l}586 \\
636 \\
649 \\
698 \\
758\end{array}$ & $\begin{array}{l}- \\
6 \overline{51} \\
702 \\
761\end{array}$ & $\begin{array}{l}691 \\
753 \\
783 \\
850 \\
916\end{array}$ & $\begin{array}{l}536 \\
583 \\
604 \\
648 \\
704\end{array}$ & $\begin{array}{l}564 \\
572 \\
607 \\
631 \\
700\end{array}$ & $\begin{array}{l}700 \\
755 \\
790 \\
836 \\
889\end{array}$ & $\begin{array}{r}7 \overline{-} \\
791 \\
838 \\
890\end{array}$ & $\begin{array}{r}771 \\
833 \\
882 \\
943 \\
1,000\end{array}$ & $\begin{array}{l}666 \\
718 \\
759 \\
800 \\
851\end{array}$ & $\begin{array}{l}660 \\
712 \\
772 \\
811 \\
858\end{array}$ \\
\hline $\begin{array}{l}1979-80 \\
1980-81 \\
1981-82\end{array}$ & $\begin{array}{l}4,912 \\
5,470 \\
6,166 \\
6,920 \\
7,508\end{array}$ & $\begin{array}{l}5,013 \\
5,594 \\
6,330 \\
7,126 \\
7,759\end{array}$ & $\begin{array}{l}5,891 \\
6,569 \\
7,443 \\
8,536 \\
9,308\end{array}$ & $\begin{array}{l}4,700 \\
5,249 \\
5,947 \\
6,646 \\
7,244\end{array}$ & $\begin{array}{l}3,751 \\
4,303 \\
4,746 \\
5,364 \\
5,571\end{array}$ & $\begin{array}{l}3,130 \\
3,498 \\
3,953 \\
4,439 \\
4,851\end{array}$ & $\begin{array}{l}3,225 \\
3,617 \\
4,113 \\
4,639 \\
5,093\end{array}$ & $\begin{array}{l}3,811 \\
4,275 \\
4,887 \\
5,583 \\
6,217\end{array}$ & $\begin{array}{l}3,020 \\
3,390 \\
3,853 \\
4,329 \\
4,726\end{array}$ & & $\begin{array}{r}827 \\
918 \\
1,038 \\
1,181 \\
1,278\end{array}$ & $\begin{array}{r}831 \\
921 \\
1,039 \\
1,181 \\
1,279\end{array}$ & $\begin{array}{l}1,001 \\
1,086 \\
1,229 \\
1,453 \\
1,531\end{array}$ & $\begin{array}{r}768 \\
859 \\
970 \\
1,083 \\
1,191\end{array}$ & $\begin{array}{r}766 \\
871 \\
1,022 \\
1,177 \\
1,253\end{array}$ & $\begin{array}{r}955 \\
1,054 \\
1,175 \\
1,300 \\
1,380\end{array}$ & $\begin{array}{r}957 \\
1,056 \\
1,178 \\
1,306 \\
1,387\end{array}$ & $\begin{array}{l}1,078 \\
1,209 \\
1,327 \\
1,501 \\
1,559\end{array}$ & $\begin{array}{r}912 \\
1,000 \\
1,124 \\
1,234 \\
1,327\end{array}$ & $\begin{array}{r}923 \\
1,019 \\
1,119 \\
1,179 \\
1,219\end{array}$ \\
\hline $\begin{array}{l}1984-85 \\
1985-86^{2} \\
1986-17^{3}\end{array}$ & $\begin{array}{r}8,202 \\
8,885 \\
9,676 \\
10,512 \\
11,189\end{array}$ & $\begin{array}{r}8,451 \\
9,228 \\
10,039 \\
10,659 \\
11,474\end{array}$ & $\begin{array}{l}10,243 \\
11,034 \\
12,278 \\
13,075 \\
14,073\end{array}$ & $\begin{array}{r}7,849 \\
8,551 \\
9,276 \\
9,854 \\
10,620\end{array}$ & $\begin{array}{l}6,203 \\
6,512 \\
6,384 \\
7,078 \\
7,967\end{array}$ & $\begin{array}{l}5,315 \\
5,789 \\
6,316 \\
6,988 \\
7,461\end{array}$ & $\begin{array}{l}5,556 \\
6,121 \\
6,658 \\
7,116 \\
7,722\end{array}$ & $\begin{array}{l}6,843 \\
7,374 \\
8,118 \\
8,771 \\
9,451\end{array}$ & $\begin{array}{l}5,135 \\
5,641 \\
6,171 \\
6,574 \\
7,172\end{array}$ & & $\begin{array}{l}1,426 \\
1,553 \\
1,658 \\
1,748 \\
1,849\end{array}$ & $\begin{array}{l}1,426 \\
1,557 \\
1,673 \\
1,760 \\
1,863\end{array}$ & $\begin{array}{l}1,753 \\
1,940 \\
2,097 \\
2,244 \\
2,353\end{array}$ & $\begin{array}{l}1,309 \\
1,420 \\
1,518 \\
1,593 \\
1,686\end{array}$ & $\begin{array}{l}1,424 \\
1,500 \\
1,266 \\
1,380 \\
1,540\end{array}$ & $\begin{array}{l}1,462 \\
1,542 \\
1,702 \\
1,775 \\
1,880\end{array}$ & $\begin{array}{l}1,469 \\
1,551 \\
1,708 \\
1,783 \\
1,889\end{array}$ & $\begin{array}{l}1,647 \\
1,720 \\
2,063 \\
2,060 \\
2,269\end{array}$ & $\begin{array}{l}1,405 \\
1,490 \\
1,587 \\
1,687 \\
1,762\end{array}$ & $\begin{array}{l}1,294 \\
1,340 \\
1,434 \\
1,537 \\
1,609\end{array}$ \\
\hline $\begin{array}{l}1989-90 \\
1990-91 \\
1991-92\end{array}$ & $\begin{array}{l}12,018 \\
12,910 \\
13,892 \\
14,634 \\
15,496\end{array}$ & $\begin{array}{l}12,284 \\
13,237 \\
14,258 \\
15,009 \\
15,904\end{array}$ & $\begin{array}{l}15,098 \\
16,503 \\
17,572 \\
18,898 \\
20,097\end{array}$ & $\begin{array}{l}11,374 \\
12,220 \\
13,201 \\
13,882 \\
14,640\end{array}$ & $\begin{array}{r}8,670 \\
9,302 \\
9,632 \\
9,903 \\
10,406\end{array}$ & $\begin{array}{r}8,147 \\
8,772 \\
9,419 \\
9,942 \\
10,572\end{array}$ & $\begin{array}{r}8,396 \\
9,083 \\
9,759 \\
10,294 \\
10,952\end{array}$ & $\begin{array}{l}10,348 \\
11,379 \\
12,037 \\
13,055 \\
13,874\end{array}$ & $\begin{array}{r}7,778 \\
8,389 \\
9,060 \\
9,533 \\
10,100\end{array}$ & & $\begin{array}{l}1,923 \\
2,063 \\
2,221 \\
2,348 \\
2,490\end{array}$ & $\begin{array}{l}1,935 \\
2,077 \\
2,241 \\
2,362 \\
2,506\end{array}$ & $\begin{array}{l}2,411 \\
2,654 \\
2,825 \\
3,018 \\
3,277\end{array}$ & $\begin{array}{l}1,774 \\
1,889 \\
2,042 \\
2,151 \\
2,261\end{array}$ & & & $\begin{array}{l}1,953 \\
2,077 \\
2,257 \\
2,354 \\
2,445\end{array}$ & $\begin{array}{l}2,339 \\
2,470 \\
2,709\end{array}$ & $\begin{array}{l}1,823 \\
1,943 \\
2,098 \\
2,197 \\
2,278\end{array}$ & $\begin{array}{l}1,811 \\
1,989 \\
2,090 \\
1,875 \\
1,970\end{array}$ \\
\hline $\begin{array}{l}1994-95 \\
1995-96 \\
1996-97\end{array}$ & $\begin{array}{l}16,207 \\
17,208 \\
18,039\end{array}$ & $\begin{array}{l}16,602 \\
17,612 \\
18,442\end{array}$ & $\begin{array}{l}21,041 \\
22,502 \\
23,520\end{array}$ & $\begin{array}{l}15,363 \\
16,198 \\
16,994\end{array}$ & $\begin{array}{l}11,170 \\
11,563 \\
11,954\end{array}$ & $\begin{array}{l}11,111 \\
11,864 \\
12,498\end{array}$ & $\begin{array}{l}11,481 \\
12,243 \\
12,881\end{array}$ & $\begin{array}{l}14,537 \\
15,605 \\
16,552\end{array}$ & $\begin{array}{l}10,653 \\
11,297 \\
11,871\end{array}$ & $\begin{array}{l}6,914 \\
7,094 \\
7,236\end{array}$ & $\begin{array}{l}2,587 \\
2,738 \\
2,878\end{array}$ & $\begin{array}{l}2,601 \\
2,751 \\
2,889\end{array}$ & $\begin{array}{l}3,469 \\
3,680 \\
3,826\end{array}$ & $\begin{array}{l}2,347 \\
2,473 \\
2,602\end{array}$ & $\begin{array}{l}2,233 \\
2,371 \\
2,537\end{array}$ & & $\begin{array}{l}2,520 \\
2,617 \\
2,672\end{array}$ & $\begin{array}{l}3,035 \\
3,218 \\
3,142\end{array}$ & $\begin{array}{l}2,362 \\
2,429 \\
2,520\end{array}$ & $\begin{array}{l}2,023 \\
2,098 \\
2,181\end{array}$ \\
\hline $1997-98$ & 18,745 & $\begin{array}{l}0,44 k \\
9,143\end{array}$ & 24,423 & $\begin{array}{r}10,712 \\
17,712\end{array}$ & 12,481 & 13,013 & 13,392 & 17,197 & 12,388 & 7,536 & $\begin{array}{l}2,010 \\
2,990\end{array}$ & $\begin{array}{l}2,009 \\
3,002\end{array}$ & $\begin{array}{l}4,020 \\
4,001\end{array}$ & 2,717 & 2,624 & $\begin{array}{l}2,000 \\
2,742\end{array}$ & 2,750 & 3,224 & 2,608 & 2,321 \\
\hline
\end{tabular}

1 Data for 1986-87 and later years reflect 20 meals per week rather than meals 7 days per week.

${ }^{2}$ Room and board data are estimated.

${ }^{3}$ Because of revisions in data collection procedures, figures are not entirely comparable with those for previous years. In particular, data on board rates are somewhat higher than earlier years because they reflect a basis of 20 day, the 1986-87 and later data reflect a more accurate accounting of total board costs. Because of their low respons ate, data for private 2-year colleges must be interpreted with caution.

4 Preliminary data based on fall 1996 enrollment weights.
-Data not available.
NOTE_-Data are for the entire academic year and are average charges paid by students. Tuition and fees were weighted by the number of full-time-equivalent undergraduates, but were not adjusted to reflect student residency. Room and board were based on full-time students. The data have not been adjusted for changes in the purchasing details may not add to totals.

SOURCE: U.S. Department of Education, National Center for Education Statistics, Higher Education General Information Survey (HEGIS), "Institutional Characteristics of Colleges and Universities" and "Fall Enrollment in Institutions of Higher Education" surveys, Integrated Postsecondary Education Data System (IPEDS), "Fall Enrollment" and "Institutional Characteristics" surveys. (This table was prepared November 1998) 
Table 312.-Average undergraduate tuition and fees and room and board rates paid by full-time-equivalent students in institutions of higher education, by control of institution and by state: 1996-97 and 1997-98

\begin{tabular}{|c|c|c|c|c|c|c|c|c|c|c|c|c|c|c|}
\hline \multirow[b]{2}{*}{ State or other area } & \multicolumn{2}{|c|}{$\begin{array}{l}\text { Public 4-year, } \\
\text { 1996-97 }\end{array}$} & \multicolumn{4}{|c|}{$\begin{array}{l}\text { Public 4-year, } \\
\text { 1997-98 }{ }^{1}\end{array}$} & \multicolumn{2}{|c|}{$\begin{array}{l}\text { Private 4-year, } \\
1996-97\end{array}$} & \multicolumn{4}{|c|}{$\begin{array}{l}\text { Private 4-year, } \\
1997-98{ }^{1}\end{array}$} & \multicolumn{2}{|c|}{$\begin{array}{l}\text { Public 2-year, tuition } \\
\text { only (in-state) }\end{array}$} \\
\hline & Total & $\begin{array}{l}\text { Tuition } \\
\text { (in- } \\
\text { state) }\end{array}$ & Total & $\begin{array}{c}\text { Tuition } \\
\text { (in- } \\
\text { state) }\end{array}$ & Room & Board & Total & Tuition & Total & Tuition & Room & Board & $1996-97$ & $1997-98^{1}$ \\
\hline 1 & 2 & 3 & 4 & 5 & 6 & 7 & 8 & 9 & 10 & 11 & 12 & 13 & 14 & 15 \\
\hline United States .... & $\$ 7,334$ & $\$ 2,987$ & $\$ 7,628$ & $\$ 3,110$ & $\$ 2,314$ & $\$ 2,204$ & $\$ 18,442$ & $\$ 12,881$ & $\$ 19,143$ & $\$ 13,392$ & $\$ 3,002$ & $\$ 2,750$ & $\$ 1,276$ & $\$ 1,318$ \\
\hline Alabama ...... & 6,002 & 2,362 & 6,354 & 2,487 & 1,888 & 1,979 & 12,164 & 8,002 & 12,724 & 8,350 & 1,958 & 2,416 & 1,359 & 1,343 \\
\hline Alaska .......... & 6,892 & 2,550 & 7,131 & 2,609 & 2,585 & 1,937 & 12,707 & 8,131 & 13,214 & 8,377 & 2,008 & 2,828 & 1,850 & 1,900 \\
\hline Arizona ...... & 6,314 & 2,009 & 6,669 & 2,058 & 2,403 & 2,208 & 12,330 & 7,886 & 11,388 & 6,992 & 2,042 & 2,354 & 783 & 820 \\
\hline Arkansas . & 5,402 & 2,258 & 5,890 & 2,451 & 1,879 & 1,560 & 10,784 & 7,037 & 11,506 & 7,581 & 1,630 & 2,296 & 937 & 942 \\
\hline California & 8,304 & 2,720 & 8,491 & 2,709 & 3,164 & 2,619 & 20,760 & 14,429 & 19,745 & 13,469 & 3,258 & 3,018 & 371 & 379 \\
\hline Colorado ... & 7,321 & 2,561 & 7,552 & 2,622 & 2,249 & 2,680 & 18,137 & 12,003 & 18,882 & 12,661 & 2,900 & 3,321 & 1,395 & 1,449 \\
\hline Connecticut & 9,256 & 4,111 & 9,652 & 4,273 & 2,855 & 2,524 & 23,916 & 17,458 & 25,083 & 18,345 & 3,814 & 2,924 & 1,722 & 1,814 \\
\hline Delaware .... & 8,886 & 4,170 & 9,165 & 4,318 & 2,589 & 2,257 & 12,602 & 7,444 & 13,354 & 7,829 & 2,950 & 2,575 & 1,330 & 1,380 \\
\hline District of Columbia .... & - & 1,502 & - & 1,910 & - & - & 22,599 & 15,586 & 23,807 & 16,496 & 4,361 & 2,949 & - & \\
\hline Florida $\ldots \ldots \ldots \ldots \ldots \ldots \ldots \ldots$ & 6,559 & 1,789 & 6,890 & 1,909 & 2,621 & 2,360 & 16,029 & 11,112 & 17,057 & 11,687 & 2,792 & 2,577 & 1,151 & 1,252 \\
\hline Georgia & 6,508 & 2,241 & 6,924 & 2,356 & 2,298 & 2,270 & 16,409 & 10,942 & 17,133 & 11,374 & 3,233 & 2,527 & 1,093 & 1,153 \\
\hline Hawaii . & & 2,294 & - & 2,790 & - & & 14,151 & 6,541 & 14,448 & 6,748 & 3,000 & 4,700 & 789 & 956 \\
\hline Idaho . & 5,681 & 1,979 & 6,074 & 2,201 & 1,615 & 2,258 & 15,722 & 12,210 & 15,167 & 11,661 & 1,312 & 2,195 & 1,043 & 1,102 \\
\hline Illinois ..... & 8,193 & 3,522 & 8,537 & 3,701 & 2,237 & 2,600 & 17,606 & 12,376 & 18,580 & 13,105 & 2,963 & 2,513 & 1,290 & 1,347 \\
\hline Indiana .......................... & 8,110 & 3,198 & 8,494 & 3,344 & 2,112 & 3,037 & 17,670 & 13,234 & 18,625 & 13,986 & 2,186 & 2,452 & 2,331 & 2,415 \\
\hline lowa ............ & 6,174 & 2,655 & 6,426 & 2,761 & 1,865 & 1,800 & 16,562 & 12,403 & 17,472 & 13,094 & 2,010 & 2,368 & 1,845 & 1,885 \\
\hline Kansas ....... & 5,895 & 2,219 & 6,098 & 2,311 & 1,833 & 1,953 & 12,995 & 9,129 & 13,737 & 9,688 & 1,685 & 2,364 & 1,248 & 1,285 \\
\hline Kentucky & 5,460 & 2,241 & 5,662 & 2,328 & 1,473 & 1,861 & 12,085 & 8,138 & 12,885 & 8,570 & 1,941 & 2,374 & 1,215 & 1,232 \\
\hline Louisiana & 5,637 & 2,233 & 5,710 & 2,269 & 1,573 & 1,868 & 18,407 & 12,885 & 18,928 & 13,212 & 2,922 & 2,794 & 1,047 & 1,080 \\
\hline Maine ...... & 8,262 & 3,648 & 8,576 & 3,880 & 2,319 & 2,378 & 22,619 & 16,956 & 24,505 & 18,645 & 2,764 & 3,096 & 2,545 & 2,594 \\
\hline Maryland & 9,179 & 3,849 & 9,717 & 4,135 & 2,976 & 2,606 & 21,967 & 32 & & 09 & 755 & 16 & 2,102 & 2,171 \\
\hline Massachusetts & 9,045 & 4,272 & 8,894 & 3,981 & 2,564 & 2,350 & 24,339 & 17,188 & 25,620 & 18,149 & 4,095 & 3,376 & 2,341 & 2,221 \\
\hline Michigan ............ & 8,645 & 3,988 & 8,947 & 4,131 & 2,190 & 2,625 & 13,930 & 9,580 & 14,459 & 10,018 & 2,210 & 2,230 & 1,576 & 1,618 \\
\hline Minnesota .......... & 7,148 & 3,546 & 7,617 & 3,776 & 2,193 & 1,649 & 17,980 & 13,623 & 18,559 & 14,046 & 2,220 & 2,293 & 2,187 & 2,245 \\
\hline Mississippi ......... & 5,532 & 2,499 & 5,534 & 2,568 & 1,526 & 1,440 & 10,482 & 7,210 & 11,226 & 7,725 & 1,773 & 1,729 & 954 & 958 \\
\hline Missouri . & 7,204 & 3,245 & 7,520 & 3,394 & 2,303 & 1,824 & 14,763 & 9,990 & 15,504 & 10,475 & 2,430 & 2,598 & 1,281 & 1,311 \\
\hline Montana ............. & 6,511 & 2,490 & 6,855 & 2,607 & 1,987 & 2,260 & 11,701 & 7,858 & 12,476 & 8,469 & 1,716 & 2,291 & 1,610 & 1,713 \\
\hline Nebraska .................. & 5,722 & 2,269 & 6,100 & 2,414 & 1,563 & 2,123 & 13,748 & 9,797 & 14,456 & 10,308 & 1,989 & 2,159 & 1,227 & 1,267 \\
\hline Nevada ................ & 7,707 & 1,815 & 7,295 & 1,884 & 3,231 & 2,179 & - & 7,731 & 12,707 & 7,391 & 3,000 & 2,316 & 1,010 & 1,106 \\
\hline New Hampshire. & 9,123 & 4,641 & 9,846 & 5,193 & 2,821 & 1,831 & 21,436 & 15,839 & 21,129 & 15,729 & 3,160 & 2,240 & 2,858 & 3,177 \\
\hline New Jersey .................. & 9,661 & 4,269 & 10,235 & 4,562 & 3,374 & 2,299 & 20,984 & 14,371 & 21,825 & 15,125 & 3,521 & 3,180 & 1,949 & 2,033 \\
\hline New Mexico ..... & 5,428 & 2,014 & 5,459 & 2,068 & 1,659 & 1,732 & 14,823 & 9,944 & 14,490 & 9,408 & 2,460 & 2,622 & 659 & 679 \\
\hline New York .......... & 9,294 & 3,802 & 9,460 & 3,844 & 3,124 & 2,492 & 21,528 & 14,544 & 22,569 & 15,246 & 4,058 & 3,265 & 2,519 & 2,576 \\
\hline North Carolina & 5,440 & 1,841 & 5,919 & 1,895 & 1,926 & 2,098 & 16,311 & 11,651 & 17,177 & 12,342 & 2,337 & 2,499 & 581 & 584 \\
\hline North Dakota .... & 5,924 & 2,381 & 6,264 & 2,545 & 1,130 & 2,590 & 10,437 & 7,434 & 10,794 & 7,705 & 1,356 & 1,732 & 1,783 & 1,798 \\
\hline Ohio & 8,490 & 3,841 & 9,022 & 4,009 & 2,668 & 2,345 & 17,905 & 12,980 & & 13,559 & 2,541 & & 2,335 & 2,388 \\
\hline Oklahoma & 5,076 & 1,937 & 5,301 & 2,054 & 1,330 & 1,917 & 11,563 & 7,622 & 12,960 & 8,881 & 1,924 & 2,155 & 1,268 & 1,285 \\
\hline Oregon ................. & 7,988 & 3,408 & 8,394 & 3,496 & 1,963 & 2,935 & 19,869 & 14,769 & 21,096 & 15,796 & 2,473 & 2,827 & 1,526 & 1,573 \\
\hline Pennsylvania ..... & 9,501 & 4,994 & 9,769 & 5,188 & 2,419 & 2,162 & 20,887 & 14,927 & 21,684 & 15,569 & 3,213 & 2,901 & 2,013 & 2,098 \\
\hline Rhode Island ................ & 9,648 & 3,903 & 9,962 & 4,013 & 3,100 & 2,848 & 22,490 & 15,675 & 23,209 & 16,263 & 3,881 & 3,066 & 1,736 & 1,746 \\
\hline South Carolina & 7,238 & 3,205 & 7,160 & 3,414 & 2,153 & 1,594 & 14,125 & 10,207 & & 10,755 & 1,994 & & 1,114 & 1,162 \\
\hline 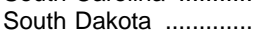 & 5,814 & 2,722 & 5,993 & 2,900 & 1,335 & 1,758 & 13,756 & 9,617 & 14,538 & 9,950 & 1,766 & 2,822 & 3,430 & 3,930 \\
\hline 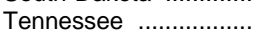 & 5,498 & 2,052 & 5,788 & 2,296 & 1,807 & 1,685 & 14,970 & 10,450 & 15,684 & 11,047 & 2,380 & 2,257 & 1,047 & 1,133 \\
\hline Texas ......... & 5,911 & 2,028 & 6,313 & 2,273 & 2,093 & 1,946 & 13,684 & 9,373 & 14,554 & 9,970 & 2,230 & 2,355 & 791 & 820 \\
\hline 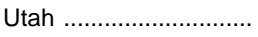 & 5,559 & 2,011 & 5,953 & 2,113 & 1,524 & 2,316 & 7,697 & 3,094 & 7,787 & 3,183 & 1,436 & 3,167 & 1,390 & 1,439 \\
\hline Vermont . & 11,360 & 6,533 & 11,469 & 6,492 & 3,259 & 1,718 & 22,855 & 16,474 & 23,917 & 17,158 & 3,774 & 2,985 & 2,516 & 2,616 \\
\hline Virginia ......... & 8,450 & 3,968 & 8,627 & 4,045 & 2,390 & 2,192 & 15,775 & 11,165 & 16,612 & 11,809 & 2,288 & 2,515 & 1,466 & 1,475 \\
\hline Washington . & 7,320 & 2,933 & 7,704 & 3,036 & 2,379 & 2,289 & 18,461 & 13,656 & 19,198 & 14,072 & 2,645 & 2,482 & 1,447 & 1,516 \\
\hline West Virginia & 6,348 & 2,091 & 6,558 & 2,168 & 2,134 & 2,256 & 15,184 & 10,774 & 15,673 & 11,166 & 1,941 & 2,567 & 1,373 & 1,404 \\
\hline 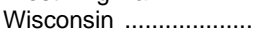 & 6,075 & 2,748 & 6,409 & 2,958 & 1,861 & 1,590 & 16,864 & 12,478 & 17,430 & 12,948 & 2,021 & 2,462 & 1,947 & 2,061 \\
\hline Wyoming …...................... & 6,016 & 2,144 & 6,450 & 2,326 & 1,724 & 2,400 & - & - & - & - & - & - & 1,048 & 1,157 \\
\hline
\end{tabular}

1 Preliminary data based on fall 1996 enrollments.

-Data not reported or not applicable.

NOTE.-Data are for the entire academic year and are average charges. Tuition and fees were weighted by the number of full-time-equivalent undergraduates in 1996, but are not adjusted to reflect student residency. Room and board are based on full-time students. Because of rounding, details may not add to totals.

SOURCE: U.S. Department of Education, National Center for Education Statistics, Integrated Postsecondary Education Data System (IPEDS), "Fall Enrollment" and "Institutional Characteristics" surveys. (This table was prepared November 1998.) 
Table 313.-Average graduate and first-professional tuition and required fees in institutions of higher education: $1987-88$ to $1997-98$

\begin{tabular}{|c|c|c|c|c|c|c|c|c|c|c|c|}
\hline \multirow[b]{2}{*}{ Year } & \multirow{2}{*}{$\begin{array}{c}\text { Average } \\
\text { full-time } \\
\text { graduate } \\
\text { tuition }\end{array}$} & \multicolumn{10}{|c|}{ Average full-time first-professional tuition } \\
\hline & & $\begin{array}{l}\text { Chiro- } \\
\text { practic }\end{array}$ & Dentistry & Medicine & Optometry & $\begin{array}{l}\text { Osteo- } \\
\text { pathic } \\
\text { medicine }\end{array}$ & Pharmacy & Podiatry & $\begin{array}{l}\text { Veterinary } \\
\text { medicine }\end{array}$ & Law & Theology \\
\hline 1 & 2 & 3 & 4 & 5 & 6 & 7 & 8 & 9 & 10 & 11 & 12 \\
\hline All institutions & & & & & & & & & & & \\
\hline $\begin{array}{l}1987-88 \text {..................... } \\
1988-89 \\
1989-90 \ldots \ldots \ldots \ldots \ldots \ldots \ldots \ldots \\
1990-91 \\
1991-92\end{array}$ & $\begin{array}{r}\$ 3,599 \\
3,728 \\
4,135 \\
4,488 \\
5,116\end{array}$ & $\begin{array}{r}\$ 6,996 \\
7,972 \\
8,315 \\
9,108 \\
10,226\end{array}$ & $\begin{array}{r}\$ 9,399 \\
9,324 \\
10,515 \\
10,270 \\
12,049\end{array}$ & $\begin{array}{r}\$ 9,034 \\
9,439 \\
10,597 \\
10,571 \\
11,646\end{array}$ & $\begin{array}{r}\$ 7,926 \\
8,503 \\
9,469 \\
9,512 \\
9,610\end{array}$ & $\begin{array}{r}\$ 10,674 \\
11,462 \\
11,888 \\
12,830 \\
13,004\end{array}$ & $\begin{array}{r}\$ 5,201 \\
4,952 \\
5,890 \\
5,889 \\
6,731\end{array}$ & $\begin{array}{r}\$ 12,736 \\
13,232 \\
14,611 \\
15,143 \\
16,257\end{array}$ & $\begin{array}{r}\$ 4,503 \\
4,856 \\
5,470 \\
5,396 \\
6,367\end{array}$ & $\begin{array}{r}\$ 6,636 \\
7,099 \\
8,059 \\
8,708 \\
9,469\end{array}$ & $\begin{array}{r}\$ 3,572 \\
3,911 \\
4,079 \\
4,569 \\
4,876\end{array}$ \\
\hline $\begin{array}{l}1992-93 \\
1993-94 \\
1994-95 \\
1995-96 \\
1996-971 \\
1997-98 \ldots \ldots \ldots \ldots \ldots \ldots \ldots \ldots \ldots \ldots \ldots \ldots \\
2\end{array}$ & $\begin{array}{l}5,475 \\
5,973 \\
6,247 \\
6,741 \\
7,111 \\
7,243\end{array}$ & $\begin{array}{l}11,117 \\
11,503 \\
12,324 \\
12,507 \\
12,740 \\
13,234\end{array}$ & $\begin{array}{l}12,710 \\
14,403 \\
15,164 \\
15,647 \\
16,400 \\
17,428\end{array}$ & $\begin{array}{l}12,265 \\
13,074 \\
13,834 \\
14,860 \\
15,722 \\
16,402\end{array}$ & $\begin{array}{l}10,858 \\
10,385 \\
11,053 \\
11,544 \\
12,247 \\
12,986\end{array}$ & $\begin{array}{l}14,297 \\
15,038 \\
15,913 \\
16,785 \\
17,782 \\
18,625\end{array}$ & $\begin{array}{l}6,635 \\
7,960 \\
8,315 \\
8,602 \\
9,320 \\
9,792\end{array}$ & $\begin{array}{l}17,426 \\
17,621 \\
18,138 \\
18,434 \\
19,042 \\
19,379\end{array}$ & $\begin{array}{l}6,771 \\
7,159 \\
7,741 \\
8,208 \\
8,662 \\
9,066\end{array}$ & $\begin{array}{l}10,463 \\
11,552 \\
12,374 \\
13,278 \\
14,162 \\
15,022\end{array}$ & $\begin{array}{l}5,331 \\
5,253 \\
5,648 \\
5,991 \\
6,444 \\
6,752\end{array}$ \\
\hline Public $^{3}$ & & & & & & & & & & & \\
\hline 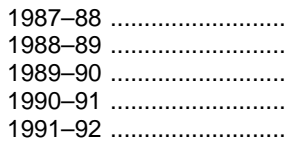 & $\begin{array}{l}1,827 \\
1,913 \\
1,999 \\
2,206 \\
2,524\end{array}$ & $\begin{array}{l}- \\
- \\
-\end{array}$ & $\begin{array}{l}4,614 \\
5,286 \\
5,728 \\
5,927 \\
6,595\end{array}$ & $\begin{array}{l}5,245 \\
5,669 \\
6,259 \\
6,437 \\
7,106\end{array}$ & $\begin{array}{l}2,789 \\
3,455 \\
3,569 \\
3,821 \\
4,161\end{array}$ & $\begin{array}{l}5,125 \\
6,269 \\
6,521 \\
7,188 \\
7,699\end{array}$ & $\begin{array}{l}2,462 \\
2,218 \\
2,816 \\
2,697 \\
2,871\end{array}$ & $\begin{array}{l}- \\
- \\
- \\
-\end{array}$ & $\begin{array}{l}3,523 \\
3,889 \\
4,505 \\
4,840 \\
5,231\end{array}$ & $\begin{array}{l}2,810 \\
2,766 \\
3,196 \\
3,430 \\
3,933\end{array}$ & - \\
\hline 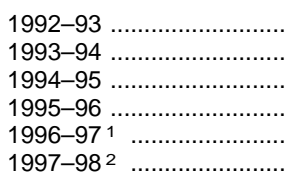 & $\begin{array}{l}2,791 \\
3,050 \\
3,250 \\
3,449 \\
3,607 \\
3,754\end{array}$ & $\begin{array}{l}- \\
- \\
- \\
-\end{array}$ & $\begin{array}{l}7,006 \\
7,525 \\
8,125 \\
8,806 \\
9,451 \\
9,821\end{array}$ & $\begin{array}{r}7,867 \\
8,329 \\
8,812 \\
9,585 \\
10,203 \\
10,653\end{array}$ & $\begin{array}{l}5,106 \\
5,325 \\
5,643 \\
6,130 \\
6,590 \\
7,316\end{array}$ & $\begin{array}{r}8,404 \\
8,640 \\
8,954 \\
9,448 \\
9,893 \\
10,358\end{array}$ & $\begin{array}{l}2,987 \\
3,567 \\
3,793 \\
4,100 \\
4,703 \\
5,032\end{array}$ & $\begin{array}{l}- \\
- \\
- \\
-\end{array}$ & $\begin{array}{l}5,553 \\
6,107 \\
6,571 \\
6,907 \\
7,320 \\
7,682\end{array}$ & $\begin{array}{l}4,261 \\
4,835 \\
5,307 \\
5,821 \\
6,556 \\
7,035\end{array}$ & - \\
\hline Private & & & & & & & & & & & \\
\hline $\begin{array}{r}1987-88 \\
1988-89 \\
1989-90 \ldots \ldots \ldots \ldots \ldots \ldots \ldots \\
1990-91 \\
1991-92\end{array}$ & $\begin{array}{l}6,769 \\
6,945 \\
7,881 \\
8,507 \\
9,592\end{array}$ & $\begin{array}{r}6,996 \\
7,972 \\
8,315 \\
9,108 \\
10,226\end{array}$ & $\begin{array}{l}16,201 \\
16,127 \\
16,800 \\
18,270 \\
20,318\end{array}$ & $\begin{array}{l}14,945 \\
15,610 \\
16,826 \\
17,899 \\
19,225\end{array}$ & $\begin{array}{l}11,635 \\
12,050 \\
13,640 \\
13,767 \\
14,366\end{array}$ & $\begin{array}{l}13,311 \\
13,536 \\
14,117 \\
15,009 \\
16,098\end{array}$ & $\begin{array}{r}8,834 \\
9,692 \\
10,656 \\
11,546 \\
12,937\end{array}$ & $\begin{array}{l}12,736 \\
13,232 \\
14,611 \\
15,143 \\
16,257\end{array}$ & $\begin{array}{l}12,544 \\
13,285 \\
14,184 \\
14,159 \\
15,816\end{array}$ & $\begin{array}{r}9,048 \\
9,892 \\
10,901 \\
12,247 \\
12,946\end{array}$ & $\begin{array}{l}3,572 \\
3,911 \\
4,079 \\
4,569 \\
4,876\end{array}$ \\
\hline 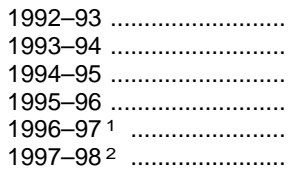 & $\begin{array}{l}10,008 \\
10,790 \\
11,338 \\
12,083 \\
12,537 \\
12,879\end{array}$ & $\begin{array}{l}11,117 \\
11,503 \\
12,324 \\
12,507 \\
12,740 \\
13,234\end{array}$ & $\begin{array}{l}21,309 \\
23,824 \\
24,641 \\
25,678 \\
26,590 \\
29,667\end{array}$ & $\begin{array}{l}19,585 \\
20,769 \\
21,819 \\
23,001 \\
24,240 \\
25,379\end{array}$ & $\begin{array}{l}14,459 \\
14,156 \\
14,497 \\
15,235 \\
16,102 \\
16,851\end{array}$ & $\begin{array}{l}17,098 \\
17,720 \\
18,422 \\
19,619 \\
20,829 \\
21,818\end{array}$ & $\begin{array}{l}13,373 \\
14,838 \\
14,894 \\
15,618 \\
16,514 \\
17,212\end{array}$ & $\begin{array}{l}17,426 \\
17,621 \\
18,138 \\
18,434 \\
19,042 \\
19,379\end{array}$ & $\begin{array}{l}17,103 \\
17,433 \\
17,940 \\
19,380 \\
20,188 \\
20,948\end{array}$ & $\begin{array}{l}13,975 \\
15,193 \\
16,201 \\
17,251 \\
18,194 \\
19,256\end{array}$ & $\begin{array}{l}5,331 \\
5,253 \\
5,648 \\
5,991 \\
6,444 \\
6,752\end{array}$ \\
\hline
\end{tabular}

${ }^{1}$ Preliminary first-professional figures based on 1995-96 graduates. 2 Preliminary graduate figures based on fall 1996 data and first-professional figures based on 1995-96 graduates.

${ }^{3}$ Data are based on in-state tuition only.

-Data not available or not applicable.

NOTE.-Average graduate student tuition weighted by fall full-time-equivalent graduate enrollment. Average first-professional tuition weighted by number of degrees conferred during the academic year. Some year-to-year fluctuations in tuition data may reflect non- reporting by individual institutions. Excludes institutions not reporting degrees conferred and institutions not reporting tuition. Some data have been revised from previously published figures.

SOURCE: U.S. Department of Education, National Center for Education Statistics, Integrated Postsecondary Education Data System (IPEDS), "Institutional Characteristics," "Fall Enrollment," and "Degrees Conferred" surveys. (This table was prepared November 1998.) 
Table 314.--Percent of undergraduates receiving financial aid, by type and source of aid and selected student characteristics: 1995-96

\begin{tabular}{|c|c|c|c|c|c|c|c|c|c|c|c|c|c|c|}
\hline \multirow{2}{*}{$\begin{array}{l}\text { Selected student } \\
\text { characteristics }\end{array}$} & \multirow{2}{*}{$\begin{array}{c}\text { Enrollment } \\
\text { of under- } \\
\text { graduates, }{ }^{1} \\
\text { in thousands }\end{array}$} & \multicolumn{3}{|c|}{ Any aid } & \multicolumn{3}{|c|}{ Grants } & \multicolumn{3}{|c|}{ Loans } & \multirow{2}{*}{$\begin{array}{c}\begin{array}{c}\text { Work } \\
\text { study }\end{array} \\
\text { Total }^{3}\end{array}$} & \multicolumn{3}{|c|}{ Other } \\
\hline & & Total $^{2}$ & Federal & $\begin{array}{c}\text { Non- } \\
\text { federal }\end{array}$ & Total & Federal & $\begin{array}{l}\text { Non- } \\
\text { federal }\end{array}$ & Total & Federal & $\begin{array}{c}\text { Non- } \\
\text { federal }\end{array}$ & & Total & Federal & $\begin{array}{l}\text { Non- } \\
\text { federal }\end{array}$ \\
\hline \multirow[t]{2}{*}{1} & 2 & 3 & 4 & 5 & 6 & 7 & 8 & 9 & 10 & 11 & 12 & 13 & 14 & 15 \\
\hline & & & & & & Percent & of all und & ergradue & ates rece & ving aid & & & & \\
\hline All undergraduates & 16,677 & 49.7 & 36.6 & 32.0 & 39.0 & 21.9 & 27.6 & 25.6 & 25.3 & 1.1 & 5.0 & 7.4 & 2.4 & 4.8 \\
\hline Sex & & & & & & & & & & & & & & \\
\hline Men …................................... & 7,197 & 46.7 & 33.1 & 31.4 & 35.8 & 18.2 & 26.4 & 24.4 & 23.9 & 1.3 & 4.3 & 8.7 & 2.7 & 5.8 \\
\hline Women .................................... & 9,481 & 51.9 & 39.2 & 32.5 & 41.4 & 24.8 & 28.5 & 26.5 & 26.2 & 0.9 & 5.6 & 6.5 & 2.2 & 4.2 \\
\hline Race/ethnicity & & & & & & & & & & & & & & \\
\hline White, non-Hispanic & 11,681 & 47.1 & 33.2 & 31.1 & 35.4 & 16.6 & 26.9 & 25.6 & 25.2 & 1.0 & 4.6 & 7.5 & 2.5 & 4.8 \\
\hline Black, non-Hispanic ............. & 2,030 & 62.9 & 50.0 & 38.3 & 52.8 & 38.1 & 31.7 & 30.9 & 30.4 & 1.3 & 6.1 & 9.8 & 2.6 & 7.0 \\
\hline $\begin{array}{l}\text { Hispanic ...................... } \\
\text { Asian American/ }\end{array}$ & 1,723 & 54.2 & 44.6 & 30.6 & 47.3 & 36.1 & 27.2 & 22.3 & 22.0 & 0.9 & 5.8 & 5.2 & 1.5 & 3.6 \\
\hline Pacific Islander & 967 & 42.9 & 33.1 & 30.8 & 35.7 & 22.9 & 27.5 & 21.3 & 20.7 & 1.3 & 6.6 & 5.7 & 2.2 & 3.5 \\
\hline Alaskan Native & 163 & 59.4 & 47.8 & 37.1 & 48.4 & 37.3 & 27.3 & 25.2 & 25.2 & 0.2 & 3.9 & 12.0 & 1.5 & 7.7 \\
\hline Age & & & & & & & & & & & & & & \\
\hline 23 years old or younger ....... & 9,116 & 53.5 & 42.1 & 34.0 & 41.7 & 22.7 & 30.9 & 31.1 & 30.7 & 1.2 & 7.7 & 7.7 & 4.4 & 3.4 \\
\hline 24 to 29 years old ................. & 3,049 & 49.0 & 37.8 & 29.2 & 38.5 & 25.5 & 23.3 & 25.8 & 25.5 & 1.0 & 2.5 & 7.1 & 0.0 & 6.9 \\
\hline 30 years old or over .............. & 4,513 & 42.5 & 24.8 & 29.9 & 33.9 & 18.0 & 23.8 & 14.5 & 14.1 & 0.8 & 1.4 & 7.1 & 0.0 & 6.4 \\
\hline Marital status & & & & & & & & & & & & & & \\
\hline Married & 3,494 & 45.2 & 27.6 & 30.5 & 35.4 & 18.7 & 24.2 & 16.8 & 16.5 & 0.7 & 1.4 & 7.3 & 0.0 & 6.8 \\
\hline Not married 4 ...... & 12,861 & 50.4 & 38.4 & 32.2 & 39.4 & 22.0 & 28.5 & 27.9 & 27.5 & 1.2 & 6.1 & 7.3 & 3.1 & 4.1 \\
\hline Separated ................................ & 322 & 70.9 & 61.6 & 38.7 & 62.0 & 54.3 & 29.1 & 30.0 & 30.0 & 0.8 & 3.3 & 13.4 & 0.1 & 12.5 \\
\hline Attendance status & & & & & & & & & & & & & & \\
\hline 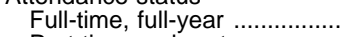 & 6,306 & 68.4 & 55.6 & 45.7 & 54.1 & 30.6 & 41.0 & 43.7 & 43.2 & 1.7 & 11.0 & 10.9 & 5.0 & 5.9 \\
\hline Part-time and part-year ........ & 10,372 & 38.3 & 24.8 & 24.0 & 29.9 & 16.6 & 19.7 & 14.4 & 14.1 & 0.7 & 1.4 & 5.4 & 0.8 & 4.3 \\
\hline Dependency status & & & & & & & & & & & & & & \\
\hline Dependent .................... & 8,201 & 50.9 & 39.2 & 33.4 & 38.8 & 18.9 & 30.7 & 30.5 & 30.1 & 1.3 & 7.8 & 7.7 & 4.9 & 3.0 \\
\hline Less than $\$ 20,000 \ldots \ldots \ldots \ldots$ & 1,543 & 70.2 & 62.9 & 43.0 & 66.3 & 57.0 & 40.4 & 35.4 & 35.2 & 1.1 & 10.9 & 6.5 & 3.0 & 3.6 \\
\hline 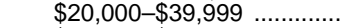 & 1,873 & 60.3 & 49.2 & 40.5 & 51.0 & 31.7 & 38.1 & 38.2 & 37.4 & 2.0 & 10.4 & 7.5 & 4.4 & 3.2 \\
\hline$\$ 40,000-\$ 59,999$ & 1,865 & 47.4 & 34.6 & 31.8 & 30.4 & 3.7 & 29.2 & 32.4 & 32.2 & 1.1 & 7.8 & 9.0 & 6.3 & 2.9 \\
\hline$\$ 60,000-\$ 79,999$ & 1,366 & 42.5 & 28.4 & 28.1 & 25.3 & 0.5 & 25.3 & 27.0 & 26.6 & 1.1 & 5.8 & 8.1 & 5.6 & 2.6 \\
\hline$\$ 80,000-\$ 99,999 \ldots$ & 681 & 37.6 & 24.4 & 24.4 & 50.4 & 0.2 & 20.3 & 23.3 & 23.1 & 0.6 & 4.9 & 9.0 & 6.0 & 3.2 \\
\hline$\$ 100,000$ or more ............. & 873 & 27.5 & 13.9 & 19.7 & 17.3 & 0.3 & 17.1 & 12.6 & 12.2 & 1.0 & 2.7 & 6.0 & 4.1 & 1.9 \\
\hline Independent ............ & 8,476 & 48.5 & 34.1 & 30.7 & 39.2 & 24.8 & 24.6 & 20.9 & 20.5 & 0.9 & 2.3 & 7.1 & 0.0 & 6.7 \\
\hline Less than $\$ 9,999$ & 2,470 & 67.4 & 59.0 & 37.5 & 60.5 & 52.3 & 30.8 & 34.0 & 33.7 & 1.1 & 5.7 & 8.4 & 0.0 & 8.2 \\
\hline$\$ 10,000-\$ 19,999$. & 1,923 & 50.6 & 38.6 & 29.8 & 38.4 & 24.4 & 23.2 & 23.7 & 23.1 & 1.3 & 1.6 & 7.7 & 0.0 & 7.2 \\
\hline$\$ 20,000-\$ 29,999$ & 1,382 & 41.9 & 26.0 & 28.3 & 34.0 & 18.3 & 22.9 & 15.7 & 15.4 & 0.9 & 0.9 & 6.3 & 0.0 & 5.9 \\
\hline$\$ 30,000-\$ 49,999$ & 1,502 & 36.3 & 16.4 & 27.3 & 24.7 & 6.0 & 21.0 & 12.3 & 12.1 & 0.4 & 0.6 & 6.9 & 0.0 & 6.2 \\
\hline$\$ 50,000$ or more. & 1,201 & 29.3 & 7.0 & 25.1 & 20.7 & 0.1 & 20.7 & 5.9 & 5.8 & 0.2 & 0.1 & 4.9 & 0.0 & 4.3 \\
\hline Housing status & & & & & & & & & & & & & & \\
\hline School-owned ................ & 2,292 & 73.6 & 60.0 & 54.6 & 59.5 & 26.6 & 51.6 & 53.1 & 52.5 & 2.4 & 18.9 & 13.7 & 9.3 & 4.7 \\
\hline $\begin{array}{c}\text { Off-campus, not with } \\
\text { parents }\end{array}$ & 10,188 & 46.1 & 32.5 & 29.0 & 35.5 & 20.6 & 23.8 & 22.2 & 21.8 & 0.9 & 2.8 & 7.0 & 1.1 & 5.5 \\
\hline With parents & 4,197 & 45.3 & 33.7 & 26.9 & 36.4 & 22.6 & 23.8 & 19.0 & 18.7 & 0.7 & 2.9 & 5.1 & 1.6 & 3.3 \\
\hline
\end{tabular}

${ }_{1}^{1}$ Numbers of undergraduates may not equal figures reported in other tables, since these data are based on a sample survey. Includes all postsecondary institutions.

2 Includes students who reported they were awarded aid, but did not specify the source or type of aid.

${ }^{3}$ Details on federal and nonfederal work study participants are not available.

${ }^{4}$ Includes students who were single, divorced, or widowed.

-Data not applicable.
NOTE.-Because of rounding and/or the fact that some students receive aid from multiple sources, row details may not add to totals. Because of rounding and survey item nonresponse, enrollment data may not add to totals. Data include undergraduates in noncollegiate and collegiate institutions.

SOURCE: U.S. Department of Education, National Center for Education Statistics, National Postsecondary Student Aid Study, 1995-96. (This table was prepared September 1997.) 
Table 315.-Average amount of financial aid awarded in 1995-96 per student, by type and source of aid and selected student characteristics

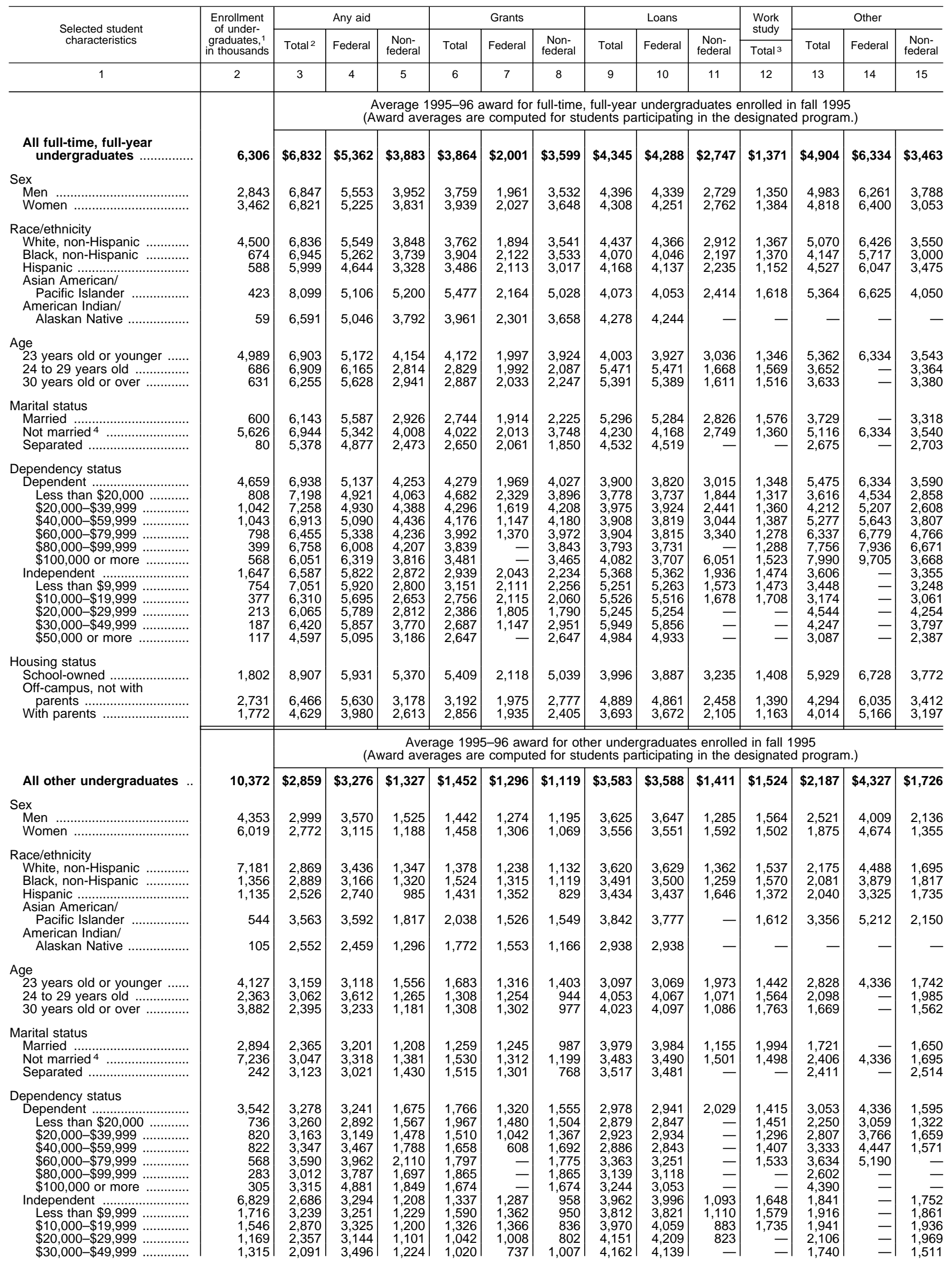


Table 315.-Average amount of financial aid awarded in 1995-96 per student, by type and source of aid and selected student characteristics-Continued

\begin{tabular}{|c|c|c|c|c|c|c|c|c|c|c|c|c|c|c|}
\hline \multirow{2}{*}{$\begin{array}{l}\text { Selected student } \\
\text { characteristics }\end{array}$} & \multirow{2}{*}{$\begin{array}{c}\text { Enrollment } \\
\text { of under- } \\
\text { graduates, }{ }^{1} \\
\text { in thousands }\end{array}$} & \multicolumn{3}{|c|}{ Any aid } & \multicolumn{3}{|c|}{ Grants } & \multicolumn{3}{|c|}{ Loans } & \multirow{2}{*}{$\begin{array}{l}\text { Work } \\
\text { study }\end{array}$} & \multicolumn{3}{|c|}{ Other } \\
\hline & & Total $^{2}$ & Federal & $\begin{array}{l}\text { Non- } \\
\text { federal }\end{array}$ & Total & Federal & $\begin{array}{l}\text { Non- } \\
\text { federal }\end{array}$ & Total & Federal & $\begin{array}{l}\text { Non- } \\
\text { federal }\end{array}$ & & Total & Federal & $\begin{array}{l}\text { Non- } \\
\text { federal }\end{array}$ \\
\hline 1 & 2 & 3 & 4 & 5 & 6 & 7 & 8 & 9 & 10 & 11 & 12 & 13 & 14 & 15 \\
\hline$\$ 50,000$ or more $\ldots \ldots \ldots \ldots \ldots$ & 1,083 & 1,705 & 3,814 & 1,273 & 1,263 & - & 1,262 & 4,350 & 4,392 & - & - & 1,250 & - & 1,135 \\
\hline $\begin{array}{l}\text { Housing status } \\
\text { School-owned .............. } \\
\text { Off-campus, not with }\end{array}$ & 490 & 2,782 & 3,362 & 1,267 & 1,371 & 1,273 & 1,045 & 3,815 & 3,828 & 1,461 & 1,669 & 1,960 & 4,356 & 1,696 \\
\hline $\begin{array}{c}\text { parents } \ldots \ldots \ldots \ldots \ldots \ldots \ldots \ldots \ldots \\
\text { With parents }\end{array}$ & $\begin{array}{l}7,456 \\
2,425\end{array}$ & $\begin{array}{l}4,827 \\
2,497\end{array}$ & $\begin{array}{l}4,218 \\
2,713\end{array}$ & $\begin{array}{l}2,513 \\
1,160\end{array}$ & $\begin{array}{l}2,481 \\
1,406\end{array}$ & $\begin{array}{l}1,460 \\
1,316\end{array}$ & $\begin{array}{r}2,305 \\
960\end{array}$ & $\begin{array}{l}3,303 \\
2,994\end{array}$ & $\begin{array}{l}3,284 \\
2,991\end{array}$ & $\begin{array}{l}1,583 \\
1,163\end{array}$ & $\begin{array}{l}1,208 \\
1,467\end{array}$ & $\begin{array}{l}4,071 \\
2,373\end{array}$ & $\begin{array}{l}4,961 \\
3,690\end{array}$ & $\begin{array}{l}2,474 \\
1,722\end{array}$ \\
\hline
\end{tabular}

${ }^{1}$ Numbers of undergraduates may not equal figures reported in other tables, since these data are based on a sample survey. Includes all postsecondary institutions.

2 Includes students who reported they were awarded aid, but did not specify the source or type of aid.

${ }^{3}$ Details on federal and nonfederal work study participants are not available.

${ }_{4}^{4}$ Includes students who were single, divorced, or widowed.

Table 316.-Undergraduates enrolled full time and part time, by aid status and source of aid during 1995-96, and control and level of institution

\begin{tabular}{|c|c|c|c|c|c|c|c|c|}
\hline \multirow{3}{*}{ Control and level of institution } & \multirow{3}{*}{\begin{tabular}{|c|} 
Number of \\
undergradu- \\
ates, \\
1995,1 \\
in thou- \\
sands
\end{tabular}} & \multirow{3}{*}{$\begin{array}{c}\text { Cumulative } \\
\text { amount bor- } \\
\text { rowed for } \\
\text { undergradu- } \\
\text { ate edu- } \\
\text { cation }\end{array}$} & \multicolumn{6}{|c|}{ Aid status, 1995-96, in percents } \\
\hline & & & \multirow{2}{*}{ Nonaided } & \multicolumn{5}{|c|}{ Receiving aid, by source } \\
\hline & & & & Any aid 2 & Federal & State & Institutional & Other $^{2}$ \\
\hline \multirow[t]{2}{*}{1} & 2 & 3 & 4 & 5 & 6 & 7 & 8 & 9 \\
\hline & \multicolumn{8}{|c|}{ Full-time students ${ }^{3}$} \\
\hline All institutions .. & 6,306 & $\$ 7,747$ & 31.6 & 68.4 & 55.6 & 19.8 & 27.7 & 10.9 \\
\hline Public ...... & 4,413 & 7,082 & 37.2 & 62.8 & 50.8 & 17.4 & 18.8 & 9.3 \\
\hline 4-year doctoral & 1,859 & 8,699 & 34.7 & 65.4 & 51.9 & 17.6 & 22.9 & 11.0 \\
\hline 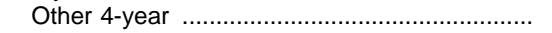 & 1,070 & 7,168 & 30.7 & 69.3 & 59.8 & 22.8 & 19.1 & 8.6 \\
\hline 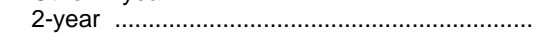 & 1,397 & 4,120 & 44.1 & 55.9 & 44.5 & 13.5 & 13.9 & 7.4 \\
\hline 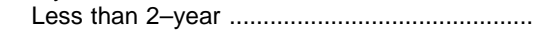 & 88 & 3,111 & 60.5 & 39.5 & 20.6 & 9.6 & 7.2 & 12.6 \\
\hline 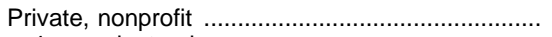 & 1,555 & 9,460 & 19.7 & 80.3 & 64.0 & 28.1 & 56.3 & 14.0 \\
\hline 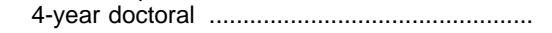 & 508 & 10,415 & 29.4 & 70.6 & 55.4 & 19.5 & 52.3 & 13.3 \\
\hline Other 4-year ..................... & 958 & 9,243 & 14.4 & 85.6 & 68.3 & 33.1 & 60.5 & 14.6 \\
\hline 2 -year or less ........................ & 89 & 6,867 & 20.8 & 79.2 & 67.5 & 24.0 & 33.9 & 11.4 \\
\hline 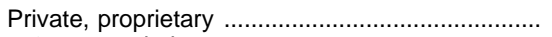 & 337 & 6,942 & 13.8 & 86.2 & 79.7 & 12.8 & 11.5 & 17.2 \\
\hline 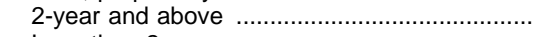 & 167 & 9,026 & 14.3 & 85.8 & 79.1 & 18.1 & 5.9 & 15.3 \\
\hline \multirow[t]{2}{*}{ Less than 2-year } & 170 & 4,745 & 13.4 & 86.6 & 80.3 & 7.6 & 17.0 & 19.1 \\
\hline & \multicolumn{8}{|c|}{ Part-time students ${ }^{3}$} \\
\hline 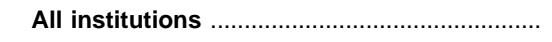 & 10,157 & $\$ 5,672$ & 61.8 & 38.3 & 24.8 & 6.5 & 8.9 & 5.4 \\
\hline Public & 8,519 & 5,265 & 66.3 & 33.7 & 20.8 & 5.5 & 7.4 & 4.7 \\
\hline 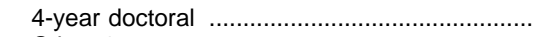 & 1,211 & 8,210 & 41.8 & 41.8 & 31.2 & 7.5 & 10.1 & 5.8 \\
\hline Other 4-year & 1,030 & 6,581 & 41.9 & 41.9 & 30.9 & 8.1 & 6.1 & 4.8 \\
\hline 2 -year .............................. & 6,174 & 3,833 & 30.7 & 30.7 & 17.2 & 4.5 & 7.1 & 4.4 \\
\hline 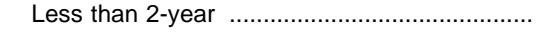 & 105 & 3,274 & 34.3 & 34.3 & 13.9 & 13.9 & 4.4 & 8.6 \\
\hline 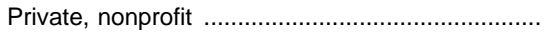 & 1,070 & 8,302 & 44.4 & 55.6 & 34.9 & 12.8 & 21.2 & 8.6 \\
\hline 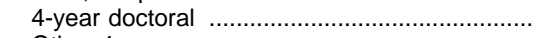 & 280 & 9,474 & 51.0 & 51.0 & 27.7 & 10.2 & 22.5 & 8.4 \\
\hline 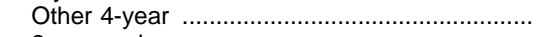 & 668 & 8,305 & 58.4 & 58.4 & 37.0 & 14.6 & 22.0 & 8.9 \\
\hline 2 -year or less & 123 & 5,529 & 50.8 & 50.8 & 39.7 & 9.0 & 14.5 & 7.8 \\
\hline Private, proprietary & 567 & 5,194 & 25.9 & 74.1 & 66.4 & 9.5 & 8.9 & 10.4 \\
\hline 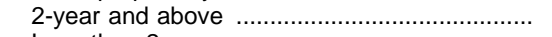 & 269 & 6,395 & 74.5 & 74.5 & 66.9 & 11.2 & 6.7 & 12.2 \\
\hline 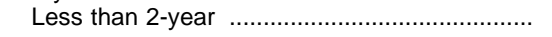 & 298 & 4,055 & 73.8 & 73.8 & 66.1 & 7.9 & 10.9 & 8.7 \\
\hline
\end{tabular}

${ }^{1}$ Numbers of undergraduates may not equal figures reported in other tables, since these data are based on a sample survey. Includes students who enrolled at any time during the academic year.

2 Includes students who reported that they were awarded aid but did not specify the source of the aid.

${ }^{3}$ Full-time students are students who attend full-time for the entire academic year. All other students, including those who attend full-time for part of the academic year, are counted as part-time students.
NOTE.-Because of rounding and/or the fact that some students receive aid from multiple sources, row details may not add to totals. Because of rounding and survey item nonresponse, enrollment data may not add to totals. Data include undergraduates in noncollegiate and collegiate institutions.

SOURCE: U.S. Department of Education, National Center for Education Statistics, $\mathrm{Na}$ tional Postsecondary Student Aid Study, 1995-96. (This table was prepared Septembe 997.)

\section{.}


Table 317.-Percent of undergraduates receiving aid, by type and source of aid received, and by control and level of institution: 1992-93 and 1995-96

\begin{tabular}{|c|c|c|c|c|c|c|c|c|c|c|c|c|c|c|c|}
\hline \multirow{3}{*}{$\begin{array}{l}\text { Control and level of insti- } \\
\text { tution }\end{array}$} & \multirow{3}{*}{$\begin{array}{c}\text { Number } \\
\text { of under- } \\
\text { grad- } \\
\text { uates, } 1 \text { in } \\
\text { thousands }\end{array}$} & \multicolumn{14}{|c|}{ Percent receiving aid, by type and source } \\
\hline & & \multicolumn{3}{|c|}{ Any aid } & \multicolumn{3}{|c|}{ Grants } & \multicolumn{3}{|c|}{ Loans } & \multicolumn{2}{|c|}{ Work-study } & \multicolumn{3}{|c|}{ Other } \\
\hline & & Total $^{2}$ & $\begin{array}{l}\text { Fed- } \\
\text { eral }\end{array}$ & $\begin{array}{c}\text { Non- } \\
\text { federal }\end{array}$ & Total & $\begin{array}{l}\text { Fed- } \\
\text { eral }\end{array}$ & \begin{tabular}{|c|} 
Non- \\
federal
\end{tabular} & Total & $\begin{array}{l}\text { Fed- } \\
\text { eral }\end{array}$ & \begin{tabular}{|c|} 
Non- \\
federal
\end{tabular} & Total & $\begin{array}{l}\text { Fed- } \\
\text { eral } 3\end{array}$ & Total & $\begin{array}{l}\text { Fed- } \\
\text { eral }\end{array}$ & $\begin{array}{c}\text { Non- } \\
\text { federal }\end{array}$ \\
\hline \multirow[t]{2}{*}{1} & 2 & 3 & 4 & 5 & 6 & 7 & 8 & 9 & 10 & 11 & 12 & 13 & 14 & 15 & 16 \\
\hline & \multicolumn{15}{|c|}{ Full-time students, ${ }^{4}$ 1992-93 } \\
\hline All institutions ........... & 6,000 & 57.9 & 45.6 & 37.9 & 48.1 & 29.4 & 34.0 & 33.6 & 32.7 & 2.7 & 10.2 & 6.8 & 9.5 & 5.2 & 4.6 \\
\hline Public & 4,110 & 51.9 & 40.0 & 33.0 & 42.3 & 27.8 & 29.1 & 26.9 & 26.1 & 2.0 & 6.8 & 4.2 & 7.9 & 3.7 & 4.4 \\
\hline 4-year doctoral & 1,772 & 53.7 & 39.3 & 34.8 & 41.9 & 23.8 & 30.8 & 33.0 & 32.2 & 2.4 & 7.1 & 4.3 & 8.6 & 5.0 & 3.9 \\
\hline Other 4-year .................... & 1,087 & 56.4 & 46.1 & 37.4 & 45.5 & 32.1 & 32.4 & 33.7 & 32.7 & 2.8 & 9.5 & 5.5 & 7.9 & 4.2 & 3.8 \\
\hline 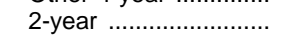 & 1,196 & 45.9 & 36.0 & 27.0 & 40.6 & 29.9 & 24.3 & 12.7 & 12.3 & 0.7 & 4.1 & 3.0 & 7.0 & 1.3 & 5.7 \\
\hline Less than 2-year ........ & 55 & 35.0 & 31.6 & 15.7 & 29.9 & 26.6 & 12.8 & 3.0 & 3.0 & 0.6 & 1.5 & 1.4 & 5.1 & 0.8 & 4.4 \\
\hline Private, nonprofit .............. & 1,469 & 69.5 & 53.4 & 58.0 & 62.1 & 27.7 & 54.1 & 46.5 & 44.9 & 4.9 & 22.2 & 15.9 & 12.1 & 7.7 & 5.0 \\
\hline 4-year doctoral ............. & 681 & 62.7 & 44.5 & 54.8 & 55.2 & 17.3 & 51.8 & 41.6 & 39.7 & 6.1 & 18.9 & 13.2 & 11.6 & 7.4 & 4.5 \\
\hline Other 4-year ..................... & 719 & 75.5 & 60.8 & 62.7 & 68.7 & 35.6 & 58.1 & 51.7 & 50.3 & 4.1 & 27.0 & 19.7 & 12.2 & 7.9 & 5.3 \\
\hline 2 -year or less ............... & 70 & 73.9 & 63.9 & 42.0 & 61.3 & 47.3 & 35.4 & 41.1 & 39.5 & 2.5 & 4.6 & 3.0 & 17.2 & 9.4 & 7.8 \\
\hline Private, proprietary ......... & 421 & 76.1 & 72.4 & 16.4 & 55.3 & 50.9 & 11.4 & 54.1 & 53.8 & 2.1 & 1.9 & 0.7 & 15.6 & 11.3 & 4.5 \\
\hline 2 -year and above ....... & 182 & 80.6 & 77.4 & 22.7 & 49.5 & 43.4 & 16.4 & 65.2 & 65.2 & 3.0 & 3.5 & 1.4 & 24.6 & 18.8 & 6.5 \\
\hline \multirow[t]{2}{*}{ Less than 2 -year .......... } & 238 & 72.7 & 68.6 & 11.5 & 59.7 & 56.7 & 7.5 & 45.6 & 45.1 & 1.5 & 0.7 & 0.2 & 8.7 & 5.6 & 3.1 \\
\hline & \multicolumn{15}{|c|}{ Full-time students, ${ }^{4}$ 1995-96 } \\
\hline All institutions ........... & 6,306 & 68.4 & 55.6 & 45.7 & 54.1 & 30.6 & 41.0 & 43.7 & 43.2 & 1.7 & 11.0 & 9.0 & 10.9 & 5.0 & 5.9 \\
\hline Public & 4,413 & 62.8 & 50.8 & 39.0 & 47.5 & 29.6 & 34.2 & 37.2 & 36.9 & 0.8 & 7.0 & 5.4 & 9.3 & 3.7 & 5.5 \\
\hline 4 -year doctoral ................. & 1,859 & 65.4 & 51.9 & 42.2 & 47.6 & 26.1 & 37.2 & 44.5 & 44.1 & 1.4 & 7.4 & 5.3 & 11.0 & 5.6 & 5.4 \\
\hline Other 4-year .................... & 1,070 & 69.3 & 59.8 & 44.5 & 52.3 & 34.4 & 40.0 & 47.4 & 47.2 & 0.4 & 9.2 & 6.7 & 8.6 & 3.7 & 4.8 \\
\hline 2-yea & 1,397 & 55.9 & 44.5 & 31.3 & 44.6 & 31.1 & 26.9 & 21.8 & 21.3 & 0.4 & 5.1 & 4.7 & 7.4 & 1.3 & 6.0 \\
\hline Less than 2-year ....... & & 39.5 & 20.6 & 27.5 & 30.9 & 18.5 & 16.0 & 4.4 & 4.4 & 0.0 & 0.1 & 0.1 & 12.6 & 0.1 & 12.0 \\
\hline Private, nonprofit .............. & 1,555 & 80.3 & 64.0 & 67.6 & 71.3 & 28.6 & 64.8 & 56.9 & 56.2 & 3.4 & 24.6 & 21.0 & 14.0 & 8.2 & 6.1 \\
\hline 4-year doctoral ............. & 508 & 70.6 & 55.4 & 61.2 & 61.6 & 19.3 & 58.7 & 50.9 & 49.9 & 3.9 & 22.6 & 20.2 & 13.3 & 8.6 & 4.9 \\
\hline Other 4-year ..................... & 958 & 85.6 & 68.3 & 72.5 & 77.3 & 32.5 & 70.1 & 60.4 & 60.0 & 2.6 & 27.6 & 23.0 & 14.6 & 8.2 & 6.7 \\
\hline 2 -year or less .................. & 89 & 79.2 & 67.5 & 52.0 & 61.9 & 40.0 & 42.0 & 52.9 & 51.7 & 9.3 & 5.3 & 4.6 & 11.4 & 5.0 & 6.3 \\
\hline Private, proprietary .......... & 337 & 86.2 & 79.7 & 32.7 & 61.3 & 53.9 & 20.2 & 67.7 & 65.5 & 5.1 & 0.5 & 0.5 & 17.2 & 7.6 & 8.9 \\
\hline ind above ....... & 167 & 85.8 & 80.3 & 33.0 & 60.0 & 49.1 & 26.0 & 70.9 & 70.9 & 1.4 & 0.7 & 0.7 & 15.3 & 7.8 & 6.9 \\
\hline \multirow[t]{2}{*}{ Less than 2-year ........ } & 170 & 86.6 & 79.1 & 32.5 & 62.5 & 58.6 & 14.5 & 64.6 & 60.3 & 8.7 & 0.3 & 0.2 & 19.1 & 7.4 & 10.9 \\
\hline & \multicolumn{15}{|c|}{ Part-time students, 4 1995-96 } \\
\hline All institutions ........... & 10,157 & 38.3 & 24.8 & 24.0 & 29.9 & 16.6 & 19.7 & 14.4 & 14.1 & 0.7 & 1.4 & 1.1 & 5.4 & 0.8 & 4.3 \\
\hline Public & 8,519 & 33.7 & 20.8 & 21.7 & 26.5 & 14.4 & 17.9 & 10.5 & 10.3 & 0.3 & 1.2 & 0.9 & 4.7 & 0.4 & 3.9 \\
\hline 4 -year doctoral ............ & 1,211 & 41.8 & 31.2 & 23.7 & 28.9 & 16.9 & 19.0 & 25.9 & 25.6 & 0.7 & 2.4 & 1.4 & 5.8 & 1.7 & 3.9 \\
\hline Other 4-year ..................... & 1,030 & 41.9 & 30.9 & 22.8 & 30.2 & 18.2 & 19.3 & 22.3 & 22.1 & 0.4 & 2.3 & 2.0 & 4.8 & 0.8 & 3.7 \\
\hline 2 -yea & 6,174 & 30.7 & 17.2 & 21.1 & 25.4 & 13.4 & 17.5 & 5.7 & 5.5 & 0.3 & 0.8 & 0.7 & 4.4 & 0.2 & 3.9 \\
\hline Less than 2-year ........ & 105 & 34.3 & 13.9 & 26.0 & 27.8 & 12.3 & 17.4 & 2.2 & 2.2 & 0.0 & 0.0 & 0.0 & 8.6 & 0.0 & 8.3 \\
\hline Private, nonprofit .............. & 1,070 & 55.6 & 34.9 & 41.5 & 44.1 & 17.9 & 36.1 & 26.4 & 26.1 & 1.3 & 4.0 & 3.1 & 8.6 & 2.0 & 6.6 \\
\hline 4-year doctoral ............ & 280 & 51.0 & 27.7 & 39.7 & 39.3 & 12.0 & 34.3 & 24.4 & 23.6 & 1.4 & 4.6 & 3.7 & 8.4 & 2.1 & 5.9 \\
\hline Other 4-year ..................... & 668 & 58.4 & 37.0 & 44.6 & 47.5 & 19.1 & 39.7 & 27.3 & 27.2 & 0.8 & 4.5 & 3.3 & 8.9 & 1.7 & 7.1 \\
\hline 2 -year or less ................ & 123 & 50.8 & 39.7 & 28.3 & 36.8 & 24.6 & 20.5 & 26.2 & 25.9 & 4.3 & 0.4 & 0.3 & 7.8 & 2.9 & 5.1 \\
\hline Private, proprietary ......... & 567 & 74.1 & 66.4 & 24.3 & 53.4 & 46.4 & 15.3 & 50.3 & 49.3 & 4.6 & 0.4 & 0.4 & 10.4 & 4.2 & 5.7 \\
\hline 2-year and above ....... & 269 & 74.5 & 66.9 & 25.5 & 53.4 & 44.8 & 17.9 & 50.2 & 49.8 & 1.7 & 0.8 & 0.7 & 12.2 & 4.9 & 6.9 \\
\hline Less than 2 -year ........ & 298 & 73.8 & 66.1 & 23.2 & 53.5 & 47.9 & 13.0 & 50.5 & 48.8 & 7.2 & 0.1 & 0.1 & 8.7 & 3.5 & 4.7 \\
\hline
\end{tabular}

${ }_{1}^{1}$ Numbers of undergraduates may not equal figures reported in other tables, since these data are based on a sample survey. Includes students who enrolled at any time during the academic year.

2 Includes students who reported they were awarded aid but did not specify the source of aid.

${ }^{3}$ Details on nonfederal work study participants are not available.

${ }^{4}$ Full-time students are students who attend full-time for the entire academic year. Al other students, including those who attend full-time for part of the academic year, are counted as part-time students.
NOTE.-Excludes students whose attendance status was not reported. Because some students receive multiple types and sources of aid and rounding, details may not add to totals.

SOURCE: U.S. Department of Education, National Center for Education Statistics, $\mathrm{Na}$ tional Postsecondary Student Aid Study, 1992-93 and 1995-96. (This table was prepared September 1997.) 
Table 318.- Undergraduates enrolled full time and part time, by federal aid program and by control and level of institution: 1995-96

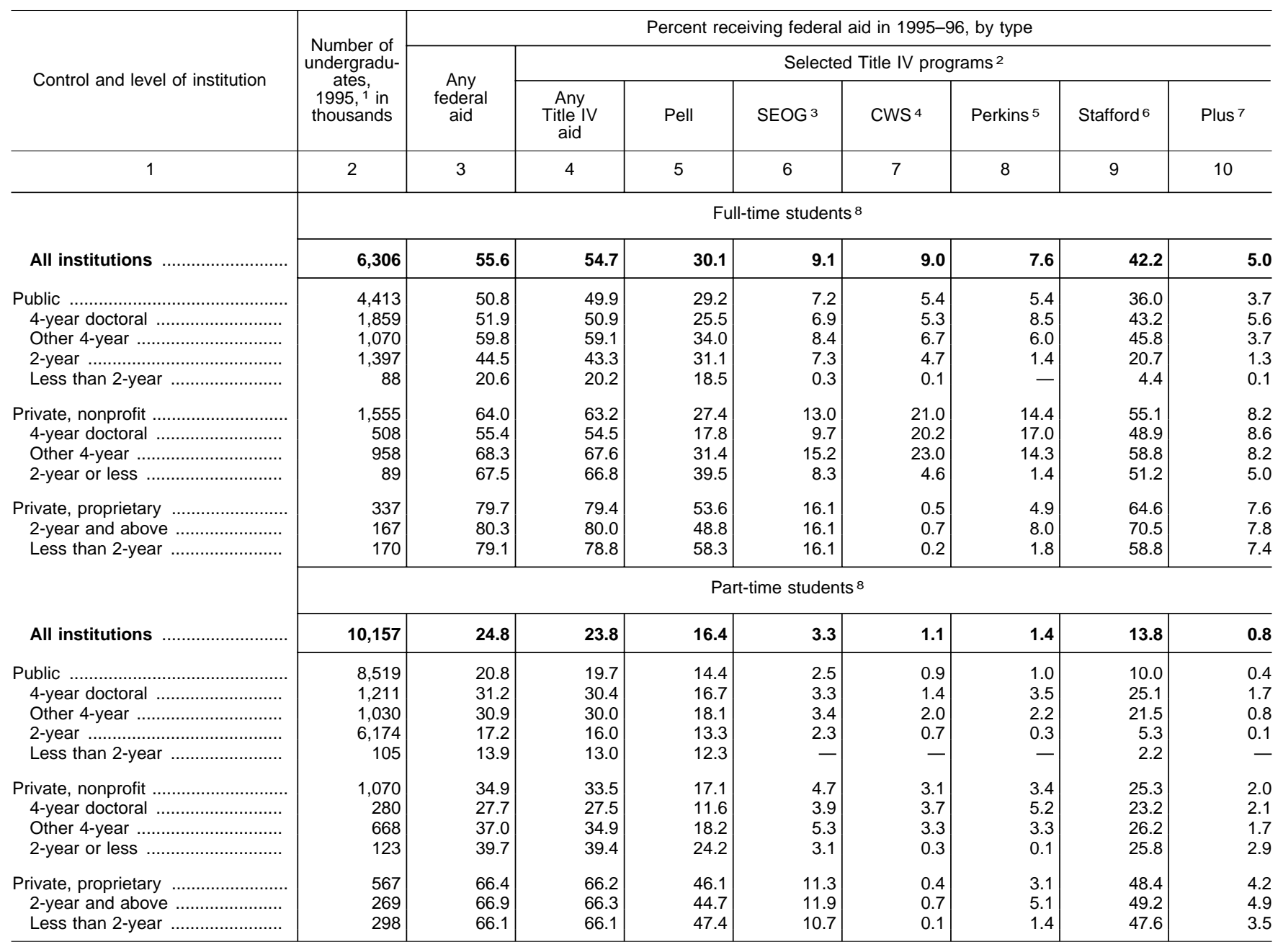

${ }_{1}$ Numbers of undergraduates may not equal figures reported in other tables, since these data are based on a sample survey. Includes students who enrolled at any time during the academic year.

2 Title IV of the Higher Education Act.

${ }^{3}$ Supplemental Educational Opportunity Grants.

${ }^{4}$ College Work Study (CWS). Prior to October 17, 1986, private, proprietary institutions were prohibited by law from spending CWS funds for on-campus work. Includes persons who participated in the program, but had no earnings.

5 Formerly National Direct Student Loans (NDSL).

${ }^{6}$ Formerly Guaranteed Student Loans (GSL).

${ }^{7}$ Parent loans for Undergraduate Students.
${ }^{8}$ Full-time students are students who attend full-time for the entire academic year. All other students, including those who attend full-time for part of the academic year, are counted as part-time students.

- Less than .05 percent.

NOTE.-Excludes students whose attendance status was not reported. Because some students receive aid from multiple sources and rounding, percents do not add to totals.

SOURCE: U.S. Department of Education, National Center for Education Statistics, National Postsecondary Student Aid Study, 1995-96. (This table was prepared October 1997.) 
Table 319._Postbaccalaureate students enrolled full time and part time, by aid status, source of aid, and by level of study and control and level of institution: 1992-93 and 1995-96

\begin{tabular}{|c|c|c|c|c|c|c|c|c|c|}
\hline \multirow{3}{*}{$\begin{array}{l}\text { Level of degree, } \\
\text { control and } \\
\text { type of institution }\end{array}$} & \multirow{3}{*}{$\begin{array}{l}\text { Postbaccalaureate } \\
\text { students, } 1 \\
\text { in thousands }\end{array}$} & \multirow{3}{*}{$\begin{array}{c}\text { Cumulative } \\
\text { amount borrowed } \\
\text { for } \\
\text { postbaccalaureate } \\
\text { education }\end{array}$} & \multicolumn{7}{|c|}{ Aid status in percents } \\
\hline & & & \multirow{2}{*}{ Nonaided } & \multicolumn{6}{|c|}{ Receiving aid, by source } \\
\hline & & & & Any aid ${ }^{2}$ & Federal & State & Institutional & Employer & Other ${ }^{3}$ \\
\hline \multirow[t]{2}{*}{1} & 2 & 3 & 4 & 5 & 6 & 7 & 8 & 9 & 10 \\
\hline & \multicolumn{9}{|c|}{ Full-time students, ${ }^{4}$ 1992-93 } \\
\hline All institutions ........ & 673 & $\$ 18,572$ & 31.9 & 68.1 & 44.4 & 7.0 & 40.6 & 5.3 & 14.6 \\
\hline 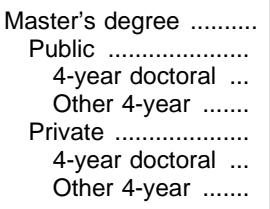 & $\begin{array}{r}281 \\
163 \\
139 \\
24 \\
118 \\
102 \\
16\end{array}$ & $\begin{array}{r}11,109 \\
9,335 \\
9,597 \\
7,970 \\
13,628 \\
13,879 \\
-\end{array}$ & $\begin{array}{l}37.5 \\
34.6 \\
34.3 \\
36.1 \\
41.6 \\
39.3 \\
56.5\end{array}$ & $\begin{array}{l}62.5 \\
65.4 \\
65.7 \\
63.9 \\
58.4 \\
60.7 \\
43.5\end{array}$ & $\begin{array}{l}33.8 \\
33.9 \\
32.4 \\
42.5 \\
33.7 \\
34.2 \\
30.5\end{array}$ & $\begin{array}{r}5.8 \\
7.8 \\
6.7 \\
14.4 \\
3.2 \\
2.9 \\
5.1\end{array}$ & $\begin{array}{l}42.4 \\
44.0 \\
46.3 \\
30.4 \\
40.2 \\
42.9 \\
22.8\end{array}$ & $\begin{array}{r}8.3 \\
7.6 \\
7.7 \\
6.8 \\
9.4 \\
8.9 \\
12.1\end{array}$ & $\begin{array}{r}12.0 \\
9.7 \\
10.1 \\
7.5 \\
15.2 \\
16.4 \\
7.4\end{array}$ \\
\hline 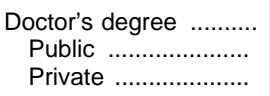 & $\begin{array}{r}120 \\
73 \\
46\end{array}$ & $\begin{array}{l}16,895 \\
12,758 \\
21,742\end{array}$ & $\begin{array}{l}30.4 \\
30.3 \\
30.4\end{array}$ & $\begin{array}{l}69.6 \\
69.7 \\
69.6\end{array}$ & $\begin{array}{l}28.3 \\
22.3 \\
37.8\end{array}$ & $\begin{array}{l}4.4 \\
6.5 \\
1.1\end{array}$ & $\begin{array}{l}51.6 \\
55.5 \\
45.5\end{array}$ & $\begin{array}{l}3.0 \\
3.9 \\
1.7\end{array}$ & $\begin{array}{l}13.2 \\
11.7 \\
15.7\end{array}$ \\
\hline $\begin{array}{l}\text { First-professional } \\
\text { Public } \\
\text { Private }\end{array}$ & $\begin{array}{l}211 \\
101 \\
110\end{array}$ & $\begin{array}{l}30,045 \\
24,469 \\
35,301\end{array}$ & $\begin{array}{l}23.0 \\
20.7 \\
25.1\end{array}$ & $\begin{array}{l}77.0 \\
79.3 \\
74.9\end{array}$ & $\begin{array}{l}68.2 \\
72.5 \\
64.3\end{array}$ & $\begin{array}{r}10.0 \\
13.4 \\
6.8\end{array}$ & $\begin{array}{l}37.0 \\
37.7 \\
36.4\end{array}$ & $\begin{array}{l}2.3 \\
2.3 \\
2.3\end{array}$ & $\begin{array}{l}20.3 \\
15.8 \\
24.4\end{array}$ \\
\hline \multirow[t]{2}{*}{ Other graduate $. . . . \ldots \ldots . . . .}$. & 61 & 13,102 & 39.3 & 60.7 & 42.4 & 6.7 & 22.9 & 6.0 & 9.1 \\
\hline & \multicolumn{9}{|c|}{ Full-time students, ${ }^{4}$ 1995-96 } \\
\hline All institutions ........ & 861 & $\$ 27,122$ & 23.9 & 76.1 & 49.3 & 4.1 & 43.4 & 9.6 & 22.7 \\
\hline 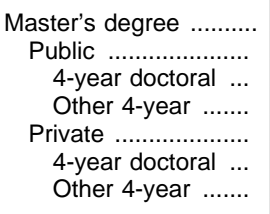 & $\begin{array}{r}387 \\
236 \\
195 \\
41 \\
151 \\
104 \\
47\end{array}$ & $\begin{array}{l}18,806 \\
15,905 \\
16,910 \\
11,417 \\
22,568 \\
23,816 \\
20,299\end{array}$ & $\begin{array}{l}27.4 \\
25.3 \\
23.5 \\
34.0 \\
30.6 \\
28.8 \\
34.6\end{array}$ & $\begin{array}{l}72.6 \\
74.7 \\
76.5 \\
66.0 \\
69.4 \\
71.2 \\
65.4\end{array}$ & $\begin{array}{l}43.6 \\
40.7 \\
40.5 \\
41.4 \\
48.2 \\
44.6 \\
56.1\end{array}$ & $\begin{array}{l}2.4 \\
3.0 \\
2.6 \\
5.1 \\
1.4 \\
1.5 \\
1.3\end{array}$ & $\begin{array}{l}42.8 \\
45.6 \\
47.9 \\
35.0 \\
38.3 \\
42.2 \\
29.7\end{array}$ & $\begin{array}{r}16.4 \\
16.7 \\
19.2 \\
4.9 \\
15.9 \\
20.2 \\
6.6\end{array}$ & $\begin{array}{r}22.5 \\
31.4 \\
34.1 \\
18.7 \\
8.7 \\
11.5 \\
2.6\end{array}$ \\
\hline 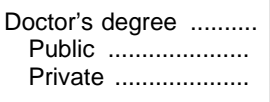 & $\begin{array}{r}147 \\
94 \\
53\end{array}$ & $\begin{array}{l}24,380 \\
22,687 \\
28,083\end{array}$ & $\begin{array}{l}17.1 \\
14.1 \\
22.5\end{array}$ & $\begin{array}{l}82.9 \\
85.9 \\
77.5\end{array}$ & $\begin{array}{l}27.6 \\
27.6 \\
27.6\end{array}$ & $\begin{array}{l}0.6 \\
1.0 \\
0.0\end{array}$ & $\begin{array}{l}75.7 \\
77.8 \\
72.0\end{array}$ & $\begin{array}{l}4.0 \\
5.1 \\
2.1\end{array}$ & $\begin{array}{l}53.4 \\
62.1 \\
37.9\end{array}$ \\
\hline 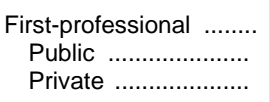 & $\begin{array}{l}253 \\
115 \\
138\end{array}$ & $\begin{array}{l}37,540 \\
34,463 \\
40,350\end{array}$ & $\begin{array}{l}16.8 \\
14.3 \\
19.0\end{array}$ & $\begin{array}{l}83.2 \\
85.7 \\
81.0\end{array}$ & $\begin{array}{l}73.9 \\
79.5 \\
69.3\end{array}$ & $\begin{array}{l}9.4 \\
9.7 \\
9.2\end{array}$ & $\begin{array}{l}31.6 \\
33.5 \\
30.0\end{array}$ & $\begin{array}{l}2.2 \\
1.2 \\
3.1\end{array}$ & $\begin{array}{l}8.7 \\
8.0 \\
9.3\end{array}$ \\
\hline $\begin{array}{c}\text { Other graduate } \ldots . . . \ldots . . . . \\
\text { Public 4-year doc- } \\
\text { toral ................ } \\
\text { Public other 4-year }\end{array}$ & $\begin{array}{l}54 \\
\\
18 \\
36\end{array}$ & $\begin{array}{r}12,057 \\
-\overline{12,057}\end{array}$ & $\begin{array}{l}43.5 \\
36.9 \\
46.8 \\
\end{array}$ & $\begin{array}{l}56.5 \\
63.1 \\
53.2\end{array}$ & $\begin{array}{l}34.0 \\
32.2 \\
35.0\end{array}$ & $\begin{array}{l}2.2 \\
4.0 \\
1.2\end{array}$ & $\begin{array}{l}31.4 \\
35.2 \\
29.4\end{array}$ & $\begin{array}{r}7.0 \\
\overline{10.5}\end{array}$ & $\begin{array}{l}14.7 \\
17.3 \\
13.4 \\
\end{array}$ \\
\hline Public other 4-year & \multicolumn{9}{|c|}{ Part-time students, ${ }^{4}$ 1995-96 } \\
\hline All institutions ....... & 1,869 & $\$ 16,193$ & 59.3 & 40.7 & 13.8 & 1.4 & 16.7 & 26.0 & 10.4 \\
\hline 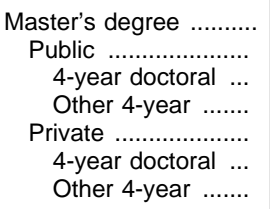 & $\begin{array}{r}1,118 \\
649 \\
432 \\
217 \\
470 \\
255 \\
215\end{array}$ & $\begin{array}{r}14,635 \\
12,971 \\
14,443 \\
9,273 \\
16,904 \\
19,948 \\
13,006\end{array}$ & $\begin{array}{l}56.3 \\
57.3 \\
52.8 \\
66.4 \\
54.9 \\
55.3 \\
54.5\end{array}$ & $\begin{array}{l}43.7 \\
42.7 \\
47.2 \\
33.6 \\
45.1 \\
44.7 \\
45.5\end{array}$ & $\begin{array}{l}15.1 \\
13.6 \\
14.8 \\
11.1 \\
17.2 \\
17.7 \\
16.6\end{array}$ & $\begin{array}{l}1.2 \\
1.7 \\
1.2 \\
2.8 \\
0.5 \\
0.6 \\
0.3\end{array}$ & $\begin{array}{r}16.5 \\
18.5 \\
22.6 \\
10.3 \\
13.7 \\
17.2 \\
9.6\end{array}$ & $\begin{array}{l}27.9 \\
24.2 \\
25.7 \\
21.4 \\
33.0 \\
29.0 \\
37.8\end{array}$ & $\begin{array}{r}10.3 \\
13.3 \\
16.5 \\
6.9 \\
6.3 \\
7.6 \\
4.7\end{array}$ \\
\hline $\begin{array}{l}\text { Doctor's degree } \ldots . . . . . . . \\
\text { Public } \\
\text { Private .......................................... }\end{array}$ & $\begin{array}{r}181 \\
119 \\
62\end{array}$ & $\begin{array}{l}19,530 \\
16,288 \\
24,882\end{array}$ & $\begin{array}{l}48.6 \\
46.1 \\
53.3\end{array}$ & $\begin{array}{l}51.4 \\
53.9 \\
46.7\end{array}$ & $\begin{array}{r}12.1 \\
9.5 \\
17.2\end{array}$ & $\begin{array}{l}0.6 \\
0.9 \\
0.0\end{array}$ & $\begin{array}{l}39.3 \\
42.5 \\
33.3\end{array}$ & $\begin{array}{r}11.9 \\
13.2 \\
9.3\end{array}$ & $\begin{array}{l}27.0 \\
32.5 \\
16.6\end{array}$ \\
\hline 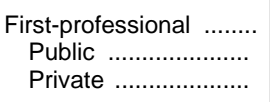 & $\begin{array}{l}60 \\
15 \\
46\end{array}$ & $\begin{array}{l}32,803 \\
31,882 \\
33,160\end{array}$ & $\begin{array}{l}32.2 \\
29.6 \\
33.1\end{array}$ & $\begin{array}{l}67.8 \\
70.4 \\
66.9\end{array}$ & $\begin{array}{l}47.4 \\
59.6 \\
43.5\end{array}$ & $\begin{array}{l}4.3 \\
4.0 \\
4.3\end{array}$ & $\begin{array}{l}27.0 \\
25.7 \\
27.4\end{array}$ & $\begin{array}{r}14.2 \\
9.3 \\
15.8\end{array}$ & $\begin{array}{l}7.0 \\
8.6 \\
6.5\end{array}$ \\
\hline $\begin{array}{l}\text { Other graduate ........... } \\
\text { Public 4-year doc- } \\
\text { toral .................................. }\end{array}$ & $\begin{array}{r}483 \\
166\end{array}$ & $\begin{array}{l}13,008 \\
11,166\end{array}$ & $\begin{array}{l}74.0 \\
67.8\end{array}$ & $\begin{array}{l}26.0 \\
32.2\end{array}$ & $\begin{array}{l}7.0 \\
9.8\end{array}$ & $\begin{array}{l}1.9 \\
0.5\end{array}$ & $\begin{array}{r}8.4 \\
12.4\end{array}$ & $\begin{array}{l}26.7 \\
24.7\end{array}$ & $\begin{array}{l}5.1 \\
4.0\end{array}$ \\
\hline Public other 4-year & 317 & 15,473 & 77.3 & 22.7 & 5.5 & 2.6 & 6.3 & 27.8 & 5.7 \\
\hline
\end{tabular}

${ }^{1}$ Numbers of postbaccalaureate students may not equal figures reported in other tables, since these data are based on a sample survey of all postbaccalaureate students. Includes students who enrolled at any time during the academic year.

2 Includes students who reported they were awarded aid but did not specify the source of aid.

${ }^{3}$ Includes aid provided by corporations, unions, foundations, fraternal organizations, community organizations, etc.

${ }^{4}$ Full-time students are students who attend full-time for the entire academic year. All other students, including those who attend full-time for part of the academic year, are counted as part-time students.

-Sample size too small to permit reliable estimate.
NOTE.-Total includes some students whose level of study was unknown. Because some students receive aid from multiple sources and rounding, percents do not add to totals.

SOURCE: U.S. Department of Education, National Center for Education Statistics, $\mathrm{Na}$ tional Postsecondary Student Aid Study, 1992-93 and 1995-96. (This table was prepared October 1997.) 
Table 320.-Postbaccalaureate students enrolled full time and part time, by type of aid and by level of study, control, and level of institution: 1992-93 and 1995-96

\begin{tabular}{|c|c|c|c|c|c|c|c|c|c|}
\hline \multirow{3}{*}{$\begin{array}{l}\text { Level of degree, control } \\
\text { and type of institution }\end{array}$} & \multirow{3}{*}{$\begin{array}{c}\text { Postbaccalaureate } \\
\text { students, }{ }^{1} \text { in thou- } \\
\text { sands }\end{array}$} & \multicolumn{8}{|c|}{ Type of aid in percents } \\
\hline & & \multirow[b]{2}{*}{$\begin{array}{l}\text { Any } \\
\text { aid }^{2}\end{array}$} & \multirow[b]{2}{*}{$\begin{array}{l}\text { Fellowship } \\
\text { grants }\end{array}$} & \multirow[b]{2}{*}{ Tuition waivers } & \multirow[b]{2}{*}{ Assistantships ${ }^{3}$} & \multirow[b]{2}{*}{ Employer } & \multicolumn{3}{|c|}{ Loans } \\
\hline & & & & & & & $\begin{array}{l}\text { Any } \\
\text { loans }\end{array}$ & Stafford 4 & $\begin{array}{l}\text { Per- } \\
\text { kins }\end{array}$ \\
\hline \multirow[t]{2}{*}{1} & 2 & 3 & 4 & 5 & 6 & 7 & 8 & 9 & 10 \\
\hline & \multicolumn{9}{|c|}{ Full-time students, 5 1992-93 } \\
\hline All institutions ................ & 673 & 68.1 & 3.5 & 12.4 & 14.3 & 3.3 & 43.5 & 41.1 & 9.0 \\
\hline 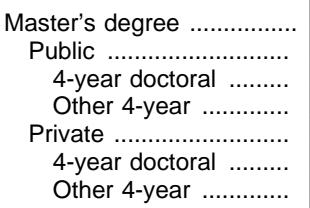 & $\begin{array}{r}281 \\
163 \\
139 \\
24 \\
118 \\
102 \\
16\end{array}$ & $\begin{array}{l}62.5 \\
65.4 \\
65.7 \\
63.9 \\
58.4 \\
60.7 \\
43.5\end{array}$ & $\begin{array}{l}3.5 \\
2.2 \\
2.4 \\
1.0 \\
5.3 \\
6.2 \\
0.0\end{array}$ & $\begin{array}{r}15.6 \\
20.5 \\
23.3 \\
4.4 \\
8.9 \\
9.5 \\
5.4\end{array}$ & $\begin{array}{r}18.1 \\
22.4 \\
23.5 \\
15.8 \\
12.1 \\
13.6 \\
3.0\end{array}$ & $\begin{array}{l}5.1 \\
4.8 \\
4.7 \\
5.3 \\
5.6 \\
5.7 \\
4.7\end{array}$ & $\begin{array}{l}32.5 \\
32.2 \\
30.6 \\
41.5 \\
32.9 \\
33.6 \\
28.7\end{array}$ & $\begin{array}{l}30.5 \\
30.8 \\
29.6 \\
38.4 \\
30.0 \\
30.8 \\
24.6\end{array}$ & $\begin{array}{l}5.0 \\
4.0 \\
3.3 \\
8.3 \\
6.4 \\
6.8 \\
4.4\end{array}$ \\
\hline $\begin{array}{l}\text { Doctor's degree } \\
\text { Public } \\
\text { Private }\end{array}$ & $\begin{array}{r}120 \\
73 \\
46\end{array}$ & $\begin{array}{l}69.6 \\
69.7 \\
69.6\end{array}$ & $\begin{array}{r}9.3 \\
4.2 \\
17.5\end{array}$ & $\begin{array}{l}19.4 \\
23.1 \\
13.6\end{array}$ & $\begin{array}{l}27.0 \\
31.6 \\
19.9\end{array}$ & $\begin{array}{l}2.2 \\
3.1 \\
0.9\end{array}$ & $\begin{array}{l}25.8 \\
20.6 \\
34.1\end{array}$ & $\begin{array}{l}23.9 \\
18.9 \\
31.9\end{array}$ & $\begin{array}{l}3.5 \\
2.9 \\
4.3\end{array}$ \\
\hline $\begin{array}{l}\text { First-professional } \\
\quad \text { Public } \\
\text { Private }\end{array}$ & $\begin{array}{l}211 \\
101 \\
110\end{array}$ & $\begin{array}{l}77.0 \\
79.3 \\
74.9\end{array}$ & $\begin{array}{l}0.9 \\
0.4 \\
1.2\end{array}$ & $\begin{array}{l}5.6 \\
5.4 \\
5.8\end{array}$ & $\begin{array}{l}4.4 \\
4.3 \\
4.5\end{array}$ & $\begin{array}{l}1.2 \\
1.3 \\
1.2\end{array}$ & $\begin{array}{l}67.8 \\
71.8 \\
64.1\end{array}$ & $\begin{array}{l}65.5 \\
69.9 \\
61.6\end{array}$ & $\begin{array}{l}19.3 \\
23.2 \\
15.7\end{array}$ \\
\hline \multirow[t]{2}{*}{ Other graduate ..................... } & 61 & 60.7 & 1.1 & 7.5 & 6.2 & 3.7 & 44.4 & 39.6 & 2.7 \\
\hline & \multicolumn{9}{|c|}{ Full-time students, 5 1995-96 } \\
\hline All institutions $\ldots \ldots \ldots \ldots . . . .$. & 861 & 76.1 & 5.2 & 11.7 & 19.5 & 5.0 & 48.7 & 48.0 & 8.1 \\
\hline 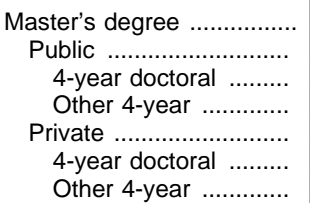 & $\begin{array}{r}387 \\
236 \\
195 \\
41 \\
151 \\
104 \\
47\end{array}$ & $\begin{array}{l}72.6 \\
74.7 \\
76.5 \\
66.0 \\
69.4 \\
71.2 \\
65.4\end{array}$ & $\begin{array}{l}4.3 \\
4.8 \\
5.2 \\
2.5 \\
3.6 \\
3.6 \\
3.7\end{array}$ & $\begin{array}{r}13.5 \\
17.8 \\
19.5 \\
9.9 \\
6.7 \\
6.4 \\
7.4\end{array}$ & $\begin{array}{r}20.2 \\
28.8 \\
31.1 \\
18.1 \\
6.6 \\
8.8 \\
1.9\end{array}$ & $\begin{array}{l}6.6 \\
7.1 \\
7.6 \\
4.5 \\
5.8 \\
7.1 \\
3.2\end{array}$ & $\begin{array}{l}43.1 \\
39.5 \\
39.2 \\
40.8 \\
48.6 \\
44.6 \\
57.4\end{array}$ & $\begin{array}{l}42.5 \\
38.8 \\
38.6 \\
39.8 \\
48.2 \\
44.6 \\
56.1\end{array}$ & $\begin{array}{l}5.1 \\
3.5 \\
4.0 \\
1.5 \\
7.6 \\
9.6 \\
3.3\end{array}$ \\
\hline $\begin{array}{l}\text { Doctor's degree } \\
\text { Public } \\
\text { Private }\end{array}$ & $\begin{array}{r}147 \\
94 \\
53\end{array}$ & $\begin{array}{l}82.9 \\
85.9 \\
77.5\end{array}$ & $\begin{array}{l}15.8 \\
13.7 \\
19.6\end{array}$ & $\begin{array}{l}24.3 \\
30.9 \\
12.4\end{array}$ & $\begin{array}{l}51.8 \\
59.9 \\
37.3\end{array}$ & $\begin{array}{l}5.5 \\
5.9 \\
4.9\end{array}$ & $\begin{array}{l}25.2 \\
26.7 \\
22.6\end{array}$ & $\begin{array}{l}25.2 \\
26.7 \\
22.6\end{array}$ & $\begin{array}{l}1.5 \\
1.4 \\
1.7\end{array}$ \\
\hline $\begin{array}{l}\text { First-professional } \\
\quad \text { Public } \\
\text { Private }\end{array}$ & $\begin{array}{l}253 \\
115 \\
138\end{array}$ & $\begin{array}{l}83.2 \\
85.7 \\
81.0\end{array}$ & $\begin{array}{l}1.4 \\
2.0 \\
0.9\end{array}$ & $\begin{array}{l}3.0 \\
3.8 \\
2.4\end{array}$ & $\begin{array}{l}4.0 \\
4.1 \\
3.8\end{array}$ & $\begin{array}{l}1.3 \\
1.5 \\
1.2\end{array}$ & $\begin{array}{l}74.4 \\
79.0 \\
70.6\end{array}$ & $\begin{array}{l}73.0 \\
78.6 \\
68.3\end{array}$ & $\begin{array}{l}18.4 \\
20.7 \\
16.4\end{array}$ \\
\hline \multirow[t]{2}{*}{ Public other 4-year ...... } & $\begin{array}{l}54 \\
18 \\
36\end{array}$ & $\begin{array}{l}56.5 \\
63.1 \\
53.2\end{array}$ & $\begin{array}{l}2.1 \\
0.0 \\
3.1\end{array}$ & $\begin{array}{r}9.8 \\
9.2 \\
10.1\end{array}$ & $\begin{array}{l}6.4 \\
6.2 \\
6.6\end{array}$ & $\begin{array}{l}6.1 \\
1.8 \\
8.3\end{array}$ & $\begin{array}{l}31.3 \\
30.2 \\
31.8\end{array}$ & $\begin{array}{l}30.9 \\
30.2 \\
31.2\end{array}$ & $\begin{array}{l}1.7 \\
3.6 \\
0.7\end{array}$ \\
\hline & \multicolumn{9}{|c|}{ Part-time students, ${ }^{5}$ 1995-96 } \\
\hline All institutions ............... & 1,869 & 40.7 & 0.8 & 6.1 & 7.4 & 16.1 & 13.4 & 13.1 & 0.9 \\
\hline 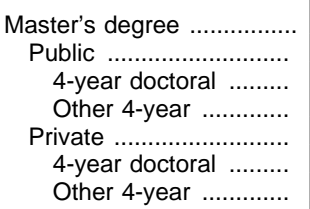 & $\begin{array}{r}1,118 \\
649 \\
432 \\
217 \\
470 \\
255 \\
215\end{array}$ & $\begin{array}{l}43.7 \\
42.7 \\
47.2 \\
33.6 \\
45.1 \\
44.7 \\
45.5\end{array}$ & $\begin{array}{l}0.8 \\
0.8 \\
1.0 \\
0.4 \\
0.9 \\
1.2 \\
0.5\end{array}$ & $\begin{array}{l}5.6 \\
6.0 \\
7.1 \\
3.9 \\
5.1 \\
4.3 \\
5.9\end{array}$ & $\begin{array}{r}7.4 \\
10.7 \\
13.7 \\
4.9 \\
2.7 \\
4.0 \\
1.2\end{array}$ & $\begin{array}{l}18.4 \\
16.0 \\
16.6 \\
14.8 \\
21.7 \\
18.3 \\
25.9\end{array}$ & $\begin{array}{l}14.5 \\
13.2 \\
14.3 \\
11.0 \\
16.4 \\
17.6 \\
15.0\end{array}$ & $\begin{array}{l}14.2 \\
12.9 \\
14.2 \\
10.5 \\
16.1 \\
17.0 \\
14.9\end{array}$ & $\begin{array}{l}0.7 \\
0.9 \\
1.0 \\
0.6 \\
0.5 \\
0.8 \\
0.1\end{array}$ \\
\hline 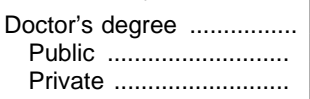 & $\begin{array}{r}181 \\
119 \\
62\end{array}$ & $\begin{array}{l}51.4 \\
53.9 \\
46.7\end{array}$ & $\begin{array}{l}2.5 \\
3.1 \\
1.4\end{array}$ & $\begin{array}{r}12.7 \\
15.6 \\
7.4\end{array}$ & $\begin{array}{l}26.0 \\
31.9 \\
14.7\end{array}$ & $\begin{array}{l}9.0 \\
9.2 \\
8.6\end{array}$ & $\begin{array}{r}12.0 \\
9.2 \\
17.2\end{array}$ & $\begin{array}{r}12.0 \\
9.2 \\
17.2\end{array}$ & $\begin{array}{l}0.4 \\
0.3 \\
0.7\end{array}$ \\
\hline $\begin{array}{l}\text { First-professional .............. } \\
\text { Public } \\
\text { Private }\end{array}$ & $\begin{array}{l}60 \\
15 \\
46\end{array}$ & $\begin{array}{l}67.8 \\
70.4 \\
66.9\end{array}$ & $\begin{array}{l}1.4 \\
1.6 \\
1.3\end{array}$ & $\begin{array}{l}3.8 \\
4.8 \\
3.5\end{array}$ & $\begin{array}{l}3.1 \\
7.9 \\
1.6\end{array}$ & $\begin{array}{l}7.0 \\
7.5 \\
6.8\end{array}$ & $\begin{array}{l}47.8 \\
58.1 \\
44.5\end{array}$ & $\begin{array}{l}45.7 \\
57.4 \\
41.9\end{array}$ & $\begin{array}{r}8.6 \\
12.2 \\
8.6\end{array}$ \\
\hline $\begin{array}{l}\text { Other graduate } \\
\text { Public 4-year doctoral ... } \\
\text { Public other 4-year ...... }\end{array}$ & $\begin{array}{l}483 \\
166 \\
317\end{array}$ & $\begin{array}{l}26.0 \\
32.2 \\
22.7\end{array}$ & $\begin{array}{l}0.2 \\
0.0 \\
0.2\end{array}$ & $\begin{array}{l}5.5 \\
8.6 \\
3.8\end{array}$ & $\begin{array}{l}1.5 \\
0.4 \\
2.1\end{array}$ & $\begin{array}{l}13.3 \\
14.9 \\
12.4\end{array}$ & $\begin{array}{l}6.7 \\
9.7 \\
5.2\end{array}$ & $\begin{array}{l}6.5 \\
9.6 \\
5.0\end{array}$ & $\begin{array}{l}0.5 \\
0.6 \\
0.4\end{array}$ \\
\hline
\end{tabular}

1 Numbers of postbaccalaureate students may not equal figures reported in other tables, since these data are based on a sample survey of all postbaccalaureate students. Includes students who enrolled at any time during the academic year.

2 Includes students who reported they were awarded aid but did not specify the source of aid.

${ }^{3}$ Includes students who received teaching or research assistantships and/or participated in work-study programs.

${ }^{4}$ Stafford loans, formerly Guaranteed Student Loans (GSL).

${ }^{5}$ Full-time students are students who attend full-time for the entire academic year. All other students, including those who attend full-time for part of the academic year, are counted as part-time students.
NOTE.-Excludes students whose attendance status was not reported. Total includes some students whose level of study was unknown. Because some students receive aid from multiple sources and rounding, details do not add to totals.

SOURCE: U.S. Department of Education, National Center for Education Statistics, National Postsecondary Student Aid Study, 1992-93 and 1995-96. (This table was prepared October 1997.) 
HIGHER EDUCATION: STUDENT CHARGES 345

Table 321.-Scholarship and fellowship awards ${ }^{1}$ of institutions of higher education and degree-granting institutions, by control of institution: $1959-60$ to $1995-96$

[In thousands]

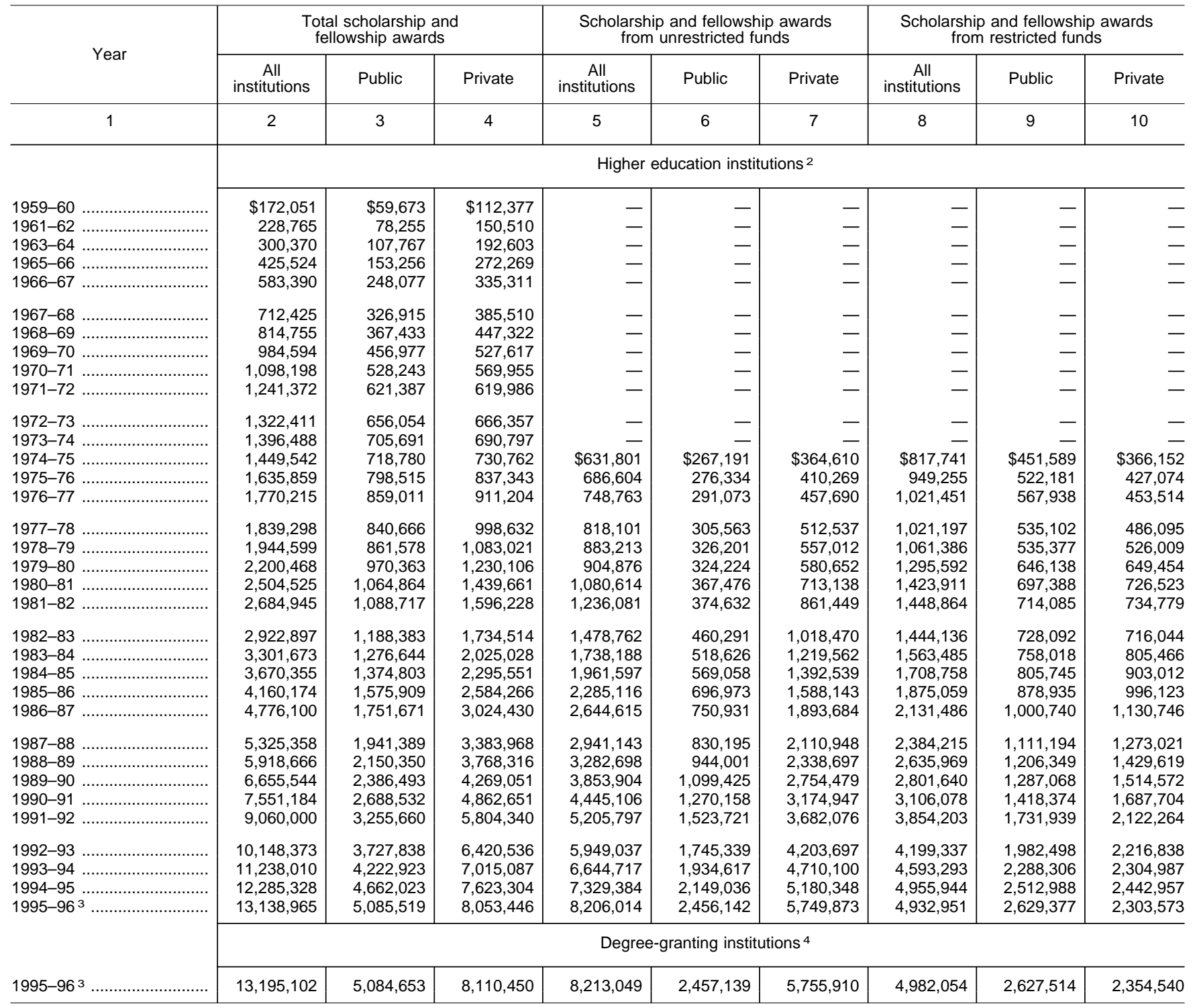

${ }^{1}$ Includes Supplemental Educational Opportunity Grants and State Student Incentive Grants, but excludes Pell Grants.

${ }^{2}$ Includes institutions with programs accreditable towards an associate or higher level degree.

3 Preliminary data.

44-year and 2-year degree-granting institutions that were eligible to participate in Title IV federal financial aid programs.
-Data not collected

NOTE.-Because of rounding, details may not add to totals.

SOURCE: U.S. Department of Education, National Center for Education Statistics, Higher Education General Information Survey (HEGIS), "Financial Statistics of Institutions of Higher Education" surveys; and Integrated Postsecondary Education Data System (IPEDS), "Finance" surveys. (This table was prepared October 1998.) 
Table 322.-Pell Grant revenue of institutions of higher education and degree-granting institutions compared to current-fund revenue and tuition,

by type and control of institution: 1985-86 to 1995-96 [Amounts in thousands]

\begin{tabular}{|c|c|c|c|c|c|c|c|c|c|c|c|c|}
\hline \multirow[b]{2}{*}{ Year and type of control of institution } & \multicolumn{4}{|c|}{ Total } & \multicolumn{4}{|c|}{ Public } & \multicolumn{4}{|c|}{ Private } \\
\hline & $\begin{array}{l}\text { Current-fund } \\
\text { revenue }\end{array}$ & Tuition & $\begin{array}{l}\text { Pell Grant } \\
\text { revenue }\end{array}$ & $\begin{array}{c}\text { Pell } \\
\text { Grants } \\
\text { as a } \\
\text { percent } \\
\text { of } \\
\text { current- } \\
\text { fund } \\
\text { revenue }\end{array}$ & $\begin{array}{l}\text { Current-fund } \\
\text { revenue }\end{array}$ & Tuition & $\begin{array}{l}\text { Pell Grant } \\
\text { revenue }\end{array}$ & $\begin{array}{c}\text { Pell } \\
\text { Grants } \\
\text { as a } \\
\text { percent } \\
\text { of } \\
\text { current- } \\
\text { fund } \\
\text { revenue }\end{array}$ & $\begin{array}{l}\text { Current-fund } \\
\text { revenue }\end{array}$ & Tuition & $\begin{array}{c}\text { Pell Grant } \\
\text { revenue }\end{array}$ & $\begin{array}{l}\text { Pell } \\
\text { Grants } \\
\text { as a } \\
\text { percent } \\
\text { of } \\
\text { current- } \\
\text { fund } \\
\text { revenue }\end{array}$ \\
\hline \multirow[t]{2}{*}{1} & 2 & 3 & 4 & 5 & 6 & 7 & 8 & 9 & 10 & 11 & 12 & 13 \\
\hline & \multicolumn{12}{|c|}{ Higher education institutions } \\
\hline 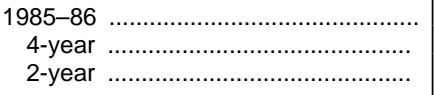 & $\begin{array}{r}\$ 100,437,616 \\
88,144,386 \\
12,293,231\end{array}$ & $\begin{array}{r}\$ 23,116,605 \\
20,498,399 \\
2,618,206\end{array}$ & $\begin{array}{r}\$ 2,565,048 \\
1,770,042 \\
795,006\end{array}$ & $\begin{array}{l}2.6 \\
2.0 \\
6.5\end{array}$ & $\begin{array}{r}\$ 65,004,632 \\
53,746,503 \\
11,258,128\end{array}$ & $\begin{array}{r}\$ 9,439,177 \\
7,539,717 \\
1,899,460\end{array}$ & $\begin{array}{r}\$ 1,873,456 \\
1,214,303 \\
659,153\end{array}$ & $\begin{array}{l}2.9 \\
2.3 \\
5.9\end{array}$ & $\begin{array}{r}\$ 35,432,985 \\
34,397,882 \\
1,035,102\end{array}$ & $\begin{array}{r}\$ 13,677,429 \\
12,958,683 \\
718,746\end{array}$ & $\begin{array}{r}\$ 691,592 \\
555,739 \\
135,853\end{array}$ & $\begin{array}{r}2.0 \\
1.6 \\
13.1\end{array}$ \\
\hline 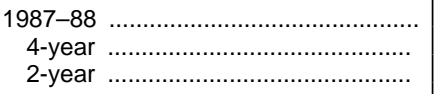 & $\begin{array}{r}117,340,109 \\
103,280,070 \\
14,060,039\end{array}$ & $\begin{array}{r}27,836,781 \\
24,779,364 \\
3,057,417\end{array}$ & $\begin{array}{r}2,496,133 \\
1,714,118 \\
782,015\end{array}$ & $\begin{array}{l}2.1 \\
1.7 \\
5.6\end{array}$ & $\begin{array}{l}74,771,255 \\
61,958,780 \\
12,812,475\end{array}$ & $\begin{array}{r}11,184,657 \\
9,032,936 \\
2,151,721\end{array}$ & $\begin{array}{r}1,876,777 \\
1,207,418 \\
669,359\end{array}$ & $\begin{array}{l}2.5 \\
1.9 \\
5.2\end{array}$ & $\begin{array}{r}42,568,854 \\
41,321,290 \\
1,247,564\end{array}$ & $\begin{array}{r}16,652,124 \\
15,746,428 \\
905,696\end{array}$ & $\begin{array}{l}619,355 \\
506,700 \\
112,656\end{array}$ & $\begin{array}{l}1.5 \\
1.2 \\
9.0\end{array}$ \\
\hline $\begin{array}{r}\text { 1989-90 } \\
4-\text { year } \\
2 \text {-year }\end{array}$ & $\begin{array}{r}139,635,477 \\
122,858,290 \\
16,777,187\end{array}$ & $\begin{array}{r}33,926,060 \\
30,302,689 \\
3,623,371\end{array}$ & $\begin{array}{l}3,348,018 \\
2,253,803 \\
1,094,215\end{array}$ & $\begin{array}{l}2.4 \\
1.8 \\
6.5\end{array}$ & $\begin{array}{l}88,911,433 \\
73,415,696 \\
15,495,738\end{array}$ & $\begin{array}{r}13,820,240 \\
11,090,012 \\
2,730,229\end{array}$ & $\begin{array}{r}2,566,209 \\
1,591,684 \\
974,525\end{array}$ & $\begin{array}{l}2.9 \\
2.2 \\
6.3\end{array}$ & $\begin{array}{r}50,724,044 \\
49,442,595 \\
1,281,449\end{array}$ & $\begin{array}{r}20,105,820 \\
19,212,677 \\
893,143\end{array}$ & $\begin{array}{l}781,809 \\
662,119 \\
119,690\end{array}$ & $\begin{array}{l}1.5 \\
1.3 \\
9.3\end{array}$ \\
\hline $\begin{array}{r}\text { 1990-91 } \\
4-\text { year } \\
2 \text {-year }\end{array}$ & $\begin{array}{r}149,766,051 \\
131,743,973 \\
18,022,078\end{array}$ & $\begin{array}{r}37,434,462 \\
33,405,241 \\
4,029,222\end{array}$ & $\begin{array}{l}3,510,537 \\
2,312,931 \\
1,197,606\end{array}$ & $\begin{array}{l}2.3 \\
1.8 \\
6.6\end{array}$ & $\begin{array}{l}94,904,506 \\
78,272,989 \\
16,631,517\end{array}$ & $\begin{array}{r}15,258,024 \\
12,188,851 \\
3,069,173\end{array}$ & $\begin{array}{l}2,725,357 \\
1,647,376 \\
1,077,981\end{array}$ & $\begin{array}{l}2.9 \\
2.1 \\
6.5\end{array}$ & $\begin{array}{r}54,861,545 \\
53,470,984 \\
1,390,562\end{array}$ & $\begin{array}{r}22,176,439 \\
21,216,389 \\
960,049\end{array}$ & $\begin{array}{l}785,180 \\
665,554 \\
119,625\end{array}$ & $\begin{array}{l}1.4 \\
1.2 \\
8.6\end{array}$ \\
\hline 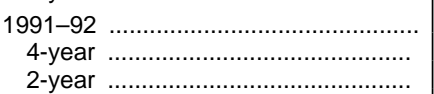 & $\begin{array}{r}161,395,896 \\
141,700,893 \\
19,695,003\end{array}$ & $\begin{array}{r}41,559,037 \\
36,910,390 \\
4,648,647\end{array}$ & $\begin{array}{l}4,238,047 \\
2,710,510 \\
1,527,537\end{array}$ & $\begin{array}{l}2.6 \\
1.9 \\
7.8\end{array}$ & $\begin{array}{r}102,202,890 \\
83,969,040 \\
18,233,850\end{array}$ & $\begin{array}{r}17,460,263 \\
13,827,245 \\
3,633,018\end{array}$ & $\begin{array}{l}3,312,386 \\
1,928,623 \\
1,383,763\end{array}$ & $\begin{array}{l}3.2 \\
2.3 \\
7.6\end{array}$ & $\begin{array}{r}59,193,006 \\
57,731,852 \\
1,461,153\end{array}$ & $\begin{array}{r}24,098,774 \\
23,083,145 \\
1,015,629\end{array}$ & $\begin{array}{l}925,661 \\
781,887 \\
143,774\end{array}$ & $\begin{array}{l}1.6 \\
1.4 \\
9.8\end{array}$ \\
\hline $\begin{array}{r}\text { 1992-93 } \\
4-\text { year } \\
2 \text {-year }\end{array}$ & $\begin{array}{r}170,880,503 \\
150,075,119 \\
20,805,384\end{array}$ & $\begin{array}{r}45,346,071 \\
40,127,624 \\
5,218,447\end{array}$ & $\begin{array}{l}4,701,905 \\
2,982,999 \\
1,718,907\end{array}$ & $\begin{array}{l}2.8 \\
2.0 \\
8.3\end{array}$ & $\begin{array}{r}108,186,484 \\
88,952,983 \\
19,233,501\end{array}$ & $\begin{array}{r}19,490,221 \\
15,406,746 \\
4,083,475\end{array}$ & $\begin{array}{l}3,663,529 \\
2,097,638 \\
1,565,890\end{array}$ & $\begin{array}{l}3.4 \\
2.4 \\
8.1\end{array}$ & $\begin{array}{r}62,694,018 \\
61,122,135 \\
1,571,883\end{array}$ & $\begin{array}{r}25,855,850 \\
24,720,878 \\
1,134,972\end{array}$ & $\begin{array}{r}1,038,377 \\
885,360 \\
153,017\end{array}$ & $\begin{array}{l}1.7 \\
1.4 \\
9.7\end{array}$ \\
\hline 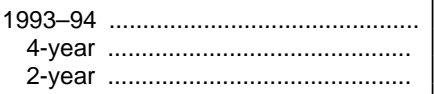 & $\begin{array}{r}179,226,601 \\
157,265,446 \\
21,961,155\end{array}$ & $\begin{array}{r}48,646,538 \\
43,052,545 \\
5,593,993\end{array}$ & $\begin{array}{l}4,564,790 \\
2,674,392 \\
1,890,399\end{array}$ & $\begin{array}{l}2.5 \\
1.7 \\
8.6\end{array}$ & $\begin{array}{r}112,968,097 \\
92,747,344 \\
20,220,753\end{array}$ & $\begin{array}{r}20,825,388 \\
16,457,225 \\
4,368,164\end{array}$ & $\begin{array}{l}3,543,643 \\
1,860,187 \\
1,683,456\end{array}$ & $\begin{array}{l}3.1 \\
2.0 \\
8.3\end{array}$ & $\begin{array}{r}66,258,504 \\
64,518,102 \\
1,740,402\end{array}$ & $\begin{array}{r}27,821,149 \\
26,595,320 \\
1,225,829\end{array}$ & $\begin{array}{r}1,021,147 \\
814,204 \\
206,942\end{array}$ & $\begin{array}{r}1.5 \\
1.3 \\
11.9\end{array}$ \\
\hline 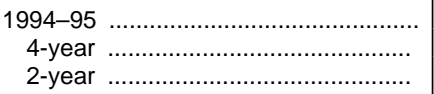 & $\begin{array}{r}189,120,570 \\
166,144,023 \\
22,976,547\end{array}$ & $\begin{array}{r}51,506,876 \\
45,863,702 \\
5,643,174\end{array}$ & $\begin{array}{l}4,524,313 \\
2,690,643 \\
1,833,670\end{array}$ & $\begin{array}{l}2.4 \\
1.6 \\
8.0\end{array}$ & $\begin{array}{r}119,312,493 \\
97,963,262 \\
21,349,231\end{array}$ & $\begin{array}{r}21,908,104 \\
17,385,587 \\
4,522,517\end{array}$ & $\begin{array}{l}3,594,407 \\
1,890,393 \\
1,704,014\end{array}$ & $\begin{array}{l}3.0 \\
1.9 \\
8.0\end{array}$ & $\begin{array}{r}69,808,077 \\
68,180,761 \\
1,627,317\end{array}$ & $\begin{array}{r}29,598,772 \\
28,478,115 \\
1,120,657\end{array}$ & $\begin{array}{l}929,906 \\
800,250 \\
129,656\end{array}$ & $\begin{array}{l}1.3 \\
1.2 \\
8.0\end{array}$ \\
\hline 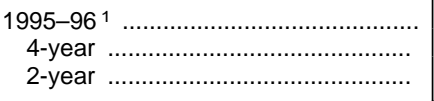 & $\begin{array}{r}197,414,848 \\
173,428,636 \\
23,986,211\end{array}$ & $\begin{array}{r}54,725,982 \\
48,892,798 \\
5,833,184\end{array}$ & $\begin{array}{l}4,504,570 \\
2,692,691 \\
1,811,879\end{array}$ & $\begin{array}{l}2.3 \\
1.6 \\
7.6\end{array}$ & $\begin{array}{r}123,378,526 \\
101,029,863 \\
22,348,663\end{array}$ & $\begin{array}{r}23,222,284 \\
18,510,094 \\
4,712,190\end{array}$ & $\begin{array}{l}3,595,360 \\
1,906,264 \\
1,689,096\end{array}$ & $\begin{array}{l}2.9 \\
1.9 \\
7.6\end{array}$ & $\begin{array}{r}74,036,321 \\
72,398,773 \\
1,637,548\end{array}$ & $\begin{array}{r}31,503,698 \\
30,382,704 \\
1,120,994\end{array}$ & $\begin{array}{l}909,210 \\
786,427 \\
122,783\end{array}$ & $\begin{array}{l}1.2 \\
1.1 \\
7.5\end{array}$ \\
\hline 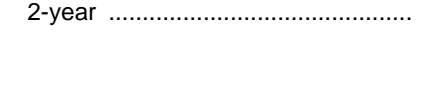 & \multicolumn{12}{|c|}{ Degree-granting institutions ${ }^{2}$} \\
\hline 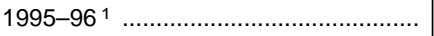 & $197,973,236$ & $55,260,293$ & 8,793 & 2.3 & $123,501,152$ & $23,257,454$ & $3,603,696$ & 2.9 & $74,472,083$ & $32,002,839$ & 995,097 & 1.3 \\
\hline 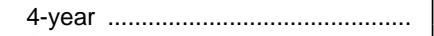 & $173,358,920$ & $48,937,146$ & $2,692,395$ & 1.6 & $101,033,907$ & $18,512,146$ & $1,906,294$ & 1.9 & $72,325,013$ & $30,425,000$ & 786,101 & 1.1 \\
\hline 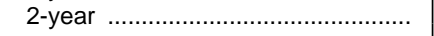 & $24,614,316$ & $6,323,147$ & $1,906,398$ & 7.7 & $22,467,245$ & $4,745,308$ & $1,697,402$ & 7.6 & $2,147,071$ & $1,577,839$ & 208,997 & 9.7 \\
\hline
\end{tabular}

1 Preliminary data.

${ }^{2}$ Data are for 4-year and 2-year degree-granting institutions that were eligible to participate in Title IV federal financial aid programs.

NOTE.-Pell Grants which are spent on campus for tuition, room, board or other college expenses are included in current-fund revenue. Because of rounding, details may not add to totals.
SOURCE: U.S. Department of Education, National Center for Education Statistics, Higher Education General Information Survey (HEGIS), "Financial Statistics of Institutions of Higher Education" surveys; and Integrated Postsecondary
Education Data System (IPEDS), "Finance" surveys. (This table was prepared October 1998.) 
Table 323.-State awards for need-based undergraduate scholarship and grant programs, by state: 1983-84 to $1995-96$

[In thousands]

\begin{tabular}{|c|c|c|c|c|c|c|c|c|c|c|c|c|}
\hline State & 1983-84 & $1985-86$ & 1987-88 & 1988-89 & $1989-90$ & 1990-91 & 1991-92 & $1992-93^{1}$ & $1993-941$ & $1994-95^{1}$ & $1995-961$ & $\begin{array}{c}\text { Percent } \\
\text { change, } \\
\text { 1983-84 } \\
\text { to } \\
1995-96^{2}\end{array}$ \\
\hline 1 & 2 & 3 & 4 & 5 & 6 & 7 & 8 & 9 & 10 & 11 & 12 & 13 \\
\hline $\begin{array}{l}\text { Need-based aid as a } \\
\text { percent of all state } \\
\text { financial aid }{ }^{3}\end{array}$ & - & - & 81.0 & 78.2 & 76.8 & 77.4 & 74.7 & 75.7 & 75.7 & 77.5 & 84.4 & - \\
\hline Need-based aid & $\$ 1,024,206$ & $\$ 1,222,112$ & $\$ 1,377,996$ & $\$ 1,423,743$ & $\$ 1,529,421$ & $\$ 1,658,221$ & $\$ 1,781,820$ & $\$ 1,923,720$ & $\$ 2,195,993$ & $\$ 2,421,952$ & $\$ 2,435,687$ & 137.8 \\
\hline Alabama & 1,731 & 2,242 & 2,260 & 2,196 & 2,984 & 2,878 & 2,183 & 2,271 & 2,283 & 2,281 & 2,142 & 23.7 \\
\hline Alaska ......... & 189 & 241 & 240 & 234 & 228 & 464 & 475 & 470 & 454 & 444 & 430 & 127.5 \\
\hline 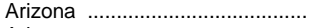 & 2,027 & 2,401 & 3,222 & 3,508 & 3,420 & 3,318 & 2,278 & 2,437 & 3,476 & 3,482 & 2,291 & 13.0 \\
\hline Arkansas & 2,226 & 4,108 & 3,759 & 3,903 & 3,946 & 3,885 & 4,742 & 6,319 & 7,701 & 8,907 & 10,765 & 383.6 \\
\hline California ……............................... & 86,031 & 112,373 & 118,819 & 129,264 & 153,045 & 161,642 & 172,852 & 151,379 & 207,969 & 232,067 & 235,582 & 173.8 \\
\hline Colorado & 7,341 & 9,282 & 9,327 & 9,395 & 10,349 & 11,276 & 12,380 & 14,812 & 16,480 & 18,252 & 21,076 & 187.1 \\
\hline Connecticut & 9,371 & 11,095 & 14,650 & 21,149 & 19,915 & 20,580 & 20,595 & 20,805 & 20,641 & 20,690 & 20,372 & 117.4 \\
\hline Delaware & 548 & 756 & 807 & 829 & 956 & 1,066 & 906 & 1,121 & 1,270 & 1,033 & 1,188 & 116.8 \\
\hline District of Columbia ........................ & 759 & 1,106 & 1,106 & 1,075 & 1,069 & 947 & 978 & 1,015 & 1,022 & 1,022 & 939 & 23.7 \\
\hline Florida & 12,515 & 14,819 & 15,245 & 16,522 & 20,134 & 24,729 & 29,279 & 29,628 & 31,277 & 36,824 & 34,822 & 178.2 \\
\hline Georgia . & 3,683 & 4,510 & 4,599 & 5,197 & 4,607 & 5,070 & 5,084 & 4,951 & 26,853 & 5,147 & 4,757 & 29.2 \\
\hline Hawaii ...................... & 493 & 604 & 563 & 598 & 726 & 612 & 632 & 724 & 748 & 732 & 499 & 1.2 \\
\hline Idaho & 378 & 509 & 343 & 348 & 346 & 350 & 483 & 580 & 634 & 779 & 763 & 101.9 \\
\hline Illinois & 104,384 & 122,300 & 135,880 & 143,373 & 171,361 & 183,508 & 184,753 & 203,532 & 214,809 & 244,352 & 256,872 & 146.1 \\
\hline 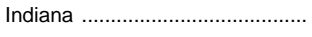 & 20,380 & 26,448 & 45,408 & 35,692 & 41,874 & 46,756 & ${ }^{4} 50,441$ & 55,814 & 55,814 & 67,742 & 68,340 & 235.3 \\
\hline lowa & 20,263 & 22,379 & 25,960 & 30,050 & 32,467 & 35,586 & 34,654 & 34,067 & 34,718 & 35,642 & 38,953 & 92.2 \\
\hline Kansas & 4,664 & 5,609 & 5,337 & 5,540 & 6,478 & 6,462 & 6,587 & 6,894 & 9,060 & 9,802 & 9,526 & 104.2 \\
\hline Kentucky & 7,886 & 8,758 & 12,161 & 12,522 & 12,605 & 19,866 & 16,996 & 20,520 & 20,619 & 25,517 & 26,215 & 232.4 \\
\hline Louisiana ................................... & 1,693 & 2,003 & 1,880 & 1,947 & 2,786 & 3,827 & 4,446 & 5,125 & 6,374 & 6,429 & 6,580 & 288.7 \\
\hline Maine & 477 & 809 & 1,418 & 1,408 & 1,877 & 4,802 & 5,002 & 5,200 & 5,170 & 5,787 & 6,988 & $1,365.0$ \\
\hline Maryland & 5,459 & 6,859 & 8,737 & 12,841 & 14,800 & 15,607 & 16,253 & 20,828 & 23,713 & 24,571 & 30,350 & 456.0 \\
\hline Massachusetts & 25,655 & 43,466 & 61,600 & 62,443 & 50,844 & 46,000 & 23,690 & 45,989 & 45,059 & 61,850 & 54,565 & 112.7 \\
\hline Michigan & 30,753 & 57,645 & 70,099 & 75,467 & 70,721 & 68,918 & 78,116 & 75,469 & 79,735 & 81,340 & 84,154 & 173.6 \\
\hline Minnesota & 46,600 & 45,486 & 63,300 & 68,293 & 58,136 & 74,656 & 81,322 & 83,170 & 102,920 & 97,920 & 92,069 & 97.6 \\
\hline Mississippi & 1,015 & 1,288 & 1,230 & 1,251 & 1,243 & 1,136 & 1,131 & 1,244 & 1,255 & 1,248 & 1,175 & 15.8 \\
\hline Missouri & 8,766 & 9,645 & 8,394 & 10,234 & 10,796 & 11,078 & 10,142 & 11,097 & 11,124 & 11,913 & 12,233 & 39.6 \\
\hline Montana & 353 & 440 & 419 & 420 & 415 & 383 & 414 & 418 & 401 & 419 & 393 & 11.3 \\
\hline 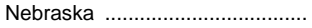 & 860 & 1,093 & 1,094 & 1,052 & 1,276 & 2,192 & 2,370 & 2,613 & 2,686 & 2,726 & 3,114 & 262.1 \\
\hline Nevada & 327 & 414 & 352 & 352 & ${ }^{4} 352$ & 321 & 326 & 341 & 342 & 342 & 2,595 & 693.6 \\
\hline 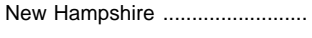 & 536 & 660 & 810 & 886 & 918 & 770 & 825 & 1,253 & 840 & 1,425 & 765 & 42.7 \\
\hline New Jersey & 47,980 & 65,173 & 70,298 & 76,204 & 84,347 & 87,054 & 100,220 & 118,868 & 135,251 & 159,683 & 132,383 & 175.9 \\
\hline 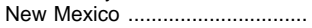 & 695 & 1,461 & 4,107 & 5,024 & 5,601 & 6,479 & 47,293 & 8,295 & 9,266 & 13,886 & 14,629 & $2,004.9$ \\
\hline 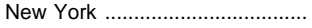 & 327,320 & 363,949 & 372,363 & 355,192 & 382,655 & 428,358 & 504,195 & 554,803 & 618,849 & 636,704 & 625,711 & 91.2 \\
\hline North Carolina ................................ & 3,974 & 4,440 & 4,559 & 4,489 & 3,046 & 2,519 & 2,908 & 3,163 & 14,436 & 13,774 & 16,659 & 319.2 \\
\hline North Dakota .................................... & 635 & 808 & 490 & 976 & 1,242 & 1,177 & 1,475 & 2,162 & 2,036 & 1,996 & 1,898 & 198.9 \\
\hline Ohio & 41,974 & 45,000 & 49,200 & 50,865 & 53,848 & 54,600 & 57,275 & 66,000 & 77,940 & 91,225 & 86,053 & 105.0 \\
\hline Oklahoma & 6,561 & 8,242 & 10,245 & 9,861 & 11,591 & 11,871 & 12,612 & 13,286 & 13,405 & 13,325 & 13,642 & 107.9 \\
\hline Oregon & 8,546 & 9,514 & 9,959 & 10,108 & 10,092 & 11,809 & 12,023 & 12,606 & 12,903 & 13,761 & 13,651 & 59.7 \\
\hline 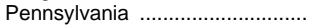 & 83,474 & 96,800 & 110,992 & 118,986 & 132,344 & 142,389 & 158,092 & 173,214 & 188,751 & 218,604 & 232,020 & 178.0 \\
\hline Rhode Island & 6,745 & 7,856 & 8,138 & 8,967 & 9,917 & 9,522 & 9,141 & 9,586 & 6,500 & 6,340 & 5,741 & -14.9 \\
\hline South Carolina & 12,588 & 15,146 & 16,346 & 17,810 & 18,150 & 17,901 & 16,800 & 17,105 & 16,795 & 17,297 & 18,622 & 47.9 \\
\hline South Dakota ....... & 440 & 624 & 516 & 506 & 504 & 468 & 480 & 587 & 589 & 589 & 562 & 27.7 \\
\hline 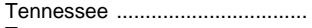 & 6,700 & 9,434 & 12,591 & 11,977 & 12,977 & 13,487 & 12,793 & 13,723 & 16,755 & 18,313 & 18,811 & 180.8 \\
\hline 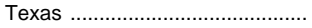 & 21,438 & 19,033 & 22,705 & 22,266 & 24,784 & 24,135 & 27,385 & 27,467 & 29,102 & 29,102 & 40,768 & 90.2 \\
\hline 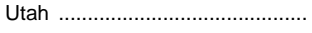 & 1,538 & 1,131 & 1,133 & 1,081 & 1,091 & 1,001 & 1,034 & 1,115 & 1,132 & 1,129 & 1,197 & -22.2 \\
\hline Vermont & 7,039 & 7,724 & 8,414 & 9,264 & 11,137 & 10,184 & 11,019 & 11,120 & 11,167 & 11,788 & 11,865 & 68.6 \\
\hline 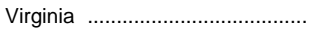 & 4,075 & 4,415 & 4,414 & 8,062 & 7,966 & 7,351 & 4,892 & 6,654 & 6,408 & 53,885 & 59,568 & 1361.8 \\
\hline ……………... & 7,530 & 8,827 & 12,425 & 12,858 & 13,925 & 21,095 & 23,527 & 23,571 & 46,617 & 53,369 & 56,573 & 651.3 \\
\hline West Virginia ................................ & 4,376 & 5,167 & 5,189 & 5,204 & 5,217 & 5,559 & 5,781 & 5,868 & 5,802 & 6,761 & 8,132 & 85.8 \\
\hline Wisconsin & 23,011 & 27,816 & 34,653 & 35,842 & 38,072 & 42,365 & 42,324 & 44,216 & 46,592 & 49,511 & 46,470 & 101.9 \\
\hline 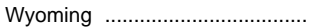 & 204 & 204 & 240 & 212 & ${ }^{4} 241$ & ${ }^{4} 212$ & 216 & 225 & 250 & 225 & 219 & 7.4 \\
\hline
\end{tabular}

${ }^{1}$ Estimated.

${ }^{2}$ Changes may reflect introduction of new programs or discontinuation of existing programs.

${ }^{3}$ Participation requirements vary from state to state.

${ }^{4}$ Data are estimated based on prior year's report.
NOTE.-Some data have been revised from previously published figures. Because of rounding, details may not add to totals.

SOURCE: National Association of State Scholarship and Grant Programs, Annual Survey Report, (1983-84 to 1994-95) and National Association of State Student Grant and Aid Programs, Annual Survey Report (1995-96). (This table was prepared August 1998.) 
Table 324.-Current-fund revenue of institutions of higher education, by source: 1980-81 to 1995-96

\begin{tabular}{|c|c|c|c|c|c|c|c|c|c|}
\hline Source & $1980-81$ & $1985-86$ & $1989-90$ & $1990-91$ & $1991-92$ & $1992-93$ & $1993-94$ & 1994-95 & $1995-961$ \\
\hline \multirow[t]{2}{*}{1} & 2 & 3 & 4 & 5 & 6 & 7 & 8 & 9 & 10 \\
\hline & \multicolumn{9}{|c|}{ In thousands } \\
\hline Total current-fund revenue ...... & $\$ 65,584,789$ & $\$ 100,437,616$ & $\$ 139,635,477$ & $\$ 149,766,051$ & $\$ 161,395,896$ & $\$ 170,880,503$ & $\$ 179,226,601$ & $\$ 189,120,570$ & $\$ 197,973,236$ \\
\hline Tuition and fees & $13,773,259$ & $23,116,605$ & $33,926,060$ & $37,434,462$ & $41,559,037$ & $45,346,071$ & $48,646,538$ & $51,506,876$ & $55,260,293$ \\
\hline Federal government ……........................ & $9,747,586$ & $12,704,750$ & $17,254,874$ & $18,236,082$ & $19,833,317$ & $21,014,564$ & $22,076,385$ & $23,243,172$ & $23,939,075$ \\
\hline 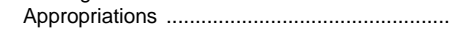 & $1,346,835$ & $1,617,510$ & $1,890,046$ & $1,840,694$ & $1,907,403$ & $1,872,840$ & $1,994,279$ & $1,984,450$ & $2,036,948$ \\
\hline Unrestricted grants and contracts & $1,126,558$ & $1,658,636$ & $2,353,119$ & $2,504,859$ & $2,703,590$ & $2,913,256$ & $3,129,307$ & $3,297,173$ & $3,652,186$ \\
\hline Restricted grants and contracts ${ }^{2}$ & $6,005,317$ & $7,190,345$ & $9,773,266$ & $10,443,977$ & $11,561,444$ & $12,589,727$ & $13,554,435$ & $14,421,419$ & $14,713,289$ \\
\hline Independent operations (FFRDC) ${ }^{3}$ & $1,268,877$ & $2,238,259$ & $3,238,442$ & $3,446,552$ & $3,660,881$ & $3,638,741$ & $3,398,364$ & $3,540,129$ & $3,536,653$ \\
\hline State governments .................................... & $20,106,222$ & $29,911,500$ & $38,349,239$ & $39,480,874$ & $40,586,907$ & $41,247,955$ & $41,910,288$ & $44,343,012$ & $45,692,673$ \\
\hline Appropriations & $19,266,186$ & $28,402,288$ & $35,223,174$ & $36,255,090$ & $36,884,957$ & $37,314,176$ & $37,824,061$ & $39,638,444$ & $40,323,301$ \\
\hline Unrestricted grants and contracts ……................ & 84,848 & 154,109 & 411,757 & 366,206 & 376,176 & 382,204 & 360,852 & 524,586 & $1,090,932$ \\
\hline Restricted grants and contracts ......................... & 755,188 & $1,355,102$ & $2,714,309$ & $2,859,577$ & $3,325,774$ & $3,551,575$ & $3,725,375$ & $4,179,982$ & $4,278,440$ \\
\hline 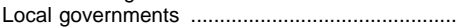 & $1,790,740$ & $2,544,506$ & $3,639,902$ & $3,931,239$ & $4,159,876$ & $4,444,875$ & $4,998,306$ & $5,165,961$ & $5,607,909$ \\
\hline 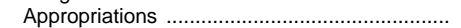 & $1,482,536$ & $2,153,160$ & $2,919,447$ & $3,177,696$ & $3,336,012$ & $3,599,983$ & $4,023,620$ & $4,247,748$ & $4,400,741$ \\
\hline Unrestricted grants and contracts ……............ & 29,629 & 56,975 & 122,404 & 116,982 & 140,135 & 139,881 & 134,491 & 134,611 & 377,754 \\
\hline Restricted grants and contracts ........................... & 278,575 & 334,371 & 598,051 & 636,561 & 683,729 & 705,011 & 840,195 & 783,602 & 829,414 \\
\hline Private gifts, grants, and contracts ....................... & $3,176,670$ & $5,410,905$ & $7,781,422$ & $8,361,265$ & $8,977,271$ & $9,659,977$ & $10,203,062$ & $10,866,749$ & $11,903,126$ \\
\hline Unrestricted …… & $1,210,903$ & $2,111,972$ & $2,634,974$ & $2,720,233$ & $2,921,997$ & $3,229,718$ & $3,400,457$ & $3,556,608$ & $4,072,454$ \\
\hline 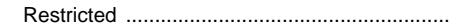 & $1,965,766$ & $3,298,933$ & $5,146,448$ & $5,641,032$ & $6,055,274$ & $6,430,259$ & $6,802,605$ & $7,310,141$ & $7,830,672$ \\
\hline Endowment income & $1,364,443$ & $2,275,898$ & $3,143,696$ & $3,268,629$ & $3,442,009$ & $3,627,773$ & $3,669,536$ & $3,988,217$ & $4,562,171$ \\
\hline 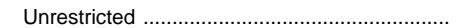 & 770,358 & $1,285,194$ & $1,614,088$ & $1,521,940$ & $1,549,930$ & $1,536,511$ & $1,557,733$ & $1,649,296$ & $2,064,490$ \\
\hline 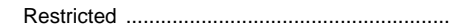 & 594,085 & 990,704 & $1,529,608$ & $1,746,690$ & $1,892,079$ & $2,091,262$ & $2,111,803$ & $2,338,921$ & $2,497,681$ \\
\hline Sales and services & $13,677,366$ & $21,274,265$ & $30,787,233$ & $34,107,502$ & $37,519,828$ & $39,824,766$ & $41,791,319$ & $43,039,561$ & $43,009,873$ \\
\hline Educational activities ………….......................... & $1,409,730$ & $2,373,494$ & $3,632,100$ & $4,054,703$ & $4,520,890$ & $5,037,901$ & $5,294,030$ & $5,603,251$ & $5,530,763$ \\
\hline Auxiliary enterprises ......................................... & $7,287,290$ & $10,674,136$ & $13,938,469$ & $14,903,127$ & $15,758,599$ & $16,662,850$ & $17,537,514$ & $18,336,094$ & $18,867,540$ \\
\hline Hospitals …w. & $4,980,346$ & $8,226,635$ & $13,216,664$ & $15,149,672$ & $17,240,338$ & $18,124,015$ & $18,959,776$ & $19,100,217$ & $18,611,570$ \\
\hline \multirow[t]{2}{*}{ 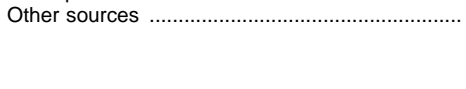 } & $1,948,503$ & $3,199,186$ & $4,753,051$ & $4,945,998$ & $5,317,651$ & $5,714,523$ & $5,931,167$ & $6,967,023$ & $7,998,116$ \\
\hline & \multicolumn{9}{|c|}{ Percentage distribution } \\
\hline 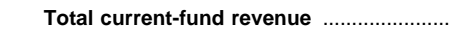 & 100.0 & 100.0 & 100.0 & 100.0 & 100.0 & 100.0 & 100.0 & 100.0 & 100.0 \\
\hline Tuition and fees ....... & 21.0 & 23.0 & 24.3 & 25.0 & 25.7 & 26.5 & 27.1 & 27.2 & 27.9 \\
\hline 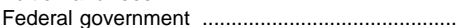 & 14.9 & 12.6 & 12.4 & 12.2 & 12.3 & 12.3 & 12.3 & 12.3 & 12.1 \\
\hline 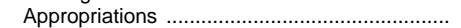 & 2.1 & 1.6 & 1.4 & 1.2 & 1.2 & 1.1 & 1.1 & 1.0 & 1.0 \\
\hline Unrestricted grants and contracts …............... & 1.7 & 1.7 & 1.7 & 1.7 & 1.7 & 1.7 & 1.7 & 1.7 & 1.8 \\
\hline Restricted grants and contracts ${ }^{2} \ldots \ldots \ldots \ldots \ldots \ldots \ldots$ & 9.2 & 7.2 & 7.0 & 7.0 & 7.2 & 7.4 & 7.6 & 7.6 & 7.4 \\
\hline Independent operations (FFRDC) ${ }^{3}$ & 1.9 & 2.2 & 2.3 & 2.3 & 2.3 & 2.1 & 1.9 & 1.9 & 1.8 \\
\hline State governments & 30.7 & 29.8 & 27.5 & 26.4 & 25.1 & 24.1 & 23.4 & 23.4 & 23.1 \\
\hline 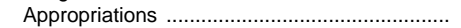 & 29.4 & 28.3 & 25.2 & 24.2 & 22.9 & 21.8 & 21.1 & 21.0 & 20.4 \\
\hline Unrestricted grants and contracts ........................ & 0.1 & 0.2 & 0.3 & 0.2 & 0.2 & 0.2 & 0.2 & 0.3 & 0.6 \\
\hline Restricted grants and contracts .......................... & 1.2 & 1.3 & 1.9 & 1.9 & 2.1 & 2.1 & 2.1 & 2.2 & 2.2 \\
\hline 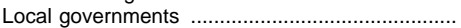 & 2.7 & 2.5 & 2.6 & 2.6 & 2.6 & 2.6 & 2.8 & 2.7 & 2.8 \\
\hline 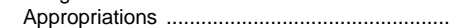 & 2.3 & 2.1 & 2.1 & 2.1 & 2.1 & 2.1 & 2.2 & 2.2 & 2.2 \\
\hline Unrestricted grants and contracts ……............... & $\left({ }^{4}\right)$ & 0.1 & 0.1 & 0.1 & 0.1 & 0.1 & 0.1 & 0.1 & 0.2 \\
\hline Restricted grants and contracts ........................... & 0.4 & 0.3 & 0.4 & 0.4 & 0.4 & 0.4 & 0.5 & 0.4 & 0.4 \\
\hline Private gifts, grants, and contracts ........................... & 4.8 & 5.4 & 5.6 & 5.6 & 5.6 & 5.7 & 5.7 & 5.7 & 6.0 \\
\hline 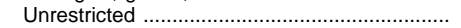 & 1.8 & 2.1 & 1.9 & 1.8 & 1.8 & 1.9 & 1.9 & 1.9 & 2.1 \\
\hline Restricted …… & 3.0 & 3.3 & 3.7 & 3.8 & 3.8 & 3.8 & 3.8 & 3.9 & 4.0 \\
\hline Endowment income & 2.1 & 2.3 & 2.3 & 2.2 & 2.1 & 2.1 & 2.0 & 2.1 & 2.3 \\
\hline 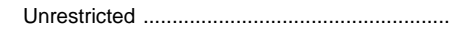 & 1.2 & 1.3 & 1.2 & 1.0 & 1.0 & 0.9 & 0.9 & 0.9 & 1.0 \\
\hline 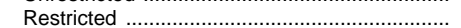 & 0.9 & 1.0 & 1.1 & 1.2 & 1.2 & 1.2 & 1.2 & 1.2 & 1.3 \\
\hline Sales and services & 20.9 & 21.2 & 22.0 & 22.8 & 23.2 & 23.3 & 23.3 & 22.8 & 21.7 \\
\hline Educational activities ………........................... & 2.1 & 2.4 & 2.6 & 2.7 & 2.8 & 2.9 & 3.0 & 3.0 & 2.8 \\
\hline 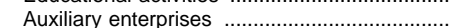 & 11.1 & 10.6 & 10.0 & 10.0 & 9.8 & 9.8 & 9.8 & 9.7 & 9.5 \\
\hline 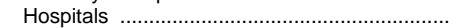 & 7.6 & 8.2 & 9.5 & 10.1 & 10.7 & 10.6 & 10.6 & 10.1 & 9.4 \\
\hline 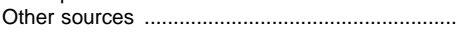 & 3.0 & 3.2 & 3.4 & 3.3 & 3.3 & 3.3 & 3.3 & 3.7 & 4.0 \\
\hline
\end{tabular}

1 Preliminary data are for 4-year and 2-year degree-granting institutions that were eligible to participate in Title IV federal financial aid programs.

${ }^{2}$ Excludes Pell Grants. Federally supported student aid that is received through students is included under tuition and auxiliary enterprises.

${ }^{3}$ Generally includes only those revenues associated with major federally funded research and development centers (FFRDC).

${ }^{4}$ Less than 0.05 percent.
NOTE.-Because of rounding, details may not add to totals.

SOURCE: U.S. Department of Education, National Center for Education Statistics, Higher Education General Information Survey (HEGIS), "Financial Statistics of Institutions of Higher Education" surveys; and Integrated Postsecondary Education Data System (IPEDS), "Finance" surveys. (This table was prepared October 1998.) 
Table 325.-Current-fund revenue of public institutions of higher education, by source: 1980-81 to 1995-96

\begin{tabular}{|c|c|c|c|c|c|c|c|c|c|}
\hline Source & $1980-81$ & $1985-86$ & $1989-90$ & $1990-91$ & $1991-92$ & 1992-93 & $1993-94$ & $1994-95$ & $1995-961$ \\
\hline \multirow[t]{2}{*}{1} & 2 & 3 & 4 & 5 & 6 & 7 & 8 & 9 & 10 \\
\hline & \multicolumn{9}{|c|}{ In thousands } \\
\hline Total current-fund revenue .......... & $\$ 43,195,617$ & $\$ 65,004,632$ & $\$ 88,911,433$ & $\$ 94,904,506$ & $\$ 102,202,890$ & $\$ 108,186,484$ & $\$ 112,968,097$ & $\$ 119,312,493$ & $\$ 123,501,152$ \\
\hline Tuition and fees. & $5,570,404$ & $9,439,177$ & $13,820,240$ & $15,258,024$ & $17,460,263$ & $19,490,221$ & $20,825,388$ & $21,908,104$ & $23,257,454$ \\
\hline Federal government & $5,540,101$ & $6,852,370$ & $9,171,488$ & $9,763,427$ & $10,783,842$ & $11,655,011$ & $12,465,038$ & $13,191,843$ & $13,672,467$ \\
\hline 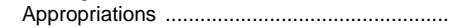 & $1,128,101$ & $1,401,367$ & $1,636,047$ & $1,604,548$ & $1,662,229$ & $1,658,052$ & $1,781,837$ & $1,766,412$ & $1,826,738$ \\
\hline Unrestricted grants and contracts ..... & 529,424 & 816,364 & $1,214,836$ & $1,319,035$ & $1,462,372$ & $1,601,201$ & $1,694,596$ & $1,802,822$ & $1,996,861$ \\
\hline Restricted grants and contracts ${ }^{2} \ldots \ldots \ldots \ldots \ldots \ldots \ldots$ & $3,812,197$ & $4,481,723$ & $6,106,112$ & $6,629,484$ & $7,426,627$ & $8,155,317$ & $8,776,458$ & $9,368,072$ & $9,598,340$ \\
\hline Independent operations (FFRDC) ${ }^{3} \ldots$ & 70,379 & 152,916 & 214,493 & 210,360 & 232,613 & 240,441 & 212,148 & 254,537 & 250,529 \\
\hline State governments & $19,675,968$ & $29,220,586$ & $37,052,307$ & $38,239,978$ & $39,107,560$ & $39,789,641$ & $40,536,393$ & $42,854,681$ & $44,242,546$ \\
\hline Appropriations ...... & $19,006,716$ & $28,071,070$ & $34,858,904$ & $35,898,653$ & $36,612,540$ & $37,073,932$ & $37,565,065$ & $39,405,865$ & $40,081,437$ \\
\hline Unrestricted grants and contracts ..... & 45,390 & 88,779 & 297,338 & 250,168 & 253,184 & 259,046 & 271,298 & 381,165 & 924,837 \\
\hline Restricted grants and contracts ……................... & 623,863 & $1,060,737$ & $1,896,065$ & $2,091,157$ & $2,241,836$ & $2,456,663$ & $2,700,030$ & $3,067,650$ & $3,236,272$ \\
\hline 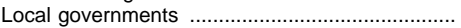 & $1,622,938$ & $2,325,844$ & $3,264,303$ & $3,531,714$ & $3,778,615$ & $4,040,897$ & $4,508,604$ & $4,756,884$ & $5,074,511$ \\
\hline 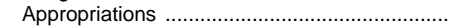 & $1,478,001$ & $2,150,459$ & $2,910,444$ & $3,159,789$ & $3,319,119$ & $3,594,207$ & $4,021,421$ & $4,243,984$ & $4,397,098$ \\
\hline Unrestricted grants and contracts …….............. & 9,915 & 27,852 & 82,405 & 73,281 & 90,257 & 84,974 & 71,098 & 60,123 & 184,597 \\
\hline Restricted grants and contracts ……................... & 135,022 & 147,533 & 271,453 & 298,644 & 369,239 & 361,717 & 416,084 & 452,777 & 492,815 \\
\hline Private gifts, grants, and contracts ……............... & $1,100,084$ & $2,109,782$ & $3,368,635$ & $3,651,107$ & $4,039,212$ & $4,330,112$ & $4,521,452$ & $4,737,529$ & $5,089,344$ \\
\hline 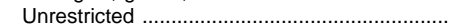 & 110,462 & 279,381 & 436,028 & 529,496 & 650,468 & 686,214 & 698,497 & 684,264 & 784,979 \\
\hline 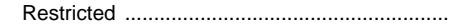 & 989,622 & $1,830,401$ & $2,932,607$ & $3,121,611$ & $3,388,743$ & $3,643,898$ & $3,822,955$ & $4,053,266$ & $4,304,365$ \\
\hline Endowment income & 214,561 & 398,603 & 461,701 & 431,235 & 593,998 & 667,711 & 639,343 & 693,313 & 721,079 \\
\hline 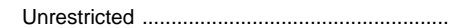 & 102,888 & 181,624 & 164,242 & 147,368 & 248,770 & 257,113 & 259,172 & 266,960 & 304,860 \\
\hline Restricted ............. & 111,673 & 216,979 & 297,459 & 283,867 & 345,228 & 410,598 & 380,172 & 426,354 & 416,219 \\
\hline Sales and services & $8,455,449$ & $12,990,670$ & $19,330,429$ & $21,546,202$ & $23,738,382$ & $25,282,113$ & $26,404,241$ & $27,517,662$ & $27,399,796$ \\
\hline 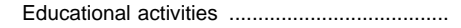 & 943,737 & $1,596,946$ & $2,423,779$ & $2,700,185$ & $2,960,980$ & $3,236,037$ & $3,329,681$ & $3,616,034$ & $3,528,610$ \\
\hline 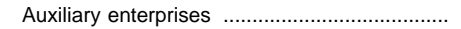 & $4,614,561$ & $6,684,794$ & $8,473,282$ & $9,058,745$ & $9,655,373$ & $10,255,044$ & $10,814,804$ & $11,373,646$ & $11,595,408$ \\
\hline Hospitals …… & $2,897,151$ & $4,708,930$ & $8,433,369$ & $9,787,271$ & $11,122,029$ & $11,791,033$ & $12,259,757$ & $12,527,982$ & $12,275,778$ \\
\hline \multirow[t]{2}{*}{ 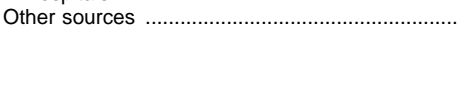 } & $1,016,110$ & $1,667,600$ & $2,442,330$ & $2,482,819$ & $2,701,019$ & $2,930,778$ & $3,067,638$ & $3,652,477$ & $4,043,955$ \\
\hline & \multicolumn{9}{|c|}{ Percentage distribution } \\
\hline Total current-fund revenue & 100.0 & 100.0 & 100.0 & 100.0 & 100.0 & 100.0 & 100.0 & 100.0 & 100.0 \\
\hline Tuition and fees. & 12.9 & 14.5 & 15.5 & 16.1 & 17.1 & 18.0 & 18.4 & 18.4 & 18.8 \\
\hline Federal government …… & 12.8 & 10.5 & 10.3 & 10.3 & 10.6 & 10.8 & 11.0 & 11.1 & 11.1 \\
\hline 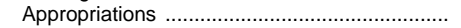 & 2.6 & 2.2 & 1.8 & 1.7 & 1.6 & 1.5 & 1.6 & 1.5 & 1.5 \\
\hline Unrestricted grants and contracts ................... & 1.2 & 1.3 & 1.4 & 1.4 & 1.4 & 1.5 & 1.5 & 1.5 & 1.6 \\
\hline Restricted grants and contracts ${ }^{2} \ldots \ldots \ldots \ldots \ldots \ldots \ldots$ & 8.8 & 6.9 & 6.9 & 7.0 & 7.3 & 7.5 & 7.8 & 7.9 & 7.8 \\
\hline Independent operations (FFRDC) ${ }^{3}$.................... & 0.2 & 0.2 & 0.2 & 0.2 & 0.2 & 0.2 & 0.2 & 0.2 & 0.2 \\
\hline State governments & 45.6 & 45.0 & 41.7 & 40.3 & 38.3 & 36.8 & 35.9 & 35.9 & 35.8 \\
\hline 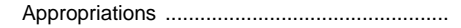 & 44.0 & 43.2 & 39.2 & 37.8 & 35.8 & 34.3 & 33.3 & 33.0 & 32.5 \\
\hline Unrestricted grants and contracts ……............... & 0.1 & 0.1 & 0.3 & 0.3 & 0.2 & 0.2 & 0.2 & 0.3 & 0.7 \\
\hline Restricted grants and contracts ....................... & 1.4 & 1.6 & 2.1 & 2.2 & 2.2 & 2.3 & 2.4 & 2.6 & 2.6 \\
\hline 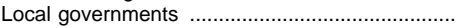 & 3.8 & 3.6 & 3.7 & 3.7 & 3.7 & 3.7 & 4.0 & 4.0 & 4.1 \\
\hline 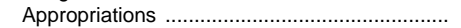 & 3.4 & 3.3 & 3.3 & 3.3 & 3.2 & 3.3 & 3.6 & 3.6 & 3.6 \\
\hline Unrestricted grants and contracts …............... & (4) & $\left({ }^{4}\right)$ & 0.1 & 0.1 & 0.1 & 0.1 & 0.1 & 0.1 & 0.1 \\
\hline 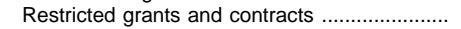 & 0.3 & 0.2 & 0.3 & 0.3 & 0.4 & 0.3 & 0.4 & 0.4 & 0.4 \\
\hline Private gifts, grants, and contracts …...................... & 2.5 & 3.2 & 3.8 & 3.8 & 4.0 & 4.0 & 4.0 & 4.0 & 4.1 \\
\hline 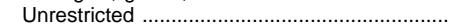 & 0.3 & 0.4 & 0.5 & 0.6 & 0.6 & 0.6 & 0.6 & 0.6 & 0.6 \\
\hline 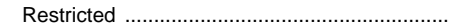 & 2.3 & 2.8 & 3.3 & 3.3 & 3.3 & 3.4 & 3.4 & 3.4 & 3.5 \\
\hline Endowment income & 0.5 & 0.6 & 0.5 & 0.5 & 0.6 & 0.6 & 0.6 & 0.6 & 0.6 \\
\hline 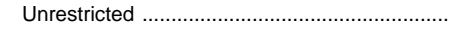 & 0.2 & 0.3 & 0.2 & 0.2 & 0.2 & 0.2 & 0.2 & 0.2 & 0.2 \\
\hline Restricted …… & 0.3 & 0.3 & 0.3 & 0.3 & 0.3 & 0.4 & 0.3 & 0.4 & 0.3 \\
\hline Sales and services & 19.6 & 20.0 & 21.7 & 22.7 & 23.2 & 23.4 & 23.4 & 23.1 & 22.2 \\
\hline 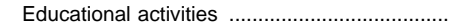 & 2.2 & 2.5 & 2.7 & 2.8 & 2.9 & 3.0 & 2.9 & 3.0 & 2.9 \\
\hline Auxiliary enterprises & 10.7 & 10.3 & 9.5 & 9.5 & 9.4 & 9.5 & 9.6 & 9.5 & 9.4 \\
\hline 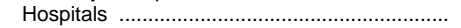 & 6.7 & 7.2 & 9.5 & 10.3 & 10.9 & 10.9 & 10.9 & 10.5 & 9.9 \\
\hline Other sources & 2.4 & 2.6 & 2.7 & 2.6 & 2.6 & 2.7 & 2.7 & 3.1 & 3.3 \\
\hline
\end{tabular}

1 Preliminary data are for 4-year and 2-year degree-granting institutions that were eligible to participate in Title IV federal financial aid programs.

${ }^{2}$ Excludes Pell Grants. Federally supported student aid that is received through students is included under tuition and auxiliary enterprises.

${ }^{3}$ Generally includes only those revenues associated with major federally funded research and development centers (FFRDC).

${ }^{4}$ Less than 0.05 percent.
NOTE.-Because of rounding, details may not add to totals.

SOURCE: U.S. Department of Education, National Center for Education Statistics, Higher Education General Information Survey (HEGIS), "Financial Statistics of Institutions of Higher Education" surveys; and Integrated Postsecondary Education Data System (IPEDS), "Finance" surveys. (This table was prepared October 1998.) 
Table 326.-Current-fund revenue of private institutions of higher education, by source: 1980-81 to 1995-96

\begin{tabular}{|c|c|c|c|c|c|c|c|c|c|}
\hline Source & $1980-81$ & $1985-86$ & $1989-90$ & $1990-91$ & $1991-92$ & $1992-93$ & $1993-94$ & 1994-95 & $1995-961$ \\
\hline 1 & 2 & 3 & 4 & 5 & 6 & 7 & 8 & 9 & 10 \\
\hline & \multicolumn{9}{|c|}{ In thousands } \\
\hline Total current-fund revenue ... & $\$ 22,389,172$ & $\$ 35,432,985$ & $\$ 50,724,044$ & $\$ 54,861,545$ & $\$ 59,193,006$ & $\$ 62,694,018$ & $\$ 66,258,504$ & $\$ 69,808,077$ & $\$ 74,472,083$ \\
\hline Tuition and fees & $8,202,855$ & $13,677,429$ & $20,105,820$ & $22,176,439$ & $24,098,774$ & $25,855,850$ & $27,821,149$ & $29,598,772$ & $32,002,839$ \\
\hline Federal government & $4,207,485$ & $5,852,380$ & $8,083,386$ & $8,472,654$ & $9,049,476$ & $9,359,554$ & $9,611,348$ & $10,051,329$ & $10,266,608$ \\
\hline 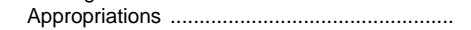 & 218,733 & 216,143 & 254,000 & 236,146 & 245,173 & 214,788 & 212,443 & 218,038 & 210,210 \\
\hline Unrestricted grants and contracts & 597,134 & 842,272 & $1,138,283$ & $1,185,824$ & $1,241,218$ & $1,312,056$ & $1,434,711$ & $1,494,351$ & $1,655,325$ \\
\hline Restricted grants and contracts ${ }^{2}$ & $2,193,119$ & $2,708,622$ & $3,667,154$ & $3,814,493$ & $4,134,817$ & $4,434,410$ & $4,777,978$ & $5,053,347$ & $5,114,949$ \\
\hline Independent operations (FFRDC) ${ }^{3}$ & $1,198,498$ & $2,085,343$ & $3,023,949$ & $3,236,192$ & $3,428,267$ & $3,398,300$ & $3,186,216$ & $3,285,593$ & $3,286,124$ \\
\hline 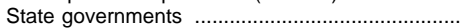 & 430,253 & 690,914 & $1,296,932$ & $1,240,896$ & $1,479,347$ & $1,458,314$ & $1,373,894$ & $1,488,332$ & $1,450,127$ \\
\hline Appropriations & 259,470 & 331,219 & 364,270 & 356,437 & 272,417 & 240,244 & 258,996 & 232,579 & 241,864 \\
\hline Unrestricted grants and contracts ……................ & 39,458 & 65,330 & 114,419 & 116,038 & 122,992 & 123,158 & 89,554 & 143,421 & 166,095 \\
\hline Restricted grants and contracts ....................... & 131,326 & 294,365 & 818,244 & 768,421 & $1,083,938$ & $1,094,912$ & $1,025,344$ & $1,112,332$ & $1,042,168$ \\
\hline 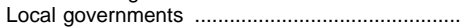 & 167,801 & 218,662 & 375,599 & 399,525 & 381,261 & 403,977 & 489,703 & 409,077 & 533,398 \\
\hline 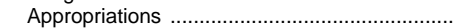 & 4,535 & 2,701 & 9,003 & 17,907 & 16,893 & 5,776 & 2,199 & 3,763 & 3,643 \\
\hline Unrestricted grants and contracts …............... & 19,714 & 29,123 & 39,999 & 43,701 & 49,878 & 54,907 & 63,393 & 74,488 & 193,156 \\
\hline Restricted grants and contracts ........................... & 143,552 & 186,838 & 326,598 & 337,917 & 314,490 & 343,294 & 424,111 & 330,826 & 336,598 \\
\hline Private gifts, grants, and contracts …................. & $2,076,585$ & $3,301,124$ & $4,412,787$ & $4,710,158$ & $4,938,060$ & $5,329,865$ & $5,681,610$ & $6,129,220$ & $6,813,782$ \\
\hline 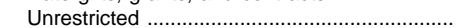 & $1,100,441$ & $1,832,592$ & $2,198,946$ & $2,190,736$ & $2,271,529$ & $2,543,504$ & $2,701,960$ & $2,872,344$ & $3,287,476$ \\
\hline Restricted .............. & 976,144 & $1,468,532$ & $2,213,841$ & $2,519,421$ & $2,666,531$ & $2,786,361$ & $2,979,650$ & $3,256,876$ & $3,526,306$ \\
\hline 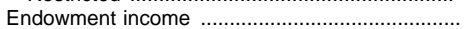 & $1,149,883$ & $1,877,295$ & $2,681,995$ & $2,837,394$ & $2,848,012$ & $2,960,062$ & $3,030,193$ & $3,294,904$ & $3,841,091$ \\
\hline Unrestricted & 667,471 & $1,103,570$ & $1,449,846$ & $1,374,572$ & $1,301,160$ & $1,279,398$ & $1,298,562$ & $1,382,336$ & $1,759,630$ \\
\hline 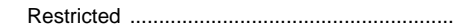 & 482,412 & 773,725 & $1,232,149$ & $1,462,822$ & $1,546,851$ & $1,680,664$ & $1,731,631$ & $1,912,567$ & $2,081,461$ \\
\hline Sales and services & $5,221,917$ & $8,283,595$ & $11,456,804$ & $12,561,301$ & $13,781,446$ & $14,542,653$ & $15,387,078$ & $15,521,899$ & $15,610,078$ \\
\hline Educational activities & 465,993 & 776,548 & $1,208,322$ & $1,354,518$ & $1,559,910$ & $1,801,865$ & $1,964,349$ & $1,987,217$ & $2,002,153$ \\
\hline Auxiliary enterprises & $2,672,729$ & $3,989,342$ & $5,465,187$ & $5,844,382$ & $6,103,226$ & $6,407,806$ & $6,722,710$ & $6,962,448$ & $7,272,132$ \\
\hline 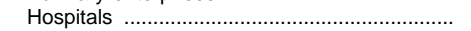 & $2,083,195$ & $3,517,705$ & $4,783,295$ & $5,362,401$ & $6,118,309$ & $6,332,982$ & $6,700,019$ & $6,572,234$ & $6,335,792$ \\
\hline \multirow[t]{2}{*}{ 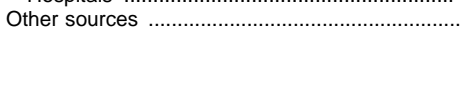 } & 932,392 & $1,531,586$ & $2,310,720$ & $2,463,178$ & $2,616,632$ & $2,783,744$ & $2,863,529$ & $3,314,546$ & $3,954,162$ \\
\hline & \multicolumn{9}{|c|}{ Percentage distribution } \\
\hline Total current-fund revenue & 100.0 & 100.0 & 100.0 & 100.0 & 100.0 & 100.0 & 100.0 & 100.0 & 100.0 \\
\hline Tuition and fees ....... & 36.6 & 38.6 & 39.6 & 40.4 & 40.7 & 41.2 & 42.0 & 42.4 & 43.0 \\
\hline 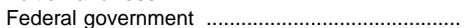 & 18.8 & 16.5 & 15.9 & 15.4 & 15.3 & 14.9 & 14.5 & 14.4 & 13.8 \\
\hline 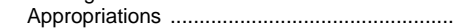 & 1.0 & 0.6 & 0.5 & 0.4 & 0.4 & 0.3 & 0.3 & 0.3 & 0.3 \\
\hline Unrestricted grants and contracts .................... & 2.7 & 2.4 & 2.2 & 2.2 & 2.1 & 2.1 & 2.2 & 2.1 & 2.2 \\
\hline Restricted grants and contracts ${ }^{2} \ldots \ldots \ldots \ldots \ldots \ldots$ & 9.8 & 7.6 & 7.2 & 7.0 & 7.0 & 7.1 & 7.2 & 7.2 & 6.9 \\
\hline Independent operations (FFRDC) ${ }^{3}$ & 5.4 & 5.9 & 6.0 & 5.9 & 5.8 & 5.4 & 4.8 & 4.7 & 4.4 \\
\hline State governments & 1.9 & 1.9 & 2.6 & 2.3 & 2.5 & 2.3 & 2.1 & 2.1 & 1.9 \\
\hline 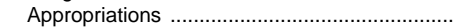 & 1.2 & 0.9 & 0.7 & 0.6 & 0.5 & 0.4 & 0.4 & 0.3 & 0.3 \\
\hline Unrestricted grants and contracts ........................ & 0.2 & 0.2 & 0.2 & 0.2 & 0.2 & 0.2 & 0.1 & 0.2 & 0.2 \\
\hline Restricted grants and contracts ......................... & 0.6 & 0.8 & 1.6 & 1.4 & 1.8 & 1.7 & 1.5 & 1.6 & 1.4 \\
\hline 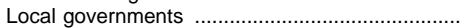 & 0.7 & 0.6 & 0.7 & 0.7 & 0.6 & 0.6 & 0.7 & 0.6 & 0.7 \\
\hline 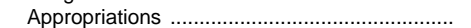 & (4) & $(4)$ & (4) & $(4)$ & (4) & $(4)$ & (4) & (4) & $(4)$ \\
\hline Unrestricted grants and contracts …................... & 0.1 & 0.1 & 0.1 & 0.1 & 0.1 & 0.1 & 0.1 & 0.1 & 0.3 \\
\hline Restricted grants and contracts ........................... & 0.6 & 0.5 & 0.6 & 0.6 & 0.5 & 0.5 & 0.6 & 0.5 & 0.5 \\
\hline Private gifts, grants, and contracts …..................... & 9.3 & 9.3 & 8.7 & 8.6 & 8.3 & 8.5 & 8.6 & 8.8 & 9.1 \\
\hline 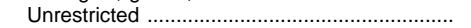 & 4.9 & 5.2 & 4.3 & 4.0 & 3.8 & 4.1 & 4.1 & 4.1 & 4.4 \\
\hline 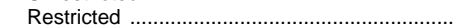 & 4.4 & 4.1 & 4.4 & 4.6 & 4.5 & 4.4 & 4.5 & 4.7 & 4.7 \\
\hline Endowment income & 5.1 & 5.3 & 5.3 & 5.2 & 4.8 & 4.7 & 4.6 & 4.7 & 5.2 \\
\hline 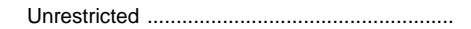 & 3.0 & 3.1 & 2.9 & 2.5 & 2.2 & 2.0 & 2.0 & 2.0 & 2.4 \\
\hline 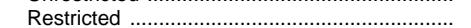 & 2.2 & 2.2 & 2.4 & 2.7 & 2.6 & 2.7 & 2.6 & 2.7 & 2.8 \\
\hline Sales and services & 23.3 & 23.4 & 22.6 & 22.9 & 23.3 & 23.2 & 23.2 & 22.2 & 21.0 \\
\hline 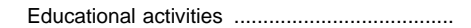 & 2.1 & 2.2 & 2.4 & 2.5 & 2.6 & 2.9 & 3.0 & 2.8 & 2.7 \\
\hline 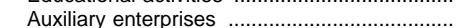 & 11.9 & 11.3 & 10.8 & 10.7 & 10.3 & 10.2 & 10.1 & 10.0 & 9.8 \\
\hline 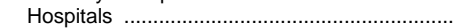 & 9.3 & 9.9 & 9.4 & 9.8 & 10.3 & 10.1 & 10.1 & 9.4 & 8.5 \\
\hline 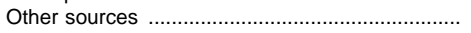 & 4.2 & 4.3 & 4.6 & 4.5 & 4.4 & 4.4 & 4.3 & 4.7 & 5.3 \\
\hline
\end{tabular}

${ }^{1}$ Preliminary data are for 4-year and 2-year degree-granting institutions that were eligible to participate in Title IV federal financial aid programs.

${ }^{2}$ Excludes Pell Grants. Federally supported student aid that is received through students is included under tuition and auxiliary enterprises.

${ }^{3}$ Generally includes only those revenues associated with major federally funded research and development centers (FFRDC).

${ }^{4}$ Less than 0.05 percent.
NOTE.-Because of rounding, details may not add to totals.

SOURCE: U.S. Department of Education, National Center for Education Statistics, Higher Education General Information Survey (HEGIS), "Financial Statistics of Institutions of Higher Education" surveys; and Integrated Postsecondary Education Data System (IPEDS), "Finance" surveys. (This table was prepared October 1998.) 
Table 327.-Current-fund revenue of private nonprofit institutions of higher education, by source: 1980-81 to $1995-96$

\begin{tabular}{|c|c|c|c|c|c|c|c|c|}
\hline Source & $1980-81$ & $1985-86$ & $1990-91$ & $1991-92$ & $1992-93$ & $1993-94$ & 1994-95 & $1995-961$ \\
\hline \multirow[t]{2}{*}{1} & 2 & 3 & 4 & 5 & 6 & 7 & 8 & 9 \\
\hline & \multicolumn{8}{|c|}{ In thousands } \\
\hline Total current-fund revenue & $\$ 22,078,144$ & $\$ 34,839,494$ & $\$ 53,652,864$ & $\$ 57,904,208$ & $\$ 61,291,366$ & $\$ 64,726,849$ & $\$ 68,215,391$ & $\$ 72,263,702$ \\
\hline Tuition and fees .... & $7,930,156$ & $13,152,750$ & $21,150,439$ & $22,990,730$ & $24,663,506$ & $26,504,664$ & $28,223,908$ & $29,988,621$ \\
\hline Federal government ..1.1. & $4,203,605$ & $5,843,729$ & $8,400,320$ & $9,011,581$ & $9,323,425$ & $9,576,958$ & $10,023,252$ & $10,189,345$ \\
\hline 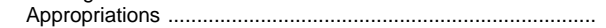 & 217,866 & 215,398 & 233,826 & 242,458 & 214,788 & 212,443 & 218,038 & 210,210 \\
\hline Unrestricted grants and contracts …………………….... & 596,257 & 840,593 & $1,164,075$ & $1,240,445$ & $1,310,776$ & $1,431,294$ & $1,490,585$ & $1,648,590$ \\
\hline Restricted grants and contracts ${ }^{2}$ & $2,190,984$ & $2,703,772$ & $3,776,751$ & $4,101,491$ & $4,399,937$ & $4,747,005$ & $5,029,036$ & $5,042,597$ \\
\hline Independent operations (FFRDC) ${ }^{3}$. & $1,198,498$ & $2,083,966$ & $3,225,668$ & $3,427,187$ & $3,397,924$ & $3,186,216$ & $3,285,592$ & $3,287,947$ \\
\hline State governments & 430,007 & 688,502 & $1,221,746$ & $1,419,019$ & $1,384,288$ & $1,297,296$ & $1,412,609$ & $1,336,890$ \\
\hline 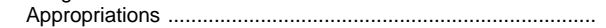 & 259,463 & 331,004 & 356,009 & 271,941 & 240,067 & 258,995 & 232,579 & 242,997 \\
\hline Unrestricted grants and contracts. & 39,349 & 65,330 & 114,495 & 121,179 & 121,755 & 88,814 & 142,522 & 160,535 \\
\hline 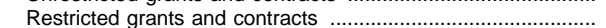 & 131,195 & 292,168 & 751,242 & $1,025,899$ & $1,022,466$ & 949,488 & $1,037,509$ & 933,358 \\
\hline 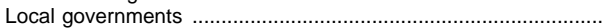 & 167,266 & 218,599 & 398,367 & 379,364 & 401,468 & 487,629 & 406,862 & 524,751 \\
\hline 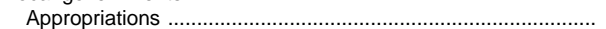 & 4,535 & 2,696 & 17,543 & 16,446 & 5,572 & 2,198 & 3,763 & 3,898 \\
\hline Unrestricted grants and contracts & 19,536 & 29,067 & 43,647 & 49,431 & 54,549 & 63,311 & 74,301 & 188,680 \\
\hline Restricted grants and contracts ……… & 143,195 & 186,836 & 337,177 & 313,487 & 341,347 & 422,119 & 328,797 & 332,174 \\
\hline 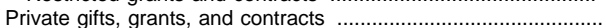 & $2,072,631$ & $3,293,435$ & $4,705,341$ & $4,934,809$ & $5,328,009$ & $5,680,389$ & $6,127,716$ & $6,854,515$ \\
\hline Unrestricted & $1,096,871$ & $1,826,109$ & $2,187,630$ & $2,269,272$ & $2,542,575$ & $2,701,866$ & $2,872,151$ & $3,327,762$ \\
\hline 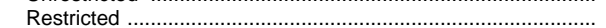 & 975,760 & $1,467,326$ & $2,517,711$ & $2,665,536$ & $2,785,434$ & $2,978,523$ & $3,255,565$ & $3,526,752$ \\
\hline 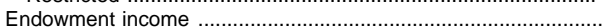 & $1,149,042$ & $1,876,203$ & $2,834,333$ & $2,846,578$ & $2,960,043$ & $3,030,193$ & $3,294,805$ & $3,849,693$ \\
\hline Unrestricted & 667,002 & $1,102,801$ & $1,373,303$ & $1,300,310$ & $1,279,388$ & $1,298,562$ & $1,382,336$ & $1,768,169$ \\
\hline 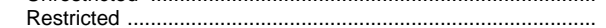 & 482,040 & 773,402 & $1,461,030$ & $1,546,268$ & $1,680,655$ & $1,731,631$ & $1,912,468$ & $2,081,523$ \\
\hline Sales and services & $5,198,255$ & $8,242,785$ & $12,501,834$ & $13,723,798$ & $14,468,452$ & $15,309,195$ & $15,436,197$ & $15,599,719$ \\
\hline 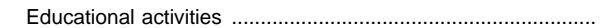 & 461,859 & 772,272 & $1,351,766$ & $1,556,995$ & $1,794,217$ & $1,952,836$ & $1,974,500$ & $2,014,598$ \\
\hline 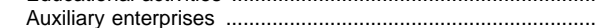 & $2,653,200$ & $3,952,809$ & $5,787,670$ & $6,048,495$ & $6,341,253$ & $6,656,340$ & $6,889,833$ & $7,188,666$ \\
\hline Hospitals & $2,083,195$ & $3,517,705$ & $5,362,398$ & $6,118,307$ & $6,332,982$ & $6,700,019$ & $6,571,863$ & $6,396,455$ \\
\hline \multirow[t]{2}{*}{ Other sources } & 927,183 & $1,523,490$ & $2,440,485$ & $2,598,329$ & $2,762,175$ & $2,840,526$ & $3,290,042$ & $3,920,169$ \\
\hline & \multicolumn{8}{|c|}{ Percentage distribution } \\
\hline Total current-fund revenue & 100.0 & 100.0 & 100.0 & 100.0 & 100.0 & 100.0 & 100.0 & 100.0 \\
\hline Tuition and fees & 35.9 & 37.8 & 39.4 & 39.7 & 40.2 & 40.9 & 41.4 & 41.5 \\
\hline Federal government & 19.0 & 16.8 & 15.7 & 15.6 & 15.2 & 14.8 & 14.7 & 14.1 \\
\hline 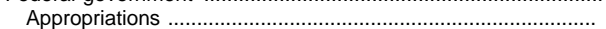 & 1.0 & 0.6 & 0.4 & 0.4 & 0.4 & 0.3 & 0.3 & 0.3 \\
\hline Unrestricted grants and contracts & 2.7 & 2.4 & 2.2 & 2.1 & 2.1 & 2.2 & 2.2 & 2.3 \\
\hline Restricted grants and contracts ${ }^{2}$ & 9.9 & 7.8 & 7.0 & 7.1 & 7.2 & 7.3 & 7.4 & 7.0 \\
\hline Independent operations (FFRDC) ${ }^{3}$ & 5.4 & 6.0 & 6.0 & 5.9 & 5.5 & 4.9 & 4.8 & 4.5 \\
\hline State governments & 1.9 & 2.0 & 2.3 & 2.5 & 2.3 & 2.0 & 2.1 & 1.9 \\
\hline 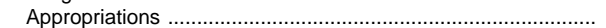 & 1.2 & 1.0 & 0.7 & 0.5 & 0.4 & 0.4 & 0.3 & 0.3 \\
\hline 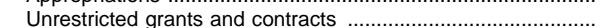 & 0.2 & 0.2 & 0.2 & 0.2 & 0.2 & 0.1 & 0.2 & 0.2 \\
\hline Restricted grants and contracts …………............................. & 0.6 & 0.8 & 1.4 & 1.8 & 1.7 & 1.5 & 1.5 & 1.3 \\
\hline 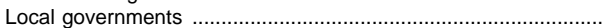 & 0.8 & 0.6 & 0.7 & 0.7 & 0.7 & 0.8 & 0.6 & 0.7 \\
\hline 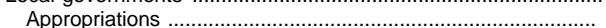 & (4) & (4) & (4) & (4) & (4) & $(4)$ & $(4)$ & (4) \\
\hline 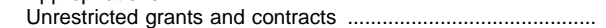 & 0.1 & 0.1 & 0.1 & 0.1 & 0.1 & 0.1 & 0.1 & 0.3 \\
\hline 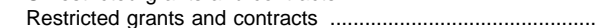 & 0.6 & 0.5 & 0.6 & 0.5 & 0.6 & 0.7 & 0.5 & 0.5 \\
\hline 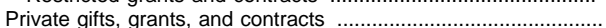 & 9.4 & 9.5 & 8.8 & 8.5 & 8.7 & 8.8 & 9.0 & 9.5 \\
\hline (2) & 5.0 & 5.2 & 4.1 & 3.9 & 4.1 & 4.2 & 4.2 & 4.6 \\
\hline Restricted ......... - & 4.4 & 4.2 & 4.7 & 4.6 & 4.5 & 4.6 & 4.8 & 4.9 \\
\hline Endowment income & 5.2 & 5.4 & 5.3 & 4.9 & 4.8 & 4.7 & 4.8 & 5.3 \\
\hline 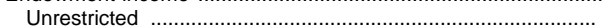 & 3.0 & 3.2 & 2.6 & 2.2 & 2.1 & 2.0 & 2.0 & 2.4 \\
\hline Restricted .......... & 2.2 & 2.2 & 2.7 & 2.7 & 2.7 & 2.7 & 2.8 & 2.9 \\
\hline 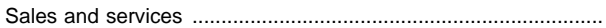 & 23.5 & 23.7 & 23.3 & 23.7 & 23.6 & 23.7 & 22.6 & 21.6 \\
\hline 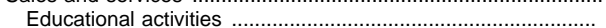 & 2.1 & 2.2 & 2.5 & 2.7 & 2.9 & 3.0 & 2.9 & 2.8 \\
\hline 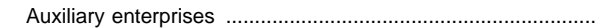 & 12.0 & 11.3 & 10.8 & 10.4 & 10.3 & 10.3 & 10.1 & 9.9 \\
\hline 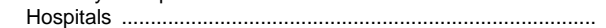 & 9.4 & 10.1 & 10.0 & 10.6 & 10.3 & 10.4 & 9.6 & 8.9 \\
\hline Other sources ‥1-1-11) & 4.2 & 4.4 & 4.5 & 4.5 & 4.5 & 4.4 & 4.8 & 5.4 \\
\hline
\end{tabular}

1 Preliminary data.

${ }^{2}$ Excludes Pell Grants. Federally supported student aid that is received through students is included under tuition and auxiliary enterprises.

${ }^{3}$ Generally includes only those revenues associated with major federally funded research and development centers (FFRDC).

${ }^{4}$ Less than 0.05 percent.
NOTE.-Because of rounding, details may not add to totals.

SOURCE: U.S. Department of Education, National Center for Education Statistics, Higher Education General Information Survey (HEGIS), "Financial Statistics of Institutions of Higher Education" surveys; and Integrated Postsecondary Education Data System (IPEDS), "Finance" surveys. (This table was prepared January 1999.) 
Table 328.-Current-fund revenue of institutions of higher education and degree-granting institutions, by source of funds: $1919-20$ to $1995-96$

[In thousands]

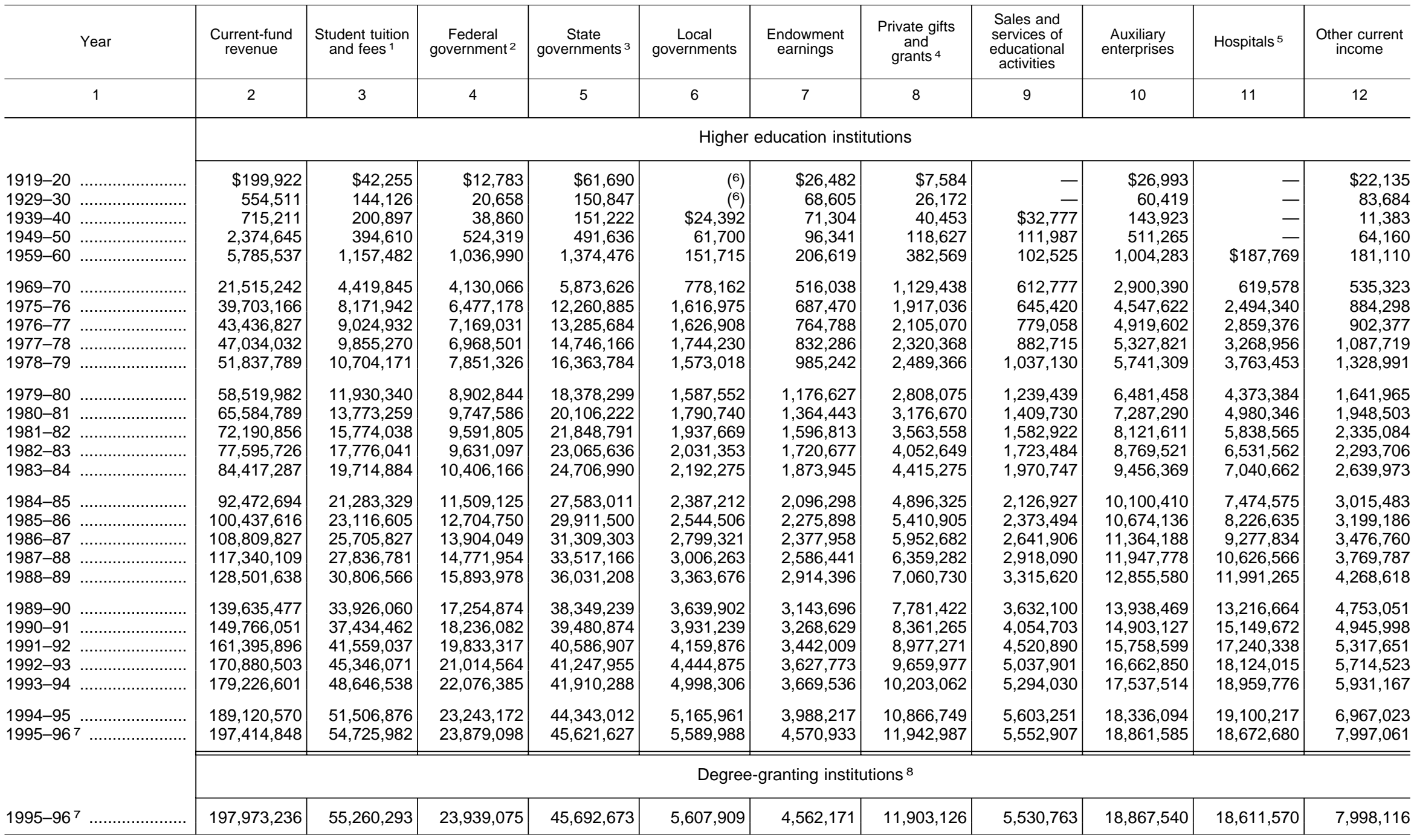

${ }^{1}$ Tuition and fees received from veterans under Public Law 550 are reported under student fees and are not under government.

Therally supported student aid that is received through students is included under tuition and auxiliary enterprises.

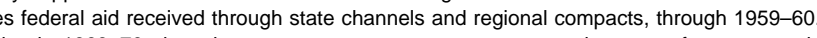

${ }^{4}$ Beginning in 1969-70, the private grants represent nongovernmental revenue for sponsored research, student aid, and other sponsored programs.

6 Prior to $1959-60$, data for hospitals are included under sales and services of educational activities.

7 Preliminary data.
${ }^{8}$ Data are for 4-year and 2-year degree-granting institutions that were eligible to participate in Title IV federal financial aid programs.

-Data not available.

NOTE. - Data for years prior to $1969-70$ are not entirely comparable with data for later years. Also, some details for 1969-70 are not directly comparable with data for later years. Because of rounding, details may not add to totals. SOURCE: U.S. Department of Education, National Center for Education Statistics, Higher Education General Informa"Financial Statistics of Institutions of Higher Education" surveys; and Integrated Postsecondary (IPEDS), "Finance" surveys. (This table was prepared October 1998.) 
Table 329.-Revenue of degree-granting institutions, by source of funds, and by control and type of institution: 1995-96

\begin{tabular}{|c|c|c|c|c|c|c|c|c|c|c|c|}
\hline Control and type of institution & $\begin{array}{c}\text { Current-fund } \\
\text { revenue }\end{array}$ & \begin{tabular}{c|}
$\begin{array}{c}\text { Student } \\
\text { tuition } \\
\text { and fees }\end{array}$ \\
\end{tabular} & $\begin{array}{l}\text { Federal } \\
\text { govern- } \\
\text { ment }^{3}\end{array}$ & $\begin{array}{l}\text { State } \\
\text { govern- } \\
\text { ments }\end{array}$ & $\begin{array}{l}\text { Local } \\
\text { govern- } \\
\text { ments }\end{array}$ & $\begin{array}{l}\text { Private } \\
\text { gifts and } \\
\text { grants }\end{array}$ & $\begin{array}{c}\text { Endow- } \\
\text { ment } \\
\text { earnings }\end{array}$ & $\begin{array}{c}\text { Edu- } \\
\text { cational } \\
\text { activities }\end{array}$ & $\begin{array}{c}\text { Auxiliary } \\
\text { enterprises }\end{array}$ & Hospitals & $\begin{array}{l}\text { Other } \\
\text { current } \\
\text { income }\end{array}$ \\
\hline \multirow[b]{3}{*}{ Total } & 2 & 3 & 4 & 5 & 6 & 7 & 8 & 9 & 10 & 11 & 12 \\
\hline & \multicolumn{11}{|c|}{ In thousands } \\
\hline & $\$ 197,973,236$ & $\$ 55,260,293$ & $\$ 23,939,075$ & $\$ 45,692,673$ & $\$ 5,607,909$ & $\$ 11,903,126$ & $\$ 4,562,171$ & $\$ 5,530,763$ & $\$ 18,867,540$ & $\$ 18,611,570$ & $\$ 7,998,116$ \\
\hline 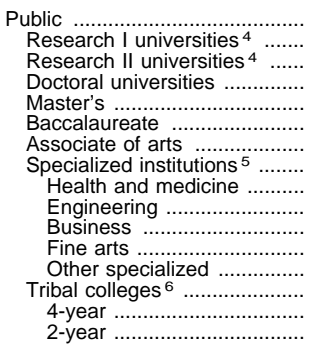 & $\begin{array}{r}123,501,152 \\
45,852,598 \\
7,435,932 \\
13,095,143 \\
19,859,470 \\
2,614,689 \\
22,390,650 \\
12,153,717 \\
10,321,242 \\
210,784 \\
29,189 \\
124,753 \\
1,467,749 \\
98,952 \\
22,357 \\
76,595\end{array}$ & $\begin{array}{r}23,257,454 \\
6,987,745 \\
1,734,166 \\
3,075,, 536 \\
5,432,628 \\
819,012 \\
4,737,100 \\
461,503 \\
307,002 \\
49,143 \\
6,881 \\
31,786 \\
66,692 \\
9,763 \\
1,555 \\
8,208\end{array}$ & $\begin{array}{r}13,672,467 \\
6,947,554 \\
850,568 \\
1,123,412 \\
1,085,117 \\
169,645 \\
1,202,053 \\
2,229,198 \\
1,092,398 \\
14,598 \\
1,143 \\
825 \\
1,120,235 \\
64,918 \\
16,263 \\
48,655\end{array}$ & $\begin{array}{r}44,242,546 \\
12,900,110 \\
2,947,146 \\
5,481,957 \\
9,175,109 \\
1,119,902 \\
9,726,884 \\
2,886,555 \\
2,626,054 \\
110,015 \\
16,022 \\
38,374 \\
96,090 \\
4,883 \\
416 \\
4,467\end{array}$ & $\begin{array}{r}5,074,511 \\
265,733 \\
16,689 \\
141,922 \\
141,683 \\
20,952 \\
4,310,097 \\
173,129 \\
148,363 \\
9 \\
25 \\
20,422 \\
4,310 \\
4,307 \\
14 \\
4,293\end{array}$ & $\begin{array}{r}5,089,344 \\
2,783,156 \\
392,881 \\
597,166 \\
402,474 \\
69,393 \\
219,693 \\
619,622 \\
595,699 \\
10,195 \\
574 \\
1,677 \\
11,476 \\
4,958 \\
1,520 \\
3,438\end{array}$ & $\begin{array}{r}721,079 \\
455,956 \\
60,092 \\
93,975 \\
42,421 \\
5,954 \\
22,723 \\
37,957 \\
37,060 \\
436 \\
20 \\
15 \\
426 \\
2,003 \\
1,137 \\
866\end{array}$ & $\begin{array}{r}3,528,610 \\
1,881,408 \\
239,868 \\
290,084 \\
334,154 \\
32,710 \\
148,172 \\
601,410 \\
595,787 \\
3,357 \\
2,008 \\
89 \\
169 \\
804 \\
58 \\
745\end{array}$ & $\begin{array}{r}11,595,408 \\
4,508,912 \\
997,861 \\
1,527,466 \\
2,548,088 \\
323,686 \\
1,321,780 \\
364,726 \\
240,458 \\
16,676 \\
2,260 \\
13,149 \\
92,183 \\
2,889 \\
281 \\
2,608\end{array}$ & $\begin{array}{r}12,275,778 \\
7,868,627 \\
0 \\
28,016 \\
213,992 \\
0 \\
0 \\
4,165,143 \\
4,095,711 \\
0 \\
0 \\
0 \\
69,432 \\
0 \\
0 \\
0\end{array}$ & $\begin{array}{r}4,043,955 \\
1,253,397 \\
196,660 \\
735,610 \\
483,804 \\
53,433 \\
702,148 \\
614,474 \\
582,711 \\
6,354 \\
256 \\
18,418 \\
6,736 \\
4,428 \\
1,113 \\
3,315\end{array}$ \\
\hline 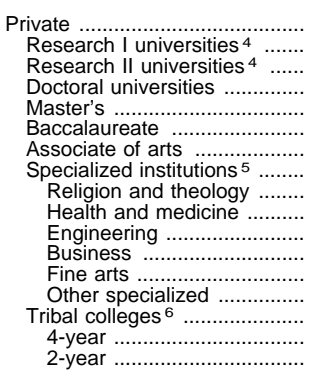 & $\begin{array}{r}74,472,083 \\
28,660,156 \\
4,223,996 \\
6,716,799 \\
10,766,428 \\
13,844,720 \\
2,126,183 \\
8,100,221 \\
1,065,614 \\
4,120,600 \\
410,164 \\
1,073,672 \\
857,648 \\
572,525 \\
33,580 \\
12,692 \\
20,888\end{array}$ & $\begin{array}{r}32,002,839 \\
6,536,105 \\
1,631,549 \\
3,828,444 \\
7,160,907 \\
8,106,924 \\
1,575,989 \\
3,159,368 \\
325,057 \\
787,812 \\
231,960 \\
776,928 \\
614,959 \\
423,052 \\
3,052 \\
1,803 \\
1,849\end{array}$ & $\begin{array}{r}10,266,608 \\
7,614,907 \\
363,920 \\
467,146 \\
482,107 \\
427,024 \\
84,814 \\
803,441 \\
15,206 \\
715,469 \\
29,620 \\
14,374 \\
16,863 \\
11,909 \\
23,249 \\
8,402 \\
14,847\end{array}$ & $\begin{array}{r}1,450,127 \\
308,927 \\
33,859 \\
159,855 \\
267,073 \\
346,823 \\
115,617 \\
216,598 \\
5,353 \\
139,812 \\
9,844 \\
36,375 \\
18,542 \\
6,672 \\
1,375 \\
438 \\
937\end{array}$ & $\begin{array}{r}533,398 \\
227,917 \\
696 \\
10,560 \\
5,147 \\
9,828 \\
9,421 \\
269,828 \\
1,789 \\
264,667 \\
325 \\
17 \\
1,499 \\
1,531 \\
0 \\
0 \\
0\end{array}$ & $\begin{array}{r}6,813,782 \\
2,751,160 \\
441,760 \\
475,027 \\
672,409 \\
1,299,133 \\
97,686 \\
1,074,991 \\
367,175 \\
504,006 \\
48,781 \\
48,388 \\
71,030 \\
35,610 \\
1,616 \\
942 \\
674\end{array}$ & $\begin{array}{r}3,841,091 \\
1,660,623 \\
247,042 \\
281,992 \\
289,055 \\
967,274 \\
20,570 \\
374,365 \\
150,378 \\
86,667 \\
30,136 \\
16,204 \\
41,239 \\
49,741 \\
171 \\
0 \\
171\end{array}$ & $\begin{array}{r}2,002,153 \\
1,535,736 \\
19,262 \\
158,168 \\
145,176 \\
39,381 \\
15,123 \\
89,285 \\
6,318 \\
53,510 \\
2,263 \\
18,951 \\
3,032 \\
5,210 \\
22 \\
22 \\
0\end{array}$ & $\begin{array}{r}7,272,132 \\
1,865,321 \\
583,118 \\
648,935 \\
1,383,871 \\
2,165,122 \\
135,206 \\
489,933 \\
141,526 \\
114,464 \\
30,511 \\
117,798 \\
66,516 \\
19,168 \\
576 \\
249 \\
327\end{array}$ & $\begin{array}{r}6,335,792 \\
4,780,755 \\
744,305 \\
109,900 \\
9,664 \\
0 \\
811 \\
690,359 \\
424 \\
689,362 \\
0 \\
0 \\
0 \\
572 \\
0 \\
0 \\
0\end{array}$ & $\begin{array}{r}3,954,162 \\
1,378,705 \\
158,486 \\
576,771 \\
351,019 \\
483,311 \\
70,946 \\
932,005 \\
52,388 \\
764,829 \\
26,723 \\
44,635 \\
24,368 \\
19,061 \\
2,918 \\
836 \\
2,082\end{array}$ \\
\hline 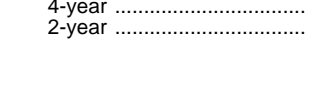 & \multicolumn{11}{|c|}{ Percentage distribution } \\
\hline Total & 100.00 & 27.91 & 12.09 & 23.08 & 2.83 & 6.01 & 2.30 & 2.79 & 9.53 & 9.40 & 4.04 \\
\hline 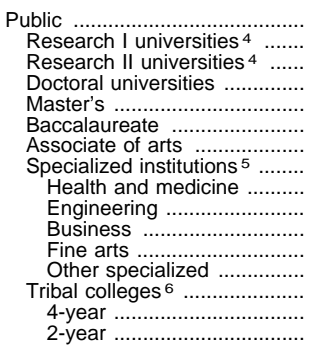 & $\begin{array}{l}100.00 \\
100.00 \\
100.00 \\
100.00 \\
100.00 \\
100.00 \\
100.00 \\
100.00 \\
100.00 \\
100.00 \\
100.00 \\
100.00 \\
100.00 \\
100.00 \\
100.00 \\
100.00\end{array}$ & \begin{tabular}{r|}
18.83 \\
15.24 \\
23.32 \\
23.49 \\
27.36 \\
31.32 \\
21.16 \\
3.80 \\
2.97 \\
23.31 \\
23.57 \\
25.48 \\
4.54 \\
9.87 \\
6.96 \\
10.72
\end{tabular} & $\begin{array}{r}11.07 \\
15.15 \\
11.44 \\
8.58 \\
5.46 \\
6.49 \\
5.37 \\
18.34 \\
10.58 \\
6.93 \\
3.92 \\
0.66 \\
76.32 \\
65.61 \\
7.61 \\
\end{array}$ & $\begin{array}{l}35.82 \\
28.13 \\
39.63 \\
41.86 \\
46.20 \\
42.83 \\
43.44 \\
23.75 \\
25.44 \\
52.19 \\
54.89 \\
30.76 \\
6.55 \\
4.93 \\
1.86 \\
5.83\end{array}$ & \begin{tabular}{r|}
4.11 \\
0.58 \\
0.22 \\
1.08 \\
0.71 \\
0.80 \\
19.25 \\
1.42 \\
1.44 \\
0.00 \\
0.09 \\
16.37 \\
0.29 \\
4.35 \\
0.06 \\
5.60
\end{tabular} & $\begin{array}{l}4.12 \\
6.07 \\
5.28 \\
4.56 \\
2.03 \\
2.65 \\
0.98 \\
5.10 \\
5.77 \\
4.84 \\
1.97 \\
1.34 \\
0.78 \\
5.01 \\
6.80 \\
4.49\end{array}$ & $\begin{array}{l}0.58 \\
0.99 \\
0.81 \\
0.72 \\
0.21 \\
0.23 \\
0.10 \\
0.31 \\
0.36 \\
0.21 \\
0.07 \\
0.01 \\
0.03 \\
2.02 \\
5.09 \\
1.13\end{array}$ & $\begin{array}{l}2.86 \\
4.10 \\
3.23 \\
2.22 \\
1.68 \\
1.25 \\
0.66 \\
4.95 \\
5.77 \\
1.59 \\
6.88 \\
0.07 \\
0.01 \\
0.81\end{array}$ & $\begin{array}{r}9.39 \\
9.83 \\
13.42 \\
11.66 \\
12.83 \\
12.38 \\
5.90 \\
3.00 \\
2.33 \\
7.91 \\
7.74 \\
10.54 \\
6.28 \\
2.92\end{array}$ & $\begin{array}{r}9.94 \\
17.16 \\
0.00 \\
0.21 \\
1.08 \\
0.00 \\
0.00 \\
34.27 \\
39.68 \\
0.00 \\
0.00 \\
0.00 \\
4.73 \\
0.00 \\
0.00 \\
0.00\end{array}$ & $\begin{array}{r}3.27 \\
2.73 \\
2.64 \\
5.62 \\
2.44 \\
2.04 \\
3.14 \\
5.06 \\
5.65 \\
3.01 \\
0.88 \\
14.76 \\
0.46 \\
4.47 \\
4.98 \\
4.33\end{array}$ \\
\hline 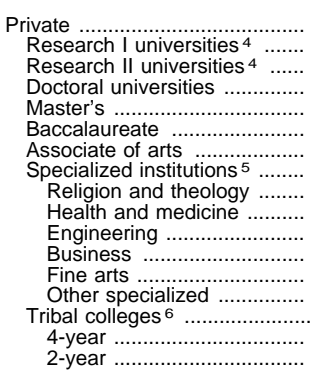 & $\begin{array}{l}100.00 \\
100.00 \\
100.00 \\
100.00 \\
100.00 \\
100.00 \\
100.00 \\
100.00 \\
100.00 \\
100.00 \\
100.00 \\
100.00 \\
100.00 \\
100.00 \\
100.00 \\
100.00\end{array}$ & $\begin{array}{r}42.97 \\
22.81 \\
38.63 \\
57.00 \\
66.51 \\
58.56 \\
74.12 \\
39.00 \\
30.50 \\
19.12 \\
56.55 \\
72.36 \\
71.66 \\
73.89 \\
10.88 \\
14.20 \\
8.85\end{array}$ & $\begin{array}{r}26.57 \\
8.62 \\
6.95 \\
4.48 \\
3.08 \\
3.99 \\
9.92 \\
1.43 \\
17.36 \\
7.22 \\
1.34 \\
1.97 \\
2.08 \\
69.24 \\
66.20 \\
71.08\end{array}$ & $\begin{array}{l}1.08 \\
0.80 \\
2.38 \\
2.48 \\
2.51 \\
5.44 \\
2.67 \\
0.50 \\
3.39 \\
2.40 \\
3.39 \\
2.16 \\
1.17 \\
4.09 \\
3.45 \\
4.49\end{array}$ & $\begin{array}{l}0.72 \\
0.80 \\
0.02 \\
0.16 \\
0.05 \\
0.07 \\
0.44 \\
3.33 \\
0.17 \\
6.42 \\
0.08 \\
0.00 \\
0.17 \\
0.27 \\
0.00 \\
0.00 \\
0.00\end{array}$ & $\begin{array}{r}9.15 \\
9.60 \\
10.46 \\
7.07 \\
6.25 \\
9.38 \\
4.59 \\
13.27 \\
34.46 \\
12.23 \\
11.89 \\
4.51 \\
8.28 \\
6.22 \\
4.81 \\
7.42 \\
3.23\end{array}$ & $\begin{array}{r}5.16 \\
5.79 \\
5.85 \\
4.20 \\
2.68 \\
6.99 \\
0.97 \\
4.62 \\
14.11 \\
2.10 \\
7.35 \\
1.51 \\
4.81 \\
8.69 \\
0.51 \\
0.00 \\
0.82\end{array}$ & $\begin{array}{l}2.69 \\
5.36 \\
0.46 \\
2.35 \\
1.35 \\
0.28 \\
0.71 \\
1.10 \\
0.59 \\
1.30 \\
0.55 \\
1.77 \\
0.35 \\
0.91 \\
0.07 \\
0.18 \\
0.00\end{array}$ & $\begin{array}{r}9.76 \\
6.51 \\
13.80 \\
9.66 \\
12.85 \\
15.64 \\
6.36 \\
6.05 \\
13.28 \\
2.78 \\
7.44 \\
10.97 \\
7.76 \\
3.35 \\
1.72 \\
1.96 \\
1.56\end{array}$ & $\begin{array}{r}8.51 \\
16.68 \\
17.62 \\
1.64 \\
0.09 \\
0.00 \\
0.04 \\
8.52 \\
0.04 \\
16.73 \\
0.00 \\
0.00 \\
0.00 \\
0.10 \\
0.00 \\
0.00 \\
0.00\end{array}$ & $\begin{array}{r}5.31 \\
4.81 \\
3.75 \\
8.59 \\
3.26 \\
3.49 \\
3.34 \\
11.51 \\
4.92 \\
18.56 \\
6.52 \\
4.16 \\
2.84 \\
3.33 \\
8.69 \\
6.59 \\
9.97\end{array}$ \\
\hline
\end{tabular}

Preliminary data.

2 Includes federally supported aid received through students.

3 Includes appropriations, grants, contracts, and revenues associated with major federally funded research and development centers (FFRDC). Excludes Pell Grants.

${ }^{4}$ Research institutions are committed to graduate education through the doctorate, and give high priority to research. Research I institutions receive $\$ 40$ million or more annually in federal support. Research II institutions receive between $\$ 15.5$ million and $\$ 40$ million annually.

${ }^{5}$ Specialized institutions award baccalaureate or higher level degrees in specific fields of study.
${ }^{6}$ Tribally controlled colleges are located on reservations and are members of the American Indian Higher Education Consortium.

NOTE.-Because of rounding, details may not add to totals.

SOURCE: U.S. Department of Education, National Center for Education Statistics, Integrated Postsecondary Education Data System (IPEDS), "Finance, 1995-96" survey. (This table was prepared November 1998.) 
Table 330.-Current-fund revenue of public institutions of higher education and degree-granting institutions, by state, $1980-81$ to $1995-96$

[In thousands of dollars]

\begin{tabular}{|c|c|c|c|c|c|c|c|c|c|c|c|}
\hline \multirow[b]{2}{*}{ State } & \multicolumn{9}{|c|}{ Institutions of higher education } & \multirow{2}{*}{\begin{tabular}{|c|} 
Percent \\
change, \\
$1990-91$ \\
to \\
$1995-96$ \\
\end{tabular}} & \multirow{2}{*}{$\begin{array}{c}\text { Degree- } \\
\text { granting } \\
\text { institutions, } \\
1995-96^{2}\end{array}$} \\
\hline & $1980-81$ & $1985-86$ & $1989-90$ & $1990-91$ & $1991-92$ & $1992-93$ & 1993-94 & 1994-95 & $1995-96^{1}$ & & \\
\hline 1 & 2 & 3 & 4 & 5 & 6 & 7 & 8 & 9 & 10 & 11 & 12 \\
\hline United States ......... & $\$ 43,195,617$ & $\$ 65,004,632$ & $\$ 88,911,433$ & $\$ 94,904,506$ & $\$ 102,202,890$ & $\$ 108,186,484$ & $\$ 112,968,097$ & $\$ 119,312,493$ & $\$ 123,378,526$ & 30.0 & $\$ 123,501,152$ \\
\hline $\begin{array}{l}\text { Alabama } \\
\text { Alaska } \\
\text { Arizona } \\
\text { Arkansas } \\
\text { California }\end{array}$ & $\begin{array}{r}889,121 \\
159,446 \\
719,835 \\
350,597 \\
5,906,729\end{array}$ & $\begin{array}{r}1,401,693 \\
221,837 \\
1,049,493 \\
539,185 \\
8,739,396\end{array}$ & $\begin{array}{r}1,926,148 \\
270,926 \\
1,483,996 \\
781,375 \\
11,776,298\end{array}$ & $\begin{array}{r}2,131,005 \\
291,826 \\
1,596,710 \\
818,079 \\
12,281,700\end{array}$ & \begin{tabular}{r|}
$2,296,665$ \\
304,857 \\
$1,655,873$ \\
920,699 \\
$13,628,928$
\end{tabular} & $\begin{array}{r}2,521,938 \\
323,740 \\
1,677,711 \\
995,482 \\
14,262,239\end{array}$ & $\begin{array}{r}2,614,224 \\
342,624 \\
1,834,035 \\
1,036,610 \\
13,868,703\end{array}$ & $\begin{array}{r}2,805,154 \\
344,877 \\
1,931,523 \\
1,113,954 \\
14,558,144\end{array}$ & $\begin{array}{r}2,852,401 \\
357,215 \\
2,037,986 \\
1,210,768 \\
14,716,907\end{array}$ & $\begin{array}{l}33.9 \\
22.4 \\
27.6 \\
48.0 \\
19.8\end{array}$ & $\begin{array}{r}2,852,401 \\
357,215 \\
2,046,890 \\
1,239,571 \\
14,726,206\end{array}$ \\
\hline 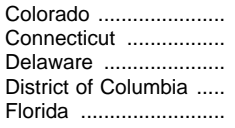 & $\begin{array}{r}747,040 \\
378,527 \\
168,522 \\
66,138 \\
1,202,788\end{array}$ & $\begin{array}{r}1,085,076 \\
578,866 \\
251,677 \\
84,144 \\
1,810,090\end{array}$ & \begin{tabular}{r|}
$1,390,413$ \\
833,154 \\
354,322 \\
96,906 \\
$2,812,644$
\end{tabular} & $\begin{array}{r}1,483,901 \\
889,831 \\
388,635 \\
95,729 \\
2,944,935\end{array}$ & $\begin{array}{r}1,594,541 \\
940,067 \\
433,186 \\
100,038 \\
3,049,921\end{array}$ & $\begin{array}{r}1,714,698 \\
976,380 \\
446,768 \\
98,170 \\
3,202,499\end{array}$ & $\begin{array}{r}1,803,735 \\
1,020,170 \\
471,017 \\
99,749 \\
3,411,727\end{array}$ & $\begin{array}{r}1,914,233 \\
1,148,389 \\
496,696 \\
103,770 \\
3,584,085\end{array}$ & $\begin{array}{r}2,027,721 \\
1,179,290 \\
505,678 \\
100,393 \\
3,790,131\end{array}$ & $\begin{array}{r}36.6 \\
32.5 \\
30.1 \\
4.9 \\
28.7\end{array}$ & $\begin{array}{r}2,027,721 \\
1,177,959 \\
505,678 \\
105,037 \\
3,777,158\end{array}$ \\
\hline $\begin{array}{l}\text { Georgia } \\
\text { Hawaii } \\
\text { Idaho }\end{array}$ & $\begin{array}{r}765,826 \\
219,633 \\
169,274 \\
1,809,981 \\
1,094,560\end{array}$ & $\begin{array}{r}1,267,472 \\
316,246 \\
235,507 \\
2,560,241 \\
1,701,421\end{array}$ & $\begin{array}{r}1,794,990 \\
433,164 \\
320,119 \\
3,370,011 \\
2,302,583\end{array}$ & $\begin{array}{r}1,953,866 \\
497,495 \\
359,710 \\
3,566,406 \\
2,494,029\end{array}$ & $\begin{array}{r}2,042,825 \\
579,805 \\
396,173 \\
3,659,328 \\
2,767,477\end{array}$ & $\begin{array}{r}2,268,331 \\
594,752 \\
416,359 \\
3,924,599 \\
2,882,592\end{array}$ & $\begin{array}{r}2,494,263 \\
628,043 \\
456,107 \\
4,100,967 \\
3,009,908\end{array}$ & $\begin{array}{r}2,760,323 \\
651,282 \\
492,918 \\
4,360,136 \\
3,080,345\end{array}$ & $\begin{array}{r}3,000,258 \\
560,760 \\
538,173 \\
4,542,868 \\
2,857,055\end{array}$ & $\begin{array}{l}53.6 \\
12.7 \\
49.6 \\
27.4 \\
14.6\end{array}$ & $\begin{array}{r}2,878,818 \\
560,760 \\
545,766 \\
4,542,868 \\
2,857,055\end{array}$ \\
\hline 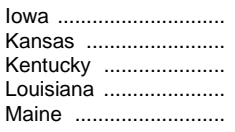 & $\begin{array}{l}784,950 \\
594,104 \\
671,414 \\
735,374 \\
157,370\end{array}$ & $\begin{array}{r}1,109,681 \\
864,119 \\
943,068 \\
1,055,941 \\
222,624\end{array}$ & $\begin{array}{r}1,653,221 \\
1,174,759 \\
1,283,778 \\
1,301,127 \\
352,024\end{array}$ & $\begin{array}{r}1,775,267 \\
1,219,129 \\
1,450,958 \\
1,447,772 \\
373,770\end{array}$ & $\begin{array}{r}1,827,776 \\
1,297,129 \\
1,565,021 \\
1,553,258 \\
375,512\end{array}$ & $\begin{array}{r}1,930,399 \\
1,350,052 \\
1,576,644 \\
1,821,190 \\
384,730\end{array}$ & $\begin{array}{r}2,014,244 \\
1,469,872 \\
1,656,119 \\
1,844,187 \\
398,639\end{array}$ & $\begin{array}{r}2,106,504 \\
1,553,593 \\
1,778,568 \\
1,968,669 \\
400,426\end{array}$ & $\begin{array}{r}2,231,113 \\
1,606,739 \\
1,881,064 \\
1,937,787 \\
410,472\end{array}$ & $\begin{array}{r}25.7 \\
31.8 \\
29.6 \\
33.8 \\
9.8\end{array}$ & $\begin{array}{r}2,231,113 \\
1,618,071 \\
1,881,064 \\
1,998,340 \\
413,730\end{array}$ \\
\hline 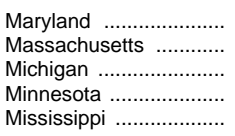 & $\begin{array}{r}818,850 \\
582,873 \\
2,094,394 \\
894,236 \\
543,209\end{array}$ & $\begin{array}{r}1,144,230 \\
1,075,348 \\
3,071,172 \\
1,373,436 \\
734,813\end{array}$ & $\begin{array}{r}1,638,822 \\
1,429,770 \\
4,322,956 \\
1,916,297 \\
956,300\end{array}$ & $\begin{array}{l}1,777,841 \\
1,457,142 \\
4,648,488 \\
2,080,637 \\
1,005,448\end{array}$ & $\begin{array}{l}1,745,479 \\
1,525,943 \\
5,127,892 \\
2,261,978 \\
1,054,530\end{array}$ & $\begin{array}{l}1,913,029 \\
1,639,854 \\
5,329,224 \\
2,363,483 \\
1,150,201\end{array}$ & $\begin{array}{l}1,984,038 \\
1,491,921 \\
5,529,883 \\
2,494,341 \\
1,215,602\end{array}$ & $\begin{array}{l}2,074,521 \\
1,586,319 \\
5,798,882 \\
2,671,566 \\
1,443,162\end{array}$ & $\begin{array}{l}2,227,596 \\
1,684,869 \\
6,047,686 \\
2,781,726 \\
1,488,765\end{array}$ & $\begin{array}{l}25.3 \\
15.6 \\
30.1 \\
33.7 \\
48.1\end{array}$ & $\begin{array}{l}2,227,596 \\
1,691,648 \\
6,047,686 \\
2,786,053 \\
1,500,350\end{array}$ \\
\hline 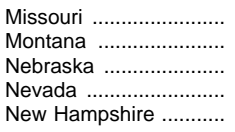 & $\begin{array}{l}717,626 \\
123,933 \\
390,372 \\
113,298 \\
131,990\end{array}$ & $\begin{array}{r}1,032,685 \\
181,462 \\
554,814 \\
184,883 \\
190,462\end{array}$ & $\begin{array}{r}1,416,556 \\
227,403 \\
787,282 \\
286,719 \\
275,121\end{array}$ & $\begin{array}{r}1,517,071 \\
258,189 \\
870,289 \\
336,841 \\
304,315\end{array}$ & $\begin{array}{r}1,566,480 \\
334,243 \\
941,062 \\
368,245 \\
324,186\end{array}$ & $\begin{array}{r}1,698,594 \\
349,102 \\
989,156 \\
392,258 \\
348,839\end{array}$ & $\begin{array}{r}1,805,266 \\
362,905 \\
1,033,731 \\
412,884 \\
373,498\end{array}$ & $\begin{array}{r}1,978,783 \\
385,984 \\
1,124,836 \\
484,276 \\
391,619\end{array}$ & $\begin{array}{r}2,095,143 \\
414,843 \\
1,216,869 \\
492,276 \\
412,456\end{array}$ & $\begin{array}{l}38.1 \\
60.7 \\
39.8 \\
46.1 \\
35.5\end{array}$ & $\begin{array}{r}2,100,852 \\
414,843 \\
1,216,869 \\
492,276 \\
412,456\end{array}$ \\
\hline $\begin{array}{l}\text { New Jersey } \\
\text { New Mexico }\end{array}$ & $\begin{array}{r}917,143 \\
334,392 \\
2,519,437 \\
1,146,931 \\
196,267\end{array}$ & $\begin{array}{r}1,446,098 \\
473,716 \\
3,830,119 \\
1,857,124 \\
286,550\end{array}$ & $\begin{array}{r}2,253,830 \\
858,989 \\
5,014,789 \\
2,480,396 \\
365,089\end{array}$ & $\begin{array}{r}2,413,530 \\
944,248 \\
5,424,379 \\
2,650,124 \\
377,960\end{array}$ & $\begin{array}{r}2,610,949 \\
1,056,819 \\
5,616,604 \\
2,873,684 \\
411,293\end{array}$ & $\begin{array}{r}2,745,100 \\
1,125,366 \\
6,117,555 \\
3,113,193 \\
431,464\end{array}$ & $\begin{array}{r}2,920,767 \\
1,190,519 \\
6,574,152 \\
3,299,213 \\
431,381\end{array}$ & $\begin{array}{r}3,106,652 \\
1,316,934 \\
6,887,321 \\
3,521,601 \\
467,926\end{array}$ & $\begin{array}{r}3,189,439 \\
1,356,644 \\
6,861,111 \\
3,640,049 \\
445,128\end{array}$ & $\begin{array}{l}32.1 \\
43.7 \\
26.5 \\
37.4 \\
17.8\end{array}$ & $\begin{array}{r}3,189,439 \\
1,369,513 \\
6,861,111 \\
3,640,049 \\
445,128\end{array}$ \\
\hline 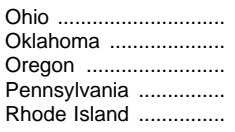 & $\begin{array}{r}1,828,079 \\
588,936 \\
647,391 \\
1,575,104 \\
156,451\end{array}$ & $\begin{array}{r}2,824,411 \\
873,446 \\
899,709 \\
2,473,794 \\
213,859\end{array}$ & $\begin{array}{r}3,871,477 \\
997,781 \\
1,242,595 \\
3,511,535 \\
291,376\end{array}$ & $\begin{array}{r}4,184,621 \\
1,072,967 \\
1,358,244 \\
3,692,745 \\
292,404\end{array}$ & $\begin{array}{r}4,484,576 \\
1,190,393 \\
1,523,505 \\
4,153,483 \\
308,383\end{array}$ & $\begin{array}{r}4,628,902 \\
1,209,863 \\
1,615,882 \\
4,262,533 \\
325,003\end{array}$ & $\begin{array}{r}4,895,812 \\
1,257,552 \\
1,687,205 \\
4,423,633 \\
329,277\end{array}$ & $\begin{array}{r}4,976,134 \\
1,300,779 \\
1,816,031 \\
4,684,460 \\
344,171\end{array}$ & $\begin{array}{r}4,975,749 \\
1,382,711 \\
1,891,391 \\
5,017,535 \\
354,437\end{array}$ & $\begin{array}{l}18.9 \\
28.9 \\
39.3 \\
35.9 \\
21.2\end{array}$ & $\begin{array}{r}4,982,846 \\
1,382,711 \\
1,891,391 \\
5,017,535 \\
354,437\end{array}$ \\
\hline $\begin{array}{l}\text { South Carolina } \\
\text { South Dakota } \\
\text { Tennessee } \\
\text { Texas } \\
\text { Utah }\end{array}$ & $\begin{array}{r}630,966 \\
127,839 \\
675,770 \\
2,858,725 \\
431,294\end{array}$ & $\begin{array}{r}957,771 \\
147,699 \\
1,104,118 \\
4,558,275 \\
686,817\end{array}$ & $\begin{array}{r}1,333,941 \\
184,954 \\
1,556,416 \\
5,777,100 \\
960,027\end{array}$ & $\begin{array}{r}1,502,709 \\
198,583 \\
1,634,491 \\
6,015,609 \\
1,020,836\end{array}$ & $\begin{array}{r}1,629,876 \\
219,751 \\
1,672,605 \\
6,664,828 \\
1,160,882\end{array}$ & $\begin{array}{r}1,733,468 \\
241,536 \\
1,839,384 \\
7,126,068 \\
1,224,127\end{array}$ & $\begin{array}{r}1,924,747 \\
2600,907 \\
1,961,312 \\
7,688,388 \\
1,307,681\end{array}$ & $\begin{array}{r}1,997,203 \\
260,853 \\
2,053,495 \\
8,123,435 \\
1,402,962\end{array}$ & $\begin{array}{r}1,960,481 \\
266,880 \\
2,110,517 \\
8,775,323 \\
1,489,664\end{array}$ & $\begin{array}{l}30.5 \\
34.4 \\
29.1 \\
45.9 \\
45.9\end{array}$ & $\begin{array}{r}1,960,481 \\
297,342 \\
2,111,127 \\
8,779,578 \\
1,489,664\end{array}$ \\
\hline $\begin{array}{l}\text { Vermont } \\
\text { Virginia } \\
\text { Washington } \\
\text { West Virginia } \\
\text { Wisconsin } \\
\text { Wyoming }\end{array}$ & $\begin{array}{r}127,337 \\
1,159,453 \\
998,146 \\
318,915 \\
1,228,414 \\
140,520\end{array}$ & $\begin{array}{r}191,559 \\
1,876,151 \\
1,445,849 \\
385,170 \\
1,761,927 \\
208,595\end{array}$ & $\begin{array}{r}267,178 \\
2,736,307 \\
1,966,838 \\
502,436 \\
2,343,203 \\
237,093\end{array}$ & $\begin{array}{r}281,526 \\
2,902,939 \\
2,188,366 \\
563,796 \\
2,487,501 \\
251,760\end{array}$ & $\begin{array}{r}298,524 \\
3,041,850 \\
2,355,445 \\
608,294 \\
2,629,388 \\
271,290\end{array}$ & $\begin{array}{r}305,477 \\
3,176,437 \\
2,539,934 \\
631,619 \\
2,775,635 \\
270,515\end{array}$ & $\begin{array}{r}316,905 \\
3,323,028 \\
2,744,035 \\
666,268 \\
2,954,564 \\
278,270\end{array}$ & $\begin{array}{r}329,679 \\
3,483,691 \\
2,877,386 \\
693,159 \\
3,033,547 \\
293,209\end{array}$ & $\begin{array}{r}341,988 \\
3,609,275 \\
3,004,118 \\
733,332 \\
3,105,328 \\
298,526\end{array}$ & $\begin{array}{l}21.5 \\
24.3 \\
37.3 \\
30.1 \\
24.8 \\
18.6\end{array}$ & $\begin{array}{r}341,988 \\
3,609,275 \\
3,040,757 \\
734,283 \\
3,108,030 \\
298,526\end{array}$ \\
\hline U.S. Service Schools .. & 586,095 & 920,790 & $1,188,896$ & $1,128,158$ & $1,181,348$ & $1,204,411$ & $1,253,468$ & $1,248,328$ & $1,361,895$ & 20.7 & $1,361,895$ \\
\hline Outlying areas .......... & 242,380 & 451,734 & 573,106 & 557,655 & 665,323 & 704,076 & 589,470 & 750,676 & 836,541 & 50.0 & 831,925 \\
\hline $\begin{array}{l}\text { American Samoa ......... } \\
\text { Federated States of }\end{array}$ & 1,305 & 2,413 & 3,585 & 3,939 & 4,057 & 4,428 & 4,610 & 4,817 & 880 & 252.3 & 13,880 \\
\hline $\begin{array}{r}\text { Micronesia } \\
\text { Guam } \ldots \ldots \ldots \ldots \ldots \ldots \ldots \ldots \ldots \ldots \ldots \ldots \ldots \ldots \ldots . . .\end{array}$ & $14, \overline{291}$ & $31, \overline{139}$ & $\begin{array}{r}1,842 \\
50,411\end{array}$ & $\begin{array}{r}2,063 \\
61,667\end{array}$ & $\begin{array}{r}2,078 \\
70,658\end{array}$ & $\begin{array}{r}3,453 \\
74,928\end{array}$ & $\begin{array}{r}3,932 \\
68,198\end{array}$ & $\begin{array}{r}6,517 \\
71,873\end{array}$ & $\begin{array}{r}8,496 \\
65,710\end{array}$ & $\begin{array}{r}311.7 \\
6.6\end{array}$ & $\begin{array}{r}8,496 \\
65,710\end{array}$ \\
\hline Marshall Islands ............ & - & - & - & - & 3,798 & 1,111 & 2,176 & 1,633 & 1,685 & - & 1,685 \\
\hline Northern Marianas ....... & - & 1,350 & 791 & 1,458 & 1,715 & 2,462 & 3,511 & 12,174 & 15,792 & 983.0 & 15,792 \\
\hline Palau & - & & 4,038 & 4,100 & 3,948 & 5,133 & 4,762 & 4,083 & 3,900 & -4.9 & 3,900 \\
\hline $\begin{array}{l}\text { Puerto Rico .................... } \\
\text { Trust Territory of the }\end{array}$ & 213,012 & 392,194 & 487,133 & 428,768 & 518,747 & 581,128 & 468,739 & 615,912 & 691,409 & 61.3 & 686,792 \\
\hline 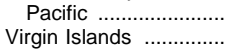 & $\begin{array}{r}1,669 \\
12,103\end{array}$ & $\begin{array}{r}5,681 \\
18,957\end{array}$ & 25,307 & 55,659 & $60,3 \overline{22}$ & $31, \overline{3}$ & $3 \overline{-}$ & $33,6 \overline{-}$ & 35,669 & $-3 \overline{5.9}$ & 35,669 \\
\hline
\end{tabular}

1 Preliminary data.

2 Preliminary data are for 4-year and 2-year degree-granting institutions that were eligible to participate in Title IV federal financial aid programs.

-Data not available or not applicable.

NOTE.-Because of rounding, details may not add to totals.

SOURCE: U.S. Department of Education, National Center for Education Statistics, Higher Education General Information Survey (HEGIS), "Financial Statistics of Institu- tions of Higher Education" surveys; and Integrated Postsecondary Education Data Sys tem (IPEDS), "Finance" surveys. (This table was prepared March 1999.) 
Table 331.-Current-fund revenue of public degree-granting institutions, by source of funds and state: 1995-96 1 [In thousands of dollars]

\begin{tabular}{|c|c|c|c|c|c|c|c|c|c|c|}
\hline State & Total & $\begin{array}{l}\text { Tuition } \\
\text { and } \\
\text { fees }\end{array}$ & $\begin{array}{c}\text { Federal } \\
\text { appropri- } \\
\text { ations, } \\
\text { grants, } \\
\text { and } \\
\text { contracts }^{2}\end{array}$ & $\begin{array}{c}\text { State } \\
\text { appropri- } \\
\text { ations, } \\
\text { grants, } \\
\text { and } \\
\text { contracts }\end{array}$ & $\begin{array}{l}\text { Local } \\
\text { appropri- } \\
\text { ations, } \\
\text { grants, } \\
\text { and } \\
\text { contracts }\end{array}$ & $\begin{array}{c}\text { Private } \\
\text { gifts, } \\
\text { grants, and } \\
\text { contracts }\end{array}$ & $\begin{array}{c}\text { Endow- } \\
\text { ment } \\
\text { income }\end{array}$ & $\begin{array}{c}\text { Auxiliary } \\
\text { enterprises }\end{array}$ & Hospitals & $\begin{array}{l}\text { Educational } \\
\text { activities } \\
\text { and other }\end{array}$ \\
\hline 1 & 2 & 3 & 4 & 5 & 6 & 7 & 8 & 9 & 10 & 11 \\
\hline United States & $\$ 123,501,152$ & $\$ 23,257,454$ & $\$ 13,672,467$ & $\$ 44,242,546$ & $\$ 5,074,511$ & $\$ 5,089,344$ & $\$ 721,079$ & $\$ 11,595,408$ & $\$ 12,275,778$ & $\$ 7,572,564$ \\
\hline Alabama & $2,852,401$ & 422,162 & 329,268 & 910,821 & 12,774 & 94,439 & 22,368 & 199,804 & 708,660 & 152,105 \\
\hline Alaska ............................ & 357,215 & 48,965 & 47,811 & 184,926 & 1,537 & 16,119 & 4,354 & 21,404 & 0 & 32,098 \\
\hline Arizona & $2,046,890$ & 446,910 & 283,416 & 717,882 & 227,935 & 101,063 & 4,576 & 184,578 & 0 & 80,530 \\
\hline 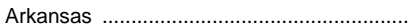 & $1,239,571$ & 170,198 & 103,826 & 482,995 & 2,549 & 30,698 & 1,877 & 97,111 & 290,677 & 59,640 \\
\hline 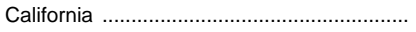 & $14,726,206$ & $1,946,651$ & $1,447,361$ & $5,364,254$ & $1,539,469$ & 466,487 & 72,189 & 884,446 & $1,801,345$ & $1,204,003$ \\
\hline 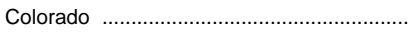 & $2,027,721$ & 558,587 & 379,708 & 562,522 & 31,803 & 94,370 & 10,003 & 250,515 & 14,247 & 125,966 \\
\hline Connecticut & $1,177,959$ & 244,852 & 81,541 & 485,531 & & 25,581 & 191 & 81,549 & 196,741 & 61,971 \\
\hline Delaware & 505,678 & 176,218 & 47,397 & 135,563 & 18,845 & 17,897 & 20,897 & 69,173 & 0 & 19,687 \\
\hline District of Columbia & 105,037 & 12,681 & 6,879 & 0 & 75,446 & 755 & 820 & 656 & 0 & 7,799 \\
\hline Florida & $3,777,158$ & 643,509 & 361,659 & $2,041,106$ & 3,430 & 182,621 & 122 & 347,172 & 0 & 197,539 \\
\hline Georgia ...... & $2,878,818$ & 442,426 & 283,325 & $1,401,323$ & 22,406 & 143,057 & 3,330 & 254,768 & 250,147 & 78,033 \\
\hline 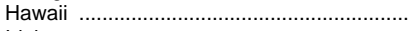 & 560,760 & 66,979 & 113,314 & 291,598 & 637 & 19,665 & 1,886 & 55,775 & 0 & 10,907 \\
\hline 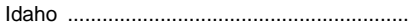 & 545,766 & 95,044 & 66,841 & 246,420 & 11,116 & 22,528 & 11,010 & 62,790 & 0 & 30,016 \\
\hline Illinois & $4,542,868$ & 821,903 & 416,940 & $1,593,582$ & 431,393 & 148,347 & 4,660 & 454,316 & 271,423 & 400,304 \\
\hline 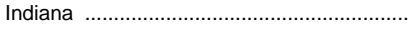 & $2,857,055$ & 707,374 & 245,947 & $1,041,265$ & 2,874 & 132,223 & 6,928 & 510,658 & & 209,785 \\
\hline lowa & $2,231,113$ & 325,677 & 293,127 & 675,733 & 31,053 & 74,743 & 3,358 & 233,981 & 436,158 & 157,282 \\
\hline Kansas ........ & $1,618,071$ & 281,686 & 140,493 & 561,416 & 127,349 & 41,348 & 34,298 & 126,427 & 201,750 & 103,304 \\
\hline Kentucky & $1,881,064$ & 322,127 & 129,500 & 745,011 & 7,571 & 66,550 & 12,450 & 144,610 & 253,189 & 200,055 \\
\hline 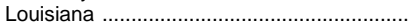 & $1,998,340$ & 385,661 & 141,488 & 749,542 & 15,448 & 55,113 & 4,502 & 228,815 & 158,532 & 259,238 \\
\hline 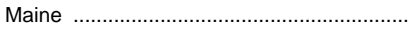 & 413,730 & 98,845 & 38,181 & 176,932 & 150 & 16,287 & 2,680 & 52,369 & 0 & 28,285 \\
\hline Maryland & $2,227,596$ & 559,473 & 262,120 & 793,161 & 140,585 & 84,244 & 6,719 & 265,687 & 0 & 115,607 \\
\hline 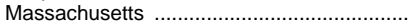 & $1,691,648$ & 498,490 & 153,230 & 724,892 & 10,531 & 48,027 & 1,554 & 183,495 & 6,092 & 65,337 \\
\hline 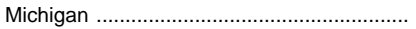 & $6,047,686$ & $1,389,680$ & 624,085 & $1,648,531$ & 233,291 & 320,338 & 38,372 & 631,299 & 868,828 & 293,261 \\
\hline 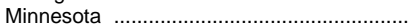 & $2,786,053$ & 484,686 & 290,132 & 994,185 & 2,511 & 213,422 & 7,832 & 267,339 & 369,987 & 155,958 \\
\hline 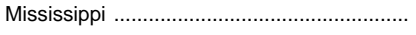 & $1,500,350$ & 221,330 & 161,794 & 621,888 & 35,514 & 37,300 & 1,461 & 153,150 & 205,265 & 62,648 \\
\hline Missouri & $2,100,852$ & 481,379 & 123,550 & 724,349 & 74,785 & 78,092 & 12,692 & 201,668 & 230,915 & 173,421 \\
\hline Montana & 414,843 & 96,889 & 71,519 & 132,339 & 4,124 & 16,976 & 516 & 57,404 & 0 & 35,074 \\
\hline 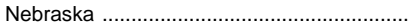 & $1,216,869$ & 152,686 & 132,136 & 393,822 & 59,522 & 53,128 & 3,078 & 129,766 & 244,850 & 47,882 \\
\hline 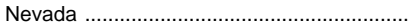 & 492,276 & 81,588 & 55,200 & 244,157 & 6,961 & 25,634 & 2,364 & 43,924 & 0 & 32,449 \\
\hline 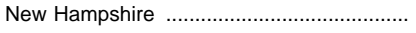 & 412,456 & 163,490 & 38,789 & 87,273 & 2,452 & 20,450 & 2,192 & 80,700 & 0 & 17,111 \\
\hline New Jersey .......................... & $3,189,439$ & 685,731 & 201,708 & $1,207,942$ & 164,063 & 96,628 & 13,225 & 250,677 & 382,962 & 186,502 \\
\hline 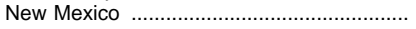 & $1,369,513$ & 117,418 & 248,205 & 463,473 & 49,249 & 69,426 & 12,901 & 87,057 & 227,577 & 94,207 \\
\hline 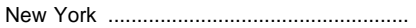 & $6,861,111$ & $1,600,781$ & 516,413 & $2,624,410$ & 465,633 & 272,804 & 13,723 & 417,880 & 793,132 & 156,334 \\
\hline North Carolina & $3,640,049$ & 418,900 & 426,178 & $1,741,318$ & 83,757 & 175,561 & 25,755 & 659,884 & 0 & 108,697 \\
\hline North Dakota ............................................... & 445,128 & 91,813 & 76,171 & 143,788 & 685 & 24,416 & 2,607 & 68,198 & 214 & 37,236 \\
\hline Ohio & $4,982,846$ & $1,364,964$ & 327,456 & $1,599,547$ & 129,006 & 210,341 & 45,987 & 495,799 & 573,353 & 236,391 \\
\hline Oklahoma & $1,382,711$ & 226,452 & 205,622 & 604,725 & 18,836 & 49,509 & 3,209 & 216,990 & 0 & 57,369 \\
\hline 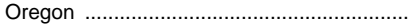 & $1,891,391$ & 337,755 & 255,654 & 478,915 & 99,424 & 121,309 & 2,594 & 177,776 & 312,935 & 105,030 \\
\hline 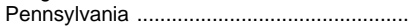 & $5,017,535$ & $1,410,114$ & 513,432 & $1,219,422$ & 86,585 & 220,138 & 40,037 & 498,576 & 779,089 & 250,140 \\
\hline 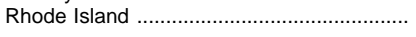 & 354,437 & 115,367 & 43,841 & 127,561 & 0 & 6,071 & 0 & 47,781 & 0 & 13,816 \\
\hline South Carolina & $1,960,481$ & 366,369 & 177,459 & 662,357 & 28,474 & 69,703 & 2,502 & 187,447 & 400,577 & 65,594 \\
\hline South Dakota & 297,342 & 72,112 & 38,370 & 121,145 & 2,376 & 9,993 & 1,151 & 30,177 & 0 & 22,018 \\
\hline Tennessee & $2,111,127$ & 333,262 & 172,386 & 891,501 & 14,777 & 100,752 & 14,821 & 182,183 & 305,736 & 95,708 \\
\hline Texas & $8,779,578$ & $1,328,120$ & 898,808 & $3,742,170$ & 433,667 & 372,938 & 160,923 & 567,359 & 286,429 & 989,165 \\
\hline 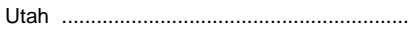 & $1,489,664$ & 196,963 & 188,104 & 437,418 & 32,240 & 48,841 & 11,984 & 116,519 & 267,239 & 190,356 \\
\hline Vermont & 341,988 & 149,199 & 40,785 & 48,474 & 62 & 26,920 & 4,897 & 39,035 & 0 & 32,617 \\
\hline Virginia & $3,609,275$ & 778,303 & 303,202 & 927,914 & 12,048 & 190,137 & 34,584 & 486,855 & 799,000 & 77,233 \\
\hline 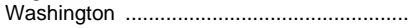 & $3,040,757$ & 541,393 & 496,527 & $1,041,168$ & 25,093 & 154,670 & 11,829 & 350,611 & 264,081 & 155,386 \\
\hline West Virginia . & 734,283 & 177,456 & 72,994 & 344,360 & 1,770 & 28,346 & 0 & 84,657 & 0 & 24,699 \\
\hline Wisconsin & $3,108,030$ & 554,169 & 360,387 & 948,994 & 278,032 & 158,991 & 15,574 & 239,038 & 305,214 & 247,631 \\
\hline Wyoming …….............................................. & 298,526 & 42,089 & 34,314 & 132,929 & 14,668 & 22,625 & 3,496 & 39,267 & & 9,138 \\
\hline U.S. Service Schools .... & $1,361,895$ & 574 & $1,203,873$ & 0 & 0 & 11,722 & 0 & 76,294 & 69,432 & 0 \\
\hline Outlying areas & 831,925 & 83,717 & 64,402 & 609,894 & 24,245 & 10,868 & 1,824 & 14,287 & 0 & 22,686 \\
\hline American Samoa & 13,880 & 807 & 891 & 1,663 & 9,443 & 0 & 0 & 235 & 0 & 841 \\
\hline Federated States of & & & & & & & & & & \\
\hline Micronesia & 8,496 & 2,788 & 1,869 & 67 & 2,978 & 239 & 0 & 499 & 0 & 55 \\
\hline Guam & 65,710 & 7,441 & 5,897 & 34,284 & 10,118 & 1,057 & 1,445 & 2,648 & 0 & 2,819 \\
\hline 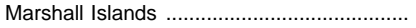 & 1,685 & 540 & 715 & 324 & 0 & 12 & 13 & 69 & 0 & 12 \\
\hline Northern Marianas ……..................................... & 15,792 & 2,058 & 3,943 & 9,477 & 16 & 15 & 0 & 0 & 0 & 283 \\
\hline Palau & 3,900 & 937 & 600 & 2,040 & 0 & 0 & 0 & 203 & 0 & 119 \\
\hline Puerto Rico & 686,792 & 63,757 & 45,451 & 544,143 & 67 & 8,014 & 113 & 7,006 & 0 & 18,241 \\
\hline Virgin Islands ......................... & 35,669 & 5,389 & 5,035 & 17,896 & 1,623 & 1,530 & 253 & 3,627 & 0 & 316 \\
\hline
\end{tabular}

\footnotetext{
${ }^{1}$ Preliminary data. ters).
}

SOURCE: U.S. Department of Education, National Center for Education Statistics, Integrated Postsecondary Education Data System (IPEDS), "Finance" survey. (This table was prepared October 1998.)

NOTE.-Because of rounding, details may not add to totals. 
Table 332.-Current-fund revenue of public institutions of higher education, by source of funds and state: 1994-95 [In thousands of dollars]

\begin{tabular}{|c|c|c|c|c|c|c|c|c|c|c|}
\hline State & Total & $\begin{array}{l}\text { Tuition } \\
\text { and } \\
\text { fees }\end{array}$ & $\begin{array}{c}\text { Federal } \\
\text { appropri- } \\
\text { ations, } \\
\text { grants, } \\
\text { and } \\
\text { contracts }{ }^{1}\end{array}$ & $\begin{array}{c}\text { State } \\
\text { appropri- } \\
\text { ations, } \\
\text { grants, } \\
\text { and } \\
\text { contracts }\end{array}$ & $\begin{array}{l}\text { Local } \\
\text { appropri- } \\
\text { ations, } \\
\text { grants, } \\
\text { and } \\
\text { contracts }\end{array}$ & $\begin{array}{l}\text { Private } \\
\text { gifts, } \\
\text { grants, and } \\
\text { contracts }\end{array}$ & $\begin{array}{l}\text { Endow- } \\
\text { ment } \\
\text { income }\end{array}$ & $\begin{array}{l}\text { Auxiliary } \\
\text { enterprises }\end{array}$ & Hospitals & $\begin{array}{l}\text { Educational } \\
\text { activities } \\
\text { and other }\end{array}$ \\
\hline 1 & 2 & 3 & 4 & 5 & 6 & 7 & 8 & 9 & 10 & 11 \\
\hline United States & $\$ 119,312,493$ & $\$ 21,908,104$ & $\$ 13,191,843$ & $\$ 42,854,681$ & $\$ 4,756,884$ & $\$ 4,737,529$ & $\$ 693,313$ & $\$ 11,373,646$ & $\$ 12,527,982$ & $\$ 7,268,511$ \\
\hline Alabama & $2,805,154$ & 394,846 & 288,564 & 932,269 & 12,827 & 108,873 & 20,115 & 196,402 & 688,581 & 162,677 \\
\hline Alaska ... & 344,877 & 44,282 & 53,125 & 183,183 & 1,484 & 8,751 & 4,424 & 20,965 & 0 & 28,663 \\
\hline 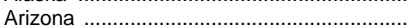 & $1,931,523$ & 417,437 & 289,468 & 677,981 & 207,387 & 94,965 & 4,951 & 172,181 & 0 & 67,154 \\
\hline Arkansas .......................... & $1,113,954$ & 157,945 & 88,617 & 428,995 & 4,836 & 28,841 & 1,561 & 91,823 & 262,342 & 48,995 \\
\hline 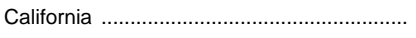 & $14,558,144$ & $1,925,425$ & $1,488,730$ & $5,136,791$ & $1,436,249$ & 467,666 & 93,966 & 977,893 & $1,786,356$ & $1,245,068$ \\
\hline Colorado & $1,914,233$ & 529,501 & 361,312 & 513,024 & 31,058 & 93,448 & 7,550 & 242,308 & 21,697 & 114,336 \\
\hline Connecticut & $1,148,389$ & 240,963 & 73,453 & 483,674 & 3 & 28,729 & 29 & 85,554 & 188,246 & 47,738 \\
\hline Delaware ... & 496,696 & 168,566 & 45,589 & 144,038 & 6,404 & 18,424 & 19,594 & 63,401 & 0 & 30,680 \\
\hline District of Columbia & 103,770 & 10,834 & 7,198 & 0 & 76,822 & 509 & 745 & 686 & 0 & 6,976 \\
\hline 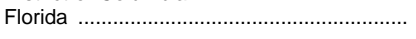 & $3,584,085$ & 630,396 & 334,083 & $1,945,909$ & 9,406 & 170,314 & 451 & 339,537 & 0 & 153,988 \\
\hline Georgia & $2,760,323$ & 421,658 & 259,024 & $1,353,550$ & 24,990 & 142,696 & 3,383 & 234,879 & 243,834 & 76,310 \\
\hline Hawaii .. & 651,282 & 49,393 & 118,703 & 400,248 & 866 & 15,809 & 1,907 & 55,564 & 0 & 8,792 \\
\hline Idaho & 492,918 & 81,763 & 40,966 & 233,397 & 10,199 & 24,089 & 8,526 & 61,439 & 0 & 32,540 \\
\hline Illinois & $4,360,136$ & 785,264 & 411,547 & $1,526,511$ & 415,509 & 128,261 & 4,540 & 439,042 & 290,289 & 359,172 \\
\hline 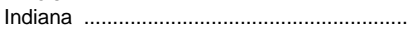 & $3,080,345$ & 667,290 & 245,079 & 997,241 & 2,485 & 131,184 & 8,592 & 505,492 & 337,027 & 185,956 \\
\hline lowa & $2,106,504$ & 306,259 & 291,733 & 644,529 & 28,206 & 67,431 & 1,189 & 211,661 & 408,107 & 147,390 \\
\hline 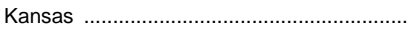 & $1,553,593$ & 270,928 & 136,406 & 534,983 & 123,932 & 35,890 & 33,176 & 126,387 & 205,404 & 86,487 \\
\hline Kentucky & $1,778,568$ & 308,502 & 126,816 & 723,541 & 6,689 & 43,558 & 10,457 & 140,923 & 254,025 & 164,056 \\
\hline 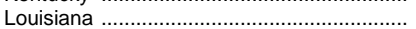 & $1,968,669$ & 361,178 & 131,191 & 722,746 & 4,842 & 52,884 & 3,788 & 215,840 & 233,197 & 243,002 \\
\hline 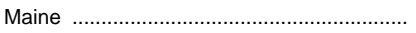 & 400,426 & 95,166 & 37,732 & 170,016 & 54 & 14,937 & 2,409 & 52,293 & 0 & 27,819 \\
\hline Maryland & $2,074,521$ & 533,817 & 231,506 & 746,749 & 135,183 & 84,204 & 5,402 & 245,288 & 0 & 92,372 \\
\hline Massachusetts & $1,586,319$ & 489,187 & 146,036 & 657,970 & 7,640 & 47,221 & 2,901 & 169,164 & 6,253 & 59,947 \\
\hline 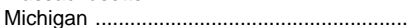 & $5,798,882$ & $1,324,433$ & 576,638 & $1,549,814$ & 270,342 & 280,757 & 31,474 & 789,543 & 693,849 & 282,031 \\
\hline Minnesota & $2,671,566$ & 452,163 & 281,445 & 944,101 & 12,140 & 204,456 & 10,967 & 228,265 & 349,949 & 188,079 \\
\hline 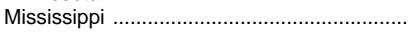 & $1,443,162$ & 211,749 & 167,756 & 577,021 & 33,999 & 41,484 & 917 & 154,065 & 193,866 & 62,305 \\
\hline Missouri .. & $1,978,783$ & 445,292 & 116,570 & 672,581 & 70,403 & 77,159 & 11,273 & 191,918 & 225,693 & 167,896 \\
\hline 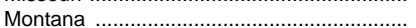 & 385,984 & 83,962 & 65,963 & 127,456 & 5,349 & 14,694 & 260 & 55,565 & 0 & 32,736 \\
\hline 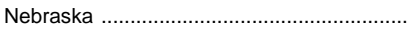 & $1,124,836$ & 143,020 & 123,956 & 376,415 & 55,893 & 54,094 & 3,656 & 116,648 & 207,068 & 44,087 \\
\hline Nevada & 484,276 & 74,680 & 52,260 & 245,977 & 6,989 & 27,855 & 1,468 & 46,037 & 0 & 29,010 \\
\hline 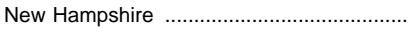 & 391,619 & 158,519 & 37,003 & 85,739 & 2,200 & 17,933 & 2,178 & 72,833 & 0 & 15,214 \\
\hline New Jersey & $3,106,652$ & 638,453 & 200,184 & $1,178,646$ & 166,050 & 93,456 & 11,405 & 236,490 & 412,290 & 169,677 \\
\hline 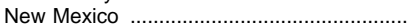 & $1,316,934$ & 111,777 & 248,072 & 435,562 & 45,947 & 60,926 & 12,343 & 91,238 & 232,906 & 78,162 \\
\hline New York & $6,887,321$ & $1,353,229$ & 511,853 & $2,936,415$ & 400,559 & 268,175 & 16,413 & 411,486 & 821,039 & 168,152 \\
\hline North Carolina …… & $3,521,601$ & 395,357 & 410,645 & $1,719,471$ & 80,338 & 160,493 & 24,455 & 568,919 & 0 & 161,922 \\
\hline North Dakota ........................................ & 467,926 & 90,081 & 69,312 & 152,737 & 10,617 & 9,330 & 2,647 & 84,185 & 13,076 & 35,941 \\
\hline Ohio & $4,976,134$ & $1,316,933$ & 338,914 & $1,496,777$ & 106,878 & 210,032 & 43,812 & 469,762 & 772,301 & 220,725 \\
\hline Oklahoma & $1,300,779$ & 212,190 & 182,377 & 588,246 & 16,827 & 46,596 & 2,463 & 206,153 & 0 & 45,927 \\
\hline Oregon .............. & $1,816,031$ & 310,600 & 263,044 & 480,700 & 108,039 & 83,535 & 5,226 & 166,731 & 311,672 & 86,484 \\
\hline Pennsylvania .... & $4,684,460$ & $1,337,745$ & 504,383 & $1,185,305$ & 86,983 & 187,252 & 37,900 & 476,893 & 679,862 & 188,138 \\
\hline 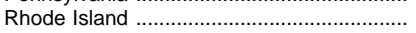 & 344,171 & 113,798 & 40,573 & 123,733 & 0 & 4,928 & 0 & 47,155 & 0 & 13,984 \\
\hline South Carolina ................. & $1,997,203$ & 349,249 & 177,590 & 632,927 & 25,902 & 73,937 & 2,718 & 182,026 & 492,824 & 60,029 \\
\hline South Dakota .. & 260,853 & 61,618 & 35,396 & 104,922 & 17 & 8,661 & 1,038 & 31,226 & 0 & 17,974 \\
\hline Tennessee …1. & $2,053,495$ & 316,665 & 177,565 & 867,689 & 14,391 & 91,514 & 14,222 & 173,029 & 304,376 & 94,043 \\
\hline Texas ........... & $8,123,435$ & $1,173,143$ & 833,823 & $3,444,421$ & 337,615 & 343,462 & 140,806 & 548,766 & 269,625 & $1,031,775$ \\
\hline 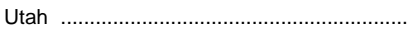 & $1,402,962$ & 185,596 & 178,645 & 414,059 & 26,961 & 39,222 & 10,343 & 111,192 & 256,821 & 180,124 \\
\hline Vermont & 329,679 & 141,177 & 39,285 & 47,322 & 114 & 26,386 & 4,785 & 37,632 & 0 & 32,979 \\
\hline Virginia & $3,483,691$ & 759,433 & 304,650 & 920,807 & 27,942 & 169,963 & 30,181 & 445,412 & 755,757 & 69,546 \\
\hline Washington & $2,877,386$ & 512,285 & 472,037 & 988,475 & 19,136 & 141,288 & 11,783 & 353,953 & 246,295 & 132,135 \\
\hline West Virginia …1. & 693,159 & 175,146 & 66,256 & 326,596 & 2,012 & 18,004 & 0 & 84,271 & 0 & 20,874 \\
\hline 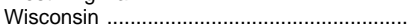 & $3,033,547$ & 527,641 & 361,851 & 945,078 & 261,078 & 145,071 & 16,156 & 230,519 & 306,372 & 239,782 \\
\hline Wyoming & 293,209 & 40,987 & 37,985 & 128,346 & 15,093 & 20,514 & 2,768 & 38,853 & 0 & 8,662 \\
\hline U.S. Service Schools & $1,248,328$ & 583 & $1,108,932$ & 0 & 0 & 7,667 & 0 & 74,163 & 56,982 & 0 \\
\hline Outlying areas & 750,676 & 75,136 & 65,845 & 548,747 & 19,394 & 8,397 & 750 & 12,892 & 0 & 19,515 \\
\hline American Samoa & 4,817 & 81 & 2,114 & 2,622 & 0 & 0 & 0 & 0 & 0 & 0 \\
\hline Federated States of Micronesia ...................... & 6,517 & 3,061 & 299 & 50 & 2,470 & 70 & 8 & 506 & 0 & 53 \\
\hline 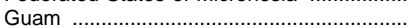 & 71,873 & 6,947 & 7,095 & 39,743 & 11,761 & 896 & 509 & 2,759 & 0 & 2,162 \\
\hline Marshall Islands ………...................................... & 1,633 & 521 & 697 & 313 & 0 & 11 & 12 & 67 & 0 & 11 \\
\hline Northern Marianas …................................. & 12,174 & 2,357 & 3,020 & 6,388 & 146 & 0 & 0 & 38 & 0 & 225 \\
\hline Palau & 4,083 & 781 & 522 & 1,993 & 0 & 0 & 0 & 598 & 0 & 189 \\
\hline 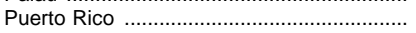 & 615,912 & 56,847 & 47,348 & 480,551 & 2,680 & 5,807 & 0 & 6,148 & 0 & 16,532 \\
\hline 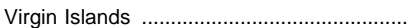 & 33,668 & 4,542 & 4,750 & 17,087 & 2,336 & 1,613 & 220 & 2,777 & 0 & 343 \\
\hline
\end{tabular}

${ }^{1}$ Includes independent operations (federally funded research and development centers).

NOTE.-Because of rounding, details may not add to totals.
SOURCE: U.S. Department of Education, National Center for Education Statistics, Integrated Postsecondary Education Data System (IPEDS), "Finance" survey. (This table was prepared July 1997.) 
Table 333.-Current-fund revenue from state and local governments of institutions of higher education and degreegranting institutions, by state: $1985-86$ to $1995-96$

[In thousands]

\begin{tabular}{|c|c|c|c|c|c|c|c|c|c|c|c|}
\hline \multirow[b]{2}{*}{ State } & \multicolumn{5}{|c|}{$\begin{array}{l}\text { Current-fund revenue from state and local governments for institu- } \\
\text { tions of higher education }\end{array}$} & \multicolumn{6}{|c|}{$\begin{array}{c}\text { Current-fund revenue from state and local governments for degree-granting insti- } \\
\text { tutions, } 1995-96^{2}\end{array}$} \\
\hline & 1985-86 & $1990-91$ & $1993-94$ & 1994-95 & $1995-96^{1}$ & Total & $\begin{array}{c}\text { State appro- } \\
\text { priations for } \\
\text { public insti- } \\
\text { tutions }\end{array}$ & $\begin{array}{c}\text { Local ap- } \\
\text { propriations } \\
\text { for public in- } \\
\text { stitutions }\end{array}$ & $\begin{array}{c}\text { State and } \\
\text { local appro- } \\
\text { priations for } \\
\text { private insti- } \\
\text { tutions }\end{array}$ & $\begin{array}{l}\text { State and } \\
\text { local grants } \\
\text { and con- } \\
\text { tracts for } \\
\text { public insti- } \\
\text { tutions }\end{array}$ & $\begin{array}{l}\text { State and } \\
\text { local grants } \\
\text { and con- } \\
\text { tracts for } \\
\text { private insti- } \\
\text { tutions }\end{array}$ \\
\hline 1 & 2 & 3 & 4 & 5 & 6 & 7 & 8 & 9 & 10 & 11 & 12 \\
\hline United States $^{3}$ & $\$ 32,456,006$ & $\$ 43,412,081$ & $\$ 46,908,594$ & $\$ 49,508,974$ & $\$ 51,211,615$ & $\$ 51,300,582$ & $\$ 40,081,437$ & $\$ 4,397,098$ & $\$ 245,507$ & $\$ 4,838,522$ & $\$ 1,738,018$ \\
\hline Alabama & 656,823 & 758,900 & 849,967 & 956,058 & 932,994 & 933,041 & 879,680 & 4,736 & 4,804 & 39,178 & 4,643 \\
\hline Alaska .......................... & 159,781 & 175,938 & 186,305 & 184,683 & 186,469 & 186,469 & 171,580 & 693 & 0 & 14,190 & 5 \\
\hline Arizona ................ & 539,054 & 768,654 & 817,274 & 885,484 & 941,265 & 947,411 & 691,335 & 217,426 & 0 & 37,057 & 1,594 \\
\hline Arkansas . & 266,898 & 332,367 & 415,536 & 436,261 & 468,365 & 487,917 & 437,257 & 2,524 & 0 & 45,764 & 2,373 \\
\hline 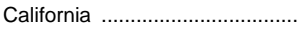 & $4,943,659$ & $6,628,037$ & $6,411,115$ & $6,620,028$ & $6,941,662$ & $6,954,655$ & $4,811,297$ & $1,353,630$ & 337 & 738,796 & 50,596 \\
\hline Colorado ... & 391,468 & 510,649 & 521,088 & 550,059 & 601,294 & 601,791 & 497,663 & 28,786 & 0 & 67,876 & 7,466 \\
\hline Connecticut & 280,012 & 406,306 & 411,711 & 517,270 & 519,140 & 518,510 & 462,183 & 0 & 5,886 & 23,350 & 27,091 \\
\hline …………..... & 88,661 & 124,881 & 140,191 & 150,656 & 154,637 & 154,637 & 107,968 & 12,379 & 0 & 34,061 & 229 \\
\hline District of Columbia ....................... & 71,761 & 84,471 & 77,727 & 81,762 & 77,794 & 79,705 & 0 & 68,257 & 0 & 7,189 & 4,259 \\
\hline Florida & $1,172,112$ & $1,863,133$ & $1,942,724$ & $2,071,336$ & $2,178,675$ & $2,168,310$ & $1,898,618$ & 116 & 15,192 & 145,801 & 108,583 \\
\hline Georgia & 689,379 & $1,001,889$ & $1,242,527$ & $1,419,447$ & $1,560,494$ & $1,469,948$ & $1,254,216$ & 17,371 & 8,470 & 152,142 & 37,748 \\
\hline Hawaii . & 195,375 & 321,195 & 400,980 & 401,145 & 292,299 & 292,299 & 280,503 & & 0 & 11,733 & 63 \\
\hline Idaho .... & 125,338 & 193,188 & 218,399 & 244,514 & 252,641 & 257,596 & 223,108 & 10,435 & 0 & 23,993 & 60 \\
\hline Illinois ........ & $1,405,622$ & $1,855,023$ & $1,931,481$ & $2,064,998$ & $2,152,959$ & $2,153,129$ & $1,161,833$ & 418,269 & 0 & 444,872 & 128,154 \\
\hline 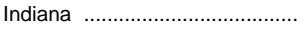 & 645,880 & 984,176 & $1,019,058$ & $1,026,788$ & $1,074,213$ & $1,074,383$ & 977,517 & 2,831 & 0 & 63,791 & 30,244 \\
\hline lowa & 431,840 & 599,407 & 673,738 & 697,177 & 727,973 & 729,291 & 649,901 & 29,098 & 0 & 27,787 & 22,505 \\
\hline Kansas ... & 422,278 & 556,372 & 630,158 & 662,454 & 686,794 & 693,030 & 528,243 & 117,684 & 0 & 42,838 & 4,264 \\
\hline 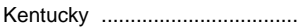 & 483,027 & 665,808 & 705,050 & 737,954 & 759,829 & 759,701 & 690,328 & 6,041 & 0 & 56,213 & 7,119 \\
\hline Louisiana .................. & 562,205 & 634,541 & 683,174 & 756,642 & 731,129 & 777,333 & 603,825 & 8,061 & 2,487 & 153,105 & 9,856 \\
\hline 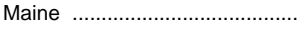 & 103,724 & 189,099 & 178,079 & 171,750 & 177,300 & 178,795 & 158,044 & 27 & 0 & 19,012 & 1,712 \\
\hline Maryland & 631,471 & 943,620 & 898,788 & 924,547 & 979,175 & 979,175 & 717,377 & 136,661 & 30,213 & 79,708 & 15,216 \\
\hline Massachusetts & 589,876 & 545,606 & 639,251 & 700,546 & 768,557 & 773,902 & 669,102 & 1,779 & 4,525 & 64,542 & 33,955 \\
\hline Michigan .............. & $1,215,291$ & $1,589,630$ & $1,769,771$ & $1,866,604$ & $1,926,437$ & $1,926,437$ & $1,572,241$ & 215,733 & 7,590 & 93,848 & 37,025 \\
\hline 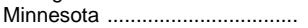 & 533,573 & 818,117 & 956,836 & 982,180 & $1,016,743$ & $1,022,884$ & 901,114 & 0 & 74 & 95,582 & 26,114 \\
\hline 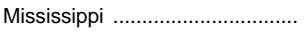 & 362,517 & 419,177 & 471,136 & 611,482 & 651,102 & 658,887 & 570,035 & 31,725 & 0 & 55,642 & 1,485 \\
\hline Missouri & 506,246 & 651,819 & 685,610 & 751,150 & 805,954 & 807,597 & 669,832 & 72,895 & 0 & 56,407 & 8,463 \\
\hline Montana & 97,672 & 119,813 & 136,263 & 133,066 & 136,988 & 136,988 & 121,730 & 3,526 & 0 & 11,208 & 524 \\
\hline 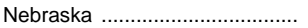 & 248,544 & 374,112 & 419,798 & 432,997 & 456,602 & 456,809 & 382,465 & 53,004 & 0 & 17,875 & 3,465 \\
\hline Nevada .......................... & 99,841 & 173,580 & 208,216 & 252,977 & 251,125 & 251,136 & 223,413 & 0 & 0 & 27,704 & 19 \\
\hline 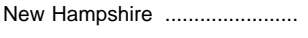 & 52,393 & 79,979 & 90,950 & 95,768 & 97,170 & 97,170 & 79,376 & 0 & 0 & 10,348 & 7,446 \\
\hline New Jersey & 837,214 & $1,190,657$ & $1,359,960$ & $1,409,358$ & $1,441,939$ & $1,441,937$ & $1,045,117$ & 156,011 & 3,327 & 170,877 & 66,605 \\
\hline 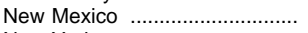 & 221,094 & 413,558 & 431,098 & 482,860 & 507,945 & 515,083 & 413,344 & 42,363 & 0 & 57,014 & 2,362 \\
\hline New York ......... & $2,726,150$ & $3,421,222$ & $3,893,354$ & $3,982,026$ & $3,746,100$ & $3,746,940$ & $2,202,186$ & 405,160 & 41,920 & 482,696 & 614,976 \\
\hline 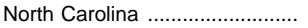 & $1,074,960$ & $1,633,096$ & $1,746,867$ & $1,852,503$ & $1,881,020$ & $1,881,041$ & $1,686,718$ & 79,490 & 1,607 & 58,867 & 54,360 \\
\hline 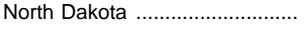 & 118,691 & 133,796 & 136,744 & 163,593 & 144,751 & 144,751 & 138,785 & 170 & 0 & 5,518 & 278 \\
\hline Ohio .. & $1,132,678$ & $1,541,996$ & $1,553,389$ & $1,659,566$ & $1,786,481$ & $1,791,873$ & $1,488,806$ & 120,161 & 5,736 & 119,586 & 57,583 \\
\hline 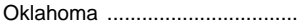 & 437,693 & 535,024 & 580,522 & 606,743 & 625,298 & 625,273 & 536,307 & 18,578 & 0 & 68,676 & 1,712 \\
\hline 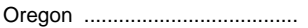 & 394,899 & 544,631 & 571,448 & 592,624 & 581,381 & 581,437 & 442,603 & 82,282 & 0 & 53,454 & 3,098 \\
\hline 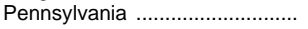 & 961,089 & $1,276,665$ & $1,379,619$ & $1,508,534$ & $1,552,669$ & $1,564,432$ & $1,110,896$ & 78,912 & 66,146 & 116,199 & 192,279 \\
\hline Rhode Island ......................................... & 107,265 & 123,502 & 117,735 & 125,567 & 129,286 & 129,286 & 121,153 & & 0 & 6,408 & 1,725 \\
\hline South Carolina . & 491,802 & 618,304 & 631,482 & 669,239 & 703,837 & 703,837 & 647,111 & 25,737 & 0 & 17,982 & 13,007 \\
\hline South Dakota ................................ & 65,151 & 86,262 & 106,452 & 105,197 & 109,075 & 123,707 & 105,090 & 957 & 0 & 17,473 & 186 \\
\hline Tennessee ........ & 528,933 & 711,103 & 824,936 & 898,678 & 922,486 & 922,904 & 850,110 & 2,113 & 1,476 & 54,055 & 15,150 \\
\hline Texas & $2,521,860$ & $3,069,099$ & $3,783,870$ & $3,895,369$ & $4,296,038$ & $4,299,323$ & $3,302,958$ & 280,141 & 33,490 & 592,738 & 89,995 \\
\hline 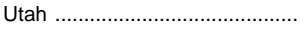 & 256,997 & 346,711 & 402,523 & 441,726 & 470,613 & 470,673 & 414,407 & 0 & 0 & 55,251 & 1,015 \\
\hline Vermont .. & 35,334 & 48,485 & 49,586 & 49,432 & 57,909 & 57,909 & 42,400 & 62 & 0 & 6,074 & 9,373 \\
\hline Virginia .. & 775,474 & 961,845 & 914,056 & 977,099 & 967,358 & 967,313 & 839,587 & 1,282 & 12,228 & 99,093 & 15,123 \\
\hline 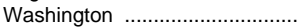 & 620,383 & 915,462 & $1,023,612$ & $1,009,039$ & $1,044,083$ & $1,067,489$ & 914,200 & 100 & 0 & 151,961 & 1,228 \\
\hline 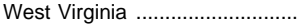 & 222,693 & 280,199 & 316,565 & 329,313 & 346,867 & 347,179 & 320,198 & 693 & 0 & 25,240 & 1,049 \\
\hline Wisconsin & 825,610 & $1,053,246$ & $1,213,191$ & $1,219,284$ & $1,241,107$ & $1,241,665$ & 937,513 & 275,712 & 0 & 13,800 & 14,639 \\
\hline 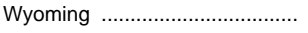 & 127,714 & 137,727 & 138,684 & 143,439 & 147,597 & 147,597 & 130,162 & 13,489 & 0 & 3,945 & 0 \\
\hline
\end{tabular}

1 Preliminary data.

2 Preliminary data are for 4-year and 2-year degree-granting institutions that were eligible to participate in Title IV federal financial aid programs.

${ }^{3}$ Excludes U.S. Service Schools.

NOTE.-Because of rounding, details may not add to totals.
SOURCE: U.S. Department of Education, National Center for Education Statistics, Higher Education General Information Survey (HEGIS), "Financial Statistics of Institutions of Higher Education" surveys; and Integrated Postsecondary Education Data System (IPEDS), "Finance" surveys. (This table was prepared October 1998.) 
Table 334.-Current-fund revenue received from the federal government by the 120 institutions of higher education receiving the largest amounts: 1995-96

[In thousands]

\begin{tabular}{|c|c|c|c|c|c|}
\hline Institution & $\begin{array}{l}\text { Rank } \\
\text { order }\end{array}$ & $\begin{array}{l}\text { Current-fund } \\
\text { revenue from } \\
\text { the federal } \\
\text { government }{ }^{1}\end{array}$ & Institution & $\begin{array}{l}\text { Rank } \\
\text { order }\end{array}$ & $\begin{array}{c}\text { Current- } \\
\text { fund reve- } \\
\text { nue from } \\
\text { the federal } \\
\text { govern- } \\
\text { ment }^{1}\end{array}$ \\
\hline 1 & 2 & 3 & 1 & 2 & 3 \\
\hline United States (all institutions) & - & $\$ 23,939,075$ & & & \\
\hline 120 institutions receiving the largest amounts ..... & - & $17,749,174$ & & & \\
\hline 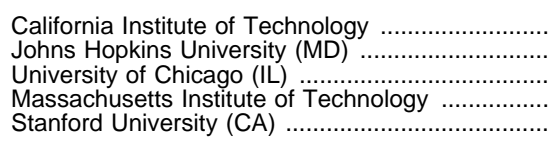 & $\begin{array}{l}1 \\
2 \\
3 \\
4 \\
5\end{array}$ & $\begin{array}{r}1,222,384 \\
817,287 \\
700,181 \\
608,625 \\
462,069\end{array}$ & 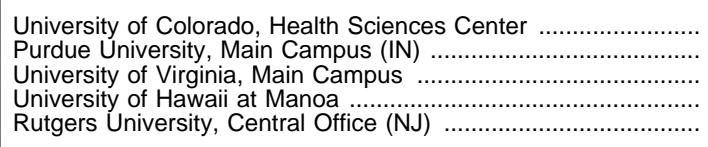 & $\begin{array}{l}61 \\
62 \\
63 \\
64 \\
65\end{array}$ & $\begin{array}{r}101,937 \\
100,898 \\
96,302 \\
93,741 \\
92,856\end{array}$ \\
\hline 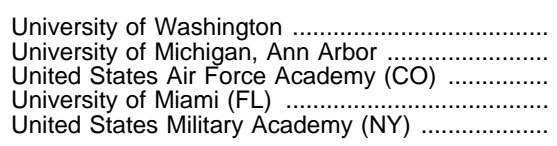 & $\begin{array}{r}6 \\
7 \\
8 \\
9 \\
10\end{array}$ & $\begin{array}{l}380,684 \\
320,239 \\
305,640 \\
286,948 \\
283,007\end{array}$ & 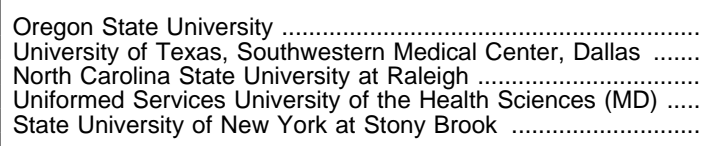 & $\begin{array}{l}66 \\
67 \\
68 \\
69 \\
70\end{array}$ & $\begin{array}{l}91,603 \\
88,857 \\
88,477 \\
88,464 \\
84,467\end{array}$ \\
\hline 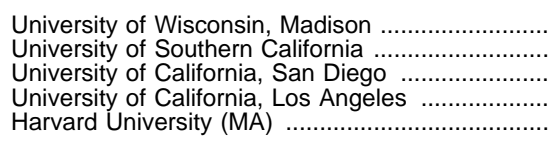 & $\begin{array}{l}11 \\
12 \\
13 \\
14 \\
15\end{array}$ & $\begin{array}{l}273,630 \\
272,429 \\
272,426 \\
259,647 \\
259,419\end{array}$ & 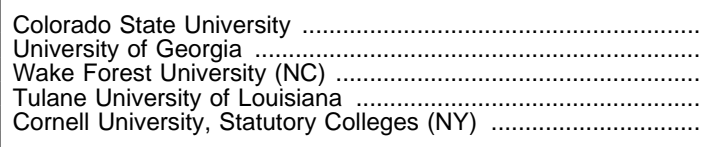 & $\begin{array}{l}71 \\
72 \\
73 \\
74 \\
75\end{array}$ & $\begin{array}{l}83,481 \\
82,148 \\
81,458 \\
76,650 \\
73,773\end{array}$ \\
\hline 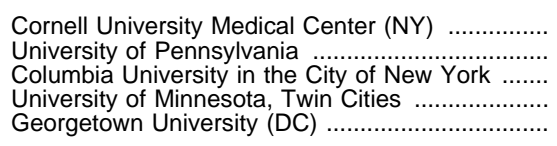 & $\begin{array}{l}16 \\
17 \\
18 \\
19 \\
20\end{array}$ & $\begin{array}{l}254,693 \\
248,881 \\
239,546 \\
238,092 \\
236,866\end{array}$ & 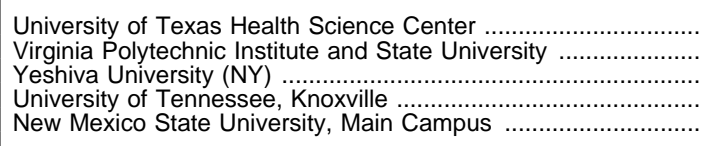 & $\begin{array}{l}76 \\
77 \\
78 \\
79 \\
80\end{array}$ & $\begin{array}{l}73,391 \\
73,340 \\
71,317 \\
71,192 \\
70,316\end{array}$ \\
\hline 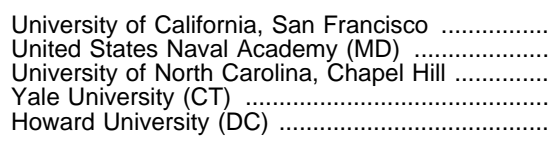 & $\begin{array}{l}21 \\
22 \\
23 \\
24 \\
25\end{array}$ & $\begin{array}{l}231,890 \\
228,590 \\
216,635 \\
202,483 \\
198,855\end{array}$ & 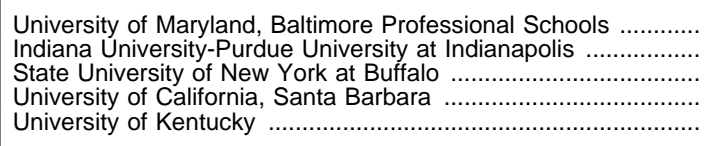 & $\begin{array}{l}81 \\
82 \\
83 \\
84 \\
85\end{array}$ & $\begin{array}{l}69,642 \\
69,165 \\
68,885 \\
68,610 \\
67,429\end{array}$ \\
\hline 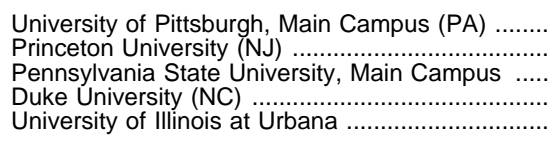 & $\begin{array}{l}26 \\
27 \\
28 \\
29 \\
30\end{array}$ & $\begin{array}{l}195,479 \\
192,874 \\
188,380 \\
187,672 \\
185,539\end{array}$ & 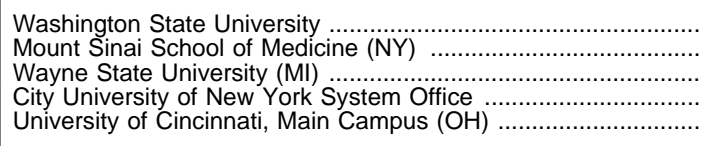 & $\begin{array}{l}86 \\
87 \\
88 \\
89 \\
90\end{array}$ & $\begin{array}{l}65,672 \\
65,242 \\
65,175 \\
64,511 \\
64,317\end{array}$ \\
\hline 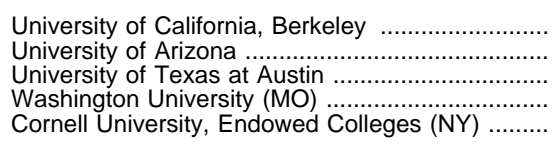 & $\begin{array}{l}31 \\
32 \\
33 \\
34 \\
35\end{array}$ & & 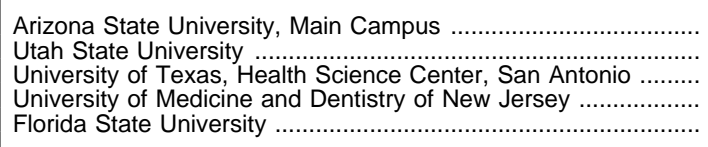 & $\begin{array}{l}91 \\
92 \\
93 \\
94 \\
95\end{array}$ & $\begin{array}{l}62,487 \\
61,984 \\
60,550 \\
59,543 \\
59,278\end{array}$ \\
\hline $\begin{array}{l}\text { University of Alabama at Birmingham ................... } \\
\text { Ohio State University, Main Campus .................. } \\
\text { University of lowa } \\
\text { Carnegie Mellon University (PA........................... } \\
\text { Georgia Institute of Technology, Main Campus ... }\end{array}$ & $\begin{array}{l}36 \\
37 \\
38 \\
39 \\
40\end{array}$ & $\begin{array}{l}147,204 \\
140,525 \\
138,791 \\
134,210 \\
131,260\end{array}$ & $\begin{array}{l}\text { Virginia Commonwealth University } \\
\text { Rush University (IL) } \\
\text { University of Massachusetts, Amherst } \\
\text { Gallaudet University (DC) } \\
\text { Thomas Jefferson University (PA) }\end{array}$ & $\begin{array}{r}96 \\
97 \\
98 \\
99 \\
100\end{array}$ & $\begin{array}{l}58,066 \\
57,999 \\
57,283 \\
56,475\end{array}$ \\
\hline $\begin{array}{l}\text { lorado at Boulder } \\
\text { w Mexico, Main Campus ................ } \\
\text { uate School (CA) } \\
\text { Reserve University (OH) } \\
\text { ersity }\end{array}$ & $\begin{array}{l}41 \\
42 \\
43 \\
44 \\
45\end{array}$ & $\begin{array}{l}129,225 \\
126,582 \\
126,176 \\
123,802 \\
120,969\end{array}$ & 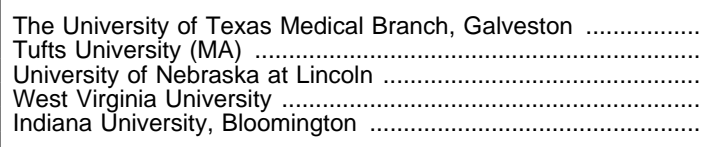 & $\begin{array}{l}101 \\
102 \\
103 \\
104 \\
105\end{array}$ & $\begin{array}{l}55,805 \\
55,611 \\
55,571 \\
53,928 \\
53,619\end{array}$ \\
\hline ity & $\begin{array}{l}46 \\
47 \\
48 \\
49 \\
50\end{array}$ & $\begin{array}{l}974 \\
234 \\
653 \\
837 \\
069\end{array}$ & 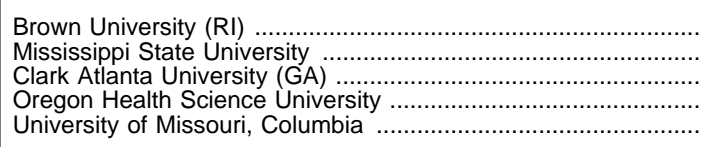 & $\begin{array}{l}106 \\
107 \\
108 \\
109 \\
110\end{array}$ & $\begin{array}{l}53,051 \\
53,017 \\
52,762 \\
48,150 \\
48,141\end{array}$ \\
\hline $\begin{array}{l}\text { rsity } \\
\text { (GA) } \\
\text { ryland, College Park Campus ..... } \\
\text { rsity (TN) } \\
\text { y (MA) }\end{array}$ & $\begin{array}{l}51 \\
52 \\
53 \\
54\end{array}$ & $\begin{array}{l}113,818 \\
113,493 \\
113,009 \\
112,906 \\
108,349\end{array}$ & 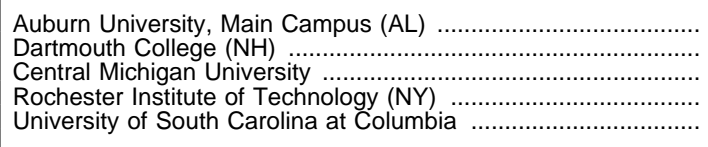 & $\begin{array}{l}111 \\
112 \\
113 \\
114 \\
115\end{array}$ & $\begin{array}{l}48,047 \\
47,817 \\
47,661 \\
47,429 \\
46,963\end{array}$ \\
\hline 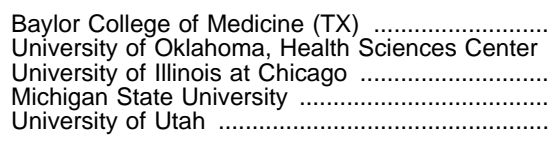 & $\begin{array}{l}56 \\
57 \\
58 \\
59 \\
60\end{array}$ & $\begin{array}{l}108,230 \\
106,500 \\
104,366 \\
104,093 \\
103,199\end{array}$ & $\begin{array}{l}\text { Air Force Institute of Technology }(\mathrm{OH}) \\
\text { United States Army Command and General Staff College (KS) } \\
\text { Medical University of South Carolina } \\
\text { University of Oregon }\end{array}$ & $\begin{array}{l}116 \\
117 \\
118 \\
119 \\
120\end{array}$ & $\begin{array}{l}45,975 \\
44,911 \\
43,870 \\
43,455 \\
42,321\end{array}$ \\
\hline
\end{tabular}

1 Includes federal appropriations, unrestricted and restricted federal contracts and grants, and revenue for independent operations. Independent operations generally include only the revenues associated with major federally funded research and development centers. Excludes Pell Grants. Federally supported student aid that is received through students is excluded.
-Data not applicable.

SOURCE: U.S. Department of Education, National Center for Education Statistics, Integrated Postsecondary Education Data System (IPEDS), "Finance, 1995-96" survey. (This table was prepared October 1998.) 
Table 335.-Current-fund expenditures and expenditures per full-time-equivalent student in institutions of higher education, by type and control of institution: 1970-71 to 1995-96

\begin{tabular}{|c|c|c|c|c|c|c|c|c|c|}
\hline \multirow{3}{*}{$\begin{array}{c}\text { Control of institution and } \\
\text { year }\end{array}$} & \multicolumn{3}{|c|}{ All institutions } & \multicolumn{3}{|c|}{ 4-year institutions } & \multicolumn{3}{|c|}{ 2-year institutions } \\
\hline & \multicolumn{2}{|c|}{$\begin{array}{c}\text { Current-fund expenditures, } \\
\text { in millions }\end{array}$} & \multirow{2}{*}{$\begin{array}{c}\text { Current-fund } \\
\text { expenditures } \\
\text { per student, } \\
\text { in constant } \\
\text { 1995-96 } \\
\text { dollars }^{1}\end{array}$} & \multicolumn{2}{|c|}{$\begin{array}{l}\text { Current-fund expenditures, } \\
\text { in millions }\end{array}$} & \multirow{2}{*}{$\begin{array}{c}\text { Current-fund } \\
\text { expenditures } \\
\text { per student, } \\
\text { in constant } \\
\text { 1995-96 } \\
\text { dollars }^{1}\end{array}$} & \multicolumn{2}{|c|}{$\begin{array}{l}\text { Current-fund expenditures, } \\
\text { in millions }\end{array}$} & \multirow{2}{*}{$\begin{array}{c}\text { Current-fund } \\
\text { expenditures } \\
\text { per student, } \\
\text { in constant } \\
\text { 1995-96 } \\
\text { dollars }^{1}\end{array}$} \\
\hline & $\begin{array}{l}\text { Unadjusted } \\
\text { dollars }\end{array}$ & $\begin{array}{l}\text { Constant } \\
\text { 1995-96 } \\
\text { dollars }{ }^{1}\end{array}$ & & $\begin{array}{l}\text { Unadjusted } \\
\text { dollars }\end{array}$ & $\begin{array}{l}\text { Constant } \\
\text { 1995-96 } \\
\text { dollars }^{1}\end{array}$ & & $\begin{array}{l}\text { Unadjusted } \\
\text { dollars }\end{array}$ & $\begin{array}{l}\text { Constant } \\
\text { 1995-96 } \\
\text { dollars }{ }^{1}\end{array}$ & \\
\hline 1 & 2 & 3 & 4 & 5 & 6 & 7 & 8 & 9 & 10 \\
\hline 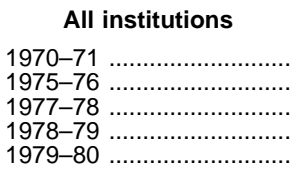 & $\begin{array}{r}\$ 23,375 \\
38,903 \\
45,971 \\
50,721 \\
56,914\end{array}$ & $\begin{array}{l}\$ 96,221 \\
116,642 \\
121,259 \\
124,680 \\
127,266\end{array}$ & $\begin{array}{r}\$ 14,281 \\
13,755 \\
14,409 \\
14,934 \\
14,995\end{array}$ & $\begin{array}{r}\$ 21,049 \\
33,811 \\
39,899 \\
44,163 \\
49,661\end{array}$ & $\begin{array}{l}\$ 86,644 \\
101,375 \\
105,242 \\
108,560 \\
111,048\end{array}$ & $\begin{array}{r}\$ 16,839 \\
17,181 \\
17,732 \\
18,300 \\
18,458\end{array}$ & $\begin{array}{r}\$ 2,327 \\
5,092 \\
6,072 \\
6,558 \\
7,253\end{array}$ & $\begin{array}{l}\$ 9,577 \\
15,267 \\
16,017 \\
16,120 \\
16,218\end{array}$ & $\begin{array}{r}\$ 6,014 \\
5,919 \\
6,458 \\
6,672 \\
6,563\end{array}$ \\
\hline $\begin{array}{l}1980-81 \\
1981-82 \\
1982-83 \\
1983-84 \ldots \ldots \ldots \ldots \ldots \ldots \ldots \ldots \ldots \ldots \ldots \\
1984-85\end{array}$ & $\begin{array}{l}64,053 \\
70,339 \\
75,936 \\
81,993 \\
89,951\end{array}$ & $\begin{array}{l}129,375 \\
129,817 \\
131,597 \\
135,586 \\
140,691\end{array}$ & $\begin{array}{l}14,670 \\
14,401 \\
14,474 \\
14,792 \\
15,717\end{array}$ & $\begin{array}{l}55,840 \\
61,333 \\
66,238 \\
71,680 \\
78,744\end{array}$ & $\begin{array}{l}112,787 \\
113,196 \\
114,791 \\
118,532 \\
123,162\end{array}$ & $\begin{array}{l}18,306 \\
18,112 \\
18,370 \\
18,740 \\
19,572\end{array}$ & $\begin{array}{r}8,212 \\
9,006 \\
9,697 \\
10,314 \\
11,207\end{array}$ & $\begin{array}{l}16,588 \\
16,621 \\
16,806 \\
17,055 \\
17,529\end{array}$ & $\begin{array}{l}6,241 \\
6,012 \\
5,912 \\
6,003 \\
6,592\end{array}$ \\
\hline 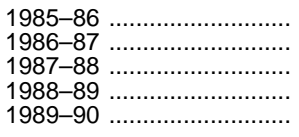 & $\begin{array}{r}97,536 \\
105,764 \\
113,786 \\
123,867 \\
134,656\end{array}$ & $\begin{array}{l}145,339 \\
151,603 \\
156,377 \\
161,643 \\
165,737\end{array}$ & $\begin{array}{l}16,251 \\
16,726 \\
16,943 \\
17,079 \\
16,945\end{array}$ & $\begin{array}{r}85,560 \\
92,985 \\
100,143 \\
109,141 \\
118,578\end{array}$ & $\begin{array}{l}127,494 \\
133,286 \\
137,627 \\
142,426 \\
145,949\end{array}$ & $\begin{array}{l}20,255 \\
20,956 \\
21,217 \\
21,372 \\
21,420\end{array}$ & $\begin{array}{l}11,976 \\
12,779 \\
13,644 \\
14,726 \\
16,077\end{array}$ & $\begin{array}{l}17,845 \\
18,318 \\
18,751 \\
19,217 \\
19,788\end{array}$ & $\begin{array}{l}6,736 \\
6,775 \\
6,835 \\
6,863 \\
6,669\end{array}$ \\
\hline 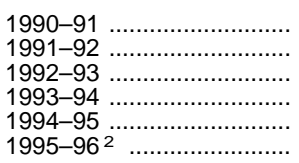 & $\begin{array}{l}146,088 \\
156,189 \\
165,241 \\
173,351 \\
182,969 \\
189,986\end{array}$ & $\begin{array}{l}170,830 \\
176,566 \\
181,242 \\
183,966 \\
188,404 \\
189,986\end{array}$ & $\begin{array}{l}17,111 \\
17,042 \\
17,366 \\
17,772 \\
18,207 \\
18,383\end{array}$ & $\begin{array}{l}128,594 \\
137,375 \\
145,300 \\
152,164 \\
160,891 \\
167,044\end{array}$ & $\begin{array}{l}150,374 \\
155,297 \\
159,370 \\
161,482 \\
165,671 \\
167,044\end{array}$ & $\begin{array}{l}21,581 \\
21,930 \\
22,354 \\
22,677 \\
23,212 \\
23,288\end{array}$ & $\begin{array}{l}17,494 \\
18,814 \\
19,941 \\
21,187 \\
22,078 \\
22,942\end{array}$ & $\begin{array}{l}20,457 \\
21,269 \\
21,872 \\
22,484 \\
22,734 \\
22,942\end{array}$ & $\begin{array}{l}6,784 \\
6,486 \\
6,613 \\
6,960 \\
7,081 \\
7,255\end{array}$ \\
\hline \multicolumn{10}{|l|}{ Public institutions } \\
\hline 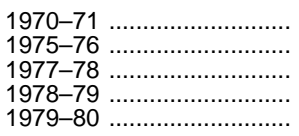 & $\begin{array}{l}14,996 \\
26,184 \\
30,725 \\
33,733 \\
37,768\end{array}$ & $\begin{array}{l}61,730 \\
78,507 \\
81,045 \\
82,921 \\
84,454\end{array}$ & $\begin{array}{l}12,463 \\
12,037 \\
12,670 \\
13,206 \\
13,211\end{array}$ & $\begin{array}{l}12,899 \\
21,392 \\
25,013 \\
27,600 \\
30,979\end{array}$ & $\begin{array}{l}53,097 \\
64,139 \\
65,978 \\
67,846 \\
69,273\end{array}$ & $\begin{array}{l}15,308 \\
15,811 \\
16,335 \\
16,978 \\
17,065\end{array}$ & $\begin{array}{l}2,097 \\
4,792 \\
5,712 \\
6,132 \\
6,789\end{array}$ & $\begin{array}{r}8,633 \\
14,368 \\
15,067 \\
15,075 \\
15,181\end{array}$ & $\begin{array}{l}5,815 \\
5,827 \\
6,391 \\
6,603 \\
6,506\end{array}$ \\
\hline $\begin{array}{l}1980-81 \\
1981-82 \\
1982-83 \\
198 \ldots \ldots \ldots \ldots \ldots \ldots \ldots \ldots \ldots \ldots \ldots \ldots \\
1984-84\end{array}$ & $\begin{array}{l}42,280 \\
46,219 \\
49,573 \\
53,087 \\
58,315\end{array}$ & $\begin{array}{l}85,397 \\
85,301 \\
85,910 \\
87,785 \\
91,209\end{array}$ & $\begin{array}{l}12,857 \\
12,579 \\
12,541 \\
12,757 \\
13,644\end{array}$ & $\begin{array}{l}34,677 \\
37,890 \\
40,616 \\
43,588 \\
48,017\end{array}$ & $\begin{array}{l}70,042 \\
69,928 \\
70,387 \\
72,078 \\
75,102\end{array}$ & $\begin{array}{l}16,844 \\
16,616 \\
16,677 \\
16,897 \\
17,722\end{array}$ & $\begin{array}{r}7,602 \\
8,330 \\
8,957 \\
9,499 \\
10,298\end{array}$ & $\begin{array}{l}15,355 \\
15,373 \\
15,523 \\
15,707 \\
16,106\end{array}$ & $\begin{array}{l}6,182 \\
5,975 \\
5,902 \\
6,005 \\
6,583\end{array}$ \\
\hline 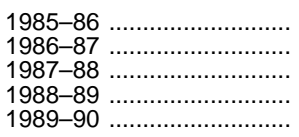 & $\begin{array}{l}63,194 \\
67,654 \\
72,641 \\
78,946 \\
85,771\end{array}$ & $\begin{array}{r}94,166 \\
96,976 \\
99,831 \\
103,022 \\
105,568\end{array}$ & $\begin{array}{l}14,123 \\
14,307 \\
14,390 \\
14,516 \\
14,321\end{array}$ & $\begin{array}{l}52,184 \\
56,003 \\
60,137 \\
65,349 \\
70,865\end{array}$ & $\begin{array}{l}77,760 \\
80,275 \\
82,646 \\
85,278 \\
87,222\end{array}$ & $\begin{array}{l}18,341 \\
18,688 \\
18,801 \\
18,926 \\
18,880\end{array}$ & $\begin{array}{l}11,010 \\
11,651 \\
12,505 \\
13,597 \\
14,906\end{array}$ & $\begin{array}{l}16,406 \\
16,701 \\
17,185 \\
17,743 \\
18,346\end{array}$ & $\begin{array}{l}6,756 \\
6,727 \\
6,761 \\
6,848 \\
6,667\end{array}$ \\
\hline 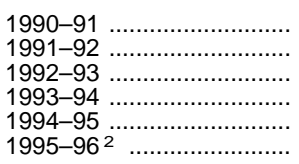 & $\begin{array}{r}92,961 \\
98,847 \\
104,570 \\
109,310 \\
115,465 \\
119,401\end{array}$ & $\begin{array}{l}108,706 \\
111,743 \\
114,696 \\
116,003 \\
118,895 \\
119,401\end{array}$ & $\begin{array}{l}14,383 \\
14,212 \\
14,497 \\
14,849 \\
15,274 \\
15,403\end{array}$ & $\begin{array}{l}76,722 \\
81,334 \\
86,065 \\
89,697 \\
94,895 \\
97,901\end{array}$ & $\begin{array}{l}89,716 \\
91,945 \\
94,399 \\
95,190 \\
97,714 \\
97,901\end{array}$ & $\begin{array}{l}18,927 \\
19,172 \\
19,675 \\
19,973 \\
20,573 \\
20,579\end{array}$ & $\begin{array}{l}16,239 \\
17,513 \\
18,505 \\
19,612 \\
20,570 \\
21,500\end{array}$ & $\begin{array}{l}18,990 \\
19,798 \\
20,297 \\
20,813 \\
21,181 \\
21,500\end{array}$ & $\begin{array}{l}6,739 \\
6,455 \\
6,518 \\
6,832 \\
6,979 \\
7,180\end{array}$ \\
\hline \multicolumn{10}{|l|}{ Private institutions } \\
\hline 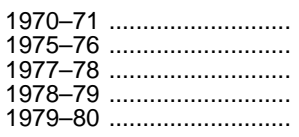 & $\begin{array}{r}8,379 \\
12,719 \\
15,246 \\
16,988 \\
19,146\end{array}$ & $\begin{array}{l}34,492 \\
38,136 \\
40,214 \\
41,759 \\
42,812\end{array}$ & $\begin{array}{l}19,327 \\
19,483 \\
19,919 \\
20,181 \\
20,438\end{array}$ & $\begin{array}{r}8,150 \\
12,419 \\
14,885 \\
16,563 \\
18,682\end{array}$ & $\begin{array}{l}33,547 \\
37,237 \\
39,264 \\
40,714 \\
41,775\end{array}$ & $\begin{array}{l}20,006 \\
20,194 \\
20,709 \\
21,027 \\
21,349\end{array}$ & $\begin{array}{l}230 \\
300 \\
360 \\
425 \\
464\end{array}$ & $\begin{array}{r}945 \\
899 \\
950 \\
1,046 \\
1,037\end{array}$ & $\begin{array}{l}8,763 \\
7,923 \\
7,733 \\
7,861 \\
7,519\end{array}$ \\
\hline $\begin{array}{l}1980-81 \\
1981-82 \\
1982-83 \\
1983-84 \ldots \ldots \ldots \ldots \ldots \ldots \ldots \ldots \ldots \\
1984-85\end{array}$ & $\begin{array}{l}21,773 \\
24,120 \\
26,363 \\
28,907 \\
31,637\end{array}$ & $\begin{array}{l}43,978 \\
44,516 \\
45,687 \\
47,801 \\
49,482\end{array}$ & $\begin{array}{l}20,204 \\
19,934 \\
20,386 \\
20,920 \\
21,827\end{array}$ & $\begin{array}{l}21,163 \\
23,444 \\
25,623 \\
28,092 \\
30,727\end{array}$ & $\begin{array}{l}42,745 \\
43,268 \\
44,404 \\
46,453 \\
48,059\end{array}$ & $\begin{array}{l}21,340 \\
21,196 \\
21,893 \\
22,557 \\
23,389\end{array}$ & $\begin{array}{l}610 \\
676 \\
740 \\
815 \\
910\end{array}$ & $\begin{array}{l}1,232 \\
1,248 \\
1,283 \\
1,348 \\
1,423\end{array}$ & $\begin{array}{l}7,098 \\
6,505 \\
6,028 \\
5,976 \\
6,705\end{array}$ \\
\hline 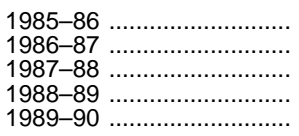 & $\begin{array}{l}34,342 \\
38,110 \\
41,145 \\
44,922 \\
48,885\end{array}$ & $\begin{array}{l}51,173 \\
54,627 \\
56,546 \\
58,621 \\
60,169\end{array}$ & $\begin{array}{l}22,487 \\
23,895 \\
24,671 \\
24,762 \\
24,974\end{array}$ & $\begin{array}{l}33,376 \\
36,982 \\
40,006 \\
43,792 \\
47,713\end{array}$ & $\begin{array}{l}49,734 \\
53,011 \\
54,980 \\
57,147 \\
58,727\end{array}$ & $\begin{array}{l}24,205 \\
25,673 \\
26,297 \\
26,477 \\
26,770\end{array}$ & $\begin{array}{r}966 \\
1,128 \\
1,139 \\
1,130 \\
1,172\end{array}$ & $\begin{array}{l}1,439 \\
1,617 \\
1,566 \\
1,474 \\
1,442\end{array}$ & $\begin{array}{l}6,515 \\
7,305 \\
7,779 \\
7,053 \\
6,691\end{array}$ \\
\hline 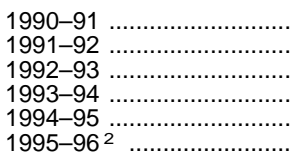 & $\begin{array}{l}53,127 \\
57,342 \\
60,671 \\
64,041 \\
67,504 \\
70,585\end{array}$ & $\begin{array}{l}62,125 \\
64,823 \\
66,546 \\
67,963 \\
69,509 \\
70,585\end{array}$ & $\begin{array}{l}25,614 \\
25,952 \\
26,354 \\
26,767 \\
27,113 \\
27,325\end{array}$ & $\begin{array}{l}51,872 \\
56,041 \\
59,235 \\
62,466 \\
65,996 \\
69,143\end{array}$ & $\begin{array}{l}60,658 \\
63,352 \\
64,971 \\
66,292 \\
67,957 \\
69,143\end{array}$ & $\begin{array}{l}27,226 \\
27,716 \\
27,867 \\
28,150 \\
28,460 \\
28,623\end{array}$ & $\begin{array}{l}1,255 \\
1,301 \\
1,436 \\
1,575 \\
1,508 \\
1,442\end{array}$ & $\begin{array}{l}1,467 \\
1,471 \\
1,575 \\
1,671 \\
1,552 \\
1,442\end{array}$ & $\begin{array}{l}7,428 \\
6,937 \\
8,135 \\
9,077 \\
8,828 \\
8,609\end{array}$ \\
\hline
\end{tabular}

1 Dollars adjusted by the Higher Education Price Index.

${ }^{2}$ Preliminary data.

NOTE.-Because of rounding, details may not add to totals.
SOURCE: U.S. Department of Education, National Center for Education Statistics, Higher Education General Information Survey (HEGIS), "Financial Statistics of Institutions of Higher Education" and "Fall Enrollment in Colleges and Universities" surveys; and Integrated Postsecondary Education Data System (IPEDS), "Fall Enrollment" and "Finance" surveys. (This table was prepared October 1998.) 
Table 336.-Current-fund expenditures and educational and general expenditures of institutions of higher education and degree-granting institutions, by purpose and per student: 1929-30 to 1995-96

[Columns 2 through 17 in thousands]

\begin{tabular}{|c|c|c|c|c|c|c|c|c|c|}
\hline \multirow[b]{2}{*}{ Year } & \multirow[b]{2}{*}{$\begin{array}{l}\text { Current-fund } \\
\text { expenditures }\end{array}$} & \multicolumn{8}{|c|}{ Educational and general expenditures } \\
\hline & & Total & $\begin{array}{l}\text { Administra- } \\
\text { tion and } \\
\text { general } \\
\text { expense }\end{array}$ & \begin{tabular}{c|} 
Instruction \\
and \\
departmental \\
research
\end{tabular} & $\begin{array}{l}\text { Organized } \\
\text { research }\end{array}$ & Libraries & $\begin{array}{c}\text { Plant } \\
\text { operation } \\
\text { and } \\
\text { maintenance }\end{array}$ & $\begin{array}{l}\text { Organized } \\
\text { activities } \\
\text { related to } \\
\text { instructional } \\
\text { depart- } \\
\text { ments }^{1}\end{array}$ & $\begin{array}{l}\text { Other } \\
\text { sponsored } \\
\text { programs }\end{array}$ \\
\hline 1 & 2 & 3 & 4 & 5 & 6 & 7 & 8 & 9 & 10 \\
\hline 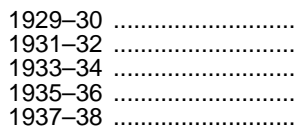 & $\begin{array}{r}\$ 507,142 \\
536,523 \\
469,329 \\
541,391 \\
614,385\end{array}$ & $\begin{array}{r}\$ 377,903 \\
420,633 \\
369,661 \\
419,883 \\
475,191\end{array}$ & $\begin{array}{r}\$ 42,633 \\
47,232 \\
43,155 \\
48,069 \\
56,406\end{array}$ & $\begin{array}{r}\$ 221,598 \\
232,645 \\
203,332 \\
225,143 \\
253,006\end{array}$ & $\begin{array}{r}6 \$ 18,007 \\
621,978 \\
617,064 \\
622,091 \\
625,213\end{array}$ & $\begin{array}{l}\$ 9,622 \\
11,379 \\
13,387 \\
15,531 \\
17,588\end{array}$ & $\begin{array}{r}\$ 61,061 \\
56,797 \\
51,046 \\
56,802 \\
62,738\end{array}$ & $\begin{array}{r}(7) \\
8 \$ 21,297 \\
814,155 \\
820,241 \\
824,031\end{array}$ & $\begin{array}{l}- \\
- \\
-\end{array}$ \\
\hline 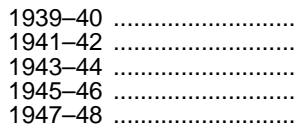 & $\begin{array}{r}674,688 \\
738,169 \\
974,118 \\
1,088,422 \\
1,883,269\end{array}$ & $\begin{array}{r}521,990 \\
572,465 \\
753,846 \\
820,326 \\
1,391,594\end{array}$ & $\begin{array}{r}62,827 \\
66,968 \\
69,668 \\
104,808 \\
171,829\end{array}$ & $\begin{array}{l}280,248 \\
298,558 \\
334,189 \\
375,122 \\
657,945\end{array}$ & $\begin{array}{r}627,266 \\
634,287 \\
658,456 \\
686,812 \\
6159,090\end{array}$ & $\begin{array}{l}19,487 \\
19,763 \\
20,452 \\
26,560 \\
44,208\end{array}$ & $\begin{array}{r}69,612 \\
72,594 \\
81,201 \\
110,947 \\
201,996\end{array}$ & $\begin{array}{l}827,225 \\
837,771 \\
848,415 \\
860,604 \\
885,346\end{array}$ & $9 \$$ \\
\hline $\begin{array}{l}1949-50 \ldots . . \\
1951-52 \ldots \\
1953-54 \ldots . \\
1955-56 \ldots . \\
1957-58 \ldots .\end{array}$ & $\begin{array}{l}2,245,661 \\
2,471,008 \\
2,882,864 \\
3,499,463 \\
4,509,666\end{array}$ & $\begin{array}{l}1,706,444 \\
1,960,481 \\
2,345,331 \\
2,861,858 \\
3,734,350\end{array}$ & $\begin{array}{l}213,070 \\
233,844 \\
288,147 \\
355,207 \\
473,945\end{array}$ & $\begin{array}{r}780,994 \\
823,117 \\
960,556 \\
1,140,655 \\
1,465,603\end{array}$ & $\begin{array}{l}6225,341 \\
6317,928 \\
6372,643 \\
6500,793 \\
6727,776\end{array}$ & $\begin{array}{r}56,147 \\
60,612 \\
72,944 \\
85,563 \\
109,715\end{array}$ & $\begin{array}{l}225,110 \\
240,446 \\
277,874 \\
324,229 \\
406,226\end{array}$ & $\begin{array}{l}8119,108 \\
8147,854 \\
8186,905 \\
8222,007 \\
8238,455\end{array}$ & $\begin{array}{l}- \\
- \\
-\end{array}$ \\
\hline $\begin{array}{l}1959-60 \\
1961-62 \\
1963-64 \\
1965-66 \\
1966-67 \\
1967-68\end{array}$. & $\begin{array}{r}5,601,376 \\
7,154,526 \\
9,177,677 \\
12,509,489 \\
14,230,341 \\
16,480,786\end{array}$ & $\begin{array}{r}4,685,258 \\
5,997,007 \\
7,725,433 \\
10,376,630 \\
10,724,974 \\
12,847,350\end{array}$ & $\begin{array}{r}583,224 \\
730,429 \\
957,512 \\
1,251,107 \\
1,445,074 \\
1,738,946\end{array}$ & $\begin{array}{l}1,793,320 \\
2,202,443 \\
2,801,707 \\
3,756,175 \\
4,356,413 \\
5,139,179\end{array}$ & $\begin{array}{r}61,022,353 \\
61,474,406 \\
61,973,383 \\
62,448,300 \\
1,565,102 \\
1,933,473\end{array}$ & $\begin{array}{l}135,384 \\
177,362 \\
236,718 \\
346,248 \\
415,903 \\
493,266\end{array}$ & $\begin{array}{r}469,943 \\
564,225 \\
686,054 \\
844,506 \\
969,275 \\
1,127,290\end{array}$ & $\begin{array}{r}8294,255 \\
8375,040 \\
8458,507 \\
8558,170 \\
591,848 \\
350,711\end{array}$ & $\begin{array}{r}- \\
- \\
155,202 \\
350,950 \\
514,294\end{array}$ \\
\hline 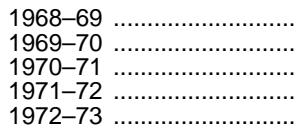 & $\begin{array}{l}18,481,583 \\
21,043,113 \\
23,375,197 \\
25,559,560 \\
27,955,624\end{array}$ & $\begin{array}{l}14,718,140 \\
16,845,212 \\
18,714,642 \\
20,441,878 \\
22,400,379\end{array}$ & $\begin{array}{l}2,277,585 \\
2,627,993 \\
2,983,911 \\
3,344,215 \\
3,713,068\end{array}$ & $\begin{array}{l}5,941,972 \\
6,883,844 \\
7,804,410 \\
8,443,261 \\
9,243,641\end{array}$ & $\begin{array}{l}2,034,074 \\
2,144,076 \\
2,209,338 \\
2,265,282 \\
2,394,261\end{array}$ & $\begin{array}{l}571,572 \\
652,596 \\
716,212 \\
764,481 \\
840,727\end{array}$ & $\begin{array}{l}1,337,903 \\
1,541,698 \\
1,730,664 \\
1,927,553 \\
2,141,162\end{array}$ & $\begin{array}{l}535,269 \\
648,089 \\
693,011 \\
779,728 \\
791,290\end{array}$ & $\begin{array}{r}668,483 \\
769,253 \\
890,507 \\
1,059,989 \\
1,284,085\end{array}$ \\
\hline 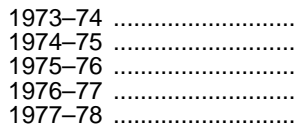 & $\begin{array}{l}30,713,581 \\
35,057,563 \\
38,903,177 \\
42,599,816 \\
45,970,790\end{array}$ & $\begin{array}{l}24,653,849 \\
27,547,620 \\
30,598,685 \\
33,151,681 \\
36,256,604\end{array}$ & $\begin{array}{l}4,200,955 \\
4,495,391 \\
5,240,066 \\
5,590,669 \\
6,177,029\end{array}$ & $\begin{array}{l}10,219,118 \\
11,797,823 \\
13,094,943 \\
14,031,145 \\
15,336,229\end{array}$ & $\begin{array}{l}2,480,450 \\
3,132,132 \\
3,287,364 \\
3,600,067 \\
3,919,830\end{array}$ & $\begin{array}{r}939,023 \\
1,001,868 \\
1,223,723 \\
1,250,314 \\
1,348,747\end{array}$ & $\begin{array}{l}2,494,057 \\
2,786,768 \\
3,082,959 \\
3,436,705 \\
3,795,043\end{array}$ & $\begin{array}{r}838,170 \\
1,253,824 \\
1,248,670 \\
1,544,646 \\
1,781,160\end{array}$ & $\begin{array}{r}1,355,027 \\
- \\
-\end{array}$ \\
\hline $\begin{array}{l}1978-79 \ldots \\
1979-80 \ldots \\
1980-81 \ldots \\
1981-82 \ldots \\
1982-83 \ldots\end{array}$ & $\begin{array}{l}50,720,984 \\
56,913,588 \\
64,052,938 \\
70,339,448 \\
75,935,749\end{array}$ & $\begin{array}{l}39,833,116 \\
44,542,843 \\
50,073,805 \\
54,848,752 \\
58,929,218\end{array}$ & $\begin{array}{r}6,832,004 \\
7,621,143 \\
8,681,513 \\
9,648,069 \\
10,412,233\end{array}$ & $\begin{array}{l}16,662,820 \\
18,496,717 \\
20,733,166 \\
22,962,527 \\
24,673,293\end{array}$ & $\begin{array}{l}4,447,760 \\
5,099,151 \\
5,657,719 \\
5,929,894 \\
6,265,280\end{array}$ & $\begin{array}{l}1,426,614 \\
1,623,811 \\
1,759,784 \\
1,922,416 \\
2,039,671\end{array}$ & $\begin{array}{l}4,178,574 \\
4,700,070 \\
5,350,310 \\
5,979,281 \\
6,391,596\end{array}$ & $\begin{array}{l}2,044,386 \\
2,252,577 \\
2,513,502 \\
2,734,038 \\
3,047,220\end{array}$ & $\begin{array}{l}- \\
- \\
-\end{array}$ \\
\hline $\begin{array}{l}1983-84 . . \\
1984-85 . . \\
1985-86 . . \\
1986-87 . . \\
1987-88 . .\end{array}$ & $\begin{array}{r}81,993,360 \\
89,951,263 \\
97,535,742 \\
105,763,557 \\
113,786,476\end{array}$ & $\begin{array}{l}63,741,276 \\
70,061,324 \\
76,127,965 \\
82,955,555 \\
89,157,430\end{array}$ & $\begin{array}{l}11,561,260 \\
12,765,452 \\
13,913,724 \\
15,060,576 \\
16,171,015\end{array}$ & $\begin{array}{l}26,436,308 \\
28,777,183 \\
31,032,099 \\
33,711,146 \\
35,833,563\end{array}$ & $\begin{array}{r}6,723,534 \\
7,551,892 \\
8,437,367 \\
9,352,309 \\
10,350,931\end{array}$ & $\begin{array}{l}2,231,149 \\
2,361,793 \\
2,551,331 \\
2,441,184 \\
2,836,498\end{array}$ & $\begin{array}{l}6,729,825 \\
7,345,482 \\
7,605,226 \\
7,819,032 \\
8,230,986\end{array}$ & $\begin{array}{l}3,300,003 \\
3,712,460 \\
4,116,061 \\
5,134,267 \\
5,305,083\end{array}$ & $\begin{array}{l}- \\
- \\
-\end{array}$ \\
\hline $\begin{array}{ll}1988-89 & \ldots . . \\
1989-90 & \ldots . \\
1990-91 & \ldots . \\
1991-92 & \ldots . \\
1992-93 & \ldots . . .\end{array}$ & $\begin{array}{l}123,867,184 \\
134,655,571 \\
146,087,836 \\
156,189,161 \\
165,241,040\end{array}$ & $\begin{array}{r}96,803,377 \\
105,585,076 \\
114,139,901 \\
121,567,157 \\
128,977,968\end{array}$ & $\begin{array}{l}17,309,956 \\
19,062,179 \\
20,751,966 \\
21,984,118 \\
23,414,977\end{array}$ & $\begin{array}{l}38,812,690 \\
42,145,987 \\
45,496,117 \\
47,997,196 \\
50,340,914\end{array}$ & $\begin{array}{l}11,432,170 \\
12,505,961 \\
13,444,040 \\
14,261,554 \\
15,291,309\end{array}$ & $\begin{array}{l}3,009,870 \\
3,254,239 \\
3,343,892 \\
3,595,834 \\
3,684,852\end{array}$ & $\begin{array}{r}8,739,895 \\
9,458,262 \\
10,062,581 \\
10,346,580 \\
10,783,727\end{array}$ & $\begin{array}{l}5,894,409 \\
6,183,405 \\
6,706,881 \\
6,981,184 \\
7,388,118\end{array}$ & - \\
\hline \multirow[t]{2}{*}{$\begin{array}{l}1993-94 \\
1994-95 \\
1995-96{ }_{11} \ldots \ldots \ldots \ldots \ldots \ldots \ldots \ldots \ldots \ldots \ldots \\
.\end{array}$} & $\begin{array}{l}173,350,617 \\
182,968,610 \\
189,986,238\end{array}$ & $\begin{array}{l}136,024,350 \\
144,158,002 \\
150,927,324\end{array}$ & $\begin{array}{l}24,489,022 \\
25,904,821 \\
27,683,381\end{array}$ & $\begin{array}{l}52,775,599 \\
55,719,707 \\
57,572,851\end{array}$ & $\begin{array}{l}16,117,610 \\
17,109,541 \\
17,519,665\end{array}$ & $\begin{array}{l}3,908,412 \\
4,165,761 \\
4,299,177\end{array}$ & $\begin{array}{l}11,368,496 \\
11,745,905 \\
12,257,540\end{array}$ & $\begin{array}{l}7,769,499 \\
8,112,930 \\
9,010,262\end{array}$ & - \\
\hline & \multicolumn{9}{|c|}{ Degree-granting institutions ${ }^{12}$} \\
\hline 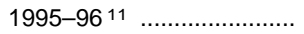 & $190,476,163$ & $151,445,605$ & $27,886,345$ & $57,810,033$ & $17,517,887$ & $4,293,363$ & $12,330,885$ & $9,003,700$ & - \\
\hline
\end{tabular}


Table 336.-Current-fund expenditures and educational and general expenditures of institutions of higher education and degree-granting institutions, by purpose and per student: 1929-30 to 1995-96-Continued

[Columns 2 through 17 in thousands]

\begin{tabular}{|c|c|c|c|c|c|c|c|c|c|}
\hline \multirow{3}{*}{ Year } & \multicolumn{3}{|c|}{ Educational and general expenditures } & \multirow{3}{*}{$\begin{array}{c}\text { Auxiliary } \\
\text { enterprises }\end{array}$} & \multirow{3}{*}{$\begin{array}{l}\text { Independent } \\
\text { operations }^{3}\end{array}$} & \multirow{3}{*}{ Hospitals } & \multirow{3}{*}{$\begin{array}{l}\text { Other current } \\
\text { expenditures }\end{array}$} & \multirow{2}{*}{\multicolumn{2}{|c|}{$\begin{array}{l}\text { Educational and general } \\
\text { expenditures per student in } \\
\text { fall enrollment } 4\end{array}$}} \\
\hline & \multirow[b]{2}{*}{$\begin{array}{l}\text { Extension } \\
\text { and public } \\
\text { service }\end{array}$} & \multirow[b]{2}{*}{$\begin{array}{l}\text { Scholarships } \\
\text { and } \\
\text { fellowships }\end{array}$} & \multirow{2}{*}{$\begin{array}{c}\text { Other } \\
\text { general } \\
\text { expenditures }\end{array}$} & & & & & & \\
\hline & & & & & & & & $\begin{array}{l}\text { Current } \\
\text { dollars }\end{array}$ & $\begin{array}{l}\text { Constant } \\
1995-96 \\
\text { dollars }^{5}\end{array}$ \\
\hline 1 & 11 & 12 & 13 & 14 & 15 & 16 & 17 & 18 & 19 \\
\hline 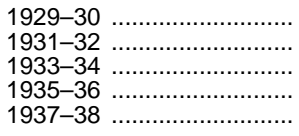 & $\begin{array}{r}\$ 24,982 \\
24,066 \\
20,020 \\
29,426 \\
34,189\end{array}$ & $\begin{array}{l}(7) \\
(7) \\
(7) \\
(7) \\
(7)\end{array}$ & $\begin{array}{r}-1, \\
7,502 \\
2,580 \\
2,020\end{array}$ & $\begin{array}{r}\$ 3,127 \\
90,897 \\
78,730 \\
95,332 \\
115,620\end{array}$ & $\begin{array}{l}(6) \\
(6) \\
(6) \\
(6) \\
(6)\end{array}$ & $\begin{array}{l}(8) \\
(8) \\
(8) \\
(8) \\
(8)\end{array}$ & $\begin{array}{r}\$ 126,112 \\
24,993 \\
20,938 \\
26,176 \\
23,574\end{array}$ & $\begin{array}{r}\$ 343 \\
364 \\
350 \\
348 \\
352\end{array}$ & $\begin{array}{r}\$ 3,099 \\
3,906 \\
4,087 \\
3,907 \\
3,794\end{array}$ \\
\hline $\begin{array}{l}1939-40 \\
1941-42 \\
1943-44 \ldots \ldots \ldots \ldots \ldots \ldots \ldots \ldots \ldots \\
1945-46 \\
1947-48\end{array}$ & $\begin{array}{l}35,325 \\
42,525 \\
44,421 \\
55,473 \\
71,180\end{array}$ & $\begin{array}{l}(7) \\
(7) \\
(7) \\
(7) \\
(7)\end{array}$ & $\begin{array}{l}- \\
- \\
-\end{array}$ & $\begin{array}{l}124,184 \\
137,328 \\
199,344 \\
242,028 \\
438,988\end{array}$ & $\begin{array}{l}(6) \\
(6) \\
(6) \\
(6) \\
(6)\end{array}$ & $\begin{array}{l}(8) \\
(8) \\
(8) \\
(8) \\
(8)\end{array}$ & $\begin{array}{l}28,514 \\
28,375 \\
20,928 \\
26,068 \\
52,687\end{array}$ & $\begin{array}{l}349 \\
408 \\
653 \\
489 \\
595\end{array}$ & $\begin{array}{l}3,862 \\
4,040 \\
5,786 \\
4,143 \\
3,946\end{array}$ \\
\hline 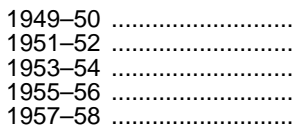 & $\begin{array}{r}86,674 \\
97,408 \\
112,227 \\
137,914 \\
175,256\end{array}$ & $\begin{array}{r}\left({ }^{7}\right) \\
\$ 39,272 \\
74,035 \\
95,490 \\
129,935\end{array}$ & $\begin{array}{r}\bar{Z} \\
\bar{Z} \\
7,439\end{array}$ & $\begin{array}{l}476,401 \\
477,672 \\
537,533 \\
637,605 \\
775,316\end{array}$ & $\begin{array}{l}(6) \\
(6) \\
(6) \\
(6) \\
(6)\end{array}$ & $\begin{array}{l}(8) \\
(8) \\
(8) \\
(8) \\
(8)\end{array}$ & $\begin{array}{r}62,816 \\
32,855 \\
- \\
-\end{array}$ & $\begin{array}{r}698 \\
933 \\
1,051 \\
1,079 \\
1,124\end{array}$ & $\begin{array}{l}4,553 \\
5,483 \\
6,039 \\
6,199 \\
6,078\end{array}$ \\
\hline $\begin{array}{l}1959-60 \\
1961-62 \\
1963-64 \\
196 \ldots \ldots \ldots \ldots \ldots \ldots \ldots \ldots \ldots \ldots \\
1965-66 \\
1966-67 \\
1967-68\end{array}$ & $\begin{array}{l}205,595 \\
244,337 \\
297,350 \\
438,385 \\
226,566 \\
597,544\end{array}$ & $\begin{array}{l}172,050 \\
228,765 \\
300,370 \\
425,524 \\
583,390 \\
712,425\end{array}$ & $\begin{array}{r}9,134 \\
13,832 \\
153,013 \\
220,453 \\
240,222\end{array}$ & $\begin{array}{r}916,117 \\
1,157,517 \\
1,452,244 \\
1,887,744 \\
2,060,130 \\
2,302,419\end{array}$ & $\begin{array}{r}(6) \\
(6) \\
(6) \\
(6) \\
\$ 951,668 \\
765,495\end{array}$ & 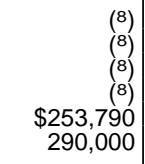 & $\begin{array}{r}- \\
\overline{-} \\
10245,1 \overline{15} \\
10239,780 \\
10275,523\end{array}$ & $\begin{array}{l}1,287 \\
1,447 \\
1,616 \\
1,753 \\
1,678 \\
1,859\end{array}$ & $\begin{array}{l}6,768 \\
7,437 \\
8,097 \\
8,486 \\
7,878 \\
8,444\end{array}$ \\
\hline 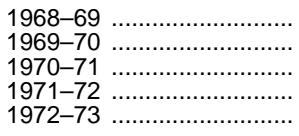 & $\begin{array}{l}536,527 \\
593,067 \\
588,390 \\
615,997 \\
669,735\end{array}$ & $\begin{array}{r}814,755 \\
984,594 \\
1,098,198 \\
1,241,372 \\
1,322,411\end{array}$ & $\begin{array}{l}- \\
- \\
-\end{array}$ & $\begin{array}{l}2,539,183 \\
2,769,276 \\
2,988,407 \\
3,178,272 \\
3,337,789\end{array}$ & $\begin{array}{r}697,317 \\
757,388 \\
829,596 \\
940,825 \\
1,033,746\end{array}$ & $\begin{array}{r}526,943 \\
671,236 \\
842,552 \\
998,585 \\
1,183,709\end{array}$ & $\begin{array}{l}- \\
- \\
-\end{array}$ & $\begin{array}{l}1,959 \\
2,104 \\
2,181 \\
2,284 \\
2,431\end{array}$ & $\begin{array}{l}8,486 \\
8,607 \\
8,482 \\
8,577 \\
8,773\end{array}$ \\
\hline 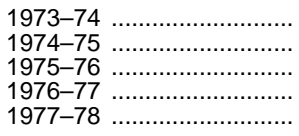 & $\begin{array}{r}730,560 \\
1,097,788 \\
1,238,603 \\
1,343,404 \\
1,425,294\end{array}$ & $\begin{array}{l}1,396,488 \\
1,449,542 \\
1,635,859 \\
1,770,214 \\
1,839,298\end{array}$ & $\begin{array}{l}532,485 \\
546,498 \\
584,515 \\
633,973\end{array}$ & $\begin{array}{l}3,613,256 \\
4,073,590 \\
4,476,841 \\
4,858,328 \\
5,261,477\end{array}$ & $\begin{array}{r}1,014,872 \\
1,085,590 \\
1,132,016 \\
1,434,738 \\
855,054\end{array}$ & $\begin{array}{l}1,431,604 \\
2,350,763 \\
2,695,635 \\
3,155,069 \\
3,597,655\end{array}$ & $\begin{array}{l}- \\
- \\
-\end{array}$ & $\begin{array}{l}2,568 \\
2,694 \\
2,736 \\
3,010 \\
3,213\end{array}$ & $\begin{array}{l}8,508 \\
8,038 \\
7,621 \\
7,925 \\
7,925\end{array}$ \\
\hline $\begin{array}{l}1978-79 \\
1979-80 \\
1980-81\end{array}$ & $\begin{array}{l}1,593,097 \\
1,816,521 \\
2,057,770 \\
2,203,726 \\
2,320,478\end{array}$ & $\begin{array}{l}1,944,599 \\
2,200,468 \\
2,504,525 \\
2,684,945 \\
2,922,897\end{array}$ & $\begin{array}{l}703,262 \\
732,385 \\
815,516 \\
783,854 \\
856,548\end{array}$ & $\begin{array}{l}5,749,974 \\
6,485,608 \\
7,288,089 \\
7,997,632 \\
8,614,316\end{array}$ & $\begin{array}{l}1,007,119 \\
1,127,728 \\
1,257,934 \\
1,258,777 \\
1,406,126\end{array}$ & $\begin{array}{l}4,130,775 \\
4,757,409 \\
5,433,111 \\
6,234,287 \\
6,986,089\end{array}$ & $\begin{array}{l}- \\
- \\
-\end{array}$ & $\begin{array}{l}3,538 \\
3,850 \\
4,139 \\
4,433 \\
4,742\end{array}$ & $\begin{array}{l}7,979 \\
7,662 \\
7,383 \\
7,278 \\
7,465\end{array}$ \\
\hline 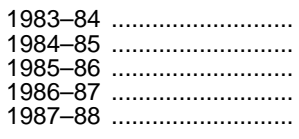 & $\begin{array}{l}2,499,203 \\
2,861,095 \\
3,119,533 \\
3,448,453 \\
3,786,362\end{array}$ & $\begin{array}{l}3,301,673 \\
3,670,355 \\
4,160,174 \\
4,776,100 \\
5,325,358\end{array}$ & $\begin{array}{r}958,321 \\
1,015,613 \\
1,192,449 \\
1,212,488 \\
1,317,633\end{array}$ & $\begin{array}{r}9,250,196 \\
10,012,248 \\
10,528,303 \\
11,037,333 \\
11,399,953\end{array}$ & $\begin{array}{l}1,622,233 \\
1,867,550 \\
2,187,361 \\
2,597,655 \\
2,822,632\end{array}$ & $\begin{array}{r}7,379,654 \\
8,010,141 \\
8,692,113 \\
9,173,014 \\
10,406,461\end{array}$ & $\begin{array}{l}- \\
- \\
-\end{array}$ & $\begin{array}{l}5,114 \\
5,723 \\
6,216 \\
6,635 \\
6,984\end{array}$ & $\begin{array}{l}7,762 \\
8,360 \\
8,826 \\
9,215 \\
9,314\end{array}$ \\
\hline 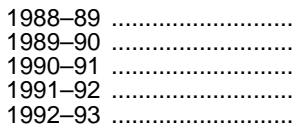 & $\begin{array}{l}4,227,323 \\
4,689,758 \\
5,076,177 \\
5,489,298 \\
5,935,095\end{array}$ & $\begin{array}{r}5,918,666 \\
6,655,544 \\
7,551,184 \\
9,060,000 \\
10,148,373\end{array}$ & $\begin{array}{l}1,458,397 \\
1,629,742 \\
1,707,063 \\
1,851,393 \\
1,990,603\end{array}$ & $\begin{array}{l}12,280,063 \\
13,203,984 \\
14,272,247 \\
14,966,100 \\
15,561,508\end{array}$ & $\begin{array}{l}2,958,962 \\
3,187,224 \\
3,349,824 \\
3,551,592 \\
3,651,891\end{array}$ & $\begin{array}{l}11,824,782 \\
12,679,286 \\
14,325,865 \\
16,104,313 \\
17,049,672\end{array}$ & $\begin{array}{l}- \\
- \\
-\end{array}$ & $\begin{array}{l}7,415 \\
7,799 \\
8,260 \\
8,466 \\
8,903\end{array}$ & $\begin{array}{l}9,453 \\
9,489 \\
9,529 \\
9,464 \\
9,651\end{array}$ \\
\hline 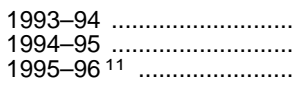 & $\begin{array}{l}6,242,414 \\
6,691,485 \\
7,045,145\end{array}$ & $\begin{array}{l}11,238,010 \\
12,285,328 \\
13,138,965\end{array}$ & $\begin{array}{l}2,115,288 \\
2,422,524 \\
2,400,338\end{array}$ & $\begin{array}{l}16,429,341 \\
17,204,917 \\
17,569,276\end{array}$ & $\begin{array}{l}3,387,323 \\
3,534,332 \\
3,492,548\end{array}$ & $\begin{array}{l}17,509,603 \\
18,071,359 \\
17,997,090\end{array}$ & - & $\begin{array}{r}9,509 \\
10,096 \\
10,583\end{array}$ & $\begin{array}{l}10,048 \\
10,371 \\
10,583\end{array}$ \\
\hline & & & & Degree & gramiting instit & ons ${ }^{12}$ & & & \\
\hline 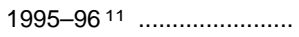 & $7,007,413$ & $13,195,102$ & $2,400,876$ & $17,599,061$ & $3,490,511$ & $17,940,986$ & - & - & - \\
\hline
\end{tabular}

1 Academic support excluding expenditures for libraries.

2 Includes all separately budgeted programs, other than research, which are supported by sponsors outside the institution. Examples are training programs, workshops, and training and instructional institutes. For years not shown, most expenditures for these programs are included under "Extension and public service."

${ }^{3}$ Generally includes only those expenditures associated with federally funded research and development centers (FFRDCs).

${ }^{4}$ Data for 1929-30 to 1945-46 are based on school year enrollment.

${ }^{5}$ Data adjusted by the Consumer Price Index computed on a school year basis.

${ }^{6}$ Expenditures for federally funded research and development centers are included under "Organized research."

7 Included under "Other current expenditures."
8 Expenditures for hospitals included under "Organized activities related to instructional "Expenditu

${ }^{9}$ Expenditures were for federal contract courses.

${ }^{10}$ Includes current expenditures for physical plant assets. In later years, the educational and general expenditures for physical plant assets are included under "Other general expenditures."
11 Preliminary data.

12 Data are for 4-year and 2-year degree-granting institutions that were eligible to participate in Title IV federal financial aid programs.

-Data not available.

NOTE.-The data in this table reflect limitations of data availability and comparability. Major changes in data collection forms in 1965-66 and 1974-75 cause significant data comparability problems among the three mostly consistent time periods, 1929-30 to $1963-64,1965-66$ to $1973-74$, and $1974-75$ to the present. The largest problems affect Hospitals, Independent operations, Organized research, Other sponsored programs, Extension and public service, and Scholarships and fellowships.

SOURCE: U.S. Department of Education, National Center for Education Statistics, Biennial Survey of Education in the United States; Higher Education General Information Survey (HEGIS), Financial Statistics of Institutions of Higher Education; and Integrated Postsecondary Education Data System, "Finance" surveys. (This table was prepared October 1998.) 
Table 337.-Expenditures of degree-granting institutions, by purpose and by control and type of institution: 1995-96 1

\begin{tabular}{|c|c|c|c|c|c|c|c|}
\hline \multirow{3}{*}{ Control and type of institution } & \multirow{3}{*}{$\begin{array}{l}\text { Current-fund } \\
\text { expenditures }\end{array}$} & \multicolumn{6}{|c|}{ Educational and general expenditures } \\
\hline & & \multirow{2}{*}{ Total } & \multirow{2}{*}{ Instruction } & \multirow{2}{*}{ Research } & \multirow{2}{*}{ Public service } & \multicolumn{2}{|c|}{ Academic support } \\
\hline & & & & & & Total & Libraries only \\
\hline 1 & 2 & 3 & 4 & 5 & 6 & 7 & 8 \\
\hline & & & & In thousands & & & \\
\hline$\ldots \ldots \ldots \ldots . .$. & $\$ 190,476,163$ & $\$ 151,445,605$ & $\$ 57,810,033$ & $\$ 17,517,887$ & $\$ 7,007,413$ & $\$ 13,297,063$ & $\$ 4,293,363$ \\
\hline Public . & $119,524,500$ & $96,085,623$ & $38,653,245$ & $12,076,357$ & $5,321,014$ & $9,004,113$ & $2,690,547$ \\
\hline Research I universities ${ }^{3}$. & $44,391,472$ & $32,554,192$ & $10,940,654$ & $7,985,405$ & $2,551,389$ & $3,164,464$ & 904,547 \\
\hline Research II universities ${ }^{3}$ & $7,321,555$ & $6,295,468$ & $2,334,613$ & $1,107,188$ & 500,296 & 653,614 & 212,284 \\
\hline Doctoral universities ……............................ & $12,654,818$ & $11,100,406$ & $4,224,600$ & $1,282,938$ & 647,497 & $1,146,700$ & 370,321 \\
\hline 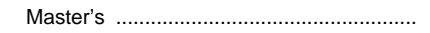 & $19,294,804$ & $16,567,809$ & $7,493,334$ & 532,501 & 584,189 & $1,579,379$ & 574,428 \\
\hline 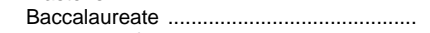 & $2,569,266$ & $2,219,738$ & 893,402 & 33,202 & 75,663 & 223,347 & 76,867 \\
\hline 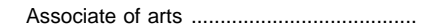 & $21,546,546$ & $20,202,436$ & $9,737,645$ & 23,168 & 475,198 & $1,691,120$ & 448,225 \\
\hline 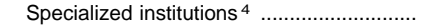 & $11,649,588$ & $7,052,919$ & $2,998,217$ & $1,111,474$ & 485,310 & 536,963 & 101,722 \\
\hline 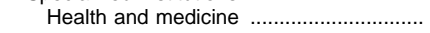 & $9,791,333$ & $5,387,219$ & $2,453,843$ & $1,015,905$ & 465,127 & 347,353 & 70,352 \\
\hline 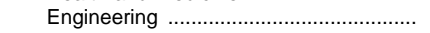 & 213,755 & 194,784 & 75,269 & 21,607 & 4,533 & 16,144 & 5,921 \\
\hline Business ....................... & 29,076 & 26,938 & 12,068 & 0 & 1,322 & 2,970 & 744 \\
\hline 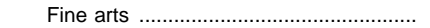 & 120,995 & 110,530 & 48024 & 0 & 1,112 & 13,832 & 3,755 \\
\hline 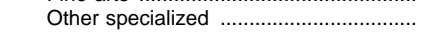 & $1,494,427$ & $1,333,449$ & 409,013 & 73,962 & 13,216 & 156,663 & 20,950 \\
\hline Tribal colleges $^{5} \ldots \ldots$ & 96,452 & 92,655 & 30,780 & 481 & 1,472 & 8,524 & 2,154 \\
\hline 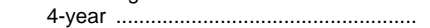 & 23,036 & 22,705 & 6,270 & 69 & 329 & 2,129 & 652 \\
\hline 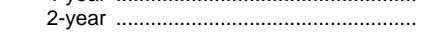 & 73,416 & 69,951 & 24,510 & 412 & 1,143 & 6,395 & 1,501 \\
\hline Private ........ & $70,951,662$ & $55,359,982$ & $19,156,788$ & $5,441,530$ & $1,686,399$ & $4,292,950$ & $1,602,816$ \\
\hline Research I universities ${ }^{3}$ & $27,593,269$ & $18,402,482$ & $6,688,949$ & $3,974,170$ & 537,817 & $1,458,295$ & 552,107 \\
\hline Research II universities ${ }^{3}$.......................... & $4,021,082$ & $2,795,688$ & $1,074,243$ & 324,401 & 22,069 & 236,600 & 93,065 \\
\hline Doctoral universities …….............................. & $6,433,667$ & $5,669,088$ & $2,095,623$ & 354,658 & 264,491 & 500,356 & 185,027 \\
\hline 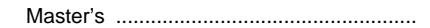 & $10,174,350$ & $9,023,040$ & $3,161,786$ & 161,815 & 122,211 & 699,872 & 259,468 \\
\hline 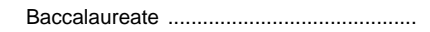 & $13,203,120$ & $11,408,175$ & $3,518,386$ & 101,988 & 77,543 & 799,360 & 339,054 \\
\hline Associate of arts & $1,883,084$ & $1,761,461$ & 544,889 & 1,315 & 3,748 & 117,272 & 22,527 \\
\hline 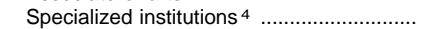 & $7,611,939$ & $6,269,565$ & $2,064,888$ & 523,176 & 653,280 & 478,615 & 151,142 \\
\hline Religion and theology & 987,438 & 869,961 & 256,000 & 4,687 & 11,446 & 88,651 & 48,877 \\
\hline Health and medicine & $3,965,671$ & $2,942,170$ & 989,420 & 482,838 & 614,131 & 167,825 & 36,170 \\
\hline 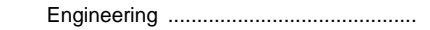 & 378,215 & 352,606 & 115,548 & 29,216 & 1,283 & 23,905 & 5,257 \\
\hline 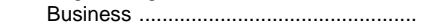 & 969,156 & 875,588 & 256,884 & 106 & 4,413 & 91,476 & 16,656 \\
\hline 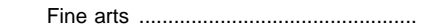 & 809,089 & 744,844 & 257,914 & 203 & 10,426 & 52,091 & 12,608 \\
\hline 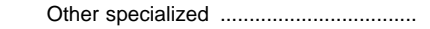 & 502,370 & 484,396 & 189,122 & 6,127 & 11,580 & 54,667 & 31,573 \\
\hline 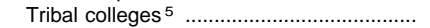 & 31,152 & 30,483 & 8,025 & 6 & 5,239 & 2,581 & 427 \\
\hline 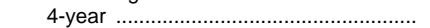 & 12,079 & 11,814 & 3,229 & 6 & 4,030 & 695 & 174 \\
\hline 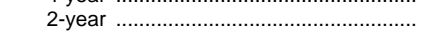 & 19,074 & 18,669 & 4,796 & 0 & 1,209 & 1,886 & 253 \\
\hline & & & Percentage distr & ion of current-fur & expenditures & & \\
\hline Total & 100.00 & 79.51 & 30.35 & 9.20 & 3.68 & 6.98 & 2.25 \\
\hline Public ........... & 100.00 & 80.39 & 32.34 & 10.10 & 4.45 & 7.53 & 2.25 \\
\hline Research I universities ${ }^{3}$ & 100.00 & 73.33 & 24.65 & 17.99 & 5.75 & 7.13 & 2.04 \\
\hline 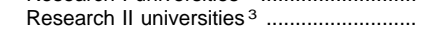 & 100.00 & 85.99 & 31.89 & 15.12 & 6.83 & 8.93 & 2.90 \\
\hline 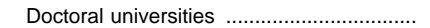 & 100.00 & 87.72 & 33.38 & 10.14 & 5.12 & 9.06 & 2.93 \\
\hline Master's ……................................................ & 100.00 & 85.87 & 38.84 & 2.76 & 3.03 & 8.19 & 2.98 \\
\hline 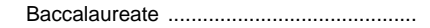 & 100.00 & 86.40 & 34.77 & 1.29 & 2.94 & 8.69 & 2.99 \\
\hline Associate of arts & 100.00 & 93.76 & 45.19 & 0.11 & 2.21 & 7.85 & 2.08 \\
\hline 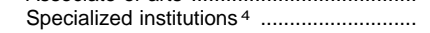 & 100.00 & 60.54 & 25.74 & 9.54 & 4.17 & 4.61 & 0.87 \\
\hline Health and medicine & 100.00 & 55.02 & 25.06 & 10.38 & 4.75 & 3.55 & 0.72 \\
\hline 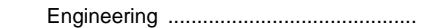 & 100.00 & 91.12 & 35.21 & 10.11 & 2.12 & 7.55 & 2.77 \\
\hline 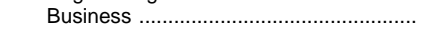 & 100.00 & 92.64 & 41.50 & 0.00 & 4.55 & 10.22 & 2.56 \\
\hline 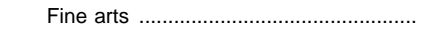 & 100.00 & 91.35 & 39.69 & 0.00 & 0.92 & 11.43 & 3.10 \\
\hline 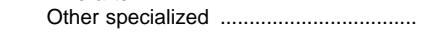 & 100.00 & 89.23 & 27.37 & 4.95 & 0.88 & 10.48 & 1.40 \\
\hline 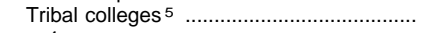 & 100.00 & 96.06 & 31.91 & 0.50 & 1.53 & 8.84 & 2.23 \\
\hline 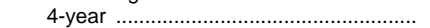 & 100.00 & 98.56 & 27.22 & 0.30 & 1.43 & 9.24 & 2.83 \\
\hline 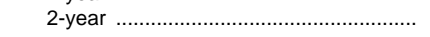 & 100.00 & 95.28 & 33.38 & 0.56 & 1.56 & 8.71 & 2.04 \\
\hline Private & 100.00 & 78.02 & 27.00 & 7.67 & 2.38 & 6.05 & 2.26 \\
\hline Research I universities $^{3}$ & 100.00 & 66.69 & 24.24 & 14.40 & 1.95 & 5.28 & 2.00 \\
\hline 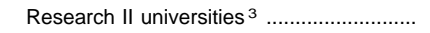 & 100.00 & 69.53 & 26.72 & 8.07 & 0.55 & 5.88 & 2.31 \\
\hline 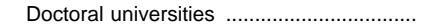 & 100.00 & 88.12 & 32.57 & 5.51 & 4.11 & 7.78 & 2.88 \\
\hline 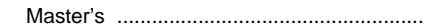 & 100.00 & 88.68 & 31.08 & 1.59 & 1.20 & 6.88 & 2.55 \\
\hline 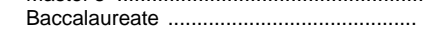 & 100.00 & 86.41 & 26.65 & 0.77 & 0.59 & 6.05 & 2.57 \\
\hline Associate of arts & 100.00 & 93.54 & 28.94 & 0.07 & 0.20 & 6.23 & 1.20 \\
\hline 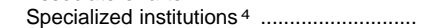 & 100.00 & 82.36 & 27.13 & 6.87 & 8.58 & 6.29 & 1.99 \\
\hline 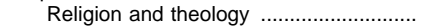 & 100.00 & 88.10 & 25.93 & 0.47 & 1.16 & 8.98 & 4.95 \\
\hline 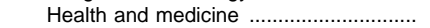 & 100.00 & 74.19 & 24.95 & 12.18 & 15.49 & 4.23 & 0.91 \\
\hline 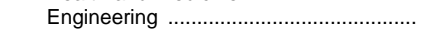 & 100.00 & 93.23 & 30.55 & 7.72 & 0.34 & 6.32 & 1.39 \\
\hline 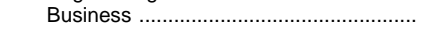 & 100.00 & 90.35 & 26.51 & 0.01 & 0.46 & 9.44 & 1.72 \\
\hline 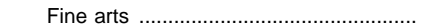 & 100.00 & 92.06 & 31.88 & 0.03 & 1.29 & 6.44 & 1.56 \\
\hline Other specialized …….......................... & 100.00 & 96.42 & 37.65 & 1.22 & 2.30 & 10.88 & 6.28 \\
\hline 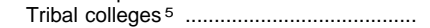 & 100.00 & 97.85 & 25.76 & 0.02 & 16.82 & 8.28 & 1.37 \\
\hline 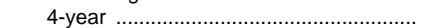 & 100.00 & 97.81 & 26.73 & 0.05 & 33.36 & 5.75 & 1.44 \\
\hline 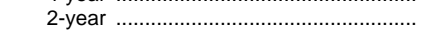 & 100.00 & 97.88 & 25.14 & 0.00 & 6.34 & 9.89 & 1.32 \\
\hline
\end{tabular}


Table 337.-Expenditures of degree-granting institutions, by purpose and by control and type of institution: 1995-96 1_Continued

\begin{tabular}{|c|c|c|c|c|c|c|c|c|}
\hline \multirow[b]{2}{*}{ Control and type of institution } & \multicolumn{5}{|c|}{ Educational and general expenditures } & \multirow[b]{2}{*}{$\begin{array}{l}\text { Auxiliary } \\
\text { enterprises }\end{array}$} & \multirow[b]{2}{*}{ Hospitals } & \multirow[b]{2}{*}{$\begin{array}{l}\text { Independent } \\
\text { operations }^{2}\end{array}$} \\
\hline & $\begin{array}{l}\text { Student } \\
\text { services }\end{array}$ & $\begin{array}{l}\text { Institutional } \\
\text { support }\end{array}$ & $\begin{array}{l}\text { Operation and } \\
\text { maintenance of } \\
\text { plant }\end{array}$ & $\begin{array}{c}\text { Scholarships } \\
\text { and fellowships }\end{array}$ & $\begin{array}{l}\text { Mandatory } \\
\text { transfers }\end{array}$ & & & \\
\hline \multirow[t]{2}{*}{1} & 9 & 10 & 11 & 12 & 13 & 14 & 15 & 16 \\
\hline & \multicolumn{8}{|c|}{ In thousands } \\
\hline$\ldots \ldots \ldots \ldots \ldots . . .$. & $\$ 9,630,576$ & $\$ 18,255,769$ & $\$ 12,330,885$ & $\$ 13,195,102$ & $\$ 2,400,876$ & $\$ 17,599,061$ & $\$ 17,940,986$ & $\$ 3,490,511$ \\
\hline Public & $5,810,403$ & $10,710,279$ & $8,005,101$ & $5,084,653$ & $1,420,459$ & $11,309,031$ & $11,878,939$ & 250,906 \\
\hline Research I universities ${ }^{3} \ldots \ldots \ldots \ldots \ldots \ldots \ldots \ldots \ldots$ & $1,096,586$ & $2,198,520$ & $2,146,919$ & $1,858,537$ & 611,717 & $4,271,937$ & $7,472,224$ & 93,118 \\
\hline Research II universities ${ }^{3}$. & 293,437 & 514,892 & 453,506 & 355,504 & 82,417 & $1,024,624$ & 0 & 1,463 \\
\hline Doctoral universities …............................. & 612,280 & $1,522,084$ & 823,667 & 659,211 & 181,428 & $1,529,439$ & 20,596 & 4,377 \\
\hline Master's …1. & $1,222,814$ & $2,156,871$ & $1,604,038$ & $1,113,893$ & 280,791 & $2,504,384$ & 208,917 & 13,693 \\
\hline 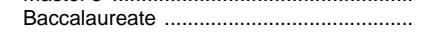 & 209,354 & 330,278 & 235,586 & 175,432 & 43,473 & 308,605 & 0 & 40,922 \\
\hline Associate of arts & $2,167,115$ & $3,110,851$ & $2,071,045$ & 773,332 & 152,962 & $1,330,303$ & 0 & 13,807 \\
\hline Specialized institutions ${ }^{4}$ & 196,586 & 857,882 & 659,023 & 141,058 & 66,407 & 336,997 & $4,177,202$ & 82,471 \\
\hline Health and medicine & 49,555 & 580,654 & 352,687 & 66,446 & 55,648 & 217,319 & $4,107,770$ & 79,026 \\
\hline 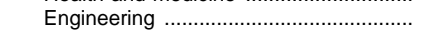 & 11,571 & 26,182 & 19,936 & 11,782 & 7,760 & 15,532 & 0 & 3,440 \\
\hline 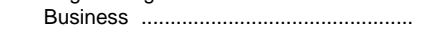 & 1,816 & 4,156 & 2,493 & 2,113 & 0 & 2,139 & 0 & 0 \\
\hline 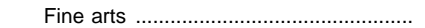 & 8,705 & 19,996 & 12,675 & 6,137 & 49 & 10,466 & 0 & 0 \\
\hline Other specialized & 124,939 & 226,893 & 271,232 & 54,581 & 2,950 & 91,542 & 69,432 & 5 \\
\hline Tribal colleges ${ }^{5} \ldots \ldots \ldots \ldots$ & 12,230 & 18,901 & 11,317 & 7,686 & 1,265 & 2,742 & 0 & 1,055 \\
\hline 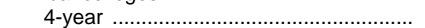 & 5,375 & 4,852 & 2,846 & 834 & & 331 & 0 & 0 \\
\hline 2-year ……….............................................. & 6,855 & 14,049 & 8,471 & 6,852 & 1,265 & 2,411 & 0 & 1,055 \\
\hline Private & $3,820,174$ & $7,545,490$ & $4,325,784$ & $8,110,450$ & 980,417 & $6,290,030$ & $6,062,047$ & $3,239,604$ \\
\hline Research I universities ${ }^{3}$ & 591,377 & $1,732,531$ & $1,258,193$ & $1,845,798$ & 315,352 & $1,750,388$ & $4,565,567$ & $2,874,832$ \\
\hline Research II universities ${ }^{3} \ldots \ldots \ldots \ldots \ldots \ldots \ldots \ldots \ldots$ & 124,817 & 322,619 & 205,766 & 441,343 & 43,830 & 513,310 & 697,841 & 14,242 \\
\hline Doctoral universities …................................. & 346,964 & 776,419 & 428,873 & 781,422 & 120,281 & 612,033 & 101,280 & 51,266 \\
\hline 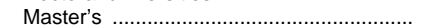 & 887,939 & $1,391,852$ & 679,744 & $1,718,153$ & 199,668 & $1,122,730$ & 9,311 & 19,269 \\
\hline 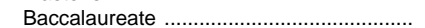 & $1,212,265$ & $1,907,387$ & 991,314 & $2,598,646$ & 201,286 & $1,748,771$ & 0 & 46,174 \\
\hline Associate of arts & 269,259 & 387,789 & 218,743 & 213,558 & 4,889 & 120,791 & 0 & 832 \\
\hline Specialized institutions ${ }^{4} \ldots \ldots \ldots \ldots \ldots \ldots \ldots \ldots \ldots$ & 383,426 & $1,021,622$ & 541,084 & 508,792 & 94,682 & 421,337 & 688,047 & 232,991 \\
\hline Religion and theology & 65,162 & 220,057 & 106,645 & 110,020 & 7,293 & 111,346 & 424 & 5,706 \\
\hline Health and medicine & 84,605 & 298,123 & 195,532 & 71,184 & 38,512 & 113,931 & 686,826 & 222,745 \\
\hline 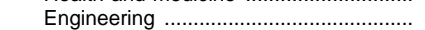 & 33,502 & 67,490 & 29,185 & 42,065 & 10,412 & 25,609 & 0 & 0 \\
\hline 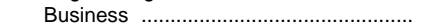 & 105,547 & 189,554 & 72,504 & 136,079 & 19,027 & 93,568 & 0 & 0 \\
\hline 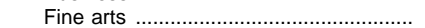 & 59,516 & 149,877 & 90,413 & 111,100 & 13,304 & 60,038 & 0 & 4,206 \\
\hline Other specialized & 35,095 & 96,521 & 46,806 & 38,344 & 6,134 & 16,844 & 797 & 333 \\
\hline 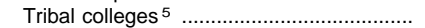 & 4,128 & 5,271 & 2,066 & 2,737 & 429 & 670 & 0 & 0 \\
\hline 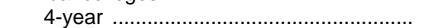 & 615 & 1,469 & 385 & 1,385 & 0 & 265 & 0 & 0 \\
\hline \multirow[t]{2}{*}{ 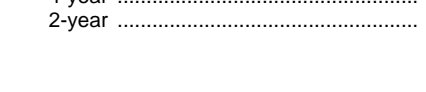 } & 3,512 & 3,803 & 1,681 & 1,352 & 429 & 405 & 0 & 0 \\
\hline & & & Percentage distrit & bution of current- $f$ & d expenditures & & & \\
\hline Total & 5.06 & 9.58 & 6.47 & 6.93 & 1.26 & 9.24 & 9.42 & 1.83 \\
\hline Public & 4.86 & 8.96 & 6.70 & 4.25 & 1.19 & 9.46 & 9.94 & 0.21 \\
\hline Research I universities ${ }^{3}$ & 2.47 & 4.95 & 4.84 & 4.19 & 1.38 & 9.62 & 16.83 & 0.21 \\
\hline 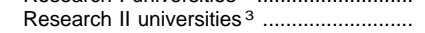 & 4.01 & 7.03 & 6.19 & 4.86 & 1.13 & 13.99 & 0.00 & 0.02 \\
\hline Doctoral universities …............................... & 4.84 & 12.03 & 6.51 & 5.21 & 1.43 & 12.09 & 0.16 & 0.03 \\
\hline Master's …1. & 6.34 & 11.18 & 8.31 & 5.77 & 1.46 & 12.98 & 1.08 & 0.07 \\
\hline 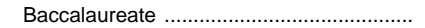 & 8.15 & 12.85 & 9.17 & 6.83 & 1.69 & 12.01 & 0.00 & 1.59 \\
\hline Associate of arts & 10.06 & 14.44 & 9.61 & 3.59 & 0.71 & 6.17 & 0.00 & 0.06 \\
\hline 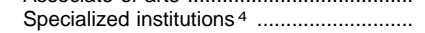 & 1.69 & 7.36 & 5.66 & 1.21 & 0.57 & 2.89 & 35.86 & 0.71 \\
\hline Health and medicine .................................. & 0.51 & 5.93 & 3.60 & 0.68 & 0.57 & 2.22 & 41.95 & 0.81 \\
\hline 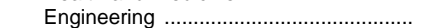 & 5.41 & 12.25 & 9.33 & 5.51 & 3.63 & 7.27 & 0.00 & 1.61 \\
\hline 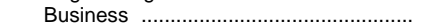 & 6.25 & 14.29 & 8.57 & 7.27 & 0.00 & 7.36 & 0.00 & 0.00 \\
\hline 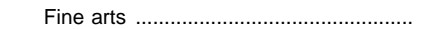 & 7.19 & 16.53 & 10.48 & 5.07 & 0.04 & 8.65 & 0.00 & 0.00 \\
\hline 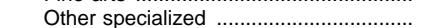 & 8.36 & 15.18 & 18.15 & 3.65 & 0.20 & 6.13 & 4.65 & 0.00 \\
\hline Tribal colleges ${ }^{5}$ & 12.68 & 19.60 & 11.73 & 7.97 & 1.31 & 2.84 & 0.00 & 1.09 \\
\hline 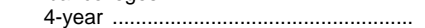 & 23.33 & 21.06 & 12.36 & 3.62 & 0.00 & 1.44 & 0.00 & 0.00 \\
\hline 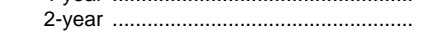 & 9.34 & 19.14 & 11.54 & 9.33 & 1.72 & 3.28 & 0.00 & 1.44 \\
\hline Private ........ & 5.38 & 10.63 & 6.10 & 11.43 & 1.38 & 8.87 & 8.54 & 4.57 \\
\hline Research I universities ${ }^{3}$.. & 2.14 & 6.28 & 4.56 & 6.69 & 1.14 & 6.34 & 16.55 & 10.42 \\
\hline Research II universities ${ }^{3} \ldots \ldots \ldots \ldots \ldots \ldots \ldots \ldots$ & 3.10 & 8.02 & 5.12 & 10.98 & 1.09 & 12.77 & 17.35 & 0.35 \\
\hline Doctoral universities & 5.39 & 12.07 & 6.67 & 12.15 & 1.87 & 9.51 & 1.57 & 0.80 \\
\hline Master's …....................................... & 8.73 & 13.68 & 6.68 & 16.89 & 1.96 & 11.03 & 0.09 & 0.19 \\
\hline 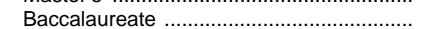 & 9.18 & 14.45 & 7.51 & 19.68 & 1.52 & 13.25 & 0.00 & 0.35 \\
\hline Associate of arts & 14.30 & 20.59 & 11.62 & 11.34 & 0.26 & 6.41 & 0.00 & 0.04 \\
\hline 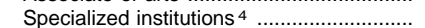 & 5.04 & 13.42 & 7.11 & 6.68 & 1.24 & 5.54 & 9.04 & 3.06 \\
\hline Religion and theology ................................. & 6.60 & 22.29 & 10.80 & 11.14 & 0.74 & 11.28 & 0.04 & 0.58 \\
\hline Health and medicine …................................ & 2.13 & 7.52 & 4.93 & 1.80 & 0.97 & 2.87 & 17.32 & 5.62 \\
\hline 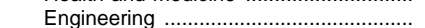 & 8.86 & 17.84 & 7.72 & 11.12 & 2.75 & 6.77 & 0.00 & 0.00 \\
\hline 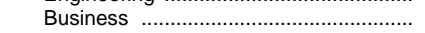 & 10.89 & 19.56 & 7.48 & 14.04 & 1.96 & 9.65 & 0.00 & 0.00 \\
\hline 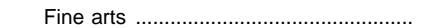 & 7.36 & 18.52 & 11.17 & 13.73 & 1.64 & 7.42 & 0.00 & 0.52 \\
\hline 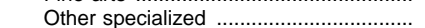 & 6.99 & 19.21 & 9.32 & 7.63 & 1.22 & 3.35 & 0.16 & 0.07 \\
\hline 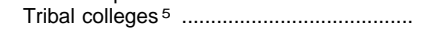 & 13.25 & 16.92 & 6.63 & 8.79 & 1.38 & 2.15 & 0.00 & 0.00 \\
\hline 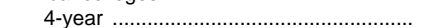 & 5.10 & 12.16 & 3.19 & 11.46 & 0.00 & 2.19 & 0.00 & 0.00 \\
\hline 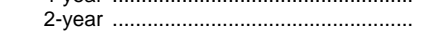 & 18.42 & 19.94 & 8.81 & 7.09 & 2.25 & 2.12 & 0.00 & 0.00 \\
\hline
\end{tabular}

${ }^{1}$ Preliminary data.

${ }^{2}$ Generally includes only those expenditures associated with major federally funded research and development centers (FFRDC).

${ }^{3}$ Research institutions are committed to graduate education through the doctorate, and give high priority to research. Research I institutions receive $\$ 40$ million or more annually in federal support. Research II institutions receive between $\$ 15.5$ million and $\$ 40$ million annually.
${ }^{4}$ Specialized institutions award baccalaureate or higher level degrees in specific fields of study.

5 Tribally controlled colleges are located on reservations. They are members of the American Indian Higher Education Consortium.

SOURCE: U.S. Department of Education, National Center for Education Statistics, Integrated Postsecondary Education Data System (IPEDS), "Finance, 1995-96" survey. (This table was prepared November 1998.) 
Table 338.-Current-fund expenditures of institutions of higher education, by purpose: 1980-81 to $1995-96$

\begin{tabular}{|c|c|c|c|c|c|c|c|c|c|}
\hline Purpose & $1980-81$ & $1985-86$ & $1989-90$ & $1990-91$ & $1991-92$ & $1992-93$ & $1993-94$ & 1994-95 & $1995-961$ \\
\hline 1 & 2 & 3 & 4 & 5 & 6 & 7 & 8 & 9 & 10 \\
\hline & \multicolumn{9}{|c|}{ In thousands } \\
\hline Total current-fund expenditures ............ & $\$ 64,052,938$ & $\$ 97,535,742$ & $\$ 134,655,571$ & $\$ 146,087,836$ & $\$ 156,189,161$ & $\$ 165,241,040$ & $\$ 173,350,617$ & $\$ 182,968,610$ & $\$ 190,476,163$ \\
\hline Educational and general expenditures & $50,073,805$ & $76,127,965$ & $105,585,076$ & $114,139,901$ & $121,567,157$ & $128,977,968$ & $136,024,350$ & $144,158,002$ & $151,445,605$ \\
\hline Instruction ... & $20,733,166$ & $31,032,099$ & $42,145,987$ & $45,496,117$ & $47,997,196$ & $50,340,914$ & $52,775,599$ & $55,719,707$ & $57,810,033$ \\
\hline Research ......... & $5,657,719$ & $8,437,367$ & $12,505,961$ & $13,444,040$ & $14,261,554$ & $15,291,309$ & $16,117,610$ & $17,109,541$ & $17,517,887$ \\
\hline 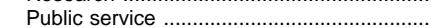 & $2,057,770$ & $3,119,533$ & $4,689,758$ & $5,076,177$ & $5,489,298$ & $5,935,095$ & $6,242,414$ & $6,691,485$ & $7,007,413$ \\
\hline Academic support & $4,273,286$ & $6,667,392$ & $9,437,644$ & $10,050,773$ & $10,577,018$ & $11,072,970$ & $11,677,911$ & $12,278,691$ & $13,297,063$ \\
\hline Libraries ................. & $1,759,784$ & $2,551,331$ & $3,254,239$ & $3,343,892$ & $3,595,834$ & $3,684,852$ & $3,908,412$ & $4,165,761$ & $4,293,363$ \\
\hline Student services & $2,908,998$ & $4,562,938$ & $6,388,148$ & $7,025,482$ & $7,509,094$ & $8,165,079$ & $8,562,783$ & $9,059,994$ & $9,630,576$ \\
\hline 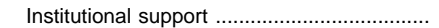 & $5,772,515$ & $9,350,786$ & $12,674,031$ & $13,726,484$ & $14,475,023$ & $15,249,898$ & $15,926,239$ & $16,844,827$ & $18,255,769$ \\
\hline Operation and maintenance of plant ........... & $5,350,310$ & $7,605,226$ & $9,458,262$ & $10,062,581$ & $10,346,580$ & $10,783,727$ & $11,368,496$ & $11,745,905$ & $12,330,885$ \\
\hline Scholarships and fellowships & $2,504,525$ & $4,160,174$ & $6,655,544$ & $7,551,184$ & $9,060,000$ & $10,148,373$ & $11,238,010$ & $12,285,328$ & $13,195,102$ \\
\hline From unrestricted funds ............................ & $1,080,614$ & $2,285,116$ & $3,853,904$ & $4,445,106$ & $5,205,797$ & $5,949,037$ & $6,644,717$ & $7,329,384$ & $8,213,049$ \\
\hline From restricted funds ${ }^{2} \ldots \ldots \ldots \ldots \ldots \ldots \ldots \ldots \ldots \ldots$ & $1,423,911$ & $1,875,059$ & $2,801,640$ & $3,106,078$ & $3,854,203$ & $4,199,337$ & $4,593,293$ & $4,955,944$ & $4,982,054$ \\
\hline 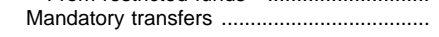 & 815,516 & $1,192,449$ & $1,629,742$ & $1,707,063$ & $1,851,393$ & $1,990,603$ & $2,115,288$ & $2,422,524$ & $2,400,876$ \\
\hline Auxiliary enterprises & $7,288,089$ & $10,528,303$ & $13,203,984$ & $14,272,247$ & $14,966,100$ & $15,561,508$ & $16,429,341$ & $17,204,917$ & $17,599,061$ \\
\hline Mandatory transfers & 508,377 & 617,171 & 836,852 & 936,876 & $1,003,299$ & $1,109,549$ & $1,158,848$ & $1,228,278$ & $1,145,366$ \\
\hline Hospitals & $5,433,111$ & $8,692,113$ & $12,679,286$ & $14,325,865$ & $16,104,313$ & $17,049,672$ & $17,509,603$ & $18,071,359$ & $17,940,986$ \\
\hline Mandatory transfers & 57,963 & 128,833 & 222,192 & 274,452 & 333,714 & 308,059 & 344,665 & 346,072 & 268,439 \\
\hline \multirow{3}{*}{$\begin{array}{l}\text { Independent operations }(\mathrm{FFRDC})^{3} \\
\text { Mandatory transfers }\end{array}$} & $1,257,934$ & $2,187,361$ & $3,187,224$ & $3,349,824$ & $3,551,592$ & $3,651,891$ & $3,387,323$ & $3,534,332$ & $3,490,511$ \\
\hline & 643 & 3,432 & 5,812 & 5,645 & 3,396 & 2,271 & 2,354 & 2,373 & 2,123 \\
\hline & \multicolumn{9}{|c|}{ Percentage distribution } \\
\hline Total current-fund expenditures ........... & 100.0 & 100.0 & 100.0 & 100.0 & 100.0 & 100.0 & 100.0 & 100.0 & 100.0 \\
\hline Educational and general expenditures .............. & 78.2 & 78.1 & 78.4 & 78.1 & 77.8 & 78.1 & 78.5 & 78.8 & 79.5 \\
\hline Instruction ... & 32.4 & 31.8 & 31.3 & 31.1 & 30.7 & 30.5 & 30.4 & 30.5 & 30.4 \\
\hline Research & 8.8 & 8.7 & 9.3 & 9.2 & 9.1 & 9.3 & 9.3 & 9.4 & 9.2 \\
\hline Public service & 3.2 & 3.2 & 3.5 & 3.5 & 3.5 & 3.6 & 3.6 & 3.7 & 3.7 \\
\hline 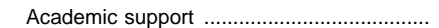 & 6.7 & 6.8 & 7.0 & 6.9 & 6.8 & 6.7 & 6.7 & 6.7 & 7.0 \\
\hline Libraries ............... & 2.7 & 2.6 & 2.4 & 2.3 & 2.3 & 2.2 & 2.3 & 2.3 & 2.3 \\
\hline Student services & 4.5 & 4.7 & 4.7 & 4.8 & 4.8 & 4.9 & 4.9 & 5.0 & 5.1 \\
\hline Institutional support ……............................ & 9.0 & 9.6 & 9.4 & 9.4 & 9.3 & 9.2 & 9.2 & 9.2 & 9.6 \\
\hline Operation and maintenance of plant ............ & 8.4 & 7.8 & 7.0 & 6.9 & 6.6 & 6.5 & 6.6 & 6.4 & 6.5 \\
\hline Scholarships and fellowships ........................ & 3.9 & 4.3 & 4.9 & 5.2 & 5.8 & 6.1 & 6.5 & 6.7 & 6.9 \\
\hline From unrestricted funds ........................... & 1.7 & 2.3 & 2.9 & 3.0 & 3.3 & 3.6 & 3.8 & 4.0 & 4.3 \\
\hline 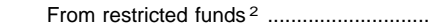 & 2.2 & 1.9 & 2.1 & 2.1 & 2.5 & 2.5 & 2.6 & 2.7 & 2.6 \\
\hline Mandatory transfers & 1.3 & 1.2 & 1.2 & 1.2 & 1.2 & 1.2 & 1.2 & 1.3 & 1.3 \\
\hline Auxiliary enterprises .......... & 11.4 & 10.8 & 9.8 & 9.8 & 9.6 & 9.4 & 9.5 & 9.4 & 9.2 \\
\hline Mandatory transfers ................. & 0.8 & 0.6 & 0.6 & 0.6 & 0.6 & 0.7 & 0.7 & 0.7 & 0.6 \\
\hline 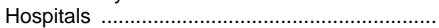 & 8.5 & 8.9 & 9.4 & 9.8 & 10.3 & 10.3 & 10.1 & 9.9 & 9.4 \\
\hline Mandatory transfers ……...................................... & 0.1 & 0.1 & 0.2 & 0.2 & 0.2 & 0.2 & 0.2 & 0.2 & 0.1 \\
\hline 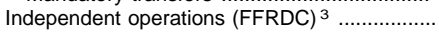 & 2.0 & 2.2 & 2.4 & 2.3 & 2.3 & 2.2 & 2.0 & 1.9 & 1.8 \\
\hline Mandatory transfers ……....................................... & (4) & $\left({ }^{4}\right)$ & $\left({ }^{4}\right)$ & $\left({ }^{4}\right)$ & $(4)$ & $\left({ }^{4}\right)$ & $\left({ }^{4}\right)$ & $\left({ }^{4}\right)$ & $\left({ }^{4}\right)$ \\
\hline
\end{tabular}

${ }_{1}^{1}$ Preliminary data are for 4-year and 2-year degree-granting institutions that were eligible to participate in Title IV federal financial aid programs.

2Excludes Pell Grants.

${ }^{3}$ Generally includes only those expenditures associated with major federally funded research and development centers (FFRDC).

${ }^{4}$ Less than 0.05 percent.
NOTE.-Because of rounding, details may not add to totals.

SOURCE: U.S. Department of Education, National Center for Education Statistics, Higher Education General Information Survey (HEGIS), "Financial Statistics of Institutions of Higher Education" surveys; and Integrated Postsecondary Education Data System (IPEDS), "Finance" surveys. (This table was prepared October 1998.) 
Table 339.-Current-fund expenditures of public institutions of higher education, by purpose: 1980-81 to 1995-96

\begin{tabular}{|c|c|c|c|c|c|c|c|c|c|}
\hline Purpose & $1980-81$ & $1985-86$ & $1989-90$ & $1990-91$ & $1991-92$ & 1992-93 & $1993-94$ & 1994-95 & $1995-961$ \\
\hline 1 & 2 & 3 & 4 & 5 & 6 & 7 & 8 & 9 & 10 \\
\hline & \multicolumn{9}{|c|}{ In thousands } \\
\hline Total current-fund expenditures. & $\$ 42,279,806$ & $\$ 63,193,853$ & $\$ 85,770,530$ & $\$ 92,961,093$ & $\$ 98,847,180$ & $\$ 104,570,101$ & $\$ 109,309,541$ & $\$ 115,464,975$ & $\$ 119,524,500$ \\
\hline Educational and general expenditures ............. & $34,173,013$ & $50,872,962$ & $69,163,958$ & $74,395,428$ & $78,554,534$ & $83,210,979$ & $87,139,226$ & $92,173,768$ & $96,085,623$ \\
\hline Instruction & $14,849,822$ & $21,880,782$ & $29,257,209$ & $31,371,394$ & $32,828,420$ & $34,260,177$ & $35,688,497$ & $37,599,194$ & $38,653,245$ \\
\hline Research .. & $3,813,350$ & $5,705,144$ & $8,542,235$ & $9,364,213$ & $9,948,580$ & $10,604,973$ & $11,180,363$ & $11,829,665$ & $12,076,357$ \\
\hline 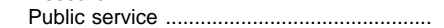 & $1,718,924$ & $2,515,734$ & $3,688,664$ & $3,990,232$ & $4,285,501$ & $4,563,397$ & $4,741,719$ & $5,034,445$ & $5,321,014$ \\
\hline Academic support & $3,029,284$ & $4,693,543$ & $6,535,076$ & $6,933,847$ & $7,274,159$ & $7,613,244$ & $8,035,556$ & $8,463,236$ & $9,004,113$ \\
\hline 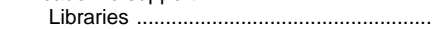 & $1,187,116$ & $1,685,052$ & $2,102,672$ & $2,167,161$ & $2,284,520$ & $2,329,625$ & $2,449,109$ & $2,614,609$ & $2,690,547$ \\
\hline 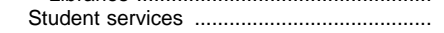 & $1,950,566$ & $2,921,758$ & $4,021,328$ & $4,398,365$ & $4,690,921$ & $5,173,239$ & $5,315,370$ & $5,614,011$ & $5,810,403$ \\
\hline 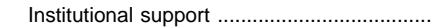 & $3,563,194$ & $5,667,144$ & $7,490,137$ & $8,030,642$ & $8,423,156$ & $9,049,589$ & $9,328,236$ & $9,929,007$ & $10,710,279$ \\
\hline Operation and maintenance of plant ............ & $3,681,921$ & $5,177,254$ & $6,333,582$ & $6,655,605$ & $6,790,215$ & $7,076,805$ & $7,433,185$ & $7,668,919$ & $8,005,101$ \\
\hline Scholarships and fellowships …….................. & $1,064,864$ & $1,575,909$ & $2,386,493$ & $2,688,532$ & $3,255,660$ & $3,727,838$ & $4,222,923$ & $4,662,023$ & $5,084,653$ \\
\hline From unrestricted funds ................................ & 367,476 & 696,973 & $1,099,425$ & $1,270,158$ & $1,523,721$ & $1,745,339$ & $1,934,617$ & $2,149,036$ & $2,457,139$ \\
\hline From restricted funds ${ }^{2} \ldots \ldots \ldots \ldots \ldots \ldots \ldots \ldots \ldots \ldots$ & 697,388 & 878,935 & $1,287,068$ & $1,418,374$ & $1,731,939$ & $1,982,498$ & $2,288,306$ & $2,512,988$ & $2,627,514$ \\
\hline Mandatory transfers …................................... & 501,087 & 735,695 & 909,234 & 962,598 & $1,057,923$ & $1,141,717$ & $1,193,379$ & $1,373,267$ & $1,420,459$ \\
\hline Auxiliary enterprises & $4,658,140$ & $6,830,235$ & $8,282,332$ & $9,049,935$ & $9,634,131$ & $10,024,352$ & $10,637,783$ & $11,235,143$ & $11,309,031$ \\
\hline Mandatory transfers ……..................................... & 344,043 & 410,777 & 551,331 & 623,146 & 655,301 & 758,644 & 784,115 & 835,993 & 793,125 \\
\hline 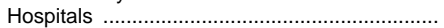 & $3,377,972$ & $5,358,699$ & $8,113,989$ & $9,315,902$ & $10,432,773$ & $11,100,602$ & $11,317,674$ & $11,801,589$ & $11,878,939$ \\
\hline Mandatory transfers ……….......................... & 26,613 & 75,569 & 156,029 & 195,961 & 224,095 & 223,241 & 242,216 & 262,343 & 213,387 \\
\hline Independent operations (FFRDC) ${ }^{3} \ldots \ldots \ldots \ldots \ldots$ & 70,681 & 131,956 & 210,252 & 199,827 & 225,742 & 234,168 & 214,858 & 254,474 & 250,906 \\
\hline \multirow{2}{*}{ Mandatory transfers } & 322 & 846 & 2,276 & 1,201 & 510 & 462 & 474 & 465 & 1,343 \\
\hline & \multicolumn{9}{|c|}{ Percentage distribution } \\
\hline Total current-fund expenditures ........... & 100.0 & 100.0 & 100.0 & 100.0 & 100.0 & 100.0 & 100.0 & 100.0 & 100.0 \\
\hline Educational and general expenditures & 80.8 & 80.5 & 80.6 & 80.0 & 79.5 & 79.6 & 79.7 & 79.8 & 80.4 \\
\hline Instruction & 35.1 & 34.6 & 34.1 & 33.7 & 33.2 & 32.8 & 32.6 & 32.6 & 32.3 \\
\hline 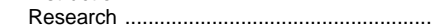 & 9.0 & 9.0 & 10.0 & 10.1 & 10.1 & 10.1 & 10.2 & 10.2 & 10.1 \\
\hline 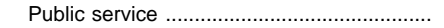 & 4.1 & 4.0 & 4.3 & 4.3 & 4.3 & 4.4 & 4.3 & 4.4 & 4.5 \\
\hline 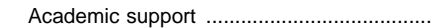 & 7.2 & 7.4 & 7.6 & 7.5 & 7.4 & 7.3 & 7.4 & 7.3 & 7.5 \\
\hline 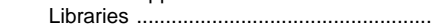 & 2.8 & 2.7 & 2.5 & 2.3 & 2.3 & 2.2 & 2.2 & 2.3 & 2.3 \\
\hline 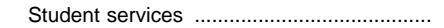 & 4.6 & 4.6 & 4.7 & 4.7 & 4.7 & 4.9 & 4.9 & 4.9 & 4.9 \\
\hline 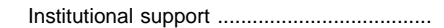 & 8.4 & 9.0 & 8.7 & 8.6 & 8.5 & 8.7 & 8.5 & 8.6 & 9.0 \\
\hline Operation and maintenance of plant ........... & 8.7 & 8.2 & 7.4 & 7.2 & 6.9 & 6.8 & 6.8 & 6.6 & 6.7 \\
\hline 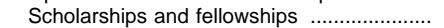 & 2.5 & 2.5 & 2.8 & 2.9 & 3.3 & 3.6 & 3.9 & 4.0 & 4.3 \\
\hline From unrestricted funds ............................... & 0.9 & 1.1 & 1.3 & 1.4 & 1.5 & 1.7 & 1.8 & 1.9 & 2.1 \\
\hline 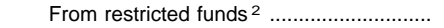 & 1.6 & 1.4 & 1.5 & 1.5 & 1.8 & 1.9 & 2.1 & 2.2 & 2.2 \\
\hline Mandatory transfers & 1.2 & 1.2 & 1.1 & 1.0 & 1.1 & 1.1 & 1.1 & 1.2 & 1.2 \\
\hline Auxiliary enterprises & 11.0 & 10.8 & 9.7 & 9.7 & 9.7 & 9.6 & 9.7 & 9.7 & 9.5 \\
\hline Mandatory transfers & 0.8 & 0.7 & 0.6 & 0.7 & 0.7 & 0.7 & 0.7 & 0.7 & 0.7 \\
\hline Hospitals …… & 8.0 & 8.5 & 9.5 & 10.0 & 10.6 & 10.6 & 10.4 & 10.2 & 9.9 \\
\hline Mandatory transfers ……..................................... & 0.1 & 0.1 & 0.2 & 0.2 & 0.2 & 0.2 & 0.2 & 0.2 & 0.2 \\
\hline Independent operations (FFRDC) ${ }^{3}$...................... & 0.2 & 0.2 & 0.2 & 0.2 & 0.2 & 0.2 & 0.2 & 0.2 & 0.2 \\
\hline Mandatory transfers ……...................................... & $\left({ }^{4}\right)$ & $\left({ }^{4}\right)$ & $(4)$ & $\left({ }^{4}\right)$ & $\left({ }^{4}\right)$ & $\left({ }^{4}\right)$ & $\left({ }^{4}\right)$ & $\left({ }^{4}\right)$ & $\left({ }^{4}\right)$ \\
\hline
\end{tabular}

${ }_{1}^{1}$ Preliminary data are for 4-year and 2-year degree-granting institutions that were eligible to participate in Title IV federal financial aid programs.

2Excludes Pell Grants.

${ }^{3}$ Generally includes only those expenditures associated with major federally funded research and development centers (FFRDC).

${ }^{4}$ Less than 0.05 percent.
NOTE.-Because of rounding, details may not add to totals.

SOURCE: U.S. Department of Education, National Center for Education Statistics, Higher Education General Information Survey (HEGIS), "Financial Statistics of Institutions of Higher Education" surveys; and Integrated Postsecondary Education Data System (IPEDS), "Finance" surveys. (This table was prepared October 1998.) 
Table 340.-Current-fund expenditures of private institutions of higher education, by purpose: 1980-81 to $1995-96$

\begin{tabular}{|c|c|c|c|c|c|c|c|c|c|}
\hline Purpose & $1980-81$ & $1985-86$ & $1989-90$ & $1990-91$ & $1991-92$ & 1992-93 & $1993-94$ & 1994-95 & $1995-96^{1}$ \\
\hline 1 & 2 & 3 & 4 & 5 & 6 & 7 & 8 & 9 & 10 \\
\hline & \multicolumn{9}{|c|}{ In thousands } \\
\hline Total current-fund expenditures ............ & $\$ 21,773,132$ & $\$ 34,341,889$ & $\$ 48,885,041$ & $\$ 53,126,743$ & $\$ 57,341,982$ & $\$ 60,670,938$ & $\$ 64,041,076$ & $\$ 67,503,635$ & $\$ 70,951,662$ \\
\hline Educational and general expenditures. & $15,900,792$ & $25,255,003$ & $36,421,118$ & $39,744,472$ & $43,012,623$ & $45,766,989$ & $48,885,124$ & $51,984,234$ & $55,359,982$ \\
\hline Instruction & $5,883,343$ & $9,151,318$ & $12,888,779$ & $14,124,723$ & $15,168,776$ & $16,080,736$ & $17,087,102$ & $18,120,513$ & $19,156,788$ \\
\hline Research ... & $1,844,369$ & $2,732,222$ & $3,963,726$ & $4,079,827$ & $4,312,973$ & $4,686,336$ & $4,937,247$ & $5,279,876$ & $5,441,530$ \\
\hline 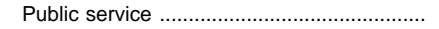 & 338,845 & 603,799 & $1,001,094$ & $1,085,945$ & $1,203,797$ & $1,371,697$ & $1,500,695$ & $1,657,040$ & $1,686,399$ \\
\hline 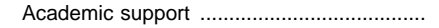 & $1,244,002$ & $1,973,849$ & $2,902,568$ & $3,116,927$ & $3,302,859$ & $3,459,726$ & $3,642,355$ & $3,815,455$ & $4,292,950$ \\
\hline 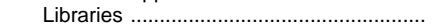 & 572,667 & 866,279 & $1,151,567$ & $1,176,731$ & $1,311,314$ & $1,355,227$ & $1,459,304$ & $1,551,152$ & $1,602,816$ \\
\hline Student services & 958,432 & $1,641,180$ & $2,366,819$ & $2,627,117$ & $2,818,174$ & $2,991,840$ & $3,247,414$ & $3,445,983$ & $3,820,174$ \\
\hline 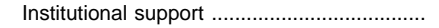 & $2,209,321$ & $3,683,642$ & $5,183,893$ & $5,695,842$ & $6,051,868$ & $6,200,308$ & $6,598,004$ & $6,915,821$ & $7,545,490$ \\
\hline Operation and maintenance of plant ............ & $1,668,389$ & $2,427,972$ & $3,124,680$ & $3,406,975$ & $3,556,365$ & $3,706,923$ & $3,935,311$ & $4,076,986$ & $4,325,784$ \\
\hline 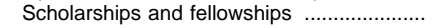 & $1,439,661$ & $2,584,266$ & $4,269,051$ & $4,862,651$ & $5,804,340$ & $6,420,536$ & $7,015,087$ & $7,623,304$ & $8,110,450$ \\
\hline From unrestricted funds …….......................... & 713,138 & $1,588,143$ & $2,754,479$ & $3,174,947$ & $3,682,076$ & $4,203,697$ & $4,710,100$ & $5,180,348$ & $5,755,910$ \\
\hline 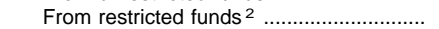 & 726,523 & 996,123 & $1,514,572$ & $1,687,704$ & $2,122,264$ & $2,216,838$ & $2,304,987$ & $2,442,957$ & $2,354,540$ \\
\hline Mandatory transfers ............................... & 314,429 & 456,754 & 720,508 & 744,465 & 793,471 & 848,886 & 921,908 & $1,049,256$ & 980,417 \\
\hline Auxiliary enterprises & $2,629,948$ & $3,698,067$ & $4,921,653$ & $5,222,312$ & $5,331,969$ & $5,537,156$ & $5,791,558$ & $5,969,773$ & $6,290,030$ \\
\hline Mandatory transfers ……....................................... & 164,335 & 206,394 & 285,521 & 313,730 & 347,999 & 350,905 & 374,733 & 392,285 & 352,241 \\
\hline Hospitals ..... & $2,055,139$ & $3,333,414$ & $4,565,297$ & $5,009,963$ & $5,671,540$ & $5,949,070$ & $6,191,929$ & $6,269,769$ & $6,062,047$ \\
\hline Mandatory transfers ……................................... & 31,349 & 53,264 & 66,164 & 78,491 & 109,619 & 84,818 & 102,449 & 83,729 & 55,052 \\
\hline \multirow{3}{*}{ 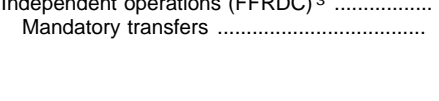 } & $1,187,253$ & $2,055,405$ & $2,976,973$ & $3,149,996$ & $3,325,850$ & $3,417,723$ & $3,172,465$ & $3,279,859$ & $3,239,604$ \\
\hline & 321 & 2,586 & 3,535 & 4,444 & 2,886 & 1,808 & 1,880 & 1,908 & 780 \\
\hline & \multicolumn{9}{|c|}{ Percentage distribution } \\
\hline Total current-fund expenditures ........... & 100.0 & 100.0 & 100.0 & 100.0 & 100.0 & 100.0 & 100.0 & 100.0 & 100.0 \\
\hline Educational and general expenditures ............... & 73.0 & 73.5 & 74.5 & 74.8 & 75.0 & 75.4 & 76.3 & 77.0 & 78.0 \\
\hline Instruction & 27.0 & 26.6 & 26.4 & 26.6 & 26.5 & 26.5 & 26.7 & 26.8 & 27.0 \\
\hline 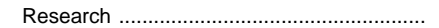 & 8.5 & 8.0 & 8.1 & 7.7 & 7.5 & 7.7 & 7.7 & 7.8 & 7.7 \\
\hline Public service & 1.6 & 1.8 & 2.0 & 2.0 & 2.1 & 2.3 & 2.3 & 2.5 & 2.4 \\
\hline 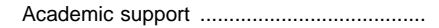 & 5.7 & 5.7 & 5.9 & 5.9 & 5.8 & 5.7 & 5.7 & 5.7 & 6.1 \\
\hline 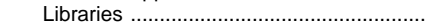 & 2.6 & 2.5 & 2.4 & 2.2 & 2.3 & 2.2 & 2.3 & 2.3 & 2.3 \\
\hline 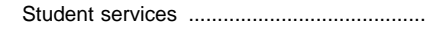 & 4.4 & 4.8 & 4.8 & 4.9 & 4.9 & 4.9 & 5.1 & 5.1 & 5.4 \\
\hline 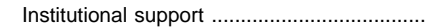 & 10.1 & 10.7 & 10.6 & 10.7 & 10.6 & 10.2 & 10.3 & 10.2 & 10.6 \\
\hline Operation and maintenance of plant ............ & 7.7 & 7.1 & 6.4 & 6.4 & 6.2 & 6.1 & 6.1 & 6.0 & 6.1 \\
\hline Scholarships and fellowships & 6.6 & 7.5 & 8.7 & 9.2 & 10.1 & 10.6 & 11.0 & 11.3 & 11.4 \\
\hline 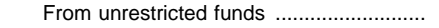 & 3.3 & 4.6 & 5.6 & 6.0 & 6.4 & 6.9 & 7.4 & 7.7 & 8.1 \\
\hline 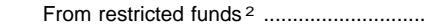 & 3.3 & 2.9 & 3.1 & 3.2 & 3.7 & 3.7 & 3.6 & 3.6 & 3.3 \\
\hline Mandatory transfers & 1.4 & 1.3 & 1.5 & 1.4 & 1.4 & 1.4 & 1.4 & 1.6 & 1.4 \\
\hline Auxiliary enterprises & 12.1 & 10.8 & 10.1 & 9.8 & 9.3 & 9.1 & 9.0 & 8.8 & 8.9 \\
\hline Mandatory transfers & 0.8 & 0.6 & 0.6 & 0.6 & 0.6 & 0.6 & 0.6 & 0.6 & 0.5 \\
\hline Hospitals & 9.4 & 9.7 & 9.3 & 9.4 & 9.9 & 9.8 & 9.7 & 9.3 & 8.5 \\
\hline Mandatory transfers ……........................................ & 0.1 & 0.2 & 0.1 & 0.1 & 0.2 & 0.1 & 0.2 & 0.1 & 0.1 \\
\hline Independent operations (FFRDC) ${ }^{3} \ldots \ldots \ldots \ldots \ldots \ldots$ & 5.5 & 6.0 & 6.1 & 5.9 & 5.8 & 5.6 & 5.0 & 4.9 & 4.6 \\
\hline Mandatory transfers ....................................... & $\left({ }^{4}\right)$ & $\left({ }^{4}\right)$ & $\left({ }^{4}\right)$ & $\left({ }^{4}\right)$ & $\left({ }^{4}\right)$ & $\left({ }^{4}\right)$ & $\left({ }^{4}\right)$ & $\left({ }^{4}\right)$ & $\left({ }^{4}\right)$ \\
\hline
\end{tabular}

${ }^{1}$ Preliminary data are for 4-year and 2-year degree-granting institutions that were eligible to participate in Title IV federal financial aid programs.

2 Excludes Pell Grants.

${ }^{3}$ Generally includes only those expenditures associated with major federally funded research and development centers (FFRDC).

4 Less than 0.05 percent.
NOTE.-Because of rounding, details may not add to totals.

SOURCE: U.S. Department of Education, National Center for Education Statistics, Higher Education General Information Survey (HEGIS), "Financial Statistics of Institutions of Higher Education" surveys; and Integrated Postsecondary Education Data System (IPEDS), "Finance" surveys. (This table was prepared October 1998.)

Table 341.-Voluntary support for institutions of higher education, by source and purpose of support: 1959-60 to 1995-96

[In millions]

\begin{tabular}{|c|c|c|c|c|c|c|c|c|c|c|c|c|c|}
\hline Source and purpose of support & $1959-60$ & $1965-66$ & $1970-71$ & $1975-76$ & $1980-81$ & $1985-86$ & $1989-90$ & $1990-91$ & 1991-92 & 1992-93 & 1993-94 & 1994-95 & 1995-96 \\
\hline 1 & 2 & 3 & 4 & 5 & 6 & 7 & 8 & 9 & 10 & 11 & 12 & 13 & 14 \\
\hline Total voluntary support ${ }^{1} \ldots \ldots \ldots$ & $\$ 815$ & $\$ 1,440$ & $\$ 1,860$ & $\$ 2,410$ & $\$ 4,230$ & $\$ 7,400$ & $\$ 9,800$ & $\$ 10,200$ & $\$ 10,700$ & $\$ 11,200$ & $\$ 12,350$ & $\$ 12,750$ & $\$ 14,250$ \\
\hline Sources & & & & & & & & & & & & & \\
\hline Alumni & 191 & 310 & 458 & 588 & 1,049 & 1,825 & 2,540 & 2,680 & 2,840 & 2,980 & 3,410 & 3,600 & 4,040 \\
\hline Nonalumni individuals .................. & 194 & 350 & 495 & 569 & 1,007 & 1,781 & 2,230 & 2,310 & 2,500 & 2,530 & 2,800 & 2,940 & 3,400 \\
\hline Corporations .................................... & 130 & 230 & 259 & 379 & 778 & 1,702 & 2,170 & 2,230 & 2,260 & 2,400 & 2,510 & 2,560 & 2,800 \\
\hline 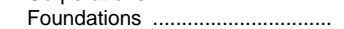 & 163 & 357 & 418 & 549 & 922 & 1,363 & 1,920 & 2,030 & 2,090 & 2,200 & 2,540 & 2,460 & 2,815 \\
\hline Religious organizations ................ & 80 & 108 & 104 & 130 & 140 & 211 & 240 & 240 & 240 & 250 & 240 & 250 & 255 \\
\hline 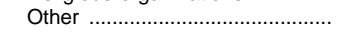 & 57 & 85 & 126 & 195 & 334 & 518 & 700 & 710 & 770 & 840 & 850 & 940 & 940 \\
\hline Purpose & & & & & & & & & & & & & \\
\hline 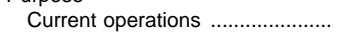 & 385 & 675 & 1,050 & 1,480 & 2,590 & 4,022 & 5,440 & 5,830 & 6,100 & 6,300 & 6,710 & 7,230 & 7,850 \\
\hline 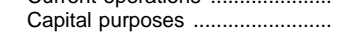 & 430 & 765 & 810 & 930 & 1,640 & 3,378 & 4,360 & 4,370 & 4,600 & 4,900 & 5,640 & 5,520 & 6,400 \\
\hline $\begin{array}{l}\text { Voluntary support as a } \\
\text { percent of total expenditures }{ }^{2} \ldots . .\end{array}$ & 11.4 & 9.2 & 6.8 & 5.5 & 6.0 & 6.9 & 6.5 & 6.2 & 6.2 & 6.2 & 6.5 & 6.3 & 6.7 \\
\hline
\end{tabular}

1 Data are based on sample surveys of institutions of higher education.

${ }^{2}$ Total expenditures include current-fund expenditures and additions to plant value.
SOURCE: Council for Aid to Education, Research Report, "Contributions to Colleges Drop for First Time Since 1975"; and "Voluntary Support of Education," various years. (This table was prepared July 1998.) 
Table 342.-Educational and general expenditures of public universities, by purpose: 1976-77 to 1995-96

\begin{tabular}{|c|c|c|c|c|c|c|c|c|c|c|}
\hline \multirow[b]{2}{*}{ Year } & \multicolumn{10}{|c|}{ Educational and general expenditures } \\
\hline & Total & Instruction & Administration ${ }^{1}$ & $\begin{array}{l}\text { Student } \\
\text { services }\end{array}$ & Research & Libraries & $\begin{array}{l}\text { Public } \\
\text { service }\end{array}$ & $\begin{array}{c}\text { Operation } \\
\text { and } \\
\text { maintenance } \\
\text { of plant }\end{array}$ & $\begin{array}{l}\text { Scholarships } \\
\text { and } \\
\text { fellowships }\end{array}$ & $\begin{array}{c}\text { Mandatory } \\
\text { transfers }\end{array}$ \\
\hline \multirow[t]{2}{*}{1} & 2 & 3 & 4 & 5 & 6 & 7 & 8 & 9 & 10 & 11 \\
\hline & \multicolumn{10}{|c|}{ Expenditures, in thousands of current dollars } \\
\hline $\begin{array}{ll}1976-77 & \ldots . \\
1977-78 & \ldots . \\
1978-79 & \ldots . \\
1979-80 & \ldots . \\
1980-81 & \ldots .\end{array}$ & \begin{tabular}{|}
$\$ 9,413,626$ \\
$10,220,191$ \\
$11,284,191$ \\
$12,540,072$ \\
$13,951,029$
\end{tabular} & $\begin{array}{r}\$ 3,670,554 \\
4,009,870 \\
4,408,025 \\
4,860,411 \\
5,374,271\end{array}$ & $\begin{array}{r}\$ 1,222,410 \\
1,344,538 \\
1,478,568 \\
1,572,523 \\
1,795,504\end{array}$ & $\begin{array}{r}\$ 346,906 \\
388,262 \\
419,231 \\
473,460 \\
525,891\end{array}$ & $\begin{array}{r}\$ 1,727,807 \\
1,896,578 \\
2,136,135 \\
2,444,471 \\
2,743,145\end{array}$ & $\begin{array}{r}\$ 331,614 \\
343,198 \\
363,875 \\
463,642 \\
451,978\end{array}$ & \begin{tabular}{|r|}
$\$ 763,809$ \\
803,309 \\
920,726 \\
$1,012,376$ \\
$1,158,512$
\end{tabular} & $\begin{array}{r}\$ 857,677 \\
938,952 \\
1,046,740 \\
1,148,942 \\
1,270,339\end{array}$ & $\begin{array}{r}\$ 377,749 \\
389,682 \\
396,356 \\
439,461 \\
492,225\end{array}$ & $\begin{array}{r}\$ 115,099 \\
105,803 \\
114,533 \\
124,786 \\
139,164\end{array}$ \\
\hline $\begin{array}{ll}1981-82 & \ldots . \\
1982-83 & \ldots . \\
1983-84 & \ldots . \\
1984-85 & \ldots . \\
1985-86 & \ldots .\end{array}$ & $\begin{array}{l}15,077,263 \\
16,089,168 \\
17,234,711 \\
18,960,810 \\
20,716,657\end{array}$ & $\begin{array}{l}5,852,958 \\
6,247,358 \\
6,646,501 \\
7,257,618 \\
7,807,522\end{array}$ & $\begin{array}{l}1,974,219 \\
2,107,933 \\
2,263,565 \\
2,598,784 \\
2,882,006\end{array}$ & $\begin{array}{l}566,366 \\
604,657 \\
643,614 \\
701,451 \\
762,324\end{array}$ & $\begin{array}{l}2,903,178 \\
3,086,846 \\
3,295,053 \\
3,682,755 \\
4,076,258\end{array}$ & $\begin{array}{l}488,939 \\
528,470 \\
577,136 \\
609,365 \\
669,253\end{array}$ & \begin{tabular}{|l|}
$1,223,417$ \\
$1,300,353$ \\
$1,385,191$ \\
$1,519,324$ \\
$1,664,917$
\end{tabular} & $\begin{array}{l}1,412,557 \\
1,512,947 \\
1,627,702 \\
1,745,825 \\
1,831,618\end{array}$ & $\begin{array}{l}525,498 \\
562,903 \\
624,642 \\
677,533 \\
780,080\end{array}$ & $\begin{array}{l}130,131 \\
137,702 \\
171,306 \\
168,155 \\
242,679\end{array}$ \\
\hline $\begin{aligned} 1986-87 & \ldots . . \\
1987-88 & \ldots . . \\
1988-89 & \ldots . \\
1989-90 & \ldots . \\
1990-91 & \ldots .\end{aligned}$ & \begin{tabular}{|}
$22,023,387$ \\
$23,848,427$ \\
$26,138,665$ \\
$28,338,312$ \\
$30,367,325$
\end{tabular} & \begin{tabular}{|r|}
$8,368,187$ \\
$8,902,624$ \\
$9,623,797$ \\
$10,364,088$ \\
$11,012,373$
\end{tabular} & \begin{tabular}{l|}
$3,088,348$ \\
$3,311,806$ \\
$3,638,424$ \\
$3,927,198$ \\
$4,157,677$
\end{tabular} & $\begin{array}{r}819,829 \\
889,528 \\
975,801 \\
1,047,364 \\
1,103,058\end{array}$ & $\begin{array}{l}4,399,405 \\
4,911,929 \\
5,476,936 \\
6,030,489 \\
6,599,209\end{array}$ & $\begin{array}{l}677,531 \\
762,858 \\
813,888 \\
871,279 \\
906,506\end{array}$ & \begin{tabular}{|l|}
$1,725,613$ \\
$1,857,008$ \\
$2,096,267$ \\
$2,273,699$ \\
$2,479,956$
\end{tabular} & $\begin{array}{l}1,829,880 \\
1,934,489 \\
2,069,744 \\
2,222,046 \\
2,305,115\end{array}$ & $\begin{array}{r}847,328 \\
949,438 \\
1,096,447 \\
1,211,690 \\
1,367,754\end{array}$ & $\begin{array}{l}267,266 \\
328,746 \\
347,362 \\
390,458 \\
435,676\end{array}$ \\
\hline $\begin{array}{ll}1991-92 & \ldots . . \\
1992-93 & \ldots . \\
1993-94 & \ldots . \\
1994-95 & \ldots . \\
1995-962 & . .\end{array}$ & $\begin{array}{l}31,565,791 \\
32,836,061 \\
34,318,548 \\
36,255,063 \\
37,693,678\end{array}$ & \begin{tabular}{|}
$11,373,749$ \\
$11,708,500$ \\
$12,115,695$ \\
$12,837,030$ \\
$13,289,323$
\end{tabular} & $\begin{array}{l}4,198,990 \\
4,317,605 \\
4,578,770 \\
4,814,366 \\
5,146,842\end{array}$ & $\begin{array}{l}1,161,633 \\
1,211,143 \\
1,273,008 \\
1,348,617 \\
1,419,733\end{array}$ & $\begin{array}{l}6,937,360 \\
7,330,922 \\
7,676,832 \\
8,082,388 \\
8,211,609\end{array}$ & $\begin{array}{r}946,098 \\
959,306 \\
1,006,301 \\
1,096,566 \\
1,134,159\end{array}$ & \begin{tabular}{|l|}
$2,609,520$ \\
$2,714,785$ \\
$2,784,869$ \\
$2,943,284$ \\
$3,082,968$
\end{tabular} & $\begin{array}{l}2,323,220 \\
2,365,942 \\
2,459,895 \\
2,526,104 \\
2,596,786\end{array}$ & $\begin{array}{l}1,556,868 \\
1,734,530 \\
1,909,173 \\
2,057,116 \\
2,235,290\end{array}$ & $\begin{array}{l}458,354 \\
493,328 \\
514,006 \\
549,593 \\
576,968\end{array}$ \\
\hline
\end{tabular}

Percentage distribution

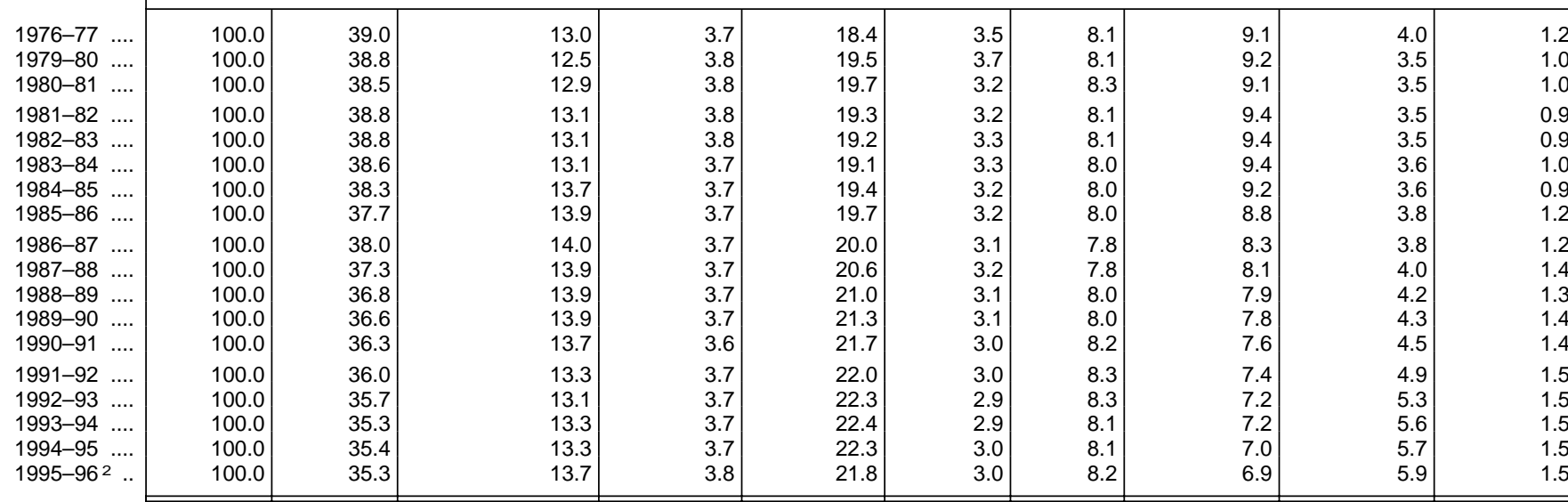

\begin{tabular}{|c|c|c|c|c|c|c|c|c|c|c|}
\hline \multirow[b]{2}{*}{$\begin{aligned} 1976-77 & \ldots . \\
1977-78 & \ldots . \\
1978-79 & \ldots . \\
1979-80 & \ldots . \\
1980-81 & \ldots .\end{aligned}$} & \multicolumn{10}{|c|}{ Expenditure per full-time-equivalent student in constant 1995-96 dollars } \\
\hline & $\begin{array}{r}\$ 15,112 \\
15,247 \\
15,801 \\
15,633 \\
15,391\end{array}$ & $\begin{array}{r}\$ 5,893 \\
5,982 \\
6,172 \\
6,059 \\
5,929\end{array}$ & $\begin{array}{r}\$ 1,962 \\
2,006 \\
2,070 \\
1,960 \\
1,981\end{array}$ & $\begin{array}{r}\$ 557 \\
579 \\
587 \\
590 \\
580\end{array}$ & $\begin{array}{r}\$ 2,774 \\
2,829 \\
2,991 \\
3,047 \\
3,026\end{array}$ & $\begin{array}{r}\$ 532 \\
512 \\
510 \\
578 \\
499\end{array}$ & $\begin{array}{r}\$ 1,226 \\
1,198 \\
1,289 \\
1,262 \\
1,278\end{array}$ & $\begin{array}{r}\$ 1,377 \\
1,401 \\
1,466 \\
1,432 \\
1,401\end{array}$ & $\begin{array}{r}\$ 606 \\
581 \\
555 \\
548 \\
543\end{array}$ & $\begin{array}{r}\$ 185 \\
158 \\
160 \\
156 \\
154\end{array}$ \\
\hline $\begin{aligned} 1981-82 & \ldots \\
1982-83 & \ldots \\
1983-84 & \ldots \\
1984-85 & \ldots \\
1985-86 & \ldots .\end{aligned}$ & $\begin{array}{l}15,172 \\
15,139 \\
15,506 \\
16,236 \\
16,868\end{array}$ & $\begin{array}{l}5,890 \\
5,878 \\
5,980 \\
6,215 \\
6,357\end{array}$ & $\begin{array}{l}1,987 \\
1,983 \\
2,036 \\
2,225 \\
2,347\end{array}$ & $\begin{array}{l}570 \\
569 \\
579 \\
601 \\
621\end{array}$ & $\begin{array}{l}2,922 \\
2,905 \\
2,964 \\
3,153 \\
3,319\end{array}$ & $\begin{array}{l}492 \\
497 \\
519 \\
522 \\
545\end{array}$ & $\begin{array}{l}1,231 \\
1,224 \\
1,246 \\
1,301 \\
1,356\end{array}$ & $\begin{array}{l}1,421 \\
1,424 \\
1,464 \\
1,495 \\
1,491\end{array}$ & $\begin{array}{l}529 \\
530 \\
562 \\
580 \\
635\end{array}$ & $\begin{array}{l}131 \\
130 \\
154 \\
144 \\
198\end{array}$ \\
\hline $\begin{aligned} 1986-87 & \ldots . \\
1987-88 & \ldots . \\
1988-89 & \ldots . \\
1989-90 & \ldots . \\
1990-91 & \ldots .\end{aligned}$ & $\begin{array}{l}17,162 \\
17,628 \\
17,961 \\
18,081 \\
18,237\end{array}$ & $\begin{array}{l}6,521 \\
6,581 \\
6,613 \\
6,613 \\
6,613\end{array}$ & $\begin{array}{l}2,407 \\
2,448 \\
2,500 \\
2,506 \\
2,497\end{array}$ & $\begin{array}{l}639 \\
658 \\
671 \\
668 \\
662\end{array}$ & $\begin{array}{l}3,428 \\
3,631 \\
3,764 \\
3,848 \\
3,963\end{array}$ & $\begin{array}{l}528 \\
564 \\
559 \\
556 \\
544\end{array}$ & $\begin{array}{l}1,345 \\
1,373 \\
1,440 \\
1,451 \\
1,489\end{array}$ & $\begin{array}{l}1,426 \\
1,430 \\
1,422 \\
1,418 \\
1,384\end{array}$ & $\begin{array}{l}660 \\
702 \\
753 \\
773 \\
821\end{array}$ & $\begin{array}{l}208 \\
243 \\
239 \\
249 \\
262\end{array}$ \\
\hline $\begin{array}{l}1991-92 \ldots \\
1992-93 \ldots \\
1993-94 \ldots \\
1994-95 \ldots \\
1995-96{ }^{2} \ldots\end{array}$ & $\begin{array}{l}18,133 \\
18,577 \\
18,957 \\
19,513 \\
19,700\end{array}$ & $\begin{array}{l}6,534 \\
6,624 \\
6,693 \\
6,909 \\
6,946\end{array}$ & $\begin{array}{l}2,412 \\
2,443 \\
2,529 \\
2,591 \\
2,690\end{array}$ & $\begin{array}{l}667 \\
685 \\
703 \\
726 \\
742\end{array}$ & $\begin{array}{l}3,985 \\
4,147 \\
4,241 \\
4,350 \\
4,292\end{array}$ & $\begin{array}{l}543 \\
543 \\
556 \\
590 \\
593\end{array}$ & $\begin{array}{l}1,499 \\
1,536 \\
1,538 \\
1,584 \\
1,611\end{array}$ & $\begin{array}{l}1,335 \\
1,338 \\
1,359 \\
1,360 \\
1,357\end{array}$ & $\begin{array}{r}894 \\
981 \\
1,055 \\
1,107 \\
1,168\end{array}$ & $\begin{array}{l}263 \\
279 \\
284 \\
296 \\
302\end{array}$ \\
\hline
\end{tabular}

1 Includes institutional and academic support less libraries. 2 Preliminary data.

NOTE.-Data in this table may differ slightly from data appearing in other tables. Data for 1976-77 through 1985-86 include only institutions which provided both enrollment and finance data. The Higher Education Price Index was used to convert the per student figures to constant dollars. Because of rounding, details may not add to totals.
SOURCE: U.S. Department of Education, National Center for Education Statistics Higher Education General Information Survey (HEGIS), "Financial Statistics of Institutions of Higher Education" surveys; Integrated Postsecondary Education Data System (IPEDS), "Finance" surveys; and Research Associates of Washington, unpublished data. (This table was prepared October 1998.) 
Table 343.-Educational and general expenditures of public 4-year colleges, ${ }^{1}$ by purpose: $1976-77$ to $1995-96$

\begin{tabular}{|c|c|c|c|c|c|c|c|c|c|c|}
\hline \multirow[b]{2}{*}{ Year } & \multicolumn{10}{|c|}{ Educational and general expenditures } \\
\hline & Total & Instruction & Administration ${ }^{2}$ & $\begin{array}{l}\text { Student } \\
\text { services }\end{array}$ & Research & Libraries & $\begin{array}{l}\text { Public } \\
\text { service }\end{array}$ & $\begin{array}{l}\text { Operation } \\
\text { and } \\
\text { maintenance } \\
\text { of plant }\end{array}$ & $\begin{array}{c}\text { Scholarships } \\
\text { and } \\
\text { fellowships }\end{array}$ & $\begin{array}{l}\text { Mandatory } \\
\text { transfers }\end{array}$ \\
\hline \multirow[t]{2}{*}{1} & 2 & 3 & 4 & 5 & 6 & 7 & 8 & 9 & 10 & 11 \\
\hline & \multicolumn{10}{|c|}{ Expenditures, in thousands of current dollars } \\
\hline $\begin{array}{lll}1976-77 & \ldots \\
1977-78 & \ldots \\
1978-79 & \ldots \\
1979-80 & \ldots . \\
1980-81 & \ldots .\end{array}$ & $\begin{array}{r}\$ 8,682,538 \\
9,568,977 \\
10,455,134 \\
11,750,398 \\
13,139,618\end{array}$ & \begin{tabular}{|r|}
$\$ 4,027,051$ \\
$4,423,487$ \\
$4,770,598$ \\
$5,271,621$ \\
$5,890,759$
\end{tabular} & $\begin{array}{r}\$ 1,445,651 \\
1,598,092 \\
1,789,534 \\
2,029,327 \\
2,258,987\end{array}$ & $\begin{array}{r}\$ 500,832 \\
572,193 \\
651,541 \\
733,557 \\
807,249\end{array}$ & $\begin{array}{r}\$ 607,235 \\
677,414 \\
786,072 \\
937,874 \\
1,043,614\end{array}$ & $\begin{array}{r}\$ 340,002 \\
369,408 \\
395,299 \\
448,190 \\
511,817\end{array}$ & $\begin{array}{r}\$ 250,152 \\
274,314 \\
301,387 \\
359,467 \\
407,816\end{array}$ & $\begin{array}{r}\$ 1,001,848 \\
1,118,393 \\
1,214,996 \\
1,375,308 \\
1,563,514\end{array}$ & $\begin{array}{r}\$ 338,432 \\
332,899 \\
337,588 \\
383,036 \\
412,972\end{array}$ & $\begin{array}{r}\$ 171,335 \\
202,777 \\
208,119 \\
212,019 \\
242,890\end{array}$ \\
\hline $\begin{array}{ll}1981-82 & \ldots . \\
1982-83 & \ldots . \\
1983-84 & \ldots . \\
1984-85 & \ldots . \\
1985-86 & \ldots .\end{array}$ & $\begin{array}{l}14,321,586 \\
15,286,145 \\
16,538,128 \\
18,333,578 \\
19,860,947\end{array}$ & $\begin{array}{l}6,537,888 \\
6,980,269 \\
7,464,035 \\
8,211,171 \\
8,945,373\end{array}$ & $\begin{array}{l}2,518,182 \\
2,660,360 \\
3,013,666 \\
3,370,676 \\
3,658,627\end{array}$ & $\begin{array}{r}834,225 \\
904,745 \\
1,041,488 \\
1,140,312 \\
1,235,418\end{array}$ & $\begin{array}{l}1,086,146 \\
1,150,011 \\
1,246,289 \\
1,420,844 \\
1,618,737\end{array}$ & $\begin{array}{l}536,080 \\
559,353 \\
622,879 \\
669,518 \\
712,112\end{array}$ & $\begin{array}{l}440,736 \\
469,841 \\
513,732 \\
603,018 \\
648,178\end{array}$ & $\begin{array}{l}1,738,210 \\
1,857,151 \\
1,873,628 \\
2,137,225 \\
2,118,522\end{array}$ & $\begin{array}{l}403,069 \\
450,067 \\
473,503 \\
489,188 \\
569,841\end{array}$ & $\begin{array}{l}227,050 \\
254,349 \\
288,908 \\
291,626 \\
354,139\end{array}$ \\
\hline $\begin{array}{lll}1986-87 & \ldots . \\
1987-88 & \ldots . \\
1988-89 & \ldots . \\
1989-90 & \ldots . \\
1990-91 & \ldots .\end{array}$ & $\begin{array}{l}21,490,078 \\
23,124,455 \\
24,639,653 \\
27,210,634 \\
28,903,790\end{array}$ & $\begin{array}{r}9,608,239 \\
10,310,532 \\
10,991,086 \\
12,079,093 \\
12,818,677\end{array}$ & $\begin{array}{l}4,019,850 \\
4,261,440 \\
4,496,286 \\
5,076,792 \\
5,374,417\end{array}$ & $\begin{array}{l}1,318,666 \\
1,434,726 \\
1,504,869 \\
1,648,526 \\
1,800,723\end{array}$ & $\begin{array}{l}1,846,712 \\
2,053,638 \\
2,305,152 \\
2,525,080 \\
2,745,613\end{array}$ & $\begin{array}{l}695,692 \\
774,274 \\
813,801 \\
888,526 \\
888,162\end{array}$ & $\begin{array}{r}766,865 \\
864,347 \\
941,434 \\
1,088,113 \\
1,145,892\end{array}$ & $\begin{array}{l}2,226,599 \\
2,340,495 \\
2,429,103 \\
2,607,385 \\
2,728,949\end{array}$ & $\begin{array}{l}660,940 \\
711,704 \\
754,412 \\
871,944 \\
963,436\end{array}$ & $\begin{array}{l}346,515 \\
373,299 \\
403,508 \\
425,175 \\
437,921\end{array}$ \\
\hline $\begin{array}{ll}1991-92 & \ldots . \\
1992-93 & \ldots . \\
1993-94 & \ldots . \\
1994-95 & \ldots \\
1995-96^{3} & . .\end{array}$ & $\begin{array}{l}30,720,827 \\
33,119,294 \\
34,477,869 \\
36,659,833 \\
38,115,758\end{array}$ & $\begin{array}{l}13,270,992 \\
13,906,211 \\
14,519,321 \\
15,321,392 \\
15,600,219\end{array}$ & $\begin{array}{l}5,805,724 \\
6,416,859 \\
6,477,847 \\
6,909,606 \\
7,502,742\end{array}$ & $\begin{array}{l}1,868,329 \\
2,164,309 \\
2,135,560 \\
2,236,127 \\
2,217,691\end{array}$ & $\begin{array}{l}2,986,474 \\
3,246,542 \\
3,473,971 \\
3,717,964 \\
3,841,169\end{array}$ & $\begin{array}{r}945,097 \\
979,635 \\
1,018,304 \\
1,084,945 \\
1,105,930\end{array}$ & $\begin{array}{l}1,310,700 \\
1,447,684 \\
1,525,406 \\
1,647,855 \\
1,761,690\end{array}$ & $\begin{array}{l}2,782,200 \\
2,960,373 \\
3,084,509 \\
3,175,330 \\
3,328,604\end{array}$ & $\begin{array}{l}1,248,220 \\
1,457,901 \\
1,685,785 \\
1,884,283 \\
2,068,459\end{array}$ & $\begin{array}{l}503,091 \\
539,779 \\
557,166 \\
682,332 \\
689,256\end{array}$ \\
\hline
\end{tabular}

Percentage distribution

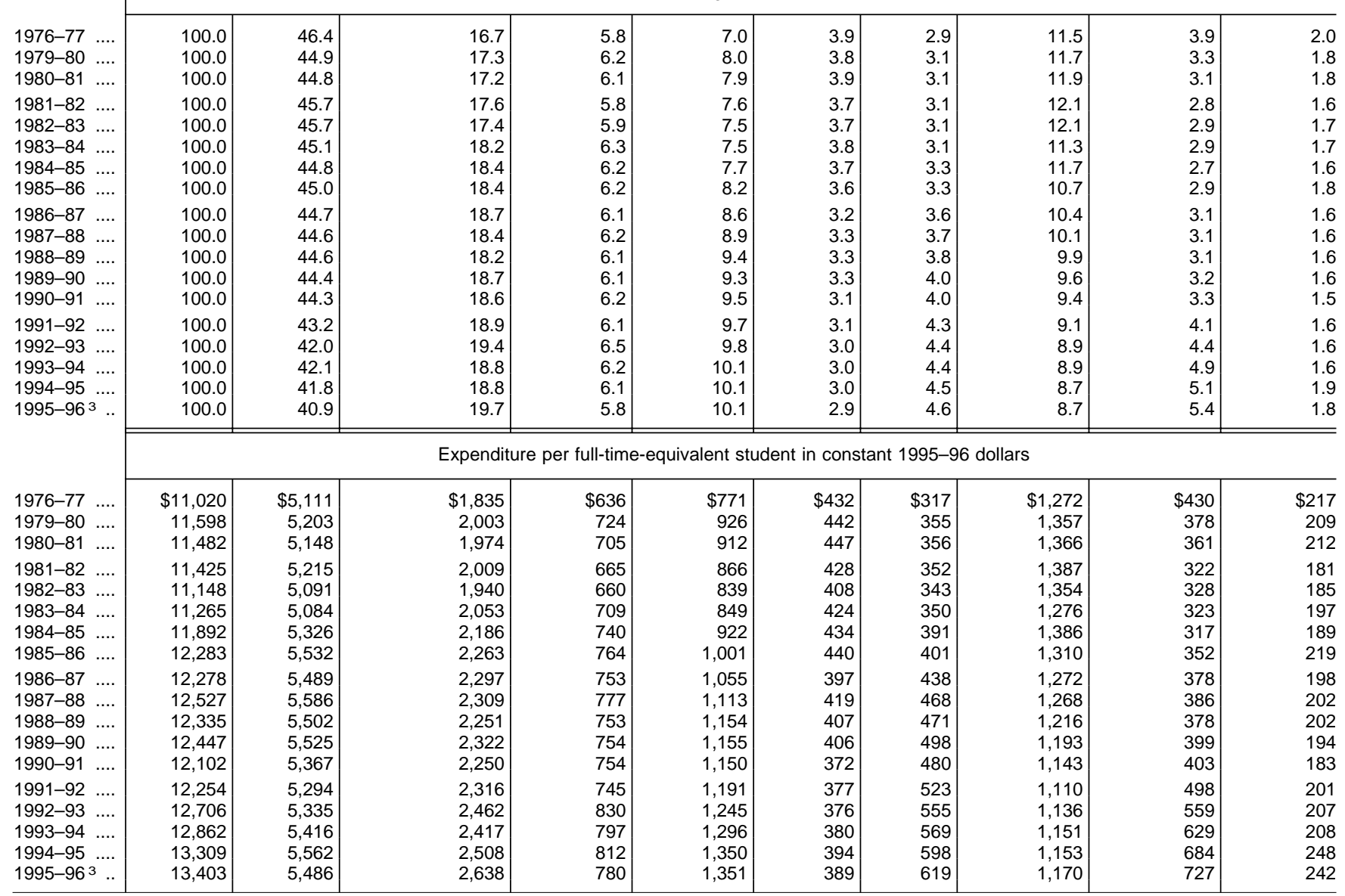

1 Excludes universities. See preceding table.

2 Includes institutional and academic support less libraries.

${ }^{3}$ Preliminary data.

NOTE.-Data in this table may differ slightly from data appearing in other tables. Data for 1976-77 through 1985-86 include only institutions which provided both enrollment and finance data. The Higher Education Price Index was used to convert the per student figures to constant dollars. Because of rounding, details may not add to totals.
SOURCE: U.S. Department of Education, National Center for Education Statistics, Higher Education General Information Survey (HEGIS), "Financial Statistics of Institutions of Higher Education" surveys; Integrated Postsecondary Education Data System (IPEDS), "Finance" surveys; and Research Associates of Washington, unpublished data. (This table was prepared October 1998.) 
Table 344.-Educational and general expenditures of public 2-year colleges, by purpose: 1976-77 to 1995-96

\begin{tabular}{|c|c|c|c|c|c|c|c|c|c|c|}
\hline \multirow[b]{2}{*}{ Year } & \multicolumn{10}{|c|}{ Educational and general expenditures } \\
\hline & Total & Instruction & Administration 1 & $\begin{array}{l}\text { Student } \\
\text { services }\end{array}$ & Research & Libraries & $\begin{array}{l}\text { Public } \\
\text { service }\end{array}$ & $\begin{array}{c}\text { Operation } \\
\text { and } \\
\text { maintenance } \\
\text { of plant }\end{array}$ & $\begin{array}{c}\text { Scholarships } \\
\text { and } \\
\text { fellowships }\end{array}$ & $\begin{array}{c}\text { Mandatory } \\
\text { transfers }\end{array}$ \\
\hline \multirow[t]{2}{*}{1} & 2 & 3 & 4 & 5 & 6 & 7 & 8 & 9 & 10 & 11 \\
\hline & \multicolumn{10}{|c|}{ Expenditures, in thousands of current dollars } \\
\hline $\begin{aligned} 1976-77 & \ldots . \\
1977-78 & \ldots . \\
1978-79 & \ldots . \\
1979-80 & \ldots . \\
1980-81 & \ldots . .\end{aligned}$ & $\begin{array}{r}\$ 4,875,998 \\
5,336,153 \\
5,734,611 \\
6,334,777 \\
7,063,474\end{array}$ & $\begin{array}{r}\$ 2,490,274 \\
2,700,489 \\
2,877,651 \\
3,185,815 \\
3,575,743\end{array}$ & $\begin{array}{r}\$ 882,813 \\
1,035,206 \\
1,119,840 \\
1,204,082 \\
1,347,020\end{array}$ & $\begin{array}{r}\$ 409,217 \\
437,060 \\
482,323 \\
547,457 \\
615,869\end{array}$ & $\begin{array}{r}\$ 15,698 \\
9,333 \\
21,289 \\
26,288 \\
26,591\end{array}$ & $\begin{array}{r}\$ 171,409 \\
188,201 \\
193,703 \\
202,583 \\
222,391\end{array}$ & $\begin{array}{l}\$ 97,635 \\
112,944 \\
110,918 \\
141,000 \\
152,597\end{array}$ & $\begin{array}{r}\$ 547,515 \\
605,464 \\
650,447 \\
743,014 \\
844,781\end{array}$ & $\begin{array}{r}\$ 142,827 \\
117,996 \\
127,633 \\
147,865 \\
159,474\end{array}$ & $\begin{array}{r}\$ 118,610 \\
129,458 \\
150,807 \\
136,672 \\
119,008\end{array}$ \\
\hline $\begin{aligned} 1981-82 & \ldots \\
1982-83 & \ldots \\
1983-84 & \ldots \\
1984-85 & \ldots \\
1985-86 & \ldots .\end{aligned}$ & $\begin{array}{r}7,757,435 \\
8,292,446 \\
8,820,575 \\
9,560,507 \\
10,252,955\end{array}$ & $\begin{array}{l}3,947,065 \\
4,218,388 \\
4,481,854 \\
4,806,050 \\
5,116,884\end{array}$ & $\begin{array}{l}1,473,733 \\
1,620,644 \\
1,748,535 \\
1,929,968 \\
2,122,060\end{array}$ & $\begin{array}{l}684,650 \\
741,179 \\
775,084 \\
841,101 \\
920,299\end{array}$ & $\begin{array}{l}15,632 \\
18,090 \\
18,189 \\
15,591 \\
10,136\end{array}$ & $\begin{array}{l}262,697 \\
248,682 \\
263,485 \\
278,363 \\
295,691\end{array}$ & $\begin{array}{l}147,385 \\
123,722 \\
150,109 \\
193,903 \\
202,440\end{array}$ & $\begin{array}{r}952,691 \\
1,016,267 \\
1,076,371 \\
1,156,074 \\
1,220,646\end{array}$ & $\begin{array}{l}160,109 \\
175,069 \\
178,500 \\
207,975 \\
225,979\end{array}$ & $\begin{array}{l}113,473 \\
130,403 \\
128,448 \\
131,482 \\
138,820\end{array}$ \\
\hline $\begin{aligned} 1986-87 & \ldots \\
1987-88 & \ldots . \\
1988-89 & \ldots . \\
1989-90 & \ldots . \\
1990-91 & \ldots .\end{aligned}$ & $\begin{array}{l}10,845,969 \\
11,666,586 \\
12,666,590 \\
13,875,566 \\
15,124,313\end{array}$ & $\begin{array}{l}5,382,631 \\
5,741,049 \\
6,278,809 \\
6,909,109 \\
7,540,344\end{array}$ & $\begin{array}{l}2,363,275 \\
2,479,661 \\
2,727,058 \\
2,977,932 \\
3,265,233\end{array}$ & $\begin{array}{l}1,020,496 \\
1,157,858 \\
1,197,748 \\
1,344,339 \\
1,494,583\end{array}$ & $\begin{array}{l}12,508 \\
11,358 \\
14,864 \\
19,213 \\
19,390\end{array}$ & $\begin{array}{l}246,131 \\
316,278 \\
328,809 \\
353,165 \\
372,492\end{array}$ & $\begin{array}{l}235,115 \\
264,809 \\
314,250 \\
336,927 \\
364,384\end{array}$ & $\begin{array}{l}1,252,152 \\
1,326,748 \\
1,414,420 \\
1,526,086 \\
1,621,542\end{array}$ & $\begin{array}{l}243,402 \\
280,247 \\
299,491 \\
314,906 \\
357,343\end{array}$ & $\begin{array}{l}90,258 \\
88,578 \\
91,142 \\
93,889 \\
89,001\end{array}$ \\
\hline $\begin{array}{l}1991-92 \ldots . \\
1992-93 \ldots . \\
1993-94 \ldots \\
1994-95 \ldots \\
1995-96^{2} \ldots\end{array}$ & $\begin{array}{l}16,267,915 \\
17,255,624 \\
18,342,808 \\
19,258,872 \\
20,161,543\end{array}$ & $\begin{array}{l}8,183,678 \\
8,645,466 \\
9,053,480 \\
9,440,773 \\
9,701,637\end{array}$ & $\begin{array}{l}3,408,080 \\
3,598,745 \\
3,858,066 \\
4,053,662 \\
4,349,565\end{array}$ & $\begin{array}{l}1,660,958 \\
1,797,787 \\
1,906,802 \\
2,029,268 \\
2,163,469\end{array}$ & $\begin{array}{l}24,747 \\
27,510 \\
29,560 \\
29,313 \\
23,676\end{array}$ & $\begin{array}{l}393,325 \\
390,684 \\
424,504 \\
433,098 \\
445,660\end{array}$ & $\begin{array}{l}365,281 \\
400,927 \\
431,444 \\
443,306 \\
472,767\end{array}$ & $\begin{array}{l}1,684,796 \\
1,750,489 \\
1,888,780 \\
1,967,485 \\
2,070,286\end{array}$ & $\begin{array}{l}450,572 \\
535,406 \\
627,964 \\
720,624 \\
781,770\end{array}$ & $\begin{array}{r}96,477 \\
108,610 \\
122,207 \\
141,342 \\
152,713\end{array}$ \\
\hline
\end{tabular}

Percentage distribution

\begin{tabular}{|c|c|c|c|c|c|c|c|c|c|c|}
\hline $\begin{array}{ll}1976-77 & \ldots . \\
1979-80 & \ldots . \\
1980-81 & \ldots .\end{array}$ & $\begin{array}{l}100.0 \\
100.0 \\
100.0\end{array}$ & $\begin{array}{l}51.1 \\
50.3 \\
50.6\end{array}$ & $\begin{array}{l}18.1 \\
19.0 \\
19.1\end{array}$ & $\begin{array}{l}8.4 \\
8.6 \\
8.7\end{array}$ & $\begin{array}{l}0.3 \\
0.4 \\
0.4\end{array}$ & $\begin{array}{l}3.5 \\
3.2 \\
3.1\end{array}$ & $\begin{array}{l}2.0 \\
2.2 \\
2.2\end{array}$ & $\begin{array}{l}11.2 \\
11.7 \\
12.0\end{array}$ & $\begin{array}{l}2.9 \\
2.3 \\
2.3 \\
2.3\end{array}$ & $\begin{array}{l}2.4 \\
2.2 \\
1.7\end{array}$ \\
\hline $\begin{aligned} 1981-82 & \ldots . \\
1982-83 & \ldots \\
1983-84 & \ldots \\
1984-85 & \ldots \\
1985-86 & \ldots .\end{aligned}$ & $\begin{array}{l}100.0 \\
100.0 \\
100.0 \\
100.0 \\
100.0\end{array}$ & $\begin{array}{l}50.9 \\
50.9 \\
50.8 \\
50.3 \\
49.9\end{array}$ & $\begin{array}{l}19.0 \\
19.5 \\
19.8 \\
20.2 \\
20.7\end{array}$ & $\begin{array}{l}8.8 \\
8.9 \\
8.8 \\
8.8 \\
9.0\end{array}$ & $\begin{array}{l}0.2 \\
0.2 \\
0.2 \\
0.2 \\
0.1\end{array}$ & $\begin{array}{l}3.4 \\
3.0 \\
3.0 \\
2.9 \\
2.9\end{array}$ & $\begin{array}{l}1.9 \\
1.5 \\
1.7 \\
2.0 \\
2.0\end{array}$ & $\begin{array}{l}12.3 \\
12.3 \\
12.2 \\
12.1 \\
11.9\end{array}$ & $\begin{array}{l}2.1 \\
2.1 \\
2.0 \\
2.2 \\
2.2\end{array}$ & $\begin{array}{l}1.5 \\
1.6 \\
1.5 \\
1.4 \\
1.4\end{array}$ \\
\hline $\begin{aligned} 1986-87 & \ldots \\
1987-88 & \ldots \\
1988-89 & \ldots . \\
1989-90 & \ldots . \\
1990-91 & \ldots .\end{aligned}$ & $\begin{array}{l}100.0 \\
100.0 \\
100.0 \\
100.0 \\
100.0\end{array}$ & $\begin{array}{l}49.6 \\
49.2 \\
49.6 \\
49.8 \\
49.9\end{array}$ & $\begin{array}{l}21.8 \\
21.3 \\
21.5 \\
21.5 \\
21.6\end{array}$ & $\begin{array}{l}9.4 \\
9.9 \\
9.5 \\
9.7 \\
9.9\end{array}$ & $\begin{array}{l}0.1 \\
0.1 \\
0.1 \\
0.1 \\
0.1\end{array}$ & $\begin{array}{l}2.3 \\
2.7 \\
2.6 \\
2.5 \\
2.5\end{array}$ & $\begin{array}{l}2.2 \\
2.3 \\
2.5 \\
2.4 \\
2.4\end{array}$ & $\begin{array}{l}11.5 \\
11.4 \\
11.2 \\
11.0 \\
10.7\end{array}$ & $\begin{array}{l}2.2 \\
2.4 \\
2.4 \\
2.3 \\
2.4\end{array}$ & $\begin{array}{l}0.8 \\
0.8 \\
0.7 \\
0.7 \\
0.6\end{array}$ \\
\hline $\begin{array}{r}1991-92 \ldots \\
1992-93 \ldots \\
1993-94 \ldots \\
1994-95 \ldots \\
1995-962 \ldots\end{array}$ & $\begin{array}{l}100.0 \\
100.0 \\
100.0 \\
100.0 \\
100.0\end{array}$ & $\begin{array}{l}50.3 \\
50.1 \\
49.4 \\
49.0 \\
48.1\end{array}$ & $\begin{array}{l}20.9 \\
20.9 \\
21.0 \\
21.0 \\
21.6\end{array}$ & $\begin{array}{l}10.2 \\
10.4 \\
10.4 \\
10.5 \\
10.7\end{array}$ & $\begin{array}{l}0.2 \\
0.2 \\
0.2 \\
0.2 \\
0.1\end{array}$ & $\begin{array}{l}2.4 \\
2.3 \\
2.3 \\
2.2 \\
2.2\end{array}$ & $\begin{array}{l}2.2 \\
2.3 \\
2.4 \\
2.3 \\
2.3\end{array}$ & $\begin{array}{l}10.4 \\
10.1 \\
10.3 \\
10.2 \\
10.3\end{array}$ & $\begin{array}{l}2.8 \\
3.1 \\
3.4 \\
3.7 \\
3.9\end{array}$ & $\begin{array}{l}0.6 \\
0.6 \\
0.7 \\
0.7 \\
0.8\end{array}$ \\
\hline & \multicolumn{10}{|c|}{ Expenditure per full-time-equivalent student in constant 1995-96 dollars } \\
\hline $\begin{aligned} 1976-77 & \ldots \\
1977-78 & \ldots \\
1978-79 & \ldots \\
1979-80 & \ldots \\
1980-81 & \ldots .\end{aligned}$ & $\begin{array}{r}\$ 5,939 \\
5,971 \\
6,174 \\
6,071 \\
5,818\end{array}$ & $\begin{array}{r}\$ 3,033 \\
3,022 \\
3,098 \\
3,053 \\
2,945\end{array}$ & $\begin{array}{r}\$ 1,075 \\
1,158 \\
1,206 \\
1,154 \\
1,109\end{array}$ & $\begin{array}{r}\$ 498 \\
489 \\
519 \\
525 \\
507\end{array}$ & $\begin{array}{r}\$ 19 \\
10 \\
23 \\
25 \\
22\end{array}$ & $\begin{array}{r}\$ 209 \\
211 \\
209 \\
194 \\
183\end{array}$ & $\begin{array}{r}\$ 119 \\
126 \\
119 \\
135 \\
126\end{array}$ & $\begin{array}{r}\$ 667 \\
677 \\
700 \\
712 \\
696\end{array}$ & $\begin{array}{r}\$ 174 \\
132 \\
137 \\
142 \\
131\end{array}$ & $\begin{array}{r}\$ 144 \\
145 \\
162 \\
131 \\
98\end{array}$ \\
\hline $\begin{array}{ll}1981-82 & \ldots . \\
1982-83 & \ldots . \\
1983-84 & \ldots . \\
1984-85 & \ldots . \\
1985-86 & \ldots .\end{array}$ & $\begin{array}{l}5,812 \\
5,499 \\
5,576 \\
6,111 \\
6,292\end{array}$ & $\begin{array}{l}2,957 \\
2,797 \\
2,833 \\
3,072 \\
3,140\end{array}$ & $\begin{array}{l}1,104 \\
1,075 \\
1,105 \\
1,234 \\
1,302\end{array}$ & $\begin{array}{l}513 \\
491 \\
490 \\
538 \\
565\end{array}$ & $\begin{array}{r}12 \\
12 \\
11 \\
10 \\
6\end{array}$ & $\begin{array}{l}197 \\
165 \\
167 \\
178 \\
181\end{array}$ & $\begin{array}{r}110 \\
82 \\
95 \\
124 \\
124\end{array}$ & $\begin{array}{l}714 \\
674 \\
680 \\
739 \\
749\end{array}$ & $\begin{array}{l}120 \\
116 \\
113 \\
133 \\
139\end{array}$ & $\begin{array}{l}85 \\
86 \\
81 \\
84 \\
85\end{array}$ \\
\hline $\begin{array}{ll}1986-87 & \ldots . \\
1987-88 & \ldots . \\
1988-89 & \ldots . \\
1989-90 & \ldots . \\
1990-91 & \ldots . \\
1991-92 & \ldots .\end{array}$ & $\begin{array}{l}6,394 \\
6,309 \\
6,379 \\
6,206 \\
6,276 \\
5,988\end{array}$ & $\begin{array}{l}3,173 \\
3,104 \\
3,162 \\
3,090 \\
3,129 \\
3,012\end{array}$ & $\begin{array}{l}1,393 \\
1,341 \\
1,373 \\
1,332 \\
1,355 \\
1,254\end{array}$ & $\begin{array}{l}602 \\
626 \\
603 \\
601 \\
620 \\
611\end{array}$ & $\begin{array}{l}7 \\
6 \\
7 \\
9 \\
8 \\
9\end{array}$ & $\begin{array}{l}145 \\
171 \\
166 \\
158 \\
155 \\
145\end{array}$ & $\begin{array}{l}139 \\
143 \\
158 \\
151 \\
151 \\
134\end{array}$ & $\begin{array}{l}738 \\
717 \\
712 \\
683 \\
673 \\
620\end{array}$ & $\begin{array}{l}143 \\
152 \\
151 \\
141 \\
148 \\
166\end{array}$ & $\begin{array}{l}53 \\
48 \\
46 \\
42 \\
37 \\
36\end{array}$ \\
\hline $\begin{array}{l}1992-93 \ldots . . \\
1993-94 \ldots . \\
1994-95 \ldots \\
1995-96^{2} \ldots\end{array}$ & $\begin{array}{l}6,078 \\
6,390 \\
6,534 \\
6,733\end{array}$ & $\begin{array}{l}3,045 \\
3,154 \\
3,203 \\
3,240\end{array}$ & $\begin{array}{l}1,268 \\
1,344 \\
1,375 \\
1,452\end{array}$ & $\begin{array}{l}633 \\
664 \\
689 \\
722\end{array}$ & $\begin{array}{r}10 \\
10 \\
10 \\
8\end{array}$ & $\begin{array}{l}138 \\
148 \\
147 \\
149\end{array}$ & $\begin{array}{l}141 \\
150 \\
150 \\
158\end{array}$ & $\begin{array}{l}617 \\
658 \\
668 \\
691\end{array}$ & $\begin{array}{l}189 \\
219 \\
245 \\
261\end{array}$ & $\begin{array}{l}38 \\
43 \\
48 \\
51\end{array}$ \\
\hline
\end{tabular}

1 Includes institutional and academic support less libraries. 2 Preliminary data.

NOTE.-Data in this table may differ slightly from data appearing in other tables. Data for 1976-77 through 1985-86 include only institutions which provided both enrollment and finance data. The Higher Education Price Index was used to convert the per student figures to constant dollars. Because of rounding, details may not add to totals.
SOURCE: U.S. Department of Education, National Center for Education Statistics Higher Education General Information Survey (HEGIS), "Financial Statistics of Institutions of Higher Education" surveys; Integrated Postsecondary Education Data System (IPEDS), "Finance" surveys; and Research Associates of Washington, unpublished data. (This table was prepared October 1998.) 
Table 345.-Educational and general expenditures of private (nonprofit) universities, by purpose: 1976-77 to 1995-96

\begin{tabular}{|c|c|c|c|c|c|c|c|c|c|c|}
\hline \multirow[b]{2}{*}{ Year } & \multicolumn{10}{|c|}{ Educational and general expenditures } \\
\hline & Total & Instruction & Administration ${ }^{1}$ & $\begin{array}{l}\text { Student } \\
\text { services }\end{array}$ & Research & Libraries & $\begin{array}{l}\text { Public } \\
\text { service }\end{array}$ & $\begin{array}{l}\text { Operation } \\
\text { and } \\
\text { maintenance } \\
\text { of plant }\end{array}$ & $\begin{array}{l}\text { Scholarships } \\
\text { and } \\
\text { fellowships }\end{array}$ & $\begin{array}{l}\text { Mandatory } \\
\text { transfers }\end{array}$ \\
\hline \multirow[t]{2}{*}{1} & 2 & 3 & 4 & 5 & 6 & 7 & 8 & 9 & 10 & 11 \\
\hline & \multicolumn{10}{|c|}{ Expenditures, in thousands of current dollars } \\
\hline $\begin{array}{l}1976-77 \quad \ldots . \\
1977-78 \ldots \\
1978-79 \\
1979-80 \\
1980-81\end{array}$ & $\begin{array}{r}\$ 4,694,593 \\
5,120,125 \\
5,675,608 \\
6,408,288 \\
7,249,102\end{array}$ & $\begin{array}{r}\$ 1,784,975 \\
1,943,031 \\
2,120,800 \\
2,426,312 \\
2,763,320\end{array}$ & $\begin{array}{r}\$ 621,733 \\
683,988 \\
796,751 \\
908,580 \\
1,009,957\end{array}$ & $\begin{array}{r}\$ 156,457 \\
172,261 \\
195,238 \\
215,646 \\
254,872\end{array}$ & $\begin{array}{r}\$ 988,656 \\
1,063,906 \\
1,175,657 \\
1,315,469 \\
1,436,318\end{array}$ & $\begin{array}{r}\$ 195,146 \\
215,068 \\
221,676 \\
236,184 \\
267,142\end{array}$ & $\begin{array}{r}\$ 105,011 \\
108,201 \\
119,082 \\
148,028 \\
149,946\end{array}$ & $\begin{array}{r}\$ 411,340 \\
447,743 \\
510,819 \\
568,806 \\
660,152\end{array}$ & $\begin{array}{r}\$ 380,821 \\
427,907 \\
460,200 \\
507,257 \\
596,241\end{array}$ & $\begin{array}{r}\$ 50,453 \\
58,019 \\
75,385 \\
82,006 \\
111,154\end{array}$ \\
\hline $\begin{array}{ll}1981-82 & \ldots . \\
1982-83 & \ldots . \\
1983-84 & \ldots . \\
1984-85 & \ldots . \\
1985-86 & \ldots .\end{array}$ & $\begin{array}{r}7,951,934 \\
8,198,167 \\
9,491,967 \\
10,431,950 \\
11,407,571\end{array}$ & $\begin{array}{l}3,105,731 \\
3,227,925 \\
3,660,650 \\
3,965,165 \\
4,308,432\end{array}$ & $\begin{array}{l}1,100,088 \\
1,214,617 \\
1,445,910 \\
1,556,854 \\
1,711,155\end{array}$ & $\begin{array}{l}289,398 \\
304,617 \\
350,096 \\
393,526 \\
438,678\end{array}$ & $\begin{array}{l}1,505,340 \\
1,464,809 \\
1,683,020 \\
1,892,570 \\
2,108,731\end{array}$ & $\begin{array}{l}294,523 \\
295,709 \\
360,238 \\
366,356 \\
397,745\end{array}$ & $\begin{array}{l}160,496 \\
169,382 \\
187,615 \\
253,010 \\
271,271\end{array}$ & $\begin{array}{l}752,673 \\
754,480 \\
859,065 \\
930,229 \\
981,131\end{array}$ & $\begin{array}{r}650,285 \\
670,390 \\
833,108 \\
931,027 \\
1,040,677\end{array}$ & $\begin{array}{r}93,401 \\
96,238 \\
112,266 \\
143,212 \\
149,751\end{array}$ \\
\hline $\begin{array}{cc}1986-87 & \ldots . \\
1987-88 & \ldots . \\
1988-89 & \ldots . \\
1989-90 & \ldots . \\
1990-91 & \ldots .\end{array}$ & $\begin{array}{l}13,013,183 \\
13,876,586 \\
15,123,369 \\
16,363,342 \\
17,827,649\end{array}$ & $\begin{array}{l}4,998,565 \\
5,209,101 \\
5,743,104 \\
6,188,447 \\
6,827,220\end{array}$ & $\begin{array}{l}1,977,175 \\
2,107,206 \\
2,293,256 \\
2,411,051 \\
2,633,605\end{array}$ & $\begin{array}{l}502,291 \\
529,261 \\
565,903 \\
607,623 \\
669,160\end{array}$ & $\begin{array}{l}2,399,976 \\
2,597,435 \\
2,786,178 \\
3,048,455 \\
3,170,083\end{array}$ & $\begin{array}{l}397,460 \\
484,987 \\
510,820 \\
555,752 \\
567,800\end{array}$ & $\begin{array}{l}332,223 \\
340,475 \\
377,820 \\
414,916 \\
456,615\end{array}$ & $\begin{array}{l}1,006,334 \\
1,073,880 \\
1,135,273 \\
1,231,028 \\
1,383,686\end{array}$ & $\begin{array}{l}1,218,002 \\
1,328,775 \\
1,472,675 \\
1,615,096 \\
1,833,124\end{array}$ & $\begin{array}{l}181,159 \\
205,464 \\
238,340 \\
290,974 \\
286,357\end{array}$ \\
\hline 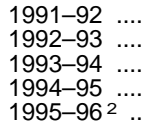 & $\begin{array}{l}19,307,030 \\
20,435,319 \\
21,702,227 \\
23,059,247 \\
24,094,517\end{array}$ & $\begin{array}{l}7,367,629 \\
7,844,576 \\
8,347,500 \\
8,838,806 \\
9,004,148\end{array}$ & $\begin{array}{l}2,852,739 \\
2,874,208 \\
3,009,434 \\
3,158,159 \\
3,691,277\end{array}$ & $\begin{array}{l}711,041 \\
719,657 \\
772,524 \\
820,099 \\
903,900\end{array}$ & $\begin{array}{l}3,364,795 \\
3,648,010 \\
3,831,668 \\
4,121,604 \\
4,243,335\end{array}$ & $\begin{array}{l}624,416 \\
644,005 \\
693,223 \\
752,683 \\
777,957\end{array}$ & $\begin{array}{l}484,871 \\
547,159 \\
603,658 \\
612,464 \\
621,908\end{array}$ & $\begin{array}{l}1,453,365 \\
1,495,825 \\
1,578,840 \\
1,632,166 \\
1,662,803\end{array}$ & $\begin{array}{l}2,142,466 \\
2,322,331 \\
2,481,742 \\
2,680,828 \\
2,754,177\end{array}$ & $\begin{array}{l}305,707 \\
339,547 \\
383,638 \\
442,438 \\
435,014\end{array}$ \\
\hline & \multicolumn{10}{|c|}{ Percentage distribution } \\
\hline $\begin{array}{l}1976-77 \ldots \\
1979-80 \ldots \\
1980-81 \ldots\end{array}$ & $\begin{array}{l}100.0 \\
100.0 \\
100.0\end{array}$ & $\begin{array}{l}38.0 \\
37.9 \\
38.1\end{array}$ & $\begin{array}{l}13.2 \\
14.2 \\
13.9\end{array}$ & $\begin{array}{l}3.3 \\
3.4 \\
3.5\end{array}$ & $\begin{array}{l}21.1 \\
20.5 \\
19.8\end{array}$ & $\begin{array}{l}4.2 \\
3.7 \\
3.7\end{array}$ & $\begin{array}{l}2.2 \\
2.3 \\
2.1\end{array}$ & $\begin{array}{l}8.8 \\
8.9 \\
9.1\end{array}$ & $\begin{array}{l}8.1 \\
7.9 \\
8.2\end{array}$ & $\begin{array}{l}1.1 \\
1.3 \\
1.5\end{array}$ \\
\hline $\begin{array}{cc}1981-82 & \ldots . \\
1982-83 & \ldots . \\
1983-84 & \ldots . \\
1984-85 & \ldots . \\
1985-86 & \ldots .\end{array}$ & $\begin{array}{l}100.0 \\
100.0 \\
100.0 \\
100.0 \\
100.0\end{array}$ & $\begin{array}{l}39.1 \\
39.4 \\
38.6 \\
38.0 \\
37.8\end{array}$ & $\begin{array}{l}13.8 \\
14.8 \\
15.2 \\
14.9 \\
15.0\end{array}$ & $\begin{array}{l}3.6 \\
3.7 \\
3.7 \\
3.8 \\
3.8\end{array}$ & $\begin{array}{l}18.9 \\
17.9 \\
17.7 \\
18.1 \\
18.5\end{array}$ & $\begin{array}{l}3.7 \\
3.6 \\
3.8 \\
3.5 \\
3.5\end{array}$ & $\begin{array}{l}2.0 \\
2.1 \\
2.0 \\
2.4 \\
2.4\end{array}$ & $\begin{array}{l}9.5 \\
9.2 \\
9.1 \\
8.9 \\
8.6\end{array}$ & $\begin{array}{l}8.2 \\
8.2 \\
8.8 \\
8.9 \\
9.1\end{array}$ & $\begin{array}{l}1.2 \\
1.2 \\
1.2 \\
1.4 \\
1.3\end{array}$ \\
\hline $\begin{array}{ll}1986-87 & \ldots . \\
1987-88 & \ldots . \\
1988-89 & \ldots . \\
1989-90 & \ldots . \\
1990-91 & \ldots .\end{array}$ & $\begin{array}{l}100.0 \\
100.0 \\
100.0 \\
100.0 \\
100.0\end{array}$ & $\begin{array}{l}38.4 \\
37.5 \\
38.0 \\
37.8 \\
38.3\end{array}$ & $\begin{array}{l}15.2 \\
15.2 \\
15.2 \\
14.7 \\
14.8\end{array}$ & $\begin{array}{l}3.9 \\
3.8 \\
3.7 \\
3.7 \\
3.8\end{array}$ & $\begin{array}{l}18.4 \\
18.7 \\
18.4 \\
18.6 \\
17.8\end{array}$ & $\begin{array}{l}3.1 \\
3.5 \\
3.4 \\
3.4 \\
3.2\end{array}$ & $\begin{array}{l}2.6 \\
2.5 \\
2.5 \\
2.5 \\
2.6\end{array}$ & $\begin{array}{l}7.7 \\
7.7 \\
7.5 \\
7.5 \\
7.8\end{array}$ & $\begin{array}{r}9.4 \\
9.6 \\
9.7 \\
9.9 \\
10.3\end{array}$ & $\begin{array}{l}1.4 \\
1.5 \\
1.6 \\
1.8 \\
1.6\end{array}$ \\
\hline \multirow[t]{2}{*}{ 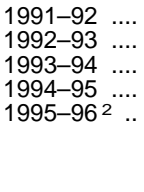 } & $\begin{array}{l}100.0 \\
100.0 \\
100.0 \\
100.0 \\
100.0\end{array}$ & $\begin{array}{l}38.2 \\
38.4 \\
38.5 \\
38.3 \\
37.4\end{array}$ & $\begin{array}{l}14.8 \\
14.1 \\
13.9 \\
13.7 \\
15.3\end{array}$ & $\begin{array}{l}3.7 \\
3.5 \\
3.6 \\
3.6 \\
3.8\end{array}$ & $\begin{array}{l}17.4 \\
17.9 \\
17.7 \\
17.9 \\
17.6\end{array}$ & $\begin{array}{l}3.2 \\
3.2 \\
3.2 \\
3.3 \\
3.2\end{array}$ & $\begin{array}{l}2.5 \\
2.7 \\
2.8 \\
2.7 \\
2.6\end{array}$ & $\begin{array}{l}7.5 \\
7.3 \\
7.3 \\
7.1 \\
6.9\end{array}$ & $\begin{array}{l}11.1 \\
11.4 \\
11.4 \\
11.6 \\
11.4\end{array}$ & $\begin{array}{l}1.6 \\
1.7 \\
1.8 \\
1.9 \\
1.8\end{array}$ \\
\hline & \multicolumn{10}{|c|}{ Expenditure per full-time-equivalent student in constant $1995-96$ dollars } \\
\hline $\begin{array}{ll}1976-77 & \ldots . \\
1977-78 & \ldots \\
1978-79 & \ldots \\
1979-80 & \ldots . \\
1980-81 & \ldots .\end{array}$ & $\begin{array}{r}\$ 23,395 \\
23,119 \\
23,411 \\
23,750 \\
24,040\end{array}$ & $\begin{array}{r}\$ 8,895 \\
8,773 \\
8,748 \\
8,992 \\
9,164\end{array}$ & $\begin{array}{r}\$ 3,098 \\
3,088 \\
3,287 \\
3,367 \\
3,349\end{array}$ & $\begin{array}{r}\$ 780 \\
778 \\
805 \\
799 \\
845\end{array}$ & $\begin{array}{r}\$ 4,927 \\
4,804 \\
4,849 \\
4,875 \\
4,763\end{array}$ & $\begin{array}{r}\$ 972 \\
971 \\
914 \\
875 \\
886\end{array}$ & $\begin{array}{r}\$ 523 \\
489 \\
491 \\
549 \\
497\end{array}$ & $\begin{array}{r}\$ 2,050 \\
2,022 \\
2,107 \\
2,108 \\
2,189\end{array}$ & $\begin{array}{r}\$ 1,898 \\
1,932 \\
1,898 \\
1,880 \\
1,977\end{array}$ & $\begin{array}{r}\$ 251 \\
262 \\
311 \\
304 \\
369\end{array}$ \\
\hline $\begin{array}{cc}1981-82 & \ldots . \\
1982-83 & \ldots . \\
1983-84 & \ldots . \\
1984-85 & \ldots . \\
1985-86 & \ldots .\end{array}$ & $\begin{array}{l}23,947 \\
24,140 \\
25,909 \\
26,964 \\
27,983\end{array}$ & $\begin{array}{r}9,353 \\
9,505 \\
9,992 \\
10,249 \\
10,569\end{array}$ & $\begin{array}{l}3,313 \\
3,577 \\
3,947 \\
4,024 \\
4,198\end{array}$ & $\begin{array}{r}871 \\
897 \\
956 \\
1,017 \\
1,076\end{array}$ & $\begin{array}{l}4,533 \\
4,313 \\
4,594 \\
4,892 \\
5,173\end{array}$ & $\begin{array}{l}887 \\
871 \\
983 \\
947 \\
976\end{array}$ & $\begin{array}{l}483 \\
499 \\
512 \\
654 \\
665\end{array}$ & $\begin{array}{l}2,267 \\
2,222 \\
2,345 \\
2,404 \\
2,407\end{array}$ & $\begin{array}{l}1,958 \\
1,974 \\
2,274 \\
2,406 \\
2,553\end{array}$ & $\begin{array}{l}281 \\
283 \\
306 \\
370 \\
367\end{array}$ \\
\hline $\begin{array}{cc}1986-87 & \ldots . \\
1987-88 & \ldots . \\
1988-89 & \ldots . \\
1989-90 & \ldots . \\
1990-91 & \ldots .\end{array}$ & $\begin{array}{l}30,544 \\
30,934 \\
31,609 \\
31,961 \\
32,945\end{array}$ & $\begin{array}{l}11,732 \\
11,612 \\
12,004 \\
12,087 \\
12,616\end{array}$ & $\begin{array}{l}4,641 \\
4,697 \\
4,793 \\
4,709 \\
4,867\end{array}$ & $\begin{array}{l}1,179 \\
1,180 \\
1,183 \\
1,187 \\
1,237\end{array}$ & $\begin{array}{l}5,633 \\
5,790 \\
5,823 \\
5,954 \\
5,858\end{array}$ & $\begin{array}{r}933 \\
1,081 \\
1,068 \\
1,085 \\
1,049\end{array}$ & $\begin{array}{l}780 \\
759 \\
790 \\
810 \\
844\end{array}$ & $\begin{array}{l}2,362 \\
2,394 \\
2,373 \\
2,404 \\
2,557\end{array}$ & $\begin{array}{l}2,859 \\
2,962 \\
3,078 \\
3,155 \\
3,388\end{array}$ & $\begin{array}{l}425 \\
458 \\
498 \\
568 \\
529\end{array}$ \\
\hline $\begin{array}{l}1991-92 \ldots . \\
1992-93 \\
1993-94 \\
1994-95 \\
1995-96^{2}\end{array}$ & $\begin{array}{l}33,901 \\
34,848 \\
35,876 \\
36,806 \\
37,200\end{array}$ & $\begin{array}{l}12,937 \\
13,377 \\
13,799 \\
14,108 \\
13,902\end{array}$ & $\begin{array}{l}5,009 \\
4,901 \\
4,975 \\
5,041 \\
5,699\end{array}$ & $\begin{array}{l}1,248 \\
1,227 \\
1,277 \\
1,309 \\
1,396\end{array}$ & $\begin{array}{l}5,908 \\
6,221 \\
6,334 \\
6,579 \\
6,551\end{array}$ & $\begin{array}{l}1,096 \\
1,098 \\
1,146 \\
1,201 \\
1,201\end{array}$ & $\begin{array}{l}851 \\
933 \\
998 \\
978 \\
960\end{array}$ & $\begin{array}{l}2,552 \\
2,551 \\
2,610 \\
2,605 \\
2,567\end{array}$ & $\begin{array}{l}3,762 \\
3,960 \\
4,103 \\
4,279 \\
4,252\end{array}$ & $\begin{array}{l}537 \\
579 \\
634 \\
706 \\
672\end{array}$ \\
\hline
\end{tabular}

1 Includes institutional and academic support less libraries. 2 Preliminary data.

NOTE.-Data in this table may differ slightly from data appearing in other tables. Data for 1976-77 through 1985-86 include only institutions which provided both enrollment and finance data. The Higher Education Price Index was used to convert the per student figures to constant dollars. Because of rounding, details may not add to totals.
SOURCE: U.S. Department of Education, National Center for Education Statistics, Higher Education General Information Survey (HEGIS), "Financial Statistics of Institutions of Higher Education" surveys; Integrated Postsecondary Education Data System (IPEDS), "Finance" surveys; and Research Associates of Washington, unpublished data. (This table was prepared October 1998.) 
Table 346.-Educational and general expenditures of private (nonprofit) 4-year colleges, ${ }^{1}$ by purpose: 1976-77 to 1995-96

\begin{tabular}{|c|c|c|c|c|c|c|c|c|c|c|}
\hline \multirow[b]{2}{*}{ Year } & \multicolumn{10}{|c|}{ Educational and general expenditures } \\
\hline & Total & Instruction & Administration ${ }^{2}$ & $\begin{array}{l}\text { Student } \\
\text { services }\end{array}$ & Research & Libraries & $\begin{array}{l}\text { Public } \\
\text { service }\end{array}$ & $\begin{array}{c}\text { Operation } \\
\text { and } \\
\text { maintenance } \\
\text { of plant }\end{array}$ & $\begin{array}{c}\text { Scholarships } \\
\text { and } \\
\text { fellowships }\end{array}$ & $\begin{array}{l}\text { Mandatory } \\
\text { transfers }\end{array}$ \\
\hline \multirow[t]{2}{*}{1} & 2 & 3 & 4 & 5 & 6 & 7 & 8 & 9 & 10 & 11 \\
\hline & \multicolumn{10}{|c|}{ Expenditures, in thousands of current dollars } \\
\hline $\begin{array}{ll}1976-77 & \ldots . \\
1977-78 & \ldots . \\
1978-79 & \ldots . \\
1979-80 & \ldots . \\
1980-81 & \ldots .\end{array}$ & $\begin{array}{r}\$ 5,139,939 \\
5,637,836 \\
6,263,692 \\
7,063,953 \\
8,061,774\end{array}$ & $\begin{array}{r}\$ 1,919,574 \\
2,114,043 \\
2,328,418 \\
2,589,908 \\
2,907,255\end{array}$ & $\begin{array}{r}\$ 1,047,932 \\
1,160,141 \\
1,299,063 \\
1,466,556 \\
1,703,307\end{array}$ & $\begin{array}{r}\$ 381,428 \\
428,265 \\
483,031 \\
549,639 \\
639,795\end{array}$ & $\begin{array}{r}\$ 259,530 \\
271,637 \\
328,042 \\
374,520 \\
407,622\end{array}$ & $\begin{array}{r}\$ 200,844 \\
221,807 \\
240,098 \\
259,969 \\
289,944\end{array}$ & $\begin{array}{r}\$ 123,717 \\
123,214 \\
136,861 \\
153,056 \\
186,399\end{array}$ & $\begin{array}{r}\$ 574,910 \\
638,330 \\
704,180 \\
807,943 \\
930,075\end{array}$ & $\begin{array}{r}\$ 511,907 \\
550,372 \\
598,487 \\
694,791 \\
811,636\end{array}$ & $\begin{array}{r}\$ 120,097 \\
130,026 \\
145,513 \\
167,570 \\
185,741\end{array}$ \\
\hline $\begin{array}{ll}1981-82 & \ldots . \\
1982-83 & \ldots . \\
1983-84 & \ldots . \\
1984-85 & \ldots . \\
1985-86 & \ldots .\end{array}$ & $\begin{array}{r}9,061,667 \\
9,805,459 \\
10,845,622 \\
11,835,351 \\
12,855,040\end{array}$ & $\begin{array}{l}3,271,255 \\
3,552,387 \\
3,900,082 \\
4,213,485 \\
4,507,505\end{array}$ & $\begin{array}{l}1,938,727 \\
2,124,446 \\
2,347,962 \\
2,564,844 \\
2,790,504\end{array}$ & $\begin{array}{r}727,382 \\
804,943 \\
890,707 \\
980,416 \\
1,067,717\end{array}$ & $\begin{array}{l}419,283 \\
437,286 \\
480,459 \\
539,322 \\
623,050\end{array}$ & $\begin{array}{l}322,702 \\
356,768 \\
388,153 \\
416,539 \\
446,766\end{array}$ & $\begin{array}{l}228,368 \\
236,142 \\
259,932 \\
289,124 \\
328,827\end{array}$ & $\begin{array}{l}1,036,118 \\
1,092,836 \\
1,184,788 \\
1,251,490 \\
1,317,062\end{array}$ & $\begin{array}{r}913,999 \\
983,887 \\
1,149,813 \\
1,312,673 \\
1,481,954\end{array}$ & $\begin{array}{l}203,834 \\
216,764 \\
243,726 \\
267,459 \\
291,654\end{array}$ \\
\hline $\begin{array}{ll}1986-87 & \ldots . . \\
1987-88 & \ldots . \\
1988-89 & \ldots . \\
1989-90 & \ldots . \\
1990-91 & \ldots .\end{array}$ & $\begin{array}{l}14,232,003 \\
15,405,503 \\
16,980,645 \\
18,717,398 \\
20,374,743\end{array}$ & $\begin{array}{l}4,886,585 \\
5,248,764 \\
5,738,789 \\
6,276,102 \\
6,809,318\end{array}$ & $\begin{array}{l}3,249,910 \\
3,403,379 \\
3,766,237 \\
4,097,242 \\
4,533,043\end{array}$ & $\begin{array}{l}1,184,395 \\
1,293,302 \\
1,437,829 \\
1,599,951 \\
1,770,071\end{array}$ & $\begin{array}{l}693,450 \\
776,022 \\
848,094 \\
909,822 \\
901,357\end{array}$ & $\begin{array}{l}410,013 \\
485,517 \\
530,032 \\
578,520 \\
589,052\end{array}$ & $\begin{array}{l}384,594 \\
456,111 \\
495,683 \\
581,730 \\
624,663\end{array}$ & $\begin{array}{l}1,386,729 \\
1,462,345 \\
1,596,786 \\
1,712,000 \\
1,809,977\end{array}$ & $\begin{array}{l}1,717,948 \\
1,966,124 \\
2,198,328 \\
2,547,600 \\
2,898,547\end{array}$ & $\begin{array}{l}318,379 \\
313,939 \\
368,866 \\
414,432 \\
438,715\end{array}$ \\
\hline \multirow[t]{2}{*}{$\begin{array}{l}1991-92 \ldots \\
1992-93 \ldots \\
1993-94 \ldots \\
1994-95 \ldots \\
1995-96^{3} \ldots\end{array}$} & $\begin{array}{l}22,121,380 \\
23,609,625 \\
25,262,199 \\
26,999,085 \\
28,875,543\end{array}$ & $\begin{array}{l}7,320,211 \\
7,743,656 \\
8,169,221 \\
8,714,437 \\
9,402,691\end{array}$ & $\begin{array}{l}4,723,853 \\
4,887,700 \\
5,199,838 \\
5,438,969 \\
5,851,682\end{array}$ & $\begin{array}{l}1,919,662 \\
2,044,830 \\
2,205,411 \\
2,350,717 \\
2,541,516\end{array}$ & $\begin{array}{r}942,407 \\
1,036,676 \\
1,104,561 \\
1,157,255 \\
1,198,549\end{array}$ & $\begin{array}{l}659,416 \\
680,457 \\
733,711 \\
764,903 \\
798,027\end{array}$ & $\begin{array}{r}714,728 \\
821,381 \\
893,500 \\
1,040,959 \\
1,100,983\end{array}$ & $\begin{array}{l}1,896,424 \\
1,995,164 \\
2,112,367 \\
2,195,045 \\
2,345,694\end{array}$ & $\begin{array}{l}3,478,153 \\
3,900,807 \\
4,316,138 \\
4,739,447 \\
5,097,295\end{array}$ & $\begin{array}{l}466,528 \\
498,954 \\
527,451 \\
597,354 \\
539,106\end{array}$ \\
\hline & \multicolumn{10}{|c|}{ Percentage distribution } \\
\hline $\begin{array}{ll}1976-77 & \ldots . \\
1979-80 & \ldots . \\
1980-81 & \ldots .\end{array}$ & $\begin{array}{l}100.0 \\
100.0 \\
100.0\end{array}$ & $\begin{array}{l}37.3 \\
36.7 \\
36.1\end{array}$ & $\begin{array}{l}20.4 \\
20.8 \\
21.1\end{array}$ & $\begin{array}{l}7.4 \\
7.8 \\
7.9\end{array}$ & $\begin{array}{l}5.0 \\
5.3 \\
5.1\end{array}$ & $\begin{array}{l}3.9 \\
3.7 \\
3.6\end{array}$ & $\begin{array}{l}2.4 \\
2.2 \\
2.3\end{array}$ & $\begin{array}{l}11.2 \\
11.4 \\
11.5\end{array}$ & $\begin{array}{r}10.0 \\
9.8 \\
10.1\end{array}$ & $\begin{array}{l}2.3 \\
2.4 \\
2.3\end{array}$ \\
\hline $\begin{array}{ll}1981-82 & \ldots . \\
1982-83 & \ldots . \\
1983-84 & \ldots . \\
1984-85 & \ldots . \\
1985-86 & \ldots .\end{array}$ & $\begin{array}{l}100.0 \\
100.0 \\
100.0 \\
100.0 \\
100.0\end{array}$ & $\begin{array}{l}36.1 \\
36.2 \\
36.0 \\
35.6 \\
35.1\end{array}$ & $\begin{array}{l}21.4 \\
21.7 \\
21.6 \\
21.7 \\
21.7\end{array}$ & $\begin{array}{l}8.0 \\
8.2 \\
8.2 \\
8.3 \\
8.3\end{array}$ & $\begin{array}{l}4.6 \\
4.5 \\
4.4 \\
4.6 \\
4.8\end{array}$ & $\begin{array}{l}3.6 \\
3.6 \\
3.6 \\
3.5 \\
3.5\end{array}$ & $\begin{array}{l}2.5 \\
2.4 \\
2.4 \\
2.4 \\
2.6\end{array}$ & $\begin{array}{l}11.4 \\
11.1 \\
10.9 \\
10.6 \\
10.2\end{array}$ & $\begin{array}{l}10.1 \\
10.0 \\
10.6 \\
11.1 \\
11.5\end{array}$ & $\begin{array}{l}2.2 \\
2.2 \\
2.2 \\
2.3 \\
2.3\end{array}$ \\
\hline $\begin{array}{ll}1986-87 & \ldots . \\
1987-88 & \ldots . \\
1988-89 & \ldots . \\
1989-90 & \ldots . \\
1990-91 & \ldots .\end{array}$ & $\begin{array}{l}100.0 \\
100.0 \\
100.0 \\
100.0 \\
100.0\end{array}$ & $\begin{array}{l}34.3 \\
34.1 \\
33.8 \\
33.5 \\
33.4\end{array}$ & $\begin{array}{l}22.8 \\
22.1 \\
22.2 \\
21.9 \\
22.2\end{array}$ & $\begin{array}{l}8.3 \\
8.4 \\
8.5 \\
8.5 \\
8.7\end{array}$ & $\begin{array}{l}4.9 \\
5.0 \\
5.0 \\
4.9 \\
4.4\end{array}$ & $\begin{array}{l}2.9 \\
3.2 \\
3.1 \\
3.1 \\
2.9\end{array}$ & $\begin{array}{l}2.7 \\
3.0 \\
2.9 \\
3.1 \\
3.1\end{array}$ & $\begin{array}{l}9.7 \\
9.5 \\
9.4 \\
9.1 \\
8.9\end{array}$ & $\begin{array}{l}12.1 \\
12.8 \\
12.9 \\
13.6 \\
14.2\end{array}$ & $\begin{array}{l}2.2 \\
2.0 \\
2.2 \\
2.2 \\
2.2\end{array}$ \\
\hline \multirow[t]{2}{*}{$\begin{array}{l}1991-92 \ldots \\
1992-93 \quad \ldots . \\
1993-94 \ldots \\
1994-95 \ldots \\
1995-96{ }^{3} \ldots \\
. . .\end{array}$} & $\begin{array}{l}100.0 \\
100.0 \\
100.0 \\
100.0 \\
100.0\end{array}$ & $\begin{array}{l}33.1 \\
32.8 \\
32.3 \\
32.3 \\
32.6\end{array}$ & $\begin{array}{l}21.4 \\
20.7 \\
20.6 \\
20.1 \\
20.3\end{array}$ & $\begin{array}{l}8.7 \\
8.7 \\
8.7 \\
8.7 \\
8.8\end{array}$ & $\begin{array}{l}4.3 \\
4.4 \\
4.4 \\
4.3 \\
4.2\end{array}$ & $\begin{array}{l}3.0 \\
2.9 \\
2.9 \\
2.8 \\
2.8\end{array}$ & $\begin{array}{l}3.2 \\
3.5 \\
3.5 \\
3.9 \\
3.8\end{array}$ & $\begin{array}{l}8.6 \\
8.5 \\
8.4 \\
8.1 \\
8.1\end{array}$ & $\begin{array}{l}15.7 \\
16.5 \\
17.1 \\
17.6 \\
17.7\end{array}$ & $\begin{array}{l}2.1 \\
2.1 \\
2.1 \\
2.2 \\
1.9\end{array}$ \\
\hline & \multicolumn{10}{|c|}{ Expenditure per full-time-equivalent student in constant 1995-96 dollars } \\
\hline $\begin{array}{ll}1976-77 & \ldots . \\
1977-78 & \ldots . \\
1978-79 & \ldots . \\
1979-80 & \ldots . \\
1980-81 & \ldots .\end{array}$ & $\begin{array}{r}\$ 11,533 \\
11,481 \\
11,623 \\
11,821 \\
11,876\end{array}$ & $\begin{array}{r}\$ 4,307 \\
4,305 \\
4,321 \\
4,334 \\
4,283\end{array}$ & $\begin{array}{r}\$ 2,351 \\
2,363 \\
2,411 \\
2,454 \\
2,509\end{array}$ & $\begin{array}{r}\$ 856 \\
872 \\
896 \\
920 \\
943\end{array}$ & $\begin{array}{r}\$ 582 \\
553 \\
609 \\
627 \\
600\end{array}$ & $\begin{array}{r}\$ 451 \\
452 \\
446 \\
435 \\
427\end{array}$ & $\begin{array}{r}\$ 278 \\
251 \\
254 \\
256 \\
275\end{array}$ & $\begin{array}{r}\$ 1,290 \\
1,300 \\
1,307 \\
1,352 \\
1,370\end{array}$ & $\begin{array}{r}\$ 1,149 \\
1,121 \\
1,111 \\
1,163 \\
1,196\end{array}$ & $\begin{array}{r}\$ 269 \\
265 \\
270 \\
280 \\
274\end{array}$ \\
\hline $\begin{array}{ll}1981-82 & \ldots . \\
1982-83 & \ldots . \\
1983-84 & \ldots . \\
1984-85 & \ldots . \\
1985-86 & \ldots .\end{array}$ & $\begin{array}{l}12,028 \\
12,279 \\
12,693 \\
13,152 \\
13,605\end{array}$ & $\begin{array}{l}4,342 \\
4,449 \\
4,564 \\
4,682 \\
4,770\end{array}$ & $\begin{array}{l}2,573 \\
2,660 \\
2,748 \\
2,850 \\
2,953\end{array}$ & $\begin{array}{r}965 \\
1,008 \\
1,042 \\
1,090 \\
1,130\end{array}$ & $\begin{array}{l}557 \\
548 \\
562 \\
599 \\
659\end{array}$ & $\begin{array}{l}428 \\
447 \\
454 \\
463 \\
473\end{array}$ & $\begin{array}{l}303 \\
296 \\
304 \\
321 \\
348\end{array}$ & $\begin{array}{l}1,375 \\
1,369 \\
1,387 \\
1,391 \\
1,394\end{array}$ & $\begin{array}{l}1,213 \\
1,232 \\
1,346 \\
1,459 \\
1,568\end{array}$ & $\begin{array}{l}271 \\
271 \\
285 \\
297 \\
309\end{array}$ \\
\hline $\begin{array}{ll}1986-87 & \ldots . \\
1987-88 & \ldots . \\
1988-89 & \ldots . \\
1989-90 & \ldots . \\
1990-91 & \ldots .\end{array}$ & $\begin{array}{l}14,409 \\
14,768 \\
14,916 \\
15,167 \\
15,417\end{array}$ & $\begin{array}{l}4,947 \\
5,032 \\
5,041 \\
5,085 \\
5,153\end{array}$ & $\begin{array}{l}3,290 \\
3,263 \\
3,308 \\
3,320 \\
3,430\end{array}$ & $\begin{array}{l}1,199 \\
1,240 \\
1,263 \\
1,296 \\
1,339\end{array}$ & $\begin{array}{l}702 \\
744 \\
745 \\
737 \\
682\end{array}$ & $\begin{array}{l}415 \\
465 \\
466 \\
469 \\
446\end{array}$ & $\begin{array}{l}389 \\
437 \\
435 \\
471 \\
473\end{array}$ & $\begin{array}{l}1,404 \\
1,402 \\
1,403 \\
1,387 \\
1,370\end{array}$ & $\begin{array}{l}1,739 \\
1,885 \\
1,931 \\
2,064 \\
2,193\end{array}$ & $\begin{array}{l}322 \\
301 \\
324 \\
336 \\
332\end{array}$ \\
\hline $\begin{array}{l}1991-92 \ldots \\
1992-93 \ldots \\
1993-94 \ldots \\
1994-95 \\
1995-963^{3} . .\end{array}$ & $\begin{array}{l}15,802 \\
15,954 \\
16,340 \\
16,789 \\
17,177\end{array}$ & $\begin{array}{l}5,229 \\
5,233 \\
5,284 \\
5,419 \\
5,593\end{array}$ & $\begin{array}{l}3,374 \\
3,303 \\
3,363 \\
3,382 \\
3,481\end{array}$ & $\begin{array}{l}1,371 \\
1,382 \\
1,427 \\
1,462 \\
1,512\end{array}$ & $\begin{array}{l}673 \\
701 \\
714 \\
720 \\
713\end{array}$ & $\begin{array}{l}471 \\
460 \\
475 \\
476 \\
475\end{array}$ & $\begin{array}{l}511 \\
555 \\
578 \\
647 \\
655\end{array}$ & $\begin{array}{l}1,355 \\
1,348 \\
1,366 \\
1,365 \\
1,395\end{array}$ & $\begin{array}{l}2,485 \\
2,636 \\
2,792 \\
2,947 \\
3,032\end{array}$ & $\begin{array}{l}333 \\
337 \\
341 \\
371 \\
321\end{array}$ \\
\hline
\end{tabular}

${ }^{1}$ Excludes universities. See preceding table.

2 Includes institutional and academic support less libraries.

${ }^{3}$ Preliminary data.

NOTE.-Data in this table may differ slightly from data appearing in other tables. Data for 1976-77 through 1985-86 include only institutions which provided both enrollment and finance data. The Higher Education Price Index was used to convert the per student figures to constant dollars. Because of rounding, details may not add to totals.
SOURCE: U.S. Department of Education, National Center for Education Statistics, Higher Education General Information Survey (HEGIS), "Financial Statistics of Institutions of Higher Education" surveys; Integrated Postsecondary Education Data System (IPEDS), "Finance" surveys; and Research Associates of Washington, unpublished data. (This table was prepared October 1998.) 
Table 347.-Current-fund expenditures of public institutions of higher education and degree-granting institutions, by state: $1980-81$ to $1995-96$

[In thousands of dollars]

\begin{tabular}{|c|c|c|c|c|c|c|c|c|c|c|}
\hline \multirow[b]{2}{*}{ State } & \multicolumn{9}{|c|}{ Institutions of higher education } & \multirow[b]{2}{*}{$\begin{array}{c}\text { Degree-granting } \\
\text { institutions, } \\
1995-96^{2}\end{array}$} \\
\hline & $1980-81$ & 1985-86 & 1990-91 & 1991-92 & 1992-93 & 1993-94 & 1994-95 & $1995-96^{1}$ & $\begin{array}{c}\text { Percent } \\
\text { change, } \\
\text { 1990-91 } \\
\text { to } \\
1995-96\end{array}$ & \\
\hline 1 & 2 & 3 & 4 & 5 & 6 & 7 & 8 & 9 & 10 & 11 \\
\hline United States ....... & $\$ 42,279,806$ & $\$ 63,193,853$ & $\$ 92,961,093$ & $\$ 98,847,180$ & $\$ 104,570,101$ & $\$ 109,309,541$ & $\$ 115,464,975$ & $\$ 119,400,868$ & 28.4 & $\$ 119,524,500$ \\
\hline $\begin{array}{l}\text { Alabama } \\
\text { Alaska } \\
\text { Arizona } \\
\text { Arkansas } \\
\text { California }\end{array}$ & $\begin{array}{r}839,366 \\
158,700 \\
691,481 \\
340,621 \\
5,775,482\end{array}$ & $\begin{array}{r}1,324,774 \\
224,042 \\
1,017,203 \\
528,831 \\
8,515,440\end{array}$ & $\begin{array}{r}2,054,798 \\
289,606 \\
1,586,891 \\
797,291 \\
12,023,304\end{array}$ & $\begin{array}{r}2,189,029 \\
306,218 \\
1,620,019 \\
878,783 \\
12,910,152\end{array}$ & $\begin{array}{r}2,428,620 \\
322,620 \\
1,621,716 \\
976,735 \\
13,537,367\end{array}$ & $\begin{array}{r}2,510,081 \\
336,405 \\
1,754,682 \\
1,002,908 \\
13,244,130\end{array}$ & $\begin{array}{r}2,648,077 \\
336,584 \\
1,854,180 \\
1,070,668 \\
13,899,338\end{array}$ & $\begin{array}{r}2,715,643 \\
352,811 \\
1,963,390 \\
1,153,714 \\
14,274,642\end{array}$ & $\begin{array}{l}32.2 \\
21.8 \\
23.7 \\
44.7 \\
18.7\end{array}$ & $\begin{array}{r}2,715,643 \\
352,811 \\
1,976,169 \\
1,181,083 \\
14,284,348\end{array}$ \\
\hline $\begin{array}{l}\text { Colorado } \\
\text { Connecticut } \\
\text { Delaware } \\
\text { District of Columbia } \\
\text { Florida }\end{array}$ & $\begin{array}{r}738,363 \\
367,850 \\
158,332 \\
71,791 \\
1,170,305\end{array}$ & $\begin{array}{r}1,057,558 \\
562,696 \\
229,377 \\
80,764 \\
1,782,180\end{array}$ & $\begin{array}{r}1,452,137 \\
886,846 \\
367,012 \\
97,556 \\
2,896,046\end{array}$ & $\begin{array}{r}1,546,642 \\
957,627 \\
396,947 \\
99,535 \\
2,988,794\end{array}$ & $\begin{array}{r}1,670,921 \\
981,286 \\
416,699 \\
98,826 \\
3,179,353\end{array}$ & $\begin{array}{r}1,760,679 \\
1,026,593 \\
442,488 \\
97,072 \\
3,408,957\end{array}$ & $\begin{array}{r}1,862,438 \\
1,134,014 \\
469,085 \\
99,351 \\
3,549,470\end{array}$ & $\begin{array}{r}1,974,306 \\
1,169,349 \\
491,597 \\
98,632 \\
3,727,585\end{array}$ & $\begin{array}{r}36.0 \\
31.9 \\
33.9 \\
1.1 \\
28.7\end{array}$ & $\begin{array}{r}1,974,306 \\
1,168,038 \\
491,597 \\
103,072 \\
3,714,984\end{array}$ \\
\hline $\begin{array}{l}\text { Georgia } \\
\text { Hawaii } \\
\text { Idaho } \\
\text { Illinois } \\
\text { Indiana }\end{array}$ & $\begin{array}{r}754,060 \\
222,718 \\
166,844 \\
1,780,403 \\
1,064,395\end{array}$ & $\begin{array}{r}1,255,964 \\
312,248 \\
238,438 \\
2,571,409 \\
1,602,203\end{array}$ & $\begin{array}{r}1,929,993 \\
498,307 \\
353,561 \\
3,528,967 \\
2,391,173\end{array}$ & $\begin{array}{r}2,015,816 \\
575,337 \\
391,441 \\
3,644,740 \\
2,643,997\end{array}$ & $\begin{array}{r}2,227,608 \\
602,346 \\
409,167 \\
3,877,243 \\
2,671,055\end{array}$ & $\begin{array}{r}2,453,100 \\
613,356 \\
445,463 \\
4,053,858 \\
2,858,990\end{array}$ & $\begin{array}{r}2,728,682 \\
653,303 \\
473,733 \\
4,293,437 \\
2,967,184\end{array}$ & $\begin{array}{r}2,953,792 \\
634,970 \\
503,014 \\
4,498,142 \\
2,783,027\end{array}$ & $\begin{array}{l}53.0 \\
27.4 \\
42.3 \\
27.5 \\
16.4\end{array}$ & $\begin{array}{r}2,835,505 \\
634,970 \\
510,601 \\
4,498,142 \\
2,783,027\end{array}$ \\
\hline $\begin{array}{l}\text { lowa } \\
\text { Kansas } \\
\text { Kentucky } \\
\text { Louisiana } \\
\text { Maine }\end{array}$ & $\begin{array}{l}767,590 \\
579,857 \\
673,775 \\
716,702 \\
153,658\end{array}$ & $\begin{array}{r}1,092,542 \\
848,602 \\
898,718 \\
1,039,177 \\
216,737\end{array}$ & $\begin{array}{r}1,734,476 \\
1,190,573 \\
1,400,529 \\
1,439,415 \\
355,074\end{array}$ & $\begin{array}{r}1,776,217 \\
1,262,215 \\
1,514,985 \\
1,541,126 \\
362,905\end{array}$ & $\begin{array}{r}1,899,159 \\
1,329,587 \\
1,516,017 \\
1,800,188 \\
375,090\end{array}$ & $\begin{array}{r}1,981,068 \\
1,429,200 \\
1,577,584 \\
1,835,151 \\
387,991\end{array}$ & $\begin{array}{r}2,051,631 \\
1,495,926 \\
1,663,738 \\
1,909,675 \\
391,269\end{array}$ & $\begin{array}{r}2,163,536 \\
1,536,701 \\
1,779,945 \\
1,911,633 \\
404,171\end{array}$ & $\begin{array}{l}24.7 \\
29.1 \\
27.1 \\
32.8 \\
13.8\end{array}$ & $\begin{array}{r}2,163,536 \\
1,547,154 \\
1,779,945 \\
1,970,177 \\
407,819\end{array}$ \\
\hline $\begin{array}{l}\text { Maryland } \\
\text { Massachusetts } \\
\text { Michigan } \\
\text { Minnesota } \\
\text { Mississippi }\end{array}$ & $\begin{array}{r}795,100 \\
553,019 \\
2,053,795 \\
876,632 \\
539,222\end{array}$ & $\begin{array}{r}1,064,430 \\
980,585 \\
2,946,336 \\
1,324,691 \\
706,380\end{array}$ & $\begin{array}{r}1,684,341 \\
1,435,063 \\
4,416,914 \\
2,012,225 \\
978,366\end{array}$ & $\begin{array}{l}1,674,918 \\
1,474,589 \\
4,741,682 \\
2,219,016 \\
1,012,544\end{array}$ & $\begin{array}{l}1,829,812 \\
1,605,121 \\
4,925,759 \\
2,286,336 \\
1,102,806\end{array}$ & $\begin{array}{l}1,940,403 \\
1,496,856 \\
5,095,422 \\
2,459,437 \\
1,200,196\end{array}$ & $\begin{array}{l}1,997,636 \\
1,557,225 \\
5,395,757 \\
2,624,464 \\
1,358,795\end{array}$ & $\begin{array}{l}2,136,898 \\
1,641,256 \\
5,653,791 \\
2,689,857 \\
1,429,107\end{array}$ & $\begin{array}{l}26.9 \\
14.4 \\
28.0 \\
33.7 \\
46.1\end{array}$ & $\begin{array}{l}2,136,898 \\
1,647,254 \\
5,653,791 \\
2,694,395 \\
1,440,692\end{array}$ \\
\hline $\begin{array}{l}\text { Missouri } \\
\text { Montana } \\
\text { Nebraska } \\
\text { Nevada } \\
\text { New Hampshire }\end{array}$ & $\begin{array}{l}687,643 \\
121,894 \\
378,928 \\
111,347 \\
134,391\end{array}$ & $\begin{array}{l}999,869 \\
182,102 \\
537,858 \\
180,107 \\
183,959\end{array}$ & $\begin{array}{r}1,453,608 \\
254,175 \\
848,778 \\
330,592 \\
281,542\end{array}$ & $\begin{array}{r}1,501,166 \\
320,876 \\
916,814 \\
363,306 \\
307,217\end{array}$ & $\begin{array}{r}1,582,746 \\
337,189 \\
968,407 \\
377,786 \\
335,575\end{array}$ & $\begin{array}{r}1,694,484 \\
350,943 \\
1,004,263 \\
415,785 \\
360,833\end{array}$ & $\begin{array}{r}1,836,878 \\
376,618 \\
1,076,670 \\
447,901 \\
371,554\end{array}$ & $\begin{array}{r}1,988,392 \\
402,792 \\
1,143,547 \\
505,518 \\
390,816\end{array}$ & $\begin{array}{l}36.8 \\
58.5 \\
34.7 \\
52.9 \\
38.8\end{array}$ & $\begin{array}{r}1,994,150 \\
402,792 \\
1,143,547 \\
505,518 \\
390,816\end{array}$ \\
\hline $\begin{array}{l}\text { New Jersey } \\
\text { New Mexico } \\
\text { New York } \\
\text { North Carolina } \\
\text { North Dakota }\end{array}$ & $\begin{array}{r}903,169 \\
325,960 \\
2,519,104 \\
1,128,383 \\
192,046\end{array}$ & $\begin{array}{r}1,406,490 \\
456,600 \\
3,802,602 \\
1,799,173 \\
288,214\end{array}$ & $\begin{array}{r}2,309,968 \\
896,299 \\
5,605,621 \\
2,581,156 \\
367,959\end{array}$ & $\begin{array}{r}2,489,088 \\
1,010,859 \\
5,681,964 \\
2,770,977 \\
408,219\end{array}$ & $\begin{array}{r}2,630,533 \\
1,069,497 \\
6,096,863 \\
3,002,915 \\
419,268\end{array}$ & $\begin{array}{r}2,809,931 \\
1,142,903 \\
6,481,594 \\
3,192,215 \\
432,190\end{array}$ & $\begin{array}{r}2,982,535 \\
1,278,741 \\
6,922,118 \\
3,406,215 \\
456,730\end{array}$ & $\begin{array}{r}3,064,901 \\
1,315,168 \\
6,728,593 \\
3,538,606 \\
440,332\end{array}$ & $\begin{array}{l}32.7 \\
46.7 \\
20.0 \\
37.1 \\
19.7\end{array}$ & $\begin{array}{r}3,064,901 \\
1,329,422 \\
6,728,593 \\
3,538,606 \\
440,332\end{array}$ \\
\hline $\begin{array}{l}\text { Ohio } \\
\text { Oklahoma } \\
\text { Oregon } \\
\text { Pennsylvania } \\
\text { Rhode Island }\end{array}$ & $\begin{array}{r}1,784,754 \\
583,174 \\
642,411 \\
1,544,586 \\
158,365\end{array}$ & $\begin{array}{r}2,718,408 \\
844,829 \\
880,696 \\
2,392,145 \\
213,253\end{array}$ & $\begin{array}{r}4,084,840 \\
1,057,248 \\
1,329,794 \\
3,602,685 \\
292,199\end{array}$ & $\begin{array}{r}4,359,943 \\
1,158,696 \\
1,484,621 \\
3,904,332 \\
303,606\end{array}$ & $\begin{array}{r}4,389,408 \\
1,177,061 \\
1,560,699 \\
4,004,062 \\
330,038\end{array}$ & $\begin{array}{r}4,640,316 \\
1,214,084 \\
1,623,771 \\
4,240,094 \\
331,359\end{array}$ & $\begin{array}{r}4,907,686 \\
1,263,002 \\
1,756,424 \\
4,506,833 \\
344,457\end{array}$ & $\begin{array}{r}4,812,773 \\
1,329,938 \\
1,815,638 \\
4,781,347 \\
353,270\end{array}$ & $\begin{array}{l}17.8 \\
25.8 \\
36.5 \\
32.7 \\
20.9\end{array}$ & $\begin{array}{r}4,818,930 \\
1,329,938 \\
1,815,638 \\
4,781,347 \\
353,270\end{array}$ \\
\hline $\begin{array}{l}\text { South Carolina } \\
\text { South Dakota } \\
\text { Tennessee } \\
\text { Texas }\end{array}$ & $\begin{array}{r}617,963 \\
124,103 \\
665,885 \\
2,736,276 \\
405,314\end{array}$ & $\begin{array}{r}951,848 \\
149,092 \\
1,081,052 \\
4,375,082 \\
669,714\end{array}$ & $\begin{array}{r}1,475,074 \\
197,853 \\
1,585,614 \\
5,959,584 \\
993,625\end{array}$ & $\begin{array}{r}1,595,552 \\
217,756 \\
1,621,202 \\
6,370,847 \\
1,116,845\end{array}$ & $\begin{array}{r}1,702,419 \\
240,061 \\
1,776,066 \\
6,982,016 \\
1,174,239\end{array}$ & $\begin{array}{r}1,766,671 \\
259,120 \\
1,911,953 \\
7,414,174 \\
1,260,797\end{array}$ & $\begin{array}{r}1,817,631 \\
252,443 \\
2,042,171 \\
7,817,433 \\
1,354,017\end{array}$ & $\begin{array}{r}1,903,952 \\
262,682 \\
2,061,946 \\
8,296,878 \\
1,442,592\end{array}$ & $\begin{array}{l}29.1 \\
32.8 \\
30.0 \\
39.2 \\
45.2\end{array}$ & $\begin{array}{r}1,903,952 \\
290,868 \\
2,062,547 \\
8,300,915 \\
1,442,592\end{array}$ \\
\hline $\begin{array}{l}\text { Vermont } \\
\text { Virginia } \\
\text { Washington } \\
\text { West Virginia } \\
\text { Wisconsin } \\
\text { Wyoming }\end{array}$ & $\begin{array}{r}122,708 \\
1,143,755 \\
993,171 \\
317,482 \\
1,208,396 \\
126,082\end{array}$ & $\begin{array}{r}188,112 \\
1,825,156 \\
1,399,780 \\
376,293 \\
1,754,395 \\
203,307\end{array}$ & $\begin{array}{r}274,746 \\
2,812,109 \\
2,157,074 \\
548,802 \\
2,469,260 \\
240,216\end{array}$ & $\begin{array}{r}294,045 \\
2,939,683 \\
2,278,549 \\
582,453 \\
2,596,853 \\
265,048\end{array}$ & $\begin{array}{r}298,626 \\
3,072,851 \\
2,486,455 \\
609,447 \\
2,726,350 \\
260,592\end{array}$ & $\begin{array}{r}306,100 \\
3,301,020 \\
2,639,504 \\
650,642 \\
2,872,001 \\
271,396\end{array}$ & $\begin{array}{r}316,455 \\
3,414,167 \\
2,807,168 \\
674,664 \\
2,941,034 \\
294,334\end{array}$ & $\begin{array}{r}329,457 \\
3,515,201 \\
2,909,056 \\
717,095 \\
3,022,205 \\
291,864\end{array}$ & $\begin{array}{l}19.9 \\
25.0 \\
34.9 \\
30.7 \\
22.4 \\
21.5\end{array}$ & $\begin{array}{r}329,457 \\
3,515,201 \\
2,945,074 \\
718,596 \\
3,024,877 \\
291,864\end{array}$ \\
\hline U.S. Service Schools . & 592,454 & 912,393 & $1,150,209$ & $1,241,392$ & $1,267,497$ & $1,309,330$ & $1,313,438$ & $1,394,800$ & 21.3 & $1,394,800$ \\
\hline Outlying areas . & 268,310 & 451,370 & 516,958 & 574,988 & 654,292 & 662,130 & 727,524 & 813,290 & 57.3 & 809,779 \\
\hline Americ & 1,609 & 1,092 & 3,187 & 3,228 & 3,356 & 3,416 & 3,483 & 15,486 & 386.0 & 15,486 \\
\hline Federated States of Micronesia & - & & 3,777 & 3,765 & 3,294 & 3,520 & 5,056 & 8,442 & 123.5 & 8,442 \\
\hline 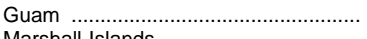 & 16,100 & 31,310 & 57,645 & 67,220 & $\begin{array}{r}71,917 \\
1298\end{array}$ & $\begin{array}{r}66,913 \\
1527\end{array}$ & 81,148 & $\begin{array}{r}68,230 \\
1282\end{array}$ & 18.4 & 68,230 \\
\hline 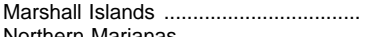 & - & $1, \overline{350}$ & $2 \overline{-798}$ & $\begin{array}{l}3,588 \\
3,194\end{array}$ & $\begin{array}{l}1,298 \\
2,505\end{array}$ & $\begin{array}{l}1,527 \\
3,214\end{array}$ & $\begin{array}{r}1,237 \\
12,366\end{array}$ & $\begin{array}{r}1,282 \\
15,029\end{array}$ & $43 \overline{7.2}$ & $\begin{array}{r}1,282 \\
15,029\end{array}$ \\
\hline $\begin{array}{l}\text { Northern Marianas } \\
\text { Palau }\end{array}$ & - & $\stackrel{1,350}{-}$ & $\begin{array}{l}2,798 \\
3,837\end{array}$ & $\begin{array}{l}3,194 \\
3,687\end{array}$ & $\begin{array}{l}2,505 \\
4,485\end{array}$ & $\begin{array}{l}3,214 \\
3,476\end{array}$ & $\begin{array}{r}12,366 \\
3,667\end{array}$ & $\begin{array}{r}15,029 \\
5,942\end{array}$ & $\begin{array}{r}437.2 \\
54.9\end{array}$ & $\begin{array}{r}15,029 \\
5,942\end{array}$ \\
\hline Puerto Rico ...................................................... & 237,319 & 394,046 & 385,511 & 434,032 & 536,917 & 546,575 & 586,910 & 663,128 & 72.0 & 659,617 \\
\hline Trust Territory of the Pacific ................... & 1,447 & 5,992 & - & - & - & - & - & - & - & - \\
\hline 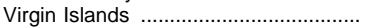 & 11,835 & 17,580 & 60,202 & 56,274 & 30,520 & 33,489 & 33,656 & 35,750 & -40.6 & 35,750 \\
\hline
\end{tabular}

1 Preliminary data.

2 Preliminary data are for 4-year and 2-year degree-granting institutions that were eligible to participate in Title IV federal financial aid programs.

-Data not reported or not applicable.
SOURCE: U.S. Department of Education, National Center for Education Statistics, Higher Education General Information Survey (HEGIS), "Financial Statistics of Institutions of Higher Education" surveys; and Integrated Postsecondary Education Data System (IPEDS), "Finance" surveys. (This table was prepared November 1998.)

NOTE.-Because of rounding, details may not add to totals. 
Table 348.-Educational and general expenditures of public institutions of higher education and degree-granting institutions, by state: $1980-81$ to $1995-96$

[In thousands of dollars]

\begin{tabular}{|c|c|c|c|c|c|c|c|c|c|c|}
\hline \multirow[b]{2}{*}{ State } & \multicolumn{9}{|c|}{ Institutions of higher education } & \multirow[b]{2}{*}{$\begin{array}{c}\text { Degree-granting } \\
\text { institutions, } \\
1995-96^{2}\end{array}$} \\
\hline & $1980-81$ & $1985-86$ & 1990-91 & 1991-92 & 1992-93 & 1993-94 & 1994-95 & $1995-96^{1}$ & $\begin{array}{c}\text { Percent } \\
\text { change, } \\
\text { 1990-91 } \\
\text { to } \\
1995-96\end{array}$ & \\
\hline 1 & 2 & 3 & 4 & 5 & 6 & 7 & 8 & 9 & 10 & 11 \\
\hline United States ....... & $\$ 34,173,013$ & $\$ 50,872,962$ & $\$ 74,395,428$ & $\$ 78,554,534$ & $\$ 83,210,979$ & $\$ 87,139,226$ & $\$ 92,173,768$ & $\$ 95,970,979$ & 29.0 & $\$ 96,085,623$ \\
\hline Alabama & 611,409 & 979,770 & $1,415,440$ & $1,456,605$ & $1,580,484$ & $1,710,955$ & $1,834,533$ & $1,880,788$ & 32.9 & $1,880,788$ \\
\hline 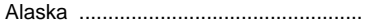 & 150,421 & 210,894 & 273,577 & 288,999 & 304,137 & 316,779 & 316,397 & 331,723 & 21.3 & 331,723 \\
\hline Arizona & 554,120 & 862,816 & $1,364,060$ & $1,407,819$ & $1,409,122$ & $1,523,655$ & $1,653,840$ & $1,747,648$ & 28.1 & $1,759,850$ \\
\hline Arkansas & 266,522 & 415,800 & 633,194 & 604,885 & 676,378 & 707,166 & 746,129 & 817,974 & 29.2 & 843,906 \\
\hline 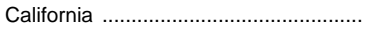 & $4,847,879$ & $7,049,635$ & $9,615,356$ & $10,341,888$ & $11,000,665$ & $10,734,842$ & $11,280,758$ & $11,709,716$ & 21.8 & $11,719,821$ \\
\hline Colorado ...... & 561,552 & 809,621 & $1,258,356$ & $1,363,615$ & $1,452,957$ & $1,529,290$ & $1,604,656$ & $1,705,832$ & 35.6 & $1,705,832$ \\
\hline Connecticut .............. & 281,581 & 439,397 & 673,182 & 736,202 & 731,570 & 771,954 & 883,759 & 912,566 & 35.6 & 911,255 \\
\hline 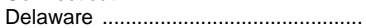 & 135,164 & 202,331 & 325,838 & 349,369 & 366,801 & 387,810 & 413,692 & 429,293 & 31.8 & 429,293 \\
\hline District of Columbia & 71,245 & 79,922 & 96,411 & 98,973 & 97,586 & 95,824 & 98,041 & 97,399 & 1.0 & 101,839 \\
\hline Florida & $1,071,754$ & $1,638,227$ & $2,657,553$ & $2,710,041$ & $2,904,932$ & $3,101,072$ & $3,234,938$ & $3,402,373$ & 28.0 & $3,390,561$ \\
\hline Georgia & 628,939 & $1,046,341$ & $1,617,020$ & $1,665,009$ & $1,834,141$ & $2,037,534$ & $2,277,756$ & $2,484,493$ & 53.6 & $2,366,561$ \\
\hline Hawaii & 202,154 & 282,058 & 454,880 & 526,269 & 546,473 & 556,567 & 590,389 & 569,448 & 25.2 & 569,448 \\
\hline Idaho & 141,296 & 202,736 & 303,224 & 334,762 & 346,932 & 375,289 & 395,733 & 420,747 & 38.8 & 428,068 \\
\hline 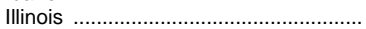 & $1,487,123$ & $2,152,955$ & $2,979,768$ & $3,068,891$ & $3,245,802$ & $3,397,183$ & $3,583,012$ & $3,794,018$ & 27.3 & $3,794,018$ \\
\hline 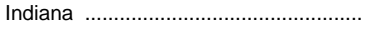 & 771,564 & $1,183,098$ & $1,842,610$ & $1,935,566$ & $2,014,834$ & $2,105,645$ & $2,196,013$ & $2,300,841$ & 24.9 & $2,300,841$ \\
\hline lowa & 512,205 & 736,894 & $1,172,328$ & $1,184,382$ & $1,267,646$ & $1,354,777$ & $1,392,753$ & $1,459,013$ & 24.5 & $1,459,013$ \\
\hline Kansas .......... & 461,979 & 660,995 & 928,772 & 994,560 & $1,059,683$ & $1,134,392$ & $1,196,211$ & $1,234,345$ & 32.9 & $1,244,531$ \\
\hline 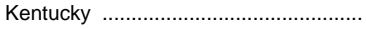 & 527,235 & 737,101 & $1,112,190$ & $1,208,448$ & $1,212,211$ & $1,254,859$ & $1,321,523$ & $1,419,040$ & 27.6 & $1,419,040$ \\
\hline Louisiana ........... & 557,825 & 810,479 & $1,135,955$ & $1,215,771$ & $1,275,446$ & $1,339,408$ & $1,449,305$ & $1,513,214$ & 33.2 & $1,570,429$ \\
\hline 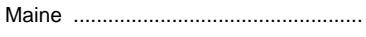 & 127,983 & 183,349 & 308,699 & 316,116 & 324,515 & 338,776 & 343,665 & 356,682 & 15.5 & 360,331 \\
\hline Maryland & 604,419 & 911,562 & $1,443,669$ & $1,428,072$ & $1,564,259$ & $1,673,163$ & $1,737,204$ & $1,878,053$ & 30.1 & $1,878,053$ \\
\hline 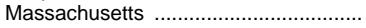 & 441,068 & 779,341 & $1,122,629$ & $1,165,598$ & $1,295,720$ & $1,339,199$ & $1,400,824$ & $1,470,591$ & 31.0 & $1,476,589$ \\
\hline 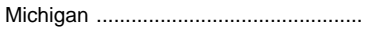 & $1,610,016$ & $2,278,217$ & $3,325,625$ & $3,556,178$ & $3,727,115$ & $3,885,984$ & $4,042,460$ & $4,306,553$ & 29.5 & $4,306,553$ \\
\hline 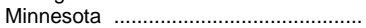 & 667,119 & $1,023,324$ & $1,563,054$ & $1,728,356$ & $1,775,640$ & $1,937,650$ & $2,068,280$ & $2,072,145$ & 32.6 & $2,076,375$ \\
\hline 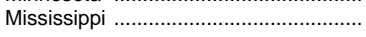 & 409,942 & 542,022 & 756,492 & 772,618 & 842,603 & 919,354 & $1,049,356$ & $1,099,535$ & 45.3 & $1,111,120$ \\
\hline Missouri & 553,793 & 802,936 & $1,155,531$ & $1,184,338$ & $1,260,304$ & $1,339,527$ & $1,456,516$ & $1,560,758$ & 35.1 & $1,566,489$ \\
\hline Montana & 99,990 & 148,099 & 210,813 & 262,480 & 279,323 & 303,495 & 322,880 & 350,086 & 66.1 & 350,086 \\
\hline 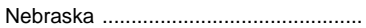 & 286,122 & 397,523 & 600,224 & 639,475 & 672,427 & 706,454 & 727,977 & 753,703 & 25.6 & 753,703 \\
\hline Nevada & 105,177 & 163,714 & 301,487 & 332,246 & 353,875 & 379,154 & 402,097 & 459,599 & 52.4 & 459,599 \\
\hline New Hampshire .................................. & 104,285 & 143,191 & 229,360 & 252,021 & 275,138 & 295,687 & 304,474 & 316,456 & 38.0 & 316,456 \\
\hline New Jersey ................... & 735,097 & $1,140,310$ & $1,875,481$ & $2,002,975$ & $2,103,355$ & $2,237,339$ & $2,363,439$ & $2,461,249$ & 31.2 & $2,461,249$ \\
\hline 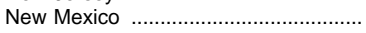 & 278,960 & 393,151 & 671,206 & 724,157 & 769,646 & 806,673 & 899,545 & 939,532 & 40.0 & 953,396 \\
\hline New York & $2,249,821$ & $3,238,773$ & $4,680,376$ & $4,768,772$ & $5,113,506$ & $5,398,182$ & $5,799,931$ & $5,630,108$ & 20.3 & $5,630,108$ \\
\hline North Carolina ...................................... & 971,928 & $1,527,535$ & $2,227,060$ & $2,406,405$ & $2,600,325$ & $2,671,176$ & $2,849,310$ & $2,881,827$ & 29.4 & $2,881,827$ \\
\hline 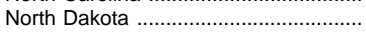 & 151,372 & 228,609 & 292,978 & 328,738 & 336,361 & 344,187 & 361,276 & 372,051 & 27.0 & 372,051 \\
\hline Ohio & $1,327,483$ & $2,019,351$ & $3,046,603$ & $3,214,612$ & $3,185,955$ & $3,362,837$ & $3,616,901$ & $3,769,392$ & 23.7 & $3,774,974$ \\
\hline Oklahoma & 404,178 & 594,561 & 830,929 & 906,908 & 930,102 & 953,027 & 996,963 & $1,037,701$ & 24.9 & $1,037,701$ \\
\hline Oregon & 497,593 & 672,175 & 996,887 & $1,086,673$ & $1,142,781$ & $1,194,805$ & $1,281,381$ & $1,351,507$ & 35.6 & $1,351,507$ \\
\hline Pennsylvania & $1,231,502$ & $1,814,384$ & $2,737,817$ & $2,963,168$ & $3,087,186$ & $3,280,879$ & $3,439,340$ & $3,562,793$ & 30.1 & $3,562,793$ \\
\hline 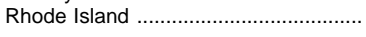 & 138,965 & 185,215 & 251,992 & 260,123 & 284,957 & 285,742 & 297,597 & 306,825 & 21.8 & 306,825 \\
\hline 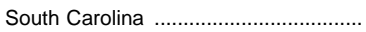 & 481,737 & 741,740 & $1,065,867$ & $1,100,035$ & $1,172,246$ & $1,244,696$ & $1,310,645$ & $1,369,352$ & 28.5 & $1,369,352$ \\
\hline South Dakota & 108,632 & 130,825 & 173,396 & 192,001 & 211,716 & 229,080 & 222,811 & 233,749 & 34.8 & 258,488 \\
\hline Tennessee & 515,578 & 865,946 & $1,231,619$ & $1,228,340$ & $1,352,125$ & $1,478,085$ & $1,581,929$ & $1,626,688$ & 32.1 & $1,627,212$ \\
\hline 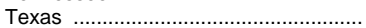 & $2,278,337$ & $3,674,109$ & $5,105,246$ & $5,439,843$ & $5,961,535$ & $6,352,088$ & $6,643,734$ & $7,023,005$ & 37.6 & $7,026,170$ \\
\hline 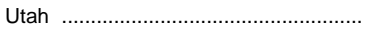 & 320,278 & 503,557 & 730,496 & 826,170 & 856,933 & 921,052 & 991,014 & $1,073,017$ & 46.9 & $1,073,017$ \\
\hline Vermont & 101,539 & 157,266 & 238,512 & 258,150 & 263,475 & 271,261 & 279,882 & 292,072 & 22.5 & 292,072 \\
\hline Virginia & 796,616 & $1,241,534$ & $1,852,416$ & $1,892,627$ & $1,991,591$ & $2,124,635$ & $2,248,402$ & $2,282,078$ & 23.2 & $2,282,078$ \\
\hline 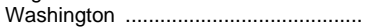 & 837,281 & $1,143,285$ & $1,757,053$ & $1,837,095$ & $2,007,044$ & $2,074,451$ & $2,211,588$ & $2,273,160$ & 29.4 & $2,308,241$ \\
\hline West Virginia . & 228,755 & 310,142 & 459,984 & 494,733 & 522,173 & 560,380 & 579,349 & 621,234 & 35.1 & 622,712 \\
\hline 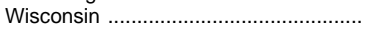 & 998,862 & $1,438,918$ & $2,057,786$ & $2,158,188$ & $2,266,312$ & $2,394,285$ & $2,437,859$ & $2,510,572$ & 22.0 & $2,513,244$ \\
\hline Wyoming & 111,170 & 171,335 & 204,028 & 225,238 & 222,188 & 231,190 & 254,469 & 251,339 & 23.2 & 251,339 \\
\hline U.S. Service Schools ....... & 555,447 & 805,892 & $1,030,399$ & $1,110,028$ & $1,130,748$ & $1,169,731$ & $1,181,234$ & $1,247,093$ & 21.0 & $1,247,093$ \\
\hline Outlying areas ... & 253,820 & 421,500 & 498,958 & 555,054 & 607,730 & 637,164 & 700,528 & 780,785 & 56.5 & 777,274 \\
\hline American Samoa & 1,609 & 1,092 & 3,187 & 3,228 & 3,356 & 3,416 & 3,483 & 14,909 & 367.8 & 14,909 \\
\hline Federated States of Micronesia .......... & - & - & 3,302 & 3,286 & 2,898 & 3,096 & 4,589 & 7,965 & 141.2 & 7,965 \\
\hline 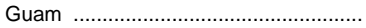 & 15,582 & 29,916 & 55,641 & 64,772 & 68,550 & 63,515 & 77,783 & 65,258 & 17.3 & 65,258 \\
\hline 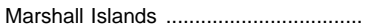 & - & & - & 3,093 & 1,220 & 1,454 & 1,183 & 1,226 & - & 1,226 \\
\hline Northern Marianas ……............................ & - & 1,328 & 2,472 & 2,803 & 2,230 & 2,838 & 12,305 & 14,989 & 506.3 & 14,989 \\
\hline 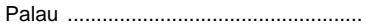 & - & - & 3,277 & 3,172 & 3,808 & 2,847 & 3,156 & 3,332 & 1.7 & 3,332 \\
\hline 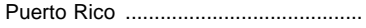 & 224,988 & 367,523 & 378,352 & 427,021 & 497,590 & 529,255 & 567,140 & 641,083 & 69.4 & 637,571 \\
\hline Trust Territory of the Pacific ................... & 1,320 & 5,992 & - & - & - & - & & & - & \\
\hline 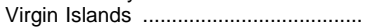 & 10,322 & 15,649 & 52,726 & 47,679 & 28,078 & 30,743 & 30,889 & 32,024 & -39.3 & 32,024 \\
\hline
\end{tabular}

${ }^{1}$ Preliminary data.

2 Preliminary data are for 4-year and 2-year degree granting institutions that were eligible to particpate in Title IV federal financial aid programs.

-Data not reported or not applicable.
SOURCE: U.S. Department of Education, National Center for Education Statistics, Higher Education General Information Survey (HEGIS), "Financial Statistics of Institutions of Higher Education" surveys; and Integrated Postsecondary Education Data System (IPEDS), "Finance" surveys. (This table was prepared November 1998.) 
Table 349.-Current-fund expenditures and educational and general expenditures of private institutions of higher education and degree-granting institutions, by state: 1985-86 to 1995-96

[In thousands of dollars]

\begin{tabular}{|c|c|c|c|c|c|c|c|c|c|c|}
\hline \multirow{3}{*}{ State } & \multicolumn{8}{|c|}{ Institutions of higher education } & \multicolumn{2}{|c|}{$\begin{array}{c}\text { Degree-granting institutions, } \\
1995-96^{1}\end{array}$} \\
\hline & \multicolumn{4}{|c|}{ Current-fund expenditures } & \multicolumn{4}{|c|}{ Educational and general expenditures } & \multirow{2}{*}{$\begin{array}{l}\text { Current-fund } \\
\text { expenditures }\end{array}$} & \multirow{2}{*}{$\begin{array}{l}\text { Educational } \\
\text { and general } \\
\text { expenditures }\end{array}$} \\
\hline & $1985-86$ & 1993-94 & 1994-95 & $1995-96^{1}$ & $1985-86$ & 1993-94 & 1994-95 & $1995-96^{2}$ & & \\
\hline 1 & 2 & 3 & 4 & 5 & 6 & 7 & 8 & 9 & 10 & 11 \\
\hline United States …….................. & $\$ 34,341,889$ & $\$ 64,041,076$ & $\$ 67,503,635$ & $\$ 70,585,370$ & $\$ 25,255,003$ & $\$ 48,885,124$ & $\$ 51,984,234$ & $\$ 54,956,345$ & $\$ 70,951,662$ & $\$ 55,359,982$ \\
\hline Alabama . & 186,596 & 299,982 & 310,329 & 329,049 & 164,093 & 265,046 & 273,268 & 291,111 & 329,527 & 291,954 \\
\hline Alaska .............................. & 10,171 & 23,199 & 19,825 & 18,352 & 9,106 & 18,140 & 15,631 & 14,705 & 17,614 & 14,264 \\
\hline Arizona & 52,887 & 118,954 & 130,973 & 145,613 & 48,600 & 111,414 & 122,573 & 136,806 & 221,992 & 211,736 \\
\hline Arkansas ............... & 70,755 & 130,253 & 140,758 & 148,871 & 56,492 & 108,969 & 118,323 & 125,776 & 148,871 & 125,776 \\
\hline California …....................................... & $3,644,031$ & $6,419,322$ & $6,841,207$ & $7,239,184$ & $2,275,958$ & $4,366,131$ & $4,630,342$ & $4,890,029$ & $7,385,479$ & $5,029,754$ \\
\hline Colorado & 160,193 & 327,275 & 342,407 & 370,975 & 142,218 & 297,087 & 312,444 & 339,143 & 381,651 & 349,390 \\
\hline Connecticut & 836,949 & $1,527,283$ & $1,608,612$ & $1,703,828$ & 733,144 & $1,363,083$ & $1,441,297$ & $1,525,586$ & $1,706,149$ & $1,527,907$ \\
\hline Delaware .... & 29,569 & 31,836 & 32,995 & 34,192 & 26,501 & 29,040 & 30,471 & 31,751 & 34,192 & 31,751 \\
\hline District of Columbia & $1,307,377$ & $2,386,469$ & $2,533,943$ & $2,577,736$ & 803,566 & $1,375,811$ & $1,463,154$ & $1,514,309$ & $2,576,230$ & $1,513,135$ \\
\hline 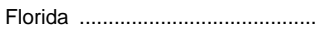 & 723,270 & $1,561,498$ & $1,672,960$ & $1,787,230$ & 553,391 & $1,234,246$ & $1,329,012$ & $1,417,897$ & $1,835,413$ & $1,460,803$ \\
\hline Georgia & 696,734 & $1,683,308$ & $1,798,384$ & $1,906,664$ & 429,639 & $1,122,545$ & $1,188,358$ & $1,269,705$ & $1,916,837$ & $1,279,641$ \\
\hline Hawaii & 32,553 & 95,803 & 100,596 & 116,244 & 25,323 & 76,909 & 81,060 & 98,308 & 118,609 & 100,594 \\
\hline Idaho ................... & 49,768 & 95,011 & 98,011 & 103,613 & 37,736 & 82,923 & 86,269 & 90,922 & 104,356 & 91,665 \\
\hline 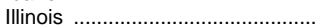 & $2,729,672$ & $4,778,173$ & $5,103,123$ & $4,958,939$ & $1,495,654$ & $2,936,263$ & $3,186,567$ & $3,425,425$ & $4,875,603$ & $3,348,573$ \\
\hline 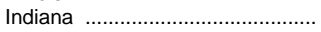 & 530,163 & $1,000,966$ & $1,073,603$ & $1,147,246$ & 426,813 & 831,223 & 895,861 & 965,305 & $1,167,186$ & 984,720 \\
\hline lowa & 353,753 & 676,124 & 701,059 & 726,685 & 292,291 & 573,136 & 595,823 & 617,065 & 739,510 & 629,919 \\
\hline Kansas ...... & 105,193 & 171,402 & 180,052 & 189,318 & 87,719 & 149,127 & 157,710 & 166,024 & 192,432 & 167,472 \\
\hline Kentucky & 194,873 & 330,341 & 348,262 & 365,573 & 159,293 & 275,986 & 291,198 & 307,379 & 365,868 & 307,915 \\
\hline Louisiana & 353,433 & 739,368 & 624,279 & 649,135 & 221,928 & 459,780 & 523,694 & 516,757 & 656,789 & 523,097 \\
\hline 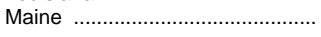 & 133,778 & 238,196 & 250,032 & 269,305 & 106,912 & 199,895 & 210,350 & 228,581 & 269,305 & 228,581 \\
\hline Maryland & 896,251 & $1,729,558$ & $1,797,362$ & $1,871,954$ & 562,773 & $1,217,678$ & $1,299,953$ & $1,355,765$ & $1,871,954$ & $1,355,765$ \\
\hline Massachusetts ....... & $3,544,867$ & $6,116,367$ & $6,416,410$ & $6,786,016$ & $2,817,687$ & $5,122,411$ & $5,430,455$ & $5,728,902$ & $6,796,569$ & $5,737,256$ \\
\hline Michigan ………...................... & 447,436 & 826,746 & 855,969 & 908,360 & 384,533 & 730,458 & 759,066 & 805,962 & 913,662 & 810,989 \\
\hline 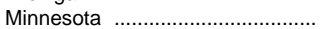 & 521,441 & 800,291 & 859,388 & 907,452 & 443,972 & 679,001 & 732,714 & 773,952 & 940,013 & 805,340 \\
\hline 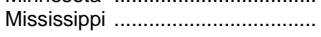 & 64,054 & 123,506 & 129,945 & 138,808 & 55,252 & 108,547 & 115,582 & 122,699 & 124,907 & 110,765 \\
\hline Missouri & 904,573 & $1,769,749$ & $1,897,323$ & $1,998,070$ & 713,411 & $1,453,221$ & $1,579,030$ & $1,610,073$ & $2,014,787$ & $1,626,355$ \\
\hline 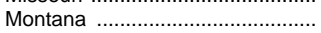 & 22,349 & 44,193 & 50,343 & 56,028 & 18,565 & 38,509 & 44,086 & 49,855 & 59,825 & 52,627 \\
\hline 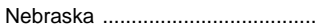 & 161,066 & 303,472 & 319,962 & 337,614 & 138,929 & 271,942 & 290,697 & 307,831 & 339,289 & 309,293 \\
\hline Nevada ...................... & 2,448 & 6,768 & 8,194 & 9,784 & 2,448 & 5,998 & 7,294 & 9,069 & 14,063 & 12,904 \\
\hline New Hampshire ............................. & 264,440 & 487,785 & 507,227 & 534,486 & 230,657 & 426,736 & 442,671 & 466,623 & 533,508 & 465,732 \\
\hline 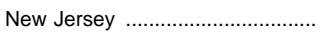 & 714,733 & $1,208,726$ & $1,252,185$ & $1,304,191$ & 540,245 & 980,224 & $1,022,274$ & $1,066,686$ & $1,303,480$ & $1,065,975$ \\
\hline 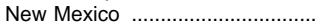 & 22,196 & 40,520 & 42,331 & 45,414 & 19,678 & 35,079 & 37,509 & 40,101 & 51,722 & 46,138 \\
\hline New York ....................................... & $5,596,257$ & $10,157,945$ & $10,653,695$ & $11,072,488$ & $4,572,405$ & $8,315,046$ & $8,721,147$ & $9,117,361$ & $11,085,580$ & $9,129,100$ \\
\hline North Carolina . & 837,291 & $2,166,337$ & $2,329,951$ & $2,439,903$ & 592,910 & $1,417,518$ & $1,515,305$ & $1,593,079$ & $2,438,635$ & $1,592,276$ \\
\hline North Dakota ...................................... & 18,853 & 36,380 & 37,350 & 45,261 & 15,860 & 31,776 & 32,912 & 40,600 & 48,441 & 43,707 \\
\hline Ohio & 976,303 & $1,807,756$ & $1,905,659$ & $2,028,849$ & 833,879 & $1,586,086$ & $1,673,414$ & $1,782,573$ & $2,051,600$ & $1,802,592$ \\
\hline 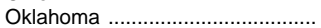 & 178,905 & 286,118 & 298,275 & 326,381 & 149,565 & 248,299 & 263,719 & 287,192 & 326,548 & 287,148 \\
\hline Oregon ……... & 171,604 & 334,424 & 365,448 & 389,397 & 149,289 & 299,529 & 327,566 & 347,864 & 403,937 & 361,277 \\
\hline Pennsylvania & $3,155,505$ & $6,008,469$ & $6,246,550$ & $6,523,828$ & $2,033,015$ & $4,115,506$ & $4,386,385$ & $4,760,938$ & $6,479,714$ & $4,769,807$ \\
\hline 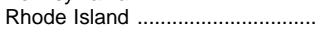 & 315,651 & 636,510 & 667,901 & 706,781 & 261,616 & 545,057 & 575,255 & 604,862 & 706,781 & 604,862 \\
\hline 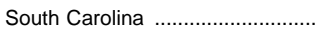 & 196,271 & 318,200 & 333,278 & 357,255 & 154,496 & 268,292 & 282,443 & 305,051 & 357,255 & 305,051 \\
\hline South Dakota ……............................. & 51,675 & 66,315 & 69,866 & 73,495 & 44,726 & 59,358 & 62,863 & 65,923 & 74,217 & 66,632 \\
\hline 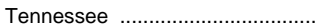 & 686,514 & $1,352,769$ & $1,410,990$ & $1,526,247$ & 440,308 & 894,506 & 955,718 & $1,030,665$ & $1,519,687$ & $1,025,044$ \\
\hline 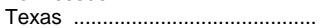 & 993,824 & $1,833,288$ & $1,955,975$ & $2,062,693$ & 855,445 & $1,653,269$ & $1,764,618$ & $1,863,376$ & $2,076,444$ & $1,878,356$ \\
\hline Utah & 183,060 & 458,878 & 492,298 & 527,193 & 110,880 & 317,681 & 333,683 & 352,033 & 533,283 & 358,123 \\
\hline Vermont & 150,689 & 269,666 & 288,223 & 305,294 & 126,299 & 232,565 & 250,310 & 264,387 & 310,422 & 269,514 \\
\hline Virginia ……..... & 387,455 & 807,849 & 874,960 & 895,065 & 313,055 & 702,430 & 766,327 & 785,505 & 900,487 & 792,130 \\
\hline 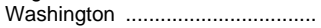 & 227,211 & 475,565 & 513,782 & 541,014 & 189,575 & 413,941 & 448,823 & 473,884 & 547,539 & 480,329 \\
\hline West Virginia ................................... & 73,716 & 143,742 & 172,925 & 173,764 & 60,900 & 126,231 & 153,757 & 154,858 & 179,167 & 160,159 \\
\hline 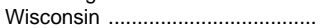 & 373,533 & 775,629 & 827,317 & 891,492 & 326,254 & 701,051 & 746,036 & 805,252 & 891,492 & 805,252 \\
\hline 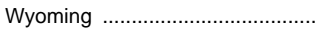 & - & 12,788 & 11,142 & 13,044 & - & 10,426 & 9,219 & 10,838 & 13,044 & 10,838 \\
\hline Outlying areas & 198,653 & 337,721 & 360,203 & 371,434 & 189,080 & 320,304 & 343,782 & 355,818 & 379,447 & 363,814 \\
\hline 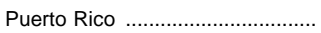 & 198,653 & 337,721 & 360,203 & 371,434 & 189,080 & 320,304 & 343,782 & 355,818 & 379,447 & 363,814 \\
\hline
\end{tabular}

1 Preliminary data are for 4-year and 2-year degree-granting institutions that were eligible to pariticipate in Title IV federal financial aid programs.

2 Preliminary data.

-Data not reported or not applicable.

NOTE.-Because of rounding, details may not add to totals.
SOURCE: US. Department of Education, National Center for Education Statistics, Higher Education General Information Survey (HEGIS), "Financial Statistics of Institutions of Higher Education" survey; and Integrated Postsecondary Education Data System (IPEDS), "Finance" surveys. (This table was prepared November 1998.) 
HIGHER EDUCATION: EXPENDITURES 375

Table 350.-Current-fund expenditures and educational and general expenditures of private nonprofit institutions of higher education, by state: $1985-86$ to $1995-96$

[In thousands of dollars]

\begin{tabular}{|c|c|c|c|c|c|c|c|c|c|c|}
\hline \multirow{2}{*}{ State } & \multicolumn{5}{|c|}{ Current-fund expenditures } & \multicolumn{5}{|c|}{ Educational and general expenditures } \\
\hline & $1985-86$ & $1990-91$ & $1993-94$ & 1994-95 & $1995-96^{1}$ & $1985-86$ & $1990-91$ & $1993-94$ & 1994-95 & $1995-96^{1}$ \\
\hline 1 & 2 & 3 & 4 & 5 & 6 & 7 & 8 & 9 & 10 & 11 \\
\hline United States & $\$ 33,796,683$ & $\$ 52,079,906$ & $\$ 62,702,212$ & $\$ 66,122,565$ & $\$ 69,102,394$ & $\$ 24,738,587$ & $\$ 38,769,871$ & $\$ 47,600,834$ & $\$ 50,662,377$ & $\$ 53,540,243$ \\
\hline Alabama & 178,766 & 239,264 & 295,574 & 305,267 & 325,421 & 156,267 & 207,496 & 260,722 & 268,310 & 287,587 \\
\hline Alaska ... & 10,171 & 20,217 & 19,000 & 15,935 & 15,825 & 9,106 & 17,465 & 13,945 & 11,741 & 12,178 \\
\hline Arizona & 29,714 & 55,142 & 68,051 & 73,978 & 79,145 & 25,426 & 48,149 & 62,256 & 67,250 & 72,212 \\
\hline Arkansas ....... & 66,123 & 105,495 & 127,431 & 140,758 & 148,871 & 51,883 & 86,400 & 106,175 & 118,323 & 125,776 \\
\hline 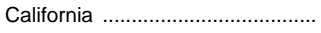 & $3,603,948$ & $5,471,945$ & $6,244,725$ & $6,664,795$ & $7,045,087$ & $2,239,751$ & $3,435,708$ & $4,195,856$ & $4,458,381$ & $4,701,163$ \\
\hline Colorado & 149,800 & 228,407 & 272,360 & 281,927 & 306,164 & 132,057 & 201,333 & 243,812 & 254,409 & 276,668 \\
\hline Connecticut & 833,406 & $1,289,575$ & $1,522,821$ & $1,604,088$ & $1,698,631$ & 729,820 & $1,139,410$ & $1,358,776$ & $1,436,899$ & $1,520,554$ \\
\hline 다. & 29,569 & 23,875 & 31,836 & 32,995 & 34,192 & 26,501 & 21,598 & 29,040 & 30,471 & 31,751 \\
\hline 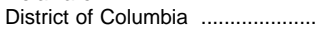 & $1,302,567$ & $1,944,605$ & $2,359,300$ & $2,502,088$ & $2,542,361$ & 798,756 & $1,167,674$ & $1,348,642$ & $1,431,299$ & $1,478,935$ \\
\hline Florida & 699,301 & $1,196,724$ & $1,463,445$ & $1,579,744$ & $1,685,909$ & 530,090 & 927,485 & $1,138,697$ & $1,238,143$ & $1,320,668$ \\
\hline Georgia & 678,129 & $1,179,901$ & $1,629,638$ & $1,737,652$ & $1,837,837$ & 413,148 & 745,739 & $1,072,149$ & $1,131,412$ & $1,205,439$ \\
\hline Hawaii . & 32,553 & 42,881 & 95,803 & 100,046 & 112,487 & 25,323 & 36,528 & 76,909 & 80,510 & 94,552 \\
\hline Idaho & 49,768 & 73,335 & 92,807 & 95,706 & 101,336 & 37,736 & 58,068 & 80,720 & 83,963 & 88,645 \\
\hline Illinois ....... & $2,697,651$ & $3,898,129$ & $4,717,431$ & $5,039,207$ & $4,886,489$ & $1,464,293$ & $2,297,177$ & $2,879,622$ & $3,126,846$ & $3,357,508$ \\
\hline Indiana & 516,649 & 816,342 & 985,351 & $1,057,524$ & $1,131,998$ & 413,628 & 669,802 & 816,341 & 880,576 & 950,855 \\
\hline lowe & 348,541 & 526,077 & 672,105 & 699,340 & 724,931 & 287,079 & 438,537 & 569,117 & 594,104 & 615,311 \\
\hline Kansas & 105,193 & 144,471 & 171,402 & 180,052 & 189,318 & 87,719 & 124,578 & 149,127 & 157,710 & 166,024 \\
\hline 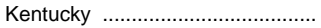 & 164,491 & 251,560 & 303,998 & 322,466 & 343,696 & 129,775 & 205,496 & 251,021 & 266,885 & 287,055 \\
\hline 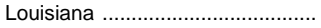 & 352,186 & 566,331 & 735,286 & 619,042 & 647,591 & 220,929 & 366,843 & 455,750 & 518,458 & 515,214 \\
\hline Maine & 130,626 & 195,243 & 231,191 & 243,003 & 261,920 & 103,759 & 162,712 & 192,943 & 203,574 & 221,447 \\
\hline Maryland & 895,453 & $1,460,393$ & $1,728,026$ & $1,795,866$ & $1,870,451$ & 562,025 & 985,902 & $1,216,146$ & $1,298,456$ & $1,354,261$ \\
\hline Massachusetts ............................. & $3,539,442$ & $5,332,122$ & $6,110,778$ & $6,410,944$ & $6,778,728$ & $2,813,131$ & $4,270,480$ & $5,116,856$ & $5,425,030$ & $5,721,614$ \\
\hline 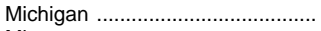 & 447,436 & 699,193 & 826,746 & 855,969 & 906,246 & 384,533 & 618,422 & 730,458 & 759,066 & 803,848 \\
\hline Minnesota & 514,606 & 704,159 & 777,317 & 835,710 & 880,488 & 437,137 & 600,818 & 656,286 & 709,344 & 747,375 \\
\hline 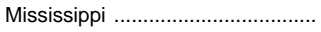 & 61,672 & 97,737 & 121,959 & 128,400 & 138,808 & 52,869 & 84,806 & 107,001 & 114,038 & 122,699 \\
\hline Missouri & 895,639 & $1,460,670$ & $1,738,375$ & $1,863,299$ & $1,961,954$ & 705,570 & $1,155,834$ & $1,423,585$ & $1,546,602$ & $1,575,734$ \\
\hline Montana & 19,882 & 33,471 & 44,193 & 50,343 & 56,028 & 16,269 & 29,165 & 38,509 & 44,086 & 49,855 \\
\hline Nebraska ….......................... & 161,066 & 243,678 & 300,276 & 316,684 & 333,719 & 138,929 & 217,590 & 268,746 & 287,419 & 303,937 \\
\hline 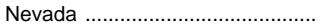 & 2,448 & 2,991 & 4,926 & 5,356 & 5,981 & 2,448 & 2,593 & 4,293 & 4,616 & 5,391 \\
\hline New Hampshire ..................... & 259,187 & 399,725 & 476,137 & 493,772 & 518,980 & 225,456 & 348,112 & 416,727 & 431,135 & 453,866 \\
\hline New Jersey & 711,478 & 957,661 & $1,176,088$ & $1,215,489$ & $1,262,798$ & 537,298 & 766,929 & 949,927 & 988,131 & $1,027,923$ \\
\hline New Mexico & 22,196 & 22,969 & 32,874 & 33,350 & 34,683 & 19,678 & 19,682 & 27,567 & 28,714 & 29,652 \\
\hline New York & $5,487,876$ & $8,113,252$ & $9,930,462$ & $10,424,477$ & $10,836,610$ & $4,467,861$ & $6,607,801$ & $8,095,536$ & $8,500,357$ & $8,888,821$ \\
\hline North Carolina ......................... & 815,258 & $1,698,373$ & $2,165,209$ & $2,328,865$ & $2,439,035$ & 576,298 & $1,117,334$ & $1,416,468$ & $1,514,290$ & $1,592,275$ \\
\hline North Dakota ................................... & 18,853 & 27,978 & 36,380 & 37,350 & 45,261 & 15,860 & 24,033 & 31,776 & 32,912 & 40,600 \\
\hline Ohio & 924,464 & $1,441,192$ & $1,755,406$ & $1,850,166$ & $1,973,986$ & 782,760 & $1,241,939$ & $1,536,893$ & $1,620,912$ & $1,730,980$ \\
\hline Oklahoma & 174,542 & 257,433 & 270,702 & 283,509 & 310,010 & 145,202 & 216,368 & 233,556 & 248,985 & 271,900 \\
\hline Oregon & 168,031 & 271,971 & 328,798 & 359,579 & 385,185 & 145,976 & 242,945 & 294,062 & 321,865 & 343,768 \\
\hline Pennsylvania & $3,106,911$ & $4,838,303$ & $5,856,506$ & $6,089,249$ & $6,361,053$ & $1,986,082$ & $3,180,299$ & $3,969,587$ & $4,237,558$ & $4,607,717$ \\
\hline 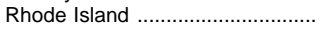 & 315,651 & 518,425 & 636,510 & 667,901 & 706,781 & 261,616 & 437,800 & 545,057 & 575,255 & 604,862 \\
\hline South Carolina & 192,141 & 315,236 & 310,486 & 324,648 & 347,026 & 151,123 & 254,390 & 260,850 & 274,049 & 294,984 \\
\hline South Dakota & 39,893 & 52,180 & 54,663 & 57,643 & 59,988 & 34,212 & 46,187 & 48,450 & 51,477 & 53,557 \\
\hline Tennessee & 676,815 & $1,084,292$ & $1,343,820$ & $1,402,160$ & $1,512,404$ & 431,327 & 694,318 & 885,665 & 946,888 & $1,017,011$ \\
\hline 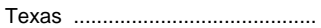 & 986,318 & $1,492,198$ & $1,781,097$ & $1,900,574$ & $2,004,583$ & 848,799 & $1,332,293$ & $1,604,014$ & $1,712,398$ & $1,808,955$ \\
\hline 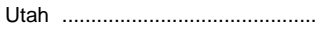 & 182,127 & 269,613 & 449,691 & 480,990 & 515,069 & 109,947 & 220,023 & 308,494 & 322,375 & 339,908 \\
\hline Vermont & 150,689 & 266,539 & 269,666 & 288,223 & 305,294 & 126,299 & 229,548 & 232,565 & 250,310 & 264,387 \\
\hline Virginia . & 384,007 & 649,347 & 775,845 & 848,456 & 864,606 & 309,665 & 559,607 & 672,359 & 741,528 & 756,700 \\
\hline 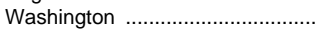 & 225,637 & 354,262 & 455,483 & 492,370 & 517,804 & 188,068 & 302,690 & 394,923 & 429,428 & 452,996 \\
\hline 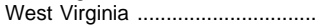 & 71,547 & 104,122 & 137,492 & 167,111 & 168,229 & 58,730 & 89,187 & 120,423 & 148,386 & 149,678 \\
\hline Wisconsin & 366,266 & 640,901 & 766,744 & 818,499 & 881,396 & 320,370 & 514,579 & 692,432 & 737,505 & 795,443 \\
\hline 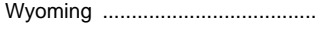 & 一 & - & - & - & 一 & - & - & 一 & 一 & - \\
\hline Outlying areas ........................... & 189,424 & 245,693 & 316,382 & 337,090 & 345,802 & 179,851 & 231,377 & 298,995 & 320,705 & 330,230 \\
\hline Puerto Rico & 189,424 & 245,693 & 316,382 & 337,090 & 345,802 & 179,851 & 231,377 & 298,995 & 320,705 & 330,230 \\
\hline
\end{tabular}

1 Preliminary data.

-Data not reported or not applicable.

NOTE.-Because of rounding, details may not add to totals.
SOURCE: U.S. Department of Education, National Center for Education Statistics, Higher Education General Information Survey (HEGIS), "Financial Statistics of Institutions of Higher Education" survey; and Integrated Postsecondary Education Data System (IPEDS), "Finance" surveys. (This table was prepared January 1999.) 
Table 351.-Current-fund expenditures per full-time-equivalent student in institutions of higher education, by control and type of institution and purpose of expenditure: 1995-96 1

\begin{tabular}{|c|c|c|c|c|c|c|c|c|c|c|c|}
\hline \multirow[b]{2}{*}{ Item } & \multicolumn{4}{|c|}{ Total } & \multicolumn{4}{|c|}{ Public } & \multicolumn{3}{|c|}{ Private } \\
\hline & $\begin{array}{c}\text { All } \\
\text { institutions }\end{array}$ & $\begin{array}{l}\text { Univer- } \\
\text { sities }\end{array}$ & $\begin{array}{l}\text { Other } \\
\text { 4-year }\end{array}$ & 2-year & $\begin{array}{c}\text { All } \\
\text { institutions }\end{array}$ & $\begin{array}{l}\text { Univer- } \\
\text { sities }\end{array}$ & $\begin{array}{l}\text { Other } \\
\text { 4-year }\end{array}$ & 2-year & $\begin{array}{c}\text { All } \\
\text { institu- } \\
\text { tions }^{2}\end{array}$ & $\begin{array}{l}\text { Univer- } \\
\text { sities }\end{array}$ & $\begin{array}{l}\text { Other } \\
\text { 4-year }\end{array}$ \\
\hline 1 & 2 & 3 & 4 & 5 & 6 & 7 & 8 & 9 & 10 & 11 & 12 \\
\hline Total current-fund expenditures ${ }^{3} \ldots \ldots \ldots$ & $\$ 18,383$ & $\$ 32,265$ & $\$ 18,304$ & $\$ 7,255$ & $\$ 15,403$ & $\$ 25,444$ & $\$ 17,307$ & $\$ 7,180$ & $\$ 27,325$ & $\$ 52,413$ & $\$ 19,907$ \\
\hline Educational and general expenditures .......... & 14,604 & 24,126 & 14,676 & 6,785 & 12,380 & 19,700 & 13,403 & 6,733 & 21,275 & 37,200 & 16,725 \\
\hline Instruction & 5,571 & 8,705 & 5,466 & 3,185 & 4,978 & 6,946 & 5,486 & 3,240 & 7,348 & 13,902 & 5,435 \\
\hline 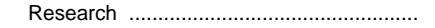 & 1,695 & 4,863 & 1,093 & 8 & 1,558 & 4,292 & 1,351 & 8 & 2,107 & 6,551 & 678 \\
\hline Public service & 682 & 1,447 & 621 & 151 & 686 & 1,611 & 619 & 158 & 669 & 960 & 623 \\
\hline Academic support & 1,288 & 2,182 & 1,280 & 576 & 1,160 & 1,865 & 1,314 & 563 & 1,671 & 3,118 & 1,224 \\
\hline 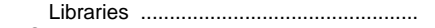 & 416 & 747 & 414 & 151 & 346 & 593 & 389 & 149 & 625 & 1,201 & 455 \\
\hline 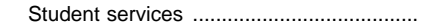 & 923 & 907 & 1,054 & 744 & 748 & 742 & 780 & 722 & 1,446 & 1,396 & 1,494 \\
\hline 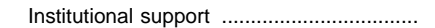 & 1,756 & 2,015 & 2,082 & 1,071 & 1,379 & 1,417 & 1,713 & 1,038 & 2,886 & 3,782 & 2,675 \\
\hline Operation and maintenance of plant ......... & 1,186 & 1,663 & 1,250 & 706 & 1,031 & 1,357 & 1,170 & 691 & 1,650 & 2,567 & 1,379 \\
\hline Scholarships and fellowships ....................... & 1,271 & 1,948 & 1,564 & 296 & 656 & 1,168 & 727 & 261 & 3,118 & 4,252 & 2,910 \\
\hline From unrestricted funds ............................. & 794 & 1,280 & 1,026 & 62 & 317 & 689 & 349 & 49 & 2,226 & 3,026 & 2,116 \\
\hline From restricted funds ${ }^{4} .$. & 477 & 668 & 538 & 234 & 339 & 479 & 379 & 212 & 892 & 1,226 & 794 \\
\hline Mandatory transfers & 232 & 395 & 267 & 50 & 183 & 302 & 242 & 51 & 380 & 672 & 306 \\
\hline
\end{tabular}

1 Preliminary data.

2 Includes private 2-year colleges.

${ }^{3}$ Includes expenditures for auxiliary enterprises, hospitals, and independent operations which are not shown separately.

${ }^{4}$ Excludes Pell Grants.
NOTE - Data for private 2-year colleges are not shown separately because of low survey response rate. Because of rounding, details may not add to totals.

SOURCE: U.S. Department of Education, National Center for Education Statistics, Integrated Postsecondary Education Data System (IPEDS), "Fall Enrollment" and "F nance" surveys. (This table was prepared November 1998. .)

Table 352.-Additions to physical plant value of institutions of higher education, by type of addition and control of institution: 1969-70 to 1995-96

[In millions]

\begin{tabular}{|c|c|c|c|c|c|c|c|c|c|}
\hline \multirow{2}{*}{ Year } & \multirow{2}{*}{$\begin{array}{l}\text { Total, all } \\
\text { institutions }\end{array}$} & \multicolumn{4}{|c|}{ Public institutions } & \multicolumn{4}{|c|}{ Private institutions } \\
\hline & & Total & Land & Buildings & Equipment & Total & Land & Buildings & Equipment \\
\hline 1 & 2 & 3 & 4 & 5 & 6 & 7 & 8 & 9 & 10 \\
\hline $\begin{array}{l}1969-70 \\
1970-71 \\
1971-72 \\
1972-73 \\
1973-74\end{array}$ & $\begin{array}{r}\$ 4,233 \\
4,165 \\
4,163 \\
3,967 \\
4,312\end{array}$ & $\begin{array}{r}\$ 2,985 \\
3,032 \\
3,054 \\
2,940 \\
3,206\end{array}$ & $\begin{array}{r}\$ 152 \\
128 \\
112 \\
126 \\
205\end{array}$ & $\begin{array}{r}\$ 2,185 \\
2,241 \\
2,277 \\
2,077 \\
2,188\end{array}$ & $\begin{array}{r}\$ 648 \\
663 \\
665 \\
737 \\
813\end{array}$ & $\begin{array}{r}\$ 1,248 \\
1,134 \\
1,109 \\
1,028 \\
1,106\end{array}$ & $\begin{array}{r}\$ 59 \\
41 \\
53 \\
53 \\
55\end{array}$ & $\begin{array}{r}\$ 967 \\
895 \\
860 \\
750 \\
816\end{array}$ & $\begin{array}{r}\$ 221 \\
198 \\
195 \\
225 \\
235\end{array}$ \\
\hline $\begin{array}{l}1974-75 \\
1975-76 \\
1976-77 \\
1977-78 \\
1978-79\end{array}$ & $\begin{array}{l}4,761 \\
4,702 \\
4,623 \\
4,527 \\
4,576\end{array}$ & $\begin{array}{l}3,476 \\
3,552 \\
3,362 \\
3,306 \\
3,377\end{array}$ & $\begin{array}{l}263 \\
168 \\
128 \\
102 \\
154\end{array}$ & $\begin{array}{l}2,246 \\
2,365 \\
2,208 \\
2,117 \\
1,944\end{array}$ & $\begin{array}{r}967 \\
1,019 \\
1,026 \\
1,087 \\
1,279\end{array}$ & $\begin{array}{l}1,284 \\
1,150 \\
1,261 \\
1,221 \\
1,199\end{array}$ & $\begin{array}{l}67 \\
58 \\
58 \\
45 \\
52\end{array}$ & $\begin{array}{l}860 \\
768 \\
838 \\
777 \\
763\end{array}$ & $\begin{array}{l}357 \\
325 \\
366 \\
400 \\
383\end{array}$ \\
\hline $\begin{array}{l}1979-80 \\
1980-81 \\
1981-82 \\
1982-83 \\
1983-84\end{array}$ & $\begin{array}{l}5,551 \\
6,471 \\
6,975 \\
7,421 \\
7,604\end{array}$ & $\begin{array}{l}3,666 \\
4,279 \\
4,594 \\
4,765 \\
5,038\end{array}$ & $\begin{array}{l}164 \\
146 \\
170 \\
374 \\
196\end{array}$ & $\begin{array}{l}2,149 \\
2,555 \\
2,679 \\
2,396 \\
2,427\end{array}$ & $\begin{array}{l}1,354 \\
1,579 \\
1,744 \\
1,994 \\
2,415\end{array}$ & $\begin{array}{l}1,886 \\
2,192 \\
2,382 \\
2,656 \\
2,566\end{array}$ & $\begin{array}{r}98 \\
104 \\
83 \\
106 \\
110\end{array}$ & $\begin{array}{l}1,220 \\
1,398 \\
1,488 \\
1,666 \\
1,507\end{array}$ & $\begin{array}{l}568 \\
690 \\
811 \\
884 \\
950\end{array}$ \\
\hline $\begin{array}{l}1984-85 \\
1985-86 \\
1986-87 \\
1987-88\end{array}$ & $\begin{array}{r}8,306 \\
10,149 \\
10,675 \\
11,589 \\
13,638\end{array}$ & $\begin{array}{l}5,390 \\
6,875 \\
6,899 \\
7,218 \\
8,162\end{array}$ & $\begin{array}{l}202 \\
237 \\
313 \\
272 \\
562\end{array}$ & $\begin{array}{l}2,455 \\
3,318 \\
3,235 \\
3,520 \\
3,845\end{array}$ & $\begin{array}{l}2,733 \\
3,320 \\
3,351 \\
3,426 \\
3,756\end{array}$ & $\begin{array}{l}2,916 \\
3,274 \\
3,776 \\
4,371 \\
5,477\end{array}$ & $\begin{array}{l}135 \\
128 \\
160 \\
250 \\
243\end{array}$ & $\begin{array}{l}1,671 \\
1,922 \\
2,408 \\
2,715 \\
3,401\end{array}$ & $\begin{array}{l}1,110 \\
1,225 \\
1,208 \\
1,406 \\
1,833\end{array}$ \\
\hline $\begin{array}{l}1989-90 \\
1990-91 \\
1991-92 \\
1992-93 \\
1993-94\end{array}$ & $\begin{array}{l}15,900 \\
17,634 \\
15,543 \\
16,494 \\
16,379\end{array}$ & $\begin{array}{r}10,616 \\
11,472 \\
9,820 \\
10,599 \\
10,263\end{array}$ & $\begin{array}{l}532 \\
449 \\
412 \\
336 \\
361\end{array}$ & $\begin{array}{l}5,438 \\
6,168 \\
5,272 \\
5,982 \\
5,582\end{array}$ & $\begin{array}{l}4,647 \\
4,855 \\
4,136 \\
4,281 \\
4,320\end{array}$ & $\begin{array}{l}5,284 \\
6,162 \\
5,723 \\
5,895 \\
6,116\end{array}$ & $\begin{array}{l}408 \\
448 \\
380 \\
491 \\
259\end{array}$ & $\begin{array}{l}3,277 \\
3,799 \\
3,419 \\
3,458 \\
3,840\end{array}$ & $\begin{array}{l}1,599 \\
1,914 \\
1,925 \\
1,946 \\
2,017\end{array}$ \\
\hline 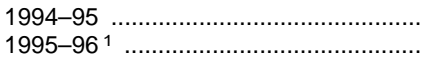 & $\begin{array}{l}18,556 \\
20,873\end{array}$ & $\begin{array}{l}12,129 \\
13,228\end{array}$ & $\begin{array}{l}448 \\
428\end{array}$ & $\begin{array}{l}7,079 \\
7,658\end{array}$ & $\begin{array}{l}4,603 \\
5,141\end{array}$ & $\begin{array}{l}6,427 \\
7,645\end{array}$ & $\begin{array}{l}277 \\
356\end{array}$ & $\begin{array}{l}3,994 \\
4,897\end{array}$ & $\begin{array}{l}2,156 \\
2,392\end{array}$ \\
\hline
\end{tabular}

${ }^{1}$ Data are for 4-year and 2-year degree-granting institutions that were eligible to participate in Title IV federal financial aid programs.

NOTE.-Because of rounding, details may not add to totals.
SOURCE: U.S. Department of Education, National Center for Education Statistics, Higher Education General Information Survey (HEGIS), "Financial Statistics of Institutions of Higher Education" surveys; and Integrated Postsecondary Education Data System (IPEDS), "Finance" surveys. (This table was prepared November 1998.) 
Table 353.- Value of property and liabilities of institutions of higher education: 1899-1900 to 1995-96

[In thousands]

\begin{tabular}{|c|c|c|c|c|c|c|c|c|}
\hline \multirow{3}{*}{ Academic year } & \multicolumn{6}{|c|}{ Property value at end of year } & \multirow{3}{*}{ 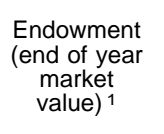 } & \multirow{3}{*}{$\begin{array}{l}\text { Liabilities of } \\
\text { plant funds }\end{array}$} \\
\hline & \multirow{2}{*}{ Total } & \multicolumn{4}{|c|}{ Physical plant value } & \multirow{2}{*}{ 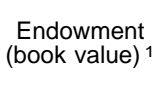 } & & \\
\hline & & Total & Land & Buildings & Equipment & & & \\
\hline 1 & 2 & 3 & 4 & 5 & 6 & 7 & 8 & 9 \\
\hline $1899-1900$ & $\$ 448,597$ & $\$ 253,599$ & - & - & - & $2 \$ 194,998$ & - & - \\
\hline $1909-10 \ldots$ & 781,255 & 457,594 & $\$ 92,359$ & $\$ 297,153$ & $\$ 68,082$ & 2323,661 & - & - \\
\hline $1919-20 \ldots$ & $1,316,404$ & 747,333 & 128,922 & 495,920 & 122,491 & 2569,071 & - & - \\
\hline $1929-30 \ldots$ & $3,437,117$ & $2,065,049$ & 304,114 & $1,490,014$ & 270,921 & $21,372,068$ & - & - \\
\hline 1935-36 ............. & $3,913,028$ & $2,359,418$ & 334,085 & $1,636,722$ & 388,611 & $21,553,610$ & - & - \\
\hline $1937-38$ & $4,208,695$ & $2,556,075$ & 313,665 & $1,811,309$ & 431,101 & $1,652,620$ & - & - \\
\hline $1939-40 \ldots$. & $4,440,063$ & $2,753,780$ & - & - & - & $1,686,283$ & - & - \\
\hline 1941-42 ................ & $4,525,925$ & $2,759,261$ & - & 一 & - & $21,766,664$ & - & - \\
\hline $1947-48 \ldots$ & $6,076,212$ & $3,691,725$ & - & 一 & 一 & $2,384,487$ & - & - \\
\hline $1949-50 \ldots$ & $7,401,187$ & $4,799,964$ & - & 一 & 一 & $22,601,223$ & - & - \\
\hline $1951-52$ & $9,241,725$ & $6,373,195$ & - & 一 & 一 & $2,868,530$ & - & - \\
\hline $1953-54 \ldots$ & $10,717,082$ & $7,523,193$ & - & 一 & 一 & $3,193,889$ & - & - \\
\hline $1955-56$ & $12,561,046$ & $8,858,907$ & 624,467 & $36,697,648$ & $1,536,792$ & $3,702,139$ & - & $\$ 894,383$ \\
\hline $1957-58$ & $15,770,197$ & $11,124,489$ & 733,182 & $38,540,429$ & $1,850,878$ & $4,645,708$ & - & $1,444,602$ \\
\hline $1959-60$ & $18,870,628$ & $13,548,548$ & 842,664 & $310,472,478$ & $2,233,407$ & $5,322,080$ & - & $1,964,306$ \\
\hline $1961-62$ & $22,761,193$ & $16,681,844$ & $1,009,294$ & $312,900,093$ & $2,772,457$ & $6,079,349$ & - & $2,806,868$ \\
\hline $1963-64 \ldots$ & $28,232,362$ & $21,279,346$ & $1,292,691$ & $316,460,867$ & $3,525,788$ & $6,953,016$ & - & $4,190,189$ \\
\hline $1965-66 \ldots \ldots$ & $35,274,597$ & $26,851,273$ & $1,758,901$ & 3 $20,653,028$ & $4,439,344$ & $8,423,324$ & $\$ 11,126,831$ & $6,071,750$ \\
\hline 1967-68 .... & - & $34,506,348$ & $2,062,545$ & ${ }^{3} 26,673,826$ & $5,769,977$ & - & - & - \\
\hline $1969-70 \ldots \ldots$ & $52,930,923$ & $42,093,580$ & $3,076,751$ & $31,865,179$ & $7,151,649$ & $10,837,343$ & $11,206,632$ & $9,384,731$ \\
\hline $1970-71 \ldots$ & $57,394,951$ & $46,053,585$ & $3,117,895$ & $35,042,590$ & $7,893,100$ & $11,341,366$ & $13,714,330$ & $9,786,240$ \\
\hline 1971-72 …..... & $62,136,459$ & $50,153,251$ & $3,287,326$ & $38,131,339$ & $8,734,586$ & $11,983,208$ & $15,180,934$ & $10,291,095$ \\
\hline $1972-73 \ldots \ldots$. & $66,814,103$ & $53,814,596$ & $3,492,611$ & $40,808,481$ & $9,513,503$ & $12,999,507$ & $15,099,840$ & $10,823,595$ \\
\hline $1973-74 \ldots$ & $71,305,817$ & $58,002,777$ & $3,888,372$ & $43,701,491$ & $10,412,914$ & $13,303,040$ & $13,168,076$ & $11,400,916$ \\
\hline 1974-75 ..... & $75,585,674$ & $62,183,078$ & $4,210,901$ & $46,453,642$ & $11,518,536$ & $13,402,596$ & $14,364,545$ & $12,413,420$ \\
\hline $1975-76$ & $80,300,595$ & $66,348,304$ & $4,345,232$ & $49,349,224$ & $12,653,847$ & $13,952,291$ & $15,488,265$ & $12,687,015$ \\
\hline $1976-77$ & $85,486,550$ & $70,739,427$ & $4,444,927$ & $52,384,393$ & $13,910,107$ & $14,747,123$ & $16,304,553$ & $13,068,341$ \\
\hline 1977-78 & $90,337,044$ & $74,770,804$ & $4,621,071$ & $55,188,603$ & $14,961,131$ & $15,566,240$ & $16,840,129$ & $13,437,861$ \\
\hline 1978-79 .... & $95,442,468$ & $78,637,991$ & $4,824,250$ & $57,563,005$ & $16,250,737$ & $16,804,477$ & $18,158,634$ & $13,712,648$ \\
\hline $1979-80 \ldots \ldots$ & $102,294,859$ & $83,733,387$ & $5,037,172$ & $60,847,097$ & $17,849,119$ & $18,561,472$ & $20,743,045$ & $14,181,991$ \\
\hline $1980-81$ & $109,701,242$ & $88,760,567$ & $5,212,453$ & $64,158,017$ & $19,390,097$ & $20,940,675$ & $23,465,001$ & $14,794,669$ \\
\hline $1981-82 \ldots$ & $117,601,954$ & $94,516,512$ & $5,402,339$ & $67,794,877$ & $21,319,297$ & $23,085,442$ & $24,415,245$ & $15,487,618$ \\
\hline $1982-83 \ldots \ldots \ldots \ldots$ & $127,345,302$ & $100,992,841$ & $5,889,080$ & $71,519,718$ & $23,584,042$ & $26,352,461$ & $32,691,133$ & $16,749,900$ \\
\hline 1983-84 ......... & $137,141,741$ & $107,640,113$ & $6,109,746$ & $75,220,765$ & $26,309,602$ & $29,501,629$ & $32,975,610$ & $18,277,315$ \\
\hline 1984-85 ... & $148,163,096$ & $114,763,986$ & $6,236,159$ & $79,133,998$ & $29,393,829$ & $33,399,110$ & $39,916,361$ & $22,105,712$ \\
\hline 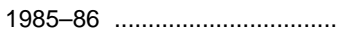 & $160,959,517$ & $122,261,355$ & $6,573,923$ & $82,886,012$ & $32,801,419$ & $38,698,162$ & $50,280,775$ & $25,699,408$ \\
\hline (1) & - & $126,426,171$ & $7,165,445$ & $84,838,657$ & $34,422,069$ & - & $56,585,153$ & - \\
\hline 1987-88 & - & $139,456,342$ & $8,307,789$ & $92,428,615$ & $38,719,937$ & - & $57,391,814$ & - \\
\hline 1988-89 & - & $158,693,085$ & $9,462,095$ & $104,743,145$ & $44,487,845$ & - & $64,155,247$ & - \\
\hline $1989-90$ & - & $164,635,000$ & $9,968,000$ & $108,609,000$ & $46,058,000$ & - & $67,978,726$ & - \\
\hline 1990-91 & - & $178,084,000$ & $10,028,000$ & $117,683,000$ & $50,373,000$ & - & $72,048,579$ & - \\
\hline 1991-92 .................. & - & $184,813,238$ & $10,528,395$ & $122,422,566$ & $51,862,277$ & - & $82,534,026$ & - \\
\hline 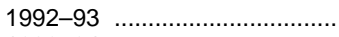 & - & $192,760,817$ & $11,006,451$ & $128,436,599$ & $53,317,767$ & - & $92,239,311$ & - \\
\hline 1993-94 …............................ & - & $199,463,715$ & $11,197,662$ & $133,124,680$ & $55,141,373$ & - & $96,012,591$ & - \\
\hline 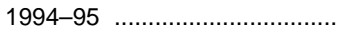 & - & $212,201,113$ & $11,710,436$ & $142,553,837$ & $57,936,840$ & - & $109,706,704$ & - \\
\hline $1995-96^{4} \ldots \ldots \ldots \ldots . . . . .$. & - & $220,400,104$ & $11,407,020$ & $150,458,886$ & $58,534,198$ & - & $128,837,030$ & - \\
\hline
\end{tabular}

1 Includes funds functioning as endowment.

2 Includes annuity funds.

${ }^{3}$ Includes improvements to land and equipment. These funds are included under appropriate categories after 1967-68.

${ }^{4}$ Data are for 4-year and 2-year degree-granting institutions that were eligible to participate in Title IV federal financial aid programs.

NOTE.-Because of rounding, details may not add to totals.

SOURCE: U.S. Department of Education, National Center for Education Statistics, Higher Education General Information Survey (HEGIS), "Financial Statistics of Institutions of Higher Education" surveys; and Integrated Postsecondary Education Data System (IPEDS), "Finance" surveys. (This table was prepared November 1998.) 
Table 354.-Endowment funds of the 120 institutions of higher education with the largest amounts: Fiscal year 1996

\begin{tabular}{|c|c|c|c|c|c|}
\hline Institution & $\begin{array}{c}\text { Rank } \\
\text { order }^{1}\end{array}$ & $\begin{array}{l}\text { Market value of } \\
\text { endowment, in } \\
\text { thousands of } \\
\text { dollars (end of } \\
\text { fiscal year) }\end{array}$ & Institution & $\begin{array}{c}\text { Rank } \\
\text { order }^{1}\end{array}$ & $\begin{array}{l}\text { Market value of } \\
\text { endowment, in } \\
\text { thousands of } \\
\text { dollars (end of } \\
\text { fiscal year) }\end{array}$ \\
\hline 1 & 2 & 3 & 1 & 2 & 3 \\
\hline United States (all institutions) ..... & - & $\$ 128,837,030$ & & & \\
\hline 120 institutions with the largest amounts ......................... & - & $85,506,186$ & & & \\
\hline Harvard University (MA) & 1 & $9,058,923$ & Wesleyan University $(\mathrm{CT})$ & 61 & 383,613 \\
\hline Yale University (CT) ........ & 2 & $4,860,582$ & Baylor University (TX) & 62 & 380,916 \\
\hline 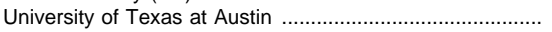 & 3 & $4,359,738$ & Tulane University of Louisiana & 63 & 370,723 \\
\hline 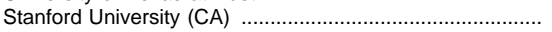 & 4 & $3,691,298$ & Lafayette College (PA) ................ & 64 & 359,861 \\
\hline 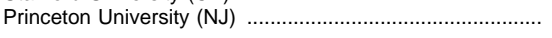 & 5 & $22,872,865$ & Rensselaer Polytechnic Institute (NY) . & 65 & 352,212 \\
\hline Columbia University (NY) & 6 & $2,698,929$ & Purdue University, Main Campus (IN) & 66 & 345,639 \\
\hline 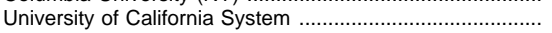 & 7 & $2,594,787$ & Syracuse University, Main Campus (NY) ... & 67 & 332,540 \\
\hline 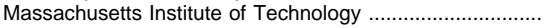 & 8 & $2,493,627$ & Agnes Scott College (GA) & 68 & 328,698 \\
\hline 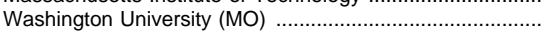 & 9 & $2,344,618$ & Oberlin College $(\mathrm{OH})$ & 69 & 328,291 \\
\hline 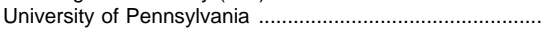 & 10 & $2,108,961$ & Loyola University of Chicago (IL) & 70 & 326,628 \\
\hline Rice University (TX) & 11 & $1,712,577$ & University of Miami (FL) & 71 & 310,481 \\
\hline University of Michigan, Ann Arbor & 12 & $1,639,285$ & The Juilliard School (NY) & 72 & 309,627 \\
\hline Northwestern University (IL) & 13 & $1,517,852$ & Cornell University Medical College (NY) & 73 & 308,374 \\
\hline 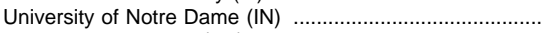 & 14 & $1,227,256$ & 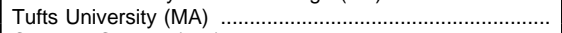 & 74 & 298,291 \\
\hline 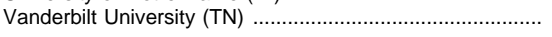 & 15 & $1,144,784$ & Carleton College (MN) & 75 & 292,689 \\
\hline Dartmouth College $(\mathrm{NH})$ & 16 & $1,142,079$ & Rochester Institute of Technology (NY) & 76 & 292,589 \\
\hline University of Southern California & 17 & $1,022,339$ & Brigham Young University (UT) .................. & 77 & 289,647 \\
\hline University of Virginia, Main Campus ....... & 18 & 944,457 & Bryn Mawr College (PA) & 78 & 289,512 \\
\hline 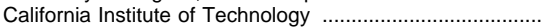 & 19 & 827,747 & University of Florida & 79 & 287,843 \\
\hline 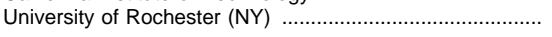 & 20 & 811,507 & University of Texas, Southwest Medical Center ..................... & 80 & 278,217 \\
\hline New York University . & 21 & 806,233 & Bowdoin College (ME) & 81 & 276,486 \\
\hline Brown University (RI) & 22 & 789,699 & Mount Sinai School of Medicine (NY) & 82 & 272,153 \\
\hline Rockefeller University (NY) & 23 & 699,928 & 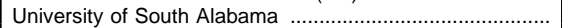 & 83 & 269,921 \\
\hline University of North Carolina at Chapel Hill ............................. & 24 & 641,934 & Mount Holyoke College (MA) .... & 84 & 258,726 \\
\hline Ohio State University, Main Campus .................................. & 25 & 640,640 & 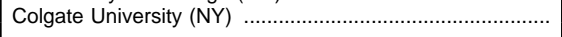 & 85 & 248,381 \\
\hline Swarthmore College (PA) & 26 & 623,981 & Thomas Jefferson University (PA) & 86 & 247,874 \\
\hline University of Washington . & 27 & 613,981 & Trinity College (CT) & 87 & 246,972 \\
\hline Princeton Theological Seminary $(\mathrm{NJ})$........ & 28 & 608,752 & Hamilton College (NY) & 88 & 246,934 \\
\hline Wellesley College (MA) & 29 & 605,509 & Rush University (IL) .... & 89 & 246,493 \\
\hline 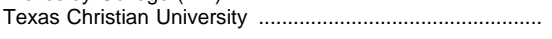 & 30 & 602,727 & Virginia Polytechnic Institute and State University ................ & 90 & 244,900 \\
\hline Boston College (MA) . & 31 & 591,609 & Brandeis University (MA) & 91 & 234,751 \\
\hline Southern Methodist University (TX) . & 32 & 589,163 & University of Tennessee (Central office) & 92 & 234,279 \\
\hline University of Delaware & 33 & 583,249 & University of Louisville (KY) & 93 & 233,020 \\
\hline Smith College (MA) & 34 & 583,163 & Rutgers, The State University, Central Office (NJ) .. & 94 & 232,679 \\
\hline 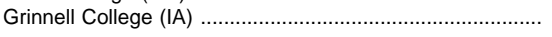 & 35 & 573,157 & Cornell University, Statutory Colleges (NY) …….................... & 95 & 231,656 \\
\hline Williams College (MA) . & 36 & 561,148 & College of the Holy Cross (MA) & 96 & 228,416 \\
\hline University of Richmond (VA) & 37 & 550,166 & Loyola University in New Orleans (LA) ...... & 97 & 227,702 \\
\hline University of Cincinnati, Main Campus $(\mathrm{OH})$ & 38 & 549,193 & Santa Clara University (CA) & 98 & 225,736 \\
\hline Baylor College of Medicine (TX) & 39 & 548,387 & 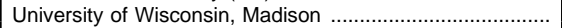 & 99 & 213,606 \\
\hline 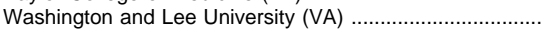 & 40 & 532,803 & 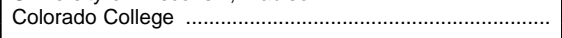 & 100 & 213,504 \\
\hline Carnegie Mellon University (PA). & 41 & 524,305 & Denison University $(\mathrm{OH})$ & 101 & 211,888 \\
\hline 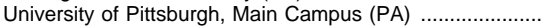 & 42 & 509,716 & North Carolina State University at Raleigh ... & 102 & 208,927 \\
\hline 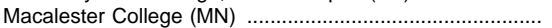 & 43 & 507,822 & 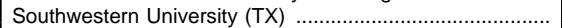 & 103 & 208,524 \\
\hline 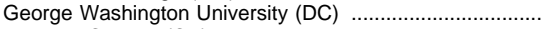 & 44 & 497,138 & Depauw University (IN) .. & 104 & 206,379 \\
\hline Pomona College (CA) & 45 & 495,413 & 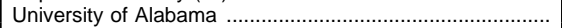 & 105 & 206,169 \\
\hline 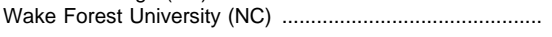 & 46 & 474,904 & 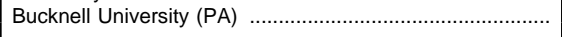 & 106 & 204,458 \\
\hline 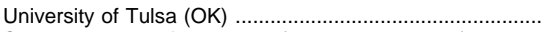 & 47 & 474,770 & University of Missouri at Columbia & 107 & 198,911 \\
\hline State University of New York (multiple campuses) ............ & 48 & 462,422 & 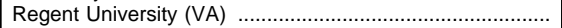 & 108 & 198,412 \\
\hline Saint Louis University, Main Campus (MO) ……................. & 49 & 448,993 & Wabash College (IN) & 109 & 194,881 \\
\hline 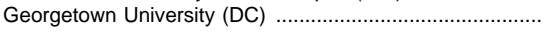 & 50 & 447,651 & State University of New York at Buffalo ................................ & 110 & 192,847 \\
\hline Berea College $(\mathrm{KY})$.. & 51 & 445,787 & University of New Mexico, Main Campus . & 111 & 192,229 \\
\hline Lehigh University (PA) & 52 & 433,571 & 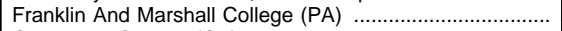 & 112 & 181,962 \\
\hline 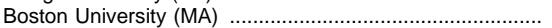 & 53 & 430,466 & Occidental College (CA) & 113 & 178,162 \\
\hline Pennsylvania State University, Main Campus ……............... & 54 & 426,599 & Worcester Polytechnic Institute (MA) & 114 & 178,037 \\
\hline 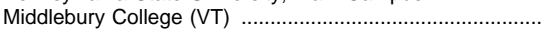 & 55 & 423,363 & 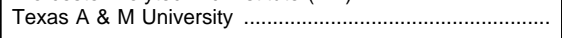 & 115 & 177,209 \\
\hline Amherst College (MA) . & 56 & 413,635 & University of the South (TN) & 116 & 175,276 \\
\hline Trinity University (TX) & 57 & 412,543 & Union College (NY) . & 117 & 174,391 \\
\hline Vassar College (NY) . & 58 & 403,287 & Whitman College (WA) & 118 & 173,416 \\
\hline 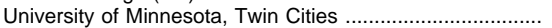 & 59 & 401,318 & Reed College (OR) & 119 & 172,994 \\
\hline 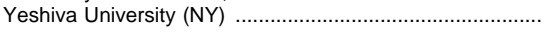 & 60 & 394,398 & Davidson College (NC) & 120 & 172,804 \\
\hline
\end{tabular}

1 Institutions ranked by size of endowment. Excludes institutions which have not reported data for 1995-96.

21995 data.

-Data not applicable.
NOTE.-Because of rounding, details may not add to total.

SOURCE: U.S. Department of Education, National Center for Education Statistics, Integrated Postsecondary Education Data System (IPEDS), "Finance, 1995-96" survey. (This table was prepared November 1998.) 
Table 355.-Participation of employed persons, 17 years old and over, in adult education during the previous 12 months, by selected characteristics of participants: 1995

\begin{tabular}{|c|c|c|c|c|c|c|c|c|c|c|c|c|c|c|}
\hline \multirow[b]{2}{*}{ Characteristics of employed persons } & \multirow[b]{2}{*}{$\begin{array}{c}\text { Em- } \\
\text { ployed } \\
\text { persons, } \\
\text { in thou- } \\
\text { sands }\end{array}$} & \multirow[b]{2}{*}{$\begin{array}{c}\text { Adult } \\
\text { edu- } \\
\text { cation } \\
\text { partici- } \\
\text { pants, in } \\
\text { thou- } \\
\text { sands }{ }^{1}\end{array}$} & \multicolumn{5}{|c|}{ Percent of adults participating } & \multirow[b]{2}{*}{$\begin{array}{l}\text { Number } \\
\text { of ca- } \\
\text { reer or } \\
\text { job-re- } \\
\text { lated } \\
\text { courses } \\
\text { taken, in } \\
\text { thou- } \\
\text { sands }\end{array}$} & \multirow[b]{2}{*}{$\begin{array}{c}\text { Num- } \\
\text { ber of } \\
\text { career } \\
\text { or job } \\
\text { related } \\
\text { courses } \\
\text { taken, } \\
\text { per em- } \\
\text { ployee }\end{array}$} & \multirow{2}{*}{$\begin{array}{l}\text { Percent } \\
\text { of ca- } \\
\text { reer or } \\
\text { job-re- } \\
\text { lated } \\
\text { courses } \\
\text { pro- } \\
\text { vided } \\
\text { by } \\
\text { busi- } \\
\text { ness- } \\
\text { es }^{2}\end{array}$} & \multirow{2}{*}{$\begin{array}{l}\text { Percent } \\
\text { of ca- } \\
\text { reer or } \\
\text { job-re- } \\
\text { lated } \\
\text { courses } \\
\text { paid for } \\
\text { by } \\
\text { busi- } \\
\text { ness- } \\
\text { es }^{2}\end{array}$} & \multirow{2}{*}{$\begin{array}{c}\text { Percent } \\
\text { of part- } \\
\text { time } \\
\text { higher } \\
\text { edu- } \\
\text { cation } \\
\text { courses } \\
\text { pro- } \\
\text { vided } \\
\text { by } \\
\text { busi- } \\
\text { ness- } \\
\text { es }^{3}\end{array}$} & & Per- \\
\hline & & & $\begin{array}{c}\text { In any } \\
\text { pro- } \\
\text { gram }\end{array}$ & $\begin{array}{l}\text { In part- } \\
\text { time } \\
\text { higher } \\
\text { edu- } \\
\text { cation }\end{array}$ & $\begin{array}{l}\text { In ca- } \\
\text { reer or } \\
\text { job re- } \\
\text { lated } \\
\text { courses }\end{array}$ & \begin{tabular}{|c|} 
In ap- \\
pren- \\
tice \\
pro- \\
grams
\end{tabular} & $\begin{array}{c}\text { Other } \\
\text { personal } \\
\text { courses }\end{array}$ & & & & & & $\begin{array}{c}\text { higher } \\
\text { edu- } \\
\text { cation } \\
\text { courses } \\
\text { paid for } \\
\text { by } \\
\text { busi- } \\
\text { ness- } \\
\text { es }^{3}\end{array}$ & $\begin{array}{l}\text { ploy- } \\
\text { ees re- } \\
\text { ceiving } \\
\text { work- } \\
\text { related } \\
\text { com- } \\
\text { puter- } \\
\text { aided } \\
\text { instruc- } \\
\text { tion }\end{array}$ \\
\hline 1 & 2 & 3 & 4 & 5 & 6 & 7 & 8 & 9 & 10 & 11 & 12 & 13 & 14 & 15 \\
\hline Total $\ldots \ldots \ldots \ldots \ldots \ldots$ & 117,826 & 59,734 & 50.7 & 8.2 & 31.1 & 1.5 & 22.0 & 91,408 & 0.78 & 49.0 & 86.5 & 11.2 & 43.4 & 17.0 \\
\hline Sex & & & & & & & & & & & & & & \\
\hline Men & 63,127 & 29,346 & 46.5 & 7.0 & 29.0 & 2.1 & 17.9 & 44,151 & 0.70 & 46.7 & 88.1 & 13.0 & 49.4 & 16.0 \\
\hline 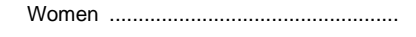 & 54,699 & 30,387 & 55.6 & 9.7 & 33.4 & 0.8 & 26.8 & 47,257 & 0.86 & 50.9 & 85.1 & 9.6 & 38.3 & 18.1 \\
\hline Age & & & & & & & & & & & & & & \\
\hline 17 to 24 years & 15,104 & 7,653 & 50.7 & 14.2 & 18.6 & 4.1 & 21.8 & 5,924 & 0.39 & 53.8 & 75.7 & 8.8 & 18.7 & 14.7 \\
\hline 25 to 29 years & 14,207 & 7,746 & 54.5 & 12.5 & 31.2 & 2.8 & 22.2 & 10,855 & 0.76 & 51.3 & 89.9 & 10.1 & 40.6 & 17.4 \\
\hline 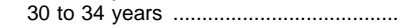 & 16,291 & 8,323 & 51.1 & 8.9 & 31.6 & 1.4 & 22.8 & 12,765 & 0.78 & 49.7 & 89.7 & 11.3 & 49.2 & 18.3 \\
\hline 35 to 39 years & 17,595 & 9,361 & 53.2 & 8.4 & 35.1 & 1.3 & 21.8 & 15,927 & 0.91 & 51.8 & 89.1 & 11.6 & 53.6 & 18.3 \\
\hline 40 to 44 years ............... & 16,049 & 8,906 & 55.5 & 8.0 & 36.6 & 1.0 & 26.0 & 14,957 & 0.93 & 44.9 & 85.9 & 13.4 & 59.7 & 18.6 \\
\hline 45 to 49 years & 13,743 & 7,586 & 55.2 & 6.3 & 39.6 & 0.6 & 23.0 & 14,127 & 1.03 & 44.8 & 85.3 & 9.3 & 47.8 & 19.2 \\
\hline 50 to 54 years & 10,408 & 5,222 & 50.2 & 4.9 & 34.4 & 0.3 & 20.9 & 9,041 & 0.87 & 49.2 & 84.5 & 19.5 & 49.3 & 20.2 \\
\hline 55 to 59 years & 6,698 & 2,667 & 39.8 & 2.3 & 26.7 & 0.3 & 18.0 & 4,432 & 0.66 & 46.8 & 84.8 & - & - & 10.3 \\
\hline 60 to 64 years & 4,435 & 1,394 & 31.4 & 0.6 & 21.1 & 0.2 & 15.3 & 2,175 & 0.49 & 58.6 & 85.5 & - & - & 10.3 \\
\hline 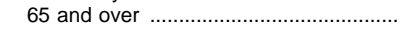 & 3,297 & 876 & 26.6 & 0.3 & 13.7 & 0.0 & 16.3 & 1,203 & 0.37 & 39.7 & 87.3 & - & - & 6.7 \\
\hline Racial/ethnic group & & & & & & & & & & & & & & \\
\hline White, non-Hispanic & 92,333 & 47,967 & 51.9 & 8.0 & 33.2 & 1.2 & 22.7 & 77,096 & 0.83 & 47.9 & 86.8 & 11.9 & 45.1 & 17.5 \\
\hline 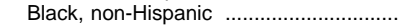 & 11,577 & 5,800 & 50.1 & 10.5 & 26.2 & 2.6 & 23.1 & 7,785 & 0.67 & 58.4 & 86.0 & 9.4 & 42.6 & 14.3 \\
\hline 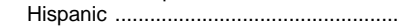 & 8,980 & 3,627 & 40.4 & 6.7 & 18.1 & 2.3 & 15.1 & 3,361 & 0.37 & 46.8 & 82.9 & 5.8 & 26.7 & 14.3 \\
\hline Asian American/Pacific Islander & 2,825 & 1,246 & 44.1 & 8.0 & 25.5 & 2.8 & 15.1 & 1,636 & 0.58 & 48.6 & 87.3 & 15.2 & - & 18.1 \\
\hline American Indian/Alaskan Native ............. & 663 & 329 & 49.6 & 13.9 & 34.0 & 0.5 & 25.2 & 570 & 0.86 & 54.6 & 81.8 & - & - & 24.4 \\
\hline $\begin{array}{l}\text { Highest level of education } \\
\text { completed }\end{array}$ & & & & & & & & & & & & & & \\
\hline Less than high school diploma ............ & 9,635 & 2,444 & 25.4 & 0.8 & 8.8 & 1.7 & 9.4 & 1,412 & 0.15 & 56.6 & 76.3 & - & - & 4.9 \\
\hline High school diploma & 38,071 & 14,639 & 38.5 & 4.9 & 20.9 & 1.9 & 16.5 & 17,072 & 0.45 & 56.7 & 91.0 & 13.9 & 48.9 & 11.8 \\
\hline Some vocational/technical ......... & 3,997 & 2,078 & 52.0 & 7.2 & 32.3 & 1.7 & 23.5 & 3,258 & 0.82 & 45.3 & 85.9 & 7.6 & - & 15.6 \\
\hline 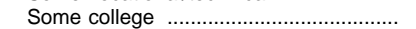 & 23,006 & 12,868 & 55.9 & 14.3 & 29.9 & 2.2 & 25.4 & 17,039 & 0.74 & 53.5 & 86.3 & 9.6 & 31.8 & 19.8 \\
\hline Associate degree & 7,591 & 4,746 & 62.5 & 13.3 & 39.2 & 1.4 & 27.7 & 7,718 & 1.02 & 49.7 & 87.9 & 13.2 & 45.2 & 20.3 \\
\hline 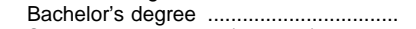 & 20,602 & 12,948 & 62.8 & 8.3 & 44.6 & 0.6 & 26.5 & 24,024 & 1.17 & 47.2 & 86.5 & 8.3 & 48.8 & 22.9 \\
\hline Some graduate work (or study) ............ & 14,924 & 10,010 & 67.1 & 9.9 & 50.2 & 0.4 & 29.6 & 20,885 & 1.40 & 40.3 & 82.9 & 11.8 & 52.6 & 24.1 \\
\hline 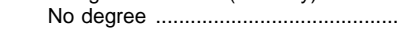 & 2,770 & 1,987 & 71.8 & 19.7 & 44.3 & 0.2 & 34.8 & 3,333 & 1.20 & 45.6 & 83.7 & 11.5 & 50.0 & 23.3 \\
\hline 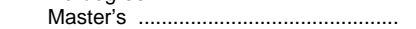 & 8,149 & 5,456 & 67.0 & 9.6 & 50.5 & 0.4 & 30.4 & 11,704 & 1.44 & 41.7 & 83.9 & 9.4 & 55.3 & 24.7 \\
\hline Doctor's & 2,060 & 1,133 & 55.0 & 5.0 & 40.4 & 0.6 & 22.4 & 2,008 & 0.98 & 35.5 & 79.5 & - & - & 24.4 \\
\hline 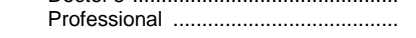 & 1,946 & 1,434 & 73.7 & 2.6 & 67.6 & 0.8 & 26.4 & 3,840 & 1.97 & 31.4 & 79.7 & - & - & 22.9 \\
\hline Metropolitan area & & & & & & & & & & & & & & \\
\hline Inside metropolitan area & 89,192 & 46,911 & 52.6 & 8.7 & 32.4 & 1.5 & 22.6 & 72,388 & 0.81 & 48.6 & 86.3 & 11.6 & 41.9 & 17.7 \\
\hline Inside central city ......... & 74,367 & 39,519 & 53.1 & 8.8 & 33.3 & 1.5 & 22.5 & 62,033 & 0.83 & 48.3 & 86.4 & 11.1 & 41.6 & 18.5 \\
\hline Outside central city & 14,825 & 7,392 & 49.9 & 8.0 & 27.9 & 1.5 & 23.1 & 10,355 & 0.70 & 50.9 & 86.0 & 14.3 & 43.7 & 13.8 \\
\hline Outside metropolitan area ......................... & 28,634 & 12,823 & 44.8 & 6.9 & 26.9 & 1.4 & 20.2 & 19,020 & 0.66 & 50.2 & 87.2 & 9.4 & 49.1 & 14.7 \\
\hline Occupation & & & & & & & & & & & & & & \\
\hline $\begin{array}{l}\text { Executive, administrative, or manage- } \\
\text { rial }\end{array}$ & 12,500 & 7,070 & 56.6 & 7.4 & 42.9 & 0.4 & 23.4 & 15,041 & 1.20 & 37.7 & 90.2 & 8.7 & 54.1 & 27.8 \\
\hline Engineers, surveyors, and architects .... & 1,702 & 1,116 & 65.6 & 14.5 & 44.2 & $\begin{array}{l}0.1 \\
1.1\end{array}$ & 23.7 & 1,828 & 1.07 & 59.0 & 94.6 & 6.1 & 82.0 & 25.0 \\
\hline Natural scientists and mathematicians & 1,648 & 1,211 & 73.5 & 10.4 & 59.7 & 0.0 & 25.6 & 2,875 & 1.75 & 44.0 & 94.6 & - & - & 30.7 \\
\hline Social scientists and workers, lawyers & 2,438 & 1,873 & 76.8 & 11.7 & 59.5 & 1.5 & 32.4 & 4,307 & 1.77 & 35.6 & 83.1 & 7.1 & 31.3 & 17.5 \\
\hline Teachers, elementary/secondary ............ & 5,207 & 4,046 & 77.7 & 16.9 & 53.9 & 0.2 & 36.9 & 7,619 & 1.46 & 50.5 & 76.3 & 8.3 & 31.6 & 18.3 \\
\hline Teachers, postsecondary ……..................... & 1,175 & 657 & 55.9 & 4.4 & 41.6 & 0.0 & 26.1 & 1,213 & 1.03 & 53.5 & 79.8 & - & - & 26.6 \\
\hline Physicians, dentists, veterinarians ......... & 828 & 590 & 71.3 & 1.3 & 68.6 & 0.9 & 18.3 & 1,656 & 2.00 & 32.4 & 64.7 & - & - & 20.0 \\
\hline $\begin{array}{l}\text { Registered nurses, pharmacists ........... } \\
\text { Writers, artists, entertainers, and ath- }\end{array}$ & 2,143 & 1,896 & 88.5 & 11.2 & 72.8 & 0.2 & 34.6 & 4,791 & 2.24 & 45.6 & 74.0 & 9.9 & 43.8 & 13.1 \\
\hline letes & 1,675 & 829 & 49.5 & 8.1 & 23.4 & 1.7 & 28.7 & 776 & 0.46 & 33.3 & 73.6 & - & - & 20.2 \\
\hline Health technologists and technicians $\ldots$ & 1,528 & 1,147 & 75.1 & 12.9 & 50.0 & 0.0 & 32.1 & 2,130 & 1.39 & 45.0 & 76.5 & 5.2 & 49.6 & 15.9 \\
\hline Technologists, except health ................... & 3,283 & 2,153 & 65.6 & 12.9 & 43.8 & 0.8 & 28.3 & 3,685 & 1.12 & 55.8 & 91.2 & 9.2 & 58.0 & 31.6 \\
\hline Marketing and sales occupations .......... & 15,666 & 7,131 & 45.5 & 6.6 & 25.2 & 1.1 & 20.2 & 8,619 & 0.55 & 51.2 & 86.5 & 10.2 & 21.6 & 19.6 \\
\hline $\begin{array}{l}\text { Administrative support, including cleri- } \\
\text { cal }\end{array}$ & 20,460 & 10,727 & 52.4 & 9.3 & 30.8 & 0.7 & 24.1 & & 9 & 52.4 & 91.5 & 10.5 & 46.6 & 24.0 \\
\hline Service occupations & 17,355 & 8,238 & 47.5 & 9.0 & 22.6 & 1.7 & $\begin{array}{l}24.1 \\
22.7\end{array}$ & $\begin{array}{l}14,064 \\
10,404\end{array}$ & 0.60 & 57.0 & 85.4 & $\begin{array}{l}10.5 \\
12.3\end{array}$ & $\begin{array}{l}46.6 \\
28.8\end{array}$ & $\begin{array}{r}24.0 \\
7.3\end{array}$ \\
\hline Agriculture, forestry, and fishing ................. & 1,908 & 500 & 26.2 & 1.8 & 12.4 & 0.4 & 14.8 & 493 & 0.26 & - & - & - & - & 6.6 \\
\hline Mechanics and repairers ........................... & 4,266 & 2,129 & 49.9 & 7.6 & 29.1 & 3.9 & 16.6 & 3,109 & 0.73 & 57.2 & 90.7 & 19.5 & 60.0 & 9.8 \\
\hline Construction and extractive occupa- & & & & & & & & & & & & & & \\
\hline tions. & 5,490 & 2,093 & 38.1 & 4.6 & 18.6 & 5.5 & 18.4 & 1,832 & 0.33 & 48.8 & 83.8 & - & - & 5.9 \\
\hline Precision production occupations ........... & 1,685 & 754 & 44.8 & 5.9 & 25.6 & 4.9 & 16.2 & 982 & 0.58 & 40.8 & 84.2 & - & - & 12.0 \\
\hline Production workers & 8,309 & 2,515 & 30.3 & 5.9 & 14.8 & 2.9 & 10.1 & 2,203 & 0.27 & 58.5 & 97.9 & 16.2 & 57.2 & 8.1 \\
\hline Transportation, material moving .............. & 4,488 & 1,295 & 28.8 & 3.8 & 15.8 & 1.0 & 12.1 & 1,274 & 0.28 & 60.6 & 82.0 & - & - & 6.0 \\
\hline $\begin{array}{l}\text { Handler, equipment, cleaners, helpers, } \\
\text { and laborers }\end{array}$ & 1,989 & 519 & 26.1 & 3.1 & 11.7 & 2.9 & 10.3 & 422 & 0.21 & 46.9 & 70.6 & - & - & 7.5 \\
\hline 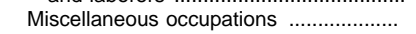 & 2,022 & 1,194 & 59.0 & 8.5 & 38.8 & 4.0 & 22.1 & 2,088 & 1.03 & 51.8 & 90.4 & -1 & -1 & 20.9 \\
\hline
\end{tabular}


Table 355.-Participation of employed persons, 17 years old and over, in adult education during the previous 12 months, by selected characteristics of participants: 1995-Continued

\begin{tabular}{|c|c|c|c|c|c|c|c|c|c|c|c|c|c|c|}
\hline \multirow[b]{2}{*}{ Characteristics of employed persons } & \multirow[b]{2}{*}{$\begin{array}{l}\text { Em- } \\
\text { ployed } \\
\text { persons, } \\
\text { in thou- } \\
\text { sands }\end{array}$} & \multirow[b]{2}{*}{$\begin{array}{l}\text { Adult } \\
\text { edu- } \\
\text { cation } \\
\text { partici- } \\
\text { pants, in } \\
\text { thou- } \\
\text { sands }{ }^{1}\end{array}$} & \multicolumn{5}{|c|}{ Percent of adults participating } & \multirow[b]{2}{*}{$\begin{array}{l}\text { Number } \\
\text { of ca- } \\
\text { reer or } \\
\text { job-re- } \\
\text { lated } \\
\text { courses } \\
\text { taken, in } \\
\text { thou- } \\
\text { sands }\end{array}$} & \multirow[b]{2}{*}{$\begin{array}{l}\text { Num- } \\
\text { ber of } \\
\text { career } \\
\text { or job } \\
\text { related } \\
\text { courses } \\
\text { taken, } \\
\text { per em- } \\
\text { ployee }\end{array}$} & \multirow{2}{*}{$\begin{array}{l}\text { Percent } \\
\text { of ca- } \\
\text { reer or } \\
\text { job-re- } \\
\text { lated } \\
\text { courses } \\
\text { pro- } \\
\text { vided } \\
\text { by } \\
\text { busi- } \\
\text { ness- } \\
\text { es }^{2}\end{array}$} & \multirow[b]{2}{*}{$\begin{array}{c}\text { Percent } \\
\text { of ca- } \\
\text { reer or } \\
\text { job-re- } \\
\text { lated } \\
\text { courses } \\
\text { paid for } \\
\text { by } \\
\text { busi- } \\
\text { ness- } \\
\text { es }^{2}\end{array}$} & \multirow{2}{*}{$\begin{array}{l}\text { Percent } \\
\text { of part- } \\
\text { time } \\
\text { higher } \\
\text { edu- } \\
\text { cation } \\
\text { courses } \\
\text { pro-- } \\
\text { vided } \\
\text { by } \\
\text { busi- } \\
\text { ness- } \\
\text { es }^{3}\end{array}$} & \multirow{2}{*}{$\begin{array}{c}\text { Percent } \\
\text { of part- } \\
\text { time } \\
\text { higher } \\
\text { edu- } \\
\text { cation } \\
\text { courses } \\
\text { paid for } \\
\text { by } \\
\text { busi- } \\
\text { ness- } \\
\text { es }^{3}\end{array}$} & \multirow{2}{*}{$\begin{array}{l}\text { Per- } \\
\text { cent of } \\
\text { em- } \\
\text { ploy- } \\
\text { ees re- } \\
\text { ceiving } \\
\text { work- } \\
\text { related } \\
\text { com- } \\
\text { puter- } \\
\text { aided } \\
\text { instruc- } \\
\text { tion }\end{array}$} \\
\hline & & & $\begin{array}{c}\text { In any } \\
\text { pro- } \\
\text { gram }\end{array}$ & $\begin{array}{c}\text { In part- } \\
\text { time } \\
\text { higher } \\
\text { edu- } \\
\text { cation }\end{array}$ & $\begin{array}{l}\text { In ca- } \\
\text { reer or } \\
\text { job re- } \\
\text { lated } \\
\text { courses }\end{array}$ & $\begin{array}{l}\text { In ap- } \\
\text { pren- } \\
\text { tice } \\
\text { pro- } \\
\text { grams }\end{array}$ & $\begin{array}{c}\text { Other } \\
\text { personal } \\
\text { courses }\end{array}$ & & & & & & & \\
\hline 1 & 2 & 3 & 4 & 5 & 6 & 7 & 8 & 9 & 10 & 11 & 12 & 13 & 14 & 15 \\
\hline \multicolumn{15}{|l|}{ Annual family income } \\
\hline$\$ 10,000$ or less & 9,776 & 3,224 & 33.0 & 6.1 & 12.6 & 1.7 & 15.6 & 2,441 & 0.25 & 50.9 & 75.2 & 19.0 & 18.7 & 9.2 \\
\hline$\$ 10,001$ to $\$ 15,000$ & 6,183 & 2,389 & 38.6 & 7.2 & 15.1 & 1.6 & 19.5 & 2,257 & 0.37 & 59.1 & 82.0 & 10.0 & 11.2 & 10.7 \\
\hline$\$ 15,001$ to $\$ 20,000$ & 7,321 & 3,040 & 41.5 & 8.0 & 20.1 & 2.4 & 18.2 & 3,110 & 0.42 & 52.8 & 83.0 & 7.5 & 26.0 & 14.6 \\
\hline$\$ 20,001$ to $\$ 25,000$ & 7,832 & 3,164 & 40.4 & 7.4 & 20.4 & 1.5 & 19.3 & 3,785 & 0.48 & 53.1 & 82.9 & 12.1 & 28.5 & 12.6 \\
\hline$\$ 25,001$ to $\$ 30,000$ & 10,133 & 4,803 & 47.4 & 8.8 & 24.7 & 2.1 & 21.4 & 5,461 & 0.54 & 55.8 & 86.9 & 8.4 & 40.7 & 14.4 \\
\hline$\$ 30,001$ to $\$ 40,000$ & 19,617 & 9,734 & 49.6 & 8.9 & 30.2 & 1.8 & 21.9 & 14,903 & 0.76 & 50.2 & 89.2 & 12.1 & 42.9 & 17.0 \\
\hline$\$ 40,001$ to $\$ 50,000$ & 15,115 & 8,127 & 53.8 & 8.0 & 34.7 & 1.3 & 22.9 & 12,430 & 0.82 & 48.3 & 85.3 & 14.0 & 55.3 & 16.8 \\
\hline$\$ 50,001$ to $\$ 75,000$ & 23,006 & 13,288 & 57.8 & 8.9 & 40.0 & 1.1 & 23.7 & 23,430 & 1.02 & 48.3 & 86.9 & 10.2 & 55.9 & 20.8 \\
\hline More than $\$ 75,000$ & 18,843 & 11,964 & 63.5 & 8.6 & 45.2 & 0.9 & 26.5 & 23,592 & 1.25 & 45.0 & 87.6 & 9.2 & 49.2 & 22.7 \\
\hline
\end{tabular}

${ }^{1}$ Adult education is defined as all education activities, except full-time enrollment in higher education credential programs. Examples of adult education activities include part-time college attendance, classes or seminars given by employers, and classes taken for adult literacy purposes, or for recreation and enjoyment. Includes adult basic education and English as a second language classes.

2Percentages based on the respondent's reports of the first six work-related courses taken.

${ }^{3}$ Percentages based on the respondent's reports of the first three part-time higher education courses taken.
NOTE.-Data are based upon a sample survey of the civilian noninstitutional population. Because of rounding and survey item nonresponse, details may not add to totals.

SOURCE: U.S. Department of Education, National Center for Education Statistics, National Household Education Survey, "Participation in Adult Education," unpublished data. (This table was prepared October 1997.) 
Table 356.-Participation in adult education during the previous 12 months by adults 17 years old and older, by selected characteristics of participants: 1991 and 1995

\begin{tabular}{|c|c|c|c|c|c|c|c|c|c|c|c|c|c|c|c|}
\hline \multirow[b]{3}{*}{ Characteristics of participants } & \multicolumn{6}{|c|}{1991} & \multicolumn{9}{|c|}{1995} \\
\hline & \multirow[b]{2}{*}{$\begin{array}{l}\text { Popu- } \\
\text { lation, in } \\
\text { thou- } \\
\text { sands }\end{array}$} & \multirow[b]{2}{*}{$\begin{array}{l}\text { Adult } \\
\text { edu- } \\
\text { cation } \\
\text { parti- } \\
\text { cipants, } \\
\text { in thou- } \\
\text { sands }{ }^{1}\end{array}$} & \multicolumn{4}{|c|}{ Percent of adults participating } & \multirow[b]{2}{*}{$\begin{array}{l}\text { Popu- } \\
\text { lation, in } \\
\text { thou- } \\
\text { sands }\end{array}$} & \multirow[b]{2}{*}{$\begin{array}{l}\text { Adult } \\
\text { edu- } \\
\text { cation } \\
\text { parti- } \\
\text { cipants, } \\
\text { in thou- } \\
\text { sands }{ }^{1}\end{array}$} & \multicolumn{7}{|c|}{ Percent of adults participating } \\
\hline & & & $\begin{array}{c}\text { In any } \\
\text { pro- } \\
\text { gram }\end{array}$ & $\begin{array}{l}\text { In } \\
\text { basic } \\
\text { edu- } \\
\text { cation }\end{array}$ & $\begin{array}{l}\text { In } \\
\text { Eng- } \\
\text { lish } \\
\text { as a } \\
\text { sec- } \\
\text { ond } \\
\text { lan- } \\
\text { guage }\end{array}$ & $\begin{array}{l}\text { In } \\
\text { part- } \\
\text { time } \\
\text { higher } \\
\text { edu- } \\
\text { cation }\end{array}$ & & & $\begin{array}{c}\text { In any } \\
\text { pro- } \\
\text { gram }\end{array}$ & $\begin{array}{l}\text { In } \\
\text { basic } \\
\text { edu- } \\
\text { cation }\end{array}$ & $\begin{array}{l}\text { In Eng- } \\
\text { lish as } \\
\text { a sec- } \\
\text { ond } \\
\text { lan- } \\
\text { guage }\end{array}$ & $\begin{array}{l}\text { In part- } \\
\text { time } \\
\text { higher } \\
\text { edu- } \\
\text { cation }\end{array}$ & $\begin{array}{l}\text { In ca- } \\
\text { reer or } \\
\text { job re- } \\
\text { lated } \\
\text { courses }\end{array}$ & $\begin{array}{l}\text { In ap- } \\
\text { pren- } \\
\text { tice } \\
\text { pro- } \\
\text { grams }\end{array}$ & $\begin{array}{c}\text { Other } \\
\text { per- } \\
\text { sonal } \\
\text { courses }\end{array}$ \\
\hline 1 & 2 & 3 & 4 & 5 & 6 & 7 & 8 & 9 & 10 & 11 & 12 & 13 & 14 & 15 & 16 \\
\hline 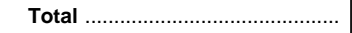 & 181,800 & 59,924 & 33.0 & 2.8 & 0.8 & 3.9 & 189,543 & 76,261 & 40.2 & 1.2 & 0.7 & 6.1 & 20.9 & 1.1 & 19.9 \\
\hline Sex & & & & & & & & & & & & & & & \\
\hline Men & $\begin{array}{l}82,154 \\
99,646\end{array}$ & $\begin{array}{l}26,817 \\
33,108\end{array}$ & $\begin{array}{l}32.6 \\
33.2\end{array}$ & $\begin{array}{l}2.6 \\
2.9\end{array}$ & $\begin{array}{l}0.8 \\
0.9\end{array}$ & $\begin{array}{l}3.5 \\
4.2\end{array}$ & $\begin{array}{l}90,256 \\
99,287\end{array}$ & $\begin{array}{l}34,450 \\
41,811\end{array}$ & $\begin{array}{l}38.2 \\
42.1\end{array}$ & $\begin{array}{l}1.2 \\
1.2\end{array}$ & $\begin{array}{l}0.7 \\
0.6\end{array}$ & $\begin{array}{l}5.6 \\
6.5\end{array}$ & $\begin{array}{l}21.8 \\
20.2\end{array}$ & $\begin{array}{l}1.7 \\
0.6\end{array}$ & $\begin{array}{l}15.8 \\
23.5\end{array}$ \\
\hline Age & & & & & & & & & & & & & & & \\
\hline 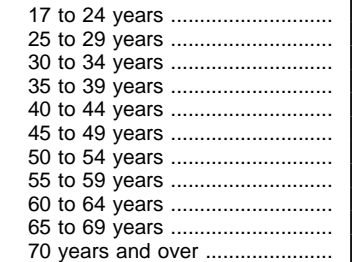 & $\begin{array}{r}21,688 \\
22,603 \\
24,641 \\
21,000 \\
17,565 \\
11,303 \\
14,072 \\
9,564 \\
10,403 \\
9,920 \\
19,040\end{array}$ & $\begin{array}{l}8,197 \\
9,049 \\
9,275 \\
8,839 \\
8,650 \\
4,523 \\
3,767 \\
2,770 \\
1,808 \\
1,409 \\
1,638\end{array}$ & $\begin{array}{r}37.8 \\
40.0 \\
37.6 \\
42.1 \\
49.2 \\
40.0 \\
26.8 \\
29.0 \\
17.4 \\
14.2 \\
8.6\end{array}$ & $\begin{array}{l}7.4 \\
4.1 \\
2.9 \\
2.8 \\
2.7 \\
2.0 \\
1.7 \\
1.7 \\
0.6 \\
0.5 \\
0.2\end{array}$ & $\begin{array}{l}1.9 \\
1.7 \\
1.0 \\
0.9 \\
0.6 \\
0.3 \\
0.6 \\
0.1 \\
0.1 \\
0.0 \\
0.0\end{array}$ & $\begin{array}{l}7.9 \\
6.7 \\
5.0 \\
5.5 \\
4.4 \\
3.2 \\
1.3 \\
1.0 \\
0.5 \\
0.3 \\
0.1\end{array}$ & $\begin{array}{l}22,407 \\
18,988 \\
21,338 \\
22,494 \\
19,810 \\
17,463 \\
14,344 \\
11,096 \\
10,728 \\
10,215 \\
20,661\end{array}$ & $\begin{array}{r}10,539 \\
9,420 \\
10,088 \\
10,737 \\
10,078 \\
8,499 \\
6,093 \\
3,577 \\
2,540 \\
1,850 \\
2,841\end{array}$ & $\begin{array}{l}47.0 \\
49.6 \\
47.3 \\
47.7 \\
50.9 \\
48.7 \\
42.5 \\
32.2 \\
23.7 \\
18.1 \\
13.8\end{array}$ & $\begin{array}{l}4.6 \\
1.4 \\
1.1 \\
1.2 \\
0.9 \\
0.6 \\
0.5 \\
0.4 \\
0.1 \\
0.1 \\
0.0\end{array}$ & $\begin{array}{l}1.4 \\
1.4 \\
0.8 \\
1.0 \\
0.8 \\
0.4 \\
0.1 \\
0.2 \\
0.3 \\
0.0 \\
0.0\end{array}$ & $\begin{array}{r}12.6 \\
10.9 \\
8.0 \\
7.5 \\
7.1 \\
5.7 \\
3.9 \\
1.7 \\
0.6 \\
0.2 \\
0.1\end{array}$ & $\begin{array}{r}14.7 \\
25.5 \\
26.1 \\
29.1 \\
31.2 \\
32.5 \\
26.3 \\
17.8 \\
10.6 \\
4.0 \\
1.4\end{array}$ & $\begin{array}{l}3.2 \\
2.5 \\
1.3 \\
1.3 \\
0.9 \\
0.5 \\
0.3 \\
0.3 \\
0.3 \\
0.0 \\
0.0\end{array}$ & $\begin{array}{l}21.5 \\
21.0 \\
23.3 \\
20.9 \\
24.9 \\
21.1 \\
19.7 \\
17.3 \\
15.2 \\
15.3 \\
12.6\end{array}$ \\
\hline Racial/ethnic group & & & & & & & & & & & & & & & \\
\hline 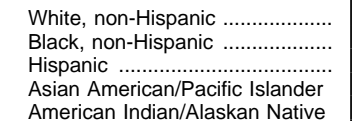 & $\begin{array}{r}143,144 \\
20,141 \\
13,804 \\
2,738 \\
997\end{array}$ & $\begin{array}{r}48,843 \\
5,207 \\
4,339 \\
984 \\
293\end{array}$ & $\begin{array}{l}34.1 \\
25.9 \\
31.4 \\
35.9 \\
29.3\end{array}$ & $\begin{array}{l}2.2 \\
4.5 \\
6.0 \\
4.1 \\
2.3\end{array}$ & $\begin{array}{l}0.2 \\
0.6 \\
6.6 \\
4.9 \\
4.2\end{array}$ & $\begin{array}{r}4.0 \\
3.2 \\
3.6 \\
6.4 \\
12.5\end{array}$ & $\begin{array}{r}144,587 \\
20,806 \\
15,689 \\
4,377 \\
1,155\end{array}$ & $\begin{array}{r}59,982 \\
7,704 \\
5,281 \\
1,739 \\
448\end{array}$ & $\begin{array}{l}41.5 \\
37.0 \\
33.7 \\
39.7 \\
38.8\end{array}$ & $\begin{array}{l}0.7 \\
2.3 \\
3.6 \\
1.9 \\
3.6\end{array}$ & $\begin{array}{l}0.1 \\
0.1 \\
5.7 \\
4.0 \\
0.0\end{array}$ & $\begin{array}{l}6.0 \\
7.3 \\
4.8 \\
6.5 \\
9.3\end{array}$ & $\begin{array}{l}22.8 \\
16.2 \\
11.8 \\
18.1 \\
20.6\end{array}$ & $\begin{array}{l}0.9 \\
1.6 \\
1.8 \\
2.6 \\
0.9\end{array}$ & $\begin{array}{l}20.8 \\
18.9 \\
13.8 \\
15.9 \\
21.6\end{array}$ \\
\hline $\begin{array}{l}\text { Highest level of education com- } \\
\text { pleted }\end{array}$ & & & & & & & & & & & & & & & \\
\hline 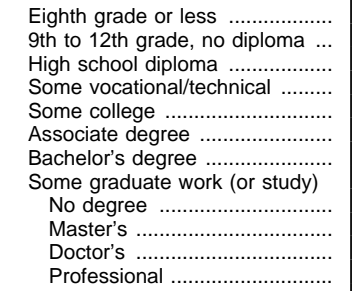 & $\begin{array}{r}10,163 \\
17,581 \\
67,129 \\
6,994 \\
36,823 \\
5,034 \\
23,545 \\
14,531 \\
- \\
- \\
-\end{array}$ & $\begin{array}{r}784 \\
2,781 \\
16,194 \\
2,392 \\
15,260 \\
2,479 \\
12,025 \\
8,009 \\
- \\
- \\
-\end{array}$ & $\begin{array}{r}7.7 \\
15.8 \\
24.1 \\
34.2 \\
41.4 \\
49.2 \\
51.1 \\
55.1 \\
- \\
- \\
- \\
-\end{array}$ & $\begin{array}{l}1.9 \\
2.9 \\
2.5 \\
1.8 \\
4.4 \\
3.7 \\
1.8 \\
2.2 \\
- \\
- \\
-\end{array}$ & $\begin{array}{l}1.2 \\
1.1 \\
0.6 \\
0.9 \\
1.3 \\
1.3 \\
0.6 \\
0.6 \\
- \\
- \\
-\end{array}$ & $\begin{array}{l}0.0 \\
0.7 \\
2.1 \\
1.3 \\
7.7 \\
7.0 \\
6.0 \\
5.9 \\
- \\
- \\
-\end{array}$ & $\begin{array}{r}12,808 \\
16,511 \\
62,956 \\
6,327 \\
34,433 \\
9,975 \\
26,858 \\
19,677 \\
4,123 \\
10,522 \\
2,564 \\
2,467\end{array}$ & $\begin{array}{r}1,283 \\
3,332 \\
19,341 \\
2,648 \\
16,978 \\
5,601 \\
15,286 \\
11,792 \\
2,563 \\
6,219 \\
1,384 \\
1,626\end{array}$ & $\begin{array}{l}10.0 \\
20.2 \\
30.7 \\
41.9 \\
49.3 \\
56.1 \\
56.9 \\
59.9 \\
62.2 \\
59.1 \\
54.0 \\
65.9\end{array}$ & $\begin{array}{l}1.8 \\
6.7 \\
1.0 \\
0.6 \\
0.5 \\
0.4 \\
0.0 \\
0.0 \\
0.0 \\
0.0 \\
0.0 \\
0.0\end{array}$ & $\begin{array}{l}2.4 \\
0.4 \\
0.7 \\
0.6 \\
0.5 \\
0.2 \\
0.4 \\
0.8 \\
0.7 \\
0.9 \\
0.4 \\
0.9\end{array}$ & $\begin{array}{r}0.1 \\
0.8 \\
3.6 \\
5.4 \\
12.1 \\
10.9 \\
7.1 \\
8.5 \\
15.2 \\
8.1 \\
4.7 \\
3.0\end{array}$ & $\begin{array}{r}1.9 \\
4.9 \\
13.9 \\
21.9 \\
22.3 \\
32.1 \\
36.1 \\
40.4 \\
32.5 \\
41.0 \\
35.0 \\
56.6\end{array}$ & $\begin{array}{l}0.5 \\
1.1 \\
1.3 \\
1.5 \\
1.8 \\
1.4 \\
0.5 \\
0.4 \\
0.5 \\
0.4 \\
0.5 \\
0.6\end{array}$ & $\begin{array}{r}4.9 \\
9.2 \\
15.4 \\
21.1 \\
25.3 \\
27.4 \\
27.0 \\
29.1 \\
33.5 \\
29.0 \\
25.1 \\
26.0\end{array}$ \\
\hline Metropolitan area & & & & & & & & & & & & & & & \\
\hline $\begin{array}{c}\text { Inside metropolitan area ............. } \\
\text { Inside central city } \\
\text { Outside central city .................... } \\
\text { Outside metropolitan area ........... }\end{array}$ & $\begin{array}{r}137,472 \\
- \\
44,328\end{array}$ & $\begin{array}{r}\frac{47,387}{-} \\
12,537\end{array}$ & $\begin{array}{c}34.5 \\
- \\
28.3\end{array}$ & $\frac{3.0}{-}$ & $\frac{0.9}{-}$ & $\frac{4.3}{-}$ & $\begin{array}{r}142,522 \\
118,170 \\
24,352 \\
47,021\end{array}$ & $\begin{array}{r}59,627 \\
49,996 \\
9,630 \\
16,634\end{array}$ & $\begin{array}{l}41.8 \\
42.3 \\
39.5 \\
35.4\end{array}$ & $\begin{array}{l}1.2 \\
1.3 \\
1.1 \\
1.0\end{array}$ & $\begin{array}{l}0.9 \\
1.0 \\
0.5 \\
0.1\end{array}$ & $\begin{array}{l}6.5 \\
6.7 \\
5.6 \\
4.9\end{array}$ & $\begin{array}{l}22.0 \\
22.7 \\
18.4 \\
17.9\end{array}$ & $\begin{array}{l}1.2 \\
1.2 \\
1.0 \\
1.0\end{array}$ & $\begin{array}{l}20.3 \\
20.2 \\
21.1 \\
18.5\end{array}$ \\
\hline Labor force status & & & & & & & & & & & & & & & \\
\hline 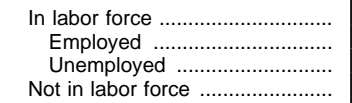 & $\begin{array}{r}125,439 \\
115,620 \\
9,820 \\
56,361\end{array}$ & $\begin{array}{r}51,068 \\
48,512 \\
2,556 \\
8,856\end{array}$ & $\begin{array}{l}40.7 \\
42.0 \\
26.0 \\
15.7\end{array}$ & $\begin{array}{l}3.4 \\
3.3 \\
4.7 \\
1.4\end{array}$ & $\begin{array}{l}0.9 \\
0.8 \\
2.3 \\
0.6\end{array}$ & $\begin{array}{l}5.1 \\
5.2 \\
3.9 \\
1.2\end{array}$ & $\begin{array}{r}125,982 \\
117,826 \\
8,155 \\
63,562\end{array}$ & $\begin{array}{r}62,717 \\
59,734 \\
2,983 \\
13,544\end{array}$ & $\begin{array}{l}49.8 \\
50.7 \\
36.6 \\
21.3\end{array}$ & $\begin{array}{l}1.3 \\
1.1 \\
5.0 \\
0.9\end{array}$ & $\begin{array}{l}0.6 \\
0.5 \\
2.3 \\
0.8\end{array}$ & $\begin{array}{l}8.1 \\
8.2 \\
5.5 \\
2.2\end{array}$ & $\begin{array}{r}29.8 \\
31.1 \\
11.1 \\
3.4\end{array}$ & $\begin{array}{l}1.5 \\
1.5 \\
2.3 \\
0.3\end{array}$ & $\begin{array}{l}21.7 \\
22.0 \\
17.4 \\
16.2\end{array}$ \\
\hline Occupation & & & & & & & & & & & & & & & \\
\hline $\begin{array}{l}\text { Executive, administrative, or } \\
\text { managerial }\end{array}$ & 14,092 & 6,949 & 49.3 & 2.5 & 0.2 & 5.8 & 13,098 & 7,313 & 55.8 & 0.0 & 0.0 & 7.3 & 42.1 & 0.4 & 23.1 \\
\hline $\begin{array}{l}\text { Engineers, surveyors, and } \\
\text { architects }\end{array}$ & 2,820 & 1,765 & 62.6 & 3.2 & 0.4 & 6.2 & 1,756 & 1,150 & 65.5 & 0.0 & 1.0 & 14.1 & 44.6 & 1.0 & 23.3 \\
\hline $\begin{array}{l}\text { Natural scientists and } \\
\text { mathematicians }\end{array}$ & 1,009 & 487 & 48.2 & 0.3 & 0.3 & 5.7 & 1,743 & 1,261 & 72.3 & 0.0 & 0.2 & 9.9 & 58.6 & 0.0 & 24.8 \\
\hline $\begin{array}{l}\text { Social scientists and workers, } \\
\text { lawyers } \\
\text { Teachers, elementary and }\end{array}$ & 3,206 & 1,781 & 55.6 & 1.2 & 0.1 & 4.4 & 2,530 & 1,938 & 76.6 & 0.0 & 0.2 & 11.5 & 59.4 & 1.5 & 32.3 \\
\hline secondary & 7,824 & 4,305 & 55.0 & 5.0 & 1.0 & 11.1 & 5,414 & 4,155 & 76.7 & 0.0 & 0.0 & 16.6 & 52.4 & 0.2 & 36.9 \\
\hline $\begin{array}{l}\text { Teachers, postsecondary .......... } \\
\text { Physicians, dentists, veterinar- }\end{array}$ & 1,247 & 568 & 45.5 & 1.5 & 0.5 & 9.4 & 1,254 & 687 & 54.8 & 0.0 & 0.3 & 4.1 & 40.8 & 0.0 & 26.0 \\
\hline ians. & 1,045 & 701 & 67.1 & 0.8 & 1.1 & 1.3 & 859 & 611 & 71.1 & 0.0 & 0.0 & 1.2 & 67.1 & 0.8 & 19.0 \\
\hline $\begin{array}{l}\text { Registered nurses, pharmacists } \\
\text { Writers, artists, entertainers, and }\end{array}$ & 4,692 & 2,798 & 59.6 & 2.5 & 0.9 & 6.9 & 2,337 & 2,026 & 86.7 & 0.1 & 0.1 & 10.6 & 71.3 & 0.2 & 33.6 \\
\hline $\begin{array}{l}\text { athletes .................................... } \\
\text { Health technologists and techni- }\end{array}$ & 3,459 & 1,485 & 42.9 & 1.5 & 0.2 & 4.0 & 1,874 & 934 & 49.9 & 0.1 & 0.6 & 7.7 & 23.1 & 1.5 & 30.0 \\
\hline & 1,233 & 846 & 68.6 & 5.9 & 2.9 & 6.6 & 1,697 & 1,270 & 74.8 & 0.0 & 0.5 & 12.8 & 47.5 & 0.0 & 33.0 \\
\hline $\begin{array}{l}\text { Technologists, except health ..... } \\
\text { Marketing and sales occupa- }\end{array}$ & 2,225 & 1,232 & 55.4 & 4.5 & 0.7 & 6.4 & 3,543 & 2,279 & 64.3 & 0.3 & 0.1 & 13.5 & 41.3 & 0.8 & 28.7 \\
\hline $\begin{array}{l}\text { tions } \\
\text { Administrative support, including }\end{array}$ & 18,787 & 6,470 & 34.4 & 2.3 & 0.6 & 3.1 & 18,174 & 8,038 & 44.2 & 1.1 & 0.4 & 6.8 & 23.2 & 1.0 & 20.4 \\
\hline 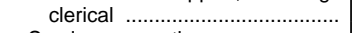 & 32,321 & 9,662 & 29.9 & 2.5 & 0.4 & 4.6 & 22,968 & 11,867 & 51.7 & 1.0 & 0.3 & 9.5 & 28.9 & 0.7 & 24.7 \\
\hline Service occupations ....................... & 25,386 & 6,409 & 25.2 & 3.8 & 1.1 & 3.4 & 20,072 & 9,342 & 46.5 & 2.4 & 0.9 & 9.0 & 20.9 & 1.6 & 22.8 \\
\hline Agriculture, forestry, and fishing & 4,800 & 686 & 14.3 & 0.6 & 0.4 & 0.7 & 2,336 & 616 & 26.4 & 0.4 & 0.5 & 1.6 & 11.5 & 0.3 & 15.6 \\
\hline $\begin{array}{l}\text { Mechanics and repairers ............ } \\
\text { Construction and extractive oc- }\end{array}$ & 6,744 & 2,165 & 32.1 & 3.1 & 0.4 & 2.5 & 4,692 & 2,231 & 47.6 & 2.1 & 0.6 & 7.1 & 27.7 & 4.5 & 15.6 \\
\hline cupations & 6,201 & 1,360 & 21.9 & 3.2 & 1.0 & 1.6 & 6,100 & 2,319 & 38.0 & 1.2 & 0.8 & 4.3 & 17.6 & 5.8 & 18.0 \\
\hline 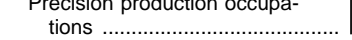 & 3,690 & 1,152 & 31.2 & 3.31 & 1.8 & 4.3 & 1,875 & 807 & 43.0 & 1.5 & 2.2 & 5.5 & 23.2 & 4.8 & 16.1 \\
\hline
\end{tabular}


Table 356.-Participation in adult education during the previous 12 months by adults 17 years old and older, by selected characteristics of participants: 1991 and 1995-Continued

\begin{tabular}{|c|c|c|c|c|c|c|c|c|c|c|c|c|c|c|c|}
\hline \multirow[b]{3}{*}{ Characteristics of participants } & \multicolumn{6}{|c|}{1991} & \multicolumn{9}{|c|}{1995} \\
\hline & \multirow[b]{2}{*}{$\begin{array}{l}\text { Popu- } \\
\text { lation, in } \\
\text { thou- } \\
\text { sands }\end{array}$} & \multirow[b]{2}{*}{$\begin{array}{l}\text { Adult } \\
\text { edu- } \\
\text { cation } \\
\text { parti- } \\
\text { cipants, } \\
\text { in thou- } \\
\text { sands }^{1}\end{array}$} & \multicolumn{4}{|c|}{ Percent of adults participating } & \multirow[b]{2}{*}{$\begin{array}{l}\text { Popu- } \\
\text { lation, in } \\
\text { thou- } \\
\text { sands }\end{array}$} & \multirow[b]{2}{*}{$\begin{array}{c}\text { Adult } \\
\text { edu- } \\
\text { cation } \\
\text { parti- } \\
\text { cipants, } \\
\text { in thou- } \\
\text { sands }^{1}\end{array}$} & \multicolumn{7}{|c|}{ Percent of adults participating } \\
\hline & & & $\begin{array}{l}\text { In any } \\
\text { pro-- } \\
\text { gram }\end{array}$ & $\begin{array}{l}\text { In } \\
\text { basic } \\
\text { edu- } \\
\text { cation }\end{array}$ & $\begin{array}{c}\text { In } \\
\text { Eng- } \\
\text { lish } \\
\text { as a } \\
\text { sec- } \\
\text { ond } \\
\text { lan- } \\
\text { guage }\end{array}$ & $\begin{array}{l}\text { In } \\
\text { part- } \\
\text { time } \\
\text { higher } \\
\text { edu- } \\
\text { cation }\end{array}$ & & & $\begin{array}{c}\text { In any } \\
\text { pro- } \\
\text { gram }\end{array}$ & $\begin{array}{l}\text { In } \\
\text { basic } \\
\text { edu- } \\
\text { cation }\end{array}$ & $\begin{array}{l}\text { In Eng- } \\
\text { lish as } \\
\text { a sec- } \\
\text { ond } \\
\text { lan- } \\
\text { guage }\end{array}$ & $\begin{array}{c}\text { In part- } \\
\text { time } \\
\text { higher } \\
\text { edu-- } \\
\text { cation }\end{array}$ & $\begin{array}{l}\text { In ca- } \\
\text { reer or } \\
\text { job re- } \\
\text { lated } \\
\text { courses }\end{array}$ & $\begin{array}{l}\text { In ap- } \\
\text { pren- } \\
\text { tice } \\
\text { pro- } \\
\text { grams }\end{array}$ & $\begin{array}{c}\text { Other } \\
\text { per- } \\
\text { sonal } \\
\text { courses }\end{array}$ \\
\hline 1 & 2 & 3 & 4 & 5 & 6 & 7 & 8 & 9 & 10 & 11 & 12 & 13 & 14 & 15 & 16 \\
\hline Production workers & 14,368 & 3,029 & 21.1 & 2.9 & 1.2 & 1.6 & 9,483 & 2,908 & 30.7 & 2.5 & 1.1 & 5.8 & 14.7 & 2.8 & 10.7 \\
\hline Transportation, material moving & 5,655 & 1,173 & 20.7 & 1.6 & 0.2 & 1.0 & 5,311 & 1,507 & 28.4 & 1.9 & 0.1 & 3.5 & 15.5 & 0.9 & 11.9 \\
\hline $\begin{array}{l}\text { helpers, and laborers ............. } \\
\text { Miscellaneous occupations ........ }\end{array}$ & 5,069 & 1,056 & 20.8 & $\begin{array}{r}3.7 \\
-\end{array}$ & 2.0 & 2.2 & $\begin{array}{l}2,456 \\
2,311\end{array}$ & $\begin{array}{r}617 \\
1,308\end{array}$ & $\begin{array}{l}25.1 \\
56.6\end{array}$ & $\begin{array}{l}2.7 \\
0.5\end{array}$ & $\begin{array}{l}0.7 \\
1.5\end{array}$ & $\begin{array}{l}3.1 \\
7.9\end{array}$ & $\begin{array}{l}11.1 \\
35.4\end{array}$ & $\begin{array}{l}3.3 \\
4.0\end{array}$ & $\begin{array}{r}9.7 \\
22.6\end{array}$ \\
\hline \multicolumn{16}{|l|}{ Annual family income } \\
\hline$\$ 5,000$ or less & 10,227 & 1,394 & 13.6 & 3.8 & 2.0 & 1.2 & 12,638 & 2,689 & 21.3 & 3.1 & 1.7 & 3.3 & 4.1 & 1.1 & 11.8 \\
\hline$\$ 5,001$ to $\$ 10,000$ & 17,277 & 3,024 & 17.5 & 2.3 & 0.8 & 2.2 & 17,560 & 4,194 & 23.9 & 2.5 & 1.5 & 4.0 & 6.7 & 1.0 & 13.2 \\
\hline$\$ 10,001$ to $\$ 15,000$ & 15,465 & 3,521 & 22.8 & 2.4 & 1.1 & 2.7 & 13,523 & 3,610 & 26.7 & 2.0 & 0.8 & 4.0 & 8.7 & 1.1 & 14.8 \\
\hline$\$ 15,001$ to $\$ 20,000$ & 16,117 & 3,525 & 21.9 & 2.7 & 1.2 & 3.1 & 13,116 & 4,176 & 31.8 & 1.3 & 1.1 & 5.4 & 13.0 & 1.5 & 15.8 \\
\hline$\$ 20,001$ to $\$ 25,000$ & 16,092 & 4,294 & 26.7 & 2.5 & 1.2 & 3.3 & 13,812 & 4,339 & 31.4 & 1.1 & 0.8 & 4.8 & 13.3 & 1.1 & 17.0 \\
\hline$\$ 25,001$ to $\$ 30,000 \ldots \ldots \ldots \ldots \ldots \ldots$ & 17,973 & 5,772 & 32.1 & 3.4 & 1.1 & 4.5 & 16,386 & 6,208 & 37.9 & 1.2 & 0.4 & 6.5 & 17.1 & 1.3 & 19.2 \\
\hline$\$ 30,001$ to $\$ 40,000 \ldots \ldots \ldots \ldots \ldots \ldots \ldots . .$. & 26,110 & 9,288 & 35.6 & 3.0 & 0.6 & 4.4 & 28,628 & 12,220 & 42.7 & 0.8 & 0.4 & 6.9 & 22.1 & 1.4 & 22.0 \\
\hline$\$ 40,001$ to $\$ 50,000$ & 21,303 & 9,550 & 44.8 & 3.0 & 0.7 & 5.4 & 20,446 & 9,567 & 46.8 & 0.7 & 0.4 & 6.8 & 27.0 & 1.0 & 22.4 \\
\hline$\$ 50,001$ to $\$ 75,000 \ldots \ldots \ldots \ldots \ldots \ldots$ & 24,540 & 11,425 & 46.6 & 3.0 & 0.3 & 5.6 & 29,161 & 15,169 & 52.0 & 0.4 & 0.3 & 7.6 & 32.8 & 1.0 & 23.6 \\
\hline More than $\$ 75,000$ & 16,695 & 8,130 & 48.7 & 1.9 & 0.3 & 4.0 & 24,274 & 14,089 & 58.0 & 0.5 & 0.3 & 7.7 & 37.3 & 0.8 & 26.8 \\
\hline
\end{tabular}

1 Adult education is defined as all education activities, except full-time enrollment in higher education credential programs. Examples of adult education activities include part-time college attendance, classes or seminars given by employers, and classes taken for adult literacy purposes, or for recreation and enjoyment.
NOTE.-Data are based upon a sample survey of the civilian noninstitutional population. Because of rounding and survey item nonresponse, details may not add to totals.

SOURCE: U.S. Department of Education, National Center for Education Statistics, "Participation in Adult Education," unpublished data. (This table was prepared February 1997.) 
Table 357.-Participants in adult basic and secondary education programs, by level of enrollment and state: Fiscal years 1980, 1990, and 1995

\begin{tabular}{|c|c|c|c|c|c|c|c|c|c|c|}
\hline \multirow{3}{*}{ State or other area } & \multicolumn{4}{|c|}{1980} & \multicolumn{3}{|c|}{1990} & \multicolumn{3}{|c|}{1995} \\
\hline & \multirow[b]{2}{*}{ Total } & \multicolumn{3}{|c|}{ Level of enrollment } & \multirow[b]{2}{*}{ Total } & \multicolumn{2}{|c|}{ Level of enrollment } & \multirow[b]{2}{*}{ Total } & \multicolumn{2}{|c|}{ Level of enrollment } \\
\hline & & $\begin{array}{l}\text { Adult basic } \\
\text { education }\end{array}$ & $\begin{array}{c}\text { Adult } \\
\text { secondary } \\
\text { education }\end{array}$ & Ungraded & & $\begin{array}{l}\text { Adult basic } \\
\text { education } 1\end{array}$ & $\begin{array}{c}\text { Adult } \\
\text { secondary } \\
\text { education }\end{array}$ & & $\begin{array}{l}\text { Adult basic } \\
\text { education } 1\end{array}$ & $\begin{array}{c}\text { Adult } \\
\text { secondary } \\
\text { education }\end{array}$ \\
\hline 1 & 2 & 3 & 4 & 5 & 6 & 7 & 8 & 9 & 10 & 11 \\
\hline United States & $2,018,906$ & 915,936 & 531,663 & 571,307 & $3,535,970$ & $2,435,649$ & $1,100,321$ & $3,875,452$ & $2,948,302$ & 927,150 \\
\hline $\begin{array}{l}\text { Alabama } \\
\text { Alaska } \\
\text { Arizona } \\
\text { Arkansas } \\
\text { California }\end{array}$ & $\begin{array}{r}51,599 \\
5,667 \\
9,996 \\
8,583 \\
267,625\end{array}$ & $\begin{array}{r}36,726 \\
2,200 \\
9,968 \\
7,308 \\
60,385\end{array}$ & $\begin{array}{r}12,372 \\
2,188 \\
22 \\
1,275 \\
\end{array}$ & $\begin{array}{r}2,501 \\
1,279 \\
6 \\
-207,240\end{array}$ & $\begin{array}{r}40,177 \\
5,067 \\
33,805 \\
29,065 \\
1,021,227\end{array}$ & $\begin{array}{r}32,984 \\
4,267 \\
24,915 \\
17,103 \\
753,282\end{array}$ & $\begin{array}{r}7,193 \\
800 \\
8,890 \\
11,962 \\
267,945\end{array}$ & $\begin{array}{r}56,488 \\
7,906 \\
52,656 \\
42,457 \\
1,088,044\end{array}$ & $\begin{array}{r}45,193 \\
6,203 \\
40,002 \\
24,344 \\
1,057,257\end{array}$ & $\begin{array}{r}11,295 \\
1,703 \\
12,654 \\
18,113 \\
30,787\end{array}$ \\
\hline 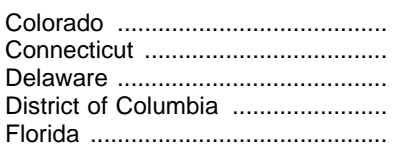 & $\begin{array}{r}9,381 \\
21,889 \\
1,797 \\
25,214 \\
467,162\end{array}$ & $\begin{array}{r}4,295 \\
8,882 \\
1,110 \\
4,928 \\
100,958\end{array}$ & $\begin{array}{r}2,644 \\
4,805 \\
503 \\
6,502 \\
184,568\end{array}$ & $\begin{array}{r}2,442 \\
8,202 \\
184 \\
13,784 \\
181,636\end{array}$ & $\begin{array}{r}12,183 \\
46,434 \\
2,662 \\
19,586 \\
419,429\end{array}$ & $\begin{array}{r}9,877 \\
25,560 \\
2,348 \\
12,631 \\
249,339\end{array}$ & $\begin{array}{r}2,306 \\
20,874 \\
314 \\
6,955 \\
170,090\end{array}$ & $\begin{array}{r}14,851 \\
26,170 \\
3,884 \\
9,138 \\
474,651\end{array}$ & $\begin{array}{r}11,020 \\
15,766 \\
3,391 \\
6,656 \\
302,990\end{array}$ & $\begin{array}{r}3,831 \\
10,404 \\
493 \\
2,482 \\
171,661\end{array}$ \\
\hline 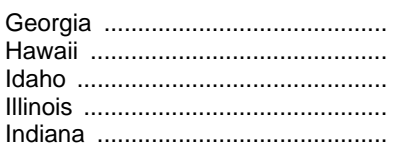 & $\begin{array}{l}50,820 \\
16,457 \\
12,851 \\
76,456 \\
20,882\end{array}$ & $\begin{array}{r}26,734 \\
16,457 \\
8,915 \\
59,314 \\
18,127\end{array}$ & $\begin{array}{r}17,008 \\
- \\
3,010 \\
17,142 \\
2,660\end{array}$ & $\begin{array}{r}7,078 \\
\frac{-}{926} \\
\frac{95}{}\end{array}$ & $\begin{array}{l}69,580 \\
52,012 \\
11,171 \\
87,121 \\
44,166\end{array}$ & $\begin{array}{r}49,622 \\
31,766 \\
9,180 \\
69,770 \\
27,138\end{array}$ & $\begin{array}{r}19,958 \\
20,246 \\
1,991 \\
17,351 \\
17,028\end{array}$ & $\begin{array}{r}92,022 \\
61,664 \\
9,828 \\
94,808 \\
38,102\end{array}$ & $\begin{array}{r}64,079 \\
36,988 \\
7,467 \\
80,122 \\
26,170\end{array}$ & $\begin{array}{r}27,943 \\
24,676 \\
2,361 \\
14,686 \\
11,932\end{array}$ \\
\hline $\begin{array}{l}\text { lowa } \\
\text { Kansas } \\
\text { Kentucky } \\
\text { Louisiana } \\
\text { Maine }\end{array}$ & $\begin{array}{r}25,851 \\
14,405 \\
27,800 \\
16,046 \\
5,327\end{array}$ & $\begin{array}{r}16,928 \\
3,687 \\
6,147 \\
12,608 \\
3,029\end{array}$ & $\begin{array}{r}5,153 \\
7,436 \\
4,735 \\
2,485 \\
942\end{array}$ & $\begin{array}{r}3,770 \\
3,282 \\
16,918 \\
953 \\
1,356\end{array}$ & $\begin{array}{l}41,507 \\
10,274 \\
28,090 \\
40,039 \\
14,964\end{array}$ & $\begin{array}{r}30,470 \\
9,191 \\
20,406 \\
20,941 \\
6,620\end{array}$ & $\begin{array}{r}11,037 \\
1,083 \\
7,684 \\
19,098 \\
8,344\end{array}$ & $\begin{array}{l}40,510 \\
13,762 \\
30,352 \\
46,087 \\
15,687\end{array}$ & $\begin{array}{r}28,961 \\
10,679 \\
23,207 \\
24,663 \\
7,050\end{array}$ & $\begin{array}{r}11,549 \\
3,083 \\
7,145 \\
21,424 \\
8,637\end{array}$ \\
\hline 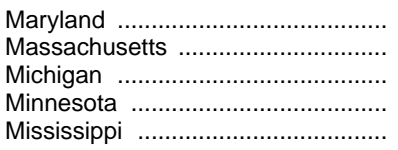 & $\begin{array}{l}34,572 \\
20,420 \\
40,973 \\
10,826 \\
14,317\end{array}$ & $\begin{array}{r}23,421 \\
10,241 \\
29,945 \\
8,627 \\
10,340\end{array}$ & $\begin{array}{r}6,043 \\
5,044 \\
-877 \\
2,918\end{array}$ & $\begin{array}{r}5,108 \\
5,135 \\
11,028 \\
1,322 \\
1,059\end{array}$ & $\begin{array}{r}41,230 \\
34,220 \\
194,178 \\
45,648 \\
18,957\end{array}$ & $\begin{array}{l}36,244 \\
28,140 \\
80,206 \\
33,190 \\
15,834\end{array}$ & $\begin{array}{r}4,986 \\
6,080 \\
113,972 \\
12,458 \\
3,123\end{array}$ & $\begin{array}{r}30,677 \\
15,014 \\
164,075 \\
36,350 \\
22,857\end{array}$ & $\begin{array}{l}21,692 \\
11,828 \\
69,014 \\
26,556 \\
17,660\end{array}$ & $\begin{array}{r}8,985 \\
3,186 \\
95,061 \\
9,794 \\
5,197\end{array}$ \\
\hline 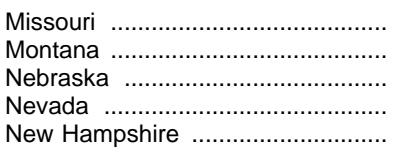 & $\begin{array}{r}33,292 \\
3,525 \\
7,514 \\
3,063 \\
4,844\end{array}$ & $\begin{array}{r}27,206 \\
1,795 \\
5,152 \\
845 \\
2,657\end{array}$ & $\begin{array}{r}3,732 \\
978 \\
2,362 \\
82 \\
1,625\end{array}$ & $\begin{array}{r}2,354 \\
752 \\
-136 \\
2,1362 \\
562\end{array}$ & $\begin{array}{r}31,815 \\
6,071 \\
6,158 \\
17,262 \\
7,198\end{array}$ & $\begin{array}{r}27,274 \\
3,962 \\
5,349 \\
7,270 \\
5,073\end{array}$ & $\begin{array}{r}4,541 \\
2,109 \\
809 \\
9,992 \\
2,125\end{array}$ & $\begin{array}{r}34,804 \\
6,545 \\
7,616 \\
16,359 \\
6,223\end{array}$ & $\begin{array}{r}29,882 \\
4,044 \\
6,974 \\
4,556 \\
3,309\end{array}$ & $\begin{array}{r}4,922 \\
2,501 \\
642 \\
11,803 \\
2,914\end{array}$ \\
\hline 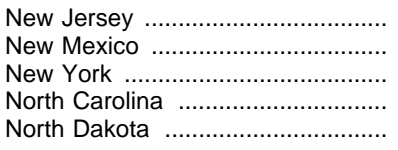 & $\begin{array}{r}35,770 \\
13,102 \\
94,574 \\
84,252 \\
2,810\end{array}$ & $\begin{array}{r}17,152 \\
3,590 \\
57,217 \\
33,854 \\
1,963\end{array}$ & $\begin{array}{r}6,790 \\
5,147 \\
20,002 \\
46,679 \\
538\end{array}$ & $\begin{array}{r}11,828 \\
4,365 \\
17,355 \\
3,719 \\
309\end{array}$ & $\begin{array}{r}64,080 \\
30,236 \\
156,611 \\
109,740 \\
3,587\end{array}$ & $\begin{array}{r}46,526 \\
18,069 \\
125,893 \\
71,698 \\
2,500\end{array}$ & $\begin{array}{r}17,554 \\
12,167 \\
30,718 \\
38,042 \\
1,087\end{array}$ & $\begin{array}{r}37,500 \\
35,080 \\
209,390 \\
120,945 \\
3,270\end{array}$ & $\begin{array}{r}29,410 \\
20,628 \\
165,892 \\
83,673 \\
2,329\end{array}$ & $\begin{array}{r}8,090 \\
14,452 \\
43,498 \\
37,272 \\
941\end{array}$ \\
\hline 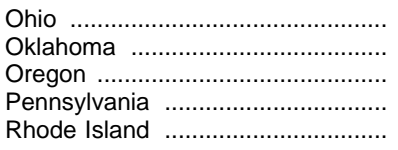 & $\begin{array}{r}50,056 \\
14,701 \\
27,645 \\
29,477 \\
5,844\end{array}$ & $\begin{array}{r}42,421 \\
6,983 \\
10,690 \\
19,246 \\
2,266\end{array}$ & $\begin{array}{r}7,635 \\
5,697 \\
12,594 \\
6,436 \\
1,357\end{array}$ & $\begin{array}{l}-\overline{-} \\
2,021 \\
4,361 \\
3,795 \\
2,221\end{array}$ & $\begin{array}{r}95,476 \\
24,307 \\
37,075 \\
52,444 \\
7,347\end{array}$ & $\begin{array}{r}79,527 \\
19,131 \\
24,915 \\
40,108 \\
5,874\end{array}$ & $\begin{array}{r}15,949 \\
5,176 \\
12,160 \\
12,336 \\
1,473\end{array}$ & $\begin{array}{r}110,305 \\
32,778 \\
40,800 \\
52,176 \\
6,182\end{array}$ & $\begin{array}{r}91,221 \\
26,621 \\
22,875 \\
37,497 \\
4,829\end{array}$ & $\begin{array}{r}19,084 \\
6,157 \\
17,925 \\
14,679 \\
1,353\end{array}$ \\
\hline 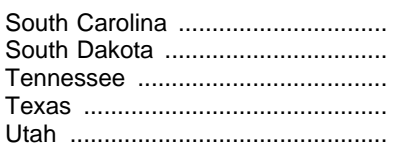 & $\begin{array}{r}69,659 \\
4,067 \\
26,268 \\
157,349 \\
18,541\end{array}$ & $\begin{array}{r}27,959 \\
2,080 \\
17,079 \\
94,245 \\
3,756\end{array}$ & $\begin{array}{r}35,165 \\
1,109 \\
3,244 \\
51,126 \\
14,785\end{array}$ & $\begin{array}{r}6,535 \\
878 \\
5,945 \\
11,978 \\
-\end{array}$ & $\begin{array}{r}81,200 \\
3,184 \\
41,721 \\
218,747 \\
24,841\end{array}$ & $\begin{array}{r}37,117 \\
2,458 \\
39,604 \\
145,067 \\
6,003\end{array}$ & $\begin{array}{r}44,083 \\
726 \\
2,117 \\
73,680 \\
18,838\end{array}$ & $\begin{array}{r}108,041 \\
4,518 \\
51,054 \\
207,921 \\
30,302\end{array}$ & $\begin{array}{r}46,644 \\
3,624 \\
39,019 \\
159,983 \\
11,147\end{array}$ & $\begin{array}{r}61,397 \\
894 \\
12,035 \\
47,938 \\
19,155\end{array}$ \\
\hline 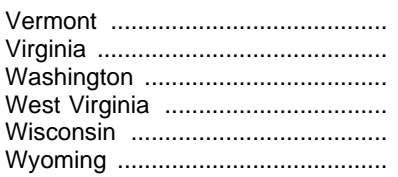 & $\begin{array}{r}4,583 \\
21,525 \\
16,286 \\
14,628 \\
16,158 \\
2,457\end{array}$ & $\begin{array}{r}3,990 \\
10,480 \\
7,245 \\
9,743 \\
14,185 \\
857\end{array}$ & $\begin{array}{r}- \\
3,804 \\
3,894 \\
3,672 \\
1,973 \\
905\end{array}$ & $\begin{array}{r}593 \\
7,241 \\
5,147 \\
1,213 \\
- \\
695\end{array}$ & $\begin{array}{r}4,808 \\
31,649 \\
31,776 \\
21,186 \\
61,081 \\
3,578\end{array}$ & $\begin{array}{r}4,452 \\
30,005 \\
25,336 \\
14,227 \\
45,116 \\
2,071\end{array}$ & $\begin{array}{r}356 \\
1,644 \\
6,440 \\
26,959 \\
15,965 \\
21,507\end{array}$ & $\begin{array}{r}4,800 \\
33,786 \\
44,728 \\
26,232 \\
78,544 \\
4,370\end{array}$ & $\begin{array}{r}4,434 \\
24,920 \\
39,061 \\
18,912 \\
60,162 \\
2,912\end{array}$ & $\begin{array}{r}366 \\
8,866 \\
5,667 \\
7,320 \\
18,382 \\
1,458\end{array}$ \\
\hline $\begin{array}{r}\text { Outlying areas } \\
\text { American Samoa ............. }\end{array}$ & 313 & 252 & 61 & - & -1 & & - & - & - & - \\
\hline 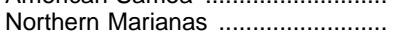 & - & - & - & - & - & - & - & 430 & 246 & 184 \\
\hline $\begin{array}{l}\text { Guam } \\
\text { Puerto Rico } \ldots \ldots \ldots \ldots \ldots \ldots \ldots \ldots \ldots \ldots \ldots\end{array}$ & $\begin{array}{r}1,346 \\
30,164\end{array}$ & $\begin{array}{r}612 \\
17,844\end{array}$ & $\begin{array}{r}471 \\
9,010\end{array}$ & $\begin{array}{r}263 \\
3,310\end{array}$ & $\begin{array}{r}1,311 \\
28,436\end{array}$ & $\begin{array}{r}414 \\
28,436\end{array}$ & ${ }^{2897}$ & $\begin{array}{r}2,034 \\
68,394\end{array}$ & $\begin{array}{r}632 \\
32,943\end{array}$ & $\begin{array}{r}1,402 \\
35,451\end{array}$ \\
\hline Trust Territory of the Pacific ........... & 3,753 & 2,138 & 699 & 916 & - & & - & & - & \\
\hline 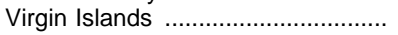 & 3,500 & 1,002 & 859 & 1,639 & 1,653 & 1,215 & 438 & 2,285 & 965 & 1,320 \\
\hline
\end{tabular}

1 Includes English as a second language.

2 Estimated.

Education Programs;" Office of Vocational and Adult Education, "Adult Education Program Facts, Program Year 1990-1991" and Division of Adult Education and Literacy, "Adult Education Program Facts, Program Year 1995-96." (This table was prepared April 1997).

SOURCE: U.S. Department of Education, National Center for Education Statistics, "Women and Minority Groups Make Up Largest Segment of Adult Basic and Secondary 
Table 358.-Number of noncollegiate institutions offering postsecondary education, by control and state: 1993-94, 1994-95, and 1995-96

\begin{tabular}{|c|c|c|c|c|c|c|c|c|c|c|c|c|c|}
\hline \multirow{3}{*}{ State or other area } & \multicolumn{3}{|c|}{ 1993-94 } & \multicolumn{5}{|c|}{ 1994-95 } & \multicolumn{5}{|c|}{$1995-96$} \\
\hline & \multirow{2}{*}{ Total } & \multirow{2}{*}{ Public } & \multirow{2}{*}{ Private } & \multirow{2}{*}{ Total } & \multirow{2}{*}{ Public } & \multicolumn{3}{|c|}{ Private } & \multirow{2}{*}{ Total } & & & Private & \\
\hline & & & & & & Total & Nonprofit & Proprietary & & rubic & Total & Nonprofit & Proprietary \\
\hline 1 & 2 & 3 & 4 & 5 & 6 & 7 & 8 & 9 & 10 & 11 & 12 & 13 & 14 \\
\hline United States ......... & 6,737 & 527 & 6,210 & 6,558 & 538 & 6,020 & 1,214 & 4,806 & 6,256 & 534 & 5,722 & 1,171 & 4,551 \\
\hline Alabama ....... & 76 & 10 & 66 & 71 & 8 & 63 & 8 & 55 & 63 & 7 & 56 & 7 & 49 \\
\hline 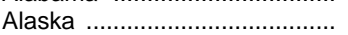 & 32 & 3 & 29 & 31 & 3 & 28 & 5 & 23 & 31 & 3 & 28 & 5 & 23 \\
\hline Arizona & 125 & 4 & 121 & 124 & 4 & 120 & 16 & 104 & 113 & 4 & 109 & 16 & 93 \\
\hline 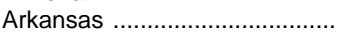 & 82 & 20 & 62 & 76 & 19 & 57 & 9 & 48 & 69 & 16 & 53 & 8 & 45 \\
\hline California & 1,126 & 32 & 1,094 & 1,041 & 35 & 1,006 & 230 & 776 & 997 & 35 & 962 & 225 & 737 \\
\hline Colorado ………..................... & 138 & 8 & 130 & 146 & 8 & 138 & 21 & 117 & 143 & 6 & 137 & 22 & 115 \\
\hline Connecticut .............................. & 100 & 1 & 99 & 105 & 1 & 104 & 21 & 83 & 97 & 2 & 95 & 20 & 75 \\
\hline Delaware ...... & 15 & 1 & 14 & 14 & 1 & 13 & 2 & 11 & 12 & 1 & 11 & 2 & 9 \\
\hline District of Columbia ...................... & 24 & 1 & 23 & 21 & 1 & 20 & 9 & 11 & 19 & 1 & 18 & 8 & 10 \\
\hline 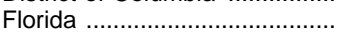 & 341 & 40 & 301 & 339 & 40 & 299 & 56 & 243 & 333 & 39 & 294 & 54 & 240 \\
\hline Georgia ........ & 102 & 4 & 98 & 104 & 4 & 100 & 15 & 85 & 101 & 5 & 96 & 16 & 80 \\
\hline 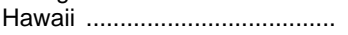 & 29 & 1 & 28 & 26 & 1 & 25 & 4 & 21 & 22 & 1 & 21 & 3 & 18 \\
\hline 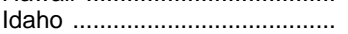 & 26 & 1 & 25 & 25 & 1 & 24 & 1 & 23 & 24 & 1 & 23 & 1 & 22 \\
\hline Illinois & 304 & 12 & 292 & 285 & 11 & 274 & 56 & 218 & 264 & 10 & 254 & 56 & 198 \\
\hline 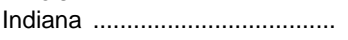 & 117 & 8 & 109 & 114 & 7 & 107 & 13 & 94 & 108 & 8 & 100 & 14 & 86 \\
\hline lowa & 72 & 0 & 72 & 66 & 0 & 66 & 17 & 49 & 62 & 0 & 62 & 16 & 46 \\
\hline Kansas ......................................... & 62 & 14 & 48 & 62 & 13 & 49 & 11 & 38 & 53 & 10 & 43 & 7 & 36 \\
\hline Kentucky …….......................... & 112 & 21 & 91 & 113 & 22 & 91 & 7 & 84 & 105 & 23 & 82 & 6 & 76 \\
\hline Louisiana .............................. & 165 & 49 & 116 & 150 & 49 & 101 & 9 & 92 & 141 & 51 & 90 & 9 & 81 \\
\hline Maine & 21 & 0 & 21 & 23 & 0 & 23 & 8 & 15 & 24 & 1 & 23 & 8 & 15 \\
\hline Maryland …………………........ & 135 & 0 & 135 & 122 & 0 & 122 & 21 & 101 & 112 & 0 & 112 & 20 & 92 \\
\hline Massachusetts ....................... & 159 & 13 & 146 & 162 & 12 & 150 & 44 & 106 & 160 & 12 & 148 & 42 & 106 \\
\hline 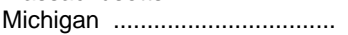 & 247 & 6 & 241 & 282 & 6 & 276 & 44 & 232 & 264 & 6 & 258 & 43 & 215 \\
\hline Minnesota ……............................ & 89 & 14 & 75 & 88 & 5 & 83 & 18 & 65 & 79 & 4 & 75 & 16 & 59 \\
\hline 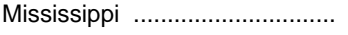 & 52 & 0 & 52 & 49 & 0 & 49 & 4 & 45 & 38 & 0 & 38 & 3 & 35 \\
\hline Missouri ............... & 168 & 30 & 138 & 170 & 31 & 139 & 25 & 114 & 159 & 31 & 128 & 24 & 104 \\
\hline Montana & 45 & 5 & 40 & 43 & 4 & 39 & 9 & 30 & 36 & 0 & 36 & 8 & 28 \\
\hline 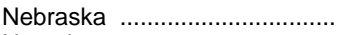 & 50 & 0 & 50 & 51 & 0 & 51 & 8 & 43 & 50 & 0 & 50 & 8 & 42 \\
\hline Nevada & 46 & 0 & 46 & 47 & 0 & 47 & 1 & 46 & 57 & 0 & 57 & 1 & 56 \\
\hline New Hampshire ..................... & 25 & 0 & 25 & 22 & 0 & 22 & 2 & 20 & 18 & 0 & 18 & 2 & 16 \\
\hline New Jersey . & 176 & 10 & 166 & 166 & 10 & 156 & 37 & 119 & 161 & 12 & 149 & 33 & 116 \\
\hline New Mexico ……………….... & 46 & 3 & 43 & 45 & 4 & 41 & 6 & 35 & 38 & 3 & 35 & 6 & 29 \\
\hline 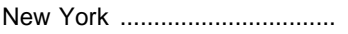 & 353 & 15 & 338 & 337 & 26 & 311 & 118 & 193 & 343 & 31 & 312 & 115 & 197 \\
\hline North Carolina .......................... & 81 & 4 & 77 & 81 & 4 & 77 & 8 & 69 & 74 & 4 & 70 & 7 & 63 \\
\hline North Dakota .............................. & 19 & 0 & 19 & 19 & 0 & 19 & 6 & 13 & 17 & 0 & 17 & 5 & 12 \\
\hline ............ & 312 & 52 & 260 & 303 & 54 & 249 & 60 & 189 & 290 & 55 & 235 & 56 & 179 \\
\hline Oklahoma & 95 & 34 & 61 & 111 & 33 & 78 & 5 & 73 & 108 & 33 & 75 & 4 & 71 \\
\hline Oregon & 109 & 0 & 109 & 99 & 0 & 99 & 9 & 90 & 94 & 1 & 93 & 11 & 82 \\
\hline Pennsylvania ............................... & 347 & 19 & 328 & 352 & 30 & 322 & 100 & 222 & 345 & 31 & 314 & 103 & 211 \\
\hline Rhode Island & 28 & 0 & 28 & 28 & 0 & 28 & 9 & 19 & 29 & 0 & 29 & 9 & 20 \\
\hline South Carolina & 60 & 2 & 58 & 56 & 2 & 54 & 11 & 43 & 57 & 1 & 56 & 11 & 45 \\
\hline South Dakota ........................... & 17 & 5 & 12 & 17 & 5 & 12 & 5 & 7 & 16 & 5 & 11 & 4 & 7 \\
\hline Tennessee ................................ & 143 & 30 & 113 & 139 & 29 & 110 & 20 & 90 & 135 & 29 & 106 & 17 & 89 \\
\hline 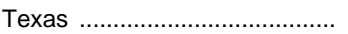 & 382 & 6 & 376 & 360 & 7 & 353 & 37 & 316 & 350 & 6 & 344 & 38 & 306 \\
\hline Utah & 43 & 6 & 37 & 42 & 6 & 36 & 2 & 34 & 39 & 5 & 34 & 2 & 32 \\
\hline Vermont & 13 & 3 & 10 & 13 & 3 & 10 & 4 & 6 & 10 & 0 & 10 & 4 & 6 \\
\hline …………..... & 148 & 11 & 137 & 144 & 11 & 133 & 32 & 101 & 139 & 12 & 127 & 31 & 96 \\
\hline 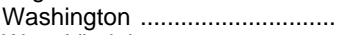 & 111 & 5 & 106 & 107 & 5 & 102 & 13 & 89 & 104 & 5 & 99 & 12 & 87 \\
\hline 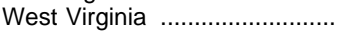 & 70 & 19 & 51 & 73 & 18 & 55 & 14 & 41 & 71 & 19 & 52 & 13 & 39 \\
\hline 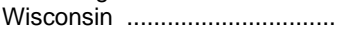 & 90 & 4 & 86 & 86 & 5 & 81 & 24 & 57 & 74 & 5 & 69 & 20 & 49 \\
\hline 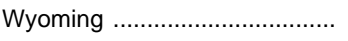 & 9 & 1 & 8 & 8 & 0 & 8 & 0 & 8 & 8 & 0 & 8 & 0 & 8 \\
\hline Outlying areas ...................... & 95 & 5 & 90 & 84 & 6 & 78 & 16 & 62 & 84 & 6 & 78 & 14 & 64 \\
\hline American Samoa & 0 & 0 & 0 & 0 & 0 & 0 & 0 & 0 & 0 & 0 & 0 & 0 & \\
\hline Guam ……….............. & 1 & 0 & 1 & 0 & 0 & 0 & 0 & 0 & 0 & 0 & 0 & 0 & 0 \\
\hline Northern Marianas ……................ & 0 & 0 & 0 & 0 & 0 & 0 & 0 & 0 & 0 & 0 & 0 & 0 & 0 \\
\hline Palau & 0 & 0 & 0 & 0 & 0 & 0 & 0 & 0 & 0 & 0 & 0 & 0 & 0 \\
\hline Puerto Rico .......................................... & 94 & 5 & 89 & 84 & 6 & 78 & 16 & 62 & 84 & 6 & 78 & 14 & 64 \\
\hline Virgin Islands ................................. & 0 & 0 & 0 & 0 & 0 & 0 & 0 & 0 & 0 & 0 & 0 & 0 & 0 \\
\hline
\end{tabular}

SOURCE: U.S. Department of Education, National Center for Education Statistics, Inegrated Postsecondary Education Data System (IPEDS), "Institutional Characteristics" surveys. (This table was prepared September 1996.) 


\section{CHAPTER 4}

\section{Federal Programs for Education and Related Activities}

This chapter provides a summary of federal funds for education to help describe the magnitude of the federal fiscal effort and give some indication of the scope and variety of the education programs. Data in this chapter reflect outlays and obligations of federal agencies. These tabulations differ from federal receipts reported in other chapters because of numerous variations in the data collection systems. Federal dollars are not necessarily spent by recipient institutions in the same year they are appropriated. In some cases, institutions cannot identify the source of federal revenues because they flow through state agencies. Some types of revenues, such as tuition and fees, are reported as revenues from students even though they may be supported by federal student aid programs. Some institutions that receive federal education funds are not included in regular surveys conducted by the National Center for Education Statistics. Thus, the revenue data tabulated in this chapter are not comparable with figures reported in other chapters. Readers should be careful about comparing data on obligations shown in some tables with data on outlays and appropriations appearing in others.

Federal on-budget funding for education showed sizable growth between fiscal years (FYs) 1965 and 1998, after adjustment for inflation. Particularly large increases occurred between 1965 and 1975. After a period of small increases between 1975 and 1980, federal funding for education, excluding estimated federal tax expenditures for education, declined approximately 16 percent between 1980 and 1985 after adjustment for inflation. From 1985 to 1998, federal on-budget funding for education increased by 30 percent (table 359).

During the 1965 to 1975 period, after adjustment for inflation, federal funds for elementary and secondary education rose by 210 percent, postsecondary education by 262 percent, other education by 144 percent, and by 7 percent for research at educational institutions. Between 1975 and 1980, federal funding for elementary and secondary education rose by 2 percent and research by 14 percent, but postsecondary education fell slightly by 2 percent and other education fell by 35 percent. After declining 22 percent between 1980 and 1985, federal funding for elementary and secondary education programs rose by 47 percent between 1985 and 1998. Postsecondary education fell by 25 percent between 1980 and 1985 then fell 3 percent between 1985 and 1998 . Between 1985 and 1998, other education rose by 66 percent, and research by 31 percent, after adjustment for inflation (table 359).

According to FY 1998 estimates, $\$ 30.7$ billion or about 41 percent of the $\$ 75.1$ billion spent by the federal government on education came from the U.S. Department of Education. Large amounts of money also came from the U.S. Department of Health and Human Services (\$13.6 billion), the U.S. Department of Agriculture ( $\$ 10.2$ billion), the U.S. Department of Labor ( $\$ 5.0$ billion), the U.S. Department of Defense (\$3.6 billion), and the U.S. Department of Energy (\$3.2 billion) (table 360$)$.

Fiscal year 1998 estimates call for federal program funds for elementary and secondary education to be $\$ 36.8$ billion; for postsecondary education, $\$ 16.0$ billion; for research at universities and related institutions, $\$ 17.1$ billion; and for other programs, $\$ 5.2$ billion (table 361).

Almost 58 percent of total federal education support, excluding estimated federal tax expenditures, went to educational institutions in FY 1998. Another 20 percent was used for student support. Banks and other lending agencies received 9 percent, and all other recipients, including libraries, museums, and federal institutions, received 14 percent (table 362).

Between FYs 1990 and 1998, U.S. Department of Education obligations rose 73 percent, after adjustment for inflation. Funds for student financial assistance increased by $\$ 19.9$ billion in 1998, a rise of 123 percent since 1990. Funds for elementary and secondary education were an estimated $\$ 11.3$ billion in 1998, an increase of 26 percent since 1990, after adjustment for inflation. Funds for the handicapped increased by 75 percent, to $\$ 7.6$ billion, and funds for vocational and adult education increased 9 percent, after adjustment for inflation (tables 38 and 363).

Of the $\$ 30.7$ billion spent by the U.S. Department of Education in FY 1998, about $\$ 11.5$ billion went to school districts, $\$ 6.0$ billion to institutions of higher education, $\$ 5.5$ billion to college students, and $\$ 3.7$ billion to state education agencies. A portion of the remaining $\$ 4.0$ billion went to banks to subsidize student loans (table 364). 
Thirty-three percent of public elementary and secondary school students in the United States received publicly funded free or reduced-price lunches in 1993-94. At public elementary schools, the participation rate was 39 percent compared with 22 percent for public secondary schools (table 373 ).

About 13 percent of all elementary and secondary school children received Title I services in 1993-94. Federally sponsored Title I programs are designed to compensate for the linkage between family poverty and low student achievement, particularly for children in schools with high concentrations of poverty. Children in rural areas (13 percent) and central cities (17 percent) were more likely to receive services than those in suburban areas (9 percent) (table 374 ).

\section{Federal Education Legislation}

A capsule view of the history of federal education activities is provided in the following list of selected legislation:

1787 Northwest Ordinance authorized land grants for the establishment of educational institutions.

1802 An Act Fixing the Military Peace Establishment of the United States established the U.S. Military Academy. (The U.S. Naval Academy was established in 1845 by the Secretary of the Navy.)

1862 First Morrill Act authorized public land grants to the states for the establishment and maintenance of agricultural and mechanical colleges.

1867 Department of Education Act authorized the establishment of the U.S. Department of Education.*

1876 Appropriation Act, U.S. Department of the Treasury, established the U.S. Coast Guard Academy.

1890 Second Morrill Act provided for money grants for support of instruction in the agricultural and mechanical colleges.

1911 State Marine School Act authorized federal funds to be used for the benefit of any nautical school in any of 11 specified state seaport cities.

1917 Smith-Hughes Act provided for grants to states for support of vocational education.

\footnotetext{
* The U.S. Department of Education as established in 1867 was later known as the Office of Education. In 1980, under Public Law 96-88, it became a cabinet-level department. Therefore, for purposes of consistency, it is referred to as the "U.S. Department of Education" even in those tables covering years when it was officially the Office of Education.
}

1918 Vocational Rehabilitation Act provided for grants for rehabilitation through training of World War I veterans.

1919 An Act to Provide for Further Educational Facilities authorized the sale by the federal government of surplus machine tools to educational institutions at 15 percent of acquisition cost.

1920 Smith-Bankhead Act authorized grants to states for vocational rehabilitation programs.

1935 Bankhead-Jones Act (Public Law 74-182) authorized grants to states for agricultural experiment stations.

Agricultural Adjustment Act (Public Law 74$320)$ authorized 30 percent of the annual customs receipts to be used to encourage the exportation and domestic consumption of agricultural commodities. Commodities purchased under this authorization began to be used in school lunch programs in 1936. The National School Lunch Act of 1946 continued and expanded this assistance.

1936 An Act to Further the Development and Maintenance of an Adequate and Well-Balanced American Merchant Marine (Public Law 74415) established the U.S. Merchant Marine Academy.

1937 National Cancer Institute Act established the Public Health Service fellowship program.

1941 Amendment to Lanham Act of 1940 authorized federal aid for construction, maintenance, and operation of schools in federally impacted areas. Such assistance was continued under Public Law 815 and Public Law 874, 81st Congress, in 1950.

1943 Vocational Rehabilitation Act (Public Law 7816) provided assistance to disabled veterans.

School Lunch Indemnity Plan (Public Law 78129) provided funds for local lunch food purchases.

1944 Servicemen's Readjustment Act (Public Law 78-346) known as the Gl Bill, provided assistance for the education of veterans.

Surplus Property Act (Public Law 78-457) authorized transfer of surplus property to educational institutions.

1946 National School Lunch Act (Public Law 79396) authorized assistance through grants-inaid and other means to states to assist in providing adequate foods and facilities for the establishment, maintenance, operation, and 
expansion of nonprofit school lunch programs.

George-Barden Act (Public Law 80-402) expanded federal support of vocational education.

1948 United States Information and Educational Exchange Act (Public Law 80-402) provided for the interchange of persons, knowledge, and skills between the United States and other countries.

1949 Federal Property and Administrative Services Act (Public Law 81-152) provided for donation of surplus property to educational institutions and for other public purposes.

1950 Financial Assistance for Local Educational Agencies Affected by Federal Activities (Public Law 81-815 and Public Law 81-874) provided assistance for construction (Public Law 815) and operation (Public Law 874) of schools in federally affected areas.

Housing Act (Public Law 81-475) authorized loans for construction of college housing facilities.

1954 An Act for the Establishment of the United States Air Force Academy and Other Purposes (Public Law 83-325) established the U.S. Air Force Academy.

Educational Research Act (Public Law 83-531) authorized cooperative arrangements with universities, colleges, and state educational agencies for educational research.

School Milk Program Act (Public Law 83-597) provided funds for purchase of milk for school lunch programs.

1956 Library Services Act (Public Law 84-597) provided grants to states for extension and improvement of rural public library services.

1957 Practical Nurse Training Act (Public Law 84911) provided grants to states for practical nurse training.

1958 National Defense Education Act (Public Law 85-864) provided assistance to state and local school systems for strengthening instruction in science, mathematics, modern foreign languages, and other critical subjects; improvement of state statistical services; guidance, counseling, and testing services and training institutes; higher education student loans and fellowships; foreign language study and training provided by colleges and universities; experimentation and dissemination of information on more effective utiliza- tion of television, motion pictures, and related media for educational purposes; and vocational education for technical occupations necessary to the national defense.

Education of Mentally Retarded Children Act (Public Law 85-926) authorized federal assistance for training teachers of the handicapped.

Captioned Films for the Deaf Act (Public Law 85-905) authorized a loan service of captioned films for the deaf.

1961 Area Redevelopment Act (Public Law 87-27) included provisions for training or retraining of persons in redevelopment areas.

1962 Manpower Development and Training Act (Public Law 87-415) provided training in new and improved skills for the unemployed and underemployed.

Migration and Refugee Assistance Act of 1962 (Public Law 87-510) authorized loans, advances, and grants for education and training of refugees.

1963 Health Professions Educational Assistance Act of 1963 (Public Law 88-129) provided funds to expand teaching facilities and for loans to students in the health professions.

Vocational Education Act of 1963 (Part of Public Law 88-210) increased federal support of vocational education schools; vocational work-study programs; and research, training, and demonstrations in vocational education.

Higher Education Facilities Act of 1963 (Public Law 88-204) authorized grants and loans for classrooms, libraries, and laboratories in public community colleges and technical institutes, as well as undergraduate and graduate facilities in other institutions of higher education.

1964 Civil Rights Act of 1964 (Public Law 88-352) authorized the Commissioner of Education to arrange for support for institutions of higher education and school districts to provide inservice programs for assisting instructional staff in dealing with problems caused by desegregation.

Economic Opportunity Act of 1964 (Public Law 88-452) authorized grants for college workstudy programs for students from low-income families; established a Job Corps program and authorized support for work-training programs to provide education and vocational training and work experience opportunities in 
welfare programs; authorized support of education and training activities and of community action programs, including Head Start, Follow Through, and Upward Bound; and authorized the establishment of Volunteers in Service to America (VISTA).

1965 Elementary and Secondary Education Act of 1965 (Public Law 89-10) authorized grants for elementary and secondary school programs for children of low-income families; school library resources, textbooks, and other instructional materials for school children; supplementary educational centers and services; strengthening state education agencies; and educational research and research training.

Health Professions Educational Assistance Amendments of 1965 (Public Law 89-290) authorized scholarships to aid needy students in the health professions.

Higher Education Act of 1965 (Public Law 89329) provided grants for university community service programs, college library assistance, library training and research, strengthening developing institutions, teacher training programs, and undergraduate instructional equipment. Authorized insured student loans, established a National Teacher Corps, and provided for graduate teacher training fellowships.

National Foundation on the Arts and the Humanities Act (Public Law 89-209) authorized grants and loans for projects in the creative and performing arts and for research, training, and scholarly publications in the humanities.

National Technical Institute for the Deaf Act (Public Law 89-36) provided for the establishment, construction, equipping, and operation of a residential school for postsecondary education and technical training of the deaf.

School Assistance in Disaster Areas Act (Public Law 89-313) provided for assistance to local education agencies to help meet exceptional costs resulting from a major disaster.

1966 International Education Act (Public Law 89698) provided grants to institutions of higher education for the establishment, strengthening, and operation of centers for research and training in international studies and the international aspects of other fields of study.
National Sea Grant College and Program Act (Public Law 89-688) authorized the establishment and operation of Sea Grant Colleges and programs by initiating and supporting programs of education and research in the various fields relating to the development of marine resources.

Adult Education Act (Public Law 89-750) authorized grants to states for the encouragement and expansion of educational programs for adults, including training of teachers of adults and demonstrations in adult education (previously part of Economic Opportunity Act of 1964).

Model Secondary School for the Deaf Act (Public Law 89-694) authorized the establishment and operation, by Gallaudet College, of a model secondary school for the deaf.

1967 Education Professions Development Act (Public Law 90-35) amended the Higher Education Act of 1965 for the purpose of improving the quality of teaching and to help meet critical shortages of adequately trained educational personnel.

Public Broadcasting Act of 1967 (Public Law 90-129) established a Corporation for Public Broadcasting to assume major responsibility in channeling federal funds to noncommercial radio and television stations, program production groups, and ETV networks; conduct research, demonstration, or training in matters related to noncommercial broadcasting; and award grants for construction of educational radio and television facilities.

1968 Elementary and Secondary Education Amendments of 1968 (Public Law 90-247) modified existing programs, authorized support of regional centers for education of handicapped children, model centers and services for deafblind children, recruitment of personnel and dissemination of information on education of the handicapped; technical assistance in education to rural areas; support of dropout prevention projects; and support of bilingual education programs.

Handicapped Children's Early Education Assistance Act (Public Law 90-538) authorized preschool and early education programs for handicapped children.

Vocational Education Amendments of 1968 (Public Law 90-576) modified existing programs and provided for a National Advisory Council on Vocational Education and collection and dissemination of information for pro- 
grams administered by the Commissioner of Education.

1970 Elementary and Secondary Education Assistance Programs, Extension (Public Law 91230) authorized comprehensive planning and evaluation grants to state and local education agencies; provided for the establishment of a National Commission on School Finance.

National Commission on Libraries and Information Services Act (Public Law 91-345) established a National Commission on Libraries and Information Science to effectively utilize the nation's educational resources.

Office of Education Appropriation Act (Public Law 91-380) provided emergency school assistance to desegregating local education agencies.

Environmental Education Act (Public Law 91516) established an Office of Environmental Education to develop curriculum and initiate and maintain environmental education programs at the elementary-secondary levels; disseminate information; provide training programs for teachers and other educational, public, community, labor, and industrial leaders and employees; provide community education programs; and distribute material dealing with the environment and ecology.

Drug Abuse Education Act of 1970 (Public Law 91-527) provided for development, demonstration, and evaluation of curricula on the problems of drug abuse.

1971 Comprehensive Health Manpower Training Act of 1971 (Public Law 92-257) amended Title VII of the Public Health Service Act, increasing and expanding provisions for health manpower training and training facilities.

1972 Drug Abuse Office and Treatment Act of 1972 (Public Law 92-255) established a Special Action Office for Drug Abuse Prevention to provide overall planning and policy for all federal drug-abuse prevention functions; a National Advisory Council for Drug Abuse Prevention; community assistance grants for community mental health centers for treatment and rehabilitation of persons with drugabuse problems, and, in December 1974, a National Institute on Drug Abuse.

Education Amendments of 1972 (Public Law 92-318) established the Education Division in the U.S. Department of Health, Education, and Welfare and the National Institute of Education; general aid for institutions of higher education; federal matching grants for state Student Incentive Grants; a National Commission on Financing Postsecondary Education; State Advisory Councils on Community Colleges; a Bureau of Occupational and Adult Education and State Grants for the design, establishment, and conduct of postsecondary occupational education; and a bureau-level Office of Indian Education. Amended current U.S. Department of Education programs to increase their effectiveness and better meet special needs. Prohibited sex bias in admission to vocational, professional, and graduate schools, and public institutions of undergraduate higher education.

1973 Older Americans Comprehensive Services Amendment of 1973 (Public Law 93-29) made available to older citizens comprehensive programs of health, education, and social services.

Comprehensive Employment and Training Act of 1973 (Public Law 93-203) provided for opportunities for employment and training to unemployed and underemployed persons. Extended and expanded provisions in the Manpower Development and Training Act of 1962, Title I of the Economic Opportunity Act of 1962, Title I of the Economic Opportunity Act of 1964, and the Emergency Employment Act of 1971 as in effect prior to June 30, 1973.

1974 Education Amendments of 1974 (Public Law 93-380) provided for the consolidation of certain programs; and established a National Center for Education Statistics.

Juvenile Justice and Delinquency Prevention Act of 1974 (Public Law 93-415) provided for technical assistance, staff training, centralized research, and resources to develop and implement programs to keep students in elementary and secondary schools; and established, in the U.S. Department of Justice, a National Institute for Juvenile Justice and Delinquency Prevention.

1975 Indian Self-Determination and Education Assistance Act (Public Law 93-638) provided for increased participation of Indians in the establishment and conduct of their education programs and services.

Harry S Truman Memorial Scholarship Act (Public Law 93-642) established the Harry S Truman Scholarship Foundation and created a perpetual education scholarship fund for 
young Americans to prepare and pursue careers in public service.

Indochina Migration and Refugee Assistance Act of 1975 (Public Law 94-23) authorized funds to be used for education and training of aliens who have fled from Cambodia or Vietnam.

Education for All Handicapped Children Act (Public Law 94-142) provided that all handicapped children have available to them a free appropriate education designed to meet their unique needs.

1976 Educational Broadcasting Facilities and Telecommunications Demonstration Act of 1976 (Public Law 94-309) established a telecommunications demonstration program to promote the development of nonbroadcast telecommunications facilities and services for the transmission, distribution, and delivery of health, education, and public or social service information.

Education Amendments of 1976 (Public Law 94-482) extended and revised federal programs for education assistance for higher education, vocational education, and a variety of other programs.

1977 Youth Employment and Demonstration Projects Act of 1977 (Public Law 95-93) established a youth employment training program that includes, among other activities, promoting education-to-work transition, literacy training and bilingual training, and attainment of certificates of high school equivalency.

Career Education Incentive Act (Public Law 95-207) authorized the establishment of a career education program for elementary and secondary schools.

1978 Tribally Controlled Community College Assistance Act of 1978 (Public Law 95-471) provided federal funds for the operation and improvement of tribally controlled community colleges for Indian students.

Education Amendments of 1978 (Public Law 95-561) established a comprehensive basic skills program aimed at improving pupil achievement (replaced the existing National Reading Improvement program); and established a community schools program to provide for the use of public buildings.

Middle Income Student Assistance Act (Public Law 95-566) modified the provisions for student financial assistance programs to allow middle-income as well as low-income stu- dents attending college or other postsecondary institutions to qualify for federal education assistance.

1979 Department of Education Organization Act (Public Law 96-88) established a U.S. Department of Education containing functions from the Education Division of the U.S. Department of Health, Education, and Welfare along with other selected education programs from HEW, the U.S. Department of Justice, U.S. Department of Labor, and the National Science Foundation.

1980 Asbestos School Hazard Detection and Control Act of 1980 (Public Law 96-270) established a program for inspection of schools for detection of hazardous asbestos materials and provided loans to assist educational agencies to contain or remove and replace such materials.

1981 Education Consolidation and Improvement Act of 1981 (Part of Public Law 97-35) consolidated 42 programs into 7 programs to be funded under the elementary and secondary block grant authority.

1983 Student Loan Consolidation and Technical Amendments Act of 1983 (Public Law 98-79) established an 8 percent interest rate for Guaranteed Student Loans and extended Family Contribution Schedule.

Challenge Grant Amendments of 1983 (Public Law 98-95) amended Title III, Higher Education Act, and added authorization of Challenge Grant program. The Challenge Grant program provides funds to eligible institutions on a matching basis as an incentive to seek alternative sources of funding.

Education of the Handicapped Act Amendments of 1983 (Public Law 98-199) added the Architectural Barrier amendment and clarified participation of handicapped children in private schools.

1984 Education for Economic Security Act (Public Law 98-377) added new science and mathematics programs for elementary, secondary, and postsecondary education. The new programs included magnet schools, excellence in education, and equal access.

Carl D. Perkins Vocational Education Act (Public Law 98-524) continued federal assistance for vocational education through FY 1989. The act replaced the Vocational Education Act of 1963. It provided aid to the states to make vocational education programs acces- 
sible to all persons, including handicapped and disadvantaged, single parents and homemakers, and the incarcerated.

Human Services Reauthorization Act (Public Law 98-558) reauthorized the Head Start and Follow Through programs through FY 1986. It also created a Carl D. Perkins scholarship program, a National Talented Teachers Fellowship program, a Federal Merit Scholarships program, and a Leadership in Educational Administration program.

1985 Montgomery Gl Bill-Active Duty (Public Law 98-525), brought about a new GI Bill for individuals who initially entered active military duty on or after July 1, 1985.

Montgomery Gl Bill-Selected Reserve (Public Law 98-525), is an education program for members of the Selected Reserve (which includes the National Guard) who enlist, reenlist, or extend an enlistment after June 30, 1985, for a 6 -year period.

1986 Handicapped Children's Protection Act of 1986 (Public Law 99-372) allowed parents of handicapped children to collect attorneys' fees in cases brought under the Education of the Handicapped Act and provided that the Education of the Handicapped Act does not preempt other laws, such as Section 504 of the Rehabilitation Act.

Drug-Free Schools and Communities Act of 1986 (Part of Public Law 99-570), part of the Anti-Drug Abuse Act of 1986, authorized funding for FYs 1987-89. Established programs for drug abuse education and prevention, coordinated with related community efforts and resources, through the use of federal financial assistance.

1987 Higher Education Act Amendments of 1987 (Public Law 100-50) made technical corrections, clarifications, or conforming amendments related to the enactment of the Higher Education Amendments of 1986.

1988 Augustus F. Hawkins-Robert T. Stafford Elementary and Secondary School Improvement Amendments of 1988 (Public Law 100-297) reauthorized through 1993 major elementary and secondary education programs including: Chapter 1, Chapter 2, Bilingual Education, Math-Science Education, Magnet Schools, Impact Aid, Indian Education, Adult Education, and other smaller education programs.

Technology-Related Assistance for Individuals with Disabilities Act of 1988 (Public Law 100-
407) provided financial assistance to states to develop and implement consumer-responsive statewide programs of technology-related assistance for persons of all ages with disabilities.

Stewart B. McKinney Homeless Assistance Amendments Act of 1988 (Public Law 100628 ) extended for 2 additional years programs providing assistance to the homeless, including literacy training for homeless adults and education for homeless youths.

Tax Reform Technical Amendments (Public Law 100-647) authorized an Education Savings Bond for the purpose of postsecondary educational expenses. The bill grants tax exclusion for interest earned on regular series EE savings bonds.

1989 Children with Disabilities Temporary Care Reauthorization Act of 1989 (Public Law 101127) revised and extended the programs established in the Temporary Child Care for Handicapped Children and Crises Nurseries Act of 1986.

Drug-Free Schools and Communities Act Amendments of 1989 (Public Law 101-226) amended the Drug-Free Schools and Communities Act of 1986 to revise certain requirements relating to the provision of drug abuse education and prevention programs in elementary and secondary schools.

Childhood Education and Development Act of 1989 (Part of Public Law 101-239) authorized the appropriations to expand Head Start Programs and programs carried out under the Elementary and Secondary Education Act of 1965 to include child care services.

1990 Excellence in Mathematics, Science and Engineering Education Act of 1990 (Public Law 101-589) promotes excellence in American mathematics, science, and engineering education by creating a national mathematics and science clearinghouse, and creating several other mathematics, science, and engineering education programs.

Student Right-To-Know and Campus Security Act (Public Law 101-542) requires institutions of higher education receiving federal financial assistance to provide certain information with respect to the graduation rates of student-athletes at such institutions. The act also requires the institution to certify that it has a campus security policy and will annually submit a uniform crime report to the Federal Bureau of Investigation (FBI). 
Americans with Disabilities Act of 1990 (Public Law 101-336) prohibits discrimination against persons with disabilities.

National and Community Service Act of 1990 (Public Law 101-610) increased school and college-based community service opportunities and authorized the President's Points of Light Foundation.

School Dropout Prevention and Basic Skills Improvement Act of 1990 (Public Law 101-600) improves secondary school programs for basic skills improvements and dropout reduction.

Asbestos School Hazard Abatement Reauthorization Act of 1990 (Public Law 101-637) reauthorized the Asbestos School Hazard Abatement Act of 1984, which provided financial support to elementary and secondary schools to inspect for asbestos and to develop and implement an asbestos management plan.

Eisenhower Exchange Fellowship Act of 1990 (Public Law 101-454) provided a permanent endowment for the Eisenhower Exchange Fellowship Program.

Public Service Assistance Education Act (Enacted as part of Department of Defense Authorization Act, Public Law 101-510) gave federal agencies authority to provide new educational benefits to employees by paying for an employee to obtain an academic degree for which there is an agency shortage of qualified personnel, and by repaying up to $\$ 6,000$ per year of the student loan of a qualified employee in exchange for a 3-year commitment.

Omnibus Budget Reconciliation Act of 1990 (Public Law 101-508) included a set of student aid provisions that were estimated to yield a savings of $\$ 2$ billion over 5 years. These provisions included delayed Guaranteed Student Loan disbursements, tightened ability-to-benefit eligibility, and expanded pro rata refund policy and the elimination of student aid eligibility at high default schools.

1991 National Literacy Act of 1991 (Public Law 10273) established the National Institute for Literacy, the National Institute Board, and the Interagency Task Force on Literacy. Amended various federal laws to establish and extend various literacy programs.

National Defense Authorization Act for Fiscal Years 1992 and 1993 (Public Law 102-190) authorized appropriations for education functions of the U.S. Department of Defense. Included Defense Manufacturing Education Program and planning for science, mathematics, and engineering education.

National Commission on Time and Learning Act (Public Law 102-62) established the $\mathrm{Na}$ tional Education Commission on Time and Learning. Directed the Secretary of Education to: (1) make grants for research in the teaching of writing; and (2) carry out a program to educate students about the history and principles of the Constitution, including the Bill of Rights. Established the National Council on Education Standards and Testing.

High-Performance Computing Act of 1991 (Public Law 102-194) directed the President to implement a National High-Performance Computing Program. Provided for: (1) establishment of a National Research and Education Network; (2) standards and guidelines for high performance networks; and (3) the responsibility of certain federal departments and agencies with regard to the Network.

Veterans' Educational Assistance Amendments of 1991 (Public Law 102-127) restored certain educational benefits available to reserve and active-duty personnel under the Montgomery GI Bill to students whose course studies were interrupted by the Persian Gulf War.

Civil Rights Act of 1991 (Public Law 102-166) amended the Civil Rights Act of 1964, the Age Discrimination in Employment Act of 1967, and the Americans with Disabilities Act of 1990, with regard to employment discrimination. Established the Technical Assistance Training Institute.

1992 Higher Education Amendments of 1992 (Public Law 102-325) amended the Higher Education Act of 1965 to revise and reauthorize funding for its various programs.

Ready-To-Learn Act (Public Law 102-545) amended the General Education Provisions Act to establish Ready-To-Learn Television programs to support educational programming and support materials for preschool and elementary school children and their parents, child care providers, and educators.

National Commission on Time and Learning, Extension (Public Law 102-359) amended the National Education Commission on Time and Learning Act to extend the authorization of appropriations for such Commission, 
amended the Elementary and Secondary Education Act of 1965 to revise provisions for (1) a specified civic education program; and (2) schoolwide projects for educationally disadvantaged children, and provided for additional Assistant Secretaries of Education.

1993 Student Loan Reform Act (Public Law 103-66) reformed the student aid process by phasing in a system of direct lending designed to provide savings for taxpayers and students. Allows students to choose among a variety of repayment options, including income contingency.

National Service Trust Act (Public Law 103-82) amended the National and Community Service Act of 1990 to establish a Corporation for National Service and enhance opportunities for national service. In addition, the Act provided education grants up to $\$ 4,725$ per year for 2 years to people age 17 years or older who perform community service before, during, or after postsecondary education.

NAEP Assessment Authorization (Public Law 103-33) authorizes the use of NAEP for state-by-state comparisons.

Migrant Student Record Transfer System Extension (Public Law 103-59) extends the operation of the migrant student record transfer system.

1994 Goals 2000: Educate America Act (Public Law 103-227) established a new federal partnership through a system of grants to states and local communities to reform the nation's education system. The Act formalized the national education goals and established the National Education Goals Panel. It also created a National Education Standards and Improvement Council (NESIC) to provide voluntary national certification of state and local education standards and assessments and established the National Skill Standards Board to develop voluntary national skill standards.

School-To-Work Opportunities Act of 1994 (Public Law 103-239) established a national framework within which states and communities can develop School-To-Work Opportunities systems to prepare young people for first jobs and continuing education. The Act also provided money to states and communities to develop a system of programs that include work-based learning, school-based learning, and connecting activities components. School-To-Work programs will provide students with a high school diploma (or its equivalent), a nationally recognized skill certificate, or an associate degree (if appropriate) and may lead to a first job or further education.

Safe Schools Act of 1994 (Part of Public Law 103-227) authorized the award of competitive grants to local educational agencies with serious crime to implement violence prevention activities such as conflict resolution and peer mediation.

Educational Research, Development, Dissemination, and Improvement Act of 1994 (Part of Public Law 103-227) authorized the educational research and dissemination activities of the Office of Educational Research and Improvement. The regional educational laboratories and university-based research and development centers are authorized under this act.

Student Loan Default Exemption Extension (Public Law 103-235) amended the Higher Education Act of 1965 to extend until July 1, 1998, the effective date for cohort default rate extension for Historically Black Colleges and Universities, tribally controlled community colleges, and Navajo community colleges.

Improving America's Schools Act (Public Law 103-382) reauthorized and revamps the Elementary and Secondary Education Act. The legislation includes Title I, the federal government's largest program providing educational assistance to disadvantaged children; professional development and technical assistance programs; a safe and drug-free schools and communities provision; and provisions promoting school equity.

1995 Amendment to the Elementary and Secondary Education Act of 1965 (Public Law 104-5) amended a provision of Part A of Title IX of the Elementary and Secondary Education Act of 1965 relating to Indian education, to provide a technical amendment and for other purposes.

1996 Contract With America: Unfunded Mandates (Public Law 104-4) a bill to curb the practice of imposing unfunded federal mandates on states and local governments; to strengthen the partnership between the federal government and state, local, and tribal governments; to end the imposition, in the absence of full consideration by Congress, of federal mandates on state, local, and tribal governments without adequate funding, in a manner that 
may displace other essential governmental priorities and to ensure that the federal government pays the costs incurred by those governments in complying with certain requirements under federal statutes and regulations; and for other purposes.

Developmental Disabilities Assistance and Bill of Rights Act Amendments of 1996 (Public Law 104-1834) amended the Developmental Disabilities Assistance and Bill of Rights Act to extend the act, and for other purposes.

Remove Grant Limits on Historically Black Colleges (Public Law 104-141) amended section 326 of the Higher Education Act of 1965 to permit continued participation by historically black graduate and professional schools in the grant program authorized by that section.

Correct Impact-Aid Payments (Public Law 104195) amends the Impact Aid Program to provide for a hold-harmless with respect to amounts for payments relating to the federal acquisition of real property, and for other purposes.

Human Rights, Refugee, and Other Foreign Relations Provisions Act of 1996 (Public Law
104-319) made certain provisions with respect to internationally recognized human rights, refugees, and foreign relations to revise U.S. human rights policy.

1997 Need-Based Educational Aid Antitrust Protection Act of 1997 (Public Law 105-43) amends the Improving America's Schools Act of 1994 to clarify the financial information exchanged between institutions of higher education.

The Taxpayer Relief Act of 1997 (Public Law 105-34) enacted the Hope Scholarship and Life-Long Learning Tax Credit provisions into law.

Individuals with Disabilities Education Act Amendments of 1997 (Public Law 105-17) amends the Individuals with Disabilities Education Act (IDEA) to revise its provisions and extend through fiscal year 2002 the authorization of appropriations for IDEA programs.

Emergency Student Loan Consolidation Act of 1997 (Public Law 105-78) amends the Higher Education Act to provide for improved student loan consolidation services. 
Figure 20.-Federal on-budget funds for education, by agency: Fiscal year 1998

Department of Agriculture, $13.6 \%$

Department of Defense, $4.8 \%$

Department of Energy, $4.2 \%$

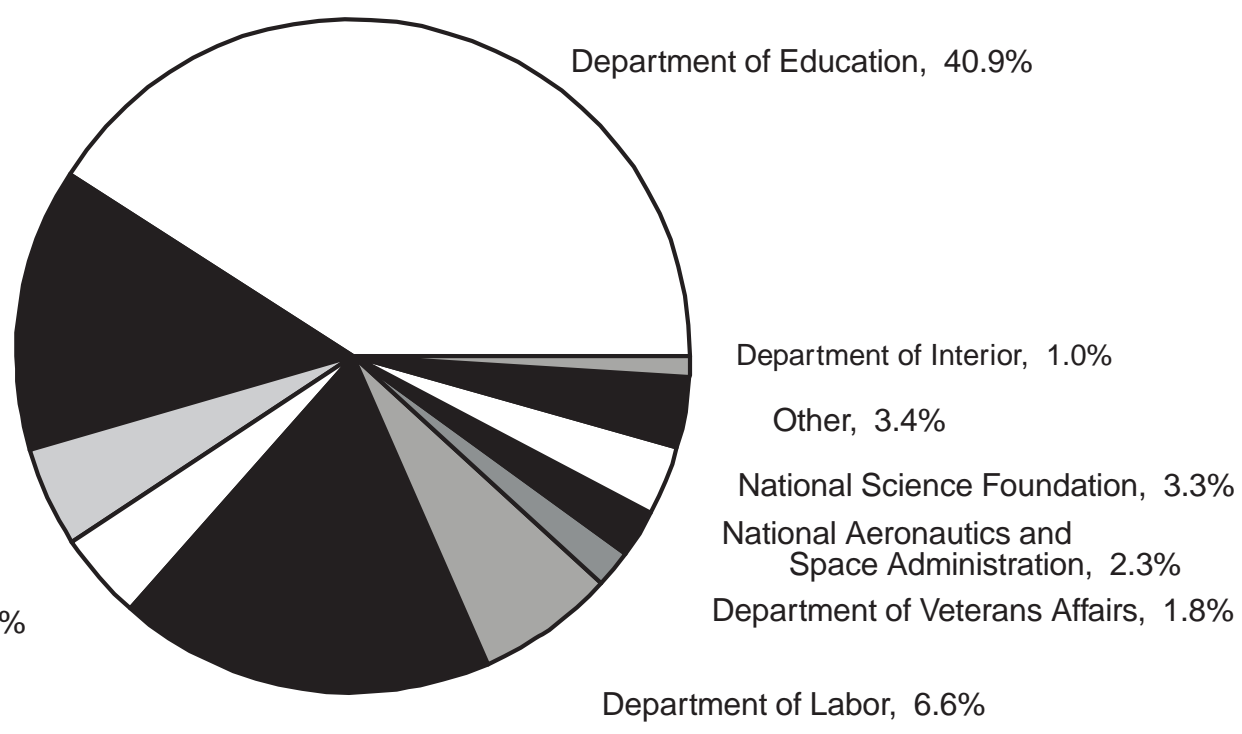

Department of Health and Human Services, $18.1 \%$

\section{Total $=\$ 75.1$ billion}

SOURCE: U.S. Office of Management and Budget, Budget of the U.S. Government, Fiscal Year 1999; and National Science Foundation, Federal Funds for Research and Development, Fiscal Years 1996, 1997, and 1998. 
Figure 21.-Federal on-budget funds for education, by level or other educational purpose: 1965 to 1998

[In constant FY 1998 dollars]

In billions of dollars

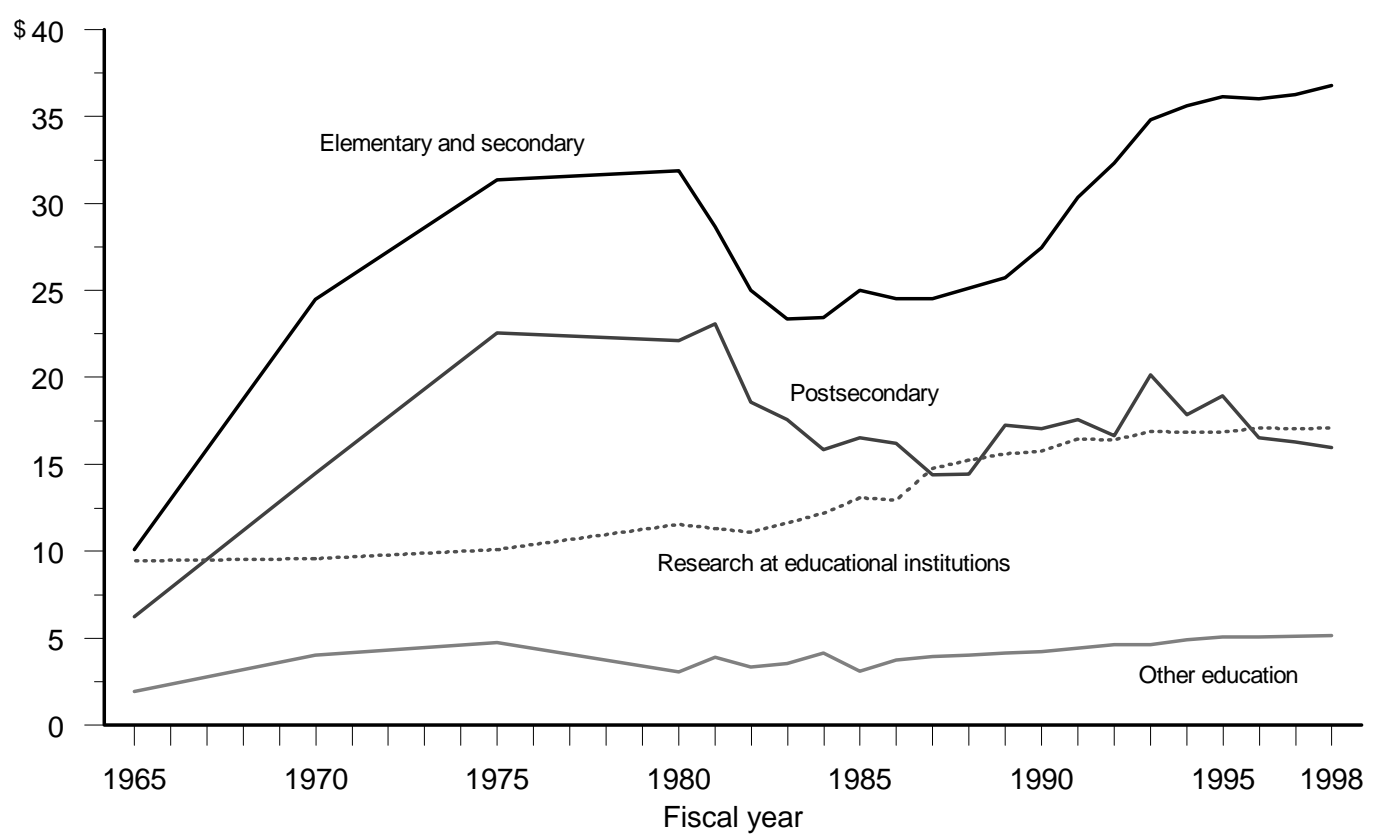

SOURCE: U.S. Office of Management and Budget, Budget of the U.S. Government, fiscal years 1967 to 1999; National Science Foundation, Federal Funds for Research and Development, fiscal years 1967 to 1998; and unpublished data.

Figure 22.-Department of Education outlays, by type of recipient: Fiscal year 1998

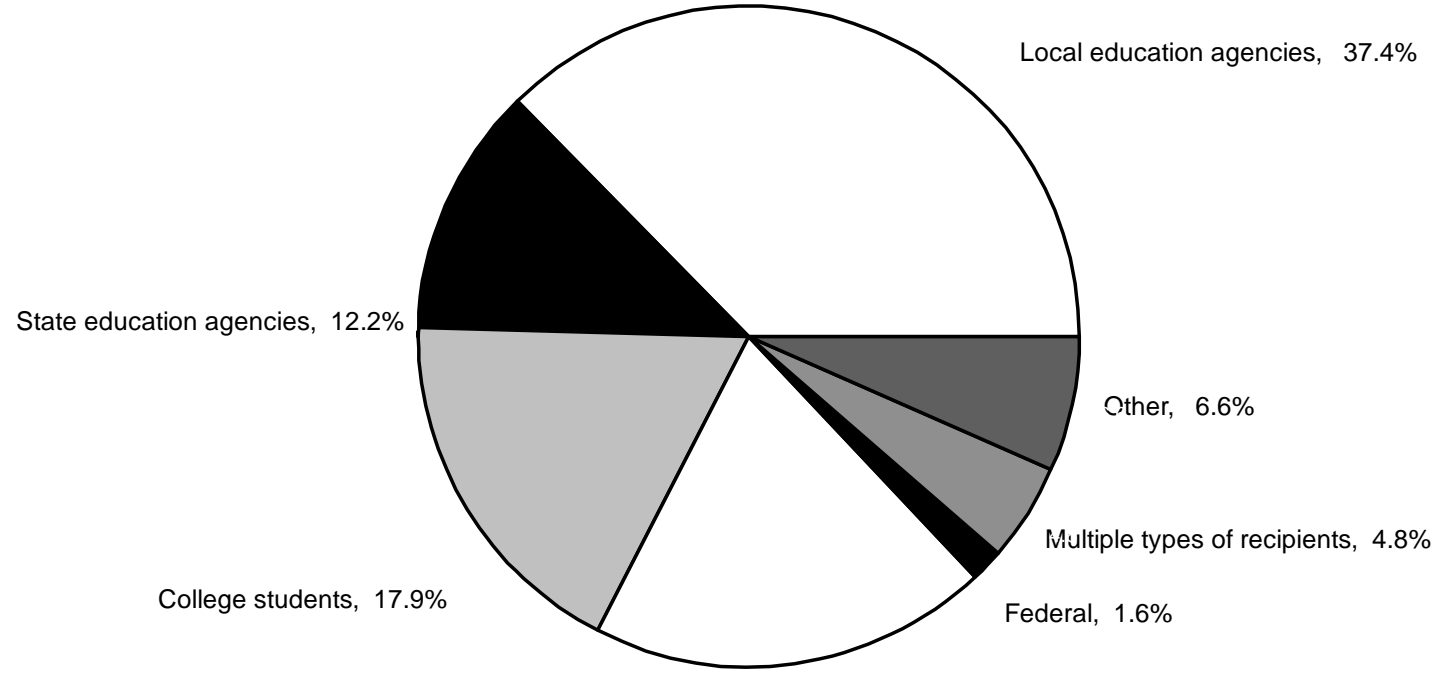

Insiitutions of higher education, $19.6 \%$

Total outlays $=\$ 30.7$ billion

SOURCE: U.S. Office of Management and Budget, Budget of the U.S. Government, Fiscal Year 1999; Catalog of Federal Domestic Assistance; National Science Foundation, Federal Funds for Research and Development, Fiscal Years 1996, 1997, and 1998; and unpublished data obtained from various federal agencies. 
Table 359.-Federal support and estimated federal tax expenditures for education, by category: Fiscal years 1965 to 1998

[In millions of dollars]

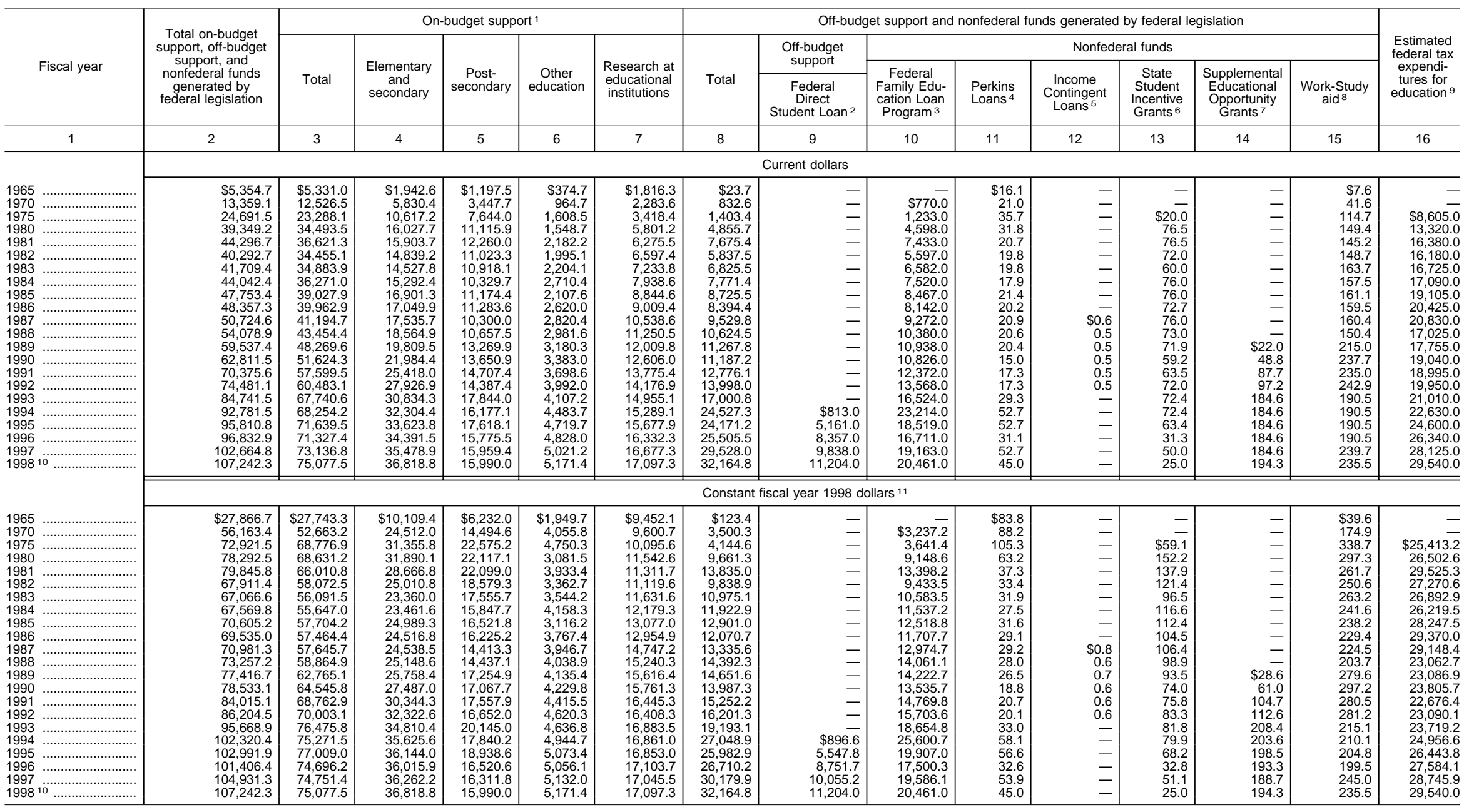

1 On-budget support includes federal funds for education programs tied to appropriations.

2 The Federal Direct Student Loan (FDSL) program, recently renamed the William D. Ford Direct Loan program, provides students with the same benefits they are currently eligible to receive under the Federal Family Education Loan
(FFEL) program but provides loans to students through federal capital rather than through private lenders. This program

is an off-budget support program.
${ }^{3}$ Formerly the Guaranteed Student Loan program. New student loans guaranteed by the federal government and disbursed to borrowers. 4 Student loans created

fred institutional matching funds (1/3 of the federal contribution). Excludes repayments of ${ }_{5}^{5}$ Student loans created from institutional matching funds (1/9 of the federal contribution). This was a demonstration project that involved only 10 institutions and had unsubsidized interest rates.

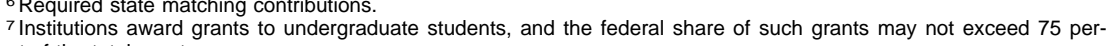
8 Employer contributior
9 Losses of tax revenue attributable to provisions of the federal income tax laws that allow a special exclusion, exemption, or deduction from gross income or provide a special credit, preferential rate of tax, or a deferral of tax liability affecting individual or corporate income tax liabilities.

Data adjusted by the federal funds composite deflator prepared by the U.S. Office of Management and Budget. -Data not available or not applicable.

NOTE.-To the extent possible, federal education funds data represent outlays rather than obligations. Because of rounding, details may not add to totals. Some data have been revised from previously published figures.

SOURCE: U.S. Department of Education, National Center for Education Statistics, compiled from data appearing in U.S. Office of Management and Budget, Budget of the U.S. Government, Appendix, fiscal years 1967 to 1999; National Science Foundation, Federal Funds for Research and Development, fiscal years 1965 to 1998; "Estimates of Federal Tax Expenditures for Education, Selected Fiscal Years, FY 1975 to FY 1990," by Stephen M. Barro; and "Federal Tax and unpublished data obtained from various federal agencies. (This table was prepared July 1998.) 
Table 360.-Federal on-budget funds for education, by agency: Fiscal years 1965 to 1998

[In thousands of current dollars]

\begin{tabular}{|c|c|c|c|c|c|c|c|c|c|c|}
\hline Agency & 1965 & 1970 & 1975 & 1980 & 1983 & 1984 & 1985 & 1986 & 1987 & 1988 \\
\hline 1 & 2 & 3 & 4 & 5 & 6 & 7 & 8 & 9 & 10 & 11 \\
\hline Total .............. & $\$ 5,331,016$ & $\$ 12,526,499$ & $\$ 23,288,120$ & $\$ 34,493,502$ & $\$ 34,883,900$ & $\$ 36,271,011$ & $\$ 39,027,876$ & $\$ 39,962,901$ & $\$ 41,194,718$ & $\$ 43,454,423$ \\
\hline Department of Education & $1,000,567$ & $4,625,224$ & $7,350,355$ & $13,137,785$ & $14,585,825$ & $15,534,737$ & $16,701,065$ & $17,740,051$ & $16,879,827$ & $18,326,916$ \\
\hline Department of Agriculture ..................... & 768,927 & 960,910 & $2,219,352$ & $4,562,467$ & $4,340,869$ & $4,616,372$ & $4,782,274$ & $5,041,317$ & $5,189,779$ & $5,481,976$ \\
\hline Department of Commerce & 9,347 & 13,990 & 38,967 & 135,561 & 55,090 & 55,160 & 55,114 & 64,613 & 38,896 & 38,553 \\
\hline Department of Defense ................................... & 587,412 & 821,388 & $1,009,229$ & $1,560,301$ & $2,487,597$ & $2,625,146$ & $3,119,213$ & $3,354,588$ & $3,695,617$ & $3,461,345$ \\
\hline Department of Energy & 442,434 & 551,527 & 764,676 & $1,605,558$ & $1,933,068$ & $2,042,881$ & $2,247,822$ & $2,181,391$ & $2,256,799$ & $2,385,966$ \\
\hline $\begin{array}{l}\text { Department of Health and Human Services .. } \\
\text { Department of Housing and Urban }\end{array}$ & $1,027,537$ & $1,796,854$ & $3,675,225$ & $5,613,930$ & $4,968,658$ & $4,902,016$ & $5,322,356$ & $5,316,853$ & $6,104,812$ & $6,505,428$ \\
\hline 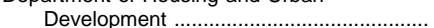 & 221,256 & 114,709 & $-52,768$ & 5,314 & 2,158 & 2,000 & 438 & 342 & 463 & 51 \\
\hline Department of the Interior & 170,088 & 190,975 & 300,191 & 440,547 & 484,314 & 576,779 & 549,479 & 454,273 & 485,922 & 528,409 \\
\hline Department of Justice .......................... & 10,252 & 15,728 & 61,542 & 60,721 & 68,700 & 62,282 & 66,802 & 72,191 & 79,815 & 83,405 \\
\hline Department of Labor & 230,041 & 424,494 & $1,103,935$ & $1,862,738$ & $1,833,392$ & $1,755,839$ & $, 948,685$ & $1,976,960$ & $2,258,631$ & 272,228 \\
\hline Department of State & 64,200 & 59,742 & 89,433 & 25,188 & 23,813 & 23,086 & 23,820 & 23,401 & 24,288 & 38,671 \\
\hline 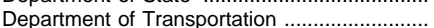 & - & 27,534 & 52,290 & 54,712 & 82,139 & 83,931 & 82,035 & 66,214 & 75,360 & 65,134 \\
\hline Department of the Treasury .................................. & 8,240 & 18 & $1,118,840$ & $1,247,463$ & 287,300 & 287,905 & 290,276 & 41,257 & 19,279 & 32,768 \\
\hline $\begin{array}{l}\text { Department of Veterans Affairs .......................... } \\
\text { Other agencies and programs }\end{array}$ & 97,237 & $1,032,918$ & $4,402,212$ & $2,351,233$ & $1,672,348$ & $1,445,049$ & $1,289,849$ & $1,055,948$ & $1,002,109$ & 966,549 \\
\hline ACTION & - & - & 7,081 & 2,833 & 1,830 & 4,975 & 1,761 & 1,368 & 3,368 & 4,110 \\
\hline Agency for International Development & 63,329 & 88,034 & 78,896 & 176,770 & 173,629 & 236,983 & 198,807 & 198,929 & 240,827 & 242,650 \\
\hline Appalachian Regional Commission .................... & - & 37,838 & 45,786 & 19,032 & 2,899 & 4,919 & 4,745 & 6,582 & 5,445 & 6,377 \\
\hline $\begin{array}{l}\text { Barry Goldwater Scholarship and Excellence } \\
\text { in Education Foundation ............................. } \\
\text { Corporation for National and Community }\end{array}$ & - & - & - & - & - & - & - & - & - & - \\
\hline 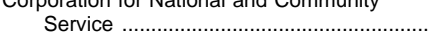 & - & - & - & - & - & - & - & - & - & - \\
\hline Environmental Protection Agency & - & 19,446 & 33,875 & 41,083 & 43,557 & 43,700 & 60,521 & 69,718 & 67,465 & 58,053 \\
\hline $\begin{array}{l}\text { imated education share of federal aid to } \\
\text { the District of Columbia }\end{array}$ & 11,350 & 33,019 & 55,487 & 81,847 & 97,516 & 97,385 & 107,340 & 101,844 & 126,942 & 122,366 \\
\hline Federal Emergency Management Agency ...... & - & 290 & 290 & 1,946 & 1,195 & 351 & 1,828 & 290 & 290 & 290 \\
\hline General Services Administration ......................... & 4,013 & 14,775 & 22,532 & 34,800 & 44,200 & 50,894 & - & - & - & - \\
\hline Harry S Truman Scholarship fund. & - & - & - & $-1,895$ & 1,795 & 1,929 & 1,332 & 2,441 & 2,717 & 2,815 \\
\hline Institute of American Indian and Alaskan & & & & & & & & & & \\
\hline $\begin{array}{l}\text { Native Culture and Arts Development } \\
\text { Institute of Museum and Library Services }\end{array}$ & - & - & - & - & - & - & - & - & - & - \\
\hline $\begin{array}{l}\text { Institute of Museum and Library Services ....... } \\
\text { James Madison Memorial Fellowship }\end{array}$ & - & - & - & - & - & - & - & - & - & - \\
\hline $\begin{array}{l}\text { Foundation ........................................ } \\
\text { Japanese-United States Friendship }\end{array}$ & - & - & - & - & - & - & - & - & 一 & 13,200 \\
\hline Commission ...... & - & - & - & 2,294 & 2,364 & 1,611 & 2,236 & 235 & 3,225 & 2,274 \\
\hline Library of Congress & 15,111 & 29,478 & 63,766 & 151,871 & 154,198 & 164,080 & 169,310 & 166,130 & 160,835 & 160,505 \\
\hline $\begin{array}{l}\text { National Aeronautics and Space } \\
\text { Administration }\end{array}$ & 208,788 & 258,366 & 197.901 & 255,511 & 367,763 & 354528 & 487624 & 490948 & 797301 & 897 \\
\hline National Archives and Records & & & $|9 /, 90|$ & 255,511 & $36 \%, / 63$ & $354,5<8$ & $48 /, 0<4$ & 490,948 & 181,391 & \\
\hline 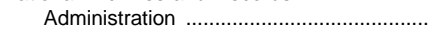 & - & - & - & - & - & - & 52,118 & 55,252 & 59,521 & 65,153 \\
\hline National Commission on Libraries and & - & - & 449 & 2090 & & & 723 & & & ५?? \\
\hline $\begin{array}{l}\text { Intormation Science } \\
\text { National Endowment for the Arts }\end{array}$ & - & $3 \overline{40}$ & $\begin{array}{r}449 \\
4,754\end{array}$ & $\begin{array}{l}2,090 \\
5,220\end{array}$ & $\begin{array}{r}681 \\
4,701\end{array}$ & $\begin{array}{r}733 \\
5,197\end{array}$ & $\begin{array}{r}723 \\
5,536\end{array}$ & $\begin{array}{r}781 \\
5,188\end{array}$ & $\begin{array}{r}512 \\
5,394\end{array}$ & $\begin{array}{r}522 \\
5,550\end{array}$ \\
\hline National Endowment for th & - & 8,459 & 63,955 & 142,586 & 123,315 & 127,571 & 125,671 & 121,125 & 124,407 & 125,230 \\
\hline National Science Foundation . & 181,216 & 295,628 & 535,294 & 808,392 & 907,917 & $1,035,746$ & $1,147,115$ & $1,147,273$ & $1,270,415$ & $1,329,520$ \\
\hline Nuclear Regulatory Commission . & & & 7,093 & 32,590 & 37,987 & 36,400 & 30,261 & 27,472 & 29,176 & 25,676 \\
\hline Office of Economic Opportunity ... & 189,871 & $1,092,410$ & 16,619 & - & - & - & - & - & - & - \\
\hline Smithsonian Institution ……………… & 2,233 & 2,461 & 5,509 & 5,153 & 6,073 & 5,758 & 7,886 & 6,191 & 6,545 & 5,393 \\
\hline United States Arms Control Agency .................. & - & 100 & - & 661 & 157 & & 395 & 276 & 3,244 & 2,633 \\
\hline United States Information Agency .. & 7,512 & 8,423 & 9,405 & 66,210 & 86,556 & 83,768 & 143,007 & 170,514 & 179,653 & 189,464 \\
\hline 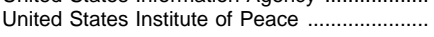 & - & - & - & 20 & - & & - & 230 & 4,083 & 3,476 \\
\hline Other agencies & 10,055 & 1,421 & 5,949 & 990 & 296 & 1,300 & 432 & 715 & 1,666 & 1,870 \\
\hline
\end{tabular}


Table 360.-Federal on-budget funds for education, by agency: Fiscal years 1965 to 1998 -Continued [In thousands of current dollars]

\begin{tabular}{|c|c|c|c|c|c|c|c|c|c|c|}
\hline Agency & 1989 & 1990 & 1991 & 1992 & 1993 & 1994 & 1995 & 1996 & 1997 & $1998^{1}$ \\
\hline 1 & 12 & 13 & 14 & 15 & 16 & 17 & 18 & 19 & 20 & 21 \\
\hline Total & $\$ 48,269,575$ & $\$ 51,624,342$ & $\$ 57,599,476$ & $\$ 60,483,092$ & $\$ 67,740,618$ & $\$ 68,254,206$ & $\$ 71,639,520$ & $\$ 71,327,361$ & $\$ 73,136,767$ & $\$ 75,077,477$ \\
\hline Department of Education .... & $21,671,232$ & $23,198,575$ & $25,391,310$ & $26,116,013$ & $30,478,215$ & $29,713,408$ & $31,403,000$ & $29,977,805$ & $30,110,555$ & $30,735,581$ \\
\hline Department of Agriculture .................................. & $5,793,616$ & $6,260,843$ & $6,875,216$ & $7,586,729$ & $8,067,050$ & $8,494,772$ & $9,092,089$ & $9,281,044$ & $9,793,122$ & $10,179,474$ \\
\hline Department of Commerce & 47,586 & 53,835 & 67,204 & 80,510 & 74,354 & 85,423 & 88,929 & 88,667 & 82,671 & 75,198 \\
\hline Department of Defense & $3,746,031$ & $3,605,509$ & $3,707,276$ & $3,948,471$ & $3,958,746$ & $3,899,582$ & $3,879,002$ & $3,841,697$ & $3,718,148$ & $3,604,849$ \\
\hline 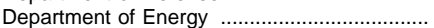 & $2,563,978$ & $2,561,950$ & $2,738,862$ & $2,917,137$ & $2,787,423$ & $2,671,660$ & $2,692,314$ & $3,035,169$ & $3,150,530$ & $3,170,735$ \\
\hline $\begin{array}{l}\text { Department of Health and Human Services .. } \\
\text { Department of Housing and Urban }\end{array}$ & $6,952,995$ & $7,956,011$ & $9,470,027$ & $9,362,010$ & $10,885,245$ & $11,921,727$ & $12,469,563$ & $12,886,323$ & $13,266,326$ & $13,565,579$ \\
\hline 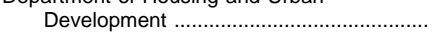 & 186 & 118 & 48 & 203 & 401 & 856 & 1,613 & 1,771 & 1,325 & 1,398 \\
\hline Department of the Interior & 542,466 & 630,537 & 844,830 & 715,382 & 723,448 & 696,649 & 702,796 & 665,251 & 774,715 & 754,914 \\
\hline Department of Justice .............. & 88,129 & 99,775 & 114,653 & 134,235 & 148,381 & 150,398 & 172,350 & 220,487 & 245,942 & 282,821 \\
\hline 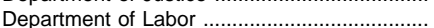 & $2,277,556$ & $2,511,380$ & $3,214,695$ & $3,709,531$ & $4,241,590$ & $4,015,434$ & $3,967,914$ & $4,089,862$ & $4,432,267$ & $4,990,139$ \\
\hline Department of State & 45,848 & 51,225 & 49,086 & 53,343 & 69,051 & 54,414 & 54,671 & 55,330 & 49,393 & 55,443 \\
\hline Department of Transportation ……................. & 90,840 & 76,186 & 73,699 & 94,733 & 115,925 & 123,106 & 135,816 & 106,214 & 119,190 & 114,974 \\
\hline Department of the Treasury & 39,511 & 41,715 & 60,356 & 51,779 & 56,912 & 63,301 & 49,496 & 59,145 & 51,085 & 75,496 \\
\hline 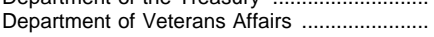 & 896,435 & 757,476 & 783,789 & $1,047,579$ & $1,145,108$ & $1,381,925$ & $1,324,382$ & $1,420,731$ & $1,396,746$ & $1,374,221$ \\
\hline \multicolumn{11}{|l|}{ Other agencies and programs } \\
\hline ACTION & 4,800 & 8,472 & 11,321 & 8,600 & - & - & - & - & - & - \\
\hline for Internatic & 227,864 & 249,786 & 209,018 & 245,199 & 242,907 & 266,582 & 290,580 & 324,900 & 367,120 & 363,430 \\
\hline 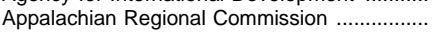 & 6,145 & 93 & 3,907 & 7,608 & 7,974 & 10,242 & 10,623 & 8,322 & 6,347 & 6,750 \\
\hline Barry Goldwater Scholarship and Excellence & & & & & & & & & & \\
\hline $\begin{array}{l}\text { in Education Foundation ........................... } \\
\text { Corporation for National and Community }\end{array}$ & 753 & 1,033 & 1,941 & 2,900 & 3,023 & 2,789 & 3,000 & 3,000 & 3,000 & 3,000 \\
\hline 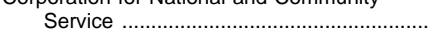 & - & - & - & - & 8,500 & 93,250 & 214,600 & 279,000 & 361,000 & 374,000 \\
\hline 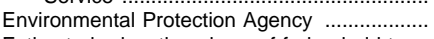 & 64,517 & 87,481 & 62,753 & 152,012 & 124,500 & 98,241 & 125,721 & 75,744 & 82,220 & 90,360 \\
\hline $\begin{array}{l}\text { Estimated education share of federal aid to } \\
\text { the District of Columbia }\end{array}$ & 103,764 & 104,940 & 125,835 & 130,371 & 139,755 & 97,752 & 78,796 & 70,427 & & \\
\hline Federal Emergency Management Agency ... & $\begin{array}{r}103,164 \\
77\end{array}$ & $\begin{array}{r}104,940 \\
215\end{array}$ & $\begin{array}{r}125,835 \\
33\end{array}$ & $\begin{array}{r}130,3 / 1 \\
261\end{array}$ & $\begin{array}{r}139,155 \\
76,467\end{array}$ & 85,200 & $\begin{array}{r}78, / 96 \\
170,400\end{array}$ & $\begin{array}{r}70,427 \\
7,500\end{array}$ & $\begin{array}{l}9 /, 146 \\
95,661\end{array}$ & $\begin{array}{r}109,900 \\
50,000\end{array}$ \\
\hline General Services Admir & - & - & - & - & - & - & - & - & - & - \\
\hline Harry S Truman Scholarship fund & 2,851 & 2,883 & 2,968 & 2,401 & 2,894 & 2,323 & 3,000 & 3,000 & 3,000 & 4,000 \\
\hline Institute of American Indian and Alaskan & & & & & & & & & & \\
\hline Native Culture and Arts Development ... & 3,094 & 4,305 & 5,447 & 6,612 & 7,462 & 12,213 & 13,000 & 6,000 & 6,000 & 4,000 \\
\hline $\begin{array}{l}\text { Institute of Museum and Library Services ....... } \\
\text { James Madison Memorial Fellowship }\end{array}$ & - & - & - & - & - & & & - & 135,000 & 192,000 \\
\hline $\begin{array}{l}\text { Foundation .................................................. } \\
\text { Japanese-United States Friendship }\end{array}$ & 10,005 & 191 & 531 & 885 & 1,298 & 1,464 & 2,000 & 2,000 & 2,000 & 2,000 \\
\hline 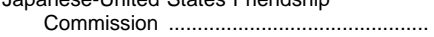 & 3,004 & 2,299 & 1,377 & 1,610 & 1,503 & 1,585 & 2,000 & 2,000 & 1,000 & 2,000 \\
\hline $\begin{array}{l}\text { Library of Congress } \\
\text { National Aeronautics and Space }\end{array}$ & 177,954 & 189,827 & 279,745 & 296,044 & 311,453 & 312,724 & 241,000 & 252,000 & 261,000 & 277,000 \\
\hline 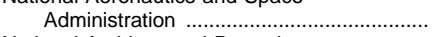 & 978,778 & $1,093,303$ & $1,275,970$ & $1,383,422$ & $1,374,042$ & $1,418,765$ & $1,757,900$ & $1,760,492$ & $1,658,142$ & $1,705,086$ \\
\hline National Archives and Records & & & & & & & & & & \\
\hline Administration ...... & 86,266 & 77,397 & 81,462 & 99,412 & 106,975 & 110,411 & 105,172 & 104,536 & 110,541 & 114,864 \\
\hline National Commission on Libraries and & & & & & & & & & & \\
\hline Information Science & 839 & 3,281 & 3,447 & 1,437 & 867 & 724 & 1,000 & 1,000 & 1,000 & 1,000 \\
\hline National Endowment for th & 5,655 & 5,577 & 6,498 & 8,286 & 7,784 & 7,221 & 9,421 & 4,548 & 7,222 & 7,703 \\
\hline National Endowment for the Humanities ......... & 137,076 & 141,048 & 149,832 & 159,103 & 160,275 & 157,468 & 151,727 & 93,359 & 94,770 & 93,175 \\
\hline National Science Foundation . & $1,472,835$ & $1,588,891$ & $1,738,471$ & $1,875,072$ & $2,080,154$ & $2,031,024$ & $2,086,195$ & $2,303,485$ & $2,395,037$ & $2,473,321$ \\
\hline 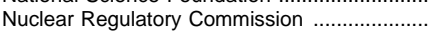 & 25,690 & 42,328 & 23,860 & 27,418 & 22,934 & 20,227 & 22,188 & 16,828 & 16,141 & 13,432 \\
\hline mic Opportunity .... & - & - & & - & - & & - & & & \\
\hline Smithsonian Institution ....... & 5,880 & 5,779 & 5,906 & 6,578 & 7,828 & 10,059 & 9,961 & 9,908 & 7,669 & 7,684 \\
\hline United States Arms Control Agency …….......... & 1,619 & 25 & 69 & 100 & 25 & & - & & & \\
\hline United States Information Agency ..... & 185,521 & 201,547 & 208,181 & 237,226 & 288,059 & 230,493 & 294,800 & 257,400 & 219,800 & 187,000 \\
\hline United States Institute of Peace .......................... & 7,232 & 7,621 & 8,238 & 11,350 & 10,468 & 10,794 & 12,000 & 11,000 & 11,000 & 12,000 \\
\hline Other agencies & 947 & 885 & 1,616 & 1,532 & 1,622 & - & 500 & 1,418 & 2,935 & 2,950 \\
\hline
\end{tabular}

${ }^{1}$ Estimated.

—Data not available or not applicable.

NOTE.-To the extent possible, amounts reported represent outlays, rather than obligations. Some data have been revised from previously published data. Because of rounding, details may not add to totals.

SOURCE: U.S. Department of Education, National Center for Education Statistics, compiled from data appearing in U.S. Office of Management and Budget, Budget of the U.S. Government, Appendix, fiscal years 1982 to 1999; National Science Foundation, Federal Funds for Research and Development, fiscal years 1965 to 1998; and unpublished data obtained from various federal agencies. (This table was prepared May 1998.) 
Table 361.-Federal on-budget funds for education, by level or other educational purpose, by agency and program: Fiscal years 1965 to 1998

[In thousands of current dollars]

\begin{tabular}{|c|c|c|c|c|c|c|c|c|c|c|}
\hline $\begin{array}{c}\text { Level or educational purpose, by agency and } \\
\text { program }\end{array}$ & 1965 & 1970 & 1975 & 1980 & 1983 & 1984 & 1985 & 1986 & 1987 & 1988 \\
\hline 1 & 2 & 3 & 4 & 5 & 6 & 7 & 8 & 9 & 10 & 11 \\
\hline Total, all programs & $\$ 5,331,016$ & $\$ 12,526,499$ & $\$ 23,288,120$ & $\$ 34,493,502$ & $\$ 34,883,900$ & $\$ 36,271,011$ & $\$ 39,027,876$ & $\$ 39,962,901$ & $\$ 41,194,718$ & $\$ 43,454,423$ \\
\hline $\begin{array}{c}\text { Elementary/secondary education } \\
\text { programs }\end{array}$ & $\$ 1,942,577$ & $\$ 5,830,442$ & $\$ 10,617,195$ & $\$ 16,027,686$ & $\$ 14,527,848$ & $\$ 15,292,409$ & $\$ 16,901,334$ & $\$ 17,049,940$ & $\$ 17,535,707$ & $\$ 18,564,859$ \\
\hline Department of Education ${ }^{10}$ & 567,343 & $2,719,204$ & $4,132,742$ & $6,629,095$ & $5,986,633$ & $6,220,820$ & $7,296,702$ & $7,551,973$ & $7,554,487$ & $8,098,436$ \\
\hline Grants for the disadvantaged & - & $1,339,014$ & $1,874,353$ & $3,204,664$ & $2,645,688$ & $3,077,304$ & $4,206,754$ & $3,404,687$ & $3,209,923$ & $4,027,559$ \\
\hline Impact aid program ${ }^{11}$. & 349,671 & 656,372 & 618,711 & 690,170 & 548,205 & 577,676 & 647,402 & 684,311 & 704,197 & 707,539 \\
\hline School improvement programs. & 72,298 & 288,304 & 700,470 & 788,918 & 552,590 & 631,537 & 526,401 & 618,850 & 889,478 & 443,468 \\
\hline Indian education ............................ & - & - & 40,036 & 93,365 & 69,603 & 71,588 & 82,328 & 62,067 & 39,638 & 18,339 \\
\hline Bilingual education & - & 21,250 & 92,693 & 169,540 & 163,268 & 167,400 & 157,539 & 119,601 & 141,483 & 159,746 \\
\hline Special education & 13,849 & 79,090 & 151,244 & 821,777 & $1,289,710$ & 952,778 & $1,017,964$ & $1,627,894$ & $1,339,241$ & $1,465,985$ \\
\hline Vocational and adult education .................... & 131,525 & 335,174 & 655,235 & 860,661 & 717,569 & 742,537 & 658,314 & $1,034,563$ & $1,230,527$ & $1,275,800$ \\
\hline Education Reform - Goa & - & - & - & - & - & - & - & - & - & - \\
\hline Agriculture .... & 623,014 & 760,477 & $1,884,345$ & $4,064,497$ & $3,727,171$ & $3,992,808$ & $4,134,906$ & $4,428,143$ & $4,562,093$ & $4,806,766$ \\
\hline $\begin{array}{l}\text { Child nutrition programs }{ }^{13} \\
\text { Agricultural Marketing Service-...................... }\end{array}$ & 178,580 & 299,131 & $1,452,267$ & $3,377,056$ & $3,278,133$ & $3,536,378$ & $3,664,561$ & $3,819,734$ & $4,044,830$ & $4,286,242$ \\
\hline commodities $^{14}$ & 340,073 & 341,597 & 248,839 & 388,000 & 362,297 & 338,764 & 336,502 & 344,350 & 350,118 & 349,670 \\
\hline $\begin{array}{l}\text { Special milk program }{ }^{13} \\
\text { Estimated education share of Forest }\end{array}$ & 86,609 & 83,800 & 122,858 & 159,293 & 14,912 & 16,000 & 15,993 & 15,267 & 15,446 & 18,342 \\
\hline $\begin{array}{l}\text { Estimated education share of Forest } \\
\text { Service permanent appropriation }\end{array}$ & & & & & & & & & & \\
\hline $\begin{array}{l}\text { Service permanent } \\
\text { Department of Commerce . }\end{array}$ & 17,752 & 35,949 & 60,381 & 140,148 & 71,829 & 101,666 & 117,850 & 248,792 & 151,699 & 152,512 \\
\hline $\begin{array}{l}\text { Department of Commerce } \\
\text { Local public works program-..................... } \\
\quad \text { school facilities }{ }^{15}\end{array}$ & - & - & - & 54,816 & 1,348 & 337 & - & - & - & - \\
\hline lities ${ }^{15}$ & $73, \overline{-}$, & $143, \overline{100}$ & 264,500 & $\begin{array}{r}54,816 \\
370,846\end{array}$ & $\begin{array}{r}1,348 \\
564,885\end{array}$ & $\begin{array}{r}337 \\
694,946\end{array}$ & 831,625 & 903,493 & 861,393 & $988, \overline{265}$ \\
\hline 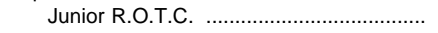 & - & 12,100 & 12,500 & 32,000 & 50,400 & 44,300 & 55,600 & 58,600 & 57,440 & 45,300 \\
\hline dependents schools .................... & 73,000 & 131,000 & 252,000 & 338,846 & 414,485 & 546,072 & 613,437 & 691,437 & 664,941 & 773,810 \\
\hline Sectic & - & - & - & - & 100,000 & 104,574 & 162,588 & 153,456 & 139,012 & 169,155 \\
\hline 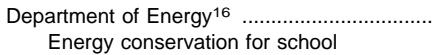 & 100 & 200 & 300 & 77,633 & 40,798 & 22,469 & 23,031 & 21,385 & 12,061 & 12,931 \\
\hline buildin & - & - & - & 77,240 & 40,634 & 22,269 & 22,731 & 21,000 & 11,761 & 12,611 \\
\hline Pre-engineering program & 100 & 200 & 300 & 393 & 164 & 200 & 300 & 385 & 300 & 320 \\
\hline Department of Health and Human Services ${ }^{18}$ & 79,999 & 167,333 & 683,885 & $1,077,000$ & $1,265,000$ & $1,472,750$ & $1,531,059$ & $1,455,315$ & $1,555,542$ & $1,651,324$ \\
\hline 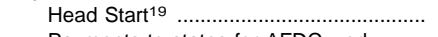 & - & - & 403,900 & 735,000 & 912,000 & 995,750 & $1,075,059$ & $1,040,315$ & $1,130,542$ & $1,206,324$ \\
\hline $\begin{array}{l}\text { Payments to states for AFDC work } \\
\text { programs }\end{array}$ & - & - & - & & - & & - & -1 & - & 一 \\
\hline dent benefits ${ }^{21}$ & 79,999 & 167,333 & 279,985 & 342,000 & 353,000 & 477,000 & 456,000 & 415,000 & 425,000 & 445,000 \\
\hline Department of the Interior ............................ & 130,096 & 140,705 & 220,392 & 318,170 & 346,242 & 393,529 & 389,810 & 308,089 & 344,183 & 379,645 \\
\hline $\begin{array}{l}\text { Mineral Leasing Act and other funds: } \\
\text { Payments to states-estimated }\end{array}$ & & & & & & & & & & \\
\hline $\begin{array}{l}\text { education share } \\
\text { Payments to counties }\end{array}$ & 11,075 & 12,294 & 27,389 & 62,636 & 123,670 & 170,645 & 127,369 & 98,606 & 87,437 & 92,227 \\
\hline $\begin{array}{l}\text { education share ............................ } \\
\text { Indian Education: }\end{array}$ & 10,731 & 16,359 & 29,494 & 48,953 & 20,220 & 24,221 & 59,016 & 5,615 & 36,455 & 34,922 \\
\hline Indian Affairs schools ..... & 92,603 & 95,850 & 141,056 & 178,112 & 176,878 & 173,141 & 177,265 & 181,235 & 195,994 & 231,512 \\
\hline stance $22 \ldots$ & 15,534 & 16,080 & 22,251 & 28,081 & 25,077 & 25,029 & 25,675 & 22,053 & 22,824 & 20,400 \\
\hline $\begin{array}{l}\text { Education expenses for children } \\
\text { of employees, }\end{array}$ & & & & & & & & & & \\
\hline Park ................. & 153 & 122 & 202 & 388 & 397 & 493 & 485 & 580 & 1,473 & 584 \\
\hline Department & 6,402 & 8,237 & 9,822 & 23,890 & 30,462 & 31,759 & 36,117 & 39,684 & 44,531 & 50,679 \\
\hline Vocatio & & & & & & & & & & \\
\hline $\mathrm{ns}^{23} \ldots . .$. & 1,466 & 2,720 & 3,039 & 4,966 & 8,230 & 7,377 & 8,292 & 8,744 & 8,744 & 8,679 \\
\hline Inmate $\mathrm{pr}$ & 4,936 & 5,517 & 6,783 & 18,924 & 22,232 & 24,382 & 27,825 & 30,940 & 35,787 & 42,000 \\
\hline Department of Labor & 230,041 & 420,927 & $1,097,811$ & $1,849,800$ & $1,827,000$ & $1,751,039$ & $1,945,268$ & $1,976,619$ & $2,258,199$ & $2,266,700$ \\
\hline Job Corps 25 & - & - & 175,000 & 469,800 & 563,000 & 595,772 & 604,748 & 632,619 & 678,599 & 712,218 \\
\hline $\begin{array}{l}\text { Training programs-estimated funds for } \\
\text { education programs } 26\end{array}$ & ,041 & 420,927 & 922,811 & $1,380,000$ & $1,264,000$ & $1,155,267$ & $1,340,520$ & $1,344,000$ & $1,579,600$ & $1,554,482$ \\
\hline Department of Transportation ${ }^{27} \ldots$. & - & 45 & 50 & 60 & 65 & 105 & 60 & 60 & 55 & 50 \\
\hline $\begin{array}{l}\text { Tuition assistance for educational } \\
\text { accreditation- }\end{array}$ & & & & & & & & & & \\
\hline personnel ${ }^{28}$ & - & 45 & 50 & 60 & 65 & 105 & 60 & 60 & 55 & 50 \\
\hline Department of the Treasury & 32 & - & 847,139 & 935,903 & 273,728 & 273,278 & 273,728 & 25,085 & - & - \\
\hline $\begin{array}{l}\text { Estimated education share of general } \\
\text { revenue sharing:29 }\end{array}$ & & & & & & & & & & \\
\hline Stat & - & - & 475,224 & 525,019 & - & - & - & - & - & - \\
\hline Local & - & - & 371,915 & 410,884 & 273,728 & 273,278 & 273,728 & 25,085 & - & - \\
\hline $\begin{array}{l}\text { Tuition assistance for educational } \\
\text { accreditation- }\end{array}$ & & & & & & & & & & \\
\hline personnel 28 & 32 & - & - & - & - & - & - & - & - & - \\
\hline Department of Veterans Affairs ${ }^{31} \ldots$ & 41,250 & 338,910 & $1,371,500$ & 545,786 & 378,663 & 351,940 & 344,758 & 251,782 & 235,297 & 196,159 \\
\hline Noncollegiate an & & & & & & & & & & \\
\hline programs $^{32}$ & 14,550 & 281,640 & $1,249,410$ & 439,993 & 244,060 & 227,991 & 224,035 & 137,805 & 119,702 & 76,367 \\
\hline Voce & & & & & & & & & & \\
\hline ? & 00 & 00 & 73,100 & 980 & 117,598 & 187 & 107,480 & 103,159 & 105,947 & 112,058 \\
\hline Dependents' education ${ }^{34}$ & 9,300 & 15,570 & 48,990 & 17,813 & 17,005 & 13,762 & 13,243 & 10,818 & 9,648 & 7,734 \\
\hline $\begin{array}{l}\text { Service members occupational } \\
\text { conversion and training }\end{array}$ & & & & & & & & & & \\
\hline act of $1992^{23,3}$ & - & - & - & - & - & - & - & - & 一 & - \\
\hline agencies & & & & & & & & & & \\
\hline Appalachian & - & 33,161 & 41,667 & 9,157 & 2,801 & 4,589 & 4,632 & 4,632 & 5,323 & 5,327 \\
\hline National Endowment for $t$ & - & - & 3,686 & 4,989 & 4,069 & 4,378 & 4,399 & 4,060 & 4,099 & 4,350 \\
\hline Arts in education ............. & - & - & 3,686 & 4,989 & 4,069 & 4,378 & 4,399 & 4,060 & 4,099 & 4,350 \\
\hline $\begin{array}{l}\text { National Endowment for the } \\
\text { Humanities }{ }^{38}\end{array}$ & - & 20 & 149 & 330 & 510 & & 321 & & 352 & \\
\hline
\end{tabular}


Table 361.-Federal on-budget funds for education, by level or other educational purpose, by agency and program: Fiscal years 1965 to 1998 -Continued

[In thousands of current dollars]

\begin{tabular}{|c|c|c|c|c|c|c|c|c|c|c|}
\hline $\begin{array}{c}\text { Level or educational purpose, by agency and } \\
\text { program }\end{array}$ & 1989 & $1990^{1}$ & $1991^{2}$ & $1992^{3}$ & $1993^{4}$ & $1994^{5}$ & $1995^{6}$ & $1996^{7}$ & $1997^{8}$ & $1998^{9}$ \\
\hline 1 & 12 & 13 & 14 & 15 & 16 & 17 & 18 & 19 & 20 & 21 \\
\hline Total, all programs & $\$ 48,269,575$ & $\$ 51,624,342$ & $\$ 57,599,476$ & $\$ 60,483,092$ & $\$ 67,740,618$ & $\$ 68,254,206$ & $\$ 71,639,520$ & $\$ 71,327,361$ & $\$ 73,136,767$ & $\$ 75,077,477$ \\
\hline $\begin{array}{l}\text { Elementary/secondary education } \\
\text { programs }\end{array}$ & $\$ 19,809,528$ & $\$ 21,984,361$ & $\$ 25,418,031$ & $\$ 27,926,888$ & $\$ 30,834,326$ & $\$ 32,304,357$ & $\$ 33,623,809$ & $\$ 34,391,501$ & $\$ 35,478,905$ & $\$ 36,818,774$ \\
\hline Department of Education ${ }^{10}$ & $8,869,300$ & $9,681,313$ & $10,865,336$ & $12,057,746$ & $13,058,974$ & $13,769,196$ & $14,029,000$ & $14,323,770$ & $14,511,199$ & $14,787,265$ \\
\hline Grants for the disadvantaged.. & $4,185,357$ & $4,494,111$ & $5,218,749$ & $6,158,813$ & $6,615,047$ & $6,845,651$ & $6,808,000$ & $7,020,460$ & $7,201,565$ & $6,235,944$ \\
\hline Impact aid program ${ }^{11}$ & 755,477 & 816,366 & 753,530 & 794,794 & 432,153 & 829,952 & 808,000 & 952,277 & 656,474 & $1,007,323$ \\
\hline School improvement programs & 975,237 & $1,189,158$ & $1,375,910$ & $1,514,892$ & $2,032,552$ & $1,469,964$ & $1,397,000$ & $1,247,360$ & $1,276,599$ & $1,391,141$ \\
\hline Indian education & 65,683 & 69,451 & 65,639 & 68,523 & 99,925 & 79,095 & 71,000 & 77,402 & 55,989 & 55,016 \\
\hline Bilingual education & 164,759 & 188,919 & 186,748 & 198,332 & 124,778 & 221,681 & 225,000 & 184,529 & 181,257 & 279,504 \\
\hline Special education & $1,880,751$ & $1,616,623$ & $2,174,358$ & $2,243,338$ & $2,564,070$ & $2,980,328$ & $3,177,000$ & $3,222,180$ & $3,305,477$ & $3,812,384$ \\
\hline Vocational and adult education & 842,036 & $1,306,685$ & $1,090,402$ & $1,079,054$ & $1,190,449$ & $1,340,762$ & $1,482,000$ & $1,348,064$ & $1,402,369$ & $1,337,861$ \\
\hline Education Reform - Goals $2000^{12} \ldots \ldots \ldots$. & - & - & - & - & - & 1,763 & 61,000 & 271,498 & 431,469 & 668,092 \\
\hline 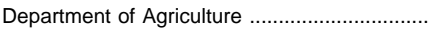 & $5,104,502$ & $5,528,950$ & $6,074,735$ & $6,714,082$ & $7,154,483$ & $7,604,447$ & $8,201,294$ & $8,408,072$ & $8,830,229$ & $9,320,189$ \\
\hline $\begin{array}{l}\text { Child nutrition programs }{ }^{13} \ldots \ldots \ldots \ldots \ldots \ldots \ldots . . . \\
\text { Agricultural Marketing Service- }\end{array}$ & $4,555,581$ & $4,977,075$ & $5,536,966$ & $6,126,983$ & 588 & $7,043,699$ & $7,644,789$ & $7,875,000$ & $8,300,000$ & $8,800,000$ \\
\hline commodities $^{14}$ & 342,071 & 350,441 & 350,859 & 400,000 & 389,900 & 400,000 & 400,000 & 400,000 & 400,000 & 400,000 \\
\hline $\begin{array}{l}\text { Special milk program }{ }^{13} \\
\text { Estimated education share of Forest }\end{array}$ & 18,544 & 18,707 & 19,900 & 19,178 & 15,535 & (12) & & (12) & (12) & $(12)$ \\
\hline Service permanent appropriations .. & 188,306 & 182,727 & 167,010 & 167,921 & 152,460 & 160,748 & 156,505 & 133,072 & 130,229 & 120,189 \\
\hline $\begin{array}{l}\text { Department of Commerce } \\
\text { Local public works program- } \\
\text { school facilities }{ }^{15}\end{array}$ & - & - & - & - & - & - & - & - & - & - \\
\hline Department of & $1,059,259$ & $1,097,876$ & $1,253,105$ & $1,197,318$ & $1,259,374$ & $1,210,168$ & $1,295,547$ & $1,313,126$ & $1,351,788$ & $1,316,587$ \\
\hline Junio & 53,930 & 39,300 & 53,174 & 54,746 & 84,100 & 95,500 & 155,600 & 163,800 & 164,226 & 162,265 \\
\hline Overseas dependents schools. & 821,365 & 864,958 & 960,293 & 912,916 & 895,674 & 849,649 & 855,772 & 813,270 & 832,577 & 852,142 \\
\hline 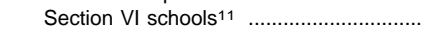 & 183,964 & 193,618 & 239,638 & 229,656 & 279,600 & 265,019 & 284,175 & 336,056 & 354,985 & 302,180 \\
\hline Department of Energy ${ }^{16}$ & 12,851 & 15,563 & 15,676 & 15,236 & 6,254 & 11,615 & 12,646 & - & - & - \\
\hline $\begin{array}{r}\text { Energy } \mathrm{c} \\
\text { build }\end{array}$ & 12,442 & 15,213 & 14,206 & 12,586 & 5,054 & 10,535 & 10,746 & - & - & - \\
\hline Pre-engine & 409 & 350 & 1,470 & 2,650 & 1,200 & 1,080 & 1,900 & - & - & - \\
\hline Department of Health and Human Services ${ }^{18}$ & $1,789,026$ & $2,396,793$ & $2,997,194$ & $3,310,200$ & $4,114,498$ & $4,669,181$ & $5,116,559$ & $5,185,871$ & $5,110,233$ & $5,195,442$ \\
\hline $\begin{array}{l}\text { Head Start }{ }^{19} \\
\text { Payments to states for AFDC work }\end{array}$ & $1,234,869$ & $1,447,758$ & $1,951,775$ & $2,201,800$ & $2,776,286$ & $3,215,946$ & $3,534,000$ & $3,570,000$ & $3,980,546$ & $4,355,000$ \\
\hline 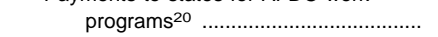 & 85,511 & 459,221 & 545,700 & 594,184 & 736,474 & 838,981 & 953,000 & 931,000 & 453,000 & 160,000 \\
\hline Social Sec & 468,646 & 814 & 499,719 & 514,216 & ,738 & 254 & 559 & 871 & 687 & 680,442 \\
\hline $\begin{array}{l}\text { Department of the Interior .............................. } \\
\text { Mineral Leasing Act and other funds: } \\
\text { Payments to states-estimated }\end{array}$ & 379,381 & 445,267 & 644,770 & 517,666 & 536,483 & 485,758 & 493,124 & 486,463 & 558,395 & 535,603 \\
\hline on share ..................... & 114,414 & 123,811 & 131,683 & 122,045 & 108,924 & 21,693 & 18,750 & 17,940 & 28,000 & 18,000 \\
\hline 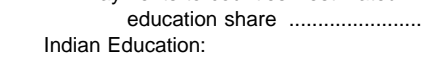 & 54,804 & 102,522 & 35,038 & 45,805 & 34,903 & 39,819 & 37,490 & 39,000 & 61,000 & 39,000 \\
\hline Idian Affa & 186,643 & 192,841 & 452,521 & 325,582 & 368,817 & 399,234 & 411,524 & 408,889 & 450,218 & 460,387 \\
\hline $\begin{array}{l}\text { Johnson-O'Malley assistance } 22 \\
\text { Education expenses for children } \\
\text { of employees, }\end{array}$ & 23,000 & 25,556 & 24,931 & 23,590 & 22,980 & 24,326 & 24,359 & 19,634 & 18,177 & 17,216 \\
\hline National Park ............... & 520 & 538 & 597 & 644 & 859 & 686 & 1,000 & 1,000 & 1,000 & 1,000 \\
\hline Department of Justice ..................................... & 58,523 & 65,997 & 78,050 & 94,724 & 107,857 & 112,447 & 128,850 & 175,900 & 191,400 & 222,200 \\
\hline $18-$ & 6,933 & 2,066 & 1,748 & 1,944 & 1,725 & 1,240 & 3,000 & $-3,500$ & 1,000 & 1,000 \\
\hline Inmat & 51,590 & 63,931 & 76,302 & 92,780 & 106,132 & 111,207 & 125,850 & 400 & 190,400 & 221,200 \\
\hline Departme & $2,271,966$ & $2,505,487$ & $3,209,147$ & $3,708,362$ & $4,240,990$ & $4,011,184$ & $3,957,800$ & $4,084,000$ & $4,432,000$ & $4,990,000$ \\
\hline Job Corps 25 & 771,966 & 739,376 & 805,270 & 925,826 & 949,287 & 964,234 & $1,029,000$ & $1,114,000$ & $1,185,000$ & $1,203,000$ \\
\hline $\begin{array}{l}\text { Training programs-estimated funds for } \\
\text { education programs }{ }^{26}\end{array}$ & 500,000 & $1,766,111$ & $2,403,877$ & $2,782,536$ & $3,291,703$ & $3,046,950$ & $2,928,800$ & $2,970,000$ & $3,247,000$ & $3,787,000$ \\
\hline Department of Transportation 27 & 40 & 46 & 31 & 60 & 60 & 60 & 62 & 40 & 40 & 40 \\
\hline $\begin{array}{l}\text { Tuition assistance for educational } \\
\text { accreditation- }\end{array}$ & & & & & & & & & & \\
\hline personnel28. & 40 & 46 & 31 & 60 & 60 & 60 & 62 & 40 & 40 & 40 \\
\hline Department of the Treasury & - & - & - & - & - & - & - & - & - & - \\
\hline $\begin{array}{l}\text { Estimated education share of general } \\
\text { revenue sharing: } 29\end{array}$ & & & & & & & & & & \\
\hline State & - & - & - & - & - & - & - & - & - & - \\
\hline Local & - & - & - & - & - & - & - & - & - & - \\
\hline $\begin{array}{l}\text { Tuition assistance for educational } \\
\text { accreditation- }\end{array}$ & & & & & & & & & & \\
\hline Coas & - & - & - & - & - & - & - & - & - & - \\
\hline Department of Veterans Affairs ${ }^{31} \ldots$ & 168,865 & 155,351 & 167,040 & 190,608 & 222,567 & 335,866 & 311,768 & 344,298 & 402,229 & 347,831 \\
\hline $\begin{array}{l}\text { Noncollegiate and job training } \\
\text { programs }^{32}\end{array}$ & 43,696 & 12,848 & - & - & - & - & - & - & - & - \\
\hline Vocation & & & & & & & & & & \\
\hline & 118,749 & 136,780 & 161,096 & 184,500 & 216,276 & 265,597 & 298,132 & 349,637 & 386,000 & 338,000 \\
\hline Dependents' education ${ }^{34}$ & 6,420 & 5,723 & 5,944 & 6,108 & 5,840 & 5,740 & 5,961 & 4,493 & 5,236 & 5,331 \\
\hline $\begin{array}{l}\text { Service members occupational } \\
\text { conversion and training }\end{array}$ & & & & & & & & & & \\
\hline act of $1992^{23}$, & - & - & - & - & 451 & 64,529 & 7,675 & $-9,832$ & 10,993 & 4,500 \\
\hline & & & & & & & & & & \\
\hline Appal & 5,145 & 93 & 790 & 182 & 5,382 & 2,529 & 2,173 & 2,862 & 1,700 & 1,900 \\
\hline National Endowment for the Arts $^{37} \ldots \ldots . .$. & 4,462 & 4,641 & 4,870 & 5,000 & 5,000 & 5,000 & 7,117 & 4,030 & 4,382 & 5,398 \\
\hline $\begin{array}{l}\text { Arts in education ................................... } \\
\text { National Endowment for the }\end{array}$ & 4,462 & 4,641 & 4,870 & 5,000 & 5,000 & 5,000 & 7,117 & 4,030 & 4,382 & 5,398 \\
\hline Humanities ${ }^{38}$ & 698 & 404 & 590 & 809 & 1,645 & 278 & 997 & 101 & 310 & 320 \\
\hline
\end{tabular}


Table 361.-Federal on-budget funds for education, by level or other educational purpose, by agency and program: Fiscal years 1965 to 1998 -Continued

[In thousands of current dollars]

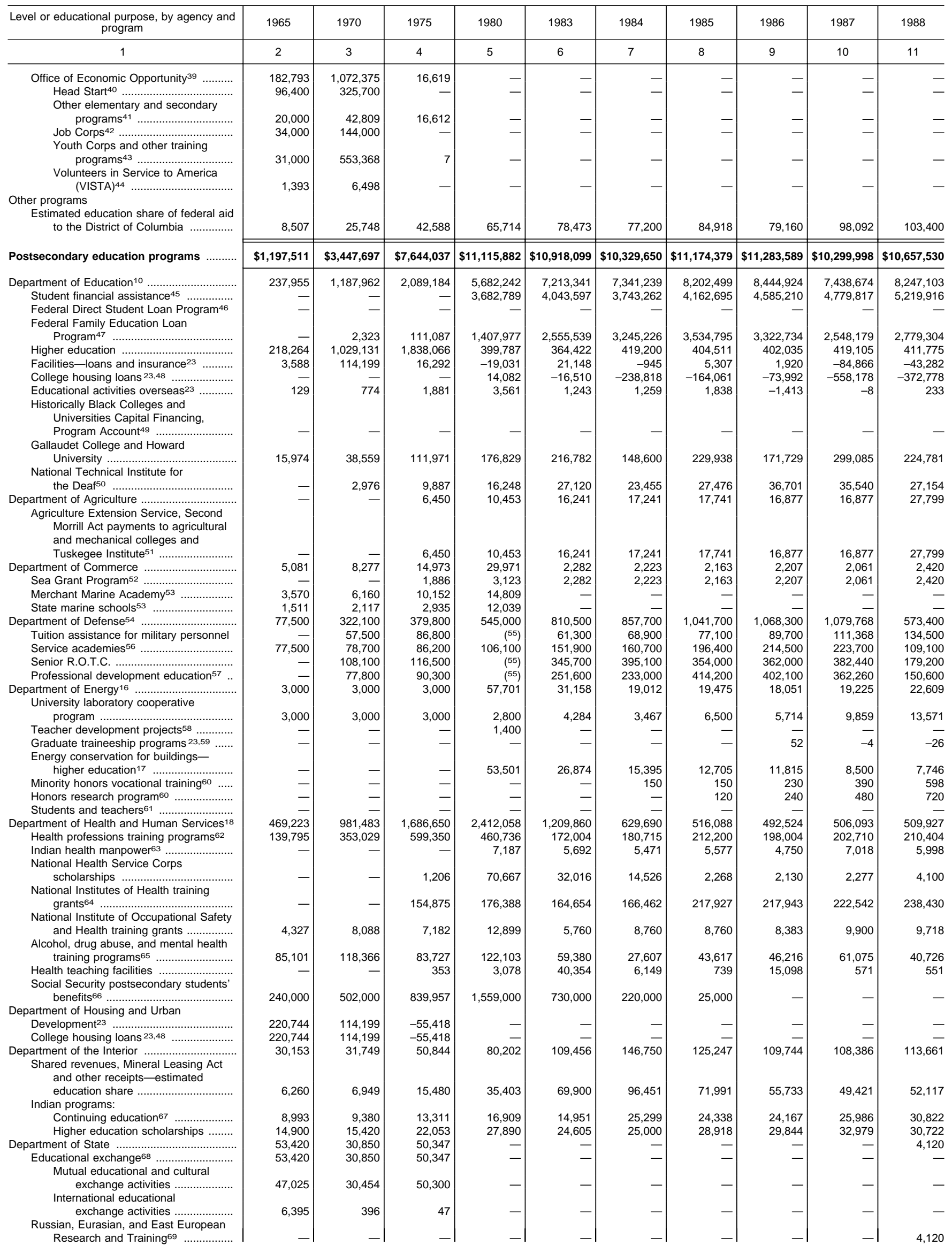


Table 361.-Federal on-budget funds for education, by level or other educational purpose, by agency and program: Fiscal years 1965 to 1998 -Continued

[In thousands of current dollars]

\begin{tabular}{|c|c|c|c|c|c|c|c|c|c|c|}
\hline $\begin{array}{c}\text { Level or educational purpose, by agency and } \\
\text { program }\end{array}$ & 1989 & $1990^{1}$ & $1991^{2}$ & $1992^{3}$ & $1993^{4}$ & $1994^{5}$ & $1995^{6}$ & $1996^{7}$ & $1997^{8}$ & $1998^{9}$ \\
\hline 1 & 12 & 13 & 14 & 15 & 16 & 17 & 18 & 19 & 20 & 21 \\
\hline Office of Economic Opportunity 39 & - & - & - & - & - & - & - & - & - & - \\
\hline Head Start40 & - & - & - & - & - & - & - & - & - & - \\
\hline $\begin{array}{c}\text { Other elementary and secondary } \\
\text { programs }\end{array}$ & - & - & - & - & - & - & - & - & - & - \\
\hline Job Corps ${ }^{42}$ & - & - & - & - & - & - & - & - & - & - \\
\hline $\begin{array}{c}\text { Youth Corps and other training } \\
\text { programs }{ }^{43}\end{array}$ & - & - & - & - & - & - & - & - & - & - \\
\hline $\begin{array}{l}\text { Volunteers in Service to America } \\
\quad(\text { VISTA })^{44}\end{array}$ & - & - & - & - & - & - & - & - & - & - \\
\hline Other programs & & & & & & & & & & \\
\hline $\begin{array}{l}\text { Estimated education share of federal aid } \\
\text { to the District of Columbia }\end{array}$ & 85,510 & 86,579 & 103,697 & 109,894 & 120,759 & 86,627 & 66,871 & 62,968 & 85,000 & 96,000 \\
\hline Postsecondary education programs ........... & $\$ 13,269,888$ & $\$ 13,650,915$ & $\$ 14,707,406$ & $\$ 14,387,386$ & $\$ 17,844,015$ & $\$ 16,177,051$ & $\$ 17,618,137$ & $\$ 15,775,507$ & $\$ 15,959,426$ & $\$ 15,989,999$ \\
\hline Department of Education ${ }^{10}$. & $10,640,044$ & $1,175,978$ & $12,002,766$ & $11,323,584$ & $14,660,704$ & $12,871,390$ & $14,234,000$ & $12,257,553$ & $12,377,033$ & $12,406,056$ \\
\hline Student financial assistance 45 & $5,859,774$ & $5,920,328$ & $6,333,839$ & $7,071,440$ & $7,678,293$ & $7,118,034$ & $7,047,000$ & $6,861,599$ & $7,247,288$ & $8,352,775$ \\
\hline $\begin{array}{l}\text { Federal Direct Student Loan Program } 46 \\
\text { Federal Family Education Loan }\end{array}$ & - & - & - & - & 10,000 & 148,247 & 840,000 & 594,761 & 659,521 & 941,029 \\
\hline Program 47 & $3,899,387$ & $4,372,446$ & $4,781,918$ & $3,253,648$ & $5,554,920$ & $4,509,696$ & $5,190,000$ & $3,663,956$ & $3,313,835$ & $1,967,843$ \\
\hline 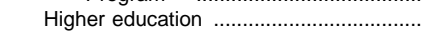 & 606,849 & 659,492 & 615,372 & 718,406 & $1,041,583$ & 796,278 & 871,000 & 846,517 & 876,944 & 855,672 \\
\hline Facilities-loans and insurance ${ }^{23} \ldots \ldots$. & 10,182 & 19,219 & 34,805 & 25,984 & $-2,976$ & $-5,605$ & $-6,000$ & 8,837 & 787 & $-1,124$ \\
\hline College housing loans ${ }^{23,48} \ldots \ldots \ldots \ldots$ & $-31,299$ & $-57,167$ & $-33,249$ & $-39,907$ & $-28,355$ & $-18,434$ & $-46,000$ & $-34,815$ & $-42,697$ & $-32,028$ \\
\hline Educational activities overseas ${ }^{23} \ldots \ldots \ldots . . .$. & 374 & 82 & -47 & - & - & - & - & - & - & - \\
\hline $\begin{array}{l}\text { Historically Black Colleges and } \\
\text { Universities Capital Financing, } \\
\text { Program Account }{ }^{49}\end{array}$ & - & - & - & - & - & 129 & - & 323 & 150 & 130 \\
\hline Gallaudet College and Howard & & & & & & & & & & \\
\hline Univers & 258,519 & 230,327 & 233,209 & 263,497 & 353,390 & 280,945 & 292,000 & 273,904 & 278,373 & 279,881 \\
\hline $\begin{array}{l}\text { National Technical Institute for } \\
\text { the Deaf50 }\end{array}$ & 36,258 & 31,251 & 36.919 & 30,516 & 53,849 & 42,100 & 46.000 & 42,471 & 42,832 & 41,878 \\
\hline Department of Agriculture & 27,799 & 31,273 & 32,302 & 34,238 & 32,730 & 25,472 & 33,373 & 32,872 & 32,639 & 32,639 \\
\hline $\begin{array}{l}\text { Agriculture Extension Service, Second } \\
\text { Morrill Act payments to agricultural } \\
\text { and mechanical colleges and }\end{array}$ & & & & & & & & & & \\
\hline 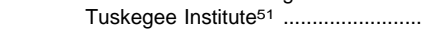 & 27,799 & 31,273 & 32,302 & 34,238 & 32,730 & 25,472 & 33,373 & 32,872 & 32,639 & 32,639 \\
\hline Department of Commer & 2,765 & 3,312 & 4,334 & 3,270 & 3,549 & 4,000 & 3,487 & 3,384 & 3,429 & 3,429 \\
\hline Sea Grant Program 5 & 2,765 & 3,312 & 4,334 & 3,270 & 3,549 & 4,000 & 3,487 & 3,384 & 3,429 & 3,429 \\
\hline 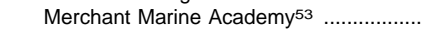 & - & - & - & - & - & - & - & - & - & - \\
\hline 1ools ${ }^{53} \ldots \ldots . . .$. & - & - & - & - & - & - & - & - & - & - \\
\hline Department of Defense ${ }^{54}$ & 746,464 & 635,769 & 665,059 & 680,194 & 696,800 & 679,000 & 729,500 & 864,900 & 913,554 & 923,462 \\
\hline Tuition assistance for military personnel & 236,089 & 95,300 & 92,800 & 102,400 & 123,400 & 130,200 & 127,000 & 260,300 & 271,892 & 275,433 \\
\hline demies $^{56}$ & 115,150 & 120,613 & 132,487 & 125,146 & 128,000 & 141,500 & 163,300 & 171,700 & 183,726 & 191,438 \\
\hline Senior & 198,325 & 193,056 & 198,072 & 348 & 184,100 & 300 & 400 & 200 & 593 & 225,377 \\
\hline velopment education ${ }^{57}$ & 196,900 & 226,800 & 241,700 & 259,300 & 261,300 & 212,000 & 219,800 & 214,700 & 229,343 & 231,214 \\
\hline Department of Energy ${ }^{16}$.. & 15,062 & 25,502 & 30,851 & 34,373 & 17,654 & 17,951 & 28,027 & - & - & - \\
\hline University laboratory cooperative & & & & & & & & & & \\
\hline $\mathrm{p}$ & 5,929 & 9,402 & 19,330 & 19,100 & 4,000 & 3,600 & 8,552 & - & - & - \\
\hline Teacher $\mathrm{d}$ & - & - & - & - & - & - & - & - & - & - \\
\hline Graduate traineeship programs ${ }^{23,59}$.. & - & - & - & - & - & - & - & - & - & - \\
\hline servation for buildings- & & & & & & & & & & \\
\hline & 6,493 & 7,459 & 7,411 & 9,573 & 6,654 & 8,051 & 7,381 & - & - & - \\
\hline training ${ }^{60}$. & 720 & - & - & - & - & - & - & - & - & - \\
\hline Honors re & 820 & 6,472 & 1,000 & 1,000 & 1,000 & 900 & 2,221 & - & - & - \\
\hline 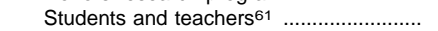 & 1,100 & 2,169 & 3,110 & 4,700 & 6,000 & 5,400 & 9,873 & - & - & - \\
\hline Departme & 542,796 & 578,542 & 697,385 & 743,456 & 720,911 & 795,914 & 796,035 & 798,596 & 801,884 & 793,072 \\
\hline programs 62 & 223,811 & 230,600 & 271,937 & 305,829 & 299,785 & 305,549 & 298,302 & 273,519 & 313,672 & 291,079 \\
\hline 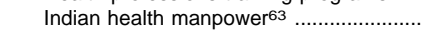 & 5,972 & 9,508 & 13,379 & 19,460 & 26,100 & 26,398 & 27,000 & 26,000 & 28,000 & 29,000 \\
\hline National Health Service Corps & & & & & & & & & & \\
\hline & 6,531 & 4,759 & 48,795 & 58,706 & 33,323 & 79,250 & 78,206 & 28,847 & 30,000 & 30,000 \\
\hline $\begin{array}{l}\text { National Institutes of Health training } \\
\text { grants }^{64}\end{array}$ & 255,558 & 241.356 & 268.492 & 348.034 & 350.804 & 372.698 & 380.502 & 457.000 & 416.992 & 429,820 \\
\hline National Institute of Occupational Safety & & & & & & & & & & \\
\hline anc & 10,095 & 10,461 & 10,472 & 10,972 & 10,472 & 11,622 & 11,660 & 12,898 & 12,923 & 12,948 \\
\hline $\begin{array}{r}\text { Alcohol, } \mathrm{dr} \\
\text { trainin }\end{array}$ & 40,301 & 81,353 & 83,829 & - & - & - & - & - & - & - \\
\hline 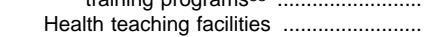 & 528 & 505 & 481 & $4 \overline{55}$ & $4 \overline{27}$ & 397 & 365 & 332 & 297 & $2 \overline{25}$ \\
\hline 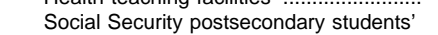 & & & & & & & & & & \\
\hline & - & - & - & - & - & - & - & - & - & - \\
\hline Department of Housi & & & & & & & & & & \\
\hline Development ${ }^{23}$ & - & - & - & - & - & - & - & - & - & - \\
\hline College housing loans 23,48 & - & - & - & - & - & - & - & - & - & - \\
\hline Department of $t$ & 123,529 & 135,480 & 141,523 & 140,266 & 132,916 & 156,734 & 159,054 & 132,478 & 165,611 & 167,832 \\
\hline $\begin{array}{l}\text { Shared revenues, Mineral Leasing Act } \\
\text { and other receipts_estimated }\end{array}$ & & & & & & & & & & \\
\hline educ & 64,669 & 69,980 & 74,430 & 68,982 & 61,566 & 79,815 & 82,810 & 59,020 & 89,310 & 86,190 \\
\hline In & & & & & & & & & & \\
\hline education 67 & 28,424 & 34,911 & 36,875 & 38,970 & 39,840 & 43,184 & 43,907 & 47,173 & 49,820 & 52,118 \\
\hline Higher education scholarships .... & 30,436 & 30,589 & 30,218 & 32,315 & 31,510 & 33,735 & 32,337 & 26,285 & 26,481 & 29,524 \\
\hline partment of State & 4,422 & 2,167 & 6,396 & 9,057 & 10,211 & 7,842 & 3,000 & 2,000 & - & - \\
\hline 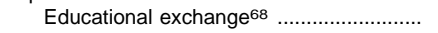 & - & - & - & - & - & - & - & - & - & - \\
\hline onal and cultural & & & & & & & & & & \\
\hline $\begin{array}{l}\text { exchange activities .... } \\
\text { International educational }\end{array}$ & & - & - & - & - & - & - & - & - & - \\
\hline & - & - & - & - & - & - & - & - & - & - \\
\hline $\begin{array}{l}\text { Russian, Eurasian, and East European } \\
\text { Research and Training69 }\end{array}$ & 4,422 & 2,167 & 6,396 & 9,057 & 10,211 & 7,842 & 3,000 & 2,000 & -1 & - \\
\hline
\end{tabular}


Table 361.-Federal on-budget funds for education, by level or other educational purpose, by agency and program: Fiscal years 1965 to 1998 -Continued

[In thousands of current dollars]

\begin{tabular}{|c|c|c|c|c|c|c|c|c|c|c|}
\hline $\begin{array}{c}\text { Level or educational purpose, by agency and } \\
\text { program }\end{array}$ & 1965 & 1970 & 1975 & 1980 & 1983 & 1984 & 1985 & 1986 & 1987 & 1988 \\
\hline 1 & 2 & 3 & 4 & 5 & 6 & 7 & 8 & 9 & 10 & 11 \\
\hline Department of Transportation 27 & - & 11,197 & 11,885 & 12,530 & 46,177 & 57,245 & 55,569 & 44,074 & 47,226 & 44,998 \\
\hline Merchant Marine Academy53 & - & - & - & - & 23,211 & 18,739 & 19,898 & 19,505 & 20,476 & 20,579 \\
\hline State marine schools ${ }^{70}$ & - & - & - & - & 9,383 & 23,733 & 19,777 & 8,363 & 12,073 & 7,961 \\
\hline Coast Guard Academy ${ }^{28} \ldots \ldots \ldots \ldots \ldots \ldots \ldots \ldots \ldots \ldots \ldots \ldots$ & - & 9,342 & 9,780 & 10,000 & 10,329 & 11,364 & 11,857 & 11,845 & 10,086 & 10,810 \\
\hline $\begin{array}{l}\text { Postgraduate training for Coast Guard } \\
\text { officers } 71\end{array}$ & - & 1,655 & 1,855 & 2,230 & 2,891 & 2,959 & 3,499 & 3,807 & 3,978 & 5,084 \\
\hline $\begin{array}{l}\text { Tuition assistance to Coast Guard } \\
\text { military personnel }\end{array}$ & - & 200 & 250 & 300 & 363 & 450 & 538 & 554 & 613 & 564 \\
\hline Department of the Treasury & 8,208 & - & 268,605 & 296,750 & - & - & - & - & - & - \\
\hline $\begin{array}{l}\text { General revenue sharing-estimated } \\
\text { state share to higher education } 29,30\end{array}$ & - & - & 268,605 & 296,750 & - & - & - & - & - & - \\
\hline Coast Guard Academy 28 ......................... & 6,815 & - & - & - & - & - & - & - & - & - \\
\hline $\begin{array}{l}\text { Postgraduate training for Coast Guard } \\
\text { officers }^{71}\end{array}$ & 1,293 & - & - & - & - & - & - & - & - & - \\
\hline $\begin{array}{c}\text { Tuition assistance to Coast Guard } \\
\text { military personnel }\end{array}$ & 100 & - & - & - & - & - & - & - & - & - \\
\hline Department of Veterans Affairs ${ }^{31}$ & 55,650 & 693,490 & $3,029,600$ & $1,803,847$ & $1,292,885$ & $1,092,609$ & 944,091 & 803,166 & 764,561 & 768,090 \\
\hline Vietnam-era veterans: ${ }^{72} \ldots \ldots \ldots$ & 33,950 & 638,260 & $2,840,600$ & $1,579,974$ & $1,077,391$ & 861,310 & 694,217 & 514,476 & 411,967 & 345,242 \\
\hline College student support ... & - & - & - & $1,560,081$ & $1,052,859$ & 839,135 & 679,953 & 504,290 & 403,527 & 337,568 \\
\hline 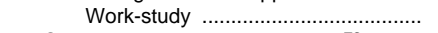 & - & - & - & 19,893 & 24,532 & 22,175 & 14,264 & 10,186 & 8,440 & 7,674 \\
\hline Service persons college support ${ }^{73} \ldots \ldots \ldots$ & - & 18,900 & 74,690 & 46,617 & 36,054 & 38,896 & 35,630 & 30,707 & 28,410 & 33,472 \\
\hline Post-Vietnam veterans ${ }^{74}$ & - & - & - & 922 & 24,871 & 52,241 & 82,554 & 121,929 & 171,752 & 203,262 \\
\hline $\begin{array}{l}\text { All-volunteer-force educational } \\
\text { assistance: } 75\end{array}$ & - & - & -1 & - & - & - & 196 & 24,171 & 45,688 & 73,731 \\
\hline Vetera & - & - & - & - & - & - & - & 2 & $\begin{array}{r}40,000 \\
107\end{array}$ & 8,386 \\
\hline 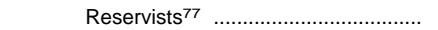 & - & - & - & - & - & - & 196 & 24,169 & 45,581 & 65,345 \\
\hline Veteran dependents' education 78 & 21,700 & 36,330 & 114,310 & 176,334 & 154,569 & 140,162 & 131,494 & 111,883 & 106,744 & 100,883 \\
\hline Payments to state education agencies ${ }^{79}$ & - & - & - & - & - & - & - & - & - & 11,500 \\
\hline Other agencies & & & & & & & & & & \\
\hline $\begin{array}{l}\text { Appalachian Regional Commission }{ }^{36} \ldots . \\
\text { National Endowment for the }\end{array}$ & - & 4,105 & 2,545 & 1,751 & - & - & - & 1,950 & 30 & 1,050 \\
\hline Humanities ${ }^{38}$ & - & 3,349 & 25,320 & 56,451 & 48,457 & 52,359 & 49,098 & 42,346 & 48,679 & 47,601 \\
\hline National Science Foundation .................. & 27,170 & 42,000 & 60,283 & 64,583 & 50,126 & 29,746 & 60,069 & 74,151 & 85,494 & 97,466 \\
\hline $\begin{array}{l}\text { Science and engineering education } \\
\text { programs }\end{array}$ & 27,170 & 37,000 & 60,283 & 64,583 & 50,126 & 29.746 & 60,069 & 74,151 & 85,494 & 97,466 \\
\hline 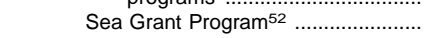 & - & $\begin{array}{r}5,000 \\
\end{array}$ & - & - & - & ${ }^{29,140}$ & - & - & - & - \\
\hline United States Information Agency 80 & 7,512 & 8,423 & 9,405 & 51,095 & 69,298 & 64,394 & 124,041 & 148,483 & 162,897 & 166,705 \\
\hline $\begin{array}{l}\text { Educational and cultural affairs68 } \\
\text { Educational and cultural exchange }\end{array}$ & - & - & - & 49,546 & 68,041 & 17,414 & 21,079 & 23,008 & 24,313 & 29,724 \\
\hline 81 - & - & - & - & - & - & 45,570 & 101,529 & 125,246 & 138,039 & 136,646 \\
\hline $\begin{array}{l}\text { Educational exchange activities, } \\
\text { international }\end{array}$ & - & - & - & 1,549 & 1,257 & 1,410 & 1,433 & 229 & 545 & 335 \\
\hline $\begin{array}{l}\text { Information center and library } \\
\text { activities }^{82}\end{array}$ & 512 & 3423 & 405 & . & 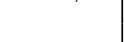 & - & 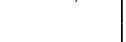 & & & \\
\hline Other programs & , 512 & 8,423 & 9,405 & - & -1 & - & -1 & - & - & - \\
\hline $\begin{array}{l}\text { Barry Goldwater Scholarship and } \\
\text { Excellence in Education }\end{array}$ & & & & & & & & & & \\
\hline Foundation 83 & - & - & - & - & - & - & - & - & - & - \\
\hline $\begin{array}{l}\text { Estimated education share of federal aid } \\
\text { to the District of Columbia }\end{array}$ & 1,895 & 513 & 10,564 & 13,143 & 16,523 & 7,513 & 15,266 & 4,351 & 310 & 14,566 \\
\hline Harry S Truman Scholarship fund $23,84 .$. & - & - & - & $-1,895$ & 1,795 & 1,929 & 1,332 & 2,441 & 2,717 & 2,815 \\
\hline $\begin{array}{l}\text { Institute of American Indian and Alaskan } \\
\text { Native Culture and Arts }\end{array}$ & & & & & & & & & & \\
\hline Development ${ }^{85}$ & - & - & - & - & - & - & - & - & - & - \\
\hline James Madison Memorial Fellowship & & & & & & & & & & \\
\hline Foundation 86 ......................... & - & - & - & - & - & - & - & - & - & 13,200 \\
\hline Other education programs & 374,652 & $\$ 964,719$ & $\$ 1,608,478$ & $\$ 1,548,730$ & $\$ 2,204,147$ & $\$ 2,710,402$ & $\$ 2,107,588$ & $\$ 2,620,021$ & $\$ 2,820,407$ & $\$ 2,981,571$ \\
\hline Departr & 21 & 630,235 & 659 & 706 & $1,326,271$ & 1,81 & 055 & 1,67 & 1,82 & $1,938,998$ \\
\hline tion .................... & 17,732 & 47,456 & 108,372 & 187,317 & 247,966 & 307,447 & 284,900 & 263,216 & 285,296 & 295,615 \\
\hline Libraries $^{87}$ & 26,111 & 108,284 & 225,810 & 129,127 & 124,451 & 87,059 & 85,650 & 96,406 & 129,062 & 101,202 \\
\hline Rehab & & & & & & & & & & \\
\hline research & 137,313 & 473,091 & 709,483 & 426,886 & 948,650 & $1,414,396$ & 798,298 & $1,311,485$ & $1,405,357$ & $1,536,905$ \\
\hline American Printing House for the Blind ... & 865 & 1,404 & 1,994 & 4,349 & 5,174 & 4,054 & 4,230 & 3,031 & 5,989 & 5,234 \\
\hline Trust & - & & - & 27 & 30 & 172 & -23 & 33 & 50 & 42 \\
\hline Agriculture .. & 87,551 & 135,637 & 220,395 & 271,112 & 322,430 & 327,123 & 336,375 & 322,599 & 330,866 & 342,523 \\
\hline Extension Se & 85,924 & 131,734 & 215,523 & 263,584 & 312,413 & 317,099 & 325,986 & 311,132 & 322,095 & 330,164 \\
\hline Nation & 1,627 & 3,903 & 4,872 & 7,528 & 10,017 & 10,024 & 10,389 & 11,467 & 8,771 & 12,359 \\
\hline Department of Commerce .... & 251 & 1,226 & 2,317 & 2,479 & - & - & - & - & - & - \\
\hline Maritime Administration: & & & & & & & & & & \\
\hline Training $f$ & & & & & & & & & & \\
\hline Department of Health and $\mathrm{H}$ & $\begin{array}{r}251 \\
3953\end{array}$ & $\begin{array}{r}1,226 \\
24273\end{array}$ & $\begin{array}{r}2,317 \\
31653\end{array}$ & $\begin{array}{r}2,479 \\
37819\end{array}$ & 44899 & $48 . \overline{76}$ & $47 . \overline{195}$ & 59306 & $597 \overline{70}$ & $62, \overline{6}$ \\
\hline $\begin{array}{l}\text { Department of Health and Human Services } \\
\text { National Library of Medicine }\end{array}$ & $\begin{array}{l}3,953 \\
3,953\end{array}$ & $\begin{array}{l}24,273 \\
24,273\end{array}$ & $\begin{array}{l}31,653 \\
31,653\end{array}$ & $\begin{array}{l}37,819 \\
37,819\end{array}$ & $\begin{array}{l}44,899 \\
44,899\end{array}$ & $\begin{array}{l}48,876 \\
48,876\end{array}$ & $\begin{array}{l}47,195 \\
47,195\end{array}$ & $\begin{array}{l}59,306 \\
59,306\end{array}$ & $\begin{array}{l}59,770 \\
59,770\end{array}$ & $\begin{array}{l}62,060 \\
62,060\end{array}$ \\
\hline Department 0 & & & & & & & & & & \\
\hline 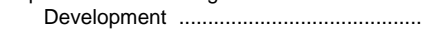 & 512 & - & - & - & - & - & - & - & - & - \\
\hline $\begin{array}{l}\text { Urban mass transportation-managerial } \\
\text { training grants } \\
88\end{array}$ & 512 & - & - & - & -1 & - & - & - & - & - \\
\hline Depart & 3,850 & 5,546 & 42,818 & 27,642 & 31,082 & 23,723 & 25,517 & 27,412 & 26,293 & 26,361 \\
\hline F.B.I. Natio & 1,850 & 2,066 & 5,100 & 7,234 & 8,832 & 4,285 & 4,189 & 3,946 & 4,408 & 5,385 \\
\hline F.B.I. Field Police Academy . & 1,450 & 2,500 & 5,254 & 7,715 & 8,792 & 8,069 & 10,220 & 9,756 & 8,984 & 9,995 \\
\hline Narcotics & 550 & 980 & 1,152 & 2,416 & 1,740 & 63 & 83 & 68 & - & 142 \\
\hline Nation & - & - & 31,312 & 10,277 & 11,718 & 11,306 & 11,025 & 13,642 & 12,901 & 10,839 \\
\hline Department of State & 10,780 & 20,672 & 28,113 & 25,000 & 23,784 & 23,086 & 23,791 & 23,371 & 23,856 & 33,308 \\
\hline Foreign Service Institute ................ & 6,395 & 15,857 & 20,750 & 25,000 & 23,784 & 23,086 & 23,791 & 23,371 & 23,856 & 33,308 \\
\hline $\begin{array}{l}\text { Center for Cultural and Technical } \\
\text { Interchange }{ }^{68}\end{array}$ & 4,385 & 4,815 & 7,363 & - & -1 & -1 & & & & \\
\hline
\end{tabular}


Table 361.-Federal on-budget funds for education, by level or other educational purpose, by agency and program: Fiscal years 1965 to 1998 -Continued

[In thousands of current dollars]

\begin{tabular}{|c|c|c|c|c|c|c|c|c|c|c|}
\hline $\begin{array}{c}\text { Level or educational purpose, by agency and } \\
\text { program }\end{array}$ & 1989 & $1990^{1}$ & $1991^{2}$ & $1992^{3}$ & $1993^{4}$ & $1994^{5}$ & $1995^{6}$ & $1996^{7}$ & $1997^{8}$ & $1998^{9}$ \\
\hline 1 & 12 & 13 & 14 & 15 & 16 & 17 & 18 & 19 & 20 & 21 \\
\hline Department of Transportation 27 & 63,559 & 46,025 & 50,459 & 57,239 & 57,576 & 59,940 & 59,257 & 53,518 & 58,337 & 59,328 \\
\hline Merchant Marine Academy53 & 20,611 & 20,926 & 22,855 & 27,007 & 26,788 & 30,241 & 30,850 & 31,000 & 31,000 & 32,000 \\
\hline State marine schools ${ }^{70}$ & 26,062 & 8,269 & 8,829 & 11,072 & 10,320 & 10,270 & 8,980 & 7,000 & 7,000 & 7,000 \\
\hline Coast Guard Academy ${ }^{28} \ldots \ldots \ldots \ldots \ldots \ldots \ldots \ldots \ldots \ldots \ldots \ldots$ & 11,740 & 12,074 & 12,074 & 13,071 & 13,602 & 13,103 & 13,500 & 9,553 & 13,918 & 13,965 \\
\hline $\begin{array}{l}\text { Postgraduate training for Coast Guard } \\
\text { officers } 71\end{array}$ & 4,621 & 4,173 & 6,060 & 5,788 & 6,306 & 6,026 & 5,513 & 5,511 & 5,519 & 5,363 \\
\hline $\begin{array}{l}\text { Tuition assistance to Coast Guard } \\
\text { military personnel28 }\end{array}$ & 525 & 582 & 641 & 301 & 560 & 300 & 414 & 454 & 900 & 1,000 \\
\hline 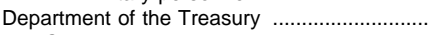 & - & - & - & - & - & - & - & - & - & - \\
\hline $\begin{array}{l}\text { General revenue sharing-estimated } \\
\text { state share to higher education } 29,30\end{array}$ & - & - & - & - & - & - & - & - & - & - \\
\hline Coast Guard Academy 28 .......................... & - & - & - & - & - & - & - & - & - & - \\
\hline 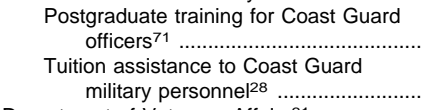 & - & - & - & - & - & - & - & - & - & - \\
\hline 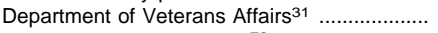 & 725,270 & 599,825 & 614,449 & 854,480 & 919,991 & $1,043,709$ & $1,010,114$ & $1,074,713$ & 992,665 & $1,024,776$ \\
\hline Vietnam-era veterans: ${ }^{72} \ldots \ldots \ldots$ & 264,702 & 46,998 & - & - & - & - & - & - & - & - \\
\hline student support ..... & 258,982 & 39,458 & - & - & - & - & - & - & - & - \\
\hline 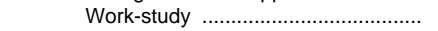 & 5,720 & 7,540 & - & - & - & - & - & - & - & - \\
\hline Service persons college $s$ & 34,399 & 8,911 & - & - & - & - & - & - & - & - \\
\hline $\begin{array}{l}\text { Post-Vietnam veterans }{ }^{74} \\
\text { All-volunteer-force educational }\end{array}$ & 195,142 & 161,475 & 118,139 & 88,500 & 65,894 & 48,114 & 33,596 & 44,387 & 16,279 & 11,731 \\
\hline ce: 75 & 122,222 & 269,947 & 380,720 & 650,540 & 745,786 & 886,951 & 868,394 & 922,807 & 863,906 & 898,759 \\
\hline Veterans $^{76}$ & 43,423 & 183,765 & 303,861 & 530,820 & 626,669 & 769,481 & 390 & 336 & 781,296 & 807,533 \\
\hline Reservists ${ }^{77}$ & 78,799 & 86,182 & 76,859 & 119,720 & 119,117 & 117,470 & 108,004 & 113,471 & 82,610 & 91,226 \\
\hline Veteran dependents' ed & 96,805 & 100,494 & 103,590 & 103,440 & 96,311 & 96,644 & 95,124 & 94,519 & 99,480 & 101,286 \\
\hline Payments to state education agencies ${ }^{79}$ & 12,000 & 12,000 & 12,000 & 12,000 & 12,000 & 12,000 & 13,000 & 13,000 & 13,000 & 13,000 \\
\hline Other agencies & & & & & & & & & & \\
\hline $\begin{array}{l}\text { Appalachian Regional Commission } 36 \ldots \\
\text { National Endowment for the }\end{array}$ & 825 & - & 92 & 1,487 & 1,587 & 3,413 & 2,741 & 2,704 & 2,981 & 3,100 \\
\hline ies 38 & 51,449 & 50,938 & 55,861 & 58,512 & 57,804 & 58,404 & 56,481 & 30,896 & 25,792 & 20,505 \\
\hline National Science Foundation ... & 130,187 & 161,884 & 191,661 & 210,375 & 246,591 & 225,168 & 211,800 & 262,000 & 355,000 & 358,000 \\
\hline $\begin{array}{l}\text { Science and engineering education } \\
\text { programs }\end{array}$ & 130,187 & 161,884 & 191,661 & 210,375 & 246,591 & 225,168 & 211.800 & 262,000 & 000 & 358,000 \\
\hline Sea Grant Program 52 & - & - & - & - & $-240,091$ & - & $-211,000$ & - & - & - \\
\hline United States Information Agency ${ }^{80}$ & 164,807 & 181,172 & 185,905 & 207,676 & 256,068 & 200,429 & 260,800 & 239,400 & 204,800 & 172,000 \\
\hline $\begin{array}{l}\text { Educational and cultural affairs68 } \\
\text { Educational and cultural exchange }\end{array}$ & 21,596 & 35,862 & 35,714 & 38,858 & 44,183 & 28,927 & 13,600 & 17,000 & 12,000 & - \\
\hline turar cxurlarige & 143,194 & 145,307 & 150,183 & 168,818 & 211,885 & 171,502 & 247,200 & 222,400 & 192,800 & 172,000 \\
\hline $\begin{array}{l}\text { Educational exchange activities, } \\
\text { international }\end{array}$ & 17 & 3 & 8 & - & - & - & - & - & - & - \\
\hline $\begin{array}{l}\text { Information center and library } \\
\quad \text { activities } 82\end{array}$ & - & - & - & - & - & - & - & - & - & - \\
\hline Other programs & & & & & & & & & & \\
\hline $\begin{array}{l}\text { Barry Goldwater Scholarship and } \\
\text { Excellence in Education }\end{array}$ & & & & & & & & & & \\
\hline Foundation 83 ........................ & 753 & 1,033 & 1,941 & 2,900 & 3,023 & 2,789 & 3,000 & 3,000 & 3,000 & 3,000 \\
\hline $\begin{array}{l}\text { Estimated education share of federal aid } \\
\text { to the District of Columbia }\end{array}$ & 14,207 & 14,637 & 17,477 & 16,382 & 14,247 & 8,896 & 9,468 & 6,494 & 11,700 & 12,800 \\
\hline Harry S Truman Scholarship fund $23,84 .$. & 2,851 & 2,883 & 2,968 & 2,401 & 2,894 & 2,323 & 3,000 & 3,000 & 3,000 & 4,000 \\
\hline $\begin{array}{l}\text { Institute of American Indian and Alaskan } \\
\text { Native Culture and Arts }\end{array}$ & & & & & & & & & & \\
\hline Development 85 & 3,094 & 4,305 & 5,447 & 6,612 & 7,462 & 12,213 & 13,000 & 6,000 & 6,000 & 4,000 \\
\hline James Madison Memorial Fellowship & & & & & & & & & & \\
\hline Foundation $86 \quad \ldots \ldots . .$. & 10,005 & 191 & 531 & 885 & 1,298 & 1,464 & 2,000 & 2,000 & 2,000 & 2,000 \\
\hline Other education programs & $\$ 3,180,334$ & $\$ 3,383,031$ & $\$ 3,698,617$ & $\$ 3,991,955$ & $\$ 4,107,193$ & $\$ 4,483,704$ & $\$ 4,719,655$ & $\$ 4,828,038$ & $\$ 5,021,163$ & $\$ 5,171,360$ \\
\hline Depart &, 574 & $2,251,801$ & 277 & $2,579,883$ & 372 & 984 & 000 & 3,08 & 329 & $2,961,776$ \\
\hline 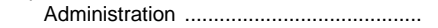 & 301,260 & 328,293 & 365,681 & 368,420 & 353,545 & 403,877 & 404,000 & 502,949 & 412,629 & 437,080 \\
\hline Libraries $^{8}$ & 140,398 & 137,264 & 142,596 & 214,928 & 181,219 & 142,223 & 117,000 & 167,585 & - & - \\
\hline Reha & & & & & & & & & & \\
\hline resea & $1,623,255$ & $1,780,360$ & $1,902,338$ & $1,991,875$ & $1,983,848$ & $2,244,226$ & $2,333,000$ & $2,410,178$ & $2,462,236$ & $2,515,356$ \\
\hline American Printing House for the Blind ... & 6,645 & 5,736 & 8,242 & 4,587 & 7,774 & 5,636 & 7,000 & 4,693 & 7,308 & 9,220 \\
\hline Trust & 16 & 148 & 420 & 73 & 14 & 22 & - & 182 & 156 & 120 \\
\hline Departm & ,021 & 352,511 & 2,343 & 442 & 650 & 426,316 & 878 & 412,878 & 413,634 & 408,737 \\
\hline Exten & 333,571 & 337,907 & 366,176 & 385,087 & 424,928 & 409,110 & 405,371 & 394,878 & 393,634 & 390,737 \\
\hline Natio & 13,450 & 14,604 & 16,167 & 15,355 & 18,722 & 17,206 & 17,507 & 18,000 & 20,000 & 18,000 \\
\hline Department of Comm & - & - & - & - & - & - & - & - & - & - \\
\hline Maritime Administration: & & & & & & & & & & \\
\hline $\begin{array}{l}\text { Training for private sector } \\
\text { employees }{ }^{53}\end{array}$ & - & - & - & - & - & - & - & - & - & - \\
\hline Department of $\mathrm{He}$ & 71,912 & 77,962 & 094 & 643 & 6,860 & 896 & 000 & 000 & 000 & 155,000 \\
\hline National Libra & 71,912 & 77,962 & 89,094 & 97,643 & 96,860 & 107,896 & 138,000 & 117,000 & 144,000 & 155,000 \\
\hline epartn & & & & & & & & & & \\
\hline elopment & - & - & - & - & - & - & - & - & - & - \\
\hline $\begin{array}{l}\text { Urban mass transportation-man } \\
\text { training grants }{ }^{88}\end{array}$ & - & - & - & - & -1 & - & -1 & - & - & - \\
\hline Depart & 23,906 & 26,920 & 30,543 & 525 & 37,028 & 65 & 36,296 & 35,072 & 055 & 39,821 \\
\hline F.B.I. $\mathrm{N}$ & 5,513 & 6,028 & 6,368 & 10,631 & 14,388 & 10,311 & 12,831 & 14,411 & 22,260 & 18,699 \\
\hline F.B.I. Field Police Academy & 7,673 & 10,548 & 12,700 & 12,578 & 10,563 & 11,790 & 11,140 & 10,277 & 11,375 & 8,902 \\
\hline & 824 & 850 & 1,180 & 695 & 230 & 275 & 325 & 384 & 420 & 220 \\
\hline Natio & 9,896 & 9,494 & 10,295 & 10,621 & 11,847 & 11,689 & 12,000 & 10,000 & 12,000 & 12,000 \\
\hline Department of State & 40,157 & 47,539 & 41,790 & 44,086 & 58,840 & 46,557 & 51,648 & 53,330 & 49,378 & 55,428 \\
\hline Foreign Service Institute .................... & 40,157 & 47,539 & 41,790 & 44,086 & 58,840 & 46,557 & 51,648 & 53,330 & 49,378 & 55,428 \\
\hline $\begin{array}{l}\text { Center for Cultural and Technical } \\
\text { Interchange }{ }^{68}\end{array}$ & -1 & - & -1 & - & -1 & -1 & & & & \\
\hline
\end{tabular}


Table 361.-Federal on-budget funds for education, by level or other educational purpose, by agency and program: Fiscal years 1965 to 1998 -Continued

[In thousands of current dollars]

\begin{tabular}{|c|c|c|c|c|c|c|c|c|c|c|}
\hline $\begin{array}{c}\text { Level or educational purpose, by agency and } \\
\text { program }\end{array}$ & 1965 & 1970 & 1975 & 1980 & 1983 & 1984 & 1985 & 1986 & 1987 & 1988 \\
\hline 1 & 2 & 3 & 4 & 5 & 6 & 7 & 8 & 9 & 10 & 11 \\
\hline Department of Transportation ${ }^{27} \ldots . .$. & - & 3,964 & 11,877 & 10,212 & 6,175 & 4,781 & 3,785 & 1,865 & 2,895 & 3,153 \\
\hline $\begin{array}{l}\text { Highways training and education } \\
\text { grants } 90\end{array}$ & - & 2,418 & 3,250 & 3,412 & 3,527 & 2,050 & 1,500 & - & 1,000 & 1,416 \\
\hline $\begin{array}{l}\text { Maritime Administration: } \\
\text { Training for private sector } \\
\quad \text { employees }{ }^{53}\end{array}$ & - & - & - & - & 1,448 & 1,381 & 1,135 & 1,143 & 1,291 & 1,517 \\
\hline $\begin{array}{l}\text { Urban mass transportation-managerial } \\
\text { training grants } 88\end{array}$ & - & 1,546 & 2,627 & 500 & 1,200 & 1,350 & 1,150 & 722 & 604 & 220 \\
\hline $\begin{array}{l}\text { Alr tramic controlle } \\
\text { program }^{92} \ldots . .\end{array}$ & - & - & 6,000 & 6,300 & - & - & - & - & - & - \\
\hline $\begin{array}{l}\text { Department of the Treasury ...................... } \\
\text { Federal Law Enforcement Training }\end{array}$ & - & 18 & 3,096 & 14,584 & 13,334 & 14,327 & 16,160 & 15,982 & 19,110 & 32,768 \\
\hline Center $^{93}$ & - & 18 & 3,096 & 14,584 & 13,334 & 14,327 & 16,160 & 15,982 & 19,110 & 32,768 \\
\hline Other agencies & & & & & & & & & & \\
\hline ACTION $^{9}$ & - & - & 7,045 & 2,833 & 1,830 & 4,975 & 1,761 & 1,368 & 3,368 & 4,110 \\
\hline Estimated education funds ${ }^{95}$. & - & - & 7,045 & 2,833 & 1,830 & 4,975 & 1,761 & 1,368 & 3,368 & 4,110 \\
\hline Agency for International Development ... & 63,329 & 88,034 & 78,896 & 99,707 & 130,257 & 127,383 & 141,847 & 154,627 & 186,175 & 193,115 \\
\hline $\begin{array}{l}\text { Education and human resources .... } \\
\text { American schools and hospitals }\end{array}$ & 53,968 & 61,570 & 58,349 & 80,518 & 109,624 & 101,408 & 115,104 & 126,132 & 152,332 & 160,051 \\
\hline 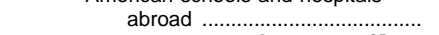 & 9,361 & 26,464 & 20,547 & 19,189 & 20,633 & 25,975 & 26,743 & 28,495 & 33,843 & 33,064 \\
\hline Appalachian Regional Commission ${ }^{35} \ldots .$. & - & 572 & 1,574 & 8,124 & 98 & 330 & 113 & - & 92 & - \\
\hline & & & & & & & & & & \\
\hline $\begin{array}{l}\text { Service } 94 \\
\text { Estimated education funds }\end{array}$ & - & - & - & - & - & - & - & - & - & - \\
\hline & - & - & - & - & - & - & - & - & - & - \\
\hline 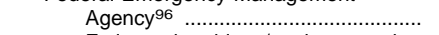 & - & 290 & 290 & 281 & 390 & 351 & 405 & 290 & 290 & 290 \\
\hline $\begin{array}{l}\text { Estimated architect/engineer student } \\
\text { development program }{ }^{97}\end{array}$ & - & 40 & 40 & 31 & 90 & 71 & 155 & 40 & 40 & 40 \\
\hline Estimated other training programs 98 & - & 250 & 250 & 250 & 300 & 280 & 250 & 250 & 250 & 250 \\
\hline Estimate & - & - & - & - & - & - & - & - & - & - \\
\hline General Services Administration 100 & & & & & & & & & & \\
\hline $\begin{array}{c}\text { Libraries and other archival } \\
\text { activities }\end{array}$ & 4,013 & 14,775 & 22,532 & 34,800 & 44,200 & 50,894 & - & - & - & - \\
\hline Institute of Museum and Library & & & & & $44,<\cup 0$ & & - & - & - & \\
\hline $\begin{array}{l}\text { Services } \\
\text { Japanese-United States Friendship }\end{array}$ & - & - & - & - & - & - & - & - & - & - \\
\hline Commission 101 & - & - & - & 2,294 & 2,364 & 1,611 & 2,236 & 235 & 3,225 & 2,274 \\
\hline Library of Congress . & 15,111 & 29,478 & 63,766 & 151,871 & 154,198 & 164,080 & 169,310 & 166,130 & 160,835 & 160,505 \\
\hline Salaries and expenses ......... & 11,421 & 20,700 & 48,798 & 102,364 & 122,823 & 127,935 & 130,354 & 126,747 & 124,878 & 122,356 \\
\hline $\begin{array}{l}\text { phy } \\
\text { Special }\end{array}$ & $\begin{array}{l}2,317 \\
1,187\end{array}$ & $\begin{array}{l}6,195 \\
2273\end{array}$ & $\begin{array}{r}11,908 \\
2333\end{array}$ & $\begin{array}{r}31,436 \\
3,492\end{array}$ & $\begin{array}{r}26,116 \\
3578\end{array}$ & $\begin{array}{r}30,399 \\
3745\end{array}$ & $\begin{array}{r}32,954 \\
-4621\end{array}$ & $\begin{array}{r}35,460 \\
2,372\end{array}$ & 33,813 & $\begin{array}{r}36,245 \\
405\end{array}$ \\
\hline hd furnishings ................ & $\begin{array}{r}1 \\
186\end{array}$ & $\begin{array}{r}2,273 \\
310\end{array}$ & $\begin{array}{r}2,333 \\
727\end{array}$ & 14,579 & $\begin{array}{l}3,578 \\
1,681\end{array}$ & 1,661 & $\begin{array}{l}4,621 \\
1,381\end{array}$ & $\begin{array}{l}2,3 / 2 \\
1,551\end{array}$ & $\begin{array}{r}809 \\
1,335\end{array}$ & $\begin{array}{r}405 \\
1,499\end{array}$ \\
\hline National Aeronautics and Space & & & & & & & & & & \\
\hline $\begin{array}{l}\text { Administration } \\
\text { Aerospace edu }\end{array}$ & & & & & & & & & & \\
\hline project & 100 & 350 & 600 & 882 & 1,323 & 1,628 & 1,800 & 1,900 & 2,250 & 2,400 \\
\hline $\begin{array}{l}\text { National Archives and Records } \\
\text { Administration }{ }^{102}\end{array}$ & & & & & & & & & & \\
\hline $\begin{array}{c}\text { Libraries and other archival } \\
\text { activities }\end{array}$ & - & - & - & - & - & - & 52,118 & 55,252 & 59,521 & 65,153 \\
\hline $\begin{array}{l}\text { National Commission on Libraries and } \\
\text { Information Science }{ }^{103}\end{array}$ & - & -1 & 449 & 2,090 & 681 & 733 & 723 & 781 & 512 & 522 \\
\hline National Endowment for the Arts ${ }^{37} \ldots \ldots$ & - & 340 & 1,068 & 231 & 632 & 819 & 1,137 & 1,128 & 1,295 & 1,200 \\
\hline $\begin{array}{l}\text { National Endowment for } \\
\text { Humanities }{ }^{38} \ldots \ldots \ldots .\end{array}$ & - & 5,090 & 38,486 & 85,805 & 74,348 & 74,750 & 76,252 & 78,319 & 75,376 & 76,803 \\
\hline Smithsonian Institution & 2,233 & 2,461 & 5,509 & 5,153 & 6,073 & 5,758 & 7,886 & 6,191 & 6,545 & 5,393 \\
\hline ograms and related & & & & & & & & & & \\
\hline research …............................... & 2,133 & 2,261 & 4,203 & 3,254 & 3,365 & 2,642 & 4,665 & 2,341 & 2,506 & 1,223 \\
\hline $\begin{array}{c}\text { National Gallery of Art extension } \\
\text { service }\end{array}$ & 100 & 200 & 300 & 426 & 617 & 692 & 675 & 662 & 731 & 656 \\
\hline Woodrow Wilson International & & & . & & & & | & 002 & | & 030 \\
\hline Center for Scholars ...................... & - & - & 1,006 & 1,473 & 2,091 & 2,424 & 2,546 & 3,188 & 3,308 & 3,514 \\
\hline $\begin{array}{l}\text { U.S. Information Agency-Center for } \\
\text { Cultural and Technical }\end{array}$ & & & & & & & & & & \\
\hline In & - & - & - & 15,115 & 17,258 & 19,374 & 18,966 & 20,531 & 16,756 & 22,759 \\
\hline U.S. Institute of Peace ${ }^{104}$ & - & - & - & & & - & & 230 & 4,083 & 3,476 \\
\hline $\begin{array}{l}\text { Other programs: } \\
\text { Estimated education share of federal aid } \\
\text { for the District of Columbia .................. }\end{array}$ & 948 & 1,758 & 2,335 & 2,990 & 2,520 & 2,672 & 7,156 & 8,333 & 11,540 & 4,400 \\
\hline 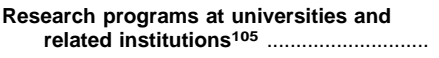 & $1,816,276$ & $2,283,641$ & $3,418,410$ & $\$ 5,801,204$ & $7,233,806$ & $\$ 7,938,550$ & $8,844,575$ & $\$ 9,009,351$ & $\$ 10,538,606$ & $\$ 11,250,464$ \\
\hline Depa & 248 & 87,823 & 82,770 & 742 & 59,580 & 550 & 28,809 & 68,983 & 60,912 & 42,379 \\
\hline & & 64,796 & & 405 & 275,027 & 279,200 & & 273,698 & 279,943 & 304,888 \\
\hline Dep & 4,015 & 4,487 & 21,677 & 48,295 & 51,460 & 52,600 & 52,951 & 62,406 & 36,835 & 36,133 \\
\hline Department of Defense & 436,912 & 356,188 & 364,929 & 644,455 & $1,112,212$ & $1,072,500$ & $1,245,888$ & $1,382,795$ & $1,754,456$ & $1,899,680$ \\
\hline Department of Energy & 439,334 & 548,327 & 761,376 & $1,470,224$ & $1,861,112$ & $2,001,400$ & $2,205,316$ & $2,141,955$ & $2,225,513$ & $2,350,426$ \\
\hline Hump? & & & & & & & & & & \\
\hline Services & 474,362 & 623,765 & $1,273,037$ & $2,087,053$ & $2,448,899$ & $2,750,700$ & $3,228,014$ & $3,309,708$ & $3,983,407$ & $4,282,117$ \\
\hline Departn & & & & & & & & & & \\
\hline Deve & - & 510 & 2,650 & 5,314 & 2,158 & 2,000 & 438 & 342 & 463 & 51 \\
\hline Department of the Interior & 9,839 & 18,521 & 28,955 & 42,175 & 28,616 & 36,500 & 34,422 & 36,440 & 33,353 & 35,103 \\
\hline & & 1,945 & 8,902 & 9,189 & 7,156 & 6,800 & 5,168 & 5,095 & 8,991 & 6,365 \\
\hline abor . & - & 3,567 & 6,124 & 12,938 & 6,392 & 4,800 & 3,417 & 341 & 432 & 5,528 \\
\hline 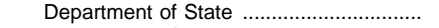 & - & 8,220 & 10,973 & 188 & 29 & & 29 & 30 & 432 & 1,243 \\
\hline Department of Transportation .................. & - & 12,328 & 28,478 & 31,910 & 29,722 & 21,800 & 22,621 & 20,215 & 25,184 & 16,933 \\
\hline ury ............... & - & - & - & 226 & 238 & 300 & 388 & 190 & 169 & - \\
\hline Department of Veterans Affairs ............... & 337 & 518 & 1,112 & 1,600 & 800 & 500 & 1,000 & 1,000 & 2,251 & 2,300 \\
\hline
\end{tabular}


Table 361.-Federal on-budget funds for education, by level or other educational purpose, by agency and program: Fiscal years 1965 to 1998 -Continued

[In thousands of current dollars]

\begin{tabular}{|c|c|c|c|c|c|c|c|c|c|c|}
\hline $\begin{array}{c}\text { Level or educational purpose, by agency and } \\
\text { program }\end{array}$ & 1989 & $1990^{1}$ & $1991^{2}$ & $1992^{3}$ & $1993^{4}$ & $1994^{5}$ & $1995^{6}$ & $1996^{7}$ & $1997^{8}$ & $1998^{9}$ \\
\hline 1 & 12 & 13 & 14 & 15 & 16 & 17 & 18 & 19 & 20 & 21 \\
\hline 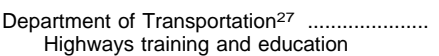 & 4,415 & 1,507 & 2,022 & 2,419 & 500 & 500 & 650 & 700 & 750 & 725 \\
\hline grants 90 & 1,416 & - & 1,371 & 1,945 & - & - & - & - & - & - \\
\hline $\begin{array}{l}\text { Maritime Administration: } \\
\text { Training for private sector } \\
\text { employees } 53\end{array}$ & 1,499 & 1,507 & 651 & 474 & 500 & 500 & 650 & 700 & 750 & 725 \\
\hline $\begin{array}{l}\text { Urban mass transportation-managerial } \\
\text { training grants }\end{array}$ & 1,500 & - & - & - & - & - & - & - & - & - \\
\hline $\begin{array}{l}\text { Federal Aviation Administration }{ }^{91} \\
\text { Air traffic controllers second career } \\
\text { program }\end{array}$ & - & - & - & t & 1 & (1) & & Sol & & \\
\hline $\begin{array}{l}\text { Department of the Treasury ............................. } \\
\text { Federal Law Enforcement Training }\end{array}$ & 39,100 & 41,488 & 60,127 & 51,694 & 56,779 & 61,992 & 48,000 & 59,000 & 51,000 & 73,000 \\
\hline 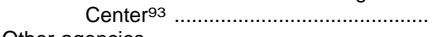 & 39,100 & 41,488 & 60,127 & 51,694 & 56,779 & 61,992 & 48,000 & 59,000 & 51,000 & 73,000 \\
\hline $\begin{array}{c}\text { Other agencies } \\
\text { ACTION94 }\end{array}$ & & & & & & & & & & \\
\hline $\begin{array}{l}\text { ACTION } 94 \text {.... } \\
\text { Estimated education funds }{ }^{95}\end{array}$ & $\begin{array}{l}4,800 \\
4,800\end{array}$ & $\begin{array}{l}8,472 \\
8,472\end{array}$ & $\begin{array}{l}11,321 \\
11,321\end{array}$ & $\begin{array}{l}8,600 \\
8,600\end{array}$ & - & - & - & - & - & - \\
\hline Agency for Inter & 182,839 & 170,371 & 154,021 & 212,220 & 215,248 & 241,948 & 260,408 & 307,000 & 355,600 & 347,700 \\
\hline $\begin{array}{l}\text { Education and human resources .... } \\
\text { American schools and hospitals }\end{array}$ & 146,915 & 142,801 & 122,231 & 195,570 & 190,020 & 221,988 & 248,408 & 302,000 & 348,600 & 344,700 \\
\hline abroad & 35,924 & 27,570 & 31,790 & 16,650 & 25,228 & 19,960 & 12,000 & 5,000 & 7,000 & 3,000 \\
\hline $\begin{array}{l}\text { Appalachian Regional Commission } 35 \\
\text { Corporation for National and Community }\end{array}$ & 175 & - & 25 & 938 & 1,005 & 4,299 & 5,709 & 2,756 & 1,666 & 1,750 \\
\hline Service 94 & - & - & - & - & 8,500 & 93,250 & 214,600 & 279,000 & 361,000 & 374,000 \\
\hline $\begin{array}{l}\text { Estimated education funds }{ }^{95} \\
\text { Federal Emergency Management }\end{array}$ & - & - & - & - & 8,500 & 93,250 & 214,600 & 279,000 & 361,000 & 374,000 \\
\hline Agency96 ...................... & 77 & 215 & 33 & 261 & 76,467 & 85,200 & 170,400 & 7,500 & 95,661 & 50,000 \\
\hline $\begin{array}{l}\text { Estimated architect/engineer student } \\
\text { development program } 97 \text {........... }\end{array}$ & 50 & 200 & 28 & 250 & 375 & 一 & - & - & - & - \\
\hline Estimated other training programs ${ }^{98}$ & 27 & 15 & 5 & 11 & 92 & - & - & - & - & - \\
\hline Estimated disaster relief 99 & - & - & - & - & 76,000 & 85,200 & 170,400 & 7,500 & 95,661 & 50,000 \\
\hline $\begin{array}{c}\text { General Services Administration } 100 \\
\text { Libraries and other archival } \\
\text { activities }\end{array}$ & - & - & - & - & - & - & . & - & - & \\
\hline Institute of Museum and Library & & & - & - & - & -1 & 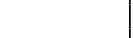 & - & - & \\
\hline $\begin{array}{r}\text { Services } \\
\text { Japanese-Uni }\end{array}$ & - & - & - & - & - & - & - & - & 135,000 & 192,000 \\
\hline Comm & 3,004 & 2,299 & 1,377 & 1,610 & 1,503 & 1,585 & 2,000 & 2,000 & 1,000 & 2,000 \\
\hline Library of $\mathrm{C}$ & 177,954 & 189,827 & 279,745 & 296,044 & 311,453 & 312,724 & 241,000 & 252,000 & 261,000 & 277,000 \\
\hline $\begin{array}{l}\text { Salaries and expenses .......... } \\
\text { Books for the blind and the }\end{array}$ & 137,637 & 148,985 & 239,429 & 252,623 & 260,918 & 261,814 & 198,000 & 201,000 & 208,000 & 223,000 \\
\hline apped ............... & 38,233 & 37,473 & 36,878 & 38,688 & 45,261 & 46,600 & 39,000 & 47,000 & 46,000 & 47,000 \\
\hline program .. & & 10 & 10 & 10 & 30 & - & - & - & - & - \\
\hline Furniture & 1,985 & 3,359 & 3,428 & 4,723 & 5,244 & 4,310 & 4,000 & 4,000 & 7,000 & 7,000 \\
\hline $\begin{array}{l}\text { National Aeronautics and Space } \\
\text { Administration } \\
\text { Aerospace education services }\end{array}$ & & & & & & & & & & \\
\hline & 2,300 & 3,300 & 5,900 & 6,100 & 6,500 & 6,100 & 5,923 & 5,927 & 5,926 & 6,119 \\
\hline $\begin{array}{l}\text { National Archives and Records } \\
\text { Administration } 102\end{array}$ & & & & & & & & & & \\
\hline $\begin{array}{l}\text { Libraries and other archival } \\
\text { activities ................................ } \\
\text { National Commission on Libraries and }\end{array}$ & 86,266 & 77,397 & 81,462 & 99,412 & 106,975 & 110,411 & 105,172 & 104,536 & 110,541 & 114,864 \\
\hline Inform & 839 & 3,281 & 3,447 & 1,437 & 867 & 724 & 1,000 & 1,000 & 1,000 & 1,000 \\
\hline $\begin{array}{l}\text { National Endowment for the } \text { Arts }^{37} \ldots \ldots \ldots . \\
\text { National Endowment for the }\end{array}$ & 1,193 & 936 & 1,628 & 3,286 & 2,784 & 2,221 & 2,304 & 518 & 2,840 & 2,306 \\
\hline Humanitie & 84,929 & 89,706 & 93,381 & 99,782 & 100,826 & 98,786 & 94,249 & 62,362 & 68,667 & 72,350 \\
\hline $\begin{array}{l}\text { Smithsonian Institution ............................... } \\
\text { Museum programs and related }\end{array}$ & 5,880 & 5,779 & 5,906 & 6,578 & 7,828 & 10,059 & 9,961 & 9,908 & 7,669 & 7,684 \\
\hline research & 870 & 690 & 440 & 93 & 1,165 & 3,060 & 3,190 & 3,180 & 1,000 & 1,000 \\
\hline $\begin{array}{l}\text { National Gallery of Art extension } \\
\text { service ............................. } \\
\text { Woodrow Wilson International }\end{array}$ & 650 & 474 & 641 & 793 & 763 & 816 & 771 & 728 & 669 & 684 \\
\hline $\begin{array}{l}\text { Center for Scholars .................. } \\
\text { U.S. Information Agency-Center for } \\
\text { Cultural and Technical }\end{array}$ & 4,360 & 4,615 & 4,825 & 5,692 & 5,900 & 6,183 & 6,000 & 6,000 & 6,000 & 6,000 \\
\hline Inter & 20,714 & 20,375 & 22,276 & 29,550 & 31,991 & 30,064 & 34,000 & 18,000 & 15,000 & 15,000 \\
\hline U.S. Institute of Peace 104 & 7,232 & 7,621 & 8,238 & 11,350 & 10,468 & 10,794 & 12,000 & 11,000 & 11,000 & 12,000 \\
\hline $\begin{array}{l}\text { Estimated education share of federal aid } \\
\text { for the District of Columbia }\end{array}$ & 4,047 & 3,724 & 4,661 & 4,095 & 4,749 & 2,229 & 2,457 & 964 & 446 & 1,100 \\
\hline $\begin{array}{l}\text { Research programs at universities and } \\
\text { related institutions } \mathbf{1}^{105}\end{array}$ & $\$ 12,009,825$ & $\$ 12,606,035$ & $\$ 13,775,422$ & $\$ 14,176,863$ & $\$ 14,955,083$ & $\$ 15,289,094$ & $\$ 15,677,919$ & $\$ 16,332,315$ & $\$ 16,677,273$ & $\$ 17,097,344$ \\
\hline $\mathrm{De}$ & 314 & 483 & & 800 & & 838 & & & 994 & \\
\hline & 294 & & & 967 & & & & & 620 & 909 \\
\hline Depa & 44,821 & 50,523 & 62,870 & 77,240 & 70,805 & 81,423 & 85,442 & 85,283 & 79,242 & 71,769 \\
\hline Depa & 308 & $, 871,864$ & $, 789,112$ & $, 070,959$ & $2,002,572$ & $2,010,414$ & $1,853,955$ & $1,663,671$ & $1,452,806$ & $1,364,800$ \\
\hline Depar & $, 536,065$ & $2,520,885$ & $2,692,335$ & $2,867,528$ & $2,763,515$ & $2,642,094$ & $2,651,641$ & $3,035,169$ & $3,150,530$ & $3,170,735$ \\
\hline $\mathrm{D}$ & & & & & & & & & & \\
\hline Services .... & $4,549,261$ & $4,902,714$ & $5,686,354$ & $5,210,711$ & $5,952,976$ & $6,348,736$ & $6,418,969$ & $6,784,856$ & $7,210,209$ & $7,422,065$ \\
\hline$n$ & & & & & & & & & & \\
\hline Development ................. & 186 & 118 & 48 & 203 & 401 & 856 & 1,613 & 1,771 & 1,325 & 1,398 \\
\hline Depar & 39,556 & 49,790 & 58,537 & 57,449 & 54,049 & 54,157 & 50,618 & 46,310 & 50,709 & 51,479 \\
\hline $\mathrm{De}$ & 5,700 & 6,858 & 6,060 & 4,986 & 3,496 & 3,886 & 7,204 & 9,515 & 8,487 & 20,800 \\
\hline Depar & 5,590 & 5,893 & 5,548 & 1,169 & 600 & 4,250 & 10,114 & 5,862 & 267 & 139 \\
\hline 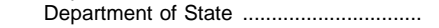 & 1,269 & 1,519 & 900 & 200 & - & 15 & 23 & - & 15 & 15 \\
\hline portation ................... & 22,826 & 28,608 & 21,187 & 35,015 & 57,789 & 62,606 & 75,847 & 51,956 & 60,063 & 54,881 \\
\hline Department of the Treasury ....................... & 411 & 227 & 229 & 85 & 133 & 1,309 & 1,496 & 145 & 85 & 2,496 \\
\hline Department of Veterans Affairs ................ & 2,300 & 2,300 & 2,300 & 2,491 & 2,550 & 2,350 & 2,500 & 1,720 & 1,852 & 1,614 \\
\hline
\end{tabular}


Table 361.-Federal on-budget funds for education, by level or other educational purpose, by agency and program: Fiscal years 1965 to 1998 -Continued

[In thousands of current dollars]

\begin{tabular}{|c|c|c|c|c|c|c|c|c|c|c|}
\hline $\begin{array}{c}\text { Level or educational purpose, by agency and } \\
\text { program }\end{array}$ & 1965 & 1970 & 1975 & 1980 & 1983 & 1984 & 1985 & 1986 & 1987 & 1988 \\
\hline 1 & 2 & 3 & 4 & 5 & 6 & 7 & 8 & 9 & 10 & 11 \\
\hline ACTION & - & - & 36 & - & - & - & - & - & - & - \\
\hline $\begin{array}{l}\text { Agency for International Development ... } \\
\text { Corporation for National and Community }\end{array}$ & - & - & - & 77,063 & 43,372 & 109,600 & 56,960 & 44,302 & 54,652 & 49,535 \\
\hline 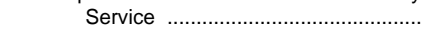 & - & - & - & - & - & - & 一 & - & - & - \\
\hline $\begin{array}{l}\text { Environmental Protection Agency } \\
\text { Federal Emerg.... }\end{array}$ & - & 19,446 & 33,875 & 41,083 & 43,557 & 43,700 & 60,521 & 69,718 & 67,465 & 58,053 \\
\hline 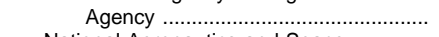 & - & - & - & 1,665 & 805 & - & 1,423 & - & - & - \\
\hline National Aeronautics and Space & & & & & & & & & & \\
\hline 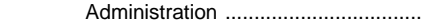 & 208,688 & 258,016 & 197,301 & 254,629 & 366,440 & 352,900 & 485,824 & 489,048 & 785,141 & 897,497 \\
\hline National Science Foundation ....................... & 154,046 & 253,628 & 475,011 & 743,809 & 857,791 & $1,006,000$ & $1,087,046$ & $1,073,122$ & $1,184,921$ & $1,232,054$ \\
\hline Nuclear Regulatory Commission .............. & - & - & 7,093 & 32,590 & 37,987 & 36,400 & 30,261 & 27,472 & 29,176 & 25,676 \\
\hline $\begin{array}{l}\text { Office of Economic Opportunity ........... } \\
\text { U.S. Arms Control and Disarmament }\end{array}$ & 7,078 & 20,035 & - & - & - & - & - & - & - & - \\
\hline 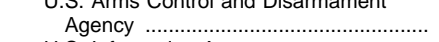 & - & 100 & - & 661 & 157 & - & 395 & 276 & 3,244 & 2,633 \\
\hline U.S. Information Agency ............................ & - & - & - & - & - & - & - & 1,500 & - & - \\
\hline 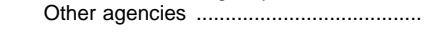 & 10,055 & 1,421 & 5,949 & 990 & 296 & 1,300 & 432 & 715 & 1,666 & 1,870 \\
\hline
\end{tabular}

\section{Footnotes}

1 Excludes $\$ 4,440,000,000$ for federal support for medical education benefits under Medicare in the U.S. Department of Health and Human Services. Is not included in the total because data before fiscal year 1990 are not available. This program has existed since Medicare began, but was not available as a separate budget item until FY 90.

${ }^{2}$ Excludes $\$ 4,900,000,000$ for federal support for medical education benefits under Medicare. See footnote 1.

3 Excludes $\$ 5,350,000,000$ for federal support for medical education benefits under Medicare. See footnote 1.

${ }^{4}$ Excludes $\$ 5,710,000,000$ for federal support for medical education benefits under Medicare. See footnote 1.

5 Excludes $\$ 6,150,000,000$ for federal support for medical education benefits under Medicare. See footnote 1.

${ }^{6}$ Excludes $\$ 7,510,000,000$ for federal support for medical education benefits under Medicare. See footnote 1.

7 Excludes $\$ 8,010,000,000$ for federal support for medical education benefits under Medicare. See footnote 1.

${ }^{8}$ Excludes $\$ 8,700,000,000$ for federal support for medical education benefits under Medicare. See footnote 1.

9 Estimated. Excludes $\$ 9,460,000,000$ for federal support for medical education benefits under Medicare. See footnote 1 .

10 The U.S. Department of Education was created in May 1980. It formerly was the Office of Education in the U.S. Department of Health, Education, and Welfare.

11 Section VI was funded by the U.S. Department of Education in FYs $65-81$ in the Impact Aid program. This program provides for the education of dependents of federal employees residing on federal property in cases where free public education is unavailable in the nearby community.

12 This program creates a national framework for education reform and meeting the National Education Goals. This program includes the School-To-Work Opportunities program which will initi- ate a national system to be administered jointly by the U.S. Departments of Education and Labor. Both departments are to establish a national framework within which all states can create statewide systems to help youth acquire the knowledge, skills, abilities, and labor market information they need to make an effective transition from school to work or to further their education or training.

${ }^{13}$ Starting in FY 94, the Special Milk program was included in the Child Nutrition program.

${ }^{14}$ These commodities are purchased under Section 32 of the Act of August 24, 1935, for use in the child nutrition programs.

${ }^{15}$ This program assisted in the construction of public facilities, such as vocational schools, through grants or loans. No funds have been appropriated for this account since FY 77, and it was completely phased out in FY 84.

${ }^{16}$ The U.S. Department of Energy was created in 1977. It formerly was the Energy Research and Development Administration and before that the Atomic Energy Commission. No funds were designated for any of the education programs listed on this table in FYs 96 and 97.

17 This program was established in 1979. Funds were first appropriated for this program in FY 80.

${ }_{18}$ The U.S. Department of Health and Human Services was part of the U.S. Department of Health, Education, and Welfare until May 1980.

19 The Head Start program was formerly in the Office of Economic Opportunity, and funds were appropriated to the U.S. Department of Health, Education, and Welfare, Office of Child Development, beginning in 1972.

20 This program was created by the Family Support Act of 1988. It provides funds for the Job Opportunities and Basic Skills Training program.

${ }^{21}$ After age 18, benefits terminate at the end of the school term or in 3 months, whichever is less. 
FEDERAL PROGRAMS 409

Table 361.-Federal on-budget funds for education, by level or other educational purpose, by agency and program: Fiscal years 1965 to 1998 -Continued

[In thousands of current dollars]

\begin{tabular}{|c|c|c|c|c|c|c|c|c|c|c|}
\hline $\begin{array}{l}\text { Level or educational purpose, by agency and } \\
\text { program }\end{array}$ & 1989 & $1990^{1}$ & $1991^{2}$ & $1992^{3}$ & $1993^{4}$ & $1994^{5}$ & $1995^{6}$ & $1996^{7}$ & $1997^{8}$ & $1998^{9}$ \\
\hline 1 & 12 & 13 & 14 & 15 & 16 & 17 & 18 & 19 & 20 & 21 \\
\hline ACTION & - & - & - & - & - & - & - & - & - & - \\
\hline $\begin{array}{l}\text { Agency for International Development ... } \\
\text { Corporation for National and Community }\end{array}$ & 45,025 & 79,415 & 54,997 & 32,979 & 27,659 & 24,634 & 30,172 & 17,900 & 11,520 & 15,730 \\
\hline 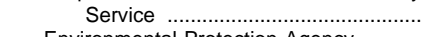 & - & - & - & - & - & - & - & - & - & - \\
\hline $\begin{array}{l}\text { Environmental Protection Agency .......... } \\
\text { Federal Emergency Management }\end{array}$ & 64,517 & 87,481 & 62,753 & 152,012 & 124,500 & 98,241 & 125,721 & 75,744 & 82,220 & 90,360 \\
\hline $\begin{array}{l}\text { Agency ......................................... } \\
\text { National Aeronautics and Space }\end{array}$ & - & - & - & - & - & - & - & - & - & - \\
\hline Administration & 976,478 & $1,090,003$ & $1,270,070$ & $1,377,322$ & $1,367,542$ & $1,412,665$ & $1,751,977$ & $1,754,565$ & $1,652,216$ & $1,698,967$ \\
\hline National Science Foundation ..................... & $1,342,648$ & $1,427,007$ & $1,546,810$ & $1,664,697$ & $1,833,563$ & $1,805,856$ & $1,874,395$ & $2,041,485$ & $2,040,037$ & $2,115,321$ \\
\hline Nuclear Regulatory Commission .............. & 25,690 & 42,328 & 23,860 & 27,418 & 22,934 & 20,227 & 22,188 & 16,828 & 16,141 & 13,432 \\
\hline Office of Economic Opportunity ............... & - & - & - & - & - & - & - & 一 & - & 一 \\
\hline $\begin{array}{l}\text { U.S. Arms Control and Disarmament } \\
\text { Agency }\end{array}$ & 1,619 & 25 & 69 & 100 & 25 & - & - & - & - & - \\
\hline 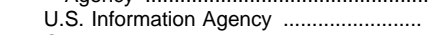 & - & - & - & - & - & - & - & - & - & - \\
\hline 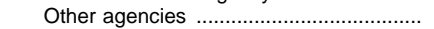 & 947 & 885 & 1,616 & 1,532 & 1,622 & - & 500 & 1,418 & 2,935 & 2,950 \\
\hline
\end{tabular}

\section{Footnotes-Continued}

22 This program provides funding for supplemental programs for eligible Indian students in public schools.

${ }^{23}$ Negative amounts occur when program receipts exceed outlays.

24 This program finances the cost of academic, social, and occupational education courses for inmates in federal prisons.

25 The Job Corps program was formerly in the Office of Economic Opportunity, and funds were appropriated to the U.S. Department of Labor beginning in 1971 and 1972.

26 Some of the work and training programs included in this program were in the Office of Economic Opportunity and were transferred to the U.S. Department of Labor in 1971 and 1972. Beginning in FY 94, the School-to-Work Opportunities program is included. This program is administered jointly by the U.S. Departments of Education and Labor.

27 The U.S. Department of Transportation was created in 1967.

28 This program was transferred from the U.S. Department of the Treasury to the U.S. Department of Transportation in 1967.

${ }^{29}$ This program was established in FY 72 and closed in FY 86.

${ }^{30}$ The states' share of revenue-sharing funds could not be spent on education in FYs 81-86.

31 The U.S. Department of Veterans Affairs, formerly the Veterans Administration, was created in March 1989.

32 This program provides educational assistance allowances in order to restore lost educational opportunities to those individuals whose careers were interrupted or impeded by reason of active military service between January 31, 1955, and January 1, 1977. Includes "Readjustment Benefits," Chapter 34, for education other than college and also includes the Veterans Job Training program for service persons and veterans. The Chapter 34 program closed December 31, 1989. The Veterans Job Training Program was put in the program Payments to State Education Agencies. Veterans who were still eligible to receive benefits under Chapter 34 were covered by Chapter 30 (The All-Volunteer-Force Educational Assistance program).

${ }^{33}$ This program is in "Readjustment Benefits" program, Chapter 31 , and covers the costs of subsistence, tuition, books, supplies, and equipment for disabled veterans requiring vocational rehabilitation.

${ }^{34}$ This program is in the "Readjustment Benefits" program, Chapter 35, and provides benefits to children and spouses of veterans.

${ }^{35}$ The purpose of this program is to provide stable and permanent employment to those men and women who have served on active duty on or after August 2, 1990, and are unemployed.

36 This agency was established March 9, 1965. Its first year of appropriations was 1966. The outlays were larger in the years 1970 and 1975 for elementary and secondary education because of the construction of facilities for vocational schools.
37 This agency was established in 1965. In 1970, $\$ 900,000$ was appropriated through the Office of Education, U.S. Department of Health, Education, and Welfare, for the National Endowment for the Arts, Arts in Education program.

38 This agency was established in 1965. First year of appropriations was 1966.

39 The Economic Opportunity Act of 1964 authorized 10 major action programs, including Job Corps, Neighborhood Youth Corps, Adult Literacy, Work Experience, College Work-Study, and Community Action programs, including Head Start, Follow Through, and Upward Bound, and authorized the establishment of Volunteers in Service to America (VISTA). These programs were transferred to the U.S. Department of Health, Education, and Welfare, U.S. Department of Labor, and the Action Agency in the 1970s. An act on January 4, 1975 established the Community Services Administration as the successor agency to the Office of Economic Opportunity.

40 Head Start program funds were transferred to the U.S. Department of Health, Education, and Welfare, Office of Child Development, in 1972.

${ }^{41}$ Most of these programs were transferred to the U.S. Department of Health, Education, and Welfare, Office of Education, in 1972.

42 The Job Corps programs were transferred to the U.S. Department of Labor in 1971 and 1972.

43 These programs were transferred to the U.S. Department of Labor in 1971 and 1972.

44 These programs were transferred to the Action Agency in 1972.

45 Similar programs were included in the "higher education" program in 1965 through 1975.

46 The Student Loan Reform Act of 1993 authorized a new Federal Direct Student Loan (FDSL) program, recently renamed the William D. Ford Direct Loan program. This program is a new streamlined lending system that simplifies the process of obtaining and repaying loans for student and parent borrowers and provides borrowers with greater choice in repayment plans.

47 Similar programs were included in the "higher education" program in 1965 through 1975, formerly called the "Guaranteed Student Loan" program. The large drop in FY 94 reflects a $\$ 4.79$ billion loan prepayment from the Student Loan Marketing Association of its outstanding debt to the Treasury Department.

${ }^{48}$ This program was transferred from the U.S. Department of Housing and Urban Development to the U.S. Department of Health, Education, and Welfare, Office of Education, in FY 79.

49 The Historically Black Colleges and Universities (HBCUs) Capital Financing program was authorized by the Higher Education Act Amendments of 1992 to provide HBCUs with private funds for repair, renovation, and construction projects. 


\section{Footnotes-Continued}

50 First year of appropriations for this program was 1967.

51 Program funds were first appropriated for Tuskegee Institute in 1972.

52The Sea Grant College Program Act of 1966 established a matching fund grant program that provides for the establishment of a network of programs in fields related to development and preservation of the nation's coastal and marine resources. This program was transferred from the National Science Foundation to the U.S. Department of Commerce, October 1970.

53This program was transferred to the U.S. Department of Transportation in FY 81 by Public Law 97-31, from the U.S. Department of Commerce.

54The U.S. Department of Defense funds for FYs 90 to 96 exclude military pay and reserve accounts which were included in previous years. FY 65 data are not available except for service academies.

55 Included in total above.

${ }^{56}$ Instructional costs only are included. These include academics, audiovisual, academic computing center, faculty training, military training, physical education, and libraries.

57Includes special education programs (military and civilian); legal education program; flight training; advanced degree program; college degree program (officers); and "Armed Forces Health Professions Scholarship" program.

${ }^{58}$ No funds have been appropriated since FY 82.

59This program receives funds periodically.

${ }^{60}$ Appropriations began in FY 84

${ }^{61}$ Appropriations began in FY 89

62Does not include higher education assistance loans.

${ }^{63}$ Appropriations began in FY 78 .

${ }^{64} \mathrm{Alcohol}$, drug abuse, and mental health training programs are included starting in fiscal year 1992

${ }^{65}$ Beginning in fiscal year 1992, data were included in the $\mathrm{Na}$ tional Institutes of Health training grants program

${ }^{66}$ Postsecondary student benefits were ended by the Omnibus Budget Reconciliation Act of 1981 (Public Law 97-35) and were completely phased out by August 1985 .

67Includes adult education, tribally-controlled community colleges, postsecondary instruction, and other education.

68This program was transferred from the U.S. Department of State to the International Communication Agency (I.C.A.) in 1977 , which consolidated the functions of the U.S. Information Agency and the U.S. Department of State's Bureau of Educational and Cultural Affairs. In FY 82 the I.C.A. became the U.S.I.A.

69This program provides funds for advanced study and research projects of the Russian, Eurasian, and Eastern European countries by American institutions of higher education and private research firms. Appropriations began in FY 88.

70This program was transferred to the U.S. Department of Transportation in FY 81 by Public Law 97-31 from the U.S. Department of Commerce.

71 Includes flight training. This program was in the U.S. Department of the Treasury in 1965 and was transferred to the U.S. Department of Transportation in 1967.

${ }^{72}$ Includes benefits for Vietnam-era veterans under Chapter 34 (GI Bill) of the "Readjustment Benefits" education and training program. This program provides educational assistance allowances, primarily on a monthly basis, in order to restore lost educational opportunities to those individuals whose careers were interrupted or impeded by reason of active military service between January 31, 1955, and January 1, 1977. This program closed December 31, 1989. Some veterans who were still eligible were put in Chapter 30 (the All-Volunteer-Force Educational Assistance program).

${ }^{73}$ Includes service persons under Chapter 34 (Gl Bill) of the "Readjustment Benefits" education and training program. Service persons with over 180 days of active duty, any part of which was before January 1,1977 , are eligible to participate in this program.

${ }^{74}$ Includes post-Vietnam-era veterans, under Chapter 32, of the post-Vietnam-era "Veterans Education Account." Provides education and training assistance payments to veterans and service persons with no active duty time before January 1, 1977. Funding is provided through participants' contributions while on active duty and through transfers from the U.S. Department of Defense (DOD). The U.S. Department of Veterans Affairs funds are not appropriated for this program, so these data represent obligations, which are funded through other agencies' appropriations.

75Public Law 98-525, enacted October 19, 1984 (New GI Bill), established two new peacetime educational programs: an assistance program for veterans who entered active duty during the period beginning July 1, 1985 to June 30, 1988, and an assistance program for certain members of the Selected Reserve.

${ }^{76}$ Chapter 30, also called the Montgomery Bill, and the new GI Bill are for eligible veterans who have agreed to have their military pay reduced $\$ 100$ per month for their first 12 months of active duty. The "Readjustment Benefits" account under the U.S. Department of Veterans Affairs pays only the basic allowance, up to a maximum of $\$ 300$ per month, for full-time training. "Supplemental Benefits" are paid by the U.S. Department of Defense (DOD)

${ }^{77}$ Chapter 106 is for members of the Selected Reserve. The reserve components include the Army, Navy, Air Force, Marine Corps Reserve, Army National Guard and Air National Guard under the U.S. Department of Defense (DOD), and the Coast Guard Reserve, which is under the U.S. Department of Transportation (DOT) when it is not operating as a service in the Navy. Eligible persons can receive up to $\$ 140$ per month for full-time training. The DOD and DOT pay for this program, and the U.S. Department of Veterans Affairs administers it.

78Includes dependents of veterans under Chapter 35, the "Readjustment Benefits" education and training program. Provides education and training benefits to dependents of veterans who died of a service-connected disability or whose service-connected disability is rated permanent and total.

${ }^{79}$ Payments have been made to state education agencies for a number of years but were not listed separately until FY 88.

80The USIA was called the "International Communication Agency" in FYs 80 and 81

81This program was in the "Educational and Cultural Affairs" program in FYs $80-83$, and became an independent program in FY 84.

82This program was combined with the "Educational and Cultural Affairs" program in FY 77.

${ }^{83}$ Public Law 99-661 established this program to operate the Foundation which awards scholarships and fellowships to outstanding graduate and undergraduate students who intend to pursue careers or advanced degrees in science or mathematics. It may also award honoraria to outstanding individuals who have made significant contributions to improve the instruction of science and mathematics in secondary schools.

${ }^{84}$ Appropriations for this program began in FY 76 .

${ }^{85}$ Public Law 99-498 established this Institute as an independent non-profit corporation to provide Native Americans with an opportunity to obtain a postsecondary education in various fields of Indian art and culture.

${ }^{86}$ Public Laws 99-500 and 99-591 established the James Madison Memorial Fellowship Foundation to operate a fellowship program to encourage graduate study of the American Constitution. First year of appropriations was FY 88.

87This program was transferred to the Institute of Museum and Library Services in fiscal year 1997. Program was formerly in the U.S. Department of Education. 


\section{Footnotes-Continued}

88This program was transferred to the U.S. Department of Transportation in FY 68 from the U.S. Department of Housing and Urban Development.

89This program was established by the Juvenile Justice and Delinquency Prevention Act of 1974 to provide education and training and to provide leadership in improving correctional programs and practices in prisons.

90Appropriations for this program began in FY 70.

91The Federal Aviation Administration, originally an independent agency, was transferred to the U.S. Department of Transportation in FY 67.

${ }^{92}$ Appropriations began in $\mathrm{FY} 72$.

93First year of appropriations was FY 70

94The National Service Trust Act of 1993 established the Corporation for National and Community Service. In 1993, ACTION became part of this agency.

95These programs included the Service Learning programs, University Year for ACTION, Volunteers in Service to America, Youth Challenge program, and the National Student Volunteer program in FY 1975. In FY 80, programs included were the University Year for ACTION, Young Volunteers for ACTION, and National Service Learning programs. In fiscal year 1985, the program included was the Service Learning programs, and in FYs 89 to 94, programs included were the Literacy Corps and the Student Community Services program. In FYs 94 through 98 the AmeriCorps program was included. This program provides education grants to help pay for college or to repay student loans for people who perform community service before, during or after postsecondary education.

96The Federal Emergency Management Agency was created in 1979, representing a combination of five existing agencies. The two largest were the Defense Civil Preparedness Agency in the U.S. Department of Defense and the Federal Preparedness Agency in the General Services Administration. The funds for the Federal Emergency Management Agency in FY 70 to FY 75 were in the other agencies.

97First year of appropriations was FY 68

98First appropriations for the "other training programs" were in the late 1960s. These programs include the Fall-Out Shelter Analysis, Blast Protection Design through 1992. Starting in FY 1993, earthquake training and safety for teachers and administrators for grades 1 through 12 are included.
99The disaster relief program repairs and replaces damaged and destroyed school buildings. In FY 94 and FY 95 funds were for repairs due to the Northridge Earthquake in California. In FY 94, \$37.2 million was spent on school districts; $\$ 4.2$ million was spent on community colleges and $\$ 43.8$ million spent on universities. In FY 95, \$74.4 million was spent on school districts; $\$ 8.4$ million on community colleges and $\$ 87.6$ million on colleges and universities.

100 This program was transferred from the General Services Administration to the National Archives and Records Administration in April 1985.

${ }^{101}$ This program makes grants for the promotion of scholarly, cultural, and artistic exchanges between Japan and the United States. Appropriations began in FY 76.

102The National Archives and Records Administration became an independent agency in April 1985

${ }^{103}$ This program was established by the act of July 20, 1970, Public Law 91-345.

104This program was established by Congress to conduct and support research and scholarships in the fields of peace, arms control, and conflict resolution.

${ }^{105}$ Includes federal obligations for research and development centers administered by colleges and universities. FYs 97 and 98 are estimated.

106Total outlays for FYs 65 and 70 include the "Research and Training" program. FY 75 includes the "National Institute of Education" program. FYs 80 to 98 include outlays for the Office of Educational Research and Improvement.

-Data not available or not applicable.

NOTE.-Some data have been revised from previously published figures. To the extent possible, amounts reported represent outlays rather than obligations. Because of rounding, details may not add to totals.

SOURCE: U.S. Department of Education, National Center for Education Statistics, compiled from data appearing in U.S. Office of Management and Budget, Budget of the U.S. Government, fiscal years 1967 to 1999; National Science Foundation, Federal Funds for Research and Development, fiscal years 1965 to 1998; and unpublished data obtained from various federal agencies. (This table was prepared May 1998.) 
Table 362.-Estimated federal support for education, by agency and type of ultimate recipient: Fiscal year 1998 [In millions of dollars]

\begin{tabular}{|c|c|c|c|c|c|c|c|c|}
\hline Agency & Total & $\begin{array}{l}\text { Local } \\
\text { education } \\
\text { agencies }\end{array}$ & $\begin{array}{l}\text { State } \\
\text { education } \\
\text { agencies }\end{array}$ & $\begin{array}{l}\text { College } \\
\text { students }\end{array}$ & $\begin{array}{l}\text { Institutions } \\
\text { of higher } \\
\text { education }\end{array}$ & Federal & $\begin{array}{l}\text { Multiple } \\
\text { types of } \\
\text { recipients }\end{array}$ & Other ${ }^{1}$ \\
\hline 1 & 2 & 3 & 4 & 5 & 6 & 7 & 8 & 9 \\
\hline Total $^{2}$ & $\$ 107,242.3$ & $\$ 21,430.2$ & $\$ 5,639.4$ & $\$ 21,408.2$ & $\$ 34,656.7$ & $\$ 3,292.7$ & $\$ 11,296.5$ & $\$ 9,518.6$ \\
\hline Total program funds - on-budget & $\$ 75,077.5$ & $\$ 21,430.2$ & $\$ 4,674.5$ & $\$ 8,220.6$ & $\$ 23,399.0$ & $\$ 3,292.7$ & $\$ 11,296.5$ & $\$ 2,764.0$ \\
\hline 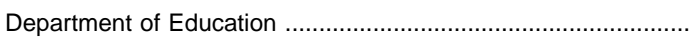 & $30,735.6$ & $11,486.7$ & $3,737.8$ & $5,502.1$ & $6,031.0$ & 484.6 & $1,475.8$ & $2,017.4$ \\
\hline Department of Agriculture & $10,179.5$ & $9,167.5$ & 152.7 & - & 450.5 & 18.0 & - & 390.7 \\
\hline Department of Commerce ..... & 75.2 & - & - & - & 75.2 & - & - & - \\
\hline 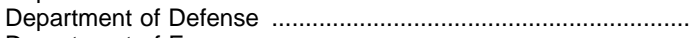 & $3,604.8$ & 162.3 & - & 285.5 & $1,580.1$ & $1,345.7$ & 231.2 & - \\
\hline 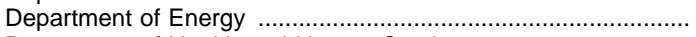 & $3,170.7$ & - & - & - & $3,170.7$ & - & - & - \\
\hline Department of Health and Human Services .......... & $13,565.6$ & 435.5 & - & 825.7 & $7,763.0$ & 155.0 & $4,386.4$ & - \\
\hline Department of Housing and Urban Development . & 1.4 & - & - & - & 1.4 & - & - & - \\
\hline 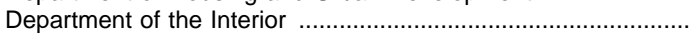 & 754.9 & 57.2 & 18.0 & 29.5 & 137.7 & 460.4 & 52.1 & - \\
\hline Department of Justice & 282.8 & - & - & - & 20.8 & 262.0 & - & - \\
\hline Department of Labor & $4,990.1$ & - & 748.5 & - & 0.1 & - & $4,241.5$ & - \\
\hline 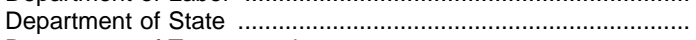 & 55.4 & - & - & - & - & 55.4 & - & - \\
\hline 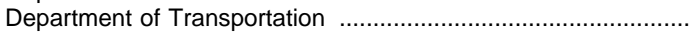 & 115.0 & - & - & 3.6 & 57.6 & 46.0 & 0.7 & 7.0 \\
\hline 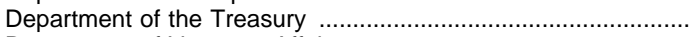 & 75.5 & - & - & - & 2.5 & 73.0 & - & - \\
\hline $\begin{array}{l}\text { Department of Veterans Affairs } \ldots \ldots \ldots \ldots \ldots \ldots \ldots \ldots \ldots \ldots \ldots \ldots \ldots \ldots \ldots \ldots \ldots \ldots \ldots \ldots \ldots \\
\text { Other agencies and programs }\end{array}$ & $1,374.2$ & - & 17.5 & $1,355.1$ & 1.6 & - & - & - \\
\hline Agency for International Development & 363.4 & - & - & - & 15.7 & - & - & 347.7 \\
\hline Appalachian Regional Commission ...................... & 6.8 & - & - & - & 3.1 & - & 3.7 & - \\
\hline \multicolumn{9}{|l|}{ Barry Goldwater Scholarship and Excellence in } \\
\hline 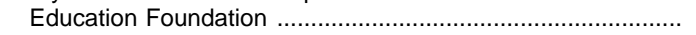 & 3.0 & - & - & - & - & - & 3.0 & - \\
\hline Corporation for National and Community Service ............. & 374.0 & - & - & - & - & - & 374.0 & - \\
\hline Environmental Protection Agency ................................ & 90.4 & - & - & - & 90.4 & - & - & - \\
\hline \multicolumn{9}{|l|}{ Estimated education share of federal aid to the } \\
\hline 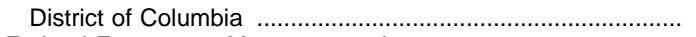 & 109.9 & 96.0 & - & - & 12.8 & - & 1.1 & - \\
\hline Federal Emergency Management Agency ..... & 50.0 & 25.0 & - & - & - & - & 25.0 & - \\
\hline General Services Administration .................... & - & - & - & - & - & - & - & - \\
\hline 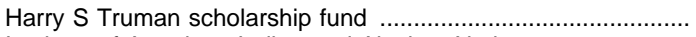 & 4.0 & - & - & - & - & - & 4.0 & - \\
\hline \multicolumn{9}{|l|}{ Institute of American Indian and Alaskan Native } \\
\hline 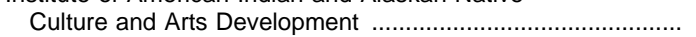 & 4.0 & - & - & - & - & - & 4.0 & - \\
\hline 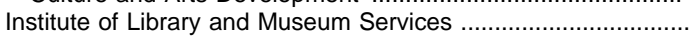 & 192.0 & - & - & - & - & - & 192.0 & - \\
\hline James Madison Memorial Fellowship Foundation ..................... & 2.0 & - & - & - & - & - & 2.0 & - \\
\hline Japanese-United States Friendship Commission .. & 2.0 & - & - & - & - & - & 2.0 & - \\
\hline 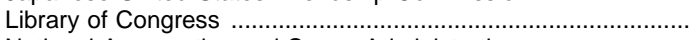 & 277.0 & - & - & - & - & 277.0 & - & - \\
\hline National Aeronautics and Space Administration & $1,705.1$ & - & - & - & $1,699.0$ & - & 6.1 & - \\
\hline National Archives and Records Administration ............................ & 114.9 & - & - & - & - & 114.9 & - & - \\
\hline \multicolumn{9}{|l|}{ National Commission on Libraries and } \\
\hline Information Science .......................... & 1.0 & - & - & - & - & - & - & 1.0 \\
\hline National Endowment for the Arts ............. & 7.7 & - & - & - & - & - & 7.7 & - \\
\hline National Endowment for the Humanities & 93.2 & - & - & - & - & - & 93.2 & - \\
\hline National Science Foundation & $2,473.3$ & - & - & 204.1 & $2,269.3$ & - & - & - \\
\hline Nuclear Regulatory Commission & 13.4 & - & - & - & 13.4 & - & - & - \\
\hline Smithsonian Institution & 7.7 & - & - & - & - & 0.7 & 7.0 & - \\
\hline U.S. Arms Control and Disarmament Agency & - & - & - & - & - & - & - & - \\
\hline 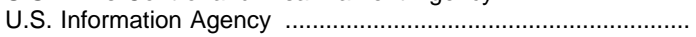 & 187.0 & - & - & 15.0 & - & - & 172.0 & - \\
\hline U.S. Institute of Peace ........... & 12.0 & - & - & - & - & - & 12.0 & - \\
\hline Other agencies ...................... & 3.0 & - & - & - & 3.0 & - & - & - \\
\hline $\begin{array}{l}\text { Off-budget support and nonfederal funds } \\
\text { generated by federal legislation }\end{array}$ & $32,164.8$ & - & 964.9 & $13,187.6$ & $11,257.7$ & - & - & $6,754.6$ \\
\hline
\end{tabular}

1 Other recipients include Indian tribes, private nonprofit agencies, and banks. ${ }^{2}$ Includes on-budget support, off-budget support, and nonfederal funds generated by federal legislation. Excludes federal tax expenditures.

-Data not available or not applicable.

NOTE.-Outlays by type of recipient are estimated based on obligation data. Because of rounding, details may not add to totals.
SOURCE: U.S. Department of Education, Office of the Undersecretary, unpublished tabulations; U.S. Office of Management and Budget, Budget of the U.S. Government, Fiscal Year 1999; National Science Foundation, Federal Funds for Research and Development, Fiscal Years 1996, 1997, and 1998; and unpublished data obtained from various federal agencies. (This table was prepared May 1998.) 
Table 363.-Federal on-budget funds obligated for programs administered by the U.S. Department of Education: Fiscal years 1980 to 1998

[In thousands of dollars]

\begin{tabular}{|c|c|c|c|c|c|c|c|c|c|}
\hline \multirow{2}{*}{ Program } & \multicolumn{9}{|c|}{ (In current dollars) } \\
\hline & 1980 & 1985 & 1990 & 1993 & 1994 & 1995 & 1996 & $1997^{2}$ & $1998^{3}$ \\
\hline 1 & 2 & 3 & 4 & 5 & 6 & 7 & 8 & 9 & 10 \\
\hline Total & $\$ 14,102,165$ & $\$ 18,818,201$ & $\$ 25,214,923$ & $\$ 33,748,670$ & $\$ 36,735,985$ & $\$ 46,433,000$ & $\$ 45,540,000$ & $\$ 57,478,000$ & $\$ 54,525,000$ \\
\hline Elementary and secondary education . & $4,239,022$ & $4,732,864$ & $7,169,693$ & $8,565,459$ & $8,820,052$ & $9,124,000$ & $7,824,000$ & $10,387,000$ & $11,310,000$ \\
\hline 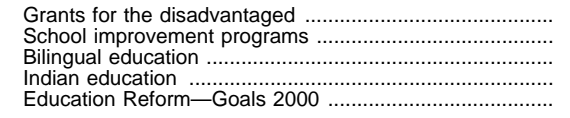 & $\begin{array}{r}3,204,664 \\
788,918 \\
169,540 \\
75,900\end{array}$ & $\begin{array}{r}3,745,855 \\
748,000 \\
171,605 \\
67,404\end{array}$ & $\begin{array}{r}5,383,960 \\
1,524,001 \\
188,152 \\
73,580 \\
-\end{array}$ & $\begin{array}{r}6,659,203 \\
1,600,013 \\
225,693 \\
80,550\end{array}$ & $\begin{array}{r}7,038,334 \\
1,368,108 \\
239,805 \\
82,762 \\
91,043\end{array}$ & $\begin{array}{r}7,200,000 \\
1,343,000 \\
206,000 \\
81,000 \\
294,000\end{array}$ & $\begin{array}{r}5,893,000 \\
1,220,000 \\
178,000 \\
53,000 \\
480,000\end{array}$ & $\begin{array}{r}7,831,000 \\
1,428,000 \\
261,000 \\
61,000 \\
806,000\end{array}$ & $\begin{array}{r}7,881,000 \\
1,543,000 \\
354,000 \\
63,000 \\
1,469,000\end{array}$ \\
\hline School assistance in federally affected areas & 812,873 & 695,746 & 815,573 & 760,456 & 911,716 & 783,000 & 703,000 & 737,000 & 851,000 \\
\hline $\begin{array}{l}\text { Maintenance and operations } \\
\text { Construction } \\
\text { Disaster assistance }\end{array}$ & $\begin{array}{r}690,000 \\
110,873 \\
12,000\end{array}$ & $\begin{array}{r}665,000 \\
23,037 \\
7,709\end{array}$ & $\begin{array}{r}717,354 \\
22,929 \\
75,290\end{array}$ & $\begin{array}{r}713,108 \\
5,291 \\
42,057 \\
\end{array}$ & $\begin{array}{r}787,263 \\
8,584 \\
115,869 \\
\end{array}$ & $\begin{array}{r}715,000 \\
2,000 \\
66,000 \\
\end{array}$ & $\begin{array}{r}689,000 \\
13,000 \\
1,000 \\
\end{array}$ & $\begin{array}{r}680,000 \\
12,000 \\
45,000\end{array}$ & $\begin{array}{r}742,000 \\
19,000 \\
90,000\end{array}$ \\
\hline Education for the handicapped & $1,555,253$ & $2,666,056$ & $3,480,122$ & $4,752,116$ & $5,965,688$ & $5,767,000$ & $5,849,000$ & $6,552,000$ & $7,605,000$ \\
\hline 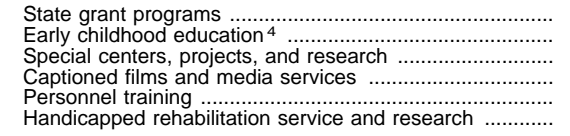 & $\begin{array}{r}815,805 \\
38,745 \\
55,075 \\
17,778 \\
55,375 \\
572,475\end{array}$ & $\begin{array}{r}1,245,219 \\
27,625 \\
53,430 \\
35,670 \\
68,025 \\
1,236,087\end{array}$ & $\begin{array}{r}1,258,871 \\
280,341 \\
72,966 \\
15,191 \\
70,838 \\
1,781,915\end{array}$ & $\begin{array}{r}1,842,956 \\
476,180 \\
139,265 \\
17,571 \\
90,120 \\
2,186,024\end{array}$ & $\begin{array}{r}2,779,228 \\
661,665 \\
101,605 \\
18,608 \\
104,012 \\
2,300,570\end{array}$ & $\begin{array}{r}2,467,000 \\
661,000 \\
132,000 \\
19,000 \\
91,000 \\
2,397,000\end{array}$ & $\begin{array}{r}2,350,000 \\
820,000 \\
110,000 \\
19,000 \\
91,000 \\
2,459,000\end{array}$ & $\begin{array}{r}3,066,000 \\
723,000 \\
124,000 \\
46,000 \\
81,000 \\
2,512,000\end{array}$ & $\begin{array}{r}3,866,000 \\
869,000 \\
144,000 \\
53,000 \\
82,000 \\
2,591,000\end{array}$ \\
\hline 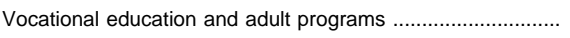 & $1,153,743$ & 856,271 & $1,138,674$ & $1,575,268$ & $1,456,185$ & $1,461,000$ & $1,366,000$ & $1,484,000$ & $1,552,000$ \\
\hline 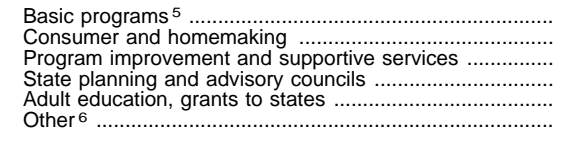 & $\begin{array}{r}744,653 \\
63,169 \\
162,512 \\
13,423 \\
153,724 \\
16,262\end{array}$ & $\begin{array}{r}725,624 \\
33,138 \\
5,202 \\
7,584 \\
84,723 \\
-\end{array}$ & $\begin{array}{r}858,716 \\
34,517 \\
7-923 \\
7,923 \\
188,280 \\
49,238\end{array}$ & $\begin{array}{r}1,049,834 \\
35,872 \\
8, \\
8,928 \\
309,810 \\
170,824\end{array}$ & $\begin{array}{r}950,244 \\
33,895 \\
-1 \\
9,087 \\
254,724 \\
208,235\end{array}$ & $\begin{array}{r}1,004,000 \\
1,000 \\
-000 \\
9,000 \\
299,000 \\
148,000\end{array}$ & $\begin{array}{r}1,083,000 \\
\overline{-} \\
4,000 \\
272,000 \\
7,000\end{array}$ & $\begin{array}{r}1,015,000 \\
100,000 \\
354,000 \\
15,000\end{array}$ & $\begin{array}{r}1,044,000 \\
103,000 \\
375,000 \\
30,000\end{array}$ \\
\hline Postsecondary student financial assistance & $5,108,534$ & $8,534,205$ & $11,112,068$ & $16,065,617$ & $17,400,855$ & $26,956,000$ & $27,705,000$ & $36,064,000$ & $31,018,000$ \\
\hline 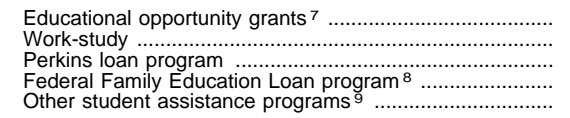 & $\begin{array}{r}2,534,378 \\
596,065 \\
322,749 \\
1,597,877 \\
57,465\end{array}$ & $\begin{array}{r}3,558,440 \\
599,467 \\
219,850 \\
4,130,920 \\
25,528\end{array}$ & $\begin{array}{r}4,919,264 \\
615,269 \\
157,415 \\
5,341,039 \\
79,081\end{array}$ & $\begin{array}{r}6,764,683 \\
625,043 \\
183,262 \\
8,380,619 \\
112,010\end{array}$ & $\begin{array}{r}7,092,393 \\
620,878 \\
177,413 \\
8,444,937 \\
1,065,234\end{array}$ & $\begin{array}{r}6,484,000 \\
620,000 \\
187,000 \\
10,461,000 \\
9,204,000\end{array}$ & $\begin{array}{r}5,545,000 \\
619,000 \\
118,000 \\
10,722,000 \\
10,701,000\end{array}$ & $\begin{array}{r}8,158,000 \\
825,000 \\
182,000 \\
11,732,000 \\
15,167,000\end{array}$ & $\begin{array}{r}5,193,000 \\
830,000 \\
165,000 \\
8,295,000 \\
16,535,000\end{array}$ \\
\hline Direct aid to postsecondary institutions & 277,068 & 329,714 & 341,634 & 518,908 & 740,677 & 780,000 & 830,000 & 887,000 & 952,000 \\
\hline $\begin{array}{l}\text { Aid to minority and developing institutions } \\
\text { Special programs for the disadvantaged } \\
\text { Cooperative education }\end{array}$ & $\begin{array}{r}114,680 \\
147,389 \\
14,999 \\
\end{array}$ & $\begin{array}{r}140,374 \\
174,940 \\
14,400 \\
\end{array}$ & $\begin{array}{r}99,812 \\
241,822\end{array}$ & $\begin{array}{l}130,743 \\
388,165\end{array}$ & $\begin{array}{l}211,054 \\
529,623\end{array}$ & $\begin{array}{l}231,000 \\
549,000\end{array}$ & $\begin{array}{l}304,000 \\
526,000\end{array}$ & $\begin{array}{l}321,000 \\
566,000\end{array}$ & $\begin{array}{l}334,000 \\
618,000\end{array}$ \\
\hline Higher education facilities & 268,493 & 194,556 & 84,305 & 81,026 & 49,888 & 46,000 & 51,000 & 24,000 & 29,000 \\
\hline $\begin{array}{l}\text { Construction loans and insurance } \\
\text { Interest subsidy grants } \\
\text { College housing loans }\end{array}$ & $\begin{array}{r}35,362 \\
24,626 \\
208,505\end{array}$ & $\begin{array}{r}33,188 \\
24,968 \\
136,400\end{array}$ & $\begin{array}{l}30,000 \\
38,741 \\
15,564\end{array}$ & $\begin{array}{l}46,472 \\
22,647 \\
11,907\end{array}$ & $\begin{array}{l}20,607 \\
18,188 \\
11,093\end{array}$ & $\begin{array}{l}15,000 \\
21,000 \\
10,000\end{array}$ & $\begin{array}{r}1,000 \\
17,000 \\
33,000\end{array}$ & $\begin{array}{r}1,000 \\
23,000\end{array}$ & $\begin{array}{r}1,000 \\
28,000\end{array}$ \\
\hline Other higher education programs & 34,927 & 74,340 & 188,999 & 201,734 & 129,951 & 120,000 & - & 一 & - \\
\hline $\begin{array}{l}\text { International education and foreign languages } 10 \\
\text { Funds for Improvement of Postsecondary Education } 11\end{array}$ & $\begin{array}{r}19,977 \\
12,000 \\
2,950\end{array}$ & $\begin{array}{l}32,050 \\
12,710 \\
29,580\end{array}$ & $\begin{array}{r}86,337 \\
99,450 \\
3,212\end{array}$ & $\begin{array}{r}114,761 \\
86,257 \\
716\end{array}$ & $\begin{array}{r}129,554 \\
397\end{array}$ & $\begin{array}{r}116,000 \\
4,000\end{array}$ & $(\overline{11})$ & $\overline{(12)}$ & $\overline{(12)}$ \\
\hline Public library services & 101,218 & 116,027 & 132,583 & 144,380 & 149,591 & 150,000 & 128,000 & $\left({ }^{13}\right)$ & $\left({ }^{13}\right)$ \\
\hline $\begin{array}{l}\text { Public library services } \\
\text { Interlibrary cooperation } \\
\text { Public library construction } \\
\text { Research libraries }\end{array}$ & $\begin{array}{r}66,451 \\
\overline{-} \\
28,992 \\
28,775\end{array}$ & $\begin{array}{r}75,000 \\
18,000 \\
16,027 \\
6,000 \\
1,000\end{array}$ & $\begin{array}{r}82,505 \\
19,551 \\
14,837 \\
6,593 \\
9,097\end{array}$ & \begin{tabular}{r|}
83,227 \\
19,749 \\
14,871 \\
5,808 \\
20,725
\end{tabular} & \begin{tabular}{r|}
83,227 \\
19,749 \\
21,074 \\
5,808 \\
19,733
\end{tabular} & $\begin{array}{l}83,000 \\
24,000 \\
24,000 \\
19,000\end{array}$ & $\begin{array}{r}93,000 \\
18,000 \\
12,000 \\
3,000 \\
2,000\end{array}$ & $\begin{array}{l}(13) \\
(13) \\
(13) \\
(13) \\
(13)\end{array}$ & $\begin{array}{c}(13) \\
(13) \\
(13) \\
(13) \\
(13)\end{array}$ \\
\hline Payments to special institutions & 273,860 & 253,622 & 292,736 & 320,455 & 321,753 & 340,000 & 314,000 & 324,000 & 343,000 \\
\hline 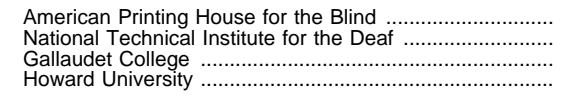 & $\begin{array}{r}4,349 \\
19,799 \\
49,409 \\
200,303\end{array}$ & $\begin{array}{r}5,500 \\
31,400 \\
59,092 \\
157,630\end{array}$ & $\begin{array}{r}5,663 \\
35,594 \\
67,643 \\
183,836\end{array}$ & $\begin{array}{r}6,298 \\
40,964 \\
77,589 \\
195,604\end{array}$ & $\begin{array}{r}6,463 \\
41,836 \\
78,435 \\
195,019\end{array}$ & $\begin{array}{r}7,000 \\
43,000 \\
80,000 \\
210,000\end{array}$ & $\begin{array}{r}7,000 \\
42,000 \\
78,000 \\
187,000\end{array}$ & $\begin{array}{r}7,000 \\
43,000 \\
79,000 \\
195,000\end{array}$ & $\begin{array}{r}8,000 \\
44,000 \\
81,000 \\
210,000\end{array}$ \\
\hline Departmental accounts . & 277,174 & 364,800 & 458,536 & 763,251 & 789,629 & 906,000 & 770,000 & $1,019,000$ & 865,000 \\
\hline $\begin{array}{l}\text { Educational research and improvement } \\
\text { Departmental management account } \\
\text { Other }\end{array}$ & $\begin{array}{r}51,415 \\
223,857 \\
1,875 \\
27\end{array}$ & $\begin{array}{r}60,556 \\
300,885 \\
3,349 \\
10\end{array}$ & $\begin{array}{r}87,074 \\
370,844 \\
618\end{array}$ & $\begin{array}{r}283,078 \\
480,166 \\
7\end{array}$ & $\begin{array}{r}294,323 \\
495,249 \\
57\end{array}$ & $\begin{array}{r}327,000 \\
579,000 \\
-\end{array}$ & $\begin{array}{r}353,000 \\
416,000 \\
1,000\end{array}$ & $\begin{array}{r}598,000 \\
416,000 \\
5,000 \\
-\end{array}$ & $\begin{array}{r}431,000 \\
433,000 \\
1,000 \\
-\end{array}$ \\
\hline
\end{tabular}


Table 363.-Federal on-budget funds obligated for programs administered by the U.S. Department of Education: Fiscal years 1980 to 1998 -Continued

[In thousands of dollars]

\begin{tabular}{|c|c|c|c|c|c|c|c|c|c|}
\hline \multirow{2}{*}{ Program } & \multicolumn{9}{|c|}{ (In constant 1998 dollars) ${ }^{1}$} \\
\hline & 1980 & 1985 & 1990 & 1993 & 1994 & 1995 & 1996 & $1997^{2}$ & $1998^{3}$ \\
\hline 1 & 11 & 12 & 13 & 14 & 15 & 16 & 17 & 18 & 19 \\
\hline Total & $\$ 28,058,872$ & $\$ 27,823,436$ & $\$ 31,526,144$ & $\$ 38,100,576$ & $\$ 40,512,843$ & $\$ 49,913,211$ & $\$ 47,690,912$ & $\$ 58,746,942$ & $\$ 54,525,000$ \\
\hline Elementary and secondary education . & $8,434,320$ & $6,997,722$ & $8,964,246$ & $9,669,979$ & $9,726,849$ & $9,807,855$ & $8,193,537$ & $10,616,314$ & $11,310,000$ \\
\hline 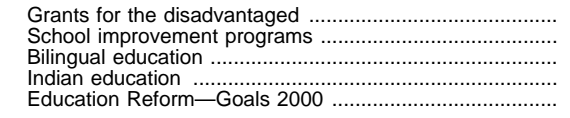 & $\begin{array}{r}6,376,273 \\
1,569,699 \\
337,331 \\
151,017 \\
-\end{array}$ & $\begin{array}{r}5,538,391 \\
1,105,947 \\
253,725 \\
99,659 \\
-\end{array}$ & $\begin{array}{r}6,731,549 \\
1,905,454 \\
235,246 \\
91,997 \\
-\end{array}$ & $\begin{array}{r}7,517,910 \\
1,806,335 \\
254,796 \\
90,937 \\
-\end{array}$ & $\begin{array}{r}7,761,951 \\
1,508,764 \\
264,460 \\
91,271 \\
100,403\end{array}$ & $\begin{array}{r}7,739,649 \\
1,443,660 \\
221,440 \\
87,071 \\
316,036\end{array}$ & $\begin{array}{r}6,171,334 \\
1,277,622 \\
186,407 \\
55,503 \\
502,671\end{array}$ & $\begin{array}{r}8,003,885 \\
1,459,526 \\
266,762 \\
62,347 \\
823,794\end{array}$ & $\begin{array}{r}7,881,000 \\
1,543,000 \\
354,000 \\
63,000 \\
1,469,000\end{array}$ \\
\hline School assistance in federally affected areas. & $1,617,362$ & $1,028,687$ & $1,019,709$ & 858,517 & $1,005,450$ & 841,687 & 736,204 & 753,271 & 851,000 \\
\hline $\begin{array}{l}\text { Maintenance and operations } \\
\text { Construction } \\
\text { Disaster assistance }\end{array}$ & $\begin{array}{r}1,372,883 \\
220,602 \\
23,876\end{array}$ & $\begin{array}{r}983,228 \\
34,061 \\
11,398\end{array}$ & $\begin{array}{r}896,906 \\
28,668 \\
94,135\end{array}$ & $\begin{array}{r}805,064 \\
5,973 \\
47,480 \\
\end{array}$ & $\begin{array}{r}868,202 \\
9,467 \\
127,782 \\
\end{array}$ & $\begin{array}{r}768,590 \\
2,150 \\
70,947\end{array}$ & $\begin{array}{r}721,542 \\
13,614 \\
1,047 \\
\end{array}$ & $\begin{array}{r}695,012 \\
12,265 \\
45,993\end{array}$ & $\begin{array}{r}742,000 \\
19,000 \\
90,000\end{array}$ \\
\hline Education for the handicapped & $3,094,464$ & $3,941,867$ & $4,351,186$ & $5,364,903$ & $6,579,026$ & $6,199,244$ & $6,125,256$ & $6,696,649$ & $7,605,000$ \\
\hline 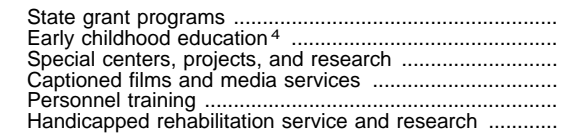 & $\begin{array}{r}1,623,195 \\
77,090 \\
109,582 \\
35,373 \\
110,179 \\
1,139,045\end{array}$ & $\begin{array}{r}1,841,104 \\
40,845 \\
78,998 \\
52,739 \\
100,578 \\
1,827,602\end{array}$ & $\begin{array}{r}1,573,963 \\
350,510 \\
91,229 \\
18,993 \\
88,569 \\
2,227,923\end{array}$ & $\begin{array}{r}2,080,606 \\
537,584 \\
157,223 \\
19,837 \\
101,741 \\
2,467,913\end{array}$ & $\begin{array}{r}3,064,963 \\
729,691 \\
112,051 \\
20,521 \\
114,706 \\
2,537,094\end{array}$ & $\begin{array}{r}2,651,905 \\
710,543 \\
141,894 \\
20,424 \\
97,821 \\
2,576,658\end{array}$ & $\begin{array}{r}2,460,993 \\
858,730 \\
115,195 \\
19,897 \\
95,298 \\
2,575,142\end{array}$ & $\begin{array}{r}3,133,688 \\
738,962 \\
126,738 \\
47,016 \\
82,788 \\
2,567,457\end{array}$ & $\begin{array}{r}3,866,000 \\
869,000 \\
144,000 \\
53,000 \\
82,000 \\
2,591,000\end{array}$ \\
\hline Vocational education and adult programs & $2,295,586$ & $1,266,030$ & $1,423,681$ & $1,778,400$ & $1,605,897$ & $1,570,504$ & $1,430,518$ & $1,516,762$ & $1,552,000$ \\
\hline 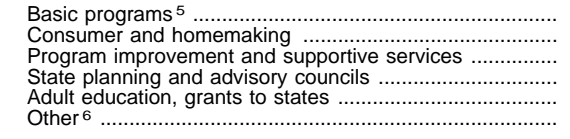 & $\begin{array}{r}1,481,625 \\
125,686 \\
323,348 \\
26,708 \\
305,862 \\
32,356\end{array}$ & $\begin{array}{r}1,072,863 \\
48,996 \\
7,691 \\
11,213 \\
125,266 \\
\end{array}$ & $\begin{array}{r}1,073,650 \\
43,157 \\
9,906 \\
935,406 \\
61,562\end{array}$ & $\begin{array}{r}1,185,211 \\
40,498 \\
10,079 \\
349,760 \\
192,852\end{array}$ & $\begin{array}{r}1,047,939 \\
37,380 \\
10,021 \\
280,912 \\
229,644\end{array}$ & $\begin{array}{r}1,079,251 \\
1,075 \\
9,675 \\
321,410 \\
159,093\end{array}$ & $\begin{array}{r}1,134,151 \\
\overline{-} \\
4,189 \\
284,847 \\
7,331\end{array}$ & $\begin{array}{r}1,037,408 \\
102,208 \\
361,815 \\
15,331\end{array}$ & $\begin{array}{r}1,044,000 \\
103,000 \\
375,000 \\
30,000\end{array}$ \\
\hline Postsecondary student financial assistance & $10,164,376$ & $12,618,151$ & $13,893,386$ & $18,137,286$ & $19,189,852$ & $28,976,386$ & $29,013,542$ & $36,860,185$ & $31,018,000$ \\
\hline $\begin{array}{l}\text { Educational opportunity grants }{ }^{7} \\
\text { Work-study } \\
\text { Perkins loan program } \\
\text { Federal Family Education Loan program }{ }^{8} \\
\text { Other student assistance programs }{ }^{9}\end{array}$ & $\begin{array}{r}5,042,615 \\
1,185,982 \\
642,169 \\
3,179,273 \\
114,337\end{array}$ & $\begin{array}{r}5,261,291 \\
886,335 \\
325,057 \\
6,107,725 \\
37,744\end{array}$ & $\begin{array}{r}6,150,541 \\
769,269 \\
196,816 \\
6,677,885 \\
98,875\end{array}$ & $\begin{array}{r}7,636,992 \\
705,643 \\
206,894 \\
9,461,304 \\
126,454\end{array}$ & $\begin{array}{r}7,821,568 \\
684,711 \\
195,653 \\
9,313,168 \\
1,174,752\end{array}$ & $\begin{array}{r}6,969,984 \\
666,470 \\
201,016 \\
11,245,065 \\
9,893,851\end{array}$ & $\begin{array}{r}5,806,897 \\
648,236 \\
123,573 \\
11,228,414 \\
11,206,422\end{array}$ & $\begin{array}{r}8,338,104 \\
843,214 \\
186,018 \\
11,991,007 \\
15,501,842\end{array}$ & $\begin{array}{r}5,193,000 \\
830,000 \\
165,000 \\
8,295,000 \\
16,535,000\end{array}$ \\
\hline Direct aid to postsecondary institutions & 551,278 & 487,495 & 427,144 & 585,821 & 816,827 & 838,462 & 869,202 & 906,582 & 952,000 \\
\hline $\begin{array}{l}\text { Aid to minority and developing institutions } \\
\text { Special programs for the disadvantaged } \\
\text { Cooperative education }\end{array}$ & $\begin{array}{r}228,177 \\
293,258 \\
29,843\end{array}$ & $\begin{array}{r}207,548 \\
258,656 \\
21,291\end{array}$ & $\begin{array}{r}124,795 \\
302,349 \\
-\end{array}$ & $\begin{array}{r}147,602 \\
438,219 \\
-\end{array}$ & $\begin{array}{r}232,753 \\
584,074 \\
-\end{array}$ & $\begin{array}{l}248,314 \\
590,148\end{array}$ & $\begin{array}{r}318,358 \\
550,844 \\
-\end{array}$ & $\begin{array}{r}328,087 \\
578,496 \\
-\end{array}$ & $\begin{array}{l}334,000 \\
618,000\end{array}$ \\
\hline Higher education facilities & 534,217 & 287,659 & 105,406 & 91,474 & 55,017 & 49,448 & 53,409 & 24,530 & 29,000 \\
\hline $\begin{array}{l}\text { Construction loans and insurance } \\
\text { Interest subsidy grants } \\
\text { College housing loans }\end{array}$ & $\begin{array}{r}70,359 \\
48,998 \\
414,859 \\
\end{array}$ & $\begin{array}{r}49,070 \\
36,916 \\
201,673 \\
\end{array}$ & $\begin{array}{l}37,509 \\
48,438 \\
19,460\end{array}$ & $\begin{array}{l}52,465 \\
25,567 \\
13,442\end{array}$ & $\begin{array}{l}22,726 \\
20,058 \\
12,233\end{array}$ & $\begin{array}{l}16,124 \\
22,574 \\
10,750\end{array}$ & $\begin{array}{r}1,047 \\
17,803 \\
34,559\end{array}$ & $\frac{1,022}{23,508}$ & 28,000 \\
\hline Other higher education programs & 69,494 & 109,915 & 236,305 & 227,748 & 143,311 & 128,994 & - & - & - \\
\hline $\begin{array}{l}\text { International education and foreign languages }{ }^{10} \\
\text { Funds for Improvement of Postsecondary Education }{ }^{11} \text {... } \\
\text { Other }\end{array}$ & $\begin{array}{r}39,748 \\
23,876 \\
5,870 \\
\end{array}$ & $\begin{array}{l}47,387 \\
18,792 \\
43,735\end{array}$ & $\begin{array}{r}107,947 \\
124,342 \\
4,016\end{array}$ & $\begin{array}{r}129,559 \\
97,380 \\
808\end{array}$ & $\begin{array}{r}142, \overline{874} \\
438\end{array}$ & $\begin{array}{r}124,6 \overline{4} \\
4,300\end{array}$ & $\overline{-}$ & $\left({ }^{12}\right)$ & $(\overline{12})$ \\
\hline Public library services & 201,392 & 171,550 & 165,768 & 162,998 & 164,971 & 161,243 & 134,046 & $\left({ }^{13}\right)$ & $\left({ }^{13}\right)$ \\
\hline $\begin{array}{l}\text { Public library services } \\
\text { Interlibrary cooperation } \\
\text { Public library construction } \\
\text { Research libraries }\end{array}$ & $\begin{array}{r}132,217 \\
\overline{-} \\
11,922 \\
57,253\end{array}$ & $\begin{array}{r}110,890 \\
26,614 \\
23,697 \\
8,871 \\
1,479 \\
\end{array}$ & $\begin{array}{r}103,156 \\
24,445 \\
18,551 \\
8,243 \\
11,374 \\
\end{array}$ & $\begin{array}{r}93,959 \\
22,296 \\
16,789 \\
6,557 \\
23,397\end{array}$ & $\begin{array}{r}91,784 \\
21,779 \\
23,241 \\
6,405 \\
21,762\end{array}$ & $\begin{array}{l}89,221 \\
25,799 \\
25,799 \\
20,424\end{array}$ & $\begin{array}{r}97,393 \\
18,850 \\
12,567 \\
3,142 \\
2,094\end{array}$ & $\begin{array}{l}(13) \\
(13) \\
(13) \\
(13) \\
(13)\end{array}$ & 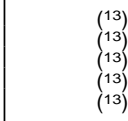 \\
\hline Payments to special institutions & 544,895 & 374,990 & 366,007 & 361,778 & 354,833 & 365,483 & 328,831 & 331,153 & 343,000 \\
\hline 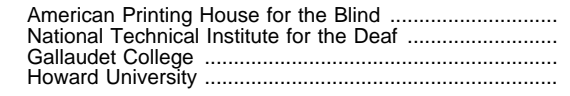 & $\begin{array}{r}8,653 \\
39,394 \\
98,308 \\
398,540\end{array}$ & $\begin{array}{r}8,132 \\
46,426 \\
87,370 \\
233,062\end{array}$ & $\begin{array}{r}7,080 \\
44,503 \\
84,574 \\
229,850\end{array}$ & $\begin{array}{r}7,110 \\
46,246 \\
87,594 \\
220,827\end{array}$ & $\begin{array}{r}7,127 \\
46,137 \\
86,499 \\
215,069\end{array}$ & $\begin{array}{r}7,525 \\
46,223 \\
85,996 \\
225,740\end{array}$ & $\begin{array}{r}7,331 \\
43,984 \\
81,684 \\
195,832\end{array}$ & $\begin{array}{r}7,155 \\
43,949 \\
80,744 \\
199,305\end{array}$ & $\begin{array}{r}8,000 \\
44,000 \\
81,000 \\
210,000\end{array}$ \\
\hline Departmental accounts & 551,489 & 539,371 & 573,306 & 861,673 & 870,811 & 973,906 & 806,368 & $1,041,496$ & 865,000 \\
\hline $\begin{array}{l}\text { Educational research and improvement } \\
\text { Departmental management account } \\
\text { Other }\end{array}$ & $\begin{array}{r}102,300 \\
445,405 \\
3,731 \\
54\end{array}$ & $\begin{array}{r}89,534 \\
444,870 \\
4,952 \\
15\end{array}$ & $\begin{array}{r}108,868 \\
463,665 \\
773\end{array}$ & $\begin{array}{r}319,581 \\
542,084 \\
\frac{8}{2}\end{array}$ & $\begin{array}{r}324,583 \\
546,166 \\
\frac{63}{3}\end{array}$ & $\begin{array}{r}351,509 \\
622,397 \\
- \\
-\end{array}$ & $\begin{array}{r}369,673 \\
435,648 \\
1,047 \\
-\end{array}$ & $\begin{array}{r}611,202 \\
425,184 \\
5,110 \\
-\end{array}$ & $\begin{array}{r}431,000 \\
433,000 \\
1,000 \\
-\end{array}$ \\
\hline
\end{tabular}

${ }^{1}$ Data adjusted by the federal funds composite deflator prepared by the U.S. Office of Management and Budget.

${ }^{2}$ Revised from previously published data.

${ }^{3}$ Estimated.

4 Includes preschool incentive grants.

${ }^{5}$ Includes programs of national significance and special programs for the disadvantaged.

${ }^{6}$ Includes national programs for research, demonstrations, evaluation and technical assistance, literacy training for homeless adults, and some other small programs.

7 Includes Pell Grants, Supplemental Education Opportunity Grants, State Student Incentive Grants, and Income Contingent Loans.

8 Formerly the Guaranteed Student Loan program.

9 Includes Federal Direct Student Loan program starting in fiscal year 1994.

10 Starting in fiscal year 1994 this program is included under the program, "Funds for Improvement of Postsecondary Education."

11 International education and foreign languages are included under this program starting in fiscal year 1994.

${ }_{12}$ This program is included under the "Special programs for the disadvantaged" program.

${ }^{13}$ This program was transferred to the Institute of Museum and Library Services in fiscal year 1997.

—Data are not available or not applicable.

NOTE.-Because of rounding, details may not add to totals. Data presented in this tabulation are obligations, which differ from outlay figures reported in other tables in this chapter.

SOURCE: U.S. Office of Management and Budget, Budget of the United States Government, fiscal years 1982 to 1999 . (This table was prepared May 1998.) 

Table 364.-U.S. Department of Education outlays, by level of education and type of recipient:
Fiscal years 1980 to 1998

[In millions of dollars]

\begin{tabular}{|c|c|c|c|c|c|c|c|c|}
\hline Year and area of education & Total & $\begin{array}{l}\text { Local } \\
\text { education } \\
\text { agencies }\end{array}$ & $\begin{array}{l}\text { State } \\
\text { education } \\
\text { agencies }\end{array}$ & $\begin{array}{l}\text { College } \\
\text { students }\end{array}$ & $\begin{array}{l}\text { Institutions } \\
\text { of higher } \\
\text { education }\end{array}$ & Federal & $\begin{array}{l}\text { Multiple } \\
\text { types of } \\
\text { recipients }\end{array}$ & Other ${ }^{1}$ \\
\hline 1 & 2 & 3 & 4 & 5 & 6 & 7 & 8 & 9 \\
\hline 1980 total & $\$ 13,137.8$ & $\$ 5,313.7$ & $\$ 1,103.2$ & $\$ 2,137.4$ & $\$ 2,267.2$ & $\$ 249.8$ & $\$ 693.8$ & $\$ 1,372.7$ \\
\hline 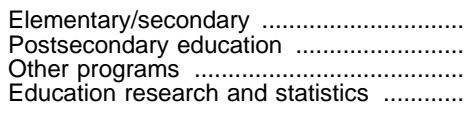 & $\begin{array}{r}6,629.1 \\
5,682.2 \\
747.7 \\
78.7\end{array}$ & $\frac{5,309.4}{4.3}$ & $\begin{array}{r}662.2 \\
99.5 \\
341.5 \\
-\end{array}$ & $\begin{array}{r}34.2 \\
2,103.2 \\
-\end{array}$ & $\begin{array}{r}22.0 \\
2,166.5 \\
78.7\end{array}$ & $\begin{array}{r}62.5 \\
187.3 \\
-\end{array}$ & $\begin{array}{r}513.4 \\
180.4 \\
-\end{array}$ & $\begin{array}{r}25.5 \\
1,313.0 \\
34.2 \\
-\end{array}$ \\
\hline 1984 total & $15,534.7$ & $5,256.5$ & $1,879.0$ & $2,193.4$ & $2,167.4$ & 330.2 & 516.7 & $3,191.4$ \\
\hline 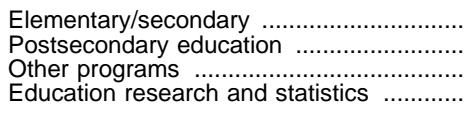 & $\begin{array}{r}6,220.8 \\
7,341.2 \\
1,813.1 \\
159.6 \\
\end{array}$ & $\frac{5,252.4}{4.1}$ & $\begin{array}{r}536.0 \\
211.5 \\
1,131.5 \\
-\end{array}$ & $\begin{array}{r}55.5 \\
2,137.9 \\
- \\
\end{array}$ & $\begin{array}{r}35.3 \\
1,972.5 \\
159.6 \\
\end{array}$ & $\begin{array}{r}22.9 \\
307.3 \\
-\end{array}$ & $\begin{array}{r}259.9 \\
256.8 \\
-\end{array}$ & $\begin{array}{r}58.8 \\
3,019.3 \\
113.3 \\
- \\
\end{array}$ \\
\hline 1988 total $\ldots \ldots \ldots . . . .$. & $18,326.9$ & $6,614.8$ & $2,234.6$ & $3,103.4$ & $2,519.5$ & 319.4 & 838.8 & $2,696.3$ \\
\hline 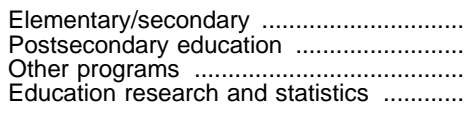 & $\begin{array}{r}8,098.4 \\
8,247.1 \\
1,939.0 \\
42.4\end{array}$ & $\frac{6,606.3}{8.5}$ & $\begin{array}{r}717.9 \\
184.6 \\
1,332.1 \\
-\end{array}$ & $\begin{array}{r}66.2 \\
3,037.2 \\
-\end{array}$ & $\begin{array}{r}39.5 \\
2,437.6 \\
42.4\end{array}$ & $\begin{array}{r}23.8 \\
295.6 \\
-\end{array}$ & $\begin{array}{r}616.7 \\
222.1 \\
-\end{array}$ & $\begin{array}{r}28.0 \\
2,587.7 \\
80.6 \\
-\end{array}$ \\
\hline 1990 total & $23,198.6$ & $8,000.7$ & $2,490.3$ & $3,859.6$ & $3,649.8$ & 441.4 & 912.2 & $\overline{3,844.4}$ \\
\hline 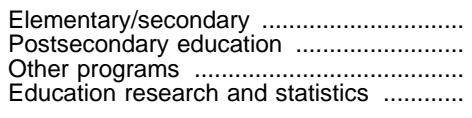 & $\begin{array}{r}9,681.3 \\
11,176.0 \\
2,251.8 \\
89.5 \\
\end{array}$ & $\begin{array}{r}7,995.0 \\
5.7 \\
-\end{array}$ & $\begin{array}{r}700.3 \\
261.6 \\
1,528.5 \\
-\end{array}$ & $\begin{array}{r}80.5 \\
3,779.1 \\
- \\
\end{array}$ & $\begin{array}{r}85.4 \\
3,475.0 \\
89.5 \\
\end{array}$ & $\frac{113.1}{328.3}$ & $\begin{array}{r}650.7 \\
261.5 \\
-\end{array}$ & $\begin{array}{r}56.3 \\
3,660.4 \\
127.8 \\
-\end{array}$ \\
\hline 1992 total & $26,116.0$ & $9,834.7$ & $2,883.2$ & $4,090.7$ & $4,107.4$ & 418.3 & $1,189.4$ & $3,592.4$ \\
\hline 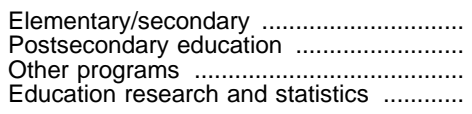 & $\begin{array}{r}12,057.7 \\
11,323.6 \\
2,579.9 \\
154.8\end{array}$ & $\frac{9,830.1}{4.6}$ & $\begin{array}{r}1,011.0 \\
245.5 \\
1,626.6 \\
-\end{array}$ & $\begin{array}{r}92.9 \\
3,997.7 \\
-\end{array}$ & $\begin{array}{r}232.7 \\
3,719.9 \\
154.8\end{array}$ & $\frac{49.8}{368.5}$ & $\frac{762.3}{427.0}$ & $\begin{array}{r}78.8 \\
3,360.5 \\
153.1 \\
-\end{array}$ \\
\hline 1994 total ...... & $29,713.4$ & $10,935.6$ & $3,264.8$ & $4,800.5$ & $4,831.3$ & 504.5 & $1,258.2$ & $4,118.5$ \\
\hline 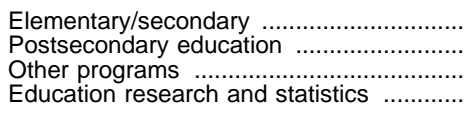 & $\begin{array}{r}13,769.2 \\
12,871.4 \\
2,796.0 \\
276.8\end{array}$ & $\begin{array}{r}10,929.2 \\
\frac{6.4}{-}\end{array}$ & $\begin{array}{r}1,354.0 \\
53.0 \\
1,857.8 \\
-\end{array}$ & $\begin{array}{r}159.9 \\
4,640.6 \\
-\end{array}$ & $\begin{array}{r}275.2 \\
4,279.3 \\
276.8\end{array}$ & $\frac{60.9}{443.6}$ & $\begin{array}{r}902.1 \\
356.1 \\
-\end{array}$ & $\begin{array}{r}87.9 \\
3,898.5 \\
132.1 \\
-\end{array}$ \\
\hline 1995 total & $31,403.0$ & $11,210.7$ & $3,584.0$ & $4,964.7$ & $5,016.1$ & 485.4 & $1,349.2$ & $4,792.9$ \\
\hline 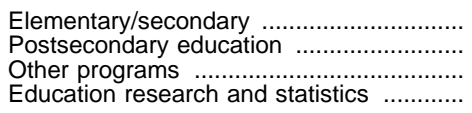 & $\begin{array}{r}14,029.0 \\
14,234.0 \\
2,861.0 \\
279.0\end{array}$ & $\begin{array}{r}11,203.3 \\
7.4 \\
-\end{array}$ & $\begin{array}{r}1,410.0 \\
250.8 \\
1,923.2 \\
-\end{array}$ & $\begin{array}{r}190.5 \\
4,774.2 \\
-\end{array}$ & $\begin{array}{r}170.1 \\
4,567.0 \\
279.0\end{array}$ & $\frac{70.3}{415.1}$ & $\frac{946.9}{402.3}$ & $\begin{array}{r}37.9 \\
4,642.0 \\
113.0 \\
-\end{array}$ \\
\hline 1996 total & $29,977.8$ & $11,077.8$ & $3,669.6$ & $5,129.8$ & $5,053.4$ & 562.1 & $1,682.3$ & $2,802.9$ \\
\hline 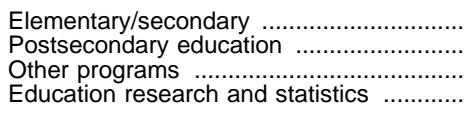 & $\begin{array}{r}14,323.8 \\
12,257.6 \\
3,085.6 \\
310.9\end{array}$ & $\begin{array}{r}11,073.1 \\
4.7\end{array}$ & $\begin{array}{r}1,650.7 \\
90.7 \\
1,928.2 \\
-\end{array}$ & $\begin{array}{r}161.1 \\
4,968.7 \\
-\end{array}$ & $\begin{array}{r}141.5 \\
4,601.0 \\
310.9\end{array}$ & $\begin{array}{r}59.2 \\
502.9 \\
\end{array}$ & $\begin{array}{r}1,201.4 \\
480.9 \\
-\end{array}$ & $\begin{array}{r}36.8 \\
2,597.2 \\
168.9 \\
-\end{array}$ \\
\hline 1997 total & $30,110.6$ & $11,229.1$ & $3,698.5$ & $5,200.5$ & $5,480.0$ & 467.9 & $1,535.4$ & $2,499.1$ \\
\hline 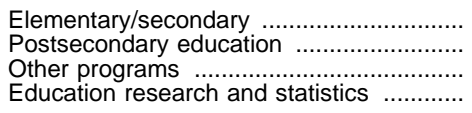 & $\begin{array}{r}14,511.2 \\
12,377.0 \\
2,882.3 \\
340.0\end{array}$ & $\begin{array}{r}11,220.3 \\
8.8 \\
\end{array}$ & $\begin{array}{r}1,654.2 \\
48.6 \\
1,995.7 \\
-\end{array}$ & $\begin{array}{r}165.4 \\
5,035.1 \\
=\end{array}$ & $\begin{array}{r}149.5 \\
4,990.5 \\
340.0\end{array}$ & $\begin{array}{r}58.3 \\
409.6 \\
-\end{array}$ & $\begin{array}{r}1,224.1 \\
311.3 \\
-\end{array}$ & $\begin{array}{r}39.4 \\
2,302.8 \\
156.9 \\
-\end{array}$ \\
\hline 1998 total & $30,735.6$ & $11,486.7$ & $3,737.9$ & $5,502.1$ & $6,031.0$ & 484.6 & $1,475.8$ & $2,017.5$ \\
\hline 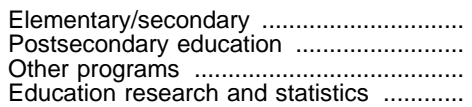 & $\begin{array}{r}14,787.3 \\
12,406.1 \\
2,961.8 \\
580.5\end{array}$ & $\frac{11,477.5}{9.2}$ & $\begin{array}{r}1,662.2 \\
63.4 \\
2,012.3 \\
\end{array}$ & $\begin{array}{r}241.8 \\
5,260.3 \\
\end{array}$ & $\begin{array}{r}153.4 \\
5,297.1 \\
580.5\end{array}$ & $\begin{array}{r}47.5 \\
437.1 \\
-\end{array}$ & $\begin{array}{r}1,148.8 \\
327.0 \\
-\end{array}$ & $\begin{array}{r}56.0 \\
1,785.3 \\
176.2\end{array}$ \\
\hline
\end{tabular}

1 Other recipients include Indian tribes, private nonprofit agencies, and banks. -Data are not available or not applicable.

NOTE.-Outlays by type of recipient are estimated based on obligation data. Some data have been revised from previously published figures. Because of rounding, details may not add to totals.
SOURCE: U.S. Office of Management and Budget, Budget of the U.S. Government, Fiscal Years 1982 to 1999, and Catalog of Federal Domestic Assistance; National Science Foundation, Federal Funds for Research and Development, Fiscal Years 1980 to 1998; and unpublished data obtained from various federal agencies. (This table was prepared July 1998.) 
Table 365.-U.S. Department of Education obligations for major programs, by state or other area: Fiscal year 1997

[In thousands]

\begin{tabular}{|c|c|c|c|c|c|c|c|c|c|c|c|c|}
\hline State or other area & Total & $\begin{array}{c}\text { Grants for } \\
\text { the disad- } \\
\text { vantaged } 1\end{array}$ & $\begin{array}{l}\text { Block } \\
\text { grants to } \\
\text { states for } \\
\text { school } \\
\text { improve- } \\
\text { ment }^{2}\end{array}$ & $\begin{array}{l}\text { School } \\
\text { assist- } \\
\text { ance in } \\
\text { federally } \\
\text { affected } \\
\text { areas }^{3}\end{array}$ & $\begin{array}{l}\text { Vocational } \\
\text { and adult } \\
\text { education }{ }^{4}\end{array}$ & $\begin{array}{l}\text { Education } \\
\text { for the } \\
\text { handi- } \\
\text { capped } 5\end{array}$ & \begin{tabular}{|} 
Bilingual \\
edu- \\
cation $^{6}$
\end{tabular} & $\begin{array}{c}\text { Indian } \\
\text { edu- } \\
\text { cation }\end{array}$ & $\begin{array}{c}\text { Higher and } \\
\text { continuing } \\
\text { education } 7\end{array}$ & $\begin{array}{l}\text { Student } \\
\text { financial } \\
\text { assist- } \\
\text { ance }^{8}\end{array}$ & $\begin{array}{l}\text { Rehabili- } \\
\text { tation } \\
\text { services }^{9}\end{array}$ & $\begin{array}{l}\text { Goals } \\
200010\end{array}$ \\
\hline 1 & 2 & 3 & 4 & 5 & 6 & 7 & 8 & 9 & 10 & 11 & 12 & 13 \\
\hline Total & $\$ 28,611,252$ & $\$ 7,782,801$ & $\$ 1,181,345$ & $\$ 655,500$ & $\$ 1,446,611$ & $\$ 3,787,023$ & $\$ 254,025$ & $\$ 57,947$ & $\$ 1,178,199$ & $\$ 9,357,369$ & $\$ 2,254,099$ & $\$ 656,333$ \\
\hline $\begin{array}{l}\text { Alabama } \\
\text { Alaska } \\
\text { Arizona } \\
\text { Arkansas } \\
\text { California }\end{array}$ & $\begin{array}{r}461,534 \\
139,173 \\
467,681 \\
277,119 \\
3,052,628\end{array}$ & $\begin{array}{r}131,021 \\
26,454 \\
119,447 \\
81,904 \\
914,350\end{array}$ & $\begin{array}{r}18,772 \\
5,792 \\
18,020 \\
11,376 \\
130,884\end{array}$ & $\begin{array}{r}1,916 \\
59,153 \\
78,919 \\
275 \\
39,479\end{array}$ & $\begin{array}{r}28,154 \\
5,114 \\
23,335 \\
16,768 \\
156,381\end{array}$ & $\begin{array}{r}56,607 \\
13,523 \\
10,674 \\
39,446 \\
343,137\end{array}$ & $\begin{array}{r}436 \\
865 \\
10,232 \\
144 \\
86,600\end{array}$ & $\begin{array}{r}\$ 1,101 \\
6,493 \\
6,951 \\
116 \\
3,838\end{array}$ & $\begin{array}{r}39,535 \\
2,278 \\
7,771 \\
15,211 \\
73,696\end{array}$ & $\begin{array}{r}133,282 \\
8,453 \\
147,061 \\
76,199 \\
1,014,151\end{array}$ & $\begin{array}{r}47,175 \\
8,035 \\
35,300 \\
28,778 \\
214,884\end{array}$ & $\begin{array}{r}3,536 \\
3,012 \\
9,972 \\
6,903 \\
75,228\end{array}$ \\
\hline $\begin{array}{l}\text { Colorado } \\
\text { Connecticut } \\
\text { Delaware } \\
\text { District of Columbia } \\
\text { Florida }\end{array}$ & $\begin{array}{r}323,443 \\
246,311 \\
76,054 \\
762,360 \\
1,238,872\end{array}$ & $\begin{array}{r}74,354 \\
69,789 \\
18,908 \\
23,452 \\
346,594\end{array}$ & $\begin{array}{r}14,189 \\
11,553 \\
5,792 \\
5,760 \\
51,936\end{array}$ & $\begin{array}{r}4,855 \\
5,200 \\
36 \\
629 \\
6,356\end{array}$ & $\begin{array}{r}17,801 \\
13,326 \\
5,457 \\
5,468 \\
68,165\end{array}$ & $\begin{array}{r}46,376 \\
51,352 \\
10,966 \\
4,934 \\
201,975\end{array}$ & $\begin{array}{r}3,669 \\
2,005 \\
100 \\
1,032 \\
16,911\end{array}$ & $\begin{array}{r}377 \\
23 \\
0 \\
0 \\
52\end{array}$ & $\begin{array}{r}11,749 \\
6,578 \\
4,633 \\
321,434 \\
23,242\end{array}$ & $\begin{array}{r}115,047 \\
63,245 \\
19,380 \\
387,105 \\
388,960\end{array}$ & $\begin{array}{r}27,580 \\
17,299 \\
8,041 \\
11,547 \\
105,809\end{array}$ & $\begin{array}{r}7,446 \\
5,943 \\
2,741 \\
1,000 \\
28,872\end{array}$ \\
\hline $\begin{array}{l}\text { Georgia } \\
\text { Hawaii } \\
\text { Idaho } \\
\text { Illinois }\end{array}$ & $\begin{array}{r}652,130 \\
107,957 \\
119,569 \\
1,131,926 \\
531,780\end{array}$ & $\begin{array}{r}198,098 \\
20,820 \\
26,509 \\
338,289 \\
118,630\end{array}$ & $\begin{array}{r}29,998 \\
5,879 \\
5,774 \\
51,290 \\
22,041\end{array}$ & $\begin{array}{r}5,694 \\
23,226 \\
3,442 \\
6,343 \\
99\end{array}$ & $\begin{array}{r}41,888 \\
6,791 \\
7,780 \\
57,554 \\
33,445\end{array}$ & $\begin{array}{r}91,689 \\
11,400 \\
16,871 \\
186,266 \\
87,240\end{array}$ & $\begin{array}{r}1,644 \\
1,370 \\
1,548 \\
10,524 \\
250\end{array}$ & $\begin{array}{r}0 \\
0 \\
262 \\
77 \\
7\end{array}$ & $\begin{array}{r}34,959 \\
7,413 \\
3,408 \\
31,952 \\
13,142\end{array}$ & $\begin{array}{r}167,380 \\
20,077 \\
39,310 \\
335,849 \\
198,131\end{array}$ & $\begin{array}{r}63,828 \\
8,151 \\
11,596 \\
83,775 \\
46,941\end{array}$ & $\begin{array}{r}16,951 \\
2,829 \\
3,068 \\
30,006 \\
11,854\end{array}$ \\
\hline $\begin{array}{l}\text { lowa } \\
\text { Kansas } \\
\text { Kentucky } \\
\text { Louisiana } \\
\text { Maine }\end{array}$ & $\begin{array}{l}275,983 \\
254,806 \\
445,232 \\
585,124 \\
139,869\end{array}$ & $\begin{array}{r}54,582 \\
64,875 \\
139,631 \\
201,296 \\
32,678\end{array}$ & $\begin{array}{r}10,791 \\
10,578 \\
17,901 \\
24,774 \\
5,760\end{array}$ & $\begin{array}{r}75 \\
9,017 \\
295 \\
3,091 \\
2,434\end{array}$ & $\begin{array}{r}16,222 \\
13,904 \\
26,360 \\
29,675 \\
7,285\end{array}$ & $\begin{array}{l}42,279 \\
35,940 \\
62,191 \\
64,848 \\
21,056\end{array}$ & $\begin{array}{r}1,218 \\
982 \\
259 \\
1,239 \\
1,459\end{array}$ & $\begin{array}{r}113 \\
320 \\
0 \\
461 \\
100\end{array}$ & $\begin{array}{r}13,798 \\
12,334 \\
15,444 \\
25,678 \\
5,531\end{array}$ & $\begin{array}{r}104,749 \\
79,038 \\
129,299 \\
169,749 \\
47,274\end{array}$ & $\begin{array}{l}26,453 \\
21,980 \\
42,592 \\
48,421 \\
13,149\end{array}$ & $\begin{array}{r}5,701 \\
5,839 \\
11,260 \\
15,894 \\
3,142\end{array}$ \\
\hline $\begin{array}{l}\text { Maryland } \\
\text { Massachusetts } \\
\text { Michigan } \\
\text { Minnesota } \\
\text { Mississippi }\end{array}$ & $\begin{array}{l}393,007 \\
649,815 \\
935,139 \\
410,126 \\
395,297\end{array}$ & $\begin{array}{r}100,045 \\
146,133 \\
340,860 \\
91,077 \\
130,376\end{array}$ & $\begin{array}{l}18,454 \\
22,079 \\
44,979 \\
18,377 \\
15,546\end{array}$ & $\begin{array}{r}4,306 \\
858 \\
4,137 \\
5,466 \\
2,566\end{array}$ & $\begin{array}{l}21,742 \\
25,616 \\
50,097 \\
22,416 \\
19,458\end{array}$ & $\begin{array}{r}73,649 \\
101,520 \\
123,749 \\
60,312 \\
41,600\end{array}$ & $\begin{array}{r}1,349 \\
5,661 \\
1,505 \\
1,576 \\
322\end{array}$ & $\begin{array}{r}150 \\
74 \\
2,559 \\
2,180 \\
222\end{array}$ & $\begin{array}{l}17,359 \\
19,211 \\
25,931 \\
15,045 \\
18,636\end{array}$ & $\begin{array}{l}113,315 \\
273,196 \\
235,206 \\
146,666 \\
121,673\end{array}$ & $\begin{array}{l}33,118 \\
43,206 \\
78,461 \\
37,595 \\
34,662\end{array}$ & $\begin{array}{r}9,519 \\
12,261 \\
27,654 \\
9,416 \\
10,237\end{array}$ \\
\hline 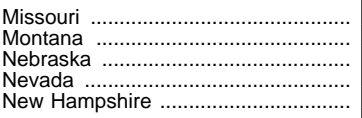 & $\begin{array}{r}504,818 \\
136,611 \\
180,656 \\
90,539 \\
96,755\end{array}$ & $\begin{array}{r}128,588 \\
27,077 \\
37,092 \\
22,496 \\
17,768\end{array}$ & $\begin{array}{r}21,442 \\
5,760 \\
6,578 \\
5,920 \\
5,921\end{array}$ & $\begin{array}{r}6,983 \\
23,452 \\
7,428 \\
2,367 \\
7\end{array}$ & $\begin{array}{r}29,972 \\
6,272 \\
9,158 \\
7,165 \\
6,729\end{array}$ & $\begin{array}{l}77,151 \\
13,981 \\
24,807 \\
19,652 \\
18,465\end{array}$ & $\begin{array}{r}1,370 \\
3,059 \\
499 \\
951 \\
100\end{array}$ & $\begin{array}{r}41 \\
1,889 \\
406 \\
445 \\
0\end{array}$ & $\begin{array}{r}14,786 \\
7,484 \\
4,365 \\
1,737 \\
2,814\end{array}$ & $\begin{array}{r}163,385 \\
37,326 \\
71,831 \\
17,331 \\
32,948\end{array}$ & $\begin{array}{r}49,256 \\
9,310 \\
14,820 \\
9,611 \\
9,278\end{array}$ & $\begin{array}{r}11,844 \\
1,000 \\
3,671 \\
2,864 \\
2,724\end{array}$ \\
\hline 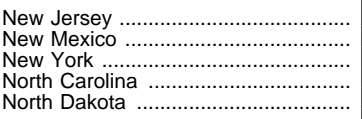 & $\begin{array}{r}622,211 \\
272,387 \\
2,319,571 \\
616,830 \\
104,531\end{array}$ & $\begin{array}{r}163,840 \\
64,799 \\
687,951 \\
144,895 \\
18,994\end{array}$ & $\begin{array}{r}28,294 \\
8,874 \\
83,470 \\
26,398 \\
5,760\end{array}$ & $\begin{array}{r}9,939 \\
46,475 \\
9,456 \\
5,913 \\
12,704\end{array}$ & $\begin{array}{r}33,320 \\
10,915 \\
80,184 \\
41,928 \\
5,500\end{array}$ & $\begin{array}{r}125,751 \\
32,930 \\
269,268 \\
106,773 \\
8,967\end{array}$ & $\begin{array}{r}3,960 \\
6,246 \\
37,482 \\
1,250 \\
1,315\end{array}$ & $\begin{array}{r}106 \\
5,026 \\
1,081 \\
2,091 \\
1,002\end{array}$ & $\begin{array}{r}13,363 \\
8,745 \\
37,972 \\
35,847 \\
4,927\end{array}$ & $\begin{array}{r}183,341 \\
64,845 \\
939,864 \\
168,573 \\
34,586\end{array}$ & $\begin{array}{r}45,237 \\
18,178 \\
120,175 \\
69,162 \\
8,014\end{array}$ & $\begin{array}{r}15,060 \\
5,355 \\
52,668 \\
13,997 \\
2,763\end{array}$ \\
\hline $\begin{array}{l}\text { Ohio } \\
\text { Oklahoma } \\
\text { Oregon } \\
\text { Pennsylvania } \\
\text { Rhode Island }\end{array}$ & $\begin{array}{r}1,124,159 \\
379,079 \\
277,649 \\
1,148,244 \\
125,983\end{array}$ & $\begin{array}{r}312,174 \\
88,452 \\
80,981 \\
338,831 \\
25,127\end{array}$ & $\begin{array}{r}48,148 \\
14,437 \\
12,594 \\
49,098 \\
5,760\end{array}$ & $\begin{array}{r}2,600 \\
16,138 \\
1,861 \\
1,037 \\
1,363\end{array}$ & $\begin{array}{r}60,914 \\
20,856 \\
16,660 \\
60,797 \\
7,017\end{array}$ & $\begin{array}{r}142,022 \\
48,982 \\
43,454 \\
139,082 \\
17,940\end{array}$ & $\begin{array}{r}306 \\
5,791 \\
2,764 \\
1,355 \\
1,063\end{array}$ & $\begin{array}{r}7 \\
11,129 \\
1,230 \\
0 \\
0\end{array}$ & $\begin{array}{r}21,944 \\
16,978 \\
7,754 \\
24,023 \\
5,328\end{array}$ & $\begin{array}{r}406,862 \\
119,934 \\
76,576 \\
402,446 \\
50,469\end{array}$ & $\begin{array}{r}100,889 \\
34,025 \\
26,581 \\
102,727 \\
9,017\end{array}$ & $\begin{array}{r}28,293 \\
2,358 \\
7,195 \\
28,848 \\
2,898\end{array}$ \\
\hline $\begin{array}{l}\text { South Carolina } \\
\text { South Dakota } \\
\text { Tennessee } \\
\text { Texas }\end{array}$ & $\begin{array}{r}377,008 \\
165,003 \\
503,587 \\
2,068,166 \\
233,330\end{array}$ & $\begin{array}{r}97,056 \\
20,831 \\
131,125 \\
679,899 \\
35,922\end{array}$ & $\begin{array}{r}15,340 \\
5,796 \\
20,982 \\
90,396 \\
8,930\end{array}$ & $\begin{array}{r}2,406 \\
18,276 \\
1,108 \\
24,613 \\
4,691\end{array}$ & $\begin{array}{r}24,138 \\
5,602 \\
31,873 \\
111,243 \\
14,047\end{array}$ & $\begin{array}{r}54,508 \\
12,385 \\
83,347 \\
311,994 \\
34,609\end{array}$ & $\begin{array}{r}100 \\
2,509 \\
364 \\
18,274 \\
1,795\end{array}$ & $\begin{array}{r}32 \\
2,025 \\
0 \\
172 \\
720\end{array}$ & $\begin{array}{r}22,265 \\
3,844 \\
21,278 \\
51,167 \\
6,972\end{array}$ & $\begin{array}{r}112,855 \\
82,849 \\
149,617 \\
565,249 \\
101,474\end{array}$ & $\begin{array}{r}39,461 \\
8,053 \\
52,002 \\
160,646 \\
19,741\end{array}$ & $\begin{array}{r}8,847 \\
2,833 \\
11,890 \\
54,513 \\
4,427\end{array}$ \\
\hline $\begin{array}{l}\text { Vermont } \\
\text { Virginia } \\
\text { Washington } \\
\text { West Virginia } \\
\text { Wisconsin } \\
\text { Wyoming }\end{array}$ & $\begin{array}{r}86,520 \\
677,327 \\
465,961 \\
225,620 \\
509,542 \\
74,179\end{array}$ & $\begin{array}{r}17,715 \\
112,577 \\
122,852 \\
74,995 \\
129,779 \\
16,806\end{array}$ & $\begin{array}{r}5,760 \\
22,475 \\
20,877 \\
8,839 \\
22,038 \\
5,797\end{array}$ & $\begin{array}{r}2 \\
23,334 \\
22,395 \\
6 \\
7,327 \\
5,672\end{array}$ & $\begin{array}{r}5,273 \\
33,577 \\
25,774 \\
12,827 \\
27,673 \\
5,110\end{array}$ & $\begin{array}{r}6,986 \\
98,488 \\
69,712 \\
30,757 \\
78,166 \\
10,852\end{array}$ & $\begin{array}{r}124 \\
1,609 \\
4,375 \\
100 \\
694 \\
524\end{array}$ & $\begin{array}{r}88 \\
14 \\
2,979 \\
0 \\
1,654 \\
336\end{array}$ & $\begin{array}{r}4,721 \\
23,599 \\
14,512 \\
8,600 \\
17,840 \\
3,128\end{array}$ & $\begin{array}{r}35,093 \\
298,932 \\
132,873 \\
61,662 \\
166,162 \\
16,801\end{array}$ & $\begin{array}{r}8,042 \\
51,186 \\
38,337 \\
22,040 \\
45,941 \\
6,439\end{array}$ & $\begin{array}{r}2,716 \\
11,536 \\
11,276 \\
5,794 \\
12,270 \\
2,713\end{array}$ \\
\hline $\begin{array}{l}\text { Indian tribe setaside } \\
\text { Undistributed }\end{array}$ & $\begin{array}{l}103,406 \\
160,275\end{array}$ & $\begin{array}{l}37,250 \\
20,406\end{array}$ & $\begin{array}{l}7,837 \\
2,031\end{array}$ & $\begin{array}{r}0 \\
129,108\end{array}$ & $\begin{array}{r}482 \\
0\end{array}$ & $\begin{array}{r}41,882 \\
7,243\end{array}$ & $\begin{array}{l}0 \\
0\end{array}$ & $\begin{array}{l}0 \\
0\end{array}$ & $\begin{array}{l}0 \\
0\end{array}$ & $\begin{array}{l}0 \\
0\end{array}$ & $\begin{array}{r}12,000 \\
738\end{array}$ & $\begin{array}{r}3,955 \\
750\end{array}$ \\
\hline 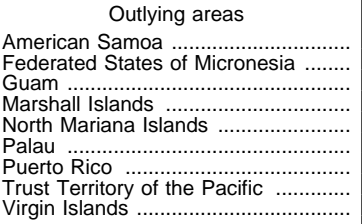 & $\begin{array}{r}18,029 \\
562 \\
31,535 \\
395 \\
12,084 \\
1,191 \\
790,120 \\
1,619 \\
32,834\end{array}$ & $\begin{array}{r}9,191 \\
0 \\
8,794 \\
0 \\
4,603 \\
0 \\
278,114 \\
0 \\
15,647\end{array}$ & $\begin{array}{r}1,555 \\
0 \\
3,973 \\
0 \\
886 \\
1 \\
27,803 \\
0 \\
3,279\end{array}$ & $\begin{array}{r}0 \\
0 \\
0 \\
0 \\
0 \\
0 \\
823 \\
0 \\
150\end{array}$ & $\begin{array}{r}373 \\
100 \\
766 \\
100 \\
365 \\
100 \\
28,683 \\
0 \\
915\end{array}$ & $\begin{array}{r}4,550 \\
0 \\
10,828 \\
0 \\
2,526 \\
502 \\
31,684 \\
0 \\
7,180\end{array}$ & $\begin{array}{l}355 \\
100 \\
916 \\
100 \\
219 \\
100 \\
351 \\
728 \\
281\end{array}$ & $\begin{array}{l}0 \\
0 \\
0 \\
0 \\
0 \\
0 \\
0 \\
0 \\
0\end{array}$ & $\begin{array}{r}651 \\
89 \\
1,521 \\
195 \\
1,801 \\
180 \\
19,416 \\
890 \\
1,492\end{array}$ & $\begin{array}{r}280 \\
274 \\
2,041 \\
0 \\
849 \\
159 \\
324,380 \\
0 \\
1,706\end{array}$ & $\begin{array}{r}834 \\
0 \\
2,199 \\
0 \\
721 \\
150 \\
59,139 \\
0 \\
1,775\end{array}$ & $\begin{array}{r}241 \\
0 \\
496 \\
0 \\
114 \\
0 \\
19,727 \\
0 \\
410\end{array}$ \\
\hline
\end{tabular}

1 Title I, formerly called Chapter 1, Education Consolidation and Improvement Act of 1981, includes Grants to Local Education Agencies, Migrant Education-Basic State Grants, Program for Neglected and Delinquent Children, Capital Expenses, and Even Start-State Educational Agencies.

2 Title VI, formerly called Chapter 2 Education Consolidation and Improvement Act of 1981, includes Eisenhower Professional Development Grants, Safe and Drug-Free Schools and Communities-State Grants, Education for Homeless Children and Youth, and Innovative Education Program Strategies.

${ }_{3}$ Impact Aid-Basic Support Payments and Impact Aid-Payments for Children with Disabilities.

${ }^{4}$ Includes Vocational Education-Basic Grants to States, Tech-Prep Education, and Adult Education-State Grant Program.

5 Includes Special Education-Grants to States, Preschool Grants, and Grants for Infants and Families with Disabilities.

${ }^{6}$ Includes Emergency Immigrant Education Program and Bilingual Education State Grants.

7 Includes Institutional Aid to Strengthen Higher Education Institutions serving significant numbers of low-income students, Other Special Programs for the Disadvantaged, Cooperative Education, Fund for the Improvement of Postsecondary Education, Fellowships and Scholarships, and annual interest subsidy grants for facilities construction.

8 Includes Pell Grants, State Student Incentive Grants, Federal Supplemental Educational Opportunity Grants, Federal Work-Study, and Federal Perkins Loans-Capital Contributions, and Guaranteed Student Loan interest subsidies.

${ }^{9}$ Includes Rehabilitation Services-Vocational Rehabilitation Grants to States, Supported Employment Services for Individuals with Severe Disabilities, Rehabilitation Services-Client Assistance Program, and Independent Living-State Grants, and Protection and Advocacy of Individual Rights.

10 Includes State and Local Education Systemic Improvement Grants and Innovative Education Program Strategies.

NOTE.-Data reflect revisions to figures in the Budget of the United States Govern ment, Fiscal Year 1999. To the extent possible, data represent obligations rather than outlays. Because of the exclusion of certain programs, totals in this table are lower than those reported in other tables. Because of rounding, details may not add to totals.

SOURCE: U.S. Department of Education, National Center for Education Statistics, based on unpublished tabulations from the Office of Management and Budget; and U.S. Department of Commerce, Bureau of the Census, Federal Expenditures by State for Fiscal Year 1997. (This table was prepared February 1998.) 
Table 366.-U.S. Department of Education obligations for major programs, by state or other area: Fiscal year 1996

[In thousands]

\begin{tabular}{|c|c|c|c|c|c|c|c|c|c|c|c|c|c|}
\hline State or other area & Total & $\begin{array}{l}\text { Grants for } \\
\text { the disad- } \\
\text { vantaged } 1\end{array}$ & $\begin{array}{c}\text { Block } \\
\text { grants to } \\
\text { states for } \\
\text { school } \\
\text { improve- }^{2} \\
\text { ment }^{2}\end{array}$ & \begin{tabular}{|c|} 
School \\
assist- \\
ance in \\
federally \\
affected \\
areas $^{3}$
\end{tabular} & $\begin{array}{l}\text { Vocational } \\
\text { and adult } \\
\text { education }{ }^{4}\end{array}$ & $\begin{array}{l}\text { Education } \\
\text { for the } \\
\text { handi-- } \\
\text { capped } 5\end{array}$ & $\begin{array}{l}\text { Bilingual } \\
\text { edu- } \\
\text { cation } 6\end{array}$ & $\begin{array}{l}\text { Indian } \\
\text { edu- } \\
\text { cation }\end{array}$ & $\begin{array}{l}\text { Higher and } \\
\text { continuing } \\
\text { education }\end{array}$ & $\begin{array}{l}\text { Student } \\
\text { financial } \\
\text { assist- } \\
\text { ance }^{8}\end{array}$ & $\begin{array}{c}\text { Public } \\
\text { library } \\
\text { pro- } \\
\text { grams } 9\end{array}$ & $\begin{array}{r}\text { Reh } \\
\text { tat } \\
\text { servi }\end{array}$ & \\
\hline 1 & 2 & 3 & 4 & 5 & 6 & . & 8 & 9 & 10 & 11 & 12 & 13 & 14 \\
\hline Total .......... & $3,169,044$ & $\$ 5,877,908$ & $, 014,622$ & \$21,707 & $\$ 1,324,769$ & $\$ 3,144,751$ & $\$ 186,524$ & $\$ 50,180$ & $\$ 1,037,480$ & $\$ 7,275,673$ & $\$ 122,624$ & $\$ 2,191,920$ & $\$ 320,885$ \\
\hline 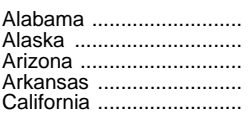 & $\begin{array}{r}401,419 \\
115,798 \\
410,975 \\
221,201 \\
2,517,806\end{array}$ & \begin{tabular}{r|}
104,932 \\
22,498 \\
87,262 \\
64,679 \\
691,965
\end{tabular} & $\begin{array}{r}16,386 \\
4,974 \\
15,136 \\
9,837 \\
111,557\end{array}$ & $\begin{array}{r}50,357 \\
67,929 \\
889 \\
52,700\end{array}$ & $\begin{array}{r}25,534 \\
4,984 \\
20,932 \\
15,057 \\
140,435\end{array}$ & $\begin{array}{r}55,413 \\
10,390 \\
40,807 \\
29,434 \\
344,881\end{array}$ & $\begin{array}{r}214 \\
1,016 \\
7,185 \\
100 \\
66,018\end{array}$ & \begin{tabular}{r|}
1,205 \\
5,715 \\
5,864 \\
101 \\
3,494
\end{tabular} & \begin{tabular}{r|}
39,758 \\
2,456 \\
7,282 \\
14,102 \\
74,588
\end{tabular} & \begin{tabular}{r|}
99,388 \\
4,618 \\
117,446 \\
57,400 \\
765,436
\end{tabular} & $\begin{array}{r}2,343 \\
899 \\
1,982 \\
1,328 \\
13,004\end{array}$ & $\begin{array}{r}46,370 \\
7,862 \\
33,596 \\
28,204 \\
210,819\end{array}$ & $\begin{array}{r}\$ 6,054 \\
29 \\
5,554 \\
699 \\
42,909\end{array}$ \\
\hline 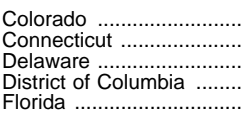 & $\begin{array}{r}254,932 \\
181,800 \\
63,584 \\
369,884 \\
979,634\end{array}$ & $\begin{array}{r}57,264 \\
45,962 \\
14,308 \\
17,857 \\
252,802\end{array}$ & $\begin{array}{r}12,210 \\
9,703 \\
4,974 \\
4,874 \\
43,463\end{array}$ & $\begin{array}{r}6,140 \\
5,411 \\
67 \\
1,515 \\
11,227\end{array}$ & $\begin{array}{r}16,096 \\
12,061 \\
5,253 \\
4,363 \\
61,095\end{array}$ & $\begin{array}{r}41,004 \\
42,656 \\
9,124 \\
4,756 \\
172,852\end{array}$ & $\begin{array}{r}2,129 \\
1,754 \\
160 \\
716 \\
8,532\end{array}$ & $\begin{array}{r}321 \\
21 \\
0 \\
0 \\
40\end{array}$ & $\begin{array}{r}11,759 \\
6,326 \\
4,636 \\
198,518 \\
26,151\end{array}$ & $\begin{array}{r}75,903 \\
39,105 \\
15,357 \\
123,567\end{array}$ & $\begin{array}{r}1,564 \\
1,660 \\
562 \\
570 \\
5,548\end{array}$ & $\begin{array}{r}26,538 \\
17,077 \\
7,874 \\
11,595 \\
103,138\end{array}$ & $\begin{array}{r}4,004 \\
66 \\
1,267 \\
1,552 \\
15,014\end{array}$ \\
\hline 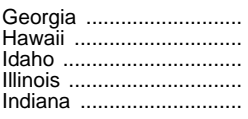 & $\begin{array}{r}517,636 \\
86,306 \\
102,623 \\
864,739 \\
420,921\end{array}$ & $\begin{array}{r}143,475 \\
16,056 \\
22,888 \\
266,003 \\
92,514\end{array}$ & $\begin{array}{r}25,677 \\
4,974 \\
4,975 \\
44,193 \\
19,058\end{array}$ & $\begin{array}{r}6,058 \\
17,414 \\
3,230 \\
9,063 \\
538\end{array}$ & $\begin{array}{r}37,781 \\
6,247 \\
6,904 \\
51,800 \\
30,439\end{array}$ & $\begin{array}{r}71,144 \\
10,427 \\
14,720 \\
133,309 \\
68,549\end{array}$ & $\begin{array}{r}686 \\
1,550 \\
747 \\
5,639 \\
301\end{array}$ & $\begin{array}{r}0 \\
0 \\
213 \\
68 \\
8\end{array}$ & $\begin{array}{r}35,486 \\
6,736 \\
3,351 \\
31,564 \\
12,979\end{array}$ & $\begin{array}{r}123,752 \\
13,863 \\
30,615 \\
235,991 \\
143,409\end{array}$ & $\begin{array}{r}2,796 \\
1,007 \\
650 \\
4,497 \\
2,324\end{array}$ & & $\begin{array}{l}9,129 \\
26 \\
3,076 \\
303 \\
6,681\end{array}$ \\
\hline $\begin{array}{l}\text { wa } \\
\text { ansas } \\
\text { entucky } \\
\text { puisiana } \\
\text { laine }\end{array}$ & & $\begin{array}{r}42,509 \\
49,909 \\
109\end{array}$ & $\begin{array}{r}9,446 \\
9,092 \\
15,497 \\
21,338 \\
4,974\end{array}$ & $\begin{array}{r}124 \\
9,759 \\
966 \\
5,346 \\
2,443\end{array}$ & $\begin{array}{r}14,669 \\
12,565 \\
23,672 \\
27,048 \\
6,495\end{array}$ & & $\begin{array}{r}615 \\
989 \\
275 \\
2,011 \\
743\end{array}$ & $\begin{array}{r}88 \\
281 \\
0 \\
405 \\
112\end{array}$ & & $\begin{array}{r}79,920 \\
66,239 \\
91,289 \\
111,605\end{array}$ & $\begin{array}{r}1,440 \\
1,369 \\
1,626 \\
2,630 \\
899\end{array}$ & & $\begin{array}{l}6,359 \\
3,160 \\
5,659 \\
7,793 \\
1,567\end{array}$ \\
\hline 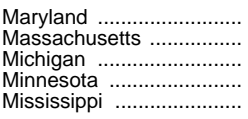 & & & & & $\begin{array}{l}2 \\
9 \\
8 \\
9 \\
1\end{array}$ & $\begin{array}{l}53,545 \\
91,048 \\
99,024 \\
56,709 \\
34,158\end{array}$ & $\begin{array}{r}1,116 \\
3,951 \\
9,90 \\
2,158 \\
100\end{array}$ & $\begin{array}{r}129 \\
61 \\
2,081 \\
1,880 \\
184\end{array}$ & & & $\begin{array}{l}2,209 \\
2,522 \\
4,166 \\
2,490 \\
1,207\end{array}$ & & $\begin{array}{r}5,118 \\
13,166 \\
13,926 \\
10,541 \\
5,191\end{array}$ \\
\hline 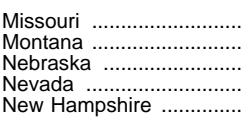 & & 13,604 & $\begin{array}{r}18,601 \\
4,974 \\
5,542 \\
5,026 \\
4,974\end{array}$ & $\begin{array}{r}6,040 \\
20,219 \\
6,728 \\
3,047 \\
986\end{array}$ & $\begin{array}{r}26,773 \\
5,751 \\
8,170 \\
6,515 \\
6,208\end{array}$ & & $\begin{array}{r}1,008 \\
1,606 \\
506 \\
413 \\
412\end{array}$ & $\begin{array}{r}35 \\
1,604 \\
342 \\
409 \\
0\end{array}$ & $\begin{array}{r}13,893 \\
7,064 \\
4,526 \\
1,777 \\
2,729\end{array}$ & $\begin{array}{r}87 \\
48 \\
34\end{array}$ & $\begin{array}{r}2,152 \\
685 \\
829 \\
927 \\
652\end{array}$ & & $\begin{array}{r}12,782 \\
1,590 \\
2,024 \\
1,330 \\
1,315\end{array}$ \\
\hline 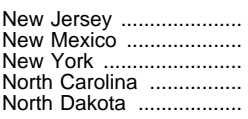 & $\begin{array}{r}476,660 \\
223,086 \\
1,896,975 \\
486,613 \\
92,451\end{array}$ & $\begin{array}{r}118,721 \\
49,780\end{array}$ & $\begin{array}{r}24,258 \\
7,619 \\
71,682 \\
22,433 \\
4,974\end{array}$ & $\begin{array}{r}11,571 \\
36,628 \\
17,716 \\
7,820 \\
14,665\end{array}$ & $\begin{array}{r}29,886 \\
9,840 \\
73,572 \\
38,172 \\
5,278\end{array}$ & $\begin{array}{r}99,695 \\
24,248 \\
214,036 \\
77,113 \\
7,230\end{array}$ & $\begin{array}{r}2,086 \\
4,303 \\
27,341 \\
875 \\
1,464\end{array}$ & $\begin{array}{r}97 \\
4,327 \\
958 \\
1,785 \\
859\end{array}$ & & & $\begin{array}{r}3,103 \\
1,181 \\
7,661 \\
2,801 \\
597\end{array}$ & & $\begin{array}{r}8,959 \\
2,663 \\
513 \\
147 \\
2,626\end{array}$ \\
\hline 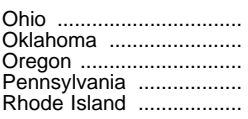 & & & & $\begin{array}{r}3,537 \\
18,309 \\
2,516 \\
2,611 \\
2,492\end{array}$ & $\begin{array}{r}55,788 \\
18,847 \\
14,935 \\
54,771 \\
6,416\end{array}$ & $\begin{array}{r}126,415 \\
37,096 \\
33,291 \\
125,741 \\
13,187\end{array}$ & $\begin{array}{r}829 \\
7,715 \\
2,289 \\
1,668 \\
630\end{array}$ & $\begin{array}{r}6 \\
9,493 \\
1,071 \\
0 \\
0\end{array}$ & $\begin{array}{r}21,717 \\
16,285 \\
8,061 \\
24,468 \\
2,681\end{array}$ & $\begin{array}{r}338,348 \\
88,959 \\
45,714 \\
310,111 \\
35,950\end{array}$ & $\begin{array}{r}4,762 \\
1,600 \\
1,430 \\
5,196 \\
742\end{array}$ & $\begin{array}{r}99,296 \\
33,192 \\
26,047 \\
101,323 \\
7,965\end{array}$ & $\begin{array}{r}29,341 \\
4,480 \\
3,876 \\
294 \\
2,868\end{array}$ \\
\hline 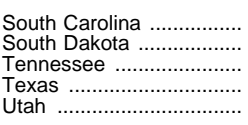 & $\begin{array}{r}317,256 \\
149,118 \\
401,598 \\
1,710,624 \\
183,397\end{array}$ & $\begin{array}{r}75,967 \\
16,314 \\
100,063 \\
515,462 \\
28,066\end{array}$ & $\begin{array}{r}13,344 \\
4,974 \\
18,114 \\
77,550 \\
7,820\end{array}$ & $\begin{array}{r}5,562 \\
13,497 \\
2,067 \\
26,965 \\
5,934\end{array}$ & $\begin{array}{r}22,092 \\
5,355 \\
28,832 \\
100,123 \\
12,736\end{array}$ & $\begin{array}{r}49,661 \\
9,196 \\
63,771 \\
223,335 \\
30,149\end{array}$ & $\begin{array}{r}129 \\
1,881 \\
283 \\
13,402 \\
850\end{array}$ & $\begin{array}{r}21 \\
1,755 \\
0 \\
143 \\
592\end{array}$ & $\begin{array}{r}19,326 \\
3,628 \\
22,784 \\
48,108 \\
7,109\end{array}$ & & $\begin{array}{l}2,027 \\
513 \\
2,231 \\
6,897 \\
1,023\end{array}$ & $\begin{array}{r}38,894 \\
7,866 \\
50,489 \\
156,266 \\
19,294\end{array}$ & $\begin{array}{r}4,800 \\
1,439 \\
6,509 \\
27,741 \\
2,502\end{array}$ \\
\hline 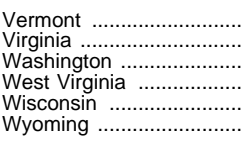 & $\begin{array}{r}68,681 \\
457,917 \\
400,936 \\
179,339 \\
409,962 \\
61,614\end{array}$ & $\begin{array}{r}13,469 \\
84,425 \\
94,508 \\
57,100 \\
101,937 \\
13,287\end{array}$ & $\begin{array}{r}4,974 \\
19,420 \\
17,813 \\
7,753 \\
18,972 \\
4,974\end{array}$ & $\begin{array}{r}10 \\
29,334 \\
21,761 \\
16 \\
6,474 \\
5,460\end{array}$ & $\begin{array}{r}5,106 \\
30,343 \\
22,930 \\
11,636 \\
25,106 \\
4,977\end{array}$ & $\begin{array}{r}8,194 \\
73,577 \\
57,742 \\
23,449 \\
57,479 \\
7,562\end{array}$ & $\begin{array}{r}274 \\
628 \\
2,514 \\
45 \\
981 \\
595\end{array}$ & $\begin{array}{r}82 \\
10 \\
2,597 \\
0 \\
1,435 \\
287\end{array}$ & $\begin{array}{r}4,259 \\
23,651 \\
15,319 \\
8,275 \\
16,147 \\
3,046\end{array}$ & $\begin{array}{r}22,633 \\
143,359 \\
120,064 \\
42,450 \\
127,609 \\
13,002\end{array}$ & $\begin{array}{r}552 \\
3,014 \\
2,176 \\
1,237 \\
2,306 \\
532\end{array}$ & & $\begin{array}{l}1,250 \\
0 \\
6,177 \\
5,641 \\
6,707 \\
1,287\end{array}$ \\
\hline $\begin{array}{l}\text { ian tribe setaside } \ldots . . . . . . . . \\
\text { distributed }\end{array}$ & $\begin{array}{r}70,234 \\
389,922\end{array}$ & $\begin{array}{r}0 \\
22,843\end{array}$ & $\begin{array}{l}6,763 \\
1,120\end{array}$ & $\begin{array}{r}0 \\
67,549\end{array}$ & $\begin{array}{r}12,311 \\
2,812\end{array}$ & $\begin{array}{r}35,848 \\
0\end{array}$ & $\begin{array}{l}0 \\
0\end{array}$ & $\begin{array}{l}0 \\
0\end{array}$ & $\begin{array}{r}0 \\
2,138\end{array}$ & 292,717 & 2,540 & $\begin{array}{r}0,572 \\
735\end{array}$ & \\
\hline O & 7 & 0 & 1,32 & 0 & 349 & 3,096 & 94 & 0 & 614 & 822 & 89 & 819 & 58 \\
\hline & & $\begin{array}{l}0 \\
0\end{array}$ & & & & & & $\begin{array}{l}0 \\
0\end{array}$ & & & 124 & $\begin{array}{r}0 \\
1,352\end{array}$ & $\begin{array}{l}302 \\
195\end{array}$ \\
\hline rian & & & 756 & & & & & & $\begin{array}{l}0 \\
9 \\
9\end{array}$ & 89 & 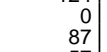 & & \\
\hline & $\begin{array}{r}1,204 \\
652,497\end{array}$ & & & & & & 490 & 0 & $\begin{array}{r}0 \\
18,104\end{array}$ & $\begin{array}{r}0 \\
258,262\end{array}$ & $\begin{array}{r}57 \\
1,516\end{array}$ & & 9,791 \\
\hline 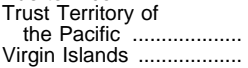 & 14,954 & 0 & 2,552 & 137 & 847 & 6,045 & 352 & & 1,618 & 1,194 & 87 & 1,742 & 380 \\
\hline
\end{tabular}

${ }^{1}$ Title I, formerly called Chapter 1, Education Consolidation and Improvement Act of 1981, includes Grants to Local Education Agencies, Migrant Education-Basic State Grants, Program for Neglected and Delinquent Children, Capital Expenses, and Even Start-State Educational Agencies.

2 Title VI, formerly called Chapter 2 Education Consolidation and Improvement Act of 1981, includes Eisenhower Professional Development Grants, Drug-Free Schools and Communities-State Grants, Education for Homeless Children and Youth, and Innovative Education Program Strategies.

${ }^{3}$ Impact Aid-Basic Support Payments and Impact Aid—Payments for Children with Disabilities.

4 Includes Vocational Education-Basic Grants to States, Tech-Prep Education, and Adult Education-State Grant Program.

${ }^{5}$ Includes Special Education-Grants to States, Preschool Grants, Special Education-Grants for Infants and Families with Disabilities, and Education of Children with Disabilities.

${ }^{6}$ Includes Emergency Immigrant Education Program and Bilingual Education State Grants.

7 Includes Institutional Aid to Strengthen Higher Education Institutions serving significant numbers of low-income students, Other Special Programs for the Disadvantaged Cooperative Education, Fund for the Improvement of Postsecondary Education, Fellowships and Scholarships, and annual interest subsidy grants for facilities construction.
${ }^{8}$ Includes Pell Grants, State Student Incentive Grants, and Guaranteed Student Loan interest subsidies.

9 Includes Public Library Services, Public Library Construction and Technology Enhancement, and Interlibrary Cooperation and Resource Sharing.

10 Includes Rehabilitation Services-Vocational Rehabilitation Grants to States, Sup ported Employment Services for Individuals with Severe Disabilities, Rehabilitation Services-Client Assistance Program, Independent Living-State Grants, and Program of Protection and Advocacy of Individual Rights.

11 Includes State and Local Education Systemic Improvement Grants.

NOTE.-Data reflect revisions to figures in the Budget of the United States Govern ment, Fiscal Year 1998. To the extent possible, data represent obligations rather than outlays. Because of the exclusion of certain programs, totals in this table are lower than those reported in other tables. Because of rounding, details may not add to totals.

SOURCE: U.S. Department of Education, National Center for Education Statistics, based on unpublished tabulations from the Office of Management and Budget; and U.S. Department of Commerce, Bureau of the Census, Federal Expenditures by State for Fiscal Year 1996. (This table was prepared April 1997.) 
Table 367.-Appropriations for Title I and Title VI, Elementary and Secondary Education Act (ESEA) ${ }^{1}$ of 1994, by state or other area: 1996-97 and 1997-98

[In thousands]

\begin{tabular}{|c|c|c|c|c|c|c|c|c|c|c|}
\hline \multirow{3}{*}{ State or other area } & \multirow{3}{*}{\begin{tabular}{|c|} 
Title I total, \\
school \\
year \\
$1996-97^{2}$
\end{tabular}} & \multicolumn{7}{|c|}{ Title I, ${ }^{3}$ school year $1997-98^{4}$} & \multicolumn{2}{|c|}{ Title VI5 } \\
\hline & & \multirow[b]{2}{*}{ Total } & \multicolumn{3}{|c|}{ Local education grants } & \multirow{2}{*}{$\begin{array}{l}\text { Neglected } \\
\text { and } \\
\text { delinquent } \\
\text { children }\end{array}$} & \multirow{2}{*}{$\begin{array}{l}\text { Migrant } \\
\text { children }\end{array}$} & \multirow[b]{2}{*}{ Other ${ }^{6}$} & \multirow{2}{*}{$\begin{array}{c}1996 \\
\begin{array}{c}19 p p r o- \\
\text { priations } \\
\text { for }\end{array} \\
1996-97\end{array}$} & \multirow{2}{*}{$\begin{array}{c}1997 \\
\text { appro- } \\
\text { priations } \\
\text { for } \\
1997-98\end{array}$} \\
\hline & & & Total $^{7}$ & $\begin{array}{l}\text { Basic } \\
\text { grants }\end{array}$ & $\begin{array}{l}\text { Concentra- } \\
\text { tion grants }\end{array}$ & & & & & \\
\hline 1 & 2 & 3 & 4 & 5 & 6 & 7 & 8 & 9 & 10 & 11 \\
\hline Total $^{8}$ & $\$ 7,215,249$ & $\$ 7,783,127$ & $\$ 7,295,232$ & $\$ 6,207,799$ & $\$ 1,012,028$ & $\$ 39,311$ & $\$ 305,473$ & $\$ 143,111$ & $\$ 275,000$ & $\$ 310,000$ \\
\hline $\begin{array}{l}\text { Alabama } \\
\text { Alaska } \\
\text { Arizona } \\
\text { Arkansas } \\
\text { California }\end{array}$ & $\begin{array}{r}128,784 \\
25,348 \\
105,959 \\
78,937 \\
830,700\end{array}$ & $\begin{array}{r}131,409 \\
26,662 \\
121,119 \\
80,476 \\
924,684\end{array}$ & $\begin{array}{r}125,698 \\
16,935 \\
112,826 \\
75,042 \\
820,147\end{array}$ & $\begin{array}{r}106,699 \\
15,302 \\
95,305 \\
64,318 \\
694,666\end{array}$ & $\begin{array}{r}18,999 \\
1,633 \\
17,521 \\
10,724 \\
125,481\end{array}$ & $\begin{array}{r}617 \\
172 \\
803 \\
385 \\
3,640\end{array}$ & $\begin{array}{r}3,381 \\
9,071 \\
5,774 \\
3,995 \\
84,472\end{array}$ & $\begin{array}{r}1,714 \\
484 \\
1,716 \\
1,054 \\
16,425\end{array}$ & $\begin{array}{r}4,220 \\
1,365 \\
4,312 \\
2,541 \\
31,703\end{array}$ & $\begin{array}{r}4,684 \\
1,539 \\
5,032 \\
2,866 \\
35,956\end{array}$ \\
\hline $\begin{array}{l}\text { Colorado } \\
\text { Connecticut } \\
\text { Delaware } \\
\text { District of Columbia } \\
\text { Florida }\end{array}$ & $\begin{array}{r}69,894 \\
55,932 \\
17,074 \\
21,703 \\
306,097\end{array}$ & $\begin{array}{r}74,147 \\
71,835 \\
19,069 \\
23,309 \\
358,106\end{array}$ & $\begin{array}{r}69,612 \\
67,008 \\
17,723 \\
21,490 \\
328,272\end{array}$ & $\begin{array}{r}60,653 \\
58,097 \\
15,250 \\
18,099 \\
280,197\end{array}$ & $\begin{array}{r}8,959 \\
8,911 \\
2,473 \\
3,391 \\
48,075\end{array}$ & $\begin{array}{r}277 \\
775 \\
202 \\
847 \\
1,326\end{array}$ & $\begin{array}{r}3,238 \\
2,732 \\
398 \\
308 \\
23,513\end{array}$ & $\begin{array}{r}1,020 \\
1,320 \\
746 \\
664 \\
4,995\end{array}$ & $\begin{array}{r}3,797 \\
3,020 \\
1,365 \\
1,365 \\
12,480\end{array}$ & $\begin{array}{r}4,280 \\
3,426 \\
1,539 \\
1,539 \\
14,442\end{array}$ \\
\hline $\begin{array}{l}\text { Georgia } \\
\text { Hawaii } \\
\text { Idaho } \\
\text { Illinois } \\
\text { Indiana }\end{array}$ & $\begin{array}{r}175,799 \\
19,751 \\
27,055 \\
327,388 \\
113,324\end{array}$ & $\begin{array}{r}200,419 \\
20,746 \\
26,092 \\
334,055 \\
117,423\end{array}$ & $\begin{array}{r}191,891 \\
20,124 \\
21,879 \\
324,606 \\
111,758\end{array}$ & $\begin{array}{r}164,749 \\
17,290 \\
19,128 \\
278,804 \\
100,338\end{array}$ & $\begin{array}{r}27,141 \\
2,835 \\
2,751 \\
45,802 \\
11,420\end{array}$ & $\begin{array}{r}1,377 \\
120 \\
100 \\
1,719 \\
632\end{array}$ & $\begin{array}{r}4,596 \\
0 \\
3,588 \\
2,048 \\
3,248\end{array}$ & $\begin{array}{r}2,556 \\
502 \\
524 \\
5,682 \\
1,784\end{array}$ & $\begin{array}{r}7,289 \\
1,365 \\
1,366 \\
11,763 \\
5,784\end{array}$ & $\begin{array}{r}8,247 \\
1,539 \\
1,553 \\
13,249 \\
6,486\end{array}$ \\
\hline $\begin{array}{l}\text { lowa } \\
\text { Kansas } \\
\text { Kentucky } \\
\text { Louisiana } \\
\text { Maine }\end{array}$ & $\begin{array}{r}52,283 \\
59,938 \\
132,963 \\
192,972 \\
29,334\end{array}$ & $\begin{array}{r}53,355 \\
64,479 \\
137,956 \\
197,894 \\
32,818\end{array}$ & $\begin{array}{r}51,587 \\
53,947 \\
127,104 \\
191,287 \\
28,085\end{array}$ & $\begin{array}{r}47,050 \\
47,957 \\
107,970 \\
161,779 \\
25,272\end{array}$ & $\begin{array}{r}4,537 \\
5,991 \\
19,134 \\
29,509 \\
2,814\end{array}$ & $\begin{array}{l}237 \\
539 \\
859 \\
656 \\
132\end{array}$ & $\begin{array}{r}608 \\
9,112 \\
7,944 \\
2,564 \\
4,095\end{array}$ & $\begin{array}{r}923 \\
881 \\
2,049 \\
3,386 \\
506\end{array}$ & $\begin{array}{l}2,937 \\
2,748 \\
3,845 \\
4,870 \\
1,365\end{array}$ & $\begin{array}{l}3,249 \\
3,066 \\
4,276 \\
5,426 \\
1,539\end{array}$ \\
\hline $\begin{array}{l}\text { Maryland } \\
\text { Massachusetts } \\
\text { Michigan } \\
\text { Minnesota } \\
\text { Mississippi }\end{array}$ & $\begin{array}{r}88,763 \\
125,917 \\
319,188 \\
85,557 \\
126,428\end{array}$ & $\begin{array}{r}101,037 \\
148,846 \\
340,649 \\
90,942 \\
127,989\end{array}$ & $\begin{array}{r}97,405 \\
142,984 \\
321,769 \\
86,178 \\
124,675\end{array}$ & $\begin{array}{r}85,142 \\
121,950 \\
276,704 \\
76,809 \\
106,146\end{array}$ & $\begin{array}{r}12,263 \\
21,033 \\
45,065 \\
9,369 \\
18,529\end{array}$ & $\begin{array}{r}1,113 \\
743 \\
958 \\
197 \\
279\end{array}$ & $\begin{array}{r}320 \\
2,196 \\
12,852 \\
2,562 \\
1,137\end{array}$ & $\begin{array}{l}2,199 \\
2,924 \\
5,070 \\
2,005 \\
1,898\end{array}$ & $\begin{array}{l}4,795 \\
5,431 \\
9,893 \\
4,957 \\
2,978\end{array}$ & $\begin{array}{r}5,432 \\
6,123 \\
11,037 \\
5,557 \\
3,325\end{array}$ \\
\hline $\begin{array}{l}\text { Missouri } \\
\text { Montana } \\
\text { Nebraska } \\
\text { Nevada } \\
\text { New Hampshire }\end{array}$ & $\begin{array}{r}117,408 \\
26,226 \\
34,365 \\
19,543 \\
16,648\end{array}$ & $\begin{array}{r}128,881 \\
26,509 \\
36,505 \\
22,897 \\
17,689\end{array}$ & $\begin{array}{r}124,488 \\
25,308 \\
31,736 \\
21,881 \\
16,730\end{array}$ & $\begin{array}{r}107,700 \\
21,716 \\
28,834 \\
19,364 \\
15,324\end{array}$ & \begin{tabular}{r|}
16,788 \\
3,592 \\
2,902 \\
2,517 \\
1,407
\end{tabular} & $\begin{array}{r}709 \\
68 \\
297 \\
170 \\
347\end{array}$ & $\begin{array}{r}1,097 \\
620 \\
3,562 \\
348 \\
89\end{array}$ & $\begin{array}{r}2,587 \\
514 \\
911 \\
499 \\
523\end{array}$ & $\begin{array}{l}5,442 \\
1,365 \\
1,768 \\
1,417 \\
1,365\end{array}$ & $\begin{array}{l}6,082 \\
1,539 \\
1,978 \\
1,679 \\
1,539\end{array}$ \\
\hline 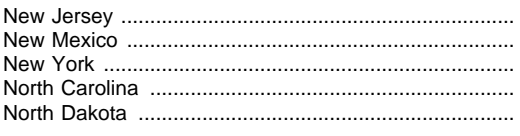 & $\begin{array}{r}145,386 \\
61,052 \\
627,760 \\
136,057 \\
17,773\end{array}$ & $\begin{array}{r}165,699 \\
64,712 \\
691,343 \\
144,469 \\
18,866\end{array}$ & $\begin{array}{r}158,037 \\
62,366 \\
665,779 \\
137,011 \\
17,675\end{array}$ & $\begin{array}{r}136,704 \\
52,663 \\
568,981 \\
119,980 \\
15,393\end{array}$ & \begin{tabular}{r|}
21,333 \\
9,703 \\
96,799 \\
17,031 \\
2,282
\end{tabular} & $\begin{array}{r}2,464 \\
292 \\
2,786 \\
1,001 \\
46\end{array}$ & $\begin{array}{r}1,133 \\
1,037 \\
7,094 \\
4,636 \\
571\end{array}$ & $\begin{array}{r}4,064 \\
1,018 \\
15,684 \\
1,820 \\
574\end{array}$ & $\begin{array}{r}7,333 \\
1,941 \\
16,973 \\
6,759 \\
1,365\end{array}$ & $\begin{array}{r}8,330 \\
2,174 \\
19,091 \\
7,723 \\
1,539\end{array}$ \\
\hline $\begin{array}{l}\text { Ohio } \\
\text { Oklahoma } \\
\text { Oregon } \\
\text { Pennsylvania } \\
\text { Rhode Island }\end{array}$ & $\begin{array}{r}307,328 \\
85,198 \\
79,527 \\
315,880 \\
21,939\end{array}$ & $\begin{array}{r}307,721 \\
89,482 \\
80,243 \\
338,981 \\
25,482\end{array}$ & $\begin{array}{r}298,122 \\
86,346 \\
67,462 \\
323,243 \\
24,175\end{array}$ & $\begin{array}{r}257,641 \\
73,844 \\
59,481 \\
280,804 \\
21,094\end{array}$ & $\begin{array}{r}40,481 \\
12,502 \\
7,981 \\
42,440 \\
3,081\end{array}$ & $\begin{array}{r}2,118 \\
359 \\
1,198 \\
670 \\
357\end{array}$ & $\begin{array}{r}1,598 \\
1,608 \\
10,614 \\
6,572 \\
122\end{array}$ & $\begin{array}{r}5,882 \\
1,170 \\
969 \\
8,496 \\
829\end{array}$ & $\begin{array}{r}11,232 \\
3,486 \\
3,112 \\
11,385 \\
1,365\end{array}$ & $\begin{array}{r}12,541 \\
3,892 \\
3,530 \\
12,769 \\
1,539\end{array}$ \\
\hline $\begin{array}{l}\text { South Carolina } \\
\text { South Dakota } \\
\text { Tennessee } \\
\text { Texas } \\
\text { Utah }\end{array}$ & $\begin{array}{r}93,480 \\
19,921 \\
123,385 \\
625,538 \\
34,293\end{array}$ & $\begin{array}{r}95,786 \\
20,536 \\
130,600 \\
682,084 \\
35,270\end{array}$ & $\begin{array}{r}93,292 \\
19,289 \\
128,056 \\
627,681 \\
33,044\end{array}$ & $\begin{array}{r}79,932 \\
16,676 \\
108,973 \\
532,726 \\
29,508\end{array}$ & $\begin{array}{r}13,360 \\
2,613 \\
19,083 \\
94,955 \\
3,536\end{array}$ & $\begin{array}{r}871 \\
191 \\
620 \\
2,034 \\
445\end{array}$ & $\begin{array}{r}433 \\
536 \\
173 \\
42,739 \\
1,274\end{array}$ & $\begin{array}{r}1,190 \\
519 \\
1,750 \\
9,630 \\
508\end{array}$ & $\begin{array}{r}3,680 \\
1,365 \\
5,049 \\
20,300 \\
2,661\end{array}$ & $\begin{array}{r}4,095 \\
1,539 \\
5,677 \\
22,947 \\
2,949\end{array}$ \\
\hline Vermont & 16,327 & 17,774 & 16,307 & 14,525 & 1,781 & 104 & 845 & 518 & 1,365 & 1,539 \\
\hline - & 102,822 & 111,611 & 108,448 & 95,505 & 12,944 & 932 & 661 & 1,570 & 6,151 & 6,903 \\
\hline 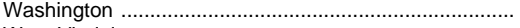 & 113,398 & 123,404 & 107,699 & 93,183 & 14,515 & 778 & 13,339 & 1,588 & 5,499 & 6,204 \\
\hline West Virginia & 70,426 & 74,226 & 72,921 & 61,857 & 11,064 & 228 & 110 & 967 & 1,742 & 1,895 \\
\hline Wisconsin & 125,368 & 128,105 & 124,316 & 113,849 & 10,467 & 936 & 595 & 2,258 & 5,406 & 6,065 \\
\hline 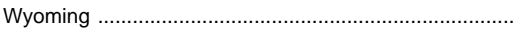 & 16,270 & 16,624 & 15,894 & 14,313 & 1,581 & 87 & 153 & 490 & 1,365 & 1,539 \\
\hline \multicolumn{11}{|l|}{ Other activities } \\
\hline Bureau of Indian Affairs ..................... & 41,609 & 45,458 & 45,458 & 0 & 0 & 0 & 0 & 0 & 0 & 0 \\
\hline Migrant coordination activities & 5,999 & 5,998 & & 0 & 0 & 0 & 5,998 & 0 & 0 & 0 \\
\hline Even Start Migrant, Indian, and Territory setaside ..... & 8,600 & 8,600 & 3,500 & 0 & 0 & 0 & 0 & 5,100 & 0 & 0 \\
\hline Even Start Evaluation/ Technical Assistance ................ & 1,374 & 1,369 & 0 & 0 & 0 & 0 & 0 & 1,369 & 0 & 0 \\
\hline 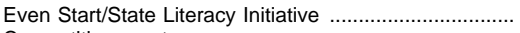 & & & 0 & 0 & 0 & 0 & 0 & 0 & 0 & 0 \\
\hline Competitive grants & 5,000 & 5,000 & 5,000 & 0 & 0 & 0 & 0 & 0 & 0 & 0 \\
\hline Outlying areas & & & & & & & & & & \\
\hline American Samoa & 4,978 & 5,141 & 5,141 & 0 & 0 & 0 & 0 & 0 & 330 & 373 \\
\hline Guam & 4,846 & 4,819 & 4,819 & 0 & 0 & 0 & 0 & 0 & 771 & 869 \\
\hline 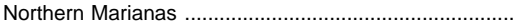 & 2,362 & 2,734 & 2,734 & 0 & 0 & 0 & 0 & 0 & 188 & 212 \\
\hline 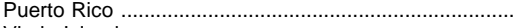 & 261,604 & 274,238 & 262,487 & 221,557 & 40,929 & 497 & 4,164 & 7,090 & 4,624 & 5,122 \\
\hline Virgin Islands & 8,474 & 8,753 & 8,753 & 0 & 0 & 0 & 0 & 0 & 635 & 716 \\
\hline
\end{tabular}

${ }^{1}$ Elementary and Secondary Education Act was most recently revised through the Improving America's Schools Act (IASA) of 1994.

${ }^{2}$ Data are based on fiscal year 1997 budget authorizations. Excludes $\$ 3,359,000$ for Title I evaluation.

${ }^{3}$ Formerly Chapter 1.

${ }^{4}$ Data are based on fiscal year 1998 budget authorizations. Excludes $\$ 6,977,000$ for Title I evaluation.

${ }^{5}$ Formerly Chapter 2.

6 Includes capital expenses, and Even Start grants.

${ }^{7}$ Includes other programs not shown separately.

8 Total includes other activities and outlying areas.
NOTE.-Because of rounding, details may not add to totals.

SOURCE: U.S. Department of Education, Budget Service, Elementary, Secondary, and Vocational Education Analysis Division, unpublished data. (This table was prepared March 1998.) 
Table 368.-Federal science and engineering obligations to colleges and universities, by agency and state: Fiscal year 19961

[In thousands]

\begin{tabular}{|c|c|c|c|c|c|c|c|c|c|c|}
\hline State or other area & Total & $\begin{array}{l}\text { Department } \\
\text { of } \\
\text { Agriculture }\end{array}$ & $\begin{array}{l}\text { Department } \\
\text { of Defense }\end{array}$ & $\begin{array}{l}\text { Department } \\
\text { of Education }\end{array}$ & $\begin{array}{l}\text { Department } \\
\text { of Energy }\end{array}$ & $\begin{array}{c}\text { Environmental } \\
\text { Protection } \\
\text { Agency }\end{array}$ & $\begin{array}{l}\text { Department } \\
\text { of Health } \\
\text { and Human } \\
\text { Services }\end{array}$ & $\begin{array}{c}\text { National Aer- } \\
\text { onautics and } \\
\text { Space Ad- } \\
\text { ministration }\end{array}$ & $\begin{array}{l}\text { National } \\
\text { Science } \\
\text { Foundation }\end{array}$ & Other ${ }^{2}$ \\
\hline 1 & 2 & 3 & 4 & 5 & 6 & 7 & 8 & 9 & 10 & 11 \\
\hline United States & $18,397,350$ & 863,033 & $2,119,199$ & 173,637 & $3,222,520$ & 102,440 & $7,311,754$ & $1,837,491$ & $2,329,520$ & 437,756 \\
\hline Alabama & 237,514 & 25,523 & 18,304 & 3,621 & 4,848 & 592 & 137,543 & 33,052 & 12,630 & 1,401 \\
\hline Alaska & 32,650 & 3,772 & 752 & 433 & 98 & 15 & 2,403 & 9,194 & 6,742 & 9,241 \\
\hline Arizona & 213,828 & 8,824 & 22,040 & 3,600 & 6,686 & 5,146 & 65,455 & 25,291 & 70,822 & 5,964 \\
\hline Arkansas & 57,442 & 23,547 & 6,271 & 3,745 & 200 & 75 & 19,624 & 532 & 2,167 & 1,281 \\
\hline 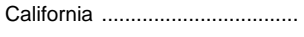 & $4,042,474$ & 33,411 & 232,421 & 20,683 & $1,054,028$ & 10,262 & $1,007,776$ & $1,252,030$ & 393,446 & 38,417 \\
\hline Colorado & 352,771 & 12,041 & 18,085 & 5,533 & 8,917 & 2,734 & 130,906 & 21,391 & 120,507 & 32,657 \\
\hline Connecticut ................................ & 271,161 & 7,813 & 14,067 & 857 & 10,465 & 157 & 210,166 & 1,654 & 22,027 & 3,955 \\
\hline Delaware ........................................... & 42,632 & 7,888 & 7,395 & 2,572 & 1,768 & 1,434 & 5,851 & 1,424 & 11,106 & 3,194 \\
\hline District of Columbia ....................... & 175,363 & 1,774 & 37,130 & 3,775 & 4,561 & 828 & 82,213 & 7,466 & 11,359 & 26,257 \\
\hline 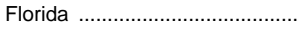 & 317,244 & 22,024 & 39,291 & 5,063 & 14,617 & 2,173 & 131,576 & 22,863 & 64,165 & 15,472 \\
\hline Georgia & 324,462 & 28,383 & 82,375 & 3,626 & 13,007 & 3,378 & 130,685 & 14,504 & 36,611 & 11,893 \\
\hline Hawaii ................... & 70,073 & 11,643 & 2,894 & 633 & 2,810 & 192 & 17,155 & 7,708 & 17,444 & 9,594 \\
\hline Idaho & 18,838 & 7,887 & 1,544 & 672 & 1,298 & 266 & 1,345 & 396 & 3,285 & 2,145 \\
\hline 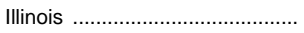 & $1,075,285$ & 23,485 & 52,699 & 9,162 & 578,120 & 1,527 & 264,876 & 12,133 & 124,322 & 8,961 \\
\hline Indiana & 209,979 & 22,549 & 17,198 & 1,373 & 18,180 & 1,420 & 94,404 & 3,522 & 48,385 & 2,948 \\
\hline lowa & 195,030 & 26,080 & 5,162 & 896 & 32,346 & 4,205 & 92,384 & 8,091 & 19,540 & 6,326 \\
\hline 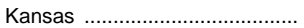 & 80,368 & 13,137 & 3,446 & 5,605 & 6,328 & 1,516 & 33,942 & 2,190 & 13,311 & 893 \\
\hline 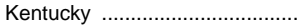 & 88,395 & 23,299 & 3,506 & 1,408 & 5,488 & 381 & 43,680 & 1,144 & 9,032 & 457 \\
\hline 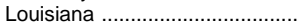 & 148,158 & 20,089 & 26,667 & 1,325 & 15,231 & 1,260 & 57,870 & 4,890 & 14,366 & 6,460 \\
\hline 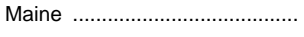 & 17,013 & 7,204 & 1,314 & 236 & 511 & 277 & 872 & 116 & 3,726 & 2,757 \\
\hline Maryland & 938,400 & 15,993 & 375,385 & 3,670 & 15,627 & 4,029 & 362,325 & 84,121 & 52,343 & 24,907 \\
\hline 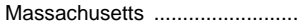 & $1,187,272$ & 10,309 & 411,724 & 4,496 & 86,732 & 6,347 & 421,414 & 56,712 & 162,272 & 27,266 \\
\hline 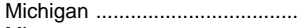 & 454,959 & 23,757 & 40,888 & 3,477 & 14,446 & 5,207 & 253,966 & 17,111 & 82,381 & 13,726 \\
\hline 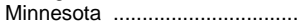 & 225,288 & 19,735 & 13,842 & 2,730 & 6,127 & 2,551 & 134,473 & 2,878 & 37,490 & 5,462 \\
\hline 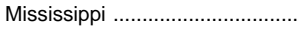 & 74,365 & 33,220 & 7,060 & 1,545 & 3,671 & 776 & 12,627 & 2,471 & 8,568 & 4,427 \\
\hline Missouri ...... & 293,247 & 26,888 & 9,291 & 3,514 & 5,584 & 392 & 218,661 & 4,638 & 22,500 & 1,779 \\
\hline Montana & 38,938 & 8,914 & 4,528 & 2,048 & 1,591 & 508 & 5,165 & 2,202 & 12,888 & 1,094 \\
\hline Nebraska & 65,110 & 15,974 & 3,393 & 706 & 897 & 24 & 22,531 & 1,352 & 14,538 & 5,695 \\
\hline 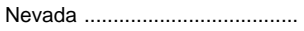 & 27,301 & 3,232 & 1,332 & 198 & 3,908 & 1,004 & 6,497 & 922 & 7,666 & 2,542 \\
\hline New Hampshire ............................ & 77,345 & 4,104 & 3,375 & 459 & 1,142 & 356 & 39,056 & 12,957 & 12,446 & 3,450 \\
\hline New Jersey ....... & 285,297 & 11,268 & 25,827 & 1,073 & 75,165 & 4,045 & 95,162 & 8,064 & 54,410 & 10,283 \\
\hline New Mexico .......... & 678,817 & 9,454 & 45,516 & 3,284 & 555,757 & 395 & 24,077 & 23,136 & 14,928 & 2,270 \\
\hline New York & $1,463,124$ & 26,916 & 62,246 & 10,149 & 378,262 & 3,565 & 720,571 & 23,153 & 220,194 & 18,068 \\
\hline North Carolina .................................. & 543,479 & 36,996 & 34,707 & 8,340 & 11,556 & 7,231 & 361,143 & 8,146 & 51,803 & 23,557 \\
\hline North Dakota ........ & 39,418 & 9,942 & 2,781 & 1,067 & 14,842 & 492 & 3,765 & 944 & 4,497 & 1,088 \\
\hline Ohio & 400,015 & 22,127 & 53,047 & 3,843 & 9,183 & 3,862 & 234,896 & 15,802 & 47,300 & 9,955 \\
\hline Oklahoma ……............................. & 79,505 & 17,842 & 5,395 & 1,667 & 3,087 & 1,168 & 22,899 & 8,351 & 14,543 & 4,553 \\
\hline Oregon & 173,839 & 21,584 & 14,527 & 6,153 & 9,704 & 4,464 & 70,470 & 4,689 & 29,993 & 12,255 \\
\hline 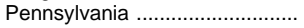 & 895,194 & 24,754 & 166,944 & 8,168 & 45,040 & 3,602 & 502,846 & 15,917 & 121,083 & 6,840 \\
\hline 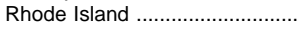 & 74,012 & 7,379 & 12,190 & 0 & 3,069 & 275 & 24,751 & 2,358 & 16,390 & 7,600 \\
\hline South Carolina .............................. & 111,858 & 16,260 & 17,010 & 1,357 & 24,071 & 299 & 34,920 & 2,269 & 11,256 & 4,416 \\
\hline South Dakota & 19,334 & 9,910 & 967 & 328 & 0 & 0 & 926 & 1,368 & 5,384 & 451 \\
\hline 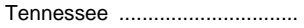 & 207,613 & 25,466 & 12,290 & 2,442 & 7,512 & 1,069 & 134,230 & 6,360 & 14,847 & 3,397 \\
\hline Texas & 772,016 & 39,769 & 90,591 & 7,835 & 25,241 & 2,779 & 465,015 & 35,699 & 91,032 & 14,055 \\
\hline Utah & 136,090 & 7,331 & 25,351 & 2,251 & 7,005 & 509 & 66,192 & 4,630 & 21,557 & 1,264 \\
\hline Vermont & 44,143 & 9,325 & 1,419 & 1,802 & 1,023 & 74 & 25,809 & 470 & 3,622 & 599 \\
\hline Virginia & 328,581 & 20,692 & 23,115 & 4,467 & 88,957 & 1,044 & 116,181 & 20,056 & 40,999 & 13,070 \\
\hline 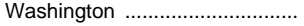 & 393,809 & 21,250 & 36,798 & 3,182 & 22,859 & 2,218 & 228,671 & 10,025 & 55,561 & 13,245 \\
\hline 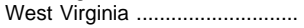 & 84,002 & 8,139 & 7,823 & 855 & 2,076 & 4,794 & 8,016 & 18,119 & 34,080 & 100 \\
\hline Wisconsin & 297,040 & 19,942 & 14,841 & 7,477 & 18,538 & 1,369 & 162,865 & 12,283 & 50,537 & 9,188 \\
\hline 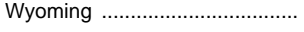 & 17,259 & 4,188 & 2,435 & 236 & 341 & 154 & 908 & 697 & 7,419 & 881 \\
\hline Outlying areas ........................ & 73,615 & 20,351 & 3,822 & 1,613 & 1,049 & 424 & 24,270 & 3,154 & 18,170 & 762 \\
\hline American Samoa ........................ & 1,173 & 1,029 & 0 & 94 & 50 & 0 & 0 & 0 & 0 & 0 \\
\hline Guam & 3,696 & 2,289 & 200 & 102 & 0 & 354 & 553 & 0 & 158 & 40 \\
\hline Puerto Rico & 64,010 & 12,351 & 3,622 & 1,417 & 999 & 70 & 23,717 & 3,154 & 17,978 & 702 \\
\hline Trust Territory of the Pacific .... & 2,731 & 2,731 & 0 & 0 & 0 & 0 & 0 & 0 & 0 & 0 \\
\hline Virgin Islands & 2,005 & 1,951 & 0 & 0 & 0 & 0 & 0 & 0 & 34 & 20 \\
\hline
\end{tabular}

1 Dollars reflect actual obligations during the fiscal year regardless of when the funds were actually spent by a recipient institution. Data include obligations to federally funded research and development centers administered by colleges and universities.

2 Includes U.S. Department of Commerce, U.S. Department of Housing and Urban Development, U.S. Department of the Interior, Agency for International Development, U.S.
Department of Labor, U.S. Department of Transportation, and Nuclear Regulatory Commission.

SOURCE: National Science Foundation, Federal Support to Universities, Colleges, and Nonprofit Institutions, Fiscal Year 1996. (This table was prepared May 1998.) 
Table 369.-Summary of federal funds for research, development, and R\&D plant: Fiscal years 1990 to 1998

[In millions]

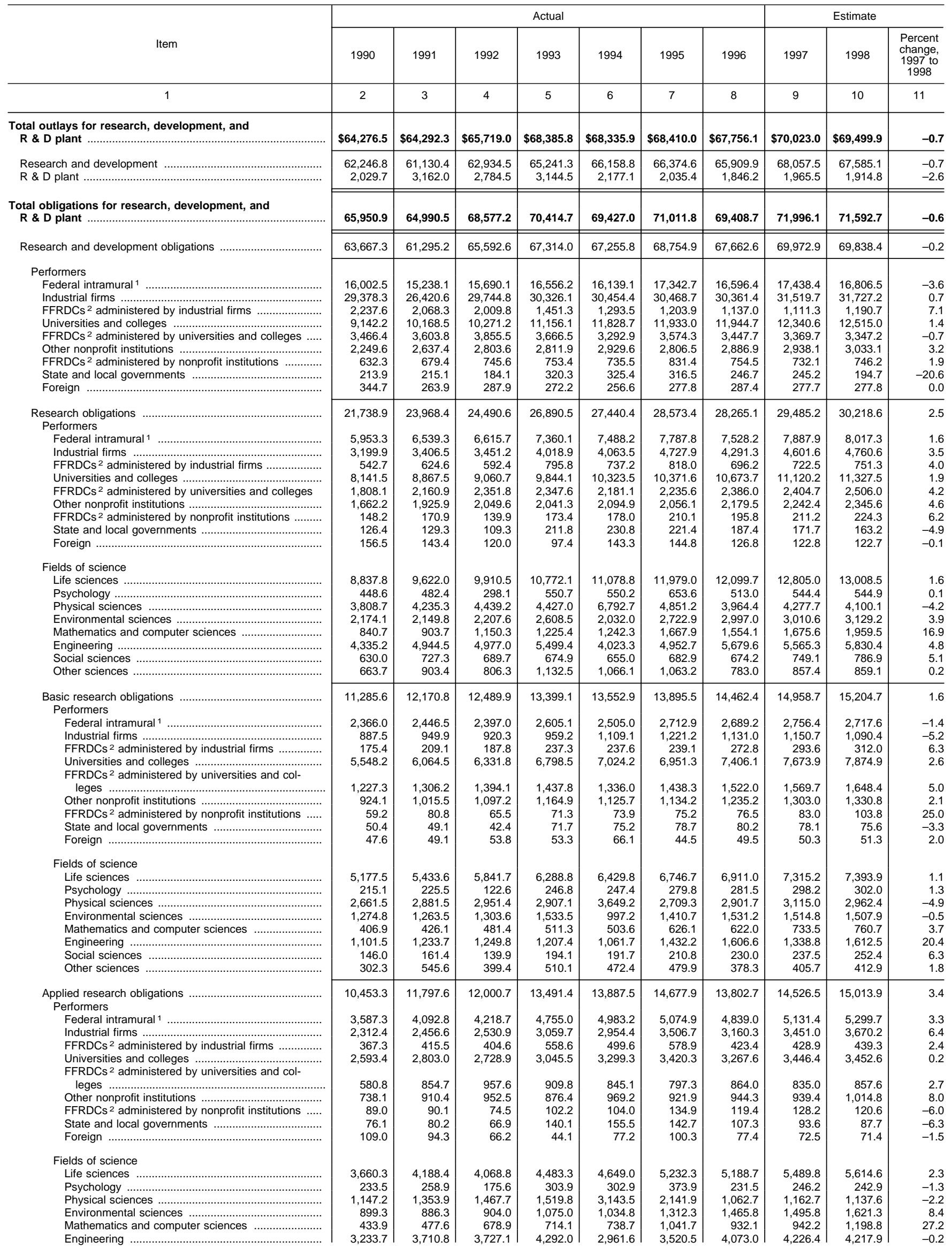


Table 369.-Summary of federal funds for research, development, and R\&D plant: Fiscal years 1990 to 1998 -Continued

[In millions]

\begin{tabular}{|c|c|c|c|c|c|c|c|c|c|c|}
\hline \multirow[b]{2}{*}{ Item } & \multicolumn{7}{|c|}{ Actual } & \multicolumn{3}{|c|}{ Estimate } \\
\hline & 1990 & 1991 & 1992 & 1993 & 1994 & 1995 & 1996 & 1997 & 1998 & $\begin{array}{c}\text { Percent } \\
\text { change, } \\
1997 \text { to } \\
1998\end{array}$ \\
\hline 1 & 2 & 3 & 4 & 5 & 6 & 7 & 8 & 9 & 10 & 11 \\
\hline $\begin{array}{l}\text { Social sciences } \\
\text { Other sciences }\end{array}$ & $\begin{array}{l}484.0 \\
361.5\end{array}$ & $\begin{array}{l}566.0 \\
357.8\end{array}$ & $\begin{array}{l}549.8 \\
406.8\end{array}$ & $\begin{array}{l}480.8 \\
622.4\end{array}$ & $\begin{array}{l}463.3 \\
593.8\end{array}$ & $\begin{array}{l}472.0 \\
583.3\end{array}$ & $\begin{array}{l}444.2 \\
404.7\end{array}$ & $\begin{array}{l}511.6 \\
451.7\end{array}$ & $\begin{array}{l}534.5 \\
446.1\end{array}$ & $\begin{array}{r}4.5 \\
-1.2\end{array}$ \\
\hline $\begin{array}{l}\text { Development obligations } \\
\text { Performers }\end{array}$ & $41,928.4$ & $37,326.8$ & $41,102.0$ & $40,423.5$ & $39,815.4$ & $40,181.4$ & $39,397.5$ & $40,487.7$ & $39,619.8$ & -2.1 \\
\hline Federal intramural ${ }^{1}$ & $10,049.2$ & $8,698.8$ & $9,074.4$ & $9,196.2$ & $8,650.9$ & $9,554.9$ & $9,068.1$ & $9,550.5$ & $8,789.1$ & -8.0 \\
\hline 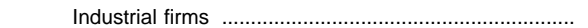 & $26,178.4$ & $23,014.1$ & $26,293.6$ & $26,307.2$ & $26,390.9$ & $25,740.7$ & $26,070.1$ & $26,918.1$ & $26,966.6$ & 0.2 \\
\hline FFRDCs ${ }^{2}$ administered by industrial firms ...................... & $1,694.9$ & $1,443.7$ & $1,417.4$ & 655.5 & 556.3 & 385.9 & 440.7 & 388.9 & 439.4 & 13.0 \\
\hline Universities and colleges …….................................... & $1,000.5$ & $1,301.0$ & $1,210.6$ & $1,312.0$ & $1,505.2$ & $1,561.4$ & $1,271.0$ & $1,220.4$ & $1,187.5$ & -2.7 \\
\hline FFRDCs ${ }^{2}$ administered by universities and colleges & $1,658.3$ & $1,442.9$ & $1,503.7$ & $1,318.9$ & $1,111.8$ & $1,338.7$ & $1,061.6$ & 965.0 & 841.2 & -12.8 \\
\hline 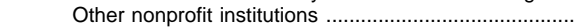 & 587.4 & 711.5 & 753.9 & 770.6 & 834.8 & 750.4 & 707.4 & 695.7 & 687.5 & -1.2 \\
\hline FFRDCs ${ }^{2}$ administered by nonprofit institutions .......... & 484.0 & 508.5 & 605.7 & 580.0 & 557.6 & 621.3 & 558.7 & 520.8 & 521.9 & 0.2 \\
\hline 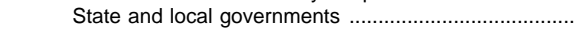 & 87.5 & 85.8 & 74.8 & 108.5 & 94.7 & 95.1 & 59.3 & 73.5 & 31.5 & -57.2 \\
\hline 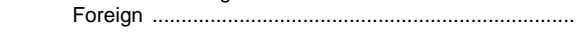 & 188.1 & 120.5 & 167.9 & 174.8 & 113.3 & 133.0 & 160.5 & 154.8 & 155.1 & 0.2 \\
\hline $\begin{array}{l}\text { R \& D plant obligations } \\
\text { Performers }\end{array}$ & $2,283.6$ & $3,695.4$ & $2,984.6$ & $3,100.7$ & $2,171.2$ & $2,256.9$ & $1,746.1$ & $2,023.3$ & $1,754.3$ & -13.3 \\
\hline Federal intramural ${ }^{1}$ & 359.9 & 461.1 & 506.2 & 432.0 & 392.6 & 482.6 & 405.1 & 678.4 & 508.5 & -25.0 \\
\hline Industrial firms & 884.0 & $1,889.2$ & $1,014.4$ & $1,048.2$ & 746.8 & 696.6 & 465.4 & 464.8 & 372.9 & -19.8 \\
\hline FFRDCs ${ }^{2}$ administered by industrial firms . & 231.0 & 279.6 & 202.2 & 124.4 & 119.4 & 95.1 & 43.9 & 54.9 & 53.5 & -2.5 \\
\hline Universities and colleges …................ & 155.8 & 253.3 & 241.5 & 361.4 & 209.0 & 323.8 & 243.1 & 187.1 & 120.3 & -35.7 \\
\hline FFRDCs ${ }^{2}$ administered by universities and colleges ...... & 495.8 & 624.6 & 579.5 & 619.5 & 608.8 & 543.9 & 497.8 & 564.0 & 671.3 & 19.0 \\
\hline Other nonprofit institutions & 121.3 & 154.6 & 393.9 & 415.6 & 20.9 & 25.6 & 23.4 & 15.6 & 6.7 & -57.2 \\
\hline FFRDCs ${ }^{2}$ administered by nonprofit institutions ............. & 31.4 & 19.7 & 46.3 & 65.5 & 72.9 & 62.6 & 66.1 & 57.9 & 20.6 & -64.5 \\
\hline State and local governments & 0.5 & 0.6 & 0.5 & 0.5 & 0.8 & 0.5 & 1.0 & 0.5 & 0.5 & 0.0 \\
\hline Foreign ‥к-1) & 3.9 & 12.8 & 0.0 & 33.4 & 0.2 & 26.1 & 0.5 & 0.0 & 0.0 & 0.0 \\
\hline
\end{tabular}

1 Includes costs associated with the administration of intramural and extramural programs by federal personnel as well as actual intramural performance.

2 Federally funded research and development centers.
NOTE.-Some data have been revised from previously published figures. Because of rounding, details may not add to totals.

SOURCE: National Science Foundation, Federal Funds for Research and Development, various years. (This table was prepared May 1998.) 
Table 370.-Federal obligations to colleges and universities for research and development, by field: United States and outlying areas, 1980 to 1995

\begin{tabular}{|c|c|c|c|c|c|c|c|c|c|c|c|}
\hline Field of science or engineering & 1980 & 1981 & 1986 & 1988 & 1989 & $1990^{1}$ & $1991^{1}$ & 19921 & $1993^{1}$ & 19941 & $1995^{1}$ \\
\hline 1 & 2 & 3 & 4 & 5 & 6 & 7 & 8 & 9 & 10 & 11 & 12 \\
\hline Total, all fields & $\$ 4,160,543$ & $\$ 4,410,931$ & $\$ 6,456,743$ & $\$ 7,719,237$ & $\$ 8,525,212$ & $\$ 9,009,235$ & $\$ 10,031,252$ & $\$ 10,851,509$ & $\$ 10,951,143$ & $\$ 11,811,097$ & $\$ 12,081,192$ \\
\hline Engineering, total & 612,456 & 792,223 & 998,312 & $1,129,303$ & $1,157,047$ & 474,709 & 543,530 & 587,404 & 683,676 & 706,452 & 287,098 \\
\hline Aeronautical & 28,044 & 31,056 & 42,257 & 47,946 & 66,096 & 45,965 & 44,207 & 48,539 & 50,114 & 82,826 & 63,166 \\
\hline Astronautical & 4,634 & 4,875 & 24,147 & 32,516 & 42,276 & 11,803 & 20,977 & 21,407 & 13,402 & 16,071 & 14,555 \\
\hline Chemical ............. & 22,210 & 27,667 & 50,379 & 67,647 & 45,829 & 56,845 & 67,968 & 63,900 & 67,234 & 58,293 & 5,610 \\
\hline 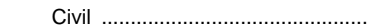 & 48,130 & 58,300 & 35,402 & 30,947 & 43,026 & 37,306 & 34,064 & 30,756 & 44,252 & 68,240 & 39,364 \\
\hline Electrical . & 86,916 & 115,011 & 212,175 & 251,336 & 240,638 & 53,162 & 60,299 & 68,416 & 69,045 & 74,686 & 8,074 \\
\hline Mechanical .. & 42,593 & 37,954 & 56,416 & 60,551 & 71,137 & 52,652 & 54,674 & 60,748 & 67,471 & 52,118 & 13,206 \\
\hline Metallurgy and materials ..... & 63,057 & 52,815 & 101,457 & 121,228 & 146,253 & 81,678 & 91,686 & 76,926 & 180,553 & 164,272 & 23,230 \\
\hline Engineering, other .................. & 316,872 & 464,545 & 476,079 & 517,132 & 501,792 & 135,298 & 169,655 & 216,712 & 191,605 & 189,946 & 119,893 \\
\hline All sciences, total & $3,548,087$ & $3,618,708$ & $5,458,431$ & $6,589,934$ & $7,368,165$ & $8,534,526$ & $9,487,722$ & $10,264,175$ & $10,267,433$ & $11,104,608$ & $11,793,855$ \\
\hline Physical sciences & 507,884 & 500,657 & 770,254 & 859,764 & 980,297 & 891,596 & $1,022,807$ & $1,136,460$ & $1,024,928$ & $1,138,746$ & $1,009,330$ \\
\hline Astronomy & 52,736 & 54,835 & 78,435 & 89,791 & 103,271 & 98,804 & 115,212 & 149,417 & 139,579 & 214,549 & 132,640 \\
\hline 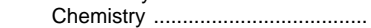 & 170,048 & 165,189 & 255,593 & 281,573 & 299,417 & 272,929 & 295,576 & 325,224 & 321,105 & 324,213 & 134,622 \\
\hline 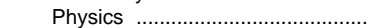 & 249,661 & 250,342 & 379,289 & 426,005 & 506,983 & 454,690 & 518,840 & 546,081 & 513,084 & 542,800 & 698,846 \\
\hline Physical sciences, other ............... & 35,439 & 30,291 & 56,937 & 62,395 & 70,626 & 65,173 & 93,179 & 115,738 & 51,160 & 57,184 & 43,222 \\
\hline Mathematical sciences & 53,987 & 53,668 & 96,405 & 119,217 & 134,998 & 109,587 & 125,893 & 140,544 & 131,875 & 77,337 & 21,856 \\
\hline Computer sciences & 37,585 & 37,493 & 82,691 & 84,424 & 123,197 & 99,214 & 113,545 & 124,962 & 137,893 & 159,963 & 38,369 \\
\hline Environmental sciences & 379,453 & 330,079 & 468,882 & 474,695 & 555,679 & 522,767 & 572,778 & 623,757 & 653,092 & 786,446 & 351,675 \\
\hline Atmospheric sciences ........................ & 86,486 & 95,112 & 124,657 & 132,379 & 131,959 & 139,914 & 149,426 & 171,557 & 162,385 & 235,810 & 81,960 \\
\hline Geological sciences ……................... & 109,523 & 101,207 & 118,401 & 131,913 & 152,449 & 147,517 & 173,492 & 149,913 & 163,011 & 186,542 & 30,552 \\
\hline 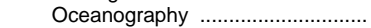 & 92,079 & 91,863 & 121,855 & 129,473 & 163,035 & 117,636 & 94,448 & 107,897 & 103,472 & 116,367 & 43,424 \\
\hline Environmental sciences, other .... & 91,365 & 41,897 & 103,969 & 80,930 & 108,236 & 117,700 & 155,412 & 194,390 & 224,224 & 247,727 & 195,739 \\
\hline (1) & $2,137,751$ & $2,290,587$ & $3,463,114$ & $4,349,268$ & $4,730,663$ & $4,773,434$ & $5,319,947$ & $5,633,514$ & $5,572,481$ & $6,313,516$ & $5,915,567$ \\
\hline Agricultural sciences . & 111,739 & 34,660 & ,249 & 772 & 908 & 453 & 763 & 936 & 0,033 & 944 & 2,635 \\
\hline Biological sciences ... & $1,085,602$ & $1,192,756$ & $1,849,516$ & $2,345,433$ & $2,558,987$ & $2,578,470$ & $2,820,183$ & $2,950,701$ & $2,931,726$ & $3,191,651$ & $2,935,783$ \\
\hline Environmental biology ……............... & 13,137 & 14,636 & 86,088 & 97,126 & 108,584 & 104,053 & 124,218 & 130,633 & 109,351 & 171,332 & 96,164 \\
\hline Medical sciences & 885,898 & 904,963 & $1,325,157$ & $1,689,606$ & $1,829,888$ & $1,853,979$ & $2,102,127$ & $2,252,375$ & $2,253,419$ & $2,689,279$ & $2,598,691$ \\
\hline 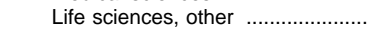 & 41,375 & 43,572 & 59,104 & 61,331 & 52,296 & 55,479 & 79,656 & 87,869 & 87,952 & 77,310 & 92,294 \\
\hline Psycholo & 86,459 & 87,734 & 138,338 & 186,924 & 209,344 & 225,987 & 258,886 & 254,311 & 277,667 & 318,832 & 298,545 \\
\hline 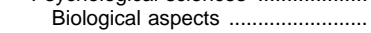 & 28,269 & 26,273 & 39,049 & 53,287 & 66,959 & 71,705 & 80,438 & 75,307 & 8,542 & 3,792 & 1,390 \\
\hline Social aspects & 31,129 & 28,846 & 38,589 & 52,113 & 59,502 & 66,960 & 82,257 & 75,285 & 4,754 & 7,357 & 3,519 \\
\hline Psychological sciences, other ..... & 27,061 & 32,615 & 60,700 & 81,524 & 82,883 & 87,322 & 96,191 & 103,719 & 264,371 & 307,683 & 293,636 \\
\hline Social sciences & 203,948 & 197,695 & 172,148 & 184,539 & 218,404 & 250,366 & 303,798 & 301,056 & 267,080 & 279,575 & 228,978 \\
\hline 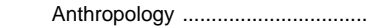 & 7,757 & 5,543 & 6,455 & 5,972 & 7,054 & 7,061 & 8,768 & 9,015 & 8,474 & 8,115 & 1,297 \\
\hline 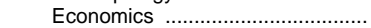 & 51,414 & 56,704 & 43,764 & 48,039 & 51,806 & 58,441 & 60,142 & 70,582 & 68,102 & 60,478 & 62,295 \\
\hline 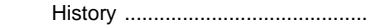 & 1,688 & 1,069 & 1,508 & 1,527 & 1,665 & 1,890 & 2,116 & 2,166 & 2,014 & 0 & 0 \\
\hline Linguistics & 2,997 & 2,745 & 2,481 & 3,248 & 3,402 & 3,055 & 3,383 & 3,684 & 3,554 & 0 & 100 \\
\hline Political science & 5,890 & 5,122 & 5,003 & 5,926 & 6,988 & 7,415 & 8,287 & 8,894 & 7,687 & 6,625 & 2,067 \\
\hline Sociology & 34,903 & 38,136 & 34,580 & 55,204 & 75,404 & 96,240 & 113,829 & 104,430 & 35,666 & 30,602 & 11,066 \\
\hline Social sciences, other $\ldots \ldots \ldots \ldots \ldots \ldots \ldots$ & 99,299 & 88,376 & 78,357 & 64,623 & 72,085 & 76,264 & 107,273 & 102,285 & 141,583 & 173,755 & 152,153 \\
\hline Other sciences & 141,020 & 120,795 & 266,599 & 331,103 & 415,583 & $1,661,575$ & $1,770,068$ & $2,049,571$ & $2,202,417$ & $2,030,193$ & $3,929,535$ \\
\hline Residual amounts & 0 & 0 & 0 & 0 & 0 & 0 & 0 & -70 & 34 & 37 & 239 \\
\hline
\end{tabular}

${ }^{1}$ All U.S. Department of Defense data are reported as other sciences.

NOTE.-Some data have been revised from previously published figures. Fields of science and engineering are no longer reported as of fiscal year 1996.
SOURCE: National Science Foundation, Science Resources Studies Division, unpublished data. (This table was prepared May 1998.) 
Table 371.-U.S. Department of Agriculture obligations for child nutrition programs, by state or other area: Fiscal years 1996 and 1997

[In thousands]

\begin{tabular}{|c|c|c|c|c|c|c|c|c|c|c|}
\hline \multirow[b]{2}{*}{ State or other area } & \multirow[b]{2}{*}{$\begin{array}{l}\text { Total, } \\
\text { fiscal } \\
\text { year } 1996\end{array}$} & \multicolumn{9}{|c|}{ Fiscal year 1997} \\
\hline & & Total & Special milk & $\begin{array}{l}\text { School } \\
\text { lunch }{ }^{1}\end{array}$ & $\begin{array}{c}\text { School } \\
\text { breakfast }\end{array}$ & $\begin{array}{c}\text { State } \\
\text { administra- } \\
\text { tive } \\
\text { expenses }\end{array}$ & $\begin{array}{l}\text { Commodities } \\
\text { and cash in } \\
\text { lieu of } \\
\text { commodities }^{2}\end{array}$ & $\begin{array}{l}\text { Child and } \\
\text { adult care }\end{array}$ & $\begin{array}{c}\text { Summer } \\
\text { food service }\end{array}$ & $\begin{array}{l}\text { Nutrition } \\
\text { education } \\
\text { and training }\end{array}$ \\
\hline 1 & 2 & 3 & 4 & 5 & 6 & 7 & 8 & 9 & 10 & 11 \\
\hline Total $\ldots \ldots$. & $\$ 8,527,590$ & $\$ 8,980,908$ & $\$ 18,008$ & $\$ 5,032,061$ & $\$ 1,212,745$ & $\$ 104,079$ & $\$ 743,017$ & $\$ 1,608,801$ & $\$ 258,456$ & $\$ 3,741$ \\
\hline 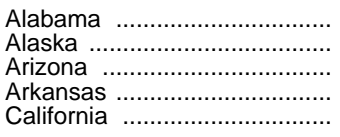 & $\begin{array}{r}162,114 \\
22,384 \\
152,469 \\
100,111 \\
1,069,307\end{array}$ & $\begin{array}{r}173,635 \\
23,034 \\
160,756 \\
102,716 \\
1,129,777\end{array}$ & $\begin{array}{r}42 \\
3 \\
175 \\
35 \\
833\end{array}$ & $\begin{array}{r}99,921 \\
14,110 \\
88,352 \\
57,434 \\
660,923\end{array}$ & $\begin{array}{r}22,334 \\
2,039 \\
22,917 \\
17,669 \\
174,666\end{array}$ & $\begin{array}{r}2,018 \\
417 \\
1,912 \\
1,299 \\
12,423\end{array}$ & $\begin{array}{r}15,525 \\
1,021 \\
11,375 \\
9,111 \\
74,571\end{array}$ & $\begin{array}{r}27,937 \\
5,365 \\
32,178 \\
15,103 \\
182,270\end{array}$ & $\begin{array}{r}5,791 \\
13 \\
3,780 \\
1,999 \\
24,023\end{array}$ & $\begin{array}{l}67 \\
67 \\
67 \\
67 \\
67\end{array}$ \\
\hline $\begin{array}{l}\text { Colorado } \\
\text { Connecticut ............................ } \\
\text { Delaware ........................... } \\
\text { District of Columbia } \\
\text { Florida ......................................... }\end{array}$ & $\begin{array}{r}89,243 \\
65,571 \\
23,224 \\
23,245 \\
433,007\end{array}$ & $\begin{array}{r}91,754 \\
68,093 \\
25,591 \\
22,694 \\
472,852\end{array}$ & $\begin{array}{r}144 \\
503 \\
50 \\
12 \\
166\end{array}$ & $\begin{array}{r}47,550 \\
38,446 \\
10,467 \\
13,542 \\
288,338\end{array}$ & $\begin{array}{r}7,744 \\
8,863 \\
2,777 \\
3,213 \\
72,451\end{array}$ & $\begin{array}{r}1,341 \\
876 \\
451 \\
368 \\
4,663\end{array}$ & $\begin{array}{r}8,788 \\
5,658 \\
2,344 \\
1,252 \\
34,415\end{array}$ & $\begin{array}{r}24,456 \\
11,433 \\
8,493 \\
2,924 \\
50,465\end{array}$ & $\begin{array}{r}1,663 \\
2,248 \\
942 \\
1,316 \\
22,287\end{array}$ & $\begin{array}{l}67 \\
67 \\
67 \\
67 \\
67\end{array}$ \\
\hline 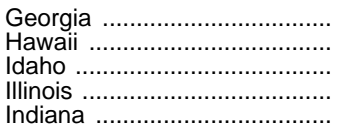 & $\begin{array}{r}289,944 \\
35,625 \\
32,386 \\
313,903 \\
126,965\end{array}$ & $\begin{array}{r}320,047 \\
38,368 \\
33,821 \\
334,452 \\
134,757\end{array}$ & $\begin{array}{r}41 \\
8 \\
216 \\
2,769 \\
347\end{array}$ & $\begin{array}{r}181,186 \\
23,527 \\
20,926 \\
194,736 \\
75,590\end{array}$ & $\begin{array}{r}57,595 \\
5,263 \\
3,289 \\
30,868 \\
15,865\end{array}$ & $\begin{array}{r}3,108 \\
507 \\
484 \\
3,740 \\
1,629\end{array}$ & $\begin{array}{r}29,095 \\
4,259 \\
3,752 \\
28,627 \\
17,444\end{array}$ & $\begin{array}{r}41,479 \\
4,419 \\
4,206 \\
58,725 \\
22,242\end{array}$ & $\begin{array}{r}7,477 \\
318 \\
882 \\
14,919 \\
1,574\end{array}$ & $\begin{array}{l}67 \\
67 \\
67 \\
67 \\
67\end{array}$ \\
\hline 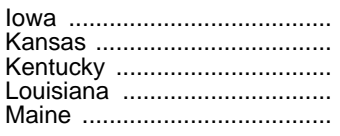 & $\begin{array}{r}77,341 \\
91,049 \\
143,730 \\
239,544 \\
34,389\end{array}$ & $\begin{array}{r}78,346 \\
92,226 \\
145,383 \\
241,719 \\
34,963\end{array}$ & $\begin{array}{r}167 \\
149 \\
109 \\
56 \\
122\end{array}$ & $\begin{array}{r}43,465 \\
42,164 \\
85,250 \\
132,446 \\
16,685\end{array}$ & $\begin{array}{r}7,213 \\
9,450 \\
27,425 \\
40,111 \\
3,250\end{array}$ & $\begin{array}{r}1,065 \\
1,445 \\
1,639 \\
2,996 \\
594\end{array}$ & $\begin{array}{r}9,953 \\
7,500 \\
14,246 \\
17,106 \\
2,644\end{array}$ & $\begin{array}{l}15,717 \\
30,542 \\
13,546 \\
42,809 \\
10,833\end{array}$ & $\begin{array}{r}698 \\
909 \\
3,101 \\
6,128 \\
767\end{array}$ & $\begin{array}{l}67 \\
67 \\
67 \\
67 \\
67\end{array}$ \\
\hline 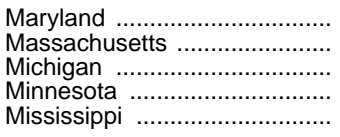 & $\begin{array}{l}120,036 \\
145,662 \\
223,117 \\
153,856 \\
152,096\end{array}$ & $\begin{array}{l}127,386 \\
148,911 \\
231,960 \\
157,173 \\
158,118\end{array}$ & $\begin{array}{r}435 \\
535 \\
957 \\
1,094 \\
9\end{array}$ & $\begin{array}{r}67,123 \\
73,729 \\
123,346 \\
62,579 \\
92,222\end{array}$ & $\begin{array}{l}14,596 \\
17,116 \\
27,614 \\
11,467 \\
29,613\end{array}$ & $\begin{array}{l}1,684 \\
1,942 \\
2,865 \\
2,546 \\
1,850\end{array}$ & $\begin{array}{l}10,516 \\
13,374 \\
22,306 \\
15,154 \\
11,303\end{array}$ & $\begin{array}{l}30,127 \\
38,231 \\
51,224 \\
61,405 \\
19,622\end{array}$ & $\begin{array}{l}2,839 \\
3,916 \\
3,582 \\
2,862 \\
3,432\end{array}$ & $\begin{array}{l}67 \\
67 \\
67 \\
67 \\
67\end{array}$ \\
\hline 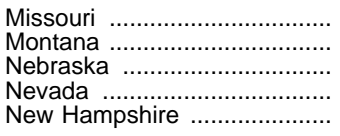 & $\begin{array}{r}148,921 \\
27,096 \\
60,179 \\
31,112 \\
19,190\end{array}$ & $\begin{array}{r}162,424 \\
27,484 \\
61,420 \\
34,911 \\
19,304\end{array}$ & $\begin{array}{r}462 \\
48 \\
223 \\
149 \\
234\end{array}$ & $\begin{array}{l}86,798 \\
13,387 \\
26,443 \\
20,491 \\
10,624\end{array}$ & $\begin{array}{r}23,020 \\
2,494 \\
3,966 \\
5,530 \\
1,976\end{array}$ & $\begin{array}{r}1,942 \\
487 \\
1,054 \\
421 \\
332\end{array}$ & $\begin{array}{r}16,561 \\
2,338 \\
5,455 \\
3,321 \\
2,903\end{array}$ & $\begin{array}{r}29,233 \\
8,245 \\
23,596 \\
3,344 \\
2,849\end{array}$ & $\begin{array}{r}4,341 \\
417 \\
615 \\
1,587 \\
319\end{array}$ & $\begin{array}{l}67 \\
67 \\
67 \\
67 \\
67\end{array}$ \\
\hline 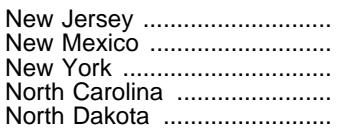 & $\begin{array}{r}159,973 \\
94,822 \\
599,469 \\
231,740 \\
25,613\end{array}$ & $\begin{array}{r}166,617 \\
97,302 \\
647,236 \\
255,432 \\
25,142\end{array}$ & $\begin{array}{r}991 \\
5 \\
1,199 \\
148 \\
70\end{array}$ & $\begin{array}{r}101,998 \\
43,073 \\
368,219 \\
140,685 \\
9,739\end{array}$ & $\begin{array}{r}14,260 \\
11,817 \\
85,357 \\
41,289 \\
1,439\end{array}$ & $\begin{array}{r}1,865 \\
1,422 \\
6,701 \\
2,835 \\
536\end{array}$ & $\begin{array}{r}15,207 \\
4,961 \\
48,234 \\
23,347 \\
2,518\end{array}$ & $\begin{array}{l}25,694 \\
30,398 \\
97,823 \\
43,618 \\
10,508\end{array}$ & $\begin{array}{r}6,536 \\
5,559 \\
39,637 \\
3,444 \\
266\end{array}$ & $\begin{array}{l}67 \\
67 \\
67 \\
67 \\
67\end{array}$ \\
\hline 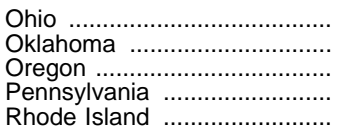 & $\begin{array}{r}246,381 \\
122,854 \\
88,585 \\
251,751 \\
21,961\end{array}$ & $\begin{array}{r}258,079 \\
126,341 \\
92,504 \\
268,039 \\
23,161\end{array}$ & $\begin{array}{r}944 \\
87 \\
199 \\
866 \\
125\end{array}$ & $\begin{array}{r}144,691 \\
67,842 \\
42,552 \\
156,703 \\
14,018\end{array}$ & $\begin{array}{r}30,239 \\
19,566 \\
12,357 \\
30,187 \\
1,977\end{array}$ & $\begin{array}{r}3,095 \\
1,666 \\
1,321 \\
2,880 \\
342\end{array}$ & $\begin{array}{r}29,049 \\
9,092 \\
6,821 \\
29,220 \\
2,063\end{array}$ & $\begin{array}{r}45,949 \\
26,009 \\
27,977 \\
33,739 \\
3,321\end{array}$ & $\begin{array}{r}4,045 \\
2,012 \\
1,211 \\
14,376 \\
1,246\end{array}$ & $\begin{array}{l}67 \\
67 \\
67 \\
67 \\
67\end{array}$ \\
\hline 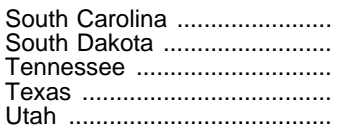 & $\begin{array}{r}148,417 \\
29,023 \\
164,136 \\
776,792 \\
73,697\end{array}$ & $\begin{array}{r}156,390 \\
28,311 \\
176,847 \\
821,197 \\
78,243\end{array}$ & $\begin{array}{r}29 \\
48 \\
40 \\
113 \\
76\end{array}$ & $\begin{array}{r}88,422 \\
14,821 \\
99,282 \\
484,339 \\
34,898\end{array}$ & $\begin{array}{r}28,249 \\
2,619 \\
27,334 \\
137,657 \\
4,602\end{array}$ & $\begin{array}{r}1,665 \\
484 \\
2,006 \\
8,940 \\
1,204\end{array}$ & $\begin{array}{r}12,346 \\
2,796 \\
16,954 \\
64,264 \\
7,030\end{array}$ & $\begin{array}{r}18,334 \\
6,705 \\
26,800 \\
106,880 \\
28,433\end{array}$ & $\begin{array}{r}7,279 \\
772 \\
4,364 \\
18,936 \\
1,932\end{array}$ & $\begin{array}{l}67 \\
67 \\
67 \\
67 \\
67\end{array}$ \\
\hline 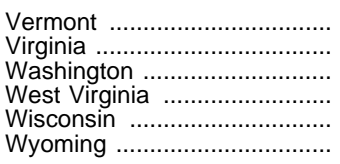 & $\begin{array}{r}15,150 \\
152,677 \\
140,536 \\
59,791 \\
115,045 \\
15,382\end{array}$ & $\begin{array}{r}15,737 \\
164,514 \\
146,789 \\
64,961 \\
113,994 \\
15,601\end{array}$ & $\begin{array}{r}98 \\
341 \\
285 \\
32 \\
1,645 \\
15\end{array}$ & $\begin{array}{r}7,143 \\
96,341 \\
76,972 \\
35,438 \\
65,032 \\
7,619\end{array}$ & $\begin{array}{r}1,706 \\
23,623 \\
18,353 \\
12,601 \\
7,001 \\
1,273\end{array}$ & $\begin{array}{r}350 \\
1,242 \\
1,933 \\
819 \\
1,485 \\
347\end{array}$ & $\begin{array}{r}1,587 \\
16,517 \\
12,270 \\
5,077 \\
11,590 \\
1,523\end{array}$ & $\begin{array}{r}4,528 \\
24,109 \\
34,132 \\
9,378 \\
25,146 \\
4,696\end{array}$ & $\begin{array}{r}258 \\
2,274 \\
2,778 \\
1,549 \\
2,029 \\
62\end{array}$ & $\begin{array}{l}67 \\
67 \\
67 \\
67 \\
67 \\
67\end{array}$ \\
\hline Administrative costs ................ & 6,396 & 5,643 & 0 & 0 & 0 & 0 & 5,643 & 0 & 0 & 0 \\
\hline $\begin{array}{c}\text { Department of Defense } \\
\text { dependents schools } \ldots . . . \\
\text { Outlying areas }\end{array}$ & 5,566 & 5,893 & 0 & 5,485 & 3 & 0 & 405 & 0 & 0 & 0 \\
\hline 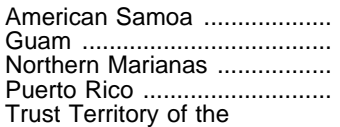 & $\begin{array}{r}63 \\
4,769 \\
63 \\
165,018\end{array}$ & $\begin{array}{r}67 \\
4,711 \\
67 \\
158,057\end{array}$ & $\begin{array}{l}0 \\
0 \\
0 \\
0\end{array}$ & $\begin{array}{r}0 \\
2,824 \\
0 \\
104,721\end{array}$ & $\begin{array}{r}0 \\
909 \\
0 \\
23,977\end{array}$ & $\begin{array}{r}0 \\
230 \\
0 \\
1,688\end{array}$ & $\begin{array}{r}0 \\
441 \\
0 \\
9,351\end{array}$ & $\begin{array}{r}0 \\
240 \\
0 \\
14,952\end{array}$ & $\begin{array}{r}0 \\
0 \\
0 \\
3,301\end{array}$ & $\begin{array}{l}67 \\
67 \\
67 \\
67\end{array}$ \\
\hline 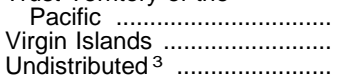 & $\begin{array}{r}57 \\
5,583 \\
199,464\end{array}$ & $\begin{array}{r}46 \\
6,335 \\
203,576\end{array}$ & $\begin{array}{r}0 \\
4 \\
554\end{array}$ & $\begin{array}{r}0 \\
4,312 \\
103,087\end{array}$ & $\begin{array}{r}0 \\
175 \\
1,781\end{array}$ & $\begin{array}{r}0 \\
239 \\
686\end{array}$ & $\begin{array}{r}45 \\
438 \\
2,309\end{array}$ & $\begin{array}{r}0 \\
696 \\
85,723\end{array}$ & $\begin{array}{r}0 \\
403 \\
9,445\end{array}$ & $\begin{array}{r}1 \\
67 \\
-9\end{array}$ \\
\hline
\end{tabular}

${ }^{1}$ Special Meal Assistance program is combined with "School Lunch" program.

${ }^{2}$ Commodities are based on preliminary food orders for fiscal year 1997.

SOURCE: U.S. Department of Agriculture, Food and Nutrition Service, Budget Divi-

Undistributed amount reflects the difference between preliminary state earnings re sion, unpublished data. (This table was prepared January 1998.)

NOTE.-Data are based on obligations as reported September 30, 1997. Negative amounts occur when program receipts exceed the obligations. Because of rounding, details may not add to totals. 
Table 372.-U.S. Department of Health and Human Services allocations for Head Start and enrollment in Head Start, by state or other area: Fiscal years 1994 to 1997

\begin{tabular}{|c|c|c|c|c|c|c|c|c|}
\hline \multirow[b]{2}{*}{ State or other area } & \multicolumn{2}{|c|}{1994} & \multicolumn{2}{|c|}{1995} & \multicolumn{2}{|c|}{1996} & \multicolumn{2}{|c|}{1997} \\
\hline & $\begin{array}{l}\text { Head Start } \\
\text { allocations } \\
\text { (in thousands) }\end{array}$ & $\begin{array}{l}\text { Head Start } \\
\text { enrollment }{ }^{1}\end{array}$ & $\begin{array}{l}\text { Head Start } \\
\text { allocations } \\
\text { (in thousands) }\end{array}$ & $\begin{array}{l}\text { Head Start } \\
\text { enrollment }{ }^{2}\end{array}$ & $\begin{array}{l}\text { Head Start } \\
\text { allocations } \\
\text { (in thousands) }\end{array}$ & $\begin{array}{l}\text { Head Start } \\
\text { enrollment }^{3}\end{array}$ & $\begin{array}{l}\text { Head Start } \\
\text { allocations } \\
\text { (in thousands) }\end{array}$ & $\begin{array}{l}\text { Head Start } \\
\text { enrollment }\end{array}$ \\
\hline 1 & 2 & 3 & 4 & 5 & 6 & 7 & 8 & 9 \\
\hline Total & $\$ 3,215,946$ & 740,493 & $\$ 3,402,947$ & 750,696 & $\$ 3,438,268$ & 752,077 & $\$ 3,876,707$ & 793,809 \\
\hline $\begin{array}{l}\text { Alabama } \\
\text { Alaska } \\
\text { Arizona } \\
\text { Arkansas } \\
\text { California }\end{array}$ & $\begin{array}{r}54,282 \\
6,295 \\
44,416 \\
30,719 \\
371,227\end{array}$ & $\begin{array}{r}14,525 \\
1,209 \\
9,846 \\
9,065 \\
70,995\end{array}$ & $\begin{array}{r}57,542 \\
6,534 \\
47,208 \\
32,681 \\
392,331\end{array}$ & $\begin{array}{r}14,552 \\
1,209 \\
10,029 \\
9,244 \\
72,650\end{array}$ & $\begin{array}{r}58,265 \\
6,748 \\
47,617 \\
33,153 \\
392,965\end{array}$ & $\begin{array}{r}14,429 \\
1,299 \\
9,818 \\
9,193 \\
72,606\end{array}$ & $\begin{array}{r}65,970 \\
7,581 \\
53,478 \\
36,396 \\
458,841\end{array}$ & $\begin{array}{r}14,979 \\
1,212 \\
10,561 \\
9,637 \\
79,929\end{array}$ \\
\hline 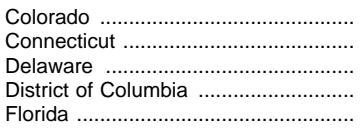 & $\begin{array}{r}31,787 \\
26,061 \\
5,815 \\
12,854 \\
118,976\end{array}$ & $\begin{array}{r}8,118 \\
5,660 \\
1,455 \\
2,841 \\
27,398\end{array}$ & $\begin{array}{r}35,757 \\
27,022 \\
6,027 \\
14,329 \\
125,508\end{array}$ & $\begin{array}{r}8,576 \\
5,625 \\
1,574 \\
2,913 \\
27,623\end{array}$ & $\begin{array}{r}36,364 \\
27,382 \\
6,239 \\
14,530 \\
127,325\end{array}$ & $\begin{array}{r}8,647 \\
5,567 \\
1,455 \\
3,339 \\
27,535\end{array}$ & $\begin{array}{r}40,902 \\
32,985 \\
8,314 \\
17,361 \\
144,663\end{array}$ & $\begin{array}{r}8,952 \\
6,190 \\
2,077 \\
3,273 \\
29,523\end{array}$ \\
\hline $\begin{array}{l}\text { Georgia } \\
\text { Hawaii } \\
\text { Idaho } \\
\text { Illinois } \\
\text { Indiana }\end{array}$ & $\begin{array}{r}81,974 \\
9,939 \\
9,574 \\
139,137 \\
46,558\end{array}$ & $\begin{array}{r}19,445 \\
2,260 \\
1,912 \\
30,537 \\
11,730\end{array}$ & $\begin{array}{r}85,792 \\
10,312 \\
10,009 \\
148,120 \\
48,871\end{array}$ & $\begin{array}{r}19,523 \\
2,226 \\
1,841 \\
31,579 \\
11,739\end{array}$ & $\begin{array}{r}86,596 \\
10,981 \\
10,043 \\
148,915 \\
49,804\end{array}$ & $\begin{array}{r}19,563 \\
2,517 \\
1,869 \\
31,817 \\
11,847\end{array}$ & $\begin{array}{r}96,295 \\
12,632 \\
12,529 \\
170,193 \\
55,293\end{array}$ & $\begin{array}{r}20,505 \\
2,539 \\
2,213 \\
33,924 \\
12,415\end{array}$ \\
\hline 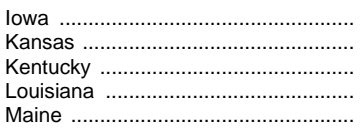 & $\begin{array}{l}23,430 \\
22,095 \\
54,364 \\
75,876 \\
12,610\end{array}$ & $\begin{array}{r}5,946 \\
5,793 \\
14,071 \\
19,344 \\
3,439\end{array}$ & $\begin{array}{l}25,539 \\
24,772 \\
58,383 \\
78,691 \\
13,118\end{array}$ & $\begin{array}{r}6,199 \\
6,158 \\
14,267 \\
19,344 \\
3,439\end{array}$ & $\begin{array}{l}25,968 \\
25,129 \\
58,935 \\
79,596 \\
13,734\end{array}$ & $\begin{array}{r}6,178 \\
6,074 \\
14,447 \\
19,344 \\
10,816\end{array}$ & $\begin{array}{l}28,458 \\
28,815 \\
65,587 \\
87,261 \\
15,536\end{array}$ & $\begin{array}{r}6,341 \\
6,355 \\
14,828 \\
19,998 \\
3,392\end{array}$ \\
\hline 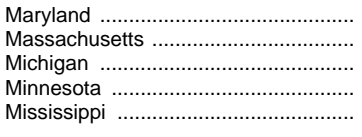 & $\begin{array}{r}38,810 \\
57,264 \\
126,686 \\
36,930 \\
92,012\end{array}$ & $\begin{array}{r}8,509 \\
10,794 \\
30,701 \\
8,576 \\
24,110\end{array}$ & $\begin{array}{r}42,023 \\
61,129 \\
132,990 \\
38,281 \\
95,493\end{array}$ & $\begin{array}{r}8,874 \\
10,990 \\
30,936 \\
8,576 \\
24,150\end{array}$ & $\begin{array}{r}42,461 \\
61,742 \\
135,349 \\
38,812 \\
97,001\end{array}$ & $\begin{array}{r}8,915 \\
3,466 \\
31,198 \\
8,641 \\
24,081\end{array}$ & $\begin{array}{r}47,688 \\
68,913 \\
150,074 \\
43,536 \\
103,523\end{array}$ & $\begin{array}{r}9,514 \\
11,499 \\
32,440 \\
9,117 \\
24,693\end{array}$ \\
\hline 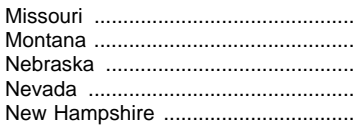 & $\begin{array}{r}55,979 \\
9,563 \\
14,342 \\
8,017 \\
5,699\end{array}$ & $\begin{array}{r}14,063 \\
2,304 \\
3,644 \\
1,793 \\
1,156\end{array}$ & $\begin{array}{r}58,752 \\
9,772 \\
15,456 \\
8,315 \\
6,379\end{array}$ & $\begin{array}{r}14,064 \\
2,304 \\
3,764 \\
1,793 \\
1,232\end{array}$ & $\begin{array}{r}59,241 \\
10,048 \\
15,890 \\
8,213 \\
6,558\end{array}$ & $\begin{array}{r}14,035 \\
2,304 \\
3,800 \\
1,823 \\
1,235\end{array}$ & $\begin{array}{r}66,763 \\
11,500 \\
19,037 \\
9,942 \\
7,430\end{array}$ & $\begin{array}{r}14,899 \\
2,510 \\
4,088 \\
2,019 \\
1,267\end{array}$ \\
\hline 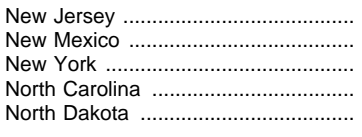 & $\begin{array}{r}71,189 \\
24,241 \\
215,678 \\
66,643 \\
6,723\end{array}$ & $\begin{array}{r}12,898 \\
6,397 \\
39,062 \\
15,695 \\
1,738\end{array}$ & $\begin{array}{r}74,610 \\
27,269 \\
226,840 \\
71,603 \\
6,966\end{array}$ & $\begin{array}{r}13,016 \\
6,821 \\
39,491 \\
16,161 \\
1,738\end{array}$ & $\begin{array}{r}75,151 \\
27,731 \\
228,243 \\
72,594 \\
7,206\end{array}$ & $\begin{array}{r}13,085 \\
6,587 \\
40,365 \\
16,002 \\
1,874\end{array}$ & $\begin{array}{r}82,650 \\
33,971 \\
261,541 \\
80,559 \\
8,733\end{array}$ & $\begin{array}{r}13,746 \\
7,187 \\
43,716 \\
16,825 \\
2,121\end{array}$ \\
\hline 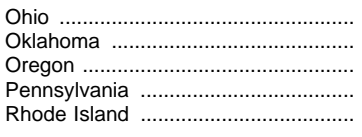 & $\begin{array}{r}133,913 \\
39,073 \\
27,080 \\
119,354 \\
10,060\end{array}$ & $\begin{array}{r}33,919 \\
11,165 \\
4,638 \\
25,672 \\
2,476\end{array}$ & $\begin{array}{r}139,497 \\
40,705 \\
29,086 \\
126,251 \\
10,453\end{array}$ & $\begin{array}{r}34,215 \\
11,165 \\
4,698 \\
26,149 \\
2,434\end{array}$ & $\begin{array}{r}141,607 \\
41,397 \\
29,460 \\
127,086 \\
10,549\end{array}$ & $\begin{array}{r}33,919 \\
11,165 \\
4,695 \\
26,198 \\
2,567\end{array}$ & $\begin{array}{r}155,354 \\
45,865 \\
34,466 \\
142,973 \\
13,135\end{array}$ & $\begin{array}{r}35,441 \\
11,631 \\
5,222 \\
27,515 \\
2,676\end{array}$ \\
\hline $\begin{array}{l}\text { South Carolina } \\
\text { South Dakota } \\
\text { Tennessee } \\
\text { Texas }\end{array}$ & $\begin{array}{r}40,772 \\
7,985 \\
58,610 \\
213,394 \\
15,832\end{array}$ & $\begin{array}{r}10,142 \\
2,025 \\
14,380 \\
51,521 \\
4,028\end{array}$ & $\begin{array}{r}44,021 \\
8,258 \\
61,630 \\
223,309 \\
18,145\end{array}$ & $\begin{array}{r}10,415 \\
2,025 \\
14,213 \\
51,925 \\
4,334\end{array}$ & $\begin{array}{r}44,540 \\
8,480 \\
62,163 \\
224,923 \\
18,219\end{array}$ & $\begin{array}{r}10,164 \\
2,258 \\
14,291 \\
52,107 \\
4,201\end{array}$ & $\begin{array}{r}51,714 \\
10,139 \\
69,365 \\
253,186 \\
20,132\end{array}$ & $\begin{array}{r}10,822 \\
2,374 \\
14,553 \\
54,624 \\
4,419\end{array}$ \\
\hline $\begin{array}{l}\text { Vermont } \\
\text { Virginia } \\
\text { Washington } \\
\text { West Virginia } \\
\text { Wisconsin } \\
\text { Wyoming }\end{array}$ & $\begin{array}{r}5,957 \\
46,411 \\
45,968 \\
26,014 \\
49,461 \\
4,925\end{array}$ & $\begin{array}{r}1,271 \\
10,993 \\
8,260 \\
6,402 \\
11,953 \\
1,323\end{array}$ & $\begin{array}{r}7,636 \\
48,896 \\
53,385 \\
27,626 \\
52,633 \\
5,099\end{array}$ & $\begin{array}{r}1,486 \\
11,147 \\
8,803 \\
6,522 \\
12,171 \\
1,313\end{array}$ & $\begin{array}{r}7,811 \\
49,706 \\
52,311 \\
28,125 \\
54,013 \\
5,195\end{array}$ & $\begin{array}{r}1,531 \\
11,028 \\
8,878 \\
6,515 \\
12,283 \\
1,279\end{array}$ & $\begin{array}{r}8,433 \\
54,571 \\
59,644 \\
31,064 \\
58,550 \\
5,814\end{array}$ & $\begin{array}{r}1,379 \\
11,480 \\
9,387 \\
6,858 \\
12,556 \\
1,395\end{array}$ \\
\hline Migrant programs …............................... & 130,409 & 35,063 & 138,802 & 35,243 & 139,438 & 35,117 & 153,788 & 36,458 \\
\hline $\begin{array}{l}\text { American Indian/Alaskan } \\
\text { Native programs } \\
\text { Special projects }\end{array}$ & $\begin{array}{r}90,793 \\
76\end{array}$ & $\begin{array}{r}18,738 \\
-\end{array}$ & $\begin{array}{r}95,130 \\
-\end{array}$ & $\begin{array}{r}18,821 \\
-\end{array}$ & $\begin{array}{r}96,836 \\
-\end{array}$ & $\begin{array}{r}19,071 \\
-\end{array}$ & $\begin{array}{r}113,920 \\
-\end{array}$ & 21,019 \\
\hline Outlying areas & & & & & & & & \\
\hline $\begin{array}{l}\text { Puerto Rico } \\
\text { Pacific Territories } \\
\text { Virgin Islands }\end{array}$ & $\begin{array}{r}127,066 \\
9,019 \\
6,009\end{array}$ & $\begin{array}{r}32,145 \\
5,849 \\
1,501\end{array}$ & $\begin{array}{r}132,423 \\
9,309 \\
6,228\end{array}$ & $\begin{array}{r}32,118 \\
5,849 \\
1,430\end{array}$ & $\begin{array}{r}134,072 \\
9,541 \\
6,267\end{array}$ & $\begin{array}{r}31,744 \\
5,849 \\
1,446\end{array}$ & $\begin{array}{r}143,121 \\
9,963 \\
6,560\end{array}$ & $\begin{array}{r}32,221 \\
5,849 \\
1,446\end{array}$ \\
\hline
\end{tabular}

${ }^{1}$ The distribution of enrollment by age was: 6 percent were 5 years old and over; 64 percent were 4-year-olds; 27 percent were 3-year-olds; and 3 percent were under 3 years of age. Handicapped children accounted for 13.0 percent in Head Start programs. The racial/ethnic composition was: American Indian/Alaskan Native, 4 percent; Hispanic, 24 percent; black, 36 percent; white, 33 percent; and Asian, 3 percent.

2 The distribution of enrollment by age was: 7 percent were 5 years old and over; 61 percent were 4-year-olds; 28 percent were 3-year-olds; and 4 percent were under 3 years of age. Handicapped children accounted for 13.1 percent in Head Start programs. The racial/ethnic composition was: American Indian/Alaskan Native, 4 percent; Hispanic 25 percent; black, 36 percent; white, 33 percent; and Asian, 3 percent.

${ }^{3}$ The distribution of enrollment by age was: 6 percent were 5 years old and over; 62 percent were 4-year-olds; 29 percent were 3 -year-olds; and 4 percent were under 3 years of age. Handicapped children accounted for 12.8 percent in Head Start programs.
The racial/ethnic composition was: American Indian/Alaskan Native, 3.5 percent; Hispanic, 25.2 percent; black, 36 percent; white, 32.3 percent; and Asian, 3 percent.

4 The distribution of enrollment by age was: 6 percent were 5 years old and over; 60 percent were 4-year-olds; 30 percent were 3-year-olds; and 4 percent were under 3 years of age. Handicapped children accounted for 13 percent in Head Start programs. The racial/ethnic composition was: American Indian/Alaskan Native, 4 percent; Hispanic, 26 percent; black, 36 percent; white, 31 percent; and Asian, 3 percent.

-Not applicable.

NOTE.-Because of rounding, details may not add to totals.

SOURCE: U.S. Department of Health and Human Services, Office of Human Development Services. (This table was prepared March 1998.) 
Table 373.-Public school students receiving federally funded free or reduced price lunches, by selected school characteristics: School year 1993-94

\begin{tabular}{|c|c|c|c|c|}
\hline \multirow{2}{*}{ School characteristics } & \multicolumn{4}{|c|}{ Percent of students participating in program } \\
\hline & Total & Elementary & Secondary & Combined $^{1}$ \\
\hline 1 & 2 & 3 & 4 & 5 \\
\hline Total & $33.2(0.5)$ & $38.8(0.7)$ & $22.0(0.4)$ & $39.1(1.7)$ \\
\hline \multicolumn{5}{|l|}{ Community type } \\
\hline Central city $\ldots$. & $44.9(1.0)$ & $52.1(1.3)$ & $28.9(0.9)$ & $52.2(3.0)$ \\
\hline Urban fringe/large town & $23.5(0.9)$ & $28.3(1.4)$ & $14.6(0.6)$ & $23.9(3.8)$ \\
\hline Rural/small town & $32.2(0.6)$ & $36.3(0.8)$ & $23.0(0.4)$ & $39.9(1.9)$ \\
\hline \multicolumn{5}{|l|}{ School size (students) } \\
\hline Less than $150 \ldots \ldots . . . .$. & $38.6(1.3)$ & $38.4(1.9)$ & $35.8(1.5)$ & $50.2(2.4)$ \\
\hline 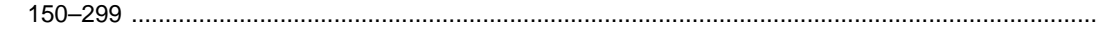 & $38.1(0.9)$ & $39.5(1.2)$ & $28.4(1.1)$ & $51.8(4.9)$ \\
\hline 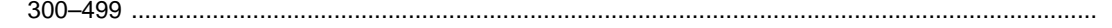 & $37.0(0.9)$ & $38.8(1.0)$ & $26.2(1.1)$ & $37.3(2.6)$ \\
\hline $500-749 \ldots \ldots \ldots . .$. & $33.5(0.9)$ & $36.0(1.0)$ & $22.3(0.7)$ & $34.7(2.2)$ \\
\hline 750 or more ........ & $29.7(0.9)$ & $42.5(1.8)$ & $20.6(0.5)$ & $34.3(3.2)$ \\
\hline \multicolumn{5}{|l|}{ Minority students } \\
\hline 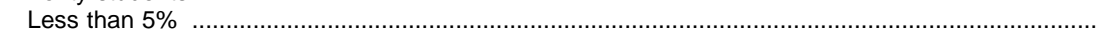 & $22.0(0.5)$ & $24.4(0.7)$ & $17.0(0.6)$ & $28.6(1.6)$ \\
\hline (1) & $18.9(0.5)$ & $22.2(0.8)$ & $11.7(0.4)$ & $30.6(2.3)$ \\
\hline (1) & $32.0(0.7)$ & $38.1(1.0)$ & $20.1(0.4)$ & $38.6(5.0)$ \\
\hline $50 \%$ or more & $57.3(1.1)$ & $65.5(1.2)$ & $38.9(1.0)$ & $60.6(3.2)$ \\
\hline
\end{tabular}

${ }^{1}$ Includes schools beginning with grade 6 or below and ending with grade 9 or above. NOTE.- Some data have been revised from previously published figures. Standard errors appear in parentheses.
SOURCE: U.S. Department of Education, National Center for Education Statistics, "Schools and Staffing Survey, 1993-94." (This table was prepared June 1998.)

Table 374.-Public and private school students receiving federally funded Chapter $1^{1}$ services, by selected school characteristics: School year 1993-94

\begin{tabular}{|c|c|c|c|c|c|c|c|c|c|}
\hline \multirow{3}{*}{ School characteristics } & \multicolumn{9}{|c|}{ Percent of students participating in program } \\
\hline & \multirow{2}{*}{ All schools } & \multicolumn{4}{|c|}{ Public } & \multicolumn{4}{|c|}{ Private } \\
\hline & & Total & Elementary & Secondary & Combined $^{2}$ & Total & Elementary & Secondary & Combined $^{2}$ \\
\hline 1 & 2 & 3 & 4 & 5 & 6 & 7 & 8 & 9 & 10 \\
\hline Total & $13.1(0.4)$ & $14.3(0.4)$ & $18.5(0.6)$ & $6.1(0.3)$ & $13.6(0.7)$ & $3.3(0.2)$ & $4.6(0.3)$ & $1.9(0.4)$ & $1.4(0.2)$ \\
\hline $\begin{array}{l}\text { Community type } \\
\text { Central city .................. } \\
\text { Urban fringe/large town } \\
\text { Rural/small town ........... }\end{array}$ & $\begin{array}{r}17.0(0.7) \\
9.1(0.7) \\
13.2(0.5)\end{array}$ & $\begin{array}{l}19.4(0.8) \\
10.1(0.8) \\
13.7(0.5)\end{array}$ & $\begin{array}{l}24.2(1.2) \\
13.0(1.2) \\
18.2(0.7)\end{array}$ & $\begin{array}{l}9.2(1.0) \\
4.6(0.6) \\
5.2(0.2)\end{array}$ & $\begin{array}{r}14.4(2.3) \\
8.3(1.3) \\
14.9(1.0)\end{array}$ & $\begin{array}{l}4.4(0.4) \\
2.0(0.2) \\
3.0(0.5)\end{array}$ & $\begin{array}{l}6.7(0.6) \\
2.4(0.3) \\
4.0(0.6)\end{array}$ & $\begin{array}{l}2.5(0.7) \\
0.9(0.3) \\
2.3(0.6)\end{array}$ & $\begin{array}{l}0.8(0.2) \\
1.9(0.6) \\
1.8(0.7)\end{array}$ \\
\hline $\begin{array}{l}\text { School size (students) } \\
\text { Less than } 150 \ldots \ldots \ldots \ldots \\
150-299 \\
300-499 \\
500-749 \ldots \ldots \ldots \ldots \ldots \ldots \ldots \ldots \ldots \ldots \\
750 \text { or more }\end{array}$ & $\begin{array}{r}9.8(0.6) \\
13.1(0.6) \\
14.7(0.6) \\
14.7(0.6) \\
11.3(0.7)\end{array}$ & $\begin{array}{l}16.7(0.9) \\
16.7(0.8) \\
16.3(0.6) \\
15.5(0.7) \\
11.7(0.7)\end{array}$ & $\begin{array}{l}20.0(1.3) \\
19.2(1.0) \\
18.0(0.7) \\
17.6(0.9) \\
20.1(1.7)\end{array}$ & $\begin{aligned} 11.1(0.9) \\
7.6(0.8) \\
7.0(0.9) \\
6.0(0.7) \\
5.8(0.4)\end{aligned}$ & $\begin{array}{l}15.6(1.4) \\
11.6(1.7) \\
13.1(1.0) \\
18.3(2.4) \\
11.4(1.0)\end{array}$ & $\begin{array}{l}3.8(0.5) \\
5.1(0.4) \\
2.6(0.4) \\
2.0(0.6) \\
1.3(0.3)\end{array}$ & $\begin{array}{l}3.3(0.5) \\
6.2(0.5) \\
3.7(0.7) \\
3.8(1.3) \\
4.5(1.6)\end{array}$ & $\begin{array}{l}8.1(3.0) \\
4.1(1.9) \\
0.9(0.2) \\
1.1(0.3) \\
0.8(0.2)\end{array}$ & $\begin{array}{l}3.8(0.9) \\
1.4(0.5) \\
0.8(0.2) \\
0.3(0.2) \\
0.4(0.2)\end{array}$ \\
\hline 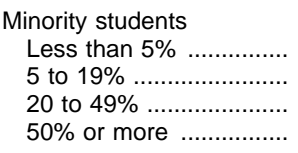 & $\begin{array}{r}7.8(0.2) \\
6.0(0.2) \\
10.2(0.7) \\
27.8(1.0)\end{array}$ & $\begin{array}{r}8.8(0.2) \\
6.6(0.3) \\
10.8(0.7) \\
29.0(1.1)\end{array}$ & $\begin{array}{r}11.6(0.3) \\
8.6(0.4) \\
14.6(1.1) \\
35.8(1.6)\end{array}$ & \begin{tabular}{r|}
$3.7(0.3)$ \\
$2.3(0.2)$ \\
$3.3(0.2)$ \\
$14.9(1.2)$
\end{tabular} & $\begin{array}{r}9.7(0.6) \\
14.2(1.7) \\
13.7(1.5) \\
18.2(2.1)\end{array}$ & $\begin{array}{r}1.7(0.1) \\
2.1(0.2) \\
2.7(0.4) \\
10.0(1.1)\end{array}$ & $\begin{array}{r}2.4(0.2) \\
3.0(0.3) \\
2.7(0.6) \\
12.4(1.3)\end{array}$ & $\begin{array}{l}0.6(0.2) \\
1.6(0.5) \\
3.7(1.2) \\
2.5(0.7)\end{array}$ & $\begin{array}{l}0.8(0.3) \\
0.9(0.4) \\
1.7(0.5) \\
5.2(1.6)\end{array}$ \\
\hline
\end{tabular}

${ }^{1}$ Chapter 1 was reauthorized under the Improving America's Schools Act (IASA) of 1994 and is now called Title I.

${ }^{2}$ Includes schools beginning with grade 6 or below and ending with grade 9 or above.

NOTE.-Some data have been revised from previously published figures. Standard errors appear in parentheses.
SOURCE: U.S. Department of Education, National Center for Education Statistics, "Schools and Staffing Survey, 1993-94." (This table was prepared June 1998.) 



\section{CHAPTER 5}

\section{Outcomes of Education}

This chapter contains tables comparing educational attainment and work force characteristics. The data show labor force participation and income levels of high school dropouts and high school and college graduates. Population characteristics are provided for many of the measures to help evaluate disparities among various demographic groups. Tables 377 to 383 contain data from the U.S. Bureau of the Census on educational attainment and income of the labor force, and data from the Bureau of Labor Statistics on employment and unemployment. These tables provide information on the educational attainment of the labor force, by occupation, sex, and race/ethnicity; income, by level of education attained; and unemployment rates, by levels of education attained, sex, and race/ethnicity.

The second group of tables was compiled from $\mathrm{Bu}$ reau of Labor Statistics data on high school dropouts and graduates. These data show the labor force participation and college enrollment of high school students within the year after they leave school. The tabulations also provide comparative labor force participation and unemployment rates for graduates and dropouts. Additional information on college enrollment rates by race/ethnicity and sex have been included to help form a more complete picture of high school outcomes. The third set of tables has been prepared from the Recent College Graduates and Baccalaureate and Beyond surveys from National Center for Education Statistics, and from a U.S. Bureau of the Census survey on earnings and education. These tables provide data on employment outcomes for college graduates. A table provides a salary comparison by field of college degree for the entire population. Trends in salaries received by college graduates also are featured in this section.

Statistics on educational attainment of the entire population are in chapter 1 . More detailed data on the numbers of high school and college graduates are contained in chapters 2 and 3 . Chapter 3 contains trend data on the proportion of high school graduates going to college. Additional data on the income of persons by educational attainment may be obtained from the U.S. Bureau of the Census in the Current Population Reports, Series P-60. The Bureau of Labor Statistics has a series of publications dealing with the educational characteristics of the labor force. The last tables in the chapter deal with community service and literacy skills. Further information on survey methodologies is in the "Guide to Sources" in the appendix and in the publications cited in the source notes.

\section{Opinions}

One life goal consistently rated "very important" by young men and women was "being successful in work." A survey of 1992 high school seniors found that 89 percent of the men and 90 percent of the women rated "being successful in work" as a "very important goal." Two of the other most highly rated goals in the 1992 survey were "finding steady work" ("very important" for 87 percent of men and 89 percent of women) and "having strong friendships" ("very important" for 80 percent of both men and women). Two years later in 1994, these values continued to be highly rated by the former high school seniors. Another value that was highly rated 2 years after high school was "Providing better opportunities for my children" which was cited by 91 percent of the young adults as "very important" (table 376 ).

\section{Labor Force}

Adults with higher levels of education were more likely to participate in the labor force than those with less education. About 79 percent of adults, 25 years old and over with a bachelor's degree, participated in the labor force in 1997 compared with 66 percent of persons who were high school graduates. In contrast, 39 percent of those 25 and older, who were not high school graduates, were in the labor force. The labor force participation rates for blacks age 25 and older with bachelor's degrees and high school diplomas were higher than the average for all people with similar levels of education (table 377).

Persons with lower levels of educational attainment were more likely to be unemployed than those who had higher levels of educational attainment. The 1997 unemployment rate for adults (25 years old and over) who had not completed high school was 8.1 percent compared with 4.3 percent for those with 4 years of high school and 2.0 percent for those with a bachelor's degree or higher. Younger people with high school diplomas tended to have higher unem- 
ployment rates than persons 25 and over, even after allowing for level of educational attainment (table 379).

One year after graduating from college in 1992-93, 87 percent of those receiving bachelor's degrees were employed (73 percent full time and 14 percent part time), 4.5 percent were unemployed, and 8.5 percent were not in the labor force (table 386).

\section{Income}

Between 1995 and 1997, median annual income of male full-time year-round workers, when adjusted for inflation, remained stable while the income for females rose by 3 percent. Women's incomes remain much lower than men's incomes, even after adjusting for level of education. The average 1997 incomes for full-time year-round workers with a bachelor's degree were $\$ 48,616$ for men and $\$ 35,379$ for women (table $380)$.

\section{Dropouts and Graduates}

The difficulties in entering the job market for dropouts, and youth in general, are highlighted by examining their labor force and unemployment status. About 60 percent of 1996-97 dropouts were in the labor force (employed or looking for work), and 25 percent of those were unemployed. Of the 1997 high school graduates who were not in college, 81 percent were in the labor force, and 17 percent of those in the labor force were unemployed (tables 382 and 383).

About two-thirds of the employed college graduates of the class of 1992-93 had jobs in professional, managerial, and technical areas in 1994. The remainder were employed in nonprofessional, nonmanagerial, and nontechnical areas. Overall, about 56 percent of the employees reported that their bachelor's degree was necessary to obtain their current job (table 386).

Figure 23.-Labor force participation of persons 16 years old and over, by age and highest level of education: 1997

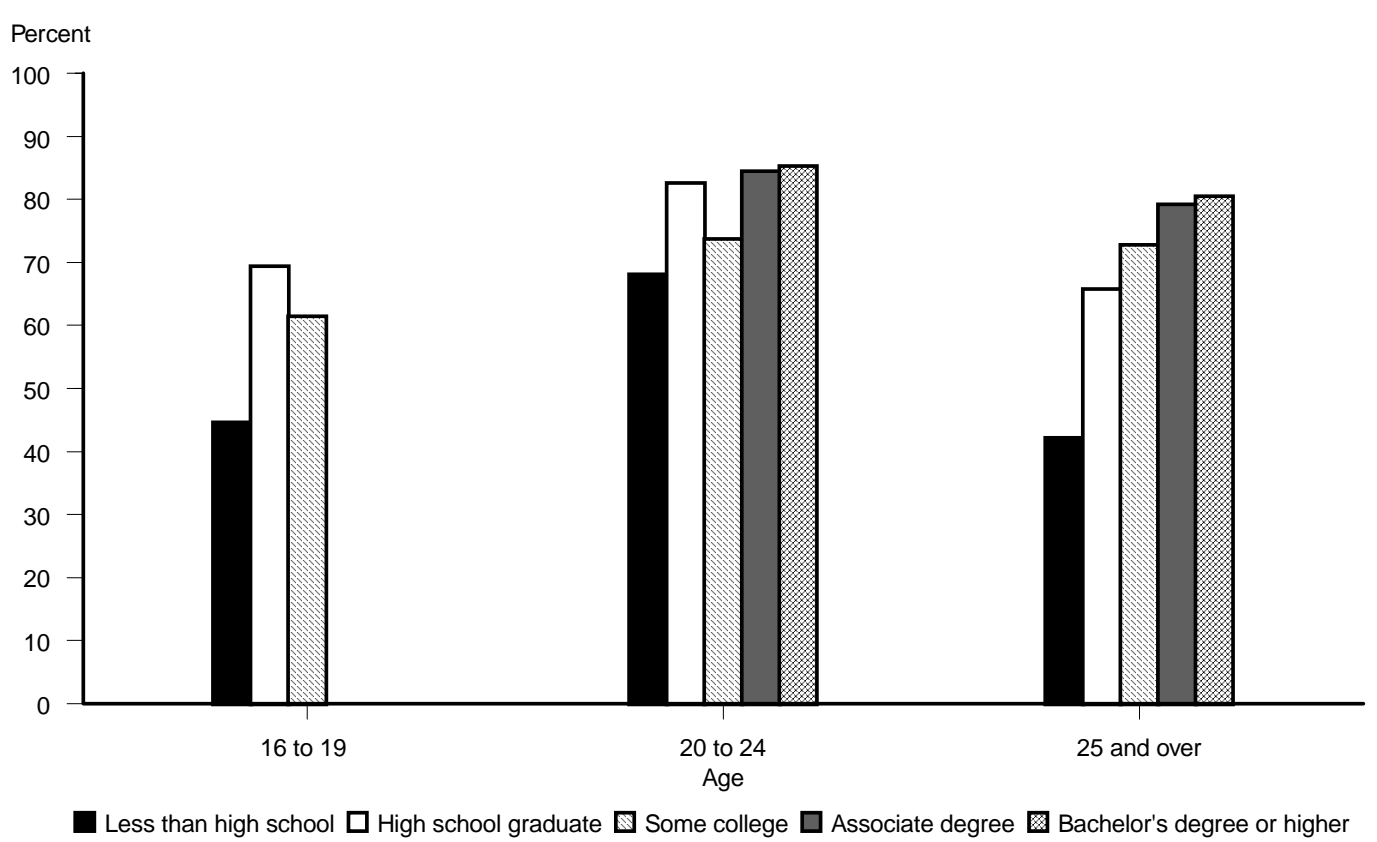

NOTE.-Data for 16- to 19-year olds who have associate or bachelor's degrees are not available. 
Figure 24.-Unemployment rates of persons 25 years old and over, by highest degree attained: 1997

Percent unemployed

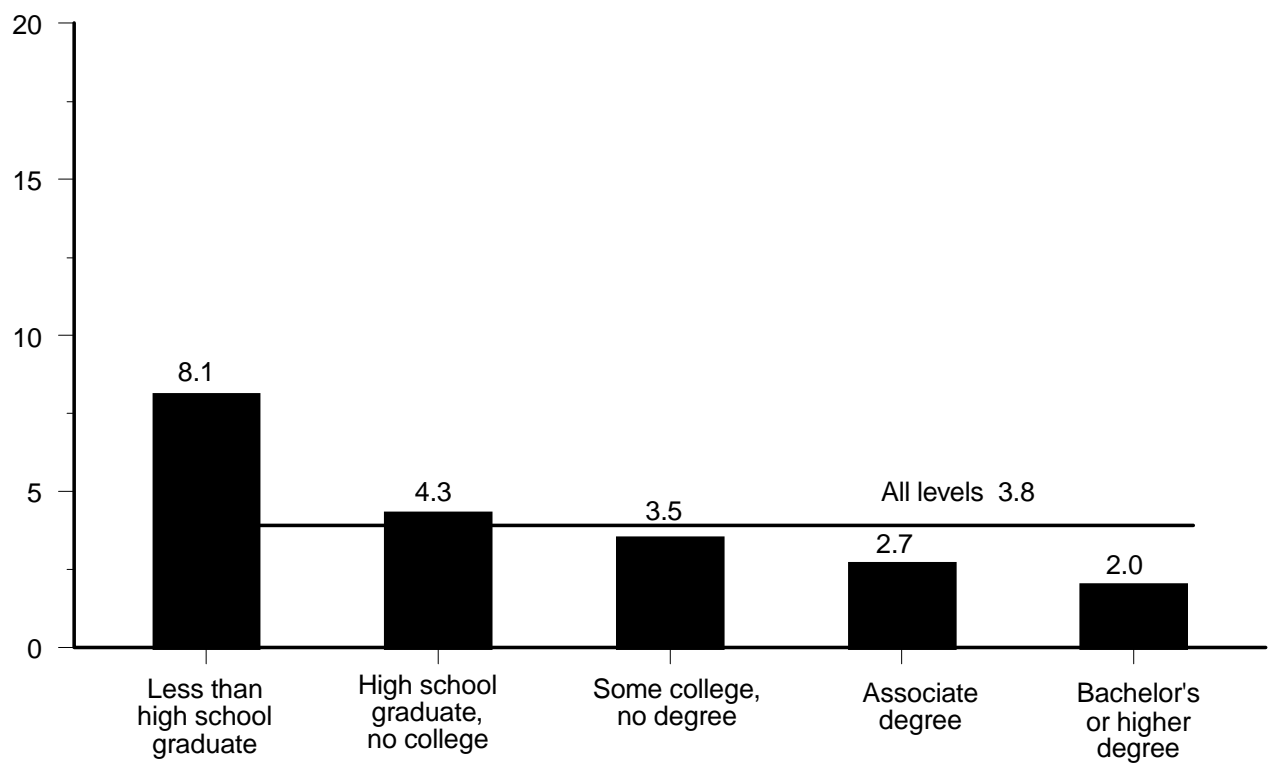

SOURCE: U.S. Department of Labor, Bureau of Labor Statistics, Office of Employment and Unemployment Statistics, Current Population Survey, 1997.

Figure 25.-Labor force status of 1996-97 high school dropouts and graduates not enrolled in college: October 1997

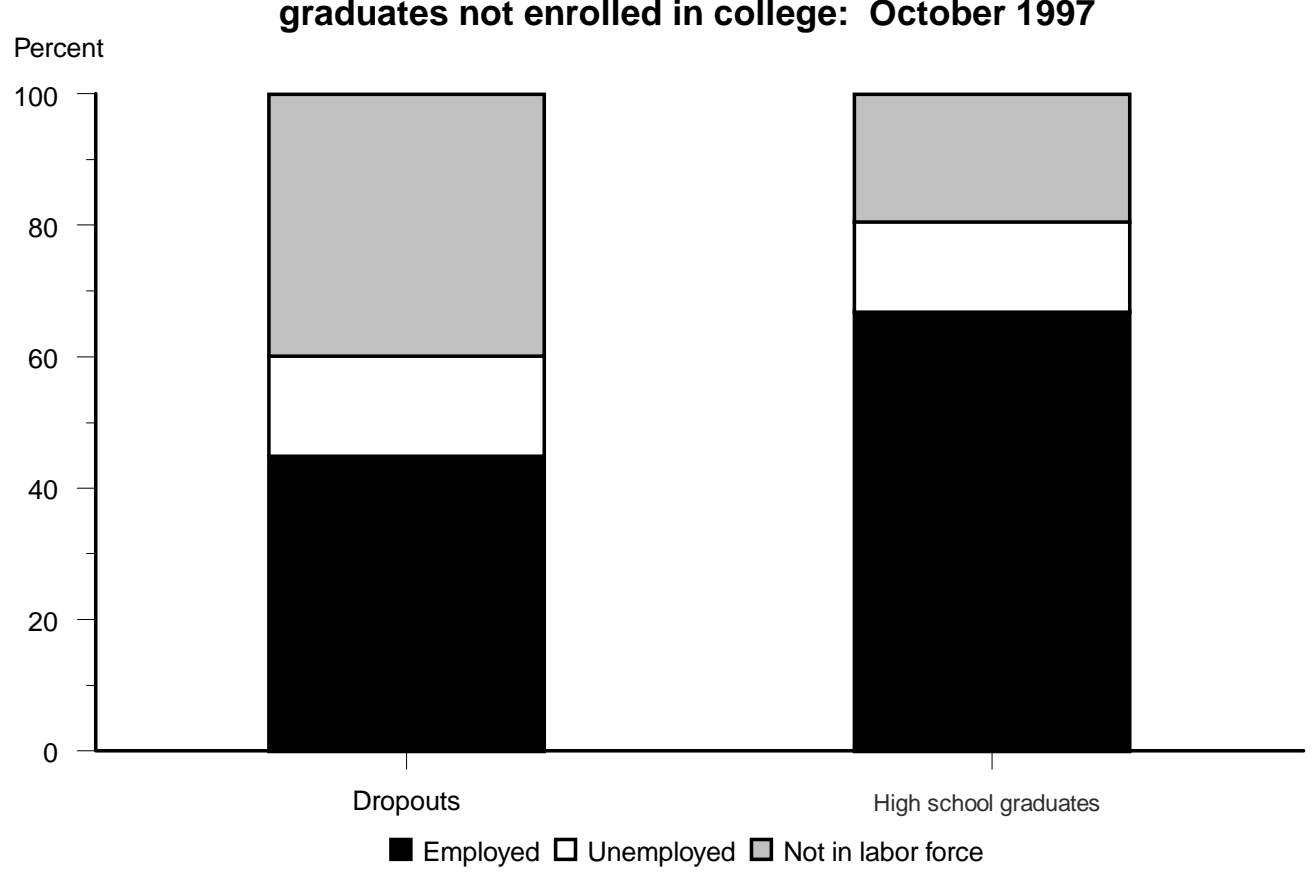

SOURCE: U.S. Department of Labor, Bureau of Labor Statistics, "Employment Status of School Age Youth, High School Graduates and Dropouts, 1997." 
Figure 26.-Median annual income of persons with income 25 years old and over, by highest degree attained and sex: 1996

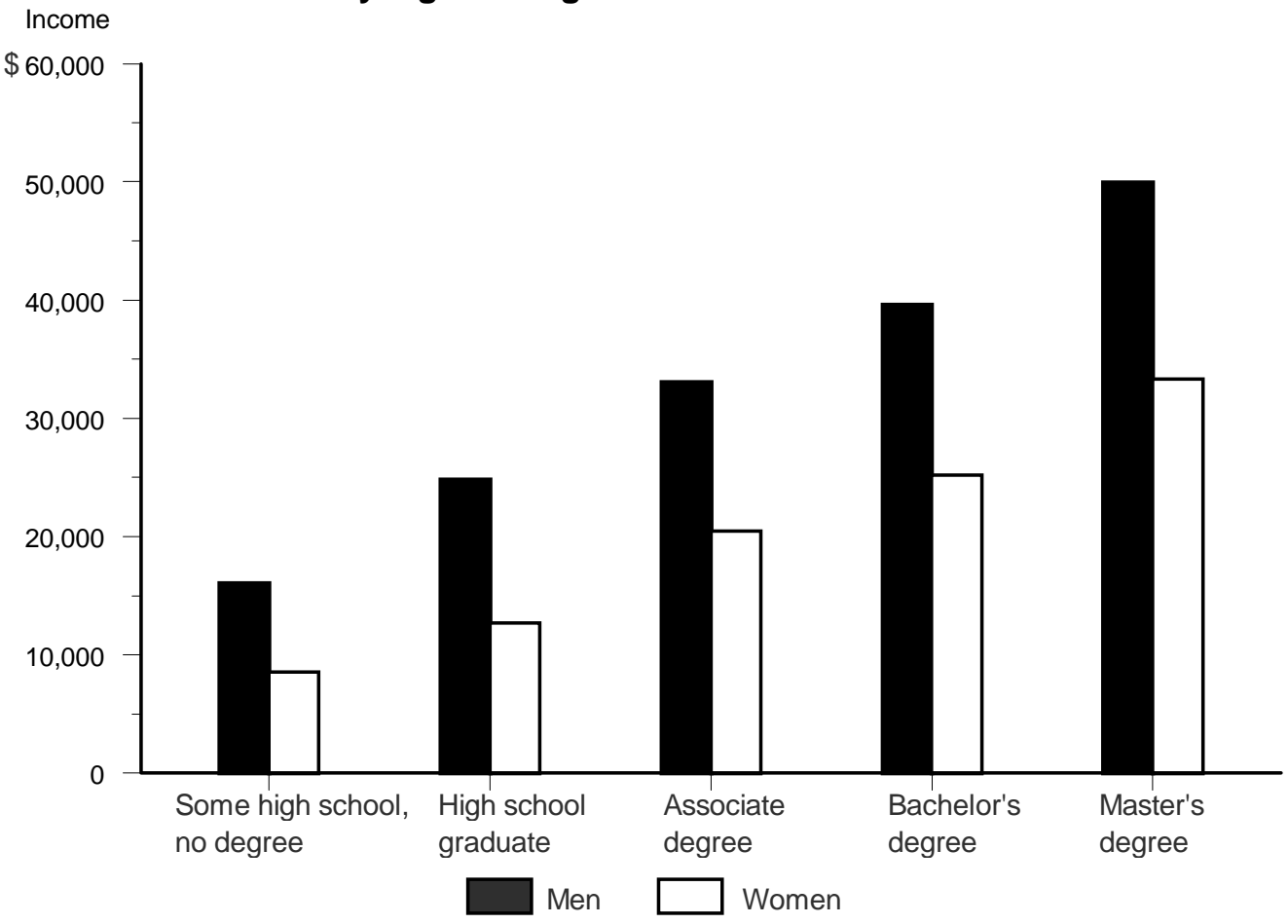

SOURCE: U.S. Department of Commerce, Bureau of the Census, Current Population Reports, Series P-60, "Money Income in the United States: 1996."

Figure 27.-Salaries of recent bachelor's degree recipients

1 year after graduation, by field: 1987, 1991, and 1994

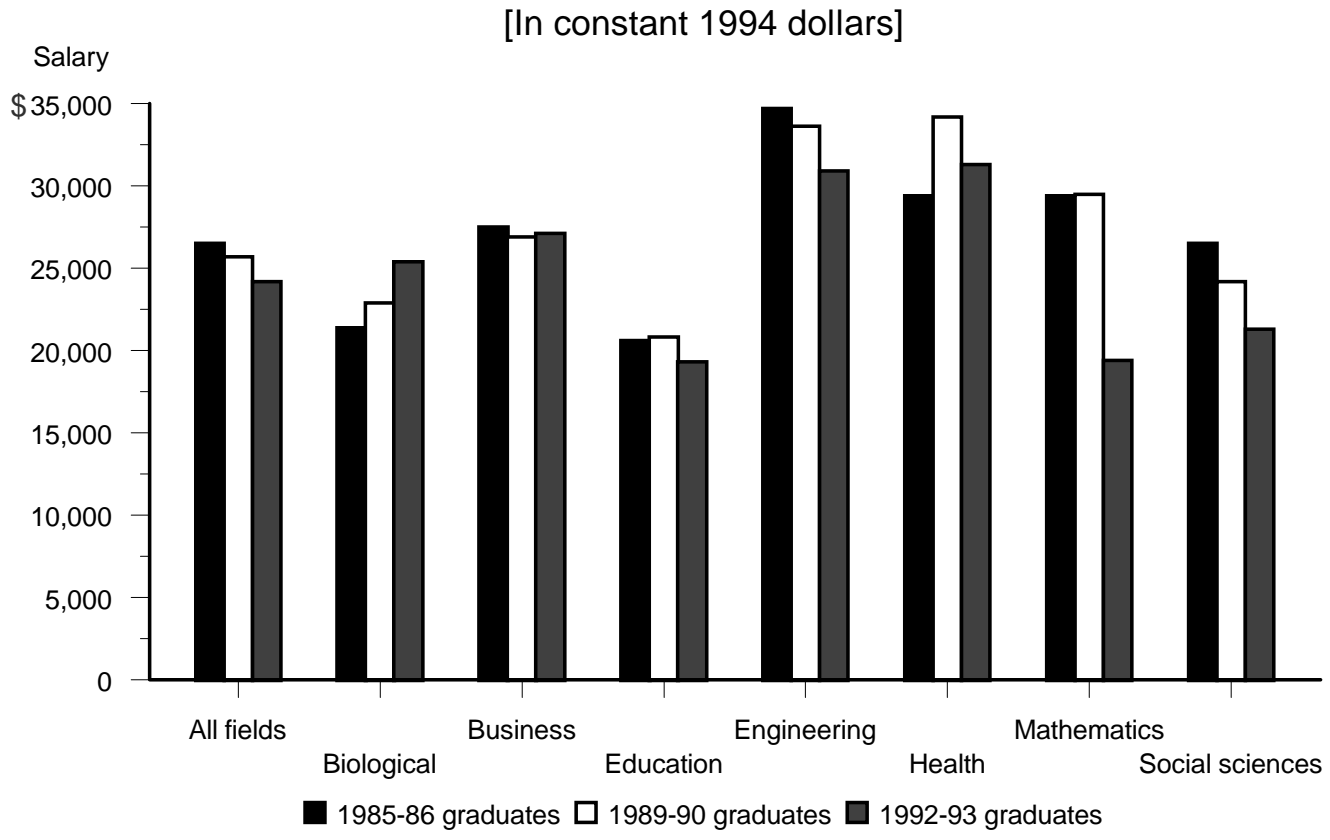

SOURCE: U.S. Department of Education, National Center for Education Statistics, "Recent College Graduates" surveys, 1987 and 1991, and "Baccalaureate and Beyond Longitudinal Study, First Follow-up" survey. 
Table 375.-Percent of 18- to 25-year-olds reporting drug use during the past 30 days and the past year: 1982 to 1996

\begin{tabular}{|c|c|c|c|c|c|c|c|c|c|c|}
\hline Drug & 1982 & 1985 & 1988 & 1990 & 1991 & 1992 & 1993 & 1994 & 1995 & 1996 \\
\hline 1 & 2 & 3 & 4 & 5 & 6 & 7 & 8 & 9 & 10 & 11 \\
\hline & \multicolumn{10}{|c|}{ Percent reporting drug use during past 30 days } \\
\hline 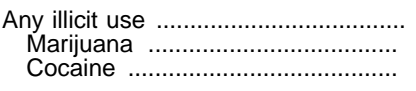 & $\begin{array}{r}-\overline{2} \\
7.2\end{array}$ & $\begin{array}{r}25.3 \\
21.7 \\
8.1\end{array}$ & $\begin{array}{r}17.9 \\
15.3 \\
4.8\end{array}$ & $\begin{array}{r}15.0 \\
12.7 \\
2.3\end{array}$ & $\begin{array}{r}15.4 \\
12.9 \\
2.2\end{array}$ & $\begin{array}{r}13.1 \\
10.9 \\
2.0\end{array}$ & $\begin{array}{r}13.6 \\
11.1 \\
1.6\end{array}$ & $\begin{array}{r}13.3 \\
12.1 \\
1.2\end{array}$ & $\begin{array}{r}14.2 \\
12.0 \\
1.3\end{array}$ & $\begin{array}{r}15.6 \\
13.2 \\
2.0\end{array}$ \\
\hline \multirow[t]{2}{*}{ 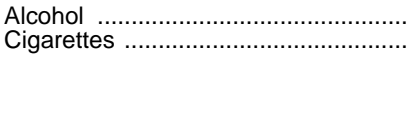 } & $\underset{66.6}{-}$ & $\begin{array}{l}70.1 \\
47.4\end{array}$ & $\begin{array}{l}64.7 \\
45.6\end{array}$ & $\begin{array}{l}62.8 \\
40.9\end{array}$ & $\begin{array}{l}63.1 \\
41.7\end{array}$ & $\begin{array}{l}58.6 \\
41.5\end{array}$ & $\begin{array}{l}58.7 \\
37.9\end{array}$ & $\begin{array}{l}63.1 \\
34.6\end{array}$ & $\begin{array}{l}61.3 \\
35.3\end{array}$ & $\begin{array}{l}60.0 \\
38.3\end{array}$ \\
\hline & \multicolumn{10}{|c|}{ Percent reporting drug use during past year } \\
\hline $\begin{array}{c}\text { Any illicit use } \\
\text { Marijuana } \\
\text { Cocaine }\end{array}$ & $\begin{array}{l}3 \overline{-} \\
15.9\end{array}$ & $\begin{array}{l}37.4 \\
34.0 \\
13.6\end{array}$ & $\begin{array}{l}29.1 \\
26.1 \\
10.5\end{array}$ & $\begin{array}{r}26.1 \\
23.0 \\
6.5\end{array}$ & $\begin{array}{r}26.6 \\
22.9 \\
6.7\end{array}$ & $\begin{array}{r}24.1 \\
21.2 \\
5.5\end{array}$ & $\begin{array}{r}24.2 \\
21.4 \\
4.4\end{array}$ & $\begin{array}{r}24.6 \\
21.8 \\
3.6\end{array}$ & $\begin{array}{r}25.5 \\
21.8 \\
4.3\end{array}$ & $\begin{array}{r}26.8 \\
23.8 \\
4.7\end{array}$ \\
\hline $\begin{array}{l}\text { Alcohol } \ldots \ldots \\
\text { Cigarettes } \ldots \ldots \ldots \ldots \ldots \ldots \ldots\end{array}$ & $\stackrel{80.6}{-}$ & $\begin{array}{l}84.2 \\
49.9\end{array}$ & $\begin{array}{l}79.6 \\
50.9\end{array}$ & $\begin{array}{l}78.1 \\
45.1\end{array}$ & $\begin{array}{l}80.7 \\
46.9\end{array}$ & $\begin{array}{l}75.6 \\
46.8\end{array}$ & $\begin{array}{l}76.9 \\
43.7\end{array}$ & $\begin{array}{l}78.5 \\
41.1\end{array}$ & $\begin{array}{l}76.5 \\
42.5\end{array}$ & $\begin{array}{l}75.3 \\
44.7\end{array}$ \\
\hline
\end{tabular}

Table 376.-Percent of 1972, 1982, and 1992 high school seniors who felt that certain life values were "very important," by sex: 1972 to 1994

\begin{tabular}{|c|c|c|c|c|c|c|c|c|c|c|c|c|c|c|c|c|c|}
\hline \multirow{3}{*}{ Value } & \multicolumn{6}{|c|}{ Percent of 1972 seniors } & \multicolumn{6}{|c|}{ Percent of 1982 seniors } & \multicolumn{5}{|c|}{ Percent of 1992 seniors } \\
\hline & \multicolumn{2}{|c|}{1972} & \multicolumn{2}{|c|}{$\begin{array}{c}1974 \text { (2 years } \\
\text { after high } \\
\text { school) }\end{array}$} & \multicolumn{2}{|c|}{$\begin{array}{c}1976 \text { (4 years } \\
\text { after high } \\
\text { school) }\end{array}$} & \multicolumn{2}{|c|}{1982} & \multicolumn{2}{|c|}{$\begin{array}{c}1984 \text { ( } 2 \text { years } \\
\text { after high } \\
\text { school) }\end{array}$} & \multicolumn{2}{|c|}{$\begin{array}{c}1986 \text { (4 years } \\
\text { after high } \\
\text { school) }\end{array}$} & \multicolumn{2}{|c|}{1992} & \multicolumn{3}{|c|}{$\begin{array}{c}1994 \text { (2 years after } \\
\text { high school) }\end{array}$} \\
\hline & Male & Female & Male & Female & Male & Female & Male & Female & Male & Female & Male & Female & Male & Female & Total & Male & Female \\
\hline 1 & 2 & 3 & 4 & 5 & 6 & 7 & 8 & 9 & 10 & 11 & 12 & 13 & 14 & 15 & 16 & 17 & 18 \\
\hline Being successful in work & 86.5 & 83.0 & 81.2 & 74.9 & 80.3 & 69.7 & 88.2 & 85.5 & 88.7 & 84.2 & 84.0 & 77.2 & 89.0 & 89.6 & 90.1 & 89.9 & 90.3 \\
\hline 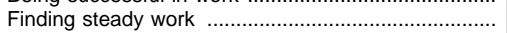 & 82.3 & 73.7 & 74.7 & 59.9 & 79.3 & 62.1 & 88.0 & 84.4 & 87.4 & 83.3 & 84.2 & 76.3 & 87.1 & 88.6 & 89.7 & 88.7 & 90.7 \\
\hline Having lots of money & 26.0 & 9.8 & 17.8 & 9.1 & 17.7 & 9.4 & 41.3 & 24.1 & 35.8 & 20.9 & 27.8 & 16.9 & 45.3 & 29.4 & 35.2 & 39.5 & 30.9 \\
\hline Being a leader in the community & 14.9 & 8.0 & 8.5 & 4.4 & 9.2 & 4.2 & 11.3 & 5.9 & 13.7 & 6.4 & 9.5 & 4.5 & - & - & - & - & - \\
\hline Correcting inequalities ..................... & 22.5 & 31.1 & 16.6 & 18.2 & 16.2 & 17.1 & 11.8 & 11.7 & 13.3 & 13.9 & 10.7 & 10.9 & 17.0 & 23.6 & - & - & - \\
\hline Having children & - & - & - & - & - & - & 37.0 & 47.0 & 42.7 & 56.3 & 41.4 & 56.2 & 39.0 & 49.2 & - & - & - \\
\hline Having a happy family life . & 78.6 & 85.7 & 83.1 & 86.7 & 84.2 & 86.4 & 81.6 & 86.3 & 86.1 & 90.2 & 86.8 & 87.8 & - & - & - & - & 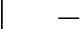 \\
\hline Providing better opportunities for my children ........... & 66.6 & 66.2 & 59.5 & 61.6 & 59.8 & 58.8 & 71.0 & 68.7 & 72.1 & 69.9 & 68.4 & 67.4 & 74.5 & 76.5 & 90.5 & 90.3 & 90.8 \\
\hline Living closer to parents or relatives ...................... & 6.8 & 8.2 & 8.3 & 12.4 & 7.7 & 11.9 & 15.0 & 15.7 & 15.6 & 20.1 & 12.9 & 19.8 & 15.2 & 18.7 & - & - & - \\
\hline Moving from area & 14.3 & 14.6 & 8.3 & 7.4 & 6.7 & 6.4 & 14.4 & 12.8 & 10.5 & 9.1 & 9.0 & 7.4 & 20.7 & 20.1 & - & - & - \\
\hline Having strong friendships & 81.2 & 78.7 & 76.5 & 74.7 & 76.1 & 72.1 & 80.4 & 79.1 & 80.1 & 79.7 & 76.5 & 75.0 & 79.8 & 80.0 & 87.6 & 88.1 & 87.0 \\
\hline 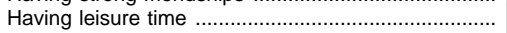 & - & - & 60.9 & 55.1 & 65.4 & 60.1 & 70.2 & 68.8 & 74.5 & 72.0 & 70.1 & 68.9 & 65.3 & 62.0 & - & - & - \\
\hline
\end{tabular}

-Question not asked

SOURCE: U.S. Department of Education, National Center for Education Statistics, "National Longitudinal Study," "High School and Beyond" surveys, and "National Edu- cation Longitudinal Study," second and third followup surveys. (This table was prepared June 1995.) 
Table 377.-Labor force participation of persons 16 years old and over, by age, sex, race/ethnicity, and highest level of education: 1997

\begin{tabular}{|c|c|c|c|c|c|c|c|c|c|c|c|c|}
\hline \multirow{3}{*}{ Age, sex, and race/ethnicity } & \multicolumn{6}{|c|}{ Labor force participation rate ${ }^{1}$} & \multicolumn{6}{|c|}{ Employment/population ratio ${ }^{2}$} \\
\hline & \multirow[b]{2}{*}{ Total } & \multirow{2}{*}{$\begin{array}{l}\text { Less than } \\
\text { high } \\
\text { school } \\
\text { graduate }^{3}\end{array}$} & \multirow{2}{*}{$\begin{array}{c}\text { High } \\
\text { school } \\
\text { graduate }\end{array}$} & \multicolumn{3}{|c|}{ College } & \multirow[b]{2}{*}{ Total } & \multirow{2}{*}{$\begin{array}{c}\text { Less than } \\
\text { high } \\
\text { school } \\
\text { graduate }^{3}\end{array}$} & \multirow{2}{*}{$\begin{array}{l}\text { High } \\
\text { school } \\
\text { graduate }\end{array}$} & \multicolumn{3}{|c|}{ College } \\
\hline & & & & $\begin{array}{c}\text { Some col- } \\
\text { lege, no } \\
\text { degree }\end{array}$ & $\begin{array}{l}\text { Associate } \\
\text { degree }\end{array}$ & $\begin{array}{c}\text { Bachelor's } \\
\text { degree or } \\
\text { higher }\end{array}$ & & & & $\begin{array}{c}\text { Some col- } \\
\text { lege, no } \\
\text { degree }\end{array}$ & $\begin{array}{l}\text { Associate } \\
\text { degree }\end{array}$ & $\begin{array}{l}\text { Bachelor's } \\
\text { degree or } \\
\text { higher }\end{array}$ \\
\hline 1 & 2 & 3 & 4 & 5 & 6 & 7 & 8 & 9 & 10 & 11 & 12 & 13 \\
\hline 16 to 19 years old 4 . & 51.6 & 44.7 & 69.4 & 61.5 & (5) & (5) & 43.4 & 36.2 & 59.6 & 56.2 & (5) & (5) \\
\hline 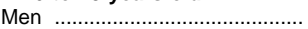 & 52.3 & 46.1 & 72.1 & 58.3 & $(5)$ & (5) & 43.4 & 37.0 & 62.1 & 52.9 & $(5)$ & $(5)$ \\
\hline Women & 51.0 & 43.1 & 66.7 & 63.8 & (5) & (5) & 43.3 & 35.3 & 57.3 & 58.7 & (5) & (5) \\
\hline White 6 & 55.2 & 48.2 & 72.5 & 64.6 & (5) & (5) & 47.7 & 40.4 & 64.0 & 60.0 & (5) & (5) \\
\hline 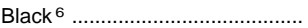 & 38.7 & 32.5 & 58.2 & 47.9 & (5) & (5) & 26.1 & 20.6 & 41.9 & 37.8 & (5) & (5) \\
\hline Hispanic ${ }^{7}$ & 43.0 & 37.0 & 62.8 & 57.1 & $(5)$ & $(5)$ & 33.7 & 27.5 & 53.0 & 50.7 & $(5)$ & $(5)$ \\
\hline 20 to 24 years old 4 . & 77.6 & 68.1 & 82.6 & 73.8 & 84.5 & 85.3 & 71.0 & 56.5 & 74.6 & 68.8 & 80.9 & 82.2 \\
\hline Men ……….................... & 82.5 & 83.0 & 89.5 & 74.6 & 87.2 & 85.9 & 75.2 & 70.5 & 80.9 & 69.3 & 83.6 & 82.3 \\
\hline ……............. & 72.7 & 50.1 & 75.1 & 73.0 & 82.2 & 84.9 & 66.8 & 39.5 & 67.8 & 68.4 & 78.6 & 82.1 \\
\hline White ${ }^{6}$. & 79.6 & 71.3 & 84.3 & 75.8 & 85.4 & 86.7 & 74.1 & 61.7 & 77.6 & 71.5 & 82.5 & 84.0 \\
\hline Black 6 .. & 70.9 & 56.6 & 76.4 & 68.3 & 82.2 & 88.0 & 57.9 & 36.3 & 62.3 & 58.7 & 73.6 & 82.3 \\
\hline Hispanic $^{7}$..................... & 76.4 & 71.0 & 80.7 & 78.7 & 79.6 & 79.7 & 68.6 & 61.7 & 72.7 & 72.1 & 74.5 & 76.7 \\
\hline 25 and older & 67.4 & 42.2 & 65.8 & 72.8 & 79.3 & 80.5 & 64.9 & 38.8 & 63.0 & 70.2 & 77.2 & 78.9 \\
\hline Men & 76.4 & 55.0 & 76.6 & 80.3 & 86.3 & 85.0 & 73.6 & 51.1 & 73.3 & 77.6 & 84.0 & 83.4 \\
\hline Women …....................... & 59.3 & 30.7 & 56.8 & 65.9 & 74.1 & 75.5 & 57.0 & 27.7 & 54.4 & 63.5 & 72.0 & 73.8 \\
\hline 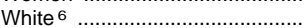 & 67.3 & 42.6 & 65.1 & 71.9 & 79.0 & 80.2 & 65.1 & 39.6 & 62.7 & 69.7 & 77.1 & 78.7 \\
\hline Black $^{6}$. & 67.2 & 39.4 & 70.2 & 78.4 & 82.3 & 84.5 & 62.3 & 34.2 & 64.5 & 73.6 & 78.7 & 81.4 \\
\hline 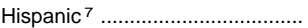 & 69.8 & 58.6 & 75.2 & 81.3 & 82.3 & 83.9 & 65.6 & 53.7 & 70.9 & 77.9 & 79.0 & 81.0 \\
\hline
\end{tabular}

${ }_{1}^{1}$ Percent of the civilian population who are employed or seeking employment.

2 Number of persons employed as a percent of civilian population.

3 Includes persons reporting no school years completed.

${ }^{4}$ Excludes persons enrolled in school.

${ }^{5}$ Sample size too small for stable estimates.
6 Includes persons of Hispanic origin.

Hispanics may be of any race.

SOURCE: U.S. Department of Labor, Bureau of Labor Statistics, Office of Employmen and Unemployment Statistics, unpublished tabulations of annual averages from the Current Population Survey. (This table was prepared September 1998.)

Table 378.-Occupation of employed persons 25 years old and over, by educational attainment and sex: 1997

\begin{tabular}{|c|c|c|c|c|c|c|c|c|c|}
\hline \multirow{3}{*}{ Sex and occupation } & \multirow{3}{*}{$\begin{array}{c}\text { Total } \\
\text { employed, } \\
\text { in } \\
\text { thousands }\end{array}$} & \multicolumn{8}{|c|}{ Percentage distribution, by years of school completed } \\
\hline & & \multirow[b]{2}{*}{ Total } & \multirow[b]{2}{*}{$\begin{array}{l}\text { Less than } \\
\text { one year of } \\
\text { high school }\end{array}$} & \multicolumn{2}{|c|}{ High school } & \multicolumn{4}{|c|}{ College } \\
\hline & & & & $\begin{array}{l}\text { 1-4 years } \\
\text { of high } \\
\text { school, no } \\
\text { diploma }\end{array}$ & $\begin{array}{l}\text { High school } \\
\text { graduate }\end{array}$ & $\begin{array}{l}\text { Some col- } \\
\text { lege, no } \\
\text { degree }\end{array}$ & $\begin{array}{l}\text { Associate } \\
\text { degree }\end{array}$ & $\begin{array}{l}\text { Bachelor's } \\
\text { degree }\end{array}$ & $\begin{array}{c}\text { More than a } \\
\text { bachelor's } \\
\text { degree }\end{array}$ \\
\hline 1 & 2 & 3 & 4 & 5 & 6 & 7 & 8 & 9 & 10 \\
\hline \multicolumn{10}{|l|}{ All persons } \\
\hline All occupational groups & 106,757 & 100.0 & 3.5 & 6.6 & 32.7 & 18.8 & 8.9 & 19.7 & 9.8 \\
\hline Managerial and professional specialty ........... & 34,446 & 100.0 & 0.3 & 1.4 & 13.1 & 13.8 & 8.7 & 36.3 & 26.3 \\
\hline Executive, administrative, and managerial & 16,965 & 100.0 & 0.5 & 2.2 & 20.8 & 19.6 & 8.4 & 33.9 & 14.6 \\
\hline Professional specialty occupations .................... & 17,481 & 100.0 & 0.2 & 0.5 & 5.7 & 8.2 & 9.1 & 38.6 & 37.6 \\
\hline Teachers, except college and university ...................... & 4,342 & 100.0 & 0.1 & 0.5 & 5.3 & 6.0 & 3.2 & 48.5 & 36.3 \\
\hline Teachers, college and university .................. & 751 & 100.0 & 0.0 & 0.0 & 0.5 & 2.3 & 1.7 & 15.8 & 79.5 \\
\hline Technical, sales, and administrative support & 30,459 & 100.0 & 0.8 & 3.5 & 35.6 & 25.6 & 11.3 & 19.8 & 3.4 \\
\hline 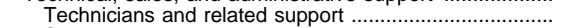 & 3,688 & 100.0 & 0.2 & 1.4 & 19.8 & 24.2 & 23.9 & 24.8 & 5.7 \\
\hline Sales occupations & 11,722 & 100.0 & 1.3 & 4.7 & 33.0 & 23.0 & 7.8 & 25.8 & 4.5 \\
\hline Administrative support, including clerical ........ & 15,049 & 100.0 & 0.6 & 3.0 & 41.6 & 27.9 & 11.0 & 13.9 & 2.0 \\
\hline 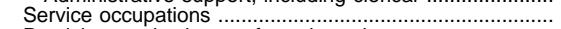 & 12,354 & 100.0 & 7.6 & 12.6 & 43.6 & 19.7 & 7.8 & 7.6 & 1.2 \\
\hline 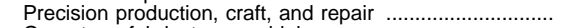 & 12,380 & 100.0 & 5.5 & 11.0 & 47.5 & 20.2 & 9.0 & 5.8 & 1.0 \\
\hline 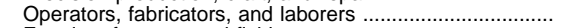 & 14,594 & 100.0 & 8.6 & 15.7 & 50.4 & 15.3 & 5.2 & 4.2 & 0.6 \\
\hline 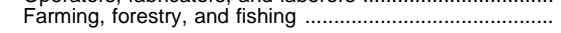 & 2,524 & 100.0 & 18.5 & 12.2 & 37.3 & 14.3 & 6.2 & 9.5 & 1.9 \\
\hline \multicolumn{10}{|l|}{ Men } \\
\hline All occupational groups & 57,507 & 100.0 & 4.3 & 7.4 & 32.2 & 18.3 & 7.7 & 19.6 & 10.5 \\
\hline Managerial and professional specialty .............. & 17,574 & 100.0 & 0.5 & 1.6 & 12.1 & 13.6 & 6.6 & 36.2 & 29.4 \\
\hline Executive, administrative, and managerial & 9,436 & 100.0 & 0.7 & 2.5 & 18.1 & 18.1 & 7.1 & 36.5 & 17.0 \\
\hline Professional specialty occupations ................. & 8,139 & 100.0 & 0.2 & 0.5 & 5.2 & 8.4 & 5.9 & 35.9 & 43.8 \\
\hline Teachers, except college and university ....................... & 1,045 & 100.0 & 0.1 & 0.4 & 4.3 & 6.7 & 3.3 & 44.3 & 41.1 \\
\hline Teachers, college and university ............... & 430 & 100.0 & 0.0 & 0.0 & 0.7 & 2.1 & 1.6 & 15.1 & 80.5 \\
\hline Technical, sales, and administrative support & 11,029 & 100.0 & 1.1 & 3.1 & 27.5 & 24.8 & 10.1 & 28.0 & 5.3 \\
\hline 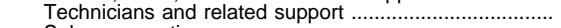 & 1,754 & 100.0 & 0.3 & 1.3 & 17.7 & 25.0 & 20.0 & 28.6 & 7.0 \\
\hline Sales occupations ………........................... & 6,226 & 100.0 & 1.3 & 3.2 & 26.6 & 23.9 & 7.7 & 31.5 & 5.8 \\
\hline Administrative support, including clerical . & 3,048 & 100.0 & 1.3 & 3.7 & 34.9 & 26.7 & 9.6 & 20.5 & 3.2 \\
\hline Service occupations & 4,816 & 100.0 & 8.4 & 10.3 & 38.0 & 22.2 & 8.9 & 10.2 & 1.8 \\
\hline 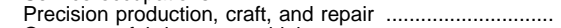 & 11,273 & 100.0 & 5.5 & 10.8 & 47.3 & 20.5 & 9.2 & 5.6 & 1.0 \\
\hline 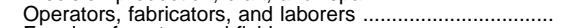 & 10,816 & 100.0 & 7.7 & 15.3 & 50.1 & 16.3 & 5.4 & 4.5 & 0.6 \\
\hline 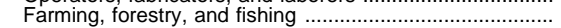 & 2,000 & 100.0 & 20.2 & 13.0 & 37.0 & 13.4 & 5.6 & 9.1 & 2.0 \\
\hline \multicolumn{10}{|l|}{ Women } \\
\hline All occupational groups ...... & 49,250 & 100.0 & 2.5 & 5.7 & 33.4 & 19.3 & 10.2 & 19.9 & 9.0 \\
\hline Managerial and professional specialty & 16,872 & 100.0 & 0.2 & 1.2 & 14.2 & 14.0 & 11.0 & 36.3 & 23.1 \\
\hline Executive, administrative, and managerial & 7,530 & 100.0 & 0.3 & 1.9 & 24.1 & 21.5 & 10.0 & 30.6 & 11.6 \\
\hline 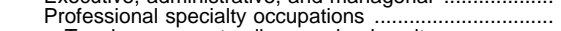 & 9,342 & 100.0 & 0.2 & 0.5 & 6.2 & 8.0 & 11.9 & 41.0 & 32.2 \\
\hline Teachers, except college and university ......................... & 3,297 & 100.0 & 0.1 & 0.5 & 5.6 & 5.8 & 3.3 & 49.9 & 34.7 \\
\hline Teachers, college and university .............. & 321 & 100.0 & 0.0 & 0.0 & 0.3 & 2.5 & 1.6 & 16.8 & 78.5 \\
\hline Technical, sales, and administrative support & 19,431 & 100.0 & 0.6 & 3.7 & 40.2 & 26.0 & 12.0 & 15.1 & 2.4 \\
\hline 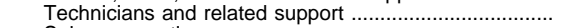 & 1,933 & 100.0 & 0.1 & 1.4 & 21.7 & 23.4 & 27.6 & 21.3 & 4.6 \\
\hline 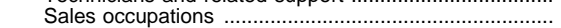 & 5,496 & 100.0 & 1.3 & 6.5 & 40.1 & 22.0 & 8.0 & 19.2 & 3.0 \\
\hline Administrative support, including clerical .... & 12,001 & 100.0 & 0.4 & 2.8 & 43.3 & 28.2 & 11.4 & 12.2 & 1.7 \\
\hline 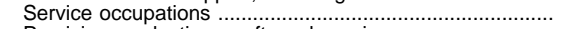 & 7,538 & 100.0 & 7.0 & 14.0 & 47.2 & 18.1 & 7.0 & 5.9 & 0.8 \\
\hline Precision production, craft, and repair .............. & 1,107 & 100.0 & 6.1 & 12.2 & 48.8 & 17.0 & 7.1 & 7.8 & 1.1 \\
\hline 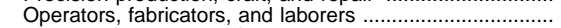 & 3,778 & 100.0 & 11.0 & 16.7 & 51.1 & 12.5 & 4.7 & 3.4 & 0.5 \\
\hline 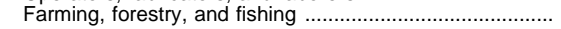 & 524 & 100.0 & 12.2 & 9.7 & 38.5 & 17.7 & 8.8 & 11.3 & 1.9 \\
\hline
\end{tabular}

NOTE.-Because of rounding, details may not add to totals.

SOURCE: U.S. Department of Labor, Bureau of Labor Statistics, Office of Employment and Unemployment Statistics, unpublished tabulations from the Current Population Survey. (This table was prepared August 1998.) 
Table 379.-Unemployment rate of persons 16 years old and over, by age, sex, race/ethnicity, and highest degree attained: 1995, 1996, and 1997

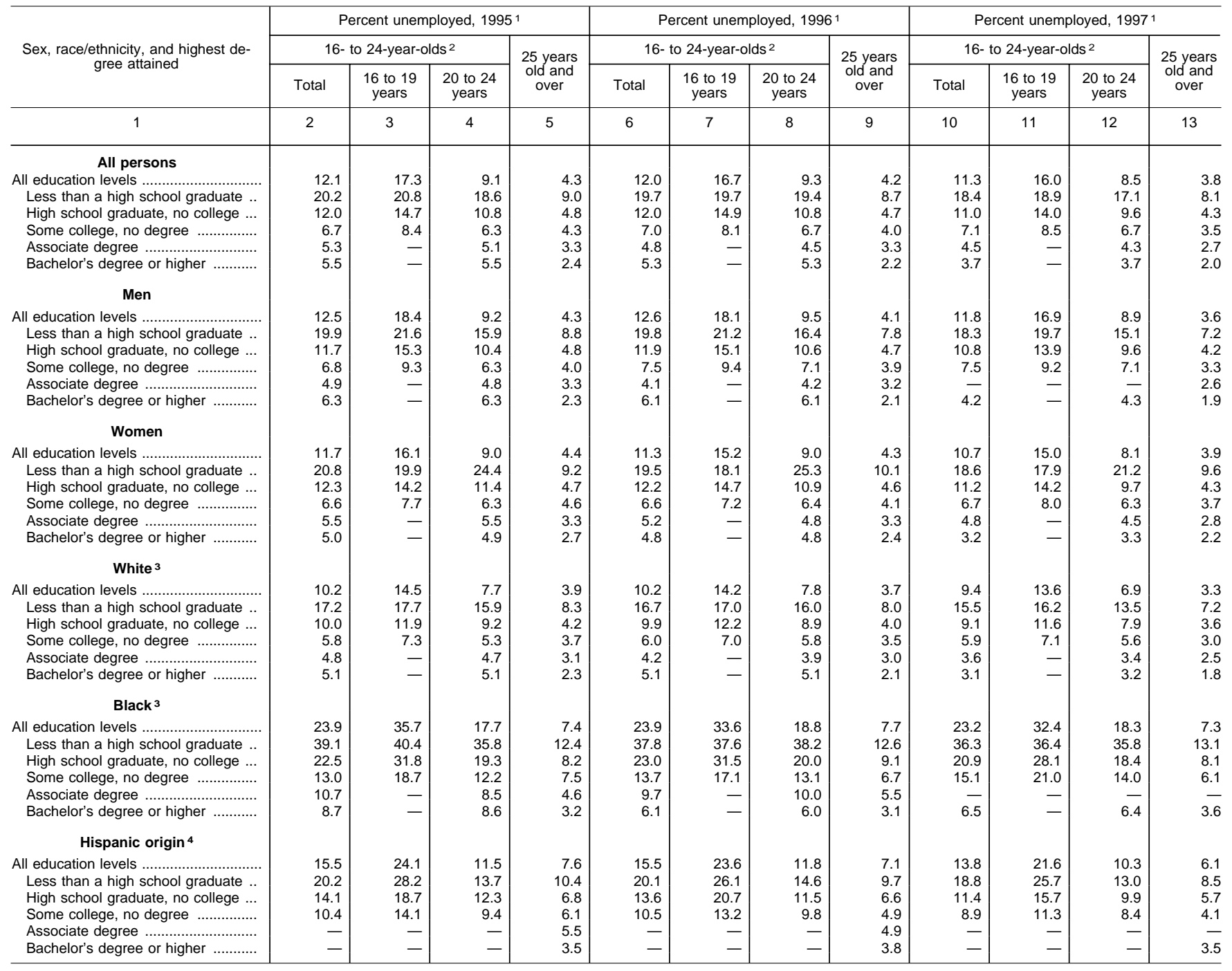

${ }^{1}$ The unemployment rate is the percent of individuals in the labor force who are not working and who made specific efforts to find employment sometime during the prior 4 weeks. The labor force includes both employed and unemployed persons.

2Excludes persons enrolled in school.

3 Includes persons of Hispanic origin.

-Data not available.

SOURCE: U.S. Department of Labor, Bureau of Labor Statistics, Office of Employment and Unemployment Statistics, unpublished tabulations of annual everages from the Current Population Survey. (This table was prepared September 1998.) 
Table 380.-Median annual income of year-round full-time workers 25 years old and over, by level of education completed and sex: 1989 to 1997

\begin{tabular}{|c|c|c|c|c|c|c|c|c|c|c|c|}
\hline \multirow{3}{*}{ Sex and year } & \multirow{3}{*}{ Total } & \multicolumn{3}{|c|}{ Elementary/secondary } & \multicolumn{7}{|c|}{ College } \\
\hline & & \multirow{2}{*}{$\begin{array}{l}\text { Less than } \\
\text { 9th grade }\end{array}$} & \multirow{2}{*}{$\begin{array}{c}\text { 9th to } \\
12 \text { th } \\
\text { grade, no }^{\text {diploma }}{ }^{1}\end{array}$} & \multirow{2}{*}{$\begin{array}{l}\text { High } \\
\text { school } \\
\text { grad-- } \\
\text { uate }^{2}\end{array}$} & \multirow{2}{*}{$\begin{array}{l}\text { Some } \\
\text { college, } \\
\text { no de- } \\
\text { gree }^{3}\end{array}$} & \multirow{2}{*}{$\begin{array}{l}\text { Associate } \\
\text { degree }{ }^{4}\end{array}$} & \multicolumn{5}{|c|}{ Bachelor's degree or higher 5} \\
\hline & & & & & & & Total $^{5}$ & $\begin{array}{l}\text { Bach- } \\
\text { elor's } 6\end{array}$ & Master's ${ }^{7}$ & $\begin{array}{l}\text { Profes- } \\
\text { sional } 7\end{array}$ & $\begin{array}{l}\text { Doctor- } \\
\text { ate }^{7}\end{array}$ \\
\hline 1 & 2 & 3 & 4 & 5 & 6 & 7 & 8 & 9 & 10 & 11 & 12 \\
\hline & \multicolumn{11}{|c|}{ Current dollars } \\
\hline Men & & & & & & & & & & & \\
\hline 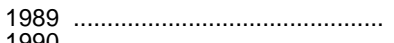 & $\$ 30,465$ & $\$ 17,555$ & $\$ 21,065$ & $\$ 26,609$ & $\$ 31,308$ & - & $\$ 41,892$ & $\$ 38,565$ & - & - & - \\
\hline 1990 & 30,733 & $\begin{array}{l}17,394 \\
17,6 ? 2\end{array}$ & 20,902 & 26,653 & 31,734 & & 42,671 & 39,238 & & & \\
\hline 2) & $\begin{array}{r}31,613 \\
32,057\end{array}$ & $\begin{array}{r}17,623 \\
17,294\end{array}$ & $\begin{array}{r}21,402 \\
21\end{array} \mid$ & 26,779 & $\begin{array}{l}31,663 \\
2,102\end{array}$ & $\$ 33,817$ & $\begin{array}{l}45,138 \\
45802\end{array}$ & 40,906 & $\$ 49,734$ & $\$ 73,996$ & $\$ 57,187$ \\
\hline 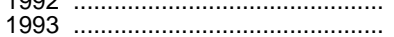 & $\begin{array}{l}32,051 \\
32,359\end{array}$ & $\begin{array}{l}11,294 \\
16,863\end{array}$ & $\begin{array}{r}21,214 \\
21,752\end{array}$ & 27,370 & 32,077 & $\begin{array}{r}33,433 \\
33,690\end{array}$ & $\begin{array}{l}43,802 \\
47,740\end{array}$ & $\begin{array}{l}41,355 \\
42,757\end{array}$ & $\begin{array}{l}49,9 / 3 \\
51,867\end{array}$ & $\begin{array}{l}76,220 \\
80,549\end{array}$ & $\begin{array}{l}57,418 \\
63,149\end{array}$ \\
\hline $994 \ldots . . .$. & 33,440 & 17,532 & 22,048 & 28,037 & 32,279 & 35,794 & 49,228 & 43,663 & 53,500 & 75,009 & $\begin{array}{l}03,149 \\
61,921\end{array}$ \\
\hline $5 \ldots \ldots \ldots \ldots \ldots \ldots \ldots . .$. & 34,551 & 18,354 & 22,185 & 29,510 & 33,883 & 35,201 & 50,481 & 45,266 & 55,216 & 79,667 & 65,336 \\
\hline 1996 & 35,622 & 17,9 & 22,717 & 30,709 & 34,8 & 37,131 & 51, & 45 , & 60,508 & 85,963 & 71,227 \\
\hline 1997 & 36,678 & 19,291 & 24,726 & 31,215 & 35,945 & 38,022 & 53,450 & 48,616 & 61,690 & 85,011 & 76,234 \\
\hline Women & & & & & & & & & & & \\
\hline 1989 & 20,570 & 12,188 & 13,923 & 17,528 & 21,631 & - & 28,799 & 26,709 & - & - & - \\
\hline 1990 & 21,372 & 12,251 & 14,429 & 18,319 & 22,227 & 15000 & 30,377 & 28,017 & & & \\
\hline 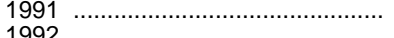 & 22, & 12, & 14,455 & 18,8 & 22, & 25,000 & 31,310 & 29,079 & 34,949 & 46,742 & 43,303 \\
\hline 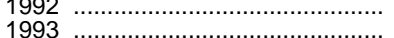 & $\begin{array}{r}23,139 \\
23629\end{array}$ & $\begin{array}{l}12, \\
12\end{array}$ & 14,5 & $\begin{array}{ll}19,4 \\
19\end{array}$ & 23, & $\begin{array}{r}25,624 \\
25882\end{array}$ & 32,304 & 30 , & $\begin{array}{r}36,037 \\
38612\end{array}$ & $\begin{array}{r}46,257 \\
50211\end{array}$ & $\begin{array}{l}45,790 \\
47,248\end{array}$ \\
\hline 1994 & $\begin{array}{l}23,629 \\
24,399\end{array}$ & 12,430 & $\begin{array}{l}15,366 \\
15,133\end{array}$ & 20,373 & $\begin{array}{l}23,056 \\
23,514\end{array}$ & 25,940 & $\begin{array}{l}34,301 \\
35,378\end{array}$ & $\begin{array}{l}31,197 \\
31,741\end{array}$ & $\begin{array}{l}38,612 \\
39,457\end{array}$ & 50,615 & $\begin{array}{l}47,248 \\
51,119\end{array}$ \\
\hline$\ldots . .$. & 24,875 & 13,5 & 15,825 & 20,463 & 23,997 & 27,311 & 35,259 & 32,051 & 40,263 & 50,000 & 48,141 \\
\hline .......... & 25 & 14 & 16. & 21, & 25 & 28,083 & 36,461 & 33 , & 41,901 & 57,624 & 56,267 \\
\hline 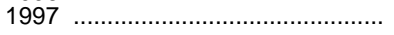 & 26,974 & 14,161 & 16,697 & 22,067 & 26,335 & 28,812 & 38,038 & 35,379 & 44,949 & 61,051 & 53,037 \\
\hline & & & & & Cons & $997 \mathrm{~d}$ & rs & & & & \\
\hline Men & & & & & & & & & & & \\
\hline $1989 \ldots . . .$. & $\$ 39,433$ & $\$ 22,722$ & $\$ 27,266$ & $\$ 34,441$ & $\$ 40,524$ & - & $\$ 54,223$ & $\$ 49,917$ & - & - & - \\
\hline 0 & $\begin{array}{r}37,740 \\
37,253\end{array}$ & 21,360 & 25,668 & $\begin{array}{l}32,730 \\
31557\end{array}$ & 38,969 & & 52,400 & 48,184 & & & \\
\hline $\begin{array}{l}1991 \ldots \ldots . \\
1992 \ldots \ldots .\end{array}$ & $\begin{array}{l}37,253 \\
36,672\end{array}$ & $\begin{array}{l}20,767 \\
19,784\end{array}$ & $\begin{array}{l}25,220 \\
24,337\end{array}$ & $\begin{array}{l}31,557 \\
31,208\end{array}$ & $\begin{array}{l}37,312 \\
36,725\end{array}$ & $\begin{array}{r}\$ 39,850 \\
38,247\end{array}$ & $\begin{array}{l}53,191 \\
52,396\end{array}$ & $\begin{array}{l}48,204 \\
47,309\end{array}$ & $\begin{array}{r}\$ 58,607 \\
57,168\end{array}$ & $\begin{array}{r}\$ 8 /, 198 \\
87,194\end{array}$ & $\begin{array}{r}\$ 6 /, 390 \\
65,685\end{array}$ \\
\hline 1993. & 35,942 & 18 & 24,1 & 30,4 & 35, & 37,420 & 53,026 & 47,491 & 57,610 & 89,468 & 70,141 \\
\hline $4 \ldots . . .$. & & 18 & 23, & & 34 & 38,765 & & 47, & 57,940 & 81,234 & 67,060 \\
\hline $1995 \ldots \ldots$ & 36, & 19, & 23,3 & 31,0 & 35, & 37,072 & 53,164 & 47,672 & 58,151 & 83,901 & 68,809 \\
\hline ........ & 36,439 & 18, & 23,2 & 31,4 & 35,6 & 37,983 & 52,616 & 46,898 & 61,896 & 87,935 & 72,861 \\
\hline 1997 .......... & 36,678 & 19,291 & 24,726 & 31,215 & 35,945 & 38,022 & 53,450 & 48,616 & 61,690 & 85,011 & 76,234 \\
\hline Wome & & & & & & & & & & & \\
\hline 1989 & 26,625 & 15,776 & 18,021 & 22,687 & 27,998 & - & 37,276 & 34,571 & - & - & - \\
\hline 1990 & 26,245 & 15, & 17, & & & & & & & & \\
\hline ........ & 25 & 14, & 17,0 & 22 , & 26 & 29,460 & 36 & & 41,184 & 55,081 & 51,029 \\
\hline & & 14,8 & & & & & & & & & \\
\hline & & 13, & 17, & & & 28,749 & & & & & \\
\hline . & 26 & 13, & 16,3 & 22, & 25 & 28,093 & 38 & 34, & 42,732 & 54,816 & 55,362 \\
\hline 1995. & 26 & 14, & 16,6 & 21,5 & 25 & 28,763 & 37 & & 42,403 & 52,657 & 50,700 \\
\hline $1996 \ldots \ldots$ & 26 & 14 & 17,3 & 21,6 & 25,7 & 28,727 & & & 42 & 58,946 & 57,558 \\
\hline 1997 & 26,974 & 14,161 & 16,697 & 22,067 & 26,335 & 28,812 & 38,038 & 35,379 & 44,949 & 61,051 & 53,037 \\
\hline & & & & & ber v & ee & ids & & & & \\
\hline Mer & & & & & & & & & & & \\
\hline 1989 & 44,596 & 2,425 & 3,312 & 16,392 & 9,028 & - & 13,439 & 7,473 & - & - & - \\
\hline 90 & 44, & & 5 & & & & & 7,569 & - 073 & 1117 & \\
\hline. & & & & $\begin{array}{l}15, \\
14\end{array}$ & & & & & 78 & 1 & $\begin{array}{l}674 \\
745\end{array}$ \\
\hline $\begin{array}{l}1992 . \\
1993 .\end{array}$ & & & & 14 & & $\begin{array}{l}3,200 \\
3,557 \\
3\end{array}$ & & $\begin{array}{l}9,119 \\
9,178\end{array}$ & & 1,231 & 808 \\
\hline 1994. & & 1,8 & 3,0 & 15,109 & 8,7 & 3,735 & 14, & & 3,225 & 1,258 & 868 \\
\hline 19 & & 1,9 & 3,3 & 15 & 8,9 & 3,926 & & & 3,395 & 1,208 & 853 \\
\hline $19 \varsigma$ & 49 & 2,041 & 3,4 & 15,8 & 9,173 & 3,931 & 15 & 9,898 & 3,272 & 1,277 & 893 \\
\hline $1997 \ldots . .$. & 50,807 & 1,914 & 3,548 & 16,225 & 9,170 & 4,086 & 15,864 & 10,349 & 3,228 & 1,321 & 966 \\
\hline Women & & & & & & & & & & & \\
\hline 1989. & 28,056 & 906 & 1,830 & 11,7 & 6,217 & - & 7,318 & 4,465 & -1 & - & - \\
\hline & & 8 & & & & & & & & $\overline{210}$ & 206 \\
\hline & & & 1,8 & & 5,6 & 2,523 & & 5,263 & 2,025 & 312 & 206 \\
\hline & & & 1,6 & & & 2,655 & & & & 33 & 225 \\
\hline & & & 1,5 & & & & & & & 32 & 2 \\
\hline 1994 & & 65 & 1,6 & 10 & 6 & 3,210 & 8 & & 2 , & $3 s$ & 283 \\
\hline 1995 & 32,673 & 774 & 1,763 & 11,064 & 6,329 & 3,336 & 9,406 & 6,434 & 2,268 & 421 & 283 \\
\hline ㄱ. & & 750 & 1,751 & 11,363 & 6,582 & 3,468 & 9,636 & 6,689 & 2,213 & 413 & 322 \\
\hline & 34,624 & 791 & 1,765 & 11,475 & 6,628 & 3,538 & 10,427 & 7,173 & 2,448 & 488 & 318 \\
\hline
\end{tabular}

1 Includes 1 to 3 years high school for 1989 and 1990 .

2 Includes 4 years of high school for 1989 and 1990, and equivalency certificates for the other years.

${ }^{3}$ Includes 1 to 3 years of college and associate degrees for 1989 and 1990.

${ }^{4}$ Not reported separately for 1989 and 1990 .

5 Includes 4 or more years of college for 1989 and 1990.

6 Includes 4 years of college for 1989 and 1990

7 Data not collected in 1989 and 1990
—Data not available or not applicable.

NOTE.-Data for 1982 and later years are based on 1990 census counts. Due to rounding, numbers may not add to totals.

SOURCE: U.S. Department of Commerce, Bureau of the Census, Current Population Reports, Series P-60, "Money Income of Households, Families, and Persons in the United States," "Income, Poverty, and Valuation of Noncash Benefits," various years, "Money Income in the United States: 1995," P60-193, and "Money Income in the United States: 1997" P60-200. (This table was prepared October 1998.) 
Table 381.-Total annual money income and median income of persons 25 years old and over, by educational attainment and sex: 1996

\begin{tabular}{|c|c|c|c|c|c|c|c|c|c|c|c|}
\hline \multirow{3}{*}{ Sex, earnings, and age } & \multirow{3}{*}{ Total } & \multirow{3}{*}{$\begin{array}{l}\text { Less than } \\
\text { 9th grade }\end{array}$} & \multirow{3}{*}{\begin{tabular}{|c|} 
Some \\
high \\
school \\
(no \\
diploma)
\end{tabular}} & \multirow{3}{*}{$\begin{array}{c}\text { High } \\
\text { school } \\
\text { graduate } \\
\text { (includes } \\
\text { equiva- } \\
\text { lency) }\end{array}$} & \multicolumn{7}{|c|}{ College } \\
\hline & & & & & \multirow{2}{*}{$\begin{array}{l}\text { Some } \\
\text { college, } \\
\text { no } \\
\text { degree }\end{array}$} & \multirow[b]{2}{*}{$\begin{array}{c}\text { Associate } \\
\text { degree }\end{array}$} & \multicolumn{5}{|c|}{ Bachelor's degree or higher } \\
\hline & & & & & & & Total & $\begin{array}{l}\text { Bachelor's } \\
\text { degree }\end{array}$ & $\begin{array}{l}\text { Master's } \\
\text { degree }\end{array}$ & $\begin{array}{l}\text { Profes- } \\
\text { sional } \\
\text { degree }\end{array}$ & $\begin{array}{l}\text { Doctor's } \\
\text { degree }\end{array}$ \\
\hline \multirow[t]{2}{*}{1} & 2 & 3 & 4 & 5 & 6 & 7 & 8 & 9 & 10 & 11 & 12 \\
\hline & \multicolumn{11}{|c|}{ Number, in thousands } \\
\hline \multirow{3}{*}{ 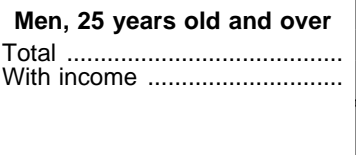 } & & & & & & & & & & & \\
\hline & $\begin{array}{l}81,620 \\
79,423\end{array}$ & $\begin{array}{l}6,477 \\
6,139\end{array}$ & $\begin{array}{l}8,212 \\
7,671\end{array}$ & $\begin{array}{l}26,226 \\
25,510\end{array}$ & $\begin{array}{l}14,033 \\
13,756\end{array}$ & $\begin{array}{l}5,299 \\
5,210\end{array}$ & $\begin{array}{l}21,374 \\
21,136\end{array}$ & $\begin{array}{l}13,672 \\
13,510\end{array}$ & $\begin{array}{l}4,776 \\
4,709\end{array}$ & $\begin{array}{l}1,708 \\
1,702\end{array}$ & $\begin{array}{l}1,218 \\
1,215\end{array}$ \\
\hline & \multicolumn{11}{|c|}{ Percentage distribution of men with income } \\
\hline 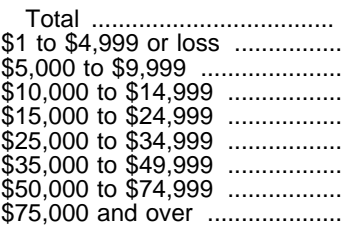 & $\begin{array}{r}100.0 \\
4.3 \\
9.4 \\
11.2 \\
20.1 \\
17.3 \\
17.2 \\
12.4 \\
8.2\end{array}$ & $\begin{array}{r}100.0 \\
8.9 \\
28.8 \\
24.8 \\
22.5 \\
8.9 \\
3.5 \\
1.7 \\
0.9\end{array}$ & $\begin{array}{r}100.0 \\
8.3 \\
17.2 \\
20.8 \\
27.8 \\
14.6 \\
7.1 \\
3.0 \\
1.1\end{array}$ & $\begin{array}{r}100.0 \\
4.5 \\
9.5 \\
11.9 \\
24.5 \\
20.1 \\
18.0 \\
8.7 \\
2.8\end{array}$ & $\begin{array}{r}100.0 \\
3.5 \\
7.0 \\
9.0 \\
20.9 \\
20.6 \\
20.1 \\
13.2 \\
5.6\end{array}$ & $\begin{array}{r}100.0 \\
3.1 \\
4.6 \\
7.1 \\
17.6 \\
20.8 \\
24.7 \\
16.4 \\
5.7\end{array}$ & $\begin{array}{r}100.0 \\
2.2 \\
3.4 \\
5.2 \\
11.2 \\
14.2 \\
20.2 \\
21.8 \\
21.7\end{array}$ & $\begin{array}{r}100.0 \\
2.5 \\
3.9 \\
6.2 \\
13.1 \\
16.3 \\
21.5 \\
21.3 \\
15.1\end{array}$ & \begin{tabular}{r|}
100.0 \\
2.1 \\
2.7 \\
3.6 \\
9.1 \\
12.4 \\
20.1 \\
23.7 \\
26.3
\end{tabular} & $\begin{array}{r}100.0 \\
1.3 \\
2.6 \\
2.5 \\
6.0 \\
8.0 \\
14.4 \\
17.2 \\
48.1\end{array}$ & $\begin{array}{r}100.0 \\
1.4 \\
1.7 \\
3.5 \\
5.9 \\
7.0 \\
14.7 \\
26.3 \\
39.3\end{array}$ \\
\hline \multirow[t]{2}{*}{ Median income ................... } & $\$ 27,248$ & $\$ 12,174$ & $\$ 16,058$ & $\$ 24,814$ & $\$ 29,160$ & $\$ 33,065$ & $\$ 44,161$ & $\$ 39,624$ & $\$ 50,003$ & $\$ 71,869$ & $\$ 62,255$ \\
\hline & \multicolumn{11}{|c|}{ Number, in thousands } \\
\hline \multicolumn{12}{|l|}{$\begin{array}{c}\text { Women, } 25 \text { years old and } \\
\text { over }\end{array}$} \\
\hline \multirow[t]{2}{*}{ 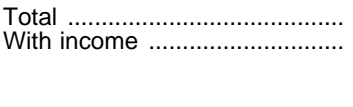 } & $\begin{array}{l}88,961 \\
83,056\end{array}$ & $\begin{array}{l}6,836 \\
5,775\end{array}$ & $\begin{array}{l}9,000 \\
7,929\end{array}$ & $\begin{array}{l}31,360 \\
29,212\end{array}$ & $\begin{array}{l}15,335 \\
14,528\end{array}$ & $\begin{array}{l}7,107 \\
6,839\end{array}$ & $\begin{array}{l}19,323 \\
18,775\end{array}$ & $\begin{array}{l}13,685 \\
13,247\end{array}$ & $\begin{array}{l}4,356 \\
4,285\end{array}$ & $\begin{array}{l}739 \\
715\end{array}$ & $\begin{array}{l}543 \\
527\end{array}$ \\
\hline & \multicolumn{11}{|c|}{ Percentage distribution of women with income } \\
\hline 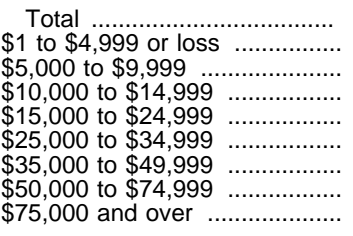 & $\begin{array}{r}100.0 \\
16.2 \\
20.1 \\
14.5 \\
21.2 \\
13.0 \\
8.9 \\
4.4 \\
1.9\end{array}$ & $\begin{array}{r}100.0 \\
24.5 \\
45.8 \\
16.5 \\
9.5 \\
2.1 \\
0.8 \\
0.6 \\
0.2\end{array}$ & $\begin{array}{r}100.0 \\
22.5 \\
36.1 \\
19.3 \\
15.7 \\
3.9 \\
1.6 \\
0.5 \\
0.3\end{array}$ & $\begin{array}{r}100.0 \\
17.1 \\
21.8 \\
18.0 \\
24.9 \\
10.8 \\
5.0 \\
1.8 \\
0.6\end{array}$ & $\begin{array}{r}100.0 \\
15.3 \\
16.5 \\
14.7 \\
24.8 \\
14.8 \\
9.2 \\
3.6 \\
1.0\end{array}$ & $\begin{array}{r}100.0 \\
12.5 \\
12.1 \\
12.9 \\
23.8 \\
19.5 \\
13.1 \\
4.9 \\
1.2\end{array}$ & $\begin{array}{r}100.0 \\
11.4 \\
8.5 \\
6.9 \\
17.4 \\
19.8 \\
18.7 \\
11.6 \\
5.8\end{array}$ & $\begin{array}{r}100.0 \\
12.9 \\
9.5 \\
7.7 \\
19.3 \\
20.5 \\
16.5 \\
9.5 \\
4.0\end{array}$ & $\begin{array}{r}100.0 \\
8.0 \\
6.1 \\
5.3 \\
13.3 \\
20.0 \\
25.6 \\
15.6 \\
6.2\end{array}$ & $\begin{array}{r}100.0 \\
9.0 \\
4.6 \\
3.6 \\
9.4 \\
13.0 \\
16.6 \\
18.9 \\
24.9\end{array}$ & $\begin{array}{r}100.0 \\
5.5 \\
5.7 \\
3.2 \\
13.5 \\
11.2 \\
20.3 \\
19.7 \\
20.9\end{array}$ \\
\hline Median income .................... & $\$ 14,682$ & $\$ 7,276$ & $\$ 8,544$ & $\$ 12,702$ & $\$ 16,255$ & $\$ 20,460$ & $\$ 27,556$ & $\$ 25,192$ & $\$ 33,302$ & $\$ 42,059$ & $\$ 42,431$ \\
\hline
\end{tabular}


Table 382.-College enrollment and labor force status of 1996 and 1997 high school graduates, by sex and race/ethnicity: October 1996 and October 1997

[Numbers in thousands]

\begin{tabular}{|c|c|c|c|c|c|c|c|c|c|c|}
\hline \multirow{3}{*}{ Item } & \multicolumn{3}{|c|}{ Civilian noninstitutional population } & \multicolumn{6}{|c|}{ Civilian labor force $^{1}$} & \multirow{3}{*}{$\begin{array}{l}\text { Not in } \\
\text { labor } \\
\text { force }\end{array}$} \\
\hline & \multirow[b]{2}{*}{ Number } & \multirow[b]{2}{*}{ Percent } & \multirow{2}{*}{$\begin{array}{c}\text { Percent of } \\
\text { high } \\
\text { school } \\
\text { graduates }\end{array}$} & \multirow[b]{2}{*}{ Number } & \multirow{2}{*}{$\begin{array}{l}\text { Labor } \\
\text { force par- } \\
\text { ticipation } \\
\text { rate }\end{array}$} & \multicolumn{2}{|c|}{ Employed } & \multicolumn{2}{|c|}{ Unemployed } & \\
\hline & & & & & & Number & $\begin{array}{l}\text { Percent of } \\
\text { population }\end{array}$ & Number & $\begin{array}{c}\text { Unem- } \\
\text { ployment } \\
\text { rate }\end{array}$ & \\
\hline 1 & 2 & 3 & 4 & 5 & 6 & 7 & 8 & 9 & 10 & 11 \\
\hline $\begin{array}{l}1996 \text { high school graduates } \\
\text { Total }\end{array}$ & 2,660 & 100.0 & 100.0 & 1,528 & 57.4 & 1,225 & 46.1 & 303 & 19.8 & 1,132 \\
\hline Men … & $\begin{array}{l}1,297 \\
1,363\end{array}$ & $\begin{array}{l}48.8 \\
51.2\end{array}$ & $\begin{array}{l}48.8 \\
51.2\end{array}$ & $\begin{array}{l}771 \\
756\end{array}$ & $\begin{array}{l}59.5 \\
55.5\end{array}$ & $\begin{array}{l}605 \\
620\end{array}$ & $\begin{array}{l}46.6 \\
45.5\end{array}$ & $\begin{array}{l}167 \\
136\end{array}$ & $\begin{array}{l}21.6 \\
18.0\end{array}$ & $\begin{array}{l}526 \\
606\end{array}$ \\
\hline 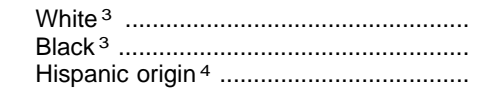 & $\begin{array}{r}2,092 \\
416 \\
227 \\
\end{array}$ & $\begin{array}{r}78.6 \\
15.6 \\
8.5 \\
\end{array}$ & $\begin{array}{r}78.6 \\
15.6 \\
8.5 \\
\end{array}$ & $\begin{array}{r}1,253 \\
231 \\
138 \\
\end{array}$ & $\begin{array}{l}59.9 \\
55.6 \\
60.6\end{array}$ & $\begin{array}{r}1,047 \\
150 \\
100 \\
\end{array}$ & $\begin{array}{l}50.0 \\
36.1 \\
44.1\end{array}$ & $\begin{array}{r}206 \\
82 \\
37 \\
\end{array}$ & $\begin{array}{l}16.5 \\
35.4 \\
27.1\end{array}$ & $\begin{array}{r}839 \\
185 \\
89 \\
\end{array}$ \\
\hline Enrolled in college, October $1996 \ldots \ldots \ldots . .$. & 1,729 & 100.0 & 65.0 & 801 & 46.3 & 676 & 39.1 & 126 & 15.7 & 928 \\
\hline 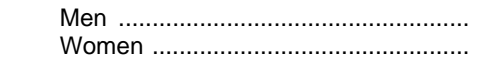 & $\begin{array}{l}779 \\
950\end{array}$ & $\begin{array}{l}45.1 \\
54.9\end{array}$ & $\begin{array}{l}29.3 \\
35.7\end{array}$ & $\begin{array}{l}348 \\
453\end{array}$ & $\begin{array}{l}44.7 \\
47.7\end{array}$ & $\begin{array}{l}286 \\
390\end{array}$ & $\begin{array}{l}36.7 \\
41.1\end{array}$ & $\begin{array}{l}63 \\
63\end{array}$ & $\begin{array}{l}18.0 \\
14.0\end{array}$ & $\begin{array}{l}431 \\
497\end{array}$ \\
\hline 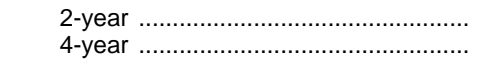 & $\begin{array}{r}615 \\
1,115\end{array}$ & $\begin{array}{l}35.6 \\
64.5\end{array}$ & $\begin{array}{l}23.1 \\
41.9\end{array}$ & $\begin{array}{l}379 \\
422\end{array}$ & $\begin{array}{l}61.7 \\
37.9\end{array}$ & $\begin{array}{l}310 \\
366\end{array}$ & $\begin{array}{l}50.4 \\
32.8\end{array}$ & $\begin{array}{l}69 \\
57\end{array}$ & $\begin{array}{l}18.3 \\
13.4\end{array}$ & $\begin{array}{l}235 \\
692\end{array}$ \\
\hline $\begin{array}{l}\text { Full-time students } \\
\text { Part-time students }\end{array}$ & $\begin{array}{r}1,589 \\
140\end{array}$ & $\begin{array}{r}91.9 \\
8.1\end{array}$ & $\begin{array}{r}59.7 \\
5.3\end{array}$ & $\begin{array}{l}681 \\
120\end{array}$ & $\begin{array}{l}42.8 \\
86.1\end{array}$ & $\begin{array}{l}562 \\
113\end{array}$ & $\begin{array}{l}35.4 \\
80.7\end{array}$ & $\begin{array}{r}119 \\
7\end{array}$ & $\begin{array}{r}17.5 \\
5.8\end{array}$ & $\begin{array}{r}908 \\
19\end{array}$ \\
\hline 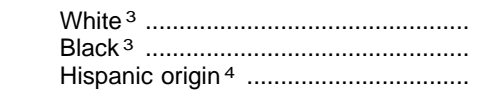 & $\begin{array}{r}1,377 \\
230 \\
115\end{array}$ & $\begin{array}{r}79.6 \\
13.3 \\
6.7\end{array}$ & $\begin{array}{r}51.8 \\
8.6 \\
4.3\end{array}$ & $\begin{array}{r}679 \\
94 \\
66\end{array}$ & $\begin{array}{l}49.4 \\
40.9 \\
57.4\end{array}$ & $\begin{array}{r}584 \\
74 \\
55\end{array}$ & $\begin{array}{l}42.4 \\
32.2 \\
47.8\end{array}$ & $\begin{array}{l}96 \\
21 \\
12\end{array}$ & $\begin{array}{r}14.1 \\
21.8 \\
(5)\end{array}$ & $\begin{array}{r}697 \\
136 \\
49\end{array}$ \\
\hline Not enrolled in college, October 1996 .. & 931 & 100.0 & 35.0 & 726 & 78.1 & 549 & 59.0 & 177 & 24.4 & 204 \\
\hline Men & $\begin{array}{l}518 \\
413\end{array}$ & $\begin{array}{l}55.6 \\
44.4\end{array}$ & $\begin{array}{l}19.5 \\
15.5\end{array}$ & $\begin{array}{l}423 \\
303\end{array}$ & $\begin{array}{l}81.7 \\
73.5\end{array}$ & $\begin{array}{l}319 \\
231\end{array}$ & $\begin{array}{l}61.6 \\
55.9\end{array}$ & $\begin{array}{r}104 \\
73\end{array}$ & $\begin{array}{l}24.6 \\
23.9\end{array}$ & $\begin{array}{r}95 \\
109\end{array}$ \\
\hline $\begin{array}{l}\text { White } 3 \\
\text { Black }^{3} \\
\text { Hispanic origin }^{4}\end{array}$ & $\begin{array}{l}716 \\
186 \\
112 \\
\end{array}$ & $\begin{array}{l}76.9 \\
20.0 \\
12.0\end{array}$ & $\begin{array}{r}26.9 \\
7.0 \\
4.2 \\
\end{array}$ & $\begin{array}{r}574 \\
137 \\
71 \\
\end{array}$ & $\begin{array}{l}80.2 \\
73.8 \\
63.9\end{array}$ & $\begin{array}{r}463 \\
76 \\
46 \\
\end{array}$ & $\begin{array}{l}64.7 \\
40.9 \\
41.1\end{array}$ & $\begin{array}{r}111 \\
61 \\
26 \\
\end{array}$ & $\begin{array}{r}19.3 \\
44.8 \\
(5)\end{array}$ & $\begin{array}{r}142 \\
49 \\
40 \\
\end{array}$ \\
\hline $\begin{array}{ll}1997 \text { high school graduates } & \\
& \\
\text { Total }\end{array}$ & 2,769 & 100.0 & 100.0 & 1,590 & 57.4 & 1,362 & 49.2 & 228 & 14.3 & 1,179 \\
\hline Men & $\begin{array}{l}1,354 \\
1,415\end{array}$ & $\begin{array}{l}48.9 \\
51.1\end{array}$ & $\begin{array}{l}48.9 \\
51.1\end{array}$ & $\begin{array}{l}793 \\
798\end{array}$ & $\begin{array}{l}58.6 \\
56.4\end{array}$ & $\begin{array}{l}675 \\
688\end{array}$ & $\begin{array}{l}49.8 \\
48.6\end{array}$ & $\begin{array}{l}118 \\
110\end{array}$ & $\begin{array}{l}14.9 \\
13.8\end{array}$ & $\begin{array}{l}561 \\
618\end{array}$ \\
\hline 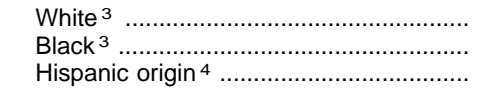 & $\begin{array}{r}2,228 \\
394 \\
336\end{array}$ & $\begin{array}{l}80.5 \\
14.2 \\
12.1\end{array}$ & $\begin{array}{l}80.5 \\
14.2 \\
12.1\end{array}$ & $\begin{array}{r}1,337 \\
193 \\
188\end{array}$ & $\begin{array}{l}60.0 \\
49.0 \\
56.0\end{array}$ & $\begin{array}{r}1,168 \\
140 \\
141\end{array}$ & $\begin{array}{l}52.4 \\
35.5 \\
41.9\end{array}$ & $\begin{array}{r}169 \\
53 \\
47\end{array}$ & $\begin{array}{l}12.6 \\
27.6 \\
25.1\end{array}$ & $\begin{array}{l}891 \\
201 \\
148\end{array}$ \\
\hline Enrolled in college, October $1997 \ldots \ldots \ldots$. & 1,856 & 100.0 & 67.0 & 853 & 46.0 & 751 & 40.5 & 102 & 11.9 & 1,003 \\
\hline $\begin{array}{l}\text { Men } \\
\text { Women }\end{array}$ & $\begin{array}{l}860 \\
995\end{array}$ & $\begin{array}{l}46.3 \\
53.6\end{array}$ & $\begin{array}{l}31.1 \\
35.9\end{array}$ & $\begin{array}{l}364 \\
489\end{array}$ & $\begin{array}{l}42.3 \\
49.1\end{array}$ & $\begin{array}{l}311 \\
440\end{array}$ & $\begin{array}{l}36.2 \\
44.2\end{array}$ & $\begin{array}{l}52 \\
49\end{array}$ & $\begin{array}{l}14.4 \\
10.1\end{array}$ & $\begin{array}{l}497 \\
506\end{array}$ \\
\hline 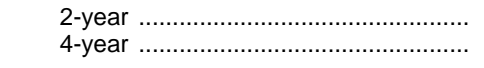 & $\begin{array}{r}630 \\
1,225\end{array}$ & $\begin{array}{l}33.9 \\
66.0\end{array}$ & $\begin{array}{l}22.8 \\
44.2\end{array}$ & $\begin{array}{l}398 \\
454\end{array}$ & $\begin{array}{l}63.2 \\
37.1\end{array}$ & $\begin{array}{l}346 \\
405\end{array}$ & $\begin{array}{l}54.9 \\
33.1\end{array}$ & $\begin{array}{l}52 \\
49\end{array}$ & $\begin{array}{l}13.1 \\
10.8\end{array}$ & $\begin{array}{l}232 \\
771\end{array}$ \\
\hline $\begin{array}{l}\text { Full-time students } \\
\text { Part-time students }\end{array}$ & $\begin{array}{r}1,680 \\
176\end{array}$ & $\begin{array}{r}90.5 \\
9.5\end{array}$ & $\begin{array}{r}60.7 \\
6.4\end{array}$ & $\begin{array}{l}704 \\
149\end{array}$ & $\begin{array}{l}41.9 \\
84.6\end{array}$ & $\begin{array}{l}615 \\
137\end{array}$ & $\begin{array}{l}36.6 \\
77.6\end{array}$ & $\begin{array}{l}89 \\
12\end{array}$ & $\begin{array}{r}12.7 \\
8.3\end{array}$ & $\begin{array}{r}976 \\
27\end{array}$ \\
\hline $\begin{array}{l}\text { White } \\
\text { Black }^{3} \\
\text { Hispanic origin }^{4}\end{array}$ & $\begin{array}{r}1,504 \\
235 \\
220\end{array}$ & $\begin{array}{l}81.0 \\
12.7 \\
11.9\end{array}$ & $\begin{array}{r}54.3 \\
8.5 \\
7.9\end{array}$ & $\begin{array}{r}744 \\
70 \\
101\end{array}$ & $\begin{array}{l}49.5 \\
29.9 \\
45.8\end{array}$ & $\begin{array}{r}659 \\
55 \\
80\end{array}$ & $\begin{array}{l}43.8 \\
23.4 \\
36.5\end{array}$ & $\begin{array}{l}85 \\
15 \\
21\end{array}$ & $\begin{array}{r}11.4 \\
(5) \\
20.4\end{array}$ & $\begin{array}{l}760 \\
165 \\
119\end{array}$ \\
\hline Not enrolled in college, October 1997 . & 913 & 100.0 & 33.0 & 738 & 80.7 & 611 & 66.9 & 126 & 17.1 & 176 \\
\hline Men & $\begin{array}{l}493 \\
420\end{array}$ & $\begin{array}{l}54.0 \\
46.0\end{array}$ & $\begin{array}{l}17.8 \\
15.2\end{array}$ & $\begin{array}{l}429 \\
309\end{array}$ & $\begin{array}{l}86.9 \\
73.5\end{array}$ & $\begin{array}{l}363 \\
248\end{array}$ & $\begin{array}{l}73.7 \\
59.0\end{array}$ & $\begin{array}{l}66 \\
61\end{array}$ & $\begin{array}{l}15.3 \\
19.7\end{array}$ & $\begin{array}{r}64 \\
111\end{array}$ \\
\hline $\begin{array}{l}\text { White } \\
\text { Black }^{3} \\
\text { Hispanic origin } 4\end{array}$ & $\begin{array}{l}724 \\
159 \\
116\end{array}$ & $\begin{array}{l}79.3 \\
17.4 \\
12.7\end{array}$ & $\begin{array}{r}26.1 \\
5.7 \\
4.2\end{array}$ & $\begin{array}{r}593 \\
123 \\
87\end{array}$ & $\begin{array}{l}81.9 \\
77.2 \\
75.4\end{array}$ & $\begin{array}{r}509 \\
85 \\
60\end{array}$ & $\begin{array}{l}70.3 \\
53.3 \\
52.3\end{array}$ & $\begin{array}{l}84 \\
38 \\
27\end{array}$ & $\begin{array}{l}14.1 \\
31.0 \\
30.7\end{array}$ & $\begin{array}{r}131 \\
36 \\
28\end{array}$ \\
\hline
\end{tabular}

1 The labor force includes all employed persons plus those seeking employment. The labor force participation rate is the percentage of persons either employed or seeking employment.

2 Includes 16- to 24-year-olds who graduated from high school between January and October 1996.

3 Includes persons of Hispanic origin.

4 Persons of Hispanic origin may be of any race.

5 Data not shown where base is less than 75,000

6 Includes 16- to 24-year-olds who graduated from high school between January and October 1997.

NOTE.-Data are based upon sample surveys of the civilian noninstitutional population. Percents are only shown when the base is 75,000 or greater. Even though the standard errors are large, smaller estimates are shown to permit users to combine categories in various ways. Because of rounding, details may not add to totals. Detail for the above race and Hispanic-origin groups will not sum to totals because data for the "other races" groups are not presented and Hispanics are included in both the white and black population groups.

SOURCE: U.S. Department of Labor, Bureau of Labor Statistics, "College Enrollment and Work Activity of 1997 High School Graduates." (This table was prepared June 1998.) 
Table 383.-Labor force status of 1979-80 to 1996-97 high school dropouts, by sex and race/ethnicity: October 1980 to October 1997

[Numbers in thousands]

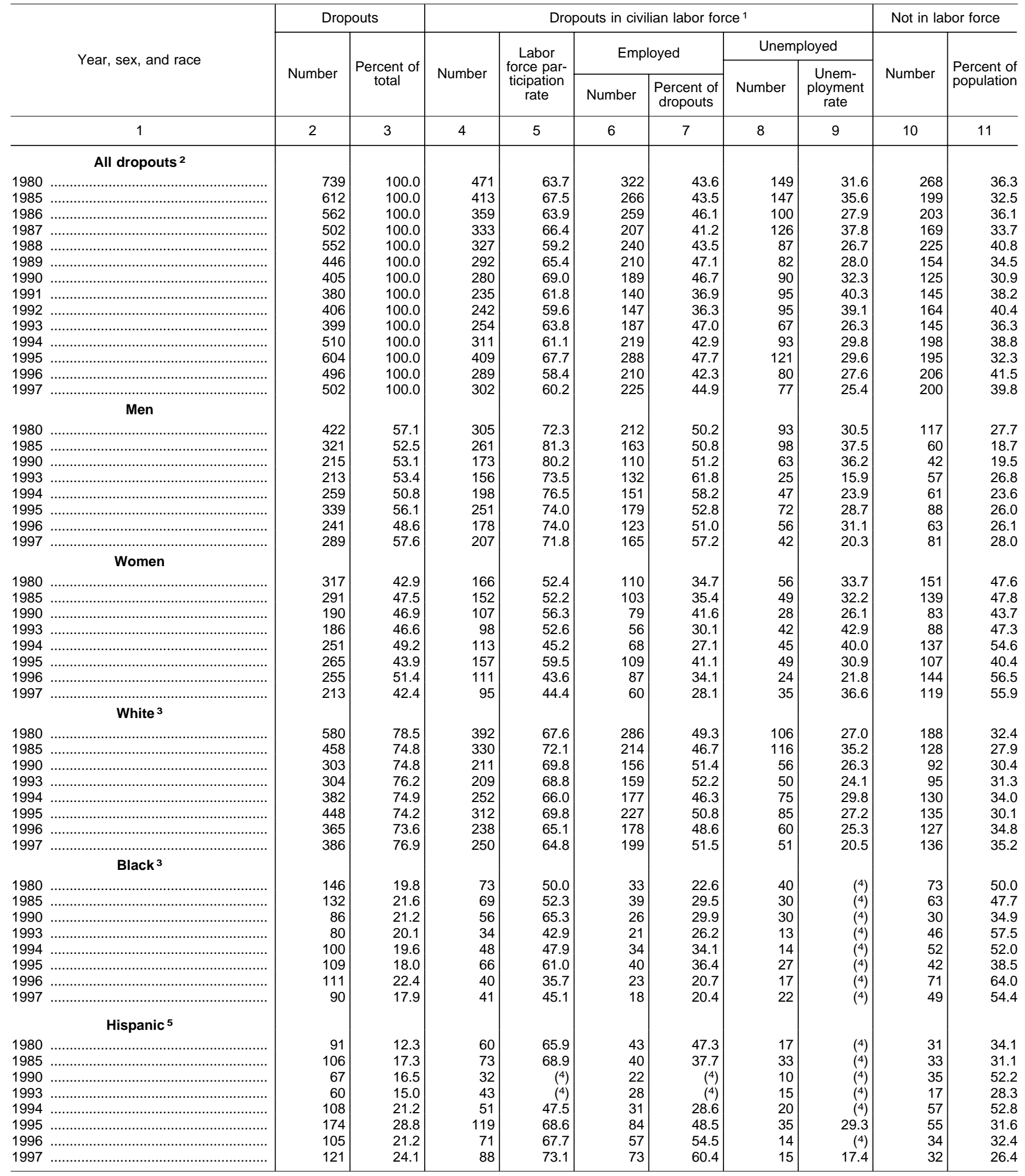

1 The labor force includes all employed persons plus those seeking employment. The labor force participation rate is the percentage of persons either employed or seeking employment. The unemployment rate is the percent of persons in the labor force who are seeking employment.

2 Persons, 16 to 24 years old, who dropped out of school in the 12-month period ending in October of years shown.

3 Includes persons of Hispanic origin.

${ }^{4}$ Data not shown where base is less than 75,000 .

${ }_{5}^{5}$ Persons of Hispanic origin may be of any race.
NOTE.-Data are based upon sample surveys of the civilian noninstitutional population. Includes dropouts from any grade, including a small number from elementary and middle schools. Percents are only shown when the base is 75,000 or greater. Even though the standard errors are large, smaller estimates are shown to permit users to combine categories in various ways. Detail for the above race and Hispanic-origin groups will not sum to totals because data for the "other races" group are not presented and Hispanics are included in both the white and black population groups. Because of rounding, details may not add to totals.

SOURCE: U.S. Department of Labor, Bureau of Labor Statistics, College Enrollment of High School Graduates, various years. (This table was prepared June 1998.) 
Table 384.-Employment of 12th-graders, by selected student characteristics: 1992

\begin{tabular}{|c|c|c|c|c|c|c|c|c|c|c|c|c|c|c|c|}
\hline \multirow{2}{*}{$\begin{array}{c}\text { Employment } \\
\text { characteristics }\end{array}$} & \multirow[b]{2}{*}{ Total } & \multicolumn{2}{|c|}{ Sex } & \multicolumn{5}{|c|}{ Race/ethnicity } & \multicolumn{4}{|c|}{ Socioeconomic status ${ }^{1}$} & \multicolumn{3}{|c|}{$\begin{array}{l}\text { Location of school } \\
\text { attended }\end{array}$} \\
\hline & & Male & Female & White & Black & Hispanic & Asian & $\begin{array}{c}\text { American } \\
\text { Indian }\end{array}$ & Low & $\begin{array}{l}\text { Middle } \\
\text { low }\end{array}$ & $\begin{array}{l}\text { Middle } \\
\text { high }\end{array}$ & High & Urban & Suburban & Rural \\
\hline 1 & 2 & 3 & 4 & 5 & 6 & 7 & 8 & 9 & 10 & 11 & 12 & 13 & 14 & 15 & 16 \\
\hline & \multicolumn{15}{|c|}{ Percentage distribution } \\
\hline \multicolumn{16}{|l|}{ Average hours worked per week during senior year } \\
\hline Total & 100.0 & 100.0 & 100.0 & 100.0 & 100.0 & 100.0 & 100.0 & 100.0 & 100.0 & 100.0 & 100.0 & 100.0 & 100.0 & 100.0 & 100.0 \\
\hline Did not work during year & 31.8 & 33.0 & 30.7 & 27.6 & 47.4 & 38.9 & 43.3 & 45.0 & 38.2 & 29.8 & 28.2 & 32.5 & 35.6 & 29.4 & 31.6 \\
\hline 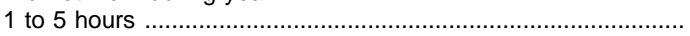 & 6.8 & 6.0 & 7.6 & 7.0 & 4.9 & 6.0 & 9.5 & 8.5 & 5.2 & 5.5 & 5.8 & 10.1 & 6.7 & 6.6 & 7.2 \\
\hline 6 to 10 hours & 9.8 & 8.9 & 10.7 & 11.2 & 6.5 & 5.3 & 6.7 & 5.6 & 6.7 & 8.3 & 10.6 & 12.6 & 9.4 & 9.6 & 10.6 \\
\hline 11 to 15 hours & 12.7 & 11.1 & 14.4 & 14.1 & 7.2 & 11.3 & 9.3 & 6.2 & 9.5 & 11.9 & 13.7 & 15.0 & 12.2 & 13.6 & 12.1 \\
\hline 16 to 20 hours & 16.1 & 15.0 & 17.2 & 17.3 & 11.9 & 13.3 & 13.5 & 12.5 & 13.4 & 18.6 & 18.4 & 14.0 & 14.3 & 18.3 & 14.9 \\
\hline More than 20 hours & 22.7 & 26.0 & 19.5 & 22.8 & 22.1 & 25.2 & 17.7 & 22.3 & 27.1 & 25.9 & 23.3 & 15.8 & 21.7 & 22.5 & 23.7 \\
\hline (1) & 9.8 & 10.2 & 9.5 & 10.0 & 8.8 & 10.7 & 8.1 & 12.0 & 10.2 & 10.9 & 10.8 & 8.0 & 9.5 & 10.6 & 9.1 \\
\hline 26 to 30 hours & 5.6 & 6.5 & 4.8 & 5.5 & 6.4 & 6.6 & 4.4 & 3.8 & 6.8 & 6.4 & 5.9 & 3.4 & 5.3 & 5.7 & 5.8 \\
\hline 31 to 35 hours & 2.5 & 3.1 & 1.9 & 2.6 & 2.4 & 2.4 & 0.8 & 5.0 & 3.6 & 3.2 & 2.4 & 1.3 & 2.3 & 2.5 & 2.7 \\
\hline 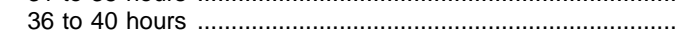 & 3.3 & 4.2 & 2.4 & 3.3 & 2.9 & 4.1 & 3.7 & 0.9 & 4.3 & 4.2 & 2.7 & 2.1 & 3.3 & 2.4 & 4.3 \\
\hline 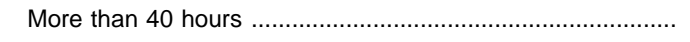 & 1.5 & 2.0 & 1.0 & 1.5 & 1.7 & 1.4 & 0.8 & 0.7 & 2.2 & 1.4 & 1.6 & 1.0 & 1.3 & 1.4 & 1.8 \\
\hline \multicolumn{16}{|l|}{ Most recent type of work for employed students } \\
\hline Total & 100.0 & 100.0 & 100.0 & 100.0 & 100.0 & 100.0 & 100.0 & 100.0 & 100.0 & 100.0 & 100.0 & 100.0 & 100.0 & 100.0 & 100.0 \\
\hline Lawn work or odd jobs & 2.2 & 4.2 & 0.3 & 2.5 & 0.8 & 0.9 & 1.7 & 5.3 & 2.3 & 2.0 & 2.1 & 2.5 & 1.3 & 2.2 & 2.9 \\
\hline 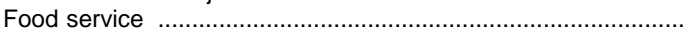 & 24.0 & 22.2 & 25.7 & 22.8 & 34.8 & 24.8 & 22.9 & 24.6 & 28.0 & 26.6 & 25.1 & 18.6 & 23.6 & 23.1 & 25.4 \\
\hline 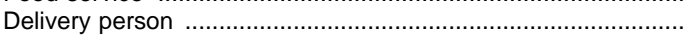 & 1.6 & 2.5 & 0.6 & 1.5 & 1.9 & 1.1 & 3.2 & 1.3 & 0.8 & 1.7 & 1.3 & 2.1 & 1.5 & 1.7 & 1.5 \\
\hline 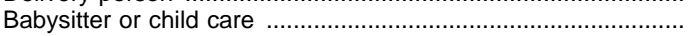 & 4.3 & 0.6 & 7.9 & 4.8 & 2.4 & 2.2 & 5.0 & 1.1 & 3.2 & 3.9 & 4.5 & 5.4 & 4.9 & 4.4 & 3.9 \\
\hline Camp counselor/life guard . & 0.7 & 0.8 & 0.7 & 0.9 & (2) & 0.5 & 0.6 & (2) & 0.2 & 0.3 & 0.9 & 1.3 & 0.8 & 0.9 & 0.5 \\
\hline 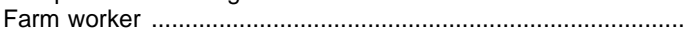 & 2.2 & 4.4 & 0.1 & 2.7 & (2) & 1.1 & (2) & (2) & 3.7 & 3.3 & 1.6 & 1.1 & 0.2 & 1.1 & 5.5 \\
\hline 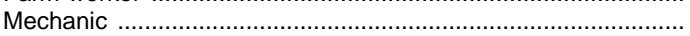 & 1.4 & 2.8 & (2) & 1.5 & 0.7 & 1.5 & 1.0 & 1.4 & 2.0 & 1.8 & 1.5 & 0.6 & 1.0 & 1.3 & 1.9 \\
\hline Grocery clerk or cashier & 14.5 & 12.5 & 16.4 & 14.8 & 15.9 & 11.6 & 8.5 & 25.7 & 15.5 & 16.6 & 14.5 & 12.3 & 14.2 & 13.4 & 16.4 \\
\hline Beautician & 0.2 & 0.1 & 0.3 & 0.1 & 1.1 & 0.3 & (2) & (2) & 0.6 & 0.2 & 0.2 & 0.1 & 0.2 & 0.2 & 0.3 \\
\hline 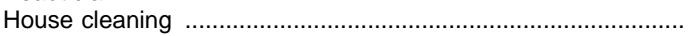 & 0.9 & 0.7 & 1.1 & 0.8 & 0.8 & 2.0 & 0.6 & ${ }^{(2)}$ & 1.5 & 0.6 & 1.2 & 0.6 & 0.7 & 0.6 & 1.4 \\
\hline 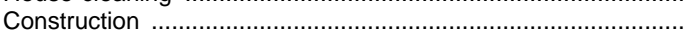 & 2.0 & 4.0 & 0.1 & 2.1 & 1.0 & 1.9 & 0.9 & 2.0 & 2.6 & 2.3 & 1.9 & 1.4 & 1.4 & 1.8 & 2.7 \\
\hline Office or clerical & 6.9 & 2.9 & 10.7 & 6.3 & 9.2 & 8.7 & 12.1 & 5.8 & 6.3 & 6.0 & 7.2 & 8.0 & 9.0 & 6.8 & 5.4 \\
\hline Health services & 1.6 & 0.9 & 2.3 & 1.6 & 2.1 & 1.1 & 1.0 & 4.5 & 2.5 & 2.0 & 1.4 & 0.9 & 1.5 & 1.6 & 1.7 \\
\hline 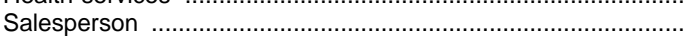 & 11.8 & 9.8 & 13.7 & 12.0 & 8.7 & 11.9 & 15.0 & 7.9 & 7.2 & 8.8 & 12.5 & 15.8 & 13.4 & 14.1 & 7.3 \\
\hline 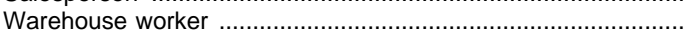 & 2.1 & 3.9 & 0.4 & 2.2 & 1.3 & 1.7 & 2.0 & 2.3 & 1.7 & 2.5 & 1.9 & 2.1 & 2.0 & 2.3 & 1.9 \\
\hline Other & 23.5 & 27.7 & 19.6 & 23.5 & 19.3 & 28.8 & 25.4 & 18.3 & 22.0 & 21.4 & 22.3 & 27.4 & 24.4 & 24.6 & 21.3 \\
\hline \multicolumn{16}{|l|}{ Most recent hourly wage for employed students } \\
\hline Total & 100.0 & 100.0 & 100.0 & 100.0 & 100.0 & 100.0 & 100.0 & 100.0 & 100.0 & 100.0 & 100.0 & 100.0 & 100.0 & 100.0 & 100.0 \\
\hline Less than $\$ 4.25$ per hour. & 9.9 & 7.2 & 12.4 & 10.3 & 8.3 & 8.8 & 7.9 & 5.8 & 12.2 & 11.4 & 9.0 & 8.0 & 7.9 & 7.5 & 14.8 \\
\hline$\$ 4.25$ to $\$ 6.00$ per hour & 77.5 & 75.6 & 79.2 & 76.7 & 80.9 & 81.1 & 77.0 & 79.3 & 79.0 & 76.8 & 80.0 & 74.8 & 80.1 & 77.0 & 75.8 \\
\hline$\$ 6.01$ to $\$ 8.00$ per hour & 7.7 & 10.3 & 5.3 & 8.0 & 5.8 & 6.1 & 10.7 & 6.7 & 5.3 & 8.3 & 6.8 & 9.3 & 7.3 & 9.2 & 6.1 \\
\hline 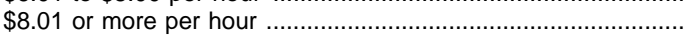 & 5.0 & 6.9 & 3.2 & 5.1 & 5.0 & 4.0 & 4.5 & 8.3 & 3.5 & 3.5 & 4.1 & 7.9 & 4.8 & 6.3 & 3.4 \\
\hline
\end{tabular}

1 Socioeconomic status was measured by a composite score of parental education and occupations and family income. The "Low" SES group is the lowest quartile.

${ }^{2}$ Less than 0.05 percent.
NOTE.-Because of rounding, details may not add to totals.

SOURCE: U.S. Department of Education, National Center for Education Statistics, "National Education Longitudinal Study of 1988," Second Followup survey. (This table was prepared August 1995.) 
Table 385.-Full-time employment status of bachelor's degree recipients 1 year after graduation, by field of study: 1976 to 1991

\begin{tabular}{|c|c|c|c|c|c|c|c|c|c|c|c|c|c|c|c|}
\hline \multirow[b]{2}{*}{ Field of study } & \multicolumn{5}{|c|}{$\begin{array}{l}\text { Percent employed } \\
\text { full-time }\end{array}$} & \multicolumn{5}{|c|}{$\begin{array}{l}\text { Percent employed full-time in a job closely } \\
\text { related to field of study }\end{array}$} & \multicolumn{5}{|c|}{$\begin{array}{l}\text { Percent employed full-time in } \\
\text { nonprofessional job }{ }^{1}\end{array}$} \\
\hline & $\begin{array}{c}1974-75 \\
\text { graduates } \\
\text { in May } \\
1976\end{array}$ & $\begin{array}{c}1979-80 \\
\text { graduates } \\
\text { in May } \\
1981\end{array}$ & $\begin{array}{c}1983-84 \\
\text { graduates } \\
\text { in June } \\
1985\end{array}$ & $\begin{array}{c}1985-86 \\
\text { graduates } \\
\text { in June } \\
1987\end{array}$ & $\begin{array}{c}1989-90 \\
\text { graduates } \\
\text { in April } \\
1991\end{array}$ & $\begin{array}{c}1974-75 \\
\text { graduates } \\
\text { in May } \\
1976\end{array}$ & $\begin{array}{c}1979-80 \\
\text { graduates } \\
\text { in May } \\
1981\end{array}$ & $\begin{array}{c}1983-84 \\
\text { graduates } \\
\text { in June } \\
1985\end{array}$ & $\begin{array}{c}1985-86 \\
\text { graduates } \\
\text { in June } \\
1987\end{array}$ & $\begin{array}{c}1989-90 \\
\text { graduates } \\
\text { in April } \\
1991\end{array}$ & $\begin{array}{c}1974-75 \\
\text { graduates } \\
\text { in May } \\
1976\end{array}$ & $\begin{array}{c}1979-80 \\
\text { graduates } \\
\text { in May } \\
1981\end{array}$ & $\begin{array}{c}1983-84 \\
\text { graduates } \\
\text { in June } \\
1985\end{array}$ & $\begin{array}{c}1985-86 \\
\text { graduates } \\
\text { in June } \\
1987\end{array}$ & $\begin{array}{c}1989-90 \\
\text { graduates } \\
\text { in April } \\
1991\end{array}$ \\
\hline 1 & 2 & 3 & 4 & 5 & 6 & 7 & 8 & 9 & 10 & 11 & 12 & 13 & 14 & 15 & 16 \\
\hline Total . & 67 & 71 & 73 & 74 & 74 & 35 & 38 & 38 & 38 & 39 & 10 & 12 & 13 & 14 & 13 \\
\hline $\begin{array}{l}\text { Professional/technical fields } \\
\text { Arts and sciences fields } \\
\text { Other }\end{array}$ & $\begin{array}{l}77 \\
56 \\
65\end{array}$ & $\begin{array}{l}80 \\
56 \\
74\end{array}$ & $\begin{array}{l}82 \\
56 \\
75\end{array}$ & $\begin{array}{l}81 \\
62 \\
74\end{array}$ & $\begin{array}{l}80 \\
64 \\
73\end{array}$ & $\begin{array}{l}51 \\
18 \\
36\end{array}$ & $\begin{array}{l}51 \\
17 \\
43\end{array}$ & $\begin{array}{l}47 \\
15 \\
47\end{array}$ & $\begin{array}{l}47 \\
25 \\
36\end{array}$ & $\begin{array}{l}48 \\
26 \\
38\end{array}$ & $\begin{array}{r}9 \\
12 \\
9\end{array}$ & $\begin{array}{l}10 \\
14 \\
19\end{array}$ & $\begin{array}{l}13 \\
15 \\
12\end{array}$ & $\begin{array}{l}11 \\
15 \\
17\end{array}$ & $\begin{array}{l}11 \\
14 \\
13\end{array}$ \\
\hline Newly qualified to teach & & & 73 & & 74 & 43 & 56 & & & & 7 & 8 & 9 & 9 & 6 \\
\hline Not newly qualified to tea & 67 & 71 & 73 & 74 & 73 & 33 & 36 & 36 & 37 & 36 & 12 & 13 & 13 & 14 & 14 \\
\hline Professional/technical fields ............. & 80 & 81 & 82 & 82 & 83 & 52 & 49 & 47 & 47 & 48 & 10 & 10 & 13 & 11 & 12 \\
\hline Engineering . & 79 & 84 & 84 & 83 & 84 & 57 & 55 & 53 & 46 & 50 & 4 & 2 & 3 & 5 & 3 \\
\hline Business and management ............... & 84 & 83 & 85 & 85 & 83 & $\begin{array}{l}49 \\
71\end{array}$ & 44 & 41 & 40 & 42 & 15 & 14 & 19 & 17 & 16 \\
\hline Health ............ & 75 & 77 & 75 & 76 & 86 & 71 & 66 & 70 & 65 & 83 & 2 & $\begin{array}{r}4 \\
-10\end{array}$ & 2 & 3 & 1 \\
\hline 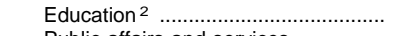 & 66 & 67 & 63 & 73 & 67 & 22 & 29 & 24 & 57 & 39 & 12 & 18 & 16 & 9 & 11 \\
\hline Public affairs and services & - & 77 & 74 & 72 & 66 & - & 46 & 31 & 37 & 49 & - & 10 & 15 & 20 & 9 \\
\hline Arts and sciences fields & 57 & 56 & 56 & 63 & 64 & 17 & 16 & 15 & 25 & 23 & 13 & 15 & 15 & 15 & 15 \\
\hline Biological sciences ........ & 56 & 45 & 43 & 42 & 50 & 26 & 18 & 17 & 15 & 26 & 6 & 8 & 11 & 11 & 8 \\
\hline $\begin{array}{l}\text { Physical sciences and mathe- } \\
\text { matics }^{3}\end{array}$ & & & & & & & & & & & & & & & \\
\hline 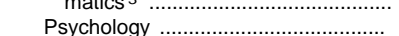 & 61 & 56 & 57 & 66 & $\begin{array}{l}12 \\
59\end{array}$ & $\begin{array}{l}19 \\
22\end{array}$ & $\begin{array}{l}29 \\
17\end{array}$ & $\begin{array}{l}20 \\
12\end{array}$ & $\begin{array}{l}48 \\
22\end{array}$ & $\begin{array}{l}48 \\
22\end{array}$ & $\begin{array}{r}6 \\
18\end{array}$ & $\begin{array}{r}2 \\
17\end{array}$ & $\begin{array}{r}7 \\
16\end{array}$ & \begin{tabular}{r|r}
9 & \\
19 &
\end{tabular}$-10$ & $\begin{array}{r}7 \\
14\end{array}$ \\
\hline Social sciences ........... & 59 & 61 & 61 & 61 & 68 & 12 & 10 & 13 & 12 & 16 & 15 & 21 & 14 & 17 & 20 \\
\hline Humanities ……………………....... & 56 & 55 & 59 & 59 & 59 & 12 & 14 & 17 & 19 & 11 & 17 & 18 & 19 & 19 & 21 \\
\hline Other . & 68 & 75 & 77 & 75 & 73 & 36 & 43 & 42 & 36 & 37 & 10 & 20 & 14 & 21 & 14 \\
\hline 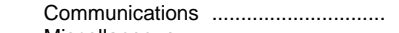 & - & 71 & 76 & 77 & 75 & - & 31 & 31 & 33 & 29 & - & 24 & 16 & 18 & 17 \\
\hline 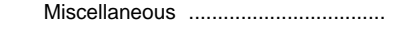 & 66 & 76 & 77 & 74 & 73 & 35 & 46 & 46 & 38 & 38 & 11 & 19 & 13 & 23 & 13 \\
\hline
\end{tabular}

1 Includes those not working in technical, managerial, or administrative types of jobs who reported that they did not need a college degree to obtain their job.

${ }^{2}$ Includes those who have not finished all requirements for teaching certification or were previously qualified to teach. Includes computer sciences.

-Data not available.
NOTE.-Data are from sample surveys of recent college graduates. Notes on methodology are included in the Guide to Sources. Data exclude bachelor's recipients from U.S. Service Schools. Deceased graduates and graduates living at foreign addresses at the time of the survey are not included.

SOURCE: U.S. Department of Education, National Center for Education Statistics, "Recent College Graduates" surveys. (This table was prepared August 1993.) 
Table 386.-Employment status of 1992-93 bachelor's degree recipients 1 year after graduation, by field of study and occupational area: 1994

[Percentage distribution]

\begin{tabular}{|c|c|c|c|c|c|c|c|c|c|c|c|c|c|}
\hline \multirow[b]{2}{*}{ Status in April 1994} & \multirow[b]{2}{*}{$\begin{array}{l}\text { All fields } \\
\text { of study }\end{array}$} & \multicolumn{5}{|c|}{ Professional/technical fields } & \multicolumn{6}{|c|}{ Arts and sciences } & \multirow[b]{2}{*}{$\begin{array}{l}\text { Other } \\
\text { fields }\end{array}$} \\
\hline & & $\begin{array}{l}\text { Business and } \\
\text { management }\end{array}$ & Education & $\begin{array}{c}\text { Engineer- } \\
\text { ing }\end{array}$ & $\begin{array}{l}\text { Health pro- } \\
\text { fessions }\end{array}$ & 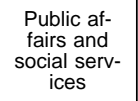 & $\begin{array}{l}\text { Biological } \\
\text { sciences }\end{array}$ & $\begin{array}{l}\text { Mathematics, } \\
\text { computer, and } \\
\text { physical } \\
\text { sciences }\end{array}$ & Social sciences & History & Humanities & $\begin{array}{l}\text { Psychol- } \\
\text { ogy }\end{array}$ & \\
\hline 1 & 2 & 3 & 4 & 5 & 6 & 7 & 8 & 9 & 10 & 11 & 12 & 13 & 14 \\
\hline Total 1992-93 graduates & 100.0 & 100.0 & 100.0 & 100.0 & 100.0 & 100.0 & 100.0 & 100.0 & 100.0 & 100.0 & 100.0 & 100.0 & 100.0 \\
\hline $\begin{array}{l}\text { Time between high school graduation and degree } \\
\text { completion }\end{array}$ & & & & & & & & & & & & & \\
\hline 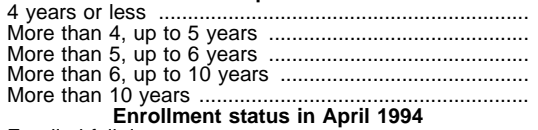 & $\begin{array}{l}31.1 \\
27.6 \\
11.2 \\
12.7 \\
17.4\end{array}$ & $\begin{array}{r}27.5 \\
27.2 \\
9.4 \\
13.3 \\
22.6\end{array}$ & $\begin{array}{l}28.0 \\
30.9 \\
10.5 \\
12.1 \\
18.5\end{array}$ & $\begin{array}{l}21.4 \\
35.2 \\
16.2 \\
13.4 \\
13.8\end{array}$ & $\begin{array}{l}18.0 \\
26.2 \\
12.7 \\
15.1 \\
28.1\end{array}$ & $\begin{array}{l}24.3 \\
28.3 \\
11.9 \\
14.5 \\
21.0\end{array}$ & $\begin{array}{r}47.7 \\
22.7 \\
11.7 \\
6.8 \\
11.1\end{array}$ & $\begin{array}{l}35.0 \\
22.8 \\
10.1 \\
16.1 \\
15.9\end{array}$ & $\begin{array}{r}45.1 \\
24.7 \\
10.1 \\
12.7 \\
7.4\end{array}$ & \begin{tabular}{r|r}
43.2 \\
19.3 \\
16.8 \\
6.5 \\
14.3
\end{tabular} & $\begin{array}{l}34.3 \\
26.0 \\
11.0 \\
14.1 \\
14.6\end{array}$ & $\begin{array}{r}36.6 \\
26.5 \\
7.2 \\
9.8 \\
20.0\end{array}$ & $\begin{array}{l}29.9 \\
30.3 \\
13.3 \\
11.7 \\
14.7\end{array}$ \\
\hline 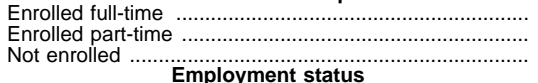 & $\begin{array}{r}12.0 \\
52.8 \\
82.2\end{array}$ & $\begin{array}{r}5.0 \\
4.7 \\
90.3\end{array}$ & $\begin{array}{l}10.9 \\
80.2 \\
80.9\end{array}$ & $\begin{array}{r}14.6 \\
6.6 \\
78.8\end{array}$ & $\begin{array}{r}10.5 \\
6.8 \\
82.7\end{array}$ & $\begin{array}{r}8.7 \\
55.4 \\
85.9\end{array}$ & $\begin{array}{r}26.6 \\
8.6 \\
64.9\end{array}$ & $\begin{array}{r}20.5 \\
4.5 \\
75.1\end{array}$ & $\begin{array}{r}14.4 \\
4.9 \\
80.7\end{array}$ & $\begin{array}{r}18.2 \\
5.3 \\
76.6\end{array}$ & $\begin{array}{r}14.2 \\
50.1 \\
80.7\end{array}$ & $\begin{array}{r}18.4 \\
9.9 \\
71.7\end{array}$ & $\begin{array}{r}10.5 \\
4.5 \\
85.0\end{array}$ \\
\hline 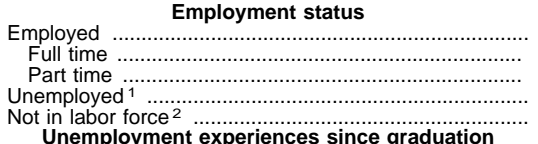 & $\begin{array}{r}87.0 \\
73.1 \\
13.9 \\
4.5 \\
8.5\end{array}$ & $\begin{array}{r}92.4 \\
84.7 \\
7.7 \\
3.6 \\
3.9\end{array}$ & $\begin{array}{r}89.4 \\
68.3 \\
21.1 \\
3.4 \\
7.3\end{array}$ & $\begin{array}{r}85.0 \\
75.8 \\
9.2 \\
6.2 \\
8.8\end{array}$ & $\begin{array}{r}88.7 \\
73.4 \\
15.3 \\
4.5 \\
6.7\end{array}$ & $\begin{array}{r}87.8 \\
74.6 \\
13.2 \\
4.6 \\
7.6\end{array}$ & $\begin{array}{l}68.8 \\
51.6 \\
17.3 \\
7.4 \\
23.8\end{array}$ & $\begin{array}{r}81.6 \\
67.8 \\
13.9 \\
4.9 \\
13.5\end{array}$ & $\begin{array}{r}85.5 \\
72.5 \\
12.9 \\
4.8 \\
9.8\end{array}$ & $\begin{array}{r}86.1 \\
71.7 \\
14.4 \\
5.4 \\
8.5\end{array}$ & $\begin{array}{r}84.3 \\
64.1 \\
20.2 \\
4.9 \\
10.8\end{array}$ & $\begin{array}{r}81.4 \\
66.9 \\
14.5 \\
55.1 \\
13.6\end{array}$ & $\begin{array}{r}88.3 \\
74.6 \\
13.8 \\
4.5 \\
7.2\end{array}$ \\
\hline 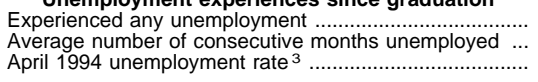 & $\begin{array}{r}28.7 \\
5.1 \\
4.9\end{array}$ & $\begin{array}{r}27.2 \\
5.4 \\
3.8\end{array}$ & $\begin{array}{r}34.0 \\
4.6 \\
3.6\end{array}$ & $\begin{array}{r}33.1 \\
5.7 \\
6.8\end{array}$ & $\begin{array}{r}19.1 \\
5.1 \\
4.9\end{array}$ & $\begin{array}{r}26.8 \\
5.1 \\
4.9\end{array}$ & $\begin{array}{r}28.3 \\
5.7 \\
9.7\end{array}$ & $\begin{array}{r}25.7 \\
5.8 \\
5.7\end{array}$ & $\begin{array}{r}31.3 \\
5.1 \\
5.3\end{array}$ & $\begin{array}{r}34.8 \\
5.0 \\
5.9\end{array}$ & $\begin{array}{r}30.0 \\
4.8 \\
5.5\end{array}$ & $\begin{array}{r}23.8 \\
5.8 \\
5.8\end{array}$ & $\begin{array}{r}28.8 \\
4.6 \\
4.8\end{array}$ \\
\hline Total employed ........ & 100.0 & 100.0 & 100.0 & 100.0 & 100.0 & 100.0 & 100.0 & 100.0 & 100.0 & 100.0 & 100.0 & 100.0 & 100.0 \\
\hline 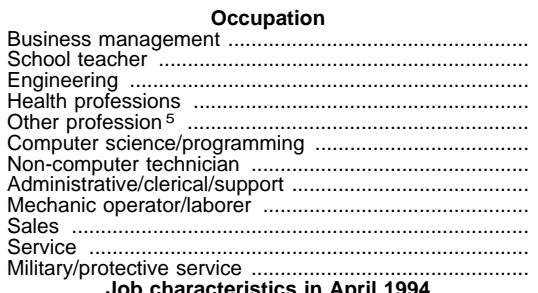 & $\begin{array}{r}20.1 \\
11.7 \\
4.4 \\
5.8 \\
15.5 \\
3.9 \\
3.0 \\
17.9 \\
4.1 \\
7.1 \\
4.2 \\
2.3\end{array}$ & $\begin{array}{r}31.4 \\
1.2 \\
0.5 \\
(4) \\
19.6 \\
3.9 \\
1.1 \\
23.6 \\
3.2 \\
11.7 \\
2.4 \\
1.1\end{array}$ & $\begin{array}{r}9.2 \\
57.1 \\
(4) \\
1.5 \\
7.0 \\
0.8 \\
0.7 \\
13.3 \\
2.4 \\
2.5 \\
4.5 \\
0.7\end{array}$ & $\begin{array}{r}12.2 \\
1.5 \\
54.3 \\
(4) \\
2.7 \\
7.9 \\
5.4 \\
5.1 \\
5.9 \\
2.1 \\
1.3 \\
1.5\end{array}$ & $\begin{array}{r}7.2 \\
2.0 \\
1.5 \\
60.2 \\
5.3 \\
0.7 \\
7.9 \\
7.4 \\
1.2 \\
2.3 \\
3.7 \\
0.6\end{array}$ & $\begin{array}{r}16.3 \\
1.2 \\
144 \\
1.4 \\
27.5 \\
0.6 \\
1.7 \\
15.4 \\
4.1 \\
4.4 \\
5.4 \\
21.9\end{array}$ & $\begin{array}{r}9.3 \\
7.7 \\
0.7 \\
6.6 \\
14.5 \\
3.4 \\
15.9 \\
16.8 \\
8.1 \\
9.0 \\
6.2 \\
2.1\end{array}$ & $\begin{array}{r}8.0 \\
11.9 \\
6.9 \\
1.3 \\
11.3 \\
25.9 \\
4.7 \\
16.6 \\
4.8 \\
4.6 \\
3.0 \\
1.1\end{array}$ & $\begin{array}{r}26.4 \\
3.2 \\
(4) \\
1.0 \\
15.5 \\
2.3 \\
11.7 \\
26.7 \\
3.4 \\
10.0 \\
5.5 \\
4.3\end{array}$ & $\begin{array}{r}23.9 \\
15.1 \\
(4) \\
0.5 \\
12.6 \\
1.4 \\
1.4 \\
18.0 \\
3.8 \\
7.7 \\
6.8 \\
8.9\end{array}$ & $\begin{array}{r}16.7 \\
11.3 \\
1.0 \\
1.3 \\
24.5 \\
3.4 \\
1.1 \\
21.3 \\
5.1 \\
7.8 \\
5.4 \\
1.2\end{array}$ & $\begin{array}{r}25.6 \\
6.9 \\
(4) \\
5.0 \\
19.5 \\
1.5 \\
2.9 \\
22.2 \\
2.2 \\
4.4 \\
8.7 \\
0.7\end{array}$ & $\begin{array}{r}26.9 \\
6.0 \\
1.7 \\
1.9 \\
20.2 \\
1.7 \\
3.4 \\
16.2 \\
6.7 \\
7.9 \\
5.4 \\
2.1\end{array}$ \\
\hline 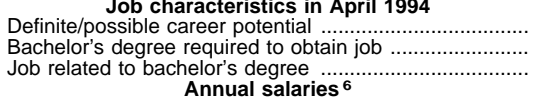 & $\begin{array}{l}72.0 \\
55.9 \\
75.1\end{array}$ & $\begin{array}{l}77.2 \\
51.4 \\
85.1\end{array}$ & $\begin{array}{l}75.4 \\
65.7 \\
78.5\end{array}$ & $\begin{array}{r}81.5 \\
78.6 \\
87.4\end{array}$ & $\begin{array}{l}80.0 \\
73.0 \\
90.5\end{array}$ & $\begin{array}{l}67.8 \\
49.4 \\
71.6\end{array}$ & $\begin{array}{l}57.4 \\
48.8 \\
64.3\end{array}$ & $\begin{array}{l}75.1 \\
67.7 \\
82.3\end{array}$ & $\begin{array}{l}68.0 \\
46.5 \\
57.2\end{array}$ & $\begin{array}{l}66.5 \\
41.2 \\
41.6\end{array}$ & $\begin{array}{l}65.5 \\
44.6 \\
58.2\end{array}$ & $\begin{array}{l}52.6 \\
45.3 \\
57.3\end{array}$ & $\begin{array}{l}67.6 \\
51.5 \\
73.6\end{array}$ \\
\hline $\begin{array}{l}\text { Annual salaries } \\
\text { Less than } \$ 5,000 \\
\$ 5,000 \text { to } \$ 9,999\end{array}$ & $\begin{array}{r}1.0 \\
3.5 \\
17.8 \\
17.3 \\
22.7 \\
24.5 \\
9.9 \\
2.5 \\
0.7 \\
\$ 24,195\end{array}$ & $\begin{array}{r}0.4 \\
1.7 \\
12.5 \\
14.9 \\
22.5 \\
31.1 \\
11.8 \\
3.9 \\
1.1 \\
1.1 \\
\$ 27,069\end{array}$ & $\begin{array}{r}1.3 \\
5.8 \\
29.8 \\
21.3 \\
27.5 \\
10.9 \\
2.0 \\
0.9 \\
0.4 \\
\$ 19,280\end{array}$ & $\begin{array}{r}0.6 \\
0.8 \\
3.4 \\
4.5 \\
12.6 \\
46.2 \\
30.4 \\
1.2 \\
0.4 \\
\$ 30,948\end{array}$ & $\begin{array}{r}1.0 \\
3.1 \\
6.3 \\
5.5 \\
13.6 \\
38.1 \\
24.1 \\
7.8 \\
0.6 \\
\$ 31,302\end{array}$ & $\begin{array}{r}0.6 \\
1.8 \\
24.7 \\
24.6 \\
21.4 \\
16.9 \\
7.6 \\
2.0 \\
0.4 \\
\$ 22,042\end{array}$ & $\begin{array}{r}1.5 \\
3.7 \\
26.3 \\
17.6 \\
24.2 \\
19.9 \\
3.9 \\
1.8 \\
1.1 \\
\$ 22,763\end{array}$ & $\begin{array}{r}0.2 \\
3.5 \\
14.5 \\
12.8 \\
20.2 \\
32.1 \\
14.2 \\
2.1 \\
0.4 \\
\$ 25,414\end{array}$ & $\begin{array}{r}0.7 \\
4.8 \\
19.3 \\
20.2 \\
28.1 \\
20.1 \\
4.2 \\
1.7 \\
0.9 \\
\$ 22,082\end{array}$ & $\begin{array}{r}5.9 \\
6.8 \\
21.1 \\
19.2 \\
16.9 \\
22.8 \\
2.5 \\
4.8 \\
.4 \\
(4) \\
\$ 21,047\end{array}$ & $\begin{array}{r}1.5 \\
5.7 \\
24.3 \\
17.9 \\
27.5 \\
14.4 \\
7.3 \\
0.8 \\
0.5 \\
\$ 21,307\end{array}$ & $\begin{array}{r}1.5 \\
7.4 \\
25.4 \\
22.4 \\
23.4 \\
14.7 \\
4.8 \\
0.4 \\
04 \\
\$ 19,463\end{array}$ & $\begin{array}{r}1.6 \\
3.4 \\
19.5 \\
26.1 \\
23.1 \\
19.1 \\
4.4 \\
1.8 \\
0.8 \\
\$ 21,619\end{array}$ \\
\hline
\end{tabular}

1 Percent not working, but looking for work.

${ }^{2}$ Percent not working and not looking for work.

Excluding those not in the labor force.

5 All other professional occupations excluding business, teaching, engineering, and health.
6 Salaries for those employed full time in April 1994.

${ }^{7}$ Respondents reporting salaries less than $\$ 1,000$ or more than $\$ 500,000$ were excluded.

NOTE.-Because of rounding, details may not add to totals.

. Department of Education, National Center for Education Statistics, "Baccalaureate and Beyond Longi(This table was prepared August 1997.) 
Table 387.-Percentage of 1992-93 bachelor's degree recipients pursuing further education within one year after graduation, by type of enrollment and undergraduate major: April 1994

\begin{tabular}{|c|c|c|c|c|c|c|}
\hline Undergraduate major field of study & $\begin{array}{c}\text { Ever enrolled } \\
\text { since gradua- } \\
\text { tion }\end{array}$ & $\begin{array}{l}\text { Enrolled } \\
\text { full-time }\end{array}$ & $\begin{array}{l}\text { Enrolled } \\
\text { part-time }\end{array}$ & $\begin{array}{l}\text { Enrolled } \\
\text { and em- } \\
\text { ployed }\end{array}$ & $\begin{array}{l}\text { Enrolled } \\
\text { and not em- } \\
\text { ployed }\end{array}$ & $\begin{array}{c}\text { Enrolled in } \\
\text { degree pro- } \\
\text { gram } \\
\text { beyond } \\
\text { bachelor's }\end{array}$ \\
\hline 1 & 2 & 3 & 4 & 5 & 6 & 7 \\
\hline All graduates & 27.3 & 12.0 & 5.8 & - & - & 17.0 \\
\hline Professional fields ................... & 23.5 & 8.6 & 6.1 & - & - & 14.2 \\
\hline Engineering & 28.3 & 14.6 & 6.6 & 7.0 & 8.1 & 20.8 \\
\hline 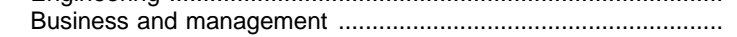 & 15.7 & 5.0 & 4.7 & 13.9 & 8.9 & 8.8 \\
\hline Health professions & 23.9 & 10.5 & 6.8 & 7.8 & 6.1 & 14.7 \\
\hline Education .................................. & 33.9 & 10.9 & 8.2 & 15.2 & 11.3 & 19.9 \\
\hline Public affairs and social services ........ & 24.7 & 8.7 & 5.4 & 2.7 & 2.9 & 13.8 \\
\hline Arts and sciences fields ... & 34.5 & 17.5 & 5.9 & - & - & 22.5 \\
\hline Biological sciences & 50.0 & 26.6 & 8.6 & 6.4 & 13.2 & 32.6 \\
\hline Mathematics and other sciences ......... & 36.0 & 20.5 & 4.5 & 6.7 & 10.3 & 25.0 \\
\hline Psychology & 38.0 & 18.4 & 9.9 & 5.8 & 5.7 & 24.0 \\
\hline Social sciences & 31.2 & 14.4 & 4.9 & 10.0 & 10.4 & 19.6 \\
\hline 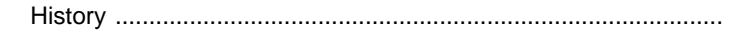 & 38.4 & 18.2 & 5.3 & 2.1 & 2.7 & 28.8 \\
\hline 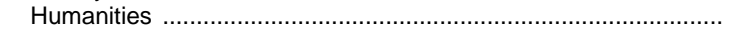 & 27.5 & 14.2 & 5.1 & 10.1 & 10.1 & 17.5 \\
\hline Other ................. & 23.6 & 10.5 & 4.5 & 12.2 & 10.4 & 14.0 \\
\hline Highest degree graduate expects to obtain & & & & & & \\
\hline 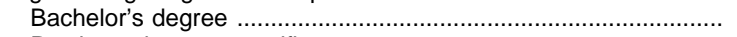 & 8.5 & 1.1 & 2.0 & - & - & 0.5 \\
\hline Postbaccalaureate certificate .................... & 31.7 & 5.3 & 0.8 & - & - & 11.5 \\
\hline 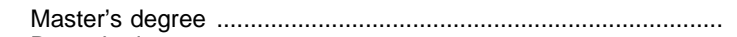 & 22.9 & 7.4 & 6.0 & - & - & 12.8 \\
\hline Doctor's degree & 50.5 & 29.5 & 8.6 & - & - & 38.6 \\
\hline First-professional degree & 52.3 & 34.8 & 6.3 & - & - & 41.7 \\
\hline Other degree & 31.0 & 11.9 & 8.7 & - & - & 15.1 \\
\hline
\end{tabular}

\section{-Data not available.}

NOTE.-Data are from a sample survey of recent college graduates. Notes on methodology are included in the Guide to Sources.
SOURCE: U.S. Department of Education, National Center for Education Statistics, "Baccalaureate and Beyond Longitudinal Study, First Follow-up" survey. (This table was prepared July 1997.)

Table 388.-Average annual salary of bachelor's degree recipients employed full time 1 year after graduation, by field of study: 1976 to 1994

\begin{tabular}{|c|c|c|c|c|c|c|c|c|c|c|c|c|c|}
\hline \multirow{2}{*}{ Field of study } & \multicolumn{2}{|c|}{$\begin{array}{c}\text { Average salary }{ }^{1} \text { of } \\
1974-75 \text { degree } \\
\text { recipients in February } \\
1976\end{array}$} & \multicolumn{2}{|c|}{$\begin{array}{c}\text { Average salary }{ }^{1} \text { of } \\
1979-80 \text { degree } \\
\text { recipients in May } \\
1981\end{array}$} & \multicolumn{2}{|c|}{$\begin{array}{c}\text { Average salary }{ }^{1} \text { of } \\
1983-84 \text { degree } \\
\text { recipients in June } \\
1985\end{array}$} & \multicolumn{2}{|c|}{$\begin{array}{c}\text { Average salary of } \\
1985-86 \text { degree } \\
\text { recipients in June } \\
1987\end{array}$} & \multicolumn{2}{|c|}{$\begin{array}{l}\text { Average salary of } \\
1989-90 \text { degree re- } \\
\text { cipients in June } 1991\end{array}$} & \multirow{2}{*}{$\begin{array}{c}\text { Average } \\
\text { salary }{ }^{1} \text { of } \\
1992-93 \\
\text { degree } \\
\text { recipients } \\
\text { in April } \\
1994\end{array}$} & \multirow{2}{*}{$\begin{array}{c}\text { Percent } \\
\text { change } \\
\text { in con- } \\
\text { stant } \\
\text { dollars, } \\
1976 \text { to } \\
1994\end{array}$} & \multirow{2}{*}{$\begin{array}{c}\text { Percent } \\
\text { change } \\
\text { in con- } \\
\text { stant } \\
\text { dollars, } \\
1991 \text { to } \\
1994\end{array}$} \\
\hline & $\begin{array}{l}\text { Current } \\
\text { dollars }\end{array}$ & $\begin{array}{l}\text { Constant } \\
1994 \\
\text { dollars }\end{array}$ & $\begin{array}{l}\text { Current } \\
\text { dollars }\end{array}$ & \begin{tabular}{c|} 
Constant \\
1994 \\
dollars
\end{tabular} & $\begin{array}{l}\text { Current } \\
\text { dollars }\end{array}$ & $\begin{array}{l}\text { Constant } \\
1994 \\
\text { dollars }\end{array}$ & $\begin{array}{l}\text { Current } \\
\text { dollars }\end{array}$ & $\begin{array}{l}\text { Constant } \\
1994 \\
\text { dollars }\end{array}$ & $\begin{array}{l}\text { Current } \\
\text { dollars }\end{array}$ & $\begin{array}{l}\text { Constant } \\
1994 \\
\text { dollars }\end{array}$ & & & \\
\hline 1 & 2 & 3 & 4 & 5 & 6 & 7 & 8 & 9 & 10 & 11 & 12 & 13 & 14 \\
\hline Total & $\$ 7,600$ & $\$ 19,800$ & $\$ 15,200$ & $\$ 24,800$ & $\$ 17,700$ & $\$ 24,400$ & $\$ 20,400$ & $\$ 26,500$ & $\$ 23,600$ & $\$ 25,700$ & $\$ 24,200$ & 22.2 & -5.8 \\
\hline Engineering . & 12,200 & 31,800 & 22,400 & 36,500 & 24,100 & 33,200 & 26,600 & 34,700 & 30,900 & 33,600 & 30,900 & -2.8 & -8.0 \\
\hline Business and management & 10,200 & 26,600 & 16,300 & 26,600 & 18,700 & 25,800 & 21,100 & 27,500 & 24,700 & 26,900 & 27,100 & 1.9 & 0.7 \\
\hline Health professions & 8,600 & 22,400 & 17,300 & 28,200 & 20,800 & 28,600 & 22,600 & 29,400 & 31,500 & 34,200 & 31,300 & 39.7 & -8.5 \\
\hline $\begin{array}{l}\text { Education }{ }^{2} \text {............................ } \\
\text { Public affairs and social }\end{array}$ & 6,300 & 16,400 & 11,500 & 18,700 & 13,800 & 19,000 & 15,800 & 20,600 & 19,100 & 20,800 & 19,300 & 17.7 & -7.2 \\
\hline services ............................ & - & - & 13,700 & 22,300 & 15,100 & 20,800 & 17,700 & 23,100 & 20,800 & 22,600 & 22,000 & - & -2.7 \\
\hline Biological sciences ....... & 6,500 & 16,900 & 14,500 & 23,600 & 15,100 & 20,800 & 16,400 & 21,400 & 21,100 & 22,900 & 22,800 & 34.9 & -0.4 \\
\hline $\begin{array}{l}\text { Mathematics and other } \\
\text { sciences }\end{array}$ & 7,000 & 18,200 & 16,300 & 26,600 & 17,500 & 24,100 & 22,500 & 29,400 & 27,200 & 29,500 & 25,400 & 39.6 & -13.9 \\
\hline Psychology ......................... & - & & 12,500 & 20,400 & 14,600 & 20,100 & 17,300 & 22,600 & 19,200 & 20,800 & 19,500 & - & -6.3 \\
\hline 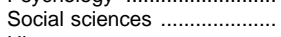 & 6,700 & 17,500 & 14,000 & 22,800 & 15,800 & 21,800 & 20,300 & 26,500 & 22,200 & 24,200 & 22,100 & 26.3 & -8.7 \\
\hline 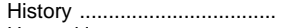 & - & - & - & - & - & - & - & - & - & - & 21,000 & - & - \\
\hline Humanities ............. & 5,800 & 15,100 & 12,600 & 20,500 & 14,000 & 19,300 & 16,200 & 21,200 & 19,100 & 20,700 & 21,300 & 41.1 & 2.9 \\
\hline Communications $^{3}$. & - & & & - & 16,200 & 22,300 & - & & - & - & & - & - \\
\hline Miscellaneous .............................. & 6,800 & 17,700 & 15,100 & 24,600 & 18,600 & 25,600 & 17,600 & 23,000 & 20,800 & 22,600 & 21,600 & 22.0 & -4.4 \\
\hline
\end{tabular}

${ }^{1}$ Reported salaries of full-time workers under $\$ 2,600$ in $1976, \$ 4,200$ in $1981, \$ 5,000$ in 1985 , and $\$ 1,000$ in 1994 were excluded from the tabulations. Also, those with salaries over $\$ 500,000$ in 1994 were excluded.

2 Most educators work 9- to 10-month contracts.

${ }^{3}$ In 1994, data were not collected in Communications as a separate field of study.

-Data not available.
NOTE.-Data exclude bachelor's recipients from U.S. Service Schools and graduates living at foreign addresses at the time of the survey. Constant dollar adjustments based on the Consumer Price Index.

SOURCE: U.S. Department of Education, National Center for Education Statistics, "Recent College Graduates" surveys and "Baccalaureate and Beyond Longitudinal Study, First Follow-up" survey. (This table was prepared July 1997). 
Table 389.-Participation of young adults in voluntary or community service activities, by selected characteristics: 1992 to 1994

\begin{tabular}{|c|c|c|c|c|c|c|c|c|c|c|c|c|c|c|}
\hline \multirow[b]{2}{*}{ Young adult characteristics } & \multicolumn{9}{|c|}{ Percent participating in voluntary or community service activity } & \multicolumn{5}{|c|}{ Percentage distribution of volunteer hours per week } \\
\hline & $\begin{array}{c}\text { Any } \\
\text { activity }\end{array}$ & $\begin{array}{l}\text { Sports teams } \\
\text { or clubs }\end{array}$ & $\begin{array}{l}\text { Church } \\
\text { activities }\end{array}$ & $\begin{array}{l}\text { Union, farm, } \\
\text { trade, or } \\
\text { professional } \\
\text { associations }\end{array}$ & $\begin{array}{c}\text { Educational } \\
\text { organizations }\end{array}$ & $\begin{array}{l}\text { Youth } \\
\text { organizations }\end{array}$ & Political clubs & $\begin{array}{l}\text { Organized } \\
\text { volunteer } \\
\text { work }^{1}{ }^{1}\end{array}$ & $\begin{array}{c}\text { Other } \\
\text { voluntary } \\
\text { group }\end{array}$ & None $^{2}$ & $\begin{array}{c}\text { Less than } \\
2 \text { hours }\end{array}$ & $\begin{array}{l}2 \text { to } 4 \\
\text { hours }\end{array}$ & $\begin{array}{l}4 \text { to } 6 \\
\text { hours }\end{array}$ & $\begin{array}{l}6 \text { hours } \\
\text { or more }\end{array}$ \\
\hline \multirow[t]{2}{*}{1} & 2 & 3 & 4 & 5 & 6 & 7 & 8 & 9 & 10 & 11 & 12 & 13 & 14 & 15 \\
\hline & \multicolumn{14}{|c|}{1992 to $1994^{3}$} \\
\hline Total & 37.2 & 7.2 & 11.8 & 1.8 & 6.0 & 10.3 & 3.0 & 10.4 & 7.3 & 62.7 & 15.2 & 7.9 & 5.8 & 8.3 \\
\hline Sex & & & & & & & & & & & & & & \\
\hline 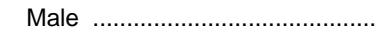 & 36.8 & 9.5 & 11.1 & 1.9 & 4.6 & 11.2 & 2.9 & 8.3 & 7.3 & 63.2 & 14.7 & 7.7 & 5.6 & 8.8 \\
\hline Female & 37.9 & 4.9 & 12.7 & 1.6 & 7.1 & 9.4 & 3.2 & 12.6 & 7.3 & 62.2 & 15.8 & 8.2 & 6.1 & 7.9 \\
\hline \multicolumn{15}{|l|}{ Race/ethnicity } \\
\hline White, non-Hispanic ................... & 38.5 & 7.5 & 11.3 & 2.0 & 5.8 & 10.3 & 3.1 & 11.6 & 7.8 & 61.5 & 17.1 & 8.0 & 5.5 & 7.9 \\
\hline Black, non-Hispanic ...................... & 35.9 & 6.3 & 15.8 & 1.1 & 6.4 & 11.5 & 3.1 & 5.8 & 6.2 & 64.1 & 9.6 & 8.1 & 7.7 & 10.6 \\
\hline 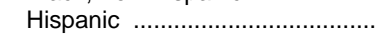 & 31.7 & 6.3 & 11.2 & 0.8 & 6.5 & 9.6 & 2.3 & 6.7 & 5.4 & 68.4 & 9.8 & 7.3 & 6.0 & 8.5 \\
\hline 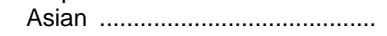 & 35.8 & 5.7 & 10.5 & 1.4 & 7.1 & 8.1 & 3.4 & 13.0 & 8.4 & 64.2 & 14.9 & 8.7 & 4.3 & 8.0 \\
\hline 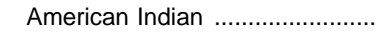 & 34.1 & 12.1 & 14.6 & 3.6 & 6.1 & 11.9 & 3.8 & 5.1 & 3.9 & 65.9 & 8.7 & 6.3 & 8.1 & 11.1 \\
\hline \multicolumn{15}{|l|}{ Socioeconomic status ${ }^{4}$} \\
\hline 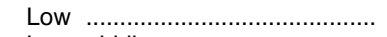 & 26.4 & 5.0 & 10.4 & 0.9 & 4.0 & 7.4 & 1.5 & 5.9 & 5.0 & 73.6 & 8.2 & 5.8 & 4.5 & 7.9 \\
\hline Low-middle & 30.4 & 6.3 & 10.8 & 1.3 & 3.9 & 8.3 & 2.1 & 7.1 & 6.3 & 69.6 & 11.0 & 6.0 & 5.9 & 7.5 \\
\hline High-middle ………………..... & 38.6 & 7.0 & 13.0 & 2.0 & 5.8 & 10.9 & 3.3 & 9.2 & 7.5 & 61.4 & 16.9 & 7.9 & 6.1 & 7.8 \\
\hline 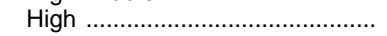 & 51.1 & 9.2 & 14.7 & 2.7 & 9.7 & 14.2 & 4.9 & 18.0 & 10.3 & 48.9 & 24.6 & 11.4 & 5.9 & 9.2 \\
\hline
\end{tabular}

\section{1'E.g., hospital volunteer}

2Not a volunteer.
${ }^{3}$ Sample survey in 1994 based on people who were high school seniors in spring 1992. Respondents to the survey were asked about their voluntary participation in selected organizations over the previous 24-month period.
NOTE.-Some persons participated in more than one organization.

SOURCE: U.S. Department of Education, National Center for Education Statistics, "National Education Longitudinal Study, Third Followup." (This table was prepared July 1995.) 
Table 390.-Literacy skills of adults, 16 years old and over, by selected characteristics: 1992

\begin{tabular}{|c|c|c|c|c|c|c|c|c|c|c|c|c|c|c|c|c|c|c|}
\hline \multirow{3}{*}{ Selected characteristics } & \multicolumn{6}{|c|}{ Prose literacy ${ }^{1}$} & \multicolumn{6}{|c|}{ Document literacy ${ }^{2}$} & \multicolumn{6}{|c|}{ Quantitative literacy ${ }^{3}$} \\
\hline & \multirow{2}{*}{$\begin{array}{l}\text { Average } \\
\text { score }\end{array}$} & \multicolumn{5}{|c|}{ Percent of adults with profiency at level } & \multirow{2}{*}{$\begin{array}{l}\text { Average } \\
\text { score }\end{array}$} & \multicolumn{5}{|c|}{ Percent of adults with profiency at level } & \multirow{2}{*}{$\begin{array}{c}\text { Average } \\
\text { score }\end{array}$} & \multicolumn{5}{|c|}{ Percent of adults with profiency at level } \\
\hline & & 1 & 2 & 3 & 4 & 5 & & 1 & 2 & 3 & 4 & 5 & & 1 & 2 & 3 & 4 & 5 \\
\hline 1 & 2 & 3 & 4 & 5 & 6 & 7 & 8 & 9 & 10 & 11 & 12 & 13 & 14 & 15 & 16 & 17 & 18 & 19 \\
\hline Total & 272 & 21 & 27 & 32 & 17 & 3 & 267 & 23 & 28 & 31 & 15 & 3 & 271 & 22 & 25 & 31 & 17 & 4 \\
\hline \multicolumn{19}{|l|}{ Sex } \\
\hline 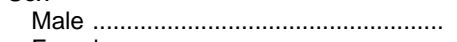 & 272 & 22 & 26 & 31 & 18 & 4 & 269 & 23 & 27 & 31 & 17 & 3 & 277 & 21 & 23 & 31 & 20 & 5 \\
\hline Female ………… & 273 & 20 & 28 & 33 & 17 & 3 & 265 & 23 & 30 & 31 & 14 & 2 & 266 & 23 & 28 & 31 & 15 & 3 \\
\hline \multicolumn{19}{|l|}{ Age } \\
\hline 16 to 18 years old & 271 & 16 & 35 & 38 & 11 & 1 & 274 & 15 & 34 & 38 & 12 & 1 & 268 & 20 & 35 & 33 & 12 & 1 \\
\hline 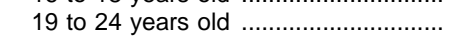 & 280 & 14 & 29 & 37 & 18 & 2 & 280 & 14 & 29 & 37 & 18 & 2 & 277 & 16 & 28 & 37 & 16 & 2 \\
\hline 25 to 39 years old & 284 & 15 & 24 & 34 & 22 & 5 & 282 & 16 & 25 & 35 & 21 & 4 & 283 & 17 & 23 & 33 & 21 & 5 \\
\hline 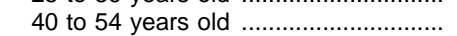 & 286 & 15 & 23 & 34 & 22 & 5 & 278 & 17 & 27 & 33 & 19 & 3 & 286 & 16 & 22 & 33 & 23 & 6 \\
\hline 55 to 64 years old . & 260 & 26 & 31 & 30 & 12 & 1 & 249 & 30 & 34 & 26 & 8 & 1 & 261 & 25 & 30 & 30 & 13 & 2 \\
\hline 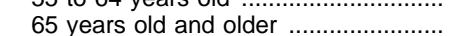 & 230 & 44 & 32 & 19 & 5 & 1 & 217 & 53 & 32 & 13 & 2 & (4) & 227 & 45 & 26 & 20 & 7 & 2 \\
\hline \multicolumn{19}{|l|}{ Race/ethnicity } \\
\hline White ................ & 286 & 14 & 25 & 36 & 21 & 4 & 280 & 16 & 27 & 34 & 19 & 3 & 287 & 14 & 24 & 35 & 21 & 5 \\
\hline ㄱ..………...... & 237 & 38 & 37 & 21 & 4 & $(4)$ & 230 & 43 & 36 & 18 & 3 & (4) & 224 & 46 & 34 & 17 & 3 & $(4)$ \\
\hline Asian or Pacific Islander ........................... & 242 & 36 & 25 & 25 & 12 & 2 & 245 & 34 & 25 & 28 & 12 & 2 & 256 & 30 & 23 & 27 & 16 & 4 \\
\hline 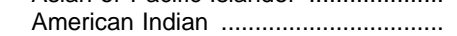 & 254 & 25 & 39 & 28 & 7 & 1 & 254 & 27 & 37 & 29 & 7 & $(4)$ & 250 & 33 & 32 & 28 & 7 & 1 \\
\hline Hispanic, Mexican ………… & 206 & 54 & 25 & 16 & 5 & (4) & 205 & 54 & 25 & 16 & 4 & (4) & 205 & 54 & 25 & 17 & 4 & $(4)$ \\
\hline 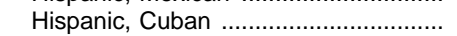 & 211 & 53 & 24 & 17 & 6 & 1 & 212 & 48 & 30 & 16 & 4 & 2 & 223 & 46 & 20 & 25 & 6 & 3 \\
\hline Hispanic, Puerto Rican .......................... & 218 & 47 & 32 & 17 & 3 & (4) & 215 & 49 & 29 & 18 & 3 & $(4)$ & 212 & 51 & 28 & 17 & 3 & 1 \\
\hline Hispanic, Central/South American ....... & 207 & 56 & 22 & 17 & 4 & (4) & 206 & 53 & 25 & 16 & 4 & (4) & 203 & 53 & 25 & 18 & 4 & $(4)$ \\
\hline Hispanic, other . & 260 & 25 & 27 & 33 & 13 & 2 & 254 & 28 & 26 & 32 & 12 & $\begin{array}{r}1 \\
2\end{array}$ & 246 & 31 & 25 & 31 & 11 & 1 \\
\hline \multicolumn{19}{|l|}{ Highest level of education } \\
\hline Still in high school ................ & 271 & 16 & 36 & 37 & 11 & (4) & 274 & 15 & 35 & 38 & 12 & 1 & 269 & 19 & 35 & 32 & 12 & 1 \\
\hline 0 to 8 years, not enrolled ... & 177 & 75 & 20 & 4 & $(4)$ & (4) & 170 & 79 & 18 & 3 & $(4)$ & (4) & 169 & 76 & 18 & 5 & 1 & $(4)$ \\
\hline 9 to 12 years, not enrolled ................... & 231 & 42 & 38 & 17 & 2 & $(4)$ & 227 & 46 & 37 & 15 & 2 & (4) & 227 & 45 & 34 & 17 & 3 & $(4)$ \\
\hline GED …… & 268 & 14 & 39 & 39 & 7 & (4) & 264 & 17 & 42 & 34 & 7 & (4) & 268 & 16 & 38 & 35 & 10 & 1 \\
\hline High school diploma ………………. & 270 & 16 & 36 & 37 & 10 & 1 & 264 & 20 & 38 & 33 & 9 & 1 & 270 & 18 & 33 & 37 & 12 & 1 \\
\hline ……1........ & 294 & 8 & 23 & 45 & 22 & 3 & 290 & 9 & 27 & 42 & 20 & 2 & 295 & 8 & 23 & 42 & 23 & 4 \\
\hline Associate degree ………… & 308 & 4 & 19 & 41 & 32 & 4 & 299 & 6 & 23 & 43 & 25 & $\begin{array}{ccc}3 \\
3\end{array}$ & 307 & 4 & 19 & 43 & 29 & 5 \\
\hline Bachelor's degree . & 322 & 4 & 11 & 35 & 40 & 10 & 314 & 4 & 15 & 37 & 36 & 8 & 322 & 4 & 12 & 35 & 38 & 12 \\
\hline 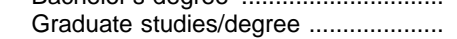 & 336 & $\begin{array}{r}4 \\
2\end{array}$ & 7 & 28 & 47 & 16 & 326 & 3 & 10 & 34 & 41 & 12 & 334 & 2 & 9 & 30 & 42 & 17 \\
\hline \multicolumn{19}{|l|}{ Region } \\
\hline Northeast & 270 & 22 & 28 & 31 & 16 & 3 & 264 & 24 & 29 & 30 & 14 & 2 & 267 & 24 & 25 & 31 & 16 & 4 \\
\hline Midwest ....…………….... & 279 & 16 & 28 & 35 & 18 & 3 & 274 & 19 & 30 & 33 & 16 & 2 & 280 & 17 & 26 & 34 & 19 & 4 \\
\hline South ………............... & 267 & 23 & 28 & 30 & 15 & 3 & 262 & 26 & 29 & 29 & 14 & 2 & 265 & 25 & 27 & 29 & 15 & 4 \\
\hline 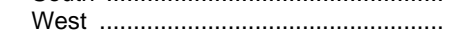 & 276 & 20 & 23 & 33 & 21 & 4 & 271 & 22 & 24 & 32 & 18 & 3 & 276 & 20 & 22 & 32 & 20 & 5 \\
\hline Prison population & 246 & 31 & 37 & 26 & 6 & $\left({ }^{4}\right)$ & 240 & 33 & 38 & 25 & 4 & $\left({ }^{4}\right)$ & 236 & 40 & 32 & 22 & 6 & 1 \\
\hline
\end{tabular}

1 Prose literacy is the ability to understand and use information contained in various kinds of textual material. A level 1 task rated 0 to 225 requires the reader to locate a single piece of information in a short text. A level 2 task rated 226 to 275 requires the reader to locate a single piece of information in the text with several distractors or to make low-level inferences. A level 3 task rated 276 to 325 requires the reader to make literal or synonymous matches between the text and information given in the task, or to make low-level inferences. A level 4 task rated 326 to 375 requires the reader to perform multiple-feature matches and to integrate or synthesize information from complex pas-
sages. A level 5 task rated 376 to 500 requires the reader to search for information in dense text which contains a number of distractors.

作 to 275 requires the reader to match a single piece of information based on a literal match. A level 2 task rated 226 to 325 requires the reader to integrate multiple pieces of information from one or more documents. A level 4 task rated 326 to 375 requires the performance of multiple-feature matches, cycling through documents, and integrating informa-

tion. A level 5 task rated 376 to 500 requires the reader to search through complex displays that contain multiple distractors, to make high-level text-based inferences.

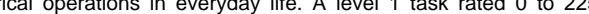
requires the reader to perform a single, relatively simple, arithmetic operation. A level 2 task rated 226 to 275 requires a A 4 task rated 326 to 375 r 276 iro 325 requires the reader to use iwo or more numbers to solvi the problem. A leve the multiple operations sequentially. They must extract the features of the problem from text or rely on background knowldge to determine the quantities or operations needed.

ess than .5 percent.

SOURCE: U.S. Department of Education, National Center for Education Statistics, National Adult Literacy Survey, Adult Literacy in America, 1992, prepared by Educational Testing Service. (This table was prepared February 1994.) 



\section{CHAPTER 6}

\section{International Comparisons of Education}

This chapter offers a broad perspective on education across the nations of the world. It also provides an international context for examining the condition of education in the United States. In the early 1990s, the National Center for Education Statistics (NCES) expanded its role in collecting international data by serving as the national research center for the International Association for the Evaluation of Educational Achievement (IEA) Reading Literacy Study. In addition, NCES has provided funding for international research studies comparing mathematics and science education, including the Third International Mathematics and Science Study (TIMSS) and the Second International Assessment of Educational Progress. NCES is also cooperating with international agencies in the compilation of statistics and the development of education indicators.

Some of the data in this chapter were drawn from materials prepared by the United Nations Educational, Scientific, and Cultural Organization (UNESCO), the Institute of International Education, the Organization for Economic Cooperation and Development (OECD), and the International Assessment of Educational Progress (IAEP). The basic summary data on enrollments, teachers, enrollment ratios, and finances were synthesized from information appearing in Education at a Glance published by OECD. Even though OECD tabulations are very carefully prepared, international data users should be cautioned about the many problems of definition and reporting involved in the collection of data about the educational systems in the world.

This chapter provides information from the Third International Mathematics and Science Study (TIMSS), carried out by the International Association for the Evaluation of Educational Achievement (IEA). The mathematics and science performance of 8thgrade students in 41 countries, and 4th-grade students in 26 countries, was studied through assessments administered during 1994-95. The mathematics and science performance of students at the end of secondary schooling (12th grade in the United States) was also assessed at the same time.

A different perspective is provided by data on foreign students enrolled in U.S. institutions of higher education. These data from the Institute of Inter- national Education provide information on the number of foreign students and their countries of origin.

Further information on survey methodologies is in the "Guide to Sources" in the appendix and in the publications cited in the source notes.

\section{Population}

The percent of young people in a population can influence the proportion of national income spent per student. Countries with a greater proportion of young people must set aside larger proportions of domestic product for their education. Among the OECD countries, Turkey had the largest percentage of young people ages 5 to 13 at 19.7 percent in 1995. The closest followers were Ireland at 15.2 percent, and Korea at 14.5 percent. Countries with relatively small numbers of persons in this age group included Italy at 9.1 percent, and Denmark at 9.7 percent. The proportion of 5- to 13-year-olds in the United States was 13.0 percent, which was higher than most other OECD countries (table 391).

\section{Enrollments}

In 1995, over 1 billion students were enrolled in schools around the world. Of these students, 650 million were in elementary-level programs, 372 million were in secondary programs, and 82 million were in higher education programs (table 393 ).

Between 1980 and 1995, enrollment changes varied from region to region. Elementary enrollment changes ranged from increases of 54 percent in Africa and 25 percent in Central and South America to a 9 percent decrease in Europe. Enrollment increases at the secondary level generally outpaced increases at the primary (elementary) level, especially in Africa (112 percent), Oceania (76 percent), Central and South America (52 percent), and Asia (51 percent). Secondary-level enrollment increased in Europe by 11 percent, and decreased in Northern America (United States, Canada, and Greenland) by 1 percent (table 393).

Pupil/teacher ratios in elementary and secondary schools vary from country to country. Developed countries with relatively low pupil/teacher ratios at the elementary level in 1995 were Italy (11.0) and Denmark (11.1). Countries with relatively high ratios in- 
cluded Turkey (27.7) and Ireland (23.4) (table 395). At the postsecondary level, developing areas of the world had substantial increases in enrollment between 1980 and 1995. Postsecondary enrollment rose by 146 percent in Africa and by 116 percent in Asia. Postsecondary enrollment in Oceania and Central and South America increased by 181 percent and 65 percent, respectively, followed by Europe at 30 percent and Northern America at 22 percent. These increases are due to growth in the postsecondary attendance rates and increased population (tables 393 and 394).

Postsecondary enrollment varied among countries partially due to differing definitions of postsecondary education and at what age it begins. In 1994, among the OECD countries, Canada reported the largest proportion of 18- to 21-year-olds enrolled in postsecondary education at 40 percent, followed by the United States (35 percent), France (33 percent), Ireland (31 percent), and New Zealand (31 percent). For the 22 to 25 age group, Finland's enrollment rate was highest at 27 percent, with Norway following at 24 percent, Canada at 23, Denmark at 22 percent, and the United States at 21 (table 392).

In 1996-97 there were 458,000 foreign students studying at U.S. colleges and universities. This was about the same as the year before. Approximately 57 percent of the students were from South and East Asian countries (table 414).

\section{Achievement}

TIMSS is the largest, most comprehensive comparative study of education that has ever been undertaken, testing a half million students. The study was designed to focus on students at different stages in school: midway through elementary school, midway through lower secondary school, and at the end of upper secondary school. Results from the 4th- and 8th-grade levels were released in late 1996 and 1997, respectively. Findings for 12th-grade were released in early 1998.

The results of the 1994-95 TIMSS show U.S. 4thgraders performing above the international average in both mathematics and science, and showing a stronger standing relative to other countries than 8thand 12th-graders in both subjects. In addition, U.S. students perform better in science overall than in mathematics compared to their international counterparts at the 4th- and 8th-grade levels.

\section{Mathematics}

In the 1994-95 TIMSS assessment in mathematics, U.S. 4th-graders scored above the international average of the 26 countries that participated. Fourth-graders performed below students in 7 countries, not significantly different from students in 6 countries, and above students in 12 countries. U.S. 4th-graders scored below Japan, not significantly different from Canada, and above England (table 403). U.S. 8th-graders scored below the international average of the 41 countries that were tested. In mathematics, U.S. 8th-graders scored below their counterparts in 20 countries, including top performer Singapore, but not significantly different from England and Germany (table 397). U.S. 12th-graders performed below the international average, and among the lowest of the 21 TIMSS countries on the assessment of mathematics general knowledge. U.S. students were outperformed by those in 14 countries, outperformed students in 2 countries, and were not significantly different from those in 4 countries (table 405).

\section{Science}

U.S. 4th-graders performed above the international average of the 26 countries assessing 4th-grade students in science. Only Korea scored above the United States, with U.S. 4th-graders outperforming 19 other countries, including England and Canada. The remaining countries' scores, including Japan's, were not significantly different from those of U.S. 4th-grade students (table 404). U.S. 8th-graders compared more favorably with other countries in science than in mathematics, scoring above the international average of 41 countries. U.S. 8th-grade students scored below their peers in 9 countries, not significantly different from 16 countries, including Canada, England, and Germany, and outperformed students in 15 nations (table 399). U.S. 12th-graders performed below the international average and among the lowest scoring of the 21 TIMSS countries on the assessment of general science knowledge. U.S. students were outperformed by students in 11 countries, outperformed students in 2 countries, and did not score significantly different from students in 7 countries (table 406).

U.S. 4th-grade students were above the international average in all four science content areas studied by TIMSS. Among the five science content areas assessed at the 8th-grade level in TIMSS, U.S. students performed above the international average in earth science, life science, and environmental issues, and no different from the international average in chemistry and physics (table 404).

\section{Degrees}

Ratios of bachelor's degrees conferred per hundred 22- or 23-year-olds in 1994 ranged from 7 in Turkey and 9 in Switzerland to 32 in the United States and 35 in Australia. In 1994, women had higher bachelor's degree ratios than men in 13 out of 16 countries reporting data (table 409).

Countries pay careful attention to the percent of graduates in the fields of mathematics and science. Regarding the percent of undergraduate degrees 
awarded in science fields (including natural sciences, mathematics and computer science, and engineering), OECD countries reported rates from 15 to 37 percent for 1995. Ireland, Germany and Finland were over 30 percent, while Canada, Australia, Italy, Norway, Portugal, and Spain were under 20 percent (table 410). The proportion of graduate degrees awarded in science fields also ranged widely across countries in 1991. Among the countries with the highest proportions were Japan (54 percent), Sweden (44 percent), and Austria (37 percent). Among the countries with the lowest proportions were the United States (14 percent), Australia (14 percent), New Zealand (19 percent), and Canada (20 percent) (table 411).

\section{Finances}

In general, higher income countries spend more per student than lower income countries. At the pri- mary level of education, Sweden, the United States, and Switzerland ranked at the upper end of per pupil expenditures in 1993. For primary education per student, Sweden spent about $\$ 4,900$ per student, the United States spent $\$ 5,500$, and Switzerland spent about $\$ 5,800$. At the secondary level, Switzerland, Austria, United States, Germany and Denmark had expenditures over $\$ 6,000$ per student. Switzerland, the United States, and Sweden spent relatively large amounts per student in higher education, with each having expenditures per student over $\$ 12,000$ (table 412).

A comparison of public expenditures on education as a percent of gross domestic product (GDP) in OECD countries shows that national investment in education in 1994 ranged from 3.3 percent of GDP in Turkey to 6.9 percent in Norway (table 413 ).

\section{Figure 28.-Percent change in enrollment, by area of the world and level of education: 1980 to 1995}

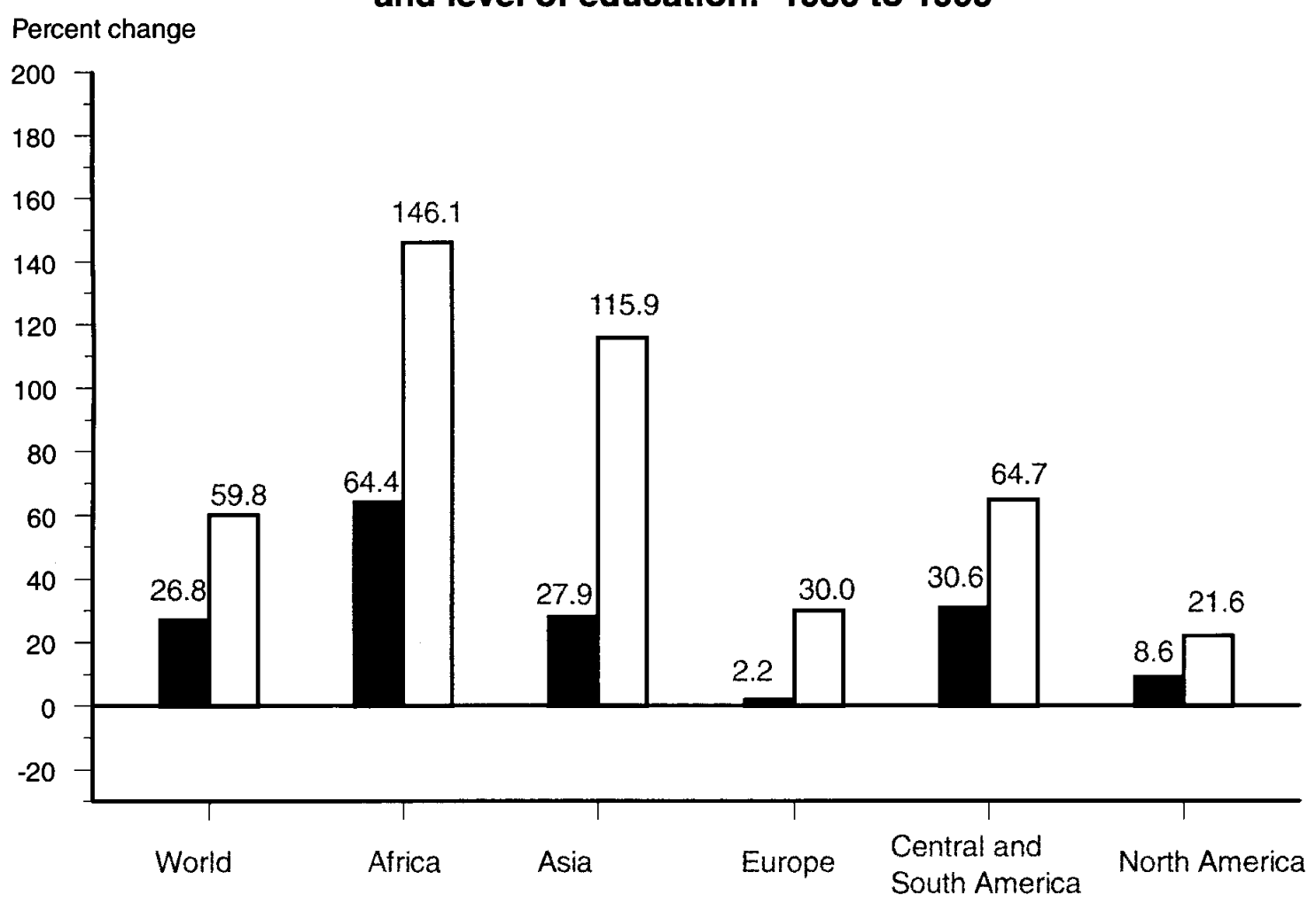

Elementary and secondary education $\square$ Postsecondary education

SOURCE: United Nations Educational, Scientific, and Cultural Organization, Paris, Statistical Yearbook, various vears. 
Figure 29.-Public expenditures for education as a percentage of the gross domestic product: Selected countries, 1994

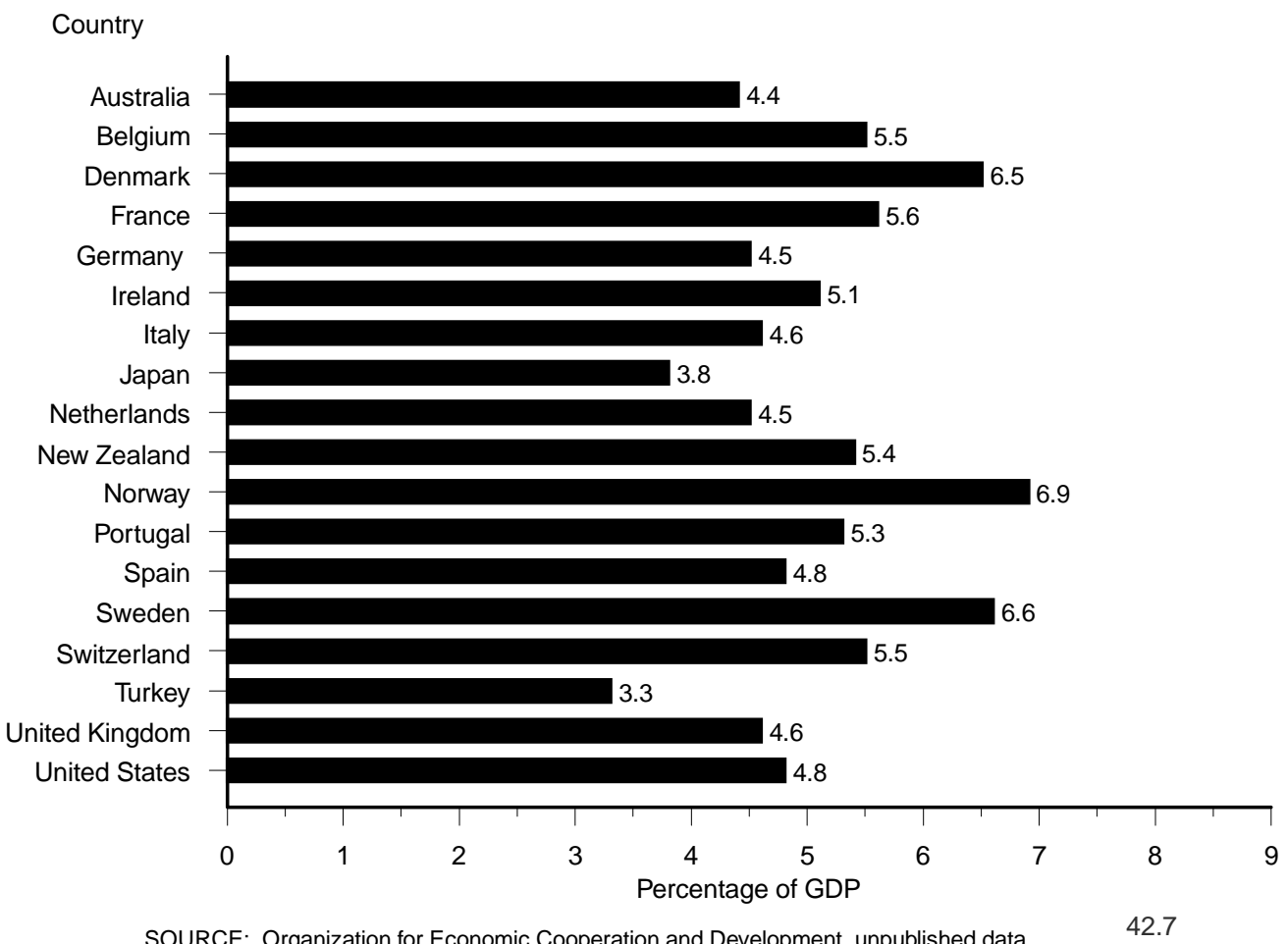

SOURCE: Organization for Economic Cooperation and Development, unpublished data.

Figure 30--Bachelor's degree recipients as a percentage of population of the Country theoretical age of graduation, by sex: Selected countries, 1995

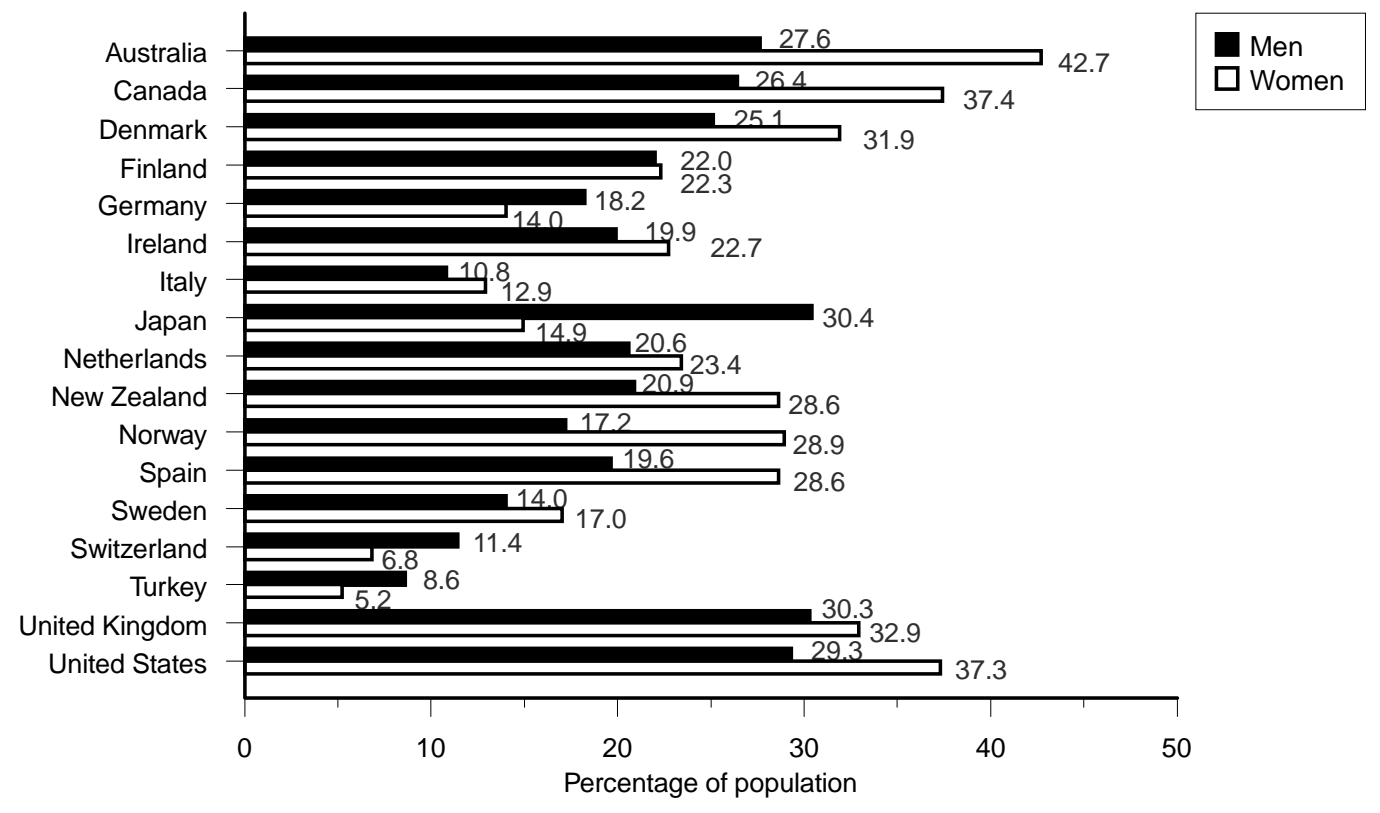

SOURCE: Organization for Economic Cooperation and Development, unpublished data. 


\section{Figure 31.-Average mathematics performance of other countries compared with the United States: 1995 \\ Fourth grade \\ Twelfth grade}

Average scores significantly higher than the United States

\section{Singapore}

Korea

Japan

Hong Kong

(Netherlands)

Czech Republic

(Austria)

Average scores not significantly different from the United States

$\begin{array}{ll}\text { (Slovenia) } & \begin{array}{l}\text { Canada } \\ \text { Ireland }\end{array} \\ \text { (Hungary) } & \end{array}$

(Australia)

Average scores significantly lower than the United States

$\begin{array}{lll}\text { (Latvia) } & \text { Norway } & \text { Portugal } \\ \text { Scotland } & \text { New Zealand } & \text { Iceland } \\ \text { England } & \text { Greece } & \text { Iran, Islamic Republic } \\ \text { Cyprus } & \text { (Thailand) } & \text { (Kuwait) }\end{array}$

Average scores significantly higher than the United States

$\begin{array}{lll}\text { (Netherlands) } & \text { (Norway) } & \text { (Austria) } \\ \text { Sweden } & \text { (France) } & \text { (Slovenia) } \\ \text { (Denmark) } & \text { New Zealand } & \text { (Germany) } \\ \text { Switzerland } & \text { (Australia) } & \text { Hungary } \\ \text { (Iceland) } & \text { (Canada) } & \end{array}$

Average scores not significantly different from the United States

(Italy)

(Russian Federation)

(Lithuania)

Czech Republic

Average scores significantly lower than the United States

(Cyprus)

(South Africa)

NOTE: Nations not meeting international guidelines are shown in parentheses.

SOURCE: U.S. Department of Education, National Center for Education Statistics, Pursuing Excellence: A Study of U.S. Fourth-Grade Mathematics and Science Achievement in International Context, 1997 and Pursuing Excellence: A Study of U.S. Twelfth-Grade Mathematics and Science Achievement in International Context, 1998.

\section{Figure 32.-Average science performance of other countries compared} with the United States: 1995

\section{Fourth grade}

Average scores significantly higher than the United States

Korea

Average scores not significantly different from the United States

Japan

(Austria)

(Australia)

(Netherlands)

Czech Republic

Average scores significantly lower than the United States

$\begin{array}{lll}\begin{array}{ll}\text { England } \\ \text { Canada }\end{array} & \begin{array}{l}\text { Hong Kong } \\ \text { (Hungary) }\end{array} & \begin{array}{l}\text { Iceland } \\ \text { Greece }\end{array} \\ \text { Singapore } & \text { New Zealand } & \text { Portugal } \\ \text { (Slovenia) } & \text { Norway } & \text { Cyprus } \\ \text { Ireland } & \text { (Latvia) } & \text { (Thailand) } \\ \text { Scotland } & \text { (Israel) } & \text { Iran, Islamic Republic } \\ & & \text { (Kuwait) }\end{array}$

\section{Twelfth grade}

Average scores significantly higher than the United States

$\begin{array}{lll}\text { Sweden } & \text { (Canada) } & \text { (Austria) } \\ \text { (Netherlands) } & \text { New Zealand(Slovenia) } & \\ \text { (Iceland) } & \text { (Australia) } & \text { (Denmark) } \\ \text { (Norway) } & \text { Switzerland } & \end{array}$

Average scores not significantly different from the United States

$\begin{array}{ll}\text { (Germany) } & \text { (Italy) } \\ \text { (France) } & \text { Hungary } \\ \text { Czech Republic } & \text { (Lithuania) } \\ \text { (Russian Federation) } & \end{array}$

Average scores significantly lower than the United States

(Cyprus)

(South Africa)

NOTE.-Nations not meeting international guidelines are shown in parentheses.

SOURCE: U.S. Department of Education, National Center for Education Statistics, Pursuing Excellence: A Study of U.S. Fourth-Grade Mathematics and Science Achievement in International Context, 1997 and Pursuing Excellence: A Study of U.S. Twelfth Grade Mathematics and Science Achievement in International Context, 1998. 
Table 391.-School-age populations as a percent of total population: Selected countries, 1985, 1990, and 1995

\begin{tabular}{|c|c|c|c|c|c|c|}
\hline \multirow{2}{*}{ Country } & \multicolumn{3}{|c|}{$\begin{array}{l}\text { 5- to 13-year-olds as a percent of total } \\
\text { population }\end{array}$} & \multicolumn{3}{|c|}{$\begin{array}{c}\text { 14- to 17-year-olds as a percent of total } \\
\text { population }\end{array}$} \\
\hline & 1985 & 1990 & 1995 & 1985 & 1990 & 1995 \\
\hline 1 & 2 & 3 & 4 & 5 & 6 & 7 \\
\hline Australia & 14.5 & 13.1 & 12.9 & 6.6 & 6.4 & 5.6 \\
\hline 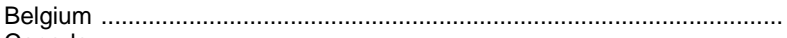 & 11.4 & 10.9 & 10.7 & 5.8 & 5.1 & 4.9 \\
\hline 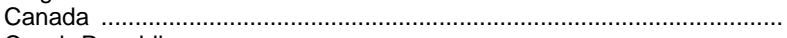 & 12.8 & 12.4 & 12.2 & 6.1 & 5.5 & 5.4 \\
\hline (n) & - & - & 11.6 & - & - & 6.5 \\
\hline 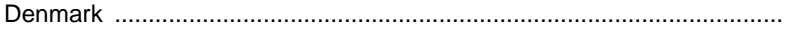 & 12.0 & 10.1 & 9.7 & 5.8 & 5.7 & 4.7 \\
\hline Finland & 11.5 & 11.8 & 11.4 & 5.6 & 4.9 & 5.1 \\
\hline France $\ldots . . .$. & 12.8 & 12.1 & 12.0 & 6.2 & 5.8 & 5.3 \\
\hline (n) & 9.1 & 8.7 & 10.0 & 6.1 & 4.1 & 4.3 \\
\hline Greece & - & - & 10.7 & - & 5.5 & 5.8 \\
\hline Iceland & 15.7 & 15.0 & 14.3 & 6.7 & 6.8 & 6.4 \\
\hline 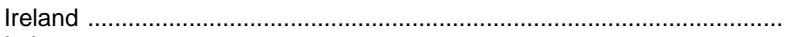 & 17.9 & 17.5 & 15.2 & 7.7 & 8.0 & 7.8 \\
\hline Italy .......... & 12.7 & 10.3 & 9.1 & 6.5 & 6.0 & 4.8 \\
\hline Japan ................ & 14.0 & 11.8 & 10.2 & 6.2 & 6.5 & 5.4 \\
\hline Korea ................ & - & - & 14.5 & - & - & 7.1 \\
\hline 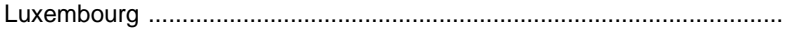 & 10.2 & 10.1 & 10.5 & 5.5 & 4.4 & 4.4 \\
\hline Netherlands ........ & 12.0 & 10.7 & 10.8 & 6.8 & 5.4 & 4.8 \\
\hline 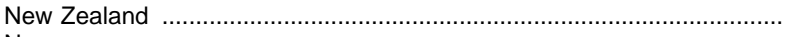 & 15.3 & 13.5 & 13.5 & 7.5 & 6.7 & 5.7 \\
\hline 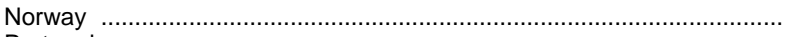 & 12.5 & 11.0 & 11.2 & 6.4 & 5.8 & 4.9 \\
\hline${ }_{1}$ & 15.3 & 14.3 & 10.9 & 6.9 & 6.8 & 6.1 \\
\hline Russian Federation .................... & - & - & 14.3 & - & - & 5.8 \\
\hline Spain ..... & 15.0 & 12.9 & 10.2 & 6.8 & 6.8 & 6.2 \\
\hline Sweden & 11.3 & 10.2 & 10.8 & 5.4 & 5.2 & 4.6 \\
\hline 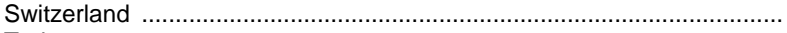 & 10.6 & 10.1 & 10.4 & 5.8 & 4.8 & 4.5 \\
\hline 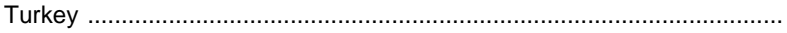 & 20.6 & 20.6 & 19.7 & 8.7 & 8.9 & 8.8 \\
\hline 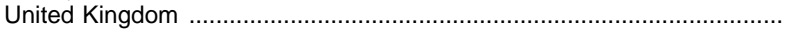 & 11.4 & 11.1 & 11.6 & 6.3 & 5.2 & 4.8 \\
\hline United States & 12.6 & 12.8 & 13.0 & 6.2 & 5.4 & 5.5 \\
\hline
\end{tabular}

1 Data for 1985 are for the former West Germany.

-Data not available.
SOURCE: Organization for Economic Cooperation and Development, Education at a Glance, 1996; and unpublished data. (This table was prepared July 1997.)

Table 392.-Percent of population enrolled in secondary and postsecondary institutions, by age group: Selected countries, 1985, 1990, and 1995

\begin{tabular}{|c|c|c|c|c|c|c|c|c|c|c|c|c|c|c|c|}
\hline \multirow{3}{*}{ Country } & \multirow{2}{*}{\multicolumn{3}{|c|}{$\begin{array}{l}\text { Secondary schools, } \\
16 \text { years old }{ }^{1}\end{array}$}} & \multirow{2}{*}{\multicolumn{3}{|c|}{$\begin{array}{l}\text { Secondary schools, } \\
17 \text { years old } 1\end{array}$}} & \multicolumn{9}{|c|}{ Postsecondary institutions } \\
\hline & & & & & & & \multicolumn{3}{|c|}{18 to 21 years old } & \multicolumn{3}{|c|}{22 to 25 years old } & \multicolumn{3}{|c|}{26 to 29 years old } \\
\hline & 1985 & 1990 & 1995 & 1985 & 1990 & 1995 & 1985 & 1990 & 1995 & 1985 & 1990 & 1995 & 1985 & 1990 & 1995 \\
\hline 1 & 2 & 3 & 4 & 5 & 6 & 7 & 8 & 9 & 10 & 11 & 12 & 13 & 14 & 15 & 16 \\
\hline Belgium & 90.0 & - & 98.9 & 80.9 & - & 96.7 & 24.5 & - & 40.7 & 7.2 & - & 16.5 & 1.5 & - & 4.4 \\
\hline Canada & - & - & 86.5 & - & - & 68.5 & - & - & 37.9 & - & - & 22.0 & - & - & 9.5 \\
\hline Denmark & 31.2 & 34.6 & 28.9 & 69.3 & 73.1 & 73.3 & 7.4 & 7.4 & 8.9 & 16.3 & 17.9 & 22.6 & 8.2 & 9.3 & 11.2 \\
\hline Finland ............ & 74.6 & 89.7 & 84.3 & 80.5 & 81.7 & 88.5 & 9.3 & 13.6 & 17.5 & 17.3 & 20.7 & 27.4 & 7.9 & 10.2 & 12.9 \\
\hline France & 67.0 & 68.2 & 78.6 & 72.4 & 79.7 & 86.5 & 19.3 & 24.6 & 34.2 & 10.0 & 11.8 & 17.7 & 4.3 & 3.9 & 4.6 \\
\hline Germany ${ }^{2}$ & 52.3 & 46.5 & 42.6 & 82.7 & 81.2 & 80.1 & 8.8 & 8.5 & - & - & 15.9 & 17.0 & 8.9 & 10.3 & 11.4 \\
\hline Ireland ............. & - & 79.2 & 83.8 & - & 68.0 & 74.9 & - & 20.5 & 29.1 & - & - & 15.0 & - & - & - \\
\hline Japan & - & 93.5 & 100.4 & - & 88.6 & 96.6 & - & - & - & - & - & - & - & - & - \\
\hline 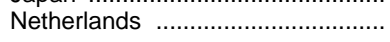 & 41.7 & 45.0 & 53.0 & 55.6 & 58.5 & 73.7 & 14.4 & 17.9 & 23.2 & 11.9 & 13.4 & 18.7 & 5.7 & 4.7 & 5.6 \\
\hline New Zealand . & - & 79.9 & 98.5 & - & 57.2 & 76.9 & - & 20.7 & 27.9 & - & 14.8 & 11.9 & - & - & 7.3 \\
\hline Norway .................. & 83.4 & 90.4 & 94.1 & 76.1 & 82.6 & 90.2 & 8.6 & 13.5 & 17.5 & 13.9 & 17.4 & 23.6 & 6.2 & 7.5 & 10.0 \\
\hline Portugal ........... & 18.0 & 一 & 49.3 & 22.3 & - & 58.8 & 5.9 & - & 17.9 & 5.4 & - & 15.7 & 2.3 & - & 5.9 \\
\hline Spain .......... & 58.2 & 70.6 & 82.3 & 50.9 & 62.1 & 74.4 & 15.0 & 21.3 & 25.6 & 10.7 & 13.5 & 17.5 & 4.0 & 4.5 & 5.5 \\
\hline Sweden ......... & 86.7 & 83.1 & 92.4 & 82.4 & 84.6 & 95.6 & 7.8 & 8.7 & 13.0 & 11.3 & 11.4 & 16.6 & 6.5 & 6.1 & 7.5 \\
\hline Switzerland & 58.1 & 61.9 & 52.9 & 78.8 & 81.7 & 76.4 & 5.7 & 6.4 & 7.7 & 10.6 & 12.1 & 14.7 & 5.2 & 6.4 & 7.2 \\
\hline Turkey ................... & 20.5 & 27.3 & 37.8 & 12.7 & 17.3 & 23.9 & - & 7.3 & 10.3 & - & 4.3 & 7.3 & - & 2.2 & 3.2 \\
\hline United Kingdom . & 67.0 & 75.6 & 83.9 & 45.9 & 57.4 & 72.0 & 15.0 & 16.1 & 26.2 & 7.4 & 10.6 & 9.4 & - & - & 4.8 \\
\hline United States ${ }^{3} \ldots .$. & 83.6 & 84.8 & 81.7 & 78.1 & 78.4 & 73.9 & 33.2 & 35.6 & 34.1 & 14.6 & 17.3 & 21.2 & 8.2 & 8.6 & 10.8 \\
\hline
\end{tabular}

1 Includes full-time and part-time enrollment.

2 Data for 1985 are for the former West Germany.

${ }^{3}$ Postsecondary includes higher education only.

-Data not available.
NOTE.-Some increases in enrollment rates may be due to more complete reporting by countries.

SOURCE: Organization for Economic Cooperation and Development, Education at a Glance, 1996; andunpublished data. (This table was prepared September 1998.) 
Table 393.-Estimated population, school enrollment, teachers, and public expenditures for education in major areas of the world: 1980, 1990, 1994, and 1995

\begin{tabular}{|c|c|c|c|c|c|c|c|}
\hline \multirow[b]{2}{*}{ Item } & \multirow[b]{2}{*}{ World total ${ }^{1}$} & \multicolumn{6}{|c|}{ Major areas of the world } \\
\hline & & Africa $^{2}$ & Asia $^{3}$ & Europe 4 & $\begin{array}{l}\text { Central and } \\
\text { South Amer- } \\
\text { ica } 5\end{array}$ & $\begin{array}{l}\text { Northern } \\
\text { America }^{5}\end{array}$ & Oceania $^{6}$ \\
\hline 1 & 2 & 3 & 4 & 5 & 6 & 7 & 8 \\
\hline 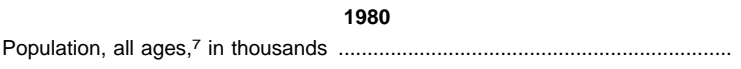 & $4,447,405$ & 475,714 & $2,641,312$ & 693,264 & 359,306 & 255,109 & 22,700 \\
\hline $\begin{array}{l}\text { Enrollment, all levels, } 8 \text { in thousands } \\
\text { First (primary) level } 9 \\
\text { Second level } 10\end{array}$ & $\begin{array}{r}857,017 \\
541,002 \\
264,855 \\
51,160\end{array}$ & $\begin{array}{r}78,024 \\
62,128 \\
14,354 \\
1,542\end{array}$ & $\begin{array}{r}494,813 \\
335,946 \\
144,617 \\
14,250\end{array}$ & $\begin{array}{r}132,112 \\
52,255 \\
63,352 \\
16,505\end{array}$ & $\begin{array}{r}87,211 \\
65,310 \\
16,972 \\
4,930\end{array}$ & $\begin{array}{l}60,042 \\
22,611 \\
23,913 \\
13,516\end{array}$ & $\begin{array}{r}4,815 \\
2,752 \\
1,647 \\
416\end{array}$ \\
\hline $\begin{array}{l}\text { Teachers, all levels, } 8 \text { in thousands } \\
\text { First (primary) level } 9 \text { (a) } \\
\text { Second level }{ }^{10}\end{array}$ & $\begin{array}{r}38,158 \\
19,009 \\
15,360 \\
3,788\end{array}$ & $\begin{array}{r}2,340 \\
1,663 \\
583 \\
94\end{array}$ & $\begin{array}{r}19,554 \\
10,849 \\
7,491 \\
1,215\end{array}$ & $\begin{array}{l}8,245 \\
2,530 \\
4,411 \\
1,304\end{array}$ & $\begin{array}{r}3,731 \\
2,260 \\
1,083 \\
388\end{array}$ & $\begin{array}{r}4,015 \\
1,580 \\
1,679 \\
756\end{array}$ & $\begin{array}{r}272 \\
129 \\
112 \\
31\end{array}$ \\
\hline $\begin{array}{l}\text { Public expenditures on education, in millions of U.S. dollars } \\
\text { As a percent of gross national product }\end{array}$ & $\begin{array}{r}\$ 516,400 \\
4.8\end{array}$ & $\begin{array}{r}\$ 22,900 \\
5.3\end{array}$ & $\begin{array}{r}\$ 93,800 \\
4.0\end{array}$ & $\begin{array}{r}\$ 200,600 \\
115.1\end{array}$ & $\begin{array}{r}\$ 33,500 \\
3.8\end{array}$ & $\begin{array}{r}\$ 155,100 \\
5.2\end{array}$ & $\begin{array}{r}\$ 10,400 \\
5.6\end{array}$ \\
\hline 1990 & & & & & & & \\
\hline Population, all ages, ${ }^{7}$ in thousands ............. & $5,282,359$ & 629,390 & $3,184,342$ & 722,317 & 437,822 & 282,020 & 26,468 \\
\hline $\begin{array}{l}\text { Enrollment, all levels, } 8 \text { in thousands } \\
\quad \text { First (primary) level } 9 \\
\text { Second level } 10\end{array}$ & $\begin{array}{r}981,455 \\
596,637 \\
316,154 \\
68,665 \\
\end{array}$ & $\begin{array}{r}107,796 \\
80,595 \\
24,345 \\
2,856 \\
\end{array}$ & $\begin{array}{r}569,719 \\
364,117 \\
182,222 \\
23,380 \\
\end{array}$ & $\begin{array}{r}131,789 \\
48,889 \\
64,079 \\
18,821 \\
\end{array}$ & $\begin{array}{r}104,937 \\
75,504 \\
22,079 \\
7,353 \\
\end{array}$ & $\begin{array}{l}62,007 \\
24,811 \\
21,569 \\
15,628\end{array}$ & $\begin{array}{r}5,208 \\
2,721 \\
1,859 \\
628 \\
\end{array}$ \\
\hline $\begin{array}{l}\text { Teachers, all levels, } 8 \text { in thousands } \\
\text { First (primary) level } 9 \\
\text { Second level } 10\end{array}$ & $\begin{array}{r}47,001 \\
22,571 \\
19,362 \\
5,068 \\
\end{array}$ & $\begin{array}{r}3,791 \\
2,390 \\
1,240 \\
161 \\
\end{array}$ & $\begin{array}{r}24,396 \\
12,684 \\
9,893 \\
1,819 \\
\end{array}$ & $\begin{array}{l}9,389 \\
2,765 \\
5,114 \\
1,511 \\
\end{array}$ & $\begin{array}{r}5,166 \\
3,006 \\
1,519 \\
641\end{array}$ & $\begin{array}{r}3,927 \\
1,582 \\
1,449 \\
896 \\
\end{array}$ & $\begin{array}{r}331 \\
143 \\
146 \\
41\end{array}$ \\
\hline $\begin{array}{l}\text { Public expenditures on education, in millions of U.S. dollars } \\
\text { As a percent of gross national product }\end{array}$ & $\begin{array}{r}\$ 986,500 \\
4.8\end{array}$ & $\begin{array}{r}\$ 25,700 \\
5.6\end{array}$ & $\begin{array}{r}\$ 199,800 \\
3.7\end{array}$ & $\begin{array}{r}\$ 367,500 \\
125.1\end{array}$ & $\begin{array}{r}\$ 44,600 \\
4.1\end{array}$ & $\begin{array}{r}\$ 330,300 \\
5.4\end{array}$ & $\begin{array}{r}\$ 18,600 \\
5.6\end{array}$ \\
\hline Population, all ages, 7 in thousands & $5,607,060$ & 700,695 & $3,387,959$ & 727,604 & 468,945 & 293,882 & 27,975 \\
\hline $\begin{array}{l}\text { Enrollment, all levels } 8 \text { in thousands } \\
\text { First (primary) level } 9 \text { (9) } \\
\text { Second level } 10\end{array}$ & $\begin{array}{r}1,078,000 \\
639,762 \\
358,867 \\
79,371 \\
\end{array}$ & $\begin{array}{r}125,746 \\
92,902 \\
29,216 \\
3,627 \\
\end{array}$ & $\begin{array}{r}628,247 \\
389,493 \\
209,251 \\
29,503 \\
\end{array}$ & $\begin{array}{r}138,196 \\
47,925 \\
69,413 \\
20,857 \\
\end{array}$ & $\begin{array}{r}112,931 \\
80,295 \\
24,686 \\
7,950 \\
\end{array}$ & $\begin{array}{l}66,135 \\
26,243 \\
23,597 \\
16,294 \\
\end{array}$ & $\begin{array}{l}6,746 \\
2,903 \\
2,703 \\
1,140 \\
\end{array}$ \\
\hline $\begin{array}{l}\text { Teachers, all levels, } 8 \text { in thousands } \\
\text { First (primary) level } 9 \\
\text { Second level } 10\end{array}$ & $\begin{array}{r}50,848 \\
24,024 \\
21,050 \\
5,773\end{array}$ & $\begin{array}{r}4,263 \\
2,706 \\
1,364 \\
193 \\
\end{array}$ & $\begin{array}{r}26,285 \\
13,353 \\
10,801 \\
2,131 \\
\end{array}$ & $\begin{array}{r}10,121 \\
2,874 \\
5,548 \\
1,699\end{array}$ & $\begin{array}{r}5,651 \\
3,318 \\
1,618 \\
714\end{array}$ & $\begin{array}{r}4,099 \\
1,622 \\
1,503 \\
974 \\
\end{array}$ & $\begin{array}{r}428 \\
150 \\
216 \\
62 \\
\end{array}$ \\
\hline $\begin{array}{l}\text { Public expenditures on education, in millions of U.S. dollars } \\
\text { As a percent of gross national product }\end{array}$ & $\begin{array}{r}\$ 1,329,900 \\
4.9\end{array}$ & $\begin{array}{r}\$ 29,100 \\
5.9\end{array}$ & $\begin{array}{r}\$ 302,100 \\
3.6\end{array}$ & $\begin{array}{r}\$ 492,600 \\
5.4\end{array}$ & $\begin{array}{r}\$ 72,800 \\
4.5\end{array}$ & $\begin{array}{r}\$ 408,900 \\
5.5\end{array}$ & $\begin{array}{r}\$ 23,500 \\
6.0\end{array}$ \\
\hline Population, all ages, ${ }^{7}$ in thousands............ & $5,687,174$ & 719,497 & $3,437,791$ & 728,249 & 476,641 & 296,644 & 28,352 \\
\hline $\begin{array}{l}\text { Enrollment, all levels, } 8 \text { in thousands } \\
\text { First (primary) level } 9 \\
\text { Second level } 10\end{array}$ & $\begin{array}{r}1,103,959 \\
650,179 \\
372,037 \\
81,742 \\
\end{array}$ & $\begin{array}{r}129,552 \\
95,378 \\
30,378 \\
3,795 \\
\end{array}$ & $\begin{array}{r}645,271 \\
395,658 \\
218,851 \\
30,762 \\
\end{array}$ & $\begin{array}{r}139,580 \\
47,663 \\
70,458 \\
21,459\end{array}$ & $\begin{array}{r}115,582 \\
81,678 \\
25,784 \\
8,121 \\
\end{array}$ & $\begin{array}{l}66,975 \\
26,861 \\
23,675 \\
16,438\end{array}$ & $\begin{array}{l}6,999 \\
2,941 \\
2,891 \\
1,168\end{array}$ \\
\hline $\begin{array}{l}\text { Teachers, all levels, } 8 \text { in thousands } \\
\text { First (primary) level } 9 \\
\text { Second level }{ }^{10}\end{array}$ & $\begin{array}{r}51,919 \\
24,329 \\
21,670 \\
5,919\end{array}$ & $\begin{array}{r}4,451 \\
2,782 \\
1,460 \\
209\end{array}$ & $\begin{array}{r}26,851 \\
13,491 \\
11,167 \\
2,193 \\
\end{array}$ & $\begin{array}{r}10,220 \\
2,851 \\
5,627 \\
1,742 \\
\end{array}$ & $\begin{array}{r}5,814 \\
3,386 \\
1,699 \\
728 \\
\end{array}$ & $\begin{array}{r}4,155 \\
1,668 \\
1,504 \\
984 \\
\end{array}$ & $\begin{array}{r}428 \\
153 \\
212 \\
64 \\
\end{array}$ \\
\hline $\begin{array}{l}\text { Public expenditures on education, in millions of U.S. dollars } \\
\text { As a percent of gross national product }\end{array}$ & - & - & - & - & - & - & - \\
\hline
\end{tabular}

1 Enrollment and teacher data exclude the Democratic People's Republic of Korea. Expenditure data exclude Albania, Cambodia, Democratic People's Republic of Korea, Lao People's Democratic Republic, Lebanon, Mongolia, Mozambique, South Africa, and Vie Nam.

Excludes Rodrigues and other small islands.

${ }^{3}$ Excludes the former U.S.S.R., the Democratic People's Republic of Korea, and Arab states, but includes both the Asian and the European portions of Turkey.

${ }^{4}$ Includes the former U.S.S.R.

5 Northern America includes Bermuda, Canada, Greenland, St.Pierre, and the United States of America. Hawaii is included in Northern America rather than Oceania. Central and South America includes Latin America and the Caribbean.

6 Includes American Samoa, Australia, Cook Islands, Fiji, French Polynesia, Guam, Kiribati, Marshall Islands, Federated States of Micronesia, Nauru, New Caledonia, New Zealand, Niue, Norfolk Island, Northern Mariana Islands, Pacific Islands, Papua New Guinea, Pitcairn, Samoa, Solomon Islands, Tokelau, Tonga, Tuvalu, Republic of Vanuatu, and Wallis and Fortuna Islands.
7 Estimate of midyear population.

${ }^{8}$ Excludes special and adult education provided outside regular schools. Data prior to 1992 exclude preprimary.

9 First level enrollment generally consists of elementary school, grades 1-6.

${ }^{10}$ Second level enrollment includes general education, teacher training (at the second level), and technical and vocational education. This level generally corresponds to secondary education in the United States, grades 7-12.

11 Third level enrollment includes college and university enrollment, and technical and vocational education beyond the high school level. There is considerable variation in reporting from country to country.

12 This figure is for Europe, not including the former U.S.S.R

-Data not available.

SOURCE: United Nations Educational, Scientific, and Cultural Organization, Paris, 1996 Statistical Yearbook, Facts on Education, Technology, and Culture Worldwide. (This table was prepared October 1998.) 
Table 394.-Selected statistics for countries ${ }^{1}$ with populations over 10 million, by continent: 1980, 1990, and 1995

\begin{tabular}{|c|c|c|c|c|c|c|c|c|c|c|}
\hline \multirow{3}{*}{ Country } & \multicolumn{3}{|c|}{ Population in millions } & \multirow{3}{*}{$\begin{array}{c}\text { Persons } \\
\text { per square } \\
\text { kilometer } \\
\text { in } 1995\end{array}$} & \multicolumn{6}{|c|}{ First level ${ }^{2}$} \\
\hline & \multirow{2}{*}{1980} & \multirow{2}{*}{1990} & \multirow{2}{*}{1995} & & \multicolumn{3}{|c|}{ Enrollment in thousands } & & IIment ratio & \\
\hline & & & & & 1980 & 1990 & 1995 & 1980 & 1990 & 1995 \\
\hline 1 & 2 & 3 & 4 & 5 & 6 & 7 & 8 & 9 & 10 & 11 \\
\hline World total 7 & 4,447.4 & $5,282.4$ & $5,687.2$ & 42 & 541,002 & 596,637 & 650,179 & 96 & 99 & 100 \\
\hline Africa & & & & & & & & & & \\
\hline 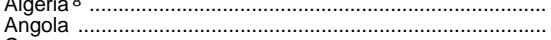 & $\begin{array}{r}18.7 \\
7.0\end{array}$ & $\begin{array}{r}24.9 \\
9.2\end{array}$ & $\begin{array}{l}28.1 \\
10.8\end{array}$ & $\begin{array}{r}12 \\
9\end{array}$ & 1,301 & $\begin{array}{r}4,189 \\
990\end{array}$ & 4,618 & $\begin{array}{r}94 \\
174\end{array}$ & $\begin{array}{r}100 \\
91\end{array}$ & 107 \\
\hline 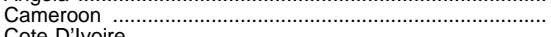 & 8.7 & $\begin{array}{r}11.5 \\
11.7\end{array}$ & $\begin{array}{r}13.2 \\
13.7\end{array}$ & 28 & 1,379 & 1,964 & $\begin{array}{l}9 \\
9\end{array}, 897$ & 98 & 101 & 988 \\
\hline $\begin{array}{l}\text { Cote D'lvoire } \\
\text { Egypt }\end{array}$ & $\begin{array}{r}8.2 \\
43.7\end{array}$ & $\begin{array}{l}11.7 \\
56.3\end{array}$ & $\begin{array}{l}13.7 \\
62.1\end{array}$ & $\begin{array}{r}42 \\
62\end{array}$ & $\begin{array}{l}1,025 \\
4,663\end{array}$ & $\begin{array}{l}1,415 \\
6,964\end{array}$ & $\begin{array}{r}1,662 \\
15 \\
7,470\end{array}$ & $\begin{array}{l}75 \\
73\end{array}$ & $\begin{array}{r}67 \\
94\end{array}$ & $\begin{array}{r}69 \\
100\end{array}$ \\
\hline Ethiopia & 36.4 & 48.1 & 56.4 & 51 & 2,131 & 2,466 & $\begin{array}{r}9,722 \\
9\end{array}$ & $\begin{array}{l}36 \\
36\end{array}$ & $\begin{array}{r}94 \\
33 \\
\end{array}$ & 931 \\
\hline Ghana .. & 10.8 & 15.0 & 17.3 & 73 & 191,378 & 1,945 & $2,1,2$ & 79 & 77 & r \\
\hline Kenya $^{8} \ldots \ldots . . . .$. & 16.6 & 23.5 & 27.2 & 47 & 3,927 & 5,392 & 5,545 & 115 & 95 & 85 \\
\hline Madagascar ${ }^{8}$ & 9.1 & 12.6 & 14.9 & 25 & 1,724 & 1,571 & $\begin{array}{ll}10 & 1,505 \\
1,105 & 1\end{array}$ & 133 & 84 & 1072 \\
\hline Morocco........ & 19.4 & 24.0 & 26.5 & 59 & 2,172 & 2,484 & 3,102 & 83 & 67 & 83 \\
\hline 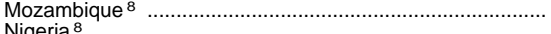 & 12.1 & $\begin{aligned} 14.2 \\
962 .\end{aligned}$ & $\begin{array}{r}17.3 \\
111 .\end{array}$ & $\begin{array}{r}22 \\
121\end{array}$ & $\begin{array}{r}1,387 \\
22 \\
2,117\end{array}$ & $\begin{array}{r}1,260 \\
1,607\end{array}$ & $\begin{array}{r}1,415 \\
9\end{array}$ & 99 & 67 & 60 \\
\hline 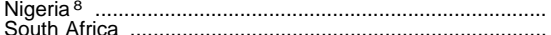 & $\begin{array}{cc}72.0 \\
292\end{array}$ & 96.2 & $\begin{aligned} 111.7 \\
415\end{aligned}$ & $\begin{array}{r}121 \\
34\end{array}$ & 2212,117 & $\begin{array}{r}13,607 \\
6952\end{array}$ & $\begin{array}{l}9 \\
16,191\end{array}$ & $\begin{array}{r}105 \\
85\end{array}$ & 85 & 989 \\
\hline $\begin{array}{l}\text { South Africa } \\
\text { Sudand }\end{array}$ & $\begin{array}{l}29.2 \\
18.7\end{array}$ & $\begin{array}{l}37.1 \\
24.1\end{array}$ & $\begin{array}{l}41.5 \\
26.7\end{array}$ & $\begin{array}{c}34 \\
11\end{array}$ & $\begin{array}{l}4,353 \\
1,464\end{array}$ & $\begin{array}{r}6,952 \\
2,043\end{array}$ & $\begin{array}{l}8,061 \\
3,024\end{array}$ & $\begin{array}{r}85 \\
50\end{array}$ & $\begin{array}{r}109 \\
50\end{array}$ & $\begin{array}{l}117 \\
954\end{array}$ \\
\hline Uganda ……................. & 13.1 & 16.6 & 19.7 & 82 & 1,292 & 2,470 & 2,912 & 2650 & 2674 & $\begin{array}{l}2674 \\
26\end{array}$ \\
\hline United Republic of Tanzania ......... & 18.6 & 25.5 & 30.0 & 34 & 273,368 & 273,379 & 3,878 & 93 & 70 & 67 \\
\hline Zaire & 27.0 & 37.4 & 45.5 & 19 & 4,196 & 4,562 & $\begin{array}{r}95,418 \\
\end{array}$ & 92 & 70 & 972 \\
\hline Zimbabwe ……………….......... & 7.1 & 9.9 & 11.2 & 29 & 1,235 & 2,116 & 2,483 & 85 & 116 & 116 \\
\hline Asia & & & & & & & & & & \\
\hline 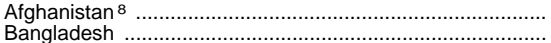 & $\begin{array}{r}16.1 \\
88 ?\end{array}$ & $\begin{array}{r}14.8 \\
109.8\end{array}$ & $\begin{array}{c}19.7 \\
118 ?\end{array}$ & $\begin{array}{r}30 \\
821\end{array}$ & $\begin{array}{l}1,116 \\
8240\end{array}$ & 623 & 1,312 & 34 & $\begin{array}{l}27 \\
69\end{array}$ & 49 \\
\hline 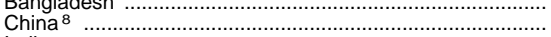 & $\begin{array}{r}898.2 \\
998\end{array}$ & $1,155.3$ & $\begin{array}{r}1,220.2 \\
1,2\end{array}$ & $\begin{array}{l}821 \\
127\end{array}$ & $\begin{array}{r}8,240 \\
146,270\end{array}$ & $\begin{array}{r}1,22,414 \\
124\end{array}$ & 131,951 & $\begin{array}{r}61 \\
113\end{array}$ & 127 & $1 \overline{18}$ \\
\hline$\ldots \ldots \ldots \ldots \ldots \ldots \ldots \ldots \ldots$ & 688.9 & $\begin{array}{l}850.8 \\
188.8\end{array}$ & $\begin{array}{l}929.0 \\
1975\end{array}$ & 283 & $\begin{array}{r}73,873 \\
25,537\end{array}$ & $\begin{array}{r}99,118 \\
29754\end{array}$ & $\begin{array}{r}109,734 \\
9\end{array}$ & 83 & $\begin{array}{r}97 \\
115\end{array}$ & $\begin{array}{r}100 \\
9\end{array}$ \\
\hline $\begin{array}{l}\text { Indonesia } \\
\text { Iran, Islamic Republic of }{ }^{8} \text {. }\end{array}$ & $\begin{array}{r}151.0 \\
39.3\end{array}$ & $\begin{array}{r}182.8 \\
59.2\end{array}$ & $\begin{array}{r}197.5 \\
68.4\end{array}$ & $\begin{array}{r}104 \\
42\end{array}$ & $\begin{array}{r}25,537 \\
4,799\end{array}$ & $\begin{array}{r}29,754 \\
9,370\end{array}$ & $\begin{array}{r}929,722 \\
99,746\end{array}$ & $\begin{array}{r}107 \\
87\end{array}$ & $\begin{array}{l}115 \\
110\end{array}$ & $\begin{aligned} \begin{array}{r}1114 \\
9\end{array} 99 & \end{aligned}$ \\
\hline Iraq ............................. & 13.0 & 18.1 & 20.1 & 46 & 2,616 & 3,328 & & 113 & 111 & 20 \\
\hline Japan ........... & 116.8 & 123.5 & 125.1 & 331 & 11,827 & 9,373 & 8,370 & 101 & 100 & 102 \\
\hline 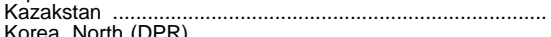 & $\begin{array}{r}14.9 \\
17\end{array}$ & 16.7 & $\begin{array}{l}16.8 \\
201\end{array}$ & $\begin{array}{r}6 \\
183\end{array}$ & 1,064 & $\begin{array}{r}1,197 \\
29\end{array}$ & 1,373 & 84 & 87 & 96 \\
\hline $\begin{array}{l}\text { Korea, North (DPR) } \\
\text { Korea, South (Republic of). }\end{array}$ & $\begin{array}{c}17.7 \\
381\end{array}$ & $\begin{array}{c}20.4 \\
42.9\end{array}$ & $\begin{array}{l}22.1 \\
44.9\end{array}$ & $\begin{array}{l}183 \\
452\end{array}$ & 5658 & $\begin{array}{ll}29 & 1,543 \\
4869\end{array}$ & 3.916 & 110 & 105 & - \\
\hline 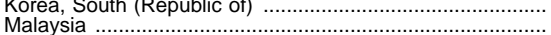 & $\begin{array}{l}38.1 \\
13.8\end{array}$ & $\begin{array}{l}42.9 \\
17.9\end{array}$ & 20.1 & $\begin{array}{r}452 \\
61\end{array}$ & 2,009 & $\begin{array}{l}4,869 \\
2,456\end{array}$ & 2,803 & 93 & 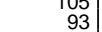 & $\overline{91}$ \\
\hline Myanmar (former Burma) ..... & 33.8 & 41.4 & 45.1 & 67 & 4,148 & 5,385 & 5,414 & 91 & 105 & 100 \\
\hline Nepal ${ }^{8}$. & 14.5 & $\begin{array}{r}18.8 \\
1191\end{array}$ & $\begin{array}{r}21.5 \\
126\end{array}$ & 152 & 1,068 & 2,789 & 103,092 & 86 & 108 & 10110 \\
\hline $\begin{array}{l}\text { Pakistan } . . . \\
\text { Philinnipos }\end{array}$ & 85.3 & 119.1 & 136.3 & 171 & 5,474 & 11,451 & 1015,532 & 39 & 61 & 1074 \\
\hline $\begin{array}{l}\text { Philippines } \\
\text { S }\end{array}$ & 48. & 60 & 67.8 & 226 & 198,034 & 10,427 & 11,542 & 112 & 113 & 116 \\
\hline Saudi Ar & 9. & $\begin{array}{l}16.0 \\
17.1\end{array}$ & 18.3 & 278 & 927 & 1,877 & 2,248 & $\begin{array}{r}61 \\
103\end{array}$ & $\begin{array}{r}73 \\
105\end{array}$ & 78 \\
\hline $\begin{array}{l}\text { Sri Lanka } \\
\text { Syrian Arab Republic }\end{array}$ & $\begin{aligned} 14.8 \\
8.7\end{aligned}$ & 12.4 & 14.2 & 273 & $\begin{array}{l}2,081 \\
1,566\end{array}$ & $\begin{array}{l}2,112 \\
2,452\end{array}$ & $\begin{array}{l}1,962 \\
2,673\end{array}$ & $\begin{array}{l}103 \\
100\end{array}$ & 108 & $\begin{array}{l}113 \\
101\end{array}$ \\
\hline Thailand 8 . & \begin{tabular}{c|c}
0.1 \\
46.7
\end{tabular} & 55.6 & 58.2 & 114 & 7,393 & 6,957 & $\begin{array}{l}2,013 \\
5,962\end{array}$ & 99 & 99 & 87 \\
\hline Turkey ………………………........... & 44.4 & 56.1 & 60.8 & 79 & 5,656 & 6,862 & 96,467 & 96 & 99 & 9105 \\
\hline 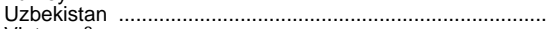 & 16.0 & 20.5 & 22.8 & 51 & 1,391 & 1,778 & & 81 & 81 & 977 \\
\hline$\ldots \ldots \ldots \ldots \ldots \ldots \ldots \ldots$ & 53.7 & 66. & 73.8 & 222 & 7,887 & 8,862 & & 109 & 103 & 114 \\
\hline Yemen ... & 8.2 & 11.6 & 15.0 & 28 & 703.369 & 311,671 & 102,679 & & 1 & 1079 \\
\hline Europe & & & & & & & & & & \\
\hline $\begin{array}{l}\text { Belarus } \\
\text { Czechosiovakia (former) }{ }^{8} . \cdots . . . . .\end{array}$ & 9.7 & 10.3 & 10.4 & 50 & 750 & 615 & 632 & 104 & 95 & 97 \\
\hline oslovakia (former) $)^{8} \ldots . . . .$. & 15.3 & 15.6 & 15.6 & & 1,904 & 1,924 & $\begin{array}{r}9,34 \\
9\end{array} 611$ & & 96 & $\begin{array}{l}9103 \\
9103\end{array}$ \\
\hline $\begin{array}{l}\text { CZech Republic .................... } \\
\text { Slovakia }\end{array}$ & $\begin{array}{r}10.3 \\
50\end{array}$ & $\begin{array}{r}10.3 \\
5.3\end{array}$ & $\begin{array}{r}10.3 \\
5.3\end{array}$ & $\begin{array}{l}130 \\
109\end{array}$ & 二 & 546 & $\begin{array}{l}9539 \\
930\end{array}$ & 二 & 96 & $\begin{array}{l}9103 \\
100\end{array}$ \\
\hline France & 53.9 & 56.7 & 58.1 & 105 & $4,6 \overline{10}$ & $4,1 \overline{49}$ & 94,072 & $1 \overline{11}$ & 108 & 9106 \\
\hline 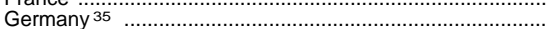 & 78.3 & 79.4 & 81.6 & 229 & 3,636 & 3,431 & 93,727 & & 101 & 9102 \\
\hline Gre & 9.6 & 10.2 & 10.5 & 79 & 901 & 813 & 971 & 103 & 98 & \\
\hline Hungary .... & 10.7 & 10.4 & 10.1 & 109 & 1,162 & 1,131 & 9985 & 96 & 95 & 997 \\
\hline Ita & 56.4 & 57.0 & 57.2 & 190 & 4,423 & 3,056 & 16 & 100 & 97 & 998 \\
\hline Netherlands ${ }^{8}$ & 14.1 & 15.0 & 15.5 & 379 & 1,333 & & 91,189 & 100 & 102 & 9107 \\
\hline Pola & 35.6 & 38.1 & 38.6 & 119 & 4,167 & 5,189 & ${ }^{9} 5,205$ & 100 & 98 & 998 \\
\hline Romania _.................. & $\begin{array}{r}22.2 \\
138 .\end{array}$ & $\begin{array}{r}23.2 \\
148.3\end{array}$ & $\begin{array}{r}22.7 \\
1485\end{array}$ & 95 & 3,237| & 1,253 & 1,392 & 102 & $\begin{array}{r}91 \\
109\end{array}$ & 100 \\
\hline 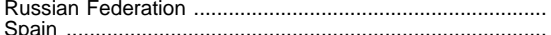 & $\begin{array}{r}138.7 \\
37.5\end{array}$ & $\begin{array}{r}148.3 \\
39.3\end{array}$ & $\begin{array}{r}148.5 \\
39.6\end{array}$ & $\begin{array}{r}9 \\
78\end{array}$ & $\begin{array}{l}6,009 \\
3,610\end{array}$ & 7,596 & $\begin{array}{l}9 \\
9 \\
9\end{array}$ & 102 & 109 & $\begin{array}{lll}9 & 108 \\
9 & 105\end{array}$ \\
\hline Ukrainian S.S.R. 군) & 50.0 & 51.9 & 51.8 & 86 & 3,592 & 3,991 & $\begin{array}{rl}9,38 & 2,659\end{array}$ & 102 & 89 & 1087 \\
\hline Unit & 56.3 & 57.6 & 58.1 & 238 & 194,911 & 194,533 & $9,195,209$ & 103 & 104 & 9,40115 \\
\hline Yugoslavia, Federal Republic & 9.5 & 10.2 & 10.3 & 100 & 1,432 & 467 & 449 & & 72 & \\
\hline North America & & & & & & & & & & \\
\hline 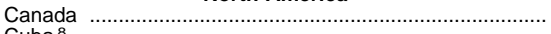 & 24.6 & 27.8 & 29.4 & 3 & 2,185 & 2,376 & 92,413 & 99 & 103 & 9102 \\
\hline $\mathrm{CL}$ & 9.7 & $\begin{array}{c}10.6 \\
83\end{array}$ & $\begin{array}{ll}11.0 \\
01.1\end{array}$ & $\begin{array}{r}99 \\
47\end{array}$ & 1, & $\begin{array}{r}888 \\
14402\end{array}$ & & 106 & $\begin{array}{r}98 \\
114\end{array}$ & $\begin{array}{r}105 \\
9115\end{array}$ \\
\hline & 67.6 & 83.2 & 91.1 & 47 & 14,666 & 14,402 & & 120 & 114 & 9115 \\
\hline United States $^{42}$ & 230.4 & 254.1 & 267.1 & 29 & 20,420 & 22,429 & 923,824 & 99 & 102 & ${ }^{9} 102$ \\
\hline South America & & & & & & & & & & \\
\hline Arg & 28.1 & 32.5 & 34.8 & 13 & 3,917 & 4,965 & 95 & 106 & 106 & 44113 \\
\hline $\mathrm{Br}$ & 121.7 & $\begin{array}{l}148.0 \\
131\end{array}$ & 159.0 & $\begin{array}{r}19 \\
19\end{array}$ & 22,598 & $\begin{array}{r}28,944 \\
27\end{array}$ & 93 & $\begin{array}{r}98 \\
109\end{array}$ & 106 & $\begin{array}{l}9112 \\
-199\end{array}$ \\
\hline Chile & $\begin{array}{l}11.1 \\
265\end{array}$ & 13.1 & $\begin{array}{l}14.2 \\
35.8\end{array}$ & $\begin{array}{l}19 \\
31\end{array}$ & 2,185 & $\begin{array}{lll}27 & 1,991 \\
4 & & \end{array}$ & $\begin{array}{r}2,150 \\
, 693\end{array}$ & 109 & 100 & $\begin{array}{r}99 \\
114\end{array}$ \\
\hline 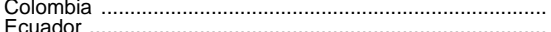 & 26.5 & 32.6 & $\begin{array}{l}35.8 \\
11.5\end{array}$ & $\begin{array}{r}31 \\
40\end{array}$ & $\begin{array}{l}4,168 \\
1,534\end{array}$ & $\begin{array}{r}4,247 \\
1,846\end{array}$ & $\begin{array}{r}4,693 \\
9 \\
9\end{array}$ & $\begin{array}{l}124 \\
117\end{array}$ & 112 & $\begin{array}{rl}114 \\
9 & 114\end{array}$ \\
\hline Ecuador .. & $\begin{array}{r}8.0 \\
17.3\end{array}$ & $\begin{array}{l}70.3 \\
21.6\end{array}$ & $\begin{array}{l}71.5 \\
23.5\end{array}$ & 40 & $\begin{array}{l}1,534 \\
3,161\end{array}$ & $\begin{array}{l}1,846 \\
3,855\end{array}$ & 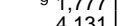 & 1114 & $\begin{array}{l}116 \\
118\end{array}$ & $\begin{array}{lll}9 & 109 \\
9 & 101\end{array}$ \\
\hline $\begin{array}{l}\text { Peru ........ } \\
\text { Venezuela }\end{array}$ & 15.3 & $\begin{array}{l}21.6 \\
19.5\end{array}$ & 21.8 & $\begin{array}{r}18 \\
24\end{array}$ & $\begin{array}{l}3,161 \\
3,158\end{array}$ & $\begin{array}{ll}45 & 3,855 \\
45 & 4553\end{array}$ & 4 & $\begin{array}{r}114 \\
93\end{array}$ & $\begin{array}{r}118 \\
96\end{array}$ & $\begin{array}{l}9121 \\
1094\end{array}$ \\
\hline Venezuela & & & & & & & & & 96 & \\
\hline Australia . & 14.6 & 4716.9 & 17.9 & 2 & 1,718 & 1,583 & 1,647 & 112 & 108 & 108 \\
\hline
\end{tabular}

1 Selection based on total population for midyear 1993.

2 First level enrollment generally consists of elementary school, grades 1-6.

${ }^{3}$ Second level enrollment includes general education, teacher training (at the second level), and technical and vocational education. This level generally corresponds to secondary education in the United States, grades 7-12.

${ }^{4}$ Third level enrollment includes college and university enrollment, and technical and vocational education beyond the high school level. There is considerable variation in reporting from country to country.

5 In many countries, a child may be exempt from school attendance if there is no suitable school within a reasonable distance of his/her home.

${ }^{6}$ Data are the total enrollment of all ages in the school level divided by the population of the specific age groups which correspond to the school level. The year shown in this column is the one in which the school or academic year starts. Adjustments have been made for the varying lengths of first and second level programs. Because some countries have many students from outside the normal age range, ratios may exceed 100

${ }^{7}$ Enrollment totals and ratios exclude Democratic People's Republic of Korea. Data do not include adult education or special education provided outside regular schools.
${ }^{8}$ Classification of first and/or second levels have been revised. Data by level may not be comparable over time.

9 Data for 1994-95.

10 Data for 1993-94.

${ }^{11}$ Data exclude Ecole Nationale d'Administration et de Magistrature (ENAM).

12 Eastern Cameroon.

13 Data for $1986-87$.

14 Data for $1988-89$.

${ }^{15}$ Data do not include Al Azhar.

16 Excludes all private institutions.

17 Data for $1985-86$.

${ }^{18}$ Data for 1992.

19 Data refer to public education only.

20 Data for 1989-90.

21 The educational system allows for other alternatives.

22 Data for 1979.

${ }^{23}$ Data for 1984.
${ }^{24}$ Data for 1981. 
Table 394.-Selected statistics for countries ${ }^{1}$ with populations over 10 million, by continent: 1980, 1990, and 1995-Continued

\begin{tabular}{|c|c|c|c|c|c|c|c|c|c|c|c|c|}
\hline \multicolumn{6}{|c|}{ Second level ${ }^{3}$} & \multicolumn{6}{|c|}{ Third level ${ }^{4}$} & \multirow{3}{*}{$\begin{array}{c}\text { Age for } \\
\text { compulsory } \\
\text { attendance } 5\end{array}$} \\
\hline \multicolumn{3}{|c|}{ Enrollment in thousands } & \multicolumn{3}{|c|}{ Enrollment ratio ${ }^{6}$} & \multicolumn{3}{|c|}{ Enrollment in thousands } & \multicolumn{3}{|c|}{ Enrollment ratio ${ }^{6}$} & \\
\hline 1980 & 1990 & 1995 & 1980 & 1990 & 1995 & 1980 & 1990 & 1995 & 1980 & 1990 & 1995 & \\
\hline 12 & 13 & 14 & 15 & 16 & 17 & 18 & 19 & 20 & 21 & 22 & 23 & 24 \\
\hline 264,855 & 316,154 & 372,037 & 46 & 52 & 58 & 51,160 & 68,665 & 81,742 & 12.2 & 13.8 & 16.2 & - \\
\hline 1,028 & 2,176 & 2,545 & 33 & 61 & 62 & 79 & 286 & 9299 & 5.9 & 11.4 & 10.9 & $6-15$ \\
\hline 191 & 186 & & 21 & 12 & - & 2 & 7 & & 0.4 & 0.8 & - & $7-15$ \\
\hline 234 & 500 & 10550 & 18 & 28 & ${ }^{9} 27$ & 1112 & 33 & ${ }^{10} 51$ & 1.6 & 3.3 & - & $126-12$ \\
\hline 222 & & 9475 & 19 & 22 & 23 & 20 & ${ }^{13} 24$ & - & 2.8 & ${ }^{14} 3.1$ & $9-$ & $7-13$ \\
\hline 2,929 & 155,507 & $\begin{array}{rl}15 & 6,143 \\
9 & 756\end{array}$ & $\begin{array}{r}50 \\
9\end{array}$ & $\begin{array}{l}76 \\
14\end{array}$ & $\begin{array}{r}74 \\
911\end{array}$ & 716 & 16628 & 一 & 16.1 & 15.9 & 918.1 & $6-13$ \\
\hline $\begin{array}{r}17666 \\
693\end{array}$ & $\begin{array}{r}866 \\
20830\end{array}$ & ${ }^{9} 756$ & $\begin{array}{r}9 \\
41\end{array}$ & $\begin{array}{l}14 \\
37\end{array}$ & ${ }^{911}$ & $\begin{array}{r}14 \\
8\end{array}$ & 34 & 二 & 0.4 & $\begin{array}{l}0.8 \\
14\end{array}$ & ${ }^{9} 0.7$ & $\begin{array}{r}7-13 \\
216-14\end{array}$ \\
\hline 428 & 17458 & - & $\begin{array}{l}41 \\
20\end{array}$ & $\begin{array}{l}37 \\
24\end{array}$ & $\overline{24}$ & $\begin{array}{r}8 \\
13\end{array}$ & $\begin{array}{l}{ }_{20} 30 \\
201\end{array}$ & 二 & $\begin{array}{l}1.6 \\
0.9\end{array}$ & $\begin{array}{l}1.4 \\
1.6\end{array}$ & 二 & 6-14 \\
\hline 22234 & & - & 2329 & 17 & 1014 & 23 & 36 & - & 2.6 & 3.1 & - & $6-13$ \\
\hline 797 & 1,194 & 1,412 & 26 & 35 & 39 & 112 & 256 & ${ }^{9} 295$ & 5.9 & 10.6 & 911.3 & $7-13$ \\
\hline 24108 & 160 & 185 & 5 & 8 & 7 & 1 & 185 & & 0.1 & ${ }^{17} 0.1$ & & $216-12$ \\
\hline 221,865 & 2,908 & 94,451 & 16 & 23 & 930 & 150 & 20336 & - & 2.2 & 173.3 & 184.1 & $6-12$ \\
\hline & 25 2,939 & 93,571 & 1355 & 68 & 84 & & 439 & 9618 & - & 12.8 & 17.3 & $7-16$ \\
\hline 384 & 732 & ${ }^{9} 254$ & 16 & 23 & $\begin{array}{rl}913 \\
26 & 10\end{array}$ & 29 & 2060 & $-\frac{1}{00}$ & 1.7 & 3.0 & $-\bar{c}$ & $6-14$ \\
\hline 87 & 268 & 292 & ${ }^{26} 5$ & 2613 & 2612 & 6 & 18 & ${ }^{9} 28$ & ${ }^{26} 0.5$ & 261.2 & 91.5 & - \\
\hline 2779 & 27167 & 213 & 3 & 5 & 5 & - & 205 & 13 & & 170.3 & 0.5 & $7-13$ \\
\hline 862 & 251,097 & 91,541 & 24 & 1723 & ${ }^{9} 26$ & 28 & 80 & 993 & 1.2 & 2.4 & $\begin{array}{l}9 \\
9\end{array} .3$ & $6-12$ \\
\hline 75 & 661 & 711 & 8 & 49 & 47 & 8 & 49 & 46 & 1.3 & 5.2 & 6.9 & $7-15$ \\
\hline 137 & 182 & 513 & 10 & 9 & 22 & 1322 & 24 & - & - & 1.8 & - & $7-13$ \\
\hline 2,659 & 3,593 & & 18 & 21 & - & 240 & 434 & - & 2.8 & 4.4 & - & $6-10$ \\
\hline 56,778 & 53,063 & 63,800 & 46 & 49 & 67 & 281,161 & 283,822 & 5,622 & 1.7 & 2.9 & 5.3 & $217-16$ \\
\hline 32,748 & 1744,485 & 66,634 & 30 & 44 & 49 & 3,545 & 4,951 & 5,582 & 5.2 & 6.0 & 6.4 & $6-14$ \\
\hline 5,722 & 10,965 & 912,224 & 29 & 44 & 948 & 543 & 1,591 & 2,303 & 3.6 & 9.2 & - & $7-13$ \\
\hline 2,718 & 5,085 & 97,653 & 42 & 54 & ${ }^{9} 69$ & 17184 & 312 & 1,048 & 0.0 & 9.6 & 914.8 & $6-10$ \\
\hline 1,033 & 171,191 & 181,145 & 57 & 47 & - & 107 & 14210 & & 8.7 & 12.6 & & $6-12$ \\
\hline 9,558 & 11,026 & 99,879 & 93 & 97 & 999 & 2,412 & 252,899 & 93,918 & 30.5 & 29.1 & 940.3 & $216-15$ \\
\hline 1,996 & $\begin{array}{r}2,144 \\
29\end{array}$ & ${ }^{10} 2,020$ & 93 & 98 & 83 & 525 & $\begin{array}{r}537 \\
29\end{array}$ & 419 & 34.1 & 40.1 & 32.7 & $6-18$ \\
\hline 4,286 & 4,560 & 4,707 & $\overline{78}$ & 90 & $1 \overline{01}$ & $306 \overline{48}$ & 1,691 & 2,225 & $14 \overline{7}$ & 38.6 & 52.0 & $\begin{array}{l}5-15 \\
6-15\end{array}$ \\
\hline 1,084 & 1,456 & 1,625 & 48 & 58 & 57 & 58 & 121 & 9191 & 4.1 & 7.2 & - & $216-16$ \\
\hline 1,066 & 1,281 & 91,753 & 22 & 23 & 32 & 163 & 25196 & ${ }^{9} 245$ & 4.7 & 4.3 & ${ }^{9} 5.4$ & 5-10 \\
\hline 512 & 709 & 10910 & 22 & 33 & 1038 & 1934 & & 10102 & 2.7 & 4.4 & 5.2 & $6-11$ \\
\hline 2,166 & 4,345 & & 14 & 23 & $\overline{70}$ & 17268 & 20337 & & 182.5 & 2.9 & & - \\
\hline 2,929 & 4,034 & 4,810 & 64 & 73 & 79 & 1,276 & 1,709 & 91,833 & 24.4 & 27.4 & 927.4 & $7-13$ \\
\hline 349 & 893 & 1,425 & 29 & 44 & 58 & 62 & 154 & 9234 & 7.1 & 11.6 & 915.3 & - \\
\hline 1,267 & 2,082 & 2,314 & 55 & 74 & 75 & 43 & 2555 & & 2.7 & 4.6 & & $5-15$ \\
\hline 604 & 914 & 941 & 46 & 52 & 44 & 140 & 222 & 18194 & 16.9 & 18.2 & 1017.9 & $6-11$ \\
\hline 1,920 & 2,230 & 3,794 & 29 & 30 & 55 & 171,027 & 20952 & 1,220 & 14.7 & 15.7 & 20.1 & $6-11$ \\
\hline 2,218 & 3,808 & 94,726 & 35 & 47 & 956 & 246 & 750 & $\begin{array}{l}9 \\
1,174\end{array}$ & 5.4 & 13.1 & 918.2 & $6-14$ \\
\hline 2,879 & 3,195 & 93,319 & 105 & 99 & 993 & 516 & 603 & - & 28.5 & 30.4 & 1831.7 & $\overline{11}$ \\
\hline 73 & 32421 & $10 \overline{212}$ & 42 & 32 & $\begin{array}{l}1027 \\
1023\end{array}$ & $\begin{array}{r}115 \\
8\end{array}$ & $\begin{array}{r}130 \\
2553\end{array}$ & 298 & 2.1 & $\begin{array}{r}1.9 \\
254.4\end{array}$ & 4.1 & $\begin{array}{l}6-11 \\
6-15\end{array}$ \\
\hline 760 & 968 & 1,055 & 98 & 93 & 94 & 340 & 322 & 314 & 38.9 & 45.7 & 42.6 & $21,336-15$ \\
\hline 781 & 864 & $91 \overline{7}$ & 89 & 83 & 90 & 197 & 190 & $1 \overline{70}$ & 17.4 & 16.0 & & $6-16$ \\
\hline - & 二 & $\begin{array}{l}9 \\
1,193 \\
666\end{array}$ & 二 & 二 & $\begin{array}{r}996 \\
91\end{array}$ & $\underline{120}$ & $\begin{array}{r}118 \\
1866\end{array}$ & $\begin{array}{r}9179 \\
92\end{array}$ & 17.5 & 16.0 & $\begin{array}{l}20.8 \\
20 ?\end{array}$ & $\begin{array}{l}6-15 \\
6-15\end{array}$ \\
\hline 5,014 & 5,522 & 96,004 & 85 & 100 & 9111 & 1,077 & 1,699 & 102,083 & 25.3 & 39.6 & 1049.6 & $6-16$ \\
\hline 368,457 & 7,398 & 98,152 & & 98 & 9103 & 1,624 & 2,049 & 92,140 & 27.2 & 33.9 & 942.7 & $6-18$ \\
\hline 740 & 851 & 10851 & 81 & 93 & 995 & 121 & 283 & 9296 & 17.1 & 24.8 & 938.1 & $216-15$ \\
\hline 357 & 514 & 9523 & 70 & 79 & 981 & 101 & 102 & 9155 & 14.1 & 14.0 & $\begin{array}{l}9 \\
19.1\end{array}$ & $6-16$ \\
\hline 5,308 & 5,118 & 104,938 & 72 & 79 & 988 & 1,118 & 1,452 & 91,792 & 27.0 & 30.8 & 940.6 & $6-13$ \\
\hline 371,391 & 1,402 & 91,509 & 93 & 120 & 9139 & 360 & 479 & 10532 & 29.3 & 39.8 & 1048.9 & $215-16$ \\
\hline 1,674 & 1,888 & 92,443 & 77 & 81 & 996 & 589 & 545 & 10748 & 18.1 & 21.7 & 1027.4 & $7-14$ \\
\hline 871 & 2,838 & 2,223 & 71 & 92 & 78 & 193 & 20165 & 337 & 12.1 & 208.5 & 18.3 & $7-14$ \\
\hline 12,991 & 13,956 & 1013,732 & 96 & 93 & 1087 & 5,700 & 5,100 & 94,458 & 46.1 & 52.2 & 942.9 & $217-17$ \\
\hline 3,977 & 4,755 & 94,745 & 87 & 105 & 9118 & 698 & 1,222 & 91,527 & 23.2 & 36.7 & 946.1 & $6-15$ \\
\hline 3,406 & 3,408 & 104,731 & 94 & 93 & 1091 & 391,684 & 391,652 & 1,541 & 41.6 & 46.6 & 1040.6 & $21,337-15$ \\
\hline 5,342 & 4,336 & ${ }^{9} 6,678$ & 83 & 85 & 134 & 827 & 1,258 & 91,813 & 19.1 & 30.2 & 948.3 & $5-16$ \\
\hline 一 & 788 & 832 & & 63 & 65 & & 25133 & 160 & - & 18.2 & 21.1 & $7-15$ \\
\hline 2,323 & 2,292 & 92,470 & 88 & 101 & 9106 & 411,173 & 1,917 & 102,011 & 57.1 & 94.7 & 10102.9 & $216-16$ \\
\hline 1,146 & 1,002 & 705 & 81 & 89 & 80 & 152 & 242 & 122 & 17.3 & 20.9 & 12.7 & $6-11$ \\
\hline 4,742 & 6,704 & 97,265 & 49 & 53 & 958 & 930 & 1,311 & 91,420 & 14.3 & 14.5 & 914.3 & $6-14$ \\
\hline 4321,585 & 4319,270 & $9,4321,123$ & 91 & 93 & 997 & 12,097 & 13,710 & 14,419 & 55.5 & 75.2 & 981.1 & $217-16$ \\
\hline 1,327 & 2,160 & 442,594 & 56 & 68 & & 491 & 251,008 & 91,070 & 21.8 & 2538.1 & - & $216-14$ \\
\hline 2,819 & 3,499 & 94,510 & 33 & 38 & 945 & 1,409 & 1,540 & 91,716 & 11.1 & 11.2 & 911.3 & $7-14$ \\
\hline 538 & 699 & 679 & 53 & 73 & 69 & 145 & 25262 & 343 & 12.3 & 2523.2 & 28.2 & $6-13$ \\
\hline 1,733 & 25 2,378 & 3,025 & 41 & 1861 & 67 & 272 & 25511 & 588 & 9.1 & 14.7 & 17.2 & $6-12$ \\
\hline 592 & 17730 & 18814 & 53 & 55 & 950 & 270 & 207 & & 34.9 & 20.0 & & $6-14$ \\
\hline $\begin{array}{r}1,203 \\
46\end{array}$ & 251,711 & 1,863 & 59 & 67 & $\begin{array}{r}69 \\
10\end{array}$ & 306 & 682 & 9756 & 17.3 & 30.4 & 931.1 & $6-16$ \\
\hline 40222 & ${ }^{46} 281$ & 10,45311 & 21 & 35 & 1035 & 307 & 550 & & 20.6 & 29.0 & & $5-15$ \\
\hline 1,100 & 1,278 & 2,182 & 71 & 82 & 147 & 324 & 485 & 965 & 25.4 & 35.5 & 71.7 & $216-16$ \\
\hline
\end{tabular}

25 Data for 1991-92.

26 Data refer to government maintained and aided schools only.

27 Data refer to Tanzania mainland only.

28 Includes full time students only.

${ }^{29}$ Data for $1987-88$.

${ }^{30}$ Data do not include Air and Correspondence courses.

31 Data for Former Democratic Yemen do not include schools for nomads.

${ }^{32}$ Former Yemen Arab Republic only.

${ }^{33}$ Grade levels changed for compatibility with ISCED.

${ }^{34}$ Data are a combination of data for the Czech Republic and Slovakia.

${ }^{35}$ Data include both former East and West Germany.

${ }^{36}$ Excludes technical education, consisting of both on the job training and school education.

${ }^{37}$ Data do not include apprenticeships and health care training.

38 Enrollment data refer to grades 1-4 only.

39 Excludes students enrolled in third level programs in secondary specialized schools.

40 Includes infant classes in primary schools, previously considered as preprimary education.

${ }^{41}$ Excludes trade and vocational programs.
${ }^{42}$ Population data are from the U.S. Bureau of the Census, Current Population Reports, Population Estimates. Enrollment totals and ratios are based on data compiled by the Nationat Center for E. Eation Statistics and the U.S. Bureau of the Census. First level includes grades 1 through 6 (ages 5-10), second level includes grades 7 through 12 (ages 11-16), and third level includes ages 20-24.

${ }^{43}$ Revised data series corresponding to grades $7-12$

${ }^{44}$ Data for $1996-97$.

45 Data refer to grades 1 to 9 (basic education).

${ }^{46}$ Data refer to grades 10 and 11.

47 Includes Norfolk Island.

-Data not available.

NOTE.-Some data have been revised from previously published figures.

SOURCE: United Nations Educational, Scientific, and Cultural Organization (UNESCO), Paris, Statistical Yearbook, various years; U.S. Department of Commerce, Bureau of the Census, Current Population Reports, Series P-20; and U.S. Department of Education, National Center for Education Statistics, Common Core of Data and "Fall Enrollment in Institutions of Higher Education" surveys, and Integrated Postsecondary Education Data System (IPEDS), "Fall Enrollment" surveys. (This table was prepared October 1998.) 
Table 395.--Pupils per teacher in public and private elementary and secondary schools, by level of education: Selected countries, 1985 to 1995

\begin{tabular}{|c|c|c|c|c|c|c|c|c|c|c|c|c|c|c|c|}
\hline \multirow{2}{*}{ Country } & \multicolumn{5}{|c|}{ Elementary } & \multicolumn{5}{|c|}{$\begin{array}{l}\text { Junior high schools } \\
\text { (lower secondary) }\end{array}$} & \multicolumn{5}{|c|}{$\begin{array}{l}\text { Senior high schools } \\
\text { (upper secondary) }\end{array}$} \\
\hline & 1985 & 1990 & 1992 & 1994 & 1995 & 1985 & 1990 & 1992 & 1994 & 1995 & 1985 & 1990 & 1992 & 1994 & 1995 \\
\hline 1 & 2 & 3 & 4 & 5 & 6 & 7 & 8 & 9 & 10 & 11 & 12 & 13 & 14 & 15 & 16 \\
\hline Australia & 113.8 & - & 218.4 & 18.5 & 18.1 & - & - & - & - & - & 3.2 & - & - & - & - \\
\hline Austria & 11.3 & 11.6 & 12.2 & 11.9 & 12.9 & 9.2 & 7.7 & 7.7 & 8.3 & 9.0 & 15.2 & 12.4 & 11.6 & 7.8 & 8.2 \\
\hline Belgium & - & - & 13.7 & 13.3 & 12.8 & - & - & - & - & - & - & - & - & - & - \\
\hline Canada & 18.1 & 17.1 & - & 16.5 & 16.7 & 16.0 & 15.5 & - & 19.1 & 19.7 & 16.0 & 15.3 & - & 19.1 & 19.2 \\
\hline Denmark ................................. & 12.7 & 11.2 & 310.9 & 11.0 & 11.1 & 10.2 & 9.3 & 9.1 & 9.0 & 9.4 & 14.8 & 13.3 & 310.4 & 9.1 & 9.9 \\
\hline France & - & - & ${ }^{4} 20.4$ & 19.6 & 19.5 & - & - & - & - & - & - & - & - & - & - \\
\hline 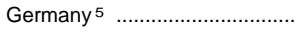 & 20.7 & 20.3 & 619.6 & 20.5 & 20.7 & 16.9 & 14.6 & 14.6 & 15.7 & 15.8 & 23.7 & 21.0 & 619.0 & 12.0 & 13.0 \\
\hline Ireland & - & - & 25.6 & 24.3 & 23.4 & - & - & - & - & - & 7.2 & 8.3 & - & - & - \\
\hline Italy & 12.8 & 10.7 & 10.9 & 10.2 & 11.0 & 9.6 & 8.5 & 9.0 & 8.0 & 9.9 & 10.8 & 10.7 & 8.8 & 8.9 & 9.3 \\
\hline Japan & - & ${ }^{1} 20.8$ & 719.8 & 19.2 & 19.5 & - & 18.6 & 16.8 & 16.2 & 16.6 & - & 16.2 & 716.4 & 15.8 & 16.4 \\
\hline 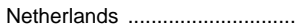 & 20.2 & 19.2 & 823.6 & 22.4 & - & 12.7 & 12.4 & - & 16.9 & - & - & - & - & 16.5 & - \\
\hline New Zealand .............................. & 20.1 & 19.1 & 18.5 & 20.2 & 22.3 & - & - & - & 16.7 & 18.4 & - & - & - & 13.2 & 15.6 \\
\hline Norway ......................................... & - & - & - & - & - & - & - & - & - & - & - & - & - & - & - \\
\hline 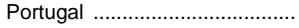 & - & - & - & 12.2 & - & - & - & - & - & - & - & - & - & - & - \\
\hline Spain & 26.8 & 21.2 & 21.2 & 19.2 & 17.8 & 21.4 & 18.8 & 17.6 & 18.2 & 17.5 & 15.3 & 14.8 & 15.9 & 14.8 & 14.8 \\
\hline Sweden & 11.6 & 10.6 & 11.9 & 12.5 & 12.3 & 10.8 & 10.2 & 10.6 & 10.9 & 12.2 & 13.1 & 11.9 & 16.0 & 14.6 & 14.8 \\
\hline Turkey & 31.1 & 30.6 & 29.3 & 27.4 & 27.7 & 41.3 & 48.4 & 47.5 & 45.6 & 41.2 & 11.0 & 12.1 & 13.2 & 14.1 & 14.9 \\
\hline United Kingdom ....................... & 19.7 & 22.0 & 20.8 & 20.7 & 21.0 & - & 18.5 & 15.9 & 16.9 & 16.0 & 11.1 & 13.9 & 914.8 & 15.1 & 15.9 \\
\hline United States …… & 17.0 & 15.6 & - & - & 17.1 & 16.5 & 15.9 & 16.8 & - & 17.6 & 16.2 & 15.8 & 15.0 & - & 1014.7 \\
\hline
\end{tabular}

1 Public schools only.

${ }_{2}$ Teachers include principals, deputy principals and senior teachers mainly involved in administrative tasks.

${ }^{3}$ Full-time and part-time teachers are estimates. Distribution by school level (elementary and junior high school levels) is also an estimate. Kindergartens are classified as public institutions.

${ }^{4}$ The number of full-time equivalent teachers does not take into account the additional hours given by teachers. In public secondary education institutions, an increase of 6.6 per cent of total full-time equivalents would be observed if the additional hours were taken into account. The number of teachers in independent private secondary education institutions are entirely estimates. About 18 per cent of all the pedagogical and support staff, and about 7 per cent of all the staff employed in education have been estimated.

${ }^{5}$ Data for 1985 are for the former West Germany.
${ }^{6}$ Most components are estimates.

${ }^{7}$ Principals and vice-principals are included. Full-time equivalents of part-time teachers are not included.

8 Teaching staff do not include direction staff.

${ }^{9}$ Some teachers at lower secondary education are included in upper secondary education.

10 Teachers and pupils in independent upper secondary vocational education and nursing and paramedical establishments are excluded.

-Data not available.

SOURCE: Organization for Economic Cooperation and Development, Education at a Glance, various years; and unpublished data. (This table was prepared July 1998.)

Table 396.-Geography proficiency of 13-year-olds in educational systems participating in the International Assessment of Educational Progress: 1991

\begin{tabular}{|c|c|c|c|c|}
\hline \multirow[b]{2}{*}{ Country } & \multicolumn{4}{|c|}{ Average percent correct } \\
\hline & All geography items ${ }^{1}$ & $\begin{array}{c}\text { Geographic skills and } \\
\text { tools }^{2}\end{array}$ & $\begin{array}{c}\text { Physical geography } \\
\text { items }^{3}\end{array}$ & $\begin{array}{c}\text { Cultural geography } \\
\text { items }{ }^{4}\end{array}$ \\
\hline 1 & 2 & 3 & 4 & 5 \\
\hline $\begin{array}{l}\text { Hungary } \\
\text { Slovenia } \\
\text { Canada } 5 \\
\text { Soviet Union (former) } \\
\text { United States } \\
\text { Spain }\end{array}$ & $\begin{array}{l}69.8(0.6) \\
65.3(0.6) \\
63.0(0.5) \\
62.6(1.1) \\
61.9(0.8) \\
60.1(0.7) \\
59.7(0.5) \\
58.5(0.6) \\
58.3(0.6)\end{array}$ & $\begin{array}{l}76.3(0.5) \\
67.9(0.5) \\
69.5(0.4) \\
72.2(0.9) \\
69.4(0.6) \\
62.4(0.9) \\
67.8(0.5) \\
62.7(0.6) \\
66.2(0.5)\end{array}$ & $\begin{array}{l}67.8(0.7) \\
63.6(0.7) \\
61.0(0.6) \\
61.2(1.0) \\
58.3(1.0) \\
58.9(0.7) \\
52.1(0.7) \\
59.5(0.8) \\
57.1(0.8)\end{array}$ & $\begin{array}{l}65.0(0.7) \\
64.3(0.9) \\
58.2(0.6) \\
53.4(1.8) \\
58.1(1.0) \\
58.9(1.1) \\
60.3(0.6) \\
52.3(0.8) \\
50.6(0.8)\end{array}$ \\
\hline
\end{tabular}

${ }^{1}$ All 24 geography items.

2 Eight items testing ability to use maps, charts, and globes.

${ }^{3}$ Nine items testing knowledge of location of physical features and concepts of climate.

${ }^{4}$ Seven items testing knowledge of cultural entities and interactions between people and their environment.

5 Eight provinces.

${ }^{6}$ Schools in 14 republics where instruction is in Russian.
${ }^{7}$ Schools where instruction is in Spanish, in all regions except Cataluna.

NOTE.-Standard errors appear in parentheses.

SOURCE: U.S. Department of Education, National Center for Education Statistics, International Assessment of Educational Progress, Learning About The World, 1992 (This table was prepared May 1993.) 
Table 397.-Average 8th-grade mathematics scores by content areas, and average time spent studying out of school, by country:

1994-95

\begin{tabular}{|c|c|c|c|c|c|c|c|c|c|c|c|c|c|c|c|}
\hline \multirow{3}{*}{ Country } & \multicolumn{7}{|c|}{ Average percent correct by content area } & \multicolumn{8}{|c|}{ Distribution of daily out-of-school study time in all subjects, with mean mathematics scores } \\
\hline & \multirow{2}{*}{$\begin{array}{l}\text { Mathe- } \\
\text { matics } \\
\text { overall }\end{array}$} & \multirow{2}{*}{$\begin{array}{l}\text { Fractions } \\
\text { and num- } \\
\text { ber sense }\end{array}$} & \multirow{2}{*}{ Geometry } & \multirow{2}{*}{ Algebra } & \multirow{2}{*}{$\begin{array}{l}\text { Data rep- } \\
\text { resentation, } \\
\text { analysis and } \\
\text { probability }\end{array}$} & \multirow{2}{*}{ Measurement } & \multirow{2}{*}{$\begin{array}{l}\text { Proportion- } \\
\text { ality }\end{array}$} & \multicolumn{2}{|c|}{ Less than 1 hour } & \multicolumn{2}{|c|}{$\begin{array}{l}\text { At least } 1 \text {, but less than } 2 \\
\text { hours }\end{array}$} & \multicolumn{2}{|c|}{2 to 3 hours } & \multicolumn{2}{|c|}{ More than 3 hours } \\
\hline & & & & & & & & Percent & Mean score & Percent & Mean score & Percent & Mean score & Percent & Mean score \\
\hline 1 & 2 & 3 & 4 & 5 & 6 & 7 & 8 & 9 & 10 & 11 & 12 & 13 & 14 & 15 & 16 \\
\hline $\begin{array}{l}\text { International average } \\
\text { percent correct } \ldots \ldots . . .\end{array}$ & $55(0.1)$ & $58(0.1)$ & $56(0.1)$ & $52(0.2)$ & $62(0.1)$ & $51(0.1)$ & $45(0.2)$ & -- & -- & -- & -- & -- & -- & -- & -- \\
\hline Australia ${ }^{1}$ & $58(0.9)$ & $61(0.9)$ & $57(1.0)$ & $55(1.0)$ & $67(0.8)$ & $54(1.0)$ & $47(0.9)$ & $15(0.9)$ & $486(5.7)$ & $46(1.0)$ & $541(4.4)$ & $22(0.6)$ & $543(5.2)$ & $17(0.7)$ & $532(4.8)$ \\
\hline Austria ${ }^{1}$............................. & $62(0.8)$ & $66(0.8)$ & $57(1.0)$ & $59(0.8)$ & $68(0.8)$ & $62(1.0)$ & $49(0.9)$ & $9(0.8)$ & $524(6.7)$ & $46(1.3)$ & $551(4.1)$ & $21(0.9)$ & $544(4.5)$ & $24(1.2)$ & $528(5.3)$ \\
\hline Belgium (Flemish) . & $66(1.4)$ & $71(1.2)$ & $64(1.5)$ & $63(1.7)$ & $73(1.3)$ & $60(1.3)$ & $53(1.8)$ & $2(0.4)$ & -- & $25(1.3)$ & $552(8.9)$ & $28(1.1)$ & $592(5.9)$ & 45 (1.6) & $560(4.6)$ \\
\hline Belgium (French) 1 & $59(0.9)$ & $62(1.0)$ & $58(1.0)$ & $53(1.1)$ & $68(1.0)$ & $56(1.0)$ & $48(0.9)$ & $7(0.8)$ & $466(7.4)$ & $32(1.0)$ & $543(4.6)$ & $21(1.3)$ & $544(5.5)$ & $40(1.5)$ & $519(4.5)$ \\
\hline Bulgaria ${ }^{1}$........................... & $60(1.2)$ & $60(1.4)$ & $65(1.3)$ & $62(1.5)$ & $62(1.1)$ & $54(1.6)$ & $47(1.5)$ & -- & -- & -- & -- & -- & -- & -- & -- \\
\hline Canada ........................... & $59(0.5)$ & $64(0.6)$ & $58(0.6)$ & $54(0.7)$ & $69(0.5)$ & $51(0.7)$ & $48(0.7)$ & $14(1.2)$ & $514(5.6)$ & $47(1.1)$ & $538(2.8)$ & $18(0.7)$ & $534(3.7)$ & $21(1.1)$ & $511(3.6)$ \\
\hline 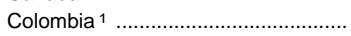 & $29(0.8)$ & $31(0.9)$ & $29(0.9)$ & $28(0.9)$ & $37(1.0)$ & $25(1.5)$ & $23(0.9)$ & $2(0.4)$ & -- & $17(1.1)$ & $394(5.2)$ & $20(1.2)$ & $389(3.6)$ & $61(1.9)$ & $390(3.5)$ \\
\hline Cyprus ……………........... & $48(0.5)$ & $50(0.6)$ & $47(0.6)$ & $48(0.7)$ & $53(0.6)$ & $44(0.9)$ & $40(0.7)$ & $9(0.5)$ & $442(5.8)$ & $19(0.7)$ & 475 (3.9) & $26(0.8)$ & $491(4.0)$ & $46(0.9)$ & $475(2.9)$ \\
\hline Czech Republic ....... & $66(1.1)$ & $69(1.1)$ & $66(1.1)$ & $65(1.3)$ & $68(0.9)$ & $62(1.2)$ & $52(1.3)$ & $13(1.1)$ & $551(7.1)$ & $57(1.1)$ & $571(5.1)$ & $17(0.9)$ & $568(8.2)$ & $13(0.8)$ & $542(7.6)$ \\
\hline Denmark $^{1}$............................ & $52(0.7)$ & $53(0.9)$ & $54(0.9)$ & $45(0.7)$ & $67(0.9)$ & $49(1.0)$ & $41(0.8)$ & 39 (1.6) & $517(4.4)$ & $39(1.4)$ & $508(3.8)$ & $13(0.8)$ & $479(4.1)$ & $9(0.7)$ & $468(6.9)$ \\
\hline England ${ }^{1} \ldots . . .$. & $53(0.7)$ & $54(0.8)$ & $54(1.0)$ & $49(0.9)$ & $66(0.7)$ & $50(0.9)$ & $41(1.1)$ & -1 & -1 & -- & -- & -- & -1 & -- & -- \\
\hline France ............ & $61(0.8)$ & $64(0.8)$ & $66(0.8)$ & $54(1.0)$ & $71(0.8)$ & $57(0.9)$ & $49(0.9)$ & $8(0.7)$ & $505(8.0)$ & $33(1.2)$ & 545 (3.6) & $28(1.0)$ & $547(4.5)$ & $31(1.2)$ & $537(3.7)$ \\
\hline Germany ${ }^{1} \ldots \ldots \ldots \ldots \ldots$ & $54(1.1)$ & $58(1.1)$ & $51(1.4)$ & $48(1.3)$ & $64(1.2)$ & $51(1.1)$ & $42(1.3)$ & $14(1.1)$ & $476(6.7)$ & $51(1.2)$ & $521(4.3)$ & $18(1.0)$ & $524(7.0)$ & $17(0.9)$ & $498(5.0)$ \\
\hline Greece $^{1} \ldots . . .$. & $49(0.7)$ & $53(0.8)$ & $51(0.7)$ & $46(0.8)$ & $56(0.8)$ & $43(0.9)$ & $39(1.1)$ & $6(0.6)$ & $450(7.4)$ & $14(0.7)$ & $483(5.2)$ & $21(0.7)$ & $485(3.9)$ & $59(1.2)$ & 491 (3.3) \\
\hline 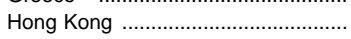 & $70(1.4)$ & $72(1.4)$ & $73(1.5)$ & $70(1.5)$ & $72(1.3)$ & $65(1.7)$ & $62(1.4)$ & $13(1.0)$ & $539(9.3)$ & $32(0.9)$ & $586(6.6)$ & $25(0.9)$ & $607(6.1)$ & $30(1.1)$ & $604(7.2)$ \\
\hline Hungary …………………... & $62(0.7)$ & $65(0.8)$ & $60(0.8)$ & $63(0.9)$ & $66(0.7)$ & $56(0.8)$ & $47(0.9)$ & $4(0.4)$ & 483 (11.3) & $33(1.1)$ & $536(5.0)$ & $22(0.9)$ & $541(5.2)$ & $41(1.3)$ & $545(3.7)$ \\
\hline Icelanc & (1.1) & $54(1.2)$ & $51(1.4)$ & $40(1.3)$ & 1.1) & $45(1.4)$ & 38 (1.4) & $5(1.0)$ & $450(12.0)$ & $46(1.7)$ & $501(5.1)$ & $25(1.3)$ & $489(5.4)$ & $23(1.4)$ & $477(7.3)$ \\
\hline Iran, Islamic Republic ……………....... & $38(0.6)$ & $39(0.6)$ & $43(0.8)$ & $37(0.8)$ & $41(0.6)$ & $29(1.2)$ & $36(0.8)$ & $1(0.2)$ & -- & $5(0.5)$ & $428(5.6)$ & $12(1.0)$ & $436(4.8)$ & $82(1.3)$ & $431(2.4)$ \\
\hline Ireland ........................... & $59(1.2)$ & $65(1.2)$ & $51(1.3)$ & $53(1.3)$ & $69(1.1)$ & $53(1.3)$ & $51(1.2)$ & $5(0.6)$ & $465(8.8)$ & $29(1.0)$ & $517(5.3)$ & $40(1.1)$ & $547(5.5)$ & $26(1.2)$ & $533(5.7)$ \\
\hline 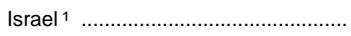 & $57(1.3)$ & $60(1.4)$ & $57(1.4)$ & $61(1.6)$ & $63(1.3)$ & $48(1.6)$ & $43(1.6)$ & $5(0.6)$ & $539(10.9)$ & $36(2.2)$ & $546(6.3)$ & $26(1.5)$ & $521(6.8)$ & $33(2.1)$ & $502(6.3)$ \\
\hline ...…….... & $73(0.4)$ & $75(0.4)$ & $80(0.4)$ & $72(0.6)$ & $78(0.4)$ & $67(0.5)$ & $61(0.5)$ & $13(0.8)$ & $578(5.3)$ & $39(0.8)$ & $607(2.6)$ & $20(0.6)$ & $609(4.0)$ & $28(1.0)$ & $612(2.7)$ \\
\hline Korea .... & $72(0.5)$ & $74(0.5)$ & $75(0.6)$ & $69(0.6)$ & $0.6)$ & $66(0.7)$ & $62(0.6)$ & $15(0.9)$ & $582(4.9)$ & $32(1.1)$ & $604(3.5)$ & $25(0.8)$ & $607(4.0)$ & $29(1.2)$ & $628(4.3)$ \\
\hline Kuwait ${ }^{1}$.......................... & $30(0.7)$ & $27(0.8)$ & $38(1.0)$ & $30(1.0)$ & $38(1.0)$ & $23(1.0)$ & $21(0.7)$ & $3(0.6)$ & $358(10.3)$ & $13(1.5)$ & $401(5.5)$ & $19(1.3)$ & $397(5.1)$ & $65(1.8)$ & $392(2.0)$ \\
\hline Latvia (Latvian-speaking schools) ${ }^{1}$ & $51(0.8)$ & $53(0.9)$ & $57(0.8)$ & $51(0.9)$ & $56(0.8)$ & $47(0.9)$ & $39(0.9)$ & $4(0.5)$ & $467(9.4)$ & $35(1.1)$ & $507(4.4)$ & $32(1.2)$ & $497(4.9)$ & $29(1.2)$ & $487(3.4)$ \\
\hline Lithuania 1 & $48(0.9)$ & $51(1.0)$ & $53(1.1)$ & $47(1.2)$ & $52(1.0)$ & $43(0.9)$ & $35(0.9)$ & $5(0.6)$ & $453(9.4)$ & $39(1.4)$ & $487(3.9)$ & $28(1.0)$ & $481(4.6)$ & $28(1.4)$ & $474(5.4)$ \\
\hline Netherlands ${ }^{1} \ldots \ldots \ldots \ldots . . . .$. & $60(1.6)$ & $62(1.6)$ & $59(1.8)$ & $53(1.6)$ & $72(1.7)$ & $57(1.6)$ & $51(1.9)$ & $3(0.9)$ & 492 (16.2) & $54(1.7)$ & $539(9.0)$ & $27(1.7)$ & $562(7.0)$ & $16(0.8)$ & $524(6.0)$ \\
\hline New Zealand ........ & $54(1.0)$ & $57(1.1)$ & $54(1.1)$ & $49(1.1)$ & $66(1.0)$ & $48(1.2)$ & $42(1.0)$ & $12(0.9)$ & $472(5.6)$ & $51(1.2)$ & $519(4.7)$ & $21(1.0)$ & $518(6.1)$ & $17(0.9)$ & $495(5.6)$ \\
\hline 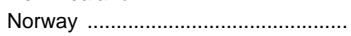 & $54(0.5)$ & $58(0.6)$ & $51(0.6)$ & $45(0.7)$ & $66(0.6)$ & $51(0.6)$ & $40(0.6)$ & $6(0.5)$ & $481(6.8)$ & $50(1.2)$ & $514(2.9)$ & $24(0.9)$ & $510(3.6)$ & $21(0.9)$ & $483(3.6)$ \\
\hline Portugal ………….......... & $43(0.7)$ & $44(0.7)$ & $44(0.8)$ & $40(0.8)$ & 0.7)] & 39 & 32 & $3(0.3)$ & $458(8.1)$ & $41(1.1)$ & $463(3.1)$ & $18(0.7)$ & $455(3.3)$ & $38(1.2)$ & $448(3.0)$ \\
\hline 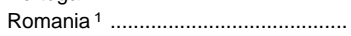 & $49(1.0)$ & $48(1.0)$ & $52(0.9)$ & $52(1.3)$ & $49(1.0)$ & $48(1.1)$ & $42(1.2)$ & $9(0.7)$ & $459(10.4)$ & $16(1.0)$ & $464(7.0)$ & $15(0.7)$ & $481(5.4)$ & $60(1.6)$ & $494(4.2)$ \\
\hline Russian Federation ... & $60(1.3)$ & $62(1.2)$ & $63(1.4)$ & $63(1.5)$ & $60(1.2)$ & $56(1.5)$ & $48(1.5)$ & $4(0.5)$ & $493(10.3)$ & $33(1.1)$ & $538(5.3)$ & $25(1.0)$ & $538(5.2)$ & $38(1.4)$ & $544(6.9)$ \\
\hline & $52(1.3)$ & $53(1.3)$ & $52(1.4)$ & $46(1.5)$ & (1.3) & $48(1.6)$ & $40(1.4)$ & $17(1.4)$ & $461(4.8)$ & $54(1.2)$ & $506(5.7)$ & $17(1.0)$ & $517(8.6)$ & $12(0.8)$ & $503(7.4)$ \\
\hline Singapore .................. & $79(0.9)$ & $84(0.8)$ & $76(1.0)$ & $76(1.1)$ & $79(0.8)$ & $77(1.0)$ & $75(1.0)$ & $2(0.3)$ & -- & $7(0.4)$ & $642(8.0)$ & $13(0.6)$ & $652(6.6)$ & $78(0.9)$ & $643(4.9)$ \\
\hline Slovak Republic ………………...... & $62(0.8)$ & $66(0.8)$ & $63(0.8)$ & $62(0.9)$ & $62(0.7)$ & $60(0.9)$ & $49(1.0)$ & $6(0.5)$ & $549(8.3)$ & $46(0.9)$ & $556(3.9)$ & $25(0.7)$ & $548(4.4)$ & $23(1.0)$ & $532(4.1)$ \\
\hline 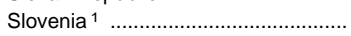 & $61(0.7)$ & $63(0.7)$ & $60(0.9)$ & $61(0.8)$ & $66(0.7)$ & $59(0.9)$ & $49(0.8)$ & $5(0.5)$ & $551(9.8)$ & $36(1.0)$ & $561(4.1)$ & $21(0.8)$ & $537(4.8)$ & $37(1.1)$ & $523(3.4)$ \\
\hline South Africa ${ }^{1} \ldots \ldots \ldots$ & $24(1.1)$ & $26(1.4)$ & $24(1.0)$ & $23(1.1)$ & $26(1.2)$ & $18(1.1)$ & $21(0.9)$ & -- & -- & -- & -- & -- & -- & --1 & - \\
\hline Spain & $51(0.5)$ & $52(0.5)$ & $49(0.6)$ & $54(0.8)$ & $60(0.7)$ & $44(0.7)$ & $40(0.8)$ & $3(0.4)$ & $443(5.5)$ & $26(1.0)$ & $490(3.1)$ & $18(0.9)$ & 495 (3.3) & $53(1.3)$ & $487(2.4)$ \\
\hline & $56(0.7)$ & $62(0.8)$ & $48(0$ & $44(0.9)$ & $70(0.7)$ & 56( & $44(0$ & $7(0.6)$ & $496(6.9)$ & $55(1.2)$ & $528(3.1)$ & $17(0.8)$ & $525(4.3)$ & $21(0.9)$ & $503(4.2)$ \\
\hline Switzer & $62(0.6)$ & $67(0.7)$ & $60(0.8)$ & $53(0.7)$ & $72(0.7)$ & $61(0.8)$ & $52(0.7)$ & $4(0.3)$ & $523(7.9)$ & $44(1.2)$ & $556(3.4)$ & $19(0.8)$ & $548(5.1)$ & $33(1.1)$ & $536(4.0)$ \\
\hline Thailand 11 & $57(1.4)$ & $60(1.5)$ & $62(1.3)$ & $53(1.7)$ & $63(1.1)$ & $50(1.4)$ & $51(1.5)$ & $3(0.3)$ & $495(11.9)$ & $26(1.0)$ & $514(5.4)$ & $18(0.7)$ & $515(5.7)$ & $54(1.5)$ & $531(6.6)$ \\
\hline United States & $53(1.1)$ & $59(1.1)$ & $48(1.2)$ & $51(1.2)$ & $65(1.1)$ & $40(1.1)$ & $42(1.1)$ & $17(1.1)$ & $471(7.2)$ & $42(0.9)$ & $514(4.2)$ & $17(0.7)$ & $507(5.5)$ & $24(0.8)$ & $498(5.9)$ \\
\hline
\end{tabular}

${ }^{1}$ Countries not meeting all International Association for the Evaluation of Educational Achievement's sampling specifications.

ble or not applicable.

NOTE.-Data are for 8th grade or equivalent in most countries. Standard errors appear in parentheses.
SOURCE: International Association for the Evaluation of Educational Achievement, Mathematics Achievement in the Middle School Years: IEA's Third International Mathematics and Science Study, 1997, by Albert E. Beaton et al. Copyright @ 1996 Boston College, Chestnut Hill, MA. (This table was prepared June 1997.) 
Table 398.--Instructional practices and time spent teaching mathematics in 8th-grade, by country: 1994-95

\begin{tabular}{|c|c|c|c|c|c|c|c|c|c|c|c|c|c|c|}
\hline \multirow{3}{*}{ Country } & \multicolumn{6}{|c|}{$\begin{array}{c}\begin{array}{c}\text { Percent of students whose teachers report using each organizational approach "most } \\
\text { of every lesson" }\end{array} \\
\end{array}$} & \multicolumn{8}{|c|}{ Average number of hours mathematics is taught weekly to mathematics classes } \\
\hline & \multirow{2}{*}{\begin{tabular}{|c|} 
Work to- \\
gether as a \\
class and \\
students re- \\
spond to \\
one another
\end{tabular}} & \multirow{2}{*}{\begin{tabular}{|} 
Work to- \\
gether as a \\
class and \\
teacher \\
teaches \\
whole class
\end{tabular}} & \multirow{2}{*}{$\begin{array}{c}\text { Work indi- } \\
\text { vidually } \\
\text { with assist- } \\
\text { ance from } \\
\text { teacher }\end{array}$} & \multirow{2}{*}{$\begin{array}{l}\text { Work individ- } \\
\text { ually without } \\
\text { assistance } \\
\text { from teacher }\end{array}$} & \multirow{2}{*}{$\begin{array}{c}\text { Work in pairs } \\
\text { or groups with } \\
\text { assistance } \\
\text { from teacher }\end{array}$} & \multirow{2}{*}{$\begin{array}{c}\text { Work in pairs } \\
\text { or groups } \\
\text { without assist- } \\
\text { ance from } \\
\text { teacher }\end{array}$} & \multicolumn{2}{|c|}{ Less than 2 hours } & \multicolumn{2}{|c|}{$\begin{array}{l}\text { At least 2, but less than } 3.5 \\
\text { hours }\end{array}$} & \multicolumn{2}{|c|}{\begin{tabular}{|c|}
$\begin{array}{c}\text { At least } 3.5, \text { but less than } 5 \\
\text { hours }\end{array}$ \\
\end{tabular}} & \multicolumn{2}{|c|}{5 hours or more } \\
\hline & & & & & & & Percent & Mean score & Percent & Mean score & Percent & Mean score & Percent & Mean score \\
\hline 1 & 2 & 3 & 4 & 5 & 6 & 7 & 8 & 9 & 10 & 11 & 12 & 13 & 14 & 15 \\
\hline 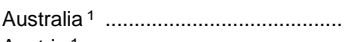 & 214 & 246 & 264 & 227 & 225 & 29 & $25(1.7)$ & 528 (19.5) & $50(3.7)$ & $518(6.2)$ & $44(3.7)$ & $552(7.6)$ & $1(0.7)$ & -- \\
\hline Austria ${ }^{1}$................... & 26 & 252 & 251 & 223 & 219 & 27 & $20(0.0)$ & -- & $99(0.1)$ & $549(4.1)$ & $1(0.1)$ & -- & $0(0.0)$ & -- \\
\hline Belgium (Flemish) ....... & 10 & 59 & 57 & 36 & 6 & 5 & ${ }^{3} 0(0.0)$ & -- & $50(4.4)$ & $572(5.6)$ & $50(4.4)$ & $603(5.4)$ & $0(0.0)$ & -- \\
\hline Belgium (French) ${ }^{1} \ldots \ldots \ldots$ & 37 & ${ }^{3} 38$ & 355 & ${ }^{3} 29$ & ${ }^{3} 11$ & 35 & ${ }^{3} 0(0.0)$ & -- & $3(1.8)$ & 486 (12.9) & $83(4.2)$ & $544(4.7)$ & $14(3.8)$ & $564(10.0)$ \\
\hline Bulgaria $^{1} \ldots \ldots \ldots \ldots \ldots \ldots$ & - & - & - & - & - & - & -- & -- & -- & -- & -- & -- & -- & -- \\
\hline Canada ............................. & 212 & 37 & 57 & 225 & 228 & 214 & $3(1.2)$ & $528(11.8)$ & $31(3.8)$ & $521(5.0)$ & $50(3.6)$ & $537(4.3)$ & $17(3.1)$ & $520(10.2)$ \\
\hline Colombia $^{1}$. & 25 & 41 & 55 & 219 & 44 & 222 & $24(2.0)$ & $389(8.2)$ & $25(5.5)$ & $367(8.8)$ & $58(5.4)$ & $397(3.9)$ & $13(3.3)$ & $390(8.2)$ \\
\hline 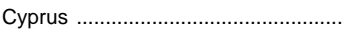 & 213 & 261 & 273 & 223 & 226 & 29 & -- & -- & -- & -- & -- & -- & -- & -- \\
\hline Czech Republic ......... & 5 & 47 & 72 & 42 & 13 & 8 & $1(0.9)$ & -- & $6(2.0)$ & 587 (17.2) & $90(2.7)$ & $561(5.1)$ & $3(1.6)$ & $535(10.2)$ \\
\hline 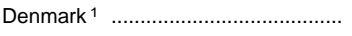 & 5 & 41 & 74 & 16 & 18 & 4 & -- & -- & -- & -- & -- & -- & -- & -- \\
\hline England $^{1}$...................... & ${ }^{3} 19$ & 346 & ${ }^{3} 57$ & ${ }^{3} 25$ & ${ }^{3} 14$ & ${ }^{3} 8$ & -- & -- & -- & -- & -- & -- & -- & -- \\
\hline France …….............. & 11 & 48 & 56 & 26 & 17 & 4 & $22(1.4)$ & -- & $10(3.2)$ & $532(13.4)$ & $87(3.3)$ & $539(3.9)$ & $2(1.3)$ & -- \\
\hline Germany ${ }^{1}$.................. & ${ }^{3} 23$ & 370 & ${ }^{3} 54$ & ${ }^{3} 15$ & ${ }^{3} 20$ & 39 & ${ }^{3} 2(1.5)$ & -- & $85(3.1)$ & $523(5.3)$ & $12(2.9)$ & $463(13.3)$ & $1(0.9)$ & -- \\
\hline Greece ${ }^{1}$................. & 4 & 58 & 60 & 18 & 14 & 3 & $4(1.7)$ & $459(10.8)$ & $88(2.8)$ & $486(3.5)$ & $3(1.6)$ & $459(12.3)$ & $4(1.6)$ & $480(8.9)$ \\
\hline Hong Kong ..................... & 11 & 37 & 62 & 17 & 9 & 4 & $5(2.4)$ & $612(47.4)$ & $26(5.2)$ & $590(19.5)$ & $63(5.8)$ & $590(7.6)$ & $6(2.9)$ & $567(30.1)$ \\
\hline Hungary ……………........ & 11 & 60 & 65 & 22 & 7 & 1 & $0(0.0)$ & -- & 75 (3.6) & $538(3.9)$ & $23(3.6)$ & $536(7.0)$ & $1(1.0)$ & -- \\
\hline Iceland ………………......... & 22 & 239 & ${ }^{2} 82$ & 238 & ${ }^{2} 32$ & 217 & ${ }^{2} 0(0.0)$ & -- & $90(2.9)$ & $492(5.3)$ & $8(2.9)$ & $467(3.5)$ & $1(0.2)$ & -- \\
\hline Iran, Islamic Republic . & 33 & 66 & 55 & 8 & 42 & 10 & -- & -- & & -- & & & -- & -- \\
\hline Ireland .............................. & 27 & 67 & 47 & 37 & 29 & 26 & $21(0.7)$ & -- & $86(3.7)$ & $524(6.4)$ & $12(3.4)$ & 555 (15.2) & $1(1.1)$ & -- \\
\hline Israel ${ }^{1}$. & 270 & 265 & 235 & 268 & 251 & 262 & ${ }^{2} 6(4.1)$ & $523(13.7)$ & $41(8.0)$ & $520(12.7)$ & $47(8.1)$ & $514(9.2)$ & $6(3.7)$ & $579(22.6)$ \\
\hline Japan & 22 & 78 & 27 & 15 & 7 & 1 & $4(1.8)$ & 607 (24.3) & $91(2.3)$ & $602(2.7)$ & $4(1.4)$ & $649(18.5)$ & $0(0.5)$ & -- \\
\hline Korea. & 39 & 89 & 41 & 30 & 12 & 11 & $1(0.7)$ & -- & $90(3.0)$ & $610(2.8)$ & $5(1.8)$ & 608 (13.8) & $5(2.3)$ & $604(19.5)$ \\
\hline Kuwait ${ }^{1} \ldots \ldots \ldots \ldots \ldots \ldots \ldots \ldots \ldots$ & 3 & 34 & 48 & 14 & 7 & 5 & $2(1.6)$ & -- & $21(6.5)$ & $396(6.8)$ & $76(6.6)$ & $391(2.3)$ & $1(1.0)$ & -- \\
\hline Latvia (Latvian-speaking schools) ${ }^{1}$ & 24 & 86 & 90 & 255 & 28 & 211 & $1(0.5)$ & -- & $30(4.8)$ & $491(5.8)$ & $62(5.3)$ & $492(4.3)$ & $8(2.6)$ & $489(15.0)$ \\
\hline Lithuania $^{1}$....................... & 10 & 55 & 72 & 25 & 32 & 10 & $1(0.8)$ & -- & $61(4.1)$ & $482(5.0)$ & 29 (3.9) & $481(7.5)$ & $9(2.3)$ & $448(13.8)$ \\
\hline Netherlands ${ }^{1} \ldots \ldots \ldots \ldots \ldots$ & 7 & 56 & 65 & 38 & 49 & 34 & $3(1.9)$ & $529(54.2)$ & $97(1.9)$ & $542(8.1)$ & $0(0.0)$ & -- & $0(0.0)$ & -- \\
\hline New Zealand ........... & 19 & 52 & 63 & 28 & 25 & 14 & $5(1.8)$ & 484 (11.6) & $42(4.3)$ & $514(7.1)$ & $50(4.3)$ & $507(6.4)$ & $3(1.5)$ & $503(27.3)$ \\
\hline Norway ............ & 217 & 258 & 271 & ${ }_{44}$ & 236 & ${ }^{4} 6$ & $27(2.6)$ & $502(5.0)$ & $80(3.9)$ & $508(3.1)$ & $8(2.8)$ & $502(7.7)$ & $5(2.1)$ & $513(7.7)$ \\
\hline Portugal .......................... & 10 & 67 & 69 & 5 & 50 & 4 & $1(0.8)$ & -- & 89 (2.9) & $455(2.7)$ & $10(2.8)$ & $452(7.8)$ & $0(0.0)$ & -- \\
\hline Romania $^{1}$.................... & 12 & 86 & 56 & 19 & 18 & 3 & $8(2.6)$ & 497 (17.6) & $80(3.4)$ & $481(5.0)$ & $9(2.5)$ & $482(12.4)$ & $2(0.6)$ & -- \\
\hline Russian Federation .... & 6 & 66 & 65 & 37 & 22 & 13 & $0(0.0)$ & -- & 17 (3.6) & $519(8.6)$ & $70(5.6)$ & $533(5.1)$ & $14(4.8)$ & $567(18.0)$ \\
\hline Scotland $^{1}$................. & 25 & 234 & ${ }^{2} 62$ & 228 & 27 & 23 & $5(2.0)$ & $473(14.7)$ & $35(4.4)$ & 500 (11.6) & $60(4.6)$ & $494(7.1)$ & $0(0.0)$ & -- \\
\hline Singapore . & 15 & 61 & 48 & 27 & 20 & 6 & $0(0.0)$ & -- & $52(4.7)$ & $654(6.9)$ & $48(4.7)$ & $633(7.6)$ & $0(0.0)$ & -- \\
\hline Slovak Republic ........ & 35 & 47 & 50 & 31 & 8 & 7 & $0(0.0)$ & -- & $2(1.3)$ & -- & $86(3.0)$ & $544(3.2)$ & $11(2.9)$ & $561(11.0)$ \\
\hline Slovenia ${ }^{1}$................... & 211 & 260 & 287 & 234 & 240 & 211 & $20(0.0)$ & -- & $87(3.4)$ & $542(4.0)$ & $12(3.3)$ & $525(9.5)$ & $1(0.8)$ & -- \\
\hline South Africa ${ }^{1}$........ & - & - & - & - & - & - & -- & -- & -- & -- & -- & -- & -- & -- \\
\hline ……………........ & 215 & 268 & 258 & 224 & ${ }^{2} 15$ & 210 & $22(1.1)$ & -- & $28(4.0)$ & $480(5.5)$ & $62(4.7)$ & $490(3.6)$ & $8(2.6)$ & $494(9.2)$ \\
\hline Sweden. & 224 & 250 & 272 & 21 & 243 & 25 & $23(1.2)$ & $506(24.2)$ & $97(1.3)$ & $520(3.2)$ & $0(0.4)$ & -- & $0(0.3)$ & -- \\
\hline Switzerland 11 ................ & 34 & 348 & 361 & 325 & ${ }^{3} 35$ & 320 & $32(1.4)$ & -- & $14(3.4)$ & $520(17.8)$ & $71(3.5)$ & $557(6.5)$ & $13(3.0)$ & $566(12.4)$ \\
\hline Thailand 1 . & 219 & ${ }^{3} 58$ & 241 & 218 & 222 & 25 & -- & -- & -- & -- & -- & -- & -- & -- \\
\hline United States . & ${ }^{2} 22$ & 249 & 250 & 219 & 226 & 212 & $38(1.4)$ & $492(26.2)$ & $24(3.4)$ & $501(9.9)$ & $58(4.4)$ & $507(5.4)$ & $11(2.8)$ & $498(10.0)$ \\
\hline
\end{tabular}

1 Countries not meeting all International Association for the Evaluation of Educational Achievement's sampling specifications.

2Teacher response data available for 70 to 84 percent of students.

-Data not available or not applicable.
NOTE.-Data are for 8th grade or equivalent in most countries. Standard errors appear in parentheses.

SOURCE: International Association for the Evaluation of Educational Achievement, Mathematics Achievement in the Middle School Years: IEA's Third International Mathematics and Science Study, 1997,
right $\odot 1996$ Boston College, Chestnut Hill, MA. (This table was prepared June 1997.) 
Table 399.-Average 8th-grade science scores by content areas, and average time spent studying out of school, by country: 1994-95

\begin{tabular}{|c|c|c|c|c|c|c|c|c|c|c|c|c|c|c|}
\hline \multirow{3}{*}{ Country } & \multicolumn{6}{|c|}{ Average percent correct by content area } & \multicolumn{8}{|c|}{ Distribution of daily out-of-school study time in all subjects, with mean science scores } \\
\hline & \multirow{2}{*}{$\begin{array}{l}\text { Overall } \\
\text { science } \\
\text { scores }\end{array}$} & \multirow{2}{*}{$\begin{array}{l}\text { Earth } \\
\text { science }\end{array}$} & \multirow{2}{*}{ Life science } & \multirow{2}{*}{ Physics } & \multirow{2}{*}{ Chemistry } & \multirow{2}{*}{$\begin{array}{l}\text { Environmental } \\
\text { issues and the } \\
\text { nature of } \\
\text { science }\end{array}$} & \multicolumn{2}{|c|}{ Less than 1 hour } & \multicolumn{2}{|c|}{$\begin{array}{c}\text { At least } 1 \text {, but less than } 2 \\
\text { hours }\end{array}$} & \multicolumn{2}{|c|}{2 to 3 hours } & \multicolumn{2}{|c|}{ More than 3 hours } \\
\hline & & & & & & & Percent & Mean score & Percent & Mean score & Percent & Mean score & Percent & Mean score \\
\hline 1 & 2 & 3 & 4 & 5 & 6 & 7 & 8 & 9 & 10 & 11 & 12 & 13 & 14 & 15 \\
\hline $\begin{array}{l}\text { International average } \\
\text { percent correct } . . . . . .\end{array}$ & $56(0.1)$ & $55(0.1)$ & $59(0.1)$ & $55(0.1)$ & $51(0.2)$ & $53(0.2)$ & -- & -- & -- & -- & -- & -- & -- & -- \\
\hline Australia $^{1} \ldots . .$. & $60(0.7)$ & $57(0.8)$ & $63(0.8)$ & $60(0.7)$ & $54(0.9)$ & $62(1.0)$ & $15(0.9)$ & $505(6.9)$ & $46(1.0)$ & $556(4.1)$ & $22(0.6)$ & $557(4.9)$ & $17(0.7)$ & $546(5.0)$ \\
\hline Austria $^{1}$........................................ & $61(0.7)$ & $62(0.8)$ & $65(0.7)$ & $62(0.7)$ & $58(1.1)$ & $55(0.9)$ & $9(0.8)$ & $551(9.9)$ & $46(1.3)$ & $563(4.8)$ & $21(0.9)$ & $561(5.0)$ & $24(1.2)$ & $553(4.8)$ \\
\hline 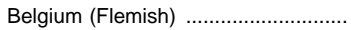 & $60(1.1)$ & $62(1.2)$ & $64(1.1)$ & $61(1.1)$ & $51(1.3)$ & $58(1.5)$ & $2(0.4)$ & -- & $25(1.3)$ & $545(5.0)]$ & $28(1.1)$ & $562(5.9)$ & $45(1.6)$ & $547(3.6)$ \\
\hline Belgium (French) $)^{1}$ & $50(0.7)$ & $50(0.9)$ & $55(0.9)$ & $51(0.7)$ & $41(0.8)$ & $46(1.0)$ & $7(0.8)$ & $428(6.9)$ & $32(1.0)$ & $481(4.7)$ & $21(1.3)$ & $481(4.5)$ & $40(1.5)$ & $467(4.0)$ \\
\hline 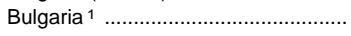 & $62(1.0)$ & $58(1.2)$ & $64(1.0)$ & $60(1.0)$ & $65(1.7)$ & $59(1.5)$ & -- & -- & -- & -- & -- & -- & -- & -- \\
\hline Canada …………………… & $59(0.5)$ & $58(0.6)$ & $62(0.6)$ & $59(0.4)$ & $52(0.7)$ & $61(0.7)$ & $14(1.2)$ & $524(6.1)$ & $47(1.1)$ & $541(2.8)$ & $18(0.7)$ & $531(3.9)$ & $21(1.1)$ & $517(3.6)$ \\
\hline Colombia ${ }^{1}$ & $39(0.8)$ & $37(0.8)$ & $44(0.9)$ & $37(0.8)$ & $32(1.0)$ & $40(1.1)$ & $2(0.4)$ & -- & $17(1.1)$ & $421(5.3)$ & $20(1.2)$ & $422(4.9)$ & $61(1.9)$ & $413(5.8)$ \\
\hline Cyprus .................................... & $47(0.4)$ & $46(0.6)$ & $49(0.5)$ & $46(0.4)$ & $45(0.6)$ & $46(0.8)$ & $9(0.5)$ & $430(7.0)$ & $19(0.7)$ & $468(4.4)$ & $26(0.8)$ & $475(3.4)$ & $46(0.9)$ & $466(2.9)$ \\
\hline Czech Republic ..................................... & $64(0.8)$ & $63(1.2)$ & $69(0.8)$ & $64(0.7)$ & $60(1.2)$ & $59(1.1)$ & $13(1.1)$ & $558(9.0)$ & $57(1.1)$ & 579 (3.9) & $17(0.9)$ & $582(7.2)$ & $13(0.8)$ & $560(6.4)$ \\
\hline 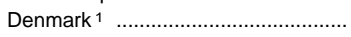 & $51(0.6)$ & $49(0.7)$ & $56(0.7)$ & $53(0.7)$ & $41(0.8)$ & $47(1.0)$ & $39(1.6)$ & $494(4.4)$ & $39(1.4)$ & $479(4.1)$ & $13(0.8)$ & $459(5.5)$ & $9(0.7)$ & $457(6.8)$ \\
\hline England ${ }^{1} \ldots . .$. & $61(0.6)$ & $59(0.8)$ & $64(0.8)$ & $62(0.6)$ & $55(0.8)$ & $65(1.0)$ & -- & -- & -- & -- & -- & -- & -- & -- \\
\hline 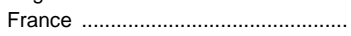 & $54(0.6)$ & $55(0.8)$ & $56(0.8)$ & $54(0.5)$ & $47(0.9)$ & $53(0.9)$ & $8(0.7)$ & $481(6.8)$ & $33(1.2)$ & 497 (3.3) & $28(1.0)$ & $506(4.0)$ & $31(1.2)$ & $499(3.4)$ \\
\hline 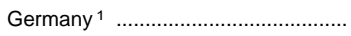 & $58(1.0)$ & $57(1.0)$ & $63(1.1)$ & $57(1.0)$ & $54(1.3)$ & $51(1.3)$ & $14(1.1)$ & $505(8.2)$ & $51(1.2)$ & 541 (4.6) & $18(1.0)$ & $544(7.0)$ & $17(0.9)$ & $525(6.5)$ \\
\hline Greece $^{1}$ & $52(0.5)$ & $49(0.6)$ & $54(0.6)$ & $53(0.5)$ & $51(0.5)$ & $51(1.0)$ & $6(0.6)$ & $473(4.8)$ & $14(0.7)$ & $497(5.0)$ & $21(0.7)$ & $500(3.1)$ & $59(1.2)$ & $502(2.5)$ \\
\hline 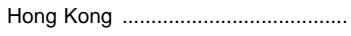 & $58(1.0)$ & $54(1.0)$ & $61(1.0)$ & $58(0.9)$ & $55(1.0)$ & $55(1.3)$ & $13(1.0)$ & $489(7.3)$ & $32(0.9)$ & $519(4.7)$ & $25(0.9)$ & $534(4.8)$ & $30(1.1)$ & $534(5.2)$ \\
\hline 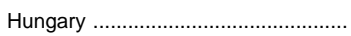 & $61(0.6)$ & $60(0.8)$ & $65(0.7)$ & $60(0.6)$ & $60(0.8)$ & $53(0.8)$ & $4(0.4)$ & $519(10.0)$ & $33(1.1)$ & $553(4.4)$ & $22(0.9)$ & $557(5.6)$ & $41(1.3)$ & $557(3.0)$ \\
\hline Iceland ……………............ & $52(0.9)$ & $50(1.2)$ & $58(1.0)$ & $53(0.9)$ & $42(0.8)$ & $49(1.0)$ & $5(1.0)$ & $470(8.7)$ & $46(1.7)$ & 505 (5.6) & $25(1.3)$ & $493(4.5)$ & $23(1.4)$ & $488(7.5)$ \\
\hline Iran, Islamic Republic ……………......... & $47(0.6)$ & $45(0.6)$ & $49(0.6)$ & $48(0.7)$ & $52(0.8)$ & $39(1.1)$ & $1(0.2)$ & -- & $5(0.5)$ & $476(6.0)$ & $12(1.0)$ & $479(5.2)$ & $82(1.3)$ & $471(2.7)$ \\
\hline Ireland & $58(0.9)$ & $61(1.0)$ & $60(1.1)$ & $56(0.8)$ & $54(1.0)$ & $60(1.1)$ & $5(0.6)$ & $475(9.0)$ & $29(1.0)$ & 529 (5.4) & $40(1.1)$ & $550(4.7)$ & $26(1.2)$ & $550(4.9)$ \\
\hline Israel ${ }^{1} \ldots$ & $57(1.1)$ & $55(1.1)$ & $61(1.1)$ & $57(1.1)$ & $53(1.5)$ & $52(1.6)$ & $5(0.6)$ & $532(13.5)$ & $36(2.2)$ & $555(7.7)$ & $26(1.5)$ & $523(6.9)$ & $33(2.1)$ & $505(5.2)$ \\
\hline Japan & $65(0.3)$ & $61(0.4)$ & $71(0.4)$ & $67(0.3)$ & $61(0.5)$ & $60(0.7)$ & $13(0.8)$ & $551(4.4)$ & $39(0.8)$ & $573(2.2)$ & $20(0.6)$ & $572(3.0)$ & $28(1.0)$ & $577(2.4)$ \\
\hline 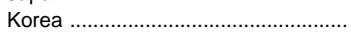 & $66(0.3)$ & $63(0.5)$ & $70(0.4)$ & $65(0.5)$ & $63(0.6)$ & $64(0.8)$ & $15(0.9)$ & $544(5.0)$ & $32(1.1)$ & $564(2.9)$ & $25(0.8)$ & $562(3.1)$ & $29(1.2)$ & $581(3.7)$ \\
\hline Kuwait ${ }^{1}$. & $43(0.9)$ & $43(1.0)$ & $45(1.1)$ & $43(0.7)$ & $40(1.5)$ & $39(1.3)$ & $3(0.6)$ & $400(10.4)$ & $13(1.5)$ & $436(7.8)$ & $19(1.3)$ & $432(7.1)$ & $65(1.8)$ & $431(3.4)$ \\
\hline Latvia (Latvian-speaking schools) ${ }^{1}$ & $50(0.6)$ & $48(0.8)$ & $53(0.7)$ & $51(0.7)$ & $48(0.8)$ & $47(1.0)$ & $4(0.5)$ & $468(8.5)$ & $35(1.1)$ & $492(4.1)$ & $32(1.2)$ & $490(4.1)$ & $29(1.2)$ & $481(3.0)$ \\
\hline Lithuania ${ }^{1}$ & $49(0.7)$ & $46(0.9)$ & $52(0.9)$ & $51(0.7)$ & $48(0.9)$ & $40(1.0)$ & $5(0.6)$ & $457(9.1)$ & $39(1.4)$ & $484(4.5)$ & $28(1.0)$ & $483(3.8)$ & $28(1.4)$ & $472(4.7)$ \\
\hline Netherlands ${ }^{1} \ldots . . .$. & $62(1.0)$ & $61(1.4)$ & $67(1.4)$ & $63(0.9)$ & $52(0.9)$ & $65(1.6)$ & $3(0.9)$ & $519(17.1)$ & $54(1.7)$ & $559(6.1)$ & $27(1.7)$ & $578(5.4)$ & $16(0.8)$ & $545(5.7)$ \\
\hline New Zealand .............. & $58(0.8)$ & $56(0.9)$ & $60(1.0)$ & $58(0.7)$ & $53(1.1)$ & $59(1.2)$ & $12(0.9)$ & $488(7.6)$ & $51(1.2)$ & 536 (4.6) & $21(1.0)$ & $537(5.7)$ & $17(0.9)$ & $516(5.7)$ \\
\hline Norwa & $58(0.4)$ & $61(0.6)$ & $61(0.5)$ & $57(0.4)$ & $49(0.6)$ & $55(0.8)$ & $6(0.5)$ & $501(7.3)$ & $50(1.2)$ & $533(2.5)$ & $24(0.9)$ & $536(3.4)$ & $21(0.9)$ & $516(3.7)$ \\
\hline Portugal . & $50(0.6)$ & $50(0.7)$ & $53(0.6)$ & $48(0.5)$ & $50(0.9)$ & $45(0.8)$ & $3(0.3)$ & $465(8.8)$ & $41(1.1)$ & $488(2.9)$ & $18(0.7)$ & $478(4.1)$ & 38 (1.2) & $474(2.8)$ \\
\hline 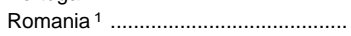 & $50(0.8)$ & $49(1.0)$ & $55(1.0)$ & $49(0.8)$ & $46(1.0)$ & $42(1.0)$ & $9(0.7)$ & $460(11.7)$ & $16(1.0)$ & $468(7.0)$ & $15(0.7)$ & $487(5.7)$ & $60(1.6)$ & $499(5.2)$ \\
\hline Russian Federation . & $58(0.8)$ & $58(0.8)$ & $62(0.7)$ & $57(0.9)$ & $57(1.3)$ & $50(0.8)$ & $4(0.5)$ & $511(10.1)$ & $33(1.1)$ & $542(4.4)$ & $25(1.0)$ & $538(4.4)$ & $38(1.4)$ & $543(4.6)$ \\
\hline 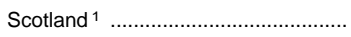 & $55(1.0)$ & $52(1.0)$ & $57(1.1)$ & $57(0.8)$ & $51(1.3)$ & $57(1.4)$ & $17(1.4)$ & $470(5.3)$ & $54(1.2)$ & $526(5.1)$ & $17(1.0)$ & $537(8.5)$ & $12(0.8)$ & $532(6.5)$ \\
\hline Singapore & $70(1.0)$ & $65(1.1)$ & $72(1.0)$ & $69(0.8)$ & $69(1.2)$ & $74(1.1)$ & $2(0.3)$ & -- & $7(0.4)$ & $604(8.4)$ & $13(0.6)$ & $617(7.3)$ & $78(0.9)$ & $607(5.4)$ \\
\hline Slovak Republic …………………..... & $59(0.6)$ & $60(0.7)$ & $60(0.6)$ & $61(0.6)$ & $57(0.8)$ & $53(0.9)$ & $6(0.5)$ & $551(7.1)$ & $46(0.9)$ & $552(3.7)$ & $25(0.7)$ & $541(3.8)$ & $23(1.0)$ & $536(4.7)$ \\
\hline Slovenia ${ }^{1} \ldots . . . . . . . . .$. & $62(0.5)$ & $64(0.7)$ & $65(0.6)$ & $61(0.6)$ & $56(0.9)$ & $59(0.9)$ & $5(0.5)$ & $559(9.2)$ & $36(1.0)$ & 580 (3.5) & $21(0.8)$ & $557(3.2)$ & $37(1.1)$ & $544(3.3)$ \\
\hline South Africa ${ }^{1}$ & $27(1.3)$ & $26(1.1)$ & $27(1.3)$ & $27(1.4)$ & $26(1.4)$ & $26(1.3)$ & -- & -- & -- & -- & -- & -- & -- & -- \\
\hline Spain . & $56(0.4)$ & $57(0.5)$ & $58(0.5)$ & $55(0.4)$ & $51(0.7)$ & $53(0.6)$ & $3(0.4)$ & $482(7.9)$ & $26(1.0)$ & $522(2.8)$ & $18(0.9)$ & $522(3.5)$ & $53(1.3)$ & $516(2.2)$ \\
\hline Sweden & $59(0.6)$ & $62(0.7)$ & $63(0.7)$ & $57(0.5)$ & $56(0.7)$ & $52(0.8)$ & $7(0.6)$ & $520(6.0)$ & $55(1.2)$ & $544(3.2)$ & $17(0.8)$ & 539 (4.9) & $21(0.9)$ & $523(4.9)$ \\
\hline Switzerland ${ }^{1} \ldots \ldots \ldots . . . . .$. & $56(0.5)$ & $58(0.6)$ & $59(0.6)$ & $58(0.5)$ & $50(0.7)$ & $51(0.8)$ & $4(0.3)$ & $500(8.3)$ & $44(1.2)$ & $530(3.1)$ & $19(0.8)$ & $526(6.2)$ & $33(1.1)$ & $514(3.5)$ \\
\hline 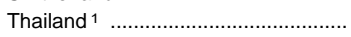 & $57(0.9)$ & $56(1.0)$ & $66(0.9)$ & $54(0.7)$ & $43(1.2)$ & $62(1.1)$ & $3(0.3)$ & $510(8.8)$ & $26(1.0)$ & $520(4.0)$ & $18(0.7)$ & $519(4.3)$ & $54(1.5)$ & $532(4.1)$ \\
\hline United States & $58(1.0)$ & $58(1.0)$ & $63(1.1)$ & $56(0.8)$ & $53(1.2)$ & $61(1.0)$ & $17(1.1)$ & $507(9.5)$ & $42(0.9)$ & $548(4.1)$ & $17(0.7)$ & $541(5.2)$ & $24(0.8)$ & $533(5.7)$ \\
\hline
\end{tabular}

1 Countries not meeting all International Association for the Evaluation of Educational Achievement's sampling specifications.

-Data not available or not applicable.

NOTE.-Data are for 8th grade or equivalent in most countries. Standard errors appear in parentheses.
SOURCE: International Association for the Evaluation of Educational Achievement, Science Achievement in the Mid. (0) 1996 Boston College, Chestnut Hill, MA. (This table was prepared June 1997.) 
Table 400.-Instructional practices and time spent teaching science in 8th-grade, by country: 1994-95

\begin{tabular}{|c|c|c|c|c|c|c|c|c|c|c|c|c|c|c|}
\hline \multirow{3}{*}{ Country } & \multicolumn{6}{|c|}{$\begin{array}{l}\text { Percent of students whose teachers report using each organizational approach "most } \\
\text { of every lesson" }\end{array}$} & \multicolumn{8}{|c|}{ Average number of hours science is taught weekly to science classes } \\
\hline & \multirow{2}{*}{\begin{tabular}{|} 
Work to- \\
gether as a \\
class and \\
students re \\
spond to \\
one anothe
\end{tabular}} & \multirow{2}{*}{\begin{tabular}{|c|} 
Work to- \\
gether as a \\
class and \\
teacher \\
teaches \\
whole class
\end{tabular}} & \multirow{2}{*}{$\begin{array}{c}\text { Work indi- } \\
\text { vidually } \\
\text { with assist- } \\
\text { ance from } \\
\text { teacher }\end{array}$} & \multirow{2}{*}{$\begin{array}{l}\text { Work individ- } \\
\text { ually without } \\
\text { assistance } \\
\text { from teacher }\end{array}$} & \multirow{2}{*}{$\begin{array}{l}\text { Work in pairs } \\
\text { or groups with } \\
\text { assistance } \\
\text { from teacher }\end{array}$} & \multirow{2}{*}{$\begin{array}{c}\text { Work in pairs } \\
\text { or groups } \\
\text { without assist- } \\
\text { ance from } \\
\text { teacher }\end{array}$} & \multicolumn{2}{|c|}{ Less than 2 hours } & \multicolumn{2}{|c|}{$\begin{array}{l}\text { At least 2, but less than } 3.5 \\
\text { hours }\end{array}$} & \multicolumn{2}{|c|}{$\begin{array}{c}\text { At least } 3.5 \text {, but less than } 5 \\
\text { hours }\end{array}$} & \multicolumn{2}{|c|}{5 hours or more } \\
\hline & & & & & & & Percent & Mean score & Percent & Mean score & Percent & Mean score & Percent & Mean score \\
\hline 1 & 2 & 3 & 4 & 5 & 6 & 7 & 8 & 9 & 10 & 11 & 12 & 13 & 14 & 15 \\
\hline 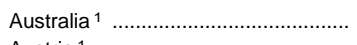 & - & - & - & - & - & - & -- & -- & -- & -- & -- & -- & -- & -- \\
\hline 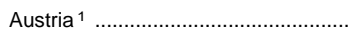 & 23 & 265 & 213 & 23 & 218 & 212 & -- & -- & -- & -- & -- & -- & -- & -1 \\
\hline 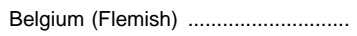 & 211 & ${ }^{2} 62$ & 219 & 26 & 213 & 27 & -- & -- & -- & -- & -- & -- & -- & -1 \\
\hline 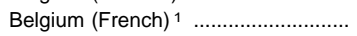 & ${ }^{3} 11$ & ${ }^{3} 53$ & 324 & 38 & 38 & 34 & -- & -- & -- & -- & -- & -- & -- & -1 \\
\hline 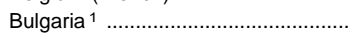 & - & - & - & - & - & - & -- & -- & -- & -- & -- & -- & -- & -1 \\
\hline 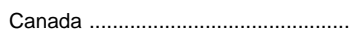 & 317 & 228 & 226 & 223 & 233 & 324 & $211(2.1)$ & $512(8.9)$ & $69(3.9)$ & $540(3.8)$ & $11(2.5)$ & $528(5.5)$ & $8(2.1)$ & $517(10.3$ \\
\hline Colombia $^{1} \ldots . . .$. & 233 & 248 & 255 & 210 & 243 & 213 & $26(2.3)$ & $416(4.5)$ & 75 (4.2) & $415(5.6)$ & $13(3.2)$ & $404(5.5)$ & $6(2.4)$ & $403(18.6$ \\
\hline Cyprus …………........ & 33 & 374 & ${ }^{3} 35$ & ${ }^{3} 3$ & ${ }^{3} 17$ & ${ }^{3} 6$ & $4-$ & --1 & -- & -- & -- & -- & --1 & -1 \\
\hline Czech Republic ......... & 11 & 70 & 246 & 15 & 14 & 4 & -- & -- & -- & -- & -- & -- & -- & -1 \\
\hline 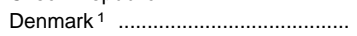 & 32 & $\begin{array}{l}322 \\
32\end{array}$ & 325 & 33 & ${ }^{3} 46$ & ${ }_{3} 13$ & -- & -- & -- & -- & -- & -- & -- & -1 \\
\hline England ${ }^{1} \ldots \ldots \ldots \ldots \ldots \ldots \ldots$ & - & - & - & - & - & - & -- & -- & -- & -- & -- & -- & -- & -1 \\
\hline 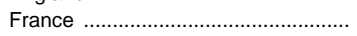 & 16 & 57 & 34 & 16 & 27 & 12 & -- & -- & -- & -- & -- & -- & -- & -1 \\
\hline 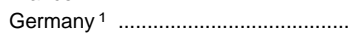 & ${ }^{3} 30$ & ${ }^{3} 69$ & ${ }^{3} 28$ & 37 & ${ }^{3} 19$ & 35 & -- & -- & -- & -- & -- & -- & -- & -1 \\
\hline Greece $^{1}$...................... & 3 & 67 & 45 & 10 & 13 & 1 & -- & -- & -- & -- & -- & -- & -- & -1 \\
\hline Hong Kong ........................................... & 12 & 45 & 35 & 2 & 44 & 13 & $7(2.3)$ & $492(29.9)$ & $82(3.9)$ & $526(5.3)$ & $9(3.3)$ & $518(8.6)$ & $2(1.6)$ & -1 \\
\hline Hungary …………………………....... & 7 & 80 & 54 & 13 & 11 & 2 & -- & -- & -- & -- & -- & -- & -- & -1 \\
\hline eland & 31 & 235 & 230 & 29 & 216 & 26 & -- & -- & -- & -- & -- & -- & -- & -1 \\
\hline Iran, Islamic Republic ….................... & 25 & 57 & 36 & 2 & 25 & 11 & -- & -- & -- & -- & -- & -- & -- & -- \\
\hline 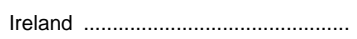 & 37 & ${ }^{3} 62$ & 325 & 36 & 320 & 36 & $34(1.9)$ & $578(16.5)$ & $94(2.1)$ & $540(6.2)$ & $2(0.8)$ & -- & $0(0.0)$ & -1 \\
\hline Israel ${ }^{1} \ldots \ldots \ldots . . . . . .$. & 317 & 241 & 230 & 215 & 232 & 218 & $319(7.9)$ & 547 (19.6) & 77 (7.2) & $520(9.1)$ & $4(3.5)$ & $529(0.0)$ & $0(0.0)$ & -1 \\
\hline Janan & 19 & 79 & 12 & 8 & 12 & 6 & $5(1.6)$ & 618 (15.2) & $94(1.7)$ & $569(1.5)$ & $0(0.0)$ & -- & $1(0.6)$ & -1 \\
\hline orea & 34 & 83 & 28 & 8 & 15 & 3 & $43(2.9)$ & $569(3.3)$ & $51(3.2)$ & $561(3.1)$ & $1(0.8)$ & -- & $5(2.3)$ & $568(12.7$ \\
\hline 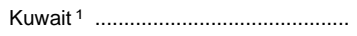 & 29 & 246 & 245 & 20 & 236 & 22 & $23(2.6)$ & $409(1.9)$ & $97(2.6)$ & $426(4.4)$ & $1(0.5)$ & -- & $0(0.0)$ & -1 \\
\hline 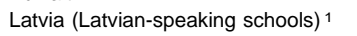 & ${ }^{3} 25$ & ${ }^{3} 84$ & 359 & 332 & ${ }^{3} 24$ & 38 & -- & -- & -- & -- & -- & -- & -- & -1 \\
\hline 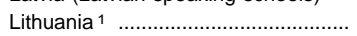 & 216 & ${ }^{2} 60$ & 257 & 222 & 226 & 28 & -- & -- & -- & -- & -- & -- & -- & -1 \\
\hline Netherlands ${ }^{1} \ldots \ldots \ldots \ldots \ldots \ldots \ldots \ldots$ & 25 & 263 & 236 & 223 & 225 & 218 & -- & -- & -- & -- & -- & -- & -- & -1 \\
\hline New Zealand .......... & 15 & 41 & 33 & 26 & 44 & 20 & $1(0.9)$ & -- & $52(4.1)$ & $527(6.3)$ & $47(4.2)$ & $525(6.6)$ & $0(0.0)$ & -1 \\
\hline 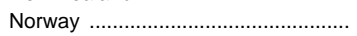 & ${ }^{3} 24$ & ${ }^{3} 62$ & ${ }^{3} 23$ & 31 & ${ }^{3} 23$ & 34 & ${ }^{3} 27(4.9)$ & $526(3.0)$ & $73(4.9)$ & $524(2.6)$ & $1(0.6)$ & -- & $0(0.0)$ & -1 \\
\hline 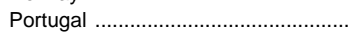 & 14 & 66 & 54 & 3 & 54 & 5 & -- & -- & -- & -- & -- & -- & -- & -1 \\
\hline 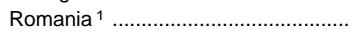 & 15 & 86 & 47 & 8 & 27 & 22 & -- & -- & -- & -- & -- & -- & -- & -1 \\
\hline Russian Federation ... & 9 & 68 & 43 & 21 & 13 & 7 & -- & -- & -- & -- & -- & -- & -- & -1 \\
\hline 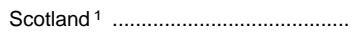 & 37 & ${ }^{3} 22$ & ${ }^{3} 27$ & 311 & ${ }^{3} 56$ & ${ }^{3} 19$ & $314(3.1)$ & $538(23.4)$ & $83(3.6)$ & $519(4.8)$ & $3(1.7)$ & $488(22.5)$ & $0(0.0)$ & -1 \\
\hline Singapore & 12 & 59 & 41 & 17 & 40 & 19 & $0(0.0)$ & -- & $24(4.4)$ & $618(14.6)$ & $76(4.4)$ & $603(6.0)$ & $0(0.0)$ & -1 \\
\hline Slovak Republic .... & 248 & 264 & 245 & 215 & 23 & 21 & -- & -- & -- & -- & -- & -- & -- & -1 \\
\hline 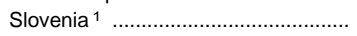 & 27 & 265 & 257 & 219 & 234 & 213 & -- & -- & -- & -- & -- & -- & -- & -1 \\
\hline South Africa ${ }^{1}$ & - & - & - & - & - & - & -- & -- & -- & -- & -- & -- & -- & -1 \\
\hline Spain …………........... & 214 & ${ }^{2} 65$ & 246 & 214 & 218 & 27 & $25(2.6)$ & $532(2.5)$ & $84(3.9)$ & $518(2.1)$ & $11(3.0)$ & $502(9.4)$ & $1(0.7)$ & -1 \\
\hline Switzerland ${ }^{1} \ldots$ & 33 & ${ }^{3} 56$ & ${ }^{3} 21$ & 36 & ${ }^{3} 30$ & 8 & ${ }^{3} 41(4.7)$ & $532(6.6)$ & $37(4.4)$ & $524(8.4)$ & $9(3.1)$ & 486 (13.7) & $13(3.5)$ & $519(15.6$ \\
\hline Thailand ${ }^{1}$........................... & 216 & 238 & 233 & 210 & 232 & 211 & -- & -- & -- & -- & -- & -- & -- & - \\
\hline United States ... & - & - & - & - & - & - & -- & -- & -- & -- & -- & -- & -- & -- \\
\hline
\end{tabular}

${ }^{1}$ Countries not meeting all International Association for the Evaluation of Educational Achievement's sampling specifications.

${ }^{2}$ Teacher response data available for 70 to 84 percent of students.

-Data not available or not applicable.

NOTE.-Data are for 8 th grade or equivalent in most countries. Standard errors appear in parentheses.
SOURCE: International Association for the Evaluation of Educational Achievement, Science Achievement in the Middle School Years: IEA's Third International Mathematics and Science Study, 1997, by Albert E. Beaton et al. Copyrigh 
Table 401.-Average size of 8th-grade mathematics classes, and frequency teachers assign mathematics homework, by country: 1994-95

\begin{tabular}{|c|c|c|c|c|c|c|c|c|c|c|c|}
\hline \multirow{3}{*}{ Country } & \multicolumn{4}{|c|}{ Average size of mathematics classes } & \multicolumn{7}{|c|}{$\begin{array}{l}\text { Percent of students, } \\
\text { by frequency and average length of mathematics assignments }\end{array}$} \\
\hline & \multirow{2}{*}{$\begin{array}{l}1 \text { to } 20 \\
\text { students }\end{array}$} & \multirow{2}{*}{$\begin{array}{l}21 \text { to } 30 \\
\text { students }\end{array}$} & \multirow{2}{*}{$\begin{array}{l}31 \text { to } 40 \\
\text { students }\end{array}$} & \multirow{2}{*}{$\begin{array}{l}41 \text { or more } \\
\text { students }\end{array}$} & \multirow{2}{*}{$\begin{array}{c}\text { Never } \\
\text { assigning } \\
\text { homework }\end{array}$} & \multicolumn{2}{|c|}{$\begin{array}{l}\text { Assigning homework less } \\
\text { than once a week }\end{array}$} & \multicolumn{2}{|c|}{$\begin{array}{l}\text { Assigning homework once } \\
\text { or twice a week }\end{array}$} & \multicolumn{2}{|c|}{$\begin{array}{c}\text { Assigning homework } 3 \text { or } \\
\text { more times a week }\end{array}$} \\
\hline & & & & & & $\begin{array}{l}30 \text { minutes } \\
\text { or less }\end{array}$ & $\begin{array}{l}\text { More than } \\
30 \text { minutes }\end{array}$ & $\begin{array}{l}30 \text { minutes } \\
\text { or less }\end{array}$ & $\begin{array}{l}\text { More than } \\
30 \text { minutes }\end{array}$ & $\begin{array}{l}30 \text { minutes } \\
\text { or less }\end{array}$ & $\begin{array}{l}\text { More than } \\
30 \text { minutes }\end{array}$ \\
\hline 1 & 2 & 3 & 4 & 5 & 6 & 7 & 8 & 9 & 10 & 11 & 12 \\
\hline Australia 1 & $213(2.4)$ & $71(3.3)$ & $16(2.6)$ & $1(0.5)$ & $21(0.8)$ & $6(1.6)$ & $0(0.2)$ & $21(2.6)$ & $4(1.9)$ & $62(3.4)$ & $5(1.7)$ \\
\hline Austria $^{1}$... & -- & -- & -- & -- & $20(0.0)$ & $1(0.5)$ & $0(0.0)$ & $24(4.4)$ & $3(1.4)$ & $63(5.0)$ & $10(2.1)$ \\
\hline 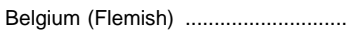 & $49(3.6)$ & $51(3.6)$ & $0(0.0)$ & $0(0.0)$ & $0(0.0)$ & $17(3.5)$ & $2(1.1)$ & $52(4.8)$ & $10(2.6)$ & $15(2.9)$ & $5(2.1)$ \\
\hline 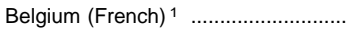 & $343(5.3)$ & $57(5.3)$ & $0(0.0)$ & $0(0.0)$ & $1(1.2)$ & $2(1.4)$ & $0(0.0)$ & $30(5.1)$ & $5(2.2)$ & $55(5.5)$ & $7(2.8)$ \\
\hline Bulgaria $^{1}$.................... & -- & -- & -- & -- & -- & -- & -- & -- & -- & -- & -- \\
\hline Canada & $211(2.1)$ & $65(4.0)$ & $23(3.6)$ & $1(0.5)$ & $22(1.1)$ & $2(0.9)$ & $1(0.7)$ & $22(3.4)$ & $2(0.9)$ & $59(3.7)$ & $13(2.7)$ \\
\hline 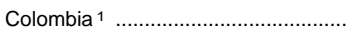 & $216(4.2)$ & $6(2.2)$ & $29(4.0)$ & $48(4.6)$ & $0(0.0)$ & $1(0.9)$ & $1(0.8)$ & $17(4.7)$ & $13(2.9)$ & $29(4.2)$ & $39(4.2)$ \\
\hline 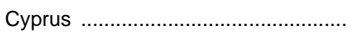 & $1(0.0)$ & $37(3.9)$ & $62(3.9)$ & $0(0.0)$ & $20(0.0)$ & $0(0.0)$ & $0(0.0)$ & $0(0.0)$ & $0(0.0)$ & $50(5.3)$ & $50(5.3)$ \\
\hline 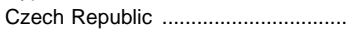 & $13(3.3)$ & $77(5.3)$ & $11(4.5)$ & $0(0.0)$ & $0(0.4)$ & $14(4.5)$ & $0(0.0)$ & $62(5.2)$ & $0(0.3)$ & $23(3.5)$ & $1(0.6)$ \\
\hline 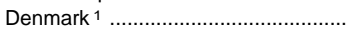 & $249(4.8)$ & $51(4.8)$ & $0(0.0)$ & $0(0.0)$ & $0(0.0)$ & $4(1.8)$ & $0(0.0)$ & $42(4.7)$ & $3(1.6)$ & $49(5.2)$ & $2(1.0)$ \\
\hline England ${ }^{1}$ & $318(3.1)$ & $62(3.7)$ & $20(3.4)$ & $0(0.0)$ & $0(0.0)$ & $3(1.0)$ & $1(0.6)$ & $44(3.8)$ & $47(3.7)$ & $3(1.4)$ & $2(1.1)$ \\
\hline France ........ & $11(2.6)$ & $86(2.9)$ & $3(1.8)$ & $0(0.0)$ & $0(0.0)$ & $0(0.0)$ & $2(0.9)$ & $7(2.5)$ & $4(1.2)$ & 77 (3.9) & $10(2.8)$ \\
\hline Germany ${ }^{1}$ & $325(4.4)$ & $72(4.5)$ & $3(1.8)$ & $0(0.0)$ & $1(1.4)$ & $1(1.4)$ & $0(0.0)$ & $22(4.4)$ & $0(0.0)$ & $73(5.0)$ & $3(1.8)$ \\
\hline Greece $^{1}$ & $9(2.3)$ & $64(4.4)$ & $27(3.9)$ & $0(0.0)$ & $0(0.0)$ & $1(0.9)$ & $0(0.0)$ & $0(0.0)$ & $0(0.2)$ & $31(3.4)$ & $67(3.5)$ \\
\hline 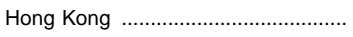 & $3(1.9)$ & $4(2.2)$ & $56(5.7)$ & $37(5.9)$ & $1(1.4)$ & $4(2.2)$ & $3(1.8)$ & $25(4.7)$ & $15(4.1)$ & $38(6.0)$ & $14(4.1)$ \\
\hline Hungary & $37(4.0)$ & $57(4.1)$ & $6(2.2)$ & $0(0.0)$ & $0(0.0)$ & $1(0.7)$ & $0(0.0)$ & $2(1.3)$ & $0(0.0)$ & $82(3.0)$ & $15(3.1)$ \\
\hline Iceland. & $236(5.9)$ & $64(5.9)$ & $0(0.0)$ & $0(0.0)$ & $0(0.0)$ & $0(0.0)$ & $0(0.0)$ & $5(2.0)$ & $1(1.0)$ & $75(5.5)$ & $19(5.5)$ \\
\hline 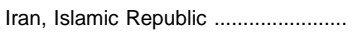 & $21(0.9)$ & $26(4.5)$ & $54(5.3)$ & $19(4.4)$ & $0(0.0)$ & $1(0.5)$ & $3(1.4)$ & $10(3.0)$ & $59(4.4)$ & $2(1.1)$ & $26(4.3)$ \\
\hline Ireland & $212(2.7)$ & $68(4.5)$ & $20(3.9)$ & $0(0.0)$ & $0(0.0)$ & $0(0.0)$ & $0(0.0)$ & $1(0.9)$ & $0(0.0)$ & $94(2.2)$ & $5(2.0)$ \\
\hline Israel ${ }^{1}$ & $214(5.1)$ & $36(7.4)$ & $49(9.1)$ & $2(1.6)$ & $20(0.0)$ & $1(1.2)$ & $0(0.0)$ & $3(2.2)$ & $0(0.0)$ & $48(7.1)$ & $48(6.8)$ \\
\hline 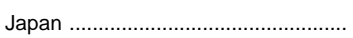 & $0(0.2)$ & $4(1.4)$ & $88(2.0)$ & $8(1.5)$ & $0(0.0)$ & $27(4.0)$ & $4(1.7)$ & $37(3.7)$ & $10(2.3)$ & $16(2.9)$ & $6(1.5)$ \\
\hline Korea & $2(1.2)$ & $1(1.0)$ & $4(1.5)$ & $93(2.0)$ & $0(0.0)$ & $5(1.6)$ & $8(2.2)$ & $27(3.7)$ & $21(3.3)$ & $21(3.2)$ & $18(3.4)$ \\
\hline Kuwait ${ }^{1}$ & $0(0.0)$ & $49(6.5)$ & $49(6.3)$ & $2(1.9)$ & $0(0.0)$ & $0(0.0)$ & $0(0.0)$ & $19(6.1)$ & $2(2.0)$ & $60(8.3)$ & $18(6.0)$ \\
\hline Latvia (Latvian-speaking schools) 1 & $241(4.0)$ & $51(3.8)$ & $4(2.1)$ & $4(2.0)$ & $0(0.0)$ & $0(0.0)$ & $0(0.0)$ & $8(2.8)$ & $1(0.9)$ & $83(3.9)$ & $9(2.4)$ \\
\hline Lithuania ${ }^{1}$ & $243(3.8)$ & $54(3.7)$ & $3(1.6)$ & $0(0.0)$ & $0(0.0)$ & $0(0.0)$ & $0(0.0)$ & $2(1.3)$ & $0(0.0)$ & $76(3.9)$ & $22(3.9)$ \\
\hline Netherlands ${ }^{1}$ & $16(4.7)$ & $77(5.6)$ & $7(3.6)$ & $0(0.0)$ & $1(1.2)$ & $1(0.9)$ & $0(0.0)$ & $12(3.5)$ & $2(1.4)$ & $81(4.2)$ & $4(2.2)$ \\
\hline 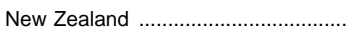 & $11(2.2)$ & $68(3.8)$ & $21(3.1)$ & $0(0.0)$ & $0(0.0)$ & $5(1.9)$ & $2(0.1)$ & $34(4.3)$ & $4(1.5)$ & $54(4.2)$ & $2(1.2)$ \\
\hline 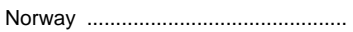 & $220(3.5)$ & 79 (3.7) & $1(0.5)$ & $1(0.8)$ & $20(0.0)$ & $0(0.0)$ & $0(0.0)$ & $7(2.7)$ & $8(2.7)$ & $67(4.3)$ & $18(4.0)$ \\
\hline 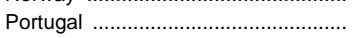 & $12(2.8)$ & $80(3.7)$ & $7(2.6)$ & $0(0.0)$ & $0(0.0)$ & $1(0.9)$ & $1(0.5)$ & $30(4.0)$ & $2(1.1)$ & $57(4.1)$ & $9(2.4)$ \\
\hline 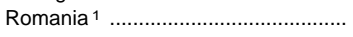 & $23(2.7)$ & $51(4.3)$ & $24(4.1)$ & $2(1.2)$ & $0(0.0)$ & $0(0.0)$ & $0(0.0)$ & $1(0.8)$ & $1(0.6)$ & $11(2.8)$ & $87(2.8)$ \\
\hline Russian Federation & $15(2.7)$ & 75 (3.6) & $9(2.3)$ & $0(0.0)$ & $0(0.0)$ & $0(0.0)$ & $0(0.0)$ & $2(0.9)$ & $1(0.8)$ & $42(3.5)$ & $55(3.4)$ \\
\hline Scotland 1 .................... & $212(2.8)$ & $80(3.8)$ & $8(2.7)$ & $0(0.0)$ & $20(0.4)$ & $20(4.3)$ & $4(2.0)$ & $46(5.1)$ & $6(2.3)$ & $24(4.1)$ & $0(0.0)$ \\
\hline 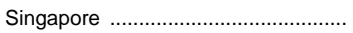 & $1(0.7)$ & $10(2.5)$ & $72(4.3)$ & $18(4.0)$ & $0(0.0)$ & $1(0.9)$ & $0(0.0)$ & $3(1.5)$ & $11(3.1)$ & $26(4.1)$ & $58(4.5)$ \\
\hline 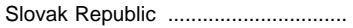 & $15(2.8)$ & $67(4.2)$ & $19(3.6)$ & $0(0.0)$ & $0(0.0)$ & $1(0.9)$ & $0(0.0)$ & $12(2.8)$ & $1(0.7)$ & $83(3.4)$ & $4(1.7)$ \\
\hline Slovenia $^{1}$ & $215(3.1)$ & $80(3.6)$ & $5(1.8)$ & $0(0.0)$ & ${ }^{2} 0(0.0)$ & $0(0.0)$ & $0(0.0)$ & $2(1.4)$ & $0(0.0)$ & $74(4.4)$ & $24(4.2)$ \\
\hline South Africa ${ }^{1} \ldots . .$. & -- & -- & -- & -- & -- & -- & -- & -- & -- & -- & -- \\
\hline Spain & $213(2.8)$ & $48(4.0)$ & $36(4.2)$ & $4(1.7)$ & $20(0.0)$ & $4(1.6)$ & $0(0.0)$ & $18(3.3)$ & $9(2.7)$ & $47(4.4)$ & $22(3.7)$ \\
\hline 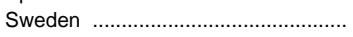 & ${ }^{2} 36(3.9)$ & $61(4.0)$ & $2(1.2)$ & $0(0.0)$ & $20(0.4)$ & $19(3.0)$ & $7(1.9)$ & $45(4.0)$ & $26(3.3)$ & $2(1.2)$ & $1(1.2)$ \\
\hline 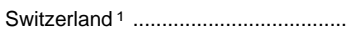 & ${ }^{3} 56(4.5)$ & $44(4.5)$ & $0(0.0)$ & $0(0.0)$ & $0(0.0)$ & $1(0.4)$ & $1(0.3)$ & $26(4.2)$ & $4(1.5)$ & $61(4.4)$ & $6(2.3)$ \\
\hline Thailand ${ }^{1}$ & -- & -- & -- & -- & $20(0.0)$ & $0(0.0)$ & $0(0.0)$ & $6(3.5)$ & $20(4.8)$ & $16(4.7)$ & $58(6.6)$ \\
\hline 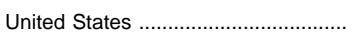 & ${ }^{3} 24(3.0)$ & 59 (3.9) & $12(2.2)$ & $4(1.8)$ & ${ }^{2} 0(0.1)$ & $3(1.3)$ & $0(0.0)$ & $7(1.8)$ & $3(0.9)$ & $64(2.9)$ & $23(3.1)$ \\
\hline
\end{tabular}

${ }^{1}$ Countries not meeting all International Association for the Evaluation of Educational Achievement's sampling specifications.

2 Teacher response data available for 70 to 84 percent of students.

${ }^{3}$ Teacher response data available for 50 to 69 percent of students.

-Data not available or not applicable.
NOTE.-Data are for 8 th grade or equivalent in most countries. Standard errors ap pear in parentheses.

SOURCE: International Association for the Evaluation of Educational Achievement, Mathematics Achievement in the Middle School Years: IEA's Third International Mathematics and Science Study, 1997, by Albert E. Beaton et al. Copyright $\odot 1996$ Boston College, Chestnut Hill, MA. (This table was prepared June 1997. 
Table 402.-Eighth-grade students' perceptions about mathematics achievement and hours spent on leisure activities, by country: 1994-95

\begin{tabular}{|c|c|c|c|c|c|c|c|c|c|c|c|c|c|c|}
\hline \multirow{3}{*}{ Country } & \multicolumn{8}{|c|}{ Students' self-perceptions about usually doing well in mathematics } & \multicolumn{6}{|c|}{ Average hours each day } \\
\hline & \multicolumn{2}{|c|}{ Strongly disagree } & \multicolumn{2}{|c|}{ Disagree } & \multicolumn{2}{|c|}{ Agree } & \multicolumn{2}{|c|}{ Strongly agree } & \multirow{2}{*}{$\begin{array}{l}\text { Watching TV } \\
\text { or videos }\end{array}$} & \multirow{2}{*}{$\begin{array}{l}\text { Playing or } \\
\text { talking with } \\
\text { friends }\end{array}$} & \multirow{2}{*}{$\begin{array}{c}\text { Doing jobs at } \\
\text { home }\end{array}$} & \multirow{2}{*}{$\begin{array}{l}\text { Playing } \\
\text { sports }\end{array}$} & \multirow{2}{*}{$\begin{array}{l}\text { Reading for } \\
\text { enjoyment }\end{array}$} & \multirow{2}{*}{$\begin{array}{l}\text { Playing com- } \\
\text { puter games }\end{array}$} \\
\hline & Percent & Mean score & Percent & Mean score & Percent & Mean score & Percent & Mean score & & & & & & \\
\hline 1 & 2 & 3 & 4 & 5 & 6 & 7 & 8 & 9 & 10 & 11 & 12 & 13 & 14 & 15 \\
\hline Australia 1 . & $3(0.3)$ & $457(7.9)$ & $17(0.7)$ & $487(5.6)$ & $60(0.8)$ & 530 (3.9) & $20(0.9)$ & $586(4.7)$ & $2.4(0.05)$ & $1.4(0.03)$ & $0.9(0.02)$ & $1.6(0.03)$ & $0.6(0.02)$ & $0.6(0.02)$ \\
\hline Austria $^{1}$...................... & $3(0.4)$ & $512(10.1)$ & $21(1.1)$ & $508(5.4)$ & $45(1.2)$ & $535(4.0)$ & $31(1.4)$ & $572(4.3)$ & $1.9(0.06)$ & $2.9(0.08)$ & $0.8(0.03)$ & $1.9(0.07)$ & $0.8(0.03)$ & $0.6(0.03)$ \\
\hline Belgium (Flemish). & $5(0.4)$ & $512(6.7)$ & $29(1.0)$ & $548(5.9)$ & $48(1.1)$ & $567(6.4)$ & $17(0.9)$ & $609(7.2)$ & $2.0(0.05)$ & $1.6(0.05)$ & $1.1(0.03)$ & $1.8(0.07)$ & $0.7(0.03)$ & $0.5(0.06)$ \\
\hline Belgium (French) ${ }^{1}$... & $3(0.4)$ & $467(7.8)$ & $19(1.3)$ & $505(5.4)$ & $48(1.3)$ & $528(3.8)$ & $29(1.5)$ & $550(5.0)$ & $1.9(0.08)$ & $1.7(0.10)$ & $0.8(0.03)$ & $1.8(0.04)$ & $0.8(0.03)$ & $0.7(0.03)$ \\
\hline Bulgaria $^{1}$................... & & -- & -- & -- & -- & -- & -- & -- & & & & & & \\
\hline Canada . & $3(0.3)$ & $480(9.0)$ & $13(0.6)$ & $480(4.9)$ & $49(1.1)$ & $514(2.3)$ & $35(1.1)$ & $570(3.4)$ & $2.3(0.04)$ & $2.2(0.05)$ & $1.0(0.02)$ & $1.9(0.03)$ & $0.8(0.02)$ & $0.5(0.02)$ \\
\hline Colombia $^{1} \ldots . . . . . . . . .$. & $2(0.4)$ & -- & $17(1.3)$ & $373(3.7)$ & $51(1.9)$ & $385(4.6)$ & $30(1.4)$ & $398(5.3)$ & $2.2(0.07)$ & $1.9(0.06)$ & $2.3(0.07)$ & $1.9(0.06)$ & $0.9(0.05)$ & $20.4(0.06)$ \\
\hline Cyprus ............ & $5(0.4)$ & $411(7.6)$ & $18(0.8)$ & $432(3.7)$ & $46(1.0)$ & 469 (2.6) & $31(1.0)$ & $521(4.4)$ & $2.3(0.04)$ & $1.7(0.04)$ & $1.0(0.03)$ & $1.4(0.04)$ & $0.8(0.02)$ & $0.8(0.03)$ \\
\hline Czech Republic.. & $2(0.3)$ & -- & $37(1.4)$ & $516(4.2)$ & 48 (1.4) & $584(5.2)$ & $13(1.0)$ & $640(8.0)$ & $2.6(0.05)$ & $2.9(0.09)$ & $1.3(0.04)$ & $1.9(0.06)$ & $1.0(0.03)$ & $0.6(0.03)$ \\
\hline Denmark ${ }^{1}$. & $1(0.2)$ & -- & $8(0.6)$ & $431(7.0)$ & $53(1.4)$ & $492(3.0)$ & $38(1.3)$ & 537 (4.0) & $2.2(0.06)$ & $2.8(0.07)$ & $1.1(0.04)$ & $1.7(0.06)$ & $0.7(0.03)$ & $0.7(0.03)$ \\
\hline England ${ }^{1}$. & $1(0.2)$ & -- & $6(0.6)$ & $475(8.3)$ & $69(1.0)$ & $500(3.0)$ & $24(1.0)$ & $538(5.8)$ & $2.7(0.07)$ & $2.5(0.06)$ & $0.8(0.03)$ & $1.5(0.05)$ & $0.7(0.03)$ & $0.9(0.05)$ \\
\hline France & $6(0.7)$ & $495(6.1)$ & $26(1.1)$ & $513(4.0)$ & $46(1.0)$ & $548(3.4)$ & $22(0.8)$ & $564(5.1)$ & $1.5(0.04)$ & $1.5(0.05)$ & $0.9(0.03)$ & $1.7(0.04)$ & $0.8(0.03)$ & $0.5(0.02)$ \\
\hline Germany ${ }^{1}$.. & $7(0.5)$ & $474(7.1)$ & $24(1.0)$ & 491 (5.2) & $33(1.1)$ & $511(5.1)$ & $36(1.1)$ & 529 (5.3) & $1.9(0.04)$ & $3.5(0.07)$ & $0.9(0.02)$ & $1.7(0.04)$ & $0.7(0.02)$ & $0.8(0.04)$ \\
\hline Greece $^{1} \ldots . . .$. & $2(0.3)$ & -- & $16(0.7)$ & $454(3.6)$ & $55(0.8)$ & 481 (3.2) & $27(0.8)$ & 515 (4.2) & $2.1(0.04)$ & $1.5(0.04)$ & $0.9(0.03)$ & $1.8(0.04)$ & $1.0(0.03)$ & $0.7(0.03)$ \\
\hline Hong Kong ....…….......... & $11(0.9)$ & $536(9.5)$ & $51(1.2)$ & $577(6.7)$ & $33(1.2)$ & $620(6.7)$ & $5(0.5)$ & $643(8.2)$ & $2.6(0.05)$ & $1.2(0.04)$ & $0.7(0.02)$ & $0.9(0.03)$ & $0.9(0.02)$ & $0.8(0.03)$ \\
\hline Hungary & $3(0.3)$ & 469 (11.7) & $25(0.9)$ & $490(4.2)$ & $57(1.0)$ & $545(3.4)$ & $15(0.8)$ & 608 (4.8) & $3.0(0.06)$ & $2.3(0.05)$ & $2.0(0.04)$ & $1.7(0.04)$ & $1.2(0.04)$ & $0.7(0.03)$ \\
\hline Iceland. & $3(0.6)$ & $421(10.1)$ & $14(1.4)$ & 447 (4.9) & $55(1.6)$ & $486(4.5)$ & $28(1.8)$ & $519(9.5)$ & $2.2(0.05)$ & $3.1(0.06)$ & $0.8(0.03)$ & $1.8(0.06)$ & $0.9(0.06)$ & $0.7(0.06)$ \\
\hline Iran, Islamic Republic . & $1(0.4)$ & -- & $8(0.7)$ & $403(4.3)$ & $62(1.4)$ & $423(2.6)$ & $29(1.4)$ & $450(3.7)$ & $1.8(0.06)$ & $1.2(0.04)$ & $1.8(0.06)$ & $1.2(0.09)$ & $1.1(0.04)$ & $20.2(0.02)$ \\
\hline Ireland. & $3(0.3)$ & $475(7.7)$ & $18(1.0)$ & $492(5.5)$ & $61(0.9)$ & $530(5.2)$ & $18(1.0)$ & $572(7.6)$ & $2.1(0.03)$ & $1.5(0.06)$ & $0.9(0.03)$ & $1.4(0.05)$ & $0.6(0.02)$ & $0.5(0.03)$ \\
\hline 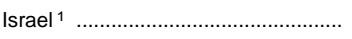 & $2(0.4)$ & -- & $12(1.3)$ & $494(10.1)$ & $45(1.9)$ & $513(6.2)$ & $41(1.9)$ & $549(8.3)$ & $3.3(0.10)$ & $2.4(0.08)$ & $1.2(0.05)$ & $1.9(0.09)$ & $1.0(0.04)$ & $0.9(0.04)$ \\
\hline Japan …………......... & $10(0.5)$ & $523(3.7)$ & $45(0.7)$ & $577(2.3)$ & $40(0.7)$ & $650(2.5)$ & $4(0.3)$ & $669(7.8)$ & $2.6(0.04)$ & $1.9(0.04)$ & $0.6(0.01)$ & $1.3(0.03)$ & $0.9(0.02)$ & $0.6(0.02)$ \\
\hline Korea .. & $9(0.5)$ & $535(5.7)$ & $53(1.0)$ & $572(3.0)$ & $32(0.9)$ & $669(3.0)$ & $6(0.6)$ & $702(5.7)$ & $2.0(0.04)$ & $0.9(0.03)$ & $0.5(0.02)$ & $0.5(0.02)$ & $0.8(0.03)$ & $0.3(0.02)$ \\
\hline Kuwait 1 . & $3(0.7)$ & $364(11.3)$ & $9(0.9)$ & $382(3.6)$ & $49(1.7)$ & $386(2.4)$ & $39(2.1)$ & 405 (3.9) & $1.9(0.07)$ & $1.5(0.11)$ & $1.2(0.08)$ & $1.5(0.10)$ & $1.0(0.04)$ & $0.7(0.05)$ \\
\hline Latvia (Latvian-speaking schools) ${ }^{1}$ & $2(0.3)$ & -- & $43(1.2)$ & 471 (3.5) & $43(1.2)$ & $505(3.7)$ & $12(0.8)$ & $542(5.5)$ & $2.6(0.05)$ & $2.1(0.06)$ & $1.5(0.04)$ & $1.2(0.04)$ & $1.1(0.03)$ & $0.7(0.04)$ \\
\hline Lithuania 1 & $5(0.5)$ & $446(7.5)$ & 46 (1.2) & 454 (3.4) & $38(1.2)$ & $492(4.3)$ & $11(0.8)$ & $544(6.0)$ & $2.8(0.05)$ & $2.7(0.06)$ & $1.2(0.03)$ & $1.2(0.04)$ & $1.0(0.03)$ & $0.9(0.04)$ \\
\hline Netherlands & $4(0.5)$ & 487 (12.4) & $21(1.4)$ & $504(7.1)$ & $43(1.3)$ & $537(8.4)$ & $32(1.6)$ & $580(7.3)$ & $2.5(0.09)$ & $2.8(0.08)$ & $0.9(0.04)$ & $1.8(0.06)$ & $0.6(0.03)$ & $0.7(0.04)$ \\
\hline New Zealand. & $2(0.3)$ & -- & $13(0.8)$ & $466(6.1)$ & $62(0.9)$ & $501(4.5)$ & $22(0.8)$ & $559(5.5)$ & $2.5(0.05)$ & $1.5(0.04)$ & $0.9(0.02)$ & $1.5(0.04)$ & $0.8(0.02)$ & $0.7(0.03)$ \\
\hline Norway ............ & $3(0.3)$ & $434(7.4)$ & $18(0.9)$ & 455 (3.2) & $58(1.0)$ & $504(2.2)$ & $21(0.8)$ & $555(4.4)$ & $2.5(0.04)$ & $3.2(0.06)$ & $1.1(0.03)$ & $1.9(0.05)$ & $0.7(0.02)$ & $0.8(0.03)$ \\
\hline Portuga & $7(0.5)$ & 419 (3.6) & $37(1.1)$ & $435(2.3)$ & $42(1.1)$ & $463(2.5)$ & $14(0.8)$ & $502(5.2)$ & $2.0(0.04)$ & $1.7(0.05)$ & $1.0(0.04)$ & $1.7(0.04)$ & $0.7(0.02)$ & $0.7(0.03)$ \\
\hline Romania 1 & $6(0.6)$ & $455(12.0)$ & $25(1.0)$ & $459(4.6)$ & $49(0.9)$ & $488(4.3)$ & $20(1.0)$ & $505(6.3)$ & $1.9(0.06)$ & $1.5(0.06)$ & $1.9(0.08)$ & $1.3(0.05)$ & $1.3(0.07)$ & $0.6(0.05)$ \\
\hline Russian Federation . & $2(0.3)$ & -- & $37(1.4)$ & $501(7.1)$ & $43(1.1)$ & $547(5.1)$ & $18(0.8)$ & $590(4.9)$ & $2.9(0.05)$ & $2.9(0.05)$ & $1.5(0.03)$ & $1.0(0.03)$ & $1.3(0.04)$ & $1.0(0.04)$ \\
\hline Scotland 1 .. & $2(0.3)$ & -- & $10(0.8)$ & $455(5.5)$ & $66(1.3)$ & $491(4.8)$ & $22(1.3)$ & $553(9.3)$ & $2.7(0.05)$ & $2.8(0.08)$ & $0.7(0.02)$ & $1.9(0.05)$ & $0.7(0.02)$ & $1.0(0.04)$ \\
\hline Singapore & $6(0.4)$ & $587(9.0)$ & $38(1.2)$ & $624(5.2)$ & $46(1.1)$ & 659 (4.9) & $11(0.6)$ & 677 (6.2) & $2.7(0.05)$ & $1.5(0.04)$ & $1.0(0.03)$ & $0.7(0.03)$ & $1.1(0.02)$ & $0.6(0.03)$ \\
\hline Slovak Republic .. & $1(0.2)$ & -- & $28(1.1)$ & $496(3.8)$ & $55(1.1)$ & $555(3.8)$ & $15(0.7)$ & $619(5.2)$ & $2.7(0.05)$ & $2.9(0.07)$ & $1.5(0.05)$ & $1.8(0.04)$ & $1.0(0.03)$ & $0.6(0.03)$ \\
\hline Slovenia 1 1........... & $2(0.3)$ & -- & $24(1.1)$ & $497(4.0)$ & $53(1.0)$ & $538(3.6)$ & $21(0.9)$ & $602(4.2)$ & $2.0(0.04)$ & $1.7(0.05)$ & $1.6(0.05)$ & $1.6(0.03)$ & $0.9(0.02)$ & $0.6(0.02)$ \\
\hline South Africa ${ }^{1}$. & -- & -- & -- & -- & -- & -- & -- & -- & -- & -- & -- & -- & -- & -- \\
\hline Spa & $5(0.5)$ & $441(4.6)$ & $23(1.0)$ & $456(2.6)$ & $45(1.1)$ & $488(2.6)$ & $27(1.0)$ & $522(3.4)$ & $1.8(0.05)$ & $1.8(0.06)$ & $1.1(0.03)$ & $1.7(0.04)$ & $0.6(0.02)$ & $0.3(0.02)$ \\
\hline Sweden & $2(0.3)$ & -- & $16(0.7)$ & 475 (3.4) & $61(0.9)$ & $517(3.0)$ & $21(0.8)$ & 565 (3.8) & $2.3(0.04)$ & $2.3(0.05)$ & $0.9(0.02)$ & $1.6(0.04)$ & $0.7(0.02)$ & $0.6(0.02)$ \\
\hline Switzerland 1 . & $3(0.4)$ & $497(10.1)$ & $21(0.9)$ & $528(4.0)$ & $47(0.9)$ & $541(3.0)$ & $28(1.1)$ & 575 (3.3) & $1.3(0.03)$ & $2.4(0.05)$ & $1.0(0.03)$ & $1.8(0.03)$ & $0.8(0.02)$ & $0.4(0.02)$ \\
\hline Thailand ${ }^{1}$ & $2(0.3)$ & -- & $38(1.5)$ & $510(5.1)$ & $45(1.1)$ & $529(6.6)$ & $15(0.9)$ & $537(7.4)$ & $2.1(0.07)$ & $1.2(0.03)$ & $1.6(0.03)$ & $1.1(0.02)$ & $1.0(0.02)$ & $0.3(0.02)$ \\
\hline United States & $3(0.3)$ & $430(5.1)$ & $11(0.6)$ & $462(4.8)$ & $52(0.9)$ & $491(4.3)$ & $34(1.0)$ & $534(5.9)$ & $2.6(0.07)$ & $2.5(0.06)$ & $1.2(0.04)$ & $2.2(0.05)$ & $0.7(0.02)$ & $0.7(0.03)$ \\
\hline
\end{tabular}

${ }^{1}$ Countries not meeting all International Association for the Evaluation of Educational Achievement's sampling specifications.

udent response data available for 70 to 84 percent of students.

-Data not available or not applicable.
NOTE. - Data are for 8th grade or equivalent in most countries. Standard errors appear in parentheses.

SOURCE: International Association for the Evaluation of Educational Achievement, Mathematics Achievement in the Middle School Years: IEA's Third International Mathematics and Science Study, 1997, by Albert E. Beaton et al. Copy- 
Table 403.-Average 4th-grade mathematics scores, ${ }^{1}$ by content areas, and average time spent studying mathematics out of school, by country:

1994-95

\begin{tabular}{|c|c|c|c|c|c|c|c|c|c|c|c|c|c|c|}
\hline \multirow{3}{*}{ Country } & \multicolumn{7}{|c|}{ Average percent correct by content area } & \multicolumn{7}{|c|}{ Amount of daily out-of-school study time in mathematics } \\
\hline & \multirow[b]{2}{*}{$\begin{array}{c}\text { Overall } \\
\text { mathematics } \\
\text { scores }\end{array}$} & \multirow[b]{2}{*}{$\begin{array}{l}\text { Whole } \\
\text { numbers }\end{array}$} & \multirow[b]{2}{*}{$\begin{array}{c}\text { Fractions } \\
\text { and } \\
\text { proportionality }\end{array}$} & \multirow{2}{*}{$\begin{array}{l}\text { Measure- } \\
\text { ment, } \\
\text { estimation, } \\
\text { and } \\
\text { number } \\
\text { sense }\end{array}$} & \multirow{2}{*}{$\begin{array}{l}\text { Data } \\
\text { representation, } \\
\text { analysis, } \\
\text { and } \\
\text { probability }\end{array}$} & \multirow[b]{2}{*}{ Geometry } & \multirow{2}{*}{$\begin{array}{l}\text { Patterns, } \\
\text { relations, } \\
\text { and } \\
\text { functions }\end{array}$} & \multicolumn{2}{|c|}{ No time } & \multicolumn{2}{|c|}{ Less than 1 hour } & \multicolumn{2}{|c|}{1 hour or more } & \multirow[b]{2}{*}{$\begin{array}{l}\text { Average } \\
\text { hours }^{2}\end{array}$} \\
\hline & & & & & & & & Percent & $\begin{array}{l}\text { Mean } \\
\text { score }\end{array}$ & Percent & $\begin{array}{l}\text { Mean } \\
\text { score }\end{array}$ & Percent & $\begin{array}{l}\text { Mean } \\
\text { score }\end{array}$ & \\
\hline 1 & 2 & 3 & 4 & 5 & 6 & 7 & 8 & 9 & 10 & 11 & 12 & 13 & 14 & 15 \\
\hline Australia $^{3}$ & $63(0.6)$ & $67(0.6)$ & $51(0.7)$ & $60(0.7)$ & $67(0.8)$ & $74(0.7)$ & $64(0.9)$ & $15(0.9)$ & $526(5.6)$ & $61(1.2)$ & 559 (3.2) & $24(1.0)$ & $530(4.4)$ & $0.8(0.02)$ \\
\hline Austria $^{3} \ldots \ldots \ldots . .$. & $65(0.7)$ & $74(0.8)$ & $51(0.8)$ & $69(0.8)$ & $66(1.1)$ & $67(0.8)$ & $64(1.1)$ & $4(0.7)$ & $555(8.6)$ & $58(1.8)$ & $571(3.8)$ & $38(1.6)$ & $546(4.1)$ & $1.0(0.03)$ \\
\hline 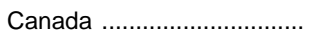 & $60(1.0)$ & $68(0.9)$ & $48(1.0)$ & $54(1.1)$ & $68(1.4)$ & $72(1.4)$ & $62(1.5)$ & $14(1.1)$ & $526(4.4)$ & $60(1.4)$ & $544(4.0)$ & $26(1.2)$ & $522(5.0)$ & $0.8(0.02)$ \\
\hline Cyprus .................... & $54(0.6)$ & $65(0.7)$ & $48(0.7)$ & $48(0.8)$ & $52(0.9)$ & $53(0.9)$ & $55(1.1)$ & $9(0.7)$ & $473(6.1)$ & $51(1.9)$ & 519 (3.6) & $40(1.6)$ & $495(3.8)$ & $1.1(0.03)$ \\
\hline Czech Republic .................... & $66(0.6)$ & $75(0.6)$ & $53(0.8)$ & $68(0.7)$ & $67(0.9)$ & $71(0.7)$ & $67(0.9)$ & $9(0.9)$ & $547(6.6)$ & $69(1.2)$ & $576(3.6)$ & $22(1.1)$ & $560(4.3)$ & $0.7(0.02)$ \\
\hline 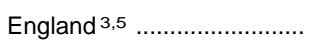 & $57(0.7)$ & $58(0.7)$ & $45(0.8)$ & $52(0.7)$ & $64(0.9)$ & $74(0.8)$ & $55(1.0)$ & -- & -- & -- & -- & -- & -- & -- \\
\hline Greece ............ & $51(0.9)$ & $62(1.0)$ & $42(1.1)$ & $48(1.0)$ & $50(1.2)$ & $53(1.2)$ & $47(1.2)$ & $6(0.5)$ & $453(6.8)$ & $38(1.6)$ & $512(4.1)$ & $56(1.7)$ & $493(4.0)$ & $1.6(0.04)$ \\
\hline Hong Kong ........ & $73(0.9)$ & $79(0.9)$ & $66(1.0)$ & $69(0.9)$ & $76(1.0)$ & $74(0.8)$ & $73(1.2)$ & $6(0.7)$ & $550(7.9)$ & $44(1.2)$ & $595(4.2)$ & $50(1.2)$ & $586(4.5)$ & $1.3(0.03)$ \\
\hline Hungary ${ }^{3} \ldots \ldots \ldots \ldots \ldots \ldots \ldots \ldots$ & $64(0.8)$ & $76(0.7)$ & $49(0.9)$ & $64(0.9)$ & $60(1.0)$ & $66(0.8)$ & $69(1.1)$ & $5(0.7)$ & $543(10.8)$ & $58(1.3)$ & $563(3.9)$ & $37(1.4)$ & $533(4.2)$ & $1.0(0.03)$ \\
\hline 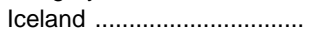 & $50(0.8)$ & $56(0.9)$ & $36(1.0)$ & $44(0.9)$ & $58(1.2)$ & $63(1.0)$ & $48(1.4)$ & $10(0.8)$ & $457(4.3)$ & $63(1.4)$ & $483(3.5)$ & $27(1.4)$ & $472(3.2)$ & $0.8(0.02)$ \\
\hline Iran, Islamic Republic ${ }^{4} \ldots .$. & $38(0.9)$ & $51(1.2)$ & $32(1.0)$ & $36(0.9)$ & $23(0.9)$ & $42(0.9)$ & $40(1.4)$ & $5(0.7)$ & $402(6.6)$ & $17(1.3)$ & $433(6.0)$ & $78(1.5)$ & $443(4.5)$ & $2.3(0.07)$ \\
\hline Ireland …................... & $63(0.8)$ & $70(0.8)$ & $58(1.0)$ & $56(0.9)$ & $69(0.9)$ & $66(0.8)$ & $64(1.0)$ & $7(0.6)$ & $516(7.1)$ & $70(1.3)$ & 565 (3.2) & $23(1.2)$ & $530(4.9)$ & $0.8(0.02)$ \\
\hline Israel 3,4 & $59(1.0)$ & $71(1.0)$ & $48(1.1)$ & $54(1.0)$ & $64(1.2)$ & $62(1.0)$ & $60(1.5)$ & $14(1.3)$ & $525(6.4)$ & $46(2.2)$ & $535(4.7)$ & $40(1.9)$ & $528(4.1)$ & $1.1(0.05)$ \\
\hline Japan $\ldots \ldots \ldots \ldots \ldots \ldots$ & $74(0.4)$ & $82(0.4)$ & $65(0.6)$ & $72(0.5)$ & $79(0.5)$ & $72(0.6)$ & $76(0.6)$ & $10(0.7)$ & $558(4.3)$ & $60(1.1)$ & $598(2.3)$ & $31(1.2)$ & $610(3.0)$ & $0.9(0.02)$ \\
\hline Korea & $76(0.4)$ & $88(0.3)$ & $65(0.5)$ & $72(0.5)$ & $80(0.6)$ & $72(0.6)$ & $83(0.7)$ & $14(0.8)$ & $593(4.2)$ & $44(1.1)$ & $610(2.5)$ & $42(1.2)$ & $621(2.3)$ & $1.0(0.02)$ \\
\hline Kuwait & $32(0.5)$ & $36(0.5)$ & $25(0.5)$ & $35(0.6)$ & $26(0.6)$ & $36(0.6)$ & $33(1.0)$ & $5(0.7)$ & $372(5.7)$ & $34(1.4)$ & $410(3.0)$ & $60(1.5)$ & $401(2.8)$ & $1.9(0.05)$ \\
\hline $\begin{array}{l}\text { Latvia (Latvian-speaking } \\
\text { schools) }{ }^{3}\end{array}$ & & & & & & & & & & & & & & \\
\hline $\begin{array}{l}\text { schools) }^{3} \\
\text { Netherlands }^{3}\end{array}$ & $\begin{array}{l}59(1.0) \\
69(0.7)\end{array}$ & $68(0.9)$ & $44(1.3)$ & $60(1.0)$ & $54(1.3)$ & $67(1.0)$ & $65(1.2)$ & $7(0.7)$ & $476(7.5)$ & $61(1.9)$ & $542(6.3)$ & $33(1.7)$ & $518(5.1)$ & $1.0(0.03)$ \\
\hline Netherlands ${ }^{3} \ldots \ldots \ldots \ldots \ldots$ & $69(0.7)$ & $75(0.8)$ & $60(0.9)$ & $70(0.8)$ & $75(0.9)$ & $71(0.8)$ & $65(1.1)$ & $47(2.7)$ & $593(4.3)$ & $39(2.3)$ & $578(3.6)$ & $14(1.5)$ & $541(6.1)$ & $0.5(0.03)$ \\
\hline New Zealand . & $53(1.0)$ & $57(1.0)$ & $41(1.1)$ & $49(1.1)$ & $61(1.3)$ & $66(1.1)$ & $52(1.2)$ & $21(1.6)$ & $488(9.7)$ & $54(1.7)$ & $512(4.4)$ & $25(1.4)$ & $493(5.2)$ & $0.8(0.03)$ \\
\hline Norway .................................. & $53(0.7)$ & $61(0.8)$ & $38(0.7)$ & $56(0.7)$ & $59(0.9)$ & $58(0.9)$ & $50(1.2)$ & $23(1.3)$ & $503(4.1)$ & $58(1.2)$ & $512(3.3)$ & $19(1.1)$ & $497(5.3)$ & $0.6(0.02)$ \\
\hline Portugal ..... & $48(0.7)$ & $57(0.8)$ & $38(0.7)$ & $49(0.8)$ & $43(1.1)$ & $52(1.0)$ & $47(1.1)$ & $3(0.5)$ & $420(9.1)$ & $55(1.7)$ & 489 (3.9) & $42(1.6)$ & $470(3.9)$ & $1.3(0.03)$ \\
\hline Scotland 4 & $58(0.8)$ & $61(0.8)$ & $46(1.0)$ & $53(0.9)$ & $66(1.0)$ & $72(0.8)$ & $57(1.0)$ & $26(1.8)$ & $519(7.2)$ & $63(2.0)$ & $528(3.8)$ & $11(1.0)$ & $501(8.9)$ & $0.5(0.02)$ \\
\hline Singapore ............................. & $76(0.8)$ & $83(0.7)$ & $74(1.0)$ & $67(1.0)$ & $81(0.8)$ & $72(0.8)$ & $76(0.9)$ & -- & -- & -- & -- & -- & -- & -- \\
\hline Slovenia $^{3}$ & $64(0.6)$ & $74(0.6)$ & $50(0.9)$ & $64(0.9)$ & $64(1.0)$ & $72(0.8)$ & $68(0.8)$ & $3(0.4)$ & $502(11.4)$ & $57(1.5)$ & $563(3.7)$ & $40(1.4)$ & 548 (3.7) & $1.0(0.03)$ \\
\hline Thailand $^{3}$............................... & $50(1.1)$ & $58(1.3)$ & $44(1.0)$ & $44(1.0)$ & $56(1.5)$ & $53(1.2)$ & $50(1.3)$ & $17(1.3)$ & $470(4.3)$ & $44(1.6)$ & $496(4.5)$ & $39(1.8)$ & $489(6.1)$ & $1.0(0.03)$ \\
\hline United States ....................... & $63(0.6)$ & $71(0.7)$ & $51(0.8)$ & $53(0.6)$ & $73(0.9)$ & $71(0.7)$ & $66(0.9)$ & $8(0.5)$ & $516(4.4)$ & $60(1.1)$ & $561(3.1)$ & $32(1.1)$ & $528(2.9)$ & $1.0(0.03)$ \\
\hline
\end{tabular}

1 Fourth grade students or equivalent in most countries.

${ }^{2}$ Average hours based on: No time $=0$; Less than 1 hour $=.5 ; 1-2$ hours $=1.5 ; 3-4$ hours $=3.5$; More than 4 hours $=5$.

-Data not available or not applicable.

${ }^{3}$ Countries not meeting all International Association for the Evaluation of Educational Achievement's sampling speci-

NOTE.-Standard errors appear in parentheses.

SOURCE: International Association for the Evaluation of Educational Achievement, Mathematics Achievement in the right 01997 Boston College, Chestnut Hill, MA. (This table was prepared July 1997.) 
Table 404.-Average 4 th-grade science scores, ${ }^{1}$ by content areas, and average time spent teaching science in school, by country: $1994-95$

\begin{tabular}{|c|c|c|c|c|c|c|c|c|c|c|c|c|c|}
\hline \multirow{3}{*}{ Country } & \multicolumn{5}{|c|}{ Science content areas } & \multicolumn{8}{|c|}{ Average number of hours science is taught weekly to science classes } \\
\hline & \multirow{2}{*}{$\begin{array}{c}\text { Overall } \\
\text { science } \\
\text { scores }\end{array}$} & \multirow{2}{*}{$\begin{array}{l}\text { Earth } \\
\text { science }\end{array}$} & \multirow[b]{2}{*}{ Life science } & \multirow{2}{*}{$\begin{array}{l}\text { Physical } \\
\text { science }\end{array}$} & \multirow{2}{*}{\begin{tabular}{|} 
Environmental \\
issues \\
and the \\
nature of \\
science
\end{tabular}} & \multicolumn{2}{|c|}{ Less than 1 hour } & \multicolumn{2}{|c|}{1 to 2 hours } & \multicolumn{2}{|c|}{2 to 3 hours } & \multicolumn{2}{|c|}{ More than 3 hours } \\
\hline & & & & & & Percent & Mean score & Percent & Mean score & Percent & Mean score & Percent & Mean score \\
\hline 1 & 2 & 3 & 4 & 5 & 6 & 7 & 8 & 9 & 10 & 11 & 12 & 13 & 14 \\
\hline Australia 2,3 & $66(0.5)$ & $61(0.6)$ & $72(0.5)$ & $63(0.7)$ & $63(0.8)$ & $35(3.9)$ & $556(5.0)$ & $55(4.0)$ & $568(5.9)$ & $5(1.5)$ & $562(18.1)$ & $5(2.1)$ & $562(8.4)$ \\
\hline Austria $^{2}$................. & $66(0.7)$ & $62(0.8)$ & $72(0.7)$ & $64(0.8)$ & $54(1.0)$ & $0(0.0)$ & -- & $0(0.0)$ & -- & $97(1.8)$ & 566 (3.6) & $3(1.8)$ & $540(30.3)$ \\
\hline Canada . & $64(0.6)$ & $62(0.6)$ & $68(0.6)$ & $61(0.7)$ & $56(0.7)$ & $8(2.0)$ & $536(10.1)$ & $42(3.8)$ & $542(5.1)$ & 27 (3.3) & $567(5.4)$ & $23(3.2)$ & $550(4.6)$ \\
\hline Cyprus ..................... & $51(0.5)$ & $48(0.7)$ & $55(0.5)$ & $50(0.7)$ & $42(1.0)$ & -- & -- & -- & -- & -- & -- & -- & -- \\
\hline Czech Republic ................... & $65(0.5)$ & $64(0.6)$ & $71(0.5)$ & $62(0.7)$ & $56(0.9)$ & $2(1.1)$ & -- & 79 (3.6) & $557(3.9)$ & $3(1.4)$ & $572(6.8)$ & $16(3.2)$ & $563(7.3)$ \\
\hline England 4,5 & $63(0.6)$ & $61(0.6)$ & $68(0.6)$ & $60(0.8)$ & $56(1.0)$ & $6(1.7)$ & $540(8.7)$ & $27(4.1)$ & $548(7.5)$ & $44(4.8)$ & $556(5.9)$ & $23(3.8)$ & $550(8.2)$ \\
\hline Greece & $54(0.8)$ & $52(0.9)$ & $61(0.9)$ & $49(0.9)$ & $43(1.2)$ & -- & -- & -- & -- & -- & -- & -- & -- \\
\hline Hong Kong …….................. & $62(0.7)$ & $61(0.6)$ & $68(0.7)$ & $60(0.8)$ & $50(1.1)$ & $13(3.4)$ & $530(13.3)$ & $84(3.7)$ & $534(4.3)$ & $2(1.5)$ & -- & $1(0.8)$ & -- \\
\hline Hungary $2 \ldots \ldots \ldots \ldots \ldots \ldots \ldots$ & $62(0.6)$ & $62(0.7)$ & $66(0.6)$ & $59(0.8)$ & $50(0.9)$ & $6(2.2)$ & 556 (13.3) & $72(4.1)$ & $529(3.7)$ & $8(3.0)$ & $521(8.4)$ & $14(3.1)$ & $549(10.5)$ \\
\hline Iceland $^{3}$............... & $55(0.7)$ & $55(0.7)$ & $60(0.8)$ & $52(0.7)$ & $47(1.2)$ & $17(4.1)$ & $513(7.3)$ & $41(5.6)$ & $504(7.7)$ & $30(5.1)$ & $499(6.5)$ & $12(4.3)$ & $523(6.8)$ \\
\hline Iran, Islamic Republic & $40(0.7)$ & $38(0.7)$ & $44(0.7)$ & $40(0.9)$ & $26(0.9)$ & -- & -- & -- & -- & -- & -- & -- & -- \\
\hline Ireland & $61(0.6)$ & $60(0.8)$ & $66(0.6)$ & $57(0.7)$ & $55(0.9)$ & $47(5.0)$ & $536(5.6)$ & $40(4.4)$ & $540(5.8)$ & $11(3.1)$ & $550(7.1)$ & $2(0.9)$ & -- \\
\hline 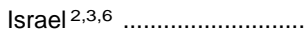 & $57(0.8)$ & $51(0.8)$ & $61(0.9)$ & $55(0.9)$ & $51(1.3)$ & $0(0.0)$ & -- & $53(5.6)$ & $508(5.5)$ & $32(5.8)$ & $494(6.9)$ & $15(4.3)$ & $493(10.6)$ \\
\hline Japan & $70(0.3)$ & $66(0.4)$ & $73(0.3)$ & $70(0.4)$ & $62(0.6)$ & $2(1.3)$ & -- & $1(0.6)$ & -- & $95(1.8)$ & $575(1.8)$ & $2(1.2)$ & -- \\
\hline Korea & $74(0.4)$ & $72(0.5)$ & $76(0.4)$ & $75(0.5)$ & $70(0.8)$ & $0(0.0)$ & -- & $1(0.6)$ & -- & $95(1.8)$ & $597(1.9)$ & $5(1.7)$ & $588(10.3)$ \\
\hline Kuwait 2,3 . & $39(0.5)$ & $36(0.6)$ & $45(0.6)$ & $37(0.5)$ & $25(0.7)$ & $0(0.0)$ & -- & $1(0.7)$ & -- & $96(2.0)$ & $402(3.9)$ & $4(1.8)$ & $416(42.2)$ \\
\hline $\begin{array}{l}\text { Latvia (Latvian-speaking } \\
\text { schools) }{ }^{2}\end{array}$ & $56(0.8)$ & $57(1.0)$ & $60(0.8)$ & $54(0.9)$ & $46(1.2)$ & $89(2.9)$ & 505 (5.7) & $5(2.2)$ & $538(47.2)$ & $5(2.2)$ & $532(11.9)$ & $1(0.8)$ & -- \\
\hline 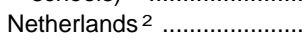 & $67(0.5)$ & $61(0.6)$ & $73(0.5)$ & $65(0.6)$ & $61(0.9)$ & $38(5.1)$ & $559(4.0)$ & $44(4.8)$ & $556(4.5)$ & $9(2.6)$ & $556(7.2)$ & $9(2.7)$ & $549(20.1)$ \\
\hline New Zealand ${ }^{3}$.. & $60(0.9)$ & $57(0.9)$ & $66(0.9)$ & $57(1.1)$ & $54(1.2)$ & $29(4.2)$ & $542(8.3)$ & $48(4.4)$ & $536(6.1)$ & $14(3.1)$ & $537(17.2)$ & $9(2.6)$ & 509 (21.2) \\
\hline Norway ${ }^{3}$ & $60(0.6)$ & $60(0.6)$ & $67(0.7)$ & $55(0.7)$ & $53(0.9)$ & $73(5.0)$ & $527(5.4)$ & $27(5.0)$ & $535(7.6)$ & $0(0.0)$ & -- & $0(0.0)$ & -- \\
\hline Portugal ................. & $50(0.7)$ & $50(0.8)$ & $54(0.8)$ & $49(0.9)$ & $39(1.0)$ & $2(1.1)$ & -- & $3(1.4)$ & $486(28.2)$ & $12(3.1)$ & $474(8.8)$ & $84(3.6)$ & $481(4.8)$ \\
\hline Scotland $^{3,4} \ldots \ldots \ldots \ldots \ldots \ldots$ & $60(0.8)$ & $58(0.9)$ & $65(0.8)$ & $57(0.8)$ & $53(1.2)$ & $35(4.7)$ & $543(5.9)$ & $44(4.7)$ & $534(6.4)$ & $14(3.3)$ & 531 (13.2) & $7(2.5)$ & 529 (12.5) \\
\hline Singapore & $64(0.8)$ & $58(0.8)$ & $70(0.8)$ & $64(0.8)$ & $53(1.1)$ & $0(0.0)$ & -- & $4(1.5)$ & $548(18.9)$ & $96(1.5)$ & $547(5.1)$ & $0(0.0)$ & -- \\
\hline Slovenia $^{2} \ldots \ldots \ldots \ldots \ldots \ldots$ & $64(0.7)$ & $64(0.7)$ & $68(0.7)$ & $61(0.8)$ & $54(0.8)$ & $3(1.9)$ & $544(18.9)$ & $60(5.3)$ & $541(4.6)$ & $18(4.0)$ & $550(9.5)$ & $19(3.4)$ & $548(6.8)$ \\
\hline 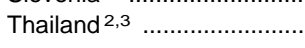 & $49(0.9)$ & $48(0.9)$ & $52(0.8)$ & $46(1.0)$ & $48(1.4)$ & $2(1.2)$ & -- & $9(3.5)$ & $463(21.5)$ & $17(6.1)$ & $469(16.5)$ & $73(6.6)$ & $477(6.5)$ \\
\hline United States ${ }^{3}$ & $66(0.5)$ & $64(0.7)$ & $71(0.6)$ & $60(0.6)$ & $65(0.8)$ & $9(2.1)$ & $562(11.5)$ & $16(2.9)$ & $550(10.2)$ & $33(3.8)$ & $578(5.9)$ & $42(4.1)$ & $565(5.1)$ \\
\hline
\end{tabular}

${ }^{1}$ Fourth grade or equivalent in most countries. ${ }^{2}$ Did not satisfy one or more guidelines for sample participation rates, age/grade specification, or classroom sampling

procedures.
3 Teacher response rate for number of hours science is taught is 84 percent or less.

5 National defined population covers less than 90 percent of international desired population.

-Data not available or not applicable.

desired population

NOTE.-Standard errors appear in parentheses.

6 National defined population does not cover all of international desired population.

SOURCE: International Association for the Evaluation of Educational Achievement, Science Achievement in the Primary School Years: IEA's Third International Mathematics and Science Study, 1997, by Albert E. Beaton et al. Copyright @ 1997 Boston College, Chestnut Hill, MA. (This table was prepared July 1997.) 
Table 405.-Average 12th-grade mathematics scores, ${ }^{1}$ by sex, and average time spent studying mathematics out of school, by country: 1994-95

\begin{tabular}{|c|c|c|c|c|c|c|c|c|c|c|}
\hline \multirow{3}{*}{ Country } & \multicolumn{3}{|c|}{ Average score in mathematics } & \multicolumn{7}{|c|}{ Amount of daily out-of-school study time in mathematics } \\
\hline & \multirow{2}{*}{$\begin{array}{l}\text { Mathe- } \\
\text { matics } \\
\text { overall }\end{array}$} & \multirow[b]{2}{*}{ Males } & \multirow[b]{2}{*}{ Females } & \multicolumn{2}{|c|}{ Less than 1 hour } & \multicolumn{2}{|c|}{ One to two hours } & \multicolumn{2}{|c|}{ Three or more hours } & \multirow{2}{*}{$\begin{array}{c}\text { Average } \\
\text { hours }^{2}\end{array}$} \\
\hline & & & & Percent & $\begin{array}{l}\text { Mean } \\
\text { score }\end{array}$ & Percent & $\begin{array}{l}\text { Mean } \\
\text { score }\end{array}$ & Percent & $\begin{array}{l}\text { Mean } \\
\text { score }\end{array}$ & \\
\hline 1 & 2 & 3 & 4 & 5 & 6 & 7 & 8 & 9 & 10 & 11 \\
\hline Australia $^{3}$ & $522(9.3)$ & $540(10.3)$ & $510(9.3)$ & $59(2.2)$ & $521(8.3)$ & $36(2.2)$ & $557(10.2)$ & $5(0.8)$ & $534(13.4)$ & $1.0(0.04)$ \\
\hline Austria $^{3}$ & $518(5.3)$ & $545(7.2)$ & $503(5.5)$ & 77 (1.7) & $526(5.8)$ & $19(1.6)$ & $533(9.4)$ & $4(0.8)$ & 502 (13.7) & $0.6(0.04)$ \\
\hline Canada $^{3}$ & 519 (2.8) & 537 (3.8) & 504 (3.5) & $56(2.1)$ & $539(5.1)$ & $38(1.9)$ & $547(5.0)$ & $7(1.0)$ & $526(14.6)$ & $1.1(0.05)$ \\
\hline Cyprus $^{3}$. & $446(2.5)$ & $454(4.9)$ & 439 (3.7) & $63(2.1)$ & 435 (4.3) & $29(1.8)$ & 471 (4.8) & $8(1.3)$ & 451 (9.0) & $1.0(0.05)$ \\
\hline Czech Republic .. & $466(12.3)$ & $488(11.3)$ & $443(16.8)$ & $92(1.5)$ & $464(13.8)$ & $8(1.4)$ & $482(17.8)$ & $0(0.2)$ & - - & $0.4(0.03)$ \\
\hline Denmark $^{3}$ & 547 (3.3) & $575(4.0)$ & $523(4.0)$ & $68(2.0)$ & 571 (4.9) & $28(1.6)$ & $563(4.7)$ & $4(0.7)$ & 562 (11.9) & $0.9(0.04)$ \\
\hline France $^{3}$ & $523(5.1)$ & $544(5.6)$ & $506(5.3)$ & 59 (2.3) & $517(5.1)$ & $35(2.3)$ & 539 (6.7) & $5(0.7)$ & 505 (14.7) & $1.0(0.04)$ \\
\hline Germany ${ }^{3}$ & 495 (5.9) & 509 (8.7) & $480(8.8)$ & -- & -- & -- & -- & -- & -- & -- \\
\hline Hungary & 483 (3.2) & $485(4.9)$ & $481(4.8)$ & $74(0.9)$ & $480(3.2)$ & $24(0.8)$ & $496(5.5)$ & $2(0.2)$ & -- & $0.7(0.02)$ \\
\hline Iceland 3 & $534(2.0)$ & $558(3.4)$ & $514(2.2)$ & $79(1.1)$ & $553(3.2)$ & $19(1.1)$ & $542(7.0)$ & $2(0.4)$ & - - & $0.7(0.02)$ \\
\hline Italy ${ }^{3}$ & $476(5.5)$ & $490(7.4)$ & $464(6.0)$ & $55(2.6)$ & $479(6.3)$ & $40(2.2)$ & $486(7.2)$ & $5(0.9)$ & 477 (11.2) & $1.0(0.05)$ \\
\hline Lithuania $^{3}$ & 469 (6.1) & 485 (7.3) & 461 (7.7) & $67(1.8)$ & $472(5.8)$ & $29(1.7)$ & $480(5.2)$ & $4(0.5)$ & 484 (11.5) & $0.8(0.03)$ \\
\hline Netherlands ${ }^{3}$ & $560(4.7)$ & $585(5.6)$ & $533(5.9)$ & $82(1.7)$ & 606 (6.2) & $16(1.6)$ & 581 (11.1) & $1(0.3)$ & -- & $0.7(0.03)$ \\
\hline 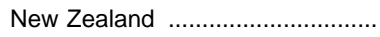 & $522(4.5)$ & $536(4.9)$ & 507 (6.2) & $75(1.4)$ & $544(6.1)$ & $23(1.4)$ & $552(5.9)$ & $2(0.3)$ & -- & $0.7(0.03)$ \\
\hline 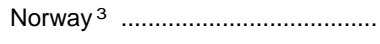 & $528(4.1)$ & $555(5.3)$ & $501(4.8)$ & $85(1.4)$ & $541(5.1)$ & $14(1.3)$ & 558 (9.5) & $1(0.3)$ & -- & $0.5(0.03)$ \\
\hline Russian Federation ${ }^{3}$ & 471 (6.2) & $488(6.5)$ & $460(6.6)$ & $56(2.0)$ & $463(5.9)$ & $33(1.4)$ & $484(7.5)$ & $11(1.2)$ & $494(8.1)$ & $1.2(0.06)$ \\
\hline 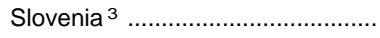 & $512(8.3)$ & $535(12.7)$ & $490(8.0)$ & $72(2.7)$ & $521(9.4)$ & $25(2.6)$ & $518(9.5)$ & $2(0.6)$ & -- & $0.7(0.05)$ \\
\hline South Africa ${ }^{3}$ & $356(8.3)$ & $365(9.3)$ & $348(10.8)$ & $33(1.8)$ & $394(17.1)$ & $51(1.8)$ & $375(10.9)$ & $17(1.2)$ & $344(7.2)$ & $1.7(0.05)$ \\
\hline 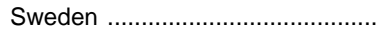 & $552(4.3)$ & $573(5.9)$ & $531(3.9)$ & $90(0.9)$ & $579(5.4)$ & $9(0.9)$ & $580(7.8)$ & $1(0.2)$ & -- & $0.4(0.02)$ \\
\hline 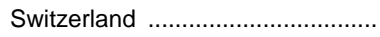 & $540(5.8)$ & $555(6.4)$ & $522(7.4)$ & $67(1.6)$ & $569(4.9)$ & $28(1.3)$ & $550(5.6)$ & $5(0.9)$ & $522(10.6)$ & $0.9(0.04)$ \\
\hline 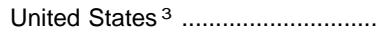 & 461 (3.2) & $466(4.1)$ & $456(3.6)$ & $76(1.5)$ & $475(3.8)$ & $22(1.5)$ & $486(5.9)$ & $2(0.2)$ & -- & $0.7(0.02)$ \\
\hline
\end{tabular}

1 Twelfth grade students or equivalent in most countries.

${ }^{2}$ Average hours based on: No time $=0$; Less than 1 hour $=.5 ; 1-2$ hours $=1.5 ; 3$ 5 hours $=4$; More than 5 hours $=7$.

${ }^{3}$ Countries not meeting all International Association for the Evaluation of Education Achievement's sampling specifications.

-Data not available or not applicable.
NOTE.-_Standard errors appear in parentheses.

SOURCE: International Association for the Evaluation of Educational Achievement, Mathematics Achievement in the Primary School Years, and Science Achievement in the Primary School Years: IEA's Third International Mathematics and Science Study, 1997, by Albert E. Beaton et al. Copyright (c) 1998 Boston College, Chestnut Hill, MA. (This table was prepared October 1998 . 
Table 406.-Average 12th-grade science scores, ${ }^{1}$ by sex, and average time spent studying science out of school, by country: 1994-95

\begin{tabular}{|c|c|c|c|c|c|c|c|c|c|c|}
\hline \multirow{3}{*}{ Country } & \multicolumn{3}{|c|}{ Average score in science } & \multicolumn{7}{|c|}{ Amount of daily out-of-school study time in science } \\
\hline & \multirow{2}{*}{$\begin{array}{l}\text { Science } \\
\text { overall }\end{array}$} & \multirow[b]{2}{*}{ Males } & \multirow[b]{2}{*}{ Females } & \multicolumn{2}{|c|}{ Less than 1 hour } & \multicolumn{2}{|c|}{ One to two hours } & \multicolumn{2}{|c|}{ Three or more hours } & \multirow{2}{*}{$\begin{array}{l}\text { Average } \\
\text { hours }^{2}\end{array}$} \\
\hline & & & & Percent & $\begin{array}{l}\text { Mean } \\
\text { score }\end{array}$ & Percent & $\begin{array}{l}\text { Mean } \\
\text { score }\end{array}$ & Percent & $\begin{array}{l}\text { Mean } \\
\text { score }\end{array}$ & \\
\hline 1 & 2 & 3 & 4 & 5 & 6 & 7 & 8 & 9 & 10 & 11 \\
\hline Australia $^{3}$ & $527(9.8)$ & 547 (11.5) & $513(9.4)$ & $58(1.8)$ & $540(9.5)$ & $35(1.7)$ & $575(6.9)$ & $7(1.0)$ & $588(33.0)$ & $1.0(0.04)$ \\
\hline Austria $^{3}$ & $520(5.6)$ & $554(8.7)$ & $501(5.8)$ & $87(1.4)$ & $529(6.0)$ & $11(1.4)$ & $526(13.8)$ & $1(0.3)$ & -- & $0.4(0.03)$ \\
\hline Canada $^{3}$ & $532(2.6)$ & $550(3.6)$ & $518(3.8)$ & $57(2.1)$ & 554 (4.2) & $35(1.8)$ & 567 (6.8) & $8(0.9)$ & 537 (18.0) & $1.1(0.05)$ \\
\hline Cyprus $^{3}$ & $448(3.0)$ & $459(5.8)$ & 439 (3.0) & $80(1.1)$ & 436 (3.7) & $16(0.9)$ & $483(10.7)$ & $4(0.6)$ & $552(11.8)$ & $0.5(0.03)$ \\
\hline Czech Republic ... & $487(8.8)$ & $512(8.8)$ & $460(11.0)$ & $84(2.6)$ & $520(11.6)$ & $14(2.3)$ & $571(11.5)$ & $3(0.5)$ & $583(13.6)$ & $0.5(0.05)$ \\
\hline Denmark $^{3}$ & 509 (3.6) & $532(5.4)$ & $490(4.1)$ & $73(1.8)$ & 555 (4.7) & $25(1.6)$ & $570(6.1)$ & $3(0.6)$ & $565(15.0)$ & $0.7(0.03)$ \\
\hline France $^{3}$ & $487(5.1)$ & 508 (6.7) & 468 (4.8) & $59(2.0)$ & $497(5.7)$ & $35(1.8)$ & $525(7.0)$ & $6(0.8)$ & $515(9.1)$ & $1.0(0.04)$ \\
\hline Germany ${ }^{3}$ & $497(5.1)$ & 514 (7.9) & 478 (8.5) & -- & -- & -- & -- & -- & -- & -- \\
\hline Hungary & 471 (3.0) & $484(4.2)$ & 455 (4.3) & $67(1.2)$ & 475 (3.9) & $27(0.9)$ & 486 (4.9) & $6(0.6)$ & 497 (11.5) & $0.4(0.03)$ \\
\hline Iceland ${ }^{3}$.. & $549(1.5)$ & $572(2.7)$ & $530(2.1)$ & $87(1.0)$ & $566(2.5)$ & $12(1.0)$ & $575(4.6)$ & $1(0.3)$ & -- & $0.9(0.01)$ \\
\hline Italy ${ }^{3}$ & 475 (5.3) & $495(6.7)$ & $458(5.6)$ & 70 (2.8) & 487 (6.3) & $25(2.5)$ & 482 (9.7) & $5(1.2)$ & 462 (13.9) & $0.8(0.06)$ \\
\hline Lithuania $^{3}$ & 461 (5.7) & $481(6.4)$ & 450 (7.3) & $69(1.5)$ & $465(5.5)$ & 26 (1.3) & 469 (6.5) & $5(0.6)$ & $470(11.4)$ & $0.8(0.03)$ \\
\hline Netherlands $^{3}$ & 558 (5.3) & $582(5.7)$ & 532 (6.2) & $78(2.8)$ & $593(6.4)$ & $20(2.9)$ & 605 (16.9) & $1(0.4)$ & -- & $0.7(0.03)$ \\
\hline New Zealand & $529(5.2)$ & $543(7.1)$ & 515 (5.2) & $80(1.1)$ & 551 (6.3) & $18(1.1)$ & 581 (6.6) & $3(0.5)$ & 553 (15.3) & $0.6(0.02)$ \\
\hline 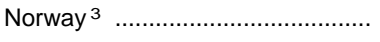 & $544(4.1)$ & $574(5.1)$ & $513(4.5)$ & $74(2.4)$ & $592(7.1)$ & $23(2.2)$ & $598(10.8)$ & $3(0.7)$ & $583(23.8)$ & $0.5(0.02)$ \\
\hline Russian Federation ${ }^{3}$ & $481(5.7)$ & $510(5.7)$ & $463(6.7)$ & $61(1.6)$ & $478(6.0)$ & $30(1.3)$ & $488(7.0)$ & $10(0.8)$ & $501(8.0)$ & $1.1(0.04)$ \\
\hline Slovenia ${ }^{3}$ & 517 (8.2) & 541 (12.7) & $494(6.4)$ & $85(2.0)$ & $528(8.1)$ & $13(1.9)$ & 548 (8.9) & $2(0.6)$ & -- & $0.5(0.04)$ \\
\hline South Africa ${ }^{3}$ & 349 (10.5) & 367 (11.5) & $333(13.0)$ & $47(1.6)$ & 373 (15.5) & $35(1.3)$ & $367(12.2)$ & $18(1.4)$ & 326 (7.3) & $1.5(0.05)$ \\
\hline Sweden . & $559(4.4)$ & $585(5.9)$ & $534(3.5)$ & 81 (1.9) & $599(7.4)$ & $17(1.8)$ & $632(10.1)$ & $2(0.5)$ & -- & $0.6(0.03)$ \\
\hline Switzerland & $523(5.3)$ & $540(6.1)$ & $500(7.8)$ & $76(2.3)$ & $564(6.6)$ & 21 (2.3) & 564 (10.9) & $3(0.9)$ & $508(29.0)$ & $0.7(0.04)$ \\
\hline United States ${ }^{3} \ldots$. & 480 (3.3) & $492(4.5)$ & 469 (3.9) & $76(2.1)$ & 505 & $21(2.1)$ & $517(5.7)$ & $2(0.4)$ & -- & $0.7(0.04)$ \\
\hline
\end{tabular}

1 Twelfth grade students or equivalent in most countries.

${ }^{2}$ Average hours based on: No time $=0$; Less than 1 hour $=.5 ; 1-2$ hours $=1.5 ; 3$ 5 hours $=4$; More than 5 hours $=7$.

${ }^{3}$ Countries not meeting all International Association for the Evaluation of Education Achievement's sampling specifications.

-Data not available or not applicable.
NOTE.-Standard errors appear in parentheses.

SOURCE: International Association for the Evaluation of Educational Achievement, Mathematics Achievement in the Primary School Years, and Science Achievement in the Primary School Years: IEA's Third International Mathematics and Science Study, 1997, by Albert E. Beaton et al. Copyright (c) 1998 Boston College, Chestnut Hill, MA. (This table was prepared October 1998 . 
Table 407.--Reading literacy test scores of 9-year-olds: Selected countries, 1992

\begin{tabular}{|c|c|c|c|c|c|c|c|c|}
\hline Country & $\begin{array}{l}\text { Grade } \\
\text { tested }\end{array}$ & Mean age & $\begin{array}{l}\text { Overall } \\
\text { mean score } \\
(\text { s.e. })^{1}\end{array}$ & $\begin{array}{l}\text { Narrative }{ }^{2} \\
\text { 1st quartile }\end{array}$ & $\begin{array}{l}\text { Narrative }^{2} \\
\text { mean score } \\
\text { (s.e. })^{1}\end{array}$ & $\begin{array}{l}\text { Narrative }^{2} \\
\text { 3rd quartile }\end{array}$ & $\begin{array}{l}\text { Expository }{ }^{3} \\
\text { mean score } \\
\text { (s.e. })^{1}\end{array}$ & $\begin{array}{c}\text { Docu- } \\
\text { ments }{ }^{4} \\
\text { mean score } \\
(\text { s.e. })^{1}\end{array}$ \\
\hline 1 & 2 & 3 & 4 & 5 & 6 & 7 & 8 & 9 \\
\hline $\begin{array}{l}\text { Finland } \\
\text { United States } \\
\text { Sweden } \\
\text { France }\end{array}$ & $\begin{array}{l}3 \\
4 \\
3 \\
4 \\
4\end{array}$ & $\begin{array}{r}9.7 \\
10.0 \\
9.8 \\
10.1 \\
9.9\end{array}$ & $\begin{array}{l}569(3.4) \\
547(2.8) \\
539(2.8) \\
531(4.0) \\
529(4.3)\end{array}$ & $\begin{array}{l}508 \\
476 \\
467 \\
467 \\
468\end{array}$ & $\begin{array}{l}568(3.0) \\
553(3.1) \\
536(2.6) \\
532(4.1) \\
533(4.0)\end{array}$ & $\begin{array}{l}602 \\
619 \\
592 \\
580 \\
576\end{array}$ & $\begin{array}{l}569(3.1) \\
538(2.6) \\
542(2.7) \\
533(4.1) \\
538(4.0)\end{array}$ & $\begin{array}{l}569(4.0) \\
550(2.7) \\
539(3.2) \\
527(3.9) \\
517(4.9)\end{array}$ \\
\hline 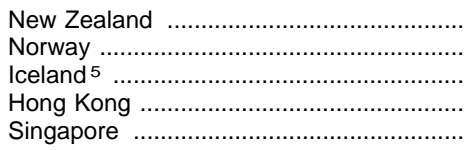 & $\begin{array}{l}5 \\
3 \\
3 \\
4 \\
3\end{array}$ & $\begin{array}{r}10.0 \\
9.8 \\
9.8 \\
10.0 \\
9.3\end{array}$ & $\begin{array}{l}528(3.3) \\
524(2.6) \\
518(0.0) \\
517(3.9) \\
515(1.0)\end{array}$ & $\begin{array}{l}452 \\
455 \\
448 \\
431 \\
450\end{array}$ & $\begin{array}{l}534(3.5) \\
525(2.8) \\
518(0.0) \\
494(4.1) \\
521(1.1)\end{array}$ & $\begin{array}{l}594 \\
576 \\
571 \\
548 \\
567\end{array}$ & $\begin{array}{l}531(3.1) \\
528(2.3) \\
517(0.0) \\
503(3.4) \\
519(1.0)\end{array}$ & $\begin{array}{l}521(3.3) \\
519(2.8) \\
519(0.0) \\
554(4.2) \\
504(1.0)\end{array}$ \\
\hline 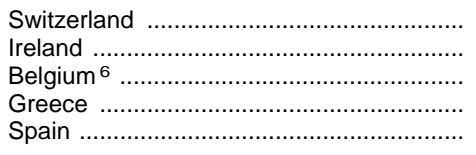 & $\begin{array}{l}3 \\
4 \\
4 \\
4 \\
4\end{array}$ & $\begin{array}{r}9.7 \\
9.3 \\
9.8 \\
9.3 \\
10.0\end{array}$ & $\begin{array}{l}511(2.7) \\
509(3.6) \\
507(3.2) \\
504(3.7) \\
504(2.5)\end{array}$ & $\begin{array}{l}438 \\
445 \\
439 \\
447 \\
429\end{array}$ & $\begin{array}{l}506(2.6) \\
518(3.7) \\
510(3.3) \\
514(3.8) \\
497(2.4)\end{array}$ & $\begin{array}{l}566 \\
571 \\
558 \\
567 \\
543\end{array}$ & $\begin{array}{l}507(2.7) \\
514(3.2) \\
505(2.8) \\
511(3.6) \\
505(2.3)\end{array}$ & $\begin{array}{l}522(2.8) \\
495(3.8) \\
506(3.5) \\
488(3.8) \\
509(2.7)\end{array}$ \\
\hline 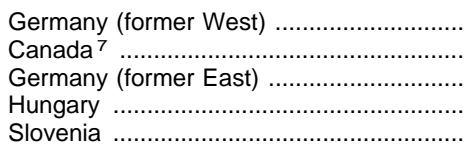 & $\begin{array}{l}3 \\
3 \\
3 \\
3 \\
3\end{array}$ & $\begin{array}{l}9.4 \\
8.9 \\
9.5 \\
9.3 \\
9.7\end{array}$ & $\begin{array}{l}503(3.0) \\
500(3.0) \\
499(4.3) \\
499(3.1) \\
498(2.6)\end{array}$ & $\begin{array}{l}421 \\
437 \\
414 \\
437 \\
435\end{array}$ & $\begin{array}{l}491(2.8) \\
502(3.5) \\
482(4.2) \\
496(2.9) \\
502(2.7)\end{array}$ & $\begin{array}{l}543 \\
566 \\
531 \\
541 \\
570\end{array}$ & $\begin{array}{l}497(2.9) \\
499(2.7) \\
493(3.6) \\
493(3.1) \\
489(2.5)\end{array}$ & $\begin{array}{l}520(3.2) \\
500(2.8) \\
522(5.0) \\
509(3.5) \\
503(2.5)\end{array}$ \\
\hline 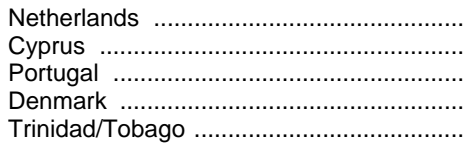 & $\begin{array}{l}3 \\
4 \\
4 \\
3 \\
4\end{array}$ & $\begin{array}{r}9.2 \\
9.8 \\
10.4 \\
9.8 \\
9.6\end{array}$ & $\begin{array}{l}485(3.6) \\
481(2.3) \\
478(3.6) \\
475(3.5) \\
451(3.4)\end{array}$ & $\begin{array}{l}425 \\
421 \\
419 \\
386 \\
383\end{array}$ & $\begin{array}{l}494(3.3) \\
492(2.4) \\
483(3.3) \\
463(3.4) \\
455(3.6)\end{array}$ & $\begin{array}{l}539 \\
548 \\
531 \\
539 \\
502\end{array}$ & $\begin{array}{l}480(3.4) \\
475(2.3) \\
480(3.0) \\
467(3.5) \\
458(3.4)\end{array}$ & $\begin{array}{l}481(3.9) \\
476(2.1) \\
471(4.5) \\
496(3.6) \\
440(3.3)\end{array}$ \\
\hline 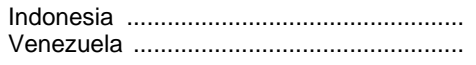 & $\begin{array}{l}4 \\
4\end{array}$ & $\begin{array}{l}10.8 \\
10.1\end{array}$ & $\begin{array}{l}394(3.0) \\
383(3.4)\end{array}$ & $\begin{array}{l}351 \\
322\end{array}$ & $\begin{array}{l}402(2.8) \\
378(3.2)\end{array}$ & $\begin{array}{l}436 \\
426\end{array}$ & $\begin{array}{l}411(3.2) \\
396(3.3)\end{array}$ & $\begin{array}{l}369(3.0) \\
374(3.7)\end{array}$ \\
\hline \multicolumn{9}{|c|}{$\begin{array}{l}{ }^{5} \text { Iceland tested all students, therefore standard errors are not applicable. } \\
6 \text { Only French-speaking students were tested. } \\
{ }^{7} \text { British Columbia only. } \\
\text { SOURCE: International Association for the Evaluation of Educational Achievement, } \\
\text { tow in the World Do Students Read?, 1992. (This table was prepared April 1993.) }\end{array}$} \\
\hline
\end{tabular}


Table 408.-Reading literacy test scores of 14-year-olds: Selected countries, 1992

\begin{tabular}{|c|c|c|c|c|c|c|c|c|}
\hline Country & $\begin{array}{l}\text { Grade } \\
\text { tested }\end{array}$ & Mean age & $\begin{array}{c}\text { Overall } \\
\text { mean score } \\
(\text { s.e. })^{1}\end{array}$ & $\begin{array}{c}\text { Narrative }^{2} \\
\text { mean score } \\
(\text { s.e. })^{1}\end{array}$ & $\begin{array}{l}\text { Expository }{ }^{3} \\
\text { 1st quartile }\end{array}$ & $\begin{array}{c}\text { Expository }^{3} \\
\text { mean score } \\
(\text { s.e. })^{1}\end{array}$ & $\begin{array}{l}\text { Expository }{ }^{3} \\
\text { 3rd quartile }\end{array}$ & $\begin{array}{c}\text { Docu- } \\
\text { ments }{ }^{4} \\
\text { mean score } \\
(\text { s.e. })^{1}\end{array}$ \\
\hline 1 & 2 & 3 & 4 & 5 & 6 & 7 & 8 & 9 \\
\hline $\begin{array}{l}\text { Finland } \\
\text { France } \\
\text { Sweden } \\
\text { New Zealand } \\
\text { Hungary }\end{array}$ & $\begin{array}{r}8 \\
9 \\
8 \\
10 \\
8\end{array}$ & $\begin{array}{l}14.7 \\
15.4 \\
14.8 \\
15.0 \\
14.1\end{array}$ & $\begin{array}{l}560(2.5) \\
549(4.3) \\
546(2.5) \\
545(5.6) \\
536(3.3)\end{array}$ & $\begin{array}{l}559(2.8) \\
556(4.2) \\
556(2.6) \\
547(5.7) \\
530(3.1)\end{array}$ & $\begin{array}{l}493 \\
484 \\
469 \\
457 \\
469\end{array}$ & $\begin{array}{l}541(2.2) \\
546(4.3) \\
533(2.4) \\
535(5.7) \\
536(3.6)\end{array}$ & $\begin{array}{l}575 \\
580 \\
576 \\
597 \\
577\end{array}$ & $\begin{array}{l}580(2.5) \\
544(4.2) \\
550(2.4) \\
552(5.3) \\
542(3.2)\end{array}$ \\
\hline 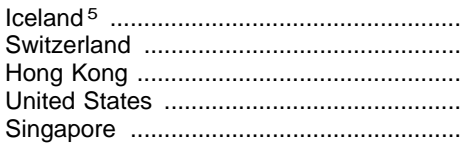 & $\begin{array}{l}8 \\
8 \\
9 \\
9 \\
8\end{array}$ & $\begin{array}{l}14.8 \\
14.9 \\
15.2 \\
15.0 \\
14.4\end{array}$ & $\begin{array}{l}536(0.0) \\
536(3.2) \\
535(3.7) \\
535(4.8) \\
534(1.1)\end{array}$ & $\begin{array}{l}550(0.0) \\
534(3.4) \\
509(3.7) \\
539(4.9) \\
530(1.1)\end{array}$ & $\begin{array}{l}472 \\
466 \\
480 \\
456 \\
476\end{array}$ & $\begin{array}{l}548(0.0) \\
525(3.2) \\
540(3.8) \\
539(5.6) \\
539(1.2)\end{array}$ & $\begin{array}{l}617 \\
572 \\
576 \\
599 \\
574\end{array}$ & $\begin{array}{l}509(0.0) \\
549(3.0) \\
557(3.8) \\
528(4.0) \\
533(1.1)\end{array}$ \\
\hline 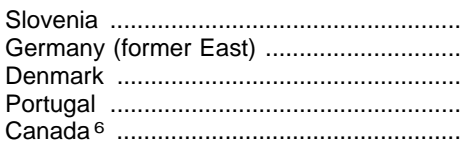 & $\begin{array}{l}8 \\
8 \\
8 \\
9 \\
8\end{array}$ & $\begin{array}{l}14.7 \\
14.4 \\
14.8 \\
15.6 \\
13.9\end{array}$ & $\begin{array}{l}532(2.3) \\
526(3.5) \\
525(2.1) \\
523(3.1) \\
522(3.0)\end{array}$ & $\begin{array}{l}534(2.6) \\
512(3.9) \\
517(2.0) \\
523(2.5) \\
526(3.1)\end{array}$ & $\begin{array}{l}471 \\
464 \\
458 \\
469 \\
449\end{array}$ & $\begin{array}{l}525(2.2) \\
523(3.5) \\
524(2.2) \\
523(3.4) \\
516(3.1)\end{array}$ & $\begin{array}{l}576 \\
566 \\
573 \\
556 \\
569\end{array}$ & $\begin{array}{l}537(2.2) \\
543(2.9) \\
532(2.1) \\
523(3.4) \\
522(2.7)\end{array}$ \\
\hline 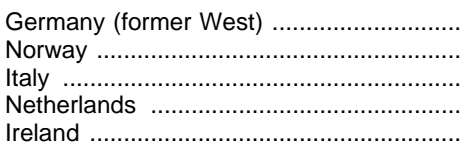 & $\begin{array}{l}8 \\
8 \\
8 \\
8 \\
9\end{array}$ & $\begin{array}{l}14.6 \\
14.8 \\
14.1 \\
14.3 \\
14.5\end{array}$ & $\begin{array}{l}522(4.4) \\
516(2.3) \\
515(3.4) \\
514(4.9) \\
511(5.2)\end{array}$ & $\begin{array}{l}514(4.9) \\
515(2.1) \\
520(3.6) \\
506(4.8) \\
510(5.3)\end{array}$ & $\begin{array}{l}453 \\
464 \\
459 \\
442 \\
439\end{array}$ & $\begin{array}{l}521(4.5) \\
520(2.4) \\
524(3.2) \\
503(4.7) \\
505(5.3)\end{array}$ & $\begin{array}{l}573 \\
569 \\
565 \\
546 \\
555\end{array}$ & $\begin{array}{l}532(3.9) \\
512(2.4) \\
501(3.3) \\
533(5.3) \\
518(4.9)\end{array}$ \\
\hline 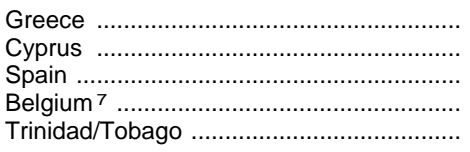 & $\begin{array}{l}9 \\
9 \\
8 \\
8 \\
9\end{array}$ & $\begin{array}{l}14.4 \\
14.8 \\
14.2 \\
14.3 \\
14.4\end{array}$ & $\begin{array}{l}509(2.9) \\
497(2.2) \\
490(2.5) \\
481(4.9) \\
479(1.7)\end{array}$ & $\begin{array}{l}526(2.9) \\
516(2.2) \\
500(3.0) \\
484(5.1) \\
482(1.7)\end{array}$ & $\begin{array}{l}450 \\
427 \\
435 \\
415 \\
408\end{array}$ & $\begin{array}{l}508(3.1) \\
492(2.4) \\
495(2.6) \\
477(4.8) \\
485(1.8)\end{array}$ & $\begin{array}{l}548 \\
536 \\
536 \\
522 \\
537\end{array}$ & $\begin{array}{l}493(2.6) \\
482(2.0) \\
475(2.0) \\
483(4.7) \\
472(1.7)\end{array}$ \\
\hline $\begin{array}{l}\text { Thailand } \\
\text { Philippines } \\
\text { Venezuela } \\
\text { Nigeria } 8,9 \\
\text { Zimbabwe } 9 \\
\text { Botswana }\end{array}$ & $\begin{array}{l}9 \\
8 \\
9 \\
9 \\
9 \\
9\end{array}$ & $\begin{array}{l}15.2 \\
14.5 \\
15.5 \\
15.3 \\
15.5 \\
14.7\end{array}$ & $\begin{array}{l}477(6.2) \\
430(3.9) \\
417(3.1) \\
401(-) \\
372(3.8) \\
330(2.0)\end{array}$ & $\begin{array}{l}468(6.6) \\
421(3.6) \\
407(2.9) \\
402(-) \\
367(3.3) \\
340(1.6)\end{array}$ & $\begin{array}{l}429 \\
378 \\
381 \\
351 \\
326 \\
294\end{array}$ & $\begin{array}{l}486(5.9) \\
439(4.1) \\
433(3.3) \\
406(-) \\
374(3.6) \\
339(1.9)\end{array}$ & $\begin{array}{l}533 \\
472 \\
482 \\
441 \\
411 \\
371\end{array}$ & $\begin{array}{l}478(6.2) \\
430(3.9) \\
412(3.0) \\
394(-) \\
373(4.6) \\
312(2.4)\end{array}$ \\
\hline
\end{tabular}

${ }^{1}$ s.e.=standard error.

${ }^{2}$ Narrative prose is continuous text in which the writer's aim is to tell a story.

${ }^{3}$ Expository prose is continuous text designed to describe factual information to the reader.

4 Documents are structured information presented in the form of charts, tables, maps, graphs, lists, or sets of instructions.

5 Iceland tested all students, therefore standard errors are not applicable.

${ }^{6}$ British Columbia only.
${ }^{7}$ Only French-speaking students were tested.

8 Insufficient data to calculate the standard error.

${ }^{9}$ Sampling response rate of schools was below 80 percent.

-Data not available.

SOURCE: International Association for the Evaluation of Educational Achievement, How in the World Do Students Read?, 1992. (This table was prepared April 1993.) 
Table 409.-Number of bachelor's degree recipients per 100 persons of the theoretical age of graduation, ${ }^{1}$ by sex: Selected countries, 1989 to 1995

\begin{tabular}{|c|c|c|c|c|c|c|c|c|c|c|c|c|c|c|c|c|c|c|}
\hline \multirow{2}{*}{ Country } & \multicolumn{6}{|c|}{ Men and women } & \multicolumn{6}{|c|}{ Men } & \multicolumn{6}{|c|}{ Women } \\
\hline & 1989 & 1990 & 1991 & 1992 & 1994 & 1995 & 1989 & 1990 & 1991 & 1992 & 1994 & 1995 & 1989 & 1990 & 1991 & 1992 & 1994 & 1995 \\
\hline 1 & 2 & 3 & 4 & 5 & 6 & 7 & 8 & 9 & 10 & 11 & 12 & 13 & 14 & 15 & 16 & 17 & 18 & 19 \\
\hline Australia & 19.6 & - & 24.1 & 28.5 & 32.2 & 34.9 & 18.9 & - & 21.0 & 23.7 & 25.9 & 27.6 & 21.1 & - & 27.3 & 33.6 & 38.7 & 42.7 \\
\hline Austria .. & 6.6 & 7.7 & 7.7 & - & 9.2 & 9.8 & 7.6 & 8.5 & 8.5 & - & 10.1 & 10.6 & 5.5 & 6.8 & 6.9 & - & 8.4 & 8.9 \\
\hline 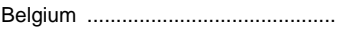 & 16.5 & 17.1 & 13.2 & - & - & - & 18.9 & 19.5 & 15.0 & - & - & - & 14.1 & 14.7 & 11.4 & - & - & - \\
\hline Canada . & - & - & 31.1 & 32.2 & 30.3 & 31.8 & - & - & 26.6 & 27.6 & 25.5 & 26.4 & - & - & 35.8 & 37.6 & 35.3 & 37.4 \\
\hline 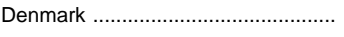 & 12.9 & 15.0 & 16.6 & 22.3 & 30.5 & 28.5 & 11.5 & 13.3 & 14.4 & 17.7 & 26.4 & 25.1 & 14.4 & 16.9 & 18.9 & 27.2 & 34.9 & 31.9 \\
\hline Finland ....................... & 16.9 & 17.1 & 17.1 & - & 22.2 & 22.2 & 17.1 & 17.0 & 16.9 & - & 22.2 & 22.0 & 16.6 & 17.1 & 17.3 & 17.9 & 22.1 & 22.3 \\
\hline France & 13.8 & 14.9 & 16.3 & - & - & - & 13.7 & 14.7 & 14.9 & - & - & - & 13.9 & 15.1 & 17.7 & - & - & - \\
\hline Germany ${ }^{2}$ & 13.2 & 12.9 & 12.4 & - & 14.6 & 16.2 & 16.1 & 15.7 & 14.3 & - & 16.4 & 18.2 & 10.1 & 10.0 & 10.4 & - & 12.6 & 14.0 \\
\hline Ireland & 16.4 & 17.4 & 16.8 & 17.8 & - & 21.2 & 31.9 & 17.5 & 17.0 & 17.9 & - & 19.9 & - & 17.3 & 16.6 & 17.7 & - & 22.7 \\
\hline Italy & 8.9 & 9.2 & 9.5 & - & 11.3 & 11.8 & 9.1 & 9.3 & 9.5 & - & 10.3 & 10.8 & 8.7 & 9.0 & 9.5 & - & 12.4 & 12.9 \\
\hline apan & - & 22.1 & 23.2 & 23.2 & 23.2 & 22.8 & - & 31.5 & 32.7 & 31.9 & 31.0 & 30.4 & - & 12.4 & 13.4 & 14.0 & 15.2 & 14.9 \\
\hline Netherlands . & 10.2 & 8.0 & 8.3 & 17.6 & - & 22.0 & 12.3 & 9.4 & 9.6 & 17.3 & - & 20.6 & 7.9 & 6.5 & 6.9 & 17.8 & - & 23.4 \\
\hline New Zealand & 36.1 & 15.3 & 15.2 & 17.2 & - & 24.7 & 16.6 & 15.4 & 15.4 & 16.9 & - & 20.9 & 15.5 & 15.1 & 15.0 & 17.4 & - & 28.6 \\
\hline Norway ................. & 24.6 & 27.5 & 30.7 & 19.0 & 23.0 & 23.0 & 18.1 & 19.1 & 22.3 & 14.5 & 17.4 & 17.2 & 31.7 & 36.3 & 39.4 & 23.7 & 28.8 & 28.9 \\
\hline Portugal ....................................... & - & 7.6 & - & . & 13.8 & 14.6 & - & 5.9 & 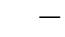 & - & 10.4 & 10.8 & - & 9.3 & - & - & 17.2 & 18.3 \\
\hline Spain & 17.7 & 18.6 & 19.9 & - & - & 24.0 & 14.6 & 15.3 & 16.3 & - & - & 19.6 & 21.0 & 22.0 & 23.6 & - & - & 28.6 \\
\hline Sweden & 13.0 & 12.2 & 12.5 & 14.1 & 13.7 & 15.5 & 11.1 & 10.5 & 10.9 & 11.8 & 12.0 & 14.0 & 15.1 & 14.0 & 14.3 & 16.4 & 15.4 & 17.0 \\
\hline Switzerland . & 7.7 & 7.7 & 7.6 & - & 8.5 & 9.1 & 10.1 & 10.3 & 9.8 & - & 10.7 & 11.4 & 5.3 & 5.1 & 5.4 & - & 6.3 & 6.8 \\
\hline Turkey ………… & 6.0 & 6.1 & 6.1 & 6.1 & - & 7.0 & 7.3 & 7.5 & 7.5 & 7.5 & - & 8.6 & 4.6 & 4.5 & 4.5 & 4.6 & - & 5.2 \\
\hline 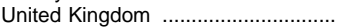 & - & - & - & 20.4 & 25.9 & 31.6 & - & - & - & 21.0 & 25.5 & 30.3 & - & - & - & 19.8 & 26.3 & 32.9 \\
\hline United States ........................... & 27.3 & 28.6 & 29.3 & 27.4 & 32.2 & 33.2 & 25.5 & 26.2 & 26.5 & 24.6 & 28.7 & 29.3 & 29.2 & 31.1 & 32.3 & 30.3 & 35.9 & 37.3 \\
\hline
\end{tabular}

1 The graduation rate relates the number of people with bachelor's degrees to the number of people in the population at typical age of graduation.

2 Data for 1989 are for the former West Germany.

-Data not available.
SOURCE: Organization for Economic Cooperation and Development, unpublished tabulations. (This table was prepared August 1998.)

Table 410.-Percent of bachelor's degrees awarded in science: Selected countries, 1985 to 1995

\begin{tabular}{|c|c|c|c|c|c|c|c|c|c|c|c|c|c|c|c|c|}
\hline \multirow{2}{*}{ Country } & \multicolumn{4}{|c|}{ All science degrees } & \multicolumn{4}{|c|}{ Natural sciences } & \multicolumn{4}{|c|}{$\begin{array}{l}\text { Mathematics and } \\
\text { computer science }\end{array}$} & \multicolumn{4}{|c|}{ Engineering } \\
\hline & 1985 & 1990 & 1994 & 1995 & 1985 & 1990 & 1994 & 1995 & 1985 & 1990 & 1994 & 1995 & 1985 & 1990 & 1994 & 1995 \\
\hline 1 & 2 & 3 & 4 & 5 & 6 & 7 & 8 & 9 & 10 & 11 & 12 & 13 & 14 & 15 & 16 & 17 \\
\hline 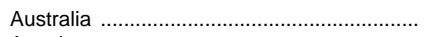 & - & - & 19.2 & 19.3 & - & - & 10.2 & 9.9 & - & - & 3.6 & 3.8 & - & - & 5.4 & 5.6 \\
\hline 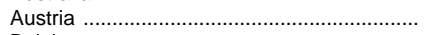 & 16.8 & 19.6 & 20.7 & 21.1 & 5.0 & 5.3 & 5.5 & 6.0 & 4.1 & 5.2 & 5.4 & 5.3 & 7.7 & 9.0 & 9.8 & 9.9 \\
\hline Belgium & - & - & - & - & 4.6 & - & - & - & 1.7 & - & - & - & - & - & - & - \\
\hline Canada & 17.1 & 16.4 & 16.3 & 16.7 & 4.9 & 6.0 & 6.2 & 6.5 & 4.5 & 4.2 & 3.8 & 3.8 & 7.7 & 6.2 & 6.3 & 6.4 \\
\hline 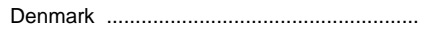 & - & - & - & - & 6.3 & 4.4 & 4.2 & 2.5 & - & - & - & - & 16.2 & 21.7 & - & 17.0 \\
\hline Finland & 39.3 & 33.5 & 37.0 & 37.2 & 7.7 & 4.1 & 4.4 & 4.0 & 6.3 & 5.9 & 7.4 & 6.9 & 25.3 & 23.4 & 25.1 & 26.3 \\
\hline Germany ${ }^{1}$ & 23.8 & 31.3 & 31.7 & 31.6 & 5.0 & 7.2 & 6.9 & 6.7 & 2.3 & 3.5 & 5.2 & 5.2 & 16.5 & 20.5 & 19.6 & 19.7 \\
\hline 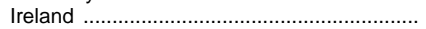 & 28.8 & 34.1 & - & 32.3 & 12.8 & 14.1 & - & 16.9 & 4.0 & 6.3 & - & 4.7 & 12.0 & 13.7 & - & 10.7 \\
\hline 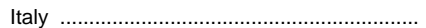 & 19.5 & 19.7 & 19.1 & 19.5 & 8.1 & 7.6 & 7.0 & 6.8 & 3.1 & 3.9 & 3.4 & 3.8 & 8.3 & 8.3 & 8.7 & 8.9 \\
\hline 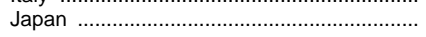 & 22.7 & 23.5 & 22.8 & 22.8 & 2.4 & 2.4 & 3.4 & 3.4 & - & - & - & - & 20.3 & 21.0 & 19.3 & 19.3 \\
\hline Netherlands & 21.8 & 21.1 & - & - & 8.5 & 7.1 & - & - & 1.2 & 1.6 & - & 1.6 & 12.1 & 12.4 & - & - \\
\hline New Zealand & 20.5 & 19.5 & - & - & 11.7 & 8.2 & - & - & 5.5 & 5.5 & - & - & 3.3 & 5.8 & - & 3.2 \\
\hline 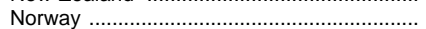 & - & 12.9 & 18.6 & 16.8 & 2.5 & 2.1 & 4.1 & 3.1 & 1.8 & 0.6 & 0.4 & 0.5 & - & 10.2 & 14.2 & 13.2 \\
\hline 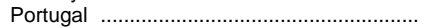 & - & - & 15.9 & 15.0 & 6.5 & 6.7 & 2.6 & 2.2 & - & - & 2.4 & 2.8 & - & 10.5 & 11.0 & 9.9 \\
\hline Spain & 13.9 & 15.0 & - & 18.2 & 5.5 & 5.7 & - & 4.3 & 1.3 & 2.6 & - & 4.5 & 7.0 & 6.7 & - & 9.4 \\
\hline Sweden & 15.4 & 24.0 & 25.0 & 26.4 & 2.6 & 4.1 & 3.9 & 3.9 & 1.6 & 4.7 & 5.3 & 5.5 & 11.3 & 15.2 & 15.9 & 17.0 \\
\hline 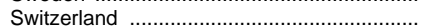 & 20.2 & 23.0 & 22.1 & 22.3 & 10.3 & 11.2 & 10.4 & 10.4 & 2.1 & 3.7 & 3.3 & 3.7 & 7.9 & 8.1 & 8.4 & 8.3 \\
\hline ……… & 23.0 & 20.6 & - & 20.9 & 3.6 & 4.6 & - & 5.1 & 1.6 & 2.1 & - & 2.7 & 17.8 & 13.8 & - & 13.1 \\
\hline United States & 21.7 & 16.9 & 15.9 & - & 6.3 & 5.1 & 6.0 & - & 5.5 & 4.0 & 3.3 & 3.3 & 9.8 & 7.8 & 6.7 & 6.7 \\
\hline
\end{tabular}


Table 411.-Percent of graduate degrees awarded in science: Selected countries, 1985, 1990, and 1991

\begin{tabular}{|c|c|c|c|c|c|c|c|c|c|c|c|c|}
\hline \multirow{2}{*}{ Country } & \multicolumn{3}{|c|}{ All science degrees } & \multicolumn{3}{|c|}{ Natural sciences } & \multicolumn{3}{|c|}{$\begin{array}{l}\text { Mathematics and } \\
\text { computer science }\end{array}$} & \multicolumn{3}{|c|}{ Engineering } \\
\hline & 1985 & 1990 & 1991 & 1985 & 1990 & 1991 & 1985 & 1990 & 1991 & 1985 & 1990 & 1991 \\
\hline 1 & 2 & 3 & 4 & 5 & 6 & 7 & 8 & 9 & 10 & 11 & 12 & 13 \\
\hline Australia & - & - & 13.9 & - & - & 9.6 & - & - & - & - & - & 4.3 \\
\hline Austria ...... & 43.3 & 37.7 & 37.4 & 14.2 & 12.3 & 13.4 & 7.3 & 4.6 & 6.1 & 21.7 & 20.8 & 17.9 \\
\hline 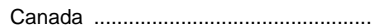 & 19.7 & 20.0 & 19.7 & 7.5 & 7.8 & 7.7 & 2.8 & 3.4 & 3.4 & 9.4 & 8.8 & 8.7 \\
\hline Denmark & 16.0 & 22.2 & 22.9 & 4.1 & 5.8 & 5.4 & 2.7 & 4.8 & 4.5 & 9.2 & 11.6 & 13.0 \\
\hline 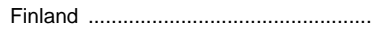 & 47.6 & 30.6 & 29.2 & 24.0 & 14.7 & 12.4 & 6.3 & 5.4 & 4.6 & 17.2 & 10.5 & 12.2 \\
\hline Germany ${ }^{1}$ & 27.7 & 33.2 & 33.9 & 18.7 & 23.5 & 23.3 & 1.8 & 2.3 & 2.2 & 7.2 & 7.4 & 8.4 \\
\hline 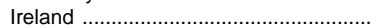 & 31.4 & 34.5 & 28.4 & 18.9 & 19.5 & 15.7 & 2.6 & 5.8 & 4.1 & 9.9 & 9.3 & 8.6 \\
\hline Japan & 50.1 & 54.6 & 54.2 & 9.5 & 9.5 & 9.5 & - & - & - & 40.5 & 45.1 & 44.7 \\
\hline Netherlands & - & 28.9 & 29.9 & 20.6 & 17.7 & 16.7 & - & 1.5 & 1.6 & 7.5 & 9.7 & 11.6 \\
\hline New Zealand ......................................... & 45.1 & 22.6 & 19.3 & 24.6 & 13.8 & 11.5 & 5.4 & 4.7 & 3.6 & 15.1 & 4.0 & 4.2 \\
\hline 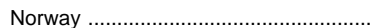 & 40.1 & 33.4 & 33.8 & 17.9 & 8.0 & 7.9 & 3.5 & 2.1 & 2.5 & 18.7 & 23.3 & 23.4 \\
\hline Spain & 35.6 & 26.9 & 26.6 & 28.6 & 19.7 & 19.1 & 1.8 & 1.4 & 2.5 & 5.1 & 5.7 & 5.0 \\
\hline Sweden & 48.0 & 48.5 & 44.4 & 21.2 & 19.4 & 15.1 & 6.8 & 9.2 & 8.2 & 20.0 & 19.9 & 21.1 \\
\hline Switzerland & 30.7 & 30.2 & 32.6 & 20.3 & 22.0 & 23.1 & 2.8 & 1.7 & 1.8 & 7.6 & 6.5 & 7.6 \\
\hline 다. & 35.8 & 24.0 & 21.7 & 6.6 & 7.6 & 6.4 & 2.8 & 3.3 & 2.8 & 26.3 & 13.2 & 12.4 \\
\hline United States & 13.5 & 14.5 & 13.8 & 4.5 & 4.2 & 3.8 & 2.8 & 3.4 & 3.2 & 6.3 & 6.9 & 6.7 \\
\hline
\end{tabular}

1 Data for 1985 are for the former West Germany. -Data not available.

SOURCE: Organization for Economic Cooperation and Development, unpublished data. (This table was prepared May 1995.)

Table 412.-Public education expenditures per student, by level of student: Selected countries, 1985 to 1993 [In constant 1993 dollars]

\begin{tabular}{|c|c|c|c|c|c|c|c|c|c|c|c|c|c|c|c|}
\hline \multirow{2}{*}{ Country } & \multicolumn{5}{|c|}{ Primary } & \multicolumn{5}{|c|}{ Secondary } & \multicolumn{5}{|c|}{ Higher education } \\
\hline & 1985 & 1990 & 1991 & 1992 & $1993^{1}$ & 1985 & 1990 & 1991 & 1992 & $1993^{1}$ & 1985 & 1990 & 1991 & 1992 & $1993^{1}$ \\
\hline 1 & 2 & 3 & 4 & 5 & 6 & 7 & 8 & 9 & 10 & 11 & 12 & 13 & 14 & 15 & 16 \\
\hline 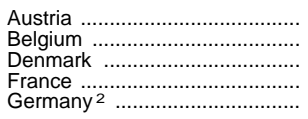 & $\begin{array}{r}\$ 3,554 \\
2,299 \\
3,677 \\
-\end{array}$ & $\begin{array}{r}\$ 3,632 \\
2,195 \\
4,579 \\
- \\
-\end{array}$ & $\begin{array}{r}\$ 3,791 \\
2,273 \\
4,665 \\
2,749 \\
-\end{array}$ & $\begin{array}{r}\$ 4,130 \\
2,462 \\
4,346 \\
2,987 \\
3,069\end{array}$ & $\begin{array}{r}\$ 4,291 \\
2,953 \\
4,745 \\
3,154 \\
2,815\end{array}$ & $\begin{array}{r}\$ 4,061 \\
5,437 \\
5,196 \\
-\end{array}$ & $\begin{array}{r}\$ 4,771 \\
4,949 \\
5,459 \\
- \\
-\end{array}$ & $\begin{array}{r}\$ 4,965 \\
5,305 \\
5,706 \\
4,923 \\
-\end{array}$ & $\begin{array}{r}\$ 6,612 \\
5,304 \\
5,088 \\
5,593 \\
4,388\end{array}$ & $\begin{array}{r}\$ 6,721 \\
5,373 \\
6,175 \\
5,685 \\
6,481\end{array}$ & $\begin{array}{r}\$ 6,753 \\
7,310 \\
8,826 \\
-\end{array}$ & $\begin{array}{r}\$ 6,560 \\
6,363 \\
8,582 \\
- \\
-\end{array}$ & $\begin{array}{r}\$ 6,834 \\
6,615 \\
8,153 \\
5,050 \\
-\end{array}$ & $\begin{array}{r}\$ 5,994 \\
6,787 \\
6,911 \\
6,200 \\
\end{array}$ & $\begin{array}{r}\$ 8,642 \\
6,380 \\
8,045 \\
6,033 \\
7,902\end{array}$ \\
\hline 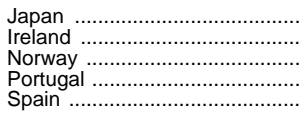 & $\begin{array}{l}1, \overline{63} \\
3,505 \\
1,369 \\
1,482\end{array}$ & $\begin{array}{l}1,4 \overline{72} \\
3,995 \\
1,989 \\
1,854\end{array}$ & $\begin{array}{l}1,636 \\
4,122 \\
2,239 \\
1,974\end{array}$ & $\begin{array}{r}3,636 \\
1,823 \\
4,614 \\
2,091\end{array}$ & $\begin{array}{r}3,960 \\
1,882 \\
2,581 \\
2,293\end{array}$ & $\begin{array}{l}2, \overline{4} \\
4,961 \\
1,811 \\
2,058\end{array}$ & $\begin{array}{r}2,4 \overline{75} \\
5,30 \overline{7} \\
2,7 \overline{87}\end{array}$ & $\begin{array}{l}-\overline{40} \\
5,704 \\
2,508 \\
2,896\end{array}$ & $\begin{array}{r}4,017 \\
2,853 \\
6,386 \\
3,234\end{array}$ & $\begin{array}{l}4,356 \\
3,031 \\
2,491 \\
3,033\end{array}$ & $\begin{array}{l}5,327 \\
8,092 \\
3,844 \\
1,964\end{array}$ & $\begin{array}{r}5,693 \\
8,887 \\
3,250\end{array}$ & $\begin{array}{l}5, \overline{27} \\
8,917 \\
6,536 \\
3,440\end{array}$ & $\begin{array}{r}12,205 \\
7,488 \\
8,981 \\
3,883\end{array}$ & $\begin{array}{l}7,556 \\
7,076 \\
8,343 \\
5,667 \\
3,835\end{array}$ \\
\hline 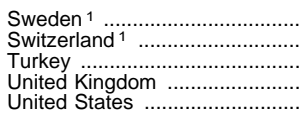 & $\begin{array}{r}\bar{Z} \\
2,406 \\
4,495\end{array}$ & $\begin{array}{r}5,429 \\
\overline{-} \\
2,984 \\
5,380\end{array}$ & $\begin{array}{r}5,803 \\
5,779 \\
599 \\
2,964 \\
5,492\end{array}$ & $\begin{array}{r}4,985 \\
3,667 \\
3,213 \\
5,768\end{array}$ & $\begin{array}{r}4,917 \\
5,835 \\
832 \\
3,295 \\
5,492\end{array}$ & $\begin{array}{r}\bar{Z} \\
3,979 \\
5,440\end{array}$ & $\begin{array}{r}6,480 \\
\overline{-} \\
5,664 \\
6,742\end{array}$ & $\begin{array}{r}7,039 \\
6,963 \\
535 \\
4,514 \\
6,866\end{array}$ & $\begin{array}{r}6,231 \\
\overline{-} \\
4,521 \\
6,664\end{array}$ & $\begin{array}{r}5,651 \\
7,024 \\
587 \\
4,494 \\
6,541\end{array}$ & $\begin{array}{r}\bar{z} \\
\bar{z} \\
10,527\end{array}$ & $\begin{array}{r}8,929 \\
\overline{-} \\
12,373\end{array}$ & $\begin{array}{r}9,083 \\
15,577 \\
2,965 \\
10,207 \\
12,521\end{array}$ & $\begin{array}{r}7,333 \\
13,286 \\
10,680 \\
12,236\end{array}$ & $\begin{array}{r}12,693 \\
15,731 \\
2,696 \\
8,241 \\
14,607\end{array}$ \\
\hline
\end{tabular}

${ }^{1}$ Change in definition of expenditures in 1992

${ }^{2}$ Data for 1985 are for the former West Germany.

-Data not available.
NOTE._Data adjusted to U.S. dollars using the purchasing-power-parity (PPP) index. Public subsidies for students' living expenses are excluded. The figures include public expenditures per student in public and private institutions.

SOURCE: Organization for Economic Cooperation and Development, Education at a Glance, 1996; and unpublished data. (This table was prepared September 1997.) 
Table 413.-Total public direct expenditures for education as a percentage of gross domestic product, by level of education:

Selected countries, 1985 to 1994

\begin{tabular}{|c|c|c|c|c|c|c|c|c|c|c|c|c|c|c|c|c|c|c|c|c|c|c|c|c|c|c|}
\hline \multirow{2}{*}{ Country } & \multicolumn{8}{|c|}{ All levels ${ }^{1}$} & \multicolumn{6}{|c|}{ Primary education } & \multicolumn{6}{|c|}{ Secondary education } & \multicolumn{6}{|c|}{ Higher education } \\
\hline & 1985 & 1988 & 1989 & 1990 & 1991 & 1992 & 1993 & 1994 & 1985 & 1990 & 1991 & 1992 & 1993 & 1994 & 1985 & 1990 & 1991 & 1992 & 1993 & 1994 & 1985 & 1990 & 1991 & 1992 & 1993 & 1994 \\
\hline 1 & 2 & 3 & 4 & 5 & 6 & 7 & 8 & 9 & 10 & 11 & 12 & 13 & 14 & 15 & 16 & 17 & 18 & 19 & 20 & 21 & 22 & 23 & 24 & 25 & 26 & 27 \\
\hline str & & 8 & - & - & 4.4 & & & 4 & & - & - & - & 1. & .4 & 1.9 & - & & 2.8 & 2.0 & 8 & 1.7 & - & 1.9 & .5 & 1.1 & 1.1 \\
\hline & & & 5.3 & 5.2 & & & & & & 0.9 & 1.0 & 1.0 & & . & & 2.5 & & & & & 1.0 & 1.0 & & & 0 & - \\
\hline 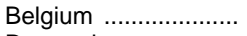 & 6. & & & & & & & 5 & 1 & 0. & 0.9 & 1. & & 1.2 & 2.9 & 2 & & & 2.5 & 2.6 & 1.0 & 0.8 & & 6 & 1.0 & 1.0 \\
\hline ........... & 6.2 & 6.4 & 6 & 6 & 6. & 6. & 6.7 & 6.5 & 1.8 & 1. & - & 1.4 & 1.5 & 1.5 & 2.9 & 2.7 & - & 2.6 & 2.9 & 2.8 & 1.2 & 1.3 & 1.3 & 3 & 1.3 & 1.4 \\
\hline ………. & - & - & 5.0 & 5 & 5.2 & 5.4 & 5.6 & 5. & - & 1.0 & 1.0 & 1.0 & 1.1 & 1.1 & - & 2.4 & 2.5 & 2.7 & 2.9 & 2.9 & - & 7 & 8 & 0.8 & 0.9 & 0.9 \\
\hline rmany & 4.6 & 4.3 & - & - & - & - & 4 & 4.5 & 0.6 & - & - & - & 0. & 0. & 2. & - & - & - & 2.3 & 2.1 & 1.0 & - & - & - & 9 & 9 \\
\hline & 5. & 5 & 5.0 & 4.9 & 5.1 & 5.0 & & & & 1.4 & 1.5 & 1.4 & 1. & 1. & 2.3 & 2.0 & 2.1 & 2.0 & 2. & & 0.9 & 1.0 & 1.0 & 1.0 & & 1.0 \\
\hline$\ldots \ldots$ & 4. & 4. & 5 & 5 & - & 5.0 & 5.0 & 4.6 & 1.2 & 1.1 & - & 1.1 & 1.1 & 1.1 & 2.1 & 2.2 & - & 2.3 & 2.4 & 2.2 & 0.6 & 1.0 & - & 0.8 & 0.8 & 0.7 \\
\hline & - & 3. & & 3.4 & 3.4 & 3.5 & 3.6 & 3.8 & - & - & - & 1.3 & 1.4 & 1.4 & - & - & - & 1.4 & 1.5 & 1.6 & - & - & - & 0.3 & 0.4 & 0.5 \\
\hline Luxembourg . & - & 5.2 & 5.0 & - & & - & - & - & - & - & - & - & - & - & - & - & - & - & - & - & - & - & - & - & - & - \\
\hline thorlande & 6.2 & 6. & 5 & 5 & - & 4. & 4 & 4 & 1.6 & 1.3 & - & 1.1 & 1.2 & 1.2 & 2.5 & 2.2 & - & 1.8 & 1.8 & 1.8 & 1.5 & 1.6 & - & 12 & 1.2 & 1.2 \\
\hline & - & & & & & & & & - & 1.6 & 1.5 & 1. & & & - & 1.5 & 1.4 & 1 & 2. & 2. & - & 2.2 & 1.8 & & 2 & 1.1 \\
\hline & 5.1 & 5. & & 5.9 & & 6.8 & & & 1.6 & 1.5 & 1.5 & 1.6 & 1. & 2. & 2.5 & 2.4 & & 2.9 & 2.4 & 1. & 0.7 & 1.1 & & 1.3 & 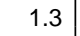 & 1.4 \\
\hline & 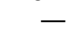 & 4. & & & 4. & - & 5. & 5. & - & - & 2.0 & - & 2.0 & 1.8 & - & - & 1.8 & - & 1.9 & 2.1 & - & - & 0 & - & 0.8 & 0.8 \\
\hline Spain . & 3.6 & 3.9 & 4.1 & 43 & 4.4 & 4.4 & 4.5 & 4.8 & 1.1 & 1.0 & 1.0 & 1.0 & 1.0 & 1.0 & 1.8 & 2.3 & 2.3 & 2.3 & 2.4 & 2.5 & 0.4 & 0.7 & 0.8 & 0.8 & 0.8 & 0.8 \\
\hline 1 & 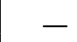 & 5.5 & 5.2 & 5 & 5 & & & & - & 1.9 & 2.1 & 1. & 2 & 2 & - & 2.3 & 2.6 & 2 & 2 & 2 & - & 1.0 & 1. & & 1.4 & 1.5 \\
\hline Switz & 4.9 & 5.0 & & & 5.4 & 5.2 & & 5 & 2.7 & - & 1.4 & 1.2 & 1.6 & 1. & 1.3 & - & 2.3 & 2.6 & 2.5 & 2.5 & 0.9 & - & 1.2 & 1.1 & 1.1 & 1.1 \\
\hline & - & - & - & - & & & & & & - & - & - & 1. & 1. & - & - & - & - & 0. & 0. & - & - & - & - & & 1.2 \\
\hline & 4.9 & 4.5 & 4.4 & 4.7 & 4.8 & 4.7 & 4 & & 1.1 & 1.2 & 1.3 & 1.5 & 1. & 1 & 2.0 & 2.1 & 2.1 & 2.3 & 2.3 & 2.2 & 1.0 & 0.9 & 0.9 & 0.8 & & 0.7 \\
\hline United Stat & 4.7 & 4.9 & 4.8 & 0.0 & 5.5 & 5.0 & 5.0 & 4.8 & 1.4 & 1.7 & 1.8 & 1.8 & 1.8 & 1.6 & 1.8 & 1.9 & 1.9 & 1.8 & 1.9 & - & 1.3 & 1.4 & 1.5 & 1.2 & 1.2 & 1.1 \\
\hline
\end{tabular}

1 Includes primary, secondary, and higher education and other expenditures not classified by level of education. 2 Data prior to 1991 are for the former West Germany.

SOURCE: Organization for Economic Cooperation and Development, unpublished data. (This table was prepared -Data not available. 
Table 414.-Foreign students enrolled in institutions of higher education in the United States and outlying areas, by continent, region, and selected countries of origin: 1980-81 to 1996-97

\begin{tabular}{|c|c|c|c|c|c|c|c|c|c|c|c|c|c|c|c|c|}
\hline \multirow[b]{2}{*}{ Continent, region, and country } & \multicolumn{2}{|c|}{$1980-81$} & \multicolumn{2}{|c|}{$1985-86$} & \multicolumn{2}{|c|}{$1990-91$} & \multicolumn{2}{|c|}{$1992-93$} & \multicolumn{2}{|c|}{ 1993-94 } & \multicolumn{2}{|c|}{ 1994-95 } & \multicolumn{2}{|c|}{$1995-96$} & \multicolumn{2}{|c|}{$1996-97$} \\
\hline & Number & $\begin{array}{l}\text { Per- } \\
\text { cent }\end{array}$ & Number & $\begin{array}{l}\text { Per- } \\
\text { cent }\end{array}$ & Number & $\begin{array}{l}\text { Per- } \\
\text { cent }\end{array}$ & Number & $\begin{array}{l}\text { Per- } \\
\text { cent }\end{array}$ & Number & $\begin{array}{l}\text { Per- } \\
\text { cent }\end{array}$ & Number & $\begin{array}{l}\text { Per- } \\
\text { cent }\end{array}$ & Number & $\begin{array}{l}\text { Per- } \\
\text { cent }\end{array}$ & Number & $\begin{array}{l}\text { Per- } \\
\text { cent }\end{array}$ \\
\hline 1 & 2 & 3 & 4 & 5 & 6 & 7 & 8 & 9 & 10 & 11 & 12 & 13 & 14 & 15 & 16 & 17 \\
\hline Total ................... & 311,880 & 100.0 & 343,780 & 100.0 & 407,530 & 100.0 & 438,620 & 100.0 & 449,704 & 100.0 & 452,635 & 100.0 & 453,787 & 100.0 & 457,984 & 100.0 \\
\hline Africa & 38,180 & 12.2 & 34,190 & 9.9 & 23,800 & 5.8 & 20,520 & 4.7 & 20,569 & 4.6 & 20,724 & 4.6 & 20,844 & 4.6 & 22,078 & 4.8 \\
\hline Eastern Africa & 6,260 & 2.0 & 6,730 & 2.0 & 7,590 & 1.9 & 6,950 & 1.6 & 7,093 & 1.6 & 7,139 & 1.6 & 7,596 & 1.7 & 8,628 & 1.9 \\
\hline Central Africa .. & 1,130 & 0.4 & 1,540 & 0.4 & 1,650 & 0.4 & 1,470 & 0.3 & 1,472 & 0.3 & 1,430 & 0.3 & 1,346 & 0.3 & 1,187 & 0.3 \\
\hline North Africa ....... & 7,310 & 2.3 & 5,980 & 1.7 & 4,540 & 1.1 & 3,730 & 0.9 & 3,614 & 0.8 & 3,522 & 0.8 & 3,422 & 0.8 & 3,469 & 0.8 \\
\hline Southern Africa & 1,480 & 0.5 & 2,360 & 0.7 & 2,840 & 0.7 & 2,560 & 0.6 & 2,563 & 0.6 & 2,672 & 0.6 & 2,657 & 0.6 & 2,678 & 0.6 \\
\hline West Africa ........ & 22,000 & 7.1 & 17,580 & 5.1 & 7,180 & 1.8 & 5,800 & 1.3 & 5,804 & 1.3 & 5,943 & 1.3 & 5,818 & 1.3 & 6,115 & 1.3 \\
\hline Nigeria .... & 17,350 & 5.6 & 13,710 & 4.0 & 3,710 & 0.9 & 2,490 & 0.6 & 2,285 & 0.5 & 2,147 & 0.5 & 2,093 & 0.5 & 2,184 & 0.5 \\
\hline Europe & 25,330 & 8.1 & 34,310 & 10.0 & 49,640 & 12.2 & 58,010 & 13.2 & 62,442 & 13.9 & 64,811 & 14.3 & 67,358 & 14.8 & 68,315 & 14.9 \\
\hline Eastern Europe & 1,670 & 0.5 & 1,770 & 0.5 & 4,780 & 1.2 & 9,800 & 2.2 & 12,929 & 2.9 & 15,906 & 3.5 & 18,032 & 4.0 & 19,471 & 4.3 \\
\hline Western Europe ....................... & 23,660 & 7.6 & 32,540 & 9.5 & 44,860 & 11.0 & 48,210 & 11.0 & 49,496 & 11.0 & 48,905 & 10.8 & 49,326 & 10.9 & 48,844 & 10.7 \\
\hline France ............................... & - & - & 3,680 & 1.1 & 5,630 & 1.4 & 5,660 & 1.3 & 5,976 & 1.3 & 5,843 & 1.3 & 5,710 & 1.3 & 5,692 & 1.2 \\
\hline Republic of 1 & 3,310 & 1.1 & 4,730 & 1.4 & 7,000 & 1.7 & 7,880 & 1.8 & 8,508 & 1.9 & 8,592 & 1.9 & 9,017 & 2.0 & 8,990 & 2.0 \\
\hline Greece …….......................... & 3,750 & 1.2 & 4,440 & 1.3 & 4,360 & 1.1 & 4,350 & 1.0 & 4,144 & 0.9 & 3,699 & 0.8 & 3,365 & 0.7 & 3,010 & 0.7 \\
\hline Spain ……........................... & - & - & 1,740 & 0.5 & 4,300 & 1.1 & 5,160 & 1.2 & 5,246 & 1.2 & 5,126 & 1.1 & 4,809 & 1.1 & 4,673 & 1.0 \\
\hline United Kingdom .............. & 4,440 & 1.4 & 5,940 & 1.7 & 7,300 & 1.8 & 7,630 & 1.7 & 7,828 & 1.7 & 7,786 & 1.7 & 7,799 & 1.7 & 7,357 & 1.6 \\
\hline Latin America ..... & 49,810 & 16.0 & 45,480 & 13.2 & 47,580 & 11.7 & 43,250 & 9.9 & 45,246 & 10.1 & 47,239 & 10.4 & 47,253 & 10.4 & 49,592 & 10.8 \\
\hline Caribbean & 10,650 & 3.4 & 11,100 & 3.2 & 12,610 & 3.1 & 10,270 & 2.3 & 10,672 & 2.4 & 11,286 & 2.5 & 10,737 & 2.4 & 11,796 & 2.6 \\
\hline Central America & 12,970 & 4.2 & 12,740 & 3.7 & 15,950 & 3.9 & 13,460 & 3.1 & 13,886 & 3.1 & 14,923 & 3.3 & 14,220 & 3.1 & 14,524 & 3.2 \\
\hline Mexico ............... & 6,730 & 2.2 & 5,460 & 1.6 & 6,740 & 1.7 & 7,580 & 1.7 & 8,021 & 1.8 & 9,003 & 2.0 & 8,687 & 1.9 & 8,975 & 2.0 \\
\hline South America ……................. & 26,190 & 8.4 & 21,640 & 6.3 & 19,020 & 4.7 & 19,530 & 4.5 & 20,708 & 4.6 & 21,030 & 4.6 & 22,296 & 4.9 & 23,272 & 5.1 \\
\hline Brazil ................. & - & - & 2,840 & 0.8 & 3,900 & 1.0 & 4,540 & 1.0 & 4,977 & 1.1 & 5,017 & 1.1 & 5,497 & 1.2 & 6,168 & 1.3 \\
\hline Colombia …....................... & - & - & 4,010 & 1.2 & 3,180 & 0.8 & 2,850 & 0.6 & 3,077 & 0.7 & 3,208 & 0.7 & 3,462 & 0.8 & 3,636 & 0.8 \\
\hline Venezuela ........................... & 11,750 & 3.8 & 7,040 & 2.0 & 2,890 & 0.7 & 3,440 & 0.8 & 3,742 & 0.8 & 4,092 & 0.9 & 4,456 & 1.0 & 4,590 & 1.0 \\
\hline Middle East & 84,710 & 27.2 & 52,720 & 15.3 & 33,420 & 8.2 & 30,240 & 6.9 & 29,509 & 6.6 & 30,246 & 6.7 & 30,563 & 6.7 & 29,841 & 6.5 \\
\hline Iran ........................ & 47,550 & 15.2 & 14,210 & 4.1 & 6,260 & 1.5 & 4,090 & 0.9 & 3,621 & 0.8 & 2,896 & 0.6 & 2,628 & 0.6 & 2,129 & 0.5 \\
\hline 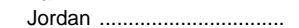 & 6,140 & 2.0 & 6,590 & 1.9 & 4,320 & 1.1 & 3,260 & 0.7 & 2,826 & 0.6 & 2,431 & 0.5 & 2,222 & 0.5 & 2,094 & 0.5 \\
\hline Lebanon ............ & 6,770 & 2.2 & 7,090 & 2.1 & 3,900 & 1.0 & 2,540 & 0.6 & 2,165 & 0.5 & 1,835 & 0.4 & 1,554 & 0.3 & 1,370 & 0.3 \\
\hline Saudi Arabia ......................... & 10,440 & 3.3 & 6,900 & 2.0 & 3,590 & 0.9 & 3,750 & 0.9 & 3,721 & 0.8 & 4,075 & 0.9 & 4,191 & 0.9 & 4,264 & 0.9 \\
\hline Turkey …................................. & & - & 2,460 & 0.7 & 4,080 & 1.0 & 4,980 & 1.1 & 5,474 & 1.2 & 6,716 & 1.5 & 7,678 & 1.7 & 8,194 & 1.8 \\
\hline North America ${ }^{2}$ & 14,790 & 4.7 & 16,030 & 4.7 & 18,950 & 4.6 & 21,550 & 4.9 & 23,288 & 5.2 & 23,394 & 5.2 & 23,644 & 5.2 & 23,611 & 5.2 \\
\hline Canada ................................ & 14,320 & 4.6 & 15,410 & 4.5 & 18,350 & 4.5 & 20,970 & 4.8 & 22,655 & 5.0 & 22,747 & 5.0 & 23,005 & 5.1 & 22,984 & 5.0 \\
\hline Oceania & 4,180 & 1.3 & 4,030 & 1.2 & 4,230 & 1.0 & 4,300 & 1.0 & 3,857 & 0.9 & 4,327 & 1.0 & 4,202 & 0.9 & 3,690 & 0.8 \\
\hline South and East Asia & 94,640 & 30.3 & 156,830 & 45.6 & 229,830 & 56.4 & 260,670 & 59.4 & 264,693 & 58.9 & 261,789 & 57.8 & 259,893 & 57.3 & 260,743 & 56.9 \\
\hline East Asia & 51,650 & 16.6 & 80,720 & 23.5 & 146,020 & 35.8 & 168,410 & 38.4 & 171,279 & 38.1 & 168,190 & 37.2 & 166,717 & 36.7 & 167,935 & 36.7 \\
\hline China ……..................... & 2,770 & 0.9 & 13,980 & 4.1 & 39,600 & 9.7 & 45,130 & 10.3 & 44,381 & 9.9 & 39,403 & 8.7 & 39,613 & 8.7 & 42,503 & 9.3 \\
\hline Hong Kong ............................ & 9,660 & 3.1 & 10,710 & 3.1 & 12,630 & 3.1 & 14,020 & 3.2 & 13,752 & 3.1 & 12,935 & 2.9 & 12,018 & 2.6 & 10,942 & 2.4 \\
\hline ……............. & 13,500 & 4.3 & 13,360 & 3.9 & 36,610 & 9.0 & 42,840 & 9.8 & 43,770 & 9.7 & 45,276 & 10.0 & 45,531 & 10.0 & 46,292 & 10.1 \\
\hline Korea, Republic of .......... & 6,150 & 2.0 & 18,660 & 5.4 & 23,360 & 5.7 & 28,520 & 6.5 & 31,076 & 6.9 & 33,599 & 7.4 & 36,231 & 8.0 & 37,130 & 8.1 \\
\hline Taiwan ....... & 19,460 & 6.2 & 23,770 & 6.9 & 33,530 & 8.2 & 37,430 & 8.5 & 37,581 & 8.4 & 36,407 & 8.0 & 32,702 & 7.2 & 30,487 & 6.7 \\
\hline South Central Asia .............. & 14,540 & 4.7 & 25,800 & 7.5 & 42,370 & 10.4 & 50,430 & 11.5 & 48,941 & 10.9 & 47,836 & 10.6 & 45,401 & 10.0 & 44,256 & 9.7 \\
\hline 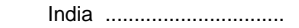 & 9,250 & 3.0 & 16,070 & 4.7 & 28,860 & 7.1 & 35,950 & 8.2 & 34,796 & 7.7 & 33,537 & 7.4 & 31,743 & 7.0 & 30,641 & 6.7 \\
\hline Pakistan & 2,990 & 1.0 & 5,440 & 1.6 & 7,730 & 1.9 & 8,020 & 1.8 & 7,299 & 1.6 & 6,989 & 1.5 & 6,427 & 1.4 & 6,095 & 1.3 \\
\hline South East Asia ...................... & 28,450 & 9.1 & 50,310 & 14.6 & 41,440 & 10.2 & 41,830 & 9.5 & 44,461 & 9.9 & 45,763 & 10.1 & 47,774 & 10.5 & 48,550 & 10.6 \\
\hline Indonesia ............................... & 3,250 & 1.0 & 8,210 & 2.4 & 9,520 & 2.3 & 10,920 & 2.5 & 11,744 & 2.6 & 11,872 & 2.6 & 12,820 & 2.8 & 12,461 & 2.7 \\
\hline Malaysia ……....................... & 6,010 & 1.9 & 23,020 & 6.7 & 13,610 & 3.3 & 12,660 & 2.9 & 13,718 & 3.1 & 13,617 & 3.0 & 14,015 & 3.1 & 14,527 & 3.2 \\
\hline 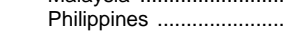 & - & - & 3,920 & 1.1 & 4,270 & 1.0 & 3,700 & 0.8 & 3,528 & 0.8 & 3,472 & 0.8 & 3,127 & 0.7 & 2,796 & 0.6 \\
\hline Singapore ............................ & - & - & 3,930 & 1.1 & 4,500 & 1.1 & 4,860 & 1.1 & 4,823 & 1.1 & 4,473 & 1.0 & 4,098 & 0.9 & 3,727 & 0.8 \\
\hline Thailand …….................. & 6,550 & 2.1 & 6,940 & 2.0 & 7,090 & 1.7 & 8,630 & 2.0 & 9,537 & 2.1 & 10,889 & 2.4 & 12,165 & 2.7 & 13,481 & 2.9 \\
\hline Stateless $^{3} \ldots \ldots \ldots \ldots \ldots \ldots$ & 240 & 0.1 & 190 & 0.1 & 80 & (4) & 80 & $(4)$ & 100 & (4) & 105 & (4) & 30 & $(4)$ & 109 & $\left({ }^{4}\right)$ \\
\hline
\end{tabular}

11990-91 and later years data are for Germany, which includes the former Federal Republic of Germany and the former Democratic Republic of Germany.

${ }^{2}$ Excludes Mexico and Central America, which are included with Latin America.

${ }^{3}$ Home country unknown or undeclared.

${ }^{4}$ Less than .05 percent.

-Data not available.
NOTE.-Data are for "nonimmigrants," i.e., students who have not migrated to this country. Because of rounding, details may not add to totals.

SOURCE: Institute of International Education, "Open Doors," various years; and unpublished data. (Latest edition copyright (c) 1997 by the Institute of International Education. All rights reserved.) (This table was prepared July 1998 .) 


\section{CHAPTER 7}

\section{Learning Resources and Technology}

This chapter contains statistics on libraries and on the use of information technologies. These data show the extent of America's access to information technologies outside of formal classroom activities. The data also provide a capsule description of the magnitude and availability of library resources. Access to information has been widely cited as the key to success in a growing number of endeavors. Thus, how information is made available and to whom are matters of concern.

The first section of the chapter deals with public libraries, public and private school libraries, and college and university libraries. It contains data on collections, population served, staff, and expenditures. Two tables provide institutional-level information for the largest public libraries and the largest college libraries in the country.

The second half of the chapter provides information on the availability and use of technology. For example, the proportion of children using computers at school is shown over time. Also included are data on the use of home computers by adults and school children, with comparisons among various demographic groups.

Related data may be found in various sections of this report. For example, statistics on the number of degrees conferred in computer and information sciences and library sciences are in chapter 3 . Further information on survey methodologies is in the "Guide to Sources" and in the publications cited in the source notes.

\section{Resources}

In 1993-94, there were 83 school library visits each week per 100 public school students. Elementary school students were more likely to visit their school libraries (89 visits per 100 students each week) than secondary school students (69 per 100). Private school students were slightly less likely to visit their libraries (77 per 100). The average number of library staff per school was 1.8 at public schools, and 1.2 at private schools. Public school libraries generally had smaller numbers of books on a per student basis than private school libraries. In 199394, public school libraries held an average of 2,585 books per 100 students compared to an average of 3,716 per 100 students at private schools. Although public elementary school libraries had slightly smaller holdings than public secondary schools on a per student basis, the elementary school students checked out twice as many books on a per student basis (1.5 per week compared to .7 per week) (table 415).

In 1995, there were 8,981 public libraries in the United States with 695 million books and serial volumes. The annual attendance per capita was 3.9 and the reference transactions per capita was 1.1 (table 423).

The increase in college library resources kept pace with increases in enrollment between 1984-85 and 1994-95. The library staff to student ratio decreased slightly from 153 students per staff member to 150 students per staff member. The library operating expenditure per student average rose 9 percent in constant dollars to $\$ 417$ in 1994-95. However, other college expenditures rose faster than library expenditures and the proportion of college education budgets spent on libraries fell from 3.4 percent in 1984-85 to 2.9 percent in 1994-95 (table 420).

\section{Technology}

There has been widespread introduction of computers into the schools in recent years. In 1997, the average public school contained 75 computers. One important technological advance that has come to schools following the introduction of computers has been connections to the Internet. The proportion of schools with Internet access has increased rapidly from 35 percent in 1994 to 89 percent in 1998. Although some access is now widespread, most schools are not extensively connected. About 51 percent of instructional rooms had access to the Internet in 1998 (table 419).

The total computer usage rate of students at school increased from 59 percent in 1993, to 69 percent in October 1997. The rate for grades 1 to 8 increased from 69 percent in 1989 to 79 percent in 1997. The computer usage rate in 1997 was 70 percent for students in high school and 55 percent for students in college. Sizable percentages of students used computers at home, though fewer actually used them for schoolwork. About 43 percent of elementary school children used computers at home and about 24 percent used them for schoolwork. Students at the high school and undergraduate level were much 
more likely than elementary school children to use home computers for schoolwork. In general, students in higher income families were more likely to use computers at home and use them for schoolwork than students from lower income families. About 13 percent of the high school students in the $\$ 25,000$ to $\$ 29,999$ household income group used computers at home for school work compared to 45 percent in the $\$ 75,000$ and over income group (table 428 ).

The use of computers has become widespread in the workplace. In October 1997, 50 percent of all workers used computers on the job. More frequent use of computers was associated with higher levels of education and higher incomes. Only 36 percent of the high school graduates and 12 percent of the high school dropouts used computers compared to 79 percent of those with master's degrees. Among those who did use computers, the master's degree recipients were more likely to use the computers for a wider variety of applications than high school graduates. Among the most common applications for all employees using computers on the job were: bookkeeping/invoicing (66 percent), word processing (57 percent), communications (47 percent), analysis/ spreadsheets (41 percent), and calendar/schedule (38 percent). Workers in the 25- to 59-year-old age range were more likely to use computers than younger or older workers. Elementary and secondary teachers were less likely to use computers than persons employed in other managerial or professional fields (table 424).

\section{Figure 33.- Percent of all public schools and instructional rooms having Internet access: Fall 1994 to fall 1998}

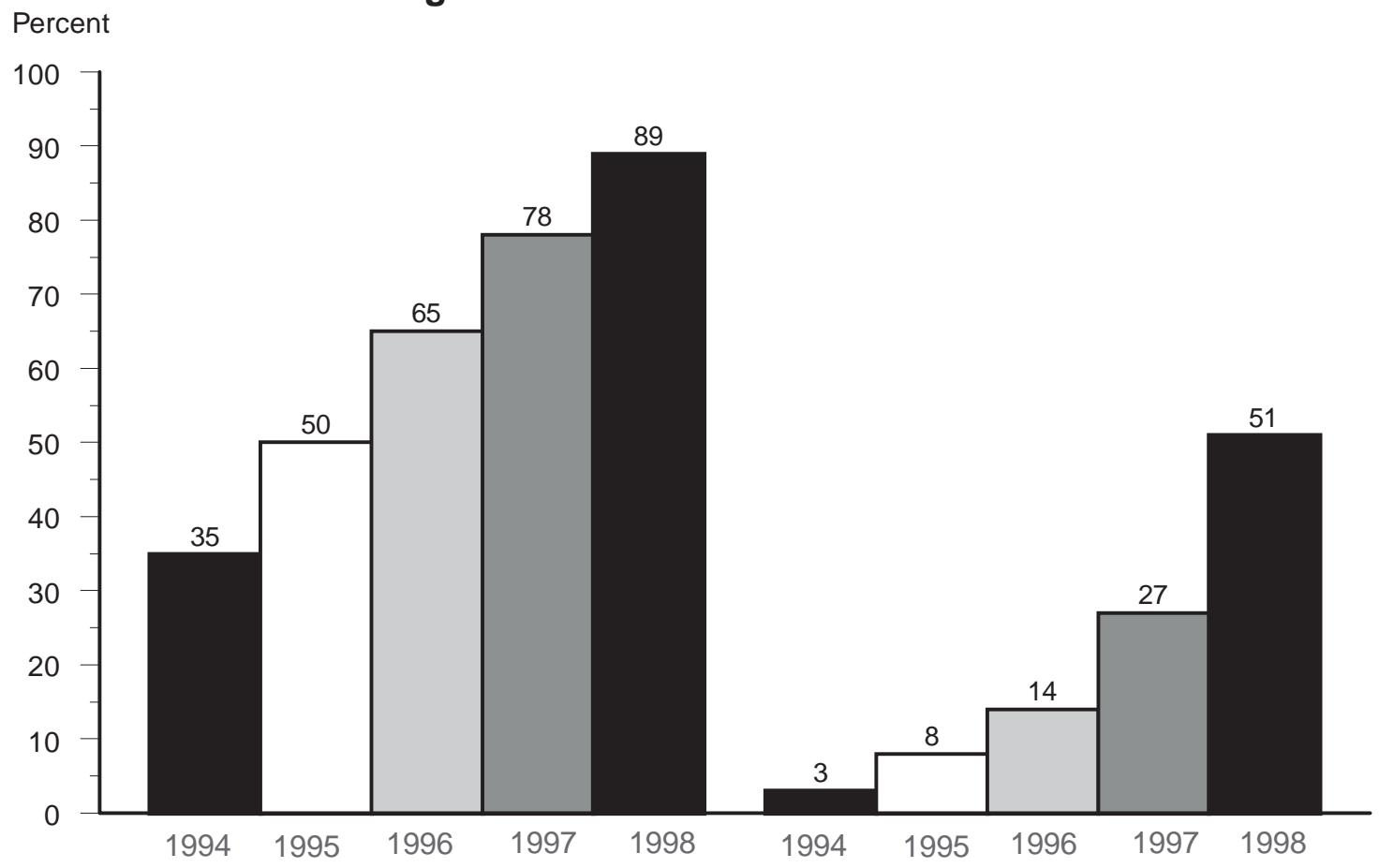

SOURCE: U.S. Department of Education, National Center for Education Statistics, Fast Response Survey System, Advanced Telecommunications in U.S. Elementary and Secondary Public Schools, Fall 1996, and Internet Access in Public Schools and Classrooms: 1994-98. 
Table 415.-Percentage of school library/media centers that offered selected services and equipment, and library/media center expenditures, by control and level of school: 1993-94

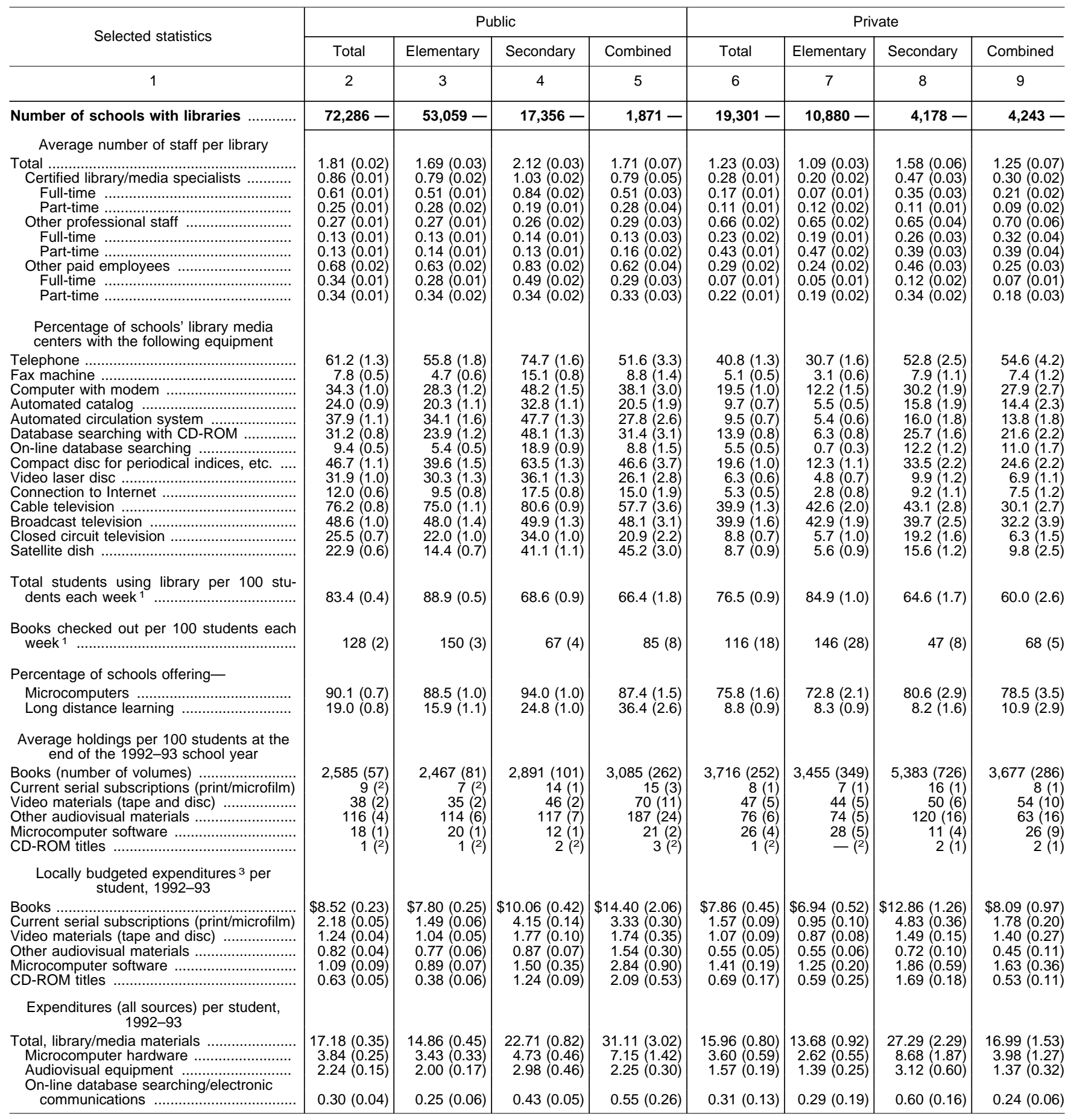

${ }^{1}$ During the most recent full week of school.

${ }^{2}$ Standard error less than .5 .

${ }^{3}$ Locally budgeted expenditures exclude federal gifts and grants.

-Data not available.
NOTE.-Percentages are based on schools that have library/media centers. In school year 1990-91, 96 percent of public schools had library/media centers. Standard errors appear in parentheses.

SOURCE: U.S. Department of Education, National Center for Education Statistics, Schools and Staffing Survey, 1993-94, unpublished data. (This table was prepared August 1997.) 
Table 416.-Selected statistics on public school library/media centers, by level and enrollment size of school: 1993-94

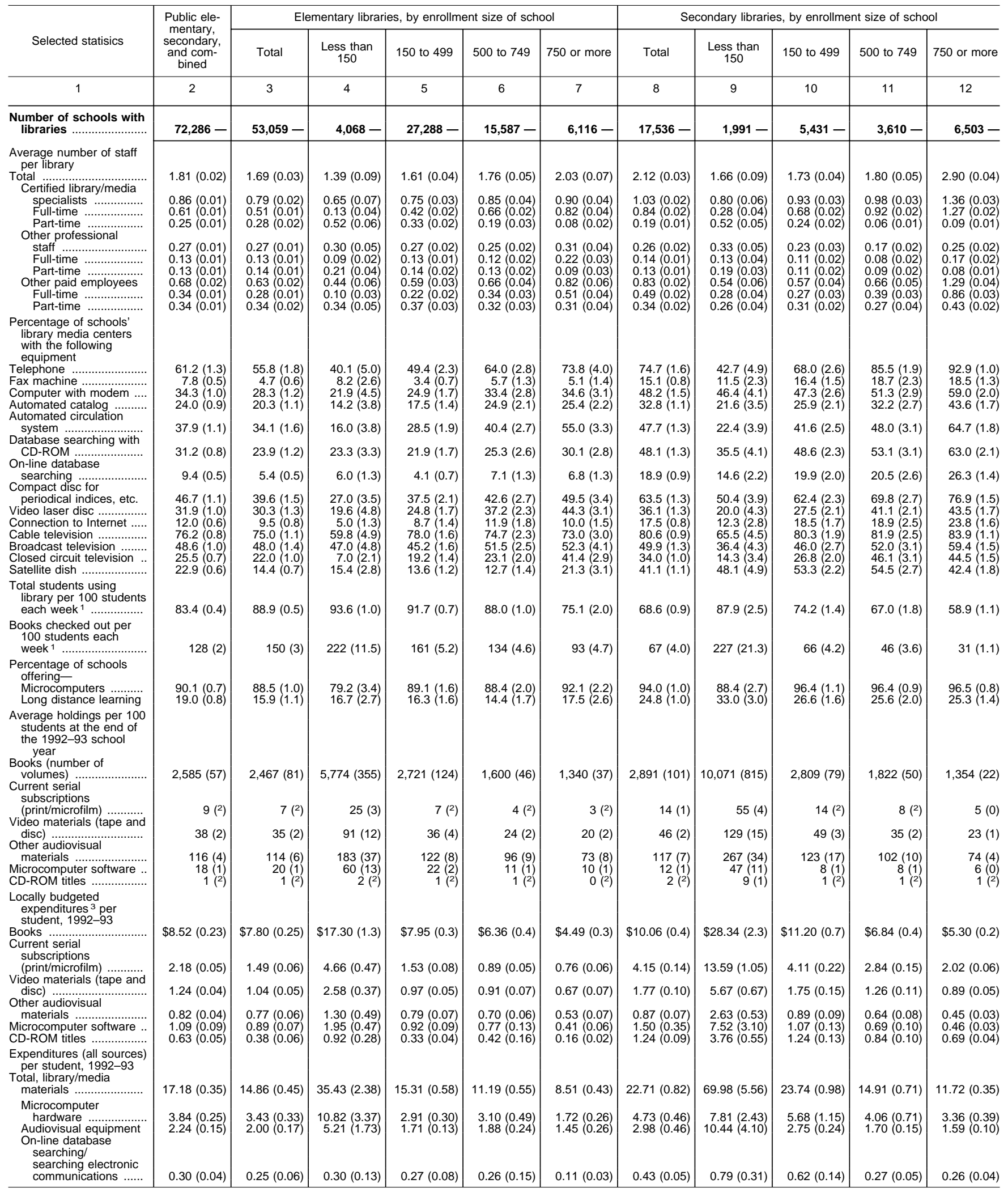

1 During the most recent full week of school.

${ }^{2}$ Standard error less than .5 .

${ }^{3}$ Locally budgeted expenditures exclude federal gifts and grants.

-Data not available.

NOTE.-Percentages are based on schools that have library/media centers. In schoo year 1990-91, 96 percent of public schools had library/media centers. Standard errors appear in parentheses.
SOURCE: U.S. Department of Education, National Center for Education Statistics, Schools and Staffing Survey, 1993-94, unpublished data. (This table was prepared August 1997.) 
Table 417.-Selected statistics on public school library/media centers, by state: 1993-94

\begin{tabular}{|c|c|c|c|c|c|c|c|c|c|c|c|}
\hline \multirow[b]{2}{*}{ State or other area } & \multicolumn{6}{|c|}{ Percent of centers offering selected services/equipment } & \multirow[b]{2}{*}{$\begin{array}{l}\text { Books held } \\
\text { per } 100 \text { stu- } \\
\text { dents }\end{array}$} & \multirow{2}{*}{$\begin{array}{c}\text { Total stu- } \\
\text { dents using } \\
\text { library per } \\
100 \text { stu- } \\
\text { dents each } \\
\text { week }^{1}\end{array}$} & \multirow[b]{2}{*}{$\begin{array}{l}\text { Total expend- } \\
\text { itures for ma- } \\
\text { terials per } \\
\text { student }\end{array}$} & \multirow{2}{*}{$\begin{array}{l}\text { Expenditure } \\
\text { for micro- } \\
\text { computers for } \\
\text { library per } \\
\text { student }\end{array}$} & \multirow{2}{*}{$\begin{array}{c}\text { Expenditure } \\
\text { for audio- } \\
\text { visual mate- } \\
\text { rials for li- } \\
\text { brary per } \\
\text { student }\end{array}$} \\
\hline & $\begin{array}{c}\text { Computer } \\
\text { with modem }\end{array}$ & $\begin{array}{l}\text { Automated } \\
\text { catalog }\end{array}$ & $\begin{array}{c}\text { Database } \\
\text { searching } \\
\text { with CD- } \\
\text { ROM }\end{array}$ & $\begin{array}{l}\text { On-line } \\
\text { database } \\
\text { searching }\end{array}$ & $\begin{array}{l}\text { Compact } \\
\text { disc for in- } \\
\text { dices, etc. }\end{array}$ & $\begin{array}{c}\text { Connection } \\
\text { to the } \\
\text { Internet }\end{array}$ & & & & & \\
\hline 1 & 2 & 3 & 4 & 5 & 6 & 7 & 8 & 9 & 10 & 11 & 12 \\
\hline United States & $34.3(1.0)$ & $24.0(0.9)$ & $31.2(0.8)$ & $9.4(0.5)$ & $46.7(1.1)$ & $12.0(0.6)$ & $2,585(57)$ & $83.4(0.4)$ & $\$ 17.18(0.35)$ & $\$ 3.84(0.25)$ & $\$ 2.24(0.15)$ \\
\hline Alabama & $33.0(4.2)$ & $37.6(5.9)$ & $29.3(4.0)$ & $5.7(2.0)$ & $44.1(4.6)$ & $3.2(1.5)$ & $1,510(61)$ & $76.3(2.2)$ & $11.22(0.62)$ & $1.91(0.39)$ & $0.91(0.22)$ \\
\hline Alaska .... & 34.7 (3.6) & $34.3(4.0)$ & $39.7(4.7)$ & $6.8(1.9)$ & $44.6(4.5)$ & $15.1(2.3)$ & $4,167(260)$ & $85.0(2.0)$ & $47.38(5.86)$ & $9.76(2.55)$ & $1.94(0.30)$ \\
\hline Arizona . & $28.1(3.5)$ & $38.3(5.3)$ & $28.0(4.0)$ & $5.6(2.2)$ & $43.0(4.4)$ & $6.0(1.9)$ & $2,552(211)$ & $81.0(3.3)$ & $17.55(3.05)$ & $4.66(1.37)$ & $1.56(0.31)$ \\
\hline Arkansas. & $19.0(4.0)$ & $18.7(4.0)$ & $20.5(4.1)$ & $5.6(2.4)$ & $29.7(4.6)$ & $8.5(2.5)$ & $2,377(355)$ & $78.3(2.8)$ & $15.03(1.45)$ & $1.92(0.53)$ & $1.56(0.29)$ \\
\hline California . & $19.9(4.3)$ & $14.0(3.4)$ & $23.4(3.7)$ & $3.1(1.0)$ & $38.0(5.7)$ & $6.2(2.3)$ & $1,751(193)$ & $77.9(2.7)$ & $7.26(1.00)$ & $3.13(0.87)$ & $0.59(0.17)$ \\
\hline Colorado & $47.0(4.7)$ & $43.6(5.7)$ & $43.3(5.5)$ & $30.7(4.7)$ & $60.7(5.5)$ & $16.3(3.5)$ & $2,190(177)$ & $80.6(2.5)$ & $16.42(1.81)$ & $3.01(0.57)$ & $1.63(0.25)$ \\
\hline Connecticl & $43.8(6.5)$ & $12.8(2.7)$ & $45.4(5.3)$ & $17.9(3.8)$ & $54.4(6.0)$ & $6.5(2.6)$ & 2,289 (129) & $88.0(2.2)$ & $15.71(2.06)$ & $2.84(1.01)$ & $1.21(0.21)$ \\
\hline Delaware & $41.8(3.6)$ & $22.5(3.0)$ & $34.7(3.5)$ & $14.4(2.5)$ & $48.2(3.5)$ & $5.7(2.0)$ & $1,587(84)$ & $80.5(2.3)$ & $8.68(0.87)$ & $1.63(0.24)$ & $0.64(0.23)$ \\
\hline District of Columbia & $23.5(4.0)$ & $4.4(2.2)$ & $25.4(2.8)$ & $10.4(3.3)$ & $31.2(3.2)$ & $1.7(1.1)$ & $1,578(74)$ & $65.6(2.9)$ & $8.06(0.69)$ & $0.49(0.13)$ & $1.46(0.30)$ \\
\hline Florida ......................... & $45.3(3.8)$ & $29.8(3.3)$ & $39.9(3.6)$ & $11.8(2.8)$ & $71.0(4.0)$ & $21.1(3.4)$ & 1,855430 & $76.6(2.6)$ & $13.61(1.98)$ & $1.85(0.29)$ & $2.30(0.33)$ \\
\hline eorgia & $29.8(4.7)$ & $48.2(4.4)$ & $34.5(4.6)$ & $13.6(2.6)$ & $46.6(4.7)$ & $10.8(2.7)$ & $1,535(72)$ & $83.9(1.6)$ & $13.02(0.65)$ & $2.99(0.71)$ & $2.21(0.38)$ \\
\hline Hawaii .. & $75.3(5.3)$ & $27.1(4.4)$ & $47.7(5.7)$ & $24.3(4.9)$ & $64.8(4.9)$ & $29.4(5.0)$ & $1,592(100)$ & $83.3(2.6)$ & & $2.77(0.46)$ & $1.59(0.42)$ \\
\hline Idaho & $29.9(4.2)$ & $15.4(4.0)$ & $21.6(4.4)$ & $6.2(2.3)$ & $32.1(5.1)$ & $8.6(3.1)$ & $2,457(289)$ & $86.6(1.9)$ & $12.20(1.24)$ & $2.50(0.63)$ & $1.12(0.24)$ \\
\hline Illinois . & $32.2(3.5)$ & $17.7(3.8)$ & $23.0(3.4)$ & $7.9(1.7)$ & $36.6(4.2)$ & $7.1(2.2)$ & $2,517(264)$ & $85.7(1.8)$ & $13.40(1.34)$ & $4.09(1.48)$ & $1.59(0.19)$ \\
\hline Indiana .. & $29.9(6.7)$ & $31.0(4.9)$ & $32.0(5.9)$ & $2.4(0.7)$ & $66.1(6.3)$ & $5.5(1.2)$ & $2,518(387)$ & $86.2(2.4)$ & $14.40(1.12)$ & $12.45(3.24)$ & $2.20(0.45)$ \\
\hline lowa. & 4) & $17.4(5.0)$ & 7) & 6) & & 8 & 8) & 8) & 3) & 3) & 1) \\
\hline Kansas & 0) & 31.5 & 1) & $9.7(2.0)$ & $46.6(4.5)$ & $10.6(2.5)$ & $3,797(218)$ & $89.1(1.8)$ & $30.85(2.76)$ & $11.16(2.26)$ & $2.93(0.49)$ \\
\hline Kentucky ... & $30.1(6.2)$ & $33.1(7.0)$ & $32.3(5.5)$ & $4.3(2.2)$ & $60.3(6.3)$ & $5.3(2.4)$ & $1,732(110)$ & $84.8(2.3)$ & $15.16(1.08)$ & $2.32(0.51)$ & $2.40(0.31)$ \\
\hline Louisiana . & $24.2(3.9)$ & 13.9 (3.5) & 21.9 (3.4) & $2.3(0.8)$ & 28.1 (3.8) & $6.2(2.4)$ & $1,784(74)$ & 64.8 (3.9) & $16.18(3.82)$ & $1.43(0.42)$ & $0.50(0.08)$ \\
\hline Main & $33.3(5.4)$ & $18.9(4.4)$ & $25.5(3.8)$ & $5.4(2.0)$ & $38.9(6.7)$ & $5.4(1.6)$ & $2,331(169)$ & $89.4(2.7)$ & $17.83(2.74)$ & $2.21(0.58)$ & $0.64(0.16)$ \\
\hline Mar & 9) & 4) & 5) & 22.3 & 7) & 5) & )) & 8) & 3) & 6) & 15) \\
\hline Massachusetts & $38.2(4.9)$ & $9.1(1.6)$ & $45.3(4.8)$ & $8.9(1.6)$ & $46.3(4.8)$ & $24.1(3.8)$ & $2,523(224)$ & $74.8(3.9)$ & $10.14(1.22)$ & $1.50(0.29)$ & $1.77(0.52)$ \\
\hline Michis & $2(7.6)$ & 12.1 (3.9) & ( $(6.3)$ & $10.2(3.8)$ & & & & $4.1)$ & & 55) & $.39)$ \\
\hline Minnesota & $35.6(4.8)$ & $53.4(6.1)$ & $52.9(6.1)$ & $13.8(3.0)$ & $69.0(5.6)$ & $17.3(3.6)$ & $4(253)$ & $86.5(2.8)$ & $22.39(3.60)$ & $6.01(0.96)$ & $4.93(1.70)$ \\
\hline Mississippi ....................... & $9.4(2.0)$ & $5.2(2.1)$ & $14.2(3.9)$ & $3.0(1.4)$ & $23.2(3.6)$ & $3.1(1.3)$ & $1,593(69)$ & $74.6(2.5)$ & $16.26(4.13)$ & $1.58(0.62)$ & $1.30(0.30)$ \\
\hline Missou & $3(4.3)$ & 7) & ) & ) & 9) & 2) & 2,6 & 6) & 4) & 2.8 & 20) \\
\hline Mon & & & & & & & & .3) & & $6.03)$ & .22) \\
\hline Nebraska & $31.6(5.0)$ & $29.0(4.9)$ & $3(5.7)$ & $12.1(2.5)$ & $58.8(6.0)$ & $15.8(3.0)$ & $7,103(817)$ & $90.3(2.7)$ & $41.70(4.30)$ & $23.16(10.55)$ & $13.52(6.68)$ \\
\hline Nevada .................... & $18.4(4.0)$ & $48.2(5.5)$ & $32.2(4.5)$ & $3.0(1.3)$ & $37.1(4.2)$ & $9.4(2.9)$ & $1,827(168)$ & $87.0(1.7)$ & $11.15(1.00)$ & $1.46(0.38)$ & $0.77(0.14)$ \\
\hline New Hampshire ...... & $43.9(6.6)$ & $21.4(4.8)$ & $39.8(6.6)$ & $8.2(2.6)$ & $51.2(5.9)$ & $17.4(4.4)$ & $2,221(182)$ & $87.1(1.8)$ & $18.97(1.75)$ & $2.83(0.86)$ & $1.41(0.24)$ \\
\hline Now de r a & $39.1(6.8)$ & $28.5(6.5)$ & 6.4) & $7.2(1.4)$ & $46.2(7.2)$ & 5.2 & (400) & 3.0) & 3.96) & $3.52(1.37)$ & 38) \\
\hline $\mathrm{Ne}$ & .1) & (5.3) & 4.3) & $3.9(1.5)$ & 5.5) & 7.8 & (223) & $82.9(2.8)$ & 05) & .44) & $0.32)$ \\
\hline New York & $39.5(5.5)$ & $14.3(3.9)$ & $25.2(3.4)$ & $12.5(2.4)$ & $44.8(5.1)$ & $16.0(3.6)$ & $2,207(213)$ & $82.0(3.4)$ & $13.67(1.21)$ & $1.56(0.46)$ & $1.15(0.35)$ \\
\hline North Carolina .. & $40.4(4.6)$ & $29.4(4.0)$ & $42.0(4.3)$ & $10.8(1.7)$ & $65.0(4.1)$ & $7.9(2$ & $1,630(50)$ & $80.8(2.4)$ & $14.19(0.94)$ & $4.39(0.53)$ & $2.10(0.28)$ \\
\hline 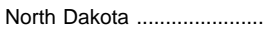 & $65.8(5.3)$ & $18.0(3.6)$ & $27.3(5.1)$ & $39.1(5.7)$ & $41.1(6.5)$ & $36.8(5.5)$ & $6,607(689)$ & $93.0(1.3)$ & $29.45(2.25)$ & $3.77(0.84)$ & $5.02(1.77)$ \\
\hline Ohi & 1) & & & & 1 & & 3 & 3) & & 5) & \\
\hline Oklah & ) & 1 & 5) & 6 & & & 3) & (1.5) & $6(4.69)$ & $(0.60)$ & $7.51(4.23)$ \\
\hline Oregon …………….... & $38.6(5.8)$ & $39.2(5.2)$ & $51.5(6.7)$ & $18.9(4.7)$ & $49.5(6.5)$ & $11.7(4.2)$ & $3,154(362)$ & $84.3(3.2)$ & $21.32(2.14)$ & $7.59(2.49)$ & $2.75(0.86)$ \\
\hline Pen & $33.9(6.9)$ & $17.3(4.0)$ & $32.6(5.5)$ & $2.5(1.1)$ & $39.2(6.4)$ & 6.4 & $2,562(203)$ & $6(2.6)$ & $15.33(2.09)$ & $2.23(0.60)$ & $1.97(0.67)$ \\
\hline Rhode Island ... & $25.0(4.9)$ & $11.8(3.2)$ & $13.0(3.5)$ & $1.0(0.6)$ & $21.7(4.8)$ & $18.6(4.2)$ & $1,835(232)$ & $84.0(2.5)$ & $8.58(1.51)$ & $0.23(0.10)$ & $0.34(0.14)$ \\
\hline Sol & 1 & & & & & & & & & & \\
\hline South $\mathrm{D}$ & $56.2(6.8)$ & $12.6(3.4)$ & $37.7(6.2)$ & $23.1(4.2)$ & $60.2(5.5)$ & $9.0(2.7)$ & $5,049(542)$ & $89.8(2.0)$ & $45.53(5.37)$ & $8.26(1.61)$ & $3.73(1.41)$ \\
\hline Tennessee & $15.1(4.3)$ & $18.9(5.1)$ & $16.6(4.5)$ & $2.5(2.3)$ & $34.9(6.5)$ & $3.6(1.9)$ & $1,677(102)$ & $85.4(2.2)$ & $8.60(0.68)$ & $2.65(1.04)$ & $0.91(0.20)$ \\
\hline Texas & $39.4(4.6)$ & $20.5(4.2)$ & $27.2(3.1)$ & $9.9(2.8)$ & $33.9(3.8)$ & $24.7(4.2)$ & $1,885(123)$ & $83.3(2.0)$ & $18.94(1.79)$ & $3.75(1.18)$ & $2.95(0.40)$ \\
\hline Utah & $22.2(3.6)$ & $37.4(4.1)$ & $28.6(3.6)$ & $5.1(2.3)$ & 39.1 (3.6) & $6.7(1.9)$ & $1,557(105)$ & $79.5(2.2)$ & $9.08(0.95)$ & $1.62(0.26)$ & $1.82(0.32)$ \\
\hline Vern & $47.0(4.9)$ & 2 & & 1 & & 3 & & & & $.57)$ & $(0.52)$ \\
\hline Virgini & $61.7(8.3)$ & $35.5(6.1)$ & $38.6(5.8)$ & $10.6(2.9)$ & $72.4(7.0)$ & $31.4(5.6)$ & $1,974(108)$ & $88.2(2.2)$ & $15.20(1.09)$ & $3.48(0.66)$ & $3.71(1.01)$ \\
\hline Washington & $40.2(5.2)$ & $35.7(5.6)$ & 43.1 (3.6) & $11.7(2.9)$ & $53.1(4.9)$ & $13.0(2.6)$ & $2,004(84)$ & $89.7(1.3)$ & $14.70(1.27)$ & $3.34(0.69)$ & $1.52(0.29)$ \\
\hline West & $24.7(6.0)$ & $16.7(4.2)$ & $18.0(4.0)$ & $8.3(3.5)$ & $31.0(5.5)$ & $6.4(3.2)$ & $2,039(201)$ & $76.0(4.7)$ & $7.37(1.41)$ & $0.77(0.25)$ & $0.17(2)$ \\
\hline Wisconsin & $34.2(6.5)$ & $27.2(4.7)$ & $36.1(5.0)$ & $14.8(3.8)$ & $57.1(6.1)$ & $9.0(2.6)$ & 2,895 (157) & $86.5(2.8)$ & $23.99(1.18)$ & $5.40(1.55)$ & $4.10(0.74)$ \\
\hline 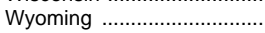 & $39.0(3.4)$ & $28.0(4.2)$ & $32.1(5.7)$ & $8.1(2.5)$ & $41.7(4.5)$ & $6.6(2.3)$ & $10,729(1,185)$ & $83.5(3.4)$ & $46.04(5.36)$ & $3.23(0.59)$ & $3.92(0.85)$ \\
\hline
\end{tabular}

${ }^{1}$ During the most recent full week of school.

NOTE.-Percentages are based on schools that have library/media centers. In school year 1990-91, 96 percent of public schools had library media centers. Standard errors appear in parentheses.
SOURCE: U.S. Department of Education, National Center for Education Statistics, Schools and Staffing Survey, 1993-94, unpublished data. (This table was prepared August 1997.) 
Table 418.-Percent of public and private schools having access to selected telecommunication capabilities, by location of access site and control of school: 1995

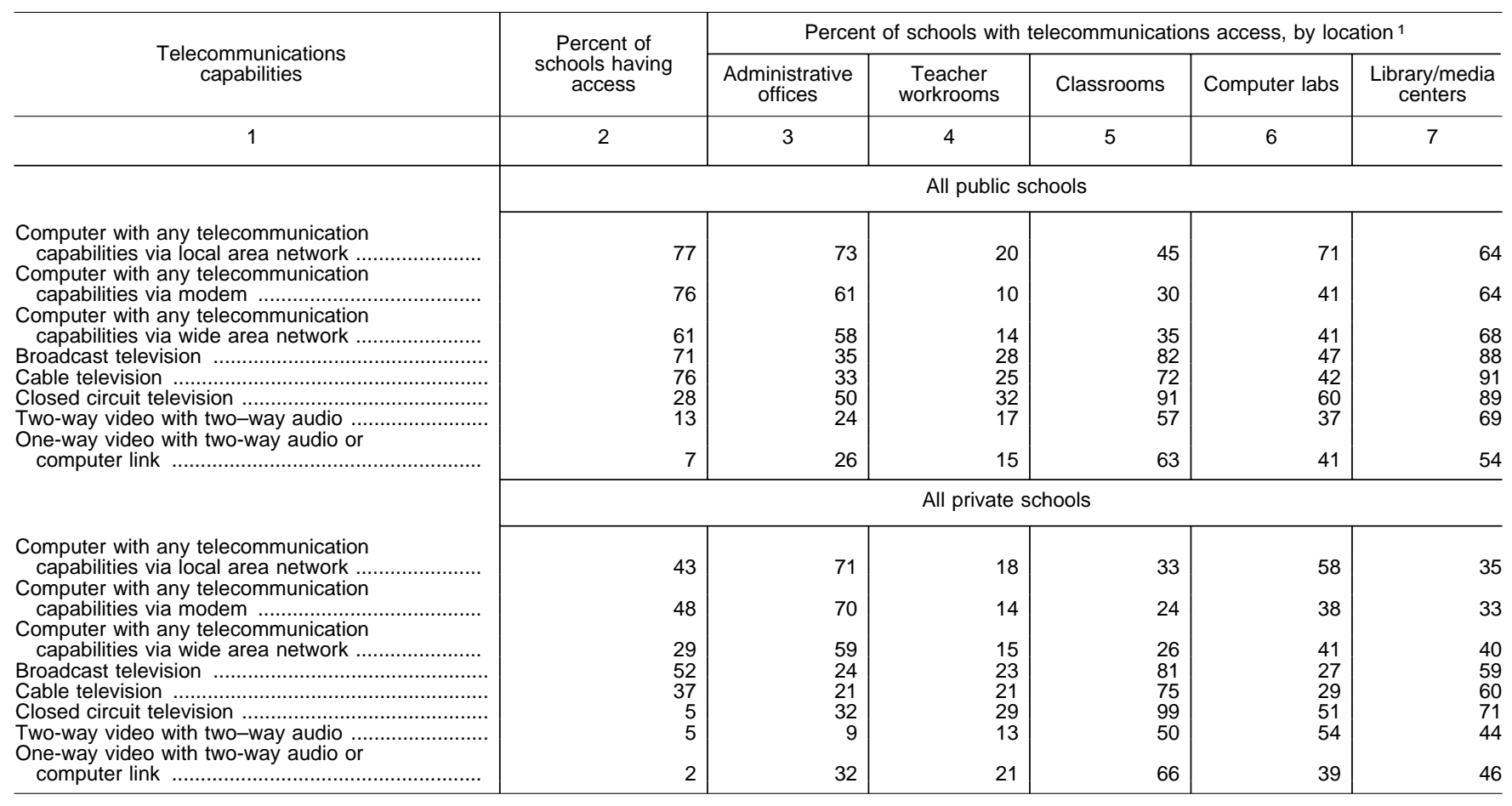

${ }^{1}$ Location estimates are based on those schools having access to each type of telecommunication capability. Percents of schools reporting telecommunication locations do not sum to 100 because many schools have access in more than one location.

NOTE.-Data are derived from a sample survey and are subject to sampling error.
SOURCE: U.S. Department of Education, National Center for Education Statistics, Fast Response Survey System, Advanced Telecommunications in U.S. Public Elementary and Secondary Schools, 1995; and Advanced Telecommunications in U.S. Private Schools, K-12, Fall 1995. (This table was prepared September 1997.) 
Table 419.-Percent of public schools and school classrooms having access to the Internet, by school characteristics: 1994 to 1998

\begin{tabular}{|c|c|c|c|c|c|c|c|c|c|c|c|c|c|c|}
\hline \multirow{2}{*}{$\begin{array}{l}\text { Schools, computers, } \\
\text { instruction rooms, and } \\
\text { access }\end{array}$} & \multirow{2}{*}{$\begin{array}{c}\text { All } \\
\text { public } \\
\text { schools }\end{array}$} & \multicolumn{2}{|c|}{ Instructional level ${ }^{1}$} & \multicolumn{3}{|c|}{ Size of school enrollment } & \multicolumn{4}{|c|}{ Metropolitan status } & \multicolumn{4}{|c|}{$\begin{array}{l}\text { Percent of students eligible for free or } \\
\text { reduced-price lunch }\end{array}$} \\
\hline & & Elementary & Secondary & $\begin{array}{l}\text { Less } \\
\text { than } \\
300\end{array}$ & $\begin{array}{c}300 \text { to } \\
999\end{array}$ & $\begin{array}{l}1,000 \text { or } \\
\text { more }\end{array}$ & City & $\begin{array}{l}\text { Urban } \\
\text { fringe }\end{array}$ & Town & Rural & $\begin{array}{l}\text { Less } \\
\text { than } 11 \\
\text { percent }\end{array}$ & $\begin{array}{l}11 \text { to } \\
30 \\
\text { percent }\end{array}$ & $\begin{array}{c}31 \text { to } \\
70 \\
\text { percent }\end{array}$ & $\begin{array}{c}71 \\
\text { percent } \\
\text { or more }\end{array}$ \\
\hline 1 & 2 & 3 & 4 & 5 & 6 & 7 & 8 & 9 & 10 & 11 & 12 & 13 & 14 & 15 \\
\hline \multicolumn{15}{|l|}{$\begin{array}{l}\text { Estimated number of } \\
\text { schools }\end{array}$} \\
\hline 1995 & 77,853 & 57,705 & 18,083 & 20,673 & 50,044 & 7,136 & 17,906 & 18,464 & 19,539 & 21,944 & 13,192 & 21,876 & 28,017 & 14,651 \\
\hline $\begin{array}{l}1997 \\
\text { Percent of schools having } \\
\text { access to the Internet }\end{array}$ & 79,125 & 59,695 & 19,430 & 20,540 & 51,169 & 7,416 & 21,071 & 23,419 & 12,637 & 21,998 & 10,677 & 21,686 & 32,666 & 14,097 \\
\hline 1994 & 35 & 30 & 49 & 30 & 35 & 58 & 40 & 38 & 29 & 35 & - & - & - & \\
\hline 1995 & 50 & 46 & 65 & 39 & 52 & 69 & 47 & 59 & 47 & 48 & 62 & 59 & 47 & 31 \\
\hline 1996 & 65 & 61 & 77 & 57 & 66 & 80 & 64 & 75 & 61 & 60 & 78 & 72 & 58 & 53 \\
\hline 1997 & 78 & 75 & 89 & 75 & 78 & 89 & 74 & 78 & 84 & 79 & 88 & 83 & 78 & 63 \\
\hline $\begin{array}{c}\text { Number of computers, } \\
\text { in thousands }\end{array}$ & 89 & 88 & 94 & 87 & 89 & 95 & 92 & 85 & 90 & 92 & 87 & 94 & 91 & 80 \\
\hline $1995^{2}$ & 5,621 & 3,453 & 2,021 & 850 & 3,600 & 1,171 & 1,497 & 1,526 & 1,404 & 1,195 & 1,017 & 1,712 & 1,919 & 951 \\
\hline 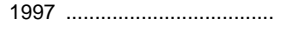 & 5,959 & 3,701 & 2,258 & 839 & 3,767 & 1,353 & 1,727 & 2,084 & 934 & 1,214 & 1,008 & 1,782 & 2,211 & 959 \\
\hline \multicolumn{15}{|l|}{$\begin{array}{l}\text { Mean number of computers } \\
\text { per school }\end{array}$} \\
\hline 1995 & 72 & 60 & 112 & 41 & 72 & 164 & 84 & 83 & 72 & 54 & 77 & 78 & 68 & 65 \\
\hline 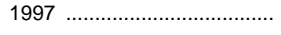 & 75 & 62 & 116 & 41 & 74 & 183 & 82 & 89 & 74 & 55 & 94 & 82 & 68 & 68 \\
\hline \multicolumn{15}{|l|}{$\begin{array}{l}\text { Number of computers } \\
\text { with Internet access, } \\
\text { in thousands }\end{array}$} \\
\hline 1995 & 448 & 232 & 187 & 59 & 315 & 73 & 96 & 131 & 126 & 94.279 & 111 & 163 & 123 & 39 \\
\hline $\begin{array}{l}\text { Percent of all computers } \\
\text { with access to the Internet }\end{array}$ & & & & & & & & & & & & & & \\
\hline 1995 & 8 & 7 & 9 & 7 & 9 & 6 & 6 & 9 & 9 & 8 & 11 & 10 & 6 & \\
\hline $\begin{array}{l}\text { Number of instructional } \\
\text { rooms, }{ }^{3} \text { in thousands. }\end{array}$ & & & & & & & & & & & & & & \\
\hline 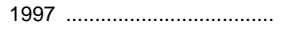 & 2,625 & 1,720 & 906 & 335 & 1,725 & 566 & 830 & 902 & 388 & 505 & 412 & 758 & 976 & 480 \\
\hline $\begin{array}{c}\text { Percent of instructional } \\
\text { rooms }{ }^{3} \text { with access to } \\
\text { the Internet }\end{array}$ & & & & & & & & & & & & & & \\
\hline $\begin{array}{l}1994 \\
1995\end{array}$ & $\begin{array}{l}3 \\
8\end{array}$ & $\begin{array}{l}3 \\
8\end{array}$ & $\begin{array}{l}4 \\
8\end{array}$ & $\begin{array}{l}3 \\
9\end{array}$ & $\begin{array}{l}3 \\
8\end{array}$ & $\begin{array}{l}3 \\
4\end{array}$ & $\begin{array}{l}4 \\
6\end{array}$ & $\begin{array}{l}4 \\
8\end{array}$ & $\begin{array}{l}3 \\
8\end{array}$ & $\begin{array}{l}3 \\
8\end{array}$ & $\overline{9}$ & $\overline{10}$ & $\overline{7}$ & - \\
\hline 1996 & 14 & 13 & 16 & 15 & 13 & 16 & 12 & $\begin{array}{r}0 \\
16\end{array}$ & 14 & 14 & 18 & 16 & 14 & \\
\hline 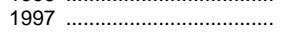 & 27 & 24 & 32 & 27 & 28 & 25 & 20 & 29 & 34 & 30 & 36 & 32 & 27 & 14 \\
\hline 1998 & 51 & 51 & 52 & 54 & 53 & 45 & 47 & 50 & 55 & 57 & 62 & 53 & 52 & 39 \\
\hline
\end{tabular}

${ }_{1}^{1}$ Excludes combined elementary/secondary schools because of small sample size. 2 Includes computers used for instructional or administrative purposes.

SOURCE: U.S. Department of Education, National Center for Education Statistics, 3 Includes all classrooms, computer labs, and library/media centers.

-Data not available. Fast Response Survey System, Internet Access in Public Schools and Classrooms: rooms: 1994-98; and Advanced Telecommunications in U.S. Public Elementary and

NOTE.-Data are derived from sample surveys and are subject to sampling error. Derooms: 1994-98; and Advanced Telecommunications in U.S. Public Elementary and
Secondary Schools, 1995; and unpublished data. (This table was prepared March 1999.) tails may not add to totals because of rounding of weighted estimates. 
Table 420.-General statistics of college and university libraries: 1974-75 to 1994-95

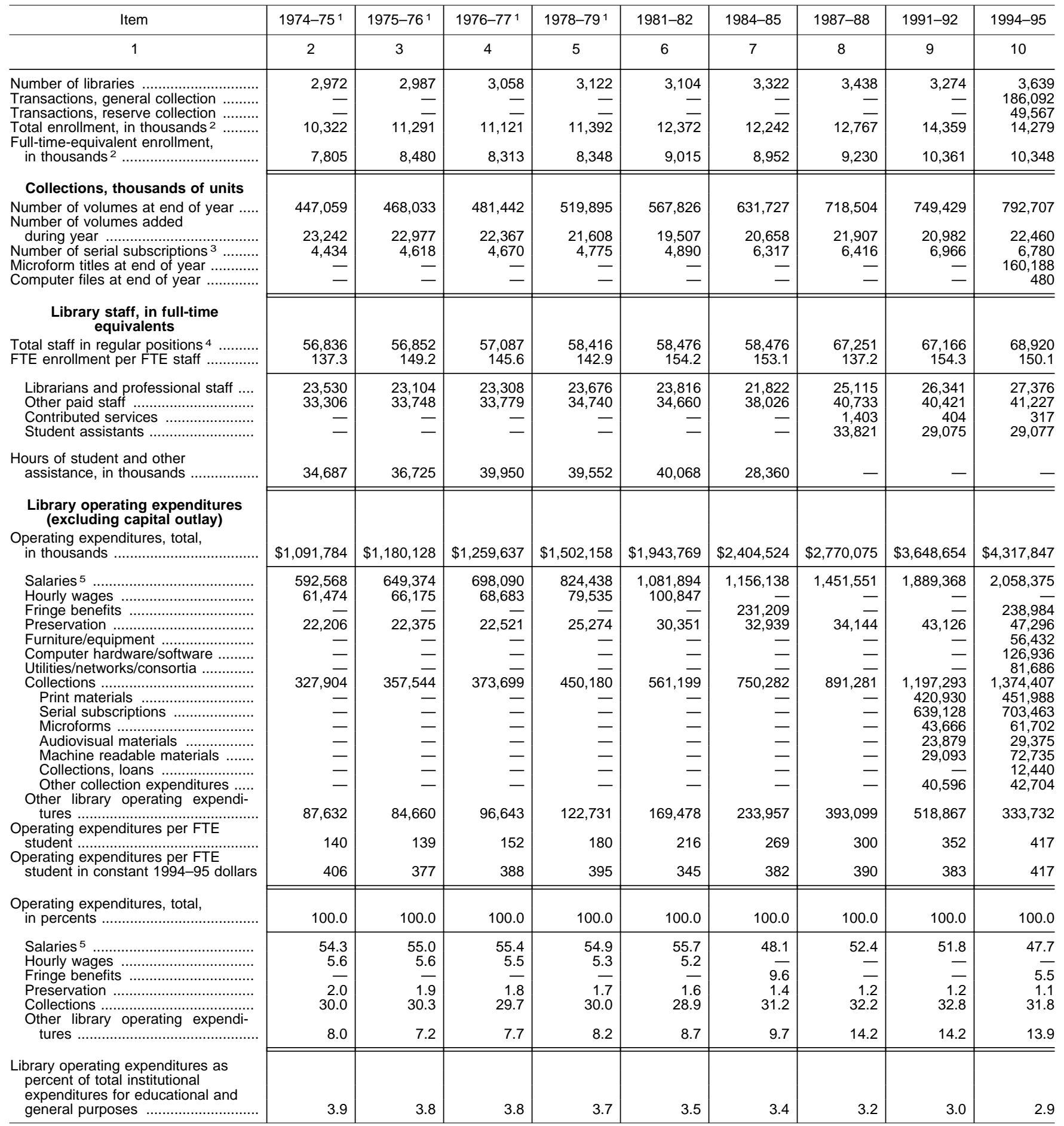

1 Includes data for U.S. territories.

${ }^{2}$ Fall enrollment for the academic year specified.

3 Data are for end of year.

${ }^{4}$ Excludes student assistants.

5 Includes expenditures for fringe benefits (except for 1984-85 and 1987-88) and salary equivalents of contributed services staff.

-Data not available.
NOTE.-Because of rounding, details may not add to totals.

SOURCE: U.S. Department of Education, National Center for Education Statistics, Library Statistics of Colleges and Universities, various years; and Integrated Postsecondary Education Data System, "Academic Library Survey." (This table was prepared July 1997.) 
Table 421.-Selected statistics on the collections, staff, and operating expenditures of 60 large college and university libraries: 1994

\begin{tabular}{|c|c|c|c|c|c|c|c|c|c|}
\hline \multirow[b]{2}{*}{ Institution } & \multirow{2}{*}{$\begin{array}{l}\text { Rank } \\
\text { order, by } \\
\text { number } \\
\text { of vol- } \\
\text { umes }\end{array}$} & \multirow{2}{*}{$\begin{array}{l}\text { Number } \\
\text { of vol- } \\
\text { umes at } \\
\text { end of } \\
\text { year, in } \\
\text { thou- } \\
\text { sands }\end{array}$} & \multicolumn{2}{|c|}{$\begin{array}{c}\text { Full-time-equivalent } \\
\text { staff }\end{array}$} & \multicolumn{2}{|c|}{$\begin{array}{l}\text { Operating expendi- } \\
\text { tures, in thousands }\end{array}$} & \multirow{2}{*}{$\begin{array}{c}\text { Public } \\
\text { service } \\
\text { hours per } \\
\text { week }\end{array}$} & \multirow{2}{*}{$\begin{array}{l}\text { Gate } \\
\text { count per } \\
\text { week }\end{array}$} & \multirow{2}{*}{$\begin{array}{l}\text { Ref- } \\
\text { erence } \\
\text { trans- } \\
\text { actions } \\
\text { per week }\end{array}$} \\
\hline & & & Total & $\begin{array}{l}\text { Profes- } \\
\text { sional }\end{array}$ & Total & $\begin{array}{c}\text { Salaries } \\
\text { and } \\
\text { wages }\end{array}$ & & & \\
\hline 1 & 2 & 3 & 4 & 5 & 6 & 7 & 8 & 9 & 10 \\
\hline 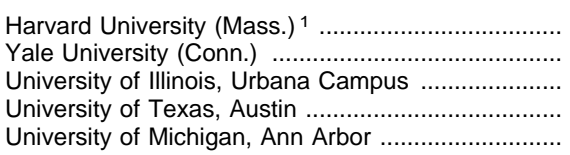 & $\begin{array}{l}1 \\
2 \\
3 \\
4 \\
5\end{array}$ & $\begin{array}{r}12,395 \\
10,503 \\
8,475 \\
7,020 \\
6,664\end{array}$ & $\begin{array}{r}1,096 \\
623 \\
513 \\
643 \\
590\end{array}$ & $\begin{array}{l}363 \\
191 \\
152 \\
144 \\
140\end{array}$ & $\begin{array}{r}\$ 54,451 \\
38,333 \\
21,535 \\
22,387 \\
30,521\end{array}$ & $\begin{array}{r}\$ 29,467 \\
16,254 \\
10,704 \\
12,517 \\
13,424\end{array}$ & $\begin{array}{r}95 \\
90 \\
94 \\
107 \\
99\end{array}$ & $\begin{array}{r}\left({ }^{2}\right) \\
\left({ }^{2}\right) \\
\left({ }^{2}\right) \\
170,346 \\
(2)\end{array}$ & $\begin{array}{r}\left({ }^{2}\right) \\
\left({ }^{2}\right) \\
13,516 \\
13,664 \\
\left({ }^{2}\right)\end{array}$ \\
\hline 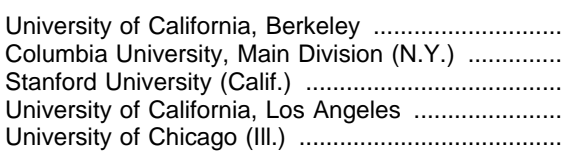 & $\begin{array}{r}6 \\
7 \\
8 \\
9 \\
10\end{array}$ & $\begin{array}{l}6,654 \\
6,532 \\
6,409 \\
6,306 \\
5,710\end{array}$ & $\begin{array}{l}543 \\
568 \\
555 \\
560 \\
362\end{array}$ & $\begin{array}{r}132 \\
170 \\
162 \\
126 \\
75\end{array}$ & $\begin{array}{l}32,954 \\
27,916 \\
36,203 \\
27,313 \\
18,124\end{array}$ & $\begin{array}{r}16,696 \\
14,768 \\
18,658 \\
13,141 \\
8,781\end{array}$ & $\begin{array}{r}82 \\
103 \\
49 \\
87 \\
109\end{array}$ & $\begin{array}{r}\left({ }^{2}\right) \\
(2) \\
(2) \\
79,871 \\
24,370\end{array}$ & $\begin{array}{r}\left({ }^{2}\right) \\
\left({ }^{2}\right) \\
\left({ }^{2}\right) \\
12,996 \\
1,407\end{array}$ \\
\hline 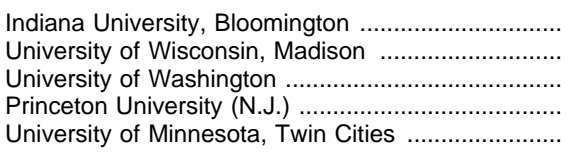 & $\begin{array}{l}11 \\
12 \\
13 \\
14 \\
15\end{array}$ & $\begin{array}{l}5,554 \\
5,536 \\
5,355 \\
5,186 \\
5,101\end{array}$ & $\begin{array}{l}471 \\
533 \\
485 \\
400 \\
446\end{array}$ & $\begin{array}{l}142 \\
150 \\
130 \\
121 \\
104\end{array}$ & $\begin{array}{l}22,761 \\
25,320 \\
23,846 \\
23,608 \\
23,870\end{array}$ & $\begin{array}{l}11,400 \\
13,245 \\
12,704 \\
11,556 \\
11,883\end{array}$ & $\begin{array}{l}101 \\
131 \\
104 \\
120 \\
122\end{array}$ & $\begin{array}{r}\left({ }^{2}\right) \\
129,254 \\
(2) \\
\left({ }^{2}\right) \\
\left({ }^{2}\right)\end{array}$ & $\begin{array}{r}15,644 \\
10,314 \\
\left({ }^{2}\right) \\
\left({ }^{2}\right) \\
6,450\end{array}$ \\
\hline 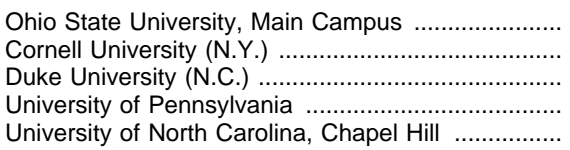 & $\begin{array}{l}16 \\
17 \\
18 \\
19 \\
20\end{array}$ & $\begin{array}{l}4,786 \\
4,705 \\
4,330 \\
4,210 \\
4,155\end{array}$ & $\begin{array}{l}409 \\
458 \\
330 \\
376 \\
430\end{array}$ & $\begin{array}{l}103 \\
134 \\
104 \\
108 \\
122\end{array}$ & $\begin{array}{l}19,772 \\
20,415 \\
20,929 \\
21,498 \\
20,668\end{array}$ & $\begin{array}{r}9,304 \\
9,768 \\
8,619 \\
10,200 \\
10,006\end{array}$ & $\begin{array}{r}168 \\
79 \\
113 \\
137 \\
110\end{array}$ & $\begin{array}{r}50,616 \\
(2) \\
(2) \\
51,923 \\
(2)\end{array}$ & $\begin{array}{r}18,926 \\
4,818 \\
3,734 \\
8,433 \\
6,401\end{array}$ \\
\hline $\begin{array}{l}\text { University of Arizona } \\
\text { University of Virginia, Main Campus } \\
\text { Michigan State University } \\
\text { University of lowa } \\
\text { New York University }\end{array}$ & $\begin{array}{l}21 \\
22 \\
23 \\
24 \\
25\end{array}$ & $\begin{array}{l}4,126 \\
4,059 \\
3,904 \\
3,567 \\
3,335\end{array}$ & $\begin{array}{l}361 \\
353 \\
290 \\
304 \\
440\end{array}$ & $\begin{array}{r}84 \\
92 \\
64 \\
94 \\
140\end{array}$ & $\begin{array}{l}17,171 \\
17,011 \\
13,369 \\
15,095 \\
24,418\end{array}$ & $\begin{array}{r}7,272 \\
8,157 \\
6,871 \\
7,250 \\
11,889\end{array}$ & $\begin{array}{l}158 \\
111 \\
109 \\
107 \\
115\end{array}$ & $\begin{array}{r}55,783 \\
(2) \\
(2) \\
(2) \\
50,000\end{array}$ & $\begin{array}{r}4,068 \\
3,400 \\
(2) \\
(2) \\
6,000\end{array}$ \\
\hline 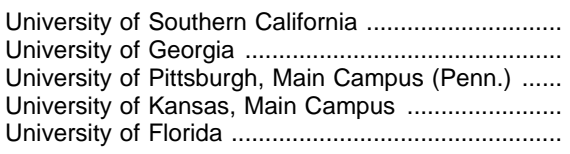 & $\begin{array}{l}26 \\
27 \\
28 \\
29 \\
30\end{array}$ & $\begin{array}{l}3,248 \\
3,216 \\
3,201 \\
3,117 \\
3,092\end{array}$ & $\begin{array}{l}346 \\
317 \\
379 \\
282 \\
400\end{array}$ & $\begin{array}{r}107 \\
83 \\
95 \\
88 \\
110\end{array}$ & $\begin{array}{l}17,794 \\
14,455 \\
18,671 \\
11,760 \\
15,780\end{array}$ & $\begin{array}{l}9,061 \\
6,534 \\
7,689 \\
5,420 \\
8,553\end{array}$ & $\begin{array}{r}168 \\
114 \\
121 \\
100 \\
74\end{array}$ & $\begin{array}{r}6,433 \\
26,398 \\
42,017 \\
(2) \\
187,737\end{array}$ & $\begin{array}{r}5,731 \\
2,775 \\
6,203 \\
(2) \\
15,000\end{array}$ \\
\hline 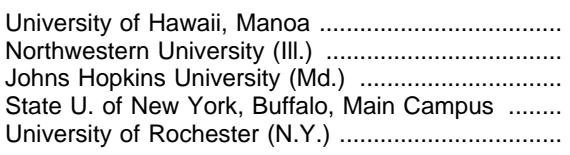 & $\begin{array}{l}31 \\
32 \\
33 \\
34 \\
35\end{array}$ & $\begin{array}{l}2,942 \\
2,932 \\
2,874 \\
2,864 \\
2,843\end{array}$ & $\begin{array}{l}258 \\
315 \\
281 \\
257 \\
218\end{array}$ & $\begin{array}{l}74 \\
84 \\
81 \\
91 \\
69\end{array}$ & $\begin{array}{r}13,203 \\
12,663 \\
16,853 \\
12,681 \\
9,841\end{array}$ & $\begin{array}{l}7,277 \\
6,422 \\
6,771 \\
6,554 \\
4,377\end{array}$ & $\begin{array}{r}106 \\
119 \\
123 \\
90 \\
97\end{array}$ & $\begin{array}{l}55,620 \\
22,401 \\
15,219 \\
69,700 \\
17,385\end{array}$ & $\begin{array}{r}3,165 \\
2,727 \\
1,579 \\
6,215 \\
635\end{array}$ \\
\hline 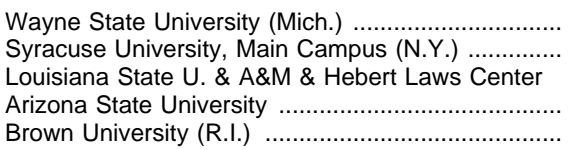 & $\begin{array}{l}36 \\
37 \\
38 \\
39 \\
40\end{array}$ & $\begin{array}{l}2,834 \\
2,779 \\
2,778 \\
2,777 \\
2,710\end{array}$ & $\begin{array}{l}261 \\
251 \\
201 \\
314 \\
264\end{array}$ & $\begin{array}{l}79 \\
70 \\
48 \\
86 \\
79\end{array}$ & $\begin{array}{r}12,938 \\
9,435 \\
9,444 \\
14,053 \\
13,028\end{array}$ & $\begin{array}{l}6,023 \\
4,910 \\
4,466 \\
6,892 \\
5,746\end{array}$ & $\begin{array}{r}97 \\
105 \\
99 \\
97 \\
111\end{array}$ & $\begin{array}{r}46,709 \\
23,318 \\
(2) \\
6,000 \\
25,329\end{array}$ & $\begin{array}{l}9,649 \\
2,193 \\
3,400 \\
5,260 \\
2,019\end{array}$ \\
\hline 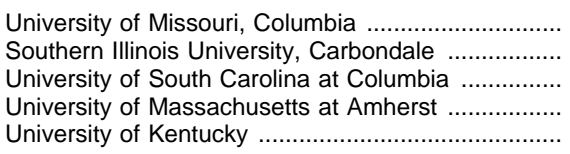 & $\begin{array}{l}41 \\
42 \\
43 \\
44 \\
45\end{array}$ & $\begin{array}{l}2,684 \\
2,648 \\
2,639 \\
2,604 \\
2,557\end{array}$ & $\begin{array}{l}248 \\
215 \\
236 \\
189 \\
325\end{array}$ & $\begin{array}{l}58 \\
42 \\
69 \\
51 \\
78\end{array}$ & $\begin{array}{r}10,166 \\
9,508 \\
10,549 \\
10,432 \\
11,652\end{array}$ & $\begin{array}{l}4,444 \\
4,453 \\
5,008 \\
5,493 \\
5,950\end{array}$ & $\begin{array}{r}105 \\
92 \\
111 \\
95 \\
146\end{array}$ & $\begin{array}{l}42,000 \\
22,974 \\
39,392 \\
28,892 \\
47,034\end{array}$ & $\begin{array}{l}2,503 \\
2,660 \\
5,110 \\
3,137 \\
8,876\end{array}$ \\
\hline 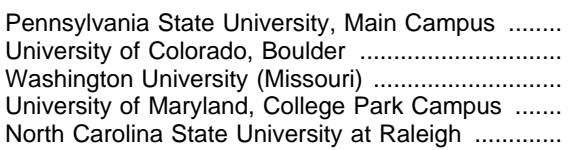 & $\begin{array}{l}46 \\
47 \\
48 \\
49 \\
50\end{array}$ & $\begin{array}{l}2,541 \\
2,504 \\
2,476 \\
2,454 \\
2,399\end{array}$ & $\begin{array}{l}419 \\
249 \\
188 \\
464 \\
244\end{array}$ & $\begin{array}{r}84 \\
62 \\
52 \\
104 \\
63\end{array}$ & $\begin{array}{l}18,067 \\
13,512 \\
10,355 \\
14,473 \\
11,937\end{array}$ & $\begin{array}{l}9,558 \\
5,841 \\
4,039 \\
7,538 \\
4,943\end{array}$ & $\begin{array}{l}168 \\
107 \\
102 \\
126 \\
107\end{array}$ & $\begin{array}{l}65,231 \\
74,629 \\
16,811 \\
72,844 \\
39,954\end{array}$ & $\begin{array}{r}8,426 \\
5,029 \\
5,292 \\
12,636 \\
3,109\end{array}$ \\
\hline 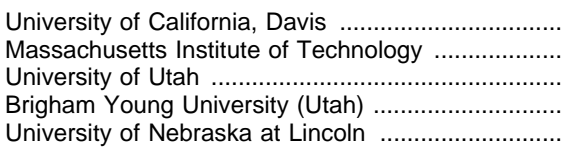 & $\begin{array}{l}51 \\
52 \\
53 \\
54 \\
55\end{array}$ & $\begin{array}{l}2,391 \\
2,366 \\
2,350 \\
2,326 \\
2,324\end{array}$ & $\begin{array}{l}306 \\
226 \\
319 \\
291 \\
221\end{array}$ & $\begin{array}{r}65 \\
85 \\
65 \\
100 \\
56\end{array}$ & $\begin{array}{r}13,132 \\
11,771 \\
12,856 \\
12,421 \\
9,445\end{array}$ & $\begin{array}{l}7,066 \\
6,072 \\
5,713 \\
5,877 \\
4,339\end{array}$ & $\begin{array}{r}87 \\
100 \\
100 \\
101 \\
108\end{array}$ & $\begin{array}{l}20,167 \\
30,000 \\
32,672 \\
73,668 \\
18,556\end{array}$ & $\begin{array}{r}4,939 \\
3,000 \\
1,307 \\
13,231 \\
1,243\end{array}$ \\
\hline 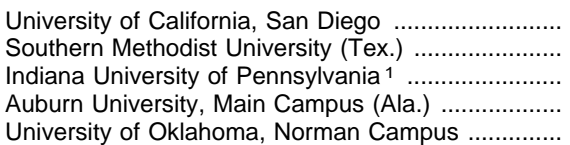 & $\begin{array}{l}56 \\
57 \\
58 \\
59 \\
60\end{array}$ & $\begin{array}{l}2,297 \\
2,240 \\
2,236 \\
2,234 \\
2,225\end{array}$ & $\begin{array}{l}335 \\
159 \\
232 \\
191 \\
149\end{array}$ & $\begin{array}{l}81 \\
50 \\
60 \\
51 \\
42\end{array}$ & $\begin{array}{r}15,078 \\
7,752 \\
10,707 \\
8,911 \\
6,957\end{array}$ & $\begin{array}{l}8,166 \\
3,737 \\
5,111 \\
3,733 \\
2,862\end{array}$ & $\begin{array}{r}100 \\
116 \\
104 \\
99 \\
97\end{array}$ & $\begin{array}{r}43,753 \\
\left({ }^{2}\right) \\
\left({ }^{2}\right) \\
24,714 \\
30,402\end{array}$ & $\begin{array}{r}3,333 \\
2,500 \\
(2) \\
3,999 \\
4,017\end{array}$ \\
\hline
\end{tabular}

1 Data estimated based on previous year's report.

2 Data not available.
SOURCE: U.S. Department of Education, National Center for Education Statistics, Integrated Postsecondary Education Data System, 1994 Academic Library Survey. (This table was prepared July 1997 . 
Table 422.-General statistics of public libraries, by population of legal service area: 1995

\begin{tabular}{|c|c|c|c|c|c|c|c|}
\hline \multirow[b]{2}{*}{ Item } & \multicolumn{7}{|c|}{ Population of legal service area } \\
\hline & Total & Under 10,000 & $\begin{array}{c}10,000 \text { to } \\
49,999\end{array}$ & $\begin{array}{l}50,000 \text { to } \\
99,999\end{array}$ & $\begin{array}{c}100,000 \text { to } \\
249,999\end{array}$ & $\begin{array}{c}250,000 \text { to } \\
499,999\end{array}$ & $\begin{array}{l}500,000 \text { and } \\
\text { over }\end{array}$ \\
\hline 1 & 2 & 3 & 4 & 5 & 6 & 7 & 8 \\
\hline $\begin{array}{l}\text { Number of public library service } \\
\text { outlets }\end{array}$ & 16,972 & 5,795 & 4,110 & 1,793 & 2,085 & 1,138 & 2,051 \\
\hline $\begin{array}{l}\text { Central libraries } \\
\text { Branch libraries } \\
\text { Bookmobiles }\end{array}$ & $\begin{array}{r}8,937 \\
7,057 \\
978\end{array}$ & $\begin{array}{r}5,465 \\
255 \\
75\end{array}$ & $\begin{array}{r}2,504 \\
1,265 \\
341\end{array}$ & $\begin{array}{r}493 \\
1,094 \\
206\end{array}$ & $\begin{array}{r}324 \\
1,582 \\
179\end{array}$ & $\begin{array}{r}81 \\
982 \\
75\end{array}$ & $\begin{array}{r}70 \\
1,879 \\
102\end{array}$ \\
\hline 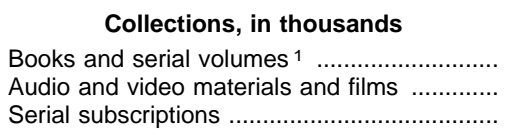 & $\begin{array}{r}695,331 \\
35,715 \\
1,837\end{array}$ & $\begin{array}{r}96,675 \\
3,477 \\
272\end{array}$ & $\begin{array}{r}169,876 \\
8,345 \\
482\end{array}$ & $\begin{array}{r}84,203 \\
4,400 \\
225\end{array}$ & $\begin{array}{r}98,539 \\
5,304 \\
237\end{array}$ & $\begin{array}{r}73,450 \\
3,305 \\
169\end{array}$ & $\begin{array}{r}172,587 \\
10,884 \\
450\end{array}$ \\
\hline 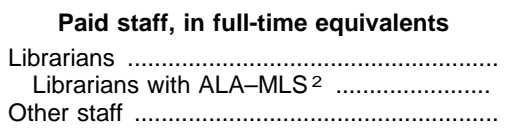 & $\begin{array}{l}38,694 \\
26,636 \\
77,140\end{array}$ & $\begin{array}{l}5,639 \\
1,069 \\
5,087\end{array}$ & $\begin{array}{r}9,840 \\
6,067 \\
18,408\end{array}$ & $\begin{array}{r}4,561 \\
3,448 \\
10,502\end{array}$ & $\begin{array}{r}5,370 \\
4,296 \\
12,918\end{array}$ & $\begin{array}{l}4,028 \\
3,248 \\
8,527\end{array}$ & $\begin{array}{r}9,256 \\
8,508 \\
21,698\end{array}$ \\
\hline $\begin{array}{l}\text { Income, in thousands } \\
\text { Total operating income }\end{array}$ & $\$ 5,594,069$ & $\$ 377,585$ & $\$ 1,281,141$ & $\$ 705,908$ & $\$ 884,573$ & $\$ 658,645$ & $\$ 1,686,216$ \\
\hline & \multicolumn{7}{|c|}{ Percentage distribution } \\
\hline $\begin{array}{l}\quad \text { Source of operating income } \\
\quad \text { Total } \\
\text { Federal }{ }^{3} \\
\text { State } \\
\text { Local }\end{array}$ & $\begin{array}{r}100.0 \\
1.0 \\
12.0 \\
78.3 \\
8.7\end{array}$ & $\begin{array}{r}100.0 \\
1.3 \\
9.6 \\
73.1 \\
16.0\end{array}$ & $\begin{array}{r}100.0 \\
0.9 \\
10.9 \\
79.2 \\
9.0\end{array}$ & $\begin{array}{r}100.0 \\
0.8 \\
13.8 \\
78.3 \\
7.2\end{array}$ & $\begin{array}{r}100.0 \\
1.0 \\
9.8 \\
82.8 \\
6.3\end{array}$ & $\begin{array}{r}100.0 \\
1.2 \\
10.4 \\
82.4 \\
6.0\end{array}$ & $\begin{array}{r}100.0 \\
1.0 \\
14.5 \\
74.6 \\
9.8\end{array}$ \\
\hline
\end{tabular}

1 Some data are different from other tables due to a different population base.

${ }^{2}$ ALA-MLS $=$ A master's degree from a graduate library education program accredited by the American Library Association (ALA).

${ }^{3}$ Excludes some federal funds received through state library agencies.
NOTE.-Because of rounding, details may not add to totals. Totals may be underestimated due to nonresponse on item or legal service area.

SOURCE: U.S. Department of Education, National Center for Education Statistics, Public Libraries in the United States: FY 1995. (This table was prepared October 1998.)

Table 423.-Public libraries, books and serial volumes, library visits, and reference transactions, by state: 1995

\begin{tabular}{|c|c|c|c|c|c|c|c|c|c|c|c|c|c|}
\hline State & $\begin{array}{l}\text { Number } \\
\text { of } \\
\text { public } \\
\text { libraries }\end{array}$ & $\begin{array}{c}\text { Number of } \\
\text { books and } \\
\text { serial } \\
\text { volumes }{ }^{1} \\
\text { (in thou- } \\
\text { sands) }\end{array}$ & $\begin{array}{l}\text { Number } \\
\text { of books } \\
\text { and } \\
\text { serial } \\
\text { volumes } \\
\text { per } \\
\text { capita }\end{array}$ & $\begin{array}{c}\text { Library } \\
\text { visits per } \\
\text { capita }^{2}\end{array}$ & $\begin{array}{l}\text { Circula- } \\
\text { tion } \\
\text { per } \\
\text { capita }\end{array}$ & \begin{tabular}{|c|} 
Public \\
library \\
reference \\
transactions \\
per \\
capita $^{3}$
\end{tabular} & State & $\begin{array}{l}\text { Number } \\
\text { of } \\
\text { public } \\
\text { libraries }\end{array}$ & $\begin{array}{c}\text { Number of } \\
\text { books and } \\
\text { serial } \\
\text { volumes }{ }^{1} \\
\text { (in thou- } \\
\text { sands) }\end{array}$ & $\begin{array}{c}\text { Number } \\
\text { of books } \\
\text { and } \\
\text { serial } \\
\text { volumes } \\
\text { per } \\
\text { capita }\end{array}$ & $\begin{array}{c}\text { Library } \\
\text { visits per } \\
\text { capita }^{2}\end{array}$ & $\begin{array}{l}\text { Circula- } \\
\text { tion } \\
\text { per } \\
\text { capita }\end{array}$ & $\begin{array}{l}\text { Public } \\
\text { library } \\
\text { reference } \\
\text { transactions } \\
\text { per } \\
\text { capita } \\
\end{array}$ \\
\hline 1 & 2 & 3 & 4 & 5 & 6 & 7 & 1 & 2 & 3 & 4 & 5 & 6 & 7 \\
\hline United States ........ & 8,981 & 695,331 & 2.8 & 3.9 & 6.4 & 1.1 & & & & & & & \\
\hline 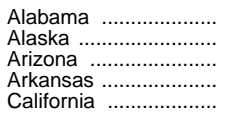 & $\begin{array}{r}207 \\
84 \\
39 \\
35 \\
171\end{array}$ & $\begin{array}{r}8,133 \\
1,926 \\
7,946 \\
4,883 \\
59,847\end{array}$ & $\begin{array}{l}2.1 \\
3.1 \\
2.0 \\
2.2 \\
1.9\end{array}$ & $\begin{array}{l}3.2 \\
4.6 \\
4.5 \\
2.6 \\
3.4\end{array}$ & $\begin{array}{l}3.9 \\
5.8 \\
6.3 \\
4.0 \\
4.5\end{array}$ & $\begin{array}{l}0.5 \\
0.8 \\
1.2 \\
0.4 \\
1.1\end{array}$ & 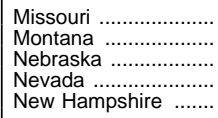 & $\begin{array}{r}148 \\
82 \\
269 \\
23 \\
229\end{array}$ & $\begin{array}{r}20,137 \\
2,567 \\
5,159 \\
3,296 \\
5,004\end{array}$ & $\begin{array}{l}4.1 \\
3.1 \\
4.0 \\
2.1 \\
4.5\end{array}$ & $\begin{array}{l}4.3 \\
3.6 \\
4.7 \\
2.9 \\
4.9\end{array}$ & $\begin{array}{l}7.9 \\
6.2 \\
8.0 \\
4.8 \\
7.6\end{array}$ & $\begin{array}{l}0.9 \\
0.8 \\
1.1 \\
0.7 \\
0.7\end{array}$ \\
\hline 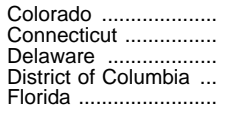 & $\begin{array}{r}120 \\
195 \\
30 \\
1 \\
97\end{array}$ & $\begin{array}{r}9,471 \\
14,202 \\
1,320 \\
2,662 \\
23,673\end{array}$ & $\begin{array}{l}2.5 \\
4.3 \\
2.0 \\
4.4 \\
1.8\end{array}$ & $\begin{array}{l}4.5 \\
6.1 \\
3.4 \\
3.4 \\
-\end{array}$ & $\begin{array}{l}8.3 \\
8.3 \\
4.4 \\
3.0 \\
5.3\end{array}$ & $\begin{array}{l}1.4 \\
1.2 \\
0.5 \\
2.2 \\
2.1\end{array}$ & \begin{tabular}{|l} 
New Jersey \\
New Mexico ................... \\
New York ............... \\
North Carolina .......... \\
North Dakota ............
\end{tabular} & $\begin{array}{r}308 \\
72 \\
741 \\
74 \\
79\end{array}$ & $\begin{array}{r}30,052 \\
3,910 \\
72,347 \\
13,956 \\
1,950\end{array}$ & $\begin{array}{l}3.8 \\
3.4 \\
4.4 \\
2.0 \\
3.6\end{array}$ & $\begin{array}{l}4.9 \\
4.1 \\
5.3 \\
3.2 \\
5.1\end{array}$ & $\begin{array}{l}5.9 \\
6.5 \\
7.3 \\
5.7 \\
7.5\end{array}$ & $\begin{array}{l}0.9 \\
1.9 \\
0.8 \\
0.7\end{array}$ \\
\hline 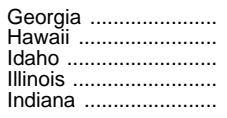 & $\begin{array}{r}54 \\
1 \\
106 \\
613 \\
238\end{array}$ & $\begin{array}{r}13,290 \\
3,502 \\
3,145 \\
36,803 \\
21,069\end{array}$ & $\begin{array}{l}1.8 \\
3.0 \\
3.3 \\
3.6 \\
4.1\end{array}$ & $\begin{array}{l}2.8 \\
2.7 \\
4.9 \\
5.3 \\
5.3\end{array}$ & $\begin{array}{r}4.5 \\
6.4 \\
7.8 \\
7.7 \\
10.2\end{array}$ & $\begin{array}{l}0.7 \\
1.8 \\
0.9 \\
1.4 \\
1.0\end{array}$ & 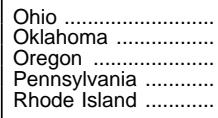 & $\begin{array}{r}250 \\
112 \\
124 \\
455 \\
51\end{array}$ & $\begin{array}{r}41,974 \\
5,786 \\
7,130 \\
25,053 \\
4,228\end{array}$ & $\begin{array}{l}3.8 \\
2.3 \\
2.4 \\
2.2 \\
4.2\end{array}$ & $\begin{array}{l}4.8 \\
- \\
3.1 \\
5.3\end{array}$ & $\begin{array}{r}12.0 \\
6.4 \\
9.7 \\
4.6 \\
6.6\end{array}$ & $\begin{array}{l}1.5 \\
0.7 \\
0.7 \\
0.7 \\
0.9\end{array}$ \\
\hline 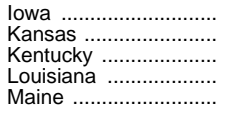 & $\begin{array}{r}527 \\
324 \\
116 \\
65 \\
266\end{array}$ & $\begin{array}{r}11,407 \\
9,276 \\
7,384 \\
9,951 \\
5,472\end{array}$ & $\begin{array}{l}4.0 \\
4.5 \\
2.0 \\
2.3 \\
5.3\end{array}$ & $\begin{array}{l}4.9 \\
5.1 \\
2.8 \\
2.5 \\
-\end{array}$ & $\begin{array}{l}8.9 \\
9.3 \\
5.3 \\
4.3 \\
7.8\end{array}$ & $\begin{array}{l}\overline{1.3} \\
0.4 \\
0.7 \\
-\end{array}$ & 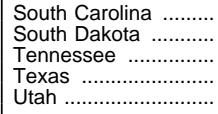 & $\begin{array}{r}40 \\
112 \\
140 \\
499 \\
69\end{array}$ & $\begin{array}{r}6,448 \\
2,431 \\
7,931 \\
32,206 \\
4,969\end{array}$ & $\begin{array}{l}1.8 \\
4.6 \\
1.6 \\
2.0 \\
2.6\end{array}$ & $\begin{array}{l}2.8 \\
4.5 \\
2.6 \\
2.9 \\
-\end{array}$ & $\begin{array}{l}4.3 \\
8.7 \\
4.1 \\
4.3 \\
9.0\end{array}$ & $\begin{array}{l}1.1 \\
1.0 \\
1.0 \\
-\end{array}$ \\
\hline $\begin{array}{l}\text { Maryland .................. } \\
\text { Massach } \\
\text { Michigan ……............... } \\
\text { Minnesota ............... } \\
\text { Mississippi ................. }\end{array}$ & $\begin{array}{r}24 \\
372 \\
382 \\
130 \\
47\end{array}$ & $\begin{array}{r}12,916 \\
28,747 \\
25,767 \\
13,138 \\
5,084\end{array}$ & $\begin{array}{l}2.6 \\
4.8 \\
2.8 \\
2.9 \\
1.9\end{array}$ & $\begin{array}{l}4.3 \\
3.8 \\
4.0 \\
2.4\end{array}$ & $\begin{array}{l}9.1 \\
7.2 \\
5.3 \\
9.4 \\
3.0\end{array}$ & $\begin{array}{l}1.1 \\
0.9 \\
1.6 \\
0.4\end{array}$ & 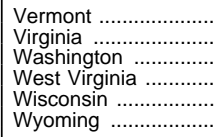 & $\begin{array}{r}200 \\
90 \\
69 \\
97 \\
381 \\
23\end{array}$ & $\begin{array}{r}2,626 \\
16,248 \\
14,957 \\
4,744 \\
16,864 \\
2,344\end{array}$ & $\begin{array}{l}5.0 \\
2.5 \\
2.8 \\
2.6 \\
3.3 \\
4.9\end{array}$ & $\begin{array}{l}4.4 \\
4.2 \\
\\
3.6 \\
5.3 \\
4.9\end{array}$ & $\begin{array}{r}7.0 \\
7.4 \\
10.0 \\
4.7 \\
8.9 \\
7.9\end{array}$ & $\begin{array}{l}\overline{1.1} \\
\overline{0.9} \\
1.2 \\
0.9\end{array}$ \\
\hline
\end{tabular}

${ }_{1}^{1}$ Some data are different from other tables due to a different population base.

${ }^{2}$ The total number of persons entering the library for whatever purpose during the year.

${ }^{3} \mathrm{~A}$ reference transaction is an information contact which involves the knowledge, use, recommendations, interpretation or instructions in the use of one or more information sources by a member of the library staff.
-Response rate less than 70 percent.

NOTE.-Totals may be underestimated due to nonresponse.

SOURCE: U.S. Department of Education, National Center for Education Statistics, Public Libraries in the United States: FY 1995. (This table was prepared October 1998.) 
Table 424.-Percent of workers, 18 years old and over, using computers on the job, by selected characteristics and computer activities: October 1993 and October 1997

\begin{tabular}{|c|c|c|c|c|c|c|c|c|c|c|c|c|c|}
\hline \multirow[b]{3}{*}{ Selected characteristics } & \multirow{3}{*}{$\begin{array}{l}\text { Percent } \\
\text { using } \\
\text { comput- } \\
\text { ers at } \\
\text { work, } \\
1993\end{array}$} & \multicolumn{12}{|c|}{1997} \\
\hline & & \multirow[b]{2}{*}{$\begin{array}{c}\text { Percent using } \\
\text { computers at } \\
\text { work }\end{array}$} & \multirow{2}{*}{$\begin{array}{l}\text { Number } \\
\text { using } \\
\text { comput- } \\
\text { ers at } \\
\text { work, in } \\
\text { thou- } \\
\text { sands }\end{array}$} & \multicolumn{10}{|c|}{ Percent of on-the-job computer workers using specific computer applications 1} \\
\hline & & & & $\begin{array}{l}\text { Analysis/ } \\
\text { spreadsheets }\end{array}$ & \begin{tabular}{|c|} 
Book- \\
keeping, \\
invoicing, \\
and inven- \\
tory
\end{tabular} & $\begin{array}{l}\text { Com- } \\
\text { muni- } \\
\text { ca- } \\
\text { tions }{ }^{2}\end{array}$ & $\begin{array}{l}\text { Cal- } \\
\text { endar/ } \\
\text { sched- } \\
\text { ule }\end{array}$ & $\begin{array}{l}\text { Data } \\
\text { bases }\end{array}$ & $\begin{array}{l}\text { Desktop } \\
\text { publish- } \\
\text { ing/ } \\
\text { graphics }\end{array}$ & $\begin{array}{c}\text { Program- } \\
\text { ming }\end{array}$ & $\begin{array}{c}\text { Sales } \\
\text { and tele- } \\
\text { marketing }\end{array}$ & $\begin{array}{l}\text { Word } \\
\text { process- } \\
\text { ing }\end{array}$ & $\begin{array}{l}\text { Using } 4 \\
\text { or more } \\
\text { cat- } \\
\text { egories }\end{array}$ \\
\hline 1 & 2 & 3 & 4 & 5 & 6 & 7 & 8 & 9 & 10 & 11 & 12 & 13 & 14 \\
\hline 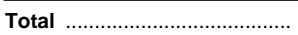 & 45.8 & $49.8(0.2)$ & 63,885 & 40.9 & 66.4 & 47.0 & 37.5 & 34.1 & 26.1 & 15.0 & 22.1 & 57.0 & 44.0 \\
\hline 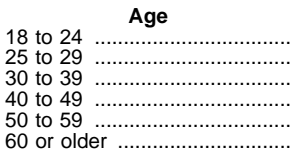 & $\begin{array}{l}34.4 \\
48.3 \\
50.7 \\
51.3 \\
43.9 \\
27.2\end{array}$ & $\begin{array}{l}37.1(0.7) \\
52.5(0.7) \\
53.3(0.5) \\
54.9(0.5) \\
50.7(0.6) \\
32.6(0.9)\end{array}$ & $\begin{array}{r}6,007 \\
7,984 \\
18,864 \\
18,182 \\
10,092 \\
2,755\end{array}$ & $\begin{array}{l}28.2 \\
41.7 \\
44.0 \\
43.6 \\
39.1 \\
33.5\end{array}$ & $\begin{array}{l}70.3 \\
69.8 \\
67.0 \\
65.8 \\
62.8 \\
62.1\end{array}$ & $\begin{array}{l}35.3 \\
46.6 \\
49.1 \\
48.6 \\
49.0 \\
42.2\end{array}$ & $\begin{array}{l}28.0 \\
38.3 \\
39.6 \\
33.5 \\
37.2 \\
29.4\end{array}$ & $\begin{array}{l}23.4 \\
35.0 \\
35.4 \\
36.9 \\
33.5 \\
28.8\end{array}$ & $\begin{array}{l}18.4 \\
25.8 \\
28.3 \\
27.1 \\
22.1 \\
21.6\end{array}$ & $\begin{array}{l}11.0 \\
16.3 \\
16.7 \\
15.7 \\
13.5 \\
10.0\end{array}$ & $\begin{array}{l}23.5 \\
23.4 \\
24.0 \\
20.6 \\
19.6 \\
21.3\end{array}$ & $\begin{array}{l}43.1 \\
58.3 \\
58.5 \\
58.9 \\
58.8 \\
54.1\end{array}$ & $\begin{array}{l}30.5 \\
45.7 \\
46.8 \\
46.4 \\
43.1 \\
35.9\end{array}$ \\
\hline $\begin{array}{l}\text { Educational attainment and } \\
\text { sex }\end{array}$ & & & & & & & & & & & & & \\
\hline 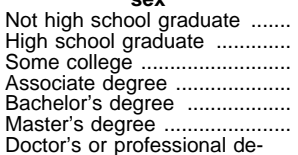 & $\begin{array}{l}10.0 \\
34.2 \\
50.4 \\
58.2 \\
68.8 \\
71.2\end{array}$ & $\begin{array}{l}11.9(0.5) \\
36.4(0.4) \\
53.6(0.5) \\
60.7(0.8) \\
73.9(0.5) \\
78.7(0.8)\end{array}$ & $\begin{array}{r}1,645 \\
15,395 \\
14,172 \\
6,580 \\
17,335 \\
6,004\end{array}$ & $\begin{array}{l}18.6 \\
28.7 \\
36.5 \\
38.9 \\
52.7 \\
53.8\end{array}$ & $\begin{array}{l}68.9 \\
72.0 \\
71.6 \\
69.8 \\
63.9 \\
51.7\end{array}$ & $\begin{array}{l}23.4 \\
34.1 \\
42.6 \\
43.7 \\
57.1 \\
63.4\end{array}$ & $\begin{array}{l}22.1 \\
29.0 \\
36.0 \\
36.0 \\
44.0 \\
48.1\end{array}$ & $\begin{array}{l}17.3 \\
23.1 \\
31.3 \\
33.0 \\
43.1 \\
45.8\end{array}$ & $\begin{array}{l}10.7 \\
16.6 \\
24.1 \\
25.5 \\
32.4 \\
39.7\end{array}$ & $\begin{array}{r}8.7 \\
10.1 \\
13.7 \\
15.1 \\
18.9 \\
20.8\end{array}$ & $\begin{array}{l}19.7 \\
21.0 \\
24.0 \\
19.7 \\
25.8 \\
18.4\end{array}$ & $\begin{array}{l}30.7 \\
41.5 \\
52.7 \\
52.7 \\
67.6 \\
80.1\end{array}$ & $\begin{array}{l}20.2 \\
30.7 \\
40.6 \\
41.2 \\
55.3 \\
59.8\end{array}$ \\
\hline gree & 66.9 & $74.6(1.2)$ & 2,754 & 46.6 & 47.5 & 64.9 & 42.0 & 39.0 & 30.3 & 16.2 & 10.5 & 75.2 & 50.2 \\
\hline $\begin{array}{l}\text { Male } \\
\text { Not high school graduate ... } \\
\text { High school graduate ........ } \\
\text { Some college .................. } \\
\text { Associate degree .............. } \\
\text { Bachelor's degree .............. } \\
\text { Master's degree ............. } \\
\text { Doctor's or professional de- }\end{array}$ & $\begin{array}{r}40.3 \\
8.5 \\
24.2 \\
42.8 \\
52.6 \\
69.8 \\
75.4\end{array}$ & $\begin{aligned} & 44.1(0.3) \\
& 9.8(0.5) \\
& 27.1(0.5) \\
& 46.0(0.7) \\
& 55.2(1.2) \\
& 74.3(0.7) \\
& 79.8(1.1)\end{aligned}$ & $\begin{array}{r}30,336 \\
854 \\
6,096 \\
6,188 \\
2,790 \\
9,258 \\
3,201\end{array}$ & $\begin{array}{l}46.5 \\
20.9 \\
29.5 \\
39.3 \\
42.8 \\
60.0 \\
63.3\end{array}$ & $\begin{array}{l}64.3 \\
70.1 \\
67.4 \\
69.4 \\
64.2 \\
64.0 \\
56.6\end{array}$ & $\begin{array}{l}51.4 \\
25.6 \\
33.1 \\
44.4 \\
45.5 \\
62.1 \\
70.6\end{array}$ & $\begin{array}{l}39.2 \\
22.6 \\
25.3 \\
35.5 \\
34.9 \\
47.4 \\
54.6\end{array}$ & $\begin{array}{l}36.8 \\
15.6 \\
22.9 \\
31.3 \\
34.9 \\
46.9 \\
50.8\end{array}$ & $\begin{array}{l}29.4 \\
11.8 \\
17.8 \\
27.0 \\
28.7 \\
35.7 \\
41.9\end{array}$ & $\begin{array}{r}20.0 \\
9.3 \\
11.8 \\
19.6 \\
20.4 \\
24.1 \\
27.8\end{array}$ & $\begin{array}{l}24.6 \\
17.8 \\
20.5 \\
27.1 \\
20.6 \\
30.5 \\
23.8\end{array}$ & $\begin{array}{l}53.9 \\
26.1 \\
29.4 \\
46.4 \\
45.3 \\
66.6 \\
80.5\end{array}$ & $\begin{array}{l}47.2 \\
20.6 \\
27.7 \\
41.4 \\
41.8 \\
60.0 \\
67.4\end{array}$ \\
\hline $\begin{array}{l}\text { Doctor's or professional de- } \\
\text { gree }\end{array}$ & 66.5 & $73.4(1.4)$ & 1,949 & 47.9 & 50.3 & 67.3 & 43.7 & 38.6 & 31.9 & 18.2 & 11.6 & 74.6 & 52.0 \\
\hline $\begin{array}{l}\text { Female } \\
\text { Not high school graduate ... } \\
\text { High school graduate ........ } \\
\text { Some college .................. } \\
\text { Associate degree ............... } \\
\text { Bachelor's degree ............. } \\
\text { Master's degree ............. }\end{array}$ & $\begin{array}{l}52.4 \\
12.5 \\
45.2 \\
58.6 \\
63.7 \\
67.6 \\
66.5\end{array}$ & $\begin{array}{l}56.5(0.3) \\
15.4(0.8) \\
46.9(0.6) \\
61.5(0.7) \\
65.4(1.0) \\
73.5(0.7) \\
77.5(1.1)\end{array}$ & $\begin{array}{r}33,549 \\
791 \\
9,299 \\
7,984 \\
3,790 \\
8,077 \\
2,804\end{array}$ & $\begin{array}{l}35.8 \\
16.0 \\
28.3 \\
34.4 \\
36.0 \\
44.4 \\
43.0\end{array}$ & $\begin{array}{l}68.3 \\
67.7 \\
75.0 \\
73.2 \\
73.9 \\
63.8 \\
46.0\end{array}$ & $\begin{array}{l}43.1 \\
20.9 \\
34.7 \\
41.1 \\
42.4 \\
51.4 \\
55.2\end{array}$ & $\begin{array}{l}36.0 \\
21.6 \\
31.5 \\
36.4 \\
36.8 \\
40.1 \\
40.7\end{array}$ & $\begin{array}{l}31.6 \\
19.1 \\
23.3 \\
31.3 \\
31.7 \\
38.8 \\
40.1\end{array}$ & $\begin{array}{r}23.1 \\
9.4 \\
15.9 \\
21.8 \\
23.2 \\
28.7 \\
37.3\end{array}$ & $\begin{array}{r}10.5 \\
8.0 \\
8.9 \\
9.1 \\
11.2 \\
12.9 \\
12.8\end{array}$ & $\begin{array}{l}19.9 \\
21.7 \\
21.4 \\
21.7 \\
19.0 \\
20.4 \\
12.2\end{array}$ & $\begin{array}{l}59.8 \\
35.6 \\
49.4 \\
57.5 \\
58.1 \\
68.8 \\
79.7\end{array}$ & $\begin{array}{l}41.0 \\
19.8 \\
32.6 \\
40.1 \\
40.7 \\
50.0 \\
51.0\end{array}$ \\
\hline $\begin{array}{l}\text { Doctor's or professional de- } \\
\text { gree }\end{array}$ & 68.2 & $77.6(2.1)$ & 805 & 43.7 & 41.0 & 59.1 & 37.8 & 39.9 & 26.4 & 11.4 & 7.9 & 76.8 & 45.9 \\
\hline $\begin{array}{l}\text { Race/ethnicity } \\
\text { White, non-Hispanic } \\
\text { Black, non-Hispanic ………......... } \\
\text { Hispanic } \\
\text { Other }\end{array}$ & $\begin{array}{l}48.7 \\
36.2 \\
29.3 \\
43.9\end{array}$ & $\begin{array}{l}53.8(0.3) \\
40.0(0.7) \\
30.2(0.8) \\
49.2(1.3)\end{array}$ & $\begin{array}{r}51,904 \\
5,462 \\
3,843 \\
2,675\end{array}$ & $\begin{array}{l}42.1 \\
33.1 \\
32.2 \\
45.8\end{array}$ & $\begin{array}{l}67.1 \\
64.3 \\
67.0 \\
57.4\end{array}$ & $\begin{array}{l}47.7 \\
43.7 \\
40.5 \\
49.5\end{array}$ & $\begin{array}{l}38.0 \\
36.1 \\
33.7 \\
35.8\end{array}$ & $\begin{array}{l}34.9 \\
29.6 \\
27.0 \\
37.8\end{array}$ & $\begin{array}{l}27.1 \\
21.2 \\
20.2 \\
25.0\end{array}$ & $\begin{array}{l}15.2 \\
14.1 \\
10.6 \\
19.3\end{array}$ & $\begin{array}{l}23.2 \\
17.1 \\
19.0 \\
16.2\end{array}$ & $\begin{array}{l}57.9 \\
52.0 \\
50.0 \\
59.4\end{array}$ & $\begin{array}{l}45.3 \\
37.2 \\
35.1 \\
44.7\end{array}$ \\
\hline $\begin{array}{l}\text { Occupatio } \\
\text { Managerial and } \\
\text { specialty } \ldots . . . .\end{array}$ & 67.7 & $74.6(0.4)$ & 28,427 & 52.4 & 61.0 & 58.6 & 45.2 & 42.6 & 36.3 & 19.1 & 20.6 & 71.7 & 56.0 \\
\hline $\begin{array}{l}\text { administrative, } \\
\text { nagerial r.ive..... }\end{array}$ & 72.3 & $77.5(0.5)$ & 14,528 & 60.1 & 76.3 & 61.4 & 49.7 & 47.2 & 32.6 & 17.6 & 30.9 & 74.5 & 63.7 \\
\hline $\begin{array}{l}\text { specialty oc- } \\
\text { except colleae }\end{array}$ & 68.3 & $71.7(0.6)$ & 13,900 & 44.4 & 45.1 & 55.8 & 40.4 & 37.8 & 40.3 & 20.8 & 9.8 & 68.7 & 47.8 \\
\hline $\begin{array}{l}\text { and } \\
\text { Teache }\end{array}$ & 49.1 & $60.3(1.2)$ & 2,961 & 33.1 & 31.9 & 39.7 & 38.4 & 27.5 & 42.3 & 10.8 & 4.6 & 73.6 & 39.8 \\
\hline minis- & 72.5 & $79.9(2.2)$ & 759 & 51.5 & 27.1 & 74.6 & 37.3 & 40.2 & 41.3 & 23.9 & 5.4 & 83.5 & 48.9 \\
\hline $\begin{array}{l}\text { and adminis- } \\
\text { hd related }\end{array}$ & 65.5 & $79.1(0.4)$ & 25,739 & 35.1 & 74.6 & 41.8 & 33.9 & 30.4 & 19.4 & 11.9 & 28.1 & 52.1 & 39.5 \\
\hline $\begin{array}{l}\text { sup } \\
\text { Sales } \\
\text { Admin }\end{array}$ & $\begin{array}{l}69.9 \\
48.8\end{array}$ & $\begin{array}{l}75.1(1.1) \\
54.8(0.7)\end{array}$ & $\begin{array}{l}3,226 \\
8,277\end{array}$ & $\begin{array}{l}42.9 \\
38.4\end{array}$ & $\begin{array}{l}51.8 \\
83.0\end{array}$ & $\begin{array}{l}49.4 \\
43.0\end{array}$ & $\begin{array}{l}35.5 \\
34.3\end{array}$ & $\begin{array}{l}36.9 \\
31.3\end{array}$ & $\begin{array}{l}26.1 \\
21.0\end{array}$ & $\begin{array}{l}31.2 \\
10.5\end{array}$ & $\begin{array}{r}7.7 \\
57.2\end{array}$ & $\begin{array}{l}49.6 \\
46.1\end{array}$ & $\begin{array}{l}41.4 \\
44.8\end{array}$ \\
\hline s.................... & $\begin{array}{l}76.7 \\
14.7\end{array}$ & $\begin{array}{l}77.6(0.5) \\
16.4(0.5)\end{array}$ & $\begin{array}{r}14,235 \\
2,752\end{array}$ & $\begin{array}{l}31.4 \\
15.7\end{array}$ & $\begin{array}{l}75.0 \\
52.3\end{array}$ & $\begin{array}{l}39.4 \\
27.6\end{array}$ & $\begin{array}{l}33.3 \\
27.9\end{array}$ & $\begin{array}{l}28.3 \\
17.4\end{array}$ & $\begin{array}{r}17.0 \\
9.6\end{array}$ & $\begin{array}{l}8.3 \\
6.6\end{array}$ & $\begin{array}{l}15.9 \\
11.0\end{array}$ & $\begin{array}{l}56.2 \\
34.4\end{array}$ & $\begin{array}{l}36.0 \\
17.9\end{array}$ \\
\hline $\begin{array}{l}\text { duction, craft, } \\
\text { bricators and la- }\end{array}$ & 23.2 & $25.0(0.6)$ & 3,501 & 29.6 & 62.8 & 31.6 & 27.0 & 22.5 & 18.2 & 16.3 & 11.1 & 29.0 & 26.2 \\
\hline $\begin{array}{l}\text { borers .......................... } \\
\text { Farming, forestry, and fishing }\end{array}$ & $\begin{array}{r}14.9 \\
8.5\end{array}$ & $\begin{aligned} 17.3 & (0.5) \\
9.3( & (0.9)\end{aligned}$ & $\begin{array}{r}3,154 \\
311\end{array}$ & $\begin{array}{l}19.1 \\
40.2\end{array}$ & $\begin{array}{l}63.1 \\
79.3\end{array}$ & $\begin{array}{l}21.3 \\
22.8\end{array}$ & $\begin{array}{l}19.0 \\
27.3\end{array}$ & $\begin{array}{l}14.6 \\
33.0\end{array}$ & $\begin{array}{l}12.6 \\
11.2\end{array}$ & $\begin{array}{r}9.7 \\
10.2\end{array}$ & $\begin{array}{r}9.2 \\
19.1\end{array}$ & $\begin{array}{l}17.4 \\
33.7\end{array}$ & $\begin{array}{l}15.4 \\
33.0\end{array}$ \\
\hline 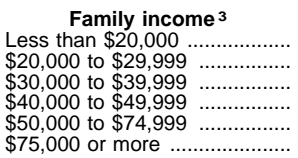 & $\begin{array}{l}25.1 \\
38.4 \\
45.7 \\
51.9 \\
60.6 \\
65.9\end{array}$ & $\begin{array}{l}26.7(0.5) \\
38.4(0.6) \\
45.8(0.6) \\
52.3(0.7) \\
59.9(0.5) \\
69.7(0.5)\end{array}$ & $\begin{array}{r}5,915 \\
7,310 \\
8,915 \\
7,737 \\
16,966 \\
17,042\end{array} \mid$ & $\begin{array}{l}27.6 \\
30.3 \\
35.7 \\
40.0 \\
42.7 \\
51.4\end{array}$ & $\begin{array}{l}67.8 \\
69.4 \\
67.4 \\
69.0 \\
65.8 \\
63.6\end{array}$ & $\begin{array}{l}34.0 \\
36.9 \\
42.2 \\
43.6 \\
48.6 \\
58.4\end{array}$ & $\begin{array}{r}28.7 \\
30.2 \\
33.7 \\
36.9 \\
38.9 \\
44.6\end{array}$ & $\begin{array}{l}24.0 \\
26.1 \\
29.4 \\
31.8 \\
36.1 \\
42.3\end{array}$ & $\begin{array}{l}19.4 \\
21.8 \\
23.8 \\
25.4 \\
27.2 \\
30.6\end{array}$ & $\begin{array}{l}11.7 \\
10.5 \\
12.8 \\
15.0 \\
16.5 \\
17.8\end{array}$ & $\begin{array}{l}22.2 \\
20.0 \\
20.8 \\
21.0 \\
20.6 \\
25.7\end{array}$ & $\begin{array}{l}44.9 \\
48.0 \\
50.8 \\
53.8 \\
58.4 \\
68.4\end{array}$ & $\begin{array}{l}31.4 \\
34.3 \\
38.0 \\
42.5 \\
45.5 \\
54.7\end{array}$ \\
\hline
\end{tabular}

${ }^{1}$ Individuals may be counted in more than one computer activity.

${ }^{2}$ Includes bulletin boards and electronic mail.

${ }^{3}$ Excludes persons whose income data were not available.
NOTE.-Data are based on a sample survey of households and are subject to sampling and nonsampling error. Standard errors appear in parentheses.

SOURCE: U.S. Department of Commerce, Bureau of the Census, Current Population Survey, October 1997, unpublished data. (This table was prepared August 1998.) 
Table 425.-Access to and use of home computers, by selected characteristics of students and other users: October 1997

\begin{tabular}{|c|c|c|c|c|c|c|c|c|c|c|c|}
\hline \multirow{2}{*}{$\begin{array}{c}\text { Selected } \\
\text { characteristics }\end{array}$} & \multirow{2}{*}{$\begin{array}{c}\text { Percent with } \\
\text { computers at } \\
\text { home }\end{array}$} & \multirow{2}{*}{$\begin{array}{l}\text { Percent } \\
\text { using } \\
\text { comput- } \\
\text { ers at } \\
\text { home, in } \\
\text { thou- } \\
\text { sands }\end{array}$} & \multirow{2}{*}{$\begin{array}{l}\text { Percent } \\
\text { using com- } \\
\text { puters at } \\
\text { home }\end{array}$} & \multicolumn{4}{|c|}{$\begin{array}{l}\text { Distribution of frequency of use per week for } \\
\text { persons using computers in home }\end{array}$} & \multicolumn{4}{|c|}{$\begin{array}{l}\text { Percent of persons whose home } \\
\text { computer has specific capabilities }{ }^{1}\end{array}$} \\
\hline & & & & 6 or 7 days & 4 or 5 days & 2 or 3 days & 1 day or less & $\begin{array}{c}\text { CD-ROM } \\
\text { drive }\end{array}$ & Printer & Modem & Internet \\
\hline 1 & 2 & 3 & 4 & 5 & 6 & 7 & 8 & 9 & 10 & 11 & 12 \\
\hline Total, all persons ... & $43.0(0.2)$ & 81,013 & $30.3(0.2)$ & $23.4(0.2)$ & $20.1(0.2)$ & $32.6(0.2)$ & $24.0(0.2)$ & $71.3(0.2)$ & $85.5(0.2)$ & $71.1(0.2)$ & $52.1(0.3)$ \\
\hline $\begin{array}{l}\text { Sex } \\
\text { Male } \ldots \ldots \ldots \ldots \ldots \ldots \ldots \ldots . . . \\
\text { Female } \ldots \ldots \ldots \ldots \ldots \ldots \ldots \ldots \ldots\end{array}$ & $\begin{array}{ll}44.3 & (0.2) \\
41.7 & (0.2)\end{array}$ & $\begin{array}{l}41,260 \\
39,753\end{array}$ & $\begin{array}{l}31.6(0.2) \\
29.1(0.2)\end{array}$ & $\begin{array}{l}27.1(0.2) \\
19.6(0.2)\end{array}$ & $\begin{array}{l}20.1(0.2) \\
20.0(0.2)\end{array}$ & $\begin{array}{l}30.6(0.2) \\
34.6(0.2)\end{array}$ & $\begin{array}{ll}22.2 & (0.2) \\
25.8 & (0.2)\end{array}$ & $\begin{array}{ll}72.1 & (0.3) \\
70.6 & (0.3)\end{array}$ & $\begin{array}{ll}85.5 & (0.2) \\
85.6(0.2)\end{array}$ & $\begin{array}{ll}71.7 & (0.3) \\
70.5 & (0.3)\end{array}$ & $\begin{array}{l}52.9(0.3) \\
51.2(0.3)\end{array}$ \\
\hline $\begin{array}{c}\text { Race/ethnicity } \\
\text { White, non-Hispanic } \ldots . . \\
\text { Black, non-Hispanic ..... } \\
\text { Hispanic ..................... }\end{array}$ & $\begin{array}{ll}49.2 & (0.2) \\
22.8 & (0.4) \\
22.2 & (0.5)\end{array}$ & $\begin{array}{r}68,026 \\
4,943 \\
4,081\end{array}$ & $\begin{array}{ll}35.5 & (0.2) \\
14.7 & (0.3) \\
13.5 & (0.4)\end{array}$ & $\begin{array}{l}23.5(0.2) \\
20.8(0.7) \\
23.3(0.8)\end{array}$ & $\begin{array}{l}20.2(0.2) \\
20.5(0.7) \\
17.3(0.7)\end{array}$ & $\begin{array}{l}32.1(0.2) \\
37.6(0.8) \\
36.4(0.9)\end{array}$ & \begin{tabular}{ll|}
24.3 & $(0.2)$ \\
21.2 & $(0.7)$ \\
23.1 & $(0.8)$
\end{tabular} & $\begin{array}{l}72.4(0.3) \\
58.2(1.0) \\
69.1(1.1)\end{array}$ & $\begin{array}{l}87.1(0.2) \\
75.2(0.9) \\
78.2(1.0)\end{array}$ & $\begin{array}{l}72.8(0.3) \\
57.7(1.0) \\
60.8(1.2)\end{array}$ & $\begin{array}{l}53.7(0.3) \\
40.3(1.0) \\
44.4(1.2)\end{array}$ \\
\hline $\begin{array}{l}\text { Age } \\
\text { Under } 5 \\
5 \text { to } 9 \\
10 \text { to } 14 \\
15 \text { to } 19 \\
20 \text { to } 24 \\
25 \text { to } 29 \\
30 \text { to } 39 \\
40 \text { to } 49 \\
50 \text { to } 59 \\
60 \text { to } 69 \ldots \ldots \ldots \ldots \ldots \ldots \\
70 \text { or older }\end{array}$ & $\begin{array}{l}39.0(0.6) \\
46.4(0.6) \\
55.1(0.6) \\
53.0(0.6) \\
41.2(0.6) \\
39.3(0.6) \\
47.0(0.4) \\
54.0(0.4) \\
44.2(0.5) \\
27.5(0.6) \\
13.2(0.4)\end{array}$ & $\begin{array}{r}1,675 \\
7,599 \\
9,500 \\
8,395 \\
4,975 \\
5,963 \\
15,393 \\
15,346 \\
7,679 \\
3,162 \\
1,327\end{array}$ & $\begin{aligned} & 8.5(0.3) \\
& 37.1(0.6) \\
& 48.7(0.6) \\
& 43.1(0.5) \\
& 28.5(0.6) \\
& 31.7(0.6) \\
& 35.8(0.4) \\
& 38.3(0.4) \\
& 28.5(0.5) \\
& 16.2(0.5) \\
& 5.9(0.3)\end{aligned}$ & $\begin{array}{l}12.2(0.5) \\
11.8(0.4) \\
21.1(0.5) \\
24.7(0.5) \\
28.3(0.8) \\
26.1(0.7) \\
24.2(0.4) \\
24.3(0.4) \\
26.6(0.5) \\
29.7(0.8) \\
29.4(1.1)\end{array}$ & $\begin{array}{ll}16.3 & (0.5) \\
17.6 & (0.5) \\
21.8 & (0.5) \\
22.4(0.5) \\
20.2(0.7) \\
22.3(0.6) \\
20.6(0.4) \\
18.8(0.3) \\
19.8(0.5) \\
17.5(0.7) \\
17.8(1.0)\end{array}$ & $\begin{array}{l}38.1(0.7) \\
44.2(0.6) \\
38.0(0.6) \\
32.4(0.6) \\
28.9(0.8) \\
30.0(0.7) \\
32.0(0.4) \\
30.3(0.4) \\
28.0(0.5) \\
24.1(0.8) \\
25.4(1.1)\end{array}$ & $\begin{array}{l}33.5(0.7) \\
26.4(0.6) \\
19.1(0.5) \\
20.5(0.5) \\
22.6(0.7) \\
21.7(0.6) \\
23.2(0.4) \\
26.6(0.4) \\
25.7(0.5) \\
28.6(0.8) \\
27.5(1.1)\end{array}$ & $\begin{array}{l}71.9(0.8) \\
74.7(0.7) \\
75.5(0.7) \\
73.7(0.7) \\
69.5(1.0) \\
70.1(0.9) \\
71.9(0.5) \\
73.9(0.5) \\
66.5(0.7) \\
61.0(1.2) \\
59.0(1.6)\end{array}$ & $\begin{array}{l}83.3(0.7) \\
83.8(0.6) \\
87.9(0.5) \\
88.0(0.5) \\
83.4(0.8) \\
80.4(0.8) \\
84.5(0.4) \\
87.4(0.4) \\
86.2(0.5) \\
86.8(0.8) \\
86.1(1.1)\end{array}$ & $\begin{array}{l}74.5(0.8) \\
71.5(0.8) \\
70.6(0.7) \\
69.9(0.7) \\
69.8(1.0) \\
75.8(0.9) \\
72.8(0.5) \\
73.0(0.5) \\
67.6(0.7) \\
63.5(1.1) \\
60.4(1.5)\end{array}$ & $\begin{array}{l}53.8(0.9) \\
50.5(0.8) \\
50.3(0.8) \\
52.3(0.8) \\
53.0(1.1) \\
58.4(1.0) \\
53.5(0.6) \\
54.4(0.6) \\
50.7(0.8) \\
42.3(1.2) \\
38.6(1.5)\end{array}$ \\
\hline 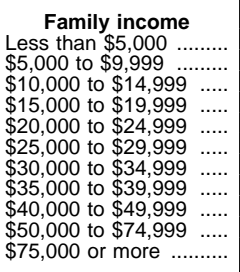 & $\begin{array}{l}19.4(0.6) \\
12.1(0.4) \\
15.6(0.4) \\
18.4(0.5) \\
25.5(0.5) \\
31.4(0.6) \\
38.3(0.6) \\
43.6(0.6) \\
51.1(0.5) \\
62.3(0.4) \\
77.6(0.4)\end{array}$ & $\begin{array}{r}1,517 \\
1,575 \\
2,197 \\
2,084 \\
3,645 \\
4,174 \\
5,003 \\
5,367 \\
9,627 \\
21,685 \\
24,138\end{array}$ & $\begin{aligned} & 13.3(0.5) \\
& 8.1(0.3) \\
& 9.7(0.3) \\
& 12.0(0.4) \\
& 17.1(0.4) \\
& 21.0(0.5) \\
& 25.7(0.5) \\
& 29.1(0.6) \\
& 35.4(0.5) \\
& 44.6(0.4) \\
& 58.0(0.4)\end{aligned}$ & $\begin{array}{ll}31.1 & (1.3) \\
24.8 & (1.2) \\
26.2 & (1.1) \\
25.9 & (1.1) \\
25.1 & (0.8) \\
23.3(0.7) \\
22.5(0.7) \\
22.7(0.6) \\
22.2(0.5) \\
22.1(0.3) \\
24.1(0.3)\end{array}$ & $\begin{array}{l}16.7(1.1) \\
19.6(1.1) \\
17.7(0.9) \\
20.4(1.0) \\
18.9(0.7) \\
19.3(0.7) \\
20.5(0.6) \\
18.5(0.6) \\
19.5(0.4) \\
20.2(0.3) \\
21.1(0.3)\end{array}$ & $\begin{array}{l}26.8(1.3) \\
29.4(1.3) \\
31.4(1.1) \\
29.9(1.1) \\
31.4(0.9) \\
33.3(0.8) \\
32.9(0.7) \\
34.1(0.7) \\
33.3(0.5) \\
32.5(0.4) \\
32.8(0.3)\end{array}$ & $\begin{array}{l}25.3(1.3) \\
26.1(1.3) \\
24.8(1.0) \\
23.8(1.1) \\
24.5(0.8) \\
24.1(0.8) \\
24.1(0.7) \\
24.7(0.6) \\
25.1(0.5) \\
25.1(0.3) \\
22.0(0.3)\end{array}$ & $\begin{array}{l}63.2(1.8) \\
59.6(1.8) \\
55.9(1.5) \\
60.5(1.5) \\
59.9(1.2) \\
62.2(1.1) \\
66.4(1.0) \\
65.9(0.9) \\
68.2(0.7) \\
73.9(0.4) \\
80.9(0.4)\end{array}$ & $\begin{array}{l}81.9(1.4) \\
81.0(1.4) \\
74.5(1.3) \\
77.8(1.3) \\
80.9(0.9) \\
77.6(0.9) \\
82.6(0.8) \\
84.3(0.7) \\
86.0(0.5) \\
87.2(0.3) \\
89.8(0.3)\end{array}$ & $\begin{array}{l}66.2(1.8) \\
56.7(1.8) \\
54.7(1.5) \\
60.0(1.5) \\
58.1(1.2) \\
61.0(1.1) \\
64.1(1.0) \\
66.3(0.9) \\
67.6(0.7) \\
74.3(0.4) \\
81.1(0.4)\end{array}$ & $\begin{array}{l}44.6(1.8) \\
40.5(1.8) \\
38.7(1.4) \\
42.7(1.5) \\
38.8(1.2) \\
42.0(1.1) \\
43.7(1.0) \\
46.1(1.0) \\
46.4(0.7) \\
53.9(0.5) \\
64.5(0.5)\end{array}$ \\
\hline $\begin{array}{l}\text { Total, all students ....... } \\
\text { Preprimary ............. } \\
\text { 1st to 8th grade ...... } \\
\text { 9th to 12th grade .... } \\
\text { Undergraduate ........ } \\
\text { Graduate ................. }\end{array}$ & $\begin{array}{l}54.6(0.3) \\
45.2(0.9) \\
50.7(0.5) \\
55.7(0.6) \\
64.7(0.7) \\
75.3(1.2)\end{array}$ & $\begin{array}{r}32,459 \\
2,493 \\
14,056 \\
7,699 \\
6,179 \\
2,032\end{array}$ & $\begin{array}{l}45.1(0.3) \\
29.6(0.8) \\
43.4(0.5) \\
48.8(0.6) \\
49.8(0.7) \\
67.2(1.3)\end{array}$ & $\begin{array}{l}\mathbf{2 1 . 7}(\mathbf{0 . 2 )} \\
10.8(0.6) \\
16.5(0.4) \\
23.9(0.5) \\
30.8(0.7) \\
34.1(1.2)\end{array}$ & $\begin{array}{ll}21.2 & (0.2) \\
17.7 & (0.8) \\
19.9 & (0.4) \\
22.8 & (0.5) \\
22.3(0.6) \\
25.4(1.1)\end{array}$ & $\begin{array}{l}36.3(0.3) \\
41.2(1.0) \\
41.5(0.5) \\
33.6(0.6) \\
29.0(0.7) \\
26.9(1.1)\end{array}$ & $\begin{array}{l}\mathbf{2 0 . 8}(\mathbf{0 . 2 )} \\
30.3(0.9) \\
22.1(0.4) \\
19.6(0.5) \\
17.9(0.6) \\
13.6(0.9)\end{array}$ & $\begin{array}{l}74.6(0.3) \\
74.8(1.2) \\
75.2(0.6) \\
74.6(0.7) \\
73.3(0.9) \\
73.6(1.5)\end{array}$ & $\begin{array}{l}86.9(0.3) \\
85.4(0.9) \\
86.0(0.4) \\
88.6(0.5) \\
86.9(0.7) \\
89.4(1.0)\end{array}$ & $\begin{array}{l}71.9(0.4) \\
73.4(1.2) \\
71.0(0.6) \\
70.2(0.8) \\
73.6(0.9) \\
78.9(1.4)\end{array}$ & $\begin{array}{l}\mathbf{5 2 . 9}(\mathbf{( 0 . 4 )} \\
53.5(1.3) \\
50.3(0.6) \\
51.5(0.8) \\
57.6(1.0) \\
65.1(1.6)\end{array}$ \\
\hline $\begin{array}{l}\text { Sex } \\
\text { Male ....................... } \\
\text { Preprimary ............ } \\
\text { 1st to 8th grade ...... } \\
\text { 9th to 12th grade ..... } \\
\text { Undergraduate ......... } \\
\text { Graduate ................ }\end{array}$ & $\begin{array}{l}54.8(0.4) \\
46.5(1.3) \\
50.9(0.6) \\
56.1(0.9) \\
66.6(1.0) \\
73.8(1.9)\end{array}$ & $\begin{array}{r}16,213 \\
1,308 \\
7,257 \\
3,971 \\
2,841 \\
834\end{array}$ & $\begin{array}{l}45.2(0.4) \\
30.3(1.2) \\
43.6(0.6) \\
49.3(0.9) \\
51.3(1.0) \\
64.1(2.0)\end{array}$ & $\begin{array}{l}24.4(0.4) \\
13.4(0.9) \\
18.0(0.5) \\
27.3(0.8) \\
36.9(1.1) \\
40.3(1.9)\end{array}$ & $\begin{array}{ll}21.1 & (0.3) \\
20.1 & (1.1) \\
20.8 & (0.5) \\
21.8 & (0.7) \\
20.4 & (0.9) \\
24.5 & (1.7)\end{array}$ & $\begin{array}{l}35.1(0.4) \\
37.1(1.3) \\
41.2(0.7) \\
31.4(0.8) \\
26.9(1.0) \\
25.4(1.7)\end{array}$ & $\begin{array}{r}19.4(0.3) \\
29.4(1.3) \\
20.1(0.5) \\
19.6(0.7) \\
15.8(0.8) \\
9.8(1.2)\end{array}$ & $\begin{array}{l}75.5(0.5) \\
74.3(1.6) \\
75.1(0.8) \\
76.4(1.0) \\
76.9(1.3) \\
74.2(2.2)\end{array}$ & $\begin{array}{l}86.5(0.4) \\
83.3(1.4) \\
85.6(0.6) \\
88.7(0.7) \\
87.2(1.0) \\
88.3(1.7)\end{array}$ & $\begin{array}{ll}72.3 & (0.5) \\
72.3 & (1.6) \\
70.8 & (0.8) \\
71.9 & (1.0) \\
76.1 & (1.3) \\
77.8 & (2.1)\end{array}$ & $\begin{array}{l}53.4(0.6) \\
53.6(1.8) \\
50.2(0.9) \\
53.0(1.1) \\
60.8(1.5) \\
63.7(2.5)\end{array}$ \\
\hline 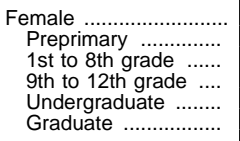 & $\begin{array}{l}54.4(0.4) \\
43.9(1.3) \\
50.5(0.7) \\
55.2(0.9) \\
63.1(0.9) \\
76.5(1.6)\end{array}$ & $\begin{array}{r}16,246 \\
1,185 \\
6,799 \\
3,728 \\
3,337 \\
1,197\end{array}$ & $\begin{array}{l}44.9(0.4) \\
28.8(1.2) \\
43.3(0.7) \\
48.1(0.9) \\
48.6(0.9) \\
69.6(1.7)\end{array}$ & $\begin{array}{r}19.0(0.3) \\
8.0(0.8) \\
15.0(0.5) \\
20.3(0.7) \\
25.7(0.9) \\
29.7(1.5)\end{array}$ & $\begin{array}{l}21.3(0.3) \\
15.0(1.0) \\
18.9(0.5) \\
23.9(0.8) \\
23.9(0.9) \\
26.0(1.4)\end{array}$ & $\begin{array}{l}37.4(0.4) \\
45.6(1.4) \\
41.7(0.7) \\
36.1(0.8) \\
30.7(0.9) \\
28.0(1.5)\end{array}$ & $\begin{array}{l}22.3(0.4) \\
31.4(1.3) \\
24.3(0.6) \\
19.7(0.7) \\
19.7(0.8) \\
16.3(1.2)\end{array}$ & $\begin{array}{l}73.7(0.5) \\
75.5(1.7) \\
75.3(0.8) \\
72.6(1.1) \\
70.4(1.2) \\
73.2(1.9)\end{array}$ & $\begin{array}{l}87.3(0.4) \\
87.7(1.3) \\
86.4(0.6) \\
88.5(0.8) \\
86.7(0.9) \\
90.2(1.3)\end{array}$ & $\begin{array}{l}71.6(0.5) \\
74.7(1.7) \\
71.3(0.8) \\
68.4(1.1) \\
71.7(1.2) \\
79.7(1.7)\end{array}$ & $\begin{array}{l}52.4(0.6) \\
53.4(1.9) \\
50.4(0.9) \\
49.9(1.2) \\
55.0(1.3) \\
66.0(2.1)\end{array}$ \\
\hline $\begin{array}{c}\text { Race/ethnicity } \\
\text { White, non-Hispanic } \ldots . . \\
\text { Preprimary ............. } \\
\text { 1st to 8th grade ...... } \\
\text { 9th to 12th grade .... } \\
\text { Undergraduate ........ } \\
\text { Graduate ................. }\end{array}$ & $\begin{array}{l}65.4(0.3) \\
56.9(1.1) \\
62.0(0.6) \\
68.7(0.7) \\
71.3(0.7) \\
78.9(1.3)\end{array}$ & $\begin{array}{r}26,229 \\
2,080 \\
11,340 \\
6,265 \\
4,927 \\
1,617\end{array}$ & $\begin{array}{l}54.9(0.4) \\
38.4(1.1) \\
54.4(0.6) \\
60.9(0.7) \\
55.1(0.8) \\
70.3(1.5)\end{array}$ & $\begin{array}{l}21.4(0.3) \\
11.2(0.7) \\
16.0(0.4) \\
23.9(0.6) \\
31.1(0.8) \\
33.0(1.3)\end{array}$ & $\begin{array}{ll}21.4 & (0.3) \\
17.4 & (0.8) \\
20.3 & (0.4) \\
23.0(0.6) \\
22.1(0.7) \\
25.8(1.2)\end{array}$ & $\begin{array}{l}35.8(0.3) \\
41.8(1.1) \\
41.1(0.5) \\
32.8(0.6) \\
27.9(0.8) \\
27.1(1.2)\end{array}$ & $\begin{array}{l}21.4(0.3) \\
29.6(1.0) \\
22.6(0.4) \\
20.3(0.5) \\
18.9(0.7) \\
14.0(1.0)\end{array}$ & $\begin{array}{l}76.4(0.4) \\
77.1(1.3) \\
77.2(0.6) \\
76.3(0.8) \\
74.6(1.0) \\
74.3(1.6)\end{array}$ & $\begin{array}{l}89.1(0.3) \\
87.3(1.0) \\
88.5(0.5) \\
90.6(0.5) \\
89.0(0.7) \\
90.5(1.1)\end{array}$ & $\begin{array}{ll}74.1 & (0.4) \\
74.9 & (1.3) \\
74.0 & (0.6) \\
72.1 & (0.8) \\
75.4 & (1.0) \\
78.6 & (1.5)\end{array}$ & $\begin{array}{l}55.2(0.4) \\
54.9(1.5) \\
53.2(0.7) \\
53.5(0.9) \\
59.9(1.1) \\
65.2(1.8)\end{array}$ \\
\hline 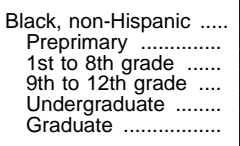 & \begin{tabular}{ll|}
28.2 & $(0.7)$ \\
17.8 & $(1.5)$ \\
26.8 & $(0.9)$ \\
26.6 & $(1.4)$ \\
37.8 & $(2.0)$ \\
63.0 & $(4.4)$
\end{tabular} & $\begin{array}{r}2,330 \\
139 \\
1,078 \\
534 \\
394 \\
185\end{array}$ & $\begin{aligned} & 21.1(0.6) \\
& 9.8(1.2) \\
& 20.6(0.8) \\
& 21.0(1.3) \\
& 25.6(1.8) \\
& 56.3(4.5)\end{aligned}$ & $\begin{array}{l}20.3(1.0) \\
11.3(2.4) \\
19.7(1.3) \\
19.9(2.1) \\
19.2(2.7) \\
34.4(4.3)\end{array}$ & $\begin{array}{ll}21.9 & (1.0) \\
19.8 & (3.0) \\
17.2 & (1.3) \\
27.6 & (2.4) \\
26.4(3.0) \\
24.7(3.9)\end{array}$ & $\begin{array}{l}41.1(1.2) \\
31.0(3.5) \\
47.3(1.7) \\
38.4(2.6) \\
38.4(3.3) \\
26.5(4.0)\end{array}$ & $\begin{array}{l}16.6(0.9) \\
37.8(3.7) \\
15.8(1.2) \\
14.1(1.8) \\
16.0(2.5) \\
14.3(3.2)\end{array}$ & $\begin{array}{l}57.8(1.5) \\
55.5(4.7) \\
58.3(2.0) \\
56.2(3.1) \\
56.2(4.1) \\
67.0(5.5)\end{array}$ & $\begin{array}{l}75.3(1.3) \\
80.5(3.8) \\
74.0(1.8) \\
73.8(2.8) \\
73.1(3.6) \\
87.6(3.8)\end{array}$ & $\begin{array}{l}58.6(1.5) \\
62.0(4.6) \\
55.4(2.0) \\
57.5(3.1) \\
61.3(4.0) \\
75.6(5.0)\end{array}$ & $\begin{array}{l}39.1(1.5) \\
43.0(4.7) \\
34.8(1.9) \\
39.4(3.1) \\
40.3(4.0) \\
61.0(5.7)\end{array}$ \\
\hline $\begin{array}{l}\text { Hispanic } \\
\text { Preprimary ................. } \\
\text { 1st to 8th grade ...... } \\
\text { 9th to 12th grade .... } \\
\text { Undergraduate ......... } \\
\text { Graduate ................. }\end{array}$ & $\begin{array}{l}27.2(0.8) \\
21.2(1.5) \\
24.0(0.8) \\
25.8(1.7) \\
45.8(2.6) \\
\left({ }^{2}\right)\end{array}$ & $\begin{array}{r}1,944 \\
134 \\
863 \\
458 \\
430 \\
(2)\end{array}$ & $\begin{array}{l}21.1(0.7) \\
11.2(1.1) \\
18.6(0.7) \\
21.6(1.6) \\
37.3(2.5) \\
(2)-\end{array}$ & $\begin{array}{r}22.2(1.1) \\
9.6(1.9) \\
18.0(1.1) \\
25.0(2.5) \\
29.1(2.9) \\
(2)\end{array}$ & $\begin{aligned} & 18.7(1.1) \\
& 17.3(2.4) \\
& 17.3(1.1) \\
& 19.3(2.3) \\
& 21.1(2.6) \\
&(2)\end{aligned}$ & $\begin{array}{l}41.1(1.4) \\
43.3(3.1) \\
44.2(1.5) \\
37.1(2.8) \\
38.7(3.1) \\
(2)-\end{array}$ & \begin{tabular}{rl|}
18.0 & $(1.1)$ \\
$29.9(2.9)$ \\
$20.4(1.2)$ \\
$18.6(2.2)$ \\
$11.2(2.0)$ \\
$(2)$
\end{tabular} & $\begin{aligned} 72.8 & (1.6) \\
65.8 & (3.7) \\
72.8 & (1.7) \\
73.2 & (3.3) \\
74.4 & (3.6) \\
(2) & -\end{aligned}$ & $\begin{array}{l}77.9(1.5) \\
74.7(3.4) \\
75.7(1.6) \\
81.0(2.9) \\
81.1(3.2) \\
(2)-\end{array}$ & $\begin{array}{l}60.8(1.7) \\
67.4(3.7) \\
57.7(1.9) \\
58.0(3.7) \\
65.0(3.9) \\
(2)-\end{array}$ & $\begin{array}{l}45.2(1.8) \\
46.0(3.9) \\
43.6(1.9) \\
41.0(3.7) \\
50.9(4.1) \\
(2)-\end{array}$ \\
\hline 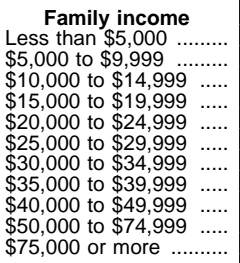 & $\begin{array}{l}29.5(1.2) \\
20.8(0.9) \\
23.7(0.9) \\
27.1(1.1) \\
36.8(1.0) \\
44.2(1.1) \\
48.6(1.1) \\
55.5(1.1) \\
61.4(0.9) \\
73.0(0.6) \\
86.7(0.5)\end{array}$ & $\begin{array}{r}812 \\
790 \\
1,004 \\
854 \\
1,541 \\
1,649 \\
2,014 \\
2,187 \\
3,801 \\
8,577 \\
9,231\end{array}$ & $\begin{array}{l}22.6(1.1) \\
15.8(0.8) \\
18.4(0.8) \\
20.7(1.0) \\
30.5(1.0) \\
34.6(1.1) \\
38.7(1.0) \\
44.1(1.1) \\
50.6(0.9) \\
61.7(0.6) \\
74.2(0.6)\end{array}$ & $\begin{array}{l}30.7(1.7) \\
27.0(1.7) \\
26.2(1.6) \\
28.6(1.7) \\
26.3(1.3) \\
21.2(1.1) \\
20.3(1.0) \\
22.8(1.0) \\
18.8(0.7) \\
19.1(0.5) \\
22.2(0.5)\end{array}$ & $\begin{array}{l}16.7(1.4) \\
18.9(1.5) \\
17.0(1.3) \\
21.1(1.5) \\
19.8(1.1) \\
23.0(1.2) \\
21.4(1.0) \\
18.8(0.9) \\
21.3(0.7) \\
22.0(0.5) \\
21.9(0.5)\end{array}$ & $\begin{array}{ll}31.2 & (1.7) \\
32.7(1.8) \\
37.0(1.7) \\
35.7(1.8) \\
33.0(1.3) \\
35.3(1.3) \\
37.3(1.2) \\
36.4(1.1) \\
39.0(0.9) \\
36.3(0.6) \\
36.4(0.5)\end{array}$ & $\begin{array}{l}21.4(1.5) \\
21.5(1.6) \\
19.7(1.4) \\
14.5(1.3) \\
20.8(1.2) \\
20.5(1.1) \\
20.9(1.0) \\
22.0(0.9) \\
20.9(0.7) \\
22.6(0.5) \\
19.6(0.4)\end{array}$ & $\begin{array}{ll}66.8 & (2.3) \\
63.6(2.3) \\
58.6(2.1) \\
63.9(2.2) \\
61.8(1.8) \\
62.8(1.7) \\
69.6(1.4) \\
68.9(1.4) \\
71.2(1.0) \\
78.4(0.6) \\
85.2(0.6)\end{array}$ & $\begin{array}{l}86.1(1.7) \\
81.4(1.9) \\
74.0(1.9) \\
77.5(1.9) \\
82.4(1.4) \\
76.6(1.4) \\
83.4(1.2) \\
86.3(1.0) \\
86.9(0.8) \\
89.6(0.5) \\
91.6(0.4)\end{array}$ & $\begin{array}{l}69.3(2.2) \\
58.7(2.4) \\
54.2(2.2) \\
62.0(2.3) \\
60.2(1.8) \\
60.6(1.7) \\
62.8(1.5) \\
67.2(1.4) \\
69.0(1.1) \\
75.7(0.7) \\
82.7(0.6)\end{array}$ & $\begin{array}{l}49.5(2.4) \\
43.3(2.4) \\
39.5(2.1) \\
45.6(2.3) \\
39.9(1.8) \\
41.5(1.7) \\
44.5(1.5) \\
45.8(1.5) \\
45.5(1.2) \\
55.2(0.8) \\
66.7(0.7)\end{array}$ \\
\hline
\end{tabular}

${ }^{1}$ Data are for the most recently purchased computer for families with more than one computer. Percent based on persons who have a computer in their home.

2 Sample size too small for reliable results.

-Data not available or not applicable.
NOTE.-Data are based on a sample survey of households and are subject to sampling and nonsampling error. Standard errors appear in parentheses.

SOURCE: U.S. Department of Commerce, Bureau of the Census, Current Population Survey, October 1997, unpublished data. (This table was prepared November 1998.) 
Table 426.-Percent of home computer users using specific applications, by selected characteristics: October 1997

\begin{tabular}{|c|c|c|c|c|c|c|c|c|c|c|c|c|}
\hline \multirow[b]{2}{*}{ Selected characteristics } & \multirow[b]{2}{*}{$\begin{array}{l}\text { Number of } \\
\text { home computer } \\
\text { users, in thou- } \\
\text { sands }\end{array}$} & \multicolumn{11}{|c|}{ Percent of computer users using specific applications ${ }^{1}$} \\
\hline & & $\begin{array}{l}\text { Home } \\
\text { book- } \\
\text { keeping } 2\end{array}$ & $\begin{array}{c}\text { School } \\
\text { assignments }\end{array}$ & Games & $\begin{array}{l}\text { Job- } \\
\text { related }{ }^{2}\end{array}$ & $\begin{array}{c}\text { Home } \\
\text { connection } \\
\text { to } \\
\text { school or } \\
\text { work }\end{array}$ & $\begin{array}{l}\text { Word } \\
\text { process- } \\
\text { ing }\end{array}$ & $\begin{array}{c}\text { Data } \\
\text { bases }^{2}\end{array}$ & $\begin{array}{c}\text { Graph- } \\
\text { ics }\end{array}$ & $\begin{array}{c}\text { Desktop } \\
\text { publishing } 2\end{array}$ & Spreadsheets $^{2}$ & Internet \\
\hline 1 & 2 & 3 & 4 & 5 & 6 & 7 & 8 & 9 & 10 & 11 & 12 & 13 \\
\hline $\begin{array}{l}\text { Total, all persons } \ldots \\
\text { Total, all persons } \\
\text { over } 15\end{array}$ & $\begin{array}{l}81,013(600) \\
53,845(461)\end{array}$ & $\begin{array}{c}-- \\
45.2(0.4)\end{array}$ & $\begin{array}{l}29.9 \\
16.0\end{array}$ & $\begin{array}{l}62.6 \\
53.2\end{array}$ & $\begin{array}{r}- \\
35.5\end{array}$ & $\begin{array}{l}10.6(0.2) \\
14.6(0.3)\end{array}$ & $\begin{array}{l}60.9 \\
70.6\end{array}$ & $\begin{array}{r}- \\
26.7\end{array}$ & $\begin{array}{l}23.4 \\
26.0\end{array}$ & $\begin{array}{r}- \\
17.9\end{array}$ & $\begin{array}{r}- \\
29.4\end{array}$ & $\begin{array}{l}44.9(0.3) \\
52.4(0.4)\end{array}$ \\
\hline $\begin{array}{l}\text { Sex } \\
\text { Male } \ldots \ldots \ldots \ldots \ldots \ldots \ldots \ldots \ldots \\
\text { Female } \ldots \ldots \ldots \ldots \ldots \ldots \ldots \ldots \ldots \ldots \ldots \ldots \ldots \ldots \ldots \ldots \ldots\end{array}$ & $\begin{array}{ll}41,260 & (413) \\
39,753 & (304)\end{array}$ & $\begin{array}{ll}32.4 & (0.4) \\
28.8 & (0.4)\end{array}$ & $\begin{array}{l}28.5 \\
31.3\end{array}$ & $\begin{array}{l}66.4 \\
58.5\end{array}$ & $\begin{array}{l}26.8 \\
21.8\end{array}$ & $\begin{array}{r}12.9(0.3) \\
8.3(0.2)\end{array}$ & $\begin{array}{l}57.0 \\
64.9\end{array}$ & $\begin{array}{l}21.0 \\
16.4\end{array}$ & $\begin{array}{l}24.0 \\
22.8\end{array}$ & $\begin{array}{l}12.4 \\
13.2\end{array}$ & $\begin{array}{l}23.1 \\
17.8\end{array}$ & $\begin{array}{l}48.4(0.4) \\
41.3(0.4)\end{array}$ \\
\hline 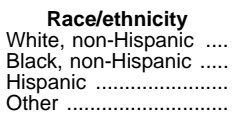 & $\begin{array}{r}68,026(330) \\
4,943(108) \\
4,081(93) \\
3,963-\end{array}$ & $\begin{array}{l}31.5(0.3) \\
28.1(1.1) \\
24.3(1.3) \\
24.3(1.3)\end{array}$ & $\begin{array}{l}28.9 \\
32.9 \\
34.6 \\
38.3\end{array}$ & $\begin{array}{l}62.9 \\
62.5 \\
59.6 \\
59.1\end{array}$ & $\begin{array}{l}24.8 \\
22.5 \\
19.9 \\
22.4\end{array}$ & $\begin{aligned} & 10.9(0.2) \\
& 8.8(0.7) \\
& 7.5(0.8) \\
& 11.7(1.0)\end{aligned}$ & $\begin{array}{l}61.7 \\
55.6 \\
55.8 \\
59.1\end{array}$ & $\begin{array}{l}19.3 \\
15.2 \\
14.3 \\
17.7\end{array}$ & $\begin{array}{l}24.0 \\
20.5 \\
20.1 \\
21.3\end{array}$ & $\begin{array}{l}13.2 \\
11.0 \\
10.4 \\
10.0\end{array}$ & $\begin{array}{l}21.1 \\
17.9 \\
14.6 \\
19.4\end{array}$ & $\begin{array}{l}46.1(0.3) \\
34.3(1.2) \\
38.1(1.5) \\
44.2(1.6)\end{array}$ \\
\hline $\begin{array}{l}\text { Age } \\
\text { Under } 15 \\
15 \text { to } 19 \\
20 \text { to } 24 \\
25 \text { to } 29 \ldots \ldots \ldots \ldots \ldots \ldots \ldots \ldots \ldots . . . . . . \\
30 \text { to } 39 \\
40 \text { to } 49 \\
50 \text { to } 59 \\
60 \text { to } 69 \\
70 \text { or older }\end{array}$ & $\begin{array}{r}18,774(222) \\
8,395(153) \\
4,975(119) \\
5,963(130) \\
15,393(203) \\
15,346(203) \\
7,679(147) \\
3,162(96) \\
1,327(62)\end{array}$ & $\begin{aligned} &- \\
& 5.6(0.4) \\
& 24.0(1.0) \\
& 44.3(1.1) \\
& 48.3(0.7) \\
& 46.5(0.7) \\
& 48.2(1.0) \\
& 51.3(1.5) \\
& 44.5(2.4)\end{aligned}$ & $\begin{array}{r}49.0 \\
75.9 \\
51.3 \\
23.4 \\
13.3 \\
12.2 \\
8.3 \\
3.5 \\
2.1\end{array}$ & $\begin{array}{l}87.0 \\
67.7 \\
60.9 \\
58.5 \\
58.3 \\
50.4 \\
43.7 \\
47.9 \\
43.0\end{array}$ & $\begin{array}{r}7.1 \\
16.4 \\
34.8 \\
39.2 \\
39.2 \\
41.2 \\
25.1 \\
17.3\end{array}$ & $\begin{aligned} & 1.2(0.1) \\
& 6.1(0.5) \\
& 16.3(0.9) \\
& 17.9(0.9) \\
& 15.8(0.5) \\
& 14.9(0.5) \\
& 13.5(0.7) \\
& 5.8(0.7) \\
& 4.4(1.0)\end{aligned}$ & $\begin{array}{l}31.5 \\
64.2 \\
70.9 \\
71.5 \\
68.7 \\
71.4 \\
73.4 \\
69.9 \\
63.8\end{array}$ & $\begin{array}{r}9 . \\
9.3 \\
19.0 \\
26.3 \\
27.0 \\
28.0 \\
30.3 \\
25.1 \\
22.4\end{array}$ & $\begin{array}{l}17.2 \\
20.9 \\
22.6 \\
25.1 \\
27.7 \\
27.3 \\
25.8 \\
22.4 \\
17.1\end{array}$ & $\begin{array}{r}8 . \overline{8} \\
12.1 \\
19.8 \\
19.3 \\
18.9 \\
18.0 \\
15.1 \\
9.2\end{array}$ & $\begin{array}{r}\overline{9.4} \\
21.6 \\
30.5 \\
31.1 \\
30.8 \\
30.7 \\
25.7 \\
20.2\end{array}$ & $\begin{array}{l}22.8(0.5) \\
46.1(0.9) \\
55.9(1.2) \\
59.0(1.1) \\
53.2(0.7) \\
52.8(0.7) \\
50.0(1.0) \\
42.3(1.5) \\
35.3(2.3)\end{array}$ \\
\hline 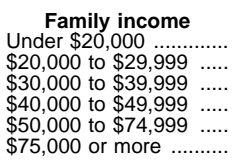 & $\begin{array}{r}7,374(144) \\
7,819(148) \\
10,370(169) \\
9,627(164) \\
21,685(236) \\
24,138(247)\end{array}$ & $\begin{array}{l}25.8(0.9) \\
29.3(0.9) \\
30.2(0.8) \\
29.3(0.8) \\
30.4(0.5) \\
33.4(0.5)\end{array}$ & $\begin{array}{l}34.2 \\
30.8 \\
29.4 \\
28.3 \\
29.9 \\
29.1\end{array}$ & $\begin{array}{l}61.8 \\
66.4 \\
64.5 \\
66.3 \\
63.6 \\
58.2\end{array}$ & $\begin{array}{l}16.2 \\
18.7 \\
20.4 \\
20.4 \\
24.6 \\
31.7\end{array}$ & $\begin{aligned} & 9.3(0.6) \\
& 6.7(0.5) \\
& 7.6(0.5) \\
& 8.1(0.5) \\
& 10.4(0.4) \\
& 14.9(0.4)\end{aligned}$ & $\begin{array}{l}58.0 \\
57.2 \\
55.3 \\
55.5 \\
61.7 \\
66.8\end{array}$ & $\begin{array}{l}15.3 \\
15.6 \\
17.5 \\
16.6 \\
18.6 \\
22.2\end{array}$ & $\begin{array}{l}21.8 \\
22.4 \\
23.2 \\
23.9 \\
24.0 \\
23.7\end{array}$ & $\begin{array}{r}9.9 \\
12.4 \\
12.0 \\
12.1 \\
13.2 \\
14.1\end{array}$ & $\begin{array}{l}17.4 \\
16.6 \\
17.4 \\
18.0 \\
20.7 \\
25.0\end{array}$ & $\begin{array}{l}38.9(1.0) \\
37.6(0.9) \\
38.7(0.8) \\
38.6(0.9) \\
45.6(0.6) \\
53.6(0.6)\end{array}$ \\
\hline
\end{tabular}

1 Individuals may be counted in more than one computer activity.

2 Data are for persons 15 years old and over.

-Data not available or not applicable.
NOTE.-Data are based on a sample survey of households and are subject to sampling and nonsampling error. Standard errors appear in parentheses.

SOURCE: U.S. Department of Commerce, Bureau of the Census, Current Population Survey, October 1997, unpublished data. (This table was prepared October 1998.)

Table 427.-Percent of student home computer users using specific applications, by selected characteristics: October 1997

\begin{tabular}{|c|c|c|c|c|c|c|c|c|c|c|c|c|}
\hline \multirow[b]{2}{*}{ Selected characteristics } & \multirow[b]{2}{*}{$\begin{array}{l}\text { Number of home } \\
\text { computer users, } \\
\text { in thousands }\end{array}$} & \multicolumn{11}{|c|}{ Percent of computer users using specific applications ${ }^{1}$} \\
\hline & & $\begin{array}{c}\text { Home } \\
\text { book- } \\
\text { keeping }\end{array}$ & $\begin{array}{c}\text { School } \\
\text { assignments }\end{array}$ & Games & $\begin{array}{l}\text { Job- } \\
\text { related }\end{array}$ & $\begin{array}{l}\text { Home } \\
\text { connection to } \\
\text { school or } \\
\text { work }\end{array}$ & $\begin{array}{c}\text { Word } \\
\text { processing }\end{array}$ & $\begin{array}{c}\text { Data } \\
\text { bases }\end{array}$ & Graphics & $\begin{array}{l}\text { Desktop } \\
\text { publishing }\end{array}$ & $\begin{array}{l}\text { Spread- } \\
\text { sheets }\end{array}$ & Internet \\
\hline 1 & 2 & 3 & 4 & 5 & 6 & 7 & 8 & 9 & 10 & 11 & 12 & 13 \\
\hline 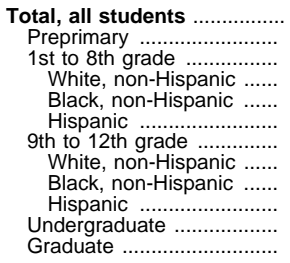 & $\begin{aligned} & \mathbf{3 2 , 4 5 9}(\mathbf{3 1 0}) \\
& 2,493(83) \\
& 14,056(205) \\
& 11,340(182) \\
& 1,078(50) \\
& 863(37) \\
& 7,699(139) \\
& 6,265(125) \\
& 534(38) \\
& 458(37) \\
& 6,179(124) \\
& 2,032(70)\end{aligned}$ & $\begin{array}{r}\text { 二 } \\
\bar{Z} \\
\bar{Z} \\
2.9 \\
2.8 \\
1.7 \\
3.1 \\
22.5 \\
38.1\end{array}$ & $\begin{aligned} & 65.9(0.4) \\
& 5.2(0.7) \\
& 58.3(0.7) \\
& 55.6(0.8) \\
& 49.8(2.3) \\
& 51.0(2.1) \\
& 84.8(0.6) \\
& 80.4(0.8) \\
& 74.3(3.1) \\
& 73.0(3.6) \\
& 82.0(0.8) \\
& 73.4(1.5)\end{aligned}$ & $\begin{array}{l}78.0 \\
89.5 \\
93.0 \\
89.1 \\
84.1 \\
77.5 \\
76.0 \\
72.5 \\
69.7 \\
64.2 \\
54.3 \\
44.3\end{array}$ & $\begin{array}{r}- \\
\text { Z } \\
\text { Z } \\
5.2 \\
4.2 \\
9.9 \\
4.4 \\
17.8 \\
43.4\end{array}$ & $\begin{array}{l}7.4(0.2) \\
0.4(0.2) \\
1.3(0.2) \\
1.2(0.2) \\
1.0(0.5) \\
2.0(0.6) \\
3.1(0.3) \\
3.1(0.3) \\
1.4(0.8) \\
2.2(1.2) \\
20.3(0.8) \\
32.0(1.6)\end{array}$ & $\begin{array}{r}52.5 \\
4.6 \\
36.1 \\
35.7 \\
23.6 \\
28.2 \\
65.9 \\
64.3 \\
47.2 \\
55.2 \\
79.7 \\
88.0\end{array}$ & $\begin{array}{l}\overline{0.0} \\
0.0 \\
0.0 \\
0.0 \\
0.0 \\
6.1 \\
6.0 \\
2.4 \\
4.1 \\
0.0 \\
0.0\end{array}$ & $\begin{array}{r}\mathbf{2 1 . 4} \\
10.8 \\
19.2 \\
19.5 \\
9.5 \\
14.3 \\
22.3 \\
22.2 \\
15.3 \\
13.4 \\
25.4 \\
32.9\end{array}$ & $\begin{array}{r}\bar{Z} \\
\overline{-} \\
\overline{-} \\
7.0 \\
7.1 \\
4.0 \\
3.9 \\
14.3 \\
25.5\end{array}$ & $\begin{array}{r}= \\
\text { 二 } \\
\text { 二 } \\
\text { - } \\
6.5 \\
6.3 \\
2.2 \\
4.5 \\
24.6 \\
36.6\end{array}$ & $\begin{array}{rr}36.3 & (0.4) \\
4.4 & (0.7) \\
25.1 & (0.6) \\
26.4 & (0.7) \\
16.0 & (1.7) \\
19.4 & (1.7) \\
42.2 & (0.9) \\
43.6 & (1.0) \\
27.6 & (3.2) \\
37.3 & (3.9) \\
57.9 & (1.0) \\
65.9 & (1.6)\end{array}$ \\
\hline 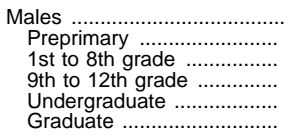 & $\begin{aligned} 16,213 & (208) \\
1,308 & (60) \\
7,257 & (144) \\
3,971 & (98) \\
2,841 & (83) \\
834 & (45)\end{aligned}$ & $\begin{array}{r}7.2 \\
\bar{Z} \\
3.0 \\
23.5 \\
44.2\end{array}$ & $\begin{array}{r}62.5(0.6) \\
5.5(1.0) \\
54.8(1.0) \\
78.6(1.0) \\
82.7(1.1) \\
73.7(2.3)\end{array}$ & $\begin{array}{l}79.9 \\
90.3 \\
89.8 \\
78.8 \\
59.8 \\
50.4\end{array}$ & $\begin{array}{r}7.2 \\
\overline{-} \\
5.5 \\
18.8 \\
48.1\end{array}$ & \begin{tabular}{rl|}
7.7 & $(0.3)$ \\
$0.8(0.4)$ \\
$1.4(0.2)$ \\
$3.4(0.4)$ \\
$23.7(1.2)$ \\
$39.0(2.6)$
\end{tabular} & $\begin{array}{r}47.0 \\
3.8 \\
31.3 \\
58.9 \\
78.8 \\
85.9\end{array}$ & $\begin{array}{l}0.0 \\
0.0 \\
0.0 \\
0.0 \\
0.0 \\
0.0\end{array}$ & $\begin{array}{l}20.3 \\
11.2 \\
16.3 \\
21.9 \\
28.6 \\
34.5\end{array}$ & $\begin{array}{r}5.4 \\
\overline{-} \\
6.6 \\
13.8 \\
26.0\end{array}$ & $\begin{array}{r}8.9 \\
\overline{-} \\
6.7 \\
28.4 \\
43.0\end{array}$ & $\begin{aligned} & 37.3(0.6) \\
& 5.9(1.1) \\
& 25.0(0.8) \\
& 44.5(1.2) \\
& 63.6(1.4) \\
& 68.8(2.5)\end{aligned}$ \\
\hline 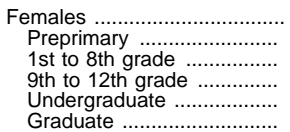 & $\begin{aligned} 16,246 & (208) \\
1,185 & (57) \\
6,799 & (139) \\
3,728 & (95) \\
3,337 & (90) \\
1,197 & (54)\end{aligned}$ & $\begin{array}{r}7.5 \\
\overline{-} \\
21.5 \\
33.9\end{array}$ & $\begin{aligned} 64.3(0.6) \\
4.9(1.0) \\
55.4(1.0) \\
81.3(1.0) \\
81.5(1.0) \\
73.2(2.0)\end{aligned}$ & $\begin{array}{l}70.2 \\
88.6 \\
85.9 \\
64.0 \\
49.5 \\
40.0\end{array}$ & $\begin{array}{r}7.4 \\
\overline{-} \\
4.1 \\
17.0 \\
40.2\end{array}$ & $\begin{array}{rl}6.6 & (0.3) \\
0.0 & 0.0 \\
1.1 & (0.2) \\
2.5 & (0.4) \\
17.4(1.0) \\
27.0(2.0)\end{array}$ & $\begin{array}{r}54.1 \\
5.3 \\
37.0 \\
65.5 \\
80.6 \\
89.4\end{array}$ & $\begin{array}{l}0.0 \\
0.0 \\
0.0 \\
0.0 \\
0.0 \\
0.0\end{array}$ & $\begin{array}{l}20.8 \\
10.4 \\
20.0 \\
20.0 \\
22.7 \\
31.8\end{array}$ & $\begin{array}{r}6.4 \\
\overline{-} \\
6.5 \\
14.7 \\
25.2\end{array}$ & $\begin{array}{r}8.0 \\
\overline{5} \\
5.5 \\
21.3 \\
32.2\end{array}$ & $\begin{aligned} & 35.4(0.6) \\
& 2.7(0.8) \\
& 25.1(0.9) \\
& 39.7(1.2) \\
& 53.1(1.3) \\
& 63.8(2.1)\end{aligned}$ \\
\hline
\end{tabular}

${ }^{1}$ Individuals may be counted in more than one computer activity.

-Data not available or not applicable.

NOTE.-Data are based on a sample survey of households and are subject to sampling and nonsampling error. Standard errors appear in parentheses.
SOURCE: U.S. Department of Commerce, Bureau of the Census, Current Population Survey, October 1997, unpublished data. (This table was prepared October 1998.) 
Table 428.-Student use of computers, by level of instruction and selected characteristics: 1984 to 1997

\begin{tabular}{|c|c|c|c|c|c|c|c|c|c|c|c|c|c|c|}
\hline \multirow[b]{2}{*}{$\begin{array}{l}\text { Student and school } \\
\text { characteristics }\end{array}$} & \multirow[b]{2}{*}{$\begin{array}{l}\text { October, } \\
1984 \\
\text { total }\end{array}$} & \multirow[b]{2}{*}{$\begin{array}{l}\text { October } \\
1989 \\
\text { total }\end{array}$} & \multicolumn{6}{|c|}{ October 1993} & \multicolumn{6}{|c|}{ October 1997} \\
\hline & & & Total & $\begin{array}{l}\text { Pre- } \\
\text { kinder- } \\
\text { garten } \\
\text { and } \\
\text { kinder- } \\
\text { garten }\end{array}$ & $\begin{array}{c}\text { Grades } \\
1 \text { to } 8\end{array}$ & $\begin{array}{l}\text { Grades } \\
9 \text { to } 12\end{array}$ & $\begin{array}{l}\text { 1st to } \\
4 \text { th year } \\
\text { of } \\
\text { college }\end{array}$ & $\begin{array}{l}\text { 5th or } \\
\text { later } \\
\text { year of } \\
\text { college }\end{array}$ & Total & $\begin{array}{c}\text { Pre- } \\
\text { kinder- } \\
\text { garten } \\
\text { and } \\
\text { kinder- } \\
\text { garten }\end{array}$ & $\begin{array}{c}\text { Grades } \\
1 \text { to } 8\end{array}$ & $\begin{array}{l}\text { Grades } \\
9 \text { to } 12\end{array}$ & $\begin{array}{l}\text { 1st to } \\
4 \text { th year } \\
\text { of } \\
\text { college }\end{array}$ & $\begin{array}{l}\text { 5th or } \\
\text { later } \\
\text { year of } \\
\text { college }\end{array}$ \\
\hline \multirow[t]{2}{*}{1} & 2 & 3 & 4 & 5 & 6 & 7 & 8 & 9 & 10 & 11 & 12 & 13 & 14 & 15 \\
\hline & \multicolumn{14}{|c|}{ Percent of students using computers at school } \\
\hline Total & 27.3 & 42.7 & 59.0 & 26.2 & 68.9 & 58.2 & 55.2 & 52.1 & 68.8 & 36.5 & $79.3(0.4)$ & $70.5(0.6)$ & 64.7 & 55.5 \\
\hline 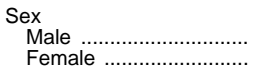 & $\begin{array}{l}29.0 \\
25.5\end{array}$ & $\begin{array}{l}43.5 \\
41.9\end{array}$ & $\begin{array}{l}59.4 \\
58.7\end{array}$ & $\begin{array}{l}25.9 \\
26.5\end{array}$ & $\begin{array}{l}69.5 \\
68.4\end{array}$ & $\begin{array}{l}56.5 \\
60.0\end{array}$ & $\begin{array}{l}57.5 \\
53.3\end{array}$ & $\begin{array}{l}56.7 \\
47.8\end{array}$ & $\begin{array}{l}70.1 \\
67.6\end{array}$ & $\begin{array}{l}37.1 \\
35.7\end{array}$ & $\begin{array}{l}79.5(0.5) \\
79.0(0.5)\end{array}$ & $\begin{array}{l}71.3(0.8) \\
69.6(0.8)\end{array}$ & $\begin{array}{l}67.8 \\
62.2\end{array}$ & $\begin{array}{l}59.9 \\
52.1\end{array}$ \\
\hline 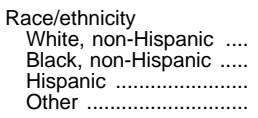 & $\begin{array}{l}30.0 \\
16.8 \\
18.6 \\
28.6\end{array}$ & $\begin{array}{l}45.7 \\
32.6 \\
34.9 \\
42.7\end{array}$ & $\begin{array}{l}61.6 \\
51.5 \\
52.3 \\
59.0\end{array}$ & $\begin{array}{l}29.4 \\
16.5 \\
19.2 \\
23.5\end{array}$ & $\begin{array}{l}73.7 \\
56.5 \\
58.4 \\
65.7\end{array}$ & $\begin{array}{l}59.9 \\
54.5 \\
54.1 \\
57.3\end{array}$ & $\begin{array}{l}54.9 \\
56.9 \\
51.9 \\
60.9\end{array}$ & $\begin{array}{l}49.8 \\
57.9 \\
53.7 \\
69.4\end{array}$ & $\begin{array}{l}71.1 \\
66.3 \\
61.5 \\
65.3\end{array}$ & $\begin{array}{l}38.7 \\
33.5 \\
31.0 \\
32.7\end{array}$ & $\begin{array}{l}84.0(0.4) \\
71.6(0.9) \\
68.3(0.9) \\
74.9(1.3)\end{array}$ & $\begin{array}{l}71.9(0.7) \\
72.9(1.4) \\
63.1(1.8) \\
63.6(2.9)\end{array}$ & $\begin{array}{l}64.3 \\
69.2 \\
63.3 \\
63.1\end{array}$ & $\begin{array}{l}53.8 \\
55.8 \\
54.7 \\
68.9\end{array}$ \\
\hline 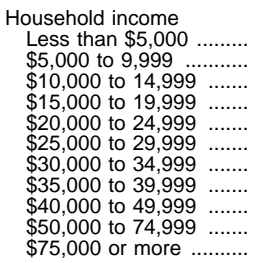 & $\begin{array}{l}18.7 \\
21.0 \\
22.4 \\
25.9 \\
26.7 \\
30.5 \\
30.5 \\
32.3 \\
32.8 \\
35.5 \\
36.0\end{array}$ & $\begin{array}{l}36.7 \\
36.1 \\
38.4 \\
41.5 \\
42.4 \\
46.1 \\
44.2 \\
45.2 \\
44.7 \\
47.0 \\
51.2\end{array}$ & $\begin{array}{l}51.2 \\
53.3 \\
56.4 \\
58.1 \\
56.4 \\
60.0 \\
59.1 \\
60.7 \\
59.3 \\
62.6 \\
64.6\end{array}$ & $\begin{array}{l}19.6 \\
24.4 \\
20.1 \\
23.8 \\
23.7 \\
28.0 \\
23.7 \\
27.1 \\
28.5 \\
28.6 \\
33.5\end{array}$ & $\begin{array}{l}55.0 \\
60.3 \\
64.7 \\
67.5 \\
64.3 \\
70.1 \\
69.6 \\
72.1 \\
70.3 \\
75.6 \\
78.7\end{array}$ & $\begin{array}{l}50.6 \\
51.9 \\
56.7 \\
57.4 \\
53.0 \\
60.3 \\
59.7 \\
61.7 \\
57.2 \\
61.5 \\
62.5\end{array}$ & $\begin{array}{l}61.7 \\
53.9 \\
50.7 \\
51.2 \\
57.4 \\
51.5 \\
51.7 \\
49.2 \\
53.9 \\
57.4 \\
60.9\end{array}$ & $\begin{array}{l}66.7 \\
56.2 \\
76.1 \\
58.5 \\
52.4 \\
58.0 \\
45.3 \\
47.9 \\
48.6 \\
44.2 \\
47.7\end{array}$ & $\begin{array}{l}62.1 \\
63.5 \\
66.2 \\
65.9 \\
66.9 \\
68.5 \\
67.6 \\
69.0 \\
70.5 \\
71.7 \\
72.1\end{array}$ & $\begin{array}{l}25.4 \\
35.1 \\
33.3 \\
33.0 \\
34.2 \\
38.9 \\
34.6 \\
34.6 \\
34.7 \\
39.3 \\
43.2\end{array}$ & $\begin{array}{l}69.6(1.9) \\
70.1(1.6) \\
74.1(1.4) \\
74.9(1.6) \\
74.9(1.5) \\
77.7(1.5) \\
79.9(1.3) \\
79.9(1.4) \\
81.6(1.1) \\
84.0(0.8) \\
85.7(0.8)\end{array}$ & $\begin{array}{l}67.9(2.9) \\
61.6(2.4) \\
68.2(2.1) \\
66.7(2.4) \\
69.2(2.0) \\
72.0(2.2) \\
70.4(2.1) \\
70.1(2.2) \\
74.1(1.6) \\
72.8(1.2) \\
71.6(1.3)\end{array}$ & $\begin{array}{l}61.1 \\
69.8 \\
64.1 \\
62.1 \\
64.0 \\
63.1 \\
55.2 \\
61.5 \\
63.3 \\
67.2 \\
68.1\end{array}$ & $\begin{array}{l}74.1 \\
74.8 \\
70.5 \\
69.4 \\
65.8 \\
53.7 \\
47.7 \\
55.2 \\
52.0 \\
48.5 \\
50.1\end{array}$ \\
\hline \multirow[t]{2}{*}{ 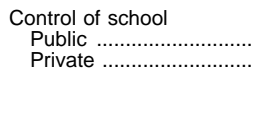 } & $\begin{array}{l}27.4 \\
26.5\end{array}$ & $\begin{array}{l}43.3 \\
38.9\end{array}$ & $\begin{array}{l}60.2 \\
52.1\end{array}$ & $\begin{array}{l}30.1 \\
18.7\end{array}$ & $\begin{array}{l}68.6 \\
72.5\end{array}$ & $\begin{array}{l}58.1 \\
60.7\end{array}$ & $\begin{array}{l}53.9 \\
60.7\end{array}$ & $\begin{array}{l}54.1 \\
48.0\end{array}$ & $\begin{array}{l}41.2 \\
37.8\end{array}$ & $\begin{array}{l}40.1 \\
29.6\end{array}$ & $\begin{array}{l}79.0(0.4) \\
82.1(1.1)\end{array}$ & $\begin{array}{l}70.5(0.6) \\
69.6(2.1)\end{array}$ & $\begin{array}{l}63.4 \\
70.4\end{array}$ & $\begin{array}{l}56.7 \\
53.0\end{array}$ \\
\hline & \multicolumn{14}{|c|}{ Percent of students using computers at home } \\
\hline Total & 11.5 & 18.8 & 27.0 & 15.6 & 24.7 & 28.7 & 32.8 & 52.6 & 45.1 & 29.6 & $43.4(0.5)$ & $48.8(0.6)$ & 49.8 & 67.2 \\
\hline 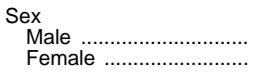 & $\begin{array}{r}14.0 \\
9.0\end{array}$ & $\begin{array}{l}20.7 \\
17.0\end{array}$ & $\begin{array}{l}27.4 \\
26.6\end{array}$ & $\begin{array}{l}15.1 \\
16.1\end{array}$ & $\begin{array}{l}24.8 \\
24.6\end{array}$ & $\begin{array}{l}28.2 \\
29.2\end{array}$ & $\begin{array}{l}36.6 \\
29.7\end{array}$ & $\begin{array}{l}56.1 \\
49.5\end{array}$ & $\begin{array}{l}45.2 \\
44.9\end{array}$ & $\begin{array}{l}30.3 \\
28.8\end{array}$ & $\begin{array}{l}43.6(0.6) \\
43.3(0.7)\end{array}$ & $\begin{array}{l}49.3(0.9) \\
48.1(0.9)\end{array}$ & $\begin{array}{l}51.3 \\
48.6\end{array}$ & $\begin{array}{l}64.1 \\
69.6\end{array}$ \\
\hline 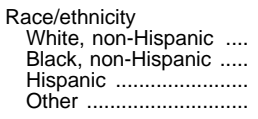 & $\begin{array}{r}13.7 \\
4.9 \\
3.6 \\
9.0\end{array}$ & $\begin{array}{r}22.7 \\
7.3 \\
7.5 \\
18.8\end{array}$ & $\begin{array}{l}32.8 \\
10.9 \\
10.4 \\
28.7\end{array}$ & $\begin{array}{r}19.4 \\
4.2 \\
5.7 \\
17.0\end{array}$ & $\begin{array}{r}31.4 \\
9.0 \\
7.5 \\
23.2\end{array}$ & $\begin{array}{r}35.9 \\
10.4 \\
9.8 \\
37.0\end{array}$ & $\begin{array}{l}36.0 \\
19.4 \\
22.0 \\
33.0\end{array}$ & $\begin{array}{l}53.6 \\
48.1 \\
52.2 \\
47.1\end{array}$ & $\begin{array}{l}54.9 \\
21.1 \\
21.1 \\
49.1\end{array}$ & $\begin{array}{r}38.4 \\
9.8 \\
11.2 \\
34.1\end{array}$ & $\begin{array}{l}54.4(0.6) \\
20.6(0.8) \\
18.6(0.7) \\
46.9(1.5)\end{array}$ & $\begin{array}{l}60.9(0.7) \\
21.0(1.3) \\
21.6(1.6) \\
51.8(3.0)\end{array}$ & $\begin{array}{l}55.1 \\
25.6 \\
37.3 \\
55.2\end{array}$ & $\begin{array}{l}70.3 \\
56.3 \\
56.1 \\
59.1\end{array}$ \\
\hline 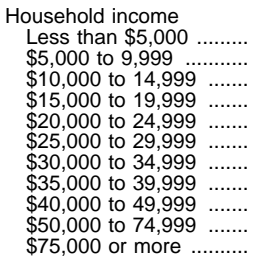 & $\begin{array}{r}2.9 \\
3.2 \\
5.0 \\
7.5 \\
9.9 \\
12.8 \\
15.8 \\
19.4 \\
20.4 \\
24.2 \\
22.1\end{array}$ & $\begin{array}{r}8.4 \\
5.4 \\
7.2 \\
11.3 \\
12.9 \\
17.0 \\
17.7 \\
21.4 \\
25.7 \\
31.6 \\
43.8\end{array}$ & $\begin{array}{r}9.7 \\
8.0 \\
11.4 \\
15.1 \\
16.8 \\
21.1 \\
24.1 \\
27.1 \\
32.2 \\
43.0 \\
56.1\end{array}$ & $\begin{array}{r}1.1 \\
0.9 \\
4.6 \\
6.9 \\
7.4 \\
12.3 \\
18.7 \\
13.0 \\
21.6 \\
25.5 \\
38.2\end{array}$ & $\begin{array}{r}4.1 \\
4.5 \\
6.4 \\
10.9 \\
13.1 \\
19.3 \\
20.5 \\
26.3 \\
32.9 \\
45.3 \\
62.3\end{array}$ & $\begin{array}{r}6.8 \\
5.3 \\
8.7 \\
14.1 \\
17.9 \\
22.0 \\
29.1 \\
28.1 \\
33.9 \\
46.4 \\
61.0\end{array}$ & $\begin{array}{l}25.6 \\
21.3 \\
29.8 \\
28.9 \\
27.7 \\
26.1 \\
26.4 \\
32.7 \\
32.5 \\
40.1 \\
47.0\end{array}$ & $\begin{array}{l}45.2 \\
45.6 \\
50.0 \\
43.0 \\
49.6 \\
47.0 \\
44.4 \\
52.7 \\
45.9 \\
58.2 \\
64.7\end{array}$ & $\begin{array}{l}22.6 \\
15.8 \\
18.4 \\
20.7 \\
30.5 \\
34.6 \\
38.7 \\
44.1 \\
50.6 \\
61.7 \\
74.2\end{array}$ & $\begin{array}{r}4.7 \\
7.6 \\
9.4 \\
9.4 \\
14.5 \\
20.9 \\
22.7 \\
28.1 \\
37.3 \\
44.3 \\
58.5\end{array}$ & $\begin{aligned} & 17.4(1.6) \\
& 9.9(1.0) \\
& 12.8(1.1) \\
& 16.4(1.4) \\
& 26.1(1.5) \\
& 32.2(1.6) \\
& 36.4(1.6) \\
& 44.5(1.7) \\
& 51.0(1.4) \\
& 64.2(1.0) \\
& 80.3(0.9)\end{aligned}$ & $\begin{aligned} & 17.3(2.3) \\
& 9.1(1.4) \\
& 18.1(1.8) \\
& 20.6(2.1) \\
& 31.7(2.0) \\
& 37.9(2.3) \\
& 42.3(2.3) \\
& 45.9(2.4) \\
& 56.2(1.9) \\
& 67.3(1.3) \\
& 80.7(1.1)\end{aligned}$ & $\begin{array}{l}40.8 \\
41.0 \\
34.9 \\
35.1 \\
44.1 \\
42.8 \\
45.8 \\
47.0 \\
51.1 \\
56.3 \\
62.8\end{array}$ & $\begin{array}{l}57.1 \\
55.4 \\
64.2 \\
74.8 \\
61.3 \\
53.4 \\
65.4 \\
67.4 \\
54.1 \\
73.2 \\
76.1\end{array}$ \\
\hline \multirow[t]{2}{*}{ 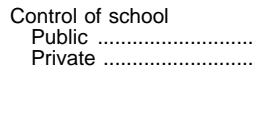 } & $\begin{array}{l}11.2 \\
13.8\end{array}$ & $\begin{array}{l}17.9 \\
24.4\end{array}$ & $\begin{array}{l}25.3 \\
37.4\end{array}$ & $\begin{array}{l}12.1 \\
22.4\end{array}$ & $\begin{array}{l}23.0 \\
41.5\end{array}$ & $\begin{array}{l}27.2 \\
47.2\end{array}$ & $\begin{array}{l}31.9 \\
36.9\end{array}$ & $\begin{array}{l}50.0 \\
57.7\end{array}$ & $\begin{array}{l}30.2 \\
35.9\end{array}$ & $\begin{array}{l}24.0 \\
40.2\end{array}$ & $\begin{array}{l}41.2(0.5) \\
65.0(1.4)\end{array}$ & $\begin{array}{l}46.9(0.6) \\
72.8\end{array}$ & $\begin{array}{l}49.7 \\
50.3\end{array}$ & $\begin{array}{l}66.1 \\
69.5\end{array}$ \\
\hline & \multicolumn{14}{|c|}{ Percent of students using computers at home for school work } \\
\hline Total $\ldots \ldots \ldots \ldots \ldots \ldots \ldots \ldots \ldots \ldots \ldots \ldots \ldots$ & 4.6 & 8.9 & 14.9 & 0.6 & 10.8 & 20.9 & 23.1 & 36.6 & 28.6 & 1.5 & $23.9(0.4)$ & $39.0(0.6)$ & 40.8 & 49.3 \\
\hline 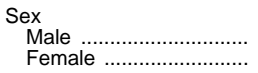 & $\begin{array}{l}5.9 \\
3.3\end{array}$ & $\begin{array}{l}9.5 \\
8.3\end{array}$ & $\begin{array}{l}14.8 \\
15.0\end{array}$ & $\begin{array}{l}0.9 \\
0.4\end{array}$ & $\begin{array}{l}10.1 \\
11.5\end{array}$ & $\begin{array}{l}20.5 \\
21.4\end{array}$ & $\begin{array}{l}26.3 \\
20.5\end{array}$ & $\begin{array}{l}40.3 \\
33.2\end{array}$ & $\begin{array}{l}28.3 \\
28.9\end{array}$ & $\begin{array}{l}1.7 \\
1.4\end{array}$ & $\begin{array}{l}23.8(0.5) \\
24.0(0.6)\end{array}$ & $\begin{array}{ll}38.8 & (0.8) \\
39.1 & (0.9)\end{array}$ & $\begin{array}{l}42.4 \\
39.6\end{array}$ & $\begin{array}{l}47.2 \\
50.9\end{array}$ \\
\hline $\begin{array}{l}\text { Race } \\
\quad \text { White, non-Hispanic .... } \\
\text { Black, non-Hispanic ..... } \\
\text { Hispanic ..................... } \\
\text { Other ................................. }\end{array}$ & $\begin{array}{l}5.4 \\
2.3 \\
1.4 \\
3.8\end{array}$ & $\begin{array}{r}10.7 \\
3.4 \\
3.6 \\
9.1\end{array}$ & $\begin{array}{r}18.2 \\
5.7 \\
5.6 \\
16.0\end{array}$ & $\frac{0.8}{\overline{1.1}}$ & $\begin{array}{r}13.8 \\
4.0 \\
2.9 \\
9.3\end{array}$ & $\begin{array}{r}26.5 \\
6.9 \\
6.7 \\
27.0\end{array}$ & $\begin{array}{l}25.7 \\
11.5 \\
15.9 \\
23.7\end{array}$ & $\begin{array}{l}37.8 \\
30.1 \\
36.8 \\
29.2\end{array}$ & $\begin{array}{l}35.0 \\
12.5 \\
12.5 \\
33.6\end{array}$ & $\begin{array}{l}1.7 \\
1.5 \\
0.7 \\
1.9\end{array}$ & $\begin{aligned} & 30.2(0.5) \\
& 10.3(0.6) \\
& 9.5(0.5) \\
& 28.2(1.4)\end{aligned}$ & $\begin{array}{l}49.0(0.8) \\
15.6(1.2) \\
15.8(1.4) \\
44.9(3.0)\end{array}$ & $\begin{array}{l}45.9 \\
19.2 \\
27.6 \\
45.2\end{array}$ & $\begin{array}{l}51.3 \\
39.8 \\
46.2 \\
45.8\end{array}$ \\
\hline 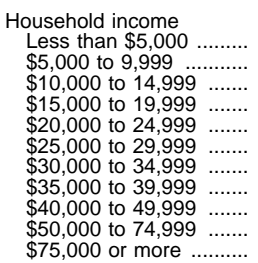 & $\begin{array}{r}1.0 \\
1.5 \\
1.9 \\
3.0 \\
3.1 \\
5.1 \\
4.9 \\
7.1 \\
9.2 \\
11.5 \\
9.8\end{array}$ & $\begin{array}{r}5.0 \\
3.2 \\
3.5 \\
4.5 \\
5.7 \\
6.4 \\
8.0 \\
10.5 \\
11.9 \\
15.2 \\
22.0\end{array}$ & $\begin{array}{r}6.7 \\
4.8 \\
7.3 \\
8.6 \\
9.8 \\
10.4 \\
13.0 \\
15.4 \\
17.1 \\
23.2 \\
30.4\end{array}$ & $\begin{array}{l}\bar{Z} \\
\overline{-} \\
0.4 \\
0.7 \\
1.1 \\
0.8 \\
0.8 \\
1.1 \\
1.0 \\
0.8\end{array}$ & $\begin{array}{r}2.5 \\
1.1 \\
2.6 \\
4.7 \\
5.1 \\
6.3 \\
8.1 \\
12.4 \\
14.7 \\
19.7 \\
29.4\end{array}$ & $\begin{array}{r}4.0 \\
3.6 \\
5.6 \\
10.8 \\
12.6 \\
13.4 \\
21.9 \\
21.0 \\
24.2 \\
35.0 \\
45.2\end{array}$ & $\begin{array}{l}18.7 \\
16.1 \\
25.9 \\
18.7 \\
22.9 \\
19.5 \\
18.0 \\
22.6 \\
22.2 \\
27.0 \\
30.6\end{array}$ & $\begin{array}{l}36.0 \\
35.5 \\
34.6 \\
31.0 \\
35.0 \\
34.9 \\
35.1 \\
37.2 \\
32.1 \\
38.2 \\
41.5\end{array}$ & $\begin{array}{l}15.1 \\
10.4 \\
11.4 \\
13.2 \\
19.4 \\
21.9 \\
24.4 \\
26.5 \\
30.1 \\
39.3 \\
48.3\end{array}$ & $\begin{array}{l}1 . \overline{1} \\
0.8 \\
1.0 \\
1.7 \\
2.1 \\
0.8 \\
0.4 \\
2.9 \\
1.2 \\
2.8\end{array}$ & $\begin{array}{r}8.8(1.2) \\
3.9(0.7) \\
5.3(0.7) \\
8.4(1.0) \\
12.5(1.2) \\
18.6(1.4) \\
19.0(1.3) \\
22.3(1.4) \\
26.7(1.2) \\
36.1(1.0) \\
48.5(1.2)\end{array}$ & $\begin{array}{r}11.7(2.0) \\
7.3(1.3) \\
13.5(1.6) \\
13.2(1.7) \\
25.4(1.9) \\
27.5(2.2) \\
33.2(2.2) \\
35.5(2.3) \\
45.5(1.9) \\
54.9(1.4) \\
66.4(1.4)\end{array}$ & $\begin{array}{l}31.6 \\
35.3 \\
28.9 \\
31.0 \\
35.2 \\
34.4 \\
38.7 \\
38.7 \\
38.9 \\
46.9 \\
51.5\end{array}$ & $\begin{array}{l}53.7 \\
44.8 \\
50.1 \\
63.3 \\
44.6 \\
40.8 \\
48.9 \\
55.7 \\
36.8 \\
53.1 \\
50.4\end{array}$ \\
\hline 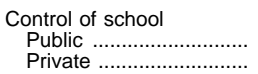 & $\begin{array}{l}4.5 \\
5.4\end{array}$ & $\begin{array}{r}8.5 \\
11.4\end{array}$ & $\begin{array}{l}14.2 \\
18.8\end{array}$ & $\begin{array}{l}0.5 \\
1.0\end{array}$ & $\begin{array}{l}10.1 \\
17.8\end{array}$ & $\begin{array}{l}19.8 \\
35.4\end{array}$ & $\begin{array}{l}22.7 \\
24.8\end{array}$ & $\begin{array}{l}34.7 \\
40.1\end{array}$ & $\begin{array}{l}21.8 \\
24.6\end{array}$ & $\begin{array}{l}1.5 \\
1.6\end{array}$ & $\begin{array}{l}22.5(0.4) \\
37.7(1.4)\end{array}$ & $\begin{array}{ll}37.1 & (0.6) \\
62.0(2.3)\end{array}$ & $\begin{array}{l}40.6 \\
42.0\end{array}$ & $\begin{array}{l}48.7 \\
50.6\end{array}$ \\
\hline
\end{tabular}

-Data not available.

NOTE.-Data are based on a sample survey of households and are subject to sampling and nonsampling error. Standard errors appear in parentheses.
SOURCE: U.S. Department of Commerce, Bureau of the Census, Current Population Survey, October 1984, 1989, 1993, and 1997, unpublished data. (This table was prepared September 1998.) 


\section{Guide to Tabular Presentation}

This section is intended to assist the reader in following the basic structure of the Digest tables and to provide a legend for some of the common symbols and indexes used throughout the book. Unless otherwise noted, all data are for the 50 states and the District of Columbia.

\section{Table Components}

Title Describes the table content concisely.

Unit Indicator Informs the reader of the measurement united in the table- "In thousands," "In millions of dollars," etc. Noted below the title unless several units are used, in which case the unit indicators are generally given in the spanner or individual column heads.

Spanner Describes a group of two or more columns.

Column head Describes specific column.
Stub Describes a row or a group of rows. Each stub is followed by a number of dots (leaders) or by a semicolon if no data appears in the data fields.

Field The area of the table which contains the data elements.

\section{Rules in the field}

Single horizontal rules indicate

- that the data below the line add to the figure immediately above the line, or

- in the case of derived figures (e.g., percents, medians) that the datum above the line represents a cumulative figure.

Double horizontal rules demarcate groups of related rows.

Single vertical rules delineate columns.

Double vertical rules divide the table into sections with unique stubs.

\section{Example of Table Structure}

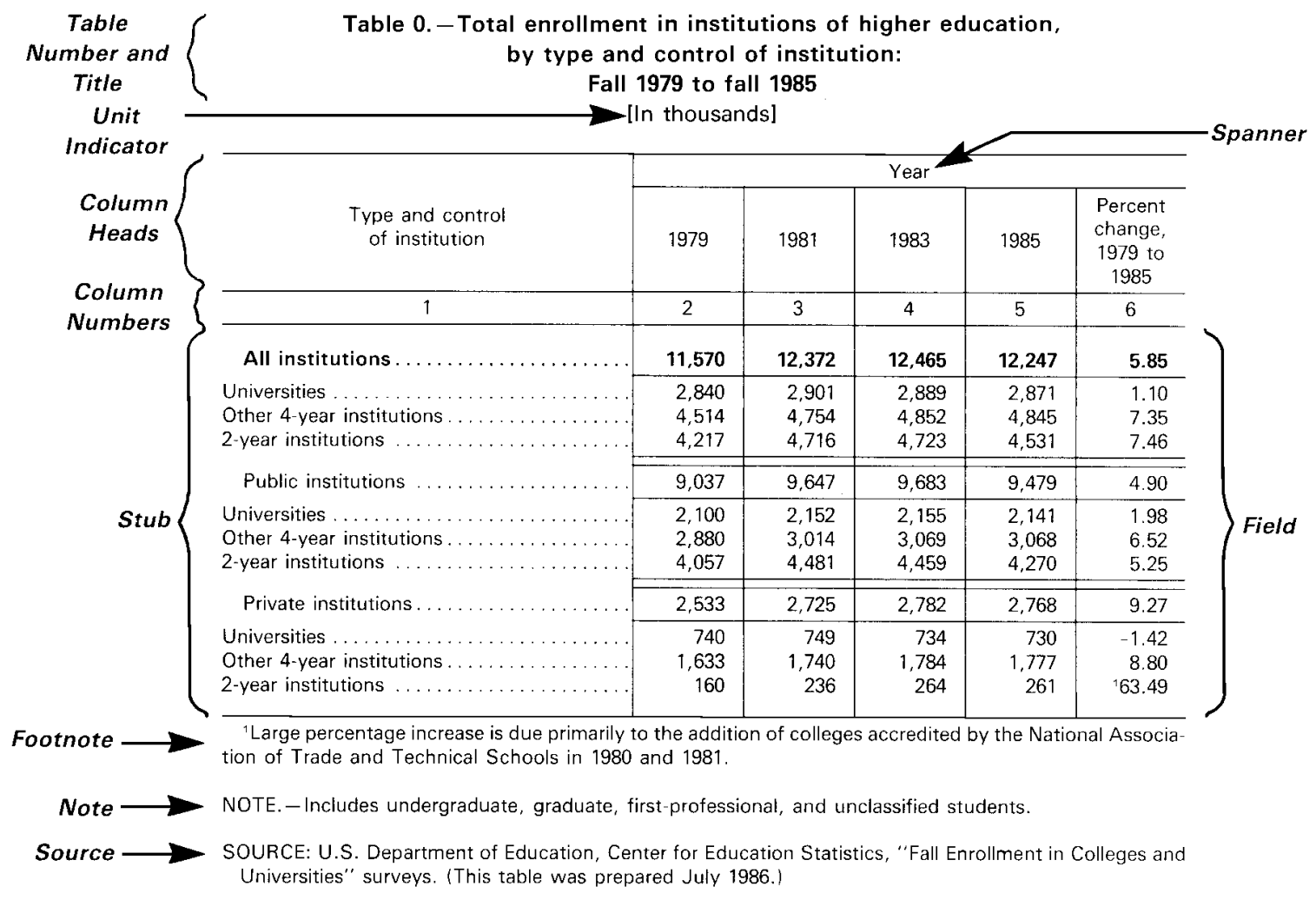


Footnote Describes a unique circumstance relating to a specific item within the table. Usually listed below the bottom rule of the table.

Note Furnishes general information that relates to the entire table.

Source The document or reference from which the data are drawn. This note may also include the organizational unit responsible for preparing the data.

\section{Descriptive Terms}

Average A number that is used to represent the "typical value" of a group of numbers. It is regarded as a measure of "location" or "central tendency" of a group of numbers.

Arithmetic mean is the most commonly used average. It is derived by summing the individual item values of a particular group and dividing that sum by the number of items. This value is often referred to simply as the "mean" or "average."

Median is the measure of central tendency that occupies the middle position in a rank order of values. It generally has the same number of items above it as below it. If there is an even number of items in the group, the median is the average of the middle two items.

Per capita, or per person, figure represents an average computed for every person in a specified group, or population. It is derived by dividing the total for an item (such as income or expenditures) by the number of persons in the specified population.

Index number A value that provides a means of measuring, summarizing, and communicating the nature of changes that occur from time to time or from place to place. An index is used to express changes in prices over periods of time but may also be used to express differences between related subjects at a single point in time.
The Digest most often uses the Consumer Price Index to compare purchasing power over time.

To compute a price index, a base year or period is selected. The base year price is then designated as the base or reference price to which the prices for other years or periods are related.

A method of expressing the price relationship is:

Index number $=$

Price of a set of one or more items for related year

Price of the same set of items for base year $x 100$

When 100 is subtracted from the index number, the result equals the percent change in price from the base year.

Current and constant dollars are used in a number of tables to express finance data. Unless otherwise noted, all figures are in current dollars, not adjusted for inflation. Constant dollars provide a measure of the impact of inflation on the current dollars.

Current dollar figures reflect actual prices or costs prevailing during the specified year(s).

Constant dollar figures attempt to remove the effects of price changes (inflation) from statistical series reported in dollar terms.

The constant dollar value for an item is derived by dividing the base year price index (for example, the Consumer Price Index for 1996) by the price index for the year of data to be adjusted and multiplying by the item to be adjusted. The result is an adjusted dollar value as it would presumably exist if prices were the same as the base year-in other words, as if the dollar had constant purchasing power. Any changes in the constant dollar amounts would reflect only changes in the real values.

NOTE: Tables may not include data for all years implied in table titles. 


\section{Guide to Sources Sources and Comparability of Data}

The information presented in this report was obtained from many sources, including federal and state agencies, private research organizations, and professional associations. The data were collected using many research methods, including surveys of a universe (such as all colleges) or of a sample, compilations of administrative records, and statistical projections. Digest users should take particular care when comparing data from different sources. Differences in procedures, timing, phrasing of questions, interviewer training, and so forth mean that the results from the different sources may not be strictly comparable. Following the general discussion of data accuracy below, descriptions of the information sources and data collection methods are presented, grouped by sponsoring organization. More extensive documentation of a particular survey's procedures does not imply more problems with the data, only that more information is available.

\section{Accuracy of Data}

The accuracy of any statistic is determined by the joint effects of "sampling" and "nonsampling" errors. Estimates based on a sample will differ somewhat from the figures that would have been obtained if a complete census had been taken using the same survey instruments, instructions, and procedures. In addition to such sampling errors, all surveys, both universe and sample, are subject to design, reporting, and processing errors and errors due to nonresponse. To the extent possible, these nonsampling errors are kept to a minimum by methods built into the survey procedures. In general, however, the effects of nonsampling errors are more difficult to gauge than those produced by sampling variability.

\section{Sampling Errors}

The samples used in surveys are selected from a large number of possible samples of the same size that could have been selected using the same sample design. Estimates derived from the different samples would differ from each other. The difference between a sample estimate and the average of all possible samples is called the sampling deviation. The standard or sampling error of a survey estimate is a measure of the variation among the estimates from all possible samples and, thus, is a measure of the precision with which an estimate from a particular sample approximates the average result of all possible samples.

The sample estimate and an estimate of its standard error permit us to construct interval estimates with prescribed confidence that the interval includes the average result of all possible samples. If all possible samples were selected under essentially the same conditions and an estimate and its estimated standard error were calculated from each sample, then: (1) approximately $2 / 3$ of the intervals from one standard error below the estimate to one standard error above the estimate would include the average value of all possible samples; and (2) approximately $19 / 20$ of the intervals from two standard errors below the estimate to two standard errors above the estimate would include the average value of all possible samples. We call an interval from two standard errors below the estimate to two standard errors above the estimate a 95 percent confidence interval.

To illustrate this concept, consider the data and standard errors appearing on table 105. For the 1997 estimate that 11.0 percent of 16- to 24-year-olds were high school dropouts, the table shows that the standard error is .3 percent. Therefore, we can create a 95 percent confidence interval which is approximately 10.4 to 11.6 (11.0 percent +2 times .3 percent).

Analysis of standard errors can help assess how valid a comparison between two estimates might be. The standard error of a difference between two independent sample estimates is equal to the square root of the sum of the squared standard errors of the estimates. The standard error (se) of the difference between independent sample estimates "a" and " $b$ " is:

$$
\mathrm{se}_{\mathrm{a}, \mathrm{b}}=\left(\mathrm{se}_{\mathrm{a}}^{2}+\mathrm{se}_{\mathrm{b}}{ }^{2}\right)^{1 / 2}
$$

It should be noted that most of the standard error estimates presented in subsequent sections and in the original documents are approximations. That is, to derive estimates of standard errors that would be applicable to a wide variety of items and could be prepared at a moderate cost, a number of approxi- 
mations were required. As a result, the standard error estimates provide a general order of magnitude rather than the exact standard error for any specific item. The preceding discussion on sampling variability was directed toward a situation concerning one or two estimates. Determining the accuracy of statistical projections is more difficult. In general, the further away the projection date is from the date of the actual data being used for the projection, the greater the probable error in the projections. If, for instance, annual data from 1970 to 1996 are being used to project enrollment in institutions of higher education, the further beyond 1996 one projects, the more variability in the projection. One will be less sure of the 2008 enrollment projection than of the 2000 projection. A detailed discussion of the projections methodology is contained in Projections of Education Statistics to 2008 (National Center for Education Statistics 1998).

\section{Nonsampling Errors}

Universe and sample surveys are subject to nonsampling errors. Nonsampling errors may arise when respondents or interviewers interpret questions differently, when respondents must estimate values, or when coders, keyers, and other processors handle answers differently, when persons who should be included in the universe are not, or when persons fail to respond (completely or partially). Nonsampling errors usually, but not always, result in an understatement of total survey error and thus an overstatement of the precision of survey estimates. Since estimating the magnitude of nonsampling errors often would require special experiments or access to independent data, these nonsampling errors are seldom available.

To compensate for nonresponse, adjustments of the sample estimates are often made. An adjustment made for either type of nonresponse, total or partial, is often referred to as an imputation, which is often a substitution of the "average" questionnaire response for the nonresponse. Imputations are usually made separately within various groups of sample members which have similar survey characteristics. Imputation for item nonresponse is usually made by substituting for a missing item the response to that item of a respondent having characteristics that are similar to those of the nonrespondent.

Although the magnitude of nonsampling error in the data compiled in this Digest is frequently unknown, idiosyncrasies that have been identified are noted on the appropriate tables.

\section{U.S. Department of Education} National Center for Education Statistics
(NCES)

\author{
Baccalaureate and Beyond Longitudinal \\ Study
}

The Baccalaureate and Beyond Longitudinal Study (B\&B) is based on the National Postsecondary Student Aid Study (NPSAS) and provides information concerning education and work experience after completing the bachelor's degree. B\&B provides cross-sectional information 1 year after bachelor's degree completion (comparable to the Recent College Graduates study), while at the same time providing longitudinal data concerning entry into and progress through graduate level education and the workforce. It also provides information on entry into, persistence and progress through, and completion of graduate level education-information not available through follow-ups involving high school cohorts or even college entry cohorts, both of which are restricted in the number who actually complete a bachelor's degree and continue their education.

B\&B will follow NPSAS baccalaureate degree completers for a 12-year period after completion, beginning with NPSAS:93. About 11,000 students who completed their degrees in the 1992-93 academic year were included in the first B\&B (B\&B:93/94). In addition to the student data, $B \& B$ collected postsecondary transcripts covering the undergraduate period, providing complete information on progress and persistence at both the undergraduate and graduate levels. New B\&B cohorts will alternate with BPS in using NPSAS as their base.

For additional information about B\&B contact:

Paula R. Knepper

Postsecondary Studies Division

National Center for Education Statistics

555 New Jersey Avenue NW

Washington, DC 20208-5652

Paula_Knepper@ed.gov

\section{Beginning Postsecondary Student Longitudinal Study}

The Beginning Postsecondary Student Longitudinal Study (BPS) provides information on persistence, progress, and attainment from initial time of entry into postsecondary education through leaving and entering the workforce. BPS includes traditional and nontraditional (e.g., older) students and is representative of all beginning students in postsecondary education. BPS follows first-time, beginning students for at least 
5 years at approximately 2-year intervals, collecting student data, and financial aid reports. By starting with a cohort that has already entered postsecondary education, and following it for 5 years, BPS will be able to determine to what extent students who start postsecondary education at various ages differ in their progress, persistence, and attainment. The first BPS study was conducted in 1989-90, with follow up surveys in 1992 and 1994. The second BPS cohort of students began with a survey in 1995-96 and a follow-up in 1998.

Further information on the Beginning Postsecondary Student Longitudinal Study may be obtained from:

Aurora M. D’Amico
Postsecondary Studies Division
National Center for Education Statistics
555 New Jersey Avenue NW
Washington, DC 20208-5652
Aurora_D'Amico@ed.gov

\section{Common Core of Data}

NCES uses the Common Core of Data (CCD) survey to acquire and maintain statistical data from each of the 50 states, the District of Columbia, and the outlying areas. Information about staff and students is collected annually at the school, LEA (local education agency or school district), and state levels. Information about revenues and expenditures is also collected at the state and LEA levels.

Data are collected for a particular school year (July 1 through June 30) via survey instruments sent to the state education agencies during the subsequent school year. States have 1 year in which to modify the data originally submitted.

Since the CCD is a universe survey, the CCD information presented in this edition of the Digest is not subject to sampling errors. However, nonsampling errors could come from two sources-nonreturn and inaccurate reporting. Almost all of the states submit the six CCD survey instruments each year, but submissions are sometimes incomplete or too late for publication.

Understandably, when 57 education agencies compile and submit data for approximately 88,000 public schools and 16,000 local school districts, misreporting can occur. Typically, this results from varying interpretation of NCES definitions and differing recordkeeping systems. NCES attempts to minimize these errors by working closely with the Council of Chief State School Officers (CCSSO) and its Committee on Evaluation and Information Systems (CEIS).

The state education agencies report data to NCES from data collected and edited in their regular reporting cycles. NCES encourages the agencies to incor- porate into their own survey systems the NCES items they do not already collect so that those items will also be available for the subsequent CCD survey. Over time, this has meant fewer missing data cells in each state's response, reducing the need to impute data.

NCES subjects data from the education agencies to a comprehensive edit. Where data are determined to be inconsistent, missing, or out of range, NCES contacts the education agencies for verification. NCES-prepared state summary forms are returned to the state education agencies for verification. States are also given an opportunity to revise their statelevel aggregates from the previous survey cycle.

Questions concerning the Common Core of Data can be directed to:

John Sietsema

Elementary/Secondary and Libraries Studies Division National Center for Education Statistics

555 New Jersey Avenue NW

Washington, DC 20208-5651

John_Sietsema@ed.gov

\section{Federal Support for Education}

NCES prepares an annual compilation of federal funds for education. Data for U.S. Department of Education programs come from the Budget of the United States Government. Budget offices of other federal agencies provide information for all other federal program support except for research funds, which are obligations reported by the National Science Foundation in Federal Funds for Research and Development. Some data are estimated, based on reports from the federal agencies contacted and the Budget of the United States Government.

Except for money spent on research, outlays were used to report program funds to the extent possible. Some tables are obligations as noted in the title of the table. Some federal program funds not commonly recognized as education assistance are also included in the totals reported. For example, portions of federal funds paid to some states and counties as shared revenues resulting from the sale of timber and minerals from public lands have been estimated as funds used for education purposes. Parts of the funds received by states (in 1980) and localities (throughout the period) under the General Revenue Sharing Program are also included, as are portions of federal funds received by the District of Columbia. The share of these funds allocated to education was assumed to be equal to the share of general funds expended for elementary and secondary education by states and localities in the same year as reported by the U.S. Bureau of the Census in its annual publication, Governmental Finances. 
All state intergovernmental expenditures for education were assumed earmarked for elementary/secondary education. Contributions of parent governments of dependent school systems to their public schools amounted to approximately 9 percent of local government revenues and local government revenue sharing in each year. Therefore, 9 percent of local government revenue-sharing funds were assumed allocated each fiscal year to elementary and secondary education. Parent government contributions to public school systems were obtained from the U.S. Bureau of the Census, Finances of Public School Systems. The amount of state revenue-sharing funds allocated for postsecondary education in 1980 was assumed to be 13 percent, the proportion of direct state expenditures for institutions of higher education reported in Governmental Finances for that year.

The share of federal funds for the District of Columbia assigned to education was assumed to be equal to the share of the city's general fund expenditures for each level of education.

For the job training programs conducted by the Department of Labor, only estimated sums spent on classroom training have been reported as educational program support.

During the 1970s, The Office of Management and Budget (OMB) prepared annual reports on federal education program support. These were published in the Budget of the United States Government [Special Analyses]. The information presented in this report is not, however, a continuation of the OMB series. A number of differences in the two series should be noted. OMB required all federal agencies to report outlays for education-related programs using a standardized form, thereby assuring agency compliance in reporting. The scope of education programs reported here differs from OMB. Off-budget items such as the annual volume of guaranteed student loans were not included in OMB's reports. Finally, while some mention is made of an annual estimate of federal tax expenditures, OMB did not include them in its annual analysis of federal education support. Estimated federal tax expenditures for education are the difference between current federal tax receipts and what these receipts would be without existing education deductions to income allowed by federal tax provisions.

Recipients' data are estimated based on Estimating Federal Funds for Education: A New Approach Applied to Fiscal Year 1980, "Federal Support for Education, Fiscal Years 1980 to 1984," and Catalog of Federal Domestic Assistance. The recipients' data are estimated and tend to undercount institutions of higher education (IHEs), students, and local education agencies (LEAs). This is because some of the federal programs have more than one recipient receiving funds. In these cases, the recipients were put into a "mixed recipients" category, because there was no way to disaggregate the amount each recipient received.

Further information on federal support for education may be obtained from:

Charlene Hoffman

Early Childhood, International and Crosscutting

Studies Division

National Center for Education Statistics

555 New Jersey Ave NW

Washington, DC 20208-5652

Charlene_Hoffman@ed.gov

\section{High School and Beyond}

High School and Beyond (HS\&B) is a national longitudinal survey of 1980 high school sophomores and seniors. The base-year survey was a probability sample of 1,015 high schools with a target number of 36 sophomores and 36 seniors in each of the schools. A total of 58,270 students participated in the base-year survey. Substitutions were made for noncooperating schools-but not for students-in those strata where it was possible. Overall, 1,122 schools were selected in the original sample and 811 of these schools participated in the survey. An additional 204 schools were drawn in a replacement sample. Student refusals and absences resulted in an 82 percent completion rate for the survey.

Several small groups in the population were oversampled to allow for special study of certain types of schools and students. Students completed questionnaires and took a battery of cognitive tests. In addition, a sample of parents of sophomores and seniors (about 3,600 for each cohort) was surveyed.

HS\&B first follow-up activities took place in the spring of 1982. The sample design of the first followup survey called for the selection of approximately 30,000 persons who were sophomores in 1980. The completion rate for sophomores eligible for on-campus survey administration was about 96 percent. About 89 percent of the students who left school between the base year and first follow-up surveys (dropouts, transfer students, and early graduates) completed the first follow-up sophomore questionnaire.

As part of the first follow-up survey of HS\&B, transcripts were requested in fall 1982 for an 18,152 member subsample of the sophomore cohort. Of the 15,941 transcripts actually obtained, 1,969 were excluded because the students had dropped out of school before graduation, 799 were excluded because they were incomplete, and 1,057 were excluded because the student graduated before 1982 or the transcript indicated neither a dropout status nor graduation. Thus 12,116 transcripts were utilized for the overall curriculum analysis presented in this publication. All courses in each transcript were as- 
signed a six-digit code based on $A$ Classification of Secondary School Courses (developed by Evaluation Technologies, Inc. under contract with NCES). Credits earned in each course were expressed in Carnegie units. (The Carnegie unit is a standard of measurement that represents one credit for the completion of a 1-year course. To receive credit for a course, the student must have received a passing grade"pass," "D," or higher.) Students who transferred from public to private schools or from private to public schools between their sophomore and senior years were eliminated from public/private analyses.

In designing the senior cohort first follow-up survey, one of the goals was to reduce the size of the retained sample, while still keeping sufficient numbers of minorities to allow important policy analyses. A total of 11,227 (94 percent) of the 11,995 persons subsampled completed the questionnaire. Information was obtained about the respondents' school and employment experiences, family status, and attitudes and plans.

The sample for the second follow-up, which took place in spring 1984, consisted of about 12,000 members of the senior cohort and about 15,000 members of the sophomore cohort. The completion rate for the senior cohort was 91 percent, and the completion rate for the sophomore cohort was 92 percent.

HS\&B third follow-up data collection activities were performed in spring of 1986 . Both the sophomore and senior cohort samples for this round of data collection were the same as those used for the second follow-up survey. The completion rates for the sophomore and senior cohort samples were 91 percent and 88 percent, respectively.

Table A1 contains the maximum number of cases that are available for the tabulations of the specific classification variables used throughout this publication.

The standard error (se) of an individual percentage (p) based on HS\&B data can be approximated by the formula

$$
\mathrm{se}_{\mathrm{p}}=\operatorname{DEFT}[\mathrm{p}(100-p) / n]^{1 / 2}
$$

where $\mathrm{n}$ is the sample size and DEFT, the square root of the design effect, is a factor used to adjust for the particular sample design used in HS\&B. Table A2 provides the DEFT factors for different HS\&B samples and subsamples.

In evaluating a difference between two independent percentages, the standard error of the difference may be conservatively approximated by taking the square root of the sum of the squared standard errors of the two percentages. For example, in the 1986 follow-up of 1980 sophomores, 84.0 percent of the men and 77.2 percent of the women felt that being successful in work was "very important," a difference of 6.8 percentage points. Using the formula and the sample sizes from table A1 and the DEFT factors from table A2, the standard errors of the two percentages being compared are calculated to be:

$$
\begin{aligned}
& 1.43[(84.0)(16.0) /(5,391)]^{1 / 2}=.714 \\
& 1.43[(77.2)(22.8) /(5,857)]^{1 / 2}=.784
\end{aligned}
$$

The standard error of the difference is therefore

$$
\left(.714^{2}+.784^{2}\right)^{1 / 2}=(.510+.615)^{1 / 2}=1.06
$$

The sampling error (95 chances in 100) of the difference is approximately double the standard error, or approximately 2.1 percentage points, and the 95 percent confidence interval for the difference is $6.8 \pm$ 2.1 , or 4.7 to 8.9 percentage points.

The standard error estimation procedure outlined above does not compensate for survey item nonresponse, which is a source of nonsampling error. (Table A1 reflects the maximum number of responses that could be tabulated by demographic characteristics.) For example, of the 10,925 respondents in the 1984 follow-up survey of 1980 high school graduates, 372 , or 3.4 percent, did not respond to the particular question on whether they had ever used a pocket calculator. Item nonresponse varied considerably. A very low nonresponse rate of 0.1 percent was obtained for a question asking whether the respondent had attended a postsecondary institution. A much higher item nonresponse rate of 12.2 percent was obtained for a question asking if the respondent had used a micro or minicomputer in high school. Typical item nonresponse rates ranged from 3 to 4 percent.

The Hispanic analyses presented in this report relied on students' self-identification as members of one of four Hispanic subgroups: Mexican, MexicanAmerican, Chicano; Cuban; Puerto-Rican, Puertorriqueno, or Boricua; or other Latin American, Latino, Hispanic, or Spanish descent.

An NCES series of technical reports and data file users manuals, available electronically, provides additional information on the survey methodology.

Further information on the High School and Beyond survey may be obtained from:

Aurora M. D'Amico

Postsecondary Studies Division

National Center for Education Statistics

555 New Jersey Avenue NW

Washington, DC 20208-5652

Aurora_D'Amico@ed.gov 


\section{High School Transcript Study Tabulations}

The two most recent transcript studies in 1990 and in 1994 were based on surveys conducted as part of the National Assessment of Educational Progress. The 1990 study involved analysis of transcripts of approximately 21,500 1990 high school graduates from 330 schools. The 1994 study involved about 25,000 graduates. Approximately 21,500 1990 graduates were selected for the National Assessment of Educational Progress (NAEP) transcript study in 1990. The study collected information such as course lists, graduation requirements, and the definition of units of credit and grades, on a school-level basis.

Similar studies were conducted of course-taking patterns of 1987 and 1982 graduates. The 1987 data are based on approximately 22,799 transcripts from 433 schools obtained as part of the 1987 High School Transcript Study. The 1982 data are based on approximately 12,000 transcripts collected by the High School and Beyond Project.

Because the 1982 High School and Beyond study used a different method for identifying handicapped students than did the 1987 and 1990 transcript studies, and in order to make the statistical summaries as comparable as possible, all the counts and percentages in this report are restricted to students whose records indicate that they had not participated in a special education program. This restriction lowers the number of 1990 graduates represented in the tables to 20,866 .

Further information can be obtained from:

Janis Brown

Assessment Division

National Center for Education Statistics

555 New Jersey Avenue NW

Washington, DC 20208-5653

Janis_Brown@ed.gov

\section{Integrated Postsecondary Education Data System}

The Integrated Postsecondary Education Data System (IPEDS) surveys approximately 10,000 postsecondary institutions, including universities and colleges, as well as institutions offering technical and vocational education beyond the high school level. This survey, which began in 1986, replaced the Higher Education General Information Survey (HEGIS).

IPEDS consists of eight integrated components that obtain information on who provides postsecondary education (institutions), who participates in it and completes it (students), what programs are offered and what programs are completed, and both the human and financial resources involved in the provision of institutionally based postsecondary education. Specifically, these components include: Institutional Characteristics, including instructional activity; Fall
Enrollment, including age and residence; Enrollment in Occupationally Specific Programs; Completions; Finance; Staff; Salaries of Full-Time Instructional Faculty; and Academic Libraries.

The higher education portion of this survey is a census of accredited 2- and 4-year colleges. Prior to 1993, data from the technical and vocational institutions were collected through a sample survey. Beginning in 1993, all data are gathered in a census of all postsecondary institutions. The tabulations on "Institutional Characteristics" developed for this edition of the Digest are based on lists of all institutions and are not subject to sampling errors.

Recently the definition of institutions to be counted under the higher education category has been modified. The older standard for higher education included those institutions that had courses leading to an associate degree or higher, or were accepted for credit toward those degrees. Tables that use this standard are labeled "higher education" in the Digest. The newer category includes institutions which award associate or higher level degrees that are eligible to participate in Title IV federal financial aid programs. These tables or columns are labeled as "degree-granting" institutions. The impact of this change has generally not been large. For example, tables on faculty salaries and benefits were only affected to a very small extent. Also, degrees awarded at the bachelor's level or higher were not heavily affected. The largest impact has been on private 2-year college enrollment. In contrast, most of the data on public 4-year colleges has been affected only to a minimal extent. The impact on enrollment in public 2-year colleges was noticeable in certain states, but relatively small at the national level. Overall, enrollment for all institutions was about 0.5 or one-half a percent higher for degree-granting institutions compared to the total for higher education institutions.

Prior to the establishment of IPEDS in 1986, HEGIS acquired and maintained statistical data on the characteristics and operations of institutions of higher education. Implemented in 1966, HEGIS was an annual universe survey of institutions accredited at the college level by an agency recognized by the Secretary of the U.S. Department of Education. These institutions were listed in NCES's Education Directory, Colleges and Universities.

Most trend tables presented in this report draw on HEGIS surveys which solicited information concerning institutional characteristics, faculty salaries, finances, enrollment, and degrees. Since these surveys were distributed to all higher education institutions, the data presented are not subject to sampling error. However, they are subject to nonsampling error, the sources of which varied with the survey instrument. Information concerning the nonsampling error of the enrollment and degrees surveys draws 
extensively on the "HEGIS Post-Survey Validation Study" conducted in 1979.

Further information on IPEDS may be obtained from:

Susan Broyles

Postsecondary Studies Division

National Center for Education Statistics

555 New Jersey Avenue NW

Washington, DC 20208-5652

Susan_Broyles@ed.gov

\section{Institutional Characteristics}

This survey provides the basis for the universe of institutions presented in the Directory of Postsecondary Institutions. The universe comprises institutions that met certain accreditation criteria and offered at least a 1-year program of college-level studies leading toward a degree. All of these institutions were certified as eligible by the U.S. Department of Education's Division of Eligibility and Agency Evaluation. The survey collects basic information necessary to classify the institutions including control, level, and kinds of programs; information on tuition, fees, and room and board charges; and unduplicated full-year enrollment counts and instructional activity.

\section{Fall Enrollment}

This survey has been part of the HEGIS and IPEDS series since 1966. The enrollment survey response rate is relatively high; the 1996 response rate was 96 percent for degree-granting institutions, or 95 percent overall. Major sources of nonsampling error for this survey as identified in the 1979 report were classification problems, the unavailability of needed data, interpretation of definitions, the survey due date, and operational errors. Of these, the classification of students appears to have been the main source of error. Institutions had problems in correctly classifying first-time freshmen and other first-time students for both full-time and part-time categories. These problems occurred most often at 2-year institutions (private and public) and private 4-year institutions. In the 1977-78 HEGIS validation studies, the classification problem led to an estimated overcount of 11,000 full-time students and an undercount of 19,000 part-time students. Although the ratio of error to the grand total was quite small (less than 1 percent), the percentage of errors was as high as 5 percent for detailed student levels and even higher at certain aggregation levels.

Beginning with fall 1986, the survey system was redesigned with the introduction of the Integrated Postsecondary Education Data System (IPEDS) (see above). The IPEDS system comprises all postsecondary institutions, but also maintains comparability with earlier surveys by allowing HEGIS institutions to be tabulated separately. The survey allows (in alternating years) for the collection of age and residence data.

\section{Salaries, Tenure, and Fringe Benefits of Full- Time Instructional Faculty}

This institutional survey has been conducted for most years from 1966-67 to 1987-88, and annually since 1989-90. Although the survey form changed a number of times during those years, only comparable data are presented in this report.

Between 1966-67 and 1985-86 this survey differed from other HEGIS surveys in that imputations were not made for nonrespondents. Thus, there is some possibility that the salary averages presented in this report may differ from the results of a complete enumeration of all colleges and universities. Beginning with the surveys for 1987-88, the IPEDS data tabulation procedures included imputations for survey nonrespondents. The response rate for the 1996-97 survey was 92 percent for degree-granting institutions. Because of the higher response rate for public colleges, it is probable that the public colleges' salary data are more accurate than the data for private colleges. Although data from these surveys are not subject to sampling error, sources of nonsampling error may include computational errors and misclassification in reporting and processing. NCES reviews individual colleges' data for internal and longitudinal consistency and contacts the colleges to check inconsistent data.

\section{Completions}

This survey was part of the HEGIS series throughout its existence. However, the degree classification taxonomy was revised in 1970-71, 1982-83, and 1991-92. Collection of degree data has been maintained through the IPEDS system.

Though information from survey years 1970-71 through 1981-82 is directly comparable, care must be taken if information before or after that period is included in any comparison. Degrees-conferred trend tables arranged by the 1991-92 classification are included in the Digest to provide consistent data from 1970-71 to 1995-96. Data in this edition on associate and other formal awards below the baccalaureate, by field of study, cannot be made comparable with figures prior to 1982-83. The nonresponse rate did not appear to be a significant source of nonsampling error for this survey. The return rate over the years has been high, with the degree-granting institutions response rate for the 199596 survey at 98 percent. The overall response rate including the noncollegiate institutions was 88 percent in 1994-95. Because of the high return rate for the institutions of higher education, nonsampling error caused by imputation is also minimal. 
The major sources of nonsampling error for this survey were differences between the NCES program taxonomy and taxonomies used by the colleges, classification of double majors, operational problems, and survey timing. In the 1979 HEGIS validation study, these sources of nonsampling contributed to an error rate of 0.3 percent overreporting of bachelor's degrees and 1.3 percent overreporting of master's degrees. The differences, however, varied greatly among fields. Over 50 percent of the fields selected for the validation study had no errors identified. Categories of fields that had large differences were business and management, education, engineering, letters, and psychology. It was also shown that differences in proportion to the published figures were less than 1 percent for most of the selected fields that had some errors. Exceptions to these were: master's and Ph.D. programs in labor and industrial relations (20 percent and 8 percent); bachelor's and master's programs in art education (3 percent and 4 percent); bachelor's and Ph.D. programs in business and commerce, and in distributive education (5 percent and 9 percent); master's programs in philosophy (8 percent); and Ph.D. programs in psychology (11 percent).

\section{Financial Statistics}

This survey was part of the HEGIS series and has been continued under the IPEDS system. Changes were made in the financial survey instruments in fiscal years (FY) 1976, 1982, and 1987. The FY 76 survey instrument contained numerous revisions to earlier survey forms and made direct comparisons of line items very difficult. Beginning in FY 82, Pell Grant data were collected in the categories of federal restricted grants and contracts revenues and restricted scholarships and fellowships expenditures. The introduction of IPEDS in the FY 87 survey included several important changes to the survey instrument and data processing procedures. While these changes were significant, considerable effort has been made to present only comparable information on trends in this report and to note inconsistencies. Finance tables for this publication have been adjusted by subtracting the largely duplicative Pell Grant amounts from the later data to maintain comparability with pre-FY 82 data.

Possible sources of nonsampling error in the financial statistics include nonresponse, imputation, and misclassification. The response rate has been about 85 to 90 percent for most of the years reported. The response rate for the FY 1996 survey was 94 percent for higher education institutions, or 83 percent overall.

Two general methods of imputation were used in HEGIS. If the prior year's data were available for a nonresponding institution, these data were inflated using the Higher Education Price Index and adjusted according to changes in enrollments. If no previous year's data were available, current data were used from peer institutions selected for location (state or region), control, level, and enrollment size of institution. In most cases estimates for nonreporting institutions in IPEDS were made using data from peer institutions.

Beginning with FY 87, the IPEDS survey system included all postsecondary institutions, but maintained comparability with earlier surveys by allowing 2- and 4-year HEGIS institutions to be tabulated separately. Unless specified otherwise, the finance data tabulated for this publication reflect totals for the HEGIS or higher education institutions only. For FY 87 through FY 91, in order to maintain comparability with the historical time series of HEGIS institutions, data were combined from two of the three different survey forms that make up the IPEDS survey system. The vast majority of the data were tabulated from Form 1, which was used to collect information from public and private nonprofit 2- and 4-year colleges. Form 2, a condensed form, was used to gather data for the 2-year proprietary institutions. Because of the differences in the data requested on the two forms, several assumptions were made about the Form 2 reports so that their figures could be included in the institutions of higher education totals.

In IPEDS, the Form 2 institutions were not asked to separate appropriations from grants and contracts, nor state from local sources of funding. For the Form 2 institutions, all the federal revenues were assumed to be federal grants and contracts and all of the state and local revenues were assumed to be restricted state grants and contracts. All other Form 2 sources of revenue, except for tuition and fees and sales and services of educational activities, were included under "other." Similar adjustments were made to the expenditure accounts. The Form 2 institutions reported instruction and scholarship and fellowship expenditures only. All other educational and general expenditures were allocated to academic support.

To reduce reporting error, NCES uses national standards for reporting finance statistics. These standards are contained in College and University Business Administration: Administrative Services (1974 Edition), and the Financial Accounting and Reporting Manual for Higher Education (1990 Education), published by the National Association of College and University Business Officers; Audits of Colleges and Universities (as amended August 31, 1974), by the American Institute of Certified Public Accountants; and HEGIS Financial Reporting Guide (1980), by NCES. Wherever possible, definitions and formats in the survey form are consistent with those in these four accounting texts. 


\section{Staff}

The fall staff data presented in this publication were collected by NCES, through the IPEDS system, which collected data from postsecondary institutions, including all 2- and 4-year higher education institutions. The NCES collects staff data biennially in odd numbered years in institutions of postsecondary education.

The IPEDS "Fall Staff" questionnaires were mailed out by NCES; the respondents reported the number of employees in their institutions as of January 15, 1996. The "Fall Staff" questionnaires were mailed out by NCES between October and November 1995; the respondents reported the employment statistics in their institution that cover the payroll period closest to October 1 of the survey year.

The "Fall Staff, 1995" survey had an overall response rate of 87 percent. The response rate for higher education institutions was 94 percent. Further information on the "Fall Staff" survey may be obtained from:

\section{Rosa Fernandez}

Postsecondary Studies Division

National Center for Education Statistics

555 New Jersey Avenue NW

Washington, DC 20208-5652

Rosa_Fernandez@ed.gov

\section{Library Statistics Program}

Nationwide, public library statistics are collected using the Public Libraries Survey and disseminated annually through the Federal-State Cooperative System for public library data (FSCS). Descriptive statistics are produced for nearly 9,000 public libraries. The Public Libraries Survey includes information about staffing; operating income and expenditures; type of governance; type of administrative structure; size of collection; and service measures such as reference transactions, public service hours, interlibrary loans, circulation, and library visits. In FSCS, respondents supply the information electronically, and data are edited and tabulated in machine-readable form.

The respondents are 8,921 public libraries identified in the 50 states and the District of Columbia by state library agencies. At the state level, FSCS is administered by State Data Coordinators, appointed by the Chief Officer of each State Library Agency. The State Data Coordinator collects the requested data from local public libraries and submits these data to NCES. An annual training conference sponsored by NCES is provided for the State Data Coordinators. A steering committee representing State Data Coordinators and other public library constituents is active in the development of FSCS data elements and software. Technical assistance to states is provided by phone and in person by the FSCS steering committee and by NCES staff and contractors. All 50 states and the District of Columbia have submitted data which are available for individual public libraries and are also aggregated to state and national levels.

Since 1990, data have been collected electronically. The most recent software is called DECPLUS. It includes identifying information on all known public libraries and their outlets, some state libraries, and some library systems and cooperatives. Beginning in 1994, this resource will be available for drawing samples for special surveys on such topics as literacy, access for the disabled, and library construction.

Under the Academic Libraries Survey (ALS), NCES surveyed academic libraries on a 3-year cycle between 1966 and 1988. Since 1988, ALS has been a component of the Integrated Postsecondary Education Data System and is on a 2-year cycle. ALS provides data on about 3,500 academic libraries. In aggregate, these data provide an overview of the status of academic libraries nationally and statewide. The survey collects data on the libraries in the entire universe of accredited higher education institutions and on the libraries in nonaccredited institutions with a program of 4 years or more. ALS produces descriptive statistics on academic libraries in postsecondary institutions in the 50 states, the District of Columbia and the outlying areas.

The School Library Statistics Survey collected data on school libraries/media centers in 1990-91 and 1993-94. This survey asked questions on libraries in public and private schools as part of the Schools and Staffing Survey (SASS). These questionnaires were revised and a sample survey of about 7,600 schools was conducted during school year 1993-94. The library components of the 1990-91 SASS include: number of students served and number of professional staff and aides; at the district level, number of full-time equivalent librarians/media specialists, vacant positions, positions abolished, and approved positions; and amount of librarian input in establishing curriculum. The 1993-94 survey was much more extensive and added questions concerning media centers and collections of libraries.

Additional information on these academic and school library studies is available from:

Jeff Williams

Elementary/Secondary and Library Studies Division National Center for Education Statistics

555 New Jersey Avenue NW

Washington, DC 20208-5652

Jeffrey_Williams@ed.gov

\section{National Adult Literacy Survey}

The National Adult Literacy Survey was created as a new measure of literacy and funded by the Depart- 
ment of Education and by 12 states. It is the third and largest assessment of adult literacy funded by the federal government. The aim of the survey is to profile the English literacy of adults in the United States based on their performance across a wide array of tasks that reflect the types of materials and demands they encounter in their daily lives.

To gather the information on adults' literacy skills, trained staff interviewed nearly 13,600 individuals aged 16 and older during the first 8 months of 1992 . These participants had been randomly selected to represent the adult population in the country as a whole. Black and Hispanic households were oversampled to ensure reliable estimates of literacy proficiencies and to permit analyses of the performance of these subpopulations. In addition, some 1,100 inmates from 80 federal and state prisons were interviewed to gather information on the proficiencies of the prison population. In total, over 26,000 adults were surveyed.

Each survey participant was asked to spend approximately an hour responding to a series of diverse literacy tasks as well as questions about his or her demographic characteristics, educational background, reading practices, and other areas related to literacy. Based on their responses to the survey tasks, adults received proficiency scores along three scales which reflect varying degrees of skill in prose, document and quantitative literacy. The results of the survey were published in a report, Adult Literacy in America, in September 1993.

Further information on the National Adult Literacy Survey may be obtained from:

\author{
Sheida White \\ Assessment Division \\ National Center for Education Statistics \\ 555 New Jersey Avenue NW \\ Washington, DC 20208-5653 \\ Sheida_White@ed.gov
}

\section{National Assessment of Educational Progress}

The National Assessment of Educational Progress (NAEP) is a series of cross-sectional studies designed and initially implemented in 1969. NAEP has gathered information about selected levels of educational achievement across the country. NAEP has surveyed the educational attainments by age and grade (9-, 13-, and 17-year-olds, and 4th-, 8th-, and 12th-graders), and young adults (ages 25 to 35), in 10 learning areas. NAEP administers two different types of tests. The NAEP long-term trend assessments are separate from a series of newer NAEP assessments (called "main assessments") that involve more recently developed instruments. Long-term trend assessments use the same sets of questions and tasks to measure trends across time, while main assessments reflect current educational content and assessment methodology.

The assessment data presented in this publication were derived from tests designed and conducted by the Education Commission of the States (19691983) and by the Educational Testing Service (1983 to present). Three-stage probability samples have been used. The primary sampling units have been stratified by region and, within region, by state, size of community, and, for the two smaller sizes of community strata, by socioeconomic level. The first stage of sampling entails defining and selecting primary sampling units (PSUs). For each age/grade level (grades 4, 8, and 12) the second stage entails enumerating, stratifying, and randomly selecting schools, both public and private, within each PSU selected at the first stage. The third stage involves randomly selecting students within a school for participation in NAEP. Assessment exercises have been administered either to individuals or to small groups of students by specially trained personnel.

Sample sizes for the reading proficiency portion of the 1995-96 NAEP long-term trends study were: 5,019 for the 9 -year-olds, 5,493 for the 13-year-olds, and 4,669 for the 17-year-olds. Response rates were 96 percent, 92 percent, and 84 percent, respectively. Response rates for earlier years (1970-71, 1974-75, and 1979-80) were generally lower. For example, the lowest response rate for the 9-year-olds was 88 percent in 1974-75, and the lowest response rate overall was 70 percent for the 17-year-olds in 197475.

Sample sizes in math and science portions of the 1995-96 long-term trends were: 5,414 9-year-olds, 5,658 13-year-olds, and 3,539 17-year-olds. Response rates were 95,93 , and 84 percent, respectively.

Assessments focusing on particular subject areas are conducted separately from long term assessments. The 1993-94 U.S. history data in this report are based on a nationally representative sample of 5,499 4th-graders, 8,767 8th-graders, and 7,818 12th-graders. The response rates were: 90 percent for 4th-graders, 90 percent for 8th-graders, and 89 percent for 12th-graders.

The 1991-92 writing assessment was administered to 7,166 4th-graders, 11,112 8th-graders, and 11,532 12th-graders. Student response rates for the 199293 writing assessment were 93 percent for the 4thgraders, 89 percent for the 8th-graders, and 81 percent for the 12th-graders. Sample sizes varied depending on the test items and the scoring method used.

In 1995-96, a science assessment was administered to 7,305 4th-graders, 7,774 8th-graders, and 7,537 12th-graders. The response rates were 94 per- 
cent for the 4th-graders, 94 percent for the 8th-graders, and 93 percent for the 12th-graders.

The 1993-94 geography assessment was administered to 5,507 4th-graders, 6,878 8th-graders, and 6,23412 th-graders. The response rates for the assessment were 93 percent for the 4th-graders, 93 percent for the 8th-graders, and 90 percent for the 12th-graders.

In 1990, representative state-level data were produced for mathematics at the 8th-grade level. This was the first time NAEP had produced data on a state-by-state level. In 1996, state-level assessments were conducted in 4th-and 8th-grade mathematics and 8th-grade science.

Information from NAEP is subject to both nonsampling and sampling error. Two possible sources of nonsampling error are nonparticipation and instrumentation. Certain populations have been oversampled to assure samples of sufficient size for analysis. Instrumentation nonsampling error could result from failure of the test instruments to measure what is being taught and, in turn, what is being learned by the students.

For further information on NAEP, contact:

\author{
Peggy Carr \\ Assessment Division \\ National Center for Education Statistics \\ 555 New Jersey Avenue NW \\ Washington, DC 20208-5653 \\ Peggy_Carr@ed.gov
}

\section{National Education Longitudinal Study of 1988}

The National Education Longitudinal Study of 1988 (NELS:88) is the third major longitudinal study sponsored by the National Center for Education Statistics. The two studies that preceded NELS:88, the National Longitudinal Study of the High School Class of 1972 (NLS-72) and High School and Beyond (HS\&B) in 1980 , surveyed high school seniors (and sophomores in HS\&B) through high school, postsecondary education, and work and family formation experiences. Unlike its predecessors, NELS:88 begins with a cohort of 8th-grade students. In 1988, some 25,000 8th-graders, their parents, their teachers, and their school principals were surveyed. Follow-ups were conducted in 1990, 1992, and 1994, when a majority of these students were in 10th and 12th grades, and then 2 years after their scheduled high school graduation. A fourth follow-up is planned for the year 2000.

NELS:88 is designed to provide trend data about critical transitions experienced by young people as they develop, attend school, and embark on their careers. It complements and strengthens state and local efforts by furnishing new information on how school policies, teacher practices, and family involvement affect student educational outcomes (i.e., academic achievement, persistence in school, and participation in postsecondary education). For the base year, NELS:88 included a multifaceted student questionnaire, four cognitive tests, a parent questionnaire, a teacher questionnaire, and a school questionnaire.

In 1990, when the students were in 10th grade, the students, school dropouts, their teachers, and their school principals were surveyed. The 1988 survey of parents was not a part of the 1990 follow-up. In 1992, when the students were in 12th grade, the second follow-up conducted surveys of students, dropouts, parents, teachers, and school principals. Also, information on the students' transcripts, the schools' course offerings, and enrollments were collected, and there was a school effects survey. Tables A3 and A4 present the respondent counts and design effects of NELS:88 and the 1990 and 1992 follow-ups.

Further information about the NELS:88 survey can be obtained from:

Jeffrey A. Owings

Elementary/Secondary and Library Studies Division National Center for Education Statistics

555 New Jersey Avenue NW

Washington, DC 20208-5651

Jeffrey_Owings@ed.gov

\section{National Household Education Survey}

The National Household Education Survey (NHES) is a data collection system that is designed to address a wide range of education-related issues. Surveys were conducted in 1991, 1993, 1995, and 1996.

The NHES targets specific populations for detailed data collection. It is intended to provide more detailed data on the topics and populations of interest than are collected through supplements to other household surveys.

The topics addressed by the NHES:91 were early childhood education and adult education. About 60,000 households were screened for the NHES:91. In the Early Childhood Education component, about 14,000 parents/guardians of 3- to 8-year olds completed interviews about their children's early educational experiences. Included in this component were participation in nonparental care/education, care arrangements and school, and family, household, and child characteristics. In the NHES:91 Adult Education component, about 9,800 persons 16 years of age and older, identified as having participated in an adult education activity in the previous 12 months, were questioned about their activities. Data were collected on programs and up to four courses, including the subject matter duration, sponsorship, purpose, and cost. Information on the household and the 
adult's background and current employment also was collected. In the NHES:95 survey, 23,969 adults were sampled for the adult education component and 80 percent $(19,722)$ completed the interview.

In the NHES:93, nearly 64,000 households were screened. Approximately 11,000 parents of 3- to 7year olds completed interviews for the School Readiness component. Topics included were the developmental characteristics of preschoolers, school adjustment and teacher feedback to parents for kindergartners and primary students, center-based program participation, early school experiences, home activities with family members, and health status. In the School Safety and Discipline component, about 12,700 parents of children in grades 3 through 12 , and about 6,500 youth in grades 6 through 12, were interviewed about their school experiences. Topics included the school learning environment, discipline policy, safety at school, victimization, the availability and use of alcohol/drugs, and alcohol/drug education. Peer norms for behavior in school and substance use were also included in this topical component. Extensive family and household background information was collected, as well as characteristics of the school attended by the child.

In the NHES:95 survey, the Early Childhood Program participation component and the Adult Education component were similar to those in 1991. In the Early Childhood component, about 14,000 parents of children from birth to third grade were interviewed. For the Adult Education component, about 19,500 civilian adults were interviewed.

In the spring of 1996, Parent and Family Involvement in education and Civic Involvement were covered. For the Parent and Family Involvement component, nearly 21,000 parents of children grades 3 to 12 were interviewed. For the Civic Involvement component, about 8,000 youth grades 6 to 12, about 9,000 parents, and about 2,000 adults were interviewed. The 1996 survey also addressed public library use. Adults in almost 55,000 households were interviewed to support state-level estimates of household public library use.

For more information contact:

Kathryn Chandler

Early Childhood, International and Crosscutting

Studies Division

National Center for Education Statistics

555 New Jersey Avenue NW

Washington, DC 20208-5651

Kathryn_Chandler@ed.gov

\section{National Longitudinal Study of the High School Class of 1972}

The National Longitudinal Study of the High School Class of 1972 (NLS-72) began with the collection of base-year survey data from a sample of about 19,000 high school seniors in the spring of 1972. Five more follow-up surveys of these students were conducted in 1973, 1974, 1976, 1979, and 1986. The NLS-72 was designed to provide the education community with information on the transitions of young adults from high school through postsecondary education and the workplace.

The sample design for the NLS-72 was a stratified, two-stage probability sample of students from all schools, public and private, in the 50 states and the District of Columbia with a 12th-grade enrollment during the 1971-72 school year. During the first stage of sampling, about 1,070 schools were selected for participation in the base-year survey. As many as 18 students were selected at random from each of the sample schools. The size of both the school and student samples were increased during the first follow-up survey. Beginning with the first follow-up and continuing through the fourth follow-up, about 1,300 schools participated in the survey and slightly under 23,500 students were sampled. The response rates for each of the different rounds of data collection have been 80 percent or higher.

Sample retention rates across the survey years have been quite high. For example, of the individuals responding to the base-year questionnaire, the percentages who responded to the first, second, third, and fourth follow-up questionnaires were about 94 , 93, 89, and 83 percent, respectively.

Further information may be obtained from:

Aurora M. D'Amico

Postsecondary Studies Division

National Center for Education Statistics

555 New Jersey Avenue NW

Washington, DC 20208-5652

Aurora_D'Amico@ed.gov

\section{National Postsecondary Student Aid Study}

The National Postsecondary Student Aid Study (NPSAS) is a comprehensive nationwide study of how students and their families pay for postsecondary education. It covers national representative samples of undergraduates, graduates, and first-professional students; students attending less than 2-year institutions, 2- to 3-year schools, 4-year colleges, and major universities. Participants included students who do not receive aid and their parents as well as students who do receive financial aid and their parents. Study results are used to help determine future federal policy regarding student financial aid. The study was conducted every 3 years. Beginning in 19992000 , the survey will be conducted every 4 years.

The first NPSAS was conducted during the 198687 school year. Data were gathered from about 1,074 colleges, universities, and other postsecondary 
institutions; 60,000 students; and 14,000 parents. These data provided information on the cost of postsecondary education, the distribution of financial aid, and the characteristics of both aided and nonaided students and their families.

As a part of the 1992-93 NPSAS, information on 77,000 undergraduates and graduate students enrolled during the school year was collected at 1,000 postsecondary institutions. The sample included students enrolled at any time between July 1, 1992, and June 30, 1993. About 66,000 students and a subsample of their parents were interviewed by telephone. The 1996 NPSAS contains information on more than 48,000 undergraduate and graduate students from 973 postsecondary institutions. Students were enrolled at any time during the 1995-96 school year.

Further information may be obtained from:

Andrew G. Malizio

Postsecondary Studies Division

National Center for Education Statistics

555 New Jersey Avenue NW

Washington, DC 20208-5652

Andrew_Malizio@ed.gov

\section{National Study of Postsecondary Faculty}

This study is in response to a continuing need for data on faculty and instructors-persons who directly affect the quality of education in postsecondary institutions. They often determine curriculum content, student performance standards, and the quality of students' preparation for careers. Faculty members perform important research and development work and perform public service activities. The National Study of Postsecondary Faculty (NSOPF) was designed to provide data about faculty to postsecondary researchers, planners, and policymakers. NSOPF is the most comprehensive study of faculty in postsecondary educational institutions ever undertaken.

The first cycle of NSOPF was conducted by the National Center for Education Statistics (NCES) with support from the National Endowment for the Humanities (NEH) in 1987-88 (NSOPF:88) with a sample of 480 colleges and universities, over 3,000 department chairpersons, and over 11,000 instructional faculty. The second cycle of NSOPF was conducted by NCES with support from NEH and the National Science Foundation (NSF) in 1992-93 (NSOPF:93). NSOPF:93 was limited to surveys of institutions and faculty, but with a substantially expanded sample of 974 colleges and universities, and 31,354 faculty and instructional staff.
Further information may be obtained from:

Linda J. Zimbler

Postsecondary Studies Division

National Center for Education Statistics

555 New Jersey Avenue NW

Washington, DC 20208-5652

Linda_Zimbler@ed.gov

\section{Projections of Education Statistics}

Since 1964, NCES has published projections of key statistics for elementary and secondary schools and institutions of higher education. These projections include statistics such as enrollments, instructional staff, graduates, earned degrees, and expenditures. The Projections reports include several alternative projection series and a methodology section describing the techniques and assumptions used to prepare them. Data in this edition of the Digest reflect the middle alternative projection series.

Differences between the reported and projected values are, of course, almost inevitable. An evaluation of past projections revealed that, at the elementary and secondary level, projections of enrollments have been quite accurate: mean absolute percentage differences for enrollment were less than 1 percent for projections from 1 to 5 years in the future, while those for teachers were less than 4 percent. At the higher education level, projections of enrollment have been fairly accurate: mean absolute percentage differences were 5 percent or less for projections from 1 to 5 years into the future.

For further information about projection methodology and accuracy, contact:

Debra E. Gerald

Early Childhood, International and Crosscutting

Studies Division

National Center for Education Statistics

555 New Jersey Avenue NW

Washington, DC 20208-5654

Debra_Gerald@ed.gov

\section{Survey of Recent College Graduates}

Since 1976, NCES has conducted six surveys of baccalaureate and master's degree recipients 1 year after graduation. The Recent College Graduates (RCG) surveys have concentrated on those graduates entering the teaching profession. The surveys link major field of study with outcomes such as whether the respondent entered the labor force or was seeking additional education. Data on labor force includes employment status (unemployed, parttime or full-time employed), occupation, salary, career potential, relation to major field of study, and need for a college degree. To obtain accurate results 
on teachers, graduates with a major in education were oversampled. The latest two surveys continued to oversample education majors, but increased the sampling of graduates with majors in other fields.

The survey involved a two-stage sampling procedure. First, the universe of institutions awarding bachelor's and master's degrees was stratified by number or percentage of degrees awarded to education graduates and by control of institution (public or private). A sample of institutions within each stratum was then selected. Second, for each of the selected institutions, a list of their graduates by major field of study was obtained and a sample of graduates was drawn by major field of study. Graduates in certain major fields of study (e.g., education, mathematics, physical sciences) were sampled at higher rates than graduates in other fields. Roughly one year after graduation, the sample of graduates was located, contacted by mail or telephone, and asked to respond to the questionnaire.

The locating process was more detailed than in most surveys. Nonresponse rates were directly related to the time, effort, and resources used in locating graduates, rather than to graduates' refusals to participate. Despite the difficulties in locating graduates, response rates for recent studies are comparable to studies without locating problems.

The 1976 survey of 1974-75 college graduates was the first and smallest of the series. The sample consisted of 211 schools, of which 200 (96 percent) responded. Of the 5,854 graduates in the sample, 4,350 responded, for a response rate of 79 percent.

The 1981 survey was somewhat larger, with a coverage of 297 institutions and 15,852 graduates. Responses were obtained from 283 institutions, for an institutional response rate of 95 percent, and from 9,312 graduates (716 others were determined to be out of scope), for a response rate of 74 percent.

The 1985 survey sampled 404 colleges and 18,738 graduates of whom 17,853 were found to be in scope. Responses were obtained from 13,200 students, for a response rate of 78 percent. The response rate for the colleges was 98 percent. The 1987 survey form was sent to 21,957 graduates. Responses were received from 16,878 , for a response rate of 79.7 percent.

The 1991 RCG study involved a sample of 18,135 graduates of 400 bachelor's and master's degreegranting institutions. The 18,135 graduates consisted of 16,172 bachelor's degrees recipients and 1,963 master's degree recipients between July 1, 1989, and June 30, 1990. Random samples of graduates were selected from lists stratified by field of study. Graduates in education, mathematics, and the physical sciences were sampled at a higher rate, as were minority graduates to provide a sufficient number of these graduates for analysis purposes. The grad- uates included in the sample were selected in proportion to the institution's number of graduates. The institutional response rate was 95 percent and the graduate response rate was 83 percent.

Table A5 contains sample sizes for number of graduates, by field, for the 1976, 1981, 1985, 1987, and 1991 surveys.

This survey system has been replaced by a new data collection entitled Baccalaureate and Beyond Longitudinal Study. Further information on the RCG survey may be obtained from:

\section{Peter Stowe}

Postsecondary Studies Division

National Center for Education Statistics

555 New Jersey Avenue NW

Washington, DC 20208-5652

Peter_Stowe@ed.gov

\section{Public School Principal Survey on Safe, Disciplined, and Drug-Free Schools}

This sample survey used the NCES Fast Response Survey System (FRSS), which is designed to gather timely information for policymakers. The survey was conducted in 1991 by Westat, Inc. A national sample of 830 public school principals, represented by a response rate of 94 percent, answered questions regarding the extent of discipline problems within their schools. They were also questioned about the nature and effectiveness of their schools' current policies and drug education programs.

This survey categorized principals by instructional level (elementary, secondary), type of school location (city, urban fringe, town, rural), enrollment size (less than 300,300 to $999,1,000$ or more), region (Northeast, Central, Southeast, and West), and percentage of students receiving free or reduced-price lunches (10 percent or less, 11 to 40 percent, 41 percent or more).

For more information about this survey contact:

Bernie Greene

Early Childhood, International and Crosscutting

Studies Division

National Center for Education Statistics

555 New Jersey Avenue NW

Washington, DC 20208-5651

Bernard_Greene@ed.gov

\section{Public School Kindergarten Teachers' Views on Children's Readiness for School}

This sample survey of 1,448 public school kindergarten teachers was conducted as part of a national early childhood assessment system for National Education Goal One: "By the year 2000, all American children will start school ready to learn." The survey obtained data on kindergarten teachers' views of chil- 
dren's readiness and on the teacher's classroom practices.

For more information about this survey contact:

Bernie Greene

Early Childhood, International and Crosscutting

Studies Division

National Center for Education Statistics

555 New Jersey Avenue NW

Washington, DC 20208-5651

Bernard_Greene@ed.gov

\section{Advanced Telecommunications in U.S. Public Elementary and Secondary Schools, 1997}

Current information regarding the availability and use of telecommunications, and in particular, access to the Internet, was requested by this sample survey. The data were gathered from a nationally representative sample of public elementary and secondary schools in fall 1997. The survey was commissioned in response to the National Information Infrastructure (NII) set forth by the President to encourage an acceleration of the goal to connect all of the nation's school classrooms, as well as libraries, hospitals, and law enforcement agencies, to the "Information Superhighway."

For more information about this survey contact:

\section{Bernie Greene}

Early Childhood, International and Crosscutting

Studies Division

National Center for Education Statistics

555 New Jersey Avenue NW

Washington, DC 20208-5651

Bernard_Greene@ed.gov

\section{Schools and Staffing Survey}

The Schools and Staffing Survey (SASS) is a set of linked questionnaires that covers public school districts, public and private schools, principals, and teachers as its core components. SASS was first conducted for the National Center for Education Statistics by the U.S. Bureau of the Census during the 1987-88 school year. SASS subsequently was conducted in 1990-91 and in 1993-94. The next SASS is scheduled for school year 1999-2000. SASS is a mailed questionnaire with telephone follow-up that collects data on the nation's public and private elementary and secondary teaching force, characteristics of schools and school principals, demand for teachers, and school/school district policies. The 1990-91 and 1993-94 SASS also collected data on Bureau of Indian Affairs (BIA) schools. The SASS data are collected through a sample survey of schools, the school districts associated with sampled schools, school principals, and teachers. The 199394 SASS expanded as well to cover school libraries and librarians, and field tested an administrative student records questionnaire.

The 1993-94 SASS estimates are based upon a sample consisting of approximately 9,900 public schools, 3,300 private schools, and 5,500 public school districts associated with the public schools in the sample. From these schools, about 57,000 public school teachers and 11,500 private school teachers were selected for the 1993-94 SASS teacher survey.

The public school sample for the 1993-94 SASS was based upon the 1991-92 school year Common Core of Data (CCD), the compilation of all the nation's public school districts and public schools. CCD is collected annually from state education agencies. The frame includes regular public schools, Department of Defense-operated military base schools in the United States, and nonregular schools such as special education, vocational, and alternative schools. SASS is designed to provide national estimates for public and private school characteristics and state estimates for school districts, public schools, principals, and teachers. The teacher survey is designed as well to allow comparisons between new and experienced teachers, and between bilingual/ESL teachers and other teachers.

The private school sample for the 1993-94 SASS was selected from the 1991-92 Private School Universe Survey (PSS), supplemented with list updates from states and some associations available in time for sample selection. PSS collects basic data on all of the nation's private schools from two sources: the list frame and the area search frame. The list frame was compiled from a set of private school associations that provide NCES with their membership lists and states that gather lists of private schools. The area search frame consisted of schools not included on the list frame that were compiled from local sources in a sample of counties around the United States. Private school estimates are available at the national level and by type of private school.

The Teacher Demand and Shortage (school district) and School Principal Questionnaires were mailed out first in October 1993, along with School Library/Media Center and Library Media Specialist/Librarian Questionnaires. The weighted response rate for the Teacher Demand and Shortage Questionnaire was 93.9 percent. Weighted response rates for the Public School Principal Questionnaire and the Private School Questionnaire were 96.6 percent and 87.6 percent, respectively.

In December 1993, public, private, and BIA school questionnaires were mailed out. The public, private, and BIA teacher questionnaires were sent out in several batches, between mid-December 1993 and early February 1994. Weighted response rates for the Public School Questionnaire and the Private School Questionnaire were 92.3 percent and 83.2 percent, 
respectively. Five percent of public schools and 9 percent of private schools did not provide a list of teachers in their schools and were thus ineligible for sampling. Weighted response rates were 88.2 percent for public school teachers and 80.2 percent for private school teachers.

Item response rates were varied, but generally high, ranging from 67 to 100 percent for the TDS, 65 to 100 percent for public school principal questions, 55 to100 percent for private school principal items, 83 to 100 percent for public school items, 61 to 100 percent for private school survey items, 71 to 100 percent for public school teacher items, and 69 to 100 percent for private school teacher items.

Public-use and restricted-use microdata files are available on CD-ROM. Summary data from the 1993-94 SASS can be found in Schools and Staffing in the United States: Selected Data for Public and Private Schools, 1993-94 (NCES 95-191). More detailed results from the 1993-94 SASS are published in Schools and Staffing in the United States: A Statistical Profile, 1993-94 (NCES 96-124). Data by state are available in SASS by State-1993-94 Schools and Staffing Survey Selected State Results (NCES 96-312). Further information about the sample may be obtained from 1993-94 Schools and Staffing Survey: Sample Design and Estimation (NCES 96-086). Data from previous SASS collections are published in the 1987-88 and 1990-91 Profile reports (NCES 92-127 and 93-146, respectively), as well as the 1987-88 and 1990-91 versions of the sample design report (NCES 91-127 and 93-449, respectively).

For more information about this survey or to order reports, contact:

Kerry Gruber

Elementary/Secondary and Library Studies Division

National Center for Education Statistics

555 New Jersey Avenue NW

Washington, DC 20208-5651

Kerry_Gruber@ed.gov

\section{The Third International Mathematics and Science Study}

The Third International Mathematics and Science Study (TIMSS) is the largest, most comprehensive, and most rigorous international comparison of education ever undertaken. During the 1995 school year, the study tested the mathematics and science knowledge of half a million students from 41 nations at 5 different grade levels. At the same time, the students, their teachers, and the principals of their schools were asked to respond to questionnaires about their backgrounds and their attitudes, experiences, and practices in the teaching and learning of mathematics and science.
TIMSS is a collaborative research project sponsored by the International Association for the Evaluation of Educational Achievement (IEA). The TIMSS International Study Center is housed in the Center for the Study of Testing, Evaluation, and Educational Policy (CSTEEP) at Boston College. The TIMSS International Study Director, Albert E. Beaton, directs the international activities of the study, together with his staff at the International Study Center. To contact the TIMSS International Study Center:

Dr. Albert Beaton

TIMSS International Study Director

CSTEEP, Campion Hall 323

Boston College

Chestnut Hill, MA 02167

\section{Office for Civil Rights}

\section{Civil Rights Survey of Elementary and Secondary Schools}

The Office for Civil Rights (OCR), U.S. Department of Education, conducts biennial surveys of public school districts and of schools within those districts. Data are obtained on the characteristics of pupils enrolled in public schools throughout the nation. Such information is required under Title VI of the Civil Rights Act of 1964, Title IX of the Education Amendments of 1972, and Section 504 of the Rehabilitation Act of 1973 to enable OCR to carry out its compliance responsibilities. The 1990 survey included the 100 largest public school districts, those of special interest (i.e., court order, compliance review), and a stratified random sample of approximately 3,500 districts representing approximately 40,000 schools. School, district, and national data are currently available.

Further information is available from:

Peter McCabe

Office for Civil Rights

U.S. Department of Education

330 C Street SW

Washington, DC 20202

\section{The Office of Special Education and Rehabilitative Services}

\section{Annual Report to Congress on the Implementation of the Education of the Handicapped Act}

The Individuals with Disabilities Education Act (IDEA), formerly the Education of the Handicapped Act (EHA), requires the Secretary of Education to transmit to Congress annually a report describing the progress in serving the nation's handicapped children. The annual report contains information on children served by the public schools under the provi- 
sions of Part B of the IDEA and for children served in state-operated programs (SOP) for the handicapped under Chapter I of the Elementary and Secondary Education Act (ESEA). Statistics on children receiving special education and related services in various settings and school personnel providing such services are reported in an annual submission of data to the Office of Special Education and Rehabilitative Services (OSERS), by the 50 states, the District of Columbia, and the outlying areas. The child count information is based on the number of handicapped children receiving special education and related services on December 1st of each year.

Since each participant in programs for the handicapped is reported to OSERS, the data are not subject to sampling error. However, nonsampling error can occur from a variety of sources. Some states follow a noncategorical approach to the delivery of special education services, but produce counts by handicapping condition because EHA-B requires it. In those states that do categorize their handicapped students, definitions and labeling practices vary.

Further information on the Annual Report to Congress may be obtained from:

Office of Special Education Programs

Office of Special Education and Rehabilitative

Services

330 C Street SW

Washington, DC 20202

\section{National Longitudinal Transition Study of Special Education Students}

As part of the 1983 amendments to the Education of the Handicapped Act (EHA), Congress requested that the U.S. Department of Education conduct a national longitudinal study of the transition of secondary special education students to determine how they fare in terms of education, employment, and independent living. A 5-year study was mandated, which was to include youth from ages 13 to 21 who were in special education at the time they were selected and who represented all 11 federal disability categories. Data were drawn from extensive telephone interviews with parents, from school records, and from a survey of educators in secondary schools attended by youth in the study.

The study was conducted by SRI International and began in April, 1987. The National Transition Study involves a nationally representative sample of more than 8,000 secondary-age youth with disabilities. A sample of 450 school districts was randomly selected from the universe of approximately 14,000 school districts serving secondary special education students. An additional replacement sample of 176 additional districts was selected due to a low rate of agreement to participate from the initial group of dis- tricts. Participation in the study was invited from the approximately 80 special schools serving secondaryage deaf, blind, and deaf-blind schools. A total of approximately 300 school districts and 25 special schools agreed to have youth selected for the study.

For further information about this study, contact:

Office of Special Education Programs

Office of Special Education and Rehabilitative

Services

330 C Street SW

Washington, DC 20202

\section{Other Governmental Agencies}

\section{U.S. Bureau of the Census}

\section{Current Population Survey}

Current estimates of school enrollment rates, as well as social and economic characteristics of students, are based on data collected in the Census Bureau's monthly household survey of about 60,000 households. The monthly Current Population Survey (CPS) sample consists of 729 areas comprising 1,973 counties, independent cities, and minor civil divisions throughout the 50 states and the District of Columbia. The samples are initially selected based on the decennial census files and are periodically updated to reflect new housing construction.

The monthly CPS deals primarily with labor force data for the civilian noninstitutional population (i.e., excluding military personnel and their families living on post and inmates of institutions). In addition, in October of each year, supplemental questions are asked about highest grade completed, level and grade of current enrollment, attendance status, number and type of courses, degree or certificate objective, and type of organization offering instruction for each member of the household. In March of each year, supplemental questions on income are asked. The responses to these questions are combined with answers to two questions on educational attainment: highest grade of school ever attended, and whether that grade was completed.

The estimation procedure employed for the monthly CPS data involves inflating weighted sample results to independent estimates of characteristics of the civilian noninstitutional population in the United States by age, sex, and race. These independent estimates are based on statistics from decennial censuses; statistics on births, deaths, immigration, and emigration; and statistics on the population in the armed services. Generalized standard error tables are provided in the Current Population Reports. The data are subject to both nonsampling and sampling errors. 
Further information is available in the Current Population Reports, Series P-20, or by contacting:

Education and Social Stratification Branch

Population Division

Bureau of the Census

U.S. Department of Commerce

Washington, DC 20233

\section{School Enrollment}

Each October, the Current Population Survey (CPS) includes supplemental questions on the enrollment status of the population 3 years old and over, in addition to the monthly basic survey on labor force participation. The main sources of nonsampling variability in the responses to the supplement are those inherent in the survey instrument. The question of current enrollment may not be answered accurately for various reasons. Some respondents may not know current grade information for every student in the household, a problem especially prevalent for households with members in college or in nursery school. Confusion over college credits or hours taken by a student may make it difficult to determine the year in which the student is enrolled. Problems may occur with the definition of nursery school (a group or class organized to provide educational experiences for children), where respondents' interpretations of "educational experiences" vary.

The 1997 CPS sample was selected from the 1990 Decennial Census files with coverage in all 50 states and the District of Columbia. The sample is continually updated to account for new residential construction. The United States was divided into 2,007 geographic areas. In most states, a geographic area consisted of a county or several contiguous counties. In some areas of New England and Hawaii, minor civil divisions are used instead of counties. A total of 754 geographic areas were selected for sample. About 50,000 occupied households are eligible for interview every month. Interviewers are unable to obtain interviews at about 3,200 of these units. This occurs when the occupants are not found at home after repeated calls or are unavailable for some other reason. For the October 1997 basic CPS, the nonresponse rate was 6.3 percent and for the school enrollment supplement the nonresponse rate was an additional 4.7 percent for a total supplement nonresponse rate of 10.7 percent. Examples of sampling variability in the estimates of school enrollment rates are given in table A6. Further information on the CPS survey may be obtained from:

http://www.bls.census.gov/cps/cpsmain.htm
Questions concerning the CPS "School Enrollment" survey may be directed to:

Education and Social Stratification Branch
Population Division
Bureau of the Census
U.S. Department of Commerce
Washington, DC 20233

Educational Attainment

Data on years of school completed are derived from two questions on the Current Population Survey (CPS) instrument. Formal reports documenting educational attainment are produced by the U.S. Bureau of the Census using March CPS results. The latest report is Educational Attainment in the United States, March 1994 and 1993, Series P-20, No. 476, which is available from the Government Printing Office.

In addition to the general constraints of the CPS, some data indicate that the respondents have a tendency to overestimate the educational level of members of their household. Some inaccuracy is due to a lack of the respondent's knowledge of the exact educational attainment of each household member and the hesitancy to acknowledge anything less than a high school education. Another cause of nonsampling variability is the change in the numbers in the armed services over the years.

Caution should also be used when comparing newer data, which reflect 1990 census-based population controls, with data from March 1993 and earlier years, which reflect 1980 or earlier census-based population controls. This change in population controls had relatively little impact on summary measures such as means, medians, and percentage distributions. It did have a significant impact on levels. For example, use of 1990 based population controls results in about a 1 percent increase in the civilian noninstitutional population and in the number of families and households. Thus, estimates of levels for data collected in 1994 and later years will differ from those for earlier years by more than what could be attributed to actual changes in the population. These differences could be disproportionately greater for certain subpopulation groups than for the total population.

Examples of the sampling variability in the estimates of educational attainment are given in table A7. For the March 1997 basic CPS, the nonresponse rate was 7.2 percent and for the suppplement the nonresponse rate was an additional 9.2 percent for a total supplement nonresponse rate of 15.7 percent.

The figures shown in the table hold for total or white population estimates only. The variability in estimates for subgroups (region, household relationships, etc.) can be estimated using the tables pre- 
sented in Current Population Reports. Further information on the Current Population Survey may be obtained from the CPS web site at:

http://www.bls.census.gov/cps/cpsmain.htm

Questions concerning "Educational Attainment in the United States" may be directed to:

Education and Social Stratification Branch

Population Division

Bureau of the Census

U.S. Department of Commerce

Washington, DC 20233

\section{Government Finances}

The Census Bureau conducts an annual survey of Government Finances as authorized by law under Title 13, United States Code, Section 182. This survey covers the entire range of government finance activities: revenue, expenditure, debt, and assets. Revenues and expenditures comprise actual receipts and payments of a government and its agencies, including government-operated enterprises, utilities, and public trust funds. The expenditure reporting categories comprise all amounts of money paid out by a government and its agencies with the exception of amounts for debt retirement and for loan, investment, agency, and private trust transactions.

Most of the federal government statistics are based on figures that appear in The Budget of the United States Government. Since the classification used by the Census Bureau for reporting state and local government finance statistics differs in a number of important respects from the classification used in the United States Budget, it was necessary to adjust the federal data. For this report, federal budget expenditures include interest accrued, but not paid, during the fiscal year; Census data on interest are on a disbursement basis.

The state government finances are based primarily on the annual Census Bureau survey of state finances. Census staff compiled figures from official records and reports of the various states for most of the state financial data.

The sample of local governments is drawn from the periodic Census of Governments and consists of certain local governments taken with certainty plus a sample below the certainty level.

The statistics in Governmental Finances that are based wholly or partly on data from the sample are subject to sampling error. State government finance data are not subject to sampling error. Estimates of major United States totals for local governments are subject to a computed sampling variability of less than one-half of 1 percent. The estimates are also subject to the inaccuracies in classification, response, and processing which would occur if a com- plete census had been conducted under the same conditions as the sample.

Further information can be obtained from:

Governments Division

Bureau of the Census

U.S. Department of Commerce

Washington, DC 20233

\section{Census of Population-Education in the United States}

This report is based on a part of the decennial census which consists of questions asked of a 1-in6 sample of persons and housing units in the United States. This sample was asked more detailed questions about income, occupation and housing costs in addition to general demographic information.

\section{School Enrollment}

Persons classified as enrolled in school reported attending a "regular" public or private school or college at any time between February 1, 1990 and the time listed. Questions asked were whether the institution attended was public or private, and level of school in which the student was enrolled.

\section{Educational Attainment}

Data for educational attainment were tabulated for persons 15 years and over, and classified according to the highest grade completed or the highest degree received. Instructions were also given to include the level of the previous grade attended or the highest degree received for persons currently enrolled in school.

\section{Poverty Status}

To determine poverty status, answers to income questions were used and compared to the appropriate poverty threshold. All persons except institutionalized persons, persons in military group quarters and in college dormitories, and unrelated persons under 15 years old were considered. If total income of each family or unrelated individual in the sample was less than the corresponding cutoff, that family or individual was classified as "below the poverty level."

Further information can be obtained from:

Education and Social Stratification Branch

Population Division

Bureau of the Census

U.S. Department of Commerce

Washington, DC 20233

\section{National Institute on Drug Abuse}

The National Institute on Drug Abuse of the U.S. Department of Health and Human Services is the primary supporter of the long-term study entitled "Monitoring the Future: A Continuing Study of the Life- 
styles and Values of Youth," conducted at the University of Michigan, Institute for Social Research. One component of the study deals with student drug abuse. Results of a national sample survey have been published annually since 1975 . Approximately 125 to 135 schools have participated each year. With the exception of 1975 when about 9,400 students participated in the survey, the annual senior samples are comprised of roughly 17,000 students. They complete self-administered questionnaires given to them in their classrooms by University of Michigan personnel. Beginning in 1991, similar surveys of nationally representative samples of 8 th- and 10thgrade students have been conducted annually. The 10th-grade samples involve about 15,000 students in 125 schools each year, while the 8th-grade samples have approximately 18,000 students in 160 schools. Over the years, the response rate has varied from 77 to 84 percent. Table A8 provides examples of the survey's sampling error.

Understandably, there will be some reluctance to admit illegal activities. Also, students who were out of school on the day of the survey were nonrespondents. The survey did not include high school dropouts. The inclusion of these two groups would tend to increase the proportion of individuals who had used drugs. A 1983 study found that the inclusion of the absentees could increase some of the drug usage estimates by as much as 2.7 percentage points. (Details on that study and its methodology were published in Drug Use Among American High School Students, College Students, and Other Young Adults, by Lloyd D. Johnston, Patrick M. O'Malley, and Jerald G. Bachman, available from the National Clearinghouse on Drug Abuse Information, 5600 Fishers Lane, Rockville, MD 20857.)

Further information on this survey may be obtained from:

National Institute of Drug Abuse

Division of Epidemiology and Statistical Analysis

5600 Fishers Lane

Rockville, MD 20857

\section{National Science Foundation}

\section{Survey of Earned Doctorates Awarded in the United States}

The Survey of Earned Doctorates Awarded in the United States has collected basic statistics from the universe of doctoral recipients in the United States each year since 1958. It has been supported by five federal agencies: the National Science Foundation, in conjunction with the U.S. Department of Education; the National Endowment for the Humanities; the United States Department of Agriculture; and the National Institutes of Health.
A survey form is distributed, with the assistance of graduate deans, to each person completing the requirements for a doctorate. Of the approximately 40,000 persons eligible for the survey, approximately 95 percent respond. The questionnaire obtains information on sex, race/ethnicity, marital status, citizenship, handicaps, dependents, specialty field of doctorate, educational institutions attended, time spent in completion of doctorate, financial support, educational debt, postgraduation plans, and educational attainment of parents. The data are collected, edited, and published by the National Academy of Sciences.

For further information contact:

Science and Engineering Education and Human
Resources Program
Division of Science Resources Studies
National Science Foundation
4201 Wilson Boulevard
Arlington, VA 22230

\section{Federal Obligations to Universities, Colleges and Nonprofit Institutions}

Each year, the National Science Foundation collects data on obligations to colleges and universities from federal agencies. Obligations differ from expenditures in that funds obligated during one fiscal year may be spent by the recipient in later years. Obligation amounts include direct federal support, so that amounts subcontracted to other institutions are included. Those funds received through subcontracts from prime contractors are excluded. Also excluded from the data are certain types of financial assistance, such as the U.S. Department of Education's Guaranteed Student Loan Program and obligations to the U.S. service academies. For purposes of tabulations in this publication, university-administered federally funded research and development centers (FFRDCs) have been included in appropriate state totals.

The universe of academic institutions for this survey is based on the Integrated Postsecondary Education Data System conducted by the National Center for Education Statistics (see above). Institutions without federal support were excluded and some systems were combined into single reporting units.

Further information on this survey may be obtained from Federal Support to Universities, Colleges, and Nonprofit Institutions, published by the National Science Foundation, or by contacting:

Science and Engineering Activities Program

Division of Science Resources Studies

National Science Foundation

4201 Wilson Boulevard

Arlington, VA 22230 


\section{Survey of Scientific and Engineering Expenditures at Universities and Colleges}

The National Science Foundation's annual academic survey collects data on research and development expenditures in the sciences and engineering from a sample of 459 institutions in the United States and outlying areas. Those institutions were selected from the universe of 595 schools that grant a graduate science or engineering degree and/or perform activities for which at least $\$ 50,000$ has been funded from separately budgeted R\&D expenditures. In addition, the survey includes 19 university-affiliated, federally funded research and development centers (FFRDCs).

The 459 institutions sampled for FY 1991 include all doctorate-granting institutions, all historically black colleges and universities with any R\&D expenditures, and a random sample of all other institutions. The response rate was 97 percent. Data presented are assembled from the most recently completed survey and represent the latest totals available.

Further information on this survey may be obtained from Academic Science/Engineering, R\&D Funds, published by the National Science Foundation, or by contacting:

Science and Engineering Activities Program

Division of Science Resources Studies

National Science Foundation

4201 Wilson Boulevard

Arlington, VA 22230

\section{Other Organization Sources}

\section{American College Testing Program}

The American College Testing (ACT) Assessment is designed to measure educational development in the areas of English, mathematics, social studies, and natural sciences. The ACT Assessment is taken by college-bound high school students and the test results are used to predict how well students might perform in college.

Prior to the 1984-85 school year, national norms were based on a 10 percent sample of the students taking the test. Since then, national norms are based on the test scores of all students taking the test. Moreover, beginning with 1984-85, these norms have been based on the most recent ACT scores available from students scheduled to graduate in the spring of the year. Duplicate test records are no longer used to produce national figures.

Separate ACT standard scores are computed for English, mathematics, social studies, science reasoning, and, as of October 1989, reading. ACT standard scores are reported for each subject area on a scale from 1 to 36 . The four ACT standard scores have a mean (average) of about 19 and a standard deviation of about 6 for college-bound students nationally. A composite score is obtained by taking the simple average of the four standard scores and is an indication of a student's overall academic development across these subject areas. Beginning with the October 1989 test date, a new version of the ACT was introduced.

It should be noted that college-bound students who take the ACT Assessment are not representative of college-bound students nationally. First, students who live in the Midwest, Rocky Mountains and Plains, and the South are overrepresented among ACT-tested students as compared with collegebound students nationally. Second, ACT-tested students tend to enroll in public colleges and universities more frequently than do college-bound students nationally.

For further information, contact:

The American College Testing Program

2201 North Dodge Street

P.0. Box 168

lowa City, IA 52243

\section{American Federation of Teachers}

The American Federation of Teachers (AFT) has reported national and state average salaries and earnings for teachers, other school employees, government workers, and professional employees over the past 25 years. The AFT's survey of state departments of education obtains information on minimum salaries, experienced teachers reentering the classroom, and teacher age and experience. Most data from the survey are reported as received, although some data are confirmed by telephone. These data are available in the AFT's annual report Survey and Analysis of Salary Trends. While this serves as the primary vehicle for reporting the results of the AFT's annual survey of state departments of education, several other data sources are also used in the report.

Further information on this survey can be obtained from:

American Federation of Teachers

555 New Jersey Avenue NW

Washington, DC 20001

\section{College Entrance Examination Board}

The Admissions Testing Program of the College Board comprises a number of college admissions tests, including the Preliminary Scholastic Assessment Test (PSAT) and the Scholastic Assessment Test (SAT). High school students participate in the testing program as sophomores, juniors, or seniorssome more than once during these 3 years. If they have taken the tests more than once, only the most 
recent scores are tabulated. The PSAT and SAT report subscores in the areas of mathematics and verbal ability.

The SAT results are not representative of high school students or college-bound students nationally since the sample is self-selected. Generally, tests are taken by students who need the results to attend a particular college or university. The state totals are greatly affected by the requirements of its state colleges. Public colleges in a number of states require ACT scores rather than SAT scores. Thus, the proportion of students taking the SAT in these states is very low and is inappropriate for any comparison. In recent years, more than 1 million high school students have taken the examination annually.

Further information on the SAT can be obtained from:

\section{College Entrance Examination Board \\ Educational Testing Service \\ Princeton, NJ 08541}

\section{Council for Aid to Education}

The Council for Aid to Education, Inc., (CFAE) is a not-for-profit corporation funded by contributions from businesses. CFAE largely provides consulting and research services on voluntary support to corporations and information services to education institutions. Each year CFAE conducts a survey of colleges and universities and private elementary and secondary schools to obtain information on the amounts, sources, and purposes of private gifts, grants, and bequests received during the academic year.

In the 1991-92 study, survey forms were sent to approximately 2,900 colleges and universities and 1,280 responded. The response rates were much higher for the 4-year colleges than for the 2-year colleges. For example, 89 percent of the doctoral-level institutions and 55 percent of the comprehensive and general baccalaureate colleges participated in the survey, but only 12 percent of the 2-year colleges responded. CFAE estimates that about 84 percent of all voluntary support is reported in the survey because of the high participation of institutions receiving large amounts of funding.

Survey forms are reviewed by CFAE for internal consistency before preparing a computerized database. Institutional reports of voluntary support data from the CFAE "Survey of Voluntary Support of Education" are more comprehensive and detailed than the related data in the "Financial Statistics of Institutions of Higher Education" survey conducted by NCES. The results from the "Survey of Voluntary Support of Education" are published in the annual Voluntary Support of Education, which may be purchased from CFAE.
Further information is available from:

Director of Research

Council for Aid to Education, Inc.

51 Madison Avenue

Suite 2200

New York, NY 10010

\section{Council of Chief State School Officers}

The Council of Chief State School Officers (CCSSO) is a nonprofit organization of the 57 public officials who head departments of public education in every state, the outlying areas, the District of Columbia, and the Department of Defense Dependents Schools. In 1985, the CCSSO founded the State Education Assessment Center to provide a locus of leadership by the states to improve the monitoring and assessment of education. State Education Indicators, 1993 is the principal report of the Assessment Center's program of indicators on education. Most of the data are obtained from a member questionnaire; the remainder of the data are obtained from federal government agencies. Information on mathematics education was taken from CCSSO, State Policies on Science and Mathematics Evaluation, 1992.

For additional information, contact:

Edward Roeber

State Education Assessment Center

Council of Chief State School Officers

One Massachusetts Avenue NW

7th Floor

Washington, DC 20001

\section{Council of State Directors of Programs for the Gifted}

The Council of State Directors of Programs for the Gifted is composed of the director or individual in the leadership position for gifted education in each of the 50 states, the District of Columbia, and the outlying areas. The Council has conducted many surveys in the past and most recently conducted two comprehensive state surveys in order to produce a profile of gifted education throughout the nation. These data are reported in the 1985, 1987, 1990, and 1994 "State of the States Gifted and Talented Education" reports. This edition of the Digest uses data from the 1995-96 school year.

Further information is available from:

Michael Hall, Executive Director

Council of State Directors of Programs for the Gifted c/o Office of Public Instruction

P.O Box 202501

Helena, MT 59620-2501 


\section{Education Commission of the States}

The Education Commission of the States (ECS) Clearinghouse collects information on laws and standards in the field of education and reports them periodically in "Clearinghouse Notes." The Commission collects information about administrators, principals, and teachers. It also examines policy areas, such as assessment and testing, collective bargaining, early childhood issues, quality education, and school schedules. The information is collected by reading state newsletters, tracking state legislation, and surveying state education agencies. Data are verified by the individual states when necessary. Even though ECS monitors state activity on a continuous basis, it updates the reports only when there is significant change in state activity.

Further information is available from:

Shawni Arora

Education Commission of the States

707 17th Street, Suite 2700

Denver, CO 80202-3427

\section{Gallup Poll}

Each year the Gallup Poll conducts the "Public Attitudes Toward the Public Schools" survey, funded by Phi Delta Kappa. The survey includes interviews with adults representing the civilian noninstitutional population 18 years old and over.

The sample used in the 27th annual survey was made up of a total of 1,311 respondents and is described as a modified probability sample of the nation. Personal, in-home interviewing was conducted in representative communities.

The survey is a sample survey and is subject to sampling error. The size of error depends largely on the number of respondents providing data. Table A9 shows the approximate sampling errors associated with different percentages and sample sizes for the survey. Table A10 provides approximate sampling errors for comparisons of two sample percentages.

For example, an estimated percentage of about 10 percent based on the responses of 1,000 sample members has an approximate sampling error of 2 percent at the 95 percent confidence level. The sampling error for the difference in 2 percentages (50 percent versus 41 percent) based on 2 samples of 750 members and 400 members, respectively, is about 8 percent at the 95 percent confidence level.

Further information on this survey can be obtained from:

Neville Robertson

Phi Delta Kappa

P.O. Box 789

Bloomington, IN 47402-0789

\section{Independent Sector}

The Independent Sector has commissioned the Gallup Poll to conduct a national survey on the giving and volunteering behavior of Americans. This survey is part of a series of surveys that will be conducted every 2 years. The 1991 information was obtained from in-home personal interviews conducted from April 3 to May 17, 1992, with a representative national sample of 2,671 adult Americans 18 or more years old. The sampling procedure did not include those with incomes above $\$ 200,000$ because they constitute such a small percentage of the population.

The results from this survey are published in Giving and Volunteering in the United States and may be purchased from:

Independent Sector

1828 L Street NW

Washington, DC 20036

\section{International Association for the Evaluation of Educational Achievement (IEA)}

The International Association for the Evaluation of Educational Achievement, known as the IEA, is comprised of research centers and scholars from around the world whose aim is to investigate education problems common among countries. In 1988, the IEA General Assembly, composed of the research institutes participating in IEA projects, decided to undertake a study of reading literacy. The study held its first National Research Coordinator (NRC) meeting in November 1988. The construction and pilot testing of instruments was conducted in the period from November 1988 to July 1990. The main testing took place in the period October 1990 to April 1991 depending on the school year in each country. Thirtytwo school systems were involved in the IEA Reading Literacy Study. Data were collected from 210,059 students, 10,518 teachers, and 9,073 schools. All students took reading tests for two sessions totaling 75 minutes at the 9-year-old level and two sessions totaling 85 minutes at the 14-year-old population. All students responded to a background questionnaire about their reading at home and at school. Teachers and school principals responded to questionnaires about themselves, their teaching and the school organization. Each national center (NCES was the center for the United States) completed a National Case Study Questionnaire.

For more information, contact:

Marilyn Binkley, NRC USA

National Center for Education Statistics

555 New Jersey Avenue NW

Washington, DC 20208-5650 


\section{Institute of International Education}

Each year the Institute of International Education (IIE) conducts a survey of the number of foreign students studying in American colleges and universities and reports these data in Open Doors. All of the regionally accredited institutions in the Education Directory, Colleges and Universities published by NCES are surveyed by IIE. The data presented in the Digest are drawn from the IIE survey which requests the total enrollment of foreign students in an institution and information on student characteristics, such as country of origin. For the 1994-95 survey, 2,684 out of 2,758 (97.3 percent) institutions reported data for the survey.

Additional information can be obtained from the publication Open Doors or by contacting:

Todd M. Davis

Institute of International Education

809 United Nations Plaza

New York, NY 10017-3580

\section{Metropolitan Life Insurance Company}

The Metropolitan Life Survey of the American Teacher for the Metropolitan Life Insurance Company was conducted by Louis Harris and Associates. This survey was designed to measure the experiences of new public school teachers who began their first year of teaching in the 1990-91 school year. It includes questions on their experiences with students, administrators, other teachers, and parents. There were three surveys of this cohort of new teachers. The first survey was conducted during the summer of 1990 to measure the expectations of new graduates from teaching schools immediately prior to their first year of teaching in public schools. The second survey compared how these new teachers' experiences in their first year of teaching affected their attitudes, and how the actual experience of teaching compared with their prior expectations. The current survey focuses on these teachers' experience two years into their teaching career. It includes questions which allow comparisons on their attitudes toward teaching now versus one and two years ago.

A total of 1,000 teachers who began their first year of teaching in the public schools in the 1990-91 school year were surveyed. The sample was designed to be representative of all new teachers in the public schools who graduated from teaching colleges in 1990 and taught for the first time in a public school in the 1990-91 school year.

The sample was drawn from lists of 1990 graduates from a probability sample of colleges listed by the American Association of Colleges for Teacher Education. Graduates who did not teach full time in public schools in 1990-91 were excluded from the sample.
The priority for fielding the sample was as follows: first, any respondents from the second phase of the study (after the first year of teaching); second, any respondents from the first phase (before teaching) who were not also included in the second phase; finally, any remaining teachers from the original sample group who were not used in the first phase.

All interviews were conducted by telephone in May and June 1992.

For more information contact:

Metropolitan Life Survey of the American Teacher Louis Harris and Associates

111 Fifth Avenue

New York, NY 10003

\section{National Association of State Student Grant and Aid Programs}

The National Association of State Student Grant and Aid Programs (NASSGAP) is an association of states with general programs of scholarship or grant assistance for undergraduate study. Executive officers responsible for grant program administration represent each state in the Association. The 26th Annual Survey Report: 1994-95 Academic Year is produced by the New York State Higher Education Services Corporation, and data are reported for all 50 states, the District of Columbia, and Puerto Rico.

For more information on this survey, contact:

Charles Treadwell

New York State Higher Education Services

Corporation

99 Washington Avenue, Room 1438

Albany, NY 12255

Attention: NASSGAP

\section{National Education Association}

The National Education Association (NEA) reports enrollment, expenditure, revenue, graduate, teacher, and instructional staff salary data in its annual publication, Estimates of School Statistics. Each year NEA prepares regression-based estimates of financial and other education statistics and submits them to the states for verification. Generally about 30 states adjust these estimates based on their own data. These preliminary data are published by NEA along with revised data from previous years. States are asked to revise previously submitted data as final figures become available. The most recent publication contains all changes reported to the NEA.

\section{Status of the American Public School Teacher}

The "Status of the American Public School Teacher" survey is conducted every 5 years by the National Education Association (NEA). The survey was 
designed by the NEA Research Division and initially administered in 1956. The intent of the survey is to solicit information covering various aspects of public school teachers' professional, family, and civic lives.

Participants for the survey are selected using a two-stage sample design, with the first-stage stratum determined by the number of students enrolled in the districts. Selection probabilities are determined so that the resulting sample is self-weighting. In 1990 91, questionnaires were sent to a sample of 1,981 of the nation's approximately 2,400,000 public school teachers. With an initial and four follow-up mailings, 1,499 questionnaires were returned, of which 145 were not usable. The sample was adjusted to 1,836 to reflect the 145 unusable responses. The response rate was 73.7 percent.

Possible sources of nonsampling errors are nonresponses, misinterpretation, and-when comparing data over years-changes in the sampling method and instrument. Misinterpretation of the survey items should be minimal, as the sample responding is not from the general population but one knowledgeable about the area of concern. Also, the sampling procedure changed after 1956 and some wording of items has changed over the different administrations.

Since sampling is used, sampling variability is inherent in the data. An approximation to the maximum standard error for estimating the population percentages is 1.4 percent (table A11). To estimate the 95 percent confidence interval for population percentages, the maximum standard error of 1.4 percent is multiplied by $2(1.4 \times 2)$. The resulting percentage (2.8) is added and subtracted from the population estimate to establish upper and lower bounds for the confidence interval. For example, if a sample percentage is 60 percent, there is a 95 percent chance that the population percentage lies between 57.2 percent and 62.8 percent (60 percent +2.8 percent).

Questions concerning the "Status of the American Public School Teacher" survey may be directed to:

Brooke E. Whiting

National Education Association-Research

1201 16th Street NW

Washington, DC 20036

\section{Organization for Economic Cooperation and Development}

The Organization for Economic Cooperation and Development (OECD) publishes analyses of national policies in education, training, and economics in more than 20 countries. The countries surveyed are: Australia, Austria, Belgium, Canada, Czech Republic, Denmark, Finland, France, Germany, Greece, Hungary, Iceland, Ireland, Italy, Japan, Korea, Luxembourg, Mexico, Netherlands, New Zealand, Norway, Poland, Portugal, Spain, Sweden, Switzerland, Tur- key, United Kingdom, and the United States. In addition to these OECD countries, a number of other countries are participating in the related World Education Indicators (WEI) project including: Argentina, Brazil, Chile, China, Indonesia, Jordan, Malaysia, Paraguay, Philippines, Russian Federation, Thailand, and Uruguay.

In the past several years, OECD has revised its data collection procedures to highlight current education issues and improve data comparability. The Centre for Educational Research and Innovation (CERI) has developed an Indicators of Education Systems (INES) project involving representatives of the OECD countries and the OECD Secretariat to improve international education statistics. Large improvements in data quality and comparability among OECD countries have resulted from the country to country interaction sponsored through the INES and WEI projects. The most recent publication in this series is Education at a Glance, OECD Indicators, 1998.

More complete information on INES may be obtained from:

\section{Andreas Schleicher \\ INES/OECD \\ 2, rue Andre-Pascal \\ 75775 Paris CEDEX 16 \\ France}

\section{Research Associates}

Research Associates annually compiles the Higher Education Price Index (HEPI) which measures average changes in prices of goods and services purchased by colleges and universities through educational and general expenditures. Sponsored research and auxiliary enterprises are not priced by the HEPI.

The HEPI is based on the prices (or salaries) of faculty and of administrators and other professional service personnel; clerical, technical, service, and other nonprofessional personnel; and contracted services, such as data processing, communication, transportation, supplies and materials, equipment, books and periodicals, and utilities. These represent the items purchased for current operations by colleges and universities. Prices for these items are obtained from salary surveys conducted by various national higher education associations, the American Association of University Professors, the Bureau of Labor Statistics, and the National Center for Education Statistics; and from components of the Consumer Price Index (CPI) and the Producer Price Index (PPI) published by the U.S. Department of Labor, Bureau of Labor Statistics.

The quantities of these goods and services have been kept constant based on the 1971-72 buying 
pattern of colleges and universities. The weights assigned the various items priced, which represent their relative importance in the current-fund educational and general budget, are estimated national averages. Variance in spending patterns of individual institutions from these national averages reduces only slightly the applicability of the HEPI to any given institutional situation. Modest differences in the weights attached to expenditure categories have little effect on overall index values. This is because the HEPI is dominated by the trend in faculty salaries and similar salary trends for other personnel hired by institutions, which absorbs or diminishes the effects of price changes in other items purchased in small quantities.

For more information, contact:

Research Associates

Kent Halstead

1200 North Nash St., \#225

Arlington, VA 22209

\section{United Nations Educational, Scientific, and Cultural Organization}

The United Nations Educational, Scientific, and Cultural Organization (UNESCO) conducts annual surveys of education statistics of its member countries. Besides official surveys, data are supplemented by information obtained by UNESCO through other publications and sources. Each year more than 200 countries reply to the UNESCO surveys. In some cases, estimates are made by UNESCO for particular items such as world and continent totals. While great efforts are made to make them as comparable as possible, the data still reflect the vast differences among the countries of the world in the structure of education. While there is some agreement about the reporting of first- and second-level data, the third level (postsecondary education) presents numerous substantial problems. Some countries report only university enrollment while other countries report all postsecondary, including vocational and technical schools and correspondence programs. A very high proportion of some countries' third-level students attend institutions in other countries. While definition problems are many in this sort of study, other survey problems should not be overlooked. The member countries that provide data to UNESCO are responsible for their validity. Thus, data for particular countries are subject to nonsampling error and perhaps sampling error as well. Some countries may furnish only rough estimates, while data from other countries may be very accurate. Other difficulties are caused by the varying periodicity of data collection among the countries of the world. In spite of such problems, many researchers use UNESCO data because they are the best available for such a large group of countries. Users should examine footnotes carefully to recognize some of the data limitations.

More complete information may be obtained from the Statistical Yearbook published by UNESCO or from:

Office of Statistics

UNESCO

7, Place de Fontenoy

75700 Paris

France 
Table A1.-Respondent counts for selected High School and Beyond surveys

\begin{tabular}{|c|c|c|c|c|c|c|}
\hline Classification variable and subgroup & $\begin{array}{l}\text { Follow-up } \\
\text { survey of } 1980 \\
\text { sophomores in } \\
1982\end{array}$ & $\begin{array}{l}\text { Follow-up } \\
\text { survey of } 1980 \\
\text { seniors in } \\
1982\end{array}$ & $\begin{array}{l}\text { Follow-up } \\
\text { survey of } 1980 \\
\text { sophomores in } \\
1984\end{array}$ & $\begin{array}{l}\text { Follow-up } \\
\text { survey of } 1980 \\
\text { seniors in } \\
1984\end{array}$ & $\begin{array}{l}\text { Follow-up } \\
\text { survey of } 1980 \\
\text { sophomores in } \\
1986\end{array}$ & $\begin{array}{l}\text { Follow-up } \\
\text { survey of } 1980 \\
\text { seniors in } \\
1986\end{array}$ \\
\hline Total respondents (unweighted) ...... & 25,830 & 11,227 & 11,463 & 10,925 & 11,248 & 10,536 \\
\hline 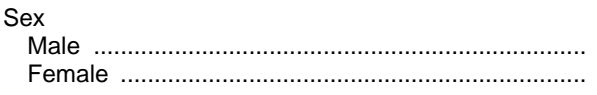 & $\begin{array}{l}12,717 \\
13,113\end{array}$ & $\begin{array}{l}5,213 \\
6,014\end{array}$ & $\begin{array}{l}5,514 \\
5,949\end{array}$ & $\begin{array}{l}5,058 \\
5,867\end{array}$ & $\begin{array}{l}5,391 \\
5,857\end{array}$ & $\begin{array}{l}4,832 \\
5,704\end{array}$ \\
\hline 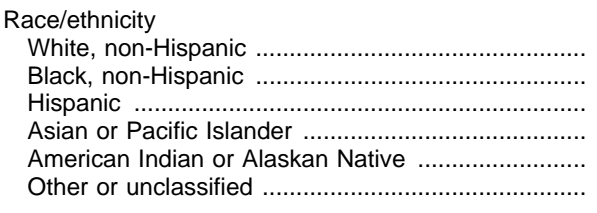 & $\begin{array}{r}17,295 \\
3,338 \\
4,439 \\
413 \\
248 \\
97\end{array}$ & $\begin{array}{r}5,180 \\
2,724 \\
2,749 \\
367 \\
191 \\
16\end{array}$ & $\begin{array}{r}7,285 \\
1,651 \\
1,795 \\
425 \\
253 \\
54\end{array}$ & $\begin{array}{r}5,057 \\
2,625 \\
2,654 \\
355 \\
185 \\
49\end{array}$ & $\begin{array}{r}7,194 \\
1,585 \\
1,745 \\
413 \\
246 \\
65\end{array}$ & $\begin{array}{r}5,246 \\
2,726 \\
1,950 \\
356 \\
200 \\
58\end{array}$ \\
\hline 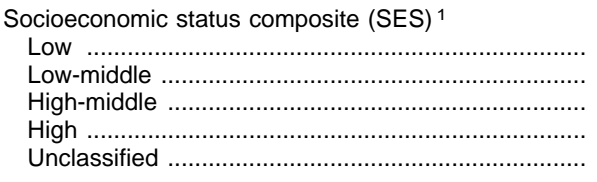 & $\begin{array}{r}6,752 \\
6,234 \\
6,134 \\
6,341 \\
369\end{array}$ & $\begin{array}{r}3,940 \\
2,390 \\
2,168 \\
1,988 \\
741\end{array}$ & $\begin{array}{r}2,831 \\
2,624 \\
2,849 \\
3,086 \\
73\end{array}$ & $\begin{array}{r}3,857 \\
2,314 \\
2,107 \\
1,936 \\
711\end{array}$ & $\begin{array}{r}2,751 \\
2,559 \\
2,817 \\
3,044 \\
77\end{array}$ & $\begin{array}{r}3,668 \\
2,289 \\
1,995 \\
1,900 \\
684\end{array}$ \\
\hline 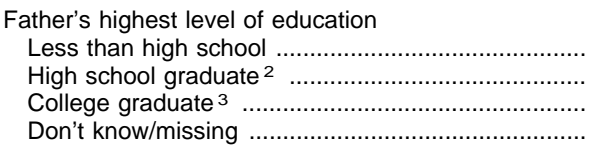 & $\begin{array}{r}5,179 \\
11,961 \\
5,169 \\
3,521\end{array}$ & $\begin{array}{l}- \\
- \\
-\end{array}$ & $\begin{array}{l}- \\
- \\
-\end{array}$ & $\begin{array}{l}- \\
- \\
-\end{array}$ & $\begin{array}{l}- \\
- \\
-\end{array}$ & $\begin{array}{l}- \\
- \\
-\end{array}$ \\
\hline 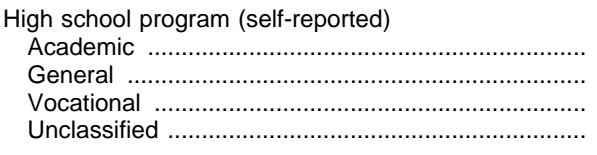 & $\begin{array}{r}10,152 \\
8,789 \\
6,664 \\
225\end{array}$ & $\begin{array}{r}4,145 \\
3,829 \\
2,660 \\
593\end{array}$ & $\begin{array}{r}6,547 \\
3,468 \\
3,611 \\
56\end{array}$ & $\begin{array}{r}4,007 \\
3,764 \\
2,581 \\
573\end{array}$ & $\begin{array}{l}- \\
- \\
-\end{array}$ & $\begin{array}{r}3,899 \\
3,602 \\
2,481 \\
554\end{array}$ \\
\hline 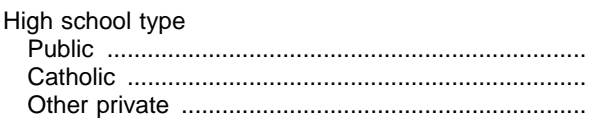 & - & $\begin{array}{r}9,969 \\
964 \\
294\end{array}$ & $\begin{array}{r}8,647 \\
2,479 \\
337\end{array}$ & $\begin{array}{r}9,727 \\
911 \\
287\end{array}$ & - & $\begin{array}{r}9,385 \\
876 \\
275\end{array}$ \\
\hline 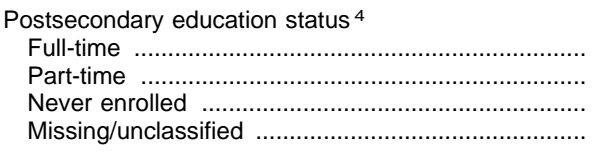 & $\begin{array}{l}- \\
- \\
-\end{array}$ & $\begin{array}{l}- \\
- \\
-\end{array}$ & $\begin{array}{r}4,466 \\
3,275 \\
3,678 \\
44\end{array}$ & $\begin{array}{l}- \\
- \\
-\end{array}$ & $\begin{array}{l}- \\
- \\
-\end{array}$ & $\begin{array}{l}- \\
- \\
-\end{array}$ \\
\hline 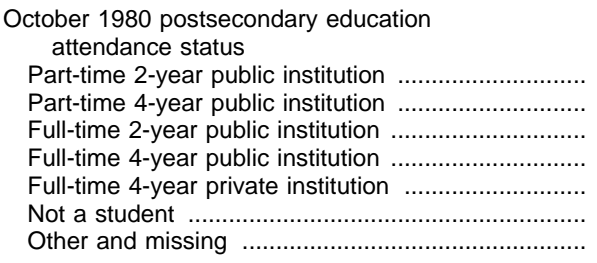 & $\begin{array}{l}- \\
- \\
- \\
- \\
-\end{array}$ & $\begin{array}{l}- \\
- \\
- \\
- \\
-\end{array}$ & $\begin{array}{l}- \\
- \\
- \\
- \\
-\end{array}$ & $\begin{array}{l}- \\
- \\
- \\
- \\
-\end{array}$ & $\begin{array}{l}- \\
- \\
- \\
- \\
- \\
-\end{array}$ & $\begin{array}{r}352 \\
152 \\
1,312 \\
1,986 \\
1,015 \\
4,523 \\
1,196\end{array}$ \\
\hline 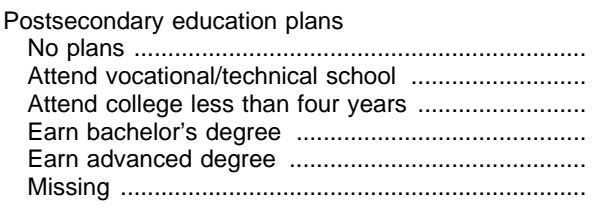 & $\begin{array}{l}- \\
- \\
- \\
-\end{array}$ & $\begin{array}{l}- \\
- \\
- \\
-\end{array}$ & $\begin{array}{l}- \\
- \\
- \\
-\end{array}$ & $\begin{array}{l}- \\
- \\
- \\
- \\
-\end{array}$ & $\begin{array}{l}- \\
- \\
- \\
- \\
-\end{array}$ & $\begin{array}{r}1,623 \\
1,835 \\
1,528 \\
2,631 \\
2,265 \\
654\end{array}$ \\
\hline 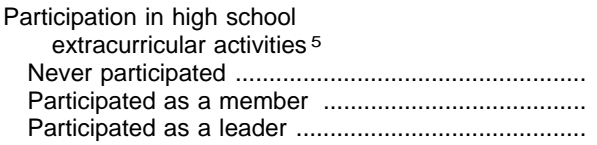 & $\begin{array}{l}- \\
-\end{array}$ & $\begin{array}{l}- \\
-\end{array}$ & $\begin{array}{c}- \\
-\end{array}$ & $\begin{array}{c}- \\
-\end{array}$ & $\begin{array}{l}- \\
-\end{array}$ & $\begin{array}{l}1,024 \\
4,104 \\
4,457\end{array}$ \\
\hline
\end{tabular}

${ }^{1}$ The SES index is a composite of five equally weighted measures: father's education, mother's education, family income, father's occupation, and presence of certain items in the respondent's household.

2 Includes attendance at a vocational, trade, or business school, or 2-year college; or attendance at a 4-year college resulting in less than a bachelor's degree.

3 Includes those with a bachelor's or higher level degree.

${ }^{4}$ Postsecondary education status was determined by students' enrollment in academic or vocational study during the four semesters-fall 1982, spring 1983, fall 1983, and spring 1984-following their scheduled high school graduation. Students who enrolled in full-time study in each of the four semesters were classified as full time. Students who were enrolled in part-time study in any of the four semesters and those who were enrolled in full-time study in fewer than four semesters were classified as part time. Stu- dents who had neither enrolled on a full-time nor part-time basis in each of the four se mesters were classified as never enrolled.

${ }^{5}$ Responses to questions concerning participation in each of 15 different extracurricular activity areas (i.e., varsity sports, debate, band, subject-matter clubs, etc.) were used to classify students' overall level of participation in extracurricular activities. The difference between the sum of the three category respondent counts and the total sample size is due to missing data.

-Data not available or not applicable.

NOTE.-Data from students who dropped out of school between the 10th and 12th grades were not used in analyses of sophomore samples.

SOURCE: U.S. Department of Education, National Center for Education Statistics, High School and Beyond surveys. 
Table A2.-Design effects (DEFF) and root design effects (DEFT) for selected High School and Beyond surveys and subsamples

\begin{tabular}{|c|c|c|c|c|}
\hline Classification variable and subgroup & $\begin{array}{c}\text { Follow-up } \\
\text { survey of } 1980 \\
\text { sophomores in } \\
1984\end{array}$ & $\begin{array}{c}\text { Follow-up } \\
\text { survey of } 1980 \\
\text { seniors in } \\
1984\end{array}$ & $\begin{array}{c}\text { Follow-up } \\
\text { survey of } 1980 \\
\text { sophomores in } \\
1986\end{array}$ & $\begin{array}{l}\text { Follow-up } \\
\text { survey of } 1980 \\
\text { seniors in } \\
1986\end{array}$ \\
\hline Total sample .......... & $2.40(1.54)$ & 2.87 (1.69) & $2.19(1.47)$ & $2.28(1.50)$ \\
\hline \multicolumn{5}{|l|}{ Sex } \\
\hline Male & - & - & $2.07(1.43)$ & $2.13(1.45)$ \\
\hline Female ....................... & - & - & $2.06(1.43)$ & $2.26(1.50)$ \\
\hline \multicolumn{5}{|l|}{ Race/ethnicity } \\
\hline White and other & $2.06(1.42)$ & $2.09(1.44)$ & $1.92(1.38)$ & $1.70(1.30)$ \\
\hline 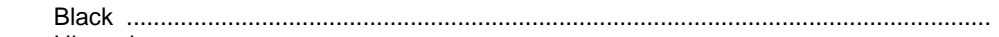 & $2.22(1.47)$ & $2.26(1.50)$ & $2.19(1.47)$ & $2.40(1.54)$ \\
\hline 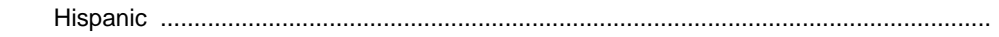 & $3.15(1.73)$ & $3.72(1.92)$ & $3.11(1.76)$ & $4.06(2.01)$ \\
\hline \multicolumn{5}{|l|}{ Socioeconomic status composite (SES) } \\
\hline Low & $1.91(1.37)$ & $2.28(1.50)$ & $1.83(1.35)$ & $2.31(1.51)$ \\
\hline Middle & $1.95(1.39)$ & $1.81(1.34)$ & $2.06(1.42)$ & $2.02(1.42)$ \\
\hline (1) & $2.05(1.42)$ & $1.93(1.38)$ & $1.92(1.38)$ & $1.71(1.30)$ \\
\hline
\end{tabular}

\section{-Not available.}

NOTE.-The average design effect for the 1980 sophomore cohort first follow-up (1982) survey is 3.59(1.89) and the average design effect for the 1980 senior first followup (1982) survey is $2.64(1.62)$.
SOURCE: U.S. Department of Education, National Center for Education Statistics, High School and Beyond surveys.

Table A3.-Respondent counts for the National Education Longitudinal Study: 1988, 1990, and 1992

\begin{tabular}{|c|c|c|c|}
\hline Classification variable and subgroup & Base Year, 1988 & First follow-up, 1990 & Second follow-up, 1992 \\
\hline Total respondents (unweighted) & 24,599 & 20,706 & 21,188 \\
\hline \multicolumn{4}{|l|}{ Sex } \\
\hline Male ........... & 12,241 & 10,462 & 10,713 \\
\hline Female & 12,358 & 10,244 & 10,475 \\
\hline \multicolumn{4}{|l|}{ Race/ethnicity } \\
\hline White, non-Hispanic & 16,317 & 13,837 & 14,024 \\
\hline 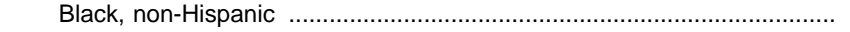 & 3,009 & 2,218 & 2,260 \\
\hline 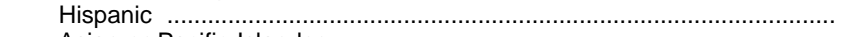 & 3,171 & 2,751 & 2,922 \\
\hline 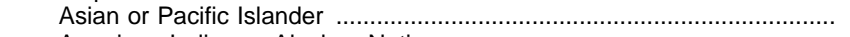 & 1,527 & 1,302 & 1,406 \\
\hline American Indian or Alaskan Native & 299 & 259 & 266 \\
\hline Other or unclassified & 276 & 399 & 310 \\
\hline \multicolumn{4}{|l|}{ Socioeconomic status composite (SES) } \\
\hline Low …….......................................... & 5,934 & 4,556 & 4,395 \\
\hline 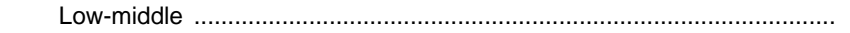 & 5,788 & 4,472 & 4,501 \\
\hline High-middle & 5,836 & 4,378 & 4,516 \\
\hline 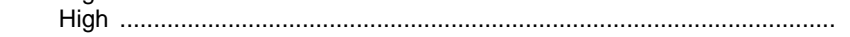 & 7,030 & 5,262 & 5,437 \\
\hline 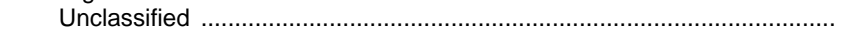 & 11 & 2,038 & 2,339 \\
\hline \multicolumn{4}{|l|}{ High school program (self-reported) } \\
\hline Academic & 7,298 & 6,420 & 7,567 \\
\hline General ... & 3,369 & 7,990 & 6,125 \\
\hline Vocational & 4,161 & 1,806 & 1,911 \\
\hline 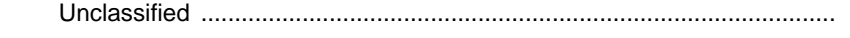 & 9,771 & 4,490 & 5,585 \\
\hline \multicolumn{4}{|l|}{ High school type } \\
\hline Public .......... & 19,396 & 16,813 & 15,145 \\
\hline Catholic ................... & 2,602 & 1,012 & 934 \\
\hline Other private & 2,601 & 1,602 & 1,530 \\
\hline 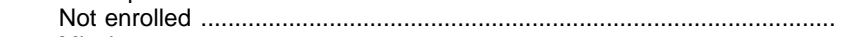 & - & 1,043 & 2,725 \\
\hline 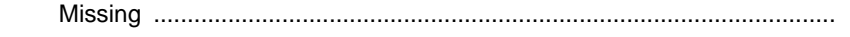 & 一 & 236 & 854 \\
\hline \multicolumn{4}{|l|}{ Postsecondary education plans } \\
\hline 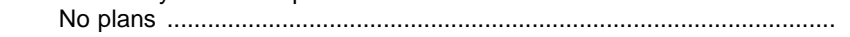 & 2,685 & 2,483 & 2,646 \\
\hline 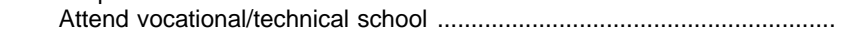 & 2,102 & 2,323 & 2,072 \\
\hline Attend college less than 4 years & 3,078 & 3,074 & 2,457 \\
\hline 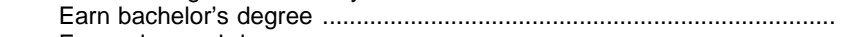 & 10,251 & 5,874 & 5,631 \\
\hline Earn advanced degree & 6,268 & 5,269 & 5,580 \\
\hline 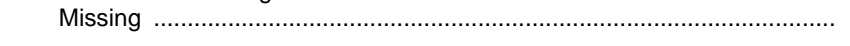 & 215 & 1,683 & 2,802 \\
\hline \multicolumn{4}{|l|}{ School academic clubs and extracurricular activities } \\
\hline 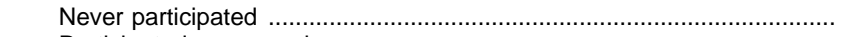 & 21,516 & 15,292 & 17,117 \\
\hline 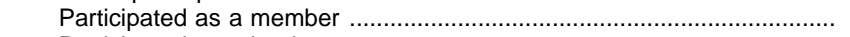 & 2,798 & 5,144 & 3,355 \\
\hline 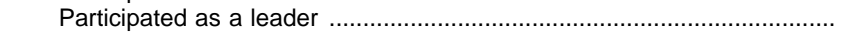 & 285 & 270 & 716 \\
\hline
\end{tabular}


Table A4.-Design effects (DEFF) and root design effects (DEFT) for selected National Education Longitudinal Survey samples

\begin{tabular}{|c|c|c|c|c|c|c|}
\hline \multirow{2}{*}{ Subsample characteristic } & \multicolumn{2}{|c|}{ Base year, 1988} & \multicolumn{2}{|c|}{ First follow-up, 1990} & \multicolumn{2}{|c|}{ Second follow-up, 1992} \\
\hline & Mean DEFF & Mean DEFT & Mean DEFF & Mean DEFT & Mean DEFF & Mean DEFT \\
\hline All students $\quad$ Dropouts & $\stackrel{2.54}{-}$ & $\underline{1.56}$ & $\begin{array}{l}3.802 \\
4.705\end{array}$ & $\begin{array}{l}1.912 \\
1.997\end{array}$ & $\begin{array}{l}3.668 \\
2.919\end{array}$ & $\begin{array}{l}1.881 \\
1.686\end{array}$ \\
\hline Sex & $\begin{array}{l}1.98 \\
1.93\end{array}$ & $\begin{array}{l}1.39 \\
1.38\end{array}$ & $\begin{array}{l}3.456 \\
3.324\end{array}$ & $\begin{array}{l}1.817 \\
1.783\end{array}$ & $\begin{array}{l}3.094 \\
3.238\end{array}$ & $\begin{array}{l}1.729 \\
1.785\end{array}$ \\
\hline 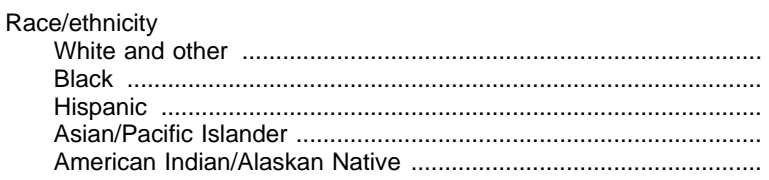 & $\begin{array}{r}2.25 \\
1.65 \\
2.06 \\
2.00 \\
-\end{array}$ & $\begin{array}{r}1.48 \\
1.27 \\
1.41 \\
1.40 \\
-\end{array}$ & $\begin{array}{l}3.101 \\
3.804 \\
2.643 \\
2.758 \\
2.066\end{array}$ & $\begin{array}{l}1.729 \\
1.867 \\
1.591 \\
1.609 \\
1.362\end{array}$ & $\begin{array}{l}3.084 \\
2.938 \\
2.772 \\
2.511 \\
3.292\end{array}$ & $\begin{array}{l}1.737 \\
1.654 \\
1.626 \\
1.562 \\
1.687\end{array}$ \\
\hline 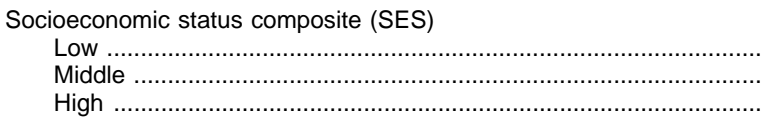 & $\begin{array}{l}1.58 \\
1.66 \\
1.84\end{array}$ & $\begin{array}{l}1.25 \\
1.28 \\
1.34\end{array}$ & $\begin{array}{l}2.797 \\
3.138 \\
3.576\end{array}$ & $\begin{array}{l}1.644 \\
1.732 \\
1.817\end{array}$ & $\begin{array}{l}2.931 \\
2.516 \\
3.849\end{array}$ & $\begin{array}{l}1.680 \\
1.569 \\
1.921\end{array}$ \\
\hline High school type & $\begin{array}{l}2.27 \\
2.70 \\
8.80\end{array}$ & $\begin{array}{l}1.48 \\
1.59 \\
1.83\end{array}$ & $\begin{array}{l}3.147 \\
2.619 \\
6.529\end{array}$ & $\begin{array}{l}1.736 \\
1.513 \\
2.391\end{array}$ & $\begin{array}{l}3.116 \\
2.545 \\
6.049\end{array}$ & $\begin{array}{l}1.733 \\
1.564 \\
2.334\end{array}$ \\
\hline $\begin{array}{l}\text { Community type } \\
\quad \text { Urban } \\
\text { Suburban } \\
\text { Rural }\end{array}$ & - & - & $\begin{array}{l}3.463 \\
3.412 \\
2.634\end{array}$ & $\begin{array}{l}1.842 \\
1.788 \\
1.571\end{array}$ & $\begin{array}{l}3.742 \\
2.998 \\
3.311\end{array}$ & $\begin{array}{l}1.897 \\
1.705 \\
1.687\end{array}$ \\
\hline
\end{tabular}

-Data not available.

SOURCE: U.S. Department of Education, National Center for Education Statistics, National Education Longitudinal Survey.

Table A5.-Respondent counts of full-time workers from the Recent College Graduates survey: 1976 to 1991

\begin{tabular}{|c|c|c|c|c|c|}
\hline \multirow[b]{2}{*}{ Field of study } & \multicolumn{5}{|c|}{ Number employed full time } \\
\hline & $\begin{array}{c}1974-75 \\
\text { graduates in } \\
\text { May } 1976\end{array}$ & $\begin{array}{l}1979-80 \\
\text { graduates in } \\
\text { May } 1981\end{array}$ & $\begin{array}{l}1983-84 \\
\text { graduates in } \\
\text { April } 1985\end{array}$ & $\begin{array}{l}1985-86 \\
\text { graduates in } \\
\text { April } 1987\end{array}$ & $\begin{array}{l}1989-90 \\
\text { graduates in } \\
\text { April } 1991\end{array}$ \\
\hline Total respondents (unweighted) & 2,464 & 5,521 & 6,799 & 15,024 & 9,451 \\
\hline Professions ............................. & 1,840 & 4,260 & 3,730 & 8,987 & 3,825 \\
\hline Arts and sciences & 514 & 811 & 2,586 & 4,869 & 2,256 \\
\hline 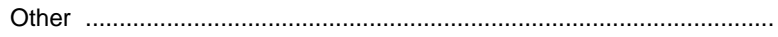 & 110 & 450 & 483 & 1,168 & 3,370 \\
\hline 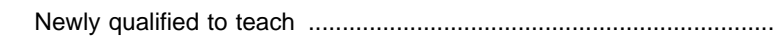 & 1,337 & 2,469 & 1,109 & 2,546 & 1,966 \\
\hline Not newly qualified to teach & 1,127 & 3,052 & 5,690 & 12,478 & 7,485 \\
\hline Professions & 601 & 1,841 & 2,809 & 7,043 & 2,549 \\
\hline Engineering & 80 & 270 & 601 & 915 & 411 \\
\hline Business and management fon. & 290 & 749 & 1,532 & 2,407 & 1,598 \\
\hline Health & 72 & 252 & 387 & 3,106 & 281 \\
\hline Education 1 & 141 & 464 & 146 & 521 & 188 \\
\hline Public affairs and services & 18 & 106 & 143 & 94 & 71 \\
\hline 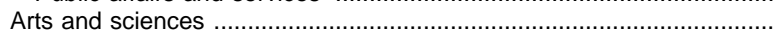 & 433 & 770 & 2,430 & 4,369 & 2,006 \\
\hline Biological sciences & 83 & 116 & 243 & 380 & 179 \\
\hline Physical sciences and mathematics & 40 & 103 & 1,062 & 1,782 & 466 \\
\hline Psychology & 64 & 105 & 189 & 366 & 316 \\
\hline Social sciences & 107 & 252 & 449 & 780 & 813 \\
\hline Humanities & 139 & 194 & 487 & 1,061 & 232 \\
\hline 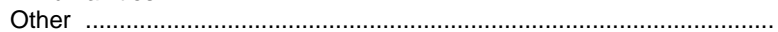 & 93 & 441 & 451 & 1,066 & 2,930 \\
\hline Communications & 7 & 73 & 240 & 392 & 217 \\
\hline Miscellaneous & 86 & 368 & 211 & 674 & 2,713 \\
\hline
\end{tabular}


Table A6.-Estimated standard errors for enrollment rates in the October Current Population Survey: 1996 or 1997

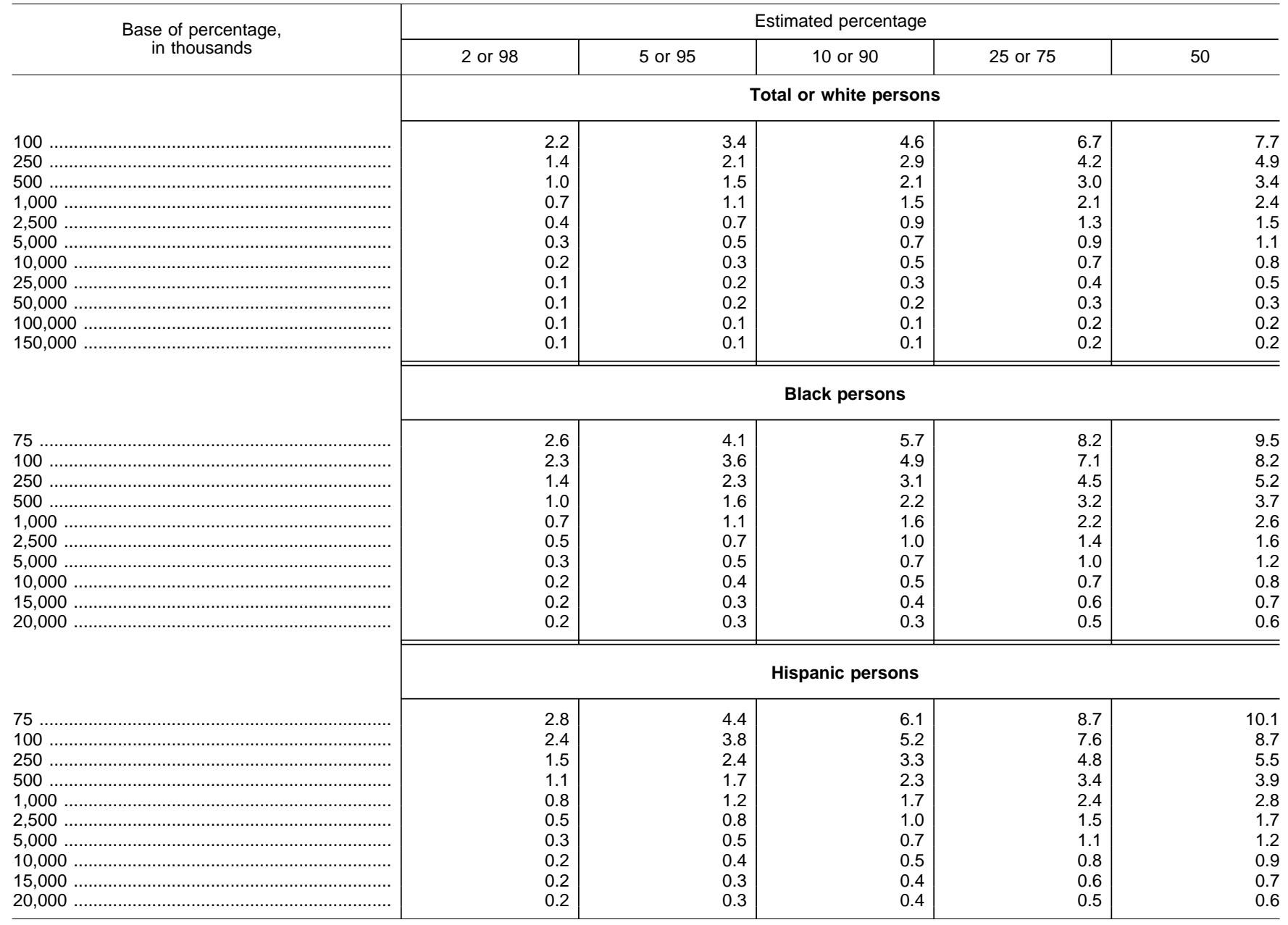

SOURCE: U.S. Department of Commerce Bureau of the Census, School Enrollment: Social and Economic Characteristics of Students.

Table A7.-Estimated educational attainment rates and standard errors in the March Current Population Survey

\begin{tabular}{|c|c|c|c|c|c|c|}
\hline \multirow{2}{*}{ Estimate } & \multirow{2}{*}{$\begin{array}{l}\text { Base of percentage } \\
\text { in thousands }\end{array}$} & \multirow{2}{*}{ Standard error } & \multicolumn{2}{|c|}{90 percent confidence interval ${ }^{1}$} & \multicolumn{2}{|c|}{$\begin{array}{l}95 \text { percent confidence inter- } \\
\text { val }{ }^{1}\end{array}$} \\
\hline & & & Lower bound & Upper bound & Lower bound & Upper bound \\
\hline \multirow[t]{2}{*}{ 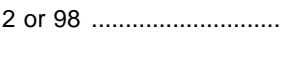 } & 100 & 2.15 & 0.0 & 5.5 & 0.0 & 6.2 \\
\hline & 100,000 & 0.07 & 1.9 & 2.1 & 1.9 & 2.1 \\
\hline \multirow[t]{2}{*}{10 or 90} & 100 & 4.61 & 2.4 & 17.6 & 1.0 & 19.0 \\
\hline & 100,000 & 0.15 & 9.8 & 10.2 & 9.7 & 10.3 \\
\hline & 100 & 7.68 & 37.3 & 62.7 & 34.9 & 65.1 \\
\hline & 100,000 & 0.24 & 49.6 & 50.4 & 49.5 & 50.5 \\
\hline
\end{tabular}

1 The confidence interval for the larger values can be found by taking the complement of that shown, e.g., for 98 it would be 93.8 to 100 for 95 percent confidence.

SOURCE: U.S. Department of Commerce, Bureau of the Census, Educational Attainment in the United States.

Table A8.-Standard errors for the proportion of seniors who had used drugs in the previous 12 months: 1975 to 1997

\begin{tabular}{|c|c|c|c|c|c|c|c|c|c|c|c|}
\hline Drug & 1975 & 1980 & 1985 & 1990 & 1991 & 1992 & 1993 & 1994 & 1995 & 1996 & 1997 \\
\hline Alcohol .................... & 0.4 & 0.3 & 0.3 & 0.3 & 0.3 & 0.3 & 0.3 & 0.4 & 0.4 & 0.4 & 0.3 \\
\hline 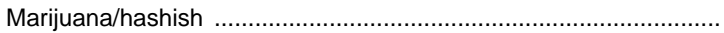 & 0.5 & 0.4 & 0.4 & 0.4 & 0.3 & 0.3 & 0.3 & 0.4 & 0.4 & 0.4 & 0.4 \\
\hline Any illicit drug other than marijuana & 0.5 & 0.4 & 0.4 & 0.3 & 0.3 & 0.3 & 0.3 & 0.3 & 0.3 & 0.3 & 0.3 \\
\hline LSD & 0.3 & 0.2 & 0.2 & 0.2 & 0.2 & 0.2 & 0.2 & 0.2 & 0.2 & 0.2 & 0.2 \\
\hline Cocaine $\ldots \ldots \ldots \ldots \ldots \ldots \ldots \ldots$ & 0.2 & 0.3 & 0.3 & 0.2 & 0.2 & 0.1 & 0.1 & 0.2 & 0.2 & 0.2 & 0.2 \\
\hline
\end{tabular}

SOURCE: University of Michigan, Survey Research Center, Institute for Social Research, Monitoring the Future Study. 
Table A9._Sampling errors (95 percent confidence level) for percentages estimated from the Gallup Poll: 1992 and 1993

\begin{tabular}{|c|c|c|c|c|c|c|c|}
\hline \multirow{2}{*}{ Percent } & \multicolumn{7}{|c|}{ Size of sample } \\
\hline & 1,500 & 1,000 & 750 & 600 & 400 & 200 & 100 \\
\hline & \multicolumn{7}{|c|}{ Recommended allowance for sampling error of a percentage } \\
\hline Percentages near 10 or 90 & 2 & 2 & 3 & 3 & 4 & 5 & 8 \\
\hline 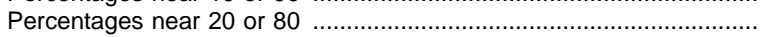 & 3 & 3 & 4 & 4 & 5 & 7 & 10 \\
\hline 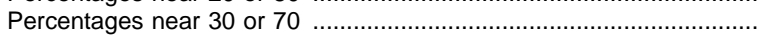 & 3 & 4 & 4 & 5 & 6 & 8 & 12 \\
\hline 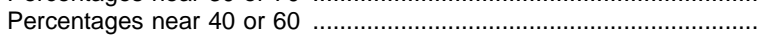 & 3 & 4 & 5 & 5 & 6 & 9 & 12 \\
\hline 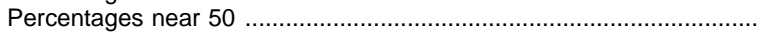 & 3 & 4 & 5 & 5 & 6 & 9 & 13 \\
\hline
\end{tabular}

SOURCE: Phi Delta Kappan, "The Annual Gallup Poll of the Public's Attitudes Toward the Public Schools."

Table A10.-Sampling errors (95 percent confidence level) for the difference in 2 percentages estimated from the Gallup Poll: 1992 and 1993

\begin{tabular}{|c|c|c|c|c|c|c|c|}
\hline \multirow{2}{*}{ Size of sample } & \multicolumn{7}{|c|}{ Size of sample } \\
\hline & 1,500 & 1,000 & 750 & 600 & 400 & 200 & \\
\hline & \multicolumn{7}{|c|}{ Recommended allowance for sampling error of a difference in percentages (percentages near 80 or 20) } \\
\hline 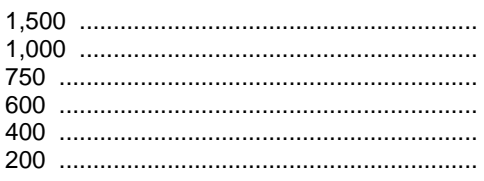 & $\begin{array}{l}4 \\
4 \\
5 \\
5 \\
6 \\
8\end{array}$ & $\begin{array}{l}5 \\
5 \\
5 \\
6 \\
8\end{array}$ & $\begin{array}{l}5 \\
6 \\
6 \\
8\end{array}$ & \begin{tabular}{l|}
6 \\
7 \\
8
\end{tabular} & $\begin{array}{l}7 \\
9\end{array}$ & & 10 \\
\hline 200 & \multicolumn{7}{|c|}{ Recommended allowance for sampling error of a difference in percentages (percentages near 50) } \\
\hline 1,500 & $\begin{array}{r}5 \\
5 \\
6 \\
6 \\
7 \\
10\end{array}$ & $\begin{array}{r}6 \\
6 \\
7 \\
8 \\
10\end{array}$ & $\begin{array}{r}7 \\
7 \\
8 \\
10\end{array}$ & $\begin{array}{r}7 \\
8 \\
10\end{array}$ & $\begin{array}{r}9 \\
11\end{array}$ & & 13 \\
\hline
\end{tabular}

SOURCE: Phi Delta Kappan, "The Annual Gallup Poll of the Public's Attitudes Toward the Public Schools."

Table A11.-Maximum differences required for significance ( 90 percent confidence level) between sample subgroups from the "Status of the American Public School Teacher" survey

\begin{tabular}{|c|c|c|c|c|c|c|c|}
\hline \multirow{2}{*}{ Size of one subgroup } & \multicolumn{7}{|c|}{ Size of other subgroup } \\
\hline & 100 & 200 & 300 & 400 & 500 & 600 & 700 \\
\hline 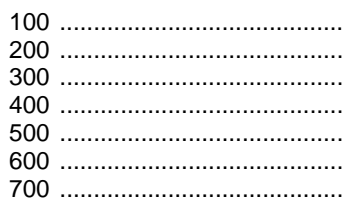 & $\begin{array}{r}11.6 \\
10.1 \\
9.5 \\
9.2 \\
9.0 \\
8.9 \\
8.8\end{array}$ & $\begin{array}{r}10.1 \\
8.2 \\
7.5 \\
7.1 \\
6.9 \\
6.7 \\
6.6\end{array}$ & $\begin{array}{l}9.5 \\
7.5 \\
6.7 \\
6.3 \\
6.0 \\
5.8 \\
5.7\end{array}$ & $\begin{array}{l}9.2 \\
7.1 \\
6.3 \\
5.8 \\
5.5 \\
5.3 \\
5.2\end{array}$ & $\begin{array}{l}9.0 \\
6.9 \\
6.0 \\
5.5 \\
5.2 \\
5.0 \\
4.8\end{array}$ & $\begin{array}{l}8.9 \\
6.7 \\
5.8 \\
5.3 \\
5.0 \\
4.7 \\
4.6\end{array}$ & $\begin{array}{l}8.8 \\
6.6 \\
5.7 \\
5.2 \\
4.8 \\
4.6 \\
4.4\end{array}$ \\
\hline
\end{tabular}

SOURCE: National Education Association, "Status of the American Public School Teacher." (Copyright by the National Education Association. All rights reserved.) 



\section{Definitions}

Academic support This category of college expenditures includes expenditures for support services that are an integral part of the institution's primary missions of instruction, research, or public service. Includes expenditures for libraries, galleries, audio/ visual services, academic computing support, ancillary support, academic administration, personnel development, and course and curriculum development.

Achievement test An examination that measures the extent to which a person has acquired certain information or mastered certain skills, usually as a result of specific instruction.

Administrative support staff Includes personnel dealing with salary, benefits, supplies, and contractual fees for the office of the principal, full-time department chairpersons, and graduation expenses.

Agriculture Courses designed to improve competencies in agricultural occupations. Included is the study of agricultural production, supplies, mechanization and products, agricultural science, forestry, and related services.

American College Testing Program (ACT) The ACT assessment program measures educational development and readiness to pursue college-level coursework in English, mathematics, natural science, and social studies. Student performance on the tests does not reflect innate ability and is influenced by a student's educational preparedness.

Appropriation (federal funds) Budget authority provided through the congressional appropriation process that permits federal agencies to incur obligations and to make payments.

Appropriation (institutional revenues) An amount (other than a grant or contract) received from or made available to an institution through an act of a legislative body.

Associate degree A degree granted for the successful completion of a sub-baccalaureate program of studies, usually requiring at least 2 years (or equivalent) of full-time college-level study. This includes degrees granted in a cooperative or workstudy program.

Auxiliary enterprises This category includes those essentially self-supporting operations which exist to furnish a service to students, faculty, or staff, and which charge a fee that is directly related to, although not necessarily equal to, the cost of the service. Examples are residence halls, food services, college stores, and intercollegiate athletics.

Average daily attendance (ADA) The aggregate attendance of a school during a reporting period (normally a school year) divided by the number of days school is in session during this period. Only days on which the pupils are under the guidance and direction of teachers should be considered days in session.

Average daily membership (ADM) The aggregate membership of a school during a reporting period (normally a school year) divided by the number of days school is in session during this period. Only days on which the pupils are under the guidance and direction of teachers should be considered as days in session. The average daily membership for groups of schools having varying lengths of terms is the average of the average daily memberships obtained for the individual schools.

Bachelor's degree A degree granted for the successful completion of a baccalaureate program of studies, usually requiring at least 4 years (or equivalent) of full-time college-level study. This includes degrees granted in a cooperative or work-study program.

Books Non-periodical printed publications bound in hard or soft covers, or in loose-leaf format, of at least 49 pages, exclusive of the cover pages; juvenile nonperiodical publications of any length found in hard or soft covers.

Budget authority (BA) Authority provided by law to enter into obligations that will result in immediate or future outlays. It may be classified by the period of availability (1-year, multiple-year, no-year), by the timing of congressional action (current or permanent), or by the manner of determining the amount available (definite or indefinite).

Business Program of instruction that prepares individuals for a variety of activities in planning, organizing, directing, and controlling business office systems and procedures. 
Capital outlay Funds for the acquisition of land and buildings; building construction, remodeling, and additions; the initial installation or extension of service systems and other built-in equipment; and site improvement. The category also encompasses architectural and engineering services including the development of blueprints.

Carnegie unit A standard of measurement that represents one credit for the completion of a 1-year course.

Catholic school A private school over which a Roman Catholic church group exercises some control or provides some form of subsidy. Catholic schools for the most part include those operated or supported by: a parish, a group of parishes, a diocese, or a Catholic religious order.

Central cities The largest cities, with 50,000 or more inhabitants, in a Metropolitan Statistical Area (MSA). A smaller city within a MSA may also qualify if it has at least 25,000 inhabitants or has a population of one-third or more of that of the largest city and a minimum population of 25,000. An exception occurs where two cities have contiguous boundaries and constitute, for economic and social purposes, a single community of at least 50,000 , the smaller of which must have a population of at least 15,000 .

Class size The membership of a class at a given date.

Classroom teacher A staff member assigned the professional activities of instructing pupils in self-contained classes or courses, or in classroom situations. Usually expressed in full-time equivalents.

Cohort A group of individuals that have a statistical factor in common, for example, year of birth.

College A postsecondary school which offers general or liberal arts education, usually leading to an associate, bachelor's, master's, doctor's, or first-professional degree. Junior colleges and community colleges are included under this terminology.

Combined elementary and secondary school A school which encompasses instruction at both the elementary and the secondary levels. Includes schools starting with grade 6 or below and ending with grade 9 or above.

Computer science A group of instructional programs that describes computer and information sciences, including computer programming, data processing, and information systems.

Constant dollars Dollar amounts that have been adjusted by means of price and cost indexes to elimi- nate inflationary factors and allow direct comparison across years.

Consumer, personal, and miscellaneous services A group of instructional programs that describes the fundamental skills a person is normally thought to need in order to function productively in society. Some examples are child development, consumer education, and family relations.

Consumer Price Index (CPI) This price index measures the average change in the cost of a fixed market basket of goods and services purchased by consumers.

Consumption That portion of income which is spent on the purchase of goods and services rather than being saved.

Control of institutions A classification of institutions of elementary/secondary or higher education by whether the institution is operated by publicly elected or appointed officials (public control) or by privately elected or appointed officials and derives its major source of funds from private sources (private control).

Credit The unit of value, awarded for the successful completion of certain courses, intended to indicate the quantity of course instruction in relation to the total requirements for a diploma, certificate, or degree. Credits are frequently expressed in terms such as "Carnegie units," "semester credit hours," and "quarter credit hours."

Current dollars Dollar amounts that have not been adjusted to compensate for inflation.

Current expenditures (elementary/secondary) The expenditures for operating local public schools, excluding capital outlay and interest on school debt. These expenditures include such items as salaries for school personnel, fixed charges, student transportation, school books and materials, and energy costs. Beginning in 1980-81, expenditures for state administration are excluded.

Current expenditures per pupil in average daily attendance Current expenditures for the regular school term divided by the average daily attendance of full-time pupils (or full-time equivalency of pupils) during the term. See also Current expenditures and Average daily attendance.

Current-fund expenditures (higher education) Money spent to meet current operating costs, including salaries, wages, utilities, student services, public services, research libraries, scholarships and fellowships, auxiliary enterprises, hospitals, and independ- 
ent operations. Excludes loans, capital expenditures, and investments.

Current-fund revenues (higher education) Money received during the current fiscal year from revenue which can be used to pay obligations currently due, and surpluses reappropriated for the current fiscal year.

\section{Current Population Survey See Guide to Sources.}

Degree-granting institutions postsecondary institutions that are eligible for Title IV federal financial aid programs and that grant an associate's or higher degree. For an institution to be eligible to participate in Title IV financial aid programs it must offer a program of at least 300 clock hours in length, have accreditation recognized by the U.S. Department of Education, have been in business for at least 2 years, and have signed a participation agreement with the Department.

Disposable personal income Current income received by persons less their contributions for social insurance, personal tax, and nontax payments. It is the income available to persons for spending and saving. Nontax payments include passport fees, fines and penalties, donations, and tuitions and fees paid to schools and hospitals operated mainly by the government. See also Personal income.

Doctor's degree An earned degree carrying the title of Doctor. The Doctor of Philosophy degree (Ph.D.) is the highest academic degree and requires mastery within a field of knowledge and demonstrated ability to perform scholarly research. Other doctorates are awarded for fulfilling specialized requirements in professional fields, such as education (Ed.D.), musical arts (D.M.A.), business administration (D.B.A.), and engineering (D.Eng. or D.E.S.). Many doctor's degrees in academic and professional fields require an earned master's degree as a prerequisite. First-professional degrees, such as M.D. and D.D.S., are not included under this heading.

Educational and general expenditures The sum of current funds expenditures on instruction, research, public service, academic support, student services, institutional support, operation and maintenance of plant, and awards from restricted and unrestricted funds.

Educational attainment The highest grade of regular school attended and completed.

Elementary education/programs Learning experiences concerned with the knowledge, skills, appreciations, attitudes, and behavioral characteristics which are considered to be needed by all pupils in terms of their awareness of life within our culture and the world of work, and which normally may be achieved during the elementary school years (usually kindergarten through grade 8 or kindergarten through grade 6), as defined by applicable state laws and regulations.

Elementary school A school classified as elementary by state and local practice and composed of any span of grades not above grade 8. A preschool or kindergarten school is included under this heading only if it is an integral part of an elementary school or a regularly established school system.

Elementary/secondary school As reported in this publication, includes only regular schools (i.e., schools that are part of state and local school systems, and also most not-for-profit private elementary/ secondary schools, both religiously affiliated and nonsectarian). Schools not reported include subcollegiate departments of institutions of higher education, residential schools for exceptional children, federal schools for American Indians, and federal schools on military posts and other federal installations.

Employment Includes civilian, noninstitutional persons who: (1) worked during any part of the survey week as paid employees; worked in their own business, profession, or farm; or worked 15 hours or more as unpaid workers in a family-owned enterprise; or (2) were not working but had jobs or businesses from which they were temporarily absent due to illness, bad weather, vacation, labor-management dispute, or personal reasons whether or not they were seeking another job.

Endowment A trust fund set aside to provide a perpetual source of revenue from the proceeds of the endowment investments. Endowment funds are often created by donations from benefactors of an institution, who may designate the use of the endowment revenue. Normally, institutions or their representatives manage the investments, but they are not permitted to spend the endowment fund itself, only the proceeds from the investments. Typical uses of endowments would be an endowed chair for a particular department or for a scholarship fund. Endowment totals tabulated in this book also include funds functioning as endowments, such as funds left over from the previous year and placed with the endowment investments by the institution. These funds may be withdrawn by the institution and spent as current funds at any time. Endowments are evaluated by two different measures, book value and market value. Book value is the purchase price of the endowment investment. Market value is the current worth of the endowment investment. Thus, the book value of a stock held in an endowment fund would be the pur- 
chase price of the stock. The market value of the stock would be its selling price as of a given day.

Engineering Instructional programs that describe the mathematical and natural science knowledge gained by study, experience, and practice and applied with judgment to develop ways to utilize the materials and forces of nature economically for the benefit of mankind. Include programs that prepare individuals to support and assist engineers and similar professionals.

English A group of instructional programs that describes the English language arts, including composition, creative writing, and the study of literature.

Enrollment The total number of students registered in a given school unit at a given time, generally in the fall of a year.

Expenditures Charges incurred, whether paid or unpaid, which are presumed to benefit the current fiscal year. For elementary/secondary schools, these include all charges for current outlays plus capital outlays and interest on school debt. For institutions of higher education, these include current outlays plus capital outlays. For government, these include charges net of recoveries and other correcting transactions other than for retirement of debt, investment in securities, extension of credit, or as agency transactions. Government expenditures include only external transactions, such as the provision of perquisites or other payments in kind. Aggregates for groups of governments exclude intergovernmental transactions among the governments.

Expenditures per pupil Charges incurred for a particular period of time divided by a student unit of measure, such as average daily attendance or average daily membership.

Extracurricular activities Activities that are not part of the required curriculum and that take place outside of the regular course of study. As used here, they include both school-sponsored (e.g., varsity athletics, drama and debate clubs) and communitysponsored (e.g., hobby clubs and youth organizations like the Junior Chamber of Commerce or Boy Scouts) activities.

Family A group of two persons or more (one of whom is the householder) related by birth, marriage, or adoption and residing together. All such persons (including related subfamily members) are considered as members of one family.

Federal funds Amounts collected and used by the federal government for the general purposes of the government. There are four types of federal fund ac- counts: the general fund, special funds, public enterprise funds, and intragovernmental funds. The major federal fund is the general fund, which is derived from general taxes and borrowing. Federal funds also include certain earmarked collections, such as those generated by and used to finance a continuing cycle of business-type operations.

Federal sources Includes federal appropriations, grants, and contracts, and federally-funded research and development centers (FFRDCs). Federally subsidized student loans and Pell Grants are not included.

First-professional degree A degree that signifies both completion of the academic requirements for beginning practice in a given profession and a level of professional skill beyond that normally required for a bachelor's degree. This degree usually is based on a program requiring at least 2 academic years of work prior to entrance and a total of at least 6 academic years of work to complete the degree program, including both prior-required college work and the professional program itself. By NCES definition, first-professional degrees are awarded in the fields of dentistry (D.D.S. or D.M.D.), medicine (M.D.), optometry (O.D.), osteopathic medicine (D.O.), pharmacy (D.Phar.), podiatric medicine (D.P.M.), veterinary medicine (D.V.M.), chiropractic (D.C. or D.C.M.), law (J.D.), and theological professions (M.Div. or M.H.L.).

First-professional enrollment The number of students enrolled in a professional school or program which requires at least 2 years of academic college work for entrance and a total of at least 6 years for a degree. By NCES definition, first-professional enrollment includes only students in certain programs. (See First-professional degree for a list of programs.)

Fiscal year The yearly accounting period for the federal government, which begins on October 1 and ends on the following September 30. The fiscal year is designated by the calendar year in which it ends; e.g., fiscal year 1988 begins on October 1, 1987, and ends on September 30, 1988. (From fiscal year 1844 to fiscal year 1976, the fiscal year began on July 1 and ended on the following June 30 .)

Foreign languages A group of instructional programs that describes the structure and use of language that is common or indigenous to people of the same community or nation, the same geographical area, or the same cultural traditions. Programs cover such features as sound, literature, syntax, phonology, semantics, sentences, prose, and verse, as well as the development of skills and attitudes used in communicating and evaluating thoughts and feelings through oral and written language. 
Full-time enrollment The number of students enrolled in higher education courses with total credit load equal to at least 75 percent of the normal fulltime course load.

Full-time-equivalent (FTE) enrollment For institutions of higher education, enrollment of full-time students, plus the full-time equivalent of part-time students. The full-time equivalent of the part-time students is estimated using different factors depending on the type and control of institution and level of student.

Full-time instructional faculty Those members of the instruction/research staff who are employed full time as defined by the institution, including faculty with released time for research and faculty on sabbatical leave. Full time counts exclude faculty who are employed to teach less than two semesters, three quarters, two trimesters, or two 4-month sessions; replacements for faculty on sabbatical leave or those on leave without pay; faculty for preclinical and clinical medicine; faculty who are donating their services; faculty who are members of military organizations and paid on a different pay scale from civilian employees; academic officers, whose primary duties are administrative; and graduate students who assist in the instruction of courses.

Full-time worker In educational institutions, an employee whose position requires being on the job on school days throughout the school year at least the number of hours the schools are in session. For higher education, a member of an educational institution's staff who is employed full time.

General administration support services Includes salary, benefits, supplies, and contractual fees for boards of education staff and executive administration. Excludes state administration.

General Educational Development (GED) program Academic instruction to prepare persons to take the high school equivalency examination. See GED recipient.

GED recipient A person who has obtained certification of high school equivalency by meeting state requirements and passing an approved exam, which is intended to provide an appraisal of the person's achievement or performance in the broad subject matter areas usually required for high school graduation.

General program A program of studies designed to prepare students for the common activities of a cit-

izen, family member, and worker. A general program of studies may include instruction in both academic and vocational areas.

Geographic region (1) One of four regions used by the Bureau of Economic Analysis of the U.S. Department of Commerce, the National Assessment of Educational Progress, and the National Education Association, as follows: (The National Education Association designated the Central region as Middle region in its classification.)

\begin{tabular}{ll} 
Northeast & Southeast \\
Connecticut & Alabama \\
Delaware & Arkansas \\
District of Columbia & Florida \\
Maine & Georgia \\
Maryland & Kentucky \\
Massachusetts & Louisiana \\
New Hampshire & Mississippi \\
New Jersey & North Carolina \\
New York & South Carolina \\
Pennsylvania & Tennessee \\
Rhode Island & Virginia \\
Vermont & West Virginia \\
Central (Middle) & West \\
Illinois & Alaska \\
Indiana & Arizona \\
lowa & California \\
Kansas & Colorado \\
Michigan & Hawaii \\
Minnesota & Idaho \\
Missouri & Montana \\
Nebraska & Nevada \\
North Dakota & New Mexico \\
Ohio & Oklahoma \\
South Dakota & Oregon \\
Wisconsin & Texas \\
& Utah \\
& Washington \\
& Wyoming \\
\hline & Taisions
\end{tabular}

(2) One of the regions or divisions used by the U.S. Bureau of the Census in Current Population Survey tabulations, as follows:

\section{Northeast}

(New England)

Maine

New Hampshire

Vermont

Massachusetts

Rhode Island

Connecticut

\section{Midwest}

(East North Central)

Ohio

Indiana

Illinois

Michigan

Wisconsin 


\begin{tabular}{|c|c|}
\hline $\begin{array}{l}\text { (Middle Atlantic) } \\
\text { New York } \\
\text { New Jersey } \\
\text { Pennsylvania }\end{array}$ & $\begin{array}{l}\text { (West North Central) } \\
\text { Minnesota } \\
\text { lowa } \\
\text { Missouri } \\
\text { North Dakota } \\
\text { South Dakota } \\
\text { Nebraska } \\
\text { Kansas }\end{array}$ \\
\hline $\begin{array}{l}\text { South } \\
\text { (South Atlantic) } \\
\text { Delaware } \\
\text { Maryland } \\
\text { District of Columbia } \\
\text { Virginia } \\
\text { West Virginia } \\
\text { North Carolina } \\
\text { South Carolina } \\
\text { Georgia } \\
\text { Florida }\end{array}$ & $\begin{array}{l}\text { West } \\
\text { (Mountain) } \\
\text { Montana } \\
\text { Idaho } \\
\text { Wyoming } \\
\text { Colorado } \\
\text { New Mexico } \\
\text { Arizona } \\
\text { Utah } \\
\text { Nevada }\end{array}$ \\
\hline $\begin{array}{l}\text { (East South Central) } \\
\text { Kentucky } \\
\text { Tennessee } \\
\text { Alabama } \\
\text { Mississippi }\end{array}$ & $\begin{array}{l}\text { (Pacific) } \\
\text { Washington } \\
\text { Oregon } \\
\text { California } \\
\text { Alaska } \\
\text { Hawaii }\end{array}$ \\
\hline $\begin{array}{l}\text { (West South Central) } \\
\text { Arkansas } \\
\text { Louisiana } \\
\text { Oklahoma } \\
\text { Texas }\end{array}$ & \\
\hline
\end{tabular}

Government appropriation An amount (other than a grant or contract) received from or made available to an institution through an act of a legislative body.

Government grant or contract Revenues from a government agency for a specific research project or other program.

Graduate An individual who has received formal recognition for the successful completion of a prescribed program of studies.

Graduate enrollment The number of students who hold the bachelor's or first-professional degree, or the equivalent, and who are working towards a master's or doctor's degree. First-professional students are counted separately. These enrollment data measure those students who are registered at a particular time during the fall. At some institutions, graduate enrollment also includes students who are in postbaccalaureate classes but not in degree programs. In specified tables, graduate enrollment includes all students in regular graduate programs and all students in postbaccalaureate classes but not in degree programs (unclassified postbaccalaureate students).
Graduate Record Examination (GRE) Multiplechoice examinations administered by the Educational Testing Service and taken by college students who are intending to attend certain graduate schools. The tests are offered in a variety of subject areas. Ordinarily, a student will take only the exam that applies to the intended field of study.

Graduation Formal recognition given an individual for the successful completion of a prescribed program of studies.

Gross domestic product (GDP) The total national output of goods and services valued at market prices. GDP can be viewed in terms of expenditure categories which include purchases of goods and services by consumers and government, gross private domestic investment, and net exports of goods and services. The goods and services included are largely those bought for final use (excluding illegal transactions) in the market economy. A number of inclusions, however, represent imputed values, the most important of which is rental value of owner-occupied housing. GDP, in this broad context, measures the output attributable to the factors of production-labor and property-supplied by U.S. residents.

Handicapped Those children evaluated as having any of the following impairments, who because of these impairments need special education and related services. (These definitions apply specifically to data from the U.S. Office of Special Education and Rehabilitative Services presented in this publication.)

Deaf Having a hearing impairment which is so severe that the student is impaired in processing linguistic information through hearing (with or without amplification) and which adversely affects educational performance.

Deaf-blind Having concomitant hearing and visual impairments which cause such severe communication and other developmental and educational problems that the student cannot be accommodated in special education programs solely for deaf or blind students.

Hard of hearing Having a hearing impairment, whether permanent or fluctuating, which adversely affects the student's educational performance, but which is not included under the definition of "deaf" in this section.

Mentally retarded Having significantly subaverage general intellectual functioning, existing concurrently with defects in adaptive behavior and manifested during the developmental period, which adversely affects the child's educational performance.

Multihandicapped Having concomitant impairments (such as mentally retarded-blind, mentally 
retarded-orthopedically impaired, etc.), the combination of which causes such severe educational problems that the student cannot be accommodated in special education programs solely for one of the impairments. Term does not include deafblind students but does include those students who are severely or profoundly mentally retarded.

Orthopedically impaired Having a severe orthopedic impairment which adversely affects a student's educational performance. The term includes impairment resulting from congenital anomaly, disease, or other causes.

Other health impaired Having limited strength, vitality, or alertness due to chronic or acute health problems such as a heart condition, tuberculosis, rheumatic fever, nephritis, asthma, sickle cell anemia, hemophilia, epilepsy, lead poisoning, leukemia, or diabetes which adversely affects the student's educational performance.

Seriously emotionally disturbed Exhibiting one or more of the following characteristics over a long period of time, to a marked degree, and adversely affecting educational performance: an inability to learn which cannot be explained by intellectual, sensory, or health factors; an inability to build or maintain satisfactory interpersonal relationships with peers and teachers; inappropriate types of behavior or feelings under normal circumstances; a general pervasive mood of unhappiness or depression; or a tendency to develop physical symptoms or fears associated with personal or school problems. This term does not include children who are socially maladjusted, unless they also display one or more of the listed characteristics.

Specific learning disabled Having a disorder in one or more of the basic psychological processes involved in understanding or in using spoken or written language, which may manifest itself in an imperfect ability to listen, think, speak, read, write, spell, or do mathematical calculations. The term includes such conditions as perceptual handicaps, brain injury, minimal brain dysfunction, dyslexia, and developmental aphasia. The term does not include children who have learning problems which are primarily the result of visual, hearing, or environmental, cultural, or economic disadvantage.

Speech impaired Having a communication disorder, such as stuttering, impaired articulation, language impairment, or voice impairment, which adversely affects the student's educational performance.

Visually handicapped Having a visual impairment which, even with correction, adversely affects the student's educational performance. The term includes partially seeing and blind children.

Higher education Study beyond secondary school at an institution that offers programs terminating in an associate, baccalaureate, or higher degree.

\section{Higher education institutions (alternative classi- fication)}

Doctoral-granting Characterized by a significant level and breadth of activity in commitment to doctoral-level education as measured by the number of doctorate recipients and the diversity in doctorallevel program offerings.

Comprehensive Characterized by diverse postbaccalaureate programs (including first-professional) but not engaged in significant doctoral-level education.

General baccalaureate Characterized by primary emphasis on general undergraduate, baccalaureate-level education. Not significantly engaged in postbaccalaureate education.

Specialized Baccalaureate or postbaccalaureate institution emphasizing one area (plus closely related specialties), such as business or engineering. The programmatic emphasis is measured by the percentage of degrees granted in the program area.

2-year Conferring at least 75 percent of its degrees and awards for work below the bachelor's level.

New These institutions, though not necessarily newly organized, are new additions to the Integrated Postsecondary Education Data survey universe. When degree and award data become available, they will be reclassified.

Non-degree-granting Offering undergraduate or graduate study but not conferring degrees or awards. In this volume, these institutions are included under Specialized.

\section{Higher education institutions (traditional classi- fication)}

4-year institution An institution legally authorized to offer and offering at least a 4-year program of college-level studies wholly or principally creditable toward a baccalaureate degree. In some tables, a further division between universities and other 4-year institutions is made. A "university" is a postsecondary institution which typically comprises one or more graduate professional schools (also see University). For purposes of trend com- 
parisons in this volume, the selection of universities has been held constant for all tabulations after 1982. "Other 4-year institutions" would include the rest of the nonuniversity 4-year institutions.

2-year institution An institution legally authorized to offer and offering at least a 2-year program of college-level studies which terminates in an associate degree or is principally creditable toward a baccalaureate degree. Also includes some institutions that have a less than 2-year program, but were designated as institutions of higher education in the Higher Education General Information Survey.

Higher Education Price Index A price index which measures average changes in the prices of goods and services purchased by colleges and universities through current-fund education and general expenditures (excluding expenditures for sponsored research and auxiliary enterprises).

High school A secondary school offering the final years of high school work necessary for graduation, usually including grades $10,11,12$ (in a 6-3-3 plan) or grades $9,10,11$, and 12 (in a 6-2-4 plan).

High school program A program of studies designed to prepare students for their postsecondary education and occupation. Three types of programs are usually distinguished-academic, vocational, and general. An academic program is designed to prepare students for continued study at a college or university. A vocational program is designed to prepare students for employment in one or more semiskilled, skilled, or technical occupations. A general program is designed to provide students with the understanding and competence to function effectively in a free society and usually represents a mixture of academic and vocational components.

Historically black colleges and universities ACcredited institutions of higher education established prior to 1964 with the principal mission of educating black Americans. Federal regulations (20 USC 1061 (2)) allow for certain exceptions of the founding date.

Household All the persons who occupy a housing unit. A house, apartment, or other group of rooms, or a single room, is regarded as a housing unit when it is occupied or intended for occupancy as separate living quarters, that is, when the occupants do not live and eat with any other persons in the structure, and there is direct access from the outside or through a common hall.

Housing unit A house, an apartment, a mobile home, a group of rooms, or a single room that is occupied as separate living quarters.
Imaginative writing This type of writing can take a variety of forms, such as stories, poems, plays, or lyrics. It represents a special approach to sharing experiences and understanding the world and ourselves. In this form of writing, special attention is given to rhythm and tone; the use of anecdote; the presence of metaphor and simile; shifts in plots; and the unexpected use of words, phrases, or punctuation.

Income tax Taxes levied on net income, that is, on gross income less certain deductions permitted by law. These taxes can be levied on individuals or on corporations or unincorporated businesses where the income is taxed distinctly from individual income.

Independent operations A group of self-supporting activities under control of a college or university. For purposes of financial surveys conducted by the $\mathrm{Na}$ tional Center for Education Statistics, this category is composed principally of federally funded research and development centers (FFRDC).

Informative writing This type of writing is used to share information and to convey messages, directions, and ideas. It often involves reporting or retelling events or experiences that have already occurred.

Institutional support The category of higher education expenditures that includes day-to-day operational support for colleges, excluding expenditures for physical plant operations. Examples of institutional support include general administrative services, executive direction and planning, legal and fiscal operations, and community relations.

Instruction That category including expenditures of the colleges, schools, departments, and other instructional divisions of higher education institutions and expenditures for departmental research and public service which are not separately budgeted. Includes expenditures for both credit and noncredit activities. Excludes expenditures for academic administration where the primary function is administration (e.g., academic deans).

Instruction (elementary and secondary) Instruction encompasses all activities dealing directly with the interaction between teachers and students. Teaching may be provided for students in a school classroom, in another location such as a home or hospital, and in other learning situations such as those involving co-curricular activities. Instruction may be provided through some other approved medium such as television, radio, telephone, and correspondence. Instruction expenditures include: salaries, employee benefits, purchased services, supplies, and tuition to private schools. 
Instructional staff Full-time-equivalent number of positions, not the number of different individuals occupying the positions during the school year. In local schools, includes all public elementary and secondary (junior and senior high) day-school positions that are in the nature of teaching or in the improvement of the teaching-learning situation. Includes consultants or supervisors of instruction, principals, teachers, guidance personnel, librarians, psychological personnel, and other instructional staff. Excludes administrative staff, attendance personnel, clerical personnel, and junior college staff.

Instructional support services Includes salary, benefits, supplies, and contractual fees for staff providing instructional improvement, educational media (library and audiovisual), and other instructional support services.

Junior high school A separately organized and administered secondary school intermediate between the elementary and senior high schools, usually including grades 7,8 , and 9 (in a 6-3-3 plan) or grades 7 and 8 (in a 6-2-4 plan).

Labor force Persons employed as civilians, unemployed (but looking for work), or in the armed services during the survey week. The "civilian labor force" comprises all civilians classified as employed or unemployed.

Land-grant colleges The First Morrill Act of 1862 facilitated the establishment of colleges through grants of land or funds in lieu of land. The Second Morrill Act in 1890 provided for money grants and for the establishment of black land-grant colleges and universities in those states with dual systems of higher education.

\section{Local education agency See School district.}

Mandatory transfer A transfer of current funds that must be made in order to fulfill a binding legal obligation of the institution. Included under mandatory transfers are debt service provisions relating to academic and administrative buildings, including (1) amounts set aside for debt retirement and interest and (2) required provisions for renewal and replacement of buildings to the extent these are not financed from other funds.

Master's degree A degree awarded for successful completion of a program generally requiring 1 or 2 years of full-time college-level study beyond the bachelor's degree. One type of master's degree, including the Master of Arts degree, or M.A., and the Master of Science degree, or M.S., is awarded in the liberal arts and sciences for advanced scholarship in a subject field or discipline and demonstrated ability to perform scholarly research. A second type of master's degree is awarded for the completion of a professionally oriented program, for example, an M.Ed. in education, an M.B.A. in business administration, an M.F.A. in fine arts, an M.M. in music, an M.S.W. in social work, and an M.P.A. in public administration. A third type of master's degree is awarded in professional fields for study beyond the first-professional degree, for example, the Master of Laws (L.L.M.) and Master of Science in various medical specializations.

Mathematics A group of instructional programs that describes the science of numbers and their operations, interrelations, combinations, generalizations, and abstractions and of space configurations and their structure, measurement, transformations, and generalizations.

Mean test score The score obtained by dividing the sum of the scores of all individuals in a group by the number of individuals in that group.

Metropolitan population The population residing in Metropolitan Statistical Areas (MSAs). See Metropolitan Statistical Area.

Metropolitan Statistical Area (MSA) A large population nucleus and the nearby communities which have a high degree of economic and social integration with that nucleus. Each MSA consists of one or more entire counties (or county equivalents) that meet specified standards pertaining to population, commuting ties, and metropolitan character. In New England, towns and cities, rather than counties, are the basic units. MSAs are designated by the Office of Management and Budget. An MSA includes a city and, generally, its entire urban area and the remainder of the county or counties in which the urban area is located. An MSA also includes such additional outlying counties which meet specified criteria relating to metropolitan character and level of commuting of workers into the central city or counties. Specified criteria governing the definition of MSAs recognized before 1980 are published in Standard Metropolitan Statistical Areas: 1975, issued by the Office of Management and Budget. New MSAs were designated when 1980 counts showed that they met one or both of the following criteria:

1. Included a city with a population of at least 50,000 within their corporate limits, or

2. Included a Census Bureau-defined urbanized area (which must have a population of at least $50,000)$ and a total MSA population of at least 100,000 (or, in New England, 75,000).

Migration Geographic mobility involving a change of usual residence between clearly defined geo- 
graphic units, that is, between counties, states, or regions.

Minimum-competency testing Measuring the acquisition of competence or skills to or beyond a certain specified standard.

\section{National Assessment of Educational Progress} (NAEP) See Guide to Sources.

Newly qualified teacher Persons who: (1) first became eligible for a teaching license during the period of the study referenced or who were teaching at the time of survey but were not certified or eligible for a teaching license; and (2) had never held full-time, regular teaching positions (as opposed to substitute) prior to completing the requirements for the degree which brought them into the survey.

Nonmetropolitan residence group The population residing outside Metropolitan Statistical Areas. See Metropolitan Statistical Area.

Nonprofit institution A private institution in which the individual(s) or agency in control receives compensation other than wages, rent, or other expenses for the assumption of risk. Nonprofit institutions may be either independent nonprofit (i.e., having no religious affiliation) or religiously affiliated.

Nonresident alien A person who is not a citizen of the United States and who is in this country on a temporary basis and does not have the right to remain indefinitely.

Nonsupervisory instructional staff Persons such as curriculum specialists, counselors, librarians, remedial specialists, and others possessing education certification but not responsible for day-to-day teaching of the same group of pupils.

Normal school A normal school was an institution which was engaged primarily in the preparation of teachers for positions in elementary and secondary schools. Prior to 1900, normal schools were often secondary schools with teacher training programs. During the early 20th century, normal schools gradually developed into higher education institutions.

Obligations Amounts of orders placed, contracts awarded, services received, or similar legally binding commitments made by federal agencies during a given period that will require outlays during the same or some future period.

Occupational home economics Courses of instruction emphasizing the acquisition of competencies needed for getting and holding a job or preparing for advancement in an occupational area using home economics knowledge and skills.
Occupied housing unit Separate living quarters with occupants currently inhabiting the unit.

Off-budget federal entities Organizational entities, federally owned in whole or in part, whose transactions belong in the budget under current budget accounting concepts but that have been excluded from the budget totals under provisions of law.

Operation and maintenance services Includes salary, benefits, supplies, and contractual fees for supervision of operations and maintenance, operating buildings (heating, lighting, ventilating, repair, and replacement), care and upkeep of grounds and equipment, vehicle operations and maintenance (other than student transportation), security, and other operations and maintenance services.

Other foreign languages and literatures Any instructional program in foreign languages and literatures not described in table 253, including language groups and individual languages such as the non-Semitic African languages, Native American languages, the Celtic languages, Pacific language groups, the Ural-Altaic languages, Basque, and others.

Other support services Includes salary, benefits, supplies, and contractual fees for business support services, central support services, and other support services not otherwise classified.

Other support services staff All staff not reported in other categories. This group includes media personnel, social workers, bus drivers, security, cafeteria workers, and other staff.

Outlays The value of checks issued, interest accrued on the public debt, or other payments made, net of refunds and reimbursements.

Part-time enrollment The number of students enrolled in higher education courses with a total credit load less than 75 percent of the normal full-time credit load.

Per capita income The mean income computed for every man, woman, and child in a particular group. It is derived by dividing the total income of a particular group by the total population in that group.

Personal income Current income received by persons from all sources minus their personal contributions for social insurance. Classified as "persons" are individuals (including owners of unincorporated firms), nonprofit institutions serving individuals, private trust funds, and private noninsured welfare funds. Personal income includes transfers (payments not resulting from current production) from govern- 
ment and business such as social security benefits and military pensions but excludes transfers among persons.

Persuasive writing This type of writing attempts to bring about some action or change. Its primary purpose is to influence others. It is concerned with the positions, beliefs, and attitudes of the readers.

Physical plant assets Includes the values of land, buildings, and equipment owned, rented, or utilized by colleges. Does not include those plant values which are a part of endowment or other capital fund investments in real estate. Excludes construction in progress.

Postbaccalaureate enrollment The number of graduate and first-professional students working towards advanced degrees and of students enrolled in graduate-level classes but not enrolled in degree programs. See also Graduate enrollment and First-professional enrollment.

Postsecondary education The provision of formal instructional programs with a curriculum designed primarily for students who have completed the requirements for a high school diploma or equivalent. This includes programs of an academic, vocational, and continuing professional education purpose, and excludes avocational and adult basic education programs.

Private school or institution A school or institution which is controlled by an individual or agency other than a state, a subdivision of a state, or the federal government, which is usually supported primarily by other than public funds, and the operation of whose program rests with other than publicly elected or appointed officials. Private schools and institutions include both nonprofit and proprietary institutions.

Property tax The sum of money collected from a tax levied against the value of property.

Proprietary (for profit) institution A private institution in which the individual(s) or agency in control receives compensation other than wages, rent, or other expenses for the assumption of risk.

Public school or institution A school or institution controlled and operated by publicly elected or appointed officials and deriving its primary support from public funds.

Pupil-teacher ratio The enrollment of pupils at a given period of time, divided by the full-time-equivalent number of classroom teachers serving these pupils during the same period.
Racial/ethnic group Classification indicating general racial or ethnic heritage based on self-identification, as in data collected by the U.S. Bureau of the Census or on observer identification, as in data collected by the Office for Civil Rights. These categories are in accordance with the Office of Management and Budget standard classification scheme presented below:

White A person having origins in any of the original peoples of Europe, North Africa, or the Middle East. Normally excludes persons of Hispanic origin except for tabulations produced by the U.S. Bureau of the Census, which are noted accordingly in this volume.

Black A person having origins in any of the black racial groups in Africa. Normally excludes persons of Hispanic origin except for tabulations produced by the U.S. Bureau of the Census, which are noted accordingly in this volume.

Hispanic A person of Mexican, Puerto Rican, Cuban, Central or South American, or other Spanish culture or origin, regardless of race.

Asian or Pacific Islander A person having origins in any of the original peoples of the Far East, Southeast Asia, the Indian subcontinent, or the $\mathrm{Pa}$ cific Islands. This area includes, for example, China, India, Japan, Korea, the Philippine Islands, and Samoa.

American Indian or Alaskan Native A person having origins in any of the original peoples of North America and maintaining cultural identification through tribal affiliation or community recognition.

Remedial education Instruction for a student lacking those reading, writing, or math skills necessary to perform college-level work at the level required by the attended institution.

Resident population Includes civilian population and armed forces personnel residing within the United States. Excludes armed forces personnel residing overseas.

Revenue All funds received from external sources, net of refunds, and correcting transactions. Noncash transactions such as receipt of services, commodities, or other receipts in kind are excluded as are funds received from the issuance of debt, liquidation of investments, and nonroutine sale of property.

Salary The total amount regularly paid or stipulated to be paid to an individual, before deductions, for personal services rendered while on the payroll of a business or organization. 
Sales and services Revenues derived from the sales of goods or services that are incidental to the conduct of instruction, research, or public service. Examples include film rentals, scientific and literary publications, testing services, university presses, and dairy products.

Sales tax Tax imposed upon the sale and consumption of goods and services. It can be imposed either as a general tax on the retail price of all goods and services sold or as a tax on the sale of selected goods and services.

Scholarships and fellowships This category of college expenditures applies only to money given in the form of outright grants and trainee stipends to individuals enrolled in formal coursework, either for credit or not. Aid to students in the form of tuition or fee remissions is included. College work-study funds are excluded and are reported under the program in which the student is working. In the tabulations in this volume, Pell Grants are not included in this expenditure category.

Scholastic Assessment Test (SAT) An examination administered by the Educational Testing Service and used to predict the facility with which an individual will progress in learning college-level academic subjects.

School A division of the school system consisting of students in one or more grades or other identifiable groups and organized to give instruction of a defined type. One school may share a building with another school or one school may be housed in several buildings.

School administration support services Includes salary, benefits, supplies, and contractual fees for the office of the principal, full-time department chairpersons, and graduation expenses.

School climate The social system and culture of the school, including the organizational structure of the school and values and expectations within it.

School district An education agency at the local level that exists primarily to operate public schools or to contract for public school services. Synonyms are "local basic administrative unit" and "local education agency."

Science The body of related courses concerned with knowledge of the physical and biological world and with the processes of discovering and validating this knowledge.

Secondary instructional level The general level of instruction provided for pupils in secondary schools (generally covering grades 7 through 12 or 9 through 12) and any instruction of a comparable nature and difficulty provided for adults and youth beyond the age of compulsory school attendance.

Secondary school A school comprising any span of grades beginning with the next grade following an elementary or middle school (usually 7,8 , or 9) and ending with or below grade 12. Both junior high schools and senior high schools are included.

Secondary enrollment The total number of students registered in a school beginning with the next grade following an elementary or middle school (usually 7,8 , or 9) and ending with or below grade 12 at a given time.

Senior high school A secondary school offering the final years of high school work necessary for graduation.

Serial volumes Publications issued in successive parts, usually at regular intervals, and as a rule, intended to be continued indefinitely. Serials include periodicals, newspapers, annuals, memoirs, proceedings, and transactions of societies.

Social studies A group of instructional programs that describes the substantive portions of behavior, past and present activities, interactions, and organizations of people associated together for religious, benevolent, cultural, scientific, political, patriotic, or other purposes.

Socioeconomic status (SES) For the High School and Beyond study and the National Longitudinal Study of the High School Class of 1972, the SES index is a composite of five equally weighted, standardized components: father's education, mother's education, family income, father's occupation, and household items. The terms high, middle, and low SES refer to the upper, middle two, and lower quartiles of the weighted SES composite index distribution.

Special education Direct instructional activities or special learning experiences designed primarily for students identified as having exceptionalities in one or more aspects of the cognitive process or as being underachievers in relation to general level or model of their overall abilities. Such services usually are directed at students with the following conditions: (1) physically handicapped; (2) emotionally handicapped; (3) culturally different, including compensatory education; (4) mentally retarded; and (5) students with learning disabilities. Programs for the mentally gifted and talented are also included in some special education programs. See also Handicapped. 
Standardized test A test composed of a systematic sampling of behavior, administered and scored according to specific instructions, capable of being interpreted in terms of adequate norms, and for which there are data on reliability and validity.

Standardized test performance The weighted distributions of composite scores from standardized tests used to group students according to performance.

\section{Standard Metropolitan Statistical Area (SMSA)} See Metropolitan Statistical Area (MSA).

Student An individual for whom instruction is provided in an educational program under the jurisdiction of a school, school system, or other education institution. No distinction is made between the terms "student" and "pupil," though "student" may refer to one receiving instruction at any level while "pupil" refers only to one attending school at the elementary or secondary level. A student may receive instruction in a school facility or in another location, such as at home or in a hospital. Instruction may be provided by direct student-teacher interaction or by some other approved medium such as television, radio, telephone, and correspondence.

Student support services Includes salary, benefits, supplies, and contractual fees for staff providing attendance and social work, guidance, health, psychological services, speech pathology, audiology, and other support to students.

Subject-matter club Organizations that are formed around a shared interest in a particular area of study and whose primary activities promote that interest. Examples of such organizations are math, science, business, and history clubs.

Supervisory staff Principals, assistant principals, and supervisors of instruction. Does not include superintendents or assistant superintendents.

Tax base The collective value of objects, assets, and income components against which a tax is levied.

Tax expenditures Losses of tax revenue attributable to provisions of the federal income tax laws that allow a special exclusion, exemption, or deduction from gross income or provide a special credit, preferential rate of tax, or a deferral of tax liability affecting individual or corporate income tax liabilities.

Technical education A program of vocational instruction that ordinarily includes the study of the sciences and mathematics underlying a technology, as well as the methods, skills, and materials com- monly used and the services performed in the technology. Technical education prepares individuals for positions-such as draftsman or lab technician-in the occupational area between the skilled craftsman and the professional person.

Total expenditure per pupil in average daily attendance Includes all expenditures allocable to per pupil costs divided by average daily attendance. These allocable expenditures include current expenditures for regular school programs, interest on school debt, and capital outlay. Beginning in 1980-81, expenditures for state administration are excluded and expenditures for other programs (summer schools, community colleges, and private schools) are included.

Trade and industrial occupations The branch of vocational education which is concerned with preparing persons for initial employment or with updating or retraining workers in a wide range of trade and industrial occupations. Such occupations are skilled or semiskilled and are concerned with layout designing, producing, processing, assembling, testing, maintaining, servicing, or repairing any product or commodity.

Transcript An official list of all courses taken by a student at a school or college showing the final grade received for each course, with definitions of the various grades given at the institution.

Trust funds Amounts collected and used by the federal government for carrying out specific purposes and programs according to terms of a trust agreement or statute, such as the social security and unemployment trust funds. Trust fund receipts that are not anticipated to be used in the immediate future are generally invested in interest-bearing government securities and earn interest for the trust fund.

Tuition and fees A payment or charge for instruction or compensation for services, privileges, or the use of equipment, books, or other goods.

Unclassified students Students who are not candidates for a degree or other formal award, although they are taking higher education courses for credit in regular classes with other students.

\section{Unadjusted dollars See current dollars.}

Undergraduate students Students registered at an institution of higher education who are working in a program leading to a baccalaureate degree or other formal award below the baccalaureate, such as an associate degree.

Unemployed Civilians who had no employment but were available for work and: (1) had engaged in any 
specific job seeking activity within the past 4 weeks; (2) were waiting to be called back to a job from which they had been laid off; or (3) were waiting to report to a new wage or salary job within 30 days.

U.S. Service Schools These institutions of higher education are controlled by the U.S. Department of Defense and the U.S. Department of Transportation. The 10 institutions counted in the NCES surveys of higher education institutions include: the Air Force Institute of Technology, Community College of the Air Force, Naval Postgraduate School, Uniformed Services University of the Health Sciences, U.S. Air Force Academy, U.S Army Command and General Staff College, U.S. Coast Guard Academy, U.S. Merchant Marine Academy, U.S. Military Academy, and the U.S. Naval Academy.

University An institution of higher education consisting of a liberal arts college, a diverse graduate program, and usually two or more professional schools or faculties and empowered to confer de- grees in various fields of study. For purposes of maintaining trend data in this publication, the selection of university institutions has not been revised since 1982.

Visual and performing arts A group of instructional programs that generally describes the historic development, aesthetic qualities, and creative processes of the visual and performing arts.

Vocational education Organized educational programs, services, and activities which are directly related to the preparation of individuals for paid or unpaid employment, or for additional preparation for a career, requiring other than a baccalaureate or advanced degree.

Vocational home economics Vocational courses of instruction emphasizing the acquisition of competencies needed for getting and holding a job or preparing for advancement in an occupational area using home economics knowledge or skills. 


\section{Index of Table Numbers}

A

Academic programs in high school, 136-139, 147

Accounting, degrees conferred, 247-253

Achievement tests. See Assessment

Activities

elementary school, 143

college faculty, 227, 228

high school, 144, 146, 147

kindergarten, 50, 143

young adults, 389

Additions to plant value, higher education, 352

Administration expenditures

elementary and secondary schools, 160-162, 165, 166

institutions of higher education, 335, 336, 338-340, 342-346, 351

Administrative units (school districts), 90-95

Adult basic education, 357

Adult education participants in, 355, 356

Adult and vocational education, 213, 247-249, 355, 356, 358

Federal funds for, 361, 363, 365, 366

Affiliation, religious

elementary and secondary schools, 60-63, 140142, 144-146

institutions of higher education, 179

Age

enrollment, 6, 7

for compulsory school attendance, 152

of college students, 174-176, 186, 211-213

Agriculture

degrees conferred, 10, 247-252, 255-258, 262,

263, 265, 266, 268, 269, 271, 272, 276

enrollment, higher education, 213, 214

faculty in higher education, 229, 232, 233

formal awards, organized occupational curricula,

247-249

units earned by high school graduates, 137

Alcohol use by students or adults, 148-151, 377

All levels of education, 1-38

American Indians

activities, 144-146

attendance patterns, 153

attitudes about schools, 142

courses taken by high school students, 136-140

degrees conferred, 260-274, 297-303, 305

educational attainment, 12

enrolled in colleges and universities, 206-211, 316 enrolled in public schools, 45

expected occupations, 141

financial aid, 313, 314

testing, 112, 116, 131

Annual expenditure per pupil, public schools, 39, 90, 95, 167, 169, 412

Annual salary. See Salaries.

Applications, college, 185

Applied research funds, 335, 336, 338-340, 342-

346, 351, 359, 369, 370

Architecture

degrees conferred, 247-252, 255-258, 262, 263,

265, 266, 268, 269, 271, 272, 277

enrollment, higher education, 213

Area studies,

degrees conferred, 247-252, 255-258, 262, 263, 265, 266, 268, 269, 271, 272

Art, degrees conferred, 247-252, 255-258, 262, 263, 265, 266, 268, 269, 271, 272, 297

Asian or Pacific Islander

activities, 144-147

attendance patterns, 153

attitudes about schools, 142

courses taken by high school students, 136-140

degrees conferred, 12, 261-275, 298-304, 306

educational attainment, 12

enrolled in colleges and universities, 206-211, 314

enrolled in public schools, 45

expected occupations, 141

financial aid, 314, 315

testing, 112, 116, 117, 128, 130

Assessment

American College Testing, 135

Graduate Record Examination, 310

international, 396-408

minimum-competency, 155, 156

National Assessment of Educational Progress, 109-128

National Education Longitudinal Study, 129

Scholastic Assessment Test, 130-134

Associate degrees, 9, 11, 170, 171, 216-218, 244249, 254-258, 261-263

Athletics, participation in school activities, 144, 146, 147

Attendance patterns, 153

Attitudes about

education, 22-29, 70, 75-77

life values, 376

selected classes, 140 
school climate, 142

Attrition, college student, 306, 309

Auxiliary enterprises, higher education, 324-329, 331, 332, 336-340, 351

Average daily attendance, 39, 44, 52

Average daily membership, 39

Average length of school year, 39, 124

\section{B}

Bachelor's degrees, 9-14, 170, 171, 217, 244-246, 250, 253, 254-258, 264-266, 276-297

Basic administrative units, 90-95

Basic student charges, higher education, 311-313

Behavior, student, 27, 28, 140-151, 153

Benefits expenditure, 162, 163

Biological sciences

credits earned by college graduates, 307

credits earned by high school graduates, 136, 138

degrees conferred, 10, 247-253, 255-258, 262, 263, 265, 266, 268, 269, 271, 272, 278, 279, 298, 302

enrollment, higher education, 213

faculty, 229

Graduate Record Examination, 310

Blacks

activities, 144, 146, 147

adult education, 355, 356

attendance patterns, 153

attitudes about schools, 142

courses taken by high school students, 136-140

degrees conferred, 9, 10, 12, 218, 261-275, 298304, 306

dropouts, 105, 106, 383

drug use, 148

educational attainment, 8-10, 12

enrolled in colleges and universities, 183, 186,

206-212, 218, 219, 309, 314, 382

enrolled in public schools, 45

enrolled in school, 7

expected occupations, 141

family characteristics, 19

financial aid, 314, 315

historically black colleges and universities, 218220

labor force participation, 377, 382, 383

literacy, 390

parental involvement in school activities, 26

persistence in higher education, 306, 309

population, 16

poverty status, 21

testing, 109, 112-115, 118-121, 125, 126, 128131

unemployment rate, $379,382,383$

years of school completed, 8-10, 12

Black colleges, 218-220

Board rates, 311,312

Business and management credits earned by college graduates, 307

credits earned by high school graduates, 137

degrees conferred, 10, 247-252, 255-258, 262,

263, 265, 266, 268, 269, 271, 272, 280, 298

enrollment, higher education, 213

faculty in higher education, 228, 233

vocational programs, $247-249$

\section{C}

Cable television, 418

Capital outlay

higher education, 35, 352

public elementary and secondary schools, 35, 39, $161,162,165,166$

Carnegie classification of colleges, 329, 336

Catholic schools

achievement test scores, 1297

elementary and secondary, 60-63

expected occupations of students, 141

institutions of higher education, 179

participation in extracurricular activities, 144, 146

student attitudes about classes, 140

student attitudes about school climate, 142

student attendance patterns, 153

Center-based programs for preschool, 41, 42, 46, 47, $49,51,143$

Chapter 1 (Title 1), 89, 361, 363, 365-367, 374

Cheerleading, participation in school activities, 144, 147

Chemical engineering, 253, 285

Chemistry, degrees conferred, 253, 292

Chemistry, Graduate Record Examination, 310

Child care, 47, 49, 51

Church affiliation

elementary and secondary schools, 60-63, 129,

140, 144-147, 153

institutions of higher education, 179

City school systems, 89, 93-95, 145, 151, 373, 374

Civil engineering, 253, 285

Class rank, 133

Classrooms, number of, 419

Class size, 69, 70, 227, 228

Classroom teachers

attitudes about schools, 27-28, 75-77, 151

characteristics of private school teachers, 68

characteristics of public school teachers, 68-70, 72

mobility, 73

new teachers' experiences, 75-77

opinions about teaching, 27-28, 75-77

private schools, $4,61,63-65,68,73,74$

public schools, 4, 39, 65-80, 83-86, 89, 93

salaries of private school teachers, 74

salaries of public school teachers, $74,78-80$

satisfaction with teaching, 26-28, 70, 75-77

teaching assignments, 71,72

Climate in schools, 27, 28, 142

Closing of institutions of higher education, 244 
Clubs, participation in school activities, 144, 147

College faculty. See Faculty, higher education.

College and university education, 170-354

College plans and applications, 146, 185

Communications

degrees conferred, 247-253, 255-258, 262, 263, $265,266,268,269,271,272,281$

enrollment, 213

faculty, 229

Competency testing

students, 124, 155

teachers, 156

Compulsory attendance, age for, 152

Computer and information sciences

courses taken by high school graduates, 136, 142 credits earned by college graduates, 308

degrees conferred, 247-253, 255-258, 262, 263, 265, 266, 268, 269, 271, 272, 283

enrollment in college, 213, 214

faculty, 229

Computers, use of, 418, 419, 424-428

Consumer Price Index, 38

Courses completed by college graduates, 307

Courses completed by high school graduates, 136139

Current expenditures

higher education, 171, 216-218, 335-340, 347, 349,350

public schools, 39, 89, 93, 161, 162, 164-169

Current-fund revenues in higher education, 171, 216, 218, 322, 324-334

\section{D}

Daily attendance as a percent of enrollment, 39

Day care, 47, 49

Degrees, earned

associate, 9, 11, 170, 171, 216-218, 244-249, 254-258, 261-263

bachelor's and higher, 9-12, 170, 171, 216-218, 245, 246, 251-305

by race, $9,10,12,218,261-275,298-304$

by sex, $9,10,170,171,218,244,247-249,253$, 259-278, 280-284, 286, 287, 289-291, 293295, 297-304

first-professional, 9, 170, 171, 216-218, 244, 246, 254, 259, 260, 273-275

historical summary, 171, 244

historically black colleges, 217,218

international comparison, 409-411

large institutions of higher education, 216

major field of study, 10, 247-253, 255-260, 262, 263, 265, 266, 268, 269, 271, 272, 274-304

number of institutions, by field, 257-259

Denominational affiliation

elementary and secondary schools, 60-63, 129, 140, 144-147, 153

institutions of higher education, 179
Dentistry

degrees conferred, 259, 260, 274, 275

dental assisting, awards in, 247-249

enrollment, higher education, 213

Department of Education outlays, 360-368

For other Departments, see Federal funds.

Disabled, 53-56, 59, 107, 108, 211

Discipline problems, 23, 27, 28, 142, 148, 151

Disposable personal income, 37

Districts, school, 90-94

Doctor's degrees, 9, 11, 170, 171, 216-218, 244, 246, 253, 254, 255, 256-258, 270-272, 276-305

Dormitory rooms, charges for, 311,312

Dramatic arts, degrees conferred, 253

Dropouts (high school)

employment and unemployment, 377, 379, 351, 383

income of, 380,381

number, 383

percent, by age group, 8, 9, 11-14, 105, 106

Dropouts (college), 306, 309

Drug abuse, 23, 27, 148-151, 375

\section{E}

Earned degrees. See Degrees, earned.

Earnings by years of school completed, 380-381, 388

Earnings of recent college graduates, 388

Economics, degrees conferred, 253, 296

faculty, 229

Education

adult, 355-357

all levels, $1-38$

bilingual, 59, 361, 363, 365, 366

credits earned by college graduates, 307

degrees conferred, 170, 171, 216-218, 244-305

degrees conferred in education, 10, 247-253, 255$258,263,265,266,269,269,271,272,283$, 298, 299

elementary and secondary, 39-169

enrollment, higher education, 1-3, 170-220

faculty in higher education, 221-233

federal programs, 359-374

Graduate Record Examination, 310

handicapped students, 53-56, 59, 107, 108, 211

higher, 170-358

international, 391-414

outcomes, 8-14, 101-139, 244-310, 375-390, 396-411

price indexes, 38

statistics related to, $375-390$

structure, (figure 1)

vocational, 59, 71, 72, 136, 137, 247-249, 355, $357,361,363,365,366$

Education in the U.S., structure of, (figure 1) 
Educational administration and supervision, degrees conferred, 253

Educational attainment, 8-14

Educational attainment in the work force, 377-381

Electrical engineering, 253, 285

Elementary and secondary education, 1-5, 31-33, $35,36,39-169$

Elementary education, degrees conferred, 253

Elementary schools, number

private, 5, 60, 62-64, 90

public, 5, 90, 96-99

Employees

colleges, 221-224

private elementary and secondary schools, 61

public elementary and secondary schools, 83-87

Employment

college graduates, 377-379, 381, 385-387

handicapped students, 108

high school dropouts, 377-379, 381, 383

high school graduates, 377-379, 381, 382

high school seniors, 384

Endowment funds, 171, 353, 354

Endowment funds, revenue from, 324-329, 331, 332

Engineering

credits earned by college graduates, 307

degrees conferred, 10, 247-253, 255-258, 262,

$263,265,266,268,269,271,272,284,285$,

298, 300

enrollment, higher education, 213, 214

faculty in higher education, 229, 232, 233

Graduate Record Examination, 310

graduates, organized occupational curricula, 247249, 262, 263

\section{English}

credits earned by high school graduates, 136, 139

enrollment in higher education, 213

faculty, 229

degrees conferred, 247-253, 255-258, 262, 263, $265,266,268,269,286$

requirements for graduation, 154

teachers, public high schools, 71

Enrollment

adult basic education, 357

adult education, 355-357

affiliation,

elementary and secondary schools, 60, 62, 63

institutions of higher education, 179

ages, 6, 7, 174-176, 186, 212, 213, 314, 355, 356

all levels of education, 1-3, 6, 7

by grade, $41-43$

by grade span of school, 97

by race, $7,45,60,179,183,206-210,212,218$, $355,356,382$

by sex, $6,7,170-172,174,175,177-179,181$, 182, 184, 187-189, 193-195, 207, 211, 212,

$216,218,355,356,382$

elementary and secondary private, $1-3,46,57,59,60,62-64$

public, 1-3, 39-46, 52, 57-56, 67, 87, 89, 91, 93, 95, 97

total, $1-3$

elementary schools

private, $2,3,56,62,63$

public, 2, 3, 39-43, 59, 97

total, 1-3

engineering, 213, 214

exceptional children, 53-56, 59, 107, 108, 211

foreign languages, public secondary schools, 58

foreign students in American colleges, 206-210, 414

handicapped, 53-55, 59, 107, 108, 211

higher education

affiliation, 179

age, 174-176, 186, 212, 213, 355, 356

disabled, 108, 211

engineering, 213, 214

first-professional, 2, 175, 177, 189, 197-199, 207

four-year colleges, 170, 173, 176-178, 181, 196, 198-201, 205, 206, 209, 213-220, 309

freshmen, 181-184, 203-205, 212

full-time, 172, 174-182, 187-189, 193-195, 217, 218

full-time-equivalent, 200-202, 216

graduate, 2, 175, 177, 188, 197-199, 207, 213, $214,216,319,320$

historically black colleges and universities, 218220

large institutions of higher education, 215-216

major field of study, 213, 214

minority, 183, 185, 186, 206-212, 218, 219

part-time, 172, 174-182, 187-189, 193-195, 216, 218

private institutions, $2,3,170,172,173,176-182$, 187-189, 192, 195, 196, 198-202, 206, 209, 215-220

public institutions, $2,3,170,172,173,176-182$, 187-189, 191, 194, 196, 198-202, 206, 209, 215-220

race, 183, 186, 206-212, 218, 219

rate, $6,7,179-182,300,306,382,391,392$

sex, 170-172, 174, 175, 177-182, 184, 187-

189, 193-195, 207, 211, 212, 216, 218

total, 1-3, 170-179, 190-199, 206-210, 212, 213, 215-220

traditionally black colleges, $218-220$

two-year colleges, 170, 173, 176-178, 181, 196, 198-201, 205, 206, 209, 213, 215-219, 309

type of institution, 170, 173, 176-178, 181, 196, 198-201, 205, 206, 209, 213-220, 309

undergraduate, 2, 175, 177, 187, 197-199, 207, 211-213, 216, 314-318

high schools. See Secondary schools.

international, 391-393 
kindergarten, 41, 43, 46, 47, 50, 53, 54, 56

large school districts, 89, 91, 93, 95

mathematics, higher education, 136, 138, 213, 214

preprimary programs, $41-43,46,47,49,53,54$, 56

race, elementary and secondary schools, 45

science, 136, 138, 213, 214

secondary schools

private, $2,3,57,59,62,63$

public, 2, 3, 39-43, 57, 59, 97

total, $1-3,57,59$

school districts, 91, 93, 95

social sciences, higher education, 213, 214

special education for exceptional children, 53-56, 59,211

two-year colleges, 170, 173, 176-178, 181, 196, 198-201, 205, 206, 213, 215-219, 309

Ethnicity. See Spanish origin and race.

Exceptional children, enrollment, 53-56, 59, 107, 108, 211

Expenditures

all schools, 31-33

administration, 160-162, 165, 166, 335, 336, 338, 342-346, 351

by other countries, 393, 412, 413

federal government, 33, 34, 359-374

governmental, 33-37

higher education, 31-36, 171, 216, 218, 219, 334351

instruction, 89, 94, 161-163, 165, 166, 335, 336, $338,339,342-346,351$

libraries, 335, 336, 338-340, 342-346, 351, 420422

per pupil, public schools, 39, 89, 94, 167-169

per pupil, by country, 412

per student, higher education, 335, 337, 342-346, 351

public elementary and secondary schools, 31-33,

$35,36,39,89,94,160-169$

private elementary and secondary schools, 31-33

pupil transportation, 52, 162, 165, 166

research, 335, 336, 338-340, 342-346, 351, 369, 370

state and local expenditures, 34-37. Also see

Revenues.

Extracurricular activities participation, 50, 143, 144, 146,147

\section{$\mathbf{F}$}

Faculty, higher education

academic rank, 226, 230-232, 235, 235, 238-240

age, 230-232

classes taught, 227, 228

control of institution, 1, 4, 221, 225, 227-231, 233240

employment status, 222, 225, 227-232

field, 229, 232, 323 productivity, 227, 228

race/ethnicity, 222, 229, 229, 230-232

salary, 230, 231, 233-239

sex, 171, 222, 223, 226, 229-232, 234, 235, 240

tenure, 240

Faculty salaries, 230, 231, 233-239

Families

income, 37

number, 18, 19

parental involvement with school activities, 25, 26

poverty status, 21

with children, 18, 19

Federally affected areas, aid to, $361,363,365,366$

Federal funds for education, 356-374

Federal sources, receipts from

higher education, 33, 324-329, 331, 332, 334

public elementary and secondary schools, 33, 39, $89,94,157-160$

Fees, higher education students, 311-313

Fellowships and scholarships, 314-321, 336-340, 342-346, 351

Field of study

achievement scores. See Tests.

characteristics of the population, 10

earned degrees, 10, 247-260, 262, 263, 265, 266, $268,269,271,272,274-304$

enrollment in higher education, 213, 214

employment, 385, 386, 388

faculty in higher education, 229, 232, 233

federal funds for colleges, 370

salaries, 388

Finances. See Capital outlay, Current expenditures, Expenditures, Income, Property, Revenues,

Salaries.

Financial aid to college students, 314-323

Fine and applied arts

degrees conferred, 247-253, 255-258, 262, 263, $265,266,268,269,271,272,297$

faculty in higher education, 229, 232, 233

First-professional degrees, 9, 170, 171, 216-218, 244, 246, 254, 259, 260, 273-275

First-professional enrollment, 2, 175, 177, 189, 197199, 207

Freshmen, 180-184, 203-205, 207, 212

Foreign languages degrees conferred, 247-253, 255-258, 262, 263, 265, 266, 268, 269, 271, 272, 287, 288 courses taken by high school students, 136, 139 enrollment, public high schools, 57

Foreign students in American colleges, 206-210, 414

Forestry, degrees conferred, 253

Four-year institutions

enrollment, 170, 173, 176-178, 180, 181, 196,

198-201, 205, 206, 209, 213-220, 306, 316-320

faculty, 223-225, 227, 228, 230, 233-240

finance, 216, 218, 219, 321, 329, 335, 337, 342, $343,345,346,351$ 
number, 5, 210, 236-238

staff, 223, 224

French

degrees conferred, 253, 288

enrollment, public secondary schools, 58

Full-time college students, 172, 174-182, 187-189, 193-195, 216, 218

Full-time-equivalent enrollment, 200-202, 216

Funds, Federal, for education, 34, 39, 89, 94, 157160, 324-329, 331, 332, 334, 359-374

\section{G}

GED, 104

Geography assessment, 118, 119, 396

Geography, degrees conferred, 253

Geology, degrees conferred, 253, 292

German

degrees conferred, 253, 288

enrollment, public secondary schools, 58

Gifted and talented, state legislation, 55

Gifts and grants, higher education, 324-329, 331, 341

Governmental finances, 33-37

Government and political science, degrees conferred, 253, 296

Grade enrollment, 41-43

Graduate enrollment, 2, 175, 177, 188, 197-199, $207,211,213,214,216,319,320$

Graduates

high school

attainment, 8-14

attainment in the work force, 377-381

college attendance of, 183-185, 382

employment, 382

GED, 102

number, 39, 64, 93, 102, 104, 183, 184, 382

institutions of higher education. See Degrees.

organized occupational curricula, 247-250

Graduate Record Examination, 310

Graduation rate, college, 306, 309

Graduation requirements, 154

Greek, degrees conferred, 253

Gross domestic product, 31, 37

Gross domestic product price deflator, 38

Guidance personnel, public elementary and secondary schools, 83-85

Guidance personnel, private elementary and secondary schools, 61

\section{H}

Health and physical education, activities of high school students, 144, 146, 147

Handicapped, special education for the, 53-56, 59, 107, 108, 211

Head Start, 48, 361, 372
Health professions

degrees conferred, 247-253, 255-258, 262, 263, $265,266,268,269,271,272,289$

enrollment, higher education, 213, 214

faculty in higher education, 229, 232, 233

High school graduates

attainment, 8-14

attainment in the work force, 377-381

college attendance of, 183-185, 382

employment, 382

GED, 104

number, 39, 64, 100, 102, 183, 184, 382

private, 64,100

public, 39, 93, 101, 102

total, $100,183,184,382$

High school seniors

activities, 144, 146, 147

attitudes, 140, 142

attendance patterns, 153

college applications, 185

college plans, 145

drug use, 150

employment, 384

enrollment, 41-43

expected occupations, 141

reasons for taking math and science courses, 140

High school students' extracurricular activities, 144, 146, 147

High schools. See Secondary schools.

Higher education, 1-5, 170-358

Higher Education Price Index, 38

Hispanics

activities, 144, 146, 147

adult education, 355, 356

attendance patterns, 153

attitudes about school climate, 142

courses completed by high school students, 136139

degrees conferred, 8, 9, 12, 261-275, 298-305, 306

dropouts, 105, 106, 383

drug use, 148

educational attainment, 8, 9, 12

enrolled in colleges and universities, 183, 186,

206-212, 309, 310, 314, 382

enrolled in public schools, 45

enrolled in school, 7

expected occupations, 141

family characteristics, 19

financial aid, 314, 315

labor force participation, 377, 382, 383

literacy, 390

parental involvement in school activities, 25, 26

persistence in higher education, 306, 309

population, 16

poverty, 21

testing, 109, 112, 113, 115, 118-121, 125-131 
unemployment rate, 379, 382, 383

years of school completed, 8, 9, 12

Historically black colleges and universities, 218-220

Historical summary statistics

enrollment, all levels, 3

higher education, 170

public schools, 39

History,

degrees conferred, 253, 296

faculty, 229

testing, 117, 118, 130

Home activities, 50, 111, 113, 120, 124, 143, 144, $146,147,402,425,427,428$

Home computers, 425, 427, 428

Home economics

courses taken by high school students, 137

degrees conferred, 247-253, 255-258, 262, 263, $265,266,268,269,271,272$

graduates, organized occupational curricula, 247249

Homework, 111, 124, 397, 399, 401, 403, 404

Hospitals, university, 324-329, 331, 332, 336-340

Household income, 20

Humanities

degrees conferred, 247-253, 255-258, 262, 263, $265,266,268,269,271,272,286-288,295-$

297, 298, 301, 304

faculty in higher education, 229, 232, 233

I

Illiteracy, 390. Also see Educational attainment.

Income

by years of school completed, 380-381

graduates, 380-381, 388

higher education institutions, 171, 216-219, 321, 324-334

personal, 37

public schools, 39, 89, 93, 157-160

Institutions of higher education

by control, 5, 171, 179, 215, 241-243, 257-259

by denominational affiliation, 179

by size of enrollment, 215, 217

by type, $5,215,241-243$

closing, 243

conferring most doctor's degrees, 305

enrolling largest numbers of students, 216, 217

historically black, 218-220

offering remedial instruction, 308

receiving most federal funds, 335

traditionally black, 218-220

with large endowments, 354

with large libraries, 421

Instruction practices, higher education, 227, 228

Instruction expenditures, 89, 94, 161-163, 165, 166, 336-340, 342-346, 351

Instructional rooms, number of, 419

Instructional staff, elementary and secondary schools private, 61,63

public, 39, 81-85

Interest on school debt, 39, 161, 162, 165, 166

International educational comparisons, 391-412

Internet access, 416, 417, 419, 424-427

Italian

degrees conferred, 253

enrollment, public secondary schools, 56

\section{J}

Journalism, degrees conferred, 253

Junior colleges

faculty, 223-225, 227, 228, 230, 231, 234-237, 240

finance, $216,218,219,321,329,335,338,344$, 351

number, 5, 210, 236-238

staff, 223, 224

enrollment, 167, 170, 173-175, 177, 192, 194-

$197,201,202,204,208,210-214,306,316-$ 318

number, 5, 210, 236-238

Junior high schools, 96, 100

Junior-senior high schools, 5, 96-98, 100

\section{K}

Kindergarten

activities, 50, 143

enrollment, 41-43, 46-48, 55, 143

readiness, 49

$\mathbf{L}$

Labor force status

by educational attainment, 377-379, 382-387

disabled persons exiting the education system, 107, 108

recent college graduates, 385-387

recent high school dropouts, 383

recent high school graduates, 382

Latin

degrees conferred, 253

enrollment, public secondary schools, 58

Law

first-professional degrees conferred, 259, 260,

274, 275

enrollment, 206

other degrees conferred, 247-253, 255-258, 262 , $263,265,266,268,269,271,272$

Letters, degrees conferred, 247-253, 255-258, 262, 263, 265, 266, 268, 269, 271, 272, 286

Level of school completed, 8-14

Librarians

higher education institutions, 420, 421

public, 422

private schools, 61,415

public schools, 83-85, 415-417 


\section{Libraries}

college and university, 420, 421

large university, 421

private school, 415

public, 422, 423

public school, 415-418

technology use, 415-419

Library expenditures

college and university, 336-340, 342-346, 351, 420, 421

public, 422,423

Library science, degrees conferred, 247-253, 255-

258, 262, 263, 265, 266, 268, 269, 271, 272

Life sciences

courses completed by high school graduates, 136, 138

credits earned by college graduates, 307

degrees conferred, 247-253, 255-258, 262, 263-

$265,266,268,269,271,272,278,279,298$,

302

enrollment, higher education, 213, 214

faculty, 229

Graduate Record Examination, 310

Life values, 376

Literacy, 390, 407, 408

Literature, degrees conferred, 247-253, 255-258, 262, 263, 265, 266, 268, 269, 271, 272, 286

Literature, Graduate Record Examination, 310

Local basic administrative units, 90-95

Local public school systems with largest enrollments, 93-95

Local sources, receipts from

higher education, 33-36, 324-329, 331-343

public schools, 33-36, 39, 89, 94, 157-159

Lunch, school program, 162, 165, 166, 361, 371, 373

\section{M}

Major field of study

earned degrees, 247-253, 255-258, 262, 263,

$265,266,268,269,271,274-304$

enrollment in higher education, 213, 214

federal obligations to colleges, 370

Master's degrees, 9, 11, 170, 171, 216, 218, 219, 244, 246, 251, 253-258, 267-269, 276-297

Mathematics

attitudes about classes, 140

courses taken by high school students, 123, 136, 138

credits earned by college graduates, 307

degrees conferred, 241-248, 250-253, 256, 257, $262,263,265,266,268,269,271,272,290$

enrollment, higher education, 213, 214

faculty, 229

testing, 120-125, 129, 131-135, 310, 397, 398, 401-403, 405

Medical laboratory technologies, degrees conferred, 247-249
Medicine

degrees conferred, 253

first-professional degrees, 259, 260, 274, 275

enrollment, 213, 214

Membership, public schools, 39. Also see

Enrollment.

Mentally retarded, special education, 53, 54, 107, 108

Metropolitan area,

internet access, 419

participation in federal programs, 373, 374

public school statistics, 89

testing, 109, 115, 129

years of school completed, 14

Microcomputers, use of, 415-417, 424-428

Middle schools, number, 96, 99

Migration of college students, 203-205

Military sciences, degrees conferred, 247-253, 255258, 262, 263, 265, 266, 268, 269, 271, 272

Minimum-competency testing for students, 122, 155

Minimum-competency testing for teachers, 156

Minorities

college graduation rates, 306, 309

degrees conferred, 218, 261-275, 298-304, 306

educational attainment, 8-10, 12

enrolled in colleges, 183, 184, 186, 206-212, 217

enrolled in elementary and secondary schools, 45

enrolled in school, 7

high school courses taken, 136-139

high school dropouts, 105, 106, 383

high school graduates, 183, 382

testing, 109, 112, 115, 117-121, 125-131

Mobility of teachers, 73,77

Music, degrees conferred, 253

Music education, degrees conferred, 253

Music, participation in high school activities, 144, 146,147

\section{N}

National Assessment of Educational Progress

art, 130

geography, 118, 119

history, 117, 118, 129

international geography, 396

international reading literacy, 407, 408

mathematics, 120-123, 125, 129

music, 130

reading, 109-114, 130

science, $127-129$

theatre, 130

visual arts, 130

writing, 115, 116

Natural science

courses taken by high school students, 136, 138, 139

faculty in higher education, 229, 232, 233

Nonprofit higher education institutions 
enrollment, 170, 172, 178, 179, 196, 209, 215, 216, 217

degrees, 170, 216,

finances, 216, 327, 345, 346, 350

institutions, 179, 209, 215

staff, 170

Nonpublic schools. See Private schools.

Nursery school, 41, 42, 46-48, 143

Nursing, degrees conferred, 247-249, 253

\section{0}

Occupational programs (higher education)

awards, 247-249

enrollment, 213

schools offering, 5

Occupational programs (secondary), 137

Occupation and employment

college graduates, 377-381, 385-388

expected occupations of 8th, 10th and 12th graders, 141

high school graduates, 107, 108, 377-382

high school seniors, 384

school dropouts, 377-381, 383

Office occupations (vocational) credits, 137

One-teacher schools, public, 90, 96

Operation and maintenance expenditures elementary and secondary, 89, 161, 162, 165, 166 higher education, 336-340, 342-346, 351

Opinions on education

attitudes about classes, 140

average grade for schools, 22

opinions about school climate, 28, 142

opinions about schools, 22-29, 70, 75-77

perception about student behavior, 27, 142, 151

problems in schools, 23, 27, 28, 142, 148, 151

school choice, 24

teachers' attitudes, 27, 28, 70

Organized occupational curricula, formal awards based on, 247-249

Outcomes of education, 375-390. Also see Degrees and Graduates.

Parental involvement, 23, 25-28, 140, 143

Part-time college students, 172, 174-182, 187-189, 193-195, 217, 218

Pell grants, finance, 323, 361, 363, 365, 366

Pell grants, received by students, 319

Per capita personal income, 37

Per pupil cost of transportation, 52

Per pupil expenditures, 39, 89, 94, 167-169, 413

Per student expenditures (higher education), 335, 336, 342-346, 351

Persistence in higher education, 306, 309

Personal income, 37

Pharmacy, degrees conferred, 253, 260, 274, 275
Philosophy and religion, degrees conferred, 241-248, 250-253, 256, 257, 260, 262, 263, 265, 266, 268, $269,271,272,274,275$

Physical education, degrees conferred, 253

Physical plant additions, 352

Physical plant, higher education, value of, 171, 353

Physical sciences

courses taken by high school students, 136, 138, 139

credits earned by college graduates, 307

degrees conferred, 241-248, 250-253, 256, 257, $260,262,263,265,266,268,269,271,272$, 291, 292, 298, 303

enrollment in higher education, 213, 214

faculty, 229

Physics, degrees conferred, 253, 292

Plant value, higher education, 171, 353

Preschool education, 41, 42, 46-48, 143

Political science

degrees conferred, 253, 296

faculty, 229

Population

by continent, 393

by country, 394

by years of school completed, 8-14

percent enrolled in school, 6,7

poverty, 20, 21

school-age, 15-17

total, $15,17,37,39$

Postsecondary education, 5, 170-358. Also see

Higher education.

Poverty, 20, 21

Preprimary programs, enrollment in, 41-43, 46-48, 53, 54, 56

Price indexes, 38

Principals, private schools, 61,88

Principals, public schools, 83-85, 88

Private elementary and secondary schools college application rates, 185

enrollment, 1-3, 46, 57, 59, 60, 62-64

expenditures, 32,33

graduates, 64, 101

libraries, 415

mobility of teachers, 73

number, 5, 60, 62, 64, 90

opinions of teachers, 27,28

principals, 61,88

pupils per teacher, 61,65

salaries of teachers, 74

staff, 1,61

teachers, 1, 4, 61, 63-65, 68, 73, 74

Private gifts and grants, higher education, 324-329, 331, 332, 341

Private institutions of higher education degrees conferred, 170, 245, 254-259

endowment, 354 
enrollment, 2, 3, 170, 172, 173, 176-182, 187$189,192,195,196,198-202,206,209,215-$ 220, 317-320

expenditures, 32, 33, 335, 337, 340, 345, 346, 349-351

faculty number, 4, 221-225, 230, 231, 233, 234

faculty salaries, 228, 233-239

faculty tenure, 240

financial aid, 316-322

number, 5, 179, 209, 215, 241-243, 257-259

opinions, 29

physical plant additions, 352

revenues, 33, 322, 326, 329, 333

student charges, 311-313

Professional degrees. See Degrees and Firstprofessional degrees.

Property, higher education, value of, 171, 353, 354

Protective services, degrees conferred, 241-248, 250-253, 256, 257, 260, 262, 263, 265, 266, 268, 269, 271, 272

Protestant institutions of higher education, 179

Psychology

degrees conferred, 241-248, 250-253, 256, 257, $260,262,263,265,266,268,269,271,272$, 293

enrollment, 213, 214

faculty, 229

Public affairs, degrees conferred, 241-248, 250-253, $256,257,260,262,263,265,266,268,269,271$, 272

Public elementary and secondary schools

districts, 90-94

college application rates, 185

enrollment, 1-3, 39-46, 52, 57, 59, 67, 87, 89, 91, $94,95,96$

expenditures, 32, 33, 35, 36, 39, 89, 94, 161-169

finance, 34-36

graduates, 93, 101, 102

graduation requirements, 154

instructional staff, 39, 83-85

librarians, 83-85

libraries, 415-417

minimum-competency testing, 124, 155, 156

number, 5, 89, 90, 93, 96-100

principals, 83-85, 88

revenue receipts, $39,89,94,157-160$

teachers, 1, 4, 39, 65-70, 83-86, 89, 93

telecommunications use, $415-419$

Public institutions of higher education

degrees conferred, 170, 245, 254-259

endowment, 354

enrollment, 2,3 , 170, 172, 173, 176-182, 187-

$189,192,195,196,198-202,206,209,215-$

220, 317-320

expenditures, 32, 33, 335, 337, 339, 342-345, 347,348 faculty number, 4, 221-225, 227, 228, 230, 231, 234

faculty salaries, 230, 233-239

faculty tenure, 240

financial aid, 316-322

number, 5, 179, 209, 215, 241-243, 257-259

opinions, 29

physical plant additions, 352

revenues, 33, 322, 325, 329-333

student charges, 311-313

Public opinions on schools, 22-24, 27, 29, 70, 74377

Public school systems, 90-95

Pupils. See Enrollment.

Pupil/staff ratio, 61, 83, 87

Pupil/teacher ratio, 61, 65, 67, 83, 89, 92

Pupil, expenditure per, 39, 89, 93, 168, 169, 412

Pupils transported at public expense, 52

\section{$\mathbf{R}$}

Race

adult education, 355, 356

college faculty, 222, 226, 230, 231-233

college graduation rates, 306, 309

courses completed by high school students, 136139

degrees conferred, 9, 10, 12, 218, 261-275, 298304, 306, 309, 314

enrolled in college, 183, 186, 206-212, 218

enrolled in preprimary education, 46,48

enrolled in public elementary and secondary

schools, 45

enrolled in school, 7

going to college, $145,183,185,186,382$

high school dropouts, 8-10, 12, 106, 107, 383

high school graduates, 8-10, 12, 183, 382

high school program, 135

labor force participation, 377, 382, 383

literacy, 390

parental involvement in education, 25, 26

persistence in higher education, 306, 309

population, 16

poverty, 21

testing, 109, 112, 113, 115, 118-121, 125-131

unemployment, 379, 382, 383

years of school completed, 8-10, 12

Readiness for school, 49

Reading tests, 109-114, 129, 131-135, 407, 408

Receipts. See Revenue.

Regular 4-year high schools, 96, 100

Religion degrees conferred, 253. Also see

Philosophy and religion.

Religious affiliation

elementary and secondary schools, 60-63, 140142, 144-146

institutions of higher education, 179

Remedial instruction, 58, 308 
Research funds, 336-340, 342-346, 351, 359, 361, 369, 370

Residence and migration of college students, 203205

Resident population, 15-17, 39

Retention rates in higher education, 306, 309

Revenues, institutions of higher education, 33, 171, 322, 324-333

Revenues, receipts, public schools, 33, 39, 89, 94, 157-160

Room charges, 311, 312

Russian

degrees conferred, 253

enrollment, public secondary schools, 58

\section{S}

Salaries

higher education

bachelor's degree recipients, 380, 381, 388

faculty, 230, 231, 233-239

library expenditures for, 420, 421

private school teachers, 74

public schools

outlays, 162,163

teachers, 74, 78-82

total instructional staff, 39, 81, 82

Scholarships and fellowships, 320-323, 338-340, 336-340, 342-346, 351

Scholastic Assessment Test, 131-134

School-age population, 16, 17, 39

School assistance in federally affected areas, 89, $361,363,365,366$

School districts, 90-95

School lunch program, 361, 371, 373, 418

School readiness, 65

School systems, 90-95

School year, length, 39, 124, 152, 397

School years completed, 8-14

Schools

climate, 27, 28, 142

elementary and secondary

private, $5,60,62,64,90$

public, 5, 89, 90, 93, 96-100

higher education, 5, 171, 179, 209, 215, 241-243, 257-259

noncollegiate postsecondary, 358

Science

attitudes about classes, 140

courses taken by college graduates, 307

courses taken by high school students, 136, 138, 139

degrees conferred, 241-248, 250-253, 256, 257, $260,262,263,265,266,268,269,271,272$,

276, 278, 279, 291, 292, 298, 302, 303

enrollment in higher education, 213, 214

faculty in higher education, 229, 232, 233

testing, 126-129, 135, 310, 399, 400, 404, 406
Secondary schools

private, $5,60,62,63,90$

public

junior high, 96, 100

total, 5, 90, 96-98, 100

Secondary school teachers, public, by field, 71, 72

Senior high schools, 96, 100

Size of enrollment

institutions of higher education, 215

largest colleges, 216, 217

largest school districts, 93-95

school districts, 91

schools, 97, 416

Social sciences

credits earned by college graduates, 307

degrees conferred, 241-248, 250-253, 256, 257, $260,262,263,265,266,268,269,271,272$, 295, 296, 298, 304

enrollment, higher education, 213, 214

faculty in higher education, 229, 232, 233

Social work, degrees conferred, 253

Sociology

degrees conferred, 253, 296

faculty, 229

Software, use of, 426, 427

Spanish

degrees conferred, 253, 288

enrollment, public high schools, 58

Spanish origin. See Hispanic.

Special education

completions, 107, 108

degrees conferred, 253

enrollment, 53-56, 59, 211

Speech, degrees conferred, 253

Sports, participation in school activities, 144, 146, 147

Staff. See Faculty, Classroom teachers, Instructional.

Staff,

private elementary and secondary schools, 1, 60

public elementary and secondary schools, 1, 39, $83-87,160$

all schools, 1

pupil/staff ratio, $61,83,87$

State

adult basic education, 357

assessment, 113, 114, 122, 123

class size, 69

compulsory school attendance, 152

degrees conferred, 245, 246

Department of Agriculture obligations, 371

Department of Education obligations, 365-367

Department of Health and Human Services

allocations, 372

educational attainment, 11-14

enrollment in higher education, 182, 190-199,

201-205, 210

enrollment in private schools, 64 
enrollment in public schools, 40-42, 44, 45, 67, 87 expenditure per pupil, 167, 168 expenditures for public higher education, 347-350 expenditures for public schools, 160, 164-168 federal obligations to colleges, 365, 366, 369 governmental expenditures, 35, 36 graduation requirements, 154 Head Start allocations, 372 high school graduates, private, 64 high school graduates, public, 102 homework, 124 household income, 20 instruction expenditures, 163, 165, 166 mathematics, 122-124 minimum-competency testing, 124, 155, 156 number of institutions of higher education, 242 number of noncollegiate institutions, 358 number of public schools, 98-100 number of school districts, 92 population, 17 poverty, 20 proficiency in mathematics, 122,123 proficiency in reading, 113,114 pupil/teacher ratio, 67 residence and migration of college students, 203205 revenues for higher education, 330-333 revenues for public schools, $158-160$ salaries, public instructional staff, 81 salaries, public school teachers, 79,80 salaries, higher education faculty, 236-239

Scholastic Assessment Test, 134 staff, public schools, 84-87, 160 state education agencies, 160 state regulations, $55,152,154-156$ state student financial aid, 324 teachers, private schools, 64 teachers, public schools, $66,67,84-86$ teachers, characteristics of public school, 69 television watching, 114, 126 testing, 113, 114, 122, 123, 135 tuition and fees in higher education, 312 years of school completed, 11-14

State governments, receipts from higher education, 324-329, 329-333 public schools, 157-159

Statistics, degrees conferred, 253

Statistics related to American education, 375-390

Structure of education in the U.S., figure 1

Student fees, higher education, 311-313 private elementary and secondary, 62

Student loan (Federal) program, 314-320, 359, 361, 363

Students. See Enrollment.

Students receiving financial aid, 314-320

Supplies expenditure, 162, 163

\section{$\mathbf{T}$}

Teachers

all levels of education, 1, 4

elementary and secondary schools

by field, 71

by sex, 39, 68, 70

characteristics, 68-73

large districts, 93

opinions, 27, 28, 50, 70, 75-77, 151

private, $1,4,61,63-65,68,73,74$

pupil/teacher ratio, $61,65,67,83,89,93$

public, 1, 4, 39, 65-80, 83-86, 89, 93

salaries, 74, 78-80

higher education instructional staff

number, 4, 221-233

salaries, 230, 231, 233-239

tenure, 240

Technology, use of, 415-419, 424-428

Technical education, enrollment, 213, 355, 356

Technical programs, degrees, 247-249

Telecommunications, 415-419, 424-427

Television, 114, 120, 124, 143, 146, 402, 415-417

Tenure of higher education faculty, 240

Tests

American College Testing, 135

Graduate Record Examination, 310

international, 396-408

minimum-competency, 124, 154, 155

National Assessment of Educational Progress, 107-128, 130

National Education Longitudinal Study, 129

Scholastic Assessment Test, 131-134

Theology, degrees conferred, 241-248, 250-253, 255-258, 260, 262, 263, 265, 266, 268, 269, 271, $272,273,274$

Total expenditures. See Expenditures.

Trade and industry courses taken by high school students, 136, 137

Traditionally black colleges, 218-220

Transportation of public school pupils, 52, 161, 162, 164, 165

Tuition and fees, higher education, 311-313

Tuition, private elementary and secondary schools, 62

Tuition revenues, higher education, 322, 324-329, 331, 332

Two-year institutions enrollment, 170, 173, 176-178, 180, 181, 196, 198-201, 206, 209, 213, 215, 216, 217-220, 314-318

faculty, 222-225, 227, 228, 230, 231, 234-238

finance, 216, 322, 329, 335, 337, 344, 351

number, 5, 209, 215, 241-243

staff, 222, 223 


\section{U}

Undergraduate enrollment, 2, 175, 177, 180, 187, 197-199, 207, 208, 211-213, 216, 314-318

Unemployment, 51, 379, 382, 383, 386

U.S. education, structure of, (figure 1)

Universities

enrollment, 173, 209, 215

finances, 329, 337, 342, 435, 351

number, 209, 215, 242

\section{V}

Value of physical plant, higher education, 171, 352354

Value of endowment funds, higher education, 171, 353, 343

Value of property, higher education, 171, 353

Values, life, 376

Veterinary medicine

degrees conferred, 260, 274, 275

enrollment for professional degrees, 214

Violence, student exposure to, 23, 27, 142, 148, 151

Visual and performing arts, degrees conferred, 241248, 250-253, 256, 257, 260, 262, 263, 265, 266, $268,269,271,272297$

Vocational education

awards, 170, 247-249

credits earned by high school students, 136, 137

enrollment, 170, 355, 356

federal funds, 361, 363, 365, 366

institutions offering, 358

teachers, 68

Volumes

college and university libraries, 420, 421

public libraries, 422-423

private school libraries, 415

public school libraries, 415-417

Voluntary support for education, 30, 341

\section{W}

Wages. See Income.

Whites activities, 144, 146, 147

adult education, 355, 356

attendance patterns, 153

attitudes about schools, 142

courses taken by high school students, 136-140

degrees conferred, 9, 10, 12, 218, 261-275, 298304, 306

dropouts, 105, 106, 383

drug use, 148

educational attainment, 8-10, 12

enrolled in colleges and universities, 183, 186,

206-212, 218, 219, 309, 314, 382

enrolled in public schools, 45

enrolled in school, 7

expected occupations, 141

family characteristics, 19

financial aid, 314, 315

historically black colleges and universities, 218220

labor force participation, 377, 382, 383

literacy, 390

parental involvement in school activities, 26

persistence in higher education, 306, 309

population, 16

poverty status, 21

testing, 109, 112-115, 118-121, 125, 126, 128131

unemployment rate, 379, 382, 383

years of school completed, 8-10, 12

Writing tests, 115, 116

\section{$\mathbf{Y}$}

Years of school completed

adult population, 8-14

income, 380, 381

labor force, 377

occupations, 378

unemployment, 379

\section{Z}

Zoology, degrees conferred, 253 